A. RAILLIET

\title{
TRAITE
}

\author{
DI:
}

Z0OLOAL MÉDIOAJ

\section{ET AGRICOLIS}

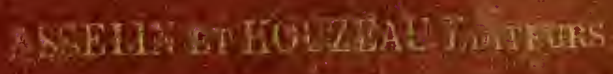




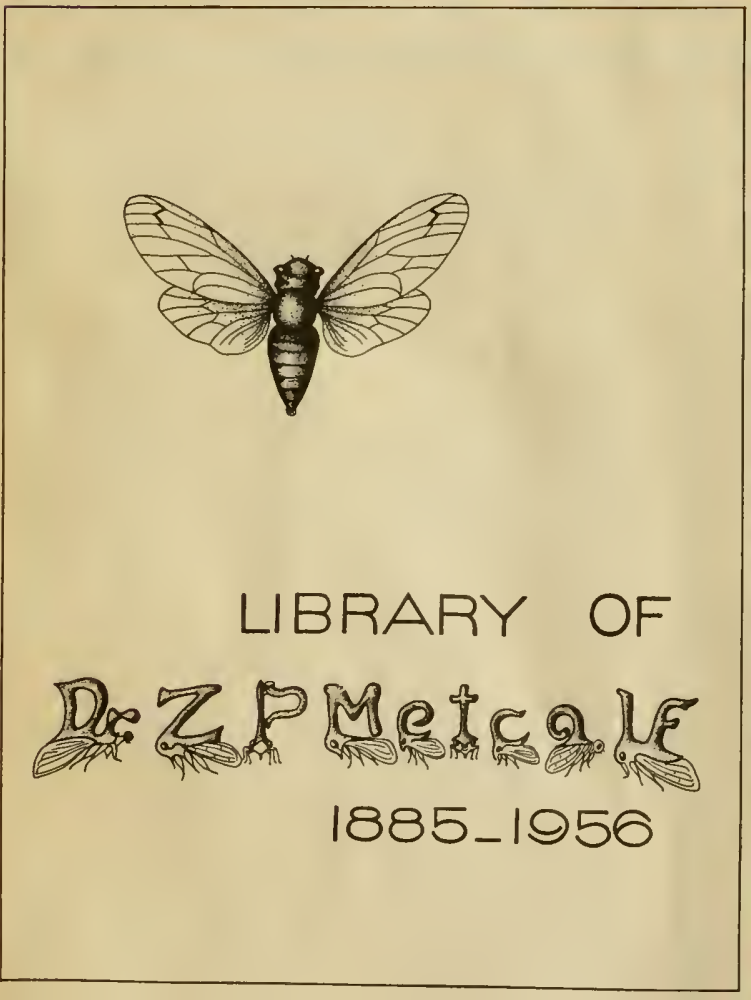





$$
\text { - }
$$




\section{TRAITE}

\section{DE \\ ZOOLOGIE MÉDICALE \\ ET AGRIGOLE}


4585-93. - CorbelL. Imprimerie Ed. Créré. 


\section{TRA I TE}

DE

\section{T00LOCIIE VIÉDICALE}

\section{ET AGRICOLE}

P A 1 i

A. RAILLIET

PROFESSEUR D'IUISTOIRE NATURELLE A L'ÉCOLE VÉTÉRINAIRE D'ALFORT

DEUXIEME EDITION

Avec 892 figures intercalées dans le texte

\section{PARIS}

ASSELIN ET HOLZEAU

LIBRAIRES DE LA FACULTÉ DE MÉDECINE

et de la Socièté centrale de médecine vétérinaire PLACE DE L'ÉCOLE-DE-MÉDECINE 



\section{PRÉFACE}

\section{DE LA PREMIERE EDITION}

Le titre même de cet ouvrage nous paraît en indiquer clairement le but et la portée. Ces Éléments de zoologie médicale et agricole ne sont autres que le développement du cours que nous professons à Alfort depuis plusieurs années, - car nous avons toujours conçu notre enseignement comme devant répondre à ces deux indications essenlielles: applications à la médecine et à l'agriculture.

Ce n'est point à dire pour cela que nous ayons cru devoir nous limiter à des considérations pratiques. Il est impossible de méconnaître que, dans le cours entier de leur carrière, les élèves auxquels nous nous adressons doivent avoir l'esprit dirigé vers les études biologiques: partant, nous sommes tenus de ne pas négliger les principes généraux qui servent de base à ces études. D’autre part, ces élèves ont déjà acquis, dans l'enseignement universitaire, des notions élémentaires sur les choses de la zoologie : nous devons donc rappeler et au besoin compléter ces notions, avant d'aborder les points d'application.

D'après ces données, nous avons tenté de produire un exposé élémentaire, concis et méthodique, de l'organisation, des fonctions et de la classification des animaux, en profitant de ce cadre pour faire une étude spéciale des formes animales qui intéressent la médecine et l'agriculture. Noús avons cherché à donner de ces formes une description abrégée, mais aussi précise que possible, de manière à permettre même aux débutants d'en faire la détermination. Ilnous a paru convenable d'insister plutot sur leur évolution, qui permet dans beaucoup de cas de mettre en lumière leur mode d'action et de préciser leur riole dans le développement des maladies.

Il ne faut pas s'étonner de voir l'étude des parasites tenir ici le premier rang: on sait trop combien s'étend chaque jour le champ de 
la nosologie parasitaire. Nous avons d'ailleur's étudié comparativement les parasites de l'Homme el ceux des animaux domestiques, d'abord parce que les premiers sont, en général, mieux connus et servent en quelque sorte de types pour l'étude des autres; ensuite parce qu'il en est un grand nombre qui sont communs à l'Homme et aux animaux. Une place importante a été réservée également aux espèces comestibles, en vue de l'inspection des denrées alimentaires.

Enfin, nous avons considéré qu'un ouvrage de cette nature devait servir comme d'introduction aux études zootechniques, et c'est cette idée surtout qui nous a guidé dans la distribution et l'exposé des matières de la zoologie générale. C'est dans le même but que nous arons traité des animaux domestiques avec une attention particulière; et, si nous nous sommes quelque peu étendu sur les données de l'anthropologie, c'est qu'elles fournissent encore un guide utile pour l'étude même de nos auxiliaires.

En ce qui concerne le plan de l'ourrage, nous avions à choisir entre deux voies: ou bien faire l'analyse de quelques types pour arriver à la connaissance générale du sgroupe auquel ils appartiennent, ou bien débuter par l'exposé synthétique des caractères du groupe, pour étudier ensuite les différentes formes qui le composent. La méthode analylique, inaugurée arec tant de succès par M. de Lacaze-Duthiers, nous parait excellente en tous points lorsqu'il s'agit d'un enseignement oral; mais elle nous a semblé ne pas convenir à la rédaction d'un livre, qui doit nécessairement exclure les digressions et les répétitions. Nous avons done préféré donner d'abord une idée générale, et en quelque sorte schématique, de chaque groupe, sauf à décrire ensuite, avec des détails particuliers, l'organisation des formes les plus intéressantes.

Pour rendre notre ouvrage aussi complet que possible, il nous a fallu dépouiller un nombre considérable de monographies et d'articles dirers, disséminés dans les journaux, les bulletins et les mémoires des sociétés savantes. Nous avons cherché à en extraire seulement les points essentiels; mais, afin de permettre au lecteur de recourir lui-même aux sources originales sans fatiguer son attention par des renvois multiples, nous avons indiqué, en lête de chaque groupe, les principaux travaux dans lesquels nous avons puisé les éléments de nos descriptions. De plus, nous avons nous-même rérifié, toutes les fois que la chose nous a été possible - et souvent rectifié - les données fournies par les auteurs : ce n'est point, du reste, le lieu d'insister sur les résultats de nos recherches particulières. 
Quelque nombreuses qu'aient été nos investigations bibliographiques, il faut cependant reconnaître que les résultats en seraient demeurés très incomplets si nous n'avions mis à contribution les documents rassemblés dans un grand nombre d'ouvrages classiques, parmi lesquels nous citerons, en première ligne, les excellents traités généraux de Milne-Edwards, Claus, Sicard, Brehm, puis les ourrages d'application de Richard, Grognier, P. Gerrais et Van Beneden, Moquin-Tandon, Cauret, Davaine, Leuckart, Cobbold, Zürn, Perroncito, elc., etc. Ce n'est que justice de constater ici l'usage courant que nous arons fait de ces divers travaux, dont il eût été fastidieux de répéter le titre à propos de chaque groupe.

Ajoutons que notre tâche a été facilitée encore par le concours amical et empressé de plusieurs de nos collègues, et en particulier de I. G. Neumann, de Toulouse, à qui nous sommes heureux de témoigner publiquement notre reconnaissance.

Nous derons aussi les plus vifs remerciements à nos éditeurs, MiI. Asselin et Houzeau, dont nous avons été à même d'apprécier, en toutes circonstances, les bons et affectueux offices. C'est grâce à leur libéralité que nous avons pu joindre au texte un nombre aussi considérable de figures. Quelques-unes ont été empruntées aux traités d'anatomie de Cruveilhier et de Leyh, d'autres au traité de physiologie de M. J. Béclard; d'autres encore à des ourrages classiques de zoologie, notamment à ceux de Richard et de MilneEdwards, ou bien à des monographies diverses. Un plus grand nombre étaient jusqu'alors inédites. Parmi celles-ci, plusieurs ont été gracieusement mises à notre disposition par MM. Laboulbène, Colin, Moniez, Neumann; beaucoup sont tirées des remarquables planches dessinées à Alfort par $H$. Nicolet sous la direction de Delafond; la plupart enfin sont originales et ont été dessinées d'après nature par M. G. Nicolet, en qui nous avons trouvé un collaborateur aussi zélé qu'habile; la graviure en a été confiée à M. A. Martin, qui s'en est acquitté avec son talent habituel.

\section{A. RAILLIET.}

Alfort, le 10 arril 1886.

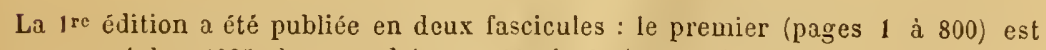
paru en octobre 1885 ; le second (pages 801 á 1053), en juin 1886. 


\title{
PRÉFACE
}

\author{
DE LA DEUXIEME ÉDITION
}

Nous devons toul d'abord nous exeuser du retard apporté à la publieation de cette nouvelle édition. Tous ceux qui ont souei de se tenir au courant des recherches seientifiques en comprendront faeilement la raison: la somme de matériaux à rassembler et à étudier est aujourd'hui tellement considérable, lorsqu'il s'agit d'envisager l'emsemble du règne animal, que le travail devient excessivement pénible pour qui doit compter sur ses propres forces.

L'ouvrage que nous livrons maintenant au publie est conçu à peu près sur le même plan que son aîné, mais il eomporte l'examen d'un nombre beaucoup plus élevé de formes animales, et celles-ei sont étudiées d'une façon plus précise, particulièrement au point de vue de leur utilité ou deleur nocuité. Presque tous les chapitres ont été remaniés et ont reçu des développements nouveaux; nombre de parasites à peine mentionnés dans l'édition précédente ont été décrits avec tous leurs caractères essentiels.

C'est que, dans notre esprit, un Traité de zoologie appliquée ne doit pas avoir pour but unique d'initier les élèves à la connaissance des animaux qui les intéressent direetement; il doit permettre en outre la détermination pratique et facile de ces animaux et de ceux avec lesquels ils peuvent être confondus. Dans eette vue, nous avons employé deux textes différents : texte ordinaire pour les données classiques ou d'importance primordiale, petit texte pour les questions de détail ou d'ordre secondaire.

Le nombre des figures a été augmenté de plus de 180. La plupart de ces figures nouvelles sont originales; d'autres sont dues à M. le professeur Neumann, de Toulouse, et à M. Phisalix, du Muséum, que nous remereions de leur excellent concours.

Comme dans la première édition, nous avons indiqué en tête des 
chapitres les principaux travaux dans lesquels nous avons pu puiser des documents; nous donnons d'ailleurs, ci-après, la liste des ouvrages dont nous avons fait un usage général. Nais, à notre grand regret, nous avons dù renoncer à produire la bibliographie complète des sujets exposés : cela nous eût entrainé presque à doubler le volume, déjà beaucoup trop chargé à notre gré. Nous nous sommes limité presque partout aux indications bibliographiques récentes, n’ayant pas encore trouvé place dans les ourrages classiques.

\section{A. RAILLIET.}

Alfort, le 10 avill 1895.

La :ce édition a été publice aussi en deux fascicules : le premier (pages 1 à 736 est paru en décembre 1593; le second (pages 737 à 1303), en mai 1895. 


\section{BIBLIOGRAPHIE GÉNÉRALE}

Balfour (F.-M.), Tiaité d'embryologie et d'organogénie comparées. Paris, 1885.

Buanchard (R.), Traité de Zoologie médicale. Paris, 1885-1890.

Braux (Max), Die thierischen Parasiten des Menschen. 2tc Aufl. Würzburg, 1895.

Bнепи (A.-E.), Merveilles de la nature. L'Homme et les animaux. Paris.

Broccin (P.), Traité de Zoologie agricole. Paris, 1886.

Cauvet (D.), Nouveaux eléments d'Histoire naturelle médicale, 2e éd. Paris, 1877.

Claus (C.), Traite de Zoologie, 2e éd. Paris, 1853-1884.

Cobrolo (T. Sp.), Parasiles. London, 1879.

Connevix (Ch.), Traité de Zootechnie générale. Paris, 1891.

Darmin (Ch.), De la variation des animaux et des plantes à l'état domestique. Paris, 1879.

Ercolani (G.-B.), Nuovi elementi teorico-pratici di medicina veterinaria : Dei parasiti e dei morbi parasitari. Bologna, 1859.

Gegexbaur (C.), Manuel d'anatomie comparée. Paris, 1874.

Geofrror Saint-Ililane (Is.), Acclimatation et domestication des animaux utiles. 4c éd.. Paris, 1861.

Gervais (P.) et Vax Beneden (P.-J.), Zoologie médicale. Paris, 1859.

Grogsien (L.-F.), Précis d'un cours de Zoologie vétérinaire, Paris et Lyon, 1833.

Hlcxley (Th.-11.), Eléments d'anatomie comparée des animaux vertébrés. Paris, 1875.

- Éléments d'anatomie comparée des animaux invertébrés. Paris, $18 i$ i.

Lï̈nexmeister (F.), Die in und an dem Körper des lebenden. Menschen vorkommenden Parasiten. Leipzig, 1855. 1898.

- und Z̈̈вn (F.-A.), Die Parasiten des Menschen (thierischen Parasilen). Leipzig,

Leuckart(R.), Die P'arasiten des Menschen und die von ihnen herrührenden Krankheiten. 2te Autl. Leipzig, 1879-1894....

Milne-Edwarns (II.), Éléments de Zoologie. 2e éd. Paris, $18 \$ 1$.

Moxiez (R.), Les parasiles de l'Homme (animaux et végétaux). Paris, 1889.

Moquin-Taxdox, Éléments de Zoologic médicale. Paris, 1862.

Neunaxx (L.-G.), Traité des maladies parasilaires (non microbiennes) des animaux. domestiques. $2^{\mathrm{c}}$ éd. Paris, 1892.

Perrier (Ed.), Traité de Zoologie. Paris....

Perroncito (E.), I parassiti dell' uomo e degli animali utili. Mlilano, 188 ?.

Plateau (F.), Zoologie élémentaire. Mons, 1880.

Ricuard (A.), Éléments d'Histoire naturelle médicale. $4^{\mathrm{c}}$ éd. Paris, 18 9.9.

Sarsox (A.), Traité de Zootechnie, 30 éd. Paris, 1882.

Sicard (H.), Elements de Zoologie. Paris, 1883.

Vogt (C.) et Yuxg (E.), Traite danatomie comparee pratique. Paris, 1882-1894.

Zürv (F.-A.), Die Schmarotzer auf und in dem Körper unserer Haussïugetiere, u. s. w. $2^{\text {tc }}$ Aufl. Weimar, 18s?-1889. 


\section{TABLE MLÉTHODIQUE DES MIATIËRES}

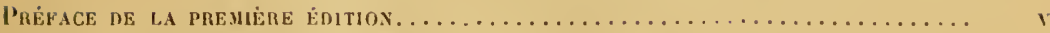

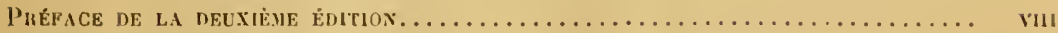

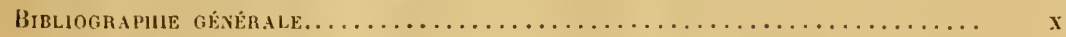

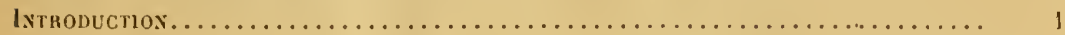

\section{PREMIERE PARTIE}

\section{ZOOLOGIE GÉNÉRALE}

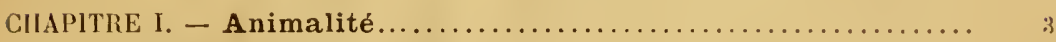

$\$ 1$. Corps inorganiques et corps organisés................. 4

§ 2. - Végétaux et auiutux..........................

CIIAP. If. - Organisation et développement des animaux...... 10

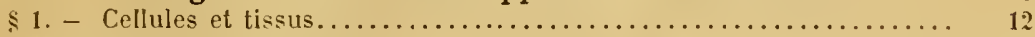

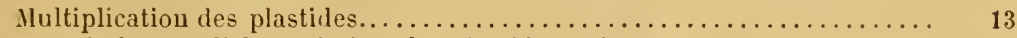

Association et différenciation des plastiles : tissus ............. 15

\$ 2. - Spécialisation et rapports des fonctions et des organes.......... 22

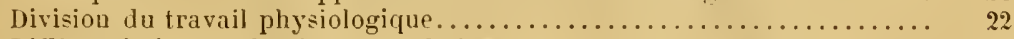

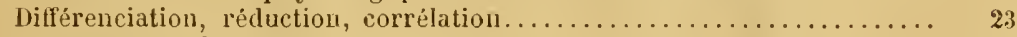

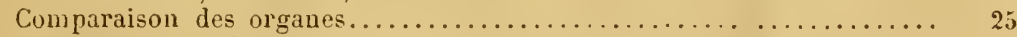

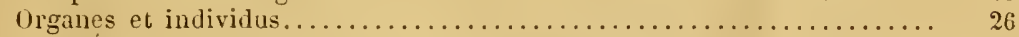

$\$ 3$. - Etude anatonique et physiologique des organes........... 27

I. - Organes et fouctions de relation..................... 27

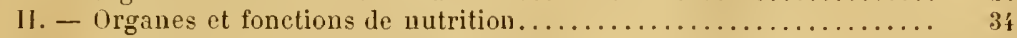

111. - Organes et fonctions de reproduction.................. 41

$\$$ 4. - Développement des animaux...................... 45

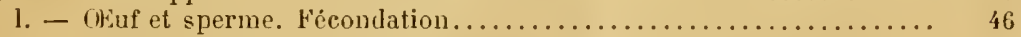

11. - Développement de l'embryon. Embryogénie............... 50

111. - Développement post-embryounair .................. 53

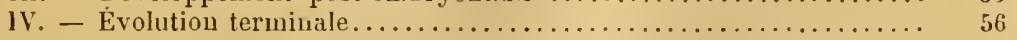

CH $\Lambda$ P. 111. - Rapports de l'organisme avec son milieu......... 58

$\$ 1$. - Rapports des animaux avec le moude inorganique et les êtres vi-

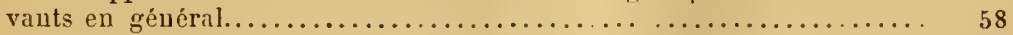

Adaptation, variabilité des formes animales................ 59

Concurrence vitale................................. 61

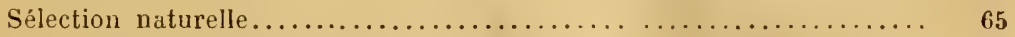

$\$$ 2. - Rapports des animaux avec l'Homme................... 6 i

I. - Animaux vuisibles............................ 67

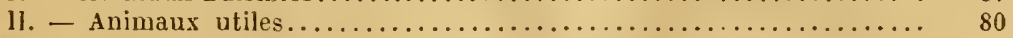

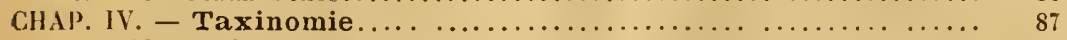

$\$$ 1. - Valeur des groupes taxinomiques . ................... 88

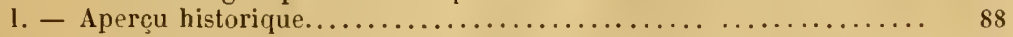

Il. - Groupes principaux des systémes zoologiques............... 90

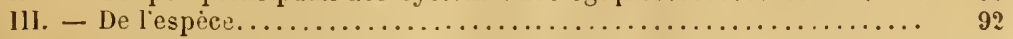

\$ . - Nomenclature zoologique........................... 108

\$. 3. - Division du Règne animal en embranchements............... 103 


\section{SECONDE PARTIE}

\section{ZOOLOGIE SPÉCIALE}

PRE.HIER EMBRANCHEMENT. - Protozoaires................. 112

Classe 1. - Rhizoporles................................

Sous-classe I. - Moneres......................... 11 i

Sous-classe JI. - Amcbiens........................ 116

Sous-classe III. - Foraminifères....................... 119

Sous-classe IV. - Héliozoaires........................ 120

Sous-classe V. - Radiolaires......................... 120

Sous-classe aunexe. - Hémamuebiens.................. 122

Classe II. - Sporozocires........................... 127

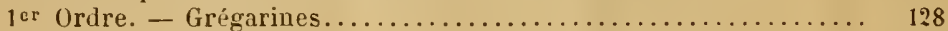

ze Ordre. - Coccidies........................... 130

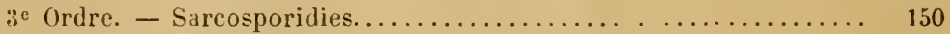

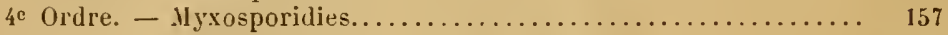

5 ordre. - Microsporidies ........................ 160

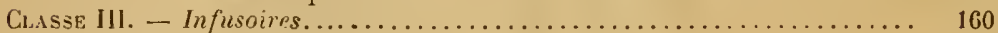

Sous-classe 1. - Flagellés........................ 162

1er Ordre. - Eutlagellés.......................... 163

Sous-classe II. - Ciliés......................... 171

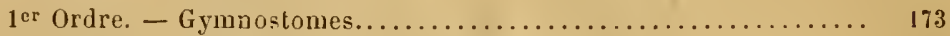

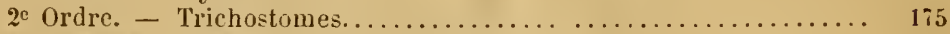

DEUXIËIE EMBRANCHEIENT. - Spongiaires................ 184

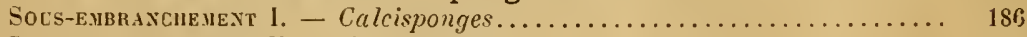

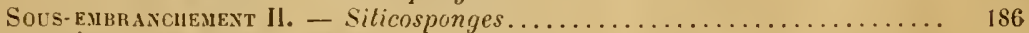

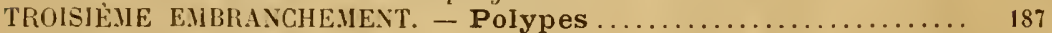

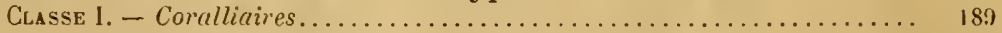

1er Ordre. - Alcyonaires........................ 191

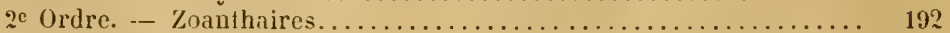

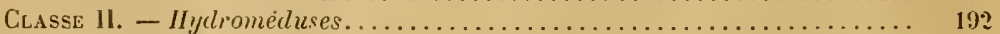

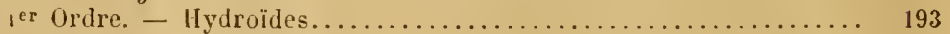

$2^{\text {e }}$ Ordre. - Siphonophores........................ 195

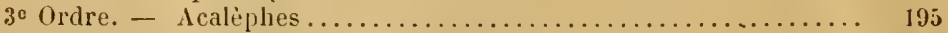

CLasse 111. - Cténophores.......................... 197

QUATRIĖ.IE EMBRANCHE.IENT. - Echinodermes............. 198

Classe I. - Crinö̈des........................... 202

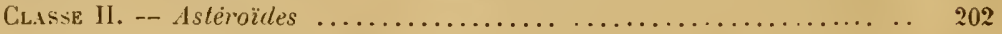

ler Ordre. - Stellérides............................. 203

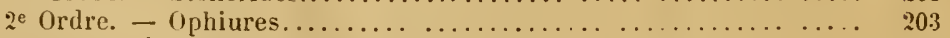

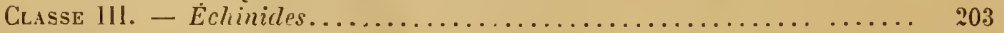

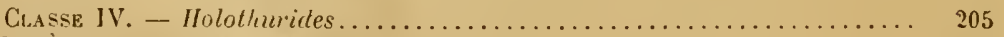

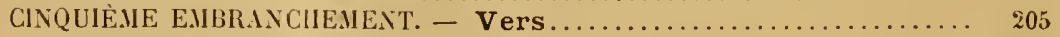

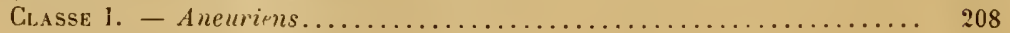

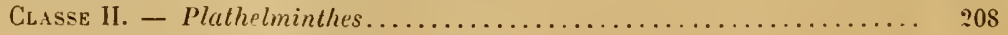

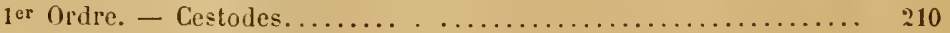

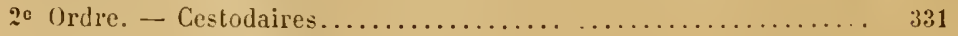

$3^{\mathrm{c}}$ Ordre. - Trématodes............................. 332

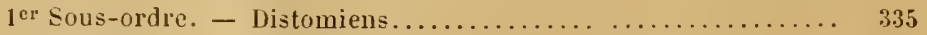

3 e Sous-ordre. - Polystomiens.................... 383

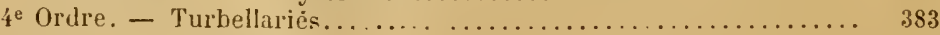

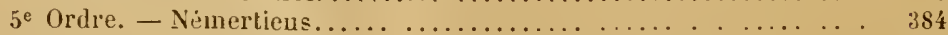

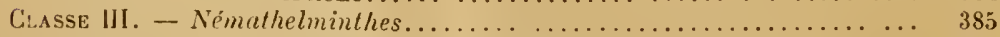

1er Ordre. - Nématodes............................ 385

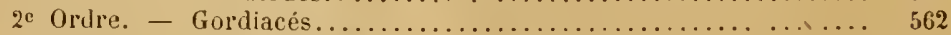

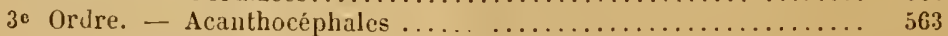

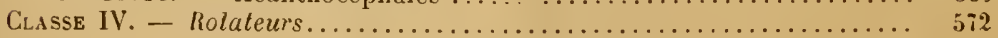


Classe V. - Bryozocites........................... 573

Classe VI. - Brachiopodes.............................. 5 í

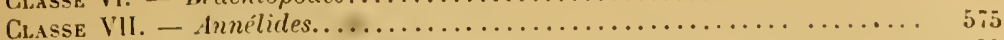

Sous-classe IIl. - Ilirudinces...................... 577

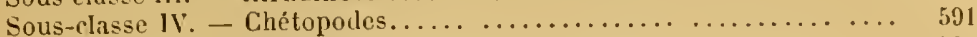

1er Ordre. - Oligochètes.......................... 591

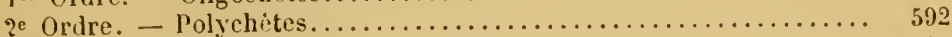

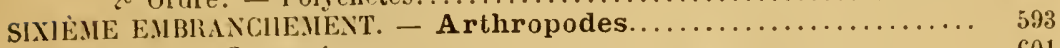

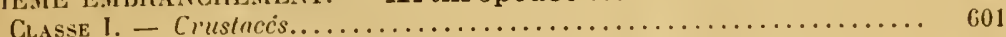

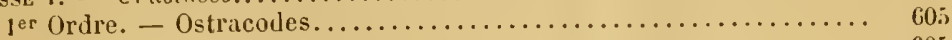

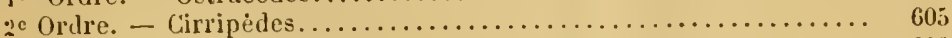

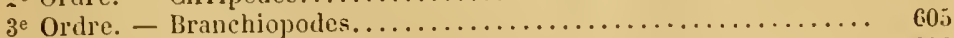

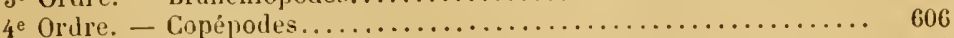

$5^{\text {e Ordre. }}$ - Implipodes........................... 606

Ge Ordre. - Isopodes............................ 606

fe Ordre. - Stomatopodes......................... G06

Se Ordre. - Décapodes........................... 60 i

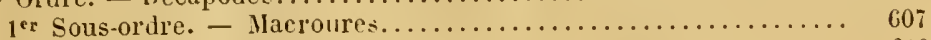

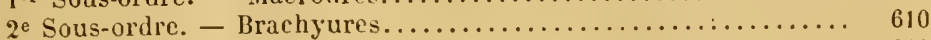

Classe 1I. - Mérostomacés........................... 610

1 er Ordre. - Xiphosures........................... 610

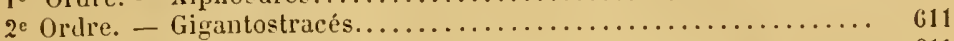

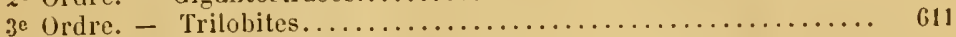

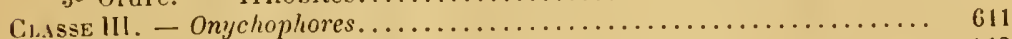

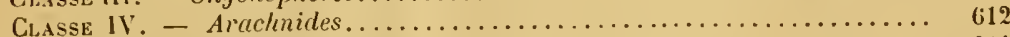

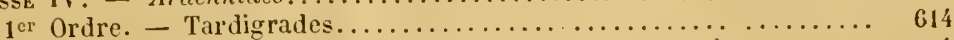

2 Ordre. - Pantupodes.......................... 614

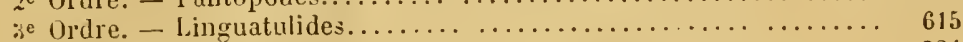

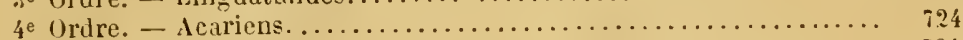

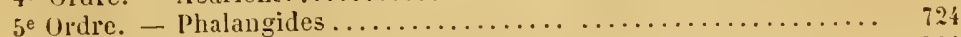

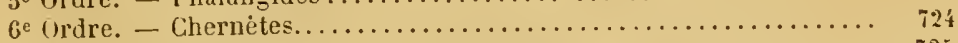

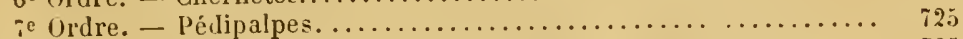

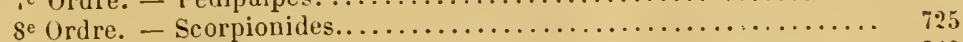

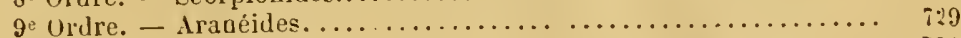

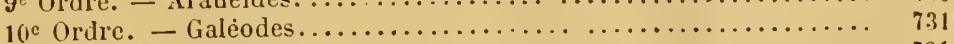

Classe V. - Myriapodes........................... 731

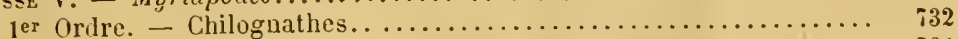

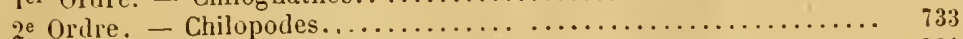

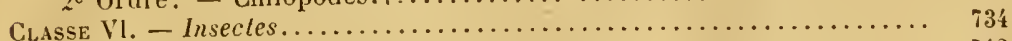

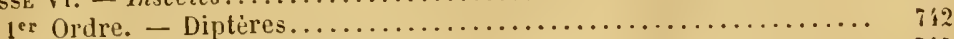

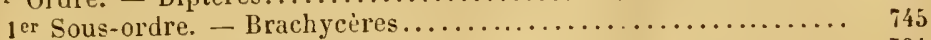

2e Sous-ordre. - Némocères....................... 794

3c Sous-ordre. - Aphaniptères..................... 799

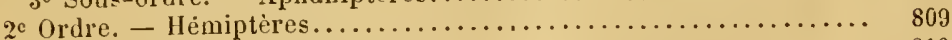

$1^{\mathrm{er}}$ Sous-ordre. - Homoptères..................... 810

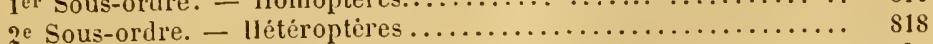

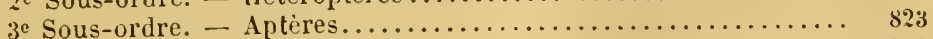

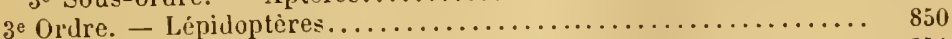

fer Sous-ordre. - Hétérocères..................... 851

¿e Sous-ordre. - Rhopalocères..................... 860

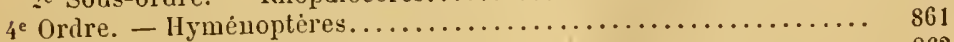

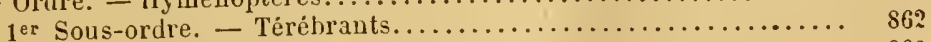

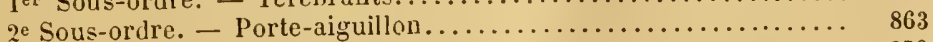

5 e Ordre. - Névroptères......................... 878

6e Ordre. - Psendo-Névroptères...................... 878

1er Sous-ordre. - Thysanoptères...................... 879

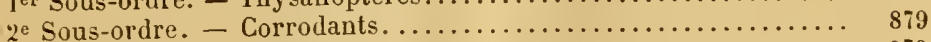

3e Sous-ordre. - Amphibiotiques..................... 8 8 9

4e Sous-ordre. - Odonates........................ 879

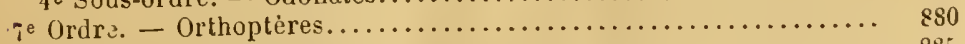

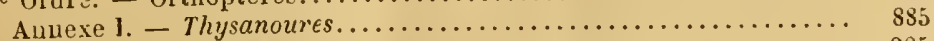

Aunexe II. - Strepsiptères........................ 885 
se Ordre. - Coléoptères........................... 886

SEPTIẺ.IE E.IBRANCHEMENT. - Mollusques.................. 901

CLASSE 1. - Lamellibranches.............................. 904

Sous-classe I. - Asiphonidés......................... 907

Sous-classe II. - Siphonidés.......................... 914

CL.ssse 11. - Scuphopodes............................ 915

Classe III. - Ptéropodes................................. 915

CLAsse IV. - Gastéroporles............................... 915

1 or Ordre. - Hétéropodes........................... 919

$2^{\text {e }}$ Ordre. - Opisthobranches........................... 919

$3^{\text {e }}$ Ordre. - Prosobranches........................... 920

4e Ordre. - Pulmonés.............................. 921

Classe V. - Céphalopodes............................... 923

1 er Ordre. - Tétrabranches.......................... 926

2e Ordre. - Dibranches............................. 927

HUITIËHE EMBRANCHE.IENT. - Ghordés .................. 9?9

Sous-embran cuenent 1. - Entéropneusles..................... 929

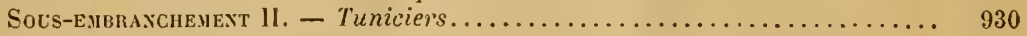

Chasse I. - Appendiculariés................................ 932

Classe II. - Ascidiacés ................................ 932

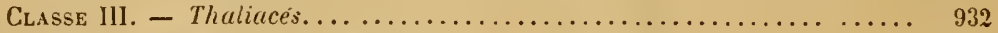

Sous-embranchenext III. - Acraniens ...................... 933

Sous-enbranchenent IV. - Verlébrés......................... 93'

Classe I. - Poissons.................................. 949

1er Ordre. - Cyclostomes............................ 959

$2^{e}$ Ordre. - Sélaciens............................ 960

1er Sous-ordre. - Chimériens....................... 960

$2 \circ$ Sous-ordre. - Plagiostomes...................... 960

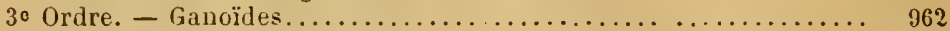

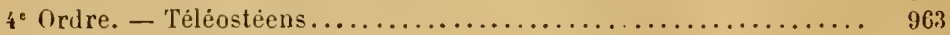

$1^{\text {er }}$ Sous-ordre. - Lophobranches..................... 963

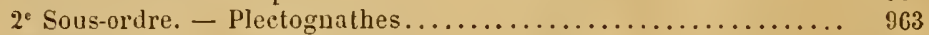

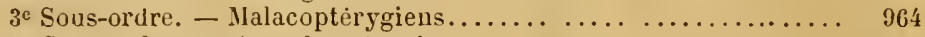

40 Sous-ordre. - Acanthoptérygiens.................. 971

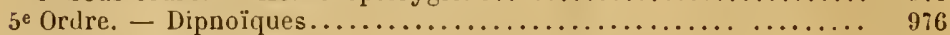

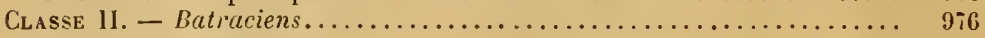

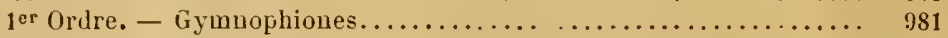

2e Ordre. - Urodèles............................. 98.

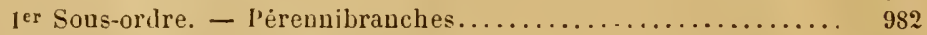

2e Sous-ordre. - Dérotrimes....................... 982

$3^{e}$ Sous-ordre. - Salamandrides....................... 982

3e Ordre. - Anoures.............................. 985

$1^{\mathrm{er}}$ Sous-ordre. - Aglosses.............................. 985

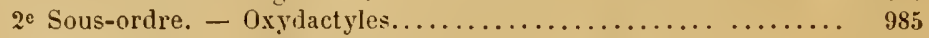

3e Sous-ordre. - Discodactyles..................... 987

CLasse 11I. - Reptiles................................ 988

$1^{\text {er }}$ Ordre. - Ophidiens.................................. 993

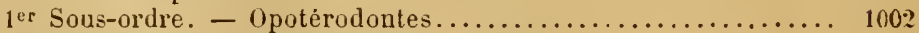

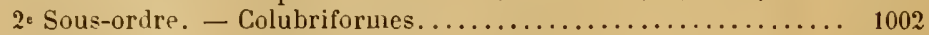

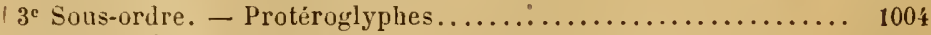

$4^{\text {e }}$ Sous-ordre. - Solénoglyphes . .................. 100t

2 Ordre. - Sauriens.................................. 1012

1er Sous-ordre. - Amphisbéuiens ........................ 1013

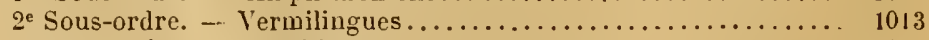

$3^{\mathrm{e}}$ Sous-ordre. - Crassilingues. ...................... 1013

$4^{e}$ Sous-ordre. - Brévilingues..................... 1013

$5^{c}$ Sous-ordre. - Fissilingues........................... 1013

$3^{\text {e }}$ Ordre. - Crocodiliens............................. 1014

4e Ordre. - Chẻloniens.............................. 1015

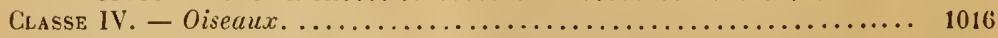

$1^{\text {er }}$ Ordre. - Coureurs................................ 1030

2e Ordre. - Palmipèdes.............................. 1031 
1er Sous-ordre. - Brachypteres................... 1032

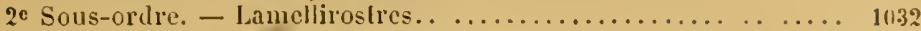

3e Sous-ordrc. - Totipalmes....................... 1041

$4^{c}$ Sous-ordre. - Longipennes...................... 10.1

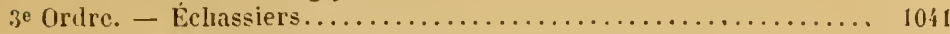

\&e Ordre. - Gallinacés.......................... 1043

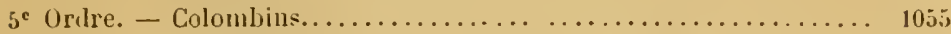

6 Ordre. - Grimpeurs........................... 1059

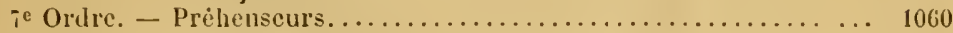

se Ordre. - Passereaux......................... $106 \mathrm{f}$

1er Sous-ordre. - Lévirostres..................... 1061

2 Sous-ordre. - Témuirostres..................... 106 i

3e Sous-ordre. - Conirostres...................... 1062

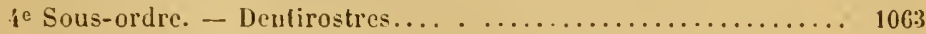

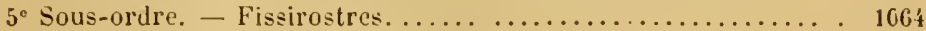

ge Ordre. - Rapisces.......................... 1065

ler Sous-ordre. - Nocturnes....................... 1065

2e Sous-ordre. - Diurnes........................ 1066

Classe V. - Mammifères........................... 1066

fer Ordre. - Monotrèmes........................... 1092

2e Ordre. - Marsupiaux. . ........................... 1093

1er Sous-ordre. - Polyprotodoules.................. 1095

2e Sous-ordre. - Diprotodontes...................... 1095

3e Ordre. - Édentés............................. 1095

4e Ordre. - Cétacés............................ 1096

$1^{\text {er }}$ Sous-ordre. - Denticiles..................... 1097

2.e Sous-ordre. - Mysticètes...................... 1100

5e Ordre. - Sirénes........................... 1100

6e Ordre. - Bisulques........................... 1101

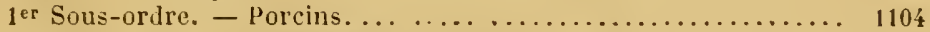

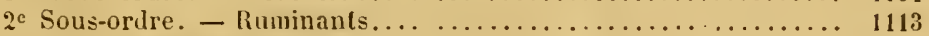

¡c Ordre. - Jumentés.......................... 1147

8e Ordre. - Hyraciens.......................... 1175

$9^{e}$ Ordre. - Proboscidieus.......................... 1175

10 e Ordle. - Rougeurs........................... 1176

jer Sous-ordre. - Protrogomorphes................. 1178

$2^{\mathrm{e}}$ Sous-ordre. - Sciuromorphes.................... 11is

$3^{\text {e }}$ Sous-ordre. - Myomorphes..................... 1181

4c Sous-ordre. - IIystricomorphes..................... 1184

je Sous-ordre. - Lagomorphes..................... 1188

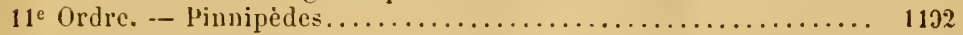

12 C Ordre. - Caruivores.......................... 1193

$13^{e}$ Ordre. - Inscctivores............................. 1213

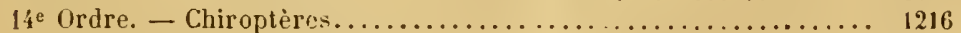

er Sous-ordre. - Frugivores.................... 1217

$2^{e}$ Sous-ordre. - Insectivores..................... 1217

$15^{\star}$ Ordre. - Léunurieus.......................... 1218

$16^{e}$ Ordre. - Primates........................... 1219

[er Sous-ordre. - Simiens........................ 1219

: Sous-ordre. - Hominiens....................... 1223

Table alphabétique des matières......................... 1246

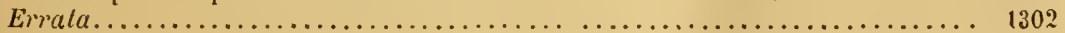

FIN DE LA TABLE MÉTHODIQQUE DES MATIÉRES. 



\section{TRAITÉ}

$\mathrm{DE}$

\section{ZOOLOGIE MÉDICALE}

\section{ET AGRICOLE}

\section{INTRODUCTION}

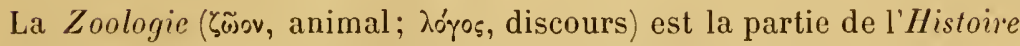
nalurelle qui a pour objet l'étude des animaux.

Son domaine est donc des plus vastes, et il n'est pas besoin d'insister sur son importance. En dehors de l'utilité qu'elle tire de ses applications, on ne peut méconnaître, en effet, qu'elle concourt, aussi bien que les autres branches des sciences naturelles, à élever l'esprit, à donner de la rectitude au jugement, et qu'elle fournit à la philosophie des éléments de la plus haute valeur.

Du moins ces résultats sont-ils attribuables à la Zoologie vraiment scientifique, à celle qu'ont établie les recherches des naturalistes modernes, à dater des Lamarck et des Cuvier.

Les premiers observateurs s'étaient à peu près bornés à considérer les caractères extérieurs des animaux et à les grouper plus ou moins artificiellement d'après ces caractères. Cuvier montra la nécessité de faire reposer la Zoologie sur des bases plus sérieuses, et créa l'anatomie comparée. Puis, von Baer vint ajouter aux données fournies par l'organisation des éléments non moins importants tirés de l'embryologie.

C'est en s'appuyant sur ces bases que les zoologistes ont pu, non seulement établir un groupement rationnel de l'immense quantité d'êtres qui s'offraient à leur étude, mais chercher même à déterminer l'origine de ces êtres.

L'étude superficielle des animaux est donc devenue tout à fait insuffisante. Le temps est déjà loin où pouvait être réputé naturaliste quiconque savait discourir élégamment sur les beautés de la nature, 
ou ranger avec art des insectes de toutes couleurs dans des boîtes vitrées et retenir par cœur les noms plus ou moins barbares de quelques milliers d'entre eux.

Il est certain qu'on ne peut se faire une idée exacte de l'organisation, de l'évolution et des rapports des animaux qu'en étudiant la nature avec patience, le scalpel à la main. Partant, la Zoologie ne s'apprend pas dans les livres seuls. Rien n'est plus vrai, dit Huxley, que ces paroles de Harvey : "Ceux qui lisent sans acquérir, à l'aide de leurs propres sens, une vue distincle des choses, n'arrivent pas au savoir réel et ne conçoivent que des fantômes. "

En résumé, la Zoologie, sans négliger l'étude des formes extérieures, se base avant tout sur l'anatomie et l'embryogénie. De plus, lorsqu'il s'agit de déterminer l'évolution d'un animal donné, elle doit, en général, recourir à l'expérimentation : c'est par cette voie seulement que le zoologiste arrive à reconnaître, par exemple, les migrations d'un helminthe.

Au point de vue didactique, la Zoologie se divise en deux parties:

$1^{\circ}$ La Zoologie générale, qui étudie les lois de l'organisation, des fonctions, de la genèse, de l'évolution et de la classification des animaux ;

$2^{\circ}$ La $Z$ oologie spéciale, qui s'occupe, au contraire, des animaux en particulier, de leurs caractères, de leurs mœurs et de leurs rapports.

Nous aurons à ahorder successivement ces deux parties, sans oublier toutefois qu'il ne doit pas s'agir ici de Zoologie pure, mais bien de Zoologie appliquée, c'est-à-dire d'une étude spéciale des animaux envisagés au point de vue de leur rôle utile ou nuisible. Les applications de cette science sont d'ailleurs assez variées, et l'on a pu, à cet égard, étudier isolément la Zoologie médicale, la Zoologie agricole, la $Z$ oologie industrielle, etc., que leur seule qualification suffit à définir.

Pour répondre au titre de cet ouvrage, nous nous oceuperons donc, de préférence, des animaux qui fournissent des substances employées en médecine, de ceux qui nuisent directement à l'homme ou aux animaux domestiques, et de ceux qui dévastent ou protègent les récoltes. 


\title{
PREMIÈRE PARTIE
}

\author{
ZOOLOGIE GÉNÉRALE
}

\section{CHAPITRE PREMIER}

\section{ANIMALITÉ}

Lorsqu'on soumet à un examen rigoureux la généralité des corps répandus dans l'univers, on est amené à reconnaître que tous sont réductibles à un certain nombre d'éléments ou corps simples, qui constituent la matière primitive, et qui eux-mêmes ne sont peut-être que des états divers d'agrégation moléculaire d'une substance unique.

Toutefois, dans l'état où ils se présentent à nous, ces corps naturels diffèrent entre eux par des propriétés d’importance variable, en raison desquelles on peut les diviser en groupes plus ou moins étendus.

Ainsi, tout le monde sait que Linné les répartissait entre trois règnes distincts : le règne minéral, le règne végétal et le règne animal. De fait, en ce qui concerne les représentants les plus élevés et partant les plus connus de chacun de ces groupes, la distinction est facile et du domaine vulgaire.

Le grand naturaliste croyait l'avoir sûrement établie dans l'aphorisme longtemps resté classique: Lapides crescunt; vegetabilia crescunt et vivunt; animalia crescunt, vivunt et sentiunt. Mais ces données sont devenues aujourd'hui tout à fait insuffisantes, et les modifications mêmes que les successeurs de Linné ont introduites dans les définitions des trois règnes n'ont guère une plus grande valeur absolue.

On sait d'ailleurs qu'il existe entre les minéraux ou corps bruts, d'une part, et les végétaux et animaux, ou corps organisés, d'autre part, une différence beaucoup plus tranchée qu'entre le règne végétal et le règne animal. C'est pourquoi Pallas a cru devoir réunir ces deux derniers groupes sous le nom d'empire organique, par opposition à l'empire inorganique, constitué par les minéraux.

Pour aborder arec fruit l'étude de la zoologie, on conçoit donc qu'il 
importe de déterminer d'abord quels sont les caractères de l'animalité. C'est dans cette vue que nous allons consacrer ce chapitre à l'étude des analogies et des différences que présentent entre eux les empires organique et inorganique, puis les deux règnes organisés. Toutefois, en raison du cadre même de cet ouvrage, nous nous bornerons à exposer les principes généraux de la question.

\section{$\S 1^{\mathrm{er}}$. - CORPS INORGANiQues ET CORPS ORGANISÉS.}

En comparant les principaux caractères de ces deux ordres de corps, on ne tarde pas à se convaincre que les différences signalées entre eux ont été singulièrement exagérées, bien que quelques-unes aient une importance réelle et constituent des barrières qui n'ont pu encore être franchies.

Cette comparaison doit porter sur les diverses manières d'être des corps, notamment sur leur origine, leur constitution, leur mode d'existence, leur résistance à l'action des milieux, enfin leur mode de destruction.

A. Genėse. - Un minéral trouve son origine dans l'action des agents physiques et la mise en jeu des affinités chimiques. Il n'en est pas de mème des ètres vivants, animaux ou plantes, qui paraissent au contraire, dans tous les cas, dériver de parents, c'est-à-dire d'ètres préexistants, comme eux doués de la vie. En principe, rien ne s'oppose, il est vrai, à ce qu'on admette la génération spontanée de ces ètres; mais nous verrons plus loin que, jusqu'à ce jour, la science n'a pu démontrer la réalité de celte conception.

B. Morphologie. - Envisagée d'une manière superficielle, la morphologie des corps bruts et des corps vivants parait comporter, dans la plupart des cas, de profondes différences. Aussi est-il classique de faire remarquer combien la simplicité géomètrique des cristaux s'éloigne de la forme complexe et variable des corps organisés. Mais il ne faut pas perdre de vue que le cristal est précisément le corps brut qui s'écarte le plus des règnes organiques, et que c'est au contraire dans les substances minérales non cristallines, ainsi que dans les composés de la chimie organique, qu'il faut chercher les points de rapprochement. D'ailleurs, de nombreux ètres vivants inférieurs affectent des formes relativement régulières.

En ce qui a trait au volume, on sait que celui des corps bruts est susceptible de s'accroitre d'une manière indéfinie, tandis que les êtres vivants sont assujettis à se tenir, à cet égard, dans des limites plus ou moins étroites.

On a pu invoquer enfin, comme caractère morphologique propre à établir la distinction entre les deux empires de la nature, la structure intime des corps vivants, sur laquelle nous aurons à nous étendre plus loin.

C. Composition chimique. - Non seulement on peut rencontrer, dans la substance des animaux et des plantes, la plupart des éléments qui composent les corps inorganiques; on $y$ trouve aussi de nombreux composés minéraux, tels que l'eau, la silice, le carbonate de chaux, etc. Par contre, il existe d'autres composés, remarquables par leur instabilité, produits sous l'influence de la vie et partant propres aux corps organisés: ce sont les 
matieres organiques, qui ont pour base le carbone, auquel sont associés de l'hydrogène et de l'oxygène, arec ou sans azote, et parfois aussi du soufre, du phosphore, du fer, etc. On leur donne le nom de substances quaternaires ou temaires, suivant qu'elles contiennent ou non de l'azote. La chimie molerne est parvenue à former artificiellement un certain nombre de ces corps; mais ce qu'elle est impuissante à produire, c'est la matiere vivante, lors mème qu'elle se présente dans son état le plus élémentaire, celui de protoplasma. Nous verrons, du reste, qu'il est impossible de définir chimiquement cette substance, attendu qu'elle varie selon le corps ou la partie du corps à laquelle on l'emprunte, et suivant l'instant auquel on l'examine : c'est que la vie, en effet, consiste en un échange continuel s'effectuant entre le corps organisé et le milieu ambiant; et ce mouvement incessant se montre en opposition aver le repos des corps inorganiques.

D. Evolution. - Les corps bruts, une fois constitués, demeurent dans un état de véritable inertie; ils ne possèdent aucune activité propre et ne sont subordonnés qu'à la seule influence des agents physiques et chimiques. Aussi leur accroissement s'effectue-t-il par simple apport de matériaux à la périphérie, ou, comme on le dit, par apposition: les pertes qu'ils peuvent subir se produisent elles-mèmes d'une facon tout accidentelle et d'après le fait de causes extérieures. Tout au contraire, les corps organisés sont dans un état d'incessante activité; leur substance est le siège d'échanges moléculaires constants, de façon qu'ils sont toujours en voie de rénovation; ils s'assimilent des molécules puisées à l'extérieur (absorption) et en rejettent d'autres qu'ils rendent au milieu ambiant (excrétion); en outre, ces mouvements moléculaires s'effectuent dans toute la masse du corps, c'est-à-dire par intussusception.

C'est à l'ensemble de ces phénomènes qu'on a donné le nom de nutrition. Pour qu'ils puissent se produire, il est nécessaire que les substances chimiques qui constituent les corps soient dissoutes : corpora non agunt nisi soluta; et c'est là ce qui explique la nécessité de la présence de l'eau dans les ètres vivants (Rotifères, Anguillules, etc.), ainsi que la moindre fixité de leur forme. De mème, une certaine quantité de clıaleur est indispensable, comme on le constate, par exemple, pour l'évolution des œufs.

Les ètres vivants possèdent encore des caractères dynamiques, que nous ne ferons qu'indiquer et qui se rattachent intimement à leur évolution : à un degré variable, tous dégagent des forces vives (chaleur, mouvement mécanique, etc.), et, d'une manière générale, transforment les forces. Quant aux composés inorganiques, ils ne produisent guère de chaleur qu'au moment de leur formation ou de leur décomposition.

Suivant le milieu dans lequel on les observe, les ètres vivants présentent d'ailleurs une manière d'ètre particulière. Non seulement ce milieu leur fournit les matériaux nutritifs proprement dits, mais il leur donne le mouvement nécessaire aux fonctions vitales, sous forme de lumière, de chaleur, etc. L'action des influences extérieures sur les êtres vivants est du reste suivie d'une réaction de ceux-ci, qui, ainsi que nous le démontrerons, s'adaptent au milieu en raison de leur variabilité. Nous aurons à nous étendre plus tard sur ces influences mésologiques. ?

En dernier lieu, il faut remarquer que les corps inorganiques ont une durée indélinie : ils ne cessent d'exister que lorsqu'une force étrangère vient 
les détruire. Les corps organisés, au contraire, ont une existence limitée, et l'on a dit avec raison que la mort est le corollaire obligé de la vie : tout être vivant subit une évolution déterminée dont l'aboutissant est fatal. C'est que cette fin est elle-même nécessitée par le mode de genèse de ces corps, ainsi qu'on le verra lorsque nous exposerons le théorème de Malthus.

En résumé, on voit que, s’il existe entre les corps bruts et les corps vivants des différences assez nombreuses quand on compare les mieux caractérisés de ces corps, ces différences tendent à s'atténuer de plus en plus lorsqu'on s'adresse aux types inférieurs. Est-ce à dire cependant qu'elles arrivent, dans certains cas, à disparaître tout à fait ? Dans l'état actuel de la science, rien n'autorise à répondre affirmatirement à cette question. Et quelle que soit, du reste, l'idée qu'on se fasse des propriétés particulières aux êtres vivants, ou propriétés biologiques, on ne peut se refuser à en admettre l'existence. Resterait à examiner en quoi elles consistent ou, en d'autres termes, quel est le principe de la vie. Les uns admettent une force vitale particulière, indépendante de l'action des forces physico-chimiques; les autres, au contraire, rapportent la vie à la seule influence de ces forces agissant sur une matière complexe, le protoplasma, et développant des effets spéciaux, en raison du mode de groupement de ses molécules.

En réalité, les recherches modernes tendent à nous représenter les actes vilaux, à l'égal des actes physico-chimiques, comme des formes du mouvement, dont la complexité rend toutefois l’interprétation fort difficile.

A ce titre, on peut considérer la vie comme une force; mais il y a loin de cette force vitale, soumise aux lois de la mécanique, à la force vitale indépendante, au caractère capricieux et irrégulier, qu'araient dès longtemps admise les partisans de l'école dite vitaliste. C'est un des plus beaux titres de gloire de Claude Bernard d'avoir démontré que les phénomènes organiques ont leur déterminisme, aussi bien que ceux de la physique et de la chimie, c'est-à-dire qu'ils sont sous la dépendance directe d'un certain nombre de causes, lesquelles sont la condition nécessaire et suffisante de leur production. "Toute manifestation de l'être virant, dit l'éminent auteur, est un phénomène physiologique et se trouve liée à des conditions physico-chimiques déterminées, qui le permettent quand elles sont réalisées, qui l'empêchent quand elles font défaut. " Tout le monde sait, en effet, que les plus simples de ces manifestations sont suspendues par une privation d'air, de chaleur ou d'humidité. Conséquemment, la force vitale ne peut être conçue que comme une puissance directrice, non déterminante (Arloing). C'est ainsi, pensons-nous, qu'il faut interpréter cette conclusion de Claude Bernard, que «les phénomènes organiques ou vitaux sont réglés dans leur apparition par des conditions matérielles, tangibles, physiques, chimiques et mécaniques, réglés dans l'ordre et la forme par des lois préétablies". 
Rappelons, en terminant, que les actes les plus frappants de la vie consistent dans la nutrition et la reproduction, de telle manière qu'on peut, avec H. Milne-Edwards, définir les êtres vivants "des êtres qui se nourrissent et qui- se reproduisent ".

\section{§ 2. - VÉgÉTAUX ET ANIMAUX.}

La plante et l'animal représentent les deux aspects distincts sous lesquels se manifeste la vie; mais il est, facile de prévoir que les relations établies entre ces deux ordres d'êtres sont beaucoup plus étroites que celles qu'entretiennent les corps bruts et les corps organisés. Tellement çu'on ne peut tracer entre les formes inférieures des règnes animal et végétal qu'une délimitation arbitraire. On ne saurait nier toutefois que, dans les degrés supérieurs de l'organisation, il existe des différences notables entre les animaux et les plantes : personne, en effet, ne confond un arbre de nos forêts avec un des animaux qui nous entourent.

On a vu quels sont les caractères distinctifs invoqués dans l'aphorisme de Linné; Cuvier et de Blainville, quoique plus explicites, n'en ont pas, en somme, indiqué d'une raleur plus absolue. Nous allons, d'ailleurs, examiner successivement les principaux d'entre ceux qu'ils ont signalés.

A. Organisation. - La plante est, sans aucun doute, constituée sur un plan beaucoup plus simple que l'animal; elle ne possède que des organes peu nombreux, et la division du travail se trouve, par le fait même, assez bornée; de plus, c'est sa surface externe qui se développe pour exécuter les fonctions. L'animal, au contraire, montre une organisation relativement complexe, et chez lui, la multiplicité des instruments de la vie s'accompagne du développement interne des surfaces. On notera cependant que la présence d'une cavité digestive et d'un appareil circulatoire n'est pas constante dans le règne animal : à mesure qu'on descend vers les formes inférieures, on voit l'organisation se simplifier; les organes se suppriment peu à peu, et la confusion semble apparaître entre les deux règnes.

On a signalé aussi une différence dans la structure: il est certain, en effet, que les cellules végétales conservent plus nettement que celles du corps animal leur forme primitive et leur individualité. Mais le fait trouve son explication dans cette particularité que, chez les premières, la membrane albuminoïde qui limite extérieurement le protoplasme s'est revètue d'une couche rigide de cellulose, tandis que, chez les cellules animales, cette membrane conserve davantage ses caractères primitifs, reste souple et se prête mieux, par suite, à la déformation et aux mouvements. Pourtant, dans son état primitif, la cellule végétale ne possède pas de revètement cellulosique; d'un autre côté, on connaît des cellules animales qui s'entourent de capsules résistantes (cartilage) et conservent par suite une plus grande indépendance. Enfìn, le rapprochement s'établit encore par les ètres unicellulaires qui occupent les confins des deux règnes.

B. Composition chimique. - S'il est vrai que les plantes sont principale- 
ment formées de substances ternaires, et qu'elles ont pour élément essentiel le carbone, tandis que les animaux sont formés surtout de substances azotées, il faut reconnaitre cependant que ces deux ordres de matières se rencontrent dans les deux règnes. Il existe de l'albumine, de la fibrine, de la caséine, dans les plantes comme dans les animaux. Le glycogène, si répandu dans le corps animal, a été relrouvé dans des Champignons et dans d'autres plantes. La chlorophylle, qui manque dans certains végétaux, tels que les Champignons et quelques plantes parasites, se retrouve chez divers animaux, par exemple, chez l'Hydre verte, l'Euglena viridis, le Stentor polymorphus, etc. En somme, la composition chimique ne permet pas de distinguer, d'une facon absolue, les plantes des animaux.

C. Nutrition. - L'irritabilité du protoplasma, et en particulier l'irritabilité nutritive, comme l'a montré Claude Bernard, est un fonds commun aux animaux et aux végétaux, et entre en jeu sous des conditions bien définies : eau, chaleur, oxygène, substances dissoutes dans le milieu ambiant; conditions qui, en tous cas, ne sont pas plus différentes de l'animal à la plante que d'un animal à un autre, voire d'un tissu à l'autre du même individu. Et cette irritabilité peut ètre suspendue ou supprimée dans les corps des deux règnes sous l'influence des mèmes agents.

Quant aux phénomènes essentiels de la nutrition, on doit aussi les considérer comme identiques chez les animaux et chez les végétaux. D'abord, toutes les plantes ou parties de plantes dépourvues de chlorophylle exigent des aliments de nature organique, aussi bien que les animaux. De plus, il serait facile de démontrer que les trois actes intimes de la diges. tion s'accomplissent également dans les deux règnes: transformation des fécules en sucre, émulsion et dédoublement des corps gras, transformation des matières albuminoïdes en substances solubles ou peptones. Enfin, les observations faites sur les végétaux carnivores montrent que les préambules les plus extérieurs de la nutrition, tel que la capture de la proie, la trituration des aliments, etc., ne sont pas l'apanage exclusif des animaux.

De mème, la respiration est identique chez tous les êtres organisés. Tout élément qui fonctionne a besoin d'oxygène, et le protoplasma végétal ne peut se comporter, à cet égard, autrement que le protoplasma animal : toujours la respiration se traduit par une introduction d'oxygène et une élimination d'acide carbonique.

Il est certain cependant que la résultante des échangres gazeux se montre différente dans les deux cas : c'est que, chez les végétaux, des phénomènes particuliers d'assimilation se manifestent et prédominent. Nous voulons parler de l'assimilation du carbone, qui s'effectue par l'intermédiaire de la chlorophylle, et se traduit par une absorption d'acide carbonique et une élimination d'oxygène. Du reste, cette fonction s'exécute au mène titre chez les animaux qui contiennent de la chlorophylle.

Les caractères dynamiques ne diffèrent pas non plus d'une facon essentielle dans les deux règnes. Toutefois, si la nutrition des végétaux implique des phénomènes de synthèse qui ont pour résultat la transformalion des forces vives (chaleur, lumière) en forces latentes ou forces de tension, l'ahoutissant général des phénomènes nutritifs des animaux est tout opposé. Mais, la preuve que ces caractères ne sont pas absolus, c'est qu'on peut 
observer aussi, dans certaines circonstances, un dégagement de lumière, de chaleur, etc., chez les végétaux.

D. Mouvements volontaires et sensibilitè. - Les végétaux supérieurs, à l'état de complet développement, ne sont pas susceptibles de mouvements spontanés au mème titre que les animaux, et, pour la plupart, ils ne réagissent pas, comme le font ceux-ci, aux excitalions mécaniques. Nous avons douné déjà l'explication de ce fait en montrant que les mouvements du protoplasme végétal sont limités d'ordinaire par l'enveloppe résistante de cellulose ; Iorsque cette enveloppe fait défaut (Myxomycètes, Volvocinées), le mouvement se manifeste tout aussi nettement que chez nombre d'animaux inférieurs.

D'autre part, en ce qui concerne ces derniers, il est permis de se demander si les mourements sont ou ne sont pas rolontaires, et l'on concoit l'embarras de répondre d'une façon positive à celte question.

Quant anx mouvements provoqués, on les constate dans beaucoup de plantes phanérogames : feuilles des Sensitives, des Droséracées, étamines des Centaurées, etc.; et il est intéressant de remarquer que tous sont adaptés à des buts utilitaires: conservation de linndividu ou de l'espèce.

Il est a peine besoin de faire ressortir comment ces mouvements provoqués témoignent de la sensibilité des plantes dont il s'agit, sensibilité beaucoup plus manifeste que celle d'une foule d'animaux inférieur's dépourvus de système nerreux et d'organes des sens. Rappelons seulement, à cet égard, l’identité d’action des anesthésiques chez les animaux et chez les plantes.

Si maintenant nous cherchons à exprimer en quelques mots les principaux caractères distinctifs des animaux et des végétaux, et la diversité de leur rôle dans l'économie du globe, nous dirons que le végétal offre une organisation relativement simple, qu'il est formé surtout de substances ternaires, qưil ne manifeste cn général ni sensibilité, ni mouvements volontaires. Il puise dans l'air et dans le sol des matériaux inorganiques très simples, riches en oxygène, qu'il transforme en substances organiques complexes, riches en carbone, sous l'influence des rayons lumineux absorbés par la chlorophylle : c'est donc un organisme de réduction et de synthèse, qui emmagasine l'énergie actuelle de la radiation solaire pour la transformer en énergie potentielle. L'animal, au contraire, a une organisation complexe; les matières azotées dominent dans sa constitution; il est doué de serısibilité et capable de mouvements volontaires. Il est obligé de se nourrir, soit directement (herbivores), soit indirectement (carnivores), des matières organiques qu'il trouve toutes formées dans les plantes. Il fait subir à ces matières une oxydation lente, gràce à laquelle elles sont définitivement converties en acide carbonique et en eau. C'est donc un organisme de combustion et d'analyse, qui dépense rapidement l'énergie potentielle accumulée peu à peu par le végétal, en la transformant en énergie actuelle.

protistes. - Des considérations dans lesquelles nous venons d'entrer, il résulte que les deux règnes organisés se touchent de très près par leurs 
groupes inférieurs et arrivent mème à se confondre, de telle sorte que nous ne possédons aucun critérium absolu pour les distinguer. Hæckel a essayé de trancher la difficulté en créant, pour cette légion d'ètres ambigus qui se rapportent à peu près également aux animaux et aux végétaux, un règne spécial, celui des Protistes. Longtemps avant lui, Bory de Saint-Vincent avait tenté de mème d'établir un règne des Psychodiaires.

Mais on a fait à la création de ce groupe des objections sérieuses. Il ne parait pas convenable, par exemple, de séparer aussi nettement et des animaux et des régétaux, des êtres qui s'y rattachent d'une façon intime. En outre, la difficulté de la distinction des règnes, loin d'être aplanie, se trouve doublée, car les limites entre les Prostistes d'une part, et les animaux ou les végétaux de l'autre, ne peuvent être tracées encore que d'une facon arbitraire.

Hæckel admet huit classes dans son rẻgne des Protistes : $1^{\circ}$ Monères; $2^{\circ}$ Amibes; $3^{\circ}$ Flagellates ; $4^{\circ}$ Catallacles; $5^{\circ}$ Labyrinthulées ; $6^{\circ}$ Diatomées; $7^{\circ}$ Myxomycètes; $8^{\circ}$ Rhizopodes. Il ajoute qu'on pourrait y rattacher en outre les quatre groupes suivants: $9^{\circ}$ Phycochromacées; $10^{\circ}$ Champignons; $11^{\circ}$ Éponges; $12^{\circ}$ Noctiluques.

Nous rejetterons un certain nombre de ces classes dans le règne végétal; quant aux autres, nous les réunirons, pour la plupart, à l'embranchement des Protozoaires, le crilérium de cette séparation artificielle reposant sur la présence ou l'absence d'une enveloppe cellulosique, soit à toutes les périodes de la vie, soit seulement à l'époque de la reproduction (enkystement).

\section{CHAPITRE II}

\section{ORGANISATION ET DÉVELOPPEMENT DES ANIMAUX}

La substance qui sert de base à l'organisation, la véritable substance vivante, c'est, nous l'avons déjà dit, le protoplasme (protoplasma).

Jusqu’à ces derniers temps, on regardait le protoplasme comme ayant une constitution homogène. C'est seulement en 1880, et à la suite des recherches de Heitzmann, Fromann, Hanstein, qu'on a commencé à reconnaîlre sa réelle complexilé. Il se compose en effet de deux parties : l'hyaloplasma, substance fibrillaire, hyaline, réfringente, disposée en un réseau plus ou moins serré, et le paraplasma, substance fluide, moins réfringente, remplissant les mailles de ce réseau. Le sarcode de Dujardin correspond au paraplasina et non, comme on l'a cru, au proloplasma toul entier.

On a vu plus haut que le protoplasme vivant n'offre pas une constitution chimique définie, en raison même de son activité incessante : si l'analyse chimique le montre formé d'un mélange de substances albuminoïdes, c'est qu'elle ne peut l'étudier précisément qu'après cessation de la vie. 
C'est dire que les propriétés du protoplasme sont les attributs mêmes de la vie. Examinons en quelques mots ces propriétés.

Au contact de l'air, le protoplasme absorbe de l'oxygène et exhale de l'acide carbonique : donc, il respire. Par le fait même de cette respiration, il perd une partie de son carbone, et les substances albuminoïdes qui entrent dans sa constitution se résolvent ainsi peu à peu en produits impropres à la vie et destinés à être expulsés. Ces phénomènes de destruction fonctionnelle constituent la désassimilation. S'ils se continuaient sans compensation, le protoplasma ne tarderait pas à disparaître; mais en général il répare sans cesse les pertes qu'il subit, grâce à la faculté (qu'il possède de s'incorporer, en les décomposant, de nouveaux matériaux ou aliments qu'il puise dans le milieu ambiant. L'acte par lequel ces matériaux deviennent partie intégrante de la substance vivante s'appelle l'assimilation.

L'assimilation et la désassimilation constituent les actes essentiels de la mutrition, dont les résultats varient suivant leur intensité relative. Si les entrées l'emportent sur les sorties, la masse protoplasmique s'accroit; dans le cas contraire, elle dépérit et meurt; enfin, elle reste stationnaire s'il y a équivalence entre l'apport et la dépense.

Le protoplasme est doué de contractilité ; et cette propriété semble appartenir spécialement à l'hyaloplasma. Lorsque la masse protoplasmique est libre, elle émet ainsi des prolongements obtus ou s'étire en filaments délicats; si au contraire elle est emprisonnée dans une enveloppe plus ou moins résistante, la contractilité ne se manifeste guère qu'à l'intérieur: l'hyaloplasma modifiant sans cesse la longueur de ses filaments, et par suite la largeur de ses mailles, met en mouvement le paraplasma contenu dans celles-ci et détermine des phénomènes de translation que l'examen des granules protoplasmiques permet de suivrefacilement : on a donné à ces mouvements le nom de circulation protoplasmique ou de cyclose.

Enfin, le protoplasme est le siège d'une véritable sensibilité, comme en témoignent les réactions que, grâce à sa contractilité, il manifeste à l'endroit des différents excitants extérieurs (irritabilité protoplasmicque).

Les granules flottant dans le protoplasme sont de nature variable. Les uns sont des produits de son activité formatrice, et s'y trouvent mis en réserve ou destinés à être rejetés : tels sont les grains de piğment, les granules glycogènes, les globules adipeux, divers cristaux, etc. Les autres sont des inclusions, c est-à-dire des corps étrangers qu'il a saisis et englobés. Lorsque ces substances sont liquides ou en solution aqueuse, elles distendent parfois les mailles de l'hyaloplasma et s'accumulent en certains points du paraplasma sous forme de suc cellulaire; mais ce fait est relativement rare lans les protoplasmes animaux. 


\section{$\S 1^{\mathrm{er}}$. - CELLULES ET TISSUS.}

La croissance d'une masse protoplasmique n'est jamais indéfinie. Dans certains cas, il est vrai, cette masse peut acquérir de très grandes dimensions : sans parler de la Fleur de $\tan$ (Fuligo septica), qui n'est pas de notre domaine, on connait certaines espèces de Foraminifères qui atteignent plusieurs centimètres de diamètre. Ces masses volumineuses sont appelées plasmodes.

Mais, en général, les dimensions ne dépassent pas quelques dixièmes de millimètre, et toute masse ainsi limitée reçoit le nom de plastide, qu'elle demeure isolée ou qu'elle se trouve associée avec d'autres pour constituer un organisme complexe. Dans ce dernier cas, les plastides représentent ce qu'on appelle les éléments.anatomiques.

Aussi bien, ces divers corps ne conservent-ils pas toujours leur simplicité primitive; nous les voyons au contraire, le plus souvent, se compliquer par la production de parties nouvelles, souvent impor. tantes, telles que noyau et membrane d'enveloppe.

Le noyau, découvert au xviı ${ }^{\mathrm{e}}$ siècle par Fontana, est d'une telle constance qu'on arrive à se demander s'il existe des plasmodes ou des plastides qui en soient réellement dépourvus. Les exceptions signalées à cet égard deviennent de plus en plus rares et commandent dès à présent de sérieuses réserves. En tout cas, on peut constater que l'immense majorité des masses protoplasmiques renferment un ou plusieurs noyaux. La forme et les dimensions de ces corps sont des plus variables, mais leur structure mérite une mention particulière. Un noyau se compose d'un corps protoplasmique à caractères spéciaux, souvent entouré d'une membrane. et contenant une formation dite nucléinienne, d'aspect très variable. Le corps nucléaire se montre formé d'un réseau hyaloplasmique baigné d'un paraplasma qui renferme des granules dont quelques-uns, assez volumineux, répondent à certaines des formations décrites sous le nom de nucléoles. L'existence de la membrane nucléaire n'est pas constante; du reste, cette membrane ne représente qu'une simple couche pariétale de protoplasma, différenciée par sa réfringence et son pouvoir chromatique. Quant à la formation nucléinienne, ses caractères et sa constitution offrent les plus grandes variations; elle peut se présenter sous la forme de filament pelotonné, de ruban, de réseau, de sphère ou même de fragments épars; et, au point de vue de sa différenciation chimique, nous dirons seulement que certaines de ses parties possèdent une grande avidité pour les matières colorantes (chromatine), alors que les autres ne possèdent pas ce pouvoir électif (achromatine). Il faut mentionner enfin les corps décrits par les auteurs sous le nom de nucléoles. Ce sont en réalité des parties très dissemblables. Les uns, en effet, représentent des amas condensés du protoplasma nucléaire 
(mucléoles plasmatiques); les autres appartiennent à la formation nucléinienne (nucléoles nucléiniens) : parmi ces derniers, il en est qui répondent à cette formation tout entière, d'autres à des parties renflées du filament ou du ruban nucléinien, ou à des segments résultant de sa rupture, etc. - Ce noyau paraitjouer, comme on le verra plus loin, un rôle essenticl dans la multiplication des plastides; mais en outre, il exerce une action très importante, sinon nécessaire, sur leur nutrition même.

Ajoutons que, dans le voisinage du noyau, on observe un petit corps d'origine protoplasmique (sphère directrice), constitué par un corpuscule central ou centrosome qui en est l'élément essentiel et par une zone périphérique plus ou moins large. Nous indiquerons dans un instant la signification de ce corps.

Hreckel a donné le nom de cytodes (xúros, cavité) aux plastides qui seraient dépourrus de noyaux, réservant la dénomination de cellules à ceux qui possèdent cette formation.

Avec ou sans noyaux, d'ailleurs, ils peuvent être pourvus ou dépourvus de membrane d'enveloppe. Celle-ci n'est en somme qu'une portion condensée du protoplasma périphérique. Très sourent, en effet, les. mailles de l'hyaloplasma se resserrent dans la zone extérieure du corps, et la couche plus ou moins épaisse ainsi différenciée reçoit le nom d'ectoplasme ou ectosarque, par opposition à la région interne, pourvue d'un réseau lâche, qui est dite endoplasme ou endosarque. La couche ectoplasmique est donc vivante; mais elle est souvent envahie par des substances incrustantes qui en font une membrane inerte; ou bien, dans certains cas, elle donne naissance à une couche de sécrétion qui représente une sorte de cuticule.

Cytodes et cellules ont reçu des noms différents suirant qu'ils sont privés ou pourvus d'une membrane d'enveloppe: c'est ainsi qu'on les nomme gymnocytodes

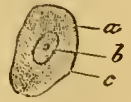

Fig. 1. - Lépocyte, $-a$, mem brane cellulaire. $b$, noyau. $e$, protoplasma. et gymnocytes (rupvós, nu) dans le premier cas, lépocytodes et lépocytes

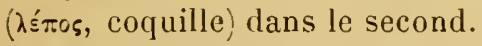

Multiplication des plastides. - Nous avons constaté plus haut que les plastides présentent en général une taille très limitée; dès que cette taille est atteinte, ils se divisent en deux ou plusieurs parties : on dit alor's qu'ils se sont multipliés ou reproduits. La faculté de reproduction, que posséde le protoplasma, nous apparaît donc comme un corollaire de l'accroissement, et partant de la nutrition.

A. Scission. - Cette multiplication des plastides s'effectue généralement par scission ou scissiparité.

Lorsqu'il s'agit de cytodes, le phénomène paraît être très simple : la masse protoplasmique se divise en deux parties qui virent isolément et s'accroissent pour se subdiviser de la même manière.

La division des cellules, beaucoup plus intéressante, peut s'accomplir de deux façons : elle est directe ou indirecte. 
a. On a observé la division directe non seulement chez les Protozoaires, mais aussi dans les cellules des Arthropodes, les leucocytes des Vertébrés, etc. Dans ce processus, on voit le noyau s'étrangler dans son milieu, puis se diviser en deux; le protoplasme suit ce mouvement, et deux cellules se trouvent ainsi constituées.

$\beta$. La division indirecte est plus connue sous le nom de karyokinèse

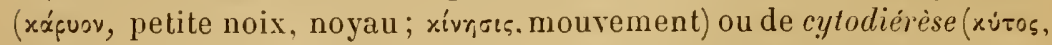
cellule;òıxip๕oıs, division): elle s'observe avec la plus grande fréquence dans les deux règnes, et offre d'ailleurs d'innombrables variations; nous ne pouvons donc en donner ici qu'une idée toute schématique. - Lorsque la cellule se dispose à entrer en division, le centrosome se divise en deux moitiés qui se séparent en entraînant chacune une partie de la zone périphérique: ainsi se trouvent constituées deux sphères directrices, qui s'éloignent l'une de l'autre et vont occuper deux points directement opposés. On remarque alors que de chacune d'elles partent des stries rayonnantes plus ou moins nombreuses: bientôt ces stries prennent un développement plus marqué vers le centre de la cellule, où elles se rejoignent en s'écartant de manière à figurer un fuseau.

En même temps que se produisent ces changements, la formation
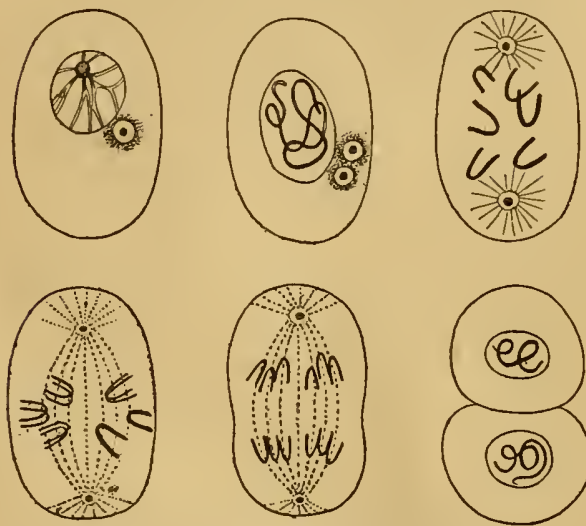

Fig. 2. - Schéma de la karyokinèse. nucléinienne se dispose en peloton et se divise en un certain nombre de segments. Puis ces segments prennent la forme d'anses ou d'U et se rassemblent sur un plan perpendiculaire à la ligne de réunion des deux sphères directrices (plaque équatoriale). Après quoi chacune des anses se fend suivant sa longueur, et se dédouble ainsi en deux anses identiques, qui ne tardent pas à se séparer et à se mettre en rapport avec les stries du fuseau. Dansleur mouvement de séparation, elles s'orientent toujours de telle sorte que le sommet de l'une se dirige vers une des sphères directrices, et le sommet de l'autre vers celle qui lui est opposée. Elles suivent alors la direction des stries et arrivent peu à peu à gagner le voisinage des sphères, lesquelles se sont ellésmêmes divisées dès le début de cette translation.

Dans chacun de ces deux groupes polaires, les anses chromatiques se rejoignent bout à bout, se disposent en peloton, et reconstituent enfin la formation nucléinienne d'un nouveau noyau.

Quant au protoplasma de la cellule, il n'entre en divison que tar- 
divement. Au moment où les anses secondaires se réunissent, il montre au niveau de la région équatoriale un étranglement qui s'accuse peu ì peu, jusqu’à séparation complète. Ainsi sont constituées deux cellules filles, dont les noyaux représentent exactement la moitié du noyau primitif, et qui sont aptes à se multiplier immédiatement de la mème manière.

B. Bowromnement. - Il arrive assez souvent qu'un plastide, au lieu de se diviser en deux plastides égaux, donne naissance à un ou plusieurs petits plastides qui s'en séparent et dont la masse reste inférieure à la sienne. On donne à ce mode de division le nom de bourgeonnement ou gemmation: ce n’est, en réalité, qu’un cas particulier de la multiplication par scission.

Association et différenciation des plastides. - Un grand nombre d’animaux inférieurs, qu'on réunit sous le nom de Protozoaires, sont représentés par un seul plastide. Mais tous les autres animaux, qui composent le vaste groupe des Métazoaires, se montrent constitués au contraire par une association de plastides nés les uns des autres. D’abord semblables entre eux, ces plastides prennent peu à peu des caractères différents, ou, sclon l'expression consacrée, se differencient quant à leur constitution morphologique et à leurs fonctions. C'est ainsi que se forment les cellules et les fibres nerveuses, musculaires, etc.

Or, les associalions d'éléments anatomiques de même ordre, ayant un rôle déterminé, sont désignés sous le nom de tissus. Exemple: tissu musculaire, tissu nerveux.

La science qui s occupe de l'étude des tissus porte le nom d'histologie

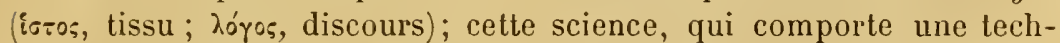
nique spéciale et complexe, est universellement reconnue aujourd'hui comme l'auxiliaire indispensable de l'anatomie et par suite de toutes les branches de la biologie qui ont celles-ci pour base.

Pour éviter de revenir à propos de chaque groupe sur les divers tissus qui entrent dans la constitution des organismes animaux, nous allons en esquisser, d'une facon très sommaire, les principaux caractères. A l'exemple de Ranvier, nous les classerons de la manière suivante :

$1^{\circ}$ Ceux daus lesquels la substance qui unit et sépare les cellules, ou substance intercellulaire, est caracléristique par sa forme, ses propriétés physiques et chimiques : tissus conjonctifs ;

2o Ceux dans lesquels la cellıle principale s'est modifiée au point de devenir méconnaissable : tissus musculaire et nerveux;

$3^{\circ}$ Ceux qui sont composés de cellules á évolution régulière et constante, soudées les unes aux autres par une substance unissante peu abondante: epithéliums.

Enfin, nous étudierons, à còté des tissus, les liquides de l'organisme contenant en suspension des éléments anatomiques, et qu'on a pu regarder pour cela comme des tissus à substance unissante liquide.

$1^{\circ}$ Tissus conjonctifs. - Le groupe des tissus connectifs, conjonctifs, 
ou de substance conjonctive comprend plusieurs types plus ou moins distincts :

A. Tissu conjonctif cellulairf. - Formé de cellules assez régulières, pourvues de membrane et contiguës. Ex. : parenchyme des Trématodes, corde dorsale des Vertébrés.

B. Tissu conjonctif diffus. - Comprend des faisceaux de fibrilles (fibres

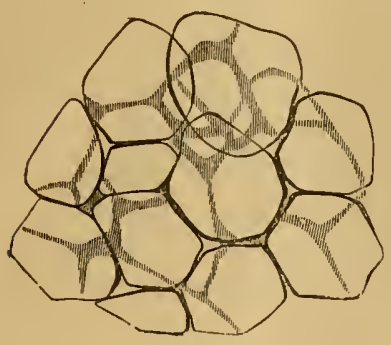

Fig. 3. - Cellules adipeuses de l'épiploon du veau. conjonctives) entre lesquels se trouvent des cellules qui souvent se moulent sur eux. D'autres fibrilles plus résistantes et anastomosées (fibres élastiques) s'y joignent en proportion variable. Plusieurs variétés :

a. Tissu gélatineux ou muqueux. -- Demifluide, transparent, ne comprenant que des fibres conjonctives. Ex. : ombrelle des Méduses; gélatine de Wharton du cordon ombilical des Mammifères.

b. Tissu conjonctif lâche. - Le tissu cellulaire des chirurgiens. Nombreux faisceaux de fibres conjonctives serrés de place en place par des fibres annulaires, et entremèlés de fibres élastiques. Dans les interstices, des cellules lymphatiques flottent librement au milieu du plasma qui baigne le tissu. Ex. : tissu conjonctif sous-cutané des Mammifères.

c. Tissu adipeux. - Variété de tissu conjonctif làche, présentant de nombreuses cellules qui deviennent le siège de surcharge graisseuse. Ex. : lard et panne du Porc.

d. Tissu conjonctif réticulé. - Faisceaux de fibres conjonctives anastomosés

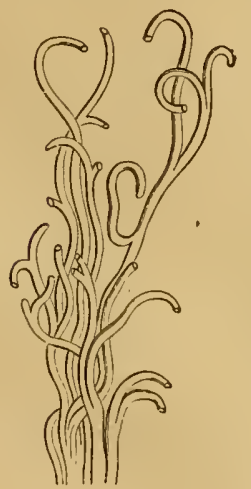

Fig. 4. - Fibres élasliques du ligament cervical du veau. en un réseau très serré, dans les mailles duquel abondent des cellules libres. Se rencontre dans les lacunes des Mollusques, les ganglions lymphatiques des Vertébrés, etc.

C. Tissu conjonctif modelé. - Même constitution que le lissu conjonctif diffus, mais modelé en organes distincts. Trois formes principales :

a. Tissu conjonctif engainant. -- Disposé en lamelles superposées. Ex. : gaines des nerfs des Vertëbrés.

b. Tissu fibreux. - Faisceaux connectifs parallèles ou entre-croisés suivant une règle uniforme.Ex.: tendons, ligaments, aponévroses.

c. Tissu élastique. - Les fibres élastiques prédominent et parfois existent seules. Ex. : ligaments jaunes compris entre les lames des vertèbres.

I). Tissu cartilagineux. - Les cartilages sont formés de cellules spéciales assez régulières, et d'une substance interstitielle très épaisse, relativement rigide, qui donne de la chondrine par l'ébullition. Les cellules cartilagineuses s'entourent chacune d'une capsule de même nature que la substance fondamentale : l'ensemble de la cellule et de la capsule constitue un chondroplaste.

Les cartilages sont nus (c. articulaires) on enveloppés d'une membrane fibreuse dite périchondre. Suivant que la substance fondamentale est homo- 
gène, envahie par des éléments étrangers, on en distingue plusieurs variétés: le cartilage hyalin (c. costaux), le fibro-cartilage (disques intervertébraux), le cartilage réticulé (épiglotte), le cartilage calcifié (squelette des Squales).

E. Tissu osseux. - Propre aux Vertébrés, ce tissu se compose d'une substance fondamentale incrustée de sels calcaires et creusée de cavités microscopiques (corpuscules osseux) donl chacune contient une cellule propre (cellule osseuse) : l'ensemble du corpuscule et de la cellule constitue un ostioplaste.

La substance fondamentale est formée de deux tiers à peine de substances minérales, notamment de phosphate et de carbonate de chaux, et l'un tiers environ de matière organique (osséine) se résolvant en gélatine.

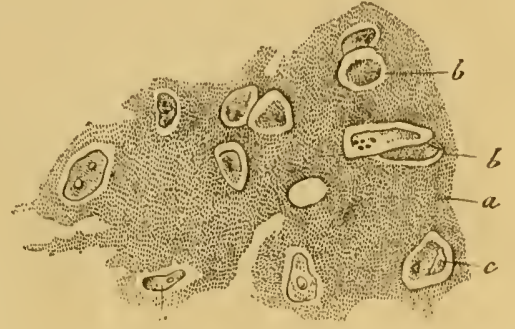

Fig. 5. - Cartilage hralin de la trachée du cheva - $a$, substance hyaline. $b . b$, chondroplastes. $c$, cellules cartilagineuses avec des noyaux. Gro:sissemeut : 310 diamitres. par la coction. Les corpuscules osseux y sont disposés de manière à délimiter des systèmes variés de lamelles (lamelles osseuses) ; chacun d'eux émet des canalicules s'anastomosant avec: ceux des corpuscules voisins ou se jetant dans les canaux vasculaires (canaux (le Havers).

Dans toutes les cavités intérieures des os, se trouve une substance molle (moelle osseuse), sorte de tissu conjonctif très vasculaire et riclıe en éléments cellulaires spéciaux.

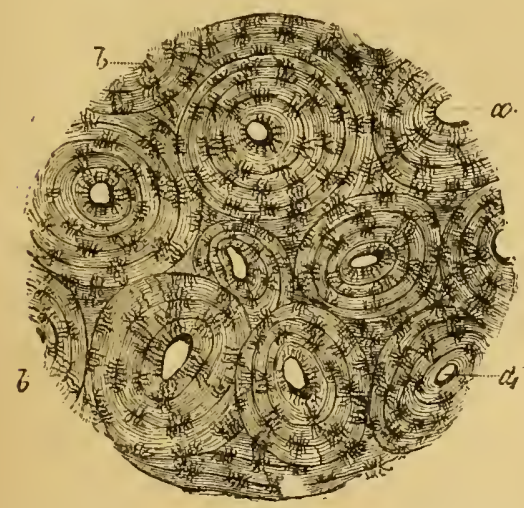

Fig. 6. - Coupe transversale d'un libia de cheval. $a, a$, canaux de Havers, entourés de lamelles concentriques. $b, b$, nombreux ostéoplastes avec les canalicules ramifiés, Grossisscment : 150 diamètres.

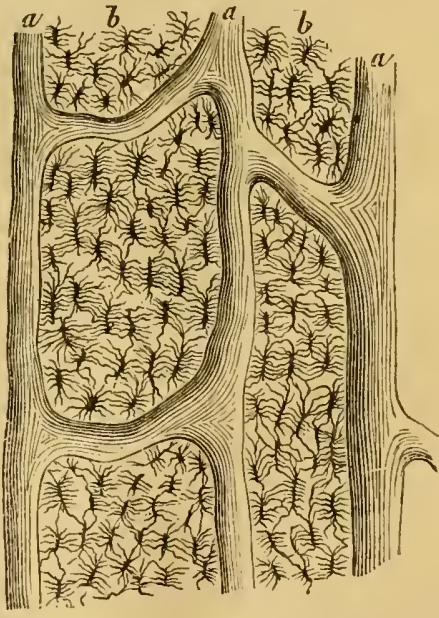

Fig. 7. - Coupe longitudinale d'un tilia de cheval. - $a, a$, canaux de Havers. $b, b$, ostéoplastes. Grossissement : 3 to diamètres.

Enfin, les os sont enveloppés, sauf au niveau des cartilages articulaires, par une membrane fibreuse très vasculaire, le périoste.

2 Tissus musculaire et nerveux. - Dans ces deux tissus, la cellule a subi le plus souvent des modifications profondes et a acquis des propriétés physiologiques toutes spéciales.

RaIlliet, - Zoologie. 
A. Tissu musculare. - Nous avons vu que le protoplasma jouit de la faculté de se contracter, et que cette faculté se trouve localisée dans l'hyaloplasma. Aussi les éléments qui possèdent un hyaloplasma très abondant ont-ils pour fonction essentielle la contractilité : ce sont les éléments musculaires. Dans certains cas (myoblastes des Polypes), une partie seulem ent de la cellule se différencie en filament contractile; mais le plus souvent la cellule entière subit cette modification. D'après les caractères qu'elle présente alors, on distingue deux formes principales de tissu musculaire.

a. Le tissu musculaire lisse est constitué par des fibres cellules ou fibres lisses, rarement isolées, mais plutôt réunies en faisceaux (muscles lisses); ce sont les éléments fusiformes, nus, pourvus d'un noyau, et se laissant décomposer par l'alcool faible en fibrilles longitudinales. Les fibres lisses ont une contraction lente, mais assez prolongée. Chez les Invertébrés, dont un grand

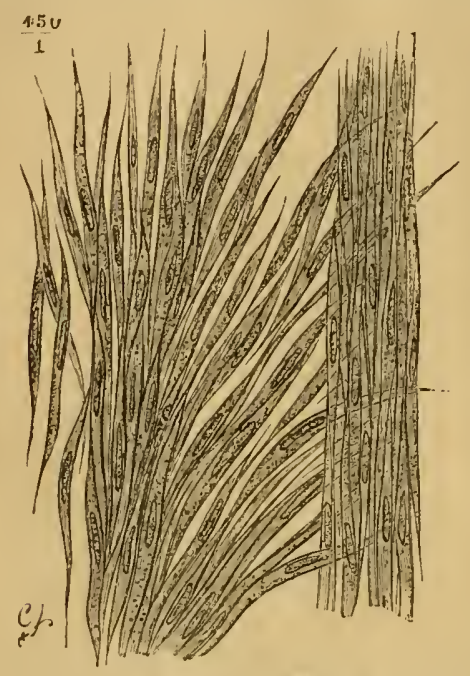

Fig. 8. - Iluseles à fibres lisses (J. Béclard). - A droitc un fragment de muscle dans lequel les fibres-cellules sont groupées. A gauche, des fibres-cellúles dissociées.

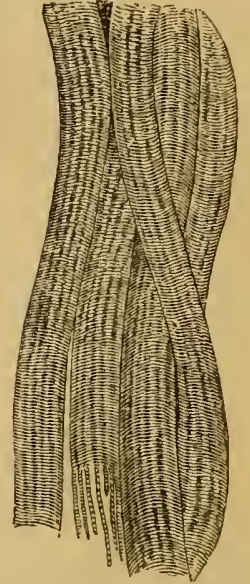

Fig. 9. - Fibres ou faisceaux musculaires striés du cheval. Grossissement : 310 diamètres.

nombre ne possèdent pas d'autres éléments musculaires, elles servent à la locomotion, et leur contraction est par conséquent soumise à l'influence de la volonté. Au contraire, chez les Vertébrés, où on les rencontre surtout dans les parois des viscères, elle est toujours involontaire (muscles de la vie organique).

b. Le tissu musculaire strié se compose de cellules ou de fibres essentiellement caractérisées par leur striation transversale, et dont la contraction est brusque, mais de courte durée.

$\alpha$. Les cellules musculaires striées sont dépourvues de membrane d'enveloppe. Elles possèdent chacune un noyau central et montrent en général des saillies latérales qui se soudent entre elles, de manière à former un réseau : cette apparence les avait fait prendre autrefois pour des fibres musculaires ramifiées. On ne Ies rencontre guère que dans la paroi du cœur (myocarde! des Vertébrés.

ß. Les fibres striees à contraction volontaire sont assez épaisses, simples. 
allongées, et disposées parallèlement les unes aux autres. On les appelle encore fuisceaux primitifs, parce qu'elles se laissent dissocier en un certain nombre de fibrilles, qu'on avait prises d'abord pour l'élément musculaire fondamental, et qui sont d'allleurs indiquées par une striation longitudinale. Ces fibrilles primitives offrent une succession de segments alternativement clairs et obscurs, d'où résulte l'apparence striée. Chaque faisceau primitif est entouré d'une membrane a morphe, le sarcolemme ou myolemme, montrant des noyaux i sa face interne. Ces faisceatux primitifs, unis entre eux par du tissu conjonctif, forment cnsemble des fuisceaux secondaires, eux-mèmes groupés pour constituer les muscles. On trouve des libres striées daus certains organes des Échinodermes, des Mollusques, des Vers (appareil génital des Acanthocéphales); chez les Arthropodes, elles constituent tout l'appareil musculaire; enfin, chez les Vertébrés, elles forment tous les muscies a contraclion volontaire et quelques autres (

B. Tissu xerveux. - Le tissu nerveux comprend deux sortes de formations : des cellules et des fibres, celles-ci n’étant que le prolongement des premières.

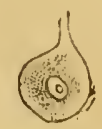

lig. 10. - Cel. lule nerveuse unipolaire.

Les cellules nerveuses sont formées de protoplasma granuleux renfermant un ou deux gros noyaux et offrant un, deux ou plusieurs prolongements, qui leur font donner le nom de cellules unipolaires, bipolaires ou multipolaires. Parmi ces prolongements, il en est. un, dans le cerveau et la moelle épinière des Vertébrés, qui reste indivis (prolongement de Deiters) et se continue avec le cylindraxe d'une fibre nerveuse; les autres (prolongements protoplasmiques) se divisent pour s'anastomoser avec les ramitications des cellules roisines.

Les filres nervenses sont de deux sortes: $1^{\circ}$ Les fibres à myéline ou ì double contour sont formées d'un cordon central (eylindraxe) entouré d'une couche de matière réfringente (myéline), laquelle est comprise ellemème entre deux membranes délicates, l'une externe, la gaine de Schwann, l'autre interne, la yaine de Juthner. Elles paraissent just̨u'ici propres aux Vertébrés; $2^{\circ}$ Les fibres sans myéline ou fibres pàles, fibres de liemak, sont réduites au cylindraxe, qui se montre revètı, de rlistance en

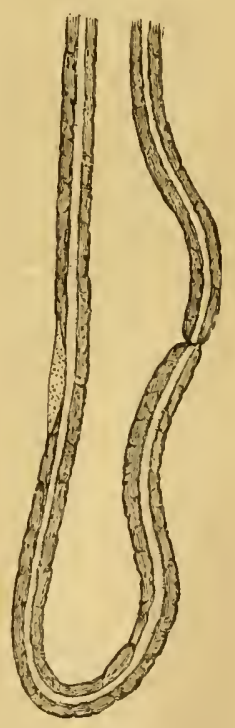

Fig. 12. - Fibre nerrense à myéline, prise sur I'animal vivant.Grossissement: 500 diamètres (J. Béclard).

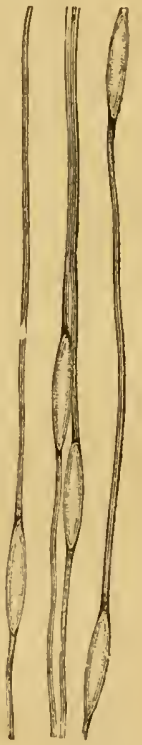

Fig. 13. - Fibres de Kemak. Grossissement: 300 diamètres (J. Béclard). distance, de noyaux contenus dans une couche discontinue de protoplasma. On les rencontre encore fréquemment chez les Vertébrés, mais ce sont les seules qui existent chez les Invertébrés. 
$3^{0}$ Tissus épithéliaux. - Ce sont des tissus composés de cellules juxtaposées, de forme variable et revêtant des surfaces. Celui qui couvre l'extérieur du corps reçoit le nom d'épiderme, tandis que la dénomination d'épithiliums est réservée plus spécialement à ceux qui tapissent les cavités du corps. - D'après la forme des cellules, on distingue plusieurs sortes d'épithéliums :

a. Epithélium parimenteux. - Formé de cellules aplaties et contiguës. On le dit simple quand il comprend une seule couche de cellules, stratifie s'il offre plusieurs couches superposées. L'épithélium pavimenteux simple est constitué en général par des cellules lamelleuses, qui tapissent des cavités : on l'appelle souvent endothélium (séreuses, vaisseaux, poumons). L'épithélium pavimenteux stratifié est tantòt mou (bouche, vagin), tantòt corné (couche superficielle de l'épiderme).

b. Épithélium cylindrique. - Composé de cellules cylindriques (hypoderne des Insectes) plus rarement coniques (gros intestin des Mammifères), dont le grand axe est perpendiculaire à la surface qu'elles revêtent. Ces cellules ont

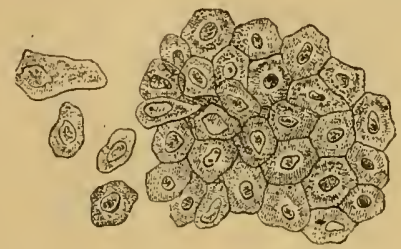

Fig. 14. - Épithélium pavimenteux de la séreuse péricardique dı cheval. Grossissement : 310 diamètres.

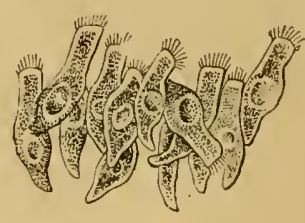

Fig. 15. - Épithélium vilratite de la trachéc de la rache. Grossissement : 310 diamitres.

souvent leur extrémité libre surmontée d'un platêu (intestin grèle des Mammifères).

c. Épithélium vibratile. - Caractérisé par des cellules de forme variée, le plus souvent cylindriques, offrant a leur surface de petits filaments protoplasmiques animés d'un mourement rapide de va-et-vient (cils vibratiles), ou un seul prolongement assez long (flagellum).

d. Épithélium glandulaire. - Constitué en général par des cellules nues et. sphéroïdales, disposées dans des invaginations qui pénètrent de la surface des organes dans la profondeur. Une glande consiste généralement en une cavité limitée par une membrane propre, anhisté ou conjonctive, tapissée d̀ sa face libre par l'épithélium et sourent (Vertébrés) parcourue a sa face profonde par un réseau vasculaire. Le produit sécrété s'écoule d'ordinaire par un conduit vecteur (canal excréteur) dont l'épithélium n'est pas sphéroïdal. D'après la disposition des cavités, on distingue leux ordres de glandes : les glandes en tube (glandes de Lieberkiihn, glandes sudoripares) et les glandes en grappes (glandes sébacées, glandes salivaires). Il existe d'ailleurs des glandes unicellulaires.

Liquides nourriciers. - Le liquide qui baigne les tissus des animaux, et qui constitue ce qu'on appelle leur "milieu intérieur ", présente des caractères variables suivant les formes chez lesquelles on l'examine; cependant, il n'existe pas, comme on l'a cru longtemps, une dissemblance absolue dans la constitution qu'il présente chez les Vertébrés et chez les Invertébrés. 
Le liquide nutritif des Invertibrés recoit souvent le nom d'hemolymphe, frarce qu’il représente i la fois le sang et la lymphe des animaux supérieurs. (Yu'il soit reufermé dans les lacunes du corps ou dans des vaisseaux propres, il se compose d'un plasma tenant presque toujours en suspension des gfobules blancs (amibocyles Cuénol). Le plasma est souvent incolore; d'aulres fois il est coloré en rouge, en bleu, en vert, etc., par des matières colorantes dissoutes hémoglobine, hémocyanine, chlorocruoriue, etc.) qui peuvent former avec l'oxygène des combinaisons làches; c'est alors ce plasma yui sert en mème lemps ì la respiration et à la nutrition. Dans certains cas enfin, on peut trouver, comme chez les Vertébrés, des hématies bien 'aractérisées, renfermant soit de l'hémoglobine ou de l'héméryłhrine (Géphyriens), soit des albuminoïdes incolores (Ascidies) : et le plasma ne conserve qu'un rỏle nutritif, les hématies servant de véhicule à l'oxygène.

Chez les Vertébrés, le liquide nutritif se présente sous deux états principaux, constituant le sany el la lymphe.

Le sung est rouge, sauf chez l'Amphioxus el quelques Poissons, où il reste incolore. Il se compose d'uu plasma dans lequel nagent des globules blancs et des globules rouges. - Les globules rouges on hématies sont des disques biconcaves, sans noyau, chez les Mammifères : leur contour est circulaire, rarement elliptique (Camélidés). Chez les autres Vertébrés, ils sont pourvus d'un noyau central saillant et leur contour est elliptique, rarement circulaire (Cyclostomes). Ils sont imprégnés d'une matière colorante ronge (hémoglobinc) qui forme avec l'oxygène une combinaison peu stable, d'un rouge très vif (orylhémoglobine): une partie de cet oxygène est cédée aux tissus (respiration), et l'hémoglobine réduite doit aller de nouveau s'oxygéner dans l'appareil respiratoire. - Les globules blancs ou lcucocytes sont des cellules granuleuses, sphériques ou à contour irrégulier, possédant des mouvements amiboïdes. Clıargés de granulations protéiques, graisseuses et de glycogène, ils jouent le ròle de cellules nulritives; en outre, ils neuvent absorber les produits de destruction des tissus, et mème les microorganismes introduits accidentellement dans la circulation, de manière à les digérer (phagocytose). Ils sont beaucoup noins nombreux que les hématies. - Outre ces deux sortes Wéléments, on rencontre dans le sang de petits corps à peine colorés, très délicals (globulins): Hayem, les considérant comme de jeunes hématies, leur donne le nom d'hématoblastes. - Quant au plasma dans lequel nagent les Hobules, c'est un liquide alcalin qui, en dehor's des vaisseaux, se coagule à la température ordinaire. Cette coagulation est due à la fibrine, substance qui apparaît déjà dans le sang des Arthropodes, où elle a un ròle hémostatique des plus nels? rendu nécessaire par la rigidité des tissus.

La lymphe est formée d'un plasna coagulable, légèrement teinté en jaune par une matière colorante spéciale (hémaphéine), et de cellules identiques aux clobules blancs du sang. Ces cellules lynphatiques se forment, comme les amibccytes des Invertébrés, qui leur correspondent, dans des glandes lymphatiques (ganglions, rate, thymus, etc.). - On appelle chyle la lymphe qui revient de l'intestin, chargée, au moment de la digestion, des produits absorbés, et en particulier de corpuscules graisseux. 


\section{§ 2. - SPÉCIALISATION IET RAPPORTS DES FONCTIONS NT DES ORGANES.}

Division du travail physiologique. - Nous avons reconnu précédemment que les plastides associés pour constituer un organisme se " différencient " quant à leur constitution morphologique et ì leurs fonctions.

Or, à mesure que ces éléments deviennent plus nombreux, la modification de leurs caractères s'accuse davantage, et leurs fonctions arrivent à un plus haut degré de spécialisation. Déjà, dans les tỵpes inférieurs de Métazoaires, on constate que ceux qui entrent dans la constitution de la surface interne jouent un rôle très différent de ceux qui revêtent la surface externe. Celle-ci, en effet, sert principalement à protéger l'organisme, et à le mettre en rapport avec le milieu extéricur; la surface interne, de son côté, est préposée à la digestion et à l'absorption des aliments. Mais peu à peu l'organisation se complique. A l'invagination primitive, qui avait donné lieu à la formation de cette cavité digestive, s'ajoutent des invaginations secondaires, qui correspondent elles-mèmes à de nouvelles spécialisations de fonctions (glandes). Puis, entre les deux couches externe et interne et à leurs dépens se produisent de nouveaux tissus (muscles, os, etc.). C'est également entre ces deux couches, et parfois même dans les nouveaux tissus que se forme la cavité dite viscérale dans laquelle se développent le sang et le ș̣stème vasculaire. Enfin, à l'extérieur, apparaissent, au lieu d'invaginations, des bourgeons qui servent à la respiration (branchies) ou à la locomotion (tentacules, membres). Notons ici que la différenciation cles organes va de pair avec celle des tissus.

En résumé, nous constatons qu'à l'accroissement des êtres organisés correspond la division du travail physiologique. Or, cette spécialisation est précisément une des conditions indispensables au perfectionnement des êtres dont il s'agit. A cet égard, on a souvent comparé, d'une façon très heureuse, l'organisme animal à un atelier dont les ouvriers ont une certaine somme de produits à fournir. Si tous sont chargés d'accomplir le même travail, leur nombre n influera que sur la quantité, non sur la qualité des produits; mais si, au contraire. chaque ouvrier a une tâche spéciale qu'il répète constamment, il acquiert en sa matière une habileté beaucoup plus grande. De même, en ce qui concerne les êtres organisés, la spécialisation des fonetions détermine toujours un perfectionnement de l'organisme (1).

Phẻnomènes morphologiques consécutifs. - Ces principes posés, il con-

(1) Cette importante question de la division du travail a été magistralement traitée par Adam Smith au point de vue de l'industrie, et par H. Milne Edwards au point de vue zoologique. - Voy. MrLae EDwards, Leçons sur la physiol. el l'anat. comp., t. I. p. 16, 1857. 
rient de jeter un coup d'uil sur quelques phénomènes morphologiques qui sont la conséquence de la division du travail.

Différenciation. - Selon la défuition de Giard, la différenciation consiste dans "l'adaptation morphologrique à une fonction spéciale d'unc partie primitivement emplorée à des fonctions multiples. "Il est constant, en effet, que des fonctions peurent ètre accomplies par des parties non spécialisées : les animaux inférieurs fournissent de nombreux exemples de ce lait, et chez les plus simples d'entre eux, le protoplasma qui conslitue la masse entière du corps remplit à la fois toutes les fonctions. L'apparition des organes n'est 'que le résultat de la division du travail; les fonctions les plus importantes se localisent les premières, et cette particularité peut ètre citée à l'appui de l'aphorisme bien connu : la fonction fuit l'organe.

Rriduction. - Un second phénomène qui se rattache a la différenciation, cest celui auquel on a donné les noms de réduction, rétrogradution, développement rétrograde, métamorphose régressive, etc. Il consiste surtout dans la suppression oul l'atrophie des organes, par suite de la suppression des fonctions, ou de leuradaptation à desconditions nouvelles. En thèse gónérale, les résultats de la rélrogradation sont absolument contraires à ceux de la différenciation : au lieu de compliquer l'organisme, elle tend à le simplifier. Elle peut porter sur tout ou partie des organes et mème sur l'organisme entier, en modifiant la forme, le volume, le nombre ou la structure des parties: enfin, elle pent frapper, soit un individu seulement, soit une espèce, un çenre et même un groupe d'ordre plus élevé.

C'est à ce phénomène qu'il nous faudra plus tard demander compte de la signification des organes rudimentaires, si utiles en anatomie comparée pour la détermination des rapports de parenté.

Étant donné, comme nous venons de le voir, que la réduction est sous la dépendance des conditions fonctionnelles des organes, il nous sera certainement facile d'en découvrir les principaux facteurs.

D'abord, nous pouvons signaler les conditions particulières dans lesquelles sont appelés à vivre certains animaux. Un exemple nous en est fourni par les Protées, Amphibiens pérennibranches qui habitent des eaux souterraines, et dont les yeux, rendus tout à fait inutiles, sont rudimentaires el cachés sous la peau.

Le parasitisme, qui est (pour le parasite) un des agents les plus communs de la réduction, peut ètre regardé comme un cas particulier de l'influence du mode de vie. Les Linguatules, Arthropodes parasites qui, à la sortie de l'œuf, possèlent une armature buccale assez puissante pour perforer les tissus, perdent cette armature dès qu'elles sont parvenues en un point où elles peuvent puiser directement leurs matériaux de nutrition. Cependant, l'action du parasitisme sur la réduction parait se rattacher, dans certains cas, à une véritable division du travail : l'hòte, en effet, qui héberge le parasite, effectue une partie du travail qui devait primitivement revenir à celui-ci; par suite, la fonction correspondante du parasite se restreint de plus en plus, parfois mème jusqu'à disparaitre; et, comme conséquence, on observe une atrophie plus ou moins complète des organes chargés de l'accomplir. Ainsi s'expliquerait, par exemple, l'absence du tube digestif chez les Ténias, qui trouvent dans l'intestin de leur hòte une substance alimentaire tout élaborée.

Enfin, l'association aboutit sourent aux mèmes résultats, et il est manifeste 
'qu'ici encore, les phénomènes de réduction sont sous la dépendance d'une division du travail. Dans une colonie d'Abeilles, les mâles ou faux-bourdons sont dépourvus d'aiguillon et de corbeille, les onvrières ont les organes génitaux atrophiés, etc. C'est que le travail de la ruche est partagé entre les divers ordres d'individus qui la composent, que les organes utiles s'adaptent plus spécialement à la fonclion qui leur est dévolue, et que, par contre, les organes inutiles s'atrophient. On sait d'ailleurs qu'il suffit de donner aux ouvrières une nourriture plus abondante et plus choisie pour développer leurs organes sexuels et les transformer en reines. Mais, ce qu'il est intéressant de constater, c'est que la réduction, quoique tendant à la simplification des organismes, peut devenir un élément de complication pour une espèce donnée. Elle concourt, en effet, à prodnire le polymorphisme des individus sociaux.

Corrélation. - Les organes et mème les appareils s'associent pour constituer un ensemble auquel on donne précisément le nom d'organisme lorsquiil possède une individualité distmcte. Mais de cette association résultent de nombreux rapports et une subordination réciproque. C'est ce qui a fait dire que la vie est l'expression harmonique d'une somme de phénomènes dérivant les uns des autres, de telle sortequ'aucune fonction n'est indépendante. Donc, au point de vue fonctionnel d'abord, mais aussi au point de vue morphologique, les organes offrent des relations étroites se traduisant en définitive par la dépendance de chacun d'eux relativement aux autres. C'est là ce que Cuvier a appelé le principe de la corrélation des formes, principe d'après lequel un changement supposé dans un appareil appelle certaines modifications dans d'autres appareils. Au surplus, voici comment ce principe a été formulé jar l'illustre anatomiste (1): "Tout ètre organisé forme un ensemble, un système unique et clos, dont les parties se correspondent mutuellement, et concourent à la nıème action définitive par une réaction réciproque. Aucune de ces parties ne peut changer sans que les autres changent aussi, et par conséquent chacune d'elles, prise séparément, indique et donne toutes les autres. " Bien qu'il y ait là quelque exagération, il est certain que le principe en question a rendu de nombreux services à l'anatomie comparée. Les modifications qui se rattachent à cet ordre de phénomènes sont encore peu connues, il est vrai, en ce qui concerne les organismes inférieurs; mais elles peuvent ètre souvent saisies avec beaucoup de précision quand il s'agit des Vertébrés. C'est en les prenant pour base que Cuvier, à l'aide de quelques dents et de quelques fragments d'os fossiles, a pu reconstituer des espèces animales disparues. " Si les intestins d'un animal, disait-il, sont organisés de manière à ne digérer que de la chair et de la chair récente, il faut aussi que ses màchoires soient construites pour dévorer une proie; ses griffes pour la saisir et la déchirer; ses dents pour la couper et la diviser; le système entier de ses organes de mouvement pour la poursuivre et pour l'atteindre; ses organes des sens pour l'apercevoir de loin; il faut même que la nature ait. placé dans son cerveau l'instinct nécessaire pour savoir se cacher et tendre des pièges à ses victimes. Telles seront les conditions générales du régime carnivore; tout animal destiné pour ce régime les réunira infailliblement, car sa race n'aurait pu subsister sans elles... ) Toutefois, nous devons ajouter que certaines découvertes de Gaudry ont démontré que ces principes ont

(1) G. Cuvien, Discour's sur les révolutions de la surface du globe, se édit., p. 98. 
quelque chose de trop absolu, et que leur application directe, sans çontrole, pourrait conduire quelquefois à les résultats erronés.

$1 l$ est aussi descas où la corrẻlation n'est pas aussi facile à saisir que dans les exemples qui viennent d'itre cilés. C'est ainsi qu'on voit des modificalions diverses se manifester dans certains organes, par suite de changements de mème ordre surveuus dans d'autres organes n'offrant guère avec les premiers de rapports apparents. Signalons, par exemple, le développement du liırynx corrélatif à celıi des organes génitaux.

Pour Cuvier, comme on vient de le voir, le prineipe de la corrélation des formes n’était que la conséquence du principe plus général des ronditions d'existence, en vertu duquel un animal, créé pour vivre dans des conditions déterminées, était nécessairement pourvu des organes les mieux disposés dans ce but. Ce principe, toutefois, était tout à fait impuissant à rendre compte des orgunes mulimentaires. Étienne Geoffroy Saint-Hilaire, peu satisfait des rues de Cuvier, tentia d'y substituer l'lypothèse, demeurée célèbre, le l'unité de composition du règne animal. D'après sa manière de voir, les animaux formaient une série continue : tous étaient composés des mêmes parties, ne différant entre elles que par leur forme, leur degré de développentent et leur fonction (théorie des amulogues); de plus, ces parties devaient occuper toujours la mème situation relative (principe des connexions). Lorsçı’un organe venait à s'accroitre dans des proportions excessives, les organes voisins devaient, au contraire, subir une atrophie plus ou moins accusée : aimsi s'expliquait la présence des organes rudimentaires (principe du balancement des oryanes). Ce fut ce dernier principe qui conduisit l'auteur à l'étahlissement de la térutologic ou science des monstruosités.

Comparaison des organes. - Quoique ni l'une ni l'autre des deux théories émises par ces deux illustres savants ne soit, propre à nous satisfaire complètement, toutes deux, et en particulier la dernière, nous enseignent à tenir le plus grand compte de la valeur relative des organes.

0r', la détermination de cette valeur, qui ne peut ètre que le résultat de leur comparaison, est essentiellement différente suivant c[u'on envisage les ítres organisés au point de vue de leur constitution morphologique ou qu'on rtudie seulement leurs fonctions, c'est-à-dire leur physiologie. Aussi, la biologie distingue-t-elle avec soin, aujourd'hui, les homologies et les analogies.

On dit que deux ou plusieurs orgaues sont analogues lorsqu'ils ont le mème róle à remplir ou la mème valeur physiologique; tandis qu'ils sont homoloyues lorsqu'ils ont une égale valeur morphologique, une mème constitution fondamentale, ou mieux "quand ils sont formés en des points correspondants de l'embryon et suivent un développement parallèle » (Giard). Ainsi, l'aile de l'Oiseau et l'aile de l'Insecte, qui n'ont pas la mème base de constiuntion, mais qui loutes deux sont destinées au mème mode de locomotion, sont simplement analogues. Il en est de mème des branchies des Poissons et des poumons des Mammifères. Au contraire, si l'on compare à l'aile de l'Oiseau le membre antérieur du Mammifère, on reconnait que ces organes, bien ıu'ils aient à jouer un ròle tout différent, sont réellement homologues. La mème remarque s’appliquerait ì la ressie natatoire des Poissons comparée au poumon des Mammifères, etc.

On distingue, d'ailleurs, diverses sortes d'homologies. Ainsi, on appelle homotypes les organes qui se font pendantl'un ì l'autre, par exemple les reins 
ou les yeux d'un Vertébré; on qualifie de parties homodynames celles qui se répètent dans l'organisme en raison de sa forme, comme les bras d'une Étoile de mer, les segments d'un Articulé, etc.

Organes et individus. - Il résulte des données précédentes que le corps des animaux est formé d'un ensemble de parties affectant entre elles des rapports plus ou moins étroits. Il nous reste à préciser la nomenclature de ces parties, que nous avons jusqu'à présent désignées sous le nom général d'organes.

Toute partie définie, chargée d'une fonction spéciale, reçoit le nom d'appareil. Or, les appareils eux-mèmes peuvent se subdiviser en un nombre variable de parties secondaires, à chacune desquelles est dévolu un certain rôle dans l'accomplissement de la fonction commune : ce sont là les organes proprement dits, dont le mode d'activité reçoit le nom d'usage. Un organe peut l'ailleurs remplir des usages multiples, se rapportant même à des fonctions distinctes.

On appelle système anatomique l'ensemble des organes ou parties d'organes qui offrent la même texture (parties similaires). C'est ainsi qu'on distingure les systèmes musculaire, nerveux, veineux, dentaire, etc. L'étude des systèmes est une branche importante de l'anatomie générale : elle établit la transition entre l'histologie et l'anatomie descriptive.

Au surplus, les rapports qui existent entre les différentes parties d'un organisme sont loin d'être constants. C'est même la raison qui rend si peu précise la notion d'individualité, an sujet de laquelle on a si souvent discuté.

En ce qui concerne les êtres les plus inférieurs, celte notion, à la vérité, se présente souvent à l'esprit sans aucune ambiguïté. On sait, par exemple, qu'un grand nombre d'entre eux sont constitués, pendant tonte la durée de leur vie, par un seul plastide : en pareil cas, l'individu est caractérisé par sa forme définie el son existence autonome. On pourrait mème ajouter qu'il répond à la donnée étymologique d'individualité, car on ne pourrait en retrancher une partie de quelque importance sans compromettre la vie.

Tous les êtres, au début de leur évolution, c'est-à-dire à l'état d'ovule, offrent cette mème constitution; mais, en général, les plastides résultant de la division de cet élément primitif s'associent pour former des orgunes (1).

Ces orgaues eux-mèmes s'assemblent de manière à composer d'ordinaire un tout de forme définie et doué d'une existence propre : lá encore, il y a un individu caractérisé morphologiquement. IIæckel donne à cet individu le nom de personne. Tels sont les animaux supérieurs.

Mais il est beaucoup de formes inférieures chez lesquelles, au contraire, les deux éléments, morphologique et physiologique, cessent d'être en concordance; en d'autres termes, on observe des individus morphologiquement bien définis qui n'ont pas une existence propre, mais sont réunis en un certain nombre pour l'accomplissement des fonctions vitales. Si donc on peul considérer chacun d'eux comme une individualité morphologique, l'ensemble n'en forme pas moins une individualité physiologique d'ordre évidemment supérieur. Hæckel donne à de semblables colonies le nom de cormes (cormus).

(1) Dans son bel ouvrage sur les Colonies unimales, Ed. Perrier propose d'appeler mérides les associations de plastides, zoïdes les colonies de mérides, et démes les colonies dans lesquelles on peut distinguer des groupes distincts ayant la valeur de zoïdes. 
Ainsi, un Magosphæra est un corme de Catallactes unicellulaires; les colonies: de Coralliaires, les Vers rubanés sont également des cormes. L'individualité morplıologique est done subordonnée ì l'individualité physiologique, de manière à jouer vis-à-vis d'elle le simple rỏle d'organe.

Quelle que soit, d'ailleurs, l'importance absolue ou relative des individualités, on est conveun de leır appliquer des qualifications spéciales suivan! la position qu'elles affectent les unes à l'égard des autres. Sont-elles, par exemple, disprosées symétriquement par rapport à un point, on leur donne le nom de centromeres: c'estle cas des Magosphara. Lorsqu'elles sont symétriques relativement à un axe (synétrie rayonnée), comme on le voit chez les l'olypes, on les appelle antimèrcs. Enfin, lorsque le corps ne présente qu'un seul plan de symétrie (symétrie bilatérale), il arrive souvent que les oræanes se répètent le long de cet axe longitudinal ; on donne alors aux secrments successifs ainsi constitués le nom de métameres ou de zomites : tel: sout les segments des Irthropodes, les vertèbres, etc.

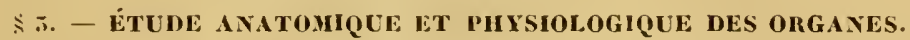

Les fonctions de l'organisme peuvent être divisées en trois classes principales : $1^{\circ}$ les fonctions de mutrition, qui ont pour objet la conservation de l'individu; 2 o les fonctions de relation, qui mettent l'organisme en rapport avec le monde extérieur ; $3^{\circ}$ les fonctions de reproluction, qui ont pour but d'assurer la conservation de l'espèce.

Toutefois, il ne faudrait pas considérer cette classification comme l'indice d'une séparation absolue entre ces trois groupes. Il serait facile de démontrer, par exemple, que les fonctions de relation viennent en aide à celles des deux autres classes, si nous n'avions suffisamment insisté, au paragraphe précédent, sur la dépendance réciproque des fonctions et des organes.

Les fonctions de nutrition, communes à tous les êtres vivants, sont encore appelées fonctions de la vie végétative, et quelques auteurs classent sous le même chef les fonctions de reproduction; quant aux fonctions de relation, qui sont principalement accusées chez les animaux, elles sont qualifiées de fonctions de la vie animale.

\section{Orfianes Et Fonctions Je Relation.}

Les actes par lesquuels l'organisme se met en relation avec le monde extérieur se rapportent principalement à la sensibilité et au mouvement.

Appareil locomoteur. - Chez les êtres les plus simples, la locomotion se manifeste par la contraction du protoplasma tout entier dont le corps est formé. La masse se déplace alors au moyen des processus yu'elle émet et qui ont reçu le nom de pseudopodes. Une différenciation un peu plus accusée nous montre déjà, chez les Infusoires, des organes locomoteurs bien nets, sous la forme de cils vibratiles ou de fligellums. 
Si l'on passe à des types plus élevés, on ne tarde pas à distinguer l'élément moteur par excellence, la cellule ou la filre musculaire. Tout d'abord, les muscles se montrent intimement unis à la peau, de ma-

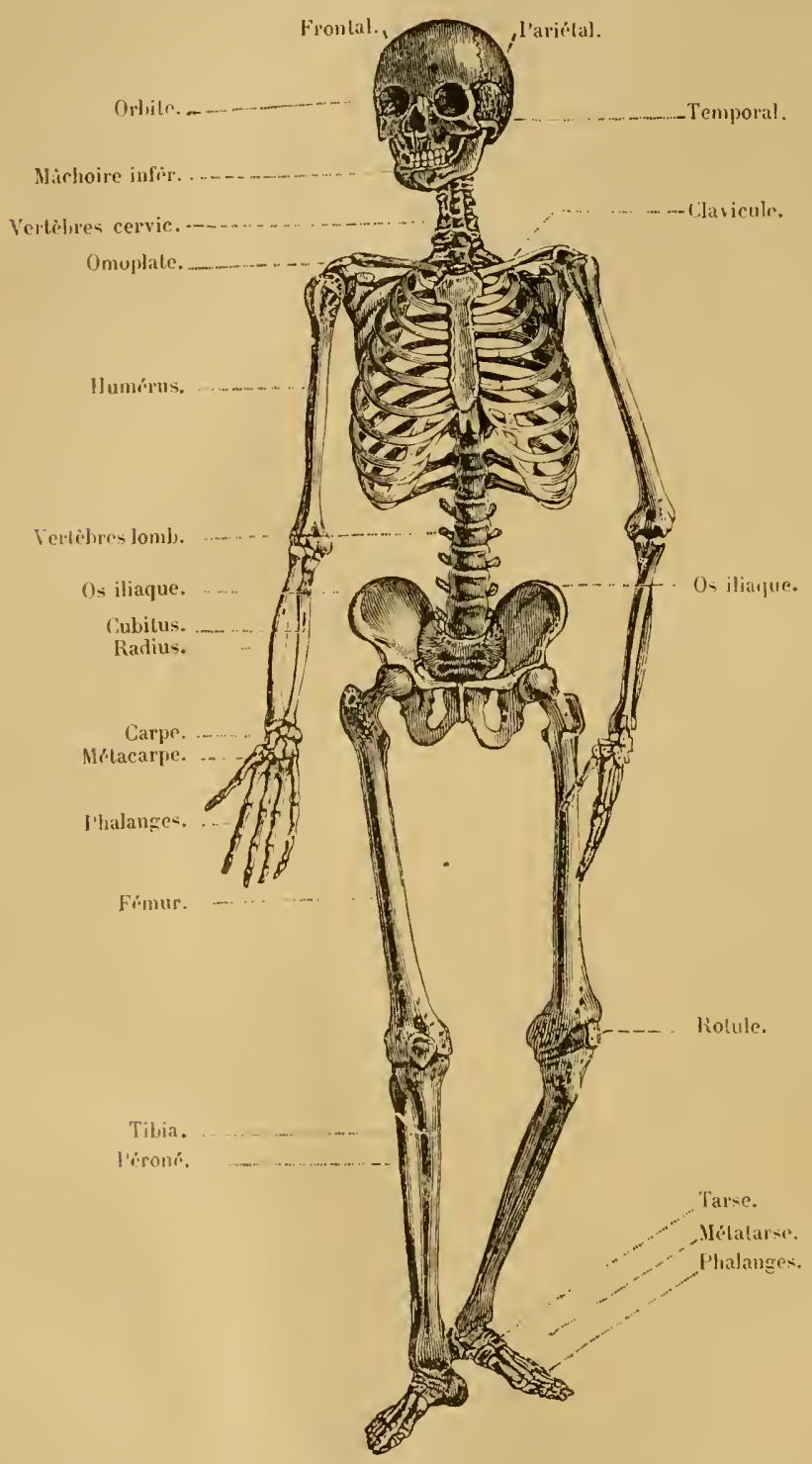

Fig. 16. - sipuelelte de lillomme.

nière à former une enveloppe musculo-cutamée dont la contraction détermine le déplacement du corps (Vers). Dans certains cas. ils se concentrent sur une région spéciale, telle que la face ventrale du 
corps (pied des Mollusques). Enfin, ils peurent s'isoler darantage encore des téguments et se diviser en groupes similaires, placés les uns derrière les autres (Arthropodes et Vertébrés). Il existe alors des parties solides destinćes à leur fournir des points d'appui, comme it servir de soutien et à proteger les organes internes: squelettr: dermiqur: des Arthropodes, squrlefte interrier des Vertébrés, dont les diflérentes parties sont mobiles les unes sur les autres. En même temps, apparaissent des appendices, ou membres, qui représentent des leviers particulièrement puissants et out une constitution analogur i celles des parties centrales.

Organes de sensation. - Comme le mourement, la sensibilité est d'abord diffuse dans toute la masse du corps; mais, en général, on voit se diflérencier les frmments nerveur eu même temps qu'apparaissent les muscles.

Lorsqu’il est complètement développé, le systime mereux comporte trois dispositions fondamentales:

$1^{\circ}$ Type rayom des Echinodermes: aux rayons du corps correspondent autant de centres nerveux, réunis eux-mêmes par des commissures qui forment un anneau entourant l'oesophage.

20 Type bilutriral des Arthropodes, des Vers et des Molluspres. Les animaux dont il s'agit ayant leurs principaus organes symétriques par rapport à un plan médian, le sytème nerreux suit cette disposition générale. Quelques Vers possèdenl seulement une paire de ganglions situés sur les côtés ou au-dessus de l'cesophage, ou sourent ils se confondent en une masse, émettant des filets nerreux dans différentes directions. Tel est le cas des Turbellariés et des Rotateurs. A un degré plus éleré, ces ganglions, dits asophagiens ou críbroüdes, sont unis à une autre masse ganglionnaire double située au-dessous de l'osoplage (ganglions sous-œsophagiens), au moyen de deux cordons latéraux qui forment ce qu'on appelle un collier wsophagien. En arrière des ganglions sous-cesophagiens, il existe quelquefois une seule paire ganglionnaire située comme eux au-dessous du tube digestif (Mollusques acéphales); mais, chez les animaux dont le corps est composé de métamères, on trouve toute une série de paires semblables, réunies par deux connectifs (1) souvent con-

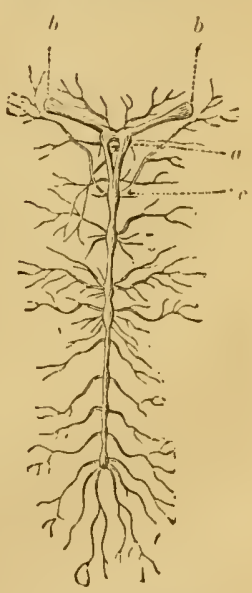

Fig. 17. - šrslème nerveus de la vie de relalion d'un Insecte. $a$, collier osophagien. $b, b$, nerfs optiques. $c$, chaine ganglionnatire ventrale. tigus; ainsi se trouve constituée la double châne gangliomaire ventrale des Arthropodes et des Annélides. Les nerf́s destinés aux or-

(1) Il. Milne Edwards a proposé d'appeler commissures les cordons qui unissent transversalement les masses nerveuses, et connectifs ceux qui les joignent dans le sens longitudinal. 
ganes des sens sont toujours fournis par les ganglions cérébroïdes.

$3^{\circ}$ Type bilaléral des Vertébrés. - Dans tous les animaux de ce groupe, le système nerveux central se présente sous la forme d'un long cordon (axe cérébro-spinal) renfermé dans une

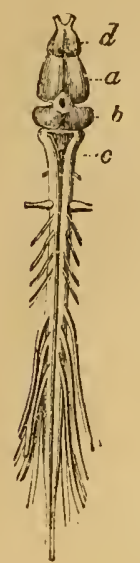

Fig. 18.-Axecérébrospinal de la Grenouille. $-d$, lobes elfaclifs. $a$, hémisplères cérébraux en arrière desquels se voit la glande pinćale. $b$, lobes optiques. $c$, moelle allongée. Le cervelet est représentí par la bandeletle yui règne au-dessus de la partie antérieure de la moelle allongće. cavité spéciale, située dans la région dorsale du corps, et entièrement distincte de celle qui contient les viscères. Les filets nerveux qui se rendent dans les différentes parties du corps naissent de cet axe par paires symétriquement disposées.

Chez les animaux inférieurs, les organes de nutrition et de reproduction recoivent directement leurs nerfs des masses ganglionnaires centrales; mais, dans les types d'une organisation plus élevée (Vertébrés, Arthropodes, etc.), les viscères sont innervés par un appareil autonome, formé de ganglions et de filets disposés en réseaux (plexus). Ce système, particulier, quoique relié aux centres nerveux, demeure soustrait à l'empire de la volonté : on lui donne le nom de système du grand sympathique ou système nerveux vixciral.

Les nerfs qui unissent le système central à la périphérie sont moteurs ou sensitifs. Les premiers transmettent aux muscles les incitations motrices parties des centres. Les autres portent aux centres nerveux les excitations venues du monde extérieur et recueillies par des appareils périphériques, les organes des sens

Le tact ou toucher est celui des sens qui est le plus disséminé. Il a pour siège l'enveloppe du corps ou certains appendices qui en dérivent, tels que les tentacules des Polypes et des Mollusques, les palpes et les antennes des Arthropodes, etc. Chez les Vertébrés supérieurs, les nerfs cutanés se terminent dans des organes tactiles particuliers (corpuscules du tact, de Pacini, de kirause).

Le sens du goût, dont on ne peut bien constater l'existence que chez les animaux supérieurs, est localisé dans la bouche, du moins chez les Vertébrés. Les impressions gustatives, recueillies par des papilles situées sur la langue, sont transmises aux centres par les nerfs lingual et glosso-pharyngien.

L'odorat parait assez répandu chez les Invertébrés; mais il ne se distingue pas nettement du goût chez les animaux à respiration branchiale. On regarde comme des organes olfactifs, chez les Vers et les Mollusques, des fossettes revêtues d'un épithélium à cils vibratiles et auxquelles aboutit un nerf spécial. Chez les Vertébrés, ces organes sont représentés par une double cavité creusée dans les os de la face et 
tapissée par une muqueuse, la membrane pituitaire, dans laquelle se ramifient les nerfs olfactifs.

Lorgane de l'ouie, dans beaucoup de formes inférieures, est constitué par une résicule (olocyste) renfermant un liquide dans lequel flottent des concrétions calcaires (otolithes); la paroi de cette vésieule, ciliée ou garnie de poils, reçoit la terminaison du nerf acous-

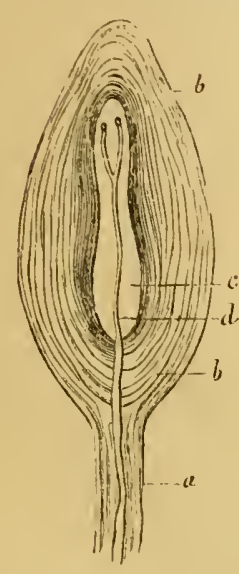

Fig. 19. - Corpuseule de Pacini du Chat. - $a$, pédicule. $b$, eouches conjonclives concentriques. $c$, cavité centrale. $d$, crlindre-axe à lerminaison ramifiée, engagé dans le corpuscule. Grossissemenl : 310 diamètres.

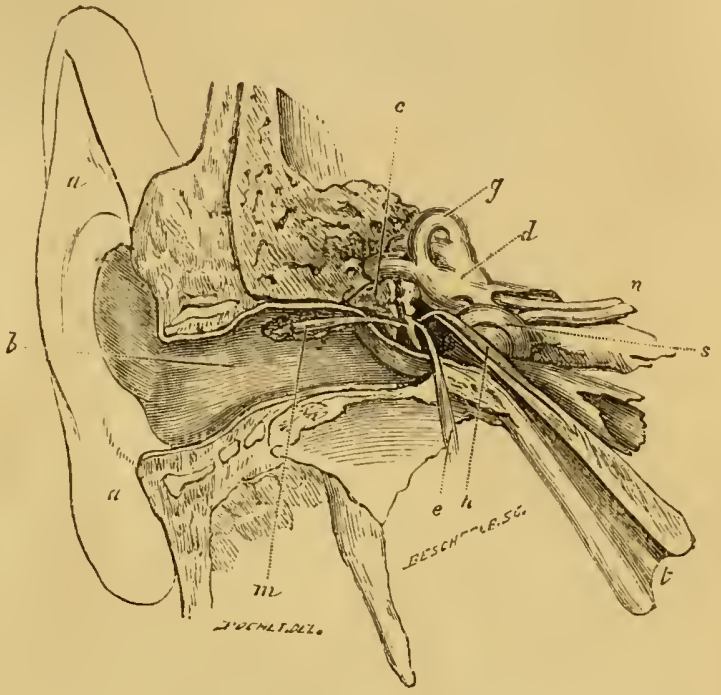

Fig. 20. - Oreille de lHomme. - $a$, pavillon. $b$, condui auditi evierne. $c$, cliaine des osselets. $d$, vestibule. $e$, muscle antérieur du marleau. $g$, canaux semi-circulaires. $h$, muscle interne du marteau. $s$, limaçon. $m$, musele externe du marteau. $n$, nerf acoustique. $t$, trompe d'Eustache.

tique ou auditif. Quand la résicule n'est pas elose, les otolithes sont remplacés par de petits corps étrangers, tels que des grains de sable. Chez les Vertébrés, la vésicule auditive offre une structure plus complexe (labyrinthe membraneux); il s'y ajoute d'ailleurs des organes propres à recueillir et à renforcer le son (oreille externe et oreille moyenne).

Les organes de la vuc, les plus communs après ceux dı tact, sont souvent représentés, chez les animaux inférieurs, par une simple tache de pigment placée à l'extrémité d'un nerf (taches oculaires). C'est à peine si de tels yeux peuvent permettre à l'animal de distinguer la lumière de l'obscurité; ils ne sont guère sensibles qu'aux rayons calorifiques. Chez les animaux plus élerés, l'weil se complique graduellement par la différenciation des terminaisons nerveuses (cônes et bàtonnets); mais, pour que la perception d'une image puisse avoir lieu, il faut que des appareils de réfraction (cornée, cristallin, etc.) 
soient placés au-devant de la membrane sensible (rétine) formée par l'expansion terminale du nerf optique.

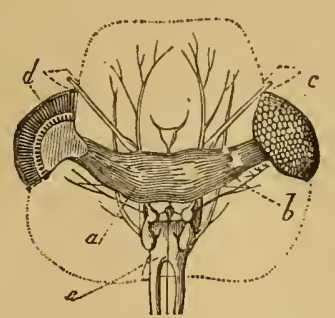

Fig. 21 . - Veux à facelles du flameton. $a$, cerveau. $b$, nerfs optiques. $c$, œii enlier. $d$, ail coupé longitudinalemenl.

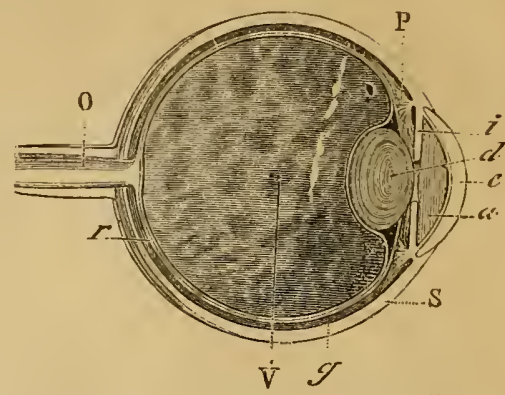

Fig. 9.. - Coupe sehématique de l'cril de l'Homme. $c$, cornée transparenl e. $\$$, sclérolique. $g$, choroïde. $r$, rétine. $a$, lumeur aqueuse. $i$. iris. $\mathrm{P}$, procès eiliaires, d, cristallin. $\mathrm{V}$, corps vitré entouré de la membrane livalö̈de. 0. nerf oplique (J. Béclard).

Instinct et intelligence. - Il ne saurait être dans notre intention d'aborder ici l'étude des opérations complexes qui ont pour siège le système nerveux et desquelles résultent l'instinct et l'intelligence. Nous renverrons pour cette étude aux traités de physiologie, et nous nous bornerons ȧ exposer en quelques mots ce que les auteurs qualifient de facultés instinctives el intellectuelles.

L'observation des mœurs si variées des animaux nous montre que, cleez un grand nombre d'entre eux, les actions sont déterminées par des impulsions intérieures, innées, inconscientes, qui conduisent à des résultats avantageux à la conservation de l'individu ou à celle de l'espèce. On dit que ces actions sont instinctices, et l'on appelle instinct la faculté qui préside à leur accomplissement. L'art avec lequel le Castor construit sa cabane et l'Oiseau son nid, la merveilleuse industrie dont fait preuve tel ou tel insecte pour se procurer sa nourriture, tant d'autres faits remarquables que nous pourrions citer, témoignent de l'extension de cette faculté. Les animaux doués d'instinct agissent sans se rendre compte $d u$ but de leurs actes; ils continuent mème d'agir lorsque ce but est atteint ou supprimé, et nous ne les voyons pas modifier leur manière de faire en vue d'obtenir un résultat nouveau; enfin, ils exécutent tous ces actes sans les avoir appris, comme nous le montrent, d'une façon certaine, ceux qui éclosent après la mort de leurs parents.

Tous ces caractères sont assez distincts de ceux qui appartiennent ì l'intclligence. Effectivement, celle-ci suppose que l'animal a conscience de l'acte accompli, du but à atteindre, et qu'il est apte à modifier sa façon d'agir suivant les circonstances, en mettant à profit ce que lui a enseigné l'expérience. L'intelligence, déjà bien manifeste chez certaines formes inférieures. notamment chez les especes sociales (Abeilles, Fourmis, etc.), acquiert toutefois un degré beaucoup plus élevé chez les Vertébrés supérieurs, et en particulier ehez nos animaux domestiques. Il y a lieu de penser, du reste, que la vie sociale n'a pas été étrangère au développement de l'intelligence; et c'est, en effet, nous le montrerons plus loin, parmi les animaux sociables que l'homme a choisi la presque totalité de ses serviteurs. 
On peut ajonter que l'intelligence des animaux ne diffère point qualitativement de l'intelligence humaine; la différence n'existe, en réalité, que dans le degré de perfection, et II. Milne Edwards a établi qu'il n'est pas une scule faculté de l'entendement humain qu'il ne soit possible de retrouver, au moins en germe, chez les animaux.

11 ne faudrait pas croire, d'ailleurs, qu'il soit toujours facile d'établir une ligne de démarcation bien tranchée entre les phénomènes le l'instinct et ceux de l'intelligence.

Le chant des Oiseaux, qu'oı a longtemps regardé comme un phénomène purement instinctif, n'est en réalité que le résultat de l'éducation; et il n'est pas certain que l'édification des nids ne puisse ètre, du moins en partie, rattachée à la mème cause.

D'autre part, les actes aceomplis sous l'influenee de l'instinct ne sont pas absolumenl inmuables. F. Pouchet a constaté que, dans les quartiers neufs de Rouen, l'Hirondelle de fenètre ne construit pas son nid de la mème facon que dans les vieux quartiers. Les rares Castors qu'on rencontre encore aujourd'hui dans la vallée du Rhòne ne bàtissent plus de cabanes : sans cesse dérangés par l'homme, ils se contentent de se creuser des terriers sur les bords du fleuve, à la manière des Loutres. Enfin, les animaux domestiques pourraient nous fournir des preuves multiples de la modification des instincts. Or, en laissant de còté ces derniers faits, qui sont déterminés par l’intelligence humaine, ne voit-on pas que si l'Hirondelle et le Castor ont transformé leurs construetions pour répondre à de nouvelles conditions de milieu, ce ne peut ètre que par l'effet d'une comparaison et d'un raisonnement, c'est-à-dire par un acte d'intelligence ? Mais, gràce à la puissance de l'hérédité, le résultat de cet acte n'est pas limité aux seuls animaux qui l'ont accompli : il se transmet aux générations successives.

Par contre, il serait facile de démontrer que des actes qui se rapportent en propre à l'intelligence peuvent s'exécuter dans certains cas d'une façon absolument inconsciente. Sans parler des sujets affectés de certaines maladies nerveuses, nous n'aurions qu'à rappeler une l'oule d'actes qu'une longue habitude nous amène à effectuer en quelque sorte machinalement. C'est pourquoi divers anteurs ont cru pouvoir défnir l’instinct " une habitude transmise par hérédité ").

En résumé, il n'y a pas, comme on l'a souvent affirmé, une opposition complète, fondamentale, entre les phénomènes de l'instinct et ceux de l'intelligence. Les opérations mentales qui se rattachent le plus nettement à l'instinct peuvent au contraire se relier, par une série d'actes intermédiaires, aux manifestations les plus élevées le l'activité intellectuelle. Sous sa forme élémentaire, l'instinct est, comme nous l'avons vu, tout à fait inconscient, et se transmet par hérédité, d'une facon à peu près invariable. Lorsque la conseience se dégage, l'intelligence apparaît et, dès lors, arrive aisément à provoquer des modifications qui affectent souvent un caractère de permanence en rapport avec la persistance des causes qui les ont amenées. " Peu à peu la conscience devient plus étendue, les idées plus claires, les rapports compris plus nombreux : l'intelligence se distingue netiernent. Elle se mélange d'abord, à tous les degrés, à l'instinct; enfin, arrive le moment oì elle masque à peu près complètement les instincts innés, où ee qu'ils ont de fixe disparait sous le llot ehangeant de ses inces-

Rallliet. - Zoologie. 
santes innovations, où ce qui se fixe par l'hérédité, ce n'est plus l'aptitude ì concevoir presque inconsciemment tel ou tel rapport, c'est l'aptitude à rechercher et à découvrir des rapports nouveaux, jusqu'ả ce qu'enfin se montre le merveilleux épanouissement de la raison humaine. "(Ed. Perrier.)

\section{ORGaNes et Fonctions de Nutrition.}

L'entretien de la vie individuelle est sous la dépendance des fonctions de nutrition, accomplies par les organes de la vie végétative.

La nutrition, dans son ensemble, consiste en des échanges incessants qui s'opèrent entre le corps de l'animal et le monde extérieur. Les manifestations de la vie, en effet, sont liées nécessairement à l'usure des éléments organiques (dés-

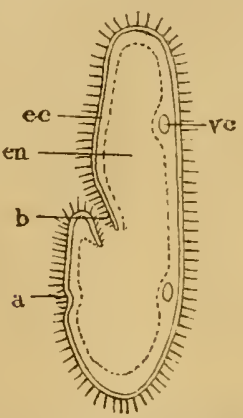

Fig. 23. - Schéma d'une l'atamécie, d'après Hayek. $-b$, orifice buccal, $a$, fente anale. $r c$, vacuoles contractiles. $e c$. ecloplasme. en, endoplasme.

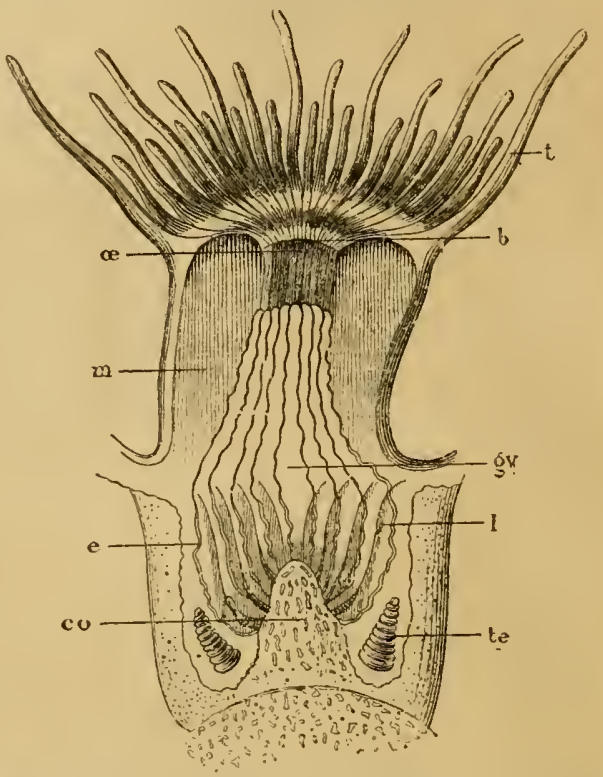

Fig. 24. - Section diun I'olype (Astroides calicularis), montrant la cavilé gastro-vasculaire gv, l'esophage $(P$, et la bouche $b$ (Lacaze-[uthiers).

assimilation), et les matériaux usés sont rejetés à l'extérieur. Mais cette usure même nécessite une réparation continuelle des éléments dont il s'agit (assimilation), réparation qui s'effectue par l'absorption de principes nouveaux puisés dans le milieu ambiant.

Fort simples clez les formes inférieures, ces deux phénomènes nutritifs primordiaux se compliquent graduellement: les actes qu'ils comportent se multiplient, et l'on voit par suite les appareils organiques se différencier de plus en plus.

Ainsi, l'animal recueille tout d'abord à l'extérieur ses matériaux nutritifs ou aliments et les élabore dans un appareil spécial (digestion). Les substances ainsi élaborées forment un liquide nourricier qui se répand dans un système de lacunes ou de canaux pour aller baigner les tissus (circulation). Ce liquide, qui recoit le nom de sang, fournit 
aux lissus non seulement les matériaux propres à leur croissance et à leur réparation, mais aussi une certaine quantité d'oxygène, en échange duquel les tissus lui cèdent de l'acide carbonique. Ainsi modifié, le sang va se régénérer dans un autreappareil, oì il abandonne son acide carbonique et se charge d'oxygène (respiration). L'oxydation des tissus donne lieu d'ailleurs à une production de claleur qui en partie se manifeste directement (chaleur animale) et en partie se transforme en travail mécanique. Enfin, les matériaux usés non gazeux, qui rendraient le sang impropre à l'entretien de la vie, sont expulsés par diverses voies (excrétion).

\section{Appareil digestif.}

Les Protozoaires inférieurs ne possèdent pas, a proprement parler, d'appareil digestif : ce sont des processús protoplasmiques qui vont au-devant des corps étrangers et les englobent. Chez les Infusoires, apparait une ouverture buccale permanente, en mème temps que le corps offre une zone centrale (endoplasme) dans laquelle sont digérées les substances alimentaires. Les Polypes sont toutefoisles premiersanimaux qui présentent une ca-
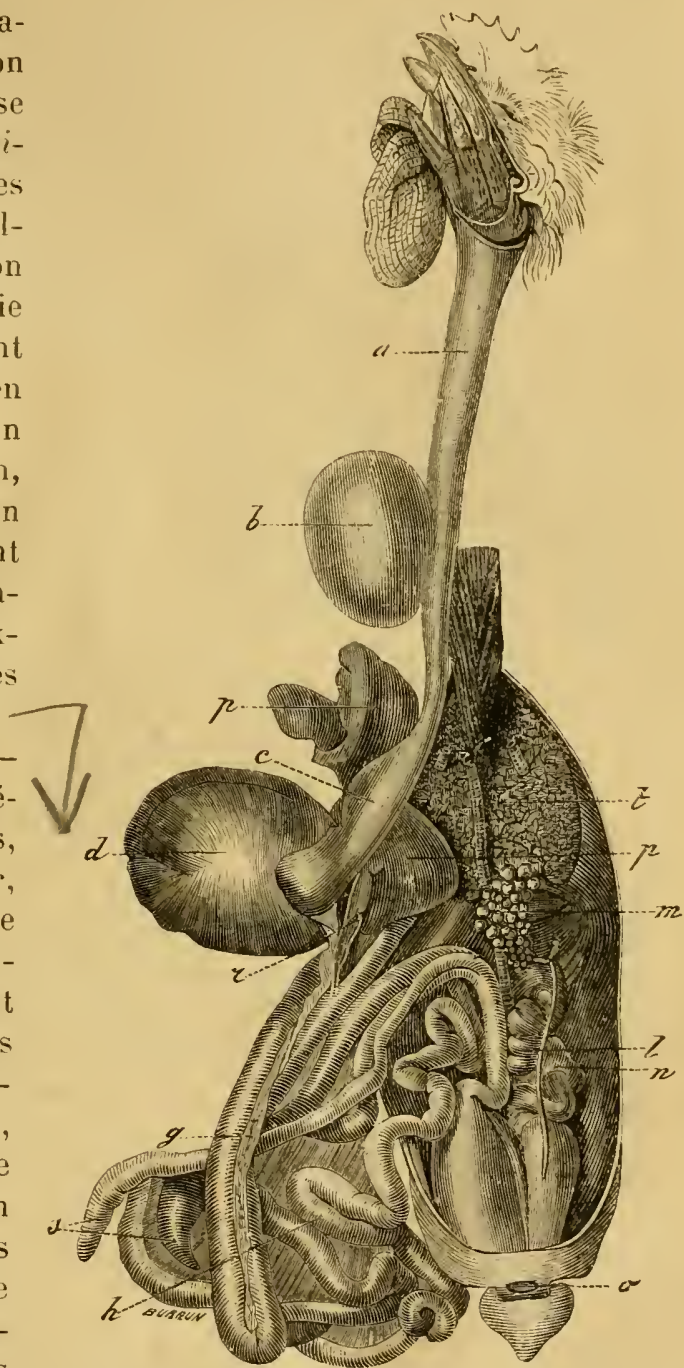

Fig. 25. - Tube digestif d'une Dinde. - a, cesophage. b, jabot. $c$, ventricule succenturié. d, gésier. $g$, pancréas entouré par. le duodénum. $h$, intestin grềlc. $l$, gros intestin. $m$, ovaire. $n$, oviducte. $o$, cloaque. $p$, fuie. $r$, vésicule biliaire. $s$, cacum (J. Béclard

vilé digestive bien définie : c'est un cul-de-sac, dont l'orifice sert ì la fois de bouche et d'anus, c'est-ì-dire de porte d'entrée et de sortie. A un degré supérieur, le tube digestif est ouvert ì ses deux extrémités, 
et l'anus se montre distinct de la bouche. Enfin, ce tube se subdivise en plusieurs régions, ayant chacune un rôle spécial à remplir. On y reconnaît alors trais parties principales : intestin buccal, intestin moyen et intestin terminal. L'intestin buccal offre à sa partie antérieure une cavité dite buccale, souvent armée de formations solides destinées à saisir et à broyer les aliments; cette cavité est suivie de l'cesophage, qui conduit les aliments dans une portion dilatée,

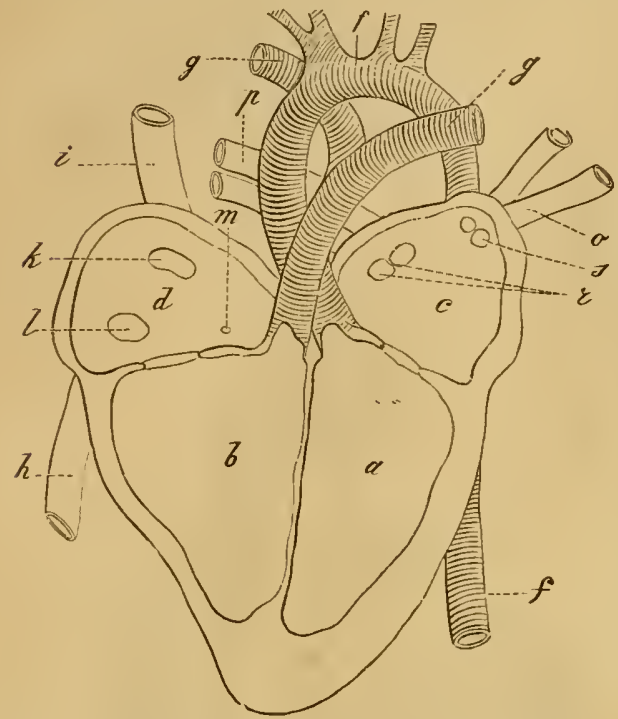

Fig. 26. - Coupe demi-schématique du ceur de l'Homme. $a$, ventricule gauche. $b$, ventricule droit. $c$, oreillette gauche. $d$, oreillette droite. $f$, artère aorte. $g, g$, brauches de l'artère pulmonaire. $h$, veine cave inférieure. $i$, veine cave supérieure. $k$, orifice de la veine cave supérieure. $l$, orifice de la veine care inférieure. $m$, orifice de la veine coronaire. $o$, veines pulmonaires gauches. $p$, veines pulmonaires droites. $r$, orifices des reiues pulmonaires droites. $s$, orifices des veines pulmonaires gauches (J. Béclard).

l'estomac, où ils subissent d'importantes transformations. Ce produit passe de là dans l'intestin moyen ou intestin grêle, où se complète son élaboration. Il est alors absorbé par les parois intestinales. Quant à l'intestin terminal ou gros intestin, qui aboutit à l'anus, il n'a le plus souvent qu'une faible action sur les substances alimentaires; il est surtout destiné à recevoir les résidus de la digestion, qui s'y accumulent sous forme d'excréments, et à les expulser.

A mesure que se compliquent les réservoirs digestifs, on voit apparaître des glandes dont les sécrétions servent à modifier les aliments: glandes salivaires, déversant leur produit dans

la bouche; glandes à pepsine, s'ouvrant dans l'estomac; foie et pancréas, amenant la bile et le suc pancréatique dans l'intestin moyen, etc. Remarquons cependant qu'un foie véritable n'existe que chez les Vertébrés; les glandes analogues des Crustacés et des Mollusques, par exemple, sécrètent un produit dont les propriétés diffèrent entièrement de celles de la bile, et l'on s'accorde assez aujourd'hui à les classer à part, sous le nom d'hépatopancréas.

Appareil circulatoire. - Le liquide nourricier formé dans le tube digestif se trouve répandu dans l'organisme par un système de cavités d'une complexité fort variable. Chez les Polypes, ce sont de simples diverticules de la cavité digestive, laquelle mérite par conséquent' le nom de cavité gastro-vasculaire. A un degré plus élevé, l'appareil de la circulation se montre distinct du tube intestinal, mais le li- 
quide nourricier occupe les espaces ou lacunes que les organes laissent entre eux, et la circulation est dite lacmuaire. En continuant a s'élever dans la série, on voit les lacunes remplacées plus ou moins complètement par des vaisseau.r à paroi propre. Chez les Annélides et quelques autres Vers, il existe même un liquide nourricier dans la cavité viscerale (liquide plasmatique) et unautre dans des vaisseaux clos (liquide himal). Sur certains points, ces vaisseaux sont contractiles, de manière à communiquer au sang un mourement régulier. Peu à peu, enfin, on voit se différencier l'unc de ees parties contractiles, sous la forme d'un organe particulier, appclé corur, qui acquiert son plus haut degré de complication ehez les Vertébrés supérieurs.

Les raisseaux qui conduisent le sang du cour dans les organes recoivent le nom d'artères; ceux qui le ramènent au cœur sont appelés veines. Entre ces deux ordres de vaisseaux, qui peuvent d'ailleurs manquer entièrement, se trouve quelquefois interposé un système de lacunes (Arthropodes); ou bien il existe un réseau de fins canalicules, les vaisseanx crpilluires (Vertébrés'. Dans ce dernier cas, on distingue, à côté dı système vasculaire sanguin, d'autres vaisseaux eontenant un liquide blane puisé dans les voies digestives (vairserux chyliferes), ou un liquide transparent recueilli dans les interstices des organes ivaissenux lymphatiques).

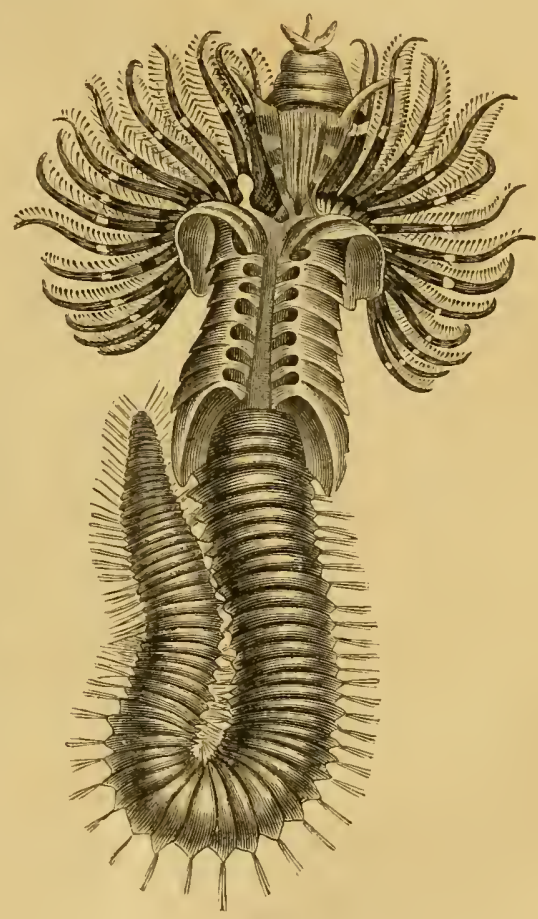

Fig. 27. - Branchies d'une Amnélide (S'rpula contortuplicata).

Appareil respiratoire. - Le sang ra porter aux tissus, avec les éléments de lcur nutrition, l'oxygène nécessaire à l'entretien de leur activité physiologique; il leur enlève d'autre part, pour les rejeter à l'extérieur, l'acide earbonique et la vapeur d'eau qui résultent des oxydations ainsi produites: conséquemment, il doit puiser sans cesse de nouvelles quantités d'oxygène dans le milieu ambiant. C'est l'ensemble de ces échanges gazeux qui constitue la respirution.

Dans les tỵpes les plus simples, c’est par la surface cutanée que s'effectue la fonction respiratoire. Du reste, la respiration. cutanép persiste assez souvent chez des animaux d'une organisation 
compliquée et munis d'un appareil respiratoire bien développé.

Dès que l'organisme se perfectionne, on voit apparaitre les traces de cet appareil, qui consiste essentiellement en une membrane perméable interposée entre le liquide nourricier et l'air, mais dont les dispositions varient suivant que la respiration est aquatique ou aérienne. La respiration aquatique s'accomplit au moyen d'expansions cutanées, parfois très divisées, dans l'intérieur desquelles circule le sang (branchies); elle utilise seulement l'oxygène de l'air dissous dans l'eau. Quant aux organes de la respiration aérienne, ils sont formés par des invaginations de la surface tégumentaire dans l'intérieur du corps. Chez les Arthropodes terrestres, ce sont des trachées, tubes ramifiés soutenus par une spirale chitineuse, et dans la lumière des-

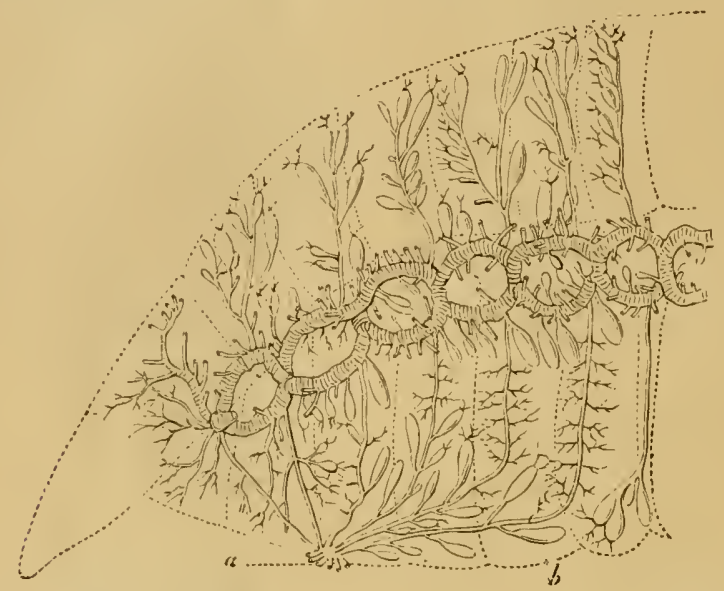

Fig. 25. Moitio droite de l'abdomen d'un Hanneton, grossie luil fois pour montrer, par sa face interne, la prenière couche de trachées. - $a$, faisceau de trachres résiculaiıes. $b$, vésicule (Siraus-Durcklseim).

quels l'air s'engage pour aller à la rencontre du fluide sanguin; chez les Vertébrés et quelques Mollusques, ce sont des poumons, système plus ou moins compliqué de poches dont les parois sont tapissées de vaisseaux.

Chaleur animale. - Les combustions qui s'effectuent dans l'organisme ont pour résultat une production de force vive, qui se transforme en partie en travail extérieur, et se manifeste d'autre part en communiquant à l'organisme une température propre : c'est là ce qu'on appelle la chaleur animale.

$0 \mathrm{r}$, cette température propre est très variable suivant les animaux. Chez les Invertébrés, ainsi que chez les Vertébrés inférieurs, y compris les Reptiles, elle est toujours très faible, de telle sorte que ces animaux sont, en définitive, soumis aux variations du milieu ambiant. C'est pourquoi on les désigne sous le nom d'animaux ì sang froid, ou mieux ì lempérahure variable. Les Oiseaux et les Mammi- 
fères produisent, au contraire, une quantité de chaleur suffisante pour que l'organisme puisse résister, dans une certaine mesure, àl'intluence des circonstances extérieures : c'est ce qui leur a valu le nom

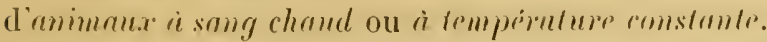

Phénomènes Iumineux. - La forè vive calorilique peutaussi se transformer en lumière et en électricité. Un grand nombre d'animaux marins sont phosphorescents : tels sont les Noctiluques, certaines Méduses, des Annélides, les Tuniciers, des Poissons, ete. 11 en est de même de diver's Insectes ou Myriapodes.

Dans certains cas, l'émission de la lumière est proroquée par une excitation quelconque; d'autres fois, elle parait soumise à l'empire de la volonté (Lampyres). Du reste, elle est presque toujours limitée à une partie restreinte du corps.

Production d'électricité. -- Sous l'influence des réactions chimiques qui s'effectuent au sein des tissus, il se manifeste, dans la plupart de ceux-ci, des courants de direction constante. Mais la produetion d'électricité est beaucoup plus manifeste chez certains Poissons, tels que les Torpilles et les Gymnotes, qui ont des appareils spéciaux pour cet usage et sont eapables de produire ì volonté de véritables décharges électriques.

Appareil sẻcréteur. - Outre l'acide carbonique et la vapeur d'eau rejetés par la respiration, il se forme dans l'économie de nombreux produits de désassimilation liquides ou solubles qui passent dans le sang, d'où ils sont expulsés par des glandes (voir p. 20): c'est à ce phénomène qu'on donne le nom de sécrétion. Il ne faut pas confondre la sécrétion avec la production d'éléments anatomiques; le testicule et l'ovaire ne sont pas, à proprement parler, des glandes, puisque celles-ci sricretrnt des humeurs, tandis que les organes dont il s'agit donurnt naissance à des éléments anatomiques (spermatozoïde. orule).

Les glandes fabriquent des produits nouveaux, plus ou moins directenient utiles à l'organisme (sécrétion proprement dite), ou bien ne servent qu'à l'élimination de produits préexistant dans le sang (sécrétion excrémentitielle ou rxcrition).

L'utilisation des produits de sécrétion peut aroir lieu dans les sens les plus divers. Sans revenir sur les glandes du tube digestif qui agisscnt sur les matières alimentaires, nous citerons pour exemples les glandes a venin des Scorpions ou des Hyménoptères, les glandes odorantes des Punaises, les glandes lacrymales, sébacées, etc., des Vertébrés supérieurs.

Les produits d'excrétion les plus importants, qui sont très riches en principes azotés, sont rejetés par les organes urinaires. On assimile d'ordinaire à ces organes les vacuoles pulsatiles des Protozoaires, ainsi que les vaisseaux aquifères des Némathelminthes, vaisseaux qui prennent leur origine dans les tissus ou la cavité du corps et communiquent 
avec l'extérieur. Chez les Annélides, les organes excréteurs (néphridies) sont des tubes pelotonnés qui s'ourrent dans la cavité du corps par des entonnoirs ciliés et se répètent par paires dans les segments successifs, d'où le nom d'organes segmentaires qui leur a été donné. Chez les Arthropodes à respiration aérienne, ce sont des appendices du tube digestif, les tubs de Malpighi (fig. 29).

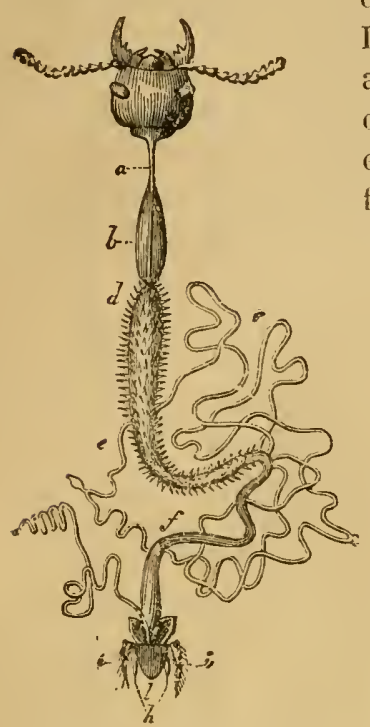

Fïg. 29. - Organes digestifs d'un Insecte. $-a$, esophage. b, jalıot. 1), ventricule cliy lifique. $f$, inteslin. $e$, lubes de Malpighi. $i$. armure copulatrice.
Les corps de Bojanus des Mollusques sont aussi des organes urinaires. Enfin, ceux-ci acquièrent leur plus haut degré d'indépendance et de complication chez les Vertébrés, où ils forment les reins.

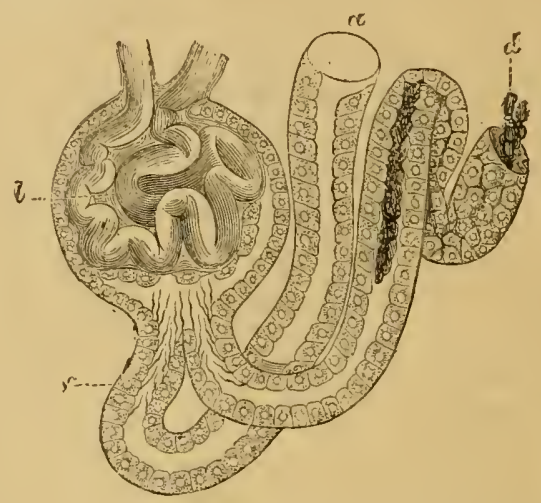

Fig. 30, - Tubes urinifires du rein dune Torlue (Testudo graca). - $a$, deux tubes formant une anse au sommet de lapuelle se trouve, en $b$. un slomérule de Maljighi. $c$, celluleipithéliales: celles qui sont situées pris du glomérule sont pourvues de cils vibratiles. $d$, concrétions urinaires (J. Isćclard,

Les produits de sécrétion ou d'excrétion renferment très sourent des leucomaines. Gautier a donné ce nom à toute une série d'alcaloïdes complexes, oxygénés, qui se forment dans les tissus vivants en pleine activité : il a voulu indiquer ainsi ( $\lambda \varepsilon^{\prime} x \omega \mu \alpha$, blanc d'ouf) que ce sont les produits basiques du dédoublement des albuminoïdes. Ces substances se forment sans cesse dans les cellules vivantes; elles s'éliminent en partie par les urines (xanthine, sarcine, guanine, carnine, créatine). On en a trouvé aussi dans les venins, dans dirers produits de sécrétions normales, etc.

A côté des leucomaïnes se placent les ptomaïnes. Selmi appelait ainsi (de $\pi \tau \tilde{\omega} \mu x$, cadavre) les alcaloïdes qui se produisent durant. la putréfaction; Gautier a étendu ce nom à tous ceux qui résultent d'une fermentation anaérobie, et à ceux qui se forment dans les tissus des animaux supérieurs lorsqu ils fonctionnent sans air ou avec une quantité insuffisante d'oxygène (cadarérine, putrescine, muscarine, etc.). 
III. ORIIANES ET FOXCTIONS DE REPRODUCTIOX.

Les fonctions que nous arons précédemment étudiées ont pour but la conservation de l'individu: la reproduction, au contraire, est destince ì assurer la conservation de l'espèce. Elle comprend un ensemble d'actes qui aboutissent à la production d'êtres nouveaux plus ou moins semblables à ceux qui leur ont donné naissance. C'est d'ailleurs cett' production même qui constitue la génération.

On a longtemps admis, et quelques physiologistes admettent cncore, que certains organismes peuvent se produire sans germes ou sans parents antérieurs; c'est là ce qu'on a appelé, par un emploi abusit des mots, la génération sponlanie (hétérogénie, archigonie, etc.) (1). Nous n'insisterons pas sur cette hypothèse, si ardemment soutenue par F. Pouchet, et à laquelle les belles expériences de Pasteur ont porté un coup dont elle ne s'est pas relevée.

Scientifiquement, on ne peut tenir compte, à l'heure actuelle, que de la génération généalogiqur ou génération proprement dite. Celle-ci offre, du reste, des modes variés. Si l'on cherche ì ramener les phénomènes qu'elle comporte à leurs éléments essentiels, on reconnait tout d'abord que le corps d'un être vivant dérive toujours, quelle que soit sa complexité, d'un corps antérieurement constitué, dont il n'est qu'une partie séparée et accrue. A son tour, ce corps détachera de si masse des parties qui constitueront les germes d'autant de corps noureaux, et ainsi de suite. Les êtres vivants se reproduisent donc comme ils sont nés, par simple dissocintion, et la reproduction se réduit à un lait de simple continuité. Or, cette continuité même entraine la conservation des propriétés de tout ordre reçues ou acquises antérieurement : la partie séparée pour former un être nouveau possède naturellement, en effet, la même forme, la mème structure et la même puissance érolutive que la masse dont elle émane; et c'est là ce qui constitue i'hérédité, (qu'on définit "le phénomène en vertu duquel les ascendants transmettent aux descendants les propriétés qui leur appartiennent à un titre quelconque ". (A. Sanson.)

On peut distinguer deux formes principales de reproduction, basées sur l'origine simple ou double de l'ètre nouveau: la reproduction monomeire ou asexuelle, et la reproduction dimerre ou sexuelle. Divers auteurs, se basant sur ce fait que la reprocluction asexuelle se réduit en somme à un phénomène de dissociation, refusent de la considérer comme un mode réel de reproduction, et lui appliquent le nom de multiplication. D’après les considérations qui précèdent, on peut juger qu'il n'y a là qu'une simple dispute de mots.

A. Reproduction monomère. - La reproduction monomire (u.óvon,

(1) II. Mitse EdWaros, Lesons sur l'anal. et la pleysiol. comp., t. VIII, p. 237, 1863. 
seul; ú́fos, partic), asexuelle ou agame repose sur ce fait qu'une portion de l'organisme peut se détacher et vivre d'une facon indépendante, comme cet organisme lui-mème. Elle s'effectue d'après trois modes différents : scission, bourgeonnement et sporulation.

$1^{0}$ La reproduction par scission ou scissiparité ne s'observe guère que chez les Protozoaires. Lorsque le corps a acquis un certain développement, il s'étrangle vers le milicu et se divise en deux fragments, dont chacun forme un individu distinct. Dans certains cas, la

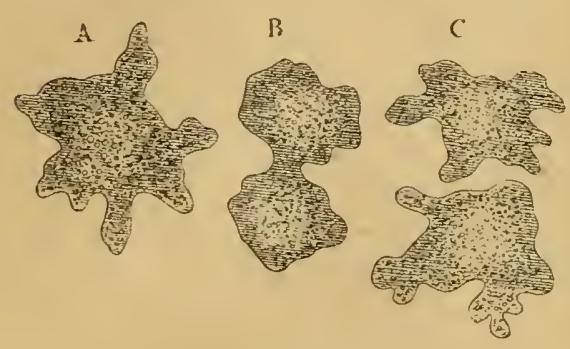

Fis. 31. - Reproduction par segmentation l'ume Mlonère d'eau douce (Protamatr primitiva), d'ajrès Hipckel. - A, Monère entière. $B$, la mème divisée en deux moitiés par un étranglement. C, les deur moiliés séprares el ennstiluaul des individus indéjendanls.

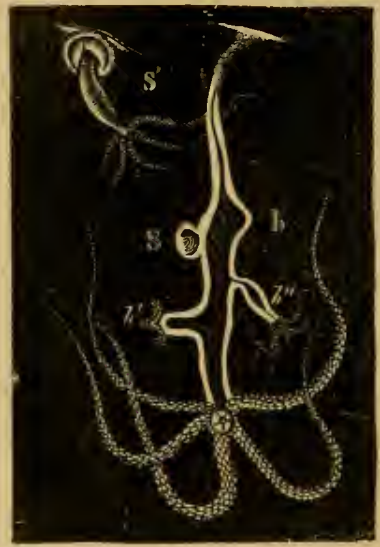

Fig. 32. - Reproduction par gemmiparilé . Hydre d'eau douce (Carlet). - $b, b^{\prime}, b^{\prime \prime}$ : lourgeons i divers degrés de développemeul.s', lourgeon complètement séparé de la mère et pourant virre indépendant. \&, point qui correspond au dótachement de ce bourgeou.

séparation n'est pas complète, et les individus noureaux restent unis en colonies.

$2^{\circ}$ La gemmiparité ou reproduction par bourgcomnement ne diffère pas essentiellement de la scissiparité : elle consiste dans la formation, sur

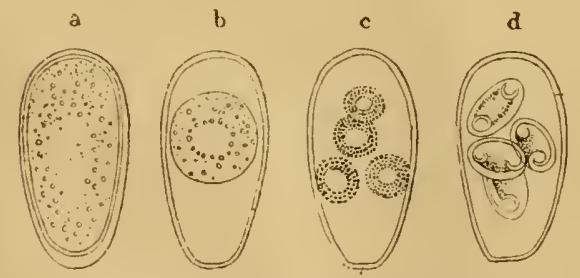

Hig. 33. - Sporulation de la Coccidie oviforme, d'apres Leuckarl. - $a, b$, Coccidies enkyslées des canaux liliaires du Lapin: en $b$, le proloplasma esl ramassé au renlre du kyste. e, 1 , formation des spores apris sijour dans l'eau. un point limité de la surface du corps, d'une excroissance ou bourgeon qui s'accroît peu à peu et se transforme en un organisme semblable à celui qui lui a donné naissance, puis se détache pour virre à part. Si les bourgeons ne se séparent pas de l'organisme générateur, il se forme une colonie animale : tel est le cas du Corail.

$3^{\circ}$ La sporulation ou reproduction par spores n'est, à proprement parler, qu'une gemmiparité interne. On ne l'observe du reste, dans le règne animal, que chez les Protozoaires. Il se produit, dans l'intérieur de la cellule qui constitue ces êtres, des collules germinatives ou spores 
qui deviennent autant d'individus nouveaux, soit sur place, soit après être sorties du corps. Les Spmozamires empruntent leur nom à ce modo le reproduction.

B. Reproduction dimère : sexualité. - La sporulation, comme les autres modes de reproduction monomère, représente toujours, en somme, une continuation directe. Mais elle conduit assez facilement ¿̀ une seconde forme de reprorluction qui s'observe chez la plupart des animaux, et clans laquelle on coustate au contraire un point d'arrêt. Là encore, cependant, c'est d'une simple dissociation que provieunent les cellules reproductrices; mais celles-ci, prises séparément, ne suffisent plus pour mener i bien l'eurre de la reproduction : isolées, elles seraient destinées à périr. Ce ne sont dore plus des spores. On leur donne le nom de gamies (үx́urs, mariage), car pour être capables de développement ultérieur, il faut qu'elles s'associent deux à deux et se combinent d'une facon plus ou moins complète. Le produit de cette fusion ou conjugaison de deux cellules en une seule est ce que les hotanistes appellent un ouf. Lorigine de

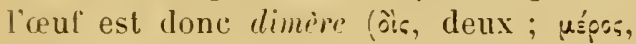
partie), contrairement à ce qu'on a vu pour la spore.

Le cas le plus simple que puisse offrir une telle union est celui où les gamètes sont semblables et se comportent de la mème manière. On dit alors que la conjugaison est égale, ou qu'il y a isogamie (Rhizopodes, Infusoires).

Mais, le plus souvent, les deux gamètes diffèrent profondément l'un de l'autre : l'un d'eux, généralement assez volumineux par suite de l'accumulation de matériaux

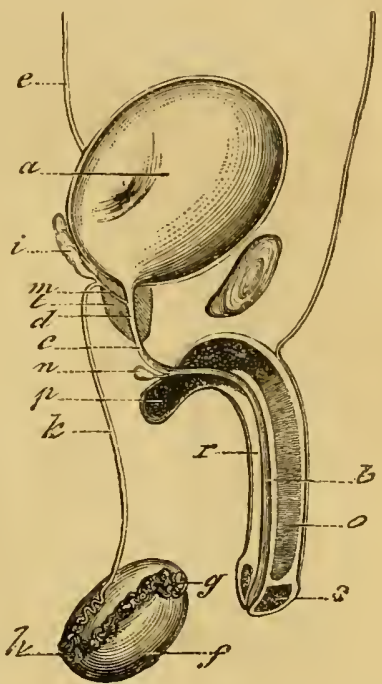

Fig. 34. - Schéma de l'appareil génilal ile l'Homme (J. Béclard). - $\alpha$, vessie. b. portion spongieuse de lurètre. $c$. portion membrancuse de l'urètre. $d$, portion prostatique de l'urètre. $p$, uretère. $f$, lesticule. $g$, têle de l'ópididyme. $h$, queur de l'épididyme. $k$, canal déférent. $i$, vésicule séminale. $o$, corps eaverneux de la verge. $p$, bulbe de l'urètre. $s$, corps caverneus du gland. $t$, prostale. de réserve, demeure immobile : c'est l'élément fonclle ou ovule; l'autre, plus petit et agile, est apte à se porter à sa rencontre : c'est l'rlément míle ou spermatozoüde. Ainsi apparait la sexualité, et cette conjugaison hautement différenciée est ce qu'on nomme la fécondation.

Chez quelques animaux inférieurs, comme les Polypes, les éléments sexués prennent naissance sur certains points non localisés de la paroi du corps. Mais, en général, ils se forment dans des organes spéciaux qu'on distingue en testicules et vvaires, suivant qu'ils produisent le sperme ou les ovules. A l'etat le plus simple, ces organes seuls constituent l'appareil sexuel, et leurs produits tombent dans la 
cavité générale du corps ou sont rejetés à l'extérieur (Échinodermes). Puis, on voit survenir graduellement diverses complications qui consistent surtout en appendices et en appareils vecteurs, destinés à protéger les éléments sexuels et à favoriser la fécondation.

Ainsi, les testicules sont munis de conduits excréteurs ou canaux déférents, qui offrent souvent sur leur trajet une dilatation faisant office de réservoir et nommée résicule séminale. Des glandes mêlent leur sécrétion au sperme, ou lui forment des sortes d'enveloppes pro-

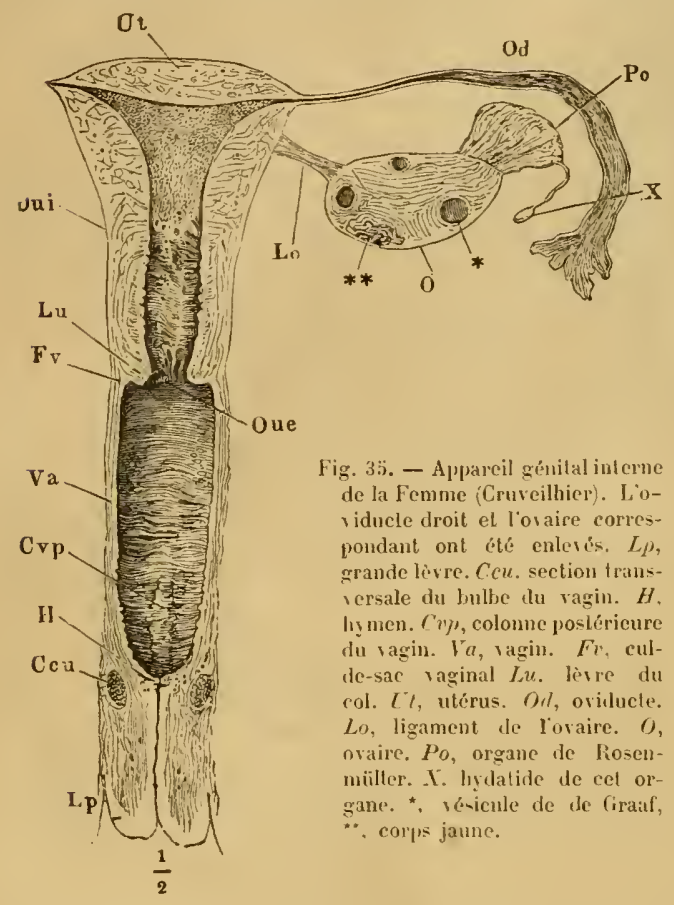
tectrices (spermatophores). Enfin, des organes spéciaux sont chargéde faciliter l'intromission du sperme dans les organes femelles : ce sont les arganes copulateur's.

Du còté de l'appareil femelle, on trouve de même des conduits vecteurs, les oviductes, qui souvent se dilatent en un point pour constituer une chambre incubatrice ou un utrirus, où l'ovule puisse accomplir son déreloppement. Des glandes annexes fournissent d'ailleurs à cet ovule des matériaux divers, et la portion terminale des oviductes offre des dispositions variables, propres à assurer le dépôt du sperme et la fécondation.

Chez un grand nombre danimaux, l'ovaire et le testicule sont réunis sur le même individu; on donne à cet état le nom d'hermurphrodisme, et les animaux qui le présentent sont appelés hermaphrodites ou monoïques(ழ̣). En thèse générale, un seul individu suffit alors à produire de nouveaux êtres, par autofécondation, et l'hermaphrodisme est qualifié de vrai ou de complet (Huitre). Mais il arrive souvent aussi qu'un individu hermaphrodite est incapable de se féconder lui-même, et a besoin du concours d'un autre: e'est lì ce qu'on a appelé l'hermaphrodisme insuffisturt (Colimaçons, Limnées).

Lorsque les organes sexuels sont répartis entre deux individus distincts, les animaux sont dits unisexués ou divïques. Cet état, qui 
se rencontre surtout chez les formes supérieures, parait ètre toujour's secondaire : dans le principe, l'embryon possède ì la fois les organes màles et femelles; mais le dévoloppement des uns s'accompagne normalement de l'atrophie des autres, de telle sorte que certains individus sont chargés de produire le sperme: ce sont les males $\left(\sigma^{x}\right)$, tandis que les autres donnent naissance aux orules: ce sont les femelles (q).

Le ròle lout diftérent quiont ì remplir ces deux ordres d'individus entraine des modilications variées le lorganisme. Le màle, par exemple, doit chercher à captiver la femelle, à s'en rendre maître, et il offre effectivement, dans beaucoup de cas, des couleurs brillantes, une voix sonore, une grande puissance, etc. La femelle, au contraire, est en général plus faible, moins agile, de teinte plus sombre. Ciest à es caractères, qui n’ont pas de rapports immédiats avec la reproduction, que Hunter a donné le nom de caraclères sexuels secondaires.

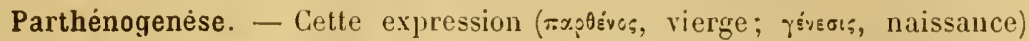
s'applique à un singulier plıénomène caractérisé par ce fait, qu'un ètre né d'un ovule donne naissance à d'aulres ètres sans avoir été fécondé.

La partlıénogenèse, encore appelée reproduction virginale, a été observée en premier lieu par Bonnet sur les Pucerons. Comme nous le verrons plus loin, en effet, les Aphis nés au printemps d'un œuf qui a passé l'hiver sont aptères et vivipares: tous sont pourvus d'un organe analogue à un ovaire (pseudovaire), mais sans réceptacle séminal, et donnent naissance, en dehors de tout accouplement, à des individus égalenent vivipares. Une série de générations semblables se succèdent pendant l'été, et à l'automne seulement, on voit apparaitre des màles et des femelles ailés: l'accouplement s'effectue alors, et les femelles pondent des cufs d'où sortiront, au printemps suivant, des individus aptères et vivipares. Chez les Abeilles, les œufs que pond la reine domnent toujours des màles lorsqu'ils n'ont pas été fécondés.

La parthénogenèse peut ètre envisagée de différentes manières : on peut y roir un simple phénomène de sporulation et la rapporter par conséquent a la reproduction asexuelle; ou bien on peut regarder les individus parthénogenésiques comme des vierges fécondes et leurs cellules reproductrices (pseudova) comme résultant d'une réelle oviparité. Il n'est guère possible d'interpréter le cas de l'Abeille que dans ce dernier sens.

Lorsçue la parthénogenèse se rencontre cliez des larves, on lui donne le nom de pédogenèse: un remarquable exemple de ce genre est fourni par certaines Cécidomyies (Miustor).

\section{S. - DÉVELOPPEMENT DES ANIMAUX.}

On entend par décrloppement d'un organisme son évolution complète depuis le moment oì il commence à s'accroitre jusqu'à sa mort.

Lorsque cel organisme est le résultat de la reproduction sexuelle, son développement commence aussitùt après la fécondation et com- 
prend deux phases assez distinctes : l'une qui s'accomplit à l'intérieur de l'œuf (déceloppement embryomnaire), l'autre postérieure à l'éclosion (développement postembryonnaire).

Avant d'étudier les phénomènes qui s'y rapportent, nous devons jeter un coup d'œil sur les éléments, générateurs el chercher à connaître comment s'effectue la fécondation.

\section{OHLF et sperme. FÉconiditon.}

Constitution de l'œuf. - Chez tous les animaux, l'orule est représenté, dans le principe, par une cellule nue, c’est-à-dire par une petite masse proloplasmique (vitellus) contenant un noyau (vésicule

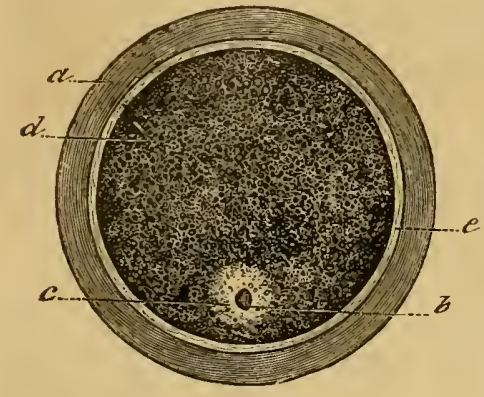

Fig. 36. - Ovule de la Femme, d'après C.h. Robin. - ", membrane vitelline. ", vitellus on janne. $c$, vésicule germinative ou de Purkinje. $b$, lache germinative on de Wagner. $e$, espace entre le jaune et la membrane vitelline. germinative) lequel montre lui-même au moins un nucléole (tache germimative).

Mais il se complique le plus souvent par l'adjonction de parties nouvelles. C'est ainsi que le vitellus s'entoure d'une enreloppe transparente (membrane vitelline), et que parfois le follicule ovarien le recouvre aussi d'une couche protectrice (chorion), sans parler de divers produits et membranes secondaires comme en présente l'œuf des Oiseaux, par exemple. On a l'habitude de donner le nom d'ouf à l'ensemble formé par l'ovule et ces parties accessoires : à la rigueur, cependant, ce nom devrait être réservé, comme on l'a vu plus haut, à l'orule fécondé, c'est-à-dire à la celllule résultant de l'union des deux éléments mâle et femelle.

A còté de la vésicule germinative, on a reconnu l'existence fréquente, au sein de l'ovule, d'un autre corps arrondi auquel H. Milne Edwards a donné le nom de vésicule embryogène. D'après Balbiani, qui l'a surtout étudié, ce serait une véritable cellule, née par bourgeonnement d'une des cellules épithéliales qui entourent l'ovule; elle jouerait le ròle d'un élément màle primordial, en exerçant sur celui-ci une préfécondation lui permettant d'accomplir les premières phases de son évolution, et mème de poursuivre dans certains cas (parthénogenèse) son entier développement.

La coque de l'œuf, formée par les membranes orulaires primaires, est quelquefois épaisse et imperméable; elle offre alors un ou plusieurs orifices (micropyles) servant à la pénétration du spermatozoïde.

Quant au vitellus, il se compose de deux parties: $1^{\circ}$ le vitellus de formation ou protoplasme, employé presque entièrement ì la forma- 


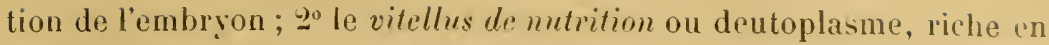
granulations alhuminoïdes et graisseuses, et destiné a fournir à cet embryon des éléments nutritifs. D’après le mode de zroupement de ces deux parties, on distingue trois sortes d'oufs:

$1^{\circ}$ Les auf's alécithes, qui ne renferment pas de vitellus nutritif ou lout au moins n'en possèdent qu'une tris faible quantiti, distribuée dine facon uniforme dans le vitellus formatif. Tels sont les ceufs des Éponges, des Méduses, de l'Amphioxus ;

go Les ouls trinlecithes, dans lesquels chacun des deux vitellus tend a occuper un pôle diflérent. On rencontre ce type chez. les Vers, les Mollusques et les Vertébrés

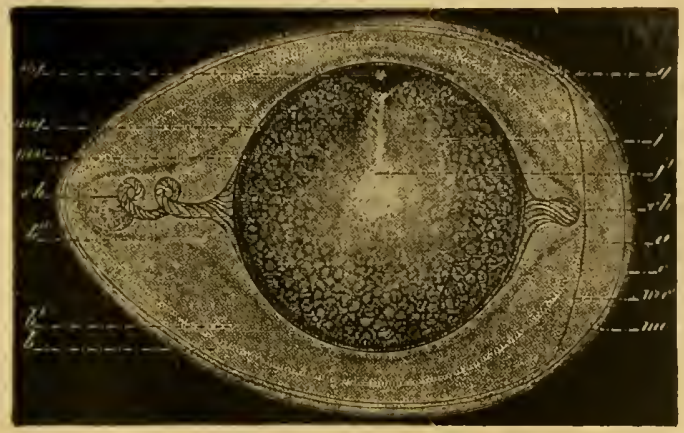

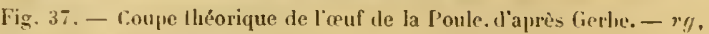
place de lit vésieule germinative, qui a disparu avant la ponte. $y$. cicalricule. $m g$, couche granuleuse très mince doublant la membrau. vilelline $m v . j$, jaune. $j^{\prime}$, latebra. $c h$, chalazes. $h, b^{\prime}, b^{\prime \prime}$. couches evlerue, moyemne et interne du blane d'ienf. mé, fenillet inleme de la membrane contuillière. me, feuillet exlerne, $a$, chamber air. r. coquillr.

(non compris l'Amphioxus). L'ouf des Mammifères, qui parait alécithe à première vue, s’y rattache d'une facon certaine, comme le montru l'inégalité de sa segmentation:

$3^{0}$ Les ceufs centrolécithes, dont le vitellus nutritif occupe le centre et se trouve entouré complètement par le vitellus formatif. Ces ceufs sont caractéristiques des Arthropoles.

Spermatozoïdes. - Les éléments mâles ou spermntosöides sont représentés par des filaments microscopiques flottant en abondance dans une petite quantité de liquide: la masse visqueuse ainsi formée recoit le nom de sperme. Chez la plupart des animaux, ces éléments offrent une partie rentlée ou tête et un appendice filiforme ou quene:

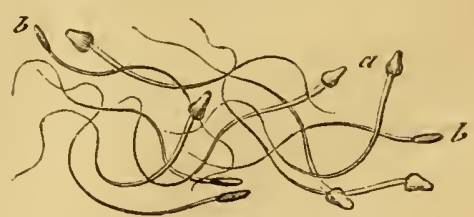

Fig. 3я. ... Spermalozoides de J'Homme, - a. us do face. $b$, ile profil. cependant, ils peurent s'éloigner beaucoup de cette conformation typique.

Fécondation. - La connaissance des phénomènes intimes de li fécondation est de date toute récente; elle remonte seulement aux recherches de Fol, Hertwig, Erl. van Beneden, elc. Arant d'en faire l'étude sommaire, nous jetterons un coup d'oil sur la maturation de l'œuf.

A. Maturation de l'ouf. - L'orule complètement formi n'est. 
pas apte à être lécondé : son noyau (vésicule germinative) doit d'abord subir des divisions successives qui aloutiront à la formation et à l'expulsion de globules polaires (ordinairement deux). Chez l'Ascaris megalocephala du Cheval, que l'on peut prendre pour type, la cellule ovulaire possède un noyau dont les éléments chromatiques (chromosomes) sont au nombre de quatre (1). Après une période de repos, ces éléments se dédoublent, puis se disposent en une plaque équatoriale comprenant de chaque côté quatre segments réunis par un fuseau (fig. 39, A). Cet ensemble se porte bientôt à la périphérie de l'ovule, et les quatre chromosomes les plus voisins de la surface s'échappent avec une portion du fuseau (B): c'est le premier globule polaire. Aussitôt après, sans aucune phase de repos intermédiaire, les
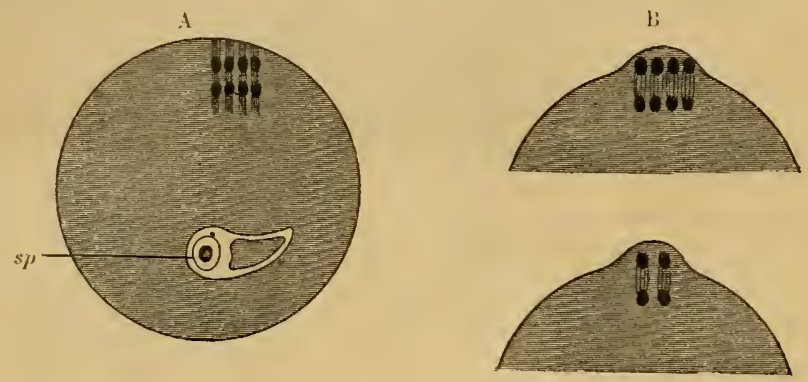

C.

Fig. 39. - Formation des globules polaires chez l'dscaris megalocpyhula. - sp, spermatozoïde.

quatre chromosomes restants se placent deux à deux sur un noureau fuseau $(\mathrm{C})$, et les deux plus voisins de la surface sont rejetés de la même manière: deuxième globule polaire. Il ne reste plus alors dans l'ovule qu'un noyau à deux chromosomes, c'est-à-dire un demi-noyau: c'est ce qui constitue le pronucleus femelle. A ce moment, l'ovule est mûr.

Le développement des spermatozoïdes de l'Asearis est tout à fait analogue à celui de l'ovule. Les cellules mères qui leur donnent naissance ont quatre chromosomes; clles se divisent deux fois coup sur coup, sans période de repos, donnant ainsi quatre cellules filles dont chacune deviendra un spermatozoïde, de sorte que celui-ci n'a plus que deux chromosomes.

B. Fécondation. - L'ovule de l'Ascaride est entouré d'une membrane qui manque cependant à l'un des pôles. Le spermatozoïde pénètre à ce niveau, puis s'enfonce dans le vitellus, pendant que la membrane s'étend pour obturer le pôle d'imprégnation, et que les globules polaires prennent naissance. Ceux-ci une fois expulsés, le spermatozoïde se transforme en un promucleus mále, constitué par son noyau et le protoplasma voisin, le reste de sa substance diffusant

(1) On distingue a cet égard deux variétés d'-1scaris: une var. univalens, don le noyau n'a que deux éléments chromatiques, et une var. bivalens, à quatre chromosomes; c'est cette dernière dont il est ici question. 
dans le vitellus. Ce pronucléus mâle, comme d'ailleurs le pronucléus femelle, est accompagné d'un centrosome (spermocentre et ovocentre).

Bientît tous deux s'accroissent; puis leurs éléments chromatiques subissent diverses modifications aboutissant, dans chacun, à la formation de deux anses chromatiques. Ceci fait, ils s'arancent it la rencontre l'un de l'autre, accompagnés de leur centrosome, el dès que leur rapprochement est opéré, on peut dire que la fécondation est opérée.

On voit alors l'ovocentre et le spermocentre se dédoubler chacun en deux corpuscules; puis les deux demi-centres de chaque groupe décrivent en sens inverse un quart de tour (quadrille des centres, H. Fol) et se fusionnent avec le demi-centre opposé: il se pro-

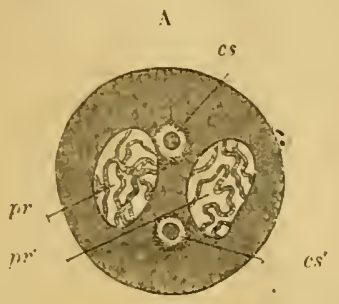

(.)

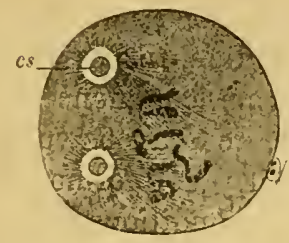

13

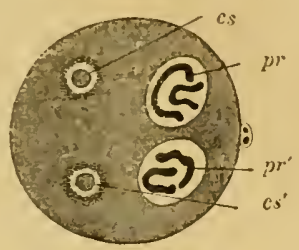

(1)

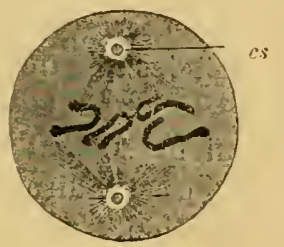

Fig. 40. - Formation des deux pronucléus et de la plaque équatoriale dans l'ouf de l'Ascaris megalocephala, d'après Boveri. - $p r, p r^{\prime \prime}$, pronucléus. $c s, c s^{\prime}$, centrosomes.

duit ainsi deux centres noureaux, les astrocentres, comprenant l'un comme l'autre un demi-ovocentre et un demi-spermocentre. Ces astrocentres correspondent aux deux extrémités du futur fuseau de division. Les quatre anses chromatiques, obéissant à leur attraction, ne tardent pas en effet à se disposer en une plaque équatoriale, et se dédoublent selon le procédé habituel de la karyokinèse; enfin, les deux anses secondaires se rendent en sens inverse aux deux pôles $d u$ fuseau, pour former les éléments chromatiques des deux premières cellules embryonnaires. De sorte que ces deux cellules comprennent chacune un noyau provenant de deux anses mâles et de deux anses femelles, et contenant par suite exactement la meme quentite de substance chromatique matemelle et paternelle.

Ainsi, malgré l'inégalité de volume du spermatozoïde et de l'orule, il n’y a pas dans l'œuf une prépondérance réelle de celui-ci. Dans certains cas, plusieurs spermatozoïdes peuvent pénétrer à l'intérieur 
de l'ovule; il n'y a pas davantage alors prédominance de l'élément mâle : ou bien, en effet, il se forme plusieurs pronucleus mâles qui s'unissent à l'unique pronucléus femelle, et le développement est monstrueux; ou bien il se constitue un seul pronucléus, et la substance des spermatozoïdes est absorbée par le vitellus, augmentant ainsi la quantité des matériaux nutritifs.

La connaissance de ces faits nous per'met de comprendre l'hérédité dans les cas de fécondation tout aussi bien que dans les cas de reproduction asexuelle. De plus, elle peut nous rendre compte de la plupart des faits de parthénogenèse. En effet, chez les Rotifères, par exemple, il existe des œufs d'hiver qui ont besoin d'être fécondés, et des œufs d'été parthénogenésiques. Or, les premiers éliminent deux globules polaires, tandis que les seconds I'en rejettent qu'un seul. Puisque nous avons vu que le second globule contient le même nombre d'éléments chromatiques que le spermatozoìde, on peut concevoir que sa non-expulsion ait la valeur d'une fécondation. C'est. dans ce cas que se trouvent encore les Pucerons, Phylloxéras, etc. Par contre, chez les Abeilles, le développement parthénogenésique des mâles est précédé de l'expulsion de deux globules polaires, et ce cas particulier n'a pas encore recu d'explication satisfaisante.

\section{DÉveloppement de l'embryon. EmrRyogénie.}

Segmentation. - La segmentation de l'œuf suit immédiatement la fécondation toutes les fois que les conditions nécessaires au développement sont réalisées. Elle peut même commencer parfois sans fécondation préalable. Chez l'Ascaride, nous avons vu qu'elle se produisait d'emblée, c'est-à-dire sans qu'il y eût formation réelle d'un noyau de segmentation. D'autres fois, les conditions du développement ne sont réunies que d'une façon tardive, et il y a par conséquent une période de repos: tel est le cas de l'œuf d'hiver du Phylloxéra, de l'ouf des Oiseaux, etc., dont l'évolution exige une température déterminée.

Le vitellus, suivant les divisions successives des noyaux, ne tarde pas à présenter à sa surface des sillons qui sont la marque extérieure

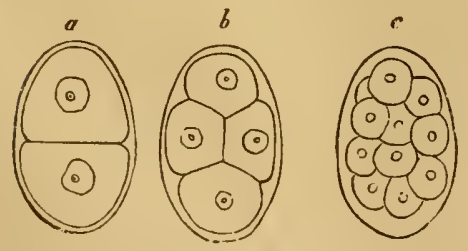

Fig. 41. - Segmentation holoblastique régulière. - $a$, deux blaslomères. $b$, quatre. $c$, morula. de la segmentation. En définitive, l'œuf se divise en un certain nombre de cellules ou blastomères, encore appelées sphères de segmentation.

Il faut cependant remarquer que la segmentation ne s'effectue pas toujours dans les mêmes conditions, et, à cet égard, on distingue deux sortes d'œufs : $1^{\circ}$ les cufs holoblastiques (ónos, entier, $\beta \lambda \dot{x} \sigma \tau r_{1}$, germe), dont la segmentation est totale, c'est-à-dire portant sur le vitellus tout entier qui se partage peu à peu en $2,4,8,16$, etc., blastomères; on la dit 
d'ailleurs ígal' ou régulière quand tous les blastomères ont les mêmes dimensions, et imigale quand un certain nombre d'entre eux se divisent plus lentement et eonservent un rolume plus considerable; $2^{\circ}$ les (eufs miroblastiqu's (ápos, partie), à segmentation partielle, ne portant que sur le vitellus formatif, mais tantôt encore régulière, tantôt irrégulière.

Dans les wufs alicithes, la segmentation est toujours totale et régulière.

Dans les wufs tilotécithes, elle est totale (Mammifères) ou partielle (Oiseaux), mais toujours inegale.

Enfin, dans les cuufs centrolécithes, elle est toujours partielle et périphérique, mais tantît régulière, tantôt irrégulière.

Blastoderme. - La segmentation totale régulière et les formes qui s'en rapprochent aboutissent à un groupement des cellules embryonnaires pouvant se ramener à deux types essentiels : un amas múriforme ou sphère pleine (morulu), et une sphère creuse (blastula), ees
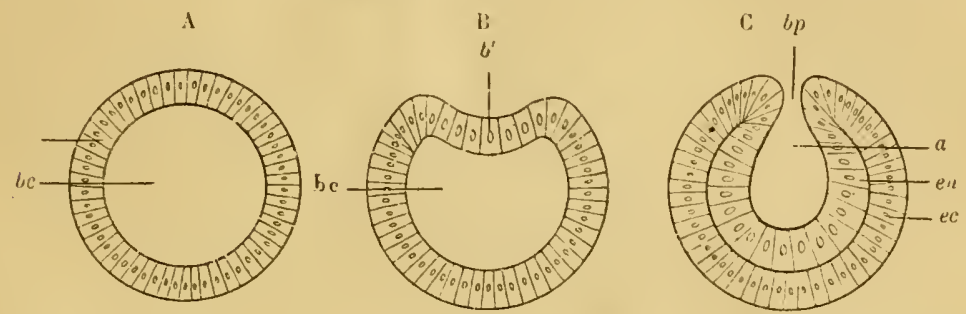

Fig. 42, - Formation d'une gastrula. - $A$, blastula. B, inragination ou embolie. C. gaslrula. - $b$, blasloderme. $b^{\prime}$, région qui sinvagine. $b c$, hlastocuele. $b p$, blastopore. $a$, arehentíron. en, endodermé. re, ectoderme.

types étant reliés entre eux par une série d'états intermédiaires, et le seeond dérivant parfois du premier.

La cavité de la blastulre s'appelle cavité de segmentation, cavité de von. Baer, ou blastoccele ; la paroi est formée de cellules d'abord toutes semblables entre elles. Mais bientit la sphère se déprime en un point, et la partie correspondante s'invagine dans le reste juqu'à disparition plus ou moins complète de la cavité. L'embryon se présente alors sous la forme d'un double sac; on a donné à cet état le nom de gastrula. La paroi de la gastrula constitue le blastoderme; son feuillet interne, dont les cellules se sont différenciées, s’appelle endoderme, et son feuillet externe, ectoderme. La cavité centrale limitée par l'endoderme forme l'intestin primitif ou archenteron; son orifice est la bouche primitive ou blastopore (il ne devient pas nécessairement la bouche définitive). Entre les deux feuillets blastodermiques primitifs, il s'en forme bientot un troisième, le mésoderme, dont l'origine est très variable, et qui souvent se dédouble en deux lames, l'une s'unissant à l'ectoderme (somatopleure), l'autre à l'entoderme (splanchnopleure): l'espace compris entre ces deux lames est le calome (cavité générale). - La forme gas- 
trula, rare chez les Colentérés, est très répandue dans les autres groupes: Échinodermes, Nématodes, Tuniciers, Amphioxus, etc.

Chez quelques Éponges et la plupart des Polypes, la segmentation donne naissance à une sphère pleine ou morulı, et ce sont sinıplement les cellules internes qui se différencient pour former l'endoderme et le mésoderme; puis une cavité apparaît au centre de la sphère, qui devient ainsi une planula.

Enfin, diverses autres variations peuvent se présenter, sur lesquelles il nous paraît inutile d'insister.

L'apparition des feuillets blastodermiques est le point de départ de la division du travail dans l'organisme. L'ectoderme, en effet, reçoit les excitations extérieures; l'endoderme se met en rapport avec les substances alimentaires introduites dans l'intestin primitif; le mésoderme ne recoit que des excitations indirectes transmises par les autres feuillets, auxquels il sert d'intermédiaire. Aussi ces couches se différencient-elles en divers sens, de manière à produire chacune, au cours du développement, un ordre d'organes assez bien déterminé. Ainsi, l'ectoderme (feuillet sensoriel cutané) forme l'épiderme, le système nerveux central et les organes des sens. L'endoderme (feuillet intestino-glandulaire) produit le revêtement épithélial du tube digestif et de ses glandes annexes. Enfin le mésoderme donne les muscles, les vaisseaux, les tissus conjonctifs, etc.

G'est en général à partir du stade de bifoliation du blastoderme que l'embryon se développe d'après le type radié ou bilatéral; puis il prend successivement, selon la remarque de von Baer, la forme de l'embranchement, de la classe, de l'ordre... enfin de l'espèce à laquelle il appartient. Nous n'entrerons pas dans le détail de ces transformations, qui seront étudiées plus fructueusement dans la partie spéciale de cet ouvrage.

Oviparité et viviparité. - On appelle ovipares les animaux qui pondent des oufs et vivipares ceux qui mettent au monde des petits vivants. En réalité, il n'existe pas de différences essentielles entre ces deux groupes, qui sont reliés entre eux par gradations insensibles. Il arrire, en effet, que l'œuf se trouve expulsé aussitôt après avoir été fécondé et arant même d'avoir commencé son évolution (Ascarides). D'autres fois, il est pondu après avoir subi les premières phases de la segmentation (Sclérostominès) ou même après le développement complet de l'embryon (Strongle paradoxal). Enfin, il chemine parfois si lentement dans les canaux vecteurs les organes femelles, que l'éclosion a lieu dans ce trajet, el que le jeune naît à l'état de liberté (Trichine). Ce jeune individu peut même séjourner assez longtemps dans l'organisme maternel pour's'y accroître e! se trouver prêt à subir, aussitôt après la ponte, de nouvelles transformations (Mélophage). Ajoutons qu'il est possible de rendre vivipares des animaux normalement oripares: ainsi, en conservant une Cou- 
leuvre à collier dans une cage dont le fond ne contient pas de sable, cette Couleuvre garde ses oufs jusqu'à éclosion.

Cependant, on a souvent entendu la viviparité dans un sens plus restreint que celui que nous venons d'indiquer. Pour beaucoup d'auteurs, les animaux dont les petits éclosent simplement dans le corps de la mère méritent la qualification d'ovovivipares, et les vivipares proprement dits sont ceux chez lesquels il s'établit une adhérence et des échanges nutritil's entre l'embryon et la mère. Les Salpes et beaucoup de Requins offrent une communication de ce genre; mais le fait ne devient général que chez les Mammifères, où l'ưuf fécondé, se détachant de l'ovaire, est reçu dans la matrice, à la paroi de laquelle il s'attache au moyen d'un organe particulier, le placentu, et d'où l'embryon tire les éléments de sa nutrition.

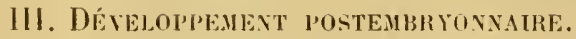

Après une série de transformations accomplies à l'intérieur de l'œuf, l'embryon se trouve mis en liberté. Mais ces transformations sont très variables quant à leur importance et à leur durée, de telle sorte que le nouveau-né est loin d'être, dans les différents groupes d'animaux, à la même phase de son évolution. Les variations dépendent principalement de la quantité des matières nutritives dont peut disposer l'embryon.

Développement direct. - Chez les Oiseaux, par exemple, où le vitellus nutritif est très développé; chez les Mammifères, où l'organisme maternel supplée à l'insuffisance du vitellus par un apport, constant de substances propres à la nutrition, le développement de l'embryon est poussé relativement loin, et le nouveau-né offre une grande ressemblance avec l'individu sexué dont il procède. Pour arriver à l'état adulte, il ne lui reste qu’à s'accroìtre et à attendre le perfectionnement de ses organes génitaux. Le développement est dit alors direct.

Métamorphose. - Lorsque l'embryon, au contraire, ne peut disposer que d'une faible quantité de materiaux nutritifs, il se trouve mis en liberté de bonne heure et à un état de développement peu avancé. Cet être naissant, dont les caractères morphologiques sont si différents de ceux de l'adulte, reçoit le nom de larve. Il ne peut parfaire directement son organisation, mais doit subir, pour arriver à la forme d'animal sexué, de nouvelles modifications plus ou moins profondes, du mème ordre que celles accomplies dans l'œuf': c'est à ces modifications qu'on donne le nom de métamorphoses. Les Batraciens et les Insectes nous en lournissent de nombreux exemples.

Gẻnération alternante. - Chez certains animaux, l'érolution de l'espèce, au lieu d'être limitée au développement d'un seul individu, s’étend à une succession de générations dérivées les unes des autres. 
Lorsqu'un individu issu d'un ceuf, c'est-à-dire produit par génération sexuelle, est eapable de donner naissance à un ou à plusieurs autres individus par génération asexuelle, on donne à ce fait physio-

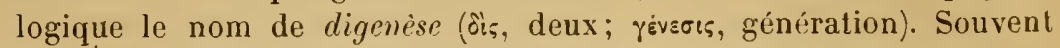
alors, ce n'est qu'après une succession plus ou moins longue d'individus asexués qu'apparaissent de nouveaux individus sexués.

Le poète Chamisso est le premier qui ait constaté des faits de cet ordre: ses observations (1819) araient porté sur des Salpes, organismes pélagiens du groupe des Tuniciers.

Van Beneden distingue deux sortes de digenèse $\mathbf{1}^{\circ}$ la digenèse homogone (jù̀;, semblable; үóvos, engendrement), dans laquelle l'individu issu de l'œuf et ceux produits par bourgeonnement sont semblables (Salpes, Bryozoaires, Naïs, Hydres, etc.); $2^{\circ}$ la digenèse hétérogone: (हैzspos, autre), caractérisée par ce fait que les individus appartenant à la génération ou aux générations asexuées sont différents des indi-

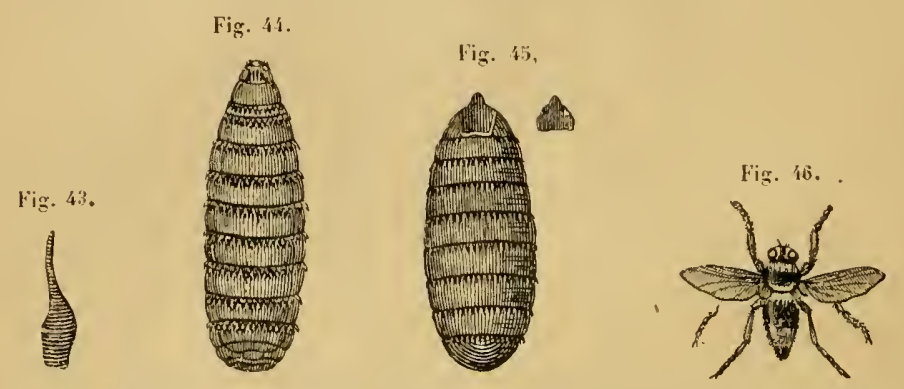

Fig. 43 à 46. - Métamorphoses d'un Insecte, riEstre hémorroïdal (Gastrophilus himorrhoidulis). - Fig. 43: cuf. - Fig. 44: larve. - Fig. 43: pupe. - Fig. 46: inseele parfait (Delafond).

vidus sexués dont ils sont issus ou qu'ils sont destinés à reproduire (Méduses, Cestodes, Trématodes, etc.).

La digenèse hétérogone est plus connue sous le nom de génération alternante, qui lui a été appliqué par Steenstrup dès 1842. C'est à cet auteur qu'on doit d'ailleurs les termes employés encore par certains naturalistes pour désigner les diverses individualités qui se succèdent dans cette érolution complexe. Pour lui, les individus sortis de l'œuf sont des nourrices (Ammen) lorsqu'ils sont appelés à reproduire directement la forme sexuée; quand, au contraire, deux générations d'êtres agames s'interposent entre les individus sexués, la première, issue de l'œuf, recoit le nom de grand'nourrice (Grossamme), et la seconde celui de nourice proprement dite (Amme).

En France, cette nomenclature a été généralement peu suivie, et lit plupart des naturalistes ont adopté celle de Van Beneden. Le savant professeur de Louvain appelle scolex la larve agame qui sort de l'œuf, et, dans le cas où deux formes agames se succèdent, la première est dite proto-scolex, la seconde deuto-scolex. Il donne le nom de strobili. à l'état ultérieur dans lequel les individus produits par le bour- 
geonnement du deuto-scolex demeurent unis entre eux et acquièrent leurs organes reproducteurs. Enfin il nomme proglottis ces éléments générateurs, sexués, qui se sont définitivement séparés. Ainsi, dans le développement des Aurélies, l’embryon eilié (fig. 17) représente le
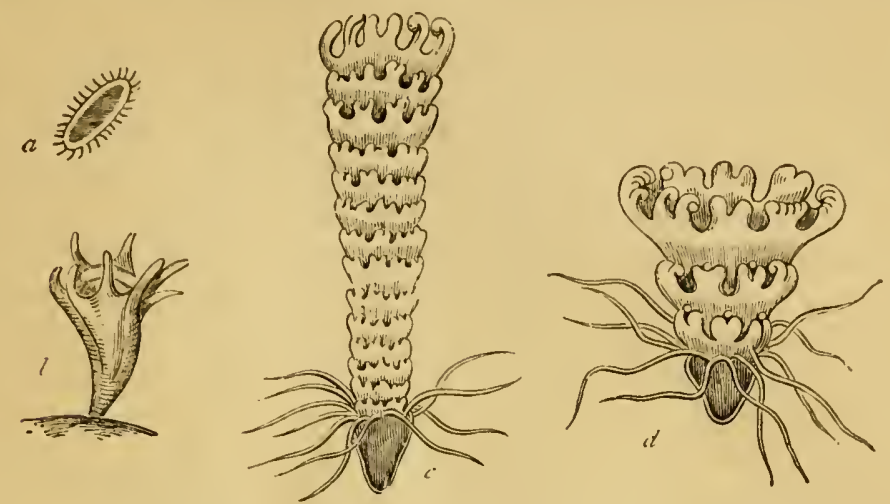

Fig. 47. - Développement d'une Méduse du genre Aurelia (Huxley). - a, embryon cilié nageant librement ou planule. $b$, forme polypoüde ou Scyphistome à luuit tentacules. $c$, la mène parveune ì l'état de strobile, c'est-à-dire divisée en segments transversaux. $d$, phase encore plus avancée, dans laquelle beaucoup de segments ou proglottis se sont déjà séparés, sous la forme d'Ëphyres, pour mener une existence indépendante et arriver ultérieurement à l'état de Héduses sexuées.

proto-scolex, la forme polypoïde ou seyphistome est un deuto-seolex, cette forme en voie de bourgeonnement est un strobile, et les Méduses libres correspondent aux proglottis.

Si l'on veut bien se rappeler la delimitation indécise que nous avons constatée entre l'organe et l'individu, on se convaincra bien vite qu'il existe un lien très étroit entre la génération dite alternante et la formation des différentes parties de l'organisme. Il est même possible d'aller plus loin, et de reconnaitre, avec Claude Bernard, que le développement de l'embryon et l'aceroissement de l'organisine tout entier peut être directement assimilé à ce phénomène. De l'œuf fécondé naissent en effet par simple multiplication, c'est-à-dire par voie agame, les innombrables générations cellulaires qui constituent d'abord le blastoderme et plus tard l'ensemble des tissus de l'organisme. Et cet organisme, avant de périr, fournit lui-même un certain nombre de cellules propres à être fécondées et à reproduire, dans les mèmes conditions, un individu nouveạu.

Ainsi comprise, la génération alternante perd évidemment toute l'importance qu'on lui avait autrefois attribuée.

Hétérogonie. - Si l'on veut s'en tenir à la manière de voir de Steenstrup et Van Beneden, il faut reconnaître que l'alternance des générations sexuelle et asexuelle est loin d'être la règle chez les animaux; beaucoup plus général, au contraire, est le cas des animaux qui ne présentent qu'un seul mode de reproduction, s'effectuantà l'aide d'œufs (monogenèse). 
Or, on peut distinguer aussi deux sortes de monogenèses : $1^{\circ}$ la monogenèse homogone, c'est-à-dire la reproduction ordinaire, dans laquelle les générations successives sont identiques; $2^{\circ}$ la monogenèse hétérogone, dans laquelle ces générations sexuées sont dissemblables et soumises à un régime différent.

La monogenèse hétérogone n'a été bien étudiée que depuis peu de temps, et en particulier par R. Leuckart, qui lui a donné le nom d'hétérogonie. Elle est de règle dans une famille de Nématodes que nous étudierons sous le nom d'Angiostomidés ou Rhabdonémidés. Citons-en ici un seul exemple. L'Angiostoma nigrovenosum vit en parasite dans les poumons des Grenouilles et des Crapauds. Tous les individus ont l'aspect de femelles, mais contiennent des spermatozoïdes, qui se sont formés avant les ovules dans les tubes génitaux. Les embryons, qui éclosent dans les utérus de ces Ver's, passent dans l'intestin des Batraciens et sont expulsés arec les excréments dans la terre humide. Là ils s'accroissent et prennent la forme de Rhabditis, les uns mâles, les autres femelles. Les embryons qui se développent dans le corps de celles-ci sont ingérés par les Batraciens et gagnent alors les poumons, où ils deviennent des Angiostoma.

\section{Evolution terminale.}

Quel que soit leur mode primitif de développement, qu'ils subissent ou non des métamorphoses, tous les organismes sont appelés à suivre une évolution dont les traits généraux sont sensiblement les mèmes, et ne sont guère altérés que par des circonstances accidentelles.

A une certaine période de leur existence, ils ont acquis la faculté de se reproduire : ils sont adultes. Puis leur activité physiologique diminue graduellement, ils deviennent vieux : leurs organes sont, en définitive, incapables de remplir les fonctions dont ils sont chargés, et la mort survient naturellement.

Un fait remarquable, c'est l'influence de la fonction de reproduction sur la rapidité de cette évolution terminale. Chez beaucoup d'Insectes, par exemple, la mort survient presque aussitôt après l'accomplissement de cette fonction. Les Êphémères vivent plusieurs années à l'état de larve, tandis que l'existence des Insectes parfaits se prolonge à peine l'espace d'une nuit : tout juste le temps de s'accoupler et d'effectuer la ponte. Si on s'oppose à l'accouplement, on arrive, au contraire, à prolonger la vie pendant plusieurs jours. Ces cas sont loin d'être isolés, et d'une façon générale on peut constater que le développement de l'individu semble avoir pour but essentiel d'assurer la conservation de l'espèce.

Mais la destruction des organismes est sous la dépendance d'une foule de circonstances accidentelles, et on est autorisé c̀ admettre qu'un bien petit nombre des animaux qui vivent à l'état sauvage arri- 
vent au terme naiurel de l'existence, c'est-à-dire succombent directement à l'altération sínile des organes. C'est que l'aflaiblissement progressif par lequel se manifeste la vieillesse rend les individus de moins en moins aptes à soutenir la concurrence vitale, et qu'alors ils ne tardent pas en général ì péril sous le coup de la faim ou des attaques de leurs ennemis. Sans compter qu'ì toutes les périodes de leur existence, mille causes diverses peuvent amener un semblable résultat.

Il est à remarquer, dailleurs, que les chances de destruction sont d'autant plus nombreuses, pour un organisme, que les parties qui le composent sont plus étroitement unies et solidaires. Il résulte, en effet, de cette solidarité même, qưune atteinte grave portée à une seule de ces parties retentit d'une façon assez séricuse sur les autres pour amener la perte de l'organisme tout entier. C'est ce qu'on observe chez la plupart des animaux supérieurs. Dans beaucoup de formes inférieures, au contraire, l̈indépendance des différentes parties du corps est suffisante pour qu'on puisse léser profondément ou mème isoler certaines de ces parties sans porter atteinte à l'ensemble. Il y a plus : les mutilations peuvent souvent se réparer diune facon complèle, et cette réparation est connue sous le nom de rédintégration. Une patte de Salamandre repousse Iorsquion l'a arrachée en conservant l'épaule. La queue d'un Lézard se reconstitue pareillement lorsqu'elle a été coupée. Chez quelques Étoiles de mer, un bras séparé de l’animal forne même une nouvelle Étoile. Enfin, on sait qu'en coupant une Hydre d'eau douce en plusieurs moreeaux, chacun de ceuxci reproduit une Hydre complète.

Les mêmes faits s'observent, d'une façon beaucoup plus nette encore, dans un grand nombre de colonies animales, ou l'indépenlance des individus composants est poussée à un degré très élevé. Ceux de ces individus qui disparaissent sont remplacés par dautres, et la durée de la colonie est en quelque sorte indéfinie (Ed. Perrier).

Il est un assez grand nombre d'animaux qui, sous lïntluence d'une dessiccation plus ou moins complète, perdent toutes les apparences de la vie, mais qui, néanmoins, peuvent être ranimés lorsquion les replace dans l'humidité : ces animaux sont dits reviviscents. Tels sont certains petits Vers (Anguillules), de nombreux Rotateurs, des Tardigrades, etc. Lorsqu'ils ont été desséchés, ils se montrent comme racornis, immobiles et paraissent absolument morts, mais ce n'est qu'une mort apparente; leurs éléments anatomiques ont conservé une vie latente (vie rulentip),

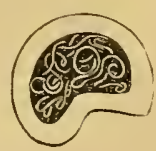

Fig. \{k. - Animaux révisiscents : Anguillutes dans un grain de blí (Davaine). qui revient à des manifestations normales sous l'influence de l'humidité (vir actior). La réviviscence peut s'observer quelquefois après des années de dessiccation.

A part ces cas particuliers, dans lesquels la vie n'est que suspendue, on considère qu'un organisme est mort lorsque ses fonctions 
sont arrètées. Un certain temps encore après cet arrêt, les éléments anatomiques peuvent cependant conserver une faible vitalité. Puis, les liquides qui les alimentent n'étant plus renouvelés, leur activité ne tarde pas à s'éteindre. Dès cet instant, le corps est soumis exclusivement aux forces physico-chimiques, et le résultat de cette action est la decomposition cadavérique. Ajoutons que, d'ordinaire, le cada'vre d'un animal devient la proie d'une foule d'êtres vivants (Carnivores, Insectes, Microbes), qui font rapidement disparaître toutes ses parties molles.

\section{CHA PITRE III}

\section{RAPPORTS DE L'ORGANISHE AVEC SON MILIEU}

Les êtres organisés entretiennent, arec le monde au sein duquel ils vivent, des rapports infiniment variés, dont l'étude offre, à notre point de vue, un intérêt tout spécial, et forme même comme une science à part, à laquelle on a donné le nom d'cecologie, ou reconomie de la nature.

Sous peine de disparaitre, tous ces êtres doivent s'adapter au milieu dans lequel ils sont appelés à vivre, y trouver leur nourriture, et au besoin la disputer à de nombreux concurrents, se soustraire aux attaques de leurs ennemis, enfin assurer la perpétuité de leur espèce.

La conservation de l'individu, d'une part, celle de l'espèce, d'autre part, tels sont donc les éléments essentiels qui servent de base aux rapports que les animaux affectent, soit avec le monde inorganique, soit avec les êtres vivants.

Or, au premier rang de ces êtres se place l'Homme, qui exerce sans contredit une influence de premier ordre sur les organismes qui l'entourent. Il est à peine utile de faire remarquer, cependant, que les rapports des animaux avec l'Homme ne diffèrent pas essentiellement de ceux qui s'exercent entre les animaux eux-mêmes. Dans un traité de zoologie pure, il n'y aurait même aucune bonne raison pour les séparer; mais la nature de cet ouvrage nous impose l'obligation de les étudier d'une façon toute particulière, et par conséquent de leur faire un cadre à part.

\section{$\$ 1^{\mathrm{er}}$. - RAPPOITS DES ANIMAUX AVEC LE MONDE INORGaNIQUE ET LES ÊTRES VIVANTS EN GÉNÉliAL.}

En premier lieu, nous allons constater que l'organisme est aple ì subir, sous l'influence du milieu extérieur, certaines modifications qui sont, en thèse générale, la condition nécessaire de sa propre conservation. 
Adaptation, variabilité des formes animales. - " l'ar adaplation ou variation, dit Hackel, nous entendons dire que, sous l'inlluence dı monde extérieur ambiant, l'organisme a aequis dans ses fonclion: physiologiques, dans sa constitution, dans sa forme, quelques particularités nouvelles qui ne lui avaient pas élé légućes (I). "

La variabilité ou faeulté d'adaptation est inhérente à tous les organismes, et les phénomènes de variation se manifestent à charjue inslant sous nos yeux.

Ces phénomènes ont pour cause fondamentale l'inlluence des conditions extérieures de l'existence sur les échanges matériels de l'organisme. Et par conditions extérieures, il faut entendre l'alimentation, l'action du climat, du sol, de l'habitat, des organismes voisins, etc.

L'adaptation est soumise à un certain nombre de lois que Haxckel ¿roupe en deux séries distinctes: la série des adaptations indirectes ou polentielles, et celle des adaptations directes ou actuelles.

A. L'adaptation indirecte ou potentielle consiste en ce que certaines modifications organiques, produites sous laction du milieu ambiant, ne se manifestent pas dans la conformation de l'individu inlluencé, mais daus celle de sa postérité... Che\% l'organisme paternel (ou maternel), li conformation nouvelle existe seulement à l'état de possibilité (in polentia); che\% l'enfanı, elle se réalise en fait (in actu) (2).

La plus générale des lois de l'adaptation indirecte est celle de l'aduptation indiciduelle, en raison de laquelle tous les individus organiques sont dissemblables, mème dès le début de leur existence. Jans une portée de Chiens ou de Chats, tous les petits se distinguent par des différences, souvent faibles à la vérité, mais toujours perceptibles, dans la taille, le pelage, la vigueur, etc.

Une seconde loi moins importante est cclle de l'udaptation monstrueuse ou par saut brusque. Elle se traduit par des modifications si accusées dans la conformation dı produit, que cetle conformation est qualifiée de monstruosité. Dans la plupart des cas, nous ne pouvons pas nous rendre uı compte exact de l'inlluence exercée sur l'organisme génératenr ; cependant, des données précieuses nous sont fournies par l'expérience: on arrive à développer certaines monstruosités par une action exercée sur l'ceuf ou sur les organes de la génération (3). Il est évident qu'il n'y a lả aucune influence héréditaire, puisque la modification communiquée au produit n'existe pas chez l'organisme générateur. C'est à ce genre d'adaptation qu'on rattache habituellement les eas d'albinisme (Souris blanches, Hirondelles blanches), de mélanisme (Renards charbonniers, Panthères noires), de sexdigitation des mains et des pieds, etc.

Enfin, Ireckel signale une loi d'aduptation sexuelle, exprimant ce fait que certaines influences exercées sur les organes génitaux des parents se traduisent far des modifications des organes correspondants chez les produits.

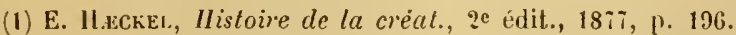

(2) Loc. cit., p. 200.

(3) Voy. C. Dareste, Recherches sur la moduction arlificiclle des monstruosites ou Essais de tératogénie expérimentate, $187 i$. 
B. Les faits dataptation directe ou actuelle diffèrent des précédenls en ce que les modifications dues à linfluence des conditions extérieures portent sur l'organisme qui subit cette influence, et non pas seulement sur sa descendance.

Il faut signaler d'abord, comme la plus importante des lois de l'adaptation directe, celle dite d'adaptation générale ou universelle, que Hreckel formule de la facon suivante: "Tous les individus organiques se différencient les uns des autres dans le cours de leur vie, par le fait de l'adaptation aux diverses conditions d'existence, bien que pourtant les individus d'une seule et mème espèce restent toujours très analogues entre eux. " En raison de cette loi, J'inégalité que nous avons vue résulter pricédemment de l'adaptation individuelle ne fait que s'accentuer, et d'une facon d'autant plus frappante que les individus sont appelés à vivre dans des conditions plus diverses. Les Chiens d'une mème portée, que nous avons déjà reconnus différents dès leur naissance, prendront sans doute des caractères beancoup plus divergents encore dans le cours de leur existence, alors qüils auront. vécu dans des conditions toutes dissemblables.

Les phénomènes de l'adaptation directe sont soumis à une séconde loi, non moins importante que la première, celle de l'adaptation cumulative. II sagit ici de modifications organiques qui s'accusent (dans une succession de zénérations) sous l'influence persistante des conditions extérieures, et par le fait de l'habitude, de l'exercice ou du défaut d'usage des organes. En réalité, ces leux élénents étiologiques ne peuvent ètre séparés: les modifications dues au milieu ambiant ne sont jamais la conséquence immédiate de cette influence; " il faut les rapporter à la réaction correspondante de l'organisme, à cette activité spontanée que l'on appelle habitude, exercice, usage ou défaut d'usage des organes". L'hérédité transmet ces propriétés acquises, et ainsi se produisent des changements parfois considérables dans la constitution des formes organiques. La domesticité, par exemple, en réduisant à l'inaction certains organes, en a souvent produit l'atroplie. Les Poules et les Canards, qui dans nos basses-cours ont presque entièrement perdu l'habitude du vol, ont les ailes beaucoup moins développées qu'à l'état sauvage. De mème, nous voyons que beaucoup de races de Chiens et de Lapins ont les oreilles pendantes, l'état de domesticité ayant rendı inutile le redressement continuel de l'oreille, destiné á épier l'approche de la proie ou le l'ennemi. Mais, parmi les formes sauvages, on peut aussi constater de nombreux exemples de variations permanentes, tenant à des intluences générates et persistantes. Tel est le cas des races dites géographiques, qui s'observent parmi les espèces répandues sur un vaste territoire.

Une troisième loi de l'adaptation directe est celle de l'alaptation corrélative, en vertu de laquelle "la modification organique ne porte pas seulement sur les parties qui ontimmédiatement subi l'inlluence extérieure, mais encore sur d'autres parties qui n'ont pas été directement impressiomnées ». C'est là une conséquence naturelle de la corrélation orqanique que nous arous étudiée au chapitre précédent; cependant il nous est souvent impossible de saisir les conditions de cette corrélation. Ainsi, les altérations pionmentaires entrainent d'ordinaire des modifications de certains tissus ou organes qui n'ont à première vue aucun rapport avec le tégument. Les Chats blancs aux yeux bleus, dit Ileckel, sont presque toujours sourds. Les Cheraux blancs at 
crins ondulés sont souvent envahis par des sarcomes mélanieques. L.es animaux dont les testicules ont été enlerés arant leur entrée con fonctions ne prennent pas les caractéres de leur scxe : ils ressemblent, plutòt aux fomelles. Chez l'llomme, le larynx subit un arrèt de développement, et les castrats conservent indéfiniment leur roix d'enfant. Les femelles sont beallcoup moins affectées par l'ablation des ovaires: d'après la renarque do Sanson, leur féminisme semblerait mème s'accuser, "c'est-i-dire yue les femelles neutralisées serairnt d'un type encore plus tin, plus sracile que celui des femelles normales (1) ". Cependant, Nirchow a fait ressortir, en termes excellents, la corrélation qui existe entre l'ovaire et l'organisme féminin. "La femme est femme, dit-il, uniquement par ses glandes génératrices. Toutes les particularités de son corps et de son esprit, sa vie nutritive, son activité uerveuse, la délicatesse, la rondeur des membres, l'élargissement du bassin; le développement de la poitrine accompagné d'un arrèt de développement des organes de la voix; sa luxuriante chevelure contrastant avec le duvet fin et imperceptible qui couve le reste du corps; en outre, la profondeur de sentiment, la perception primesautière et sure, la douceur, l'abnégation, la fidélité, en résumé tous les caractères essentiellement féminins, que nous admirons et rénérons dans la vraie femme, tout cela dépend de l'oraire. Que l'on extirpe l'ovaire, et la virago nous apparaitra dans sa hideuse imperfection ( $(\boldsymbol{\sim})$. "

Enfin, nous devons signaler la loi d'adaptation divergente, qui fait en quelque sorte opposition à la précédente, et a trait au développement différent que prennent, sous l'influence des conditions extérieures, des organes primitivement identiques. C'est ainsi que le bras droit, dont la plupart des hommes se servent de préférence, se déreloppe beaucoup plus que le gauche.

Concurrence vitale. - C'est à Ch. Darwin que revient le mérite d'avoir mis en lumière le principe si général de la concurrence vitale ou de la lutte pour l'existence (struggle for lifej, que reconnaissent aujourd'hui les naturalistes de toutes les écoles. Darwin arait puisé l'idée de ce principe dans une théorie émise par l'économiste anglais Malthus à la fin du siècle dernier. Cette théorie, plus connue sous le nom de loi ou théorème de Malthus, peut sexprimer en disant que "le nombre des hommes augmente en moyenne suivant une progression géométrique, tandis que la masse des substances alimentaires augmente seulement suivant une progression arithmétique "; ou, plus simplement, que "la population s'accroît beaucoup plus vite que la ricliesse"; de telle sorte que les moyens de subsistance ne peurent être fournis à tous, et qu'une compétition perpétuelle survient entre les hommes dans le but de se les procurer. La généralisation de la théorie malthusienne, son applieation à l'œcologie, lel est le principe de la lutte pour la vie.

"Tout être organisé, dit Darwin, se multiplie naturellenent avee tant de rapidité que, s'il n'était détruit, la terre serait bientìt couverte par la descendance d'un seul couple. "

(1) A. Sixsox, Traité de zootechnie, 3 e édit., t. II, p. $86,1898$.

(2) La femme et la cellule: cite par llieckel, op. cit., p. 217. 
Cependant, le nombre des animaux et des végétaux qui vivent à la surface du globe est sensiblement constant : les oscillations qui peuvent s'observer à cet égard dans une période donnée sont en général fort peu importantes. C'est qu'une énorme quantité des individus produits sont appelés à disparaitre, souvent mème lorsqu'ils sont encore à l'état d'œufs on de germes. Il suffira, pour se rendre compte de ce fait, de comparer la rareté relative des Ténias de l'Homme, par exemple, ì leur excessivea fécondité.

Done, il est évident que le nombre des individus appelés à jouir de la vie dépend bien moins de la quantité des germes produits que de linfluence du milieu.

Dès le début de leur existence, les organismes ont à combattre, non seulement pour se procurer les éléments nécessaires à leur subsistance, mais encore pour échapper à leurs ennemis naturels, bêtes de proie ou parasites; ils ont à lutter contre le froid, la chaleur, les intempéries et en somme contre une foule d'influences ennemies, dépendant du milieu qui les entoure.

De ces influences si complexes, nous dégagerons, pour les étudier plus spécialement, celles qui ont pour origine le règne animal luimême, ce qui revient à dire que nous nous occuperons seulement des rapports des animaux entre eux.

Or, il nous faut constater que ces rapports se manifestent de prime abord à nos yeux par une hostilité flagrante (1).

Prédation. - Cette hostilité peut se traduire d'une façon violente, même entre animaux d'une même espèce; mais la violence éclate surtout entre individus d'espèces différentes, et la concurrence vitale ne se manifeste nulle part avec autant de puissance que dans le mode d'alimentation des carnassiers, c'est-à-dire dans les rapports du prédateur avec sa proie. Là, en eflet, on voit directement l'influence de la force, de la souplesse, de la ruse, aboutissant à la destruction du plus faible. En thèse générale, la proie est représentée par un herbivore, c'est-ì-dire par un animal faible, timide, dépourvu d'armes offensives, et elle se trouve en quelque sorte désignée d'avance à un seul ou à un petit nombre de prédateurs d'espèces déterminées.

Parasitisme. - Le but du parasite est évidemment le mème que celui du prédateur, mais les moyens employés sont différents. La concurrence vitale ne se montre plus, dans le parasitisme, avec le mème caractère de brutalité ; elle affecte des allures beaucoup moins violentes. D'emblée, le carnassier tue sa proie; le parasite, souvent trop petit ou trop faible, se contente de l'attaquer lorqu'il est poussé par la faim. Ainsi font les Taons, les Puces, les Sangsues. Ou bien ce parasite šinstalle à demeure sur sa victime et y développe sa progéniture, comme il arrive pour les Acariens psoriques et beaucoup de Vers in-

(1) A. Espixas, Des sociétés animales, $2^{\mathrm{e}}$ édit., Paris, IS78. 
testinaux. Du reste, nous verrons, au paragraphe suirant, que le patrasitisne présente des formes très variées. Mais nous pourons dès maintenant faire ressortir ce principe général, quo le parasite n'a pas intérêt à tuer sa victime; il laut au contraire, pour assurer sa propre existence, que la vie de son hôte soit sauve : selon la pittoresque expression de Van Beneden, il " pratique le précepte de ne pas tucr la poule pour avoir les ceul's ». $\Lambda$ ce point de vue, c'est entre les prédateurs et les parasites qu'il faut placer les larves d'Ichneumons qui, tout en dévorant les chenilles dans lesquelles elles se déreloppent, cherchent à leur conserver la vie le plus longtemps possible.

Commensalisme. - Tandis que le parasite vit aux dépens de son hôte, el qu'ì chaque instant il menace sa santé ou sa vie, le commensal ne lui demande qu'ì partager sa nourriture. La concurrence vitale est donc beaucoup plus atténuée encore iei que dans le parasitisme; et nous pourrions même citer des cas où elle s'efface complètement, le commensal ne réclamant qu'un abri.

Van Beneden (1) distingue des " commensaux libres ", qui changent d'hôtes à chaque instant, et des " commensaux fixes ", qui, au contraire, sinstallent ì demeure sur l'ètre qu'ils ont choisi. Signalons, parmi les premiers, de petits Poissons qui se logent dans la cavité buccale d'un Siluroïde du Brésil, lequel est excellent pêcheur ; les larves des Méloés, qui se jettent sur les Hyménoptères du genre Anthophore; les nymphes hypopiales des Tyroglyphes, qui se font transporter, en cas de disette, par des animaux quelconques. Il n'est pas jusqu'aux jeunes Coucous qui ne puissent ètre signalés au même titre. Quant aux commensaux fixes, les plus intéressants sont ces nombreux Cirripèdes que l'on trouve attachés sur le dos ou sur la tête des Baleines. On en trouve parfois aussi sur le dos des Langoustes et sur les branchies de certains Crabes. Ajoutons que c'est peut-être dans le même wroupe qu'il faut placer un certain nombre d'entozoaires inoffensifs, jusqu'à présent considérés comme des parasites.

Iutualisme. - Rigoureusement parlant, nous concevons le commensal comme ne donnant rien en retour des bons offices de son hôte; mais, à dire rrai, il en est rarement ainsi. Les Crabes minuscules ou Pinnothères qui vivent dans la coquille des Moules, loin de soustraire it celles-ci une partie de leurs aliments, leur abandonnent les restes de leur chasse. Le service rendu se trouve donc payé. C'est là le point de départ de ce que les naturalistes appellent le mutualisme. Il n'y a plus, en pareil cas, aucune trace de la lutte pour l'existence entre les deux ètres en présence. Bien au contraire, ils forment une véritable association, et sont en quelque sorte solidaires.

L'étude des rapports qui existent entre les êtres organisés et plus spécialement entre les animaux nous conduit done à ce résultat assez

(1) P.-J. Vax Benedex, Les commensaux et les parasites duns le règne animal. Paris, 185.5. 
paradoxal en apparence, que la lutte pour l'existence peut aboutir à l'association et constituer le point de départ de la solidarité. Mais on reconnalt sans peine que cette réaction n'offre rien d'anormal, et que le principe de la concurrence vitale n'est atteint en aucune façon; c'en est seulement un noureau mode de manifestation, l'assoriation pour. la lutte.

Dans la seconde partie de cet ourrage, nous aurons à nous occuper d'un certain nombre d'animaux qui sont d'ordinaire classés parmi les mutualistes. Tels sont les Insectes qui rirent entre les plumes des Oiseaux ou les poils des Mammifères, et auxquels on donne le nom de Ricins. En apparence, ces Insectes ressemblent beaucoup à des Poux, mais au lieu de virre de sang, comme le font ceux-ci, ils passent pour se nourrir des pellicules et de tons les débris épidermiques qui, saccumulant entre les poils ou les plumes, sont le départ de la crasse : de sorte qu'en échange de la nourriture qui leur est fournie par l'hôte, ils entretiendraient sa peau en état de propreté et favoriseraient les fonctions cutanées. A la surface du corps des Poissons, vivent de même de petits Crustacés, les Caliges et les Arģules. Les Cheylétielles qui font la chasse aux Listrophores dans les poils des Lapins, le Pique-Bœuf qui enlève les larres d'Hypodermes sur le dos des Bœufs en Afrique, et tant d'autres qui rendent des services plus ou moins analogues, agissent aussi, en définitive, à la façon des mutualistes.

De ces rapports, nous pouvons passer graduellement à des manifestations d'un ordre plus éleré, qui nous conduiront à comprendre la domesticité comme un cas particulier du mutualisme.

Constatons d'abord, arec Espinas, que " toutes les fois qu'un même milieu rassemble plusieurs espèces douées d'habitudes semblables, des rapports ne manquent jamais de s'établir entre celles qui n'ont rien à redouter les unes des autres et ont, au contraire, à redouter les mêmes ennemis ". C'est ainsi que, en dehors de la saison des amours. nous voyons des Oiseaux d'espèces différentes s'unir en bandes : les Bruants arec les Alouettes, les Pinsons et les Litornes; les Barges arec les Pluviers et les Bécasseaux. Tous comprennent que, pour ériter l'approche d'un ennemi ou lutter contre lui, l'association offre des garanties qui ne peurent se trouver dans l'isolement.

Or, dans de telles réunions, toutes les espèces ne possèdent pas les mêmes aptitudes, et, par suite, il n'est pas rare de voir l'une d'elles prendre empire sur les autres. "Les Barges qui forment une troupe arec de plus petits oiseaux de rivage exercent toujours sur leurs compagnons une sorte d'autorité. Ce que fait le Barge, les autres l'imitent; ses mouvements et ses cris guident la troupe tout entière. " "Il n'est pas de volière, ajoute plus loin l'auteur, qui n'ait son maitre, quelque différents qu'en soient les hôtes. C'est même sur cette propension des uns à la domination, des autres à la subordination, que repose l'usage que l'on fait à la Guỵane de l'agami pour diriger les oiseaux domes- 
tiques, en Afrique de la grue cendrée pour conduirc un troupeau de moutons, dans toutle monde, du chien pour gouverner le bétail grand et petit (1)."

Tout cela, c'est encore du mutualisme, mais il ne reste plus qu'un pas à faire pour passer à la domesticité. Ce pas se trouve franchi pac les Fourmis douées d'instincts esclavagistes. Il n'est pas rare de voir des Fourmis arrêtées au milieu des Pucerons qui couvrent les rameaux d'un arbuste, et occupées ì sucer le liquide épais que distille l'abdomen de ces Insectes. Or, Huber a observé quelquefois que, pour s'assurer la possession exclusive d'une colonie de Pucerons, les Fourmis arrivent à construire un abri autour de cette colonie. Il les a même vues, sur une tige de chardon, apporter leurs larves dans l'intérieur de cet abri. D'autres fois, au lieu de transporter ainsi leur propre nid, ce sont les Pucerons, au contraire, qu'elles amènent dans ce nid. "Nous touchons enfin à l'acte caractéristique de la domestication, l'élevage. Les Pucerons, vivipares en été, sont ovipares en automne. Les œufs déposés dans la fourmilière y deviennent l'objet de soins en tout semblables à ceux que les Fourmis donnent à leurs propres œufs. Comme les leurs, elles les descendent dans les profondeurs de la fourmilière, quand le dessus est découvert; comme les leurs, elles les vernissent et les humectent de leur salive. Voilà la domestication complète (2). "

Nous pourons faire remarquer en terminant que le mutualisme ne s'exerce pas seulement entre individus d'espèces différentes : peut-ètre mème est-il plus général de le constater entre individus de la mème espèce. Les associations de ce genre ont été étudiées arec soin par Espinas, qui les désigne sous le nom de sociétés normales : sur ce point, nous renverrons le lecteur au remarquable travail de cet auteur (3).

Sélection naturelle. - Nons possédons dès maintenant les éléments qui servent de base à la constitution de formes organiques permanentes. Ces éléments ne sont autres, en effet, que l'hérédité ou faculté de transmission, et la variabilité ou faculté d'adaptation.

Ce sont ces deux propriétés fondamentales des êtres organisés qui entrent en jeu dans la sélection arfificielle, c’est-à-dire dans le procédé que l'homme met en usage lorsqu'il veut perpétuer, sous forme de race, des caractères qu'il recherche à un titre quelconque : finesse de la laine, pelage particulier, grande taille, aptitude laitière, etc. Pour obtenir ce résultat, l'éleveur met d'abord ì profit les modifications qui se manifestent parmi les animaux dans le sens désiré, modifications produites sous l'influence du milieu et relevant conséquemment de l'adaptation. Il choisit avec le plus grand soin les individus qui offrent ces modifications, et les emploie seuls à la reproduction :

(1) Loc. cit., p. 17千.

(2) Loc. cil., p. 19\%.

(3) Loc. cil., p. $20 i$.

Raillift. - Zoulogie. 
sous l'influence de l'hripridité, il obtient alors une première génération composée en partie d'individus présentant le caractère voulu. En Iriant ceux-ci avec attention, et même en ne conservant que les meilleurs d'entre eux, il obtient une nouvelle génération dans laquelle la proportion des individus bien donés est accrue; et cette méthode suivie avec persévérance pendant un temps suffisant ne peut manquer d'accentuer et de fixer, d'une facon définitive, les caractères qu'il recherche.

Tout l'art de l'élevage consiste donc à combiner adroitement les faits de variation et les phénomènes de l'hérédité. Cet art a d'ailleurs fait de tels progrès que les éleveurs sont quelquefois capables de produire une forme demandée après un nombre déterminé de générations. C'est ainsi, nous apprend Darwin, qu'un des éleveurs anglais les plus expérimentés, sir John Sebright, assurait " qu'en trois ans, il produirait chez un Oiscau une plume donnée, mais que, pour obtenir telle ou telle forme de la tête ou du bec, il lui fallait six ans ".

Or, après une étude attentive des principes de la sélection artificielle, Darwin a été conduit à se demander si les êtres qui vivent à l'état de nature subissent des conditions qui puissent déterminer un triage, une sélection plus ou moins analogue à la sélection faite sous la volonté de l'homme. Après beaucoup de recherches et de méditations, l'illustre naturaliste a affirmé qu'il existe une sélection naturelle, et que celle-ci est sous la dépendance de la concurrence vitale. Il a su montrer, en effet, que la lutte pour la vie fait un choix véritable parmi les formes animales et végétales; que les éléments sur lesquels elle agit sont également la variabilité et l'hérédité, et que le résultat de cette action inconsciente doit être pour le moins aussi fixe que celui de la sélection artificielle.

Dans la lutte souvent acharnée que les organismes se livrent entre eux, le moindre avantage personnel peut faire pencher la balance en faveur de celui qui le possède, et assurer son triomphe. Il en est de même, évidemment, à propos de la résistance qu'opposent ces organismes à l’influence du milieu ambiant.

Les animaux qui sont pourvus des armes de chasse les plus puissantes, ceux qui sont les plus agiles dans la poursuite ou dans la fuite, ceux dont l'organisation est assez forte pour résister aux attaques des parasites, en un mot, les individus les mieux doués persisteront là oủ les autres sont condamnés à périr, et eux seuls seront appelés à transmettre leurs propriétés par la reproduction. On a souvent dit, avec raison, que l'avenir est anx plus aptes.

Toute modification avantageuse, tout caractère assurant une supériorité quelconque à l'individu, peuvent donc être transmis par hérédité. Au contraire, les déviations qui se produisent en sens opposé ont toutes chances de disparaitre à bref délai, parce que, le plus souvent, les animaux qui les présentent succombent dans la lutte 
avant d'avoir pu se reproduire : la nature élimine les incapables.

On sait, en outre, qưun des modes les plus intéressants de la sélection naturelle est celui auquel Darwin a donné le nom de sélection sexuclle, et qui consiste dans le choix des mâles les plus beaux ou les plus forts pour concourir à la reproduction. Il nous parait inutile de revenir sur les détails que nous avons cités plus lıaut à ce sujet.

Quant ì l'étendue du rôle de la sélection naturelle dans les formations organiques, c'est un point que nous aurons à discuter ultérieur'ement (V. Traxinomie). Nous nous sommes borné ici à exposer le principe de celte sélection.

\section{S. - BAPPORTS DES ANIMAUX AVEC L'HOMME.}

Ainsi que nous l'avons fait pressentir au commencement de ce chapitre, les rapports que les animaux peuvent avoir avec l'Homme sont de mème nature que ceux qu’ils entretiennent entre eux. Nous allons, en effet, avoir à constater encore des rapports d'hostilité et des phénomènes d'association.

Il est clair, d'ailleur's, que nous aurons principalement en vue les animaux qui intéressent la médecine et l'agriculture. Au surplus, le tableau ci-dessous donnera une idće du rôle et de l'importance que nous leur assignerons à cet égard :

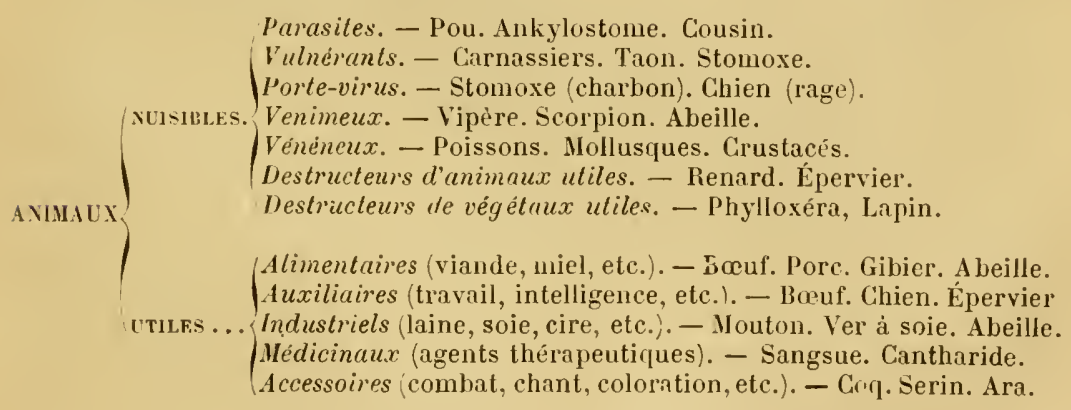

\section{Animaus nuisibles.}

Un grand nombre d'animaux sont susceptibles de causer des dommages à l'homme, soit directement, soit en s'attaquant aux êtres ou aux substances quelconques dont il peut avoir besoin. C'est à ce double point de vue que nous devons les étudier.

A. Parasites. - Nous avons déjà examiné la condition générale des ètres auxquels on donne ce nom; mais il nous reste à les considérer quant à l'application.

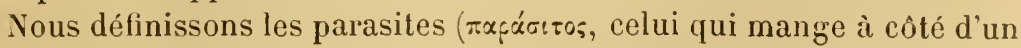
autre; de $\pi \alpha \alpha_{\alpha}$, à coté, et $\sigma: \tau o s$, aliment) des êtres organisés qui passent une partie ou la totaluté de leur vie sur d'autres ètres organisés, plus puissants queux, aux dépens desquels ils se nomrissent. 
Le parasitisme esi la condition dans laquelle sont entretenus les parasites.

On a souvent cherché à distinguer des parasites les êtres infiniment petits auxquels Sédillot a donné le nom de microbes. On s'est basé pour cela sur ce fait que ces êtres se propagent aussi bien dans des milieux inertes que dans les corps vivants. Mais, à cet égard même, il y a de nombreux points de contact entre les parasites et les microbes, et l'on sait beaucoup de larves de Nématodes, par exemple, qui se développent et s'accroissent dans des substances organiques convenables. D'ailleurs, à ce titre, il faudrait ranger parmi les microbes les Champignons tels que le Trichophyton tonsurans et l'Achorion Schœnleini, „qui développent les teignes et sont considérés universellement comme des parasites.

Remarquons cependant que, dans la pratique, on établit une distinction entre les microparasites ou microbes et les macroparasites ou parasites vulgaires, à cause de l'importance toute spéciale des premiers au point de vue pathologique, tandis que l'on confond volontiers avec les parasites proprement dits les commensaux et les mutualistes, voire les demi-prédateurs auxquels nous avons fait allusion plus haut. C'est à ce point de vue que nous nous placerons ici ; d'ailleurs, nous envisagerons de préférence les parasites de l'Homme, ainsi que ceux des Mammifères et des Oiseaux domestiques.

Nature des parasites. - On sait que le parasitisme s'étend au règne végétal aussi bien qu'au règne animal : les plantes, comme les animaux, sont susceptibles d'être attaquées par des parasites. De même, à côté des parasites animaux, il existe des parasites végétaux. Ceux-ci reçoivent le nom de phytoparasites; les autres sont appelés zooparasites.

Mais les parasiles ne constituent pas une catégorie naturelle parmi les êtres organisés: dans une même famille ou dans un même g̊enre, on peut observer des espèces qui mènent une existence libre et d'autres qui vivent en parasites. En thèse générale, les parasites appartiennent aux types inférieurs de l'un et de l'autre règne, et leurs hôtes, c'est-à-dire les êtres qui les hébergent, sont en tous cas plus élevés qu'eux en organisation. Ainsi, la plupart des parasites végétaux sont des Cryptogames, et la plupart des parasites animaux appartiennent aux embranchements des Arthropodes, des Vers et des Protozoaires.

Il faut noter aussi que le rôle de parasite se rapporte plutôt au sexe femelle qu'au sexe mâle, ce qui tient sans doute au besoin qu'éproure la femelle d'assurer le sort de sa progéniture.

Mode de vie. - On a vu plus haut que la vie parasitaire se relie insensiblement à la vie libre. Les Sangsues, par exemple, doivent être considérées comme de simples carnassiers quand elles s'attaquent à des animaux ne lépassant pas leur taille ou leur puissance, tandis qu'elles deviennent de véritables parasites lorsqu'elles empruntent 
leur nourriture à des animaux supérieurs. Des larves de Mouches, de nombreux Chaıpignons, etc., peuvent se développer indifléremment dans des matières organiques en décomposition ou dans le corps des animaux vivants. Le parasitisme de ces êtres est dit frultutif ou occasionnel. Par contre, il est un grand nombre d'ètres dont le cycle vital comporte toujours, ne füt-ce que pendant une période limitée, la condition le parasites : il s'agit alors d'un parasitisme nécessaire, obligatoire ou constant.

Mais ce mode de vie offre lui-mème des legrés divers entre lesquels il n'est pas toujours facile d'élablir une dénıarcation bien tranchée. Ainsi, certains parasites ne vivent sur leur hôte qu'au moment même où ils viennent se nourrir à ses clépens, et le quittent aussitôt pour vivre en liberté : ce sont des parasites temporairés. Tels sont les Taons, les Hippobosques, les Punaises, etc. Dautres, au contraire, ne ruittent plus leur hôte dès quïls ont fixé chez lui leur séjour : on les nomme parasites stationnaires.

Or, il faut encore remarquer que, parmi ces derniers, il en est qui vivent en liberté pendant une période plus ou moins longue, c'est-àdire dont le parasitisme n'est que pérıodique, tandis que les autres sont soumis à la condition parasitique lepuis leur éclosion jusqu'à leur mort, offrant ainsi un parasitisme permanent. Parmi les parasites périodiques. il en est qui sont libres seulement pendant le jeune âge, comme la Chique, les Ixodes, les Ankylostomes, et d'autres seulement à l'âge adulte, comme les OEstridés. Comme exemples de parasites permanents, nous pouvons citer les Poux, les Acariens psoriques, les Ascarides, les Ténias, et en somme la plupart des entozoaires.

Avec Leuckart, nous pouvons fairc remarquer que les parasites temporaires, obligés de se déplacer sans cesse pour se mettre en rapport avec leur hôte, lloivent aroir une organisation beaucoup plus parfaite que les stationnaires : aussi les voyons-nous pour la plupart munis dyeux, de pattes, d'ailes, etc. A mesure que le parasitisme s'accuse, c'est-à-dire que les parasites deviennent plus sédentaires, l'organisation devient plus simple, ou, comme on le dit, moins différenciée. C'est ce qu'il est facile de constater en étudiant les entozoaires.

Habitat. - Il est un certain nombre de parasites qui vivent à la surface mème du corps : on les appelle parasites externes ou ectoparasites; les autres habitent les organes ou les tissus profonds : ce sont les parasites internes ou endoparasites. On pourrait distinguer les premiers en retophytes et ectozoaires, les endoparasites en entophytes et entozoaires; mais ce dernier terme est généralement considéré comme synonyme d'helminthes.

Il n'y a pour ainsi dire aucune partie du corps qui soit hors de l'atteinte des parasites : on en trourc jusque dans le cerreau, dans les os, dans le sang (hrmalozoaires). Souvent, d'ailleurs, l'habitat de chacun d'eux est fort restreint: le spiroptère mrgastome ne vit que dans 
le sac droit de l'estomac des Équidés, le Strongle filaire dans les bronches de quelques Ruminants, etc. Un fort petit nombre de parasites, au contraire, n'ont point de séjour fixe (Échinocoques).

Il arrive quelquefois qu'un parasite, llans son jeune âge, pénètre chez un hôte qui ne convient pas à son développement; il périt le plus souvent, ou du moins ne se développe que d'une façon imparfaite. Davaine le nomme alors parasite égaré, et qualifie d'hôte étranger ou accidentel l’individu qui le reçoit. Il pourrait s'égarer également dans des organes impropres à son accroissement ou à son évolution. - Quand un parasite adulte quitte l'organe qui est son séjour normal pour pénétrer dans un autre organe, on le nomme parasite erratique.

Le changement d'habitat peut-il produire chez le parasite des déviations morphologiques d'une importance réelle ? La réponse à cette question ne peut être cherchée que dans l'expérimentation. Ainsi l'ont compris déjà quelques savants, et en particulier Ercolani, qui a publié le résultat de ses recherches dans deux remarquables mémoires (I) auxquels nous sommes obligé de renvoyer le lecteur. Nous dirons seulement que l'éminent professeur de Bologne est parvenu à obtenir le développement expérimental de certains helminthes chez des hôtes divers, arec des rariations morphologiques telles que des naturalistes non prévenus eussent pu croire ì l'existence d'espèces distinctes.

L'érolution des parasites, qui s'accomplit le plus souvent en entier chez un seul et même hòte (monoxènes), peut exiger, dans certains cas, le passage dans plusieurs hôtes successifs (hétéroxènes); ce passage reçoit le nom de transmigration. On appelle hôte dífinilif l'individu chez lequel ces parasites hétéroxènes acquièrent leur complet développement, le ou les autres recerant le nom d'hôtes lramsitoires. Ainsi, le Mouton est généralement l'hôte provisoire et le Chien l'hôte définitif du Tienia Cemurus. Les Distomes, les Trichines, les Linguatules offrent aussi de beaux exemples de transmigration.

Le siège de ces parasites dans les organes se troure déterminé d'après une règle qui ne souffre que fort peu d'exceptions, et qu'on peut ainsi formuler : chez l'hôte provisoire, le parasite, ordinairement agame, est logé dans l'intérieur des parenchỵmes ou des cavités closes; chez l'hòte définitif, oi il acquiert sa maturité sexuelle, il habite des organes en communication avec le monde extérieur, de manière à permettre la diffusion de sa progéniture. Pour nous en tenir à notre premier exemple, le Cénure cérébral, qui se développe dans le cerveau du Mouton, arrive à l'état adulte dans l'intestin du Chien.

Origine. - Tous les auteurs de l'antiquité se sont accordés à regarder les parasites comme le résultat d'une génération spontanée. A leur's yeux, c'étaient de simples produits organiques, recerant la vie par des forces particulières, telles que la chaleur, la fermentation, lí

(1) Ercom... Dell adatamento della specie all' ambiente. Bologna, 1881 ef 1582. 
putréfaction, etc. Aristote, par exemple, admet que les Vers intestinaux sont formés par les excréments; Galien voit leur point de départ dans les aliments, et Oribase dans toutes les humeurs.

Pendant des siècles, on se contenta de discuter le choix à faire entre ces diverses opinions des maitres. Cependant, dès la fin du dix-seplième siècle, Redi démontrait, contrairement aux anciennes croyances, que la génération sexuelle n’est pas spéciale aux animaux supérieurs : il fit connaitre les organes reproducteurs de l'Ascaride de l'Ilomme (1684), et bientót après (1712) l'évolution et les métamorphoses de divers Insectes. Swammerdam (1752) montra de même que les Poux se reproduisent par des œufs.

Malgré ces observations, malgré les efforts de Hartzoeker, Wolfi, Van Doveren. Pallas, etc., cherchant à prouver que les entozoaires s'engendrent comme les autres animaux, la question n'avancait pas beaucoup. On se demandait, en effet, comment les oufs des parasites pouvaient pénétrer dans les cavités closes et dans les organes les moins accessibles: os, séreuses, œil, foie, cerveau, etc. Et d'ailleurs, les Cysticerques, les Cénures, les Échinocoques, ne possédant pas d'organes génitaux, ne pouvaient produire d'œufs. Aussi, d'aucuns tendaient-ils à admettre que les parasites dérivent directement d'êtres vivant à l'état de liberté (Infusoires, Vers), tandis que d'autres, et c'était le plus grand nombre, s'en tenaient à l'hypothèse de la génération spontanée, que l'on vit soutenir encore au commencement de ce siècle par' les helminthologistes les plus célèbres, tels que les Rudolphi et les Bremser.

La lumière n'éclata décidément que lorsque Steenstrup (1842) eut conçu la fameuse théorie des générations alternantes, et lorsque von Siebold, Van Beneden et Küchenmeister eurent fait connaître le mode de développement des Vers plats. Dès lors, les hétérogénistes durent se réfugier sur un terrain moins abordable, et leurs vues s'appliquèrent spécialement à l'origine des Infusoires et des autres organismes inférieurs. On sait avec quel succès Pasteur les a délogés de cette dernière position: le parasitisme des infiniment petits n'est point régi par des lois particulières.

Propagation. - La transmission des parasites s'effectue dans des conditions qui varient avec leur propre organisation, avec les milieux qu'habitent leurs hôtes, et même avec le ğenre de vie de ceux-ci.

Pour la plupart des formes dont le parasitisme est limité au jeune âge, c'est la femelle fécondée qui se charge d'assurer le sort de la progéniture (OEstridés).

S'il s'agit d'espèces parasites à l'âge adulte ou de parasites permanents, la transmission peut être le fait d'une migration active (Insectes ailés), uu résulter d'un contact, soit direct, soit indirect (Poux, Acares). Souvent, d'ailleurs, les œufs éclosant sur place, les parasites se multiplient d'une façon extraordinaire sur le même hoite, et c'est 
ainsi que se développent les phtiriases et les gales généralisées.

Mais les parasites se propagent habituellement d'une façon toute passive. Presque toujours, les produits de leur génération sont rejetés à l'extérieur, soit à l'état d'œufs, soit à l'état d'embryons, et ils restent ainsi soumis pendant un certain temps à l'influence du milieu ambiant. Beaucoup s'égarent, périclitent ou périssent; mais il en est un certain nombre qui accomplissent les phases plus ou moins complexes de leur évolution, et sont appelés à réintégrer l'organisme d'un hôte favorable.

Parmi les œufs qui ont été ainsi rejetés, il en est dont l'éclosion n'a pas lieu d'ordinaire dans le monde extérieur, nonobstant le développement de l'embryon, et dont la réintégration doit avoir lieu sous le même état (Ascarides, Trichocéphales). On les reconnaît souvent à l'épaisseur de leur coque, qui leur permet de résister aux influences extérieures. Lorsqü̈ls sont parvenus dans le tube digestif de l'hóte, la coque est dissoute ou dissociée sous l'influence du suc gastrique, et l'embryon, mis en liberté, n'a plus qu à continuer son développement.

Mais les œufs à coque mince, au contraire, éclosent dans le milieu ambiant, oì les embryons vivent en liberté (Sclérostomes). Ces embryons se comportent alors comme ceux des espèces ovovivipares, qui ont été mis en liberté soit avant, soit aussitôt après la ponte (Strongles des roies respiratoires). On ne sait pas encore, d'une façon précise, quelles sont les modifications que doivent subir tous ces embryons avant de rentrer dans l'organisme; cependant, on a constaté que les uns ne subissent aucun accroissement, tandis que les autres se nourrissent aux dépens des matières organiques contenues dans l'eau. Il en est même, comme on l'a déjà vu, qui deviennent adultes et fournissent une nouvellegénération destinée à reprendre la vie parasitaire.

Unefois que les œufs ou les embryons sont rentrés dans l'organisme, le parasite peut acherer son évolution soit dans cet organisme même (Ascarides), soit en passant dans plusieurs hôtes successifs (Ténias, Distomes), comme on l'a vu plus haut.

Dans la plupart des cas, c'est par l'intermédiaire des aliments ou des boissons que les germes des parasites sont introduits dans l'économie. Ainsi, le Mouton contracte le tournis lorsque les fourrages qu'il consomme ou les liquides dont il s'abreuve ont été souillés par des œufs de Trenia Conurus; le Chien contracte ce Ténia en ingérant des cervelles de Moutons atteints de tournis, etc.

on a prétendu pendant longtemps que les parasites étaient susceptibles de se transmettre par hérédité, et cette opinion est encore admise de nos jours par divers auteurs, du moins en ce qui concerne la voie maternelle. Il faut bien reconnaître cependant que cette manifestation de l'hérédité n'est le plus souvent qu'apparente. Quand on dit qu'une Truie ladre peut communiquer la ladrerie aux fœtus que renferme sa matrice, on commet à coup sûr une erreur. La vérité est que les em- 
bryons du Tienia Solium, quand ils ont pénétré dans le torrent circulatoire de la femelle pleine, peuvent aussibien s installer dans les tissus du fuetus que dans ceux de la mère : mais c'est là simplement de l'infirstation congénitale, et non de l'hérédité. On pourrait souvent en dire autant de la transmission des larves de Filnir immitis au fœtus du Chien, de l’infestation du Ver à soie parles corpuscules de pébrine, etc.

Fróquence. - En thèse générale, on peut constater que le nombre des espèces qui vivent chez un animal donné est peu considérable, landis que le nombre des individus se montre parfois extraordinaire. II ne faudrait pas croire, cependant, que la multiplication d'une espèce fût un obstacle à l'invasion et mème à la pullulation d'une ou de plusieurs autres. On cite volontiers, à l'appui de cette manière de voir, l'observation de Krause, de Belgrade (1), qui a trouvé chez un jeune Cheval 319 Ascaris megalncephala, 190 Oxyuris curvula, 214 Strongylus armatus, plusieurs milliers de Strongylus tetracanthus, 69 Tiznia perfoliata, 987 Filaria papillosa et 6 Cysticereus fistularis.

Certains parasites n'existent pourtant d'ordinaire qu'en petit nombre chez un même hôte: tels le strongle géant, les Cénures, etc. D'autres, au contraire, envahissent habituellement l'organisme en quantité innombrable, comme c'est le cas pour les Trichines, les Cysticerques de la ladrerie, les Poux, etc. Il faut noter en passant que les femelles sont, en général, beaucoup plus abondantes que les màles.

L'extension considérable que prennent sourent les parasites s'explique aisément par leur fíconditri et leur résistance vitale.

D'après un calcul très simple de Leeuwenhoek, deux Poux femelles puurraient devenir grand'mères de $\mathbf{1 0 . 0 0 0}$ Poux dans l'espace de huit semaines. Selon Gierlach, un couple de Sarcoptes de l'Homme serait susceptible de fournir en trois mois six générations, la dernière comprenant 000.000 mâles et 1.000 .000 de femelles. Une femelle d'Ascaride est presque tout entière constituée par son oviducte, et la Filaire de Médine n'est plus, en somme, qu'un sac à ceufs. Le Ténia inerme de l'Homme, dont les anneaux se forment et se détachent successivement, peut émettre en un an jusqu'à 150 millions d'œufs. Nous pourrions multiplier ces exemples, et montrer ainsi combien serait rapide l'envahissement du monde de la vermine, si la malthusienne intervention de la nature ne venait apporter des entraves ì cette effrayante pullulation.

Indépendamment de ces facultés prolifiques, beaucoup de parasites jouissent d'une résistance vitale remarquable. Il est des Acariens qui supportent une abstinence fort prolongée : nous arons conservé des Argas reflexus vivants pendant quatorze mois dans un flacon de verre, et Laboulbène a vu des Argas persicus demeurer actifs pendant près de cinq ans sans recevoir la moindre nourriture. De nombreux 
Nématodes résistent à la dessiccation et reviennent à la vic active sous l'influence de l'humidité. Les Trichines enkystées dans les muscles ne sont tuées que par une température d'environ $70^{\circ}$ et peuvent, d'autre part, supporter parfois un froid de plus de $20^{\circ}$. D'autres Vers continuent à vivre au milieu des substances en décomposition putride, etc. Et cette résistance s'étend même aux œufs et aux embryons. Davaine a pu conserver dans l'eau, pendant plus de quatre ans, des œufs du Trichocéphale de l'Homme dans lesquels existait un embryon vivant; G. Colin et C. Baillet ont vu les embryons du Strongle filaire s'agiter dans l'eau pendant des mois entiers, et nous avons reconnu que ceux du Strongle roussâtre sont susceptibles de reprendre leur activité, après dix mois de dessiccation, lorsqu'on vient à les humecter.

La multiplication des parasites dépend encore d'un certain nombre de conditions dont quelques-unes au moins méritent d'être signalées.

Nous pourons noter en premier lieu l'influence du régime : les Mammifères carnivores, aussi bien que les Oiseaux aquatiques, ont souvent l'intestin bourré de Vers; l'Homme contracte des Ténias en mangeant de la viande de Porc ou de Bœuf insuffisamment cuite, etc.

L'influence de l'age n'est pas moins manifeste. Les parasites sont souvent très abondants chez les vieux animaux, qui oflrent sans doute à leurs attaques une moindre résistance. Quant au jeune àge, il présente aussi d'excellentes conditions pour leur développement, surtoul lorsqu'il s'agit de parasites qui doirent immigrer dans les tissus, car ceux-ci sont plus délicats et sont par suite traversés plus facilement.

La constitution de l'hôte doit ètre également prise en considération. Cependant, les opinions ont singulièrement varié en ce qui concerne l'importance de cette condition. A l'époque où l'on croyait à la génération spontanée des parasites, il était naturel d'admettre, comme point de départ de leur développement, un trouble préalable de la santé, et l'expression d'helminthiase servait précisément à indiquer un état valétudinaire favorable à la génération des lers. Le renversement de l'lyypothèse hétérogéniste entraîna une vive réaction contre cette manière de voir, et l'on en vint à nier toute influence de la constitution sur le développement des parasites. Cette influence est cependant incontestable. Si l'on songe que le parasitisme n'est qu'un cas particulier de la lutte pour l'existence, on concevra que l'hôte puisse offrir assez de résistance pour s'opposer à la multiplication du parâsite. Et si l'on compare le parasite à une plante, on comprendra de même que celle-ci ne puisse croitre et fructificr que sur un terrain convenable. Or, Delafond a démontré précisément que cette question de terrain est essentielle pour le développement de certains Acares. Des Psoroptes déposés sur la peau de Moutons bien portants ne peuvent se multiplier et ne tardent pas à périr, tandis qu'ils pullulent bientôt, au contraire, sur des individus maigres et débiles. Il serait intéressant d'étendre ces recherches, car il est probable que les con- 
ditions qui déterminent la réceptivité ou l’ümmunité de l’hoite à l’endroit des parasites sont fort variées.

Les conditions de milieu auxquelles sont soumis les animaux peuvent exercer également une inlluence considérable sur la unultiplication des parasites. La malpropreté des habitations, l'agglomération dans un endroit restreint, favorisent cette multiplication. Le délaut de pansage permet la pullulation des épizoaires. Le séjour dans les champs ou au roisinage des bois expose les animaux à l'attaque d'un granol nombre de Diptères. Le pacağe dans les prairies humides ies expose ì contracter la distomatose, etc.

Les saisons, avec les variations de température et d'huinidite qu'elles entrainent, peuvent aussi lavoriser ou entraver la multiplication des parasites. C'est seulement pendant la saison chaude que les Diptères ailés exercent leurs sévices; les Rougets n'apparaissent quien automne; les Pédiculines se multiplient surtout en hiver; l'Oxyure de l'Homme est en général plus répandu en janvier, l'Ascaride en février, le Trichocéphale en avril; beancoup de maladies parasitaires, enfin, sont remarquables par leurs manifestations saisonnières.

Plus accusée encore est l'influence des contrées, qui tient en grande partie, sans doute, à l'action du climat, mais qui peut se rapporter aussi au régime et au mode de vie. Certains parasites sont propres i une région très limitée : la Bilharzie épaisse n’a été vue quen Égypte et en Sicile; le Gastrodisque de Sonsino, en Egypte, à la Guadeloupe, au Sénégal et dans l'Inde; les Amphistomes du Cheral, dans les Indes anglaises, françaises et néerlandaises. D’autres, sans appartenir exclusirement à une contrée, s'y montrent beaucoup plus abondants quailleurs : on connait, par exemple, la fréquence des Echinocoques en Islande: du Bothriocéphale large dans certaines localités de la Suède. de la Russie et de la Suisse; de la Trichine spirale en Allemagne et aux États-Unis. Mais on connaît aussi de nombreux parasites cosmopolites, et l'Ascaride du Cheval, l'OEstre du Mouton, le Cysticerque ladrique du Porc, ontété signalés à peu près dans tous les pays.

Action sur l'économie. - L’influence des parasites sur la santé de leur hôte a de tout temps donné lieu à d'importantes discussions. On a longtemps attribué, par exemple, à des Versimaginaires ou à des parasites inoflensifs une foule d'affections plus ou moins graves, notanment les maladies épidémiques ou endémiques, et au dix-huitième siècle encore les Vers jouaient un grand rôle dans l'explication des phénomènes morbides. Puis, une réaction se produisit, et l'on en vint à regarder la généralité des parasites comme à peu près inoffensifs, sinon comme avantageux pour la santé. Abildgaard et Gaze considéraient les Poux comme des "émonctoires naturels " destinés à l'élimination des humeurs viciées sécrétées par la peau. Bracy Clark pensait que les larves d'oEstres de l'estomac du Glieval pouvaient fitroriser la digestion. Et de nos jours encore les Abyssins ne se croicnt 
bien portants que quand ils hébergent un ou plusieurs Ténias.

En fait, nous royons souvent des animaux, tels que le Turbot et la Bécasse, dont les intestins sont presque toujours bourrés de Vers, présenter tous les caractères de la santé. La présence d'un grand nombre de larves de Gastrophiles dans l'estomac du Cheval et d'Ascarides dans son intestin ne se traduit souvent par aucun trouble marqué. Mais on ne peut inférer de là que les parasites doivent exercer normalement une influence salutaire sur l'économie. A la vérité, nous tenons pour constant que le parasitisme comporte presque toujours une modalité telle que l'action du parasite se trouve équilibrée par la résistance de l'hôte. Mais cette harmonie biolngique est bientôt rompue lorsque des modifications désavantageuses viennent à se produire dans la constitution de ce dernier. Alors apparaissent les troubles fonctionnels qui caractérisent les maladies parasitaires. Nous devons ajouter, dı reste, qu'il est des cas où le parasite, par la puissance de ses armes, son mode d'attaque ou son habitat, constitue d'emblée un danger sérieux pour l'organisme.

La nocuité des parasites tient à des modes d'action assez variables. Dans certains cas, par exemple, il s'agit d'une gême mécanique apportée à l'accomplissement des fonctions : c'est ainsi que des pelotons ou des faisceaux d'Ascarides peuvent entraver la circulation des matières alimentaires dans l'intestin. D'autres fois, c'est un tiaumatisme qui résulte de leurs morsures - venimeuses à l'occasion - ou de leur (léplacement (Taons, Simulies, strongle géanl); ou bien leur accroissement sur place atroplie les organes (Cénure). Leur seule présence peut même amener des inflammations locales, occasionner des dou. leurs variées, provoquer des désordres nerveux, soit directement, soit par action réflexe, et en général causer des troubles plus ou moins sraves suivant l'organe qu'ils affectent. Quant à leur action spoliatrice, elle est d'ordinaire peu importante: citons cependant, à ce point de vue, les Uncinaires ou Ankylostomes, dont les morsures suivies de succion sont le point de départ de l'anémie des Chiens de meute.

Il n'est pas toujours aussi facile qu'on pourrait le penser d'établir l'influence pathogène des parasites. Il ne suffit pas, en effet, de constater que l'existence d'un trouble morbide coïncide avec la présence de parasites dans l'organisme, pour conclure que celui-là est le fait de ceux-ci. Ce n'est le plus souvent qu'à la suite d'observations cliniques et surtout d'expériences précises et multiples qu'on peut arriver à élablir sérieusement la réalité d'une telle relation; et c'est faute de s'être conformés à cette manièré de faire, que certains auteurs ont surchargé jusqu'au ridicule le tableau symptomatique de certaines affections parasitaires.

Prophylaxie et traitement. - Pour se garantir d'une façon vraiment efficace contre l'attaque des parasites, il faudrait d'abord connaître le mode d'introduction de chacun d'entre eux. Or, il en est 
un grand nombre dont les premières phases de l'évolution sont'encore inconnues ou tout au moins sont à peine soupconnées. Néanmoins, nous ne sommes pas entièrement désarmés vis-ì-vis de ceux-ci. Sachant, en effet, que les parasites dérivent, comme tous les êtres vivants, d'individus ayant subi la même évolution qu'eux-mềnes sont appelés à subir, on pourra s'opposer à leur pullulation en détruisant tous ceux qu'on peut atteindre, soit par le feu, soit par l'eau bouillante ou tout autre moyen. Il faut surtout éviter de jeter au fumier les parasites rejetés par les animaux, car ils seraient fort exposés à être emportés dans les abreuroirs par les eaux de pluie. En somme, dans tous les cas, la propreté des locaux, des individus, des aliments et des boissons est le premier élément de la prophylaxie.

En ce qui concerne les parasites dont l'évolution est bien connue, les moyens préventifs à leur opposer sont évidemment suhordonnés à leur mode d'introduction. Il est bien difticile de formuler à cet égard des règles générales. Disons toutefois que, si la contagrion est ì craindre, il faut tout d'abord isoler les individus atteints et désinfecter le local qu'ils occupaient; que si les animaux contractent leurs parasites en raison du régime auquel ils sont soumis, il y a lieu de modifier ce régime, etc. Ainsi, on évitera, suivant les cas, de faire paître les animaux dans les pàturages humides ou de les abreuver dans des mares; on évitera de donner aux Chiens des cervelles de Moutons atteints de tournis, etc., etc. La cuisson des aliments sera souvent aussi un bon préservatif. Enfin, prenant en considération ce fait que les parasites envahissent de préférence les organismes affaiblis, on soutiendra l'économie par des aliments de bonne nature et par un régime reconstituant.

Ajoutons que l’inspection des viandes et les règlements de police sanitaire sont d'un utile secours pour eviter la propagation des parasites.

Lorsque les affections parasitaires se sont développées, le traitement à leur opposer comporte une indication essentielle : obtenir la disparition du parasite. La médecine de symptômes ne tient ici qu'un rang tout à fait secondaire.

Les moyens employés pour détruire les parasites sont assez variés: on pourrait les distinguer en hygiéniques, chirurgicaux et médicamenteux. Les derniers recoivent quelquefois le nom de parasiticides, bien que ce nom soit plutôt réservé aux médicaments employés contre les parasites externes, tant animaux que végétaux.

Il est évident que les ectoparasites sont plus faciles à détruire que les parasites internes. Parmi ces derniers, on ne peut mème guère songer à atteindre au moyen des agents médicamenteux que ceux qui vivent dans des cavités en communication avec l'extérieur', telles que le tube digestif et les voies respiratoires.

Ajoutons quiun certain nombre de parasites disparaissent sponta- 
nément de l’organisme, soit en raison de leur évolution (Otstridés), soit à l'arrivée de la mauvaise saison (Ixodes, Rougets), etc.

Pseudo-parasites. - Avant de quitter cette question du parasitisme, il importe de mettre les débutants en garde contre certaines chances d'erreur qui peuvent se présenter dans la détermination des parasites.

11 faut éviter, en premier lieu, de considérer comme tels des animaux qui se trouvent accidentellement sur le corps ou qui y sont apportés par les objets de pansement (Insectes, Acariens).

Souvent aussi, il arrive de prendre pour des Vers des larres de Iouches qui se développent sur les plaies, dans les urines ou même dans les cadavres. Les malades surtout se figurent volontiers avoir émis, avec les urines ou les fèces, des larves tombées dans les rases, et il ne faut accepter leurs affirmations qu'avec les plus grandes réserves. On n'oubliera pas non plus que les cas de simulation ou de supercherie ne sont pas rares chez les sujets atteints de certaines névroses, telles que l'hystérie.

Une erreur beaucoup plus grave encore consiste à prendre pour des Vers des corps étrangers quelconques. C'est ainsi que Mongrand décrirait sous le nom de Fïlaria sebra un caillot fibrineux de la saphène, que Scopoli baptisait du nom de Physis intestinalis une simple trachée d'Oiseau, qu'un autre appelait Striatule une nervure de salade (!), etc. Parmi les faits de cet ordre, un des plus communs est fourni par les poils qui composent la pulpe de l'orange, et qui sont expulsés par les vomissements ou les selles, sous forme de vésicules oblongues, effilées aux deux extrémités: nous avons eu récemment l'occasion, avec $\mathrm{X}$. Raspail, d'en relever un cas.

Quant aux parasites fabuleux, tels que la Furia infernalis et le Véroquin, il est heureusement devenu inutile d'en parler.

En touscas, il faut être très circonspect, comme le recommande Moquin-Tandon, a vant d'entreprendre la description d'un parasite nouveau, et la meilleure voie à suivre, en pareille occasion, est de s'adresser à un spécialiste.

B. Vulnérants. - Nous avons dit qu'un certain nombre de parasites exercent sur l'organisme une action mécanique. Tels sont les Ankylostomes; tels sont encore les Taons, qui déjà rentrent à peine dans le groupe des parasites.

Mais il est aussi un grand nombre d'animaux divers qui sont capables de blesser l'Homme ou ses auxiliaires, soit a vec les dents, soit avec le bec, les griffes, etc. 11 n'est pas besoin d'en faire ici l'énumération.

C. Porte-Virus. - Parmi les animaux vulnérants, il en est qui doivent être à l'occasion des agents actifs de la transmission des maladies virulentes. En se portant successivement d'un individu à l'autre, ils peuvent puiser sur un malade l'élément virulent qu'ils transportent ensuite sur un individu sain. 
C'est surtout pour les aflections charbonneuses qu'on a cite des faits de cette nature, presque toujours rapportés aux Diplères (Stomoxes, Simulies). Nous y reviendrons en traitant de ces Insectes.

Mais beaucoup d'autres animaux peuvent être également considérés comme les propagateurs de telle ou telle maladie contagieuse, sans parler de ceux qui, comme les Chiens enragés, inoculent leur propre virus.

D. Venimeux. - Morquin-Tandon appelle toxicnzoaires tous les animaux qui produisent du venin. "Ces animaux possèdent des glandes ou glandules pour sécréter !'humeur toxique et des instruments pour la transmettre. Les uns inoculent le venin avec la bouche ou une partie de la bouche disposée à cet effet, d'autres sont pourvus d'un organe spécial. "

Parmi les premiers se placent les serpents, les Araignées, les Scolopendres. Peut-être aussi pourrait-on ranger dans le même groupe les Insectes à salive irritante, tels que les Cousins, les Simulies, les Réduves.

Au nombre des toxicozoaires qui possèdent un appareil spécial pour inoculer leur venin, nous pouvons citer les Vives, les Scorpions, les Hyménoptères, etc.

Enfin, il est quelques animaux venimeux qui sont dépourvus de tout instrument d'inoculation: tels sont les Crapauds, les Tritons et les Salamandres.

L'activité des venins peut être due à des produits assez variables: leucomaïnes, substances acides, globulines, etc. Jusqu'à présent, d'ailleurs, on est beaucoup moins tixé sur la nature chimique de ces produits que sur leur activilé physiologique.

E. Vénéneux. - La consommation de la chair des animaux (parfois aussi des oufs) détermine dans certaines circonstances de véritables empoisonnements. On peut à cet égard distinguer deux cas principaux :

$1^{\circ}$ Botulisme. - Après la mort, la viande est envahie par des microorganismes (microbes de la putréfaction) qui s'y multiplient en provoquant la formation de ptomaïnes, dont la plupart constituent de violents poisons. Les intoxications qui reconnaissent un tel point de départ sont aujourd'hui assez bien connues; on leur donne le nom de botulisme ou allantiasis.

20 Siguatère. - Mais il est un grand nombre d'animaux dont la chair est toxique à l'état normal, soit d'une façon constante, soit seulement dans des conditions particulières. Nombre de faits de ce genre seront indiqués à propos des Crustacés, des Mollusques et surtout des Poissons. La toxicité est due en pareil cas encore à des substances chimiques, mais celles-ci sont produites directement par l'activité physiologique des tissus animaux: ce sont des leucomaïnes.

On peut donner aux empoisonnements provoqués par la chair 
fraiche ou les produits animaux non altérés le nom de sigurtera, appliqué spécialement par les médecins sud-américains aux accidents déterminés par l'ingestion de Poissons vénéneux.

F. Destructeurs d'animaux ou de végétaux utiles. - On pourrait certes étendre beaucoup la liste des animaux nuisibles; qu'il nous suffise d'ajouter à tous ceux que nous renons de citer la simple indication de ceux qui nuisent directement ou indirectement à l'Homme en s'attaquant soit aux animaux qui lui rendent des services, soit aux plantes qu'il cultive pour son alimentation, pour celle de ses animaux domestiques, pour son agrément, etc.

\section{Animaux utiles.}

L'utilité des animaux, à notre point de vue, est susceptible de se manifester de façons fort diverses, de telle sorte qu'elle pourrait donner lieu à de nombreuses classifications. Nous nous bornerons i reproduire, comme étant la plus simple, celle qui a été proposée en 1838 par I. Geoffroy Saint-Hilaire (1), et qui se trouve résumée dans le tableau synoptique que nous avons tracé plus haut.

A. Animaux alimentaires. - Dans ce groupe doivent être rangés tous les animaux qui nous procurent des substances alimentaires quelconques. L'Homme ayant un régime omnirore, les produits d'origine animale tiennent une place très importante dans son alimentation. Ainsi s'explique l'intérêt primordial que la zootechnie attache, en ce qui la concerne, à l'exploitation des animaux dont il s'agit. Mais, à côté des animaux de boucherie ou des bêtes laitières, il faut signaler aussi les volailles, le gibier, les Poissons, etc., etc., qui nous fournissent également leur chair; les Oiseaux, dont nous consommons en outre les œufs; les Abeilles, dont nous recueillons le miel, etc.

B. Animaux auxiliaires. - On donne ce nom à tous les animaux dont nous tirons une aide quelconque en raison de leurs facultés spéciales. Le Cheral, l'Ane, le Bœuf, par exemple, dont nous utilisons les forces, sont des animaux auxiliaires. Le Cliien, dont nous exploitons les instincts ou l'intelligence pour la garde des troupeaux, pour la chasse, etc., doit prendre place à côté de ceux-ci, et peut-être même à leur tête. Nous pourrions citer encore au même titre tous les animaux qui nous rendent service en détruisant une foule de produits ou d'êtres nuisibles: tels sont les Nécrophores et les Diptères, qui consomment les substances en putréfaction; les Coccinelles, qui dévorent les Pucerons; les Crapauds, qui débarrassent nos jardins d'Insectes, el tant d'autres animaux, dont nous méconnaissons trop sourent l'utilité.

Il faut savoir élablir, il est rrai, la balance entre l'utilité et la no-

(1) I. Geoffroy Sant-IIhane, Acclimatation et domestication des animaux utiles. 4 édit., 1861, p. 56. 
cuité des animaux qui nous entourent, et ce'st à l'égard des animaux auxiliaires surtout, que ce point offre une grande importance. Prenons un exemple. La Taupe est un animal que les jardinicrs ont en horreur, parce qu'clle bouleverse leurs plantations; aussi n'lésitent-ils jamais à la détruire lorsqu'ils le peuvent. En présence de ce fait, le naturaliste proteste de l'utilité méconnue de l'animal, qui ne se nourrit en aucune façon de substances végétales, mais détruit, au contraire, une quantité énorme d'Insectes nuisibles, notamment de larves de Hannetons. $A$ quel parti se rattacher? Nous pensons, quant à nous, qu il faut peser les services que nous rend l'animal, et les dégâts qu'il cause. C'est là une question toute de pratique, et le résultat doit varier suivant les circonstances; mais c'est ce résultat seul qui doit nous guider. L'application de ce principe, faite arec sagacité, empêcherait sans doute la destruction d'une foule d'animaux nuisibles en apparence, et d'autre part nous débarrasserait d'un certain nombre d'autres dont les services sont insignifiants en comparaison des dégâts qui sont leur fait.

C. Animaux industriels. - Les produits que l'industric peut retirer des animaux sont fort nombreux. C'est ainsi qu'on exploitc le sang, les os, la chair, la graisse de nos grands Mammifères domestiques : à ce titre, ceux-ci peuvent done ètre considérés comme des animaux qui sont élevés en vue d'une exploitation industrielle. Le Mouton, par exemple, est entretenu dans certains pays comme simple producteur de laine: c'est bien un animal industriel. De même, le Bombyx du mùrier est destiné à produire de la soie, ete.

D. Animaux médicinaux. - Les Sangsues constituent le type par excellence des animaux de ce groupe, et on trouvera à leur égard des détails suffisants dans la seconde partie de cet ouvrage; il faut ranger à còté d'elles quelques autres Hirudinées, et la qualification de médicinaux peut en outre-s'étendre aux Insectes vésicants, et à tous les animaux, en somme, qui nous fournissent des produits utilisés par la thérapcutique: Éponges, Corail, Escargots, Castor, etc.

E. Animaux accessoires. - Ce sont tous ceux que l'homme recherche pour le convictus et l'ornement. Leur nombre est en quelque sorte illimité. Citons principalement: $1^{\circ}$ Animaux de compagnie: Chat, Chien d'appartement, Singe, Marmotte; $2^{\circ}$ Diseaux parleurs ou chanteurs: Perroquet, Sansonnet, Serin, Bouvreuil ; $3^{\circ}$ Animuuct colorés : Paon, Ara, Poissons rouges, Insectes phosphorescents : $4^{\circ}$ Animaux di combal: Taureau, Chien, Coq, etc., etc.

Un certain nombre d'animaux utiles ont inérité, à des titres divers, d'être associés directement à l'homme : on leur donne, pour cette raison, le nom d'animaux domestiques.

Domestication. - L'histoire de la domestication des animaux est demeurée fort longtemps dans les limites étroites d'unc question de zoologie appliquée; c'est seulement depuis les belles études de 
F. Cuvier (1) et d'I. Geoffroy Saint-Hilaire qu'elle a pris rang parmi les thèses les plus importantes de la zoologie générale.

Mais, avant d'aborder ce sujet, il importe au plus haut point de préciser la valeur des expressions (2). Domestication vient évidemment de domestique, mot qui dérive lui-même du latin domus. Au point de vue étymologique, domestiquer un animal signifie donc "en faire l'animal de la maison ". A ce titre, le Moineau franc (Passer domesticus), la Houche commune (Musca domestica), la Souris seraient de véritables animaux domestiques. Nais les détails dans lesquels nous sommes entré plus haut au sujet des rapports mutuels des organismes suffisent pour nous faire ranger ces animaux dans la catégorie des commensaux, et personne aujourd'hui ne songe plus à prendre à la lettre les qualifications de la nomenclature.

Un Oiseau qu'on met en cage, un Loup qu'on enchaine, ne sont pas davantage des animaux domestiques: ils sont simplement cuptifs, et demeurent prêts à reprendre leur liberté à la première occasion favorable.

Il est certains de ces animaux - mais non pas tous - qui peurent passer de la captivité à l'apprivoisement. lls acceptent alors sans réserve leur état de servitude, perdent tout désir de liberté et se plient aux exigences diverses de leur nouveau mode de vie : ceux-là encore ne sont pas domestiqués; ce sont des animaux apprivoisés, ou privés. Notons que l'apprivòisement exige en général que les animaux soient pris jeunes, parce qu'on peut alors les plier plus facilement à de nouvelles habitudes, et que, d'autre part, il implique un certain degré d'intelligence, leur permettant d'acquérir la connaissance du maitre.

Mais l'apprivoisement, comme la captivité, ne porte que sur des individus isolés, et ces individus ne se reproduisent que peu ou point lorsqu'ils sont sous le joug de l'homme, comme c'est le cas pour l'Éléphant, ou leur progéniture elle-même doit être soumise à l'apprivoisement. Le Guépard, l'Épervier, le Gerfaut, que l'Homme dresse à la chasse; la Loutre, le Cormoran, qui l'aident à la pêche, sont soumis individuellement; mais à chaque génération la même ruvre doit être recommencée. La domesticité, au contraire, s'étend aux générations issues les unes des autres; c'est alors l'espèce, et non plus seulement l'individu, qui se trouve soumise à la domination de l'homme. On passe par gradations insensibles, il est vrai, de l'apprivoisement à la domesticité, mais celle-ci témoigne dans tous les cas d'une subordination beaucoup plus complète, préci-

(1) Fréd. Cuvier, Essai sur la domesticité des Mammifères. Mèm. du Muséum d'hist. nat., t. XIII, p. 55, 1826 .

(2) I. Geoproy Saint-Hilaine, Art. Donestication de l'Encyclopédie nouvelle, 1838. - Essais de sool. génér., 1841. - Acclimat. et domesticat. des anim. utiles, 1861. 
sément paree qu’elle résulte, comme le dit fieolfroy Saint-Hilaire, "de l'action d'une suite indéfinie de générations humaines sur une suite indéfinie de grénérations animales ». Au surplus, voici les définitions que nous doune l'éminent naturaliste :

"Les animaux domestiques sont ceux qui sont nourris dans la demeure de l'homme ou autour d'elle, s'y reproduisent, et y sont habituellement élevés.

"La domesticitr est l'état de l’animal domestique, et la doméstiration est la réduction à l'état domestique."

En partant de ces données, et en les rapprochant des principes exposés dans le paragraplie précédent, on verra que la domesticité, comme nous l'avons déjà dit, n'est qu'une forme du mutualisme (1), et qu'il n'y a, dans ses manifestations, rien qui diffère essentiellement des phénomènes que nous avons signalés chez les fourmis.

Dans l'état actuel des choses, nous avons à reconnaitre, en eflet, dans la domesticité, une association d'individıs appartenant à deux espèces distinctes, association volontaire de part et d'autre, et dans laquelle l'une des espèces exerce une autoritè acceptée par l'autre.

Mais comment cette association a-t-elle pris naissance? Ou, pour être plus précis, comment les animaux qui nous sont aujourdhui soumis ont-ils été domestiqués à l'origine? Il est évident qu une telle question ne comporte pas de réponse positive, tout au moins en ce qui concerne nos principales espèces. Nous possédons bien quelques Oiseaux, tels que le Dindon, le Canard musqué, les Faisans doré et argenté, dont la domestication parait assez récente; mais les renseigrnements recueillis à leur endroit sont fort peu précis, et d'ailleurs la laiblesse native de ces animaux a dû rendre cette domestication singrulièrement facile. Quoi qüil en soit, si le problème, tel que nous l'arons posé, n'est pas susceptible d'une solution rigoureuse, nous pourons du moins arriver à un résultat offrant une somme de probabilités. Pour cela, nous puiserons nos données dans les faits qui se passent encore aujourd'hui sous nos yeux.

Ce que nous arons dit plus haut a dû suffire pour démontrer que la domestication est nécessairement consécutive à la captivité et à lapprivoisement.

La captivité suppose la contrainte; l'homme a done pu d'abord s'emparel par la ruse des animaux sauvages et les soumettre par divers moyens d'intimidation : châtiments, immobilisation, privation de nourriture, ete. C'est ainsi que, de nos jours encore, on arrive à se rendre maitre des Éléphants. Et, dans certains cas, il faut bien le remarquer, la contrainte se réduit ì fort peu de chose, lorsque, par exemple, les animaux sont d'un naturel craintif, ou lorsquils sont très jeunes.

(1) A. Espixas, op. cil., p. 174. La plupart des considerations qui suivent sont cimpruntées il ce remarquable ourrage. 
Mais l'apprivoisement, au contraire, exige en général que l'homme entre dans une autre voie. Après avoir dompté les animaux, il doit se les concilier. On sait le role des témoignages d'affection dans le dressage des chevaux. On sait comment les grands Félins captifs sont sensibles aux caresses de l'homme. Lappétence particulière des animaux pour certains aliments peut être utilisée dans le même sens avec le plus grand profit. Les procédés doivent évidemment varier suivant le caractère des animaux et suivant les circonstances, "Les corrections d'ailleurs, dit Espinas, et d'autre part les aliments favoris, toujours reçus de cette mème main qui sait châtier. ont imprimé de tout temps dans les consciences neuves des animaux pris jeunes une empreinte ineffaçable, leur apprenant que l'homme est un être dont ils peuvent tout craindre et tout espérer, leur faisant sentir qu'ils sont pour ainsi dire dans sa main. Qu'on ajoute à cela l'expression de bonté suprême et d'énergie concentrée, manifestée si éloquemment dans les gestes, dans les traits, dans la voix de l'un et de l'autre sexe humain, et l'on comprendra que l'animal intelligent regarde l'homine comme un ètre infiniment supérieur à lui, dont l'association mérite d'ètre recherchée par-dessus toutes les autres. C'est ce qui explique les effusions passionnées de tendresse comme les témoignages d'humilité sans réserve que prodiguent à leur maitre ceux d'entre eux à qui la dlose d'expression a été déparlie en quelque mesure."

Il nous reste encore un pas à faire. "La domestication suppose nécessairement la reproduction sous la main de l'homme ", ainsi qu'on l'a sourent répété. Ce n’est pas à dire que les deux faits soient absolument corrélatifs : nous avons au contraire de nombreux exemples de reproduction en l'état de simple captivité. Mais la formule dont il s'agit tend à exprimer cette donnée essentielle, que la domestication doit porter ì la fois sur les individus et sur leur descendance. L'animal apprivoisé a pu aboliquer sa liberté personnelle d'une façon plus ou moins complète; mais, ou bien ses facultés procréatrices sont suspendues, ou bien ses descendants directs chercheront à retourner à la vie sauvage. A cet égard, il est sans doute difficile d'établir une démarcation bien nette entre l'apprivoisement et la domestication; cependant, les animaux domestiques, qui se reproduisent indéfiniment entre nos mains, ne manifestent guère, en général, de tendance à reconquérir leur liberté, et il est toujours assez lacile de les ramener à la vie domestique. D'ailleurs, il en est beaucoup dont la constitution a subi des modifications trop profondes pour être en état de résister encore aux rigueurs de l'état sauvage : nos Moutons perfectionnés, par exemple, abandonnés à eux-mèmes, ne tardent pas à succomber dans la lutte pour l'existence.

Or, pour arriver à cette domination complète des grénérations successives d'animaux, l'ttomme s'est appuyé, selon la remarque de F. Curier, sur une tendance héréditaire très puissante, se manifes- 
tant che\% la presque totalité d'entre eux. Il sagit de la sociabilité et plus particulièrement encore de la surbordination à un "chef naturel ". Nous ne pourons mieux faire que de citer encore Espinas: "Sauf le chat qui est reste, en eflet, plutot le commensal que le serviteur de l'homme, tous, chiens, moutons, chèvres, boufs, rennes, chevaux, sangliers, éléphants, vivent en troupes organisées plus ou moins étendues, soumises à un chel'. Retrouvant à un plus haut degré chez leur nowveau maitre lascendant qüils étaient disposés ì subir de la part de leurs congénìres, ils n'ont pas eu de peine ì se soumettre à lui. Ouand l'homme a eu cn si possession un certain nombre d'enfre eux, il est devenu naturellement le chef de leur bande, se subslituant ainsi au chef que cette bande ent suivi, ou mème obtenant de lui tout le premier une obéissance imitée de tout le troupeau. "

Une fois la domestication établie, ses effets se sont fail sentir sur les animaux aussi bien (jue sur l'Homme. Les premiers ont naturellement développé les facultés en raison desquelles ils avaient été choisis, et dans le sens même oủ l'llomme avait intérêt à les diriger. C'est ainsi que l'intelligence du Chien s'est élevée d'une façon remarquable, tandis que le Bouf, le Porc, le Mlouton se sont perfectionnés uniquement quant aux qualités physiques qui les ont fait de tout temps utilisel. Et, en ce qui a trait ì l'Homme lui-mème, on peut dire que linfluence exercée sur lui par la domestication des animaux est chose inappréciable. L'animal domestique, c'est une réserve de nourriture, partant un capital; e'est un instrument de travail, dont la puissance permet d'accumuler de la richesse ou de la transformer; el, par cet intermédiaire, l'Homme se crée des loisirs, grâce anxquels il peut se livrer aux travaux intellectuels qui développent et fortifient son cerveau, grâce auxquels il peut se mettre en garde contre les dangers qui l'assiègent et étendre son empire sur tout ce qui l'entoure. C'est là qu'est le point de départ de la civilisation : livrè à lui-même, l'Homme serait inévitablement demeuré à l'état de misérable faiblesse dans lequel nous voyons aujourd'hui encore les naturels australiens, occupés chaque jour à recueillir des graines, ou bien à prendre des Vers et des Kangourous.

En résumé, nous coneevons la domestication des animaux par l'Ilomme comme un cas particulier et complexe du mutualisme, qu'on peut qualifier de mutualisme substitutif. Historiquement, il nous est facile d'adapter à l'évolntion de l'humanité la succession des phases du phénomène, telle que nous l'avons esquissée. L'Homme chasseur a pu longtemps se passer d'auxiliaires animaux; toutefois, mis à même d'apprécier leur valeur, il a dû chercher à s'emparer de certains d'entre eux, du Chien, par exemple, pour le dresser à la chasse. La période pastorale comporte une extension considérable de la domeslication, en ce qui concerne les animaux propres à fournir leur toison, leur lait et leur chair. L'Homme agriculteur vient ensuite et sournet des 
espèces plus puissantes pour laider aux travaux de la terre. Enfin, c’est aux premières périodes de la civilisation, sans doute, qu'il faut reporter la domestication des animaux d'une utilité secondaire ou de ceux que nous avons appelés accessoires.

Quant au rôle des sociétés modernes dans la domestication, il se réduit à fort peu de chose. En cette matière, l'œuvre de nos premiers ancêtres a été si complète qu’ils ne nous ont laissé que des vides insignifiants à combler.

Acclimatation et naturalisation. - Acclimater un animal (ou un végétal), c’est, à proprement parler, l'accommoder à un nouveau climat. Or, "l'expression de climat, dit Humboldt, prise dans son acception la plus générale, sert à désigner l'ensemble des variations atmosphériques qui affectent nos organes d'une manière sensible : la température, l'humidité, les changements de la pression barométrique, le calme de l'atmosphère, les vents, la tension plus ou moins forte de l'électricité atmosphérique, la pureté de l'air ou la présence de miasmes plus ou moins délétères, enfin, le degré ordinaire de transparence et de sérénité du ciel ". On peut donc, d'après cela, définir l'acclimalation, l'accommodation aux influences très multiples et très complexes d'un nouveau climat; l'acclimatement n'est que le résultat de cette accommodation, c'est l'ćtat de l'être qui s'y est trouvé soumis.

Beaucoup d'auteurs confondent la naturalisation avec l'acclimatation : I. Geoffroy Saint-Hilaire attache pourtant beancoup d'importance à la distinction de ces deux termes. Naturaliser, dit-il, n'est et ne peut être que rendre naturel. Par conséquent, naturaliser une race, une espèce, n'est'pas seulement " l'amener et la faire vivre dans un nouveau pays, mais l'y faire virre dans les mêmes conditions que les espèces naturelles à ce pays"

L'acclimatation de certains individus est un fait constant: les Faisans qui sont depuis longtemps nourris dans nos pares s'y trouvent soumis à des conditions d'existence différentes de celles quils trouvaient dans leur patrie; ils peuvent même se reproduire sous nos yeux, mais cette reproduction, ainsi que l'éducation des jeunes, exige des soins tout spéciaux, et l'espèce, abandonnée à elle-même au milieu des rigueurs de notre climat, ne tarderait pas à disparaître. Ces animaux sont donc acclimatés, c'est-à-dire amenés à vivre dans un nouveau climat, mais dans des conditions plus ou moins éloignées de l'état de nature.

Au contraire, le Lapin de garenne (Lepus cumiculus), qui paraît originaire de l'Europe méridionale et peut-être de l'Afrique, vit et se multiplie dans nos forêts à l'état sauvage; il s'est donc, non seulement acclimaté, mais aussi naturalisé.

Il faut avouer cependant que les exemples d'acclimatation et surtout de naturalisation sont beaucoup moins nombreux qu'on ne le pense 
généralement, et ce, malgré les efforts des savants qui se sont donné pour mission de fonder dans nos pays des sociétés et des jardins d'acclimatation.

\section{CHAP'TRE IV}

\section{TAXINOMIE}

Déterminer les rapports des animaux entre eux, tel est le but le mieux défini de la zoologie : et nous voyons en effet les recherehes les plus variées dans le domaine de cette science aboutir en somme, dans la plupart des cas, à des essais de classement des formes étudiées. L'étude des lois sur lesquelles doivent reposer les classifications porte le nom de taxinomie ( $\tau \alpha \xi_{\iota \varsigma}$, ordre; vóros, loi), et c'est un des points de la zoologie générale qui méritent le plus d'attirer notre attention. Il serait, sans doute, exagéré d'affirmer, comme d'aucuns l'ont fait, que la taxinomie constitue à elle seule la biologie tout entière; mais on doit reconnaitre, du moins, qu'elle en représente un des éléments les plus importants.

Les classifications, d'ailleurs, ont un côté utilitaire dont l'intérêt ne peut échapper à personne, d'autant que le besoin de rapprocher les choses semblables résulte de la portée limitée de notre intelligence. Le nombre des êtres qui s'oflrent à l'étude du naturaliste est tellement considérable que sa vie entière lui permettrait à peine d'acquérir la connaissance individuelle d'une fraction insignifiante d'entre eux.

Pour nous former une idée de ces êtres, il est donc nécessaire de les rapprocher d'après leurs affinités, c'est-à-dire de les classer, et, selou la remarque de Milne Edwards, de se représenter chacun des groupes ainsi formés par un type idéal, abstrait, par une image mentale, si I'on veut, à laquelle on applique un nom particulier.

L'établissement de ces catégories permet de s'élever du particulier. au général et de saisir du premier abord les rapports des êtres entre eux. Avons-nous en vue un Cheval, par exemple: aussitot, et sans le moindre effort, notre esprit réunit un ensemble d'êtres qui ressemblent à celui-ci, et il arrive à embrasser progressivement tous les Chevaux, tous les Mammifères, tous les Vertébrés, tous les Animaux... Or, le Cheval, le Mammifère, le Vertébré, l'Animal ne sont que des abstractions morphologiques, n'ayant aucune existence en dehors de l'esprit, au lieu de correspondre à une forme réelle, tangible, comme l'individu déterminé sur lequel nous avions fixé notre attention.

Envisagée à ce point de vue, la classification apparait surtout comme la conséquence et la traduction d'un besoin de l'intelligence. au lieu de reposer sur l'existence réelle de groupes ou catégories 
d'êtres ayant toutes une valeur positice, ainsi que l'admettent les rares disciples d'Agassiz. Ce n'est pas à dire cependant qu'il faille, à l'exemple de Buffon, regarder la classification comme une pure invention de l'esprit. Entre ces deux opinions extrêmes, il y a place pour des vues moins absolues et plus rationnelles, et nous ne pouvons méconnaitre que les divers groupes des systèmes zoologiques reposent, en réalité, sur les rapports plus ou moins étroits qui existent entre les animaux, quant à leur organisation. Seulement, il ne faut pas oublier que ces catégories n'ont qu'une valeur relative, ce qui explique du reste les modifications qu'elles subissent suivant la manière de voir de chaque classificateur.

En tout étal de cause, on peut juger combien la division des classifications en naturelles et artificielles a perdu de son ancienne importance, puisque, dans tous les cas, notre activité intellectuelle prend une certaine part au groupement méthodique des ètres. Rappelons cependant que les classifications artificielles, encore appelées systèmes artificiels, sont basées sur des caractères tirés de certains organes choisis arbitrairement: aussi, la faveur momentanée dont elles ont pu jouir est-elle attribuable à la seule facilité de leur application.

Les classifications naturelles, au contraire, plus souvent dénommées méthodes naturelles, sont établies d'après l'ensemble des caractères fournis par l'organisation. Or, comme on le verra plus loin, tous ces caractères n'offrent pas la mème valeur, et ce n'est que par une juste appréciation de leur importance relative qu'on peut arriver à déterminer les affinités qui existent entre les animaux. Nous consacrerons ce chapitre ì rechercher quelle est la nature réelle de ces affinités.

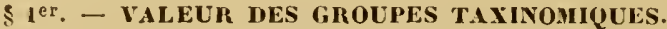

\section{Apercu Historique.}

Aristote (384-322 av. J.-C.), qui est unjversellement, et à juste titre, considéré comme le fondateur de la zoologie, divisait les animaux en deux grandes catégories: Animaux pourvus de sang et Animaux exsangues. A s'en tenir au sens littéral de la caractéristique employée, il est évident que cette classification reposerait sur une erreur; mais en réalité sa base était beaucoup plus étendue, ces deux catégories correspondant, l'une aux Vertébrés, l'autre aux Invertébrés. Chacune d'elles se subdivisait d'ailleurs en quatre groupes naturels:

Animaux pourvus De sang : Quadrupèdes vivipares, Oiseanx, Quadmpédes et apodes ovipares, Poissons.

Animaux exsangues: Mollusques, Crustucés, Insectes, Testucés.

Toutefois, il est bon de remarquer qu'Aristote n'avait pas en vue l'établissement d'une classification régulière. Ces groupes principaux étaient bien partagés en groupes secondaires, mais la valeur de ceux-ci élail loin d’ètre 
fixe : les expressions employées pour les désigner, yśros et cídos, répondent alssez bien, dans quelques cas, au genre et à l'espèce des classificateurs modernes; la première, cependant, a une signification lort peu constante, et s.rt quelquefois à désigner un groupe quelconque d'espèces, ayant la valeur. de ce que nous appelons aujourd'hui famille, ordre et mène classe.

Apres Iristote, il faut franchir une période de vingt siècles avint de constater un progrès sérieux dans la classilication zoolosique. L'illustre naturaliste suédois Ch. Linné (1707-17\%8) sauva la zoologie de la confusion dans laụuelle menaçait de la jeter l'encombrement des matériaux recueillis par une foule de savants chercheurs. Limne doit à son esprit méthodique l'action immense ıjüil a exercéc sur les sciences naturelles : il était le premier qui cùt teuté de dresser un tableau précis du système de la na: ture; et, par l'emploi d'une méthode de classification et le nomenclature aussi simple que claire, il était appelé à communiquer à la zoologie l'impulsion la plus féconde. Plus nettement que ses prédécesseurs, il distingua les espèces et les genres, et introduisit en outre les ordres et les classes dans le système de la zoologie. Voici, du reste, la classification aloplée dans lí 1.ze élition (1766) de son Systema natura :

Classe 1. Mamualia. Ord. Primates, Brula, Fera, Gilires, Pecora, Bellux, Cete. Classe 2. Aves. Ord. Accipitres, Picx, Anseres, Gralle, Gallinx, Passeres.

Classe 3. Aspusia. Ord. Reptiles, Serpentes, Nuntes.

Classe 4. Pisces. Ord. A podes, Jugulares, Thoracici, Abdominales.

Classe 3. I.ssecta. O:d. Coleoptera, Hemiptera, Lepidoptera, Neuroptera, IIymenoptera, Dipteru, Apteru.

Classe 6. Vermes. Ord. Intestina, Mollusca, Testacea, Lithophytu, Zoophyta.

Les continuateurs de Linné ne firent subir à son système que des modifications de détail, jusqu'au jour où Cuvier publia le résultat de ses belles et vastes recherches sur la struclure des animaux, et en fit une application directe à la classification (1812). En se basant sur le principe exposé plus loin de la subordination des caractères, Cuvier fut amené à reconnaitre que les animaux se rattachent i différents types ou plans d'organisation, dont il fixa le nombre à quatre, en donnant aux groupes ainsi constitués le nom d'embranchements. A ces grandes divisions, il subordonna les classes, dont le nombre fut de beaucoup augmenté; mais il ne s'arrèta pas à subdiviser celles-ci d'une façon régulière. Dans la plupart des cas, cependant, il les partagea en ordres, puis en familles, parfois mème en sections, tribus, elc., avant d'en arriver aux genres et aux espèces. Nous nous bornons à l'indication des groupes primordiaux :

Premier embranchement : Vertébrés. 4 classes : .Mammiféres, Oiseau , Reptiles, Poissons.

Deuxième embranchement : Mollusuces. 6 classes : Céphalopodes, Ptéropodes, Gasterropodes, Acéphales, Brachiopodes, Cirrhopodes.

Troisième embranchement : Articllés. 4 classes : Innelides, Crustacés, Arachides, Insectes.

Quatrième enbrancliement : RAYuxiés. \#̈ classes : Echinodermes, Inteslinaux, tculiphes, Polypes, Infusoires: 
La base fondamentale de cette classification, c'est-a-dire I'existence d'embranchements ou types d'organisation constituant les catégories les plus compréhensives, trouva le plus sérieux appui dans les travaux embryologiques de von Baer. Aussi n'est-il pas surprenant de constater que l'ouvre taxinomique de Cuvier n’a subi jusquà notre époque aucune altération essentielle.

Seulement, les constants progrès de la science devaient nécessiter quelques remaniements de ces groupes. Eı 1843̈, Siebold sépara des Rayonnés les Infusoires et les êtres voisins, pour en faire un type particulier, celui des Protozoaires. Trois ans plus tard, Leuckart divisait le reste des Rayonnés en Culentèrés et Échinodermes; et depuis lors les Cœlentérés ont été également partagésen Spongiaires et Polypes. De mème, on ne tarda pas á scinder le grand groupe des Articulés en deux catégories: les Arthropodes et les Vers. L'embranchement des Mollusques lui-mème a été démembré, et ses rameaux ont été disséminés dans d'autres groupes.

Au surplus, on a dî cesser de concevoir les embranchements comme des groupes tout ì fait séparés et ne pouvant offrir entre eux aucune liaison. Bien au contraire, les formes intermédiaires ou "formes de passage " constituent des éléments de plus en plus nombreux et embarrassants pour les zoologistes.

\section{Gruupes phincipaux des systèmes zoologiQues.}

D’après ce qui vient d'être exposé, la classification zoologique est établie actuellement d'après un mode assez uniforme. Le règne animal est divisé en plusieurs types ou embranchements; ceux-ci se subdivisent en classes, les classes en ordres, les ordres en familles, les familles en genres, et les genres en espèces. C'est ainsi que nous disons, par exemple, que l'Ours brun (Ursus arctos) est une espèce du genre Ursus, de la famille des Ursidx, de l'ordre des Carnivores, de la classe des Mammifères et de l'embranchement des Vertébrés.

Dans certains cas particuliers, la multiplicité des formes ou quelque autre motif impose même au zoologiste l'obligation de constituer, parmi ces groupes principaux, des divisions secondaires, telles que sous-classes, sous-ordres, sous-familles ou tribus, etc. Toutefois, ce sectionnement, basé avant tout sur l'utilité pratique, ne mérite pas, pour l'instant, de retenir notre attention.

Mais il serait fort important, au contraire, de déterminer la valeur de chacun des groupes principaux que nous avons énumérés plus haut, et, partant, les caractères sur lesquels on doit s'appuyer pour les établir.

L'étude de l'anatomie comparée nous montre dans quelles limites considérables varient l'étendue et la constance des rapports qu'entretiennent entre elles les diverses parties de l'organisme. C'est cette observation qui a servi de base au principe de la subordination des curactères, établi par Antoine-Laurent de Jussieu et introduit par Cuvier dans la classification des animaux. Le principe dont il s'agit 
repose essentiellement sur ce fait que les dispositions organiques les plus fixes sont colles qui ont le plus d'inlluence sur le reste de l'économie, et qu'elles doivent, par suite, fournir les caractères primuires : tandis que les particularités plus variables de l'organisation n'ont qu'une importance secondaire, de telle sorte que les caractères (ju'elles fournissent sont subordommis aux premiers. En appliquant ces données au rìgne animal, Cuvier rendit à la zoologie le plus signalé service; toutefois il eut le tort l'exagérer la valeur des rapports dont il vient d'être question. Pour lui, les caractères supérieurs ou. de premier ordre sont des cnractères dominateurs, qui entrainent toujours une modification déterminée de l'organisme et règlent, en (juelque sorte, la nature essentielle de l'être vivant. Les disciples du grand anatomiste n'ont pas hésité ì reconnaitre l'erreur du maitre; et l'un des plus éminents parmi eux, H. Milne Elwards, après avoir constaté qu'aucun caractère ne domine d'une manière absolue la constitution d'un animal ou d'une plante, conclut avec raison que, " dans chaque groupe naturel, il existe dans l'organisme certains caractères prélominants, sans qu'il y ait des mognes dominateurs (1)".

Le principe une fois posé, il reste à en faire l'application. A cet égard, c’est au tact du naturaliste qu'est laissée l'appréciation de l'importance relative des différents caractères; et e’est là, sans aucun doute, l'origine des variations, parfois très étendues, qu'on observe tous les jours dans la classification de tel ou tel groupe.

Agassiz a pensé qu’il élait possible d'éviter cet écueil. Après un exanın attenlif des principaux systèmes zoologiques, il a cru reconnaîlre que les diver's groupes admis dans ces systèmes, de l'embranchement à l'espèce, ont pour base des catégories distinctes de caracteres, et représentent autint d'entités idéales ayant leur fondement dans la nature.

"Les embranchements sont caractérisés par le plan de la structure;

"Les classes, par le mode d'exécution du plan, en ce qui concerne les voies et moyens;

"Les ordies, par le degré de complication de la structure;

"Les familles, par la forme, telle qu'elle est déterminée par la structure;

"Les genres, par les détails de l'exécution des parties;

"Les especes, par les rapports des individus, soit enlre eux, soit avec le monde ambiant, aussi bien que par les proportions des parties, l'ornementation, etc. "

Celte manière de conceroir la taxinomie, et surtout le fait de reconnaître à chacun des groupes une valeur également positive, ont suscité les critiques d'un grand nombre de naturalistes; mais, par une sorte de contradiction, facile du reste à prévoir, beaucoup ont attribué à l'espèce une raleur toute spéciale, la regardant comme plus fondér que les autres catégories. Quelques-uns même ont étendu cette con-

(1) II. MrLxe Eowards, Inlroduclion à la zoologie générale, 1853, p. 17:. 
ception au genre, en invoquant d'ailleurs un ordre de preuves idenlique en faveur de leur manière de voir. L'importance de cette question nous obligera de lui consacrer un paragraphe spécial.

\section{De L LesPĖCE.}

Peu de sujets ont soulevé des passions aussi vives et fait apparaitre des écrits aussi nombreux que celui qui a trait à la valeur et à l'origine des formes spécifiques. Il s'agit, en effet, d'un problème des plus complexes, et qui touche à la source même de notre existence.

La géologie nous apprend que, dans le principe, la vie n'a pu se manifester sur la terre. Elle y est apparue seulement après que celleci eut subi dans son état primitif de profondes modifications. Or, l'esprit se pose inévitablement cette question: comment les premiers ètres vivants ont-ils été formés? comment ont été produits les êtres de plus en plus complexes qui leur ont succédé ?

On peut prévoir, dès maintenant, les difficultés qui doivent s'offrir dans la résolution d'un tel problème. Aussi les biologistes se partazrent-ils, à cet égard, en deux camps bien distincts : $1^{\circ}$ les uns admettent que chaque espèce a nécessité un acte créateur spécial, et qu'elle possède des caractères tixes et immuables : c'est la doctrine du créationisme, des créations successives ou de l'immutabilité des "spèces; $2^{\circ}$ pour les autres, au contraire, toutes les espèces actuellement vivantes, aussi bien que celles qui sont éteintes, dérivent, par une suite ininterrompue de transformations, de quelques formes primitives et peut-être même d'une seule: c'est à cette hypothèse qu'on donne le nom de doctrine de l'évolution, théorie de la descendance, ou simplement de trunsformisme.

Nous allons exposer ces deux doctrines, et discuter les bases sur lesquelles elles s'appuient.

A. Doctrine de l'immutabilité des espèces. - 11 est certain que les prédécesseurs de Linné, en posant les premiers jalons de la taxinomie, n'a vaient pas en vue autre chose qu'un catalogue à dresser : le caractère artificiel et arbitraire de leurs classifications en témoigne suffisamment. Aussi, tout en adoptant l'espèce comme unité de mesure, ne lui attribuaient-ils qu'une valeur relative.

Linné, le premier, accorda à ce groupe un rang privilégié lorsqu'il posa la définition cosmogonique devenue célèbre: Tot momeramus species quot ab initio creavit infunitum Ens. Le caractère dogmatique de cette formule s'accordait le mieux du monde arec les connaissances scientifiques de l'époque; mais il faut bien reconnaitre que c'est là l'origine de toutes les querelles qui ont surgi entre les naturalistes au sujet de cette question si ardue de l'origine des espèces (1).

(1) Par une sorte de contradiction curieuse à signaler, Linné parait aroir admis la transformation des espèces en plusieurs points de ses ouvrages. 
La plupart des naturalistes qui ont suivi Linne se sont plu, en effet, à reconnaitre à l'espèce une valeur positive, en lui donnanl pour base deux ćléments tirés, l'un de la ressemblamer des individus, lautre de leur filialion. Cuvier la définissait : La réunion des individus descendus les uns des autres ou de parents communs, et de ceux qui leur ressemblent autant qu'ils se ressemblent entre eux (1). " Les successeurs de Cuvier ont pu modifier diversement cette délinition, mais tous en ont conservé l'idée londamentale, et lá pluparl se sont bornés à atténuer la notion de ressemblance, qui est purement empirique, en insistant sur la notion rationnelle de filiation.

G'est que, nous le savons déjà, il n'y pas dans la nature d’individus absolument identiques, el que, par conséquent, il faut bien admettre une certaine variabiliti des types spécifiques. Aussi cette variabililé est-elle reconnue par les plus ardents défenseurs de la lixité des espèces, bien qu'elle n’ait, ì leurs yeux, que des limites trìs étroites. C'est à elle seule, du reste, qu'on peut rapporter la production des variétés et des races.

"Lorsqu'un trait individuel, dit de Quatrefages (2), s'exagère et franchit une limite d'ailleurs assez mal déterminée, il devient un caractère exceptionnel distinguant nettement de tous ses plus proches roisins lindividı qui le présente. Cet individu devient une ruriété. "Donc, la variété peut être définie: " Un individu ou un ensemble d’individus appartenant à la même génération sexuelle, qui se distingue des autres représentants de la même espèce par un ou plusieurs caractères exceptionnels. "

Que, dans un troupeau de Moutons, par exemple, il vienne à naître un Agneau pourvu d'une toison soyeuse, toute différente de celle des autres, on dira que cet individu représente une variété.

Or, il peut arriver que ces particularités soient susceptibles de se transmettre de génération en génération : la variété, devenue héréditaire, constitue alors une rare, et celle-ci mérite d'ètre définie: "L'ensemble des individus semblables, appartenant à une même espèce, ayant reçu et transmettant, par voie de génération sexuelle, les caractères d'une variété primitive (3). "

Si la toison spéciale de l'Agneau dont il vient d'ètre question se montre chez ses descendants, une race nouvelle sera donc produite: telle est; en effet, l'origine de la race mérinos à laine soyeuse, dite race de Mauchamp (4), qui fut créée par Graux, à dater de $18 \geq 8$. dans une ferme du département de l'Aisne.

"On voit, conclut de Quatrefages, que le nombre des races issues

(1) Règne animal, édit. de 1829, P. 19.

(2) L'Espèce humaine, 4c édit., 1878, 1). 28.

(3) Loc. cit., p. 28.

(4) Yvint, Etudes sur la race mérinos it laine soyeuse de Mauchamp. Recueil de mérl. vèt., 1850. ए. 160 . 
directement d'une espèce peut être égal au nombre des variétés de cette même espèce et par conséquent très considérable. Mais ce nombre tend à s'accroître encore d'une manière indéfinie. En effet, chacune de ces races primaires est susceptible de subir des modifications nouvelles pouvant rester individuelles ou devenir transmissibles par voie de génération. Ainsi prennent naissance des variétés et des races secondaires, tertiaires, etc. Nos végétaux, nos animaux domestiques fournissent une foule d'exemples de ces faits (1).»

Quels que soient d'ailleurs les caractères de plus en plus divergents de ces races, elles n'en font pas moins partie de la même espèce. Et si l'on considère l'espèce comme l'unité de mesure, elles en sont des sous-multiples, de même que le genre en représente le multiple immédiatement supérieur.

Or, il est un fait d'observation vulgaire, dans lequel les disciples de Cuvier ont cherché à trouver une base expérimentale à leur conception de l'espèce: c'est que tous les animaux de ces races se reproduisent entre eux. lls ont donc tenté de démontrer que l'espèce est caraclérisée par la possibilité d'un rapprochement sexuel indéfiniment fécond entre les individus. Flourens, l'un des plus ardents parmi eux, a même voulu étendre à la notion du genre les caractères tirés de la fécondité, et a proposé de regarder comme appartenant au même genre tous les individus capables de se féconder entre eux à un degré quelconque. De telle sorte que la fécondité illimitée serait le propre de l'espèce, tandis que la fécondité bornée fournirait une caractéristique du genre.

En résumé, pour les créationistes en général, et en particulier pour les disciples de Cuvier, l'espèce répond à une idée concrète, se rapportant aux notions d'espace et de temps, et repose sur les bases suivantes : $1^{\circ}$ Tous les individus de la même espèce ont entre eux une grande ressemblance; $2^{\circ}$ ils descendent d'un couple d'ancêtres primitifs, non engendrés, par une succession ininterrompue de générations; et un critérium pratique de l'identité spécifique est fourni par la tendance et la capacité à un rapprochement sexuel indéfiniment fécond.

Ces deux points méritent d'être examinés avec une grande attention.

$1^{\circ}$ Caractères morphologiques. - Beaucoup de naturalistes, et ceux surtout qui se sont livrés à l'étude exclusive de la paléontologie et de la conchyliologie, accordent aux caractères morphologiques une importance de premier ordre; il en est de même des médecins, qui sont habitués à envisager l'individu plutôt que l'espèce.

Cependant, Lamarck a depuis longtemps mis en lumière la difficulté que présente, dans une foule de cas, la détermination des espèces, et chaque jour nous arons encore sous les yeux le spectacle de zoolo-

(1) Loc. cit., 1. 28. 
gistes discutant ì perte de vue sur la valeur spécitique de telle ou telle forme. Ce que l'un appelle espèce n'est pour l'autre qu'une simple variété, et la détermination de l'identité spécifique n'est souvent, assure-t-on, qu'une affaire de tact. "On connait depuis longtemps très exactement les Oiseaux de l'Allemagne, dit Hackel (1). Bechstein a, dans sa consciencieuse Ornithologie allemande, distingué 367 espèces, I. Reichenbach en a compté 379, Neyer et Wolff 406, et un autre ornithologiste, le pasteur Brehm, en a admis plus de 900. "

Les crèationistes répondent ì cela que l'espèce peut varier entre deux limites extrèmes représentées par des races ou variétés très distinctes, mais que ces variétés, réunies entre elles par une série de formes intermédiaires, se groupent naturellement autour d'une forme typique dont elles dérivent.

20 Caractères physiologiques. - En ce qui concerne l'espèce, "la notion de filiation, dit de Quatrefages, se joint dans l'esprit le moins cultivé ì celle de ressemblance. Pas un paysan n'hésitera à regarder comme de même espèce les enfants d'un même père et d'une même mère, quelles que soient les différences apparentes ou réelles qui les distinguent. " Et le même auteur ajoute plus loin : "Ce que la science peut affirmer, c'est que les choses sont comme si chaque espèce avait eu pour point de départ une paire primitive unique. "La plupart des créationistes sont encore beaucoup plus affirmatifs, et n'hésitent pas à proclamer que l'ensemble des individus de la même espèce "est la descendance d'un couple primitif ".

Si on leur demande comment tous les descendants de cette paire ancestrale originelle ont pu se maintenir indéfiniment dans leur type spécifique, ils répondent que cette stabilité tientà l'infécondité desindividus issus du croisement d'espèces différentes.

La vérification de cette donnée pourrait être, dans une certaine mesure, considérée comme un argument en faveur du couple primitif; de plus, elle fournirait un critérium pratique de lidentité spécifique, e'est-ì-dire qu'elle permettrait de reconnaitre si des individus donnés appartiennent à des especes ou seulement à des races différentes. C'est là ce qu'on a appelé le rnrartère pliysiologique de l'espèce.

"Les unions sexuelles, chez les plantes comme chez les animaux, dit de Quatrefages, peuvent avoir lieu entre individus de méme rspéce et de mime race, - ou bien de même espèce, mais de ruces différentes, ou bien enfin despeces differentes. Dans les deux derniers cas, il y a ce qu'on appelle un croisement;-le croisement lui-même prend des noms différents selon quil a lieu entre races ou entre especes différentes. Dans le premier cas, il constitue un métissage; dans le second cas, une hybridation. Quand ces unions croisées sont fertiles, le pro-

(1) Histoire de la créalion, 2e édit., 1877, p. 24i. 
duit du métissage porte le nom de métis; le produit de l'hybridation, celui d'hybride (1). "

Nous tenons d'abord à reproduire textuellement ces définitions de l'èminent anthropologiste français, pour éviter la confusion que quelques auteurs se sont plu à jeter dans l'emploi des mots hybride et métis. Ceci établi, voici sur quelles bases on fait aujourd'hui reposer le critérium physiologique de l'espèce $: 1^{\circ}$ Les métis sont indéfiniment féconds; 2० les hybrides n'ont d'ordinaire entre eux qu'une fécondité restreinte et très rapidement bornée; dans le cas contraire, les descendants font retour aux types primitifs.

$1^{\circ}$ Fécondité des métis. - Le métissage s'accomplit en général avec la plus grande facilité, aussi bien à l'état de nature que dans des conditions artificielles. Aussi n'hésite-t-on pas à admettre "que les résultats en sont aussi certains que ceux de l'union entre individus de même race ", et que parfois même "la fécondité s'accroît ou reparait sous linfluence de ce croisement ".

Il ne faudrait pas croire, cependant, que ces faits soient admis sans réserve. Ainsi, d'après Perrier, les éleveurs qui possèdent à la fois un grand noinbre de races de volailles prétendent que le mélange de races différentes donne souvent naissance à des œufs clairs. Et Youatt rapporte que, dans les croisements opérés autrefois, dans le Lancashire, entre le bétail à longues cornes et la race courtes cornes, le tiers des vaches cessa de concevoir à la quatrième génération.

D'autre part, il est certain que dans les races métisses, c'est-à-dire résultant du croisement de deux races, on voit sourent certains produits faire retour spontanément à l'un ou à l'autre des types parents primitifs : c'est à ce phénomène qu'on a donné le nom de réversion. Un grand nombre de faits de ce genre ont été rassemblés par Sanson (2); nous ne croyons pas utile de les rapporter ici. Mais le retour dont il s'agit est loin de s'effectuer avec régularité : dans certains cas, tout ou partie des produits reprennent les caractères de l'un ou de l'autre des parents dès les premières générations; d'autres fois, les faits de réversion ne se manifestent que de loin en loin et d'une façon irrégulière. Tout cela peut être observé dans le croisement des races de Chiens, de Poules, etc. Au degré près, il y a là une variation désordonnée comme celle que nous aurons à signaler au sujet des hybrides.

20 Fróndité limitie des hybrides. - Il nous faut tout d'abord convenir que les animaux d'espèces différentes montrent en général une grande répugnance à s'accoupler entre eux. Cependant, on a constaté le fait sur des individus appartenant à des groupes parfois très éloignés. Buffon a ru un Chien essayer de s'accoupler avec une Truie. Grognier rapporte qu'on a vu souvent le Taureau couvrir la Jument, et le Cheval couvrir la Vache. Réaumur a cité l'exemple d'une Cane qui

(1) Loc. cil., p. 46.

(2) A. Sansox, Traité de zootechnie, 3e édit., t. 11, 1. 51 et suiv., 1883. 
s'accroupissait pour recevoir les caresses de plusieurs Cous, et, ce qui serait incroyable si le savant naturaliste ne l'avait vérifié par lui-même, le fait d'une Poule qui recevait les approches d'un Lapin (1).

Toutefois, ces accouplements ne donnent pas de produits, etla fécondité parait ètre limitéc aux espèces d'un mème genre. Encore estelle loin d’ètre aussi générale que le laisserait supposer la tentalive de Flourens, de caractériser précisément le genre par la fécondité limitée des espèces. Rappelons, cependant, que beaucoup d'Équidés se fécondent entre eux; (qu'il en est de mème de divers Bovidés; qu'on a obtenu des produits du Chien et du Loup, du Tigre et du Lion, etc., ete. On a même constaté quelques faits de cette nature entre animaux sauvages et virant en liberté, surtout chez les Gallinacés.

Est-il rrai, comme on l'a souvent répété, que les produits de ces croisements d'espèces différentes soient stériles? Ce qui est bien démontré, c'est l'infécondité absolue de l'accouplement du Mulet a vec la Mule, par exemple. Mais il faut remarquer que ce fait trouve avant tout son explication physiologique dans l'absence à peu près constante de spermatozoïdes normaux chez le Mulet. Les ovaires de la Nule peuvent fonctionner, et l'on possède aujourd'hui d'assez nombreux exemples de fécondation de la Mule par le Cheral et par l'Ane (2). Mais, jusqu'à présent, cette fécondité n'a été constatée que jusqu'ì la deuxième génération.

Il n'en est pas de même pour beaucoup d'autres hybrides. Ceux qui résultent du croisement entre Chien et Loup, entre Chien et Chacal, entre Bouc et Brebis (Chabin), entre Zébu mâle et Yak femelle (Dzo), entre Lièrre et Lapin (Léporide), etc., sont capables de se reproduire inter se pendant un nombre indéfini de générations, à la façon des véritables métis.

En somme, des accouplements entre individus d'espèces réputées distinctes peurent donner : $1^{\circ}$ des résultats négatifs; $2^{\circ}$ des produits tout à fait inféconds; $3^{\circ}$ des produits dont la fécondité est exceptionnelle; $4^{\circ}$ des produits féconds pendant un petit nombre de générations; $\ddot{\partial}^{\circ}$ des produits indéfiniment féconds.

Mais, assure-t-on, les descendants de ces derniers ne conservent que peu de temps leurs caractères : ils sont soumis à la réversion d'une façon beaucoup plus accusée que les métis, et le retour s'effectue ordinairement de telle façon que, ì chaque génération, un certain nombre d'individus reprennent les caractères, soit du père, soit de la mère. Naudin, qui a découvert ce phénomène, lui a donnéle nom de variation désordonnée. C'est ainsi que se comportent, d'après divers auteurs, et les Chabins et les Léporides. Pourtant le règne régétal nous fournit un fait - unique à la vérité - en opposition avec la loi de réversion.

(1) Art de faire éclore et d'é'evor en toute saison des oisenux drmestiques, 1749.

(2) Lorsque l'infécondité est unilatérale, elle se montre toujours en elfet du côté dư mâle.

Railleter. - Zoologie. 
En fécondant l'Égilops ovata à l'aide du pollen du froment, Godron obtint un hỵloride appelé EEgilops triticoides; celui-ci, croisé de nouveau avee le blé, donna un hybride de seconde génération, l'. Egilops spellieformis, lequel, à l'aide de soins minutieux et spéciaux, put se conserver indéfiniment sans offrir de retour.

Il faul conclure de lì que si, à l'état de nature et dans des conditions toutes spontanées, il ne se produit pas de formes hylrides capables de se propager et de s'élablir d'une facon définitive, il n'y a pas toutefois de différence essentielle entre les hybrides et les métis. Done, le prétendu critérium physiologique n'a point la valeur que lui accordent les partisans de la fixité des espèces.

On a comparé très heureusement les résultats des unions sexuelles à ceux que fournit la greffe. Comme tous les auteurs le constatent, la faculté que possèdent les végétaux de se greffer l'un sur l'autre repose sur la simple conformité de leurs conditions anatomiques el physiologiques : de même, il semble que le degré de fécondité des êtres vivants soil sous la dépendance exclusive des rapports de cette nature, et n'offre par suite qu'une relation indirecte arec l'identité spécifique.

B. Doctrine de l'évolution. - La doctrine de l'évolution ou de la descendance. qui a pour base l'hypothèse de la variabilité illimitée des espèces, arait été vaguement exposée dès 1748 par un écrivain français, de Maillet, et quelque peu soutenue parBuffon. Maiscen'est qu'au commencement de ce siècle que Lamarck la formula d'une manière précise et sut lui donner un corps (1). Lamarck, en eflet, doit être considéré comme le fondateur de la théorie généalogique, car il est le premier qui ait rattaché les animaux fossiles aux animaux actuels et affirmé que les espèces dérivent les unes des autres, en adinettant que leurs ancêtres primitifs s’étaient formés par génération spontanée, eí qu'ils araient dû offrir une organisation très simple. Pour lui, les transformations des espèces sont dues aux changements dans les conditions d'existence, ainsi qu'à l'usage ou au défaut d'usage des organes. L'hérédité transmet les modifications ainsi produites, qui se consolident peu à peu, mais ne sont réellement assises qu'au bout d'un temps très long. Les idées de Lamarck passèrent presque inaperçues de son temps, et la doctrine de Curier, soutenue arec éclat par l'illustre anatomiste, continua de dominer l'histoire des êtres vivants.

Cependant, Étienne Geoffroy Saint-Hilaire défendait avec ardeur, contre Cuvier, l'hypothèse de l'unité de composition du r'ègne animal (Voy. p. 23). Comme Lamarck, il admettait que les animaux vivants dérivent des fossiles; mais son principe même l'obligeait à supposer que, de tout temps, araient existé des animaux très complexes; il attribuait, en outre, une influence plus marquée à l'action du monde 
ambiant. Cuvier sortit triomphant de cette lutte et la doctrine de la fixite parut définitivement admise.

Pourtant une révolution se préparait. Sous l'impulsion de Isyell, les principes fondamentaux de la géologie étaient attaqués dans leur base. A la theorie cuviériste, expliquant par des cataclysmes universels la transformation des faunes de l'écorce terrestre, se trourait sulstituéc la doctrine des "causes actuelles ", rattachant les principales moditications géologiques a l'action continue et longtemps prolongée des forces qui se manifestent encore sous nos yeux. Comme consérquence de cette manière de voir, les géologues se trouraient conduits à admettre la continuité de la vie à traver's les périodes successives de la formation les terrains, et partant la transformation graduelle des especes.

La révolution éclata en 18\%9, quand parut le livre célèbre de Ch. Darwin Sur l'Origine des esprecs. A Darwin (1809-1882) revient en efret le mérite d'aroir développé la théorie généalogique avec une puissance et une netteté jusqualors inconnues, et surtout de lavoir appuyée sur des données d'une incontestable valeur, au premier rang desquelles se place le principe, exposé plus haut, de la sélection naturelle.

A peine formulée, cette théorie devint l'objet des plus vires controverses, excitant l'enthousiasme des uns, soulevant les protestations des autres, et provoquant de toutes parts des recherches et des publications innombrables.

C'est en raison de l'influence décisive de Darwin sur l'établissement de la doctrine érolutive, qu’on a souvent désigné celle-ci sous le nom de Darwinisme. Cependant, dès le commencement de ce siècle, comme on vient de le voir, Lamarck en avait jeté les fondements. Aussi convient-il d'appliquer, arec Heckel, la dénomination de Lamarclisme i cette partie de la théorie qui consiste à regarder les espèces comme descendues les unes des autres, et celle de Darwinisme à la théorie de la sélection.

Sans insister davantage sur cette distinction, nous allons examiner les bases sur lesquelles s'appuie l'ensemble de la doctrine.

Nous arons précédemment étudié la sélection naturelle comme reposant sur des faits positifs bien observés. En dehors mème de tout ròle hypothétique, elle nous a offert un intérèt de premier ordre. Mais son importance devient bien autrement grande, si l'on considère que c'est sur elle que repose toute la théorie darwinienne.

On se rappelle que la sélection naturelle est sous la dépendance directe de la concurrence vitale, et que les éléments mis en jeu par celle-ci ne sont autres que la variabilité et l'hérédité. Or, Darwin part de cette hypothèse que la variabilité ou faculté d'adaptation est illimitée. Dès lors, il arrive sans peine à admettre que la sélection naturelle, en s'exercant pendant les longues périodes géologiques, - avec une extrême 
lenteur, il est vrai, - enregistre les modifications qui se sont produites et qui s'accumulent peu à peu dans le même sens, sans qu'il y ait aucune limite à ces changements. Les individus les plus favorisés dans la lutte pour l'existence, les mieux doués, qui seuls peurent transmettre leurs propriétés, forment une souche dans laquelle la divergence des caractères s'accentue de plus en plus, de telle sorte que les variétés et les races ne représentent qu'une étape dans l'évolution des organismes, et arrivent peu à peu au rang d'espèces. En d'autres termes, et pour parler le langage précis de Darwin, la variété est une espèce en voie de formation.

Cependant, on peut se demander pourquoi, étant donnée la loi de perfectionnement dont il vient d'être question, il existe encore des formes inférieures, et pourquoi le développement de certains types se traduit par une métamorphose régressive. Darwin répond qu'en effet la sélection naturelle doit amener le perfectionnement de l'organisme, mais qu'il faut entendre par là une adaptation plus parfaite aux conditions du milieu; or, ces conditions peuvent demeurer indéfiniment les mêmes, et alors toute modification ne pourrait être qu'inutile ou nuisible; ou bien leur changement entraîne l'inutilité de certains organes, et ceux-ci, par suite, tendent à disparaître.

En somme, au point de vue transformiste, l'espèce, loin de correspondre à une unité fixe, comme dans la doctrine de l'immutabilité, représente au contraire une réunion de formes transitoires, ne persistant quautant que les conditions de milieu restent identiques. C'est "l'ensemble des cycles de générations correspondant à des conditions d'existence définies, et conservant, tant que celles-ci ne varient point, une certaine constance dans leurs caractères essentiels ".

L'extension des données précédentes conduit à admettre que les modifications dues à la sélection naturelle peuvent s'accuser de façon à dépasser les limites des caractères génériques; c'est-à-dire que les espèces sont susceptibles d'acquérir des caractères assez dissemblables pour donner lieu à des genres distincts, lorsque les formes intermédiaires ont disparu dans la lutte pour l'existence. De même, les genres dérivant d'une même souche donnent lieu à des familles, celles-ci à des ordres, puis à des classes, et enfin à des types ou embranchements distincts. La valeur de ces divers groupes n'a done rien de plus absolu que celle de l'espèce, mais tous témoignent d'une parenté de plus en plus éloignée, et la classitication, dans son ensemble, doit représenter un arbre généalogique. Seulement, nous ne connaissons qu'une minime fraction des formes innombrables qui ont dû peupler la terre aux diverses époques géologiques, et qui devaient constituer les rameanx les plus importants de cet arbre.

Telle est, brièvement résumée, la théorie évolutive basée sur la sélection, théorie qui, développée par son auteur avec le plus remarquable talent, a séduit d'emblée tant d'imaginations. 
Avant d'aller plus loin, nous derrons reconnaître, toutefois, que celte théorie n’a jamais élé et ne sera peut-être jamais appuyée par une démonstration directe. L'un des lacteurs essentiels qu'elle invoque échappe en effet ì notre action: nous voulons parler du temps. La sélection naturelle repose, comme nous l'arons montré, sur des lails bien élablis, mais aucune des transformations qu'elle peut amener sous nos yeux ne lranclrit les limites du type spécifique.

Au surplus, nous allons aborder lexamen des principaux faits invoqués en faveur de la doctrine. Nous envisagerons successivement les faits relatifs ì la morphologie, à l'embryologie, à la géographie zoologique et à la paléontologie.

$1^{\circ}$ Morphologie. - Les relations morphologiques des êtres vivants trouvent dins la théorie transformiste une explication tellement rationnelle, que les zoologistes ont toujours été portés à employer par métaphore l"expression de parenté pour exprimer les affinilés qui servent de loase a la classitication. Ce que Cuvier et Agassiz appellent "plan d'organisation" se rrouve ètre, pour les Iransformistes, un résultat naturel de la commune origine. Et la théorie donne de mème la raison d'ètre de ces nombreuses formes intermédiaires qui embarrassent si souvent les classificateurs, comme elle rend compte de la nécessilé où nous nous trouvons parfois d'étahlir des groupes de haute raleur pour des formes isolées, telles que l'Amphioxus ou les Limules.

Quoi de plus facile à comprendre encore que les homologies, lorsqu'on admet qu'il s'agit d'un mème organe primitif, modifié pour s'adapter à un mode de vie et à des usages différents? et les analogies elles-mèmes ne s'expliquent-elles pas aussi bien par l'adaptation de parties différentes à des conditions de rie semblables?

C'est encore l'adaptation qui peut le mieux nuus rendre comple du dimorphisme sexuel si accusé chez certains animaux, notammentchez les parasites (Trichodes crassicaud $\iota$ ), et dı polymorphisme des individus sociaux (Abeilles, . Fourmis). Eu thèse générale, c’est à l'inlluence du genre de vie, bieı plus qu’à la sélection sexuelle, que sont attribuables ces diffíremces profondes. Dans certains cas, une espèce peut même revêtir diverses formes qui sont en rapport direct arec les saisons : ainsi, la Vanesse Carte grégraphique se montre deux fois par an : au printemps, avec des ailes fauves, en été avec des ailes noires, chacune de ces formes descendint immédiatement de l'autre. Cependant, on a relevé des exemples de dimorphisme qüil est impossible de rattacher à une cause extérieure : certains Papil ons, et entre antres le Papilio Memmon, des îles de la Sonde, ont deux sortes de femelles tout à fait dissemblables. Chez quelques Crustacés (Tanais dulius), ce sont les máles qui sont dimorphes.

D’autres faits non moins intéressants peuvent êlre encore rapporlés à l'alaplation : ce sont cenx auxupels on a donné le nom le mimitisme, el qui consistent daus la ressemblance yue prend une forme animale avec les oljjets ou les ètres qui l'entourent. Ainsi, quelques Poissons prennent momenlanément la couleur du fond sur lequel ils se trouvent, mais ils prrient cet.te faculté lorsqu'on leur crève les jeux (G. Pouclıet). D'autres animaux conser- 
vent toujours la teinte générale du milieu où ils vivent (Sauterelles), ou l'aspect des corps sur lesquels ils reposent (Phyllies, Phasmes). Mais, ce qui est beancoup plus curieux, c'est le cas où une espèce imite à s'y méprendre nne autre espèce de la même région, mais d'une organisation différente. En pareil cas, la forme imifatrice est presque toujours rare, et l'autre commune; de plus, celle-ci jouit à certains égards d'mne immunité doni la première tire un profit direct. Bornons-nous à citer les Sésies, Papillons erépusculaires de nos pays, qui ont à la fois la livrée et les allures des Guèpes et des Frelons, ce qui les sonstrait en grande partie a l'attaque des Oiseaux. Il nous parait inutile d'insister sur les avantages qu'ofl'rent de tels déguisenents dans la sélection naturelle.

L'existence d'organes rudimentaires, qui a toujours embarrassé les eréationistes, recoit encore une explication des plus simples de par la théorie transformiste. Par suite du défaut d'usag's résultant d'un changement dans le mode de vie, les organes s'atrophient et tendent à disparaíre dans la suite des généralions. Leur persistance à l'état de rudiments n'est que le résultal de la puissance hérédilaire. Ainsi s'explique la présence de lenls aux màchoires des fœtus de Baleines, d'une aile atrophiée et sans usage ehez l'Aptéryx, de ebàtaignes aux membres des Chevaux, elc. Nuus derons reconnaître pourtant qu'à ce point de vue, certains organes sont assez embarrassants : les mamelons des Mammifères màles, par exemple, ont fourni plus d'une lois des arguments aux partisans de l'unité de plan.

Il ne fant pas confondreavec les organes rudimentaires ceux qui,bien que peu développés, ont une utilité mauifeste pour l'animal: par exemple, les glandes mammaires de l'Ornithorynque et les nageoires filiformes des Lepidosiren. Darwin les considère comme des organes naissants, qui doivent tendre à se développer par le fait de la sélection naturelle.

$2^{\circ}$ Embryologie. - Nous avons vu que toutes les formes animales tirent leur origine de la petite masse protoplasmique ovulaire; or, à mesure que se développent les embryons, leurs caractères tendent à diverger; mais cette divergence est d'autant plus tardive qu'ils appartiennent à des espèces plus rapprochées les unes des autres. Entre animaux du même embranchement, mais de classes différentes, la distinction demeure mènie assez longlemps impossible. Darwin cite à eet égard une autorité qui ne peut ètre coutestée : "Je possède, conservés dans l'alcool, dit von Baer, deux petils embryons dont j'ai omis d'inserire le nom, et il me serait absolument impossille de dire à quelle classe ils appartiennent. Ce sont peut-ètre des Lézards, de petils Oiseaux on de très jeunes Mammifères... "

Parfois, cependant, on constate que des lormes voisines évoluent dans un sens assez différent: c'est qu'il faut tenir compte de ce fait, que l'influence de l'hérédité se trouve modifiée par des phénonsènes d'adaptation. La métamorphose régressive, qui s'observe dans le cours du développement d'un grand nombre de parasites, peut s'expliquer de la mème manière.

Mais les données les plus intéressantes de l'embryologie on t trait aux relations qui apparaissent entre l'évolution de l'individı et celle de l'espèce. Él. Geoffroy Saint-Hilaire avait déjả reconnu chez les Poissons des particularilés d'organisation qui ne se montrent que temporairement chez les Vertébrés supérieurs. Les recherches des naturalistes modernes ont donné à cette 
observation un earactìre de haute gŕncirilité, et dimontré que, dans les premieres plases de son existenee, m animal d'ordre supricur offre sucessiriment des earactires quon retronve ì l'élat prunanent chez les animatux inférieurs. Il y a done un parallélisme frappant pntre l'évolution de l’individu lonlugŕnie) ot celle le l'espèce (phylogénie). C'est ce qu'a foul hien

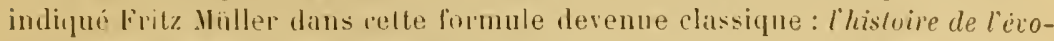
lution indiciduelle est une ripritition courte et ubrégée, une récupitulation, en quelyne sorle, de lhistoire de l'écolution de lespece.

11 fat remirnger, toulefois, que la phylogénie est loin d'ètre exprimée d’une façon complète par les classifications, pour ce motif que la paléontologie ne unus a fiit comnaitre encore un'un petit nombre des formes disparues. D'autre part, le parallélisme dont il vieut d'être question pent être trouble, soit par la simplifiration, la condensation, si l'on veut, de l'évolution indiriduelle, qui supprime certaines phases de la phylogénie, soit par des modifieations de ces phases, le tout résultant d'adaplations ì des conditions particulières, subies pendant les premières périodes de l'existence. Enfin, il ne faut pas oublier que le développement paléontologique forme, selon la remarque de Ilorkel, une série évolutive ramifiée, un arbre généalugique, tandis que le développement indiviluel représente une chaine simple.

$3^{\circ}$ Distribution géographique. - I.es lois qui régissent la répartition des animaux il la surface du globe sont trop complexes et trop peu commes pour ètre inroq̣uées ì titre de preures directes et frappantes en faveur de la théorie transformiste; mais, à défaut de lois, on cite un eertain nombre de faits qui trourent dans cette théorie une explieation rationnelle. On ne doit pas perdre de vue, d'ailleurs, que la grógraphie zoologiqque est intimement liée à la gáologie, etıue la distribulion actuelle des animaux résulte, non seulement de la répartition primitive de leurs ancètres, mais aussi des transformalions féologiques qui ont modifié l'étendue, la position et les communications des mers el des continents.

Et d'abord, il est impossible d'expliquer, par la seule influence des conditions climatériques, la ressemblance on la dissemblance qui existe entre les faunes de direrses régions. Lorsqu'on pareourt l'Amérique, par exemple, on rencontre d'un point a l'autre les conditions loeales les plus variées : températures élevées, basses ou moyennes, montagnes ou l'laines, déserts arides ou marécages herbeux, etc., etc., toutes particularités qui s'ohservent également dans l'ancien continent. Or, tandis qu'il est fatcile de reconnaitre aux espèces américaines, sous les latitudes les plus diverses et dans les climats les plus opposés, un cachet de commune ressemblance, on est frappé de la grande différence que présentent entre elles la faune de l'A mérique et celle de l'aneien monde, saufen ce qui se rapporte aux contrées polaires. Ces faits trouvent leur explication dans la théorie de l'évolution, si l'on s’appuie sur l'influence des migrations et des harrières „ui font obstacle à celles-ci.

L'espace qu'occupent naturellement, à la surface đu globe, les représentants d'une espèce quelconque, est. l'uire ycogruphique de cette espèce, et le point où celle espèce est apparue en premier lieu, l'où elle s'est répandue, s'appelle son centre de créution on de rayomement, ou plus simplement son berceat. On concoit que, pour la plupart des espèces, ce berceau doive ètre cherché dans les époques géologiques antérieures. 
Une forme nouvelle étant donnée, la concurrence vitale contraint à rayonner, loin de son séjour primitif, les individus qui en dérivent, et ainsi se constitue l'aire géographique, laquelle peut ètre figurée schématiquement. par un cercle. D'après cette manière de roir, il est évident que les individus apparlenant à une mème espèce ne doiveut pas se rencontrer dans des régions qui sont séparées par des barrières naturelles, telles que hautes montagnes, bras le mer, climats trop doux ou trop sévères, etc. Lors donc qu'une pareille solution de continuité se présente, la théorie doit, sous peine d'ètre mise en défaut, trouver l'explication du fait dans les phénomènes géologiques connus, ou dans la puissance des moyens de locomotion des animaux.

Or, Darwin a, dans nombre de cas, fourni cette explication. Les semls Mammifères, par exemple, qu'on découvre dans beaucoup d'iles océaniques, sont des Chauves-Souris : la raison en est, sans doute, dans la locomolion aérienne de ces animaux. Dans le nord de l'Amérique et de l'ancien continent, on trouve un certain nombre d'espèces communes, telles que l'Ours blanc, le Renne, l'Hermine; mais il est démontré que l'espace occupé aujourd'hui par le détroit de Belıring était, à une époque antérieure, comblé par un isthme qui reliait l'Amérique à la Sibérie. - On rencontre assez souvent, sur le sommet des hautes monlagnes éloignées les unes des autres, comme les Alpes ou les Pyrénées, une ou plusieurs espèces communes, bien que, par suite des conditions climalériques des intermédiaires, toute communication soit impossible pour elles entre ces points. L'explication de ce fait est fournie par l'existence de la période glaciaire, pendant laquelle les régions actuellement tempérées de notre hémisphère élaient sounises à une température très basse el partant peuplées d'espèces aptes à supporter les frimas. Lorsque la chaleur revint, ces espèces durent se retirer, soit vers le nord, soit surles cimes des monlagnes: il n'est donc pas étonnant de les voir, aujourd'hui, en des points séparés.

La distribution des animaux d'eau douce ne répond pas, à première vue, ‘ l'indication que semble devoir donner la théorie de la descendance. En effet, on constate que les mèmes espèces sont fréquemment répandues dans des rivières et des lacs séparés par de grands espaces de terre, alors qu'on s'attendrait à les trouver tout à fait localisées. On peut cependant trouver la raison de cette extension dans des changements de niveau du sol, dans des inondations ou des trombes, et enfin dans le transport passif des animaux ou de leurs oufs par des Oiseaux ou des Insectes aquatiques.

Quant aux faunes insulaires, on a sourent remarqué, depuis Wallace, combien est grande leur ressemblance avec la faune du cuntinent voisin, bien qu'elles ne soient pas toujours composées des mèmes espèces. C'estque, dans nombre de cas, ces îles ont été séparées du continent par suite d'abaissements séculaires, analogues à ceux qui se manifestent encore sous nos yeux. Il faut admettre alors que les changements physiques qui se sont fait sentir dans ces iles ont amené l'extinction ou la transformation des espèces primitives. La population animale des îles dı Cap-Vert, par exemple, porte le cachet de la fiune africaine, quoiqu'elle se compose d'espèces distinctes. Tous ces rapports s'expliquent par une colonisation suivie d'adaptalion à des conditions nouvelles : l'isolement doit mème ètre considéré comme un des éléments les plus arantageux de la sélection naturelle, car il supprime 
les chances de réversion dues au croisement des formes nouvelles avec la souche primitive.

En somme, malgré la difficulté qu’offre le sujet, on voit que la théoric érolutive est à mème de fournir une explication rationnelle des principaux faits observés relativement à la distribution géographique des aninaux.

4" Paléontologie. - On sait que la surface du globe a subi, daus la série les temps, des cliangements considérables, et que de grandes élendues de terre ontété souvent engrouties au fond des mers ou soulevées au-dessus des flots. Par suite, la nombrense population, animale ou régétale, de chaque contineıt ou de chaque mer a dù, ì différentes reprises, laisser sur place ses débris ćpars ou accumulés, ossements, coquilles, etc., sous forme de fossiles. La palcontologie, qui a pour objet l'étude de ces fossiles, doit donc avoir îurni des éléments de premicr ordre aux partisans des diverses théories relatives à l'origine des espèces.

Effectivement, deux doctrines sont en présence pour rendre compte des cliangements survenus dans la constitution de l'écorce terrestre. La première, exposée par Cuvier, est celle des révolutions ou catastroples subites et universelles, détruisant à un moment donné tous les ètres existants, el par suite exigeant cliacune la création d'espèces nouvelles. L'autre, soutenue par sir Ch. Lyell, est la doctrine dite des causes achuelles ou de la continuité, d'après laquelle les modifications du globe s'expliquent simplement par l'action continue et longtemps prolongée des causes qui agissent encore sous nos yeux.

Nous avons déjà recounu que les progrès incessants de la science tendent à asseoir de plus en plus cette dernière doctrine. En général, on est d'accord aujourd'hui pour admettre que les périodes géologiques se suivent sans interruption, qu'elles ne sont limitées ni à leur début ni à leur terminaison, et qu'il ne faut les accepter que comme un moyen de faciliter l'étude de la croute terrestre. Ia théorie de l'évolution est en parfaite concordance avec cette manière de voir, puisqu'elle exige également une longue série de siècles et reconnait surtout des varialions lentes et graduelles.

Reste à savoir si la succession des formes animales conservées dans les diverses couches géologiques répond à l’idée de progression constante qu'im. plique cette théorie. En réalité, on constate, d'unc manière générale, que la constitution des types éteints se perfectionne de plus en plus à mesure qu'on se rapproche de l'époque actuelle; mais, pour que la paléontologie apportàt au transformisme un appui décisif, il faudrait que toutes les formes de transition reliant les espèces vivantes aux types primitifs fussent représentées, à l'état fossile, dans les couches successives. Malheureusement il existe à cet. endroit de nombreuses et importantes lacunes que ne nous permet pas de combler limperfection des archives géologiques, beancoup d'individus n’oyant pas laissé de débris, et bien peu de régions ayant été explorées jusqu'i présent.

Il est déjà cerlain, cependant, qu'il existe d'une part, dans bien des groupes de fossiles, des passages d'cspèce à espéce, de gemre à genre, de famille à famille, et que d'autre part, un certain nombre de Mammifères actuellement vivants ont des rapports de parenté très intimes avec les espèces fossiles (A. Gaudry).

Conclusions. - De la discussion rapide à laquelle nous renons de 
soumettre les deux doctrines de la fixité des espèces et de vo tion, on peut tout d'abord dégager le fait que celle-ci rend compte, d'une façon claire et simple, d'une foule de faits que celle-là doit laisser sans aucune explication.

Aussi bien, commence-t-il à être superflu de plaider en faveur de la doctrine de l'évolution, qui est acceptée en principe par l'immense majorité des naturalistes, à quelque école qu'ils appartiennent. A cet égard, il est précieux de recueillir la profession de foi de notre éminent paléontologiste français, Albert Gaudry : "Quand nous constatons dans les couches terrestres, dit-il, la preuve de la multiplicité des changements des êtres, ceux d'entre nous qui croient à l'indépendance des espèces sont obligés de supposer le Créateur se remettant sans cesse à l'œuvre. Il me semble bien difficile d'établir une limite entre la production de l'espèce et sa conservation. J'ai de la peine à me représenter l'Auteur du monde comme une force intermittente qui, tour à tour, agit et se repose; un tel mode d'opérer est bon pour nous, pauvres êtres humains que le travail d'un jour épuise; j'aime mieux me représenter un Dieu qui ne connaît ni nuits, ni réveils, et développe toute la nature d'une manière continue, de même que, sous nos yeux, il fait sortir lentement d'une humble graine un arbre magnifique. "

Ceci dit pour bien établir que la doctrine de l'évolution n'est nullement inconciliable avec les idées philosophiques les plus arrêtées d'un homme de science, il resterait encore à montrer que la question de l'origine des espèces peut et doit ètre posée, contrairement à l'opinion des positivistes, qui croient devoir la négliger sous prétexte qu'elle n'est pas susceptible d'une détermination scientifique directe. Mais il est inutile de s'attarder à des discussions de ce genre: après tout, on n'enraye pas à volonté la marche de l'esprit humain, et c'est même un des plus nobles attributs de notre espèce que cette tendance à aborder les problèmes les plus ardus et à rechercher l'origine des choses.

En somme, la doctrine de l'évolution nous paraît dès aujourd'hui solidement assise. Les seuls points que les naturalistes auront encore ì discuter, ce sont les causes qui la déterminent et le mode selon lequel elle s'accomplit. Nous avons indiqué à ce sujet l'opinion de Lamarck, qui admet comme facteurs principaux les conditions de milieu et l'usage ou le défaut d'usage des organes; puis celle de Darwin, qui fait intervenir spécialement la sélection naturelle; nous aurions pu en exposer d'autres encore. Mais, que la vérité se trouve exclusirement dans l'une de ces théories, ou qu'elle repose en partie sur chacune d'elles, ou encore qu'elle ne soit ni dans l'une ni dans l'autre, la doctrine de l'évolution n'a aucune atteinte à subir de ce chef, contrairement aux vues de certains esprits, qui s'imaginent volontiers l'aroir ruinée quand ils ont démontré que l'hypothèse de Lamarck ou de Darwin est inapplicable à tel ou tel cas particulier. 
Applications taxinomiques. - L'adoption de la théorie érolutive a pour résultat direct de modifier, au fond, le sens des anciennes classilications. Le but de la taxinomie se trouve indicué, en eflet, par létahlissement d’un arbre généalogique. Nais nos connaissinces en paléontologie sont, comme on l'a vu, encore bien incomplètes; et d'ailleurs, de nombreux rameaux, non conservés par la fossilisation, représentent antant de vides qu’il sera, sans doute, à jamais impossible de combler. On roit la diflientté de décourrir la filiation des formes animales: aussi ne derons-nous citer que pour mémoire les tentatives faites daus ce sens par divers naturalistes, el en particulier par Heckiel.

Au total, la doctrine de l'évolution n’a pas apporté dans la classifieation un trouble sensible: elle en a seulement changé la signification. Les procédés employés pour déterminer les rapports des animaux entre eux restent les mèmes, mais l'expression de parenté perd son sens métaphorique pour acquérir une valeur réelle. En fait, on arrive ì concevoir les groupes taxinomiques comme correspondant à peu près aux branches, rameanx et ramuscules de l'arbre généalogique. A telles enseignes que, d'après IIreckel lui-même, les embranchements ou types de la plupart des auteurs ont sensiblement la mème valeur que les phyles ou lignées organiques qui réunissent les catégories d'animaux ayant entre eux une parenté non douteuse.

Il n'est pas jusqu' ì l'espèce qui ne soil maintenue dans la classification des transformistes: ceux-ci, en effet, reconnaissent, comme leurs adversaires, des caractères spéeifiques; ils nient seulement la valeur absolue de ces caractères. Il y a plıs: à ne considérer que l'état actuel des choses, on peut s'en tenir, sans inconvénient, ¿̀ la définition de l'espèce donnée par Cuvier.

On regardera done, par exemple, le Dromadaire (Camelus dromedarius L.), le Chameau à deux bosses (Cumelus bactrianus L.), Ia Viggogne (Auchenia vicuma Desm.), comme représentant chacun une espèce distincte.

Les deux premières de ces espèces, qui ont entre elles une grande ressemblance: bosses dorsales, doigts réunis par une plante commune, cou long et recourbé, appartiennent au mème genre (Camelus L.). - Quelquefois on établit, dans le genre, des sections ou sous-genres. Ainsi, l'Ane à pieds bandés (Equus tieniopns Heuglin) possède une robe presque unie, tandis que le Zèbre (Equus sebra L.) a un pelage orné de raies foncées sur fond clair: ces deux animaux sont par suite classés dans deux sous-genres distincts du grenre Éques.

Les Chameaux (Camelus) et les Lamas (Auchenia), qui offrent un certain nombre de traits communs, composent ensemble une famille, celle des Camelide. - Sourent aussi la famille se divise en sousfamilles ou tribus: c'est ainsi que les Bovide forment les trois sousfamilles des Antilopinie, des Ovinie et des Bovinie. 
Nous pourrions montrer de même que les Camelidxa, les Bovidxe et quelques autres familles composent un ordre (Bisulques); que les ordres des.Bisulques, des Jumentés, des Carnivores, etc., constituent une classe (Mammifères); enfin que les classes des Mammifères, des Oiseaux, des Reptiles, etc., concourent ì former un type ou cmbranchement (C'hordés). Tous ces groupes, d'ailleurs, peuvent se subdiviser comme les précédents.

\section{§ 2. - NOMENGLATURE ZOOLOGIOUE.}

Le point de vue utilitaire, qui paraît avoir dominé l'établissement des classifications, a sans aucur doute guidé aussi les naturalistes dans la création d'une nomenclature rationnelle.

Lorsqu'on ne connaissait qu'un petit nombre d'êtres organisés, un seul nom était attribué à chacun d'eux; mais la découverte d'un grand nombre d'espèces nouvelles ne devait pas tarder à rendre ces dénominations insulfisantes.

La création de la nomenclature binaire fut, sans contredit, un service immense rendu à l'histoire naturelle. On regarde en général Linné comme le véritable fondateur de cette nomenclature : en réalité, quelques auteurs, et en particulier Pierre Belon, l'avaient précédé dans cette voie.

Les principes sur lesquels elle doit reposer n'avaient cependant pas été établis d'une facon bien précise, et son application avait par suite donné lieu à une foule d'abus contre lesquels il était temps de réagir. C'est ce qu'a fait surtout le Congrès international de zoologie, dans ses deux premières sessions, tenues à Paris en 1889 et à Moscou en 1892. On trouvera dansles comptes rendus de ces deux sessions l'ensemble des règles adoptées (1): le détail en est trop étendu pour trouver place ici, et nous devons nous borner à en énoncer les principes les plus importants:

I. De la nomenclature des étres organisés. - «La nomenclature adoptée pour les êtres organisés est binaire et binominale. Elle est essentiellement latine. Chaque être y est distingué par un nom de genre suivi d'un nom d'espèce. Exemple: Corvus corax.

"Dans les cas spéciaux où il esl utile de distinguer des variétés, l’adjonction d'un troisième nom ì ceux du genre et de l'espèce est permise. Exemple : Corvus corax kamtschaticus ou Corvus corax var. kumtschatica.

"Dans la notation des hybrides, le nom du procréateur mâle sera cité en premier lieu et sera réuni au nom du procréateur femelle par le signe $X$. Dès lors, l'emploi des signes sexuels est inutile. Exemple: Capra hircus $0^{\top} \times$ Ovis aries + et Capra hircus $>$ Ovis aries sont deux formes également bonnes (2). "

(1) Compte rendu des séances du Congrès international de Zoologie. Paris, 1889, p. 419. - Revue scientifique, L, p. 458, 1592.

(2) D'antres méthodes encore sont indiquées; on outre, pour les hybrides congénères, on se borne souvent à citer le nom générique suivi d'un nom double, 
II. Du nom génerique. - "Les noms génériques doivent consister eu un mot simple ou composé, mais toujours unique, soit latin, soil littinisé, soit considéré et traité comme tel, s’il ne vient pas du latin. "

III. Du nom spicifique. - "Les noms spéciliques, qu'ils soient substiuntifs ou adjectifs, devront également ètre uniroques. Cependant, par exception, seront admises des dénominations spécifiques à vocable donble, qui anraient pour but de dédier à une personne dont le nom est louble, ou d'étiblir une comparaison avec un ohjet simple. Exemple: Suncta-Cuturinx, Jun-.Mayeni, cornu-pastoris, cor-anguiuum, etc. Dins ce eas, les deux mols qui composent le nom spécifịue seront toujours réunis par un trait d'union."

IV. De la manière d'écrive tés noms de genre et d'espéce. - " Le nom de genre devra ètre écrit avec une première lettre majuscule.

"Le nom spécifique prendra la majuscule ou la minuscule, suivant la règle ordinairement suivie dans l'écriture. Exemple : viridis, magnus, Cuvieri, Casar. "

V. Du nom de famille. - "Les noms de famille seront formés en ajoutant la désinence idæe an radical du genre servant de type. On dénommera les subdivisions le la famille en itjoutant la désinence inx au nom du genre servant de type. ")

VI. Loi de priorité. - " Le nom attribué à chaque genre et à chaque espèce ne peut ètre que celui sous lequel ils ont été le plus anciennement désignés, à la condition :

a. Que ce nom ait été divulgué dans une publication où il aura été elairement et suffisamment défini.

b. Que l'auteur ait effectivement entendu appliquer les règles de la nomenclature binaire. "

Nous avons, en thèse générale, adopté dans cet ouvrage les règles en question, dont un des principaux avantages est de supprimer une foule de noms encombrants, dus pour la plupart à la puérile vanité de certains auteurs.

Cependant, il est parfois difficile d'en faire une application rigoureuse, et nous avons cru, dans quelques cas, pouvoir les transgresser provisoirement, dans la crainte d'égarer le lecteur par des changements brusques et radicaux.

\section{§ 3. - DIVISION DU REGNE ANIMAL IN EMBIANCIEMENTS.}

Les animaux se laissent tout d'abord classer, comme on l'a vu précédemment, en deux grands groupes primordiaux, suivant qu'ils sont constitués par une cellule unique ou par un agrégat de cellules. Les premiers, ou animaux unicellulaires, sont les Protozoaires; les animaux pluricellulaires sont les Métazoaires.

Parmi ceux-ci, les uns ont à l'état adulte un mésoderme compact, c’est-à-dire formé par la réunion de deux noms, dont ļe premier est cclui du père, le second celui de la mère. Ainsi, le Mulet, qquelquefois appelé Equus mulus, sera dénommé plus loin Equus asino-cuballus; le Bardot, ou Equus hinnus de quelques auteurs, s'appetlera Equus caballo-asinus. 
non creusé de cavités indépendantes du tube digestif: ce sont les Colentérés ou Accolomates; les autres possèdent, entre la paroi du tube digestif et celle du corps, une cavité générale (cœlome), parfois cependant très réduite; ils reçoivent pour cette raison le nom de Cœlomates.

Les Cœlentérés comprennent deux embranchements: celui des Spongiaires, à corps massif ou irrégulièrement ramifié, et celui des Polypes ou Cnidaires, à corps offrant des rayons réguliers.

A còté des Coelentérés, mais dans le groupe des Cœ̊lomates, se placent d'autres animaux également rayonnés, et pourvus d'un système de canaux (système ambulacraire) dont les dépendances servent à la locomotion; ils constituent l'embranchement des Échinodermes. Spongiaires, Polypes et Échinodermes, avec leur corps généralement ramifié, offrent à un certain degré l'apparence de végétaux; c'est pourquoi on les réunit quelquefois sous le nom de Zoophytes ou Phytozoaires. Les Spongiaires, n'ayant pas de symétrie déterminée, sont dits Amorphozacires; les Polypes et Échinodermes, à symétrie rayonnée, tout au moins dans les formes adultes, s'appellent Actinozoaires on simplement liayomés.

Tous les autres animaux ont le corps bilatéralement symétrique et forment ainsi le groupe des Artiozoaires.

Les uns sont dépourvus de squelette interne; ils composent les trois embranchements des Vers, des Arthropodes et des Mollusques. Les deux premiers ont ordinairement le corps dirisé en anneaux, et, en raison de ce fait, on les a quelquefois réunis sous le nom d'Amnelés. Les Arthropodes sont caractérisés par la présence de membres articulés, qui lont toujours défaut chez les Vers.'Quant aux Mollusques, ils ont le corps ramassé, non segmenté, et se distinguent en outre des autres groupes par la disposition spéciale du système nerveux.

Enfin, un dernier embranchement est celui des Chordés, qui possèdent à l'état larraire une corde dorsale ou notocorde, sorte de corlon cellulaire rigide qui se développe aux dépens de l'endoderme, dans la région dorsale de l'axe longitudinal, et qui a pour office de soutenir el de protéger le système nerveux central. Chez tous ces animaux (Entéropneustes, Tunicier's, Leptocardes et Vertébrés), l'appareil respiratoire dérive en outre de la portion antérieure du tube digestif de l'embryon. - Le nom de Vertébrés est étendu par quelques auteurs aux Leptocardes; tous les autres animaux reçoivent celui d'Invertébrés.

Le tableau ci-clessous résume la division du règne animal en 8 embranchements : 
TAXINOMIE.

\section{Règne animal.}

Embranchements.

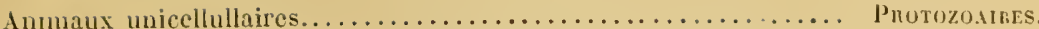

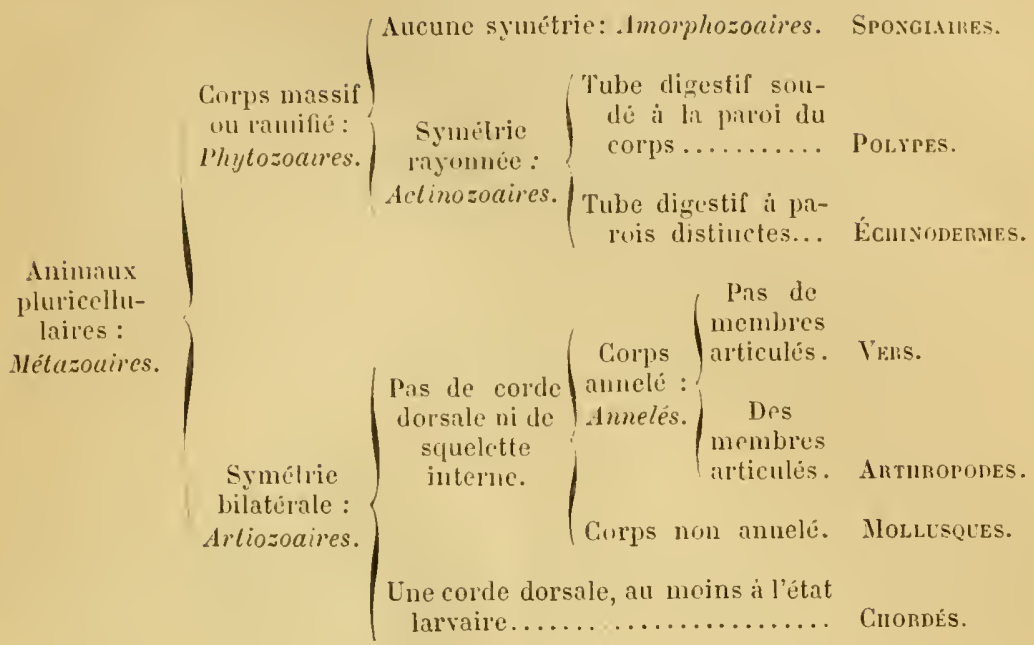




\title{
SECONDE PARTIE
}

\section{ZOOLOGIE SPÉGIALE}

\author{
PREMIER EMBRANCHEMENT
}

PROTOZOAIRES

$\hat{E}$ tres de très petite taille, dont toutes les parties résultent de la différenciation d'un seul plastide (cytode ou cellule), et qui se reproduisent sans le secours d'éléments sexuels dissemblables, aufs et spermatozoïdes.

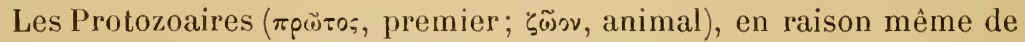
leur insuffisance de différenciation, constituent un groupe dont les

Fig. 49. - Protogenes porrecta, Monère à pseudopodes rhizoïdes.

limites sont fort peu précises, et qui se relie insensiblement aux formes élémentaires du règne végétal. 
D’après les recherches de Bütschli, Fabre-Domergue, etc., le protoplasme qui les forme montre souvent, d'une façon bien nette, la constitution complexe (hyaloplasme el paraplasme) que nous avons indiquée plus haut. Dans la plupart des cas, d'ailleurs, on observe un ectoplasme et un endoplasme distincls.

La couche périphérique peut toutefois rester libre, el alors la forme du corps varie sans cesse (Khizopodes); ou bien elle se montre limitée par une membrane, et la forme demeure fixe.

Chez la plupart des Protozoaires, sinon che\% tous, il existe une formation comparable au noyau cellulaire, et qu'on désigne quelquefois sous le nom d'endoplaste. Ce noyau préside aux fonctions de multiplication.

Fréquemment, le protoplasme émet des prolongements mobiles, de forme et de longueur variables, grâce auxquels s'accomplit la trans-
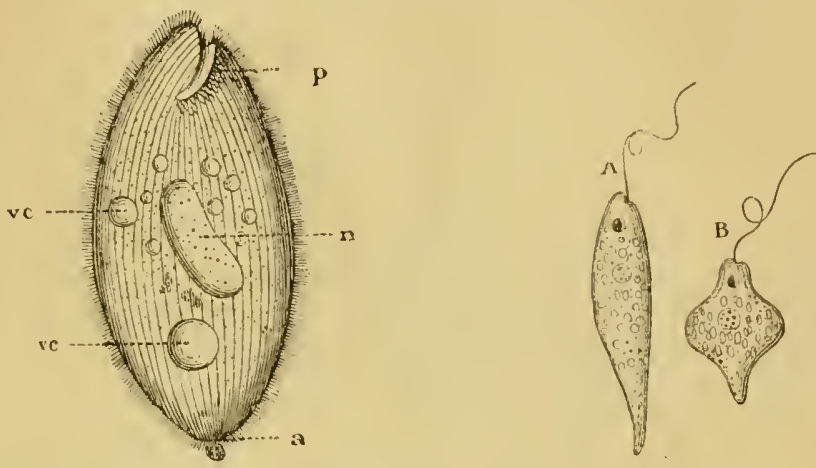

Fïg. s0. - Balantidium coli, Infusoire cilić. $-p$, péristome. Fig. öl. - Eueglena viridis, Infusoire $a$, anus. $n$, noyau. $v c$, vacuoles contractiles (Stein). flagellé (Stein).

lation du corps. On leur donne le nom de psendopodes (

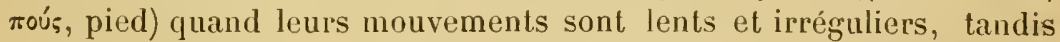
qu'on les appelle cils ou flagellums lorsque ces mouvements s'effectuent rapidement et avec régularité. Les pseudopodes s'allongent et se contractent de façons très variées; souvent ils rentrent dans la masse du corps, pour ètre bientôt remplacés par de nouveaux processus. Les cils vibratiles et les flagellums ont au contraire un siège fixe. En ce qui concerne les formes privées de ces divers appendices, le mécanisme du mouvement n'est pas encore connu.

L'introduction des aliments dans le corps a lieu souvent à la faveur des pseudopodes, qui les saisissent au passage et les amènent dans la masse protoplasmique, où ils doivent être digérés. Chez les formes limitées par une membrane rigide, cette membrane se prête parfois aux phénomènes osmotiques (Grégarines); mais le plus souvent (Infusoires.) on y remarque de véritables ouvertures servant aux fonctions digestives.

Railliet. - Zoologie. 
La respiration a lieu par osmose; elle est du reste favorisée par la formation des pseudopodes.

Chez un assez grand nombre de Protozoaires, on observe une ou plusieurs vacuoles contractiles : ce sont de petits espaces qui apparaissent dans le protoplasma et se dilatent peu à peu, en se remplissant de liquide aqueux, pour se contracter ensuite, toujours avec lenteur, jusqu'à disparition complète. Ces mouvements, qu'on pourrait qualifier de diastolique et de systolique, se reproduisent avec le même rythme d'une façon en quelque sorte indéfinie. Il est probable que les vacuoles dont il s'agit, et dont le siège est fixe, sont toujours en communication avec l'extérieur par une.petite ouverture (tache claire). Leur rôle paraît être d'éliminer les résidus des échanges moléculaires: ce sont des organes d'excrétion.

La multiplication des Protozoaires s'effectue par scission, bourgeonnement ou sporulation. Elle est quelquefuis précédée d'un phénomène désigné sous le nom de conjugaison, qui consiste dans la fusion permanente ou passagère de deux ou plusieurs individus; mais on ne voit jamais intervenir les éléments sexuels, œufs et spermatozoïdes, que sont capables de produire tous les Métazoaires.

Le développement ne comporte que l'accroissement et la différenciation de l'individu nouveau, puisque la substance de tous les Protozoaires n'est formée que d'une seule masse protoplasmique.

Le genre de vie des Protozoaires est extrêmement varié. Tous vivent dans des milieux liquides: on les rencontre dans l'eau douce, dans l'eau de mer, dans les matières organiques en décomposition, etc. Un grand nombre d'entre eux ont la faculté de s'enkyster, c'est-à-dire de s'entourer d'une enveloppe chitineuse (kyste) formée par une sécrétion du protoplasma. Cet enkystement est quelquefois lié à la multiplication: plus souvent, il paraît avoir un but protecteur. : On peut diviser ce groupe en trois classes: Rhizopodes, Sporozoaires et Infusoires.

3 classes:

Pas de membrane d'enveloppe; des pseudopodes.............. Rhizopodes.

Une cuticule; $\quad$ Ni flagellums, ni cils, ni tentacules....... SPonozonires. pas de pseudopodes. Flagellums, cils ou tentacules........... Infusolres.

\section{CLASSE I}

\section{RHIZOPODES}

Protozoaires dont la couche externe du protoplasme demeure libre et peut développer des pseudopodes.

Ces êtres sont constitués par une petite masse de protoplasme pourvue ou non d'un noyau, nue ou revètue d'une carapace, mais toujours libre au moins en partie. Ils se déplacent parfois en masse, mais le plus souvent on les voit 
émettre despseudopodes, qui se présentent sous deux aspects principaux : tantôt ils sont courts et arrondis, ou bien acuminés et un peu ramifiés, mais non susceptibles de s'anastomoser : on les dit alors lobés ou amiboïdes; tantòt, au contraire, ils s'allongent et forment de nombreuses ramifications très déliées, s'anastomosant volonliers entre elles, auquel cas on les qualitie de rhizoides.

õ sous-classes :

Pas de noyau : Cylodiques..................................

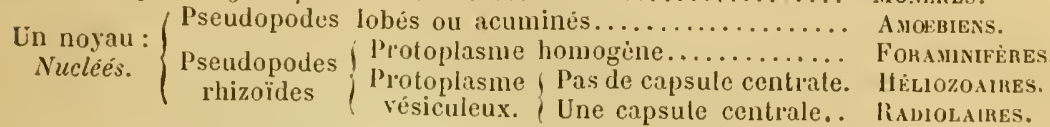

$S U U S-C L A S S E \quad I$

\section{MONÉRES}

\section{Étres formés d'une musse de protoplasma dépourvue de noyau (cytodes).}

Le groupe des Monères, établi par Hæckel, comprend les êlres les plus simples qui se rencontrent dans la nature : ce sont des masses de protoplasma de forme sans cesse changeante et toujours dépourvues de noyau.

Ces masses émettent des pseudopodes d'aspect varié, tantòt lobés, c'est-à-dire obtus et non anastomosés, tantòt rhizoïdes ou en forme de racines déliées et susceptibles en ce cas de s'anastomoser ou de se fusionner pour englober des particules nutritives.

Les pseudopodes, en effet, serrent non seulement à la loco-

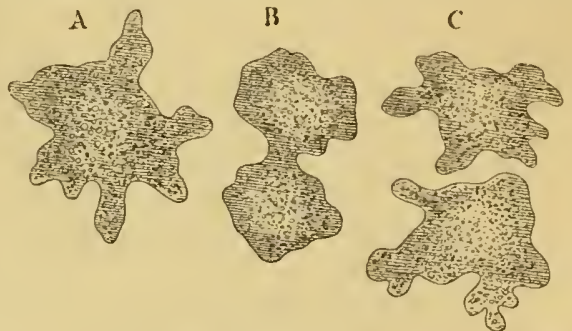

Fig. 52. - Protamaba primitiva, Monère il eau douce, se reproduisaut par scission. - A, Monère entière. $\mathrm{B}, \mathrm{la}$ mème diviscé en deux moitiés par un étranglement. C, les deux moitiés sćparées et constituant des individus iudépendants (Hæckel).

motion, mais aussi à la préhension des aliments, qui pénètrent peu à peu dans le protoplasme, où ils disparaissent s'ils sont assimilables, et d'où ils sont rejetés dans le cas contraire.

La reproduction a lieu, soit par scissiparité, soit par sporulation après enkystement.

Les Monères habitent la mer ou les eaux douces. Il est des formes qui s'associent de manière à constituer des sortes de colonies : la réunion a lieu par l'intermédiaire des pseudopodes.

Nous devons ajouter que le nombre des ètres classés parmi les Monères diminue de jour en jour, les perfectionnements de la technique moderne permettant d'établir la présence du noyau dans des organismes où il était demeuré jusqu'alors inaperçu.

2 ordres:

I. Lobomonères. - Monères à pseudopodes lobés. - Genres Protamœba et Gloidium. 
II. Rhizomonères. - Monères à pseudopodes rhizö̈des. - Genres Protoyenes (fig. 49), Protobathybius, etc. On peutciter aussi pour mémoire le fameux Bathybius Hackeli Iluxley, prétendu tapis vivant des mers profondes, que Huxley lui-mème a reconnu pour un précipité gélatineux de sulfate de chaux.

SOUS-CLASSE 11

\section{AMGEBIENS}

Rhizopodes nuclés, sans cils ni flagellums à l'état adulte, émettant des pseuclopodes ordinairement larges, obtus, a contours nets.

Une particularité importante sépare des Monères les Protoplastes ou Amœbiens : c'est la présence d'un noyau.

La masse protoplasmique qui constitue ces petits ètres émet des pseudopodes digitiformes ou lobés, c'est-à-dire courts, obtus, non anastomosés, analogues à ceux des Lobomonères. Elle se divise assez nettement en deux zones : un ectoplasme hyalin et un endoplasme granuleux. Le plus souvent, le corps est nu; mais il existe aussi des formes, assez nombreuses, chez lesquelles il est revètu d'une carapace chitineuse, calcaire, siliceuse, etc., englobant mème des corps étrangers, et ne laissant sortir les pseudopodes que par des ouvertures spéciales.

La nutrition s'effectue comme chez les $\mathrm{Ho-}$ nères. Souvent il existe, dans l'endoplasme, une ou plusieurs vacuoles contracliles.

La reproduction a lieu par scissiparité ou par sporulation.

Ces organismes habitent pour la plupart les eaux douces ou les eaux salées; quel-
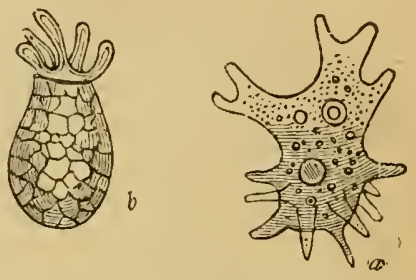

Fig. 53. - a, Amopba radiosa, montran les pseudopodes, la vésicule contractile et le nojau. $b$, Difflugia, avec les pseudopodes sortant de l'extrémité supérieure de la carapace (Huxley). ques-uns se rencontrent dans la terre, etc. Enfin, il en est qui ont été signalés comme vivant en parasites chez l'Homme et chez divers animaux.

2 ordres' :

I. Gymnamœbiens. - Corps nu.

Genre Amibe (Amiba Bory St.-V.; Amœba Ehrenb.). - Les Amibes ou mieux Amcbes ont un endoplasme très granuleux, entouré d'un ectoplasme hyalin et comprenant, outre le noyau, une ou plusieurs vacuoles contractiles; leurs pseudopodes sont digitiformes ou quelquefois lobés, et se montrent remplis de granules quand ils ont atteint certaines dimensions.

Ce sont les plus anciennement connus des organismes à formes sans cesse changeantes (protées), ce qui leur a valu leur nom (äu.cibr̀, changement). La plupart de ceux qui vivent en liberté se nourrissent de substances végétales.

Citons Amaba princeps, A. radiosa, A. crassa, etc., espèces communes dans les eaux douces contenant des matières organiques en décomposition.

Amibe du côlon (A. coli Lösch, 1873). - Le corps, fortement granuleux, mesure de 20 à 33 u à l'état de repos. Il n'émet d'ordinaire qu'un seul ou un petit nombre de pseudopodes larges et mousses, clairs au début, qui apparaissent et disparaissent souvent d'une façon 
brusque, de sorte que la forme primitivement arrondie devient ovalaire, pyriforme ou même irrégulière. Outre les granulations et les corpuscules alimentaires, on distingue à l'intérieur un noyau pàle, nucléolé, et une ou plusieurs vacuoles qui ne paraissent pas contracliles.

Cette Amibe a été découverte par Lösch, en 187\%, à Saint-Pétersbourg, dans les selles dysentériques d'un paysin du gouvernement

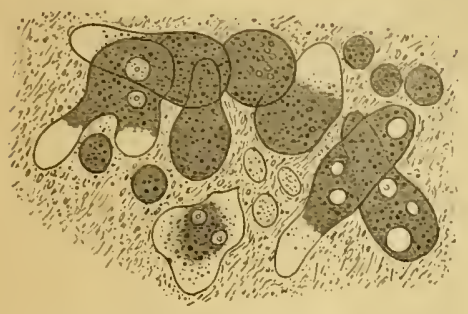

Fig. 5\%. - Amaba coli dans le mucus intestinal (Lösch). d'Arkangel, qui souffrait d'une inllammation ulcéreuse du gios intestin. Ce malade resta quatre mois à l'hôpilal, etl'on put constater pendant longtemps la présence et labondance du parasite; celui-ci ne disparut que sous l'influence de lavements répétés de quinine. La diarrhée cessa en même temps; mais survint une pleurésie suivie de pneumonie, qui entraîna la mort. A l'autopsie, on trouva une violente inflamnation du gros intestin, avec quelques ulcérations.

Lösch admet que ces lésions avaient été produites ou tout au moins étaient entretenues par le parasite. Il a même cherché à démontrer l'action nocive de celui-ci en faisant prendre à des chiens, par la bouche et par l'anus, de la matière diarrhéique expulsée par le malade : chez l'un de ces animaux, les Amibes se multiplièrent en déterminant une inflammation ulcéreuse du rectum.

L'A. coli ressemble beaucoup à une espèce trouvée par Mérejkovsky dans les marécages de Jelagin, près Saint-Pétersbourg, où précisément le malade de Lösch travaillait comme manœuvre, espèce qui a reçu le nom d'A. Jelaginia Mérejk. Aussi a-t-on supposé que l’individu en question s'était infesté en buvant de cette eau. Mais Leuckart fait des réserves formelles sur l’identité de ces deux espèces.

Lewis et Cunningham, dans l'Inde, ont aussi trouvé des Amibes dans les selles des individus atteints de choléra ou de diarrhée simple. Beaucoup d'autres observateurs ont fait des constatations du même genre dans différents pays. Grassi, en Italie, dans le sud de la France et en Afrique, en a observé dans les déjections des individus sains comme dans celles des sujets affectés de maladies variées: fièvre typhoïde, choléra, pellagre, diarrhéc ab ingestis, etc. Aussi affirme-t-il que ce sont des êtres inoffensifs. Avec Calandruccio, il a constaté que l'A. coli s'enkyste à la façon de l'A. blattarum Bütschli, et que les kystes ainsi forınés, contenant lrois, six, neuf noyaux ou spores, sont susceptibles de communiquer des Amibes à l'Ilomme qui les ingère: une fois développées dans l'intestin, celles-ci se multiplieraient abondamment par scissiparité. 
Amibe du vagin (A. vaginalis $B \rightsquigarrow l^{2}, 1883$ ). - Forme semblable à $A$. coli; diamètre $50 \mu$.

Trouvée par le professeur Bælz, de Tokio, dans la vessie et le vagin d'une jeune fille morte de tuberculose du poumon et des organes génito-urinaires.

Jürgens aurait fait récemment, à Berlin, une observation analogue.

Amibc buccale (A. buccalis Steinberg, 1862). - Forme peu connue, signalée par Steinberg dans le tartre dentaire, en mème temps que diverses Bactériacées et des Flagellés qu'il rapporte aux espèces suivantes: Monas crepusculum Ehrbg., M. globulus Duj., M. lens Duj., M. elongatu Duj., Bodo socialis Elırbg., B. intestinalis Ehrbg., Cercomomas biflagellata Stbg., C. acuminata Duj.. ('. globulus Duj. Comme la plupart de ces espèces ne sont connues qu'à l'élat de vie libre, il est possible que cette Amibe ne représente pas davantage une forme parasite.

En 1879, Grassi a signalé aussi une A. dentalis, ressemblant beaucoup à A. coli, et Perroncito dit l'avoir retrouvée deux fois. Plus tard, Grassi s'est demandé s’il n'avait pas eu affaire à un corpuscule salivaire.

Amibe parasite (A. parasitica v. Lendenfeld, 188\%). - Celte forme ne différerait pas morphologiquement de l'A. princeps Ehrbg., dont il a été fait mention plus haut.

Elle a été découverte en Australie, par R. von Lendenfeld (1), sur des agneaux affectés d'une maladie spéciale, simulant un cancer épithélial et siégeant sur les pieds, en arrière des onglons, sur les narines, les lèvres et les gencives. Le réseau muqueux de Malpighi était enflammé, et la couche cornée de l'épiderme, fortement épaissie, se détachait sous forme de croùtes. Entre les assises de la couche cornée se trouvaient des masses granuleuses d'apparence parasitaire, pourvues de noyaux. L'auteur suppose que ce. sont des Amibes, à l'action irritante desquelles on devrait attribuer les lésions dont il s'agit. Il a réussi à élever ces organismes dans un. milieu humide, et semble disposé à admettre qu'ils vivent normalement dans l'eau, d'où ils pénétreraient dans l'épiderme, à la faveur de blessures préalables.

D'autres Amibes ont été rencontrées encore dans l'intestin du Rat, de la Grenouille, etc., dans le cloaque de la Poule (Artault) et dans les fèces de nombreux animaux. Cunningham dit en avoir observé très fréquemment dans les excréments du Cheval et de la Vache.

II. Thècamœbiens. - Corps protégé par une carapace dont l'aspect, la consistance et la nature sont des plus variables.

Nous ne signalerons ici que les Diffugia, dont l'enveloppe paraît être formée par la réunion de petits corps étrangers, et les Arcella, qui possèdent un test véritable, sécrélé par le protoplasma. Lambl dit avoir trouvé des représentants de ces deux genres dans le mucus intestinal d'un enfant mort d'entérite : ils avaient sans doute été introduits dans le tube digestif avec les boissons, car ce sont des organismes çommuns dans les eaux fangeuses.

(1) Proceed. Linn. Soc. N. S. Wales, X, p. 35 (avec une pl.), 1885. 
SOUS-CLASSE III

\section{FORA MINIFERES}

Rhizopodes ordinairement pourvus l'une cnveloppe chitineuse arénucéc oucalcaire; $p$ sculopodes mous, réticules ; protoplasme homogine.

Les Foraminifères sont rarement uus; ils possèdent parfois une carapace chitineuse ou arénacée, e'est-à-dire formée de grains de sable que le protoplasme extérieur a agglutinés; mais le plus souvent ils sont protégés par un lest calcaire, sécrété par le protoplasme. Cette coquille ne présente parfois qu'une seule chambre pourvue d'une large ouverture (Monothalames); d'autres fois, elle en offre plusieurs (Polythalınes), communiquant toutes entre elles. Il existe une ou plusienrs ouvertures permettant au protoplasme d'émettre ses pseudopodes à l'extérieur.

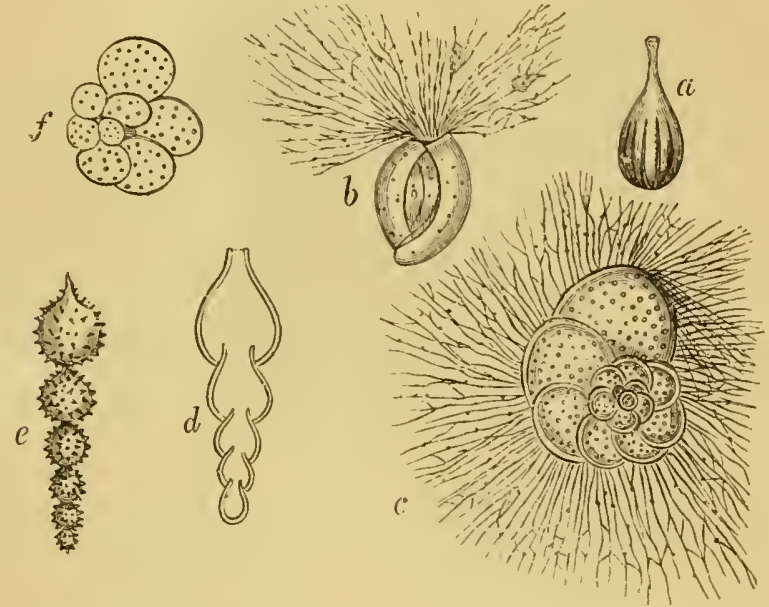

ig. 50.. - Morphologie des Foraminifères. - a, Lagena vulgaris, monothalane. $b$, Miliola, montrant l'émission des pseudopodes par l'onverture ovale de la coquille (Schultze). c. Discorbina, montrant la coquille nautiloöde (Schultze). d, section de Nodosaria (Carpenter). e, Nodosaria hispida. f. Globigerina bulloides (Huxle!).

La reproduction s'effectue d'ordinaire par scissiparité; la sporulation est beaucoup plus rare.

Dans les époques géologiques antérieures à la nôtre, les Foraminifères ont joué un ròle important dans la formation des roches, principalement de la craie.

2 groupes :

I. Imperforès. - Coquille présentant une seule ouverture assez large pour la sortie des pseudopodes. - Cette coquille est tantòt chitineuse (Gromia), tantòt constituée par des grains de sable (Lituola) ou des spicules d'éponges (Squamulina), tantòt calcaire, à une (Cornuspira) ou plusieurs chambres (Miliola, Alveolina).

II. Perforés. - Coquille percée d'une foule de petits pertuis par lesquels 
sortent les pseudopodes. - Le plus souvent calcaire, elle peut offrir aussi une seule chambre (Lagena) ou plusieurs (Nodosaria, Globigerina, Discorbina, Nummulites, etc.).

\section{SOUS-CLASSE IV}

\section{HÉLIOZOA IRES}

Rhizopodes à protoplasme creusé de nombreuses vacuoles non contractiles, et munis parfois d'un squelette siliceux rayonné; pseudopodes grêles, rigides, rayonnants.

Beaucoup de formes sont nues (Actinoph'ys sol, Actinospharium Eichorni); d'autres sont entourées d'une carapace siliceuse tantôt lisse (Heterophrys), tantôt munie de rayons également siliceux (Acanthocystis).
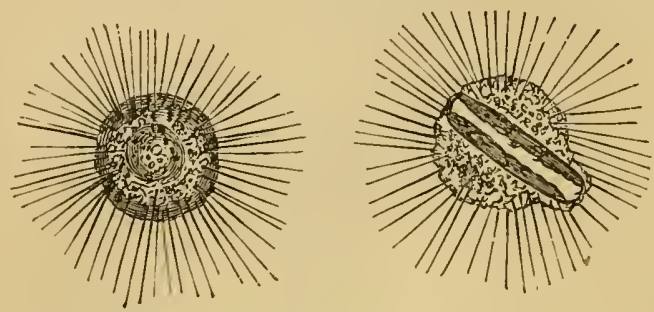

Fig. 50. - Actinophrys sol. - Lïndividu représenté à droite a avalé une Diatoméc (Huxley).

Le protoplasme, outre les vacuoles simples dont il est creusé, peut contenir aussi des vacuoles contractiles. Les pseudopodes qu'il émet sont souvent permanents, non susceptibles de s'anastomoser, et se rapprochent ainsi des flagellums.

La reproduction est fissipare, gemmipare ou zoosporée.

La plupart des Héliozoaires habitent les eaux douces; on ne connaît qu'un fort petit nombre d'espèces marines.

\section{SOUS-CLASSE V}

\section{RADIOLAIRES}

Rhizopodes à protoplasme creuse de nombreuses vacuoles non contractiles; une capsule centrale séparant l'ectoplasme de l'endoplasme; souvent un squelette siliceux rayonne; psenidopodes rayonnants, réticules, parfois rigides.

Comme chez les Héliozoaires, le jrotoplasme se différencie assez nettement en ectoplasme et endoplasme; mais ces deux parties sont séparées l'une de l'autre par une membrane chitinoïde percée de fins canalicules et nommée capsule centrale. Les pseudopodes offrent à peu près les mêmes caractères que dans le groupe précédent; ils sont disposés d'une façon très régulière.

L'endoplasme, qui renferme un ou plusieurs noyaux, est creusé d'un: grand nombre de vacuoles non contractiles renfermant un liquide qui tient 
en suspension des goutteletles graisseuses. Il est rare que l'ectoplasme présente de semblables vaeuoles; il contient souvent des Algues unicellulaires, qu'on a longtemps décrites sous le nom de cellules jaunes, et qui vivent en symbiose avec le Radiolaire.

On connait des formes nues, d'autres qui sont pourvues de spicules sili-
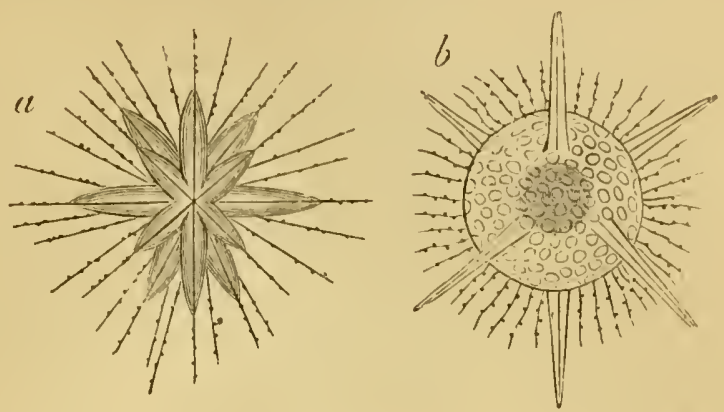

Fig. 57. - a, Acanthometra lanceolata. b, Haliomma hexacanthum (biiller).

ceux indépendants, el d'autres enfin qui ont un squelette formé d'une splère fenètrée ou de plusieurs sphères emboitées les unes dans les autres, avec des épines rayonnantes pénétrant parfois jusqu'au centre de la capsule.

La reproduction des Radiolaires paraît se faire par scission, en donnant alors lieu à la formation de colonies, ou par production de spores aux dépens de l'endoplasme.

Ces ètres vivent à la surface des mers, d'où leurs squelettes siliceux tombent au fond pour constituer d'immenses dépôts sableux. On en connait aussi
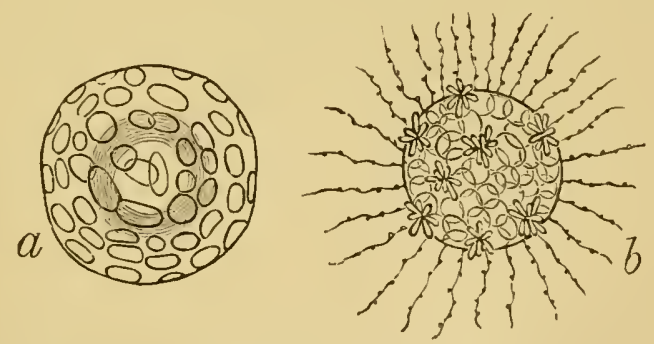

Fig. 58. - $a$, squelelte siliceux fenètré du Collosphara Huxleyi. $b$, Thalassicola morum, montrant des corps en forme de cellules, des groupes de spicules et des pseudopodes rayonnés (Huxley).

de nombreuses formes fossiles, et certaines roches tertiaires résultent en grande partie de l'agglomération de leurs débris.

2 ordres:

I. Monocyttariens. - Radiolaires isolés, ne possédant qu'une capsule centrale. Ex. : Thalassicola, forme nue; Acanthometra, à spicules rayonnés; Haliómma, à plusieurs coquilles treillissées.

II. Polycyttariens. - Colonies de Radiolaires présentant d'ordinaire une forme arrondie; les individus sont unis par leur ectoplasme, tandis que l'endoplasme de chacun reste distinet, entouré de sa eapsule. Ex. : Collo- 
zoum, sans squelette; Sphærozoum, à spicules siliceux indépendants; Collosphæra, à squelette entier, sphérique, percé de fenêtres.

SOUS-CLASSE ANNEXE

\section{HÉMAMOEIENS}

Nous croyons devoir classer provisoirement entre les Rhizopodes et les Sporozoaires les curieux organismes qui ont été découverts par Laveran dans le sang de l'Homme atteint de paludisme, et ceux qui ont été rencontrés par divers observateurs dans le sang des Oiseaux (1).

Hémamibe de la malaria (Hxmamœba malarix Grassi et Feletti, 1890). - Le parasite de la malaria humaine se présente sous des formes assez variées, que l'on peut toutefois ramener aux quatre types suivants : $1^{\circ}$ corps sphériques; $2^{\circ}$ flagellums $; 3^{\circ}$ corps en croissant; $4^{\circ}$ corps segmentés ou en rosace (fiğ. 59).

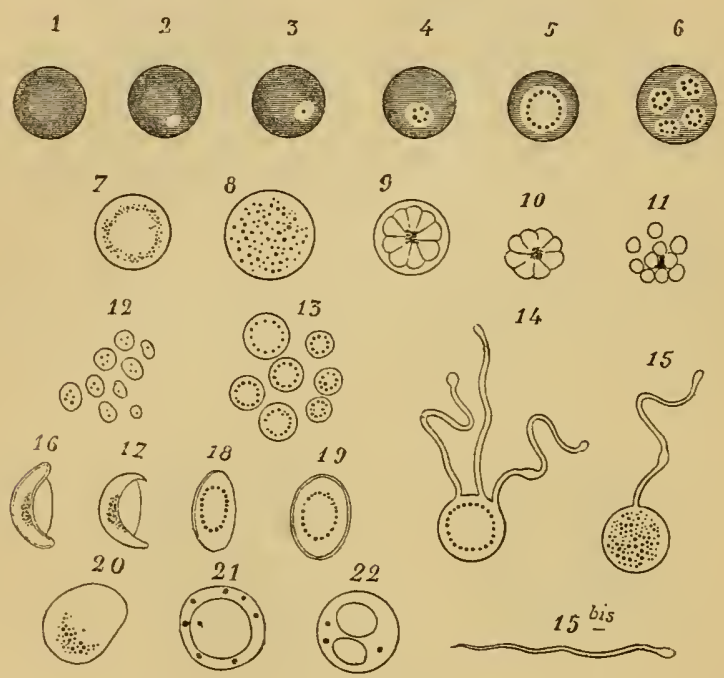

Fig. 59. - Hématozoaire du paludisme. - 1, límatie normale. 2, hèmatie avec un petit corps sphérique non pigmenté. 3 a 6 , hématies avec un ou plusieurs corps splıériques pigmentés. 7,8 , corps sphériques libres ayant atteint leur développement complet. 9, corps segmenté adliérent à une hématic. 10, corps segmenté litre. 11, segments sarrondissant et devenant libres. 12, 13, pctits corps sphériques libres. 14, corłs sphérique avec trois flagellums 1 , avec un seul flagellum. Is bis, flagellum libre. 16, 17, corps en croissant. 18. 19, corps oralaires dérivés de corps en croissant. 20, corps sp̨hérique après le départ des flagellums. 21, 22, leucocyltes mèlanifères (Laveran).

$1^{\circ}$ Corps sphériques. - Ces corps représentent la forme la plus commune des éléments parasitaires: ils apparaissent comme des ğlobules à contours nets, de dimensions très variables, les plus petits $(2,3)$ mesurant à peine $1 \mu$, les plus gros $(4,5)$ dépassant le volume des

(1) A. Laveran, Du paludisine el de son hematozocire. Paris, 1891. - ID., Dupaludisme. Paris, 1892 (bibliographie). 
hématies. lls sont constitués par une substance liyaline, incolore, et contiennent presque toujours des granules de pigment noir; le nombre de ces granules augmente arec la taille du parasite: les plus petits n’en montrent guère qu'un ou deux; les plus gros en possèdent un grrand nombre, disposés en couronne (7) ou d'une façon irréggulière (8). Les colps sphériques sont souvent animés de mouvements amiboïdes, coïncidant avee une agitation particulière des grains de pigment. Ces corps sont tantôt libres dans te plasma sanguin $(7,8)$, tantôt aecolés, un ou plusicurs à la fois, aux ghlobules rouges ou plutôt inclus dans cenx-ci ( I a 6). Ils s'aceroissent aux dépens des hématies, qui pâlissent peu à peu, diminuent de volume et linissent par disparaitre. A l'aide de différents procédés de coloration, on a décelé dans l'intérieur des corps sphlériques la présence d'un noyau généralement excentrique, acenlé à la paroi.

Qo Flagellums. - Les corps sphériques de moyennes dimensions, libres dans le plasma, montrent assez souvent á leur périphérie des filaments mobiles ou flagellums $(14,15)$, longs de 21 ì 28 !n, qui sagitent arec vivacité et refoulent les lématies. Ces filaments sont très fins et transparents; chacun des corps en émet un, deux, trois ou quatre.

A un monnent donné, les flagellums se détachent et nagent en liberté (1亏 bis) au milieu des globules, de sorte qu'il devient difficile de les suivre. Les corps pigmentés qui les portaient se déforment alors, deviennent immobiles, et les grains de pigment s'aceumulent sur un ou plusieur's points (20).

$3^{\circ}$ Corps en croissant. - Ce sont des éléments cylindriques, atténués à leurs extrémités et d'ordinaire recourbés en croissant $(16,17)$. Ils mesurent en général 8 à $9 \mu$ de long, sur une largeur de 2 à $3 \mu$ vers leur partic moyenne. Comme les corps spleériques, ils sont transparents et renferment des grains de pigment, mais ceux-ci sont presque toujours" rassemblés dans la région moyenne (plus rarement. à une extrémité. L'emploi des réactifs colorants permet de leur reconnaître un double conlour, témoignant de l'existence d'une membrane d'enveloppe (kyste). On remarque souvent, du côté de la concavité, une ligne très fine qui relie les deux cornes du croissant, et qui paraît représenter une partie du contour de l'hématie dans laquelle le parasite s'était déreloppé. - Enfin, on peut voir dans certains cas $(18,19)$, le corps en croissant se transformer en un corps ovalaire, puis sphérique.

$.1^{\circ}$ Corps segmentès. - Les corps segmentés ou en rosace paraissent correspondre it une phase de reproduction du parasite. On peut voir, en effet, sur le contour d'un corps sphérique, que celui-ci soit libre ou accolé à une hématie, apparaitre des dentelures peu profondes, en mème temps que le pigment se rassemble en un seul amas central $(9,10)$ : c'est le premier degré de la segmentation. Bientôt ces dentelures s'accusent: et le corps sphérique se trouve divisé en plusicurs 
secteurs, ce qui lui donne l'aspect qui a été désigné sous le nom de corps en rosace ou en marguerite. Puis ces secteurs s'arrondissent et se séparent les uns des autres, le corps segmenté donnant ainsi naissance à une série de petits corps sphériques qui deviennent libres (11, 12).

On trouve aussi dans le sang palustre des leucocytes mélanifères $(21,22)$, qui se distinguent des lormes cadavériques du parasite (20) par la présence d'un ou de plusieurs noyaux faciles à mettre en évidence.

Les quatre formes principales de l'Hémamibe ne se montrent pas avec la même fréquence. La plus commune de beaucoup est représentée par les corps sphériques sans llagellums. Viennent ensuite les corps à flagellums, puis les corps en croissant. Quant aux corps en rosace, il est difficile de les rencontrer; il faut les chercher surtout à la première période des accès de fièvre.

D'après Laveran, ces diverses formes doivent être considérées comme des états successifs d'un mème parasite polymorphe. Les petits corps non pigmentés (2) en représentent la forme embryonnaire; ces corps s'accroissent en se chargeant de granules pigmentaires, puis développent des flagellums qui, à un moment donné, se détachent et deviennent libres. Le savant médecin français ajoute que la relation des corps en croissant avec les corps sphériques et les flagellums n'est pas douteuse, bien qu'on ne sache pas pourquoi les corps en croissant, très communs chez certains malades, font défaut chez d'autres. On constate quelquefois, en effet, une série de formes intermédiaires entre les petits corps sphériques des hématies et les croissants arrivés à leur développement complet; de plus, on voit assez souvent ceux-ci se transformer en corps sphériques d'où s'échappent des flagellums. En résumé, le parasite du paludisme se trouverait dans le sang sous deux états principaux : $1^{\circ}$ corps amiboïdes libres dans le plasma ou accolés aux globules rouges ; $2^{\circ}$ corps enkystés dans ces globules, présentant d'abord une forme sphérique, puis s'incurvant pour suivre le contour extérieur de l'hématie, le développement étant limité du côté interne par la dépression centrale de celle-ci.

Par contre, plusieurs observateurs italiens admettent l'existence de plusieurs espèces de parasites. Grassi et Feletti en reconnaissent cinq, se répartissant entre deux genres et correspondant à des manifestations cliniques spéciales du paludisme :

Genre Hæmamœba : corps sphériques. - H. malarix, de la fièvre quarte simple, double ou triple. - H. vivax, de la fièvre tierce simple ou double. - H. præcox, des fièvres pernicieuses. - H. immaculata, forme n'existant qu'à Rome et produisant les mêmes accidents que la précédente, mais caractérisée par l'absence de pigment.

Genre Laverania : corps en croissant. - L. malarix, donnant naissance aux fièvres quolidiennes, aux subcontinues et aux intermittentes à longs intervalles d'apyrexie.

Il est certain queles observations cliniques donnent à l'opinion de Laveran le plus sérieux appui, et quoiqu'il soit séduisant à première vue de rattacher chaque type de fièvre palustre à l'évolution d'une espèce particulière 
de parasite, l'étude attentive des faits est décidément favorable à la thèse du polynorplisme.

C'est en 1880 que Laveran a Ionné la première description de ce parasile, qüil avait observé en Mlgérie dans le sang des individus atleints de paludisme. Depuis cetle éporque, le même organismo a été retrouvé et éludié par un grand nombre d'observateurs français et étrangers.

Nous n'avons pas à faire ici l'histoire clinique du paludisme. Rappelons seulement qu'on dome ce nom, ou ceux de fièrres palustres, fièvres paludéennes, fièvros inlermittentes, impaludisme, malaria, ete., à un ensemble d'accidents sévissant sur les habitants des régions marécageuses, et se manifestant sous la forme do fièrre et de cachexie. Ces accidents peuvent se ramener en définitive à trois types essentiels: fièvre intermittente, fièvre continue et cachexie palustre. En France, le paludisme est endémique dans les régions du littoral oủ séjournent des caux saumâtres (Camargur, Landes, Charentes, Vendée) el sur divers points de l’intérieur bien connus pour l'état marécageux de leur sol (Sologne, Brenne, Bresse, Dombes).

Il ne parait pas douteux que le parasite décrit ci-dessus soit l'agent pathogène du paludisme. Sous l'intluence de la médication quinique, on le voit disparaître en même temps que la fièvre. D’ailleurs, l'injection intra-veineuse, à des individus sains, du sang qui le renferme, est suivie, après une incubation de huit à dix jours, de toutes les manifestations du mal, y compris la multiplicalion du parasite.

On ne sait encore rien du mode d’infection. II est probable que les Hémamibes, comme beaucoup de Sporozoaires, doivent accomplir dans le milieu extérieur (eaux stagnantes) une partie de leur évolution, et pénétrer dans l'organisme à la faveur des eaux de boisson.

Pour rechercher le parasite dans les cas de fièvre intermittente, il faut choisir les instants qui précèdent l'accès, ou le début de l'accès lui-même, el s'adressel" de préférence aux sujets qui n ont pas encore pris de quinine. On aura recours aux préparations de sang frais, qui ont lavantage de laisser aux flagellums leur mobilité.

Hémamibe des Oiseaux (Hiemamoba Danilevslìyi). - On trouve assez souvent, dans le sang de certains Oiseaux, tels que Geai, Hibou, Corneille, Alonette, Moineau, Pinson, Pigeon, etc., des organismes analogues à ceux du paludisme, auxquels plusieurs auteurs ont même voulu les identifier.

Ces hématozoaires (fig. 60) semblent être inclus le plus souvent dans les globules rouges. A leur premier degré de développement, ils se présentent sous la forme de petites taches claires, arrondies ou allongées, rentermant des grains de pigment en nombre variable suivant leurs dimensions ( 2 à 6 ). Il n'est pas rare d'en trourer plusieurs dans le même globule. A mesure qu'ils se développent, ils déforment celui- 
ci en refoulant le noyau $(7,8)$, qui cependant persiste le plus souvent. 11 est même commun de retrouver ce noyau accolé au parasite, alor's que le reste de l'hématie a disparu (9 à 12 et 15 ). Une fois complètement déreloppé, l'hématozoaire devient libre et prend, s'il ne l'avait déjà, une forme ovalaire ou sphérique; ses granules pigmentaires s'agitent et à la périphérie apparaissent des flagellums (18) qui bientôt se détachent et deviennent libres. Les corps en rosace se montrent rarement.

L'analogie entre ces parasites et ceux du paludisme de l'homme est évidemment très grande; mais il ne paraîl cependant pas y avoir identité. Its ne produisent généralement aucun trouble chez les Oiseaux;

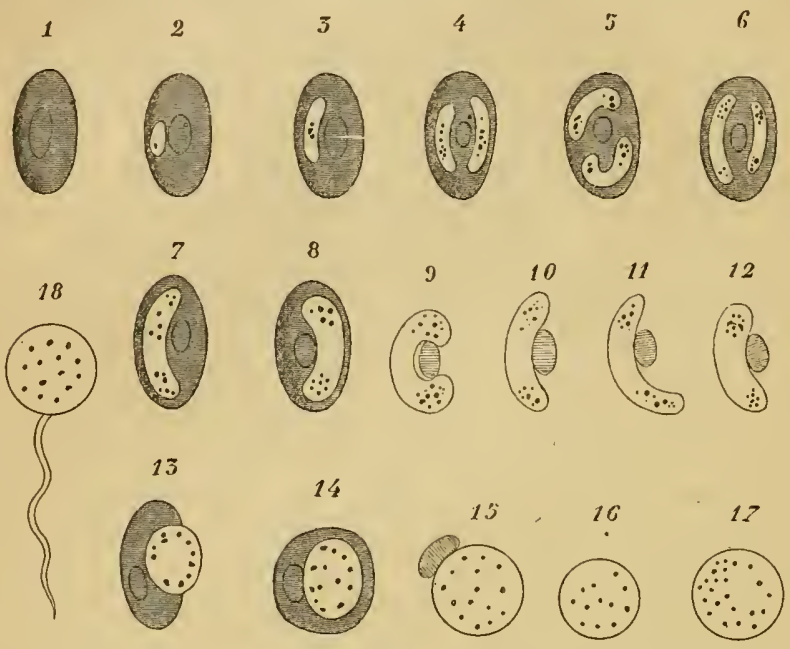

Fig. 60, - llémamuebiens du Pigeon. -1, hématie normale. 2 à 8 , hémalozoaires intraglobulaires 〈un ou deux dans chaque hématie). 9 à 12, hématozoaires cylindriques devenus libres, arec le noyau de l'hématie délruite à côté de chaqne vermicule. 13, 14, hématozoaires intraglobulaires sphériques. 15, hématozoaire sphérique arec le noyau de l'hématie détruite. 16, 17, hématozoaires spluériques libres. 18, hématozoaire sphérique libre avec un flagellum (laveran, inédite).

pourtant, Danilersky a constaté que les sujets qui montrent des corps en rosace sont souvent malades et meurent quelquefois; et Laveran a vu mourir de même des Alouettes et des Pinsons ne présentant pas ces corps segmentés. Ce dernier observateur n’a pas réussi à trouver des hématozoaires chez les Pigeons d'origine française, mais il en a vu souvent chez ceux d'origine italienne.

L'inoculation du sang palustre de l'Homme aux Oiseaux ne donne aucun résultat; l'inoculation du sang d'Oiseau ì des sujets sains de la même espèce ne réussit que dans certaines circonstances encore mal déterminées.

L'étude des Hémamœbiens des Oiseaux et des Batraciens (1) per-

(1) A. LabBÉ, Sur les hématozoaires des vertébrés à sang froid. Comptes rendus Acad. sc., 24 octobre 1892. 
mettra sans doute de combler les lacunes qui existent encore daus l'histoire de l'hématozoaire de la malaria.

HÉmıtococcus. - Il ne faut pas confondre avec les Hémamcebiens d'autres parasites intraglobulaires décrits par Babes et par Smith, et que le premier de ees auteurs propose de classer entre les Bactéries et les Protozoaires. Nous nous bornerons a les mentionner en quelques mots (1).

En 1888, Babes a filit comnaitre, sous le nom d'hémogtobinurie bactérienne $d u$ bæuf, une redoutable affeetion endémique eu Roumanie, surtonl dans les régions basses et marécageuses qui avoisinent le Danube. Il a constaté que cette affection est due à l'envahissement des globules rouges par un corpuscule rond, pàle, du diamètre de 1 y. environ, que les réactifs colorants montrent pourvus d'une ligne de division. - Plus récemment, le même observateur a rencontré un parasite semblable dans une maladie du Nouton sévissant dans les mêmes localités et connue sous le nom de cârceag.

D'autre part, Th. Smith a reconnu que la fievre du Texas (Texus fever), qui décime les troupeaux de Bœufs dans le sud des États-Unis, est déterminée également par un parasite des globules rouges, auıuel il donne le nom de Pyrosoma bigeminum. On trouve en effet, dans un certain nombre d'hématies, des corpuseules pilles, pyriformes, associés deux à deux. Ces corpuscules, longs de 2 à $4 \mu$, larges au maximum de $1 \mu$ ä à $2 \mu$, se montrent le plus souvent parallèles et dirigés dans le nı̀me sens; dans leur partie renllée, on remarque un petit corps arrondi. L'histoire de ces organismes n'est pas encore bien connue, mais on sait déjà que les Tiques (Rhipicephulus) sont leurs principaux agents de transport.

\section{CLASSE II}

\section{SP OROZOAIRES}

Protozoaires nuclés, de forme plus ou moins défirie, diabord nus, mais généralement limités à l'état adulte par une cuticule lisse; sans cils, ni flagellums, ni tentacules; se reproduisant par des spores; vivant en parasites.

A l'exemple de Leuckart et de Balbiani, nous réunissons provisoirement aux Grégariniens, représentants typiques de ce groupe, les ètres divers connus sous le nom de Psorospermies, qui offrent avec eux une grande analogie dans le mole de reproduction (2).

Tous les Sporozoaires, en effé, se multiplient par la segmentation de leur protoplasme en un certain nombre de spores, qui elles-mèmes donnent naissance chacune à un ou plusieurs éléments aniboïdes, destinés à reproduire plus ou moins directement l'individu adulte.

Ces ètres vivent en parasites chez les animaux les plus divers.

(1) V. Babes, Comptes rendus Ac. sc., CVII, p. 692, 1888 ; CX, p. 800 et 975,1890 ; CXV, p. 359, 1892. - Tи. Sмтн and F. L. Kilborne, Investigalions into the nature, causation and prevention of Texas on southern calle fever. Washington, 1893.

(2) A. Railliet, Article SPorozoares du Nouveau Dictionnaire prat. de méd., chir. et liyg. veit., XX, p. 333, 1892 (bibliographie). 
On peut, avec Balbiani, les répartir dans cinq groupes ou ordres distincts : $1^{\circ}$ Grégarines ; $2^{\circ}$ Psorospermies oviformes ou Coccidies; $3^{\circ}$ Psorospermies utriculiformes ou Sarcosporidies; $4^{\circ}$ Psorospermies des Poissons ou Myxosporidies; 5० Psorospermies des Articulés ou Microsporidies. - Labbé propose même d'en ajouter un sixième, celui des Hémosporidies, pour certaines formes d'hématozoaires différentes des Hémamœbiens (Drepanidium).

\section{PREMIER ORDRE}

\section{GREGARINES}

Les principaux représentants du groupe des Sporozoaires sont, avonsnous dit, les Grégarines (grex, gregis, troupeau) ou Protozoaires apodes. Ce dernier nom tient à l'absence de pseudopodes chez les individus adultes; ce sont alors des organismes cellulaires, vermiformes, limités nettement par une membrane cuticularisée (cuticule ou épicyte). Le protoplasma qui les constitue, fluide el granuleux dans la partie centrale (endoplasme ou entocyle), est plus dense et transparent à la périphérie (ectoplasme ou sarcocyle), où il présente une couche de stries transversales auxquelles on a attribué des propriétés contractiles (myocyte). Il existe un noyau avec un ou plusieurs nucléoles. Assez souvent, le corps est étranglé en avant, et offre à ce niveau une fausse cloison transversale, qui sépare un petit segment auquel Stein applique le nom de tête. Parfois mème, il y a deux cloisons, qui donnent à la Grégarine une apparence tricellulaire : en pareil cas, Aimé Schneider désigne les segments, d'avant en arrière, sous les noms d'épimérite, protomérite et dentomérite. D'après cet anteur, c'est l'épimérite qui est le moins constant: c'est lui qui manque lorsqu'il n'existe que deux segments. II porte souvent des appendices variés (dents, crochets, disques étoilés) jouant le ròle d'appareil fixateur. Les Grégarines formées d'un seul segment sont dites Monocystidées; celles à deux et à trois segments recoivent le nom général de Polycystidées.

Les mouvements des Grégarines sont, en général, assez énergiques. Tantòt ce sont des mouvements de contraction très nets, à l'aide desquels l'animal se fraye un chemin; tantôt, au contraire, c'est un glissement lent et uniforme, s'effectuant dans le sens de l'axe du corps, sans contraction apparente.

Li nutrition est purement osmotique.

La reproluction a lieu par formation de spores. Le corps se raccourcit et devient sphérique, puis la membrane d'enveloppe se dissou ou se déchire, et le protoplasma s'entoure de nouvelles couches d'une substance résistante et transparente qu'il sécrète; on dit alors que la Grégarine est enkystée. Quel.juefois l'enkystement n'a lieu qu'après la réunion (syzygie) de deux ou mème trois individus. Selon Schneider, ces individus se sépareraient au moment de la reproduction, poür s'enkyster isolément. Pour Bütschli, au contraire, la syzygie aboutirait à une véritable conjugaison, les individus s'enfermant dans un mème kyste pour y mélanger leur substance.

Après cet enkystement, le protoplasme se divise en un grand nombre de sphères ou sporoblastes. Puis chacune de ces sphères s'entoure d'une paroi simple ou double, et prend un aspect le plus souvent fusiforme ou losan- 
gique. La ressemblance de ces corpuscules avec certaines Diatomées leur a valu le nom de navicelles (Stein, von Siebold) ou de pseudo-navicelles (Frantzius). On les désigne souvent aussi sous celui de psorospermies, par suite de leur analogie avec certaines formations parasites des Poissons, sur lesquelles nous reviendrons plıs loin. Aimé Schneider a substitué à ces expressions celle plus simple et plus significative de spores.

Les matériaux protoplasmiques non utilisés pour la constitution de ces spores forment une masse résiduelle (reliquat de segmentation) qui sc liquéfie dans la généralité des cas, et sert à faire éclater le kyste; d'autres fois, ce résidu s'entoure d'une paroi et simule un petit kyste inclus dans le grand.

Les spores, destinées à ètre éliminées dans le monde extérieur par déhiscence du kyste, ne sont elles-nièmes que des kystes en miniature. Leur noyau subit des divisions successives, et les noyaux secondaires ainsi formés se portent à la périplérie ; la masse protoplasmique bourgeonne à leur niveau et donne ainsi naissance à un nombre variable de petits corps nucléés, en forme de croissants (corpuscules falciformes ou sporozoites); assez souvent, mais non toujours, une partie de cette masse n'est pas employée et reste au centre sous forme de résidu (mucléus de reliquat Schneider, ou mieux reliquat de différenciation). Les spores ainsi constituées montrent une ligne de déhiscence destinée à l'issue des sporozoïtes.

Lorsque ceux-ci sont arrivés dans le milieu qui leur convient, ils se dégagent donc de la spore, et chacun d'eux s'introduit dans une cellule épithéliale, où il s'accroit et se revèt d'une membrane. Bientòt il bourgeonne du còté de la surface libre de la cellule; le mamelon ainsi

A

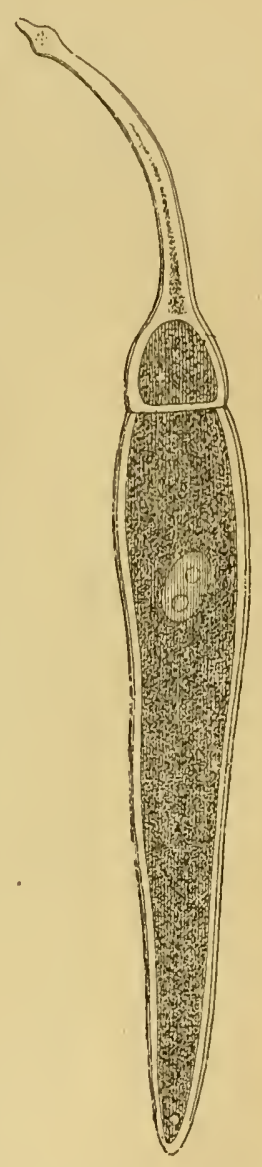

Fig. 61. - A, céphalin et B, sporadin du Stylorhynchus longicollis, de l'intestin du Blaps mortisaga (A. Schneider). produit perce le plateau de celle-ci et fait hernie dans le tube digestif; il prend alors uı développement de plus en plus considérable et représente le corps de la Grégarine, la partie intérienre ne constituant plus qu'un appareil de fixation. Si l'on a affaire à une Monocystidée, le développement est complet : l'animal n'a plus qu'à se dégager de la cellule pour vivre en liberté.

S'agit-il an contraire d'une Polycystidée, le prolongement qui baigne dans le tube digestif se divise de bonne heure en deux régions : la distale sera le 
deutomérite, et la proximale, le protomérite; quant au corps maternel, à la masse primitive, elle a généralement cédé son noyau au deutomérite et constitue simplement la tête de la Grégrarine, ou l'épimérite. La Grégarine se trouve ainsi complètement formée ; elle n'a plus qu'à s'accroître et à différencier sa substance pour arriver à l'état adulte. Elle se détache enfin de la muqueuse, soit en emportant la tête et parfois même la cellule qui renferme celle-ci, soit en se séparant de l'épimérite, pour vivre en liberté dans le tube digestif. En tout cas, l'épimérite finit par tomber tòt ou tard. Schneider donne à la forme complète le nom de céphalin ; celle qui a perdu l'épimérite reçoit le nom de sporadin. C'est ce sporadin qui représente le corps destiné à la reproduction.

En résumé, l'évolution des Grégarines comprend un double cycle, qu'on pourrait se représenter par deux circonférences se coupant en deux points : l'un de ces points correspondrait à l'état de sporozoîte, l'autre à celui de Grégarine.

$1^{\circ}$ Sporozoüte; masse protoplasmique intracellulaire; Grégarine.

$2^{\circ}$ Grégarine; kyste; spore; sporozoïte.

Tous les Grégariniens, à l'état adulte, vivent en parasites dans le tube digestif ou dans les cavités du corps des Invertébrés, notamment des Annélides et des Arthropodes; ils se nourrissent des substances élaborées par leur hôte. C'est à tort qu'on avait autrefois signalé des Grégarines parasites del'Homme: on ne trouve chez les Vertébrés que des Psorospermies, non des Grégariniens véritables. Néanmoins, il était nécessaire de les étudier : leur histoire, mieux connue que celle des autres groupes, doit servir utilement d'introduction à l'étude de ceux-ci.

Les affinités de ces ètres sont assez difficiles à déterminer : ils ont sans doute d'étroits rapports avec les Amœbiens, mais leur mode de vie donne à penser que ce sont peut-être des organismes assez élevés, dégradés par le parasitisme.

Léger (1) divise les Grégarines en deux groupes principaux :

Gymnosporées. - Spores nues. Ex. : Porospora gigantea Ed. Van Ben., du Homard; facile à trouver en raclant l'intérieur de l'intestin mojen; kystes dans l'intestin terminal.

Angiosporées. - Spores revètues d'une coque. Ex. : Monocystis, Stylorhynchus, etc.

\section{DEUXIÈME ORDRE}

\section{COCCIDIES}

Sporozoaires à corps nu pendant le jeune âge, mais s'entourant, après avoir acquis tout leur développemenl, d'une coque résistante, i l"intérieur de laquelle le protoplasme se convertit en une ou plusieurs spores, qui se diffèrencient elles-mêmes en un nombre variable de corpuscules falciformes.

Ces êtres, longtemps désignés sous les noms de Cellules, Corps ou Psorospermies oviformes, ont reçu de Leuckart celui de Coccidies, tiré du genre type Coccidium.

(1) L. LËGER, Recherches sur les G'régarines. Tablettes zoologiques, III, p. 1, 1892. 
Leur déreloppement ofle à considérer deux périodes: une période d'accroissement ou de régétation el une périnde de réproduclion.

Tout dabord, en effet, les Coceidies se montrent formées par de petites masses de proloplasma granuleux, masses arrondies, régulières et probablement toujours nuclées, qui out pénétré dans les cellules épithéliales ou conjonctives d'un organe déterminé (foie, intestin, corps adipeux, etc.) et s̀ développent peu à peu.

A la fin de cette période d'aceroissement, chacune de ces masses amiboïdes s'entoure d'une enveloppe transparente, plus ou moins complexe (kyste ou coque), rompt habiluellement la cellule qui la renfermait et tombe dans la eavité de l'organe. C'est là d'ordinaire qu'on la troure enkystée. Le contenu protoplasmique remplit d'abord tout le liyste, mais il ne tarde pas à se contracter en boule.

La suite du développement ne sobserve généralement qu'en dehors de l'hòte: on roit alor's presque toujours la boule, après division successive du noyau, comme chez les.Grégarines, se segmenter en plusieurs sphères (sporoblastes) qui s'entourent ordinairement d'une paroi propre et constituent ainsi autant de spores. Chacune de celles-ci se différencie alors en $u n$ nombre variable de sporozoïtes ou corpuscules falciformes, nucléés, et souvent en un on plusieurs noyaux de reliquat. On doit admettre que ces corpuscules falciformes, une fois ćchappés de la coque el dégagés de la spore, se transforment en une masse amiboïde qui pénètre dans une cellule épithéliale, où elle grossit et revient à la phase primitive.

Il y a lonc, entre cette évolution et celle des Grégarines, des rapports très étroits; seulement le cycle, au lieu d'ètre double, reste toujours simple et se réduit aux phases suivantes :

Sporozoïte; masse protoplasmique intracellulaim; Coccidie libre ou liyste; spore.

On peut même roil ce cycle se restreindre davantage encore, car dans les Monosporées, comme Eimerin, par exemple, il n'y a pas à proprement parler de spore, la division du noyau donnant lieu directement à des corpuseules falciformes.

Les Coccidies ont été rencontrées, parmi les Vertébrés, chez les Mammifères, les Oiseaux, les Batraciens et les Poissons; on en a aussi observé sur quelques Mollusques, Arthropodes et Vers.

Aimé Sclıneider a proposé, pour les Coccidies, une classification basée sur les différences qu'elles présentent dans la période de reproduction. Le tableau suivant, que le savant professeur de Poitiers a bien voulu compléter à notre intention, résume cette classification. 
I. Tout le contenu du kyste se convertit en une spore unique :

Genres : Monosporées.

a. Spore renfermant un seul corpuscule : Monozoïpues?

b. Spore renfermant des corpuscules en nombre dẻfini : oLIgozoïques. Corpuscule au nombre de quatre.............

c. Spore renfermant un nombre indéfini de corpuscules:

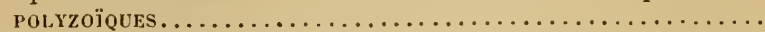

II. Contenu du kyste se convertissant en un nombre constant et défini de spores: Oligosporées.

A. Deux spores: DIsporéEs.

a. Corpuscules des spores au nombre de deux........... Cyclospora.

b. Corpuscules des spores en nombre indėfini............. Isospora.

B. Quatre spores : tÉTrASPORÉES.

Corpuscules des spores au nombre de deux..............

III. Contenu du kyste se convertissant en un grand nombre de spores: Polysporẻes.

a. Spores Ienticulaires; deux corpuscules symétriques.......

b. Spores ellipsoïdales; un seul corpuscule.................

$c$. Spores sphériques; un ou plusieurs corpuscules..........

Coccidium.

Adelea.

Barrouxia.

Klossia.

Le genre Orthospore (Orthospora A. Schn., 1881) est donc caractérisé, dans son sens général, par une spore unique renfermant quatre corpuscules falciformes.

Schneider avait établi ce genre, en 1881, pour des Coccidies qui vivent dans lintestin de divers Tritons; mais il a reconnu depuis (1887) que ces parasites appartiennent en réalité au genre Coccidium.

Orthospore du rein ( $O$. nova Raill., 1892). - Espéce observée par Pachinger (1) dans l'oesophage, l'estomac et l'intestin d'un Chat, puis dans les reins d'un Chien.

Genre Eimérie (Eimeria A. Schn., 1881). - Une seule spore, donnant un nombre indéfini de corpuscules falciformes.

Eimérie falciforme \{Eim. falciformis [Eimer]. - Syn. : Gregarina falciformis Eimer, 1870; Eim. falciformis A. Schn., 1875; Gregarina muris Riv., 1878). - Cette petite Coccidie a été découverte par Eimer dans l'intestin de la Souris. Les cellules épithéliales renfermaient des masses protoplasmiques arrondies ou ovoïdes, nucléées, refoulant le noyau propre de la cellule. Dans la cavité de l'intestin, on rencontrait les mêmes masses, mises en liberté et entourées d'une double membrane, l'interne très fine et l'externe plus épaisse, formant coque; le tout mesurant en moyenne $26 \mu$ de long sur 16 de large. D'autres kystes se trouvaient à des stades plus avancés, la masse interne se divisant en un certain nombre de petites sphères bientôt transformées en corpuscules falciformes. Ceux-ci, d'abord appliqués contre la membrane interne à.la façon des méridiens d'une sphère et accompagnés d'un nucléus de reliquat (reliquat de segmentation). perdaient ensuite cette disposition régulière el prenaient une situation quelconque.

En examinant le contenu de l'intestin, Eimer y trouva des corpuscules semblables, mais libres, animés de mouvements énergiques et se transformant peu à peu en une masse amiboïde. Il admet que cette Amibe doit pénétrer dans une celtule épithéliale et reproduire directement la Coccidie.

Les Souris doivent s'infester par l'ingestion de kystes rejetés avecles excréments; elles succombent assez rapidement à cette infestation.

(1) Al. Pachinger, Mittheilungen über Sporozoen. Zool. Anzeiger, IX, p. 471, 1886. 
D'après quelques observations malheusement peu précises, l'Eimérie falciforme pourrail s'observer chez d'autres animaux (1). C'est ainsi que Pachinger dit l'avoir rencontrée trois tois dans les reins de Chevaux dont elle paraissait avoir causé la mort, et que Rivolta déclare l'avoir trouvée dans le foie du Lapin, à côté de la Coceidie oviforme.

b'autre part, Virchow a signalé, en 1860, l'existence de liystes particuliers daus une petite tumeur recueillic sur le loie d'une vieille femme. Ces liystes, de lorme ovoüde, longs en moyenne de $56 \mu$, oflraient une mombrane externe assez épaisse, à double contour, el une membrane interne très délicale. Le contenu, d'aspect variable, se montrait l'ormé le plus souvent de nombreux globules. Virchow pensait aroir affaire à des oufis de Pentastome en voie de segmentation, mais il est bien évident qüil s'agnissait d'une Coccidie. Probablement. même faut-il voir, dans les globules intérieurs, des corpuseules falciformes en formation, et ranger par conséruent cette Coccidie dans le genre Eimeria.

Enfin, Küunstler et Pitres ont trouvé, dans le liquide purulent extrait par thoracentèse de la cavité pleurale d'un malade atteint de pleurésic chronique latente, des corpuscules falcilormes munis d'un noyau el mesurant 18 à $20 \mu$ de long, par exception 60 et jusqu’à $100 \mu$. En même temps, il existait des spores volumineuses, renfermant 10 à 20 de ces corpuseules accolés à la membrane et accompagnés d'un reliquat de diflérenciation. En l'absence d'aulopsie, l'observation est demeurée incomplète, mais il est fort probable qu’il s'agissait encore d'inne Coccidie monosporée à nombreux corpuscules, c'est-à-dire d'une Eimérie.

Eimérie douteuse (Eim. dubia Raill., 1892. - Syn. : Gregarina avium inteslinalis Riv., 1878). - Organisme de forme ronde, ovoïde on oblongue, du diamètre de 40 à $48 \mu$, limité par une nince membrane homogène, et rempli de corpuscules fusiformes ou falciformes, granuleux ou comme creusés de vacuoles, longs de 11 à $14 \mu$.

C'est pour ordre seulement et titre provisoire que nous rangeons ce parasite parmi les Eimeria. D'après les figures qu'en donne Rivolta, il semble représenter, en effet, une Coccidie monosporée à nombreux corpuscules falciformes. A la vérité, on pourrait y trouver aussi des analogies avec les Sarcosporidies (Balbiania), et livolta le regarde comme un Utricule de Miescher.

Cet observateur l'a découvert dans le tissu conjonctif sous-muqueux de l'intestin de la Poule et de divers autres Oiseaux, comme les Merles et les Corbeaux. Sa présence se traduit par des ponctuations blanchàtres, du volume d'une graine de pavot, correspondant à un certain nombre d'indi-

(1) Al. Pachingen, loc. eit. - Rivorta, Detla Gregarinosi, ecc. Giomale di anat., fis, e patol. degli animali, 1878. - R. Vırcuow, Helminthologische Notizen : Zur Kenntniss der Wurmknoten. Virchow's Archiv, XVIIl, p. 523, 1860. - J. Küsstcer et A. Pitres, !Sur une Psorospermie trouvée dans une humeur pleurétique. Journal de micrographie, 1884. 
vidus agglomérés. Quand il n'existe qu'un petit nombre de ces amas, les Oiseaux ne paraissent pas en souffrir; mais lorsque l'intestin en est couvert et qu'il existe en même temps des Coccidies de l'épithélium, la mort peut survenir.

Genre Isospore (Isospora A. Schn., 1881). - Kyste à deux spores donnant chacune un nombre indéfini de corpuscules falciformes.

Isospore des oiseaux (I. arium [Riv.]. - Syn. : Psorospermium avium Riv., 1878; 1. avium Raill., 1885). - Coccidie de dimensions inférieures à celle de la Coccidie oviforme; coque plus mince; contenu se divisant, après séjour dans l'eau, en deux spores, dans chacune desquelles se forment dix à quinze corpuscules.

Trouvée par Rivolta et Piana dans lintestin des petits Passereaux captifs, que sa multiplication conduit au marasme et à la mort.

Rivolta dit en avoir obtenu le développement dans l'intestin du Moineau et de la .Poule, par l'ingestion de pulpe remplie de parasites à la phase ultime de la segmentation.

Genre Coccidie (Coccidium R. Leuckart, 1879). - Kyste à deux spores, chacune donnant deux corpuscules falciformes (un seul en apparence).

Nous avons à étudier dans ce genre quelques formes particulièrement intéressantes.

Coccidie oviforme (Coccidium oviforme Leuck., 1879. - Syn. : Psorospermium cuniculi Rivolta, 1878. - Priorité: Coccidium cuniculi [Riv.]). - Coccidie à coque oroïde, lisse, assez épaisse, présentant à l'un des póles, ordinairement le plus étroit, une petite dépression en forme de micropyle. Longueur maximum 40 à $49 \mu$; largeur, 22 à $28 \mu$.

On rencontre ces petits corps dans le foie (conduits biliaires) de divers Mammifères, notamment du Lapin.

Évolution. - Pour étudier le développement des Coccidies hépatiques, il convient de pratiquer des coupes fines dans les parties du foie qu'elles ont envahies. Si l'on exa-

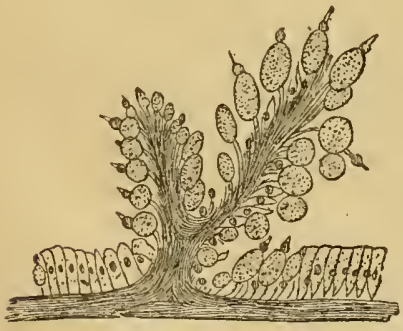

Fig. 62. - Coccidium oviforme dans les cellules épithéliales des conduits hépatiques et refoulant les notaux des cellules (Balbiani). mine de la sorte des canalicules biliaires encore peu altérés, on remarque dans leurs cellules épithéliales des parasites très jeunes, récemment introduits, sous l'aspect de masses protoplasmiques arrondies, de 9 à $10 \mu$ de diamètre, légèrement granuleuses, dépourvues de membrane, mais contenant une sorte de gros noyau nucléolé. Les masses grossissent peu à peu, en dilatant les cellules et refoulant le noyau propre de celles-ci vers le sommet; finalement, elles cons-

tituent une boule sphérique d'environ $26 \mu$ de diamètre, ne montrant plus de noyau distinct. A cet état, elles présentent une ressemblance 
indiscutable avec les Grégarines. Il n'est pas rare d'observer dans une même cellule deux ou trois masses parasitaires, parfois même davantage. Il nous a paru que ce fait résulte plus souvent de la division répétée d'une masse primitive que de lïmmigralion successive de plusieurs germes.

Dès que les masses granuleuses ont acquis leur taille maximum, elles passent ì l'étal de Coccidies proprement dites: de rondes qu’elles étaient, elles prennent une forme ovoüde, assez allongée, et s'entourent dlune coque qui šépaissit rapidement (enkystement). Cette coque lisse, al double contour, leur donne l'aspect d'un wut' d'helminthe; elle peut du reste varier dans ses earactères, et parfois mème se montrer double, ee qui est peut-être l'indice de mues. En tout cas, elle est uniformément remplie par le protoplasma granuleux, et l'on

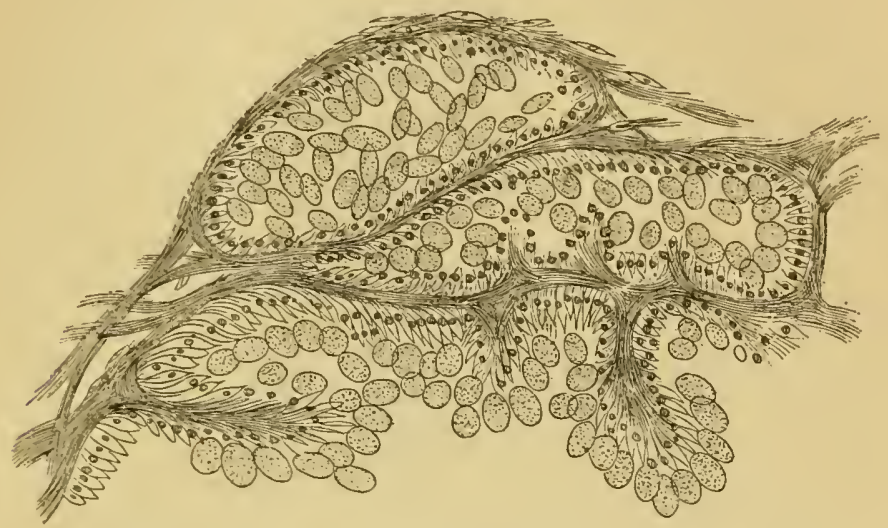

Fig. 63. - Coupe d'un foie de Lapin envahi par le Coccidium oviforme, d’après Balbiani. Les conduits lı́platiques sont dilatés par les productions parasitaires.

remarque souvent à l'un de ses pôles une dépression mieropylaire plus ou moins aceusée (fig. $61, d)$. La longueur moyenne est, à eette période, de 32 à $40 \mu$, sur une largeur de 18 à $20 \mu$. Cependant, cette Coccidie continue de grossir: sa coque devient plus bombée et plus épaisse, et atteint les dimensions de 40 à $49 \mu$ sur 22 à $28 \mu$, en même temps que le contenu se sépare de la paroi et se contracte en une masse globuleuse plus ou moins centrale, montrant une sphère pâle qu'on a décrite commè un noyau $(f)$.

Finalement, les Coccidies enkystées rompent la paroi des cellules ou tombent avec elles dans la lumière des canaux biliaires, où elles s'accumulent au milieu d'un détritus granuleux mẻlé de noyaux et de débris de cellules épithéliales.

La dernière forme que nous venons d'étudier (kyste à double contour, avec contenu ramassé en boule au centre) est la phase ultime du développement des Coecidies dans le foie. Elles tombent du reste en grande partie dans l'intestin et sont emportées avec les excréments. 
Leur développement ultérieur, qui s'effectue dans l'eau ou dans la terre humide, dans des bouillons divers, parfois même dans l'alcool étendu, dans des solutions faibles d'acide chromique, de bichromate de potasse, d'acide salicylique, ete., exige un temps variable suivant les conditions dans lesquelles elles sont placées : sous une couche d'eau de 2 nu 3 centimètres, Balbiani a vu la segmentation de la masse se produire après quinze jours à trois semaines; sous une couche plus mince ou dans du sable humide, elle survenait en deux ou trois jours, et l'évolution complète était terminée dans l'espace de dix à quinze jours en été. Les Coccidies à contenu non rassemblé en boule périssent dans les chambres d'incubation. - Le protoplasma commence donc par se segmenter: il se divise d'une façon constante
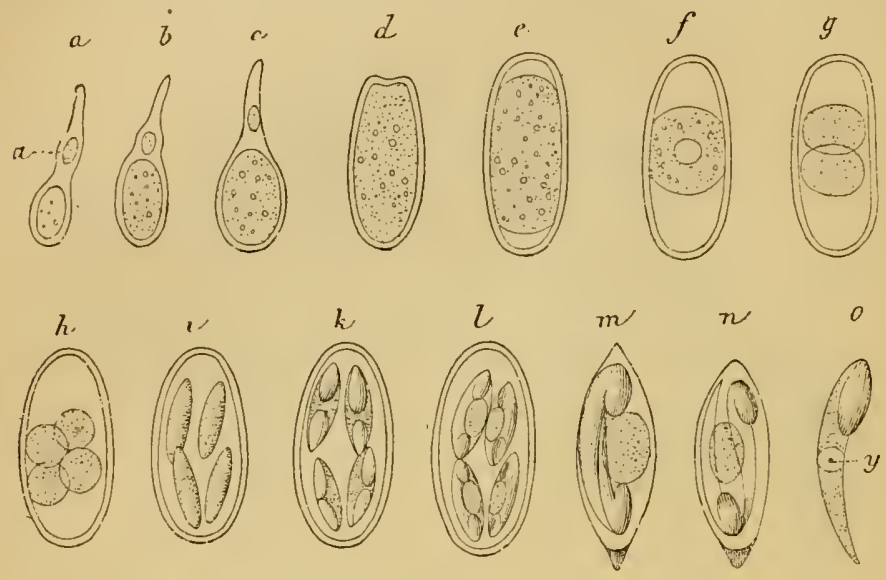

Fig. 64. - Évolutions du Coccidium oviforme du foie du Lapin, d'après Balbiani. - $a, b, c$, jeunes Coccidies renfermées dans les cellules épithéliales des eanalicules hépatiques: $a$, noyau de la eellule épithéliale. $d, e, f$, Coccidies adultes enkystées. $g, h, i, k, l$, développement des spores. $m$, spore mûre isolée, très grossie, monlrant les deux corpuscules falciformes dans leur position naturelle, arec le nueléus de reliquat. $n$, spore comprimée arec les deux corpuseules c'cartés l'un de l'autre. 0 , un corpuscule falciforme. $y$, son noyau.

en deux, puis en quatre masses' arrondies ou sporoblastes $(h)$. Puis chacune de ces sphères s'allonge, s'enveloppe d'une délicate membrane et constitue alors une spore (i). Enfin, cette spore elle-même produit une sorte de bâtonnet légèrement recourbé, avec les deux extrémités renflées en boule : dans la concavité de ce petit corps, on rencontre toujours un reliquat de la masse granuleuse du sporoblaste. Balbiani a démontré que ce bàtonnet résulte en réalité de l'accolement de deux corpuscules falciformes nucléés, placés en sens inverse.

A cet état, les Coccidies se conservent sans modification appréciable pendant une période indéfinie; mais on n’est pas fixé sur leur mode d'introduction dans l'organisme. Il est probable que les kystes, ayant évolué dans un milieu humide, sont ingérés avec les eaux de boisson, ou mieux sont entraînés avec les poussières atmosphériques ou de 
toute autre facon, sur les aliments des animaux. Il est probable aussi que lorsqu ils sont parrenus daus le tube digestif, ils se rompent, que l's spores se déchirent ensuite et mettent en liberté leurs corpuscules falciformes, enfin que ceux-ci se transforment en petites masses amiboüdes destinées à pénétrer dans les conduits biliaires par le canal cliolédoque et a envahir les cellules épithóliales. Mais la démonstration expérimentale de cette manière le voir reste à faire.

Pathologie. - La coccidiose hŕpalique, èest-ìt-dire l'affection causée par la présence des Coceidies dans le foie, oflee chez le lapin les caractères généraux d’une anémie pernicicuse.

A l'aulopsiej des sujels envahis, on troure d'ordinaire les tissus pàles el décolorés, le sang pâle et aqueux. Le foie est plus ou moins hypertrophié, et montre gà et là des nodules blanchâtres de la grosseur d'un grain de mil à celle d'une noiselle, isolés ou disposés en traînées. L'ouverture de ces nodules donne issue à une masse crémeuse, contenant, avec divers produits de dégénérescence, de nombreuses Coccidies enkystées. Il est facile de reconnaître qưils représentent des conduits biliaires altérés et transformés (Nicati et Richaud). L'examen histologique y fait voir de nombreuses travées revêtues d'un épithélium dont les cellules sont envahies par les parasites(Malassez). Les lobules hépatiques voisins sont souvent atrophiés.

Les troubles résultant de ces altérations sont peu caractéristiques. Les animaux sont faibles, anémiques, présentent de la tympanite, de l'ascite (gros ventre), de la diarrhée, et succombent au bout de deux ou trois mois, dans le marasme et les convulsions.

Les sujets jeunes sont surtout exposés aux atteintes de la maladie. Celle-ci est très répandue aux environs de Paris, comme dans tous les endroits où les Lapiṇs sont entassés dans des clapiers étroits et mal tenus. Elle cause en somme des pertes sćrieuses et peut compromettre l'élevag’e.

Il y a donc lieu de prendre à son cndroit des mesures prophylactiques: isolement des individus malades ou suspects; incinération des viscères envahis; désinfection de la litière et des cages; distribution d'aliments secs et d'eau très propre. - D'après les données qui précèdent, en effet, il est facile de conceroir que, dans les conditions naturelles, les Coccidies enliystées tombent des canaux biliaires dans l'intestin, sont rejelées avec les excréments, et se développent dans la litière humide ou dans les flaques d'eau; et que, dans le cas où les animaux sont sacrifiés, le foie, abandonné en raison des lésions qu ïl présente, peut mettre également les parasites en liberté dans un milieu favorable à leur évolution.

La Coccidie oviforme ne s'observe pas seulement chez le Lapin domestique; elle se développe aussi dans le foie du Lapin de garenne, et donne lieu parfois à des épidémies assez sérieuscs.

Ch. Robin parait lavoir vue aussi chez le Cobaye, et Johne la 
signale chez le Porc; mais ce dernier observateur a eu probablement affaire à une autre espèce.

On sait enfin qu'elle peut envahir le foie de l'Homme, ainsi qu'en témoignent les observations de Gubler, Dressler, Perls et Sattler, von Sommering (Leuckart), Silcock, etc. Il paraît bien évident que l'Homme tire ses Coccidies du Lapin, et qu'il contracte ces parasites en faisant usage d'eaux non filtrées ou de salades souillées par des kystes qu'a rejetés cet animal.

Coccidie perforante (C. perforans Leuckart, 1879. - Syn. : Cytospermium hominis Rivolta, 1878. - Priorité : Coccidium hominis [Riv.]).

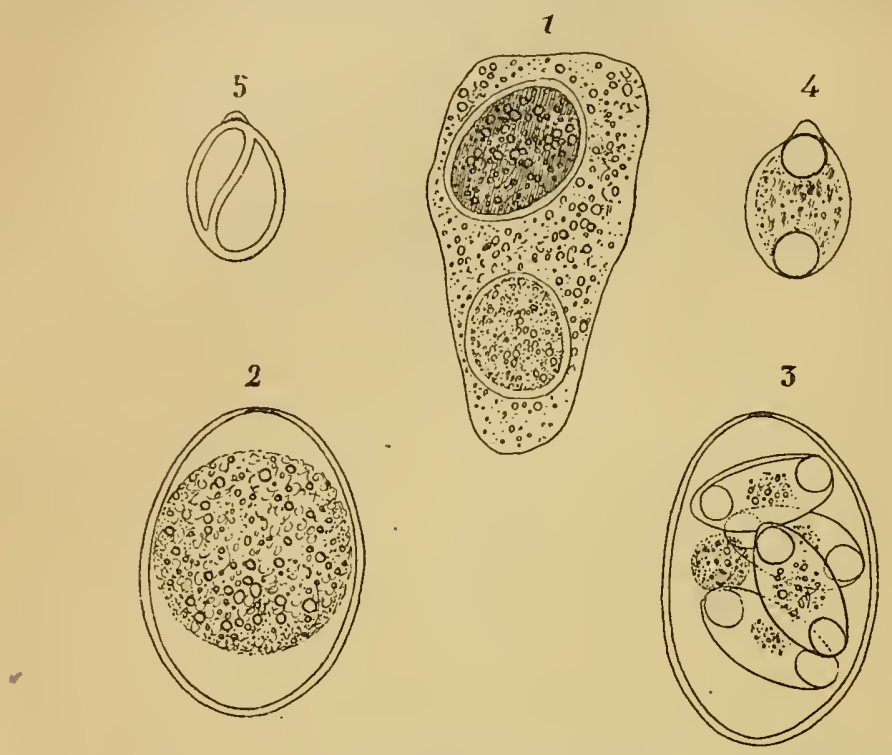

Fig. 65.. - Coccidium perforans, de l'iutestin du Lapin domestique. - 1, cellule épithéliale altérée, envahic par deux Coccidies. 2, Coccidie libre, recueillie dans l'intestin. 3 , Coccidie avec quatre spores et un reliquat de seguentation. 4, une spore isolée. 5, spore montrant les deux corpuscules falciformes. Grossissement : 1140 diamètres (Orig.).

- Au point de vue morphologique, cette espèce diffère très peu de la Coccidie oviforme; elle est cependant un peu plus petite : à la phase parasitaire ultime (protoplasma ramassé en boule), elle mesure 26 à 30 à $\mu$ de long sur 14 à 20 de large.

Elle se développe dans l'épithélium intestinal du Lapin, de l'Homme et probablement de divers autres Mammifères. Son nom rappelle que c'est sur l'épithélium intestinal qu'on a observé d'abord la perforation des cellules au moment où les Coccidies les abandonnent pour tomber à l'état de kystes dans la cavité de l'intestin.

Remak paraît être le premier qui l'ait signalée chez le Lapin; elle a été ensuite retrourée chez le même animal et étudiée attentivement par un grand nombre d'observateurs. 
Évolutron. - Cette espèce suit dans son développement une marche parallèle à celle de la Coccidie oviforme, et nous pourons par conséquent nous contenter d'un exposé rapide. Sur des coupes de l'intestin grêle du Lapin, on voit les cellules épithéliales des villosités et des glandes de Lieberkülnn occupées par des masses protoplasmiques de dimensions variables, soit nues, soit entourées d'une membrane simple ou d'une coque épaisse à double contour. Dans une mème cellule, on trouve parfois jusqu'à cinf ou six de ces masses, qui ne sont autres que des Coccidies, et comme on les rencontre souvent à divers degrés de développement, cela suffit à montrer que cette multiplicité ne tient pas toujours ì la division des cellules primitives, mais qu'elle peut provenir d'invasions successives. Au bout d'un certain temps, ces Coccidies quittent leurs cellules en les perforant, et tombent dans la lumière de l'intestin, oì on les trouve mélangées al mucus. Leur protoplasma ne tarde pas à se rassembler en boule au centre, et elles doivent être alors expulsées avec les excréments. Stieda dit en avoir trouvé avec quatre sporoblastes dans l'intestin même.

Mises en incubation dans l'eau, par exemple, elles subissent la segmentation au bout d'un temps variable. Leuckart prétendait que l'évolution de cette espèce était au moins sept fois plus rapide que celle de la Coccidie du foie; mais, pas plus qu’à Rieck, il ne nous a paru exister entre les deux formes, à ce point de rue, de différence bien sensible. Balbiani attribue même nettement les variations observées par Leuckart ì l'épaisseur plus ou moins grande de la couche d'eau qui recouvre les kystes en incubation. Le protoplasme se divise encore en quatre sporoblastes, mais il laisse entre ceux-ci une masse arrondic, grossièrement granuleuse, qu'on peut désigner sous le nom de " reliquat de segmentalion ". Bientot après, les sporoblastes s'organisent en spores, dans chacune desquelles apparaissent deux corpuscules falciformes, accompagnés d'un " reliquat de différenciation".

Waldenburg, ayant fait prendre à un Lapin de quatre semaines des Coccidies intestinales à quatre spores, arait trouvé au bout de quatre jours, à la surface de la muqueuse intestinale, outre quelques "psorospermies " mûres, de nombreux corps ronds, granuleux, nucléés, nus ou revêtus d'une membrane mince. Des animaux témoins n'avaient rien présenté de semblable. Ces faits n'avaient été accucillis qu'avec de grandes réserves, d'autant que Waldenburg professait, sur l'évolution des Coccidies, des idées fort erronées. Nous avons repris l'expérience, Lucet et moi, dans les conditions suivantes : après avoir obtenu le développement des spores et des corpuscules falciformes, nous arons fait prendre à deux Lapins, ùgés d'environ deux mois et reconnus préalablement indemnes, un grand nombre de Coccidies. Ces animaux sont morts au bout de huit ì dix jours, en présentant toutes les lésions de la coccidiose intestinale; les cellules épithéliales 
de l'intestin grèle renfermaient des Coccidies à tous les âges, qu'on retrouvait également dans le mucus de lintestin. Deux individus de la mème portée, conserrés comme témoins, ne présentaient aucun de ces parasites.

Rirolta préteud, d'autre part, aroir fait développer la Coccidie perforante du Lapin dans lintestin de la Poule, mais le fait aurait besoin d'être sérieusement contrôlé. Nous avons, avec Lucet, complètement échoué sur des Poulets et des Cobayes.

Pathologie. - Les lésions de la coccidiose intestinale du Lapin se traduisent tout dabord par des taches blanchâtres, punctiformes ou plus ou moins étendues, siégeant le plus sourent sur l'intestin grêle. La muqueuse est enflammée et parfois ulcérée; dans l'exsudat qui la revêt, on trouve de nombreuses Coccidies enkystées, et même des masses protoplasmiques encore nues. Les taches correspondent à des amas de Coccidies occupant les cellules épithéliales des villosités et des glandes de Lieberkühn. Ces cellules se dilatent et se déforment, leur noyalu se trourant refoulé à la partie inférieure. Les glandes de Lieberkühn sont quelquefois bourrées de parasites; Klebs aurait même ru ceux-ci pénétrer dans le tissu conjonctif sous-muqueux, et Reincke en aurait trouvé les stades jeunes jusque dans les ganglions mésentériques. Si la maladie a érolué lentement, on observe en outre les altérations de l'anémie.

Les symptômes de l'affection sont assez analogues à ceux de la coccidiose hépatique: la mort ne survient parfois qu'au bout d'une assez longue période. par cachexie ; mais, dans les cas d'infestation étendue, elle arrive au bout de quelques jours, avant que le marasme ait eu le temps de s'accuser. - Le diagnostic différentiel peut être établi par l'examen microscopique des fèces; à première rue même, on reconnait que le nombre des parasites est plus élevé que dans la coccidiose hépatique. Les deux affections comportent du reste les mêmes indications prophylactiques.

Eimer rapporte qu'il a trouvé deux fois, sur des cadarres de l'Institut pathologique de Berlin, l'intestin rempli de "Psorospermies semblables à celles des animaux ». Dans les deux cas, l'épithélium intestinal était en grande partie détruit et perforé par les parasites: il s'agissait donc rraisemblablement du Coccidium perforans ou d'une forme voisine. Quant au cas souvent cité de Kjellberg, nous le rapportons au Coccidium bigeminum.

Dirers obserrateurs, entre autres Grassi, Rirolta, Railliet et Lucet, ont signalé d'autre part la découverte de Coccidies dans les excréments de l'Homme, mais on ne peut préciser l'origine et partant l'espèce de ces parasites. Dans les observations de Railliet et Lucet, les Coccidies mesuraient 1 ว̆ $\mu$ sur $10 \mu$, ce qui tend à les rapprocher de $C$. bigeminum; elles étaient émises par une femme et son enfant, tous deux atteints depuis longtemps de diarrhée chronique. 
Enfin, les Coceidies intestinales du Chien et du Chat, rapportées par Leuckart au $C$. perforans, nous paraissent appartenir à d'autres espèces, dont il sera question plus loin. Cependant, Dages nous a signalé un cas inédit de Coccidies de l'épithélium intestinal chez de très jeunes Chiens.

Zürn a décrit, sous le nom de rhinite psorospermique, une grave affection qui sévit assez fréquemment sur le lapin domestique, en Allemagne, et qui esl due à l'invasion des muqueuses du nez, du pharynx et de l'oreille moyenne par des Coccidies. Peut-ètre s'agit-il d'une localisation particulière dıI C. perforuns.

Les symptòmes de cette maladie consistent en un violent catarrhe nasal, accompagné de toux et d'éternuements. Parfois il se manifeste en mème temps de l'angine; enfin, dans le cas où il existe des lésions de l'oreille moyenne, on observe des troubles nerveux plus ou moins marqués. La fièvre, assez légère d'abord, s'accuse peu ì peu; les malades s'afficiblissent et meurent dans des convulsions. L'examen microscopique du mucus nasal révèle la présence des Coccidies.

Coccidie de Zürı (C. Zürni [Rivolta]. — Syn.: Cytospermium Zürnii Riv., 1878; Coccidium Zürni Raill., 1892). - Nous ne possédons aucun détail sur les caractères morphologiques de cette espèce nominale.

Elle a été découverte par Zürn dans l'intestin et les ganglions mésentériques d'un Veau mort, après trois autres, arec les symptomes et les lésions d'une entérite violente. La surface entière de l'intestin était tapissée d'une couche de mucus purulent. La muqueuse du gros intestin était criblée de boutons jaunâtres, de la grosseur d'une tête d'épingle.

A l'examen microscopique, on reconnut que les cellules épithéliales étaient envahies au plus haut degré par des Coccidies, amassées en quantité énorme dans les glandes de l’intestin grêle et dans les follicules solitaires, d'où l'apparence de boutons miliaires. Le contenu de l'intestin charriait une proportion incroyable de ces parasites.

Les Veaux en question n'avaient jamais cohabité arec des Lapins. Rivolta fait remarquer, d'ailleurs, que très souvent des Lapins atteints de coccidiose sont élevés dans des étables sans que les Veaux contractent cette affection, et il tire argument de ce fait pour considérer la Coccidie de Zürn comme une espèce particulière.

E. Zschokke et Hess (1) ont observé en Suisse une maladic très répandue chez les bêtes bovines, la "dýsenterie rouge ", qui est déterminée par des Coccidies de l'épithélium intestinal. Le premier de ces auteurs a étudié les parasites à toutes les phases de leur évolution dans lintestin, évolution en tous points semblable à celle de la

(1) E. Zscnokke, Bcobachtungen über die rothe Ruhr. Schweizer Archiץ lür Thierheilk., XXXIV, p. 1 et 49, 18:12. - E. Hess, Die rothe Ruhr des Rindes (dysenteria hæmomhagica coccidiosa). Ibid., p. 105. 
Coccidie perforante. Ils se montrent tantôt arrondis, tantôt ovoïdes; à la phase ultime, ils peuvent atteindre $26 \mu$ de long sur $18 \mu$ de large.

On les rencontre de préférence dans le gros intestin et surtout dans le rectum. La muquense de ce dernier organe est pigmentée et couverte d'exsudats sanguinolents. En dehors de symptômes généraux souvent alarmants, les sujets atteints présentent une diarrhée sérosanguinolente avec ténesme, amenant parfois un prolapsus rectal. 11 n'est pas rare de voir la mort survenir rapidement; d'autres fois, le mal s'atténue, pour disparaître complètement ou récidiver après une période plus ou moins longue.

La dysenterie rouge peut se montrer en toute saison, mais elle fait surtout des ravages en été, sur les animaux au pâturage. Elle est inconnue chez les Veaux à la mamelle, rare sur les individus âgés de moins d'un an et de plus de deux ans. Dans certains districts, elle attaque 5 p. 100 de la population bovine et en fait périr 2 à 4 p. 100.

Au point de vue prophylactique, Hess recommande avec raison l'usage exclusif de fourrages secs; comme traitement, il emploie le soufre sublimé, l'hyposulfite de soude, le crésyl, le lysol.

- Rivolta rattache encore an $C$. Z Zürni des Coccidies trouvées par Zürn dans l'intestin d'un Cochon de lait qui avait succombé à une entérite, et qui provenait d'une ferme dans laquelle une série de Porcelets étaient morts à peu d’intervalle.

- Stiles (1) a décrit sommairement des Coccidies trouvées par C. Curtice et Th. Smith dans l'épithélium de l'intestin grêle du Mouton, en Amérique. Il tend à les rapporter au $C$. perforans. Elles mesuraient 18 à $21 \mu$ de long sur 15 à $16 \mu$ de large.

Rivolta en Italie (1874) et Nocard en France (1891) avaient déjà fait de semblables observations; mais les Coccidies examinées par Nocard ne mesuraient que 10 à $12 \mu$ de long sur 7 à $9 \mu$ de large : elles avaient provoqué la formation de véritables tumeurs.

- Enfin, on a signalé des Coccidies intestinales, non déterminées, chez le Cobaye et chez la Taupe.

Coccidic délicate (C. tenellum Raill. et Lucet, 1891. - Syn. : C. Rivoltæ Harz, 1886, nec Grassi, 1881). - Espèce de forme plus ramassée que les Coccidies oviforme et perforante, plutôt ellipsoïde qu'ovoïde, les deux pôles étant également larges; coque plus mince, plus délicate; dimensions plus faibles, soit en moyenne 21 à $2 \breve{o r} \mu$ de long sur 17 à $19 \mu$. de large à la phase ultime du développement.

Cette Coccidie vit dans l'intestin de la Poule, où elle a été vue par Rivolta et Silvestrini, par Perroncito, par Railliet et Lucet, etc.

(1) Ch. W. Strues, A case of intestinal Coccidies in Sheep. Journal of compar. Med. and veter. Archives, XIII, p. 319, 1892. - Ed. Nocard, Tumeur's à Coccidies de l'intestin grêle du Mouton. Transact. of the 7th internat. Congress of Hygiene in London, 1891; vol. II, p. 94, 1893. 
Elle se développe à la façon de la Coccidie perforante; cependant, nous n'y avons pas remarqué de reliquat de segmentation. Rivolta et Silvestrini auraient réussi, d'après Leuckart, à infester des Poules avec cette espèce; mais ces expériences paraissant peu décisives, nous les avons reprises, Lucet et moi, en faisant usage de Coccidies recueillies daus les cacums de Poussins dont leur multiplication avait amené la mort.

Après en aroir suivi le développement jusqüì la formation des corpuscules falciformes, nous les Fig. 66. - Coccidium tenellum de l'intestin de la arons fait prendre à deux Poussins de quinze jours à trois semaines: ces deux sujets sont morts au bout de vingt et trente-un jours, avec des Coccidies nombreuses et

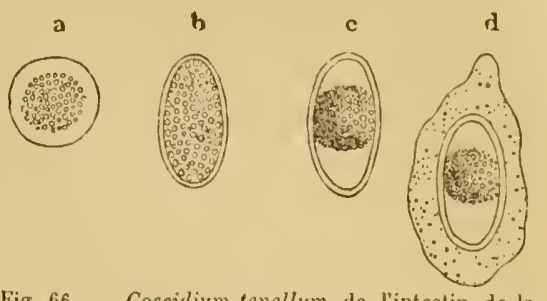
Poule, daprès Perroucilo. - $a, b$, Coccidies extraites des cellules épithétiales de l'iulestin el représentant les premières phases tlu développement. $c$, Coccidie adulte enkystíe, trouvéc en liberté dans l'intestin. $d$, Coccidie adulle enlystéc dans une cellule épithéliale grossie et déformée.

bien développées dans les cxcums. Deux témoins n’ont rien présenté.

Pathologie. - Les lésions sont le plus souvent localisées à une région de l'intestin grèle, et en particulier du duodénum. La muqueuse est parsemée de tàches et de trainées blanchâtres constituées par des Coccidies accumulées dans les glandes, et tantòt libres, tantòt enfermées dans des cellules épithéliales altérées. D’autres fois, ces lésions sont restreintes aux çecums (typhlite coccidienne).

Comme symptòmes principaux, on peut noter : affaiblissement progressif, torpeur, diarrhee ou constipation, cris plaintifs. La mort survient d'ordinaire en quelques jours, et il n'est pas rare de voir périr tous les Poulets d'une mème couvée, voire les couvées successives d'un mème élevage.

Des Coccidies analogues ou peut-être identiques ont été rencontrées dans lintestin de divers Oiseaux de basse-cour.

Ainsi, Rivolta et Delprato ont observé une coccidiose intestinale chez le Pigeon; les Pigeonneaux au nid étaient infestés par leurs parents; la marche de la maladie était ordinairement lente. L. Pfeiffer a fait des observations du mème genre à Weimar; d'après lui, la Coccidie du Pigeon mesure $18 \mu$ de long sur $16 \mu$ de large.

Zürn signale aussi une entérite coccidienne clıez les Oies et les Canards; elle est caractérisée par la faiblesse extraordinaire et le dépérissement des sujets atteints, bientòt suivis d'une diarrhée profuse qui emporte brusquement les animaux. Avec Lucet, nous avons observé des nodules coccidiens dans l'intestin de Canards qui n’avaient présenté pendant la vie aucun symptòme particulier; les parasites nous ont paru être identiques à ceux de la Poule.

Coccidies dans les fufs de poule. - Dans l'automne de 1889, Podvissotzky jeune a trouré les œufs de Poule provenant de la petite ville de Fastov, près Kiev, endémiquement envahis par les Coccidies. Par contre, les œufs recueillis l'hiver se montrèrent indemnes, ainsi que ceux obtenus en diverses saisons dans d'autres localités.

Les parasites existent seulement dans l'albumen, à l'état de colonies qui, 
sur une coupe de l'œuf durci, apparaissent comme de petites taches d'un brun grisàtre ou jaunàtre, pouvant atteindre le diamètre d'une tète d'épillgle. A l'œil nu, on peut confondre ces colonies avec les taches vulgaires dues à des amas de pigment ou à des parcelles de jaune; mais l'examen microscopique lève immédiatement tous les doutes. Sur chaque coupe, on peut voir, surtout après coloration par l'lématoxyline, tous les stades de la formation des spores; on remarque en outre, à còté de colonies qui renferment des Coccidies encore munies de leur coque, des amas de spores libres, avec des débris de vieilles coques provenant d'individus morts. Les colonies coccidiennes doivent leur coloration spéciale à un pigment contenu dans les vieilles Coccidies nortes: à leur périphérie, on trouve quelquefois un petit nombre d'individus isolés, mais les points qu'ils occupent sont à peine perceptibles à l'œil nu. Le microscope montre des Coccidies remplies de spores arrondies ou fusiformes, et, à côté d'elles, de vieux individus morts, conslitués par une coque brillante renfermant un pigment brun noiràtre. Enfin, on trouve aussi dans l'albumen des amas de spores libres et des fragments de coque d'une réfringence particulière.

Comment ces parasites parviennent-ils dans l'œuf? On ne peut répondre à cette question d'une façon positive, car les Poules n'ont pas été examinées; mais il faut admettre ou bien l'existence d'une coccidiose de l'oviducte, permettant l'incorporalion directe des Coccidies à I'albumen, ou bien la pénéIration dans l'oviducte de Coccidies intestinales parvenues dans le cloaque: cette seconde hypothèse est la plus probable, mais il y aura lieu de la vérifier à l'occasion des épidémies de coccidiose de l'intestin. Eı tout cas, les parasites semblent trouver dans la couche d'albumine un milieu favorable à leur développement.

Ces Coccidies avaient les mèmes dimensions et la mème forme que celles

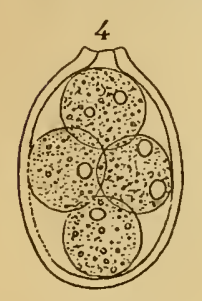

1

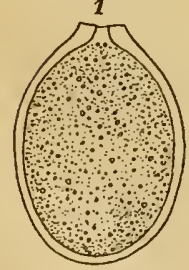

Fig. 67. - Coccidium truncalum, des reins de l'Oie. - 1 et 2, phases parasitaires. 3 et 4 , formation des sporoblasles. Grossissement: 1140 diamdtes (Orig.). du foie du Lapin et de l'Homme. Podvissotzky les croit identiques à celles qu'il a observées dans les cellules hépatiques de l'Homme, et qu'il a décrites sous le nom de Karyophagus hominis. L'invasion du foie résulterait donc, d'après lui, de l'ingestion d'œufs de Poule insuffisamment cuits. Cette hypothèse nous parait peu fondée.

Coccidie tronquée $(C$. truncatum Raill. et Lucet, 1891). - Coque subglobuleuse, offrant à l'un des pôles une légère saillie tronquée qui correspond à un micropyle très distinct et relativement large; dimensions à la phase ultime du développement: 20 à $22 \mu$ sur 13 à $16 \mu$.

Nous avons découvert, Lucet et moi, cette Coccidie dans l'épithélium des tubes urinifères de l'Oie domestique. Elle donne lieu en général à des nodules blanchàtres gros comme des tètes d'épingle; plus rarement les lésions sont diffuses. 
L'évolution est analogue à celle de la Coccidie oviforme. Une fois développés, les parasites tombent dans les canaux urinifères et sont rejetés à l'cxtérieur. En les maintenant dans l'eau, nous avons vu la masse protoplasmique se diviser en quatre sporoblastes.

Les Oies atteintes de coccidiose rénale maigrissent d'abord, puis deviennent incapables de se trainer et restent immobiles, le ventre à terre. Il en est qui présentent des manifestations bizarres : elles se placent sur le dos, les pattes écarlées, quelque soin qu'on prenne de les redresser. En tout cas, elles finissent par ne plus prendre de nourriture et ne tardent pas à succomber.

On a rencontré aussi, dans les reins de l'Homme et de divers Mammifères, des Coccidies qu'il est encore impossible de classer. La plupart des auteurs se contentent de les déclarer identiques ì la Coccidie oviforme.

Brown-Séquard en a trouvé dans les voies urinaires d'un Lapin; il les regardait comme des oufs d'lielminthe.

Sclon Arnold, une forme d'hématurie du Bœuf serait due au développement, dans l'épithélium de la ressie, d'une Coccidie qui donnerait lieu à des excroissances variqueuses et hémorragiques (1).

Chez l'Homme, Lindemann avait décrit et liguré des Psorospermies de la tunique propre du rein ; cependant rien, dit Leuckart, ne justifie sa manière de voir. Mais plus récemment, diver's médecins: Bland-Sutton, Targett, etc., ont rapporté des exemples authentiques de coccidiose des reins et des uretères.

Coccidie bigéminée $(C$. bigeminum Stiles, 1891. - Syn. Cyfospermium villorum intestinalium canis Rivolta, 1878). - Coque généralement ellipsoïde et un peu asymétrique, à double contour, mais cependant très mince; contenu rariable suivant la phase du développement. Nous en connaissons actuellement trois variétés : var. canis, 12 ì 100 o de long sur 7 à $10 \mu$ de large; var. cati, 8 à $10 \mu$

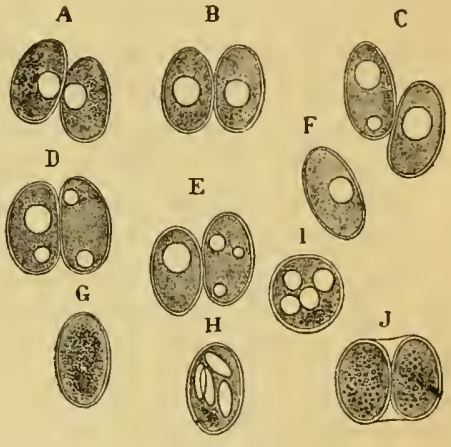

Fig. 68. - Coccidium biyeminum, des villosites intestinales du Chien. - A, B, C, D, $\mathrm{E}$, Coccidies géminés, montrant la formalion progressivedes sporoblastes. F, G, H, $\mathrm{I}$, Coccidies isolies: $\mathrm{G}$, a proloplasme granuleux; 1 , rue par l'un des poles ; $H$, à quatre spores fusiformes et un reliquat de segmenlation. $\mathbf{J}$, deux Coccilties dans une même enveloppe. Grossiscement : fj:0 diamilres 10 rig.). de long sur 7 à $9 \mu$ de large; var. putorii, 8 à $12 \mu$ de long sur 6 à $8 \mu$ de large.

Cette Coccidie vit à l'intérieur des villosités intestinales dı Chien, du Chat et du Putois (et non pas dans les cellules épithéliales). C'est

(1) Dr. Ansold, Das stallroth und seine Behandlung. Thierärztliche Mittheilungen, XXV, P. 33, 1890.

Railliet. - Zuologic. 
Finck qui le premier l'a observée, en étudiant l'absorption intestinale, chez le Chat; Virchow l'a rue ensuite chez le Chien; Railliet et Lucet l'ont rencontrée chez le Putois. Enfin, il faut sans doute rapporter à cette espèce, comme nous l'arons dit, les Coccidies trouvées par Kjellberg sur un cadavre de l'Institut pathologique de Stockholm, car elles étaient situées à l'intérieur et vers la pointe des villosités, et ressemblaient à celles qu'arait observées Virchow chez le Chien.

La qualification de bigéminée indique que ces Coccidies sont généralement accolées deux à deux, ce qui nous avait paru être l'indice d'une division longitudinale. Stiles (1) a établi la réalité du fait par l'étude des premières phases du développement. La Coccidie jeune, mais enkystée, divise son contenu granuleux en deux masses. Il arrive parfois que l'une de ces deux masses avorte; mais le plus souvent toutes deux s'entourent d'une coque et restent accolées. Puis chacune des deux cellules filles ou jumelles divise son protoplasme en quatre sporoblastes, avec un reliquat de segmentation. Finalement, ces sporoblastes s'organisent en spores fusiformes.

L'influence de ces parasites sur la santé des animaux nous parait insignifiante: nous les avons rencontrés chez de nombreux Chiens sains ou ayant succombé à des maladies très diverses.

Coccidie de Rivolta (Coccidium (?) Rivoltai Grassi, 1881). - Coccidie à coque mince, ovoïde ou ellipsoïde, pourvue au pôle le plus étroit d'une sorte de micropyle, et mesurant a l'état de maturité (protoplasma ramassé en boule) 27 a $30 \mu$ de long sur 22 à $24 \mu$. de large.

Observée à Rovellasca (Italie) dans le contenu de l'intestin zrêle et du gros intéstin du Chat, par Grassi.

Elle se dévelop'pe dans les cellules épithéliales, oì on la trouve sous l'aspect d'une masse ovalaire d'abord nue, puis revètue d'une coque très mince; s'accroissant peu à peu, elle présente bientòt une coque plus épaisse, dédoublée au pôle le plus large et munie à l'autre pôle d'un micropyle distinct. A cet état, elle est mise en liberté par rupture de la cellule, et tombe dans l'intestin. Le contenu achève alors de se rassembler en boule au centre, et parfois mème se segrmente en deux masses au milieu des matières alimentaires. Mais en général la segmentation ne se produit qu'ì l'extérieur du corps, comme pour la Coccidie oviforme. Après séjour dans l'eau, on voit la masse protoplasmique se diviser en deux, puis en quatre sporoblastes qui s'organisent en spores donnant chacune quatre (?) corpuscules falciformes et un reliquat de différenciation. Au delà de cette période, les Coccidies meurent et se décomposent; aussi Grassi a-t-il supposé qu'elles étaient arrivées au terme de leur développement. Cependant, il en fit avaler un grand nombre à deux jeunes Chats, sans aucun succès.

Il faut reconnaitre que, si les spores produisent réellement quatre corpuscules falciformes, ce que l'auteur n'ose pas affirmer, l'espèce dont il s'agit devra être distraite du genre Coccidium pour devenir la base d'un genre nouveau.

(1) Ch. W. Stiles, Notes on parasites, 11. 11. Journal of comp. Medicine and veter. Archives, XIII, p. 517, 189 ?. 
Grassi ne donne ạucune indication sur les troubles que peuvent occasionner ces Coccidies.

Coccidies (?) DEs Cheveux (Gregarina Lindemanni Rivolta, 1878). En 1863, Lindemann (1) arait rencontré sur les cheveux d'une jeune fille des granulations brunatres dans lesquelles il crut reconnaître des amas de Psorospermies. Des recherches ultérieures lui montrèrent que ces productions étaient très communes à Nijni-Novgorod, principalement sur les cheveux destinés à la confection des faux chignons et en général des coiffures artificielles. Il crut mème pouvoir admettre que ces parasites se développaient a l'état de Grégarines dans l'intestin des Poux, qui abondent sur les cheveux des femmes de ce pays. Mais, comme le faitremarquer Leuckart, si de nombreuses observations, faites avant et après celles de Lindemann, établissent l'existence fréquente de telles productions sur les cheveux, rịen ne permet de les regarder comme des Psorospermies, et les curieuses migrations signalées par l'auteur russe rentrent dans le domaine de la pure fantaisie.

Coccidioses douteuses. - Rivolta, le premier, a signalé en 1868 l'existence de Coccidies dans des lésions cutanées, chez les Oiseaux. "Sur une poule, dit-il, j'ai trouvé un nodule mou, de la forme d'une aveline, situé à peu de distance du croupion; il contenait une substance gélatineuse, brunâtre, qui, à l'examen microscopique, se trouva renfermer une espèce de petit boyau farci de psorospermes de couleur brune; ces derniers étaient un peu plus petits que ceux du lapin. "Mais il y a lieu de se demander si ces Psorospermies brunes, renfermées dans un tube, ne seraient pas simplement des œufs d'helminthe enlevés avec l'oviducte qui les contenait.

Quelques années plus tard, ce même observateur étudiait avec Silvestrini une épizootie sévissant sur les Poules et les Chapons des environs de Pise, et se trạduisant par le développement de nodules ou de fausses membranes en des points variés de l'organisme. Ils étaient amenés par ce fait à distinguer dans cette affection un assez grand nombre de formes : laryngite, stomatite, conjonctivite croupales psorospermiques, psorospermose de la crète, entérite psorospermique. Ces dénominations montrent qu'ils considéraient l'affection comme déterminée par des Psorospermies ou Coccidies. Et de fait, les figures que donne Rivolta de corpuscules trouvés dans l'épithélium laryngien d'une poule malade semblent bien représenter des Coccidies ( $P a-$ rassiti vegetali, fig. 46 ).

Presque en même temps, Arloing et Tripier signalaient une affection d'apparence tuberculeuse, observée sur des Poulets, transmissible par les voies digestives à des animaux sains de la même espèce, et provoquée, à leur avis, par un parasite que Balbiani tendait à rapprocher de l'Eimeria falciformis. Mais ce parasite est décrit comme une cellule aplatie, ovalaire, allongée, munie à ses deux pôles d'une "sorte de trompe ou de ventouse ", et il est au moins difficile, par suite, d'y reconnaître une Coccidie. Les auteurs avaient évidemment affaire à de la tuberculose.

Des recherches du mème genre se poursuivaient ả la même époque en Allemagne. Bollinger, étudiant l'affection noduleuse de la tête et du bec, si

(1) Carl Linderanx, Die Gregarinen und Psorospermien als Parasiten des Menschen. Bullet. de la Soc. impér. des Natural. de Moscou, 1863, p. 425, et 1865, p.28:. - Gazette médic. de Paris, 1870, p. 86. 
commune chez les Pigeons, les Poules, les Dindons et mème chez les Oies, la rapprochait de la maladie connue chez l'Homme sous le nom de molluscum contagiosum ou d'épithélioma contagiosum, et la rattachait également à des parasites.

Quelques années plus tard, Piana publia la relation d'une épizootie qui avait régné aux environs de Bologne, en septembre 1875, sur les Poules, les Dindons et mème sur les Oies et les Canards. Les lésions siégeaient principalement sur Je mésentère, qui était injecté, de teinte noiràtre ou verdàtre, et parfois revêtu de fausses membranes. Cette coloration particulière était due à des amas de corpuscules sphériques, ovoïdes ou pyriformes, tantòt verts, tantòt noirs, d'un diamètre variant de 10 à $70 \mu$. Piana regardait ces corpuscules comme des Psorospermies, et Rivolta partagea un certain temps cette manière de voir, en les décrivant sous le nom de Cytospermium viride Paulicki, 1872: mais leur aspect et leur coloration éveillent en nous les plus grands doutes au sujet de leur nature.

Mégnin reproduisit ensuite et étendit mème les donuées fournies par Rivolta, Silvestrini el Piana, en décrivant la maladie sous le nom de tuberculodiphtérie ou simplement de diphtérie. Comme ces auteurs, il en admettait la nature psorospermique. Johne, Csokor et d'autres se prononcèrent dans le mème sens.

Cependant, Rivolta et Delprato furent amenés, en 1880, à émettre des doutes sur la nature du parasite incriminé, et, après s'ètre demandé si c'était une Psorospermie ou une Amibe (Psorosperma crouposus? ou Amœba croupogena?), ils en firent un champignon (Epitheliomyces nodulogenus et croupogenus).

Enfin, à la suite des recherches de Klebs et de Löffler d'une part, de Koch, Ribbert, Babes d'autre part, Cornil et Mégnin établirent que les lésions noduleuses et pseudo-membraneuses des oiseaux devaient ìtre rapportées à la diphtérie et à la tuberculose.

Il convient de remarquer, toutefois, que nous avons démontré l'existence réelle d'une entérite coccidienne.

Des observations analogues à celles dont il vient d'ètre question ont èté également poursuivies chez l'Homme. Perroncito, après Virchow et Bollinger, décrivit comme des Coccidies des corpuscules trouvés dans les cellules épidermiques d'individus affectés de molluscum contagiosum, et qui avaient été signalés aussi par Bizzozero et Manfredi.

Plus récemment, Malassez et Albarran découvrirent des corps analoğues dans les épithéliomes, et les rattachèrent également aux Coccidies. Puis, Darier signala comme de nouvelles maladies psorospermiques l'acné cornée ou acné sébacée concrète (psorospermose folliculaire végétante) et la maladie de Paget du mamelon. Et dès ce moment, les recherches se multipliant dans le mème sens, de nombreuses observations furent publiées, annonçant la présence de Coccidies dans des lésions cutanées ou dans des tumeurs variées (1). Par contre, divers observateurs furent amenés ả contester d'une manière plus ou moins formelle la nature parasitaire des corps observés, qui ne seraient, d'après eux, que des éléments cellulaires déformés.

(1) W. Pouwissuzk und Sawrschenko, Ueber Parasitismus bei Carcinomen... Centralbl. für Bakter. u. Paras., XI, p. 493, 1892.-Alexis KовотNEFF, Rhopalocephalus carcinomatosus n. y. und sp. Kor. (Krebsparasit). Ibid., XIII, p. 373, 1893. 
Mais cette question n'en est encore qu'à la période des études préliminaires, et nous croyons qu'il convient pour le moment de garder à sou endroit une prudente réserve.

Appendice à l'étude des Coccidies. - L. Pfeiffer a récemment signalé, dans lérolution des Coccidies, des faits qui, s'ils étaient reconnus exacts, renverseraient complètement la classification actuelle de ces ètres (1).

Ses observations ont porté principalement sur les Coccidies du foie et de l'intestin du lapin, qu'il considère comme appartenant à une seule et même espèce. Sur les jeunes animaux de quatre à six semaines qui habitent un clapier depuis longtemps infesté et qui commencent à prendre des aliments verts, la maladie affecte, dit-il, une forme très aiguë, se traduisant par une diarrhée intense et un amaigrissement rapide, ef les animaux sont emportés en peu de jours. Des lésions profondes se rencontrent sur toute la longueur de l'intestin, et en particulier lans le crecunı. On obtient un résultat analogue et mème plus prompt encore, en faisant ingérer des Coccidies sporifìres à des lapereaux à la mamelle.

Or, cette marche suraiguë de la maladie serait due à un mode de multiplication des Coccidies non signalé jusqu'à présent, et correspondant à une forme spéciale de kystes. - On a vu que, dans les conditions ordinaires, les Coccidies, munies d'une coque assez épaisse, ne poursuivent leur évolution qu’à l'extérieur du corps, et donnent seulement quatre spores avec deux corpuscules falciformes pour chacune. Pfeiffer donne à cette forme vulgaire le nom de hyste durable (Dauercyste). C'est elle qu'on rencontre dans les nodules du foie et en général dans les lésions á marche lente ; elle n'a qu'une influence pathogène insignifiante, puisque les expériences de Ponfick ont démontré qu'on peut enlever aux lapins jusqu'à 73 p. 100 de la masse totale du foie sans provoquer de troubles notables dans l'organisme. - Mais, en dehors de cette forme coccidienne qu'ont reconnue tous les observateurs, Pfeiffer a vu, dans les cas de coccidiose aiguë, des kystes à enveloppe molle, lonnant d'emblée un grand nombre de corpuscules falciformes ou zoospores, par division du noyau et de la masse protoplasmique. Ces formes particulières reçoivent le nom de kystes essaimants (Schwärmercysten); ils évoluent sur place, dans l'organisme même, et laissent échapper leurs corpuscules falciformes, qui vont par myriades envahir de nouvelles cellules épithéliales, amenant ainsi, par leur action directe et peut-ètre en mème temps par la production d'une substance toxique, les désordres violents qui caractérisent la maladie aiguë.

D'après ce court résumé, on voit que, pour Pfeiffer, le mode de multiplication des Coccidies dépend simplement des conditions de milieu, et que le nombre des spores et des corpuscules falciformes, dans une espèce donnée, est susceptibie de varier dans de très grandes limites. La classification ne peut donc pas reposer sur ces caractères : dans le cas particulier qui vient d'ètre signalé, les kystes durables appartiendraient bien, en effet, au genre Coccidium, mais les kystes essaimants devraient ètre rattachés au genre $\mathbf{E i}$ -

(1) L. Preifrer, Die Protozoen als Krankheitserreger. 2te Aufl., Iéna, 1891. R. Preiffer, Die Coccidienkrankheit der Kaninchen. Berlin, 1892, - Schuberg, Ueber Coccidien der Müusedarmes. Sitzungsber. der Würzburger Phys. med. Gesellschaft, 18 März 1 \$? 
meria. Il s'agit done bien, comme nous le disions, du renversement de toutes les données acquises antérieurement.

Mais, avant d'accepter des transformations aussi profondes, il faudrait que les faits annoncés eussent été contròlés. Schuberg a bien cru roir l'Eimeria falciformis de la Souris évoluer, dans une chambre humide, comme un véritable Coccidium; mais avait-il bien affaire à un Eimeria? Aimé Schneider, en examinant des préparations de Schwïrmercysten qui lui avaient élé communiquées par L. Pfeiffer, a retrouvé le noyau indivis au milieu des prétendus zoospores. En présence de ces contradictions, nous avons cru bon de nous en tenir aux données classiques.

TROISIENME ORDRE

\section{SARCOSPORIDIES}

Sporozoaires limités par une cuticule et divisés intérieurement cn un certain nombre de loges (spores?) qui contiennent chacune plusieurs corpuscules reniformes ou falciformes.

Les Sarcosporidies ou Psorospermies utriculiformes, Utricules psorospermiques, se rencontrent d'ordinaire dans les muscles, surtout chez les Vertébrés; mais on peut les observer aussi dans le tissu conjonctif.

Leur constitution, leur mode de développement et leurs affinités sont encore peu connus, si bien que certains auteurs hésitent encore à les classer dans le règne animal. C'est Balbiani qui les a rangées parmi les Sporozoaires.

Nous les étudierons d'après la classification provisoire qu'a proposée $R$. Blanchard, et qui est basée sur leur siège ainsi que sur la constitution de la cuticule.

Famille des MIESGHÉRIDÉS. - Utricules siégeant dans les muscles striés.

Ces organismes ont été observés pour la première fois par Miescher, de Bâle, dans les muscles striés d'une Souris; Herbst, puis Rainey, les retrouvèrent ensuite chez le Porc, Hessling chez le Chevreuil, le Bouf et le Mouton, etc. D'où les noms d'Utricules de Miescher ou de Rainey, sous lesquels on les désigne encore fréquemment.

2 genres :

Genre Sarcocyste (Sarcocystis Ray Lankester, 1882.). - Membrane d'enveloppe épaissie et traversée de fins canalicules.

Le Salcocyste de Miescher $(S$. Miescheri [Kühn]. - Syn. : Synchytrium Miescherianum Kühn, 1865̃; Gregarina Miescheriana Rivolta, 1878; Sarcocystis Miescheri Ray Lankester, 1882; Miescheria utriculosa Harz, 1886) se présente sous la forme de corps allongés, peu réfringents, d'apparence grenue, atténués aux extrímités et généralement plus à l'une quà l'autre; leur longueur atteint rarement 
¿ a 3 millimètres (moyenne $0^{\mathrm{m}}$, (i) et leur largeur ne dépasse guère 200 à $300 \mu$. Ces "tubes " ont pour paroi une cuticule ferme, épaisse,

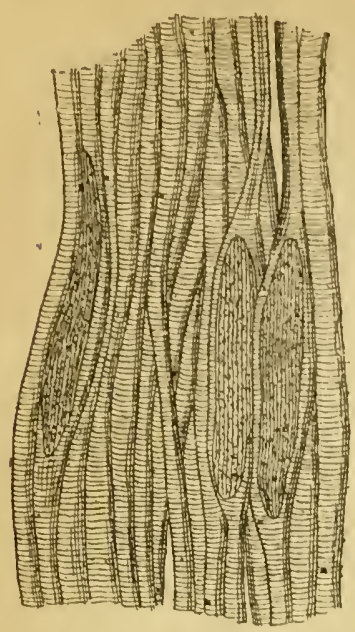

Fig. 6!) - Ciricules psorospermicues dans les tibres museulaires du l'ore (Orig.). montrant une striation transversale que Lenckart attribue it la présence de nombreux canalicules: par lia compression, cette paroi se clésagrège el oflre alor's l'apparence d'un revètement ciliaire qu'on

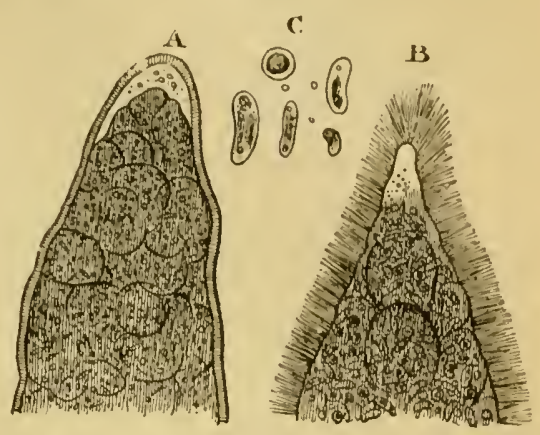

Fig. 70. - Utricules propospermigues du l'ore isolíps et forlement grossies. - $\Lambda$, exlrèmilé d' un ulricule dont la entipule est iutacte. Ii, autre ntricule, dont lit culieule est écrasce ut donne lien it une apparence de cils. L, coryus(ules riniformes el granules siparis (0rig.).

a longtemps regardé comme une disposition normale. La cavité intérieure est occupée par un nombre variable de sphères de $20 \%$ ì $.0 \mu$ de diamètre, devenant polygonales par pression réciprorjue; aux extrémités, rependant, il reste un espace libre occupé seulement par des granules réfringents. Dans chacune de ces sphères, qui paraissent représenter des spores, se développent de nombreux corpuscules d'abord arrondis, puis réniformes, montrant un ou plus souvent deux points très brillants (vaeuoles), et mélangecis aussi à des granules.

Cet oryanisme se rencontre dans les muscles du Porc, oì it a été observé d'abord, comme nous l'avons dit, par'

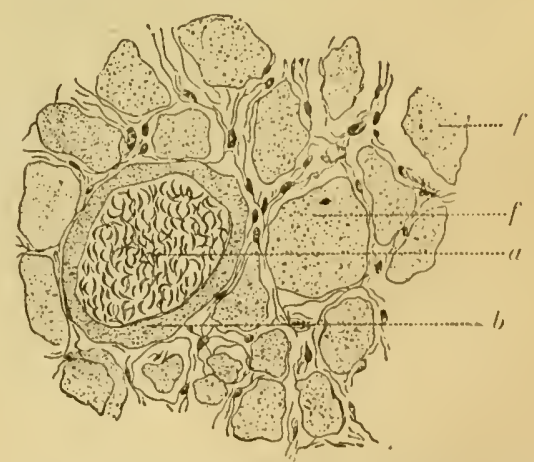

Fig. 7I. - Coupe transrersale d'un groupe de faisceaus primitifs du Pore, dont l'un est oceup par un Sarcorysle. - $a$, eoupe du parasile. $b$, sa gatime contractile forme par la sulstance du faiseau primilif repoussece sous le sarcolemme. $f$, faisceaus frimitifi (Latulimió).

Herhst, puis par Rainey, hrause, etc. Tous les inuscles striés peuvent en renfermer, et on les distingue parfois à l'oxil nu sous l'aspect de petites lignes hlanchattres. Ils sont situés a l'intérieur des faisceatux 
primitils, comme on peut s'en rendre compte aisément sur des coupes transversales; dans bien des cas, ces laisceaux se montrent simplement dilatés à leur niveau; mais souvent aussi on remarque une

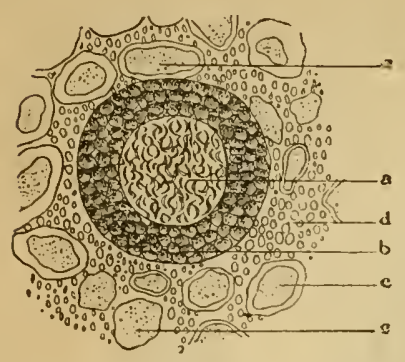

Fig. 72. - Granulation jsorospermique des muscles du l'orc, au délout de son développement. - $a$, section transversale du Sarcocyste, $b$, couronne purulente. $c, c$, faisceaux primitifs atrophics. $d$, infiltratiou embryonnairc (Laulanié). multiplication des noyaux du sarcolemme. Il nous est arrivé de rencontrer deux de ces parasites placés côte à còte. D’après Perroncito, ils peuvent royager ì l'intérieur du sarcolemme, en laissant des traces évidentes de leur passage.

Ils sont d'ailleurs susceptibles de déterminer parfois des altérations assez profondes. Laulanié a fait connaître un cas dans lequel le tissu musculaire était criblé de granulations fusiformes, jaunâtres, souvent disposées en séries de deux ou trois dans le sens des fibres musculaires. Par la dissociation de ces petites masses, on obtenait des globules purulents, des grains calcaires et rarement des cellules épithélioides. Quelques-unes d'entre elles siégeaient à l'intérieur des faisceaux secondaires, mais li plupart s'étaient développées au roisina ge des cloisons conjonctives qui entourent ces fais-

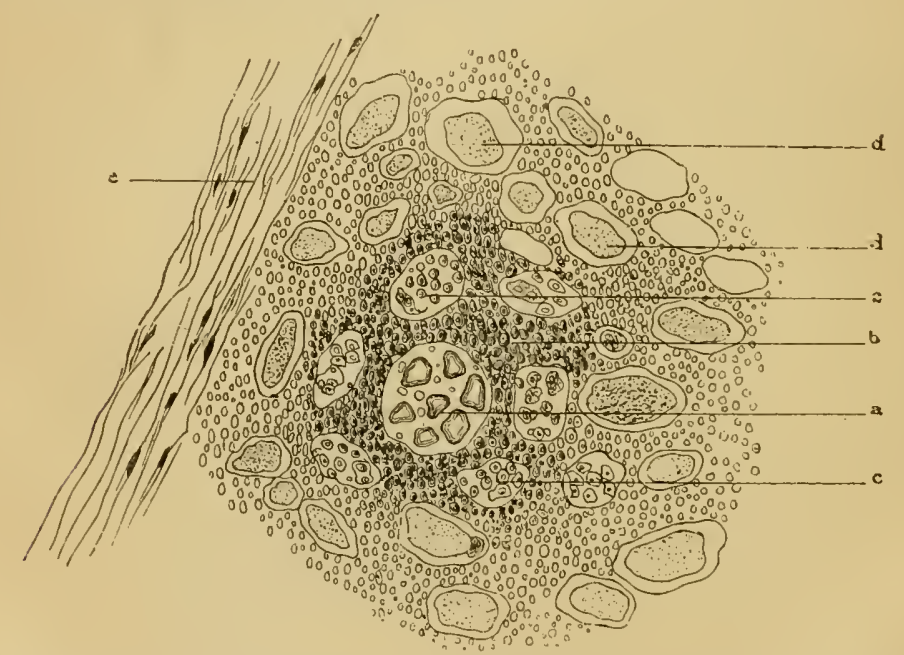

Fig. 73, - Granulation psorospermique des muscles du Porc complètenent formée : le parasite a disparu au milieu des produits de la dégénérescence. - $a$, zone centrale représentée par un petit foyer de dégénérescence calcaire. $b$, zone périphérique de prolifération embryonnaire. $c$, $c$, espaces prinitivement occup's par des faisceau primitifs et actuellement remplis de cellules. $d$. $d$. faisccaus primitifs atrophiés englobés dans la prolifération. $e$, cloison conjonctive (Iaulanié).

ceaux. Elles se montraient constituées par une zone centrale plus ou moins dégénérée et une zone périphérique de prolifération, et offraient par conséquent une certaine analogie avec des granulations tuberculeuses. La zone centrale était formée le plus souvent d'un amas de globules purulents ayant 
subi la dégénérescence caséeuse, et souvent mème l'infiltration crétacée. lál zone de proliférition, constituée par des cellules embryonnaires et quelques celtules épithélioïdes, s’étendait à la périphérie entre les faisceaux primitils, qui se trouvaient incorporés el détruits sur place. Le processus se déroule en empruntant ì la fois les procédés de la myosite interstitielle et de la myosite parenclymateuse. - Nous avons eu plusieurs fois l'occasion d'étudier, a rec Moulé, des muscles de Porc offrant des granulations semblables.

Rieck prétend d'antre part avoir observé de la myosite chronique due à la pénétration des spores (?) dans les fibres musculaires et à leur enkystement.

Les animaux envahis par les sarcocystes ne laissent généralement percevoir, pendant la vie, aucun trouble appréciable; cependant Virchow dit aroir constaté, sul quelques Pores, de la laiblesse ou de la paralysie du train postérieur, une soif ardente, des rougeurs passagères de la peau, un aspect terne et larmoyant des yeux; mais la relation existant entre ees manifestations et la présence des parasites n'est pas suffisamment élablie.

La fréquence des Sarcosporidies chez le Porc varie suivant les localités : Koch l'estime ì 8 p. 100, Perroncito à 2\% p. 100, Leuckiart, à 28 p. 100 , Moulé à 40 p. 100 , Herlost et Rupprecht ì 5ั0 p. 100, Kühn ì $98, \dddot{p}$ p. 100 .

On ne connait pas encore le mode de developpement de ces parasites. Les essais poursuivis par Virchow et par Manz, en vue de les transmettre i des animaux sains (Chats, Lapins, Cobayes, Rats, Souris) par l'ingestion de viande infestée, n’ont donné que des résultats négatifs. Pourtant, dans une expérience du mème genre, Leuckart vit un Pore, reconnu sain au préalable, se montrer envahi quand ou le sacrifia six semaines plus tard. Mais, comme le dit l'auteur luimême, ce fait n'est pas suffisamment démonstratif, d'abord parce qu’i] est unique, ensuite parce que l'infestation a pu se produire par une autre voie au cours de l'expérience. Manz affirmait que les Utricules psorospermiques se détruisent au contact des sucs digestifs, sans laisser aucune trace dans l'intestin, non plus que dans les muscles.

La consommation de la viande de Porc envahie par des Sarcocystes paraît être ordinairement sans inconrénient pour l'Homme. Cependant, Rabe a fait connaitre un cas de catarrhe intestinal grave chez un individu qui avait fait usage de chair infestée à un haut degré.

Sarcocrste du Mourux. - La Sarcosporidie qui se développe à l'intérieur des faisceaux primitifs des muscles du Mouton nous a paru être munie d'une cuticule moins épaisse que celle du Porc, et nous l'avons désignée provisoirement sous le nom de Sarcocystis tenella. Elle mesure en moyenne $0 \mathrm{~mm}$. 5 de long sur 60 à 100 « de large.

Moulé l'a trouvée 44 fois sur 100 chez les Moutons gras, et 98 fois sur 100 chez les cachectiques. Elle s'y trouvait, du reste, en quantité d'autant plus grande que la cachexie était plus accusée.

Von Hessling, Cobbold, Moulé, Sticker, ont trouvé des Sarcosporidies dans 
les fibres musculaires et Brusaferro dans les fibres du Purkinje du cœur : nous y en avons vu nous-mème, mais il nous a toujours été impossible de déceler la moindre striation dans leur mince cuticnle. Krause en a déconvert dans les muscles de l'œil.

Sarcocsite de la Chèvre. - Sarcosporidie plus grande et plus srosse que celle du Mouton, et pourvue d'une cuticule plus épaisse, plus résistante, plus nettement striée.

Moulé l’a trouvée chez 33 p. 100 des Chèvres grasses, et chez 46 p. 100 des Chèvres maigres ou cachectiques, mais toujours en quantité relativement faible. Il est plus difficile de lisoler du faiscean primitif que celle du Mouton, d'autant que les fibres musculaires sont beaucoup plus serrées et beaucoup moins distendues par les liquides, mème chez les cachectiques.

Sarcocyste du Bøef. - Dimensious très variables : jusqu'à 5 millimètreset mème 1 centimèlre de long; cuticule assez épaisse, nettement striée, et se désagrégeant volontiers en cils.

Moulé en a rencontré chez 6 p. 100 des Bœufs en hon état, et chez 37 p. 100 des Boufs saisis pour maigreur extrème; Beale en a vu daus les muscles de presque tous les animaux atteints de peste bovine, et Klein leur arait mème attribué un ròle dans le développement de cette maladie. Tokarenko a signalé chez un jeune Bœuf de la race des steppes une affection grave, due, selon lui, à une multiplication extraordinaire des utricules psorospermiques dans les muscles.

Des Sarcosporidies ont été vues en outre chez le Bœuf dans les fibres du cœur, par von Hessling, Cobbold, Perroncito, dans les muscles de l'œil par Krause, dans le crémaster d'un Taureau par Hanz.

Cobbold, daus le but de montrer limnocuité de la viande envahie par ces parasites, a consommé en deux repas un cœur de Mouton et un cœur de Bouvillon contenant ensemble plus de 18,000 Sarcosporidies.

Sarcoctste du Cheval. - Les Psorospermies des muscles du Cheval sont assez semblables, par leur aspect et leurs dimensions, à celles du Bœuf.

Les Chevaux en bon état en ont fourni à Moulé à peine 6 p. 100 et les Chevaux maigres 20 p. 100 ; mais Friedberger et Fröhner déclarent que, chez les animaux àcrés, il semble en exister presque constamment.

Siedamgrotzky en a trouvé sur 13 Chevaux sacrifiés pour les dissections ou morts d'affections diverses dans les hòpitaux de l'École vétérinaire de Dresde. Ils se montraient surtout dans la couche musculeuse de l'œsophage, formant dans les fibres transversales des stries blanchàtres visibles à l'œil nu; mais on en rencontrait aussi dans les muscles du pharynx, dans les muscles cervicaux inférieurs et dans le diaphragme.

Cobbold dil avoir observé des Psorospermies utriculiformes dans la valvule mitrale d'un Cheval, mais les détails qu'il en donne nous laissent concevoir quelques doutes sur la nature réelle de ces productions.

Sarcosporidies des autres anlmaus domestiques. - Mentionnons simplement la découverte de ces parasites par lirause dans les muscles oculaires du Chien et du Chat, par Manz daus les muscles du squelette du Lapin, par Kühn dans cenx de la Poule.

Sarcosport chez r'Homme. - On n'a pas encore démontré d'une manière préc..s l'existence de Sarcosporidies dans les muscles de 
l'Homme (1). Lindemann a bien décrit et liguré des " Psorospermies " observées dans les valvules sigmoïdes de l'aorte et dans la ralsule mitrale; mais il est manifeste que ces productions n’ont rien ì roir arec des Sarcosporidies, pas plus que celles qu'il arait vues dans le rein (voir p. 143̈). Rosenberg a trouvé, à l'autopsie d'une femme tle 40 ans, morte à la suite de pleurésie et d'endocardite végétante, une hyperplasic considérable de l'endocarde sur un des muscles papillaires du ventricule gauche. En sectionnant ce muscle, il décourrit un kyste d'environ 3 millimètres de lonğ sur 2 millimètres de large, possédant une enreloppe striée, et un contenu formé de petites masses protoplasmiques, les unes granuleuses, les autres hyalines, arec ou sans noyau, des corps faleiformes, etc. Rosenberg regarde ce kyste comme un Sarcocyste (Sarrocystis hominis); mais cette détermination nous parait un peu prématurée.

Genre Mieschérie (Miescheria R. BI., 1883̈). - Membrane d'enveloppe mince et anhiste.

Nous ne signalerons dans ce genre que le . Niescheriu muris R. Bl., des muscles de la Souris et du Rat, et le .y. Inueti R. Bl., des muscles de l'otarie de Californie.

Famille des BALBIANIDÉS. - Utricules siégeant dans le tissu conjonctif (au moins à l'état de développenent complet).

Genre Balbianie (Balbiana R. Bl., 188ö). Membrane d'enveloppe mince et anhiste; cavité intérieure divisée en loges nombreuses et irrégulières par des cloisons mitoyennes.

Balbianie géante (B. gigantea Raill., 1886). - Celte Sarcosporidie se présente sous l'aspect d'un nodule blanchàtre, dont le volume varie de celui d'un grain de millet à celui d'une petite noisette. Sur une coupe, on reconnaît qu'elle est limitée par une membrane transparente très clélicate, et qu'elle offre à l'intérieur un cloisonnement complexe. domnant lieu à la formation d'un résean dont les mailles (représentant des spores)

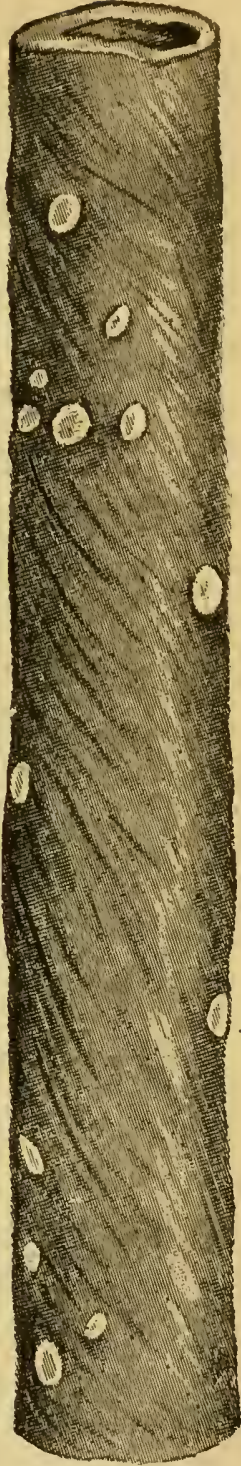

Fig. 7f. - Fragment d'cesophage de Houton envali par des balluianies gíantes. Grandeur nilurelle(Orig.). sont de dimensions variables. Dans les plus gros exemplaires, la!par-

(1) Carl Linoemaxy, los. cil., p. 425; tab. VII, fig. 1, 1863.-Ber, ilt Rosenbekg, Ein Befund von Psorospermien (Sarcosporidien) im Hersmuske ; Menschen. Zeitschrift fül IIygiene, XI, p. 435, 1892. 
tie centrale laisse un vide de l'épaisseur d'une tête d'épingle. Les mailles voisines de la périphérie sont remplies de corpuscules falciformes très réguliers, pourvus ou non de deux points brillants et parfois mélangés de corpuscules arrondis.

La Balbianie géante a été rencontrée d'abord chez le Mouton par Winkler et Leisering, puis par Dammann, Roloff, Fürstenberg, Zürn, Morot, Brusaferro, etc. $\Lambda$ première vue, elle offre assez l'apparence d'un petit abcès ou d'un amas de graisse, mais l'examen microscopique de son contenu lacto-puriforme ou caséeux révèle immédiatement sa nature en montrant un nombre immense de corpuscules en croissant. Elle siège principalement dans la musculeuse de l'œsophage, mais on la trouve aussi dans la langue, dans les muscles du pharynx, du larynx, des joues, des lèvres, du cou, de l'épaule, du thorax, de l'ab-

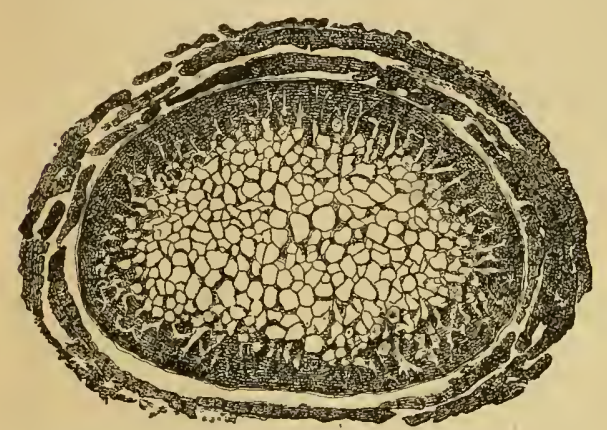

Fig. 75. - Coupe transversale d'une Balbianie géante du Mouton enveloppée par les fibres musculaires de l'usophiage. Grossissement : 20 diamètres (Orig.). domen, des cuisses, dans la portion charnue du diaphraģme et même dans le peaucier. Il n'est pas rare

d'en observer sous la plèvre, sous le péritoine ou même sous le péricarde, et Zürn en a vu deux sous la dure-mère cérébrale d'un Mouton. Ces parasites sous-séreux présentent généralement une forme un peu plus allongée que ceux des antres régions du corps.

Les premiers observateurs allemands avaient rencontré cette Sarcosporidie chez des animaux qui étaient morts, les uns subitement, les autres après avoir présenté des symptòmes d'asphyxie ou des accès épileptiformes. Ils en avaient conclu que la perte de ces animaux devait ètre attribuée au parasite. Mais les recherches de Fürstenberg et surtout celles de Morot ont établi que les Balbianies, mème en très grand nombre, se rencontrent chez les animaux les mieux portants. Sur environ 900 bêtes bovines sacrifiées pour la boucherie à l'abattoir de Troyes, $2 \tau_{2}$ offraient des nodules œsophagiens ; 6 en avaient en mème temps sous la plèvre, 10 sous le péritoine, 27 a la fois sous la plèvre et le péritoine. L'existence et mème l'abondance des parasites paraissaient être absolument indépendantes de l'état d'embonpoint, de l'âge et du sexe des animaux. Une Brebis bien portante, de 8 a 10 ans, en avait un grand nombre dans toutes les parties du corps, et en particulier 227 dans l'œsophage et 128 dans la langue.

Fürstenberģ prétendait qu'on en rencontre chez tous les Moutons im- 
portés de France en Allemagne; on vient de voir, en outre, qu'ils sont communs à Troyes; ils s'observent aussi très souvent à Reims, asse\% rarement à Paris.

Iorsque les Balbianies sont anciennes, elles peuvent subir, comme les aulres Sarcosporidies, la dégénérescence calcaire.

On ne comnait rien du mode de développement de ces Sporozoaires; nous n'avons pas réussi ì les transmettre par ingestion; Pfeiffer a également échoué dans ses essais dinoculation, mais ses animaux d'expériences ont succombé à une sorte d'intoxication, due peut-ètre à une ptomaîne.

- Les Balbianies géantes sobservent aussi chez la Chèvre, où elles out été rencontrées par IIarms, von Niederhœusern, Railliet.

De Jough en a trouvé un grand nombre dans les muscles des Buflles de Java et de Sumatra. Un boucher de cette dernière île lui a assuré, en outre, que de semblables proluclions s'observaient souvent chez les Poules, et de temps en temps chez le Porc, la Chèvre, le Mouton et le Bouf. Van Eecke en a vi chez le Bœuf et chez le Buffle.

Enfin, quelques auteurs rapportent à cette forme, mais sans preuves suffisantes, des Psorospermies signalées par divers observateurs dans l'œesophase du Cheval.

- Le type du genre (B. mucosa R. Bl., 1883̈), a été découvert par R. Blanchard dans le tissu conjonetif sous-muqueux de l'intestin d'un Kangourou. - Stiles, en Amérique, en a tronvé également une forme (B. Rileyi Stiles, 1893) dans le tissu conjonctif intermusculaire d'un Anatidé (Spatula cly peutu, où elle déternine ce qu'on appelle la ladrerie des Canards.

\section{(UU.ITRIĖUE ORDRE}

\section{YXOSPORIDIES}

Les Myxosporidies ou Psorospermies des Poissons n’ollient que des analogies assez éloignées avec les autres Sporozoaires. C'est Jean IIiller qui, le premier, a spécialement attiré l'attention des naturalistes sur ces productions; il les avait rencontrées chez divers Poissons d'eau douce affectés d'une maladie siégeant sur la pean, sur les nuqueuses et jusque dans les muscles; mais, n’ayant observé en réalité que les cor'ps reproducteurs, qu'il comparait à des spermatozoïdes, il leur avait douné le nom de Psorosper-

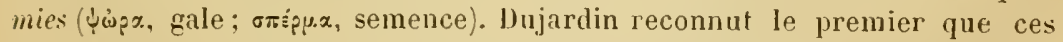
corps naissent aux dépens d'une misse protoplasmique, et fut amené à émettre l'idée d'une parenté entre ces organismes et les lirégarines. Appuyée par Bütschli, cette opinion a fini par prévaloir.

Les Myxnsporidies consistent en des masses protoplasmiques granuleuses, nucléées, souvent pressées les unes contre les autres et douées de mourements amiboïdes; on peut $y$ distinguer un ectoplasme dense, ne renfermant que de fines granulations et s'allongeant en pseudopodes tantòt larges, tantòt grèles, et un endoplasme de teinte souvent jaune ou brunìtre. 
C'est à l'intérieur de ces masses que se développent les psorospermies de J. Müller, corpuscules auxquels Bütschli accorde la signification de corps reproducteurs ou spores. Leur structure est complexe. Ils ont pour enveloppe une coque solide, formée de deux valves. Le contenu se compose d'une masse protoplasmique montrant parfois une vacuole et d'une ou plusieurs capsules, situées presque toujours à l'un des pỏles et inclinées l'une vers l'autre; ces capsules polaires elles-mêmes ont une paroi épaisse et contiennent un filament spiralé, qui peut se dérouler et sortir sous l'influence de divers réactifs (1).
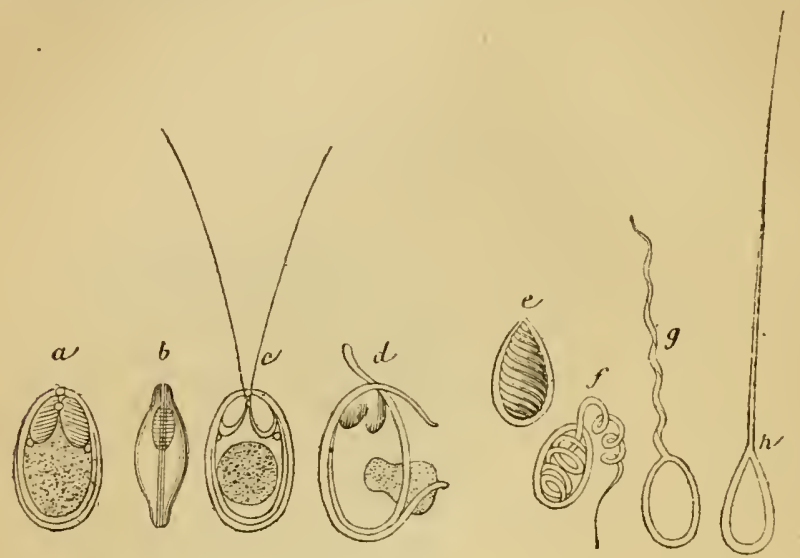

Fig. 77. - Psorospermies de la Tanche, d’après Balbiani. - $a$, Psorospermie vue de face. $b$, de profil. $c$, arec les filaments déroulés. $d$, Psorospermie laissant échapper son contenu sarcodique. sous la forme d'une amibe, à travers ses valves écartées et montrant les bandes ćlastiques de la coque dízalız; $e$, vésicule contenant le filament spiral. $f, g, h$ : vésicule arec le filament déroulç.

Lorsque ces corpuscules psorospermiques arrivent à maturité, on constate ia présence d'un ruban élastique occupant la ligne de suture des deux valves. Ce ruban constitue un appareil de déhiscence; il est destiné à provoquer l'écartement des valves pour permettre la sortie du globule protoplasmique. Celui-ci rampe alors à la surface des tissus, se nourrit à Jeurs dépens et forme une nouvelle Myxosporidie.

On rencontre ces parasites dans la plupart des organes et des tissus des Poissons : à la surface du corps, sur l'épiderme des nageoires, dans le tissu conjonctif sous-cutané, dans les muscles, dans le foie, la rate, les reins, et leur siège de prédilection se trouve le long des ramifications artérielles. Chez les Cyprinidés, ils sont communs sur les branchies et dans la portion antérieure de la ressie aérienne. Leur multiplication excessive peut devenir la cause d'états morbides fort graves.

Tel est le cas de la "maladie des Barbeaux". D'après les auteurs allemands, cette maladie aurait fait sa première apparition dans la Moselle, vers la fin de 1870. De 1883 à 1885, elle a sévi dans la Meuse, au voisinage de Charleville, avec les caractères d'une véritable épidémie. Cette épidémie

(1) L. Pfeiffer dit avoir observé une vésicule spiralée analogue dans les corpuscules réniformes des Utricules de lliescher du Youton; il en donne même la figure. 
a été étudiée avec soin par Ladague, de Mézières, et sal cause réelle a étrí déterminée par Nocard et Railliet. En 1886, Mégnin a observé la mème allection dans la Meurthe et reconnu á son tour qu'elle était due í des Psorospermies. En 1888-89, II. Ludwigr, de Bonn, l'a retrouvée dans la Moselle et dans le Rhin. Enfin nous l'avons vue gagner peu à peu l'Aisne, la Marne et la Seine. I.e plus souvent, ses attaques sont saisonnières, et on l'observe surtout en été.

Les symptomes sont ássez faciles à saisir. Les Barbeaux atteints sont moins rifs qưa l'élat normal ; ils ont beaucoup le peine a remonter les courants, et recherchent les endroits calmes, oì on les prend facilement. On constate alors yu'ils sont souvent ballonnés; la surface du corps est terne; le tégument est recouvert d'une sorte de mucus huileux, et les Poissons glissent des mains quand on veut les saisir. Le plus souvent, ils présentent des lésions extérieures bien ałparentes, tumeurs on ulcères, ceux-ci dérivant de celles-lả. Les tumeurs, lémisphériques ou un peu allongées, siègent principalement sur le ventre ou sur les còtés du corps; elles sont en nombre assez variable et leurs dimensions varient également depuis la grosseur d'une noisette jusqu'à celle d'un œuf de poule. $\Lambda$ leur niveau, les écailles sont soulevées, peu adhérentes, et finissent par se détacher. Souvent alors la tumeur s'ourre en laissant échapper une matière puriforme d'un gris jaunàtre; elle prend ainsi l'aspect d'un ulcère profond, à bords saillants, enllammés ef d'un aspect sanguinolent. Au fond de cet ulcére, ainsi que lans la matière qui s'en échappe, on trouve des myriades de " psorospermies "(Myxobolus).

L. Pfeiffer a reconnu que, dans les tumeurs, le parasite envahit non seulement le tissu conjonctif, mais aussi les faisceaux primitifs des muscles, et Thélohan a pu constater qu’il provoque la dégénérescence vitreuse de ces éléments. Cértains microbes, trouvant dans le tissu musculaire ainsi altéré un terrain favorable, s'y développent, entrainant la mortification et la fonte puriforme de ce tissu ainsi que du tissu conjonctif voisin, et déterminent ainsi l'ouverture des lumeurs.

Tous les Barbeaux malades sont envahis par ces parasites. Dans certains cas, à la vérité. les tumeurs ne s'ouvrent pas à l'extérieur, ou mème on n'en remarque pas d'apparentes, mais on trouve alors les kystes parasitaires il l'intérieur, soit dans les muscles, soit dans la cavité viscérale. En tout cas, la chair est jaunàtre, molle, et prend par la cuisson une saveur amère plus ou moins prononcée.

La maladie n'est pas loujours mortelle : dans la Meuse, comme dans le Rhin, on a vu des cas de guérison spontanée; d'autre part, Ladague a constaté qu'en ouvrant les tumeurs et en les vidant, on prolonge de beaucoup l'existence des sujets et on parvient mème à les guérir.

on ignore encore par quelle voie se fait l'infestation. Mais on a cru trouver les conditions qui la favorisent, soit dans la malpropreté des cours d'eau, soit dảns l'établissement des barrages qui ralentissent les courants, etc.

Pour combattre la maladie, il convient avant tout de recueillir les Poissons malades et de les incinérer ou de les enterrer a une certaine profondeur et à une grande distance des cours d'eau.

Les Myxosporidies ne se montrent pas seulement chezles Poissons; elles 
ont été observées aussi chez des Annélides, des Bryozoaires, des Insectes, des Crustacés.

Pour leur classificalion, nous renverrons aux travaux de Thélohan (1).

\section{CINQUIÈME ORDRE}

\section{IICROSPORIDIES}

Primitivement désignées sous le nom de Psorospermies des Articules, les Microsporidies se rencontrent en réalité chez des animaux très variés : Vertébrés, Arthropodes, Vers. Il y a beaucoup d'analogie, comme l'a dẻmontré Balbiani, entre ces organismes et les Psorospermies des Poissons. Cet auteur, qui les a principalement étudiés sur les Vers à soie atteints de pébrine, leur a donné le nom de Microsporidies en raison le leur extrème petitesse.

Lorsqu'on fait ingérer à des Vers sains des corpuscules pébrineux (Nosema bombycis), on ne tarde pas à constater, dans les cellules épithéliales et dans les tuniques musculaires de l'intestin, de petites masses protoplasmiques qui saccroissent assez rapidement. Puis on voit apparaitre dans ces masses des globules pàles qui grossissent et prennent une forme ovalaire ou pyriforme : ce sont de jeunes spores. Au bout d'un temps assez court, ces spores ont pris plus de consistance, présentent l'aspect de corpuscules ovoïdes brillants, et, après avoir absorbé toute la gangue protoplasmique, se disséminent dans l'organisme; elles sont alors mùres, et reproduisent bientòt de nouvelles masses de protoplasma. Celles-ci ne sont formées en effet yue par le contenu des spores, qui s'échappe à la faveur d'une ouver. ture percée à l'un des pòles.

Outre la Microsporidie de la pébrine, nous derons signaler encore le Nosema helminthorum Moniez, 1887. qui vit chez certains Téniadés inermes (Moniezia expansa, 1 . denticulatu); les spores de ce parasite s'observent en énorme quantité dans les mailles des tissus; elles pénètrent à l'intérieur des ovules dont elles n'empèchent pas toujours l'évolution, et c'est ainsi qu'elles passent à de nouveaux hòtes; ces spores sont ovales et mesurent près de z̆ u. sur $2, u, 3$. - La mème espece ou une forme très voisine a été vue par Bischoff, yunk et lieferstein chez l'Ascaris mystax, dont les canaux sexuels en renferment quelquefois une quantité prodigieuse.

\section{CL.ASSE III}

\section{INFUSOIRES}

Protosocires nucléés, de forme plus ou moins definir, munis de cils, de flagellums on de tentacules.

C'est en 1676 que Leeuwenhoek, observant une infusion de poivre à l'aide d'un microscope qu'il avait construit lui-mème, y découvrit les animalcules auxquels Ledermiiller et Wrisberg donnèrent plus tard le

1) P. Thélohan, Observalions sur les Myxosporidiés et essai de classification de ces oryanismes. Bullet. de Ia Soc. philomathique de Paris, (8), IV, P. 165, IS93. 
nom d'Infusoires, nom liré précisément de leur abondance dans les infusions de substances animales ou végétales. Mais longtemps on comprit sous cette dénomination, avec les Infusoires véritables, un grand nombre de pelits animaux beaucoup plus élevés en organisation, notamment les Rotifères, ainsi qu'une foule de végétaux inféricurs.

Le corps ollire en général une différenciation plus ou moins accusée en ectoplasme el endoplasme, ce dernier représentant ce que les ancicus observateurs prenaient ponr une cavité digestive remplie de chyme. L'ectoplasme, qui peut d'aillenrs oflrir diverses modifications de structure, renferme parfois de la chlorophylle, soit à l'état diffus, soit en grains (Englena viridis, Stentor polymorphus', ou bien des grains d'amidon, etc. : en outre, il sécrète le plus souvent à sa périphérie une mutirule ou membrane d'enveloppe.

La mutrition seffectue quelquefois par endosmose, que cette cuticule existe (Opalines) ou non (Monades). Mais, dans le plus grand nombre des cas, on observe une houche et un anus. Les aliments solides tombent daus l'endoplasme et sont reçus, avec la petite quantité d'eau qui les accom-

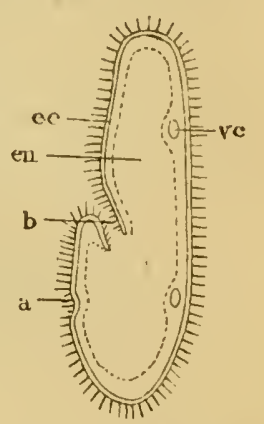

Figr. 78. - Schéma diun faramécic, daprís llasch. - b, orifice. luccal. $a$, fente anale. ne, vacuoles contractiles. ee, reloplasme. en, endoplasme. pagne toujours, dans des vacuoles temporaires, à contour régulier, siège d'une digestion active. La présence de ces vacuoles ou bols alimentaires avait trompé Ehrenberg, qui croyait à l'existence d'estomaes multiples et décrivait des Infusoires polygastriques. Chez les Tentaculifères, les aliments sont saisis et ingérés au mosen des sucoirs.

L’appareil excréteur est représenté en général par une ou plusieurs vacuoles contractiles logées dans l'ectoplasme et communiquant avec l'extérieur par un petit pore. Le noyau esi ordinairement accolé ì l'ectoplasme.

La multiplicalion a lieu le plus souvent par scissiparité : le corps se divise en deux parties égales, et le noyau s'étranglant de la même manière laisse ses deux moitiés dans les nouveaux individus. Parfois cette division (simple ou répétée) s'effectue à l’état de vie latente, après que l'individu s'est entouré d'un kyste muqueux (kyste de division), comme on le voit chez les Colpodes. Plus rarement, on observe une sorte de gemmation. Enfin, nous constaterous che\% les Ciliés des phénomènes de conjugaison.

Les Infusoires se rencontrent en abondance dans les eaux douces et salées, tout au moins quand elles contiennent des matières organiques en décomposition. Ils s’alimentent souvent. en effel, aux lépens de cessubstances; mais il en est beaucoup aussi qui se nourrissent de 
végétaux inférieurs et d'autres Infusoires. Quelques-uns vivent en parasites ou en commensaux à la surface ou dans l'intérieur du corps de divers animaux. En dehors de l'enkystement lié à la multiplication, un grand nombre de Ciliés et surtout de Flagellés jouissent de la faculté de s'enfermer dans un kyste chitineux (kyste de conservation) lorsque les conditions de milieu deviennent impropres à leur existence. Dans cet état, ils sont capables de résister à une dessiccation poussée même assez loin ; de plus, ces individus enkystés peuvent être emportés par le vent à de grandes distances, ce qui explique l'ubiquité des Infusoires et leur apparition subite lorsque les circonstances sont favorables.

3 sous-classes:

Un ou plusieurs hlagellums.................. Flagellés.

Des cils à tous les âges...................... CiLiés.

Des tentacules; pas de cils chez l'adulte........... Tentaculifères.

SOUS-CLASSE I

\section{FLAGELLES}

Infusoires sans cils vibratiles, mais toujours pourvus d'un ou de plusieurs flagellums et parfois d'une membrane ondulante.

Les Flagellés sont des animalcules d'une observation assez difficile, d'autant que leurs dimensions sont en général beaucoup plus petites que celles des autres Infusoires.

Leur corps est formé d'une masse protoplasmique ne présentant

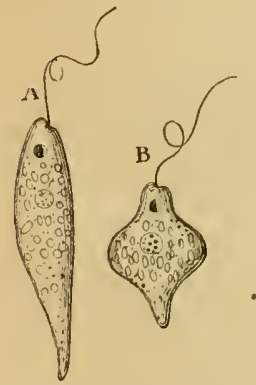

Fig. 79. - Euglena vi-. ridis, à divers élats de contraction, d'apris Stein. qu'une faible différenciation. Il est parfois nu, et susceptible alors de présenter des mouvements amiboïdes (Trypanosomes, Monades); mais, dans la plupart des cas, il se montre limité par une cuticule.

Ce qui caractérise essentiellement ces êtres, c'est la présence d'un ou de plusieurs flagellums, longs appendices très mobiles, servant surtout à la locomotion, et dans l'épaisseur desquels on a constaté une striation analogue à celle des fibres musculaires. Jamais on n'observe en même temps de cils vibratiles, mais il existe parfois une membrane ondulante.

La bouche peut faire défaut (Monades); d'ordinaire, cependant, il existe une ourerture permanente qui conduit, par un court œsophage, les aliments dans la partie centrale du corps. Cet orifice buccal se trouve généralement situé à la base du point d'insertion des flagellums. La présence d'un anus n'a pu être constatée jusqu'à présent chez la plupart des espèces; mais, che\% les 
Flagellés les plus élevés, cet organe semble exister réellement.

Les vacuoles contractiles manquent chez les Dinollagellés, les Cystollagellés adultes et quelques Eullagellés. Par eontre, on observe toujours un noyau simple, arrondi ou ovalaire, renfermant le plus souvent un nucléole.

La mulliplication s'eflectue par scission (transversale, longitudinale ou oblique) ou par sporulation. Elle est quelquefois précédée d'une véritable conjugaison.

Le groupe des Flagellés est lort difficile it déliniter ; on y a compris des formes, telles que les Volvocinées, dont les affinités avec les Algues sont asse\% prononeées pour qu'on les relègue aujourd'hui dans le règne végétal. D'autre part, il possède des relations évidentes avec les Amibes.

On le divise en quatre ordres: Liuflagellés, Dinoflagellís (Péridiniens), Choanoflagellés (Codosiga) et Cystoflagellés (Noctiluques). Le premier seul nous occupera. Celui des Dinoflagellés parait deroir être rattaché aux Algues.

\section{PREMIER ORURE}

\section{EUFLAGELLÉS}

Un assez grand nombre de formes se rencontrent dans le corps des animaux ì sang froid ou à sang chaud. Il en existe presque toujour's, par exemple, dans les réservoirs digestifs des herbivores (panse des Ruminants, ceecum du Cheval et du Pore, etc.), ou ils vivent en compagnie d'Infusoires ciliés; mais on ne les connaît encore que très imparfaitement. 11 importe de les rechercher immédiatement après la mort, car ils ne tardent pas à périr et deviennent alors difficiles à distinguer des corps qui les entourent. Selon la remarque de Leuckart, une température supérieure à $50^{\circ}$ C. ou inférieure à $14^{\circ} \mathrm{C}$. leur est fatale; en outre, ils meurent d'emblée au contact d'une solution, mème très ètendue, de sublimé corrosif.

Il est possible que quelques-uns d'entre eux jouent un rôle actif dans la production de divers troubles pathologiques; mais il parait certain que la plupart des auteurs ont singulièrement exagéré l'étendue de ce rôle.

Un pourra s'étonner de ne pas voir mentiunnées ici les nombreuses formes yui ont été décrites par les auteurs sous les noms de Monas et de Cercomonas. C'est que, selon Grassi, aucun représentant de ces genres n'est parasite; tous mènent une vie libre, et les espèces parasites qui ont été rattachées à ces genres ne sont en réalité que des Monocercomonas ou des Trichomonas imparfaitement observès.

Famille des GERGOMONAdidÉS. - Les Flagellés qui composent ce groupe possèdent un ou plusieurs llagellums à l'extrémité 
antérieure, ou sont munis d'une membrane ondulante généralement terminée par un flagellum; l'extrémité postérieure est tantôt simplement amincie, tantôt prolongée elle-même par un ou deux flagellums.

Genres Herpetomonas Kent (Monomita Grassi, Trypanomonas Danilersky), Trypanosoma Gruby, Paramecioides Grassi, Plagiomonas Grassi, Bodo Ehr. (Heteromita Duj.), Monocercomonas Grassi (Trichomastyx Blochm.), Trichomonas Donné, Costifera Grassi (Polymastyx? Bütsch.), Hexamita Duj. (Dicercomonas Grassi, Giardia? Künstler).

Les Trypanosomes (Trypanosoma Gruby, 1843) sont caractérisés par une membrane ondulante qui se termine en un flagellum; la forme de leur corps est très changeante.

Une forme curieuse vil dans le sang des Grenouilles : c'est le $T$. sangutinis Gruby, 1843, que Ray Lankester a décrit plus récemment (1871) sous le nom d'Undulina ranarum.

Danilevsky a aussi rencontré dans le sang des Oiseaux un Trypanosoma sanguinis arium.

Jolyet et de Nabias (I) ont découvert, dans le sang du Lapin, un Trypanosome long de 30 à $36 \mu$, large de 2 à $3 \mu$ dans la région moyenne. Dans ces dimensions sont compris un flagellum long de $15 \mu$, et une courte pointe occupant l'extrémité opposée (antérieure dans les déplacements), longue d'environ 3 … Le corps est atténué de part et d'autre; en avant de l'insertion de la membrane ondulante, on voit un espace clair portant un corpuscule arrondi; au niveau de cette membrane, le protoplasme est granuleux et renferme un noyau.

Fig. 80. - Try- Sur 10 Lapins sains ou malades, 4 ont présenté cet hépanosome du (Jolvel el de Nabias\}.

matozoaire. Il semble que les animaux amaigris, chétifs et ayant eu de la diarrhée en soient plus souvent porteurs que les autres.

Künstler a trouvé un semblable parasite dans le sang d'un Cobaye.

D'après Danilersky (2), les Herpetomonas ou Trypanomonas représenteraient la phase jeune, prolongée, du développement des Trypanosomes.

Ainsi, on a souvent observé, dans le sang des Muridés - et nous trouvons pour ainsi dire à volonté, dans la belle saison, à Alfort, chez le Surmulot et le Rat noir - des organismes auxquels on a donné le nom d'Herpetomonas Lewisi Sav. Kent (Trypanomonas murium Danilevsky); selon le naturaliste de Charkov, ce sont des formes jeunes, dont la persistance serait due à ce

(1) F. Jolyet et B. de Nabias, Sur un hématozoaire du Lapin domestique. Travaux du laboratoire de M. Jolyet, I, p. 39, 1891.

(2) В. Daxilewsкy, La parasitologie comparée du sang. I. Nouvelles recherches sur les parasites dusang des Oiseaux. Charkov, 1889. Voir p. 72, 79, 81, 93. - A. LAVERan, Des Trypanosomes parasiles du sang. Archives de méd.expérim., IV, p. 25i. 1892. 
que le sang de ces animaux constitue un milieu défavorable à la métamorphose complète.

Ces organismes ressemblent beaucoup ì ceux qui ont été trouvés ì Calcutta, en 188.), par T. R. Lewis, clans le sang d'un jeune Chien, à ceux aussi que le mime observateur a vus dans le sang du Cheval ot du Chameau. Si l'on tient compte de la tendance au polymorphisme que présentent tous ces êtres suirant leurs conditions d'existence, on reconnaitra également qüils sont fort semblables au Flagellé rencontré par Griffith Evans dans le sang des Chevaux, Mulets et Chameaux affectés de "surra », et décrit sous le nom d'Hiematomonas Evansi Osler (Trichomonas Evansi Crookshank). Il s'agit tout au moins d'une forme parente, qüil conviendrait, par suite, d'appeler Trypanosoma Evansi. - Le surra est une grave affection contagieuse qui sévit dans ïlnde, principalement sur les animaux de transport de l'armée (1). Décrite pour la première fois en 1880 par le $)^{\mathbf{r}}$ Griffith Evans, inspecteur vétérinaire de l'armée anglaise, cette affection présente tous les caractères d'une animie pernicicuse progressive. Evans a reconnu qu'elle était transmissible par inoculation, et que le sang des animaux malades, comme de ceux infectés expérimentalement, contenait l'organisme en question. Il est fort probable que e'est la même maladie

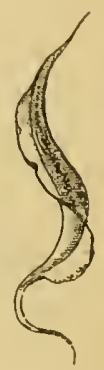

Fig. 81. - Trypanosome du sang des animaux atteints de surrit (Burke). qu a observée Blanchard au Tonkin sur des Mulets importés pour le service de l’armée française (2).

Les Plagiomonades (Plagiomonas Grassi, 1882; Cystomonas R. Bl., 1886) ont deux tlagellums antérieurs, lirigés en avant, et un postérieur ou caudal.

Plagiomonade urinaire ( $/$ l. urinaria [Küunstler]. - Syn. Bodo urinarius Künstler, 1883; Cystomonas urinaria R. Bl., 188\%). - D'après Kïnstler, cet organisme ne mesure pas en général plus de $10 \mu$ de longueur; il a le corps renflé et obtus en avant, atténué en arrière, l'extrémité antérieure porte deux longs flagrellums très fins ; l'extrémité postérieure se termine par un autre llagellum plus gros. Un espace clair (noyau) se montre à la partie antérieure.

Künstler a découvert cette espèce dans les urines fraîches d'un individu atteint de pyélite chronique. Peut-être est-elle identique au Trichomonas irregularis observé en 1868 par Salisbury, à Philadelphie, dans l'urine et le mucus vaginal d'une jeune fille. Quant au Bodo urinurius signalé par Hassal, en 185̆9, dans l'urine des cholériques et

(1) Rec. de mèd. vét., 1388, p. 298.

(2) Molnene.u, Rapport sur une maladie des Mulets au Tonkin. Bull. Sor. centr. de méd. vèt., 18s8, p. 69'. 
des albuminuriques, il est possibie que ce soil une forme non parasite, développée dans l'urine après son exposition à l'air libre.

Les Monocercomonades (Monocercomonus (irassi; Trichomastyx Blochmann) ont quatre flagellums antérieurs, trois dirigés en avant et un plus long renversé en arrière, dépassant l'extrémité postérieure du corps ; pas de flagellum postérieur.

Il serait sans doute témériire d'affirmer que les nombreuses formes parasites décrites parles auteurs sous le nom de Cercomonas appartiennent a ce genre plutôt qu'à tout autre groupe de la famille des Cercomonadidés: aussi ne placons-nous ici qu'à titre provisoire, et en faisant toutes réserves sur leur classification définitive, les types ci-après :

Cercomonas canis Davaine, trouvé par Gruby et Delafond dans l'estomac du Chien. Ne serait-ce pas Lambliaintestinalis?

Bodo salians Ehr., des eaıx stagnantes, recueilli par Wedl sur des ulcėres sordides de l'llomme.

Cercomonas gallinæ Rivolta, des Oiseaux de basse-cour. Rivolta et Delprato décrivent ce parasite comme ayant un corps ovoïde ou discoïde long de $14, u, 2 \ddot{*}$, large de $5 \mu, 7$, possédant au pỏle obtus un prolongement aussi long que le corps, et au pôle aigu trois llagellums réunis par leur base. Ces auteurs lui attribuent la production d'une forme d'angine croupale observée sur les Poulets et les Pigeonneaux.

L. Pfeiffer le rattache aux Trichomonas et lui attribue deux à quatre flagellıms, ainsi qu'une membrane ondulante; il le considère comme lı cause essentielle de la diphtérie des Oiseaux (Flagellatendiphterie). Mais il est plus vraisemblable d'admettre, avec Cornil et Babes, que son ròle pathogénique est insignifiant : le bacille de Löffler, qui existe toujours en mème temps que lui, se retrouve seul en effet chez les Lapins auxquels on a transmis la maladie par inoculation.

Cercomonas hepatica Riv. des Pigeons; provoquerait une sorte d'lıépatite caséeuse.

Monas cariz Davaine, du gros intestin du Cobaye. Perroncito en admet trois espèces (Ccrcomonus ovalis, pisiformis et spharica) et leur attribue la production d'une maladie qui décime fréquemment les élevages de Cochons d'Inde.

Monas anatis Davaine, du caecum dun Canard. Une forme très peu différente a été trouvée plusieurs fois dans le gros intestin de la Poule. Peutêtre s'agit-il du Trichomonas Eberthi.

Les Trichomonades (Trichomonas Donné; Sanolophus Leuck.; Cimxnomonas Grassi) ont quatre ou cinq flagellums antérieurs, dont trois ou quatre dirigés en arant et un renversé en arrière, plus long. que le corps et fixé à celui-ci, sur une grande partie de sa longueur. par une membranelle très mince; pas de flagellum postérieur; squelette interne constitué par un bâtonnet longitudinal.

Trichomonade vaginale ( $T$ rr. vaginalis Donné, 1837). - Corps de forme changeante, généralement ovoïde ou pyriforme, long d'environ 13 à $2 \% \mu$. et le plus souvent de 16 à $18 \mu$; extrémité antérieurc 
munie normalement de cinq flagellums : quatre dirigés en avant, adhérant d'ordinaire entre eux sur une certaine longueur a partir de leur base, et le cinquième (pris autrefois pour une rangée de cils vibratiles) renversé en arrière suivant une ligne spirale, très onduleux el réuni au corps, sur la plus grande partie de sa longueur, par une délicatr. membranelle ; extrémité postérieure atténuée en une queue de forme et de dimensions très variables. Vel's l'extrémité an térieure, une bouche infundibuliforme, se continuant par une sorte de tube asoplıgien. Parenchyme du corps granuleux, limité par une cuticule anhiste; un noviu ovoïde sans nuclénle. situé

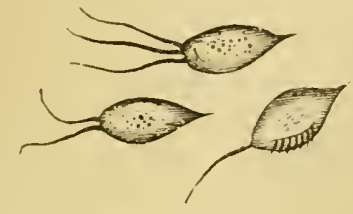

Fig. 82. - Trichomonas raginalis, lel que le représentail külliker.
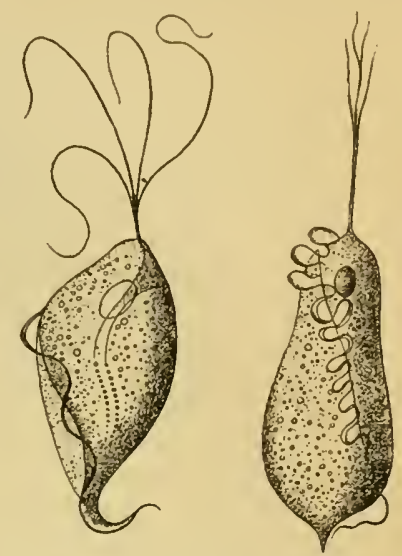

Fig. 83. - Trichomonas vaginalis, d’après Kïünstler.

dans la région antérieure, le long de l'uesophage; pas de vacuole contractile.

Ce parasite a été découvert en 1837 par Donné. Depuis lors, il a été étudié par diflérents auteurs, et en particulier par Kiünstler. Il vit dans le mucus raginal de la femme, lorsque celui-ci est fortement acicle, et pullule principalement dans le cas de vaginite purulente; il manque toujours dans le mucus normal. Sa présence se décèle, au dire de Donné et de Davaine, par l'aspect spumeux du produit de la sécrétion vaginale.

Les injections d'eau pure ou de solutions alcalines, etc., le font périr rapidement; il disparait aussi dans la période menstruelle et au moment de l'accouchement.

Il se rencontre de préférence chez les adultes, mais on l'a signalí aussi chez des petites filles de 6 à 7 ans et chez des femmes ayant dépassé l'àge de la ménopause. Haussmann l'a rencontré plus fréquemment chez les femmes enceintes que chez les non gravides. Enfin Künsiler affirme quon peut le trouver chez toute femme atteinte d'écoulement purulent, à moins que celle-ci ne fasse un usage fréquent des injections froides et alcalines.

Nous devons ajouter cependant que l'influence pathogénique de ce Flagellé est encore sérieusement contestée.

Trichomonade de lHomme (Tr. hominis [Davaine]. - Syn.: Cercomonas hominis Dar., 18:1; Cercomonas intestinalis Lambl, 1875 , 
nec 1859; Cercomonas intestinalis Marchand, 1875; Tr. intestinalis Leuck., 1879 ; Monocercomonas hominis Grassi, 1882; Cimænomonas hominis Grassi, 1888; $T_{r}$. hominis Grassi, 1888). - Corps pyriforme, ovalaire ou subovalaire, un peu asymétrique, long au plus de 10 à $11 \mu$ sur 5 à 6 u de large ; extrémité antérieure pourvue de quatre flagellums dirigés en avant, difficiles à voir, s'accolant facilement l'un à
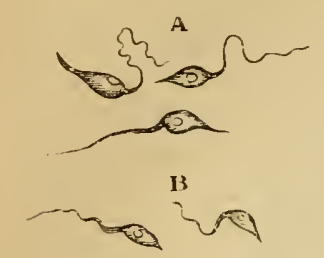

Fig. 84. - Cercomonas hominis, tel que le représentait l)avaine. - A, grande variété. bi, petite variélé. l'autre; un cinquième flagellum ondulant renversé en arrière suivant une direction oblique, plus fort que les autres et réuni au corps par une délicate membranelle difficile à voir : ce flagellum se prolonge au delà du corps par un filament grèle et aussi long que le corps luimême. Extrémité postérieure présentant une queue plus ou moins détachée, parfois assez longue. Bouche située au voisinage de l'insertion des tlagellums. Bâtonnet interne longitudinal, non toujours visible. Noyau avec nucléole, situé antérieurement et correspondant à la partie courbée du bàtonnet. Couche superficielle du corps un peu épaissie, mais sans cuticule distincte.

Cette espèce offre la plus grande ressemblance avec la précédente, à laquelle on devra peut-être l'assimiler. Elle a été découverte en 1853-1854 dans les selles des cholériques par Davaine, qui la considéra comme une Cercomonade. Le même auteur en décrivit également une petite variété provenant des déjections d'un malade atteint de fièvre typhoïde : cette distinction était d'ailleurs toute superficielle.

Depuis Davaine, ces organismes ont été rencontrés par un grand nombre d'auteurs, dans des diarrhées de diverse nature et d'origine très variable, et mème chez des individus sains.

On en a signalé jusque dans l'estomac, le foie et la bouche, et l'imperfection des observations les a fait décrire sous des noms multiples. C'est Grassi qui les a définitivement rattachés au genre Trichomonas.

Quelques auteurs ont voulu considérer leur présence comme la cause de la diarrhée; mais les observations et les expériences de Grassi semblent avoir établi qu'ils ne possèdent aucunement cette influence pathogénique. Il est probable que ce sont, comme les Amibes, des parasites vivant à l'état normal dans l'intestin, et se multipliant à l'excès lorsque les conditions morbides de ce milieu les placent dans des conditions plus favorables à leur développement.

Quelques autres espèces de Trichomonas ont été indiquées comme vivant en parasites chez les animaux domestiques, mais la plupart sont fort imparfaitement connues et réclament de nouvelles études. Citons :

Tr. caviæ Dav., trouvé en grand nombre dans le gros intestin d'un Cobaye.

Tr. suis Dav., recueilli par Gruby et Delafond dans l'estomac du Porc. 
Könstler dit aussi aroir observé un Trichomonas dans l'intestin du Porc. Il en a vu un, dautre part, dans le vagin de la Vache.

Tr. Ebeithi, trouvé dans les glaudes de Lieberkühn de la Poule et du Cimard par Eberth, à qui la présence des flagellums avait échappé. Leuckart en avait fait un peu hitivement le type d'un nouveau genre Sanolophus.

Tr. columbx, observé par Rivolta dans l’intestin grèle du l’igeon; je l'avais rapporté antérieurement, mais à tort, au genre Lophomonas.

Famille des LAMBLIADÉs. - Les Lambliadés ou Mégastomidés sont caractérisés par une dépression antérieure en forme de ventouse, et par la présence de deux llagellums à l'extrémité postérieure.

Genre Lamblie (Lamblia R. Bl., 1886. - Syn . : Cercomonas Lambl, 185̈9; Jimorphus Crassi, 1879; Megastoma Grassi, 1881). - Ce genre, qui jusqu’à présent représente ì lui seul la famille des Lambliadés, doit prendre le nom qui lui a été appliqué en 1886 par R. Blanchard, les autres noms ayant été cmployés déjà pour désigner des animaux divers.

La Lamblie intestinale (Lamblia intestinalis [Lambl]. - Syn.: Cercomonas intestimalis Lambl, 18399 ; Hexamita duodenalis Dav., 187̈; Dimorphus muris Grassi, 1879 ; Megastoma entericum Grassi, 1881 ; M. intestinale R. Rl.. 188;; ;. intestinalis R. Bl., 1886) est pyriforme, à gros pôle antérieur, long en moyenne de 10 à 16 u et large de ¿ à 7 u, J. Sur liune de ses laces, le corps montre, dans les deux cinquièmes antérieurs, une dépression ou ventouse profonde, réniforme, ì hile postérieur. Il offre quatre paires de flagellums dirigés normalement en arrière, trois insérées sur les bords de la dépression et la 'juatrième continuant lc corps en arrière. Le protoplasme, hyalin et linement granuleux, est limité par une cuticule très délicate. Il contient deux noyaux situés au fond de la ventouse, munis chacun d'un nucléole et unis entre eux par un tractus plus ou moins épais.

Ce parasite (1) vit dans lintestin grêle de divers Mammifères, oủ il se fixe, par sa ventouse à bords contractiles, sur les cellules épithéliales ıles villosités. On le rencontre surtout dans le duodénum et le jéjunum. Dans la première portion du gros intestin, il se montre déjà enkysté, sous l'aspect de corpuscules ellipsoïdes, pourvus d'une enveloppe assez épaisse, comme l'a constaté Perroncito. C'est à cet état d'enkystement qu'il se trouve expulsé avec les fèces, quand celles-ci offrent une certaine consistance; mais on peut aussi l'observer en vie, avec ses flagellums, ou bien en roie de scission longitudinale, ou encore aux diverses phases de la période d'enkystement, dans les selles diarrhéiques.

Lambl paraît l'avoir observé le premier, en 18\%9, dans les inucosités grélatineuses de l'intestin des enlants; mais il n'avait point vu les llagellums, peut-ètre parce qưil avait eu affaire à des individus morts

(1, B. Grassi und W. Schewrakor , Beitrag zu* Kenntniss des Mlegastoma entericum. Zeitschrift f. wiss. Zoologie, XLVI, p. 143. Leipzig, 1888. 
ou en voie de s'enkyster. Il le décrivit sous le nom de Cercomonas intestinalis. Depuis cette époque, il a été revu assez fréquemment chez l'Homme, en Italie, par Grassi et Perroncito; en Allemagne, par Moritz et Hölzl, et peut-être à Calcutta, par Cunningham.

On l'a observé aussi chez les Muridés (Souris, Rats, Campagnols), où il paraît être très commun. Grassi l'a rencontré en outre chez le Chat, le Chien, le Mouton et le Lapin. C'est évidemment le même parasite que Davaine avait trouvé dans le duodénum d'un Lapin et dé-

2
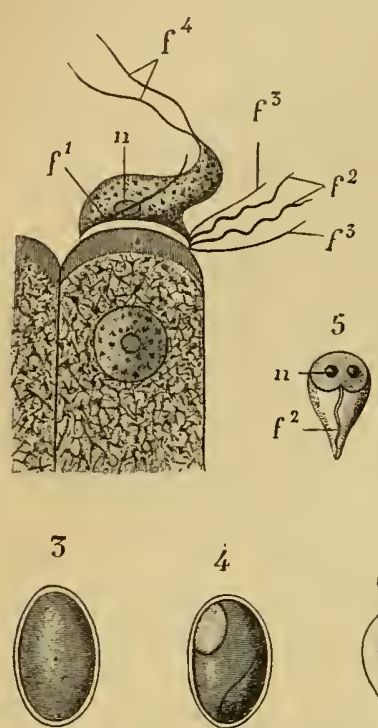

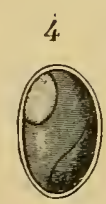

1

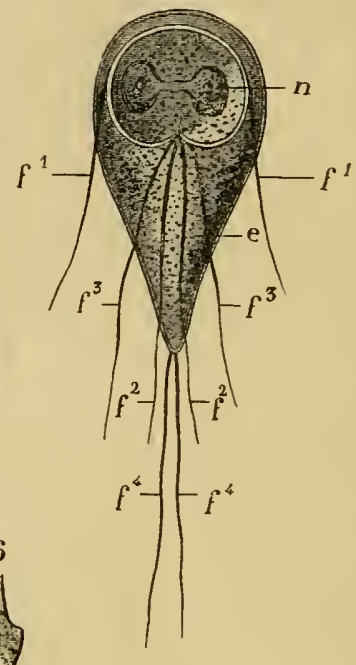

Fig. 83̈. - Lamblia intestinalis. - 1, ru par la faec ventrale $(X 1 \varepsilon 60)$. 2. fixé sur un" cellule épithr. liale $(\times 1070)$. 3, kyste provenant du gros inlestin $(\times 1070)$. 4, individu enkysté vu par côté $(X 1070)$. 5 , iudividu mort, recueilli daus les fèces $(\times 530) .6$, le mème, vu de côlé $(X \mathbf{X} 53)$. n, noyau. e, erloplasme. $f$. flagellums (Grassi et Schewiakoff).

crit en 1875 sous le nom d'Hexamita duodenalis, le même aussi que Rivolta avait figuré en 1868.

Ce Flagellè possède-t-il réellement une influence pathogénique? On est porté à l'admettre quand on constate quill existe sourent en nombre assez considérable pour que chaque cellule épithéliale en porte un ou plusieurs, occupés sans doute à la sucer. Et de fait, selon Grassi, certaines diarrhées chroniques accompagnées d'anémie résultent manifestement de la présence du Lamblia. Mais, par contre, on rencontre des individus porteurs d'un grand nombre de parasites et jouissant néanmoins d'une santé parfaite; el beaucoup d'animaux sont dans le même cas.

La transmission du parasite doit se faire par les individus enhystés: c'est probablement le Rat qui, dans la généralité des cas, le commu- 
nique à lllomme, en souillant de ses excrements le pain ou les autres substances alimentaires.

SOUS-CLASSE 11

\section{GILIĖS}

Infusoires pomrvus, à tous les riges, de rils vibratiles comremt tout ou parlic du coips.

Les Cilies sont les Infusoires par excellence. Leur corps oflre toujours un ectoplasme et un endoplasme bien distincts. L'ectoplasme est susceptible de présenter diverses modifications de structure. Dans certains cas, il se condense en fibres longitudinales contractiles, qu'on a nommées fibres musculaires (Stentors. Vorticelles). D’autres fois, il présente dans son épaisseur des bâtonnets urticants ou trichocystes. II est ordinairement limité par une cuticule, lont l'épaisseur est des plus variables.

Les cils dont le corps est revètu sont diversement répartis, et e'est précisément sur cette répartilion qu’est basée la classification de Stein.
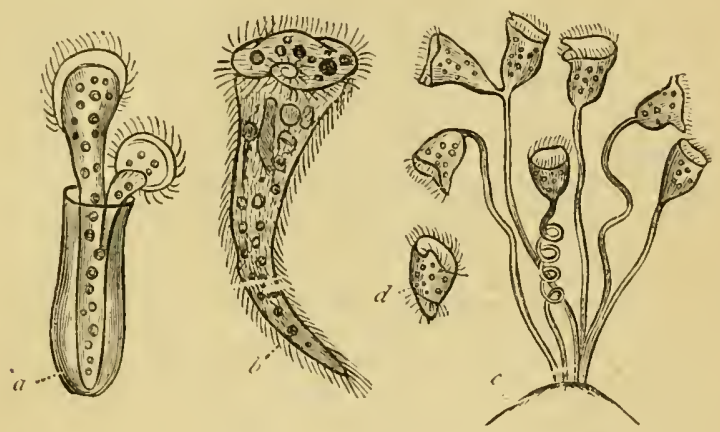

Fig. St. - Infusoires ciliés. - $a$. Vaginicola crystallina. $b$, Stentor J/ülleri. $c$, groune de Vorticelles. $d$, bourgeon détachó de Vorticelle, montrant la couronne poslérieure de cils (Huxles).

Ils peuvent d'ailleurs se différencicr pour former des appendices particulier's : cirres, soies, lanières vibratiles el membranes ondulantes.

Chez quelques formes, la bouche est absente, et la nutrition s'effectue alors par endosmose (Opalines). Mais la plupart des Ciliés sont, au contraire, pourvus d'un orifice buccal, qui conduit dans l'endoplasme par une sorte de tube cesophagien: ils possèdent aussi un anus, apparaissant sous la forme d'une fente étroite au moment de l'expulsion des résidus alimentaires. La digestion est souvent facilitée par un mouvement cilculaire de la masse endoplasmique (cyclose! : les vacuoles alimentaires font ainsi plusieurs tois le tour du corps, et sont enfin expulsées lorsqu'elles passent au niveau de l'anus. Lors même que ces bols n'obéissent pas à la cyelose (Oxylrichidés), on les 
voit se rapprocher de l'anus à mesure que leur contenu diminue en passant à l'état résiduel, et se trouver finalement expulsés. Dans quelques cas, on a même constaté une tendance du réseau endoplasmique ¿t s'ouvrir devant les aliments dans une direction déterminée, et à constituer ainsi un tube digestif sans parois propres, de la bouche à l'anus.

Toujours on trouve une ou plusieurs vacuoles contractiles.

Quant au noyau, macronucléus ou endoplaste, il est très variable dans sa forme : rond, ovale, oblong, allongé en boudin, contourné en fer à cheval, etc., quelquefois même divisé en articles ou en grains. Le plus fréquemment, il est accompagné d'un ou de plusieurs corpuscules qu'on nomme nucléoles, micronucléus, endoplastules, etc. Le nucléole est toujours situé à côté du noyau, auquel il est souvent même accolé ; il a, en réalité, la signification d'un petit noyau.

Les lnfusoires ciliés se multiplient d'ordinaire par scissiparité: en pareil cas, c'est la division transversale qui prédomine; la scission longitudinale est beaucoup plus rare. Parfois, il se produit une division répétée après enkystement (Colpodes). On peut observer aussi des exemples de gemmiparité.

Nais, chez un grand nombre de formes, la série des générations qui se succèdent d'après ces procédés se montre limitée, et il semble nécessaire qu'un rajeunissement intervienne par la conjugaison de deux individus. Les phénomènes qui se manifestent dans cette circonstance ont été récemment étudiés avec soin par Naupas, sous le nom de rajeunissement liaryogamique; mais il est juste de reconnaitre que les premières observations précises sur ce sujet sont dues à Balbiani. La conjugaison s'annonce souvent par une série de manifestations comparables à celles qui préludent au rapprochement sexuel chez les animaux supérieurs. Elle est, d'ailleurs, provoquée par l'appauvrissement nutritif du milieu. -- C'est généralement le matin qu'on voit les individus (gamètes) s'accoler deux à deux.

Mais le phénomène essentiel de la conjugaison consiste dans l'évolution du nucléole, que Maupas est arrivé à schématiser d'une façon assez simple. Cet auteur distingue huit stades principaux, qu'il désigne par les huit premières lettres de l'alphabet. $-A$. Le nucléole se sépare du noyau et augmente de volume. $-\boldsymbol{B}$. ll se divise en deux suivant les phases ordinaires de la karyokinèse. $-C$. Ceux-ci se divisent de la mème manière. $-D$. Des quatre corpuscules nucléolaires ainsi formés, trois disparaissent par résorption (corpuscules de rebut). Le corpuscule persistant dans claque individu se divise de nouveau en deux : l'un de ceux-ci est destiné à jouer le rôle de pronucléus màle, ou élément fécondateur; l'autre remplit celui d'élément fécondé, ou pronucléus femelle. $-\boldsymbol{E}$. Chaque pronucléus màle pénètre dans le corps de l'autre conjoint et va se fusionner avec le pronucléus femelle de celui-ci. $-F$. Le noyau mixte résultant de cette fusion se divise en deux, puis $-G$. en quatre. $-H$. Les produits de cette division se diffé- 
rencient en noyaux et nucléoles, un certain nombre d'entre eux étant susceptibles de se résorber.

Les six premiers stades, A-F, sont constants. Le septième ou stade $\mathrm{G}$ peut manquer ou au contraire présenter une plus grande complication.

Pendant toute cetle évolution, le noyau primitif est demeuré inerte; mais, au moment du slade $\mathbf{H}$, il s'étire et se fragmente, pour disparaitre en totalité ou en partie par résorption. Il ne joue donc aucun rôle essentiel dans la conjugaison.

l.a dissolution de la syzygie ou, pour parler plus simplement, la disjonction des individus s'effectue dans l'un quelconque des stades qui suivent l'échange des pronucléus màles; mais ee n'est qu'à la fin du stade II que ces ex-conjugués sont aptes a se multiplier par scission ou gemmation.

Les Infusoires ciliés abondent surtout dans les eaux douces, mais on en rencontre aussi dans l'eau de mer. Il est mème un certain nombre de formes qui vivent dans les réservoirs digestifs des animaux.

La classification généralement adoptée jusqu'ả ces derniers temps pour ce groupe d'Infusoires était celle de Stein, qui répartissait les Ciliés, d'après la disposition de leur revètement, entre quatre ordres, ceux des Holotriches, des Hétérotriches, des llypotriches et des Péritriches. Mais elle est devenue insuffisante en beaucoup de points, et il convient de lui substiluer celle de Bütschli, établie sur des bases beanconp plus rationnelles.

2 ordres :

Bouche dépourvue de membrane............. Gruvostones.

Bouche pourvue d'une membiane ondulante..... Trichostons.

\section{PREMIER ORDRE}

\section{GY M NOSTOMES}

Bouche arrondie ou en fente, ourerte seulement lors de la préhension des aliments, et ne montrant pas de membrane ondulante, bien que les cils soient parfois un peu modifiés dans la région buccale. OEsophage non cilié. Les corpuscules alimentaires sont toujours engloutis et non pris par un tourbillon. Revètement ciliaire complet ou réduit: cils courts, tous semblables.

Cet ordre se divise en 3 familles, dont la première seule doit nous retenir.

Famille des ENGHÉrids. - Boucle terminale, presque toujours arrondie. OEsophage formant un tube dirigé en arrière et généralement entouré de trichocystes plus ou moins distincts. Anus le plus souvent terminal.

Parmi les nombreuses sections de celte famille, nous n'avons á ciler que la suivante :

Sous-famille des Prorotrichinés. - Forme globuleuse ou ovale; extrémité antérieure sourent un peu tronquée. OEsoplage court. Revêtement ci- 
liaire borné à l'extrémité antéro-externe, ou comprenant en outre quelques bonquets ou séries transversales de cils sur divers points du corps.

(ienre Bütschlie (Bütschlia Schuberg, 1888). - Corps ovale, brusquement tronquéa à son extrémité antérieure, nu sur la plus grande partie de sa surface, mais densément cilié en avant, et paraissant toujours présenter, en outre, d'autres zones ciliaires ; vers le quart antérieur du corps et par côté, une vésicule contenant des concrétions cristallines. Noyau sphérique; pas de nucléole. Ectoplasme épaissi antérieurement. Endoplasme homogène, finement granuleux, dépourvu de bols alimentaires.

Biitsehlie naine (B. parva Schub., 1888). - Corps légèrement ovale, souvent presque globuleux. Bouche située au milieu de la partie antérieure tronquée et suivie d'un court pharynx conique. La partie antérieure est couverte de cils sur toute l'étendue de la zone ectoplasmique épaissie; peutètre existe-t-il, en outre, d'autres cils vers le milieu du corps. Longueur 30 à $53 \mu$; largeur 26 à $38 \mu$.

Trouvée très rarement dans la panse du Bœuf.

Bütsehlie négligée (B. neglecta Schub., 1888). - Diffère de l'espèce précédente en ce que le corps est creusé, à son pòle postérieur, de quatre profondes échancrures. Outre l'épaisse zone ciliaire antérieure, il en existe d'autres moins importantes à la surface du corps: ainsi, une courte rangée semble se trouver en avant de la vésicule à concrétions; on remarque parfois des "épaulettes ciliaires " au fond des quatre échancrures; enfin, l'extrémité postérieure offre aussi quelques cils semblables aux autres. Longueur 57 u; largeur 42 u.

Trouvée aussi très rarement dans la panse du Bœuf.

Bütschlie lancéolée (B. lanceolutu Fior., 1889). - Corps lancéolé, présentant, au cinquième antérieur du corps, un étranglement suivi d'une sorte de petite tête conique converte de cils très fins. Par exception, la vésicule à concrétions cristallines est située vers le cinquième postérieur du corps. Longueur $48 \mu$; largeur $20 \mu$.

Panse du Bæuf.

Genre Didesme (Didesmis Fiorentini, 1890). - Péristome avec largre pharynx; deux groupes de cils fins et très longs, l'un antérieur entourant le péristome, l'autre postérieur environnant l'anus. Protoplasme vert jaunàtre et très granuleux; vésicule à concrétions cristallines plus grande et plus apparente que dans le genre précédent. Toujours un gros noyau et une grosse vacuole contractile.

Didesme ovale (D. ovalis Fior., 1890). - Corps presque ovale. Noyau central gros et oblong, avec un nucléole. Longueur $60 \mu$; largeur $40 \mu$.

Gros intestin des Équidés.

Didesme carré (D. quadratus Fior., 1890). - Corps presque carré, déprimé, marqué d’un sillon hyalin médian. Longueur $60 \mu$; largeur $40 \mu$.

Gros intestin des Équidés. 


\section{UEUXIEME ORDRE}

\section{TRICHOSTOMES}

Bouche généralement ouverte d'une façon permanente, rarement ferméc au repes. Bord de la bouclıe (péristome) pourvu d'une membrane ondulante. (Wsophage tubuleux, parfois absent, pourvu d'un prolongement de la membrame ondulante ou revètu de cils.

l.es particules alimentaires sont le plus souvent saisies par un tourbillon ou dirigées dans la bouche piu le revètement ciliaire de la zone adorale.

2 sous-ordres :

PREMLR SOUS-ONDRE

\section{AsPInotricIES}

Forme ellipsoïde ou réniforme, ordinairement asymélrique. Bouche représentée en ğénéral par une ouverture ovale, réniforme ou mème semilunaire, située sur la face ventrale en arrière de l'extrémité antérieure. (Ksophage sans appareil de bitonnets. Au bord de la bouche ou dans l'œsophage, une ou deux membranes en forme de lèvres, sauf peut-ètre dans les plus petites formes.

6 familles, parmi lesquelles nous citerous les Paramœcidés et les Isotri. chicles.

Les Paramécies (Porumucium) ont le corps oblong, asymétrique, la bouche ventrale et précédée d'un péristome oblique. - Ex. : P. Aurélie (P.Aureliu 0 . F. Ilüller), à corps allongé; P. verte ( $P$. bursarir Focke), à corps ramassé et contenant des grains de chlorophylle. Ces espèces sont très communes dans les infusions de substances organiques. List croyait aroir trouvé la dernière dans le rumen du Mouton.

Les Colpodes (Colpoda) ont le corps ovalaire, aplati latéralement, la bouche en forme de fente, située sur le bord ventral. Ex. : C. cucullus Ehrbg., des infusions de foin. Grande résistance vitale a l'état d'enkystement. List et Balbiani disent avoir observé des Colpodes dans l'estomac des liuminants : Schuberg révoque ce fait en doute. En tout cas, ce ne serait que d'une façon accidentellc.

Famille des ISOTRICHIdÉS. - Corps flexible, mais non contractile; ovale ou oblong. Revètement ciliaire général, dense. Bouche lortement reportée en arrière sur la face ventrale, parfois jusqu'au pôle postérieur. (Hsophage tubuleux, parfois a!longé en vis. Noyau ovale, arec nucléoles. Espèces parasites.

Genre Isotrique (Isotricha Stein, 1838). - Corps légèrement obové, un peu comprimé dans le sens dorso-ventral ; surface revètue de cils longs et serrés, et striée longitudinalement, de façon que les stries se réunissent le long d'une ligne allant de la bouche à l'extrémité postérieure; fente anale représentée probablement par une strie claire au tiers postérieur du corps; pharynx long, situé à l'extrémité antérieure ou dans son voisinage, et à fine striation spiralée ; plusieurs vacuoles contractiles dans la région antérieure du corps; 
noyau avec nucléole adhérent, entouré d’une sorte de capsule qui est réunie à l'ectoplasme par les pédoncules nucléaires (1). Ectoplasme épais. Endoplasme homogène, sans vacuoles alimentaires.

Isotrique prostome (l. prostoma Stein, 1861). - Corps cylindrique, atténué aux deux extrémités, mais plus fortement en arrière; non contractile, et cependant très souple et élastique. Bouche à l'extrémité antérieure et un peu vers la face ventrale. Noyau ovoïde, à petit pòle postérieur, avec un nucléole lui adhérant d'ordinaire en dessus. Houvements vermiformes, mais vifs; l'extrémité postérieure généralement en avant. Grande espèce .

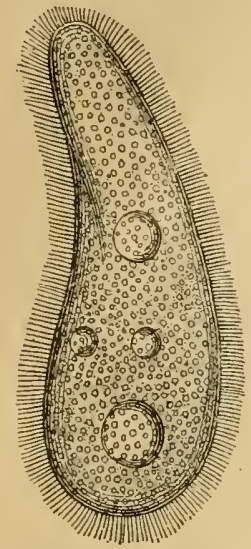

Fig. 87. - Isotricha in. testinalis (G. Colin). longueur 80 à $160 \mu$; largeur ว̆3 à 120 u.

Très commune dans la panse des Ruminants.

Isotrifue intestinale (1. intestinalis Stein, 1858). - Dilfère de l'espèce précédente en ce que la bouche est un peu plus éloignée de l'extrémilé antérieure et située dans une dépression carénée de la face ventrale; le noyau est plus court et plus arrondi, arec le nucléole généralement à son extrémité postérieure et vers la face ventrale. Jongueur 97 à 131 y.; largeur 68 à $8 \tau$. .

A peu près aussi commune que la précédente.

Ce sont probablement des Isotriques qui ont été observées par Perroncito dans des nodules miliaires des poumons d'une Brebis, puis par Brusaferro dans une tumeur à contenu lactescent, purulent, spumeux, du poumon droit dun jeune Bouf, et que ces auteurs avaient rapportées au Balantidium coli (2).

Genre Dasytrique (Dasytíicha Schuberg, 1888). - Corps légèrement ovale, un peu comprimé dans le sens dorso-ventral; revètement ciliaire comme chez les Isotriques; stries du corps contournées en spirale et se joignant aux extrémités antérieure et postérieure; pas de fente anale. A l'extrémité postérieure, l'endoplasme renferme des sortes de fibrilles qui remontent jusque vers le milieu du corps, et dont la signification est inconnue. Pharynx à l'extrémité antérieure, avec striation droite, différente du còté dorsal et du còté ventral. Une seule vacuole contractile, près du pharynx. Noyau ordinairement ovale, avec nucléole adhérent, mais sans capsule membraneuse et sans pédoncules nucléaires. Pas de couche ectoplasmique distincte. Endoplasne dépourvu de vacuoles alimentaires.

Dasytrique des IRminants (Dasytricha muminantium Schub., 1888). Corps ovale, un peu recourbé vers la face ventrale à l'extrémité postérieure. Bouche placée antérieurement, un peu du còté de la face ventrale. Assez souvent deux et mème trois noyaux. Longueur 30 à 100 u. ; largeur 25 à 66 u.

Très commune dans la panse des Ruminants.

(1) Les Isotriques sont en effet remarquables par la présence de prolongements de la couche ectoplasmique dans l'endoplasme, qui se trouve ainsi coupé par des cloisons se rendant au noyau. Ce sont ces prolongements que Schuberg nomme pédoncules nuclẻaires (Kernstiele).

(2) E. Perroxcito, I parassiti dell'uomo e degli animali utiti. Mlilano, 1882, p. 105 - Brusaferho, in Giornale di med. vet. prat. 1881, p. 249. 
lienre Paraisotrique (Puraisotricha Fiorentini, 1890). - Diffère des précédents par la présence d'une vésicule à concrétions cristallines surmontée l'une longue louffe de cils; de longrs cils également au péristome; anus presque constant.

Paraisotrique colpoïle $(l$. colpoidea Fior., 1890). - Corps oroïde, rappelant celui des Colpodes. Péristome antérieur et liteiral. En avant, la vésieule a concrétions crislallines, suivie d'un noyau gros et allongé, avec uucléole. En arrière. presque au-dessus de l'anus, une grosse vacuole contractile. Longueur ito ; ; larfeur $70 \mu$.

Paraisotrique oblongue $(P$. oblonga Fior., 1890). - Differe de la précédente en ce que l'extrémité postérieure est triangulaire. On la trouve du reste beaucoup plus rarement. Longueur $120 \mathrm{k}$; largeur $60 \mathrm{k}$.

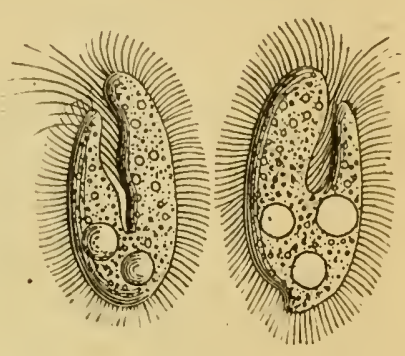

Fig. 88. - Paraisotricha colpaidea (f. Colin).

Paraisotrique ovale (P. ovalis lior., 1890). - Corps ovalaire. Péristome antérieur large, entouré de cils très longs. Noyau avec nucléole, vers le milieu du corps.

Vésicule à concrétions cristallines latérale, produisant une saillie de l'ectoplasme. Longueur 70 \% ; largeur 60 i.

Paraisotrique triangulaire $(P$. triangularis Fior., 1890). - Diffère de la précédente en ce que l'extrémité postérieure est triangulaire. Présente une grosse vacuole contractile en arrière du milieu, Longueur 90 u. ; lars greur 40 i.

Paraïsotrique Aacon '(P. ampulla Fior., 1890). - Corps en forme de flacon, dont le col est revêtu de cils beaucoup plus longs que ceux du reste de la surface. Noyau latéral. Péristome très petit, terninal. Longueur 110 «; largeur $40 \mu$.

Paraisotrique entaillée ( $P$. incisc Fior., 1890). - Corps arrondi, avec une incision latérale correspondant au péristome. Noyau latéral. Longueur $60 \mu$; largeur $\mathbf{t} 0$ i.

Toutes ces formes habitent le gros intestin des Equidés; la dernière est rare.

IELXIËME SOLS-ORDRE

\section{SPIROTRICIES}

Poujours une zone adurate, consistant d'ordinaire en une nembräne plús ou moins spiralée qui limite en partie ou en totalité un champ péristomien. Souvent, en outre, celui-ci se distingue, pat d'autres particularités, du reste le la surface du corps.

Ce sous-ordre se subdivise en quatre sections : Hétérotriches, Oligotriches; Hypotriches et Péritriches.

fre Section : Hétérotriches. - I la présence d'uné zoné adorale asséz développée et directe, oblique ou spirale, ces formes joignent un retètefinenit ciliaire uniforme et généralement complet.

Genres Plagiotoma, Bulantidium, Bursaria, Stentor, etc.

R.illiet. - Zoologie. 
Famille des BURSARIDÉs. - Corps en forme de bourse, parfois un peu aplati dans le sens dorso-ventral, rarement dans le sens latéral. Le péristome, court et large, suit une ligne directe ou oblique, mais jamais spirale, qui de l'extrémité antérieure du corps s'étend en général du còté droil de la surface ventrale jusqu'à la bouche; il n'est bordé que du còté gauche par les cils adoraux; le bord droit porte aussi parfois une membrane ondulée. (IEsophage nul ou peu distinct.

Cienre Balantidium (Balantidium Claparède et Lachmann, 1858). - Corps ovale ou allongé, à surfaces dorsale et ventrale à peu près également bombées, un peu tronrué en avant, avec un péristome en forme de fente, qui se rétrécit en arrière et ne se dévie que légèrement à droite de la ligne médiane ventrale. Cils adoraux à peine plus longs et plus épais que ceux du corps. Au fond du péristome s'ouvre la bouche, qui se continue par uu court œsophage. Anus terminal. Un noyau ovoïde ou rubanaire. En général, deux ou trois vacuoles contractiles.

Toutes les espèces de ce genre vivent en parasites dans le tube digestif des Vertébrés, et en particulier des Batraciens.

Balantidium du côlon (Balantidium coli [Malmsten]. - Syn.: Paramocium coli Malmsten, 183̈7; B. coli Stein, 1862). - Grand Infu-

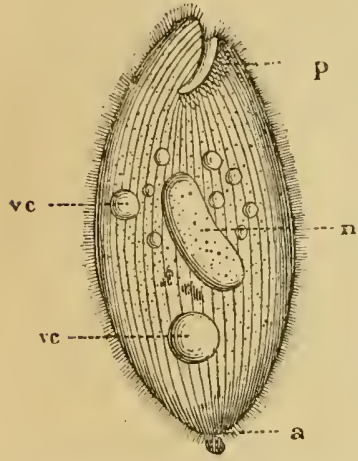

Fig.s9.-Balantirlium coli, d’après Slein. - $p$, péristome. $a$, auus. $n$, noyau. $v e$, vacuoles contractiles. soire, de 70 à $100 \mu$ de long sur 50 à $70 \mu$ de large, de forme ovalaire, à endoplasme finement granuleux, renfermant des gouttelettes de graisse et d'autres corps plus gros, tels que des aliments ingérés et peut-être des masses fécales; à ectoplasme transparent, offrant de nombreuses stries qui vont du péristome à l'extrémité postérieure. Cuticule mince, revêtue de cils implantés dans l'intervalle de ces stries. Au pôle antérieur, légèrement tronqué, un court péristome en entonnoir, naissant d'ordinaire à droite sur la face ventrale et se dirigeant obliquement vers le plan médian; l'extrémité postérieure, très rétrécie, de ce péristome. représentant la bouche, se continue par un court wophage qui traverse l'ectoplasme et aboutit ì l'endoplasme. Noyau elliptique et légèrement incurvé situé vers la face ventrale et dans le voisinage de la ligne médiane; pas de nucléole. Vacuoles contractiles ordinairement au nombre de deux, dont une postérieure presque toujours plus grande; tontes deux oecupant en général le côté droit du corps et ne présentant que des contractions faibles et lentes. Anus au pôle postérieur, ne se distinguant que par la sortie des excréments. - La reproduction a lieu par scission transversale. Wising a observé en outre le début d'un processus de conjugaison, deux individus s'accolant par la région du péristome et se fusionnant en ce point. 
Le Balantidium coli a été découvert en 1830 par le professeur Malmsten, de Stockholm, dans les selles d'un homme qui, deux ans auparavant, avait soulfert d'une violente altaque de choléra, et qui depuis lors se plaignait de troubles digestifs s'accompagnant alternativement de diarrhée et de constipation. Peu de temps après, cet observateur retrouva le même Infusoire dans le ciecum et le côlon d'une femme qui avait succombé à une colite chronique.

Depuis lors, divers médecins l'ont retrouré chez l'Ilomme, dans des cas de typhus, de diarrhée, de dysenterie, etc., tant en Suède qu'en Russie, en Italie, en Cochinchine, etc.

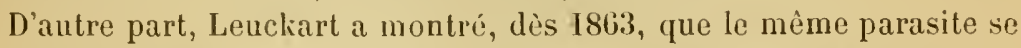
rencontre constamment, et en grande abondance, dans le gros intestin du Porc, en Saxe. Il a été ensuite observé, arec une fréquence variable, dans les différentes parties de l'Allemagne, en Suède, en Italie, en Russie et en France, chez le même animal: à Alfort, nous l'avons trouvé sur tous les Porcs examinés (1886); Neumann l'a vu également à Toulouse.

Perroncito croit en outre l'avoir observé dans des nodules pulmonaires, chez un Mouton, el Brusaferro l'a signalé dans une tumeur du poumon droit d'un jeune Becuf, mais, comme nous l'avons dit plus haut, il s'agit vraisemblablement d'Infusoires de la panse (Isotricha?')

Il suffit, pour le découvrir, de recueillir à l'aide d'une sonde les matières fécales ou les mucosités du rectum, ou bien d'examiner des excréments très récents de Porc. En déblayant ces matières dans un peu d'eau, on distingue, même à la simple loupe, de petits points incolores qui se déplacent en tous sens et ne sont autre chose que les Infusoires. Au bout d'un certain temps, ceux-ci s'arrêtent et se contractent. Les cils du corps disparaissent, puis les cils adoraux et enfin l'épistome lui-même, et le corps se présente sous l'aspect d'une boule de 80 à $100 \mu$, dont l'endoplasme, renferme des gouttelettes graisseuses, et dont l'ectoplasme clair est limité par la cuticule épaissie en forme de capsule. Dans les excréments de Porce en partie desséchés, on retrouve des kystes semblables. Or, les Infusoires ainsi protégés sont doués d'une grande force de résistance aux influences extérieures; ils se dispersent à la facon des œufs d'helminthes, et c'est vraisemblablement à cet état qu'ils pénètrent dans lẹ tube digestif de l'Homme ou des animaux, à la faveur des aliments ou des boissons. Cependant, nous derons dire que Calandruccio et Grassi n'ont pu développer le Balantidium chez l'Homme par l'ingestion de kystes provenant du Porce, ce qui leur fait émettre le soupçon d'une différence spécifique entre les parasites de ces deux hôtes. Déjì Wising arait noté que l'Infusoire atteint chez l'Homme une taille moins considérable $(60$ à $i 0 \mu)$ que chez le Porc.

En tout cas, l'influence pathogénique du Balantidium coli n'est pas encore nettement établie: tout ce que nous pouvons dire jusqu'à pré- 
sent, c'est que, chez le Porc, il vit dans un intestin tout à fait sain, tandis qu'on ne l'a encore vu che\% l'Homme que dans des cas de maladie.

Pour le détruire, on a employé l'acide chlorhydrique dilué, l'acide acétique et le tannin, l'acide salicylique, etc., per os et anum.

2 Section : Olıgotriches. - Corps de dimensions médiocres, peu allongé. Le champ péristomien, situé près de l'extrémité antérieure, est orienté perpendiculairement à l'axe longitudinal. La zone adorale forme un cercle plus ou moins complet. Le revêtement ciliaire du reste du corps est assez variable.

Genres principaux: Halteria, Tintinnus, Ophryoscolex, etc.

Famille des OPHRYOSGOLÉGIDÉS. - Corps de dimensions variables, rigide, à cuticule épaisse : seul, le péristome est rétractile; zone adorale demicirculaire, son extrémité orale s'enfonçant profondément dans la cavité infundibuliforme du péristome. Celle-ci est largement ouverte en avant et se conlinue en arrière par un æesophage peu distinct, recourbé à gauche. Les cils adoraux sont disposés en spirale. En avant du milieu du corps, sur les parties dorsale et latérale gauche, on observe parfois une ceinture ciliaire incomplète (ceinture équatoriale). L'extrémité postérieure porte souvent des prolongements styliformes, recourbés, entre lesquels se trouve l'anus terminal, précédé d'ordinaire d'un court canal.

Genre Entodinion (Entodinium Stein, 1858). — Corps ovoïde, nu, aplati dans le sens dorso-ventral, brusquement tronqué en avant. Ouverture buccale très large, comprenant presque toute la portion tronquée, et entourée d'une spirale de cils épais insérés dans un sillon et descendant dans le pharynx. Pas de ceinture équatoriale. Noyau cylindrique avec un nucléole el placé contre la face gauche du corps. Une vésicule contractile. Endoplasme rempli de débris végétaux.

Entodinion minuscule (Ent. minimum Schub., 1888). - Corps allongé, alténué en arrière el terminé en pointe obtuse, délicatement strié en long. Bord droit régulier ou légèrement concave; bord gauche fortement bombé. Vésicule contractile au milieu de la face dorsale. Longueur 38 „.; largeur $23 \mu$.

Entodinion bourse (Ent. Lursa Stein, 183̈8, pro parte). - Corps assez large, arrondi en arrière, où existe une légère échancrure (vestibule anal), transparent, strié longitudinalement. Vésicule contractile logée à droite du pharynx. Longueur šo ì 114 k; largeur 37 à $78 \mu$.

Entodinion à queue (Ent. caudatum Stein, 183̈8). 一 Ovö̈de; face dorsale légèrement bombée; face ventrale offrant à grauche une cavité en forme de coquille. Le corps se prolonge, du còté gauche de la face ventrale, en un ong appendice caudiforme aplati el un peu recourbé; du còté droit, il forme deux lobes pointus beaucoup plus courls, l'un dorsal, l'autre ventral. Vésicule contractile à droite du pharynx. Longueur $53 \mu$; largeur $26 \mu$.

Entodinion à bec (Ent. rostratum Fior., 1889). - Jiffère surlout de l'Entodinion à queue en ce que le corps n'est prolongé que par un court appendice en forme de crochet. Longueur $60 \mu$; largeur $24 \mu$.

Ces quatre espèces se trouvenl, en médiocre abondance, dans la panse des Bœufs et des Moutons. 
Entolinion valvé (E? valvatum Fior., 1890). - Corps conique, à base anlérieure. P'éristome entouré de cils et recouvert d'une sorte de valvule fixe. Fn arrière, une courome de cils autour de l'anus, qui communique par un court canal avec une grosse vacuole contractile. Longueur $60 \mu$; largenr $20 \mu$.

Gros intestiu des Equidés.

Entodinion bipalmé (E? bipalmatum Fior., 1890). - Corps rectangulaire, déprimé, plıs épais sur un borl que sur l'autre. Cuticule fiıement chawrinée, surtout en avant. Bord droit offrant une bande marquée de zones alternativement trausparentes et opaques, sous laquelle on trouve le noyau ot le nucléolè, puis ö ou 6 vacuoles contractiles. Péristome large, entouré de cils, occupant tont le hord intérieur. Vers la partie postérieure et de clarque crité, une touffe de cils portée par un large pédoncule. Longueur 21 ' is-; largenr $14 \%$.

Très abondant dans le ciecum des Ėquidés. F. Colin l'a représenté sous plusieurs aspects.

fiemre Diplodinion (Diplodinium Schuberg, 1888). - Schuberg a proposé d'élablir ce genre pour les formes qui présentent les caractères généraux des Entodinions, mais possèdent une courome postérieure plus ou moins incomplète de cils (ceinture équutoriule).

Diplodinion bonrse (I). Bursa [Stein]. - Syn. : Entodinium bursu Stein, 1838, pro parte; It. Bursa Fior., 1889). - Corps cordiforme, aplati ; extrémité antérieure tronquée, avec une seule couronne de cils; extrémité postérienre divisée en deux par unc échancrure au fond de laquelle souvre l'anns. Ceinture équatoriale très petite. Longneur $100 \mu$; largeur $60 \mu$.

Panse du Bæuf.

Diplodinion de Maggi (D. Maggii Fior., 1889). - Corps cordiforme ; extrémité antérieure tronquée avec deux couronnes de cils dont la plus grande limite le péristome; à peu de distance de l'extrémité postérieure, une légère échancrure ou vestilsule anal. Ceinture équatoriale très incomplète, incons. lante (?). Très grande espèce: longueur $180 \mu$; largeur 120 $\mu$.

Diplodinion à mamelons (D. mammosum Raill., 1890. - Syn.: D. denlatum Fior., 1889, nec Stein, 1838). - Corps aplati de dessus en dessous, concave-convexe; extrémité antérieure tronquée, avec une seule couronne de cils; extrémilé postérieure à trois lobes mamelonnés. Longueur $100 \mu$; lar geur $48 \mu$.

Diplodinion denté (D. dentatum [Stein, nec Fior.]. - Syn. : Entodinium dentatum Stein, 1838; D. denticulatum Fior., 1889; D. dentatum Railt., 1890). - Corps légèrement incurié dans le sens latéral, divisé par une saillie lonwitudinale en deux zones inégales distinctes; extrémité antérieure tronquée offrant six fortes dentelures recourbées en crochets. Ceinture équatoriale inconstante (?). Dimensions presque égales à celles du 1 . Bursa.

Panse du Bœuf.

Diplodinion à queue en bee (D. rostratum Fior., 1889). - Corps trapu, gibbeux; extrémité antérieure tronquée, avec une seule couronne de cils; extrémité postérieure pourvue d'une courte quene recourbée en forme de bec. Longueur $80 \mu$; largeur $40 \mu$.

Panse du Bœuf.

Diplodinion à crochet ( $D$ ? uncinatum Fior., 1890). - Corps légèrement pyriforme. montrant à la partie antérieure denx couronnes de cils entourant 
deux orifices buccaux (?) qui conduisent à un pharynx unique. Un crochet creux, né du fond de ce pharynx, dépasse l'extrémité antérieure. En arrière, l'anus, entouré de cils, communique par un court canal avec une grosse vacuole contractile. Longueur $90 \mu$; largeur $30 \mu$.

Commun dans le gros intestin des Équidés.

Diplodinion unifaseiculé (D? unifusciculatum Fior., 1890). - Corps couri, un peu anguleux. Cuticule striée en long et obliquement en travers. Péristome sans cils. Un peu en arrière, deux couronnes ciliaires. Extrémilé postérieure offrant latéralement deux groupes de cils. Longueur $230 \mu$, largeur 90 i..

Dans le còlon des Équidés; très rare.

Genre Ophryoscolex (Ophryoscolex Stein, 1858). - Corps trapu, vermiforme, nu et raide, un peu souple seulement à l'extrémilé antérieure, tronqué en avant, arrondi en arrière et terminé souvent par un ou plusieurs appendices styliformes flexibles. Face dorsale fortement bombée; face ventrale avec une élroile sole limitée par deux stries granuleuses. A l'extrémilé antérieure du corps, un organe ondulatoire en forme de manchette, à cils puissants, protraclile et rétractile; à l'extrémité postérieure, au-dessus de l'origine des stylets caudiformes, se trouve l'anus. En avanl du milieu du corps, une ceinture de cils épais, entourant les parties dorsale et latérale (ceinture équatoriale). Sur le côté droit, un noyau elliptique, et sur celui-ci un nucléole arrondi. Quelques vésicules lentement contractiles.

Ophryoseolex de Purkynje (O. Purkynjei Stein, 1858. - Syn. : Diplodinium vortex Fior., 1889). Corps irrégulier, gibbeux, un peu alténué en avant, assez large en arrière. Trois verticilles de stylets très fortement recourbés à l'extrémité postérieure du corps, à l'exception de la face ventrale. Longueur $200 \mu$; largeur $80 \mu$.

Très commun dans la panse des Ruminants, particulièrement du Mouton. - Je crois pouvoir rapporter à cette espèce l'animalcule

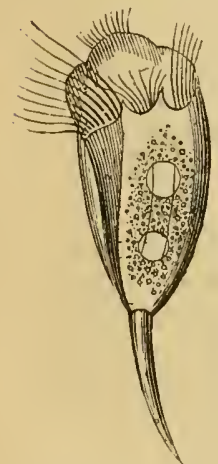

Fig. 90. - Ophryoscolex inermis var. caudatus (G. Colin). que Perroncito a trouvé en 1872 dans des nodules pulmonaires du Mouton el qu'il a décrit comme un Rotifère.

Ophryoscolex inerme $(0$. inermis Stein, 18ä8. - Syn.: Diplodinium ecaulatum Fior., 1889). - Corps allongé, subcylindrique, concave en dessus, convexe en dessous. Anus dans une échancrure de la partie postérieure, qui est arrondie, sans'stylets. Longueur $120 \mu$; largeur $44 \mu$.

Fiorentini décrit à côté de cette espèce, sous le nom de D. caudatum, une forme qui n'en est probablement qu'une variété, car elle n'en diffère que par la présence d'un stylet caudiforme long de $40 \mu$.

Commun dans la panse des Ruminants.

Ophryoscolex de Cattaneo (0. Catlaneoi [Fior.]. Syn. : Diplodinium Cattunei Fior., 1889; O. Cattunei Schuberg, 1893). - Corps allongé, marqué de quelques lignes spiralées; extrémité antérieure tronquée, avec une couronne de cils; extrémité postérieure avec cinq longs prolongements caudiformes, dont un dépassant notablement les autres. Longueur $180 \mu$; largeur $64 \hat{\mu}$.

Panse du Bœuf. 
lienre Spirodinion (Spirodinium Fior., I8901). - Lue rangée de cils disposés en spirale, conlouruant plusieurs fois le corps et entourant le péristome eu arant. Culicule résistante. Noyan allougé et irrégulier. Débris alimentaires daus l'endoplasme.

Spirodinion dn Cheval (Sp. equi Fior., 1890). - Corps oblong; spirale ciliaire déerivant trois tours et se terminant an quart postérieur. Extrémité postérieure du corjus un peu acuminée et montrant par còté l'échancrure anale. Noyau presque central. Cuticule striće longitudinalement. Longueur จ30 $\mu$; largeur $60 \mu$.

Dans le gros intestin des Équidés. Rare.

Genre Triadinion (Triudinium Hior., 1890). - Trois couronnes de cils. Cuticule résistante. Noyau allongé, lyriforme, a vec nucléole. Endoplasme rempli de débris végétaux.

Triadinion ì quene (Tr. caudatum lior., 1890). - Corps arrondi en arant, terminé en arrière par une sorte de queue conique asymétrique. Péristome latéral, entouré d'une couronue de cils. Une seconde couronne en avant. Lne troisième sur le bord opposé au péristome et plus en arrière. A lextrémité de la queue, une touffe de 6 à 8 cils très longs et très fins. Lon= gueur 130 u; largeur $90 \mu$.

Dans le cólon des Equidés. Assez ràre.

Les Infusoires de la panse des Ruminants (1) appartiennent, comme on l'a ru, à des groupes divers. On les rencontre seulement dans les deux premiers réservoirs stomacaux, le rumen et le réseau; ils ne peúrent virre que dans ce milieu spécial et meurent dès que le liquide commence à saltérer ou n'est plus à la température de l'organisme. lls manquent chez les animaux jeunes, encore soumis à l'allaitement, et n'apparaissent qu’à l'époque où les Ruminants se nourrissent exclusirement de subslances régétales (Fiorentini). Certains d'entre eux, tels que les Diplodinium, ont un tégument assez résistant pour qu'on le retrouve dans les derniers réservoirs gastriques et jusque dans l’intestin. En tout cas, le protoplasme est digéré, et, en se basant sur ce fait, Gruby et Delafond ont attribué à ces Infusoires un róle important dans la nutrition. Ces auteurs estimaient que, che\% le Mouton, leur poids total peut atteindre 600 à 1000 grammes. Ajoutons que Certes a signalé la présence du glycogène dans le protoplasme de ces animalcules, qui jouent peut-être un ròle spécial dans la digestion des Ruminants. On peut affirmer cependant que ce sont des commensaux, et non des parasites.

Les mèmes observations peurent sappliquer aux Infusoires du gros intestin des Equidés (2). On les rencontre surtout dans le cæcum et dans les portions antérieures du gros còlon. lls meurent dans les

(1) A. Scuuberg, Die Protoznen des Wiederkauermagens. Zoologische Jahrbücher, III, p. 365, 1888. - ID., Ueber einige Organisationsverhälmisse der Infusorien des Wiederkünermagens. Sitzungsber. der Würzburger Physik-medic. Gesellschaft, 1991. - A. Fonentivi, Intorno ai Protisti dello stomaco dei Bovini. Pavia, 1889.

(2) A. Fronexrovi, Intomo ai r'rotisli dell' intestino degli Éfuini. Pavia, 1890. 
dernières portions de l'intestin, et l'on ne retrouve plus que les débris de leurs carapaces dans les excréments (G. Colin).

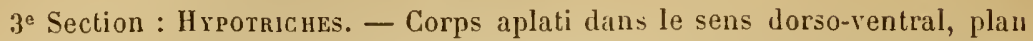
en dessous, convexe en dessus. Champ péristomien large et triangulaire. Zone adorale s'étendant en général de la bouche à l'angle antérieur droit dı péristome. Face dorsale nue ou garnie de séries longitudinales de soies raides, immobiles. Les formations ciliaires servant au mouvement sont limitées à la face rentrale : chez les formes primitives, elles recouvrent cellesci d'un revêtement uniforme; dans les types plus développés, elles constituent de gros appendices en forme de soies, de stylets, de crochets, ete. (cirres).

Citons les Euplotes, les 0xytriches, etc.

$4^{\mathrm{e}}$ Section : Péritriches. - Revètement ciliaire limité à la zone adorale spiralée, ou comprenant en outre une couronne située dans la moitié postérieure de la face ventrale. Bouche tonjours ouverte; œsophage cilié. Vacuoles contractiles dans la région buccale.

C'est it ce groupe que se rattachent les Vorticelles (fig. 86), des eaux stagnantes.

\section{DEUXIËME EMBRANCHEMENT}

\section{SPONGIAIRES}

Animaux à corps massif ou ramifié, mais non rayomé; mésoderme très développé, pas de cavité générale; surface présentant de nombreux. orifices d'entrée (pores inhalants) et des ouvertures d'expulsion (oscules) plus rares et plus larges.

Les Porifères ou Spongiaires (spongia, Éponge) ont été longtemps réunis aux Polypes, sous le nom de Crplentérés; ils ont de commun arec eux, en

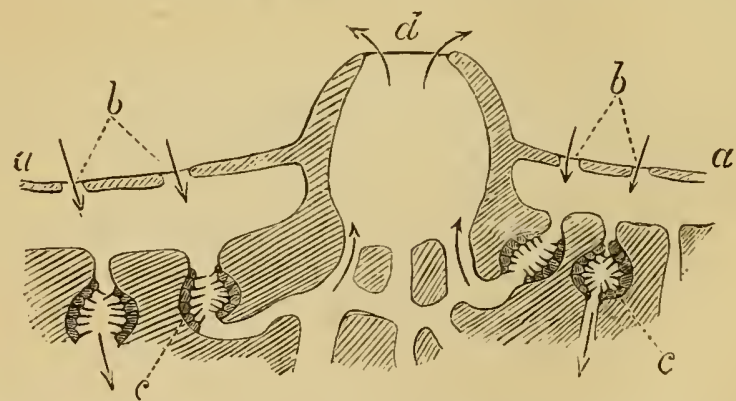

rìg. 91. - Coupe schémalique de la Spongille. $-a, a$, couche superficielle. $b, b$. pores inhalants. $c$, $c$, chambies ou corbeilles ciliées, $d$, oscule. Les flèches indiquent la dircetion des courants (Huxley).

effet, un mésoderme compact, non creusé de cavité propre (acœlomates:. Mais ils s'en distinguent par leur corps non rayonné, leur ectoderne dépourvu de nématocystes ou cnidocils, et leur mode de développement. 
l.a forme li plus simple l'une Eponge est celle d'une urne fixée par li base. Lintéricur de cette urne constilue ce qu'ou appelle la carité gastrique, bien que ce ne soit guère en somme qu'un réservoir d'expulsion; la communication avecl'exterieur's'établit au moyen de nombreux petits canaux (canaur "fférents) dont est percée la paroi, et d'un large orifice (oscule) situé au pòle libre. la paroi se compose de trois couches : $1^{\circ}$ un éctoderme formé d'une seule assise de cellules polygonales portant un cil unique; $2^{\circ}$ un endoderme compreuant de mème une seule assiso collulaire dontles éléments sont pourvus d'un Inng lligellum ontouró l'une colleretle, et ressemblent ainsi, l'une faron

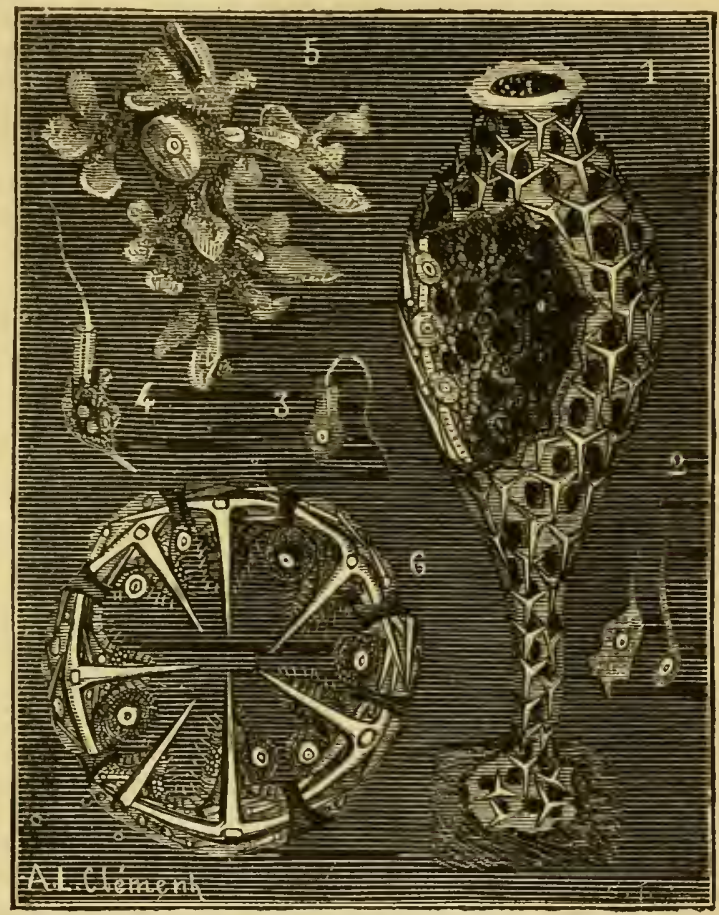

Figg. 92. - Eponges calcaires, d'aprẻs Perrier. - 1. Olynthus primordialis Haeckel, type do l'individu spongiaire. 2, éléments mâles du mèue. 3, 4, ccllulẹs flagellifères du mène. 5 , cellule amiboïde eon-idérée comme un auf. 6, conpe trausversale d'un A scaltis Geganbauri, monlrant la couche amiboïte los spicules, les oufs et la couche de cellules flagellifères.

étonnante, à certaines formes d'Infusoires llagrellés; $3^{\circ}$ un mésoderme, formé d'éléments très divers, et constituant en somme un parenchyme dans lequel $\therefore$ développent souvent des productions squelettiques : fibres cornées, spi'ules siliceux ou calcaires.

Les cellules i collerette de l'endoderme peuvent disparaitre de la cavité centrale; on les retrouve alor's dans les canaux afférents ou seulement dans des dilatations sphériques de ceux-ci, auxquelles on donne le nom de corbeilles vibratiles. Les cellules flarellées, attirent l'eau dans l'intérieur de l'Éponge: cette eau, arec les particules alimentaires qu'elle contient, entre par les orifices extérieurs des canaux afférents (pores inhulints), qui repré- 
sentent autant de bouches, et sort par l'oscule, qui joue ainsi le ròle d'orifice exhalant ou de cloaque.

A côté de ces formes simples, dont on doit chercher le type parmi les Éponges calcaires, on voit se manifester de nombreux degrés de complication, dus en grande partie à la formation de colonies. Celles-ci résultent du bourgeonnement des Éponges simples ou de la réunion de plusieurs individus primitivement isolés. Dans ces conditions, les diverses cavités centrales s'anastomosent et le système des canaux devient très compliqué; quant aux oscules, tantôt ils demeurent distincts, tantòt ils se confondent ou disparaissent en partie, et c'est ainsi que se forment ces Éponges irrégulières dans lesquelles il est impossible de distinguer les individus composants.

La reproduction est surtout asexuelle, et s'effectue alors, soit par division, soit par bourgeonnement interne (gemmules) ou externe. Mais la reproduction sexuelle s'observe en outre chez tons les Spongiaires; les œufs, comme les spermatozoïdes, sont formés par des cellules amiboïdes du mésoderme. La plupart des espèces paraissent être monoïques, mais les éléments màles et femelles n'arrivent pas en mème temps à maturité.

Toutes les Éponges sont marines, à l'exception des Spongilles. Les débris fossiles apparaissent dès l'époque silurienne, mais c'est surtout dans la craie qu'ils abondent.

2 sous-embranchements :

I. Calcisponges. - Squelette formé de spicules calcaires. - Genres Ascetta, Ascaltis, Sycetta, ete.

II. Silicosponges. - Squelette contenant des spicules siliceux, ou de la spongine, ou nul. - Genres Euplectella, Halisarca, Spongilla, Euspongia, etc.

La famille des SPONGIDÉS, qui appartient à ce second groupe, est surtout caractérisée par son squelette, qui est formé d'un réseau de fibres cornées toujours lépourvues de spicules. Elle fournit les Éponges usitées en chirurgie et dans l'économie domestique.

On les pêche surtout dans la Méditerranée, sur la côte de Syrie, dans l'Archipel grec, aux environs de Tunis, etc. Certains pêcheurs se servent du trident, les autres plongent. Pour livrer les Éponges au commerce, on les dépouille d'abord, par des lavages, de la matière animale qui enveloppe le réseau fibreux, et des impuretés qu'il ren-

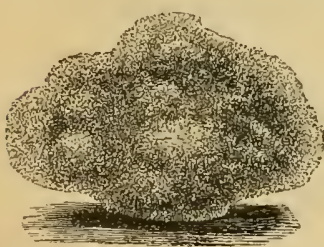

Fig. 93. - Éponge de Dalmatie fine.

f'erme; on en détache ensuite les corps solides adhérents en les frappant légèrement avec un maillet; on les baigne même dans de l'eau acidulée pour enlever les sels calcaires, puis on les lave de nouveau, et souvent on les soumet à l'action du chlore atin de les blanchir.

Les espèces les plus usitées sont : Éponge équine (Hippospongia equina O. S.), ou Eponge commune, assez grossière, à tissu dense, creusé de larges cavités; elle sert aux usages domestiques et est employée pour le pansage des chevaux. Eponge fine douce (Euspongia mollissima 0. S.), de Syrie, en forme de coupe; elle est réservée 
pour la toilette et la chirurgie. Eponge du Zimokika (E. Zimocca O.S.), Éponge de Dahnatie (E. adriatica 0 . S.), etc. Actuellement, on trouve aussi dans le commerce quelques variétés qui proviennent des mers d'. Amérique.

Usages midico-chimergicnux. - En médecine, on a longtemps emplové les liponges à titre de résolutil, surtout dans le traitement des serofules et du goiltre. 1)'ordinaire, on les réduisait en poudre après torréfaction, et on les administrait sous cette forme. Leur's propriétes itaient dues sans doute à la présence de liode.

En chirurgie, l'Éponge est utilisée comme moyen dilatant, après aroir été. préparée à la cire, à lia gomme ou ì la ficelle.

Pour préparer l'Éponge i la cire, on la coupe en tranches qu'on plonge dans de la cire vierge fondue, et qu'on presse ensuite entre deux plaques de ler, de manière à les empècher de reprendre leur forme primitive. On découpe alors ces tranches en étroites lanières, destinées ì être introduites dans les conduits fistulcux. La chaleur de la plaie ramollit la cire, et l'Éponge, obéissant à son élasticité, dilate la fistule; mais la présence mème de cette cire empêche l'absorption des liquides ambiants.

L'Éponge à la gomme se prépare à peu près de la mème manière; les tranches sont imprégnées de gomme, puis pressées dans du papier ciré jusqu'à dessiccation. Elle présente d'ailleurs les mêmes inconvénients et n'est que rarement usitée.

On préfère en général l'Éponge à la ficelle. Pour la confection de celle-ci, on choisit une Épong̈e régulière, qu'on divise au besoin en fragments cylindriques, et, après a voir humecté chacun de ces éléments, on les serre très étroitement avec une ficelle câblée, de façon que les tours ne laissent entre eux ancun intervalle; puis on fait sécher à l'étuve. Quand on veut s'en servir, on enlève la ficelle, et on régularise la surface à l'aide d'un instrument tranchant. Cette Éponge offre l'avantage d'absorber le pus et par conséquent de nettoyer la plaie tout en la dilatant.

\section{TROISIEME EMBRANCHEUENT}

\section{POLYPES}

Animaux à corpls rayonné; mésoderme tiès réduit, pas de cavité gínérale; ectoderme pourvu de nématocystes; cavité digestive se contimuant l'ordinaire avee des canaux ereusés dans la paroi du corps (cavité gastrovasculaire), et s'ouvrant par un seul orifice (bouche) entouré de tentacules préhenseurs.

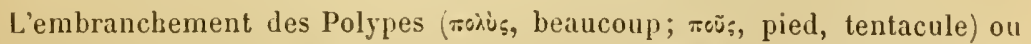
des Cnidaires (avidr, ortie) correspond aux Coelentives proprement dits. Il 
comprend des animaux dont la symétrie radiaire est en général bien évilente, quoiqu'elle pnisse ètre dans certains cas altérée par des irrégularités d'accroissement, et passer même à la symétrie bilatérale. Les organes équi. ralents disposés autour de l'axe du corps (antimères) sont d'ordinaire au nombre de 4 ou de 6 , ou de leurs multiples.

Ln Polype peut ètre décrit schématiquement comme un sac charnu à double paroi, dont la cavité représente l'appareil digestif, l'ouverture servant à la fois de bouche et d'anus. La paroï externe est l'ectoclerme, la paroi interne l'endoderme, et entre les deux se développe une autre couche tissulaire plus ou moins épaisse, constituant le mésoderme. L'orifice buccal est le plus souvent entouré de tentacules, appendices creux en communication directe avec la cavité interne. Celle-ci doit élaborer un liquide nourricier qui se mélange à l'eau venue de l’intérieur et pénètre fréquemment dans un système de diverticules latéraux ou de canaux creusés dans l'épaisseur du corps. L'ensemble de cet appareil est désigné sous le nom de système gastro-vasculaire.

Un autre caractère important du groupe repose sur la présence, daus l'ectoderme, de cellules urticantes ou enidoblastes. Chacune de ces cellules développe dans son intérieur une capsule à paroi élastique (nématocyste) contenant un liquide irritant et un long filament replié sur lui-mème ou enroulé en hélice (cnidocil), dont la base se continue avec la paroi de la capsule, tandis que l'extrémité est libre. Le moindre attouchement provoque la sortic brusque du cnidocil, et l'extrémité libre de celıi-ci déverse le venin dans la petite plaie qu'elle a produite. Beaucoup de Cnidaires déterminent une violente urtication sur la pealı de l'Homme, et leur piqùre amène la mort rapide Jes petits animaux qui leur servent de proie.

La reproduction asexuelle, très répandue, donne lieu souvent à la formation de colonies. Quant à la reproduction sexuelle, on la constate en oulre ‘lans toutes les formes, les sexes étant réunis ou plus souvent séparés.

Enfin, le développement est rarement direct. La plupart des Cnidaires naissent sous la forme d'une larve ciliée ou planule, qui doit subir des métamorphoses plus ou moins profondes pour acquérir l'organisation et la forme rayonnée de l'adulte.

Presque tous les animaux de cet embranchement sont marins : ils sont tantòt libres, tantòt fixés; un très petit nombre vivent dans les eaux donces. 3 classes :

Symétrie ( Cavité à cloisons multiples..... Coralliatres. unultiradiaire. Gavité simple ou à 4 cloisons.... HYdnonéneses.

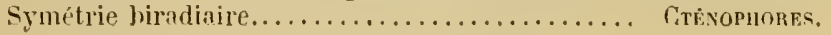

CLASSE I

\section{GORALLIAIRES}

Polypes fixés à l'âge adulte et munis d'un tube resophagien suspendu dans la cavité du corps, laquelle est divisée en loges par des cloisons rayonnantes (mésentéroïdes).

Les Colentérés qui composent cette classe recoivent encore le nom d'An- 


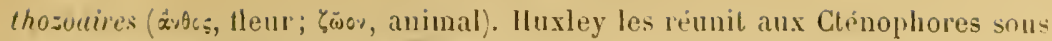
celui d'Actinozoaires (áx-ín, rayon).

Ce sont des Polypes au sens propre du mol. Ils ont la forme d'un sac cylindrique fixé par son fond et dont l'unique ouverture (bouche), situéc ì l'extrémité libre, est entourée d'une ou de plusieurs couronnes de tentaculecrenx. Cet orifice domne entrée dans un conduit a'sophagien dont l'extrémité inférieure, parfois susceptible de se fermer, débonche dans la caviti du corps ou carilé gastro-rasculaire. Celle-ci n'est pas simple, commo dans les Polypes de la classe suivante : elle se montre divisée, a la faron d'une capsule de parot, par des cloisons charnues incomplètes septums) qui naissent de la paroi et se dirigent vers le centre. A la partie supérieure, ces cloisous séparent les points d'origine des tentacules, ot leur bord interne s'unit au tube usophagien; sur le reste d. leur longueur, ce bord demenr. libre. Elles divisent donc lil cavité du corps en un certain nombre de loges périphériques qui se prolongent chacune dans un tentacule, et communiquent en outre assez souvent arec un système de viaisseaux ramifiés dans la paroi du corps. La partie libre de chaque cloison est connue sous le nom de mesenteroüde; elle porte d'ordinaire, le long de son bord, un corilon très flexueux appelé cutèroüde, garni de nématocystes et de cellules glandulaires.

La paroi du corps présente trois couches : un cetoderme

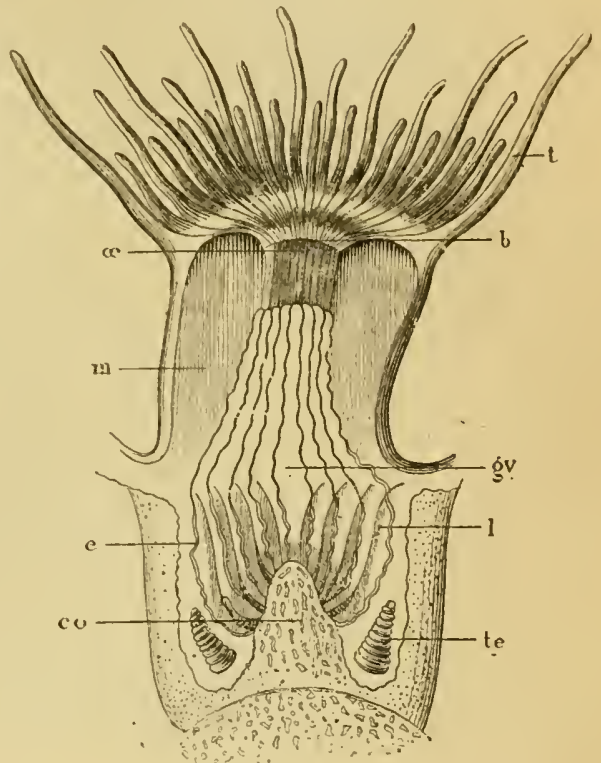

Fig. 9.. - Islivites culycularis, - t, lenlacules. b. or fice buccal. oP, tube cesophagien. go, cavité gastro-vacculaire. $m$, clojions charmues (mésentéroïdes) portant les entéroïles. $l$, lames calcaires émances de la muraille. co, columelle. e, culéroïles, te, testieules 1lacazeDutlier'sl.

comprenant des nématocystes et des cellules glandulaires qui sécrètent des mucosités visqueuses; un endolerme ì cellules ciliées lapissant la carilé centrale et le système des cananx; enfin, un mésoderme formé d'une substance conjonctive dans la(juelle se montrent des fibres musculaires.

A l'exception des Actinies et les Cérianthes (Malucodermés), lous les Coralliaires sont pourrus de formations squelettiques (Sclérodermés), qui prennent naissance dans le mésoderme et constituent ce quon appelle un polypier. Le squelette est parfois corné, mais plus souvent calcaire; chez les Madréporaires, il est constitué par des plaques denses de matière calcaire qui envahissent la base et les parois latérales du corps, de sorte qu'il représente plus ou moins exactement une coupe à lames rayonnantes, à laquelle on donne le nom de calice. La paroi de cette coupe est dite muraillc (theca). Des lames calcaires qui en émanent et se dirigent vers le centre divisent la cavité 
en un certain nombre de chambres, qu'il ne faut pas confondre avec les loges du polype : chaque lame du polypier est en effet située entre deux mésentéroïdes, et par suite chaque chambre correspond à deux deni-loges. Quelquefois on observe au centre du calice une colonne calcaire, la columelle, et mème, autour de celle-ci, une couronne de colonnes secondaires, les palis. Les faces latérales des lames peuvent émettre de minces baguettes calcaires (synapticules) ou des tablettes horizontales (dissépiments). Enfin, il existe sonvent, en dehors de la muraille, des lames verticales appelées côtes, lesquelles sont anssi, dans certains cas, réunies par des dissépiments.

Quand les Coralliaires sont groupés en colonies, ce qui est la règle, les polypes penvent être distincts ou communiquer entre eux par des canaux pariétaux, de telle façon que les aliments absorbés par l'un des individus servent à la nutrition de l'ensemble. La substance molle qui unit les polypes est alors appelée sarcosome; la substance calcifiée qui joint les polypiers élémentaires est dite cunenchyme : un cœnenchyme revètu de sarcosome est un soanthodème (Lacaze-Duthiers).

Les fonctions des Coralliaires sont peu connues. Les tentacules constituent des organes de tact et de préhension : ils se rétractent quand on les touche, et si une proie vient à passer à leur portée, ils la saisissent pour l'entrainer dans le tube œsophagien, d'où elle lombe dans la cavité gastrique. Les produits de la digestion, mélangés d'eau de mer, circulent le long des parois de la cavité, ainsi que dans les canaux pariétaux, sous l'action des cils vibratiles, et sont absorbés par la membrane endodermique. Quant aux aliments non digérés, ils sont expulsés par la bouche, qui joue par conséquent le ròle d'anus. - Il n'existe pas d'appareil spécial pour la respiration, et la présence d'un système nerveux n'a pas encore été positivement établie.

C'est la reproduction asexuelle, par scissiparité ou par bourgeonnement, qui doune lieu à la formation de colonies. Mais il y a en outre production d'éléments sexuels dans les mésentéroides: les sexes sont le plus sourent séparés, et les colonies peuvent être monoïques, dioïques ou polygames.

Les premières phases du déreloppement n'ont été suivies que dans un petit nombre d'espèces. En ce qui concerne la formation des tentacules et des lames calcaires, les recherches de Lacaze-Duthiers ont démontré qu'elle est loin d'offrir la régularité schématique qu'on lui attribuait depuis longtemps.

Tous les Coralliaires sont marins; ils abondent surtout dans les régions chaudes. Un grand nombre vivent en société, surtout au voisinage des còtes, et l'accumulation progressive de leurs squelettes calcaires donne lieu à des sortes de rochers immenses dits récifs de polypier's (coral-r'eefs). La zone dans laquelle se rencontrent ces récifs ne dépasse guère le $30^{\text {e }}$ degré de latitude nord et sud; les mers oì ils sont le plus répandus sont l'océan Indien, l'océan Pacifique et la mer des Antilles. Darwin a reconnu que la formation de ces polypiers est parfois très rapide : un vaisseau qui avait coulé à fond dans le golfe Persique était recouvert au bout de vingt mois d'une couche de polypiers épaisse de 2 pieds. Aux époques géologiques antérieures à la nôtre, les Coralliaires ont joué un rôle plus important encore dans la formation des terrains.

Les espèces rivantes composent deux ordres. 
f.r ORnRE: Alcyonaires ou Octactiniaires. - Corulliaires poureus de huit loges et de huil tentacules it bords dentelis.

Liespèce la plus intéressante de ce groupe est le Corail rougre (Corallinm rubrum Lamouroux, I816), de la Méditerrance el de l'océan Atlantique. Longrtemps le Corail a citi pris pour une plante : c'est seulement en 172̈ qu’un médecin de Marseille, Peyssonnel, en a reconuu la nalure animale.

On en recueille sur les cites d." lirance, d’ltalie, du Sénégal, mais la pêche la plus imporlante a lieu le lons de la cotte de Barbarie, aux environs de Bine et de la Calle. Le Corail se fixe el se déreloppe ì la face infirimure des rochers, et on se sert pour l'atteindre de filets particulicrs, les fanberts. suspendus à une croix de bois qu'on traine ḋ l'aide d'un câble. Ce sont surtout des Italiens et des Espazrnols qui se livrent à cotte pèche ex-

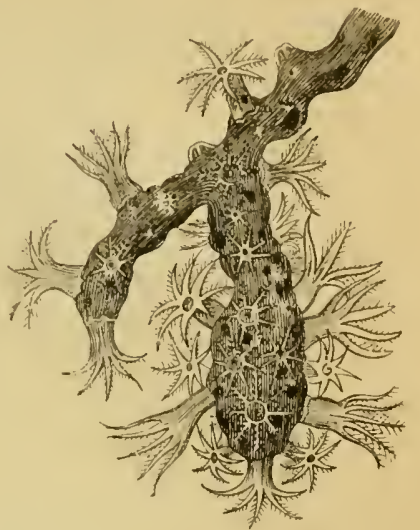

lig. 95. - Estrinité d'une branche de Corail rouge (Corallitm rubrum), de grandeur naturelle, avec les polypes épanouis (Lacazc-1)ulliers). trèmement pénible (1). Toutefois, on commence à substituer arantageusement à ces procédés grossiers l'emploi du scaphandre.

Le Corail était autrefois employé en médecine comme tonique et absorbant; on ladministrait sous forme de poudre, de bol, d'électuaire, etc. On ne sen sert plus aujourd'hui que pour la confection de certains dentifrices.

Voici, d'ailleurs, quelle est sa composition, d’après une analyse de Tischer, faite à la demande des frères Canestrini :

\begin{tabular}{|c|c|c|}
\hline & $\begin{array}{l}\text { Corial } \\
\text { rouge. }\end{array}$ & $\begin{array}{l}\text { Corail } \\
\text { noir: }\end{array}$ \\
\hline Carbonate de chaux, .................. & $86,97 \mathrm{t}$ & $85,80 \mathrm{I}$ \\
\hline Carbonate de magnésie.................. & 6,804 & $6 ; 770$ \\
\hline sulfale de chaux $\ldots . \ldots \ldots \ldots \ldots \ldots \ldots \ldots \ldots \ldots \ldots \ldots$ & 1,271 & 1,100 \\
\hline 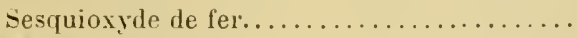 & 1,720 & 0,800 \\
\hline Matiere organique................... & 1,350 & 3,070 \\
\hline 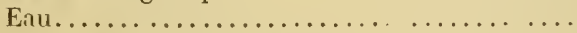 & 0,550 & 0,600 \\
\hline \multirow{2}{*}{ 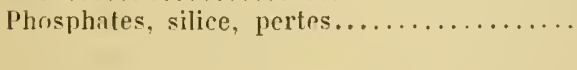 } & 1,331 & $1,5.59$ \\
\hline & $\overline{100,000}$ & 100,000 \\
\hline
\end{tabular}

La coloration rouge du produit a été attribuée à l'oxyde de fer; cependant, Guibourt fait remar fuer avec quelle facilité elle disparait sous diverses influences pour se reproduire au contact de l'air, ce qui ne répond pas à cette manière de voir. La chaleur, les corps gras, les cataplasmes, etc., suffisent ì faire blanchir les objets de

(1) II. LaC.ne-Ditufres, Histoire naturelle du Corail. Paris, 1864. 
corail. Du reste, sur des échantillons naturels, la coloration peut varier du rouge vif au rose pâle et mème au blanc le plus pur. Quant au corail noir, il résulte d'une altération: si des rameaux brisés, par exemple, tombent sur les fonds, leurs polypes se putréfient et l'acide sulfhydrique qui se dégage noircit le polypier.

2 ORdre: Zoanthaires ou Hexactiniaires. - Coralliaires pourvus de tentacules non dentclés ot de loges au nombre de 6 ou d'un multiple de 6 .

A ce groupe appartiennent les Antipathes, les Actinies ou Anémones de mer, les Madréporaires.

Le polypier des Antipathes était désigné dans la vieille pharmacupée sous le nom de corail noir; il était recommandé, on ne sail

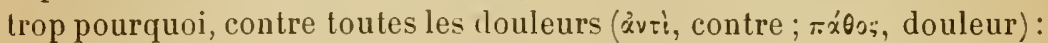
on doit éviter de le confondre avec la variété noire du Corail rouge. - Quant au corail blanc, il était fourni par divers Madréporaires, notamment par l'Oculina virginea Lmk., de l'océan Indien.

Parmi les Actinies, nous citerons le Cul d'Ane (Actinia equina), de teinte pourpre ou verte, à surface lisse, et le Cul de Mulet(A. coriacea), à surface verruqueuse, qui se mangent sur les coites de France.

\section{LL.ASSE II}

\section{H Y D R OMÉDUSES}

Corlentèrés fixés ou nageurs, sans tube wsophagien interne; à cavité gastro-vasculaire généralement simple et se continuant avec des canaux périphériques. En général deux formes: l'une cylindrique (polypoïde), agame, l'autre campanulée (médusoïde), scxurc.

Les animaux qu'on éludie aujourd'hui sous les noms d'Hydro-Méduses, Polypo-Méduses, etc., étaient autrefois rangés dans deux groupes différents, celui des Polypes et celui des Méduses, suirant qu'on les étudiait dans leur premier état ou sous leur forme sexuée. C'est en 1837 seulement que le pasteur norvégien Nichaël Sars attira l’attention sur la parenté de ces denx formes.

la plupart des Hydroméduses, en effet, passent d'abord par l'état de Polype, et celui-ci donne naissance, par roie agame, à la forme sexuée que représentent les Méduses.

Lélément fondamental du groupe est done le Polype hydraire ou hydrule. Il s'agit d'un sac cylindríue dont l'extrémité ouverte est lıabituellement untourée de tentacules pleins, grèles et contractiles; entre ces tentacules se montre souvent un cône percé à son extrémité : c'est le tulbe œsophagien qui, au lieu d'être suspendu à l'intérieur de la carité centrale comme chez les Coralliaires, fait au contraire saillie à l'extérieur. Quant à cette carité gastro-rasculaire, elle est simple ou plus rarement divisée en quatre logeses par des cloisons. - Presque jamais il n'existe de squelette calcaire, et les 
formations solides qu'on peut observer consistent en de simples revêtements chitineux d'origine ectodermique.

Les formes sexuées, bourgcons médusoïdes ou Mérluses, qui le plus souvent sont issues de l'lyydrule, ont une organisation complexe; les dernières mènent d'ailleurs une existence indépendante. Une Méduse se présente en effet sous la forme d'une cloche gélatincuse et transparente, qui recoit le nom d'ombrelle et dont le bord offre (Craspédotes) ou non (Acraspèdes) un velum ou rebord musculo-membraneux. Au fond de cette cloche et suspendu à la façon d'un battant, se voit un sac étroit, le mamubrium ou tube cesophagien, percé d'une bouclıe ì son extrémité libre. Ce manubriun, qui n'est autre que lappareil digeslif de la Méduse, se continue par sa base avec plusieurs canaux rayonuants; ceux-ci sont réunis entre eux, à la périphérie, par un canal circulaire qui court le long du bord de l'ombrelle. Sur ce bord existent presque toujours des corpuscules marginaux, représentant des taches oculaires munies ou non de corps réfringents, et des vésicules auditives; en outre, des tentacules qui flottent d'ordinaire à la périphérie constituent des organes de tact. Les organes des sens sont innervés par un cordon annulaire qui accompagne le canal périphérique.

Les organes sexuels consistent en des amas cellulaires développés dans la région orale de la paroi du corps et se transformant en oufs ou en spermatozoïdes. En général, les sexes sont séprarés. La Méduse, comme nous l'avons dit, nage librement: pour cela, elle contracte son ombrelle, chasse l'eau et s'avance ainsi par saccades, le plus souvent dans une position inclinée.

Les Hydroméduses se nourrissent pour la plupart de substances animales. On les rencontre surtout dans les mers chaudes.

3 ordres : Hydroüdes, Siphonophores, Acalephes.

$1^{\text {er }}$ ordre : Hydroïdes. Hydroméduses ordinairement réunics en colonies ramifiées et fixées; forme médusaire craspédote.

Les Polypes qui représentent la génération agame de

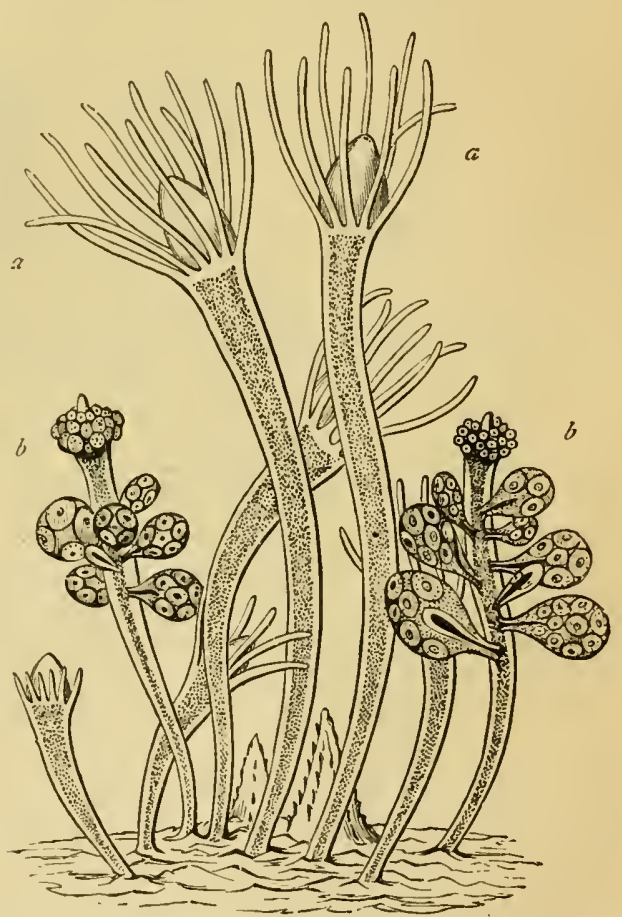

Fig. 96. - Fragment amplifié d'une colonie de Synhydraires (Hydractinia echinata), d’après Hıncks, $-a, a$, individus nourriciers ou gastrozoides. $b, b$, individus reproducleurs ou gonozoides, portant des sacs remplis d'œurs. ce groupe ne sont presque jamais solitaires (Hydres); ils vivent au contraire en petites colonies ramifiées, qui résultent du bourgeonnement d'une larve ciliée issue de la forme sexuée ou médusoïde. Ces colonies sont en général 
fixées par des sortes de stolons qui rampent sur les corps solides; au premier abord, elles ressemblent assez bien à de petites plantes. Bientôt elles donnent naissance à des bourgeons médusoïdes, dans lesquels se forment les éléments sexuels, et leur constitution se montre alors très complexe. Souvent elles sont soutenues par des tubes cornés (périsarque) que sécrète l'ectoderme.

En somme, une colonie d'Hydroïdes se compose de deux sortes d'individus ou mieux de zooïdes, les uns nourriciers, les autres reproducteurs.

Les zooides nourriciers peuvent varier quant à leur organisation et au ròle qu'ils ont à remplir; les uns, par exemple, possédant une bouche et des tentacules, sont chargés de nourrir la colonie (gastrozoïdes); d'autres, privés de ces organes, ont pour office de saisir les proies au passage (dactylozoïdes), etc. Il en est même qui sont réduits à l'état d'appendices épineux et constituent de simples organes protecteurs.

Quant aux zoö̈des reproducteurs (gonozoïdes), ils représentent tantòt des Polypes analogues aux précédents, mais porlant sur leurs parois des bourgeons sexués ou gonophores, tantòt ces bourgeons eux-mêmes développés directement sur les stolons. - Les gonophores, qui parfois demeurent fixés à la colonie (bourgeons médusoïdes), et d'autres fois se détachent pour vivre

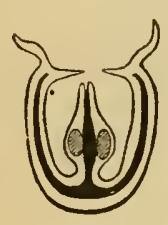

$d$

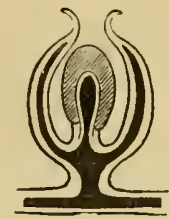

$c$

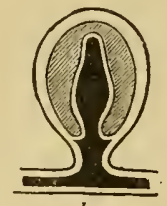

$b$

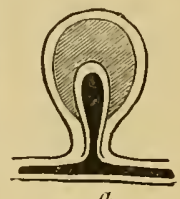

$a$

Fig. 97. - Reproduction des Hydroïdes. - $a$,[sporosac. $b$, bourgeon médusoïde déguisé. $c$, bourgeon médusoïde. $d$, médusoïde libre. Les parties ombrées indiquent les organes reproducteurs. Les parties noires représentent la cavité du manubrium ct les canaux rayounants (Huxley).

isolément (Méduses), offrent des degrés divers dans leur organisation, mais peuvent ètre ramenés à deux formes principales. La première est celle d'un sac ovoïde clos, ou sporosac, renfermant à son intérieur un diverticule de la cavité gastro-vasculaire des Polypes : c'est autour de ce cul-de-sac ou spadice que se développent les éléments sexuels. Dans la seconde forme, le sac est ouvert, et présente la forme d'une cloche: on lui donne le nom de médusoïde. Au degré le plus élevé de son organisation, cette médusoïde est pourvue à son centre d'un pédicule creux ou manubrium et possède un système de canaux gastro-vasculaires rayonnants; les produits sexuels se développent dans les parois de l'une ou de l'autre de ces deux parties. Dans ces conditions, les médusoïdes se détachent le plus souvent de la colonie et constituent alors de petites Méduses qui nagent librement: on leur donne le nom de Méduses hydroides pour les distinguer des formes du groupe des Discoméduses ou Méduses Ephyra. L'ouverture de leur ombrelle est rétrécie par un velum circulaire et leurs corps marginaux sont à nu.

2 sous-ordres: Hydraires (isolés) et Synhydruires (en colonies).

Au premier de ces groupes appartiennent les Hydres (Hydra), qui comprennent plusieurs espèces, dont trois habitent nos eaux douces: l'Hydre verte (H. viridis), l'Hydre brune ou aux longs bras $(H$. fusca) et l'Hydre grise (H. vulgaris ou grisea). Ce sont de petits Polypes allongés, fixés souvent, par 
exemple, à la face inférieure de nos Lemna ou Lentilles d'eau. L'extrémité libre offre un orifice buccal entouré de plusieurs tentacules riches en nématocystes. Ces ètres se reproduisent par bourgeonnement sur les parois latérales (fig. 32 et $98, c$ ), mais la reproduction sexuelle s'observe aussi : des
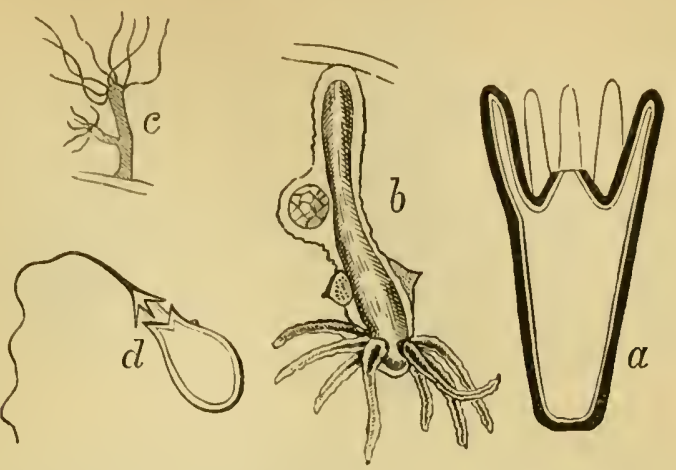

rig. 98. - Morphologie des Hydroïłes, d'après Husley. - a, coupe schématique d'nne Hydre : l'ectoderme est représenté par la ligne épaisse, l'endoderme par la ligne fine et l'espace clair adjacent. $b$, Hydra viridis, montrant un ceuf isolé contenu dans la paroi du corps, et au-dessous, près de la base des tentacules, deux élévations contenant des spermatozuïdes. $c$, Hydra vulgaris, avec un bourgeon non détaché. $d$, nématocyste fortement grossi, avec le filament déroulé.

spermatozoïdes et des œufs se forment dans des proéminences de la paroi du corps, probablement aux dépens de l'ectoderme. D'ordinaire, les testicules apparaissent au voisinage des tentacules; les ovaires sont plus rapprochés de la base du corps (fig. 98, $b$ ). Dans chacun de ces ovaires se forme un œuf qui s'entoure d'une coque épineuse. - Les Hydres ont une remarquable puissance de rédintégration : si on les coupe en plusieurs fragments, chacun de ceux-ci reproduit un animal entier. Enfin, tout le monde connait la curieuse expérience de Trembley, consistant à retourner ces Polypes à la façon d'un doigt de gant : l'animal retourné continue à vivre et à digérer.

$2 \mathrm{c}$ ordre : Siphonophores. - Hydroméduses en colonies polymorphes, flottantes ou nageuses, soutenues par une lige creuse.

Ce groupe, auquel se rattachent les Physophores, les Physalies, les Vélelles, etc., est surtout remarquable par le polymorphisme des individus composant la colonie, et par la division du travail qui se trouve liée à cette condition.

Les Siphonophores sont des animaux pélagiques, très urticants et par suite très redoutés des baigneurs. On cite principalement, à cet égard, la Galère (Physalia pelagica), de l'océan Atlantique, qui provoque une sensation de cuisson intolérable. - D'autre part, on a considéré la chair de cet animal comme toxique; mais cette croyance ne parait pas être justifiée.

$3^{\text {e }}$ ordre: Acalèphes. - Méduses acraspèdes, à bords de l'ombrelle découpès en lobes; developpement direct ou par scission transversale d'un individu primitif (scyphistome) habituellement fixé. 
Sans nous arrêter aux Lucernalres, petites Méduses à quatre loges gastrovasculaires peu marquées, et à développenent direct, non plus qu'aux
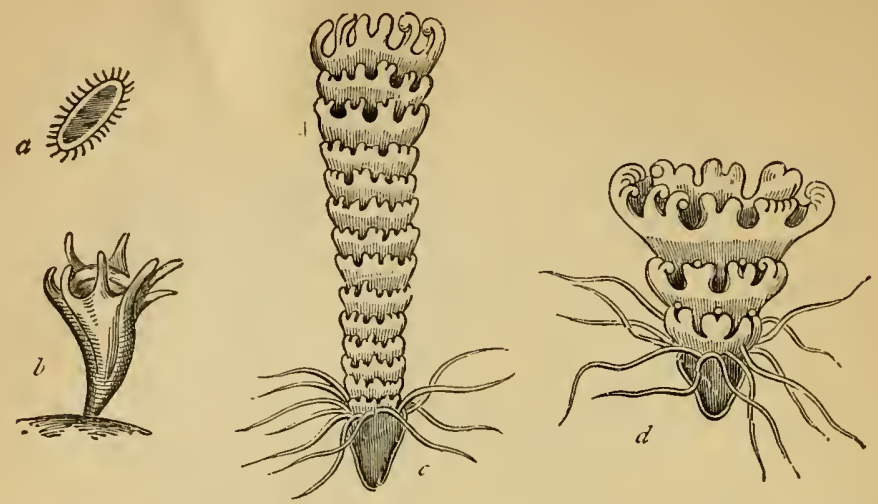

Fig. 99. - Développement d'nne Méduse du genre Aurelia (Huxley). - $a$, embryon eilié nageant libremeut on planule. $b$, forme polypoïde ou Scyphistome à hnit tentacules. $c$. la mème parvenue à l'état de strobile, c'est-à-dire divisée en segments transversaux. $d$, phase encore plus avancée, dans laquelle beaucoup de segments ou proglottis se sont déjà séparés, sous la forme d'Éphyres, pour mener une existence indépendante et arriver ultérieurement à l'état de Mćduses sexuées.

CHARYBdÉEs, pourvues d'un rebord simulant un velum, nous mentionnerons simplement ici les Discoménuses ou Méduses proprement dites. Toujours

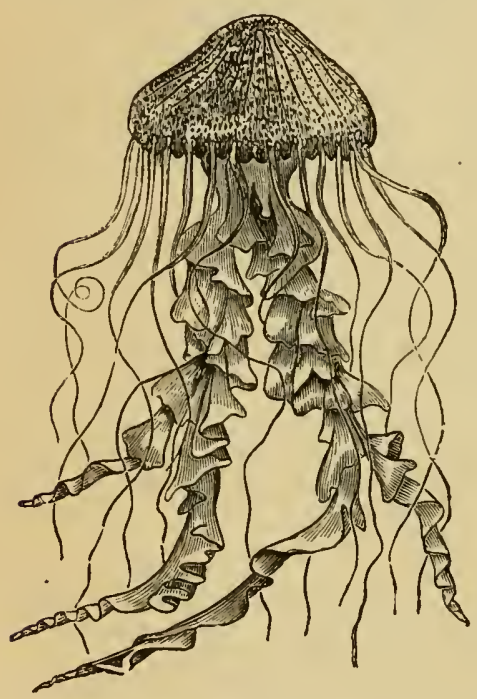

Fig. 100. - Méduse (Chrysaora hyocella) montrant ses quatre bras buccaux et ses fildments marginaux (Gosse).

libres, elles possèdent une ombrelle dont le bord est en général divisé en huit lobes. Les glandes génitales occu- pent d'ordinaire quatre cavités creusées dans l'ombrelle.

Le développement des Discoméduses est souvent signalé comme un des exemples les plus frappants de la génération alternante. De l'œuf fécondé de la Méduse sort une larve ciliée ou planula, qui ne tarde pas à se fixer et à perdre ses cils vibratiles. Une bouche apparaît à son extrémité libre, puis une couronne de tentacules, et l'organisme ainsi constitué, qui représente une jeune Méduse et non un Polype, prend le nom de Scyphistome. Il survient alors, audessous du cercle de tentacules, un étranglement annulaire, suivi d'une série d'autres, qui apparaissent progressivement de haut en bas. Chacun des segments ainsi formés acquiert une couronne de lobes périphériques, tandis que sa partie inférieure non divisée reproduit les tentacules. On a donc une série de petiles Méduses qui adhèrent entre elles par le tube buccal, et cet ensemble constitue un Strobile. Bientôt cependant ces Méduses se détachent de la colonie, en commençant par la première formée : ce sont 
les Méduses Éphyres, caractérisées par les huit lobes bifides de leur ombrelle. Elles mènent une existence indépendante et peu à peu acquièrent la forme et l'organisation des Méduses sexuées. - Chez les Pelagia, la larve ciliée donne naissance directement à nne Méduse.

Parmi les formes les plus connues, on peut citer les Pélagies, les Aurélies, les Cyanées, à bouche centrale cntourée de quatre bras ; et les Rhizostomes, à huit bras buccaux munis de nombreux petits sucoirs.

Les Acalèphes, comme l'indique leur nom ( $\alpha x \alpha \lambda \gamma_{\text {ŕp }}$, ortie), possèdent de nombreux nématocystes et sont des plus urticants. On cite surtout, à ce point de vue, le Rhizostoma Cuvieri Pér. et Les., de la Manche et de l'océan Atlantique, et le Rh. pulmo L., de la Méditerranée, qui souvent incommodent les pecheurs.

Cette propriété a même été utilisée dans un but thérapeutique: à l'établissement thermal de Sandifjord, en Norvège, on traite les névralgies et les douleurs rlumatismales par des applications de Méduse oreillarde (Aurelia aurita L.). On saisit celle-ci par la face convexe de l'ombrelle, qui est inoflensive, et on touche avec la face inférieure les points sur lesquels on veut opérer une révulsion. Cette médication inattendue aurait fourni dans certains cas d'excellents résultats (Spencer Wells).

\section{CLASSE III}

\section{CTENOPHORES}

Colentérés nageur's, à symétrie birayonnée; tube cosophagien suspendu dans la cavité du corps, qui communique avec un système de canaux périphériques. En général huit rangées méridiennes de palettes natatoires.

Les Cténophores (x:ás, peigne; opopó, porteur) sont des animaux marins de consistance gélatineuse, nageant librement, et de forme arcondie, ovoïde, cylindrique ou rubanée. La symétrie est biradiaire et non bilatérale, car si les parties similaires sont disposées de chaque coté d'un plan longitudinal, on ne peut distinguer ni face antérieure ni face postérieure. - La progres. sion est déterminée par l'action de petiles palettes ciliées disposées à la surface du corps suivant huit méridiens : ces palettes résultenl de la soudure partielle de grands cils formant des rangées transversales comme les dents d'un peigne, ce cqui a valu à ce groupe son nom particulier. - La bouche, située à l'un des póles du corps, conduit dans un tube stomacal (œsophase) qui s'ouvre dans la cavité du corps ou entonnoir. D'ordinaire, cet. entonnoir émet, au voisinage du póle aboral, deux branches qui débouchent au dehors par de très petits pores, lesquels, toutefois, ne remplissent jamais le ròle d'anus. Entre ces branches, se trouve un organe cellulaire regardé comme sensoriel et nommé cténocyste. D'autre part, il nait de l'entonnoir deux canaux latéraux (radiaires), qui se divisent bientòt en deux, puis ceux-ci en 
deux autres en se dirigeant vers la périphérie; ces huit canaux radiaires pénètrent finalement dans autant de conduits longitudinaux ou cténophoriques

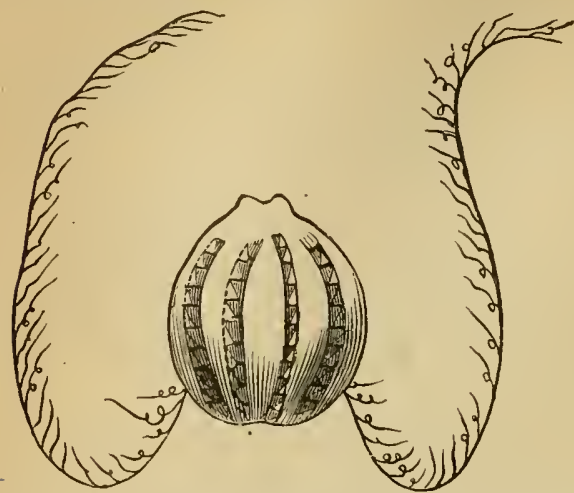

Fig. 101. - Cténophores : P'eurobrachia pileus, d'après Huxley. situés au-dessous des rangées de rames. En outre, l'entonnoir fournit deux canaux qui remontent vers la bouche et se terminent en cul-de-sac : ce sont les canaux paragastriques. Enfin, quand il existe des tentacules, leur cavitó communique aussi avec l'infundibulum : ces tentacules sont rétractiles et chargés de nématocystes modifiés (cellules adhésives).

Les sexes sont, en général, réunis sur le mème individu. Les œufs et les spermatozoïdes prennent naissance dans les parois latérales des canaux cténophoriques. Le développement parait direct dans la plupart des cas.

A cette classe appartiennent les Béroés, les Ciestes, etc.

\section{QUATRIEME EMBRANCHEMENT}

\section{ÉCHINODERMES}

Animaux à symétrie rayonnée généralement alliée à une symétrie bilatérale; à squelette dermique incrusté de calcaire et souvent hérissé de piquants; une cavité générale séparant le tube digestif de la paroi du corps; un appareil ambulacraire spécial.

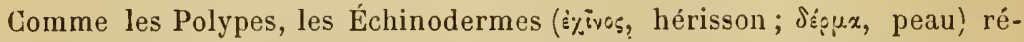
sultent du démembrement des Rayonnés de Cuvier. Leur symétrie est en apparence très nettement radiaire, mais en réalité il existe toujours des organes impairs situés en dehors de l'axe (plaque madréporique, canal hydrophore), et chez de nombreuses formes supérieures (Holothuries), aussi bien qu'à l'état larvaire, la symétrie bilatérale devient évidente.

Les Echinodermes sont d'ordinaire constitués selon le type quinaire, c'està-dire que les antimères sont au nombre de 5. Ainsi, une Astérie offre cinq branches, un Crinoïde a cinq bras ramifiés; un Oursin représente une sphère avec cinq bandes renfermant toutes les mêmes organes; une Holothurie montre un corps cylindrique avec cinq bandes analogues. On peut, chez ces divers animaux, reconnaître cinq plans verticaux équidistants, correspondant aux antimères : ce sont les plans radiaires ou rayons, entre lesquels s'en trouvent cinq autres ou interrayons.

La ligne de réunion des cinf rayons constitue l'axe longitudinal du corps: la bouche occupe l'une de ses extrémités (póle oral) et l'anus s'ouvre d'ordinaire à l'extrémité opposée (pôle aboral). 
La paroi du corps, qui est séparée du tube digestif par une cavité générale entéroculique, se montre constituée en général par une couche épithéliale externe, une couche fibro-cellulaire moyenne, et une couche épithéliale interue. L'épithélium exterue, d'origine ectodermique, manque souvent chez les adultes, surtout au niveau des parties calcifiées. Le revètement interne, endodermique, est un épithélium pavimenteux généralement vibratile. Quant à la couclıe moyenne ou mésodermique, elle a pour base un tissu conjonctif particulier, différencié sur certains points en fuisceaux contractiles, et laisse s'effectuer dans son épaisseur des dépôts calcaires, sous forme de spicules disséminés ou plus souvent de plaques polygonales qui constituent un véritable squelette dernique. A la surface de ce test se montrent divers appendices, parmi lesquels on remarque principalement des piquants et des pédicellaires. Les piquunts sont de simples pointes immobiles (Astérides) ou mobiles (Échinides, Ophiurides), celles-ci articulées sur de petits tu-

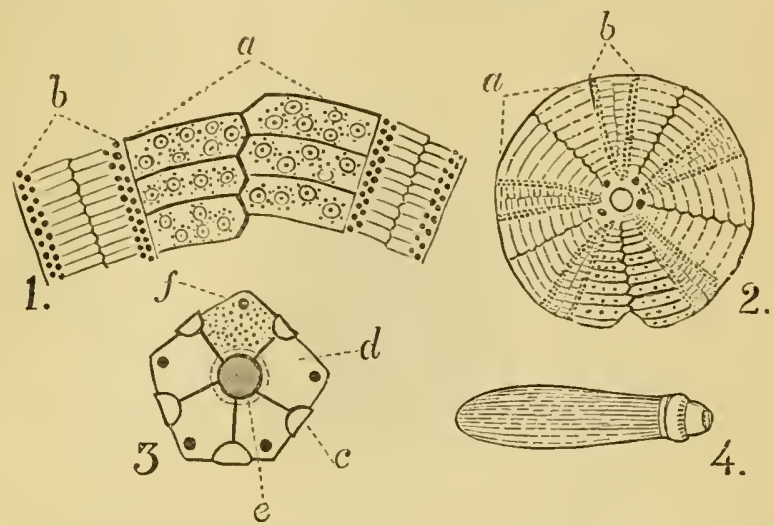

Fig. 102. - Morphologie des Ėchinides, d'après Forbes. - 1, portion du test du Galerites hemisphxricus, grossie, montrant une aire ambulacraire $b$, et une aire interambulacraire $a$. 2, face supérieure du mẻme : lettres correspondant aux mèmes régions. 3, disque génital el ocellaire de l'Hemicidaris intermedia, grossi : $c$, plaque ocellaire; $d$, plaque génilale; $e$, ouverture anale ; $f$, tubercule madréporiforme. 4, piquaut du méme. Pour plus de clarté, on a omis la plupart des lubercules dans les figures 2 et 3 .

bercules du test et mues par des muscles spéciaux. Quant aux pélicellaires, ils consistent en des sortes de tenailles à deux ou trois branches unies par des fibres musculaires striejes et capables de saisir les corps peu volumineux qui arrivent à leur portée : ce sont donc des organes de préhension; mais on a signalé chez diverses espèces des pédicellaires, dits gemmiformes, qui paraissent sécréter une substance venimeuse.

L'appareil locomoteur est représenté par un système ambulacraire, qui est une dépendance directe d'un appareil particulier et très caractéristique, l'appareil aquifère. Celui.ci se compose d'un canal annulaire qui entoure l'œsophage et émel dans chacun des rayons du corps une branche qui gagne la périphérie : ces cinq branches rayonnantes sont dites canaux ambulacraires. A l'anneau péricsopluggien sont annexées, chez la plupart des Échinodermes, des sortes d'ampoules contractiles appelées vésicules de Poli, qui mettent en mouvenent le liquide contenu dans tout le système. En outre, il part de ce mème anneau un conduit plus ou moins sinueux, le canal hy= 
drophore (ancien canal du sable), destiné à l'introduction de l'eau ambiante dans le système aquifère : ce conduit aboutit à une plaque calcaire poreuse, la plaque madréporique, située en un point variable de la surface du corps, et s'ouvre au dehors par des entonnoirs vibratiles. Lorsqu'il existe plusieurs plaques madréporiques, on observe un nombre correspondant de canaux hydrophores. Chez les Holothuries, la communication avec l'extérieur disparait à l'état adulte, $\epsilon t$ le tube hydrophore s'ouvre dans la cavité générale. Quant aux canaux rayonnants ou ambulacraires, ils émettent de nombreuses petites branches latérales, constituant des tubes grèles qui traversent le test et se renflent en de petites ampoules membraneuses, sortes de ventouses dites pieds ambulacraires. Ces tubes présentent d'ordinaire à leur point d'origine une petite vésicule ovoïde (vésicule ambulacraire), destinée à

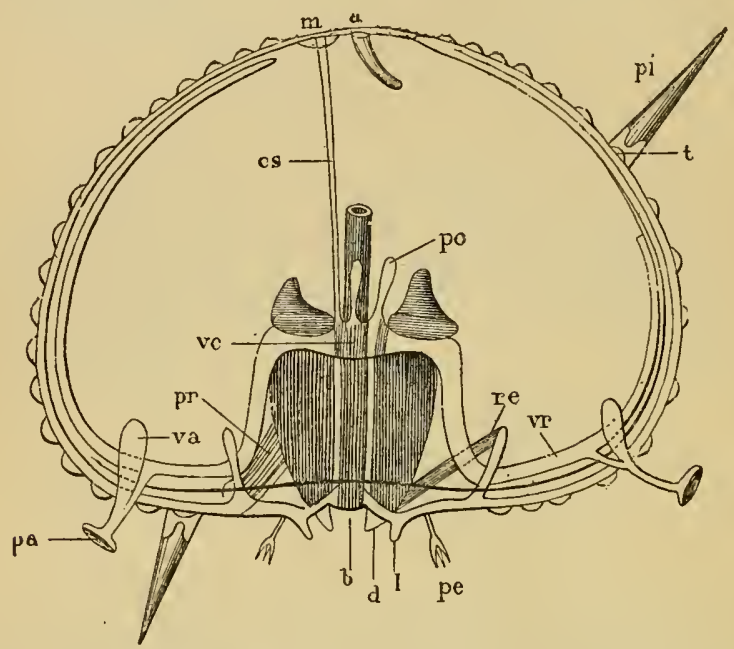

Fig. 103. - Sehéma de l'organisation d'un Oursin, d'après Huxley. - $b$, bouche. $d$, deuts. $l$, lèvres. $a$, anus. $p e$, pédıcellaires. $p r$, propulseur et re, rétracteur de la lanterne. $p i$, piquants. $t$, tubercules sur lesquels ils sont implantés. po, vésicules de Poli. vc, vaisseau annulaire de l'appareil aquifère. $v r$, vaisseau radiaire. $v a$, vésicule ambulacraire. $p a$, pieds ambulacraires. $c s$, canal du sable. $m$, plaque madréporique.

pousser le liquide du système aquifère dans les pieds ambulacraires et à les distendre : à la suite de cette distension se produit une contraction des éléments musculaires contenus dans l'épaisseur de leurs parois, et c'est de la sorte que le corps se déplace lentement. Pour permettre le passage des tubes ambulacraires, le test se montre percé, dans la zone qui avoisine chaque rayon, de rangées régulières de petits trous (pores ambulacraires), et les régions du corps ainsi perforées recoivent le nom d'aires ambulacraires; par suite, on donne celui d'aires interambulacraires aux intervalles imperforés qui les séparent, et dont l'axe est marqué par les interrayons (fig. 102).

Le système nerveux se compose essentiellement d'un anneau péribuccal qui émet cinq troncs radiaires. Chez les Astéries, l'ensemble de ces parties est sous-épithélial. Chez les Ophiures, les Oursins et les Holothuries, le système nerveux abandonne cette situation superficielle pour s'enfoncer dans les tissus sous-jacents. Enfin, chez les Crinoïdes, on ne trouve pas moins de 
trois systèmes : un système profond, à branches radiaires doubles, un second sous-épithélial, et un troisième représenté par un gros anneau aboral, envoyant de nombreuses ramifications dans les bras et le pécloncule.

L.es organes des sens sont peu importants. Chez les Astéries, il cxiste des yeux représentés par des taches pigmentaires rouges sitıées à la face inférieure de l'extrémité des bras. On a décrit en outre des vésicules auditives clicz les Syuaptes.

Il cxiste toujours un tube digestif distinct de la cavité générale (cœlome) dans laquelle il est suspendu. La bonche, tantòt centrale, tantòt excentrique, est parfois munie d'un appareil masticateur, tel que la lanterne d'Aristote des Oursins; elle est suivie d'un court œsophage qui sc renfle bientôt en une sortede sac stomacal; enfin, l'intestin s'ouvre le plus souvent par un anus dont la situation est variable, mais il peut aussi se terminer en cul-desac (Opliures, Astropecten).

On décrivait autrefois, sous lc nom très impropre d'appareil circulatoire, un ensemble de formations particulières aux Échinodermes, et qui ne constiluent pas moins de trois systèmes : cavités sous-ambulacraires, appareil plastidogrène et système absorbarıt. - $1^{\circ}$ Les cavités sous-ambulacraires entrent en communication avec la cavité générale; elles comprennent un anneau oesophagien ou labial (absent chez les Oursins et les Holothuries) dans lequel s'ouvrent cinq branches radiaires situées en dessous ou en dehors des canaux ambulacraires. Ces cavités constituent des gaines protectrices pour les nerfs et pour l'appareil suivant. - 20 L'appareil plastidogéne donne naissance aux globules (amibocytes) qui flottent dans le liquide de la cavité générale, et aux organes génitaux. Il offre une partie centrale, prise autrefois pour un cœur : c'est la glande ovoïde, souvent annexée au canal hydrophore, et dont un prolongement s'ouvre dans un anneau péricsophagien qui émet cinq cordons radiaires. - $3^{\circ}$ Le systeme absorbant, qui manque chez les Astéries, apporte à l'appareil plastidogène les substances assimilées nécessaires à la formation des amibocytes. Il se compose de lacunes développées dausles parois de l'intestin et déhouchant dans l'anneau osophagien de l'appareil précédent; il entre en outre, sur certains points, en relation avec le système aquifère. - Mais il n'y a en somme, dans tout cela, ni sang, ni vaisseaux, ni appareil circulatoire quelconque (Perrier).

Il ne semble pas exister d'appareil respiratoire bien spécialisé : les tissus recoivent surtout l'oxygène dont ils ont besoin par l'intermédiaire de l'eau do mer qui s'introduit dans le système aquifère et par suite daus l'appareil absorbant. On a cependant décrit, chez divers Échinodermes, des organes problématiques auxquels certains auleurs ont attribué un rỏle dans la respiration.

La reproduction est généralement sexuelle. A quelques exceptions près, les Échinodermes sont dioïques. Les organes des deux sexes sont des glandes en grappe dont on ne distingue la nature à l'œil nu que par la teinte souvent blanchâtre des spermatozoïdes et rougeàtre des œufs.

Le développement s'accompagne presque toujours de métamorphoses complexes: on observe des formes larvaires à symétrie bilatérale, munies de bandes ciliées (Echinopædium Iluxley); en général, c'est aux dépens d'une partie seulement de ces larves que se forme l'Échinoderme rayonné.

Tous les animaux de ce groupe sont marins; ils se nourrissent surtout de Mollusques ou de fucus. 
4 classes:

Squelette dermique (Pas de plaque madréporique............. Chinoïdes.

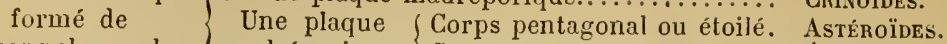
plaques polygonales. $\{$ madréporique. $\{$ Corps globuleux ou discoïde. Écunides.

Tégument formé de corpuscules calcaires; corps vermiforme...... Holothurides.

\section{CLASSE I}

\section{CRINOÏ}

Échinodermes en forme de coupe ou de calice, portés, dans le jeune age ou pendant toute la vie, par une tige calcaire multi-articulée, et

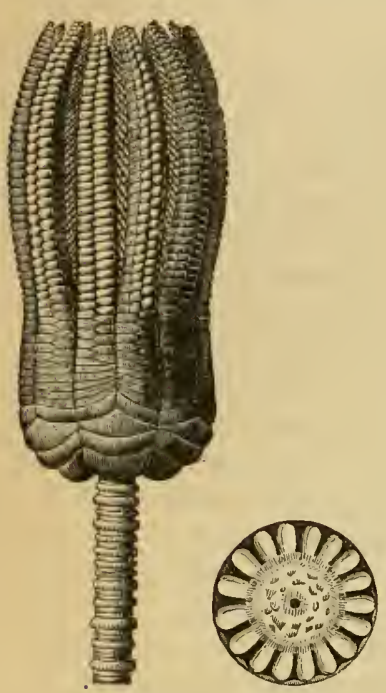

Fig. 104. - Encrinus liliiformis, du Trias (Muschelkalk). pourvus de bras articules qui sont garnis de petites branches latérales ou pinnules. Squelette dermique composé de plaques calcaires polygonales mobiles. Pas de plaque madréporique.

Les Encrines ou Crinoïdes (xpivov, lis ; ki idcs, apparence) ont un corps étoilé : la partie centrale ou disque contient le tube digestif, dont les deux orifices sont très apparents et assez. rapprochés (bouche centrale, anus excentrique); les organes génitaux sont situés dans les bras. Ces animaux se tiennent la bouche tournée en haut, fixés d'ordinaire aux rochers par une tige articulée qui naît de leur région aborale ou dorsaie. Dans quelques genres cependant, tels que les Antedon ou Comatules, ce pédoncule n'existe que pendant le jeune àge; il se rompt ultérieurement, et l'animal mène alors une vie libre.

Les Encrines ont apparu dès l'époque paléozoïque; on en trouve encore un assez grand nombre dans les terrains secondaires. Les entroques des paléontologistes ne sont autre chose que les articles dissociés de la tige.

\section{CLASSE I}

\section{ASTÉROÏDES}

Échinodermes à corps déprimé, pentagonal ou étoilé. Squelette dermique formé de plaques polygonales mobiles. Une ou plusieurs plaques madréporiques.

Comme leur nom l'indique, les Astéroïdes (ảarìn, astre; sỉos, ressemblance) ont généralement le corps étoilé, c'est-à-dire muni de bras disposés en rayons. La bouche est située au centre de la face inférieure; l'anus, lorsqu'il existe, s'ouvre au pôle opposé. Les pieds ambulacraires se trouvent li- 
mités à la face buccale. Les pédicellaires sont d'ordinaire i deux branches.

2 ordres :

$1^{\text {cr }}$ ordre: Stellérides ou Astérides. - Les Étoiles de mer ont les bras epais, peu mobiles, largement unis au disque, et contenant des prolongements cæcaux du tube digestil, ainsi que les organes reproducteurs.

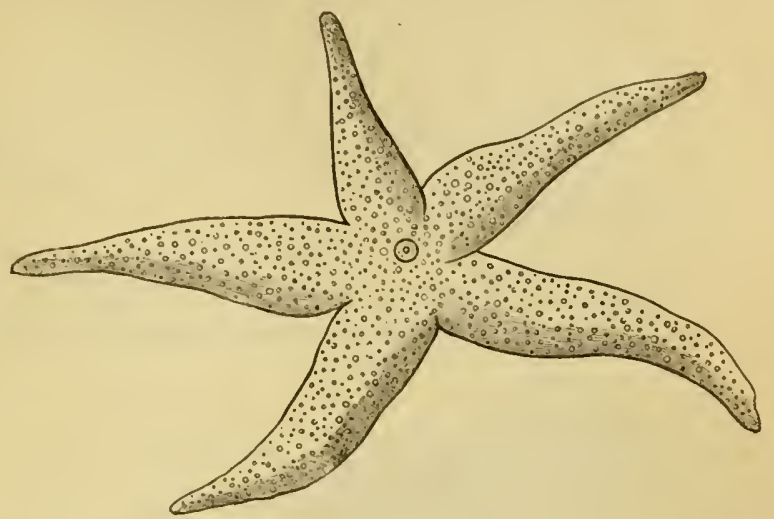

Fig. 105. - Astéride : Cribrella oculata, d'après Forbes.

Les Étoiles de mer se nourrissent surtout de Mollusques; aussi sont-elles redoutées des éleveurs de Moules. L'Étoile de mer commune (Diplasterias rutiens) existe en si grande abondance sur les cótes de la Manche et de la mer du Nord, qu'on la recueille pour fumer les terres.

On a accusé, probablement à tort, cerlaines Astéries, comme Diplasterias rubens et Crossaster papposus, de communiquer aux Huitres et aux Moules des propriétés toxiques, en déposant leur frai entre les valves de ces Mollusques.

Néanmoins, il parait établi que les Étoiles de mer sont elles-mêmes vénéneuses dans certains cas. Parker a tué rapidement deux Chats en leur faisant ingérer des fragments de Crossaster papposus, el Max Wolff a vu qu'en cerlains points du port de Wilhelmshaven, le Diplasterias rubens présentait une toxicité allant de pair avec celle des Noules. Il est probable que ces propriétés sont dues à une leucomaïne.

2e ordre : Ophiures. - Les bras sont allongés, mobiles comme des Serpents; ils ne renferment pas de prolongements du tube digestif ni de glandes sexuelles. L'anus fait défaut.

\section{CLASSE III}

\section{E CHINIDES}

Échinodermes à corps sphérique, ovoüde, discoïde ou cordiforme. Test formé de plaques polygonales immobiles, ot revêtu de piquants mobiles. Plaque madréporique. 
Les Échinides (غ̌ivs, Oursin) peuvent ètre ramenés au type des Étoiles de mer, en supposant que les cinq bras de celles-ci soient réunis en se recourbant vers la face dorsale. La bouche est donc située à la face inférieure, l'anus au pôle aboral. Souvent on conslate la présence d'un appareil masticateur (lanterne d'Aristote). Les pédicellaires sont en général à trois branches. En outre, il existe presque toujours, dans le voisinage de la bouche, de petits boutons mobiles, pédiculés et ciliés, les sphéridies, qui paraissent représenter des organes des sens. Les pieds ambulacraires sont disposés en zones verticales.

Les Oursins sont herbivores. - On en trouve déjà des espèces fossiles dans le Silurien, mais leur nombre est beaucoup plus considérable dans les terrains secondaires el tertiaires.

Sous le nom vulgaire de Chátaignes de mer, les Oursins entrent pour une certaine part dans l'alimentation des habitants du littoral. On

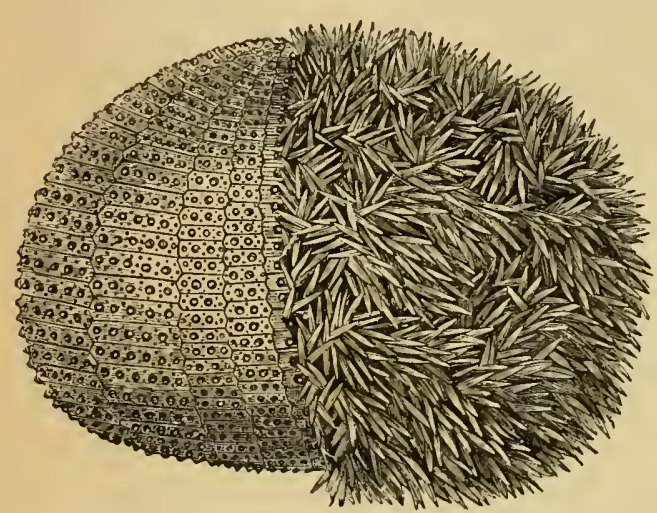

Fig. 10t. - Oursin comestible. - Les piquants ont élé enlevés sur la moitié gauche, pour mettre le test à découvert. en expédie même aujourd'hui sur nos marchés. Les espèces les plus recherchées sont : l'Oursin commun (Strongylocentrotus lividus), répandu sur presque toutes les côtes européennes; l'Oursin comestible(Echinus esculentus), de l'Atlantique et de la Méditerranée; l'Oursin melon (Ech. melo), de la Méditerranée, etc. On rejette le canal digestif, qui est toujour's rempli d'Algues et de sable, et on ne mange que les glandes génitales de l’animal vivant. Dans certaines localités du Midi de la France, on boit en outre le liquide de la cavité générale, comme excitant des fonctions digestives: la dose convenable est d'un demiverre par jour, d'après Mourson et Schlagdenhauffen.

Ces auteurs ont étudié avec grand soin le liquide de l'Oursin commun, qu'ils ont trouré quelque peu différent de l'eau de mer. Ce liquide renferme, en particulier, de l'urée et une leucomaïne particulière. C'est probablement à cette dernière qu'il faut attribuer les phénomènes d'intoxication souvent observés dans les pays chauds après ingestion d'Oursins. Ces accidents sont surtout communs au moment du frai, et il est indiqué, par suite, de ne faire usage de cet aliment qu'en dehors de la période de reproduction, c'est-à-dire de septembre à avril. Dans les mois d'été, l'activité des glandes génitales entraîne sans doute la production d'une plus grande quantité de leucomaïne. 


\section{CLASSE IV}

\section{H OLOTHURIDES}

Échinodermes cylindriques, vermiformes. Tigument incrusté d'une multitude de corpuscules calcaires. Pas de plaque madréporique.

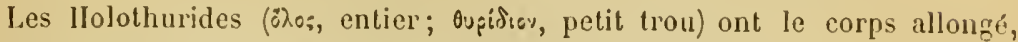
parfois recourbé en U. Leur tégument est coriace, mais flexible; les plaques calcaires sont remplacées par de nombreux spicules disséminés dans son épaisseur. La bouche, située à l'extrémité antérieure, est entourée d'une couronne de tentacules. L'anus occupe l'autre extrémité; dans le cloaque débouclınt, chez certaines formes, deux ou plusieurs or zanes creux, dans lesquels pénètre l'eau ambiante, qui en est bientòt expulsée : ces organes sont souvent désignés sous le nom de poumons.

Ces Échinodermes vivent d'ordinaire près des côtes, où il est facile de les pècher.

Diverses espèces d'Holothurides sont comestibles. A Naples, par exemple, on mange l'Holothuria tubulosa; aux îles Mariannes, l'H. guamensis; mais ce sont les Chinois surtout qui recherchent cette sorte d'aliments. Les espèces qu'ils consomment, $H$. cdulis, tremula, vagabunda, etc., sont connues sous le nom rulgaire de "Cornichons Fig. 107. - Hotothurie: Thyone papillosa, d'après Forbes. de mer ». Les Malais vont

les pècher principalement dans le sud-ouest de l'océan Pacifique, soit à la main, soit à l'aide de longs bambous terminés par un harpon, soit encore en plongeant. 11 les font cuire dans de l'eau de mer, puis dessécher à la fumée de Mimosa, après aroir enlevé les viscères. Ainsi préparé, le produit, connu sous le nom malais de trépang ou tripang, et sous le nom portugais de bicho do mar, est expédié en Chine. On lui altribue des propriétés aphrodisiaques.

\section{CINQUIEME EMBRANCHEMENT}

\section{VERS}

Animaux à symétrie bilalérale, à corps généralement divisé en nombreux anneaux semblables (homonomes); jamais de membres articulés.

Tel qu'il est entendu aujourd'hui par la grandc majorité des naturalistes, le groupe des Vers ne comprend qu'une partie des Vermes de 
Linné. Néanmoins, c'est encore l'embranchement le plus vaste et le plus hétérogène de tout le règne animal. Il est représenté par des animaux essentiellement conformés pour vivre dans des milieux humides : leur corps, souvent allongé, plat ou cylindrique, mou et contractile, est toujours dépourvu de membres articulés, et se montre en général composé d'une série linéaire d'anneaux semblables (métamères ou zoonites).

Le tégument est constitué par une cuticule d'épaisseur très variable, formant parfois une sorte de squelette dermique, et reposant sur une couche cellulaire ou tout au moins sur une couche de protoplasma nucléé dont elle tire son origine, et à laquelle on donne les noms d'épiderme ou d'hypoderme, ou plus simplement de couche sous-cuticulaire. Pendant la période larvaire, on rencontre assez souvent des cils vibratiles. Mais, en outre, il est commun d'observer chez les adultes des productions cuticulaires variées: soies, poils, crochets, etc. Ajoutons que les Vers sont susceptibles d'éprouver des mues dans leur jeune âge: la résistance de la cuticule opposant un obstacle à l'accroissement, l'animal s'en débarrasse, sauf à reproduire aussitôt après une nouvelle enveloppe protectrice.

Au-dessous de la couche sous-cuticulaire, on découvre une zone musculaire dite enveloppe musculo-cutanée, dont la disposition, quoique assez variable, comporte d'ordinaire une couche de fibres circulaires et une couche de fibres longitudinales. C'est de cette enveloppe que dépendent les divers organes accessoires adaptés à la fixation ou à la locomotion (ventouses, parapodes).

Le système nerveux est représenté, dans les formes les plus élevées du groupe (Annélides), par une chaîne ganglionnaire ventrale, réunie à des ganglions sus-œsophagiens (cerveau) par une sorte d'anneau ou de collier qui entoure l'œsophage. Mais cette disposition tend à se simplifier considérablement à mesure qu'on descend vers les types inférieurs, et la dégradation s'accuse surtout dans les espèces parasites.

Divers organes des sens sont à signaler chez les Vers. Les yeux, très répandus parmi les formes non parasites, sont constitués par de simples taches de pigment ou taches oculaires, en connexion avec des filets nerveux et parfois accompagnées de corps propres à réfracter la lumière, les baguettes cristallines ou cônes cristallins. - Parfois aussi, on rencontre des vésicules auditives ou otocystes, sortes de petits sacs ciliés sur leur face interne et contenant des concrétions solides connues sous le nom d'otolithes. - Enfin, il existe souvent des organes tactiles constitués par des soies (baguettes) ou des papilles.

Le tube digestif, lorsqu'il est complet, se différencie en trois régions chargées de fonctions distinctes: intestin buccal, moyen et terminal. La bouche est d'ordinaire située à la partie antérieure et toujours sur la face ventrale; elle est, en général, suivie d'un pharynx ou œsophage musculeux très caractéristique. L'anus s'ouvre vers la partie posté- 
rieure, soit sur la face dorsale, soit sur la face ventrale. Quelquefois (Trématodes) l'intestin terminal fait défaut, et le tube digestif forme alors un cul-de-sac. Enfin, la réduction parasitique peut être complète, et, en l'absence de tube digestif, la nutrition s'effectue par endosmose au travers des téguments (Cestodes).

Il n'existe pas d'appareil circulatoire spécial dans la plupart des groupes inférieurs: le liquide nourricier s'infiltre directement dans le parenchyme du corps, ou gagne la cavité périviscérale (cœlome) s'il y en a une; ce liquide est incolore et renferme souvent des éléments cellulaires ou globules. Mais che\% de nombreux Vers supérieurs (Annélides), on observe deux appareils cireulatoires distincts, l'un représenté par la cavité viscérale, l'autre constitué par un système de vaisseaux souvent clos.

Dans la plupart des cas, la respiration est cutanée; plus rarement elle s’éffectue par des branchies filiformes ou ramifiées.

L'appareil excréteur est représenté par les vaisseaux aquifères : on entend sous ce nom un système de canaux symétriquement disposés, dont le contenu aqueux tient en suspension quelques fines granulations; ces canaux, souvent ciliés, prennent leur origine, soit par de fins canalicules dans les lacunes interorganiques, soit dans la cavité viscérale, par un orifice en forme d'entonnoir; ils s'ouvrent au dehors par des pores cutanés, de manière à mettre en communication les tissus ou les organes internes avec le monde extérieur. Chez les Vers annelés, ces vaisseaux se répètent par paire dans chacun des somites (organes segmentaires ou néphridies).

La reproduction asexuelle est assez fréquente : elle a lieu par scissiparité ou gemmiparité; parfois (larves de Trématodes) il y a formation de germes, dont la signification est encore discutée. Mais la reproduction sexuelle est beaucoup plus répandue, et les sexes sont tantôt réunis, tantôt séparés.

Le développement comporte assez souvent des métamorphoses et parfois même une alternance de générations coïncidant arec des migrations plus ou moins complexes et des changements remarquables dans le mode de vie.

Les Vers vivent, soit à l'état de liberté, dans la mer, dans les eaux douces ou dans la terre humide, soit ì l'état de parasites temporaires ou permanents. On n'en connaît pas qui soient terrestres, c'est-à-dire qui puissent vivre librement à l'aịr.

7 classes: 
Pas de système nerveux.

Aneuriens.

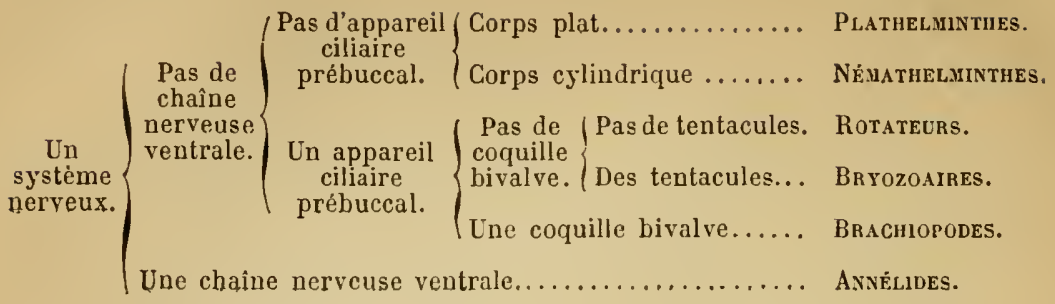

\section{CLASSE I}

\section{ANEURIENS}

Animaux composés seulement de deux feuillets, l'un interne (endoderme), l'autre externe (ectoderme). Pas de système nerveux.

Les Aneuriens, encore appelés Mionelminthes, Plamuloidés, ont été regardés par Ed. Van Beneden comme les représentants d'un embranchement spécial. (Mésozoaires), intermédiaire entre les Protozoaires et les Métazoaires, se distinguant des premiers par une organisation pluricellulaire, et des seconds par l'absence de mésoderme. Mais il semble plutòt qu'on doive, avec Giard, les regarder comme des Métazoaires, peut-être même comme des Plathelminthes dégradés par le parasitisme. - Ils comprennent deux ordres : Rhombozoaires et Orthonectides.

Les Rhombozoaires (Diryémides et Hétérocyémides) sont de petits ètres vermiformes qui vivent dans les reins des Céphalopodes. Leur arganisation comporte, en somme $: 1^{\circ}$ une vaste cellule interne ou aviale, qui représente l'endoderme; $2^{\circ}$ une couche superficielle de cellules plates et ciliées correspondant à l'ectoderme. Il n'existe donc pas de cavité du corps. Contrairement à ce qui s'observe dans tous les vrais Métazoaires, la reproduction est exclusivement asexuelle; elle se résume en une production intra-endodermique de cellules qui se multiplient par segmentation, pour se différencier bientòt en deux couches.

Les Orthonectides vivent chez les 0phiures, les Turbellariés, les Némertiens. Ils sont aussi composés de deux couches cellulaires : un ectoderme annelé, à cellules ciliées pour la plupart, et un endoderme à cellules plus grosses et granuleuses. Cet endoderme est revêtu d'une couche fibrillaire qui peut-être correspond au mésoderme des Métazoaires.

\section{CLASSE II}

\section{PLATHELMINTHES}

Vers plats, sans appareil ciliaire prébuccal, pourvus d'un système nerveux variable, mais non disposé en chaine ventrale. Généralement hermaphrodites.

Les Vers de ce groupe n'ont pas de véritable cavité générale : leurs 
organes sont disposés au sein d'un tissu conjonctif constituant une sorte de parenchyme. Ils ont le corps aplati ( $-\lambda x x_{s}$, large, plat; $\varepsilon \lambda_{\imath \iota \nu}$, ver), formé ou non de segments successifs, et généralement pourvu d'organes de fixation représentés par des crochets et des ventonses. A l'exception des Némertiens, ils ne possèdent ni vaisscaux sanguins, ni organes respiratoires: mais ils montrent un système de vaisseaux aquifères très développé. Presque tous sont hermaphrodites. I.eur fécondité est souvent considérable, et leur développennent comporte, dans la plupart des cas, des métamorphoses accompagnées de migrations.

Au point le vue de l'habitat, ce sont, en grande majorité, des parasites internes, ou, d'unc facon plus précise, des helminthes. Le

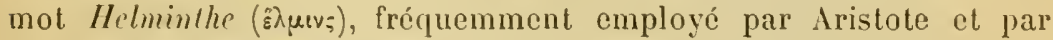
Hippocrate, s'appliquait en effel uniquement aux Vers parasites de l'IIomme ou des animaux. En dépit de quelques tentatives faites pour en étendre ou en restreindre le sens, c'est encore dans celle acception cu’il est pris aujourd'hui par la généralité des auteurs (1). Il est done synonyme de Ver intestinal ou d'Entozoaire, bien qu'on applique rolontiers ce dernier nom à tous les parasites internes, qu’ils appartiennent ou non au groupe des Vers. - L'hchminthologie constituant comme une science spéciale, nous avions cru, dans la première édition de ce livre, devoir rassembler pratiquement dans une même classe les Plathelminthes et Ies Némathelminthes; mais la distance qui sépare ces deux groupes est réellement trop considérable pour autoriser un tel rapprochement, et d'ailleurs tous leurs représentants ne sont pas des Entozoaires.

o̊ ordres :

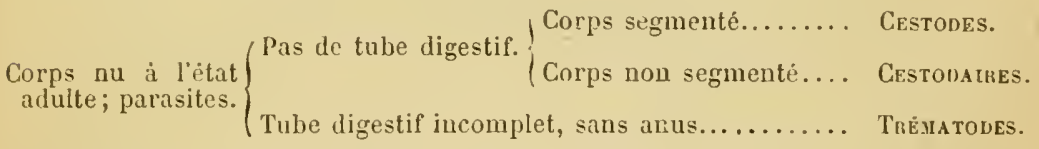

Corps couvert de $\int$ Tube digestif incomplet, sans anus........... Turbellartés.

cils; libres..... Tube digestif complet................ Némertiexs.

(1) C. A. Redoupur, Entozoorum sive vermium inteztinalium historia naturalis. Austelardami, 1808-1810. - In., Entozoom synopsis. Berolini, 1819. - F. Dusardix,

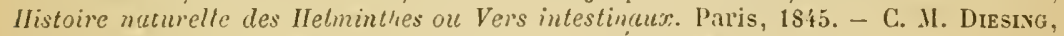
Systema Iletminthum. Vindobonæ, 1850-1851. - É. Blaxcunno, Recherches sur l'org'unisation des Vers. Ann. des se. nat. (3), VII ḋ Xll. - C. Davane, Traile des Entozonires et des maladies vermineuses de t'Homme et des animaux domestique:, "2e rd. Paris, 1877. - C. Ballet, Article nelnixtes dı nouveau Dict. vétér., t. VIII. Paris, 1866. - R. Leuckır, Die P'arasiten des Menschen. 20 éd. Leipziğ, 1s79. T. S. Cobbuld, Parasites. London, ISi9. - F. A. Zür. Die Schmaratzer auf und in dem Kärper unserer Ilaussäugethiere. 2le Autl., Weimar, 1852. - R. Buavcirarn, Traité de zoologie médicale. Paris, 1856-1890. - L. G. Neumax, Traité des maladies

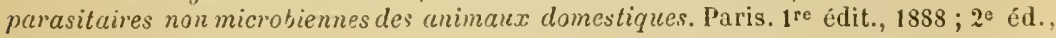
189?. 


\section{PREMIER ORDRE}

\section{CESTODES}

Plathelminthes nus, de forme rubanée, toujour's segmentés, au moins interieurement, dépourvus de tube digestif el munis d'organes de fixation (ventouses, crochets) à une extrémité. Endoparasiles.

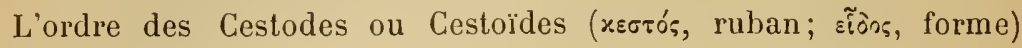
constitue un des groupes de Vers les plus intéressants et les plus utiles à connaître (1).

Le corps est allongé sous forme de bandelette et divisé en articles, bien que ceux-ci ne soient quelquefois pas distincts à l'extérieur. A l'une des extrémités - qui correspond, comme nous le verrons, à la partie postérieure de l'embryon et qu'on décrit néanmoins comme la tête (2) - existe un appareil de fixation, dont les principaux éléments consistent en ventouses et en crochets. ,

La masse entière du corps a pour base un réseau conjonctif à mailles serrées, formé de cellules pluripolaires dont les prolongements s'anastomosent entre eux. Tous les organes paraissent naître aux dépens de ces cellules. Déjà les corpuscules calcaires, sortes de concrétions réfringentes qui abondent dans les tissus de ces Vers, ne sont autre chose que des cellules encroûtées (Moniez). Le réseau se termine à la périphérie par une couche sous-cuticulaire très active, formée de grosses cellules contractiles : c'est la partie externe de ces cellules qui se modifie pour constituer la cuticule, de telle sorte qu'il est inexact de dire que celle-ci est un produit d'excrétion. Quoique d'apparence anhiste, en effet, elle renferme des fibres qui peuvent, en certains points, la traverser de manière à lui donner un aspect cilié (pseudo-cils).

Au-dessous de la couchesous-cuticulaire, et en connexion intimearec le réseau conjonctif, on trouve des faisceaux de fibres contractiles, qu'on qualifie de muscles, "bien que ces éléments n’aient aucun rapport avec les véritables muscles des autres animaux ". Ces muscles comprennent une couche superficielle longitudinale, parfois dédoublée, et une couche profonde, dite circulaire, mais se perdant, en réalité, vers les bords, dans la couche sous-cuticulaire.

On peut, avec Moniez, distinguer sous le nom de zone centrale la partie interne du corps circonscrite par les muscles circulaires; mais il ne faut pas perdre de vue que cette distinction est établie pour la

(1) R. Mosiez, Essai monographique sur les Cysticerques. Paris, 1880. - ID., Mémoire sur les Cestodes. Paris, 1881. - Fr. ZsсноккE, Rechcrches sur la structure anatomique et hislologique des Cestodes. Genève, $18 \$ 8$.

(2) G. Neumann, Sur l'homologie de ta têle des Cestodes. Comptes rendus de la Soc. d'hist. nat. de TouInuse, XXIII, p. 82, 1889. 
seule commodité de l'exposition, et que tous les tissus sont continus entre eux. C'est à l'intéricur de cette zone que naissent tous les éléments qui nous restent ì étudier.

Le système nerveux, dont l'existence a tour à tour été admise ou niée par les auteurs, consiste en deux cordons longitudinaux qui ne communiquent entre eux qu'au niveau de la têle: ces cordons sont formés de cellules bipolaires ou multipolaires.

L'appareil digestif fait defaut: les Cestodes rivant au milieu de liquides nutritif's tout élaborés, ces liquides pénètrent dans leurs tissus par endosmose, ou mieux ì la faveur de pores très lins qui traversent la cuticule. Partant, il n'existe pas davantage d'appareil circulatoire. Quant à la respiration, elle est exclusivement cutanée, et du reste fort peu active.

Mais un système bien déreloppé chez les Cestodes est celui des vaisséux aquifères, qui roprésentent, comme on le sait, l'appareil rxcréteur. Ce sont des canaux longitudinaux qui suivent les parties latérales du corps et peurent communiquer entre eux par des anastomoses transversales. Ils souvrent à la partic postérieure du corps par un seul orifice, le foramen caudale, qui se reforme chaque fois qu'un anneau s est détaché. Parfois on observe quelques orifices secondaires à la partic antérieure. Ces canaux sont les collecteurs vers lesquels convergent des systèmes de canalicules qui prennent leur origine, ainsi que l'a démontré Fraipont, dans de petits enton-

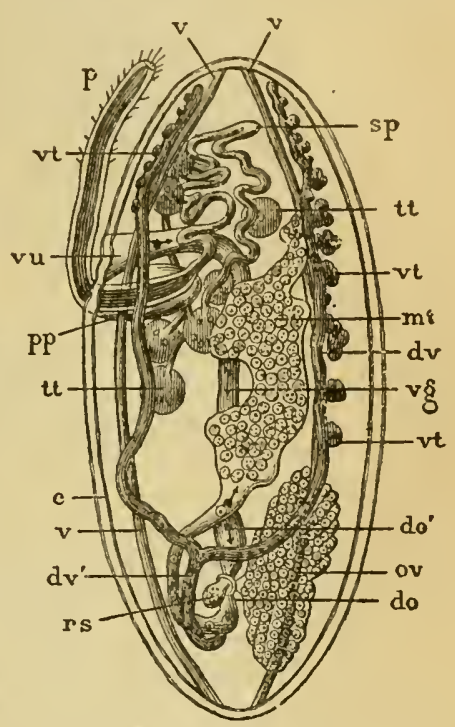

Fig. 108. - Sclı́ma de l'organisation d'un anneau de Ceslode, d'après P. J. Van Beneden. - $t t$, lesticules. $s p$, canal déférent ou spermiducte. $p p$, sac du cirre ou poche péniale. $p$, cirre ou pénis. ov, germigène (ovaire). do, germiducle (oviducte). $v t$, vitellogine $d v$, vilelloducte. $m t$, matrice montrant le mode de formation des çeums latéraux. rs, réservoir séminal. $v g$, vagin. $v u$, vulve. $v$, vaisseaux excréteurs. $c$, enveloppe tígumentaire. noirs ciliés ou flagellés (organes segmentaires) situés à la limite des zones centrale et périphérique.

Les orgunes reproducleui's sont assez complexes. Chaque anneau est hermaphrodite, mais les organes mâles se développent avant les organes femelles.

Les testicules sont formés par des amas de spermatozoïdes qui se rendent, suivant un mode variable, dans un canal déférent ou spermiducte, aboutissant lui-même à une poche péniale, en dehor's de las quelle il peut se renverser pour constituer un organe copulateur appelé pénis ou cirre.

Les organes femelles comprennent un ou plusieurs ovaires (germi- 
gènes Van Beneden). Les œufs sont recueillis par un pavillon et passent ainsi dans l'oviducte (germiducte), qui les conduit dans la matrice. A son origine, l'oviducte reçoit le vagin : c'est par ce canal, souvent dilaté en réservoir séminal sur un point de son trajet, que les spermatozoïdes sont amenés au contact des œufs. En général, des glandes spéciales sont chargées de sécréter le vitellus: ce sont les follicules vitellogènes, dont les produits sont recueillis par un collecteur ou vitelloducte qui les déverse dans l'oviducte. La matrice consiste souvent en un tube qui se distend par l'accumulation des œufs et développe ainsi des ramifications herniaires, en effaçant peu à peu tous les autres organes: les parois finissent quelquefois par se rupturer et les œufs pénètrent alors librement dans la zone centrale; enfin la tension arrive à être telle que la couche corticale elle-même se déchire, et c'est ainsi que les œufs s'échappent au dehors. 11 est rare que l'oviducte entier joue le rôle de matrice et s'ourre à l'extérieur (Bothriocéphale).

Le développement embryonnaire des Cestodes est plus ou moins rapide: souvent l'cuf, au moment de la ponte, contient déjà un embryon pourvu de six crochets (hexacanthe), parfois de quatre: ou bien cet embryon n'apparait qu'après un séjour prolongé de l'œuf dans l'eau.

Quant au développement post-embryonnaire, qui peut être assez compliqué, il s'accompagne le plus souvent de migrations.

La classification des formes larvaires n'a pu ètre établiejusqu'à présent que d'une façon imparfaite; nous croyons cependant utile d'eu signaler ici quelques points relatifs aux Téniadés et aux Bothriocéphalidés, d'après les travaux de Leuckart, Villot, Braun, etc. (1).

On peut d'abord, avec Villot, diviser ces formes larvaires en Cystiques et Pseudocystiques.

I. Les Cystiques comprennent toutes les larves pourvues de vésicule caudale.

lls se subdivisent en Cysticerciens (Cysticerques s.l.) et Cyslicercoïdes.

A. Les Cysticerciens sont caractérisés par leur grande taille, l'abondance du liqquide qui remplit leur vésicule caudale et la supériorité relative de leur organisation.

On range dans ce groupe les Cysticerques s. str., les Cénures et les Échinocoques, que nous aurons à étudier plus loin.

B. Les Cysticercoüles se distinguent par leurs plus faibles dimensions, l'état moins développé de leur vésicule caudale et leur organisation moins parfaite.

Villot les divise en endogènes et exogènes.

a. - Les Cysticercoïdes endogènes sont remarquables en ce que leur vésicule caudale est invaginée dans une portion appendiculaire postérieure ou queue. -2 genres:

(1) A. VILLot, Mémoire sur les cystiques des Ténias. Annales des sc. nat. (Zoologie) (6), XV, 1883. - ID., Sur la classification des cystiques. Rerue biol. du Nord de la France, 1, p. 386, 1889. - B. Grasst et G. Rovecti, Embryologische Forschungen. Centralbl. f. Bakter. u. Paras., V, p. 3 ĩ et 401, 1889. 
Polycercus Villot. - Le kyste constitué par la queue renferme plusieur's vésicules caulales, contenant chacune un seul corps et une seule tète.

Honocercus Villot. - La queue ne renferme qu'une seule vésicule caudale.

b. - Chez les Cysticercoüles cxoyenes, la vésicule caudale n'est pas iuvaginée dans la quene, qui forme un simple appendice. - 3 genres :

Ccrcocystis Villot. - Queue terminant une seule vésicule caudale.

Stuphylocystis Villot. - Cercocystis prolifère, montrant une grappe de vésicules caudales pour une seule queue vésiculeuse.

Urocystis Villot. - Quene vésiculcuse portant une série linéaire de vésicules qui souvent se délachent dès qu'elles contiennent une tête entièrement développée.

II. Les Psecdocistiques sont représentés par les formes larvaires dépourvues de résicule caudale.

Cryptocystis Villot. - Petite larve solide, terminée par une queue.

Plerocercus M. Braun. - Larve solide, globuleuse.

Plerocercoides M. Braun (Piestocystis Dies. ; Dithyridium Rud.). - Larre solide, rubanaire ou ovale, allongie.

Tous les Cestodes sont endoparasites. Chez un premier hote, le Ver demeure agame; puis il est transporté, d'une manière passive, dans le tube digestif d'un second animal (exceptionnellement du mème), où il aequiert ses organes sexuels.

Famille des TÉNIADÉS. - Les Téniadés se reconnaissent à leur tête munie de quatre ventouses, à leurs anneaux bien séparés et à leur's orifices grénitaux situés sur les bords (sauf chez Mesocestoides).

Les diverses phases de l'érolution ne sont encore connues que pour un petit nombre de Téniadés. En ce qui concerne ceux-ci, on a constaté que le developpement post-embryonnaire comporte des métamorphoses complexes. L'œuf mûr contient un embryon muni de six erochets (embryon hexacanthe). Mis en liberté dans un milieu favorable, cet hexacanthe donne naissance, suivant livers modes, à une larve variable, qui produit une ou plusieurs têtes caractéristiques, et s'enkyste généralement dans les tissus ou les cavités closes de lhòte. Pour continuer son évolution, chacune de ces têtes doit être introduite dans le tube digestif d'un hote convenable, presque toujours différent du premier; elle donne alors une série linéaire danneaux (chaine) qui peu à peu arrivent à l'état sexué et finissent par se séparer de l'ensemble (cucurbitins).

Les larves se développent chez des animaux à sang chaud ou à sang froid, mème chez des Invertébrés. Quant aux Téniadés parfaits, on ne les rencontre que chez des Vertébrés, et presque exclusivement dans le canal intestinal.

La classification des Téniadés n'a pas été, jusqu'à présent, établie sur des bases bien rigoureuses, ainsi qu'on peut en juger par les tentatives de Rudolphi, de Dujardin et de Diesing. Nous ne pourons pas encore aujourd'hui songer à établir un groupement définitif, et force 
sera de nous en tenir aux données fournies par l'armature céphalique, la disposition des organes génitaux et la constitution des larves.

Remarques historiques. - Les helminthologistes ont longtemps méconnu le lien qui rattache les, unes aux autres les direrses phases de l'évolution des Ténias.

Cependant, dès 1781, Abildgaard avait reconnu et démontré expérimentalement que les Šchistocéphales des Épinoches achèvent leur développement chez les Canards.

Mais ce fait était demeuré pour ainsi dire isolé, et en 1842, von Siebold, quoique ayant constaté liidentité spécifique du Cysticercus fasciolaris de la Souris et du Tænia crassicollis du Chat, ne sut pas reconnaître le rapport génétique de ces deux formes : pour lui, le Ténia du Chat, en quelque sorte égaré dans le foie de la Souris, était devenu malade et hydropique dans ce nilieu anormal. Pallas avait professé des idées presque identiques.

Peu de temps après (18ว0), dans un important travail présenté à l'Académie royale de Belgique, Van Beneden démontra que les Tétrarhynques enkystés dans les Poissons osseux ne sont autres que des larves ou scole $x$ de Vers qui parviennent à l'état sexué chez les Poissons carnassiers (Raies, Squales) lorsque ceux-ci ont mangé les Poissons osseux.

La voie expérimentale était alors toute tracée. C'est à Kïichenmeister que revient l'honneur d'avoir le premier fourni la preuve que les Vers vésiculaires sont appelés à se transformer en Vers rubanés : en 1831, le savant médecin de Zittau fit ingérer à des Chiens des Cysticerques pisiformes dı Lapin, et constata que ces Cysticerques avaient donné naissance à des Ténias.

L'année, suivante, Siebold et lewald répétèrent cette expérience avec le mème succès. A leur suite, un grand nombre d'helminthologistes : Van Beneden, IIaubner, Leuckart, Humbert, Baillet, etc., et plus récemment Redon, Moniez, Villot, ont multiplié les recherches du mème ordre, élargissant le cadre expérimental et précisant les résultats obtenus.

Sous-famille des суғтотæniø. - Corps généralement de grande taille. Tête presque toujours pourvue d'une double ou même triple couronne de crochets de dimensions différentes dans chaque rangée. Ces crochets, en forme de petits poignards, ont une garde saillante et un manche assez long, surtout dans la première rangée. Anneaux mûrs plus longs que larges, pourvus d'un utérus longitudinal, médian, à branches latérales. Pores génitaux irrégulièrement alternes. OEufs pourvus d'une membrane mince, délicate, se détruisant facilement, et d'une seconde enveloppe intérieure, épaisse, brunâtre (embryophore), qui entoure directement l'embryon hexacanthe. - La larve est un Cysticercien, c'est-ì-dire un Cystique de grande taille, dont la vésicule caudale renferme un liquide abondant.

Les Téniadés n'ont guère été observés jusqu'à présent que chez les Mammifères, aussi bien à l'état adulte que pendant la phase cystique. C'est à eux, en particulier, que s'applique la loi formulée par Van Beneden, et qu'on peut ainsi résumer: les Vers adultes vivent dans le 
tube digestif des animaux carnivores; leurs larves, dans les carités closes du corps des herbivores; les omnirores seuls peurent être porteurs de Cystiques et de Ténias.

Nous n'admetlrons dans celte sous-famille qu'un seul genre, auquel nous conserverons l'ancien nom de Ténia (Tienia L.), et que nous diviserons, aver Villot, en trois sections ou sous-genres: Cysticercus, Camurus et Echimococeus, d'après la constitution de leurs Gystiques.

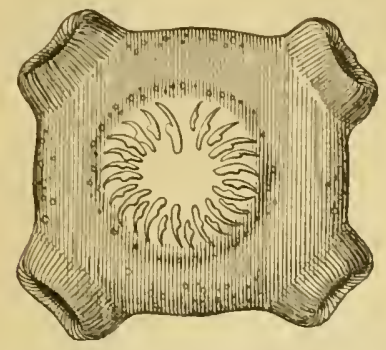

Fig. 109. - Tלle du Trmia solium, vue de devaul, avec les reutouses saillantes (Laboulbène).

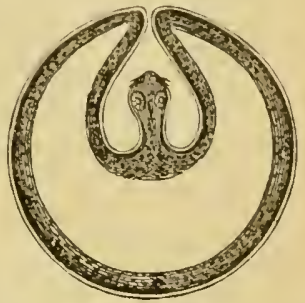

Fig. 110. - Coupe sehémalique diu Cystieerque.

$1^{\circ}$ Les Cysticeroues (Cysticercus Zeder, 1803) sont caractérisés par ce fait que leur vésicule caudale donne naissance à un seul corps, contenant une tête unique (Cystiques monosomatiques et monoéphales).

Nous prendrons pour type de ce sous-genre et du genre entier le Tienia scrrata, en raison de l'ensemble de ses caractères, aussi bien que des recherches dont il a été l'objet, et de la facilité qu'on peut avoir de se le procurer sous ses divers états.

Ténia en scie ( $\boldsymbol{T}$. serratu Gœze, 1782. - Syn. : T. [Cystotrnia] serrata Leuckart, 1863). - Long de $0^{\mathrm{m}}, 30$ à 2 mètres (ordinairement 1 mètre). Tète globuleuse-tétragrone, largre de $\mathrm{I}^{\mathrm{mm}}, 3$; rostre puissant, armé d'une double couronne de $3 \dot{t}$ à 48 crochets (en moyenne 40 ) : les grands longs de 220 a $230 \mu, \dot{a}$ manche cylindrique, épais, plus long que la lame; les petits longs de 120 à $160 \mu$, à mauche court, à garde bifide. Cou un peu plus mince que la tète, long de 1 à 2 millimètres. Anneaux d'abord étroits et beaucoup plus courts que larges, devenant carrés à environ 23 centimètres de la tète; offrant alors un aspect évasé en arrière, le bord postérieur étant manifestement plus large que l'antérieur; ce bord postérieur est rectiligne, à angles saillants, d'où l'aspect denté en scie de la chaine; pore génital très saillant, rendant convexe le bord qui le porte; anneaux mùrs au nombre de 30 à 40 , représenlant les $2 / 30$ de la longueur totale de la chaine, longs de 10 à 17 millimètres, larges de $千$ à 6 . Utérus formé d'un tronc longitudinal médian, assez long, portant de chaque còté $S$ à 10 branches irrégulièrement ramifiées. Embryophores ovoïdes, longs de 36 à $40 \mu$, larges de 31 à $36 \mu$.

Le $T$. serrata vit dans l'intestin grêle du Chien domestique.

Sa larve, connue sous le nom Cysticercus pisiformis Zeder, habite le péritoine des Lapins domestiques ou sauvages, du Lièvre commun et 
du Lièvre variable; Gœeze et Leuckart l'ont même signalée chez la Souris. Elle se présente sous l'aspect d'une petite ampoule du volume d'un pois, remplie de liquide et entourée d'un kyste. Le prétendu

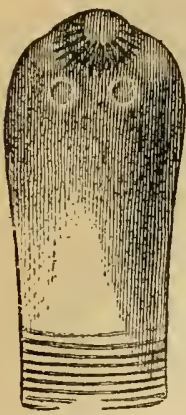

Fig. 111. - Tête du Txnia serrata, vue de trois quarts et grossie.

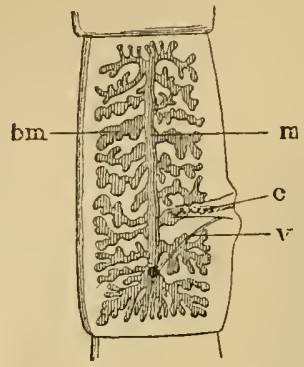

Fig. 112, - Un asmeau mûr du Tænia serrata, grossi trois fois. $-c$, canal déférent ou spermiducte pelotonné. $v$, vagin. $m$, corps de la matrice. $t m$, brauches de la matrice (0rig.).

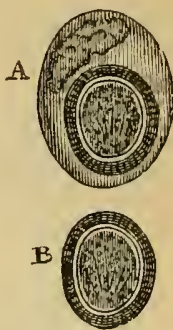

Fig. 113. - OEufs du Tænia serrata. $-\mathrm{A}$, wul entouré de la membrane vitelline et contenant encore les masses vitellines. B, embryophlore, ou œuf dégagé de ces parties accessoires (Orig.).

Monostoma leporis Kuhn n'est autre chose, comme nous l'avons montré, que ce Cysticerque incomplètement développé.

Évolution. - C'est à Küchenmeister, on le sait déjà, que revient l'honneur d'avoir démontré la

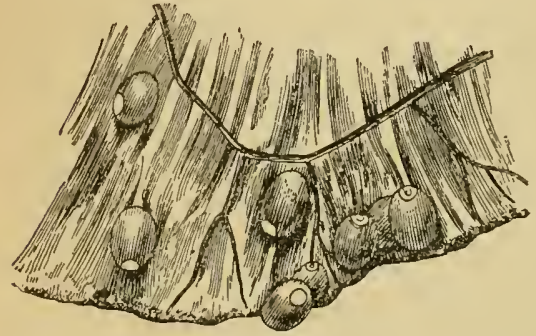

Fig. 114. - Fragment de mésentère du Lapin envahi par de Cyslicerques pisifornes. Grandeur nalurelle (Orig.). transformation du Cysticerque pisiforme en Trenia serrata dans l'intestin du Chien. A sa suite, divers expérimentateurs, von Siebold, Lewald, Van Beneden, Baillet, etc., vérifièrent l'exactitude du fait. D'autres, tels que Röll, May, etc., obtinrent de même le développement du Cysticerque pisiforme chez le Lapin par l'administration d'œufs du Tznia serrata.

Depuis lors, cette question a été fouillée jusque dans les détails, et l'examen rapide que nous allons faire des différentes phases de ce Ténia sera basé principalement sur les excellents travaux du professeur Moniez (de Lille), un des savants qui ont le plus contribué à étendre nos connaissances au sujet des Cestodes.

10 Embryogénie. - Le développement de l'embryon s'accomplit alors que l'œuf est encore renfermé dans les anneaux du Ver. L'ovule du 'T. serrata ou des espèces du mème type est une cellule riche en granulations vitellines. Après la fécondation, il se divise en deux masses qui restent soudées, mais dont les granulations sont inégalement réfringentes (fig. 11\%, 1). Ces 
deux masses vitellines renferment dans leur intérieur un gros noyau ou mieux une véritable cellule eachée parles granulations. L'une de ces cellıles parait n'ètre pas employée à la formation de l'embryon. L'autre se divise en deux éléments : un premier, lui-mème inactif, et un second représentaut une cellule embryonnaire qui se dégage lientòt, en mème temps quiapparait la membrane vitelline (2). P'uis cette cellule se multiplic $(3, \mathbf{4})$, et l'ensemble des éléments blastodermiques qui en dérivent constitue une sorte de morula dépourvue de membrane propre $(\ddot{3}\rangle$. l'endant ce temps, les masses vitellines diminuent sensiblement, de volume : l'une d'elles tend mème à se désagrréger de bonne heure; toutes deux, du reste, cessent désormais de prendre part ì la vie de l'embryon et n'offrent plus d'intérèt au point de vue de l'embryogénie. - La molula s'arrondit peu à peu, puis sa couclie cellulaire périphérique se sépare des éléments sous-jacents, en formant (par délamination) une sorte de membrane cellulaire autour des autres cellules

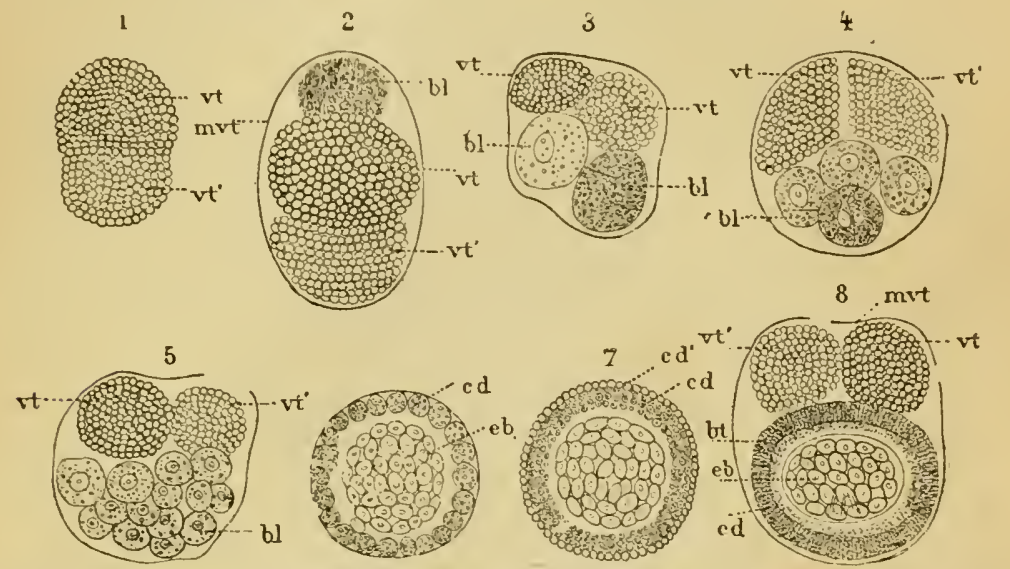

Fig. 115. - Embryogénie des Ténias du tỵe Tænia serrata, d'après R. Moniez. - vt, v't', les dẹux masses vilellines, mvt, menbrane vilelline. $b l$, cellules blastodermiq̨ues. $c d$, couche délaminće. $c d$, couche de grauules dérivaul de la précédenle el se transformant en bt, couclie de bâtounets, $e b$, embryon.

blastodermiques $(6, c d)$. Les éléments de cette couche délaminée paraissent ensuite se résoudre en granules $(\tau, c d)$, dont les plus extérieurs se soudent entre eux, deviennent plus rélringents $\left(\bar{i}, c l^{\prime}\right)$, puis se transforment en corps très allongés $(8, b t)$ : telle est l'origine de la coque de batonnets qui entoure l'embryon des Ténias du type T. serrata. Quant aux granules intérieurs, ils se disposent en une couche persistante $(8, c d)$, dont la partie interne prend l'aspect d'une mince lane chitineuse. Enfin, en mème temps que la couche de bàtonnets, on voil apparaitre, dans la masse cellulaire qui constitue l'embryon, les trois paires de stylets ou crochets caractéristiques.

En définitive, l'œů du T. scrrata se montre formé d'une mince membrane vitelline, qui renferme normalement deux masses vitellines plus ou moins épuisées, et un embryon hexacanthe (oncosphère) protégé par une épaisse coque de bàtonnets (fig. 113, A et fig. 113̈,8).

Jais la membrane et les masses vitellines ne tardent pas à disparaitre, et il ne reste plus que l'embryon arec sa coque, qui se présente sous l'aspect 
d'un corps ovoïde, brunàtre, mesuranten moyenne $38 \mu$ de long sur $33 \mu$ de large (fig. 113, B). Ce corps, auquel on donne habiluellement le nom d'œuf, n'est donc en réalité qu'un embryophore.

go Phase cystique. - L'embryon renfermé dans sa coque peut y rester en état de vie latente pendant un temps variable, suivant les eonditions dans lesquelles il se trouve placé. Mais il ne peut poursuivre son évolution que s'il est introduit dans le tube digestif d'un hôte favorable, tel que le Lièvre ou le Lapin. Cette introduction est d'ailleurs toute passive, et s'effeetue par l'intermédiaire des boissons ou des aliments.

La résistance vitale des embryons du $T$. serrata paraît être assez eonsidérable, du moins tant qu'ils demeurent dans un milieu humide. Röll, de Vienne, a pu infester des Lapins en leur faisant prendre des anneaux abandonnés depuis dix jours en plein air, et déjà couverts de moisissures. Leuckart a obtenu le même succès en les laissant pendant douze jours dans l'eau. Enfin, Davaine dit avoir conservé pendant plusieurs années, également dans l'eau, des embryons vivants et nullement altérés. Par eontre, la mort de ces embryons paraît survenir assez rapidement sous linfluence de la dessiceation. - Et il est certain, en définitive, que sur l’immense quantité d'œufs produits par un Ténia, un fort petit nombre sont appelés à poursuivre leur évolution.

Dès qu'ils sont parvenus dans l'intestin, leur coque est détruite sous l'action du sue gastrique, et l'éelosion a lieu. Les embryons hexacanthes, mis en liberté, se fraient un chemin dans les tissus à l'aide de leurs trois paires de erochets. Probablement même gagnent-ils les

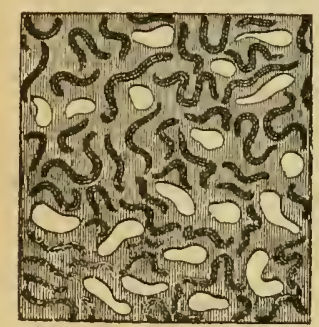

Fig. 116. - Portion de la surface du foie d'un Lapin infesté artificiellement, montrant des trainécs vasculaires et les Cysticerques pisiformes au douzième jour de leur développement. Vu à la loupe (G. P. l'iana). vaisseaux pour se faire transporter à la faveur du mouvement eireulatoire : Leuckart a pu en recueillir dans la veine porte, et il ne répugne pas d'admettre que ce soit là leur voie normale. En définitive, les embryons parviennent dans le milieu qui convient à leur développement. Nous ne parlons pas de ceux qui s'égarent dans l'organisme même : ceux-là encore sont destinés à périr.

Quelques jours après l'ingestion des œufs, on trouve, à la surface et dans la profondeur du foie, de petites nodosités et de fines traînées distribuées dans tous les sens. Les premières paraissent être des kystes formés autour des embryons morts; quant aux traînées, elles représentent des galeries, que Laulanié a reeonnues pour être toujours des vaisseaux veineux sous-hépatiques. Dans ces galeries, on découvre de petits organismes dérivant de l'embryon hexacanthe, 
mais ne possédant déjà plus les six erochets de celui-ci : ils sont très ćlroits, mesurent à peine 1 millimètre de long, et se montrent formés d'un réticulum délicat, enveloppé d'une mince cuticule. Au bout de douze jours, ils ont déjà 3 millimètres de long et présentent des mouvements obseurs, dus à la contraction des cellules sous-cuticulaires.

Ces jeunes Vers se développent graduellement, s'allongent et élargissent les galeries qui les contiennent. Honiez a constaté, sur les individus àgés de vingt-deux jours, un phénomène très intéressunt. Ils ont à cette époque 1 centimètre de long sur moins d'un millimètre de large: leur partic moyenne subit alors, sur une certaine étendue, une constriction donnant naissance à une sorte de cordon plus ou moins tordu; ils se trourent ainsi divisés en deux parties, creusées chacune d'une dépression dans laquelle s'insère ce cordon (fig. 117); puis celui-ci s'atrophie de plus en plus et finit par être résorbé. La séparation des deux moitiés est alors complète: l'une d'elles parait devoir se détruire; l'autre ne tarde pas à bourgeonner une tête de Ténia, et constitue, par conséquent, le Cysticerque définitif. La dépression signalée par Leuckart à l'extrémité postérieure de ce Cysticerque, el à laquelle il avait donné le nom de for $a-$ men caudale, a sans doute pour origine le phénomìne que nous venons d'indiquer.

Étudions maintenant le mode de formation de la tête du futur Ténia, à l'intérieur de la vésicule. A l'une des extrémités se produit une invaggination, en mème temps que se manifeste une prolifération cellulaire active, déjà facile ì constater le vingt-deuxième jour. Bientôt, à la partie profonde, légèrement élargie, de cette gaine, un peu sur le cóté, on voit se soulever un mamelon cellulaire: c’est le point de départ de la tête, le rudiment céphalique, à la base duquel se for-

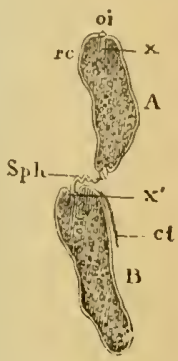

Fig. 117. - Cysticerque pisiforme en voie de division au vingt-denvième jour. Un corton $s p h$ unit les deux parties diune larve primilivenent simple et marqque une portion splacélice du Cysticerque.Al"extrénité supérieure du segment $A$, on voil le rudiment de la tète el du receptaculum ( $r c$, $x)$; il $y$ a quelque chose danalogne dans la prartie B. - ct, lame de cuticule qui se đélache. oi, orifice d'invagination. La partie A forme lanimal futur; la partie B doit se détruire (R. Moniez). ment ensuite quatre protubérances secondaires, rudiments des ventouses. Puis, l’invagination s'accentue, et les crochets se développent. Ils ont d'abord la forme d'aiguillons faiblement courbés, disposés en trois ou quatre rangées irrégulières autour du mamelon criphalique. Plus tard cette disposition se régularise; il ne reste plus que deux rangées alternes de crochets, et ceux-ci, bientôt chitinisés, acquièrent leur forme définitive. Il est à remarquer que cette partie, à laquelle on donne le nom de tête, se forme toujours à l'extrémité de l'embryon opposée aux six crochets, c'est-à-dire à l'extrémité postérieure, puisque les crochets sont à l'avant dans la progression. D'apıès Moniez, cette tête ne serait done, morphologiquement, qu'un 
organe de fixation, développé à la partie postérieure du Ténia et comparable aux armatures des Trématodes Polystomiens. Néanmoins, comme l'a fait remarquer Neumann, il y a lieu de s'en tenir au langage adopté couramment.

Un mois à peine après l'infestation, les Cysticerques quittent les galeries du foie, qui sont remplacées par des cicatrices. Ils ont alors plus d'un centimètre de long; doués de mouvements énergiques, ils

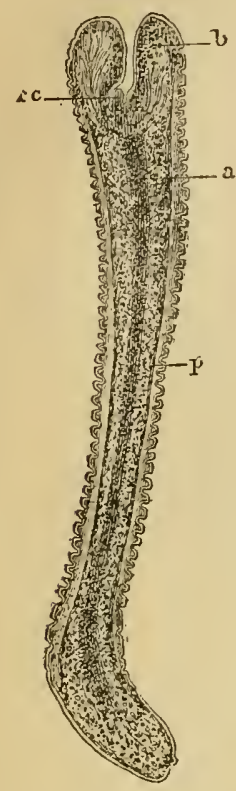

Fig. 118. - Développement du Cysticercus pisiformis, d'après R. Mloniez. - Larve âgée d'un mois environ, prise daus une galerie superlicielle du foie d'un Lapin. Elle est déja marquée de nombreux plis ou papilles $p$ et ne présente encore aucune trace d'hydropisie. - $a$, partie centrale finement grenue, yui marque le point où se fera la déchirure des tissus. La partie marquée $b$, jusqu'au rudiment de la lite $r c$, représente le futur receptaculum copitis. Grossissement : 15 diamètres.

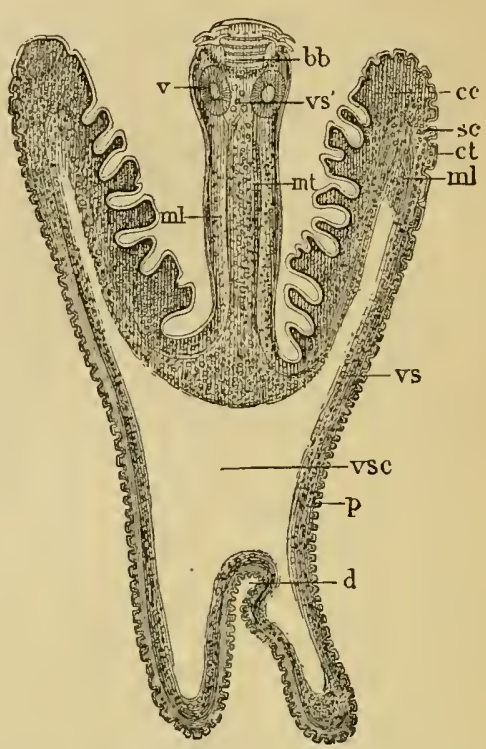

Fig. 119. - Coupe du Cysticercus pisiformis complètement developpé, d'après R. Moniez. - La tète est évaginće et suivie dune longue portion qui passera presque entière à l'ćtat adulte. - $d$, dépression constante à la partie postérieure du Cyslicerque, due à l'atrophie d'une partie du corps à un stade antérieur (représenté fig. 117), vs, coupe des vaisseaux dans la vesicule. vs', coupe des vaisseaux au moment où ils s'anastomosent. vsc, vésicule. $p$, papilles. $c t$, cuticule. $s c$, couche sous-cuticulaire. $c c$, corpuseules calcaires. $m l$, fibres musculaires longitudinales. $m t$, fibres musculaires transversales. $v$, rentouses. $b b$, bulbe céplalique. Grossissement : 15 diamètres.

se contractent, rampent ou glissent à la surface des tissus; à l'état de repos, ils ont un aspect vermiforme et sont renflés au point où bourgeonne la tête (fig. 118). La partie centrale (a) se montre alors grenue et entre en régression; quant à la partie périphérique, elle est garnie de papilles ou plis circulaires irréguliers.

Parvenus dans le sac péritonéal, les jeunes Cysticerques ne tardent pas à devenir hydropiques, puis ils s'enkystent sur divers points de la séreuse, notamment au niveau de la grande courbure de l'estomac 
et dans la région du bassin. Le liquide hydropique s'accumule dans la partie centrale et postérieure du corps, par suite de la déchirure du tissu granuleux que nous arons vu entrer en régression : ainsi se trouve constituée la vésicule caudale, laquelle, on le voit, dérive directement de l'hexacanthe.

Le Cysticerque offre trois parties distinctes : la tête ou scolex (Kopf), le corps (Wurmleib), qui lui fait suite et forme les parois de la cavité d'invagination; enfin la vésicule caudale (Schwanzblase). Quant au kyste, que certains auteurs rattachent au Ver lui-mème, ce n'est autre chose qu'une enveloppe adventice fournie par les tissus de l'hôte.

L'examen histologique du Cysticerque montre d'ailleurs une constitution tout ì fait analoggue ì celle du Ténia adulte, et sur laquelle nous reviendrons plus loin; la tète, en particulier, s'est organisée d'une façon complète : on y distingue les ventouses, les crochets, le bulbe, les masses nerreuses, les vaisseaux.

Mourson et Schlagdenhauffen ont reconnu, dans le liryuide des Cysticerques, la présence d'une quantité relativement considérable d'albumine, et d'une leucomaïne qui lui communique des propriétés vénéneuses très accusées. Un Lapin, dans le péritoine duquel on injecte ce liquide, meurt avec des signes de décomposition du sang.

$3^{\circ}$ État rubanaire. - L’érolution du Ténia est suspendue tant que le Cysticerque demeure enkysté chez le Lapin. Ce Cysticerque doit donc être introduit - encore d'une manière passive - dans l'intestin du Chien. La vésicule caudale ne tarde pas alors à se flétrir et à se détacher, et la chute du corps suit de près. Ces deux parties ne prennent donc aucune part à la formation du Ténia adulte. C'est aux dépens du cou, c'est-à-dire de la partie postérieure de la tête, que se développent par gemmation les productions nouvelles. Celles-ci consistent en une série d'anneaux qui demeurent unis en une chaine d'aspect rubané: on a donné à cette chaine le nom de strobile. Une dizaine de jours après leur introduction dans le tube digestif du Chien, les jeunes Ténias mesurent déjà de 1 à 3 centimètres de lonģ, et au bout de deux mois les premiers anneaux formés sont déjì mûrs et commencent à se détacher.

Le T'enia serrata ainsi constitué est donc représenté par un long ruban, dont l'une des extrémités, graduellement atténuée, se termine par un renflement qu'on est convenu d'appeler la tête. L'extrémité libre de celle-ci offre un petit prolongement conique appelé trompe ou rostre (rostellum), qui porte ì sa base une double couronne de crochets chitineux. Ceux-ci (fig. 120) comprennent une partie libre ou lame, recourbée en faucille, un long manche obtus, sur lequel viennent se fixer les fibres contractiles du rostre (bulbe); et enfin, au point de réunion de ces deux parties et du côté de la concavité, une saillie apophysaire ou garde (dent. talon, hypomochlion), sur laquelle s"insèrent également des fibres musculaires. Les crochets des deux rau- 
gées n'ont pas les mêmes dimensions. Aussi les distingue-t-on en grands et petits. Ces derniers ont la garde bifide. La disposition de ces organes leur permet de basculer autour de leur partie moyenne, sous l'influence de la contraction des muscles du bulbe, et la lame s'enfonce de la sorte dans la muqueuse intestinale. - Au-dessous des crochets, on observe quatre ventouses, cupules hémisphériques saillantes, conprenant un système complexe de fibres musculaires (radiales, circulaires et longitudinales); la contraction de ces fibres tend à produire le vide dans la cupule, et il en résulte une adhérence très puissante de la ventouse à la muqueuse intestinale.

En zoologie descriptive, on donne le nom de cou à la partie inarticulée qui fait suite à la tête. A 2 ou 3 millimètres de celle-ci,

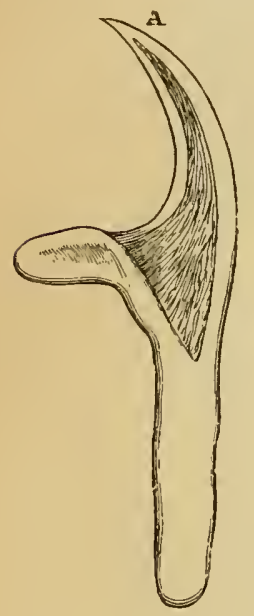

Fig. 120. - Crochets du Trnia servata, grossis 250 fois. A, grand crochet. B, petit crochet (Orig.).

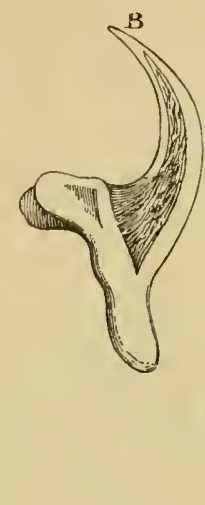

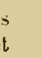 (1)}

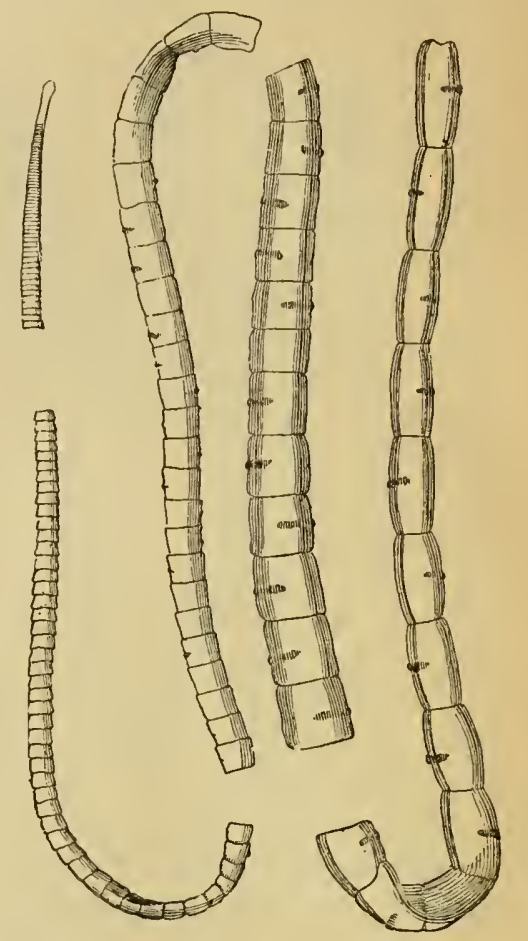

Fig. 121. - Tænia serrata, grandeur nalurelle. (Orig.).

dans l'espèce qui nous accupe, on y distingue déjà des stries qui séparent les premiers anneaux, ceux de récente formation. Ces anneaux sont courts et étroits; à 20 centimètres environ de la tête, ils sont carrés et mesurent alors $\breve{5}$ à 6 millimètres de côté; ceux qui viennent ensuite s'allongent de plus en plus, et les derniers ont d'ordinaire 10 à 12 millimètres de long sur 4 à 6 de large. Lorsqu'il ne s'en est encore détaché aucun, le dernier porte souvent une échancrure que von Siebold a appelée cicatrice terminale, et qui résulte de la séparation de la vésicule caudale. Le nombre total est d'environ 400.

Dans chacun de ces anneaux, se développent peu à peu des organes 
génitaux, qui sont déjì bien nets vers le $175^{\circ}$ anneau, et dont les orifices sont situés sur de petits tubercules saillants, visibles sur la marge (pores génitaux), et placés alternativement, quoique d'une façon peu régulière, d'un côté el de l'autre.

Pendant que le bourgeonnement continue ì l'extrémité céphalique, les oufs se développent et s'aceumulent dans les dernier's anneaux; on dit alors que ceux-ci sont parvenus ì maturité. Enfin, ees anneaux ovifères mùrs se détachenl tour à tour de la colonie, et peuvent vivre librement dans l'intestin. Èn général, cependant, ils ne tardent pas à ètre expulsés, et ront répandre au dehor's les milliers d'œufs qu'ils contiennent, par des déchirures de leurs tissus ou, comme l'a dil Van Beneden, par une véritable opération césarienne spontanée. Ce sont ces articles séparés qu'on connail depuis longtemps sous le nom de cucurbitins, et qu'on a cru devoir distinguer comme autant d'individus distincts, représentant l'état adulte et définitif du Ténia, sous le nom de proglollis.

En résumé, le Tienia serrala contenu dans l'intestin du Chien abandonne ses anneaux ou cucurbitins ì mesure de leur maturité. Ces anneaux, rejetés avec les excréments, laissent échapper leurs œufs, qui peuvent alors se répandre sur les aliments ou parmi les hoissons. Ingérés à l'occasion par les Lièrres ou les Lapins, ces œufs, qui renferment un embryon hexacanthe, donnent naissance à des Cysticerques pisiformes, lesquels s'enkystent dans les replis du péritoine. Puis, lorsque les entrailles du Lapin sont dévorées par un Chien, le Cysticerque perd sa résicule, reproduit un T'ania serrala dans l'intestin de cet animal, et le cycle recommence.

Organsatiox. - 11 nous reste à étudier l'organisation interne du Ténia sous sa forme rubanée ou strobilaire. - Comme cliez tous les Cestodes, le corps est revètu d'une cuticule, au-dessous de laquelle s'étend une couche cellulaire active (fig. 122). En dedans de celle-ci, et au milieu du réseau conjonctif qui forme la masse du corps, on distingue, sur une coupe transversale, deux séries de muscles longitudinaux et une rangée plus profonde de muscles circulaires ou mieux transversaux.

Dans la zone centrale, on trouve d'abord les deux cordons nerveux longitudinaux principaux qui suivent les còtés du corps jusqu'au niveau de la tète, où il existe un système très complexe de ganglions et de commissures, d'où dérivent les filets qui vont innerver les muscles des ventouses et de la trompe. Ce système a été bien étudié par É. Blanchard, Moniez et Niemiec. En dedans des nerfs, on observe de chaque còté deux vaisseaux longitudinaux, semblables au niveau de la tète, où ils forment une anastomose circulaire, mais prenant à quelque distance des caractères assez dilférents. Le phus voisin de la face ventrale devient extérieur, s'élargit beaucoup et semble dépourvu de paroi : Iloniez l'appelle lacune longitudinale ou simplement lıcunc. L'autre conserve sa situation, demeure étroit et se montre en général limité par des cellules: on lui laisse le nom de vaisscau. Les lacunes sont reliées entre elles par une large anastomose située à la partie postérieure de 
chaque anneau; les vaisseaux ne présentent jamais cette communication.

L'étude des organes reproducteurs offre un grand intérèt. Chacun des anneaux est hermaphrodite, mais les organes màles se développent avant les organes femelles, et ceux-ci persistent seuls en dernier lieu : il y a là un phénomène comparable à ce qu'on appelle, chez les végétaux, la dichogamie protandrique.

Les organes mâles sont représentés par des amas de spermatozoïdes situés

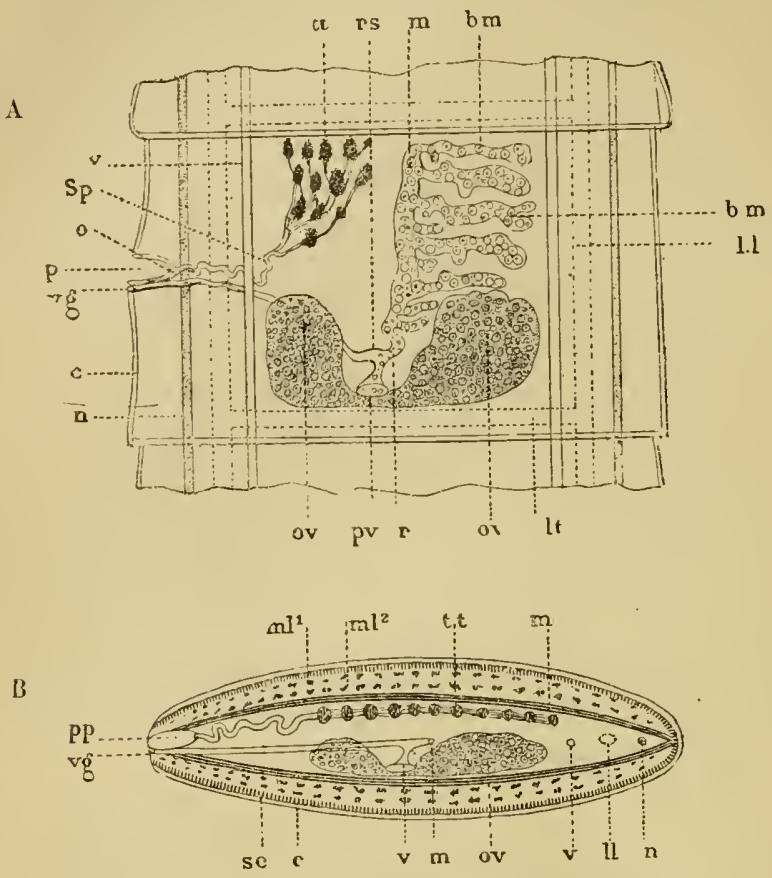

Fig. 129. - Schéma de l'organisation d'un anneau de Ténia du lype Tænia serrata, d'après R. Monicz. - A, coupe horizonlale. La moitié gauclıe de la coupe est prise au voisinage de la face dorsale, pour montrer la disposition des follicules testiculaires; la moitié droile au niveau de la face ventrale, pour moutrer les ramificalions de la matrice. $\mathrm{B}$, coupe verticile. $-c$, cuticulc. $s c$, couche sous-cnticulaire. $m / 1$ et $m l^{2}$, faisceaux musculaires longitudinaux. $m c$, fibres musculaires dites circulaires, $n$, cordon nerveux. $\iota$, lacune longitudinaic. $l t$, lacune transversale. $y s$, vaisseau. $t t$, follicules testiculaires. $s p$, spermiducte, $p p$, poche péniale. o, orifice du spermiducle. ov, ovaires (pour simplifier la figure, le 3. ovaire [vitellogène] n'a pas été représenté). pv, pavillon. $r$, point de rencontre des spermatozoïdes et des oufs. $r s$, réservoir séminal. $v g$, orifice du vagin. $m$, corps de la matrice. $l m$, ses brauches lalérales.

à la partie supérieure de l'anneau, et connus sous le nom de testicules. Ces amas sont peu abondants en arrière, au point où se développe l'ovaire. Il ne parait pas exister de véritables tubes de communication entre ces testicules et le conduit excréteur màle (cunal déférent ou spermiducte); les spermatozoïdes, pourvus l'une petite tète et d'une longue queue, y arrivent en serpentant à travers le réseau conjonctif, et en traçant, dans leur trajet, des voies qu'on a prises pour des tubes. Quant au spermiducte, il consiste en un canal à parois propres, qui s'allonge peu à peu et décrit de nombreuses circonvolutions, à mesure c[ue les spermalozoïdes l'envahissent. Il s'ouvre finalement au fond d'une dilatation dite poche péniale ou poche du cirre, à la 
partie supérienre de laquelle se fixent des fibres musculaires émanées du plan supérieur des muscles circulaires. L’extrémité du sperniducte preut se renverser et faire saillie a l'extérieur : telle est l'origine de l'organe qu'on a décrit sous le nom de cirre ou de munis.

l.es oryunes femelles oceupent la partie ventrale de l'anneat. Its sont constitués essentielloment par trois masses glandulaires sitnées dans la moitié postérieure. D'après Moniez, toutes trois ont lit mème constitution : elles sont formées par un assemblage de follieules qui dounent naissance aux anfs dont nous avons étudić l'évolution; ce sont donc bien des oraires, dans le sens propre du mot. Deux d'entre elles, latérales et symétriques, sont réunies par une bande inférieure, formant une sorte de canal transversal. laa troisième est étendue entre celles-ci et la lacune anastomotique. - Les auls sont recueillis par un pavillon a parois musculaires, ouvert contre le tube qui réunit les denx lobes ovariens latéraux. Du fond de ce pavillon part un canal ou oviducte qui se diriłge en arrière, recoit bientòt le vagin, puis remonte vers la face dorsale en décrivant une ou deux boucles, el aboutit à un organe ovoüde connu sous le nom de corps de Mehlis. Ciest au niveau de cet organe qưil recoit le tuhe collecteur du troisième ovaire, né à la base de celui-ci par un pavillon spécial. Il se continue enlin par un tube grèle qui redescend hrusquement ct va se joindre au rudinent de l'utérus.

Lenckirt et Defîke n’interprètent pas ces oroanes de la mème manière. Pour eux, les deux lobes latéraux représentent seuls des ovaires, et le lobe impair ou postérieur est un ritellogène ou une glande albuninipare. Quant au corps de Mehlis, ils le regardent, avec Sommer, comme une glunde corrillière; mais cette opinion est inadmissible, puisque nous avons vu que la coque qui entoure l'enuryon n'est nullement un produit de sícrétion. Moniez a fait voir que cet organe n'est autre qu'une dilatation fusiforme de l'oviducte (col de la matrice), entouré d'une sorte de bulbe à fibres entre-croisées.

L.e vuyin nait sur la papille génitale immédiatement en arrière de la poche péniale; il se dirige en arrière et en bas pour gagner le tube qui émane du pavillon; mais, avant de s'aboucher avec celui-ci, il se dilate en un réservoir destiné à l'accumılation des spermatozoïdes (receptaculum seminis).

La mutrice ou utérus part de la base du col, descend un peu vers la face ventrale, et s'étend parallèlement à celle-ci, sur la ligne médiane, en se dirigeant vers le bord antérieur. Cette matrice, représentée dans le principe par un cylindre plein, se creuse bientòt d'une cavité dans laquelle pénètrent les aufs. L'accumulation progressive de ceux-ci, de mème que leur accroissement, détermine la formation de hernies latérales, plus ou moins ramifiées, qui ne tardent pas à se rompre: les cufs se répandent alors dans la zone centrale, oì ils se disposent d'une façon assez régulière, quoique n'étant plus maintenus par une membrane propre.

Comment s'effectue la fécondation? Sommer admet que, par la rétraction de la papille génitale, il se forme au sommet de cette papille une sorte de cloaque (sinus gènital); pendant l'acte de lit fécondation, une énergique contraction des muscles longiludinaux, resserrant les bords de cette cavité, la transformerait en une poche fermée, dans laquelle serait versé le sperme, qui de là passerait dans le vagin. Mais Leuckart et Van Bencden ont observé, dans divers Ténias, une pénétration directe du pénis dans le vagin. En tout

Rarliet. - Zoologie. 
cas, ces auteurs sont d'accord pour admettre une autofécondation dans chaque anneau. Le sperme va s'amasser dans le réceptacle séminal, en attendant la formarion et le passage des œufs. Mais si l'on considère, avec Moniez, que la glande postérieure représente un ovaire, force est d'admettre en outre qu'une partie des spermatozoïdes doivent suivre l'oviducte jusqu'au corps de Mehlis, pour aller féconder les œufs émanés de ce troisième ovaire.

Ce sont tous ces œufs fécondés qui vont s'accumuler dans l'utérus, pendant que les autres organes s'atrophient. Les testicules disparaissent les premiers, puis les lobes latéraux de l'ovaire, et plus tard le lobe impair. Le corps de Mehlis se conserve assez longtemps; mais, sur les anneaux mùrs, on ne voit plus qu'une partie du canal déférent et du vagin. Les œufs ne sont pas sans avoir subi eux-mèmes d'importantes modifications : ils ont perdu leur membrane et leurs deux masses vitellines, dont les résidus ont donné naissance à un système de mailles étroites, réfringentes, dans lesquelles sont renfermés les embryophores.

C'est à cette période que les anneaux se détachent spontanément de la chaîne, soit un à un, soit quelquefois en petits groupes; et grâce aux solutions de continuité qu'ils subissentainsi, un certain nombre d'œufs s'échappent souvent dans l'intestin mème, ce qui permet de reconnaitre la présence dès Ténias dans l'intestin par le simple examen microscopique des matières fécales. Les premiers anneaux commencent à être expulsés huit semaines après l'ingestion des Cysticerques.

Un dernier point mérite de retenir notre attention : c'est l'interprétation à donner de l'évolution des Ténias se rattachant au type dont nous venons de nous occuper.

Dès que cette évolution eut été déterminée, les naturalistes, sous l'empire des idées de Steenstrup, s'empressèrent de la citer comme un des exemples les plus frappants de la génération alternante. Ainsi, pour von siebold et Leuckart, l'embryon hexacanthe, produit par génération sexuée, représentait une grand'nourrice; pour Van Beneden, ce fut un proto-scolcx. On considéra que cet embryon, parvenu dans le corps d'un premier hòte, engendrait, par voie agame, un nouvel individu qui demeurait invaginé dans sa propre mère, devenue vésiculaire (hydatide), et on regarda comme une seconde larve ou nourrice cet être nouveau, qui prit le nom de deuto-scolex dans la nomenclalure de Van Beneden. P'uis, cet auteur appela strobile l'élat ultérieur, dans lequel le Ver, parvenu chez son hôte définitif, a acquis par bourgeonnement une série d'articles et pris la forme rubanée. Enfin, chacun de ces anneaux arrivé à maturité et séparé du reste de la chaîne, fut regardé comme un individu distinct, chargé de reproduire, par voie sexuée, l'embryon hexacanthe primitif : cet individu générateur reçut le nom de proglottis.

On a contesté la justesse de cette manière de voir. Pour Moniez, par exemple, le Cysticerque, qui est constitué, comme on l'a vu, par une vésicule l'ésultant de l'accroissement de l'embryon hexacanthe, et par un organe de fixation pris à tort pour une tète, ce Cysticerque représente un seul être, un jeune Ténia, dont l'individualité n'est pas distincte de celle de l'embryon hexacanthe. Ce Ténia bourgeonne comme la généralité des autres Vers (Annélides), à la partie postérieure du corps, entre la tète et la vésicule. Celle-ci, dont l'auteurne distingue pas le corps, "représente le premier anneau de la chaine future; elle tombe dans la plupart des cas, sans rien pro- 
duire, après avoir servi d'organe de protection ". En se basant sur ces considérations, Moniez se refuse à admettre l'existence de la génération alternante.

En cette malière, la discussion nous parait avoir pen de chances d'aboutur, a moins de s'entendre tout d'abord sur la valeur des expressions. Si l'on admet qu'il n'y a de génération que par voie sexuée, et si l'on considère que les cucurbitins sont des organes et non des individus, il est évident qu'il n'y a point de génciation alternanle. Dans le cas contraire, il faul bien reconnaître chez les Ténias ce mode de génération, qui est, du reste, admis par la majorité des auteurs. Miris nous n iltachons, pour notre part, aucune importance à cette question d'interprétation.

Axomalies. - Leidy a décrit des T. serrala pourvus d'une seule couronne de crochets (var. a monostephunu Dies.); Bremser en a signalé comme étant inernes (var. $\beta$ astephana Dies.); ce sont là des faits sans importance: il s'agissail peut-être d'individus recueillis sans soin, ou très vieux, ou altérés.

Le musée d'Alfort possède une préparation de Cysticercus pisiformis, venant de Delafond, et dans laquelle la tète montre six ventouses, avec $4 \dot{4}$ crochets. - Le C'ysticercus elonyatus F. Leuckart n'est autre qu'un Cysticerque pisiforme très allongé. Cel aspect, d'ailleurs, n'est pas très rare.

PAthologie. - La fréquence du $T$. serrata est assez variable suivant les régions. En Islande, Krabbe n’en a pas rencontré un seul exemplaire; à Copenhague, il en a vu un seul, sur 500 Chiens examinés. Zschokke, à Zurich, en a rencontré chez 2,3 p. 100 des Chiens; Bertolus et Chaureau, ¿̇ Lyon, chez 27 p. 100. A Paris, c'est de beaucoup le plus commun des Cestodes du Chien après Dipylidium caninum.

On n'en trouve généralement qu'un petit nombre ì la fois dans l’intestin. En pareil cas, la santé de l'animal n'est pas altérée. Mais l'accumulation d'un grand nombre de Téniadés, qu'ils appartiennent ì cette espèce ou ì d'autres, donne lieu assez souvent à des troubles de diverse nature: catarrhe intestinal, coliques, irrégularité de l’appétit, parfois même attaques épileptiformes et accidents nerveux variés, dont l'origine est peut-ètre attribuable d̀ une substance excrétée par les Vers (leucomaïne?).

Cadéac é Lahogue ont signalé des cas de perforation de lintestin grèle par ce Ver chez des Chiens qui araient présenté pendant la vie des symptômes rabiformes. - Wolpert, chez un sujet abattu pour la mème cause, a trouvé un Ténia dans l'œsophage, plusieurs dans l'intestin, un autour du rein gauche et un dans le bassinet de chacun des deux reins.

Quant aux Cysticercus pisiformis, nous avons vu qu ils natteignent d'ordinaire leur complet développement que dans le péritoine, rarement dans le foie. On les trouve surtout dans l'épiploon et dans le bassin, où ils forment parfois de véritables grappes. S'ils sont très nombreux, ils peurent amener le sujet i un élat cachectique qui aboutit à la mort, ainsi que l'a constaté Neumann. Mais ils provoquent 
VERS.

surtout de dangereuses lésions pendant leur passage dans le foie et plus spécialement au moment de leur émigration dans le péritoine.

Ténia bordé (T. marginata Batsch. 1786. -- Syn. : T. è cysticerco tenuicolli Küchenmeister, 18333; T. [Cystotrnia] marginata Leuck., 1863). - Le plus grand des Ténias du chien : long de $1^{\mathrm{m}}, 50$ à 5 mètres (en moyenne 2 mètres). Tête réniforme, large de 1 millimètre; rostre long et mince, armé d'une double couronne de 30 à $4 \dot{4}$ crochets (ordinairement 36 à 38) : les grands longs de 180 à $220 \mu$, à manche mince, ondulé sur les bords, légèrement plus

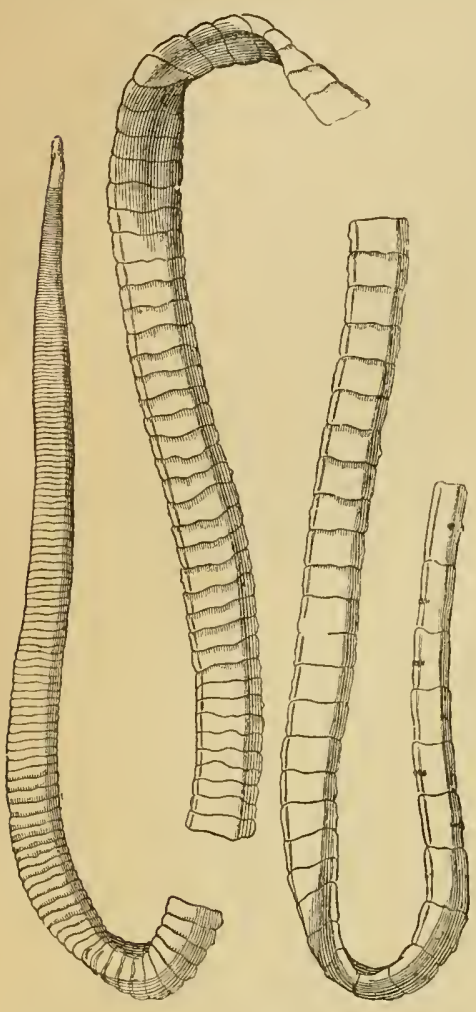

Fig. 123. - Trinia marginalı, grandeur long que la lame; les petits longs de 110 à $160 \mu$, à manche assez long, à garde simple. Cou assez long, presque aussi large que la tête. Anneaux plus larges et relativement plus courts que dans l'espèce précédente, ne devenant carrés qu'à 60 centimètres au moins de la tète ; bord postérieur emboitant comme une manchette l'anneau suivant, et irrégulièrement ondulé ou crénelé (marginatus); pore génital peu saillant; anneaus mùrs au nombre de 20 à 70, longs de 10 a 14 millimètres sur \& à 7 de large. Utérus
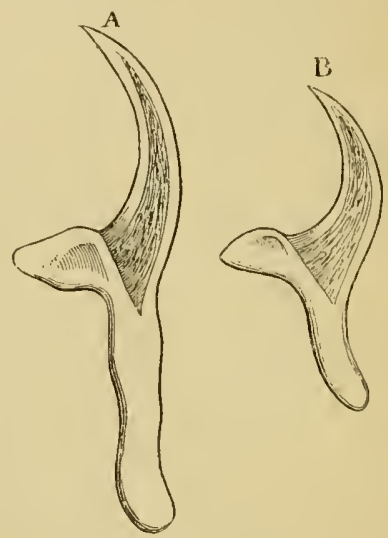

formé d'un tronc médian court, portant de chaque còté 5 à 8 fortes branches, dont les ramifications, très profondes, s'étendent au loin en avant et en arrière. Embryophores à peu près sphériques, de 31 à $36 \mu$ de diamètre.

Le T. marginala vit dans la région antérieure de l’intestin grêle du Chien et du Loup.

Son Cysticerque (Cysticercus tenuicollis Rud.) se rencontre dans le péritoine, plus rarement dans la plèvre ou le péricarde de divers animaux: Singes, Ecureuils, Ruminants, Porcins; il représente en 
grande partie ce que les anciens vélérinaires désignaient sous le non de Ténia globuleux, et ce que les bouchers qualifient de boule d'eau. Il est remarquable par le grand développement de la résicule caudale, qui atteint d'ordinaire le volume d'un ouf de Pigeon ou même de Poule, mais peut acquérir dans certains cas des dimensions colossales: ainsi, la collection de Giessen possède un exemplaire provenant du Bœuf, dont la vésicule mesure 16 centimètres (1) de long sur 6 it 7 centimètres de large, et Diesing parle d'un autre spécimen, provenant du Pore, mesurant presque uı pied de long sur 4 pouces de large. La vésicule caudale se prolonge en un col a l'extrémité duquel la tête du jeune Ver avec son réceptacle (corps) se trouve invaginée; ce col lui-mème rentre d'ordinaire dans la vésicule, où il flotte. L'extrémité postérieure du réceptacle se prolonge, à l'intérieur de la cavité de la vésicule, par un appendice assez long, connu sous le nom de queue du cysticerque, et qui n'est autre qu un reste de l'ancien parenchyme

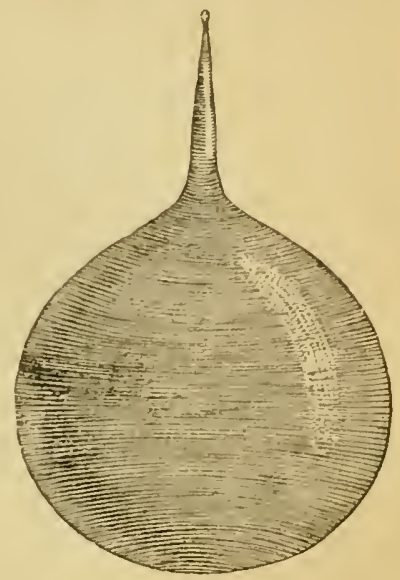

rig. 125. - Cysticercus tenuicollis, grandeur naturelle, avee la tête évaginée (Orig.). de la vésicule, détruit par l'accumulation du liquide hydropique.

Évolution. - En 18:32, von Siebold a vait réussi à obtenir le développement du C. tenuicollis en Ténia dans l'intestin du Chien (2), mais il ne sut pas reconnaitre la spécilité de ce Ténia, qu'il considérait comme identique aux $T$. serratn, cœenurus et solium. C'est Küchenmeister qui, l'année suivante, après des expériences du même genre, distingua nettement le Ver comme espèce, sous le nom de $T$. è cyslicerco temuicolli. Dix ans plus tard, Leuckart montra qu'il était identique au T. marginata du Loup, décrit par Batsch en 1786.

Dans un autre sens, Küchenmeister, Baillet, etc., développèrent le Cysticercus tenuicollis chez des animaux tels que Houton, Chèvre, Porc, auxquels ils firent prendre des anneaux mûrs de $T$. marginata. Lorsque ces anneaux sont donnés en trop grande abondance, les sujets d'expérience meurent d'ordinaire au bout d'une dizaine de jours, par le fait d'une hémorrhagie hépatique due à l'émigration des jeunes Cysticerques vers le péritoine (b). Ces larves sont ovoïdes et montrent le rudiment de la tête à l'un des póles.

(t) Leuckart écrit, évidemment par errour, 160 cent.

(2) Une expérience faite par le Dr Möller, d'Altona, sur lui-mime, a montré que cette transformation n'a pas lieu chez l'llnmme.

(3) A. Ratidet, Diveloppement expérimental du Cysticercus tenuicollis chez le Chevrean. Bullet. de la Soc. zoolog. de Frince, XVI, P. 157, 1891. 
Dans les expériences de Leuckart, les Cysticerques étaient complètement développés au bout de sept à huit semaines. - Quant au déreloppement du Ténia dans l'intestin du Chien, on constate qu'il faut en général dix à douze semaines avant l'expulsion des premiers anneaux.

ANomalies. - Moniez a décrit un T. marginata qui était bifurqué en deux prints, formant ainsi chaque fois deux chaines qui s'étendaient côte à còte, l'une beaucoup plus faible que l'autre.

Le mème observateur a fait connaitre aussi diverses modifications tératologiques du C. tenuicollis, notamment une déformation de la tète, qui était pourvue de crochets très irréguliers. - Fromage de Feugré et Rudolphi ont vu des exemplaires de ce Cysticerque qui étaient munis de deux tètes. -Enfin, Leuckart dit avoir reçu du $\mathrm{D}^{\mathrm{r}}$ Schmidt un C. tenuicollis dont la vésicule renfermait trois vésicules-filles stériles.

Pathologie. - Le T. marginata est surtout commun chez les Chiens de boucher et de berger, pour un motif facile à saisir. En Islande, Krabbe l'a rencontré chez 73 p. 100 des sujets examinés; à Copenhague, chez 14 p. 100 seulement. Les autres observateurs déjà cités l'ont ru, à Zurich, chez ö p. 100, et à Lyon, chez 13 p. 100 de ces animaux.

On le trouve souvent isolé ou tout au moins en petit nombre. Malgré sa grande taille, il ne doit done jouer qu'un róle assez secondaire dans la production des troubles imputables au téniasis du Chien.

Le Cysticercus tenuicollis est commun chez nos Ruminants domestiques: Mouton, Chèrre, Bceuf; on l'observe assez sourent aussi chez le Porc, et nous avons montré que, dans ce cas, un examen attentif est parfois nécessaire pour le distinguer dı $C$. cellulosæ. Son siège habituel est dans les séreuses, comme il a été dit plus haut, mais on l'a rencontré aussi dans le foie, dans le poumon et même dans les muscles. Il n'existe d'ordinaire qu'en petit nombre sur un même sujet, et ne détermine pas de troubles appréciables; cependant, il peut arriver qu'un animal ingère d'un seul coup tout un fragment de Ténia, et il survient alors, au moment où les larves émigrent du foie dans le péritoine, des accidents identiques à ceux que nous avons signalés à propos de l'évolution. Leuckart, le premier, a constaté un fait de ce genre chez le Porc; Puitz en a recueilli un chez une Vache.

En 1863, Cobbold découvrit, dans les muscles du Mouton, un Cysticerque armé qu'il regarda comme une espèce nouvelle, à laquelle il donna le nom de C'ysticercus ovis. D’après lui, ce Cysticerque est plus petit que celui du Porc; la tête a $0^{\mathrm{mm}}, 7$ de large et porte une double couronne de 26 crochets, dont les plus grands mesurent $157 \mu$. L'helminthologiste anglais soupçonnait, malgré le résultat négatif d'un essai d'infestation du Mouton, que ce Cysticerque était la larve d'un Ténia de l'Homme décrit, d'après de petits exemplaires sans tête, sous le nom de $T$. tenella Cobbold (nec Pallas, 1781, nec Pruner, 1847). 
Cet envahissement des museles ayant été constaté de nouveau par divers observateurs, la viande de Mouton, réputée jusqu’alors pour la plus saine, menaçait donc de se trouver condamnée, à l'égal des riandes de Porc et de Bauf, pour ses propriétés ténigènes, et déjà quelques médecins militaires araient cru pouxoir attribuer ì des Cysticerques du Houton plusieurs cas de Ténias observés en Algérie. - Mais les recherches de J. Chatin ont démontré, d'une facon riggoureuse, que ces craintes n’étaient pas fondées. Les prétendus $T$. terella Cobhold n'étaicnt que des T. solium de petite taille; quant aux $C$. ovis, cétaient de simples $C$. temirollis, peu développés. A plusieurs reprises, J. Chatin ingéra de ces Cysticerques virants, répondant autant que possible ì la diagnose de Cobbold, et jamais il ne constata le moindre indiec de la présence d'un Ténia. Administrés au contraire à des Chiens, ils dennèrent lieu au développement du T'. marginata.

Avec Ch. Morot, nous avons observé de nombreux Cysticerques analogues dans le foie et le diaphragme d'un Chevreau de quatre ì six semaines; il en existait aussi quelques-uns dans le poumon; les crochets étaient au nombre de 26 , les grands longs de 160 ì $170 \mu$, les petits longs de 190 ü $\mu$.

Bremser a observé deux fois le $C$. tenuirollis dans les parois du cœur, chez le Boul.

C. Baillet en a recueilli deux exemplaires dans le tissu conjonctif de la région sous-lombaire, chez un Chat.

Rudolphi a décrit, sous le nom de $C$. fistularis, un Cysticerque que Chabert avait trouvé dans le péritoine d'un Cheval et dont plusieurs individus étaient conservés au musée de l'École d'Alfort, où ils n'existent plus aujourd'hui. Quelques années après, Reckleben retrouva le même parasite à l'École vétérinaire de Berlin. D'après Gurlt, le Ver entier est long de 63 à 130 millimètres, épais en arrière de 6 à 13 millimètres; il est blanchâtre, transparent, tantôt grêle et allongé, tan tôt large et court. La tête est très petite, tétragone, munie de crochets en avant; les quatre rentouses sont arrondies et très petites. - Comme le font remarquer Cobbold et Leuckart, il s'agit probablement d'un C. tenuicollis très allongé.

Sur la foi de plusieurs auteurs anciens, et en particulier de Bonet. le Cysticercus tenuicollis a été longtemps classé, en outre, parmi les parasites de l'Homme (Tienia visceralis Treutler, C. visceralis Zeder). Cependant, on en était arrivé à mettre le fait en doute, quand Eschricht, étudiant des hydatides recueillies chez les Islandais par le $\mathrm{D}^{\mathrm{r}}$ Schleisner, eut la surprise de constater'qu’il s'agissait du $C$. temuicollis. Cette découverte fit quelque bruit, jusqu'au jour où Eschricht et Schleisner lui-même reconnurent qu'une méprise avait dù aroir lieu, et que ces Cysticerques devaient provenir d'un Mouton(1).

(1) H. Kranbe, Recherches helminthologiques en Danemark et en Islande. Copenhague, 1866, p. 43. 
Ténia de lirabbe ( $T$. Krabbei Mz., 1879). - Ver un peu plus long que le T. canurus. Tète petite, se continuant insensiblement avec le cou comme dans cette espèce, mais formant un renflement plus marqué; rostre armé de 26 à 34 crochets, les grands longs de $215 \mu$, les petits de $160 \mu$. Anneaux beaucoup plus larges que longs, sauf à l'extrémité de la chaine, où ils s'allongent brusquement et prennent une forme un peu caténulée ; pore génital très développé, formant une papille saillante qui occupe toute la longueur du bord de l'anneau tant que celui-ci reste court, et qui mesure parfois 1 millimètre de diamètre; souvent plusieurs pores génitaux se succèdent du mème còté. Embryophores à peu près sphériques, de $30 \mu$ de diamètre.

Ce Ver a été développé expérimentalement, par Moniez, chez un jeune Cliien auquel il avait fait prendre, 80 jours auparavant, des Cysticerques trouvés en abondance dans les muscles de plusieurs Rennes morts au jardin zoologique de Lille. Peut-être les Chiens des Lapons en sont-ils les hòtes habituels.

Le Cysticerque (C. turandi) est remarquable par le peu de développement de la vésicule.

Ténia inerme de I'llomme $\{T$. sayinat L., 1767, pro parte; T. mediocanellata Lüchenmeister, 1852; Tæniarhynchus mediocanellatus Weinland, 18:8; T. inermis Moquin-Tandon, 1860; T. [Cystu-

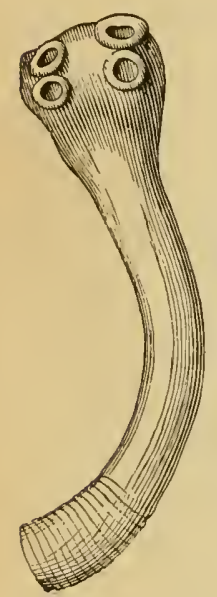

Fig. 126. - Tête de Tæmia saginala, vue de trois quarts (Laboulbène).

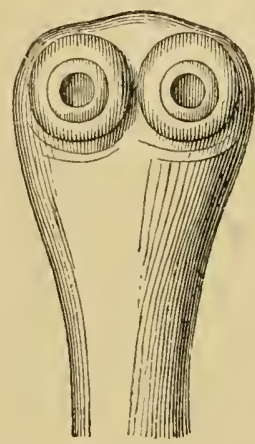

Fiğ. 127. - Tète de Trrnia saginata, vue de profil (Laboulbène). tænia] sayinata Leuck., 1879). - Ver long en moyenne de 3 à 8 metres, mais atteignant parfois des dimensions beaucoup plus considérables (1). Tète subtétragone, large de $1^{\mathrm{m} m}, 5$ à 2 millimètres, dépourvue de crochets, le rostre faisant défaut et se trouvant remplacé fréquemment par une légère dépression; ventouses arrondies, larges de $0^{\mathrm{mm}}, 8$, souvent entourées d'une bordure noiràtre plus ou moins large, formée par des granulalions pigmentaires. Cou assez lonษ, en général de moitié plus étroit que la tète. Premiers anneaux très courts, les suivants augmentant fort lentement de longueur, de sorte qu'ils demeurent plus larges que longs sur une très grande étendue de la chaîne; s'allongreant enfin assez rapidement, de sorte que les anneaux mûrs, qui sont épais, légèrement cucumiformes, arrivent à mesurer environ 18 à 20 millimètres de long sur ž à 7 de large. Pores génitaux très irrégulièrement alternes, faisant saillie en arrière du milieu du bord latéral. Utérus formé d'un tronc médian long, portant de chaque còté 20 à 30 branches latérales grèles, indivises ou divisées par dichotomie. Embryophores généralement ovoïdes, longs de 30 à $40 \mu$, larges de 20 à $33 \mu$, presque toujours entourés encore de la membrane

(1) Jusqu'à if mètres, selon Bérenger-Féraud. 
vitelline; coque moins opaque et laissant mieux voir l'embryon que dans ceux du T. solium.
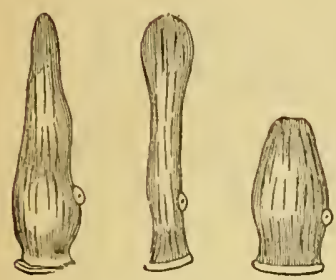

Fig. 128, - Cucurbilin du Trnia saginata: formes successives en quelques instants (Laboulbène).

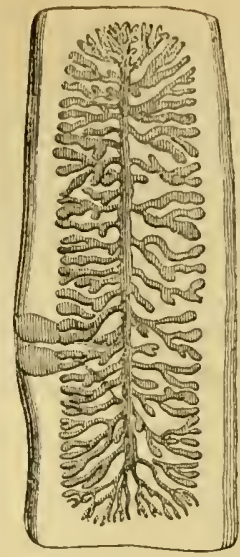

Fig. 129. - Cucurbitin libre du Tæria saginata, grossi trois fois (Orig.).
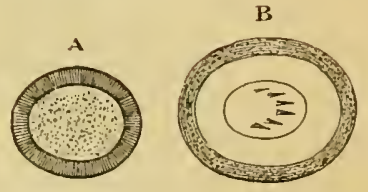

Fig, 130. - (Euf du Tænia saginata, grossi 3.50 fois. - A, vu dans lat glvcérine. $\mathrm{B}$, après avoir été traité par une solution concentrée de polasse (Laboulbène).

Ce Ténia vit dans l'intestin grêle de l'Homme.

Il est représenté, à l'état résiculaire, par le Cysticercus bovis Cobbold (C. Tirnix mediocanellalx Davaine;

C. T'. saginativ Leuck.), qui n'a encore été rencontré ì l'état spontané que dans les muscles et les viscères du Bouf, de la Girafe (Möbius) et peut-èlre de l'Homme. Ce Cysticerque se présente, ̀̀ l'état de complet développement, sous la forme d'une vésicule oblongue, de 4 à 8 millimètres de longueur, en moyenne, sur 3 millimètres de largeur, montrant, en un point de la zone équatoriale, une tache blanc jaunàtre qui correspond à la tête invaginée. Si on le place dans de l'eau tiède ( 37 à $40^{\circ} \mathrm{C}$.). on voit souvent l'évagination se produire; elle peut être obtenue, d'ailleurs, par une pression méthodique entre le pouce et l'index, mais ce procédé amène souvent la dé- F chirure de la vésicule. En tout cas, il est

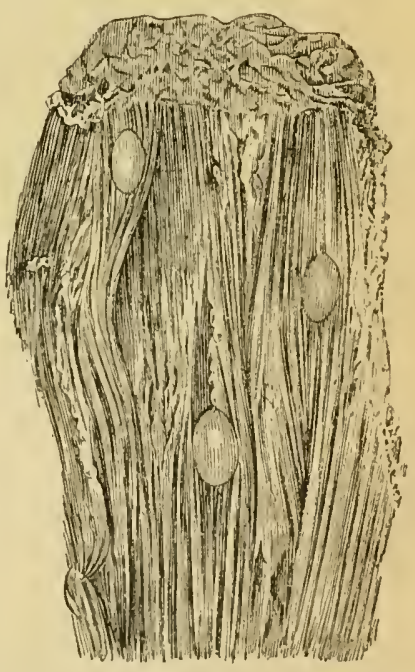

Fig. 131. - Fragment d'un muscle de Génisse contenant des Cysticercus bovis (Orig.). facile de reconnaître ainsi l'existence d'une tête inerme, pourvue de quatre ventouses et d'une dépression centrale, et suivie d'un cou fortement plissé. 


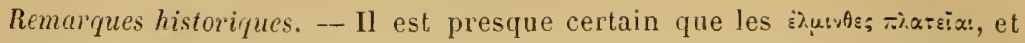
les :aıvia. on xnciat des frecs, ainsi que les Lumbrici lati et les Tæniæ de leurs traducteurs et commentateurs, se rapportent ou $T$. saginata Gœze. Mais, en ce qui concerne le Ver décrit et liguré en 1700, par Nicolas Andry, sous le nom de Solium ou Ténia sans épine, le fait est indiscutable.

Andry employait ce nom de solium comme indiquant que le Ver " est toujours seul de son espèce dans le corps où il se trouve "; mais il n'en est pas le créateur, car Arnauld de Villeneuve, en 1300, le cite déjà dans le mème sens. Krehl, de Leipzig, voudrait le faire dériver du mot syriaque schuschl, qui signifie chaine, mais il est beaucoup plus probable que c'est une simple altération populaire de l'adjectif latin solum.

La $12^{\circ}$ édition du Systema naturx de Linné désigna sous le nom de T. solium un parasite de l'Homme se rapportant à la fois au Ver qui porte actuellement ce nom et surtont an $T$. sayinuta.

C'est à Gœze (1) que nous devons la première distinction un peu précise de ces deux espèces : il qualifia la première de translucide, aplatie (pellucida), et la seconde de charnue, engraissée (saginata).

Après lui, cependant, on continua de les confondre, et comme certains observateurs trouvaient chez l'Homme des Ténias armés de crochets, tandis que d'autres en recueillaient d'inermes, on en vint à adme!tre, avec Bremser, Mehlis et F. Leucliart, que ces Vers perdaient leurs crochets en vieillissan!, de mème que l'Homme perd ses cheveux. Il faut dire toutefois que Seeger, en 18322 , formulait des réserves expresses sur cette manière de voir, en faisant remarquer que, chez des Ténias de tout àge, on pouvait constater tantòt la présence, tantót l'absence de la couronne de crochets.

Tel était l'état de la question lorsque Kïchenmeister, en 1852, déclara qu'il y avait lieu de reconnaìtre décidément, parmi les Ténias de l'Homme, deux espèces distinctes, non seulement par les caractères de leur tète, mais aussi par la structure de leur ovaire : l'une armée, à laquelle il conserva le nom de T. solium, l'autre inerme, plus grande, plus large et plus épaisse, qu'il dénomma T. mediocunelluta.

11 eùt été sans duute préférable d'appliquer le nom de $T$. solium à l'espèce inerme, que Linné avait prise pour type, et d'appeler $T$. pellucida la forme pourvue de crochets; mais la nomenclature de Rudolphi régnait en maìtresse, et cet auteur avait classé le $T$. solinm parmi les espèces armées; c'eùt été d'ailleurs une nouvelle source de confusion. Leuckart a proposé de remplacer le nom de mediocanellata, dont la signification est du reste assez peu claire, par celui de T. saginata Goze. Encore que ce dernier helminthologiste n'ait pas fait usage d'une nomenclature rigoureusement binaire, cette substitution a été adoptée presque partout, et nous l'admettrons pour éviter toute complication.

Évolutiox. - La transformation du Cysticercus bovis en $T$. saginala dans l'intestin de l'Homme, a été établie successivement par des observations et par des expériences. Depuis longtemps, en effet, divers médecins avaient remarqué la fréquence du Ténia inerme chez. les individus qui faisaient usage de viande de Bœuf crue ou insuff-

(1) Gœze, Nalurgeschichte. Blankenburg, 1782, p. 42 et 278. 
samment cuite. Mais la preuve directe de l'origine bovine de ce Ténia ne ful donnée que par les expériences d'Oliver, dans l'Inde (1869), et de Perroncito, en Italie (1877), consistant à faire prendre à des Hommes des Cysticerques du Bouf : au bout de 67 jours, Perroncito fit évacuer un Tienia saginala qui, avec les anneaux rendus antérieurement, pouvait mesurer $4^{\mathrm{m}}, 80$; ec Ver s'était done accru par jour de 72 millimètres, en produisant 13 à 1.4 anneaux.

Le développement du Cysticerque chez le Bœuf a été démontré aussi par des observations établissant la présence, dans les organes de cet animal, d'une forme cystique pourvue d'une tête identique à celle du T'. saginala, et par des expériences ayant pour base l'administration, à des Veaux, d'anneaux mûrs du Ténia en question. Lespremières de ces expériences furent entreprises par Leuckart (1861), elles donnèrent des résultats positifs, qui ont été confirmés depuis par un grand nombre d'autres.

La rapidité de l'évolution a été déterminée principalement par les recherches de Hertwigr (1). Leuckart avait déjà constaté que, 17 à 23 jours après l'infestation, les Cysticerques avaient environ $0^{\mathrm{mm}}, \dot{x}$ à $0^{\mathrm{mm}}, 7$ de diamètre; ils étaient globuleux, parfois atténués à l'un des pòles, les plus grands montrant déjà, aı pòle opposé, un rudiment de tête. Voici, en résumé, les résultats de Hertwig :

Après quatre semaines, le diamètre des Cysticerques (extraits de leur enveloppe ou hyste) est de $2^{\mathrm{mm}}, 23 \%$ le diamètre de la tète est de $0^{\mathrm{mm}}, \ddot{5}$. Un exemplaire était déjà dégénéré.

Après six semaines : forme un peu ovoïde; longueur 3 millimètres, largeur s; diamètre de la lète 1 millimètre.

Huit semaines : Cysticerque long de $3^{\mathrm{mm}}, 2 \%$, larıge de $2^{\mathrm{mm}}, 70 \%$; tète longue de $1^{\mathrm{mm}}, \ddot{\partial}$, large de $\mathrm{t}$ millimètre.

Dix semaines : Cysticerque long de $3^{\mathrm{mm}}, \ddot{3}$, large de $3^{\mathrm{mm}}, \tilde{a} ;$ tête sinueuse, longue de $1^{\mathrm{mm}}, 7 \mathrm{\partial}$, large de $\mathrm{t}$ millimètre.

Douze semaines : Cysticerque long de 4 millimètres, large de 4 millimètres; tète longue de $1^{\mathrm{mm}}, 8$, large de 1 millimètre. Dans ces deux derniers cas, les Cysticerques enfermés dans leur kyste sont allongés; dégagés de l'enveloppe, ils se montrent sphériques.

Qualorze semaines : Cysticerque long de 5 millimètres, large de $4^{\mathrm{mm}}, \ddot{a}$; tète longue de 2 millimètres, large de 1 millimètre. - Ln certain nombre d'exemplaires étaient subglobuleux et plus petits.

Seize semaines: Cysticerque long de 5 millimètres, large de $4^{\mathrm{mm}}, 0$; tète longue de 2 millimètres, large de 1 millimètre, comme dans l'essai précédent. - Du reste, formes et dimensions assez variables.

Dix-huit semaines : Cysticerque long en moyeune de 6 millimètres, large de 4 millimètres; tète longue de 2 millimètres, large de $1^{\mathrm{mm}}, 2 \mathrm{\partial}$.

Vingt-deux semaines : Cysticerque long de 6 millimètres, large de $\mathbf{t}^{\mathrm{mm}}, \mathbf{\imath 3}$; tête longue de $2^{\mathrm{mm}}, 2 \mathrm{ö}$, larğe de $1^{\mathrm{mm}}, 7 \ddot{\text {. }}$.

Vingt-huit semaines : Cysticerque long de 7 millimètres, large de 3 milli-

(1) Ilentwig, Beilrag zur Frage der Entwicklung der Rinderfinne. Zeitschr. f. Fleisch- und lilchhygiene, I, 1). 107 (.I. 1 Taf.), 1891. 
mètres; tête longrue de $2^{\mathrm{mm}}, 5$, large de 2 millimètres. - Revètu de son kyste, le Cysticerque, à cette date, mesurait $7^{\mathrm{mm}, \%}$ à 9 millimètres de long sur $\tilde{j}^{\mathrm{mm}}, 5$ de large.

La durée de la vie de ces Vers paraît être assez courte: Saint-Cyr les a trouvés complètement calcifiés au bout de sept mois et demi. Leur résistance à l'action de la chaleur a été étudiée par Perroncito, qui les a vus mourir quelquefois à $44^{\circ} \mathrm{C}$., souvent à $45,46^{\circ}$, et toujours entre 47 et $48^{\circ}$; mais ces déterminations ont été faites sur des exemplaires isolés, et d'ailleurs les parties centrales des viandes rôties sont loin d'atteindre toujours cette température.

De nombreuses tentatives ont été faites en vue d'infester d'autres animaux que le Bœuf; elles ont porté sur le Porc, le Mouton, la Chèvre, le Lapin, le Cobaye, les Singes et le Chien. Toutes ont donné des résultats négatifs, à l'exception d'une seule, dans laquelle Zenker a obtenu, chez une Chèvre, deux Cysticerques bien développés et un grand nombre d'autres en état de dégénérescence caséeuse ou calcaire. (D'après R. Blanchard, Heller aurait infesté la Chèvre et le Mouton.)

Avoralies. - Le T. saginata paraît ètre particulièrement sujet à des anomalies, d'ailleurs assez variées.

Signalons d'abord celles qui ont trait à la coloration. Nous avons dit que les ventouses sont souvent bordées de noir; cette pigmentation peut s'étendre à leur fond et se répandre à leur voisinage, de sorte que la tète dans son ensemble prend une teinte noiràtre. Dans certains cas, la production du pigment gağne même la chaine : telle est évidemment l'oriģine du Tæniu. nigra Laboulbène, 187\%, d'un noir ardoisé, rendu par un Français qui avait longtemps habité les États-Unis, ainsi que du Tænia algérien, de teinte grise, mais à ventouses non pigmentées, observé par Redon chez des soldats faisant partie des colonnes du Sud-Oranais.

Le nombre des ventouses est quelquefois porté a 6 , et l'on soupconnait depuis longtemps que cette augrmentalion était, comme chez $T$. crassicollis, T. solium, elc., en rapport avec l'aspect prismatique ou mieux Iriquètre de la chaîne, que Bremser avait décrit comme résultant de la coalescence de deux Ténias. Trabut a montré que cette supposition était fondée. Chez ces Ténias dits trièdres, triquètres on à crète, la coupe transversale d'un anneau présente assez bien l'aspect d'un Y, dont la branche médiane ou inférieure porte les orifices sexuels. C'est à ce gronpe qu'il faut rattacher évidemment le Ténia du Cap de Boune-Espérance ( $\boldsymbol{T}$. capensis), signalé par Küchenmeister, et le T. lophosoma Cobbold (1).

On observe parfois sur un mème anneau deux pores génitaux situés, soit sur un seul bord, soit d'un còté et de l'autre : en pareil cas, un appareil génital hermaphrodite est en rapport avec chacun de ces orifices, et il n'est pas rare de constater d'ailleurs, sur cet anneau anormal, un commencenent

(1) L. Trabut, Observations tératologiques sur un Tænia saginata à six ventorses et de forme triquêtre (avec fig... Arch. de zool. expér. (2), VII, Notes, p. 10, 18s9. J. Cuars, A specimen of the prismatic variety of the Tænia saginata (mediocanellataj. Glasgow med. Journal, p. 103, 1891. 
de segmentation; on peut done admettre que cette anomalie tient à la fusion plus ou moins complète de plusicur's anneaux, ou, ce qui revient au mème, à labsence de segmentation sur un point de la chaine (I).

Si ce défaut de segmentation se manifeste sur toute une série d'anneaux, la partie correspondante du Ver prend l'aspect d'un ruban simple, pourvu sur ses bords d'un nombre variable de pores génitalı irrégulièrement répartis : divers observateurs ont rapporté des faits de ee grenre, notamment Welch, qui a vu la segmentation faire cléfaut sur une longueur de ¿ centimètres.

R. Blanchard a constaté, sul un auneau double, demi-segrmenté, une inversion des organes génitaux dans la moitié antérieure : les ovaires étaient situés en avant $(2)$.

Assez souvent on trouve un anneau surnuméraire intercalé, à la facon d’un coin, entre deux autres anneaux. Le I)" Pauli, de Francforl, a mème vu naitre d'un anneau mur une petite clıaine formée de deux anneaux étroits et allongés.

Enfin, une anomalie assez commune consiste dans la perforation des anneaux, observée d'abord chez T. saginatı par Andry, puis par llasars de Cazeles, ce dernisr croyant avoir affaire ä une espèce nouvelle, le Ténia fenêtré. Depuis lors, hien des observateurs ont rapporté des cas analogues, dont la signification n'est cependant pas encore établie d'une façon très précise. La perforation se montre d'ordinaire sur toute une série d'anneaux; elle apparait dans la région noyenne et s'étend peu à peu vers la périphérie, de sorte qu'elle est plus marquée à mesure qu'on s'éloigne de la tète. En se basant sur ces observations, on a surtout admis que la lésion se produit de dedans en dehors, et qu'elle est due ì une rupture des parois de l'anneau occasionnée par l'accumulation excessive des aufs. Marfan, ayant observé des érosions superficielles, a supposé qu'elles dérivaient d'une tixation momentanée de la tète du Ténia sur les anneaux. Eufin Danysz pense qu'il s'agit d'une maladie propre dı Ver, amenant la nécrose du tégument, et permettant ainsi aux sucs digestifs d'attaquer les tissus sous-jacents $\{3$;

Quant au prétendu $T$. solium var. abietiu décrit par Weinland, d'après un exemplaire recueilli par Agassiz chez un Indien Chippewa, ce n'est en réalité qu'une petite variété de l'espèce qui nous occupe.

Ajoutons, enfin, que Ileller a vu des embryons de $T$. saginata pourvus de 12. 16 et même 22 crochets; ils étaient alors de très grande taille.

En ce qui concerne le Cyst. bovis, Cobbold a observé, dans le carur d'un Veau, des exemplaires plus ou moins avortés, dont la tète ne portait que deux ou trois ventouses; dans un cas mème il n'en existait qu'une seule, et, sur d'autres, les ventouses faisaient entièrement défaut.

Distribution géographlque. - Puisque, comme nous l'avons vu, le Ténia in erme se développe par la consommation de la viande de Buenf, il est facile

(1) Le T. vulyaris Werner, 1;8: (T. dentata Batsch, 1;S6), à pores génitaux doubles et opposés, n'est probablement qu'un $T$. saginata présentant cette anomalie sur un grand nombre d'anneaux.

(2) R. Blaxchard, Anomalie des organes génitaux chez un Tænia saginata Geze (avec 1 fig.). Bull. Soc. zool. de France, XV, p. 166, 1890.

(3) Axpry, De la génération des Vers' dans le comps de l'Homme. Paris, 3e édit. 1í1, p. 22'́, fig. F. - J. Daxrsy, Recherches sur un Ténia fenétıé. Journal de lanat.. XXIV, p. 518, pl. XVII, 18ss. - A. Magiona. leber einer fall von Tænia inermis fenestrata. Centralbt. f. Bakt. u. Paras., X, p. 11́5, 1891. 
de prévoir que ce Ver doit se rencontrer à peu près dans tous les pays.

En France, la fréquence des Ténias s'est accrue, d'une façon progressive et très sensible, depuis un demi-siècle, et presque partout le Ténia inerme se nontre plus commun que le $T$. salium, qu'on prétend, sans preuves suffisantes, avoir été autrefois le plus répandu.

Il résulte des recherches récentes de Bérenger-Féraud (1) que, dans les six périodes quinquennales de 1861 à 1890 , le nombre des hommes atteints de Ténias, relativement à la totalité des individus admis dans les hòpitaux maritimes, a présenté les rapports suivants :

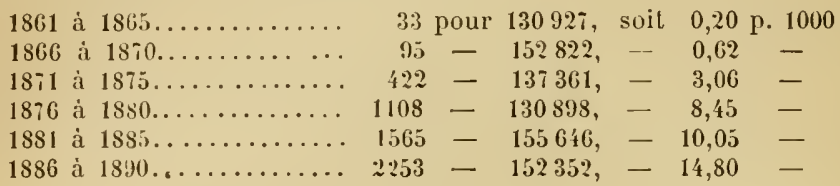

Dans les lıôpilaux civils de Paris, l'augmentation de fréquence est également démontrée, quoique la proportion des cas soit beaucoup moindre. Dans les départements, autant qu'on peut en juger par les rapports des médecins de l'armée, les chillres sont encore moins élevés, sauf dans trois régions qui correspondent aux frontières de Belgique, de Suisse, et au littoral méditerranéen, points par lesquels le bétail étranger pénètre en France.

En Allemagne, le T. solium était autrefois abondant surtout dans le nord, landis que le $T$. saginata s'y rencontrait rarement et régnait au contraire dans le sud; aujourd'hui, cetle dernière espèce prend une grande extension et tend à prédominer parlout. - En Angleterre, en Danemark, en Suisse, en Autriche, en Italie, c'est également le Ténia inerme qui se propage, tandis que le $T$. solium devient de plus en plus rare.

Mèmes observations pour l'Asie, l'Afrique et l'Amérique, avec une exception cependant en faveur des États-Unis, où le $T$. saginata paraît encore très rare.

La cause de l'extension considérable de cette espèce se trouve naturellement dans l'usage de plus en plus répandu de la viande de Bœuf insuffisamment cuite. II faut donc admettre que le Cysticercus bovis existe sur le bétail de toutes les régions que nous venons d'indiquer; et si cette donnée ne parait pas en rapport avec les résultats de l'observation, c'est que, dans les abattoirs ou sur les marchés, la viande de Bœuf n'est soumise le plus souvent qu'à un contròle illusoire. Disons cependant que ce parasite a été rencontré déjà en Russie, en Suisse, en Allemagne, en Hongrie, en Alsace, en Suède, en Italie. Chez nous, le premier cas a été relevé par Bascou, en 1888, sur une Vache de quatre ans sacrifiée à l'abattoir de Boulogne-sur-Seine. A Berlin, sa constatation est devenue aujourd'hui des plus communes, ainsi que nous l'indiquerons plus loin.

Mais il se montre surtout extrèmement répandu en Afrique et en Asie. Citons spécialement l'Algérie (Arnould, Gauvet, etc.), la Tunisie (Alix), le Sénégal (Dupuy), l'Abyssinie (Schimper), la Syrie (Talairacli), et surtout l'Inde (J. Fleming). Cette fréquence est en rapport arec le mode d'élevage

(1) Bérevger-Féraud, Sur l'augmenlation de fréquence du Tænia en France depuis un demi-siècle. Bull. Acad. de méd. (3), XxVII, p. 112, 1892. 
des bestiaux, dont les aliments ou les eaux de boisson se trouvent souvent souillés par les excréments de l'Homme.

Patholonile - Les Téniadés en général, el plus particulièrement les grands T'énias de l'llomme, sont désignés vulgairement sous le nom de Ters solitaires, en raison de la croyance fort anciemne que l'intestin n'en renferme qu'un seul à la fois. C'est en eflet le cas le plus orảinaire; mais il n'est pas très rare d'en roir évacuer en même temps 2, 3, ou même darantage, jusqu'à 20, 30, 50 el au delì, qu il s'agisse de $T$. saginata, de T. solium ou des deux en même temps, ou encore de leur association avec Bolriocephalus latus (1).

C'est à l'époque moyenne de la vie que l'llomme contracte le plus souvent les Ténias: lirabbe les a surtout observés chez des individus de vingt à trente ans; mais on en rencontre aussi che\% des vieillards, el même, chose assez difficile à expliquer, chez des nourrissons et des enfants nouveau-nés. La plupart des observateurs constatent en outre leur plus grande fréquence chez les femmes.

Nous avons dil que le Ténia incrme siège dans l’intestin grêle : il se fixe d'ordinaire à peu de distance du pylore, engage sa tête entre les villosités, et développe sa chaîne en arrière, mais ne la laisse que très rarement pénétrer dans le gros intestin. De neême, il est très exceptionnel de la voir remonter dans l'estomac. Quoique dépourru de crochets, il adhère plus solidement à la muqueuse, au moyen de ses ventouses, que le Ténia armé. On ne possède que d'assez rares renseignements sur sa longévité; on a cependant vu des malades expulser des anneaux pendant de longues années, jusqu'à trente-cinq ans (Wawruch). Comme il peut produire par jour, ainsi qu'on l'a vu plus haut, 13 ou 14 anneaux, et que chacun de ceux-ci renferme en moyenne 8,800 oufs, on arrive pour une telle période au chiffre formidable d'un milliard et demi d'œufs rejetés au dehors.

Les symptômes qui se rapportent à la présence des Ténias dans lintestin sont de deux ordres: les uns sont des troubles locaux, les autres des accidents nerveux variés, d'origine réflexe. Le plus souvent du reste ils sont très peu marqués ou font complètement défaut.

Les troubles locaux consistent en un sentiment de gêne ou de pesanteur, en douleurs abdominables vagues ou fixes, légères au début, pouvant s'exagérer plus tard, et parfois accompagnées de borborygmes. Ces sensations s'accusent principalement au moment des repas. Dans beaucoup de cas l'appétil devient capricieux, tantôt immodéré, tantôt nul. Il peut survenir aussi de la diarrhée, de la constipation, des vomissements; quelques patients maigrissent el deviennent anémiques.

Quant aux phénomènes nerveux, qu'on voit se manifester plus rare-

(1) Bérexger-Féraud, Du nombre et de la lingueur des Tanias que l'on rencontre chez l'homme. Bullet. de 1'Acad. de méd. (3), XXIX, p. 12, 1893. 
VERS.

ment, ils se traduisent par des vertiges, des bourdonnements d'oreille, des troubles de la vue, des accidents choréiques ou épileptiformes, etc. Le prurit nasal ou anal est aussi des plus communs.

Nous ne pouvons passer en revue ici toutes les manifestations du téniasis de l'Homme; ajoutons seulement que si le Ver est presque toujours évacué par l'anus, on l'a vu quelquefois aussi ètre rendu par la bouche; entin qu'il peut s'échapper à la faveur d'une lésion de l'intestin, pénétrer dans le péritoine, dans le canal de l'urètre et même apparaitre au dehor's par une fistule.

Lor'squ'on soupçonnc l'existence d'un Ténia chez un malade, il est facile d'assurer le diagnostic par l'examen des selles.

La forme et les dimensions des oeufs permettront souvent de reconnaître l'espèce à laquelle on a affaire. D'ailleurs, on sait que les anneaux mûrs du Ténia inerme sont plus grands que ceux du Ténia armé, qu'ils sont presque toujours isolés et sont expulsés spontanément dans l'intervalle des selles: enfin, qu'ils sont très vivaces et s'agitent assez longtemps après leur sortie, notamment lorsqu'on les place dans l'eau tiède. Au besoin même, on peut se rendre compte de la disposition de l'utérus, en comprimant l'anneau entre deux lames de verre, surtout après action de la potasse à 1 p. 100 ou de l'acide acétique à 1 p. 5 .

Les substances propres à déterminer l'expulsion du Ver sont extrêmement nombreuses. Celles qu'on emploie les plus sourent aujourd'hui sont les sulfates de pelletiérine et d'isopelletiérine, avec addition de tannin (Dujardin-Beaumetz), l'cxtrait éthéré de fougère mâle, les semences de courge, les sels de strontium (Laborde), etc. En tout eas, il importe de constater si la tête a été expulsée, puisque c'est le point de départ de la formation de la chaine: eette recherche doit être faite avee la plus grande précaution, en déposant le Ténia dans l'eau tiède, car la partie antérieure est très grêle et passe facilement inapercue.

Le Cysticercus bovis siège dans le tissu conjonetif de la plupart des organes, principalement des muscles striés, et sa présence dans l'organisme caractérise l'affection connue sous le nom de ladrerie du Bauf, dont la connaissance est assez récente, ainsi qu'on l'a vu plus haut. D’après Hertwiğ, les Cysticerques se trouvent de préférence dans les muscles de la région massétérine, et en particulier dans les ptérygoïdiens externe et interne. Pour les mettre en évidence, il convient de pratiquer dans ces muscles des sections parallèles à la branche du maxillaire inférieur, dans la direction de la base du erâne. Avant la mise en usage de ce procédé à l'abattoir de Berlin, on n'avait trouvé, dans l'espace de plusieurs années, que cinq Boufs atteints de ladrerie. Dans les neuf mois qui suivirent son adoption, on en trouva 55 ; en 1890 , le nombre s'est élevé à 390 , et sur ce chiffre, 316 individus ne portaient de parasites que dans les ptérygö̈diens. La distribution 
des Cysticerques est indiquée par le tableau suivant (exclusion faite de 22 cas d'invasion générale): ptérygö̈diens, 360 fois; curur, 41 ; langue, 10 ; muscles cervicaux, 3 ; muscles thoracipues, 1 .

A priori, on deviail admettre que le jeune àge est plus favorable à l'infestation: les expériences dont nous avons parlé ont du reste été faites sur des Veanx, et G. Colin (1) n'a réussi à infester ancun animal adulte on un peu éloigné de la jeunesse. Cependant, les faits d'observation contredisent cette manière de voir, et, it l'abattoir de Barlin, la très grande majorite des cas de ladrerie est fournie par des adultes.

D'autre part, la question du sexe parait n être pas indifférente, car, sur 60 animaux enrahis, on a compté 28 Taureaux, 14 Boufs et 18 Vaches ou Génisses.

Le plus souvent, la ladrerie ne se décèle, du vivant de l'animal, par aucun symptòme; on ne peut guère la reconnaître que par l'exploration de la langue, qui montre parfois, à la face inféricure et sur les côtés, des saillies formées par les Cysticerques.

Sur l'animal mort, les Cysticerques apparaissent conme de délicates vésicules, du volume d'un grain de moutarde ì celui d'un pois; ils sont quelquefois entourés d'un kyste conjonetif très épais et résistant. Mais comme ils sont en général disséminés et peu abondants, ils échappent facilement à l'examen. Laboulbène a fait voir, en outre, qu'ils perdent rapidement leur aspect vésiculeux, s'affaissent et deviennent ainsi beancoup moins apparents, lorsque le muscle est exposé directement it l'air': pour leur rendre leur aspect primitif, il convient d'humecter la surface de la pièce. Il n'est pas rare de les trouver morts et calcifiés, et cette dégénérescence donne à la viande ladrique une cerfaine ressemblance arec les lésions tuberculeuses (Cestoden Tuberculosic).

En dehors des conditions expèrimentales, on n’a guère observé le Cysticercus bovis que sur les bètes bovines: Schimper note expressément son absence chez la Chèvre, en Abyssinie. Moniez dit cependant qu'on aurait observé ce Ver chez le Mouton, en Afrique. D'autre part,

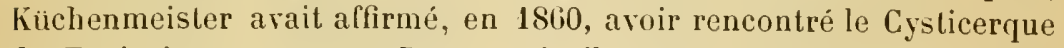
du Ténia inerme sur un Pore; mais il parail avoir abandonné plus tard cette indication, et peut-ètre ne s'agissait-il que d'un $C$. celluloset dépourvu de rostre, comme Lewin en a figuré un en $187 \%$.

Enfin, Heller, Arndt et Bitot ont signalé chez l'Homme, dans l'œil et dans le cerveau, des Cysticerques inermes qui ont été rapportés également au $C$. bovis ( $\boldsymbol{(})$. Mais cette détermination est surtoul basée sur l'absence de rostre et de crocheis, et, comme on vient de le voir, ces organes peuvent faire cléfaut dans le $C$. cellulosir, de sorte qu'il

(1) G. Coun, Sur la fréquence relative des dicerses espèces de Trnias. Bullet. Acad. de mèd. (3), XXVII, p. 176, 1892.

(2) E. Bitot el J. Sabrazès, Étude sur ies Cysticerques en grappe de l'encéphale et de la moelle chez l'Honme. Gaz. méd. de Paris (i), VII, 1890. Voir p. 31 '́ et 355. 
reste un doute relativement à la possibilité du développement, chez l'Homme, du Cysticerque du Bœuf.

Ténia armé de I'llomme (T. solium Rud., 1810. - Syn. : T. solium

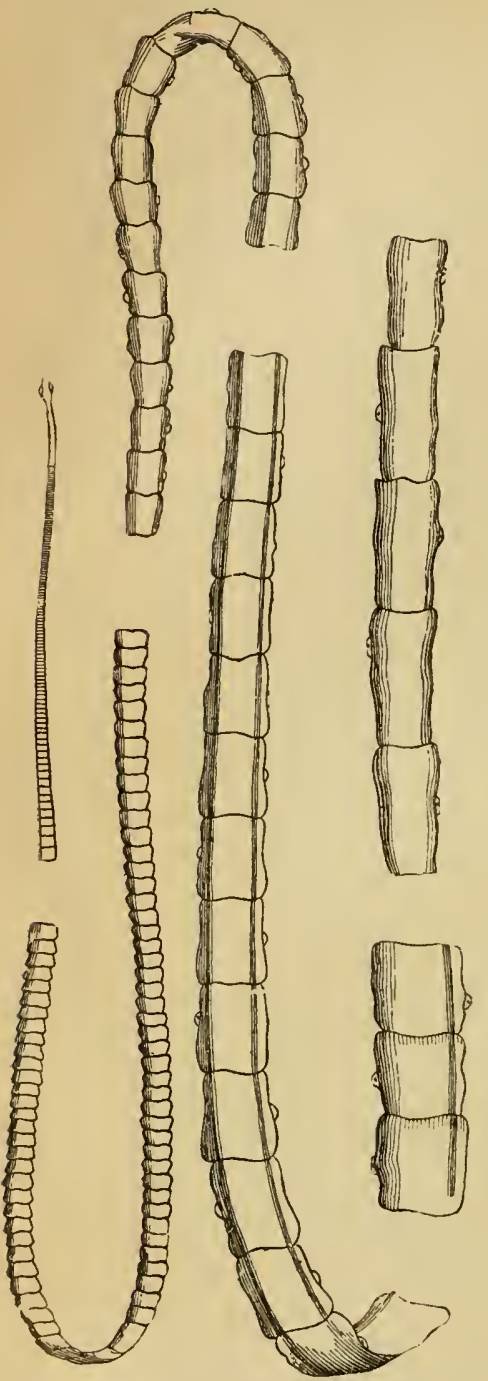

Fig. 132. - Tirnia solium, grandeur naturell.

Fig. 132. - Tirnea solium, grandeur naturell? Fig. 133.- Tite du T\&nia solium.
(Orig.).
(Laboulbène). L., 1767, pro parte; T. pellucida Gœze, $1782 ; T$. [Cystotraia] solium Leuck., 1862). - Long en moyenne de 2 à 3 mètres, alteignant parfois 6 à 8 mètres. Tète glo. buleuse-tétragone, large de $0^{\mathrm{mm}}, 6$ à $0^{\mathrm{mm}}, 8$; rostre court, souvent teinté en noir par des granulations pigmentaires, et armé d'une double couronne de 24 i 32 crochets : les grands longs de 160 à 180 :., ì manche ondulé, à lame à peu près aussi longue que le manche; les petits longs de 110 à $140 \mu$, à garde légèrement bilobée; ventouses arrondies, saillantes, larges de $0^{\mathrm{mm}}, 4$ à $0^{\mathrm{mm}}, 5$. Cou long et grèle. Premiers anneaux très courts, les suivants augmentant graduellement de longueur, mais ne devenant carrés qu'à plus d'un mètre de la tète: inneaux mùrs mesurant 10 à 12 millimètres de long sur 3 à 6 de large. Pores génitaux assez régulièrement alternes, situés en arrière du milieu du bord latéral. Utérus à tronc médian portant de chaque còté 7 à 10 branches épaisses, écartées, à ramifications dendritiques. Embryophores globuleux ou ì peine

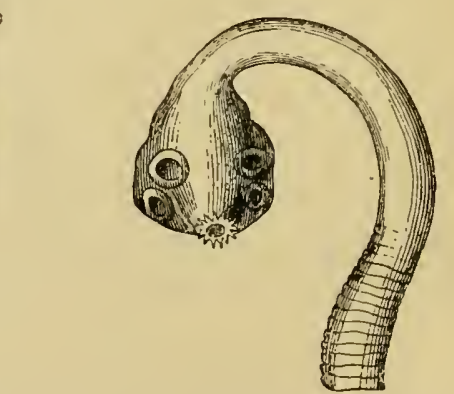

ovoïdes, du diamètre de 31 à $36 \mu$, parfois encore enlourés de la membrane vitelline.

Ce Ver habite, comme le précédent, l'intestin grêle de l'Homme. Son Cysticerque est connu sous le nom de Cysticercus cellulosi Rud.; 
il vit surtout dans les muscles et les viscères du Pore domestique, mais on l'a rencontré aussi chez le Sanglier, l'Homme, le Chien, le

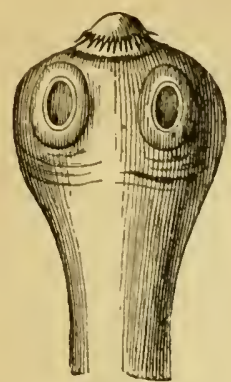

Fig. 13.4. - Têle dı Tipnic solium, vue de profil (Laboulbène).
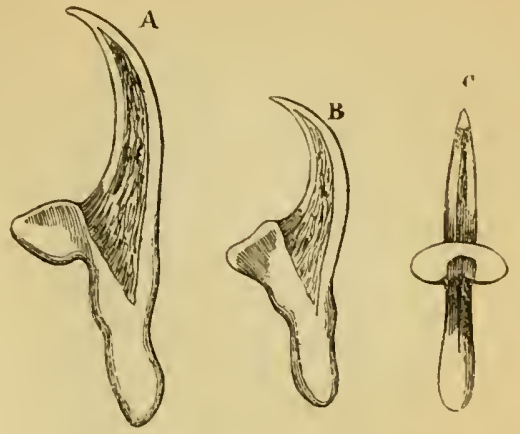

iig. 133. - Crochels du Trmia solium, grossis 230 fois. - A. giand eroeliel. B et C, pelit crocliet vu de profil et te lace (Orig.).

Chat, le Chevreuil, le Rat noir, l'Ours brun et divers Singes. Il se montre sous la forme d'une vésicule ellipsoüde, de 6 à 20 millimètres de long sur ă à 10 de large, offrant sur sa zone équatoriale, c'est-à-dire vers le milieu de sa longueur, une tache blanche qui cor-

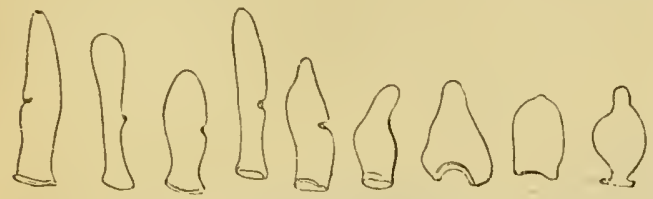

Fig. 136. - Cucurbilin du Trma solium : formes successives en quelques minules (I)avaine).

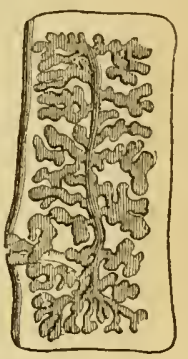

fig. 137, - Cucurbilin libre du Taniu solium, grossi trois fois (Orig.).

respond à la tète invaginée. En provoquant la sortie de celle-ci suivant les procédés indiqués à propos du Cysticerque du Bœul, on constate qu'elle est identique à celle du Tieni" solinm.

Érolutiox. - Il est probable que, dès la plus haute antiquité, on avait reconnu la fréquence du Ver solitaire chez les individus faisant usage de viande de Pore, et c'est ì une telle constatation, sans doute, qu'il faut attribuer linterdiction de cette viande faite par Moïse aux Hébreux et par Mahomel aux Musulmans.
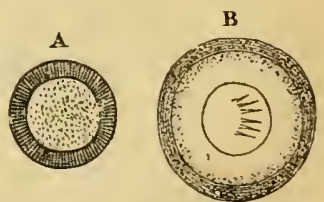

Fig. 138. - (Euf du Trnia solium, grossi 330 fois. $-\mathbf{A}$. daus la glycérine. B, mème grossissemeul, après avoir éli trailí par une solution de polasse (lahoulbinej.

Mais c'est seulement à une époque très rapprochée de nous que fut émise lïdée d'une transformation du Gỵsticerque du Porcen Ténia 
VERS.

dans l'ıntestin de l'Homme (Küchenmeister). La preuve de cette trans-

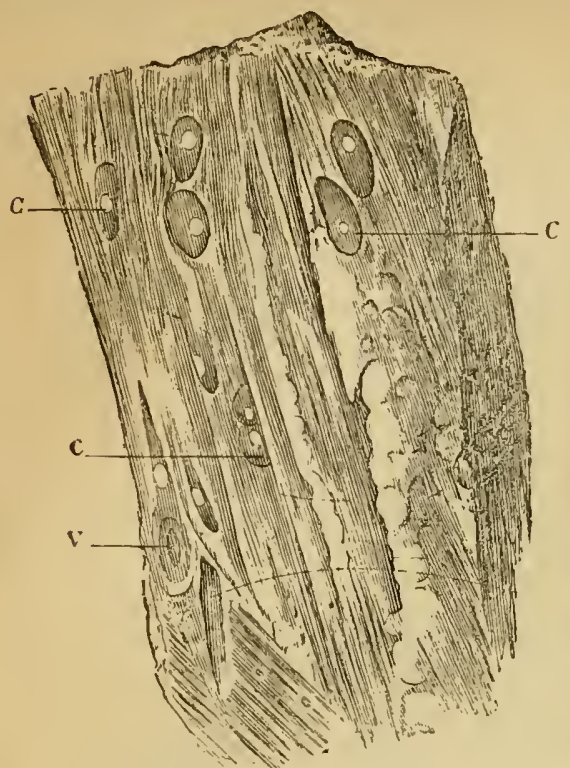

Fig. 139. - Fragment d'un muscle de Porc ladre, $c, c$, Cysticerques, $v$, alvéole marquant la place diun Cysticerque enlevé (Orig.). formation fut bientôt donnée expérimentalement : Humbert (1830), puis Küchenmeister (18\%̋), Leuckart, Hollenbach, Heller firent développer le Tienia solium chez des Hommes auxquels ils avaient administré des Cysticerques du Porc. En général, les premiers anneaux furent expulsés au bout de deux mois et demi. Redon a démontré sur lui-même que les Cysticerques de l'Homme donnent un résultat identique. - Des expériences du même genre ont été tentées sans succès chez le Porc (G. Colin), le Chien, le Cobaye, le Lapin et chez Macacus cynomolgus.

On a montré de même que les œufs du Trenia solium donnés au Porc se développent en Cysticercus rellulosa dans l'organisme de

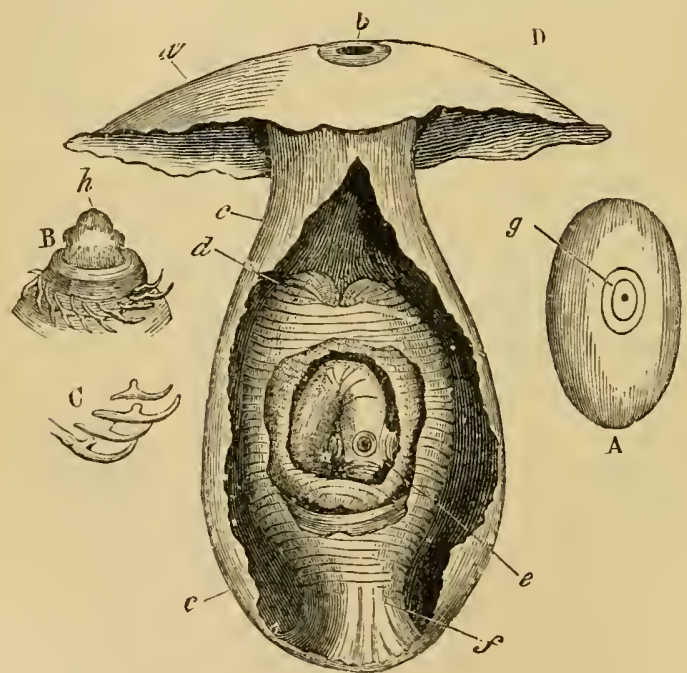

Fig. 140. - Cysticcrque ladrịue. - A, vésicule entière un peu grossie. B, trompe portant les crochets à sa base. C, crocliets isolés. I), fragment de Cysticerque fortement grossi : la vésicule n'est représentéc que par un segment $a$ correspondant à son orifice d'invagination $b$ ? Cls. Robin).

cet animal. La première expérience dans ce sens a été réalisée en 1853 
par P. I. van Beneden; un grand nombre d’autres onl été répétées, presque toujours avec succès, par Haubner et Küichenmeister, Leuckart. Baillet, etc. Ilaubner et Gerlach ont reconnu que l'infestation ladrique est très difficile, sinon impossible, che\% les Porcs un peu àgés. Leuckart et Railliet n'ont pas réussi ì infester le Chien; Neumann a été un peu plus heureux : sur quatre jeunes Chiens soumis à l'expérience, un seul a présenté ì l'autopsie quelques Cysticerques disséuninés dans les muscles olécrìniens et cruraux.

On ne connaìt encore que d'une manière imparfaite les diverses phases de l'évolution du Cysticercus cellulosit. Le 9 jour après l'inf'estation, Mosler l’a vu représenté par des vésicules ovales, longues de $33 \mu$, larges de 24, situées entre les fibres musculaires et encore dépourvues de liystes. Le $21^{\mathrm{e}}$ jour, Leuckart l'a vu également dans les muscles, sous forme de

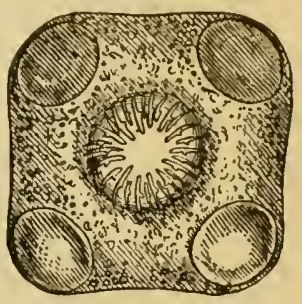

Fig. 141. - Tête du Cysticercus

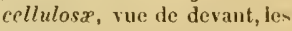
ventouses nou saillantes (Orig.). vésicules libres mesurant au plus $0^{\mathrm{mm}}, \mathbf{8}$, de forme sphérique et légèrement atténuées vers un point qui portait un rudiment céphalique.

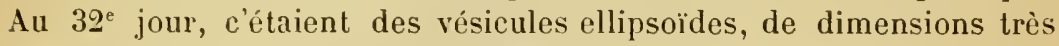
diverses, le grand diamètre variant de 1 à 6 millimètres, le petit diamètre de $0^{\mathrm{mm}}, 7$ à $2^{\mathrm{mm}}, \breve{b}$. Autour des plus petites, le tissu conjonctif commençait à proliférer; les plus grandes, parcourues par des vaisseaux ramifiés et montrant des entonnoirs vibratiles, étaient entourées déjà d'un liyste très délicat; le rudiment céphalique occupait, non plus l'un des pôles, mais la zone équatoriale. Parvenu à ce degré, le Cysticerque n’a plus qu'à s'accroître et à organiser sa tête : celle-ci prend naissance, comme d'habitude, au fond du receptaculum capitis et un peu obliquement ; mais, au cours du développement, elle se recourbe et arrive parfois à décrire un tour et demi; le réceptacle lui-même, qui est formé, comme on le sait, par les parois de l'invagination primitive, offre un plissement très accusé et caractéristique.

Pour arriver à son complet développement, le Gysticerque exige trois ou quatre mois; mais comme, au bout de deux mois et demi, la tête est déjà pourvue de ventouses et de crochets, il est probable qu'à cette période elle serait déjà propre à se développer en 'Ténia : les changements ultérieurs sont limités à l'élongation du corps cylindrique qui lui fait suite.

Il est difficile de préciser la longévité du C'ysticercus cellulosæ. Elle doit du reste varier suivant diverses circonstances. Parfois le parasite entre en dégénérescence dans les premières phases de son développement, mais le plus souvent cette modification est le résultat de l'âge : il perd son liquide et prend l'aspect d'un grain arrondi, dur et imprégné de calcaire (I). — Quant à sa résistance vitale, les expé-

(1) On en a vu cependant continuer á produire des troubles graves dans le cer- 
riences de Perroncito ont montré qu'elle est un peu supérieure à celle du $C$. bovis; il périt à une température de 47 à $48^{\circ}$. Dans la chair, on l'a trouvé encore vivant au bout de vingt-neuf jours.

Anomalıs. - Elles paraissent moins fréquentes que chez $T$. saginata, mais sont à peu près de même ordre.

Laker a observé deux T. solium à six ventouses et à corps non triquêtre. Par contre, Zenker a trouvé, à l'autopsie d'un tuberculeux, un exemplaire non encore parvenu à maturité, dont la tète portait 6 ventouses et 28 crochets, et dont les anneaux étaient prismatiques, avec les pores génilaux situés sur l'arête médiane.

On a signalé aussi dans cette espèce une fusion incomplète (Weinland) ou complète (Leuckart) de deux anneaux; Cobbold et L. Colin ont même étudié des individus non segmentés sur une grande longueur - jusqu'à 1 ö centimètres - et montrant des pores sexuels répartis sans ordre à droite et à gauche : c'est à cette forme que Colin a donné le non de T. fus

Rudolphi, Taruffi et Delle Chiaje ont décrit divers cas de Tænia solium fenestrata.

L'ensemble de la chaine est quelquefois très grèle, et les exemplaires ainsi conformés ont été quelquefois regardés comme représentant une variété ou une espèce particulière ( $T$. tenella Cobbold, $T$. solium var. minor Guzzardi).

Le Cysticercus cellulosæ est lui-mème sujet à diverses anomalies. - Ainsi, Krause en a trouvé un spécimen pourvu de six ventouses, dans le cerveau d'un idiot. Lewin en a décrit et figuré un autre, provenant du Porc, dans lequel le rostre et ses crochets avaient disparu et se trouvaient remplacés par une dépression médiane simulant une cinquième ventouse.

Les crochets peuvent, au contraire, augmenter de nombre et se disposer sur trois rangs, comme l'ont vu Dallinger et Redon. - C'est à des Cysticerques semblables, recueillis par Wyman en Virginie, chez une femme phtisique de race blanche, que Weinland a donné le nom de Cysticercus acanthotrias (18008). Chaque rangée comprenait 14 à 16 crochets, longs d'après Leuckart de 196, 140 et $70 \mu$, le forme générale plus grêle et à manche un peu plus long que dans le $C$. cellulosæ normal. Weinland et Leuckart regardent ce parasite comme représentant la forme cystique d'un Ténia encore inconnu, que Leuckart appelle Tænia acanthotrias.

Une variété intéressante de $C$. cellulosæ est celle que Zenker a appelée C. racemosus, Heller C. botryoides et Küchenmeister $C$. multilocularis, et qui est caractérisée par sa forme souvent très irrégulière. Contrairement à ce qu'on observe pour les Cénures, qui prennent surtout un aspect diverticuliforme lorsqu'ils siègent en dehors du système nerveux, les Cysticerques ladriques ne se montrent avec ce caractère que lorsqu'ils sont encéphaliques.

Zenker reconnait quatre formes de Cysticerques racémeux : $1^{\circ}$ vésicules irrégulièrement bosselées, gràce à des saillies de la paroi ; حo vésicules doubles ou multiples, de diverses dimensions, reliées par des portions rétrécies; $3^{3}$ vésicules secondaires acineuses, réunies à la vésicule principale par de minces pédicules, l'ensemble simulant une grappe de raisin; $4^{\circ}$ forme en grappe complexe, de grandes dimensions, se rattachant à la fois aux trois

veau de l'Homme pendant douze á quinze ans, et l'ophtalmoscope a permis d'en observer dans l'neil pendant vingt ans. 
groupes précédents. Cette division, comme it esl facile de le voir, est tout artificielle. Il arrive du reste parfois qu'un pédicule s'ollitère : la vésicule secondaire cesse alors de communiquer arec la resicule principale.

Les dimensious de ces Cysticerques deviennent dans certiins cas cousidérables: Heller évaluait la longueur de l'un d'eux it 2 ï centimètres. La tète, se développant en un point quelconque, mème sur un pédicnle, est diffieile it découvir; elle est du reste souvent incomplète.

I.es Cysticerques racémeux coïncident souvent avec des exemplaires normaux; leur siège de prédilection est la base du eerveau. lls ne sont presque jamais entourés d'm kyste, et e'est sáns doute grice il eette circonstance qu'ils s'étendent dans les espaces plus ou moins irrérguliers oì ils sont eontenus, et prenment leurs formes singulières.

Distributiox géognaphiưs. - l'aire de répartition du T. solium est naturellement la mème que eelle dı Porc, et e'est partant un parasite quasi-cosmopolite. Il fait defaut dans la zone torride, où l'élevage du Pore ne réussit pas; il manque également chez les populations juives, musulmanes et autres, qui ne font point usige de viande de Porc.

Yous arons déjà dit que la diminution progressive de cette espèce a été constatée dans presque toute l'Europe, et particulièrement en France : cette diminution n'est pas liée d'une foçon étroite à eelle du Cysticeryue ladrique; elle résulte plutòt d'une surveillance plus sévère de la viande de Pore, et de l'habitude qui s'est répandue de faire cuire plus complètement cette viande. Cependant le T. solium prédomine encore en diverses régions de l'Angleterre et de l'Allemagne du Nord, où l'élevage du Porc est florissant, et où la ehair de cet animal constitue la base principale de l'alimentation, aree cette circonstance aggravante qu'elle est souvent consommée à l'état cru.

Le Ténia armé est relativement rare en Asie, en Afrique et dans l'Amérique du Sud; il est au eontraire assez répandu dans l'Imérique du Nord, oì l'élevage des Pores a pris une énorme extension.

Quant à la distribution géographique du $C$. cellulosx, elle est en rapport surtout avec les conditions d'élevage du Pore. Ainsi, le parasite est commun dans les localités où cet animal est entretenu en demi-liberté, où les troupeaux de "coureurs " sont conduits aux champs ou a la glandée : tel est le eas, en partieulier, de l'Auvergne, de la Manche, du Limousin, de la Bretaune; il est plus rare, sans faire entièrement défaut, dans celles oủ les Pores sont nourris à la ferme, et où ils courent seulement le risque de trouver les exerénents déposés dans les cours ou sur les fumiers. Les renseignements fournis par divers anteurs donnent les proportions suivantes : ¿ Cassel, 1 Pore infesté pour 9ł6; en Prusse, 1 p. 370; en Autriche, I P. 307 ; à Turin, 1 p. $20 ̈ 0$; à Milan, 1 p. 70 . Ces chiffres, bien entendu, ne sont qu'approximatifs, et Leuckart estime que, dans liverses rígions de l'Allemagne, le nombre des animaux infestés s'élève à 2 ou 3 p. 100. Le parasile est aussi extrèmement répandu en Irlande, en Esclavonie et aux Etats-Ĺnis.

P.ituologie, - Les troubles occasionnés par la présence du $T$. solinu dans l'inlestin de l'llomme ne diffèrent pas de ceux qui sont altribuables au T'. saginata, et nous navons qu’i renvoyer le lecteur aux indications que nous arons données en traitant de celte espèce.

Notons seulement que les anneaux rendus par les patients sont plus 
petits, moins vivaces que ceux du Ténia inerme, quils se détachent assez souvent par petits groupes (fragments de chaîne) et qu'ils ne sont presque jamais expulsés qu'avec les fèces.

Mais, ce qui donne au Trenin solium une gravité spéciale, c'est la possibilité et la fréquence du développement dẻ son Cysticerque dans l'organisme de l'Homme, point sur lequel nous aurons à revenir dans un instant.

Comme celui du Ténia inerme, le Cysticerque du $T$. solium se développe dans le tissu conjonctif, d'où le nom qui lui a été appliqué par Rudolphi de Cysticercus (telie) cellulosir; il pent envahir des organes variés, mais on le rencontre plus spécialement dans les masses musculaires, et depuis longtemps on appelle ladrerie l'état des animaux qui en sont porteurs.

La ladrerie du Porc était déjà connue d'Aristophane (Ire siècle ar. J.-C.). Les muscles le plus fréquemment envahis sont ceux de la langue, du cou et des épaules; viennent ensuite, par ordre de fréquence décroissante, les intercostaux, les psoas, les muscles de la cuisse et enfin ceux de la région vertébrale postérieure. Quand les Cysticerques ladriques (vulgairement grains ou graines de ladre) sont peu nombreux, il faut les chercher surtout dans les niuscles de la face profonde de l'épaule, dans ceux du cou, dans la portion charnue du diaphragme, etc. Mais dans certains cas ils sont en nombre immense, et la moindre section musculaire en fait apparaitre plusieurs : Küchenmeister en a compté 133 dans un fragment de viande de 17 grammes. Ils sont logés entre les faisceaux secondaires et parallèlement à leur direction.

On les trouve assez souvent aussi dans le tissu conjonctif sousmuqueux de la face inférieure de la langue, ainsi que dans le cœur; plus rarement sous la peau ou dans le lard; mais ils peuvent se voir en outre dans presque tous les organes: cerreau, moelle épinière, yeux, poumon, foie, reins, rate, ganglions lymphatiques, testicules.

Les Cysticerques apparents sur les coupes de viande sont quelquefois enlevés au couteau pour tromper la surveillance des inspecteurs; mais un examen attentif montre les alvéoles qü̈ls occupaient. Quand ils ont perdu leur liquide et subi la dégénérescence calcaire, les charcutiers donnent à l'affection le nom de ladrerie sèche.

Les symptômes de la ladrerie sont en général des plus vagues; un seul est earactéristique, c'est la présence de Cysticerques sous des muqueuses accessibles à l'exploration, et en particulier à la face inférieure de la langue, sur les côtés du frein, où ils constituent souvent des élevures opalines, demi-transparentes. Cette remarque a donné lieu à la pratique du langueyage, déjà connue du temps d'Aristophane et aujourd'hui encore répandue sur les marchés de bestiaux, pratique qui consiste à visiter la langue du vivant de l'animal, et qui permet d'écarter de la eonsommation un grand nombre de Pores ladres. Il est vrai que parfois les vendeurs font disparaittre les vésicules 
apparentes par l'épinglage, e'est-ì-dire par une simple piquire qui vide le Cysticerque, ou par une incision qui permet de l'enlever.

Nous n'avons pas à nous arrèter ici sur la ladrerie du Chien, donl on connaît aujourd'hui une vingtaine de cas; les symptòmes en sont d'ailleur's très variables suivant le siège et l'abondance des Cyslicerques. - Dans un de ces cas, que nous avons étudié avec Trasbot, nous avous montré qu’il šagissait bien du $C$. cellulosex. Les Vers recueillis par Chabert et décrits par Rudolphi sous le nom de Cysticercus canis (180:3) appartenaient aussi ì cette espèce.

Chez l'Homme. la ladrerie est connue depuis fort longtemps. En l:;is, Rumler avait déjà trouvé, sur la dure-mère d'un épileptique, des tumeurs dans lesquelles il est facile de reconnaître des Cysticerques ; depuis lors, bien des observations précises onl été publiées sur ce sujet. Comme cette affection est des plus graves, il importe de déterminer d'abord selon quel mode peut avoir lieu l'infestation. - Pour que l'embryon puisse se développer, il est nécessaire, on le sait, qu’il arrive dans l'estomac, où sa coque doit être dissoute. Or, cette pénétration dans le tube digestif doit s'effectuer le plus souvent par l'intermédiaire des boissons et des aliments: eaux non filtrées, salades et légumes ayant subi le contact direct du fumier, etc. Elle est favorisée d'ailleurs par les habitudes de malpropreté, et c'est ainsi que Stich a constaté la plus grande fréquence de la ladrerie lıumaine dans les classes paurres. L'invasion parasitaire pourra même être très étendue si la cause d'infestation persiste longtemps, et c'est ce qu'on observe chez les individus qui cohabitent avec des personnes atteintes de Ténia, ou, mieux encore, chez les coprophages.Enfin, il n'est pas très rare d'observer des Cysticerques chez les sujets porteurs de $T$. solium, fait qu'expliquent suffisamment les cunsidérations précédentes.

L'auto-infestation n'exige même pas le passage des œufs par la bouche. Nous savons, en effet, que les Ténias remontent parfois jusque dans l'estomac; de plus, les contractions antipéristaltiques de l'intestin grêle peurent amener dans cet organe des anneaux entiers ou des cufs du Ver, et ainsi se trouvent remplies les conditions que requiert la mise en liberté de l'hexacanthe.

Les Cysticerques ladriques paraissent se loger de préférence, comme chez le Pore, dans le tissu conjonctif des muscles striés; mais ils sont aussi très communs dans l'encéphale et ses enveloppes, ainsi que dans l'œil et ses annexes; on les a trouvés encore dans le cœur, le poumon, le foie, le pancréas, les reins, le tissu conjonctif souscutané, etc. Leur localisation sous la muqueuse linguale est infiniment moins fréquente que chez le Porc. - Quant aux phénomènes pathologiques qu'ils peuvent provoquer, ils varient naturellement suivant leur siège et leur abondance.

Ténia crassicol ( $T$. crassicollis Rud., 1810). - Ver tong de 15 à 60 cen- 
timètres. Tète cpaisse, cylindroüde en avant, large de $1^{\mathrm{mm}}, 7$; rostre très court armé d'une double couronne de 26 à 52 crochets (souvent 3í), les grands longs de 380 à 420 u., les petits de 2000 à $270 \mu$; ventouses très saillantes. Cou peu distinct, aussi large ou plus largse que la tète. Premiers anneaux Irès courts, les suivants cunéiformes, les
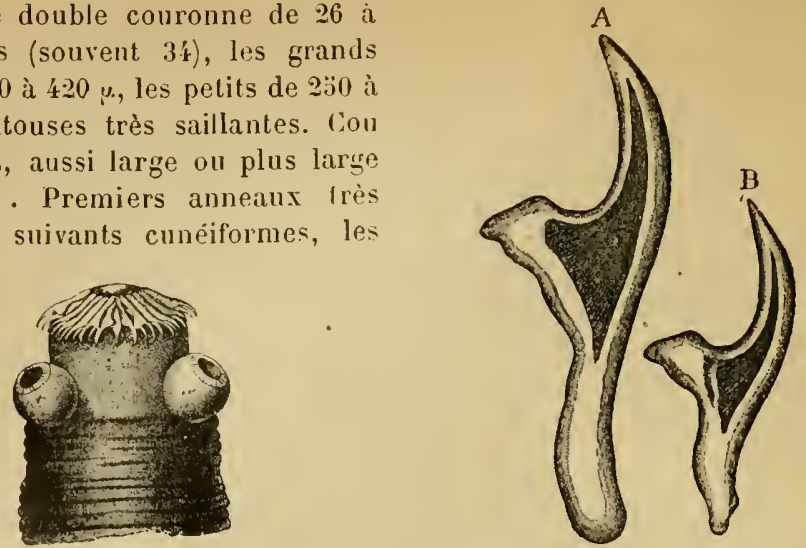

Fig. 142. - Tète du Trnia crassicollis, grossie Fig. l43. - Crochets du Trnir erassicollis, grossis 15 fois (fi. Neumann).

223 fois. - A, grand crochet. B, pelit crochet. (G. Neumamn).

derniers longrs de 8 à 10 millimètres, larges de ä à 6 . Embryophores globuleux, de 31 à $37 \mu$ de diamètre.

Assez commun dans l’intestin grèle du Chat domestique et de direrses espèces sauvages du mème genre; trouvé aussi chez l'Hermine.

A l'état vésiculaire, il est représenté par le Cysticerque fasciolaire (C. fasciolaris Rud.), qui liabite le foie des Rats, Souris, Campagnols et Chauves-Souris. Ce Cysticerque, toujours pelotonné dans un kyste dont sa présence a provoqué la formation, offre une disposition intéressante: la résicule est peu développée, tandis que le corps, au contraire, s'accroît rapidement et par suite ne tarde pas à faire saillie à l'extérieur; il se présente alors sous l'aspect d'une chaine formée d'anneaux très nets, courts et assez larges, mais sans organes génitaux. Cet aspect l'avait fait considérer comme un Ténia par les anciens auteurs. A l'extrémité antérieure, large de 4 à 3 millimètres, on voit la fente au fond de laquelle la tète est invaginée. Bien que la longueur totale du Ver varie de 3 à 20 centimètres et au delà, le volume de la vésicule dépasse rarement celui d'un petit pois.

La ressemblance qui existe entre la tête du $C$. fasciolaris et celle du T. crassicollis avait déjà frappé Pallas et Göze; mais ce fut von Siebold qui attira spécialement l'attention sur ce point (1843), et montra l'identité des deux formes. En 18ă', R. Leuckart fit prendre des œufs du Ténia à des Souris blanches et obtint le développement du Cysticerque (1). L'expérience inverse donna également des résul-

(1) Raum a trouri des embryons hexacanthes dans le sang de la reine porte des Souris, 9, 27 et 52 heures aprés l'infestation; il s'en trouvait également dans les capillaires du foie, mais non dans les canalicules biliaires. - Voy. Ravı, Beitrüge zur Entwicklungsgeschichte der Cysticercen. Dorpat, 1883, p. 30. - L. VogeL, Ueber Bau und Entwicklung des Cyst. fasciolaris. Rundschau auf. d. Geb. d. Thiermed. u. vergl. Pathol., IV, ]. 41, i9 et $5 \%, 1888$. 
tats positifs. Il faut remarquer, à ce sujet, que tous les anneaux qui composent le corps du Cysticerque se détruisent dès que celui-ci arrive dans l'intestin dı Chat: il s'en forme de nouveaux pour constituer le Ténia (Leuckart, 1878).

L.es anomalies signalées chez T. crassicollis sont èncore peu nombreuses. Disons seulement que Bremser a observé un exemplaire triquètre, it six ventonses, et que tiwze a décrit un individu fenètré. - Quant au T. ammonitiformis Baird, 1862, du Punıa, et au T. semiteres Baird, 1862 , dı Chat de Perse, ce ne sont mìme pas, comme le supposait Diesing, des monstruosités du T. crassicollis; Monticelli a constaté qu'il s'agit d'exemplaires normaux de cette espèce, déformés par un alcool trop concentré.

Lüpke a observé un Cyst. fasciolaris à denx tètes.

Pathologie. - La présence d un grand nombre de Ténias dans l'intestin du Chat peut amener un état inflammatoire, mortel pour les jeunes animaux (Anacker). De ré- Fig. 14.4.-Cysritables épizooties causées par ces Vers ont même été ticercus fassignalées, après des invasions de Campagnols (Lydtin) près Leuchart. ou de Rats (Romano), donnant lieu à des chasses fructueuses de la part des Chats. Il n'est pas très rare de trouver le Ténia dans l'eslomac, et il cause alors une gastrite fort grave (Zschokke). - Divers cas de perforation de l'intestin chez le Chat ont été attribués à ce Ver (Rudolphi, famba, Grassi et Parona, Perroncito).

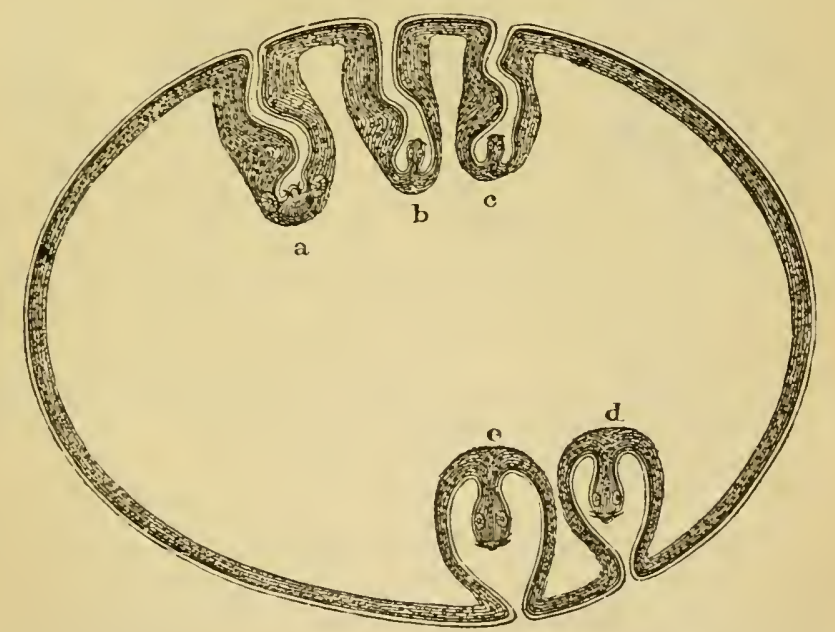

Fig. If3. - Coupe schemalique d'un cinure. - $a$, scolex avec sa disposilion normale, $b, c, d, e$, disposition de plus en plus schimaliøue, destinée a montrer la conformití des Cénures el des Cysticerques.

20 Les Céxures (Crenurus Rud., 1810) sont des Cystiques dont la résicule caudale donne naissance à des corps multiples. chacun d'eux 
ne produisant toutefois qu'une seule tête (cystiques polysomatiques et monocéphales).

Ténia cénure ( $\boldsymbol{T}$. cœnurus Küchenmeister, 1853. - Syn. : T. [Cystotænia] cœnurus Leuck., 1863). - Long en moyenne de 40 à 60 centimètres, arrivant rarement à dépasser $1 \mathrm{~m}$ ètre. Tête pyriforme, large de $0^{\mathrm{mm}}, 8$; rostre faible, armé d'une double couronne de 22 à 32 crochets : les grands longs

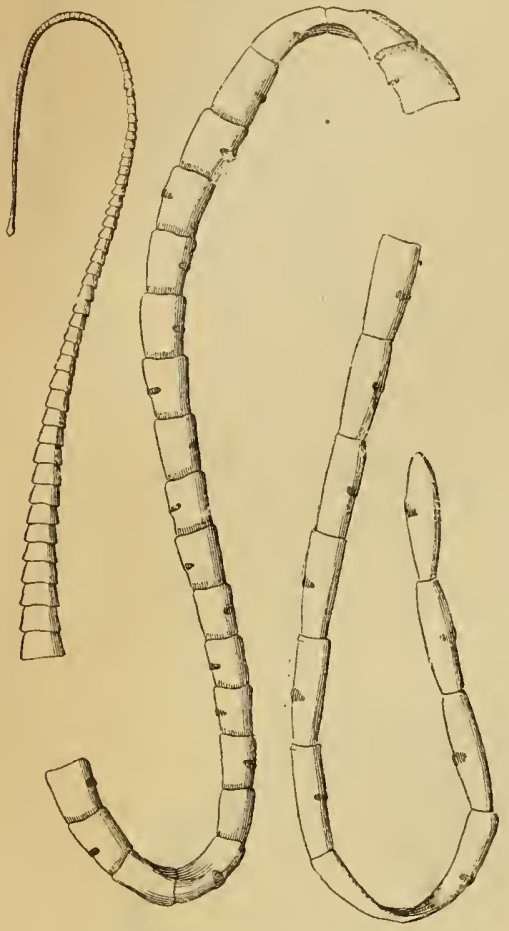

Fig. 146. - Tæxia conurus, grandeur naturelle (Orig.)

te 150 à $170 \mu$, à manche mince, un peu ondulé sur ses bords, à peine aussi long que la lame, à garde cordiforme; les petits longs de 90 i $130 \mu$, à manche atténué en arrière, à garde simple. Cou assez long, sensiblement plus grêle que la tête. Anneaux relativement étroits, devenant carrés à 15 ou 20 centinètres de la tête; bord postérieur rectiligne, à angles légèrement saillants; anneaux mûrs au nombre de 12 à 15 , un peu caténulés, longs de 8 a 12 millimètres, larges le 3 à 4 .

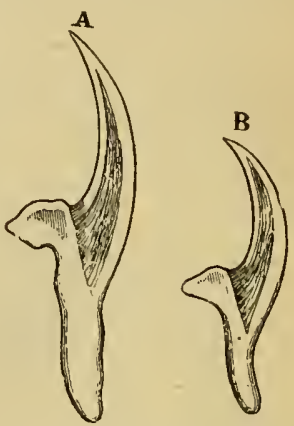

Fig. 147. - Crochets de Timia comurus, grossis 250 fois (Orig.)

Utérus formé d'un tronc médian de longueur moyenne, portant de chaque côté 18 à 26 branches presque parallèles, peu ramifiées. Embryophores à peu près sphériques, de 31 à $36 \mu$ de diamètre.

Le $T$. conurus vit dans la moitié postérieure de l'intestin grêle du Chien; Möbius l'a trouvé aussi chez un Vulpes lagopus.

Sa forme cystique est le Cénure cérébral (Cœnurus cerebralis Rud.), qui se développe d'ordinaire dans l'encéphale du Mouton, plus rarement dans la moelle épinière, mais qu'on peut observer aussi chez d'autres herbivores domestiques ou sauvages: Bœuf, Chèvre, Dromadaire, Renne, Chevreuil, Antilopes, Cheval. Ce Cénure consiste en une vésicule d'un volume variable, pouvant atteindre et même dé- 
passer celui d'un ouf de Poule: il offre l'aspect d'une vésicule dont la paroi tris mince, translucide, contractile, est plus ou moins distendue par un liquide incolore et se montre parsemée de petites taches blanches, rassemblées en groupes irréguliers. Ces taches, dont le nombre est très variable, mais s'élève parfois jusqu'ì 300 , correspondent ì autant de têtes de Ténia invaginées, oflrant d'ailleurs des degrés divers de déreloppement: on peut en trouver de rudimentaires, alor's que d'autres sont complètes. D’après Davaine, ces tètes peuvent s'é-

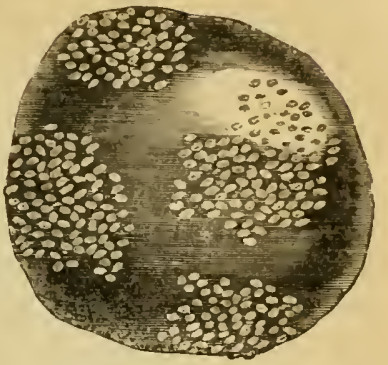

Fig. 148. - Cénure ećrébral ayau scijourné dans l'alcool. vaginel d'elles-mèmes et venir faire saillie ì la surface de la résicule.

On rapporte généralement au Conurus cerebralis les Cénures trouvés par Eichler dans le tissu conjonctif souscutané d'un Mouton, par Nathusius dans celui d'un Veau et par Heinclie dans l'oeil d'un Cheval. Rabe dit en outre avoir trouvé chez une Antilope chevaline (Hippotragus equimus) des exemplaires de ce Ver siégant à la fois dans le cerveau, les muscles, les ganglions lymphatiques et le corps thyroïde (1).

Évolution: - Comme il avait fait pour le Cysticercus temuicollis, von Siebold obtint, dès $18 \% 2$, la transformation du $C e-$ nurus cerebralis en Ténia dans l'intestin du Chien, mais il confondit le Ver ainsi développé avec le $T$. serrata, et c'est encore Küchenmeister qui, en 1833 , le reconnut comme représentant une espèce nouvelle, à laquelle il donna le nom de $T$. $c a^{\prime}-$ nurus.

Depuis cette époque, de nombreuses expériences ont été effectuées soit dans le mème sens, soit en sens opposé, c'està-dire en provoquant le développement

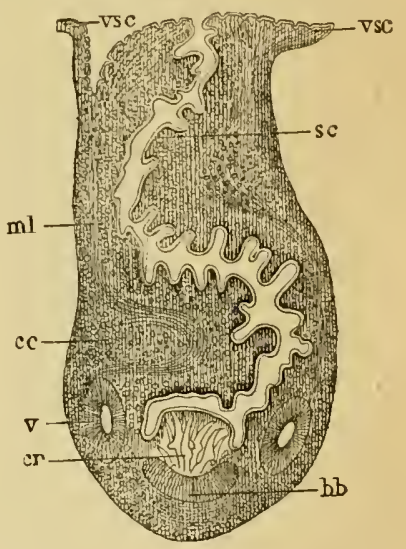

lig. 149. - Coupe de Canurus cerebralis, d'après R. Moniez. - Les crochels sont fortement pélractés et le bulbe, changeant sa forme primilive, les eutoure à sa base. vsc, vésicule dont un fragment seulement est représenté. $b b$, bullue. $c r$, crochels. ', rentouses. $c c$, corpuscules calcaires. $m l$, fibres musculaires longiludinales. sc, couche sous - cuticulairc. Girossissement 20 diamètres. du Cénure chez les Ruminants par l'administration des anneaux du

(1) Eichlek, in Sächs. Bericht, 1858-59, 1). 47. - Natuvsus, in Ibid., 1861. lleincke, in Preuss. Nittleil. 1S82, p. 74. - C. Rabe, in Berl. thierärztl. Wochenschi., 1889, p. 219. - C'est par erreur que Numan, et a sa suite Leuckart et Cobbold, citent Engelmeyer comme ayant trouvé un Cinure dans le foie d'un Chat: il s'agissait en réalitẻ d'Échinocurques observés chez une Vache. 
Ténia; elles ont conduit à démontrer l'exactitude des vues de Kü̈chenmeister.

Lorsqu'on fait prendre ces anneaux mûrs à un Agneau, par exemple, les embryons hexacanthes se trouvent mis en liberté comme ceux du T. serrata chez le Lapin; ils traversent alors les parois de l'intestin, et cheminent à travers les tissus ou, plus probablement, pénètrent dans les vaisseaux et sont ainsi emportés par les courants sanguins. Il en est un grand nombre qui font fausse route et se rendent dans les poumons, le foie, le diaphragme, l'asophage, sous le péritoine, la plèvre, le péricarde et même l'endocarde ; ils se creusent en ces divers points des galeries sinueuses, jaunâtres, d'une longueur de 15 millimètres au plus. Haubner et Baillet ont trouvé quelquefois dans ces galeries une très petite vésicule; mais le développement ne se poursuit pas : cette jeune larve meurt, et plus tard on trouve en effet dans le point correspondant une nodosité blanchâtre qui diminue bientôt de volume et disparaît. Les Cénures erratiques que nous avons signalés plus haut ont probablement pour origine quelques uns de ces embryons égarés.

Par contre, les embryons qui parviennent aux centres nerveux se trouvent dans les conditions voulues pour continuer leur évolution. Dans l'encéphale, dit Baillet, on constate dès le $\mathbf{8}^{\mathrm{e}}$ jour une violente congestion. Du $14^{e}$ au $38^{e}$ jour, on remarque à la surface de l'organe ou même dans les ventricules des sillons d'un jaune pâle, diversement contournés, à l'extrémité ou au voisinage desquels se rencontrent des vésicules analogues à celles dont il vient d'être parlé. Parfois ces vésicules ont pénétré dans l'épaisseur même de l'organe, où elles sonl entourées d'une couche de cellules granuleuses qui se transforme bientôt en une étroite galerie. Au bout de deux à trois semaines, elles mesurent $0^{\mathrm{mm}}, 6$ à 3 millimètres de diamètre; le $2 \mathbf{z}^{\mathrm{e}}$ jour, elles peuvent avoir le volume d'un pois, mais leur paroi est encore uniformément mince et translucide. Le premier indice de la formation des têtes de Ténia est apparu sur des larves de $\mathbf{3 8}$ jours, grosses comme des cerises, et ces têtes n'ont semblé complètement développées qu'au bout de deux mois et demi à trois mois. Après cette période, d'ailleurs, la vésicule continue de s'accroître et de former de nouvelles têtes.

La résistance vitale des ceufs (embryophores) du Tania cœnurus a été déterminée par quelques expériences. Leuckart a constaté qu'ils avaient perdu leur pouvoir évolutif après vingt-quatre heures, ayant été exposés pendant le jour aux rayons du soleil d'août. Dans l'humidité, ils avaient conservé ce pouvoir au bout de trois semaines (Gerlach), mais l'avaient perdu au bout de huit semaines (Leuckart).

Le développement du $T$. cunurus dans l'intestin du Chien s'effectue assez rapidement; d'après Leuckart, les derniers anneaux arrivent à maturifé au bout de trois ou quatre semaines.

Je n'ai pas réussi à infester le Chat. 
Axounzes. - Kinehenmeister el Leuckart ont signalé des $T$. crrnurus à tète munie de six ventouses et à chaine triquètre. Le dernier de ces auteurs a vu aussi, dans un mème Cínure, des têtes hexacotylées à còté des tèles tétracotylées ou normales. - Il a observé, d'aulre part, une inversion des organes sexuels, les glandes femelles étant situées à la partie antéricure dans un certain nombre d'anneaux.

P.thologie. - On comprend sans peine que le 1 . cemurus se rencontre de préférence chez les Chiens de berger, auxquels on livr d'ordinaire, par ignorance, la tête des Moutons envahis par des Ciénures. Au point de vue de la fréquence, ce Ver a été rencontré, en Islande, chez 19 p. 100 des Chiens ; à Copenhague, chez 1 p. 100 ; ì Zurich, chez 1,7 p. 100 ; à Lyon, chez 1,2 p. 100.

Le nombre d'exemplaires trourés chez le mème sujet s'est montró aussi très variable, d'après líabbe : ordinairement inférieur à 10, souvent aussi supérieur, jusqu'a 30 , il s'est élevé dans deux cas ì 1500 et 180 . Le nombre de têtes que porte un mème Cénnre expliqque ces chiffres élevés, et si de tels cas ne sont pas la règle, e'est que les têtes de Mouton sont sourent altérées lorsqu'on les livre aux Chiens, et que la dent de ces animaux peut broyer une grande partie des jeunes Ténias.

Leucliart a vu mourir en dix-huit heures, arec une irritation extrème de l'estomac et de l'intestin grêle, un Chien auquel il avait fait prendre des fragments de Cénure formant un bol du volume d'un auf d'Oic.

Ainsi que nous l'avons fait remarquer plus haut, le Conurus cembralis se développe ordinairement dans l'encéphale; il donne alors lieu à une affection particulière, caractérisée surtout par le tournoiement de l'animal, et désignée pour cette raison sous le nom de toumis. Cette affection ne s'observe guère que chez les animaux jeunes, dont les tissus se laissent aisément pénétrer par les embryons hexacanthes.

Elle est beaucoup plus fréquente chez le Mouton que chez les autres herbivores. Dans certains cas, étudiés d'abord par Girard, elle affecte une marche rapide (tournis ì forme aiguë): c'est que les embryons sont parvenus en grande quantité dans le cerveau. En pareil cas, les Cénures ne peuvent acquérir qu'un très faible volume; ils sont constitués par de simples résicules ayant à peine la grosseur d'une tête d'épingle, analogues à celles dont nous avons parlé en traitant de l'évolution; les aniinaux sont alors emportés en un temps très court. Nais, le plus ordinairement, il ne se déreloppe qu'un petit nombre de Cénures, sourent même un seul; les symptômes propres au tournis n'apparaissent alors nettement qu'au bout de plusieurs mois; ils s'accusent ensuite pendant quelques semaines, et l'animal finit par succomber. - Les Cénures siègent de préférence au roisinage de la séreuse, soit rers les rentricules, soit à la surlace de l'en- 
céphale; ils acquièrent parfois le volume d'un œuf de Poule, en refoulant et atrophiant la substance cérébrale.

Plus rarement, le parasite se développe dans la moelle épinière ; il prend alors une forme allongée. Sa présence se traduit surtout par une paralysie du train postérieur, qu'on qualifie de parnplégie hyda-

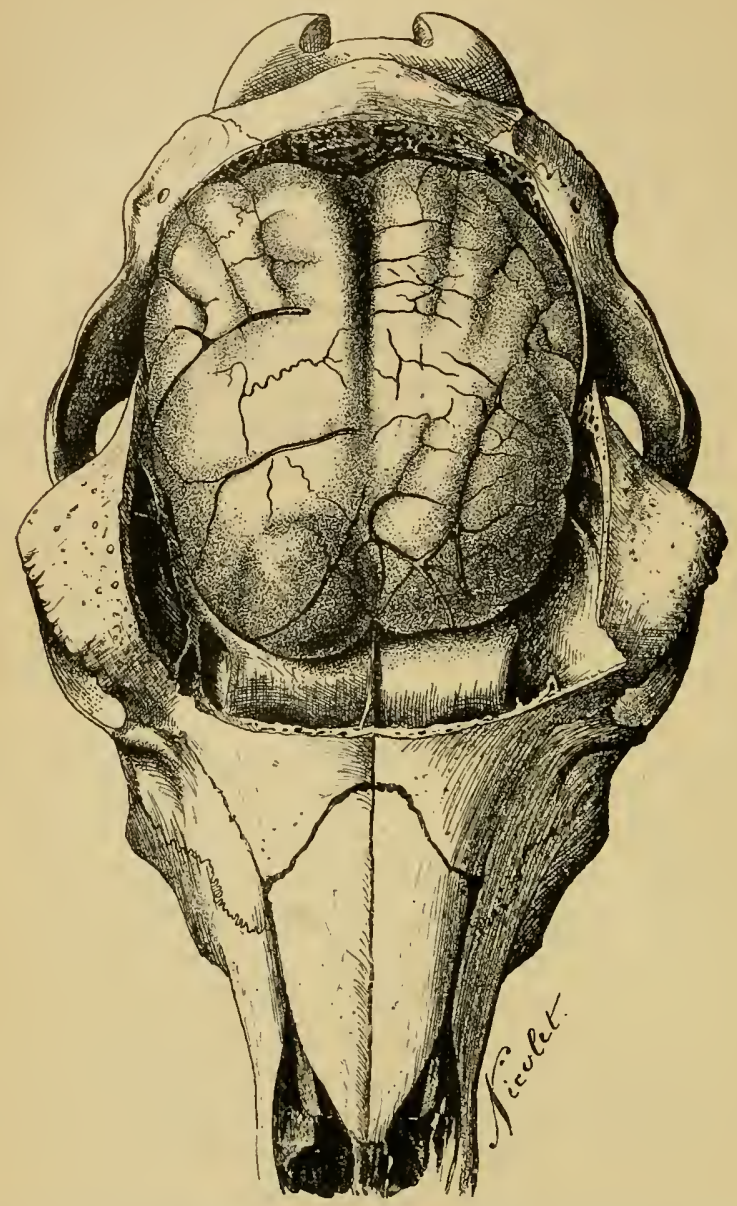

Fig. 150. - Tète d'un Nouton affecté de lournis. Le Cénure, assez régulièrement arrondi, siègc dans la partie antérieure de l'hémisphère cérébral d’oit et refoule un peu l'hémisphère gauche. $2 / 3$ de grandeur naturelle (Orig.).

tique. La morl est amenée dans ce cas par l'épuisement progressif du sujet.

Le tournis est plus rare chez la Chèvre et chez le Bouf, plus rare encore chez le cheval.

Les moyens à employer contre cette maladie, qui sévit souvent à l'état épizootique et occasionne des pertes très sérieuses, sont surtout 
d'ordre prophylactique. Il convient de débarrasser les Chiens de berger de leurs 'énias, el de détruire par le feu les tètes de Moutons affectés de Lournis. On a proposé d'extraire les Cénures de l'encéphale par la trépanation, ou de les tuer sur place par la réfrigération dı crâne (Zinmermann, Gierer, llartenstein); mais, en bonne pratique, il y a toújours avantage à sacrifier les animaux atteints.

Ténia sérial (T. seriulis Baillet, 1863). - Forme très voisine du T. cœe murus, représentée par un Ver long de 43 à 72 centimètres. Tête globuleuse-tétragrone, large de $0^{\mathrm{mm}}, 8 ;$ it $1^{\mathrm{mm}}, 3$; rostre assez saillant, armé d'une double couronne de 26 i 32 crochets : les grands longs de 13:i i $1: 37 \mu$, a manche ondulé sur ses bords, de mème longueur ou uı peu plus long que la lame; les petits longs de 83 ì 112 in, à mauche court, à garde bilobée. Cou assez long. Anneaux semblables à ceux du T. canurus: cependant, les anmeaux mìrs sont un peu plus étroits et offrent, au moment oì ils se détachent, des angles postérieur's plus saillants; en outre, la poche du cirre est beaucoup moins dilatée à son extrémité interne, et le vagin est sensiblement élargi à son origine, près du pore génital. Embryophores ovoüdes, longs de 33 it 41 ip, larges de $\approx 6$ à 31 .

Ce Ténia se développe dans l'intestin grêle du Chien.

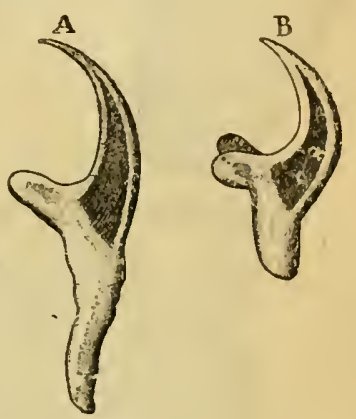

Fig. 1ว̈l. - Crochets de Trnia serialis, grossis 250 fois. A, grand crochet. B, pelit crochet (G. Neumann).

Son Cystique (Cunurus serialis P. Gervais, 1843̈), vit principalement chez le Lapin de garenne, assez souvent aussi chez le Lapin domestique; on l'a vu en outre chez le Lièvre et chez des Écureuils (Cobbold, Cagny), peut-être chez le Coypou (Pagenstecher), et Stiles nous le signale chez le Cheval, aux Êtats-Unis. Il a pour habital spécial le tissu conjonctif des diverses régions du corps et les grandes séreuses. Selon les remarques de C. Baillet, sa vésicule peut acquérir le volume d'un œuf de Poule, mais elle porte déjà de nombreuses tète: invaginées lorsqu'elle est de la grosseur d'une noix; ces invaginations sont beaucoup plus volumineuses que celles du Cénure eérébral, et souvent un peu contournées sur elles-mèmes. Elles sont quelquefois distribuées en séries linéaires non parallèles, d'oủ le nom spécifique. Comme dans l'espèce précédente, elles n'occupent qu'une zone (le la vésicule, correspondant vraisemblablement à la partie postérieure de l'embryon. Cette vésicule se montre parfois assez régulière, mais, lans la plupart des cas, elle présente des diverticules plus ou moins accusés. En outre, elle offre une particularité qui n'a pas encore été signalée chez le Cénure cérébral : e'est celle de produire quelquefois par bourgeonnement, soit à sa face externe, soil à sa face interne, des vésicules filles organisées comme elle et capables de dé- 
VERS.

velopper également des têtes de Ténia. Les vésicules externes restent souvent fixées par-un pédicelle à la vésicule mère; les vésicules

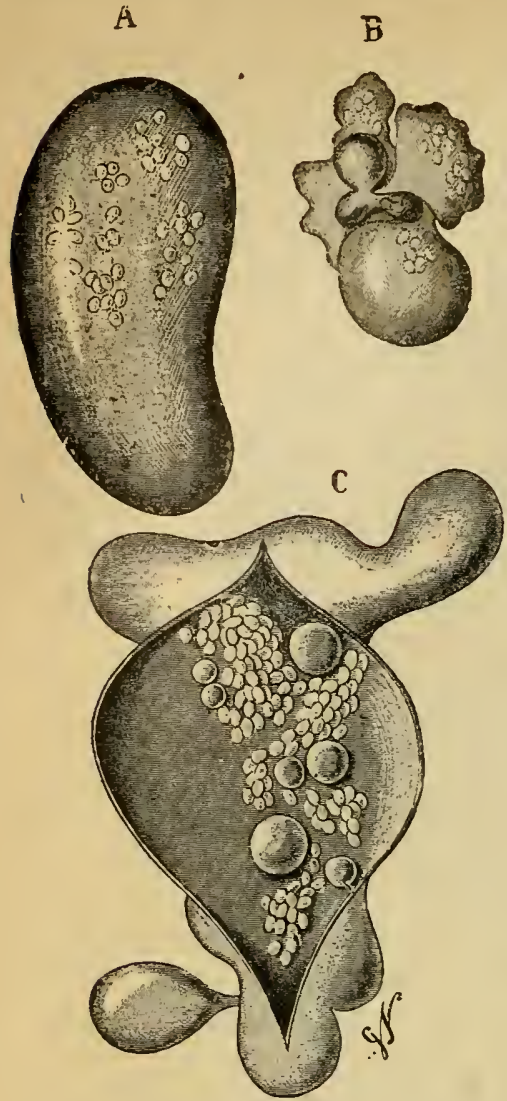

Fig. 152. - Conurus serialis du tissu conjonctif sous-cutané du Lapin domestique. -- A, forme régulière, simple. $\mathrm{B}$, forme à vésicules filles externes irrégulières. C, In Cénure ouvert montrant, à còté des tètes de Tænia, sept vésicules filles internes; en bas, à gauche, une vésicule fille externe. Grandeur naturelle (Orig.). internes, au contraire, se détachent après un certain temps et flottent à son intérieur.

Le Conurus serialis administré à des Chiens par C. Baillet a donné le Ténia décrit plus haut. Perroncito, Neumann, Railliet sont arrivés aux mèmes résultats. Les cufs de ce Ténia, donnés à des Lapins, ont reproduit le même Cénure, mais tous les essais poursuivis sur le Mouton par ces expérimentateurs sont restés négatifs, ce qui confirme la distinction établie entre $T$. coenurus et $T$. serialis.

Les troubles occasionnés par le $C$. serialis sont en général peu importants. Les garenniers anglais appellent " bladdery rabbits " les sujets qui sont porteurs de ce Ver; ils ont depuis longtemps l'habitude de crever les vésicules avant d'expédier les Lapins sur les marchés. Nous avons fait connaitre, avec Mollereau, un cas de paraplégie observé chez un Lapin domestique qui présentait un long Cénure dans l'arachnoïde, au niveau de la région lombaire.

Les Échinocoques (Echinococcus Rud, 1810), ont une résicule caudale fortement cuticularisée, qui donne naissance à de nombreux corps (vésicules proligères), lesc[uels portent des têtes multiples. Ce sont donc des Cystiques polysomatiques et polycéphales.

Ténia échinocoque (T. echinococcus von Siebold, 18̈̈3. - Syn. : Echinococcifer echinococcus Weinland, 1861). - Très petit Ver, long de $2^{\mathrm{mm}}, 5$ à z millimètres, n'atteignant que très exceptionnellement $6^{\mathrm{mm}}, 5$. Tète petite, subglobuleuse, large à peine de $0^{\mathrm{mm}}, 3$; rostre saillant, armé d'une double couronne de 28 a $ّ 0$ crochets, peu différents dans les deux rangées, et tous à garde et à manche très épais; les grands longs de 22 à $30 \mu$ (40 à $43 \ddot{\mu} \mu$ Leuckart), les petits longs de 18 a $22 \mu$ (30 à $38 \mu$. Leuckart). La tète se rétrécit 
en arrière en forme de cou, et se trouve suivie d'une courte chaine composée de trois ou quatre anneaux, dont le dernier mesure environ 2 millimètres le long sur $0^{\mathrm{mm}}, 6$ de large, et montre un utérus formé d'un Ironc médian pourvu de plusieurs branches latérales courtes, peu ramifiées. Embryophores légèrement ovoïdes, longs de 32 à $36 \mu$, largres de $2 \ddot{3}$ à $30 \mu$.

Ce Ténia se reneontre d'ordinaire en grand nombre dans la première partie de l'intestin grêle du Chien; la tête est fixée entre les villosités, de sorte qu'on aperçoit seulement les anneaux mûrs, de teinte blanchàtre. Les individus détachés se distinguent, par un examen attentif, sous la forme de filaments jaunâtres à extrémité

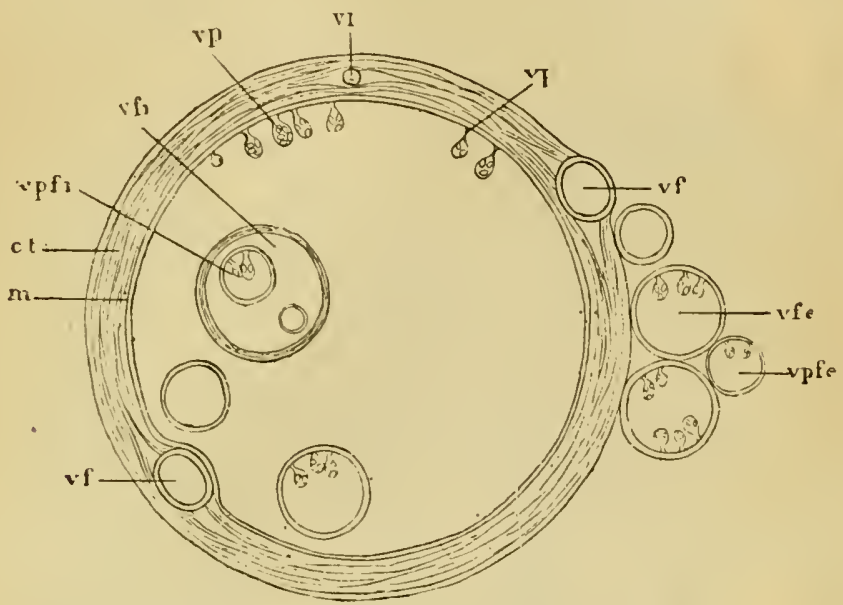

Fï. 153. - Echinococcus polymorphus: schéma de la fornation des vésicules proligères et des vésicules secondaires. - ct, cuticule, dite membrane hydatique. $n$, membrane germinale ou parencliymale. $v f$, vésicule secondaire ou vésicule fille, au début de sa formation. vf', vésicule fille gagnant l'intérieur. $v f^{\prime \prime}$, vésicule fille gagnant l'extérieur. vfe, vósicule fille externe ou exogène. vfi, vésicule fille interne ou endogène. vpfi, vésicule pelite-fille interne. vpfe, vésicule petite-fille externe, qui parait se produire dans l’Échinocoque nulliloculaire.

postérieure renflée, nageant dans le contenu liquide de l'intestin. Le même Ver a été observé dans l'intestin du Dingo (von Lendenfeld), du Chacal (Panceri), du Loup (Cobbold) et probablement aussi du Couguar (Natterer).

L'état larvaire on hydatique (1) est représenté par l'Échinocoque

(1) Le nom d'hydatides était employé autrefois pour désigner toutes les tumeurs enkystées contenant un liquide aqueux et transparent; il a été ensuite appliqué, soit aux Cystiques en général (Van Beneden), soit à la cuticule des Échinocoques (Darainc); on l'applique aujourd'hui á la vésicule tout entiẻre de l'Échinocoque. Or, quand ces larves se développent dans les parenchymes, elles sont enveloppées d'un kyste formé aux dépens du tissu conjonctif de l'organe (dans les cavités séreuses, c'est la membrane elle-mème qui fait l'office de kyste). II importe donc, Ior'squ'on parle de kystes hydaliques, de bien distinguer ce kyste, enveloppe adventicc appartenant en propre à l'hóte, de l'liydalide ou Échinocoque, c'est-ì-dire de la vésicule qui constitue le Ver. 
polymorphe (Echinococcus polymorphus Diesing) qui se déreloppe chez des hôtes très divers, et dans la plupart des organes. On en a signalé la présence chez l'Homme, chez divers Singes, chez des Carnivores (Chien, Chat, Ours, Panthère, Mangouste), chez des Rongeurs (Lapin domestique, Souris, Écureuil), chez des Jumentés (Tapir, Zèbre, Cheval, Ane), chez des Ruminants (Girafe, Elan, Antilope, Argali, Mouton, Chèvre, Bøuf, Chameau, Dromadaire), chez le Porc, chez des Marsupiaux (Kangourou géant), et même chez des Oiseaux (Dindons.

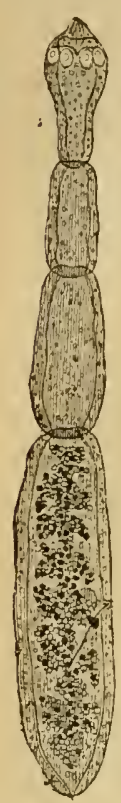

Fig. 154. $-T x$ nia echinococcus, grossi (Perroncito). Goura?, Paon spicifère?). - Nous étudierons plus loin la constitution assez complexe de ce Cystique.

Érolttox. - Le $T$. echinacoccus avait été observé par divers helminthologistes, mais regardé comme la forme jeune d'espèces déjà connues : c'est ainsi que Rudolphi le rapportait au Dipylidium caninum, Diesing au Tenia crassicollis, Röll au $T$. serrata. C'est en 18500 seulement que Van Beneden le reconnut pour une espèce distincte; peu après (185̃), ron Siebold le développa en faisant ingérer à des Chiens des Échinocoques du Mouton. La même expérience fut répétée plus tard, arec le même succès, au moven des Échinocoques du Mouton, du Porc, du Bouf et du Cheval, par liüchenmeister, Van Beneden, Leuckart, Nettleship et Railliet. Arec les Echinocoques

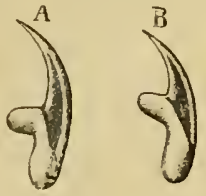

Fig. 13j. - Cirochets de Tænia echinococcus, grossis $\ddot{1}) 0$ fois. $-A$, grand erochet. B, petit crochet (G. Yeumann). de l'Homme, les premiers essais furent infructueux ; cependant, Naunyn à Berlin, Krabbe et Finsen en Islande, Thomas en Australie, sont parvenus à obtenir aussi des résultats positifs. La maturité du Ténia survient après un temps très variable : de quatre à douze semaines.

L infestation des Herbivores par ingestion d'ceufs du T. echinococcus pa-

raît être plus difficile à réaliser. Leuckart et Haubner ne purent l'obtenir chez des Agneaux, des Moutons et des Chèvres, mais le premier de ces auteurs finit par reconnaître que le Cochon de lait, au contraire, s'infeste très facilement, et il put suivre, de la sorte, les premières phases de l'évolution. Celle-ci affecte une marche très lente. Un mois après l'ingestion des œufs, on troure, sous le revêtement séreux du foie, de petits nodules mesurant à peu près 1 millimètre. nodules formés d'un kyste conjonctif renfermant un jeune Échinocoque sphérique, solide, large de $2 כ 00$ à $3 \check{0} 0$; à deux mois, ces larres ont au moins doublé de taille et sont devenues hydropiques: leur paroi s'est déjà différenciée en une membrane granuleuse interne, rerêtue d'une épaisse cuticule lamellaire; ì cinq mois, elles ont acquis 
un diamètre moyen de 10 it 12 millimètres, mais n'olirent encore aucune formation ì l'intérieur (1).

L'organisation des Échinocoques et leur mode de multiplication sont assez complexes pour mériter une description particulière. Ces points ont été éludiés par Leucliart, Naunyn, etc.; mais c'est encore Moniez qui nous fournit, ì leur endroit, les données les plus rigoureuses.

In Échinocoque entièrement développé, et sorti du kyste qui le contient, se montre constitué par une vésicule tremblotante (vésicule mère, Mutterblase), à paroi épaisse, de teinte un peu laiteuse. Cette paroi comprend denx ordres de tissus, constituant chacun une memhrane spéciale: l'interne, fort mince, d'aspect conjonctif, dépourvue

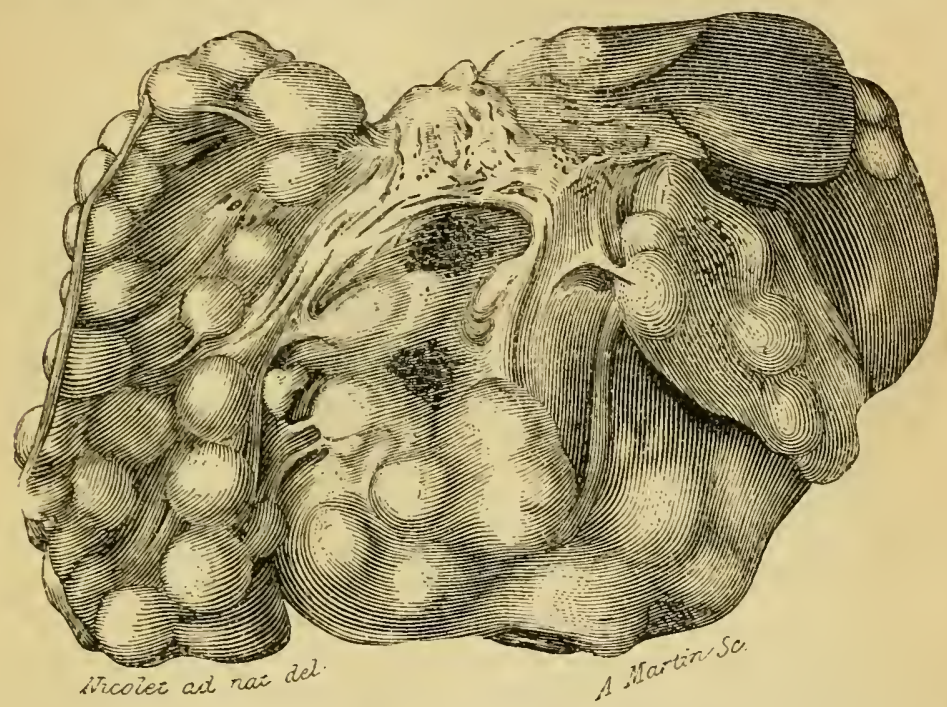

Fig. 1506 . - Foie de Pore envahi par une énorme quantité d'Échinocoques. Ce foie mesurait $0^{m}, 56 \mathrm{~d}$ " large sur $0^{\mathrm{m}}, 41$ de haut, et pesait 12 kil. 500 (Orig.).

de muscles, mais offrant des corpuscules calcaires, a été décrite par Goodsir sous le nom impropre de membrane germinale; elle est analogue au parenchyme de la vésicule des Cysticerques, et divers auteurs l'appellent plus justement membrane parenchymale; l'externe, qualifiée, également à tort, de membrane hydatique, n'est autre chose qu'une très épaisse cuticule, disposée en lames concentriques; il convient donc de la dénommer inembrane cuticulaire.

A la face in terne de la membrane parenchymale, on trouve des groupes plus ou moins serrés de petites expansions vésiculeuses fournies par elle, et en continuité arec ses propres tissus par un pédicule : ce sont les vésicules proligères (Brutkapseln), identiques, en somme, au corps

(1) Lebeder et Andreev ont réussi à transplanter des Échinocoques de l'Homme dans la cavité abdominale du Lapin (Vratsh, p. 285, 1889). 
VERS.

des Cysticerques et des Cénures. Le déreloppement de ces vésicules débute par une prolifération locale de la membrane germinale, donnant naissance à un petit mamelon; puis le centre de celui-ci se creuse d'une cavité qui s'agrandit peu à peu, et qui se montre de bonne heure tapissée d'une mince cuticule. C'est à la face interne de ces vésicules que naissent les jeunes Ténias (1); on en trouve d'ordinaire cinq à dix dans chacune d'elles : Moniez en a compté exceptionnellement jusqu'à trente-quatre. Leur mode de formation a été fort discuté ; nous nous bornerons à indiquer comment les choses se passent en réalité, d'après Moniez. Sur la membrane de la résicule proligère, se produil un épaississement en disque, d'où résulte un mamelon qui reste toujours solide, et qui finit par faire entièrement saillie à l'intérieur de cette vésicule. Ce mamelon, d'abord arrondi, devient ovale,

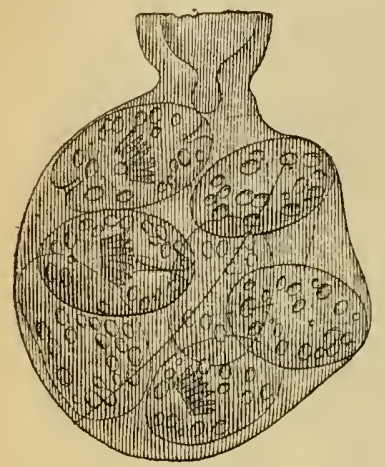

Fig. 15̈7. - Une vésicule proligère fortemenl grossie (Orig.).

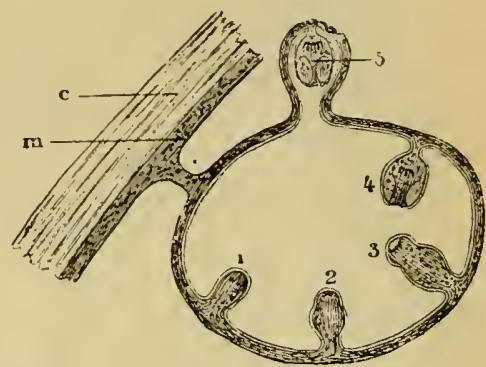

Fig. 158.- Schéna d'une vésicule proligère, pour nontrer le mode de formation des têtes de Ténia à son intérieur.

et développe vers son extrémité une sorte de collerette au-dessous de laquelle apparaissent les crochets : cette extrémité céphalique ne tarde pas à s'invaginer, en même temps que la base du mamelon se pince pour constituer un pédicule; puis les crochets achèvent leur développement, et le jeune Ténia prend l'aspect indiqué par la figure 1ə̆9, A. Dans certains cas, on peut voir en outre les têtes bourgeonner au fond de petits diverticules extérieurs de la vésicule proligère; mais ces formations ne résultent pas, comme le croyait Naunyn, de l'évagination des bourgeons internes sous l'influence du froid.

Les têtes de Ténia renfermées dans une même vésicule proligère diffèrent sourent d'âge et de taille. Elles portent des crochets qui se distinguent de ceux du Ténia adulte par leur longueur moindre et l'aspect plus grêle de la garde et du manche, surtout accusé dans les grands. La modification se produit graduellement et assez lentement lorsque le Ver se développe dans l'intestin du Chien.

(1) Plusieurs auteurs réservent à ces jeunes Ténias ou scolex le nom d'Échinocoques; il nous semble beaucoup plus rationnel de l'appliguer, avec la plupart des helminthologistes, à la vésicule elle-même. 
Les vésicules proligères ne représentent pas le seul élément de multiplication de l'Échinocoque : celui-ci peut se reproduire, en outre, par des vésicules secondaires ou vésicules filles (Tochterblasen), qui sont revêtues extérieurement d'une ćpaisse cuticule et ont en somme tous les caractères de la vésicule mère. Ces vésicules secondaires prennent naissance dans l'épaisseur nème de la cuticule : d'après Leuckart et Moniez, on voit apparaitre entre deux lamelles de celle-ci un amas de granules qui s'entourent bientôt d'une couche cuticulaire; puis cet amas grossit et se creuse d'une cavité qui se remplit de liquide, en même temps que de nouvelles couches cuticulaires se développent : une vésicule secondaire est alors constituée. Pour comprendre cettc formation an sein d'une production d'apparence amorphe comme la cuticule, il importe de se rappeler que cette production, chez les Cestodes, n'est pas un produit de sécrétion, mais résulte de

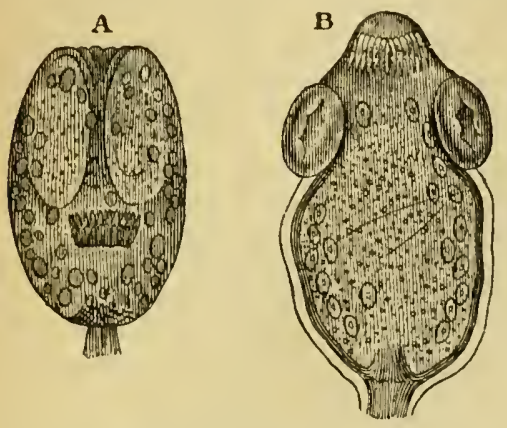

Fig. 1.30. - Echinococcus polymorphus. - A, jeune Ténia détaché do la vésicule prolifère, à laquelle il ćtait fixé par son pédicule inférieur: la tête est rétractée à l'ilıtérieur du cou. B, le mème, d'après Perroncito, avec la lềle éragincé.
A

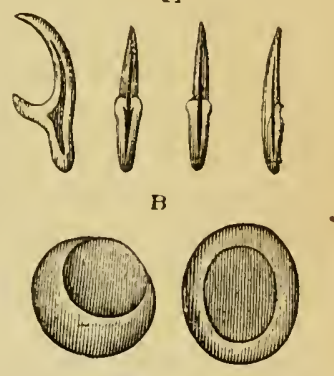

ig. 160. - Echinococcus polymorphus. $A$, crochets vus de profil et de face. B ventouses isolies.

la modification directe de la couche cellulaire sous-cuticulaire. On conçoit alors que des éléments vivants aient été conservés dans la cuticule, et qu'ils soient le point de départ des vésicules secondaires. Celles-ci se distendent peu à peu, rompent la cuticule, et sortent tantôt au dehors, tantòt en dedans, "selon les conditions dans lesquelles le développement s'est effectué ". D'après la roie qu'elles suivent, on a donc à distinguer les vésicules secondaires en externes et internes. Leur formation avait été qualifiée, dans le premier cas, de reproduction exogène et, dans le second, de reproduction endogène : on vient de voir que cette distinction n'a rien de fondamental et que le processus est toujours le même.

Naunyn et Leuckart admettent en outre, sans preuves suffisantes, que les vésicules secondaires endogènes peuvent se développer aux dépens des vésicules proligères et même des tètes de Ténia.

Les vésicules secondaires externes ou exogènes (Échinococcus exogena Kuhn, E. scolicipariens Kü̈ch., E. simplex, E. gramulosus Leuck.) 
sont surtout communes chez les Ruminants, mais on les a observées aussi chez l'Homme. Elles restent en général fort petites, et doivent souvent passer inaperçues. On a remarqué que ce sont de préférence les Échinocoques de dimensions moyennes qui leur donnent naissance. - Quant aux vésicules secondaires internes ( $E$. endogena Kuhn, $E$. altricipariens Küch., $E$. hydatidosus Leuck.), on les a signalées principalement chez l'Homme, le Porc et le Cheval; nous en avons vu une seule fois chez le Bœuf. Leur volume dépasse.souvent de beaucoup celui des vésicules exogènes, et il n'est pas rare de les voir elles-mêmes produire d'autres vésicules endogènes, d'ordre tertiaire, ou vésicules petites-filles (Enkelblasen).

Les vésicules filles et petites-filles, endogènes ou exogènes, sont propres à développer des vésicules proligères et partant des scolex ou jeunes Ténias, aussi bien et mieux que la vésicule mère ; mais, comme elle également, elles peuvent demeurer stériles. On a dit même que les vésicules filles issues d'une mère stérile sont quelquefois fertiles; mais le fait n'est pas bien démontré. Les vésicules dépourvues de tètes de Ténias sont désignées sous le nom d'acéphalocystes ( $\alpha$ privàtif;

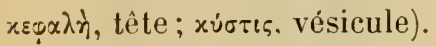

Nous devons encore signaler une forme spéciale d'Échinocoque, qui a recu le nom d'Échinocoque multiloculaire. On l'a surtout rencontrée chez l'Homme, et en particulier dans le foie; mais le Bœuf, et plus rarement le Porc, en ont aussi fourni des exemples. Les anciens médecins l'avaient prise pour une tumeur colloïde ou un carcinome gélatineux (cancer colloïde alvéolaire). Elle est représentée par une tumeur dont le volume peut atteindre et dépasser celui de la tête d'un Homme. Le tissu qui en forme la base est en général très résistant, et se montre creusé d'une foule de petites cavités ou alvéoles de la dimension. d'un grain de mil à celle d'un grain de chènevis ou même d'un pois ; dans certains cas, on remarque au centre une poche beaucoup plus volumineuse. Dans l'intérieur de ces alvéoles se trouvent de petites masses molles, gélatineuses, transparentes. Or, un examen attentif montre que le stroma est constitué par un tissu fibro-conjonctif, dont les éléments se propagent en traînées dans les tissus voisins, et que les masses gélatineuses renfermées dans les alvéoles ne sont autres que de petites hydatides repliées sur elles-mêmes, l'espace restreint qu'elles occupent ne leur ayant pas permis de prendre la forme globuleuse normale. La tumeur a une tendance marquée à l'ulcération. Un petit nombre seulement de ces Échinocoques minuseules produisent des têtes de Ténia, toujours peu abondantes du reste. - Le mode de développement n'est pas encore bien connu; il est probable cependant qu'il s'agit là d'une formation de vésicules filles et petites-filles, pour la plupart exogènes, aux dépens d'une seule ou de quelques vésicules mères. Klemm a constaté nettement, en effet, l'existence de vésicules endogènes et exogènes. Peut-être aussi doit-on faire inter- 
venir l'isolement des diverticules fue poussent les vésicules primitives daus les points oir le tissu ambiant offre une moindre résistance. En tout cas, on ignore jusqu'ì présent la cause de l'aspect particulier que présentent ces tumeurs; il y a évidemment une réaction spéciale le lorgane envahi, grâce d̀ laquelle se manifeste une vive prolifération conjonctive qui limite de bonne heure l'accroissement des vésieules; et on a cté amené à supposer que cette réaction est due à la pénétration de l'embryon dans des organes particulièrement délicats vaisseaux lymphatiques, d'après Virchow; vaisseaux sanguins, d'après Leuckart; canaux biliaires, d'après Friedreich'. - Un arait supposé I'Échinocoque alréolaire spécifiquement distinct de l'Échinocoque ordinaire; mais klemm a montré quil donne chez le Chien, comme celui-ci, le véritable 'Ténia richinocoque.

En résumé, on voit que les Échinocoq̣ues ne diffèrent pas essentiellement des Cénures et des Cysticerques. Chaque vésicule proligère correspond ì un corps de Cysticerque ou de Cénure produisant plusieurs tètes; seulement ces tètes se trouvent ici à l'intérieur et non plus à l'extérieur de la vésicule.

La cuticule des Échinocoques parait ètre de nature chitineuse; sa composition chimique subil d'ailleur's avec l'îge diverses variations. Le liquide qui remplit la vésicule est incolore ou légèrement jaunâtre. de réaction neutre ou faiblement acide. Il peut renfermer des substances très diverses, dont la plupart n'ont pas été élaborées par le Ver, mais sont venues, par endosmose, du sang ou des organes envahis. On y trouve de l'albumine en faible quantité, bien qu'il ne se coagule pas par la chaleur. Hais, ce qu'il importe de noter, c'est la présence normale d'une leucomaïne, signalée par Mourson et Schlagdenhauffen; cette substance se présente en proportions variables, et parait être la cause des accidents graves (urticaire, péritonite) souvent observés chez l'Homme dans les cas où l'hydatide vient à s'ouviril dans une des grandes cavités séreuses.

Les unomalies signalées dans l'espèce qui nous occupe sont encore peu nombreuses. Von Siebold a décrit et figuré un T. echinococcus à six ventouses, mais il ne dit rien de l'aspect de la chaine. - Quant à l'Echinococcus polymorphus, il présente quelquefois, surtout lorsqu'il siège dans le foie ou le poumon, des diverticules assez comparables á ceux que nous avons signalés chez les Cysticerques ladriques du cerveau humain, et qu'on peut désigner avec Leuckart sous le nom d'Ech. racemosus. Il existe des rapports évidents entre cette forme et l'Échinocoque multiloculaire.

Distribution géogr.ppHeve. - Le T. echinoéccus est surlout commun chez les Chiens de boucher ou le berger. Il s'est rencontré, en Islande, chez 280 p. 1000 des Chiens examinés; à Copenhague, chez \& p. 1000); à Zurich, chez 39 p. 1000; à Lyon, chez 71 p. 1000. Il esi aussi très commun en AusIralie, mais pour ainsi dire inconnu aux Etats-Unis. Chez un mème animal, on le trouve toujours en nombre considérable. 
Les kystes hydatiques dont ce Ver provoque le développement chez l'Homme et les animaux sont de même répandus presque partout. Ils ne sont pas rares en France, non plus que dans la plupart des autres contrées de l'Europe; cependant, on ne les a trouvés que rarement chez l'Homme, en Danemark et en Norvège. Par contre, ils sont très répandus dans le Mecklembourg. Mais c'est l'Islande qui est la patrie classique des Échinocoques: Finsen en a constaté chez $1 / 43$ des individus. Le fait n'a rien de surprenant si l'on songe qu'il y a dans ce pays 28 Chiens, 36 Bœufs et 488 Moutons pour 100 habitants, et que, pendant les longs mois d'hiver, hommes et bêtes vivent dans les mêmes cabanes, sans le moindre souci des règles de l'hygiène. Les viscères des Ruminants sont livrés aux Chiens, qui contractent ainsi le Ténia échinocoque et deviennent à leur tour une source constante d'infestation. Les kystes hydatiques sont aussi très communs en Australie, et très rares aux Etats-Unis.

En ce qui concerne l'Échinocoque multiloculaire, c'est surtout en Suisse et dans l'Allemagne du Sud qu'il a été observẻ, chez l'Homme aussi bien que chez les animaux.

Patnologie. - Dans l'intestin du Chien, le $T$. echinococcus détermine parfois une violente irritation qui se traduit par des symptômes rabiformes, ainsi qu'en témoignent les observations de Pillwax, Bollinger et Leisering.

Mais c'est principalement sous sa forme hydatique que ce Ver se montre dangereux. Nous avons dit qu'il se rencontre à cet état chez l'Homme aussi bien que chez les animaux. Rudolphi distinguait, d'après l'habitat, trois espèces d'Echinocoques: $E$. veterinorum, $E$. simia et $E$. hominis. Dujardin n'en admit plus qu'une seule, à laquelle il conserva le premier de ces noms; mais Diesing, estimant avec raison qu'aucune de ces formes ne devait imposer son nom aux autres, les réunit sous celui d' $E$. polymorphus.

Chez l'Homme, l'affection hydatique ou échinocorcose s'observe à tous les âges, mais surtout de vingt à quarante ans; elle est plus commune chez les femmes que chez les hommes, sans qu'on puisse s'en expliquer clairement la raison: elle est surtout fréquente, comme il est facile de le prévoir, chez les individus qui vivent en contact arec des Chiens, bien que l'infestation puisse se produire aussi à la faveur des légumes ou des salades, ou encore par l’intermédiaire des eaux de boisson non filtrées.

Les Echinocoques peuvent se rencontrer, chez l'Homme et chez les animaux, dans presque tous les organes, même dans les os; c'est cependant le foie qui se montre le plus souvent envahi : viennent ensuite, par ordre de fréquence décroissante, le poumon, les reins, la rate, le cerveau, etc.

Les symptômes de cette affection sont assez vagues, et varient du reste suivant le siège des Échinocoques. Il en est un cependant qui a été signalé chez l'Homme, et qui est connu sous le nom de frémissement liydatique: Briançon, qui l'a découvert, le compare à la sensation 
que fait éprourer un corps en vibration. On le provoque en appliquant une main sur la région occupée par le kyste, et en frappant un coup sec avec l'autre main sur la tumeur. Ce frémissement a été attribué par les uns à la présence de vésicules filles internes, ou de plusieurs vésicules contiguës; mais on l'a observé aussi dans le cas d'lyylatides solitaires, et comme on le pereoit fort bien en agitant une de ees hydatides placée dans la main, il doit s'expliquer par l'élasticité de la membranc épaisse qui limite le parasite. - La ponction, aidée de l'examen mieroscopique, permel de confirmer le diagnostic.

La ponetion est aussi employée comme moyen de traitement, et plus d'une fois elle a réussi en dehors de toute autre intervention chirurgicale. Mais il importe de se rappeler qu'clle est sourent suivie d'une éruption d'urticaire. Cet accident a même été constaté quelquefois dans des conditions toutes spontanées; mais il est surtout à craindre dans le cas où les hydatides viennent à s'ouvrir dans une cavité séreuse ou dans un tronc vasculaire. L'urticaire hydatique s'accompagne dans certains cas d'une dyspnée intense, et peut amener une mort rapide. La gravité de l'accident est d'ailleurs assez variable. ce qui tient peut-être au degré d'impressionnabilité des sujets et à l'état de prolifération ou de repos de l'Échinocoque. Nous arons dit plus haut que tous ces troubles sont attribuables à une leucomaïne (1). On n'a rien signalé de semblable jusqu'à présent ehez les animaux, bien que cette leucomaïne existe, non seulement dans leurs Échinoeoques, mais aussi dans leurs Cysticerques.

La durée de la vie des Échinocoques n’a pas encore été fixée d'une façon précise. Disons cependant que Raymond en a vu persister un pendant sept ans ehez un Cheval, et que Courty a observé ehez. l'Homme un kyste hydatique de la région iliaque qui datait de trente-einq ans.

En vieillissant, l'hydatide subit diverses modifications. Elle s'aceroit parfois jusqu'à acquérir jusqu'à 15 centimètres de diamètre; mais le plus souvent son volume reste inférieur à celui du poing. En même temps sa cuticule va s'épaississant, de manière à atteindre parfois jusqu'à 1 millimètre. En tout eas, le Ver finit par se détruire. Le point de départ de cette destruction parait se trouver dans le kyste adventif, dont la face interne, primitivement lisse et luisante, devient peu à peu opaque, et ne tarde pas à produire des couches d'une substance crémeuse ou caséeuse qui refoule l'hydatide. Celle-ci ne semble pas d'abord atteinte, mais un examen minutieux montre pourtant que la membrane germinale ou parenchymale est ramollie et a subi la dégénérescence graisseuse, que sur quelques points elle s'est séparée de la cuticule, et que les têtes, plus ou moins altérées, nagent dans le liquide. Celui-ei finit par exsuder à travers la paroi, et se mélange à la matière produite à la surface interne du kyste, de manière à former

(1) Ch. Achard, De l'intoxication hydatique. Archives génér. de méd. (i), XX, p. 410 et 572,1888 . 
une masse épaisse, ayant un aspect de colle ou de miel, qui s'épaissit et se concrète avec le temps. L'hydatide s'affaisse et se plisse, perd son apparence pellucide et forme un paquet gélatineux qui, à la longue, dégénère en une masse amorphe. Assez souvent, la couche qui tapisse le kyste s'imprègne de sels calcaires, particulièrement de carbonate, et la matière concrète qui s'amasse au centre peut subir la même infiltration. En définitive, le volume primitif du kyste hydatique se montre extrèmement réduit, et souvent un simple nodule représente la dernière trace d'un Ëchinocoque de grandes dimensions. On a donné à cette transformation le nom peu précis de dégénérescence athéromateuse. La nature de ces hydatides altérées se reconnaît à l'examen microscopique, qui peut faire découvrir des lambeaux de la cuticule lamellaire et surtout des crochets.

La prophylaxie de l'échinococcose doit être basée sur la connaissance du mode habituel d'infestation. Il suffit donc de rappeler que les animaux herbivores trouvent surtout dans les pâturages les oufs d'où dérivent les Échinocoques. Pour ce qui a trait à l'Homme, il faut plutôt incriminer les eaux non filtrées, sans oublier, cependant, les salades, les fruits tombés à terre, les aliments et les ustensiles de cuisine souillés au contact direct du Chien.

Sous-famille des anoplocípHalinés. - C'est le groupe auquel nous

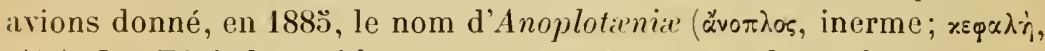
tête). Les Téniadés qui le composent ont un corps lancéolé en avant; une tête sans trompe ni crochets; des anneaux serrés, en général plus larges que longs; enfin, des cufs pourvus d'une mince membrane vitelline et d'un chorion souvent irrégulier, renfermant un embryon entouré d'une enveloppe résistante, presque toujours prolongée par deux cornes (appareil pyriforme).

L'évolution est encore inconnue; cependant, C. Curtice a fait sur le Lepus sylvaticus une observation intéressante, qui pourra mettre les expérimentateurs sur la voie des recherches à entreprendre pour la déterminer. Il a trouvé, en effet, dans l'intestin, un grand nombre de petits Téniadés encore très jeunes, quoique à divers degrés de développement. Les uns, longs de $\ddot{~}$ millimètres, non segmentés, offraient entre les ventouses une dépression cupuliforme bordée de 8 à à !10 crochets; d'autres, plus âgés, avaient perdu ces crochets, et quelques-uns ne montraient même plus la dépression correspondante; enfin, il en existait un certain nombre dont la segmentation était commencée, mais tous ceux-ci étaient inermes. On est ainsi porté à supposer que l'état larvaire des Anoplocéphalinés peut être représenté par un Cysticercoïde armé, et que les crochets disparaissent au cours du développement.

Les Vers de ce groupe vivent, à l'état adulte, dans l'intestin grêle des Mammifères herbivores. 
Leur classification ne peut itre encore donnée d'une facon tris précise : cependant, divers auteurs ont entrepris, dans ces derniers temps, des recherches importantes qui pourront servir bientot ả l'établir sur des bases sérieuses (1). Nous nous bornerons pour l'instant ì répartir les formes qui nous intéressent dans quelques genres, dont plusieurs u’ont toutefois encore qu'une villeur provisoire.

Genre Moniezzia (Moniesia R. BI., 1891). - Utérus double; poren génitaux doubles; reufs avec un appareil pyriforme bien développé.

Intestin des Ruminants.

On peut noter que dans ce genre, d'après Stiles, les conduils sexuels passent au-dessus des canaux longitudinaux (dorsally). De plus, cet auteur a constaté que, dans certaines espèces, il existe entre deux anneaux consécutils de la chaine desglandes speciales (ylandes interproglottidiemes on interammulaires) tantòt disposées en série linéaire, tantòt groupées autour de dépressious en cul-de-sac de la cuticule. D'après ces caractères, les espèces de ce genre se laissent disposer en trois groupes :

A. Section planissimı, caractérisée par la disposilion linéaire des glandes interannulaires. - M. planissima, $\boldsymbol{M}$. Benedeni, M. Neumumi.

B. Section expansı, caractérisée par la disposition sacculaire des glandes. - M. expansa, M. oblongiceps, M. Irigonophor't.

C. Section denticulalu, comprenant les formes dépourvues de glandes interannulaires. - M. dentieulata, M. alba.

Nous prendrous pour type le Monieza expansa.

Moniézia étendu (11. expansa [Rud.]. - Syn. : ? Trnia ovina liœze, 1782 ; T. expansa Rud., 1810 ; 1 . expansa R. BI., 1891). - Ver ordinairement blanchàtre dans sa portion antérieure, et jaunàtre dans sa portion postérieure; atteignant 4 à 5 mètres de longueur (2). Tète obtuse, plus on moins carrée, légèrement lobée, large de 360 à 700 ب. ; ventouses neltemenl. saillantes, à ouverture dirigée obliquement en avant. Anneaux loujours

(1) Ė. Blaxchano, Recherches sur loorganisation des Vers. Anmales des se. nat. (zoologie) (3), X. p. 344. - G. Neumax, Observations sur les Ténias du Mouton. Soc. d'hist. nat. de Toulonse, 18 mar's 1891. - R. Buancinad, Notiees helminthologiques, $2^{e}$ série. Mém. de la Soc. zool. de France, IV, p. 420, 1891. - R. Moxız, Noles su. les Helminthes, VI, V'II et VIII. Revue biol. du Nord de la France, IV, p. 65, 1891. C. W. Stiles and A. Hassalt, Revision of the Adult Cestodes of Cattle, slieep and allied Inimals. Washington, 1893.

(2) Raulin mentionne un fragment de Ténia de 26 pieds provenant d'un Agneau de trois mois. Gaze dit avoh trouvé chez un Agnean à la nmamelle, âgé de quatre semaines, un Ténia long de 51 aunes. Divers autres observateurs cilent des faits semblables, mais il s'agirait de savoir s'ils n'ont pas eu alraire i des fragments séparús provenant de diver's exemplaires. 
beaucoup plus larges que longs, les derniers très épais, pouvant atteindre une largeur de 16 millimètres. Glandes interannulaires localisées autour

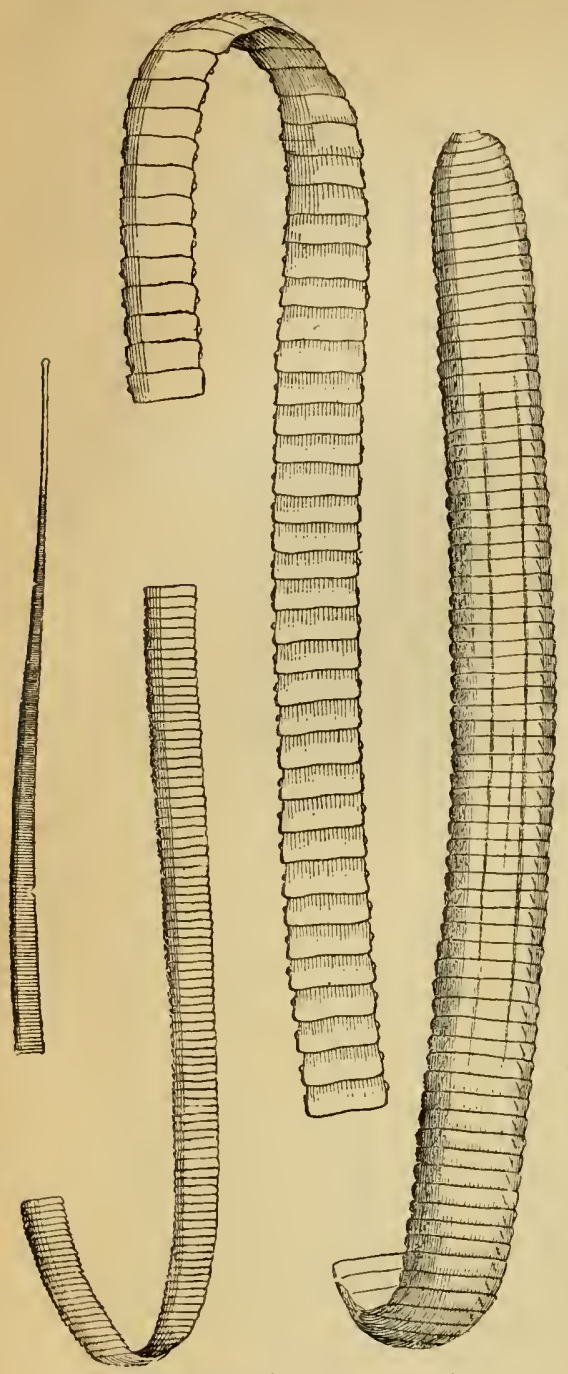

Fig. 162. - Moniezia expansa, grandeur naturelle (Orig.).

d'une série de culs-de-sac qui s'ouvrent entre les anneaux. Testicules disposés généralement en une figure quadrangulaire, rarement en deux triangles. OEufs cuboïdes ou globuleux, de 50 à $90 \mu$ de diamètre; bulbe de l'appareil pyriforme large de 20 u. (1).
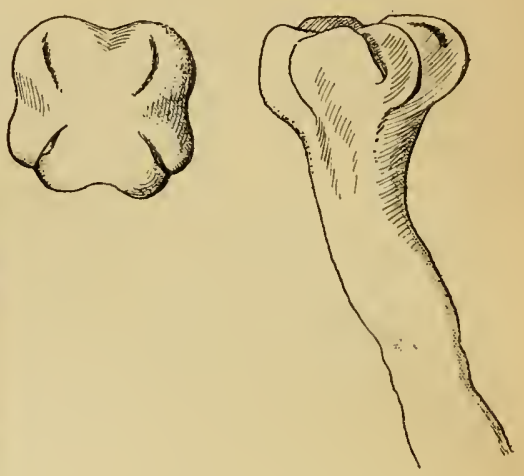

Fig. 163. - Extrémité céplalique du Moniesia errpansa, vue de face el de profil, d'après ur échantillon autheutique de la collection de Rudolphi (Stiles, inéd.).

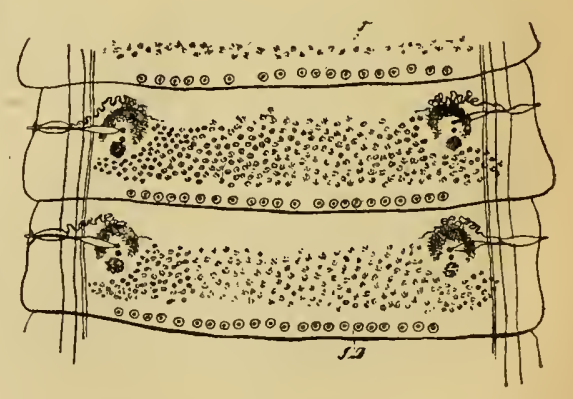

Fig. 164. - Diagramme de Moniesia expansa, face dorsale. $-t$, testicules. $i d$, glandes interannulaires. en cul-du-sac (Stiles).

Le Moniezia expansa habite l'intestin grêle de divers Ruminants, notamment du Mouton, de la Chèvre et du Bœuf.

(1) La forme des ceufs est variable chez la plupart des Anoplocéphalinés, suivant les conditions de leur pression réciproque : on peut en trouver en même temps de cubiques et de sphériques, avec toutes les formes intermédiaires. - Quant à l'appareil pyriforme, ses caractères sont plus fixes. Les dimensions que nous en donnons se rapportent toujours ạ plus grand diametre, les cornes exclues. 
$1^{\circ}$ Embryogénie. - L’ovule du M. expansa apparait au premier abord comme III élément cellulaire chargé de granulations vitellines et pourvu d'une sorte de noyau excentrique nucléolé ; en réalité, c'est ce noyau qui constitue la véritable cellule, et les granules vitellins ne sont que des éléments accessoires (fig. 163, 1). - Aussitòt après la fécondation, apparait une membrane vitelline, et la cellule se segmente : l'un des deux éléments ainsi. formés fait en général immédiatement saillie en dehors de la masse vitel-

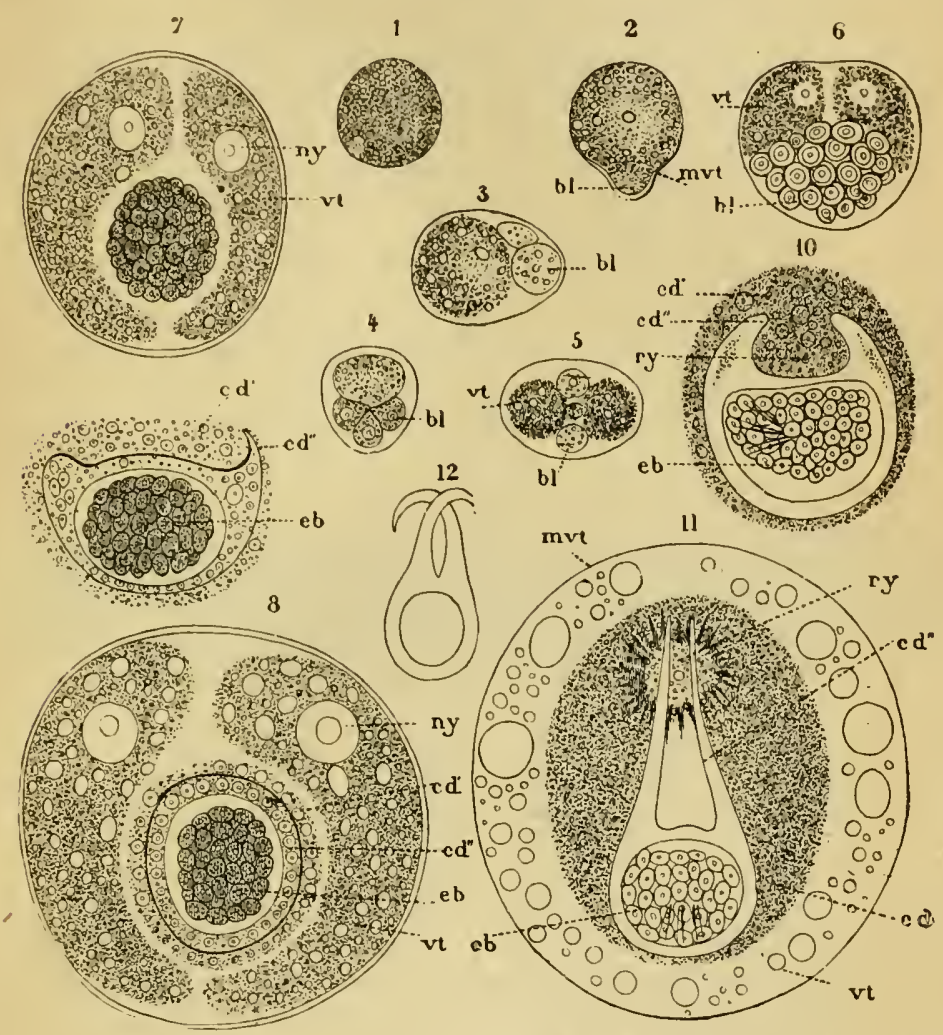

Fig. 163. - Embrygogénie des Anoplocéphalinés du type Moniezia expansa, d'après R. Moniez. $v t$, masses vilellines. mvt, membrane vilelline. $b l$, cellules blastodermiques. $c d^{\prime}$, jremière couche délaminée. $c d^{\prime \prime}$, seconde couche délaminée formant l'appareil pyriforme. $n y$, globules polaires. $r y$, masse granuleuse provenant de $c d^{\prime}$, et entrainée par les cornes de l'appareil. $e b$, embryon. - 1 à 11 , Ioniezia expansa, 12, appareil pyriforme de l'Andrya wimerosa, pour montrer comment les cornes peuvent s'entre-croiser.

line $(2)$, et se multiplie (3 et 4 ) ; l'autre reste inclus dans la masse vitelline, devient très réfringent et perd ses granulations (corpuscule polaire). - La masse vitelline se divise ensuite en deux parties (5) qui présentent bientòt chacune un gros élément cellulaire vitreux, pendant que les cellules blastodermiques continuent à se multiplier et arrivent à constituer une morula (6): les faits se passent lonc comme chez le Trnia serrata; il n'y a qu'un retard lans la division de la masse vitelline. Plus tard, l'œuf, qui a acyuis de grandes dimensions, offre une morula bien regulière et deux grosses masses vitel- 
lines en forme de virgules, situées sur lescòtés, et tendant à se rejoindre par leurs extrémités ; les globules polaires sont alors très nets (7): - Survient ensuite la délamination : une couclıe de cellules rejetées à la périphérie de la masse embryonnaire forme ì celle-ci une membrane d'enveloppe; puis ces cellules se résolvent en granules. Peu après, une seconde couche se détache de la même facon ( 8 ; ; puis la sphère creuse qu'elle constitue s'aplatit sur presque la moitié de son étendue, et aux deux extrémités de la moitié aplatie, elle pousse deux prolongements qui s'accusent de plus en plus, en s’amincissant à leur extrémité $(9)$, et en se redressant peu à peu $(10,11)$. En mêmetemps, les granulations qui composaient cette couche disparaissent, de sorte qu'elle forme une enveloppe homogène, réfringente, revètant l'embryon et munie de deıx cornes : c'est là ce qu'on appelle l'uppareil pyriforme (11, 12). La masse grenue et rayonnée qui s'aperçoit entre les pointes des deux cornes n'a aucune signification morphologique : c'est simplement une portion de la première couche délaminée qui a été entrainée par ces deux prolongements.

Une fois la double délamination effectuée, l'embryon acquiert ses six crochets, et bientỏt on le voit entrer en mouvement. Il parait présenter une cavité à son intérieur. Quant aux masses vitellines, elles se creuseut de vacuoles de plus en plus grandes, et fondent entre elles leurs vésicules (11).

2 Les phases post-EMbryonxaires de l'érolution ne sont pas conmues. Diesing a émis l'opinion que cette évolution doit être directe, et la plupart des auteurs ont accepté cette manière de voir ; mais les essais expérimentaux tentés dans ce seıs n'ont donné jusquà présent que des résultats négatifs.

Il est fort possible que, selon la supposition de C. Baillet, l'embryon doive pénétrer tout d'abord dans le corps de certains Insectes ou d'autres animaux inférieurs.

Pour ce qui a trait à l'organisution de ce Ver', nous ne pouvons entrer ici dans tous les détails qu'elle comporte, et nous nous bornerons ả renvoyer le lecteur à l'étude spéciale qu'en a faite Zschokke (1).

Patnologie. - De toutes les espèces d'Anoplocéphalinés qui habitent le tube digestif des Ruminants, c'est le $\boldsymbol{M}$. expansa qui paraît se rencontrer le plus fréquemment et qui, par suite des dimensions qu’il peut atteindre, est susceptible de jouer le rile pathogénique le plus mportant.

Lorsque ces Vers sont peu nombreux, ils ne provoquent pas de troubles appréciables; mais ils se inultiplient quelquefois à tel point qu'ils causent dans les troupeaux de Moutons une affection redoutable. Ce téniasis (Banduramseuche dles Allemands), à caractère épizootique, sévit de préférence sur les Agneaux et les Antenais, dans les localités humides et au cours des années pluvieuses; il affecte d'ordinaire la forme d'une anémie pernicieuse.

Chez la Chèvre et le Boeuf, on n'a que rarement attribué aux Téniadés la production de troubles sérieux.

(1) F. Zsснокке, Recherches sur la structure anatomique et histologique des Ténias. Genère, 1888, p. 93; fig. 31-38. 
Moniczia Irigomophore (M. Wigonophora Stiles et IIassall, 1893). Longueur, $1^{\text {m }}, 60$ à 2 metres ; teinte blanchàtre. Tête large de $0^{\mathrm{mm}}, 622^{\prime}$ à $0^{\mathrm{mm}}, 70 q$; ventouses non saillantes, mesurant $0^{\mathrm{mm}}, 2.30$ sur $0^{\mathrm{m}}, 200$, à ouvertures en fente. Cou filiforme, long de 2 millimètres. Anneaux généralement plus larges que longs; pirfois cepentant les derniers aussi longs ou mème un peu plus longs que larges; dépassant rarement 2 millimètres de long sur 6 millimètres de large. Topographie grénérale des organes comme dans $\boldsymbol{M}$. expansa; tontefois, testicules ordinairement disposés en deux triangles et disparaissant sur la ligne médiane ; utérus laissant le plus souvent un espace vide sur la ligne mécilane. l’ores génitaux jamais en arrière du milieu de l'anneau. CLufs de 322 à $60 \mu$ : appareil pyriforme de 20 à 2 't $\mu$, ì cornes de 12 a 1 ï u..

Intestin du Mouton (France, Elats-Luis).

Monićzia Irès minee. (1I. planissima Stiles et Ilissall, 1892). - Lon«ueur, 1 à 2 mètres ; teinte jaunàtre. Tète carrée, large de $0^{\mathrm{mm}}, 8$ à $0^{\mathrm{mm}}, 9$; ventourses occupant les quatre coins, dirigées en avant et à ouverture légèrementallongée. Cou long de $0^{\mathrm{mm}}, 6$ a $1^{\mathrm{mm}}, \ddot{3}$, assez large. Anneaux toujours beaucoup plus larges que longs et plus longs qu'épais : les premiers extrèmement courts ; anneaux múrs larges de 12 à 26 millimètres, longs de 1 millimètre à

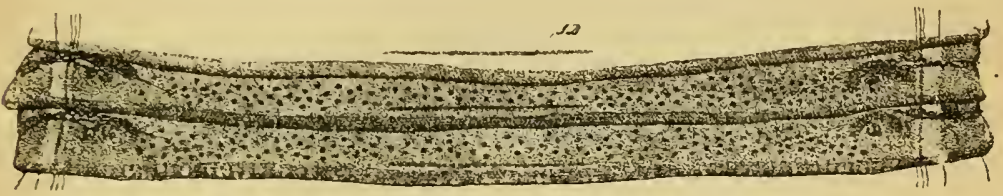

Fig. 166. - Moniezia planissimu, face dorsale. - $i d$, glandes interannulaires, sans culs-de-sac (Stiles).

$1^{\mathrm{mm}}$, ï̈, généralement très minces. Glandes iuterannulaires linéaires, grandes et très distinctes. Pores génitaux situés dans la partie antérieure du bord latéral ; du cò té droit, vagin ventral et cirre dorsal ; à gauche, cire ventral et vagin dorsal. Premières traces d'organes génitaux à 7-12 millimètres de la tète (rers le $10^{\circ}$ anneau) ; testicules apparaissant à 10 centimètres environ, d'abord disposés en deux triangles, puis remplissant tout l'anneau. Replis de l'utérus pénétrant dans les champs latéraux. OEufs de 63 \%; appareil pyriforme de $20 \mu$, à cornes de $24 \mu$; embryon de 16 à $18 \mu$, à crochets de $9 \mu$.

Intestin grèle du Ilouton et du Bœuf: Paris (Railliet, Stiles); Toulouse (Neumann) ; Washington (Hassall, Stiles et Curtice).

Moniézia de Van Beneden (M. Benedeni [Moniez]. - Syn. : Trnia Benedeni Mz., 1879 ; M. Benedeni R. Bl., 1891). - Longueur, 4 mètres et plus. Tète obtuse, carrée, volumineuse, de plus d'un millimètre d'épaisseur, nettement séparée du cou ; ventouses dirigées obliquement en avant et à ouverture circulaire, puissantes, très saillantes, se touchant toutes les quatre, ce qui fait paraitre la tète, vue de dessus, comme formée de quatre sphères contiguës. Cou presque aussi large que la tète, long d'environ $2^{\mathrm{mm}} \ddot{3}$, diminuant insensiblement de larğeur, puis présentant un léger rétrécissement plus brusque, ì partir duquel le corps s'élargit avec régularité. Anneaux toujours 
VERS.

plus larges que longs ; anneaux mùrs, à l'état de contraction, alteignant 12 millimètres de large sur 3 millimètres de long et plus d'un millimètre d'épaisseur. Couche musculaire de l'une des faces sensiblement moins fournie que l'autre. Topographie des canaux longitudinaux, des conduits génitaux et

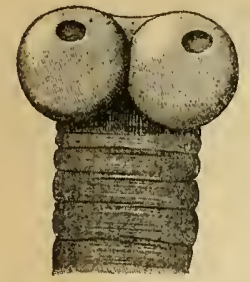

Fig. 167. - Extrémité céphalique du Monie sia Benedeni, grossie 20 fois (G. Neumann). des glandes femelles comme dans M. planissima. Glandes interannulaires peu distinctes, mais linéaires, sans sacs. OEufs de 80 à $8 \ddot{\text { p. }}$ : appareil pyriforme de 18 à 21 p. ; embryon $15 i$.

Intestin grêle du Mouton et du Bœuf, à Lille (Moniez), à Vienne (Marenzeller).

Moniézia de Neumamn (IJ. Neumanni Mz., 1891). - Longueur, 50 à 70 centimètres. Tète et cou comme dans l'espèce précédente, à cette différence près que la tète est moins nettement lobée: mais la partie antérieure de la chaîne se rétrécit brusquement et se montre très grèle, filiforme. Les anneaux sont aussi moins larges et moins épais ; les plus larges n'ont que 8 millimètres, sur $1^{\mathrm{mm}}, 0$ de long; les derniers mesurent 6 millimètres sur 2. Testicules disposés en quadrilatère. Glandes interannulaires petiles, sans sacs. OEufs de 53 à $65 \mu$; embryon de 18 à $21 \mu$.

Intestin grêle du Mouton, à Lille (Moniez).

Moniézia denticulé (M. denticulata [Rud.]. - Syn. : Tænia denticulata Rud., 1804 ; $M$. denticulata R. Bl., 1891). - Long de 32 à 40 centimètres (jusqu'à 78 centimètres?). Tète munie de ventouses relativement grandes, dịrigées en avant. Cou nul ou très court. Anneaux antérieur's très courts, s'accroissant rapidement en largeur et lentement en longueur : à 2ö millimètres de la tête, ils mesurent 4 millimètres de large ; largeur maximum, 13 à 23 millimètres. Anneaux mùrs très épais et plus étroits. Pas de glandes interannulaires. Pores génitaux dans la moitié postérieure des bords de l'an-

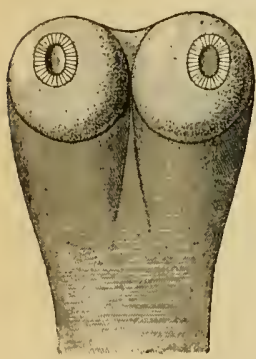

Fig. 16s. - Eslrémilé céphahịue du Moniezia alba, grossie 20 fois (G. Neumann). neau. OEufs de $48 \mu$; bulbe de l'appareil pyriforme de 12 à $16 \mu$; cornes de 8 à $16 \mu$.

Intestin grèle du Buuf. Trouvé aussi chez le Mouton, ì Lille (Moniez).

Moniézia blane (M. alba [Perroncito]. - Sýn. : Tænia alba Perr., 1878 ; M. al.ba R. BI., 1891). - Teinte blanche. Longueur, $0^{\mathrm{m}}, 60$ a $2^{\mathrm{m}}, 30$. Tête globuleuse, quadrangulaire, assez grosse, mesurant $1^{\mathrm{mm}}, 15 \mathrm{à} 1^{\mathrm{mm}}, 40$; ventouses hémisphériques, ouvertes obliquement en avant et en dehors. Cou bien distinct, long de $1^{\mathrm{mm}}, 5$ à $5^{\mathrm{mm}}, 3$. Anneaux épais, opaques, relativement étroits, n'atteignant que rarement 10 à 12 millimètres de largeur, et parfois plus longs que larges. Ammeaux mûrs larges de 8 à 14 millimètres, longs de 2 à $6^{\mathrm{mm}}, 5$, épais de $1^{\mathrm{mm}}$ ö. Glandes interannulaires totalement absentes. Pores génilaux dans la moitié antérieure des bords de l'anneau. T'esticules en quadrilatère. OWufs de 60 à $88 \mu$; bulbe de l'appareil pyriforme de 20 à $24 \mu$; cornes de 12 à $20 \mu$.

Intestin grèle du Bueuf et plus rarement du Mouton. 
Moniez a trouvé a plusieurs reprises, chez le Mouton, une variété de cette espèce (M. alba var. dubia) à tète relativement petite, mesurant 600 $\iota$, à cou plissé, plus large que la partie antérieure de la chaine ; les anneaux étaient moins longs et les oufs un peu plus petits que dans le type.

Moničzia sans •-ou (II. mullicnllis Moniez, 1891). - Longueur, 40 centimètres environ. Tète de forme cubique, arrondie en avant, hémisphérique en arrière, large de $\mathrm{I}_{\mathrm{mm}}, 3$. Con nul, les premiers anneaux commençant au point où la tète se rélrécil, c’est-à-dire immédiatement derrière les ventouses. Partie antérieure de la chaine ayant presque la largeur de la tète. Tous les anneaux très courts, ne prenant en aucun point la forme carrée; les derniers assez minces, mesurant 8 millimètres de large sur 1 millimètre de long. OEufs lle 53 à $6 \check{\not} \not \iota$ environ ; appareil pyriforme de 18 à $21 \mu$, à cornes très élargies à la base.

Trouvé deux fois chez le Mouton, ì Lille, par Moniez. - Sa place dans la classification n'a pu encore ètre cléterminée.

Moniéza de la Chèvre (M. capræ [Rud.]. - Syn. : Tænia capræ Rud., 1810). - Espèce douteuse établie par liudolphi d'après des fragments sans tête, trouvés dans l'iléon d'une Chèvre. Elle devrait ètre classée, d'après cet au-

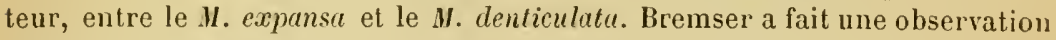
analogue. Il s'agissait probablement, dans ces deux cas, de l'une des espèces que nous avons décrites plus haut.

Nous pourons encore citer : $\boldsymbol{M}$. oblongiceps Stiles el Hassall, 1893, de l'intestin d'un Cervidé (Coassus sp. ?), et $\boldsymbol{M}$. crucigera Nitzsch, 1866, de l'intestin du Chevreuil.

Genre Thysanosome (Thysanosoma Dies., 1834). - Utérus simple, transversal, avec des sacs ovifères en forme d'asques; pores génitaux doubles ou irrégulièrement alternes; cornes de l'appareil pyriforme non développées.

Intestin des Ruminants.

Thysanosome aetinioïde (Th. actinioides Diesing, 1834. - Syn. : Txnia fimbriata Dies., 1850 ; Moniezia fimlriata R. Bl., 1891). — Longueur, 15 à 30 centimètres. Tète tétragone, large de 1 millimètre à $1^{\mathrm{mm}}, 5$; ventouses hémisphériques, contiguës, ouvertes obliquement en avant et en dehors.

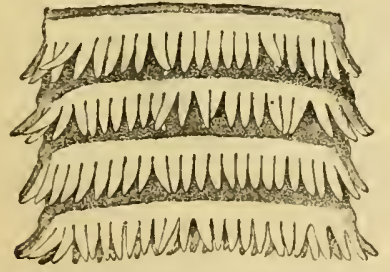

Fig. 169. - Anneaux de la région antérieure du Thysanosoma actinioides, grossis 10 fois (Orig.).

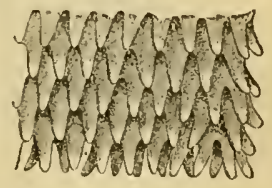

Fig. 170. - Partie latérale des derniers anneaux du Thysanosoma actinioides, grossie 10 fois (Orig.).

Cou nul. Anneaux s'élargissant progressirement et régulièrement jusqu'au voisinage de l'extrémité postérieure, où ils se rélrécissent quelque peu; leur 
plus grande largeur est de 8 millimètres. Tous ces anneaux, beaucoup plus larges que longs, sont découpés en longues franges à leur bord postérieur. OEufs groupés dans des culs-de-sac utérins; appareil pyriforme sans cornes.

Trouvée d'abord au Brésil, par Natterer, dans l'intestin de divers Cervidés, cette espèce est très abondante chez le Mouton dans les plaines de l'ouest des États-Unis (C. Curtice).

Thysanosome du Mouton (Th. ovilla [Rivolta]. - Syn. : Tænia ovilla Riv., 1878, necGmelin, 1789; T. Giardi Mz., 1879; T. aculcata Perroncito, 1882).-

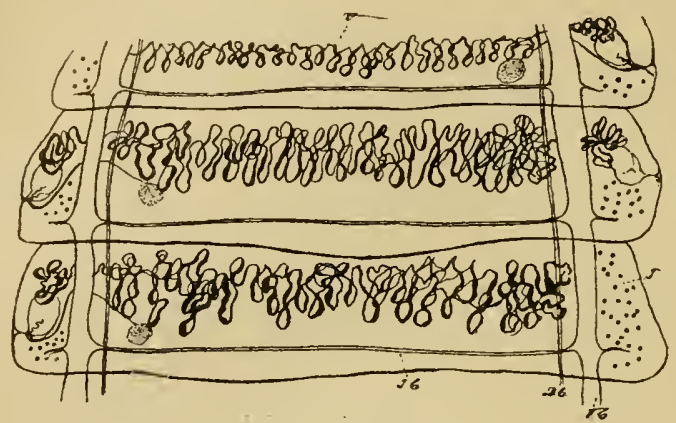

Fig. 171. - Diagramme de Thysanosoma ovilla, face ventrale. - $u$, utérus. $t$, testicules. dc, canal dorsal. $v c$, canal rentral. $t c$, canal transversal (Stiles).

Long de 2 mètres et plus, large de $ّ$ à 10 millimètres et plus. Tète tétragone, ayant parfois plus d'un millimètre de largeur. Cou assez long, d'une largeur moitié moindre que celle de la tète. Anneaux très courts, augmentant graduelle-

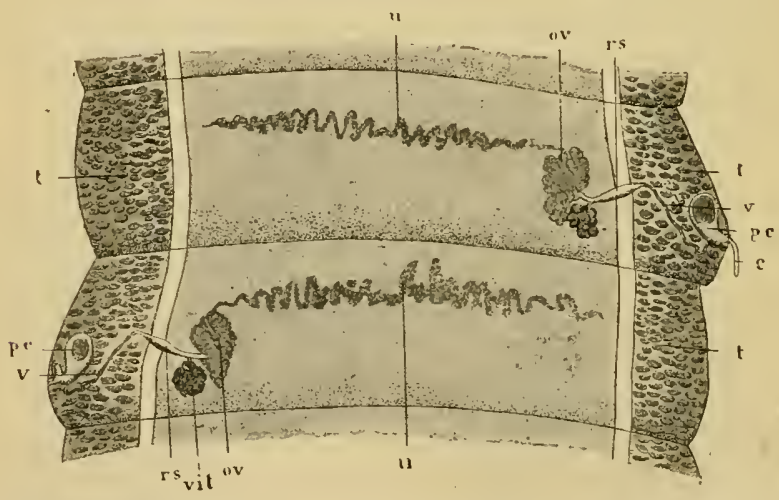

Fig. 179. - Deux anneaux de Thysanosoma ovilla, grossis 20 fois. $-t$, testicules. $p c$, poche du cirre. $c$, cirre. $v$, vagin. $r s$, réservoir séminal. $u$, ébanche de l'utérus, vit, vitellogènes $(G$. Neumann, d’après une préparation de Rirolta).

ment de longueur et de largeur jusqu'aux derniers, où ces dimensions atteignent 1 millimètre à $1^{\mathrm{mm}}, \ddot{b}$ sur 5 à 10 millimètres. Pores génitaux généralement alternes, mais parfois doubles. Testicules silués sur les còtés, au delà des canaux longitudinaux, au lieu d'ètre dorsaux et d'occuper la région centrale, comme chez la généralité des Téniadés. OEufs groupés, au nombre 
de 6 a 10, dans des direrticules globuleux de l'utérus, sortes de coques fibrillaires qui doment un aspect grenu a la cassure des anneaux ; ces oufs perdent de bonne heure leur enreloppe exlerne, qui se résout en granulalions au sein desquelles sont plongés les embryons, cntourés d'une coque chitineuse qui est lomologue de l'appareil pyriforme, et qui mesure 21 y. dans son plus grand diamètre.

Intestin du Mouton.

Moniez en décrit une variété (Th. ovillu rar. macilenta) qui peut atteindre $1^{\mathrm{m}}, \mathbf{2 0}$, mais qui offre une chaine ordinairement plus grèle, plus aplatie et moins large que dans le type; les sacs ovigères sont en outre heaucoup plus petits.

Genre Stilésia (Stilesiu Raill., 1893). Nous établissons ce genre, dédié à notre ami Stiles, de Washington, pour des formes

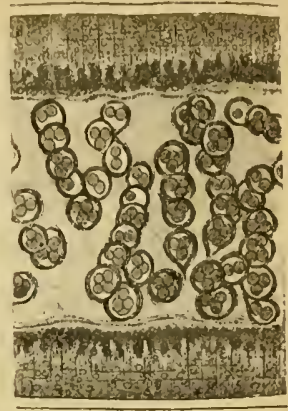

Fig. 173. - Coupe transversale d'un anneau de Thysanosom" oville, montrant la disposition des coques ovigères, grossie 40 fois (G. Neumann). très grêles d'Anoplocephalinir dont les pores génitaux sont irrégulièrement alternes, et dont les cufs, à coque simple, renferment un appareil pyriforme dépourvu de cornes. L'utérus est transversal, sans sacs ovifères. L'espèce tỵpe de ce genre est représentée par le Trrnia globipunctata Rivolta.

Intestin des Ruminants.

Stilésia globiponctué (St.ylobipunctata [Riv, ]. - Syn. : Tænia globipunctata Rivolta, 1874; T. oxipunctata Riv. 1874,). - Ver très délicat, de teinte blanchà tre ou gris jaunàtre, diaphane, long de 45 à 60 centimètres et ne dépassant pas 2mm, 5 de large. Tète carrée, large de $0^{\mathrm{mm}}, 5 \mathrm{a}$ a 1 millimètre, à ventouses plus ou moins lobées, dirigées directement ou obliquement en avant. Cou lon ¿́ de 2 millimètres et plus (Stiles), nul d'après d'autres. Anneaux antérieurs larges de $0^{\mathrm{mm}}, 33$ à $2^{\mathrm{mm}}, \breve{b}$, longs de $0^{\mathrm{mm}}, 13$ à $0^{\mathrm{mm}}, 17$; anneaux postérieurs plus étroits et plus longs, larges de $0^{\mathrm{m} n}, 60$, longs de $0^{\mathrm{mm}}, 28$. Pores génitaux irrégulièrement alternes, dans la portion antérieure du bord de l'amneau. Oraire entre les canaux longitudinaux dorsal et rentıal, du còté du pore génital ; deux utérus dans chaque anneau, situés latéralement et divisés chacun en trois corps globuleux. OEufs longs de 14 à 16 y., larges de 10 à 14 p. ; coque, avec, un prolongement épineux, long de 4 à $6 \mu$, aux deux pòles.

Intestin du Houton (Italie, Inde). - Neumann a réuni en une seule espèce les Vers décrits par Rirolta sous les noms de Tænia globipunctata et de $T$. ovipunctata. Ces derniers avaient la tète enfoncée dans la muqueuse intestinale, et leur présence avait donné lieu à la formation de nodules inflammatoires.

Stilésia centriponctué (St. centripunctata [Rivolta]. - Syn. : Tænia

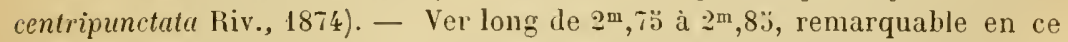
qu'il est plus large dans sa moitié antérieure que dans sa moitié postérieure. Tète suivie d'une partie plus étroite où les anneaux sont à peine marqués par une fine striation transversale. A 10 centimètres de lia tète, les anneaux 
ont 2 à 4 millimètres de large; à 1 mètre 50, ils n'ont plus que 1 millimètre, mais deviennent plus épais et plus longs; les anneaux mûrs ont à peine 1 millimètre de large sur 330 p. de long. Au centre de chaque anneau, à partir de

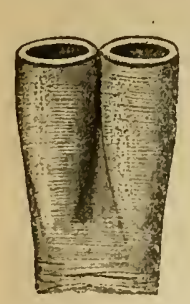

Fig. 174. - Extrémité céphalique du Stilesia centripunctala, grossie 10 fois (G. Neumana). la moitié de la chaîne, on voit à l'ceil nu une tache blanchàtre un peu saillante forméc par l'utérus. Les testicules sont symétriques et situés en dedans des canaux longitudinaux. Le pore génital s'ouvre sur le milieu d'un des bords de l'anneau. Appareil pyriforme sans cornes, de 21 à 24 u de diamètre.

Intestin du Mouton (Italie, Algérie).

Genre Cténoténia (Ctenotænia Raill., 1893. - Syn. : Dipylidium Riehm, 1881, nec Leuck., 1863). - D’après l'ensemble des caractères anatomiques, il convient de séparer des Moniezia les Anoplocéphalinés des Rongeurs, qui possèdent comme eux des orifices génitaux doubles. Nous proposons pour ces Vers le nom de Ctenotænia («тsis, peigne), en prenant pour type le Tænia marmotæ Frölich.

Le tableau ci-dessous indique les caractères extérieurs les plus saillants des formes qui vivent en parasites chez les Léporidés:

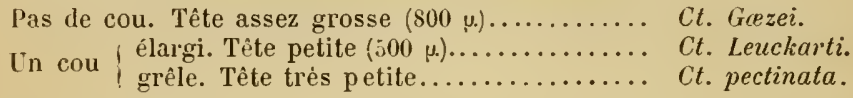

Cténoténia de Goeze (Ct. Gœzei [Baird]. - Syn. : Tænia Gœzei Baird, 1833 ; Dipylidium latissimum Riehm, 1881). - Longueur, 40 à 80 centimètres. Tête trapézoïde, un peu aplatie, large de 800 k. ; ventouses proéminentes, légèrement elliptiques, à grand axe transversal. Cou nul : la tète s'élargit en arrière et se continue directement avec la chaine, qui se développe rapidement en forme de lancette. Anneaux toujours beaucoup plus larges que longs, très épais, notamment sur les còtés ; anneaux mùrs atteignant une largeur de 13 millimètres sur 4 millimètres de long. Pores génitaux dans les angles postérieurs des anneaux, qui font saillie et donnent au bord un aspect frangé. OEuf́s de 52 à $60 \mu$; appareil pyriforme de 16 à $24 \mu$.

Intestin grêle du Lapin de garenne.

Cténoténia de Lenckart (Ct. Leuckarti [Riehm]. - Syn. : Dipylidium Leuckarti Riehm, 1881 ; Tænia ctenoides Raill., 1890). — Longueur, jusqu'à 80 centimètres. Tête petite, large de $500 \mu$, se continuant avec le cou sans séparation nette; ventouses plates. Cou s'élargissant en lancette pour se continuer avec la chaîne. Anneaux toujours beaucoup plus larges que longs; largeur des anneaux mùrs, jusqu'à $\mathbf{t}$ centimètre. Pores génitaux dans le quart postérieur des bords de l'anneau.

Intestin grèle du Lapin de garenne. - De mème que Neumann, nous avon s trouvé, chez un Lapin domestique, un Téniadé qui nous a paru se rapporter à cette espèce.

Cténoténia peetiné (Ct. pectinata [Gœze]. - Syn. : Tænia pectinata foeze, 1782, pro parte : Ct. pectinata E. Blanch., 1848, pro parte; Dipylidium pectinatum Riehm, 1881). - Longueur, 18 à 40 centimètres, tète très petite, large seulement de 250 à $340 \mu$; ventouses elliptiques, à grand axe longitu- 
dinal, ì ouverture irrégulière. Cou assez grète, un peu plus mince que la liete. Partic antérieure de lat chaine s'élargissant rapidement en forme de lancetle. Amucanx toujours beaucoup plus larges que longs; anneaux mùrs larges de 7 à 10 millimètres. Pores génitaux situés vers le milieu des bords de l'anneau. OEufs longs de 80 ì $90 \mu$; appareil pyriforme de $2:$ i i $30 \mu$.

Intestin grèle du Lièvre commun el du Lièvre variable.

Cienre Anoplocéphale (Anoplocephala Ém. Blanch., 1848). - Corps lormi d'anneaux en général très courts, assez épais, se recouvrant un peu les uns les autres de manière à paraitre comme imbriqués. Pores ţénilaux unilatéraux. Utérus transversal. Olufs pourvus d'un appareil pyriforme.

Espèces parasites des Jumentis.

Le tablean ci-dessous permettra de reconnaitre les trois principales formes ‘ui s’ohservent chez nos Équidés domestiques :

Tỉte tris grosse (sans lobes en arrière.......... A. plicala.

, à quatre lobes postérieurs.... A. perfoliata.

Tite petite, sans lobes poslérieurs............ A. mamillana.

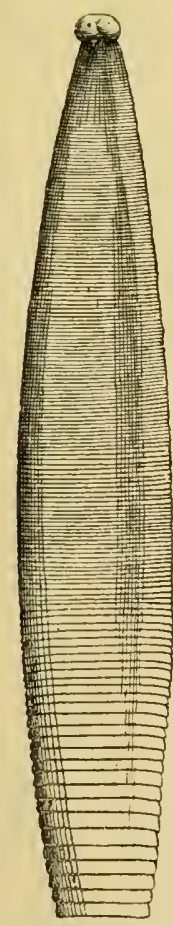

Fig. 175. - Anoplocephala plicata, grandeur naturelle (1)rig.).
Anoplocéphale plissé (A. plicatu Zeder]. - Trnia e'fuina Pallas, 1781, pro parte; T. magna Abildgaard, 1789 ; Alyselminthus plicatus Zeder, 1800; Anopl. plicata R. B1., 1891. - Priorité : 1. magna). - Long de 9 à 80 centimètres. Tète très grosse, courte, tétragone, arrondie, un peu déprimée dans le sens des deux faces, large de 4 à 6 millimètres; ventouses cupuliformes, dirigées en avant. Cou nul. Anneaux devenant rapidement plus larges que la tète, et continuant de s'accroitre en largeur tantòt jusque vers le milieı, lantòt jusque vers l'extrémité de la chaine, de manière à acquérir un maximum de $\$$ à 20 millimètres ;

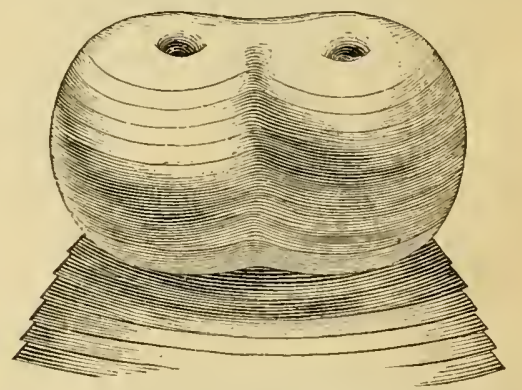

Fig. 176. - Extrémité céphalique de l'Anoplocephala plicata, grossie 10 fois (0rig.).

augmentant aussi de longueur jusqu'aux derniers, qui atteignent 1 millimètre a $1^{\mathrm{mm}}, \ddot{3}$. CEufs de 30 à $60 \mu$; appareil pyriforme de 16 a $18 \mu$. 
Se rencontre assez rarement dans l'intestin grêle et plus rarement encore dans l'estomac du Cheval (1). Nous en possédons aujourd'hui d'assez nombreux exemplaires recueillis en France, aux abattoirs de Villejuif et de Troyes (Morot). A Gabès, en Tunisie, sur 33 autopsies de Chevaux et Mulets pratiquées dans l'espace de vingt-sept mois, Beugnot a trouvé 8 fois des Anoplocéphales appartenant à cette espèce ou à la var. pediculata.

A còté de celle forme typique, il en existe plusieurs autres qui représentent peut-être des espèces distinctes, mais que nous étudierons provisoirement comme de simples variétés.

Anoplocéphale pédiculé (1. plicata var. pediculata). - Ver long de 24 à 33 centimètres. Tète létragone à coins arrondis, plus large que longue, mais aussi épaisse que large ( 4 millimètres); ventouses saillantes, à ouverture profonde, circulaire, relativement large, sillonnées régulièrement en travers et dirigées en avant. Cou nul. Partie antérieure de la chaîne beaucoup plus étroite que la tèle, naissant au fond d'une cavité de l'extrémité postérieure de celle-ci ; large de $1^{\mathrm{mm}}, 8$ à 2 millimètres : s'élargissant plus ou moins régulièrement jusque vers le tiers ou le quart postérieur, point où les anneaux mesurent 1 millimètre à $1^{\mathrm{m}}$, 3 de long sur 7 à 19 millimètres de large; derniers anneaux larges de ä à 13 millimètres, longs de $1^{\mathrm{mm}}, 2$ à $1^{\mathrm{mm}}, 8$. OEufs de $7 \%$ à $90 \mu$; appareil pyriforme de $16 \mu$.

Trouvé par Beugnol, à Gabès (Tunisie), dans lïntestin du Cheral et du Mulet.

La description qui précède a été établie d’après des échantillons conservés dans l'alcool ; à l'état frais, les Vers mesuraient de 30 à 78 centimètres de longueur sur une largeur maximum de 8 à 20 millimètres. Cette différence de longueur tient surtont à ce que la partie postérieure de la chaîne offrait, dans les plus grands exemplaires, une série d'anneaux presque aussi longs que larges (3 millimètres sur 4 chez l'un d'eux), mais se détachant facilement et n'ayant pu être conservés.

Anoplocépliale étranglé (A. plicata var. strangulata). - Long de T0 à 93 millimètres. Tète très grosse, tétragone-arrondie, plus large que longue, un peu dépıimée dans le sens des deux laces : large de 4 millimètres, épaisse de 3 millimètres; veutouses cupuliformes, à ouverture étroite et profonde, sillomnées régulièrement en travers, dirigées en avant et un peu en dehors. Cou nul. Partie antérieure de la chaine offrant un étranglement très net, long de 1 millimètre à $2^{\text {nm }}, \ddot{y}$, large de $2^{\mathrm{mm}}, \ddot{3}$ à $3^{\mathrm{mm}}, \breve{b}$. Les premiers anneaux qui suivent cette région étranglée ont 4 à 6 millimètres de large, de sorte qu'ils font une saillie brusque. Anneaux suivants s'élargissant assez régulièrement, mais restant toujours très courts ; atteignant leur largeur maximum à un centimètre environ de l'extrémité postérieure, et mesurant alors 18 à 20 millimètres de large sur $0^{\mathrm{mm}}, 40$ à $0^{\mathrm{mm}}, 6$ de long. Derniers anneaux larges de 10 à 11 millimètres sur 1 millimètre à $1^{\mathrm{mm}}, 3$ de long. OEufs de 82 à $94 \mu$; appareil pyriforme de 16 à $20 \mu$...

(1) Gilard aurait observé dans l'utérus d'une Jument des Téniadés qui, d'après leurs dimensions, se rattacheraient à cette espèce, si l'observation devait être considérée comme sérieuse. 
Cette forme, curieuse par son itranglement antérieur, qui simule un cou, a été trouvce par M. Guillod, vétérinaire à Étain (Meuse), dans le tube digestif de Poulains anémiques. Ils se montraient en quantiti extraordinaire depuis l'estomae jusqu'au côlon. Les animaux ainsi envahis succombent assez rapidement, après avoir présentẻ des coliques sourdes.

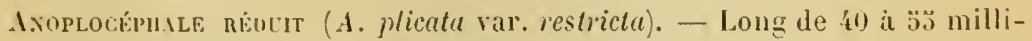
mètres. Tète très gqrosse, tétrąone-arrondie, plus large que longue, un peu déprimée dans le sens des deux faces : large de 3 à 4 millimètres, épaisse de $2^{\mathrm{mm}}, 1$ à $2^{\mathrm{mm}}, \ddot{3}$ : rentouses peu saillantes, ì ouverture étroite et profonde, sillonnées en travers, dirigées en arant et un peu en dehors. Con nul. Parlie antérieure de la chaîne immédiatement plus large que la tète; largeur maxinum vers le quart postérieur de la longueur. Premiers anneaux trés courts jusqu'á une distance de 10 à 30 millimètres de la tète, puis s'allougeant assez brusquement et mesurant alors $0^{\mathrm{mm}}, \ddot{a}$ de long sur $\ddot{3}$ millimètres de large ; atteignant au nireau du quart postérieur $0^{\mathrm{mm}}, 7$ a $0^{\mathrm{mm}}, 9$ sur 3 ì 8 millimètres ; derniers anneaux longs de 1 millimètre, larges de 3 a 4 millimètres.

Cette petite forme, qui a probablement une valeur spécifique, a été recueillie en 1883̈, par Sarciron, dans l'intestin grèle d'un Anon, à Kayes (Hant-Sénégal). Il en existait des centaines d'exemplaires.

Anoplocéphale perfolié (A. perfoliata [Göze]. - Syn. : Truia equina Pallas, 1781, pro parte; T. perfoliata Goze, 1782, nec Duj., 1845 ; Anopl. perfoliatı Blanch., 1848). - Long en général de 8 à 20 millimètres, mais pouvant atteinulre 80 millimètres. Tète grosse, courte, tétragrone-arrondie,

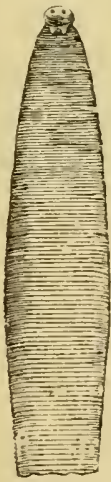

Fig. 177. - Anoplor:ephala perfoliata, grandeur naturelle ; incomplet (Orig.).

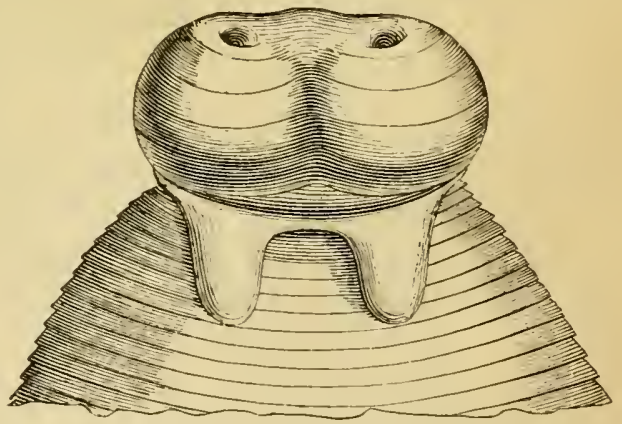

rig. 1:x. - Estrómité céphalique de l'A noplocephala perfoliata, grossie 12 fois (Orig.).

un peu aplatie, liırge de 2 ì :3 millimètres, prolongée en arrière par quatre lobes arrondis; rentouses cupuliformes, dirigées en avant. Cou nul. Anneaux devenant rapidement plus larges que la tète, et continuant de s’accroitre en largeur jusque vers le milieu de la chaine, où ils atteignent 3 à 15 millimètres, puis diminuant progressivement dans heaucoup d'exemplaires jusqu`i l'extrémité postérieure, de sorte que l'ensemble présente assez. 
l'aspect d'une graine de courge. Ces anneaux sout épais, mais tous très courts et perfoliés, chacun d'eux recouvrant ou mieux emboîtant le suivant, auquel il n'adhère que par sa partie centrale ; souvent les derniers ne conliennent plus d'oufs. OEufs de 6 à à $80 \mu$; appareil pyriforme de 19 à 22 u.

Dans le cecum, assez souvent aussi dans l'iléon, plus rarement dans le côlon du Cheval. Dujardin l'avait confondu avec le suivant; il vit $\mathrm{du}$ reste comme lui en colonies plus ou moins nombreuses. Kahane le considère comme identique à l'A. plicata, celui-ci en représentant la forme jeune (?); comme le fait remarquer cet auteur, on peut en reconnaitre deux formes, l'une atténuée en arrière, l'autre tronquée.

Neumann (1) a décrit un A. perfoliata trièdre, dont la tête portait six ventouses.

Des troubles pathologiques ont été assez souvent attribués à cette espèce. Poulton, Mégnin, Bassi, Perroncito, etc., ont vu sa présence coïncider avec le développement de culs-de-sac dans l'intestin grêle, culs-de-sac qui arrivent dans certains cas à se rupturer. La mort survient à la suite de violentes coliques.

Anoplocéphale mamillan (A. mamillana [Mehlis]. - Syn. : Tænia mamillana Mehlis, 1831 ; T. perfoliata Duj., 1845, pro parte ; A. manillana R. Bl., 1891). - Long de 6 millimètres à 5 centimètres. Tête petite, tétragone-arrondie, large de $0^{\mathrm{mm}}, 7$, souvent rétractée dans la partie antérieure de la chaìne ; ventouses latérales, elliptiques, à
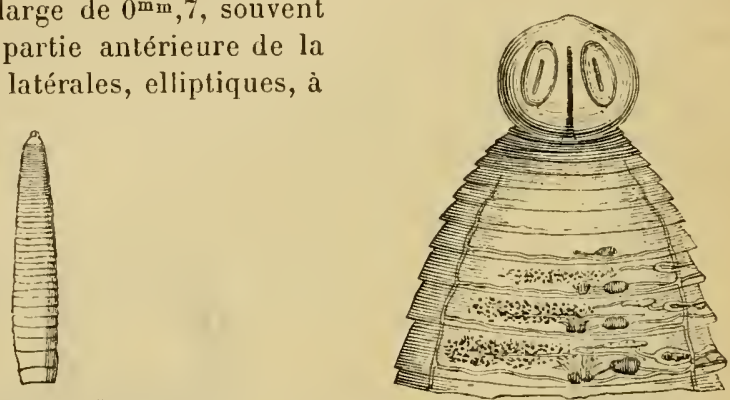

Hig. 179. - Anoplocephala mamillana, grandeur Fig. 180. - Extrémité céphalique de l'Anoplonaturelle (Orig.).

cephala mamillana, grossie 20 fois (Orig.).

ouverture en forme de fente longitudinale. Anneaux devenant rapidement plus larges que la tête et atteignant peu après leur plus grande largenr (4 à 6 millimètres), qu'ils conservent souvent jusqu'à l'extrémité.

Habite l'intestin grêle, et en particulier le jéjunum et l'iléon du Cheval. Nous ne l'avons trouvé que très exceptionnellement dans l'estomac. C'est un petit Ver assez transparent, qui peut échapper à un examen superficiel, bien qu'on en trouve toujours à la fois de nombreux exemplaires. Des trois espèces de T'éniadés qui vivent chez le Cheval, c'est celle que nous rencontrons le plus communément à Alfort.

(1) G. Neuman, a propos d'un Tínia trièdre de l'espèce Tænía perfoliata Greze. Revue vétér., XV, p. 478, 1890 . 
Genre Aulrya (Andrya Raill., 1893). - Il n'est pas douteux, bien que leur étude anatomique soit encore peu avancée, que les Anoplocéphalinés les Rougeurs, pourvus de pores génitaux alternes, doivent ètre séparés géneriquement de ceux des Equidés, qui ont les pores génitaux unilatéraux. Yous en faisons done le genre Andrya, d'apris le Tæmia rhopalocephala Riehn, et en lhouneur de Nicolas Andry, le savant médecin du xvü siècle qui a contribué l'un des premiers à élucider l'histoire des Téniadés.

Les trois espèces que nous avons à signaler peuvent se distinguer à l'aide dı tableau suirant :

Chaine, Tète grande; cou assez large.. A. pectinata. très longue ! Tête petite; cou grêle........ A. cuniculi. Chaine tris courte; pas de con............ A. wimerosa.

Indrya pectiné (A. pectinata [Zeder]. - Syn. : Alyselminthus pectinutus Zeder, 1800: Txnia rhopalocephala Riehm, 1881). - Long de 60 à 80 centimètres, large de plus de 3 millimètres. Tète grande, claviforme ; ventouses puissantes, très saillantes. Cou assez large, mais nettement détaché de la tête et naissant immédiatement en arrịre des ventouses. Anneaux trapéziformes, ¿t peu près aussi larges que longs. Pores génitaux ordinairement situés tous du même còté, et s'ourrant au nireau du quart postérieur du bord latéral de l'anneau.

Intestin grèle du Lièvre commun.

Indrya du Lapin (1. cumiculi|R. Bl.]. - Syn. : Tænia rhopaliocephala Kiehm, 1881; Anoplocephala cuniculi R. BI., 1891). - Longueur, jusqu'à 1 mètre; largeur, jusqu'à 8 millimètres. Tète petite, claviforme, s'étendant assez loin en arrière des ventouses. Cou grèle, bien séparé de la lète lorsque celle-ci n'est pas trop fortement contractée. Anneaux trapéziformes, à peu près aussi ĩarges que longs. Pores génitaux s'ouvrant un pen en arrière du milieu du bord latéral de l'anneau.

Intestin grèle du Lapin de garenne.

Indrya de Wimerenx (A. wimerosı [Mz.]. - Syn. : A.pectinuta É. Blanch., 1848, pro parte [?]; Tania wimerosa Hz., 1880 ; Anoplocephala wimerosa R. Bl., 1891). - Long à peine d'un centimètre, large de $1^{\mathrm{mm}}, \ddot{3}$. Tète grosse; ventouses écartées. Cou nul. Chaìne épaisse, formée d'une dizaine d'anneaux qui sont bordés de cils en arrière. Pores génitaux unilatéraux, débouchant à l'angle postérieur de l'anneau. OLufs à appareil pyriforme très développé (fig. 165, 12).

Intestin grèle du Lapin de garenue (Moniez). - R. Blanchard a trouvé chez le Lièvre variable, à liriancon, une forme analogue, mais à anneaux plus nombreux (2ỏ à 30 ) et ì pores génitaux s'ouvrant vers le milieu du bord latéral.

Pathologie. - On a signalé assez souvent de sérieuses épizooties sévissant dans les parcs et dans les garennes, sur les Lièvres et les Lapins, qui périssaient en grand nombre, l'intestin bourré d'Anoplocéphalinés. Comme chez les Agneaux, ce téniasis affecte la forme d'une anémie pernicieuse (gros ventre). 
Les Téniadés du Lapin pénètrent quelquefois dans la cavité péritonéale, sans laisser de traces bien nettes de leur passage. C'est un fait que Marigues a signalé, dès la fin du siècle dernier, chez le Lapin de garenne. Dans un cas semblable, Goze a trouvé l'ouverture par laquelle les Vers étaient sortis; elle était fermée par l'épaississement de ses bords et ne s'apercevait qu'à la face interne de l'intestin, c'est-à-dire sur la muqueuse (1).

Espèce non cusssée. - Nous sommes obligé de laisser à part, sous le nom de Tænia s. lat., l'espèce suivante, encore trop imparfaitement connue pour prendre rang dans la classification qui vient d'ètre donnée.

Ténia de Vogt (T. Vogti Hz., 1879. - Syn. : Anoplocephala Vogli Mz., 1891). - Espèce basée sur un échantillon sans tète, mesurant environ 50 centimètres de longueur, très grêle et très plat: Anneaux mùrs plus longs que larges (près de 5 millimètres sur $2^{\mathrm{mm}}, 3$ ). Un seul pore génital par anneau. OEufs de $29 \mu$; appareil pyriforme de $14 \mu$ ว.

Intestin du Mouton (Lille).

Sous-famille des cystoinotaniÉs. - Corps de moyenne ou de petite taille. Tête probablement toujours armée d'une couronne simple. double ou multiple, de petits crochets de forme variable. Pores génitaux alternes, unilatéraux ou opposés. OEufs à en reloppes multiples, mais transparentes, sans coque de bâtonnets.

La larve est un Cysticercoïde ou un Pseudo-cystique.

Ces Téniadés vivent à l'état adulte chez les Vertébrés, et en parlier chez les Mammifères et les Oiseaux. Leurs larves sont généralement parasites des Invertébrés (Insectes, Mollusques, etc.).

Genre Dipylidium (Dipylidium Leuckart, 1863). — Téniadés de taille relativement petite. Tête pourvue d'un rostre rétractile armé de plusieurs couronnes de petits crochets présentant souvent la forme d'aiguillons de rosier, c'est-à-dire à manche et à garde très réduits, formant une simple base discoïde. Anneaux pourvus chacun de deux pores génitaux, l'un sur le bord droit, l'autre sur le bord gauche, correspondant à des organes sexuels également doubles. OEufs à membranes transparentes, s'accumulant, après formation de l'embryon, dans des capsules distinctes.

La larve est un Cryptocystis qui vit dans la cavité viscérale de certains Insectes.

Dipylidium du Chien (D. caninum [L.]. - Syn. : Tania canina L., 176 nec Batsch, 1786 ; T. moniliformis Pallas, 1781 ; T. cucumerina Bloch, 1782; T. elliptica Batsch, 1786 ; T. [Dipylidium] cucumerina Leuck., 1863). - Ver

(1) Marigues, Observation sur des Vers Ténia trouvés dans le ventre de quelques. Lapins sunvages. Journal de physique de l'abbé Rozier, XII, 2, p. 229-221, pl. 11, fig. 3, 1778. - GözE, Versuch einer Nalurgeschichte der Eingeweidewürmer thierischer Körper. Blankenburg, 1782, p. 36x et $36 \%$. 
long de 10 à 40 centimètres en moyenne, ayant $\mathrm{tm}^{\mathrm{mm}}, 5$ a 3 millimètres dans sa plus grande largeur. Tète petite, presque rlomboïdale, surmontée d'un rostre claviforme, réträtile dans un infundibulum situé au sommet de la tète, et armé de trois ou quatre couronnes de crochets en aiguillonts de ro-

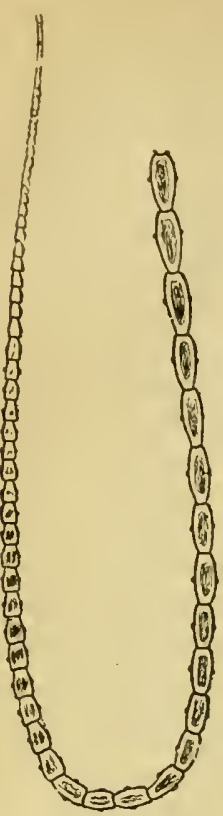

Fig. 18t. - Dipylidium caninum var. canis, petit exemplaire, grandeur naturelle (Orig.). sier, de dimensions décroissantes d'avant en arrière, ceux de lia première couronne ayant environ $13 \mu$ de hauteur, et ceux de la dernière à peine $6 \mu$; ventouses assez grandes, un peu elliptiques. Cou assez court, de moitié plus étroit que la tète. Premiers anneaux très courts et très etroits, les suivants trapézoïdes, puis devenant

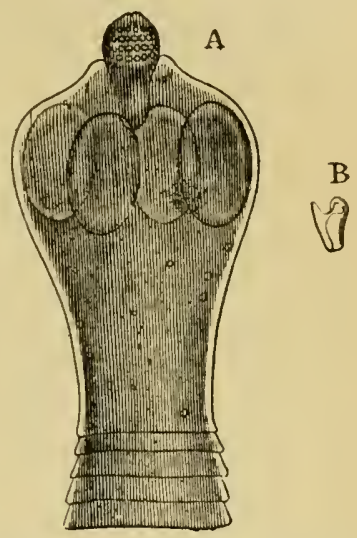

Fig. 102. - Dipylidium caninum. - A, tète grossie, avec le rostre sorti en partie. B, un des crochets du rostre, fortement grossi (Orig.).

bientòt plus longs que larges et en forme de graines de melon (cucumis). OEufs globuleux, du diamètre de $\{3$ à :0 $\mu$; embryon bexacanthe large de 32 a $36 \mu$, avec des crochets longs de 12 à $1 \dot{t} u$.

Ce Ver habite la moitié postérieure de l'intestin grèle du Chien domestique, où il acquiert des dimensions relativement assez grandes (var. canis). On le trouve également chez le Chat, mais dans cette espèce il reste généralement un peu plus petit, quoique avec des œufs légèrement plus gros (var. cati); Rudolphi et autrefois Leuckart le regardaient même comme représentant alors une espèce à part (T. elliptica Batsch). Enfin il a été signalé aussi chez l'Homme, et récemment chez le Canis aureus var. dalmatica (Stossich). Il présente souvent en arric̀re une belle teinte rosée, qui disparait dans les liquides conservateurs.

La larve (Cryptocystis trichodectis Villot) vit dans la cavité viscérale du Trichodecte et de la Puce du Chien.

10 Embryoyénie. - Le développement de l'cuf a élé suivi par Moniez. Aussitôt après la fécondation, l'ovule du $D$. caninum se sépare de la couche 
VERS.

extérieure de sou protoplasma, qui forme une membrane vitelline. En mème temps, il expulse un globule polaire d'aspect réfringent. Puis sa masse entiere se divise en deux éléments égaux, pourvus chacun d'un noyau et d'un nu-

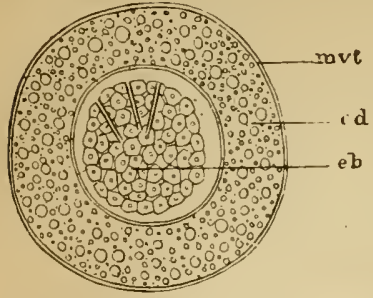

Fig. 183. - (Euf complètement développé du Dipylidium caninum. - mvt, membrane vitelline. $c d$, couche délaminće. $e b$, embryon (R. Moniez). cléole; ce sont les deux premières cellules blastodermiques, qui se segmentent ellesmèmes d'une facon irrégulière jusqu'à la formation d'une morula à cellules très petites. La délamination s'effectue alors comme chez le Tænia serrata, et les six crochets apparaissent. Puis, les éléments de la couche délaminée subissent la dégénérescence granuleuse, pendant que l'embryon s'enveloppe d'une couche mince, d'aspect chitineux.

L'œuf complètement développé, de forme globulense, n'offre donc que des enveloppes transparentes, qui permettent de distinguer sans difficulté l'embryon hexacanthe s'agitant dans l'intérieur.

$2^{\circ}$ Phase cystique. - On a longtemps ignoré quels étaient les hôtes du Dipylidium caninum à l'état larvaire. Leuckart avait cependant émis l'idée que ce devait être quelque Insecte, lorsque Melnilior, en 1869, découvrit par hasard, dans la cavité viscérale du Trichodecte du Chien (Trichodectes canis), de petits corps blancs que Leucliart reconnut pour la larve du Ver en question. Quelque temps après, l'étudiant russe parvint à infester deux Trichodectes en plaçant sur la peau d'un Chien, en un point envahi par ces Insectes, une sorte de bouillie obtenue en broyant des anneaux mùrs.

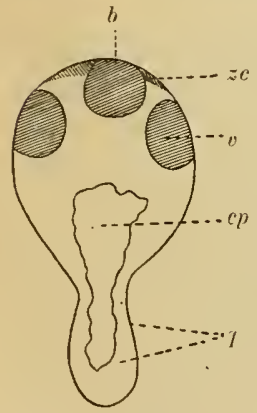

Fig. 184. - Coupe lon. gitudinale schématiq̨ue de la larve primitive du Dipylidium caninum. $-b$, bulbe. $z c$, zone circumbulbaire. $v$, ventouse. $c p$, cavilé primitive. q, queue (Grassi et Rovelli).

Malgré l'insuffisance de ces recherches, on admit généralement que l'hôte intermédiaire du D. caninum était bien le Trichodecte. Pourtanl, bien des réserves se présentaient à l'esprit, surtout lórsqu'on arrivait à meltre en parallèle la fréquence du Ver arec la rareté de l'Insecte. Quelques auteurs allaient même jusqu'à admettre la possibilité d'un développement direct. Ce fut alors que Grassi et Rovelli parvinrent à démontrer que le rôle d'hôte intermédiaire peut ètre rempli, en dehors du Trichodecte, par la Puce du Chien (Pulex serraticeps P. Gerv.) et même par la Puce de l'Homme ( $P$. irritans L.), mais seulement à l'état d'Insectes parfaits. Par contre, l'Hématopinus pilifère, qui est aussi parasite du Chien, ne peut être accusé. L'hôte principal est en réalité la Puce canine, comme l'a vu aussi Sonsino.

Si l'on suit l'évolution de cette larve dans lecorps de la Puce, on constate que l'embryon hexacanthe, formé l'un amas de cellules homogènes, se 
transforme bientòt en une larve allongée (vésirule primitive) creusée d'unu cavité excentrique remplie de liquide (cavité primitive). La partie antérieure de l'embryon, qui porte les crochets, constituera la queue de cette larve; lit partie postérieure en formera le corps, de sorte que la larre s'oriente immédiatement en sens inverse de l'embryon.

Le corps sépaissit peu il peu, et ne tarde pas à développer ì sa partie antérieure, mais d'une facon tout à fait isolée, le rostre et les ventouses. En ce qui concerne le rostre, on roit apparaitre en premier lieu, ì l'extrémité antérieure et sous la cutieule, le bulbe, qui offre une musculature très puissante. Ce bulbe ne tarde pas i s'invaginer, entrañant avec lui la cuticule et une zone cellulaire avoisinante (zone circumbulbaire), el, peu après, l'invagination subit un étıanglement, qui sépare deux dilatations, toutes deux nunies de pointes cuticulaires ou crochets rudimentaires. Ces pointes disparaissent bientỏt dans la dilatation postérieure, mais celles de l'antérieure se développent et prennent le caractère de crochets définitifs. Après diverses modifications, le bulbe se nontre complìtement organisé ; en outre, la région antérieure de la dilatatiou antérieure s'élargit davantage et constitue le réceptacle céphalique; sa région postérieure, en se renversant, recourre le rostre de crochets; quantá la dilatation postérieure, elle forme le sommet du rostre, qui souvent, en effet, offre une légère dépression chezle Ver adulte. - Les rentouses naissent sous l'aspect de masses arrondies situées sur les parties latérales du corps, et plus tard s'invaginent à la suite du bulbe. la tète dı Ver est ainsi définitivement constituée.

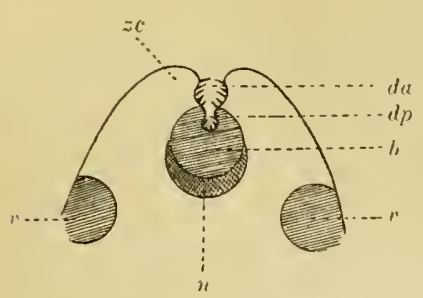

Fig. 183. - Partie antérieure de la eoupe longiludinale schématique, montrant l'invagination du bulbe et la formation du rostre. $-b$, bulbe. $z c$. zone circumbulbaire. $v, v$, rentouses. $d a$, dilatation antérieure. $d p$, dilatation postérieure. $n$, système nervenx (Grassi et Rovelli).

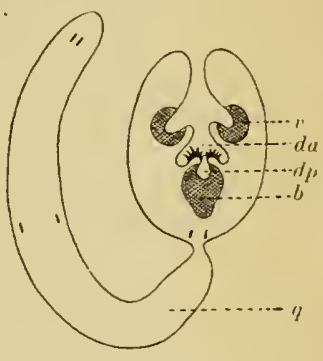

Fig. 186. - Coupe longitudinale sehémalique duue larve complètement formée. - $r$, ventouse. $d a$, dilatation antérieure. $d p$, dilatation postérieure. $b$, bulbe. $\%$, queue (firassi el Rovelli).

La partie postérieure de la vésicule primitive, qui représentela queue de la larve, montre les trois paires de crochets embrjonnaires; parfois cependant, une paire occupe la partiepostérieure du corps. Cetle quene devient tris longue ; à son point d'union arec le corps, elle finit par subir un étranglement. Comme elle ne contient pas de liquide, elle est comparable à la queue des Cercaires de Trématodes, et représente sans doute un organe qui servait à la natation chez les larres de Cestodes avant qu'elles fussent adaptées à la vie parasitaire.

La cavité primitive se montre d'ordinaire, partie dans le corps, partie dans la queue; mais tót ou tard elle est comblée par une sorte de tissu 
VERS.

conjonctif làche; il est rare de la trouver encore dansla queue complètement développée.

En mème temps que la queue s'allonge et que la cavité primitive disparait, la partie antérieure du corps sinvagrine de plus en plus dans la partie pos-

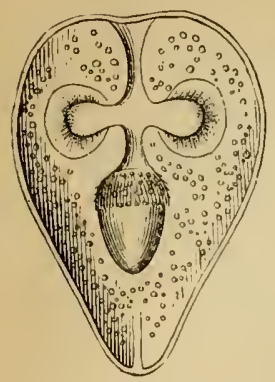

Fig. 187. - Pseudo-cyslique (Cryptocystis trichodectis) du Dipylidium caninum, d'après Leuckart. térieure, jusqu'à prendre l'aspect qu'avait observé Melnikov (fig. 187), à cette différence près que la yueue avait échappé à l'examen de celui-ci. C'est du reste cet aspect que le parasite conserve tant qu'il demeure dans le corps de l'Insecte ; quand on le dégage, on peut le voir s'évaginer sous le microscope et prendre sa position définitive.

Grassi et Rovelli considèrent l'invagination antérieure conme un stomodaum; la dilatation antérieure représenterait une cavité buccale, et la postérieure un pharynx, celui-ci possédant un épaississement musculaire (bulbe) comparable à celui des Trématodes. L'invagination serait le résultat d'une adaptation à la vie parasitaire, et aurait pour but d'empêcher le Ver, qui doit se développer dans l'intestin de l'hòte délìnitif, de se fixer dans l'estomac.

$3^{\circ}$ État rubancaire. - On sait comment le Chien fait la chasse aux parasites qui vivent sur sa peau. Or, en avalant les Puces ou les T'ichodectes pour s'en débarrasser, il ingère les Cryptocystes qu'hébergent ces Insectes. On concoit que les enfants puissent s'infester eux-mèmes en jouant avec les Chiens.

Grassi et Rovelli ont d'ailleurs donné la preuve expérimentale de ce mode de développement. On trouve des Puces qui hébergent jusqu’à cinquante larves; mais le nombre de celles-ci est généralement beaucoup plus limité, et elles prennent alors plus d'accroissement. Elles rivent librement dans la cavité viscérale, et si l'on ouvre la Puce dans un liquide albumineux, elles en sortent et apparaissent à l'œil nu comme une poudre blanche en suspension dans ce liquide. Données en cet état à des Chiens, elles meurent en général dans l'estomac de ces animaux, tandis qu'en faisant ingérer entières les Puces infestées, on obtient toujours le développement du Dipylidium caninum, qui offre alors des dimensions en rapport avec la durée de l'expérience. Les expérimentateurs jugeaient de cette infestation probable par la dissection d'un grand nombre d'exemplaires pris au hasard, et conservaient d'ailleurs des animaux témoins, qui demeuraient indemnes.

Parvenus dans le tube digestif du Chien, les Cryptocystes perdent leur queue, mais leur corps entier passe au Ver adulte.

L'organisation de celui-ci a élé bien étudiée par Leuckart, J. Chatin, Steudener. La première trace de l'appareil màle se montre déjả sur le $17^{\mathrm{e}}$ anneau ; la maturité sexuelle est alteinte vers le $50^{\mathrm{e}}$, et l'ovaire entre souvent en régression à partir du $60^{\circ}$.

Les testicules, globuleux, sont disposés en grand nombre dans la couche 
ınoyeune de l'anneau. Les spermatozoïdes qui en émanent se rendent, par de fins canalicules, vers la région médiane; à ce niveau prend naissance, de chaque còté, un spermiducte ou canal déférent qui se dirige, en lormant des lacets, vers le bord latéral, et pénètre alors dans la poche du cirre, organe allongé transversalement, dans lequel il se contourne en boucle, pour s'ourrir enfin vers le milieu dı bord.

Chaque moitié latérale de l'anneau renferme, en outre, un ovaire et un vitellorgène. Celui-ci a une structure lobulée, tandis que l'ovaire consiste

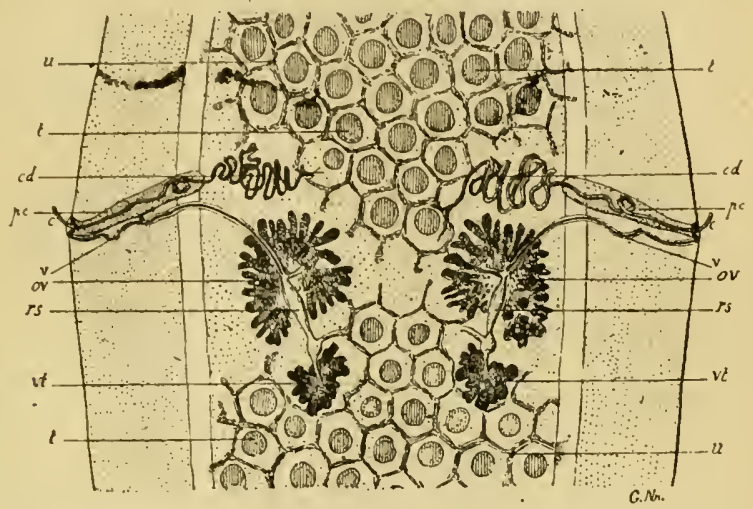

Fig. 188. - Dipylidium caninum : partie moyenne d'un anneau avant l'ovulation. - c, cire. pc, poche du cirre. $c d$, canal défẻrent. $t, t$, testicules. $v$, vagin. $r \cdot s$, réceptacle séminal. ov, ovaire. $v t$, vitellogène. $u$, réseau utérin. Grossissement : ఇŏ diamètres (G. Neumann, inéd.).

en tubes ramifiés. Les canaux excréteurs de l'ovaire se réunissent en un conduit unique, qui reçoit le vitelloducte au niveau du corps de Mehlis. - Le vagin s'owvre au dehors par un orifice situé immédiatement en arrière de la poche du eirre; il se dirige en dedans et en arrière, passe entre les deux moitiés de l'ovaire et va se jeter dans l'oviducte, après avoir formé un large réceptacle séminal.

L'oviducte communique, d'autre part, avec l'utérus qui est unique et commun aux deux groupes de glandes sexuelles. A l'époque de la maturité sexuelle, cet utérus affecte la forme d'un réseau dont Jes fils sont tendus

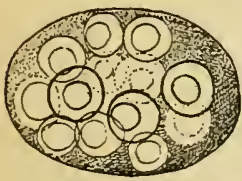

Fig. 189. - Capsule ovifère du Dipylidium caninum, grossie 125 fois (Orig.). entre les testicules et envoient par côté un grand nombre de tubes en culs-de-sac. Par suite de l'accumulation et de l'accroissement des œufs, ces tubes, ainsi que les nœuds du réseau, se dilatent en poches arrondies, qui finissent par s'isoler. La dimension de ces capsules ovifères est des plus variables, de mème que le nombre des œufs y contenus ; d'ordinaire, cependant, ce nombre n'est guère que de 8 à 10. Quand les embryons sont constitués, on constate que chaque poche renferme en outre une substance brun rougeàtre, dans laquelle sont englobés les œufs : c'est à cette substance qu'est due la coloration dont nous avous parlé plus haut.

Axomales. - Rudolphi a signalé un T. canina recueilli par Braun chez un Chien, et dont le corps était triquètre (T. prismatica Braun).

Railliet. - Zoologie. 
VERS.

Neumann a trouvé, à l'autopsie d'un Chien, 767 exemplaires de la mème espèce, dont 15 étaient fenètrés, parfois avec échancrure du bord latéral. Nous avonsaussi étudié cette même échancrure dans divers spécimens (1).

Enfin, Salzmann et Leuckart ont observé des embryons à douze crochets.

Pathologie. - Le Dipylidium caninum est sans aucun doute le plus commun des Cestodes du Chien. Zschokke, à Zurich, l'a rencontré chez 21 p. 100 des Chiens examinés; Krabbe, à Copenhague, chez 80 p. 100 ; Bertolus et Chauveau, à Lyon, chez 89 p. 100. Il en existe presque toujours un grand nombre sur le même sujet : c'est ainsi que Krabbe en a vu quelquefois moins de 10, mais souvent beaucoup plus, jusqu'à 100; dans certains cas, il en a trouvé plusieurs centaines, et une fois jusqu'à 2000.

Les troubles occasionnés par ce parasite ne diffèrent pas de ceux dus aux autres Téniadés. Gceze a cité le cas d'un Chien porteur de D. caninum et qui avait cessé d'aboyer. Wagler a vu survenir dans les mêmes conditions des troubles gastriques. Schiefferdecker a trouvé dans l'intestin grêle d'un Chien une quantité prodigieuse de ces Vers qui avaient creusé des tunnels dans la muqueuse. - Nous avons rencontré, chez un Chien, trois anneaux isolés de ce Ver dans une glande anale.

Chez le Chat, le parasite offre, comme on l'a vu, des dimensions un peu moindres, ce qui l'a fait regarder comme représentant une espèce distincte $(D$. ellipticum $)$. Krabbe appuie celte manière de voir en se basant sur ce fait qu'il ne l'a jamais rencontré chez les Chats, en Islande, alor's qu'il existe chez les Chiens de cette île dans la proportion de 61 p. 100. Au contraire, à Copenhague, il l'a trouvé sur la moitié des Chats, logé dans les deux tiers postérieurs de l'intestin grêle. En général, il n'y en avait pas plus de õ0 à la fois: mais il a pu en voir quelquefois des centaines, et jusqu'à 600 .

Nous avons dit aussi qu'on peut le rencontrer chez l'Homme. C'est à G. Dubois, élève de Linné, qüil faut rapporter la première mention de ce fait. Une dizaine de cas ont été signalés en Allemagne et en Suisse (Leuckart, Brandt, Krüger, Hoffmann). Krabbe et Friis ont rapporté aussi diverses observations du mêrne genre, recueillies en Danemark. Le parasite se rencontre surtout chez les jeunes enfants; cependant, R. Blanchard en fait connaître un cas observé chez un adulte, à Paris. - On n'a jusqu'à présent rattaché à sa présence aucun symptôme particulier.

Dipylidium de Trinchese (D. Trinchesei Diamare, 1892). - Très petit Ver, long au plus de 20 millimètres. Tête globuleuse, avec un rostre relativement uros, imbutiforme, dont le sommet renflé en massue porte environ $6 \ddot{\text { cro- }}$

(1) G. Neunanx, Sur des Ténias fenêtrés de l'espèce Tænia canina Linné. Soc. d'hist. nat. de Toulouse, séance du 25 avril 1891. - A. Ralluier, Sur des Téniadés cichancrés du Chien (Dipylidium caninum L.). Bullet. de la Soc. zoologique de France, XVII, p. 112,1892 . 
chets disposés en quatre couronnes ; ces crochets sont trois fois aussi longs que ceux de l'espèce précédente: ils ont une garde et un manche distincts, et leur lame est fortentent arquée; ventouses orbiculaires, saillantes. Cou court. Premiers anneaux reclingulaires, à bords arrondis; anneaux mùrs de forme spéciale, rappelant celle d'un vase à fleurs, et s'allongeant jusqu'i acquérir, en arrière de la chaine, une longueur quadruple de la lirgeur; pores génitaux situés assez loin en avant du milieu de chaque bord, au point oì l'anneau atteint sa plus grande largeur. Capsules utérines contenant chacune un seul aruf.

Trouvé en novembre 1891, dans l'intestin d'un Chat domestique, par $\checkmark$. Diamare (1). Ce parasite diffère en outre du D. caninum par la poche du cirre, qui est cylindrique au lieu d'ètre conique, et débouche au-dessous du vagin, par les capsules utérines, qui ne contiennent chacune qu'un seul cuf, ete.

Genre Hyménolépis (Hymenolepis Weinland, 1858). - Corps petit, souvent grêle. Têtê petite, pourvue d'un rostre rétractile, tantôt bien développé el armé de petits erochets, lantôt rudimentaire et inerme. Anneaux beaucoup plus larges que longs, à angles postérieurs saillants en dents de scie. Pores génitaux, dans toutes les espèces connues, percés sur le bord gauche des anneaux, Ia face antérieure ou ventrale correspondant à l'appareil génital femelle. OEufs à trois enveloppes très écartées les unes des autres; l'interne, qui limite l'embryon, ne montre jamais de prolongements en forme de cornes (2).

La larve est un Gysticercoïde exngène (Cercocystis ou Staphylocystis). L'évolution comporte, soit le passage par un habitat provisoire chez un hôte unique, soit le passage par un hôte intermédiaire (Insecte ou Myriapode).

Le Ver adulte vit en parasite chez l'Homme, les Chiroptères, les. Insectivores, les Rongeurs, ou même chez les Oiseaux insectivores.

\section{2 sections :}

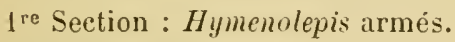

Iyménolépis des Muridés (H. murina [Duj.]. - Syn. : Tænia murina Duj., 18łว̈; H. [Lepidotrias] murina Weinland, 1861). - Long de 20 à 40 millimètres, large de $0^{\mathrm{mm}}, 3 ̋ 3 \ddot{a ̀ ~} 0^{\mathrm{mm}}, 90$. Tète large de $0^{\mathrm{mm}}, 32$; rostre court, épais, rétractile, armé d'une couronne simple de 20 à 2 '́ crochets longs de 13 à $17 \mu$; ventouses larges de $80 \mu$. Cou assez long, de largeur moitié moindre que la tète. Premiers anneaux très courts, les suivants graduellement plus longs et plus larges, jusqu’à aequérir $0^{\mathrm{mm}}, 1 \ddot{\text { à }} 0^{\mathrm{mm}}, 17$ sur $0^{\mathrm{mm}}, 8$ à $0^{\mathrm{mm}}, 9$. OEufs elliptiques, à enveloppe externe Iongue de 68 \%; enveloppe interne oblongue, mesurant 29 à $30 \mu$, et présentant à chaque pòle un manelon bien marqué; crochets de l'embryon longs de 13 à $16 \mu$.

Habite, à l'état adulte, l'intestin du Surmulot, de la Souris, du Irus pumilus et du Lérot.

(1) Vincenzo Dhimane, Ii un nuovo Cestode del genere Dipylidium Lkl. Bollett. della Soc. di Natur. in Napoli, V1, p. 46, 189?.

(2) К. Buxchand, Ilistoire zoologique et médicale des Téniadés du genre Hymenolepis Weinland. Paris, 1891. 
Grassi a fait sur cette espèce, qu'il considère comme identique à l'H. nana, des recherclies fort intéressantes, et propres à éclairer l'histoire de ce dernier Ver.

En faisant ingérer à des Rats blancs (Mus decumanus albinos), àgés de 1 à 4 mois et nourris exclusivement au pain et à l'eau pure, des anneaux mûrs d'H. murina, cet expérimentateur a toujours obtenu le développement du Ver. Par contre, il a constaté que la même expérience réussit beaucoup plus difficilement lorsque les sujets ont moins d'un mois (non sevrés) ou plus de quatre. Il en est de même avec les Surmulots gris.

La conclusion à tirer de ces expériences, c'est que l'Hymenolepis murina se développe sans hôte intermédiaire. Mais il ne s'agit point pourtant d'un développement direct : en réalité, ce Téniadé passe, comme ceux que nous avons étudiés précédemment, par une phase larvaire bien distincte; mais la migration s'accomplit dans un seul et mème organisme, entre deux points déterminés de cet organisme.

C'est là sans doute un fait très intéressant, mais qui laisse intacte la grande loi des migrations.

Suivons maintenant les diverses phases de l'évolution, telles que les a déterminées Grassi : 24 à 36 ou 50 heures aprèsl'ingestion des œufs, on trouve, vers les 12 derniers centimètres de l'intestin grêle, les embryons hexacanthes logés dans l'épaisseur de la muqueuse, surtout à la base des villosités. lls ont déjà subi un accroissement notable et se sont transformés en une larve qui offre l'aspect d'une bouteille. Le ventre de cette bouteille peut montrer un ou plusieurs étranglements ; il se continue d'ailleurs avec le col sans ligne de démarcation. Les trois paires de crochets de l'embryon se voient d'ordinaire sur ce col, plus rarement dans la région du ventre qui s'en rapproche.

De 40 à 70 heures après l'infestation, la larve s'est encore accrue et modifiée, tout en conservant la mème forme. Sur la portion rétrécie, on constate que les trois paires de crochets se sont écartées l'une de l'autre.

Le ventre, fle forme ovoïde, se montre constitué par une sorte de kyste renfermant une tète qui offre déjà tous les caractères de celles de l'Hymenolepis nana; le faible espace laissé entre ces deux parties est rempli de liquide. La tête est rattachée au kyste par un cou large et court, au niveau mème du point où le ventre de la bouteille s'atténue en col ; elle est dirigée vers le pôle opposé à celui d'où émane l'appendice caudal.

De ces données, il résulte que la tête s'est développée, comme daus les Téniadés du type T. serrata, à l'extrémité postérieure de l'embryon ; quant à l'extrémité antérieure de celui-ci, représentée par le col de la bouteille et portant les crochets, elle constitue simplement un appendice caudal. La larve de l'Hymenolepis murina doit donc être rattachée au genre Cercocystis.

Si l'on compare le développement de celle larve avec celle du Dipylidium caninum, on constate qu'une différence assez accusée se manifeste après l'invagination de la partie antérieure du corps : cette région, en effet, se réduit à une simple paroi qui porte la tête et se trouve revêtue par une autre paroi que forme la partie postérieure. La cavité primitive u'est plus alors que virtuelle, ou du moins ne contient, comme une séreuse, qu'une quantité très restreinte de liquide ; l'orifice antérieur de l'invagination (bouche, d'après Grassi) se ferme peu à peu. La partie postérieure du corps ne constitue 
donc plus ici qu'une enveloppe larvaire; elle est appelée à disparaitre et devra se régénérer pour la constitution du Ver adulte.

A cette période, la métamorphose est complète. La villosité se rompt alors et le Cysticercoïde tombe dans la lumière de l'intestin, où il passe à l'état adulte. I)e 3 à $\checkmark$ jours après le début de l'expérience, on observe déjil des individus longs de 2 à $\&$ millimètres, pourvus d'un long cou et parfois mème présentant des anneaux distincts. An bout de quinze jours, on trouve souvent des Vers dont les derniers anneaux contiennent des wufs mür; ces aufs apparaissent dans les féces vers le trentième jour.

Malgré ces conditions, en apparence si favorables, le parasite ne peut se nultiplier sur place, car l'embryon n’est mis en liberté qu’après le passage de l'œuf dans l'estomac. - Il est assez curieux de noter, en outre, que les Rats infestés par l' $H$. murina sont réfractaires à l'invasion des aulres Téniadés.

Hyménolépis main (H. nana von Siebold]. - Syn.: Tænia nana von Sieb., 1832, nec Van Ben., 1861; T. xgyptiuca Bilharz, 18\%2, nec Kirabbe, 1869 ; Diplacunthus nanus Weinland, 1838; Tænia [Hymenolepis] nana Leuck., 1863).

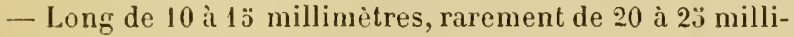
mètres; large de $0^{\mathrm{mm}}, \breve{3}$ à $0^{\mathrm{mm}}, 7$. Tète subsphérique, large de $0^{\mathrm{m} m}, 2 \ddot{3}{ }^{\mathrm{a}} 0^{\mathrm{mm}}, 33$; rostre épais, rétractile, armė d'une couronne simple de $2 \dot{q}$ à 28 et jusqu'a 30 crochets longs de 1 á à $18 \mu$; ventouses larges de 90 à $10 \ddot{3} \mu$. Cou assez long, se continuant insensiblement avec la tète, mais devenant de moitié moins large qu'elle, et s'élargissant ensuite de nouveau. Premiers ameaux très courts, à peine distincts, les suivants graduellement plus longs et plus larges, jusqu'à acquérir $0^{\mathrm{mm}}, 1^{\prime} \dot{a}$ à $0^{\mathrm{mm}}, 30$ sur $0^{\mathrm{mm}},{ }^{\prime} 1$ à $0^{\mathrm{mm}}, 92$; la chaine atteint sa plus grande largeur au dernier anneau chez les individus qui ont commencé d'éliminer leurs anneaux, un peu avint chez ceux qui sont encore vierges. OEufs arrondis ou ovalaires, à enveloppe externe longue de 30 à $37 \mu$, rarement de 30 à $3 \ddot{3} \mu$; à enveloppe moyenne de 24 a $27 \mu$ sur $20 \mu$; à enveloppe interne de 16 à $19 \mu$, présentant à chaque pôle un mamelon peu apparent. Crochets de l'einbryon peu visibles, longs de 10 à 12 et mème 14 ?.

L'Hyménolépis nain habite lintestin grêle de l'Homme.

Evolution. - Grassi considère ce parasite comme identique à l'Hymenolepis murina; mais cette opinion a été sérieusement combattue par Moniez. Si l'on compare

Fig. 190. - Hymenolepis nana, grossi 20 fois (Orig.). 
IERS.

entre elles les descriptions que nous venons de donner de ces deux espèces, on remarquera bien réellement de grandes analogies; mais, à part même la question de taille, qui pourrait tenir à l'habitat, il semble exister des différences assez nettes dans la constitution et les dimensions des crochets, de l'ouf et de l'embryon.

Il faut dire toutefois que Grassi a fait prendre à six personnes des anneaux mûrs d'H. murina; quinze jours après,

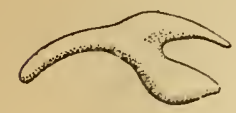

Fig. 191. - Crochet d'Hymenolepis nana, grossi 1140 fois (0rig.). les selles de l'une d'elles montrèrent des cufs d'H. nana, et un ténifuge lui fit rendre une cinquantaine de Vers de cette espèce. Mais, comme il le reconnaît lui-même, une seule expérience de ce genre est fort insulfisante, surtout dans un pays où l'H. nana est très commun chez l'Homme. Au surplus, le même expérimentateur s'est trouvé dans l'impossibilité d'infester le Rat, non plus que l'Homme, par l'ingestion d'œufs mûrs de l'H. nana.

Nous devons donc attendre de nouvelles recherches pour être fixés sur l'évolution de cette espèce.

Organisation. - Sur un Ver formé d'environ 130 anneaux, les organes sexuels commencent a se montrer vers le $0^{\circ}$, mais ne sont bien déreloppés que vers le $100^{\circ}$. Les organes mâles apparaissent, selon la règle habiluelle, les premiers, et occupent la face dorsale. Ils se composent de trois gros testicules globuleux, situés non loin du bord postérieur, deux à droite el un à gauche. Les canalicules qui en émanent se réunissent en un canal déférent unique qui se porle à gauche, puis en avant, se dilate en une vésicule séminale ovalaire, et va enfin se jeter dans la poche du cirre. Celle-ci, d'aspect claviforme, est disposée parallèlement au bord antérieur de l'anneau et sur la gauche, sa grosse extrémité étant tournée en dedans. Le canal déférent, après avoir pénétré à son intérieur, se dilate d'abord, puis s'atténue en un tube sinueux, grèle et lisse, qui n'est autre que le cirre ou pénis.

Les organes femelles occupent la région médiane et ventrale de l'anneau. Ils comprennent deux ovaires (germigènes) latéraux, et un vitellogène globuleux situé entre eux et un peu en arrière. Du pore génital, toujours peu marqué, part un vagin placé en dessous, puis en arrière de la poche du cirre, et bientòt dilaté en un réceptacle séminal ovoïde, qui se loge entre la poche du cirre el l'ovaire.

A mesure que les œufs se développent et s'accumulent dans l'utérus, les testicules, puis les ovaires et le vitellogène disparaissent; mais la poche du cirre, le réceptacle séminal et le vagin persistent, quoique refoulés vers la partie antérieure de l'anneau. Dans la portion terminale de la chaine, les cufs sont répandus dans les lacunes du parenchyme; cependant, on n'en trouve qu'une centaine au plus par anneau, en raison d'une sorte de ponte qui s'effectue à la faveur de déchirures de la cuticule, vers les bords antérieur et postérieur.

Distributiox géograpmeue. - L'Hyménolépis nain a été découvert en $\mathbf{1 8 5 1}$ par Bilharz, au Caire, dans l'iléon d'un jeune lıomme mort de méningite: 
il s'y trouvait en nombre considérable. En 1885, Walter Innès en a retrouvé un exemplaire également en Ëgypte, dans l'intestin d'une jeune Nubienne.

Spooner parait l'avoir vu aux États-Unis (1872); Wernicke l'a observé dans la République argentine (1890).

En Europe, il faut d'abord signaler l'observation de Ranson, recueillie en Angleterre, bien que ce médecin n'ait vu que les aufs dans les selles d'une fillette (18:3í). Vient ensuile un cas observé à Belgrade en 188: et signalé par R. Blanchard. Mais c'est en Italie surtout que le Ver en question s'est présenté fréquemment : il ya été signalé jusqu'à présent en Lombardie (tirassi, Comini, elc.), en Piémont (Perroncito), en Toscane (Sonsino), en Sicile (Grassi et Calandruccio). Ces derniers observateurs en ont rencontré chez 8 à 10 pour 100 des individus appartenant aux classes populaires. Ajoutons que Grassi en a trouvé chez un enfant venant de Marseille, etc.

Pathologie. - L' $I$. nana s'observe principalement chez les enfants, et le plus sourent en grand nombre, quelquefois même par milliers. II siège dans la portion moyenne de l'intestin grêle, mais peut s'étendre jusqu'à une petite distance de la valvule iléo-cacale. On le trouve assez fréquemment en compagnie dautres helminthes.

Lorsqu'il n'existe qu'un petit nombre de Vers à la fois, leur présence peut passer inaperçue; mais dès qu'ils se montrent un peu abondants chez un sujet, ils provoquent des troubles plus ou moins graves, et en général plus graves que ceux occasionnés par les grands Cestodes, quoique de même ordre. Signalons rapidement : violentes coliques: diarrhée alternant parfois avec de la constipation; gastralgie; altération de la nutrition, conduisant à la cachexie. On observe souvent aussi des accidents réflexes : troubles de la vision, céphalalgie, dyspnée, attaques épileptiformes; plus rarement, il survient de la fièvre, du coma, voire un affaiblissement des facultés intellectuelles, etc. Tous ces troubles peurent persister pendant des mois et des années; et il n’est pas impossible qu ils aboutissent dans certains cas à la mort.

Chez un sujet dont Visconti et Segré ont fait l'autopsie, la muqueuse intestinale était tuméfiée, congestionnée et revêtue de mucosités grisâtres; les follicules clos étaient également tuméfrés.

2 Section : Hymenolepis inermes.

Hyménolépis réduit (H. diminuta [Rud.]. - Syn. : Tænia diminula Rud., $1819 ;$ T. leptocephala Creplin, $1825 ; T$. flavo-punctata Weinland, 1858; $\mathrm{H}$. [Lepidotrias] flavopunctata Weinland, 1861 ; T. varesina E. Parona, 1884; T. minima Grassi, 1886; H. diminuta R. Bl., 1891). - Long de 20 à 60 centim., large de $3^{\mathrm{mm}}, 3$. Tête très petite, cuboïde ou claviforme, arrondie ou tronquée en avant el creusée d'un petit infundibulum dans lequel se cache d'ordinaire un rostre inerme, pyriforme, très réduit et à peine protractile; ventouses petites, mais profondes, assez rapprochées du sommet de la tète. Cou long de $0^{\mathrm{mm}}, \ddot{3}$, et de moitié moins large que la tète. Premiers anneaux très courts, à:peine distincts ; les suivants augmentant progressirement 
en longueur jusqu'à l'extrémité postérieure de la chaine, el en largeur jusqu'à une petite distance de cette extrémité; les plus larges mesurent ainsi $3^{\mathrm{mm}}, 5$ sur $0^{\mathrm{mm}}, 66$ de long; les derniers ont jusqu'à $0^{\mathrm{mm}}, 73$ de long sur $2^{\mathrm{mm}}, .5$ de large. OEufs arrondis ou ovalaires, à enveloppe externe un peu épaissie, jaunàtre et délicatement striée dans le sens de son épaisseur, longue de 60 à $86 \mu$; ̀̀ enveloppe moyenne offrant deux couches contiguës; à membrane interne munie de deux mamelons polaires. Embryon hexacanthe ovoïde, mesurant $36 \mu$ sur 28 , à crochets longs de $11 \mu$.

L'H. diminuta habite ordinairement la portion moyenne de l'intestin grêle de divers Rongeurs (Mus decumanus, M. rattus, M. musculus, 1\%. alexandrinus). Il a été vu aussi quelquefois chez l'Homme. - Sa larve (Cercocystis $H$. diminuta) a été observée chez un Lépidoptère (Asopia farinalis, Chenille et Papillon), chez un Orthoptère (Anisolabis annulipes), enfin chez des Coléoptères (Alis spinosa, Scaurus striatus). L'hôte habituel serait Asopia.

Évolution. - Les migrations de ce Ver ont été déterminées par Grassi et Rovelli. Le Cysticercoïde est constitué sur le même type que celui de l'H. murina, mais sa queue est très longue, et la cavité primitive, qui occupe le corps seul, est mieux circonscrite. Deux paires de crochets se trouvent sur la queue; la troisième apparaît à l'extrémité postérieure de la paroi externe. Celle-ci est plus compliquée, et parfois on trouve un kyste fourni par l'hôte. Des larves (Cercocystis) provenant d'Anisolabis annulipes ont été données à des Rats blancs, qu'on tuait à des intervalles plus ou moins éloignés : au bout de trois jours, les Vers se trouvaient dans l'intestin, formés d'une tête et d'un cou très court; au bout d'une semaine, ils avaient 5 millimètres de long, mais noffraient encore aucune trace de segmentation; au bout de quinze jours, de nombreux anneaux étaient déjà constitués.

Deux Hommes adultes reçurent de ces mêmes larves: l'un d'eux resta indemne, mais on trouva dans les selles du second, quinze jours après l'ingestion, des œufs caractéristiques, ne différant de ceux de l'H. diminuta des Rongeurs que par l'absence de mamelons polaires à la coque interne. Quelques jours plus tard, l'extrait éthéré de fougère mâle provoqua l'expulsion de nombreux Hyménolépis inermes identiques à ceux observés antérieurement dans l'espèce humaine.

Organisation. - L'anatomie de ce Ver a été récemment étudiée avec soin par F. Zschokke, au travail duquel nous renverrons pour les délails (1). Comme chez 11. nana, l'appareil màle comprend en général trois testicules globuleux, deux à droite et un à gauche. Les trois canaux qui en émanent se réunissent vers la ligne médiane, près de la face dorsale. De leur point de réunion naît le canal déférent, qui se dirige à gauche en formant de longs lacets, puis se dilate en une vésicule séminale pyriforme, dont la partie

(1) F. ZsсноккE, Recherches sur la structure anatomique et histologique des Cestodes. Genève, 1888. - Voir p. 63; pl. 1 et II, fig. 21-24. 
atténuée aboutit à la poche du cirre, après avoir décrit un double coude. Cette poche est allongée, grèle; le cirre, contiuuation du canal déférent, se montre d'ordinaire replié à son intérieur; on le voit rarement faire saillie au dehors, sous l'aspect d'un tube mince et lisse.

L'appareil femelle se compose, ici encore, le deux ovaires ou germigènes, situés à droite et ì gauche de l'axe médian, et d'un vitellogène postérieur et impair. Les deux germigènes sont réunis par un germiducte transversal ; de celui-ci part un germiducte commun qui décrit un circuit en se portant à gauche à la rencontre du vigin, et vient ensuite se réunir au vitelloducte, lans une dilatation (corps de Mehlis) entourée par les glandes de Ia coque. - Le vagin, qui nait an-dessous de l'orifice mảle, se porte à droite, s'élargit un peu, puis se rétrécit pour s'élargir bientót de nouveau en formant un

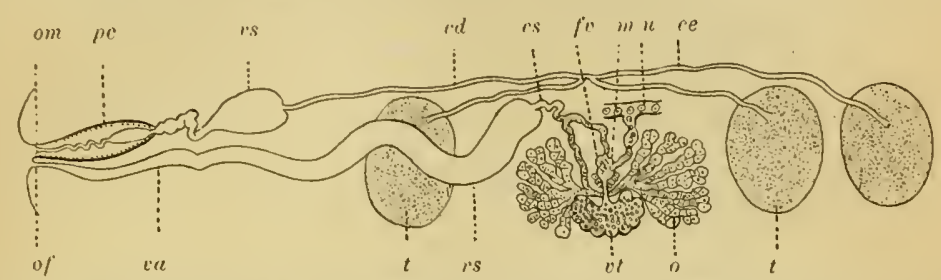

Fig. 192. - Coupe Iransversale de l'appareil génital de l'Hymenolepis diminuta, d'après F. Zsclıkke. $-t, t$, lesticules. $c e$, canaux efférents. $c d$, eanal déférent. $v s$, vésicule séminale. $p c$, poche du cirre. $o m$, orifice mile. $o$, ovaire. $2 t$, vilellogène. $f v$, fond du vagin. $c s$, canal séminal. $r s$, réceptacle séminal. $v a$, vagin. of, orifice femelle. $m$, corps de Mehlis, $u$, utérus.

long réceptable séminal trẻs allongé et contourné, duquel nait un canal séminal impair qui va se jeter dans le germiducte commun. - L'ovule (vitellus de formation), fécondé à ce niveau, se revèt ensnite du vitellus nutritif amené par le vitelloducte, et passe dans l'oviducte, qui le conduit dans l'utérus. Celui-ci, représenté d’abord par un simple canal transversal, prend plus tard l'aspect d'un fer à cheval dont les dcux branches sont dirigées du còté du pore génital ; puis des anastomosesde,plus en pius nombreuses font communiquer ces branches, jusqua à ce que, finalement, l'anneau ne constitue plus qu'un sac bourré d’œufs qui écrasent les autres organes. - On trouve pourtant encore des testicules vers la fin du second tiers de la chaine, et la poche du cirre peut ètre distinguée bien au delà de cette linite.

Distribution géographique. - En 18 '2, le Dr Ezra Palmer recueillail, en Amérique, six exemplaires sans tète d'un Cestode particulier, expulsés par un enfant de dix-neuf mois, qui jouissait d'ailleurs d'une bonne santé; il les. prit pour des Bothriocéphales, et les déposa dans un musée de Boston, où ils furent étudiés plus tard par Weinland. Celui-ci les reconnut pour des Téniadés et en donna, sous le nom de Trnia fluco-punctata, une description sommaire, bientòt complétée par Leuckart, à qui il en avait envoyé un fragment.

En 188't, Leidy publia une seconde obscrvation de T. flavo-punctata, d'après des exemplaires incomplets rendus, à Philadelphie, par un enfant de trois ans.

La mème amnée, Ern. Parona observait une fillette de deus ans, des environs de Varese (Haute Lombardie), qui depuis quelque temps avait perdu sa santé et sa gaité habituelles, et qui rendait des rubans blanchàtres : un téni- 
fuge lui fit évacuer quatre Vers longs de 12 à 20 centimètres, pourvus chacun d'une tête cuboïde et inerme, Vers qu'il rattacha, non sans quelque doute, au T. flavo-punctata. Il existait en effet certaines différences, surtout dans la description de l'œuf et de l'embryon, entre le parasite observé par Parona et celui décrit par Weinland et Leuckart.

Grassi fit voir alors que le ver de Parona devait ètre rapporté au Tænia leptocephala ou diminuta, commun chez les Muridés, et bientòt un nouveau cas, observé en Sicile sur une fillette de douze ans, lui permit d'appuyer cette manière devoir. Les expériences que nous avons relatées plus haut tendent d'ailleurs à la confirmer, et il est mème probable que les Vers recueillis en Amérique appartiennent également à l'espèce dont il s'agit.

Enfin, en 1892, j'ai trouvé dans la collection helminthologique d'Alfort deux exemplaires d'un Téniadé provenant de l'Homme et que j'ai pu, avec F. Zschokke, identifier aussi à l'H. diminutı : ces exemplaires avaient dù être recueillis par Chabert, vers $\mathbf{1 8 1 0}$, de sorte que le cas auquel ils se rapportent est certainement le plus ancien de ceux qui ont été publiés jusqu’à présent (1).

Les enfants s'infesteraient en mangeant des fruits ou d'autres aliments envahis par des Insectes.

Ajoutons que l'H. diminuta n'est pas rare chez les Rats en Italie, en France, et probablement partout où ont pénétré ces animanx. Il est donc possible qu'on arrive quelque jour à le rencontrer chez l'Homme dans des localités très diverses.

Genre Drépanidoténia (Drepanidotænia Raill., 1892). — Nous rangeons dans ce groupe les Téniadés pourvus d'une couronne simple de crochets

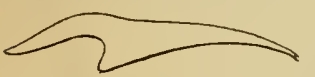

Fig. 193. - Crochet de Diepanidotxnia setigera, grossi 700 fois (Orig.). uniformes, généralement en petit nombre, à manche beaucoup plus long que la garde, qui est toujours faible, à lame dirigeant sa pointe en arrière lorsque le rostre se contracte ( $\delta \rho \S \pi x v^{\prime} \varsigma$, faux).

La plupart de ces Vers vivent chez les Oiseaux aquatiques, Palmipèdes et Échassiers ; nous en rapprochons cependant les Téniadés à crochets également falciformes, qui habitent l'inlestin des Passereaux, les Gallinacés et des Pigeons.

On a déjà rencontré les Cysticercoïdes de diverses espèces chez de pelits Crustacés d'eau douce : ils paraissent se rattacher aux Cercocystis de Villot.

Nous décrirons les espèces indiquées dans le tableau suivant:

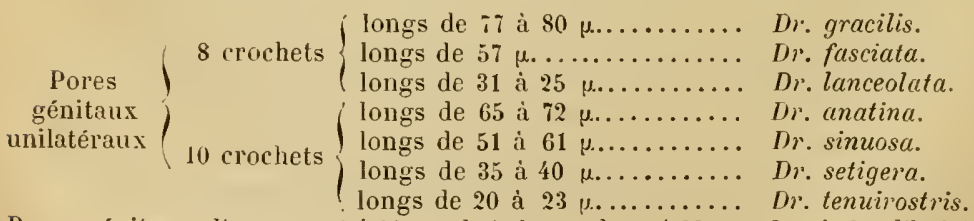

Pores génitaux alternes : 16 à 20 crochets longs de 20 i $27 \mu$. $\quad b r$. infundibuliformis.

(1) A. Ratluet, Ĺn cas très ancien de Trania (IIymenolepis) diminuta chez l'Homme. Comptes rendus Soc. de biologie (9!, IV, p. 894, 189?. 
Drépanidoténia arrèle $(D r$. grucilis [Zeder]. - Syn. : Ilulysis yrucilis Zeder, 1803 ; Truia gracilis Rud., 1810\%. - Long de 2; centimètres environ, large de $1^{\mathrm{mm}}, \ddot{3}$ a 2 millimetres. Tète subglobuleuse; rostre cylindrique, obtus, armé d'une couronne simple de 8 crochets longs de $7 \tau$ a $80 \mu$. Cou trìs court. Parlie antérieure du corps très mince sur une «rande longueur; premiers anneaux inlundibuliformes, les suivants peu à peu carrés. Pores génitaux unilatéraux.

Intestin de l'Oie et de livers Canards saurages; observé chez le Canard domestique, en Danemark, par Kirabbe.

Th. Scott a trouvé chez un Crustacé ostracode, le Candona rostrata, un Cysticercoïde que $\mathrm{R}$. Blanchard, à la suite d'une comparaison minutieuse des crochets, regarde comme l'état larvaire de cette espèce. Al. Mrázck a vu en outre ce Cysticercoïle chez le Cypris compressa Baird (Cypria ophthalmica lurine), et mème chez un Copépode, le Cyclops viridis Fischer. Il est pourvn d'un appendice caudal médiocre, sur lequel se voient épars les six crochets de l'embryon, Jongs de $9 \mu$ (Cercocystis Dr. gracilis). Moniez en a trouvé un exemplaire dans un Cypria ophthalmica provenant du lac chinois de Sitaï. Von Linstow l'avait rencontré dans l'intestin d'une Perche, celle-ci ayant sans doute avalé łles Cruslacés qui en étaient infestés.

Drépanidoténia fascié (Dr. fusciuta [Rud.]. - Syn. : T. fasciuta Rud., 1810). - Long de 6 à 16 centimètres, large de 1 à 2 millimètres. Tète hémisphérique, comprimée; rostre long, épais, cylindrique, armé d'une couronne simple de 8 crochets longs de š $z$. . Cou très long̨, des deux tiers plus mince que la tète. Anneaux beaucoup plus larges quelongs, épais au milieu, où ils sont traversés par une bande longitudinale obscure, plus minces et transparents sur les bords, plus étroits au niveau des quatre angles, ce qui donne à la chaine un aspect crénelé. Pores génitaux unilatéraux.

Intestin de l'Oie domestique (Zeder, Krabbe).

Mrázek a trouré, chez des Cyclops agilis recueillis dans une mare des environs de Pribram (Bohème), des Cysticercoïdes à corps lenticulaire, long de 120 à $180 \mu$, prolongé par un appendice caudal 20 fois plus long et décrivant des spires irrégulières (Cercocystis $D t^{\circ}$. fasciata). Le rostre portait 8 ou 9 crocliets longs de öö à 68 น, identiques à ceux du Dr. fasciata. 80 pour 100 de ces Cyclopes étaient infestés ; il n'existait d'ordinaire qu'un seul parasite dans chaque individu, et cependant, chez les femelles, les organes reproducteurs étaient en voie de dégénérescence (castration parasitaire). Les Cyclops riridis de la mème nare n'offraient aucun parasite, probablement parce qu’ils n'étaient pas encore développés au moment de l'infestation.

Drépanidoténia lancéolé (D). lanceolata [Bloch]. - Syn. : Tæria ansernm Frisch, 1727; T. lanccolata Liloch, 1782). - Long de 3 à 13 centimètres, large de $\ddot{b}$ à 18 millimètres. Tète très petite, globuleuse; rostre cylindrique, légèrement renflé au sommet, armé d'une couronne simple de 8 crochets longs de 31 à $3 \ddot{3} \mu$; ventouses arrondies. Cou très court, rétractile, ainsi que la tète, dans la partie antérieure de la chaîne. Premiers anneaux très courts, les suivants augmentant un peu de longueur, et derenant de plus en plus larges jusqu'à une petite distance de l'extrémité postérieure, pour se rétrécir ensuite, de sorte que l'eusemble présente un aspect lancéolé. Pores génitaux unilatéraux; pénis hérissé de petites épines. OEufs à enve- 
VERS.

loppe externe très mince, longue de $50 \mu$, large de $3 \ddot{\mu}$; crochets de l'embryon longs de $8 \mu$.

C'est le Téniadé le plus commun dans l'intestin de l'Oie. Frisch, qui l'a dé-

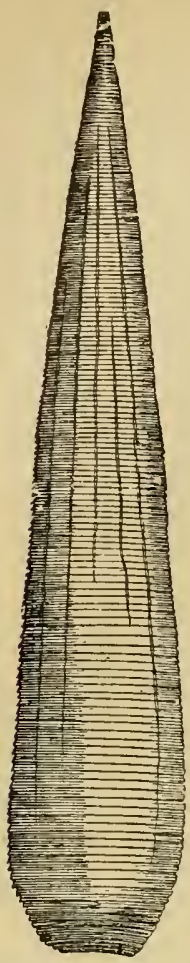

Fig. 194. - Drepanidotænia lanceolata, de lOie domestique; grandeur naturelle, dans un état moyen d'extension (Orig.). couvert en 1727 , l'a rencontré si souvent qu'il le considère comme la cause d'une affection épizootique. Nous l'avous recueilli dans les Aldennes, et Lucet dans le Loiret. Dujardin l'aurait aussi rencontré chez le Canard de Barbarie, mais comme il lui attribue dix crochets et les pores sexuels alternes, il a probablement eu affaire à une autre espèce.

\section{Drépanidoténia des Canards} (Dr. anatina [Krabbe]. - Syn. : T. anatina Krabbe, 1869;. - Longueur, jusqu'à 30 centimètres; lar-

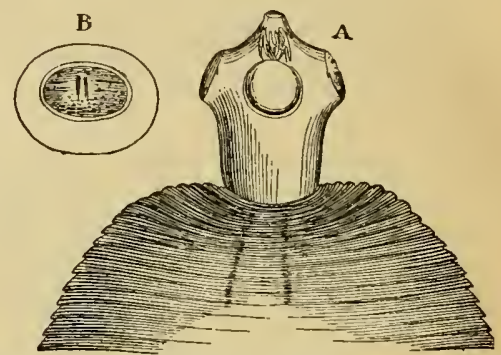

Fig. 195. - Drepanidotænia lanceolata. - A, extrémité céphalique grossie 100 fois. B. œuf grossi 300 fois (Orig.).

geur, 3 millimètres. Une couronne simple de 10 crochets longs de 65 à $72 \mu$. Cou long. Orifices génitaux unilatéraux. OEufs à 3 enveloppes, l'externe mince, ovoüde, longue de $140 \mu$, large de $90 \mu$; crochets de l'embryon longs de 10 à $11 \mu$.

Dans l'intestin de divers Canards, et en particulier du Canard domestique, en Poméramie (Creplin), en Danemark (Gad, Krabbe), à Lille (Moniez).

Irázek en Bohème et Moniez à Lille ont trouvé le Cysticercoïde de ce Ver dans le Cypris incongruens.

Drépanidoténia sinueux $(D r$. sinuosa [Zeder]. - Syn. : Tænia collaris Batsch, 1786; Alyselminthus sinuosus Zeder, 1800). - Long de 5 à 16 centimètres, large de 1 à 2 millimètres. Tète presque globuleuse ; rostre armé d'une couronne simple de 10 crochets longs de 51 à $61 \mu$. Cou très long. Premiers anneaux de largeur et de longueur variables; les suivants trapézoïdaux; les derniers arrondis. Pores génitaux unilatéraux, situés vers le 
Drépanidoténia infundibuliforme (Dr. infundibuliformis [Gœze]. Syn. : T. infundibulum Bloch, 1779, pro parte; $T$. infundibuliformis Gœze, 1792, nec Duj., 18́ä). — Long de 20 à 130 millimètres, atteignant exceptionnellement 230 millimètres. Tète globuleuse, un peu déprimẻe; rostre allongé, cylindrique ou hémisphérique, renflé all sommet, muni d'une couronne simple de 16 à 20 crochets, longs de 20 à $27 \mu$, à long manche el à garde courle ; ventouses assez petites. Cou très court. Premiers anneaux très courts, les suivants infundibuliformes, le bord antérieur élant beaucoup plus étroit que le bord postérieur ; les derniers presque aussi longs que larges. Pores génitaux irrégulièrement alternes. Pénis épais, revètu de poils peu nombreux. Crochets de l'embryon longs de 12 à $17 \mu$.

Ce parasite, que nous rattachons avec doute aux Drepanidotrnia, est commun dans l'intestin de la Poule; Bremser l'a rencontré aussi chez le. Faisan commun. D’autre part, Bellinglıam le signale chez le Canard domestique, en Irlande, mais il y a eu évidemment dans sa détermination une erreur qu'avait déjà commise Gœze.

D'après Grassi et Rovelli, l'hỏte intermédiaire de cette espèce est représenté par la Mouche domestique. Le Cysticercoïde est complètement dépourvu de queue; mais cet appendice a dû former en grande partie la paroi externe, car les crochets embryonnaires se rencontrent sur celle-ci, et mème à son point d'union avec la paroi interne.

Davaine a vu dans cette espèce de grands œufs renfermant un embryon à douze crochets.

Nous avons étudié un Téniadé du Pigeon domestique recueilli par Delafoud et paraissant se rapprocher de celui-ci : la tète portait 18 crochets longs de $20 \%$ p. ; le pénis grêle était garni de petites épines.

Genre Dicranoténia (Dicranotænia Raill., 1892). - Les Vers pour lesquels nous avons établi ce genre, et qui ont beaucoup d'affinités avec les Hymenolepis, sont caractérisés par une couronne simple de crochets uniformes, courts, généralement en petit nombre, à garde égalant ou surpassant le manche en longueur, et formant

Fig. $190 .-$ Cro- avec la lame une sorte de petite fourche (óxpy:vov, fourche).
chet de Dicra- Ils sont surtout parasites des Echassiers et des Palmipèdes; chet de Dicra- Ils sont surtout parasites des Échassiers et des Palmipèdes;
notærnia coro- mais nous en rapprochons une forme observée par von Lins-
nula $\begin{array}{ll}\text { nula, grossi } 750 & \text { tow chez les Gallinacés. } \\ \text { fois (Orig.). } & \text { tow }\end{array}$

Les Cysticercoïdes paraissent se développer chez les petits Crustacés; ils représentent des Cercocystis.

Nous aurons à décrire les espèces ci-après :

$$
\begin{aligned}
& \text { Pores génitaux } \int 18 \text { à } 26 \text { crocliets longs de } 13 \text { à } 17 \mu \ldots \quad n \text {. coronula. } \\
& \text { unilatéraux } 10 \text { crochets longs de } 27 \text { à } 32 \mu \ldots \ldots \text { D. æquabilis } \\
& \text { umiateraux } 10 \text { crochets longs de } 47 \text { à } 66 \mu \ldots . . \text { D. rhomboidea. } \\
& \text { Pores génitaux alterues: } 12 \text { crochets longs de } 32 \mu \ldots . . \quad \text { D. cuneata. }
\end{aligned}
$$

Dicranoténia coronnle (D. coronulu [Duj.]. - Syn. : T. coronula Duj., 1845). - Long de 12 à 19 centimètres, large de $1^{\mathrm{mm}}, 8$ à 3 millimètres. Tète presque rhomboïdale; rostre épais, plus large que long, entouré d'une couronne simple de 18 à 26 crochets longs de 13 à $17 \mu$; ventouses saillantes, anguleuses, irrégulières. Chaîne insensiblement amincie en avant, formée 
d'articles très courts. P’ores génitaux unilatéraux; pénis liérissé de très petites épines. Croclsets de l'embryon longs de $8 \mu$.

Trouvé dans l'intestin de divers Canards, et en particulier du Canard domestique, à Remnes (Dujardin), en Danemark (Krabbe).

Nous avons recueilli de notre cỏté, à Alfort, chez le Canard domestique également, de jeunes Ténias encore en état d'indifférence sexuelle, pourvus d'une trompe renllée au sommet, et portant 22 crochets longs de $17 \mu$. Nous les avons rapportés a cette espèce, bien que le manche de ces crochets (fig: 196) fut beaucoup plus mince que dans les figures de Krabbe. Les derniers anneaux étaient infundiluliformes.

Mrázek a tronve, daus denx petits Ostracodes d'eau douce (Cypris orum Jur. et Cypria ophthalmica Jur. Cypris compressa Baird]), vivant dans une source de prairie, en Bohòme, un Cysticercoïde légèrement déprimé, de 140 a $190 \mu$ de diamètre, pourvu de 22 à 3 t (ordinairement de 23 à 27 ) crochets dont la forme et les dimensions se rapportent ì ceux du $D$. coroula, sauf en ce qui concerne le manche, qui est plus mince que dans les figures de Krabbe. Ce Cysticercoïde est pourvı d'un appendice caudal 3 a 3 fois plus long que le diamètre du corps, et portant encore les 6 crochels embryonnaires, longs de $8 \mu$; on peut le dénommer Cercocystis D. coronulx. - Rosseter l'avait déjà trouvé, dans le kent, chez Cymis cinerea; Moniez l'a revu chez des Cypria ophthalmica provenant du nord de la France, du comté de Durham et du lac Sitaï, en Chine.

Dicranoténia régrulier (D. xquabilis [Rnd.]. - Syn. : T. xquabilis Rud., 1810). - Long de 16 à 35 centimètres, large de $3^{\mathrm{mm}}, 2$ à $4^{\mathrm{mm}}, 6$. Tête subglobuleuse; rostre obové, armé d'une couronne simple de 10 crochets longs de 27 à $32 \mu$; rentouses assez grandes, orbiculaires, saillantes. Cou très court. Premiers anneaux très grèles et très courts; les suivints trapézoïdaux, beaucoup plus larges que longs, avec les angles postérieurs aigus et saillants, mais devenant un peu obtus vers l'extrémité de la chaîne. Pores génitaux unilatéraux.

Intestin grèle du Cygmus musicus, du Cygnus olor (Bremser) et dn Fuligula matila. - Gervais et Beneden, puis von Linstow l'attribuent, probablement par erreur, au Cygne domestique, et non au Cygnus musicus.

Dicranoténia rhombö̈le (D. rhomboidea [Duj.]. - Syn. : T. rhomboidea Duj., 18千5). - Long de 33 millimètres, large de 1 millimètre. Tète rhomboidale ou prolongée en avant par une gaine lubuleuse contenant une trompe épaisse, ovoïle, oblongue, armée d'une couronne simple de 10 crochets longs de 47 à $66 \mu$; ventouses assez larges. Anneaux trapézoĩdaux, 2 a 3 fois aussi longs que larges. Pores génitaux unilatéraux; pénis lisse. Crochets de l'embryon longs de 1'tu.

Cette espèce, rencontrée par Dujardin et par divers autres observateurs dansl'intestin du Canard sauvage, est probablement identique au Trnia trilineatu Batsch, 1786, et au T. conica Molin, 1858. Or, Diesing signale par erreur le $\boldsymbol{T}$. trilineał comme ayant été recueilli par kudolphi che\% le Canard domestique. Von Linstow reproduit cette erreur et en commet une autre du mème genre au sujet du $T$. conica, de sorte que la plupart des auteurs ont cru devoir attribuer au Canarl domestique des parasites qui ne lui appartiennent pas. 
Dieranoténia cunéiforme $(D$. cuneata [Linst.]. - Syn. : $T$. cuneata von Linstow, 1872, nec Batsch, 1786; T. sphenoides Raill., 1892). — Long de 2 millimètres, large de 1 millimètre. Tète petite, à peu près aussi longue que large, légèrement rétrécie en arrière en forme de cou, munie d'une trompe rétractile armée de 12 crocliets longs de $32 \mu$, à manche court, de même longueur que la garde; ventouses oralaires, à grand axe longitudinal. Anneaux presque toujours au nombre de douze, augmentant graduellement en largeur du premier au dernier, de facon que l'ensemble présente la forme d'un coin ; le dernier contenant des œufs mûrs. Pores génitaux alternes, occupant un des angles antérieurs de l'anneau.

Intestin de la Poule (von Linstow). Ne se rattaclıe quavec doute aux Dicranotænia. - Selon Grassi et Rovelli, le Cysticercoïde de ce Téniadé se développe dans un Lombric, l'Allobophora fæida Eisen; il est complètement dépourvu de queue, comme celui du Dr. infundibuliformis (Gœze).

Genre Échinocotyle (Echinscotyle R. Bl., 1891). — Tète prolongée par un rostre rétractile armé d'une couronne simple de crochets uniformes, en petit nombre, à manche beaucoup plus long que la garde, qui est très faible; ventouses garnies de petits crochets.

Ce genre ne comprend encore qu'une seule espèce.

Échinocotyle de Rosseter (E. Rosseteri R. Bl., 1891). - Connue seulement à l'élat jeune, le plus grand exemplaire mesurant $1^{\mathrm{mm}}, 13$ de long sur $0^{\mathrm{mm}}, 18$ de large. Tête subsphérique ou elliptique; rostre allongé, portant à son extrémité 10 crochets longs de 31 à $38 \mu$; ventouses oblongues, à grand axe longitudinal, garnies de crochets disposés en trois séries : une pour chaque bord et une occupant le grand axe, chacune étant formée de plusieurs rangées de petits crochets à pointe réfléchie en arrière. Cou long, assez grêle. Anneaux plus larges que longs, les premiers à peine plus larges que le cou, les autres augmentant graduellement de longueur et de largeur, et se débordant en dents de scie. Pores génitaux unilatéraux; pénis grêle, couvert de fines spinules.

Ce Ver a été obtenu par T. B. Rosseter, de Canterbury (Kent), en faisant ingérer à un Canard des Cypris cinerea Brady provenant d'une mare des environs de cette ville et renfermant un Cercocystis particulier.

Genre Davainéa (Davainea R. Bl. et Raill., 1891). - Vers de taille petite ou moyenne, dont la tête est munie d'un rostre rétractile, lequel est armé d'une double couronne de crochets très nombreux, petits, à lame et à manche courts, mais à garde très développée (1), ce qui leur donne un peu l'aspect d'un marteau à bec recourbé. Ventouses bordées de plusieurs rangées de crochets ou spinules. Pores génitaux quelquefois irrégulièrement alternes, mais plus souvent unilatéraux; dans ce dernier cas, les œufs sont habituellement rassemblés en petits groupes dans des sortes de capsules.

(1) Les crochets doivent être néanmoins mesurés de l'extrémité de la lame à celle du manche. 
Ces Vers vivent dans l'intestin grêle des Oiseaux (Coureurs, Gallinacés, Pigeons) et même de l'lloumme (1).

Leur développement est encore peu connu; on a cependant observé la larve de quelques espèces dans des Insectes et des Mollusques; elle parail se rattacher au genre Honocereus Villot.

Les espèces qui figurent au lableau suivant sont parasites des Oiseaux domestiques:

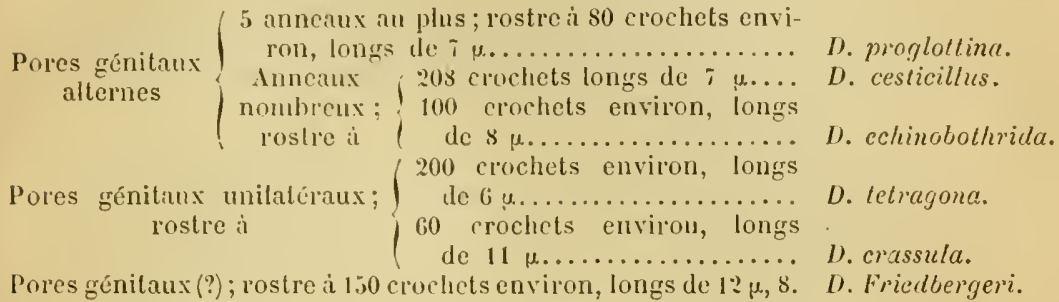

fer Groupe. - Davainea it pores génitaux alternes.

Davainéa progslottinien (D). proglotlina [Dav.]. - Syn. : Tænia proglottince Dav., 1860 ; 1). proglottina R. BI., 1891). - Long de $0^{\mathrm{mm}, 3}$ à $1^{\mathrm{mm}}, \breve{3}$, large de $0^{\mathrm{mm}}, 18$ a $0^{\mathrm{mm}}, 50$. Tète quadrangulaire, un peu arrondie en arant, lécgèrement rétrécie en arrière en forme de cou, longue de 130 à $200 \mu$, large en avant de $13 \ddot{3}$ ì $160 \mu$, munie d'une trompe convexe, rétractile, portant à sa base une couronne d'environ 80 crochets longs de $7 \mu$; ventouses assez petites, armées d'épines à base élargie 'et bilobée, longues de $6 \mu$. Chaîne composée de 2 à 5 anneaux augmentant graduellement de longueur et de largeur. Pores 'génitaux alternes, occupant l'un des angles antérieurs de l'anneau. Derniers anneaux se séparant de bonne heure de la chaine pour vivre et se développer isolément dans l'intestin, jusqu'à acquérir 2 millimètres de long sur $1^{\mathrm{mm}}, 20$ de large. OEufs sphéroïdes, de 28 à $40 \mu$; crochets de l'embryon longs de 10 a $11 \mu$.

Intestin de la Poule, à Rennes (Dujardin), dans le Nord (Daraine), dans le Loiref, oì il produisait une grave entérite épizootique (Lucet), dans Indreet-Loire (R. Blanchard), en Lombardie (Grassi et Rovelli).

D’après ces delniers anteurs, les hôtes intermédiaires de ce Téniadé sont des Limaces (Limax cinereus Lister, L. agrestis L., L. varicgatus Drap.); le Cysticercoïde s'y constitue en moins de vingt jours; avalé par la Poule, il devient adulte en huit jours. Ce Cyslicercoïde est primitivement pourvu d'une queue, qui se résorbe ensuite. Quatre des crochets embryonnaires se retrouvent sur la paroi externe, deux en avant et deux à la partie postérieure.

Davainéa rond-de-enir (D) cesticillus [Molin]. - Syn.: T. infundibuliformis Duj., 18łä, nec Gœze, 1782; T. cesticillus Molin, 1838; D. cesticillus R. Bl., 1891). - Long de 9 à 43 millimètres d'après Molin, de 100 à 130 millimètres d'après d'autres observateurs. Tète globuleuse, déprimée

(1) R. Blaxcirard, Nolices helminthologiques, 2e série. Mémoires de la Soc. zool. de France, 1V, p. 420, 1891 .

Railliet. - Zoologie. 
en forme decoussinet ou rond de cuir; trompe peu saillante, convexe ou hémisphérique, entourée à la basé d'un bourrelet lisse, el armée d'une double couronne de 208 crochets très caducs, longs de $7 \mu$, à manche très court et à garde allongée; ventouses peu saillantes. Cou nul. Premiers anneaux très courts, plus largres que la tète, les suivants de plus en plus grands, arrivant à être presque aussi longs que larges, imbriqués-perfoliés. Pores génitaux irrégulièrement alternes. OEufs elliptiques, longs de 750 à 850 ; crochets des embryons de 16 à $17 \mu$.

Intestin grèle de la Poule, en France (Dujardin), en Italie (Nolin), en Danemark (Krabbe), en Turkestan (Fedishenko), en Abyssinie (Pasquale).

D'après Grassi et Rovelli, l'hôte intermédiaire de cette espèce doit être uu Coléoptère ou un lépidoptère.

Davainéa ćehinobothridien (D. echinobothrilla [Mégn.]. - Sỵn. : Tænia echinobothrida llégn., 1881; D. echinobothrida R. Bl., 1891). — Long de ò à 10 centimètres, large de 1 à 2 millimètres. Tète petite, cuboüde, offrant à son sommet un infundibulum garni d'une centaine de petits crocliets longs d'environ $8 \mu$, disposés en une double rangée ; ventouses très grandes, bordées de sept rangs de crochets en aiguillon de rosier, ceux des rangs médians étant les plus grands; avec l'àge, ces crochets tombent et les ventouses s'effacent peu à peu. Cou nul. Premiers anneaux très minces, 50 fois plus larges qu'épais, les suivants de plus en plus grands, à bord postérieur mince et creusé, dépassant le bord antérieur de l'anneau suivant, de manière à rendre les bords de la chaîne crénelés ou en scie. OEufs sphériques, de $90 \mu$ de diamètre, groupés par 6 ou 7 dans de petites capsules arrondies.

Mégnin l'a recueilli clıez des Poules de Crèvecœur et de Houdan. Il a cru le recomnaitre aussi dans des anneaux rendus par un Pigeon, mais il s'agissait probablement du D. crassula. - Il est fort possible qu'on arrive, du reste, à constater l'identilé de celte espèce avec la précédente.

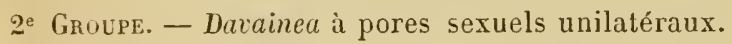

Davainéa tétragone (D. tetragona [Molin]. - Syn. : Tænia tetragona Molin, 18ä8; T. bothrioplites Piana, 1881; D. tetragona H. Bl., 1891). - Long de 12 à 90 millimètres d'après Molin, de 200 millimètres d'après Piana, de 200 millimètres d'après Krabbe; large de $1^{\mathrm{mm}}, 6$ à 3 millimètres. Tète petite, tétragone; trompe rélractile armée d'une double rangée d'environ 200 crochets longs de $6 \mu$; ventouses garnies d'un grand nombre de crochets de taille inégale, disposés sur sept ou huit rangs concentriques. Cou très long. Premiers anneaux très courts, les suivants subquadrangulaires, imbriqués. Pores génitaux s'ouvrant sur le milieu du bord de chaque anneau. OEufs renfermés, par groupes de $\ddot{3}$ à 20 , dans des capsules plus ou moins irrégulières.

Ce Ver vit dans l'intestin grèle de la Poule; il a été trouvé en Italie (Molin, Piana), dans le Turkestan (Fedtshenlio) et en Abyssinie (Pasquale).

Piana a trouvé, dans de petits Gastéropodes terrestres (Helix carthusinnella, H. muculosa), un petit Cysticercoïde invaginé dans sa queue et paraissant correspondre à cette forme (Honocercus Davaineæ tetragonx).

Davainéa crassule (D. crassula [Rud.]. - Syn. : T. crassula Rud., 1819; 
T. sphenocephula Rud., 1819, nec 1810). - I.oug de 20 à 10 ecntimètres, large de \& millimètres. Tète ovale; trompe obtuse, armée d'environ 60 crochets longs de 10 a $11 \mu$; rentouses arrondies, armées d'épines. Cou assez long, grèle. Premiers anneaux très courts, les suirants un peu plus longs et très larges, les dernieris nfundibulilormes. OLufs réunis par groupes de 10 à 12 dans des capsules (1).

Trouvé par Bremser dans l'intestin d'une Tourterelle commune et décrit alors par Rudolphi sous le nom de T. sphenocephala. Ce dernicr auteur donnait comme espeece distincle de celle-ci, sous le nom de T. crassula, un Ver recueilli par Olfers, au lirésil, chez un Pigeon domestique importé de la còte d'Afrique. Kirabbe a constaté de visu l'identité de ces deux formes. Le mème parasite a été trouvé en outre chez le Biset et la Tourterelle; Cloüet l'a revu a lionen sur le Pigeon domestique, et Zürn affirme qu'il peut produire chez cet animal du catarrhe intestinal.

Von Linstow le mentionne encore chez le Canard domestique et chez la Bartavelle, mais le fait aurait besoin d’ètre confirmé. Lüpke dit enfin l'aroir observé chez un Perroquet gris.

Davainća de Madagascar (D. madugascariensis Davaine]. - Syn. : T. mulugascariensis Dav., 1869; D. madugascuriensis R. Bl., 1891). - Ver pouvant atteindre $2 \dot{z}$ centimètres de long, et composé alors de 500 à 600 anneaux. Tète pourrue d'un rostre assez épais, rétractile dans un infundibulum, et armé d'une double couronne d'environ 90 crochets a garde longue d'environ $18 \mu$, avec la forme caractéristique du genre; rentouses assez grandes, arrondies et revètues, comme l’infundibulum céplıalique, d'une quantité innombrable de petites pointes. Premiers anneaux courts et larges, les suivants devenant carrés et mème plus longs que larges; anueaux mùrs longs de 2 millimètres, larges de $1^{\text {m }},{ }^{\prime}$. Pores géuitaux unilatéraux, situés vers le bord antérieur de l'anneau. Embryon long de $\delta \mu$ (Leuckart) a $13 \mu$ (Davaine), pourru de 6 crochels trés fins et peu recourbés, el entouré de deux membranes transparentes, l'interne lui adhérant intimement, lexterne offrant ì chaque pòle un prolongement pointu. Les œufs ainsi formés

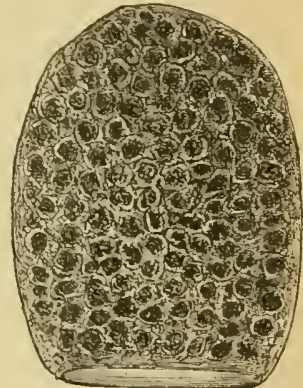

Fig. 197. - Ameau récemment mis en liberte du Davainea madagascariensis, grossi 10 fois (Davaine). sont amassés, par groupes de trois à quatre cents, daus des poches spéciales visibles à l'wil uu et contenaut en outre de nombreuses granulations. l.es anneaux mùrs et détaclıés ont l'aspect de pépins de pommes.

Le développement sexuel de ce Ver est très rapide. Les testicules, au nombre de 50 et plus dans chaque anneau, sont remplis de sperme arant l'apparition des organes femelles. A 3 centimètres en arrière de la tête, on observe déjà des anneaux fécondés, à vésicule séminale pleine. La poche du cirre est en forme de bouteille; le canal déférent, très longet très sinueux, est tapissé de cellules glandulaires

(1) Ce sont ces capsules que liudolphi a décrites et figurées comme des oufs 
(prostate) dans toute sa longueur. Le vagin se continue par une vésicule séminale très longue et très large, qui communique directement avec l'oviducte au milieu de l'anneau. L'utérus est formé d'un certain nombre de tubes qui, au début, sont enroulés de chaque côté en une masse globuleuse; dès que les œufs s'y amassent, ces circonvolutions se déroulent et occupent toute l'étendue de l'anneau. Mais les parois utérines ne tardent pas à se détruire, de sorte que les œufs en voie de développement se trouvent libres dans le parenchyme. D'abord nus, ils sont hientôt entourés, soit isolément, soit en petits groupes, par les cellules du parenchyme environnant, qui prolifèrent et s'accumulent de plus en plus autour d'eux, donnant ainsi lieu à la formation des capsules ovigères signalées plus haut.

Cette espèce a été établie par Davaine sur deux spécimens sans tête recueillis à Nayotte (Comores), par le $D^{r}$ Grenet, chez deux enfants : un petit garçon de dix-huit mois, créole des Antilles, et une petite fille de deux ans, créole de la Réunion. Le premier était à Mayotte depuis cinq mois, la seconde depuis deux mois seulement. Dans les deux cas, on avait observé des convulsions avec menace de suffocation.

Chevreau et de Clıazal ont retrouvé le même parasite à l'île Naurice, également chez des enfants en bas àge, la plupart n'offrant aucun symptome particulier. Les exemplaires obtenus, communiqués à R. Blanchard, manquaient encore de tête.

Enfin, Leuckart en a reçu de lirabbe un exemplaire complet, provenant d'un enfant de trois ans, fils d'un capitaine danois qui naviguait dans les eaux asiatiques et vivait sur son navire (1).

Davainéa de Friedberger (D. Frieulbergeri [ron Linstow]. - Syn.: Tania Friellbergeri von Linstow, $1878 ;$ D. Friclbergeri R. B1., 1891). - Long de 200 millimètres et plus, large de 2 à 3 millimètres. Tète pyriforme, raccourcie; trompe armée d'une double couronne de 150 crochets, tous semblables, longs de $12 \mu .2$; ventouses en forme d'ellipse courte, bordées d'épines à base bilobée, d'autant plus petites qu'elles sont plus rapprochées du centre. Cou très mince, long de 2 à 3 millimètres. Premiers anneaux très courts, les suivants augmentant peu à peu de longueur ; le bord postérieur déborde de chaque côté, d'où un aspect en dents de scie; à partir du dernier sixième, la chaîne devient moniliforme; enfin, les derniers anneaux sont presque globuleux, et présentent parfois une teinte jaune rougeàtre. Pores génitaux situés au milieu du bord de l'anneau. OLufs larges de $3 \dot{x}$ à $38 \mu$; crochets de l'embryon mesurant $6 \mu$.

Ce Ver vit dans l'intestin du Faisan commun; il y pullule parfois chez les jeunes individus et produit alors une entérite souvent mortelle. C'est probablement le même qui a été décrit par Mégnin sous le nom de Txnia agama, puis de $T$. infundibuliformis var. phasianorum (pores génilaux unilatéraux).

(1) P. Gıevreau, Le Tonia madagascariensis. Bullet. Soc. méd. de l'ile Maurice, $\mathbf{X}$, p. 523, 1891. - R. Buanchand, Note sur quelques Ver's parasites de l'Homme. Comptes rendus Soc. de biologie (9), 111, p. 613, 1891. - R. LeuckakT, Ueber Tienia madagascariensis Davaine. Verhandl. der deutschen zoolog. Gesellschaft, p. 6s, 1891. 
Friedberger pense que sa lare est un Cysticercoïle vivant dans la pupe des Fourmis, puisque c'est lả la nourriture exclusive des laisandeaux; mais diverses recherches pour décourrir cette larve sont restées sans résultat.

Taniadic incertx sedis. - Nous rangeons sous cette rubrique quelques formes parasites des Oiscaux domestiques, insuflisamment connues jusı̨u’à présent.

Ténia de Delafond (T. Delafondi Raill., 1892. - Syn. : T. sphenocephala Mégn., 1891, ucc Rud., 1810). - Long de 7 à 13 centimètres, large de 3 à 4 millimètres. Tète hémisphérique, sans rostre ni crochets (?) ; ventouses larges, opposées deux à deux. Coulong de $0^{\mathrm{mm}}, \ddot{\mathrm{a}}$ et plus, d'abord aussi large que la tète, puis s’élargissant en coin jusqu'à la chaîne. Premiers anneaux très courts, les suivants un peu plus longs et très larges, à borls latéraux convexes; les derniers un peu plus étroits el plus longs, mais à bords moins saillants. Pores génitaux irrégulièrement alternes, situés vers le quart antérieur du bord latéral; deux utérus latéraux rameux, marquant sur la chaine vue par transparence deux séries de taches opaques; une autre série sinueuse, submédiane, est formée par le réceplacle séminal. OEufs globuleux, de 62 à $6 \ddot{3} \mu$; crochets de l'embryon longs de $11 \mu$.

Intestin du Pigeon domestique (Delafond, Railliet, Mégnin).

Ténia ì grosse tète (T. megalops Nitzsch, 1829. - Syn. : T. anatis marilx Greplin, 1825). - Longueur, jusqu'à $: 22$ millimètres. Tète très volumineuse, globuleuse-tétragone, large de $1^{\mathrm{m} m}, \dot{4}$; rostre $n$ ul ou peu saillant, sans crochets (?); grandes ventouses. Colı très court. Premiers anneaux très courts, irréguliers; les postérieurs deux fois aussi larges que longs, évasés en arrière en forme de cloche. Pores génitaux unilatéraux, situés près du bord antérieur; pénis lisse. OEufs globuleux, à deux enveloppes, l'externe plus résistante, d'un diamètre de $4 \tau \mu$; embryon large de $32 \mu$, à crochets longs de $15 \mu$.

Intestin de divers Anatinés sauvages. Dujardin l'a trouvé à Rennes chezle Canard domestique, et Fedtshenko dans le Turkestan, probablement chez le mème animal.

Ténia mince ( $T$. cxilis Duj., 18.45). - Long d'environ 11 centimètres, large de $1^{\mathrm{mm}}, 8$. Tète tétragone; rostre court, déprimé, offrant une couronne simple de 60 crochets longs de $8 \mu$; ventouses orbiculaires. Cou long de 3 millimètres, insensiblement renllé en avant et en arrière. Anneaux tous plus larges que longs, le bord postérieur plus large que l'antérieur, d'où un aspect denté en scie; premiers anneaux très courts, les suivants de plus en plus longs et larges; les derniers opaques el reuflés au centre. Pores génitaux unilatéraux, situés vers le tiers antérieur du bord de l'anneau. OEufs globuleux, à trois enveloppes, longs de 58 à $6 \dot{t} \mu$; crochets de l'embryon longs de 12 a $16 \%$.

Trouvé par Dujardin et par Arloing dans l'intestin de la Poule, en France.

En l'absence de toute description ou figure des crochets, il est impossible de fixer la place de ce Ver dans notre classification; il nous semble assez probable toutefois qu'il s'agit d'un Davainea. 
Ténia cantanien $(\boldsymbol{T}$. cantaniana Polonio, 1860). - Long de 13 millimètres. Tète globuleuse, paraissant surmontée d'un rostre très court; ventouses grandes et arrondies. Cou nul (?). Chaine élargie en arrière; premiers anneaux campanulés, les suivants campanulés-imbriqués, trapézoïdles. Pores génitaux unilatéraux.

Ce Ver, très incomplètement connu, a été trouvé à Padoue dans l'intestin du Dindon domestique, par Polonio. Von Linstow le mentionne anssi chez le Faisan commun, et li. Blanchard tend à y rapporter un Téniadé sans tète recueilli chez une Pinlade. C'est probablement encore un Davainea.

Ténia marteau (T. malleus Gœze, 1782. - Syn. : T. fusciolaris, y malleus Pallas, 1781; Fimbriaria malleus et $F$. mitra Frölich, 1802$)$. - Long de 4 à 20 centimètres; large de 4 à 5 millimètres; terminé en avant par une dilatation transverse, formée d'articles très nombreux, peu distincts, large de 3 à 6 millimètres. Tète très petite, avec un rostre court, assez mince, armé de 12 crochets longs de $168 \mu$; ventouses larges. Cou court, resserré. Anneaux plus larges que longs, peu distincts, traversés par des stries longitudinales, et par une large bande médiane, longitudinale, contenant les ovaires. Pores génitaux? OEufs à double enveloppe, longrs de $88 \not \alpha$; embryon long de $31 \mu$, avec des crochets en S, longs de $7 \mu$.

Trouvé dans l'intestin de nombreux Anatidés sauvages, ainsi que chez le Canard domestique (Pallas, Gœze, Zeder, Bremser, Dujardin, Krabbe, R. Leuckart), chez le Canard musqué (Uujardin) et mème chez la Poule (Creplin).

Rudolphi soupconnait, et Schlothauber a affirmé qu'il s'agissait d'une monstruosité se produisant chez des espèces variées (Trnia trilineata, undulata, sphenocephala); mais Leuckart déclare au contraire que c'est une sspèce autonome bien caractérisée : pour voir la tête, il importe d'examiner le Ver immédiatement après la mort de l'hòte, car elle est déjà tombée au bout d'une demi-heure, du moins en été.

Sous-famille des mésocestordinés. - Tête munie de quatre ventouses; anneaux bien séparés; orifices génitaux situés sur la ligne médiane ventrale.

Genre Mésocestoïde (Mesocestoides Vaillant, 1863. - Syn. : Ptychophysa Hamann, 1885). - Ce genre est caractérisé principalement par la présence, dans les anneaux mûrs, d'une capsule utérine ou sac ovifère unique. Il comprend les espèces que Batsch désignait sous le nom de "Ténias margaritifères ", à cause précisément de cet utérus " en forme de flacon ou perle ». Les anneaux en activité sexuelle offrent deux orifices, l'un correspondant au vagin, l'autre, un peu en arrière, au canal déférent (1).

(1) L. Vaillaxi, Sur deux Helminthes cestö̈des de la Genetle. Extr. des seances de la Soc. philomat., in l'Institut, XXXI, n 1524, p. 87, 1863.- - F. Zsснокке, Ueber den Bau der Geschlechtswerke von Truia litterata. Zoolog. Anzeiger, VIlI, p. 380, 1885. - 0. Hamaxx, Tænia lineata Geze, eine Tænie mil flüchenstündigen Geschtechtsö/fnungen (MI. 2 Taf.). Zeitschr. f. wiss. Zool., LXII, p. 718, 1885. - F. ZsciokкE, Recherches sur ta structure anat. et histol. des Cestodes (avec pl.). Genève, 1888. 
Mésocestoüde à tache linéaire (M. lineatus [Göze]. - Syn.: Trnia lineatu Gœze, 1782; T. eanis lagopodis Rud., 1810; T. pseudo-encumerina el T. pseudo-elliptica Baillet, 1866 ; Ptychopliysa lineata IIamann, 1883̈). - Ce I'cr, qui oflre quelque ressemblance arec Dipylidium eaninum par la forme de ses anneaux, estun peu plus transparent, avec une faible teinte rougeàtre le long de la ligne médiane. Il mesure en moyenne de 30 à 50 centimètres, mais peut dépasser $2^{\mathrm{m}}, 30$. Sa téte, large de $0^{\mathrm{mm}}, 6$ à $0^{\mathrm{mm}}, 9$, a la forme d'une massue nettement tronquée cn avaut; elle est inerme, le rostre étant remplacé par une légrère dépression centrale; ses quatre ventouses sont ordinairement

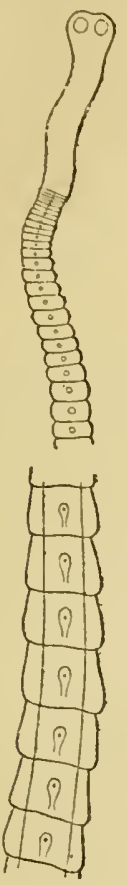
ovalaires, à fente longitudinale très ouverle. L.e cou, très court, se continue insensiblement en avant avec la tète et en arrière avec la châne. Les premiers anneaux sont lrès courts et peu dislincls; les suivants deviennent carrés, a bords latéraux un peu convexes, à angles postérieurs faiblement saillants; les derniers, mesurant 4 à 6 millimètres de long sur 2 à 3 millimètres de large, ont la forme de graines de melon, et sont gronflés, sur la ligne médiane, par la capsule utérine remplie d'œufs, capsule ovoïle, à pelit pòle postérieur. Les quelques derniers anneaux seulement renferment des œufs mùrs, ovoïdes, à double enveloppe très

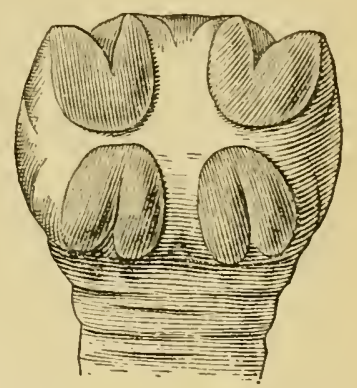

Fig. 198. - Mesocestoides lineatus : Fig. 199. - Extrémité céphalique du Mesocestoides lineatus, extrénité céplualiquo et série d’anneaux, daprès hrable. Grossissement : 6 diamétres.

mince, longs de 40 à $60 \mu$, larges de $30 ̈$ ì $43 \mu$, renfermant un embryon hexacanthe très actif.

Gœze (1782) a le premier décrit et figuré, sous le nom de Tænia lineata, un Ver qu'il avait trouvé dans l'intestin d'un Clıat sauvage du Brocken. Il faisait connaître en mème temps un $T$. cuteniformis, dont il dislinguait trois variétés, l'une vivant chez le Loup, les deux autres chez le Renard. La dernière de celles-ci reçut de Batsch le nom de $T$. litterata (1786). Quelques années plus lard (179\%), Abildgaard trouvait de son cỏté, dans l'intestin de l'Isatis (Vulpes lagopus), un Cestode ressemblant beaucoup à ceux du Chat et du Renard : Rudolphi l'appela $T$. eanis lagopodis, en le classant parmi ses espèces douteuses. 
Toutes ces formes étaient restées d’ailleurs très imparfaitement connues, lorsque lirabbe (1863) annonca qu'il avait fréquemment observé chez le Chien et chez le Chat domestiques, en Islande, un Cestode particulier, qu'il rapporta au $T$. canis lagopodis Rud. Presque au même moment, ${ }^{C}$. Baillet (1866) décrivait le mème Ver, qüil regardait comme nouveau, et en distinguait deux espèces, l'une vivant chez le Chien (T. pseudo-cucumerinu), l’autre chez le Chat (T. pseudo-elliptica). Il caractérisait cette dernière par sa longueur moindre, ses anneaux plus courts et plus étroits, et ses œufs plus petits, n'atteignant que 31 à $36 \mu$ de diamètre.

Dans la première édition de cet ourrage, nous avions rassemblé toutes ces formes sous le nom de T. litterata Batsch; mais il résulte des recherches de F. Zschokke que le parasite du Renard, auquel ce nom a été primitivement appliqué, représente une espèce bien distincte. Par contre, les différences qu'on peut relever entre le Cestode des Chats et celui du Chien ou de l'Isatis sont tellement légères que l'influence de l'habitat suffit à les expliquer, et nous considérons par suite ces deux formes comme appartenant à une seule et mème espèce, dont elles ne constituent que des variétés.

L'évolution du Mesocestoides lineatus est encore inconnue. Nous dirons donc seulement quelques mots de son organisation, qui a été bien étudiée par Zschokke et Hamann. Le développement sexuel est lent; selon la règle, les organes màles arrivent à maturité les premiers. Vers la fin du second tiers de la chaîne, la maturité sexuelle est atteinte, et, dans les anıeaux suivants, les glandes reproductrices disparaissent pour faire place à l'utérus.

Les testicules, assez grands et nombreux, remplissent tout le parenchyme, mais se montrent plus abondants vers la lace dorsale; ils siègent en dedans comme en dehors des canaux longitudinaux. Le canal déférent décrit de nombreuses sinuosités vers la ligne médiane dorsale, jusqu'à l'extrémilé antérieure de l'anneau, où il se recourbe brusquement en arrière pour aboutir à la poche du cirre. Celle-ci forme un sac médian et antérieur, sac musculeux, pyriforme, dont la parlie renflée, dirigée en arrière, montre dans son milieu, au fond d'un petit entonnoir, l'orifice màle, de forme ronde. Cet orifice est donc situé à peu près au quart antérieur de la face médiane de l'anneau. La poche du cirre disparait rapidement dans les anneaux mùrs.

L'appareil femelle comprend deux ovaires ou germigènes situés vers le quart postérieur de l'anneau et rapprochés de la face dorsale ; leurs canaux excréteurs se réunissent sur la ligne médiane et donnent naissance à un oviducte (germiducte) commun qui aboutit au vagin. Un peu en arrière, en dehors et en dessous des ovaires, sont deux vitellogènes ovalaires, donnant de mème deux vitelloductes, de la réunion desquels part un vitelloducte commun qui va se jeter au fond du vagin. De là naît un conduit excréteur commun ou oviducte définilif qui se dirige en avant et en haut, traverse un petit groupe de cellules peu distinctes (corps de Mehlis), forme une première dilatation, se rétrécit de nouveau, puis aboutit à une dilatation nouvelle. Celle-ci contourne la poche du cirre, se resserre un peu, puis se termine au bord antérieur de l'anneau en un large cul-de-sac recouvert en partie par l'extrémité antérieure de la poche. - Le vagin débute par une ouverture située un peu en avant du pore génital màle; cette ouverture est ordinaire- 
ment petite, arrondie; mais, au moment de la copulation, elle se place sur l'orifice mile á la facon d'un entonnoir : il y a done autofécondation. Ie lá, le vagiu s'irance vers le bord antérieur en décrivant plusieurs lacets ou spirales, puis se recourbe en arriere et en haut, passe entre les deux groupes de standes femelles et va s'unir au grermiducte et au vitelloducte, sans présenter aucune dilatation ou l'éservoir séminal.

$\Lambda$ mesure que les aufs se forment et se développent, les compartiments utérius se remplissent et augmentent de volume. Ces compartiments, et en particulier le postérieur, sont entourés de nombreuses cellules rondes, dont une partie se transforment bientòt en fibres musculaires destinćes à renforeer la paroi utérine; e’est ainsi que, daus cette régrion postérieure, se trouve constitué un vérilable sae musculaire qui enveloppe peu à peu liutérus primitif. A un moment donné, on constate que les oufs vont saceumuler de plus en plus dans le compartiment antérieur, tandis que la partie utérine renfermée dans le sae musculaire se vide et se ratatine, laissant à sa place un tissu liche. Puis un retour se produit : les axufs émigrent de l'utérus antérieur dans le sac musculaire, qui se gonfle rapidement et prend l'aspect d'une eapsule remplie d'œufs, entre lesquels se voient les restes du tissu liche qui remplissait le sac. Finalement, on ne distingue plus que cetle capsule

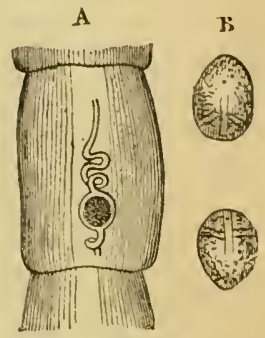

Fig. 200. - Mesocestoïdes lineatus. - A, anneau mür, grossi 6 fois. B, aufs, grossis 300 fois (Orig.). utérine, prolongée en avant par un corlon sinueux, qui représente les débris du compartiment antérieur de l'utérus, et sourent aussi en arrière par un cordon plus court, trace de l'utérus primitif.

Les anneaux mùrs se détachent et sont expulsés isolément.

Pathologie. - La fréquence du . $/$. lineatus est très variable suivani les localités. Chez le Chien, Kirabbe l'a trouré sur 21 p. 100 des sujets examinés en Islande; il ne l'a pas vu en Dinemarli. Zschokke ne l'a pas vu davantage à Zurich. A Lyon, il s'est présenté chez 8 p. 100 des animaux; à Toulouse, Neumann l'a rencontré parfois sur 30 p. 100. Nous ne le royons que très exceptionnellement à Alfort.

L'histoire pathologique de ce Ver ne diffère pas de celle des autres Cestodes du Chien. Requier a publié une observation relative à des accidents rabiformes constatés chez un Chien dont l'intestin en renfermait un grand nombre d'exemplaires. - D'ordinaire, lirabbe en trourait moins de dix chez un mème sujet, mais parfois le nombre s'en élevait jusqu'à trois ou quatre cents. Ils siégeaient dans la moitié postérieure de l'intestin grèle.

Chez le Clıat, plus du tiers des individus cxaminés en Islande étaient

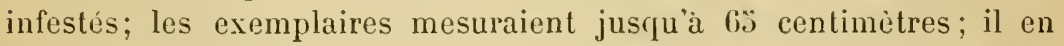
existait généralement plusieurs à la fois, mais jamais plus de ringt. A Toulouse, ce parasite n'est pas rare.

Mésocestö̈de imbutiforme (11. imbutiformis [Polonio]. - Tania imbutiformis Polonio, 1860). - Long d'environ 8 millimètres. Tête petite, à ven- 
touses circulaires. Cou nul. Chaîne épaissie en arrière; premiers anneaux linéaires, les suivants campanulés-infundibuliformes, les derniers campanulés. Pores génitaux elliptiques, situés sur l'une des faces de l'anneau.

Trouvé à Padoue, par Polonio, dans l'intestin de l'Oie sauvage. Von Linstow le mentionne aussi chez le Canard domestique. - Species inquirenda.

Nous croyons devoir annexer provisoirement aux Téniadés les formes suivantes, encore insuffisamment connues:

Genre Dithyridie (Dithyridium Rud., 1819; Piestocystis Diesing, 1830). Ce genre est basé seulement sur des larves de Cestodes dont on ne connaît pas encore l'état adulte. Elles répondent à la forme larvaire qualifiée par Braun de plérocercoĩde, et ont pour principaux caractères une tète subtétragone, invaginée dans la partie antérieure, dépourvue de trompe et de crochets, mais munie de quatre ventouses. La partie postérieure, correspondant à la vésicule caudale des Cysticerques, ne contient que peu ou point de liquide; elle est oblongue, déprimée, souvent plissée en travers.

Dithyridie allongée (D. elongatum [Blumberg]. - Syn. : Cysticercus elongatus Bl., 1883, nec F. Leuckart, 1842; C. Bailleti Raill., 1883). - Ver long de 16 à 105 millimètres, large de $1^{\mathrm{mm}}, 03$ à 2 millimètres en avant et d'environ 1 millimètre en arrière. Partie antérieure opaque, plissée, contenant une tête invaginée, tétragone, sans trompe ni crochets, mais pourvue de quatre ventouses elliptiạues souvent teintées de noir; partie postérieure pleine, en forme de queue, à peine alténuée en arrière, très
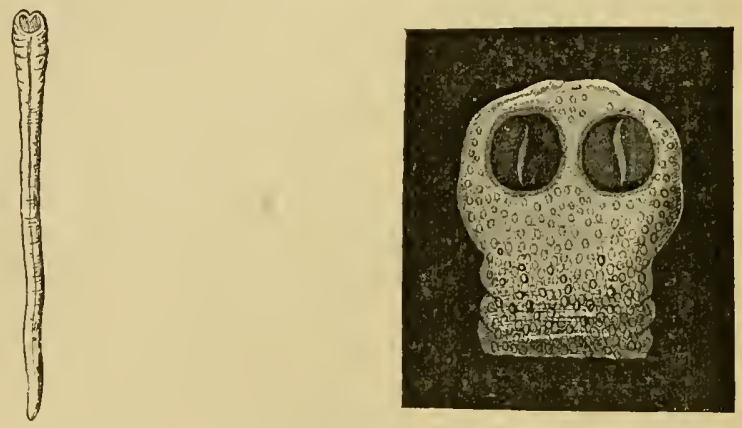

Fig. 201. - Dithyridium elongatum, grandeur Fig. 202. - Tète évaginée du Dithyridium elongatum, nalurelle (G. Neumann). grossie 50 fois (G. Neumann).

courle dans les petits exemplaires. Tout le corps rempli de corpuscules calcaires.

C. Baillet a le premier rencontré ces parasites dans la cavité pleurale ou péritonéale de deux Chats. C. Blumberg, de Kasan, les a Irouvés également chez deux Chats et chez un Chien. Ils paraissent être communs à Toulouse, où Neumann en a observé chez 19 Chats (sur 76 examinés), ainsi que chez la Mangouste, le Putois, le Renard. Ils se montrent en nombre variable, tantòt libres, tantòt enkystés dans les séreuses, plus rarement dans le foie ou le poumon. - Leur présence dans le péritoine parait provoquer parfois une légère péritonite. 
Il faudra probablement assimiler à cette forme les Piestocystis laxi et l. marlis Diesing.

Cysticerque de la Ponle. - Vésicule ovoïde, transparente, de la grosseur d'un grain de millet, remplie de liquide et parsemée de granulations. Téte à quatre ventouses, sans trompe ni crochets.

C. Baillet en a trouvé trois exemplaires enkystés dans le péritoine d'une P'oule. Peut-itre s'agit-il du Dithyridiunvariubile (Piestocystis variabilis Dies.), recueilli par Bremser, Diesingr et Leuckart dans la cavité abdominale de la Bartavelle et dans le poumon de divers Corbeaux.

Famille des BOTHRIOcÉPHALIDÉS. - Elle comprend des Vers dont la tête est munic de deux ventouses généralement allongées

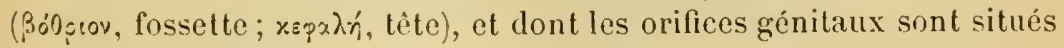
presque toujours sur la ligne médiane ventrale. L'appareil sexuel est multiple.

Cette famille peut ètre divisée en plusieurs tribus : Bothriocephalina, Duthiersine, Diphyllina et Ligulina.

A. Sous-famille des bothriocéphalinés. - Le corps est rubané; la tête est munie de deux ventouses en forme de fentes allongées (bothridies).

Le genre Bothriocéphale (Bothriocephalus Rud., 1810, pro parte. - Syn. : Dibothrius Rud., 1819; Dibothrium Dies., 18.50), qui sert de type à ce groupe, est surtout caractérisé par ses orifices génitaux, situés sur le milieu de la face ventrale.

Il renferme de nombreuses espèces, la plupart vivant chez les Poissons. Quelques-unes cependant se rencontrent chez les Oiseaux et les Mammifères, roire chez l'Homme.

Bothliocéphale large B. latus Bremser, 1819. - Syn. : Trnia prima Plater, 1603; Ténia à épine Andry, 1700; T. vulgaris et T. lata L., 1748; Dibothrium latum Dies., 18э0). - Ver long en moyenne de 2 à 7 mètres, mais pouvant atteindre jusqu à 20 mètres. Teinte générale souvent gris roussàtre. Tète oblonque, en amande, longue de 2 a $\ddot{3}$ millimètres, large de $0^{\mathrm{mm}}, 7$ à 1 millimètre, parcourue, daus presque toute sa longueur, par deux fentes latérales ou bothridies, qui fonclionnent à la façon de ventouses. Cou delongueur très variable suivant le degrẻ de contraction, parfois à peine marqué. Chaine aplatie, surtout vers les bords, et composée d'environ 3000 í 4000 anneaux. Premiers anneaux peu distincts; les suivants augmentant un peu de longueur, mais devenant surtout Irès larges; anneaux mùrs, en arrière du milieu de la chaine, montrant une tache opaque formée par l'utérus en rosette, et mesurant en moyenne 2 à 4 millimètres de long sur 10 à 12 millimètres, voire jusqu'ả 20 millimètres de large. $A$ près avoir atteint leur maturité complète, ces anneaux se rétrécissent et se raccourcissent mème, ce qui tient à l'atrophie des organes génitaux et à leur déplétion par la ponte; c'est ainsi que les deruiers, chez des individus parfaitement intacts, se montrent flétris et rillés. Orifices génitaux situés sur la ligne médiane ven- 
trale : l'orifice mâle et celui du vagin occupent le sommet d'un petit tubercule, non loin du bord antérieur de l'anneau; un peu en arrière se voit l'ouverture de l'ulérus (tocostome), par laquelle s'effectue la ponte. OEufs brunâtres, ellipsoïdes, operculés, longs de 68 à 71 p., larges de 44 à 4 ŏ $\mu$.

Le Bothriocéphale large vit ordinairement dans l'intestin grêle de l'Homme; mais il se rencontre aussi chez le Chien : Linné et Pallas

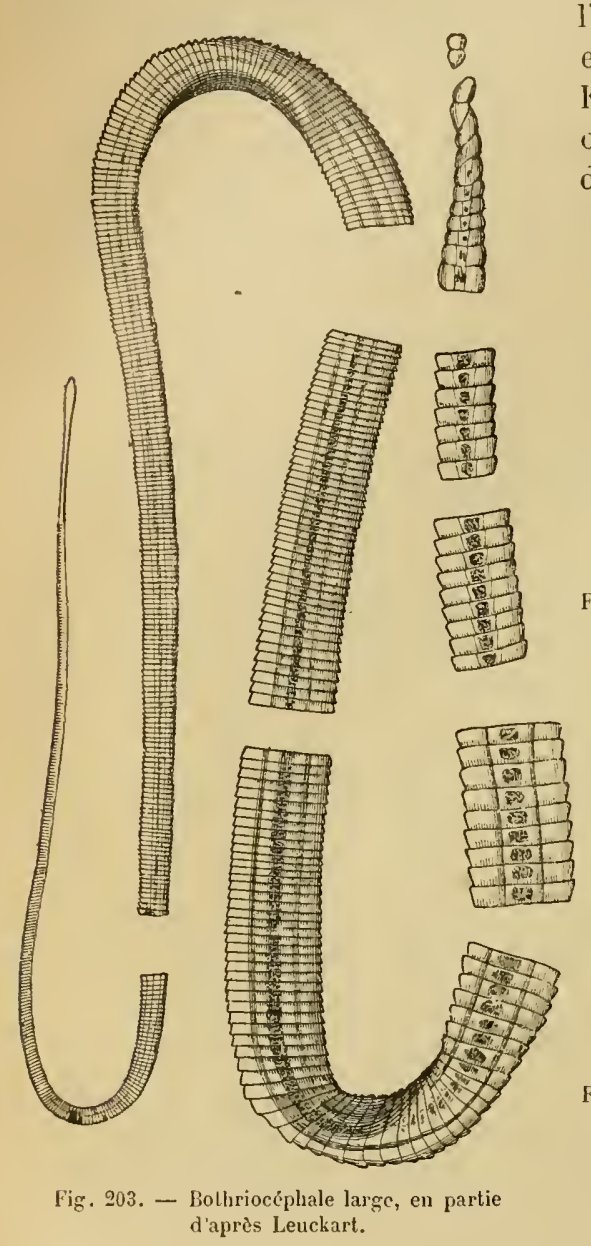

l'avaient déjà signalé dans cette espèce ; von Siebold, Cobbold, lirabbe, Perroncito, Braun, etc., ont confirmé le fait, et l'on doit évidemment rapporter à

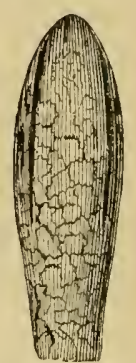

Fig. 204. - Tête du Bothriocephalus latus, monlrant les deux ventouses ou bolthidics.

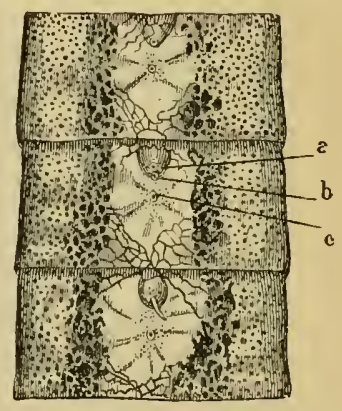

Fig. 205. - Trois anneaux de Bothriocéphale large, grossis et vus par la face ventrale, daprès Eschricht. - Au troisièmc ammeau, le pénis est saillant; il est rentré dans les aulres. $a$, orifice mâle. $b$, orifice du vagin. $c$, orifice de la malrice, par lequel s'effectuc la pontc.

la même espèce le Bothriocephalus canis Ercolani et Bassi, 1839. Le Chat héberge-t-il le même parasite dans les conditions naturelles? Greplin (18ב3) avait trouvé, à Greifswald, deux petits Bothriocéphales dans l'intestin grêle d'un Chat, mais ces exemplaires étaient trop jeunes pour être déterminés avec certitude. Il les nomma néanmoins $B$. felis, et Diesing les assimila, sans raisons suffisantes, au $B$. decipiens, qui vil dans l’intestin de divers félins sauvages. Krabbe 
en trouvi cind exemplaires à Copenhague, sur deux Chats, et il les considère comme bien différents du B. latus. Alessandrini, Bruckmüller, F. Zschokke et Perroncito ont aussi recueilli des Bothriocéphales chez le Chat; mais le dernier de ces auteur's reconnait une grande analogie entre ces Vers et ceux de l'Honme. En sorte que l'occurrence spontanée du Bothriocéphale large ehez le Chat ne nous paraît guère douteuse. Les différences constatées par les observateurs peurent fort bien tenir à l'influence du milieu.

Bertolus et Cliaureau ont enfin trouvé ce parasite chez un Renard entretenu en captivité par un restaurateur.

La larve du $B$. latus vit dans les muscles et les viseères de divers Poissons : Lotte, Brochet, Perche, Ombre-Chevalier, Truite comınune, Truite des lacs, Ombre des rivières, Féra. C'est donc par la consommation de poisson insuffisamment cuit (ou cru) que l'Homme, en particulier, contracte le Bothriocéphale : et les Poissons à leur tour s'infestent en cherchant leur nourriture dans les eaux souillées par les excréments humains. Au Japon, l'hòte intermédiaire de ce Ver est l'Onchorhynchus Perryi, Salmonidé que l'on mange cru avec une sauce piquante. - La larve en question appartient à la forme que Braun qualifie de plérocercoïde; elle se présente sous l'aspect d'un Ver assez long et étroit, cylindroïde et non aplati, long de 8 à 30 millimètres, large de $0^{\mathrm{mm}}, \ddot{3}$ à 3 millimètres. Quand elle se contracte, elle peut se raccourcir de moitié, son épaisseur augmentant en proportion. La tête est invaginée, mais elle s'évagine d'ordinaire quand on maintient la larve dans l'eau tiède, ou dans l'albumine, le suc gastrique, ctc., à une température conrenable. Il n'y a pas de vésicule caudale : le corps, criblé de corpuscules calcaires, est entièrement solide et offro une structure analogue à celle de ladulte, mais sans organes reproducteurs et sans segmentation réelle, nonobstant la présence de rides transversales. Les plérocercoïdes sont très rarement enkystés : on les trouve dans la paroi de l'intestin, dans l'ovaire, dans le foie, etc., logés dans le canal qưils se sont creusé; ils sont doués de mourements vermiculaires. On les observe souvent en grand nombre à la fois dans un même Poisson.

Érolution. - L'embryon du Bothriocéphale n'est pas formé avant la ponte comme celui des Ténias; il se déreloppe dans l'cau, oủ les œufs doivent par conséquent ètre rejetés. Bertolus l'a vu se constituer en six ì huit mois dans l'eau courante; en élevant la température jusqu'ì 30 ou $3 \ddot{3}^{\circ}$, Schauinsland est parvenu à obtenir l'éclosion du dixième au quatorzième jour.

Nous ne nous attarderons pas à suirre en détail les phases du développement embryonnaire, renvoyant pour cela au travail de Schauinsland (1). Nous dirons seulement que l'embryon une fois formé se com-

(1) Schaunstaxd, Die embryonale Entwicklung der Bothriocephalen. Jenaische Zcitschrift für Naturwiss., NIX, 1885. 
pose d'une masse solide interne (endoderme), sphérique, composée de nombreuses cellules, et d'un revêtement extérieur ou manteau (ectoderme), également cellulaire au début, revêtu de nombreux cils vibratiles. L'endoderme est pourvu de trois paires de crochets, comme l'embryon hexacanthe des Ténias.

A cette période, l'opercule de l'œuf est devenu très visible; l'embryon le soulève et, grâce à son revêtement cilié, se met à nager dans l'eau qui l'environne (Schubart). Il mesure alors 40 à $50 \mu$ de diamètre, et ses crochets ont une longueur de $13 \mu$. Il nage lentement, en roulant autour d'un axe parallèle à la paire médiane de crochets, ceux-ci étant toujours dirigés en arrière. On peut le conserver vivant pendant quelques jours, mais souvent le manteau cilié se déchire et met en liberté l'embryon hexacanthe. Il est facile, d'a-

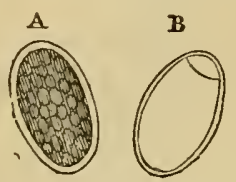

Fig. 206. - (Eufs du Botriocephalus latus. - A, vu dans la glycérine. B, après l'action de l'acide sulfurique, qui a fait apparaitre l'opercule (Laboulbène).

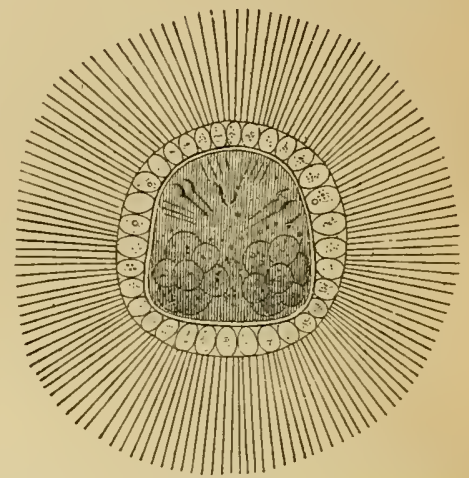

Fig. 207. - Embry on cilié du Eothriocéphale large, d'après Lcuckart.

près ce fait, de voir que, comme chez les Ténias, le Ver adulte sera dépourvu d'ectoderme.

Quel est le sort ultérieur de ces embryons? Schauinsland n'a pu les faire évoluer en les introduisant dans l'estomac de jeunes Lottes; Leucliart n’avait pas mieux réussi sur des Truiles et des Cyprinidés. Peut-être faut-il penser, avec Max Braun, qu'ils doivent pénétrer tout d'abord chez de petits animaux aquatiques dont les Poissons font leur proie (1).

Knoch, de Saint-Pétersbourg, admettait que l'embryon cilié se développe directement en Bothriocéphale dans l'intestin des Mammi-

(1) M. Bruwx, Ueber den Zwischenwirth des breiten Bandwurmes (Bothriocephalus latus Bremser). Würzburg, in-80 de 32 p., 1886. - B. Grassi et? Fenrara, Zur Bothriocephalusfrage. Deutsche med. Wochenschrift, no 40, 1836. - II. Braun, Die Finnen von B. latus. Centralbl. f. Bakt. u. Paras., I, p. 649, 1887. - E. Parova, Intorno ln genesidlel B. latus Brems. e la sua frequenza in Lombardia. Archivio per le scienze mediche, XI, no 3, 1887 (Archives ital. de biologie, 1888) - F. Zscnokin, Der B. latus in Genf. Centralbl. f. Bakt., I, p. 397, 1887. - B. Grassi e G. Rovelli, Contribusione alls stu tio dello sviluppo del Botriocefulo lato. Giorn. della R. Accad. di med. Torino, nos 11-12, 1857. - lD., Bandwurmentwichlung. Centralbl. f. Bakt., I11, p. 173, 1883. - ID., Embryologische Forschungen. lbid., V, p. 3i2, 1889. - I. Iנци , The surpe of Bothriocephalus in Japan. Journ. Coll. sc. Tokyo, 1888. - F. Zscioкке, Ein weitere, Zwischenwirth des B. latus. CentralbI. f. Bakt. 1V, p. 417, 1888. C. PAвs, De, breite Bandwurm (B. latus Brems.) 'und; seine Entwicklungsgeschichte. Naturwiss. Wochenschr., IV, p. 257, 1889. 
fères. Il se basait sur la présence de Bothriocéphales dans l'intestin de quelques-uns des Chiens auxquels il avait fait prendre de ces embryons. Mais ces expériences manquaient absolument de rigueur, d'autant que kinoch opérait dans une localité où le parasite est très abondant chez l'llomme, et que, dans ces conditions, les animaux pouvaienl sètre infestés spontanćment. En les répétant à Giessen, où le Bothriocépliale ne règne pas, Leuchart nobtint que des résultats négatifs.

Cette question du développement direct a du reste perdu presque entièrement son importance à la suite des expériences de Max Braun. Dès 1863, Bertolus arait considéré comme l’état larvaire du Bothriocéphale large le Ver agame décrit par Rudolphi sous le nom de Ligula nodosa (selon Diesing, ee ne serait qu'un fragment de Trivnophorus), et qui vil en parasite chez divers Salmonidés (1). En 1881, le professeur Max Braun, de Dorpat, eut l’idée d'examiner aitentivement les Poissons apportés au marché de cette ville, et ne tarda pas à rencontrer chez le Brochet, puis chez la Lotte,

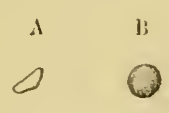

Fig. 208. - Larves du Bolbriocépluale larıe, d'après E. Parona. - A. lirie repliée sur elle-mène lelle qu'clle se trouve dans les muscles. B, larve enlisslée (kyste libre dans la cavité abdomiuale). Grandeur naturelle.

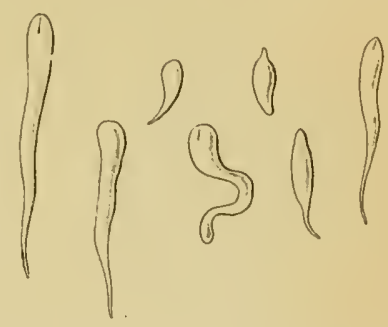

Fig. 209. - Larves du Bothriocéphale large. extrailes des tissus du Poisson, d'après E. Paruna. Grandeur nalurelle.

la forme larvaire que nous avons décrite plus haut, et que Knoch avait déjà observée sans en reconnaitre la nature. Ces Poissons provenaient des lacs Peïpous, Wirz-Jïrw et Embach ; ceux qui sont amenés au marché de Saint-Pétersbourg, et qui viennent du lac Ladoga et du golfe de Finlande, étaient infestés au même degré ; ceux du lac Burtnek l'étaient un peu moins.

A Dorpat, le Bothriocéphale est rare chez le Chien et ne solsserve pas chez le Chat. Braun administra un certain nombre de ces larves à 14 de ces animaux ( 8 Chats et 6 Chiens), dont on avait examiné avec soin les excréments, et auxquels on avait préalablement administré des anthelminthiques. On en fit l'autopsie au bout de quelques jours ou de quelques semaines. Dans denx cas seulement, chez un Chat el chez un Chien, le résultat fut négatif. Chez un troișième affecté d'entérite, on ne trouva qu'un Ver encore peu développé; mais tous les autres présentaient des Bothriocéphales dont le nombre et le degré de déreloppement étaient en rapport avec les éléments de

(1) Voir aussi C. Davine, Sur une Ligule (Ligula minuta) de la Truile du lac de Geneve. Comptes rendus de la Soc. de biol. (i), 1, p. si, 1864. 
l'expérience. - Le résultat fut négatif chez deux Canards. - Trois étudiants de Dorpat se prêtèrent également à l'expérimentation, et tous trois, au bout d'un mois environ, expulsèrent, après l'administration d'anthelminthiques, des Bothriocéphales plus ou moins eomplets.

L'observation attentive des Vers déreloppés chez les animaux et chez l'Homme, dans ees divers cas, montra des différences assez saillantes dans leurs caractères. - Ceux de l'Homme avaient atteint une longueur de $2^{\mathrm{m}}, 37$ à $4^{\mathrm{m}}: 52$, et se montraient formés de 1,000 à 1,300 anneaux, ce qui représente par jour un accroissement de 86 millimètres, pour 31 à 32 anneaux. - Les Bothriocéphales développés chez le Chat dans le même laps de temps sont plus courts que ceux de l'Homme et possèdent moins d'anneaux; leur tête est notablement plus petite; l'extrémité antérieure est large et épaisse, tandis que le reste de la chaine est étroit et mince, aree des anneaux qui, pour la plupart, sont très allongés. - Ceux trourés normalement chez le Chien sont également moins longs et moins épais que ehez l'Homme; la tète atteint seulement le tiers des dimensions ordinaires, les anneaux sont plus petits et plus aplatis, etc. - L'influence du milieu sur le développement du Ver est donc considérable.

Malgré la netteté de leurs résultats, les expérienees de Braun suseitèrent des eriliques assez vives de la part de plusieurs auteurs, notamment de Küchenmeister. Les objections étaient du reste assez semblables à celles qui araient été faites à hinoch. Cela suffit à expliquer pourquoi j’arais éerit dans la première édition de cet ourrage, en 188\%, à propos de l'embryon du Bothriocéphale : "On n'est pas encore fixé d'une façon absolue sur les pliases par lesquelles doit passer eet embryon. " E. Parona, de Milan, se basant sur cette mention restrietive, ainsi que sur une assertion négative de Vogt, relative à l'influence de la ehair des Poissons, résolut d'instituer de nouvelles expériences. Il arait déjà constaté, non seulement dans les Brochets, mais aussi dans les Perches du pays de Varèse, la présence des larves de Bothriocéphale; des recherehes étendues lui montrèrent que l'infestation était limitée aux Poissons des lacs, et il l'observa dans les lacs lombards de Varèse, de Monate, de Ternate, de Côme, d'Orta, dans le lae Majeur, ainsi que dans le lac de Genève. Il entreprit alors des essais d'infestation sur l'Homme et le Chien, arec les larves de la Perche et du Brochet: sur dix essais, huit donnèrent des résultats positifs.

A peu près en même temps, F. Zsehokke recherehait les larves du Bothriocéphale sur les Poissons du lac de Genève, et les décourrait non seulement chez le Brochet, la Lotte et la Perche, mais encore chez la Truite commune, l'Ombre-Chevalier et l'Ombre des rivières. Des expériences effectuées sur l'Homme fournirent des résultats positifs avec les larves de la Lotte et de l'Ombre-Chevalier, négatifs avee eelies de la Perche. Les œufs apparaissaient dans les selles du dix-huitième au vingt-troisième jour après l'ingestion. - Ces larves peurent survi- 
vre jusqu'à dix-huit jours à leur hôte; elles meurent rapidement dans une solution saturée de chlorure de sodium, résistent quelque temps

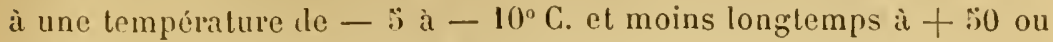
$+.33^{\circ} \mathrm{C}$.

Grassi, lierrara et Rovelli ont fait aussi sur l'homme des essais firuclueux, an moyen de larves provenant de la Perche et du Brochet. Parona a retrouvé les mèmes larves sur la Féra du lac Léman, Zschokike sur la Truite des lacs pèchée dans le Rhin, ì Bàle. Et il est évident que la liste des Poissons qui peuvent servir d'hôte intermédiaire au Bothriocéphale est loin d'ètre close.

Organisatiox. - Les détails que nous avons donnés au sujet des Ténias nous permettront d'étudier plus rapidement l'organisation interne du Bothriocéphale.

Il convient de faire remarquer d'abord que les bothridies occupent en réalité les faces supérieure el inférieure de la lète, comme le montre la situation des nerfs et des vaisseaux (fig. 210; elles n'ont pris une position latérale que par suite d'une torsion effectuée par le cou.

Aucune observation importante en ce qui concerue le tissu foudamental, les téguments et les muscles. - Le systeme nerveux est représenté par deux troncs longitudinaux situés au milieu de l'espace qui s'étend entre la ligne médiane et le bord des anneaux; d'après Niemiec, ces deux troncs latéraux, arrivés à l'extrémité de la tète, s'inclinent à la rencontre l'un de l'autre, et, après un renflement insignifiant, se réunissent par une puissante commissure olfrant dans son milieu un épaississement qui renferme des cellules gau-

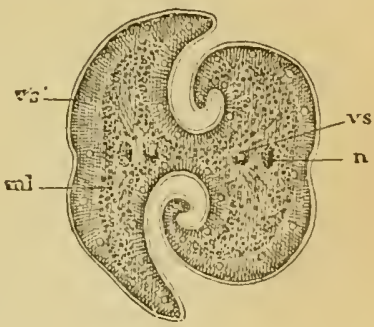

Fig. 210. - Coupe verticale passant par le milıeu de la lẻte du Bothriocephalus latus, d'iprès R. Moniez. $n$, corduns nerveux. vs, vaisseaux de la zone centrale. $2 s^{\prime}$, vaisscaux sousculiculaires. $m l$, fibres musculaires longitudinales. Les deux depressions correspondent aux bolhridies. glionnaires. Les deux troncs se prolongent encore au delà de la commissure et se terminent en émettant une série de filets nerreux courts et grèles. En deçì de la commissure, ils donment naissance, de chaque còté, à quatre nerfs qui se recourbent en arrière et se perdent dans la tète. - Il n'existe dans la zone central qu'un seul vaisseau de chaque còté de la ligne médiane, un peu en dedans du cordon nerveux; on a décrit, en outre, des vaisseaux sous-cuticulaires, au sujet desquels les renseignements sont peu précis.

Les follicules testiculaires occupent les parties latérales de l'anneau; les spermatozoïles ont une queue très courte; on ne sait pas bien exactement si cesproduits cheminent à travers les tissus ou dans des canaux à parois propres. En tout cas, ils aboutissent à un spermiducte ou canal déférent très long, replié sur lni-mème, qui va s'ouvrir au sommet d'un pelit tubercule situé à la partie antérieure de l'anneau, après avoir traversé un bulbe musculeux et une poche péniale pourvue elle-mème de fibres musculaires. Les contractions de celles-ci déterminent le renversement du spermiducte, qui fait saillie sous forme de pénis.

Rallliet. - Zoologie. 
Les organes femelles sont constitués essentiellement par un ovaire et des vitellogènes. - L'ovaire est appliqué contre la couche inférieure des muscles circulaires, dans la partie postérieure de l'anneau, et empiète un peu sur l'anneau suivant. ll présente des trainées d'ovules qui rayonnent vers un point central, où ils ront s'accumuler quand ils sont détacliés. Il existe en outre une sorte d'ovaire central, dont les éléments ont été regardés comme des glandes unicellulaires destinées à sécréter la coque de l'œuf; ces éléments ou ovules entrent en régression sur les anneaux mûrs et ne paraissent pas donner naissance à des œufs. - Les ovules sont recueillis par un pavillon qui s'ouvre contre le point central précité de l'ovaire. Ce pavillon donne entrée dans un oviducte qui rencontre bientôt un petit canal émané du réceptacle séminal, puis se continue par un tube qui deviendra la matrice, et qui lui-mème ne tarde pas à recevoir un affluent, le vitelloducte.

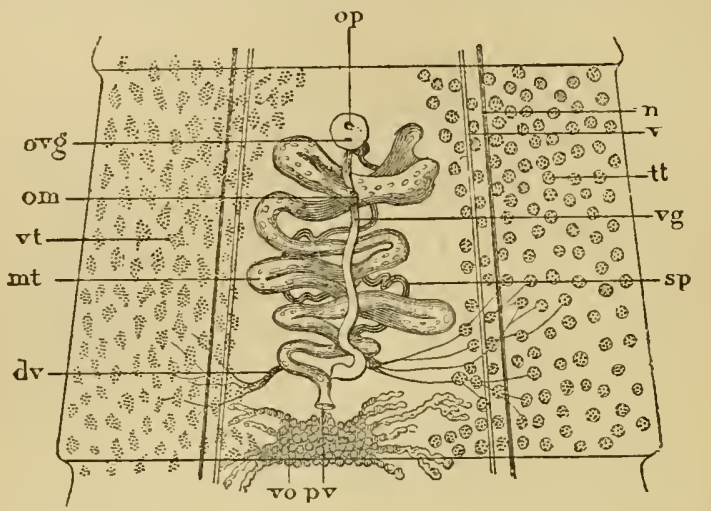

Fig. 21t. - Schéma d'un anneau de Bothriocẻphale large, vu par sa face ventrale. - v, vaisseau. $n$, nerf. $t t$, testicules $s p$, spermiducte ou caual déférent. op, orifice du pénis. vo, ovaire. pv, pavillon. $m t$, matrice. om, orifice de la matrice ou tocostome. $v t$, follicules vitellogènes. do, vitelloducte. $v g$, vagin. ovg, orifice du vagin.

Le vagin nait immédiatement en arrière de la poche péniale; il se dirige vers la partie postérieure de l'anneau, et s'élargit en un vaste réservoir séminal (receplaculum seminis), qui communique avec l'oviducte par un très court canal. Ce vagin est cilié : il amène les spermatozoides qui féconderont les orules au passage.

Les vitellogènes, que nous n'avons pas eu à signaler chez les Ténias, sont des glandes représentées par des amas cellulaires ou follicules, répandus sur les deux faces de l'anneau, sauf dans le champ médian, et situés entre la couche sous-cuticulaire et la couche des muscles longitudinaux. Leurs éléments se résolvent en granulations vitellines, qui cheminent à travers les tissus, sous forme de boyaux, comme les spermatozoüdes, et convergent vers un centre commun; de là s'élève une colonne de vitellus, qui pénètre dans un canal collecteur, le vitelloducte, et va bientòt tomber dans la matrice. Par suite de cette disposition, les granules vitellins ne sont adjoints aux ovules qu'après la fécondation.

La matrice est constituée par un tube dont la disposition est assez simple sur les anneaux jeunes; mais l'accumulation des œufs dans soll intérieur l'oblige bientôt à décrire des circonvolutions nombreuses, qui s'enchevêtrent 
avec celles du spermiducte, tout en s'écartant à mesure que l'anneau grandit. La portion terminale de ce tube matrice offe des parois épaisses; elle aboutit à un pore ventral, silué à quelque distance en arrière des orifices du spermiducte et du vagin: c'est par cette onverture (tocostome) que s'effectue la ponte.

1)'après les faits qui viennent d'ètre exposés, on roit que les ovules formés dans les branches rayomnantes de lovaire se dirigent vers un point central, où ils sont recueillis par le parillon. Dans le conduit qui émane de cet organe, ils ne lardent pas ì reneontrer les spermatozoïdes qui débouchent du réservoir séminal, et la fécondation a lieu. Un peu plus loin, ils se trouvent en contact avec les granules vitellins que le tube vitelloducte déverse daus la matrice; ils s'organisent alors définitivement, et on les roit bientòt entourés d'une coque. L'œuf ainsi formé renferme une cellule-œuf
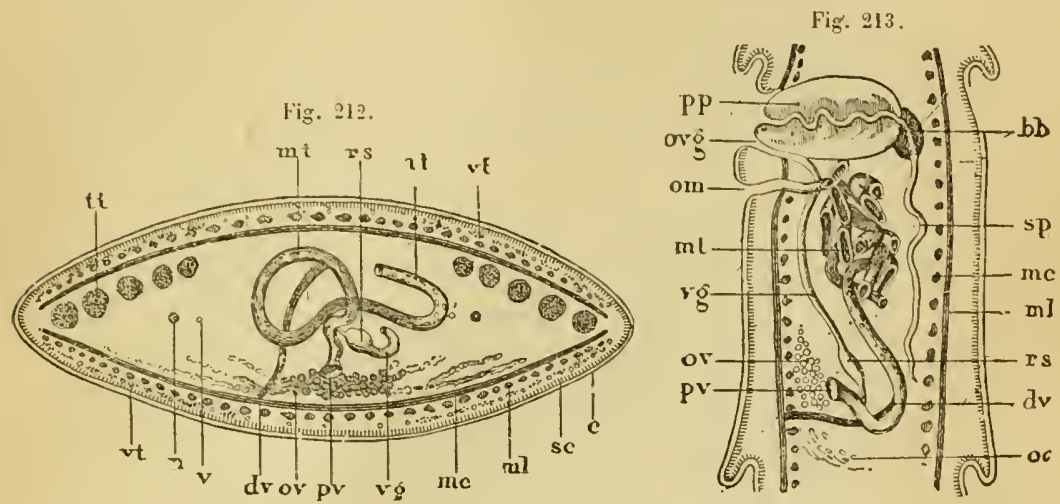

Fig. 212 et 213. - Coupes schématiques longiludinale et transversale d'un anneau de Bothriocéphale large. $-c$, cuticule. $s c$, couche sous-cuticulaire. $m l$, muscles longitudinaux. $m c$, muscles circulaires. $v$, vaisseau. $n$, nerf. $t$, testicules. $s p$, spermiducte. $b b$, bulbe. $p p$, poche péniale. ov, ovaire. oc, ovaire central. $p v$, pavillon. de, vitelloducte (les follicules vitellogènes ne sont pas dans le plan de la coupe). $m t$, matrice, arec ses circonvolutions coupées. om, tocostome ou orifice de la unatrice. $r s$, réservoir séminal. $v g$, vagin. org, orifice du vagin.

assez volumineuse, pourvue d'un gros noyau nucléolé, et des éléments accessoires plus petits, d'origine vitelline (fausses cellules), dont le noyau n'offre pas de nucléole. La coque parait n’ètre autre chose que la membrane vilelline.

Axomalies. - L'une des plus communes est à coup sûr le dédoublement des orifices génitaux, qu'on trouve placés còte à còte dans le mème anneau. Leuckart dit qu'il n'a presque jamais observé un exenılaire de Bothriocéphale n'offrant pas cette anomalie an moins sur quelques anneaux. Les deux moitiés de l'anneau sont alors plus ou moins distinctes, et possèdent chacune un appareil rénital particulier.

Kinoch a vu l'orifice màle situé sur le bord de l'anneau.

Piltard a signalé, sur un exemplaire conservé à Londres, une disposition qui rappelle celle des Ténias trièdres.

Il n'est pas rare de rencontrer aussi des Bothriocéphales perforés, et comme les anneaux sont très courts, la fenestration porte en général sur plusieurs anneaux consécutifs. Si elle est très étenduc, il en résulte une bifur. 
cation qui peut se montrer soit sur le milieu de la chaine (Delle Chiaje), soit sur la portion terminale (Bremser). Mais il est possible aussi que cette bifidité soit liée au dédoublement des orøanes sexuels.

Pallas et Grassi ont observé des formes à chaine grèle (B. latus var. tenelltt). Par contre, Bugnion, de Lausarne, a vu des exemplaires à très larges anneaux.

Distribution gÉographiquf. - Contrairement aux deux grands Ténias de l'Homme, le Bothriocéphale est loin d'ètre cosmopolite : sa distribution est en rapport avec celle des Poissons qui lui servent d'hòte intermédiaire, et partant avec la constilution hydrologique des localités. Le Ver est en somme confiné au voisinage de certains lacs ou de certaines mers.

On sail que sa patrie classique est la Suisse française, la région des lacs de Genève, de Neuchàtel, de Bienne et de Morat. Zschokke admet qu'autrefois 1 habilant sur 10 était infesté à Genève; mais, depuis une trentaine d'années, la proportion s'est abaissée jusqu'à 1 pour 100 environ. A mesure qu'on s'éloigne des lacs, la fréquence du parasite diminue graduellement, de sorte qu'il devient très rare à quatre ou cinq lieues, et qu'au delà on n'en observe plus que des cas isolés, comme daus les départements français limitrophes.

Il se rencontre aussi dans la Hante-Italie, en Lombardie, en Piémont.

Un autre foyer important - le plus important - correspond au littoral de la Ballique. Il y a là une zone immense, partant du cours inférieur de la Vistule et contournant les golfes de Riga, de Finlande et de Botnie ; elle comprend la Prusse orientale, les provinces russes de la Baltique (Kovno, Courlande, Livonie, Esthonie, Saint-Pétersbourg), la Finlande el la côte orientale de la Suède. Dans certaines régions de cette zone, notamment en Finlande et dans le nord de la Suède, le parasite est d'une fréquence extraordinaire; toutefois, il est à remarquer, en ce qui concerne celte dernière contrée, qüil disparaît à huit ou neuf lieues de la còte, de sorte qu'on devrait peut-ètre incriminer l'usage d'un Poisson de mer. Sa fréquence diminue d'ailleurs à mesure qu'on pénètre en Russie, en Pologne, etc.

Il n'est pas très rare en Danemark, non plus qu'en Irlande. Depuis quelques années, il est apparu aussi en Bavière, où le centre d'infestation paraît être le lac de Starnberg, probablement souillé par les déjections de vayageurs qui liébergeaient le Ver. On commence à en signaler aussi des cas en Belgique et en Hollande. Il est presque inconnu en France en dehors des frontières, de Suisse, et les quelques cas observés doivent provenir de Poissons importés. On peut en dire autant de l'Angleterre, de l'Allemagne du Nord et de l'Autriche.

En Asie, on l'a signalé dans le Turkestan, ainsi qu'au Japon, où Janson l'a trouvé chez 0 p. 100 des Chiens.

Pathologte. - Comme les grands Ténias, le Bothriocéphale large est ordinairement solitaire dans l'intestin; cependant, E. Parona l'a trouvé multiple dans la moitié des cas, en Lombardie; Huss en Suède et Krabbe en Danemark en ont aussi trouvé généralement plusieurs à la fois. Roux, en Suisse, a vu un malade en expulser en une seule fois 90 , et Böttcher, en Livonie, en a recueilli près d'une centaine en 
pratiquant une autopsie. Il n'est pas rare de trouver en même temps des Ténias ou des Nématodes divers.

On rencontre surtout le Bothriocéphale chez les adultes; mais il a été signalé aussi chez des enfants, voire des nourrissons, et chez des vieillards. Krabbe l'a trouvé beaucoup plus fréquemment ehez la femme que chez l'homme, ce qui est peut-ètre accidentel. Mais il est évident que sa fréquence dépend avant tout du mode d'alimentation : c'est ainsi qu’il est extrèmement répandu dans les populations ichtyophages, et en particulier chez celles qui consomment le Poisson cru. A Genève, c'est la Lotle qui joue le principal rôle dans l'infestation : elle est consommée cn très forte proportion, et les ovaires, le testicule, le foie - morceaux de choix des gourmets - sont mangés presque crus.

Le parasite peut séjourner pendant des années dans l'intestin de l'Homme. Mosler en a vu un persister quatorze ans; Seeger aurait même observé un malade atteint depuis ringt et un ans.

Les symptômes provoqués par le Bothriocéphale sont analogues à ceux dont nous avons parlé à propos des Ténias. Toutefois, il est à noter que, d'après E. Parona, les troubles intestinaux prédominent sur les accidents d'ordre sympathique. Et nous devons ajouter que divers médecins ont accusé ce Ver de produire une forme particulière d'anémic pernicieuse, ce que Shapiro attribue à l'élaboration par le parasite d'une substance toxique.

Le diagnostic est facile à assurer par l'examen des fèces. Il faut noter que les anneaux du Bothriocéphale ne se séparent pas en cucurbitins comme ceux des Ténias, et que souvent ils restent fixés à la chaine après la ponte : la séparation se fait par fragments assez longs, d'ordinaire ratatinés ou tordus. En ce qui concerme le traitement, les opinions sont ceatradictoires. Laboulbène dit que, de tous les Cestodes, le Bothriocéphale est le plus tenace et le plus difficile à évacuer; E. Parona, se basant sur un grand nombre d'essais, affirme au contraire que e'est celui dont on se débarrasse le plus aisément. - La prophylaxie est facile à régler : ne consommer la chair des Poissons qu'après une cuisson complète; empècher le déversement des excréments humains dans les lacs ou dans les rivières.

Bothriocéphale à crète ( $B$. cristatus Davaine, 187'́t). - Ver formant un ruban épais et raide, roussàtre, opaque, finement strié en travers, avec un sillon médian longitudinal sur les deux faces. Tète ap'atie, ovale, lancéolée, longue de 3 millimètres, large de 1 millimètre, épaisse de $0^{\mathrm{mm}}, 6$. Extrémité libre et pointue offrant sur chacune de ses faces planes une crète longitudinale saillante, longue de 1 millimètre, qui forme avec sa congénère un rostre rigide et couvert de papilles; chacune de ces crètes se continue en arrière, sur la face correspondante de la tète, par deux prolongenients divergents. Pas de bothridies apparentes. Cou nul. Chaine se continuant insensiblement avec la tète; d'abord très grèle $\left(\mathrm{I}^{\mathrm{mm}}\right)$, atteignant brusquement 
4 millimètres de largeur à 150 ou 20 centimètres de la tète, puis s'élargissant graduellement jusqu'à la distance de 90 centimètres, où elle mesure 9 millimètres, et décroissant ensuite jusqu'en arrière, où les anneaux les plus

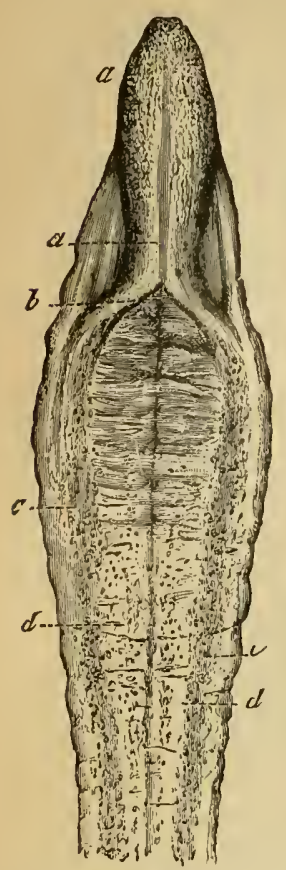

Fig. 214. - Tète du Bothriocephalus cristatus, vue de face à gauche el de profil à droite. $a, a$, crête médiane; $b$, son prolongement en arrière; $c, c$, traince externe de corpuscules calcaires; $d d$, trainée interne (Davaine). étroits n'ont plus que 3 millimètres. Tous les anneaux très courts : déjà bien distincts à 2 millimètres, ils atteignent $1 \mathrm{~mm}, 15$ de longueur à 90 centimètres et ne dépassent pas $2^{\mathrm{mm}}, \overrightarrow{3} ;$ ils sont remarquables par la saillie de leur bord postérieur, qui embrasse l'anneau suivant comme une manchette. Orifices génitaux comme dans le Bothriocéphale large; rosette utérine paraissant plus étroite et plus longue. Corpuscules calcaires nombreux, surtout dans la tète. OEufs longs en moyenne de $75 \mu$, larges de $35 \mu$. offrant assez souvent à l'un des pôles, ou même aux deux, un épaississement de la coque en forme de bouton.

Cette espèce a été établie par Davaine sur deux spécimens : le premier, recueilli par Féréol chez un enfant de cinq ans, né et élevé à Paris, se composait de plusieurs fragments dont l'un portait la tête ; il pouvait mesurer au plus 3 mètres; l'autre, long de 92 centimètres, n'avait point de tête; il avait été expulsé spontanément par un individu habitant la Haute-Saône et âgé d'environ quarante ans.

Davaine pense que ce Ver a dû être observé déjà plus d'une fois, mais confondu avec le $B$. latus. Tel est le cas d'un auteur anonyme qui, en 1776, l'a décrit et dessiné d'après un exemplaire expulsé par un homme de trente ans, à Kempten, en Bavière. Cobbold tend à y rapporter aussi des Bothriocéphales conservés au Musée de IVestminster Hospital medical College, à Londres.

On peut se demander, au surplus, s'il ne s'agirait pas là d'une monstruosité; mais la question ne pourrait être résolue que par l'étude histologique.

Bothriocéphale cordé $(\boldsymbol{B}$. cordatus Leuck., 1862). - Ce Ver est long au plus de $1^{\mathrm{m}}, 15$, et comprend alors environ 600 anneaux (ordinairement il n'en existe guère que 400). La tète est courte, large, aplatie d'un còté à l'autre, cordiforme, creusée de deux profondes bothridies situées sur les faces ventrale et dorsale; elle atteint au plus 2 millimètres en longueur comme en largeur. Le cou est nul : immédiatement en arrière de la tète, le corps se 
montre pourvu d'anneaux visibles à l'œil nu; ceux-ci s'accroissent si rapidement que l'extrémité antérieure de la chaine présente la forme d'une lancette. A 3 centimètres de la tète, ils ont déjà atteint leur maturité sexuelle; 3 centimètres plus loin, ils sont arrivés à leur plus grande largeur, qui est de 7 à 8 millimètres et mène 1 centimètre. Le nombre des anneaux non mùrs, c'est-à-dire ne contenant pas d'œufs à coque solide, est toul au plus d'une cinquantaine, et la plupart d'entre eux montrent déjà des orifices sexuels sur la ligne médiane ventrale. A mesure que la maturité s'accuse, on distingue une zone médiane cliare et des zones latérales d'un gris sombre. Les anneaux mìrs ont une longueur moyenne de 3 ì 4 millimètres, mais la contractilité du Ver est telle qu'ils se raccourcissent parfois jusqu $\grave{a} 1^{\mathrm{mm}}, 3$, en augmentant de largeur et d'épaisseur. Les derniers anneaux ont en général une forme carrée et mesurent dans les deux sens 5 à 6 millimètres. La face dorsale est parcourue,

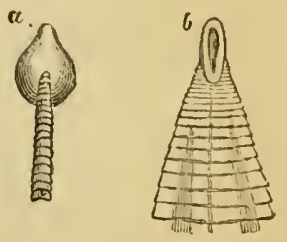

Fig. 215.-Tète du Bothriocephalus cordatus. - $a$, vue de profil et $b$ vue de face, d'après Leuckart. dans son milieu, par un sillon longitudinal; un semblable sillon se voit également ì la face ventrale, en arrière des orifices sexuels. Le parenchyme renferme de nombreux corpuscules calcaires. L'utérus est plus long et plus étroit que chez le Bothriocéphale large; il présente en outre un plus grand nombre de branches latérales (6 à 8 ). Les oufs sont ellipsoïdes, longs de 75 à $80 \mu$, larges de $30 \mu$.

Le Bothriocéphale à tête en cœur a été découvert par Olrik ì Godhavn, dans le nord du Groenland. Un seul exemplaire, long de 26 centimètres, fut rendu par une femme enceinte, en 1860; mais le même observateur en recueillit une vingtaine d'exemplaires chez six Chiens, dont trois les araient expulsés librement. Trois autres Chiens examinés par Pfaff, médecin dans le nord du Groenland, hébergeaient un total de vingt-quatre vers. Pfaff en trouva aussi quatre exemplaires dans l'intestin grêle d'un Phoque barbu de l'île de Disco, et Zimmer trois exemplaires chez un Morse. - Contrairement à ce qui a été dit par Leuckart, ce Bothriocéphale n'a pas encore été rencontré en dehors du Groenland.

On ignore quel en est l'hôte intermédiaire; mais on peut aisément prévoir quill s'agit d'un Poisson.

hrabbe signale, comme anomalies observées chez ce Ver, une courte fissure longitudinale sur la ligne médiane à l'extrémité postérieure, et une intercalation assez fréquente d'articles cunéiformes, sans dédoublement des organes génitaux.

Bothriocéphale de Manson (B. Mansoni [Cobbold]. - Syn. : Liguta Mansoni Cobbold, 1883 ; B. liguloides Leuck., 188ł; B. Mansoni R. Bl., 1886). - Ce Ver n'est encore connu qu'à l'état larvaire. Longueur de l'animal vivant 30 à 33 centimètres; largeur 3 millimètres; épaisseur $0^{\mathrm{mm}}, 4$. Corps aplati, non segmenté, marqué de plis transversaux irréguliers, progressivement rétréci en arrière, et dilaté à son extrémité antérieure en une sorte de 
disque. Celui-ci porte en avant une élévation papilliforme sur laquelle se trouve la tète proprement dite, qui est un peu comprimée et d'ordinaire plus ou moins complètement invaginée. Il n'y a aucune trace d'organes sexuels, ni mème aucune différence appréciable entre les deux surfaces du corps.

Le Dr Patrick Manson, d'Amoy, a rencontré ce Ver en 1881, à l'autopsie d'un Chinois de trente-quatre ans, atteint d'une hypertrophie éléphantiasique du scrotum et mort de dysentérie dix-huit jours après l'opération. Une douzaine d'exemplaires occupaient le tissu conjonctif sous-péritonéal, les uns pelotonnés, les autres allongés; un seul était libre dans la cavité pleurale droite. Ils étaient animés de faibles mouvements, comparables à ceux des Ténias.

Avant les communications de Manson et de Cobbold, Leuckart (1) avait déjà reçu des spécimens du même parasite, recueillis par le $\mathrm{D}^{\mathrm{r}}$ Scheube, directeur de l'hôpital de Kioto, chez un Japonais de vingthuit ans, qui a vait longtemps souffert d'hémalurie, était ensuite devenu syphilitique, et avait enfin présenté une hypertrophie du testicule gauche accompagnée de dysurie et de douleurs vésico-urétrales. Un seul fragment de Ver, comprenant la tête, fut évacué par le canal de l'urètre.

Plus récemment, ljima et Murata ont publié de nouvelles observations relatives à l'occurrence de ce parasite au Japon. Ils en ont relevé sept cas, chez des individus de neuf à quarante-deux ans : dans trois de ces cas, le Ver fut expulsé par l'urètre; dans trois autres, on le trouva sous la conjonctive; dans un dernier, il fut évacué par abcédation d'une tumeur de la cuisse. Le plus grand exemplaire, qui vécut deux heures après sa sortie du canal urétral, mesurait 364 millimètres de long sur 12 millinètres de large.

Ce parasite nous paraît offrir les plus grands rapports avec Sparganum reptans Diesing. D'ailleurs, Ijima et Murata ont déjà observé une larve analogue chez Inuus speciosus et Mustela italsi, et Sonsino en a reçu de Walter Innès un exemplaire recueilli en Égypte sous la peau d'un Chacal.

Bothriocéphale noiràtre (B. fuscus Krabbe, 186ว̈). - Ver long de 8 millimètres à 80 centimètres. Tète comprimée, lancéolée, un peu plus large que le cou. Premiers anneaux peu distincts, apparaissant à quelque distance ou immédiatement el arrière de la tète. Longueur des anneaux s'accroissant d'une façon régulière depuis $0^{\mathrm{mm}}, 5$ environ jusqu'à tres, puis diminuant, alors que la longueur augmente, de sorte que les anneaux deviennent souvent plus longs que larges. Ulérus formant une tache centrale noire bleuàtre et comprenaut dix à douze anses de chaque côlé dans

(1) R. Levckart, Demonstration einiger seltener menschlicher Entozoen. Tagebl. 57 Versamml. deutsch. Naturforsch. Magdeburg, 1884, p. 321. - I. IJma and K. MLrata, Some new cases of the occurrence of Bothriocephalus liguloides $L t$ (with I pl.). Journ. of the College of Science Imperial University, Japan, 11, p. 149, 18,8. - P. Soxsixo, Studi e notizie elmintologiche. Soc. Tosc. di Scienze natur., 12 maggio 1889. 
les anneaux postérieurs. OEufs brunàtres, ellipsoïdes, longs de 530 à $60 \mu$. Pas de corpuscules calcaires.

Kirabbe a rencontré ce Ver dans lintestin de deux Cluiens, en Islande : le premier en renfermait deux pelits exemplaires el le secom 22 de différentes g!andeurs. Dans la partie postérieure de la claine, il n’élait pas rare d'observer 2 ou 3 anneaux qui n’étaient pas séparés l'un de l'autre, ou du moins ne l'ètaient qu'al l'uu des bords.

Le mème auteur a décrit, sous les noms de B. reticulatus et B. dubius, deux espèces douteuses rencontrées aussi en Islande, chacune chez un Chien; ce ne sont peut-ètre que des viriétés de la précédente.

Genre Bothriotenia (Bothrotaniu Raill., 1892). - Deux bothridies. Orifices génilaux situés sur les bords des anneaux.

Bothrioténia longreol (B. longicollis [Molin]. - Syn. : Dibothrium longicolle Molin, 1838; Bothriveephalus longicollis von Linstow, 1878). - Longueur 18 à 2 I millimètres; largeur 4 millimètres. Tète pelite, clavilorme, épaissic, offrant deux bothridies marginales oblongues et une petite dépression centrale à son extrémité an térieure. Cou long, très grèle. Corps ténioïde, déprimé, parcouru par deux sillons lougitudinảux. Premiers anneaux très courts, les suivants presque carrés, imbriqués-perfoliés, Jes derniers en ellipse transversale, épais, à bords arrondis. Anneaux mùrs of̂ant des taches anguleuses en mosaïque, formées par łes poches ovifères. Orifices génitaux unilatéraux, situés sur le milien du bord de charque anneau.

Qualorze exemplaires trouvés dans l'intestin grèle d'une Poule, à Pavie, par Molin. L'aspect des anneaux mùrs rapprocherait ce Ver des Davainea.

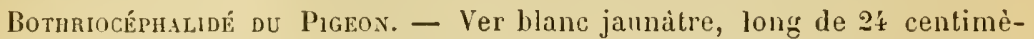
tres. Tète munie de deux bothridies aplaties. Cou court. Premiers anneaux très courts el très étroits; les suivants auşmentant en largeur jusqu'à ce qu`ils aient atteint 6 millimètres, puis se rétrécissant de nouveau vers l'extrémité postérieure. Le bord de la chaîne est denté, à dents aiguës en avant, mousses en arrière. Pores génitaux...?

Un exemplaire rendu par un Pigeon messager, à Elberfeld (Cornélius, 187千́). Cel Oiseau, qui était devenu triste et indolent, reprit toute sa gaité après l'expulsion du parasite.

Il fiut rapprocher de ce cas celui signalé par Ilzigsohn, de Neudamm (Brandebourg). Ce médecin avait élé appelé auprès d'un enfant qui, assurait-on, venait de vomir un Ver. On lui montra en effet un Bothriocéphale; mais une enquète sérieuse permit de reconmaitre que l'enfant avait joué avec un Pigeou tué la veille par son père, et dans lequel on retrouva un Ver tout a fait senblable.

Sous-famille des LIGulinés. - Le corps est formé de segments courts, souvent peu distincts et mal délimités, ou mème ne montre pas de segmentation extérieure; mais les organes géuilaux sont multiples. La tète est pourvue en grẻnéral de deux bothridies, en forme de sillons. Les orifices génitaux sont situés sur la face ventrale.

Les Ligules (Ligula Bloch, 1782) vivent à l'état larvaire dans la cavité générale des Poissons osseux, surtout des Cypriaidés : cette forme asexuée 
correspond à Ligula simplicissima Rud. Elles achèvent leur développement dans le tube digestif des Oiseaux aquatiques et y deviennent sexuées': dans cet état, on en a distingué un certain nombre d'espèces, dont quelques-unes seulement sont bien connues (1). Rudolphi et Creplin avaient déjà indiqué ces migrations et ces métamorphoses, dont Duchamp a donné la démonstration expérimentale (2).

L'œuf, rejeté par les Oiseaux aquatiques, tombe au fond de l'eau, sur la vase. Au bout de quelques semaines, il en sort un embryon hexacanthe revêtu de cils vibratiles, qui est ingéré par les Poissons et se développe dans leur cavité générale sous la forme de $L$. simplicissima. Celle-ci a la forme d'un long ruban aplati, de couleur blanc jaunàtre, assez large et arrondi à l'extrémité antérieure, graduellement atténué ell arrière, où il se termine tantòt en pointe, tantòt par une sorte d'appendice étroit et court. Placée dans l'eau froide, elle subit une élongation considérable aux dépens de sa largeur.

Le Poisson envahi par les Ligules présente un développement anormal du ventre, qui prend une teinte jaunàtre gagnant peu à peu tout le corps; ses mouvements deviennent plus lents, etc. La cavité générale est remplie d'un liquide séro-sanguinolent; sa séreuse est enflammée et revètue de fausses membranes. Les Ligules, en nombre variable, sont enchevètrées d'ordinaire entre le foie et les anses intestinales.

Ces Vers séjournent un temps plus oll moins long - jusqu'à deux ans dans les Poissons ; mais on voit finalement apparaitre en un point du corps, d'ordinaire en avant de l'anus, une saillie arrondie (bouton des pêcheurs) qui s'ouvre à un moment donné, et laisse ainsi échapper les Ligules. Dans certains cas, le Poisson ne paraît pas souffrir de cette émigration; d'autres fois il périt. Mais il arrive aussi très souvent qu'il succombe sans que les Ligules se soient échappées, et il est probable qu'alors celles-ci doivent être mises en liberté par la décomposition des tissus.

Les Ligules ainsi devenues libres peuvent vivre jusqu'à 8 et 10 jours dans l'eau; cependant, on n'en trouve que fort rarement dans les étangs, car les Poissons s'en repaissent très volontiers, et dans ces conditions elles se trouvent digérées sans poursuivre leur développement.

Elles peuvent aussi èlre ingérées de la sorte par les Oiseaux aquatiques, mais seulement d'une façon exceptionnelle. En thèse générale, elles ne pénètrent dans le tube digestif des Oiseaux qu'avec le Poisson qui les héberge. Une fois arrivées dans ce milieu, leur évolution s'achève avec une rapidité extraordinaire : au bout de 30 heures suivant Donnadieu, de 4 jours suivant Duchamp et Moniez, les oufs sont en pleine production et se trouvent émis en grande abondance. Mais cette période d'activité sexuelle n’est que de courte durée : les Ligules sont bientòt rejetées ou digérées, et,

(1) On reconnaît généralement,depuis Creplin, deux espèces de Ligules : l'une, la Ligule unisériale (L. uniserialis, etc. Rud., 1810; L. monogramma Crepl., 1839) offrant une série simple, et l’autre, la Ligule bisériale (L.alternans, etc. Rud., 1810; L. digramma Crepl., 1839), une série double et alternante d'organes reproducteurs.

(2) G. Duchamp, Recherches anatomiques et physiologiques sur les Ligules. Paris. 1870. - lD., Sur les conditions de développement des Ligules. Comptes rendus Acad. sc., LXXXV, p. 1230, 1877, et LXXXVI, p. 493, 18i8. - A. L. Doxnaniev, Contribution d̀ l'histoire de la Ligule. Journ. de l'Anat., p. 324 et 421 ; pl. XIV-XX, 1877. - G. Riens, Füllerungsversuche mit Ligula simplicissima. Zeitschr. f. Naturwiss. d. Ver. in Halle, LV, p. 328, 188?. - R. Moniez, loc. cit. 
dans les conditions expérimentales (chez le Canard domestique), il est très rare d'en retrouver des individus ovigères au bout d'une huitaine de jours.

Les fragments de Ligules se déreloppent parfois aussi bien que les individus entiers. Ajoutons que Duchamp a pu obtenir les mèmes résultats en introduisant le Ver agame dans la cavité périlonéale d'un Chien.

La lignlose sévil souvent à l'état épidémique dans les étangs, où elle amène la destruction d'un grand nombre de Poissons. On sait que de 1870 à 1880 , elle a ravagé, en particulier, les étangs de la Bresse.

Dans cerlaines localités, les gens du peuple ne dédaignent pas de faire servir les Ligules à leur alimentation. D’après Rudolphi, celles d'un petit Poisson roisin du Barbeau sont reclıerchées et mangées avec délices en Italie, sous le nom de macuroni piatti. Et à Lyon mème, au rapport de Donnadieu, certaines personnes en font usage à la manière des Italiens.

Ligule de L'Hlome. - Lars Montin a signalé, en 1763, le cas d'une femme de vingt-cinq ans qui avait rendu, en mème temps que des Ténias et des Ascarides, des fragments de Ligules. Rudolphi rapporla ce Ver à son espèce L. cingulum. Mais il est très probable qu'il s'agissait en réalité de fragments de Ténias.

Famille des TÉTRARYNGHIDES. - Le corps est rubané, nettement divisé en anneaux. Les orifices génitaux sont situés, comme chez les Téniadés, sur la tranclie des anneaux. La tète est pourvue de quatre trompes protractiles garnies de crochets. - Ces Vers se montrent, à l'étal larvaire, enkystés chez les Poissons osseux, soit au milieu des muscles, soit dans des replis du péritoine. Sous la forme adulte, on les rencontre dans le tube digestif des Sélaciens, où ils ont passé avec l'hòte primitif qui sert de proie à ces Poissons.

Le Tétrarynque hérissé (Tetrarhynchus erinaceus Van Ben.) a élé trouvé par Van Beneden enkysté dans le péritoine de la Baudroie (Lophius piscutorius) et du Cabillaud (Gadus morrhua), et sous la forme adulte dans l'intestin de la Raie ronce (Raja rubus).

M. Labully (de Sitint-Étienne) nous a communiqué, en 1892, des échantillons de Morue fraîche dont les chairs élaient envahies par de petits nodules pisiformes noiràtres. Il s'agissait de kystes renfermant chacun une larve de Tétrarynque, que nous avons cru pouvoir rapporter a cette espèce. La "Morue ladre " est assez commune; mais, comme la chair n'est nullement altérée, il n'existe aucun motif pour la soustraire à la consommation.

DEUXIËME ORDRE

\section{CESTODAIRES}

Plathelminthes nus, à corps allongé, mais non segmenté, dépourvus de tube digestif, de ventouses et de crochets. Endoparasites.

Sous le nom de Cestodaires, Monticelli (1) rassemble des formes jusqu'à présent considérées comme des Cestodes simples, monogénéliques ou monozoĭques.

(1) F. S. Moxtrcell, Appunti sui Ceslodaria. Napoli, 1892. 
VERS.

Cet ordre constitue un groupe de passage entre les Cestodes et les Trématodes. Il se rapproche des premiers par l'absence d'appareil digestif, et des seconds par la simplicité ou mieux l'unicité de l'appareil sexuel. Les orifices de cet appareil s'ouvrent sur la ligne médiane du corps.

Le développement est parfois direct (Archigetes), mais le plus souvent il comporte des mélamorphoses et des migrations.

Genres Gyrocolyle (Amphiplyches), Amphiplina, Caryoplyllaus, Archigetes.

\section{TROISIÈME ORDRE}

\section{TREUATODES}

Plathelminthes mus, non segmentés, généralement foliacés, pourvus d'un tube digestif incomplet, sans anus, et d'une ou de plusieurs ventouses. Parasiles.

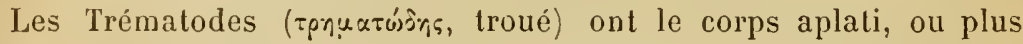
rarement cylindrique, mais toujours sans trace de segmentation (1).

Le tégument est mou, non cilié chezl'adulte; il offre une cuticule dont les caractères et le mode de formation sont identiques à ce que nous arons signalé chez les Cestodes (2). Le système musculaire comprend des fibres circulaires longitudinales, diagonales et dorsoventrales.

Il existe des organes de fixation, représentés par des crochets et des ventouses. Celles-ci occupent toujours la face ventrale; elles offrent une structure analogue à celle des Cestodes.

La zone centrale du corps, ou parenchyme médullaire, est constituée par une sorte de tissu conjonctil dans lequel sont logés les organes de nutrition et de reproduction.

Le système nerveux n'a pu être observé jusqu'à présent que chez un petit nombre de formes. Il se compose de deux ganglions susnesophagiens ou cérébroïdes reliés entre eux par une courte commissure transversale; parfois aussi on rencoutre un ganglion impair sous-œesophagien rattaché aux deux autres par deux commissures verticales. De chacun des ganglions cérébroüdes partent en général : en avant, un ou deux cordons nerveux; en arrière, trois trones longitudinaux principaux, réunis souvent par une série de commissures transverses el se distinguant en ventraux, latéraux ou cxternes, et dorsaux.

Les organes sensoriels se réduisent à des taches oculaires, qu'on observe surtout pendant la période embryonnaire.

Les Trématodes adultes sont pourvus d'un tube digestif incomplet, presque toujours bifurqué, à branches simples ou ramifiées, mais

(1) Fr. Sav. Monticeld.I, Saggio di una morfolngia dei Trematodi. Napoli, 1888.

(2) D'après Brandes, la couche sous-cuticulaire ne serait autre que la portion superficielie du tissu conjonctif parenchymateux. 
toujours en cul-de-sac; sourent la bouche est terminale et située au fond d'unc ventouse. Il est érident que cette bouche lait aussi fouction d'anus. Elle est suivie d'un pharynx toujours pourvu d'un renflement très musculeux (bulbe pharyngien), et le plus ordinairerement d'un œsophage aboutissant à l'intestin. La paroi de celui-ci est constituée par une tunique musculaire directement unie au parenchyme, et par un épithélitum dont la sépare une membrane propre.

Le système excréteur - qui peutètre sert aussi d'appareil circulatoirc ou lymphatique - est très développé; il a son point de départ dans un réseau de lins canalicules prenant leur origine, comme chez les Cestodes, dans des entonnoirs ciliés ou flagellés (organes segmentaires). Ces canalicules se joignent de manière ì constituer des vaisseaux de plus en plus larges, ciliés et non contractiles, qui convergent finalement vers un ou plusieurs canaux longitudinaux à parois contractiles non cilices, communiquant arec l'extérieur'; lorsque ces canaux sont multiples (Amphistoma), ils se réunissent en formant un renflement contractile connu sous le nom de vésicule pulsatile.

Sauf de rares exceptions, les Trématodes sont hermaphrodites. Les organes mâles sont sourent très développés : il existe en général deux testicules, représentés par des tubes ramifiés et terminés en cul-de-sac, ou par des masses arrondies et mamelonnées. De ces testicules émanent deux canaux déférents, qui se réu-

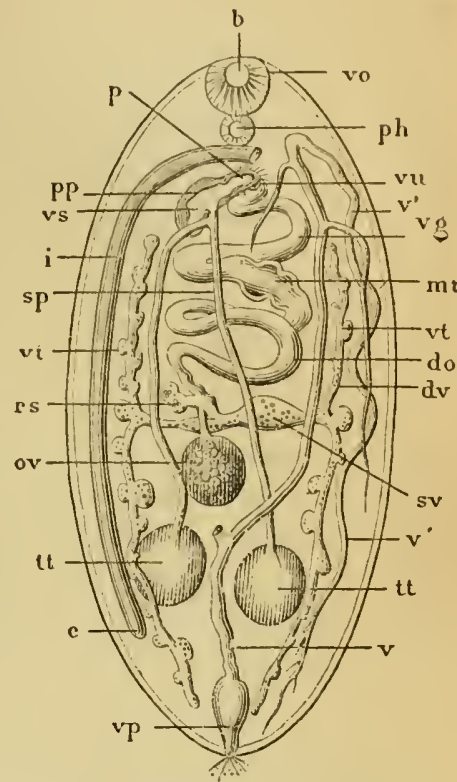

Fig. 216. - Schíma de l'organisation d'un Trémalode, d'après P.-J. Van Beneden. vo, ventouse antérieure. $b$, bouche. $p h$, bulbe pharyngien. $i$, l'un des inlestins, se terminant en cul-de-sac en $c$; l'aulre intestin est enlevé. $v, v^{\prime}$, vaisseaux excréleurs et leur's divisious. $v p$, rísicule pulsalile. $t t$, testicules. $s p$, canaux déférents ou spermiductes. $p p$, poche du pénis. vs, vésicule séminale. $p$, pénis ou cirre. ov, germigine (ovaire). $v t$, vitellogines. $d v$, vitellodnetes. $s v$, vilellosac ou confluent dilaté des vitellodueles. $r s$, réservoir séminal. do, oviducle. $m l$, utérus. $v g$, vagin, montrant son orifice ou vulve $v u$ au-dessous du pénis.

nissent avant de déboucher à l'extérieur par un orifice dont la situation esl variable.

La partie terminale de cet appareil est susceptible de présenter diverses modifications; clle est en général accompagnée de glandes dites prostatiques et enfermées, quand cclles-ci acquièrent un grand développement, dans une poche à parois musculaires, la poche du cirre.

Quant aux organes femelles, ils se composent essentiellement d'un ovaire, encore appelé germigène, parce qu'on l'a regardé comme 
donnant naissance seulement à des vésicules germinatives : en réalité, cet organe produit des ovules, qui se présentent sous la forme de cellules pourvues d'un gros noyau (résicule gerninative) et d'un protoplasme (vitellus formatif) peu abondant. De cet ovaire presque toujours simple part un canal vecteur ou oviducte (germiducte) de longueur variable. L'appareil femelle comprend en outre des glandes chargées de fournir à l'œuf son vitellus nutritif : ce sont les vitellogènes ou glandes albuminipares. Le produit de ces glandes est représenté par des cellules qui se résolvent en granulations nageant dans un liquide albumineux; il est emporté par des conduits vitellins ou vitelloductes; ceux-ci se réunissent à l'oviducte pour se continuer par un canal sinueux, l'utérus, qui va déboucher à peu de distance de l'ouverture mâle. A l'orifice de l'utérus se trouve un amas glandulaire destiné à sécréter la coque de l'œuf (glande coquillière). Enfin, nous devons citer un canal qui met encore en communication les organes femelles avec l'extérieur, le canal de Laurer.

L'œuf mûr est donc entouré d'une coque plus ou moins épaisse; il renferme une seule cellule ovulaire et un vitellus nutritif contenant des noyaux qui témoignent de son origine cellulaire.

La plupart des Trématodes sont ovipares; dans quelques cas seulement, le développement embryonnaire s'effectue en entier dans l'utérus. Quant aux phases ultérieures, elles varient suivant les formes qu'on étudie. Chez les Polystomiens, qui sont ectoparasites, et les Aspidocotylés, qui sont endoparasites, le développement est presque toujours direct; chez les Distomiens, endoparasites, il s'accompagne au contraire de métamorphoses.

Les affinités des Trématodes avec les Cestodes sont bien établies par les organes de fixation (Polystomiens), par la constitution des principaux appareils et même, jusqu'à un certain point, par le développement (Distomiens). Mlais les Trématodes se relient peut-être mieux encore aux Turbellariés. Enfin, ils ont aussi des relations évidentes avec les Hirudinées.

Monticelli (1) admet, comme Burmeister, trois sous-ordres parmi Jes Trématodes : $1^{\circ}$ les Mulacocotylés, plus connus sous les noms de Digenèses ou Distomiens; 20 les Aspidocotylés, parasites internes des Reptiles, Poissons et Mollusques; $3^{\circ}$ les Hétérocotylés, correspondant aux Monogenèses ou Polystomiens. Le second de ces groupes ne mérite pas de retenir spécialement notre attention.

(1) F. S. Monticelu, Cotylogaster Michaelis $n . g . n$. sp. e revisione degli Aspidobothridæ. Fortschritt zum siebenzigsten Geburtstage Rudolf Leuckarts. Leipzig, 1892. 
PREMIEN SOCS-ORDRE

DISTUMENS

Trématodes munis au plus de deux ventouses. Métanorphoses complexes. Presque toujour's endoparasites.

Le corps est ordinairement aplati, quelquefois cylindroïde. Les ventouses proprement dites sont situées sur la face ventrale : il en existe au maximum deux, unc antérieure, terminale ou subterminale, et une postérieure, ì siège variable. Parfois, en outre, on observe de nombreuses rentouses minuscules sur la face dorsale ou sur la face ventrale.

La bouche s'ouvre d'ordinaire dans la ventouse antérieure, plus rarement dans la postérieure. L'intestin est bifide ou simple; il fait défaut chez quelques formes.

Les orifices génitaux sont situés à la face ventrale.

L'œuf des Distomiens, rarement pourvu d'appendices polaires, est toujours plus petit que celui des Polystomiens. L'embryon qui s'y forme ne va pas, en général, au delà de la phase morula, et le développement se complique de métamorphoses, lesquelles sont liées à des phénomènes de génération alternante et à des migrations multiples.

Nous allons exposer rapidement la succession des phases de cette évolution, d’après les belles recherches de Steenstrup, Van Beneden, de Filippi, de la Valette Saint-Georges, Moulinié, Pagenstecher, G. Wagener, Ercolani, etc. Toutefois, comme l'histoire de toutes les formes de ce groupe est loin d'être connue, nous ne pourrons tracer qu'une sorte d'esquisse schématique, sauf à revenir plus loin sur quelques faits particulier's.

Lorsque les œufs des Distomiens sont déposés dans un milieu convenable, et en particulier dans l'eau, ils laissent échapper, au bout d'un certain temps, les embryons qui se sont développés dans leur intérieur. Ces embryons sont tantôt nus, et alors peu actifs, souvent pourrus de piquants à la partie antérieure, tantôt revêtus de cils qui leur permettent de se mouvoir arec rapidité, ce qui leur a valu le nom d'embryons infusoriformes.

Après aroir nagé, pendant un temps indéterminé, dans le liquide ambiant, ils doivent pénétrer, par une migration active, dans le corps d'un animal aquatique, le plus souvent d'un Mollusque (Limnée, Plitnorbe, Paludine, etc.). - Une fois fixé, l'embryon donne naissance à un organisme plus ou moins complexe, ordinairement muni d'une ventouse, et auquel on donne le nom général de sac germinatif ou sac cercarigère. Lorsque cet organisme est dépourvu de bouche et de tube digestif, Van Beneden le distingue par la dénomination de Spo- 


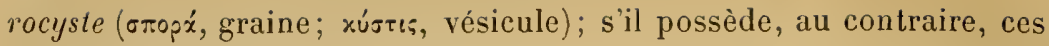
organes, de Filippi l'appelle Rédie.

Ces sacs germinatils, qui représententla seconde phase du développement extérieur, peuvent se multiplier soit par scission, soit par bourgeonnement endogène ou exogène; mais, dans les Sporocystes ou dans les Rédies ainsi produites, aussi bien que dans celles qui leur ont donné naissance, la germination interne aboutit à la formation de nouveaux organismes, appelés Cercaires. - Un Cercaire peut être comparé, pour la forme, à un têtard de Grenouille : il possède un corps plus ou moins ovalaire, terminé en arrière par une queue très

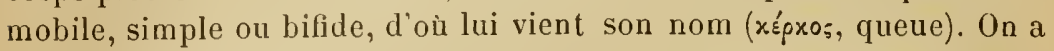
longtemps regardé les Cercaires comme des Infusoires : c'est Steenstrup qui, le premier, a reconnu leur nature et obtenu leur transformation. Ils sont quelquefois munis de taches oculaires; quant à leur organisation interne, elle est lout à fait analogue à celle des Distomiens adultes, dont ils ont déjà les ventouses caractéristiques; mais les organes génitaux font défaut.

En général, au bout d'un cerlain temps, les Cercaires s'échappent du sac qui les contient, et quittent même souvent le corps de leur hôte : c'est à cette période qu'on peut les observer nageant ou rampant en liberté dans l'eau. Ils sont alors à la recherche d'un meilleur gîte : par une nouvelle migration active, sans doute, ils pénètrent dans le corps d'un autre animal aquatique. Ce second hôte est parfois encore un Mollusque; d'autres fois, c'est un Ver, un Crustacé, un Insecte aquatique ou une larve; plus rarement, un Vertẻbré : Poisson ou Batracien. Ercolani a trouvé aussi des Cercaires chez des Mollusques terrestres, et il est mème établi que ces organismes peuvent se fixer à la surface de certaines plantes ou de corps inorganiques divers. Quel que soit du reste leur nouveau séjour, ils perdent leur appendice caudal, se contractent en boule et s'entourent d'un kyste à double paroi qu'ils sécrètent eux-mèmes. Leur organisation subit alors quelque perfectionnement, el parfois les organes sexuels commencent à se développer. Mais là ne doit pas se terminer la vie de ces jeunes Distomiens agames.

Une dernière migration a lieu, en effet, celle-là toute passive, quand l'animal ou le végétal porteur de Cercaires enkystés est ingéré par un Vertébré. Le parasite résiste à l'action des sucs digestifs, et gagne l'organe qui représente son habital définitif. C'est presque toujours une cavité en communication avec le monde extérieur: intestin, canaux biliaires, vessie urinaire, voies aériennes, sinus sousorbitaires (des Oiseaux), etc. Arrivé en ce point, le jeune Ver acquiert ses organes génitaux et devient ainsi un Distomien adulte.

En résumé, on voit que $: \mathbf{1}^{\circ}$ l'œuf donne naissance à un embryon ordinairement cilié, qui vıt en liberté dans l'eau, puis se fixe sur un animal inférieur : Van Beneden compare cet état au proscolex des 
Cestodes; $2^{\circ}$ l'embryon se transforme sur place en un sac cercarigère, correspondant at un scolex: $3^{\circ}$ ce sac germinatif engendre des Cercaires qui se mettent en liberté pour aller s'enkyster sur un hote nouveau; puis ces Cercaires, qui ne sont autres que des Distomiens imparfaits, parviennent che\% un hôte définitif qui a fail sa proie du précédent; ils deviennent alors adultes et sexués, comme les proglottis des Cestodes.

L'érolution de toutes les espèces de Distomienis ne suil pas d'une façon invariable la voie typique que nous venons d'indiquer; elle est tantôt plus, tantit moins complexe. D'ailleurs, les recherches de Pagenstecher tendent a prouver que, suivant les conditions climatćriques, la succession des phases peut varier dans des limites étendues ou, en d'autres termes, que le processus évolutif est susceptible de se condenser ou de se dilater. Ainsi, dans certains cas, le sac germinatif se montre déjà formé dans l'embryon ( $M o-$ nostoma mutubile), ainsi que l'avait observé von Siebold, qui regardait ce corps vésiculaire comme un "parasite nécessaire». G. Wagener aurait mème vu l'embryon cilié clu Diplodiscus subclavatus présenter dans l'œuf la constitution complexe d'une Rédie (fig. 217). D'autre part, on constate assez souvent que des sacs germinatifs donnent naissance à des Cercaires dépourvus de queue, c’esta-dire à des Distomiens agames; quelquefois aussi des Cercaires complets s'enkystent dans l'intérieur même du sac germinatif. Enfin, il est des Cercaires qui se transforment en Distomiens adultes sans passer par la phase asexuée, des Distomiens enkystés qui acquièrent des organes

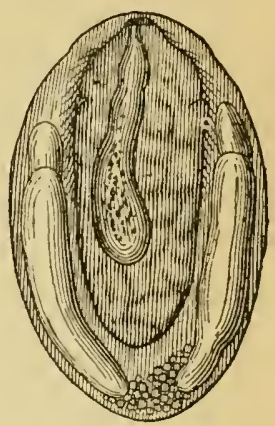

Fig. 21i. - OEuf de Diplodiscus subclatalus, contenant un embryon pourvu d'un lube digeslif (Ercolani). sexuels complets et produisent des œufs, etc. Dans un sens opposé, on a vu, chez des Cereaires, l'appendice caudal se développer en Sporocyste. Par exception, l'embryon se transforme, non en un sac germinatif, mais en une larve typique (Tetracolyle) qui s'enkyste et arrive arec l'hôte intermédiaire dans l'hote définitif (Holostomidés).

Ajoutons que les Distomiens peuvent subir d'importantes variations de forme suivant le milieu dans lequel ils se développent. C'est là un fait remarquable, qui a été mis en lumière par les expériences d'Ercolani.

Ces Vers sont endoparasites d'un grand nombre de Vertébrés, et même de quelques Invertébrés; on les trouve rarement sur les branchies ou dans la cavité buccale des Poissons. Ils se montrent surtout abondants chez les animaux aquatiques et chez les espèces terrestres qui fréquentent les lieux humides. Les formes jeunes sont endoporasites des Invertébrés et de quelques Vertébrés.

Railliet. - Zoologie. 
5 familles: Monostomidx, Wedlide (Didymozoonidx), Distomidx, Amphistomidix, llolostomidie.

Famille des MONOSTOMIDES. - Corps aplati ou rylindroïde, de forme variable. Une ventouse antérienre plu: ou moins évilente; jamais de ventouse postérienre. Bonche s'ourrant dans la ventonse antérienre. Intestin bifide. Orifices génitanx situés dans le tier's antérieur du corps ou à l'extrémité caudale.

Palasites internes des Mammifires, des Oiseaux, des Batraciens et des Poissons.

Genres Monostoma Zeder, Nocotyle Dies., Ogmogaster Jaegerskiöld, Opisthotrema Leuck.

Genre Monostome (Wonostoma Zeder, 1800). - Corj's de forme variable, sans papilles ou verrues sur la face ventrale. Vullouse antérieure ordinairement terminale, armée ou inerme. Orifices génitaux dans le liers antérieur du corps.

Monostome changeant (M. mulubile Zeder, 1800. - Syn. : Monostomum microstomm Creplin, 1829; M. attennatum Holin, 1859, nec Rud., 1809). Corps d'un jaune sale, parfois légèrement rosé, lonuc de :j à 2'́ millimètres, large de 2 à 8 millimitres, déprimé, pliur en lessous, un peu convexe en dessus, atténué antírieurement en còne, élargi et arrondi en arrière. Ventouse subterminale, très pelite. Un bulbe asophagion épais vers le milieu de la longueur de l'œsophagre. liranches de l'intestin simples, anastomosées en arrière. Testicules et ovaire globuleux, silués dans la partie postérieure du corps. Vitellogènes formant un vaste réseau qui enveloppe tous les orranes internes. Llérus décrivant de nombreuses sinuosilés sur presque toute la largem du corps. Orifices génitax contigns, s'ouvrant en avant du bulbe asophagien. OEufs brunàtres, ovoüdes, longs de $173 \mu$, Jarges de $84 \mu$.

Vit dans les sinus sous-orbitaires, sous la membrane niclitante, dans les cavilés nasales, la trachée, les cavités thoracique el abdominale (sacs aériens) et mème dans l'intestin de divers Oiseaux pour la plupart aquatiques. Wiesentlal, ron Siebolı, Diesing ef Zürn l'ont recueilli en particulier dans les sinus sous-orbitaires de l\%ie domestique; Wiesenthal aurait mème signalé, en 1799, une sorte d'épizoolie lue à la présence de ce Ver. Monticelli pense qu'il faut rapporter à la mème forme le parasite rencontré par ['olonio dans un casum de Dindon el décrit par Holin sous le nom de $\boldsymbol{M}$. allenuatun.

C'est sur celte espèce que von Siebold a fait, dès 1835 , les premières observations relalires au développement des Trématodes. Chez les individus adultes, on voit se former dans l'wuf m embryon couvert de cils vibratiles, qui ne tarle pas à sorlir de la coque en soulevant un opercule et nage alors librement dans l'utérus. Cet embryou, qui présente une lache oculaire d'abord bipartite, laisse voir, au milieu de sa partie postérieure, un corps non cilié, allongé, un peu plus épais au milieu, légèrement étranglé en avant, muni d'un appendice caudal et de deux courts ajpendices latéraux. Von Siebold regardait ce corps, dont les mouvements sont très limités, mais indépendants de ceux de l'embryon, comme "un parasile necessaire »; on sait aujourd'hui qu'il représente un sac germinatil (Sporocyste) dû à un développement précoce de cellules germinatives. 
Monostome jamor (H. flumm Muhlis, 1831). - Corps jaune d'orle,

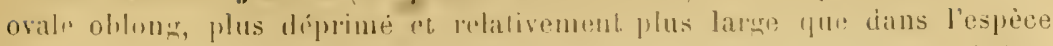

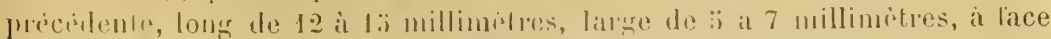

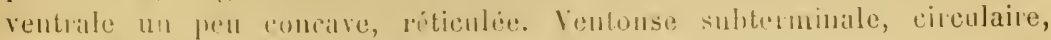

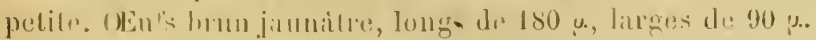

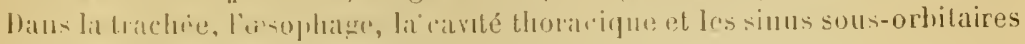

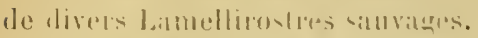

Commm alui dn M. mululite, l'ambryon du $M$. fluxum se trouve mis en

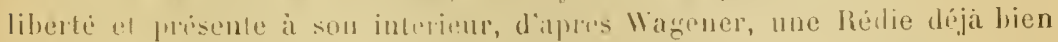

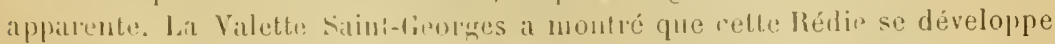

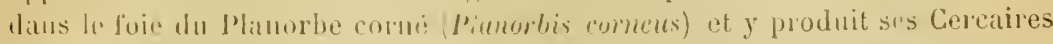

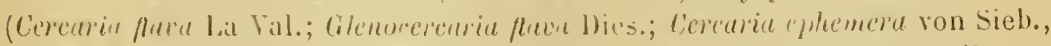

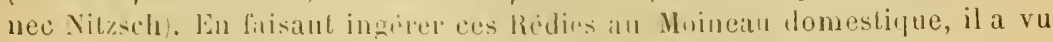
les Cercates domner des $\mathbf{y}$. fucum inzomplidrment développés.

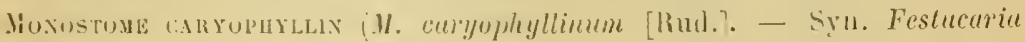

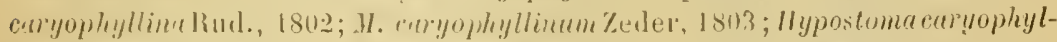

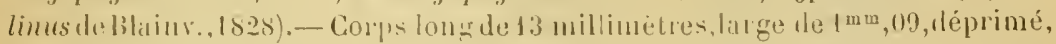
oblus en avant, rétréci an inrière. Ventousc inlèce, rlomboïlale. Intestin nou dislinct.

Espice dontense, que Creplin suppose correspondre a un jeme Bolhriocéphale. Vit dans l'intestin le L Énoche. Gurlt l'a tronvée a Berlin dans l'intestin l'ın Gilnard donestique, on elle avait cité tramsportée arec le Poisson qui l'héberıreait.

Noxustrile DU cristalun (M. Ientis von Noldmanu, 1832). - Dans le cristallin d'une vieille femme operé de la calitracte, Jüuken el von Nordmann rencontrient huit Vers logés dans les concles superficielles de l'organe. Ces Ver's mesuraient 0 mm, 21 de loug et présentaient des mourements lents.

S"izissint-il de Aunostomes? lien n'est moins prouvé. Ammon était porté à y voir plutút des Distomes, et Lenckart tend a les rapprocher du Distoma aculi humuri, dont il sera yuestion plus loin. (Voir p. 360).

MnNostume de Vay Setrex (M. Setheni Numau, 18'0). - Palasite extrait de la chambe antérieure de lusil d’une jument par Vau Selten, vétérinaire à Onderdenhimn (Hollande). Diesing le resardait, arec doute, comme un Pentastome (Prnlustoma Selleni). Nous avons montré que c'est une larve du liptère, quion doit raisemblablement rattacher aux (HEstriclés (1).

Moxusum nu Laprx (U. leporis Kuhn, 1829; M. Kuhni Cobb., 1839). - Forme déconverte par Czermack dans le péritoine du Lapin. Ce n'est cerlainement qu'un Cysticerque pisiforme en voie de déreloppenent, la cavité d'invagination le la tête s'élant forme depuis peu. Nons avons recu souvent de tels parasites dans les mèmes conditions que kuhn (2).

Genre Notocotyle (Notocotyle Diesing, 18:32\% - Con allonsé, muni à sa face ventrale de papilles on verrues disposées en séries longritudinales. Ven-

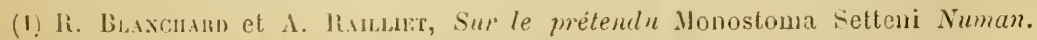
Bullet. Suc. zoot. d. liance, XV1, p. 26, 1871.

(2) A. li.nuler, sur le pétemlu Jonostomn leporis Kuhn. Ibid., XV, p. 13:, 1 s90. 
touse antérieure ordinairement terminale, inerme. Orifices génitaux dans le tiers antérieur du corps (1).

Notocotyle verruqueux ( N. verrucosum [Frölich]. - Syn.: Fasciola verrucosa Frölich, 1789; Monostoma vernucosum Zeder 1800; M. attenuatum Rud., 1809, nec Molin, 1839; M. lineare Rud., 1819; Notocotylus triserialis Dies., 1839; Notocotyle triseriale Dies., 18ว0). - Corps blanc rosé ou rougeâtre, loṇ en moyenne de 5 à 6 millimètres, large de près de la moitié, du moins pendant.

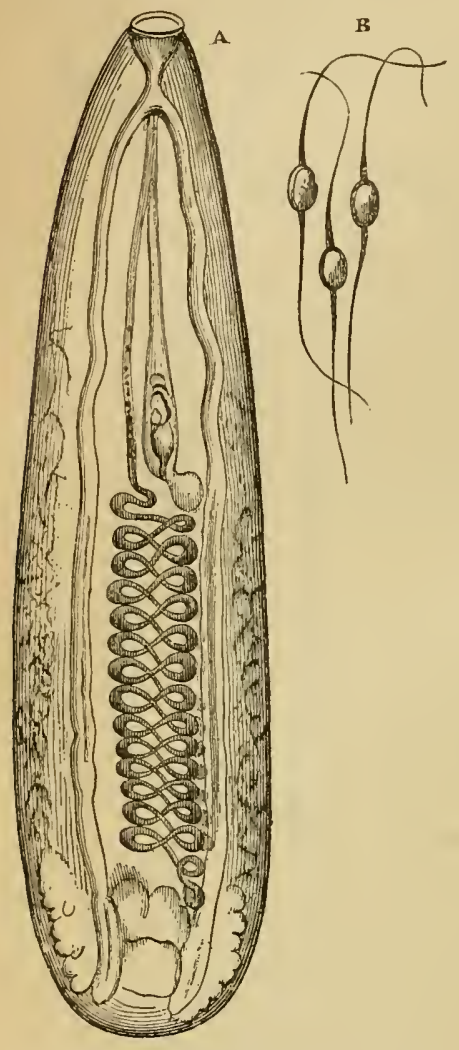

Fig. 218. - A, Notocotyle verrucosum jeune, sans papilles - venlouses, grossi 40 fois; B, trois cufs du mème, grossis 215 fois (Dujardin). la vie, atténué en avant, arrondi en arrière, très déprimé, offrant sur la face ventrale, plus ou moins concave, trois séries longitudinales de verrues ou papilles-ventouses arrondies, d'un jaune brunàtre, atteignant leurs plus grandes dimensions vers le nilieu du corps. Ventouse subterminale, circulaire. OEsophage court, suivi d'un intestin à deux branches écartées graduellement, puis rapprochées vers leur terminaison. Deux testicules à contour irrégulier, situés vers l'extrémité postérieure, en dehors des branches intestinales. Ovaire multilobé, entre ces branches et au mème niveau. Vitellogènes latéraux, dans la moitié postérieure du corps. Orifices génitaux presque contigus, immédiatement en arrière de la bifurcation de lintestin. OEufs un peu rougeâtres, elliptiques, longs de 23 , Jarges de $11 \mu$, munis à chaque pòle d'un appendice filiforme long de $160 \mu$; segmentation commencée avant la ponte.

Ce parasite a été trouvé dans le gros intestin ef les cæcums d'un grand nombre d'Oiseaux, notamment de la Poule (ron Siebold), du Canard domestique (Bremser, Van Beneden, etc.), du Canard musqué (Dujardin), de l'Oie domestique (Creplin).

Les verrues, formées par un soulèvement du tégument et de la couche musculaire. sous-jacente, paraissent manquer chez les individus jeunes, et sont mème parfois absentes chez les adultes, ce qui tient peut-

être à leur rétraction: cette forme non verruqueuse était considérée par Rudolphi comme une espèce particulière (Monostoma attenuatum). - Notons d'ailleurs que le nom de Notocotyle vient de ce que Diesing avait cru voir les papilles-ventouses sur la face dorsale.

P. J. Van Beneden a observé très fréquemment, dans le foie et dans d'autres organes des Planorbes et des Limnées, des Rédies contenant des

(1) F. S. Moxticel.r. Sul genere Notocotyle Diesing. Bollett. della Soc. di natur. in Napoli, VI, p. 26, tav. I, 1892. 
Cercaires a corps granuleux, a trois ou deux taches oculaires, à queue longue, effilée, sans expansions membraneuses; il pense que ces Cercaires sont les larves du Notocotyle verruqueux. Monticelli est tenté de les rattacher, au conlraire, à un Amphistome, dont la ventouse postérieure n'aurait pas été aperúue.

Famille des DISTOMIDÉS. - Les Distomidés ont le corps aplati ou cylindroïde, avec une venlouse antérieure terminale, el une ventouse postéricure située sur la face ventrale, soit au milieu de la longueur, soil au tiers antérieur, soit plus rarement au tiers postérieur.

Q sous lamilles : Dislominix et Gasterostominx.

Les Distominés se distinguent à leur bouche, qui s'ouvre dans la ventouse antérieure, et à leur intestin bifide.

Sous la forme adulte, ils sont parasites à l’intérieur du corps des Vertébrés el de quelques Invertébrés, rarement sur les branchies des Poissons.

Ils comprennent les 7 genres suivants :

1

2

3

4

Orifices renitaux près de la ventouse postérieure........

5 Orifices génitamx ì l'extrémité postérieure du corps........

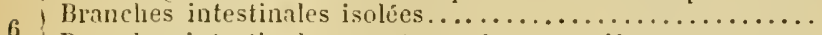

Brunches intestinales anastomosées en arrière............

\section{2} 6 3 4

Rhopalophorus. Disinma.

Cephalogonimus. 5

Mesogoninus.

Urogonimus.

Köllikeria.

Gynecophorus.

Genre Distome (Distoma Retzius, 1786 ; Fasciola L., 17 7ั8, pro parte). - Ces Vers sont plus connus sous le nom de Douves; on les reconnail surlout aux orifices génitaux, qui sont situés en avant de la ventouse postérieure. Les branches de lintestin sonl séparées sur toute leur longueur, el la ventouse antérieure est dépourvue de tentacules protractiles.

On a partagé ce genre en 9 sous-genres, dont voici le tableau :

6

Plus de deux testicule.

Un on deux testicules.............................

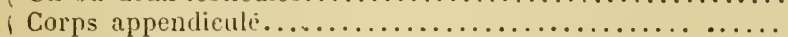

i Pas d'appendice caudal. ........................

Y Ventouse postérieure pédonculée.................. Podocotyle.

| Ventouse postériemre sessile...................

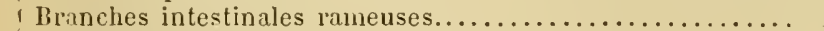

¿ Branches intestinales simples (Disloma s. str.).......... 5

1 Ventouse antérieure nue....................... 6

i Ventouse antérieure entourée de piquants ou de lobes..... \&

Branches intestinales trés courtes....................

\{ranches intestinales prolongées en arricre............

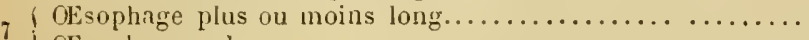

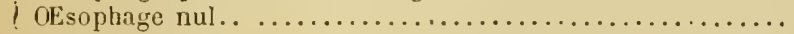

8 IVentouse antérieure entourée de piquants..............

8 ; Ventouse antérieure entourée de lobes charnus............

Pulyorchis. 2 Apoblema. Fasciola. 6 Brachycolium. 7 Dicrocalium. Brachylaimus. Echinostoma. Crossodera. 
I. Sous-genre Fasciola (L., 17i;8) Cobbold, 185̆9. Cladocolium Duj., 18.13. - Intestin à deux branches rameuses.

Distome hépatique (I). hepaticum [L.]. -- Syu : Fusciola hepatira L., 1758; D. hepulirum liolzins, 1786; F. humama Gmelin, 1789;

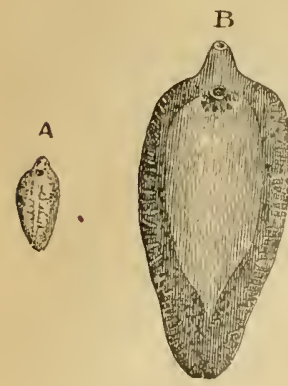

Fig. 219. - Nistoma hopaticum, grandeur naturelle. A, jeune. B, adulte (1)rig.).

D. crrix Sonsino, 1890 ; Cladocolium hepalirum Slossich, 1892). - Corps aplati, foliacé, d'mne teinte sénérale brun pille, long en moyenne de 20 à 30 millimètres sur une largenr de 8 à 13 millimètres; ovale oblong, élitrgi en avant, puis rétréci brusquement en une sorte de con conique dit "prolongement céplialique"; alténué et obus en arripre. Ventouse antérieure terminale, petite, arroudie; rentouse rentrale siluéc à 3 ou 4 millimètres en arrière de la prenière, un peu plus grande, a ouverture en lorme de triangle i base antérieure. OEsophage moins long que le fharynx. OEufs ovoïdes, brun jaunitre, longs de 130 à 1 is $\mu$, larges de 70 a $90 \mu$.

Le Distome hépalique, plus connu des vétérinarires sous le nom de Douve du foie, se rencontre surlout dans les canaux biliaires du Moulon; mais on peut lohserver aussi chez d'atutres Mammifères, tels que le Bouf, le Bullle, la Chère, le Chameau, lo Lama (Delafond), le Cheval, l'Ane, le Cochon, le Lapin domestique, le Lapin de garenne, le Lièvre, le Cobaye (Sonsino), elc. (1). On l'a même trouvé chez l'Homme à diflérentes reprises.

Érolutiox. - D'après Bollinger, les oufs sont émis par les Douves et évacués arec les fèces dans toules les saisons et à peu près dans tous les mois de l'année : les variations quantilatives de celle éracuation ne seraient que le résultat d'un degré variable d'infestation.

La segmentalion, dont les différentes phases ne sont pas encore
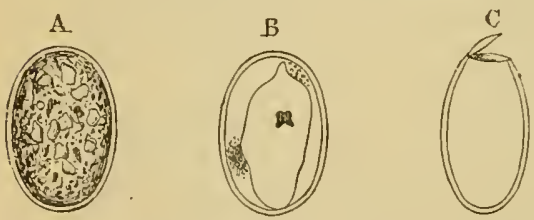

Fig. 220. - (Eufs du Distoma hepaticum, grossis 130 fois. - $\lambda$, nuf pris dans les conduits Jiliaires d'un Ioulon. B, anf ronlenaut un embryon développé. C, wuf alpris l'éclosion. connues, délnute ì l'intérienr même de l'utérus; mais le développement de l'embryon ne sachève qu’à l'extérieur, sous l'influence de l'humidilé el l'une température modérée. En été, ce développement exige en moyenne trois à six semaines; d'après Thomas, deux ì lrois semaines sulfisent lorisue la lempérature ambiante est de 23 ì $36^{\circ}$. Liembryon sort de l'reuf en soulevant un opercule qui occupe l'un des pôles; il a l'aspect d'un corps allongé, couvert de cils viluatiles, atténué en arrère el plus large à la partie antérieure, où existe une petite éminence papilli-

(1) Blavette (1840) dit l'avoir renrontré dans le foie de la Poule, mais il y a eu sans doute erreur de determination. 
forme destince à joure le rôle d'un appareil perlorateur. A quelque distance de celle-ci, on remarque une lache pigmentaire opaque, formée de denx lobes dessinant un $x$, el qu'on regarde eomme une tache oculatire. La moitié anteriente du corps est remplice par une masse granuleuse qui parail correspondre it un lube digestil rudimentailere, tandis que la seconde motitir renferme déjâ des cellules germinalives. De plus, ì lit partie moyenne, on observe de chayue colé, dans la profondenr de la paroi du rerps, an entonnoip vibratile.

Cel embryon nagse avee une wrander pipidité dans l'eau, el il est très curienx de suivre, comme nons l'avous lait souvent, ses évolutions dans une gonlle d'eall qu'on a recouverte d'une latnello scellée ì la pa-

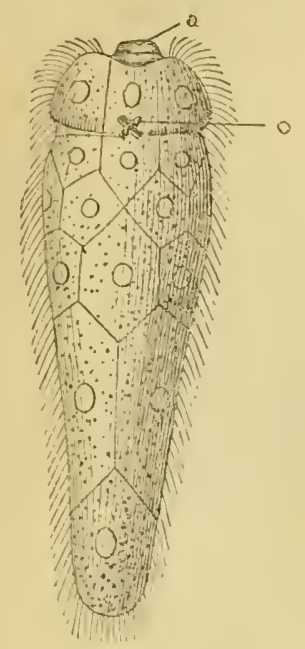
ralline. Sil ne rencontre pas l'hole qui lui convient, il ne tarde pas à périr'; d’apres Thomas, sa mort survient en moyenne au houl de huil heures.

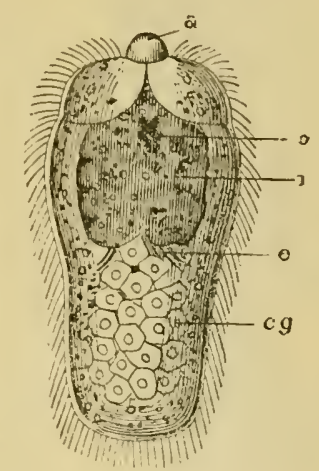

Fig. 231, - Ém!ryon cilié el libre du Distomer hepalicum, d'apres Lenckirt. - $a$, appareil perforalcus, o, lache oeulivire.

Fig. 23.. - Le mimi, contruete, avec l'obauche du lube digestif et un imas le cellules germinalives, d'apres lecuekart, - $t$, alpureil perforaleur. o, lache oculatire. i, tube digestif. e, entummoir eilit, cy, cellules gormiualives.

Longtemps cet hòte internódiaire est resté ignoré. On soupçonnait seulement que ce devait êtro suclque Molluspue terrestre on aquatique. En acrut 1873, Weinland trouva, dius les Alpes de Sonahe, une

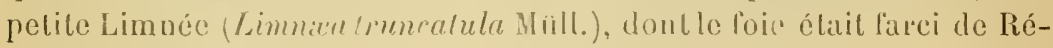
dies rentermant des Gereaires it trigument épineux, ce qui est un des caractères du Distome hépatique. Uno étude: altentive des Cercaires en question lui nontra qu’ils avaient une tendance marquéc à ramper à la surface des objels. Il pensi done qüils devaient s'enkyster sur l'herbe, et être ingérés dans cel état parr les Moutons, pour se transformer en Distomes lıépaliques.

Se basant sur cette observation, Leuckart parvint à obtenir l'infestation d'une autre espèce de Limnée (Limnieu peregra Gm.) par les embryous de Doure; mais celle infestation ne se produisait guère que 
chez les individus très jeunes, et du reste les Rédies développées mouraient au bout de quelques semaines (1).

Par l'intermédiaire de Weinland, il se procura dès lors le Limnæa truncatula, qui ne se rencontre pas aux environs de Leipzig, et ne tarda pas à constater que ce petit Mollusque se laisse infester facilement à tous les âges, et qu'il se prête à l'évolution du parasite jusqu'à l'élat de Cercaire. A peu près en même temps, Thomas, en Angleterre, arrivait à une constatation identique (2). Le véritable hôte intermédiaire étail enfin trouvé.

Les expériences entreprises avec d'autres espèces de Limnées, des Planorbes, Paludines, Limaces, etc., n'ont pas abouti. Cependant,

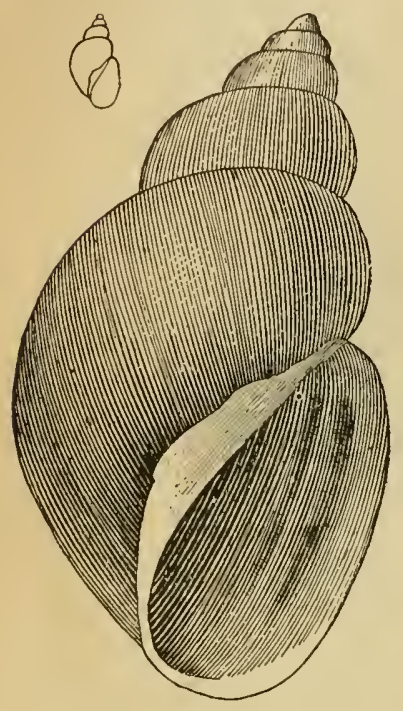

Fig. 223. - Limnxa truncatulu, graudeur naturelle et grossi (0rig.). on a fait remarquer que le Distome hépatique se rencontre dans des localités où n'existe pas le Limnxa truncatula, par exemple, aux îles Shetland, aux Etats-Unis el en Australie; mais il est possible que, par suite de ses faibles dimensions, celte Limnée ait échappé aux recherches, ou que l'hôte intermédiaire soit représenté par un Mollusque de quelque genre voisin.

Lorsqu'un embryon de Douve a rencontré le Limnxa truncatula, il enfonce dans les tissus de ce Mollusque son appareil perforateur, qui s'allonge, devient conique et se fraye un passage à la façon d'un coin : à la faveur de la brèche ainsi produite, il pénètre à l'intérieur du corps. Il se fixe d'ordinaire dans la chambre pulmonaire ou à son voisinage. - Une fois établi dans cet habitat, il perd sa couche de cellules ciliées, et se transforme en une Sporocyste ovoïde : les deux lobes de la tache oculaire se séparent et perdent leur aspect semi-lunaire; l'appareil perforateur ne persiste qu'ì l'état de rudiment, et l'appareil digestif disparait peu à peu. Cette Sporocyste est suscepti-

(1) Des observations récentes de Lutz, faites aux îles Sandwich, il semble pourtant résulter que, sous les tropiques, Limnæa peregra représente un hôte très favor'able pour le Distome hépatique. Cet auteur dit avoir inlesté des Cobayes au moyen de Cercaires extraits de ces Ilollusques (A. Lutz, in Centralbl. f. Baliter., XI, p. 783, 1892).

(2) A. P. Thonas, Report of experiments on the development of the liver-fluke (Fasciola hepatica). Journ. of the R. agricultural Soc. of England (2), XVII, p. I, april 1881. - ID., A second report, etc. Ibid., XVIII, p. 439, october 1882, et Veterinarian, p. 180, 1883. - In., The natural history of the liver-flutie and the prevention of rot. Veterinarian, p. 469, 1883.

R. Leuckant, Zur Enlwicklungsgeschichte des Leberegels. Zoologischer Anzeiger, IV, p. 641, 12 déc. 1851 ; V, p. 524, 9 oct. 1882 . Archiv für Naturg., XlVIII, Bd. I, p. 80,1882 . 
ble de se multiplier par scission transrersale, du moins lorsqu'elle est encore très jeune; en tout cas, elle grossit rapidement et devient sacciforme, arec une longueur de $0^{\mathrm{mm}}, \ddot{\mathrm{o}}$ ì $0^{\mathrm{mm}}, 7$. Ses cellules germinatives envahissent bientôt toute la cavité du corps et se disposent en amas mûriformes qui donnent naissance chacun à une Rédie. Chaque Sporocyste contient d'ordinaire cinq ì huit liédies, à divers degrés de développement. Quand l'une d'elles a alteint une certaine longueur, elle rompt la paroi du sac maternel et s'en dégage. Une fois libre, elle se fraye un chemin à travers les tissus du Mollusque et va se fixer dans des organes variés, mais de préférence dans le foie, où elle s'accroit jusqu ì acquérir une longueur de $1 \mathrm{~mm}, 0$.

Celte Rédie est cylindrique et présente, comme la plupart des Ré-

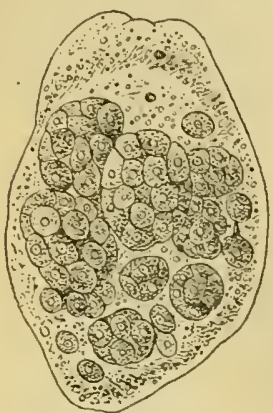

Fig. 224. - Jeune Sporocysle du Distome hípalique, quelques jours après la pénélration de l'embryon cilié dans lat Limnće (Leuckart).

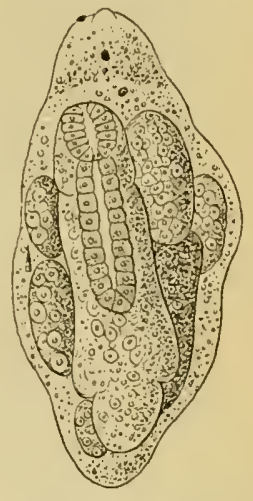

Fig. 295. - Sporocysle du Distome hípatique, contenant rles Rídies à divers degrís de développemenl. Grossissement: 200 diamèlres (Leuckart).

dies, à l'origine de l'extrémité postérieure amincie, deux courts prolongements latéraux qui jouent le rôle de membres rudimentaires; en outre, ì quelque distance de l'extrémité antérieure, on remarque une sorte de collier faisant plus ou moins saillie ì la surface du corps et destiné sans doute à donner une base solide à la régrion buccale. Mais le caractère essentiel de la Rédie est la présence d'un appareil digestif, comprenant une bouche, un pharynx et un intestin simple, terminé en cul-de-sac.

Les cellules germinatives de la Rédie donnent naissance, soit ì des Rédies filles, soit directement ì des Cercaires: les premières se forment surtout pendant l'été, les autres pendant la saison froide. Chaque Rédie produit en moyenne 1 ã à 20 Cercaires, qui se développent successivement, s'échappent à la faveur d'un petit orifice impair situé sur le côté de la Rédie, un pen au-dessous du collier, et enfin se dégagent en rampant du corps du Mollusque, de façon à se trouver bien tôt en liberté dans l'eau, où ils nagent avec agilité, se contractant en tous sens. 
VERS.

Étudiés à l'état de repos, ils montrent un corps aplati, oralaire, mesurant en mojenne $280 \mu$. de long sur $230 \mu$. de large, el une queue plus de deux fois anssi longue que le corps. Celui-ci offre deux ventouses correspondant it celles de l'adulte, mais ayant toutes deux ì peu près lia même dimension. Au fond de la ventouse antérieure s'onvre la bouche, suivie d'un bulhe pharyngien et d'un cesophage qui so bifurque en deux branches intestinales en avant de la rentouse ventrale. La partie antérieure du corps est revêtue de trìs fines épines.

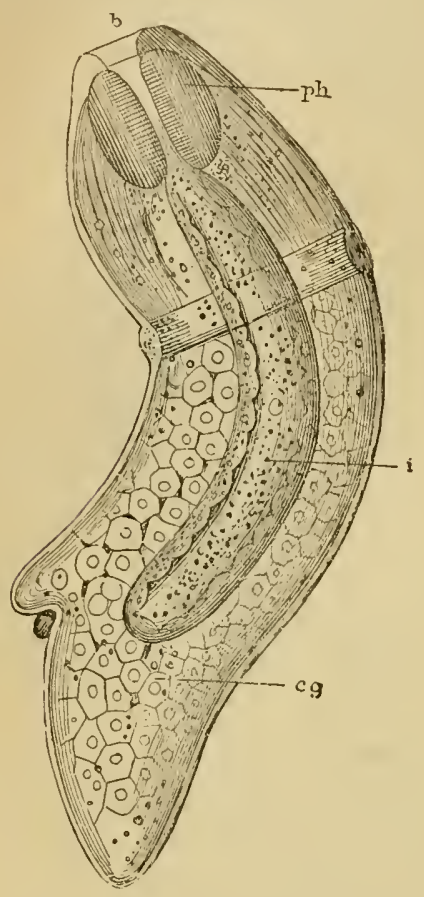

Fig. 226. - Lićdie du Distoma hepaticum, W'après Leuckart. - $b$, bouelic. $y h$, phangnx. $i$, lube digeslif. $c$, cellules dites germinalives, destinées à procluire des Cercaires.

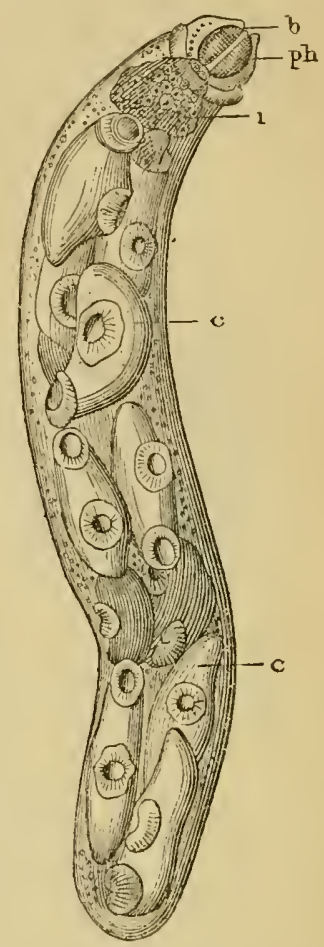

Fig. 227. - Rídie contenant des Cereaires, d'apris Leuckart. - b, bouche. ph, pharyux. $i$, lube digestif. $c$, cercaires.

Enfin, de chaque côté du corps, on remarque des cellules infiltrées de granulations réfringentes, qui masquent en grande partie les organes internes: ce sont les cellules cystogènes.

Le Cercaire ne parait vivre en liberté dans l'eau que pendant une courte période : il s'arrête bientút au contact d'un objel submergé, d'une plante aquatirque, par exemple, se contracte en boule el laisse exsuder de loute sa surface une sorte de mucus qui entraîne les ggralnulations des cellules cystogènes; la queue se détache alors, si elle n'est pas tombée avant le début de ces phénomènes. En peu de temps 
la couche exsudée dureit, et l'animal se tronve enfermé dans un kysul protecteur d'use blancheur de neige. si par des mamipulaliuns soigneuses on lextrail de ce kyste, on conslate que les celluhes granuleuses ont disparu, que le parenchyme du conps ast transpareut, el que l'intestin el l'appareil excréteur's sonut dislincts (lig. 2:31.

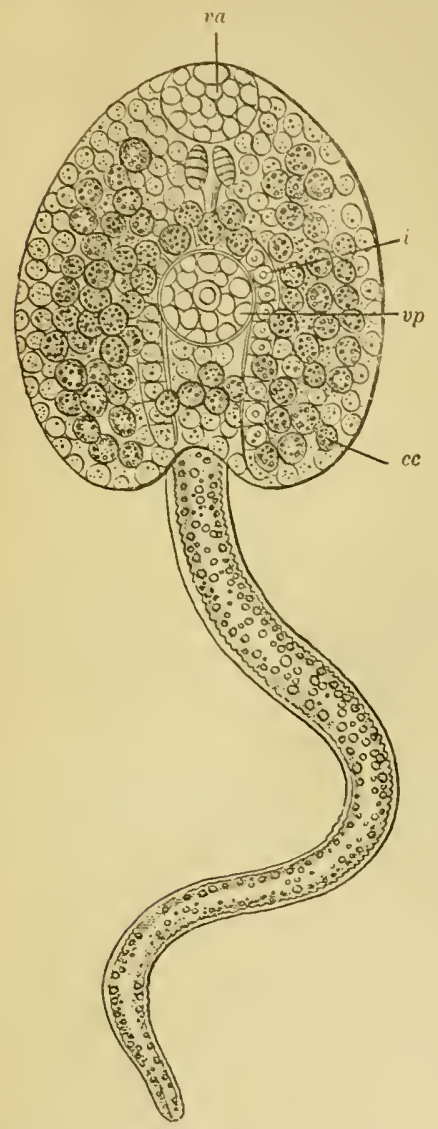

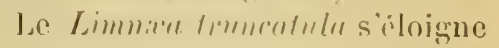
sourent des ruissman: il est facile de comprendere, par suite, que les Cerraires, cus s'échappant do teur hite, puissent s'enkyster

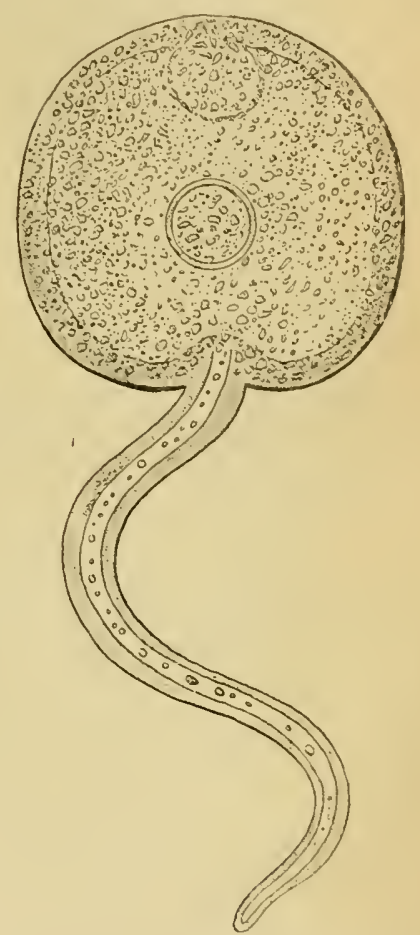

Fig. 248. - Cercanre hllre, Inlqu’il se présente nageant lïg. 29. - Cereaire en roie d'enkystement, dans l'eau, daprès Thomats. - va, ventouse antéricure. $v \%$, ventouse postírieure. $i$, intestin. $c e$, cellules cyslogìnes. firossissement : 160 dianètres.

sur l'herbe des prairies. C'est done en consommant cette herbe que les animaux doivent s'infecter : le kistr, parrenu dans l'estomae, se dissout el met en libertí le Ver, qui probablement peinetre dans le foie par le canal cholidequr.

Ainsi s'explignerail le risullat mogalil des experienees de Leuckart, qui arail lait ingriper à des Lilpins des Cereaires non encore enkivtés. Thomas fait remarefuer, diutre part, fue les kystes de Cercaires occupent surtout les feuilles inférieures des plantes : èest pourpuoi 
VERS.

sans doute les Moutons, qui tondent les pâturages de très près, sont plus souvent infestés que les Bœufs. Quant à l'Homme, il doit surtout ingérer les Cercaires à la faveur des plantes consommées en salade, notamment du cresson.

D'après l'ensemble des faits exposés plus haut, l'infestation ne peut guère se faire, duns nos climats, que pendant la belle saison: la plus favorable correspond à l'automne. Gerlach admettait même que les Douves pénètrent toujours à l'automne dans le foie des animaux, et en sont expulsées au commencement de l'été suivant;

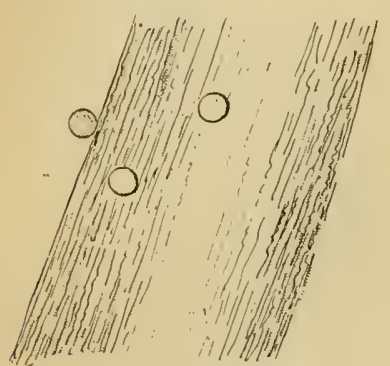

Fig. 230. - Trois kystes de Distome hépalique, fixés sur un brin d'herbe, d'apres Thomas. Grossissement : 10 diamètres.

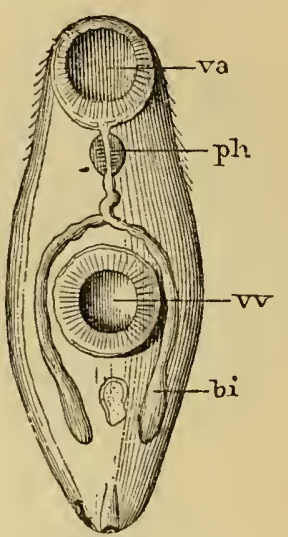

Fig. 231. - Jeune Distome extrail de son kyste, d'après leuckart. - va, ventouse antérieure. $v v$, ventouse ventrale. $p h$, pharynx. $b i$, branches de linteslin, terminées en crecum.

mais ces assertions sont contredites par les observations de chaque jour, et la preuve est faite que les Douves sónt susceptibles de demeurer plus d'un an dans les canaux biliaires de leur hôte. J'en ai trouvé (D. hepaticum et $D$. lanceolatum) chez un Mouton isolé et soustrail aux conditions d'infestation depuis près de trois ans.

Organisation. - Thomas estime à six semaines au moins le temps nécessaire pour que le Cercaire introduit dans le foie devienne un Distome adulte. Les principales modifications qu'il subit tiennent naturellement au développement des organes génitaux, qui entraine d'ailleurs une modification de forme. Il nous reste à faire connaitre la constitution anatomique de ce Dislome adulte, qui a été étudié avec soin par de nombreux observateurs, parmi lesquels Mehlis, É. Blanchard, Leuckart, Sommer, Hacé et Poirier.

La cuticule présente des plis transversaux assez réguliers; clle tapisse l'intérieur mème des ventouses et se replie dans la portion anlérieure du tube digestif, ainsi que dans la région terminale des conduits génitaux; elle est revètue de nombreux petits piquants squamiformes, dirigés en arrière, très rapprochés à la face ventrale, plus espacés et disparaissant mème dans la région postérieure de la face dorsale. Au-dessous de la cuticule existerait une couche élastique reposant sur une enveloppe musculaire composée de plusieurs couches : une superficielle, continue, de fibres annulaires; une seconde de faisceaux longitudinaux séparés, et entre les deux une couche de fibres diagonales limitée au tiers antérieur du corps. 
La zone centrale du corps a pour base un tissu conjonctif à grosses cellules polyédriques ou arrondies; elle est traversée par un système dorso-ventral de faisceaux musculaires, et entoure les différents organes internes.

Le systeme nérveux se compose de deux ganglions cérébroüdes, situés immédiatement en avant de la ventouse antérienre et reliés entre eux par une commissure transversale passant au-dessus du pharynx. Chacun de ces deux gangrlions émet deux nerfs on avant, un par còté et trois en arrière. Des deux antérieurs, l'interne se rend à la couche cellulaire et à l'enveloppe musculaire cutanées, l'externe envoie des branches dans la ventouse et dans le tégument. Le nerĺ né sur le còté du ganghlion se bifurque et va se terminer dans la couclıe musculo-cutanée. Quant aux nerfs postérieurs, on peut les distinguer en interue, moyen et externe. L'interne se dirige vers la face dorsale et reste accolé au tégument: Poirier a pu le suivre au delà de la ventouse postérieure. Le nerf moyen s'abaisse en longeant la surface externe du pharynx: d'après Sommer et Macé, il se réunirait à son congénère dans un petit ganglion sous-usophayien, de manière à former un véritable collier osophagien. Enfin, le nerf externe, ou tronc longiludinal ventral, le plus important, se rapproche de la face ventrale et s'étend jusqu'au voisinage de l'extrémité postérieure, en enroyant de fins rameaux dans les différents organes.

L'appareil digestif se compose de deux parties: l'initestin buccal, tapissé par la cuticule, el l'intestin moyen, revètu d'un épithélium à cellules cylindriques. - L'inlestin buccal ou antérieur comprend lui-mème trois régions : l'infundibulum buccal, le pharynx et l'œsophage. L'infundibulum buccal est constitué par deux culs-de-sac qui occupent le fond de la ventouse antérieure, l'un du còté dorsal, l'autre du còté ventral, et sont limilés par deux lèvres : celles-ci, qui sont susceptibles de faire saillie dans la cavité de la ventouse, circonscrivent la bouche, laquelle conduil dans un pharynx ovoïde, très musculeux, dont la

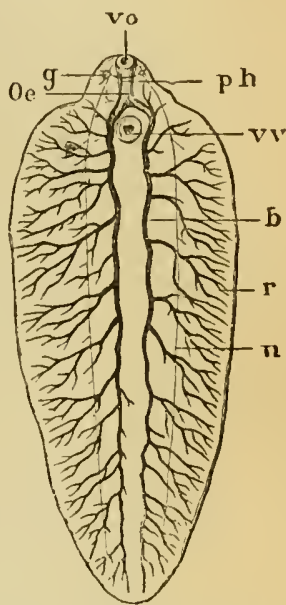

Fig. 232. - Appareil digestit el système nerveux de la Douve hépatique (le systène nerveux est schématique). - vo, ventouse buccale, $v v$, ventouse ventrale. ph, pliaryux. $a$, cesopliage. $b$, hranches de lintestin. $r$, leurs ramificalions. $g$, ganglions nerveux. $n$, nerf ventral. structure est analogue à celle des ventouses et le rend propre à aspirer les liquides nutritifs. Vient ensuite un court osoplage se divisant en deux branches en avant de la poche du cirre et de la ventouse ventrale. Ces deux branches intestinales se prolongent jusqu'au voisinage de l'extrémité postérieure, où elles se terminent en cul-de-sac; elles émettent, sur leur trajet, un grand nombre de ramifications arborescentes, aboutissant également à des cæcums.

D’après Leuckart, tous ces canaux renferment des cellules épithéliales altérées, des globules sanguins gonllés et décolorés et des corpuscules lymphoïdes. Les Douves se nourriraient donc du mucus brun qui revèt les conduits biliaires, et qui montre ces mêmes formations. Küchenmeister pensait d'abord qu'elles devaient se nourrir de bile; il admit plus tard qu'elles puisaient du sangr dans le foie. Un fait que nous avons conslaté nous a fait 
appuyer cette dernière manière de voir: dans des foies de Moutons dont le système antíniel avait élé injecté de plitre coloré, nous avons trouvé un grand nombre de bouves dont le tube digestif étail injecté de la mème manière, bien qu'il n'y eut pas trace le plàtre dans la lumière des canaux liliaires. Évidemment celte substance avatit élé empruntée par succion aux petits vaisseaux des cantux biliaires, au moment mème de l'injection.

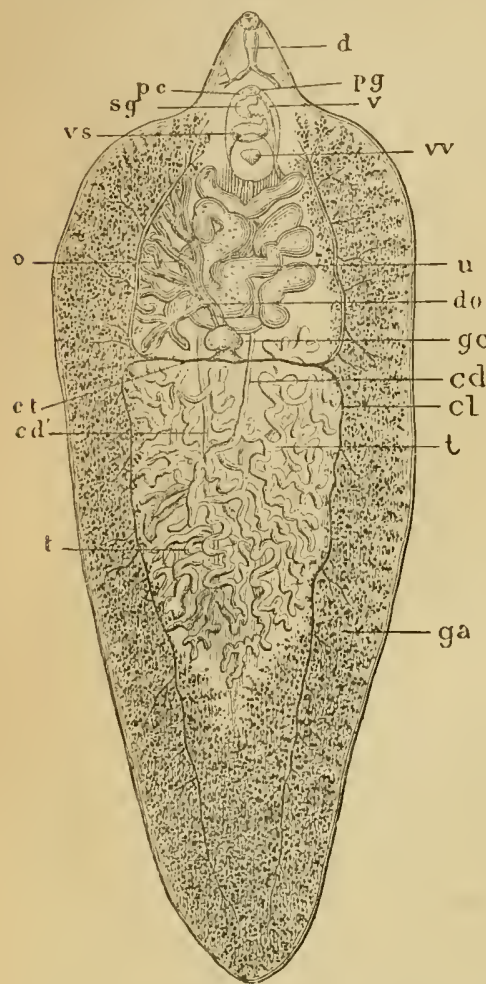

Fig. 233. - Appareil gruilal de la Jonve hépaliyae, su par lis fiace renlrale. - $\pi$, lube digeslif. on, ventouse ventrale. $t$, lesticule antórieur. ct, son camal defirent. l', lesticule jostíricur, $c t$, son canal deferent. rs, vésicule sóminale. $s g$, canal íjaculateur. $p g$, port: gínital. $p c$, poche du cirre, 0 , osaire. do,

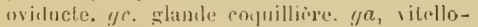
gine- cl, vifulloducte longitulinal. $c t$, sitellolucte lransversal. u, ulérus, v, lagin (Orig.).

l.es caisalicules de l'uppureil cxcréteur convergent vers un canal longitudinat unique, silué sur la ligne médiane el débouclıant à l'extrémité postérieure de la face dorsale par un orifice (pore excréteur) qui, depuis hudolphi, esı désigné sous le nom de formmen caudale.

Les deux sexes sout réunis sur le mème individı. - Les testicules sont représentés par de nombreux tubes ramifiés, lerminés en cul-de-sac et occupant un vaste espace à la partie centrale du corps; on en cistingue deux superposés, dont les ramificalions aboutisseni à deux canuux déférents. Ceux-ci pilssent au-dessus des organes femelles el se confondent, au niveau de la ventouse ventrale, en un couduit unique, qui ne tarde pas à se dilater en une vésicule s'minale pyriforme. De celte vésicule émane un canal étroit el sinueux, que Poirier désigne sous le non de cunul prostutifue, parce qu'il est. en touré de glandes unicellulaires venant déboucher dans son intérieur; il se continue lui-mème par un tube cylindrique à lumière plus étroite, mais à parois épaisses el musculaires, le canal ijaculateur, revètu intérieurement d'une cuticule garnie de pelits piquants, et allant s'ouvrir dans le cloaque génitaI, petile dépression siluée à un demimillimètre à peine en avant de la ventouse postérieure. Ce tube est susceptible de se retourner sur lui-mème à la facon d'un doignt de grant et de faire ainsi sailie à f'extérieur, en montrant sa surface culiculaire - devenue externe - liérissée des piyuants en question, qui apparaissent dirigés d’arrière en atrant: cest la ce qu'on appelle le cirve ou pénis. Toute la partie impaire de l'appareil reeteur màle - réceptacle séminal, canal prostatique, grandes prostatiques, canal éjaculateur - se trowe contenue dans un sac ovoïde, à parois musculeuses, appelé poche du cirre, dont la cavité est comblée, en dehors des organes précités, par un tissu fibrillaire réliculé. Les spermato- 
zoiddes sont filiformes, avee une tite peu renfle; ils s'itecumulent dans la vésicule síminale jusquian moment de la férondathon.

Lovate est une flande tululeuso ranitiée, situce en général dans la partie droite dn corps, et dont les divisions se rassemblent en un wridure (yermiducte) simple - Surles parlies latérales du corpset juspula l'exlrimite postérieme, on ohsure en outre de nombremx petits culs-ale-sac whalulates : ce sont lus vitellugimes ou wamles allumminipares, dont les combits excretems

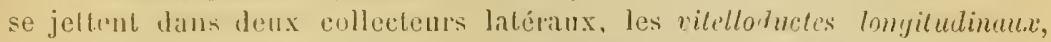

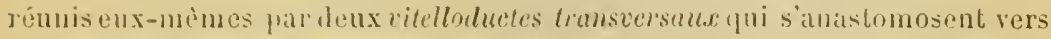
la ligne médiane en domnant naissane ì une vésicule pyriforme, le méseroir

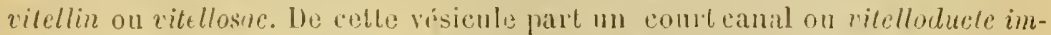
fuir, qui se dirige enavant et en haut, promseréunir licntòt à l'oviducte. Celte jonction a lieu daus l'iphisseur mème d'une glande? coquillive, dout le nom indique suffisamment le roble : cest un amas globuleux de glandes unicellulaires, munies chacune l'uu longr et fin canal excriteur yui va délouclıcrau niveau du confluent dontilvient d'ètre parle. - Il faut encore signaler, dans la rógion limitée par la slande counillière, le camal de Laurer, donl les relations exactes ont été déterminées par loirier. Il prend nais. sance sur l'oviducte, à peu le distance du conlluent, se dirige en arriere, sort de la glande, lécril une boncle el va sumrir an dehors surla ligne médiane de la face dorsale. On rencontre souvent dins ce canal des spermatozoïdes, des ovules et des globules vitellins; aussi le considere1-on généralenent comme un canal de dérivation destine a rejeler ì l'extérieur le trop-plein des glandes ginitales. - De l'union de l'oviducte et du vitelloducte inpair résulte un conduit nuique, l'utérus, qui se lirige en avant tout en décrivant de nombreuses circomvolutions et ne tarde pas a se dilater par l'accumulation des oufs : il apparaît à l'ail nu sous l'aspect de taches brun jaunatre disposées en arriere de la ventouse pos-

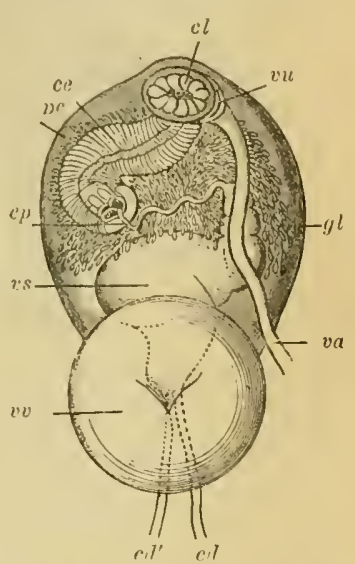

Fig. 33\%. - l'orlion antírieure ou lesminale de lapparoil ginital de lat Houve hépaliqume, dlityrès Sommer. - en, venlouse venlrile. erl, crl', camaux diffirents. 11s, visicule siminale. $c p$, canal prostatique. gl, glandes unice]lulaires annesies an canid pros. tiktipue. ce, canal çjaculatems. $c l$, eloajue ginilal. pe, poche du cirre. va, vagin. vu, rulve.

térieure. Arrivé an voisinage de cette venlouse, son calibre se rétrécit et ne laisse plus passer les anl's qu'un à un : celte rígion terninale constitue le vayin; elle passe a wanclie de la rentouse, suit li face inférienre de la poche lu cirre, el aboutil à la volve, située daus le cloaque génital, à còté de lorifice nàle ou un pen en arrière.

Le cloaque ou pore ginilul cousiste en une simptr dépression cupuliforme, elliptique, à grand axe transversal, ocenpant la partie antérienre de la poche du cirre.

Le mode suivant lequel s'ellectue la fécondation n’a pu encore ètre déterminé d'une façon alssolument positive. On a supposé d'abord qu'il devait y aroir fécondation réciproque, deux individus s'accoup'ant rentre à rentre, comme chez les Annelides el les Gastriropudes. Dinutres ont almis, avec Stieda, que la copulation avait lieu par le canal le Laurer, représentant le 
véritable vagin : l'individu jouant le rôle de màle serait alors placé sur le dos de l'autre. Mais le cirre est beaucoup trop volumineux pour s"introduire dans ce canal ou dans le vagin, ce qui doit éloigner l'idée d'un accouple-

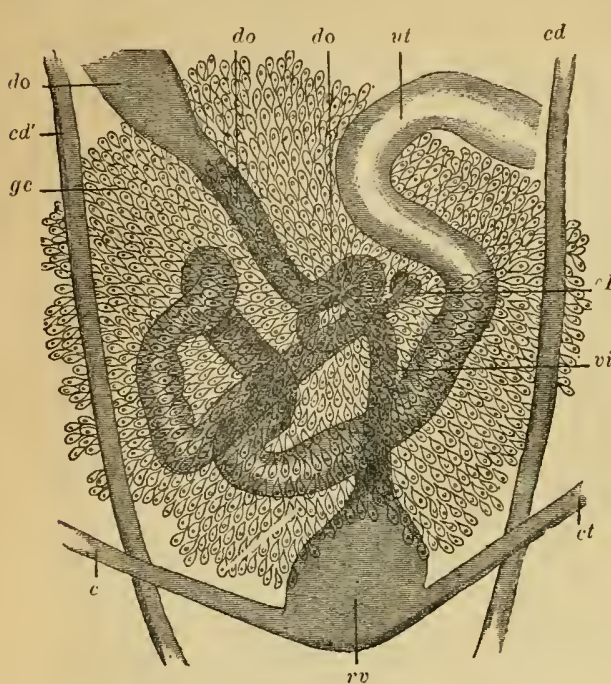

Fig. 235. - Point d'union des différentes parties de l'appareil génital femelle, d'après Sommer. - do, oviılucte ou germ iducte. $c t$, vitelloductes transversaux. $r v$, réservoir vitellin. $v i$, vitelloducte impair. $c L$, canal de Laurer. ge, glande coquillière. $u t$, premier repli de l'utérus se dégageant de la glande coquillière. $c d, c d$, canaux déférents. Grossissement : 140 diamètres. ment interne. Du reste, chez beaucoup de Trématodes, le canal éjaculateur n'esi pas susceptible dese renverser. Quant à la fécondation réciproque parjuxtaposition des cloaques, il paraît bien difficile de l'admettre. Reste l'opinion émise par Sommer, opinion analogue à celle que cet auteur professe pour les Ténias, et qui nous paraît la plus fondée : d'après lui, le cloaque gẻnital se fermerait par la contraction de son système musculaire, et le sperme, déversé dans sa cavité par le canal éjaculateur, passerait facilement dans le vagin, puis dans l'utérus. Il y aurait donc auto-fécondation sans copulation.

D'après ce qui vient d'ètre exposé, on voit que les ovules formés dans l'ovaire arrivent à la naissance de l'utérus, où ils doivent recevoir le contact des spermatozoïdes. A ce niveau également, ils rencontrent les granulations albumnineuses sécrétées par les vitellogènes, et qu'ils doivent s'adjoindre. Puis le produit de la glande coquillière se dépose à la périphérie et se durcit en formant une coque brune résistante. Un œuf mùr renferme donc une seule cellule ovulaire (vitellus de formation) et un amas de granulations vitellines (vitellus de nutrition). Les œufs ainsi constitués s'accumulent dans les circonvolutions de l'utérus; i's sont expulsés par la vulve.

Distribution géographique. - La Douve hépatique est répandue dans toute l'Europe sauf l'Islande, en Afrique, dans les deux Amérique et en Australie.

Pathologie. - Le Distome hépatique pénètre jusque dans les canaux biliaires d'un petit diamètre, et pour cela s'enroule sur lui-même en cornet, la face ventrale devenant externe; il se meut dans ces conduits en se servant de son prolongement céphalique musculeux comme d'un appareil dilatateur; ses ventouses le fixent, et il ne peut d'ailleurs revenir en arrière à cause du revêtement épineux de la cuticule, qui l’ancre dans les parois. Les exemplaires qu'on trouve dans la vésicule biliaire ou dans l'intestin sont presque toujours des individus morts. 
Les parasites sucent le sang des petits vilisseaux et provoquent unc irritation des canaux biliaires entrainant des hémorragies répétées et d'autres troubles assez. variés, qui se traduisent par des symptômes plus ou moins graves : ainsi se manifeste l'affection hylrémique, ou, si l'on veut, l'anémic pernicieuse à laquelle on donne habituellement les noms de cachexie aqueuse, pourriture ou distomatose.

Celte affection est courante dans les localités humides; mais le plus souvent elle se manifeste par épizooties, qui surviennent surtout ¿̀ la suite des inondations, et dont un certain nombre ont été constatées en France. Dans les lles Britannirues, la perte annuelle est estimée à un million de Moutons (Thomas). La proportion est à peu près la mème pour l'Europe centrale (Leuckart).

La distomatose, en tant que maladie spéciale, n’existe guère que chez les Ruminants domestiques; elle est d'ailleurs plus rare chez le Bouf et chez la Chèvre que chez le Mouton. Nous devons ajouter cependant qu'on l'a observée aussi chez le Porc, l'Ane (Cadéac), le Lapin domestique (Railliet), le Lapin de garenne et le Liève (Thomas), enfin chez l'Homme.

Les jeunes animaux (agneaux et antenais, veaux), sont plus fréquemment envahis que les adultes; on a mème signalé la présence de Douves chez les foetus ou les nouveau-nés (Willius, Fromann, Bilhuber).

A l'abattoir de Berlin, Hertwig a observé des cas de distomatose à toutes les époques de l'année, mais surtout à l'automne et au printemps.

Les symptômes de la maladie sont peı saisissables au début. Les animaux sont moins vifs; leurs muqueuses sont pâles; il existe cependant une tendance marquée à l'engraissement. - Puis l'appétit dininue; une soif intense el fréquente se manifeste; la rumination devient irrégulière; les animaux s’affaiblissent; la peau et les muqueuses se montrent d'un blanc mat légèrement jaunìtre; l'embonpoint n'est plus que factice et tient à l'inliltration séreuse du tissu conjonctif sous-cutané : si l'on écarte les paupières en les pressant légèrement entre le pouce et l'index, on roit apparaitre un bourrelet blane jaunàtre en saillie sur leur bord (wil gras). - Au bout d'un temps variable, l'amaigrissement s'accuse; les muqueuses sont d'une pàleur extrème; les animaux mangent à peine. Les cedèmes se localisent et s'aecentuent dans les parties déclives; ils se dissipent par la marche et se reproduisent pendant le repos; on remarque surtout celui qui siège dans l'espace intermaxillaire (bouteille): il disparaît à la bergerie et se reforme au paturage. Souvent il survient de l'ascite.

La marche du mal est assez variable; cependant, si l'infestation a eu lieu, comme c'est le cas ordinaire, à la fin de l'été ou en automne, on voit les troubles s'accuser au commencement de l'hiver', la période d'amaigrissement ne survenant guère que vers le mois de janvier. La 
durée moyenne est de deux à six mois. La terminaison la plus fréquente est la mort; il est rare d'observer une réelle guérison lorsque le mal est un peu avancé.

A l'autopsie, on trouve des lésions plus ou moins accusées suivant la période à laquelle les animaux ont été sacrifiés. En thèse générale, on note une diminution de la masse totale du sang, de la proportion des globules rouges et de celle de l'albumine. - Au début, il existe encore de la graisse; la viande est demeurée assez ferme, mais les tissus sont froids et imprégnés de liquide. - Plus tard, l'infiltration est excessive; il ne reste qu'un peu de graisse presque fluide; les muscles sont lavés, mous, friables: des épanchements abondants se montrent dans les séreuses.

On a parfois cependant signalé une cachexie sèche : les tissus sont pâles, blanchâtres, mais non infiltrés; il s'agit probablement d'animaux qui ont passé la dernière période de leur existence dans des localités très sèches.

Outre ces altérations générales, il existe des lésions localisées au foie. Au début, on peut observer une inflammation intense de cet organe; plus tard, les lésions prennent un caractère chronique, et se traduisent surtout par une cirrhose plus ou moins accusée. Souvent même, les parois des canaux biliaires, fortement épaissies, subissent linfiltration calcaire.

Le nombre des Distomes qu'on trouve dans ces canaux est ordinairement de quelques dizaines; parfois, il s'élève à 600 ou 800 . Dupuy en a même compté plus de 1000 dans le foie d'un seul Mouton (1). Il faut d'aillenrs remarquer qu'au $D$. hepaticum se trouve fréquemment associé le $D$. lanceolatum.

La prophylaxie de la distomatose comporte, comme indication essentielle, le maintien des animaux en dehors des pâturages humides. Le drainage rendra, dans la même vue, les plus grands services. A défaut de cette opération, on pourra saupoudrer la prairie de chaux ou de sel marin, substances qui ont la propriété de tuer, non seulement les larves de Trématodes, mais aussi les Mollusques qui les hébergent. Il conviendra, en outre, de soumettre les animaux à un régime tonique, lors de leur rentrée à la bergerie : le sel marin et l'avoine sont particulièrement à recommander.

En ce qui concerne le traitement proprement dit, on a proposé, sans grand succès, l'emploi d'une foule de substances. Nous signalerons seulement l'usage, qui semble assez rationnel, du chlorure de sodium et de divers sels de fer. Mais il faut s'attacher surtout au choix d'un régime fortifiant.

Distomes erratiques. - Si la plupart des Distomes hépatiques s'établissent à demeure dans les canaux biliaires, il en est pourtant qui, lors de leur

(1) Et Thomas admet que le nombre d'œuls émis par chaque Distome hépatique est d'environ un demi-million. 
immigration, traversent les parois de ces conduits, pénètrent dans le parenchyme hépatique et en sortent mème parlois pour tomber daus le péritoine. I'autres passent dans les racines de la veine porte, el déterminent de la thrombose et des embolies. Un petit nombre enfin peuvent arriver dans les veines sus-lıépatiques et se répandre de là dans les différentes parlies du corps. C'est surtout dans le poumon qu'on les rencontre; ils y sont mème très communs chez le Bouf, où Gurll les a le premier signalés; Horot en a vu chez plus de 4 p. 100 des animaux abaltus à Troyes; on les a tronvés aussi chez le Mouton, le Buftle (Sodero) el le Dromadaire (Burke). Mais ils se montrent assez souvent encore daus le tissu conjonctif sousséreux on intermusculaire (Drosse, Morol), dans la rate (Lucet), elc. En tous ces points, ils sont entourés d'un liyste et nagent au milieu d'un liquide sirupeux brunitre, rougeatre ou jiunatre; souvent ils sont plus ou moins atrophiés, mais, contrairement à ce qui a été signalé, nous les avons vus quelquelois produire des æufs.

Distome hépatique chez l'Homme. - On connaît actuellement une vinglaine de cas (1) de Distome hépatique dans le foie de l'Homme. Le nombre de parasites hébergés par chaque sujet reste généralement très faible: souvent il n’en existe même qu’un seul. Aussi les lésions produites sont-elles rarement importantes. Dans certains cependant, et surtout lorsque les Douves sont en grand nombre, ces lésions peuvent ètre suffisantes pour entrainer la mort.

11 est possible que la distomatose soit endémique dans certaines localités: ce serail le cas, d'après Kratter, pour les régions riveraines de la Narenta, en Dalmatie; mais jusqu’à présent cette assertion n’a pas été confirmée. Notons cependant que Perroncito a trouvé fréquemment des oufs de Distomes (D. hepaticum et lanceolatum) dans les selles des ouvriers du Saint-Gothard atleints d'uncinariose.

Chez l'Homme comme chez les animaux, le Distome hépatique a été observé ì l'état erratique, soit dans la veine porte (Duval, de Rennes), soit dans des tumeurs sous-cutanées : à la plante dı pied (Giesker), à l'occipul (Penn Harris), en arrière de l'oreille (Fox), dans la région de l'hypochondre (Dionis des Carrières).

TnÉmatodes douteux. - Nous nous bornerons à mentionner, à l'occasion de ces Distomes erratiques, quelques espèces fort douteuses de Trématodes signalées chez l'Homme.

Treuller a décrit en 1893, sous le nom d'Hexathyridium venarum, un Ver plat qu'il aurait extrait de la veine tibiale d'un jeune homme, rompue au moment où il se baignait: ce n'est peut-ètre qu'une Planaire, à moins qu'il ne s'agrisse, comme le pensait Davaine, du Distorne lancéolé ou du Distome hépatique jeune. - Brera prétend que ce mème parasite aurait élé trouvé chez une nonne, en 180i, dans le sang extraild'une veine par une saignée. D'après Delle Ghiạje, il aurait été vu également à deux reprises, par Folinea, dans le sangr d’individus phtisiques.

(1) R. Buaxcinann, Nole sur quelques Vers parasites de l'llomme. Comptes rendus de la Soc. de biologie (9). 111, p. 604, 1891 .. 
Le même auteur a fait connaître, sous le nom d'Hexathyridium pinguicola, un prétendu Ver trouvé par lui dans un nodule adipeux périovarien, chez une femme de vingt-six ans morte à la suite d'un accouchement laborieux. Rudolphi, voulant examiner ce Ver, n'a trouvé qu'un corps noir et dur, sans organisation.

Enfin, Delle Chiaje a décrit sous le nom de Tetrastoma renale un Ver trouvé à Naples, en 1826, par Lucarelli, dans les urines d'une femme, et caractérisé par un corps oblong, une bouche ventrale en arrière de laquelle était situé l'orifice génital, enfin quatre ventouses à l'extrémité postérieure. Il s'agirait alors d'un Polystomien, accidentellement introduit dans l'urine.

Grand Distome (D. magnum Bassi, 1875. - Syn. : Fasciola carnosa Hassall, 1891, nec Rud., 1819; F. americana Hassall, 1891; D. texanicum Francis, 1891; D. crassum Leidy, 1891, pro parte). - Corps aplati, foliacé, de coloration brunàtre, long en moyenne de 30 à 33 millimètres (jusquà 73 millimètres) sur une largeur de 20 ả 30 millimètres; elliptique ou ovale, un peu plus large en arrière qu'en avant, où il n'existe pas de prolongement céphalique bien défini. Yentouse antérieure terminale, petite, arrondie; ventouse ventrale située à 4 ou 5 millimètres en arrière de la première, un peu plus grande, à ouverture en forme de triangle à base antérieure. OEsophage deux fois aussi long que le pharynx. OEufs ovoïdes, brunàtres, longs de 140 à $160 \mu$, larges de 90 à $100 \mu$.

Ce Distome, remarquable par ses grandes dimensions (1), a été découvert en 1872, par R. Bassi, dans les canaux biliaires de divers Cervidés (Cervus canadensis, $C$. claphus, C. dama, C. Aristotelis et plus tard $C$. moluccensis) entretenus dans un parc royal des environs de Turin. Le même observateur l'a rencontré également chez l’Antilope Nilgau (Portax picta) et, en 1874-79, chez des Moutons et des Chèvres domestiques du même parc. Fogliata l'a vu chez une jument, dans les environs de Pise. - Il était rationnel de considérer ce nouveau parasite comme ayant été importé par un Ruminant exotique. De fait, en 1891, Hassall et Francis le découvraient dans le foie, voire dans le duodénum et dans le poumon des Bœufs de l'ouest et du sud-ouest des États-Unis.

Les troubles qu'il détermine sont semblables à ceux occasionnés par le $D$. hepaticum. - Son évolution est jusqu'à présent inconnue. Stiles, qui a étudié l'embryon, lui reconnaît une très grande analogie avec celui du $D$. hepaticum.

II. Sous-genre Dicrocœlium Duj. - Intestin à deux branches simples prolongées en arrière et précéclé d'un cesophage simple assez long; ventouse antérieure sansépines ni lobes charnus; ventouse postérieure sessile.

2 sections.

(1) R. BAssi, Sulla cachessia ittero-verminosa, o marciaia dei Cervi, causata dal Distomuin magnum (con 3 tav.). Il medico veterinario, 1875. - A. Hassall, $A$ new species of Trematode infesting cattle. American veterinary Review, XV, p. 208, 1891. - M. Fraxcrs, Liver Flukes (with plates). Bulletin of the Texas Agricultural Experiment Station, n 18, p. 127,1891 . 
$1^{\text {re }}$ section. - Testicules silués derrière la ventouse ventrale, arant ou entre les replis de l'oviducte.

Distome lancéolé(I. lanceolatum [Rud.]. - Syn.: Fúsciola lanccolata Rud., 1803; D. lunceolatum Mehlis, 1825). - Cette espèce est beancoup plus petite que la précédente : elle mesure 4 à 9 millimètres de long sur $1^{\mathrm{mm}}, \tilde{3}$ ì $2^{\mathrm{m} n}, 0$ de large. Corps déprimé, lancéolé, lisse, atténué aux deux extrémités, principalement en avant; demi-transparent, taché en brun par les œufs. Ventouse antérieure terminale, arrondie; ventouse ventrale un peu plus grande, à ouverture circulaire. Olufs oroìdes, ì coque épaisse, de teinle brune ou fauve, longs de 38 à 430 , larges de 22 à $30 \mu$.

La Douve lancéolée vit dans les canaux biliaires du Nouton el de divers autres herbivores: Ane, Bœuf, Chève, Porc, Lapin, etc. (1). En outre, quelques observateurs l'ont recueillie chez l'Homme.

On la rencontre généralement en colonies nombreuses, et souvent associée à la Douve hépatique, dont elle partage, du reste, l'influence pathogène.

Son aire de distribution, très étendue, n'est cependant pas la même. Elle manque en Angleterre, tandis qu'elle se rencontre presque seule dans la Thuringe et à Berne.

L'Érolutiox de cette espèce n'est pas encore bien connue. L'embryon se développe dans l'utérus, et on peut le roir déjà tout formé dansl'œul' au moment de la ponte. Cependant, l'éclosion n'a guère lieu qu'après trois semaines de séjour dans l’eau. Une fois en li-

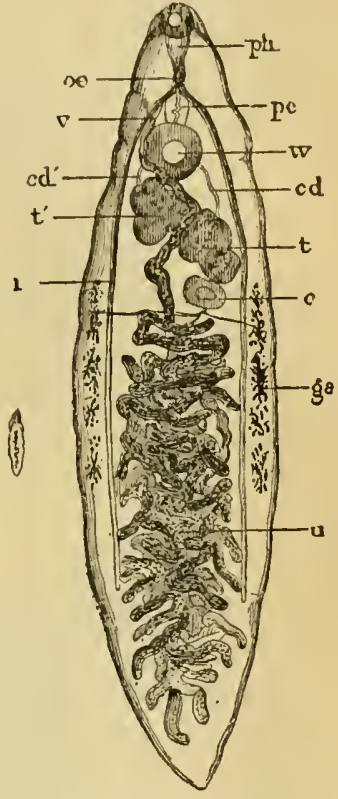

Fig.236. - Distoma lanceolatum, grandeur nalurelle et grossi 10 fois, vu par la face dorsale. $p h$, pharynx. $\propto$, œsophage. $i$, branches de liulcstin non ramifíes et lerminies en cul-de-sac. $v v$, venlouse ventrale. $t, l^{\prime}$, teslicules. $e d, r d^{\prime}$, canaux déférents. $p c$, poche du cirre. o, ovaire. $g a$, vilellogènes. $u$, ulérus. $v$ vagin (Orig.). berté, cet embryon se montre globuleux ou pyriforme, cilié seulement dans le tiers antérieur du corps et armé d'un aiguillon céphalique, en arrière duquel se voit un intestin simple; ses mourements sont moins rapides que ceux de l'embryon de la Douve hépatique. - WillemœsSuhm arait cru obtenir son développement chez une Planorbe (Planorbis marginatus). De nombreux exemplaires de ce Mollusque, placés dans un aquarium arec des cufs de Distome lancéolé, avaient été trourés, au bout de quelques mois, porteurs d'un Cercaire (Cercaria cystophora) précédemment décrit par G. Wagener et remarquable en ce qu'il possède deux queues inégales el qüil dérive d'une Rédie provenant elle-

(1) Ton Siebold croyait l'avoir rencontrée chez le Chat et van Tright chez le Chien mais tous deux avaient eu affaire évidemment au $D$. felineum Riv. 
VERS.

même d'une Sporocyste. Mais la preuve de la transformation n'avait pas, de la sorte, été rigoureusement fournie, ainsi que nous le faisions déjà ressortir dans la première édition de ce livre.

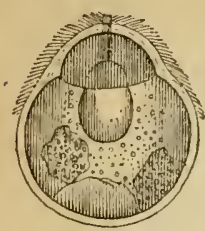

Fig. 237. - Embryon du Distoma lanceolatum, d'après Leuckart. Depuis lors, il a été bien établi qu'une erreur s'était produite dans l'observation de Willemœs Suhm, car Leuckart et Creutzburg ont fait voir que Cercaria cystophora appartient au cycle d'évolution du Distoma ovocaudatum, Ver assez commun sous la langue de la Grenouille verte. Du reste, des essais d'infestation tentés par Leuckart au moyen d'œufs embryonnés du Distome lancéolé n’ont donné aucun résultat, non seulement sur Planorbis marginatus, mais encore sur diverses espèces du même genre ou des genres roisins Limnia, Physa, Paludina, Ancylus et Cyclas (à part un cas douteux sur Limniea truncatula). Non moins infructueuses ont été les expériences portant

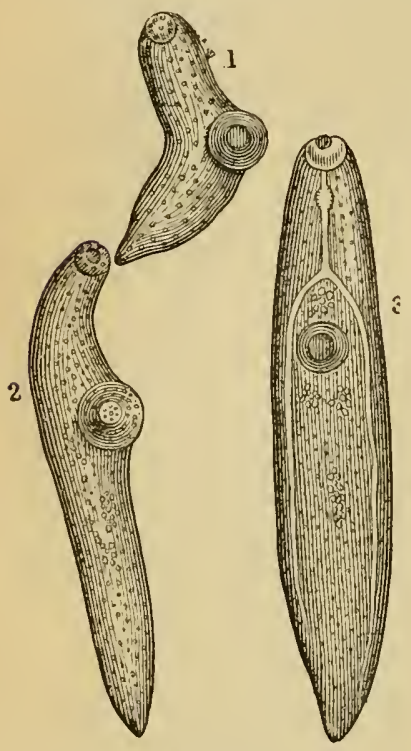

Fig. 238. - Développement du Distonza lanceolatum dans les conduits biliaires du Mouton, d’après Ercolani. - 1, première pluase : pas dappareil digestif. 9, phase ultericure: qquelques groupes cellulaires représentant les futurs leslicules. 3, phase plus arancée: lesticules plus nets; au-dessous de la ventouse ventrale, un groupe cellulaire annoncant la poche du cirle. sur les Mollusques terrestres des genres Limax, Agriolimax et Arion. Nous devons dire cependant que Piana a cru devoir incriminer une espèce d'Escargot. Il se basait sur le fait, signalé par Ercolani, de l'absence d'appareil digestif chez les très jeunes Distomes lancéolés : c’est seulement sur les individus mesurant 1 millimètre de long que commence à apparaitre cet appareil ; on voit auparavant se différencier des groupes d'éléments cellulaires qui représentent les futurs testicules, puis le canal éjaculateur et en dernier lieu l'ovaire. Or, Piana a précisément découvert, dans l'Helix carthusiana, des Sporocystes contenant des Cercaires à longue queue (Cercaria longicaudata), qui sont dépourrus de tube intestinal : c'est pourquoi il a supposé que ces Cercaires représentaient l'état larvaire du $D$. lanceolatum. Il est pourtant difficile dadmettre a priori, en raison du revêtement cilié de l'embryon, que l'hôte intermédiaire soit représenté par un Mollusque terrestre. - En somme, on ne connaîl jusqu'à présent rien de précis concernant l'évolution du Distome lancéolé : aussi nous bornerons-nous, en terminant, à rappeler une expérience déjà ancienne de Leuckart. Malgré l’immunité que nous avons signalée plus haut, les petites espèces de 
Planorbes contiennent assez souvent des kystes de Distome lonģ่ d'environ $0^{\mathrm{nm}}, \mathbf{2}$, dont les habitants rappellent la Douve lancéolée par la forme de leur corps, les dimensions relatives des ventouses, etc. Leuckart administra quelyues douzaines de ces kystes à un agneau de quatre mois qui, depuis sa naissance, n'avait été nourri qu'avec des fourrages recueillis dans un jardin : l'autopsie de cel animal, faite au bout de six semaines, montra dans les conduits biliaires huit exemplaires de Distoma lanceolatum, complètement adultes. - Peut-ètre l'embryon de ce Distome doit-il passer par un autre hôte avant de parrenir chez les Planorbes.

L'organisation du Distome lancéolé diffère un peu de celle du Distome hépatique. Les ventouses sont relatirement plus grandes. Les deux branches de l'intestin, au lien d'ètre ramifiées, sont simples et se terminent en culde-sac vers le quart postérieur du corps. L'appareil excréteur est moins compliqué : les canalicules émanés des entonnoirs vibraliles donnent naissance le chaque còlé du corps à un canal qui devient apparent dans le tiers antérieur, se porte en avant, puis se replie en arrière au niveau du phargnx, se rapproche de son congénère vers le tiers postérieur et s'unit à lui pour former un trone impair qui débouche à l'extrémité du corps par un forumen cuudale muni d'une sorte de splincter. Les testicules sont constitués par deux sacs mamelonnés placés l'un au-levant de l'autre, en arrière de la ventouse ventrale; leurs canaıx téférents se rémissent au bord antérieur de cette ventouse en un conduit unique qui pénètre dans la poclie du cirre et se dilate en une sorte de vésicule séninale : celle-ci aboutit enfin à un canal éjaculateur susc ptible de se renverser en forme de cirre mince et filiforme. La poche du cirre occupe l'espace compris entre la bifurcation du tube digestif et la rentouse postérieure. L'ovaire est un organe arrondi, situé en arrière des testicules st un peu plus petit que ceux-ci; l'oviducte qui en émane serait en communication avec un conduit provenant du testicule postérieur. Les vitellogènes sont peu étendus et occupent les còtés du corps. Les vitello luctes transversaux s'unissent à l'oviducte dans l'épaisseur de la glande coquillière, qui est formée de cellules assez làches. L'utérus constitue un cinal très long, décrivant de nombreuses sinuosités dans la partie centrale et postérieure du corps; il contient un nombre considérable d'œufs, que Leuckart évalue à plus d'un million. Ces œufs ont une coque qui brunit progressivement jusqu'à passer au noir; ils sont toujours pourvus d'un grand opercule. Revenu vers la partie antérieure, le tube utérin devient moins sinueux, passe entre les deux testicules, contourne le bord gauche de la ventouse ventrale et va se terminer dans le cloaque génital un peu en avant ou à gauche du cirre, par un vaggin garni d'une couche musculaire. Ce cloaque ou pore génital est situé à la bifurcation du tube digrestif.

Patiolorie. - Le Distome lancéolé est un peu moins commun, dans nos régions, que le Dislome hépatique; d'après Leuckart, on l'observe plus fréquemment dans le sud de l'Europe que dans le nord. Cependant, on le signale comme prédominant de beaucoup sur son congénère dans la Thuringe et à Berne. 11 paraît manquer en Angle- 
terre, mais se rencontre dans tout le reste de l'Europe, en Algérie, en Sibérie, dans le Turkestan, dans l’Amérique du Nord. Wernicke ne l'a pas trouvé à Buenos-Ayres.

Il ne paraît jouer qu'un rôle secondaire dans le développement de la cachexie aqueuse. Cependant nous l'avons vu produire seul, chez le Mouton, des lésions intenses de cirrhose.

D’après Oreste et Ercolani, les nodules crétifiés qu'on rencontre souvent dans le foie du Cheval auraient pour centre et pour point de départ des œufs de $D$. lanceolatum (1).

Chez l'Homme, il n'a été observé encore que six fois, par Buccholz, Chabert, Brera, Mehlis, Kirchner et Schiess-Bey (2). Il ne paraît pas avoir déterminé de troubles graves, siuff peut-être dans le dernier cas. Nous avons dit, en outre, que Perroncito arait trouvé des œufs de $D$. lanceolatum dans les selles des ouvriers employés au percement du Saint-Gothard.

Remarque. - A l'Exposition universelle de 1889, nous avons pu voir, parmi les collections de l'École agricole et forestière de Komaba(Japon), des flacons étiquetés : "Distoma pancreaticum, du conduit pancréatique du Mouton ", et "D. pancrcaticum var., du pancréas du Mouton ". Autant qu'il nous a été possible d'en juger, les Distomes dont il s'agit ont l'aspect général de notre D. lanceolatum; ils sont cependant un peu plus longs et un peu plus larges.

Distone de L'Gal (D. oculi humani voll Ammon 1833; D. ophthalmobium Dies., 1850). - Petit Ver trouvé par le professeur von Ammon, de Dresde, dans l'œil d'un enfant de cinq mois, affecté de cataracte congénitale. Il en existait quatre exemplaires, logés entre le cristallin et sa capsule. D'après Gescheidt, qui en a donné la description, ils mesuraient de $1 / 2$ à 1 millimèlre de long, sur une largeur trois fois moindre : ils étaient asexués. Bien évidemment il s'agit là de parasites ègarés, que Leuckart considère comme de jeunes Distomes lancéolés.

Distome coelomatique (D. colomaticum Giard et Billet, 1892). - Corps rouge sanguin, rappelant par sa forme celui du $D$. hepaticum, mais relativement plus large et plus acuminé en arrière, long de 150 millimètres, large de כ millimètres. Ventouse antérieure sub-terminale, infère, à peine plus petite que la postérieure. Pharynx globuleux, suivi d'un ossoplıage divisé presque immédiatement en deux branches simples qui se terminent vers le quart postérieur du corps. Deux testicules latéraux, à peine lobulés. Orifice génital un peu en arrière de la ventouse antérieure. OEufs à coque épaisse.

Trouvé une seule fois, par le $\mathrm{D}^{\mathrm{r}}$ Billet, dans la cavité générale, sur la plèvre et sur l'épiploon d'un Bœuf sacrifié pourla consommation des troupes, à Cao-Bang (Tonkin) (3). Il en existait. un grand nombre d'exemplaires.

(1) Pour Mazzanti (Il moderno Zooiatro, 25 aprile 1890), ces nodules seraient dus aux embryons d'une Filaire indéterminée.

(2) F. Zscioкке, Seltene Parasiten des Menschen. Centralbl. f. Bakt. u. Par., XII, p. $500,1892$.

(3) A. Giand et A. Billet, Sur quelques Trémalodes parasites des baufs du Tonkin. Comptes rendus de la Soc. de biologie (9), IV, p. 613, 1892. 
$2^{\circ}$ section. - Testicules situés ì l'extrémité postérieure du corps, ou en arrière des replis de l'oviducte.

\section{A. - Testicules arrondis ou lobés.}

Distome des Félidés (D. felincum Rivolta, 1883̈. - Syn.: 1). conus Gult. 1831, nec Creplin, 1823 ; D. lanceolatum [felis cati] von Siebold, 1836; D. lunceolutum [canis familiaris] van Tright, 1889). Corps long de 7 i 18 millimetres, large de 2 millimètres à 2mm,ä, déprimé, lancéolé ou presque ovalaire, fortement atténué en avant de manière a former une sorte de coul conique, plus obtus en arrière, rongeàtre à l'état frais, demi-transparent. T'égument lisse. Ventouse postérieure an niveau de la base du cóne, un peu plus petite que l'antérieure. Bulbe pharyngien suivi d'un œsoplage à peu près aussi long que lui; cæcums intestinaux se prolongeant jusque dans le voisinage de l'extrémité postérieure. Deux testicules situés l'un devant l'autre, dans la région postérieure du corps: le droit ì cinq lobes, le gauche ou antérieur à quatre lobes. Ovaire à peine lobé, placé un peu plus en avant. Vitellogénes latéraux, occupant le tiers moyen du corps, conslitués par sept glonérules glandulaires à gauche et huit à droite. Utérus très sinueux, situé entre l'ovaire, la ventouse postérieure et les branches de l'intestin. OEufs ovoïles, operculés, avec une petite saillie aiguë au pôle opposé à l'opercule; longs de 26 ì $30 \mu$, larges de 11 à $13 \ddot{\mu}$. .

Ce Distome parait avoir été trouvé tout d'abord par Gurlt dans la vésicule et les con-

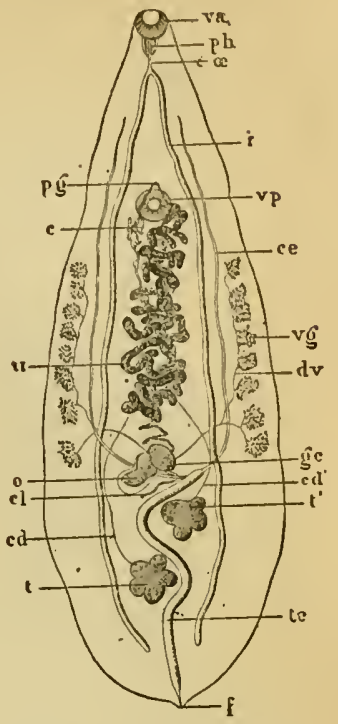

Fig. 239. - Distoma felineum, vu parla face ventrale et grossi 10 fois. - va, ventouse antéricure. $v$ ग, ventouse postérieure. $p h$, phary $n x$. $x$, œsophage, $i$, branches de l'intestin. $c e$, canaux excréteurs. te, keur tronc commun. $t, t^{\prime}$, testicules. $c d, c d$, canaux déférents. $c$, canal prostalique. $g c$, ovaire. $o$, réservoir séminal. $c l$, canal de Laurer. $v g$, vitellogènes. $d v$, vitelloducles. $u$, utérus. $p g$, pore génital. $f$, pore excréteur (Orig.). duits biliaires du Chat domestique; mais cel auteur le confondit à tort avec le $D$. comus Creplin. Plus tard, von Siebold le prit pour un D. lanceolatum. C'est Rivolta qui, en 188\%, le distingua comme espèce particulière : il l'avait trouré dans le foie dı Chien et surtout du Chat. Van Tright, en Hollande, l'a vu chez le Chien; Neumann l'a trouvé à Toulouse, et moimême à Alfort, chez le Chat. Max Braun, à Königsberg, l'a rencontré chez 27 Chats sur 3 '.

De concert avec les $D$. albidum et truncatum, il irrite les parois des canalicules biliaires et provoque, outre l'épaississement de leurs parois, des dilalations pisiformes portant souvent jusque sur les conduits du plus fin calibre,

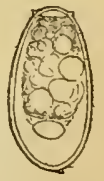

Fig. 240. (Euf du Distoma felineum, grossi 650 fois (0rig.). dilatations qui se traduisent à l'extérieur par des bosselures de la surface. II survient plus tard une cirrhose véritable, souvent complexc. 
B. - Testicules tubulaires, ramifics.

Distome de Chine (D. sinense Cobbold, 1Siö. - Syn : D. spathulatum

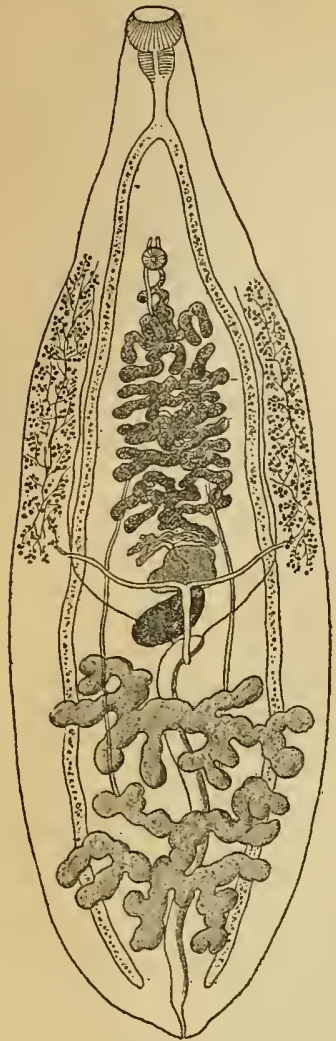

Fig. 241. - Distoma sinense, vu par la face ventrale et grossi 10 fois (Orig.). Leuck., 1876, nec Rud., 1819; D. hepatis endemicum seu perniciosum Baelz, 1883; D. hepatis innocuum Baelz, 1883; D. jupunicum R. Bl., 1886). - Corps long en moyenne de 10 à 13 millimètres (jusqu’à 20 millimètres), large de 2 à 3 millimètres, aplati, ovale oblong, atténué en avant, arrondi en arrière; rougeàtre, presque transparent pendant la vie. Tégument lisse. Ventouse buccale plus grande que la ventrale, qui est située vers le quart antérieur du corps. Bulbe pharyngien suivi d'un court œsophage se divisant en deux cæcums qui s'étendent jusque vers l'extrémité postérieure. Dans le quart postérieur du corps, deux testicules très développés, à 4-6 branches offrant quelques ramifications dendritiques, et placés l'un derrière l'autre. Ovaire trilobé, situé immédiatement en avant d'un ample réservoir séminal en forme de gourde, occupant lui-même la région médiane du corps en avant des testicules. Vilellogènes latéraux, occupant à peu près le tiers moyen du corps. Ulérus très sinueux. Cloaque génital peu marqué, sans cirre ni poche du cirre, s'ouvrant immédiatement eı avant de la ventouse ventrale. OEufs ovoïdes, devenant presque noirs, longs de 28 à $30 \mu$, larges de 16 à $17 \mu$, et renfermant, dans l'utérus mème, un embryon couvert de cils vibratiles.

Le $D$. sinense a d'abord été recueilli dans l'Inde et à l'île Maurice, par McConnell et Macgregor, en 1874-78, dans les canaux biliaires de Chinois qui avaient succombé à des troubles hépatiques paraissant tenir à la présence du parasite.

Depuis lors, il a été revu fréquemment au Japon, par divers médecins. Baelz en arait d'abord fait deux espèces dis-

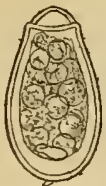

Fig. 242.-CEuf du Distoma sinense, grossi 650 fois (Orig.). tinctes, en se basant principalement sur des observations cliniques; mais il reconnut plus tard l'identité de ces deux formes, que IV. Taylor et Leucliart rattachèrent enfin au Distome de Chine. On a surtout observé ce parasite dans le voisinage de la ville d'Oliayama; dans cette région, le sol, quoique relativement sec, est coupé de canaux et de fossés dont l'eau saumâtre est sourent utilisée comme boisson par les habitants. La maladie, très redoutée, offre des degrés de gravité en rapport arec le nombre des parasites; les individus at- 
teints meurent souvent de cachexie au bout de plusieurs années.

Le même Ver a été observé au Tonkin par Grall, Caraes, Vallot, Treille. Billet, et peut-ètre au Bengale par P’filıl.

En Iอ̆\&6, Ijima a signalé la présence de ce Ver dans le foie du Chat, au Japon : déjà, du reste, Taylor avail observé chez le même animal un Distome non determiné, produisant une maladie très grave et à évolution rapide (1883). Nous avons pu voir également à l'Exposition unirerselle de Paris, en 1889, des échantillous de Distomes du foic du Chat envoyés par l'École agricole et forestière de Komaba, sous le nom de I. endemicum.

Distome de Busk ( $D$. Buski Lankester, 18377 ; D. crassum Busk, 183̈9, nec von Sieb., 1836). - C'est une fort grande espèce, longue de 33 à 73 millimètres, sur 14 à 20 millimètres de large; elle est, en outre, remarquable par son épaisseur. Le corps est plat, oblong, obtus aux extrémités, plas élroil en arant qu'en arrière. Le tégument est Jisse. Les deux ventouses sont arrondies; la postérieure est un peu plus grande que l'antérieure. Organes génitaux assez mal connus; utérus décrivant de nombreuses circonvolutions dans la parlie antérieure du corps. OEufs longs de $123 \mu$, larges de 7 ă $\mu$.

Busk, le premier, a re-

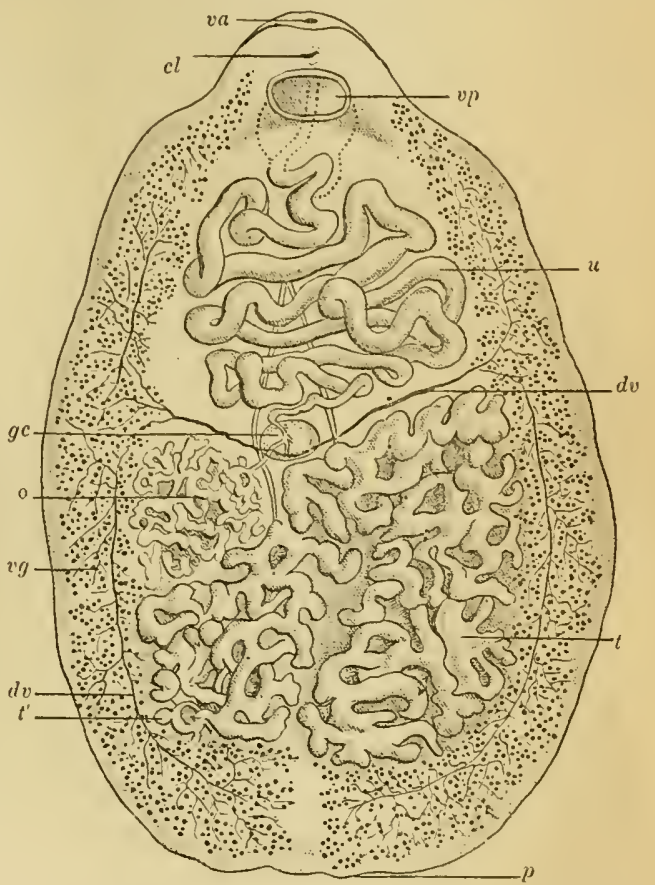

Fig. 243. - Distoma liathonisi, vu par la face ventrale, d'après Poirier. - va, ventonse antérieure, vp, ventouse postírieure. $c l$, cloaque génital. $t, t^{\prime}$, testicules. 0 , ovaire. $v y$, vilellogine. $d v$, vitelloductes. $g c$, glande coquillière. $u$, utérus. $p$, pore excréteur. Grossissemenl: 3 diamètres, 6 .

cueilli ce Distome dans le duodénum d'un lascar mort au Seamen's Hospital en 1813. Plusieurs observateurs l'ont retrouvé depuis chez des personnes liabitant la Chine ou revenant de ce pays. Johnson et Cobbold, en particulier, en ont obtenu des exemplaires rendus par un missionnaire, sa femme et sa fille, dont la nourriture habituelle se composait de substances régétales fraîches, d'huîtres el de poisson.

G'est vraisemblablement à cette espèce qu'il faut rapporter aussi le D. Räthouisi Poirier, 1887, recueilli par le Père Rathouis dans la mission de Zi-ka-wei. Ce Distome avait été rendu par une Chinoise de trente-cinq ans, qui souffrail de douleurs hẻpatiques. Il est caracté- 
VERS.

risé par deux testicules tubuleux, ramifiés, situés dans la partie postérieure du corps, et par un ovaire du même type, placé en arant de ceux-ci et par côté; les vitellogènes, latéraux, occupent presque toute la longueur du corps; le cloaque génital est situé immédiatement en avant de la ventouse ventrale.

III. Sous-genre Brachylaimus Duj., 1843. - Intestin divisé immédiatement en arrière du bulbe œsophagien.

Distome tronqué (D. truncatum [Rud.]. - Syn. : Amphistoma truncatum Rud., 1819; D. conus Creplin, 1823, necGurlt, 1831). - Corps long de $2^{\mathrm{mm}}, 2 \mathrm{~s}$, large en arrière de $0^{\mathrm{mm}}, 6$; en forme de còne dont la base postérieure est munie d'un bourrelet marginal musculeux. Teinte blanchàtre, avec une tache brune (utérus). Tégument revètu, chez les individus àgés comme chez les jeunes, de fins aiguillons régulièrement rapprochés. Ventouse postérieure située un peu en avant du milieu du corps, à peine plus grande que l'antérieure. Immédiatement en arrière du pharynx, a lieu la bifurcation de l'intestin, dont les deux branches s'étendent jusqu'à l'extrémité postérieure du corps. Testicules situés en avant de la terminaison de ces branches, còte à còte, le droit un peu plus en arrière; légèrement elliptiques, non lobulés. Ovaire globuleux, placé en avant des testicules, sur la ligne médiane ou par côté. Vitellogènes latéraux, occupant le tiers moyen du corps, constitués de chaque còté par dix à douze glomérules glandulaires. Utérus entre l'ovaire et la ventouse ventrale. Cloaque génital immédiatement en avant de celle-ci; pas de cirre. OEufs operculés, longs de $29 \mu$, larges de $11 \mu$.

Recueilli d'abord dans les conduits biliaires du Phoca vitulina par Otto, puis dans l'estomac et l'intestin du même animal par Rudolphi, le Distome tronqué fut d'abord pris, par ce dernier observateur, pour un Amphistome, à cause de l'aspect ventousiforme de l'extrémité postérieure. En 1820, Creplin reneontra, dans le foie du Chat domestique et du Renard, un Ver qu'il décrivit sous le nom de $D$. conus; mais il reconnut plus tard l'identité de cette forme et du prétendu Amphistome de Rudolphi. Le même parasite a encore été trouvé par Creplin chez l'Halichorus fotidus, et par Holzendorf chez le Gulo borealis. A Königsberg, Max Braun l'a rencontré chez 3 Chats sur 34.

Il est possible qu'on doive rapporter encore à cette espèce le Ver décrit et figuré en 1846, sous le nom de D. truncatum, par Ercolani, qui l'arait recueilli dans la vésicule biliaire du Chien; mais la figure de cet auteur, fournie évidemment par un exemplaire mal conservé et en voie de dessiccation, laisse quelque doute à cet égard. En tout cas, on peut y rapporter sans hésitation le D. campanulatum Ercolani, 1876, également trouvé dans le foie du Chien.

Distome blanchâtre (D. albidum M. Braun, 1893). - Corps long de $2^{\mathrm{mm}}, 5$ à 4 millimètres, large de 1 millimètre à 2 millimètres, formé de deux parties bien distinctes : la moitié antérieure conique, pointue, la moitié postérieure aplatie, plus large, formant en avant une saillie sur l'autre, et arron- 
die en arrière, sans bourrelet musculeux. Teinte blanche, avec une tache brune (utérus). Tégument épineux sur toute son étendue; dans la régrion postérieure, les aiğuillons sont plus petits et moins serrés. Ventouse ven trale au premier tiers du corps, un peu plus petite que l'autérieure. Bifurcation de l'intestin immédiatement en arrière du pharynx, les deux branches s'étendant jusqu'à l'extrémité postérieure du corps. Testicules situés dans l'espace que limitent ces branches en arrière, et placés l'un devant l'autre; tous deux lobés, souvent le postérieur ou droit à \& lobes, l'antéricur ou gauche à 3 lobes. Oraire globuleux ou ovö̈de, non lobé. Réreptacle séminal pyriforme. Vitellogrènes latéraux, commencant un peu en arriére du niveau du pliarynx et s'étendant jusqu'au milieu de la longueur du corps. Utérus en avant de l'ovaire, à sinuosités nombreuses recouvrant souvent la ventouse postérieure. Cloaque génital immédiatement en avant de celle-ci; pas de cirre. OEufs operculés, longs de 27 à $32 \mu$, larges de 13 à $16 \mu$.

Canaux biliaires du Chat domestique. Sur 34 Chats ouverts à Königsberg en 1893, M. Braun l’a rencontré 20 fois. Je l'ai lrouvé une seule fois sur le même animal, à Alfort, en 1892. - Enfin, je pense que les petits Distomes du foie du Chien, décrits en 1889 par Sonsino, appartiennent également à cette espèce.

Distome social (D. conjunctum Cobbold, 18ă9). - D'après McConnell, ce Ver est long de $9^{\mathrm{mm}}, 5$ (jusqu'à $12^{\mathrm{mm}}, 7$ ), large de $2^{\mathrm{mm}}, 5$, lancéolé, atténué vers les deux extrémités, mais plus obtus en arrière. Le tégument est revètu de petites épines. La ventouse postérieure est un peu plus petite que l'antérieure, dont elle est assez rapprochée. L'intestin se bifurque immédiatement en arrière du pharynx, et ses deux branches s'étendent jusque dans le voisinage de l'extrémité postérieure. Les testicules sont globuleux, un peu lobés; le postérieur est situé un peu à droite, l'antérieur à grauche de la liggne médiane. Ovaire plus en avant, sur cette ligne. Vitellogènes latéraux, commençant en arrière de la ventouse ventrale et s'étendant jusqu'au niveau des testicules. Utérus en avant de l'ovaire. Cloaque génital immédiatement en avant de la ventouse ventrale. OEufs ovoïdes, longs de $34 \mu$, larges de $19 \mu$.

Mc Connell a rencontré deux fois ce parasite chez l'Homme, à Calcutta (1876 et 1878), dans les canaux biliaires épaissis et dilatés. Il l'a rapporté au $D$. conjunctum, découvert en 1858, par Cobbold, chez un Renard ronge américain (Vulpes fulva) mort au Jardin Zoologique de Londres. Cependant, le Distome de Cobbold était plus petit (long de $6^{\mathrm{mm}}, 3$, large de $\left.2^{\mathrm{mm}}, 1\right)$ et arait la ventouse postérieure un peu plus grande que l'antérieure. Lewis et Cunninghain ont observé le même Ver, à Calcutta, dans le foie du Chien paria, où il serait assez commun.

IV. Sous-genre Echinostoma Duj. - Ventouse antérieure entourée de piquants, ou occupant le milieu d'un disque échancré en dessous et bordé de piquants latéralement et en dessus, ou accompagnée de deux larges lobes bordés de piquants.

Distome trigonocéphale $(D$. trigonocephalum Rud. - Syı. : Planaria 
putorii et $P$. melis Gœze, 1782; Fasciola armata Rud., 1795 ; F. trigonocephala Rud., 1802 ; D. armatum Zeder, 1803; D. trigonocephalum Rud., 1809. Priorité : D. putorii). - Corps blanc jaunàtre, long de 1 à 13 millimètres, large de $0^{\mathrm{mm}}, 6$ à 2 millimètres, oblong, déprimé, atténué en avaut et en arrière, et atteignant sa plus grande largeur au niveau de la ventouse postérieure. Extrémité céphalique subtriangulaire, armée d'une double couronne de gros bàtonnets oblongs. Tégument revêtu dans la moitié antérieure d'épines aiguës, rétractiles, cadıques. Ventouse antérieure terminale, orbiculaire; ventouse ventrale située vers le quart ou le cinquième antérieur, plus grande que la ventouse orale et à ouverture elliptique. Deux testicules arrondis, placés l'un devant l'autre, et précédés de l'ovaire. Pénis très long, cylindrique, flexueux et couvert de très courts aiguillons. OEufs ellipsoïdes, longs de $132, u$, larges de $92 \mu$.

vit dans l'intestin du Hérisson (où nous l'arons trouvé, avec Lucet, dans le Loiret) et de divers Carnivores sauvages. Max Braun le signale en outre chez le Chien domestique.

Distome hérissé (D. echinatum Zeder, 1803. - Syn. : Cucullanus conoideus Bloch, 1782; D. excavatum Rud., 1819;? D. militure Rud., 1809; D. echiniferum, La Val., 183̈5; D. conoideum Raill., 1883̈). - Corps rosé ou rougeàtre, loug de 4 à 15 millimètres, large de 1 à 2 millimètres, sublinéaire, aplati, prolongé en avant de la ventouse postérieure par un cou assez court terminé par une sorte de tète ou de dilatation réniforme échancrée en dessous et entourée d'épines caduques, droites, sur tout le reste de son contour. Cou revêtu de petites épines aiguës sur la lace ventrale, obtuses sur la face dorsale. Ventouse antérieure terminale, circulaire; ventouse postérieure beaucoup plus grande. OEufs jaune brunàtre, longs de 86 à $96 \mu$, larges de 65 à $72 \mu$.

A l'état adulte, ce Ver vit dans l'intestin du Canard domestique, où il a d'abord été signalé par Bloch, du Canard musqué, de l'Oie, du Cygue domestique (Bellingham), et d'un grand nombre d'Oiseaux aquatiques sauvages.

Il a mème étẻ truuvé par Generali, de Modène, dans le duodénum d'un Chien (1880).

Avec Stossich, nous pensons qu'il faut rattacher à la mème espèce le D. dilatatum Fischer de Walheim, 1840, trouvé à Vilna, par Miram, dans le cæcum et le rectum du Poulet, ainsi que le D. armatum Molin, 18308 (nec Zeder, 1803), trouvé a Padoue, dans les mèmes organes, chez la Poule.

Un intérèt spécial s'attache à ce parasite, en raison des recherches com. plètes qui ont été fartes sur son évolution, et dont les résultats ont été rectifiés par Ercolani. Il doit être confondu avec le $D$. echiniferum La Val. et probablement aussi avec le D. militare Rud.

Les formes larvaires de ce Distome sont celles qui s'observent le plus communément chez les Mollusques aquatiques. On les rencontre surtout chez des Limnées, Planorbes, Paludines, etc., mais dans des organes très divers, et, dans ces conditions, leurs caractères sont si variables qu'on avait cru devoir admettre l'existence de plusieurs formes spécifiques distinctes. Telle est l'origine du Cercaria echinatoides Fil., identique au C.echinifera La Val., et du C. spinifera La Val.

Les sacs germinatifs de cette espèce sont des Rédies (fig. 244, $n^{\circ} 1$ ), qui développent par gemmation, dans leur intérieur, d'autres Rédies ou des Cer- 
caires, el qui se reproduisent mème quelquefois par bourgeonuement externe ou par scission (n०2). - Les Cercaires qui onl pris maissance dans ces liédies sont, comme celles-ci, Irès rariables quant à leur forme, du moins
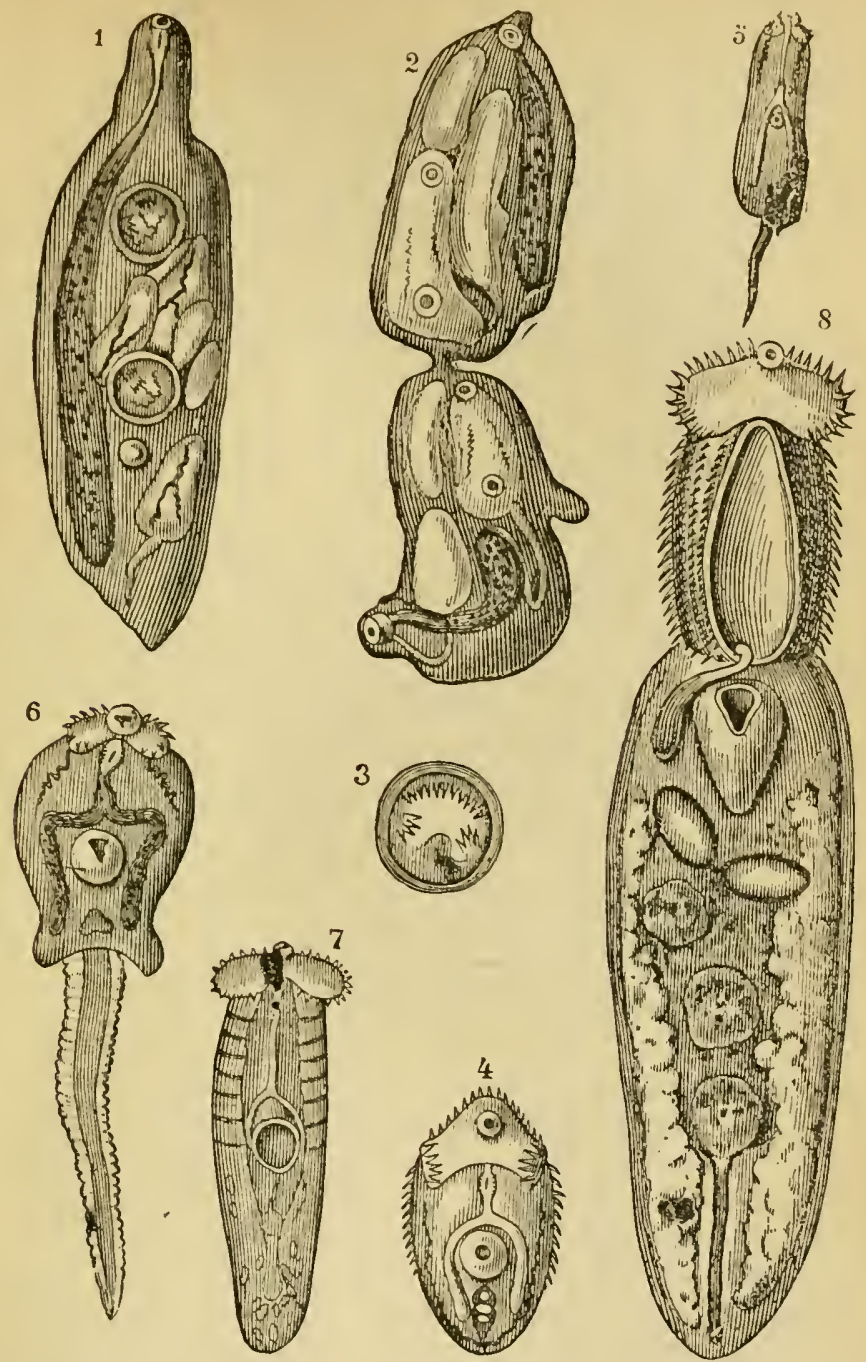

Fig. 244. - Phases de l’évolution du Distome hérissé, de l'intestin du Canard, d'après Ercolani. 1, Rédie contenant des Cercaires libres el des Cercaires enkystés. 2, multiplicalion de la Rédie par scission. 3, Cercaria echinala entissté, du coeur de la Paludine vivipare. 4 , le mème sorti de son kyste. 5, une des pelites formes à queue dn mème Cercaire. 6, une des grandes formes. 7, Distome hérissé déreloppé dans l'intestin du Surmulot. 8, le mème développé dans l'intestin du Canard.

Jorsqu'ils sont libres, mais paraissent offrir des caractères semblables dès qu'ils sont enkystís. Dans certains cas, ils quittent le corps du Mollusque qui hébergeait la liédie, pour aller s'enkyster dans la peau ou autour du cœur des Paludines, tandis que d'autres fois ils s'enkystent à peine sortis de la Rédie ou même dans son intérieur $\left(\mathrm{n}^{\circ} 1\right)$. - En allministrant à des animaux 
VERS.

à sang froid - Grenouilles, Crapauds ou Couleuvres - ces Cercaires enkystés, on n'obtient aucun résultat; ils se transforment, aı contraire, en Distomes, lorsqu'on les fait ingérer à des animaux à sang chaud. Les expériences d'Ercolani ont porté en particulier sur les Canards, el, chez ces animaux, les diverses formes de Cercaires sus-indiquées ont toutes donné le D. echinatum. Ghez les Moineaux, Souris, Rats, Taupes et Chiens, le mème Distome a été obtenu, mais avec des variations morphologiques très remarquables ( $n^{n s} 7$ el 8 ).

Distone oxycÉPH.ALe (D. oxycephalum Rud., 1819). - Le Ver que Rudolphi a décrit sous ce nom paraît être, comme l'a reconnu Dujardin, une simple variété du Distome conoïde ou hérissé, dont les épines sont très petiles ou nulles.

Il a été observé chez le Canard et chez l'Oie domestiques, plus rarement chez la Poule; il vit dans l'intestin.

V. Sous-genre Crossodera Duj., 1845. - Ventouse antérieure enlourée de papilles ou de lobes charnus.

Distome linéaire (D. lineare [Rud.]. - Syn. : Fusciola linearis Rud., 1793; D. lineare Zeder, 1803 ; Crossodera linearis Cobbold, 1839). - Corps rougeàtre, long de 11 à 16 millimètres, large de $1^{\mathrm{mm}}, 5$, déprimé, linéaire, obtus en arrière, alténué en avant en forme de cou. Ventouse antérieure petile, entourée de six papilles minuscules; ventouse postérieure beaucoup plus grande. Cirre assez grand, cylindrique, sortant en avant de celle-ci.

Rudolphi a trouvé sept exemplaires de cette espèce à Greifswald, dans le gros intestin de deux Poulets; mais il était, à cette époque, encore novice en helminthologie, et n'a pu en donner qu'une description incomplète.

Genre Céphalogonime (Cephalogonimus J. Poirier, 1883). - Se distingue du genre Distome par les orifices goćnitaux situés à la partie antérieure du corps, sur la face dorsale, un peu en avant de la ventouse antérieure.

CéphaIogonime taché (C. ovatus [Rud.]. - Syn. : Fasciola ovata Rud., 1802; Distoma ovatum Rud., 1809; D. Uursicolu. Creplin, 1846; C. ovatus Sossich, 1892). - Corps long de $\breve{3}^{\mathrm{mm}}, 2$ a $6^{\mathrm{mm}}, 5 \breve{4}$, large en arrière de $2^{\mathrm{mm}} 17$ à 4 millimètres, blanchàtre, taché de noir, apłati, ovale, plus étroit en avant. Tégument hérissé de petites épines à pointe rétrograde, serrées dans la partie antérieure, caduques, visibles seulement sur les exemplaires jeunes. Ventouse antérieure terminale, orbiculaire; ventouse postérieure deux fois aussi large que la précédente, dont elle est assez éloignée. Les circonvolutions de l'oviducte sont pressées les unes contre les autres dans le tiers postérieur, de sorte qu'à ce niveau le corps est jaune et opaque. OEufs elliptiques, très petits, jaunes, longs de 21 à $26 \mu$, larges de $18 \mu$, pourvus d'une courte épine polaire.

Ce Ver habite la bourse de Fabricius d'un grand nombre d'Oiseaux, quand ceux-ci sont jeunes, bien entendu, puisque cette poche glandulaire disparait chez l'adulte. Otto l'a trouvé dans l'oviducte de la Poule, et on comprend qu'il puisse ainsi pénétrer dans l'œuf avant la formation de la coquille. Hanow, Purkinje et d'autres observateurs l'ont en effet rencontré dans des œufs de Poule bien développés. 
Müller a signalé en 1779 , sous le nom d'Hirudo fusciolaris, un Ver (qu'il avait tronvé alhérent à la surface externe de l'intestin d'une Oie domestique, et que Rudolphi soupçone appartenir à cette espèce. L'introduction de ce parasile dans la cavité abdominale avait été évidemment accidentelle.

D'autre part, Rudolphi a décrit, sous le nom de Distoma cuneatum, une forme qu'il avait trouvée une seule fois dans l'intestin d'une Outarde, et qui ne différait du Distomu ovutum que par son corps plan en dessus, convexe en dessous, frès atténué en avant, de manière à présenter l'aspect d'un coin, et par la grande extension de ses circonvolutions utérines. Il ne parait guère douteux qu'il s'agisse d'une seule tet mème espèce, surtout si l'on considère que Gurlt a retrouvé ce Distoma cuneatum dans l'oviducte d'un Paon.

Céphalogonime pellueide (C. pelluridus [von Linstow]. - Syn.: Distoma pellucidum von Linstow, 1873; C. pellucielus Raill., 1890). - Corps long de 9 millimètres, large de 5 millimètres, rougeàtre, transparent, aplati, pyriforme, alléuné en avaut. Tégument revètu, dans la moitié postérieure, d'épines longues de $43 \mu$. Ventouse antérieure terminale, orbiculaire; ventouse postérieure à peine plus grande que la précédente. Branches de l'intestin présentant des dilatalions vésiculaires. Testicules ovoïdes, placés l'un eu face de l'autre, un peu en arrière du milieu du corps, mais en avant des circonvolutions de l'oviducte. Ovaire lobulé situé en avant et en dedans du testicule droit; vitellogènes latéraux peu étendus. Les circonvolutions de l'oviducte sont làches et disposées sans ordre, de sorte que le tiers postérieur du corps est tout à fait transparent. OEufs longs de 31 à 34 ...

Cette grande et belle espèce a été trouvée, par von Linstow, dans l'œsophage de la Poule. Le contenu de son tube digestif, d'un brun plus ou moins foncé, paraît être du sang à demi digéré.

Genre Mésogonime (Mesogonimus Monticelli, 1888). - Ce genre se distingue du précédent par la situation des orifices génitaux, qui sont placés derrière la ventouse postérieure : la ventouse antérieure est orbiculaire, plus petite ou plus grande que la postérieure, qui est sessile.

Mésogonime de Westermann (U. Westermanni [Kerbert]. - Syn. : Distoma Ringeri Cobb., 1880; D. pulmonale Bälz, 1883 ; H. Westermanni Raill., 1890). - Ver massif, long de 8 à 10 millimètres et large de 4 à 6 millimètres, rouge brunàtre, ovoïde, arrondi en avant, un peu plus atténué en arrière; très épais, de sorte que la coupe transversale est presque circulaire. Ventouses peliles et peu distinctes, l'antérjeure subterminale, infère, la postérieure un peu plus grande, située à une faible distance en avant du milieu du corps. Tégument revêtu d'épines larges, écailleuses. Bouche s'ouvrant au fond de la ventouse antérieure; bulbe pharyngien suivi d'un très court œsophage, qui se bifurque en deux cæcums intestinaux écartés, sinueux et irréguliers. Deux testicules tubuleux, ramifiés, placés quasi-symétriquement dans la parlie postérieure du corps. Pas de cirre ni de poche du cirre. Ovaire également ramifié, situé vers le milieu du corps, à gauche de la ligne médiane; en face, une glande coquillière faiblement lobulée et un utérus assez court, pelotonné. Vitellogènes latéraux, très développés, entourant le corps sur presque toute sa longueur. Vitelloductès présentant, avant leur terminaison dans l'oviducte, un large vitellosac. OEufs ovoïdes, à coque jaune et mince, longs de 80 à $100 \mu$. el larges de $50 \mu$.

Ralleiet. - Zoologie. 
VERS.

Le Mésogonime de Westermann, plus connu sous le nom de Distome pulmonaire, paraît être assez répandu dans l'Asie orientale (Japon, Chine, Corée). Il vit en parasite dans le poumon de l'Homme, où il a été rencontré pour la première fois en 1880, à Formose, par le $\mathrm{D}^{\mathrm{r}}$ Ringer. Mais il avait été déjà observé en 1878, par Kerbert, dans le poumon d'un Tigre roval mort à Amsterdam. De plus, il doit se développer aussi chez le Chien, car, parmi les échantillons de parasites envoyés par le Japon à l'Exposition de 1889, se trouvaient des Distoma pulmonale des bronches du Chien.

Ce Ver siège dans les petites bronches ou dans des sortes de cavernes situées à la périphérie de celles-ci. Les cavernes en question atteignent le volume d'une noisette ; elles renferment une bouillie rougeâtre formée de mucus, de globules sanguins, de débris de tissu pulmonaire et enfin de Distomes. Leur paroi est indurée, et elles ne communiquent avec les bronches que par d'étroits orifices, à la faveur desquels les œufs sont expulsés.

Les individus envahis par ce parasite présentent des troubles particuliers qui peuvent se résumer ainsi : toux légère ou nulle; crachats sanguinolents et paraissant un peu rouillés par suite de la présence des œufs à coque brunâtre; parfois production d'hémorragies qui peuvent se répéter d'une façon irrégulière pendant des années. Cette affection, qu'on a nommée " hémoptysie parasitaire " ou simplement "distomatose pulmonaire", parait ètre commune surtout à Formoseoù elle frapperait au moins Iö p. 100 de la population - et au Japon. Elle n'est pas incurable; elle parait même n'offrir de gravité que dans des cas exceptionnels. L'examen microscopique des crachats permet de la distinguer aisément de la tuberculose (1).

Les œufs placés dans l'eau donnent, naissance à un embryon pourvu d'un appareil perforateur et revêtu de eils vibratiles dans les deux tiers postérieurs; au bout de six semaines à deux mois, cet embryon sort de l'œuf en soulevant l'opercule et se met à nager dans l'eau (P. Manson). On ignore jusqu'à présent quel est son sort ultérieur.

Mésogonime hétérophye (M. heterophyes [von Siebold]. - Syn. : Distoma heterophyes von Siebold, 18322; M. heterophyes Raill., 1890). — Corps long de 1 millimètre à $1 \mathrm{~mm}, 5$ sur une largeur maximum de $0^{\mathrm{mm}}, 7$; rougeàtre, ovaleoblong, fortement attéuué en avant, arrondi en arrière; déprimé, un peu convexe en dessus, plan en dessous. Tégument garni, dans la moitié antérieure, de nombreuses petites épines dirigées en arrière. Ventouse antérieure subterminale, légèrement infère, petite. Ventouse postérieure subcentrale, près de trois fois plus grande que celle-ci. Bouche s'ouvrant au fond de la ventouse antérieure, suivie d'un œsophage qui offre à quelque distance un bulbe peu accusé, puis se bifurque en deux cæcums intestinaux

(1) Yamakiva et Inouye, de Tokyo, rapportent que le parasite est très répandu dans certains villages des montagnes du Japon, et qu'il y est redouté à ce point que les habitants des autres villages s'interdisent toute relation avec les localités contaminées. 
prolongés jusque dans la partie postérieure du corps. Deux testicules arrondis, situés en arrière, entre ces deux cæecums. Ovaire égalenent arrondi, placé un peu en avant des testicules et caché sous les circoinvolutions de l'oviducte. Vitellogìnes peu développés, latéraux, situés au niveau de l'ovaire. Orifices génitaux s'ouvrant en arrière de la ventouse postérieure et entourés d'un bourrelet circulaire garni de bitonnets cornés, qui simule une ventouse accessoire. OAufs ronge brunitre, ì coque épaisse, longs de $26 \mu$, larges de $1 \ddot{\partial} \mu$.

Ce petit parasite a été trouvé au Caire, par Bilharz, en avril 18\%1, dans l'intestin grêle d'un enfant, où il existait par centaines, sous l'aspeet de petits points rouges. Un second cas fut recueilli peu de temps après par le même observateur. Enfin, Waller lnnès a retrouvé le même Ver en Egypte en 1891. Mais on n'a pas signalé de troubles pathologiques pourant être attribués à sa présence.

Mésogonime dimorphe (M. dimorphus [Wagener]. - Syn. : Distoma dimorphum Wăn., 183̈2, nec llies., 1830; D. commutatum Dies., 1838; D. columbx? Mazzanti, 1889 ; 1. commutatus Sonsino, 1889; H. dimorphus, Raill.,

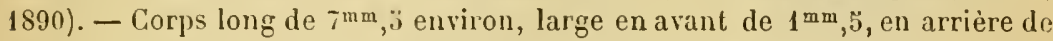
2 millimètres, blanchâtre, aplati, sublinéaire, arrondi aux deux extrémités. Ventouse antérieure terminale, circulaire, assez grande. Ventouse postérieure subcentrale, un peu plus petite que l'antérieure, à ouverture circulaire. Deux testicules arrondis, situés l'un derrière l'autre, dans la partie postérieure du corps. Ovaire un peu i droite et entre les deux testicules. Vitellogènes latéraux, s'étendant assez loin en avant. Orifices génitaux en avant du testicule antérieur. OEufs ovoïdes, jaune clair, à coque asymétrique, contenant un embryon, longs de $27 \mu$, larges de $14 \mu$.

Trouvé á Pise et à Nice, en 1831 , dans les cæcums des poulets, par Wagener. Sonsino l'a recueilli de nouveau à Pise en 1889, dans l'intestin grèle d'une Poule.

Nous croyons devoir rapporter d'ailleurs à la mème espèce les Vers rencontrés en 1889, dans l'intestin grèle d'un Pigeonneau, par Mazzanti, et décrits par cet observateur sous le nom de Distoma columbx. Ces parasites semblaient avoir provoqué uue irritation de la muqueuse intestinale.

Genre Gynécophore (Gyniccophorus Dies., 18588. - Syn. : Schistosoma Weinland, 1838 ; Bilharzia Cobb., 18:59; Thecosoma MoquinTandon, 1860). -- Les Gynécophores (ou Bilharzies) se distinguent de tous les autres Dislomidés en 'e qu'ils ont les den.x branches de lintestin réunies en un seul canal dans le quart postérieur du corps. Les sexes sont séparés: le mâle a le corps épaissi en arrière de la ventouse postérieure, avec les borls repliés en dessous, de manière à former un canal qui loge la l'emelle; celle-ci est filiforme. Les orifices génilaux sont situés immédiatement en arrière de la ventouse postérieure.

Ces Vers sont des hématozoaires.

Gynécophore hématohie (G. hamatobius [Bilharz]. - Syn.: Distomum hamatobium Billarz, 183̈2; G. hamalobius Dies., 1838 ; Schistosoma hamatolium Weinland, 1858; Bilharzia hxmatobia Cobb., 1859; Thecosoma hamatobium 
Moq.-Tand., 1860; Distoma capense Harley, 186ł). - Le mâle est blanc, mou, à peu près de la grosseur d'un Oxyure vermiculaire; il mesure 11 à 14 millimètres de long sur 1 millimètre environ de large; l'extrémité

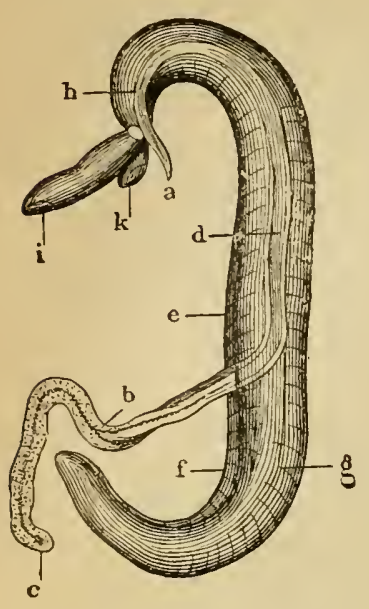

Fig. 245. - Gynecophorus hæmatobius, måle et femelle, fortemenl grossis, d'après Bilharz. - $a b c$, femelle contenue en partie dans le canal gynécophore. $a$, exlrémité anlérieure. $c$, extrémité postérieure, $d$, corps vu par Iransparence dans le canal. ig, måle. $e, f$, canal gynécophore, entr'ouvert en avant ef en arrière de la femelle, qui en a été extraite en partie. $g, h$, limile vers le dos de la dépression ventrale qui constitue le canal. $i$, ventouse buceale. $k$, ventouse ventrale. antérieure est aplatie et porte les deux ventouses, qui sont peu éloignées l'une de l'autre et assez saillantes; en arrière de la ventouse postérieure, le corps s'enroule de manière à former une gouttière par sa face ventrale et à prendre un aspect cylindrique : c'est dans cette gouttière ou canal gynécophore que se trouve logée la femelle. Le tégument est lisse daus la partie antérieure; dans le reste de la longueur du corps, il présente, sur sa face dorsale ou externe, de nombreuses petites papilles revètues d'épines, et sur sa face ventrale, de légrères saillies coniques très serrées, ne manquant que sur la ligne médiane. Le tube digestif commence à la ventouse antérieure; il offre un petit bulbe pharyngien et se continue par un osophage qui, en avant de la ventouse ventrale, se divise en deux branches : celles-ci vont se rejoindre en arrière pour se terminer en un cæcum unique. Les testicules sont représentés par cinq ou six résicules disposées immédiatement en arrière de la veutouse ventrale, et aboutissant à un canal déférent qui s'ouvre immédiatement dans le fond du canal; il n'existe pas de poche du cirre. - La femelle est filiforme. plus longue et beaucoup plus étroite que le màle; elle mesure de 15 à 20 millimètres; son épaisseur s'accuse progressivement en arrière et atteint jusqu'à $280 \mu$; les ventouses sont rapprochées et saillantes; le tégument est revètu de fines épines dirigées en avant. Le tube digrestif est assez semblable à celui du màle. L'ovaire, oblong et lobé, est situé dans l’angle formé par la réunion postérieure des cæcums intestinaux; les vitellogènes sont latéraux, l'utérus est sinueux, la vulve est en arrière de la ventouse ventrale. - Les deux individus sont accolés ventre à ven tre ; leurs orifices génitaux se correspondent; les extrémités de la femelle, el surtout l'extrémité postérieure, pendent en dehors du canal gynécophore. - Les œufs, ovoïdes, mesurent 133 à $160 \mu$ sur 50 à $66 \mu$; ils portent d'ordinaire à l'un des pòles un prolongement épineux, qui se montre parfois un peu latéral; on n'y remarque pas d'opercule.

Le dangereux Ver dont il s'agit a été découvert en 1830 par Bilharz, en Égyte, dans la veine porte de l'Homme. Plus tard, et dans la même contrée, Griesinger l'a trouvé 117 fois sur 363 autopsies, et 30 fois sur 54 autopsies. D'autres l'ont vu aussi dans le sud de l'Afrique, au Cap(Harley), à Natal et en Cafrerie (Cobbold), et on assure même qu'il se rencontre sur toute l'étendue de la côte orientale africaine. Eyles et Eden l'ont signalé sur la côte d'Or, Felkin dans la région dụ 
Nil blanc, Nachtigall dans le voisinage du lac Tchad (?). Enfin, depuis quelques années, on l'observe en Tunisie (Villeneuve, Brault). Il ne serait du reste pas propre à l'Homme: Cobbold en aurait rencontré un exemplaire (1) chez un Singe égyptien, vulgairement appelé Mangabey (Cercopilhecus fuliginosus), mort au Jardin zoologique de Londres.

Il habite la reine porte et ses branches (notamment lia reine splénique), les veines rénales, les plexus veineux de la vessie et du reclum. Il se nourrit de sang, dont les globules se retrouvent en grand nombre dans son tube digestif. Les oufs sont souvententrainés, par le torrent circulatoire, dans les capillaires de divers organes, tels que le foie, le poumon, oủ ils peuvent déterminer des lésions variables; ils sont susceptibles en outre des'accumuler dans les petits vaisseaux, au voisinage du point où ils ont été pondus, et l'obstruction vasculaire qui résulte de leur présence, aussibien que de celle du Ver lui-même, s'accompagne parfois de désordres fort graves. La ressie s'enflamme, il survient des ruptures vasculaires, entrainant une hématurie (qui toutefois n'est pas chyleuse comme celle de la filariose) avec éracuation abondante d'œufs ; ou bien ces oufs sont le point de départ des calculs vésicaux. Si les altérations se manifestent au niveau du gros intestin, elles donnent lieu à une sorte de dysenterie : le sang et les œufs sont entrainés avec les excréments. C'est à ces accidents diver qu'on donne le nom de bilhar:iose, ou mieux de gynécophorose.

Les Egyptiens paraissent contracter les Gynécophores en buvant l'eau du Nil non filtrée. Bien qu'on re connaisse pas encore l'évolution de ce parasite, il est certain, en effet, que les premières phases s'accomplissent chez un animal aquatique. L'embryon ne se développe qu'après la ponte, mais il se forme d'ordinaire alors que l'œuf est encore renfermé dans le corps de l'hòte. Cet embryon a été étudié par Cobbold, J. Chatin, Sonsino, Cahier, Railliet. Il parait immobile tant que l'œuf est maintenu dans l'urine, et son activité se manifeste seulement par le jeu des entonnoirs vibratiles. Remplace-t-on l'urine par de l'eau, l'œuf se gontle et acquiert peu à peu $173 \mu$ de long sur 80 ì $82 \mu$ de large. Les parois de la coque s'écartent par conséquent de l'embryon et celui-ci apparait plus nettement. Il est entouré d'une masse granuleuse limitée par une mince membrane et montrant au niveau des póles deux zones distinctes, l'externe un peu plus claire que l'autre. 11 offre l'aspect d'un Infusoire cilié; à l'extrémité antérieure, qui se trouve dirigée indifféremment vers l'un ou vers l'autre póle, existe une sorte de rostre inerme représentant sans doute un appareil perforateur. Le corps présente trois étranglements: deux produits par des ceintures granuleuses, et un troisième plus en arrière, vers le sixième postérieur. De la base du rostre partent deux canaux

(1) Bilharzia magna Cobbold, 1859. - Leuckart et Cobbold ont plus·tard admis l'identité de cette forme et du parasite humain, ce qui n'est pourtant pas suffisamment établi. 
qui se portent en arrière et aboutissent chacun à une sorte de grosse glande unicellulaire. Entre ces canaux, on aperçoit un espace grossièrement granuleux, qùi correspond à un tube digestif rudimentaire se terminant en cul-de-sac à sa partie postérieure. En arrière des deux étranglements antérieurs, on distingue une paire d'entonnoirs flagellés. Enfin, dans la région postérieure du corps, on observe un amas de cellules nucléées (cellules germinatives).

Après une période variable suivant le degré de pureté de l'eau, l'éclosion a lieu, tant par le fait des mouvements de l'embryon que par le gonflement endosmotique de l'œuf. L'embryon s'échappe par une ouverture latérale, qui se produit d'ordinaire dans le voisinage de la

A

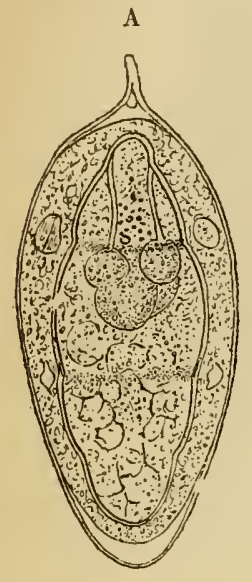

B

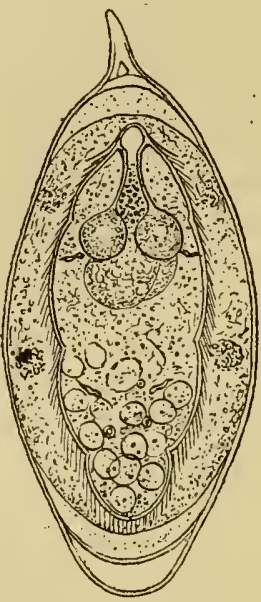

C

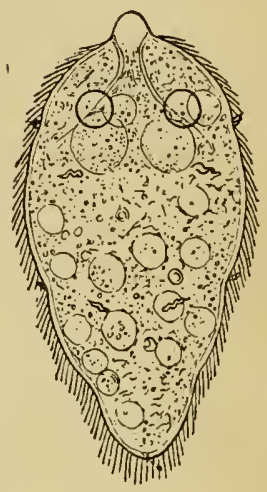

Fig. 240. - OEufs et embryon du Gynecophorus hæmatobius, grossis 330 fois, - A. œuf examiné dans

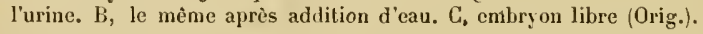

région céphalique. Puis il se met en marche, effectuant dans le milieu ambiant des mouvements très variés et subissant des changements de forme innombrables. On peut néanmoins reconnaître presque toujours les trois étranglements qui ont été signalés plus haut; il existe d ailleurs, au niveau des deux premiers, deux petits cirres latéraux situés au milieu des cils. Ceux-ci sont surtout développés à la partie antérieure du corps.

Peu après l'éclosion, lorsque l'embryon se gonfle et s'arrondit pour se mettre en mourement, les organes internes deviennent moins apparents, mais on aperȩoit, en arrière du rostre, quatre cercles clairs, deux en dessus et deux en dessous, dont le passage successif devant l'œil est des plus curieux lorsque l'embryon tourne sur luimème à la façon d'une toupie.

Après une période d'activité d'une durée assez variable, l'embryon du Gynécophore ralentit ses mourements, et finalement s'arrête. On voit alors des globules transparents apparaître à sa périphérie, aug- 
mentant peu a peu en nombre et en dimensions: ce sont des globules " sarcodiques ", c'est-à-dire formés par la diffusion d'une certaine quantité de parajlasma à travers la cuticule. Puis le corps se déforme, et la mort survient définitivement.

Quant à la sortic des cellules germinatives, je n'ai pu l'observer que sur des individus altérés, et je ne puis la considérer que comme un fait anormal ou accidentel.

Les essais d'infestation tentés par divers expérimentateurs, Cobbold, IIarley, Sonsino, sur des Mollusques d'eau douce, des Crustacés, des larres d'Insectes, des Poissons, n'araient jusqu'à présent donné aucun résultat. Mais dans des recherches toutes récentes, effectuées à Gabès (Tunisie), Sonsino croil avoir constaté que l'hòte intermédiaire est un petit Crustacé. Le mode de développement du parasite rappelle plutót celui des Ilolostomidés que celui des Distomiens typiques. Dès que l'embryon rencontre le Crustacé, il l'attaque, à l'aide de son rostre, en un point vulnérable, pénètre dans le corps après s'être dépouillé de son revêtement ciliaire, et s'y enkyste. Le siège le plus ordinaire de ce kyste est le premier segment, au voisinage de l'œil. La larre enkystée attend que le Crustacé soit ingéré par l'Homme, avec l'eau de boisson; elle est mise en liberté dans le tube digestif, traverse les parois intestinales et pénètre probablement dans la veine porte pour compléter son développement.

Gynécophore épais (G. crassus [Sonsino]. - Syn. : Bilhurzia bovis Sons., 1876; B. crassa Sons., 1877; G. erassus Stossich, 1892. - Priorité : G. bovis). - Cette forme diffère de la précédente par ses dimensions un peu plus considérables, ainsi que par ses œufs, notablement rétrécis aux deux pôles et mesurant en moyenne $170 \mu$ sur $40 \ddot{\circ}$

En 1876, Sonsino en recueillit 3ö exemplaires dans la veine porte d'un Taureau sacrifié à l'abaltoir de Zagazig (Égypte), et dont la vessie présentait les altérations analogues à celles qui s'observent dans la gynécoplıorose de l'Homme. Cobbold et Panceri regarlèrent ce parasite comme une espèce distincte, tandis que Tommasi Crudeli le considérait comme une simple variété du Gỵceophore hématobie, produite par adaptation à un nouvel hote. - Sonsino le retrouva plus tard chez

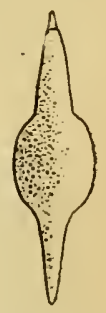

Fig. 247. - OEuf du Gynecophorus crassus, d'après Sonsino. le Mouton. Grassi et Rovelli l'ont rencontré chez $7 \%$ p. 100 environ des Moutons de la plaine de Catane, en Sicile.

Bomford a observé en 1886, à Calcutta, chez deux Taureaux abattus. pour cause de peste bovine, les lésions de la gynécophorose dans le gros intestin; mais les œufs dı parasite étaient semblables à ceux dı G. hiematobius.

(1) P. Soxsixo, Suiluppo, ciclo vitale e ospile intermedio della Bilharzia hæmatobia. Processi Verbali della Società Toscana di Scienze Naturali, seduta del 11 Agosto 1893. 
VERS.

Distomidé agame du Porc. -- Corps long de 5 millimètres environ, elliptique, grisâtre, transparent. Ventouse antérieure terminale, avec une

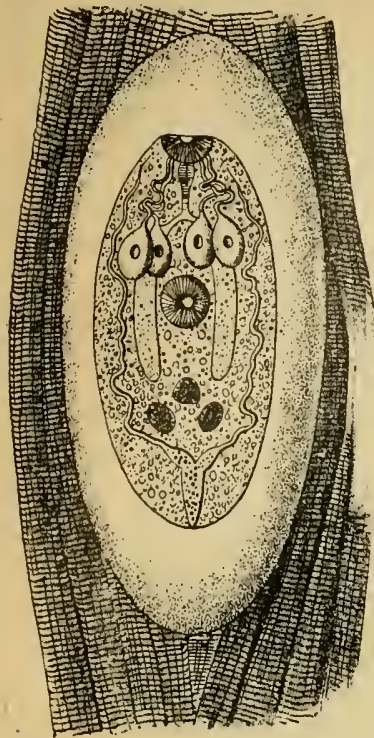

Fig. 248. - Agamodistoma des mu du Porc, grossi 80 fois (Leuckart). sorte de stylet buccal dirigé en arrière. Ventouse postérieure située vers le milieu ducorps. Pharynx suivi d'un court cesophage et de deux branches intestinales simples. Dans la moitié antérieure, règnent qualre grosses glandes dont les conduits excréteurs vont déboucher dans la ventouse orale. Organes génitaux rudimentaires.

Ce Trématode a été rencontré dans les muscles du Porc. G. Leunis l'a vu dans la portion charnue du diaphragme; Happen et Muhle l'ont trouvé dans les muscles laryngiens. Chaque individu occupait un liyste ovoïde, analogue à celui des Trichines et logé dans le lissu conjonctif interfasciculaire. Duncker en a trouvé des exemplaires encore munis de leur queue de Cercaires. Il s'agit évidemment de parasites égarés : le Porc n'est pour eux qu'un hòte accidentel, chez lequel ils ne peuvent suivre le cours de leur développement.

\section{Famille des AMPHISTOMIDÉs. -}

Dans ce groupe, le corps est de forme assez variable, avec une ventouse antérieure terminale, très petite, et une ventouse postérieure terminale on subterminale. La bouche s'ouvre toujours dans la ventouse antérieure. Les orifices génitaux sont situés sur la ligne médiane de la face ventrale, dans le tiers antérieur du corps.

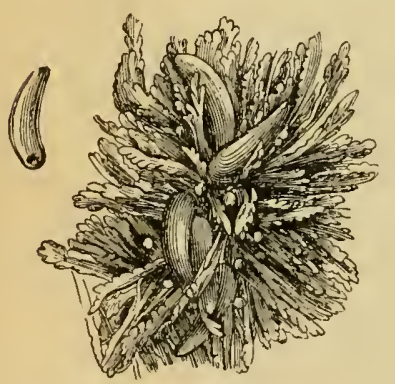

Fig. 249. - Fragment de rumen de Vaclie, montraut des Amplisiomes coniques fixés entre les papilles par leur grosse ventouse postérieure. Onı distingue les tubercules d'insertion de plusieurs individus qui ont élé enlevés. A gauche, un individu isolé. Grandeur naturelle (Orig.).

A l'état adulte, les Amphistomidés sont endoparasites des Mammifères, Oiseaux, Reptiles, Batraciens et Poissons.

Genres Amphistoma Rud., Gastrothylax Poirier, à pharynx unilobé; Diplodiscus Dies., Homalogaster Poir., Gastrodiscus Jeuck., à pharynx bilobé.

Genre Amphistome (Amphistoma Rud., 1801. - Syn. : Strigea Viborg, 1795). Corps épais. Ventouse postérieure médiocre, subterminale, à ouverture circulaire. Pharynx unilohé.

Amphistome conique (A. conicum $[\mathrm{Ze}-$ der]. - Syn. : Festucaria cervi Zeder, 1792; Fasciola elaphi Gmelin, 1789; Monostoma eonicum Zeder, 1800 ; A. conicum Rud., 1809. Priorité : Strigea cervi). - Corps long de 10 à 13 millimètres, large en arrière de 2 à 3 , de teinte carnée nuancée en avant et surtout en arrière de rouge 
plus foncé; très épais, conoïde, allénué en avant, élargri, recourbé et obtus en arrière. Ventouse antérieure urcéolée; ventouse postérieure assez large etprofonde. Orifices génitaux situés un peu en avant le la bifurcation de l'intestin, et souveut de cỏté. Oluf́s ovoïles, operculés au póle le plus étroil, et olliant un épaississement de la coque au pỏle le plus large; longrs de 133 à $162 \mu$, larges de 82 a $90 \mu$.

Daubenton a, le premier, trouvé ce Ver dans la panse duBoeuf. Depuis lor's, il a été rencontré chez le Mouton (Treutler), chez la Chèvre (Creplin) el chez de nombreux Ruminants sauvages. Il se fixe par la ventouse postérieure entre les papilles du rumen, el de préférence aux abords de la gouttière osophagienne. On le considère généralement comme inoffensif; d’après Zii rnn, on lui aurait pourtant attribué, àlorl ou à raison, une aflection meurtrière qui sévissaitsur le gros bétail, en Australie.

Amphistome étalé (A. cxplanatum Creplin, 1847). - Corps long de 9 à 10 millimètres, large de \& milliniètres à $4 \mathrm{~mm}, 5$, ovale lancéolé, très étroit en avant, épais. Ventouse antérienre petite, terminale, circulaire. Ventouse postérieure basilaire, subelliptique, rétrécie en arrière, à bord large, aplati (explanatus) sur la totalité ou sur la plus grande partie de son étendue.

Recueilli par Gurlt, à Berlin, dans les conduits hépatiques et la vésicule biliaire d'un Zćbu.

Amphistome bothriophore (A. bothriophoron M. Braun, 1892). - Espèce un peu plus grande que l'Amphistome conique, dont elle se distingue à première vue par un orifice situé sur la face ventrale, en arrière de la ventouse buccale. Cet orifice, entouré d'un bourrelet, mesure près de $0^{\mathrm{mm}}, 5$, et donne entrée dans une cavité arrondie, profonde de $0^{\mathrm{mm}}, 7$ et longue de $0^{\mathrm{mm}}, 0 x$ d'avant en arrière. Au fond de celle-ci s'ouvrent les orifices génitaux, sur une petite papille. Il s'agit done d'un atrium génital, rudiment de la poche que nous aurons à signaler chez les Gastrothylax.

Cet Amphistome a été recucilli par Siliora, dans la panse du Zébu, à Tananarive (Madagasear).

Amphistome tuberculé ( 1 . tuberculatum Cobbold, 1873). - Espèce nominale, établie par Cobbold d'après des échantillons envoyés de l'Inde, en septembre 1875, par le lieutenant-colonel Hawkes, qui les avait recueillis sur le Bœuf, "dans l'intestin seulement ». L'envoi comprenait 60 exemplaires, tous plus on moins ridés, et montrant de grandes variations dans la taille et dans l'aspect.

Amphistome de Collins (A. Collinsi Cobbold, 18i5). - Cobbold a de mème signalé sous ce nom, sans les décrire, des parasites de l'intestin du Cheval qui lui avaient été adressés de Simla (Bengale), en mars 1875, par F. F. Collins, vétérinaire principal de l'armée anglaise. Comme ceux de l'intestin de l'Éléphant el du Bouf, ces Amphistomes à l'état frais sont de couleur rouge brique, et reçoivent des indigènes le nom de Masuri. Cobbold les dit simplement plus petits que ceux de l'Éléphant.

Ils avaient été recueillis dans le cỏlon d'un Cheval mort d'une "fièvre particulière à la région ". Ils se trouvaient au nombre d'un millier environ, presque lous au voisinage du cacum, et libres dans l'intestin. 
Cinq ou six ans auparavant, Edward Stanley jeune arait envoyé de I'Inde au professeur Simonds des Amphistomes également recueillis dans le cỏlon du Cheval, et présentant des dimensions supérieures à celles des exemplaires de Collins. D'après un examen superficiel, Cobbold les a considérés comme une grande variété des précédents, se demandant mème si les différences ne tiendraient pas au degré de concentration de l'alcool dans lequel les Vers étaient conservés (A. Stanlcyi Cobbold, 1873 ; A. Collinsi var.Stanleyi Cobbold, 1879).

Sandrin a vu au Tonkin, dans l'intestin des Chevaux venant des îles de la Sonde, des myriades de ces Amphistomes rouges.

Amphistome de l'Homme (A. hominis Lewis et McConnell, 1876). Corps rouge, long de 5 à 8 millimètres et large au plus de 3 à 4 millimètres,

A B

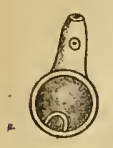

Fig. 2:0. - Amphistoma hominis, grossi deux fois, d'après Lewis et McConnell. - A, face ventrale. $B$, face dorsale. offrant un disque aplati et un prolongement antérieur ou cou cylindro-conique, l'un et l'autre à peu près de même longueur. Tégument lisse. Prolongement céphalique offrant sur sa face ventrale, à l'extrémité, la petite ventouse antérieure elliptique, transversale, et, vers le milieu de la longueur, le pore génital. Disque ayant les bords dilatés et recourbés, de manière à former une sorte de poche ventrale circulaire, à l'extrémité postérieure de laquelle est située la large ventouse postérieure. OEufs ovoïdes, operculés au pỏle étroit et mesurant en moyenne $150 \mu$ sur 72 .

Ce parasite n'a encore été vu que deux fois, dans l'Inde, chez des individus morts du choléra. Il en existait chaque fois de nombreux exemplaires, fixés par leur ventouse postérieure à la muqueuse du gros intestin, particulièrement dans le creum et le côlon ascendant, où se voyaient de nombreuses petites taches rouges semblables à des piqûres de Sangsues. - Il existe certainement de grandes affinités entre cet Amphistome el le Gastrodisque dontil sera question plus loin.

Il n'est peut-ètre pas inuitle de citer encore, parmi les représentants du. genre, l'A. lunatum Dies., 18300, trouvé au Brésil, par Natterer, dans les cæcums du Canard musqué sauvage. Il est possible qu'on arrive à le rencontrer quelque jour chez le Canarl musqué domestique.

Genre Gastrothylax (Gastrothylax J. Poirier, 1883). - Corps allongé ou ramassé. A la face ventrale, une poche à section triangulaire, s'ouvrant au dehors, un peu au-dessous de la bouche, par une fente transversale. Cette poche s'étend sur tout le corps jusqu'un peu en avant de la ventouse postérieure ( $\gamma \alpha \leftarrow \tilde{n} p$, ventre; $\theta u ́ \lambda \alpha \xi$, poche). Ventouse postérieure grande, elliptique, terminale. Pharynx unilobé.

Gastrothylax à poche $(G$. crumeniferum [Creplin]. - Syn. : Amph. crumeniferum Creplin, 1847; G. crumeniferum J. Poir., 1883). - Corps subtriquètre, légèrement atténué en avant, long de 9 à 14 millimètres, large de 5 millimètres au milieu; ventouse antérieure petite, terminale, orbiculaire ; ventouse postérieure terminale, large, à bord saillant. La fente transversale qui donne entrée dans la poche se trouve située ả peu de distance. de la ventouse antérieure. 
Trouvé par Gurlt, à Berlin, dans la panse du Zébu. Bourgès et Sandrin l'ont rencontré habituellement, et en quantité énorme, dans la panse du même animal, au Tonkin. Les sujets envahis de la sorte subissent un amaigrissement extrême (1).

Gastrothylax allonge (G. clongatum J. Poirier, 1883). - Corps de forme allongée, atténué elı avant, triquètre ensuite sur une grande étendue, puis un peu étranglé et enfin subcytindrique ; longueur 20 millimètres, largeur maximum 4 millimètres; ventouse antérieure petite, terminale, orbiculaire ; ventonse postérieure arrondie, légèrement ventrale, large de $1^{\mathrm{mm}}, \hat{;}$.

Cette espèce a été trouvée par Poirier dans la panse d'un Gayal ( $\boldsymbol{B}_{0 s}$ frontalis) provenant de Java et mort ì la ménagerie du Muséum de Paris. Nous en possédons quelques exemplaires recueillis en 1888. dans le rumen d'un Zébu mort au Jardin d'acclimatation.

Poirier a signalé en outre une troisième espèce : $G$. Cobboldi Poir., de la panse du mème Bos frontalis.

Genre Homalogastre (Homalogaster J. Poirier, 1883). - Corps plat. Ventouse postérieure terminale. Pharynx bilobé.

Momalogastre de Poirier (H. Poirieri Giard et Billet, 1892). - Ventouse antérieure entourée de fines papilles digitées. Ventouse postérieure très large. Face ventrale couverte de lignes longitudinales de papilles agissant sans doute comme ventouses accessoires.

Ce parasite a été trouvé chez les Bœufs sacrifiés pour la consommation des troupes à Cao-Bang (Tonkin), par le $\mathrm{D}^{\mathrm{r}} \mathrm{A}$. Billet (2). Il est fixé sur la muqueuse du gros intestin, à laquelle il adhère fortement par sa rentouse postérieure. On peut en trouver jusqu'à 20 exemplaires groupés sur une surface de quelques centimètres carrés.

Genre Gastrodisque (Gastrodiscus Leuck., 1877. - Syn. : Cotylegaster von Siebold, 1877, errore). - Corps formé d'un disque elliptique à face dorsale convexe, à face ventrale légèrement concave et couverte de nombreuses papilles-rentouses, et d'un prolongement antérieur ou céphalique cylindro-conique. Ventouse postérieure médiocre, circulaire, subterminale. Pharynx bilobé.

Gastrodisque ágyptien (G. xgyptiacus [Cobbold et Sonsino]. - Syn. : Hemistoma sp.? Sonsino, 1876 ; Diplostoma xyyptiacum Cobb. et Sons., 1876; Colylegaster cochleariforme von Sieb., mars 1877, errore; G. Sonsinoii Cobbold, avril 1877; G. polymastos Leuck., 1880). - Corps rouge chair à l'état frais. Prolongement céphalique long de 3 à 4 millimètres, naissant de la face dorsale du disque et portant à son extrémité la petite ventouse antérieure. Disque elliptique, long de 11 à 12 millimètres, large de 8 à 9 millimètres;

(1) A. Ratllet, Sur les Amphistomes des animaux domestiques du Tonkin. Comptes rendus soc. de biol. (9), IV, P. 633 et XIII, 1892.

(2) A. Giani et A. Bullet, Sur quelques Trématodes purasites des Baufs du Tonkin. Comptes rendus Soc, de biologie $(9 \%$, IV, p. 613, $189 ?$. 
face dorsale convexe, lisse ; face ventrale presque plane, à peine déprimée en cuiller et couverte de petites papilles-ventouses très serrées. Ventouse pos-

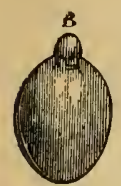

Fig. 251. - Gastrodiscus zoyptiacus, grandeur naturelle. - A, ru par lit face ventrale. B, par la face dorsale (Orig.). térieure assez grande, tangente au bord postérieur du disque. Orifices génitaux situés au pòle opposé, à peu de distance $\mathrm{du}$ bord antérieur. OEufs ovoïdes, blanchàtres, operculés au póle le plus étroit, les plus avancés se trouvant au stade morula, longs de 150 à $170 \mu$, larges de 90 à $9 \ddot{\ddot{\mu} \mu .}$

Ce Ver habite le tube digestif des Équidés : Cheval, Ane, Mulet, Zèbre. Il se tient fixé à la muqueuse par sa ventouse postérieure, tandis que

le prolongement céphalique, très mobile, demeure libre.

Il en existait de nombreux exemplaires dans l'ancienne collection helminthologique de l'École d'Alfort, mais sans aucune indication.

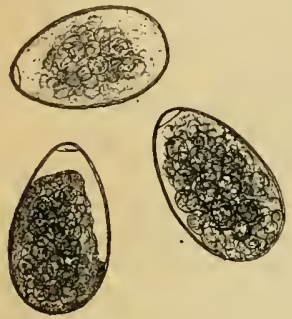

Fig. 252. - (Eufs de Gastrodiscus rgyptiacus, grossis 100 fois (Orig.).

Je soupconne qu'ils avaient été recueillis, vers 1832, par les vétérinaires français de I'École d'Abou-Zabel (Égypte). En 1876, le Dr P. Sonsino en recueillit un grand nombre dans l'iléon et le gros intestin de deux Chevaux morts à Zagazig (Égypte), au cours d'une grave épizootie, et les communiqua à divers helmin thologistes européens, notamment à Cobbold et à Leuckart. L'étude anatomique en a été faite par Lejtényi (1). Zucchinetti et Burlazzi. puis J.-B. Piot, retrouvèrent ensuite le même parasite dans diverses localités égyptiennes,

Il se rencontre également à la Guadeloupe, où Guyot et Couzin l'ont observé par milliers chez des Mulets. Le premier l'a vu sur toute la longueur du tube digestif, depuis le plıarynx jusqu'à l'anus, et même jusque dans les fosses nasales. - Un de nos regrettés élèves, Sarciron, en a recueilli cinq exemplaires dans le cacum d'un Anon, à Kayes, dans le Haut-Sénégal. - Giles l'a trouvé en abondance dans le cacum et le côlon d'un Mulet, à Shillong, dans l'Inde. - Enfin, A. Collin l'a observé dans l'intestin d'un Zèbre.

Dans la plupart des cas, ces parasites ne semblent pas avoir troublé la santé de leur hôte; c'est seulement en ce qui concerne les Mulets de la Guadeloupe qu'on a pu les considérer, en raison de leur nombre extraordinaire, comme ayant provoqué des troubles mortels.

Famille des HOLOSTOMIDÉS. - Corps divisé par un étranglement en deux régions : une postérieure cylindrique et une antérieure élargie, plus ou moins concave. Dans la région antérieure se trouvent: tout ou parlie des vitellogènes; une ventouse antérieure ordinaire-

(1) Dr LeJtÉnyi Karoli, Ueber den Bau des Gastrodiscus polymastos Leuckart (Thèse inaug.). Frankfurt a M., 1881. 
ment très petite; une ventouse postérieure également petite, plus oı moins rapplochée du centre; enfin, un peu en arrière, un appareil de fixation, qui donne un aspect très variable à cette région, et consiste, tantôt en une ouverture ovalaire ì bords saillants garnis de papilles digitiformes (Diplostomimar), lantìt en un cône très puissant, plein ou creusé d'unc eavité centrale profonde. Bouche s'ouvrant dans la ventouse antérieure. Otsophage court; intestin bifide, s'étendant sur toute la longueur du corps. Orranes génitaux situés dans la région postérieure, et allant s'ouvirir dans une vaste cavité du pôle postérieur du corps (cloaque génital ou bourse copulatrice); du fond de cette cavité s'élève une masse conirjue pouvant faire saillie au dehors (cônc génital) et portant à son sommel l'orifice mâle, à sa base l'orifice femelle. Dans l'utérus, wuf́s peu nombreux, mais de grandes dimensions, se développant dans l'eau.

Les recherehes de von Linstow, Ercolani, Brandes, ont commencé ¿ jeter quelque lumière sur l'évolution de ces Trématodes. De l'œul' sort un embryon cilié, pourvu de taches oculaires. Cel embryon pénètre chez un hôte provisoire, perd ses cils el se transforme en une larve assez bizarre, que Steenstrup avait observée dès 1842, et à laquelle de Filippi a donné en $18 \% 4$ le nom de Tetrucotyle. Celte larve offre la curieuse particularité de virre en parasite dans les Sporocystes de diverses espèces de Distomiens; cependant, on l'a rencontrée aussi, libre ou enkystée, dans les viscères d'un certain nombre de Mollusques, Annélides, Poissons, Batraciens, Reptiles, Oiseaux. Elle se présente sous l'aspect d'un corps ovoïde ou arrondi, de teinte noirâtre, enveloppé dans une membrane transparente et élastique, qui suil ses mourements de contraction et lui appartient en propre. A la face ventrale, on remarque une ventouse antérieure ou buccale arrondie, une centrale ou postérieure, el deux orifices glandulaires latéraux qui ont été longtemps pris aussi pour des ventouses. Celte larve, ingérée par l'hôte définitif, se transforme dans son intestin en un Holostomidé adulte, comme l'avait soupçonné Claparède, et comme l'ont démontré les expériences d'Ercolani et de Brandes.

3 sous-familles : Diplostominx, Hemistomina el Holostominx.

Les нÉmistominés ont la partie antérieure du corps aplatie, avec les bords lamelleux recourbés vers la face ventrale, de manière à présenter l'aspect d'une cuiller ou d'un cornet ouvert largement et obliquement en avant. Appareil de fixation en forme d'appendice épais, couvrant souvent la plus grande partie de la région antérieure du corps et cachant la ventouse postérieure. Cône génital el bourse copulatrice rarement bien développés; orifice de la bourse du côté dorsal.

Chez les Oiseaux et les Mammifères.

Le genre Hémistome (Hemistoma Dies., 1830) représente à lui seul celte sous-famille. 
VERS.

Hémistome ailé $(\boldsymbol{H}$. alatum [Gœze]. - Syn. : Planaria alata Gœze, 1782; Holostomum alatum Nitzsch, 1819; Hemistomum alatım Dies., 1850). - Corps

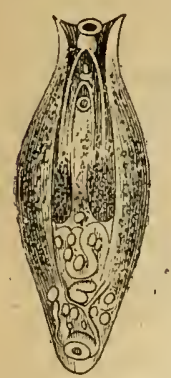

Fig. 253. - Hemistoma alatum, grandeur naturelle el grossi, d'après Gurlt.

un très jeune Chiot. d'un blanc sale, long de 3 à 6 millimètres. Région postérieure du corps beaucoup plus courte que l'antérieure. Ventouse antérieure et pharynx assez développés; ventouse postérieure un peu plus petite. En dessous de celle-ci, l'appareil de fixation représenté par un appendice peu saillant, dont les bords latéraux sont renflés en avant. Sur les còtés de la venlouse buccale, des orifices glandulaires saillants, de forme semi-lunaire. Orifices génitaux dans le milieu du petit còne génital. Bourse V: copulatrice insignifiante, tournée vers la face dorsale.

Assez commun dans l'intestin grêle du Renard et du Loup. Creplin, à Greifswald, l'a trouvé aussi dans l'intestin grêle du Chien domestique, et Maclay en a recueilli quatre exemplaires asexués chez

Les hoLostominés ont la région antérieure du corps transformée

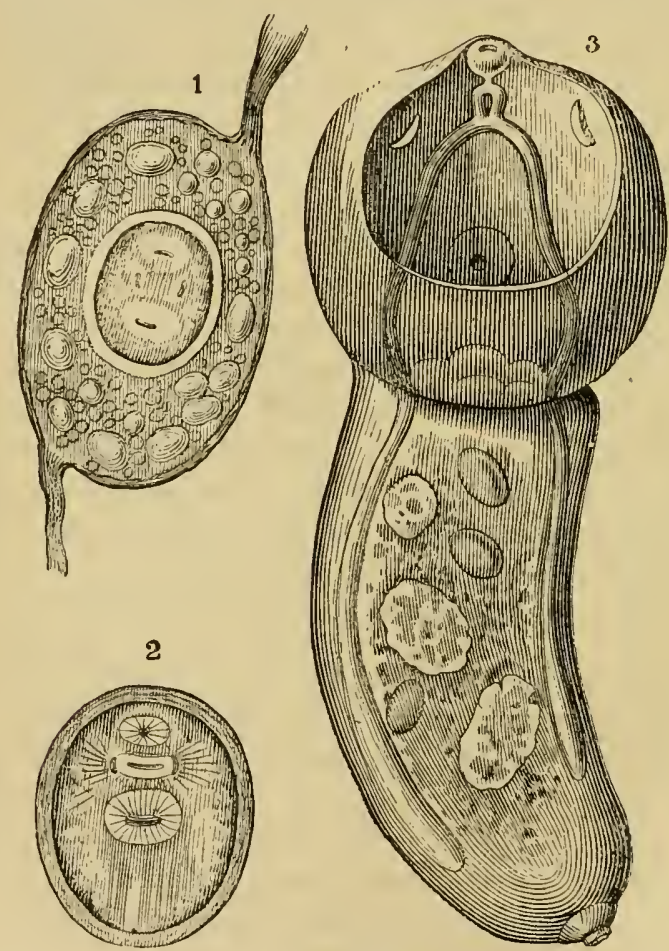

Fig. 254. - Développement d'un Holostome, d'après Ercolani. - 1, Tétracotyle parasite d'une Sporocyste. 2. Tétracotỵle libre extrait d'une Planorbe. 3, Tétracotyle développé en Holostome dans l'intestin du Canard domeslique.

en capsule par suite de la fusion des bords latéraux lamelleux. L'appa- 
pareil de fixation représente un appendice conique avec une cavité centrale profonde. Còne grénital et bourse copulatrice souvent bien visibles.

Parasites des Oiseaux, rarement des Batraciens et des Poissons.

Le genre Holostome (Illolostoma Nitzsch, 1819) est le seul représentant de ce groupe.

ll comprend un certain nombre d'espèces dont aucune n’a été rencontrée jusqu à présent à l'état spontané chez nos animaux domestiques. Citons II. variabile Xitzsch, de lintestin de divers Rapaces; II. erraticum Duj., nec von Vinst., de l"intestin du Larus muculipennis; H. gracile Duj., de l’intestin de divers Anatidés. Ercolani croyait avoir développé l'H. erraticum chez le Canard domestique, en faisant ingérer à celui-ci le Tetrucolyle typica Dies.; mais il est probable, comme le fait remarquer Brandes, qu'il s'agissait d'une autre espèce.

THOISIËME SOLS-ORDRE

\section{pOLYSTOMENS}

Trématodes munis en grnéral de deux petites ventouses antérieures et d'une ou de plusieur's ventouses postérieures, souvent accompagnées de crochets, surtout les postérieures. Développement presque toujour's direct. Généralement ectoparasites.

Le corps estaplati on à peine renflé. Les rentouses antérieures sont quelquefois remplacées par des lobes membraneux ou par des tentacules.

La bouche s'ourre en arant. Lintestin est bifide ou simple.

Les orifices génitaux sont situés sur la face ventrale.

Les œufs sont très développés et souvent pourvus d'appendices polaires. L'embryon qui s'y développe présente d'ordinaire la forme et l'organisation des parents.

Les Polystomiens vivent en parasites sur la pean, sur les branchies ou mème dans la cavité buccale des Poissons; parfois sur les Crustacés ou les Hirudinées; rarement dans la vessie urinaire des Batraciens et des Reptiles.

3 familles: Polystomidx, Temnocephalidx, Tristomidx.

Janson dit avoir trouvé un grand nombre de Tristomes dans l'intestin d'un Chien, au Japon : ce sont probablement des Distomiens mal étudiés, ou bien des pseudo-parasites, ingérés avec un Poisson.

QUATRIEME ORDRE

\section{TURBELLARIÉS}

Plathelminthes ciliés, foliacés, à tube digestif incomplet, presque toujours dépourvu d'anus. Généralement libres.

Les Turbellariés (turbellx, agitation, sous-entendu ciliaire) ont un corps 
VERS.

mou, dont l'aspect et l'organisation rappellent celui des Trématodes. Ils ne possèdent ni crochets, ni ventouses, mais leur tégument est recouvert de cils vibratiles, et renferme des organes urticants de conformation variable.

Le systeme nerveux se compose de deux ganglions sus-œsophagiens unis par une commissure ou mème fusionués, et desquels partent divers filets nerveux, en particulier deux latéraux, dirigés en arrière. - Assez souvent on observe des taches oculaires, plus rarement des otocystes.

La cavité viscérale (cœlome) n'est représentée que par d’élroites lacunes dans lesquelles prend naissance l'appareil excréteur. Le tube digestif, uni au tégument par un lissu conjonctif épais, comprend une bouche ventrale, munie d'un sphincter, un pharynx souvent protractile, et presque toujours une cavité gastro-intestinale, dont la disposition est variable. Sauf de très rares exceptions (Microstoma), l'anus fait défaut. - Il n'exisle pas d'organes pour la circulation et la respiration. - L'appareil excréteur est représenté par deux troncs latéraux plus ou moins ramifiés.

La reproduction s'effeclue queiquefois par scissiparité, mais elle est en général sexuelle. La plupart dles espèces sont hermaphrodites. Le développement est direct, sauf chez quelques formes marines, qui produisent une larve munie dappendices digités.

Les Turbellariés vivent dans les eaux douces on salées, parfois dans la terre humide.

2 sous-erdres :

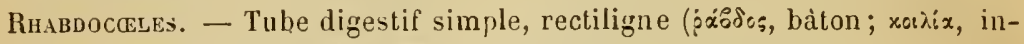
testin). - Genres Plagiostoma, Microstoma, etc.

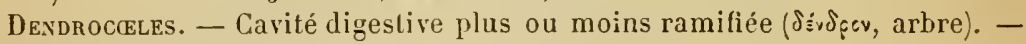
Genres Planuria, Leploplana, etc.

\section{CINQUIËME ORDRE}

\section{NÉMERTIENS}

Plathelminthes ciliés, à corps cylindroïde ou déprimé, pourvus d'un tube digestif complet. Libres.

Le corps est allongé, non annelé, cylindroïde ou plus souvent aplati, recouvert de cils. A l'extrémité antérieure, il présente un orifice conduisant dans un tube musculaire susceptible de se renverser au dehors et formant ainsi une très longue trompe, parfois armée d'un stylet central et de crochets latéraux.

Le systeme nerveux est analogue à celui des Turbellariés, mais plus développé. - Il existe des taches oculaires, des otocystes et souvent des fossettes ciliées à signification douteuse.

La cavité générale est remplie de travées conjonctives. - Le lube digestif débute par une bouche située an-dessous de l'orifice de la trompe; il est rectiligne, ordinairement cilié, parfois pourvu de cæcums latéraux, et aboutil à un anus terminal. - Il faut noter l'existence d'un appareil circulatoire composé de trois troncs longiludinaux contractiles, renfermant un sang géuéralement incolore. - Pas d'organes spéciaux pour la respiration. - Appareil excréleur comme dans le groupe précédent. 
Les sexes sont presque toujours séparés. Le développement est direct, ou se fait au moyen de larves ciliées, dont la forme la plus répandue, en casque, porte le nom de Pilidium.

Les Némertiens, autrefois confondus avec les Turbellariés, sont pour la plupart marins; quelques-uns vivent dins tes ealı douces ou saumàtres ; d'autres sont terrestres; enfin certaines formes vivent en parasites chez les Lamellıbranches et les Crustacés.

2 sous-orilres :

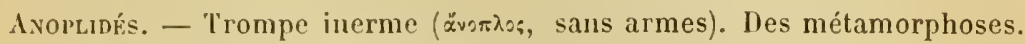
- Genres Malacobulella (parasite), Lineus.

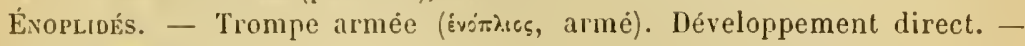
Genre Nemertes.

CL.ASSE III

\section{NÉMATHELMINTHES}

Vers cylindriques, sans appareil ciliaire prébuccal, pourvus d'un système nerveux variable, mais ne formant pas de chaine ventrale. Généralement dioïques.

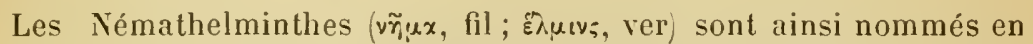
raison de leur forme cylindrique et allongée; souvent même ils sont en réalité filiformes. Ils possèdent une cavilé générale dans laquelle flottent le tube digestif quand il existe, et les organes sexuels, ces parties nétant reliées à la paroi du corps que par de rares travées conjonctives.

La plupart sont unisexués et endoparasites (helminthes).

3 ordres principaux :

Un tube digestif $\left\{\begin{array}{l}\text { complet................... Nématodes. } \\ \text { atrophié chez l'adulte..... Gordacés. }\end{array}\right.$

Pas de tube digestif chez l'adulte........... AcanthocépHales.

PREMIER ORDRE

\section{NÉNATODES}

Némathelminthes pou'vus d'un tube digestif complet.

Ainsi que l'indique leur nom, les Nématodes (1) ou Nématoïdes

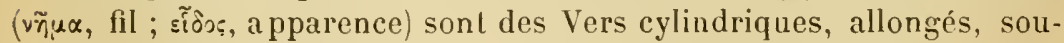
vent grêles et même filiformes; mais ils ne sont pas segrmentés: les organes reproducteurs ne se répètent jamais plusieurs fois sur la longueur du corps.

La cuticule chitineuse est transparente, ferme, élastique, et divisible en plusieurs couches : l'externe, presque toujours finement striée

(1) Diesing, Revision der Nemaloden. Sitzungsber. d. Wien. Akad. d. Wiss., XLII, p. 59i, 1861. - ld., Nachtrag. Ibid, XLIII, is62. - Inton Scineider, Monojraphie der Nemalalen. Berlin, 1866.

Railliet. - Zoologie. 
en travers, enveloppe le corps comme un fourreau, et recouvre une double ou triple couche fibrillaire souvent très épaisse. Il n'existe nulle part de cils vibratiles, mais on peut observer à la surface du corps diverses productions cuticulaires, telles que tubercules, épines, poils, etc. Parfois même la cuticule se détache sur les côtés du corps, à l'extrémité antérieure ou postérieure, de manière à constituer des expansions vésiculeuses ou aliformes. Pendant le jeune âge, il se produit des mues, qui consistent dans la chute et le renouvellement périodiques d'une partie des strates cuticulaires.

Au-dessous de la cuticule, se trouve une couche molle, granuleuse, nucléée (hypoderme ou épiderme), qui lui a donné naissance, et qui représente le tégument propre ou ectoderme. D’après J. Chatin, cette couche est primitivement cellulaire.

Presque toujours elle prend un développement considérable suivant quatre lignes longitudinales équidistantes: il se forme ainsi quatre bourrelets qui font saillie, à un degré variable, dans la cavité du corps et interrompent la couche musculaire. Les deux plus importants sont les lignes latérales - ou mieux champs latéraux situés de chaque côté du corps et souvent bien distincts à l'œil nu. Les deux autres, moins larges, recoivent, en raison de leur situation, le nom de lignes médianes (dorsale et ventrale). Quelquefois même il existe des lignes accessoires (lignes médianes secondaires ou lignes. submédianes), occupant l'intervalle des précédentes.

En dedans de la couche sous-cuticulaire, on observe une puissante enveloppe musculo-cutanée, formée d'éléments musculaires tout à fait particuliers (cellules musculaires), dont la forme et la répartition varient suivant les groupes.

Ainsi, dans certains genres (Ascaris, Heterahis, Eustrongylus, Physaloptera, Filaria, Spiroptera, etc.), ces cellules musculaires sont nombreuses et par conséquent serrées les unes contre les autres: chacune d'elles se montre alors formée de deux parties distinctes: une partie externe, striée transversalement, et une parlie interne, vésiculeuse, beaucoup plus développée que la précédente et renfermant une substance granuleuse arec un gros noyau. De la face profonde de cette vésicule partent des filaments qui vont pour la plupart former un cordon longitudinal sur les lignes médianes dorsale et ventrale. La couche musculaire est évidemment interrompue au niveau de ces lignes, comme au niveau des champs latéraux. Les Nématodes qui présentent cette structure sont dits, d'après la constitution de la cellule, colomyaries; au point de vue de la répartition, les éléments musculaires étant nombreux, on les appelle polymyaires.

D'autres fois (Oxyuris, Strongylina, Sclerostomina, Rhalditis), les cellules musculaires sont peu nombreuses; il en existe seulement deux rangées dans l'intervalle qui sépare une ligne médiane d'un champ latéral. Ce sont alors de grandes cellules aplaties, losangiques, 
à substance striée transversalement, et munies d'un gros noyau. Les genres offrant ces caractères constituent le groupe des platymyaires; d'après la répartition des éléments, on les appelle méromyaires.

Il faut ajouter que, chez certains platymyaires, dont les lignes médianes et les champs latéraux sont peu développés ou nuls (Trichocephalus, Trichosoma, Trichina, Pseudalius, Mermis, ete.), la couche musculaire, formée de nombreuses rangées de cellules, n'est plus ou presque plus interrompue, sauf parfois au niveau de la ligne ventrale. Ces Vers sont dits holomyaires, mais ce terme ne doit s'entendre que de la répartition des éléments. Ant. Schneider admettait que les Vers auxquels il donnait ce nom étaient dépourvus de véritables cellules musculaires, et possédaient seulement des fibrilles répandues dans une masse protoplasmique commune: dans ce sens, les holomyaires n'existent pas.

En dedans de l'enveloppe musculo-cutanée, on trouve une sorte de tissu conjonctif de consistance spongieuse, qui représente avec elle. le mésoderme.

Le système nerveux a pour base un anneau qui entoure l'œsophage et envoie des filets en avant et en arrière. A ce collier osophagien sont annexés des groupes de cellules ganglionnaires qui correspondent à l'origine même des nerfs, et qu'on distingue en ganglions dorsal, rentral et latéraux. Les nerfs antérieurs sont au nombre de six: deux situés dans les lignes latérales et quatre dans l'espace intermédiaire aux lignes latérales et médianes; ces nerfs se rendent dans les papilles buccales. Les nerfs postérieurs suivent les lignes médianes, ventrale et dorsale, jusqu'à l'extrémité postérieure, et émettent des fibres qui vont aux téguments. Quelques auteurs ont vu également des nerfs postérieurs dans les champs latéraux. Enfin on rencontre quelques amas ganglionnaires dans la région anale.

Les Nématodes ne possèdent, en fait d'organes sensoriels, que des papilles tactiles et quelquefois des taches oculaires. Ces dernières, placées sur l'anneau œsophagien, n'ont d'ailleurs été observées que sur des espèces non parasites. Quant aux papilles, elles sont très répandues et consistent en de petites saillies cutanées, sourent coniques, à la base desquelles se rendent habituellement des nerfs. Leur nombre, qui varie beaucoup, fournit de bons caractères pour la classification. Il est rare qu'elles soient disséminées sur toute la surface du corps (Nematoxys) ou disposées en rangées le long des champs latéraux (Eustrongylus gigas); le plus souvent, elles sont localisées au pourtour de la bouche et au voisinage de l'anus: ces dernières sont parfois très nombreuses chez les mâles, mais les femelles en possèdent rarement plus d'une paire (1).

(1) Dans le systẻme de Schneider, que nous avons adopté, les papilles caudales se comptent d'arrière en avant : ainsi, no 1 représente la papille postérieure de chaque côté, $n^{\circ} 2$ celle qui précéde, etc. Celles qui se trouvent au niveau de la fente anale sont comptées parmi les préanales ou dénommées adanales. 
Le tube digestif est en général complet, à deux ouvertures. La bouche, orbiculaire ou elliptique, est située à l'extrémité antérieure du corps; quelquefois, cependant, par suite du relèvement de cette extrémité, elle paraît n'être plus tout à fait terminale (Uncinaria). Elle est souvent pourvue de deux, trois ou six lèrres molles ou cornées, presque toujours papillifères. Dans certains cas, elle porte une armature chitineuse inunie de piquants, de cro-

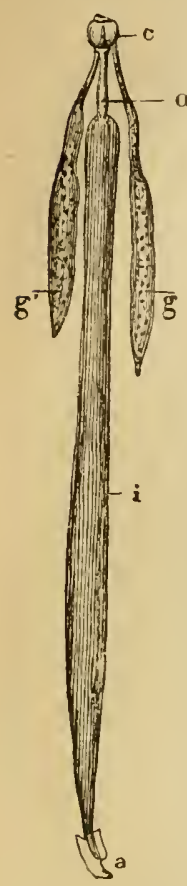

Fig. 255 Tube digestif $d$ une femelle de Sclerostoma equinum. $-c$, capsule buccale. $a$, cesophage. $i$. intestin. $a$, anus. $g, g^{\prime}$, glandes diles céphaliques ou salivaires (Delafond). chets, etc., armature qui peut se renouveler, en se modifiant, au moment des mues (Sclerostoma equinum). Elle s'ouvre directement ou par l'interméd aire d'un infundibulum de conformation variable (capse buccale, pharynx de quelques auteurs) dans un œesop iage étroit, cylindrique ou triquêtre, sourent dilaté . en massue " dans sa partie postérieure. Ce conduit, bien distinct du reste du tube digestif, est caractérisé par la présence, à sa partie externe, d'une épaisse couche de "fibres musculaires " rayonnantes qui servent à le dilater et en font un organe de succion, destiné à l'aspiration des liquides alimentaires. Il présente quelquefois (Oxyuris) un étranglement plus ou moins marqué, suivi d'une dilatation à laquelle on donne souvent le nom de ventricule. Là se termine l'intestin buccal, dont la paroi (endoderme) est tapissée par une culicule chitineuse continue arec celle du tégument et offrant dans quelques cas des saillies longitudinales ou des éminences dentiformes. - L'intestin moyen, séparé lui-même de l'œsophage par un étranglement, est un tube large et droit, rarement ondulé ou moniliforme (Trichocephalus), dont la paroi est formée d'une simple couche de cellules épithéliales, revêtue aussi d'une cuticule à sa face interne. 11 est fixẻ par des cordons fibreux à la paroi du corps, presque toujours le long des lignes latérales. - L'intestin terminal ou rectum, qui peut présenter des fibres musculaires à sa face externe, est un court canal se distinguant des autres parties par son étroitesse. Il aboutit à l'anus, qui s'ouvre, soit à une petite distance de l'extrémité caudale, soit à cette extrémité mème, mais toujours à la face ventrale.

Telle est la disposition de l'appareil digestif complet des Nématodes typiques. On peut ajouter que, dans certaines espèces, des glandes y sont annexées, soit dans la région antérieure, soit au niveau du rectum. Enfin, il est des Nématodes dépourvus d'anus (Mermis) et dont l'intestin se termine par conséquent en cul-de-sac.

Il n'existe pas d'appareil circulatoire. Toutefois, comme le canal intestinal n'est pas en connexion immédiate arec l'enveloppe mus- 
culo-cutanée, il en résulte une cavité viscérale remplie de liquide plasmatique contenant mème parfois des globules. La distribution de ce liquide dans le rorps a lieu par le fait des contractions de l'enveloppe musculo-cutanée.

Le systime excriteur se compose de canaux (vaisseaux aquiféres) situés dans les champs latéraux : il s'en troure quelquefois deux (Spiroplera) et peut-être mème trois (Sclerostoma) de chaque eité. Leur contenu est transparent, sans granulations. Au niveau de la terminaison de l'œsophage, ces canaux latéraux s'infléchissent en dedans et en bas et forment un court canal impair qui va s'ouvrir sur la ligne médiane de la face rentrale, par un très petit orifice appelé pore excréteur.

A de très rares exceptions près (Angiostoma nigrovenosum), les Nématodes sont dioïques. Les organes sexuels consistent en des tubes situés dans la carité viscérale et débouchant à l'extérieur ; l'extrémité cacale de ces tubes fonctionne comme testicule ou comme ovaire, le reste comme appareil conducteur et réceptcur; il n'existe d'organes accessoires qu'à l'ouverture extérieure. - Les individus máles se reconnaissent en grénéral à leur taille plus petite et à leur quene recourbée. lls ne possèdent d'ordinaire qu'un seul tube sexuel, qui décrit des circonvolutions plus ou moins nombreuses, et qu'en zoologie descriptive on qualifie de testicule, mais qu'on doit distinguer en testicule proprement dit et en canal déférent. Celui-ei présente quelquefois, avant sa terminaison, une dilatation regardée
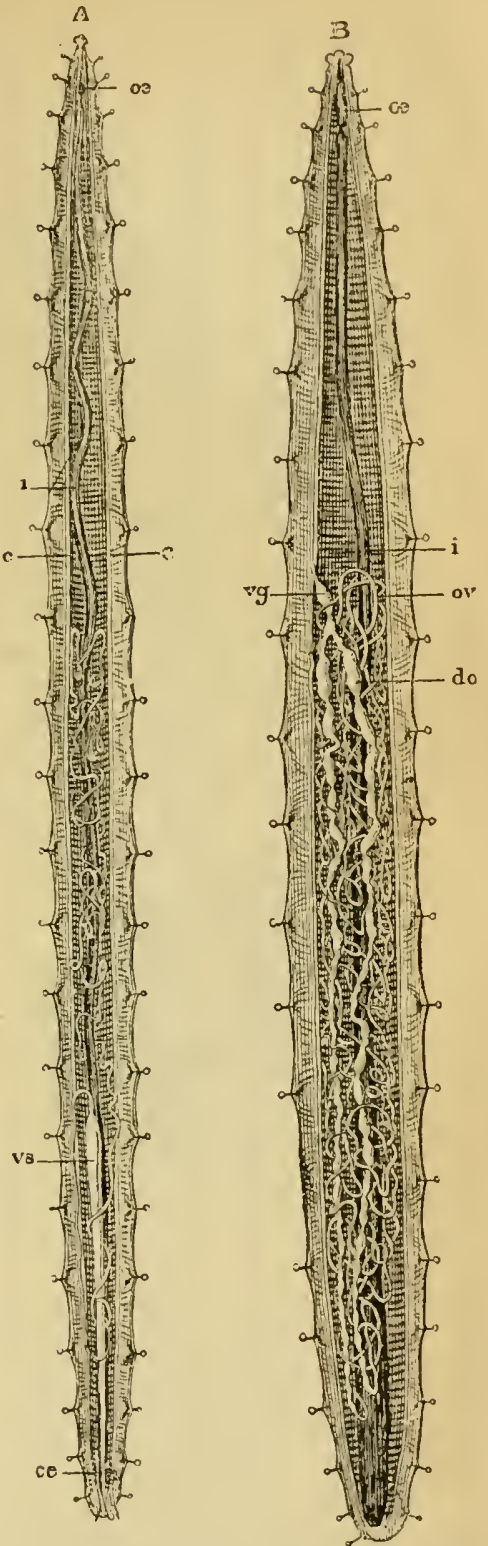

Fig. 956. - Anatomic de l'Ascaride du Porc. $\mathrm{A}$, mầle. $\mathrm{B}$, femelle. $c$, champs latéraux. $\alpha$. cesoplaage. $i$, inteslin. $v s$, vésicule séninale. $c e$, canal éjaculateur. $0 v$, ovaires. do, partie renflée de l'oviducle ou utérus. $v g$, vagin (Delafond). comme une vésicule séminale; la portion terminale, ou conduit éja- 
culateur, vient déboucher en arrière, avec le tube digestif, dans un cloaque. Au voisinage de ce cloaque, on observe souvent une ou deux pièces de chitine, auxquelles on donne le nom de spicules, et qui ne sont autres que des organes de copulation. Effectivement, ces spicules, qui peuvent être projetés au dehors par des muscles spéciaux, pénètrent dans la vulve de la femelle et la distendent de manière à permettre l'introduction du sperme dans le vagin. Dans certains cas (Strongylider), la copulation est en outre favorisée par la présence d'une bourse caudale, expansion campanuliforme qui maintient le mâle étroitement fixé à la femelle. D’autres fois, enfin, ces divers organes copulateurs font défaut, mais le cloaque peut se renverser en dehors et jouer airsi le rôle de pénis (Trichina). Les spermatozoïdes sont sphériques ou coniques: ils offrent cette particularité remarquable de présenter des mouvements amiboïdes. - Les femelles possèdent quelquefois un seul, plus souvent deux tubes sexuels, dits ovaires, décrivant plus ou moins de circonvolutions suivant leur longueur. Nous
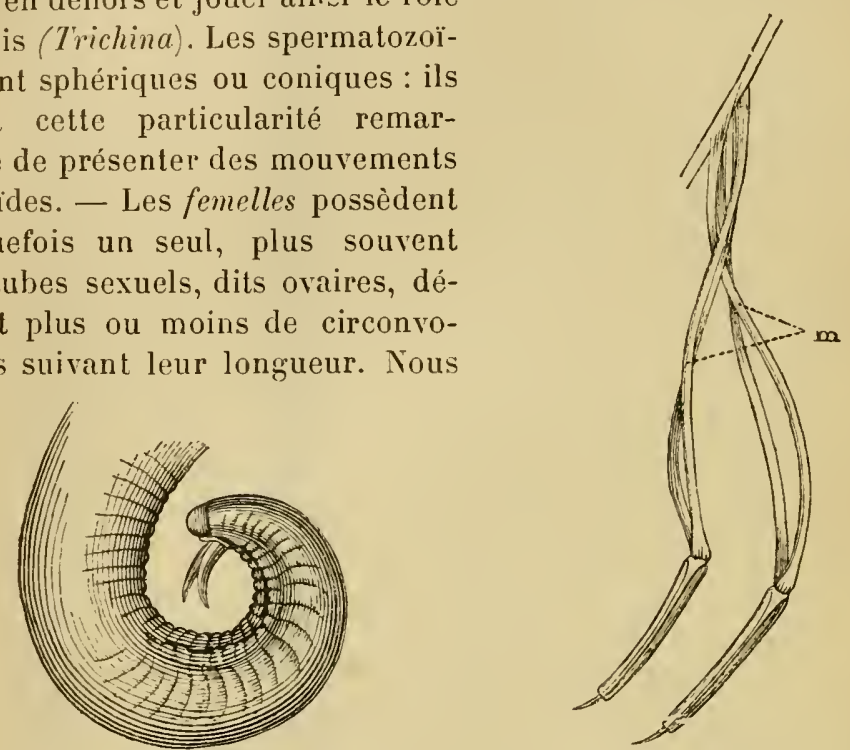

Fig. 257. - Eslrémilé caudale de l'Ascaride du Pore, Fỉ. 258. - Spicules de l’Ascaride des Équidés. vue de côté (les spicules sont figurés un peu trop $\quad-m$, muscles rétracleurs (Delafond). épais) (Delafond).

savons déjà qu'en réalité l'ovaire est représenté seulement par la portion cecale du tube, laquelle se continue par une section ordinairement plus large ou oviducte, aboutissant en général à une dilatation de forme variable désignée sous le nom d'utérus; à celui-ci fait suite un canal plus ou moins étroit, le vagin, qui débouche à l'extéricur par la vulve. Lorsqu'il existe deux tubes sexuels, ils sont presque toujours distincts jusqu à la naissance du vagin, quelquefois même plus loin. Quant à la vulve, sa situation est variable; mais, dans tous les cas, elle occupe la face ventrale. On admet généralement que les œufs, comme les spermatozoïdes, naissent par gemmation aux dépens d'une masse protoplasmique nucléée disposée sous forme de cordon (rachis) dans l'axe des tubes germinatifs : ils se pré- 
senteraient tout d'abord sous? l'aspect de cellules à noyaux, renflées en inassue et groupées autour de ce cordon.

Les Nématodes sont ovipares ou orovivipares. Dans le premier cas, les cufs, de forme ovoïde ou sphérique, sont d'ordinaire pourvus d'une coque très résistante. Assez souvent, le développement embryonnaire ne commente qu'après et même longtemps après la ponte; du reste, les circonstances extérieures le font varier : il déhute par une segmentation totale dont le résultat est la formation l'une morula souvent ovalaire. Celle-ci “ s'échancre d'un côté, et l'embryon, à mesure qu'il croit, se replie dans le sens de cette échancrure. Les cellules centrales de la morule pleine se différencient du reste du corps pour former l'endoder'me, qui nail ainsi par un procédé de délamination. " L'cmbryon prend peu à peu un aspect vermiforme et se montre enroulé dans l“intérieur de l'œuf. Les phénomènes se passent de la même façon chez les espèces orovivipares, maisl'éclosion s'effectue dans l'utérus.

Les phases ultéricures du développement comprennent une grande diversité de manifestations; on peut, avec Leuckart, les classer pour la plupart sous les chefs suivants, en ce qui a trait du moins aux espèces parasites :

A. Développement avec hôte intermédiaire. - $1^{\mathrm{er}}$ True : les parasites passent, avant ou après leur éclosion, dans un premier hote

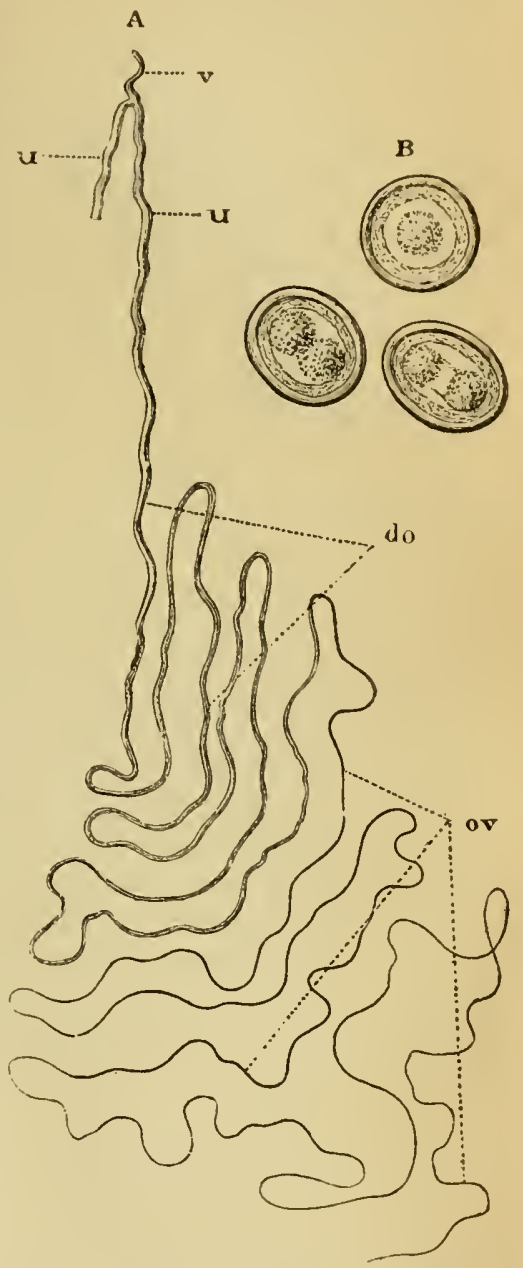

Fig. 2359. - Asearide des Ėquidés. - A, l'un des lubes sexuels de la femelle (l'autre a été sectionné à peu de distance du vagin). ov, ovaire. do, oviducte. $u$, utérus. $v$, vagin. $\mathrm{B}$, weufs grossis environ 130 fois (Delafond).

intermédiaire, sous la forme de larve (Spiroptera obtusa de la Souris ; Cucullanus elegans de la Perche). - $2^{\circ}$ TrPE : les embryons libres envahissent non seulement un hôte intermédiaire, mais aussi l'hôte même chez lequel ils éclosent (Ollulanus tricuspis). - 3 TrPE: les embryons envahissent les tissus de l'hûte qui héberge leur mère et 
chez lequel ils sont éclos (Trichina spiralis); ils arrivent à l'état adulte chez un second hôte. - $4^{\mathrm{e}}$ TYPE : l'embryon atteint un hôte intermédiaire, mais ne subil chez celui-ci que peu ou point de changements: les métamorphoses complètes ne s'accomplissent que dans I'hote définitif (Ascaris acus...).

B. Développement suns hôte intermédiaire. - 5ّe TYPE: l'embryon se développe dans l'œuf évacué et passe dans son hôte définitif pendant qu'il se trouve encore dans sa coque (Oxyuris vermicularis, Trichocephalus affinis). - $6^{\mathrm{e}}$ TYPE : les embryons abandonnent leur coque et se rendent, sous la forme de petits Rhabditis (à double renflement osophagien), dans l'eau ou dans la terre humide, oủ ils se nourrissent et s'accroissent; mais ils ne prennent leurs organes sexuels qu'après introduction dans le corps de leur hôte (Uncinaria trigonocephala). - 7e TYPE: les embryons deviennent sexués à l'état de liberté, sous la forme de Rhabditis; puis ceux-ci donnent naissance à une génération également sexuée, qui retourne à la vie parasitique (Angiostoma nigrovenosum ) : nous avons déjà signalé cette succession de générations sexuées différentes sous le nom d'hétérogonie.

Les variations morphologiques en relation avec le mode de vie (dimorpholiose), telles qu'on les observe dans ces deux derniers types, ont même été constatées chez des Nématodes libres (Rhabditis), sous la seule influence d'une alimentation abondante ou précaire.

Remarquons, d'autre part, que beaucoup de petits Nématodes, et plus spécialement des larves, résistent à la dessiccation, et reprennent leur activité en présence de I'humidité.

La plupart des Nématodes sont parasites et se nourrissent des substances liquides contenues dans l'organisme de leur hôte. Il en est qui jonent le rôle de simples commensaux; d'autres, par contre, attaquent les tissus au moyen de leur armature buccale. Leur présence peut déterminer, suivant les cas, des accidents d'une gravité variable. Nous aurons, en outre, à signaler quelques formes qui vivent aux dépens des plantes.

1. Famille des ASGARIDÉS. - Les Ascaridés ont le corps relativement épais. La bouche est d'ordinaire entourée de trois lèvres (valves céphaliques ou buccales) souvent papillifères: une occupant la face dorsale, les deux autres se touchant sur la ligne médiane de la face ventrale. L'œsophage estlong, musculeux, renflé en arrière et parfois suivi d'un butbe œsophagien (ventricule). Les mâles sont pourvus d'un seul ou de deux spicules. Les femelles paraissent aroir toujours un ovaire double. L'oviparité est la règle.

Il est vraisemblable que tous les Vers de cette famille ont un développement direct.

Genre Ascaride (Ascaris L., 1758, pro parte). — Les Ascarides sont des Polymyaires à trois fortes lèvres, dont les parties latérales sont géné- 
ralement dentées. Les mâles ont deux spicules égaux et de nombreuses papilles en avant et en arrière de l'anus. D'après Schneider, les meilleur's caractères spécifiques

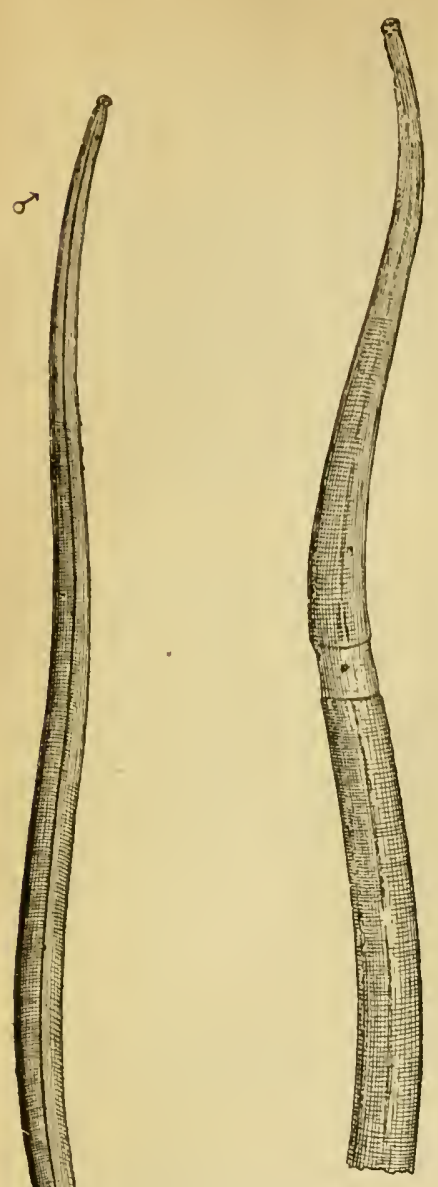
sont fournis par les papilles postanales. La vulve est située en avanl du milieu du corps. Les ceufs sont globuleux ou ellipsoïdes.

Ascaride lombricoide (A. lumilnicoides 1.,, 1758). - Le corps est d'un blanc laiteux, raide et élastique, atténué aux deux extrémités. La tète ou région labiale est petite; les trois levres ont leurs bords finement denticulés : la supérieure porte à sa base deux papilles; cliacune des deux autres n'en possède qu'une bien apparente. Le mâle mesure 15 à 17 centimètres de longueur sur 3 à $3^{\mathrm{mm}}, 2$ d'épaisseur; son extrémité caudale, conique et courbée vers la face ventrale, montre deux spicules courts, un peu arqués, cylindriques à la base, claviformes et aplatis dans leur moitié libre. Sur cette face ventrale, règnent de chaque còié 69 à 75 papilles, dont 7 (paires) post-anales: $n^{\circ} 2$ rapprochée de la ligne médiane ; 4 -ă et 6-7 géninées; les suivantes disposées sur un seul, puis sur deux rangs; une papille impaire en avant de l'anus. La femelle est longue de 20 à

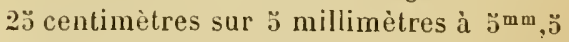
d'épaisseur; son extrémité caudale est conique et droite; la vulve est située vers le tiers antérieur du corps, dans un espace annulaire légèrement rétréci. Les œufs sont ellipsoides et mesurent 50 à

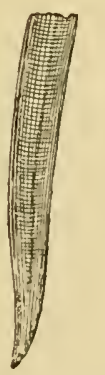

Fig. 260. - Ascaride lombricoïde, mäle, vu de cüté.Grandeur nalurelle (Orig.).
Fig. $261 .-$ Ascaride
lombricoïle, femelle, face ventrale. Grandeur naturelle (Orig.).

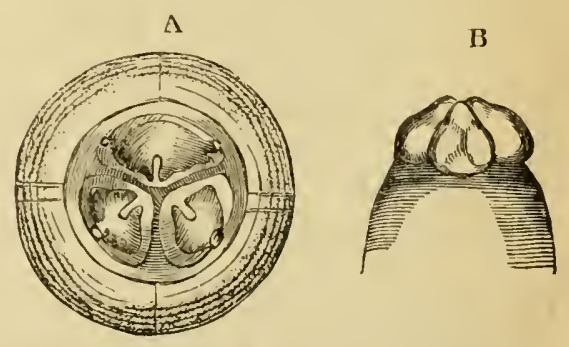

Fig. 262. - Exlrémité antérieure de l'Ascaride lombricuïde. - A, vue de devant. B, vue par la face dorsale. 
73 . $\mu$ de long sur 40 à $58 \mu$. de large; leur coque lisse est entourée d'une couche transparente, albumineuse, irrégulièrement mamelonnée.

L'Ascaride lombricoïde habite normalement l'intestin grêle de l'Homme, où il est assez commun. En raison de son aspect, il a été longlemps confondu avec les Vers de terre, et on lui donne encore vulgairement le nom impropre de Lombric.

Evolution. - Le développement embryonnaire ne se manifeste pas tant que l'œuf demeure dans l'intestin de l'Homme; il ne commence mème parlois que fort longtemps après l'expulsion. On peut le suivre aisément, en plaçant les œufs dans l'eau, sur du sable humecté et en général dans un milieu humide. Il est suspendu par la dessiccation, mais celle-ci doit être très prolongée pour que tous les œufs aient perdu leur faculté évolutive. Cette faculté résiste même à la gelée et à une température de $42^{\circ}$. L'enveloppe albumineuse se détruit souvent au cours du développement.

La segmentation est égale, et a lieu avec une rapidité variable suivant l'élévation dle la température ambiante. En hiver, le processus embryogénique ne fait aucun progrès; il est, au contraire, fortement activé par les grandes chaleurs de l'été. En prenant pour base une douce température, l'embryon est constitué au bout de 30 à 40 jours.

Cet embryon est enroulé sur lui-même en une spirale irrégulière, dont ses mouvements changent à cliaque instant l'aspect. Avec quelque précaution, il peut être extrait de la coque, et se présente alors avec une longueur moyenne de $300 \mu$ et une largeur de $14 \mu$. Il est cylindroïde, a tête obtuse munie d'une petite dent (que Stiles a vue formée en réalité par l'accolement de trois lèrres), à queue conique, mais non effilée. Il subit déjà une mue à l’intérieur de la coque, car on voil, à l'une de ses extrémités, une mince membrane se séparer de la surface du corps.

L'embryon ne sort pas de la coque tant que l'œuf demeure dans le monde extérieur (tout au moins quand on le conserve dans l'eau); d'après Davaine, il peut y prolonger son existence pendant cinq ans dans un milieu humide.

La suite de l'évolution a donné lieu à de nombreuses controverses. Leuckart, ayant ingéré sans succès des eufs contenant un embryon bien développé, admet que cet embryon doit évoluer d'abord chez un hôte différent de celui qui héberge l'adulte. Von Linstow, appuyant cette manière de voir, a cru devoir attribuer ce rôle d'lôte intermédiaire à un Myriapode (Iulus guttulatus) qui se rencontre fréquemment dans les fruits et les racines. Davaine, au contraire, étant parvenu à faire éclore les œufs de l'Ascaride lombricoïde dans l'intestin du Rat, considérait que l'embryon doit sortir de la coque chez l'individu même dans lequel il devient adulte. Deux expériences, dues à Grassi (1879) et à Calandruccio (1886), sont venues corroborer cette 
opinion. Deux mois après l’ingestion d'oul's embryonnés, Grassi recounul dans ses tèces la présence constante d'oufs d'Ascarides. Calandruccio ne pul parvenir à s̈infester lui-mème; par contre, ilobtint un résultat positif chez un enfant de sept ans qui avait eu autrefois des Ascarides, mais en avail élé totalement débarrassé depuis plusieurs semaines. On avail d'aitleurs éearlé, aulant que possible, toutes causes d’inleslation étrangères à l'expérience.

Lut\%, au Brésil, a obtemu un résultat non moins net (1). Du i au Q9) janvier 1888, il fail prendre à une personne de trente-deux ans des uxuts embryonnés encorc entourés de leur revêtement albumineux; le $1^{\text {cr }}$ lévrier, il obtient par la santonine l'expulsion de 33 Ver.s longs de $\ddot{j}^{m m}, 5$ à 13 millimètres, la plupart vivants et très agiles.

En somme, il est constant que l'uul' de l'Asearide, expulsé avec les excréments, évolue dans l'eau ou sur la terre humide, et que, réintroduit dans le tube digestif de l'llomme, il y met en liberté son embryon. L’infeslation spontanée se produit sans doute par l'intermédiaire des eaux impures et des alimenls végétaux. On s'explique de la sorte la frécuence des Ascarides dans les campagnes, et leur rareté dans les grandes villes, où les raux sont filtrées.

Lesphases par lesquelles doit passer l'embryon pour parvenir à l'état adulte ne sont pas encore connues. Les plus petits Ascarides qu'on ait encore vus dans lintestin de l'llomme ont élé signalés par Laboulbène: ils mesuraient 2 millimètres à 23 millimètres el " montraient à l'extrémilé céphalique l'aspect de trois saillies disposées en feuille de trèlle (2)".

Organisatiox. - La cuticule qui revèt le corps de l'Ascaride adulte est très épaisse surtout vers le milieu de la longueur; elle se rélléchit à l'intéjieur par les orifices buccal, anal et génital. Elle se laisse diviser en plusieurs couches : l'externe ou couche chitineuse, qui est la plus mince, offre des sillons transversaux réguliers, distants les uns des autres d'environ $12 \mu$. Elle recouvre une couche anliste très épaisse, au-dessous de laquelle se voient encore deux assises de fibrilles délicates, et deux autres plus minces, lıomogènes.

La couche sous-cuticulaire, qui représente la matrice des précédentes, a perdu sa structure cellulaire primitive; elle forme deux champs latéraux puissants qui font saillie à l'intérieur du corps et vont se perdre en s'atténuant vers les extrémités, et deux lignes médianes moins volumineuses.

Lienceloppe musculuire se rapporte au type colomyaire ou polymyaire; les cellules vésiculaires et pyriformes qui la constituent rétrécissent notablement la cavité du corps, qui se réduit à des lacunes étroites, remplies par le liquide nourricier.

Le systeme nerveux central est représenté par un collier asophagien situé immédiatement en avant du pore excréteur dont nous parlerons plus

(1) Ad. Lutz, in Centralts . f. Bakter. u. Paras., II, P. 713, 18si, et III, passim, 1888.

(2) La boulbève, Sur l'étal larvaire des Ilelminthes. Vématodes parasites du genre Ascaride. Comptes rendus Acad. sc., CIV, p. 1593, 1887. 
loin. Ce collier enserre étroitement l'œsophage et se soude en dehors aux lignes médianes, ainsi qu'aux champs latéraux. Il est formé de fibres nerveuses et de cellules ganglionnaires; celles-ci constituent en outre trois ganglions, un ventral et deux latéraux. Le ganglion ventral, qui recouvre le pore excréteur, se relie en avant au collier wosophagien. Les ganglions latéraux ne sont représentés que par quelques cellules nerveuses disséminées dans les champs latéraux, non loin du collier œsophagien. Quant au système nerveux périphérique, il ne peut guère s'étudier complètement que par la méthode des compes. En avant, on trouve deux nerfs latéraux, qui suivent les champs de ce nom, et quatre nerf́s submédians, situés dans l'intervalle des lignes médianes et des champs latéraux. En arrière, on reconnaìt deux nerfs latéraux et un nerf ventral, correspondant aux trois ganglions; Leucliart admet en outre un nerf dorsal. Le nerf venlral aboutit a un petit ganglion anal, situé immédiatement en avant de l'anus.

Nous n'arnns à signaler, comme organes des sens, que les papilles labiales et caudales.

Le tube digestif est rectiligne et débouche au dehors par ses deux extrémités. Il débute par trois lèvres dont l'ensemble simule une tète distincte. Chacune de ces lèvres représente une valve dont les parties latérales se replient en dedans, de manière à se mettre en rapport avec les lèvres voisines par une surface plane, tandis que la face externe est convexe. Cette face offre sur ses bords un ourlet denté. La lèvre supérieure porte en outre à sa base deux papilles tactiles latérales; chacune des lèvres inférieures en possède une seule, médiane. Chaque lèvre est constituée par une cuticule chitineuse et par une épaisse couche sous-cuticulaire ou pulpe qui se divise en plusieurs lobes, donnant ainsi, par son opacité, un dessin caractéristique de l'espèce. Les trois lèvres s'écartent et se rapprochent par la contraction de deux faisceaux musculaires antagonistes. En tout cas, elles laissent entre elles un canal triangulaire conduisant dans un infundibulum qui représente la cavité buccale.

Celle ci se continue avec l'osophage, tube cylindrique, renflé en massue dans sa partie postérieure et formé d'une couche épaisse de muscles radiaires revètue surses deux faces d'une cuticule chilineuse. Ia lumière de ce canal est triangulaire. Il joue simplement le ròle d'un appareil de succion.

L'intestin s’étend en ligne directe de l'œsophage, dont il est séparé par un rétrécissement, à l'extrémité postérieure du corps. Il ne possède pas de muscles propres, et se montre seulement formé d'un épithélium à longues cellules cylindriques, recouvert en dedans par une cuticule percée de très fins canaux, et limité en dehors par une autre lamelle chitineuse qui lui constitue une sorte de fourreau. L'intestin terminal ou rectum est un court canal cylindrique, plus étroit que le précédent, dont il est séparé par un étranglement, et offrant dans sa paroi externe quelques fibres musculaires. Sa lumière se rétrécit de plus en plus, et il se termine enfin à quelque distance de la pointe de la queue, sur la face rentrale, isolément chez la femelle, en commun avec le canal éjaculateur chez le mảle.

Il n'existe pas de système vus'ulaire. Le liquide nourricier, albumineux et limpide, remplit les espaces vides situés entre la couche musculaire d'une part, l'intestin et les organes sexuels de l'autre. 
L'uppareil excréteur comprend deux canaux qui occupent les champs latéraux, el se rejoignent en avaut pour former un petit tronc mélian aboutissant à un pore excréteur situé sur la ligne médiane ventrale, à 2 millimetres environ de l'extrémilé eéplıalique.

L'apparcil génital mìle n'oceupe guère que le tiers postérieur du corps; il est formé d'un seul tube itteignant sept. ou huit fois la longueur du corps, el se trouve logé en grande partie au-dessous de l'intestin, oà il se replie un grand nombre de fois sur lui-meme. A sa naissance, il a seulement un lliamètre de 3t $\mu$, mais il s'accroit peu à peu et acquiert plus d'un millimètre a sa terminaison. La première portinn de ce tube est remplie par les cellules mères des spermatozoïdes; li portion postérieure ou canal déférent a' sa lumière libre: on y rencontre seulement des cellules isolées, en voie d'émettre les spermatozolides qu'elles renferment. Ceux-ci sont des corpuscules globuleıx, dépourvus de membrane d'enveloppe et de prolongement caudal; ils se deplacent par des mouvements amihoïdes. Le canal déférent aboutit à une résicule séminule cylindrịue, qui se dirige en arrière, oủ elle s'atténue légèrement. C'est un réservoir de sperme. Elle se continue elle-même par un étroit canal éjaculateur qui sünfléchit en arrière vers le rectum et débouche dans le cloaque. Sur la paroi dorsale de ce dernier se trouvent en outre les orifices de deux poches en cul-de-sac, dans chacune desquelles est $\operatorname{logé~un~spicule~chitineux,~long~de~} 2$ millimètres environ, élargi à sa base, sur liqquelle s'insèrent deux faisceaux musculaires. Au moment de la copulation, alors que l'extrémité caudale du màle, gràce a son incurvation, embrasse intimement le corps de la fernelle, ces spicules font saillie parl'orifice cloacal et s'introduisent daus la vulve, qu'ils maintiennent béante.

Les organes femelles se composent de deux tubes, situés également du côté de la face ventrale, el atleignant chacun plus de dix fois la longueur du corps. On y distingue trois sections : l'ovaire, l'oviducte et l'utérus. L'ovaire occupe une longueur d'environ $\mathrm{I}^{\mathrm{m}}, 20$; il conımence par un cul-de-sac grèle et représente un long tube blanc, dont l'axe est occupé par un cordon fibreux ou rachis sur lequel sont fixées par un pédicule de très nombreuses cellules ovulaires. L'oviducte continue directement l'ovaire; son diamètre est à peu près le mème, mais le rachis a disparu, et la cavité est remplie d'ovules libres qui descendent vers la troisième section. L'utérus, enfin, offre un diamètre beaucoup plus considérable; il montre tout d’abord une petite poche cylindrique, lonque de 16 millimètres, que Leuckart appelle réceptacle séminal en raison de l'abonilance des spermatozoüdes qu'on y constate; c'est là que les orules sont fécondés. L'utérus proprement dit est séparé de cette poche par un rétrécissement en forme de sphincter; sa longueur est de 13 à 20 centimètres. Leuckirt estime à 1 centimètre cube la capacité des deux utérus, et à dix millions la quantité d'cufs qu'ils peuvent contenir. Les deux tubes utẻrins s'unissent enfin l'un à l'autre pour former un segment lerminal impair, le ragin, qui va s'ourrir à cólé de la ligne médioventrale, ou sur cette ligne mème, par la vulve, petite fente transversale dont les lèvres l’orment une légrère saillie.

A son arrivée dans l'utérus, l'œuf est constitué simplement par une masse vitelline ovoïde, à la surface de laquelle on aperçoit souvent des spermatozoïdes. Il ue tarde pas à s'entourer d'une mince enveloppe, qui s'épaissit 
VERS.

progressivement et finit par se dédoubler en deux membranes : une interne, très résistante; une externe, plus épaisse, mais plus friable, montrant des couches concentriques sous l'aspect de stries délicates. Les œufs arrivent ensuite dans la dernière section de l'ulérus, et se recouvrent alors d'une substance albumineuse qui se soulève bientôt en mamelons irréguliers. Gràce à ce revètement, ils se montrent souvent aggglutinés entre eux.

Distribution géographique. - L'Ascaride lombricoïde est un parasite cosmopolite; mais il est très répandu surtout dans les pays chauds. On le rencontre plus souvent à la campagne que dans les villes, sans doute parce que les paysans font usage d'eaux non filtrées et consomment beaucoup de légumes crus et defruits tombés à terre. Il est devenu très rare à Paris.

Pathologie. - La plus grande fréquence de ce Ver s'observe chez les enfants et les jeunes gens, depuis un an jusqu’à vingt ans; mais on peut le rencontrer à tous les âges de la vie. De Lille en a vu chez un enfant de onze semaines, et J. Duval chez un vieillard de quatre-vingtcinq ans. Toutes les statistiques le montrent plus commun chez la femme que chez l'homme. En outre, il est d'une remarquable fréquence chez les maniaques et chez les individus atteints de perversion du goût.

Il est rarement solitaire; les autopsies en laissent voir le plus souvent deux à six, logés dans les premières portions de l'jntestin grêle. Ce n'est que d'une façon exceptionnelle qu'on en trouve une plus grande quantité, du moins dans les climats tempérés. Ainsi, Morland en a recueilli 365 dans l'intestin grêle d'un enfant qui en avait déjà rendu un grand nombre par la bouche. Cruveilhier a vu l'intestin grêle d'une fille idiote entièrement rempli par ces Vers, et il en évalue le nombre à plus de 1000. Enfin, Fauconneau-Dufresne a fait connaître le cas d'un garcon de douze ans qui rendit plus de cinq mille Vers en moins de trois ans, la plupart par le romissement; 600 furent évacués en un seul jour. Mais, dans les pays chauds, cette grande abondance est un fait des plus communs. Levacher, en particulier, dit avoir vu souvent, aux Antilles, des enfants rendre jusqu'à 400 et 600 Vers. Le nombre des femelles est toujours trois ou quatre fois plus élevé que celui des mâles.

La présence de l'Ascaride coïncide assez souvent avec celle d'autres parasites intestinaux, Nématodes ou autres.

Lorsque les Ascarides occupent leur siège normal, c'est-à-dire l'intestin grêle, et qu'ils n'existent qu'en petit nombre, leur présence peut passer inaperçue ou se traduire seulement par des symptômes insignifiants. Mais dans certains cas pourtant, ils donnent lieu à des troubles réflexes fort graves : attaques épileptiformes, congestion cérébrale, apnée, aphonie, cécité, hystérie, etc., etc. L'origine de ces troubles n'est pas encore bien expliquée; on peut cependant supposer que ces parasites sécrètent une substance toxique qui peut être absorbée par l'intestin. 
Il n'est pas rare en effet de constater des accidents locaux chez les personnes qui manient et dissèquent des Ascarides (généralementl'Ascaride des Equidés) : éternuements, gonflement des caroncules lacrymales, abondante sécrétion de larmes, vives démangeaisons et gonflement des doigts. Miram, Cobbold, Bastian et Huber ont éprouvé des accidents de ce genre. J'ai moi-mème élé alteint, dans ces conditions, d'un gonflement énorme de toute la région oculaire, avec prurit intense. Cette action est attribuée par Leuckitrt à une substance soluble dans l'alcool, et probablement huileuse, localisée surtout dans la. partie vésiculeuse des cellules musculaires.

Bien que les Ascarides n'aient guère de tendance à quitter l'intestin, ils en sortent quelquefois, soit par leurs propres mouvements, soit par le fait des contractions intestinales. Le plus sourent, c'ést par l'anus qu'ils s'échappent ainsi ; cependant, il est assez commun de les voir remonter dans l'estomac el ètre alors expulsés par le romissement que provoque leur présence. Ils pénètrent quelquefois aussi dans l'oesophage et le pharynx, et sortent alors par la bouche ou les narines, à moins de rencontrer sur leur chemin un trajet fistuleux, ou de s'engager dans la trompe d'Eustache, roire dans le canal nasal. S'ils s'introduisent dans le larynx et la trachée, ils déterminent souvent la mort par suffocation.

De l'intestin grêle, ils peuvent passer dans le canal de Wirsung et s'enfoncer dans le pancréas, on bien, ce qui est beaucoup plus fréquent, pénétrer par l'ampoule de Vater dans les roies biliaires : les lésions qüils proroquent en pareil cas sont généralement très graves.

En outre, il n'est pas absolument rare de voir ces Vers passer de l'intestin dans la carité péritonéale. On a beaucoup discuté sur le mode de production des ouvertures ì la fareur desquelles peut aroir lieu ee passage. Les uns, avec Plater, Rudolphi, Daraine, admettent que la perforation est tout à fait indépendante de laction des Vers (abcès de l'intestin, etc.), et que ceux-ci profitent simplement de l'ourerture ainsi produite pour pénétrer, soit avant, soit après la mort, dans le sac péritonéal. D’autres, arec Spigel, Andry, van Doeveren, considèrent que les perforations sont dues à l'activité directe des parasites, qui traverseraient l’intestin soit d'emblée, soit après formation d'un foyer gangreneux ou d'un petit abcès. On a fait valoir, il est rrai, contre la possibilité de telles perforations, le fait que les Ascarides sont dépourvus d'instrumen/s perforants; mais celle objection perd beaucoup de sa valeur en présence des faits que nous arons cilés à l'occasion des Ligules et des Téniadés du Lapin de grarenne. D’autre part, si j'en juge d'après les observations que j'ai faites sur les animaux (Chien, Cheval), l'ouverture produite dans l'intestin peut résulter réellement de la présence des Vers, mais d'une façon indirecte et comme accident secondaire : il s'agit alors de véritables déchirures des tuniques de l'organe, consécutires à une obstruction intes- 
tinale occasionnée par l'accumulation des Helminthes en un point donné.

On a vu maintes fois, enfin, les Ascarides sortir à travers la paroi de l'abdomen (abcès vermineux) : l'issue a lieu d'ordinaire par l'ombilic chez l'enfant et par l'aine chez l'adulte. Plus rarement, ils pénètrent de la cavité péritonéale dans les viscères, dans la plèvre. Ils peuvent également s'introduire de l'intestin dans les voies génitourinaires et se trouver même expulsés par l'urèthre ou par le vagin.

Le diagnostic est assuré très facilement par l'examen des fèces, qui montre les œufs caractéristiques, teintés en brun par les sucs intestinaux.

D'après ce que nous avons dit de l'évolution de l'Ascaride, il est facile d'établir les règles de la prophylaxie. Quant au traitement, on sait depuis longtemps que ce Ver est principalement justiciable du semen-contra et de la santonine.

Ascaride du Pore (A. suum Gœze, 1782. - Syn. A. suilla Duj., 1845). D'après Dujardin, cet Ascaride différerait de celui de l'Homme par une plus faible épaisseur, un tégument à stries plus étroites, des spicules moinsaigus et plus aplatis, des utérus plus longs et des œufs plus petits $(66 \mu$ de diamètre). - Pour Leuckart, la différence tirée de la longueur des ntérus est tout à fait illusoire; et si l'Ascaride du Porc a en réalité une taille moindre et des $œ u f s$ plus petits que celui de l'Homme, ces caractères sont insuffisants pour justifier à ses yeux l'établissement d'une espèce nouvelle.

Le Ver dont il s'agit habite l'intestin grêle du Porc; il se rencontre

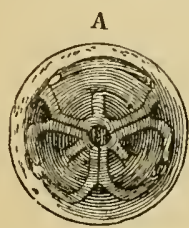

B

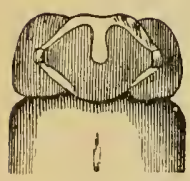

Fig. 263. -- Exlrémité antérieure de l'Asearide du Mouton, d'après $G$. Neumann. - A, vue de devanl. B, par la face dorsale. C, par la face venlrale. Grossissement : 30 diamèlres. rarement en assez grand nombre pour causer des obstructions et des coliques. Ortmann l'a vu pénétrer dans le foie, Railliet et Morot dans le pancréas.

Ascaride du Mouton (A. ovis II. C. V. [1]). - Espèce très rare, paraissant représenter une forme réduite de l'Ascaride lombricoïde. Les papilles sont moins rapprochées de la base des lèvres que dans celte dernière espèce. Le mále est long de 7 à 10 centimètres, large de 2 millimètres; son extrémité caudale est garnie, sur la face ventrale, de deux rangées de 45 à 50 papilles chacune, dont trois post-anales, une impaire, à l'extrémité mème de la partie caudale. La fem+lle est longue de 8 à 12 centimètres; sa vulve s'ourre vers le tiers antérieur du corps.

On ne connaissait jusqu’à présent l'Ascaride du Mouton que par

(1) Musée impérial de Vienne (Museum Cæsareum Vindebonense). 
un exemplaire femelle conservé au Musée de Vienne, cité parł Rudolphi qui ne l'avait pas vu, puis décrit par Diesing et par von Drasche. En 1841, Copeman en avait trouvé 2\%̈, en Angleterre, dans l'intestin d'un Agneau, mais ne les avait pas étudiés. Neumann en a retrouvé plusieurs exemplaires à Toulouse et en a donné une bonne description; mais il est à remarquer que les femelles qu'il a eues à sa disposition ne contenaient pas d'œuf́s développés. Ce Ver habite l’intestin grêle.

Von Drasche a examiné, d'autre part, deux individus du mème genre, trouvés chez le Mouton par Köbl, et qui lui ont paru ne pas appartenir à la même espèce que la femelle du Musée de Vienne. Toutefois, il est bon de faire observer que ces divers spécimens étaient mal conservés (1).

Ascaride du Veau (A. vitulorum Gœze, 1782). - Cette espèce, souvent confondue avec I'A. lumbricoides, en a été nettement distiuguée par Neumann (2). Le corps est un peu plus grêle, la tète plus petite, les lèvres rétrécies en avant, non papillifères, la queue terminée par une sorte de mucron conique. L'œsoplage est suivi d'un rudiment de ventricule. Le mâle est long de 10 à 20 et jusqu’à 26 centimètres, large de 3 millimètres ; la concavité de l'extrémité caudale montre deux rangées irrégulières, très latérales, de 10 à 1 ã papilles chacune, toutes préanales.
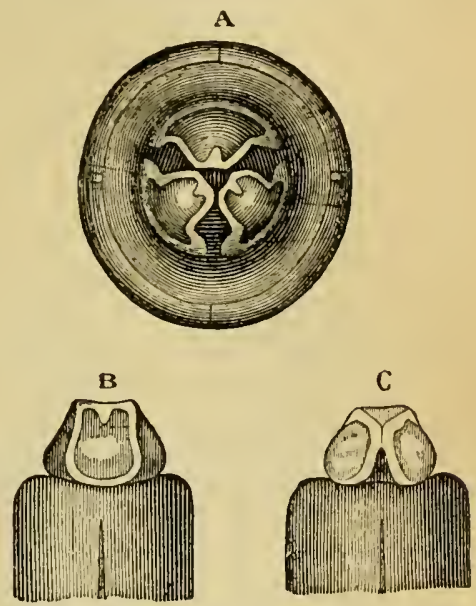

Fig. 264. - Extrómité antérieure de l'Ascaride du Veau, d'après G. Neumann. - A, rue de devant el grossie 20 fois. B, vue par la face dorsale et C, par la face ventrale, grossie 13 fois.

\section{La femelle mesure 22 à 30 centimètres de}

long sur 5 millimètres de large; la vulve est située vers le sixième antérieur du corps. Les œufs ont un diamètre de $7 \ddot{\text { à }} 80 \mu$.

Intestin grêle des bètes bovines. Rare chez les adultes, assez commun chez les Veaux, surlout dans le midi de la France. Vallisneri l'a vu en Italie, Rudolphi à Alfort, Bremser à Vienne, Barnett en Angleterre. Il existe également au Japon. On en trouve quelquefois un grand nombre, disposés en faisceaux serrés et pouvant occasionner une inflammation localisée de, la muqueuse intestinale (Neumann); mais ce n'est qu'exceptionnellement que leur présence détermine des accidents mortels (Descomps).

(1) A. S. Copenan, A verminous disease among Lambs. The Veterinarinn, 1812, p. i0. - R. von Dr.sscire, Ilelminthologische Notizen. Verhandl. d. k. k. zool.-bot. Gesellschaft. Wien, 1882, p. 141. - G. Neumans, Sur l'Ascaride du Mouton. Rev. vétér., 1883 , p. 382 (arec une pl.).

(2) G. Neunann, Sur l'Ascaride des bêles bovines. Revue rétér., 1883, p. 362 (arec deux planches).

Raillet. - Zoologie. 
Ascaride des Équidés (A. equorum Gœze, 1782. - Syn. : A. megalocephala J. Cloquet, 1824). - Le corps de cetle grande espèce est d'un blanc jaunâtre uniforme; il est très raide, élastique. La tête est plus grande que celle de l'Ascaride lombricoïde, mieux délachée du corps; les lèvres sont étranglées dans leur milieu. Le mâle est long de 15 à 25 centimètres; sa queue porte deux petites ailes latérales et des papilles ventrales au nombre de 79 à 105 de chaque còté, dont 7 préanales : $n^{0} 2$ conique; 4-5̆ et 6-7 géminées; les suivantes disposées en une seule, puis en plusieurs rangées; une papille impaire devant l'anus. La femclle est longue de 18 à 37 centimètres; sa vulve est située vers le quart antérieur du corps. Les oufs sont à peu près globuleux, du diamètre de 90 à $100 \mu$.

Pallas et Rudolphi considéraient cette forme comme identique à l'Ascaride lombricoïde. C'est surtont J. Cloquet qui l'en a spécifiquement distinguée.

On l'observe souvent dans l'intestin grêle du Cheval, de l'Ane, du Mulet; elle se rencontre aussi chez le Zèbre. Il n'en existe d'ordinaire qu'un petit nombre à la fois, mais il est aussi des cas où on les compte par centaines. Sur un seul Cheval, à Alfort, G. Colin en a recueilli plus de 1600, et Demarbaix, à Bruxelles, plus de 1800. Ils se tiennent surtout dans le duodénum, rassemblés en faisceaux, plus rarement en pelotons.

lls demeurent dans bien des cas sans altérer la santé de leur hôte; d'autres fois, ils occasionnent des troubles locaux (catarrhe intestinal chronique, diarrhée, coliques vermineuses, etc.), ou réflexes (vertige, épilepsie, tétanos, etc.). Lorsqu'ils sont nombreux, ils peuventremonter dans l'estomac. Röll en a vu s'engagerdans lecanal cholédoque, et Generali dans le canal pancréatique. Enfin, ils pénètrent quelquefois dans le péritoine : mais nous n'avons qu'à renvoyer, pour l'étude de cette question, à ce que nous avons dit de l'Ascaride lombricoïde.

Malgré le résultat négatif des expériences de Leuckart, il est probable que le développement de cette espèce a lieu selon le même mode que celui de l'Ascaris lumbricoides. Les embryons enfermés dans leur coque jouissent d'une grande résistance vitale ; ils éclosent rarement à l'extérieur (Baillet, Cobbold, Rivolta): ce fait ne se produit, d'après P. Hallez, que sur la terre humide, non dans l'eau. Il est donc inutile de revenir sur la question de la prophylaxie.

Le meilleur vermifuge à employer paraît être l'acide arsénieux, donné aux Chevaux à la dose de 1 à 2 grammes par jour pendant quinze à vingt jours.

Ascaride à moustaches (A. mystax [Zeder]. -- Syn. : Lumbricus canis Werner, 1782 ; A. cati et caniculx Schrank, 1788 ; A. tricuspidata el felis Bruguière, 1791; A. Werneri Rud., 1793 ; Fusaria mystax Zeder, 1800; A. marginata et mystax Rud., 1802; A. alatu Bellingham, 1839). - Corps blanchàtre ou un peu brunàtre. Extrémilé antérieure ordinairement recouıbée et pourvue de deux ailes membraneuses latérales qui lui donnent un peu l'aspect 
d'une pointe de flèche. Bouche entourée de trois lèvres à peu près égales, de forme variable, offrant 3 a 6 angles; bords denticulés. Lèvre supérieure a deux papilles, les inférieures á une papille normale et deux petites peu distinctes. Mále à extrémité caudale recourbée en spirale, munie de deux petites ailes membraneuses et de 26 papilles de chaque còté, dont ŏ post-anales : 1 et 2 ainsi que 3 et '́ placées còte à còte; 3 sur un bourrelet cutané. Femelle à queue obtuse; vulve située vers le quart antérieur. Olufs presque globuleux, à revètement albumineux offrant une surface alvéolée.

Ce Ver vit normalement dans l'intestin grêle du Chien, du Chat et de divers Félidés ou Canidés sauvages. On peut aussi le reneontrer chez l'Homme.

Divers helminthologistes ont considéré comme espèces distinctes l'Ascaride du Chien et celui du Chat; ce sont en réalité de simples variétés d'une seule et mème espèce.
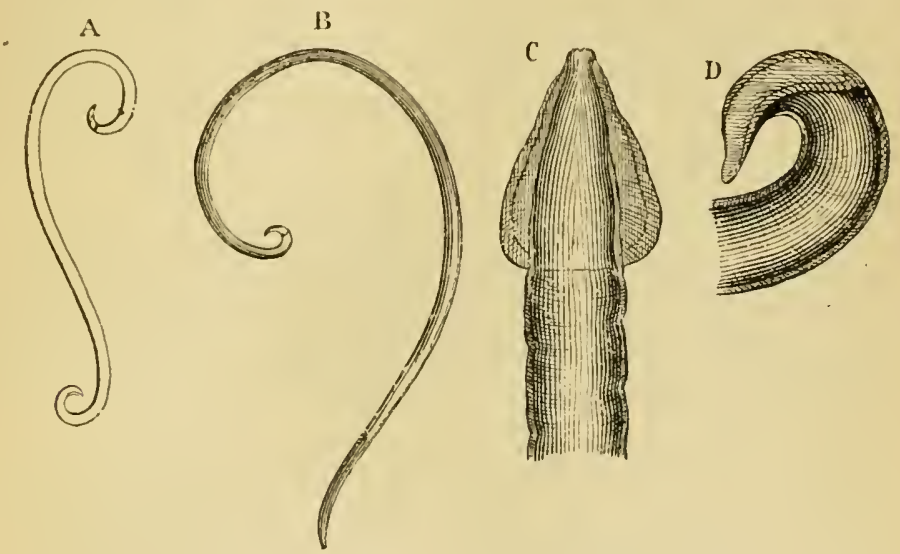

Fig. 265. - Ascaris mystax du Cliat. - A, màle et B, femelle, grandeur naturelle, vus de côté. C, extrúmité antérieure grossie et vue de face pour montrer les ailes latérales. D, vue de jrofil (Orig.).

L'Ascaride du Chat (A. mystax var. felis ; -1. mystax Rud.) est de petites dimensions : le màle est long de \& à 6 centimètres; la femelle de 6 à 10 cenlimètres, et les œufs ont $6 \check{a}$ à 7 ă de diamètre.

L'Ascaride du Chien (A. mystax var. canis; A. marginata Rud.) est de plus grande taille : le màle mesure õ à 9 centimètres, la femelle 9 à 12 centiInètres (j'en ai observé de 18 centimètres), et les $\propto u f s$ ont 75 à $80 \mu$. de diamètre.

L'Évolutrox de cette espèce a été étudiée par Nelson, Verloren, Davaine, Baillet, Grassi, etc. (1). L'embryon se développe comme

(1) H. Necsox, On the reproduction of Ascaris mystax. Philos. Transact., 1852, P. II, p. 563. - Verlores, Eijeren van A. mystax. Aantecken. Ltrecht. Genootsch. Sectic en Geneeskde, 1851-55, p. 41. - C. Davaise, Sur la constitution de l'auf de certains Entozoaires et sur la propriélé de se décel.pper à sec. Mlém. Soc. de biol. (3), IV, p. 273, 1862. - IIFRING, Beitrögen zur Enlwicklungsgeschichte einiger Einge- 
celui de l'Ascaride lombricoïde, dans l'eau ou sur la terre humide, et même, comme l'a vu Nelson, dans l'alconl, l'acide chromique et l'essence de térébenthine. D'après Davaine, il se développerait à sec, mais il y a là une certaine exagération. Les embryons une fois formés ont une grande résistance vitale. Munk les a trouvés encore vivants à l'intérieur de la coque, au bout de quinze mois, dans une solution de carbonate de potasse à 2 p. 100. Ils sont d'assez grande taille, longs de $0^{\mathrm{mm}}, 36$ à $0^{\mathrm{mm}}, 42$. Ils ne sortent que rarement de la coque, ainsi que l'a constaté C. Baillet.

Les essais d'infestation directe du Chien au moyen des œufs embryonnés n'ont donné jusqu'à présent, quand ils ont été faits sérieusement, que des résultats négatifs. Cependant, il est à peu près certain que le développement ne comporte pas d'hôte intermédiaire. Leuckart a trouvé, dans l'estomac du Chat, des embryons longs de $0^{\mathrm{mm}}, 4$ (mais jamais d'œufs ni de coques); quand ces embryons ont atteint $1^{\mathrm{mm}}, 5$ à 2 millimètres, ils passent dans l'intestin, et quand ils arrivent à une longueur de $2^{\mathrm{mm}}, 8$, ils muent, perdent la dent perforante embryonnaire et montrent les trois lèvres bien distinctes de l'adulte. Ces observations sont très favorables, on le voit, à liidée d'un développement direct.

Du reste, Grassi a élevé, dans une caisse préalablement infestée par les excréments d'une Chienne à Ascarides, de petits Chiens qui rendirent des œufs dès le vingt-huitième jour, et montrèrent à l'autopsie de nombreux Ascarides dans leurs intestins. - Une expérience de contrôle, faite dans un milieu sain, ne donna que des résultats négatifs.

Pathologie. - Les Ascarides sont très fréquents chez les jeunes Chiens, qui sourent sont infestés dès leur naissance. Krabbe, à Copenhague, en a trouvé chez 24 p. 100 des animaux examinés.

Leur présence s'accuse par des symptômes analogues à ceux que nous avons indiqués à propos des Ténias et des espèces précédentes d'Ascarides. Ils remontent assez souvent dans l'estomac et provoquent alors des vomissements.

Chez le Chat, Krabbe en a trouvé sur plus de å0 p. 100 des individus.

On rapporte aussi à cette espèce les Vers observés chez l'Homme par Pickells, Bellingham, Leuckart, Scattergood, Böhm, Olrik et Kelly. Cependant, Grassi tend à nier l'occurrence de l'Ascaris mystax dans l'espèce humaine, parce qu'il a vainement cherché, sur plus de 1000 personnes, cet Ascaride ou ses œufs, parce qu'il a ingéré, sans parvenir à les conserver vivants dans son tube digestif, des Ascarides du Chat, et enfin parce qu'il a pris, ainsi que Calandruccio, des œufs embryonnés de l'Ascaride du Chien sans obtenir aucun résultat. Il

weidewürner. Württemberg. naturwiss. Jahreshefte, XXIX, p. 305, 1873. - B. Grassı, Beitrage zur Kenntniss des Entwicklungscyclus von fünf Parasiten des Hundes. Centralbl. f. Bakt. u. Paras., IV, p. 609, 1888 (Recueil de méd. vét., 1889, p. 124). 
faut reconnaître que tous ces arguments n'ont que bien peu de valeur.

Ascaride maritime (A. maritima Leuckart, 1876). - On n’a observé jusqu'ì présent qu'un seul exemplaire femelle, long de 43 millimètres, large de 1 millimètre, non parvenu à maturité sexuelle. Les lèvres sont peu développées; il n'existe pas d'ailes latérales à l'extrémité antérieure, mais la cuticule se relève légèrement en forme de crète; l'extrémité caudale est en còne effilé.

Ce Ver avait été romi par un cnfant, dans le nord du Groenland (avril 1863 ), et recueilli par Pfaff. Il est voisin de l'A. Iransfuga Rud., de l'Ours brun. Ne s'agirait-il pas d'un pseudo-parasite, ingéré par l'enfant avec les viscères d'un animal?

Ascaride epais (1. crassa E. Deslongchamps, 1824. - Syn.:Ascaris anatis Gmeliu, 1789; Fusaria inflexa Zeder, 1800; A. inflexu Rud., 1809). - Corps blanc rougeàtre sale, atténué aux extrémités. Bouche à trois lèvres très convexes; tégument fortement strié en travers, et comne denté en scie. Mâle long de 12 à 30 millimètres, large de $0^{\mathrm{mm}}, 3 \mathrm{a} \mathrm{à} 1^{\mathrm{mm}}, 2$; queue amincie, conique, mucronée, sans ailes latérales; deux spicules atténués en pointe mousse, incurvés, ailés, longs de 3̈20 u. Femelle longue de 43 a 50 millimètres, large de $2^{\mathrm{mm}}, 2 ;$ queue amincie, conique, aiguë, droite; vulve un peu en arrière du milieu u corps.

Trouvé parZeder, Bremser, Deslongchamps, Dujardin, etc., dans l'intestin du Canard sauvage el du Canard domestique; par Bremser et Dujardin dans lintestin du Canard de Barbarie, etc. Commun à Caen (Gallier) et dans l'Aisne (Bonyenval. C'est à cette forme qu'il conviendrait de donner le nom d'Ascaris inflexa, yue Schneider, d'après Rudolphi, a indùment appliqué au grand Hétérakis de la Poule.

Genre Hétérakis (Heterakis Dujardin, 1843̈). - Les espèces qu'on fait actuellement rentrer dans ce genre sont des Polymyaires qui se distinguent des Ascarides par la présence, chez les mâles, d'une ventouse préanale et de deux spicules souvent inégaux. Chez les mâles également, l'extrémité caudale offre deux séries de papilles disposées symétriquement, el sourent deux ailes cuticulaires qu'on a considérées comme représentant une bourse. Presque tous les Hélérakis sont ovipares (1).

Ils vivent exclusircment dans l'intestin des Vertébrés, et en particulier des Oiseaux.

On en distingue deux sections :

$1^{\text {re }}$ section : Cheilostoni (Heterakis s. str.). - Bouches à trois lèvres analogues à celles des Ascarides; deux spicules inégaux; ventouse munie d'un anneau chitineux.

(1) M. Stossicn, Il genere Ileterakis Dujardin. Glasnika brv. naravoslovnoga družtva. Zagreb (Agram), 1888. 
Hétérakis à lorgnon (H. perspiciilum [Rud.]. - Syn. : Ascaris gallopavonis Gmelin, 1789 ; Fusaria reflexa Zeder, 1800, pro parte; F. strumosa, Zeder, 1800 ; A. perspicillum Rud., 1803; A. giblosa Rud., 1809 ; A. inflexa Rud., 1819, pro parte ; A. funiculus E. Deslongchamps, 1824; Het. inflexa Schn., 1866). - Corps blanc jaunàtre. Bouche à lèrres inégales, la supérieure plus grande. Múle long de 3 à 8 centimètres ; extrémité caudale tronquée obliquement; et portant de chaque còté une aile membraneuse, 10 papilles fongiformes de chaque côté, dont 3 préanales et 7 postanales; la ventouse serait munie, d'après von Linstow, d'une papille au bord postérieur; deux spicules à peu près égaux, terminés en bouton. Femelle longue de 6 à 12 centimètres; extrémité caudale droite, conique, mucronée; vulve dans la partie antérieure du corps. OEufs ellipsoïdes, longs de 75 à $80 \mu$, larges de $4: 3$ à 50 u.

Intestin grêle de la Poule ct du Dindon. Je l'ai trouvé aussi, en novembre 1889, chez une Pintade provenant du midi de la France.

Baronio, Blavette, Rossignol, etc., ont signalé des épizooties sévissant sur les Poules et attribuées à l'accumulation de ces Vers dans lintestin. D’après Zürn, on en trouverait quelquefois de libres dans la cavité abdominale. - Enfin, un grand nombre d'observateurs, après Aldrovande et Fabrice d'Acquapendente, en ont signalé la présence dans l'ceuf de la Poule, ò̀ ils s’introduisent, en remontant dans l'oviducte, avant la formation de la coque.

Ercolani croyait aroir observé dans cette espèce, ainsi que dans H. papillosa, H. maculosa, Sclerosloma equinum, Scl. tetracanthum, etc., des phénomènes d'hétérogonie; mais ses assertions reposent évidemment sur des erreurs d'observation.

IIétéralkis rayé ( $H$. lineata Schneider, 1866). - Corps jaunâtre, avec deux lignes blanches très apparentes formées par les champs latéraux. Lèvres presque égales. Hâle long de 68 millimètres; ailes de la queue peu développées; 10 papilles de chaque còté, dont 3 plus grandes au voisinage de l'anus. Femelle longue de 95 millimètres.

Intestin. - Cette espèce, découverte chez un Coq (Gallus sp.), au Brésil, par OIfers et Sello, aurait été retrouvée dans le Turkestan, par Fedtshenko, chez le Canard domestique.

Ilétérakis eomprimé (II. compressa Schneider, 1866). - Bouche à trois lèvres inégales. Mále long de 53 nillimètres. Femelle longue de 830 millimètres.

Trouvé par Schomburg dans l'intestin du Coq domestique, à Adélaïde (Australie méridionale).

IIétérakis taché $(H$. maculosa [Rud.]. - Syn. : Ascaris columbæ Gmelin, 1789; A. maculosa Rud., 1802 ; H. maculosa Schn., 1866; H. columbæ Raill., 1885). - Corps blanc, un peu translucide, atténué aux deux extrémités. Bouche à trois lèvres presque égales. Extrémité antérieure munie de deux ailes latérales semi-elliptiques. Móle long de 16 à 26 millimètres; extrémité caudale tronquée obliquement, mucronée au sommet; 10 papilles de 
chaque côté. Femelle longue de 20 à 34 millimètres; queue droite, conique, mucronée; vulve au milieu de la longueur du corps. UEufs ellipsoïdes, longs de 80 ì $90 \mu$, larges de 40 à $\ddot{0} 0 \mu$.

Intestin de divers Colombins, et en particulier du Pigeon domestique. J. Chatin l'a retrouvé chez le laisan.

Ce Ver se montre souvent en (quantilé énorme dans le lube digestif d'un même sujet, et l'on concoit que, dans ces conditions, la mort survenne rapidement, comme laviaient déjà constaté, au commencement du

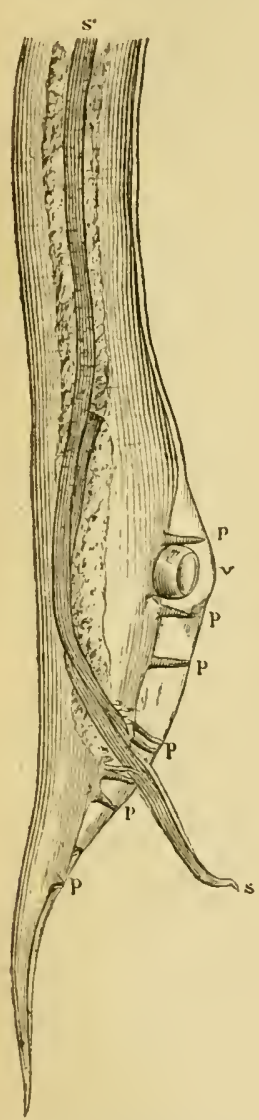

Fig. 26\%. - Extrémilé caudale de l'Heterakis papil. losa, male, de la Poule. $s$, spicule gauche, court; $s^{s}$, spicule droit, long. $v$, ventouse. $p, p$, papilles $(\mathrm{G}$. Neumann). siècle dernier, Lorenz Heister et Gebauer. Nous possédons, dans notre collection, des intestins de Pigreon littéralement bourrés par l'aceumulation de ces parasites.

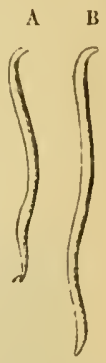

Unterberger a bien étudié le dé- Fig. 266. - Heteveloppement de cette espèce. rakis maculosa, Dans 7 grammes environ d'excré- mile. B, femelle. ments que rend en vingt-quatre relle. heures un Pigeon très malade, il

a trouvé 12,000 oufs en moyenne ; le développement de l'embryon a lieu dans un milieu humide, et se trouve complel en dix-sept jours. Donnés alors à des Pigeons sains, ces cufs embryonnés produisent, en trois semaines, des Héléralis adultes.

IIétérakis papilleux (H. papillosa [Bloch]. Syu. : Ascaris papillosa Bloch, 1782, nec Molin, 1860 ; A. vesicularis Frölich, 1791, pro parte; H. vesicularis Duj., 18ษว̈ ; H. papillosa Raill., 1883̈). - Corps blanc, atténué de part et d'autre, surtout en arrière. Bonche à lèvres égales, petites, nou dentées. Deux ailes ou membranes latérales peu saillantes sur toute la longueur du corps. Male long de 7 à 13 millimètres; extrémité caudale droite terminée par une pointe subulée, en avant de laquelle se montrent deux ailes latérales assez larges, dédoublées; 12 papilles de chaque cóté, dont $\dot{x}$ vers la pointe, 6 adanales, 2 près de la ventouse; une asymétrique en arrière de celles-ci; spicules très inégraux, ailés. Femelle longue de 10 à 13 millimètres; extrémité caudale longruement effilée; vulve non saillante, située un peu en arrière du milieu du corps. OEufs ellipsoïdes, longrs de 63 à $71 \mu$, larges de 38 à $48 \mu$, non encore segmentés au moment de la ponte.

Espèce très commune chez les Gallinacés. Sur 190 Poules ou Poulets examinés à Rennes, Dujardin l'a trouvée chez $10 \%$, toujours dans les cæcums et 
quelquefois en quantité prodigieuse. Nous l avons vue produire chez des Poussins une typhlite mortelle. On l'a observée également chez le Dindon, le Paon, la Pintade, divers Faisans, etc. C'est chez une Outarde que Bloch l'a le premier rencontrée. Enfin, elle a élé trourée aussi chez le Canard domestique, en Europe et dans le Turkestan, et chez l'Oie domestique, en France (Railliet et Lucet). Comme Leuckart, nous avons constaté que le développement embryonnaire s'accomplit dans l'eau : une Poule à laquelle nous avons fait prendre ces œufs embryonnés a présenté à l'autopsie des Hétérakis adultes dans les cæcums.

Hétérakis dissembable $(H$. dispar [Schrank]. - Syn. : Ascaris dispar Schrank, 1790; Fusaria dispar Zeder, 1800; H. dispar Duj., 1845). - Corps

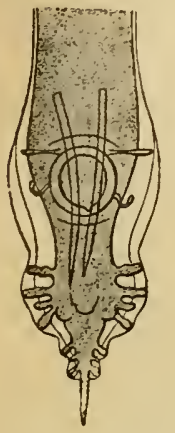

Fig. 268. - Heterakis dispar : extrémité caudale du mâle, vue par la face ventrale et grossie 50 fois (Orig.). blanc, aminci de part et d'autre, surtout en arrière. Deux ailes ou membranes latérales, devenant assez larges à quelque distance de l'extrémité antérieure, puis se rétrécissant en arrière. Bouche à lèvres très petites. Mâle long de 11 à 18 millimètres; 10 papilles, plus deux saillies adanales; spicules courts, presque égaux. Femelle longue de 16 à 23 millimètres; extrémité caudale droite, très effilée ; vulve un peu en arrière du milieu du corps, entourée d'un épaississement cutané. OEufs ellipsoïdes, longs de 59 à $62 \mu$, larges de 39 à $41 \mu$.

Ce Ver a d'abord été trouvé en Allemagne, par Frölich, Schrank et Zeder, dans le cacum des Oies grasses, rarement chez les Oies au pàturage. Je l'ai également observé, avec Lucet, chez des Oies du Loiret affectées de diverses maladies parasitaires; il était plus commun que l'Heterakis papillosa. On l'a signalé encore chez le Canard domestique, le Canard de Barbarie, etc.

Hétérakis compagnon ( $H$. compar [Schrank]. - Syn. : Ascaris compar Schrank, 1790 ; A. lagopodis Frölich, 1802; Fusaria compar Zeder, 1803; H. compar Stossich, 1888). - Corps blanchàtre, atténué surtout en arrière. Bouche à trois lèvres arrondies, pourvues chacune d’une papille centrale. Iale long de 36 à 48 millimètres; extrémité caudale droite, tronquée obliquement; ventouse entourée d'un cercle de petites papilles et de deux séries latérales de quatre papilles; un cercle de petites papilles également autour de l'orifice anal. Femelle longue de 84 à 96 millimètres.

Intestin grêle de divers Gallinacés. - Trouvé dans l'estomac d'un Poulet, par le capitaine Chierchia, à Saint-Hyacinthe, dans l'ile de Luçon (Philippines) (1).

Hétérakis brésilien (H. brasiliensis de Magalhães, 1892). — Le màle seul est connu. Corps cylindrique, jaunàtre, atténué aux extrémités, surtout en arrière. Longueur, 24 millimètres. Bouche à trois grosses lèvres inégales; papilles submédianes bien distinctes. Ventouse circulaire avec une papille cachée au bord postérieur. Ailes caudales peu marquées. Deux spicules un peu inégaux. 9 paires de papilles latérales, dont une en avant de la ventouse. Une papille asymétrique, médiane, au niveau de la paire postérieure.

(1) F. S. Monricelur, Etminti del viaggio delta R. corvetta "Vettor Pisani". Bollettine della Soc. di Natur. in Napoli, III, p. $70,1889$. 
Intestin de la Poule domestique, à Rio-de-Janeiro (Brésil) (1).

$2{ }^{\circ}$ section : Acinerostom (Slelmius Duj., Subulura Molin, etc.). Bouche sans lèvres; deux spicules, plus une pièce àccessoire ; ventouse sans anneau chitineux.

Hédérakis différent (H. differens Sonsino, 1890). - Longueur, jusqưả 13 millimètres et plus. Corps atténué aux deux extrémilés, surtout chez la femelle. Bouche sans lẻvres distinctes; œsophage suivi d'un ventricule bien distinct. Mâle avec deux spicules égaux, assez courts, non crochus à l'extrémité, et accompagnés d'une pièce accessoire; ventouse allongée, sans anneau chitineux; papilles peu nombreuses et peu développées; ailes caudales à peine apparentes. Femelle ả extrémité postérieure brusquement acuminée ; anus à peu de distance de la pointe. OLufs subglobuleux, à coque mince, contenant un embryon alors qu'ils sont encore renfermés dans les utérus.

Trouvé à Pise, par Sonsino, dans les dernières parties de l'intestin de la Poule.

Genre Oxyure (Oxyuris Rud., 1803). - Méromyaires à bouche nue ou entourée de trois lèvres peu saillantes. OEsophage long, suivi d'un bulbe ou ventricule généralement bien distinct. Mâles petits et rares, pourvus d'un seul spicule; deux paires de papilles préanales, dont une occupant en général les côtés mèmes de l'anus. Femelles ayant l'extrémité caudale très allongée, subulée; deux ovaires; vulve s'ouvrant d'ordinaire vers la partie antérieure du corps. OEufs oblongs, asymétriques, contenanl parfois un embryon tout formé avant la ponte.

Plusieurs espèces virent en parasites chez l'Homme et chez les animaux domestiques.

Oxyure vermiculaire $(0$. vermicularis [L.]. - Syn.: Ascaris vermiculteris L., 1767 ; Fusaria vermicularis Zeder, 1803 ; O. vermicularis Bremser, 1819). Ver de petites dimensions, de teinte blanchàtre, offrant ì son extrémité antérieure un renflement cuticulaire vésiculeux qui fait saillie, aux faces supérieure et inférieure, sous l'aspect d'ailes striées en travers. Bouche entourée de trois lères qui se montrent saillantes au repos, mais sont susceptibles de se rétracter plus ou moins profondément. Sur les parties latérales du corps, une crète prismatique longitudinale formée par un épaississement triquètre de la cuticule. Mále long de 3 à $\breve{b}$ millimètres, plus court et plus épais après la mort; queue sinueuse pendant la vie, s'enroulant en spirale après la mort, et portant, d'après Leuckart, six paires de papilles dont les plus longues soutiennent des ailes cuticulaires qui simulent une bourse caudale; spicule pouvant atteindre jusqu'à $70 \mu$, aminci et recourbé en hameçon à l'extrémité. Femelle longue de 9 à 12 millimètres; queue longue,

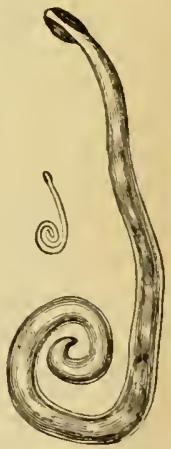

Fig. 269. - 0xyure vermiculaire, mile, de grandeur uaturelle et grossi. subulée, légèrement ondulée à son extrémité; anus situé à près de

(1) P. S. de IIagaliaes, Noles d'helminthologie brésilienne (II). Bullet. Soc.zool. de France, XVII, p. $145,1892$. 
2 millimètres de la pointe; vulve transversale, à lèvres saillantes, située un peu en avant du quart antérieur du corps. OEufs lisses, oblongs, non symétriques, longs de 50 à $3 \dot{x}^{\prime} \mu$, larges de 20 à $27 \mu$, et renfermant déjà

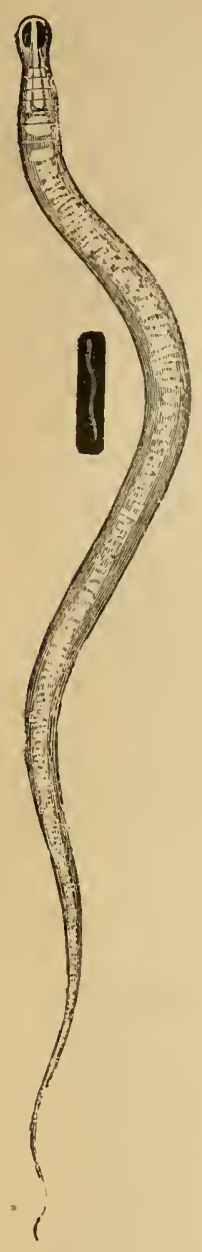

Fig. 270.- Oxyure vermículaire, femelle, grandeur naturelle et grossic. un embryon au moment de la ponte.

L'Oxyure vermiculaire, parasite connu depuis les temps les plus reculés, habite l'intestin de l'Homme, oùil se montre surtout localisé dans le cacum. - D'après Zürn, il se rencontrerait aussi chez le Chien; mais l'Oxyure qu'on a observé chez cet animal n'a pas encore fait l'objet d'études précises, et il y aurait lieu de rechercher sil ne s'agit pas plutôt de l'O. compar Leidy.

Évolution. - L'œuf possède une coque lisse, résistante, formée de trois couches superposées; de plus, il est revêtu d'une mince enveloppe albumineuse qui permet après la ponte une agglomération des cufs déposés sur un même point. II parcourt dans l'utérus même, comme nous l'avons dit, les premières phases de son développement. Au moment où il est pondu, il montre déjà un em. bryon en forme de tétard, c'est-à-dire constitué lar un corps oroïde, très épais, sous lequel est repliée une queue effilée.

Pour continuer son érolution, cet embryon gyriniforme exige une température de $30^{\circ}$ C. au moins, et un certain degré d'humidité. Il peut donc se développer dans le mucus du rectum et de la région anale, ou dans les matières fécales qui ne sont pas exposées à un refroidissement trop considérable. On trouve même d'ordinaire un grand nombre d'embryons parvenus à leur complet développement dans les fèces qui viennent d'être évacuées. $\Lambda$ cette période, ils sont longs de $1.40 \mu$ sur une largeur maximum de $10 \mu$; ils possèdent une queue effilée, longue de $21 \mu$. Le tube digestit est léjà distinct, et l'osophage montre dans sa région postérieure une dilatation pyriforme.

On a cru longtemps que ces embryons pouraient éclore dans les dernières portions du tube digestif et subir ainsi sur place toutes les phases de leur érolution : c'est ainsi qu'on expliquait l'extrême multiplication de ces parasites, observée dans certains cas. De fait, Vix a vu, dans le mucus rectal, des embryons en voie d'éclosion, mais cela ne suffit nullement à établir l'exactitude de l'opinion 
ci-dessus exprimée. Il y a tout lieu de croire avec Leuckart, au contraire, que les axul's ou les embrỵons d'Oxyure doivent être expulsés de l'intestin pour rentrer ensuite dans le lube digestil par les voies supérieures. Aussi bien, une véritable auto-infestation doit-elle souvent se produire de cetle facon: le prurit qui accompagne le passage des Oxyures dans le rectum engage le patient à se gratler, et les ongles recueillent des mucosités cliargées d'wul's, parlois même de femelles entières (Zenker, Heller); on concoit ainsi combien est facile le transporl de ces oufs à la bouche, surtout chez. les cnfiuts.

L'embryon une fois formé reste en état de vie latente pendant des semaines et des mois; il ne résiste pas à l'action prolongée de l'eau, de sorte que celle-ci ne peut jouer qu'un rôle secondaire dans la iransmission du parasite. Mais la dissémination des weufs est assurée surtout par l'effritement dés matières fécales, qui leur permet d'être emportés par le vent, et d’aller se déposer sur les fruits, les légumes, dans les eaux de boisson et en général sur tous les objets qui peuvent être portés à la bouche. Les enfants sont très souvent, d'ailleurs, contaminés par le linge ou les mains sales des personnes infestées qui les soignent.

Le développement direct de l'Oxyure vermiculaire a été établi d'abord par les expériences de Leuckart. En 186\%, ce savant et trois de ses élèves avalèrent chacun quelques douzaines d'œufs mis en incubation dans une éture el renfermant des embryons mûrs. Au bout d'une quinzaine de jours, ils rendirent des Oxyures longs de 6 à 7 millimètres. Grassi, en 1879, et Calandruccio, en 1888, ont répété cette expérience avec le même succès.

Quand l'ouf' est arrivé dans l'estomac, sa corjue est ramollie par le suc gastrique, et, sous les efforts de l'embryon, cède en un point où la couche moyenne fait défaut, point situé ì la face convexe de l'œuf, un peu en arrière du póle le plus étroit. L'embryon s'échappe par cette ouverture et gagne le duodénum, où il s'accroît rapidement en subissant une ou deux mues successives. Au bout d'un certain temps, les organes sexuels apparaissent, et, après une dernière mue, le Ver prend les caractères de ladulte. Le màle paraìt se développer plus vite que la femelle; il montre déjà des spermatozoïdes aírs qu'il mesure seulement 3 millimètres; les femelles de cette taille n'ont encore que des organes génitaux peu développés; à 6 ou 7 millimètres, leur vagin est rempli de sperme, avant même que les cufs apparaissent.

Ces jeunes Vers séjournent plus ou moins longtemps dans l'intestin grêle: c'est là surtout qu’ils paraissent s'accoupler; après quoi, les femelles fécondées et quelques mâles passent dans le cæcum. Les mâles ne tardent pas, en général, à mourir, une fois la fécondation opérée; ils sont expulsés arec les fèces avant qu'aucun symptôme ait 
VERS.

signalé la présence du parasite. Pourtant, on les trouve assez longtemps en nombre dans l'appendice iléo-cæcal (Heller). Quant aux femelles, elles demeurent en grande partie dans le cæcum tant que le déreloppement des œufs n'est pas achevé ; puis elles descendent, en continuant à pondre, le long du côlon et du rectum, et arrivent à l'anus, où l'action incessante de leurs lèvres sur la muqueuse occasionne un prurit parfois insupportable. Un grand nombre d'œufs sont donc encore déposés, soit dans le mucus anal, soit sur le tégument humide de la région voisine. Enfin, bien des femelles remplies d'ceufs sont expulsées avec les fèces.

Dans ces conditions, il est facile de comprendre que l'examen des matières fécales ne laisse découvrir qu'un nombre relativement restreint demâles: et c'est en effet ce qui avait fait longtemps attribuer à ceux-ci une rareté excessive. Mais Zenker a montré qu'on les rencontre aisément dans les autopsies, en ayant soin de racler avec un scalpel la surface de la muqueuse.

Organisation. - Nous serons très bref sur ce point, la constitution générale du Ver, sauf en ce qui concerne la musculature, pouvant être comparée à celle des Ascarides.

La cuticule est formée de trois couches, dont l'externe offre des stries transversales écartées de 18 a $23 \mu$, plus nettes en avant qu'en arrière, et disparaissant parfois chez la femelle ovigère. La vésicule céphalique renferme un liquide clair, coagulable; d'après Leuckart, elle représenterait un appareil destiné à la propulsion des lèvres. Les muscles consistent en un petit nombre de cellules, se rapportant au type platymyaire et méromyaire. L'anneau nerveux est situé au niveau de l'extrémité postérieure de la vésicule céphalique.

La carité buccale, en forme de courte pyramide triangulaire, se continue avec l'œsophage ; celui-ci s'élargit progressivement en arrière, puis s'étrangle pour communiquer avec le ventricule (bulbe pharyngien, estomac de divers auteurs), organe arrondi, également très musculeux, pourvu à sa face interne de trois dents chitineuses dont le ròle est, non pas de màcher les aliments, mais bien d'empècher le retour de ceux-ci dans l'œsophage. L'intestin se continue en ligne droite jusqu'au rectum ; il offre à ce niveau une sorte de sphincter et deux glandes unicellulaires; le rectum est étroit et s'ouvre dans le cloaque, situé à l'extrémité postérieure, chez le mâle; à l'anus, situé à la base de la queue, chez la femelle. - L'appareil excréteur n'offre rien de particulier; le pore terminal débouche à $0^{\mathrm{mm}}, 8$ en arrière $\mathrm{du}$ ventricule.

L'appareil génital màle est formé d'un tube qui naît vers le milieu de la longueur du corps, se dirige en avant, puis aussitòt se recourbe en arrière et gagne en ligne droite le cloaque. On peut y reconnaître les mêmes sectịons que chez les Ascarides; cependant, la vésicule séminale est à peine marquée. - L'appareil femelle comprend encore deux tubes, mais l'un see replie dans la partie antérieure du corps et l'autre, plus grand, dans la partie postérieure. Les deux utérus s'unissent en un court vagin qui s'étend d'arrière en avant pour aboutir à la vulve. Les oufs s'accumulent souvent 
en énorme quanlité (10 à 12,000 d'après Leuckart) dans les utérus, qui subissent alors une dilatation considérable et compriment tous les autres organes.

Distribution géoripalueve. - Comme l'Ascaride lombricoïde, l'Oxyure parait ètre cosmopolite. On le rencontre mème plus fréquenment dans les villes, et il existe sourent en grande aboudance dans les pays froids aussi bien que dans les contrées chaudes.

Patnologie. - L'Oxyure vermiculaire peut s'observer à tous les âges de la vie: Heller, à Kiel, l'a vu chez un enfant de cinq semaines et chez un vicillard de yuatre-ringt-deux ans. Mais il est surtout commun chez les enlants : le même auteur en a trouvé chez 188 p. 1000 des hommes examinés, chez 211 p. 1000 des femmes et chez 338 p. 1000 des enfants. Il parait plus abondant au printemps qu'en toute autre saison.

On en voit presque toujours un grand nombre à la fois, ce qui tient sans doute à la facilité de l'auto-infestation. Leur présence n'exclut nullement, du reste, celle des autres parasites intestinaux.

Asscz sourent, ces parasites sont presque inoffensifs, et leur action se borne au prurit anal que nous avons signalé, et qui revient périodiquement au début de la nuit, principalement quand le patient vient de se mettre au lit. Mais, lorsqu'ils sont très nombreux, les démangeaisons peuvent devenir insupportables, et s’accompagner d'élancements à l'anus, de ténesme, etc. Il survient même, dans certains cas, par voie réflexe, des accidents très variés analogues à ceux dont nous arons parlé à propos des Ascarides.

On les trouve moins souvent à l'état erratique que ces derniers Vers; cependant on en a vu dans l'estomac, dans l'œsophage, et ils sont quelquefois rendus par la bouche. Prosliauer a recueilli des embryons dans les fosses nasales. Ce qui est moins rare, surtout chez les petites filles, c'est de les voir passer de l'anus à la vulve, et pénétrer ainsi dans le vagin : ils peuvent alors provoquer l'onanisme et même des accès de nymphomanie. Leur introduction dans la vessie est exceptionnelle. Ajoutons enfin que Michelson a signalé un cas intéressant dans lequel l'épiderme du sillon génito-crural était perforé et occupé par un nombre immense d'cufs d'Oxyures.

Il est souvent difficile de débarrasser un malade de ses Oxyures, à cause surtout de l'auto-infestation qui a lieu dans nombre de cas. Le traitement consiste dans l'administration de vermifuges et de purgatifs, combinée avec l'usage de lavements à l'eau froide, salée, vinaigrée, sulfureuse, etc. On éloigne pour quelque temps les Vers de l'anus, et par conséquent on fait cesser le prurit, par une application locale de pommade mercurielle ou par une injection d'huile d'olive. En tout cas, le trailement doit être continué longlemps. 
oxyure compagnon (0. compar Leidy, 1836). - Corps fusiforme; tête

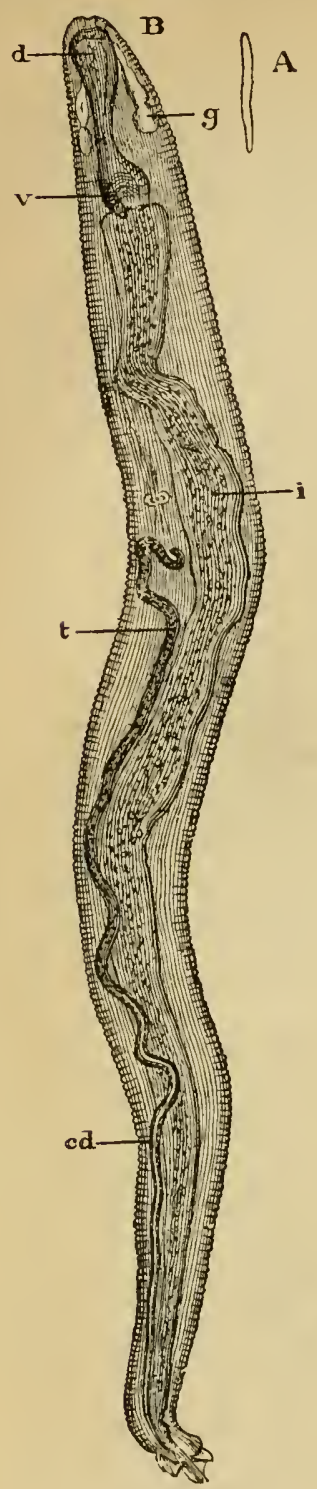

Fig. 271 - Oxyure du Cheval, mâle. A, grandeur naturelle. B, grossi. $d$, bulbe antérieur. $v$, bulbe postérieur ou ventricule. $g$, glandes dites salivaires. $i$, intestin. $t$, testicule. $c d$, canal déférent (Orig.).
A

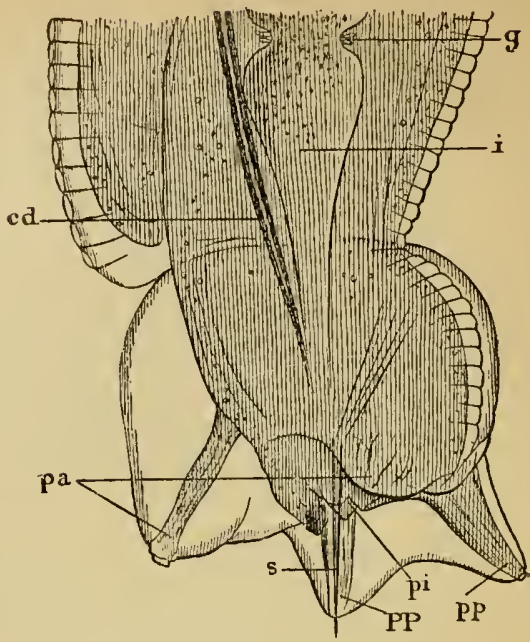

B

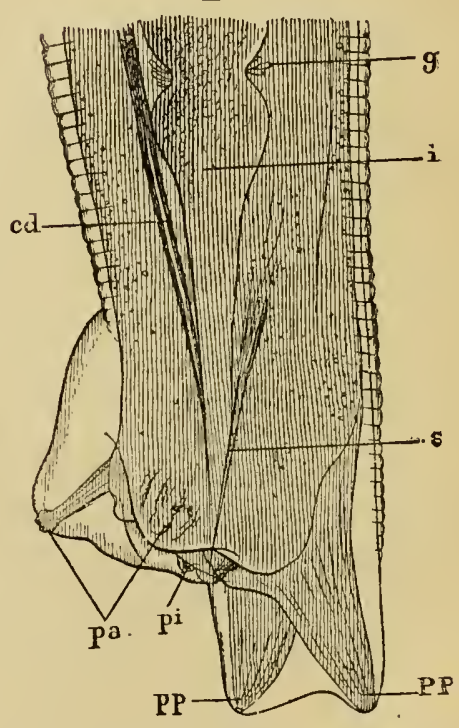

Fig. 272. - Extrémité caudale du mâle de l'Oxyure du Cheval. - A, vue par la face ventrale. B, par le cúté gauche. $i$, intestin. $g$, glandes rectales. $c d$, canal déféreut. $s$, spicule. $p a$, prapilles antérieures. $p p$ papilles postérieures. $p i$, papilles intermédiaires ou cloacales (Orig.).

continue avec le corps, amincie, pourvue d'un renflement vésiculeux ; bou- 
che petite. La fomelle seule est connue et mesure 8 a 13 millimètres de longueur sur $0^{\mathrm{mm}}, 7$ de largeur; son extrénité caudale est longuement subulée, contournée en spirale; la vulve est située au niveau du cinquième antérieur du corps.

Leidy a trouvé 17 spécimens de cette espèce, en compagnie de plusieurs exemplaires de Trnia crassicollis, dans l'intestin grèle d'un Chat, à Philitdelphie. On voit que cet Oxyure ne diffère pas sensiblement de l'Oxyure vermiculaire.

Oxyure des Équidés. - (0. equi [Schrank]. - Syn. : Trichocephalus equi Schrank, 1788; 0. curvula Rud., 1803; Mastigodes equi Zeder, 1803;

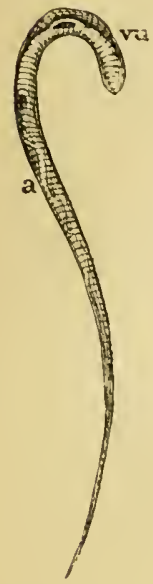

Fig. 273. - 0xyure du Cheval, femclle, grandeur naturelle. - vu, vulve. $a$. anus.

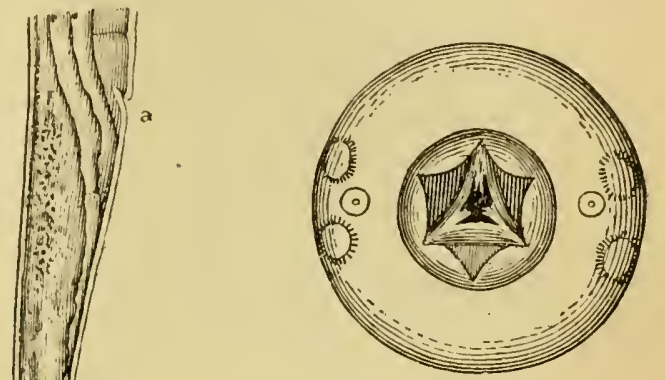

Fig. 27ä. - Extrémité céphalique de l'Oxyure du Cheval, vue de devant.

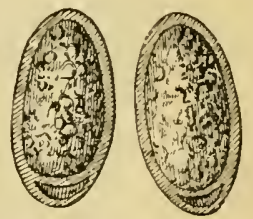

O. equi Blanch., 1849" 0 . mastigodes Nitzsch, 1866). - Corps le plus souvent blanchàtre, assez épais, sans vésicule céphalique. Bouche à trois grandes lèrres arrondies enveloppant chacune deux mamelons; usophage d'abord assez large, puis se rétrécissant et se renflant ensuite en un bulbe ou ventricule non séparé de la partie précédente par un étranglement; 6 papilles buccales: deux latérales faibles, quatre submédianes à stries radiées périphériques. Mâle long de 9 à 12 millimètres; extrémité caudale obtuse, munie de plusieurs papilles dont les plus longues soutiennent une bourse caudale très développée; spicule droit, grèle, très aigu. Femelle longue de 40 a 150 millimètres; corps épais et arqué en avant sur une longueur de 30 à 3 millimètres, puis brusquement atténué en une queue de longueur 
extrêmement variable, subulée; vulve située à 7 ou 8 millimètres de la bouche. OEufs ovoïdes, longs de 85 à $90 ̈ \mu$, larges de 40 à $40 ّ \mu$, un peu asymétriques, olfrant une sorte d'opercule à l'un des pôles, qui est obliquement tronqué.

Ce Ver peut se rencontrer dans toute la longueur du gros intestin des Équidés(Cheval, Ane, Mulet); mais, comme l'a montré G. Colin, son habitat normal est la courbure diaphragmatique du gros côlon. Le mâle est assez rare; nous croyons l'avoir décrit et figuré le premier.

Rudolphi avait déjà fait la remarque que la queue de la femelle a une longueur variable; Delafond distingua plus tard une forme à petite queue et une forme à longue queue. Cette dernière fut considérée comme une

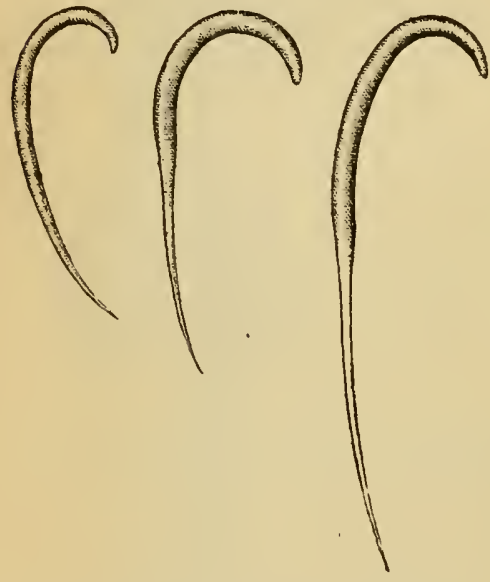

Fig. 277. - Oxyures du Cheval : femelles à queue relativement courle, répondant à la lorme curvula des auteurs. Grandeur naturelle (Orig.).

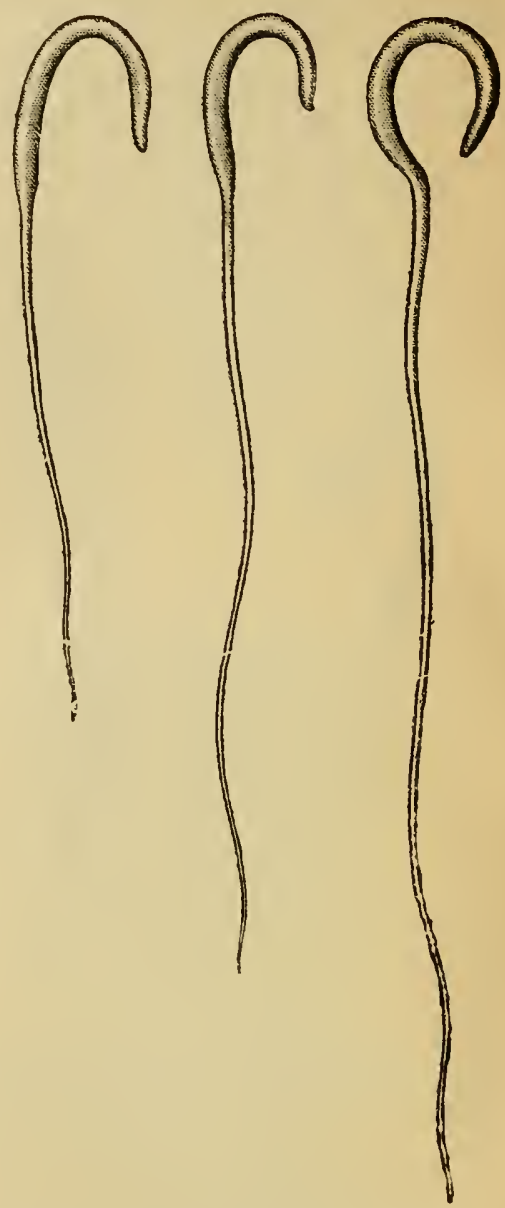

Fig. 278, - 0xyures du Cheval : femelles à queue de plus en plus longue, répondant à la forme mastigodes de Nitzsch. Grandeur naturelle (Orig.).

espèce particulière par Nitzsch et Friedberger, sous le nom d'Oxyuris mastigodes; ces auteurs lui attribuaient un seul ovaire, et des œufs englobés dans une masse gélatineuse les réunissant par รั à 8 en groupes étoilés ou irrégulièrement globuleux. Or, nous avons étudié comparativement les deux formes, et nous n'avons pu les distinguer l'une de l'autre; partout nous avons vu deux ovaires et le groupe- 
ment sus-indiqué des aufs. Nous arons même trouvé tous les intermédiaires possibles entre les Oxyures à queue très courte et ceux ì queue très longue, ainsi qu'en témoignent les figures 277 et 278 , dessinées d'après nature; de sorte qu’il n'y a là, selon nous, qu'un exemple de polymorphisme des femelles.

L'Oxyure ì longue queue a surtout été trouré dans les crottins du cheval (Nitzseh, Friedberger), ou bien attaché à la marge de l'anus (Blaise, G. Colin); mais nous l'arons aussi recueilli directement dans le gros côlon, côte ì còte arec l'Oxyure à petite queue.

L'Oxyure des Equidés est un Ver inoflensif; on ne trouve guère dans son tube digestif que des substances végétales, et c'est plutôt un commensal qu'un rèritable parasite. Cependant Emmerson, qui l'a touvé che\% la moitie des Chevaux de l'ile de Singapor'e, l'a accusé de produire chez ces animaux des affections cutanées rebelles, accompagnées d'amaigrissement. Pflug a observé un Cheval qui portait à la base de la queue des croûtes épaisses et prurigineuses, renfermant des œuls d'Oxyure à livers degrés de développement. Cobbold dit que ces œufs forment parfois des masses jaunâtres incrustées à la marge de l'anus. Enfin, Willach tend à leur attribuer le développement des nodules hépatiques du Cheral.

Nous devons signaler ici un Ver mentionné par Schlotthauber (1) sous le nom de Piguris reliculata. Cet auteur le donne comme très étroitement allié á l'espèce précédente par la texture du tégument et l'habitat, mais en différant tout à fait par l'aspect extérieur, la constitution de la bouche et la situation de l'auus à la pointe de la queue. Il en avait trouvé une seule femelle, le 6 janvier 1845 , dans le còlon d'un Cheval, à Cüttingue. D'après des renseignements aussi incomplets, il est impossible d'accorder la moindre importance à une telle indication.

Oxyure ambigu (0. ambigun Rud., 1819. - Syn. : Passalurus ambiguns Duj., 1840̃). - Corps blanc, fusiforme. Une membrane latérale refoulée à son bord libre, et interrompue en avant et en arrière du bulbe œsophagien ou ventricule. Bouche ronde, avec 6 papilles. Mâle long de 3 à 5 millimètres, atténué en arrière jusqu'au delà du cloaque, puis terminé par une queue grèle; spicule en aiguillon un peu courbé; 3 papilles caudales de chaque côté ; ailes caudales peu développées. Femelle longue de 8 à 12 millimètres, atténuée à partir de l'anus, puis terminée brusquement par une queue subulée. OEufs ressemblant à ceux de l'Oxyure vermiculaire, longs de $88 \mu$, larges de $42 \mu$, en segmentation au moment le la ponte.

Gros intestin du Lièvre, du Lapin de garenne et du Lapin domestique. Nous l'avons souvent observé à Alfort : il est du reste assez commun en France.

Famille des STRONGYLIDÉS. - Le corps est allongé, cylindroïde,

(1) Schlottinauber, Beiträge zur IIelminthologie. Amtlicher Bericht über die 31. Versamml. deutsch. Naturf. u. Aerzte zu Göttingen im Sept. 185ł. Göttingen, 1860, p. 126.

Raillet. - Zoologie. 
rarement filiforme ou capillaire. La bouche est probablement toujours munie de six papilles, dont les quatre submédianes sont d'ordinaire saillantes, sous forme de nodules ou de pointes coniques; elle est tantôt dans l'axe du corps, tantôt tournée vers la face dorsale ou vers la face ventrale, et parfois munie d'une armature chitineuse qui la maintient béante. L'œsophage est plus ou moins renflé dans sa partie postérieure, mais sans présenter de ventricule distinct. Les máles possèdent une bourse caudale ouverte ou close, entière ou divisée, avec un seul ou deux spicules. Les femelles ont un ou deux ovaires; la vulve est située tantôt en avant, tantôt en arrière du milieu du corps, parfois même dans le voisinage de l'anus. Les œufs sont pondus après avoir subi une segmentation plus ou moins complexe, et dans certains cas après la formation de l'embryon (1).

Les principaux éléments de la classification de ces Vers sont fournis par l'armature buccale et par la bourse caudale des mâles. Le plus souvent, celle-ci est pourvue de còtes ou rayons, prolongements du tissu sous-cuticu-

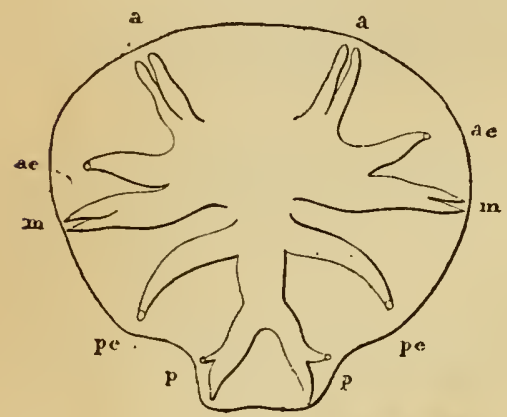

Fig. 279. - Bourse caudale de l'Esophagostona dentatum, grossie 93 fois, d'après Schneider. $p$, cótes postérieures. $p e$, côtes postérieures externes. $m$, côtes moyennes. ae, còtes anlérieures externes. $a$, còtes antérieures. laire comprenant des muscles fibrillaires et comparables à des nervures. Des papilles sont d'ailleurs annexées à l'orifice génital mûle; elles occupent parfois le bord de la bourse et, lorsqu'il existe des côtes, elles sont situées à l'extrémité de celles-ci.

D'après Schneider, on peut distinguer ces còtes de la façon suivante, en prenant pour type la bourse caudale du Strongylus dentatus (fig. 279).

$1^{\circ}$ Côtes postérieures, s'étendant de l'intérieur de la bourse jusqu'au bord: le plus souvent à deux branches.

$2^{\circ}$ Côtes postérieures externes, n'atteignant pas le bord de la bourse : presque tonjours simples.

$3^{\circ}$ Côtes moyennes, aboutissant au bord : d'ordinaire à deux branches, soit réunies (còte fendue), soit séparées (côte dédoublée).

$4^{\circ}$ Côtes antérieures externes, n'atteignant pas le bord : toujours simples.

$5^{\circ}$ Côtes antérieures, se terminant au bord : loujours à deux branches réunies ou séparées.

Nous aurons à étudier quatre sous-familles : Eustrongylinæ, Strongylinx, Sclerostominx, Physalopterinæ.

A. Sous-famille des Eustrongyuinés. - Polymyaires dont les mâles possèdent un seul spicule et une bourse caudale dépourvue de côtes.

Genre Eustrongle (Eustrongylus Dies., 18ä1). - Corps cylindroïde.

(1) R. Mous, Il sottordine degli Acrofalli. Memorie dell' Istituto veneto, IX, 1860. 
Bouche sans lèvres, entourée de papilles. Mâle à spicule filiforme. Femelle pourvie d'un seul ovaire; vulve dans la partie antérieure du corps.

On ne connait jusqu'à présent qu'une seule espèce se ratlachant à ce genre.

Eustrongle géant (E. gigas [Rud.]. - Syn. : Ascaris canis et marlis Schrank, 1788; A. visceralis et renalis Gmelin, 1789 ; Strongylus Gigas Rud., 1802 ; Eustr. Gigas Diesing, 1831 ; Strongylus renalis Moquin-Tandon, 1860 ; Eustr. visceralis Raill., 1883̈). - Le corps est en général d'un rouge sanguin, un peu alténué aux extrémités, surtoul en arant. La bouche est liexagonale, entourée de six nodules papillifères très développés. Le tégument, très mince et transparent, est finement strié en travers; all niveau des lignes latérales, il porte une série longitudinale de petites papilles punctiformes, plus écartées dans le milieu du corps qu'aux extrémités. Le mále est long de 14 à 40 centimètres; large de 4 à 6 millimètres; soll extrémité caudale est obtuse et se termine par une bourse épaisse, ovalaire, à grand diamètre transversal, dont le bord est garni de très petites papilles et légèrement échancré en avant et en arrière; vers le centre de cette bourse, on remarque une saillie en $\mathrm{Y}$, portant á son milieu, sur une petite éminence, l'orifice cloacal, par lequel il n'est pas rare de voir sortir le spicule sétiforme, long de 5 à 6 millimètres. La femelle mesure de 20 centimètres jusqu'à 1 mètre de long, sur une largeur de 5 à 12 millimètres; son extrémité caudale est obtuse et porte, tout à fait en arrière, l'anus en forme de croissant; la vulve est située à $50-\tau 0$ millimètres seulement de la bouche. Les œu?s sont ellipsoïdes, brunàtres, à coque épaisse, mais criblée de dépressions; ils mesurent 64 à $68 \mu$ de long sur 40 à $44 \mu$ de large.

Le Strongle géant, le plus grand des Nématodes, est surtout un parasite des reins. On l'a rencontré fréquemment chez des Mammifères ichthyophages, tels que le Phoque, la Loutre, le Vison d'Amérique, mais aussi chez bien d'au-

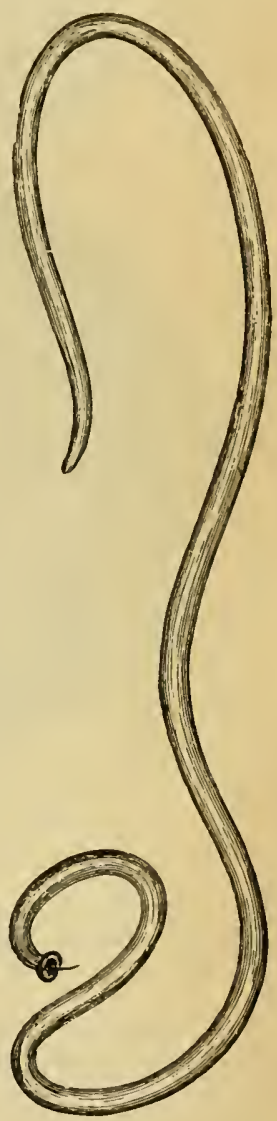

Fig. 280. - Eustrongle géant, màle, grandeur naturelle. tres : Martre, Putois, Loup, Chien, Bceuf, Cheval, Homme, etc.

Évolution. - Le développement de l'embryon a été étudié par Balbiani. Au moment de la ponte, l'œuf a déjà subi un commencement de segmentation; il est alors entrainé au dehors avec l'urine. Si on le place dans l'cau ou dans la terre humide, on voit l'embryon se développer, en hiver, dans l'espace de cinq à six mois; en été, l'évolu- 
tion serait sans doute plus rapide. Cet embryon, une fois formé, peut rester pendant cinq ans au moins dans l'œuf sans éclore et sans périr; si on l'en extrait, il s'altère rapidement dans l'eau pure et ne vit bien que dans les liquides albumineux. Il meurt même dans l'œuf, après une dessiccation de quelques jours. Il est fusiforme, long d'environ $240 \mu$ et large de $14 \mu$; son tégument est finement strié en travers, et son œsophage montre, dans la partic antérieure, une petite armature formée de trois dents chitineuses.

Balbiani a tenté vainement d'infester des Chiens en leur faisant prendre des œufs embryonnés. Il y a done lieu d'admettre que l'embryon

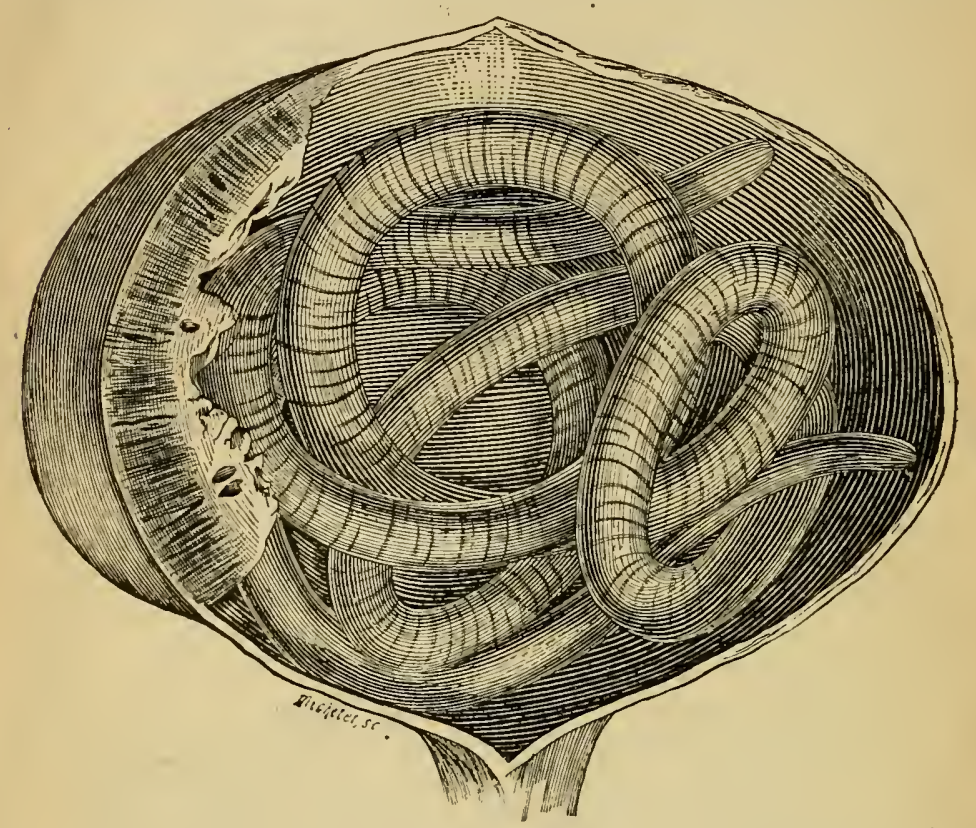

Fig. ㅃ⒈ - Eustrongle géant, femelle, dans le rein d'un Chien. La face supérieure du reiu a été excisće. Grandeur naturelle (Orig.).

doit passer par un hôte intermédiaire. Mais cet hôte reste à déterminer. Schneider a trouvé, chez quelques Poissons exotiques, des Nématodes enkystés que Rudolphi avait déjà décrits sous le nom de Filaria cystica et Diesing sous celui d'A gamonema cysticum. Or, ce sont en réalité des larres d'un Eustrongylus; mais tandis que Schneider suppose qu'il s'agit de l'E. gigas, Leuckart émet un avis opposé. Ajoutons que Balbiani n'est même pas parvenu à faire éclore les œufs embryonnés de l'Eustrongle géant dans l'intestin du Chien, du Lapin, de divers Poissons (Anguilles, Carpes, Cyprins dorés), des Couleuvres, des Tritons, ni de la Grevette des ruisseaux.

Organisation. - Le tégument dá Ver possède unè teinte rouge qui s'observe également dans le liquide nourricier de la cavité viscérale. D'après 
Aducco, cette coloration est due à une substance rouge qui a beaucoup de ressemblance avec l'oxyhémoglobine des Vertébrés, mais en diffère cependant par une plus grande résistance ì l'action de la chaleur et des réactifs (1).

Les lignes longitudinales sont étroites; au licu de quatre, on en compte huit, car chacun des quatre champs musculaires primitifs est interrompu dans son milieu par une lacune longitudinale (ligne submédiane) au niveau de laquelle viennent s'iusérer des muscles radiaires venant de l'intestin. La couche musculaire est assez faible; elle est forméc de cellules cylindriques ou fusiformes qui ne sont contractiles que par leur partie externe. La cavité générale est relativement large; elle est tapissée par une sorte de séreuse qui formc deux mésentères latéraux, indépendants des quatre lames de muscles radiaires précités.

La bouche représente une cavité à paroi chitineuse, qui devient triquêtre dans sa partie profonde, où elle se continue avec l'wsophage. Celui-ci est un canal étroit, qui s'épaissit peu à peu en arrière. L'intestin est rectiligne, de teinte jaunatre.

L'appareil génital màle comprend un seul testicule, qui prend naissance non loin de l'extrémité caudale, remonte jusqu'au voisinage de la bouche, puis s̈infléchit en décrivant quelques sinuosités, pour former le canal déférent : celui-ci va s'ouvrir en commun avec le tube digestif, au fond de la bourse caudale.

Il n'existe également qu'un scul tube femelle, naissant ì l'extrémité postérieure, s'avançant jusque vers la terminaison de l'œsophage, puis revenant vers la queue, oì il se pelotonne, pour re-

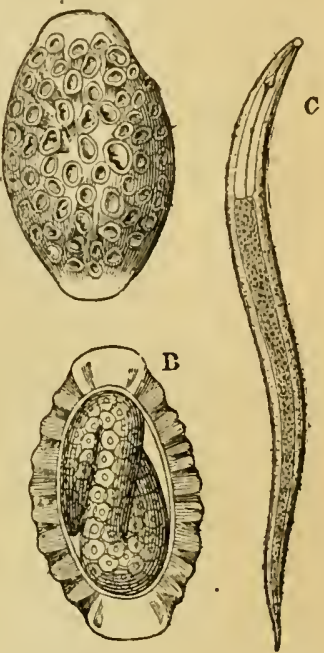

Fig. 252. - (Eufs et embryon de l'Eustrongle géant, d'après Balliani. - $A$, œuf mûr, extrait de l'utírus d'une femelle fécondée, grossi 400 fois fon remarque a sa surface les orifices des canaux nombreux qui traversent la coque de part en part) B, auf renfermaut un embryon encore celluleux. C, embryon extrail de la coque, grossi 250 fois. prendre ensuite sa marche en avant: il se dilate alors en un utérus rectiligne, qui arrive jusqu'à 2 '́ millimètres de la vulve. A ce niveau, il se continue par un vagin grêle, d'abord rétrograde, qui va déboucher à la vulve, située sur la ligne médiane ventrale.

En arrivant dans l'utérus, l'ouf est formé par une simple masse vitelline; il s'entoure alors d'une membrane mince et lisse, autour de laquelle se dépose ensuite une masse granuleuse bientôt criblée de pertuis qui la traversent de part en part, - sauf aux deux pôles, dont l'aspect reste homogène.

Patnologie. - L'Eustrongle géant paraît être répandu un peu partout, mais il est plus commun dans les contrées oủ rìgnent abondamment des eaux riches en Crustacés et en Mollusques. Il est assez rare en France, mais relativement commun en Italic. Silvestrini l'a souvent observé, en Toscane, chez les Chiens de chasse: braques, set-

(1) V. Aducco, La sostanza coloranle rossa dell' Eustrongylus Gigas. Atti R. Accad. Lincei, Rendiconti, IV, p. $18 i$ et 213, 1883. 
ters, pointers, épagneuls ou bâtards. On l'a signalé aussi en Angleterre, en Hollande, en Allemagne, en Russie, au Japon et dans les deux Amérique.

Au point de vue des troubles pathologiques occasionnés par ce parasite, nous ne possédons guère que des observations se rapportant au Chien. Le plus souvent, chez les autres animaux, la présence du Ver n'a même pas été soupçonnée pendant la vie, et n’a été révélée qu'à l'autopsie.

D'ordinaire, le Chien affecté devient triste, méchant; la marche est vacillante, la voix rauque; les urines sont sanguinolentes. Dans certains cas, les troubles nerveux sont tels que l'observateur peut croire à l'existence de la rage. D'autres fois, les animaux manifestent les souffrances qu'ils éprouvent par des cris ou des hurlements continuels; ou bien encore la présence du Ver ne se traduit que par le dépérissement du sujet atteint, et l'on a même cité plus d'un cas oủ le Chien était demeuré toujours gras et bien portant.

Le parasite paraît occuper d'abord le bassinet, mais il détruit peu à peu tout le parenchyme de l'organe, et souvent la tunique d'enveloppe persiste seule, subissant une dilatation plus ou moins considérable. En général, le bassinet et même l'uretère sont également dilatés; le Ver est quelquefois engagé dans celui-ci. Dans toutes les observations que nous avons pu relever jusqu'ici, il n'y avait qu'un seul rein d'envahi, soit par un, soit par plusieurs parasites.

Il n’est pas très rare de voir ceux-ci tomber dans la cavité péritonéale, par suite d'une déchirure de la tunique fibreuse. On en a même trouvé dans cette cavité, bien que les reins fussent parfaitement sains. On en a vuaussi dans le foie, dans la cavité thoracique, dans le cœur (?), etc.

L'Eustrongle peut encore s'échapper par l'uretère, passer dans la vessie et même dans le canal de l'urèthre; dans ce dernier cas, il s'arrête parfois en route et va se loger dans le tissu conjonctif voisin, ou bien il est expulsé au dehors.

Le diagnostic de l'eustrongylose rénale ne peut guère être affirmé que par la découverte des œufs du Ver dans les urines sanguinolentes. Il est presque impossible, du reste, d'instituer un traitement efficace (extirpation du rein).

Chez le Cheval, nous ne connaissons, relativement à la présence de l'Eustrongle géant dans le rein, que les observations de Chabert, Leblanc, Labat, et un cas douteux de Bruckmüller. Le parasite de Chabert, noyé dans un liquide purulent, était de teinte blanche, ce qui tend à montrer que la couleur rouge ordinaire tient à l'absorption du sang de l'hôte. - Chez le Bœuf, on ne cite que deux cas, un du musée d'Alfort, relevé par Rudolphi, et un autre de Greve. - Von Linstow mentionne aussi l'Eustrongle géant parmi les parasites du Porc.

Enfin, on a depuis longtemps signalé le parasitisme de ce Ver chez 
l'Homme; mais la plupart des observations qu'on a données comme s'y rapportant sont extrèmement douteuses. On ne peut en citer aujourd'hui que lıuit dont l'authenticité soit certaine.

Genre Hystrichis (Hystrichis Duj., 18.43). - Vers filiformes, à corps

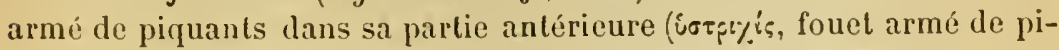
quants). Extrémité antérieure parfois renflée en tête. Mâle à bourse entière, campanulée ou patelliforme; spicule filiforme très long. Femelle pourvue d'un seul ovaire; vulve à l'extrémité caudale, contiguë à l'anus.

Vivent en parasites entre les tuniques de l'œsophage et du ventricule succenturié des Oiseaux.

Hystrichis dégant (II. elegans [Olfers]. - Syn. : Str. mergorum et anatis Rud., 1809; Str. elegans Olfers, 1816; Str. tubifex Nitzsch, 1819; Eustr. tubifex Dies., 18ä1; H. tubifex Molin, 1860). — Corps blanchàtre, fusiforme, très épais, contourné au milieu, atténué aux extrémités. Bouche orbiculaire, entourée de six papilles saillantes surmontées chacune d'une petite pointe. Extrémité antérieure armée de petits crochets qui disparaissent progressivement. Hâle atteignant jusqu'à 26 millimètres sur $1^{\mathrm{mm}}, \mathrm{a}$ à 2 millimètres d'épaisseur; extrémité caudale spiralée : bourse campaniforme, obliquement tronquée. Femelle longue de 26 à 40 millimètres, large de 2 à 3 millimètres; queue mousse. OEufs ellipsoïdes, longs de 62 à 6 f́ u, un peu. tronqués aux extrémités, à coque alvéolée comme un dé à coudre.

Trouvé dans des tubercules de l'œsophage ou du ventricule succenturié chez un assez grand nombre de Palmipèdes. Nitzsch l'appelait Strongle perforant à cause de la façon dont il s'entrage entre les tuniques de l'organe. Jurine l'a recueilli à Genève dans des nodules osophagiens du Canard domestique, et communiqué à Rudolphi. Une observation semblable est due à Chaussat (18'9).

Hystrichis tricolore (II. tricolor Duj., 184ว. - Syn. : ? Spiroptera tadornæ Bellingham, 184́; Sp. tricolor Dies., 1831). - La femelle seule est connue et tire son nom de ce qu'elle est blanche à l'extérieur, noire au centre ou dans l'intestin, rouge vif dans la couche intermédiaire et dans la région œsophagienne. Corps long de $2 \tau$ millimètres, large de $0^{\mathrm{mm}}, 3 \ddot{\mathrm{à}}$ $0^{\mathrm{mm}}, \ddot{0} 0$, obtus aux deux extrémités. Bouche ronde, un peu protractile. Tègument de la partie antérieure hérissé d’épines ou lamelles aiguës, inclinées. en arrière, disposées en quinconce sur 40 à 42 rangs et très serrées en avant. OEufs oblongs et comme tronqués aux extrémités, longs de 83 à $88 \mu$, larges de 36 a $40 \mu$, couverts de granules ou tubercules réguliers, peu saillants.

Dujardin a trouvé cet Helminthe, en assez grande abondance, chez un Canard domestique et chez un Canard saurage. Il était tellement engagé dans le tissu épaissi et "squirrenx " du ventricule succenturié, qu'on arrivait difficilement à l'extraire sans le rompre. Les galeries qu'il occupait s'étaient épaissies par suite des nues successives, et quelques-unes contenaient seulement des tubes remplis d'œufs, "reste de la décomposition. des Ilelminthes arrivés au terme de leur développement ». 
Hystrichis du Cygne (H. cygni Molin. - Syn. : Echinocephalus cygni Molin, 1858; H.cygni Molin, 1860; H. pachycephalus Molin, 1860). - La femelle seule est connue. Corps long de 3 centimètres et plus, irrégulièrement renflé au milieu et en arrière, et formant en avant une tète cesticilliforme, garnie d'environ 20 séries de grands crochets dirigés en arrière et épaissis à la base; extrémité antérieure armée de crochets plus petits disparaissant peu à peu en arrière. Bouche orbiculaire, protractile, entourée d'une couronne de petites épines.

Trouvé à Padoue, par Molin, chez le Cygnus olor, entre les tuniques externes du ventricule succenturié, dans des vésicules remplies de liquide jaune.

B. Sous-famille des strongylinés. - Méromyaires à bouche dépourvue d'armature chitineuse, à deux spicules égaux, à bourse caudale munie de côtes ou rayons. Deux ovaires.

Un seul genre :

Genre Strongle (Strongylus 0. F. Müller). — Corps grêle; extrémité antérieure parfois ailée. Bouche petite, dont les lèvres molles, souvent peu distinctes, laissent voir, lorsque leurs dimensions le permettent, six faibles papilles. OEsophage plus ou moins renflé en massue dans sa partie postérieure. Máles à bourse caudale entière ou excisée sur la face ventrale, parfois même bi, tri ou multilobée ; spicules souvent accompagnés d'un organe de soutien impair. Femelles ayant l'extrémité postérieure terminée en pointe courte; vulve presque toujours située dans la moitié postérieure du corps.

On ne connaît encore l'évolution que d'un petit nombre d'espèces de ce genre.

Les Strongles du tube digestif (type Str. contortus) ont un embryon rhabditiforme pourvu d'un bulbe cesophagien bien développé, à trois dents chitineuses, embryon qui se nourrit et s'accroît aux dépens des matières organiques contenues dans l'eau fangeuse; ils ont un développement direct.

Les Strongles des voies respiratoires (type Str. filaria), produisent des larves à bulbe œsophagien faible, sans dents, qui ne prennent pas les matières en suspension dans l'eau, ne s'y accroissent pas et vivent aux dépens des matériaux emmagasinés dans leurs tissus. - Leuckart n'a pas pu en obtenir le développement direct et admet qu'ils doivent passer par un hôte intermédiaire.

Enfin, le Strongle des vaisseaux ( $S$ lr. vasorum) nous paraît devoir être rapproché des Strongles des voies respiratoires.

Strongle filaire (Strongylus filaria Rud., 1809). - Ver filiforme, atténué seulement un peu aux extrémités, el de teinte blanchàtre. Extrémité antérieure obtuse, non ailée; bouche circulaire, nue. Male long de 3 à 8 centimètres; bourse caudale excisée en avant; côtes postérieures trilobées, les moyennes bilobées, les antérieures dédoublées; spicules bruns, courts, épais, ailés, un peu arqués. Femelle longue de 5 à 10 centimètres; extrémité 
caudale droite, conique; vulve située en arrière du milieu du corps, vers les trois cinquièmes de la longueur. OEufs ellipsoïdes, longs de 112 à $133 \ddot{\mu}$, larges de วั2 à $6 \tau$ u., renfermant au mornent de la ponte un embryon dont
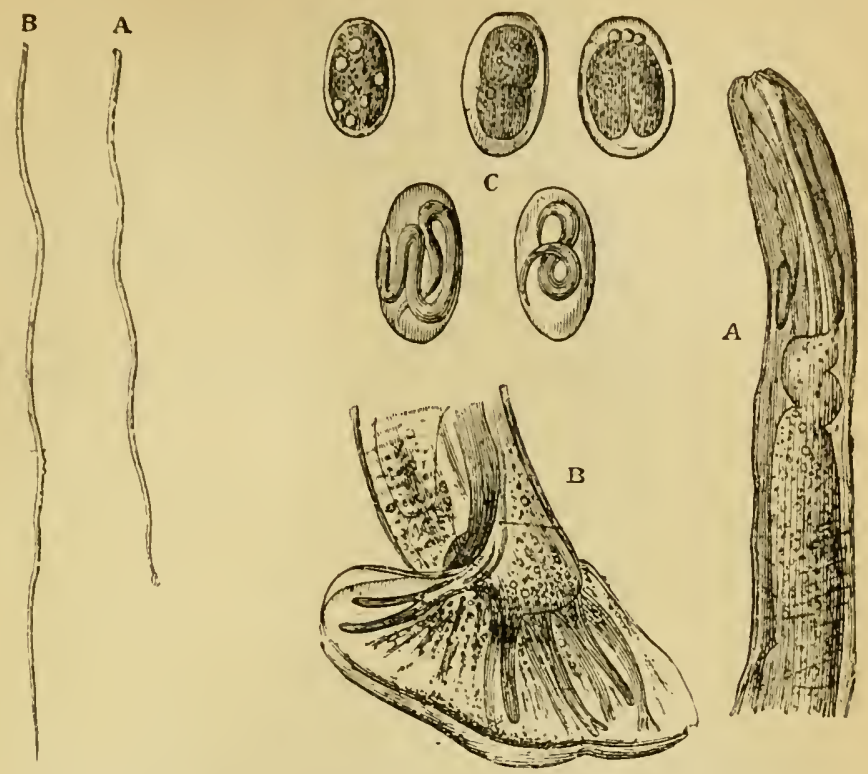

Fig. 253. - Strongle filaire. Gran- Fig. 284. - Strongle filaire. - A, extrémité antérieure, mondeur naturelle. - A, måle. B, trant l'cesophage, les glandes céplialiques et l'origine de 1 intesfemelle. tin. B, bourse caudale du mâle. C, ceufs à différents degrés de développement, grossis 120 fois (Delafond, inéd.).

les mouvements déforment à chaque instant la coque très mince. Embryons libres mesurant au moment de la naissance $3 \mathbf{t}^{0} \mu$ de long sur $20 \mu$ d’épaisseur; extrémité antérieure offrant une sorte de petit bouton protractile; extrémité caudale terminée en pointe obtuse; œsophage court.

Le Strongle filaire habite les voies respiratoires du Mouton, de la Chèvre, du Dromadaire, du Chameau et de divers Ruminants sauvages (Cerf, Chevreuil, Daim, Argali, Gazelle). Von Linstow l'a recueilli en outre chez le Veau. Il siège de préférence dans les bronches de diamètre moyen.

Évolutiox. - Les embryons du Str. filaria éclosent dans les bronches de leur hôte, où on les trouve en abondance au milieu du mucus; de là ils gagnent la Irachée et sont sans doute expulsés par la toux, ou par l'éternuement et le jetage quand ils ont pénétré dans les cavités nasales. Mais, ce qu il importe de noter, ils ne subissent sur place aucune modification.

Quand on les conserve dans l'eau, ils périssent rapidement s'ils sonl mélangés à des malières organiques qui subissent la putréfaction. Dans l'eau pure, ils résistent mieux, mais ne prennent aucune nourri- 
ture et ne s'accroissent pas. Au bout de huit à quinze jours, cependant, ils subissent une mue, après laquelle ils offrent un aspect un

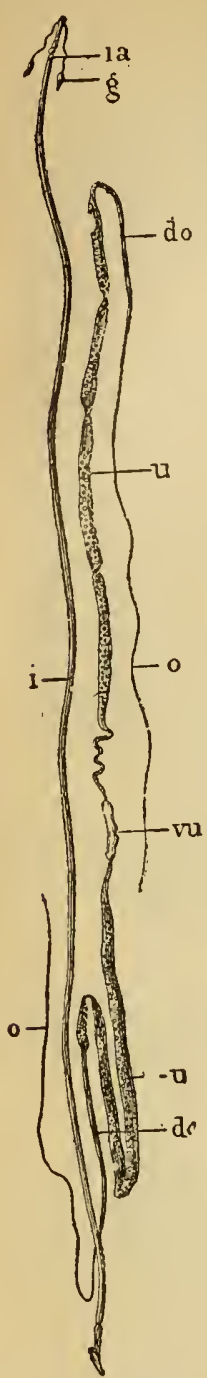

Fig. 285. - Tube digestif et organes sexuels d'une femelle de Strongle filaire. $i a$, œsophage. $i$, intestiu. 0 , ovaires. do, oviducles. $u$, leur partie renfléc ou utérus. $v u$, vulve. $g$, glandes céphaliques (Delafond). peu différent de leur état antérieur : ils ont la queue plus pointue, le bouton céphalique moins saillant et offrent une légère teinte jaune verdâtre. Un grand nombre meurent pendant cette mue; les autres peuvent continuer à vivre plusieurs mois dans l'eau. Ils ne s'y accroissent pas encore d'une façon sensible; cependant, C. Baillet dit en avoir vu atteindre une longueur de $\mathbf{1}^{\mathrm{mm}}, 2 \mathrm{O}$.

Avant la mue, leur résistance vitale est très faible : la plupart sont morts après une dessiccation de deux heures; mais, après cette crise, nous en avons vu reprendre leur activité à la suite d'une dessiccation de soixante-trois heures.

Quel est le sort ultérieur de ces embryons? On admet en général qu'ils rentrent directement dans l'organisme de leur hôte définitif par l'intermédiaire des boissons ou des aliments. Mais Leuckart n'a pas réussi à infester un Agneau avec des Vers en mue; il a échoué également sur quatre Moutons avec du mucus bronchique chargé d'embryons, et il admet pur suite que ces embryons doivent passer par un hôte intermédiaire (Insecte ou Mollusque). Les plus petits exemplaires qu'ait observés cet auteur mesuraient 3 à 5 millimètres et n'offraient pas encore de différenciation sexuclle ; ils avaient été recueillis dans la trachée de Brebis saines. Quand les Vers ont acquis une longueur de 9 à 12 millimètres, on les trouve dans le poumon.

En somme, on en est encore réduit à des hypothèses relativement à l'évolution du Strongle filaire.

Organisation. - Le tégument du Strongle filaire ne montre pas de stries transversales. La bouche s'ouvre dans un œsophage légèrement renflé en massue à sa partie postérieure; l'intestin, qui en est séparé par un étranglement peu accusé, s'étend directement jusqu'à l'anus, situé un peu en avant de l'exırémité caudale. Sur les côtés de l'œsophage et de la partie antérieure de l'intestin, se trouvent deux glandes donnant naissance chacune à un canal excréteur qui va s'ouvrir dans la bouche. L'appareil reproducteur màle est représenté par un seul tube testiculaire, qui commence en 
arrière de l'origine de l'intestin et s'étend jusqu'ả l'extrémité postérieure, en décrivant à peine quelques sinuosités. A sa portion terminale sont annexés deux spicules courts, un pelı arqués, de teinte brun rougeâtre et bordés chacun d'une aile nembraneuse qui s'élargit en avant de la pointe. En outre, la copulation est favorisée par une bourse caudale, expansion membraneuse campanulée excisée en avant et offrant de chaque cơlé, en arrière, une légère échancrure. Cette bourse est allongée et soutenue de part et d'autre par cinq còtes : la postérieure trilobée, la postérieure externe simple, la moyenne bilobée, l'antérieure externe simple, l'antérieure déloublée. - La femelle possède deux tubes ovariens symétriques formant cliacun une anse, l'un en avant, l'autre en arrière, et se dilatant bientòt en une longue poche oviductale ou utérine, souvent étranglée de distance en distance. Cette poche se rétrécit ensuite de manière à constituer enfìn un court vagin, et les deux tubes vaginaux aboutissent à une sorte de vestibule oblong, au centre duquel est percée une vulve à deux lèvres saillantes.

Les œufs sont ellipsoïdes: ils s'entassent en quantité considérable dans l'oviducte, où l'on peut suivre les diverses phases du développement embryonnaire. Vers la portion terminale de cet oviducte, on distingue l'embryon disposé en anse, en spirale ou en 8 dans l'intérieur de la coque, où il s'agite continuellement; c'est ì cet état que l'œul' est pondu.

Patiologie. - La présence dans les bronches des Strongles filaires, de leurs cufs et de leurs embryons, détermine souvent une inflam. mation catarrhale à laquelle on donne le nom de bronchite vermineuse. Dans les cas graves, les ramifications bronchiques offrent des dilatations dans lesquelles sont accumulés des paquets de Vers mélangés à du mucus spumeux, parfois teinté de rouge sanguin. La muqueuse offre sourent des traînées inflammatoires. On peut même observer des foyers étendus de pneumonie.

Les symptômes de la maladie sont ceux du catarrhe bronchique : dyspnée, toux, jetage, etc. II n'est pas rare de voir les animaux péril au bout de quelques mois, par suite de cachexie ou d'asphyxie. Le diagnostic peut être établi par l'examen du jetage ou des mucosités expectorées, qui permet de constater la présence de nombreux embryons.

La maladie sévit surtout pendant la belle saison; elle est beaucoup plus commune chez les agneaux et les antenais que chez les adultes, et donne lieu parfois à de graves épizooties, qui ont été signalées depuis longtemps.

On a recommandé, comme moyens de traitement, des fumigations de goudron, de cónes de genévrier, etc. Les injections trachéales antiparasitaires seraient plus efficaces, mais sont d'une application difficile.

Strongle roussitue (Str. rufescens Leucliart, 186̈. - Syn. : Nematoideum ovis [pulmonale] Dies., 1831; Str. minutissimus Mégn., 18;8; Pseudalius ovis pulmonalis A. Licch, 1883 ; Str.ovis pulmonalis C. Curtice, 1890). - Corps 
très grèle, offrant une teinte brun rougeâtre caractéristique, due au canal intestinal. Extrémité antérieure non ailée; bouche à trois lèvres papilliformes. Mâle long de 18 à 28 millimètres; bourse caudale excisée en avant et oflirant deux légères échancrures latérales; côtes antérieures fendues, moyennes dédoublées, postérieures ?. Deux spicules longs de 110 à $310 \mu$,

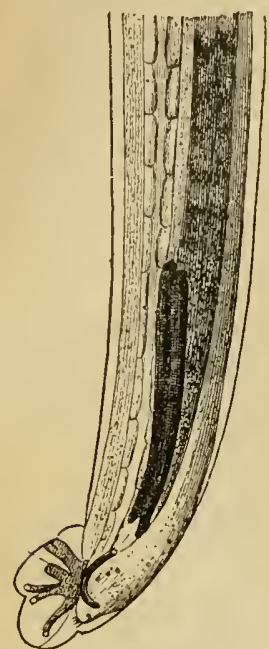

Fig. 286. - Strongylus rufescens, extrémité caudalc du màle, grossie 100 fois (0 rig.).

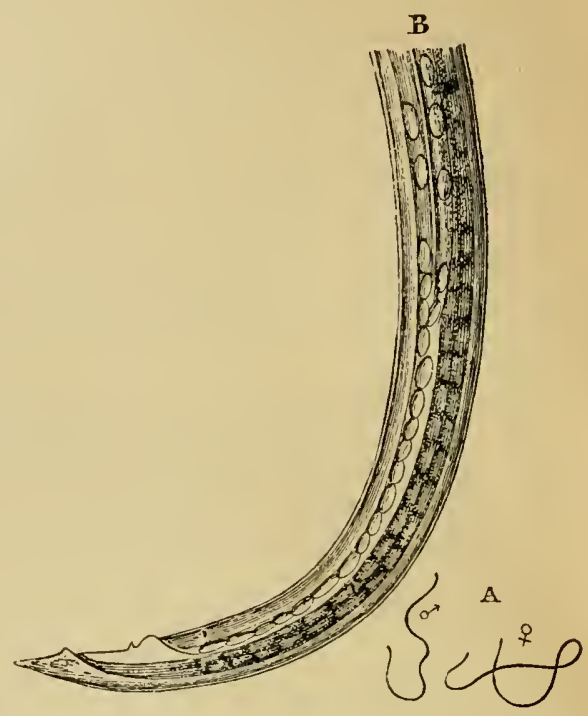

Fig. 287. - Strongylus rufescens. - A, mâle et femelle, grandeur naturclle. B, extrúmité caudale de la femelle, grossie 50 fois (Orig.).

arqués, pectinés dans le sens transversal, cylindriques en avant, aplatis en arrière. Femelle longue de 20 à 33 millimètres; queue terminée en pointe mousse; vulve située immédiatement en avant de l'anus, à la base d'une petite éminence. Ovipare : œufs ellipsoïdes, longs de 75 à $120 \mu$, larges de 45 à $82 \mu$.

Le Strongle roussâtre vit chez le Mouton, la Chèvre et le Chevreuil. Les individus adultes se rencontrent assez souvent dans les petites bronches et parfois même dans celles d'un certain calibre, mais ils semblent s'étirer en pénétrant dans les dernières ramifications, et on les trouve enfin fixés (mais non enkystés) dans le parenchyme pulmonaire, sous la forme de filaments entortillés et extrêmement grêles : à cet état, Koch les a décrits comme une espèce particulière, sous le nom de Pseudalius ovis pulmonalis.

Leurs œufs sont en voie de segmentation au moment de la ponte. Ils sont déposés dans les alvéoles pulmonaires, où ils achèvent leur développement, jusqu'à éclosion. Les embryons passent ensuite dans les bronches et la trachée, d'où ils doivent être sans doute expulsés au dehors. Ces embryons sont à peine atténués en avant, mais fortement amincis en arrière, où ils offrent un prolongement ondulé court 
et grèle; ils mesurent 300 à $400 \mu$ de long sur 16 à $18 \mu$ de large. Ils sont doués d'une résistance vitale considérable : ils se conserrent vivants dans l'eau pendant des mois entiers, et je les ai vus reprendre leur activité après quatorze mois de dessiccation complète. Leuckart n’a jamais pu en obtenir le déreloppement direct chez le Mouton, et admet qü̈ls doivent, comme ceux du Strongle Filaire, passer par un hôte intermédiaire.

Patnologie. - Les Vers adultes, ainsi que leurs œufs et leurs embryons, donnent lieu à des pliénomènes inflammatoires susceptibles de revêtir des formes variées. C'est ainsi que Bugnion distingue trois formes de pneumonie vermineuse : $1^{\circ}$ une pneumonie lobulaire, due à des Strongles adultes arrêtés dans les bronches; $2^{\circ}$ une pneumonie diffuse, déterminée par les œufs et les cunbryons répandus par mil-
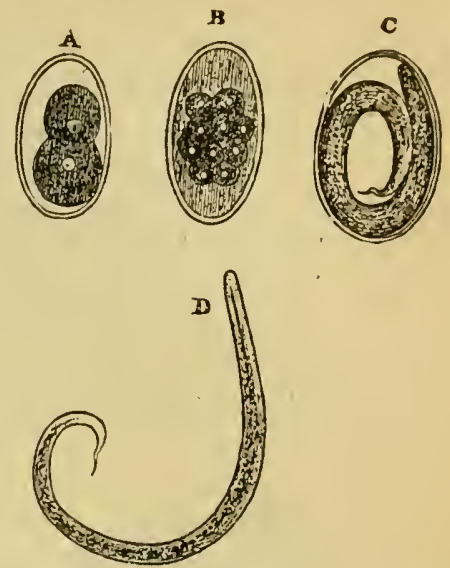

Fig. 288. - OEufs et embryons du Strongylus rufescens, grossis 150 fois. - A, B, aufs en roic de segmentation. C, cuf contenant un embryon. D, embryon libre (Orig.). liers dans le parenchyme pulmonaire $; 3^{\circ}$ une pneumonie noduleuse ou pseudo-tuberculeuse, occasionnée par l'accumulation d'œufs ou d'embryons dans des parties circonscrites du pounın. Cette dernière est la plus commune : à l'œil nu, les lésions qui s’y rapportent se présentent le plus souvent sous l'aspect de petites tumeurs d'un gris jaunâtre, demi-transparentes, dont la partie centrale est assez dense, tandis que la périphérie reste dépressible et perméable à l'air, pour se continuer ensuite progressivement avec le tissu sain. D'abord miliaires, ces foyers arrivent peu à peu à mesurer 2 ou 3 millimètres de diamètre et parfois jusqu'à plus de 2 centimètres. Plus tard ils finissent par subir la dégénérescence caséeuse et même, assure-t-on, l'infiltration crétacée. Ils siègent surtout à la surface du poumon, dont ils occupent le plus souvent Ies bords; on en trouve quelquefois des centaines sur un seul poumon. Comme l'a montré Laulanié (1), ces tumeurs représentent de simples foyers inflammatoires, dont le point de départ est formé par les œufs déposés dans les alvéoles pulmonaires. Lorsque les embryons sont dégagés de la coque, ils proroquent une irritation beaucoup plus vive, qui amène unc ábondante diapédèse des leucocytes dans les alréoles, et développe ainsi des foyers de pneumonie purulente miliaire. Contrairement à ce qu'a avancé G. Colin, il n'y a donc rien là qui ressemble à de la tubercli-

(1) F. Laulané, Sur quelques affections parasitaires du poumon et leur rapjont avec la tuberculose. Archives de physiologie (3), IV, p. 519, 1881. 
lose. Dans les produits de raclage obtenus sur la section de ces foyers, on trouve un grand nombre d'œufs et d'embryons. Souvent, en outre, on y rencontre des Vers adultes ou presque adultes, enroulés mais non enkystés. En somme, il s'agit d'une pneumonie vermineuse et non d'une phtisie vermineuse.

Cette affection, qui est fort commune, sévit plutôt sur les adultes que sur les jeunes. Les troubles qui la révèlent sont souvent peu accusés : ce n'est guère que quand il se forme des foyers purulents étendus que les animaux maigrissent, présentent des signes de cachexie et finissent par succomber.

Nous l'avons observée sur le Chevreuil.

Strongle micrure (Str. micrurus Mehlis, 1831. - Syn. : Gordius viviparus Bloch, 1782; Ascaris vituli Brugu ière, 1791 ; Str. vitulorum Rud., 1809).

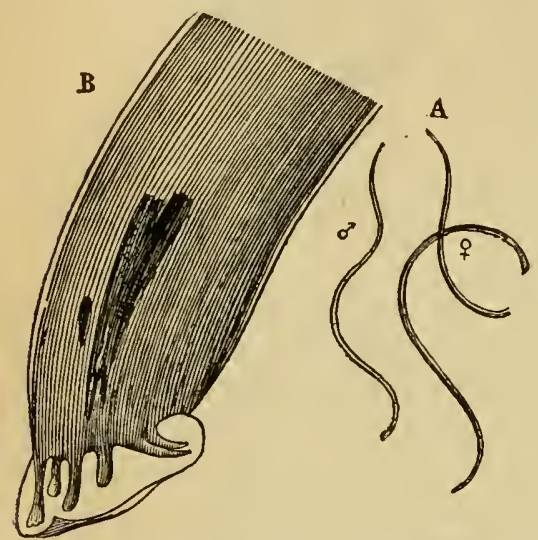

Fig. 289. - Strongle micrurc. - A, mảle et femelle, grandeur naturelle. B, extrémité caudale du mâle, grossie 100 fois (Orig.).
- Corps filiforme, atténué aux extrémités, de teinte blanchàtre. Extrémité antérieure arrondie, non ailée; bouche circulaire, nue. Mâle long de 4 centimètres environ ; bourse caudale petite, entière ; côtes postérieures trilobées, les antérieures dédoublées, les autres simples; deux spicules courts et forts, accompagués d'une pièce accessoire. Femelle longue de 6 à 8 centimètres; queue courte el pointue; vulve située vers le sixième postérieur du corps. OEufs ellipsoïdes, longs de $8 \ddot{3} \mu$, larges de $3 \breve{s} \mu$, contenant un embryon bien formé au moment de la ponte. Embryons libres longs de $280 \mu$, larges de $25 \mu$.

Le Strongle micrure habite les bronches des bêtes bovines, où il a été vu d'abord par Ruysch, Frank Nicholls et Camper. Plus tard, Mehlis l'a trouvé en outre dans les bronches du Daim.

On a rapporté d'autre part à cette espèce les Strongles qui se rencontrent parfois dans les bronches des Equidés domestiques, aussi bien chez l'Ane (Gurlt) que chez le Cheval (Gurlt, Diesing, Cobbold, Verrill); mais j'incline fort à croire qu'il s'agissait du Strongylus Arnfieldi.

Évolution. - Cobbold a constaté que les embryons récemment éclos du Strongle micrure ne résistent pas à la putréfaction ni à la dessiccation. Ils vivent assez bien dans la terre humide, mais sans subir de modifications. En examinant au bout de trois jours le contenu intestinal d'un Lombric renfermé dans ce milieu, il y trouva des œufs em- 
bryonnés et plusieurs embryons libres : ceux-ci mesuraient environ $317 \mu$ de long; leur extrémité céphalique montrait un tube buccal court, ehitineux; leur quene était un peu plus pointue et recourbée en lıaut; les granulations du corps étaient plus serrées. Au bout de cinq jours, lintestiu du même Lombric offrait de nombreux embryons longs d'environ $500 \mu$, possédant un osophage distinct et un intestin plus apparent. Quelques-uns d'entre eux furent déposés sur les lobules humides d'une fronde de fougère. Le lendemain, c'est-à-dire le sixième jour, ces larves étaient déjà visibles à l'œil nu, mesurant 846 ue de long; l'appareil digestifétait mieux défini, et on pouvait distinguer dans son voisinage une série de cellules représentant l'ébauche de l'appareil reproducteur. Le septième jour, une des larves déposées sur la fougère montrait nettement les caractères d'un mâle : le canal déférent, assez bien formé, avait repoussé l'intestin par côté, et il existait une bourse caudale à deux lobes soutenus chacun par cinq côtes. Une autre était en mue. Le huitième jour, cette dernière avait achevé sa mue el montrait, outre la bourse caudale, deux courts et forts spicules; la pointe caudale formait un très petit prolongement subulé.

Par suite d'un abaissement de la température, ces observations ne purent être poursnivies; mais les résultats qu'elles ont fournis sont néanmoins fort intéressants, car ils tendent à montrer que les Vers de terre constituent pour le Strongle micrure un hôte intermédiaire. Les embryons, après avoir subi dans l'intestin de ces animaux d'importants changements de structure, seraient rejelés avec les excréments qui sont déposés en tortillons à la surface du sol, et de lí seraient introduits passivement avec les herbes humides dans l'organisme des bêtes bovines.

Pathologie. - Le Strongle micrure entraine, lorsqu'il existe en grand nombre chez les animaux de l'espèce bovine, une bronchite vermineuse analogue à celle que nous avons vue occasionnée par le Strongle filaire chez le Mouton. Ce sont encore les jeunes sujets qui paient le plus sérieux tribut à l'affection, laquelle revêt souvent un caractère épizootique.

On a souvent confondu cette bronchite vermineuse avec la péripneumonie contagieuse; mais l'examen microscopique des matières expectorées doit suffire à lever les doutes.

La méthode des injections trachéales antiparasitaires donne de bons résultats dans le traitement de cette maladie.

Strongle pulmonaire (Str. pulmonaris Ercolani, 18509). - Sous ce nom, Ercolani a décrit, quoique d'une façon insuffisante, un Ver très voisin du Strongle micrure. "Il en diffère par la longueur du corps, qui est beaucoup plus petite, variant de 10 à 40 millimètres; les màles sont plus épais en arrière qu'en avant; la bouche est entourée d'une couronne de petites papilles 
subarrondies; la queue de la femelle est mucronée, assez mince et oblique; de celle du màle, obtuse et arrondie, partent sept languettes ou côtes qui soutiennent la bourse caudale en forme d'expansion membraneuse semi-

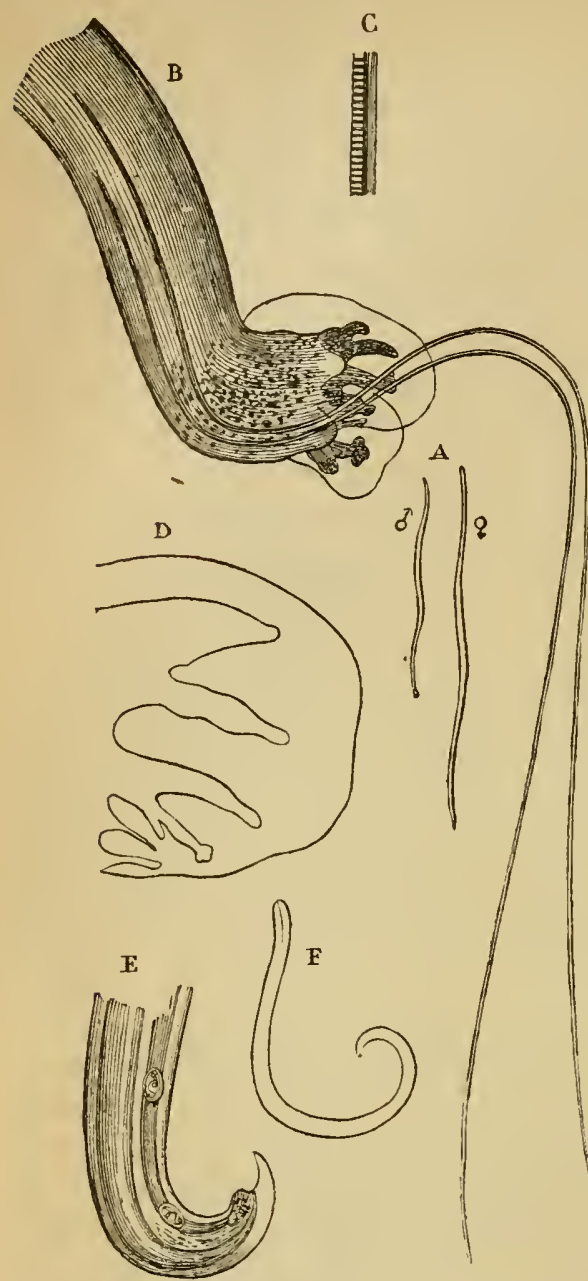

Fig. 290. - Strongle paradoxal. - A, måle et femelle, grandeur naturelle. B, extrémité caudale du mâle, grossie 50 fois. C, fragment d'un spicule très fortement grossi. D, un des lobes de la bourse caudale, grossi 100 fois. E, extrémité caudale de la femelle, grossie, э0 fois. F, embryon libre, grossi 150 fois (Orig.). campanulée; la languette dorsale impaire arrive jusqu'à la périphérie de la bourse. Orifice anal bilabié. Les femelles sont ovovivipares. "

Ercolani avait recueilli un grand nombre de ces Vers dans les bronches d'un Veau. Il reçut en outre de Prangé quelques Strongles identiques recueillis en France, également sur des Veaux.

Strongle paradoxal ( $S t r$. paradoxus Mehlis, 1831. - Syn.: Gordius pulmonalis apri Ebel, 1777; Ascaris apri Gmelin, 1789; Strongylus suis Rud., 1809; Str. elongatus Duj., 1843̈ ; Str. longevaginatus Dies., 1831 ; Metastrongylus paradoxus Molin, 1860). Corps blanc ou brunàtre. Bouche entourée de six lèvres, les deux latérales plus grandes. Iâle long de 12 à $20 ̈$ millimètres ; bourse caudale bilobée, chaque lobe soutenu par cinq còtes, la moyenne et l'antérieure dédoublées, les autres simples; spicules grèles et très allongés, mesurant $2^{\mathrm{mm}}, 5$ à 4 millimètres. Femelle longue de 20 à 50 millimètres, à queue terminée par un court appendice crochu, à la base duquel vient s'ouvrir l'anus; vulve située immédiatement en avant de celui-ci, au niveau d'une émjnence arrondie. OEufs ellipsoïdes, ou renflés dans leur milieu, longs de ว̈7 à 100 ir,larges de 39 à $72 \mu$, contenant un embryon bien formé au moment de la ponte. Embryons libres longs de 220 à $350 \mu$, larges de 10 à $12 \mu$.

Ce parasite a été découvert à la fin du $\mathrm{xv}^{\mathrm{e}} \mathrm{I}^{\mathrm{e}}$ siècle, par Ebel, en Prusse, dans les bronches d'un Marcassin, puis retrouvé par Modeer, en Suède, dans celles d'un Porc domestique. Depuis lors, il a été si- 
gnalé nombre de fois en France, en Angleterre, en Itilie, ete., même en $\Delta$ mérique et au Japon. Kioch dit l'aroir rencontré aussi chez le Mouton.

Molin le décrivait comme pourvu d'un utérus unicorne, c'est-ì-dire d'un seul ovaire; en réalité, il possède deux tubes femelles comme les espèces précédentes; tous deux naissent vers le milieu du corps : l'un se dirige en avant, se replie un peu en arrière de l'œesoplage, puis se dilate en descendant vers la queue; l'autre s'étend d'abord en arrière, mais se replie avant d'arriver i la rulve, se dilate, remonte jusque vers le milieu du corps et redescend enfin avec le premier; ces deux utérus se rémnissent, à quelque distance de la queue, en un vagin sinucux assez long qui va s'ouvrir à la rulve.

Des recherches de Colin et de Baillet, il résulte que les embryong dı Str. paradoxus ont une résistance vitale comparable à ceux du Str. filaria.

Le Strongle paradoxal vit le plus souvent dans les bronches de petit et de moyen calibre; mais il n'est pas très rare de le trouver aussi dans les plus grosses et même dans la trachée. Les troubles qu'il occasionne sont en général assez restreints; on a cependant vu des Porcs, surtout dans le jeune âge, succomber a la bronchite vermineuse. De même que Gratia, j'ai constaté quelquefois la formation de foyers inflammatoires analogues à ceux qui constituent la preumonie vermineuse du Mouton.

Diesing a décrit, sous le nom de Strongylus longevaginatus, un Ver trouvé en 18 'ŏ à klausenbourg (Transylvanie), par le médecin militaire P. Jortsits, dans le poumon d'un garçon de six ans, mort de maladie inconnue. Les exemplaires recueillis avaient été envoyés à Rokitansky, et examinés par Diesing, par Molin et par Leuckart; mais, comme ils étaient mal conservés, ils ne purent ètre étudiés que d'une façon incomplète. Molin, attribuant à ce Ver, ainsi du reste qu'au Str. paradoxus du Porc, un seul ovaire, le rangea dans son genre Meta. strongylus, arec les caractères suivants:- Bouche entourée de quatre à six papilles. Mále long de 13 à 1 ö millimètres; bourse caudale à deux lobes triradiés: le rayon médian bipartit, les autres simples ; spicules très longs, filiformes. Femelle atteignant 21 millimètres de longueur; extrémité caudale offrant un appendice conique: vulve située immédiatement en avant de l'anus, sur une éminence hémisphérique.

A part quelques détails insignifiants, qui s'expliquent d'ailleurs par l'insuffisance des méthodes d'examen, tous ces caractères se rapportent au Str.paradoxus, et la simple inspection des figures de Molin et de Leuckart confirme cette identification. Le parasite du Porc peut donc s'égarer chez l'Homme comme chez le Houton.

En 1888, J. Chatin (1) a communiqué à l'Académie de médecine une

(1) J. Chatrix, Le Strongle paradoxal chez l'homme. Bulletin de l'Académie de méd. (3). XIX, p. 483, 1888. 
observation relative à un habitant d'Oloron (Basses-Pyrénées) atteint de troubles gastro-intestinaux et dans les déjections duquel on avait trouvé, à deux reprises différentes, des exemplaires de Str. paradoxus. A notre avis, il s'agissait là d'un cas de pseudo-parasitisme, la présence de ce parasite dans le tube digestif étant un fait anormal, qui ne peut guère s'expliquer que par l'ingestion directe. Il faut noter en effet que ce malade faisait, durant une partie de l'année, un grand commerce de viande fraiche.

En 18̋̋,, Bristowe et Rainey ont décrit, sous le nom de Filaria trachealis, des embryons de Nématode trouvés en abondance sur la muqueuse de la trachée et du larynx d'un individu qui avait succombé à une affection des membres inférieurs. Ces embryons étaient longs de $0^{\mathrm{mm}}, 5$, larges de $0^{\mathrm{mm}}, \mathbf{1 6}$; ils avaient l'extrémité antérieure obtuse et arrondie, l'extrémité postérieure graduellement amincie; à peu de distance de la pointe caudale se voyait une petite papille (anus?). Quoique les dimensions de ces embryons soient un peu supérieures à celles des embryons du Str. paradoxus, il n'est pas impossible qu'ils aient été fournis par des exemplaires de cette espèce habitant les petites bronches.

Strongle d'Arnfield (Slrongylus Arnfieldi Cobbold, 1884). - Corps fili-

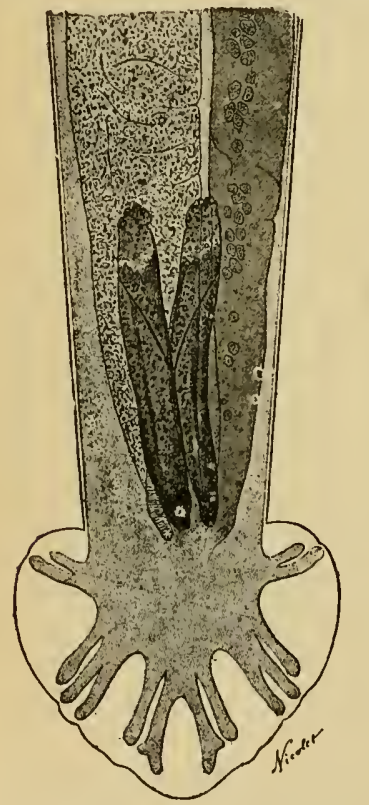

Fig. 291. - Eatrínité caudale du Strongylus Arnfieldi mâle, grossie 100 fois (Orig.). forme, blanchàtre. Extrémité antérieure non ailée. Bouche nue, orbiculaire. Mále long de 28 à 36 millimètres; bourse cau-

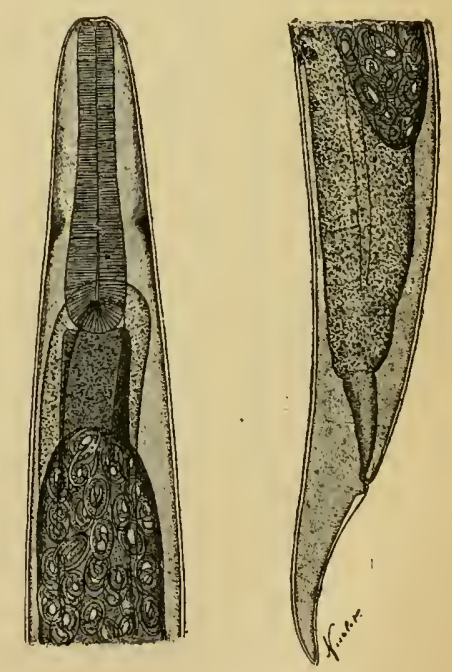

Fig. 292. - Extrémités céphalique el caudale de la fenelle du Strongylus Arnfieldi, grossies 100 fois (Orig.).

dale courte, à peine lobée sur les côtés et en arrière; còtes antérieures bifides, à branche antérieure un peu plus courte que la postérieure; còtes 
moyennes bifides, à branches égales; còtes postérieures épaisses, bilobées à l'extrémité et largrement réunies à la base ; spicules d'un brun fauve, légèrement arqués, réticulés, longs de 200 à 240 , accompagnẻs d'une pièce accessoire courte, de teinte plus påle. Femelle longue de 43 à ว̃ä millimètres, à queue courte, un peu arquée, se terminant en pointe mousse; vulve étroite et non saillante, siluée aux $3 / \ddot{3}$ antérieurs du corps. OEufs ellipsoülles, longs de 80 à $100 \mu$, larges de 50 à $60 \mu$, embryonnés au moment de la ponte. Embryons libres longs de 400 à $490 \mu$, larges de $1 \dot{t}$ à $18 \mu$, pourvus d'un petit appendice caudal mince et transparent.

Le Strongle d'Arnfield (1) habite les bronches du Cheval et de l'Ane, il est susceptible de déterminer des

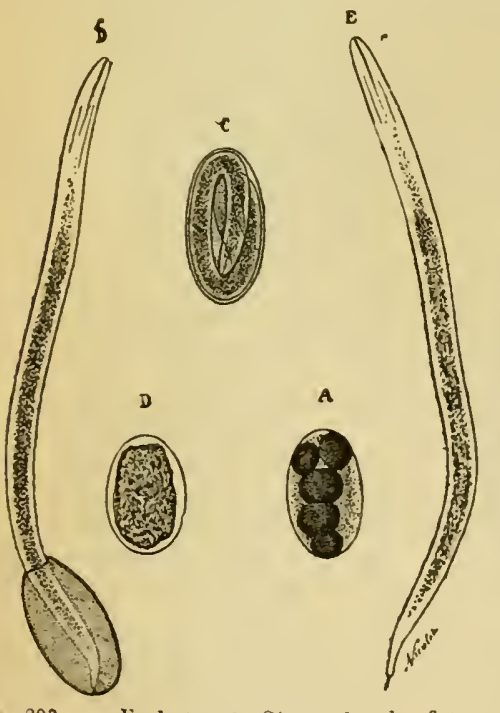

Fig. 993. - Evolution du Strongylus armfieldi. $A$, ouf en roie de segmentation. $B$, i l'itat de moru'a. C, reuf embryonné. D, ćclosion del'embryon. E, embryon éclos, Grossissement : 150 diamètres (Orig.).

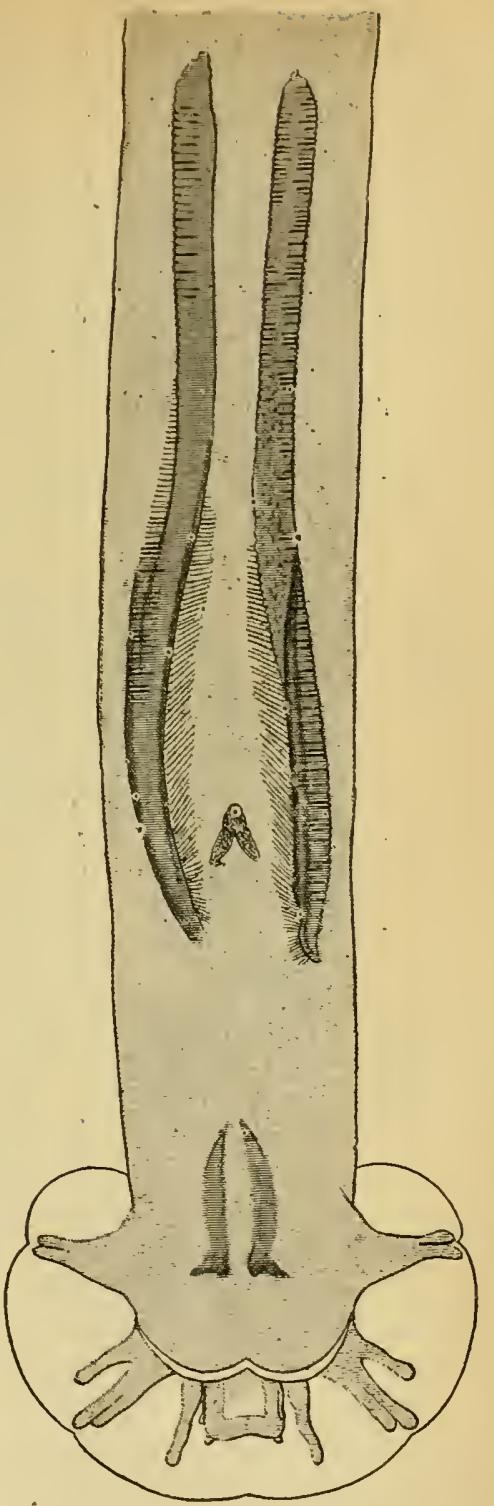

Fig. 294. - Extrémité caudale du Strongylus rommulatus mile, grossie 300 fois (Orig.).

troubles analogues à ceux produits chez le Mouton par le Strongle filaire.

Strongle débaptisé (Str. commutatus Diesing, 1831). - Corps filiforme. Extrémité antérieure arrondie, aplatie; houche inerme. Maile long de 18 à

(1) Соввог, New parasiles from the Horse and Ass. The Veterinarian, 188i, p. 4.- 
VERS.

30 millimètres; bourse caudale très petite, arrondie; côtes postérieures paraissant unies elı un large tronc; moyennes et antérieures bifides. Femelle longue de 28 à 50 millimètres; vulve située immédiatement en avant de l'anus.

Assez commune dans les bronches des Lièvres, cette espèce n'a été que rarement indiquée chez les Lapins domestiques (1) ou sauvages.

Elle détermine une broncho-pneumonie souvent mortelle. Sollmann a signalé une épizootie de ce genre sévissant sur les Lièvres de la Thuringe, en 1864-1865. Depuis quelques années, cette affection s'est aussi répandue en France, où nous avons eu l'occasion de l'observer.

StrongIe nain (Str. pusillus A. Müller, 1890). - Corps filiforme. Extrémité antérieure non ailée. Bouche nue, sans

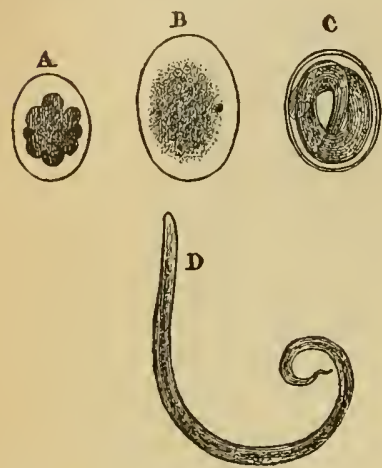

Fig. 295. - OEufs el embryons du Strongylus pusillus du Chat, grossis 150 fois. - A, B, œufs cn voie de segmentation. C, cuf contenant un embryon. D, embryon libre (Orig.). papilles. Mâle long de $4^{\mathrm{mm}}, 9$; bourse caudale courte, à peine festonnée ; còtes postérieures bilobées, les moyennes dédoublées, les antérieures bifides, les autres simples; spicules grèles, un peu courbés, longs de 100 à $130 \mu$. Femelle longue de $9^{\mathrm{mm}}, 6$ à $9^{\mathrm{mm}}, 9$, à queue courte, terminée en pointe mousse; vulve située immédiatement en avant de l'anus. OEufs ellipsoïdes ou subglobuleux, longs de 60 à $8 \check{ } \mu$, largres de 55 à $80 \mu$, non segmentés au moment de la ponte. Embryons libres longs de 370 à $450 \mu$, larges de 16 à $18 \mu$, pourvus, à l'extrémité caudale amincie, d'un petit appendice ondulé.

Ce Ver habite le poumon du Chat, où il détermine des foyers de pneumonie qui ont une ressemblance extérieure assez marquée avec ceux que nous avons signalés chez le Mouton, et dont Laulanié a publié également une excellente étude (2). Dans la première édition de cet ouvrage, je disais que nous croyions avoir surpris, avec Laulanié, le Ver adulte au milieu des petites bronches, sur des coupes du tissu enflammé. Après de nombreuses recherches, je suis en effet parvenu à trouver des fragments du corps de la femelle; G. Neumann, de son côté, trouvait une femelle non ovigère ; mais nous avions été précédés dans cette découverte par A. Müller, qui avait réussi à isoler, de certains foyers, des individus entiers, mâles et femelles.

La pneumonie vermineuse du Chat se traduit en général par une toux fréquente, revenant par accès et souvent accompagnée de vo-

JD., Description of Strongylus Arnfieldi... Journal of Linn. Soc. (Zoology), XIX, p. 284, pl. XXXVI, 1886. - A. Ralluet, Sur la strongylose bronchiale du Cheval el sur le Ver qui la détermine. Comptes rendus Soc. de biologie (9), III, p. 105, 189.

(1) E. Mazzanti, Pneumonite verminosa nel Coniglio domestico. Il moderno Zooiatro, III, p. 105, 1892.

(2) Loc cit., p. 518. 
inissements. Au bout d'un temps variable, l'animal maigrit, devient triste; son poil se hérisste; parl'ois il survient une diarrhée qui hàte le dénouement, et en définitive l'animal meurt eachectique. Cette maladie coüncide souvent avec la galo due au Sarcoptes minor. Comme traitement, il n’y aurait guère qu’à essayer des injections trachéales.

Strongle des bronches du Chien. - Le Ver décrit par Osler sous le nom de Strongylus bronchialis cunis sera étudié plus loin parmi les Filaires (Voy. Filaire tracheo-bronchique (lu Chien).

Strongle des vaisseaux (Str. vusorum Baillel, 1866). — Corps filiforme, blanchàtre ou rougeatre, montrant souvent par transparence une spirale rouge formée par le tube digestif autour duquel s'enroulent les tubes génitaux. Tégument strié en long. Extrémité antérieure nue pendant la vie, mais
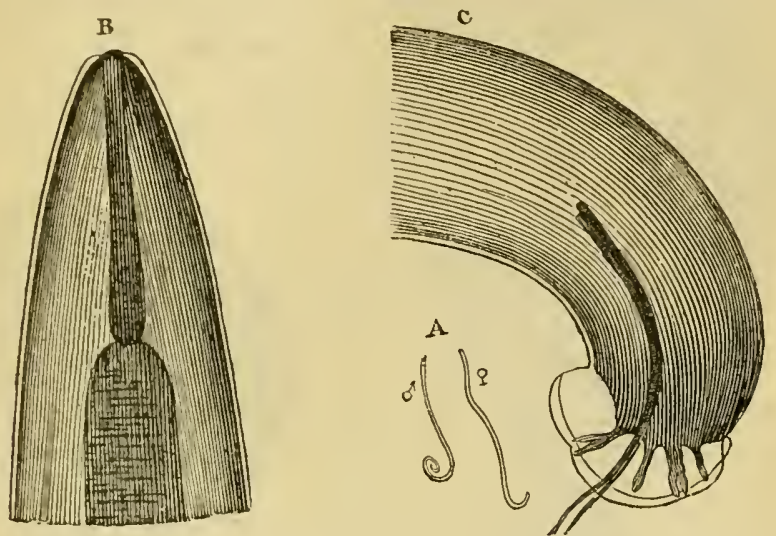

Fig. 996, - Strongylus vasorum. - A, màle el femelle, grandeur naturelle. B, extrémilé céphalique. C, extrémité caudale du måle. Grossissement: 100 diamètres (Orig.).

montrant parfois, après la mort, des expansions cuticulaires qui simulent, soit des lèvres, soit des ailes latérales. Mâle long de 14 à 18 millimètres; bourse caudale à deux lobes soutenus chacun par quatre còtes (la postérieure fait défaut), la moyenne et l'antérieure dédoublées. Femelle longue de 18 ả 21 millimètres; vulve située en arant de l’anus. OEufs ellipsoïdes, longs de 70 à $80 \mu$, larges de 40 à $50 \mu$.

Serres paraît avoir le premier trouvé ce Ver dans le cour droit et les divisions de l'artère pulmonaire, chez le Chien. Laulanié (1) a publié d“intéressantes recherches sur son évolution et sur les troubles qu'il détermine.

Evolution. - Les femelles, fécondées sur place, pondent des oufs non segmentés qui vont s'arrêter dans les plus fines artẻrioles et y

(1) Loc. cit. - Mauri, Deux cris de strongylose chez le Chíen. Revue vét., 1889, p. 371. - Railliet et Cadiot, Strongylose du cour et du poumon chez le Chien. Comptes rendus de Ia Soc. de biologie (9), IV, p. 482, 1892. - I1), Essais de transmission du Strongylus vasorum du Čien au Chien: résultats négatifs. Ibid., p. 702. 
VERS.

parcourir toutes les phases de leur développement, en donnant lieu à des granulations spéciales. Les embryons qui en sortent sont longs de 300 à $360 \mu$, larges de $13 \mu$, à extrémité caudale prolongée par un petit appendice ondulé. Ils émigrent dans les bronches de petit calibre, et peuvent enfin ètre rejetés au dehors ou se trouver déglutis.

Leur résistance vitale est faible; ils vivent seulement quelques

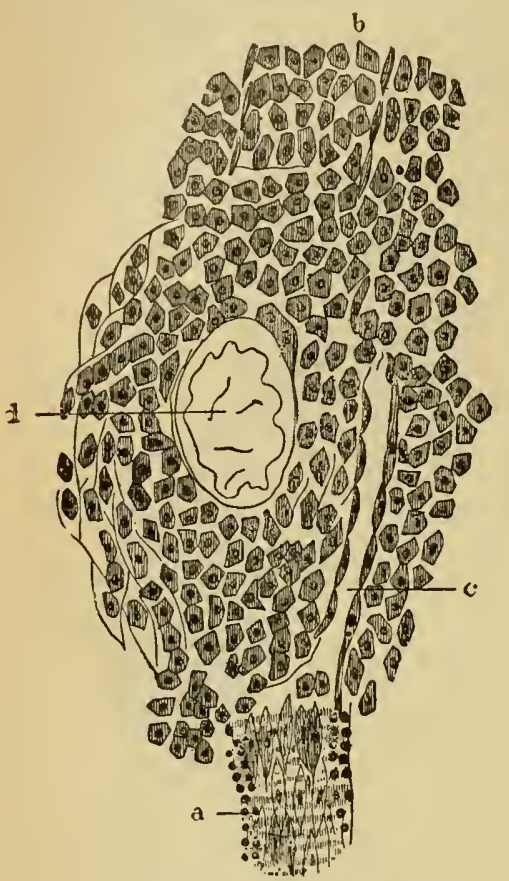

Fig. 297. - Pseudo-follicule en voie de formatiou sur le trajel d'une artériole $a$, ì deux conches de fibres musculaires, dont la direction reste indiquée en $b$ par un cordon de cellules épithélioïdes, $c$, fissure et revêtement épithélial assurant la continuité de la circulation. $d$, cavité ovulaire (Laulanié). jours dans l'eau, et ne supportent même pas une dessiccation d'une minute.

D'après les résultats de quelques expériences, Laulanié avait pensé que ces embryons, ingérés par d'autres Chiens, se développaient directement dans l'organisme de ces animaux. Mais Laulanié opérait à Toulouse, c'est-à-dire dans un mi-

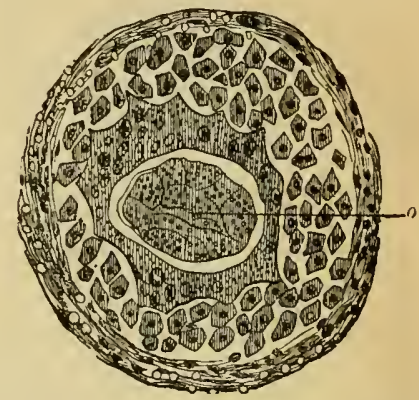

Fig. 298. - Pseudo-follicule de strongylose pulmonaire du Chien, montrant la cellule géanle ovigère; l'œuf de Strongylus vasorum (o) contenu dans cette cellule est segmentẻ (Laulauič).

lieu infesté ; deux essais que nous avons tentés dans le même sens à Alfort ne nous ayant donné que des résultats négatifs, nous avons cru devoir émettre des réserves relativement à cette manière de voir.

Pathologie. - Les lésions de la strongylose pulmonaire sont en général limitées à la base des deux lobes de l'organe, dont le tissu compact, grisâtre, plus dense que l'eau, est criblé de granulations grises et demi-transparentes, très fines, atteignant rarement le volume d'une tête d'épingle, et donnant un aspect chagriné aux surfaces libres et aux surfaces de section. Ces granulations parasitaires pourraient être prises à première vue pour des lésions tuberculeuses, mais l'examen microscopique lève rapidement tous les doutes. Elles ont pour point de départ, comme nous l'avons dit, les œufs arrêtés dans 
les tines artérioles : ceux-ci, en eflet, donnent lieu généralement i une artérite noduleuse réunissant tous les caractères des follicules élémentaires de la tuberculose. La plupart des pseudo-follicules ainsi produits offrent, en eflet: $1^{\circ}$ une zone centrale représentée par une cellule géante creusée d'une eavité renfermant un œuf ou un embryon; 2o une zone moyenne formée de cellules épithélioïles; $3^{\circ}$ une zone périphérique composée d’éléments embryonnaires disposés circulairement. - Souvent, en outre, on trouve dans le poumon des nodules plus volumineux, correspondant chacun à un caillot développé dans une branche de l'artère pulmonaire et en amont duquel sont amassés des Vers adultes.

Les symptômes de cette strongylose sont peu connus. laaffection resterait longtemps silencieuse pour se manifester tout à coup par une dyspnée pénible qui peut se calmer au bout de quelques jours ou se terminer par l'asphyxie. Mauri, Railliet et Cadiot ont noté de l'ascite. L'auscultation et la pereussion ne fournissent atcun signe saisissable. Le plus souvent la cause des troubles n'est reconnue qu'à l'autopsie; encore est-il rare que la mort survienne naturellenent: les animaux sont presque toujours abattus après de longs mois de maladic.

La strongylose est généralement sporadique, mais, dans certains cas, elle peut sévir à l'état enzootique dans une meute et y occasionner des ravages sérieux.

Lafosse et Labat disent avoir obtenu la guérison des sujets atteints par l'emploi de l'essence de térébenthine ou de la térébenthine.

Jusqu'à présent, le Str. vasorum n’a été vu d'une façon certaine qu'à Toulouse. Railliet et Cadiot l'ont rencontré à Paris, mais sur un chien d'origine toulousaine. Bossi (1870) a observé en Italie, dans le cour de deux Chiens, des Vers qu'il rapporte au genre Filaria, et qu'il appelle cependant ematozoa filaria cardiaca. Mais la description qu’il en donne est incomplète, et si le caractère tiré de la présence de la vulve au voisinage de l'anus tend à les rapprocher du Strongylus vasorum, par contre la longueur des femelles (jusqu'à 30 et $3 a^{\mathrm{mm}}$ ) et le spicule unique signalé chez le màle semblent levoir les en distinguer.

Strongle subulé. - Cobbold avait dénommé Strongylus subulutus un Ver trouvé par Leisering dans les veines du Chien et décrit par Gurlt sous le nom d'Hæmatozoon subulatum. Il en sera question plus loin (Voy. Diplogaster ${ }^{2}$.

Strongle contourné (Str. contortus Rud., 1803. - Syn. : Str. ovinus 0. Fabr., 1784; Str. ammonis Rud., 1819; Str. filicollis Molin, 1860, nec Rud., 1803.) - Corps rouge ou blanchàtre, filiforme, atténué aux extrémités. A quelque distance de l'extrémité antérieure, deux petites papilles latérales, en forme de dents dirigíes en arrière. Tégument finement strié en travers et rayé en outre par 40 a 30 arètes longitudinales. Bouche nue. Mâle long de 10 à 
20 millimètres; bourse caudaleà deux lobes allongés, spatulés, portant chacun quatre còtes, la moyenne et l'antérieure dédoublées; le lobe droit offre en outre un lobule accessoire qui porte les deux côtes postérieures légèrement divisées à leur extrémité. Deux spicules longs de $0^{\mathrm{mm}}, 3$ à $0^{\mathrm{mm}}, 5$, accompagnés d'une pièce accessoire ovalaire. Femelle longue de 20 à 30 millimètres; extrémité caudale en pointe droite, allongée, très aiguë; vulve située vers

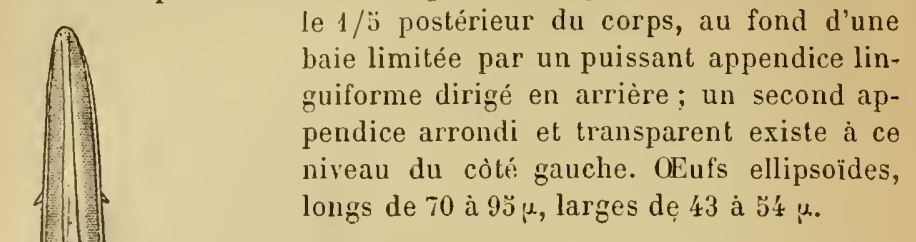
le $1 / 3$ postérieur du corps, au fond d'une baie limitée par un puissant appendice linguiforme dirigé en arrière; un second appendice arrondi et transparent existe à ce longs de 70 à $9{ }^{\prime} \mu$, , larges dẹ 43 à $54 \mu$.

Le Strongle contourné vit dans la caillette, rarement dans le duodénum du Mouton, de la Chèvre, de l'Argali et du Chamois. Railliet et Lucet l'ont trouvé dans la caillette d'une Génisse; Neumann dans celle d'une Vache. Il attaque la muqueuse pour en sucer le sang, qui donne à son intestin une coloration brune. C'est l'enroulement des

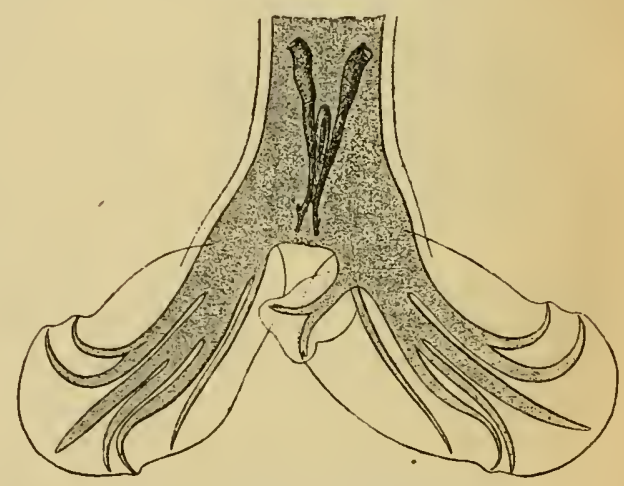

Fig. 999. - Extrénité céphalique du Strongylus contortus, grossie 40 fois (Orig.).

Fig. 300. - Extcémité caudale du Strongylus contortus male, grossie 50 fois (Orig.).

tubes ovariens autour de cet intestin qui a valu à l'espèce la qualification de contortus.

D'après les recherches de C. Baillet, les œufs de ce Ver renfermeraient, au moment de la ponte, un embryon complètement développé. Ceux qui n'en contiennent pas s'altèrent dans l'eau, tandis que les autres ne tardent pas à y éclore. Lachmann affirme au contraire que les œufs, au moment de la ponte, ont le vitellus segmenté en 2, 4 ou au plus 8 blastomères. A la naissance, les embryons sont cylindroïdes et légèrement atténués en avant; l'extrémité cépha- 
lique est un peu obtuse; l'extrémité caudale forme une pointe très aiguë. Ils mesurent 300 à $440 \mu$ de long sur 17 ì $21 \mu$ de large. Ils possèdent un asophage cylindrö̈de étroit et asse\% lonğ, terminé pal un renflement ou bulbe asophagien à trois dents chitineuses. Dans l'eau pure, ces embrgons rhabditiformes périssent au bout de quelques semaines, sans s'être accrus ni modiliés d'une facon sensible. Ilais, dans l'eau chargée de matières organiques, ils paraissent subir. comme ceux de l'Uncinaria trigonocephala, un accroissement aceompagrué de mues, les rendant aptes à réintégrer l'organisme des Ruminants. Il est done probable que ceux-ci s'infestent en buvant de l'eau souillée par les excréments d'animaux porteurs de Strongles contournés.

Patrologis. - Lorsqu'il existe un grand nombre de ces Vers dans la caillette du Mouton ou de la Chève, on voit se développer une sorte d'anémie pernicieuse qui sévit souvent à l'état enzootique, atteint surtout les agneaux et les antenais, et coïncide dans beaucoup de cas avec la bronchite vermineuse. Cette maladie est commune en Allemagne, où on la désigne sous le nom de Magenwurmseuche: elle a élé observée aussi en Angleterre, en Écosse, en Autriche, en 1talie, dans l'Anérique du Sud, el nous en avons rencontré divers cas en France arec Rossignol, Lucet, Durand. Dans ces dernières années, Lachmann l'a vue produire de sérieux ravages dans le sud de l'Algéric, où elle est connue sous le nom de R'och. En dehors des troubles locaux, les symptômes et les lésions de cette " strongylose de la caillette " rappellent ceux de la distomatose. On la combat par l'administration de divers anthelminthiques : huile empyreumatique, liamala, picrate de potasse, etc. La prophylaxie réclame d'une facon absolue le pâturage en dehors des prairies humides.

Strongle ventru (Str. ventricosus Rud., 1809). - Corps filiforme, ic extrémité céphalique très petite, quoique un peu renflée. Tégument rayé par 1 í arètes longitudinales, dont ciuf plus fortes sur chacune des faces dorsale el ventrale, et leux moins accusées de chaque côté. Bouche nue. Mấle long de 6 à 8 millimètres; bourse caudale ì deux lobes assez larges, réunis par un petit lobe nédian ; còtes postérieures un peu entaillées à l'extrémité, et portant chacune une courte branche externe: moyennes et antérieures dédoublées. Femelle longue de 11 à 12 millimètres; vulve située en arrière du milieu du corps et entourée d'un gonflement cuticulaire, de telle sorte que le corps parait dilaté (ventru) à ce niveau.

Trouvé d'abord par Rudolphi dans l'intestin grêle du Cerf d'Europe, il a été observé ensuite dans le même organe, chez les bêtes bovines.

C. Curtice l'a signalé, aux États-Unnis, dans l'intestin grêle du Mouton; cependant, d'après Giles, sa deseription ne se rapporterait pas absolument aux caractères du Strongle observé chez le Bouf, de sorte 
qu'il s'agirait peut-être d'une espèce particulière (Str. Curticei Giles, 1892).

Giles a vu souvent, dans l'Inde, le Str. ventricosus chez le Bœuf et le Zébu (Note communiquée).

Strongle instable (Str. instabilis Raill., 1893. - Syn. : ? Str. colubriformis Giles, 1892). - Corps capillaire, blanchàtre ou un peu rougeàtre, fortement atténué en avant. Extrémité céphalique parfois ailée. Tégument rayé par des arêtes longitudinales. Bouche nue. Mále long de 4 à 5 millimètres,

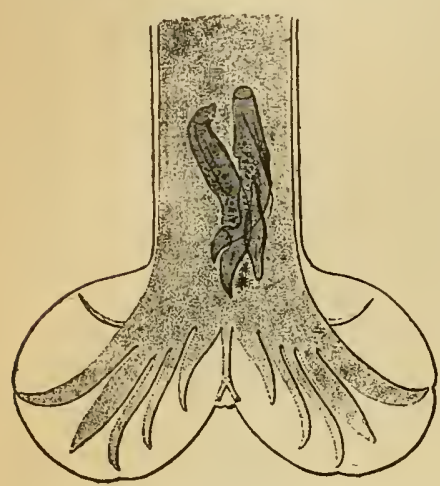

Fig. 30l. - Extrémité caudale du Strongylus instabilis måle, grossie 130 fois (Urig.). bourse caudale à deux lobes assez laryes, réunis par un très petil lobe médian ; còtes postérieures un peu fendues à l'extrémité ; moyennes et antérieures dédoublées. Deux spicules courts, tordus, avec une pièce accessoire. Femelle longue de $4^{\mathrm{mm}}, \hat{b}$ à $6 \mathrm{~mm}, 5$; vulve vers les trois quarts postérieurs du corps. OEufs ellipsoïdes, relativement grands, longs de 78 à $88 \mu$, larges de 42 à $48 \mu$, en morula au moment de la ponte.

Nous avons rencontré ce Strongle en petite quantité dans la caillette et en grande abondance dans l'intestin grêle (surtout dans le duodénum), chez les Moutons qui succombaient à l'anémie pernicieuse due au Str. contortus. Dans un cas nous l'arons même vu provoquer seul cette affection chez une Chèvre. Nous l'avons également recueilli chez le Chevreuil. C'est la forme que nous avions prise tout d'abold pour le Str. filicollis, puis pour le Str. ventricosus.

Giles a décrit en 1892, sous le nom de Str. colubriformis, un Ver très voisin de celui-ci, peut-être même identique; pourtant il ne paraìt pas avoir vu la pièce chitineuse annexée aux spicules, non plus que les côtes postérieures de la bourse caudale. Ce Ver se trouvait en abondance dans l'intestin grêle du Mouton, dans l'Inde anglaise.

Strongle filicol (Str. filicollis Rud. - Syn. Ascaris flicollis Rud., 1802; Fusaria filicollis Zeder, 1803; Str. filicollis Rud., 1803). - Corps capillaire, blanchàtre, longuement effilé dans sa partie antérieure, ainsi que l'in. dique le nom spécifique. Extrémité céphalique souvent un peu vésiculeuse. Tégument rayé par 18 arètes longitudinales. Bouche nue. Mále long de 8 a 13 millimètres, à bourse caudale bilobée, chaque lobe étant soutenu par cinq côtes: la postérieure un peu fendue à son extrémité, la moyenne et l'antérieure bifides; deux spicules grèles et très longs. Femelle longue de 10 à 2' millimètres; vulve située vers les trois quarts postérieurs du corps. OEufs ellipsoïdes, relativement énormes, longs de 110 à $113 \mu$, larges de 64 à $70 \mu$, en morula au moment de la ponte. 
Ce Ver habite l'intestin grêle du Mouton et de la Chèrre; on l'a

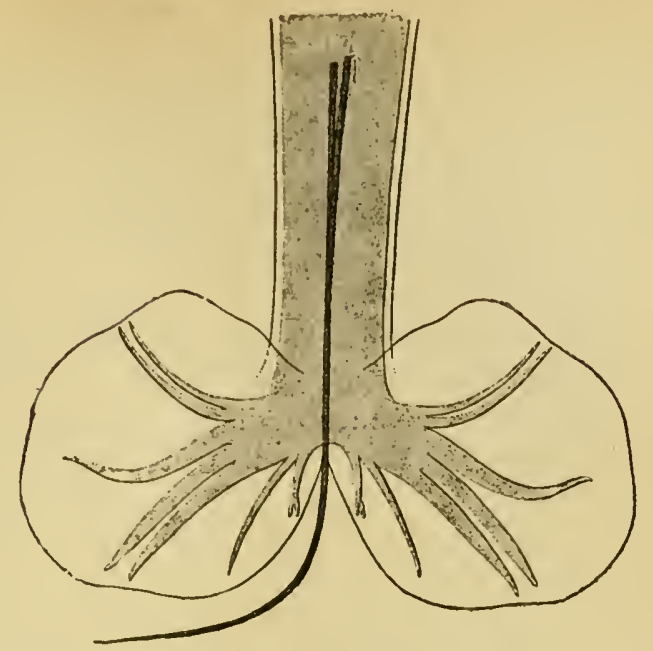

Fign, 302. - Extrémité caudale du Strongylus filicollis màle, grossie 150 fois (Orig.).

trouvé aussi chez le Chevreuil et chez le Daim. Il est plus commun chez les jeunes animaux.

Strongle dostertag (Str. Ostertagi Stiles, 1892. - Syn. : Str. convolutus Ostertag, 1890, nec Kuhn, 1829). - Corps filiforme, brun clair, atténué aux extrẻnirés. Tégument rayé par 34 arètes longitudinales. Bouche entourée de 6 papilles très petites, difficilement percepib les. Mâle long de 7 à 9 millimètres; bourse caudale à deux lobes latéraux réunis en arrière par un lobe impair plus faible; còtes postérieures bifurquées à l'extrémité ; còtes moyennes et antérieures dédoublées. Deux spicules assez complexes, longs de $200 \mu$ environ, arec une pièce accessoire peu distincte. $\mathrm{F} e$ melle longue de 10 à 13 millimètres; extrémité caudale en pointe courte; vulve située vers le dixième postérieur du corps, et recouverte d'une duplicature cutanée en forme de cloche. OEufs ellipsoïdes, en roie de segmentation au moment de la ponte.

Ce Ver a été trouvé par Ostertag

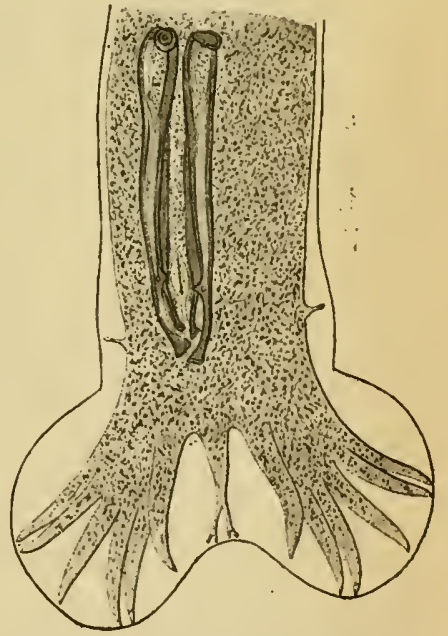

Fig. 303. - Extrémité caudale du Strongylus Ostertagi mâle, grossie 150 fois (Orig.). dans la caillette du Bœuf, à l'abaltoir de Berlin. Stiles l'a retrouvé aux États-Unis. Une étude assez complète en a été faite par Sta- 
delmann (1). Il siège sous l'épithélium, dans des nodules déprimés, d'un volume rariant de celui d'une tête d'épingle à celui d'une lentille, les plus petites grisâtres, les autres entourées d'une aréole brun jaunâtre. Ces nodules portent une petite ouverture centrale, par laquelle on voit souvent sortir l'extrémité céphalique du parasite, lequel est enroulé à l'intérieur ; les plus gros offrent parfois plusieurs de ces ouvertures, correspondant chacune à un Ver. Lorsque l'estomac commence à entrer en putréfaction, les Nématodes quittent leur habitat et se déplacent rapidement à la surface de la muqueuse.

Il est probable que le développement de cette espèce est direct. L'infestation semble se produire à l'automne. En septembre et octobre, on ne trouve presque plus de parasites dans la cailletle, bien que les nodules n'aient pas encore disparu. Fin d'octobre et en novembre, cet organe est envahi seulement par des larves à un $\mathbf{1}^{\text {er }}$ stade, qui ont à peu près $1^{\mathrm{mm}}, \tilde{y}$ de long, possèdent deux dents buccales et un bulbe pharyngien à 4 plis ou dents. En décembre et janvier apparaît un second stade larvaire, séparé du premier par une mue : les Vers ont acquis alors une longueur un peu plus considé rable et ont subi diverses modifications secondaires. Après une nouvelle mue, qui survient vers la fin de l'hiver, les parasites revêtenl la forme adulte. On trouve en moyenne deux mâles pour trois femelles.

D'après Ostertag, 90 pour 100 des sujets sacrifiés aux abattoirs de Berlin sont porteurs de ces Strongles. On n'en trouve qu'un petit nombre à la fois chez les individus en bon état, mais les cachectiques sont largement infestés. Dans les points où les nodules abondent, on observe une inflammation catarrhale plus ou moins étendue. Les Vers, au moins pendant leur jeune âge, sucent le sang des capillaires de la muqueuse : aussi a-t-on pu leur attribuer la production d'une sorte d'anémie pernicieuse, qui sévit surtout sur les jeunes animaux, et que divers auteurs rapportaient aux pulpes de betterave employées dans l'alimentation.

Strongle suppléant (Strongylus vicarius Stadelmann, 1893). - Ce Ver offre l'aspect général du Str. Ostertagi; il a la mème taille, la mème teinte et la mème situation des organes génitaux; mais la femelle adulte ne possède pas sur la vulve de duplicature cutanée en forme de cloche.

Stadelmann (2) a trouvé ce parasite dans la caillette du Mouton, où il développe des nodules semblables à ceux produits par le Str. Ostertagi chez le Bœuf. Déja Stiles, aux Etats-Unis, avait trouvé de petits Strongles dans la caillette du Mouton; mais il les rapportait à l'espèce précédente.

Strongle rouge brun (Str. mbidus Hassall et Stiles, 1892). - Corps

(1) H. Stadelmanx, Ueber den anatomischen Bau des Strongylus convolutus Ostertag, nebst einigen Bemerlungen zu seiner Biologie. Inaug. Diss. Berlin, 1891.

(2) Stadelasan, Zur Frage des Strongylus convolutus. Zeitschrift für Fleisch- und Milchhygiene, III, p. 219, 1893. 
rouge, grèle ; cuticule finement striée en travers, et possẻdant en outre 40 à ษö arètes longitudinales; lignnes latérales saillantes. Vxtrémité céphalique un peu renflée. Deux spinules cervicales latérales. Bouche petite, ronde, inerme. Mále lonğ de 5 millimèlres; bourse caudale non excisée en avant, divisẻe à son bord postéricur en deux lobes réunis par un petit lobe médian; cótes postérieures formant un tronc bifurqué à l'extrémité et portant sur sa longueur deux courtes branches lalérales; còtes moyennes et anlérieures dédoublies; spicules courts, tordus, mesurant 130 in, avec support chitinenx en avant de l'anus. Femelle longue de 8 millimètres a $8^{\mathrm{mm}}, 0$; anus à $0^{\mathrm{mm}}, 68$ de la pointe de la queue; vulve ì $1^{\mathrm{mm}}, 3-1^{\mathrm{mm}}, \ddot{\mathrm{j}}$ en avant de l'anus, immédiatement suivie d'un repli cuticularire en demi-lune. Ofufs longs de $4 \ddot{5} \mu$, larges de $36 \mu$, commençant à se segnienter avant la ponte.

Trouvé par Ilassall et Stiles dans l'estomac lles Porcs sacrifiés pour la consommation à l'abattoir de Washington. Dans certains lots, 7:3 p. 100 des animaux cn étaient porteurs, et parfois on en trouvait un nombre immense: dans ce dernier cas seulement on observit un peu de catarrlıe de la muqueuse. C'est probablement le mème parasite que Lut\% avait déji signnalé au Brésil (1).

Strongle d'Axe (Str. Axei Cobbold, 1879). - Corps filiforme, atténué aux extrémités. Bouche nue. Mâle long de $3^{\mathrm{mm}}, 8$; bourse caudale bilobée ; còtes postérieures soudées entre elles sur la plus grande partie de leur longueur et terminées cliacune par deux courtes branches; cotes moyennes et antérieures dédoublées. Deux spicules courts et tordus, longs de $10 \ddot{\text { à }} 110 \mu$, accompagnés d'une pièce accessoire. Femelle longue de ă millimètres : extrémité caudale formant en arrière de l'anus un cône a pointe fine; vulve au sixième postéricur du corps. OEufs ellipsoüdes, longs de 100 à $112 \mu$, larges de $63 \mu$, sermentés au moment de la ponte.

Ce petit Ver a été trouvé en novembre 1864, au collègre vétérinaire de Londres, par le professeur Axe, dans la muqueuse stomacale de l'Ane (2).

C'est évidemment le même qui a été recueilli depuis par Mazzanti, à l'École vétérinaire de Pise, sur la muqueuse gastrique d'un Cheval, et décrit sous le nom de Str. tenuissimus.

Strongle rayé (Str. strigosus Dujardin, 18łö. - Syn. : Str. retortæformis Bremser, 182', nec Zeder, 1800; Str. Blasii von Linstow, 1887). - Corps rouge sanguin, filiforme. Bouche nue. A quelqque distance de l'extrémité antérieure, deux petites papilles latérales, en forme de dents dirigées en arrière. Tégument portant environ $\ddot{0} 0$ arètes longitudinales. Mâle long de 8 a 16 millimètres; bourse caudale campaniforme, excisée en avant, légèrement bilobée en arrière; còtes postérieures émanant d'un tronc commun beaucoup plus long qu'elles, et divisées en deux branches dont l'interne, un peu plus longue, porte deux papilles, l'externe n'en portant qu'une; còtes

(1) A. Lutz, Klinisches ïler Parasilen des Menschen und der IIausthiere. Centralbl. f. Bakt. u. Paras., III, p. 748,1888 . - A. Hassall et Ch. Stules, Strongylus rubidus, a new species of Nematode, parasitic in Pigs. Journal of comparative lled. and vet. Archives, XIII, p. 207, 1892 .

(2) T. S. Coвmold, Parasites, p. 383, 1859. - In., New parasites from the Horse and Ass. The Veterinarian, P. 4, 1884. - 1n,, Description of SIr. Axei Cobb., preceded by Remarks on its affinities. Linn. Soc. Journ. (Zool.), XIX, p. 259, pl. XXXII, 1886. - E. Mazzaxtr, D'una specie di Strongito sopra la mucosa gastrica del Cavallo. Il moderno Zooiatro, II. p. 187, 1891. 
VERS.

moyennes et antérieures dédoublées. Deux spicules grêles, longs de $1^{\mathrm{mm}}, 1$ à $2^{\mathrm{mm}}, 4$, laciniés à leur extrémité. Femelle longue de 11 à 20 millimètres; extrémité caudale conique, obtuse à la pointe ; vulve située vers le quart postérieur du corps et divisant celui-ci en deux parties distinctes, l'antẻrieure

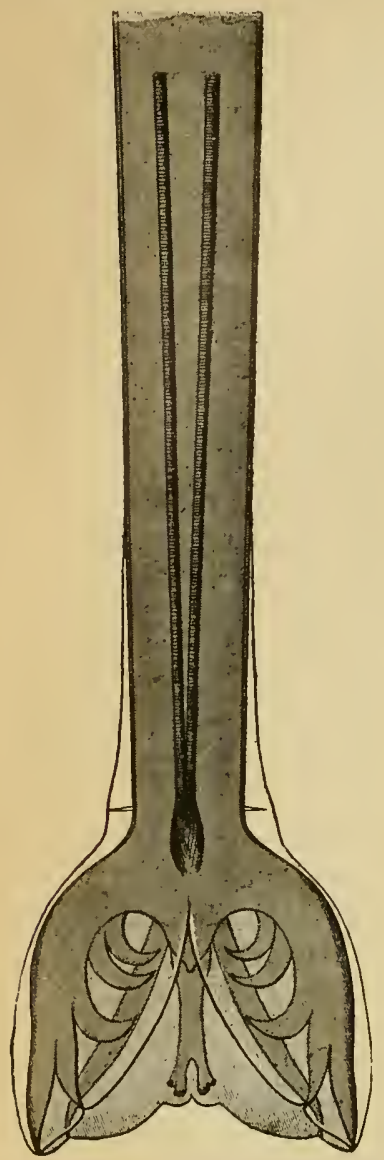

Fig. 304. - Extrémili caudnlo
du Strongylus strigosus màle, du Strongylus strie 40 fois (Orig.).

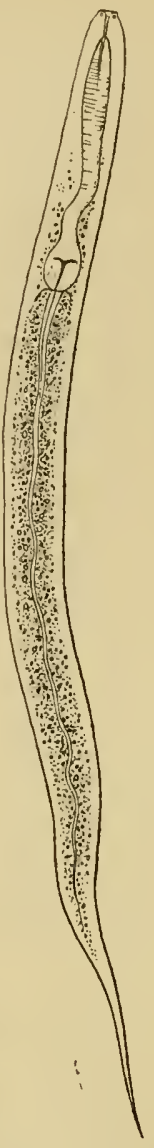

ig. 305. - larre ricemment éclose de Srongylus strigosus, grossie 200 fois (Orig.).

plus épaisse, la postérieure plus grèle, surtout immédiatement après la vulve, laquelle est recouverte par un appendice épais. OEufs ellipsoïdes, longs de 98 à $106 \mu$, larges de 50 à $58 \mu$, pondus à l'état de morula.

Ce Strongle vit dans l'eslomac et plus rarement dans l'intestin du Lapin de garenne, du Lièvre et du Lapin domeslique (1). Nous avons établi que ces œufs éclosent dans l'eau et donnent des embryons rhabditiformes dont le développernent est direct. Chez les Léporidés sauvages, ils sont dans certains cas extrêmement nombreux et, comme ils sucent le sang de la muqueuse gastrique, ils déterminent alors une anémie pernicieuse entraînant souvent une morlalité considérable. Nous arons étudié plusieurs épizooties dues à cette cause. Les symptômes et les lésions de cette maladie sont à peu près ceux de la cachexie aqueuse (gros ventre). Comme il est impossible de traiter sérieusement les animaux atteints, on devra chercher à prévenir le développement de l'épidémie par l'assèchement aussi complet que possible du sol.

(1) A. Ralluet, Sur l'identilé du Strongylus Blasii von Linstow et du Strongylus strigosus Dujardin. Bullet. Soc. zoot. de France, XIII, p. 210, 1888. - ID., Développement expérimental du Strongylus strigosus Duj. et du Str. retortæformis Zeder. Ibid., XIV, p. 375, 1889. - ID., Une nouvelle affection parasitaire du Lievre et du Lapin de garenne. Revue des sc. nat. appliquées, XXXVII, p. 345, 1890. - ID., L'anémie pernicieuse d'origine parasitaire. Revue génér. des sciences, I, p. 29', 1890. 
Strongle ì spicules tordus (Str. retortxformis Zeder, 1800, nec Bremser, 182ł). - Corps capillaire, Wanchitrc ou jaunitre, fortement atténué cu arant. lixtrẻmité céphalique souvent un peu vésiculeuse. Tégument rayé par des arètes longitudinales. Bonche nue. Male long de 6 à 7 millimètres ; bourse eaudale à deux lobes réunis par un lrès petit lobe médian; còtes postéricures à poine séparées l'une de l'autre, un peu fendues i l'extrémité; moyennes et antéricures dédoublées. Deux spicules courts, tordus (1'étortiformes), arec une pièce accessoire. Femelle longue de 7 ì a millimetres; queue en pointe conique allongée; vulve située vers les trois quarts postéricurs du corps. OHufs ellipsoïdes, relativement grands, longs de 73 à $80 \mu$, larges de 40 à 4 ï $\mu$, segmentés au moment de l:1 poute.

Vit dans l'intestin grèle et plus rarement dans l'estomac du Lapin de garenne, du Lièrre et du Lapin domestique, où je l'ai recueilli à diverses re-

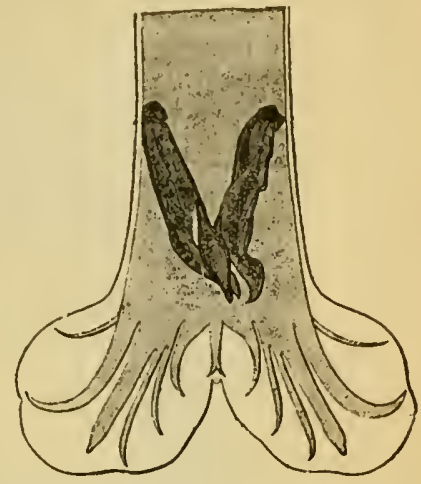

lï. 30 t. - Evirimilé caudale du Stron. gylus relorlipformis mile, grossie 1 ก0 fois (Orig.).

prises. Il coexiste généralement avec le šr. strigosus, et concourt avec lui à la production de l'anémie pernicieuse des Léporidés. Nous arons montré qu’il subit aussi une évolution directe. Il est très voisin du Str. ventricosus.

Strongledes Léporidés (Str. leporum Moniez. - Syn. : Spiroptera leporum Mz., 1880; Str. leporum Mz.,1889). - Corps rouge, aminci en avant. Tégument sans arètes longitudinales. Région buccale séparée du reste du corps, paraissant offrir quatre lèvres. Malle ayant près d'un centimètre de long; bourse caudale trilobée; cỏtes postérieures séparées seulement dans leur tiers inférieur, bilobéesà l'extrémité; moyennes et antérieures dédoublées ; deux spicules longs de $1^{\mathrm{mm}}, 98$ à $2^{\mathrm{mm}}, 03$, élargis peu à peu etréunis vers l'extrémité par une lame chitineuse. Femelle longue de plus d'un centimètre. OEufs longs de $80 \mu$, larges de $40 \mu$, segmentés au moment de la ponte.

Trouré par Moniez sous la muqueuse stomacale du Lièvre et du Lapin de garenne, dans le Nord et le Pas-de-Calais.

Strongle nodulaire (Str. noduluris Rud., 1809. - Syrn. : Ascaris mucro. nata Frölich, 1791 ; Str. anseris Zeder, 1800 ; Str. nodulosus Rud., 1803 ; Str. orispinus Molin, 1850. - Priorité : Strongylus mucronatus). - Corps grêle, atténué aux extrémités, surtout en avant, blanchàtre ou jaınàtre. Extrémité céplalique légèrement renfléc et garnie de papilles. Bouche arrondie, suivic d'une courte capsule buccale du fond de laquelle partent iles saillies coniques. Tégument rayé par des arêtes longitudinales largement espacées. Wále long de 10 à 16 millimètres; bourse caudalc trilobée; côtes séparées à leur tiers intérieur et bifurquées à l'extrémité; moyennes et antérieures Ilédoublées. Deux spicules courts, plats, bifurqués et un peu boutonnés à l'extrémité, avec une pièce accessoire. Femelle longue de 12 à 22 millimètres; 
queue rétrécie en une pointe mousse; vulve vers le dixième postérieur du corps, recouverte par un appendice saillant. OEufs ellipsoïdes, longs de 115 à $120 \mu$, larges de 62 à $68 \mu$, embryonnés au moment de la ponte.

On trouve ce Strongle sous la muqueuse du gésier, du ventricule succenturié, etc., de divers Anatidés, et en particulier de l'Oie domestique. Nous l'avons recueilli, en abondance, avec MI. Bouffard, sur de jeunes Oisons qu'il paraissait avoir fait périr.

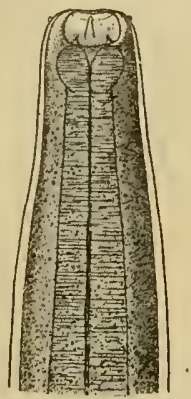

Fig. 307. - Extrémité céphalique du Strongylus nodularis, grossie 200 fois (0rig.).

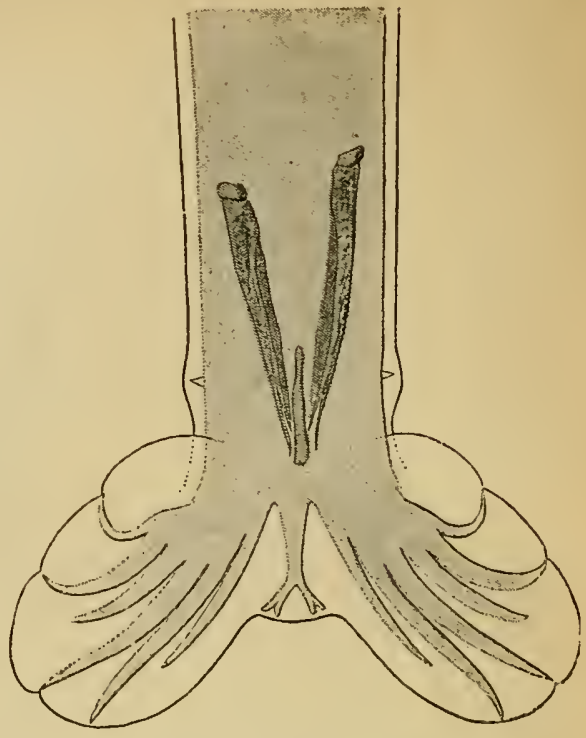

Fig. 308. - Extrémité caudale du Strongylus nodularis mâle, grossie 100 fois (Orig.).

Strongle ténu (Str. tenuis [Mehlis] Eberth, 1861. - Syn. : Str. serratus v. Linstow, 18\%6). - Corps capillaire, fortement atténué en avant. Extrémité buccale munie de 3 papilles pen distinctes. Tégıt-

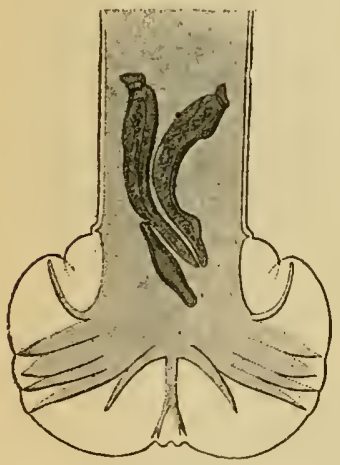

Fig. 309. - Evtrémité caudale du Strongylus temuis mâle, grossic 150 fois Orig.). ment rayé par des arètes longitudinales. Mâle long de ö millimètres à $6^{\text {mu }}, \ddot{z}$; bourse caudale à deux lobes réunis par un très petit lobe médian; còtes postérieures séparées dans leur tiers inférieur et un peu fendues à l'extrémité; còtes moyennes et surtout antérieures dédoublées. Denx spicnles courts, tordus, avec une pièce accessoire. Femelle longue de $7^{\mathrm{mm}}, 3$ à $7^{\mathrm{mm}}, 8$; queue en pointe conique aižü̈; vulve siluće vers le septième postérieur du corps. OEurs ellipsoïdes, relativement grands, longs de 66 a $\dddot{\imath a ̈} \mu$, larges de 33 a a $42 u$, segmentés au moment de la ponte.

Cette espèce, qui se distingue des Str. instabilis et retortæformis par la réunion en un faisceau 4-radié de la còte moyenne, de l'anlérieure externe et de la première branche de l'antérieure, habite le cæcum de l'Oie cendrée et de l'Oie domestique. Nous l'avons recueillie avec Lucet chez des Oies élevées dans le Loiret.

C. Sous-famille des sclérostominés. - Méromyaires à bouche munie d'une armature chitineuse plus ou moins complexe, à deux 
spicules égaux (sauf dans le genıe Stephrmurus), à bourse caudale pourvue de colles. Deux ovaires (sauf dans le genre Ollulanus).

Genve Esophagostome (WEsophagostoma Molin, 1860). - Bouche circulaire, pelile, munie d'un anneau chitineux autour duquel la cuticule se soulève en un bourrelet transparent, str lequel se voient six papilles aighës. Le bourrelet est séparé du corps par un étranglement, en arrière duquel le tégument forme dordinaire un renflement résiculeux ovoïde bien délimilé à sa partie postérieure, au niveau d'une fente transwersale qui occupe toute la largeur de la face ventrale.

OÉsophagostome à cou gouflé(OEs. inflatum [Ant. Schneider]. - Syn. : Strongylus inflatus Schn., 1866, nec Molin, 1860; Str. dilatatus Raill., 1884

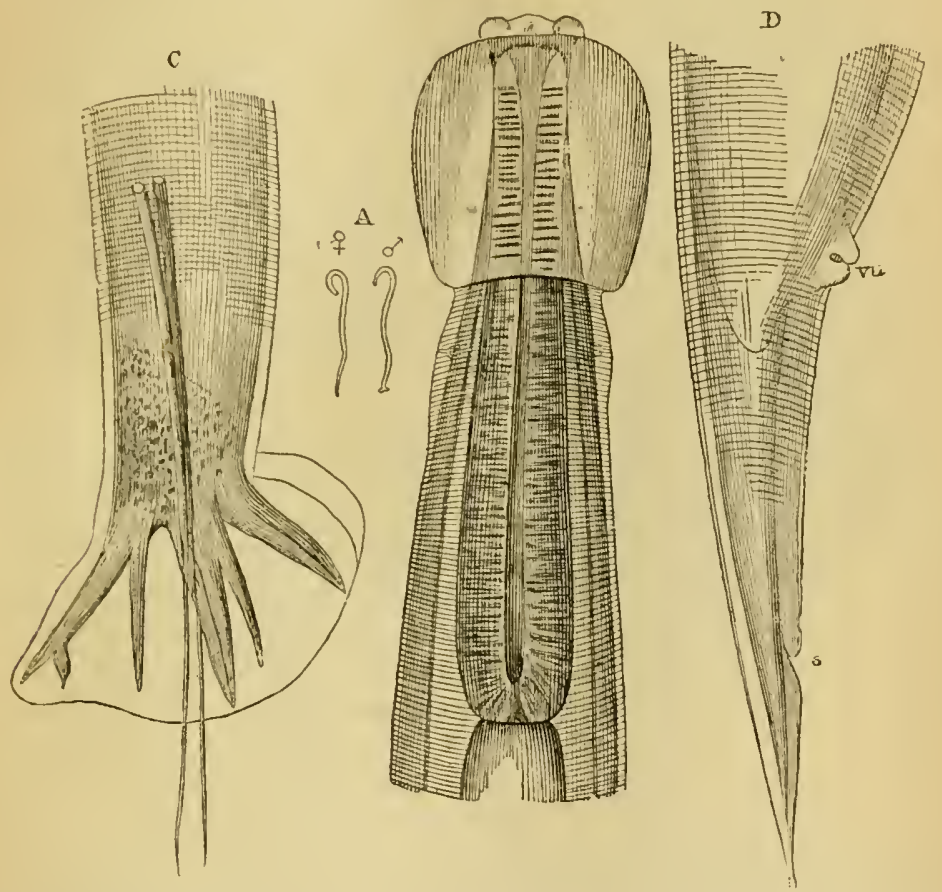

Fig. 310. - Esophagosloma inflalım. - A, màle el femelle, grandeur nalurelle. B, extrémité antérieure. C, extrémité caudale du måle. D, extrémité caudale de la femelle. Grossissement: 100 diamètres (Orig.).

OEs. inflatum Raill., 1883). - Corps blanchatre. Bouche circulaire. Un renflement vésiculeux, immédiatement suivi de deux ailes membraneuses latérales. Deux papilles traversant les ailes. Müle long de $1 \dot{4}$ à $1 \ddot{3}$ millimètres ; bourse caudale obscurément trilobée; còtes postérieures bifurquées, moyennes et antérieures fendues. Femelle longue de 16 à 20 millimètres; rulve située un peu en avant de l'anus et entourée d'un bourrelet. OEufs 
ellipsoïdes, longs de 70 à $76 \mu$, larges de 36 à $40 \mu$, segmentés au moment de la ponte.

Gros intestin du Bœuf. - Schneider, qui a trouvé cette espèce dans la collection de Rudolphi, sous l'étiquette Str. radiatus, lui avait

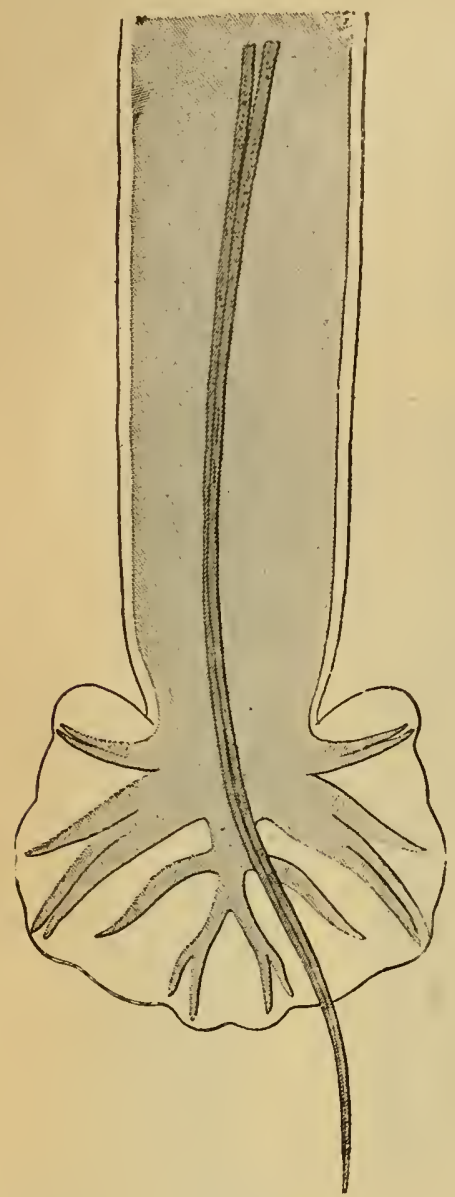

Fig. 311. - Exlrémité caudale de l'CEsophagostoma venulosum mâle, grossie 100 fois (Orig.).

fendues, légèrement dédoublées. Femelle longue de 23 à 2 't millimètres; queue souvent encroùtéc d'une matière jaunàtre; vulve un peu en avant de l'anus. OEurs ellipsoïdes, longs de $90 \mu$, larges de $5 \%$ $\mu$.

Trouvé d'abord dans l'intestin de la Chèvre, par Rudolphi, puis dans la caillette du Chamois et de l'Ovis Ammon. Nous en avons rencontré au musée d'Alfort des spécimens assez bien conservés provenant aussi de la Chèvre. C. Baillet avait certainement vu des 
individus de celte espèce chez le Mouton, mais il les avait confondus avec Sclerostoma luypostomum. D'autre part, Carità, qui en avail recueilli deux exemplaires chez la Brehis, les arait rattachés à l'GE's. inflatum. Nous en arons fréquemment observé chez le Mouton (surtout dans le cacum et le colon), chez le Chabin el cliez le Chevreuil (t).

OAsophagostome de Columbia (Obs. columbianum Curtice, 1890). Corps blanchìtre; extrénité céphalịue souvent recourbée en crochet. bouche circulaire, munie d'une double conronne de soies convergentes. Cou sans renflement résiculeux, mais offrant néanmoins une fente ventrale lrinsversale, en avant de laquelle se trouve un pli cuticulaire. Deux ailes latérales faibles, naissant immédiatement après la fente. Deux papilles latérales vers le premier tiers de l'vesophage, c'est-à-dire à l'origine des ailes. Male long de 12 a 15 millimètres; hourse caudale et còtes comme daus l'espèce précédente; deux spicules longs de $0^{\mathrm{mm}}, \tilde{7}$. Femelle longue de 14 à 18 millimètres; vulve un peu en avant de l'anus. OEufs ellipsoïdes, longs de $90 \mu$, larges de $50 \mu$, pondus à l'état de morula. Embryons, à la naissance, longs de 230 u..

Celle espèce a été trouvée par Cooper Curtice, chez le Mouton, aux États-Lnis, à l'est du Mississipi. Les Vers adultes vivent dans le côlon, mais les larres se développent dans de petites tumeurs sousmuqueuses, dont le volume varie de celui d'une tête d'épingle à celui d'une noisette, ct qu'on rencontre depuis le duodénum jusqu'à l'anus, mais plus particulièrement dans le cacum. Dans chacune de ces tumeurs habite une seule larve, qui atteint au maximum 3 à 4 millimètres de longueur.

Les animaux de tont âge peuvent être envahis de la sorte, mais l'infestation porte de préférence sur les sujets àgés. Elle survient en été, et les tumeurs s'accroissent jusqu'au printemps suivant, après. quoi on les voit diminuer. Les troubles consistent dans le développement d'une anémic insidieuse qui conduit peu à peu les animaux au marasme. Les intestins affectés ne peurent plus être utilisés à la fabrication des saucisses.

Giles (2) a observé la même affection dans l'lnde anglaise.

OEsophagostome denté (OEs. dentalum [Rud.]. - Syn. : Strony. dentatus Rud., 1803; Sclerostoma dentatum de Blainville, 1828; OEs. subulatum Molin, 1860; OEs. lentatum Raill., 1883̈). - Corps blanchàtre ou gris brunàtre. Bouche circulaire, munie d'une couronne de soies convergentes. Un renflement vésiculeux. Pas de membrane latérale. Deux papilles opposées au niveau du quart postérieur de l'œsophage. Male long de 8 à 12 millimètres; bourse caudale obscurément trilobée ; còtes postérieures bifurquées,

(1) A. Ralliet, Les parasiles du Chabin el l'Olsophagostome des petils Ruminants. Bulletin soc. zool. de France, XIII, p. 21ti, 1888.

(2) G. M. J. Giles, On nodular disease of the intestine in Sheep. Scientific Memoirs by IIedical Officers of the Army of India, I'art VII. Calcutta, $18 y 2$. 
moyennes et antérieures légèrement dédoublées (fig. 279). Deux spicules grêles, bordés d'une membrane transparente, longs de $1^{\mathrm{mm}}, 13$. Femelle longue de 12 à 15 millimètres; extrémité caudale subulée et mucronée; vulve située un peu en avant de l'anus et limitée par un rebord saillant. OEufs oroïdes, longs de 60 à $80 \mu$, larges de 35 à $45 \mu$.

Dans l’intestin du Porc, du Sanglier et du Pécari à lèvres blanches. Leidy l'a trouvé dans le foie du Porc.

D’après C. Baillet, les cufs de cette espèce éclosent dans l'eau au bout de trois ou quatre jours. Les embryons mesurent alors 200 à $2000 \mu$.

Genre Stéphanure (Stephanurus Diesing, 1839). — Extrémité antérieure tronquéc; bouche suborbiculaire, limitée par un anneau chitineux garni de dents. Les mâles possèdent un seul spicule et une bourse caudale multilobée.

Stéphanure denté (St. dentutus Diesing, 1839. - Syn. : Sclerostoma pinguicola Verrill, 1870; st. Nuttereri Cobbold, 1879). - Corps allongé, cylindroïde, rarement filiforme ou capillaire. Bouche terminale, munie de six dents, dont deux opposées plus fortes. Mâle long de 22 à 28 millimètres; bourse caudale formée de cinq languettes que réunit une délicate membrane transparente; spicule fililorme. Femelle longue de 33 à 40 millimètres; queue recourbée, obtuse, prolongée par une petite pointe et pourvue de chaque côté d'un court processus obtus; vulve située vers le milieu de la longueur du corps. OLufs longs d'environ $84 \mu$.

Ce Nématode a été découvert en 1834 au Brésil, par Natterer, chez un Porc de race chinoise; les exemplaires étaient isolés ou réunis plusieurs ensemble dans des sortes de liystes situés entre les couches adipeuses. White l'a retrouvé aux États-Unis en 183̈8, et Morris en Australie en 1871.

Dans cette dernière contrée, aussi bien que dans les deux Amérique, ce paraît être un parasite très commun. Mais c'est à tort sans doute que Flechter, aux États-Unis, l'a considéré comme la cause du Hog cholera et que Morris, en Australie, lui a attribué la production d'une mysterious disease causant parmi les Porcs une mortalité considérable.

Il siège dans les viscères abdominaux, et en particulier dans le tissu adipeux qui entoure ces organes. Mais c'est au voisinage des reins qu'il s'élablit de préférence, d'où le nom de kidney-worm que lui donnent les Américains. Il se creuse des galeries qui prennent souvent un caractère fistuleux, et entraînent parfois la production d'épanchements dans le péritoine. Il n'est pas très rare enfin de le voir pénétrer dans le rein, dans les capsules surrénales et dans le foie (Lutz, Dinwiddie).

Genre Syngame (Syngamus von Siebold, 1836). - Tête épaissie; bouche large, suivie d'une capsule chilineuse qui la maintient béante. 
Males relativement petits, avec deux spicules. F'emelles munies d'un double ovaire; vulve située dans la partic antérieure du corps. L’accouplement, qui est quelquefois perma-

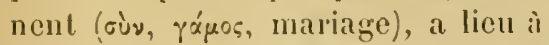
angle aigu, de telle sorte qu'on a pu prendre les individus ainsi réunis pour des Vers ì deux lètes.

Les Syngames habitent la trachée et les bronches des Oiseaux et des Mammilères. Deux espèces seulement ont été signalées chez les Oiseaux domestiques.

Syngame trachéal (S. trachealis von Siebold, 1836. - Syn. : Fusciola tracheu Montagu, 1811 ; Strongylus trachealis Creplin, $18: 6$; Sclerostomum syngamus l)ies., 1831; Syng. primitivus Molin, 1860). - Corps cylindrique, de couleur rouge. Tète élarúie et tronquée. Bouche orbiculaire, soutenue par une capsule chitineuse liémisphérique dont le fond présente six ou sept éminences chitineuses tranchantes et dont le bord épais et retroussé est découpé en six festous symétriques qu'entourent quatre lèvres membraneuses (Mégnin). Mâle long de 2 à 6 millimètres, à bourse caudale obliquement tronquée, munie de douze (?) còtes et soudée autour de la vulve. Femelle longue de 5 à 20 millimètres, amincie en avant, irrégulièrement renflée quand elle est remplie d'œufs; vulve saillante vers le quart antérieur du corps. OEufs ellipsoïdes, operculés, longs de $83 \ddot{\mu}$, larges de $30 \mu$. L'accouplement, dans cette espèce, est. permanent et si intime, qu'on ne peut séparer le màle et la femelle sáns déchirer les téguments. Cobbold a cependant vu cette séparation s'effectuer sans déchirure, chez les individus jeunes.

Le Syngame trachéal, connu des éleveurs français sous le nom de $\mathrm{Ver}$ rouge ou $V e r$ fourchu, vil dans la

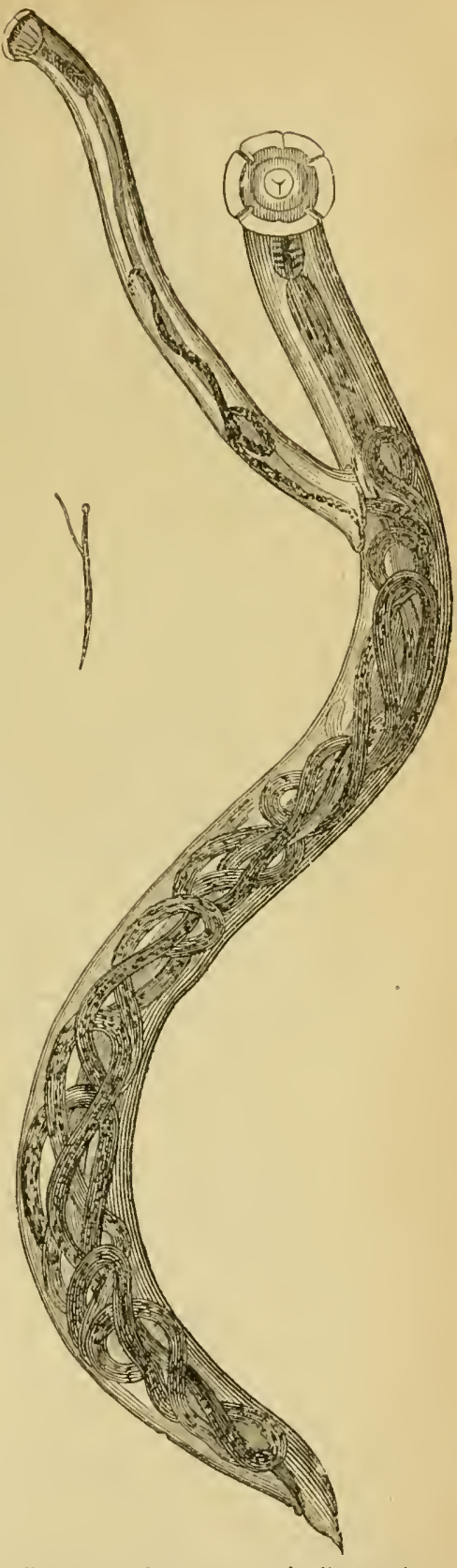

Fig. 312. - Syngamus trachealis, grandeur naturelle el grossi 10 fois (0rig.). trachée et les grosses bronches d'un assez grand nombre d'Oiseaux 
sauvages ou domestiques; mais il est surtout répandu chez les Gallinacés. Ainsi, on l'a trouvé chez la Poule, le Faisan commun, le Faisan doré (É. Thierry), le Dindon, le Paon (Bellingham, Railliet), la Perdrix grise, la Pie, la Corneille mantelée, le Chocard des Alpes, le Pic-Vert, l'Étourneau, le Martinet.

Evolution. - Le mode de développement de ce Ver a élé déterminé par Leuckart, Ehlers, Mégnin et Walker. Les œufs ne peuvent s'échapper du corps de la femelle que par le fait d'une déchirure. Chez les grandes femelles, ils présentent dans les utérus mêmes un embryon bien formé (Cobbold). Mais il arrive que les parasites soient rejetés avant d'avoir atteint leur taille définitive : leurs oufs s'échappent alors à la faveur de la décomposition cadavérique, se répandent sur le sol humide ou dans les flaques d'eau, évoluent dans ce milieu en une à six semaines suivant la température, et peuvent même arriver à éclosion. L'embryon libre mesure $280 \mu$ de long sur $13 \mu$ de dianètre; il est muni d'un petit appendice buccal provisoire qu'il abandonnera à la première mue. Ehlers a montré que cet embryon n'a nullement besoin de passer par un hote intermédiaire : en faisant ingérer à des Oiseaux des œufs embryonnés, il a constaté qu'au bout de douze jours les individus étaient déjà assez développés pour entrer en copulation, et qu'après dix-sept jours les femelles étaient déjả remplies d'œufs bien formés. Walker a même constaté que les embryous se conservent bien vivants dans le tube digestif des Vers de terre et que, après l'ingestion de ceux-ci, les Oiseaux présentent des Syngames. D’autre part, Mégnin a pu obtenir le développement de ces parasites chez une Perruche en lui faisant avaler des corps entiers de Syngames qui renfermaient sans doute des œufs embryonnés.

Pathologie. - La présence de ces Nématodes dans les voies aériennes des Oiseaux détermine une grave affection qui sévit d'habitude à l'état épizootique, surtout chez les jeunes Gallinacés, et que les auteurs américains et anglais désignent depuis longtemps sous le nom de gapes (de to gape, bâiller, ouvrir le bec). Nous avons proposé de remplacer cetle expression par celle de syngamose.

Les sujets atteints manifestent une sorte de toux sifflante; à chaque instant ils ouvrent largement le bec pour respirer, en allongeant le cou; ils sont pris d'éternuements, etc. Ils meurent asphyxiés en quelques jours ou périssent un peu plus tard par suite de cachexie. La guérison spontanée est assez rare.

A l'autopsie, on trouve les couples de Syngames fixés sur la muqueuse trachéale comme de petites Sangsues. Ils siègent d'ordinaire à la partie inférieure de la trachée ou à l'entrée des bronches. Les points où ils sont attachés sont généralement enflammés.

On a recommandé, pour traiter cette affection, des moyens très divers 
qui, dans la pratique, se montrent peu efficaces. Le mieux est d'établir une sérieuse prophylaxie, ayant pour base l'isolement, la propreté, la désinfection.

Syngame bronchial (S. bronchiulis Mühlig, 188í). - - Corps cylindrique, un pen atténué en avant. Bouche comme dans l'espèce précédente. Male long de 10 millimètres, ì bourse caudale sphérique, entière; côtes antérieures et moyennes fentlues; antérieures externes accolées aux moyennes; postérieures tridigilées, réunies à la base en un tronc commun qui a à peu près le double de leur longneur; spicules filiformes, recourbés en crochet à leur extrémité et frangés à leur bord interne. Femelle longue de 23 millimètres, à extrẻmité postérieure terminée en pointe conique; vulve peu saillante, située au premier tiers de la longueur dı corps. OEufs ellipsoïdes, non operculés, longs de $90 \mu$, larges de $60 \mu$. - La copulation n'est pas constante, et les Vers accouplés peurent ètre séparés sans déchirure par la traction.

Celte espèce a été trouvée par Mühlig chez de jeunes Oies japonaises. Peut-ètre est-ce la inème qui avait été vue antérieurement, chez de jeunes Oies également, par Przibylka et par Zürn; elle parait assez voisine, en tout cas, du Syngamus variegatus (Creplin) (Sclerostomum tracheale Dies.; Syng. sclerostomum Molin), recueilli par Nallusius et Creplin dans la trachée de la Cigogne noire. Elle vit dans le larynx, la trachée, les bronches, jusque dans les petites divisions : sa présence détermine une inflammation pulmonaire. Les symptòmes qu'elle provoque sont semblables à ceux signalés à propos du S. trachealis.

Hayem a observé en 1873, dans les voies aériennes du Canard, des Nématodes qu'il a rapportés au Sclérostome du Cheval (Sclerostoma equinum); mais il est probabłe qu'il s'agissait d'un Syngame, peut-être même du Syng. tronchialis.

Genre Globocéphale (Globocephalus Molin, 1860). - Ce genre, créé par Molin, est caractérisé par une tète sphéroïde, diaphane, et une capsule buccale soutenue par denx anneaux cornés, l'un situé au fond, l'autre à l'entrée, tous deux réunis par quatre méridiens cornés; l'orifice buccal est terminal, orbiculaire, à limbe annulaire entier, non denté.

Globocéphale mucroné (Gl. longemucronatus Molin, 1860). - Mâle long de 7 millimètres; bourse caudale légèrement trilobée: còtes postérieures tridigitées, moyennes dédoublées ainsi que les antérieures. Deux spicules. Femelle longue de 8 millimètres; extrémité caudale en pointe conique, terminée par un mucron allongé.

Trouré par Wedl dans l'intestin grèle du Porc, à Vienne.

Genre Sclèrostome (Sclerostoma de Blainville, 1828). - Extrémité antérieure tronquée, droite ou un peu recourbée vers la face ventrale; bouche circulaire, béante, transversale ou oblique, suivie d'une cavité ou capsule buccale chitineuse et garnie sur le bord de nombreux denticules disposés en une ou plusieurs séries. Les mâles possèdent deux spicules et une bourse caudale sourent trilobée. La vulve s'ourre dans la partie postérieure du corps. 
Sel6́rostonte équin (S\% equinum [0. R. MülJer]. - Syn. : Strongylus équimus 0. F. Müller, 1784; str. asinimus Vihorg, 1793; str. urmatus liud.,

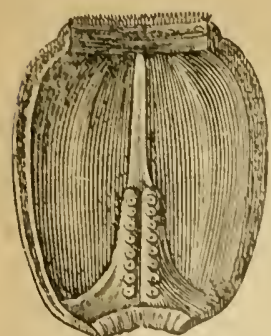

Fir. 313. - Noilis dorsile de la eapsule buecale du siclerestoma trquinum, vue par la face inlerne (l)elafond). 1803: Scl. equimum de Blainville, 1828; Scl. armatum llies, 1851). - Corps „ris on hrun rongeatre, droit, raide, plus épais en avant qu'en arrière. Bonche orbiculaire, lembe par plusieurs anneaux chitineux concentripues, dont les plus intérieurs sont garnis de denticules, tandis que le plus exterieur porte six pa.pilles: deux latérales faibles et quatre submédianes assez saillantes. Cilpsule buciale soutenue par une seule cote longitudinale dorsale et portant vers son fond deux plaques trancliontes arrondies. Male long tantòt de 18 a 20 millimetres, tantot de 26 à $3 . ;$; bourse caudale presque trilobée; eòtes postérieures tridigitées; moyenues dédoublées; antérieures fendues. Deux spicules longs et gredes, traversant uu étui chitineux. Femelle? longue tantót de 20 à 26 millimètres, tantot de $3:$ i $5: 3$; quene obtuse; vulve située vers le tiers posterieur du corps. OEnfs ellip-

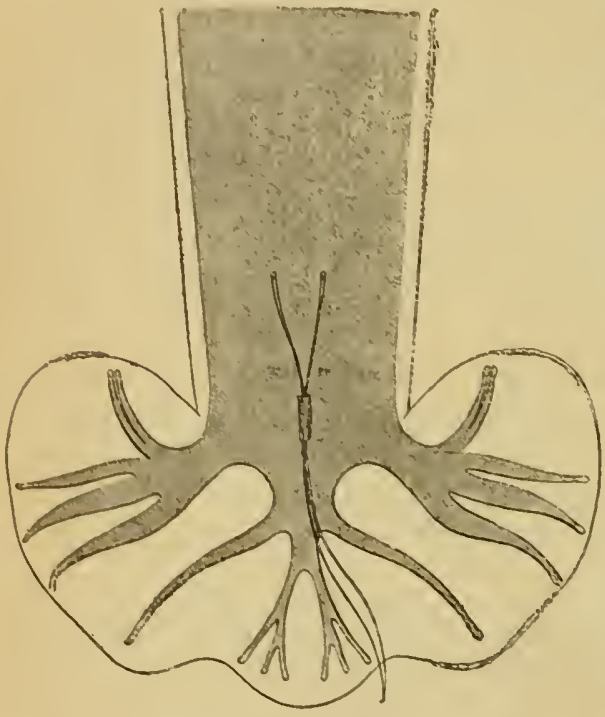

Fig. 314. - Evlrómili caudale du Sclerostoma equinum mile, grossie 30 fois (Orig.). soüles, un peu rentlés vers le milieu, longs de $92 \mu$, larges de ij. $\mu$, en segmentation au moment de la ponte.

Le Sclírostome équin, plus eonnu des vétérinaires sous le nom de Strongle arme, est tris commun chez le Cheval et chez les aulres Equidés; il habile à l'état adulte le circum, rarement le gros cilon, et se lixe à la muqueuse à l'aide de son armature buccals. On trouve bon nombre dindividus accouples.

Mais tris fréquemment aussi on le reneontre à l'itat agame dans des anérysmes de la grande mésentirique, dans les artères hépa-

tiques, rénales, testiculaires, vecipitales, coronaires, elc., dans la reine porte (Valentin), dans le paneréas (Florman, Goubaux), dans le foie (Megnin, Noeard et Railliet), dans le poumon (Morol, Michalik, Leidy, dans le testicule, tans le tissu conjonetif sous-peritonéal et sous-pleural, ele, ele., enfin dans des nodules sous-muqueux de l'intestin, notamment du circum.

Érolutiox. - Les recherches de C. Baillet ont montré que les aufs 
du Scl. equinum évoluent dans l'eau on dans les crottins humides, à la temperature de 12 à 200 , et y éclosent dans l'espace de trois a huit jours. Les embryons, it leur naissanee, mesurent 340 à $000 \mu$ de long; ils sont un peu ohtus en avant, et terminés en arrière par une queue filifurme, courbec d'abord et plus tard droite. Dans l'eau, ils peuvent vivre sans saccroitre huit ì dou\%e jours; mais dans les erottins humides, ils persistent aisément plusieurs mois et atteignent une longueur de $0^{\text {mnn }}, 8$ i $1^{\text {mm }}$, '́ö. Au bout de quinze à vingt jours, on voitse préparer une mue, qui parfois tarde beaueoup, mais après laquelle les embryons montrent une teinte blane jaunatre et une queue beaucoup

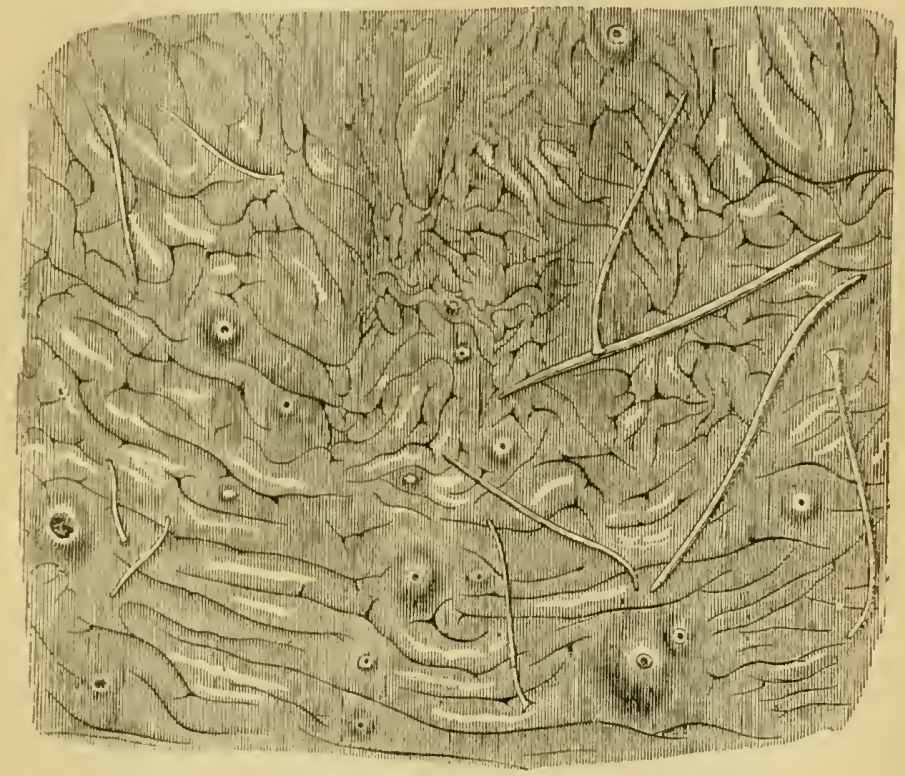

Fiğ. 31\%, - Fragnent de carcum de Cleval, montrant des lumenrs à Sclérostomes, de difrérences grosseurs, et des Selérostomes fixés à la muqueuse. A droile, Jes deux variétés du $S$. equinum; à gauche, celles du S. tetracanthum. Grandeur uaturelle (Orig.).

plus courte. Ils jouissent alor's d'une grande résistance vitale et peuvent ètre conservés dans l'eau pure des mois entiers, mème sans s'ètre débarrassés de leur première enveloppe.

Il est probable que ces cmbryons ayant subi la mue doirent réintégrer direetement l'organisme des Équidés par l'intermédiaire des eaux de boisson. Baillet en a trouvé quelques exemplaires, en effet, rui s'étaient engagés dans la muqueuse du eiceum et du eôlon. Ce n'est là, toutefois, qu'une simple hypothèse, et d'ailleurs on ne connait pas encore d'une façon positive les conditions dans lesquelles s'effectue leur développement ultérieur.

Un certain nombre d'entre eux, tout au moins, passent dans le système circulatoire, oủ ils séjournent plus ou moins longtemps : 
c'est alors qu'ils provoquent la formation d'anévryssmes vermineux. Ils doivent ensuite revenir dans le cæcum, où ils donnent naissance aux kystes sous-muqueux dont nous arons fait mention plus haut. Certains faits d'observation tendent à nous faire considérer ce passage dans le sang comme un fait normal.

Nous derons reconnaitre cependant que les plus petits individus

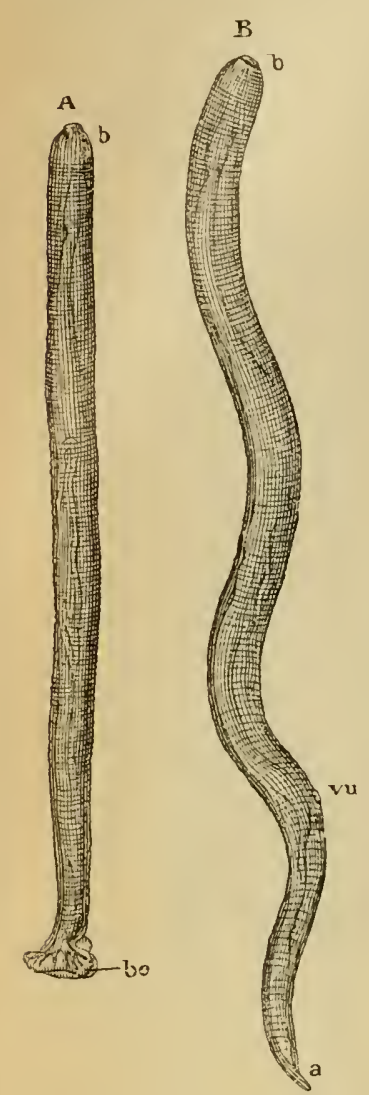

Fig. 316. - Selerostoma equinum, individus agames du pancréas, grossis 3 fois. - A, mâle. B, femelle. $b$, bouche. $a$, anus. vu, vulve. $b c$, bourse caudale (I)elafond). agames observés jusqu'à présent ont été vus dans les nodules sous-muqueux du cæcum; ils mesuraient de 1 à 8 millimètres (Baillet). Dans les anévrysmes de la grande mésentérique, on n'a trouvé jusquà présent que des exemplaires longs de 10 à 22 millimètres. Leuckart a constaté que les plus petits de ces exemplaires sont dépourvus de capsule buccale et montrent, à la périphérie de l'orifice buccal béant, une plaque en rosette avec six lamelles, d'une très élégante sculpture; l'extrémité caudale est courte et pointue. A un stade plus avancé, on remarque que certains spécimens ont la queue plus courte et plus épaisse : ce sont des mâles, dont la bourse caudale est en voie de développement; en même temps, apparaît la capsule buccale, d'abord formée de quatre segments successifs disposés en forme de terrasses en avant de l'œsophage, lequel est ramassé en bulbe à la partie antérieure du corps; lorsque l'œsophage prend son aspect définitif, ces quatre segments occupent une disposition inverse de celle qu'ils avaient primitivement.

En dernier lieu, les Sclérostomes des anévrysmes, aussi bien que ceux enliystés sous la muqueuse du cæcum, offrent une capsule buccale et une bourse caudale à peu près identiques à celles des adultes, mais les tubes génitaux demeurent à l'état rudimentaire. C'est seulement dans la lumière du cánal digestif que les Sclérostomes acquièrent les caractères délinitifs de l'état adulte (1).

Rappelons que ces Sclérostomes agames étaient autrefois regardés

(1) R. Leuckart, Zur Entwicklungsgeschichte der Nemaloden. Archiv d. Ver. f. wiss. Heilkunde, II, p. 195, 1S65. - G. CoLs, Mémoire sur le développement et les migralions des Sclérostomes. Recueil de méd. vét. (5), p. 686, 1886. - C. B.AILLET, loc. cit., et Réponse à M. Colin. Bullet. Soc. centr. de méd. vétér., 1868, p. 166. 
comme une variété spéciale : var. $\alpha$ minor, aneurismatica, qu'on opposait à la forme adulte ou intestinale : var. $\beta$ major, intestinalis (Molin).

En résumé, l’évolution du sicl. equimum parait comporter les phases suivantes: les oufs, cxpulsés avec les fèces, développent dans l'eau des mares leur embryon rhabditiforme; celui-ci réintègre l'organisme lorsque les Chevaux ront s'abreuver; il passe probablement de lintestin grè̀le dans le sỵstème circulatoire, et après un séjour variable dans ec milieu, retourne au cecum, s'arrête sous la muqueuse jusqu’a ce qu'il soit parvenu a un stade déterminé, et enfin passe dans le canal intestinal, où a lieu l'accouplement.

P'atrologie. - Les Sclérostomes adultes sont solidement fixés, comme nous l'avons dit, ì la muqueuse du caecum; celle-ci forme, au point d'adlérence, une petite saillie de teinte somble. Ces Vers se

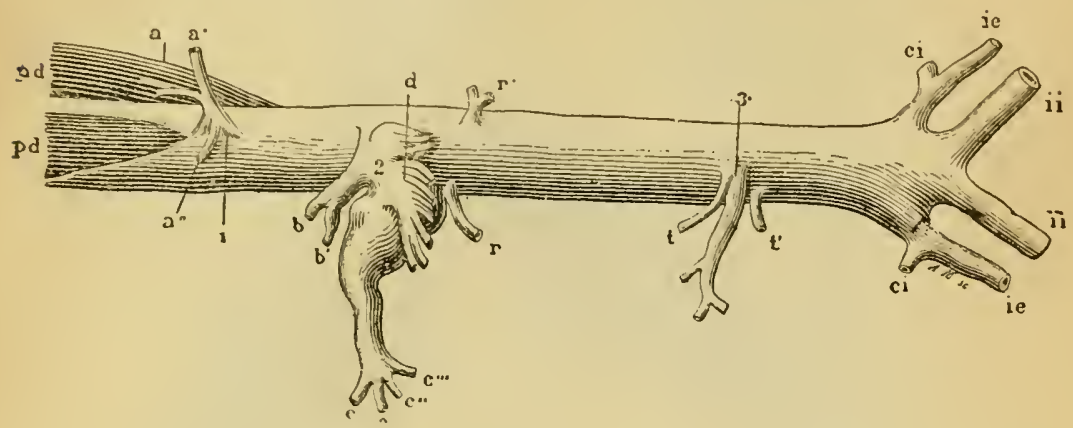

Fig. 317. - Aorle abdominale du Cheval avec ses ramificalions. - 1, tronc cœliaque : $a$, arlère gastrique; $a^{\prime}$, artère splénique; $a^{*}$, artère lıépatique. - 2. tronc de la grande méscntérique, nn peu anévrismalique : $b$, artère colique ganche $; b^{\prime}$, première artère du còlon flottaut; $c$, artère colique droite $c^{\prime}$, arlère creale inférieure; $c^{\prime \prime}$, artère çrcale supérieure; $c^{n \prime}$, artère iléo-carcale; $d$, artères de l'inlestin grêle; $r$, arlère rénale droite; $r^{\prime}$, artère rénale ganche. -3 , tronc de la petite mésentérique; $t, t^{\prime}$, arlères grandes tesliculaires gauche et droite; $i i$, iliaques internes; ie, iliaques externes; $c i$, artères circouflexes iliaques; $p d$, piliers du diaphragme $(G$. Neumann\}.

montrent dans certains cas en quantité considérable, et comme ils attaquent la muqueuse pour en sucer le sang, on les a quelquefois accusés d'avoir occasionné la morl des animaux par anémie, diarrhée, coliques, etc.; mais ces faits ne sont peut-être pas assez nettement établis.

Les tumeurs sous-muqueuses, qui avaient été prises pour des cancers par les anciens observateurs, paraissent être sans influence sur la santé. Elles varient du volume d'une tête d'épingle à celui d'une noisette, et renferment chacunc un Ver enroulé sur lui-même, avec un peu de pus ou de sang altéré; parfois le Ver fait défaut, et l'on constate qu'il s'est échappé par un petit orifice central.

Quant aux Sciérostomes erratiques dans les divers organes, ils sont susceptibles de provoquer des troubles variables suivant leur siège, et nous ne pouvons nous arrêter ici ì tous ces cas particuliers. 
Seuls, les anévrysmes vermineux méritent une mention spéciale. Ils ont été observés sur le Cheval, dès 1663 , par Ruysch; on les a vus également chez l'Ane et le Mulet, et même chez l'Hémione (Laboulbène). Ils sont extrêmement communs, surtout chez les sujets adultes ou âgés; Bollinger estime à 90 ou $94 \mathrm{p}$. 100 la proportion de ceux qui on sont affectés. Ils se rencontrent de préférence sur les branches viscérales de l'aorte postérieure, ct plus spécialement sur le

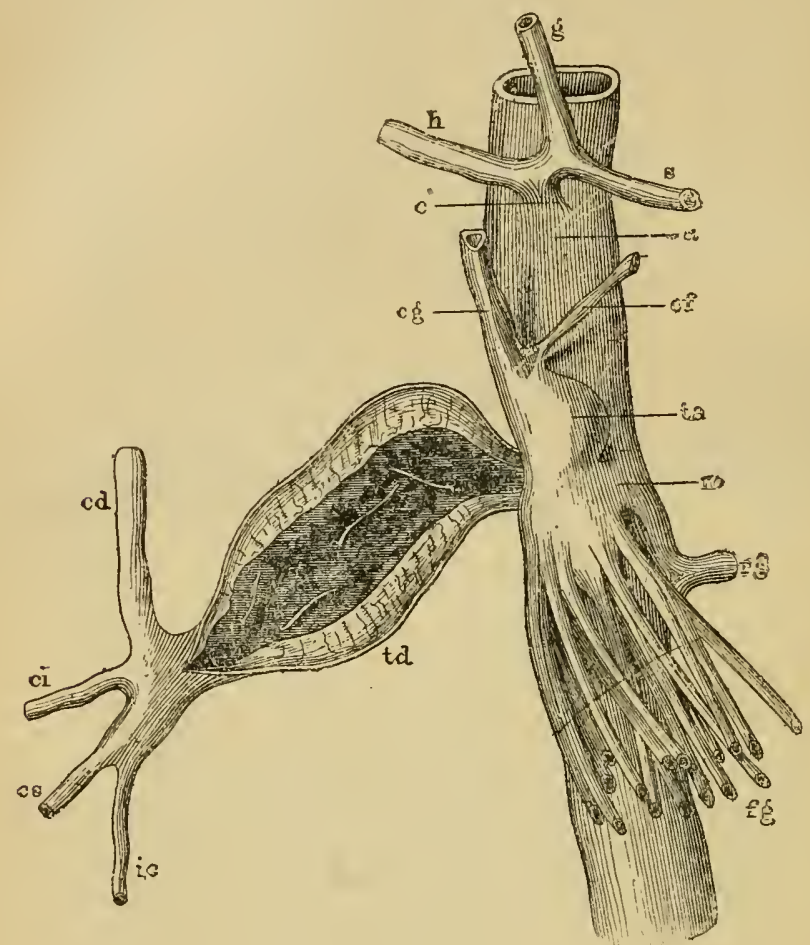

Fig. 318, - Anévrysme vermineux de la grande mésentérique, $1 / 2$ de grandeur naturelle. - $a$, aorte. $c$, tronc cœliaque. $h$, artère hépatique. $g$, artère gastrique. $s$. arière splénique. $m$, tronc de la grande mésentériquc. $t a$, tronc du faisceau antérieur, siège d'un petit anévrysme. $c g$, artère colique gauclie ou rétrograde. $c f$, première artère du côlon flottant. $f g$, artères du faisceau gauche ou de l'intestin grèle. $t d$, tronc du faisceau droit, siège d'un anévrysme : la paroi supérieure du vaisseau a été exciséc pour montrer l'épaississcmeat de la nembrane moyenne de l'artère, les caillots internes et les Sclérostomes qui y sont fixés. $c d$, artère colique droite ou directc. $c i$, artère cæcale iuférieure. $c s$, artère cæcale supérieure. ic, artère iléo-cæecale. $r g$, artère rénaic gauche (Orig.).

tronc du faisceau droit de l'artère grande mésentérique, tronc qui fournit les artères cæcales. Ils sont le pius souvent fusiformes et atteignent en moyenne le volume d'une noix. Leur formation est évidemment due à la fixation des parasites sur l'endartère, et à la formation consécutive d'un dépôt fibrineux; en définitive les lésions portent sur les trois tuniques du vaisseau, mais c'est principalement la tunique moyenne qui se montre hypertrophiée. Presque toujours on trouve des Sclérostomes au niveau de l'anévrysme: ils sont tantot libres, 
tantót engagés plus ou moins profondément dans les couches du thrombus; on observe cependant des cas oil ils ont disparu, sans doute pour gagner l'intestin. Ils sont de teinte rosée, et d'ordinaire au nombre d'une dizaine, mais parfois en beaucoup plus grande abondance. - Les anevrysmes vermineux se rupturent assez rarement, car leurs parois s'épaississent longtemps et subissent mème l'infiltration calcaire; mais le caillot interne est souvent le point de départ d'embolies qui léterminent des congestions intestinales d'une haute gravité. Ces accidents ont été surtout signalés par Bollinger.

Les Sclérostomes lihres du ciecum sont justiciables des vermifuges employés contre les Ascarıdes; néanmoins, leur expulsion est fort difficile à obtenir. Contre les Sclérostomes agames des artères, on pourrail essayer l'administration répétée de l'essence de térélienthine chez les sujets qu'on soupçonnerait d'être infestés.

\section{Sclérostome tétracanthe} (Scl. tetracanthum [Mehlis]. - Syn.: Strongylus tetracanthus Mehlis, 1831; Sel. quadridentutum Duj., 184 ; ; Scl.
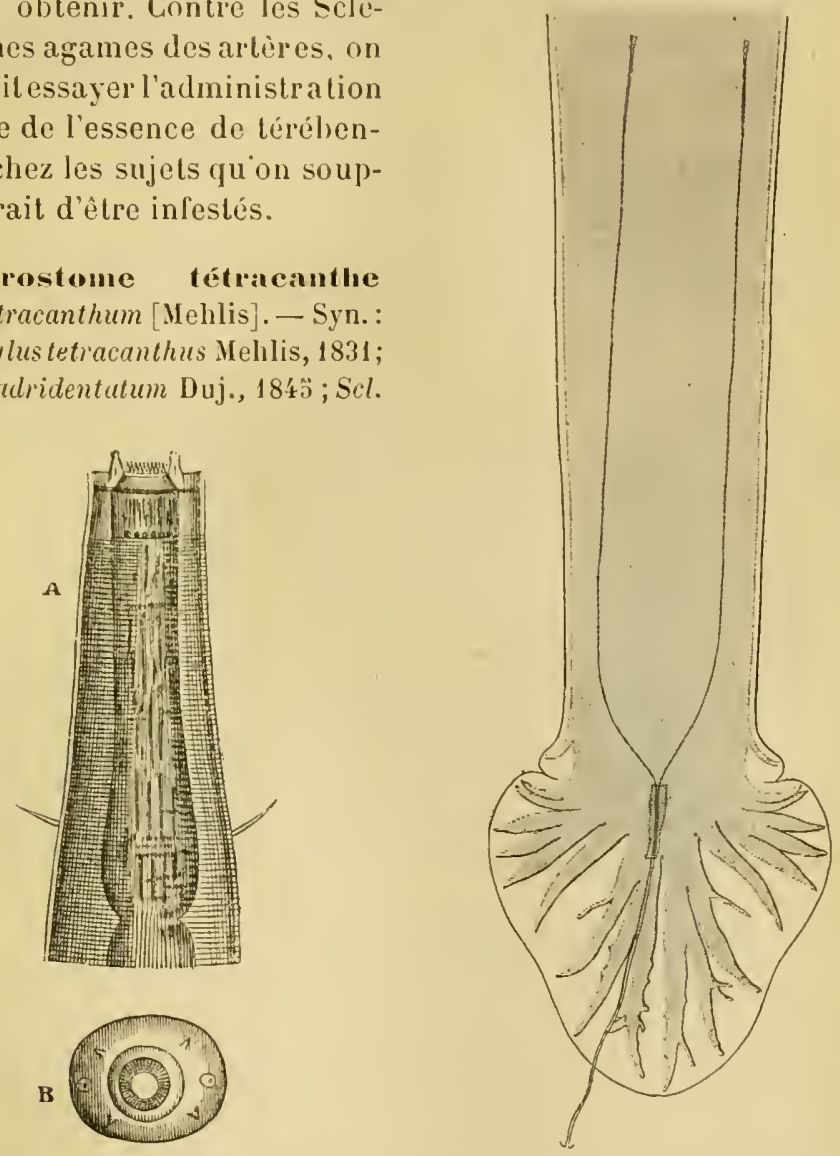

Fig. 319 - Extrémité antérieure du sčlerostoma letracanthum, d'après Schneider. A, vuepar la face dorsale. B, vue de devant. Grossissement : 93 diamèlres.

Fig. 320. - Extrémilé caudale du Scléroslome tétracanthe, grossie 30 fois (Orig.).

tetracanthum Dies., 183̈1; Scl. hexacanthum Wedl, 1836; Cyathostomum tetracanthum Molin, 1860). - Corps blanchàtŕe nuancé de rouge, un peu atténué 
en avant. Bouche munie d'un rebord cuticulaire saillant qui porte six papilles : deux latérales, puissantes, soulevant la cuticule, et quatre submédianes, plus grêles, la traversant. Capsule buccale cylindroïde, munie en avant d'un cercle de denticules triangulaires. Olisophage en massue, offrant une constriction en avant et une autre en arrière. Intestin divisé en une série de compartiments successifs par des constrictions transversales, et teinté en noir par des granulations pigmentaires. Múle long tantôt de 8 à 10 millimètres, tantôt de 12 à 17 millimètres; bourse caudale offrant un lobe postérieur plus ou moins allongé, et deux lobes latėaux principaux réunis par un lobe antérieur; côtes postérieures à trois branches rameuses; moyennes dédoublées, antérieures bifides. Deux spicules très longs et grèles, crochus à l'extrémité, glissant sur une pièce chitineuse. Femelle longue tantòt de 10 à 12 millimètres, tantôt de 14 à 24 millimètres; queue offrant des saillies ventrales et une pointe relevée; vulve un peu en avant de l'anus. OEufs ellipsoïdes, longs de 90 à $110 \mu$, larges de 4 à à $50 \mu$, en segmentation au moment de la ponte.

Celle espèce, longtemps confondue avec la précédente, vit également dans le cacum et parfois dans le côlon. Elle présente aussi, surtout dans l'armature buccale, de nombreuses variations individuelles, en rapport peut-être avec les phases de développement; c'est ainsi que divers auteurs n'ont vu que quatre papilles, d'où le nom spécifique.

D’après C. Baillet, les œufs éclosent dans l'eau après 4 à 10 jours, et dans les crottins après 3 ou 4 jours. Ils ne s'accroissent que dans ce dernier milieu. A la naissance, ils sont longs de 470 à $900 \mu$, et ressemblent assez à ceux du Scl.equinum; mais, au bout de deux ou trois jours, ils sont plus épais et ont une queue beaucoup plus longue; leurs mouvements sont en outre plus lents. Après 12 ou 103 jours, ils se préparentégalement à subir une mue. Vers l’âge de deux à trois mois, ils peuvent atteindre une longueur de 1 millimètre à $\mathbf{1}^{\mathrm{mm}}, \breve{5}$.

Giles a cru les voir se transformer alors en Rhabditis adultes (génération libre); mais il affirme le même fait en ce qui concerne l'Uncinaria duodenalis, et ses observations n'ont pas été mises suffisamment à l'abri des causes d'erreur pour qu'on puisse en accepter les résultats $(1)$.

Ils doivent probablement, à cet état, rentrer dans le tube digestif; mais ils ne semblent pas devoir passer par l'appareil circulatoire, ou on ne les a jamais rencontrés. On trouve assez souvent des individus agames enkystés sous la muqueuse du cæcum (Trichonema arcuatum Cobbold); mais, en France au moins, ces cas sont moins communs que ceux offerts par le $S c l$. equinum.

M. Bégné, de Saint-Servan, nous a communiqué des exemplaires de Selérostomes tétracanthes rejetés avec les excréments; ils étaient d'un

(1) G. M. J. GILEs, Some observations on the life-history of Sclerostomum tetracanthum Diesing, etc. Scientific Memoirs by Medical Officers of the Army of India. Part. VII. Calcutta, 1892. 
rouge vif et s'apprétaient seutement à subir la mue qui devait mettre en évidence les caractères sexuels extérieurs.

Inoffensifs quand ils sont peu abondants, les Selérostomes tétracanthes, quand ils samassent par milliers dans le cacum, sont susceptibles, dit-on, de déterminer une entérite hémorrhagique et des coliques mortelles; plus souvent ils produisent une forme grave d'anémie, capable d'entrainer la mort d'un grand nombre d'animaux, comme nous lavons observé aved $1 /$. Noeard sur des Chevaux de la Marne.

sclérostome robuste (Scl. robustum files, 1892). - Corps brun rougeàtre foncé, attémué aux extrénités. Extrémité antérieure un peu renllée. Bouche munie extérieurement de qualre papilles terminées clıcure par une pointe molle; bord de l'ouverture buccale découpé en créuclures, en dedans desquelles on roit un cerele de denticules plus grands et moins nombreux ienviron 18) que che\% le Scl. equinum. Une autre série de denticules (environ 48), placés horizontalement et se joignant presque au centre, garnit intérieurement la cavité de la bouche. Capsule buccale cupuliforme, portant en arrière trois dents puissantes, logées dans lit partie antérieure de l'wesophage. Mále long de t3 nillimètres environ; bourse caudale légèrement bilobée; ¿òtes postérieures à trois branches, réunies en un tronc comnun et pair arec la postérieure externe; moyeunes, antérieures externes et antérieures formant ensemble un autre groupe de clıaque cóté; moyennes dédoublées, à branche postérieure gibbeuse; antérieures fendnes. Femelle longue d'environ 22 millimètres ; extrémité caudale brusquement atténuée; anus près de la pointe; vulve à 1 millimèlre environ en avant de l'anus. OHufs ellipsoïdes, longs de $13 ̈ 2 \mu$, larges de $82 \mu$, en morula au moment de la ponte.

Trouvé dans le gros intestin, et en particulier dans le cacum du Cheval et du Mulet, à Shillong (Indes anglaises), par Giles (1). Se nourril de sang el concourt ainsi à produire une anémie grave chez ces animaux.

Selérostome liypostome ( $\mathrm{Scl}$. hypostomum [Rud.]. - Syn.: Str. ovinus Fabr., 1788; Str. hypostomus Rud., 1819; Scl. hypostomum Duj., 184z̈; Dochmius hypostomus Dies., 1851. - Priorité: Sclerostoma ovinum). - Corps blanc, cylindrique, raide. Extrémité céphalique renflée, un peu recourbée vers la face ventrale. Bouche orbiculaire, ouverte obliquement, munie d'une double

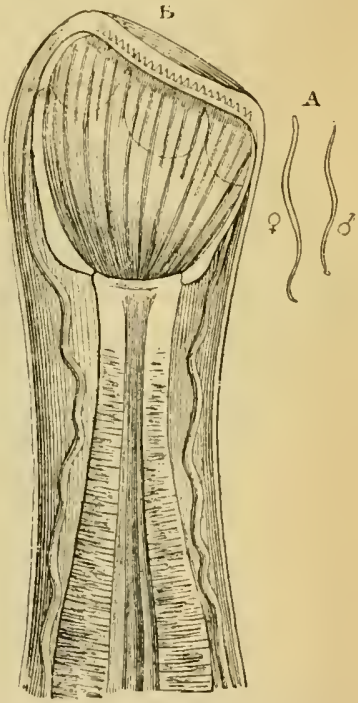

Fig. 321. - Selírostome hypostome. - A, mâle et femelle, grandenr naturelle. B, extrémité céphalique, vue de còté, grossie 50 fois (Orig.). rangée de denticules étroits et aiğus. Six papilles. Iále long de 10 à 20 millimètres; bourse caudale courte, obliquement coupée; cótes postérieures

(1) G. II. J. Gills, On a new sclerostome from the large intestine of Mules. Scientific Memoirs by Medical Officers of the Army of India. Part. VII. Calcutta, 1892 (avec une pl.). 
bifurquées, les moyennes fendues, les antérieures dédoublées. Deux spicules grêles, striés en travers, longs de $1^{\mathrm{mm}}, 3$ à $1^{\mathrm{mm}}, \tilde{}$, gllissant sur une pièce chitineuse. Femelle longue de 13 à 23 millimètres; queue presque toujours encroûtée d'une substance jaune noiràtre, et terminée par une pointe courte qui se relève vers la surface dorsale; vulve située un peu en avant de l'anus. OEufs ellipsoïdes, longs de 90 à $110 \mu$, larges de 4 ä ả $65 \mu$, en segmentation au moment de la ponte.

Ce Ver est assez commun dans le gros intestin du Mouton et de la Chèvre, ainsi que de divers Ruminants sauvages: Cerf, Chevreuil, Daim, Argali, Antilopes. Nous l'avons observé chez le Chabin.

D'après les recherches de R. Leuckart et de C. Baillet, les phases extérieures de l'évolution sont semblables à celles du Sclérostome du Cheval. L'éclosion a lieu en quatre ou cinq jours dans l'eau, et les embryons mesırent alors 350 a $500 \mu$; leur queue est relativement courle; ils ont un aspect rhabditiforme et possèdent par conséquent deux renflements asophagiens assez faibles, le postérieur pourvu de dents. Ils s'accroissent dans les crottins humides et, vers la fin de la troisième semaine, subissent une mue après laquelle les dents du bulbe œesophagien postérieur ont disparu, en mème temps que la queue s'est nolablement raccourcie. Au bout de deux mois, ils ont acquis une longueur de $0^{\mathrm{mm}}, 66$ à $0^{\mathrm{mm}}, 78$. Ils doivent probablement alors rentrer dans le tube digestif du Mouton; pourtant Leuckart a échoué dans sa tentative d'infester un agneau.

D'après ce dernier auteur, le Sclérostome du Mouton se nourrirait, comme

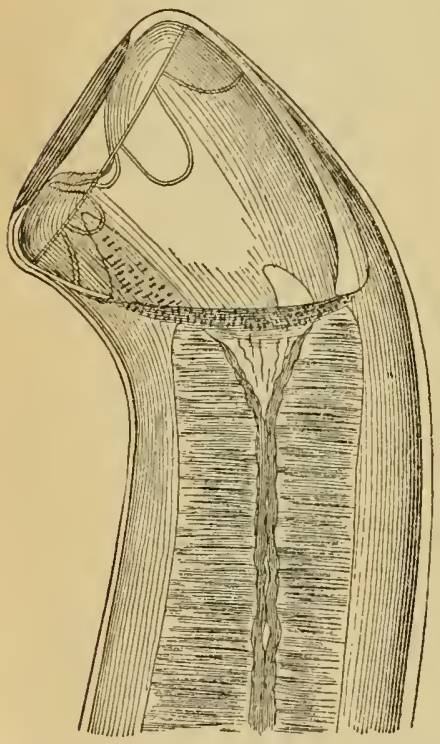

Fig. 322. - Uncinaria cernua : extrémité antérieure, rue de côté, grossie 150 fois (Orig.).

l'Oxyure du Cheval, aux dépens des matières vérétales contenues dans le gros intestin. Cependant, quelques observateurs l'ont accusé d'attaquer la muqueuse et de produire une irritation intestinale ou mème une anémie mortelle.

Genre Uncinaire (Uncinaria Frölich, 1789. - Syn.: Ankylostoma Dubini, 18.13 ; Dochmius Duj., 1845). - Extrémité antérieure recourbée vers la face dorsale. Bouche ovalaire, ouverte obliquement, limitée par un limbe transparent et suivi d'une capsule buccale chitineuse dont la paroi dorsale, plus courte que la ventrale, est soutenue par une cote conique dont la pointe fait quelquefois saillie à l'intérieur de la cavité. Au fond de la capsule existent, sur la paroi ventrale, deux dents ou lancettes tranchantes; vers le bord libre, cette même paroi porte, de chaque côté de la ligne médiane, des lames chitineuses ou dents souvent recourbées en crochet à l'extrémité; le bord dorsal peut être également denté. 
Les Uncinaires, plus connues sous les noms d'Ankylostomes ou de Dochmies, virent en parasiles dans l'intestin grêle et surtout dans le

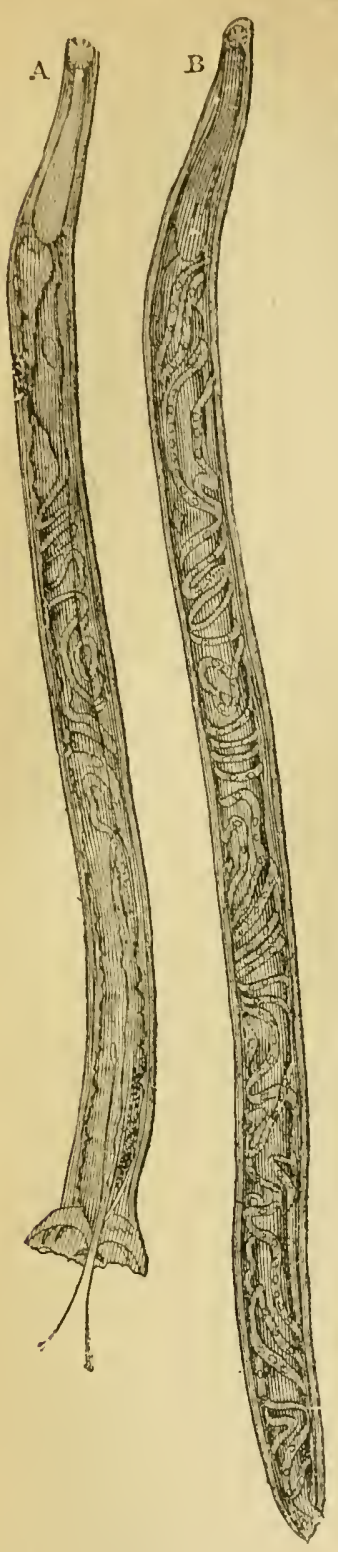

Fig. 323 - Ankılostome duodénal Lincinaria duodenalis), grossi, d'après E. Perroncito. - A, màle. $\boldsymbol{b}$, femclle. duodénum des Mammifères.

Uncinaire duodénale (Unc. duodenalis [Dubini]. - Syn. : Anchylostoma duodenale Dub., 18:3; Strongylus quadridentatus von Siebold, 1851; Dochmius Anchylostomum Molin, 1860; Sclerostoma duodenale Cobbold, 186'; Str. duodenalis Schn., 1866; 0 . duodenalis L.euck., 1876 ; Unc. duodenalis Raill., 1883̈). Corps blanc rosé, cylindrique, un peu atténué en avant. Capsule buccale légèrement renflée, à levix paires de dents recourbées en crochet; còle dorsale non saillante dans la cavité. Deux papilles opposées vers le sixième antérieur du corps. Male long de 8 à 11 millimètres; bourse caudale offrant un lobe dorsal faible et deux lobes latéraux bien développés, réunis en avant par un lobe ventral surbaissé ; còtes postérieures tridigitées, naissant d'un tronc qui offre à peu près le double de leur longueur; moyennes largement dédoublées; antérieures fendues. Deux spicules longs et grèles, glissant dans une pièce chitineuse creusée d'une rainure. Femelle longue de 10 à 18 millimètres; queue en pointe obtuse, prolongée par un mucron aiğu; vulve située vers le tiers postérieur du corps. OEufs ellipsoïdes, à coque mince, longrs de $52 \mu$, larges de $32 \mu$, en segmentation au moment de la ponte.

Ce Nématode habite lintestin grêle de

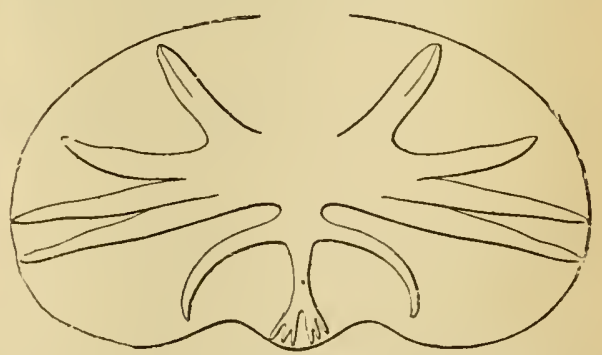

Fig. 324. - Bourse caudale de l'Ankyloslome duodénal, grossie 50 fois (demi-schénatique).

l'Homme et de quelques Singes anthropoïdes (Gorilla gina, Hylobates lar). Il a été découvert en 1838 dans l'intestin d'une jeune paysanne Ratlliet. - Zoologie. 
morte à l'hôpital de Milan, par Dubini, qui lui donna le nom d'An-

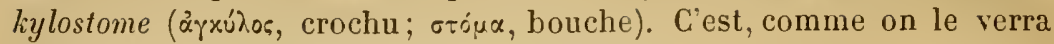
plus loin, un parasite des plus dangereux.

Évolution. -- Les premières phases du développement de l'Ankylostome duodénal ont été étudiées principalement par Grassi et Parona, Perroncito, Leichtenstern. Elles sont assez semblables à celles de l'Ankylostome du Chien, que Leuckart avait fait connaître antérieure-

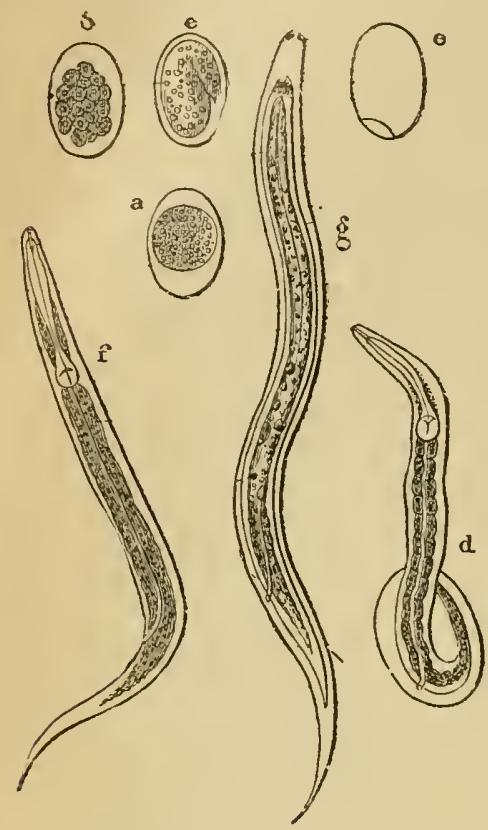

Fig. 325. - Développement de l'Ankylostome duodẻnal, d’après E. Perroncito. - $a$, œuf non segmenté. $b$, formation de la morula. $c$, apparition de l'embryon, $d$, éclosion. $e$, coque vide. $f$, larve dans la première phase de sa vie libre. $g$, phase ultime : larve encapsulée. ment.

La segmentation des œufs (fig. 325) commence dans les utérus, mais se continue tout au plus jusqu'au stade morula $(b)$. Ces œufs n'évoluent pas complètement dans l'intestin de l'Homme; ils doivent sortir de l'organisme, et sont évacués avec les fèces. Leur. incubation ne s'effectue bien que dans un milieu demi solide: dans les matières fécales pures ou additionnées d'albumine, dans la terre humide, etc. Perroncito se servait avantageusement de morceaux de viande. L'éclosion ne se produit pas dans l'eau, et les larves mêmes ne rivent pas dans ce milieu avant d'avoir subi ou préparé leur mue. Au bout de 12 à 15 heures d'incubation à la température de 20 ou $30^{\circ}$, quelques embryons éclosent; la plupart sont éclos après deux à quatre jours $(d, e)$.

Au moment de la naissance, les larves mesurent $210 \mu$ de long sur $44 \mu$ de large; leur extrémité postérieure est allongée en une queue effilée $(f)$. Elles possèdent une tête trilobée ; la cavité buccale tubuleuse conduit dans un osophage épais, musculeux, offrant un renflement antérieur atténué en arrière et un renflement ou bulbe postérieur muni intérieurement de trois dents chitineuses (larve rhabditiforme). L'intestin aboutit à un anus situé vers la naissance de la queue. Un peu au-dessus, on observe un corpuscule ovoïde qui représente le rudiment génital.

Ces larves rhabditiformes s'accroissent très vite, se nourrissant aux dépens des substances organiques du milieu; elles gagnent chaque jour 80 à $100 \mu$ en longueur et $2 \mu$ en largeur. Le troisième jour, elles 
subissentune première mue, par suite de laquelle elles perdent la pointe en alène de la queue. $\Lambda$ u bout de $t$ i 8 jours, elles ont aequis leurs dimensions maximum : òto $\mu$ de longueur sur 2 ' $\mu$ d'épaisseur. Une seconde mue se produit alors, après laquelle on constate que le renflement asophagien postérieur a perdu ses dents chitineuses $(g)$; l'ensemble de l'asoplage offre ensuite un aspect granuleux, l'intestin est rectiligne, le rudiment génital plus developpé; deux papilles cervicales sont apparues. Comme chez les Sclérostomes, il est commun de voir cette larre demeurer enlermée dans la peau de sa mue; elle continue cependant à s'y mouroir avec viracité et à perfectionner son organisation. Puis, ce tégument exterieur (capsule) s'imprègne de sels calcaires et devient en général riggide. Cette persistance de la peau de la mue a été considérée par Perroncito et plusieurs autres comme un phénomène normal (encapsulement) correspondant ì la phase d'enkystement des Vers à transmigrations. Les larves ainsi protégées sont en effet douées d'une grande résistance vitale; elles peuvent, en particulier, survirre à une dessiccation de 2 ' heures au moins. Elles seraient donc susceptibles d'être transportées à distance par le vent, en rertu de leur ténuité, arec les poussières en suspension dans l'air, et d’infester des localites jusqu'alors saines. Elles virent d'ailleurs très activement dans l'eau, et l'on conçoit qu'elles puissent ainsi, par les ruisseaux ou les rivières, gagner des points très éloignés; elles ne vivent bien cependant que dans l'eau vaseuse ou dans la boue; dans l'eau pure, elles ne tardent pas à périr.

Il est probable que, dans les conditions naturelles, les larves subissent au milieu des fèces les premières phases de leur développement, et qu'après leur seconde mue elles sont — encapsulées ou non - entraînées dans les eaux pour être ramenées dans le tube digestif de l'Homme, soit arec la boue qui souille les mains ou les objets qu'on porte à la bouche, soit avec les eaux de boisson.

Elles doivent subir de nouvelles mues dans le tube digestif, pour parvenir à l'état adulte dans l'espace de quelques semaines.

Leichtenstern a prétendu qu'un certain nombre de larves, plus résistantes que les autres, seraient aptes à se transformer en adultes rhabditiformes, se reproduisant indéfiniment en liberté; mais ces assertions manquent jusqu'à présent de tout contrôle.

Organisation. - La cuticule est formée de deux couches dont l'externe, plus épaisse, est délicatement striée en travers. On distingue à la surface du corps plusieurs papilles, dont leux latérales situées vers le milieu de l'œsopliage.

Comme chez beaucoup de Strongylidés, il existe deux glandes cervicales, fusiformes, unicellulaires, atténuées antérieurement en un canal excréteur qui va s'ouvrir au pore excréleur.

La musculature appartient, on le sait déji, au type méromyaire; mais, outre la couche de cellules périphériques, on peut remarquer un double 
système de fibres transversales qui s'étendent dans toute la longueur du corps, dans la moitié supérieure et dans la moitié inférieure de la cavité générale.

Les quatre lignes longitudinales sont bien distinctes; les deux latérales, plus larges, se montrent formées chacune de deux faisceaux de substance granuleuse creusés d'un canal central et séparés par un troisième canal. Ce dernier représente le canal excréteur; il va s'unir à son congénère en avant pour déboucher au pore excréteur, en même temps que les glandes cervicales.

On ne connaît encore bien du système nerveux que le collier œsophagien, situé un peu en avant de la partie moyenne de l'œsophage.

L'appareil digestif offre d'abord à considérer la capsule buccale. Celle-ci consiste en une coque chitineuse ovoïde, redressée vers la face dorsale et enchâssée dans la partie antérieure de l'œsophage. Son orifice antérieur ou buccal a la forme d'une ellipse transversale; il est entouré d'un bord labial transparent, mais rigide et immobile; son orifice postérieur, également

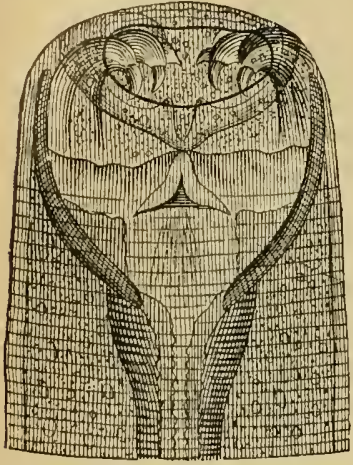

Fig. 326. - Ankyloslome duodénal : extrémité céphalique vue par la face dorsale, fortement grossie, d'après E. Perroncito. elliptique, donne entrée dans l'oesophage. - La face ventrale de la capsule est fortement bombée et entière; la face dorsale, plus courte, est divisée en deux par une fente élargie en arrière et recouverte d'une lamelle ou còte chitineuse triangulaire, laquelle est abrilée ellemême sous une autre lamelle plus large et plus courte. En avant, le bord dorsal est creusé d'une échancrure qui sépare deux petites dents saillantes; du còté ventral, sont enchàssées deux paires de dents, disposées symétriquement de chaque cùté de la ligne médiane et offrant la forme de crochets recourbés vers l'intérieur de la capsule : l'interne ou inférieure, plus petite que l'autre, porte une petite saillie latérale. Enfin, le fond de la capsule présente encore, vers la face ventrale, deux lames puissantes ou lancettes, de forme triangulaire, dont le rỏle paraît être d'inciser les tissus introduits par succion dans la capsule.

C'est ici qu'il convient de signaler les deux glandes céphaliques, analogues aux glandes cervicales, mais reportées plus en arrière et allant s'ouvrir dans la bouche.

L'œsophage, très musculeux et renflé en massue dans sa région postérieure, a une lumière triquètre; il s'enfonce largement dans l'intestin, mais offre à sa terminaison une valvule à trois lobes (appendices pyloriques des auteurs) destinée à empêcher le retour des aliments dans son canal. - L'intestin, à peu près rectiligne, se termine par un rectum court et étroit qui. chez la femelle, s'ouvre sur la face ventrale à la base de la pointe caudale, et, chez le màle, débouche, en commun avec le canal déférent, à l'extrémité d'une papille située au fond de la bourse copulatrice, après avoir reçu les canaux excréteurs de deux glandes anales. L'Ankylostome se nourrit de sang, et on retrouve en effet cette substance dans l'intestin quand on examine les exemplaires immédiatement après leur expulsion.

L'apparcil reproducteur mâle se compose d'un tube testiculaire, naissant 
un peu cn arrière du milieu du corps, savançant jusqu’au tiers antérieur, puis se repliant en arrière, en décrivant quelques sinuosités. Ce tube, revenu dans la région moyenne, se jette dans une large résicule séminale, qui se continue par un canal éjaculateur itténué en arrière, ò̀ il s'unit au rectum pour constituer un cloarue. - L.es denx spicules, grêles et striés en trarers, sont un peu élaruis à la base et effilés à l'extrémité; ils sont renfermés dans une longue gaine de tissu granuleux et sengagent, avant de sortir par l'orifice cloacal, dans une pièce chitineuse creusée d'une rainure, comme chez les sclérostomes. Nous n'avons pas à revenir sur la bourse caudale; nous noterons seulement que chacune des còtes offre à son sommet une petite papille.

Les organes femelles comprennent deux tubes qui naissent séparément en cul-de-sac, et se disliuguent en antérieur et postérieur. L'ovaire antérieur débute au nireau de la terminaison de l'osophage, se porte en arrière jusqu'auprès de l'anus, remonte jusuqu'ì l'origine de l'intestin et se replie encore pour former l'utérus antérieur. l'ovaire postérieur prend naissance un peu en arrière du précédent, s'étend de la jusque vers le milieu du corps, se réfléchit, gagne presque son point de départ, et retourne encore en arrière, où il se recourbe en lormant l'utérus postérieur. Les deux tubes utérins, plus larges, s'avancent à la rencontre l'un de l'autre, et de leur réunion nait un court canal transversal qu'on regarde comme le vagin. A l'origine des utérus, on trouve des ovules mèlés à des spermatozoïdes; c'est donc là qu'a lieu la fécondation; la coque se forme ensuite, et d'ordinaire l'œuf commence mème sa segmentation avant d’ètre expulsé par le vagin.

L'accouplement, qui parait ètre d'assez longue durée, a lieu à angle aigu, dans l'intestin: le màle fixe sa bourse caudale sur la vulve de la femelle et introduit ses spicules dans le vagin.

Distribution géographique. - L'Uncinaire duodénale parait ètre répandue sur presque toute la surface du globe. En Europe, elle a été rencontrée non seulement en Italie, mais en France, en Autriche-Ilongrie, en Allemagne, en Belgique, en Espagne. Elle n'est pas rare dans l'Asie orientale et méridionale, en Afrique, en Amérique, en Océanie.

Pathologie. - Le parasite habite, non seulement le duodénum, mais surtout les deux tiers antérieurs du jéjunum ; plus rarement j] se rencontre dans liléon. Il se fixe à la muqueuse, qu il entame pour blesser les vaisseaux sanguins, et dans laquelle il pénètre mème dans certains cas. Il suce en partie le sang qui s'écoule des blessures; le reste s'écoule dans l'intestin, qui se montre alors rempli d'un liquide épais, odorant, de teinte rouge sombre. Si l'infestation est intense ou répétée, et si le sujet envahi se trouve d'ailleurs soumis à de mauvaises conditions hygiéniques, on conçoit qu'il puisse survenir des troubles graves. La maladie ainsi produite, et qu’il convient de désigner sous le noin d'uncinariose, offre les caractères d'une anémie pernicieuse; le patient va s'affaiblissant peu à peu, souvent avec des troubles digestifs, et finit dans bien des cas par succomber. F. Lussana, du reste, a prétendu que les Vers inoculent des produits toxiques, propres à dissoudre l'hémoğlobine. 
La maladie est commune chez les mineurs, d'où le nom d'anémic des mineur's sous lequel on la désignait bien avant d'en connaître la cause. C'est en 1879 que Graziadei trouva le parasite à l'autopsie d'un ouvrier anémique qui avait travaillé au percement du SaintGothard. Peu après. Perroncito proclamait que l'anémie qui sévissait sur une grande échelle dans ce milieu était déterminée par les Ankylostomes; au bout de quelques années, il constatait également la présence de ces Vers chez les mineurs de Saint-Étienne; enfin, des observations semblables étaient faites à Anzin, à Commentry, etc. - Grassi et Parona leconnurent ensuite que le même Ver détermine l'anémie des briquetier's, observée non seulement en Italie, mais en Allemagne et en Belgique. Puis on le retrouva encore chez les ouvriers des rizières et des solfatares, provoquant partout des troubles du même ordre.

L'Ankylostome duodénal est peut-être plus répandu et plus redoutable encore dans les pays chauds. Dès 18ə̈1, Griesinger le reconnaissait comme la cause unique de la chlorose d'Égypte. Aux Antilles, il occasionne la cachexie aqueuse ou mal-cœur des Nègres; au Brésil et dans l'Afrique équatoriale, l'anémie intertropicale, etc.

L'Ankylostome peut sans doute vivre plusieurs années dans l'intestin de l'Homme. A l'autopsie des sujets envahis, on en a trouvé souvent des centaines et parfois plusieurs milliers. Le diagnostic peut s'établir par l'examen des selles, où l'on rencontre des œufs en plus ou moins grande abondance, mais très rarement les Vers eux-mêmes.

La prophylaxie de l'uncinariose est basée tout entière sur une hygiène bien entendue : empêcher les malades de disséminer leurs excréments, faire usage d'eau bouillie ou filtrée, etc. Quant au traitement, il comporte l'usage d'anthelminthiques puissants, car les Vers sont fort difticiles à détacher de la muqueuse. L'extrait éthéré de fougère màle passe pour donner de bons résultats. Il importe ensuite de relever les forces par une bonne alimentation et une médication appropriée.

Uneinaire trigonocéphale (Unc. trigonocephala [Rud.]. - Syn. : Unc. vulpis Frölich, 1789; Strongylus trigonocephalus et tetragonocephalus Rud., 1809; Dochmius trigonocephalus Duj., 18千5; Selerostoma caninum Ercolani, 1859 ; Dochmius Bulsami Grassi et Parona, 1877). - Corps

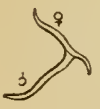

Fig. 327. - Uncinaire trigonocéphale, mâle et femelle accouplés, grandeur naturelle. blanchàtre. Capsule buccale un peu renflée, portant de chaque côté de la face ventrale trois dents recourbées en crochet, dont les dimensions vont en décroissant de dessus en dessous. Deux papilles latérales au niveau du tiers postérieur de l'œsophage. Mále long de 9 à 12 millimètres; bourse caudale et côtes sur le mème type que dans l'espèce précédente; còtes postérieures naissant d'un tronc trois fois aussi long qu'elles. Deux spicules grêles, longs de $0^{\mathrm{mm}}, 6$ à $0^{\mathrm{mm}}, 8$. Femelle longue de 9 à 21 millimètres, le plus souvent de 15 à 20 ; queue obtuse, prolongée par un mucron aigu; vulve vers le tiers 
postérieur du corps. (Wufs ellipsoïdes, de $7 x_{\text {à }} 8 \dot{4} \mu$ sur 48 a $5 \dot{4}$, en segmentalion au moment de la ponte.

L'Uncinaire trigonocéphale habite l'intestin grèle du Chien et du Chat domestiques, du Loup (C'unis lupus), du Renard commun

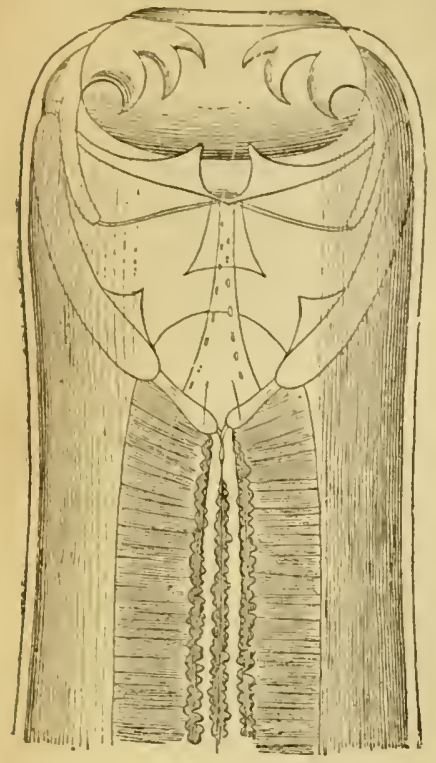

Fig. 328. - Uncinaire trigonocéphale : extrémité céplıalique vue par la face dorsale, grossie 1 50 fois (Orig.). (Vulpes vulgaris), du Renard des pampas ( $V$. Azarie) et du Renard bleu (V. lagopus), du Fennec (Mcgalotis cerdo) et du Guépard à crinière (Cynailurus jubalus).

Érolution. - Dès 186̋̈, Leuckart faisait connaitre les diverses phases de l'érolution de cette espèce, qui offrent les

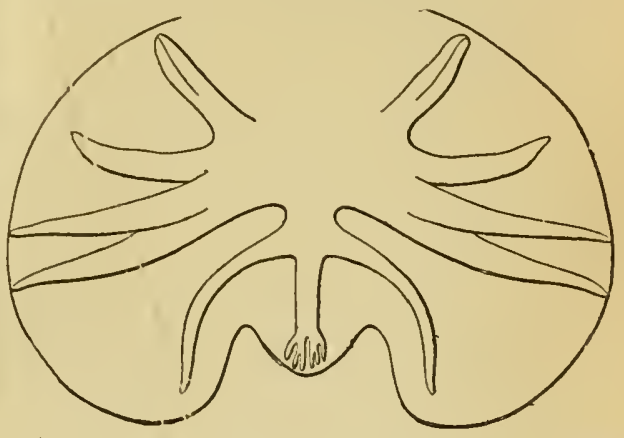

Fig. 329. - Bourse caudale de l'Uncinaire trigonocéphale' grossie 50 fois (demi-scliématique).

plus grandes analogies arec celles de l'Uncinaire duodénale.

Le développement de l'embryon s'effectue dans la terre humide, et l'éclosion a lieu au bout de trois à quatre jours en été, de quatre à six en hiver. Les embryons rhabditiformes mesurent à la naissance 300 à $340 \mu$ de long sur $9 \ddot{3} \mu$ d'épaisseur : ils sont un peu atténués en avant, tandis que leur extrémité postérieure s'effile en une queue longue et grêle, dont la pointe forme un appendice distinct. Le troisième jour après l'éclosion, ils subissent une mue, au cours de laquelle disparait la pointe caudale. Au bout d'une
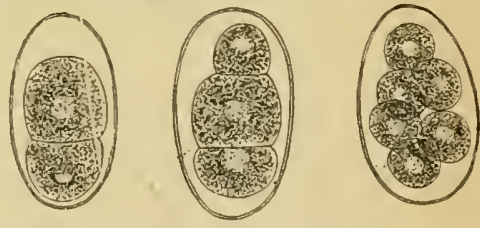

Fig. 330. - (Eufs de IUncinaire trigonocéphale, à divers degrós de segmentation, recueillis dans les fices du Chien. Grossissentent : 300 diamètres (Orig.). semaine environ, on constate que le corps s'est étiré, de manière à mesurer š60 $\mu$ de long sur $28 \mu$ de large. Une seconde mue survient alors, amenant une modification du bulbe osophagien postérieur : celui-ci a perdu ses dents: sa texture si nettement musculeuse a pris 
un aspect granuleux, et l'extrémité postérieure de l'œsophage montre deux vésicules transparentes.

La période de vie libre est alors terminée, car les larves, par suite de la perte de leur armature dentaire, sont devenues incapables de se mouvoir; elles peuvent cependant continuer à vivre dans la vase pendant des semaines et des mois, aux dépens des matériaux préalablement amassés dans leurs tissus.

Leuckart supposait d'abord qu'elles devaient passer par un hôte intermédiaire, avant de revenir dans l'intestin du Chien, et il tenta d'infester des animaux inférieurs, notamment des Mollusques et des Insectes. Après plusieurs semaines, il trouva, parmi les Limnées et les Physes soumises à l'expérience, deux individus hébergeant ces larves; mais elles n'avaient subi aucune modification, et les essais d'infestation du Chien par l'intermédiaire de ces Mollusques ne donnèrent aucun résultat.

Il s'agissait donc d'une migration purement accidentelle : et en effet, l'introduction directe, dans le tube digestif du Chien, des Larves au troisième stade contenues dans la vase, montra que leur développement se poursuivait, sans qu'il fût aucunement besoin d'un hôte intermédiaire.

Pendant une huitaine de jours, les parasites, qui rampent sur la muqueuse gastrique et plus spécialement dans la moitié cardiaque, ne présentent guère de modifications dans leur structure, mais s'accroissent, tout en conservant leur forme gracile, jusqu'à acquérir 1 millimètre de long sur $30 \mu$ de large.

C'est seulement après neuf ou dix jours qu'ils se débarrassent de leur ancienne cuticule et offrent un nouveau stade de développement, caractérisé par une forme plus ramassée et par la présence d'une capsule buccale chitineuse; celle-ci, toutefois, ne représente pas la capsule définitive: ce n'est guère qu'un simple revêtement de la cavité buccale cupuliforme, se continuant en arrière avec la couche cornée qui tapisse l'œsophaģe. Les organes sexuels sont encore très rudimentaires, quoique plus développés que dans la phase précédente.

Ce stade dure à peine trois ou quatre jours; mais il permet cependant aux Vers d'acquérir une taille de 2 millimètres. Une douzaine de jours après l'infestation, ils subissent encore une mue, à la suite de laquelle ils prennent leurs caractères définitifs. La capsule buccale se développe en arrière de la cavité primitive, et se montre d'abord comme un revêtement épais et incolore, formé de pièces séparées. Deux jours plus lard, les jeunes Uncinaires mesurent déjà 3 à $ّ$ millimètres. Leurs organes génitaux sont entièrement développés chez les mâles, quoique sans spermatozoïdes; l'appareil femelle a une évolution un peu plus lente.

Dans les conditions naturelles, c'est évidemment dans les flaques 
d'eau que les larves accomplissent en général leurs phases de vie libre, et c'est en buvant cette eau que les Chiens s'infestent.

Pathologie. - L'Uncinaire trigonocéphale agit chez le Chien de la même manière que l'Unciuaire duodénale chez l'Homme, et dès 1879 Trasbot et Railiet (1) ont rattaché à la présence de ce Ver une forme grave d’anémie dont sont fréquemment atteints les Chiens de meute.

Cette uncinariose, encore désignée sous le nom d'anémie pernicieuse des Chiens de meute, ou de saignement de nez, se traduit par un affaiblissement progressif des animaux, qui maigrissent et deviennent profondément anémiques. Somvent il se produit des épistaxis. $\Lambda$ la dernière période de la maladie, on voit survenir de l'odème des membres, de la diarrhée et même de la dysenterie. Les Chiens ineurent dans le coma ou dans les convulsions. - A l'autopsie, on trouve, outre les lésions générales dé l'anémie, une irritation intense de la muqueuse intestinale, qui est piquetée de points hémorrhagiques. Les ganglions mésentériques sont hypertrophiés.

L'uncinariose des Chiens de meute est très rebelle à la plupart des anthelminthiques; aussi convient-il d'insister sur la prophylaxie. Nous avons constaté que les Anliylostomes se développent dans des chenils relativement secs, et nous pensons qu'il faut détruire les oufs et les embryons par des substances douées d'une action énergique, comme l'eau coupée d'acide sulfurique.

C. Parona et B. Grassi ont montré en 1877 qu'il existe chez le Chat une affection analogue, connue en Italie sous le nom de tifo dei Gatti. Ces auteur's en attribuaient le développement à une espèce particulière de Dochmie, qu'ils appelaient Dochmius Balsami. J'ai pu m'assurer

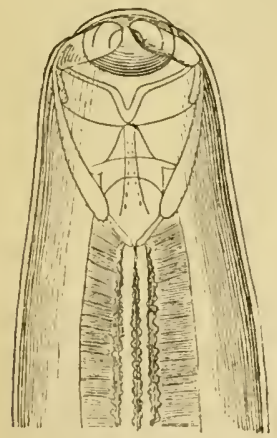

Fig. 331. - Uncindire slénocéphlıale : catrémité céphalique vue par la face dorsale, grossie 150 fois (Orig.). de visu, grâce à l'obligeance du professeur Parona, qu'il s'agissait en réalité de I'Unc. trigonocephala.

Uncinaire sténocéphale (Unc. stenocephala Raill. - Syn. : Dochmius

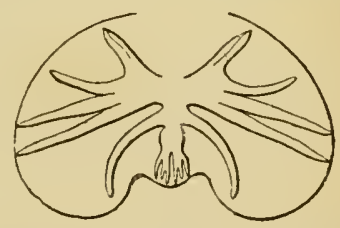

Fig. 332. - Bourse caudale de l'Uncinaire sténocéphale, grossie 50 fois (demi-schémalique).

stenocephalus Raill., 1834). - Corps plus grrèle que dans l'espèce précédente. Extrémité antérieure assez étroite. Capsule buccale portant de cliaque còté de sa paroi ventrale une lame chilineuse à tranchant arrondi, au-dessous

(1) Bulletin de Ia Soc. centr. de méd. vétér., 1880, p. 266. 
de laquelle on distingue une dent recourbée en crochet. Le bord dorsal offre une dépression médiane, mais pas de dents saillantes. Mâle long de 6 à 8 millimètres; bourse caudale et còtes sur le même type que dans les espèces précédentes; côtes postérieures naissant d'un tronc de mème longueur qu'elles. Deux spicules grêles, longs de 520 à $750 \mu$. Femelle longue de 8 à 10 millimètres; queue prolongée par un mucron aigu; vulve vers le tiers postérieur du corps. OEufs ellipsoïdes, de 63 à 76 « sur 32 à 38 .

Nous avons rencontré cette espèce, en compagnie de la précédente, dans l'intestin du Chien. Elle nous parait jouer un rôle aussi actif dans la production de l'anémie des meutes.

Uncinaire courbée (Unc. cernua [Creplin]. - Syn. : Strongylus cermus Crepl., 1829; Monodontus Wedlii Molin, 1860; Dochm. cernuus C. Baillet, 1868;

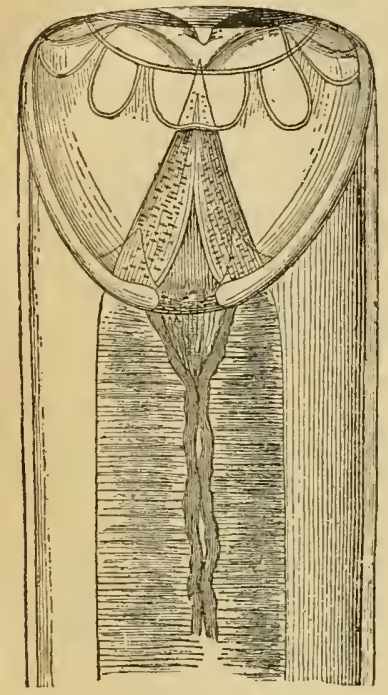

Fig. 333. - Uncinaire courbée : exirémité antérieure, vue par la face dorsale, grossie 150 fois (0rig.)

Unc. cernua Raill., 1883̈). - Corps jaunàtre ou rougeàtre, assez raide, atténué aux extrémités, surtout en avant. Extrémité antérieure mince, relevée en arrière. Bouche circulaire, s'ouvrant dans une capsule buccale ovoïde et armée de quatre dents, deux de chaque còté, dont la base est enfoncée dans la capsule et dont l'extrémité libre se recourbe en crochet vers l'intérieur de la cavité; les deux dents ventrales sont fortes el réfringentes, les dorsales étroites et peu distinctes; la còte dorsale enfonce également dans la capsule sa pointe conique; enfin, l'armature est complétée par les deux lancettes ventrales profondes. Six papilles buccales non saillantes. Mâle long de 1 à 18 millimètres; bourse caudale profonde, infundibuliforme, ne se laissant pas étendre sans se déchirer ; còtes asymétriques, celles d'un còté toujours plus longues que celles de l'autre; còtes postérieures bilobées, moyennes dédoublées, antérieures fendues. Spicules grêles, longs de 630 à $670 \mu$. Femelle longue de 20 à 28 millimètres; vulve située un peu en avant du milieu du corps. OEufs ellipsoïdes, longs de 80 à $83 \mu$, larges de 43 à $48 u$, en segmentation au moment de la ponte.

Intestin grêle et quelquefois gros intestin du Mouton, de la Chèvre et du Chamois. Dujardin et Diesing avaient à tort mis en doute l'existence de cette espèce : elle est tout à fait différente du Sclerostoma hypostomum. Molin en avait fait, non sans quelque raison, le type d'un genre à part (Monodontus), caractírisé par la puissante dent conique qui naît du fond de la capsule buccale et se dirige obliquement de la paroi dorsale vers l'intérieur de la bouche.

D'après C. Baillet, le développement de l'embryon se poursuit dans l'eau, où l'éclosion a lieu au bout de quatre à six jours. Cet embryon est rhabditiforme, atténué surtout en arrière et prolongé par une queue filiforme; il mesure à la naissance 330 à $400 \mu$ de long sur 23 à $30 \mu$ de large. 
C. Curtice signale la forme adulte comme se nourrissant de sang; sur les animaux récenıment abattus, il l’a toujours trourée attachée à la paroi de l'intestin.

Uncinaire radiée (Une. rudiata Rud. - Syn. : Strongylus raliatus Rud., 1803 ; Unc. radiata liaill., 1853). - Ver de teinte foncée. Capsule buccale conme chez I'Uncinaire courbée; à l'orilice postérieur de cette capsule, six dents recourbées en forme de crochets. Waile long de 10 à 16 millimètres; bourse caudale comme dans l'espèce précédente. Femelle longue de 24 à zS millimetres; vulve situie un peu en avant du milieu du corps.

Cette espèce, trouvée par Rudolpli dans le duodénum du Veau, n’a guère été étudiée que par Sclıneider. Elle a besoin d'ètre examinée à nouveau.

Cooper Curtice la signale en Amérique, dans l'intestin grèle du Bouf. Il a vu, en outre, une forme analogue ou identique dans l'intestin grèle du Porc.

Genre Ollulan (Ollulamus Leuckart, 1863). - Le nom de ce genre, qui ne comprend jusqu'à présent qu'une seule espèce, est tiré de l'aspect de la capsule buccale, qui est poculiforme (olla, urne). Les mâles possèdent deux courts spicules. Les femelles ont un seul ovaire.

Ollulan à trois pointes (0. tricuspis Leuck., 1863). - Petit Ver assez épais. OEsophage faiblement musculeux, d'apparence granuleuse. Male à bourse caudale bilobée, chaque lobe étant sontenu par six còtes ; deux spicules forts et courts, presque droits. Femelle. longue à peine de plus d'un millimètre et offrant trois pointes caudales; vulve un peu en avant de l'anus. Vivipare.

Ce Ver habite dans l'épaisseur de la muqueuse stomacale du Chat. On en trouve généralement un grand nombre d'individus, adultes et embryons, de sorte que la muqueuse irritée présente une teinte rouge et se montre souvent couverte d'ecchymoses. La femelle donne naissance directement ì des embryons d'une taille relativement colossale : ils mesurent en effet $320 \mu$ de long sur $10 ّ \mu$ de large; leur diamètre reste à peu près le même dans toute l'étendue, et leur courte queue est prolongée par une pointe ondulée. - Ces embryons ne demeurent que peu de temps dans l'estomac: les uns sont éliminés avec les excréments, tandis que les autres émigrent dans les tissus de leur hôte à la façon des Trichines. C'est ainsi que la plèvre, le diaphragme, le foie et surtout les poumons des Chats infestés se montrent parsemés de petits liystes, du diamètre de $0^{\mathrm{mm}}, 13 ̈$ à $0^{\mathrm{mm}}, 20$, dont chacun renferme un ou plusieurs embryons, logés isolément dans une cavité propre. L'ensemble de ces kystes offre parfois l'apparence d'une tuberculose miliaire, et donne lieu à une inflammation diffuse qui peut entraîner la mort. Le mucus bronchique, sanguinolent, contient d'ordinaire un grand nombre d'embryons mobiles. - Contrairement à ce qui s'observe pour les Trichines, les jeunes embryons ne saccroissent pas dans leur liyste; destinés tôt ou tard à périr, ils deviennent opaques, granuleux et se décomposent finalement en une masse 
VERS.

ovalaire ou arrondie qui renferme une gouttelette huileuse et pourrait être aisément prise pour un œuf ou pour une masse vitelline. La migration de ces embryons dans les viscères du Chat ne représente donc qu'un phénomène accidentel.

L'évolution ne peut se poursuivre, en réalité. que pour ceux qui sont rejetés au dehors, soit avec les excréments, soit avec le mucus bronchique. Leuckart, les ayant fait ingérer à une Souris, trouva en effet celle-ci infestée lorsqu'il la sacrifia au bout de six semaines : il existait de nombreux kystes, d'environ $0^{\mathrm{mm}}, 3$ de diamètre, dans les muscles du tronc, dans l'osophage, le cœur et le tissu conjonctif lâche de la région cervicale. Ces kystes étaient plus ronds que ceux des Trichines, et leur structure était aussi assez différente. Les Vers qu'ils renfermaient a vaient déjà subi quelques modifications et mesuraient $800 \mu$ de long sur $40 \mu$ de large. Leuckart fit manger à un Chat la chair de cette Souris, et au bout de huit jours il retrouva les parasites, non pas dans l'estomac, mais dans le cecum et le côlon. Ils n'avaient cependant subi aucune modificalion, ce qui porte à supposer qu'ils n'étaient pas encore assez mûrs au moment de l'expérience pour être aptes à se transformer en individus adultes.

D. Sous-famille des Physaloptérinés. - Polymyaires dont les mâles possèdent deux spicules inégaux et une bourse close, vésiculeuse, embrassant l'extrémité caudale tout entière.

Genre Physaloptère (Physaloptera Rud., 1819) - Ces Vers ont la bouche à deux lèvres égales et ordinairement latérales, munies chacune de trois papilles en dehors, armées de dents à l'extrémité et le plus souvent du còté interne. La cuticule forme en général des expansions variables en arrière des lèvres. L'extrémité postérieure du mîle est lancéolée, profondément excarée en cuiller et limitée de tous còtés par un rebord cuticulaire vésiculeux constituant une bourse caudale; elle porte deux sortes de papilles : les unes, externes (cótes), au nombre de quatre de chaque côté, situées au voisinage de l'anus, toujours pédonculées et soutenant la bourse caudale; les autres, internes, presque toujours sessiles; très généralement une papille impaire en avant de l'anus. Deux spicules inégaux. Les femelles ont d eux ovaires; la vulve s'ouvre vers la partie antérieure du corps. Ovipares.

Les Physaloptères habitent le tube digestif et de préférence l'estomac des Vertébrés carnivores : Mammifères, Oiseaux et Rieptiles (1).

Physaloptère tronqué ( $P$ h. truncata Schn., 1866). - Lèvres munies chacune d'une grosse dent externe épaissie en bouton au sommet; dents internes cordiformes. Male long de 2 ว millimètres; 5 papilles internes postanales et 1 préanale de claque côté, plus une préanale impaire contiguë

(1) R. HoLin, Una monngrafia del genere Physaloptera. Sitzungsberichte der kaiserlichen Akademie der Wissenschaften, XXXIX, p. 637, 1860. - M. Sтоssich, Il genere Physaloptera Rud. Bollettino della Soc. adriat. di scienze naturali in Trieste, $\mathrm{X} 1,1889$. 
à l'anus. Femelle longute de 33 millimètres; vulve située à peu près au milieu de la longueur.

Recueilli dans l'estomac (?) du Coq domestique, au Brésil, par Olfers et Sello.

Physalortére du cuat. - Lutz dit avoir trouvé dans l'estomac d'un Chat, au lirésil, un grand nombre de Vers qu’il rapporte au genre Physotoptera. - Peut-itre s'agissait-il de parasites provenant d'un autre Mammifère ou d'un Oiseau, ingérés avec leur hôte par le Chata

4. Famille des TRICHOTRAGHÉLidÉS. - Ce sont des Vers à corps très allongé, offrant une partic antérieure longue et mince, et une partie postriricure plus ou moins renflée (contenant les organes génitaux). La bouche est arrondie, nue. L'osophage est très long; point de ventricule; anus plus ou moins exactement terminal. Les mâles sont parfois dépourvus de spicule; le plus souvent, pourtant, ils en possèdent un, simple et vaginé, c'est-à-dire entouré d'une gaine, laquelle se retourne en doigt de gant lorsque le spicule fait saillie au dehors. Les femelles possèdent un ovaire simple; la vulve est située à l'origine de la partie renflée. Quelques genres sont ovovivipares, mais la plupart sont ovipares: leurs ceufs présentent, à chacun des deux pôles, une sorte de goulot translucide que recourre un bouchon albumineux. L'érolution ne parait comporter aucune mue.

Ces Vers sont parasites des Vertébrés. - Ils forment les genres Trichocephalus, Trichosoma, Trichodes, Trichina, Sclerotrichum et Oncophora.

Genre Trichocéphale (Trichocephalus Schrank, 1788. - Syn. : Trichuris Büttner, 1761, Ascaris L., 1771 ex parte ; Trichocephalos Gœze, 1782; Mastigodes Zeder, 1803). - Les Trichocéphales sont caractérisés par la différence d'épaisseur considérable et assez brusque qui existe entre la partie antérieure et la partie postérieure du corps. La partie antérieure, correspondant à l'osophage, est capillaire et très Iongue; la partie postérieure, qui contient l'intestin et les organes génitaux, devient rapidement plus épaisse et demeure toujours plus courte. L'extrémité caudale est arrondie et obtuse dans les deux sexes. L'anus est plus ou moins nettement terminal. - La face ventrale offre toujours, dans la partie antérieure, une large bande longitudinale formée d'une foule de saillies ponctiformes, dont chacune représente l'extrémité d'un bâtonnet émanant d'une des cellules cylindriques de la couche sous-cuticulaire et traversant toute l'épaisseur de la cuticule. Cette bande bacillaire ra se perdre au voisinage de la partie postérieure. Les stries transversales de la cuticule s'arrêtent à son niveau. On observe souvent, sur ses bords, des sortes de tubercules développés par un effet d'endosmose. - Les Trichocéphales sont généralement considérés comme dépourvus de champs latéraux : ceux-ci existent pourtant, mais sont très réduits et ne se distinguent que sur des coupes 
transversales. Les lignes médianes principales existent également, mais sont encore plus rudimentaires. - Le mâle a l'extrémité postérieure contournée en spirale, avec cette particularité que la concavité de la spirale correspond à la face dorsale. Il possède un seul testicule et un spicule simple, dont l'axe est occupé par une masse médullaire claire, donnant l'apparence d'un canal. Ce spicule est entouré d'une gaine, sorte de prépuce susceptible de s'évaginer et dont la face devenue ainsi externe se montre tantôt lisse, tantôt recouverte de petites écailles. - La femelle a la partie postérieure légèrement arquée, mais non enroulée en spirale. Elle possède un seul ovaire, et la vulve est située à l'origine de la partie renflée. Les œufs sont ellipsoïdes, revêtus d'une coque dure qui forme aux deux pôles une sorte de goulot surmonté souvent d'un bouton peu apparent.

On trouve les Trichocéphales dans le gros intestin, et surtout dans le cæcum des Mammifères. - Leur développement paraît toujours être direct: les œufs sont pondus sans avoir subi aucune segmentation; la formation de l'embryon a lieu dans l'eau ou tout au moins dans un milieu suffisamment humide; l'éclosion ne s'effectue que dans le tube digestif de l'hôte.

Trichocéphale de l'Homme (Tr. dispar Rud., 1801. - Syn. : Tr. hominis

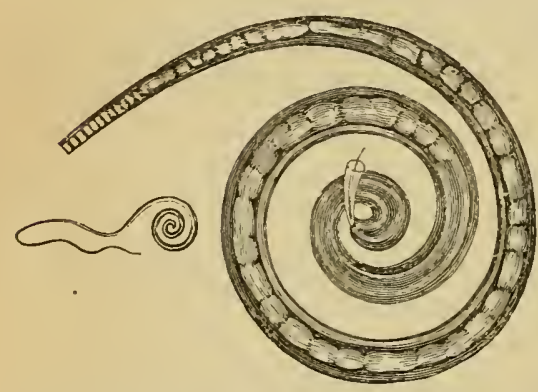

Fig. 33'. - Trichocéphale de l'Homme : mâle, grandeur naturelle et partie postérieure grossie. Schrank, 1788 ; Ascaris trichiura L., 1771). - Le mâle est long de 33 à 4 tö millimètres, le rapport de la partie antérieure effilée à la partie postérieure épaisse étant comme $3: 2$; son spicule est long de $2^{\mathrm{mm}}, 5$, cylindrique, atténué irrégulièrement en pointe à son extrémité postérieure: son contour est à peu près direct du còté dorsal, tandis qu'il est convexe, puis un peu concave avant d'aboutir à la pointe, du côté ventral; sa zone médullaire ne s'étend pas tout à fait jusqu'à la pointe.

La gaine du spicule est hérissée sur toute sa longueur de petites écailles pointues et serrées. La femelle est longue de 33 à 50 millimètres; le rapport de la partie antérieure à la partie postérieure est environ comme 2:1. Les œufs sont brunàtres, longs de 31 à $53 \mu$, larges de 21 à $23 \mu$.

Ce Ver vit habituellement dans le cæcum de l'Homme; il pénètre aussi parfois dans l'appendice eæcal; on le trouve moins souvent dans le côlon et plus rarement encore dans l'intestin grêle.

Il n'existe d'ordinaire qu'en fort petit nombre sur le même individu; cependant, Bellingham en a vu 119 dans un seul cadarre, et Rudolphi plus de 1000. Il s'observe sur des sujets de tout âge, les enfants à la mamelle exceptés.

Il est très commun dans la plupart des contrées du globe : à Paris, 
Pascal et Mérat le trouvaient, au commencenent du siècle, chez. presque tous les inclividus; mais il parait être devenu très rare aujourd'hui, par suite de l'usage comrant d'eau filtréc: on ne le trouve plus guère que chez les sujets récemment arrivés de la campagne. On le signale comme très fréquent en Egypte, en Nubie, en Algérie, au Japon, aux Etats-Unis, dans l'archipel malais; assez fréruent en Allemagne, en Suisse el en Angleterre; rare en Ecosse et en Danemark. En somme, il est plus répandu dans les régions clıaudes ou tempérées que dans les contrées froides.

Les Trichocéphales, chez l'Ilonme comme chez les animaux, paraissent aroir assez souvent la tète enfoncée dans la muqueuse; cependant, daprès Heller, ectte perforation scrait loin d'être la règle : l'extrémité antérieure s'insinuerait simplement entre les replis superlicicls de la muqueuse, en les enscruaut de ses sinuosités.

En général, la présence du Trichocéphale dans l’intestin ne s'accompagne d'aucun trouble séricux; cependant, on a cité quelques cas exceptionnels dans lesquels l'accumulation de ces parasites a coïncidé avec des phénomènes nerveux graves, parfois même mortels.

Le Trichocephalus dispar n'est pas propre à l'Homme; il a été rencontré aussi chez divers Singes (Tr. palieformis Rud.) et Lémuriens (Tr. lemuris Rud.).

Evolutıox. - Dès 185̋, Davaine faisait remarquer que les œufs du Trichocéphale n'évoluent pas dans liintestin de l'Homme, et qu'ils sont toujours expulsés dans l'élat où ils se trouvaient au moment de la ponte, c’est-à-dire avec le vitellus entier. La segmentation a lieu dans l'ean, et ne s'observe qu'au bout de plusieurs mois et même de plus d'une année. Mais l'œuf, en raison de sa coque épaisse, offre une grande résistance aux influences cxtérieures. Heller a pu obtenir l'érolution d'œufs qui avaient été gelés pendant plusieurs jours. Une fois l'embryon formé, il peut demeurer fort longtemps dans la coque sans s'altérer : Davaine a conservé pendant cinq ans des œufs dont l'embryon était resté vivant.

Si de tels cufs sont introduits - avec les eaux de boisson - dans le tube digestif, la coque se trouve dissoute par le suc gastrique, et les embryons sont mis en liberté : au bout de quelques semaines, ils acquièrent leur maturité sexuelle. Ces faits ont été définitivement établis par Grrassi. Un de ses élèves, S. Calandruccio, après s'ètre assuré, par l'examen répété de ses fèces, qu’il n'hébergeait aucun Trichocéphale, ingéra sur son conseil, le 27 juin 1886, un certain nombre d'oufs embryonnés. Le 24 juillet, il découvit pour la première fois des œufs de Trichocéphale dans ses selles. Semblable expéricnce fut répétée, avec le même succès, sur un jeune homme.

Orgavisation. - Les diverses espèces de Trichocéphales sont orçanisées d'après un plan très uniforme et ne se distinguent entre elles que par des 
caractères assez peu tranchés; l'anatomie du Trichocéphale de l'Homme, dans ses traits généraux, pourra donc servir de guide pour l'élude des autres formes. En raison des détails que nous avons donnés plus haut sur les caractères du genre, il nous suffira, du reste, d'en faire un exposé sommaire.

La cuticule va s'épaississant d'avant en arrière; elle est marquée de stries transversales écartées de 3 à $4 \mu$ et interrompues, comme nous l'avons dit, au niveau de la bande bacillaire ventrale. Celle-ci, qu'on a considérée comme un organe d'accouplement, commence à $0^{\mathrm{mm}}, 1$ de l'extrémité antérieure, s'élargit rapidement de manière à occuper à peu près toute la largeur de la face ventrale, el se termine vers l'origine de la partie postérieure du corps. - La couche musculaire, fort mince, est formée de cellules nombreuses, étroites et transformées en fibrilles : les Trichocéphales sont des platymyaires holomyaires. La partie antérieure dı Ver est assez mobile, mais la partie postérieure n'est capable d'effectuer que des mouvements fort limités.

On ne sait rien de précis sur le système excréteur ni sur le systėme nerveux.

La bouche, arrondie et dépourvue de papilles, donne entrée dans un très long œsophage qui occupe toute la partie antérieure du corps. Get œsophage est formé de deux parties assez dissemblables. L'antérieure, longue seulement de $0^{\mathrm{mm}}, 4$, constitue un tube chitineux trièdre, entouré de muscles radiaires. L'autre, qui occupe lout le reste de la longueur, est un canal chitineux dépourvu de muscles et logé dans une gouttière située à la face inférieure d'une série d'énormes cellules, offrant pour la plupart des étranglements annulaires et constituant ce qu'on est convenu d'appeler le corps cellulaire. Les deux dernières cellules de cetle série longiludinale sont disposées latéralement et forment deux sortes d'appendices. L'œsophage se termine par un étranglement à la suite duquel vient l'estomac, qu'il serait préférable d'appeler l'intestin moyen. Celui-ci, dont la lumière est assez large, renferme toujours un liquide clair; il aboutit à un étroit reclum qui, chez la femelle, s'ouvre isolément à environ $40 \mu$ de l'extrémité du corps, tandis que, chez le mâle, il s'unit à la portion terminale de l'appareil génital pour constituer le cloaque.

Les organes reproducteurs sont situés en entier dans la partie postérieure du corps, laquelle ne se renfle, d'ailleurs, qu'à mesure de leur développement. - Le testicule unique prend naissance au niveau de l'origine du cloaque; très sinueux, il se porte en avant jusque vers la naissance de l'intestin, puis se replie pour se continuer par un canal déférent très étroit, qui revient en arrière, s'élarcrit et se renfle enfin en une vésicule séminale cylindrique. De l'extrémité postérieure de celle-ci part un court conduit sinueux, aboutissant enfin à un canal éjaculateur garni de muscles puissants. -- C'est de l'union de ce canal éjaculateur et de l'intestin terminal que résulte le cloaque, canal cylindrique long d'environ 4 millimètres, incurvé comme l'extrémité caudale dumàle, et dont l'orifice, reporté sur la face dorsale, est limité en dessous par une saillie de la partie ventrale. Vers le milieu de sa longueur, le cloaque présente un diverticule dont le fond, dirigé en avant, se rattache à la paroi du corps par deux muscles assez puissants. Ce diverticule loge la base du spicule. Dans toute son ètendue, le cloaque montre, à son intérieur, un tube chitineux à paroi mince, transparente, offrant sur sa face interne de très petites écailles ou épines dont la pointe est dirigée en 
arrière. Ce tube. qui provient d'une mue du cloaque, est libre dans la cavité, et ne se troure tixú yfu'au pourtour de lioritice cloacal : de la sorte, il peut s'évaginer et apparaitre à l'extérieur comme une sorte de prépuce entourant le spicule: la face devenue ainsi externe montre alors la pointe de ses épines dirigée ell avant. On donne à ce tube préputial le nom de gaine du spicule. - L'ovaire prend naissance, comme le testicule, vers l'extrémité caudale; il se dirige en avant, puis rétrograde, au niveau de l'origine de l'intestin, pour se continuer par un oviducte qui revient en arrière; celui-ci se replie lui-mème, puis se renfle en un utérus qui s'étend en avant et se rétréeit finalement de minière à constituer un court vagin brusquement coudé à sa terminaison. La paroi interne de la portion terminale du vagin possède une cuticule revêtue de petites épines dont la pointe est dirigée vers la vulve. Celle-ci est située sur la face ventrale; elle montre souvent une évagination de la paroi vagrinale, qui doit probablement se fixer à la gaine du spicule pendant l'accouplement. L'utérus renferme un nombre d'œufs considérable, que Leuckart évalue ì š 800 , ajoutant que la ponte anuuelle d'une seule femelle peut s'élever à 3 ou $\mathbf{4 0 0} 000$ oufs.

Trichocéphale erénelé (Tr. crenatus Rud., 1809. - Syn. : Tr. suis Schrank, 1788). - Mâle long de 33 à 40 millimètres; rapport de la partie anlérieure à la partie postérieure, environ comme $5: 3$; spicule long en moyenne de $3^{\mathrm{mm}}, 3$ ö, arrondi à l'extrémité, à zone médullaire ne s'étendant pas jusqu'à la pointe; gaine du spicule garnie d'écailles courtes, mousses, clairsemées surtout dans la parlie la plus éloignée de l'orifice cloacal et finissant mème par disparâltre. Femelle longue de $3 \dot{t}$ à 50 millimètres; rapport de la partie antérieure à la partie postérieure, environ comme $2: 1$. OEufs brunàtres, longs de $\ddot{3} z$ à $36 \mu$.

Cette espèce, souvent confondue avec la précédente, habite le gros intestin et surtout le cacum du Porc, du Sanglier, du Pécari à lèvres blanches et du Phacochère africain. Elle ne détermine pas de troubles appréciables.

Leucliart a montré que les embryons encore contenus dans l'œuf, introduits dans le tube digestif du Porc, s'y développent directement et donnent, en quatre semaines, des individus sur le point d'arriver à maturité sexuelle. Dans les conditions ordinaires, l'infestation doit avoir lieu par l'intermédiaire des boissons.

Trichocéphale voisin (Tr. affinis Rud., 1801. - Syn. : Tr. ovis Alyildgaard, 1793; Mastigodes affinis Zeder, 181)3). - Extrémité céphalique munie parfois de deux renflements vésiculeux latéraux offrant l'aspect d'ailes transparentes. Bande bacillaire à bàtonnets marginaux plus forts que les autres. Wâle long de 30 à 80 millimètres, la partie antérieure représentant près des trois quarts de la longneur totale; spicule très long, mesurant 5 à 6 millimètres et plus, graduellement et régulièrement atténué en arrière, à zone médullaire s'élendant presque jusqu’à la pointe; gaine du spicule très longue, hérissée d'épines aiguës d'autant plus petites et plus rapprochées qu'elles sont plus éloignées de l'orilice cloacal. Femelle longue de 50 à 70 millimètres, la partie antérieure comprenant environ les deux tiers de la lon-

Rallutiet. - Zoologie. 
gueur totale. CEufs longs de $63 ̈ \mu$ d'un goulot à l'autre, sans compler les boutons qui les surmontent.

Le Trichocéphale roisin, qui tire son nom de sa ressemblance arec le Trichocéphale de l'Homme, habite le gros intestin, et plus particulièrement le cæcum, d'un grand nombre de Ruminants appartenant
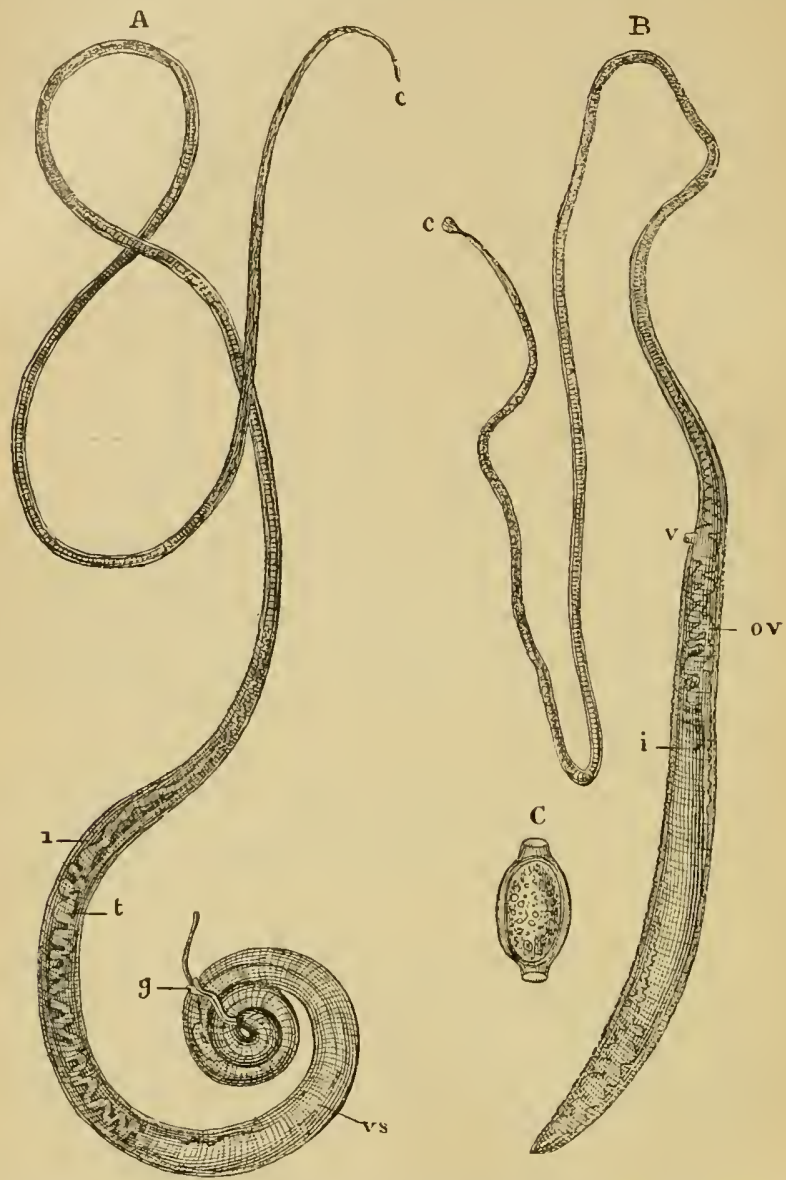

Fig. 335. - Trichocephalus affinis, individus fortement grossis. - A, mâle. B, femelle. c, extrémité céphalique. $i$, intestin. $a$, anus. $t$, testicule. $v s$, vésicule séminale. $g$, gaine du spicule. ov, ovaire. C, œuf grossi environ 200 fois (Delafond).

aux deux familles des Bovidés et des Cervidés. Il est assez commun chez le Mouton et la Ghèvre, mais plus rare chez le Bœuf. Nous l'avons trouvé chez le Chabin. Diesing l'a signalé en outre chez le PorcÉpic d'Europe, mais cette assertion aurait besoin d'être contrólée.

Jusqu'à présent, on n'a rapporté à sa présence aucun trouble pathologique; Wernicke note seulement qu'on le trouve chez presque tous les agneaux qui périssent au printemps dans la République argen- 
tine. U. Caparini a trouvé des exemplaires de ce Trichocéphale implantés dans des nodules hépatiques chez un Breuf.

Leuckart a constaté que les œufs embryonnés de cette espèce, ingérés par un agoneau, avaient donné, en seize jonr's, de petits Vers longs d’environ 1 millimètre el silués déjà dans le gros intestin.

Triehocéphale échinophỵle (Tr. echinophyllus Nitzseh, 1866. - Syn. : (?) Tr.cameli Rud., 1819). - Partieantérieure environ trois fois aussi longue que la postérienre, lans les deux sexes. Mâle à gaine du spicule très longue, renflée en bouton et gamie, sur toute sa longueur, d'épines aboudantes: spicule long, filiforme, plat, terminé en pointe. Femelle pourvue, à l'origine de la partie effilée, d'un orifice dont la signification est inconnue.

Parasite du Vromadaire.

Il convient, pensons-nous, de rapporter à cette espèce, encore qu'elle soit assez mal caractérisée, les Trichocéphales trouvés antrefois à Vieme dans le gros intestin du Chameau à deux bosses et du Dromadaire. Rudolphi les avait décrits sous le nom de Tr. cameli; Diesing les rattachail an Tr. affnis.

Trichocéphale déprimé (Tr. depressiusculus Rud., 1809. - Syn. : Tr. vulpis Frölich, 1789; Mastigodes vulpis Zeder, 1803). - Mâle long de $43 \ddot{a}$ 7ö millimètres; rapport de la partie antérieure à la partie postérieure, comme $3: 1$; spicule exLrèmement long, de 9 à 11 millimètres, se terminant en une courte pointe conique; gaine du spicule revêtue d'écailles mousses dans la moitié la plus rapprochée de l'orilice cloacal, le reste demeurant lisse. - Femelle longue de 43 à 75 millimètres; rapport de la partie antérieure à la partie postérieure, conme $3: 1$. OEufs longs de 72 à $80 \mu$, larges de 37 à $40 \mu$, à goulots étroits et à coque mince, lisse.

Dans le cæecum dı Chien et du Renard. Très commun chez les Chiens affectés de l'anémie des meutes, mais ne jouant, à nos yeux, qu'un rôle insignifiant dans le développement de cette maladie. Méguin l'a rencontré dans toute l'étendue du gros intes-

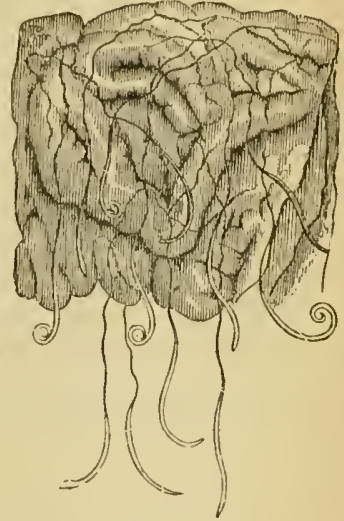

Fig. 336. - Fragment de cxcum du Cihien, sur lequel sont fixés des Trichocephalus depressiusculus. Grand, nat. (Orig.।. tin. - Nous avons trouvé, dans le jéjunum d'un Furet, un Trichocéphale femelle qui nous paraît voisin de cette espèce.

En 1884, nous avons montré que l'évolution du Trichocéphale du Chien est identique à celle des formes précédentes: des œufs, recueillis en février et conserrés dans l'eau, avaient mis cinq mois à évoluer jusqu'i la formation complète de l'embryon; ils furent alors ingérés par un Chien, dans le cecum duquel nous trourâmes, au boul de trois mois, plus de cent cinquante Vers qui avaient atteint leur complet développement.

Trichocéphale denté (Tr. serrutus von Linstow, 1879). - Corps denté 
en scie dans la région antérieure. Rapport de la partie antérieure à la partie postérieure, comme $2: 1$. Bande bacillaire mesurant les $3 / 7$ du diamètre $\mathrm{du}$ corps. Male long de 40 millimètres; spicule de $3^{\mathrm{mm}}, 9$; gaine du spicule revêtue, dans toute son étendue, d'épines coniques devenant plus fines, plus étroites, à mesure qu'on s'éloigne de l'orifice cloacal. Femelle longue de 48 millimètres; vulve offrant un appendice extérieur dù à un prolapsus du vagin extraordinairement garni d'épines. OEufs longs de $56 \mu$, larges de $39 \mu$.

Intestin du Chat domestique (von Linstow).

Trichocéphale campanule (Tr. campanula von Linstow, 1888. — Syn. : (?) Tr. felis Dies., 1851). - Corps denté en scie dans la région antérieure. Bande bacillaire large des $4 / 7$ du diamètre du corps. Mâle de longueur indéterminée; extrémité postérieure munie de deux papilles ; gaine du spicule garnie de petites saillies coniques et élargie en cloche à l'extrémité. Femelle longue de $31^{\mathrm{mm}}, 5$; œesophage occupant les $4 / 5$ de la longueur entière du corps; vulve encadrée par deux lèvres longitudinales peu saillantes. OEufs longs de $72 \mu$, larges de $36 \mu$.

Cette espèce a été trouvée dans l'intestin du Chat domestique, au Brésil. Peut-être est-elle identique au Tr. felis Dies., recueilli également au Brésil, par Natterer, dans l'intestin du Felis tigrina, mais qui n'a pas été décrit.

Trichocéphale onguiculé (Tr. unguiculatus Rud., 1809. - Syn. : Tr. leporis Frölich, 1789; Mastigodes leporis Zeder, 1803). - Bande bacillaire large environ des $4 / 5$ du diamètre du corps, s'étendant jusque sous le vagin. Mále long de 29 à 32 millimètres; rapport de la partie antérieure à la partie postérieure, comme $3: 2$; orifice cloacal un peu ventral ; spicule grêle, atteignant jusqu’à 7 millimètres de long; gaine du spicule délicate, cylindrique, garnie de petites dents pàles, ponctiformes. Femelle longue de 32 à 34 millimètres; rapport de la partie antérieure à la partie postérieure, comme 2:1; vulve arrondie. OEufs longs de $52 \mu$ (sans les boutons), larges de 31 à $34 \mu$, à coque un peu granuleuse.

Cæcum du Lièvre commun, du Lièvre variable, du Lapin de garenne et du Lapin domestique. Nous ne l'avons pourtant trouvé que rarement dans cette dernière espèce.

Genre Trichosome (Trichosoma Rud., 1809. - Syn.: Capillaria Zeder, 1803). - Ces Vers, comme l'indique leur nom, ont le corps grêle, capillaire. Ils diffèrent des Trichocéphales en ce que la partie postérieure, contenant l'intestin et les organes génitaux, n’est que légèrement et progressivement renflée. Leur tégument montre des bandes bacillaires analogues à celle que nous arons signalée chez les Trichocéphales. Ces bandes, diversement réparties suivant les espèces, suivent les lignes médianes ou les champs latéraux, et on les distingue par suite en latérales, ventrale et dorsale. Les stries transversales de la cuticule sont interrompues à leur niveau. Les champs latéraux existent, aussi bien que les lignes médianes principales. L'extrémité caudale du mále, dépourvue de papilles, montre des lobes cuticulaires plus ou moins développés, entourant l'orifice cloacal, et considérés par Eherth comme représentant une bourse. Le spicule unique est 
enveloppé d'une gaine comme celui des Trichocéphales. La femelle possède une vulve parfois renversée au dehors, et située à la jonction des deux parties du corps. Tube digestif, appareil génital et ceufs comme dans le genre préédent.

Les Trichosomes vivenl en parasites chez tous les Vertébrés, mais principalement ehe\% les Mammifères et les Oiseaux. On en connaît environ soixante-dix espèces (1). Dujardin avait proposé de les répartir entre plusieurs gentes : Trichosoma s. str., Calodium, Thominx et Eucoleus. Ce démembrement ne mérite pas d'être accepté : nous nous bornerons ì classer les Trichosomes d'après les caractères fournis par la gaine du spicule.

On ne possède encore que peu de données sur leur développement. Dans les recherehes que j'ai faites sur une espèce, il s'est montré identique à celui des Trichocéphales (2).

$1^{\text {re }}$ section : Gymmothecal. - Gaine du spicule lisse ou plissée.

Trichosome plique (Tr. plica Rud., 1819. - Syn. : Calodium plica Duj., 1845). - Corps capillaire; cuticule finement striée en travers. Bouche orbiculaire, petite, latérale. Bandes bacillaires latérales, atteignant presque en largeur la moitié du diamètre du corps; vers l'extrémité postérieure, les bàtonnets disparaissent et les bandes se rétrécissent de manière à ne plus représenter que deux canaux très étroits, composés de petites cellules. Mâle long de 13 à 30 millimètres, la partie antérieure étant à la partie postérieure comme $6: 7$; extrémité postérieure tronquée obliquement et enveloppée par une petite bourse délicate, se prolongeant en pointe en arrière; orifice cloacal légèrement ventral ; spicule très long, arrondi à son extrémité; gaine $d u$ spicule finement plissée en travers, les plis étant souvent interrompus par d'autres plis longitudinaux, de façon à donner une apparence ponctuée. Femelle longue de 30 à 60 millimètres, la partie antérieure étant à la partie postérieıre comme $2: 1$; corps peu épaissi en arrière, se terminant en pointe mousse; anus terminal; vulve ronde, arec un appendice cylindrique. OEufs longs de $60 \mu$, larges de $30 \mu$.

Ce Trichosome liabite la vessie urinaire du Renard et du Loup. Bellingham l'a recueilli dans le même organe, en Irlande, chez le Chien domestique. - Pcut-être est-ce le même Ver dont Beorchia-Nigris a trouvé, en 1888, une cinquantaine d'exemplaires fixés à la muqueuse vésicale d'un Chien d'expérience qui, pendant la vie, rendait une urine sédimenteuse chargée d'œufs à goulots. Cet auteur croyait aroir affaire à un Trichocéphale.

Trichosome très mince (Tr.tenuissimum Dies., 183̆1. - Syn. : Tr. columbæ Rud., 1819; Calodium tenue Duj., 18430, nec Eucoleus tenuis Duj., 1845).

(1) Il. Stossich, Ilgenere Trichosoma Rudolphi. Bollettino della Societá Adriatica di scienze naturali in Trieste, XII, 1890.

(2) A. RaIllat, Recherches expérimentales sur les tumeurs vermineuses du foie des Muridés. Bullet. de Ia Soc. zool. de France, XIV, p. 62, 1889. 
- Tégument vaguement strié en travers. Bandes bacillaires latérales, atteignant en largeur le $1 / 4$ du diamètre du corps. Mále long de 10 millimètres, dont $4^{\mathrm{mm}}, 7$ pour la partie antérieure; de chaque côté de l'orifice cloacal, qui est terminal, un petit appendice lobulé; gaine du spicule délicatement plissée en travers. Femelle longue de 18 millimètres, la ñartie antérieure mesurant 7 millimètres; corps médiocrement épaissi dans la partie postérieure, qui est arrondie à son extrémité. Vulve transversale, non proéminente. OEufs longs de 47 à $50 \mu$, larges de 24 à $27 \mu$.

Habite le gros intestin du Pigeon domestique et de quelques autres Colombins. Nous l'avons trouvé aussi dans l'intestin grèle : d'après Zürn, on l'observerait souvent dans cette région, parfois mème en grand nombre, et il serait alors dangereux pour son hòte.

Trichosome obtus ( $T r$. retusum Raill., 1893. - Syn. : Tr. longicolle Duj. et Eberth, nec Rud.). - Corps peu renflé en arrière. Une bande bacillaire ventrale, ayant en largeur environ la moitié du diamètre du corps; deux lignes latérales très étroites, formées de petits noyaux. Mále long de 13 millimètres, dont 4 millimètres pour la partie antérieure ; extrémité postérieure avec deux lobes latéraux arrondis; orifice cloacal assez ventral; gaine du spicule étroite, lisse. Femelle longue de 19 millimètres, dont 6 millimètres pour la partie antérieure; extrémité postérieure arrondie et mousse; anus légèrement ventral ; vulve située à peu de distance en arrière de l'origine de l'intestin, légèrement proéminente, transversale, sans véritable appendice. OEufs longs de 50 à $55 \mu$, larges de 30 à $32 \mu$; coque solide externe revêtue, entre les deux pôles, d'une couche molle, incolore, légèrement irrégulière.

Ce Ver a été trouvé dans les cæcums de la Poule par Dujardin et par Eberth. Nous l'avons recueilli, avec Lucet, dans les cæcums de la Pintade.

Dujardin et Eberth l'ont décrit sous le nom de Tr. longicolle Rud., mais la diagnose qu'ils en domnent est en contradiction flagrante avec celle de Rudolphi.

Les Vers de la Poule, du Faisan, du Coq de bruyère, etc., décrits par Gœze, Schrank, Frölich, et longs de 39, 52, 67, 80 millimètres, appartiennent évidemment à une ou à plusieurs autres espèces : c'est à eux que se rapporte le nom de $T r$. longicolle Rud.

Trichosome à con court (Tr. brevicolle Rud., 1819; Trichocephalus anatis Schrank, 1790. - Priorité : Trichosoma analis). - Corps peu renflé en arrière, arrondi et mousse à l'extrémité postérieure. Bandes bacillaires latérales, d'une largeur égale au tiers du diamètre du corps. Lignes dorsale et ventrale égrales, très étroites, composées de petits noyaux. Mále long de 11 à 13 millimètres, à extrémité postérieure fortement atténuée ; orifice cloacal plus ventral que l'anus de la femelle; gaine du spicule lisse. $F e$ melle longue de 21 à 28 millimètres, dont 8 à 11 millimètres pour la partie antérieure ; anus un peu ventral ; vulve également sur la face ventrale, à peu de distance en arrière de l'origine de l'intestin, légèrement proéminente. OEufs longs de 42 à $46 \mu$, larges de 24 à $2 \breve{2} \mu$.

Cícums de l'Oie domestique et de divers Anatidés sauvages; habite plus rarement l'intestin grèle. 
20 section : Echinotheca'. - Gaine du spicule hérissée d'épines ou de soies.

Trichosome aćrophile (Tr.acrophilum Creplin, 1839. - Syn. : Eucoleus aerophilum Duj., 18’ä). - Corps d'un blanc jaunàtre uniforme. Tégument strié en travers. Une bande bacillaire ventrale, à bàtonnets nombreux, équivalant au tiers, et une bande dorsale équivalant aux trois quarts du diamètre du corps. Lignes latérales très petites, sans bàtonnets. Male long de 2't millimètres, la partie antérieure étant à la postérieure comme 1:2; extrémité postérieure amincie, recourbée et obliquement tronquée, offrant deux lobes courts réunis par une bourse délicate; gaine du spicule revètue de spicules et de granulations. Femelle longue de 23 à 32 millimètres, la partie antérieure étant à la postérieure comme 1: 3,3; corps épaissi en arrière, puis atténué en une queue obtuse, légèrement incurvée en dessous; anus un peu ventral; vulve latérale, ronde, non saillante, exactement située à la hauteur de l'origine de l'intestin. OEufs blanes, à eoque granuleuse, longs de $68 \mu$, larges de $3 \ddot{m} \mu$, retenus ì la surface du corps dans une substance mucilagineuse.

Ce Ver était connu comme parasite de la trachée du Renard. A. Müller l'a trouvé dans le poumon d'une Martre, ainsi que dans la trachéc d’un Chat, où il en existait huit exemplaires. Neumann l'a revu également dans la trachée et, dans les grosses bronches, chez trois Chats, porteurs chacun d'un seul exemplaire femelle.

Triehosome ì collier (Tr. collare von Linstow, 1873). - Extrémité antérieure conique, obtuse et présentant, à $6 \mu$ de l'ouverture buccale, un collier linéaire. Deux bandes bacillaires latérales, dont la largeur est à celle du corps comme 1 : 3,6 ; chez les individus très àgés, ces bandes deviennent indistinctes et les bàtonnets disparaissent. Hale long de $8^{\mathrm{mm}}, 9$, la partie antérieure ou œsophagienne étant à la partie postérieure comme 41: 48; extrémité caudale divisée en deux saillies hémisphériques; gaine du spicule revètue de soies extrèmement fines. Femelle longue de $9^{\mathrm{mm}}, \ddot{3}$, la partie œsophagienne étant à la partie postérieure comme 2:1; extrémité caudale arrondie; vulve située un peu en arrière de l'origine de l'intestin : chez les femelles non ovigères, elle fait souvent une forte saillie extérieure, qui disparait dès qu'il y a des œufs. OEufs longs de $66 \mu$, larğes de $30 \mu$.

Trouvé en grand nombre, par von Linstow, dans l'intestin le la Poule. Zürn l’a rencontré, en outre, dans la musculature du gésier, et dans une vésicule développée sur l'intestin grè̀le et le mésentère d'un Coq.

Trichosome contonrné (Tr. eontortum Creplin, 1839). - Corps filiforme, progressivement renflé en arrière, puis alténué de nouveau à l'extrémité postérieure, dans les deux sexes. Bande bacillaire ventrale ayant les trois quarts du diamètre du corps; bande bacillaire dorsale ayant seulement le tiers le ce diamètre. Mâle long de 12 a 17 millimètres; rapport de la partic antérieure al la partie postérieure, environ comme 2: 5; extrémité caudale d'abord un peu atténuée, puis se renflant dans la région terminale et présentant deux saillies latérales; orifice cloacal légèrement ventral; gaine du spicule revètue de très petites épines sétacées. Femelle longue de 31 à 
38 millimètres; rapport de la partie antérieure à la partie postérieure, enviroll comme 1 : ̋̈; extrémité caudale en pointe mousse; vulve en forme de

A

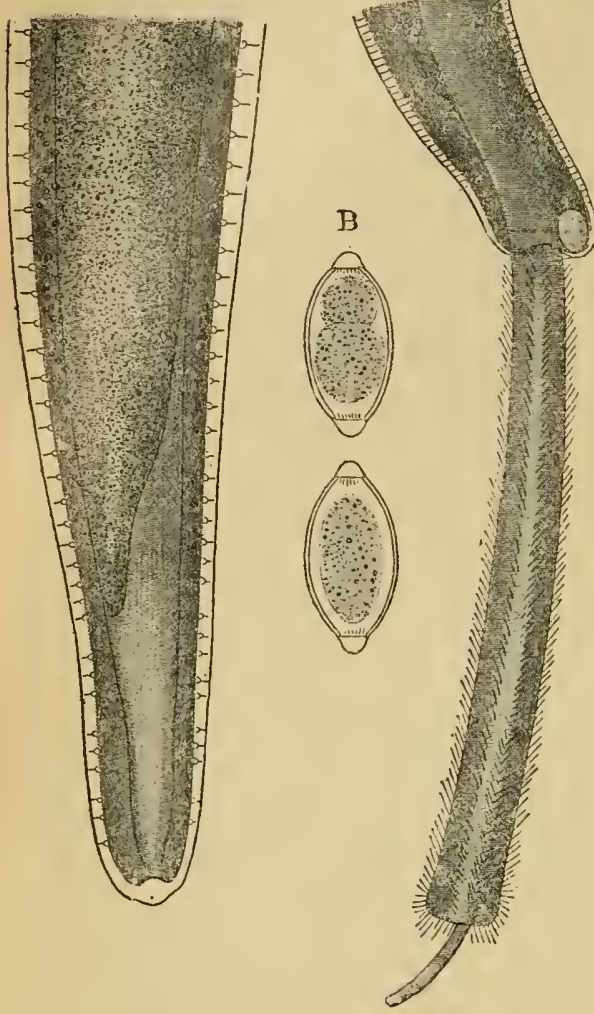

Fig. 337. - Trichosoma contortum, de l'œsopliage du Canard. - A. extrémité caudale de la femelle. $C$, extrémité caudale du mâle, avec la gaine et le spicule saillants. $\mathrm{B}$, œufs à divers états, recueillis dans l'utérus. Grossissement : 300 diamètres (0rig.). fente transversale, en dehors de la bande ventrale. OEufs longs de 48 à $56 \mu$ (d'un goulot à l'autre) sur 21 à $24 \not \alpha$ de large.

Habite l'œsophage d'un grand nombre d'Échassiers, Palmipèdes, Passereaux et Rapaces, où il se montre tantòt libre, tantôt engagé dans et même sous la muqueuse. Nous l'avons observé, avec Lucet, chez le Canard domestique, dans le tissu conjonetif sous-muqueux du renflement œsophagien qui fait office de jabol (1). Le nombre de Vers que peut héberger un seul Canard est assez considérable : nous en avons compté jusqu'à trente-trois. Ces Vers se creusent des galeries sinueuses dans lesquelles les femelles déposent leurs œufs. Leur présence entraîne une obstruction de l'œesophage (indigestion ingluviale) qui abou tit rapidement à la mort.

\section{$3^{\circ}$ Espèces incomplètement} connues. - Nous sommes obligé de classer à part un certain nombre de formes qui n'ont été décrites jusqu'à présent que d'une façon trop insuffisante pour permettre de les faire rentrer dans l'un des groupes précédents.

Trichosome du Chat (Tr. felis cati Dies., 18ä1). - La femelle, seule connue, est longue de 14 à 16 millimètres. Corps très transparent, filiforme, graduellement épaissi en arrière, puis atténué de nouveau un peu en avant de l'extrémité postérieure, qui est tronquée obliquement et arrondie. T'égument lisse. La bouche est limitée par deux lèvres saillantes. Il n’a pas

(1) A. Railuiet et A. Lucet, Indigestion ingluviale d'origine parasitaire chez des Canards. Recueil de méd. vét. (7), VII, p. 13, 1890 (avec une planche). 


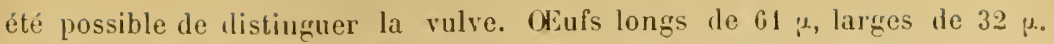

Ce petit Ver, souvent enroulé en spirale et difficilement perceptible sans le secours de la loupe, a été découvert par Bellingluam dans la vessie d'un Chat sauvage. Wedl, à qui nous avons emprunté la description ci-dessus, l'a retrouvé dans la vessie d'un Chat domestique. Il n'existait que des femelles. Schlotthauber signale, d'autre part, la présence d'un Trichosome dans le gros intestin du Chat domestique.

Trichosmue lincanire $(T r$. lineare Leidy, 1836). - Corps filiforme, à peu près également atténué vers les extrémitès. Hâle long de $3^{\mathrm{mm}}, 8$, large de $0^{\mathrm{m}}, 21$; extrémité caudale spiralíc; queue longue, conique, aiguë; orifice cloacal à une distance considérable de l'extrémité de la queue. Femelle longue de $7^{\mathrm{mm}}, 6$, large de $0^{\mathrm{mm}}, 8 \ddot{\text {; }}$; extrémité caulale euroulée en spirale; queue incurvée, obtuse, avec deux pointes coniques postérieures sur la face ventrale.

Leidy, de Philadelphie, a recueilli dans l'inteslin grèle du Chat sept exemplaires de ce Ver, que Diesing, sans motifs suffisants, proposait de rattacher à l'espèce précédente.

Trichosome annelé ( $T r$. annulatum Molin, 18\%3). - Corps blanchàtre, capillaire, très atténué en avant, à peine atténué en arrière ; extrémité céphalique séparée du reste du corps par un renflement annulaire de la cuticule; tégument à stries transversales délicales et très rapprochées. Mâle longr de 13 millimètres. Femclle longue de 80 millimètres; extrénité caudale obtuse, excavée au sommel; anus subterminal; vulve située dans la partie antérieure du corps.

Trouvé à Padoue, par Molin, sous la "membrane épilhéliale " de l'osophage de la Poule.

Tricnosoue papilleux (Tr. papillosum Wedl, 1856). - La femelle seule est connue : elle est lonq̧ue de 5 millimètres. L'extrémité céphalique est munie de quatre papilles; l'extrémité caudale se termine en une pointe conique, mousse. L'ovaire est double. La vulve s'ouvre au niveau du tiers postérieur du corps, et se présente sous l'aspect d'une papille aplatie. Les oufs sont ellipsoïdes, à coque mince, longs de 48 à $52 \mu$, larges le $28 \mu$.

Wedl a trouvé ce parasite, en assez grande abondance, dans l'intestin d'un Mouton, en compagnie du Trnia expansa. Wernicke dit l'avoir observé à Buenos-Ayres.

Ce prétendu Trichosome est évidemment un Strongle; mais les dimensions des cufs ne permettent pas de le ratlacher, comme l'a fait Curtice, au Strongylus filicollis.

Le genre Trichode (Trichodes von Linstow) établit la liaison entre les Trichosomes et les Trichines; il se distingue du précédent par l'absence de spicule et de bourse (1).

Le Trichode à qucue épaisse (Tr. crassicauda [Bellingham]. - Syn. : Trichosoma crassicauda Bellinglı.) est un curieux Ver, qui se rencontre dans

(1) Archiv. für Naturg., 187' , 1, p. 286. - Ce genre n'a pas été adoplé par la plupart des helminthologistes. 
VERS.

la vessie urinaire du Rat. Le màle, fort petit, vit en parasite dans l'utérus de la femelle : on trouve d'ordinaire trois ou quatre màles dans chaque. femelle.

Genre Trichine (Trichina Owen, 1830̈). - Très petits Vers à corps capillaire, très légèrement et progressivement renflé en arrière. Ils possèdent des champs latéraux et des lignes médianes principales. Le mále présente, à l'extrémité caudale, deux appendices coniques constituant une sorte de bourse copulatrice; il est privé de spicule. La femelle, qui est vivipare, a la vulve située au cinquième antérieur du corps.

Ce genre ne comprend qu'une seule espèce bien authentique (1).

Trichine spirale $(T r$. spiralis 0 wen, 1835). - Ver à peine visible à l'œil nu. Malle long de $1^{\mathrm{mm}}, \dot{4}$ a $1^{\mathrm{mm}}, 6$, large de $40 \mu$; orifice cloacal entre les

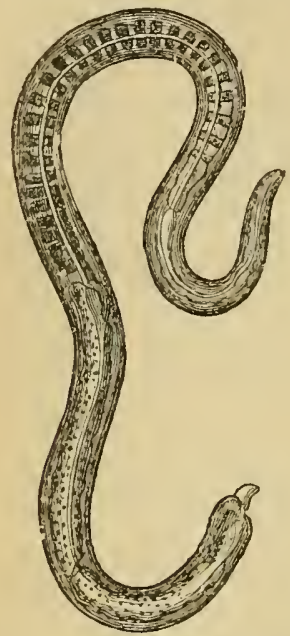

Fig. 338. - Tricline intestinale, maile (G. Colin).

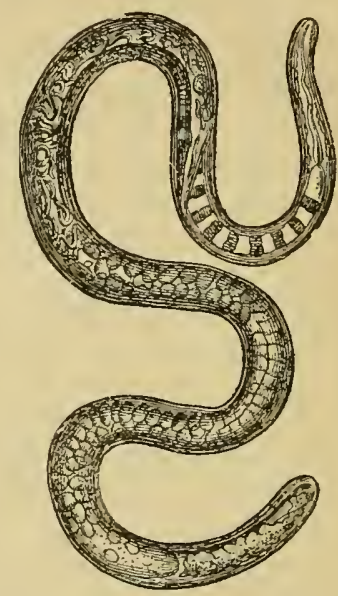

Fig. 339. - Trichine intestinale, femelle (G. Colin).

appendices de la bourse; en arrière de cet orifice, deux paires de papilles: les antérieures hémisphériques, les postérieures coniques. Femelle longue de 3 à 4 millimètres, large de $60 \mu$; vulve ventrale; anus terminal. Vivipare.

Les Trichines à l'état adulte, sexué, se trouvent dans le tube digestif, et en particulier dans l'intestin grêle de divers animaux, notamment des Mammifères (Trichines intestinales). La plupart sont libres dans la cavité intestinale; cependant, d'après Cerfontaine, un certain nombre de femelles fécondées pénètrent dans l'épaisseur de la paroi, dans la muqueuse et la sous-muqueuse, dans les couches musculaires et jusque dans le mésentère; enfin et surtout dans les.

(1) J. Chatin, La Trichine el la trichinose. Paris, 1883. 
organes lymphoïdes, plaques de Peyer et ganglions mésentériques.

Les larres émigrent directement dans les tissus, et principalement dans les muscles de l'hote mème chez lequel elles sont écloses; elles s'y entourent d'un kyste et demeurent alors à l'état de vie latente (Trichines musculaires). Dans ces conditions, elles ne peurent arriver ¿ l'étal adulte qu'après avoir été ingérées par un autre animal à sang chaut.

Les Mammifères chez lesquels on a constaté jusqu'ì présent, par l'expérience ou par l'observation, le développement des Trichines dans les tissus sont : l'Homme, le Porc, le Sanglier, l'Hippopotame, le Ilamster, le Rat noir, le Surmulot, la Souris, le Lapin, le Colaye, le Veau, l'Agneau, le Cheral, le Chien, le Chat, le Renard, la Martre, le Putois, le Blaireau, le Raton, l'Ours, la Taupe, le IIérisson (1). L'Ilomme tire presque toujours'ses Trichines du Porc, et celui-ci des petits Rongeur's. Les Rats et surtout les Surmulots paraissent être les hôtes normaux de ces parasites, qu'ils contractent en s'entre-dévorant.

Il est ì noter que tous les animaux ne s'infestent pas avec la même facilité: le Pore, l'Homme, le Rat, la Souris, le Cobaye, le Lapin peuvent être, à cet égard, placés au premier rang; les herbivores, Mouton, Chèvre, Bœuf, Cheval, constituent un terrain moins favorable; enfin, le Chat, le Chien, le Blaireau, ne sont que difficilement infestés, surtout s'ils sont un peu âgés, et ne présentent jamais qu'un petit nombre de Trichines dans leurs muscles.

D'après les recherches de G. Colin, les Trichines ne s'enkystent pas dans les tissus des Oiseaux. Les Trichines musculaires qu'on fait ingérer à ces animaux deviennent adultes dans leur intestin, mais les embryons qu'émettent les fenelles sont expulsés avec les fèces et ne franchissent pas les parois intestinales.

Chez les Vertébrés à sang froid et les Invertébrés (larves des Mouches à viande, par exemple), les Trichines enkystées passent dans le tube digestif et sont rejetées sans avoir éprouvé aucun changement; mais elles conservent la faculté d'évoluer chez les animaux à sang chaud. Il est curieux toutcfois de noter que Legros et Goujon ont obtenu le développement des Trichines musculaires chez des Salamandres maintenues à la température de $30^{\circ} \mathrm{C}$. environ.

Érolutiox. - Dans l'intestin d'un animal - un Rat, par exemple, - auquel on a fait ingérer des Trichines musculaires, on trouve, dès le second jour après l'infestation, des individus màles et femelles aptes à l'accouplement. A peine la fécondation est-elle accomplie, que l'érolution embryonnaire commence dans l'utérus des femelles. Les cufs à maturité atteignent un diamètre de $20 \mu$; ils ne tardent pas à perdre leur coque, et l'on troure dans le ragin de petits embryons libres,

(1) A cette liste il faut' ajouter le Furet, que j'ai tout récemment infesté par l'administration de chair trichiuée de Lapin. 
qui séchappent par la vulve dès le sixième jour de l'infestation : ces embryons sont obtus en avant, effilés en arrière; ils mesurent 90 à $100 \mu$ de long sur $6 \mu$ d'épaisseur dans leur partie moyenne. La ponte dure un mois environ, et l'on estime à 10 ou 150,000 le nombre d'embryons auxquels chaque femelle peut donner naissance. Au bout de cette période, et même plus tôt si les animaux sont affectés de diarrhée, les Trichines intestinales sont peu à peu éracuées avec les excréments, et c'est à peine si on en troure encore quelques-unes dans le tube digestif au bout de six semaines à deux mois.

Les embryons sortis du corps de la mère s'agitent en masse au milieu du mucus intestinal, et commencent immédiatement leurs migrations. Grâce à leur ténuité, ils perforent les parois intestinales, et se trourent dès lors en présence de trois roies : le tissu conjonctif, les vaisseaux sanguins et le système lymphatique. L'observation, citée plus haut, des femelles fécondées dans les organes lymphoïdes, semblerait indiquer qu'ils doivent être amenés généralement par la voie lymphatique dans le torrent circulatoire, pour être ensuite disséminés par le sang dans les divers organes et en particulier dans les muscles. La durée de ces migrations de l'intestin aux tissus paraît varier de six à dix jours : dans cette période, les embryons ne s'accroissent que fort peu ; ils ne dépassent guère 120 à $160 \mu$ de long sur 6 à $8 \mu$ de large.

C'est le plus ordinairement dans les muscles qu'ils vont s'installer, et on les roit s'accumuler surtout dans le roisinage des os ou des tendons, qui leur opposent un obstacle insurmontable. D'après divers auteurs (Virchow, Leuckart, Grancher, etc.), ils se logeraient à l'intérieur même du faisceau primitif; mais J. Chatin, d'accord avec G. Colin, Robin, etc., a montré au contraire qu'ils s'arrêtent dans le tissu conjonctif interfasciculaire, et que leur pénétration dans la substance striée à la suite de certaines irritations locales est très rare et presque anormale. - Une fois parrenu dans le muscle, l'embryon s'accroît, se dispose en anse, s'enroule en 3, puis en spirale lâche, et enfin s'entoure d'un kyste, dans lequel doits'achever son développement larvaire. J. Chatin a bien étudié le mode de formation de ce kyste.

La présence de l'embryon dans le tissu conjonctif interfasciculaire est le point de départ d'une irritation plus ou moins vive, qui entraîne de rapides et profondes modifications dans les éléments de ce tissu. Les fibres connectives s'hypertrophient; les cellules passent à l'état embryonnaire et se multiplient activement, de manière à former bientot une masse granuleuse d'apparence amorphe, qui écarte et comprime les faisceaux primitifs. Dans cette masse, qui montre d'abord des granulations protéiques, puis d'autres granulations de matière glycogène, on trouve la Trichine larvaire complètement enroulée et tombée déjà en état de vie latente.

C'est alors qu'on voit se produire le réritable kyste, c'est-à-dire l'enveloppe protectrice. La néoformation granuleuse s'indure vers sa 
partic extérieure; les éléments de cette zone modifient leur forme et leur texture, et constituent ainsi une couche pariétale qui, fort mince d'abord, ne tarde pas à prendre une épaisseur considérable. Tantòt cette enveloppe reste simple, tantùt elle se montre lamelleuse; parfois mème elle se revét de plicatures ou de réticulations; mais ce ne sont là que des modifications d'ordre secondaire.

En somme, done, le kịste résulte d'une irritation produite dans le tissu conjonctif interfaseiculaire. 11 est extrèmement rare de voir lil Trichine larvaire s'enliyster dans une fibre musculaire, et dans la plupart des cas le sarcolemme ne prend même aucune part à la néoformation kystique.

Le kyste trichineux est de forme variable : le plus souvent, il est ovoïde, ì grand axe parallèle aux fibres musculaires, et étiré aux deux póles en une sorte de pointe mousse. Parfois l'un de ces prolongements fail défaut; ou bien tous deux manquent, et l'on passe ainsi progressivement à la forme sphéroüdale. Les dimensions sont également variables : on peut donner comme moyenne $400 \mu$ de long sur $250 \mu$ de large. —Dans les muscles fortement trichinés, on voit quelquefois deux ou trois liystes s'unir par les sommets correspondants, et formerainsi un long liyste moniliforme, dont les loges sont tantùt en communication l'une avec l'autre, tantôt séparées par du tissu kystiqne. D'autre part, qu'il s'agisse de kystes simples ou pluriloculaires, chaque loge ne renferme d'ordinaire qu'une seule Trichine; mais il

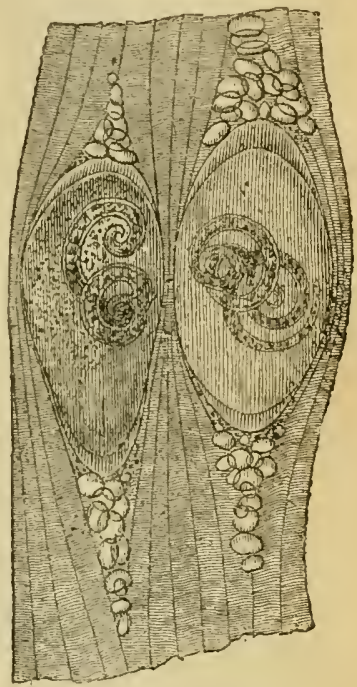

Fig. 340. - Trichines enkystées dans le tissu musculaire. - Le kysle de droite conlient deux Trichines ( $G$. Colin). n'est pas très rare cependant d'en rencontrer plusieurs, et jusqu'à 7 (J. Chatin).

Les phénomènes inflammatoires qui aboutissent à la néoformation kystique ont aussi un retentissement sur les tissus ambiants. Le tissu conjonctif subit des modifications profondes et peut même disparaitre; le kyste vient alors s'appuyer sur les faisceaux musculaires primitifs, dont la substance contractile subit une transformation granuleuse ou granulo-adipeuse. D'autres fois, un certain nombre de cellules embryonnaires se transforment en éléments connectifs qui viennent renforcer la couche protectrice du kyste. Il n'est pas rare même de voir se former de noureaux éléments musculaires, et jusquà des vaisseaux.

Enfin, la présence du liyste entraine d'ordinaire l'apparition d'abondants dépôts adipeux, qui commencent. à se former à l'un des pôles, 
puis se manifestent au pôle opposé (fig. 340) et finissent par envelopper toute la périphérie.

Au sein des masses adipeuses, ces phénomènes sont beaucoup moins actifs que dans le tissu 'cellulaire; nombre de cellules adipeuses restent inertes et ralentissent l'évolution de la néoformation, qui

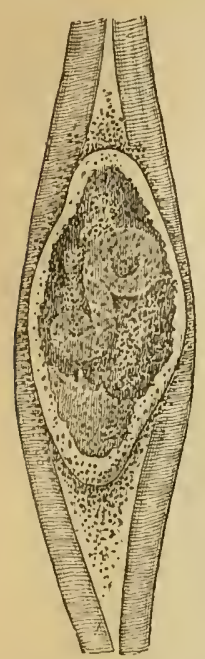

Fig. 341, - Kyste trichinıux très ancien, profondément altéré (G. Colin). peut mème se trourer complèlement suspendue : aussi voit-on souvent les Trichines du lard mortes prématurément au milieu d'une masse granulo-graisseuse peu différente du tissu ambiant.

Lorsque les parois limitantes sont constituées, le kyste demeure assez longtemps stationnaire; puis, au bout d'un certain temps, la masse granuleuse centrale subit des phénomènes régressifs divers. Aux corpuscules protéiques et glycogènes dont il a été question, s'ajoutent des granulations pigmentaires d'abord jaunâtres, puis brunâtres, parfois en telle abondance que l'ensemble du kyste apparaît comme une tache brune, rougeâtre, et que le Ver se montre recroquevillé, desséché, parfois mème rompu. En outre, le contenu du kyste peut subir la dégénérescence adipeuse : les cellules qui la constituent s'infiltrent peu à peu de granulations adipeuses, puis cette graisse se trouve ultérieurement mise en liberté et envahit l'ensemble de la masse interne. Enfin, et comme terme des méta. morphoses régressives, survient la dégénérescence calcaire, qui est toujours consécutive à la précédente, et ne se manifeste que lorsque les éléments ont perdu toute vitalité. Cette crétification se traduit par un dépót de carbonate et de phosphate tribasique de chaux, non seulement dans la masse intra-kystique, mais dans les tissus mêmes du Ver et jusque dans la paroi du kyste (J. Chatin). Il faut dire que de telles

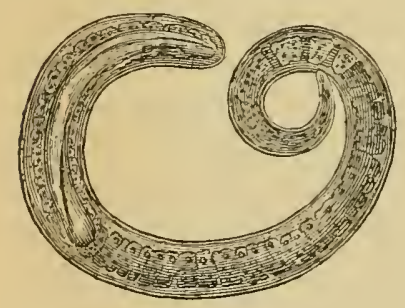

Fig. 342. - Trichine larvaire libre (G. Colin). altérations exigent, pour se produire, une longue période : en général l'infiltration calcaire ne commence pas avant le septième mois ; aussi l'observe-t-on rarement sur les Porcs et sur les animaux d'expériences. Elle est souvent complète au bout de quinze à dix-huit mois, mais dans certains cas elle n'a lieu que beaucoup plus tard. Chez le Porc, Dammann l'a trouvée très faible 11 ans après l'infestation; les Trichines étaient encore vivantes et purent se développer chez un autre animal. Chez l'Homme, on aurait vu le parasite conserver sa vitalité pendant $5,13,19$ et mème 24 ans.

La larve complètement développée (fig. 342) est longue de $0^{\mathrm{mm}}, 8$ à 
1 millimètre, large de $40 \mu$, atténuée en avant, plus épaisse el obtuse en arrière. Elle possède déjà une organisation complexe, assez. semblable à celle de l'adulte, et montre en particulier un appareil reproducteur assez développé, permettant de distinguer les scxes. Cel étal est atteint, d'après Leuckart, en quatorze jours.

Pour que cette larve puisse compléter son évolution, il est nécessaire qu'elle parvienne dans le tube digestif d'un autre animal ì sang chaud. Si l'on fail ingérer ì des Rats, Lapins, Cobayes, eté., la chair trichinée dı Rat que nous avons supposé servir à la première expérience, on constate que les kystes sont détruits sous l'influence du suc gastrique, et que les larves mises en liberté dans l'estomac passent rapidement de la vie latente à la rie active. Ces larves séjournent un certain temps dans le réservoir gastrique ou gagnent immédiatement l'intestin. Elles s'accroissent fort vite, et ne tardent pas à acquérir leur maturité sexuelle. Vers la fin clu second jour, le mâle mesure $1^{\mathrm{mm}}, 2$ à $1^{\mathrm{mm}}, l^{4}$ et la fenelle $1^{\mathrm{mm}}, \breve{3}$ à $1^{\mathrm{mm}} 8$ : c'est à ce moment qu'a lieu l'accouplement. Puis, les mâles, après un séjour plus ou moins prolongé dans l'intestin, sont expulsés aree les fèces, tandis que les femelles, qui ont continué à s'accroitre après la fécondation, effectuent leur ponte.

Organisation. - Le tégument de ces Vers ne présente que des stries transversales très légẻres, visibles seulement à un fort grossissement. Il existe des champs latéraux et des lignes médianes.

La bouche est terminale, petite, orbiculaire, dépourvue de papilles. Le tube digestif offre plusieurs régions bien distinctes. - La première, i parois minces, est á peine un peu élargie d'avant en arrière, et présente une section triquètre: on la regarde souvent comme un esophage (intestin buccal). La deuxième portion continue sans interruption la première, dont elle se distingue en ce que ses parois musculaires sont revètues de grosses cellules nucléées et très

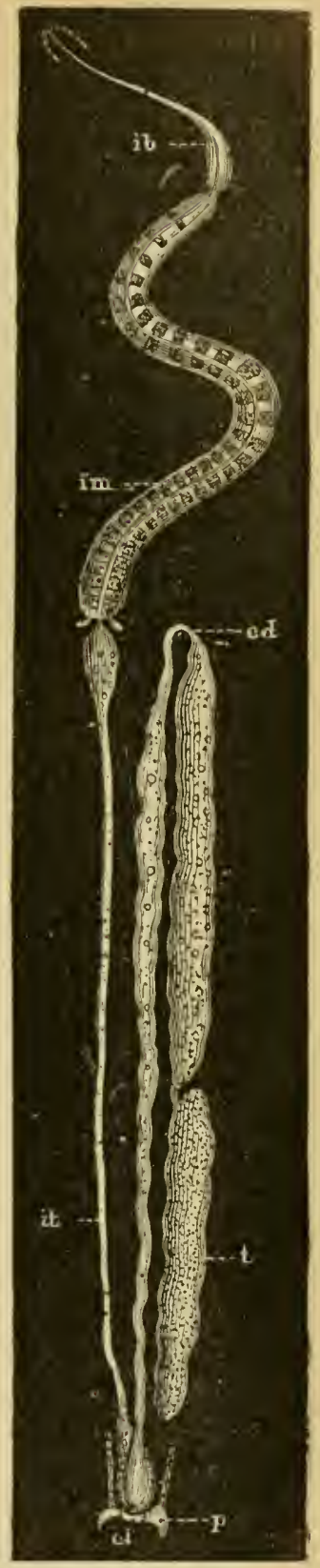

Fig. 343. - Appareils dygeslif et sexuel de la Trichine male. $i b$, intestin buccal on cesophage. im, intestin moyeu. it, intestin lerminal ou rectum. $t$, lesticule. $c d$, canal diférent. $c l$, cloaque, $p$, appendices copulaleu's (G. Colin). 


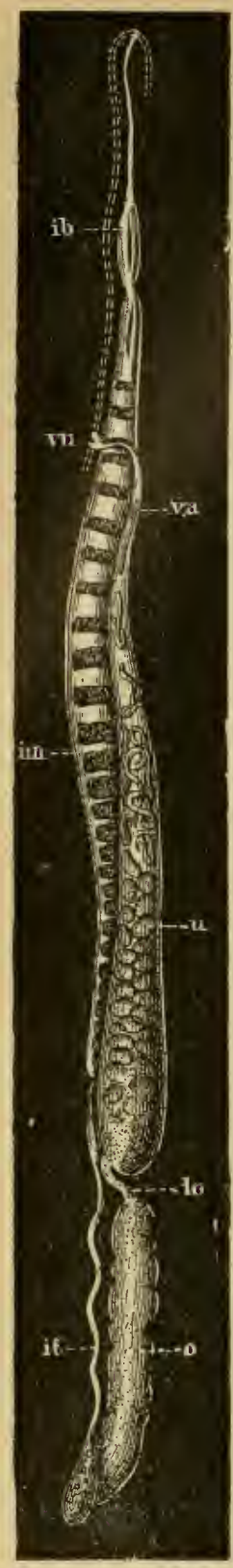

Fig. 34\%. - Appareils digestif el sexuel de la Trichine femelle. - $i b$, intestin buccal ou æesopliage. $i m$,intestin moyen. $i$, intestin terminal ou rectum. o, ovaire. do, oviducte. $u$, renflement utérin. va, vagin. vu, vulve (G. Colin). apparentes, qui jouent probablement le róle de glandes digestives, et s'atrophient à mesure que les organes génitaux prennent de l'extension. Cette région, qu'on peut regarder comme l'intestin, se termine par deux cellules un peu opaques, étendues latéralement et souvent décrites comme un appareil spécial. Elle est suivie d'un renflement dit stomacal, dont les parois transparentes sont tapissées, à l'intérieur, d'une simple couche de petites cellules aplaties. L'intestin terminal ou rectum continue ce renflement; il possède comme l'œsophage des parois musculeuses, et se dilate encore avant sa lerminaison au cloaque, lequel est situé à l'extrémité postérieure du corps.

L'appareil reproducteur du mâle consiste en un seul tube testiculaire, qui prend naissance en cul-de-sac vers l'extrémité postérieure du corps, remonte le long de l'intestin jusqu'au voisinage de l'estomac, se rétrécit alors, se recourbe et descend parallèlement à lui-mème, en formant un long canal déférent, qui se réunit enfin à l'intestin pour constituer le cloaque. Il n'y a pas de spicule; le cloaque se renverse au moment de l'accouplement et joue le ròle d'organe copulateur. Sur les côtés de l'ouverture, existent en outre deux appendices digitiformes ou papilles dont le ròle n'est pas bien déterminé.

Chez la femelle, l'ovaire unique se compose d'un tube cæcal qui nait au voisinage de l'anus et se rétrécit au niveau de l'esfomac en un très court oviducte. Celui-ci se dilate bientôt en un long et large utérus, qui se resserre enfin pour former une sorte de vagin, aboutissant à la vulve, située sur la face ventrale, au cinquième antérieur du corps.

Distribution géographlque. - Nous avons dit que les Rats paraissent être les hôtes primitifs de la Trichine, et que les Porcs sont aussi très fréquemment envahis par ce Ver. Or, ce sont lá des animaux cosmopolites, et il faut s'attendre, par conséquent, à trouver au parasite une aire de dispersion extrèmement étendue. Toutefois, on remarque dans sa fréquence des variations considérables, qui tiennent sans doute au mode d'élevage du Porc et aux habitudes culinaires de la population.

En France, on a plusieurs fois observé des Rats trichineux (Goujon, Laboulbène, G. Colin); on a mème trouvé des Trichines sur des cadavres humains (Cruveilhier, Auzias-Turenne); mais on n'y a encore relevé qu'une petite épidémie de trichinose, étudiée par Laboulbène (à Crépy-en-Valois, Oise), sur un groupe de 
personnes qui avaient consommé la viande d'un l’orc indigène (1878).

La Trichine a élé signalée aussi, che\% l'Homme on che\% les animaux, en Algérie, en Espagne, en Italie, en Belgique, en Suisse, en Angleterre, en Asie, dans l'Amérique ‘!u sud, etc. ; mais elle est assez rare dans ces contrées.

Elle est très répandue, au contraire, en Ilollande, en Suède, en I)anemark, en Russie, plus encore en Allemagne, et surlout aux Etals-Unis.

Patrologre. - Laffection déterminée par la présence des Trichines dans l'organisme a recu lo nom de trichinose. Cette afrection ne se traduit d'ailleurs par des symptômes bien aceusés que lorsque la quantite de Trichines ingrírées a été un peu considérable.

Dans les cas graves, on peut distinguer trois périodes; mais si l’inl'estation est légère, les stades se confondent et la maladie u’a rien de earactéristique.

Les premiers accidents se rapportent généralement à une irritation gastro-intestinale due au développement des Trichines dans l̈intestin ė ‘̇ l'éclosion des embryons : appétit troublé, diarrhée ou parfois constipation, vomissements, etc. - Du huitième au quinzième jour, s'établit la seconde période, qui correspond à la dissémination des Trichines : elle comprend surtout des phénomènes musculaires, tels que tension douloureuse dans les muscles, mouvements difficiles, gêne de la mastication, de la déglutition et de la respiration. - Enfin, dans la troisième et dernière période, qui fait suite à l'enkystement, les malades tombent dans un état de cachexie et d'anémie extrêmes, résultant d’une nutrition insuffisante. Des œdèmes souvent énormes surviennent, surtout accusés à la face; on observe du prurit, parfois des éruptions miliaires; dans beaucoup de cas, l'intelligence est alteinte.

La durée de la maladie est très variable suivant le degré de l’infestation. Dans les cas bénins, où la fièvre est nulle, les malarles guérissent en deux ou trois semaines. Mais lorsque se manifestent les divers sỵmptômes qui viennent d'ètre exposés, et qui s'accompagnent en général d'une ascension thermique analogue à celle de la fièvre typhoïde, la guérison ne se produit guère avant la sixième semaine, et parfois même exigge quatre mois. La mort survient rarement avant la $2^{e}$ semaine ou après la $7^{\mathrm{e}}$; elle arrive d'ordinaire de la $4^{\mathrm{e}}$ à la $6^{\mathrm{e}}$, c'està-dire quand les symptômes de myosite sont à leur maximum.

Chez les animaux, les troubles fonctionnels sont analoguesà ceux observés chez l'Homme, mais souvent plus difficiles à constater. Les petits Rongeurs, les Rats surtout, succombent facilement, avec de véritables symptômes typhoïdes. Le Porc, au contraire, offre une résistance remarquable.

Pour assurer le diagnostic, souvent difficile, on a recommandé la recherche du parasite dans les muscles, au moyen d'un harpon spécial ou mieux par une simple incision.

Les lésions anatomiques de la trichinose sont assez restreintes.

Raulliet. - Zoologie. 
A l'autopsie des sujets morts ou sacrifiés pendant la première période, on trouve les traces d'une irritation gastro-intestinale ou même d'une péritonite plus ou moins violente. A une période plus avancée, on ne trouve comme lésions essentielles que les kystes trichineux, avec les caractères que nous avons décrits.

Lorsque l'infestation est considérable, tous les muscles sont envahis; quand elle est modérée, au contraire, la répartition des parasites se montre inégale. D’après Kühn, les divers muscles peuvent, en général, se classer dans l'ordre suivant, d'après la fréquence décroissante des Trichines : diaphragme, muscles de l'épaule, psoas, muscles du larynx, de la région crurale interne, du cou, de la langue, des joues, de l'œil, de l'abdomen, fléchisseurs de la cuisse, muscles de la nuque, intercostaux, muscles du dos.

Les kystes parasitaires ne se montrent pas seulement dans les muscles striés à contraction volontaire: Harrison et Virchow en ont trouvé dans le cœur de l'Homme, et Zürn dans celui du Porc. J. Chatin a montré en outre qu'il s'en trouve dans le lard, ainsi que dans la sous-muqueuse et la musculeuse de l'intestin.

La quantité de Trichines enkystées chez un même individu est parfois extraordinaire. Leuckart a pu en compter 1,200 à 1,500 dans un gramme de chair musculaire, ce qui ferait pour l'ensemble des muscles un total de 30 à $\mathbf{4 0}$ millions.

Un traitement anthelminthique serait indiqué si la maladie pouvait être prise au début, afin de chasser les Trichines de l'intestin; il n'a plus de raison d'être lorsque les larves se sont fixées dans les muscles.

Il convient donc surtout d'établir la prophylaxie de cette redoutable affection. L'Homme, a vons-nous dit, la contracte presque toujours par la consommation de viande de Porc trichinée. Et le Porc luimème doit s'infester surtout en mangeant, soit des Rats, soit de la chair de Porc, cas qui se présente fréquemment dans les clos d'équarrissage. D'après ces données, la nécessité s'impose tout d'abord de surveiller rigoureusement l'alimentation des Pores, de les nourrir autant que possible de substances végétales, d'éviter qu'ils puissent se repaitre d'excréments humains, de résidus de boucherie et surtout de cadavres de Rats, de ne leur distribuer enfin des substances animales qu'après avoir soumis celles-ci à une cuisson suffisante.

Quant à la préservation directe de l'Homme, elle doit être basée essentiellement sur la détermination du degré de vitalité des Trichines. On sait depuis longtemps que ces parasites survirent à leur hôte et résistent fort bien à la putréfaction, puisque au bout de trois mois on peut encore les trouver vivantes dans la viande. - La salaison les tue en général plus ou moins rapidement, mais il n'y a rien d'absolu à cet égard, et on en trouve encore de parfaitement vivantes dans les jambons américains importés depuis plus d'un an. - Le fumage, quoique paraissant un peu plus efficace, est loin de suffire dans tous les cas 
it rendre les viandes inoflensives. - Reste l'action des liautes et des basses températures. On n'est pas absolument d'aceord sur l'influence du froid: II. Bouley et Gibier ont vu les Trichines périr en soumettant deux gros morceaux de jambon, pendant deux heures et demie, ì une température de - 29 a - 200 ; mais Leuckart a constaté la présence de Trichines vivantes dans des jambons frais exposés pendant trois jours i une température de - 20 a $-9 \breve{3}^{\circ}$. Du reste, cette question n’a pas une grande importance pratique, car ees expériences se placent en dehors des conditions usuelles de l'éeonomie domestique. - Il n'en est plus de mème en ce qui se rapporte ì l'inlluence de la chaleur. La plupart des expérimentateurs estiment qu une température de $+70^{\circ}$ suffit ì faire périr les larres enliystées; les exceptions à cette règle peurent être négligées. Mais les parties centrales des moreeaux de viande n'atteignent cette température qu'après un temps plus ou inoins long, variant avec leur volume et leur mode de cuisson. Pour les viandes bouillies, par exemple, il faut prolonger l'bullition pendant une demi-heure au moins par ehaque kilogramme. Les viandes rôties sont toujours plus dangereuses, car la couche extérieure " saisie " par la cuisson retarde la pénétration de la clialeur dans les parties profondes. Dans la pratique, on juge que la euisson est suffisante lorsque la viande a perdu sa coulemr rouge, et qu'il ne s'écoule plus de jus saignant sur une coupe.

Enfin, les indications de la prophylaxie comportent des mesures de police sanitaire, el en particulier une inspection minutieuse de la viande de Porc. En Allemagne, une véritable armée d'experts, hommes et femmes, est employée ì ce contrôle. - L'examen est des plus simples : on prélère, à l'aide de ciseaux fins et en suivant le sens des faisceaux, une mince tranche de muscle, qu'on étale sur une lame de verre. On dépose à la surface une goutte d'eau ou une solution d'acide acétique (de 1 à ä pour 1000), on dissocie quelque peu à l'aide d'aiguilles fines, et on recourre d'une lamelle qu'on comprimelégèrement. En cxaminant toute l'étendue de la préparation à un grossissement de 30 à 100 diamètres, on décourre les kystes aree la plus grande facilité.

Famille des FILARIDÉS. - Le corps est long, filiforme. La bouche est de forme variable, parfois entourée de lèvres et mème suivie d'une capsule buccale; elle est souvent munie de papilles. L'œsophage est grêle et non renflé en bulbe. Les mâles, dont la queue est généralement enroulée, ont un seul spicule ou deux spicules inégaux. Les femelles ont un ovaire double; la vulve est située d'ordinaire ver's la partie antérieure du corps. Un grand nombre de ces helminthes sont ovorivipares.

Genre Filaire (Filaria O. F. Müller, 1787). - Les Filaires(1) sont

(1) Raphael MoLix, Versuch einer Monographie der Filarien. Sitzungsber. d. K. Akad., XXVIII, p. 365, $185 \mathrm{~s}$. 
remarquables par leur corps grêle et très allongé, dont l'épaisseur reste à peu près la même sur toute la longueur. L'extrémité céphalique est arrondie; la bouche est souvent dépourvue de lèvres. La musculature se rapporte au type cœlomyaire. Les mâles, notablement plus petits que les femelles, ont la queue recourbée ou spiralée, par-

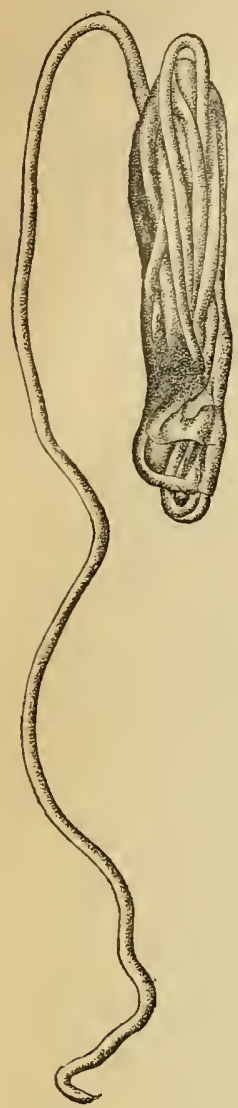

Fig. 345 . - Filaire de Médine entière, extraite du tissu conjonctif souscutané et monlrant la disposition en écheveau des anses qu'elle décrit. (irand. nat. (Orig.).

fois munie d'ailes membraneuses latérales; le plus souvent ils possèdent quatre papilles préanales et un nombre variable de postanales; les spicules sont d'ordinaire très différents comme aspect et comme dimensions. Chez les femelles, la rulve s'ouvre plus ou moins près de la bouche.

Les Filaires habitent surtout les séreuses et le tissu cellulaire sous-cutané. Le développement est encore peu connu: en thèse générale, il parait comporter le passage par un hôte intermédiaire (Crustacé, Insecte).

Il est à remarquer que, pour les médecins, ce genre est une sorte de capharnaüm où l'on range tous les Vers ronds, anciens ou nouveaux, dont l'organisation est mal connue.

Filaire de Médine (F. medinensis [Velsch]. - Syn.: Vena medinensis Velsch, 1674; Dracunculus Persarum Kämmfer, 1694; $F$. medinensis Gmelin, 1789). - A l'état adulte, on ne connait encore d'une facon précise quela femelle mûre. C'est un Ver blanc ou jaunàtre, long en moyenne de 50 à 80 centimètres, et pouvant atteindre, selnn certains auteurs, jusqu'à 4 mètres. Son diamètre, uniforme dans toute son étendue, est de $0^{\mathrm{mm}}, 5 \mathrm{~b}$ a $1^{\mathrm{mm}}, 7$. L'extrémité antérieure est mousse et présente un épaississement cuticulaire rugueux, arrondi ou transversalement ovalaire (écusson céphalique), au centre duquel on remarque l'orifice buccal, de forme triangulaire. Le bord de celui-ci porte deux grosses papilles, l'une dorsale, l'autre ventrale, simulant des lèvres ou des dents; d'autre part, il existe au bord de l'écusson deux papilles latérales arrondies, et quatre autres submédianes, un peu plus faibles. L'extrémité postérieure est constituée par une pointe émoussée, lonque d'un millimètre au plus, recourbée vers la face ventrale chez les femelles àgées. Il n'existe pas d'ouverture vulvaire : les embryons, qu'on troure éclos par myriades dans l'utérus, ne peuvent être mis en liberté que par la rupture du Ver.

Cette Filaire est souvent désignée sous le nom de Ver de Médine; on lui a donné aussi, mais à tort, celui de Dragonneau. Elle vit principalement en parasite sur l'Homme, dont elle envahit d'ordinaire le 
tissu conjonctif sous-cutané: mais on l'a signalée aussi chez quelques animaux (1).

D'après Avenzoar et de Marchais, elle s'attaquerait fréquemment au Bưf; le premicr de ces observateurs désigne mème l'affection qu'elle détermine sous le nom de mal des Baufs. Clarkson, Fleming, Burke l'ont observée chez le Cheval, lans l'Inde; elle a été vue également chez le Chien, à Buenos-Ayres et à Curaçao (Doerssel), dans I'Inde (Smyttan, Forbes, Griffith), en Egypte (Clot-Bey, J.-B. Piot, W. Innès); puis chez le Guépard (Filaria ithiopica Valenciennes), le Canis lupaster, le Chacal et le Chat sauvage.

Évolutrox. - On a vu plus haut que la Filaire est vivipare; mais comme elle est, à maturité dépourvue de vulve, les embryons nesont mis en liberte que par la destruction des parois du corps. Ces embryons

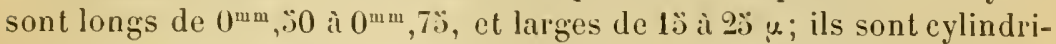
ques, striés en travers, à peine atténués en arant, mais graduellement rétrécis dans le liers postéricur, de manière ì se terminer par une queue trìs effilée; ils ont d'ordinaire la partie antérieure du corps enroulée vers la face ventrale. Ils peuvent vivre plusieurs jours dans l'eall et surtout dans la terre humide; de plus, ils résistent à une dessiceation de 6,12 et 2 t heures. Leur tube digestif est complet, terminé par un anus situé à la racine de la queue, sur la face ventrale, au nireau de deux papilles latérales.

Quel est le sort de ces embryons? C'est au royageur russe Fedtshenlio que revient le mérite d'avoir déterminé leurs migrations. Leuckart avait remarqué la grande ressemblance qu’ils présentent arec ceux du Cucullanus elegans, de la Perche, qui évoluent chez les Cyclopes. Sur son conseil, Fedtshenko, au cours de son voyage en Turkestan, expérimenta sur ces Crustacés el obtint des résultats positifs: par' contre, il ne put infester aucun autre groupe d'animaux (Insectes, Rotifères, etc.).

Quelques heures après avoir déposé dans l'eau oú vivent des Cyclopes les embryons extraits du corps de la Filaire, on peut déjà constater que cenx-ci ont envahi la cavité du corps des petits Cruslacés, en pénétrant par effraction dans l'interstice des segments de l'abdomen, Les embryons introduits dans le tube digestif sont toujours digérés. Dans la eavité générale, ils n'éplouvent d'abord que peu de modifications; l'intestin devient seulement plus apparent.

Vers le douzième jour, ils subissent une mue, à la suite de laquelle leur aspect se trouve complètement changé. La longueur totale est réduite i $0^{\mathrm{mm}}, \breve{o}$; la cuticule a perdu sa striation ; l'extrémité antérieure semble pourvue de deux papilles; la queue est tout ì fait ramassée sur elle-mème et terminée par trois courtes pointes; l'œso-

(1) A. Railuet, De l'occurrence de la Filaire de Médine chez les animaux. Bullet. de la soc. zool. de France, XIV, p. 73, 1889. 
phage, l'intestin et le rectum apparaissent nettement, ainsi qu'un rudiment des glandes génitales. - Après cette mue, le parasite s'accroît peu à peu; à la $4^{e}$ semaine, il a atteint plus d'un millimètre de long.

La suite de l'évolution reste ì déterminer. Fedtshenko a vainement essayé d'infester deux jeunes Chiens et un Chat, en leur faisant prendre dans du lait et de l'eau des Cyclopes contenant de nombreuses larves bien développées.

Il y a lieu cependant de supposer que l'Homme ou les animaux contractent la Filaire en buvant de l'eau non filtrée, renfermant des Cyclopes chargés de parasites. Cette manière de voir est en tout cas plus admissible que l'opinion ancienne, d'après laquelle les Filaires se seraient introduites directement sous la peau en pénétrant dans les conduits sudorifères ou dans les follicules pileux. - Nais on est réduit aux suppositions quant à la façon dont ces Vers évoluent dans l'organisme. Certains auteurs ont pensé qu'il s'agissait peut-être d'une espèce hermaphrodite, produisant d'abord des spermatozoïdes, puis des cufs, comme l'Angiostoma nigrovenosum. D'autres ont admis que les larves doivent arriver à maturité sexuelle dans l'intestin, où aurait lieu l'accouplement. Le mâle serait ensuite évacué, tandis que la femelle pénétrerait dans le tissu conjonctif des muscles, pour arriver plus tard sous la peau. On peut penser aussi, par comparaison avec la Filaire des boutons hémorragiques, que le mâle et la femelle vivent et s'accouplent dans le tissu conjonctif, la femelle seule passant sous la peau pour se faire jour au dehors (1).

En tout cas, on sait que cette apparition dans le tissu conjonctif sous-cutané n'a lieu que huit mois à deux ans après l'infestation.

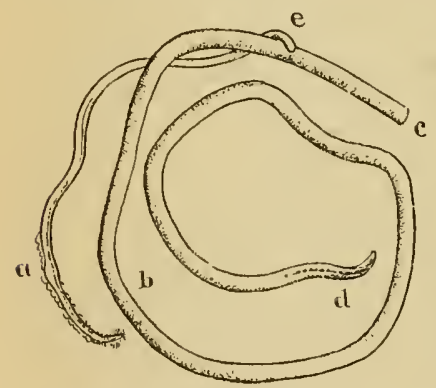

Fig. 346. - Filaire de Médine : måle et femelle accouplés, grossis 2 fois, d'après Charles. - $a$, mâle un peu altéré à l'extrémité libre ou céplalique. $b$, femelle dont le corps a sté rompu en $c$. $d$, son extrémité céplialique. $e$, vulve, sur laquelle est fixée l'extrémité caudale du mâle.

Cette donnée repose principalement sur l'observation d'individus qui ont contracté le parasite par le simple passage dans des contrées où il est endémique.

(1) Celte manière de voir semblerait appuyée par une récente observation de Charles. Sur des cadavres de l'Institut anatomique de Lahore, ce médecin a trouvé à plusieurs reprises des Filaires dans le tissu conjonctif sous-péritonéal, au niveau du " sacral promontory". Les unes étaient calcifiées, les autres normales. Sur deux de ces dernières était fixé un individu plus petit, que l'auteur croit être un mâle. Nous reproduisons ci-contre la figure donnée par cet auteur de l'un de ces couples; la femelle a été rompue en $c$; elle mesurait 148 millimètres de long sur $1 \mathrm{~mm}, 2$ de large (R. llavelock Cirarces, $A$ Contribution on the Life Histor!y of the male Filaria medinensis founded on the Examination of specimens removed from the abdominal cavity of man. Scientific Memoirs by Medical Officers of the Army of India. Part. VII. Calcutta, 1892). 
Dans le point ou la Filaire s'est arrêtée, il se forme un abcès qui s'ourre à l'extérieur el qui l'expulse soit en masse, soit par fragments. La déchirure du corps ou la putréfaction permellent alors aux embryons de s'éclapper el de se répandre sur le sol humide ou dans les eaux.

Organisation. - Le Ver possède une cuticule épaisse, résistante, striée transversalement et formée de six couches superposées. Les lignes latérales sont larges et minces; les lignes médianes sont très réduites, à peine distinctes. La musculature est disposée sur le type cœlomyaire, comme chez les Ascarides.

A la bouche triangulaire fait suite un court pharynx et un wsophage beaucoup plus long, dont la structure est assez complexe. L'intestin est atrophié, par suite du développement énorme de l'utérus; il est réduit à une sorte de rubau étroit, rejeté sur le cỏté, et dont la lumière est oblitérée aux deux extrémités; il arrive mème a disparaitre en arrière; cependant, chez des individus jeunes, on l'a vu se continuer par un rectum aboutissant à l'anus, simple pore percé à la base de la queue, sur la face ventrale.

L'utérus remplit la plus grande partie du corps, dont il occupe presque toute la longueur, ne laissant libre que $\dot{4}$ à $\ddot{z}$ centimètres en avant et 6 à i millimètres en arrière. C'est un tube cylindrique continué à ses deux extrémités par uı canal plus petit qui s'infléchit et s'insinue entre lui et la paroi du corps, et qui représente un ovaire en régression. Il n'y a plus trace de vagin ni de vulve. L'utérus est rempli d'embryons, qui nagent au nilieu d'un liquide crémeux, et l'on peut dire en somme que la filaire adulte est réduite à une simple gaine destinée à loger et à protéger ces embryons.

Distribution géographique. - La Filaire de Médine est originaire des régions chaudes de l'ancien continent, d'où elle a été transportée dans l’Amérique du Sud.

En Asie, elle est répandue non seulement à llédine, comme l'indique son nom, mais dans presque toute l'Arabie, ainsi qu'en Perse, dans le Turkestan et dans l'llindoustan.

En Afrique, elle est commune sur la còte de Guinée, d'où le nom de Guinea worm que lui donnent les Anglais; mais on l'observe en outre dans la Sénégambie, le Darfour, le Semnaar, l'Abyssinie, la Nubie, l'Égypte. - Il est curieus de renarquer qu'elle attaque fréquemment les Carnivores dans la Basse-Égypte, tandis qu'elle ne semble pas, jusqu'ả présent, s'ètre acclinatée chez les indigènes de cette région.

C'est éridemment par les nègres qu'elle a été importée en Amérique, à l'époque de la traite; elle se rencontre encore aujourd'hui a Curaçao, dans les Guyanes et au Brésil.

Pathologie. - La présence de la Filaire dans l'organisme n'est reconnue qu'au moment où elle apparaît sous la peau. On donne sou-

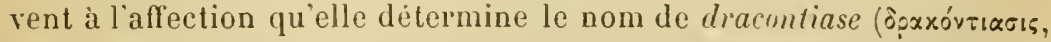
Galien). Elle peut se montrer sur des points très variés du corps: sur la paupière supérieure, sur la langue, sur le tronc, sur les organes 
génitaux, sur le périnée, sur la main et le bras, mais principalement sur les membres inférieurs, et de préférence dans la région malléolaire, au pied et à la jambe.

Le plus souvent, il n'en existe qu'une seule à la fois; pourtant il n'est pas très rare d'en observer deux, trois ou quatre, et divers médecins en ont vu jusqu'à trente et cinquante.

Elle peut se rencontrer chez tous les individus, sans distinction de race, d'âge ni de sexe. Les différences qu'on a pu signaler à cet égard tiennent simplement au genre de vie et aux habitudes sociales. $\mathrm{Au}$ surplus, ce que nous avons dit de son évolution doit suffire à montrer qu'elle doit être plus commune dans les régions marécageuses, où abondent les Cyclopes, et qu'elle doit apparaitre en plus grande abondance à la suite des années pluvieuses. Le plus grand nombre des cas s'observe, dans l'Inde, d'avril à septembre; au Sénégal, de juin à octobre.

Les symptômes par lesquels se décèle la présence du parasite sont presque toujours exclusivement locaux: il se produit une tumeur d'abord indolente, puis douloureuse, qui prend peu à peu les caractères d'un abcès. Celui-ci s'ouvre à l'extérieur par un ou plusieurs orifices, et, après évacuation du pus, on aperçoit la Filaire pelotonnée au fond de la plaie. L'expulsion du Ver a lieu quelquefois spontanément, mais dans la plupart des cas il est nécessaire d'en effectuer l'extraction. Par elle-même, la Filaire serait donc, en somme, assez peu dangereuse; mais il faut compter avec les complications redoutables qui, dans les pays tropicaux, se manifestent si souvent à la suite des plaies, et qui sont surtout à craindre lorsque les abcès sont multiples: suppuration intense, décollement, gangrène, etc. L'amputation du membre est parfois nécessaire, et trop souvent la mort survient par infection septique.

L'extraction du Ver se pratique, en Afrique, en Perse, etc., d'après une méthode très simple, que préconisait déjà Aétius d'Amide, et qu'on désigne souvent sous le nom de méthode soudanaise. Elle consiste à attirer l'extrémité du parasite en dehors de la plaie, à le saisir entre les deux sections d'un bâtonnet fendu en long, et à l'enrouler peu à peu autour de ce bâton. Cette opération doil être menée avec un grand soin et une grande lenteur: on la suspend à la moindre résistance, on la reprend souvent à un jour d'intervalle, et au bout de quelque temps on parvient ainsi à obtenir le Ver entier. La figure 343 , que nous donnons d'après un échantillon fourni par un Chacal, rend fort bien compte de la façon dont peut s'opérer cette extraction: on voit en effet que la Filaire forme des anses en 8 ou en écheveau, et qu'il suffit en quelque sorte de la dévider. Cependant, le médecin préférera sans doute substituer à ce procédé primitif l'excision pure et simple de la tumeur, qui permettra de faire l'extraction en une seule séance et d'éviter les chances d'infection. - Lorsqu'on enlève, en effet, le para- 
site en entier, la plaie se cicatrise rapidement; mais lorsqu il vient à se rompre, la partie qui reste dans la plaie se rétracte, la suppuration s'exasère, les douleurs deviennent intolérables et sourent ces accidents aboutissent ì la gangrène et ì la mort. On voit done que l'opération exige les plus grandes précautions.

Chez les auimaux, les Filaires sont souvent multiples. Les symptômes sonl à peu près les mèmes que che\% l'llomme, mais on n'observe pas les accidents grares que nous venons de signaler.

Ajoutons que Rivolla a rencontré chez le Chien un cas de maladie herpétique due à des embryons de Nématode qu'il a considérés, sans motif plausible, comme des embryons de $r$. medinensis.

La prophylaxie de la dracontiase doil être évidemment baséc sur la consommation, dans les régions infestées, d'eau soigneusement filtrée ou bouillie.

\section{Filaire des boutons hemorragiques}

(F. hamorrhagica Raill., 188\%. - Syn. : F. multipapillosa Condamine et Drouilly, 1878, nec F. multipapillu Molin, 18:57). - Corps blanc, cylindrique, à peine atténué aux extrẻmités, un peu plus en arrière qu'en arint. Extrémité antérieure en còne rétractile. Tégument garni de stries transversales très serrées; il la base du còne céphaliq̣ue, ces stries s'écartent davantage et se montrent moins régulières, limitant bientỏt des espaces en saillie, les uns allongés transversalement, les autres plus courts, elliptiques ou circulaires, représentant en définitive des saillies papilliformes très nombreuses. Bouche circulaire, inerme. Mále long de 28 millimètres, large de $0^{\mathrm{mm}}, 260$ à $0^{\mathrm{mm}}, 280$; extrémité postẻrieure largement arrondie; deux spicules inégaux, l'un long de

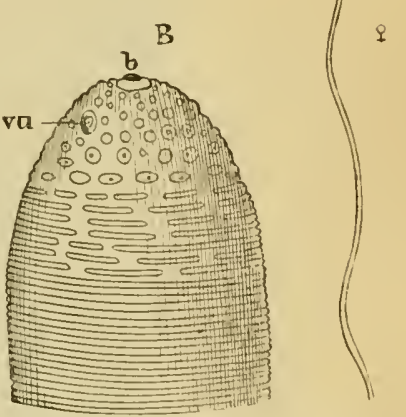

Fig. 3.47. - Filaire des boulons hémorraginues. - A, femelle adulte, grand. nat. B, extrémité céplıalique avec ses verrues, grossic 100 fois, d'après Condamine. $b$, bouche. vu, vulse. 680 à $750 \mu$., l'autre de 130 à $140 \mu$. Femelle longue de 40 à 36 et jusqu'à 70 millimètres, large de $0^{\mathrm{mm}}, 420$ à $0^{\mathrm{mm}}, 440$; extrémité candale très largement arrondie; vilve située au voisinagge de la bouche. OEufs mùrs longs de ว̈2 à $\ddot{3} 8$ u, larges de 2't ả 33, contenant un embryon.

Cette Filaire, dont la découverte est due au vétérinaire militaire Drouilly (1), habite le tissu conjonctif sous-culané et même le tissu conjonctif intermusculaire ou interfasciculaire du Cheral et de l'Ane (Railliet et Moussu).

Son évolution est encore inconnue. Le màle et la femelle vivant côte

(1) Drocilly, Letlre au sujet des boutons hémorragiques des chevaux hongrois. Journ. de méd. vét. milit., XIV, p. i69, février 1877. - Coxdayixe et Drocills, Descriptıon de la Filaire femelle (cause déterminante des boulons hémorragiques).

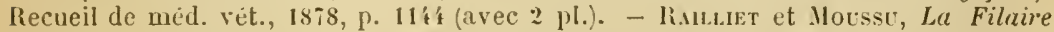
des boutons hèmorragiques observée chez l'Ane; découverte du male. Comptes rendus de la Soc. de biologie, (9), NY, P. 545, 189?. 
à côte, la fécondation doit aroir lieu dans le tissu conjonctif. Lorsqu'on maintient les femelles dans le sérum, elles continuent à y vivre deux ou trois jours. On peut constater alors qu'une partie des œufs embryonnés renfermés dans les utérus sont éclos. Les embryons libres sont longs de 220 à $230 \mu$, larges de 9 à $11 \mu$. Ils ne peuvent vivre que peu de temps dans l'eau et ne résistent pas à la moindre dessiccation. Au mois de mars 1877, nous avons injecté sans résultat, dans le tissu conjonctif sous-cutané d'une vieille jument, un assez grand

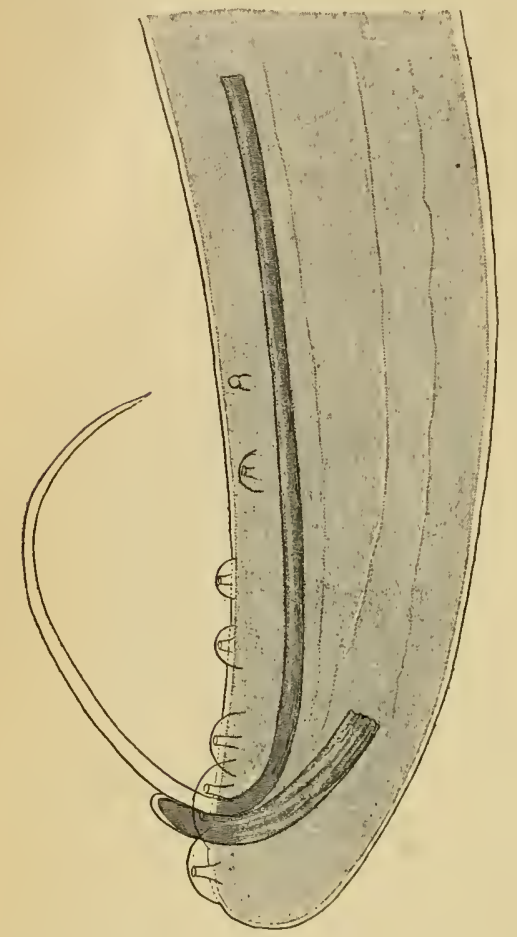

Fig. 348. - Filaire des boutons lémorragiques : extrémité caudale du mâle, vue de côté, grossic 200 fois (Orig.).

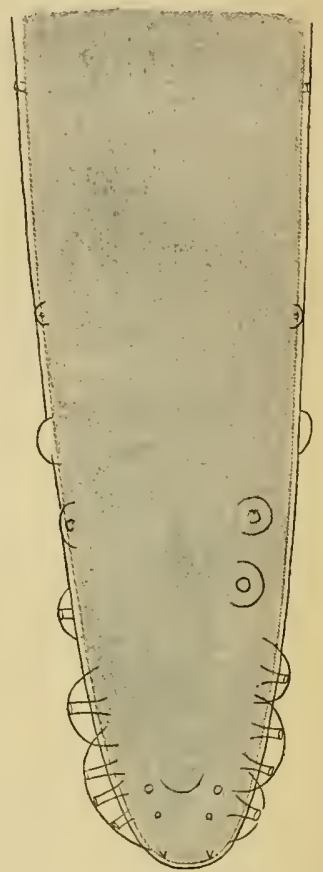

Fig. 349. - Filaire des boutons hémorragiques : extrémité caudale du mâle, vue par la face ventrale, grossie 200 fois (Orig.).

nombre de ces embryons extraits du corps de la Filaire. Comme les femelles percent la peau du Cheval en provoquant des hémorragies, nous sommes porté à croire qu'ils sont expulsés à ce moment, et qu'ils doivent passer ensuite dans le corps d'un Insecte suceur ou d'un Crustacé. C'est dans cette voie que devront chercher les helminthologistes russes ou hongrois.

PAthologie. - La Filaire hémorragique tire son nom des petites hémorragies locales qu'elle provoque sur divers points de la surface cutanée, et qu'on a signalées depuis longtemps chez. le Cheval. 
On assure que, depuis une haute antiquité, les Chinois connaissent une race de cheraux du lihodang "suant" le sang. Parmi les auteurs qui se sont occupis de cette affection, les uns, comme Sibald, affirment. qu'elle est commune chez les chevaux blanes de la Tartarie; d'autres, comme spinola, la considèrent comme spéciale a la race des steppes; Leblane l'a observée sur des Chevaux russes; mais on ne la connait sérieusement en France que depuis les achats de Chevaux de troupe effectues en Hongrie par le gouvernement français. Elle serait done propre aux Chevaux d'origine orientale, bien que Bernard et Liautard aient prétendı l'observer en Algérie sur des Cheraux et des Mulets renant d'Espagne.

La filariose hémorragi(jue se manifeste au printemps, persiste quelquefois une grande partic de la belle saison, et disparait complètement en hiver pour se reproduire l'année suivante. Dans nos pays, l'affection cesse d'elle-mème et d'une façon définitive au bout de trois ou quatre ans.

L'éruption est d'ordinaire localisée

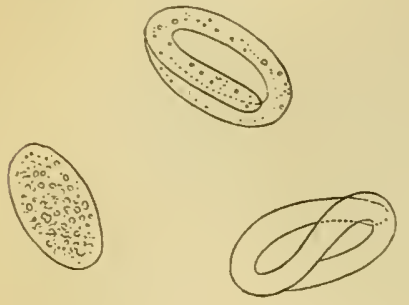

Fiz. 350. - CEufs de la Filaire lı́́morragique, grossis 300 fois (Orig.).

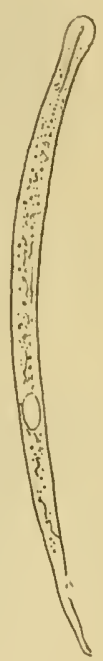

Fig. 3ว̆1. - Embryon libre de la Filaire hémorragique, grossi 300 fois (Orig.).

aux côtés du garrot, aux épaules, aux faces de l'encolure, aux côtes et à la région dorsale. On voit apparaitre à la fois plusieurs élerures hémisphériques, de la grosseur d'un pois ou d'une noisette, indolores, un peu œdémateuses à la périphérie. Une heure ou deux après la formation de ces boutons, leur sommet s'ourre, d'où un écoulement de sang qui forme des trainées sur les poils et se coagule. Puis la tuméfaction s'affaisse et le bouton disparait; dans quelques cas cependant, il survient de la suppuration. Mais, vingl-quatre ou quarante-huit heures plus tard, on roit un noureau bouton se développer à quelques centimìtres du premier.

Les Filaires semblent pouroir pénétrer dans la profondeur des tissus, et c'est probablement ce qui a lieu pendant la saison froide. Chez un Ane atteint d'une paralysie mortelle, nous avons trouvé la moelle épinière creusée de trajets filiformes attribuables à ces Vers. 
Dans le midi de la France et en Italie, les Bœufs montrent assez fréquemment des boutons hémorragiques analogues à ceux dont il
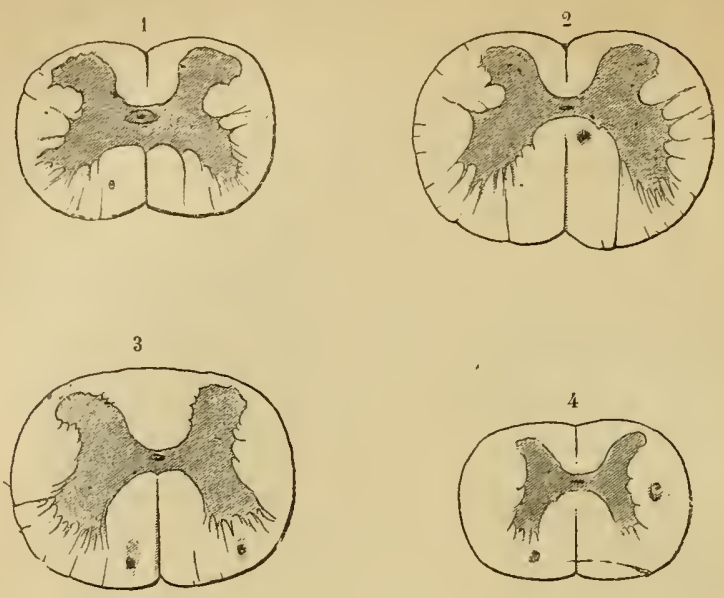

Fig. 352. - Coupes faites à divers uiveaux, et légèrement grossies, de la moelle lombaire d'un Ane, montrant les trajets creusés par la Filaire hémorragique. (Orig.)

vient d'être question; mais la constatation d'un parasite n'a pas encore été faite.

Filaire subaiguë ( $F$. acutiuscula Molin, 1857). - Corps blanc, filiforme, subégral. Extrémité antérieure épaisse; extrémité postérieure arrondie. Bouche inerme. Mâle long de 40 à 46 millimètres, large de $0^{\mathrm{mm}}$, ,ŏă; extrémité caudale enroulée en spirale, offrant de chaque còté une aile cuticulaire et cinq papilles: trois préanales et deux postanales; un spicule linéaire très long, épaissi à la base. Femelle longue de 56 à 138 millimètres, large de $0^{\mathrm{mm}}, 5 \mathrm{5} \mathrm{3}$ à $0^{\mathrm{mm}}, 73$; extrémité caudale inlléchie, obtuse.

Trouvée au Brésil, par Natterer, dans les viscères de deux espèces de Pécaris (Dicotyles allirostris et D. turquatus), et sous les muscles pectoraux du Vulpes Azarx. - Au mois de mai 1889, le comte de Ninni l'a retrouvée en Vénétie sous la peau d'un Chien domestique (1).

Filaire des plaies d'été (F. irritans [Rivolta]. - Syn. : Dermofilaria irritans Riv., 1884; F. irritans Raill., 1883̈). - On désigne sous ce nom une larve de Nématode dont le corps très grèle mesure presque 3 millimètres de long; la tête est parfois un peu distincte du corps; la queue est atténuée, terminée en pointe obtuse et dentelée. La bouche est orbiculaire, paraissant munie de lèvres. A peu de distance de l'extrémité céphalique se voit une ouverture. L'anus s'ouvre au point où le corps s'atténue pour former la queue. Le tégument est très finement strié en travers.

C'est en 1868 que Rivolta a découvert, dans les granulations des " plaies d'été » ou de la " dermite granuleuse » du Cheval, cette larve

(1) M. Stossicn, Elminti Veneti raccolli dal Dr Alessandro conte di Ninni. Bollett. della Soc. Adriat. di sc. nat. in Trieste, XII, 1890. 
dont la place dans la classification n'est donnée ici qu'ì titre provisoire. En 188', Laulanié a contirmé celte découverte.

Les plaies d'été, qui ont été bien décrites pour la première fois par I1. Bouley en 18.0, sont caractérisées par la présence, au milieu des bourgeons charnus, de granulitions offrant le volume d'un grain de mil à celui d'un pois, et constitućes par une masse caséeuse ou calcaire. C'est dans ces granulations qu'on observe le Nématode, ou ses dehris, ou encore la loge qu'il occupait. Les plaies manifestent rapidement une tendance à sétendre el sont d’une ténacité remarquable ;

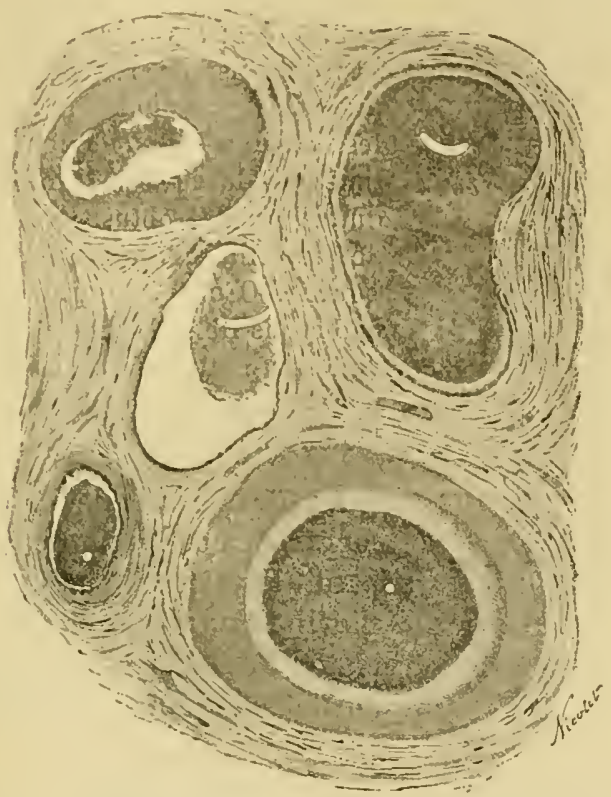

Fig. 353. - Coupe d'un fragment de peau de Cheval alleinl de dermite granuleuse ; à l'intérieur des granulations, on voil la coupe transversale ou longiludinale du Ver. D'après une préparatiou de Laulanié. Grossissement : 20 diamc̀tres (Orig.).

elles sont en outre le siège d'un prurit constant etinsupportable. Elles entrainent quelquefois des complications sérieuses.

Comme l'indique leur nom, elles coïncident d'ordinaire avec les chaleurs de l'été. On les observe aussi plus fréquemment dans les pays chauds, el l'Ane y est plus exposé encore que le Cheval.

Le traitement en est difficile; cependant Rey a oblenu de bons résultats par l'application de sulfure jaune d'arsenic (orpiment) pulvérisé. Blaise a eu recours avec le même succès à l'éther, au chloroforme et à l'iodoforme.

Filaire cruelle (F. immitis Leidy, 18306 - Syn. : F. cunis cordis Leidy, $18300 ;$ F. papillosu, hxmatica canis clomestici Gruby et Delafond, 18322). - Corps blanchàtre, filiforme, un peu atténté seulement aux extrémités, surtout en 
arrière. Extrémité antérieure arrondie. Bouche terminale, petite, orbiculaire, inerme, entourée de six papilles petites et peu distinctes. Anus très rappro-

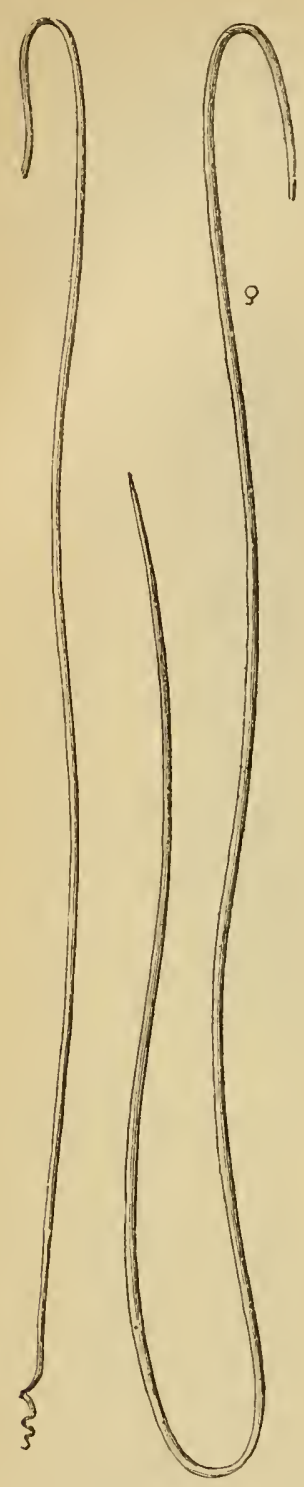

Fig. 354. - Filaria immitis. - A gauche, mâle; à droite, femelle. Grandeur naturelle (Orig.). ché de l'extrémité caudale. Wúle long de 12 à 18 centimètres, large de $0^{\mathrm{mm}}, 7$ à $0^{\mathrm{mm}}, 9$; queue effilée, contournée en spirale serrée, et munie de deux faibles ailes latérales soutenues par des papilles, dont quatre nous ont paru plus développées : trois préanales et une postanale. D'après Schneider, il y a de chaque còté 11 papilles, dont 6 postanales; elles sont marginales, sauf $2,3,6$ et 7 ; les plus fortes sont $5,8,9,10$, 11 ; de plus, on rencontre d'un seul còté une papille préanale anormale. Deux spicules inégaux. Femelle longue de 250 à 30 centimètres, large de 1 millimètre à $1^{\mathrm{mm}}, 3$; queue courte, obtuse; vulve vers l'origine de l'intestin, à 7 millimètres environ de la bouche. OEufs éclosant dans les utérus ; embryons libres longs de 285 à $295 \mu$, larges de כ̌ $\mu$, à extrémité antérieure un peu atténuée et obtuse, à extrémité postérieure effilée en une queue longue et fine.

La Filaire cruelle habite principalement le cœur droit du Chien. Sauzade paraît l'avoir vue aussi chez le Renard; Bowlby l'a même signalée récemment chez l'Homme, mais ses observations auraient besoin d'être contrôlées. Janson

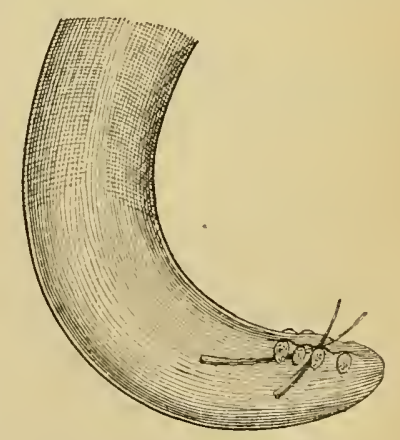

Fig. 355. - Fillarıa ımmitıs : extrémité caudale du nảle, grossie 50 fois (Urig.).

l'a observée chez un Loup du Japon. - Nous ne nous occuperons que du Chien. Les Filaires cardiaques de cet animal ont été signalées pour la première fois par Panthot (1679); elles ont été revues un siècle 
plus tard par de la Peyronnic (1778), et depuis lors par un grand nombre d'observateurs.

Les millier's d'embryons émis par les femelles se répandent dans le torrent circulatoire: on les troure dans le sang pris en un point quelconque du corps, et en nombre généralement considérable. Ils se distinguent des " Ilématozoaires de Lewis ", dont il sera question plus loin, par cette abondance même, par leur taille généralement un peu plus grande, et par ce fait qu’ils ne se fixent jamais, par leur extrémité orale, sur les lames ou lamelles de rerre.

Galeb et Pourquicr ont reconnu qu'ils sont susceptibles de passer du système circulatoire de la mère dans celui du fœlus; mais il nous parait certain que cette infestation congénitale ne peut entraîner leur développement direct en Filaires adultes.

D’après Manson, ils présentent, quoique à un moindre degré que ccux de $\boldsymbol{F}$. sanguinis hominis (nocturna), la curicuse particularité de se montrer périodiquement dans la circulation périphérique; en réalité, ils ne disparaissent jamais complètement des vaisscaux superficicls, mais ils y sont beaucoup plus nombreux que le jour. Sonsino a vérifié le fait. En faisant l'autopsie de Chiens tués par l'acide prussique ou par la strychnine, Manson a constaté que les embryons s'accumulent pendant le jour dans les gros vaisseaux du thorax et de l'abdomen.

On est loin, du reste, d'ètre fixé actuellement sur leur érolution. Bancroft disait avoir trouvé des embryons dans l'intestin de Trichodectes qui avaient sucé le sang du Chien, et supposait que ces

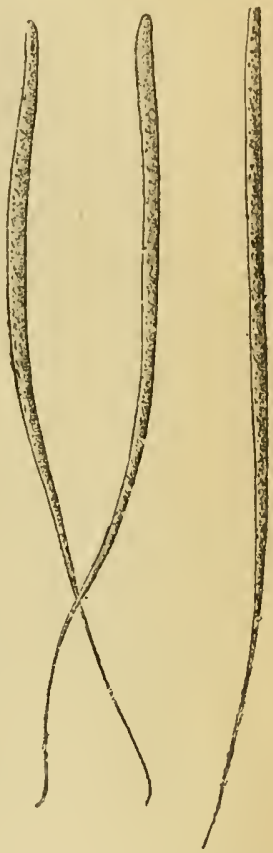

Fig. 356. - Embryous de Filaria immitis recueillis dans le sang d'un Chien, grossis 300 fois (Orig.). Insectes étaient appelés à jouer le rôle d'hôtes intermédiaires. Sonsino vérifia cette indication, mais il reconnut plus tard qu'il s'agissait, non du Trichodectes canis, qui ne suce en aucune façon le sang, mais bien de l'Hrmatopinus pilifer. Grassi et Sonsino trouvèrent également des larves de Nématode dans l'intestin el la cavité viscérale des Puces du Chien, et crurent aroir affaire, soit aux embryons du Spiroptera sanguinolenta, soit à ceux de la Filaria immitis. Ces conclusions étaient prématurées. Le Spiroptère ne fournit pas de larves hématozoaires; quant à la Filaire cruelle, les recherches ultérieures de Grassi ont démontré que ses larves ne se léveloppent pas dans les Puces, ni dans les Hématopinus, ni dans les Tiques: on ne trouve que des hématozoaires morts dans le tube digestif de ces Insectes et Acariens, quand ils ont sucé le sang des Chiens à Filaria immitis; aucune larve ne 
pénètre dans la cavité abdominale. - Les larves qui poursuivent leur développement chez quelques-uns de ces hôtes correspondent aux "Hématozoaires de Lewis ".

L'évolution de la Filaire cruelle reste donc tout entière à déterminer. Grassi a émis l'hỵpothèse que les embryons devaient s'échapper à la faveur des blessures que se font les Chiens dans les broussailles des endroits marécageux, et se développer chez de petits animaux aquatiques; mais c'est là une supposition toute gratuite.

Distribution géographique. - La Filaire cruelle ne paraît pas ètre très commune en France, bien qu'elle y ait été signalée déjả par un certain nombre d'observateurs. Elle est beaucoup plus répandue en Italie, surtout dans les régions marécageuses, comme les environs de Pise et de Milan. On l'a trouvée également en Angleterre, en Danemark, en Allemagne, aux États-Unis, au Brésil, en Australie. Mais elle est surtout ex/rèmement fréquente en Chine et au Japou : c'est au point qu'en Cline, suivant l'assertion de Somerville, on ne trouve qu'un petit nombre de Chiens non infestés; au Japon, plus de 50 p. 100 de ces animaux sont envahis.

Patiologie. - La Filaire hématique est commune chez les gros Chiens ou chez ceux de taille moyenne, qui vaguent dans la campagne, et en particulier chez les Chiens de chasse; elle est très rare, au contraire, chez les petits Chiens d'appartement. On considère, au Japon, qu'elle s'introduit dans l'organisme principalement pendant la saison de chasse, qui s'étend de novembre à fin mars. Les accidents qu'elle détermine apparaissent presque toujours, en effet, d'arril à août; on ne les roit à peu près jamais survenir en hiver.

Ces accidents sont beaucoup plus graves chez les animaux introduits ou croisés que chez les sujets indigènes, probablement parce qu'ils possèdent une moindre résistance.

L'habitat de cette Filaire est loin d'être fixe. Dans la plupart des cas, il est vrai, on la rencontre dans le cœur droit, ainsi que dans l'artère pulmonaire, jusqu'à une assez grande distance de son origine. Mais il n'est pas très rare non plus de la voir dans la veine cave postérieure (Tokishige, Labat), dans la veine cave antérieure (Schuppert, Tokishige), et dans leurs branches d'origine, telles que les veines diaphragmatiques, sus-hépatiques, iliaques externes et internes d'une part, les veines vertébrales, dorsales, jugulaires, axillaires, etc., de l'autre (Tokishige). Zeviani, de Silvestri et Tokishige l'ont rencontrée dans le cœur gauche; ce dernier en a ru un exemplaire qui arait traversé la fosse ovale et se trouvait, partie dans l'oreillette droite, partie dans la gauche; il en a observé aussi dans l'aorte abdominale, dans l'artère fémorale, dans l'artère saphène; enfin, il en a rencontré

(1) Exposition universelle de 1889 , à Paris. Vote explicative des objels exposés par l'École agricole et forestière de Komaba. Paris, 1889, p. 93. - Jaxson, Filaria immitis und andere bei Hunden in Japan vorkommende Parasiten. Archiv f. wiss. u. prakt. Thierheilk., XVIII, p. 63, 1892. 
des exemplaires libres dans la cavité thoracique, dans les bronches, dans l'esoplage. Leidy signale la Filaire non seulement dans le poumon, mais aussi dans le foie; il en a même trouvé une fois dans les matières vomies par un Chien, deux exemplaires vivants atteignant 13̈ centimètres. 1)autre part, Ercolani a montré que les Filaires se trouvent dans le tissu conjonctif sous-cutané, plus souvent même que dans le cœur. Entin, Lanzillotti-Buonsanti en a observé dans le tissu conjonctif intermusculaire, oủ existaient des kystes contenant à la fois des mitles et des lemelles encore jeunes.

Nais un fait important à noter, c'est que, dans le cas où il existe des femelles adultes et fécondées, mème en dehors de l'appareil circulatoire, on rencontre des embryons dans le sang.

Le nombre des Vers que peut héberger un animal varie de 1 à ö0; il est tout ì fait exceptionnel d'en observer davantage, et l'on peut tenir pour douteuses les assertions relatives à la présence de plusieurs eentaines de Filaires dans un seul cour. On rencontre en moyenne un mâle pour deux ou trois femelles: parfois il n'y a que des mâles ou que des femelles. Ces Vers sont d'ordinaire enchevètrés les uns dans les autres et forment souvent des bouchons qui obstruent plus ou moins complètement les cavités du cœur.

Les lésions que peut entrainer leur présence sont fort nombreuses, elles varient du reste suivant les points envahis. Lorsqüil s’agit de filariose du cœur, ce qui est la règle, on observe une hypertrophie de l'organe et une endocardite plus ou moins prononcée; si les parasites siègent dans les artères, il se produit de même de l'endartérite, de la thrombose, ete.

Quant aux symptômes qui décèlent ces altérations, ils sont également des plus variables : anémie, faiblesse, toux, ictère, ascite, boiteries, etc. La mort est une terminaison assez commune de la filariose hématique.

Aucun traitement n'est applicable en l'espèce, les parasites ne pouvant être sérieusement atteints dans l'appareil circulatoire.

Filaire cachée $(F$. reconditu Grassi, 1890). - La femelle seule est connue; elle est longue de 3 centimètres, large de $0^{\mathrm{mm}}, 178$. Corps transparent, atténué aux deux extrémités, principalement en arrière. Tégument non strié. Exirémité antérieure obtuse, offrant au moins quatre papilles très petites, à une faible distance de l'orifice buccal. Extrémité postérieure également obtuse, avec trois papilles, une terminale et deux latérales, et quelques autres petites saillies papilliformes. Bouche suivie d'un très court pharynx cylindrique. Anus à $228 \mu$ de l'extrémité de la queue. Utérus double; vulve à $840 \mu$ environ en arrière de la bouche. (Les utérus ne contenaient ni aufs, ni embryons.)

Jusqu'à présent, un seul exemplaire de ce parasite a été rencontré: Grassi l'a décourert chez un Chien, où il était enroulé, mais non enkysté, au milieu du tissu adipeux, près du hile du rein droit. Bien

Railliet. - Zoologie. 
qu'jl s'agît d'une femelle non parvenue à maturité, cette découverte offre un grand intérêt relativement à l'origine des Hématozacires de Lewis.

Grassi a donné ce nom à des embryons de Nématode qui existent assez souvent dans le sang du Chien, et qui ne peuvent être rapportés à Filaria immitis. Signalés d'abord par Gruby et Delafond, ils ont été retrouvés et étudiés par Lewis, Manson, Grassi, Sonsino, etc. C'est vraisemblablement à eux que se rapportent la plupart des données fournies par les premiers de ces auteurs sur les hématozoaires embryonnaires du Chien.

Leur élude a été l'objet de recherches persévérantes de la part de Lewis, de Sonsino et surtout de Grassi. Ce dernier a reconnu, de concert avec son élève Calandruccio, qu'ils poursuivent leur évolution dans la Puce du Chat (Pulex serraticeps), dans la Puce de l'Homme ( $P$. irritans) et dans un Ixodiné (Rhipicephalus sanguineus Latr.), mais non dans les Hiemalopinus. Ils doivent passer par quatre stades avant d'arriver à l'état adulte.

I. Embryon ou première larve. - Habitat: le sang du Chien. Quand le sang est sucé par les Puces, ces embryons passent dans l'intestin de ces Insectes, en perforent la paroi et pénètrent dans la cavité abdominale. Comme l'avait constaté Lewis, ils ont une longueur d'environ 280 y. sur une épaisseur de près de $5 \mu$. Le corps est un peu atténué en avant, mais obtus à l'extrémité; en arrière, il s'amincit en alène et se termine par une pointe presque capillaire.

lls se distinguent surtout des embryons de $\boldsymbol{F}$. immitis en ce qu'ils sont en général plus petits, et qu'on les voit souvent se fixer un certain temps, par leur orifice buccal, à la lamelle courre-objet ou à la lame porte-objet, pendant que leur corps s'agite vivement en tous sens; l'extrémité orale parait alors élargie, comme si elle était comprimée.

II. Deuxieme larve. - Habitat : ordinairement les cellules du corps adipeux de l'Insecte. Une larve occupe à elle seule une grande cellule de ce tissu, où elle s'enroule sur elle-même. Lorsqu'elle sort de la cellule pour rentrer dans la cavité du corps, elle est parfois encore à ce second stade, ou bien elle est en voie de muer pour passer au troisième.

Les larves du deuxième stade alteignent, au bout d'un certain temps, une longueur de $770 \mu$ sur une épaisseur de $31 \mu$. Elles sont à peine mobiles, mais leurs organes sont plus distincts. A l'extrémité anlérieure apparait une sorte de papille digitiforme longue de 5 à $6 \mu$; l'extrémité postérieure est prolongée par un appendice filiforne de $40 \mu$.

III. Troisième larve. - Ce stade est précédé d'une mue avec histolyse partielle, qui se prépare, soit alors que la larve est encore intra-cellulaire, soit lorsqu'elle est devenue libre. En tout cas, la cuticule des stades précédents n'est rejetée qu'après la sortie du corps adipeux.

Le corps atteint une longueur de $1^{\mathrm{mm}}, 5$, sur une épaisseur de $31 \mu$ encore. L'extrémité antérieure est obtuse et montre deux saillies, une dorsale et une ventrale. La papille antérieure de la deuxième larve a disparu, ainsi que son prolongement caudal filiforme. L'extrémité postérieure montre trois papilles: 
une terminale, dorsale, el deux subterminales, ventrales. Autour de l'orifice buceal arrondi, on peut souvent distinguer quatre papilles dispusées en croix. Les mouvements sont actifs. - Une seule Puce peut contenir plus de 30 de ces larves.

IV. Quatrième lurve. - Ce stade n'a été observé qu'une seule fois par Calandruccio. Il correspond à une phase d'enkystement, et représente probablement le seul état dans lequel la larve est apte à se transformer en Filaire adulte.

Cette larve enkystée est beaucoup plus grande et plus grosse que dans les stades précédents; les orgaues génitaux sont plus développés, et la cuticule est plus puissante. La queue, outre les trois papilles principales, montre d'autres saillies papilliformes, comme cliez l'adulte.

Daprès ces caractères, on concoit que les larves au $3^{\circ}$ ou $4^{\text {e }}$ stade soient susceptibles d'arriver à l'état adulte sans subir de véritable métamorphose. Cependant, les essais de Grassi tendant à infester des Chiens par l'ingestion de Puces sont toujours restés infructueux. L’auteur suppose que ces insuccès tiennent peut-être đ̀ l'absence de larves au $4^{\mathrm{e}}$ stade, et il se demande si ce stade ne surviendrait pas exclusivement sur des Puces rivant longtemps et pendant les mois chauds. De nouvelles recherches sont nécessaires pour élucider cette question.

La fréquence des Hématozoaires de Lewis varie suivant les localités. A Paris, Gruby et Defafond comptaient un Chien envahi sur 20 à 23 ; par contre, Sonsino à Pise, Lewis à Calcutta et Manson en Chine obtenaient en moyenne une proportion de 1 sur 3 .

D'après Gruby et Delafond, le nombre total des embryons peut varier, pour un seul Chicn, de $\mathbf{1 1 , 0 0 0}$ à 224,000 ; d'une façon générale, il est d'ailleurs moins élevé que celui des embryons de $F$. immitis.

Ils ont continué à vivre dix jours dans le sang conservé dans un vase à la température de $13^{\circ}$. Injectés dans les vaisseaux de Chiens sains avec du sang défibriné, ils ont disparu du torrent circulatoire dans l'espace de huit à quarante jours chez neuf sujets, et on persisté plus de trois ans chez deux autres. Chez un Lapin, ils ont vécu quatrevingt-neuf jours.

En général, les Chiens enrahis par ces parasites ne „présentent pas de troubles appréciables; cependant, Gruby et Delafond ont constaté des attaques épileptiformes chez trois de ces animaux : deux ont succombé à ces attaques, qui ont disparu chez le troisième.

Les médicaments anthelminthiques, non plus que l'acide arsénieux et l'acide cyanhydrique, administrés à dose toxique, n'ont aucune action sur ces parasites.

Filaire de Bancroft $(F$. Bancrofti Cobbold, 1877. - Syn. : Trichina cystica Salisbury, $1868 ; F$. sanguinis hominis Lewis, $1872 ; F$. dermathemica da Silva Araujo, 1873; F. Wuchereri da Silva Lima, 1877; F. sanguinis hominis nocturna P. Manson, 1891. - Priorité : F. cystica.) - Corps blauc opalin, capillaire, 
atténué vers les deux extrémités, qui sont obtuses. Tégument finement strié en travers. Bouche inerme, sans papilles. Male long de 83 millimètres, large de $0^{\mathrm{mm}}, 407$; queue assez effilée, formant un à deux tours de spire; quatre paires de papilles préanales, plus une saillie papilliforme impaire en avant de l'anus; quatre paires post-anales; deux spicules inégaux, dont l'un est long de $170 \mu$. Femelle longue de 1530 millimètres, large de $0^{\mathrm{m} m}, 715 \%$; vulve à $2^{\mathrm{mm}}, 56$ de l'extrémité céphalique; œufs longs de $38 \mu$, larges de $14 \mu$.

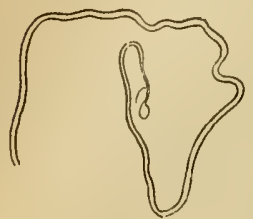

Fig. 357. - Filaire du sang de l'Homme, mảle, grandeur naturelle (deMlagalhães.

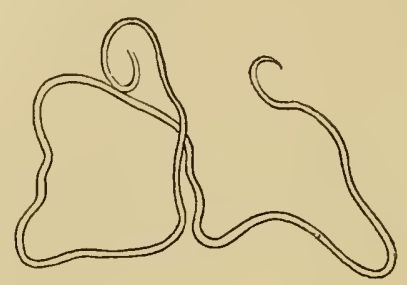

Fig. 358. - Filaire du sang de l'Homme, femelle, grandeur naturelle (de Mlagalhães).

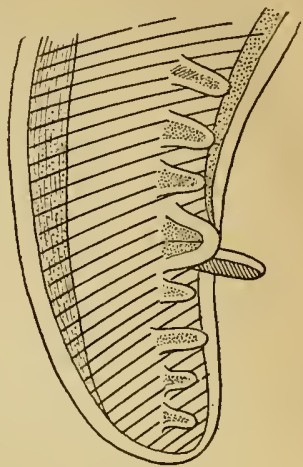

Fig. 359. - Filaire du sang de l'Homme: extrémité caudale du mâle, fortement grossie (von Linstow).

Cette Filaire, à l'état adulte, est parasite des vaisseaux lymphatiques et du cœur de l'Homme. Elle a été trouvée pour la première fois par Bancroft, en décembre 1876, dans un abcès lymphatique du bras, puis dans une hydrocèle. Peu après, Lewis, Silva Araujo, etc., la rencontrèrent dans les mêmes conditions, et enfin, Manson, en 1881, en découvrit un exemplaire dans un vaisseau lymphatique, ce qui établissait son habitat réel. Plus tard (1886), Figueira de Saboia en recueillit en outre deux exemplaires, mâle et femelle, dans le ventricule gauche du cœur d'un individu dont il faisait l'autopsie, à Rio-de-Janeiro. Ce sont ces exemplaires qui ont fourni à P.-S. de Magalhães les éléments de la diagnose que nous donnons ci-dessus.

Nais, dès le mois d'août 1863, le chirurgien français Demarquay avait trouvé à Paris, dans le liquide extrait par ponction d'une hydrocèle laiteuse, chez un Havanais, des embryons de Nématode dont il donna une description et une figure exactes. En 1866, Wucherer, ignorant cette observation, retrouva les mêmes embryons à Bahia dans l'urine d'un malade atteint de chylurie tropicale. Lewis, Salisbury, Crevaux, etc., virent également ces parasites dans des urines chyleuses. Puis, de 1872 à 1870 , Lewis les observa, en outre, dans le sang, dans les larmes, dans le produit de sécrétion des glandes de Meibomius, chez des sujets atteints de chylurie, d'éléphantiasis, ou même sains en apparence.

La découverte des Filaires adultes chez les individus atteints de semblables affections fit immédiatement admettre que les embryons dérivaient de ces Filaires, et la question parut définitivement élucidée 
lorsque Patrick Manson, médecin des douanes anglaises à $\Lambda$ moy (Chine), eut effectué ses intéressantes recherches sur les migrations des embryons.

Ceux-ci sont habituellement désignés sous le nom de Filaria sanguinis hominis Lewis. Manson ajoute aujourd'hui à ce nom le qualificatif noctuma, pour les différencier de deux autres variétés (diurna et per-

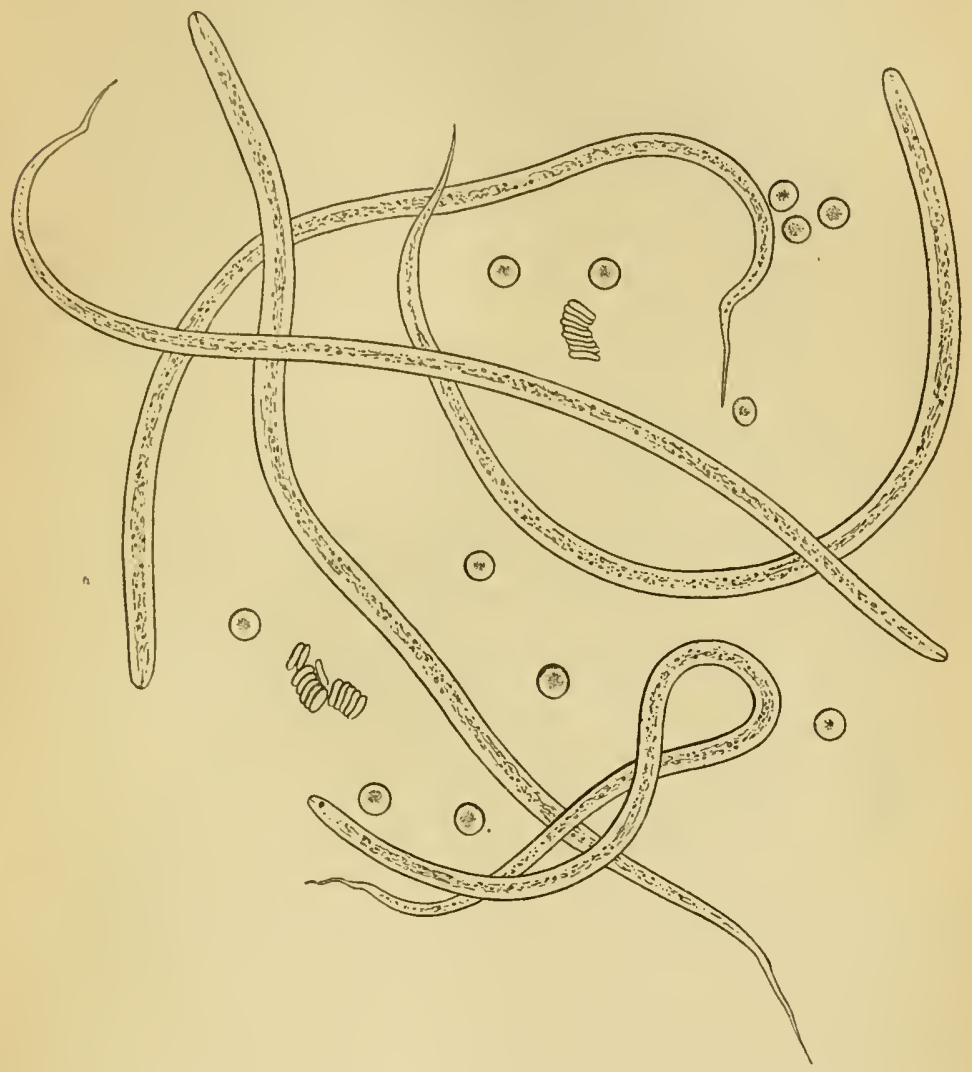

Fig. 360. - Embryons de la Filaire du sang de l'Homme, in situ. Grossissement : 400 diamètres (Orig.). stans) qu'il a découvertes récemment. On peut conserver provisoirement cette désignation.

L'habitat normal de la Filaire de Bancroft parait bien être le système lymphatique; cependant, elle ne vit pas dans les ganglions, mais dans les vaisseaux en amont de ceux-ci. La femelle est vivipare; dans certains cas pourtant, d'après Manson, elle peut émettre des œufs dépourvus decoque et entourés d'un simple chorion, qui sont entrainés dans les ganglions ; mais leurs dimensions étant trop fortes pour leur permettre de passer outre, ils sont arrêtés là jusqu'à leur éclosion. Une fois éclos, les embryons franchissent l'obstacle el pénètrent dans le torrent 
sanguin, où on peut les trouver en quantité plus ou moins considérable. Nous verrons plus loin comment ils sont susceptibles de passer aussi dans l'urine et dans d'autres produits de sécrétion; mais ceux qui s'égarent de la sorte sont sans intérêt pour l'étude de l'évolution : ils sont destinés à périr. Lewis a calculé que la masse totale du sang pouvait dans un cas en contenir 140,000, et d'autres ont fourni des chiffres beaucoup plus élevés. Ils mesurent 270 à $340 \mu$ de long sur 7 à $11 \mu$ de large; l'extrémité antérieure est mousse, et susceptible de changer un peu de forme avec les mouvements de l'animal ; la postérieure s'allonge en pointe; vers le milieu de l'axe du corps (Lewis, Manson), on remarque quelques fines granulations. Ils

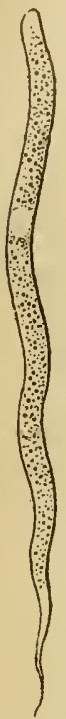

Fig. 361. - Filaire du sang de l'Homme : embryon recueilli dans le sang, grossi 300 fois (von Linstow). sont souvent entourés d'une sorte de gaine qui résulte sans doute d'une mue, et qu'on pourrait mettre en évidence par l'addition au sang d'une petite quantité d'urine.

Un fait important de leur histoire, et qui a été découvert par Manson, c'est qu'ils ne se montrent pas dans le sang à toutes les heures de la journée. Comme l'exprime la qualification de nocturna, ils n'envahissent la circulation périphérique que pendant la nuit, ou, plus exactement, pendant le sommeil, comme on a pu s'en assurer en intervertissant les périodes de sommeil et de veille chez les sujets atteints de filariose. Il est probable qu'ils se comportent à cet égard comme ceux de la Filaire cruelle du Chien, et qu'ils s'accumulent pendant le jour dans les gros vaisseaux du thorax et de l'abdomen.

Comment ces embryons peuvent-ils poursuivre leur évolution? C'est encore à Manson que nous devons la solution de cet intéressant problème. Ce savant médecin a constaté en effet qu'ils doivent émigrer dans le tube digestif d'un Moustique (Culex). Les habitudes nocturnes de ces Insectes sont d'ailleurs parfaitement en rapport avec celles des embryons. La femelle du Cousin, en se gorgeant du sang de l'Homme pendant son sommeil, en ingère de la sorte un grand nombre, souvent 30 à 40 et mème davantage. Au moment de l'ingestion, ils passent jusque dans la portion abdominale du tube digestif, où ils ne tardent pas à se débarrasser de la gaine transparente qui les enveloppait. lls remontent alors, du moins en partie, dans la portion thoracique du tube digestif, où ils subissent d'importantes modifications; ceux qui restent dans l'abdomen périssent et sont digérés. Tout d'abord, le corps se raccourcit el s'élargit, à l'exception de la queue, puis le tube digestif se dessine; du troisième au quatrième jour, cette larve mesure $0^{\mathrm{mm}}, 20 \mathrm{O}$ à $0^{\mathrm{mm}}, 30$ de long; elle est à peu près immobile. - Elle s'allonge 
ensuite, en mème temps que sa largeur diminue, que l'appareil digestif se perfectionnne et que des papilles apparaissent à l'extrémité caudale. Du sixième au septième jour, elle mesure $\mathbf{L}^{\mathrm{mm}}, \ddot{j} 8$ de long sur $0^{\mathrm{mm}}, 03$ de large; elle est alor's rederenue très active, et le contact de l'cau, qui jusque-lì lui était très funeste, semble au contraire augmenter son agilité : elle est ainsi arrivée à maturité.

Iais la plupart des femelles de Moustiques ne vivent pas assez. longtemps pour assurer cette maturité; clles pondent et meurent en effet du cinquième au sixième jour après aroir sucé le sang; c'est à peine s'il s'en trouve 10 it 13 p. 100 capables d'atteindre le septième jour, et il en résulte que la pullulation des Filaires se trouve notablement réduite.

Les Moustiques ayant gagné les eaux stagnantes, y déposent leurs ceufs et tombent ì la surface, où ils meurent. Les larves de Filaires traversent alors les tissus du cadarre et rivent en liberté dans l'eau. C'est done en burant cette eau que l'llomme doit s infester.

D'après VIanson, liverses espèces de Culer peuvent puiser les embryons dans le sang de l'Homme; mais, ¿̀ Amoy, une seule, non déterminée, offre des conditions propres ì leur déreloppement, et représente par conséquent l'hôte

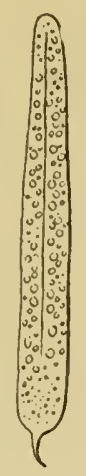

Fig. 362. - Filaire du sang de l'Homme: larve ex Iraite du corps d'un Criex, grossie 150 fois (Manson).

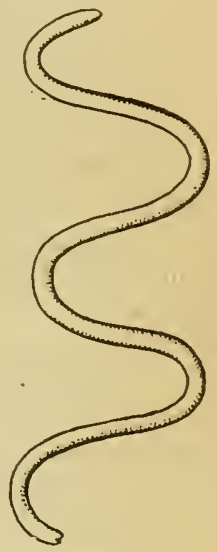

Fig. 363.- Filaire du sang de l'Homme : larve vivant dans l'eau,grossie 14 fois (Manson). intermédiaire de la Filaire. Sonsino a reconnu, en outre, que les Puces et les Punaises ne se prêtent pas darantage ì cette érolution.

Les observations de Manson ont été confirmées par Lewis; par contre, Myers est arrivé à des résultats négatifs. En présence de ce fait, et considérant d'ailleurs la rareté de la Filaire adulte, qu'on a cependant recherchéc arec ardeur, Grassi se demande si ces divers auteur's ont eu affaire aux mèmes embryons; il est mème porté ì croire qu'il existe chez l'Homme, comme chez le Chien, deux espèces d'hématozoaires : l'une correspondant aux " Hématozoaires de Lewis " et évoluant dans le Cousin, l’autre représentée par la Filaire de Bancroft et n'ayant rien à roir avec les Moustiques. - On remarquera d'ailleurs plus loin que la découverte, par Manson, de deux variétés nouvelles d'hématozoaires embryonnaires, vient encore compliquer darantage la question. 
chauds; elle est répandue en Asie, en Océanie, en Afrique el en Amérique; mais on ne l'a observée en Europe que sur des individus revenant des localités où elle est endémique.

En Asie, elle est extrêmement commune dans l'Inde (Lewis), en Chine (Manson) et au Japon (Scheube, Baelz, etc.).

Bancroft l'a étudiée dans le Queensland, en Australie; Moty la signale en Nouvelle-Calédonie.

En Afrique, elle a été rencontrée en Ėgypte (Sonsino), au Sourlan, en Algérie (Cauvet), sur les rives du Zambèze et du Jac Nyassí, sur la còte de Zauzibar (Felkin), à Maurice, à la Réunion, à Nlayotle, à Madagascar.

Enfin, en Amérique, elle est répandue dans le sud des États-Unis (Guiteras, Slaughter), aux Antilles, dans la Guyane (Winckel), à Buenos-Ayres (Wernicke), el on la trouve avec une fréquence remarquable dans une grande partie du Brésil.

Pathologie. - La présence dans l'organisme de la Filaire et de ses embryons se traduit par des troubles nombreux et variés, dont la synthèse n'a pu être faite qu'après la découverte du parasite. Il s'agit, en somme, d'une grande maladie à expressions multiples, et qu'il convient de désigner, à l'exemple des Anglais, sous le nom de filariose (1).

Cette affection peut s'observer sur des individus de toute race, quels que soient leur sexe et leur âge; on la dit cependant d'une fréquence relativement plus grande chez les Européens qui séjournent dans les régions infestées, et en particulier chez les femmes.

Pendant la période d'incubation, dont la durée est encore mal délimitée, l'individu envahi ne paraît éprouver aucun trouble. Cette période se prolonge peut-être fort longtemps dans certains cas; sur quatre-vingt-cinq sujets porteurs d'embryons, P. Manson en a trouvé neuf qui semblaient bien portants.

Dans une seconde période, apparaissent des tuméfactions lymphatiques ou cellulaires dont le siège est assez variable. La plus commune de beaucoup est l'hydrocèle chyleuse, qui occupe le testicule ou le cordon; puis la dilatation des ganglions inguinaux.

On peut citer ensuitel'éléphantiasis des Arabes (qu'il ne faut pas confondre avec l'éléphantiasis des Grecs); c'est une affection caractérisée par une intumescence plus ou moins volumineuse et plus ou moins dure de la peau et des tissus sous-jacents; elle peut se développer sur toutes les parties du corps, mais se localise de préférence aux membres inférieurs, au scrotum, aux mamelles. On y rattache, comme manifestations secondaires, les varices lymphatiques cutanées, les abcès lymphatiques, etc.

L'opinion qui rattache à la filariose l'éléphantiasis et ses variétés a été

(1) Morr, Contribution à l'étude de la filariose. Revue de chirurgie, XII, p. 1, 1892. - P. S. de Magalhaes, Note à propos des manifestations chirurgicales de la filariose. Ibid., p. 124. 
fortement combattue par divers auteurs; mais Manson la défend avec une grande habileté. I'apròs lui, la forme des accidents tient au degré d'obstruction de la circulation lympliatique dans les ganglions, obstruction produite par les oufs ou les embryons, soil directement, soit en provoquant une inflammation. - Si l'obstruction esl partielle, dit-il, il n'en rẻsulte que des rarices lymplatiques, mais la circulation de la lymplıe continue, et les embryons sont charriés dans le sang. Les accidents que l'on constate alors sont le lympho-scrotum, la chylurie et les engorgements gangliomuaires. - Si l'obshruction est complère, deux cas peuvent se présenter : $1^{\circ}$ l'accumulation de la lymphe distend les raisseaux jusqu'à en amener la rupture, et il en rísulte une lymphorragie plus ou moins permanente. Dans ce cas, la lymphe ne stagne pas absolument, mais elle circule en sens rétrograde, de sorte qu'elle reste fluide. Les symptòmes seront alors la lymphorragie du scrotum et de la jambe, et lengorgement variqueux des ganglions; on trouvera des embryons dans ceux-ci et peut-ètre dans la lymple épanchée, mais non dans le sang; $2^{\circ}$ si les lymphatiques ne se rompent pas, il y a stase complète et accumulation excessive de la lymphe en amont des ganglions. Ceuxci s'indurent, ainsi que les tissus roisins, et l'éléphantiasis apparait. On ne trouve pas d'embryons dans le sang, car pas un ne peut dépasser le filtre ganglionnaire et la Filaire mère meurt étouffée, pour ainsi dire, par sa progéniture et par la lymphe stagrnante. Par conséquent, dans l'éléphantiasis vrai, sans complication, aucun embryon ne peut ètre trouvé, ni dans le sang, ni dans les gangrions.

Enfin, plus tardivement, se manifestent des phénomènes un peu différents des précédents, tels que la chylurie et les inflammations des séreuses. La chylurie, ou hémato-chylurie, ou hématurie intertropicale, est caractérisée essentiellement par l'émission d'urine lactescente ou sanguinolente; elle s'observe à peine dans 1 p. 100 des cas de filariose. Sa pathogénie, aussi bien que celle de la diarrhée chyleuse, de l'ascite chyleuse, etc., est facile à déduire des faits exposés plus haut; il suffit d'admettre que l'accumulation des embryons en amont des ganglions obstrués s'effectue dans les lymphatiques du rein, de la vessie, du mésentère, du péritoine, etc. Les urines chyleuses contiennent de l'albumine et des granulations graisseuses extrêmement fines, que ne retiennent mème pas les filtres en papier; à la rigueur, on doit considérer qu'elles renferment toujours du sang, comme le révèle l'examen microscopique, mais il en existe parfois une proportion très considérable. Les embryons s'y rencontrent le plus souvent.

Le traitement médical de la filariose est encore à trouver; on a essayé jusquu'à présent, sans grand succès, l'administration à l'intérieur de diverses substances, telles que la glycérine, le mercure, le thymol (1). Dans le cas de chylurie, on fait surtout de la médecine de symptômes. S'il s'agit de l'éléphantiasis ou des tormes affines de la

(1) Voir en outre B. de Nabias et J. SABRaz.:s, Sur les embryons de la Filaire du sang che: l'Homme. Comptes rendus Soc. de biologie (9), IV, p. 455, 1892. 
maladie, l'intervention chirurgicale est souvent indiquée; elle est d'ailleurs ordinairement sans danger.

Quant à la prophylaxie, elle repose sur l'usage d'eaux filtrées ou bouillies.

Filaire diurue (F. diuma P. Manson, 1891. - Syn. : F. sanguinishominis var. major Manson, 1891). - On ne connaît encore de cette Filaire que les embryons, qui ressemblent d'ailleurs entièrement à ceux de la Filaire nocturne ou de Lewis; Manson a cependant indiqué l'absence de granulations dans l'axe du corps (1).

Manson a trouvé ces embryons dans le sang de plusieurs nègres de la côte occidentale de l'Afrique (Congo, Vieux Calabar).

11 tend à les considérer comme la progéniture de Filaria Loa. Un de ses sujets, qui portait à la fois $F$. diurna et $F$. perstans, lui affirma que dans son enfance il avait eu à l'œil un Loa qu'on n'avait jamais enlevé, mais qui arait disparu après application d'un peu de sel commun sur la conjonctive. D'autre part, l'aspect des embryons correspondait exactement avec les dessins des embryons de Loa communiqués par Leuckart.

Le nom spécifique de diurne, employé par Manson, confirme cette particularité intéressante que les embryons ne se montrent dans le sang que pendant le jour.

L'hôte intermédiaire serail donc un suceur de sang ayant des habitudes diurnes. Un des malades déclara que dans le Vieux Calabar il existait deux espèces de Mouches extrêmement importunes pour les travailleurs des champs : une rouge, nommée Uyo par les indigènes, et une noire appelée Ukpoj; pendant la chaleur du jour, elles attaquent les parties découvertes du corps, et une fois gorgées de sang se laissent tomber à terre où elles cherchent un refuge. Peut-être s'agit-il des "Mouches de mangliers ", bien connues des missionnaires et des voyageurs (2).

Filaire persistante $(F$. perstans $\mathrm{P}$. Manson, 1891. - Syn. : $F$. sanguinis hominis var. minor Manson, 1891). - Cette espèce a été établie d'après des embryons trouvés par Manson. Ces embryons sont beaucoup plus petits que ceux des Filaires diurne et nocturne; ils mesurent seulement $200 \mu$ de long,

(1) P. Manson, The Geographical Distrilution, Pathological Relations, nnd Life Ilistory of Filaria sanguinis hominis diurna and of F. sang. hou. perstans, in connexion with Preventive Medicine. Transactions of the 7 th Internat. Congress of Ilygiene and Demography, London, 1891 ; vol. I, p. $79,1893$.

(2) D'après une Note de Vlanson, Leuckart a reçu de la Côte de l'Or deuxtumeurs vermineuses enlevées à des indigènes par un missionnaire médecin; l'une siégeait sur le cuir chevelu, l'autre dans les téguments de la poitrine. La section de ces tumeurs montra des amas de Filaires, mâles et femelles, enroulées dans des cavités ou entrelacées en paquets. Les liquides ambiants renfermaient d'innombrables embryons, ressemblant de très près à ceux de $F$. nocturna et dizmn. Cependant. ces tumeurs semblent communiquer, non avec le système circulatoire, mais avec l'extérieur. Leuckart appelle ces nouveaux Nėmatodes Filaria volvulans (?). 
et leur diamètre est en moyenue deux fois moindre que celui des formes susindiquées. Ils ne possèdent pas de gaine: l'extrémité antérieure est munie d'une sorte de rostre rélractile, trés petit, et l'extrémité candale est mousse. Ils sont beaucoup plus agiles que les autres, et en outre jouissent de la propriété de šitendre jusçu'à réduire le diamètre du corps à une ligne extrèmement fine, ou au contraire de se rétracter à un haut degré.

Ces parasites n'ont élé trouvés jusqu’à présent que dans le sang des nigres de la cote occidentale ou des distriets adjacents de l'Afrique tropicale. De nombreuses recherches failes dans d'autres régions n'ont donné aucun résultat. Manson les a vus chez des individus qui avaient quitté l'Afrique depuis 7 mois, 9 mois et 6 ans. Chez un autre, il y avait coexistence de $F$. liurna et de $F$. perstans. Or, ce dernier était atteint d'une aflection particulière, connue sous le nom de maladie du sommeil ou léthargie des négres, et comme cetle affection est propre à l'Arrique occidentale, Manson présume qu'elle est sous la dépendance de l'un de ces parasites, - probablement $r$. perstans. Chez un autre sujet, qui montrait seulement cette dernière, il a pu constater en effet des troubles cérébraux ayant une grande analogic avec cette maladic du sommeil.

Le mème auteur tend à regarder $F$. perstans comme la cause d'une dermatose papuleuse observée à la Côte de l:Or, par O'Neil, sur les nègres, et connue de ceux-ci sous le nom de craw-craw; il est disposé même à l'identifier au parasile d'une papulose analogue, étudiée à Brest par Nielly; mais, pour cette dernière affection tout au moins, cette manière de roir ne nous parait pas justifiée (Voir Rhabditis Viellyi, p. ̋̋öl).

La caractéristique biologique de la $H^{*}$. perstans, c'est la présence des embryons dans le sang aussi bien le jour que la nuit. Elle se distingue nettement ainsi des $F$. nocturna et diuma. Manson pense que l'hôte intermédiaire est un animal vivant dans les eaux douces.

Filaire d'Evans (F. Evansi Lewis, 1882). - Nous n'avons pu jusqu'à présent nous procurer la description donnée par Lewis de cetle espèce, dont le màle et la femelle sont conuus( 1 ).

Elle a été rencontrée par le $D^{\mathrm{r}}$ Evans, vétérinaire en chef du département de Madras, à l'autopsie d'un Chameau (Dromadaire). Le sang contenait des myriades d'embryons tout à fait semblables à ceux de la Filaire de l'Homme. Evans décourrit des Vers adultes dans le poumon: les artères pulmonaires étaient obstruées par des amas de .ématodes entrelacés. Il en existait aussi dans le mésentère.

(1) Th. R. Lews, Remarks on a Vematoid Iliemalozoon discovered by Dr Griffuth Evans in a Camel. Proceedinis of the Asiatic Society of Bengal, p. 63, 1852. A. Golbaux, Nole sur les ganglions el les vaisseaux lymphatipues du Dromadaire (Camelus dromedarius). Comptes rendus de la Soc. de biologic (1), v, p. 83, 1853.

- Delafond et Borngugiox, Traité de la psore, p. 379, 1862 
Déjà, en 18วั3, Goubaux avait trouvé des Filaires chez un Dromadaire galeux, mort à l'École d'Alfort: elles siégeaient dans les ganglions lymphatiques, dans la glande lacrymale gauche, dans le poumon, dans le sang, etc.

Enfin, J. B. Piot a rencontré en Égypte, en 1886, des Filaires dans un testicule de Chameau.

Filaire équine (F. equina [Abildgaard]. - Syn. : Gordius equinus Abildg., $1789 ; F$. equi Gmelin, 1789; F. papillosa Rud., 1802; F. equina Blanchard, 1849). - Corps blanchàtre, filiforme, allongé, atlénué vers les extrémités,

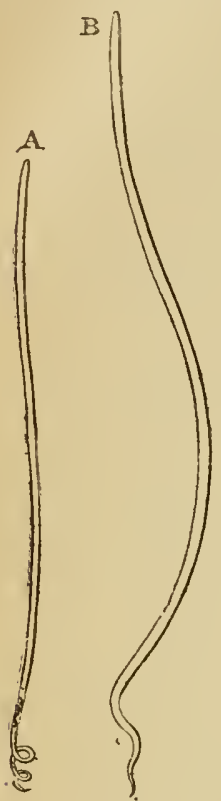

Fig. 364. - Filaria equina. - A, mâle. B, femelle. Grandeur naturelle (Orig.). surtout en arrière. Tégument finement strié en travers. Bouche petite, ronde, munie d'un anneau chitineux, dout le bord supporte latéralement deux lèvres semi-lunaires, et se relève sur chacune des lignes médianes, dorsale el ventrale, en une saillie papilliforme simple, parfois fendue au sommet; un peu en arrière se trouvent en outre quatre fortes spinules chitineuses papilliformes, submédianes. Mále long de 6 à 8 centimètres, à queue contournée en spirale làche, offrant de chaque côté quatre papilles préanales et quatre (cinq?) postanales; $n^{0} 1$ conique et un peu saillante sur le bord; deux spicules inégaux. Femelle longue de 9 à 12 centimètres; queue à peine spiralée, terminée

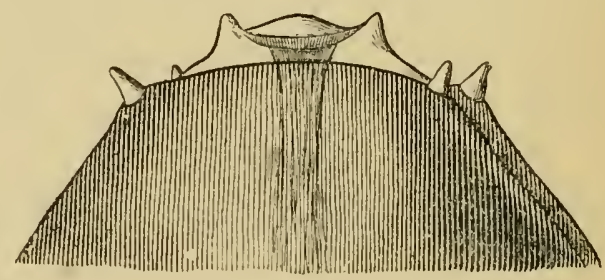

Fig. 36ว. - Extrémité céplaalique de la Filaire équine vue de côté; grossie 150 fois (G. Neumann).

par un bouton arrondi précédé de deux saillies coniques latérales. Vivipare: embryons longs en moyenne de $280 \mu$, larges de $7 u$.

Cette Filaire se rencontre assez fréquemment dans le péritoine du Cheval, de l'Ane el du Mulet. On conçoit qu elle puisse passer dans les diverticules de cette cavité. Ainsi, Ercolani l'a trouvée dans la gaine vaginale, en châtrant un Cheval. Schmidt et Pottinger en ont vu également un ou deux exemplaires dans la gaine vaginale de chevaux entiers affectés d'hydrocèle. Owen et Schmidt auraient observé une orchite et une périorchite chroniques consécutives à la présence de Filaires entre le testicule et l'épididyme. Gourdon en a recueilli un exemplaire dans une trompe de Fallope.

Elle est plus rare dans le sac pleural : cependant, Mengers en aurait 
recueilli, dans la cavité thoracique d'un Cheval, de quoi remplir un panier; le poumon droit était transformé en un vaste foyer purulent(?). Abildgaard l'a trouvée entre la dure-mère et la pie-mère cérébrales, Rudolphi dit l'avoir rencontrée dans l'intestin; il la signale, de plus, dans le tissu conjonctil sous-cutané (à moins de confusion arec $F$. hamorrhagica). Sonsino, en ligypte, et G. Colin, à Alfort, l'ont vue greflée dans le foie.

Enfin, on rapporte généralement à cette espèce la plupart des Vers qui se développent il l'intérieur du globe oculaire, chez les Equidés. On les trouve presque constamment dans l'humeur aqueuse; leurs faibles dimensions habituelles tiennent sans doute à l'exiguïté de cet liabitat et à leur état incomplet de développement. Brown, en 1821, les décrivait comme une espèce particulière d'Ascaride (Ascaris pellucida). - Voir aussi $F$. inemis, p. $\ddot{2} 28$.

On ne connait encore rien de l'évolution de cette Filaire (1). Nous avons constaté que les embryons ne résistent pas à la moindre dessiccation. D’après Deupser, ils ne vivent mème pas plus de trois à six heures dans l'eau, dans le sérum artificiel, dans l'lumeur aqueuse, soit à la température ordinaire, soit à $38^{\circ} \mathrm{C}$. Par contre, ils vivent jusqu'à trente-six heures dans le sang lu Cheral et ne périssent que par suite de la décomposition de ce liquide. Le sang serait done leur milieu normal.

Or, en 18.48, Wedl avait observé des embryons dans le sang d'un Cheval dont le péritoine renfermait

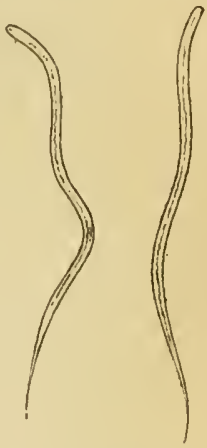

Fig. 366. - Embryons de Filaria equina grossis 150 fois (Orig.). une $F$. equina : ils étaient longs de 1/7 de nillimètre et se trouvaient au nombre de 1 à 3 dans chaque goutte de sang. - En 1876, Sonsino a également vu dans le sang d'un Cheval, en Égpte, des Nématodes embryonnaires auxquels il a donné le nom de Filaria sanguinis equi; à l'autopsie, on trouva encore des $F$. equina; les embryons étaient semblables à ceux de $F$. sanguinis hominis, mais plus petits. Enfin, Lange (de Kasan) rapportait en 1881 que Jakimoff avait trouvé, dans le sang d'un cheval atteint d'hématurie et d'ictère, de nombreux embryons - 2 ou 3 par goutte - ressemblant aussi à ceux de l'Homme. L'urine n'en contenait pas.

Deupser a vainement cxaminé le contenu du tube digestif et l'urine de chevaux envahis par $F$. equina; mais il est parvenu à trouver dans le sang des embryons qui, comme taille et comme aspect, ressemblaient aux embryons fraichement éclos de cette Filaire, à cette différence prìs que, chez quelques-uns d'entre eux, il existait une tache claire au tiers postérieur du corps. - D'autre part, en introduisant

(1) Deupser, Zur Entwickhengsgeschichte der Filaria papillosa. Zool. Anzeiger, XV, p. 129,1892 . 
des Filaires équines gravides dans le péritoine du Lapin, il a vu les embryons apparaître dans le sang de cet animal et y persister quatorze jours. - Il semble donc bien, d'après cela, que Filaria equina. doive offrir une érolution analogue à $F$. Bancrofti; aussi les recherches en vue de déterminer l'hôte intermédiaire devront-elles porter sur les Insectes qui sucent le sang du Cheval, et en particulier sur les Simulies.

Pathologie. - La présence de la Filaire équine dans les grandes séreuses ne se traduit généralement par aucun symptôme appréciable; cependant, Steel, l'ayant trouvée en énorme quantité dans le péritoine d'un Cheral cachectique, attribue la maladie à sa présence.

Lorsqu'elle siège dans l'wil, elle donne licu à une affection qu'on désigne sous le nom d'ophtalmie vermineuse. Cette filariose, exceptionnelle en Europe et en Amérique, est très fréquente sur le Cheval dans l'Inde, où elle a maintes fois été étudiée par les vétérinaires anglais. Le plus souvent, un seul œil est affecté; il contient un, deux, rarement trois Vers, nageant librement dans l'humeur aqueuse. On observe presque toujours une vive inflammation, avec épiphora et photophobie; et quand la maladie est abandonnée à elle même, le résultat habituel est l'opacité complète et définitive de la cornée. - Le traitement de cette ophtaimie vermineuse a consisté quelquefois en applications mercurielles sur l'œil atteint; mais la plupart des vétérinaires ont recours à l'extraction directe des parasites.

Baruchello a fait connaitre une autre affection, qui est peut-être attribuable encore à la Filaire équine. Il s'agit de tumeurs cutanées, du volume d'un grain de mil à celui d'un œuf de Pigeon, apparaissant, au printemps et en été, dans les régions garnies de crins, chez les chevaux d'un régiment de cavalerie. Ces tumeurs se ramollissaient au centre, puis s'ouvraient pour laisser échapper du pus, dans lequel se montraient un grand nombre de Nématodes agames, longs de 5 à 15 millimètres. Trois Chevaux étant morts fortuitement au cours de la maladie, on trouva dans leur cavité péritonéale un grand nombre de $F$. equina.

Filaire à lèvres papilleuses ( $F$. labiato-papillosa Alessandrini, 1838. - Syn. : F. cervina Duj., 1845; F. terebra Dies., 18ä1). - Cette espèce ressemble beaucoup à la précédente par son aspect exlérieur et ses dimensions. Bouche oblongue dans le sens dorso-ventral, entourée d'un anneau chitineux dont le bord supporte quatre lames courbées, une dorsale et une ventrale à concavité antérieure, et deux latérales convexes en avant. Sur les lignes médianes dorsale et ventrale, l'anneau chitineux se relève en une saillie papilliforme, qui se montre nettement géminée chez la femelle, moins chez le màle. En arrière de la bouche, quatre petites dépressions submédianes, de chacune desquelles sort une papille tactile; en avant de celle-ci, se trouve une petite épine (Stiles). Mâle long de 4 à 6 centimètres; queue en spirale assez serrée; de chaque côté, trois papilles préanales, une adanale 
et cinq postanales; de plus, en arrière de celles-ci, une forle saillie conique, ce qui lonne à l'extrémité une apparence trifurquée. Femelle longue de 6 ì 12 centimètres; queue en spirale làclıe, terminée par un faiscean de petites pointes mousses précédé de denx fortes saillies coniques latérales. Vivipare: embryons longs de 1 'to à $230 \mu$.

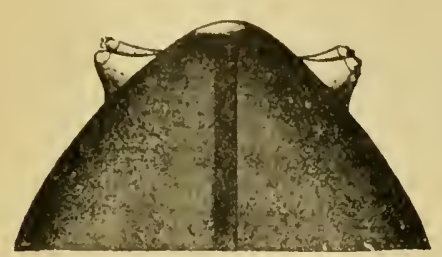

Fig. 367. - Extrénité céplaalique de Filaria labiatopapillosa, vue de còté grossic, 150 fois (G. Neumann).

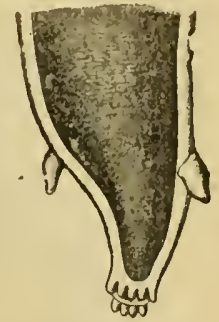

Fig. 368. - Extrémiló caudale de Filaria labiato-papillosa, femelle, grossie 150 fois (fi. Neumann).

Habite la cavité périlonéale du Bouf et de divers Cervidés (Cervus elaphus, columbianus, virginianus).

Cette Filaire ne parait avoir aucune influence fâcheuse sur la santé ; cependant, Gotti l'a trouvée en abondance dans la cavité péritonéale et dans le tissu conjonctif sous-jacent, chez un Bœuf aballu dans un état voisin du marasme, étal résultant d'une diarrhée persistante. Ch. Morot nous a communiqué un exemplaire de cette Filaire, enkysté dans le péritoine d'une Vache.

Nous devons aussi rapporter provisoirement à cette espèce les Nématodes intra-oculaires du Bœuf, qui ont été observés par Grisoni dès 1429, et retrouvés plus tard, surtout en France, par Deguillème, Santin, Chaignaud, etc. Les troubles occasionnés par ces Vers sont analogues à ceux que nous avons indiqués chez le Cheval, et justiciables des mêmes agents thérapeutiques.

Filaire lacrymale (F. lacrymalis Gurlt, 1831. - Syn. : ? Thelazia Rhodesii de Blainville, 1828 ; F. Lovis Baillet, 1858; F. palpebrarum Baillet, 1858). Corps blanchâtre, cylindrö̈de, un peu atténué aux extrémités. Tégument finement strié en travers. Bouche petite, inerme, suivie d'une capsule buccale cylindrique; anus presque terminal. Mále long de 10 à 14 millimètres, à queue recourbée en arc; deux spicules très inégaux, l'nn long de 11 ŏ $\mu$, l'autre de $730 \mu$. Femelle longue de 15 à $2 \dot{x}$ millimètres, à queue droite, conique; vulve à 1 millimètre environ de l'extrémité antérieure. OEufs ellipsoïdes, éclosant dans les utérus; embryons libres longs de 210 à $230 \mu$.

Elle vit dans les conduits excréteurs des glandes lacrynales du Bœuf, d'oủ elle vient parfois glisser entre l'œil et les paupières, ou se réfugier derrière le corps clignotant. Lorsqu'il en existe un grand nombre à la fois, il peut en résulter une irritalion intense et parfois mème des ulcérations de la cornée. On a vu cette conjonctivite vermi- 
neuse sévir à l'état enzootique. Le traitement consiste à enlever directement les Vers, ou à les expulser par des injections brusques de liquides anthelminthiques.

Filaire palpébrale ( $F$. palpebralis Er. Wilson, 18 ł'́). - Corps blanchàtre, cylindroïde, un peu atténué aux extrémités. Tégument finement strié en travers. Bouche petite, inerme, suivie d'une capsule buccale moins développée que dans l'espèce précédente; anus presque terminal. Mále long de 8 à 12 millimètres, a queue recourbée en are ; trois paires de papilles postanales; deux spicules inégaux, l'un long de $170 \mu$, l'autre de $130 \mu$. Femelle longue de 14 à 22 millimètres, à queue droite, conique; vulve à $0^{\mathrm{mm}}, 60$ ou $0^{\mathrm{mm}}, 70$ de l'extrémité antérieure. OFufs ellipsoïdes, éclosant dans les utérus; embryons libres longs de 120 à $170 \mu$.

Dans les conduits excréteurs des glandes lacrymales et sous les paupières du Cheval. Détermine les mêmes troubles que la Filaire lacrymale.

On ne connaît rien de son origine. Nous avons déposé, à la surface de l'œil d'un Cheval sain, une femelle remplie d'embryons; comme il y avait lieu de s'y attendre, ces embryons ne se sont pas développés en Vers adultes.

Filaire inerme (F. inermis Grassi, 1887. - Syn. : ? F. palpebralis Pace, 1867 , nec Wilson, 1844; F. peritonæi hominis Babes, $1880 ; F$. conjunctivæ Addario, 1880̈). - La femelle seule est connue; elle mesure environ 16 centimètres de long sur $0^{\mathrm{mm}}, 470$ d'épaisseur. Corps blanchàtre ou brunàtre, flasque, filiforme; extrémités un peu atténuées; extrémité postérieure plus effilée, se terminant par une pointe ordinairement incurvée. Tégument à stries transversales et longitudinales, qui manquent toutefois à l'extrémité céphalique. Celle-ci est mousse, sans papilles. Bouche terminale, très petite, inerme. Fente anale à $300 \mu$ de la pointe caudale. Vulve à 50 et $10 x \mu$ de la bouche. (Eufs éclosant dans les utérus; embryons libres longs de $3.0 \mu \mu$, larges de $5 \mu .5$, un peu atténués en avant, effilés en pointe très fine en arrière.

Cette Filaire vit chez l'Homme, l'Ane et le Cheval. Grassi soupconne qu'elle ne doit pas être rare chez ces deux derniers hôtes, mais qu'elle a été confondue jusqu à présent avec $F$. equina. L'exemplaire provenant de l'œil d'un Ane avait été recueilli par Rivolta, qui le rattachait en effet à cette espèce; il n'était pas mûr et mesurait 5 s̆ millimètres de long. Trois exemplaires, communiqués par Lanzilloiti-Buonsanti, araient été fournis par le Cheval (sans indication de siège). Peut-être des recherches ultérieures montreront-elles que les Nématodes intraoculaires des Équidés se rapportent à $F$. inermis et non à $F$. equina.

Cliez l'Homme, le parasite a été trouvé d'abord dans l'œil par Dubini, puis par Babes dans un nodule compris entre les lames de l'épiploon gastro-splénique, puis par Addario dans une tumeur pisiforme de la conjonctive bulbaire. - Il est possible encore qu'il s'agisse 
de la mème espẻce dans l'observation d'Angelo Pace, de Palerme, relative à un Ver filiforme de 10 centimètres extrait d'un kyste de la paupière supérieure, chez un garçon de neuf ans (1867). - Enfin, les Filaires du cristallin ( $\boldsymbol{F}$. lentis Dies, ) n'en sont peut-ètre que des formes jeunes.

Filaire Loa (F. Loa Fuyot, 1778. - Syn. : Dracunculus oculi Dies., 1860; Dr. Loa Cobbold, 186 f). - Ver long de 16 à 70 millimètres, le plus souvent de 30 à 40 millimètres, tin conme une corde de violon. Extrémité antérieure ohtuse; extrémité postérieure pointue. Bouche proéminente, inerme. OAufs muirs longs de $3 \ddot{z} \mu$, larges de $2 \ddot{z} \mu$, contenant des embryons longs de $210 \mu$.

Comme on le roit, ce parasite est encore pen connu; on ignore si certains petits individus, signalés par divers observateurs, ne seraient pas les màles.

Il siège d'ordinaire entre la conjonctive et le globe oculaire. Sa présence se traduit par une tuméfaction assez intense, a rec larmoiement, prurit et douleurs vives, surtout la nuit. Les frottements finissent par amener une véritable inflammation. Ces symptômes ne durent guère que deux ou trois jours; puis le Ver se retire et reste plusieurs semaines, parfois mème jusqu à deux mois sans manifester sa présence. Les mêmes troubles se reproduisent alors, et, après plusieurs années de semblables alternatives, le parasite disparait d'une façon définitive, sans qu'on ait appliqué le moindre traitement. - Il peut d'ailleurs se déplacer autour de l'œil, et Blot l'a vu passer d'un œil à l'autre, en rampant sous la peau de la racine du nez. On l'a observé quelquefois aussi aux paupières et aux doigts.

C'est un parasite propre à la còte occidentale de l'Afrique; il se rencontre en Guinée, à la cûte d'Angola, au Gabon, dans l'Ogooué, au Congo; c'est dans cette dernière contrée que les indigènes lui donnent le nom de Loa. Grâce à la traite des nègres, il a élé transporté en Amérique (Antilles, Guyane, ete.); on l'y a observé sur des sujets introduits depuis cinq à six ans. Néanmoins, il ne s'y est pas acclimaté, et on ne l'a plus revu depuis l'abolition de la traite.

Au sujet de son évolution, on en est encore réduit à des hypothèses; nous arons dit que Manson tend à considérer Filaria diurna comme sa larve.

Filaire de l'oeil de I'Homme ( $F$. lentis Dies., 1851. - Syn. : F. oculi humuni von Nordmann, 1832). - On range sous ce titre des Nématodes trouvés à plusieurs reprises dans le cristallin de l'Homme, et étudiés sommairement par ron Nordmann (1832), Gescheidt (1833) et Schöler (1875). Les dimensions de ces parasites varient de $1^{\mathrm{mm}}, 72$ à $12^{\mathrm{mm}}, 6$.

D'autres Nématodes, non décrits, ont été découverts dans le corps vitré (Quadri, Fano, Santos Fernandez, ete.).

11 est peu probable que tous ces Vers représentent des espèces propres; ce son plutôt des parasites égarés, ou erratiques, arrètés dans leur développement. 
Filaire de la lève de Illomme $(F$, latialis Pane, 1864). - Nom donné à une femelle de Nématode très iucomplètement connue. Corps long d'environ 30 millimètres, grêle, alténué vers les deux extrémités, mais un peu renflé tout à fait ì l'extrémité postérieure. Bonche entourée de quatre papilles disposées en couronne. Anus à $0^{\mathrm{mm}}, 5$ de l'extrémité caudale; vulve s'ouvrant $2^{\mathrm{mm}}, \tilde{\mathrm{J}}$ plus haut. Utérus double.

Ce Ver a été trouvé à Naples, en 186x, par Pane, étudiant en médecine, dans une petite pustule située à la face interne de la lèvre supérieure, chez un individu qui, depuis quelques jours, éprouvait à ce niveau une sensation de fourmillement et de brùlure.

Filaire de la bouche de l'llomme ( $F$. hominis oris Leidy, 18300). Ver long de 14 centimètres, large de $0^{\mathrm{mm}}, 16$, filiforme et d'un blanc opaque. Bouche orbiculaire, inerme. Extrémité postérieure obtuse et munie d'un crochet court, incurré, long de $50 \mu$ et large de $12 \mu$ à sa base.

Ce parasite a été décrit par Leidy, de Philadelphie, qui le signale simplement comme retiré de la bouche d'un enfant. Cel auteur se demande s'il ne s'agirait pas d'un exemplaire mảle et encore jeune

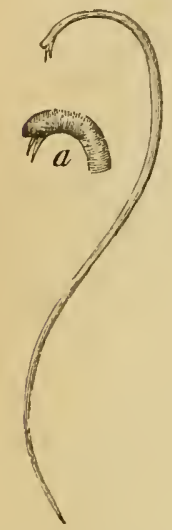

kig. 369 . - Hamularia lymphatica, tel que l'avait figuré Treutler. de la Filaire de Médine, et Leuckart appuie cette opinion. Mais la démonstration de cette manière de voir reste entièrement à faire.

Filaire des ganglions lymphatiques de l'Homme (F. lymphatice [Treutler]. - Syn. : Hamularia lymphatica Treutler, $1793 ; F$. hominis bronchialis Rud., 1819; F. lymphatica Ifoquin-Tandon, 1860). - Ver long de 26 millimètres envirou, brunàtre, tacheté de blanc, presque transparent en arrière; corps filiforme, un peu .comprimé latéralement.

Trouvé en 1790, dans les ganglions bronchiques hypertrophiés d'un Homme de vingt-huit ans, par Treutler, qui avait pris la queue pour la tète et décrit les spicules comme des crochets buccaux. C'est encore, on le voit, une espèce fort douteuse. Zahn l'a retrouvée en 1879 à Genève, mais ne l'a pas étudiée. Diesing et Weinland l'ont regardée comme identique à Strongylus longevaginatus (paradoxus); l'aspect des spicules nous empèche absolument de nous ranger ì cette opinion.

Ne serait-ce pas plutòt un màle de $F$. inermis?

Filaire restiforme (F. restiformis Leidy, 1880). - Nous devons nous borner à une simple mention de ce Ver, qu'un laboureur américain aurait rendu par l'urètre (1878), et qui n'est évidemment qu'un pseudo-parasite.

Filaire trachéo-bronchique du Chien (F. Osleri Cobbold, 1879. Syn. : Strongylus bronchialis canis Osler, 1877). - Corps filiforme; bouche entourée de deux ou trois saillies ou lèvres en arrière desquelles se trouvent trois papilles inégales; pharynx renflé. Mâle long de ä nillimètres, à extrémité postérieure arrondie; deux spicules inégaux, courbés. Femelle longue de 9 à 15 millimètres, atténuée aux deux extrémités; anus presque terminal; vulve située immédiatement en avant de l'anus. Ovovivipare. 
Rabe et Blumbergr ont déerit de la sorte, en les rapportant avee donte au genre Filuria et sans leur donner de nom spécilique, des Vers trouvés dans des tubercules du volume d"un grrain de mil it celui d'un pois, sous la muqueuse des roies aériennes, à la partie infirieure de la trachée et à l'origine des bronches. Chacun de ces nodules renfermait plusieurs individus de sexe diflérent, mais plus de femelles que de mâles, tous difliciles à isoler de la gangue fibreuse ou ils élaient enchevétrés. Ces individus, souvent marbrés de blane et de brun, viennent faire saillie ì la surface par l'une ou l'autre de leurs extrémités, en simulant des villosités.

Déjì Renault, en 1833 , arait publić une obserration analogue.

Enfin, c’est probablement au mème Ver qüil convient de rapporter les parasites signalés pal Osler, de Montréal, comme occasionnant chez le Chien une bronchite vermineuse épizootique.

En réalité, les nodules vermineux de la trachée et des bronches ne décèlent généralement leur présence par aucun symptôme appréciable. Cependant, Rabe a constaté des troubles respiratoires très accusés sur un lérrier chez lequel les parasites avaient envahi le poumon. Quant à la broncho-pneumonie observée par Osler, elle n'étail probablement qu'une manifestation de la maladie des jeunes Chiens; l'auteur déclare toutefois qu'un certain nombre d'adultes et d'embryons se trouvaient cachés dans le mucus des petites bronches.

Courtin et Mégnin ont observé, d'autre part, des embryons de Témalode dans les alvéoles pulmonaires du Chien; mais ces observations sont restées très vagues.

En tout cas, il est intéressant de rappeler qu'on a souvent trouré, dans le poumon de la Fouine, de la Martre et du Pulois, des nodules vermineux analogues à ceux dont il vient d'ètre question : ces nodules, noirâtres, de la grosseur d'un pois, renferment des Vers blancs tachés de noir qu'on désigne aujourd'hui sous le nom de Filaroides mustelarum.

Filaire de la Chève (F. capræ ron Linstow, 1883). - Espèce paraissant très longue, décrite d'après des fragments dı corps d'une femelle. liextrémité céphalique faisait défaut; la largeur atteignait $0^{\mathrm{mm}}, 36$.

Cet exemplaire avait été trouré par Fedtshenko, au Turkestan, dans les muscles de la partie inférieure de la langue, chez une Chèrre (1).

Filaire de l'wil du Chien (F.oculi canini Gescheidt, 1833. - Syn. : F. trispinulusa Dies., 183̈1). - Ver long de $8^{\mathrm{mm}}, \bar{\tau}$; corps subégal, un peu atténué en arrière. Bouche orbiculaire, garnie de trois petites papilles rondes; extrémité caudale courte, fine et droite.

C'est sans motif plausible qu'on a regardé ce parasile comme une femelle jeune de Filaire; Cobbold y voit plutòt une larve d'Ascaride. Il a été trouvé

(1) O. von Lisstow, Nematoden, Trematoden und Acanthocephalen gesammelt von Prof. Fedtschenko in Turkestan. Archiv für Naturg., XLIX, Bd. 1, p. 274, 1883. Voir p. 28\%. 
par Gescheidt dans le corps vitré d'un Mops de dix ans; il était placé, avec l'extrémité caudale repliée, au-dessus de la membrane hyaloïde. Dans son roisinage, cette membrane était un peu nébuleuse, ainsi que l'humeur vitrée.

Filaire de L'icil du Moutox. - Haselbach a également observé, dans l'œil d’un Bélier, un Ver filiforme indéterminé, qui siégeait dans la chambre antérieure et arait provoqué une inflammation de la cornée. Ce Ver disparut au bout de quelques jours, à la suite d'applications de teinture d'opium.

Filaire hépatique ( $F$. hepatica Cobbold, 1879). - Espèce nominale, établie par Cobbold pour des larves de Nimatode trourées par Mather á Édimbourg, dans le foie et l'intestin d'un Chien (1).

Cet animal avait présenté pendant une semaine des troubles profonds: agitation, dyspnée, vomissements, constipation alternant avec de la diarrhée. Finalement il devint très faible, eut des vomissements sanguinolents, avec soif intense, coloration ictérique de la peau el des muqueuses apparenles, et finit par succomber. - A l'autopsie, Mather trouva une inflammation de l'estomac, qui était ecchymosé et ulcéré, et une invagination du duodénum. L'intestin grêle était congestionné et parsemé de petites taches correspondant à des kystes de la musculeuse, dont chacun contenait une Filaire enroulée en anneau. En outre, un certain nombre de ces mèmes Versfllottaient dans les conduits biliaires, et quelques-uns mème occupaient les lobules hépatiques. Le sang ne fut pas examiné.

L'origine de ces larves reste tout entière à déterminer, aussi bien que celle des larves que Vulpian, Bochefontaine et autres ont trouvées enkystées dans le rein du Chien.

Filaire elaviforme ( $F$. clar a Wedl, 1856). - La femelle seule est connue. I'après Wedl, elle est longue de 16 à 18 millimètres, large de $n^{\mathrm{mm}}, 33$. Corps filiforme, de diamètre uniforme dans presque toute la longueur; extrémité céphalique atténuée en cône; extrémitẻ postérieure arrondie et renflée en massue. Bouche inerme, très petite, percée au milieu d'une calotle chitineuse qui enveloppe la tèle; anus dans un sillon, au niveau de la massue. Vulve à $1^{\mathrm{m} m}, 25$ de l'extrémité antérieure. OEufs à coque mince, longs de $36 \mu$, larges de 24 u, contenanl un embryon enroulé. Embryon long de $84 \mu$, large de $6 \mu$; extrémité antérieure atténuée, mais obtuse; extrémité caudale en pointe.

Trouvée par le professeur Fr. Müller dans le tissu conjonctif péritrachéal d'un Pigeon domestique tuberculeux. Diesing arait déjà vu chez cet Oiseau des Filaires du tissu conjonctif, mais il ne les avait pas décrites. Mazzanti dit en posséder une dizaine d'exemplaires.

Filaire de Mazzanti ( $F$. Mazantii). - La femelle seule est connue. Corps filiforme, bleu cendré, sans stries, long de 2o millimètres, large de 0 mm,2ö; extrémité antérieure obtuse, arrondie; extrémilé postérieure brièvement conique. Bouche orbiculaire, inerme; anus terminal. Vulve triangulaire, à $213 \mu$ de l'extrémilé antérieure. Vivipare.

Mazzanti a recueilli un seul exemplaire de celte Filaire sous la peau du cou d'un Pigeon messager (1891). Le sang de cet Oiseau contenait en outre des

(1) Th. Mather, A case of introsusception and Filarix found in the intestines of a Dog. The Veterinarian (2), II, p. 434, 1843. 
embryons de Nématode, les uns longs de $18.7 \mu$, à queue légèrement acuminée, les autres longs de $142 \mu$, à queue moins acuminée ou mème obtuse. Ces caractères se rapportaient parfaitement à ceux des embryons trouvés dans les utérus de la Vilaire.

Filaire de Manson ( $\boldsymbol{F}$. Mansoni Cobbold, 1879). - Male long de 16 millimètres. Femelle longue de 19 millimètres. - Cette Filaire a été tronvée par Manson, a Amoy (Chine), dans les yeux de la Poule.

Filate du Canard (F. anatis Rud., 1809). - Sous ce nom, Rudolphi mentionne simplement un lielminthe filiforme trouvé par Paullinus enroulé en divers sens antour du cœur d'un Canard.

Filaire du Cygne (F. cygni [Cmelin], - Syn. : Ascaris cygni Gmelin, 1789; F. cygni Rud., 1809). - Nom donné à des Vers recneillis par Redi, au nombre de plus de 200, dans la cavitẻ abdominale d'un Cygne très naigre. Ces Ver's étaient blancs, frès minces et dépassaient la longueur d'une palme (environ 20 centim.); il en existait en outre une grande quantité daus l'intestin et dans les crcums.

Genre Spiroptère Spiroptera Rud., 1819. - Syn. : Spirura É. Blanch., 1849). - Au point de vue morphologique, on peut à peine distinguer les Spiroptìres des Filaires par deux caractères: le corps est en général plus court et plus épais; la vulve est d'ordinaire moins rapprochée de la bouche. Leur nom spécifique est tiré de la queue des mâles, qui est enroulée en spirale et munie d'ailes latérales membraneuses.

Il s'agit donc d'un genre tout à fait arbitraire (1), que nous conserrons simplement dans un but d'utilité pratique, en raison de l'habitat des Vers qu'on y rattache : la plupart, en effet, se rencontrent dans des tumeurs de l'osophage, de l'estomac ou de l'intestin, chez les animaux vertébrés.

Spiroptère mégastome (Sp. megastoma Rud., 1819. - Syn. : Spirura megustoma Blanch., 1849 ; Filaria megastoma Schn., 1866). - Petit Ver blanchàtre, atténué aux deux extrémités. Bouche munie de quatre lèvres épaisses et chitineuses: une dorsale et une ventrale plus larges portant une papille vers chacun de leurs bords latéraux, et deux lalérales plus petites. Ces lèvres donnent l'apparence d'un renflement céphalique séparé, par un étranglement, du reste du corps, qui offre aussitòt après une partie élargie limitée par deux petites ailes latérales. La bouche se continue par une sorte de capsule buccale ou pharynx infundibuliforme. Male long de 7 à 10 millimètres; queue obtuse, contournée en spirale et garnie de deux ailes latérales membraneuses: celles-ci sont soutenues chacune par quatre papilles préanales et une postanale; deux spicules inégaux, longs de 240 et $400 \mu$. Femelle longue de 10 à 13 millimètres; queue droite, en pointe mousse; vulve située vers le tiers antérieur du corps. OEufs oblongs, presque linéai-

(1) Raffaele Mous, Una monografia del genere Spiroptera. Silzungsberichte der kaiserlichen Akademie der Wissenschaften, XXXVHI, p. 911, 1860. 
res, longs de 330 à $330 \mu$, larges de $8 \mu$, éclosant en général dans l'utérus commun. Embryon libre long de 660 à $700 \mu$.
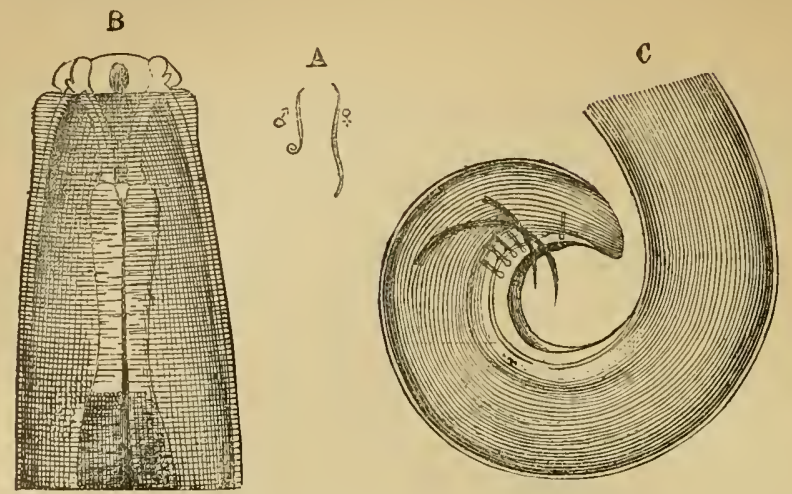

g. 370. - Striroptère mégastome. - A, mâle et femelle, grand. nat. B, extrémité céphalique, vue de cûté, grossie 100 fois. C, extrémité caudale du màle, vue de côté, grossie 50 fois (Orig.).

Les Spiroptères mégastomes, que Chabert signalait déjà en 1782, sous le nom de " crinons ", se trouvent dans des tumeurs du sac droit de l'estomae du Cheval. Ces tumeurs, résultant de l'irritation du tissu

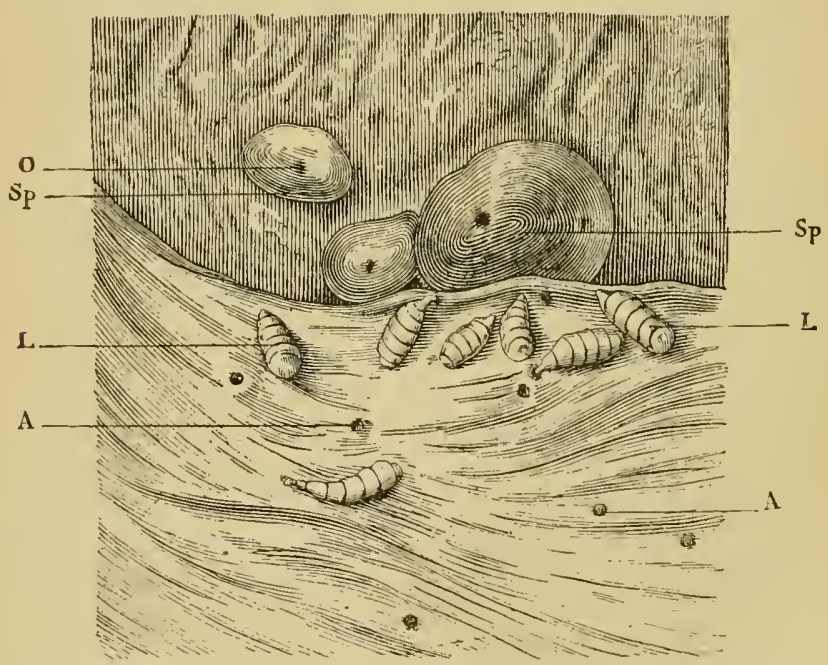

Fig. 374 - Spiroptères et larves d'(Estres dans l'estomac du Cheval. - Sp, tumeurs̀ à Spiroptera

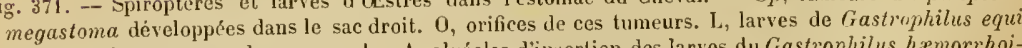
fixées sur la muqueuse du sac gauche. A, alvéoles d'insertion des larves du Gastrophilus hæmorrhoidelis, qui ont abandonné l'estomac. 1/2 de grand. nat. (Orig.).

conjonctif sous-muqueux, varient du volume d'une noisette à celui d'un œuf de Poule; elles sont creusées de petites cavités qui communiquent entre elles et renferment une matière purulente grisâtre au milieu de laquelle vivent les Vers. Une légère compression en fait 
sortir le contenu par un ou plusieurs pertuis qui établissent une communication arec l'intérieur du sac gastrique. Autrefois prises pour des cancers. ces tumeurs rermineuses paraissent n'exercer aucun trouble sur l'économic; toulefois, elles arriveraient sans doute à gènel la circulation des matières alimentaires, si elles se trouraient situées aux abords de l'orifice pylorique. D’après Valenciennes et Ercolani, elles seraient surtout fréquentes au mois de juin.

Lévolution dı Spiroplère mégistome n'est pas encore connue, mais il y a lieu de supposer qu'il a pour hôte intermédiaire un Insecte des fourrages.

Spiroptère mierastome (Sp. microstoma [Schneider]. - Syn. ; Sp. megustoma var. major Dies., $183 ̈ 1$; Filuriumicrostoma Schn., 1866 ; sp. microstomu Zürn, 1872). - Espèce plus grande que la précédente, et n'offrant pas d'étranglement en arrière de la région buccale. Bouche presque quadrangulaire, à bords dorsal et ventral munis cliacun d'une forte dent. Deux lèvres latérales, rétrécies à la base. Cápsule buccale ou plaryngiemne cylindrique ou infundibuliforme. Wule long de 10 à 22 millimètres; queue enroulée en spirale et garnie d'ailes memliraneuses; six à huit papilles de chaque còté, dont deux à quatre postanales, non symétriques; en outre, un sroupe de douze papilles minuscules à l'extrémité de la queue ; deux spicules inégaux, longs

B
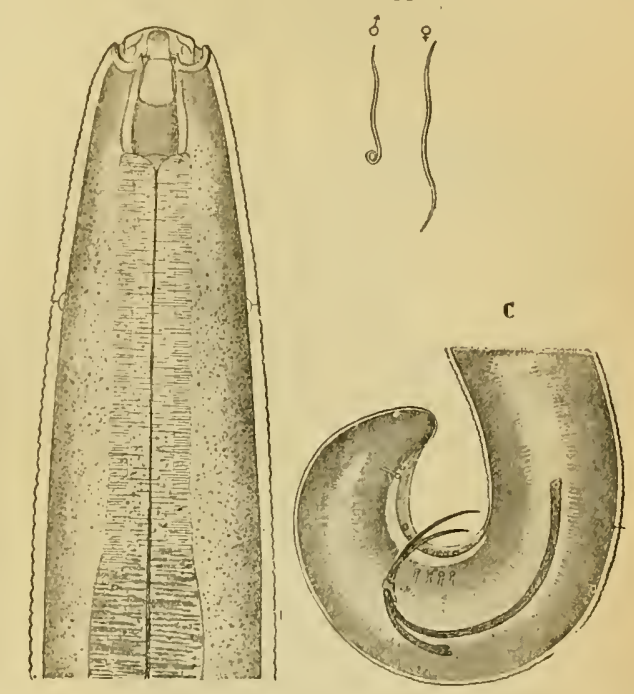

Fig. 372. - Spiroptèce microstome. - A, màle et femelle, grandeur naturelle. $B$, extrémité céphalique grossie 100 fois. C, exlrémilé caudale dı mâle, vue de côté, grossie 50 fois (Neumann et Railliet). de 750 et 320 p en moyenne. Femelle longue de 12 à 27 millimètres; queue un peu incurvée, en pointe mousse; vulve vers le tiers antérienr du corps. OEufs oblongs, tronqués aux extrémités, longs de 4 à à $49 \mu$, larges de $16 \mu$, éclosant dans l'utérus commun. Embryons libres longs de 90 à $98 \mu$.

Ces Spiroptères, que Gurlt (1831) décrivait comme une variété de l'espèce précédente, se trouvent en liberté, et sourent en grand nombre, dans l'estomac des Équidés. On les rencontre surtout à la surface de la muqueuse du sac droit, et ils ont parfois l'extrémité céphalique engagée dans les glandes de cette région. Nous avons observe plusieurs fois, en été, des ulcérations étendues sur la muqueuse gastrique des Anes sacrifiés au service de chirurgie d'Alfort 
et porteurs d'un grand nombre de ces parasites. Dupuy et Prince (1836) ont vu leur présence s'accompagner d'une inflammation et d'un épaississement de la même membrane, chez une Mule.

Spiroptère strongylin (Sp. strongylina Rud., 1819. - Syn. : Filaria strongylina Schn., 1866). - Corps blanchàtre, grêle, souvent contourné en demi-cercle. Pas d'étranglement marqué en arrière de la région buccale. Bouche entourée, d'après von Linstow, de six grosses papilles renflées au sommet; une capsule buccale ou pharyngienne profonde. Une aile latérale très étroite, d'un seul còté. Male long de 10 à 13 millimètres; queue simplement contournée, munie de deux ailes larges et inégales; six papilles de chaque coté, dont deux postanales, les autres irrégulièrement disposées : en arrière du cloaque, une demi-couronne de saillies cuticulaires en dents de scie; deux spicules inégaux, longs de 720 et $260 \mu$. Femelle longue de 12 à 20 millimètres; extrémité caudale légèrement déprimée; vulve siluée un peu en avant de l'anus. OEufs oblongs, à coque épaisse.

Ce Ver, qui paraît être assez rare, a été trouvé en Allemagne, par Gurlt, dans la cavité de l'estomac du Porc, et dans le Turkestan, par Fedtshenko, dans l'intestin du même animal. Il est un peu plus commun chez le Sanglier, et on l'a signalé aussi chez le Pécari à lèvres blanches (Dicotyles labiatus).

Spiroptère ensanglanté (Sp. sanguinolenta Rud., 1819. - Syn. : Strongylus lupi Rud., 1809 ; Filaria sanguinolenta Schn.,1866. - Priorité : Sp. lupi).

A.

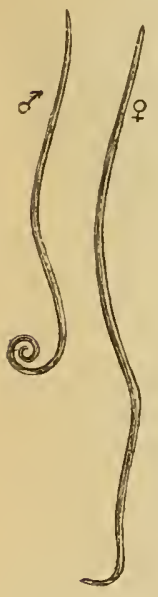

B

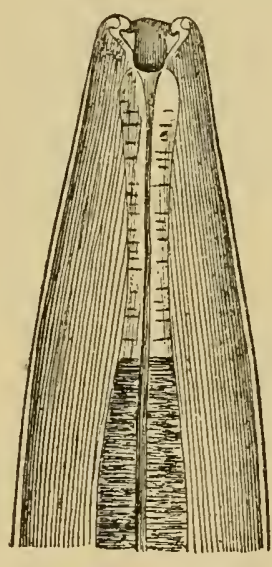

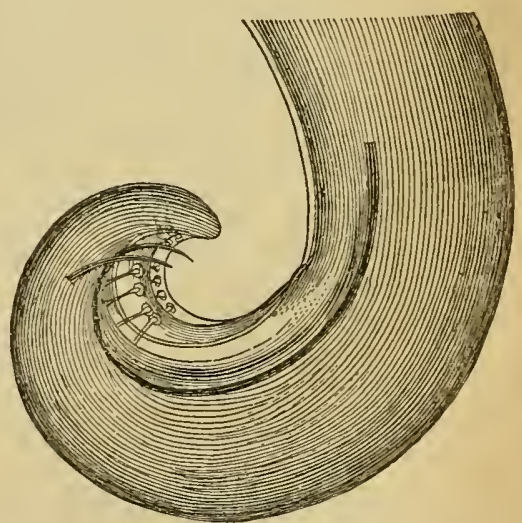

Fig. 373. - Spiroptère ensanglanté. - A, mâle et femelle, grand. nat. B, extrémité céphalique, monirant l'intérieur de la capsule buccale, grossie 50 fois. C, extrémité caudale du mâle, vue de côté, grossie 25 fois (Orig.).

- I.e corps, à peine atténué aux extrémités, offre d'ordinaire une coloration rouge de sang. Région buccale non séparée du reste du corps. Bouche hexagonale, suivie d'une courte capsule buccale en entonnoir, dans laquelle 
font saillie six dents. Six papilles en avant de l'orifice buceal. Mile long de 3 à ว̀ centimètres; queue obtuse, enroulée en spirale, à deux ailes latérales soutenues chacune par six papilles, dont deux postanales; deux spicules inégaux, longs en morenne de $2^{\mathrm{mm}}, \overrightarrow{\mathrm{m}}$ et $0^{\mathrm{mm}}, 6$. Femelle longue de 6 à 8 centimèlres; queue obtuse, à peine recourbée; vulve à 2 ou 3 millimètres de la bouche, vers le liers postérieur de l'asophage. OFufs ellipsoïdes, à coyue épaisse, tongs de 30 à $32 \mu$, larges de 11 à 1 \& $u$, contenant un embryon au moment de la ponte.

Ce Nématode, qui paraît aroir été décourert par Redi vers la fin du $x^{\prime}{ }^{\mathrm{e}}$ siccle, est parasite
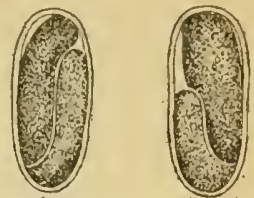

Fig. 37i. - (Nufs du Sproptère ensanglanté, grossis 600 fois (0rig.). du Chien et du Loup, peut-ètre aussi du Renard et de quelques autres Carnirores. Il siege le plus souvent dans des tumeurs de l'estomac ou de l'cesophage, mais peut se rencontrer aussi en beaucoup d'autres points le l'organisme (1). Ainsi, Morgagni et da Silva Araujo en ont vu des exemplaires en liberté dans l'œsophage du Chien. D'autre part, Courten (1712) avait observé ces Vers dans une tumeur de l'aorte, d'où ils étaient presque entièrement sortis et sur le point de passer dans la cavité thoracique. Norgagni (176.4) les vit aussi sur le trajet de ce raisseau, ainsi qu’à l'intérieur d’une tumeur située dans la cavité abdominale, au-dessous des vaisseaux rénaux, tumeur qui n'adhérait cependant ni à ces vaisseaux, ni à aucun rameau vasculaire. On sait du reste aujourd hui que la présence des tumeurs à Spiroptères dans les parois

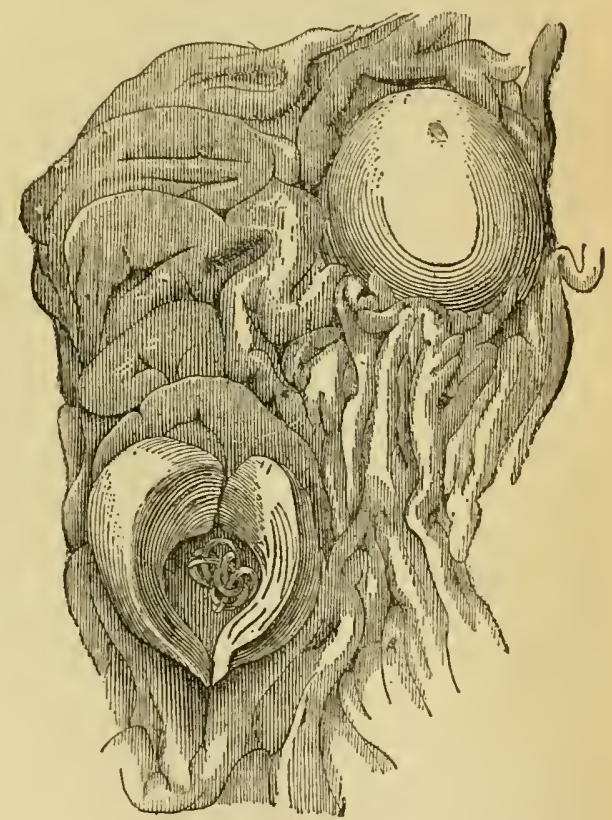

Fig. 375. - Tumeurs à Spiroptera sanguinolenta dans l'eslomac du Chien, grand. nat. Liume đ'elles a élé ineisée pour montrêr la cavité intérieure et les Vers qui y sont contenus (Orig.). de l'aorte est assez commune. Caparini (1887) a le premier observé le parasite dans les ganglions lymphatiques, où l'ont ensuite rencontré Jacoulet et Chauvat. En 1883, nous arons signalé le fait d'une tumeur vermineuse du

(1) A. Raılet, Sur la diversité d'habilat du Spiroptère ensanglanlé. Bull. Soc. centr. de mìd. vẻtér., 1892, p. 27 í. 
poumon, recueillie par Le Moine et renfermant plusieurs Spiroptères. Depuis lors, nous avons pu rattacher à la même espèce des Néma. todes rencontrés par Chauvrat dans le poumon, les bronches, la trachée et les cavités nasales de deıx Chiens. Nous en arons nous-même recueilli un exemplaire dans une petite tumeur située à la surface externe du duodénum. Enfin, le Musée d'Alfort possède desspécimens du même parasite indiqués comme provenant de l'intestin du Chat.

Le Spiroptère ensanglanté est surtout commun dans les contrées chaudes: il est déjà plus répandu en Italie qu’en France, et plus encore en Algérie. On le trouve au Japon chez 10 p. 100 des Chiens, et la proportion doit être sensiblement la mème pour la Chine et pour le Brésil.

Son évolution a été déterminée par les recherches de Grassi. Il a pour hôte intermédiaire la Blatte orientale (Periplaneta orientalis L.), un des Insectes vulgairement appelés Cafards. Dans la cavité abdominale de cet Orthoptère, on trouve facilement, à Catane, des liystes relativement gros contenant de jeunes Nématodes dont la couleur rappelle celle du Spiroptère ensanglanté. En faisant ingérer à des Chiens un grand nombre de ces liystes, Grassi a trouvé, au bout de cinq jours, les Vers virants et libres dans l'estomac; après dix jours, ils étaient plus développés et solidement fixés à la muqueuse de l'œsophage; après quinze jours, enfin, ils étaient enfoncés dans les parois de l'osophage et plus déreloppés encore. La Blatte doit donc prendre ses parasites dans les excréments des Chiens porteurs de Spiroptères (1), et les Chiens les prennent à leur tour en mangeant des Blattes. Grassi affirme d'ailleurs que beaucoup de Chiens aiment à faire la chasse à ces Insectes. Reste à savoir si d'autres Arthropodes ne peuvent pas remplir aussi le rôle d'hôte intermédiaire.

Les troubles occasionnés par le Spiroptère n'ont rien de caractéristique. La présence de tumeurs vermineuses dans l'œesophage ou dans l'estomac se traduit d'ordinaire par des romissements; souvent aussi on a trouvé le parasite chez des Chiens ayant présenté des symptômes rabiformes. - Lorsque les tumeurs siègent sur l'aorte, on a vu leur rupture dans la cavité thoracique entraìner une pleurésie mortelle (Manson); d'autres fois l'artère altérée se déchire et les animaux succombent à une hémorragie intra-thoracique ou intraabdominale (Mégnin, Blaise, Chauvrat, Perroncito, Caparini).

Spiroptère réticulé $(S p$. reticulata [Diesing]. - Syn. : Trichina reliculata Dies., 1841; Onchocerca reticulata Dies., 1841 ; Filaria reticulata Greplin, 1846; Sp. cincinnuta Eıcolani, 1865; Filaria cincinnata Zürn, 1872; Sp. reticulata Raill., 188ว̈). — Corps blanc, élastique, filiforme, un peu

(1) Nous avons constaté que les cufs du spiroptère ne perdent pas leur coque dans tout le trajet du tube digestif du Chien. 
déprimé, très allongé et généralement disposé en une spirale à lours serrés circonscrivant un espace cylindrique. Rérgion buccale non séparée du reste du corps. Couches du tigument offrant plusieurs ordres de stries à disposition complexe. Bouche orbiculaire, suivie d'une cavité rétrécie en entonnoir. Mcile lon⿺r de 9 i 1 : aplatie, recourbée en crochet; deux spicules inégaux, de chaque còté desquels Tchulorsky signale environ dix rentonses (papilles?). Femelle longue de 18 a 31 centimctres, large de $0^{\mathrm{mm}}, 3 \ddot{\text { a }} 0^{\mathrm{mm}}, 39$; vulve située a pen de distance de la bouche et représentée, d'apres Tehulorsky, par deux tuberenles crateriformes conduisant dans des vagins distincts.

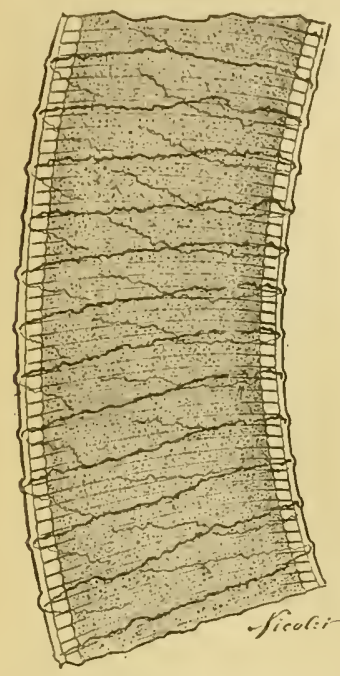

Fig. 376. - Spiroptera reticulata : fragnent du corps de la femelle montrant les stries iransversales et les créles spiralées de la culicule. Grossissement : 20 diametres (Orig.).

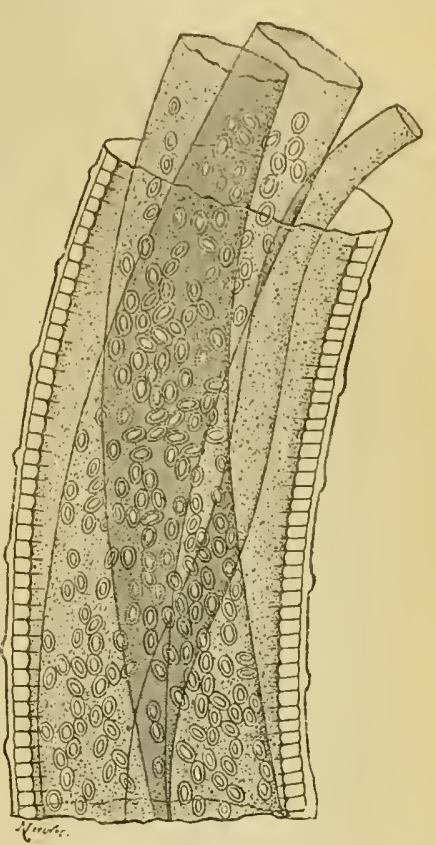

Fig. 377. - Spiroptera retieulata : fragment du corps de la femclle montrant lintestin et les denx tubes génitaux remplis d'aufs embryonnés. Grossissement : 80 diamètres (Orig.).

OLufs longs de 33 à $4 \ddot{\partial}$ u, larges de 23 à 33 y, éclosant dans les utérus. Embryons libres longs de 230 à 260 i. larges de 5 à 7 p.

Ce Ver, considéré jusquà ces derniers temps comme propre aux Équidés, a été décourert en 18.10, par le docteur Bleiweis, à I'Institut vétérinaire de Vienne. Il a été retrouvé ensuite en Allemagne par Gurlt et Zürn; en Autriche par Baumgarten; en Italie par Ercolani, Bassi, Gotti, Baruchello et Berto; en Russie par Tchulorsliy et Popor; en France par Railliet, Moussu, Barrier et Mauri.

On l'a observé quelquefois dans le ligament cervical ou dans le tissu des artères roisines, entre les fibres musculaires ou dans des nodules sous-cutanés; mais les points où il siège le plus ordinairement sont les tissus ou organes des extrémités, surtout dans la région du canon, et presque exclusirement dans les membres antérieurs. 
Citons, en particulier, les faisceaux musculaires du ligament suspenseur du boulet, les tendons fléchisseurs du pied, les parois des veines (Peschel, 1841), depuis le sabot jusqu'à l'avant-bras, le tissu conjonctif sous-cutané. Outre l'hypertrophie des tendons ou des ligaments, la présence des Vers provoque souvent la formation de nodules isolẻs; on désigne ces diverses lésions sous le nom de fibromes parasitaires. Lorsqu'elles occupent les tendons ou qu'elles sont situées

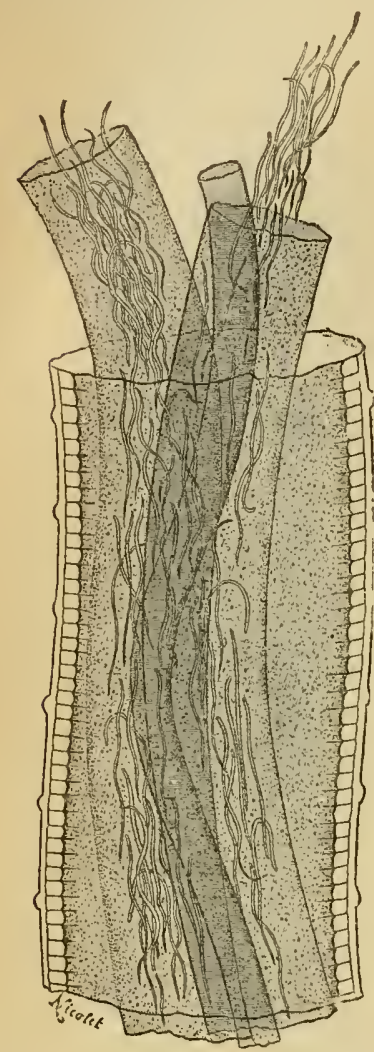

Fig. 378. - Spiroptera reticulata; fragment du corps de la femelle montrant l'intestin et les deux tubes génitaux remplis d'embryons. Grossissement : 80 diamètres (Urig.). sur le trajet des cordons nerveux, elles donnent lieu à des boiteries persistantes, à chaud ou à froid, dont le diagnostic est fort difficile à établir tant que les nodules n'ont pas acquis des dimensions qui les rendent bien apparents. L'extirpation de la tumeur peut seule amener la guérison.

Nous avons observé des embryons libres dans les tubes génitaux des femelles dès le mois de janvier, alors que Tchulovsky, à Kasan, ne les a vus apparaître qu'en mars et avril. Chez des Che-

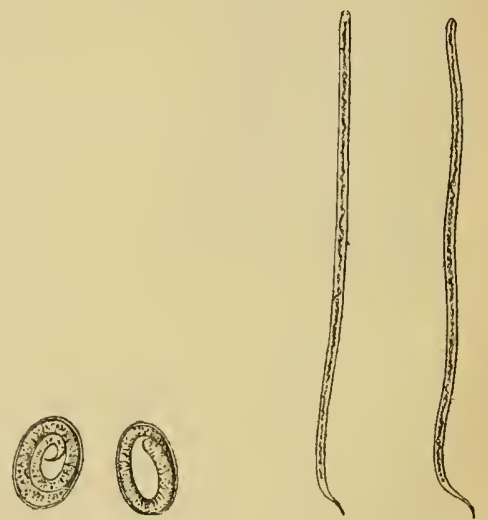

Fig. 379. - OEufs du Spirop- Fig. 380. - Embryons du tère réticulé, extraits des spiroptère réticulé, gros. tubes génitaux, grossis 200 fuis (Orig).

vaux porteurs de Spiroptères réticulés, cet observateur a trouvé les embryons dont il s'agit dans la lymphe des vaisseaux lymphatiques des extrémités, dans le tissu conjonctif périvasculaire, dans la synovie des trois articulations inférieures et jusque dans la sérosité des gaines synoviales tendineuses, notamment dans le cas d'hydropisie de ces gaines. Dans chaque goutte de lymphe ou de synovie, il constatait toujours la présence de trois ou quatre embryons au moins; ceux-ci mesuraient 300 à $330 \mu$ de long sur 6 à $9 \mu$ de large. Il semble 
done que ces embryons soient aptes ì effectuer des migrations actives; probablement même doivent-ils pénétrer dans le système circulatoire sanguin.

On a trouvé dans la rate du Bauf, aux États-Unis, un long Ver que Stiles avail d'abord dénommé Filaria lienalis (1892); nais le savant helminthologisle amérieain nous annonce aujourd'hui que ce parasite lui parait ètre identique au Spriroptera reticulata.

Genre Gongylonẻme (Gongylonema Molin, 185i. - Syn. : Myzomimus Stiles, 1892). - Les représentants de ce genre se distinguent des Filaires el des Spiroptères par la plésence, à l'extrémité antérieure du corps, de différenciations de la cuticule en forme d'écussons. En oulre, d'après Stiles, on remarque sur les lignes médianes, immédiatement en arrière de la bouche, deux dépressions semi-lunaires simulant des ventouses.

Gongylonème à écussons (G. scutatum [Müller]. - Syn. : ? G. pulchrum Molin, 1857; Spiropteru scutatu œsophagca bovis Müller, 1869; Filaria seu Spiroptera sculata Leuckart, 1876;M. scutatus Stiles, 1892; G. scutatum Raill., 1892). - Corps blanchàtre ou jaunàtre, filiforme, allongé, atténué seulement aux extrémités, comprimé par cơté en avant. Tégument strié en travers. Extrémité antérieure entourée, sur 1 à 3 millimètres de longueur, d'écussons arrondis ou ovalaires disposés plus ou moins symétriquement en deux rangées daus chacun des quatre champs submédians. Sur la lace ventrale, au niveau du pore excréteur, écussons des quatre séries fusionnés en une seule plaque. Sur les lignes latérales, deux grandes papilles cervicales circulaires, en arrière desquelles se montrent deux membranes latérales souvent découpées et ne dépassant guère la région des écussons. Bouche petile, oblongue, sans lèvres, mais arec deux papilles latérales et quatre submédianes plus petites. Anus en avant de la pointe caudale. Mále long de 32 à 52 millimètres; queue un peu déprimée de dessus en dessous, incurvée vers la face veutrale et munie de deux ailes latérales asymétriques, la droite plus courte et plus large que la gauche, qui est supportée du còté dorsal par un troisième repli asymétrique; six paires de papilles préanales et quatre à six paires de postanales; deux spicules inégaux, le gauche excessivement long, atteignant 16 millimètres à $16^{\mathrm{mm}}, \tau$; le droit mesurant seulement 140 à 180 u. Femelle longue de 80 à 145 millimètres; queue conique; vulve à 4-ว̃ millimètres de la pointe caudale. OEufs ellipsoïdes, longs de 36 à $60 \mu$, larges de 32 à $36 \mu$, renfermant, au moment de la ponte, un embryon pourvu d'un appareil perforateur.

Ce parasite a été trouvé par Müller, de Vienne, dans l'épithélium de l'œsophage, et en particulier de sa portion thoracique, sur cinq Boufs polonais et hongrois (1869). Peu après, Leucliart signalait également sa présence sur les Bœufs du nord de l'Allemagne. Th. Smith, Curtice, Hassall et Stiles l'ont observé plus tard sur les Baufs des États-Unis. Enfin, Giles l'a vu dans le réseau et le feuillet du Zébu, dans l'Inde anglaise, soit en liberté, soit plus ordinairement sous la muqueuse. 
Müller l'a rencontré aussi chez un vieux Cheval, toujours dans l'épithélium œsophagien.

Harms a trouré, dans l'œesophage des Moutons, des Gongylonèmes que Zuirn rattache à la même espèce; ils étaient ondulés comme des brins de laine de mérinos. Giles en a vu dans le rumen, et les a considérés comme une espèce particulière (Spiroptera verrucosa).

Enfin, Listiak a observé, sous l'épithélium de la langue et de l'œsophage, des parasites semblables, longs de 2 à 4 centimètres, que Korzil rapporte encore au G. scutatum. Kitt a fait une observation semblable, et Molin avait déjà décrit, en 18ä̃, un G. pulchrum du Sanglier qui n'est autre, probablement, que celui-ci.

Le Gongylonème à écussons se creuse des galeries dans la couche épithéliale de l'œsophage, galeries onduleuses dans lesquelles on trouve, soit un seul individu, soit quelquefois en même temps un mâle et une femelle. Il y a une grande analogie avec ce que nous avons signalé pour le Trichosome du Canard. Plus rarement le Ver s'enroule sur lui-même, donnant lieu à un petit nodule $(\mathbf{1})$.

Genre Dispharage (Dispharagus Duj., 1813̈). - Sous ce nom, Dujardin a voulu détacher du genre Spiroptera les espèces qui ont un

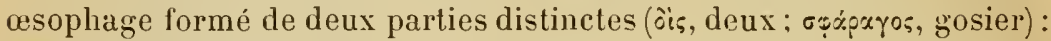
l'antérieure étroite, tubuleuse, et la postérieure longue, épaisse, musculeuse, suivie d'un ventricule encore plus épais, cylindroïde. Le corps, filiforme, offre en avant deux lèvres latérales ou dorso-ventrales desquelles partent quatre cordons cutanés qui se dirigent en arrière et parfois se replient ensuite vers l'extrémité antérieure (ces cordons sont probablement des organes tactiles). Mále à extrémité caudale plus ou moins contournée, munie d'ailes latérales; de chaque côté, quatre papilles préanales; deux spicules inégaux. Femelle à ovaire simple. Ovipares.

Dans les limites qui lui sont assignées actuellement, ce genre ne comprend que des espèces vivant dans le tube digestif des Oiseaux, et plus spécialement dans l'œsophage et les divers renflements stomacaux : elles se fixent d'ordinaire dans les parois de ces organes (2).

On les répartit en deux groupes, suivant qu'elles ont le corps inerme on garni d'aiguillons :

(1) Ch. W. Strles, Notes on parasites: 4. Preliminary Note on Myzomimus gen. nov., type species II. scutatus Müller, 69 , a parasite in crittle. Journ. of comp. Mled. and vet. Archives, XIII, p. 65, 1892. - A. RallLiet, Sur un parasite asophagien des herbivores. Recueil de méd. vét. (7), IX, p. 694, 1892. - Ch. W. Stuses, On the anatomy of Myzomimus scutatus (Müller, 1869) Stiles, 1892. Festschrift zum siebenzigsten Geburtstage Rudolf Leuckarts. Leipzig, 1892. - G. Il. J. Giles, A description of two new Nematode Parmsites found in Sheep. Scientific Mlemoirs by lledical Officers of the Army of India. Part VIl. Calcutta, 189?.

(2) R. Jouls, Una monografia del genere Dispharagus. Sitzungsber. d. k. Akademie der Wissenschaften, XXXIX, p. 479. Wien, 1860. - M. Sтоssich, Il genere Dispharagus Dujardin. Bollett. della Societả Adriat. di sc. nat. in Trieste, XII, 1891. 
$I^{\text {re }}$ section: Espèce à corps armé.

Dispharase ì queue roochue (D. uncinatus [Rul.]. - Syn. : Spiroptera uncinutu Rud., 1819; Filaria uncinata Selıneider, 1866). -- Bouche ì deux dents (lives) avec six papilles. Cordons cutanés llexueux descendant jusqu’a 2 millimètres de l'extrémité antérieure. De chaque còté du eorps, une louble série longitudinale de petites épines, s'étendant jusque jrès de l'extrémité caudile; en avant, ces rangées épineuses gagnent la face dorsale et s'avancent vers la houche, entre less cordons cutanés. Mâle long de 9 à 10 millimètres; queue offraut d'étroites ailes i bords vésiculeux: quatre papilles postanales; les préanales $\ddot{z}$ et 6 còte à côte, ainsi que 7 et 8 ; spicule principal assez long, incurvé, dilaté en coupe à son extrénité libre; l'autre épais et court. Femelle longue de 15 à 18 millimetres; vulve située à environ 1 millimètre de la pointe caudale. qui est, d'après Rudolphi, recourbće en crochet; aufs à cợue épraisse.

Ce parasite n'avait encore été trouvé que par Klug, à Berlin, dans des tubercules œsophagiens de l'Oie domestique. Zürn l’a rencontré de nouveau, non seulement dans l'œesophage, mais aussi dans le ventricule succenturié et l'intestin grèle de l'oie et du Canard. Sur celle dernière espèce, en particulier, il les a observés en grand nombre, déterminant une violente inflammation des organes envahis: les animaux mouraient presque subitement.

Stossich n’a pas cru devoir placer cette espèce parmi les Dispharages, parce que Schneider lui assigne six papilles péribuccales.

\section{$2^{\mathrm{e}}$ section : Espèces à corps inerme.}

Dispharage spiralé (D. spiralis Molin, 183̈8). - Corps enroulé en spirale, atténué aux deux extrémités. Deux petites lèvres papilliformes, d'où partent les cordons cutanés llexueux, épaissis en arrière. Wile long de 7 millimètres; einq papilles postanales; spicule pribcipal long, incurvé; l'autre court, naviculaire. Femelle longue de 9 millimètres; vulve située dans la partie postérieure du corps.

liecueilli a Padoue, par Molin, dans l'œsophage de la Poule, et dans le Turkestan, par ledtshenko, dans l'intestin du même hòte. Ce sont probablement des embryons de cette espèce que Rivolta et Delprato ont trouvés, également chez la Poule, enkystés dans le tissu conjonctif autour de l'œsophage, du jabot et du ventricule succenturié, sur la paroi de l'intestin et sur le mésentère, et qu'ils ont décrits sous le nom de Trichina papillosa.

Dispharage à larage tète (D. laticeps [Rud.]. - Sym. : Spiroptera laticeps Rud., 1819; Disph. laticeps Duj., 1840̈; Filaria laticeps Schn., 1866). Cordons cutanés se dirigeant directement en arrière, puis envoyant une boucle jusqu'à $0^{\mathrm{mm}}, 3$ environ de l'extrémité antérieure. De nombreuses papilles dans leur épaisseur. Un peu après leur terminaison, et de chaque còlé, une papille cervicale Iricuspidée. Muale long de 9 à 10 millimèlres; corps enroulé sur lui-mème; extrémité caudale à bords épais et vésiculeux; cinq papilles postanales. Femelle longue de 12 à 14 millimètres; corps droit; vulve située dans la partie postérieure du corps; œufs à coque épaisse.

OEsophage et ventricule succenturié de divers Rapaces. Stossich le signale en outre chez la Poule domestique. 
Displıarage à nez saillant ( $\nu$. nasutus [Rud.]. - Syn. : Spiroptera nasuta Rud., 1819; D. nasutus Duj., 1840̈; Filaria nasuta Schn., 1866). Corps insensiblement atténué aux deux extrémités. Deux petites lèvres latérales, d'où partent les cordons cutanés flexueux qui, après un certain trajet, reviennent en avant sans se joindre. Male filiforme, long de 5 millimètres; extrémité caudale enroulée en spirale; spicule gauche long, filiforme, incurvé; le droit court, styloïde. Ftmelle peu épaisse, longue de à à 9 millimètres; extrémité caudale conique, terminée en pointe mousse; vulve dans la partie antérieure du corps; œufs à coque épaisse, longs de $38 \mu$, contenant un embryon enroulé.

Ventricule succenturié du Moineau et de la Poule domestiques. Molin a examine le ventricule succenturié d'une Poule dans lequel un si grand nombre d'exemplaires de ce Ver élaient enfoncés dans les glandules, que la muqueuse présentait un aspect villeux. Legros a constaté, dans une bassecour, une épizootie assez grave due à cette mème espèce : les parasites siégeaient dans le gésier, les uns entièrement cachés dans l'èpaisseur de la muqueuse, les autres insérés dans cette membrane par une de leurs extrémités. Les Poules mouraient comme épuisées, sans cependant avoir perdu l’appétit.

Dispharage à eroehets (D. hamulosus [Dies.]. - Syn. : Spiroptera hamulosa Dies., 18301 ; Cheilospirura hamulosa Dies., 1860; D. hamulosus Stossich, 1891). - Corps muni de huil ailes longitudinales linéaires et dentées. Deux grandes lèvres latérales, triangulaires, chacune avec deux papilles latérales. Les cordons cutanés s'étendent jusqu'à l'extrémité postérieure et présentent une surface repliée très irrégulièrement. Mâle long de 12 à 14 millimètres; extrémité caudale arquée, à pointe légèrement nucronée; 4 papilles postanales, dont 1 et 2 très petites et rapprochées, 5 également très petite; spicule principal ou gauche très grèle, une fois plus long que le droit. Femelle longue de 16 à 25 millimètres; extrémité caudale terminée en cỏne aigu; vulve située dans la partie postérieure du corps.

Trouvé au Brésil, par Natterer, dans de petites excroissances charnues de la surface du gésier de la Poule, et en Vénétie, par le comte de Ninni, dans les parois du gésier d'une Poulette.

Genre Tropisure (Tropisurus Diesing, 183ว. - Syn.: Tetrameres Creplin, 1846 ; Tropidocerca Dies., 1830 ; Acanthophorus von Linstow, 1876). - Ce genre est remarquable par le dimorphisme sexuel des espèces qui le composent. Région buccale ou céphalique non séparée du reste du corps. Deux papilles cervicales opposées. Mâle à corps filiforme, inerme ou armé d'épines; queue droite, aiguë, excavée en

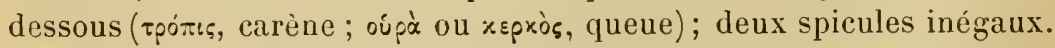
F'emelle à corps subglobuleux, marqué de quatre bandes longitudinales équidistantes; queue courte, conique ; vulve dans la partie postérieure du corps. Ovipare.

Espèces parasites entre les tuniques de l'œsophage, du ventricule succenturié et du gésier des Oiseaux.

Tropisure à épines loubles (Tr. fissispinus [Dies.]. - Syn. : Tropido- 
ecrca fissispina Dies., 1860; Acanthophorus temis von Linstow, 1876; Tropisurus fissispinus fi. Neumann, 1888). - Mile ì corps blane, grèle, finement strié en travers, long de 3 a 6 millimètres; quatre séries longitudinales d'épines aiğuës dirigies en arrière et oceupant les lignes médianes et latérales; derrière le cloatque, la série ventrale se divise en deux rangées qui tiennent liı place habituelle des papilles; à l'extrémité céphalique, jusqu’à l'origine de lintestin, des épines doubles ou fendues, caractéristiques, oceupent les lignes submédianes. Bouche à trois lèvres, suivie d'une capsule buccale. Quene arrondie à l'extrémité el recourbée en dessus. Deux spicules longs de 280 et $88 \mu$. Femelle à corps ronge sanguin, subglobuleux, un peu déprimé, marqué de très nombreuses zones transversales; diamètre longitudinal, 2 millimètres; diamètre transversal, 1 à 3 millimètres. Vulve en avant de l'anus.

Dans le ventricule suecenturié du Canard domestique (Lieberkühn) et dans l'uesophage du Mergus merganser' (von Linstow).

C'est évidemment le mème parasite que Züın a trouvé aussi dans le ventricule succenturié dı Canart et qu'il décrit à tort sous le nom de Tropidoeerca influta: la seule différence à relever dans sa diagnose réside en effet dans la longueur des spicules $(300$ et $130 \mu)$. Le màle, dit-il, vit dans la cavité de l'organe; quant à la femelle, on la rencontre parfois sur la muqueuse, mais elle se trouve le plus ordinairement dans les glandes, et sa présence se décèle par des taches rouge sanguin. Lorsque ees Vers sont abondants, la santé de l'hòte peut en ètre sérieusement troublée.

Genre Simondsie (Simondsia Cobbold, 1864). - Caractérisé principalement par une excroissance tégumentaire en forme de rosette, située vers la partie postérieure du corps de la femelle et renfermant, outre un prolongement de l'intestin, un utérus très développé qui émet de nombreuses branches terminées en cul-de-sac. Le mâle possède deux spicules inégaux et quatre papilles préanales.

D'après ces derniers caractères, ce curieux genre se rattache aux Filaires ; maisses affinités sont marquécs principalement arec le genre Tropisurus.

Simondsie paradoxale (S. paradoxa Cobbold, 1864. - Syn. : Tropidocerca paradoxu von Siebold, 1879, nec Dies., 183̆1). - Corps eylindroïde, atténué vers l'extrémité antérieure, qui est munie de deux ailes latérales étroites. Bonche avec deux papilles latérales saillantes. Mále long de 12 millimètres; queue contournée en spirale et brusquement contractée en une pointe mousse; spicules longrs et grèles. Femelle longue de 15 millimètres; rosette très développée; queue déux fois aussi épaisse que le corps, de forme conique, épaisse, el présentant, immédiatement en avant de l'anus, trois spinules à large base ; vulve paraissant s'ourrir immédiatement en avant de la rosette. Ovipare : œufs ovoïdes on ellipsoïdes, souvent contractés au milieu, longs de 28 à $29 \mu$.

Ce remarquable parasite a été découvert, au mois de mars 1832, par le professeur Simonds, du collège vétérinaire de Londres, dans les parois del'estomac d'un Porc allemand appartenant c̀ la ménagerie de la Snciété

Rallliet. - Zoologie. 
zoologique, à Regent's Park. Les mâles étaient libres, les femelles enfermées dans de petites tumeurs ou kystes, d'où elles projetaient leur tête, par un étroit orifice, dans la cavité de l'estomac. Ces kystes fai-

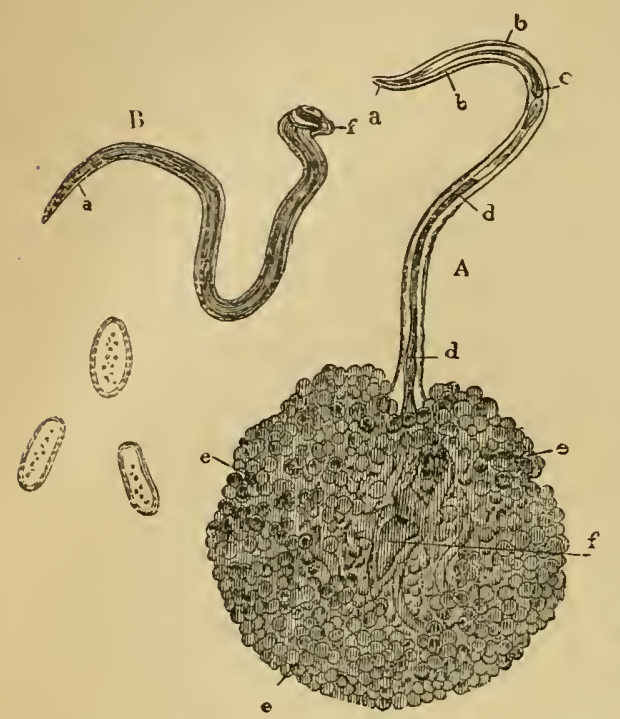

Fig. 381. - Simondsia paradoxa, d'après Cobbold. $A$, femelle extraite de son kyste. $a$, extrémité céphalique. $b, b$, ailes latérales. $c$, extrémité postérieure de l'œsophage. $d, d$, intestin. $e, e, e$, cæcums de la rosette utérine. $f$, queue. Grossissement : 5̃ diamètres. - B, mâle. $a$, extrémité cépbalique. $f$, extrémité caudale. Mème grossissement. - C, groupe d'ceufs extraits des cornes utérines. Grossissement : 250 diamètres. saient saillie à l'extérieur, sur la surface péritonéale, aussi bien que sur la muqueuse gastrique.

Le Porc était en mauvais état et avait été abattu en raison d'une maladie de peau, mais il n'avait jamais présenté le moindre signe de trouble gastrique.

Dans la première description qu'il avait donnée de ce Ver, Cobbold avait pris la tête pour la queue. Dans sa seconde étude, il crut reconnaître des affinités entre le genre Simondsia et le genre Sphærularia, dont il sera question plus loin. D’après Ant. Schneider, ces affinités n'existeraient pas: cet auteur tend à admettre qu il s'agit simplement d'une modification analogue à celle qu'offrent les Rhizocéphales

parmi les Crustacés. La phase larvaire, et probablement aussi la première période de l'état sexué, présenteraient la forme ordinaire des Nématodes; l'excroissance tégumentaire se développerait seulement pendant le séjour des femelles à l'intérieur des glandes gastriques (1).

Famille des GNATHOSTOMIDÉS. - Cette famille a été établie pour le seul genre suivant:

Genre Gnathostome (Gnathostoma Owen, 1836. - Syn. : Cheiracanthus Djesing, 1839). - Polymyaires à corps cylindroïde revêtu sur toute sa longueur, ou seulement en avant, de lamelles ou palmes chitineuses dont la plupart ont le bord postérieur découpé en spinules ( $\varepsilon_{\varepsilon} i p$, main ; $\alpha \alpha \alpha v \theta \alpha$, épine). Extrémité antérieure ordinairement renflée en une tête subglobuleuse hérissée d'épines simples. Bouche à deux

(1) T. S. Соввоцd, On Simondsia paradoxa and on its probable affinity with Sphærularia bombi. Trans. Linn. Soc. of London (Zoölogy) (2), II, p. 357, pl. XXXVII, 1883. - ID., in Linn. Soc. Journal (Zoölogy), XIX, p. 261, 1886. 
lèvres, une dorsale et une rentrale. Mâles à queue spiralée, excavée à sa surface ventrale, qui est garnie de papilles, et terminée par unc sorle de bourse cuticulaire; deux spicules. Femelles à queue droite ou infléchie ; ovaire double, vulve en alrière du milieu du corps. Ovipares.

Ce genre otrre des affinités évidentes, comme le genre Hystrichis, avec les Strongylidés et les Filaridés. Ses représentants vivent dans l'estomac des Vertélorés.

Gnathostome spinigère (Gn. spinigerum 0wen, 1836. - Syn. : Cheiracunthus robustus Dies., 1839; (rn. robustum Raill., 1883). — Corps droit, atténué en arrière; lamelles antérieures à ว̈-1-3 dents, les suivantes $2-1$ dentées, lisparaissant peu à peu en arrière. Mále long de 11 à $20 ̈$ millimètres ; queue enroulée en spirale, excavée inférieurement et munie d'une expansion cuticulaire simulant une bourse; de chaque cơté, quatre grosses papilles en forme de còtes, dont une préanale; trois papilles plus petites, dont une préanale, situées en delans des précédentes, ce qui porte le nombre total à sept paires; deux spicules longs de 1200 et $420 \mu$. Fomelle pourant atteindre jusqu'à 5 '́ millimètres; queue infléchie.

On a trouvé le Gnathostome spinigère dans l'estomac de diverses espèces sauvages du genre Chat: Felis catus, $F$. concolor, $F$. tigris.

D’autre part, Lewis a rencontré á Calcutta, chez le Chien paria, des parasites qu'il a décrits comme des Echinorynques et qui ne sont autres, comme le fait remarquer Leuckart, que des Gnathostomes. Cobbold n'hésite mème pas à les rattacher au Gn. spinigerum. Lewis n'a vu que des màles, siégeant dans de petites tumeurs du volume d'un marron, dont la cavité intérieure communiquait avec l'estomac par une étroite ouverture.

Gnathostome hispide (Gn. hispidum Fedtshenko, 1873. - Syn.: Ch. hispiłus Csokor, 1882). - Corps de teinte grise, jaunàtre et rougeàtre, revêtu d'épines sur toute sa longueur. Extrémité céphalique séparée du reste du corps par un sillon annulaire profond. Épines céphaliques en forme de crochets simples, recourbés, à pointe postérieure, et disposées en 9-11 couronnes concentriques; celles de la région cervicale en forme de lamelles complexes dont le bord postérieur est découpé en cinq à sept pointes; celles de la région œophagienne à plusieurs pointes allongées; enfin, celles de la partie postérieure du corps en soies sinıples et longues. Bouche étendue dans le sens dorso-ventral, et limitée par deux lèvres latérales à rebord sail-

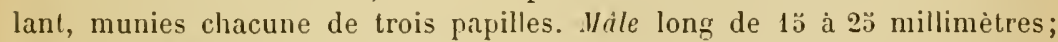
queue excarée en cuiller et formant une sorte de bourse arrondie; neuf grosses papilles et deux plus petites adanales; deux spicules inégaux, le gauche incurvé, long de $880 \mu$, le droit long de 400 u. Femelle longue de 22 à 31 millimètres; queue en pointe conique mousse; vulve un peu en arrière du milieu du corps. OEufs longs de $70 \mu$, larges de $39 \mu$; coque alvéolée, montrant à l'un des pôles une saillie hyaline.

Cet helminthe a été trouvé en Turkestan, par le voyageur russe Fedtshenko, dans les parois de l'estomac du Porc. Csokor l'a revu à Vienne, oủ les charcutiers le désignaient sous le nom de Ver tricolore. 
Ströse l'a rencontré à Göttingue, sur deux Pores hongrois. Il s'implante dans la muqueuse au moyen de ses crochets, et suce le sang. L'estomac est souvent dilaté, et on constate d'ordinaire une cachexie prononcée.

Collin a signalé laprésence du même parasite chez le Bœuf, à l'abattoir de Berlin (1).

Gnathostome de Siam (Gn. siamense [Levinsen]. - Syn. : Cheiracanthus siamensis Levinsen, 1889). - La femelle, seule connue jusqu'à présent, mesure 9 millimètres de long sur 1 millimètre d'épaisseur. L'extrémité céphalique est un peu plus étroite que le reste du corps et offre l'apparence d'une rentouse limitée par deux lèvres et armée de huit cercles d'épines. L'extrémité postérieure offre une partie trilobée qui déborde l'anus. Le revètement épineux n'est fort et serré que dans le tiers antérieur du corps; il disparait un peu en arrière du milieu. Les épines ou lamelles antérieures sont à trois dents, la médiane un peu plus grande que les autres; en arrière elles sont simples, deviennent plus éparses, plus petites, et enfin disparaissent. La vulve est située un peu en arrière du milieu du corps (2).

Le seul exemplaire de ce Ver examiné par Levinsen lui avait été envoyé par le Dr Deuntzer, de Bangkok. Il provenait d'une jeune Siamoise qui, après avoir présenté quelques jours l'apparence d'un léger état fébrile, avait éprouvé des douleurs dans un des côtés de la poitrine (sein ?). Il survint à ce niveau une faible tuméfaction, qui prit un peu plus tard une coloration bleuâtre. Cette tuméfaction ayant disparu, on perçut dans la peau des nodules arrondis de la grosseur d'un haricot, qui s'alténuèrent, puis reprirent leur volume primitif. C'est de l'un d'eux que s'échappa le Ver.

Des accidents analogues furentobservés chez deux autrespersonnes, et chez l'une d'elles 5 ou 6 Vers furent expulsés, mais aucun d'eux ne fut conservé.

Famille des ANGUILLULIDÉS. - Cette famille, assez difficile à caractériser, comprend des Nématodes de petite taille, à corps filiforme, dont le tégument est habituellement lisse et dont la bouche, petite, est souvent suivie d'une cavité étroite, cylindrique ou ovoïde (vestibule) contenant un aiguillon chitineux ou des dents. Vient ensuite un œsophage musculaire, qui se renfle d'ordinaire en un bulbe cylindrique ou fusiforme, fréquemment suivi, soit d'un second bulbe arec ou sans armature dentaire, soitd'un simple épaississement du tiers postérieur de l'œsophage. Les mâles ont deux spicules égaux, avec ou

(1) Sтвӧsе, Magenwurmseuche bei Schweinen hervorgerufen durch Cheiracanthus hispidıs. Berliner thierärztl. Wochenschrift, p. 58ł, 1892. - O. von Linstow, Cheiracanthus hispidus Fedt. Archivf. Naturg., I, p. 202, 1893. - A. Collix, Notiz über Gnathostoma hispidum Fedsch. aus dem Rinde. Zeitschr. für Fleisch- und Milchhygiene, III, p. 119, 1893.

(2) G. M. R. Levinsen, Om en ny Rundorn hos Mennesket, Cheiracanthus siamensis n. $s p$. Vidensk. Meddel. fra den naturhist. For. i. Kjöbenhavn for 1889, p. 323. 
sans pièces accessoires, et leur extrémité caudale présente quelquefois une expansion cuticulaire en forme de bourse. Les femelles ont une queue effilée, un ovaire double et la vulve située dans la moilié postérieure du corps; elles sontsouvent ovovivipares, mais ne produisent qu'un petil nombre d'embryons, dont le développementest rapide.

La plupart des Anuruillulidés vivent en liberté dans les eaux douces ou marines et dans la terre; quelques-uns se rencontrent dans les matières en fermentalion ; d'autres enfin sont parasites dans le corps des plantes.

On en connaît un très grand nombre de lormes, dont la classification a été tentée par diver's auteurs, notamment par Baslian, Bütschli ef OErsley.

Genre Anguillule (Anguillula Bütschli, 1873, ex Hemprich et Ehrenberg, 1826. - Sym. : Anguillula, Cephalobus et Plectus Bastian, 1864). - CEsophage à deux bulbes, le postérieur avec un appareil dentaire. Le plus souvent deux organes latéraux circulaires au cou. Màle sans bourse.

L'Anguilule du vinaigre (A. aceti Müller) est le représentant le plus connu . de ce genre. Dans le vinaigre de vin, la colle de farine aigre.

Anguilule vivipare (A. vivipara [Probstmayer]. - Syn. : Oxyuris vivipara Probstmayer, 1863 ; Rhabulonemi Perroncito, 1886). - La femelle seule est conuue; elle est longrue de $2^{\mathrm{mm}}, 3$, large de 40 à $80 \mu$. Corps blanchàtre, atténué en avant, effilé en une longue pointe en arrière. Tégument à stries longitudinales. Bouche entourée d'une large expansion cuticulaire et munie de trois petites saillies ou lèvres (?). Vestibule cylindrique, long, strié en travers. OEsophage avec un bulbe antérieur subglobuleux, suivi d'une partie rétrécie, puis se renflant peu à peu en arrière avant d'aboutir au bulbe postérieur, pyriforme, muni d'une armature dentaire. Intestin dilaté à sa naissance. Anus au tiers postérieur. Vulve vers le milieu de la longueur. Utérus renfermant un petit nombre d'œufs embryonnés et parfois mème des embryons libres.

Ce Ver a été rencontré d'aborıldans le cæcum du Cheval par Probstmayer, qui le considéra comme un Oxyure. Perroncito en vit également des millions dans le gros intestin, surtout dans le cỏlon, du mème animal, et les rapporta aux Rhabdonema (Strongyloides). Fiorentini en a fait une étude sommaire (1). D’après les caractères qu'il en donne, ce Nématode semble se rattacher au genre Plectus Bastian. Reste à savoir s'il s'agit bien d'une forme parasite, ou si ces Vers ne se développent pas dans les matières intestinales après la mort. Perroncito pense que ce sont les larves de cette espèce qui ont été élevées par Ercolani et lui ont fait admettre le développement hétérogonique des Sclérostomes dı Gheval.

Genre Rhabditis (Rhabditis Dujardin, 1840\%. - Syn. : Pelodera et Leptodera Ant. Schneider). - OEsophage à deux bulbes, le postérieur avec ou sans appareil dentaire. Pas d'organes latéraux. Cavité buc-

(1) A. Frorentinı, Sull' Ossiuride vivipara. Bollett. scientifico, XII, nº 1 (con 1 tav.), 1890 . 
cale sans dents ni bâtonnets. Mâle avec ou sans bourse caudale; souvent 6 à 10 papilles sur la bourse ou sur la ligne médiane ; deux courts spicules accompagnés d'une pièce accessoire. Quelques espèces sont hermaphrodites.

Rhabditis terricole (Rh. terricola Duj., 1845. - Syn. : Pelodera teres Schn., 1866). - Corps blanchàtre, fusiforme. Bouclıe à six lèvres. Vestibule ou pharynx cylindrique. OEsophage avec un bulbe antérieur fusiforme et un bulbe postérieur globuleux. Mâle long de $1^{\mathrm{mm}}, 3$ et plus; queue en pointe assez fine, dépassant généralement un peu le bord postérieur arrondi de la bourse, qui se réduit ainsi à deux ailes latérales. 10 papilles de chaque côté : 1 à 9 costiformes; 1 à 7 également espacées et de plus en plus longues, de sorte que 7 atteint le bord de la bourse; une séparation plus grande entre 7 et 8 , entre 9 et 10 ; au contraire 7 et 8 rapprochées; 10 près de la ligne médiane ventrale (1). Spicules séparés. Femelle longue de 2 millimètres au plus, à extrémité postérieure tantòt régulièrement amincie en pointe déliée, tantòt brusquement arrondie et munie d'une queue très courte et très fine; vulve vers le milieu du corps. OEufs ellipsoïdes, longs de $60 \mu$, larges de $40 \mu$, éclosant dans le corps de la mère.

Dans la terre humide et les substances en putréfaction. Contrairement à l'assertion de Dujardin, Pérez a montré qu'elle périt par le fait d'une dessiccation complète.

En 1879, à bord dı Cormwall, vaisseau-école anglais, éclata une maladie épidémique à forme typhoïde, qui sur 280 élèves en atteignit 43. L'un' d'eux succomba après 18 jours de maladie; on exhuma son cadavre deux mois après, et l'on trouva les muscles farcis de petits Vers non enkystés, qu'on prit d'abord pour des Trichines. Bastian et Cobbold reconnurent au contraire qu'il s'agissait de Rhabditis, auxquels Bastian donna le nom de Pelodera setigera et Cobbold celui de Rhabditis Cornwalli. Plus tard, OErley prouva que le Ver en question n'était autre que Rh. terricola.

Bastian estimait que l'infestation s'était produite par l'intermédiaire des aliments ou des boissons; mais on doit plutôt admettre qu'il n'y avait eu là qu'une invasion post-mortem.

Rhabditis à cuticule épaisse $\langle$ Rh. pellio [Schneider]. - Syn. : Pelodera pellio Schn., 1866; Rh. pellio Bütschli, 1873). - Schneider décrit ainsi cette espèce : - Une membrane latérale. Tégument très épais. Bouche à trois lèvres. Vestibule étendu. OEsophage avec un bulbe antérieur allongé et un bulbe postérieur arrondi. Mâle à bourse foliacée, large au milieu, pointue en arrière; 9 papilles, toutes costiformes; 1,2 et 3 se suivant à peu de distance de la pointe caudale et atteignant le bord de la bourse; séparation entre 3 et 4 , entre 4 et 5 , ces deux dernières n'arrivant pas jusqu'au bord; 6 près de $5 ; 6,7,8$ et 9 également espacées et atteignant le bord. Pas de

(1) Cette disposition est donnée d'après Schneider. Pour Pérez, 1 et 2 sont réunies, ainsi que 4 et 5 , cette dernière dépassant le bord de la bourse 
glandes au canal déférent. Femelle lonğue de 3 millimètres; queue en pointe conique.

Daus l'herbe humide et les substances en putréfaction. Larves enkystées dans la cavité du corps des Vers de terre.

D'après OErley, e’est ì cette espèce qu'il convient de rapporter le Nématode trouvé dans l'urine d'une femme, en Hongrie, par Scheiber, et décrit par ce médecin sous le nom de Rhabditis genitulis (1880). Le mále était long de $0^{\mathrm{mm}}, 83$ à $1^{\mathrm{mm}}, 03$, large de 36 à $39 \mu$ en arrière; il arait une bourse caudale foliacée soutenue de chaque cỏté par sept à dix cỏtes, mais certains exemplaires ne montraient plus que les côtes et d'autres mème en étaient dépouprus; les deux spicules, subégaux, mesuraient 27 à 33 p.. La femelle était longue de $0^{\mathrm{mm}}, 9$ a $1^{\mathrm{mm}}, 32$, large de 30 à $60 \mu$; elle avait l'extrénité antérieure atténuée et l'extrẻmité postérieure allongée en alène. La vulve était située en arrière du milieu du corps. Les tubes génitaux renfermaient quelques œufs ellipsoïdes, en voie de segmentation.

La malade qui rendait ces Vers était une Hongroise detrente-cinq ans, atteinte de pleuropneumonie droite compliquée de catarrhe gastrointestinal aigu et de pyélo-néphrite interstitielle. Ses urines étaient troubles, d'un jaune brunâtre foncé, et devenaient alcalines peu après leur émission; elles renfermaient de l'albumine, un peu de sang et beaucoup de pus. Pendant toute la durée de la maladie, on y trouva un grand nombre de Rhabditis, depuis l'état de larves jusqu'à l'état adulte.

Scheiber a reconnu pourtant qu'il ne s'agissait que d'un cas de parasitisme accidentel : les Rhabditis introduits à l'entrée du vagin y avaient pullulé, de sorte qu’ils se trouvaient entraînés par l'urine, en plus ou moins grand nombre à chaque miction. OErley a démontré du reste la possibilité du fait en expérimentant sur des Souris : les Vers se multiplient dans le vagin, mais meurent en quelques minutes dans l'urine.

Rhabditis de Nielly (Rh. Niellyi R. Bl., 1888. - Syn. : Leptodera Niellyi R. Bl., 1883). - Larves longues de $333 \mu$, larges de $13 \mu$. Corps atténué en avant, effilé en arrière. Tégument finement strié en travers. Bouche suivie d'un pharynx assez court, puis d'un œsophage à deux bulbes, le postérieur avec une armature dentaire. Anus à peu de distance de l'extrémité postérieure.

Nielly a trouvé ces larves rhabditiformes chez un candidat mousse de quatorze ans, attein t depuis cinqà six semaines d'une papulose analogue au craw-craw, et siégeant principalement aux membres. Le liquide de chaque papule montrait une ou plusieurs larres. Le patient, né dans un village des environs de Brest, n'était jamais sorti de la contrée; il buvait fréquemment l'eau des ruisseaux.

Nous avons dit que Manson voulait à tort rattacher ce Nématode à sa Filaria perstans (Voy. p. 523). 
Rhabditis douteux. - Siedamgrotzky a publié une observation relative à une éruption cutanée pustuleuse causée chez un Chien par des larves de Nématode. Dans chacune des pustules, qui occupaient la face exlerne des membres, on trouvait un, deux ou trois Vers, longs de $0^{\mathrm{mm}}, 4$ à $0^{\mathrm{mm}}, 7$, larges de 10 ả $25 \mu$, atténués en avant, effilés en arrière ; tégument finement strié; bouche à six lèvres; œsophage cylindrique avec un bulbe postérieur globuleux. Dans la poussière de la niche, on retrouva des embryons semblables, mais plus petits et desséchés, ainsi que quelques femelles adultes, également desséchées, longues de $0^{\mathrm{mm}}, 8$ à $1^{\mathrm{ma}}, 2$, larges de $70 \mu$. Siedamgrotzky rapporte ces Vers aux Anguillules.

Möller a aussi rencontré plusieurs fois des Nématodes sur la peau de Chiens qui étaient presque tous galeux. Leuckart a fait une constatation analogue sur un Renard galeux, et c'est probablement aux mêmes Vers qu il convient de rapporter le cas de Rivolta, dont nous avons parlé à propos de la Filaire de Médine (Voir p. 505). Mais on peut se demander s'il ne s'agit pas là d'un parasitisme secondaire et accidentel.

La mème réflexion s'impose aı sujet des embryons encore mal connus signalés à diverses reprises dans des affections cutanées du Cheval.

Ajoutons enfin que Cobbold a décrit, sous le nom de Pelodera Axei, un Ver trouvé par le professeur Axe dans le sabot des Chevaux affectés de fourmilière (seedly-toe); nous pensons que ce sont des Rhabditis du fumier, n'ayant aucun rapport avec la maladie.

Quant à la pénétration des Rhabditis dans le système musculaire, elle nous parait plus difficile à admettre que leur introduction dans le tégument. Cependant, Zürn (1) a observé plusieurs fois, dans la viande de Porc, de petits Nématodes qu'il rapporte aux Anguillulidés. Peut-être s'agit-il de Vers introduits d'une façon accidentelle dans l'échantillon examiné.

Genre Diplogastre (Diplogaster Max Schultze). - OEsophage à deux bulbes, le postérieur sans appareil dentaire. La cavité buccale ordinairement droite, large et profonde, avec des dents. Tégument strié en long et en travers. Màle avec une petite bourse.

Leisering a trouvé en 1864, dans le sang veineux de deux Chiens, des Nématodes vivipares offrant les caractères suivants : - Corps filiforme, blanchâtre, transparent, atténué en avant; extrémité.caudale se terminant en une pointe fine et allongée. Bouche entourée de très petits nodules. Mále long de $1^{\mathrm{mm}}, 20$ à $1^{\mathrm{mm}}, 50$, Jarge de 70 à $80 \mu$; deux spicules à peu près égaux, en arrière desquels se voit une pièce accessoire recourbée en crochet. Femelle. longue de $1^{\mathrm{mm}}, 50$ à 2 millimètres, large de 83 à $90 \mu$; vulve située en arrière $\mathrm{du}$ milieu du corps.

Chez l'un des animaıx, ces Nématodes étaient au nombre de 30 à $3 \ddot{\text { dans }}$ une sorte de nodule pulmonaire; chez l'autre, ils se trouvaient en grande quantité dans la veine dorsale de la verge. Les femelles adultes contenaient 30 à 40 œufs paraissant éclore dans l'utérus; les embryons, longs de 200 à $250 \mu$. larges de 13 à $14 \mu$, étaient répandus dans le sang.

Gurlt avait donné ả ces Vers le nom d'Hæmatozoon subulatum (1864); Cobbold les regarda ensuite comme des Strongles (Strongylus subulatus, 1879). Mais

(1) Zürr, Nematoden im Schweinefteisch. Deutsche Zeitschr. f. Thiermed., VII, p. 168,1881 . 
Schneider a émis l'avis qu'il s'igissait de pseudo-parasites qui se seraient introduits dans le sang après la mort et se seraient rapidement multipliés daus le cadarre; et Leucliart les considère sans hésitation comme des Diplogaster.

En 18s8, Reuther a observé dans le sang d'un Chien porteur de Filaria immitis, et dont l'autopsie avait été faite le jour mème de la mort, des Vers blancs, longs de $0^{\mathrm{mm}}, \ddot{a}, q u$ qul dit ètre de tous points semblables à H. subulatum riurlt.

Crenre Anguilluline (Anguillulinu Gervais et Benedeı, 1859. - Syn.: Tylenchus Bastian, 1864). - Oisophage à deux bulbes, le postérieur sans appareil dentaire. Cavilé buccale étroile, contenant un aiguillon. Màle avec une bourse dépourvue de papilles. L’térus asymétrique.

Nombreuses espèces parasites des végétaux.

Anguilluline du ble(A. tritici[Baner]. - Syn. : Vibrio tritici Bauer, 1823; Anguillula tritici Davaine, 1856 ; Anguillulina Irilici Gerv. et Ben., 18509; Tylenchus tritici Bastian, 186:; Anguillulu scandens Schn., 1866). - Corps blanchâtre, cylindrique, atténué aux deux extrémités. Tégument finement strié en travers. Bouche pelite, ronde. Vestibule ovoïde, contenant un aiguillon solide. Anus presque terminal. Bulbe antérieur fusiforme, le postérieur globuleux. Mále grèle, long de $2^{\mathrm{mm}}, 3$, large de $0^{\mathrm{mm}}, 1$; queue pourvue l'une large bourse commencant un peu en avant de l'anus et se terminant en pointe sans envelopper la pointe caudale. Spicules séparés, avec une pièce accessoire. Fcmelle plus épaisse, presque toujonrs enroulée en spirale, longue de 3 millimètres à $\dot{q}^{\text {mm }}, 0 \%$, large de $0^{\text {ma }}, 2 \ddot{3}$; vulve un peu en avant de l'anus. Oripare: $œ u f s$ oblongs, à coque membraneuse, longs de $80 \mu$.

L'Anguilluline du blé, qui a été découverte en 1743 par Needham, est le Ver qui détermine la maladie de cette céréale connue sous le nom de nielle. Davaine en a bien étudié le développement (1). Si l'on examine, après la maturité du blé, un épi atteint de nielle, on trouve un certain nombre de grains, et souvent tous les grains, complètement déformés : ils sont petits, arrondis, noirảtres, et leur coque, épaisse et dure, renferme une sorte de poussière hlanclie. Cette substance re contient aucune trace de fécule; elle est constituée par des milliers de petits Vers desséchés, qui ne sont autres que des larves d'Anguillulines. Si on les humecte, en effel, on les

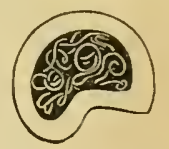

Fig. 352. - Coupe d'un grain niellé $(\mathrm{Da}$ vaine). voit peu à peu reprendre leur aspect normal et leur activité. Elles sont grêles, filiformes, longues de $800 \mu$, larges de 12 à 1 \% $\mu$; leur tégument ne paraît pas strié, mais elles possèdent déjà l'aiguillon buccal.

Quand on sème du blé niellé, les grains altérés se gonflent, se ramollissent el se pourrissent. Sous l'influence de l'humidité, les larves reprennent leur activité et s'en dégagent au bout de quelques semaines; elles rampent dans la terre et gagnent ainsi les tiges issues de grains sains. Elles pénètrent alors entre les gaines des feuilles et vont se cacher à l'aisselle des plus jeunes, c'est-í-dire des plus internes. Si la saison est humide, elles montent

(1) C. Davane, Recherches sur l'Anguillule du blé niellé considérée an point de vue de l'histoire naturelle el de lagriculture. Hémoires de la Soc. de biologie (2), III, p. 201, 1856 . 
à mesure que la lige s'accroît; si elles sont surprises par la sécheresse, elles retombent en état de vie latente jusqu'ì ce qu'une pluie vienne leur permettre de reprendre leur activité. Finalement elles atteignent l'épi alors que celui-ci est encore très jeune, s'introduisent dans les tissus parenchymateux des fleurs naissantes et y deviennent promptement adultes. Après l'accouplement, la femelle pond un grand nombre d'œufs dans lesquels on apercoit bientòt un embryon: celui-ci, une fois éclos, lemeure dans la cavité qui renferme ses parents.

Comme l'a montré Davaine, le grain niellé n'est donc pas un grain de blé envahi par les Vers : c’est une galle déve-

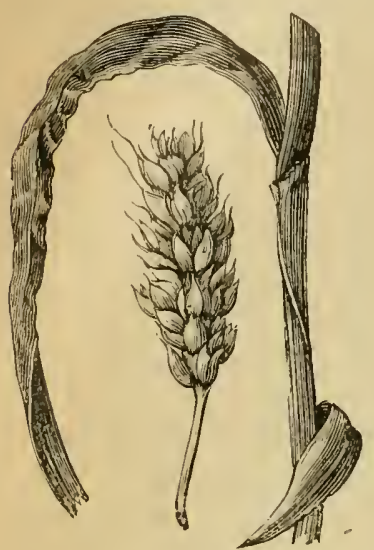

Fig. 383. - Blé niellé (Davaine). loppée aux dépens des diverses parties de la fleur.

Le blé niellé vient mal: la tige s'accroît lentement, les feuilles se dégagent avec difficulté, et leur limbe se crispe; les épis murissent en retard et restent souvent irréguliers. On le qualifie de blé avorté ou rachitique.

Les larves de l'Anguilluline du blé peuvent demeurer en vie latente pendant des années. Baker, ayant examiné en 1771 du blé niellé que Needham lui avait donné en 1744, vit les larves reprendre leurs mouvements après cette longue période de 27 ans. Par contre, Bauer n'a vu la faculté de réviviscence persister que cinq ou six ans et Pennetier quatorze ans. Dans des recherches qui nous sont personnelles, elle avait disparu au bout de neuf ans (1883-1892).

Davaine a reconnu que le meilleur moyen de se débarrasser de ces parasites consiste à laisser tremper la semence pendant vingt-quatre heures dans l'acide sulfurique étendu de 1000 parties d'eau. D'autre part, les larves ne pouvant vivre en terre plus de six mois, l'alternance de culture est à recommander. Enfin il convient de brûler les criblures provenant de récoltes niellées.

On a observé des espèces du même genre sur des plantes assez variées, par exemple: A. putrefaciens, dans les bulbes de l'oignon; A. devastator, dans ceux de la jacinthe, de l'échalote, etc. Plusieurs ont été l'objet d'études très intéressantes de la part de J. Chatin, Prillieux, etc.

Genre Hétėrodère (Heterodera A. Schmidt, 1871). - OEsophage à deux bulbes, l'antérieur cylindrique, le postérieur globuleux, sans appareil dentaire. Cavité buccale ovoïde, contenant un aiguillon. Dimorphisme sexuel très accusé. Mâle cylindrique, sans bourse. Femelle globuleuse; utérus symétrique. Métamorphoses complexes.

Hétérodère de Schacht (H. Schachti A. Sclımidt, 1871). - Mâle long de $0^{\mathrm{mm}}, 8$ en moyenne; corps allongé, cylindrique, transparent; tégument strié en travers. Extrémité céphalique surmontée d'une coiffe séparée du reste du corps et soutenue par six lamelles chitineuses; extrémité caudale légèrement recourbée, en pointe mousse; deux spicules, sans pièce accessoire. 
Femelle courte, globuleuse et opaque, de teinte variant du blanc au brun; longue de $0^{\mathrm{mm}}, 8$ a $\mathrm{I}^{\mathrm{mm}}, 3$, large de $0^{\mathrm{mm}},: ;$ à $0^{\mathrm{mm}}, 9$; striation vague. Ordinajrement pas de coiffe céphalique. Extrémité antérieure cylindrö̈de, souvent déjetée par cóté; extrémité postérieure en pointe mousse. Anus rentral. Vulve 'out à fait ì l'extrémité postérieure, ordinairement garnie d'un produit d'exsudation agunlutinalif. OHufs ellipsoüdes, souvent déprimés sur l'une des faces, longs de $80 \mu$, larges de 40 , a coque épaisse et foncée.

Ce curieux Nématode, découvert en 1859 par un botaniste de Bonn, llermann Schacht, vit principalement sur les radicelles de la betterave; mais on peut le rencontrer aussi sur une foule d'autres plantes : choux, colza, navets, moutardes, radis, cresson alénois, épinards, céréales, ete. On l'a mème vu vive librement dans la terre pendant des mois. D'abord étudié en Allemagne par Schmidt et Külın, il a été découvert en France par Aimé Girard, et a donné lieu dès lors ả d'intéressantes recherches de J. Chatin (1).

Érolution. - La femelle de l'Hetcrodera Schachti est tantòt ovipare, tantòt vivipare. Dans les conditions normales, les aufs ou les embryons sont expulsés par la vulve. Mais il n'est pas rare de voir, surtout à la fin de l'été, les tissus périplériques de la femelle subir des modifications profondes, d'où résulte une transformation du corps tout entier en un kyste brun, destiné évidemment a assurer la protection des oufs pendant la mauvaise saison.

Une fuis celle période passée, en effet, ses parois se gonflent, se ramollissent et laissent échapper les wufs et les larves, qui vont poursuivre leur évolution. Chacun de ces kystes bruns contient, comme une femelle normale, de 300 à 400 œufs.

La larve qui vient de sortir de l'œuf (1 $1^{\text {re }}$ lurve) est blanchâtre, filiforme, longue de $3 \mathrm{o}^{0} \mu$, large de $15 \mu$; elle possède une coiffe céphalique et sa queue est allongée en pointe. Elle vit en liberté dans le sol humide et ne possède même aucune résistance à la dessiccation.

Au bout d'un temps variable, elle s'introduit dans les radicelles de la betterave, gràce à son aiguillon buccal, qui lui permet de perforer la couche superficielle et de pénétrer dans le parenchyme cortical. Elle subit alors une mue qui la fait passer à l'élat de $2^{\mathrm{e}}$ larve. Celle-ci présente un tubercule céphalique qui remplace la coiffe; son extrémité caudale est mousse. Les organes génitaux se différencient progressivement, et on ne tarde pas à distinguer le sexe de chaque individu.

Bientôt la femelle a atteint son complet développement et se trouve apte à la fécondation. Mais son accroissement rapide a distendu à l'excès les tissus de la racine; la tumeur corticale se rompt et lui permet ainsi de se dégager pour vivre en liberté dans la terre ambiante, où le màle ira la retrouver plus tard.

Celui-ci, en effet, doit passer par un $3^{e}$ stade avant d'arriver à l'état adulte: e'est le stade d'encapsulement. Le tégument de la 2e larve se modifie et s'écarte du corps, de sorte que le Ver se trouve enfermé dans une sorte de capsule ou cocon. Peu après il brise cette enveloppe, perfore l'écorce de la racine et passe à son tour dans la terre, où a lieu laccouplement.

(1)J. Chatın, L'Anguillule de la belterave (Heterodera Schachtij). Bulletin du Ministère de l'Agriculture, X, p. 457, 1891 (avec 9 pl.). 
DÉGATs. - La maladie des betteraves déterminée par les Hétérodères n'a pas encore produit de grands ravages en France ; elle est cependant à redouter, car elle entraîne une diminution considérable dans la teneur en sucre.

Les premiers symptòmes se montrent d'ordinaire en juillet ou en août. Souvent ils consistent en une altération progressive des feuilles : celles-ci passent au vert jaunâtre, perdent leur brillant et semblent se flétrir; elles meurent enfin, à commencer par celles de la périphérie, les autres résistant plus longtemps. Si l'on examine alors les racines, on constate qu'elles sont arrètées dans leur développement el atleignent á peine le quart des dimensions normales : sur des coupes, on remarque des foyers de ramollissement et de décomposition, qui s'étendent très rapidement. Parfois cependant les betteraves semblent se rétablir à l'automne, en donnant de nouvelles feuilles. L'ensilage n'arrête pas la marche du mal.

L'examen des radicelles à l'œil nu ou à la loupe, au besoin celui des eaux de lavage, suffisent d'ordinaire à faire découvrir le parasite : les femelles fécondées apparaissent sous l'aspect de grains blanchàtres.

Destruction. - La méthode qui a fourni jusqu'à présent les résultats les plus sérieux dans les essais de destruction des Hétérodères est celle des plantes-pièges, préconisée par Kühn. Elle est basée sur la voracilé avec laquelle ces Nématodes se jettent, en l'absence des betteraves, sur la plupart des végétaux. On fait surtout usage des choux et de la navette, qu'on sème d'avril à août dans l'année qui précède la culture des betleraves. On en fait trois récoltes au moins; la première (choux) doit être arrachée cinq semaines après la levée; pour les deux autres (navette), l'arrachage est pratiqué après trois ou quatre semaines seulement, de manière à ne pas donner aux larves le temps d'achever leurs métamorphoses. Il importe d'arracher toutes les plantes, y compris celles développées spontanément, en évitant de secouer les racines; on les rassemble sur un point et on les détruit par l'incinération ou par la chaux vive. La culture des plantes-pièges doit toujours être étendue à une assez grande distance autour des points qui ont paru localement attaqués. Cette méthode a donné à Halle d'excellents résultats : une parcelle infestée, rapportant 13,700 kilogrammes par hectare en 1879, donnait 37,000 kilogrammes en 1881 .

Aimé Girard a proposé, d’autre part, de détruire les Nématodes de la betterave par les injections de sulfure de carbone, suivant les procédés mis en usage contre le Phylloxéra.

Famille des ANGIOSTOMIDÉs. - La famille des Angiostomidés ou Rhabdonémidés, établie par OErley, se compose de Nématodes hétérogoniques, c'est-à-dire offrant deux ordres de générations sexuées qui se succèdent indéfiniment: $1^{\circ}$ une forme dioïque et libre, revêtant tous les caractères des Rhabditis ; $2^{\circ}$ une forme hermaphrodite (ou parthénogénésique) et parasite.

On admet actuellement dans cette famille les trois genres Angiostoma Duj., 184วั, Strongyloides Grassi, 1879, et Allantonema Leuck., 1884.

Genre Strongyloïde (Strongyloides Grassi, 1879. - Syn. Pseudorhabditis Perroncito, 1881 ; Rhabdonema Leuck., 1882, pro parte). - 
Forme parasite a boucle simple, sans armature chitineuse; à osophage subcylindrique, tres long. Forme libre à bouche suivie d'un vestibule et d'un asophage à deux bulbes, l'antéricurfusiforme, le postérieur globuleux, avec une armature dentaire; mâle à deux spicules courts el égaux.

Strongyloüde intestinal (Str. intestinalis [Baray]. - Syn : Anguillula stercoralis et A. intestinatis Bavay, 1877; Lepto-
dera stercoralis et L. intestinalis Coblold, 1879;
Pseudo-rhabditis stercoralis Perroncito, 1881;
Rhabdonema strongloides Leuck., 1883; Str.

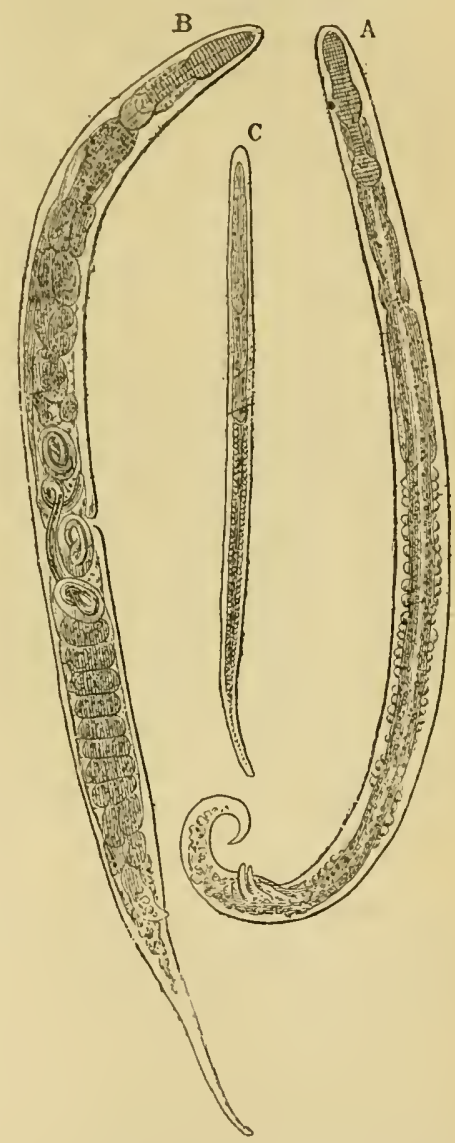

Fig. 384. - Anguillnle intestinale, femelle adulte, d'après Grassi et Parona.

Fig. 385. - Anguillule stercorale, daprès Perroncito. A, mâle. B, femelle. C, larve strongyloüde devant se transformer en Anguillule intestinale.

intestinalis Grassi, 1883; Rhabdonema intestinale R. Bl., 1885). - 10 Forme parasite ou intestinale : femelle longue de $2^{\mathrm{mm}}, 2$, large de $3 \dot{4} \mu$. Corps un peu atténué en avant, terminé en arrière par une queue conique, dont 
l'extrémité est arrondie et même un peu dilatée. Tégument finement strié en travers. Bouche à trois petites lèvres, donnant accès dans un œsophage à peu près cylindrique qui occupe environ le quart de la longueur du corps et se continue sans transition avec l'intestin, dont la teinte est différente. Anus en fente transversale, situé vers la base de la queue. Vulve au tiers postérieur du corps : dans son voisinage, l'utérus contient cinq à neuf œufs a'un jaune verdàtre, ellipsoïdes, longs de 50 à $58 \mu$, larges de 30 à $34 \mu$.

$2^{\circ}$ Forme libre ou stercorale : individus mâles et femelles. Corps cylindrique, lisse, atténué aux extrémités, surtout en arrière. Bouche à trois lèvres peu distinctes, suivie d'un vestibule court et assez large. OEsophage faisant saillie en còne surbaissé dans le vestibule et offrant deux renflements ou bulbes séparés par une partie rétrécie: l'antérieur allongé, le postérieur pyriforme, avec une armature chitineuse en forme d'Y. Intestiu un peu dilaté à sá naissance. Anus à la base de la queue, sur un mamelon, reporté à droite par le développement de l'utérus. Mále long de $0^{\mathrm{mm}}, \tilde{\imath}$, épais de $35 \mu ;$ queue recourbée en crochet; deux spicules incurvés, canaliculés, longs de 38 «; quelques papilles préanales. Femelle longue de 1 millimètre, large de $50 \mu$; queue étirée en une pointe grêle légèrement ondulée; vulve un peu en arrière du milieu du corps et à droite. OEufs ellipsoïdes, de teinte jaunàtre, à coque délicate, longs de $70 \mu$, larges de $45 \mu$, éclosant quelquefois dans les utérus.

Au mois de juin 1876, le docteur Normand, médecin de la marine française, examinant les selles des soldats renvoyés de Cochinchine à Toulon pour cause de dysenterie grave, y découvrit le petit Nématode auquel Bavay donna le nom d'Anguillula stercoralis. Un peu plus tard, à l'autopsie d'un homme mort de cette même " diarrhée de Cochinchine ", Normand trouva dans l'intestin, à côté des Anguillules stercorales, un Ver différent qui fut également étudié par Bavay et décrit sous le nom d'Anguillula intestinalis.

Ces deux formes furent regardées comme espèces distinctes jusqu'en 1882, époque à laquelle Leuckart établit qu'elles représentaient' en réalité deux générations successives, appartenant au cycle d'évolution d'une seule et même espèce. Grassi, Golgi et Monti, etc., ne tardèrent pas à appuyer de nombreux faits cette manière de voir.

Comme il a été indiqué plus haut, l'Anguillule intestinale, parfois dénommée forme strongyloïde à cause de sa ressemblance avec certains Strougles, est la génération véritablement parasite. L'intestin de l'Homme vivant ne paraît héberger que cette forme avec les embryons qui en sont issus. Tous les individus, qu'on rencontre d'ordinaire eu nombre immense dans l'intestin, ont un habitus femelle: Leuckart, se basant sur les faits observés chez l'Angiostoma nigrovenosum de la Grenouille, était d'avis qu'il s'agissait d'hermaphrodites, à dichogamie protandrique; mais Rovelli semble bien avoir établi, au contraire, que ces Vers sont des femelles parthénogénésiques.

Au moment de la ponte, les cufs sont en voie de segmentation; quelques heures après, les embryons sont déjà développés : ils ne tardent pas à éclore, mesurant à la naissance 200 à $240 \mu$ de Jong sur $12 \mu$ de large. Puis ils sont rejetés au dehors avec les excréments, parfois en telle abon- 
lance qu'on a pu évaluer à plus d'un million leur nombre dans chaque selle. A ce moment, ils ont déjà grandi, mesurant 450 à $600 \mu$ de loug sur 16 a $20 \mu$ de large, et on peut leur reconnaitre le caractère de larves rhabditiformes.

Quel est le sort de ces larves? 1)iverses expériences de Leuckart, (irassi, etc., l'ont đléterminé d'une façon assez nette. Si l'on abandonne les matières diarrhéiques ì l'air libre et à une température assez basse, les larves muent et suspendent leur évolution, enveloppées dans leur vieux tégument comme dans un liyste, jusqu'ì ce que survieunent des conditions plus favorables. Mais si l'on soumet ces matières à une température constante de 12 à $23^{\circ}$, on voit un certain nombre d'individus évoluer jusqu'à l'état sexué. Enfin, la plupart des larves se comportent généralement de la sorte quand on fait intervenir une température de 32 a $33^{\circ}$.

A $32^{\circ}$, par exemple, on voit an bout de quinze à dix-huit heures les larves subir une mue, a la suite de laquelle apparaissent les caractères sexuels. Màles et femelles n'ont plus qu'à s'accroître; vers la trentième heure leurs organes reproducteurs sont complètement développés, et ils s'accouplent. Ainsi s'est développée la grénération rhabditoide (Anguillule stercorale).

Vingt à vingt-quatre heures plus tard, la ponte a lieu. Chaque femelle émet trente à quarante œufs segmentés, à évolution rapide, et parfois mème donne naissance directement à des embryons, qui ont en moyenne une longueur de $220 \mu$ et sont un peu plus grêles que ceux dérivés de l'Anguillule intestinale. Quand ils ont subi un certain accroissement, leurs organes internes se dessinent, et la présence d'un œsophage à deux bulbes leur donne, comme aux précédents, le caractère de larves rhabditiformes.

Toutefois, elles ne tardent pas à perdre ce caractère : parvenues à une longueur moyenne de 350 u, elles muent et prennent alors un aspect strongyloïde. La queue s'est raccourcie et montre à l'extrémité deux petites saillies latérales; la bouche offre quatre prolongements labiaux; l'œsophage est presque cylindrique et ne montre plus d'armature dentaire. - Pour parvenir à cet état, il leur faut en général trente à trente-six heures.

Au bout d'une huitaine de jours, toutes les Anguillules stercorales adultes ont péri, et toutes leurs larves sont devenues strongylö̈des. Mais celles-ci ne sont pas aptes à vivre longtemps en liberté : une semaine plus tard, elles commencent à mourir d'inanition si elles n'ont pas réintégré l'organisme de l'Homme.

En résumé, l'Anguillule intestinale ou forme strongyloïde, qui vit dans l'intestin, émet des cufs d'où sortent des larves rhabditiformes. Celles-ci sont rejetées avec les fèces, et se développent dans ces matières, où elles parviennent à l'état sexué, représenté par l'Anguillule stercorale ou rhabditö̈de. Après accouplement, les femelles de cette forme donnent, directement ou indirectement, des larves d'abord rhabditiformes, mais devenant bientôt strongyloïdes, et destinées dès lors à rentrer dans le tube digestif pour passer à l'état d'Anguillule intestinale.

Ce cycle d'évolution hétérogonique ne peut cependant être considéré comme une condition indispensable à la propagation du parasile. Dès 1878, en effet, Grassi avait annoncé que les larves strongyloïdes 
peuvent provenir directement des larves rhabditiformes produites par l'Anguillule intestinale. Ce fait a été vérifié plus tard par Golgi et Monti, puis olservé de nouveau par Grassi et Segrè. Le déreloppement se trouve ainsi abrégé ; la phase intermédiaire de génération libre ou sexuée est supprimée, et l'on se retrouve en présence d'une évolution directe. Les conditions dans lesquelles se produit cette déviation ducycle primitif ne sont pas encore nettement déterminées; toutefois, on a constaté que, dans les cultures entretenues à des températures fixes, entre 12 et $33^{\circ}$, les Anguillules stercorales abondent si la température est élevée, tandis que les larves rhabditiformes de l'Anguillule intestinale se transforment surtout en larves strongyloïdes si la température est basse (1). Mais ces résultats ne sont pas constants.

En tout cas, Grassi et Segrè admettent que la transmission du parasite à l'Hoinme s'effectue le plus souvent par ces larves strongyloïdes développées directement.

Et maintenant, comment expliquer les observations de Normand, Bavay et autres, qui ont trouvé l'Anguillule stercorale en divers points du tube digestif de l'Homme? Il est assez vraisemblable que les nombreux exemplaires de cette forme, rencontrés au moment de l'autopsie, résultaient du développement des larves rhabditiformes de l'Anguillule intestinale, accompli dans l'intestin après la mort du patient. Mais ce n'est là en somme qu'une hypothèse, et à la vérité on n'est pas encore autorisé à affirmer que l'Anguillule stercorale est incapable de vivre à l'état de parasite ou de commensal dans l'intestin de l'Homme.

Distribution géographique. - Le Strongyloides intestinalis est extrêmement répandu, non seulement en Cochinchine, mais dans toute la zone torride asiatique et jusque dans l'Archipel indien. Il existe également à la Martinique (Chauvin) et au Brésil. Enfin, il n'est pas rare en Italie : Grassi et les frères Parona l'ont observé à Pavie en 1878-79, chez des individus affectés de cachexie palustre, et Perroncito l'a retrouvé en 1880 , en même temps que l'Ankylostome, chez les ouvriers occupés au percement du Saint-Gothard et affectés d'anémie pernicieuse.

Patnologie. - La découverte du parasite chez des sujets atteints de la diarrhée de Cochinchine fit tout d'abord admettre qu'il devait jouer un rôle essentiel dans le développement de cette maladie. Puis, comme il arrive généralement, on en vint à lui dénier toute influence nocive lorsque des recherches plus nombreuses eurent démontré qu'il faisait très souvent défaut chez des individus atteints à un haut degré de cette diarrhée spéciale.

La vérité est probablement entre ces deux opinions extrêmes. Sans

(1) Lorsque la culture renferme beaucoup de larves strongylö̈des et peu d'Anguillules stercorales, celles-ci sont toujours des mâles; au contraire, quand ce sont les Anguillules stercorales qui prédominent, elles présentent à peine un mâle pour sept ou huit femelles. 
doute, la plupart des Européens établis en Cochinchine sont porteurs d'Anguillules, sans être pour cela atteints de diarrhée; sans doute aussi le mal se développe indépendamment de l'Anguillule. Mais il semble bien pourtant que toute altération de l'intestin farorise la pullulation du parasite, et qu'en outre celui-ci contribue à aggraver l'affection, en entretenant un élat catarrhal de la muqueuse intestinale. Il est à remarquer que les indigènes jouissent, à l'égardd des Anguillules et de la diarrhée endémique, d'une assez sérieuse immunité, qu'on doit attribuer en partie peut-être à la résistance de la race, mais en partic aussi, aux mesures hygiéniques auxquelles s'astreignent les individus.

Des faits qu'il a observés en Italie, Sonsino tire la conclusion que l'Anguillule, lorsqu'elle se multiplie à l'excès chez l'Homme, peut entraîner une entérite intense, suivie d'une anémie capable de mettre la vie en danger.

Normand et Perroneito ont essayé sur le parasite l'action de diverses substances. Il est tué rapidement par l'extrait éthéré de fougère mâle, mais non par les préparations de kousso et de kamala.

Comme moyen prophylactique, il est recommandé de traiter les selles par l'acide phénique ou par la chaleur.

Strongyloïle long (Str. longus [Grassi et Segrè]. - Syn. : Rhabdonema Inngum Grassi et Segrè, 1887 ; str. longus Rovelli, 1888). - Forme parasite à lıabitus femelle, mais de taille supérieure à celle de l'Anguillule intestinale de l'Homme. Longueur variable, atteignant jusqu'à 6 millimètres. Corps filiforme; extrémité antérieure un peu atténuée; extrémité postérieure allant d'abord en s'amincissant, puis brusquement rétrécie en une courte queue obtuse. Tégument strié en travers. Bouche à trois lèvres (?). OEsophage triquètre, srraduellement renflé en arrièrẻ, occupant près du cinquième de la longueur totale. Anus à une très faible distance de l'extrémité de la queue. Vulve au tiers postérieur du corps, entourée de papilles. Dans les utérus, dix à douze œufs au plus, ellipsoïdes, à coque mince, longs de 40 u, larges de $20 \mu$, rarement en voie de segmentation.

Cette espèce, d'abord observée par Grassi et Perroncito dans l'intestin grèle du Lapin (moitié postérieure du duodénum, jéjunum et quelquefois origine de l'iléon), a été retrouvée ensuite par divers observateurs chez le Mouton, le Pore, la Belette, le Putois, le Surmulot.

Grassi et Segrè ont constaté que l'Anguillule du Mlouton peut présenter, comme celle de l'Homme, une génération libre ou rhabditoïde, quand on soumet ses larves à une température supérieure à $23^{\circ}$. Mais ici presque tous les Vers arrivés à maturité sexuelle sont des femelles, qui par suite montrent rarement des œufs en roie de segmentation; on n'a même pas encore ru de larves issues de cette génération libre. Le développement direct est donc la règle, et le passage par la forme rhabditoïde sexuée reste douteux ou tout au 
moins constitue une rare exception. En outre, les adultes rhabditoïdes sont plus petits que les Anguillules stercorales de l'Homme.

Lutz considère le Strongyloïde du Porc comme une espèce distincte (Str. suis) de celui de l'Homme et de celui du Mouton. Il se base sur la différence de taille $\left(3^{\mathrm{mm}}, 7 \ddot{\text { de }}\right.$ long sur $0^{\mathrm{mm}}, 08$ de large), et sur cette remarque que les cufs de la forme parasite ne pourraient éclore qu'en dehors de l'hôte.

\section{DEUXIEIE ORDRE}

\section{GORDIACÉS}

\section{Némathelminthes filiformes, pourvus d'un tube digestif en parlie atrophié à l'état adulte.}

Les Gordiacés ou Dragonneaux, souvent classés parmi les Nématodes, sont des Vers très allongés, filiformes, sans champs latéraux, ordinairement bruns ou noiràtres. Ils ont la bouche oblitérée a l'état adulte, ainsi que la partie antérieure du tube digestif. Les mâles ont l'extrémitẻ caudale bifurquée, sans spicules; ils sont pourvus de deux testicules. Les femelles ont deux ovaires et l'extrémité caudale obtuse. Dans les deux sexes, l'ouverture des organes génitaux est cloacale et postérieure.

Parasites à l'état larvaire, ces Némathelminthes vivent en liberté à l'àgre adulte: on les trouve alors dans les ruisseaux, les fontaines et surtout les flaques d'eau. Ils se reproduisent en été, et se réunissent alors par groupes de dix ì vingt individus, mâles et femelles, enchevêtrés en un lacis inextricable, sorte de nœud gordien d'où Linné a tiré le nom du genre unique de cet ordre.

Des œufs fécondés, qui sont pondus en cordon, sortent des embryons pourvus d'une trompe exsertile armée de crochets. A la faveur de cette armature, ils pénètrent dans les larves aquatiques de divers Insectes (Chironomes, etc.), parfois dans des Mollusques, où ils s'enkystent. - D'après les recherches expérimentales de Villot, ces larves enliystées passent, avec les larves d'Insectes qui les hébergent, dans l'intestin des Poissons, où elles s'enkystent de nouveau dans la muqueuse. Au bout d'un certain temps, elles se dégagent et pénètrent dans les tissus de leur hòte, aux dépens desquels elles se nourrissent. Cinq à six mois plus tard, c'est-à-dire au printemps, elles tombent dans l'intestin du Poisson et vont achever leur évolution dans l'eau : les organes sexuels se développent, tandis que le tube digestif subit une atrophie partielle. - Mais les Gordiacès virent le plus souvent dans des eaux qui ne renferment aucun Poisson : cette érolution n'est donc pas constante. Il semble établi, en effet, que les embryons enkystés chez les larves d'Insectes peuvent être ingérés avec celles-ci par les Insectes carnassiers : ills se développent alors dans la cavité viscérale de ces nouveaux hòtes, puis émigrent pour aller vivre dans l'eau.

Le genre Gordius L., seul représentant de ce groupe, comprend des espèces de dimensions variables, qui peuvent passer accidentellement, arec les eaux de boisson, dans le tube digestif de l'Homme ou des animaux.

Le Gordius aquaticus Duj., 1842, très répandu dans les régions montagne uses de l'Europe, est long de 17 à 27 centimètres (màle), de 30 à 90 cen- 
timètres (femelle). C'est probablement de cette espèce que parle Aldrovande, sous le nom de Scta ou Vitulus aquaticus, comme pouvant se rencontrer chez l'Homme. On peut y rapporter aussi le cas de Ilessling, qui vit une jeune fille, souffrante depuis de longs mois, rendre un Gordius après l'administration d'un vomitif (18.3. $\mathbf{k}$ ), et celui de von Patruban, relatif i un enfant de luit ans qui rendit par l'anus un Gordius long d'une demi-aune (1875).

Le Gordius tolosanus Duj., 1842, recueilli d'abord par Bomne dans les réservoirs des jardins de l'École vétérinaire de Toulouse, habite une grande partie de la France et de l'Allemagne. II est long de 11 à 13 centimètres. -1 la suite de I'administration d'un vomitif, un enfant de huit ans expulsa un Ver long de 14 à 16 centimètres que Degland (1823) rapporta au G. aquaticus et que Il. Cloquet décrivit sous le nom d'Ophiostoma Pontieri. D’après les

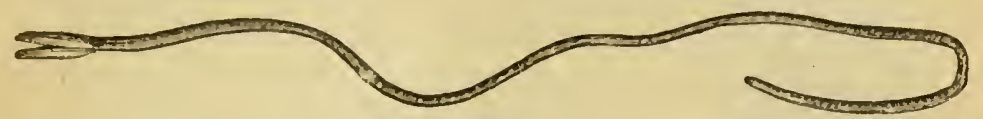

Fig. 386. - Ver décrit par Cloquet sous le nom d'Ophiostoma Pontieri.

caractères des téguments, Villot croit qu'il s'agissait d'un G. tolosamus. Plus récemment (1881), Fiori, après administration d'acide thymique à un ouvrier atteint d'uncinariose, obtint l'évacuation par l'anus d'un Ver brun long de 18 centimètres, que liosa reconnut pour un mâle de G. tolosanus.

Le G. varius Leidy, $185 \mathrm{l}$, est commun daus les fleuves de l'Amérique du Nord. Diesing rapporte, d'après liirkland, qu'une jeune fille de l'Ohio en aurait évacué un individu.

Enfin, le G. chilensis Blanch., 1849, observé au Chili par Cl. Gay, passe, d'après cet auteur, pour se rencontrer dans le corps des indigènes, et occasionner des troubles graves.

En somme, il s'agit simplement de pseudo-parasites.

TROISILME ORDRE

\section{ACANTIOCEPIIALES}

Némathelminthes sans tube digestif, pourvus l'une trompe protractile munie de crochets.

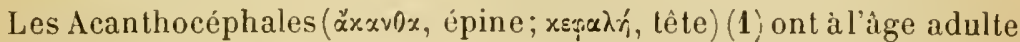
un corps allongé, cylindroïde, souvent irrégulier, ridé en travers, parfois déprimé et annelé, dont l'extrémité antérieure porte une trompe garnie de crochets recourbés. Cette trompe sert à fixer le parasite à son hôte; elle est souvent rétractile à l'intérieur d'une gaine spéciale (réceptacle de la trompe), qui se rattache aux parois du corps par l'intermédiaire de muscles insérés à sa partie postérieure ; du fond de cette gaine naît en outre un ligament suspenseur qui se dirige en arrière pour aller supporter l'appareil génital.

(1) K. M. Diesixg, Revision der Rhyngodeen. Sitzungsberichte der kais. Akad. der Wiss., XLVII, p. 719. Wien, 1859. 
Le corps est protégé par une cuticule percée de pores, reposant sur une zone granuleuse épaisse et souvent jaunâtre. Au-dessous de celleei, se trouve une puissante enveloppe musculo-cutanée, limitant la

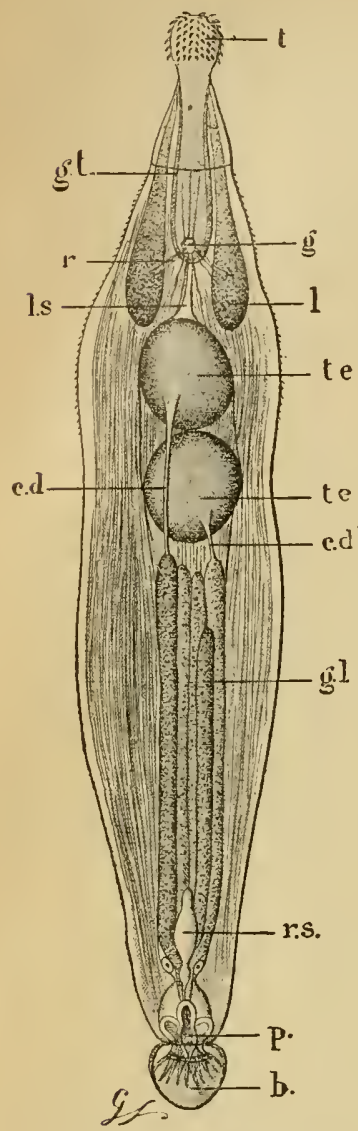

Fig. 387. - Echinorhynchus polymorphus, mâle, grossi 20 fois. -$t$, trompe. $g$, ganglion nerveux. 1 , lemnisques. $r$, rétinacles. $l s$, ligament suspenseur. $t e, t e$, testicules, $c d, c d$, canaux déférents. $g l$, glandes prostatiques. $r s$, réservoir séminal. $p$, pénis. $b$, bourse caudale. cavité viscérale.

Le système nerveux est représenté par un ganglion qui occupe en général le fond de la gaine et émet des nerfs antérieurs destinés à la trompe, ainsi que deux troncs latéraux se rendant aux parois du corps. Il n'existe pas d'organes des sens.

Le tube digestif fait aussi défaut: l'absorption des liquides nutritifs s'effectue par endosmose, à travers les téguments.

Entre la couche sous-cuticulaire et l'enveloppe musculo-cutanée, on voit régner un système de vaisseaux anastomosés, se réunissant en deux troncs longitudinaux principaux. Ces vaisseaux, non ciliés, dépourvus de parois propres, contiennent un liquide transparent, chargé de fines granulations; on les regarde habituellement comme un appareil spécial de nutrition. - D'autre part, on voit flotter, dans la partie antérieure de la cavité viscérale, deux corps particuliers, pyriformes, opaques, auxquels on donne, depuis Rudolphi, le nom de lemnisques ; ces corps se montrent eux-mêmes parcourus par des vaisseaux en communication avec ceux de la région céphalique et débouchant à la base de cette région dans un canal annulaire. On a supposé qu'ils fonctionnent comme appareil d'excrétion; mais cette opinion est abandonnée par Kaiser et Hamann; ce dernier les regarde comme des réservoirs de fluide lacunaire, aidant à l'évagination de la trompe.

La cavité viscérale renferme un liquide clair, au sein duquel flottent les organes sexuels. Tous les Acanthocéphales sont dioïques. Les mâles possèdent en général deux testicules ovoïdes, sacciformes, dont les conduits excréteurs se réunissent en un canal déférent commun, souvent muni de vésicules glanduleuses accessoires; ce canal aboutit à la partie postérieure du corps, au niveau d'un pénis conique occupant en général le fond d'une poche campanuliforme susceptible 
de se renverser à l'extérieur (appareil copulateur). - Quant aux organes femelles, ils se composent essentiellement d'un ovaire contenu dans le ligament, et donnant naissance à plusieurs masses ovulaires. L'accroissement progressif de celles-ci amène la déchirure du ligament, et les aufs, lombant dans la cavité viscérale, ne tardent pas a la remplir. lls sont alors recueillis par un utérus en forme de cloche, dont la large ouverture effectue des mouvements alternatifs de contraction et de dilatation; puis ils passent dans un court vagin qui aboutit à l'extrémité postérieure.

Les œufs sont d'ordinaire ellipsoïdes; ils sont pourrus de meınbranes protectrices épaisses, le plus sourent au nombre de trois, la moyenne étant la plus puissante. Les embryons s'y développent de bonne lieure par segmentation totale et inégale, et prennent l'aspect de petits corps fusiformes, munis antérieurement de crochets caducs. Pour arriver à l'étal adulte, ils doivent subir une métamorphose asse\%. complexe, accompagnée de migrations.

A l'état de lar'res, les Acanthocéphales habitent la cavité viscérale ou les muscles de diver's Crustacés, Insectes, Poissons, etc. Ils acquièrent leur maturité sexuelle dans le tube digestif des Vertébrés: Poissons, Mammifères, qui se nourrissent de leur premier liôte.

On n'est pas encore arrivé à déterminer d'une manière bien satisfaisante les rapports des Acanthocéphales arec les autres groupes de Vers; néanmoins, il ressort de ce qui précède qu'ils offrent d'asse\% grandes affinités arec les Nématodes et les Trématodes.

3 familles (1): Neorhynchidie, Gigantorhynchidre et Echinorhynchidx.

Les GIGANTORYNGHIDÉS sont représentés par de grandes formes à corps annelé, plus ou moins déprimé, ténioïde. Les crochets de la trompe possèdent sur toute leur étendue un revêtement chitineux transparent et offrent deux prolongements radicaux. La partie qui correspond à la gaine rostrale est entièrement comblée, et c'est l'extrémité antérieure du corps, devenue rétractile, qui sert de réceptacle à la trompe. Le système nerveux central est asymétrique : il est situé en dessous du milieu de la gaine, mais en dehors de la ligne médiane. Les lemnisques sont allongés, en forme d'utricules arrondis, à canal central.

Le genre Gigantorynque (Gigantorhynchus Hamann, 1892) est jusqu'à présent le seul que comprenne cette famille.

Gigantorynque géant (G. gigas [froze]. - Syn. : Ascaris tumbricoides Frisch, 1727, pro parte; Tænia himudinacea Pallas, 1781; E. gigas Gœze, 1782. - Priorité (2) : G. hirudinaceus). - Corps d'un blanc laiteux, parfois

(1) O. Haxaxx, Das System der Acanthocephalen. Zoologischer Anzeiger, XV, p. 195,1892 .

(2) Goze dil que Müller, dans sa Thiergeschichte, nomme ce Ver Echinorynchus 
nuancé de bleu on de brun, cylindroïde, souvent renflé en divers points de sa longueur, montrant après la mort des rides transversales irrégulières, mais réellement annelé pendant la vie, d'après Hamann. Trompe presque globuleuse, garnie de cinq ou six rangées de crochets recourbés en arrière et plus ou moins nettement disposés en quinconce; rétractile dans un cou un peu plus large qu'elle, mais beaucoup plus grêle que la partie antérieure du corps. Mále longr de 6 à 10 centimètres, large de 3 à 5 millimètres, à bourse caudale campanuliforme. Femelle longue de 20 à 35 centimètres, large de 4 à 9 millimètres ; partie postérieure obtuse. OEufs oblongs, presque cylindriques, longs de 87 à $100 \mu$, lisses, pourvus de trois enveloppes, la moyenne plus épaisse. Embryons en forme de cỏne tronqué et plus long que l'œuf, de sorte que l'extrémité effilée est repliée dans la coque; la partie antérieure

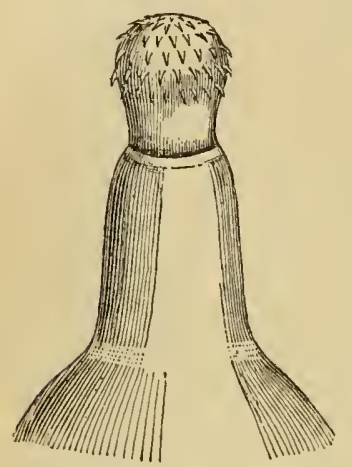

Fig. 388. - Extrémitè cêphalique du Gigantorynque óéant, grossie 10 fois, pour monIrer la trompe (Orig.).

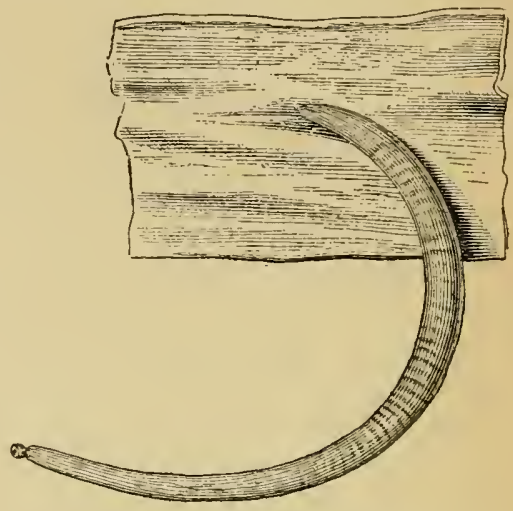

Fig. 389. - Gigantorynque géant, mile, fixé à l'inteslin du Porc. Grandeur vaturelle (Orig.).

porte quatre crochets analogues à ceux des Ténias adultes et un certain nombre d'autres plus petits ou mème en forme de simples épines.

Ce Ver habite, à l'état adulte, l'intestin du Porc, du Sanglier, du Pécari à collier, etc. S'il fallait en croire Lindemann, il serait même commun chez l'Homme sur les rives du Volga. On le trouve presque toujours dans l'intestin grêle, notamment dans le duodénum; il est rare de le rencontrer dans le gros intestin. Il est ordinairement fixé à la muqueuse par sa trompe, la partie antérieure dirigée en avant.

Son évolution a été déterminée par divers expérimentateurs. Lespès (1864) avait déjà vu les œufs éclore dans l'intestin de plusieurs Mollusques Gastéropades, et avait même retrouvé une larye dans le foie d'une Hélice. On pouvait donc prévoir l'intervention d'un hôte' intermédiaire.

Lumbricoides; nous n'avons pu vérifier cette indication, mais si elle est exacte, l'espèce derra porter le nom de $G$. lumbricoides. 
En 1868, Anton Sehneider montra que le Ver blanc, e'est-à-dire la larve du llanneton (.Melolontha vulgaris) était apte à remplir ee rôle. D'après lui, les œufs de l'Échinorynque, rejetés arec les excréments du Pore, sont répandus sur le sol ou enfouis avec les fumiers. Ils peuvent ètre alors ingérés par les Vers blanes, dans l'intestin desquels ils éclosent: les embryons, au moveen de leurs crochets provisoires, pereent aussitot les tuniques intestinales et vont s'enkyster dans la cavité du corps. Ils demeurent dans eette situation durant toute la période larvaire et même après la transformation en Insecte parfait. Si les Vers blanes et les Hannetons infestés viennent à ètre mangés par un Porc, le jeune Échinorynque se trouve mis en liberté dans l'intestin de celui-ci, s'attaehe a la muqueuse et acquiert peu ¿i peu son développement complet. - On a objecté à ces données expérimentales que la larve du Hanneton est essentiellement phytophage, ne se nourrit que de racines et ne vit pas dans les fumiers, de sorte qu'elle ne pourrait ètre considérée comme un hôte normal. Mais il suffit, pour faire tomber cette objection, de faire remarquer que les excréments des Porcs sont répandus dans le sol arec les fumiers, et que les Vers blancs abondent surtout dans les terrains richement pourvus d'engrais animaux.

Au surplus, haiser a démontré que la larve de la Cétoine dorée (Cetonia aurata) peut

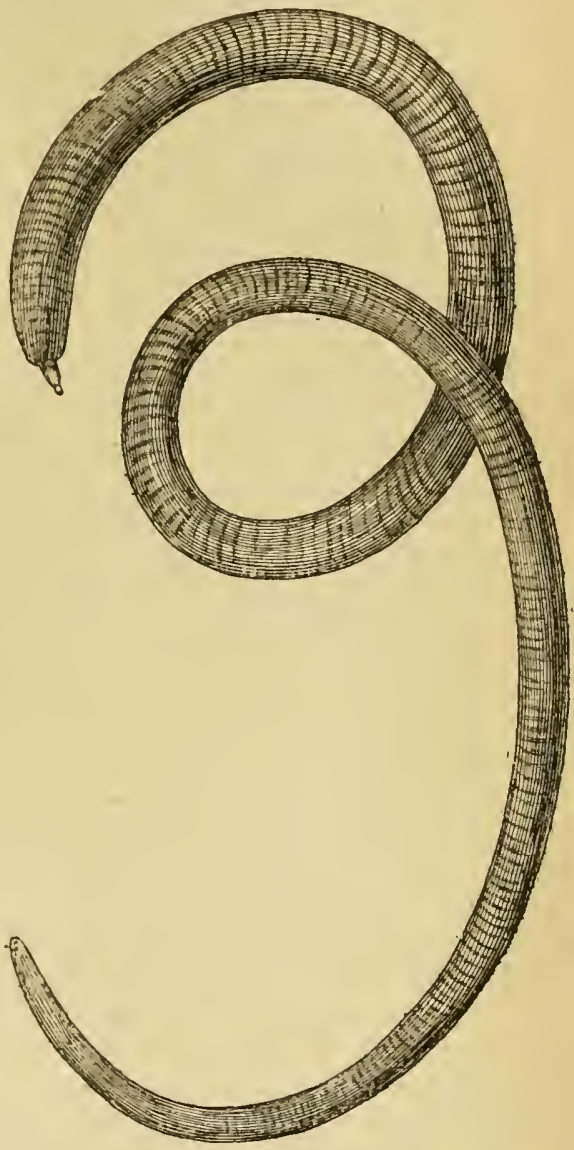

Fig. 390. - Gigantorynque géant, femelle. Grandeur nalurelle (Orig.). également servir d'hôte intermédiaire, et cette larve est le plus souvent humicole.

Mais ni le Hanneton ni la Cétoine n'existent aux États-Unis, où l'Échinorynque est cependant commun, et Verrill supposait que les Lachnosterna, qui ont les mêmes maurs que nos Hannetons, devaient ètre la source dinfestation des Porcs américains. Stiles (1891) a pu 
faire développer en effet les embryons de l'Échinorynque dans les larves de Lachnosterna arcuata (1).

Le Gigantorynque géant est assez commun en France. D'après J. Cloquet, les Pores limousins sacrifiés aux abattoirs de Paris en sont plus souvent porteurs que ceux d'autre provenance: cet auteur l'a trouvé en abondance surtout à la fin de l'hiver; les mâles étaient, relativement aux femelles, dans la proportion de $\mathbf{9} 4$ p. 100. Le parasite se rencontre plus fréquemment encore en Allemagne, en Autriche, en Italie, aux Êtats-Unis. En Sicile, Calandruccio l'a noté chez 40 p. 100 des Porcs abattus.

Les troubles qui peuvent résulter de sa présence ont été étudiés par divers auteurs: Cloquet, Hurtrel d'Arboval, liocourek, etc. On peut les résumer ainsi : - plaies de la paroi intestinale; - formation autour de la trompe d'un nodule perceptible à l'extérieur; - inflammation étendue à toute la région de l'intestin envahie par les Vers; - perforation complète de la paroi intestinale et quelquefois passage de l'Échinorynque dans la cavité abdominale; - adhérences entre les circonvolutions intestinales, abcès, etc.

Quant aux symptomes qui traduisent ces altérations, ils sont fort peu caractéristiques; ils consistent surtout en troubles digestifs, suivis d'amaigrissement, parfois de convulsions épileptiformes. On a vu des Porcelets succomber en quelques jours. Le diagnostic ne pourrait donc être établi sérieusement que par l'examen microscopique des excréments.

Le traitement est encore à expérimenter.

Gigantorynque moniliforme (G. moniliformis [Brenser]. - Syn.: E. moniliformis Bremser, 1819). - Corps atténué en avant, offrant de fines stries et des anneaux transverses, ou même des étranglements qui Jui donnent l'aspect d'une série de perles, sauf dans le quart postérieur, qui est à peu près lisse et cylindrique. Trompe longue de 425 à $450 \mu$, large de 176 à $190 \mu$, garnie de crocliets disposés plus ou moins nettement en quinconce, de manière à former au plus 15 séries transversales et environ 12 longitudinales; crochets faibles, fortement courbés, longs de $26 \mu$. Lenınisques longs de plus d'un centimètre, cylindriques, ondulés en arrière. Mâle long au plus de 4 à 4 cent. 5; bourse campaniforme, visible à l'œil nu. Femelle pouvant atteindre 7 à 8 centimètres (jusqu'à 27 centimètres d'après Westrumb). OEufs ellipsoïdes, longs de $8 \ddot{\jmath} \mu$, larges de $40 \ddot{3} \mu$; enveloppe externe mince, jaunâtre; la moyenne très épaisse, incolore et homogène; l'interne un peu moins épaisse, également incolore et assez souple. Embryon strié en travers dans ses deux tiers postérieurs et couvert d'épines qui augmentent de volume à mesure qu'elles se rapprochent de la tête, où elles se transforment en crochets offrant une griffe et un éperon.

L'Échinorynque moniliforme a été trouvé par Bremser dans l'intestin du Campagnol des champs et du Hamster.

(1) Ch. W. Stıles, Sur l'hôte intermédiaire de l'Ech. gigas en Amérique. Comptes rendus de la Soc. de biologie (9), Ill, p. i64, 1891. 
Grassi et Calandruccio (t), à qui nous avons emprunté la diagnose ci-déssus, lont rencontré en Sicile chez. Ie Surmulot et le Loir des forèts, oì il habite l'intestin grèle, principalement dans les deux tiers antérieurs.

Les observateurs italiens ont reconnu qu'il a pour lòte intermédiaire un Coléoptère assez répandı, le Blaps mucronata latr., et dans quelques cas ils ont trouvé plus de 100 larres enkystées daus le nième Blaps.

I.e 26 décembre 1887 , un certain nombre de ces larres furent administrées à un Rat blanc; Calandruccio ingéra le reste. Le 10 janvier 1888 , on retrouvait dans I'intestin du liat un grand nombre d'Échinorynques, mesurant un centimètre de longueur. Le 13 janvier, Calandruccio fut pris de violentes coliques, accompagnées d'un peu de diarrhée, de bourdonnement dans les

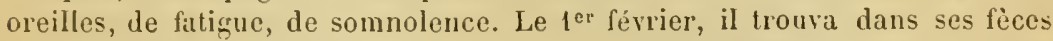
quelques œufs d'Échinorynque. Le 13 février, les douleurs abdominales devinrent tellement intenses qu'il se vit forcé de prendre un anthelminthique (8 grammes d'extrait éthéré de fougère mâle): il rendit alors 53 Échinorynques bien développés. Les troubles cessèrent deux jours plus tard.

En 1857, les mèmes auteurs avaient trouvé daus les fèces d'un jeune villageois des environs de Catane des œufs d'Échinorynque quils pensent pouvoir rapporter à cette espèce; mais cette observation est demeurée incomplète, par suite des idées superstitieuses des habitants de la localité.

En tout cas, l'expérience précédente est des plus instructives, puisqu'elle démontre que l'Échinorynque moniliforme peut évoluer dans l'organisme de lHomme. A la vérité, les conditions de ce développement doirent ètre bien rarement remplies, car il faut supposer a un homme une forte dose de distraction pour admetre qu'il puisse ingérer un Blaps, c'est-à-dire un lnsecte de la taille du Hanneton. Disons cependant qu'on a signalé une dizaine de cas de ce genre, mais dans lesquels les Insectes étaient rendus sans avoir été digérés. D’autre part, les femmes égyptiennes, an dire de Fabricius, mangent des Blaps sulcatu cuits dans le beurre, en vue de se donner de l'embonpoint.

Les ÉCHINORYNGHIDÉS ont le corps allongé, lisse. La gaine du rostre possède une double paroi et sert de réceptacle à celui-ci. Le système nerreux central est situé au milieu de cette gaine, le plus souvent au fond du cul-de-sac qu'elle représente. La pulpe des crochets ne possède de revêtement chitineux qu'à son extrémité. Les crochets n'ont qu'un prolongement inférieur.

Échinorynque polymorphe ( $E$. polymorphus Bremser, 1819, pro parte. - Syn.: E. boschadis et E. anatis Schrank, $1788 ; E$. vesiculosus et E. collaris Schrank, 1790 ; etc.; E. versicolor Rud., 1819). - Corps rouge orangé, de forme variable, le plus souvent fusiforme, atténué surtout en avant, et offrant vers le milieu un ou deux rétrécissements. Trompe ovoïde, armée de huit rangées de huit crochets chacune (donc 64), crochets Iongs de $60 \mu$. Cou inerme. Partie antérjeure du corps garnie de huit séries de crochets longs de $40 \mu$. Vále long en moyenne de 4 à 6 millimètres. Femelle pouvant atteindre

(1) B. Grassi und Calandruccio, Ueber einen Echinorhynchus, welcher auch im Menschen parasitirl und dessen Zwischenwirth ein Blaps ist. Centralbl. für Bakter. u. Parasitenk., III, p. 521, 1888. 
jusqu'à 23 millimètres, un peu plus épaisse que le màle. OEufs fusiformes, longs de $110 \mu$, larges de $19 \mu$, à trois enveloppes, la moyenne offrant à chacun des deux pòles un prolongement renflé à l'extrémité. Embryon pourvu d'un revètement épineux, et portant à sa partie antérieure une double couronne de crochets.

Ce Ver vit dans l'intestin grèle du Canard (Gœee), de l'Oie (Frölich), du Cygne (Bellingham) domestiques, et d'un grand nombre d'Anatidés et autres Oiseaux sauvages.

Greef a étudié le développement de cette espèce. Il a reconnu la forme larvaire dans la Crevette d'eau douce (Gammarus pulex), où elle présente déjà la teinte orangée; el en donnant à des Canards des exemplaires de ces Crustacés envahis de la sorte, il a obtenu la forme adulte. Les larves en question étaient déjà connues sous les noms d'Ech. miliarius Zenker, E. diffluens Zenker, conme vivant dans les Gammarus, et sous celui d'Ech. astaci fluviatilis von Siebold, comme vivant dans l'Écrevisse. Diesing Jes avait prises pour des Grégarines.

Le nom spécifique adopté par Bremser devra ètre abandonné, car cet auteur l'a employé pour réunir des formes qu'il croyait résulter de modifications produites par l'àge, et dont une au moins représente une espèce bien distincte ( $\boldsymbol{E}$. filicollis). Il reste établi néanmoins que l'Échinorynque polymorphe se transforme en vieillissant: il perd les crochets du rostre et les épines du corps, et sa trompe se transforme en une sphère lisse.

Chez le Canard, il occasionne parfois des troubles graves: il a d'ordinaire la trompe eufoncée profondément dans la paroi de l'intestin, et nous avons pu à diverses reprises reconnaître sa présence avant l'ouverture du canal, par les saillies que présente la séreuse à ce niveau. D’après Zürn, il cause parfois de violentes entérites. Gillet de Grandmont a vu, clıez un Canard pingouin, la trompe faire saillie à travers la séreuse et même se fixer sur le mésentère, en se détachant du corps: l'accumulation des parasites dans l'intestin avait d'ailleurs amené un arrèt des matières alimentaires. En 1888, a jardin zoologique de Bảle, on a vu périr un grand nombre de Palmipèdes par suite de l'inflammation intestinale provoquée par ces helminthes.

Échinorynque filicol (E. filicollis Rud., 1809. - Syn.: ? E. torquatus Frölich, 1802; E. boreulis Gmelin, 1789; E. anatis mollissimæ Müller, 1787). Corps blanc chez le màle, blanc jaunàtre chez la femelle, fusiforme, à extrémité postérieure obtuse, souvent presque tronquẻe. Trompe armée de 18 rangées de 11 à 13 crochets chacune (moyenne 216), crochets longs de 23 à $31 \mu$. Cou grèle et inerme. Partie antérieure du corps garnie le plus souvent de 14 rangées de crochets longs de $23 \mu$. Mále long de 7 à 8 millimètres. Femelle longue de 13 à 30 millimètres. OEufs ellipsoïdes, longs de 62 à $70 \mu$, larges de $19 \mu$, à trois enveloppes, la moyeune simplement arrondie aux deux pôles. Embryon pourvu d'un revêtement épineux, et portant à sa partie antérieure une couronne simple de crochets.

Longtemps confondu avec l'Échinorynque polymorphe, ce Ver en a été nettement distingué par Max Braun. Divers travaux ont été publiés relativement à son évolution; mais, en raison mème de cette confusion, ils sont lout entiers à reprendre.

L'Échinorynque filicol vit dans l'intestin du Canard domestique (M. Braun) et de plusieurs Anatinés sauvages. 
Avec l'àge, sa trompe se deforme, sans pourtant perdre ses crochets, et prend l'aspect d'une vésicule (bulla lind.).

Échinorynque sphérocéphale (E. spharocephalus Bremser, 1819). Corps long de 6 is 20 millimètres, cylindrique, inégal on présentant un double renflement. Trompe globuleuse, armée d'environ 16 rangées de erochets. Cou filiforme, long, inerme. Parlic antérieure du corps garnie d'épines. OEufs arrondis, oblongs.

Cette espèce, encore mal étudiée, trouvée par Natterer dans l'intestin de quelques Oiseaux aquatiques, a ėté rencontrée à lireslau, par liurlt, chez le Canard domestique.

Elle perd en vieillissant les crochets du corps et de la trompe, et celle-ci se transforme en une grosse vésicule lisse, enfoncée dans les parois de l'intestin.

Échionrigete de l'lloma ( $\boldsymbol{E}$. hominis Lambl, 1859). - On a décrit sous ce nom une jeune femelle, longue de $3^{\mathrm{mm}}, 6$, large de $0^{\mathrm{mm}} 6$. Trompe courte, subglobuleuse, longue de $0^{\mathrm{mm}}, 36$, large de $0^{\mathrm{mm}}, 3 \dot{x}$ en avant, armée de 12 rangées de 8 crochets chacune, crochets longs de $103 \mu$ sur la grande courbure et de $\pi \tilde{i}$ sur liı petite, larges de $20 \ddot{\mu}$ à la base et de $12 \mu$ au milieu. Corps séparé de la trompe par un étranglement et renfermant des weufs incomplètement développés.

Cet unique exemplaire a été trouvé par Lambl dans l'intestin grèle d'un enfant de neuf ans qui mourut de leucémie à Prague, en 1857. Comme on le roit, Lambl en faisait une espèce particulière. !l est fort probable, au contraire, qu'il s’agit d'un parasite accidentel, égaré. Ant. Schneider y voyait un jeune Échinorynque géant, et Leuckart tend à le rapporter soit à l'E. angustatus Rud., des Poissons d'eau douce, soit, ce qui serait plus admissible, a l'E. spirula Olfers, de certains Singes.

Welch (1) avait aussi décrit un Ėchinorynque enkysté sous la muqueuse du jéjunum d'uı soldat; mais il s'agit évidemment d'une Linguatulide.

Échinorynque dı Chien (E. Grassii Deffke, 1891). - Espèce non encore décrite, signalée par frassi et Calandruccio dans l'intes̉tin grèle du Chien, en Sicile.

Rappelons à cette occasion, que le prétendu Échinorynque trouvé par Lewis, à Calcutta, dans les parois de l'estomac du Chien paria, n'est autre qu'un Gnathostome (Voy. p. 54 i).

Max Braun dit avoir vu, à Königsberg, des Échinorynques dans l'intestin du Chat.

Échinorynque du Lapin (E. cuniculi Diesing, 185̈1. - Syn. : E. sp.? Bellingham, 1844). - Espèce nominale, signalée par Bellinghan comme ayant été rencontrée dans l'intestin grèle du Lapin, en Irlande.

Ordres secondaires. - On rattache généralement aux Némathelminthes quelques formes aberrantes qui les relient aux autres groupes de Vers. Tels sont les Desmoscolécidés, les Chètosomidés et les Chétognathes, qui noffrent, a notre point de vue spécial, aucun intérèt.

(1) WE⿺cн, The presence of an enrysted Echinorhynchus in Man. Lancet', 16 nor. 18 \%?. 


\section{CLASSE IV}

\section{ROTATEURS}

Vers aquatıques le plus sonvent microscopiques, à segmentation extérieure ne correspondant pas à une division des organes internes (hétéronome); extrémité antéricure munie d'un appareil ciliaire (appareil rota. toire).

Les Rotateurs ou Rotifères ont été longtemps confondus avec les Infusoires. Leur corps, de très petiles dimensions, offre deux parties distinctes : l'an-

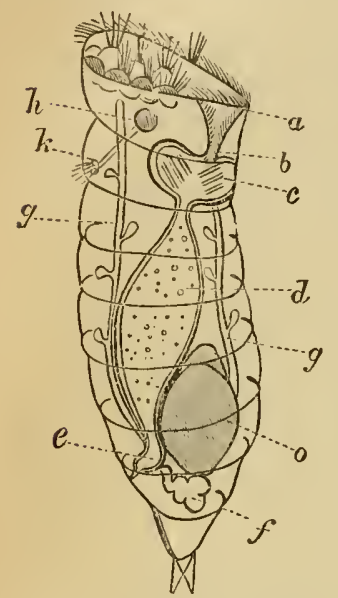

Fig. 391. - Schéma d'un Rotateur (Hydatina senta), d'après Pritchard. - $a$, vestibule cilié du tube digestif. $b$, bouche. $c$, pharynx, avec son appareil masticateur. $d$, estomac. $e$, cloaque. $f$, vésicule contractile. $g$, canaux excréteurs. $h$, ganglion nerveux envoyant un filet nerveux à la fossette ciliéc. $k 0$, ovairc. térieure, qui contient les organes internes, est souvent dépourvue de toute trace de segmentation; la postérieure, au contraire, qui joue le rôle de pied mobile, est d'ordinaire annelée et terminée par deux appendices semblables aux mors d'une pince, servant à fixer l'animal ou à le faire progresser.

A l'extrémité antérieure existe presque toujours un appareil ciliaire, le plus souvent rétractile, connu sous le nom d'appareil rotatoire. L'orifice buccal est situé sur la face ventrale de cet appareil, qui sert à attirer les particules alimentaires. Cet orifice conduit dans un pharynx musculeux, muni d'épaississements chitineux propres à broyer les aliments, et suivi d'un œsophage étroit, qui s'ouvre dans un estomac cilié. L'intestin est également cilié. L'anus, qui peut manquer, s'ouvre sur la face ventrale, au point de réunion des deux parties du corps.

Il n'existe pas d'appareil circulatoire, et la respiration est cutanée. - Les organes excréteur's consistent en deux canaux sinueux qui communiquent avec la cavité viscérale par des entonnoirs ciliés et débouchent dans le cloaque directement ou par l'intermédiaire d'une vésicule contractile.

Le système nerveux est représenté par un ganglion sus-œsophagien souvent bilobé, émettant des nerfs qui se rendent aux muscles et aux organes des sens. Parmi ceux-ci, on distingue une ou deux taches oculaires, une fossette ciliée et des.éminences tactiles cutanées.

Les sexes sont séparés. Les mâles sont rares, de petite taille, et de forme souvent bien différente de celle de la femelle; de plus, leur tube digestif est avorté. IIs sont déjà bien formés au sortir de l'œuf, ne prennent aucune nourriture et vivent peu de temps. Leurs organes sexuels se réduisent à une poche remplie de spermatozoïdes et s'ouvrant au voisinage de l'anus. - Les organes femelles possèdent un seul ovaire dont l'oviducte débouche dans le cloaque. Elles sont presque toutes ovipares et produisent deux sortes d'œufs : des œuf's d'été à coque mince, se développant-sans avoir été fécondés, et des 
aufs l'hiver à coque dure, pondus en automne et fécondés. Les màles sont issus des oufs d'été et ne se montrent qu'à la fin de cette saison.

Les Rotateurs vivent en grande partie dans l'eau douce; ils sont libres ou adhẻrents, mais jamais absolument fixés. Un grand nombre d'entre eux peuvent résister pendant un certain temps à la dessiccation, et reprendre lour activité sous l'inlluence de l'humidité.

\section{CIASSE V}

\section{BRY OZOAIRES}

Animanx aquatiques de petites dimensions, ordinairement groupés en colonies ramifies ou lamelleuses, à extrémité antérieure garmie de lentacules cilis' qui entourent la bouche. Aquatiques.

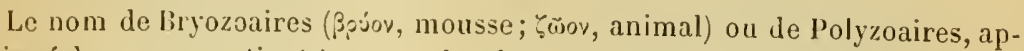
pliqué à ce groupe, tient à ce que la plupart des espèces qui le représentent

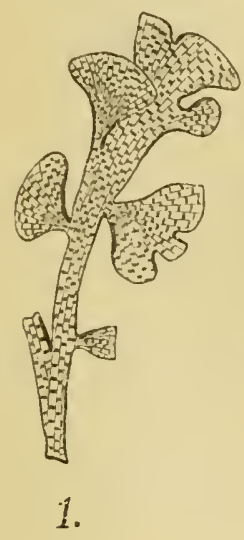

1.

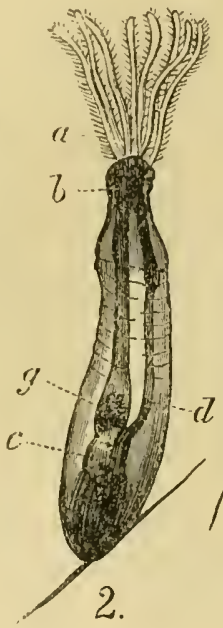

2.

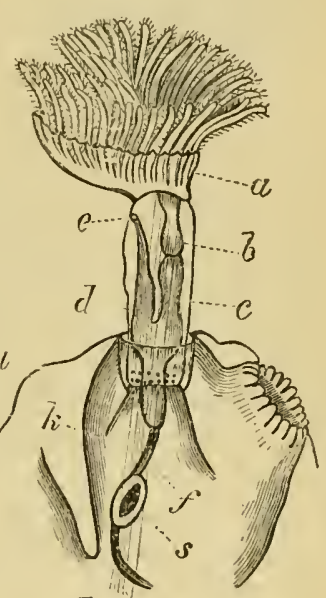

5. $m$.

Fig. 392. - Morphologie des Bryozoaires d après Iuxxley. - 1, fragment de Flustra truncala, grandeur naturelle. 2, polypide isolé de Vesicularia, grossi, montrant la couronne orbiculaire de tentacules. 3, un polypide du Lophopus crystallinus, Bryozoaire d'eau douce, fortement grossi, montrant les tentaculcs disposés en fer à cheval : $a$, couronne tentaculairc. $b$, œsoplage. $c$, estomac. $d$, intestin. ', anus. $g$, gésier. $k$, endocyste. $l$, ectocyste. $f$, funiculc.

forment des colonies ramifiées et en général fixẻes, simulant des mousses ou d'autres plantes. L'ensemble de la colonie possède un exosquelette chitineux ou calcifié, délimitant d'ordinaire un grand nombre de petites loges qui renferment chacune les parties molles d'un individu. Ces loges sont souvent pourvues d'un couvercle mobile, qui se ferme sur l'animal rétracté.

Chacun des individus offre un tube digestif à parois propres, flottant dans la cavité viscérale. La bouche, située au niveau de l'ouverture de la loge, est limitée par un disque ou lophophore dont les bords se prolongent en un nombre variable de tentacules ciliés. Le tube digestif décrit une anse assez pro- 
fonde; l'anus s'ourre à peu de distance de la bouche. L'estomac est relié à la paroi du corps par une sorte de ligament ou funicule, et on observe en outre des muscles rétracteurs chargés de ramener le disque tentaculaire à l'intérieur de la loge. Les tentacules représentent des organes respiratoires et servent en même temps à diriger vers la bouche les particules alimentaires.

Dans de nombreuses espèces de Bryozoaires marins, il existe d'ailleurs divers appendices qu'on a regardés aussi comme concourant à la préhension des aliments : les uns, en forme de tète d'Oiseau (ariculaires), son! portés sur des pédoncules flexibles et offrent une mandibule qui happe incessamment. D'autres constituent des sortes de longs fouets qui battent l'eau (vibraculaires). On a prétendu que ces appendices sont de simples loges avortées; la mandibule mobile re l'aviculaire, aussi bien que le flagellum vibraculaire, correspondrait alors à un opercule modifié : en réalité, l'origine de ces parties reste à déterminer.

On n'observe pas d'appareil circulatoire spécial : le fluide nourricier circule dans la cavité viscérale sous l'influence des cils vibratiles qui la tapissent ou par le fait des mouvements généraux.

Le système nerveux est représenté par un ganglion unique, situé entre les ouvertures buccale et anale, plus rarement par un collier œsophagien. D'après Joliet, il n'existe pas, comme on l'avait cru, de systeme nerveux colonial; les cordons signalés sous cette dénomination ne sont autres que des funicules.

Les Bryozoaires se multiplient par bourgeonnement, et Joliet a fait connaître une particularité curieuse de ce mode de reproduction. Les animaux (polypides) contenus dans les loges ont une existence assez limitée; chacun d'eux finit par se flétrir et par se résoudre en un corps brun granuleux. Un bourgeon se forme alors dans la loge, et le plus souvent expulse ce corps bruı, après l'avoir introduit dans son tube disestif et digéré en partie. Quelques formes d'eau douce se multiplient par des sortes de bourgeons oviformes ou de bulbilles (statoblastes) se développant sur le funicule à la fin de l'élé. La reproduction s'effectue aussi par voie sexuelle, et les organes màles et femelles sont presque toujours réunis sur le même individu. Les larves sont ciliées.

Ces animaux viveut dans la mer, rarement dans les eaux douces.

J. Barrois a caractérisé leurs principales aftinités en les considérant comme "fils des Rotifères et frères des Brachiopodes".

\section{CLASSE VI}

\section{B RACHIOPODES}

Animaux marins, souvent fixés, à corps déprimé, munis d'une coquille bivalve, à valves dorsale et ventrale. Un appareil vibratile prébuccal, porté sur deux bras en spirale.

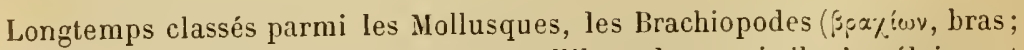
.o ̌̌ , pied) ressemblent beaucoup aux Lamellibranches, mais ils s'en éloignent par divers détails de structure et surtout par leur développement embryonnaire, qui les rattache aux Vers.

Ils possèdent uı tégument qui se replie de manière à former un manteau 
al deux lobes, l'un ventral, lautre dorsal, enveloppant le corps, et se revètant d'une coquille biralve. Cette coquille ne s'ouvre que par la contraction de muscles spéciaux.

Le corps est peu déreloppé et ne remplit qu'une petite partie de la cavilé formée par le manteau (cavité palléale). La bouclıe est percée au milieu d'un disque qui se prolonge de chaque còté en un long bras frangé de tentacules et enroulé en spirale. Ces deux hras servent à la respiration et a la préhension des matières alimentaires. Le tube digestif est suspendu dans la cavité

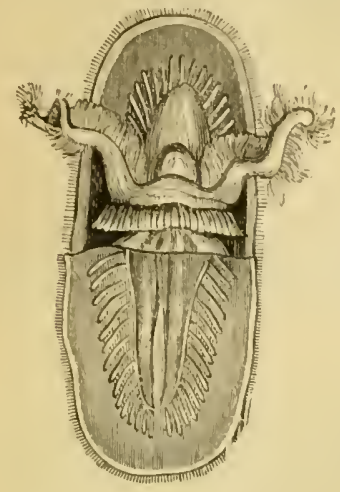

Fig. 3:3. - Lingula anatina. viscérale; il se termine en cacum ou se recourbe pour aboutira un anus voisin de la bouche. - Il existe un apparcil circulatoire distinct, comprenant des canaux anastomosés, qui offrent par place des

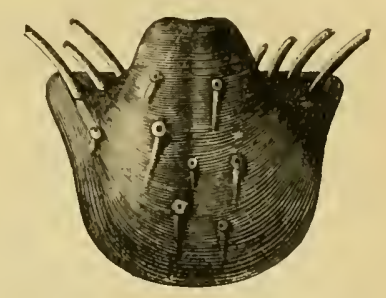

Fig. 394. - Productus harridus, du terrain pénéen.

dilatations résiculaires. - Le système nerveu.t est assez analogue à celui des IIollusques Lamellibranches. - Lippareil excritcur comprend une ou deux paires de néphridies. - La reproduction est encore peu connue. Les seres sont tantòt réunis, tantòt séparés. Les larves ressemblent d'une facon frappante à celles des Bryozoaires et des Annélides,

Deux groupes : les Inarticules ou Ecartines (c, sans; cardo, charnière), à coquille sans charnière, à bras dépourvus de squelette, à anus latéral (ex. : Lingules); et les Articulés ou Tésticardines (tcstis, témoin; cardo, charnière), à coquille pourvue d'une charnière, à squelette brachial, à tube digestif en cul-de-sac (ex.: les Térébratules, formes vivantes; les Spirifers, Productus, etc., formes fossiles).

\section{CLASSE VII}

\section{ANNÉLIDES}

Vers cylindriques ou aplatis, pourvus d'une chaine nerveuse ventrale et d'un système vasculaire sanguin.

Le corps des Annélides (annellus, anneau) est presque toujours divisé en anneaux plus ou moins marqués, semblables entre eux (segmentation homonome) et disposés de telle sorte que les segments internes correspondent, soit aux divisions extérieures elles-mêmes, soit d̀ un certain nombre de ces divisions. Les organes se répètent dans les segments, mais en réalité l'homonomie n'est jamais complète. 
La locomotion s'effectue assez fréquemmentau moyen de soies fixées sur des appendices latéraux ou parapodes. Parfois il existe des ventouses.

Le système nerveux est représenté par une chaine nerreuse ventrale le plus souvent ganglionnaire, dont les deux moitiés sont plus ou moins rapprochées sur la ligne médiane. A la partie antérieure, les cordons nerveux s'écartent pour former un collier entourant l'œsophage, et se trouvent réunis au-dessus de cet organe par des ganglions dits cérébroïdes (cerveau).

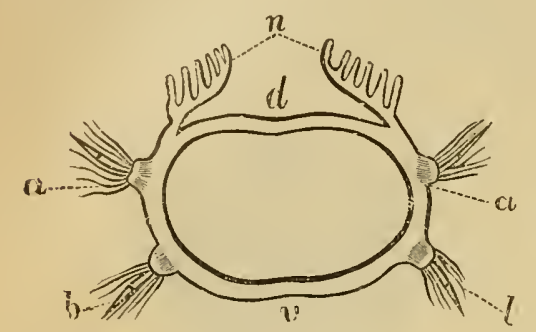

Fig. 395. - Coupe schématique transversale d'un Annélide. - $d$, arc dorsal. v, arc ventral. $n$, liranchies. $a$, larapode dorsal. $b$, yarapode ventral (Huxley).

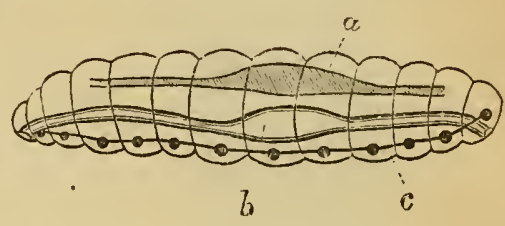

Fig. 396. - Diagramme d'un Anndide. - $a$, système vasculaire sanguin. $b$, système digestif. $c$, systeme nerreux (Huxley).

La cavité viscérale renferme un liquide plasmatique incolore, dans lequel flottent des globules animés parfois de mouvements amiboïdes. En outre, il existe un autre appareil circulatoire constitué par des vaisseaux habituellement clos (appareil hématique) et contenant un liquide souvent rouge, mais presque jamais chargé de globules. La substance colorante parait être de l'hémoglobine. Chez quelques Annélides marins dont le sang est d'un beau vert, c'est de la chlorocruorine. L'appareil hématique comprend des vaisseaux longitudinaux, principalement un dorsal et nn ventral, réunis par des anastomoses transversales. Tantôt l'une, tantôt l'autre de ces parties jouit de propriétés contractiles et met le sang en mouvement.

Les organes excréteurs se montrent d'ordinaire sous la forme de canaux enroulés, dits canaux en lacet, disposés par paire dans chaque segment (arganes segmentaires ou néphridies), prenant souvent leur origine à l'intérieur du corps par un entonnoir cilié et communiquant d'autre part avec le dehors.

On observe quelquefois une reproduction asexuelle par scission et bourgeonnement suivant l'axe longitudinal. En ce qui concerne la reproduction sexuelle, beaucoup d'Annélides sont monoïques; d'autres ont les sexes séparés.

Un grand nombre de ces Vers naissent sous la forme de trochosphère ou larve de Lovén, petite larve ovoïde, munie d'une double ceinture équatoriale de cils, au-dessous de laquelle sont situés la bouche et 
l'anus. Cette larve ne tarde pas à produire, à sa partie postérieure, un anneau, en avant duquel se formeront successivement les autres.

Les Annélides vivent dans la terre et dans l'eau; certaines espèces sont parasites à l'oceasion.

4 sous-classes, dont les deux premières ne comprennent que des animaux marins et ne doivent pas retenir notre attention :

Pas de segmentation, Tube digestif rectiligne............. AnchlannéLIdes.

extérieure. The digestif contourní............ Gíphyнens.

Segmentation (Pas de soies. Des ventouses........... HHunixéEs.

extérieure. i Des soies. Pas de ventouses.......... CuÉtopones.

SOUS-CLISSE III

\section{HIRUDINÉES}

Amnelides pourvus de deux ventouses, mis ne possédant ni soies, ni parapodes.

Les Hirudinces ou Discophnres ont le corps aplati, composé d'une série d'anneaux courts, parfois peu marqués. Les segments internes, incomplètement séparés par des cloisons transversales, sont moins nombreux que les anneaux extérieurs, et correspondent chacun à plusieurs de ceux-ci. Ces Vers sont à peu près toujours dépourvus de pieds et de soies, mais possèdent des organes de fixation représentés par une grande ventouse postérieure (ventouse anale) et souvent par une petite ventouse antérieure (ventouse orale); la rógion céphalique n'est généralement pas distinete du reste du corps. La plupart sont liermaphrodites.

Ils se nourrissent de substances animales, et en particulier de sang; un certain nombre peuvent même être considérés comme des parasites temporaires.

Les Hirudinées composent cinq familles: Histriobdellida, Acanthobdellidx, Rhynchobrlellide, Branchiobdellidie et Gnathobdellidir.

Famille des GNATHOBDELlidÉS. - Les Sangsues qui composent cette famille ont, comme leur nom l'indique, la bouche armée de mâchoires, le plus souvent au nombre de trois. Le corps est composé de vingt-six segments ou somites, chacun de ceux-ci correspondant à un nombre variable d'anneaux tégumentaires. La ventouse anale est circulaire; celle de la partie antérieure est en forme de bec de tlûte, bilabiée; presque toujours le sang est rouge et renferme de l'hémoglobine.

2 sous-familles :

5 paires dyeux; œufs dans des cocons spongienx.... IliRudinin...

4 paires d'yeux; œufs dans des capsules minces..... Nephelis.e.

Railliet, - Zoologie. 
Les HIRUdiNines comprennent un assez grand nombre de genres, parmi lesquels nous nous bornerons à signaler: Hirudo L., Limnatis Moquin-Tandon, Hemopis Sarigny (Aulastoma Moq.-Tand.), Hiemadipsa Tennent.

Genre Sangsue (Hirudo L., 17วั8, pro parte). - Les espèces de ce genre prennent une forme olivaire en se contractant. Les somites normaux ou complets comprennent chacun $ّ$ anneaux : le corps est en somme composé de 102 anneaux. La bouche est munie de trois grandes màchoires demi-oralaires, comprimées et pourvues, sur leur bord libre, de denticules forts et nombreux. L'orifice mâle est situé entre les anneaux 30 et 31 ; l'orifice femelle entre les anneaux 3.3 et 36.

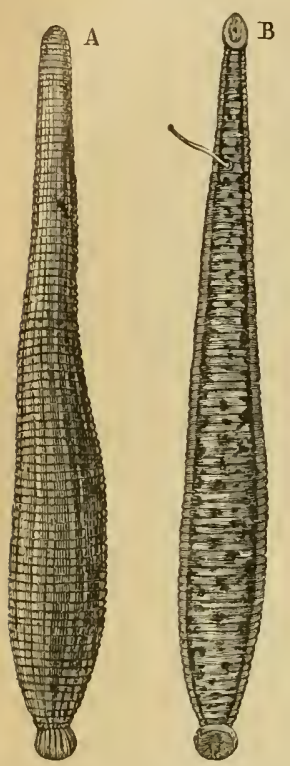

Fig. 397. - Sangsue médicinale. $-A$, we par la face dorsale. B, par la face ventrale.

Ce sont des Vers lacustres: on les rencontre dans les étangs, les mares et les fossés.

Il en existe un assez grand nombre d'espèces, dont plusieurs sont employées en médecine, soit en France, soit à l'étranger.

Sangsue médicinale (U. medicinalis L., 17ว̊). - Corps déprimé, long de 80 à 120 millimètres, large de 12 à 20 millimètres; dos généralement gris olivàtre, avec six bandes rousses plus ou moins netles; bords olivàtres; ventre bordé d'une bande noire rectiligne.

Cette espèce, dont le type est sourent désigné sous le nom de Sangsue grise, habite l'Europe et quelques parties de l'Afrique septentrionale.

Elle offre un grand nombre de variétés, caractérisées par des différences dans la teinte générale et dans la disposition des lignes et des taches du dos et du rentre. Une des plus connues est la Sangse VERTE, décrile comme une espèce particulière par Moquin-Tandon, sous le nom de H. officinalis. Elle se distingue à sa teinte verdàtre et à son ventre non maculé.

Organisation. - Le corps est demi-cylinilrique, aplati sur la face ventrale, plus large au milieu qu'en avant et en arrière. A l'extrémité antérieure existe une ventouse en forme de cuiller, à lèvre supérieure saillante, à lèvre inférieure courte. L'extrémité postérieure est aussi terminée par une ventouse, niais celle-ci est plus grande, circulaire et séparée du corps par un étranglement.

Il existe en tout 26 segments ou somites, composés en principe de cinq anneaux chacun; mais, aux deux extrémités, ces anneaux ont une tendance à se fusionner entre eux, et les somites subissent ainsi un raccourcissement plus ou moins accusé. A l'extérieur', la limite de ces divers somites est marquée par le premier anneau, qui porte toujours un certain nombre de papilles sensorielles, dites papilles segmentaires. On reconnait ainsi que les 
6 premiers et les $\&$ derniers somites se trouvent raccourcis par la perte de 2 à 4 anneaux, et que les 16 somites intermédiaires sont normanx. Le nombre total des anneaux, comptés par la face dorsale, est de 102 : si la plupart des auteursn'en indiquent que $9 \ddot{3}$, c’est qu'ils les comptent par la face ventrale, en arrière de la ventouse orale, et qu'ils négligent l'anneau rudimentaire sur lecpuel s'ouvrel'anus.

Le tégument montre d'abord une cuticule anhiste, qui se renouvelle de tempsi autre. I la face profonde de celle-ci adhère une couche de cellules en palissade, dont l'extrémite superficielle seélale en forme de marteau. Plus profonlément encore, se trouve une couche pigmentaire, de teinte variable. Le systime musculaire qui se trouve aunexé a cette enveloppe comprend une couche externe de faisceaux annulaires et une couche interne de faisceaux longitudinaux; de plus, on rencontre dans tout le corps de nombreux muscles obliques, trausversaux et dorso-ventraux. Sous le tégument, ainsi qu'entre les faisceanx musculaires, existent de nombreuses glandes cellulaires dont le conduit excréteur va déverser à la surface du corps un liquide visqueux: ce sont les glundes mucipures. - Toutes ces parties sont unies par une sorte de tissu conjonclif, qui fouruit de distance en distance des cloisons incomplètes divisant l’intérieur du corps en segments.

L'appareil digestif présente une disposition qui le rend propre ì la succion. La bouche est située au fond de la veutouse antérieure; elle a l'aspect d'une ouverture étoilée, à trois branclies, cliacune de celles-ci dounaut passage à une màchoire. En fendant lil rentouse orale, on voit ces organes rapproclıés en arrière et divergeant par leur extrémité antérieure. Ce sont des corps demi-lenticulaires, offraut un hord rectilinge qui se continue par une sorte de petit manche fixé dans l'enveloppe musculo-cutanée, et un bord libre, convexe, qui porte une série de denticules, au nombre de soixante et plus. Des faisceaux musculaires, implantés d'un còté dans la paroi du corps, vont s'insérer d'autre part sur le bord rectiligne de chaque machoire : les

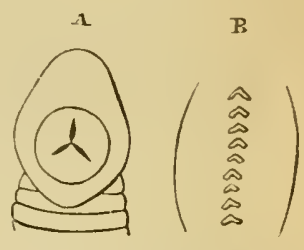

Fig. 39s. - A, ventoune orale de la sangsue. $B$, quelques denticules diune michoire (Carlet).

mus impriment à la màchoire un mouvement de dehors en dedans, les autres la ramènent de dedans en deliors.

A la bouche fait suite un court pharynx ou œsophage musculeux entouré de glandes diles salivaires et terminé par un sphincter. Ces glandes sécrètent un liquide qui empèche la coagulation du sang ingéré. L'estomac, très développé, comprend dix chambres successives, incomplètement séparées par des étranglements el des replis de la paroi interne, et formées chacune de deux poches latérales. Ces poches sont d'autant plus grandes qu'elles se trouvent plus en arrière, et les deux dernières se prolongent sous forme de ciecums jusqu'au voisinage de l'anus. L'intestin se continue entre ces deux cícums et aboutit à un anus très petit, à peine visible, situé au-dessus de la ventouse postérieure.

Quand la Sangsue veut mordre, elle se fixe par cette ventouse postérieure, el porte la tète au point (qu'elle choisit. La ventouse orale soulève un mamelon culané, puis les màchoires sont tirées l'arant en arrière, et agissent à la façon de petites scies pour diviser ce mamelon suivant trois lignes qui 
aboutissent au mème point. La blessure offre par suite l'aspect d'une petite étoiles à trois branches, à bords un peu sinueux. "La personne mordue, dit Moquin-Tandon, éprouve d'abord un sentiment de pression à l'endroit où l'annélide s'est fixée. Le tiraillement devient bientôt un peu plus fort; puis on ressent une douleur vive, pénétrante, qui ressemble à la fois à celle des piquures et à celle des déchirures." G. Carlet a établi que les màchoires de la

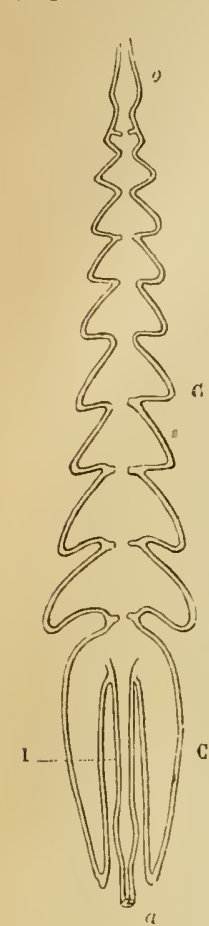

Fig. 329. - Tule digestif de la Sangsue. - 0 , œsophage. C, C, chambres stomacales r.t eircums. I, intestin terminal. $u$, anus (Carlet).

Sangsue sont les agents essentiels de la succion et de la déglutition: pour effectuer la succion, ces màchoires, en s’abaissant, s'écartent et rendent béante l'entrée de l'vesophage, où le sang s'élance; pour effectuer la déglutition, elles se rapprochent et remontent dans l'vesophage où, à la façon d'un piston, elles lancent le sang dans la direction de l'estomac. On croyait autrefois que l'ensemble du tube digestif servait a attirer le sang; la preure qu'il n'en est rien, c'est qu'une Sangsue coupée en deux continue souvent à sucer: le sang s'écoule par la partie sectionnée du troncon antérieur. Piégu avait même proposé de blesser les Sangsues au moment où elles étaient gorgées, pour que la succion continuàt plus longtemps: cette opération, connue sous le nom de bdellatomie, ne parait pas offrir de bien grands avantages, et n'est pas entrée dans le domaine de la pratique. - La quantité de sang̨ sucée varie arec la taille des Sangsues. En opérant sur des individus non gorgés de l'espèce officinale, Mloquin-Tandon est arrivé aux résultats suivants: les petites Sangsues absorbent 2 gr. 70 de sang, c'est-à-dire 2 fois $1 / 2$ leur poids; les petites moyennes 4 fois; les grosses moyennes $\ddot{a}$ fois $1 / 2$; les grosses $\breve{b}$ fois $1 / 11$. Il faut du reste ajouter à cette somme la quantité de sang qui sécoule après leur chute, soit 10 gram mes environ. - La digestion des Sangsues dure en moyenne de six mois a un an; le sang reste fluide dans leur estomac.

L'appareil circulatoire n'est guère représenté que par le système vasculaire clos: la cavité viscérale, en effet, se trouve extrêmement réduite; elle ne contient qu'une petite quantité de liquide incolore. L’appareil rasculaire sanguin, par contre, est très développé: il comprend quatre troncs longitudinaux: deux médians, situés l'un au-dessus, l'autre au-dessous du tube digestif, et deux lateraux. Les preniers se bifurquent en avant; et leurs branches se rejoignent en formant un collier qui entoure l'œsophage. Le vaisseau sus-intestinal fournit des branches transversales, les unes destinées au tube digestif et s'anastomosant avec le tronc sous-intestinal, les autres se rendant aux vaisseaux latéraux. Ceux-ci communiquent entre eux aux deux extrémités du corps; ils sont en outre réunis dans chaque segment par des branches transversales inférieures, et envoient un rameau a chacun des organes segmentaires. Ajoutons que le vaisseau sous-intestinal renferme, à son intérieur, la chaine nerveuse ganglionnaire. - Le sang contenu dans ce système vasculaire a une coloration rouge qui est propre au plasma et ne tient nullement aux globules. La circulation est déterminée par des contractions rythmiques des troncs 
longitudinaux: mais le sens du courant est soumis à des variations.

Au-lessous du tube digestif, entre les poches stomacales et de chaqur cúté du vaisseau sous-intestinal, il existe des organes segmentaires, au nombre de dix-sept paires. Clıcun de ces organes comprend deux parties: une glunde en forme de fer à cheval, dont la convexité est toumée du côté du dos, et une vesicuic situee un peu en arrière et en dedans de la glande: un conduit crlindrique (conduil vesiculuire) amine dans la vésicule la subslance hlanchitre el granuleuse sécrétie par la glande, et ce produit est définitivement expulsé par un court canal jui débouche sur la face ventrale, au bord postérieur du dernier anneau de charpue somite por's segmentaires on nephidilum.x). La première paire s'ouve entre les somites 6 et 7 , la dernière entre les somites 22 el 23 .

La respiration, simplement cutanée, est très peu actire chez les Sangsues, car ces animaux peuvent vive plusieurs jours dans un gaz inerte et mème dans le ville.

Le systime nerreux se compose d'un ganglion sus-asophagien ou céribroỉde (cerveau) et d’une chaine tanglionnaire ventrale logée, comme nous lavons dit, dans l'intérieur du vaisseau sous-intestinal. La chaine, comme le cerveau, se compose de deux parties symétriques, mais si étroitement rapprochées sur lit ligne médiane quelles se trouvent confondues. Cependant, le ganglion cérébroïde est nettement bilobé. Il fournit de petits filets dirigés en arant et destinés surtout aux tarhes oculaires. Le point de départ de la chaine rentrale est le ganglion sous-œsophagien. Celui-ci est réuni au cerveau par deux conuectifs qui s'écartent de manière à embrasser l'œsophage en lui formant un véritable collier. Les différents ganglions de la chaine, au nonlore de 23 chez l'individu adulte, sont eux-mèmes réunis par un double cordon; les filets qui en émanent se rendent aux parois lu corps.

On a signalé en outre, chez la Sangsue, un systeme nerceux visceral, analogue au sympathique des Vertébrés, et représenté par un double filet dont les rameaux se distribuent à l'intestio, mais dont les rapports arec le syslème nerveux de la vie de relation sont peu connus.

Les organes des sens sont fort imparfaits. - Le tuct s'effectue surtout par la lèrre superieure de la ventouse orale. - Un ne connait pas le siège du gorit, mass il est certain que ce sens est assez développé, puisqu'on détermine les Sangsues a attaquer la peau en l'humectant de lait et d'eau sucrée. - Il en est à peu près de mème en ce qui concerne l'oüe ou l'odorat: ces aninaux sont sensibles au bruit et refusent de sucer les parties recouvertes de substances odorantes. Leidy a d’ailleurs trouvé, dans le tégument céphalique, des organes cupuliformes, qui servent peut-ètre, d'après J. Chatin, à la fois au toucher, au goit et à l'odorat. - Enfin, les yeux sont des fossettes cupuliformes tapissées de pignent et munies de corps réfractant la lumière; ils sont situés à la face supérieure des anneaux 1, 2, 3, 3 et 8 ; on les regarde comme homologues des papilles segmentaires. - quant a la sensibilité générale, elle est très déreloppée.

Les Sangsues sont androgynes. Les organes miles comprennent neuf paires de testicules disposées au-dessous du tube digestif, dins autant de segments de la région moyenne du corps (du 12e au $\left.20^{\mathrm{e}}\right)$; les canaux vecteurs de ces testicules débouchent de chaque còté dans un canal déférent longitudinal. A lextrémité antérieure, celui-ci s'enroule en épididyme et donne naissance 
à un canal éjaculateur, qui se réunit à son congénère pour constituer une vésicule pyriforme, à laquelle se trouve annexée une glande (prostate). La sécrétion de cette glande sert à enfermer les spermatozoïdes dans une enveloppe commune (spermatophore). Enfin, de Ia vésicule part un canal assez étroit

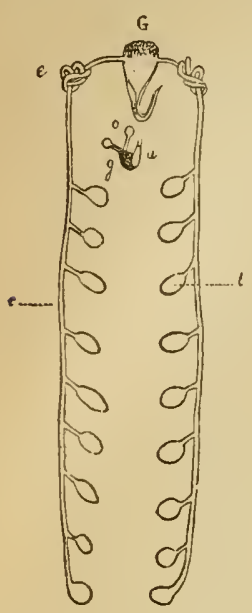

Fig. 400. - Appareil génital de la Sangsue. - $t$, testicules. $c$, canal déférent. e, épididsme. G, vésicule pyriforme. 0 , ovaires. $g$, glande albuminigène $u$, utérus (Carlet). qui aboutit à l'extérieur, sur la ligne médiane, entre les anneaux 30 et 31 , et peut faire saillie sous forme de pénis.

Les organes femelles se composent de deux ovaires arrondis pourvus chacun d'un oviducte. Le canal qui fait suite à ces oviductes décrit des sinuosités au milieu d'une glande ovoïde, dite albuminigène, dont le produit sert à agglutiner les œufs; puis il se dilate en un large utérus dont la partie antérieure ou vagin s'ourre au dehors par une vulve située en arrière de l'orifice màle, entre les anneaux $3 \ddot{z}$ et 36 .

Les Sangsues ne peuvent se reproduire que par fécondation réciproque. La copulation s'effectue par un rapprochement des deux individus ventre à ventre et en sens opposé; elle dure plusieurs heures. La ponte a lieu au bout de 25 à 40 jours. Dans cet intervalle, il se forme, autour de la partie du corps qui comprend les orifices sexuels (somites 9,10 et 11 , ou anneaux 24 à 32), un renflement olivaire qui a reçu le nom de ceinture. Au moment de la ponte, les Sangsues sorlent de l'eau et se creusent une galerie dans la terre humide. Alors, les nombreuses glandes que renferme la ceinture sécrètent un liquide visqueux et spumeux, qui peu à peu se concrète et forme une sorte de fourreau membraneux. La Sangsue en sort à reculons, après y avoir pondu en moyenne 10 à 18 petits œufs agglutinés par l'albumine. Puis, les deux ouvertures de cette bourse se ferment, sa substance se dessèche, brunit, et bientòt lui doune l'aspect d'un cocon spongieux. Chaque Sangsue produit un ou deux cocons, rarement trois.

On connaît peu le développement embryonnaire de ces animaux. L'éclosion a lieu 25 à 28 jours après la ponte. Les jeunes Sangsues traversent le cocon et en sortent par différents points; elles sont alors filiformes, cendrées, transparentes et mesurent environ 2 centimètres de longueur. Si quelque danger les menace, elles se réfugient encore dans le cocon. Elles ne subissen.t pas de métamorphose.

Hirudinculture. - Le commerce des Sangsues est certes moins important aujourd'hui que dans la première moitié de ce siècle; néanmoins il est utile de connaitre les moyens de conserver et de multiplier ces animaux.

Dans le commerce, on les distingue sous divers noms suivant leur grosseur : germement lorsqu'elles viennent de naitre, filets ou petites, petites moyennes, grosses moyennes, grosses ou mères, et enfin vaches lorsqu'elles ont acquis leurs plus grandes dimensions. Les petites pèsent en moyenne 400 gram. mes le mille et les grosses 3 kilogrammes. Ine bonne Sangsue pèse environ deux grammes; quand on la comprime dans la main, elle doit se contracter 
en olive et ne pas laisser échapper le sang rouge par la bouche. Cette dernière remarque surtout a son importance, car il est une fraude assez commune qui consiste à gorger les Sangsues arec du sang de Bouf ou de Mouton pour augmenter leur grosseur: or, les Sangsues gorgées sont impropres a la suceion ou du moins sont loin de valoir les Sangsues vierges.

Sourent on jette les Sangsues après qu'elles ont servi; mais il est possible de les faire dégorger, soil avee đu sel, des cendres, de l'eau vinaigrée, ete., soit en les soumetlunt a une douce pression d'arriere en avant. On les conserve ensuite dans des rases à moitié remplis d'eau qu'on renouvelle tous les jours.

Pour conserver, multiplier et mème transporter une petile quantité de Sangsues, on a sourent recours à un petit appareil imaginé par Vaysou, de Bordeaux, et désigné, pour ce motif, sous le nom de vaysonier. C'est un vase en terre cuite, en forme de tronc de còne renversé, percé à sa base de trous très étroits. On y dépose les Sangsues et on le remplit de lêrre tourbeuse, puis on ferme l'orifice supérieur avec une toile grossière. Pour conserrer les animaux sur place, on fait tremper le fond dans une couche d'eau peu épaisse: il se forme alors dans la terre des zones offrant divers degrés d'humidité, le sorte que les Salısues peuvent s’installer à leur guise et mème se reproduire. S'il s'agit simplement de transporter ces animaux, il suffit. d'humecter la terre et d'emballer le vase dans une caisse ou dans un panier.

Pour élever les Sangsues en grand, on établit des marais artificiels à fond d’argile et à nireau constant, traversés par un courant modéré. Les plantes aquatiques sont utiles pour purifier l'eau el abriter les Vers. Outre les bassins de nourviture, où l'on entretient les Sangsues en leur domnant des Grenouilles, Salamandres, etc., ou en leur faisant sucer le sang de vieux chevaux qu'on y promène, il importe d'avoir aussi desbassins de dégorgement, dans lesquels on soumet les Sangsues au jeủne avant de les livrer au commeree. L'hirudiniculture a pris pendant quelque temps un assez grand développement dans le midi de la France, et en particulier dans la Gironde; mais aujourd'hui, la plupart des Sangsues ulilisées en France sont impor-i tées de Hongrie, de Russie, de Turquie, etc.

Emplor médical. - Pour appliquer les Sangsues sur une région déterminée, il convient souven t d'assouplir la peau en la bassinant avec de l'eau liède; on la nettoie et on la rase s'il y a lieu, et au besoin on y étend un peu de lait, d'eau sucrée ou de sang. Enfin, on peut exciter les Sangsues en les touchant avec un peu de vin ou de vinaigre. Si l'on tient ì en fixer une seule sur un point précis, on la place dans un tube de verre ou mieux dans une carte enroulée, qu'on enlère, si l'on veut dès que la Sangsue a mordu. S'il s'agit au contraire d'en appliquer plusieurs à la fois, on les réunit dans un verre ou dans le creux de la main garni d'une compresse. Au bout de trois quarts d'heure à deux heures, les Sangsues se détachent et tombent. On maintient l'écoulement du sang au moyen de compresses imbibées d'eau tiède ou de cataplasmes. Il est rare qu'on ait besoin d'arrêter cet écoulement: on a recours alors à divers hémostatiques.

L'emploi des Sangsues exige quelques précautions : on a vu parfois 
quelques-uns de ces Annélides, mal surveillés, pénétrer dans des cavités naturelles. Il est possible aussi que leur morsure soit suivie, surtout lorsqu'elles ont déjà servi, d'accidents plus ou moins graves, dus sans doute à l'inoculation de produits infectieux.

Or, on possède aujourd'hui des instruments perfectionnés qui peuvent remplir à peu près le même rûle que les Sangsues, avec l'avantage d'une asepsie parfaite; c'est donc aux scarificateurs qu'on devra donner la préférence.

Ajeutons que, par le fait des transformations qu'ont subies les doctrines médicales, la consommation de ces Hirudinées a baissé dans des proportions énormes. De 1830 à 1842, la pharmacie centrale des hôpitaux de Paris achetait en moyenne 828,000 . Sangsues par an; de 1870 à 1873 , ce chiffre était tombé à 32,000 . Il est probable que cette baisse ne fera que s'accentuer.

Sangsue truite (H. troctinu Jolinson, 1816). - Corps subdéprimé, longr de 80 à 100 millimètres, large de 12 à 18 millimètres. Dos généralement verdàtre; garni de six rangées de petites taches ocellées; bords orangés oil rougeâtres; ventre maculé ou non, à bandes marginales en zigzag.

Cette Sangsue se troure en Algérie et dans presque toute la Barbarie. De Filippi l'a recueillie en Sardaigne. Elle est connue dans le commerce sous le nom de Dragon d'Alger. On l'emploie dans les hôpitaux de Paris, en Angleterre, et surtout dans le Midi, bien qu'elle paraisse inférieure à l'espèce précédente.

Genre Limnatis (Limnatis Moquin-Tandon, 1826. - Syn. : Bdella Savigny, juin 1817, nec Latreille, avril 1817; Hirmopis Moq.-Tand., 1826, pro parte). - Lèvre supérieure de la ventouse orale creusée à sa face inférieure d'un sillon longitudinal; mâchoires armées de dents nombreuses et portant des papilles sensorielles.

Espèces d'eau douce.

Limnatis nilotique (L. nilotica [Sarigny]. - Syn. : Btella nilotica Sav., 1820 ; L. nilotica Moq.-Tand., 1826; Hrmopis vorax Moq.-Tand., 1826, pro parte; Hæmopis sanguisuga Moq.-Tand., 1846, nec Hirudo sanguisuga Bergmann, 1757). - Le corps esl subdéprimé, graduellement atténué en avanl, long de 80 à 100 millinètres, large de 10 à 15 millimètres; il est toujours mollasse: "Quand on presse l'animal entre les doigts, dit Moquin-Tandon, il ressemble à une Sangsue médicinale morte ou malade.... Le dos parait brun, verdàtre, tirant quelquefois sur le roussàtre ou sur la terre de Sienne, đaautres fois sur l'olivàtre ou sur le vert. Il présente généralement des rangées longitudinales de points noirs très petits et très rapprochés, plus ou moins effacés. Il y en a six rangées, quelquefois quatre, plus rarement deux. Dans plusieurs individus les rangées sont remplacées par une ou deux larges bandes d'un roux plus ou moins vil, généralement un peu fondues sur les bords. Dans d'autres individus, beaucoup plus rares, le dos est tout à fait unicolore. Les bords sont à peine saillants, avec une bande étroite, orangée, jaunàtre ou brun rouge, bien tranchée, très rarement de la couleur du dos. Le 
ventre est uni, d'un noir d'ardoise, erdinairement plus foncé que le dos, quelque fois un peu roussatre ou olivâtre, d'autres fois d'un noir très net; tantùt marqué de quelques points obscurs, isolés, irréguliers, tantòt immaculé. Les ventouses sont lisses, l'anale de moitié plus grande que l'orale, mince ef de la couleur du ventre. "Moquin-Tandon a établi jusqu’à douze variétés de cette espèce, basées sur les variations de coloration que peut présenter le corps.

La Limnatis nilotique est connue sous les noms vulgaires de Sangsue de Cheval et de Voran; mais il importe de ne pas la confondre, comme on l'a souvent fait jusqu'à présent, avec la Sangsue noire (llemopis sanguisuga [Bergmann] ou Aulastoma gulo Moquin-Tandon), qu’on désigne ì tort, aux environs de Paris, sous ce mème nom de Sangsue de Ciheval (1).

Elle se trouve répandue dans lout le nord de l'Afrique continentale, principalement sur le littoral, depuis le détroit de Gibraltar jusque sur les cotes de Syric. Barlier Webb l'a observee aux Canaries, Th. Barrois aux Açores. En Asie, elle semble occuper aussi une aire considérable. Barrois l'a recueillie en Syrie, Dagavarian en Arménic, Severtzov dans le Turkestan, etc. Enfin, il est probable que c'est également cette espèce quon a signalée dans le midi de l'Espagne et de I'Italie, en Sicile, en Portugal et en Turquie.

En Algérie, on peut dire qu'elle se trouve par-

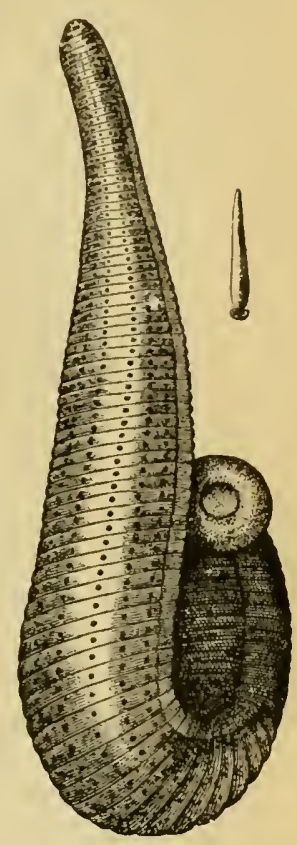

Fig. 401. - Limnatis nilntica, grandeur nalurelle. A droile, un individu jeun. recueili sur la conjonclive d'un Cheval.

tout, mème dans le voisinage du désert; cependant, on cite des localités qui ont la réputation d'en posséder en quantité: telles sont, dans le département d’Alger, Bistradem (fontaine de la servante à 10 kilomètres du chef-lieu; Sidi-Naklouf, caravansérail situé entre Djelfa et Laghouat, à 18 kilomètres de ce dernier point; Chellala, à l'ouest de la route de Laghouat, etc.

Les Limnatis virent dans les mares, les fossés et les pelites sources. Les adultes senfoncent ordinairement dans la vase. Les jeunes semblent préfẻrer les eaux vives; elles se tiennent toujours à lleur d'eau, prètes à se précipiter dans le plus léger courant. Les abreuvoirs sont particulièrement envahis. Des sources, elles passent dans les fontaines, par les aqueducs, de sorte qu'on peut les rencontrer aussi dans les maisons où loon fait usage de l'eau de ces fontaines (Guyon,

(1) R. Buxcmard, Sur la Sangsue de Cheval du nord de l'Afrique (Limnatis nilotica Savigny). Bullet. de la Soc. zool. de France, dVI, p. 218, 1891. 
VERS.

Si dans quelques localités on les observe en toute saison, elles disparaissent toutefois le plus souvent en hiver, et ce n'est guère qu'à partir d'arril et de mai qu'on les aperçoit. En tout cas, elles sont beaucoup plus abondantes en été.

Contrairement à ce qu'ont dit les auteurs anciens, les mâchoires de ces Hirudinées ne sont pas assez puissantes pour attaquer la peau du Cheval, ni même celle de l'Homme: elles ne peuvent inciser que les muqueuses (chaque mâchoire ne porte du reste qu'une-trentaine de denticules, alors qu'on en trouve une soixantaine chez les vraies Sangsues). Aussi les Limnatis cherchent-elles à pénétrer dans les cavités naturelles (1).

Chez l'Homme, on en a trouvé dans la bouche, le pharynx, l'œsophage, l'estomac, les fosses nasales, le larynx, la trachée, le vagin, et sur la conjonctive.

En ce qui concerne les animaux domestiques, les observations n'ont porté jusqu'ì présent que sur le Cheval, le Mulet, le Bœuf, le Chameau (Dromadaire) et le Chien. - Déjà les hippiâtres grecs et romains, notamment Columelle, Apsyrte, Hiéroclès et Pélagone, avaient fait mention des troubles qu'elles peurent occasionner et des moyens mis en usage pour les combattre. Plus près de nous, de nombreux documents ont été recueillis sur ce sujet en Égypte, en Espagne, au Maroc et en Algérie par de nombreux vétérinaires et médecins.

Les Limnatis pénètrent done très fréquemment dans la bouche des animaux qui vont s'abreuver dans les eaux infestées. Comme le faisait déjà remarquer le baron Larrey dans sa Relation de la campagne d'Égypte, c'est surtout dans le jeune ìge qu'elles s'introduisent ainsi dans l'organisme. Filiformes, de teinte noirâtre, longues de 2 ou 3 centimètres, elles n'attirent pas l'attention, et on peut les prendre facilement pour un brin d'herbe.

Elles se fixent de préférence en dessous de la langue, dans le roisinage du frein, mais on les trouve aussi à la face interne des lèvres et des joues, sur les gencives, le palais, le voile du palais, dans le pharynx, le larynx et la trachée. Il n'est pas très rare non plus d'en rencontrer dans les carités nasales, soit qu'elles y aient pénétré directement par les naseaux au moment où les animaux s'abreurent, soit qu'elles aient gagné cette région en passant par le pharynx. - Du reste, la plupart des muqueuses peuvent être atteintes. Bizard nous a communiqué un petit exemplaire d'Hémopis recueilli à Chellala, à la face interne de la paupière inféricure d'un Cheral

(1) Il est bon cependant de faire remarquer que les Limnatis ne sont pas les seules IIirudinées qui soient à redouter à ce point de vue. En Algérie, par exemple, on peut accuser au même titre, d'après Blaise, les diverses espèces de Sangsues qui vivent dans les eaux d'abreuvoir, notamment la Sangsue médicinale et la Sangsue dragon. 
de spahii. Le docteur Guyon en a trouvé dans le vagin de la Vache, de la Jument el de la Ilule.

Elles n'adhèrent à la muqueuse que par leur ventouse anale, promenant la tête çà et là pour recucillir le sang des anciennes morsures ou en effectuer de nouvelles. Elles entament la membrane ì la façon des Sangsues, par le jeu de leurs trois mâchoires denticulées, se gorgent de sang, et grossissent peu à peu. Au bout d'un certain temps, elles abandonnent les muqueuses pour reprendre la vie aquatique. pendant que leur loôte est à l'abreuroir.

Les troubles occasionnés par les Limnatis varient arec leur habitat et avec leur nombre.

Quand il n'en existe que quelques-unes fixées dans la bouche, ce qui est de beaucoup le cas le plus ordinaire, leur présence peut demeurer un certain temps inaperçe. Cependant, lorsque les Équidés sont au travail, la présence du mors entravant plus ou moins la déglutition et maintenant souvent la bouche ouverte, on peut voir du sang s'écouler par les commissures des lèrres. C'est sourent à ce signe qu'on reconnaît la présence des Vers dans la bouche. L'animal peut manifester en outre une certaine difficulté à prendre ou à måcher ses aliments; il arrive même parfois à refuser les aliments solides. L'exploration de la carité buccale, en pareil cas, permettra le plus souvent de reconnaitre la cause de ces manifestations.

Lorsque les Sangsues occupent les cavités nasales, et même le pharynx, clles donnent lieu à un écoulement sanguin plus ou moins abondant, s'effectuant par les naseaux. Si elles ont pénétré dans le larỵn, ou simplement si elles en garnissent l'entrée, elles sont susceptibles de provoquer une dyspnée intense qui peut aller jusqu'à laasphyxie. Dans le cas où elles siègent sur la conjonctive, elles déterminent une inflammation de cet organe.

Mais, quelle que soit la région envahie, les troubles peurent devenir graves pour peu que le nombre des parasites soit élevé. Aldrovande affirmait que neuf Sangsues suffisent pour tuer un Cheval. Cette assertion, reproduite par divers auteurs, et en particulier par Linné, a été sérieusement combattue par d'autres, et, comme il arrive souvent, la réaction a été elle-même exagérée: Huzard et Pelletier ont été jusqu à prétendre que ces Annélides ne pouraient attaquer aucun animal rertébré; ils araient en effet pris, pour la Limnatis nilotique, la Sangsue noire ou Aulastome. La rérité est entre ces deux opinions : Blaise déclare que lorsqu'il était à Constantine, au quartier du Bardo, il n'y arait pas un Cheval, pas un Mulet qui n'cût au moins neuf Sangsues adultes dans les carités nasales, la bouche ou le pharynx; le pharynx d'un Cheral dont il a fait l'autopsie en contenait 185, toutes de la grosseur du petit doigt; deux jours après, Raynaud en trourait 192 réunies au pourtour de la glotte.

Les animaux attaqués de pareille façon ne tardent pas à présenter 
tous les caractères d’une anémie profonde: ils perdent peu à peu l'appétit, deviennent mous, s'essoufflent facilement, sont incapables de fournir le moindre travail; leurs muqueuses pâlissent, leur poil se pique; ils maigrissent rapidement et finissent par succomber si la cause du mal persiste un certain temps.

On ne sait pas encore très exactement quelle peut être la durée de la vie parasitaire de ces Annélides. Des expériences de Guyon montrent cependant qu'elle peut se prolonger au delà d'un mois. En 1868, un vétérinaire anglais en a trouvé dans la bouche de Bœufs marocains expédiés de Tanger le 24 juin et débarqués en Angleterre le 2 juillet. En 1872, Danlos, à Paris, en arait extrait une du pharynx d'un soldat libéré qui avait quitté Oran depuis douze jours. Enfin, Mégnin dit en aroir recueilli à Vincennes dans la bouche de Cheraux qui avaient quitté la Tunisie depuis plus d'un mois.

Le pronostic n'est généralement grave que dans le cas où il en existe un grand nombre dans le pharynx ou l'arrière-fond des cavités nasales, et surtout lorsque, par leur séjour dans le larynx ou au roisinage de cet organe, elles sont susceptibles de provoquer l'asphyxie. - Néarmoins, on peut considérer que les Limnatis constituent un véritable fléau pour les localités où elles abondent. En Algérie et en Tunisie, notamment, elles causent des pertes sérieuses parmi les Bœufs, les Chameaux et les Équidés.

A l'autopsie, on troure les lésions de l'anémie ou de l'asphyxie. Les muqueuses altaquées montrent des traces plus ou moins étendues de congestion et d'œè̀me. Çà et là, on distingue en outre, soit des plaies récentes, soit des taches noires au centre, rouges et infiltrées à la périphérie, qui correspondent à des morsures un peu plus anciennes. Les Sangsues restent assez longtemps fixées à la muqueuse après la mort de l'animal qui les hébergeait; sur un Bœuf abattu à Alger, Guyon a constaté que, douze heures après la mort, elles ne s'étaient pas encore détachées, et adhéraient même à tel point aux muqueuses qu'il fallut, pour leur faire lâcher prise, les toucher arec le doigt mouillé d'alcool.

Comme traitement, il est indiqué tout d'abord de détacher les Vers de la muqueuse sur laquelle ils se sont fixés. Dans les cas où ils sont accessibles, on a recommandé l'avulsion avec des pinces, la section à l'aide de ciseaux, etc. Lorsqu'elles sont fixées dans la bouche du Cheval, par exemple, le plus simple est de les enlever à l'aide de la main entourée d'un linge sec (Abou Belir).

S'il est impossible de les atteindre directement, on peut avoir recours à des gargarismes vinaigrés ou salés, ou encore additionnés de sulfate de soude, de magnésie, d’alun, etc., qui leur font làcher prise. Mais ce procédé ne donne pas toujours de bons résultats, et d'ailleurs il est fort difficile de projeter ces liquides dans l'arrièrebouche, où les Sangsues sont souvent cantonnées. Blaise a employé 
arec un certain succès les fumigations de goudron ou de baies de genièrre, répétées deux fois par jour, matin et soir; cet auteur rapporte en outre que Sourigny introduisait dans le pharynx une sonde en caoutchouc munie à son extrémité d'une éponge imbibée d'éther.

Mais les moyens les plus eflicaces à opposer aux ravages des Limnatis sont d'ordre prophylaclique. Il faut éviter d'abreuver les animaux avec de l'eau contenant ces Sangsues. Or, les filtres métalliques quion a quelquefois placés à l'orifice d'entrée des eaux dans l'abreuroir niarétent que les plus grosses; les petites parviennent toujours à les traverser. Blaise avait obtenu de meilleurs résultats en employant un filtre au charbon; malheureusement, le débit d'un tel filtre doit être assez faible. Enfin Cauvet avait conseillé d interposer sur le trajet des tuyaux un siphon rempli de sable tassé.

Rappelons, en terminant, que Lemichel avait fait disparaitre les Limnalis des eaux destinces ì la garnison de Mustapha en introduisant quelques Anguilles dans le réserroir. Dautres Poissons pourraient rendre le même service.

On cite quelques espèces de Limnalis comme étant usitées en médecine, par exemple:- L. mysomelus (Henry), pelite espèce du Sénésal et du Salıara; - L. grumulosa (Sarigny), de l'Inde, employée par les médecins de Pondichéry, et sourent expédiẻe à Maurice et à la Réunion; donnerail lieu à des lémorragies difficiles à arrèler chez les enfants.

Cienre Hémadipse (Hamadips Tenuent, 1861). - Ce genre comprend uniquement des Hirudinées terrestres, longues de 2 à 3 centimètres au repos, dont les denticules des màchoires sont terminés par une pointe acérée, et dont les morsures sont souvent redoutables pour l'Homme et pour les animaux.

On en connait une douzaine d'espéces, répandues en Asie, en Océanie et jusque dans le sud de l'Amérique. La plus célèbre est l'Hémadipse de Ceylan (II. zeylanica [de Blainville]), qui habite l'île de ce nom, où elle constitue un réritable fléau. Elle vit dans les prairies et les bois lumides, dans lherbe, sous les feuilles mortes, parfois aussi sur les buissons et sur les arbres. Des milliers de ces petits Vers se jettent sur les voyayeurs ou sur leurs montures. Ils attaquent surtout les jambes, pénètrent jusqu’à la peau par les moindres ouvertures des vètements, traversent mène ceux-ci et peuvent sucer le sang durant des heures. Pendant les campagnes des Européens, elles ont causé une certaine mortalité parmi les troupes, en s'attarquant surtout aux soldats endormis. Pour se préserver de leurs atteintes, on recommande de fixer, par-dessus les vêtements qui courrent les jambes, des guêtres ou mieux des bas de cuir ou de laine très épais, qu'on serre au-dessus du genou.

Fanille des RYNCHOBDELLIDÉS. - Les Hirudinées qui composent ce groupe ont le corps allongé et cylindrique ou large et aplati, arec deux ventouses, commeles Sangsues; mais elles possèdent une trompe exsertile au lieu de mâchoires. Il existe deux yeux sur la ventouse antérieure.

Genre Hèmentérie (Hæmenteriı F. De Filippi, 1819). - Le corps est dé- 
primé, large. La bouche est percée, non au fond de la ventouse, mais dans sa lèvre supérieure ou dans sa partie anlérieure. La trompe est longue et étroite. Dans la région moyenne du corps, les $2^{e}$ et $3^{e}$ anneaux de chaque somite sont dédoublés, à la face ventrale, par un profond sillon transrersal.

Les Hémentéries portent leurs œufs et leurs petits fixés sous le ventre. Jusqu’à présent, on ne les a rencontrées qu'en Amérique.

L'Hémentérie officinale (H. officinalis De Fil.) est commune aux environs de Mexico, où elle est employée aux usages médicaux. Elle offre l'arantase de ne produire qu'une blessure insignifiante; par contre, sa piqùre provoque assez souvent des phénomènes inflammatoires, de l'urticaire el mème des troubles généraux graves, avec manifestations cérébrales, troubles qui, heureusement, disparaissent d'ordinaire en peu de temps (Niguel Jimenez). La cause deces accidents n'est pas encore bien connue; on sait cependant qu'ils ne se produisent que quand les Hémentéries sont conservées dans des eaux croupissantes ou directement recueillies dans les marécages; ils n’apparaissent d'ailleurs que chez des sujets prédisposés.

Au mème groupe appartient le genre Glossiphonie (Glossiphonia Johnson, 1816), qui comprend des espèces de petile taille, virant dans les lacs, les sources el les ruisseaux.

La Glossiphonie marquetée (Gl. tesselluta [0. F. Müller]) vit dans une grande partie de l'Europe et même en Amérique; elle n'a encore été que rarement signalée en France. Elle se fixe très volontiers au corps des Échassiers et des Palmipèdes qui virent sur les étangs (J. de Guerne); parfois elle pénètre dans les carités naturelles pour atteindre les muqueuses. Weltner rapporte que dans une ferme du village de Wanzenau, près de Strasbourgr, une bande d'Oies et une bande de Canards furent presque détruites par celte Hirudinée: les Oiseaux atleints se montraient tourmentés et maigrissaient rapidement; à lautopsie, on trouvait un certain nombre de Sangsues marquetées fixées dans l'œsophage.

Peut-ètre pourrait-on rapprocher de ce fait une observation trèsincomplète de Small, recueillie en Irlande. Ce vétérinaire rapporte que les Oies d'une basse-cour devenaient toutes aveugles et langruissantes: l'une d'elles ayant été sacrifiée, on ouvrit le globe oculaire, et il en sortit un petit Ver noir "semblable à une jeune Sangsue»; ce Ver était doué d'un grande rivacité et nageait avec aisance dans l'eau.

SOUS-CLASSE IV

\section{CHE்TOPODES}

Annélides dépourvus de ventouses, mais possédant des faisceaux de soies pairs implantés dans des cryptes ou sur des pieds inarticulés (parapodes).

Les Chétopodes (yairn, soie; $\pi \iota_{5}$, pied) représentent le type le plus complet des Annélides. Ils ont le corps cylindrique ou aplati, divisé en un certain nombre d'anneaux qui correspondent, soit à autant de segments internes, soit à un nombre moindre de ces segments. Les anneaux sont à peu près semblables entre eux, sauf ceux de la région antérieure. 
Il nexiste pas de ventouses comme chez les llirudinées, mais les anneaux portent toujours des soies, qui sont tantòt implantées dans des refoulenents de l'enveloppe tégumentaire, tantỏl portées par des pieds siallants non articulés, ou parapodes. Dans tous les cas, ces soies, de nature cuticulaire, sont réunies en faisceaux qui occupent les parties latérales des anneaux.

Presque tous les Chétopodes vivent en liberté dans l'eau, surtout dans la mer, ou dans les fonds vaseux, plus rarement dans le sol humide.

2orilres:

Pas de parapodes. Pas de métamorphoses......... OLIGocitètes.

Des parapodes. Des métamorphoses............ P'olicnétes.

1 ${ }^{\text {cr }}$ ordre: Oligochètes. - Chélopodes à soies peu nombreuses fixées duns des cryptes. Jamais de parapodes, de tentacules, de cirres ni de branthics. Ilonuiques. Développement sans métamorphoses.

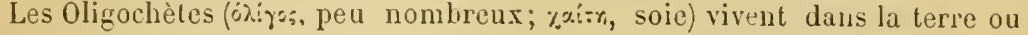
dans l'eau douce. On les divise en deux sous-ordres: les Terricoles et les Limicolcs.

I. Les Oligochites terricules sont pour la plupart, comme leur nom l'indique, des Vers terrestres; ils sont caractérisés principalement par la présence de canaux déférents et d'oviductes spéciaux disposés au voisina gre des organes segmentaires.

Ce groupe ne comprend qu'une seule famille: celle des Lombries ou Vers de terre, dont les représentants les plus comnus forment le genre Lumbricus $\mathrm{L}$. Ce genre ne renferme qu'un petit nombre d'espèces, parmi lesquelles on peut citer le Lombric terrestre (L. terrestris L., L. ayricola Ifofm. ), d'assez grandes dimensions, et le Lombric commun ( $L$. communis Halfm.) notablement plus petit.

Darwin a mis en lumière l'importance du ròle que jouent ces Vers dans les phénomènes géologiques actuels. Ils vivent pendant le jour dans les trous qu'ils se sont creusés dans la terre, mais ils en sortent la nuit. Ils mangent des feuilles, de la viande, le la graisse et mème les cadavres de leurs semblables. Ils ingurgitent aussi en partie la lerre qui leur fait obstacle lorsqu'ils creusent leurs galeries. La nuil venue, ils gagnent la surface du sol, où ils expulsent cette terre par l'anus: c'est ce qui constitue ces tortillons si abondants parfois dans les jardins. Darwin a reconnu que, de ce chef, il se forme annuellement à la surface de la terre une couche épaisse de 3 à ö millimètres. D'autre part, les Vers attirent les feuilles dans le sol, non seulement pour s'en nourrir, mais aussi pour tapisser leur tanière ; ils concourent de la sorte à leur décomposition et à la formation de la terre végétale.

Enfin, d'après Pasteur, ils pourraient ramener à la surface de sol des éléments infectieux enfouis depuis longtemps, notamment les spores du Bacille charbonneux (Bucillus anthracis).

Ces Vers ont une grande puissance de rédintégration.

Divers auteurs anciens ont relaté des cas de Lombrics rejetés par des malades. Il s'agissait sans doute le plus souvent d'Ascarides; peut-ètre faut-il admettre en outre des cas de simulation: au surplus, il n'est pas prouvé qu'un Lombric puisse vivre au delà de quelques heures clans le corps d'un Homme ou d'un animal. 
II. Quant aux Oligochètes limicoles, ce sont des Annélides dont les organes segmentaires, dans les anneaux génitaux, remplissent le ròle de spermiductes et d'oviductes. La plupart sont aquatiques. - Genres Tubifex, Nais, Enchytræus, etc.

En 1839, Curling décrivit, sous le nom de Dactylius aculeatus, un prétendu parasite qu'une fillette de cinq ans rendait avec les urines. Henle reconnut qu'il s'agissait de l'Enchytræus albidus. On peut s'expliquer ce cas de pseudo-parasitisme, soit par la présence des Vers dans l'eau servant à nettoyer le vase de nuit, soit par leur introduction accidentelle dans le vestibule.

Bügel, médecin dans l'île de Möen (Danemark), a observé plus ré cemment une paysanne de vingt-neuf ans, arrivée à la fin de sa deuxième grossesse, et accusant des chatouillements dans la bouche et le pharynx, avec production exagérée de salive. Cette femme découvrit un jour dans sa salive de nombreux petits Vers vivants, longs de 4 à 12 millimètres, que Bergh reconnut pour Enchytræus Buchholzi. Cet Annélide avait sans doute pénétré avec l'eau de boisson dans l'estomac, où sa cuticule l'avait protégé contre l'action du suc gastrique. Pourtant, on ne le retrouva point dans le puits où la pátiente puisait exclusivement son eau.

$2^{2}$ ordre: Polychètes. - Chétopodes munis de parapodes qui portent de nomhreuses soies et en générul des tentacules, les cirres et des branchies. Ordinaire ment dioiques. Développement avec métamorphoses.

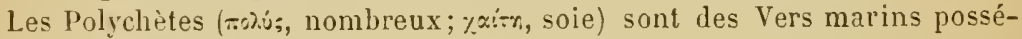
dant une orsanisation relativement élevée. Deux sous-ordres : les Sédentaires et les Errants.

I. L.es Polychètes sédentaires ont une tête peu distincte et une trompe courte, mais ils sont dépourvus de màchoires. Ils vivent pour la plupart dans des Lubes qu'ils sécrètent ou se construisent, ce qui les a fait souvent appeler tubicoles. - Tels sont les Térébelles, les Serpules, les Arénicoles, etc.

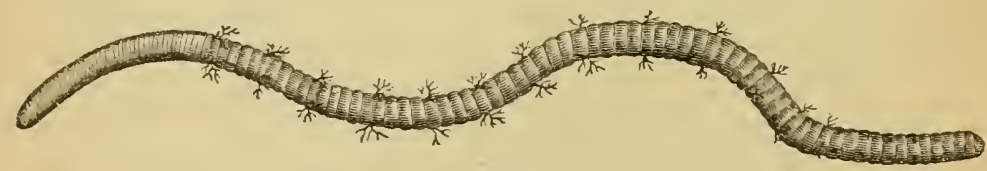

Fig. 402. - Arénicole des pêcheurs.

L'Arénicole des pècheurs (Arenicola piscatorum) vit dans le sable des plages, où il se creuse une galerie en $U$; il sert d'amorce aux pècheurs.

II. Les Polychètes errants, encore appelés Yéréides, ont une tète distincte, portant des yeux, des tentacules, des palpes et souvent des cirres tentaculaires. La partie antérieure du pharynx est protractile et munie parfois d'un appareil masticateur. Ces Annélides sont carnassiers; ils vivent en liberté dans la mer ou habitent temporairement des tubes membraneux. - Ex. : les 
Aphrodites ou Souris de mer, les Eunices, les Néréides, etc. Certaines espèces, comme IIarphysa sanguinea, ont des michoires assez puissantes pour renhre leur morsure redoutable (de Quatrefages, J. de Guerne).

\section{CINQUIEME EMBRANGHEMENT}

\section{ARTHROPODES}

Animaux à symétrie bilatérale, à corps formé d'articles dissemblables (hétéronomes), pourvus de membres articulés.

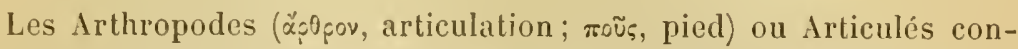
dỵlopodes (xóyôvios, articulation) élaient autrefois réunis aux Vers pour constituer le grand groupe des Annelés ou Articulés. De mème que certains Vers, en effet, ils sont tous formés d'une succession d'articles; mais ils possèdent, de plus, des appendices ou membres articulés. - La partie de la zoologic qui traite des Arthropodes porte le

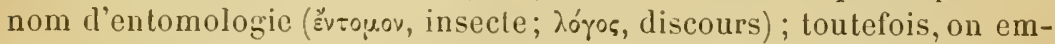
ploie les termes de carcinologie, arachnologie ou myriologie, lor'squ'il s’agit de l'étude spéciale des Crustacés, des Arachnides ou des Myriapodes.

La conforination générale des Arthropodes se rattache à la symétrie bilatérale. En outre, on peut loujours distinguer, dans le corps de ces animaux, une face dorsale ou hémale, vers laquelle se troure situé le cœur, et une face ventrale ou neurale, caractérisée par la position du système nerreux. A l'extérieur, le corps se montre divisé, aussi bien chez les individus adultes que dans les formes embryonnaires, en un nombre rariable de segments annulaires solides.

Le tégument offre une couche cuticulaire de nature chitineuse, parfois incrustée de sels calcaires et constituant un véritable squelette externe ou exosquelette. Cette enveloppe est produite, comme la cuticule des Vers, par une couche sous-cuticulaire, formée de cellules juxtaposées. - La résistance de ce revêtement s'opposerait, on le concoit, à la croissance des animaux; aussi se détache-t-il, de temps à autre, pour être remplacé par un plus ample: ces changements de peau ou mues se renourellent à des époques déterminées, soit dans l'état larvaire seulement, soit même, comme chez les Crustacés, durant une grande partie de l'existence.

Les segments chitineux annulaires sont unis entre eux par des portions plus souples du tégument. Chacun de ces anneaux, lorsqu'il offre une organisation complète, porte dans sa zone ventrale une paire d'appendices articulés; plus rarement, on observe des appendices dans la région dorsale: telles sont cependant les ailes des Insectes. On donne à ces articles du corps, y compris la partie correspondante des organes internes, le nom de métamères ou zoonites, chacun 
de ceux-ci se composant d'une partie centrale ou somite et en général d'une paire d'appendices. Un des principaux caractères des Arthro-

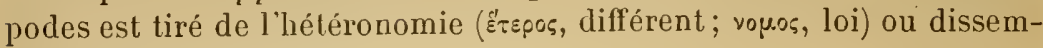
blance des métamères.

L'anneau qui constitue l'exosquelette d'un somite est formé de pièces tantôt assez distinctes, tantôt unies sans traces de séparation, et qui recoivent le nom de tegmites (tegmen, enveloppe). Ces pièces, symétriquement disposées par rapport à un plan médian, constituent deux arceaux: l'un supérieur ou tergal, l'autre ventral ou sternal. D'après H. Milne-Edwards, chacun de ces arceaux présente, comme composition typique, deux paires de tegmites

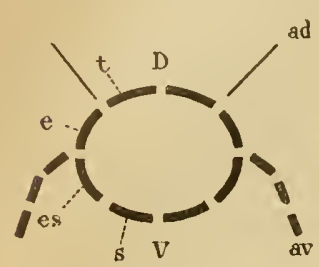

Fig. 403. - Sclééma de la constitution squelettique d'un métamère d'Arthropode. - D, arceau dorsal. $V$, arceau ventral. $t$, tergite. e, épimérite. es, épisternite. $s$, sternite. $a d$, appendice dorsal. $a v$, appeudice ventral.

(fig. 403); dans l'arceau tergal, les deux pièces supérieures sont nommées tergites, et les deux latérales, épimères ou épimérites; de même, les pièces médianes de l'arceau inférieur sont appelées sternites et les autres épisternites. Beaucoup d'auteurs, toutefois, considérant que l'arceau ventral est plus étendu que l'arceau dorsal, y rattachent les épimères. De cette façon, l'arceau dorsal ne comprend que les deux tergites, dont la réunion forme le tergum ou notum, tandis que l'arceau ventral (pectus) offre, d'une part, deux sternites constituantle sternum, et d'autre part, deux épisternums et deux épimères, représentant les flancs (pleur'x).

Quant aux appendices, ils s'insèrent entre l'épisternum et l'épimère: c'est du moins ce qui a lieu pour les membres proprement dits. Les ailes appartiennent à. l'arceau tergal et prennent leur insertion entre le tergum et l'épimère.

De même que les tegmites, les anneaux peuvent se grouper, se souder entre eux, et leur division virtuelle n'est souvent indiquée que par la présence des appendices, qui existent dans tout anneau complet. Par suite de ce groupement et des modifications corrélatives que présentent les appendices, le corps des Arthropodes se trouve généralement divisé en trois régions: la tête, le thorax et l'abdomen. Chez la plupart des Arachnides, cependant, et chez un certain nombre de Crustacés, la tête se soude au thorax pour former une région complexe appelée céphalothorax. L'abdomen peut même participer à cette fusion, comme on le voit chez les Acariens. Les Myriapodes, enfin, ont la tête distincte du reste du corps; mais on n'observe dans ce tronc aucune division en thorax et en abdomen. - Les appendices de la région céphalique sont affectés, soit aux sensations (tiges oculifères, antennes), soit à la préhension ou à la mastication des aliments (appendices buccaux ou gnathites); plus rarement, ce sont des organes de fixation ou de locomotion. Les appendices thoraciques 
servent surtout à la locomotion. Enfin, ceux de l’abdomen, qui manquent souvent, dailleurs, sont employés à la locomotion ou ì la respiration, ou destinés à porter les oufs, ou bien encore représentent des organes copulateur's.

Les muscles des Arthropodes ne s'unissent pas au tégunent comme ceux rles Vers, pour former une enveloppe musculo-cutanée. Ils oflient des filisceaux distincts de fibres, qui s̈̈nsèrent al la lace interne des anneaux ou sur des sortes d'apophyses internes connues sous le nom d'apolèmes. Les fibres musculaires sont strices transversalement.

Dans ses traits généraux, le systeme nerveux concorde avec celui des Aunélides. Il comprend, en cflet: $1^{\circ}$ un cerveau, constitué par une paire de ganglions sus-cesophagiens accolés, fusionnés parfois en une masse unique, et fournissant des nerfs aux appendices sensoríels de la tête (yeux, antennes, etc.); $2^{\circ}$ une chaîne ganglionnaire ventrale, composée de deux cordons longitudinaux plus ou moins rapprochés et souvent même confondus sur la ligne médiane, au-dessous du tube digestif. Les premiers ganglions de la chaine ventrale, ou ganglions sous-œsophagiens, sont réunis au cerveau par un double connectif qui embrasse l'csophage et forme un collier wsophagien. D'ordinaire, chaque somite possède une paire de ganglions; mais, si les segments se fusionnent, on observe une concentration analogue des masses ganglionnaires correspondantes. - Le cerreau est le siège de la volonté et de la coordination des mouvements; il joue en outre le ròle de centre moteur et sensitif à l'égard des appendices sensoriels céphaliques, comme la masse sous-œsophagienne à

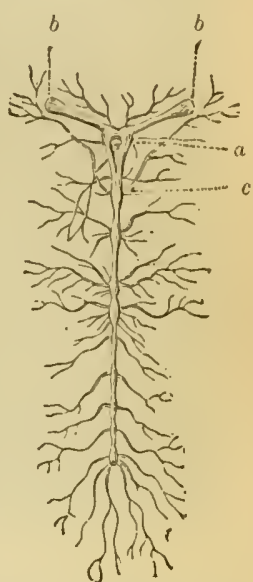

Fig. 404. - Système nerveux de la vie de relation d'un Insecte. $a$, collier asophagien. $b, b$, nerfs opliques. $c$, chaine ganglionnaire ventrale. l'égard des gnathites.

D'aprìs Viallanes et Saint-Remy, le cerveau des Insectes et des Myriapodes comprend trois masses ou segments : $1^{\circ}$ le protocérébron, formé de deux lobes optiques latéraux el de deux lobes frontaux médians; c'est le siège de la volonté, le centre des sensations spéciales ; - le deutocérébron, constitué par deux lobes antennaires inférieurs; 3० le tritocérébron, innervant la lèvre supérieure. Chez les Arachnides, le deutocérébron manque entièrement, ce qui implique l'absence du deuxième zoonite céphalique et par conséquent des antennes. Chez les Crustacés, il innerve les premières antennes, et le tritocérébron les an tennes externes.

Les ganglions de la chaine ventralc fournissent des nerfs mixtes aux somites qui les renferment; mais les racines sensitives ne tirent pas spécialement leur origine de la face inférieure de la chaine, et les racines motrices, de la face supérieure (E. Yung). 
Outre le système nerveux de la vie de relation, il existe un système nerveux viscéral ou de la vie organique, composé de deux groupes de petits ganglions et de filets nerveux très délicats : $1^{\circ}$ le groupe antérieur ou système stomato-gastrique, qui naît du cerveau et consiste en un plexus muni de ganglions accompagnant l'intestin buccal et distribuant des filets aux appareils digestif, circulatoire et respiratoire: on l'a comparé au nerf pneumogastrique des Vertébrés; $2^{\circ}$ le groupe postérieur, qui émane de la chaîne ventrale; les plexus qu'il forme se dis-

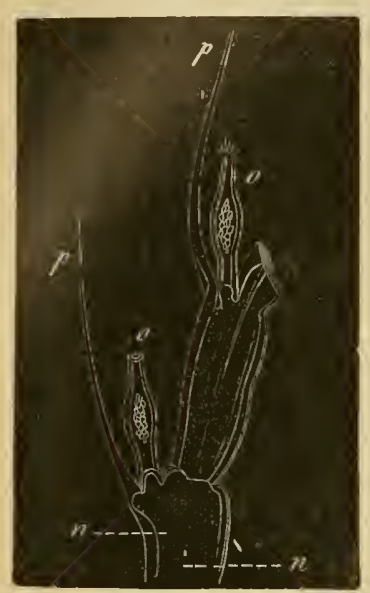

Fig. 405. - Portion d'nne antennule d'Asellus aquaticus, montrant l'appareil olfaclif, d'après Leydig et Nuhn. - $n, n$, trajet 3 des filets nerveux. $p, p$, soies protectrices. 0 , cônes olfactifs. tribuent surtout au tube intestinal et aux organes génitaux : aussi l'assimile-t-on au grand sympathique des Vertébrés.

Les organes sensoriels sont en général bien déreloppés. La plupart des Arthropodes sont pourvus d'une ou de deux paires d'appendices céphaliques, les antennes, qui sont surtout destinées au tact, mais paraissent aussi porter, dans certains cas, des organes olfactifs. Le toucher s'effectue également par les palpes, appendices secondaires annexés aux gnathites, et même par les extrémités des pattes, parties munies, comme les antennes, de baguettes tactiles analogues à celles des Vers. - Les organes auditifs n'ont guère été reconnus que chez les Crustacés : ce sont des otocystes, vésicules formées par une invagination du tégument, et tantôt ouvertes, tantôt fermées. Elles renferment des corps solides ou otolithes, et la cuticule qui les tapisse est garnie de " poils auditifs " en relation par leur base avec des terminaisons nerveuses. On a trouvé chez quelques lnsectes des organes analogues.

Les yeux, placés d'ordinaire sur la tête, font rarement défaut. Parfois, ce sont de simples taches de pigment situées sur le cerveau: on leur donne alors le nom d'yeux pigmentaires. Mais d'ordinaire l'appareil percepteur, plus complexe, consiste en des pièces allongées en forme de pyramides, les bátonnets optiques. Ces pièces, entourées d'une gaine pigmentaire, se composent de deux parties placées bout à bout: $1^{\circ}$ une portion profonde ou bátonnet proprement dit (rétinule des auteurs allemands), en connexion par sa partie effilée profonde arec les éléments du nerf optique: c'est surtout cette partie don t la gaine est chargée de pigment, et c'est elle, par suite, qui représente plus spécialement l'élément percepteur; $2^{\circ}$ une portion externe, d'apparence hyaline, appelée cône cristallin: on la regarde comme un appareil destiné à produire la convergence des rayons lumineux. Il 
faut ajouter que la surface externe de ces pyramides visuelles est revètue parr la cuticule, qui souvent devient transparente et constitue ainsi une cornée. Tous ces yeux à bàtonnets sont appelés ycux rétiniens. Lorsqui ils sont recouverts par le tégument non modifié, comme chez beaucoup de Crustacés inférieurs, on les qualifie d'yeux rétinims intemes, et on les distingue en yeux simples el yeux composés suivant qu'ils comprennent un seul ou plusieurs bâtonnets. Lorsqu'ils sont au contraire revètus d'une cornée, se sont des yeux rétimiens erternes, divisibles également en yeux simples, à un seul bầtonnet recouvert par une cornée Ienticulaire (Corycieidés), et yeux composés, formés par la réunion de plusicurs bâtonnets. Ces derniers sont partois recouverts par une cornée simple, commune: on les appelle alors stemmates ou ocelles. Mais le plus souvent ils sont pourvus de cornées multiples, tantôt distinctes seulement à l'intérieur, comme dans les yeux ì cornée lisse des Daphnies, tantòt reconnaissables même à l'extérieur, comme dans les yeux réticulés ou à facettes si communs chez les Insectes. Dans les ouvrages d'entomologie, e'est en général à ces seuls yeux ì facettes qu'on donne le nom d'yeux composés. - Daprès P. Bert, les Arthropodes ne percevraient pas de rayons du spectre solaire autres que ceux que nous royons; cependant, sir John Lubbock a fait des expériences desquelles il conclut que les Fourmis perçoivent les rayons ultra-violets, qui, pour nous, ne sont pas visibles.

L'appareil digestif est toujours complet dans les formes adultes; on peut \& reconnaitre, dans tous les cas, les trois divisions que nous arons signalées chez les Vers: intestin buccal, moyen et terminal. II cst situé entre la chaine nerveuse et le cœur. La bouche, qui s’ourre à la face inféricure de la tête, est entourée dappendices particuliers ou gnathites propres à broyer, à lécher, à sucer ou à piquer; mais il est à remarquer que ces pièces buceales, au lieu de se mouvoir de haut en bas, comme les mâchoires des Vertébrés, agissent dans le sens latéral. L'intestin buccal comprend un esophage étroit, ofrrant parfois des dilatations ou poches plus ou moins complexes; des glandes salivaires y sont annexées. L'intestin moyen est parfois dilaté sur toute sa longueur et reçoit alors le nom "d'intestin chylifique "; d'autres fois, il présente seulement à sa naissance une dilatation restreinte, le "ventricule ou estomac chylifique "; il se distingue par la présence d’appendices ceccaux ou de glandes variées (prétendus appendices hépatiques, hépatopaneréas). Quant à lintestin terminal, d'ordinaire assez court, il porte souvent à son origine, surtoul chez les Trachéates, des organes excréteurs sous forme d'appendices tubuleux, appelés tubes de Malpighi; il peut en outre offrir, à son extrémité postérieure, diverses autres glandes.

La circulation, lacunaire dans les formes inférieures, s'effectue ailleurs sous l'influence d'un organe contractile central, toujours arté- 
riel, le creur ou vaisseau dorsal. C'est une ampoule ou un tube allongé, divisé en chambres, qui se trouve plongé dans une cavité péricardique, au sein de laquelle le sang fait retour après son passage dans l'appareil respiratoire. Des orifices en forme de boutonnière permettent l'entrée dı sang dans le cœur ; de là, il est lancé en avant et répandu dans les lacunes interorganiques et dans la cavité générale; le retour a lieu par des lacunes veineuses sans parois spéciales. Le système vasculaire peut se compliquer par suite de la localisation de la fonction respiratoire, mais il n’est jamais complètement clos. Par suite, le sang est moins différencié que chez les Annélides; il est quelquefois chargé de globules, mais la coloration qu'il peut offrir exceptionnellement est toujours propre au plasma, qui joue à la fois le rôle de véhicule des substances nutritives et de véhicule de l'oxygène.

La respiration est parfois cutanée, surtout dans les formes aquatiques. Mais, le plus sourent, elle s'accomplit à l'aide d'organes spé-

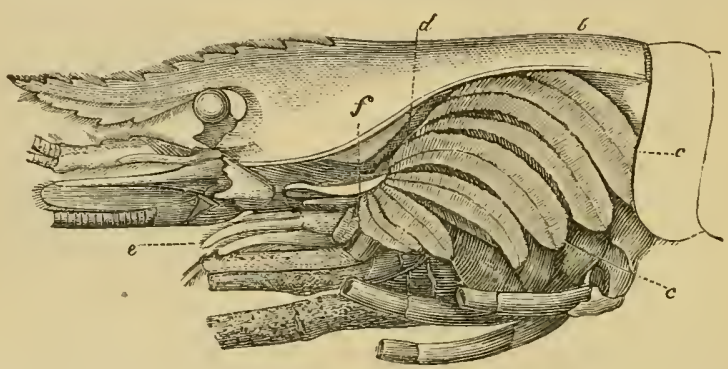

Fig. 406. - Appareil respiratoire du Palémon porte-scie (Palæmon servatus). — $b$, partie supérieure du céphalothorax. $c, c$, branchies. $d$, 'canal afférent de l'eau. $e$, pattes-mâchoires.

ciaux, variables suivant le mode de vie des animaux. Les Crustacés (Branchiés) respirent par des branchies, expansions membraneuses ou filamenteuses dans lesquelles arrive le sang veineux, qui en sort artérialisé par l'action de l'air dissous dans l'eau. Les Arachnides, Myriapodes et Insectes (Trachéates) ont, au contraire, une respiration aérienne, s'accomplissant à l'aide de trachées. Ce sont des tubes aérifères qui très généralement se ramifient à l'intérieur dı corps et s'ouvrent ì la surface par des orifices appelés stigmales, presque toujours disposés symétriquement sur les côtés et entourés d'un épaississement chitineux ou péritrème. Chacun des tubes trachéens représente une sorte d'invagination des téguments; il est done formé par deux tuniques principales : l'externe cellulaire, continue arec la conche sous-cuticulaire; l'interne chitineuse, continue arec le revêtement chitineux du corps. De plus, cette tunique interne est renforcée par des épaississements qui forment, dans la lumière du tube, comme un fil spiral saillant, destiné à la maintenir béante. Ces épaississements font toutefois défaut dans les renflements vésiculeux que présentent les trachées de certains Insectes plongeurs (Hydrophiles) 
ou it vol soutenu (Hanneton). Le mécanisme de la respiration trachéenne est fort simple : l'animal, dilatant son corps, et surtout son abdomen, introduit l'air dans les trachées, puis il l'expulse par un mourement de contraction. Les stigmates se ferment à la rolonté de l'animal : c'est ce qui explique comment des Insectes peuvent, pendant un certain temps, continuer ì vivre dans des gaz très délétères, ou résister à la submersion, comme on le constate pour les Chenilles et les Phylloxéras. On sait d'autre part, depuis Malpighi, que l'obstruction des stigmates par des corps gras détermine rapidement l'asphyxie (Poux).

Un certain nombre d'Arthropodes aquatiques respirent au moyen d'un système trachéen ouvert, en venant chercher l'air à la surface : telles sont les larres de Cousins. Chez la plupart, cependant, les tra-

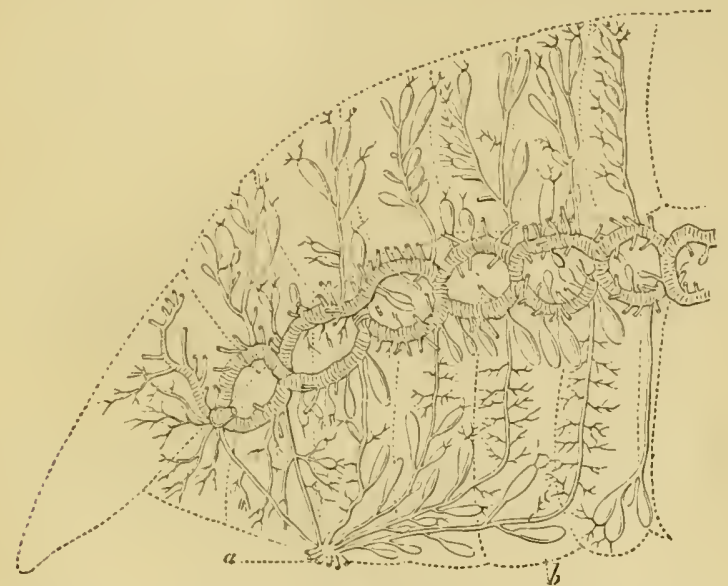

Fig. 40\%. - Moitié droite de l'abdomen d'uu Hanneton, grossie huit fois pour montrer, par sa face interne, la première couche de trachées. - $a$, faisceau de trachées vésiculaires. $b$, vésicule (StrausDurckeim).

chées sont dépourvues de stigmates (larves d'Êphémères) et reçoivent alors le nom de trachées astigmatiques : elles sont d'ordinaire ramifiées dans des appendices membraneux (trachées branchiales) situés sur les anneaux de l'abdomen; l'air dissous dans l'eau se sépare du liquide en traversant la membrane et arrive à l'état de gaz dans les trachées, de sorte qu'en réalité la respiration est encore aérienne.

Chez les Aranéides et les Scorpionides, le système trachéen subit une transformation toute particulière. Les trachées provenant d' tronc commun parti d'un stigmate prennent la forme de lamelles creuses, larges et courtes, réunies à la façon des feuillets d'un livre: ces organes reçoivent le nom de poumons (pseudo-poumons, phyllotrachées). 
Autour des intestins, dans la carité viscérale des Arthropodes, on trouve souvent une masse cellulaire connue sous le nom de corps adipeux. Ces cellules, qui se remplissent presque toujours de gouttelettes graisseuses, représentent les matériaux non utilisés dans le développement de l'animal; chez les Insectes, elles sont en partie consommées pendant la phase nymphale. Tous les Trachéates offrent d'ailleurs de nombreuses ramifications trachéennes parmi ces dépôts de graisse, auxquels on a attribıé un rôle important dans les échanges respiratoires. On sait que certains Arthropodes consomment une quantité considérable d'oxygène et développent beaucoup de chaleur. Il en est aussi qui produisent de la lumière, et l'on a constaté que les organes lumineux des Lampyridés et des Elatéridés ne sont pas sans offrir beaucoup de rapports avec le corps adipeux.

Nous avons déjà signalé, comme organes d'excrétion, les vaisseaux de Malpighi qui s'ouvrent dans l'intestin terminal de beaucoup de Trachéates. Chez les Crustacés, au contraire, on observe des glandes tubuleuses indépendantes du tube digestif et s'ouvrant à l'extérieur, comme les organes segmentaires des Vers; mais il n'est pas établi que ces glandes débouchent dans la cavité générale. Seuls, les Péripates présentent de réritables organes segmentaires inettant en communication, comme chez les Vers, la cavité du corps avec l'extérieur. Le liquide produit par les organes excréteurs renferme de l'acide urique et des urates chez les Insectes et les Myriapodes; il contient de la guanine chez les Arachnides et les Crustacés.

La reproduction est toujours sexuelle; de plus, la séparation des sexes est la règle, et les différences qu'ils présentent sont quelquefois très accusées. Les Cirripèdes et les Tardigrades seuls sont hermaphrodites. Dans quelques cas, comme nous le verrons chez les Pucerons et les Phylloxéras, par exemple, la reproduction a lieu par parthénogenèse. Les organes sexuels sont plus parfaitement organisés que chez les Vers, et surtout plus centralisés : on trouve toujours des glandes génitales distinctes, paires ou impaires, avec des conduits vecteurs plus ou moins compliqués. Dans l'appareil femelle, une partie de l'oviducte est dilatée et fonctionne comme utérus : c'est là que les ceufs s'enveloppent d'une coque; de plus, il y est annexé une cavité destinée à recevoir le sperme lors de l'accouplement: c'est le réceptacle séminal, ou poche copulatrice. L'appareil mâle, de son côté, présente une dilatation du canal déférent, la vésicule séminale, qui sert de réservoir pour le sperme. Des glandes annexées à ce canal fournissent des produits divers, dont le plus remarquable sert à l'agglutination des spermatozoïdes en petites masses entourées d'une enveloppe spéciale (spermatophores). Tantôt l'extrémité du canal déférent constitue une sorte de pénis, tantot il existe des organes copula. teurs spéciaux, résultant de la modification de certains appendices ou même de segments entiers du corps. 
Les Arthropodes sont surtout oripares, mais on constate aussi de nombreux cas d'oroviviparité.

Il est difficile de donner une idée d'ensemble du développement embryonnaire. L'ónf étant controlécithe, la segmentation est partielle et périphérique; mais elle s'effectue selon des modes très rariés, dans le détail desquels nous ne pourons entrer ici. Disons seulement que, d'une manière générale, elle aboutit à la formation d'une couche cellulaire continue ou blastoderme, enveloppant un vitellus nutritif central, destiné à l'alimentation de l'embryon.

Celui-ci, non plus que l'adulte, ne se montre jamais revêtu de cils vibratiles. Au moment de l'éclosion, le jeune animal présente quelquefois la forme de ses parents (Eerevisses, Araignées, Poux). Mais, le plus souvent, le développement s’accompagne de métamorphoses plus ou moins compliquées, dont nous nous occuperons surtoul i propos des Insectes. Ces métamorphoses sont d'ordinaire progressires; parfois cependant, sous linfluence du parasitisme, elles offrent des phénomènes de régression bien marqués, ainsi qu'on le verra chez les Linguatules.

\section{วั classes :}

Respiration arquatique: 12 paires d'antennes............. Crustacés.

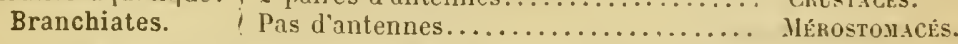

\begin{tabular}{|c|c|c|c|}
\hline & $\begin{array}{l}\text { Des organes se } \\
\text { Protrach }\end{array}$ & ǵmentaires : $\{$ Lne paire d'antennes. & Oxychophones. \\
\hline $\begin{array}{l}\text { Respiration } \\
\text { aérienne. }\end{array}$ & $\begin{array}{l}\text { Pas dorganes } \\
\text { segmentaires: } \\
\text { Trachéates. }\end{array}$ & 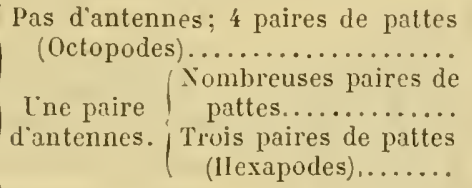 & $\begin{array}{l}\text { Arachiddes. } \\
\text { Mrriapones. } \\
\text { Ixsectes. }\end{array}$ \\
\hline
\end{tabular}

\section{CLASSE I}

\section{GRUSTACÉS}

Arthropodes à respiration aquatique, soit branchiale, soit cutanée: tête habituellement soudée au thorax et munie de deux paires d'antennes: nombreuses paires de pattes au thorax et souvent aussi à l'abdomen.

Les Crustacés, autrefois classés, comme les Arachnides et les Myriapodes, parmi les Insectes aptères, doivent leur nom à la consisłance de leurs téguments. Souvent, en effet, ceux-ci acquièrent une dureté pierreuse (crustr, croùte) par suite du dépôt de matière calcaire dans leur cuticule. On sait d'ailleurs que celle-ci se détache et se renouvelle à certaines époques. pour permettre le déreloppement des organes internes, et que ces mues se répètent pendant toute la période de croissance. La nouvelle cuticule n’acquiert qu'au bout de quelques jours sa solidité normale, et dans cet 
intervalle les animaux se montrent souvent très craintifs. Les Crustacés supérieurs ou Malacostracés possèdent, pour la plupart, le nombre typique

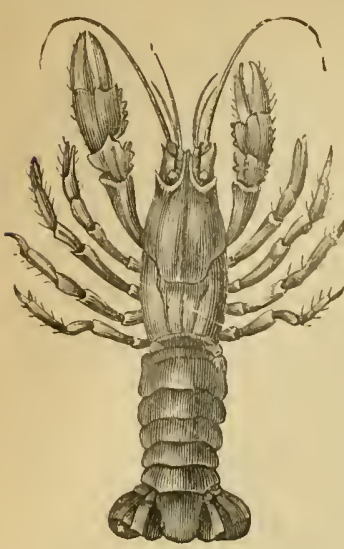

Fig. 408. - Écrevisse commune (Astacus fluviatilis). de somites, qui est de vingt et un, soit six pour la lète, luit pour le thorax et sept pour l'abdomen. Chez les Entomostracés, qui ont les léguments plus minces, le nombre des somites est très variable; quelquefois, le corps est revêtu d'une coquille calcaire bivalve ou multivalve.

La tète est, dans certains cas, mobile et distincte; mais le plus souvent elle se soude avec un ou plusieurs segments thoraciques pour former une rarapace ou céphalothorax. Elle porte d'ordinaire deux yeux et deux paires d'antennes : les antérieures ou internes sont dites antennules; les autres sont les antennes proprement dites. Les appendices suivants, placés autour de la bouche, servent a la préhension ou à la division des aliments : ils comprennent une paire de manlibules et en général deux paires de mâchoires.

Les premiers appendices de la région thoracique fonctionnent aussi comme pièces buccales ou gnathites : ils constituent les pattes-mâchoires, souvent au nombre de trois paires. Les autres servent surlout d'organes locomoteurs (pattes ambulatoires).

Quant aux appendices abdominaux, ils peuvent être également propres à

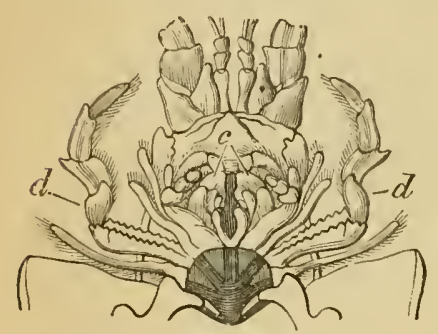

Fig. 409. - Appareil masticateur du Homard, vu par sa face inféricure. En avant, se voient les antennules et les antennes. - $c$, mandibules, suivies de deux paires de mâchoires et de trois paires de pattes-mâchoires, dont la deruière est en $d$. dinaire annexés aux gnathites. Les yeux sont tantòt simples, tantòt composés (à cornée lisse ou à facettes), et alors sessiles ou portés par des pédoncules mobiles. Des vésicules auditives existent dans beaucoup d'espèces: elles sont presque toujours situées sur l'article basilaire des antennules. Ces mèmes appendices portent également les organes olfactifs.

Le tube cligestif est à peu près rectiligne. La bouche s'ouvre sur la face ventrale. Nous avons indiqué plus haut la constitution de l'appareil masticateur qui s'y trouve annexé. Chez les Crustacés suceurs, les gnathites se modifient pour former une sorte de trompe munie à son intérieur de stylets aigus. L'in- 
testin buecal offe un court esophage, se dilate bientót en une large poche digestive (estomac masticateur ou gésier) en général arméc à l'intérieur de puissantes dents chitineuses. L'intestin moyen ou chilitique est long, à peu près droit. Il ahoutit à un intestin terminal ou rectum large et court, (qui s'oure sur le dernier serment de l'abdomen. I.es Crustacés ne possìdent jamais de glandes salivaires. I l'inlestin moyen sont parfois annexés de simples tubes glanduleux; mais, clıez les formes supérieures, il existe une volumineuse glande digestive dontles conduits excréteurs s'ouvrent un peu en arriere de l'estonac misticateur (hépatopancréas).

L'appareil circulatoire est très complexe chez les Crustacés supérieurs. Il cumprend un caur artériel logré dans un péricarde, à la régrion dorsale, et des artères qui distribuent le sang ì toutes les parties du corps. Les voies de retour sont représentées par des lacunes interorganiques et aboutissent à la base des pattes. He là, le sang aborde les organes respiratoires, puis retourne au cœur par des vaisseaux distincts, appelés canaux branchio-cardiaques. Cet appareil se simplifie beaucoup dans les formes inférieures, et le caur luimème peut disparaitre. Le sang est d'ordinaire incolore; cependant le plasma (et non les rlobules) renferme une substance analogue à l'hémoglobine, mais contenant du cuivre au lieu de fer: cette substance forme avec l'oxygène une combinaison blcue, peu stable, et, pour cette raison, a été nommée hémocyanine (Frédérieq). Dans quelques cas, le sang est teinté en rouge par de l'hémogloline également dissoute dáns le plasma (E. Van Beneden, Regnard et Blanchard).

Les organes respiratoires affectent une forme et une disposition très variables. Les tranihics proprement dites n'existent guère que chez les Podophtalmes. Elfes sont parfois (fig. 406) fixées aux membres thoraciques, et alors enfer-

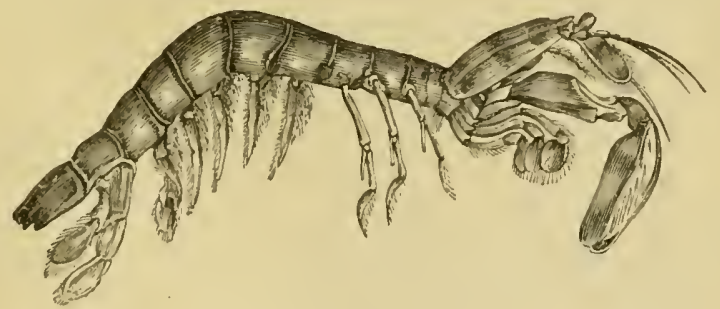

Fig. ¿l0. - Squille maculée (Lysiosquilla maculata).

mées dans une chambre située de chaque còté du thorax, sous la carapace. D'autresfois (fig. 410), elles sont portées par les pattes abdominales et flottent librement dans l'eau. Chez les autres Crustacés, les branchies sont quelquefois remplacées par des vésicules membraneuses fixées à la base des paltes thoraciques (Crevette des ruisseaux); ou bien la respiration s'effectue par la peau de certaines régions du corps, et en particulier des patles : c'est ainsi que les pattes branehiales foliacees des Branchiopodes servent à la fois à la locomotion et à la respiration. - Quelques Crustacés, tels que les Cloportes, quoique vivant à l'air libre, possèdent cependant des branchies: celles-ci sont toujours maintenues dans un état convenable d'lumidité. Enfin, les Crabes terrestres, les Armadilles, les Porcellions, etc., sont beaucoup mieux adaptés encore il la vie terrestre : leurs organes res- 
piratoires recoivent directement le contact de l'air et fonctionnent à la facon des pseudo-poumons des Arachnides.

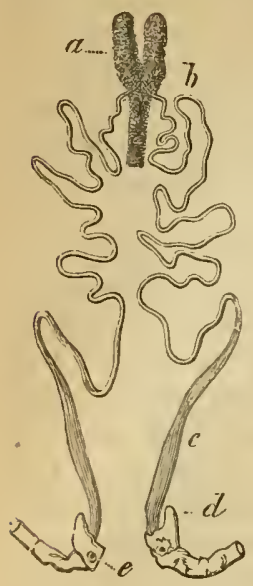

Fig. 411. - Organes mâles de l'Écrevisse. - $a$, testicules. $b, c$, canal déférent. $d$, arlicle basilaire des pattes thoraciques de la einquième paire. $e$, orifice génital.

Les organes excréteur's sont représentés par des tubes enroulés, indépendants du tube digestif et s'ouvrant à l'extérieur comme les organes segmentaires des Vers. Telles sont les glandes vertes siluées dans la cavité céphalique de l'Ecrevisse, et dont le canal excréteur débouche sur l'article basilaire de l'antenne externe. Le liquide sécrété par ces glandes contient de la guanine.

La séparation des sexes est la règle chez les Crustacés. Cependant, les Cirripèdes sont monoïques. Les organes sexucls sont habituellement pairs ; leurs conduits excréteurs débouchent à la partie postérieure du thorax ou à la partie antérieure de l'abdomen, tantòt sur le somite lui-mème, tantòt sur l'article basilaire d'une paire de paltes. Les mâles sont pelits, quelquefois nains, et, dans ce dernier cas, ils vivent en parasites sur les femelles. Celles-ci, toujours ovipares, portent souvent leurs œufs fixés aux appendices abdominaux ou renfermés dans des chambres incu. batrices. Quelques formes (Apus, Daphnies) présentent des phénoniènes de parthénogenèse.

Le développement comporte presque toujours une métamorphose complexe. Chez les Crustacés inférieurs, la larve qui sort de l'œuf est munie de deux ou Irois paires d'appendices et d'un œil frontal impair : on lui donne le nom de Nauplius (tigr. 412,a). La larve des Crustacés supérieurs ou Podophtalmes naît d'ordinaire dans un état d'organisation plus avancé : elle possède déjả six paires de membres et recoit le nom de Zuï (fig. 413).
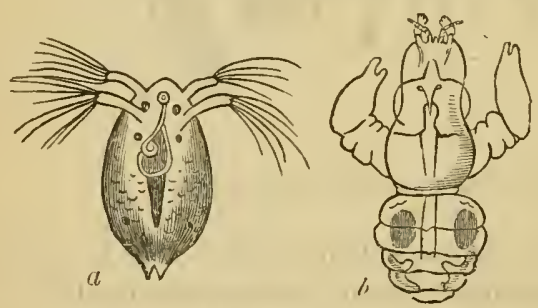

Fig. 412. - Achtheres percarum, grossi, d'après Owen. $a$, larve Nauplius, nageant librement. $b$, mảe adulte, nain.

III

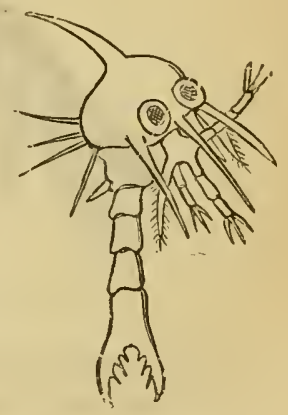

Fig. 413. - Larve Zó de Crabe (Pirimela denticulata), amplifiée, d'après Kinaban.

29

Dans quelques cas, les jeunes offrent la forme des parents : c'est ce qu'on observoy chez l'Écrevisse. Enfin, les espèces parasites subissent une métamorphose régressive.

La plupart des Crustacés sont carmassiers. Les uns se nourrissent de substances animales en décomposition; les autres sucent les hnmeurs des animaux sur lesquels ils vivent en parasites. Un certain nombre d'entre eux, 
appartenant à l'ordre les Décapoles, sont recherchés pour l'alimentation de l'Homme. Leur chair est généralement ferme, nutritive, mais d'une digestion laboricuse.

\section{8 ordres principaux :}

\begin{tabular}{|c|c|c|}
\hline \multirow{3}{*}{$\begin{array}{l}\text { Nombre rariable } \\
\text { de segments : } \\
\text { Exrouostr.ices. }\end{array}$} & \multirow{2}{*}{ Lne carapace biralve. - Dioüques, libres.... } & OSTRACODES. \\
\hline & & Crrmipèdes. \\
\hline & $\begin{array}{c}\text { carapace } \\
\text { bivalve. }\end{array} \begin{array}{c}\text { Dioïques, } \\
\text { libres. }\end{array}$ Pattes lamelleuses...... & $\begin{array}{l}\text { BuLNCHOPODES. } \\
\text { COPÉPODES. }\end{array}$ \\
\hline & 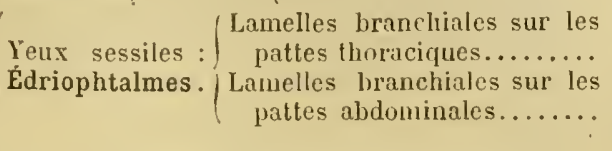 & AMPHIPODES. \\
\hline & $\begin{array}{c}\text { Yeux } \\
\text { pédonculés: } \\
\text { Podophtalmes. }\end{array}\left\{\begin{array}{c}\text { Branchies extérieures, sur les } \\
\text { pattes abdominales........ } \\
\text { Branchies intérieures, thora- } \\
\text { ciques......................... }\end{array}\right.$ & StONATOPODES. \\
\hline
\end{tabular}

$1^{\mathrm{er}}$ ordre: Ostracodes. - I'etits Crustacés à corps comprimé lateralement, sans segmentation nette, et complitement enfermés dans une carapace bivalve, conchiforme; puttes ambulatoires.

Le nom de ces animaux tient à ce que leur carapace bivalve, souvent incrustée de calcaire, ressemble à une coquille de Mollusque lamellibranche

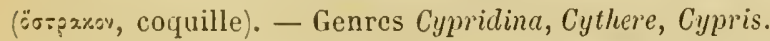

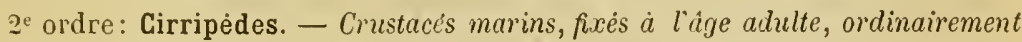
hermaphrodites; corps en gènéral inarticulé, entomé d'un repli cutané, eneroùté de plaques calcaires; pieds en formes de cirres.

Les Cirripèdes (cirrus, cire; pes, pied) établissent le passage des Arthropodes aux Mollusques. - Principaux genres: les Anatifes(Lepas), les Balanes ou filands de mer (Balanus). Diverses espèces sont comestibles.

On y rattache aussi les RiızocépHaLEs, qui subissent une métamorphose régressive si profonde, que leur corps est finalement dépourvu de membres et de tube digestif. Delage en fait un ordre à part, celui des Kentrogonides. - Genre Sacculina, parasite des Crabes.

3e ordre : Branchiopodes. - Crustacés à corps allongé, en général nettement segmenté, nu ou couvert soit d'un houclier, soit d'une carapace bivalve; pattes lamelleuses (branchialcs) servant à la natation et ì la respiration.

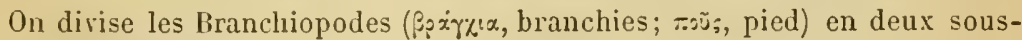
ordres :

10 Les Cladocèkes, qui ont de grandes antennes natatoires et de quatre à six paires de pattes : telles sont les Daphnies ou Puces d'eau (Daphnia), les Polyphèmes (Polyphemus), etc. - Les Daphnies constituent un aliment excellent pour les alevins, et en particulier pour les jeunes Salmonidés.

$2^{\circ}$ Les Puyzlopones, qui ont de dix à quarante paires de pattes. - Genres A pus, Branchipus, Artemia. 
$4^{\mathrm{e}}$ ordre: Copépodes. - Crustacés à corps allongé, en général nettement articulé, sans repli cutane; pattes thoraciques natatoires terminées chacune par une

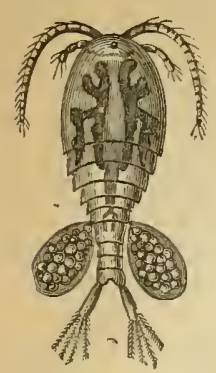

Fig. 414. - Cyclope commun (Cyclops quadricornis). ou deux rames.

Les Copépodes ( groupes:

$1^{\circ}$ Les Siphonostomes ou Épizoaires, qui comprennent un assez grand nombre d'espèces parasites souvent très dégradées. On les trouve principalement sur la peau el les branchies des Poissons. - Genre Corycée (Corycæus), Calige (Caligus), Achthère (Achtheres), Lernée (Lemæa), Argule (Argulus), etc.

$2^{\circ}$ Les Gnathostones, qui vivent en liberté dans les eaux douces ou dans la mer. - Genres Cyclope ou Monocle (Cyclops), Notodelphe (Notodelphys), etc.

らе ordre: Amphipodes. - Crustucés à yeux latèraux sessiles, a eorps comprimé latéralement, présentant sept ou six paires de pattes thoraciques ambulatoires qui portent les vésicules respiratoires.

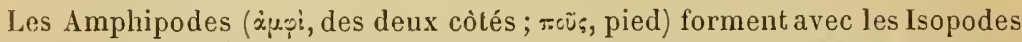

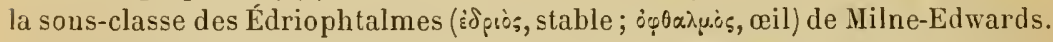
- Ils comprennent la Crevette des ruisseaux (Garnmairus pulex L.), la Puce de mer (Talitrus locusta Latr.), etc.

On y rattache souvent les LÉuODıPODEs, auxquels appartiennent les Chevrolles (Caprella) et les Poux de Baleines (Cyamus).

$6^{\circ}$ ordre: Isopodes. - Crustacés à yeux latéraux sessiles, a corps large et bombe, présentant sept paires de pattes thoraciques ambulatoires et cinq paires de pattes abdominales fonctionnant comme branchies.

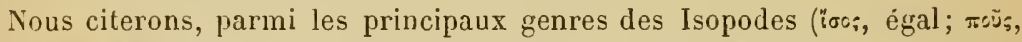

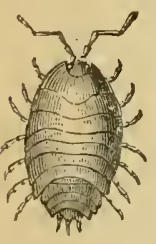

Fig. 415. - Cloporte commun. pied), les Tanaïs (Tunais), les Aselles (Asellus), les Cloportes (Oniscus), les Porcellions (Porcellio), les Armadilles (Armadillo), etc.

Le Cloporte commun (Oniscus asellus L.) et l'Armadille officinal (Armadillo officinalis Cuv.) faisaient partie de l'ancienne matière médicale; on les administrait, tantòt vivants, tantòt secs et pulvérisés, comme diurétiques, lithontriptiques et antiscrofuleux. Leur faible propriété diurétique était attribuée à la présence d'une cerlaine quantité de nitrate de potasse dans leurs tissus; mais les recherches de Méhu sur ce point n'ont pu déceler l'existence de ce sel.

Les CuMacés sont très voisins des Isopodes. - Genre Cuma.

7e ordre: Stomatopodes. - Crustacés pourvus d'yeux pédonculés mobiles, de trois paires de pattes thoraciques ambulatoires et dine courte carapace qui ne recouvre que les premiers anneuux thoraciques; branchies litres, porties par les pattes abdominales.

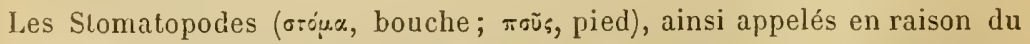
grand nombre de leurs pattes-màchoires, composent avec les Décapodes la

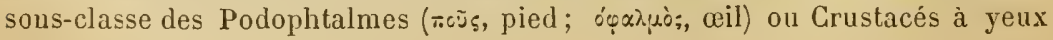


pédonculés. - Genres Squilla, Lysiosquillı (fig. 410), ete. La Cigale de mer (Squilla mantis) est commune dans la Méditerranée; elle est comestible.

On peut rattacher à cet ordre les Scmuorudes, dont quelques auteurs font un groupe distinct. - Genre IIysis.

Nous en dirons autant des Leptostracés, qui semblent représenter le type primitif de tous les Malacostracés. - Genre Nebalia.

\section{IIUITIE.ME ORDRE}

\section{DECAPODES}

Crustacés pourvus llyeux pédonculés mobiles, de trois paires de pattes-múchoires, de cinq paires de pattes thoraciques ambulatoires et d'une grande carapace céphalothoracique; branchics thoraciques et intirieures.

Les pattes de la première paire sont souvent terminées par une pince didactyle et fonctionnent alors comme organes de préluension. - Un certain nombre de Décapodes ( $\delta \dot{\kappa} \%$, dix; wošs, pied) sont recherchés pour leur chair. - 2 sous-ordres: les Macroures et les Brachyures.

1 er sous-ordre: Macroures. - Ce sont les bons nageurs; ils ont l'abdomen allongé et termine pur une large nugeoire transversule.

Famille des CARIDIDES. - Corps comprimé. Carapace non calcifiée et sans sillon transversal. Branchies lamelleuses.

Cette famille comprend les Crustacés que nous consommons sous les noms de Crevettes de sable, Cherrettes, Salicoques, Bouquets, Civudes, etc., et qui appartiennent aux genres Penæus, Palæmon, Crangon, Nika, ete.

Les Pénées (Penæus) ont les pattes des trois premières paires thoraciques terminées par une petite pince. - La Caramote ( $P$. caramota), assez commune dans la Méditerranée, a une clıair délicate.

Les Palèmons (Palxmon) ont un rostre en large lame verticale, denté en dessus et en dessous; les pattes des deux premières paires sont didactyles, celles de la deuxième étant plus fortes. - La Crevette rose ( $P$. serratus) et la Sailicoque $(P$. squilla) se pèchent en abondance sur les côtes de la Manche; la dernière est plus petite que lautre, et son rostre est plus court, moins épineux en dessous.

Les Crangons (Crangon) possèdent un rostre très court, aplati, non denté; 'les pattes des deux premières paires sont encore didactyles, mais celles de la

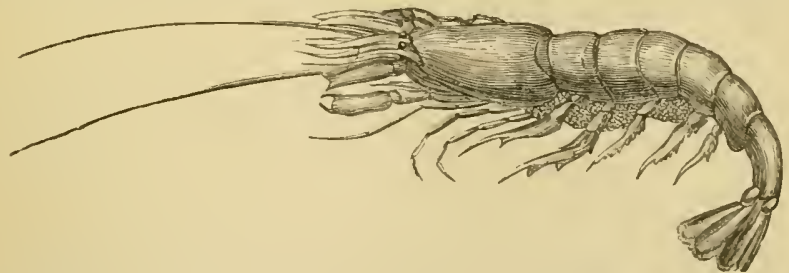

Fig. 4t6. - Crevelte grise (Crangon vulgaris).

première sont plus ėpaisses. - La Crevette grise (Cr. vulgaris) est très répandue sur tout le littoral francais; elle est moins délicate que les Palémons et ne derient pas rouge comme cux par la cuisson. 
Les Nikas (Nika) ont un rostre horizontal, en triangle allongé, non denté; les pattes de la première paire sont plus fortes que celles de la deuxième; la patte antérieure droite est terminée en pince, la gauche demeurant monodactyle. - Le Nika comestible ( $N$. edulis), d'un rose vif avec des points jaunàtres, se pèche en abondance dans la Méditerranée.

La digestion de ces divers Crustacés est assez facile, du moins lorsqu'ils sont mangés frais. Cependant, on les a vus quelquefois produire des accidents, alors même qu'ils ne paraissaient avoir subi aucune altération; c'est ainsi qu'à Amiens, en 1857, des Crevettes envoyées de Boulogne dans les conditions ordinaires produisirent de violents troubles intestinaux dans plus de trois cent cinquaute familles. - Réveil a signalé, en 1876, une fraude consistant à colorer la Crevette grise avec du minium ou de la mine orange (mélange de protoxyde et de bioxyde de plomb) pour la vendre comme Crevette rouge ou bouquet, le prix de celle-ci étant beaucoup plus élevé; cette fraude serait grave, n'était sa grossièreté.

Famille des ASTACIDÉS. - Corps cylindroïde. Carapace dure et calcifiée, avec un sillon transversal. Branchies en touffes. Pattes de la première paire très fortes, armées d'une puissante pince; celles des deux paires suivantes ordinairement terminées aussi par une petite pince.

Les Écrevisses (Astacus) ont le rostre armé de chaque còté d'une petite dent; le dernier segment thoracique est mobile; les pinces de la première paire de pattes thoraciques sont fortement renflées, à surface convexe. Toutes les espèces sont fluviatiles.

L'Écrevisse commune ( 4 . fluviatilis Rondelet) est de coloration verdâtre ou brunàtre; elle présente chez nous deux variétés regardées parfois comme espèces : l'Écrevisse à pieds blancs (A. torrentium), répandue surtout dans les petits ruisseaux, et l'Écrevisse à pieds rouges (A. nobilis), habilant de préférence les rivières et les fleuves. Celle-ci est beaucoup plus estimée que la précédente. Le mảle est facile à distinguer de la femelle : il a la queue relativement étroite; les orifices sexuels sont situés sur l'article basilaire de la cinquième ou dernière paire de pattes thoraciques; enfin, les pattes abdominales des deux premières paires sont des appendices couchés en avant au repos et servant à guider les spermatophores. La femelle a la nageoire cau-, dale plus large; les orifices sexuels occupent l'article basilaire de la troisième paire de pattes thoraciques; enfin, toutes les pattes abdominales sont conformées de la mème manière et dirigées en arrière. - La période de reproduction débute vers la fin d'octobre; le mâle dépose ses spermatophores sur le ventre de la femelle renversée, puis la femelle se creuse un abri dans les berges. Vingt-cinq jours après l'approche du mâle, elle effectue la ponte en fixant les œufs à ses pattes abdominales; on dit alors qu'elle est grenée. Au bout de six mois environ, vers le 13 mai, commence l'éclosion. Les petits restent d'abord fixés aux pattes par une mince membrane chitineuse, puis, le deuxième ou le troisième jour, ils se fixent en outre à l'aide de leurs pinces (Laguesse). Une première mue a lieu au bout d'une huitaine de jours, après quoi ils quittent temporairement la mère pour chercher leur nourriture; une seconde survient vers le trentième jour. A dater de cette période, les 
Écrevisses ne muent plus qu'une fois (femelles) ou deux (males) par an, aussi la croissance est-clle extrèmement lente. A un an, elles pèsent $18 \mathrm{~s}, 60$, à dix ans 50 grammes, à vingt ans 100 grammes; or, poul être marchandes, elles doivent pescr 430 ả $5 \ddot{3}$ grammes, c’est-ả-dire ètre àgées de neuf $\dot{a}$ dix ans.

l'élerage des Écrevisses est peu pratiqué en France; il serait cependant avantageux de s'y lirrer, aujourd'hui surtout que ces Crustacés sont devenus relativement rares. Ils ont été détruits, en effet, surtout dans les régions du nord et du centre, par une redoutable affection qui est apparue d'abord en Alsace, vers 1878. Cette maladic, qui s’étend toujours d'aval en amont et se troure arrètée seulement par les barrages, a été attribuée successivement at des Distomes (Harz), puis à des Saprolégniées (Leuckart); en réalité, elle semble ètre d'origine infectieuse, et avoir pour principal agent de propagation un Poisson encore indéterminé.

Arant les époques de mue, on troure, vers les angles antérieurs de la poche digestive, entre la cuticule qui la tapisse intérieurement et la paroi extérieure, deux concrétions calcaires ayant l'aspect de pelits boutons blanchàtres, convexes sur une face, plans ou légèrement excavés sur l'autre. Ces concrétions, formées de 63 p. 100 de carbonate de cliaux et de 18 p. 100 de phosphate de chaux, sont destinées à reproduire les nouveaux téguments aussitòt après la chute des aneiens; elles tombent en effet dans l'estomac et ne tardent pas à se dissoudre. On les utilisait autrefois en médecine comme absorbants et antiacides, sous le nom de pierres ou d'yeux d'Ecrevisses (lapides seu oculi Cancri Astaci). On ne s'en sert plus guère, aujourd'hui, que pour la confection de certaines poudres dentifrices.

Les Écrevisses, comme beaucoup d'autres Crustacés, doivent leur coloration normale à deux substances pigmentaires, l'une rouge, l'autre bleuảtre. Cette deruière est soluble dans l'eau chaude, l'alcool et les acides, ce qui explique la coloration rouge que prennent ces animaux, soit par la cuisson, soit par un lavagre dans l'eau acidulée ou alcoolisée.

Les Homards (Homarus) ont un rostre armé dle chaque còté de trois ou quatre petites dents; le dernier segment thoracique est immobile; les pinces de la première paire de pattes sont extrêmement puissantes. Toutes les espèces sont marines. - Le Homard commun (H. vulgaris) se pèche sur toutes nos còtes, mais affectionne certaines localités en dehors desquelles on les rencontre difficilement. Il est devenu fort rare dans la Méditerranée. Sa chair est très estimée, très nutritive, mais moins digeste que celle des Écrevisses.

Famille des PALINURIDÉS. - Corps cylindroïde. Carapace très épaisse. Pattes de la première paire monodactyles. Les larves ont été longtemps décrites comme des espèces d'un groupe à part, sous le nom de Phyllosomes.

Les Langoustes (Palinurus) ont le corps allongé, et des antennes externes très longues. - La Langouste commune ( $P$. vulyaris), assez répandue sur toutes nos cỏtes, est d'un irun violacé, avec des táches jaunes; sa carapace est très épineuse: le bord antérieur porte en particulier deux grosses épines en forme de cornes, qui s'avancent au-dessus des yeux et de la base des antennes. Sa chair est presque aussi estimée que celle du Homard.

Rintiet. - Zoologic. 
$2^{e}$ sous-ordre: Brachyures. - Ils ont le corps ramassé, l'abdomen court, replié en avant et dépourvu de nageoire caudale.

Un grand nombre de ces Crustacés, auxquels on peut appliquer le nom général de Crabes, sont employés comme aliment. Leur chair est blanche et passe pour aphrodisiaque. Les espèces les plus recherchées dans nos pays sont: $1^{\circ}$ le Maïa squinado (Maia squinado Rond.), vulgairement Araignée de mer, de la Manche, de l'Océan et de la Méditerranée; $2^{\circ}$ le Crabe tourteaı (Cancer pagurus L.), encore appelé Poupar', Houvet, elc., une des plus grosses espèces de nos côtes; $3^{\circ}$ le Carcin ménade (Carcinus mænas L.), appelé Cranque par les pècheurs languedociens et provençaux, Crabe enragé par les Normands; moins délicat que le précédent, mais plus commun.

On mange encore les Portunes (Portunus) ou Etrilles, les Telphuses (Telphusa) ou Crabes fluviatiles, etc.

Les Gécarcins (Gecarcinus) sont terrestres; on les connaît aux Antilles sous les noms de Tourlourous, Crabes voyageurs, Crabes violets. L'espèce commune (G. ruricola L.) a une chair succulente, mais pouvant devenir accidentellement vénéneuse: on attribue le fait à ce que ces Crabes mangent quelquefois le fruit du Mancenillier.

Ces mêmes qualités vénéneuses se retrouveraient d'habitude dans la chair des Dromies (Dromia).

\section{CLASSE II}

\section{MÉROSTOMAGÉS}

Arthropodes marins, à respiration branchiale, dépourvus d'antennes.

Cette classe comprend trois ordres : Xiphosures, Gigantostracés et Trilobites.

1 er ordre: Xiphosures. - Animaux revêtus d'un grand bouclier céphalothoracique, suivi d'un bouclier abdominal aplatiqui se termine par un stylet caudal mobile.

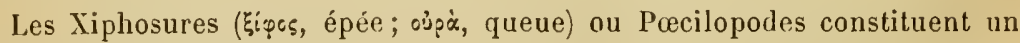
groupe spécial, étroitement liẻ aux Crustacés, mais offrant aussi des affinités avec les Arachnides.

Ces animaux ne possèdent pas les antennules ni les antemnes des Crustacés; toutefois, le céphalothorax porte six paires de pattes ambulatoires, dont la première pourrait être regardée comme représentant des antennes. Les paires suivantes agissent comme mâchoires par leur article basilaire et peuvent être, à leur tour, considérées comme des gnathites. L'abdọmen, articulé avec le bouclier céphalolhoracique, offre, à sa face ventrale, cinq paires de pattes lamelleuses qui servent à la natation et portent des lamelles branchiales.

Les Xiphosures, au sortir de l'œuf, sont dépourvus du stylet caudal et des trois dernières paires de pattes branchiales: ils ressemblent alors beaucoup aux Trilobites.

lls ne sont plus représentés, à l'époque actuelle, que par un seul genre, 
celui des limules (Limulus). - Limule ou Grabe des Moluques (L. moluccanus Clus.), de Batavia: (eufs et chair comestibles.

20 ordre : Gigantostracés. - Ce sont des Mérostomacés fossiles, très voisins des précédents. Ils s'en distinguent surtout par leur abdomen allongé et formé d'anneaux libres. - Genres Eurypterus, I'terygotus, etc., du dévouien eldu silurien.

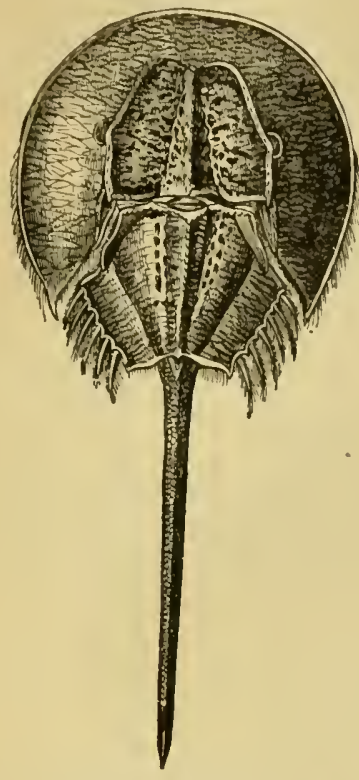

Fig. 417. - Iimule des Moluyues, v'u par lia face dorsale.

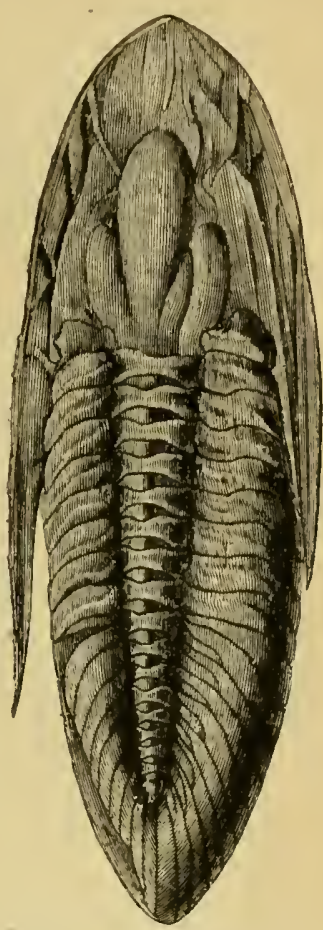

Fig. 418. - Ogygir Guettardi, Trilobite du terrain silurien.

$3^{e}$ ordre: Trilobites. - Ils composent un groupe également éteint, plus important encore. Ils ont le corps divisé en trois régions: tête, thorax, pygidium, et parcouru par deux sillons longitudinaux qui le partagent en trois lobes parallèles. Ce sont des fossiles primaires. - Genres principaux : Calymene, Ogygia, Paradoxides, Agnostus, etc.

\section{CLASSE III}

\section{O N Y GHO PHORES}

Arthropodes à respiration aérienne, s'effectuant par des trachées rudimentaires; corps composé de segments dont chacun porte une paire de pattes obscurément articulées et terminées par deux griffes; tête munie d'une paire d'antennes annelées; des organes segmentaires.

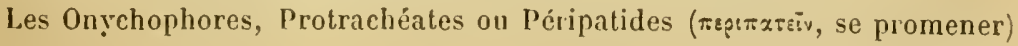


forment un groupe de transition entre les Arthropodes trachéens et les Annélides.

Leur corps allongé, vermiforme, rappelle celui des Myriapodes. La région antérieure constitue une tète qui porte, outre les deux antennes pluriarticulées, deux yeux simples. La bouche est munie d'une lèvre circulaire entourant deux paires de gnathites: des mandibules armées de griffes, et des sortes de papilles sur lesquelles débouchent les conduits excréteurs de deux glandes dont le produit est susceplible de s'étirer en fils. I.e tube digestif comprend un plarynx, un court asophage, un long estomac intestiniforme et un rectum qui s'ouvre à la partie postérieure du corps. - L'appareil circulatoire est représenté par un vaisseau dorsal et un vaisseau ventral allongés. - La respiration s'effectue par des pseudo-trachées courtes et sans épaississement spiralé, dont les orifices sont épars à la surface du corps. - Une des particularités les plus intéressantes de l'organisation des Péripalides, c'est la présence de véritables organes segmentrires, comparables à ceux des Vers annelés. Dans chaque anneau, en effet, on trouve deux tubes enroulés sur eux-mèmes et s'ouvrant, d'une part dans les lacunes de la cavilé gémérale, de l'autre à l'extérieur, vers la base des pattes. - Le système nerveux se compose d'une paire de ganglions cérébroïdes et d'un double cordon ventral offrant des commissures transversales, mais pas de renflements ganglionnaires. - Sexes séparés; ovovivipares.

Les Péripates forment un seul genre (Peripatus Guilding); ce sont des animaux terrestres, vivant sous les pierres, sous les feuilles, dans les endroits humides. Ils habitent l'Amérique du Sud, l'Australie, l'Inde, le Cap.

\section{CLASSE IV}

\section{ARACHNIDES}

Arthropodes à respiration aéricnne, s'effectuant par des trachées, par des poumons ou par la surface cutanée; tête habituellement soudée au thorax; pas dantennes; deux paires d'appendices buccaux et quatre paires d'appendices locomoteurs, tous insérés sur lc céphalothorax.

Les Arachnides ont presque toujours le corps divisé en deux régions seulement: le céphaiothorax, résultant de la fusion de la tête et du thorax, et l'abdomen. Parfois même ces deux régions sont réunies en une seule masse, comme on le voit chez les Acariens.

A la partie antérieure de la région céphalothoracique, on trouve d'abord deux paires d'appendices fonctionnant comme pièces buccales. Ceux de la première paire sont appelés mandibules ou chélicères. Leur forme est variable: ce sont tantôt des pinces didactyles, tantôt des griffes, tantôt de simples stylets. Les appendices de la seconde paire sont les maxillipèdes ou pattes-mâchoires. Leur article basilaire est toujours inséré près de la bouche, un peu en arrière; il ne porte parfois aucun prolongement (Scorpions), mais d'autres fois

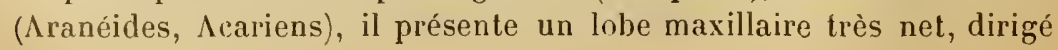


vers la bouche et rencontrant au-dessous d'elle son symétrique; on donne généralement ì ce lobe maxillaire le nom de máchoire, et au reste du maxillipède celui de palpe maxillaire. Lorsque l'organe se termine par une pince didactyle, celle-ci est formée par l'avant-dernier article opposé au dernier. Les quatre paires suivantes de membres articulés présentent nettement l'aspect de pattes ambulatoires; cependant la première concourt encore ì la mastication, par suite d'une modification de l'article basilaire, chez les Scorpions et les Pédipalpes; et mème, dans ces derniers animaux, la partie terminale est flagelliforme. Les trois dernières paires correspondent aux pattes des Insectes.

Le système nerveux, très réduit chez les Linguatules et surtout chez les Acariens, comprend d'ordinaire deux ganglions cérébrö̈des bien développés; la chaine ventrale offre presque toujours une concentration remarquable dans la région céphalothoracique. Les Araignces et les Scorpions possèdent un système nerveux viscéral ou stomato-gastrique. - Les organes des sens sont peu développés. Les yeux sont simples, au nombre de deux ì douze, el disposés symétriquement à la face supérieure du céphalothorax. Le tact s'effectue par les palpes, l'extrémité des pattes, et sans doute aussi par les poils répartis à la surface du corps.

L'appareil digestif s'étend en droite ligne de la bouche ì l'extrémité postérieure du corps; il comprend un osoplıage ou intestin buccal étroit, suivi d'un intestin moyen dont la région antérieure

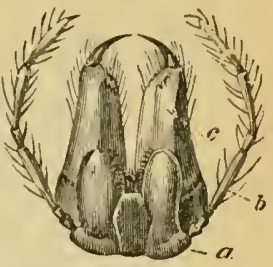

rig. 419. - Appareil buceal d'une Araignie, la Syluase lıansalyine, vu en dessous. - $c$, chélicères. $b$, palpes maxillaires. $\boldsymbol{a}$, mâchoires, réunies à leur base par une lìre ou menlonnière. ou estomac émet en général des çecums rayonnants, qui souvent pénètrent jusque dans les membres; enfin, un intestin terminal ou rectum, toujours dilaté. - A l'intestin antérieur sont annexées des glandes salivaires; à l'intestin moyen, des appendices qu'on a longtemps regardés comme hépatiques; à lintestin terminal, des tubes de Malpighi.

L'appareil circulatoire fail défaut dans les types inférieurs; quand il existe, il comprend un cceur, en forme de vaisseau dorsal, situé dans l'abdomen; un système artériel complet; enfin, des sinus veineux nettement circonscrils.

La respiration est parfois cutanée; le plus souvent, elle s'effectue par des trachées en tubes arborescents; mais, chez les Scorpions et les Araignées, les organes respiratoires consistent surtout en poumons (phyllotrachées), composés de vésicules membraneuses comprimées, appliquées les unes contre les autres et s'ouvrant en commun à la face inféricure de l'abdomen.

Nous aurons ì parler plus loin de quelques sécrétions spéciales: telles sont celles qui donnent naissance au venin des Scorpions ou des 
Araignées, et à la soie dont se servent ces dernières pour construire leur toile.

Sauf les Tardigrades, qui sont monoïques, tous les Arachnides ont les sexes séparés. Les mâles se distinguent souvent des femelles par certains caractères sexuels secondaires; leurs organes génitaux consistent en des testicules tubuleux pairs, se continuant par des canaux déférents qui recoivent le produit de diverses glandes accessoires et débouchent en commun ou séparément à la base de l'abdomen. Les ovaires, également pairs, sont d'ordinaire des glandes en grappe, dont les conduits vecteurs ou oviductes offrent aussi des glandes accessoires et se renflent en réceptacle séminal.

Les Arachnides sont ovipares, à l'exception des Scorpions et de quelques Acariens. Le développement est presque toujours direct; nous n'aurons à signaler de métamorphoses que chez les Linguatules et les Acariens.

10 ordres:

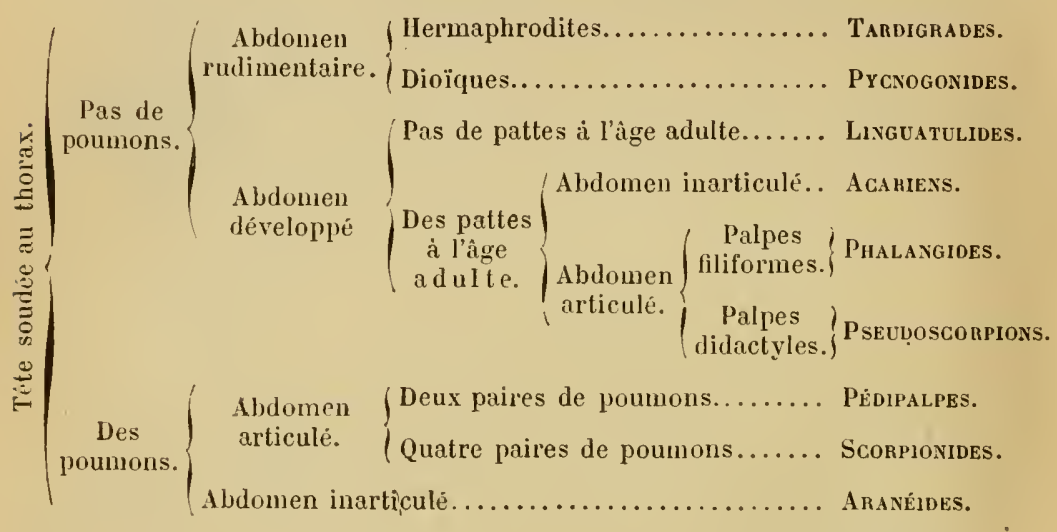

Tête distincte

$1^{\text {er }}$ ordre: Tardigrades. - Arachnides hermaphrodites; abdomen non distinct; pattes très courtes; pas de cœur; respiration cutance.

Les Tardigrades (tardus, lent; gradi, marcher) sont de petits êtres vermiformes, dont le rostre est propre à piquer et à sucer. Leurs chélicères sont styliformes. Leurs pattes sont triarticulées et terminées par des griffes. Ils se nourrissent d'autres petits animaux, par exemple de Rotifères. On les trouve en quantité dans la mousse des toits, ou dans l'eau, parmi les Algues, etc. - lls sont réviviscents: soumis à la dessiccation, ils tombent en état de mort apparente, pour reprendre leur activité vitale dès qu'on les replace dans l'humidité. - Genres Macrobiotus, Arctiscon, etc.

$2^{c}$ ordre: Pantopodes. - Arachnides dioïques; abdomen rudimentaire; pattes très développées, multiarticulees, contenant une partic les organes internes; un cœur; respirution cutanée. 
Les l'antopodes ou Pycnogonides sont de petits animaux qui vivent dans la mer, sous les pierres, dans les Algues, parfois mème sur d'autres animaux. - Genres Pycnogonum, Nymphon, etc.

TROISIËME ORDRE

\section{I N G U A T L I I) E S}

Arachrides vermiformes, apodes; corps plus ou moins neltement annelé; bouche flanquée de deux paires d'appendices (crochets); pas de caeur; respiration cutance.

Le corps de ces animaux (1) est toujours allongé, el tantôt déprimé, tantôt cylindroïde. Le céphalothorax est, dans toute sa largeur, soudé ¿̀ l'abdomen, dont il est souvent peu distinct. C'est le développement de l'abdomen en longueur qui donne au corps son aspect vermiforme.

La culicule est marquée de nombreux sillons transversaux, qui limitent des anneaux parfois à peine perceptibles. La disposition des muscles rappelle l'enveloppe musculo-cutanée des Vers.

La bouche est entourée d'un anneau corné qui la maintient béante. De chaque còté se voient deux crochets, qui peuvent se retirer chacun dans une petite gaine ou fossette. Ces crochets, formés de deux ou trois articles, sont mus par des cordons musculaires disposés en divers sens. Claus les regardait comme les vestiges des deux dernières paires de pattes de l'Arachnide: quant aux deux premières, qui existent seules chez l'embryon, elles auraient disparu sous l'influence d'une métamorphose régressire. Pour Stiles, les crochets péribuccaux sont plutôt les homologues des pièces buccales qu'on observe chez les autres Arachnides.

Le système nerveux est réduit à un simple collier œesophagien, offrant à sa partie inférieure un renflement ganglionnaire assez ćpais, d'où partent divers troncs nerveux. Van Beneden a décrit aussi un système nerveux viscéral.

La circulation est lacunaire; la respiration parait être cutanée.

Les sexes sont séparés. Les mâles sont plus petits que les femelles; leur appareil génital se compose parfois d'un seul, plus souvent de deux testicules; il s'ouvre à la face ventrale. L'appareil femelle comprend un seul tube ovarien; son orifice extérieur se trouve à l'extrémité postérieure du corps, un peu en avant de l'anus.

Les Linguatules sont ovipares. Leur développement comporte des métamorphoses avec migrations. Les embryons sont acariformes,

(1) R. Leuckart, Bau und Entwicklungsgeschichte der Pentastomen. Leipzig u. Heidelberg, 1860. - C. W. Srubs, Bau und Enlwicklungsgeschichle von Pentastomum proboscideum Rud. und Pentastomum subcylindricum Dies. Zejtschrift für wiss. Zoologie, LII, P. 85, 1891. 
acuminés en arrière, pourvus de quatre ou six (?) pieds ambulatoires et de pièces buccales. Ils pénètrent dans les organes internes des Mammifères, des Reptiles et des Poissons, et subissent là certaines transformations qui les amènent à l'état de larves; celles-ci diffèrent des individus adultes en ce qu'elles ne possèdent que des organes génitaux rudimentaires, que leurs anneaux sont dentelés ou frangés et leurs erochets sourent géminés. Elles émigrent dans les voies aériennes des Mammifères ou des Reptiles, et e'est là enfin qu'elles acquièrent leur développement complet.

La famille des LINGUATULIDÉS, qui à elle seule compose cet ordre, ne comprend que deux genres: Linguatula et Porocephalus.

Genre Linguatule (Linguatula Frölich, 1789). - Corps déprimé, à face dorsale arrondie, à bords crénelés. Cavité du corps formant des diverticules dans les parties latérales des anneaux (pectinée).

Linguatule rhinaire (L. rhinaria [Pilger]. - Syn: Trnia rhinaria Pilger, 1802; Polystoma tænioides Rud., 1810; L. tænioides Lamarck, 1816 ; Pentastoma tænioides Rud., 1819; L. rhintria Raill., 1885). - Corps lancéolé, très allongé, déprimé de dessus en dessous; extrémité antérieure assez large, arrondie; extrémité postérieure atténuée. Tégument montrant environ 90 anneaux assez saillauts, ce qui rend les bords du corps nellement crénelés. Bouche subquadrangulaire, arrondie aux angles. Crochets péribuccaux acuminés, biarticulés, à article basilaire atténué dans sa partie profonde. Mcile blanc, long de 18 à 20 millimètres, large en avant de 3 millimètres, en arrière de $0^{\mathrm{mm}}$, ö. Femelle gris blanchàtre, souvent rendue brunàtre par les œufs dans la partie moyenne, longue de 8 a 10 centimètres, large en avant de 8 à 10 millimètres, en arrière de 2 millimètres. OEufs ovoüdes, longs de $90 \mu, \cdot$ larges de $70 \mu$.

La Linguatule rhinaire ou ténioïde habite, à l'état adulte, les cavités nasales de divers animaux, notamment des Carnivores. Elle a été découverte en 1763, par Wrisberg, dans les sinus frontaux d'un Chien. Chabert, en 1787, en signala également la présence « dans les naseaux du Cheval et dans ceux du Chien ». De très nombreux observateurs l'ont, depuis cette époque, rencontrée également chez le Chien. Plus rarement elle a été trourée chez d'autres animaux : Loup (Bremser, Colin, Miram), Renard (Musée Hunter, Moniez), Cheval (U. Leblanc, C. B. Rose), Chèrre (Bruckmüller), Mouton? (Rhind). Enfin, Laudon l'a signalée chez l'Homme.

A l'état larvaire, on a observé cette même espèce dans les viscères, et en particulier dans les ganglions mésentériques, le foie et le poumon d'un grand nombre de Mammifères : Mouton, Chèvre, Bœul, Cheval, Dromadaire, Antilopes, Daim, Porc, Pécari, Lapin, Lièvre, Cobayc, Surmulot, Chat, etc., enlin, chez l'Homme. Toutefois, on a Ionglemps méconnu les relations qui existent entre les larves et la 
forme adulte, de telle sorte quion décrivait les premières comme des espèces particulières (Lingualula serrata Frölich, 1789; I'ent. serratum Rud., 1819; - Tienia capriea Abildgaard, 1789; Linguatula denticulata Rud., 1803; Pentastoma denticulatum Rud., 1819; - Pent. emarginatum Rud., 1819; - P'cut. fera Creplin, 1829; Ling. ferox (iros, 1899). C'est Leuckart qui, le premier, a donné la preure expérimentale de ces relations, dont Colin (d'Alfort) a eonfirmé l'exactitude.

Evolutiox. - Le déreloppement de l'embryon s'eflectue avant la ponte. Les aufs embryonnés, déposés en nombre immense dans les cavités nasales, sont expulsés avec le mucus, surtoul par le lait des éternuements de l'hite. Ils peuvent se trouver rejetés sur l'herbe des prairies et en général sur les aliments des herbivores, auxquels ils adhèrent grace aux plis de leur enveloppe extérieure; ingérés de la sorte par ces animaux, ils arrivent dans l'estomac, ou la corjue se trouve détruile sous l'intluence du suc gastrique. L'embryon est ainsi mis en liberté. Cel embryon offre quelque peu l'aspect d'un Acarien: il a le corps ovoïde, long de $\dddot{i} \mu$, large de $\ddot{0} \mu$, arrondi en dessus, aplati ¿ la face ventrale, et pourvu de deux paires de palles biongulées; l'extrémité postérieure. s'effile en une yueue longue de $: 0 \%$ el large de $18 \mu$, terminée par dis soies raides et courles; à l'extrémité antéricure. existe un appareil perforateur formé d'un stylet impair el de deux crochels laléraux; enfin, sur la face dorsale, on remarque en avant deux stigmates, et vers le milieu une fossette dont le fond se relève pour former une sorte de croix.

Au moyen de son rostre, l'embryon traverse la paroi du tube digestif et va s'enkyster dans les ganglions

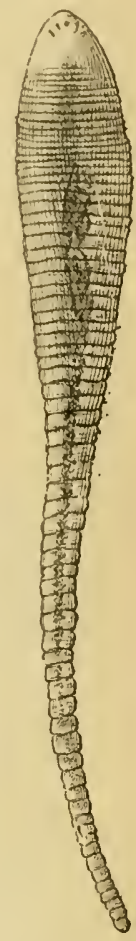

Fig. $420 .-$ Lillguatule rhinaire feuclle, grandeur naturelle (G. Teumann). mésentériques, dans le foie ou dans le poumon, ete. Dis lors, il perd son appareil perforateur et ses pattes, et se transforme en une larve ou mieux en une pupe immobile, enroulée, mesurant 250 à $\because 00 \mu$ de long sur $180 \mu$ de large. Cette pupe ne nontre aucune trace de segments, de crochets ni de soies, mais à sa face dorsale, qui est convexe, clle porte trois rangées transversales d'oscules, à chacun desquels est annexée une glande unicellulaire; elle possède en outre un tube digestif complet. Ces êtres sont si délicats que Leucliart n`a pu les étudier qu’à dater de la huitième semaine après l’infestation. On troure dans leur liyste les traces de lleux mues, ciest-it-dire les dibris de deux rutieules, dont une porte les patles, le rostre el la finssetle dorsale. 
Vers la neuvième semaine, survient une troisième mue, après laquelle la jeune Linguatule montre 8 à 10 rangées d'oscules, et des amas cellulaires correspondant au système nerveux et aux organes génitaux.

Trois autres mues suivent dans l'espace de quelques semaines; après la sixième, la larve mesure $1^{\mathrm{mm}}, 2$ de long; son tégument commence à se segmenter, et à chaque segment correspond une rangée d'oscules. Les crochets péribuccaux apparaissent.

Au bout de cinq à six mois, et après trois nouvelles mues, le développement larraire est complet, et le parasite répond à la forme connue sous le nom de Lisguatule denticulée (Linguatula serrata).
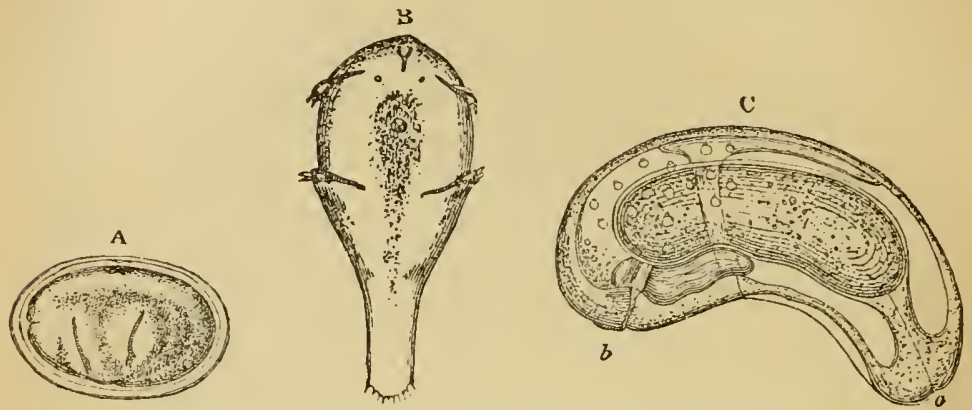

Fig, 421. - Prenières pliases de l'évolution de la Lingualule rlinaire, d'après Leuckart. - A, cuf grossi 200 fois, contenant un embryon. B, embryon acariforme, tétrapode, libre. C, nymplie ou pupe âgée de 9 semaines : $b$, bouche. $a$, anus.

C'est un animal blanchâtre, translucide, lancéolé, mesurant 4 à 6 millimètres de long sur une largeur maximum de $1^{\mathrm{nm}}, 2$ à $\mathbf{1}^{\mathrm{nm}}$, ,ŏ. Le corps présente 80 à 90 anneaux portant chacun, dans son milieu, une série de stigmates, et au bord postérieur un grand nombre d'épines à pointe dirigée en arrière. Le tube digestif est très large; la bouche est elliptique et entourée déjà des quatre crochets caractéristiques, accompagnés de crochets accessoires en forme de capuchon. L'appareil génital est encore imparfait, mais on peut déjà reconnaître les sexes, principalement à la situation des orifices.

Ces larves mûres ne restent pas toujours enkystées dans le mème point; au bout d'un certain temps, elles rompent leur kyste et tombent dans la cavité péritonéale ou pleurale. Un grand nombre y meurent, mais il en est qui réussissent à s'enkyster sur un autre point: Colin a relevé, sur des animaux d'expériences, des traces évidentes de ces migrations intérieures. Lorsque les kystes siègent dans les ganglions mésentériques ou sur l'intestin, les larves tombent souvent, comme l'a constaté Babes, dans la lumière de l'intestin; elles sont alors cxpulsées avec les fèces. Enfin, les larves enkystées dans le poumon peuvent de même tomber dans les bronches, et c'est ainsi 
que fiurlt en a trouvé de libres dans la trachée d'un licive et d'une Chève; peut-être alors peuvent-elles gagner les cavilés nasales de leur lòte et $\mathrm{y}$ achever leur développement: ainsi s'expliquerait la présence, d'ailleurs exceptionnelle, de Linguatules adulles ehez des herbivores.

En général, cependant, la migration définitive s'eflectue d'une facon quasi-passive, et les larves sont condamnées à périr si les viscères de leur hôle ne sont pas dévorés, en temps voulu, par un carnassier. Mais que ces viscères soient abandonnés à un Chien, par exemple : les larves gagneront les cavités nasales, où elles achèveront leur développement et parviendront à l'état adulte. - Par quelle voie s'effectue ce passage dans l'habitat définitif, c’est ce qui n’est pas encore bien déterminé. On a pu admettre que les larves, mises en liberté par la dent lu Chien, gagnent les cavilés nasales par les orifices gutluraux (Leucliart) ou même par les narines (G. Colin). Mais le plus souvent, ces larves arrivent enkystées dans l'estomac et ne sont libérées qu'après digestion du kyste : Gerlach pense qu'elles traversent la paroi du tube digestif, le diaphragme, le poumon et remontent dans les cavités nasales par les bronches et la trachée; peut-être aussi remontent-elles quelquefois par l'œsophage (1).

Unc fois installées dans leur habitat définitif, les Lin-

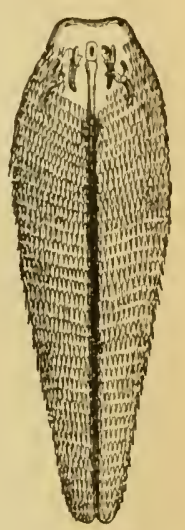

Fig. 429. - Lingualule denticulee, larve de la linguatule rhinaire, grossie 10 fois (Orig.). guatules subissent encore une mue. Celle-ci survient dans le cours de la troisième semaine, el les débarrasse de leur tégument épineux, ainsi que de leurs crochets accessoires. Dès lors, la taille augmente rapidement, surtout chez la femelle, et les organes sexuels se développent. Au bout de six à sept semaines, l'accouplement peut s'effectuer.

Orgavisatiox. - A première rue, le corps de la Linguatule adulte rappelle un peu la chaine d'un Ténia, en raison des nombreux anneaux qui le composent. Chez le màle, ces anneaux sont à peu près également longs; chez la femelle, ils atteignent leur plus grande longueur vers le troisième quart, et leur plus grande ları́cur vers le premier sixième. Leurs parties latérales sont toujours a platies : la région moyenne seule se dilate à mesure que se développent les organes internes. Sauf aux deux extrémités du corps, ils portent chacun une rangée d'oscules auxquels on donne sourent le nom de stigmates, bien qu ils correspondent simplement à de petits canaux traversant la cuticule, et que leur ròle dans la respiration reste à établir.

(1) Gerlach, ayant fait avaler id un Chien des larves de Lingualula rhinaria, les retroura au bout de quelques jour's dans la cavité viscérale. Stiles, opérant sur des Serpents avec une autre espèce, a méme ru s'enkyster un certain nombre des larves ingèrées par le second hôte. C'est pal' une ingestion de ce genre que ce dernier auteur explique la présence de la lingruatule denticulce chez les Carnassiers, - chez le Chat. par exemple. 
Par suite de l'absence de pattes, il n'est guère possible de reconnaitre une délimitation entre le céphalothorax et l'abdomen. Le second anneau porte, à sa face ventrale et de chaque còté, une papille tactile peu apparente, qui recoit un filet nerveux.

A la face ventrale encore, on trouve sur le troisième anneau, de chaque còté de la bouche, et sur le quatrième un peu pluss latéralement, un crochet composé d'un article basilaire et d'une griffe, crochet rétractile dans une invagination tégumentaire s'ouvrant par une simple fente. Nous savons que ces organes correspondent plutôt à des pièces buccales qu'à des pattes, bien qu'ils servent d'organes de fixation.

A la base de chacun de ces crochets vient déboucher un canal dans lequel on trouve un liquide clair, élaboré par nn grand nombre de glandes unicellulaires répandues sur divers points du corps.

Eı dessous de la cuticnle, règne une enveloppe musculaire formée de trois couches: une superficielle à fibres transversales, une moyenne à fibres longitudinales, et une profonde, développée seulement sur les còtés, à fibres diagonales.

Le système neveux ne montre pas de cerveau: il se compose d'un simple annea entourant l'œsophage et présentant, à sa partie inférieure, deux renflements gauglionuaires fusionués sur la ligne médiane: de cette masse partent plusieur's nerfs qui se distribuent à la région antérieure du corps, notamment à l'appareil musculaire des crochets, el deux longs cordons qui suivent les còtés de l'intestin pour aller se perdre en arrière.

La bouche, ouverte sur le troisième auneau, est toujours maintenue

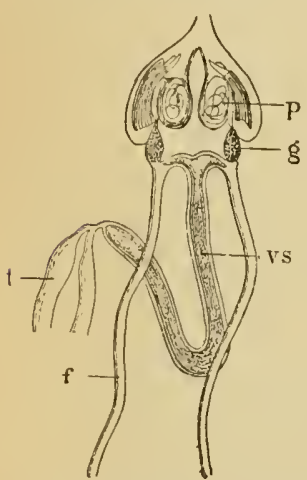

Fig. 423. - Appareil génital de la Linguatule rhinaire mâle, d'après Leuekart. - $t$, losti. cules. vs, vésicule séminale. $g$, parlie glanduleuse des eanaux déférents. $f$, flagellum. $p$, pénis enroulé. béante par un bourrelet chitineux dont sont garnis ses bords. Elle donne entrée dans une sorte de capsule buccale, laquelle est suivie d'un court pharyux dont le ròle parait ìtro d'aspirer les liquides, puis d'un étroit asophage long de 3 à 4 millimètres. Vient ensuite un tube cylindrique, plus large, dans lequel Leuckart distingue deux régions : un estomac antérieur, et un intestin caractérisé par un revètement cuticulaire. En arière, cet intestin s'alténue en uı rectum qui va déboucher à l'extrémité postérieure du corps. L'ensemble du tube digestif est rectiligne.

Il n'existe pas d'appareil circulatoire: le liquide nourricier remplit la cavité générale et ses diverticules latéraux.

La respiration paraît être cutanée; elle est peutètre favorisée par les oscules.

Les orgunes génitaux sont placés au-dessus du tube digestif. Le màle est pourvu de deux testicules sacciformes, arrivant à remplir la cavité du corps, sauf dans le quart antérieur. Ces deux tubes s'unissent en avant pour former une vésicule séminale impaire, cylindrique. L'extrémité antérieure de celle-ci se divise en deux branches qui embrassent le tube digestif et se continuent chacune par un canal plus étroit. A l'origine de celui-ci se trouve annexé un long tube en cul-de-sic (fig. $23, f$ ), ponrwu d'une puissante couche musculaire 
longitudinale et paraissant destiné à favoriser l'éjaculation. Immédiatement en avant de cette sorte de fouet, chaque canal se nıontre entouré d'un amas glandulaire, puis il va se terminer dans une poclie pyriforme, en constituant un longr pénis contourné sur lui-mème. Les deux poches sexuelles, qui renferment en outre une paire de grandes saillies chitineuses, s'ouvrent en commun au dehors par une fente transversale située sur la face ventrale, en arriere du septieme segment. L.es spermatozoïdes ont l'aspect de petits disques terminés par un filament grèle.

L.es organes femelles comprennent un seul tube ovarien qui se divise, à son extrémité antérieure, en deux petits oviductes. Ceux-ci se réunissent, en embrassaut la portion terminale de l'osopliage, en un point où débouclıent les conduits de deux vésicules copulatrices. De là part un canal qui suit à peu près le trajet de l'intestin et ahoutit à li partie postérieure du corps, un peu en avant de l'anus: on donue à ce canal les noms de vagrin, d'oviducte vaginal ou d'utérus.

L'accouplement s'effectue avant que la femelle ait atteint sa maturité sexuelle. Le màle introduit très probablement ses deux pénis dans le vagrin alors rectiligne, et va déposer son sperme dans les poches copulatrices (fig. 42' $x$, vc et $v c^{\prime}$ ) qu'on trouve en effet remplies aı mème degré (G. Colin). Cet accouplement doit ètre de courte durée; de plus, il ne peut avoir lieu qu'une seule fois, car le vagin fait l'office d'un véritable utérus, se remplit d'œu fs et prend un développement consilérable en décrivant de nombreuses sinuosités autour de l'intestin. Les $œ u f s$ sont fécondés à leur passage au niveau des orifices des poches copulatrices. Le sperme

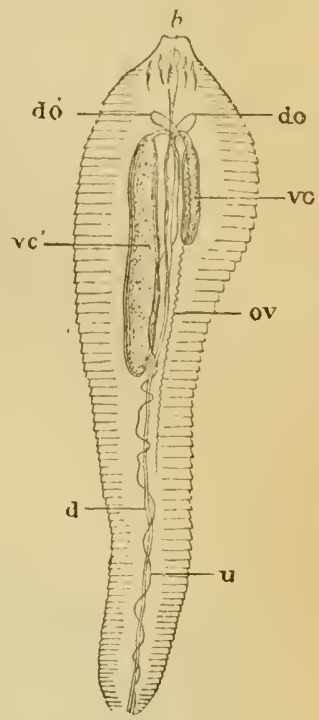

Fig. 424. - Anatomic de la Linguatule rhinaire femelle, d'après Leuckart. - $b$, bouclie. $d$, tube digestif. $a$, anus. $o v$, ovaire. $d o, d o$, oviductes. $v c, v c$, poches copulatrices, $u$, vagin ou ulérus. parait se conserver fort longtemps dans ces cavités : au bout d'une année, G. Colin y a trouvé encore de nombreux spermatozoïdes doués d'une extrème rivacité. Elles ne se vident pas simultanément, d'où l'aspect de la figure 42 '

Après l'accouplement, les femelles s'accroissent rapidement, en même temps que les œufs s'accumulent dans le vagin et prennent, en se développant, une teinte jaunàtre. Vers l'àge de six mois, commence la ponte, qui se continue pendant une période non définie, mais qui donne évidemment une énorme quantité d'œufs, puisque Leuckart a calculé qu'une seule femelle en peut contenir jusqu'à 500.000 .

Pathologie. - Les Linguatules installées dans les cavités nasales n'en occupeni pas indifféremment tous les points. Selon la remarque de G. Colin, on ne les rencontre guère qu'au fond des méats, entre les cornets et dans les interstices des volutes ethmoïdales. Par exception, cependant, elles peuvent pénétrer dans les sinus frontaux, et parfois on les y trouve à demi engagées. Mais ce n'est guère qu'a- 
près la mort de leurs hôtes qu'elles pénètrent, en cherchant à gagner les parties moins refroidies, dans le pharynx et jusque dans le larynx. Enfin, contrairement à l'assertion de Chabert, on ne les voit jamais dans les cellules ethmoïdales. - Mâles et femelles mènent d'ailleurs une vie toute différente, du moins après l'accouplement. Les premiers sont nomades et visitent les différentes régions des cavités nasales, gagnant même l'arrière-bouche et l'entrée du larynx, en quête sans doute de nouvelles amours, mais ayant soin, le plus souvent, de se mettre à l'abri dans les anfractuosités. Quant aux femelles, leur séjour farori est un diverticule assez large et régulier, qui constitue le cul-de-sac du méat moyen. Dans cet antre, elles sont à l'abri des courants respiratoires; de plus, elles paraissent trouver une alimentation abondante dans la sécrétion d'une couche glanduleuse dont la muqueuse est doublée à ce niveau. Les femelles logées dans .ce diverticule s'y tiennent en petit nombre, enroulées sur elles-mêmes. Mais

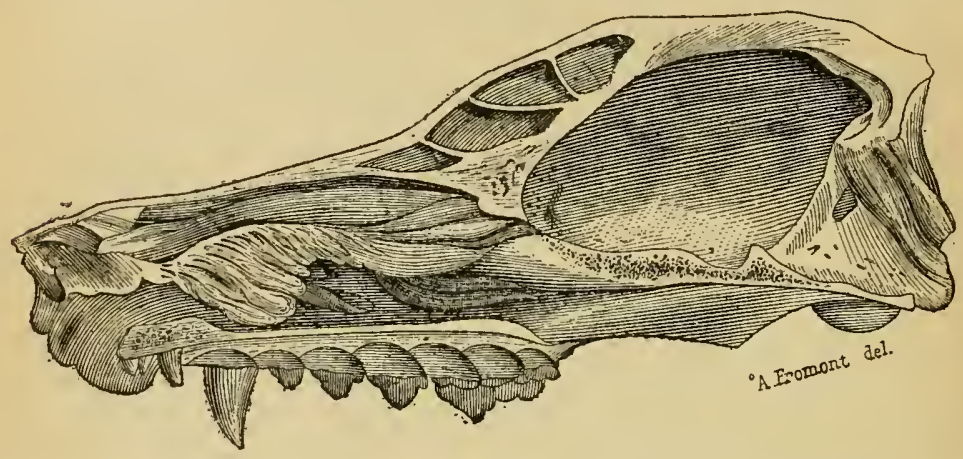

Fig. 425. - Tête de Chien fendue par le milieu, montrant trois Linguatules rhinaires (dont deux placées côte à côte) dans les cavités nasales (G. Colin).

on les trouve encore entre cette excavation et la grande volute qui tient la place du cornet supérieur, entre la masse des volutes ethmoïdales et celle des cornets; enfin, mais très rarement, dans le méat inférieur.

Pour donner une idée de la fréquence de la Linguatule rhinaire, il nous suffira de dire que, sur 630 Chiens ouverts à Alfort par G. Colin, 64 en ont offert de 1 à 11 exemplaires, en tout 146.

Les symptômes par lesquels se traduit la présence de ces parasites n'ont guère été étudiés que chez le Chien. lls consistent surtout en éternuements saccadés, irréguliers, qui d'ordinaire se manifestent d'une façon soudaine, par exemple lorsque la respiration est activée ou gênée pour une cause quelconque. Souvent ces éternuements s'accompagnent de ronflements sonores; entrecoupés d'arrêts presque complets de la respiration. Enfin, l'animal projette ses pattes sur ses narines, comme pour chercher à se débarrasser d'un corps étranger apportani un obstacle a la respiration. Il est rare que les symptômes 
s’exagèrent au point d'arriver à des accès épileptiformes ou rabiformes.

Dans les éternuements, le Chien rejette du mucus chargé d'œuls; parfois même il expulse des Linguatules: nous en possédons un exemplaire recueilli dans ces conditions.

Il n'est pas certain que ces parasites puissent déterminer, clez le Chien, des épistaxis. - En ce rui concerne l'llomme, quelques auteurs anciens ont cité le cas de malades alteints depuis longtemps d'épistaxis et guéris après aroir éracué des Vers par les narines. On a pu supposer que ces "Vers " n’étaient autres que des Linguatules. Mais un médecin allemand, Laudon, a publié à cet égard un fait précis: il s’agissait d'un soldat allemand, ayant fait la campagne de 1870 et pris, peu de temps après la guerre, d’épistaxis qui durèrent sept ans. En 1878, cet homme expulsa une Linguatule, après quoi les épistaxis cessèrent définitivement.

Chez le Chien, la durée du séjour des Linguatules dans les cavités nasales n'a pas encore été nettemenl déterminée, mais Colin l'a vue dépasser quinze mois.

Pour établir la prophylaxie de laffection que déterminent ces parasites, il suffit d'empêcher les Chiens de se repaître des entrailles des herbivores, notamment des Moutons, Lapins, ete. Quant au traitement, il doit consister surtout en injections de substances parasiticicles dans les cavités nasales.

Les Lingualules larvaires ou Linguatules denticulées envahissent, nous l'avons dit, les viscères abdominaux ou thoraciques d'un grand nombre d'animaux, où elles s'enkystent. Elles sont surtout fréquentes chez le Mouton. Ce sont les ganglions mésentériques qui se montrent le plus ordinairement envahis: ils sont creusés de cavités remplies d'une bouillie brunâtre, et parfois présentent des ouvertures témoignant de la sortie des parasites; d'autres fois, leur tissu est induré ou même a subi l'infiltration calcaire. Ces lésions n'ont pourtant pas de retentissement bien sensible sur la santé.

Chez l'llomme, les Linguatules denticulées s'enkystent de préférence dans le foie, ou Zenker, de Dresde, les a le premier rencontrées (18.5). Cependant, on en a vu aussi dans d'autres organes: rate, rein, sous-muqueuse de l’intestin grêle. Elles semblent être assez communes en Allemagne et en Autriche, plus rares en Russie et en Suisse; on n'en a pas encore observé en France. Leur présence n'est jamais reconnue qu'à l'autopsic. L'Ilomme s’infeste sans doute par l'ingestion de légumes ou autres produits souillés par les éternuements du Chien. Cependant Stiles admet, d'après l'expérience de Gerlach citée plus haut, que l'infestation pourrait aroir lieu dans cerlains cas par lintermédiaire de riscères d'herbirores consommés sans aroir subi une cuisson suffisante. 
Genre Porocéphale (Porocephalus von Humboldt, 1811. - Syn.: Pentastoma Rud., 1819, pro parte; Pentastomum Leuckart, 1860, s. str.). - Corps cylindroïde. Cavité du corps continue.

Poroeéphale moniliforme. (Por. moniliformis [Diesing]. - Syn. : Pent. moniliforme Dies., 1830̈; Por. moniliformis Stiles, 1893). — " Corps claviforme, atténué en arrière, pourvu d'étranglements successifs qui lui donnent un aspect moniliforme; partie antérieure arrondie. Bouche orbiculaire, située entre les crochets, qui sont disposés en arc. Longueur de la femelle $49^{\mathrm{mm}}, 5$; largeur en avant $4^{\mathrm{mm}}, 5$, en arrière $\left.2^{\mathrm{mm}}, 2.\right)$

A l'état adulte, ce parasite a été trouvé dans le poumon du Python tigré (Python molurus L.).

Wedl et Bruckmüller, de Vienne, ont signalé la présence des larves daus les viscères d'une Lionne, et Bassi, de Turin, dans ceux d'une Panthère. Chez un Chien d'expérience, sacrifié à Paris, Bochefontaine a recueilli dans le péritoine des milliers de larves libres ou enkystées que Mégnin rapporte, sans preuves suffisantes, à cette espèce. Ces larves étaient longues de 16 millimètres, larges de 2 à 3 millimètres, blanches, cylindriques, moniliformes, à extrémités arrondies, sensiblement égales, mais un peu atténuées en arrière.

Poroeéphale annelé (Por. constrictus [von Siebold]. - Syn. : Nema toideum hominis [viscerrum]. Diesing, 1851; Pentastomum constrictum von Sieb., 18วั2; Linguatula constricta Küchenmeister, 185ว ; Por. constrictus Stiles, 1893). - Cette forme n'est connue jusqu'à présent qu'à l'état larvaire. Elle est ainsi caractérisée : "Corps allongé, cylindrique, divisé en anneaux par une suịte de constrictions assez régulièrement espacées; extrémité antérieure arrondie; extrémité caudale terminée en còne obtus; dos convexe, ventre aplati; pas d'épines au bord postérieur des segments. Longueur $13^{\mathrm{mm}}, 4$; largeur $2^{\mathrm{mm}}, 23$. „ " D'après un dessin de von Siebold, le nombre des anneaux de l'abdomen est de 23.

Ce parasite a été découvert en Égypte, par Pruner, dans le foie de deux nègres et de la Girafe. Le même auteur en retrouva plus tard deux échantillons, provenant du foie de l'Homme, au musée de Bologne. Puis Bilharz en observa de nouveaux, à deux reprises, dans des autopsies de nègres, au Caire. Fenger en a vu plus récemment. dans les mêmes conditions: il est donc probable que le parasite est soudanais et non égyptien. Enfin, Aitken en a rapporté deux cas observés par les docteurs Crawford et Kearney sur des soldats des colonies anglaises d Afrique; les larves siégeaient dans les poumons et dans le foie.

\section{QUATRIEIE ORDRE}

\section{ACARIENS}

Arachnides à corps ramassé; abdomen inarticulé, largement uni au céphalothorax et généralement confondu avec lui; pièces buccales réumies 
en un rostre propre ì la succion; caur uniloculaire ou unl; respiralion trachéenne ou cutanie. Metamorphoses.

Lordre des deariens (Wilckenaer) (1), qu'on connait aussi sous les noms d'Acarides, Acares, llites, etc., comprend tous les animaux yui constituitient le genre Acarus de Linné, ainsi qu un grand nombre d'espèces nourelles. Le trype de cet ancien genre était le Giron du fromage, anquel Aristote arait donné, en raison de sa petitesse, le nom d'äxape (de àxapris, insécable).

La plupart des Acariens sont de petites dimensions. Le corps est convexe sur la face dorsale; il est aplati, au contraire, sur la face ventrale. Le céphalothorax, qui montre rarement des traces de segmentation, est uni dans toute sa largeur à l'abdomen, lequel est lui-même inarticulé. Les deux parties sont ainsi confondues en une seule masse, la séparation demeurant quelquefois incliquée par un sillon (Erythraus, Bdella).

Le tégument, chitineux, offre en général de fins sillons parallèles qui limitent des plis très délicats: par places se montrent en outre des épaississements d'aspect et de dimensions rariables; enfin, le tégument peut porter des appendices dirers, tels que soies. poils, pi†uants, spinules, etc.

A la partie antérieure du céphalothorax, se trouve un enfoncement destiné à loger les pièces buceales, et auquel on donne, pour cette raison, le nom de camérostome. La paroi supérieure de cette chambre, qui se prolonge souvent de manière à recourrir tout ou partie du rostre, est appelée épistome.

Les pièces buccales constituent par leur réunion l'appareil connu sous le nom de rostre, et qui est propre, soit à mordre, soit à sucer. Rarement on peut distinguer la levre supérieure, qui se montre ù l'état rudimentaire au-dessous de l'épistome; elle n'est bien développée que dans le genre Gamase et chez les Sarcoptes fou elle émet les processus que Robin appelait les joues). Viennent ensuite deux paires de gnathites: - $1^{\circ}$ Les mandibules, organes susceptibles d'effectuer des mouvements alternatifs en arant et en arrière. Che\% les tỵpes oủ elles sont bien déreloppées, ces mandibules ou chélicères sont en pinces didactyles: le doigt ou mors supérieur de la pince est

1) A. Duciès, Recherches sur l'orlie des Acariens, etc. Annales des sc. nat. Zoologie), (2), I, p. 5 et If4; II, p. 18, 183i. - C. L. Koci, Crustaceen. Myriapoden und - Arachniden Deutschlands. Regenshurg, 1833-18'i. - Walckexaer, Histoire naturetle des Insectes. Aptères, t. III, par P. Gervais, Paris, 1844. - P. IĹGxix, Les parasites et les maladies parasitaires (Articulés). Paris, 1850. - G. Ilablen, Vetser den Bau der vögelbewohnenden-Sarcoptirlen (Dermaleichidz). Zeitschr. für wiss. Zoologie, XXXII, p. 365, pl. XXIV et XXT, 1S82. - Ant. BerLese. Acari, Miriapodi e Scorpioni iluliani. Padova, 1882-1592. - G. Casestruxi, Prospetto dell' Acarofauna italiana. Padova, 188:-1892. - A. D. Micusel, On the variations in the internal ana!omy of the Gamasinx, especially in that of the Genital Organs, and on their Mode of Coition. Transactions of Linn. Soc. of London, Zoölogy (2), V, p. 281, pl. XXXll a XXXY, 1892. 
continu avec la tige et partant immobile; l'inférieur est articulé à la base du précédent et se meut verticalement. Chez les types, au contraire, où les mandibules sont faibles ou atrophiées, elles s'allongent, perdent leur mors mobile et se transforment en simples griffes ou même en stylets. - 20 Sous les mandibules sont placés des maxillipèdes (maxilles composées, pédipalpes) dont chacun présente à sa base un lobe maxillaire appelé maxille ou mâchoire, le reste de l'appendice constituant ce qu'on nomme un palpe. Ces palpes maxillaires, formés de plusieurs articles et très mobiles, sont situés de chaque côté des mandibules et presque au même niveau. Quant aux maxilles, qui se trouvent un peu plus bas et en arrière, elles sont incurvées et se joignent sur la ligne médiane en formant une gouttière. - Enfin, en avant et au-dessous des maxilles, existe une pièce membraneuse: c'est la lèvre inférieure, organe impair, mais souvent divisé antérieurement en deux lobes symétriques, et qui porte à sa face supérieure une languette lancéolée. Cette lèvre est généralement soudée par sa base avec les maxilles, et constitue avec elles le plancher du rostre, qui est disposé en cuiller (hypostome de Berlese, thécastome de Walckenaer).

Dugès, le premier, a fait ressortir l'importance de la configuration des palpes pour la classification; aussi croyons-nous utile de rappeler ici les différents noms qu'il leur a donnés (1). Ainsi : $1^{\circ}$ les palpes ravisseurs sont " ceux qui, renflés par leur milieu, ont l'avant-dernier article armé d'un ou de plusieurs crochets, et le dernier mousse et plus ou moins piriforme $; 2^{\circ}$ les palpes ancreurs ont une forme assez analogue à celle des précédens, mais le dernier article même est aigu ou armé de pointes; ils appartiennent toujours. d’ailleurs à des espèces aquatiques, comme leur nom l'indique assez; $3^{\circ}$ les. palpes fusiformes sont renflés comme les précédens, obtus au bout comme les premiers, mais sans griffe au pénultième article; $4^{\circ}$ les palpes fliformes ne diffèrent guère des fusiformes que parce qüils ne sont pas sensiblement renflés; ils sont toujours parallèles; $\check{\partial}^{\circ}$ les palpes antenniformes sont filiformes aussi, mais à articles très variés dans leur longueur: $6^{\circ}$ les palpes valićs sont aplatis, excavés, engainans; $7^{\circ}$ enfin, les palpes adhèrens sont soudés à la lèvre par la majeure partie de leur longueur et toujours peu développés. "

Les quatre paires de pattes ambulatoires présentent également une conformation variable adaptée à leur destination : elles sont composées de $\mathbf{8 , 7}, \mathbf{6}, \breve{5}$, parfois 3 articles seulement, et sont terminées par des organes divers, des poils, par exemple, ou une paire de griffes; quelquefois en même temps par un cirre en brosse ou bien par une sorte de lobe vésiculaire ou caroncule membraneuse qui sert à l'adhésion; enfin, chez la plupart des espèces parasites, par une petite ventouse pédiculée (ambulacre à ventouse de Raspail).

Suivant les modifications qu'ils présentent, les pieds ont reçu, de mème que les palpes, des noms particuliers, qui leur ont été appliqués par Dugès (2).

(1) Ant. Dugès, loc. cit., I, p. 11.

(2) Loc. cit., p. 12. 
Cet auteur appelle pieds palpeurs ceux dont le dernier article est reıflé; " marcheurs, ceux dont ce dernier article s"écarte peu, pour las dimensions en épaisseur et en longueur, de ceux qui le précèdent; nageurs, ceux qui, avec les mèmes disposilions, sont ciliés; coureurs, ceux dont le dernier article est très long et très effilé; tisscurs, ceux dont les crochets sont très courts et très courbés, et dont l'avant-dernier articte est garni de soies raides, ordinairement au nombre de quatre, qui dépassent l'extrémité du membre ; enfin, pieds parasitipues ou curonculés, ceux dont les griffes sont en srande partie engagées dans une caroncule, ou une membrane qui sert a fixer laninal sur les corps les plus polis, comme le fait la ventouse d'une sangsue."

Le systeme nerveux parait manquer dans les types inférieurs; il se réduit chez les autres à un eollier asophagien unissant deux masses ginglionnaires situćes, l'une au-dessus, l'autre au-dessous de l'cesophage. De la masse supérieure partent notamment les nerfs des palpes et des mandibules; la masse inférieure fournit des filets aux maxilles. aux pattes et aux viscères. - Les organes de la vision sont représentés par une ou deux paires d'yeux simples, qui, d'ailleurs, font souvent défaut. Quant au tact, il s'effectue par les palpes maxillaires, ainsi que par les poils ou les soies qui garnissent le corps ou les pattes.

Les organes digestifs sont parfois difficiles à distinguer: à la partie antérieure, il existe une cavité buccale prismatique, limitée en-dessus par les mandibules, sur les côtés par les palpes et en dessous par l'hypostome. Le tube digestif, qui continue cette eavité, est sourent pourvu, dès sa naissance, de glandes salivaires; il présente un court asophage, suivi diun estomac offranl presque toujours des diverticules plus ou moins étendus. Le rectum, assez large, aboutit à une fente anale longitudinale, qui se trouve située tantôt sur la face ventrale, tantùt sur la face dorsale (notogastre) de l'abdomen, tantôt enfin à la partie postérieure du corps.

L'appareil circulatoire est très réduit: le cœur n'existe que dans les formes les plus élevées (Ixodidés, certains Gamasidés), et ne comprend qu'une seule chambre avec une paire de fentes.

Chez un grand nombre d'Acariens terrestres ou aquatiques, la respiration s'effectue par des trachées, qui sont disposées en un système ramifié aboutissant à une ou ì plusieurs paires de stigmates, dont la situation est variable. Chez la plupart des formes parasites, la respiration est cutanée.

L'existence d'un système excréteur particulier est douteuse. Cependant, Pagenstecher décrit et figure un organe urinaire chez les Ixodes. Dailleurs, on rencontre, chez un certain nombre d'Acariens, des glandes de nature et de situation variables, en particulier des glandes cutanées, dont le rôle du produit n’a pas encore été déterminé.

Les sexes sont séparés chez tous les Acariens. En général, les mâles, qui sont moins nombreux que les femelles, se distinguent de celles-ci 
par leur petite taille, leur conformation, la présence d'organes spéciaux de copulation, etc.; souvent aussi leur genre de vie, voire leur régime, sont différents (1). Ils possèdent un ou plusieurs testicules vésiculeux, déversant leur produit dans des canaux déférents pairs,

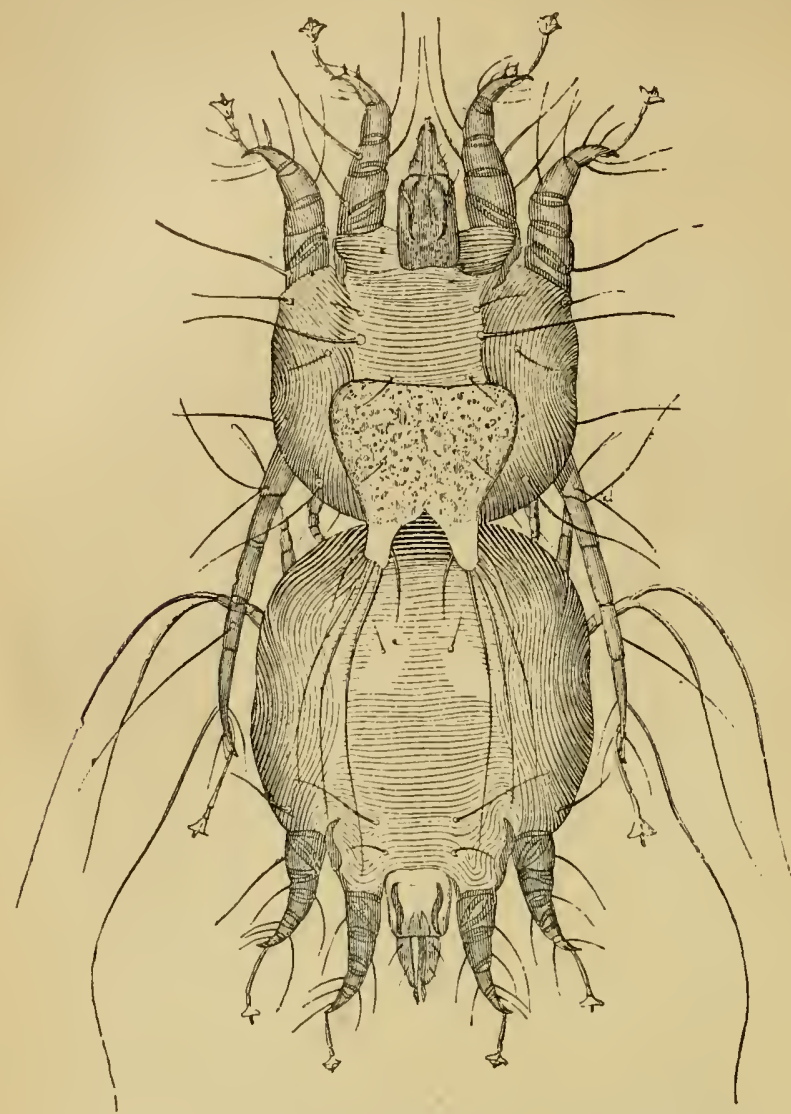

Fig. 426. - Psoroptes communis var. equi: male et femelle pubère accouplés, grossis 100 fois, vus par la face dorsale (Itelafond).

qui aboutissent à un canal éjaculateur unique; à l'orifice extérieur de celui-ci est annexé (Sarcoptidés) ou non (Gamasidés) un organe copulateur ou pénis. Les organes femelles, d'autre part, sont constitués également par un ou plusieurs ovaires, pourvus chacun d'un court oviducte; ceux-ci se réunissent en un conduit unique, parfois dilaté

(1) Les mâles offrent parfois un polymorphisme remarquable. Berlese appelle mâle homéomoryhe celui qui est semblable à la femelle, hétéromorphe celui qui s'en éloigne par ses caractères extérieurs. On peut trouver toutes les gradations entre ces deux formes (mâles intermédicires). Trouessart explique ce polymorphisme par la progenèse: d'après lui, les mâles sont homéomorphes quand, une fois leurs organes génitaux développés, ils se dégagent du tégument nymphal avant d'avoir acquis tout le développement de leurs " organes. sexuels secondaires ". (Nole communiquée.) 
en utérus, qui va le plus souvent déboucher vers la partie antérieure de la face ventrale. $A$ ces parties sont annexées des glandes accessoires. Il y a du reste, au point de rue de la disposition de l'appareil femelle, des variations importantes suivant les types considérés (1). Chez les Gamasidés, par exemple, la portion terminale de l'oviducte commun représente un ragin, et l'ouverture extérieure (vulve) sert à la fois ì l'accouplement et à la ponte. On observe en outre un réservoir spécial yue Michael nomme saccule. Chez les sarcoptidés, la véritable vulve est une ouverture ronde, très petite, semblable à un trou d'épingle et située immédiatement en avant de la commissure supérieure de l'anus. Cette ouverture donne entrée dans un canal aflérent (ragin) quelquefois très court, aboutissant ì un réceptacle séminal dont la situation est variable. L'entrée de ce ríceptacle possède souvent une sorte de sphincter dilatateur; au pôle opposé se trouve un canal eflérent, qui communique arec l'oviducte, sorte de sac très large, à parois minces (Gudden). D’après Haller, les cufs se détacheraient des ovaires pour

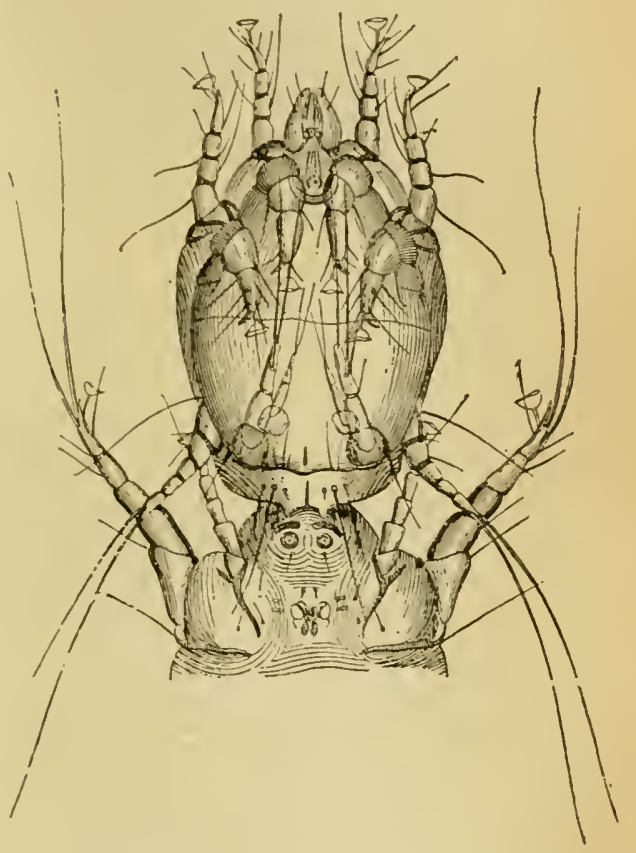

Fig. 12-. - Chorioptes auricularum rar. canis : femelle pubère se lransformanl en femelle ovigire pendaut l'accouplement. Grossissement : 100 diamèlres. Le malle a élé un preu sépari par la compression de la préparation (Orig.).

tomber dans la cavité du corps et seraient repris par l'oviducte. En tout cas, la ponte a lieu, non par la vulve, mais par l'orifice extérieur de cet oviducte, orifice auquel nous avons, pour cette raison, donné le

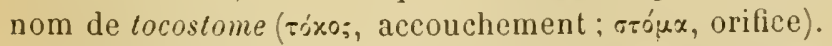

La fécondation s'opère différemment dans ces deux types. Chez les Gamasidés, qui sont privés de pénis, l'ouverture génitale du måle laisse échapper des spermatophores ou vésicules renfermant les spermatozoïdes(capsules spermatiques. Michael); le mâle saisit alors cette

(1) Gunvex, Beitrïge zu. Lehre von der Scabies. Würzburger medicinische Zeitschrift, 1861, Bd II, p. 301 (М. 3 Taf.). 一 G. HAlleh, loc. cil. - A. D. Michael, loc. cit. - E. L. Trocessart, sur la reproduction des Sarcoptides. Comptes rendus Soc. de biologie (9), Y, p. $306,1893$. 
capsule dans ses mandibules, et l'introduit dans la vulve sous-thoracique de la femelle. Il en est probablement de même chez les Ixodidés, où l'on a vu souvent le rostre du mâle introduit dans la vulve de la femelle. Chez les Sarcoptidés, l'accouplement a lieu par l'introduction du pénis dans l'étroite vulve super-anale de la nymphe pubère, alors que la dernière mue de celle-ci se prépare, et que la femelle ovigère apparaît sous son tégument (fig. 427); le sperme s'écoule par le canal capillaire du pénis, passe dans le vagin et va s'emmagasiner dans le réceptale séminal, de sorte que la femelle peut féconder ses œufs un à un, après s'être séparée du mâle. Pendant cet accouplement, la fente anale de la nymphe ou jeune femelle pubère effectue de curieux mouvements alternatifs d'ouverture et de resserrement, comme nous arons pu le constater après Trouessart: il se produit ainsi, d'après cet auteur, une véritable aspiration du sperme dans le réceptacle séminal.

Les Acariens pondent le plus souvent des œufs, parfois des larves hexapodes, plus rarement des individus déjà pourvus de leurs quatre paires de pattes.

Le déreloppement des Acariens a été étudié en premier lieu par Claparède. Nous y reviendrons en traitant des Sarcoptidés. Disons seulement ici que les Acares subissent, après leur sortie de l'œuf, des métamorphoses plus ou moins complexes - qu'il ne faut pas confondre arec les mues et qui correspondent seulement à quelques-unes de celles-ci. - Au moment où il quitte l'œuf, le jeune animal, généralement pourvu de trois paires de pattes, est désigné sous le nom de larve (larve hexapode). Lorsqu il aequiert la quatrième paire, il passe à l'état de nymple (nymphe octopode). Le développement des organes génitaux l'amène enfin à l'état adulte (mâles et femelles). - Nais il existe, dans la succession de ces diverses phases, des variations assez considérables, que Kramer (1) réduit à quatre types principaux : $1^{\circ}$ un type Tarsonemus, dans lequel l'Acarien quitte l'œuf sous la forme adulte; 20 un type Trombidium (Trombidinés et Hydrachnidés), dans lequel une nymphe octopode est interposée entre la larve hexapode et la forme adulte; $3^{\circ}$ un type Tyroglyphus (Sarcoptidés, Démodécidés, Gamasidés), présentant deux stades de nymphe; $4^{\circ}$ enfin, un type Oribates (Oribatidés) comprenant trois stades de nymphe. Pour plus de simplicité, on peut, avec Canestrini, employer les expressions de métamorphoses uninymphales, binymphales, trinymphales (2).

Les mues s'accomplissent suivant deux modes analogues à ceux qui s'observent chez les Insectes:- Dans certains cas (Sarcoptidés, Tarsonéminés), chacune d'elles comporte une sorte de retour à l'état

(1) P. KRamer, Ueber die Typen der postembryonalen Entwicklung bei den Acariden. Archiv für Naturgesch., $57^{e}$ année, I, p. 1, 1891.

(2) Berlese appelle nymphes ibontomorphes celles qui présentent tous les carac tẻres de l'adulte, sauf les organes génitaux. 
embryonnaire, une fonte de l'individu, et sa rénovation complète. r.a forme ainsi róorganisée est renfermée à l’intérieur du tégument de la premic̀e, avec toutes les pattes repliées vers le milieu du corps, celles de la précéclente restant ainsi complètement vides. - D'autres fois (Gamasidés, Trombidinés, Tétranycinés, Eupodinés) l'individu nouveau se moule exactement sur l'Acarien primitif, chacune de ses palles élant engainće dans le tégument des siennes. Il est facile de comprendre que ce second mole se prête infiniment moins aux modificalions de structure, et que, partant, les lypes qui le présentent loirent subir des métamorphoses beaucoup moins complètes.

Les moeurs el l'habitat des Aeariens sont assez variés. D'aucuns sont aquatiques, d'iutres sont terrestres; ils se nourrissent de petits animaux, ou du sue des plantes : on les trouve souvent parmi les substances organiques en décomposition; un grand nombre enfin sont parasiles, soit pendant la totalité, soit pendant une certaine période de leur existence, ou même d'une manière accidentelle.

Drvisıx. - Depuis Latreille, qui le premier a cherché à établir un groupement méthodique des Acariens, un grand nombre de classifications ont été proposées, parmi lesquelles il faut citer celles de Dugès, Koch, Kramer, Berlese, G. Canestrini et Trouessart. Celle que nous adoptons ici est établie principalement d'après les données fournies par ces deux derniers auteurs (1).

Corps allongé : Pas de trachées. $\begin{aligned} & 2 \text { paires de pattes. Palpes } \\ & \text { inermes. Mantibules sty- } \\ & \text { liformes. }\end{aligned} \mid$ Phytoptidx.

V́enmannia. \{ Pattes à épiméres. a paires de pattes. Palpes á

crochets. Ilandibules sty- Demodecidx.
liformes.

Pas de trachées :

Astigmata. Palpes adhërents, inermes. Sarcoptidx.

Patles il épimères. Mlandibules en pinces. !

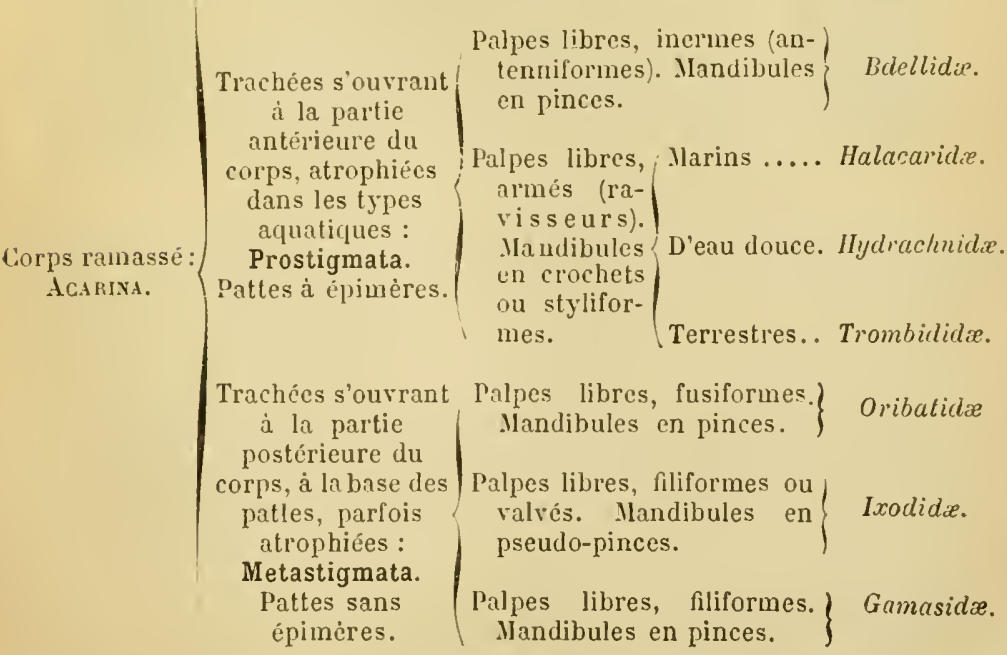

(1) G. C.nestruxi, Aboz zo del sistema acarologico. Atti del R. Istututo Veneto di 
Famille des PHytoptidés. - Ces Acariens ont le corps allongé, vermiforme, l'abdomen strié en travers et représentant une sorte d'appendice caudal trés développé. lls se distinguent de tous les autres en ce qu'ils ne possèdent, à tous les àges, que deux paires de pattes, formées de cinq articles, et insérées sur le tégument au moyen d'épimères. Les palpes sont triarticulés, libres, les mandibules styliformes. Pas de trachées. Pas d'yeux, Génération oripare.

Les Plyytoptidés vivent en parasites sur les plantes, y déterminant des alté-.

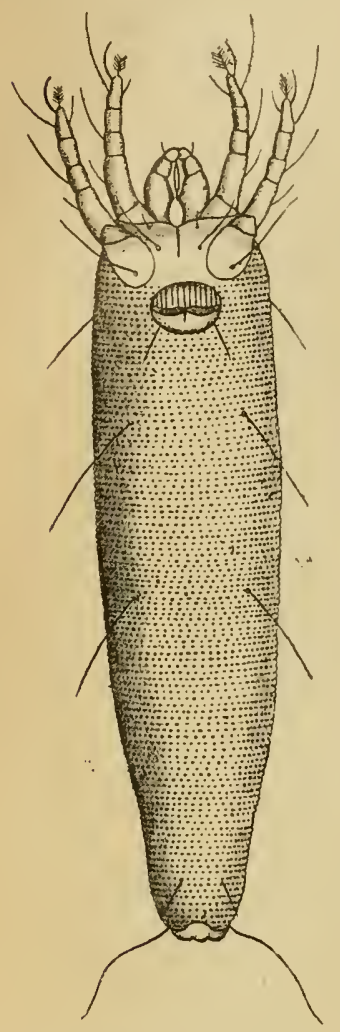

Fig. 428. - Phytoptus vitis : femelle ovigère, rue par la face ventrale, grossie 400 fois. rations variées, telles que boursouflement des fevilles avec production de poils (érinose, phyllériose), tumeurs ou galles proprement dites (acarocécidies), enroulement, atrophie, déformation des feuilles, bourgeons, rameaux, fruits, etc.

On en distingue aujourd'hui cinq genres: Phytoptus Duj., Cecidophyes Nalepa, Phyllocoptes Nal., Tegonotus Nal., Oxypleurites Nal., qui comprennent déjá un nombre considérable d'espèces. Nous ne pouvons évidemmentsonger à signaler toutes les formes qui s'attaquent aux végétaux utiles; nous dirons seulement quelques mots. d'une espèce typique et très répandue.

Le Plytopte de la vigne (Phytoplus vitis Landois, 1864) a, comme tous les Phytoptes, le corps cylindrique, lentement atténué en arrière, et les deux faces dorsale et ventrale de l'abdomen marquées de plis (semi-anneaux) qui se continuent les uns avec les autres, de sorte qu'elles en possèdent exactement le même nombre. Il existe à la surface du corps un certain nombre de soies dont la disposition est caractéristique. Le quatrième article des pattes est à peu près aussi long que le cinquième ou tarse, qui porte un seul ongle courbé et se termine par un cirre penné, à 5 paires de barbules, un peu plus court que l'ongle.

Le Phytopte de la vigne attaque très généralement la face inférieure des feuilles, où il provoque la formation de poils ou trichomes blanchàtres, puis roussâtres, allongés, comprimés ou subcylindriques, simples ou peu ramifiés, obtus à l'extrémité, contournés et feutrés. Ces productions, qui résultent de l'hypertrophie des cellules épider miques, se présentent en groupes maculiformes, isolés, puis confluents; à leur niveau, la face inférieure de la feuille est excarée, la face supérieure en saillie. On les considérait autrefois comme les filaments ou hyphes d'un Ghampignon, auquel on donnait le nom d'Erineum, d'oủ l'expresșion d'éri-

Scienze, Lettere ed Arti (7), II, p. 699, 1891. - Trouessart, Considerations générales sur la classification des Acariens, suivies d"un essai de classification nouvelle. lievue des sciences natrir. de l'Ouest, I, p. 289, 1892. 
nose employée pour désigner ce genre d'altérations, el à laquelle il convieıdrait de substituer, comnie l'ont fait les Italiens, celle de phytoptose.

La maladie ainsi produite n’est guère dangereuse que pour les très jeunes plants.On peut, du reste, l'arrèter facilement i l'aide de soufrages. Ce qui en fait le principal intérèt, c'est qu'on l'a souvent confondue avec le mildiou, lequel esı dì à la végétation d'un chanpignon. Mais, dans celte dernière malalie, les taches blanches s'enlèvent facilement à l'ongle, et la feuille nest jamais boursoullée à la face supérieure.

Famille des DÉMODÉCIDÉS. - Les Démodécidés ou Dermatophiles sont de très petits Acariens vermiformes, glabres, qui ont l'abdomen strié en travers et formant un prolongement assez distinct du céphalothorax: ils possèdent, à l'état adulte, quatre paires de pattes courtes à trois articles, insérées sur le tégument au moyen d'épimères. Les palpes sont adhérents, formés de deux articles; les mandibules sont styliformes. Pas de trachées. Pas d'yeux. Génération ovipare. Larve ì trois paires de tubercules représentant les pattes. Deux stades de nymphe octopode.

Ces Acariens, qui ne composent jusqu'à présent qu'un seul genre, rivent en parasites dans les follicules sébacés et pileux des Mammi-

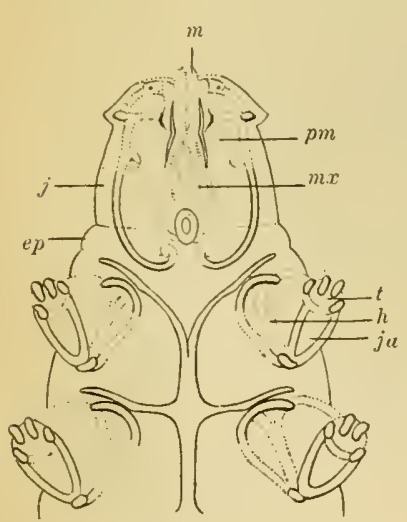

Fig. 429. - Extrémité antérieure du D.modex folliculorum du Chien, vue par la face ventrale, $m$, mandilules. $m x$, michoires. $p m$, jalpes maxillaires. $j$, joues. ep, épi stome. $h$, hanclie. ja, jambe .t, tarse. Grossissement : 730 diamètres (Orig.). fères, parfois dans le pus dont leur présence provoque la formation.

Genre Démodex (Demodex Owen, 1813). - Le rostre est large, saillant, recouvert a sa base par l'épistome, qui

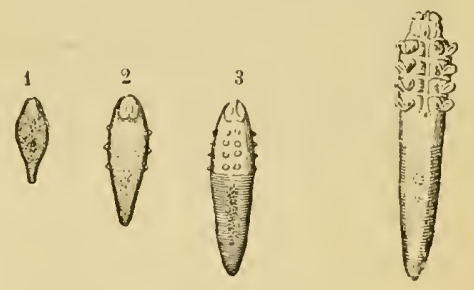

Fig. 430. - Evolution du De- Fig. 431. - Demomorlex folliculorum du Clien. dex folliculorum - 1, œuf. 2, larve hexapode, mile, du Chien, 3, nymplie octopore. Gros- grossi 100 fois sissement : 100 diamètres (Urig.). (Orig.).

fo urnit lui-même en arant des processus membraneux ou joues formant une bordure aux palpes. Les chélicères ou mandibules sont disposées en stylets aplatis, lamelleux. Les maxilles, écartées à la base, sont rapprochées en avant. Les palpes maxillaires sont formés de deux articles, le terminal court, à garniture chitineuse complexe. Le céphalothorax est finement strié en divers sens. Les pattes s'articulent par la hanche à des épimères transversaux, arqués, réunis par 
une pièce longitudinale médiane. L'abdomen est strié en travers. Il présente à la partie antérieure de sa face rentrale une petite fente longitudinale qui paraît être l'anus. — Les mâles ont l'abdomen moins développé que les femelles; ils possèdent une armure génitale préanale. Les femelles sont un peu plus grandes.

Le développement n'est pas encore très bien connu. Nous le comprenons de la façon suivante: de l'œuf, qui possède une coque mince, mais très nette, sort une larve munie de trois paires de tubercules, rudiments de pattes, et d'organes buccaux très incomplets. A la suite d'une mue, cette larve hexapode acquiert une quatrième paire de tubercules et devient ainsi nymphe octopode; puis une nouvelle mue l'amène à l'état de seconde nymphe: celle-ci est fournie de pattes articulées et d'organes buccaux distincts, et n'a plus qu'à développer ses organes sexuels pour arriver à l'état adulte.

Le genre Démodex comprend un assez grand nombre de formes, qu'on peut regarder comme des variétés d'une seule espèce, le Démodlex des follicules (D. folliculorum [Simon]. - Syn. : Acarus folliculorum Simon, 1842 ; D. folliculorum Owen, 1843 ; Macragaster platypus Miescher, 1843; Simonea folliculorum P. Gervais, 1844; Entozoon folliculorum Er. Wilson, 1845; Steatozoon folliculorum Er. Wilson, 1847). - Nous devons jeter un coup d'œil sur ces diverses variétés.

Démodex de L'Hoxme (D. folliculorum var. hominis). - Le màle a $300 \mu$ de long sur $40 \mu$ de large au niveau du céphalothorax. La femelle mesure environ $380 \mu$. sur 43 . Le rostre est assez court, large ; la longueur du rostre et du céphalothorax réunis égale environ le tiers de la longueur totale du corps. Les œufs sont cordiformes ou fusiformes, de 60 a $80 \mu$ de long sur 40 à $50 \mu$ de large.

Probablement entrevu par Ettmüller (1682) et Bassignot (1776), le Démodex de l'Homme a été découvert en 18.11 par Henle, de Zurich, dans les glandes sébacées du conduit auditif externe, et retrouvé l'année suivante par Simon, de Berlin, dans la matière des comédons de l'aile du nez. Il est en réalité très commun dans les glandes sébacées de la face, et on le décourre facilement dans le sébum qui apparait quand on exerce une pression sur les ailes du nez, les lèvres, les joues, le front, etc.; mais on l'a rencontré en outre dans le cérumen, dans les glandes de Meibomius, sur le ventre, sur le dos, dans les follicules pileux de la poitrine et du mollet, ainsi qu à " la racine des poils pudiques de la femme ». Dans les glandes saines, on n'en trouve d'ordinaire qu'un ou deux exemplaires; les comédons en montrent souvent davantage, jusqu'à 100 ou 20 . Le rostre est presque toujours tourné vers le fond du follicule, et les pattes sont souvent appliquées contre la paroi. Sur le cadavre, Henle les a trouvés encore vivants au bout de six jours.

Ces parasites se montrent surtout communs chez les adultes; 
Gruby assure que, sur 60 personnes examinées par lui, 40 en présentaient; mais, d'après les recherches de Moniez, cette statistique est fort exagérée. Les enfants très jeunes n'en ont jamais.

Le Démodex de l'Homme se multiplie très lentement, et par suite n'a pas de tendance eurahissante. Cependant, comme il se montre assez sourent dans les pustules d'acné, quelques auteurs ont cru pouvoir lui altribuer un certain ròle dans le développement de ces lésions: en tout cas, ce ròle doit ètre bien secondaire.

Gruby a essayé de transmettre au Chien le Démodex de l'Homme; il croyail y être parven dans un cas; Simon a rapporté un fait ana-

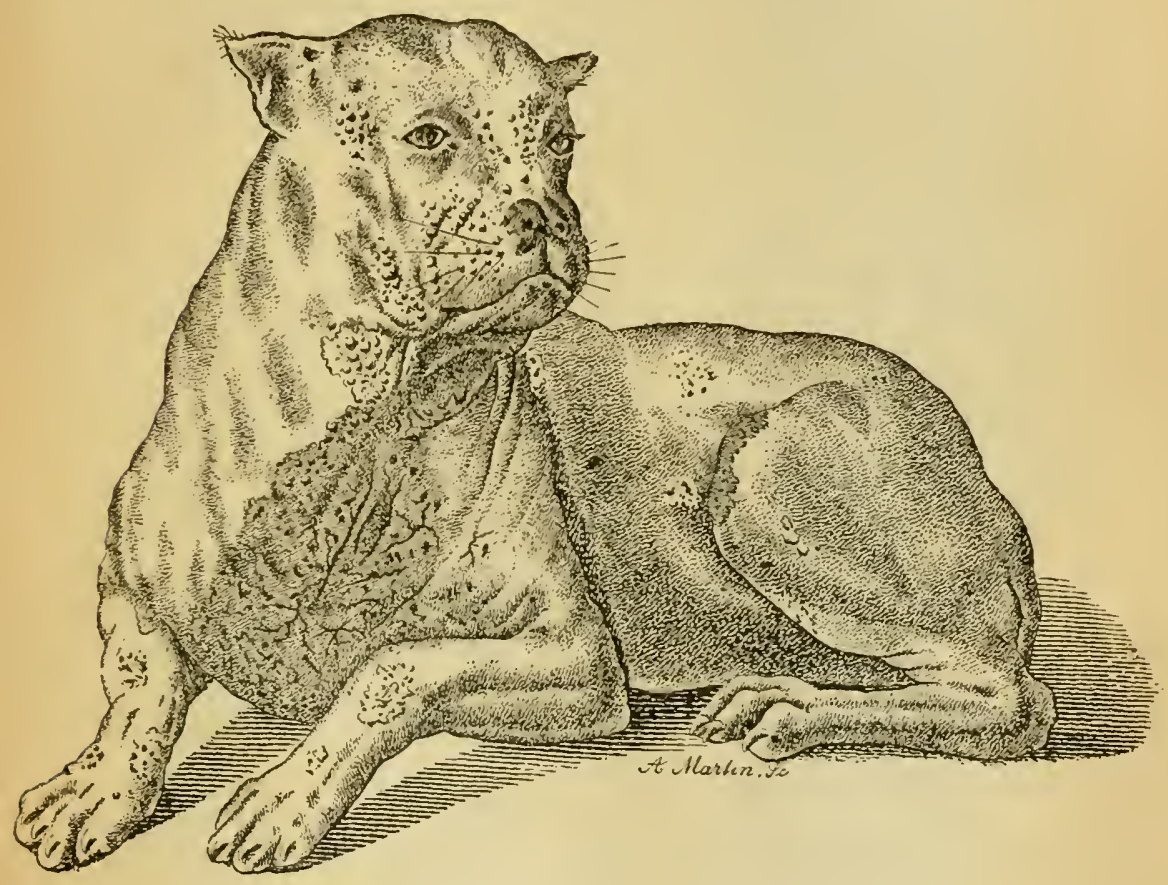

Fig. 432. - Chien atleinl de gale folliculaire avancéc (G. Neumann).

logue; mais les tentatives expérimentales de Martemucci et de Friedberger, faites dans le mème sens, ont complètement échoué.

Désodex du Chiex (D. folliculorum var. canis. - Syn.: D. caninus Tulk, 184́4). - Le màle mesure de 220 à $250 \mu$ de long sur 4 ö $\mu$ de large. La femelle est longue de 200 à 300 u. et ì peine plus large que le màle. Le rostre est à peu près aussi long que large ; la longueur du rostre et du céphalothorax réunis est un peu inférieure (comme 4 : ŏ) à la moitié de la longueur totale. Les œufs sont fusiformes, de 70 à $90 \mu$ de long sur $20 ّ \mu$ de large.

Ce parasite a été découvert en 1843 par Topping. Il est du reste fort commun et détermine une grave affection connue sous le nom de 
gale folliculaire. Celte affection débute le plus sourent par la tête, et en particulier par le pourtour des

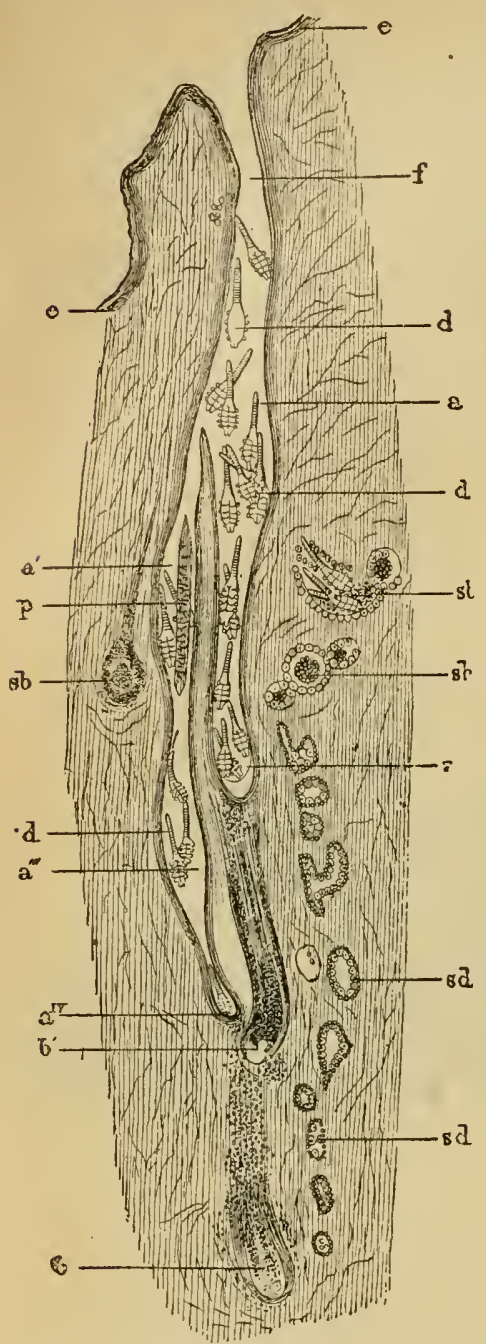

Fig. 433. - Coupe de la peau d'un Clicen affecté de gale folliculaire. - $e$, épiderme, se continuant pour former les gaines dans l: follicule $f$, lequel, sinueux et bifide à son extrémité profonde, renfermait deux poils $p$, dout on voit les bulbes en $b, b^{\prime}$. En $a, a^{\prime}, a^{\prime \prime}$, $a^{m \prime}, a \mathrm{IV}$, ce follieule présente des dilatations dues à Iaccumulation des Démodex $d$. $s b$, glandes sébacées, dont uue $\left(s b^{\prime}\right)$ contient des Démodex. $s d$, glandes sudoripares, lirossiss.: 40 diamètres (Dessiu de G. Neumann, d'après une préparation de F. Laulanié). favorable. Il est curieux de constater, en effet, combien sont vayeux, pour s'étendre peu à peu sur les autres régions du corps. Elle se traduit par la formation de pustules acnéiques, s'accompagnant d'une dépilation plus ou moins marquée. Parfois, cette sorte de gale affecte la forme circinée. Friedberger et Fröhner en ont aussi décrit une variété ou forme squameuse, qui ne se manifeste guère que par la chute des poils et l'abondance des pellicules épidermiques. En général, le prurit n'est pas excessif.

Les Démodex se montrent dans les glandes sébacées et surtout dans les follicules pileux; ceux-ci sont dilatés et renferment souvent un grand nombre d'individus, qui ont le rostre dirigé vers le fond et la face ventrale toúrnée du côté du poil ou de la place qu'il occupait; Gruby en a compté jusqu'à 200 dans un même follicule. Kroulikorsky les avus passer de là dans le derme et dans le tissu conjonctif sous-cutané. Laulanié a constaté que leur présencepeut donner lieu à une tuberculose locale très in téressante.

La gale folliculaire est très dangereuse pour le Chien, qu'elle conduit le plus souvent au marasme et à la mort. Elle est, sauf lorsquelle est encore localisée ou qu'elle revêt la forme squameuse, difficile à guérir.

La transmission du Chien au Chien se manifeste d'une façon beaucoup moins nette que dans les gales sarcoptiniques, sans doute à cause de la situation profonde des parasites, et peut-être aussi, semble-t-il, parce que ceux-ci ont besoin, pour se développer, d'un terrain particulièrement 
riables les résultats obtenus dans les essais de transmission d'un animal à l'autre, soit par cohabitation, soit par dépôt direct de Démodex sur la peau.

Jusqu'à présent, Zürn est le seul observateur qui ait signalé la contagion de cette maladie à l'llomme : il dit aroir vu un vétérinaire, un cocher et une femme, qui soignaient des Chiens atteints de gale folliculaire, présenter aux mains et aux pieds une éruption pustuleuse accompagnéed'un violent prurit: les pustules renfermaient des bémodex. C'est là un fait absolument extraordinaire, si l'on songe que, dans les Écoles et les infirmeries rétérinaires, on panse chaque jour, et sans prendre les moindres précautions, des animaux atteints de cette maladie, et qu'aucun autre cas analogue n'a jamais été relevé. Bien plus, les essais d'inoculation directe de pus démodécique du Chien à l'Homme, tentés par Martemucci, Rivolta et Cornevin, ont complètement échoué.

Dévodes ue Chat (D. folliculorum var. cuti). - Semblable à celui du Chien mais d'un quart plus petit.

Signalé d'abord par Leydig (1839), qui l'avait trouvé dans les folli-

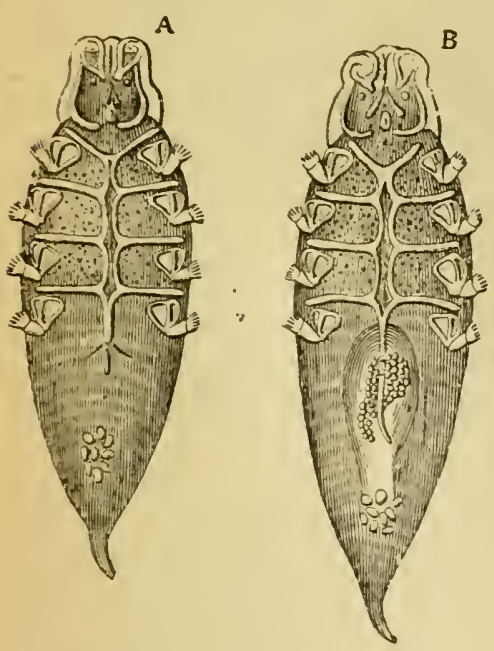

Fig. 434. - Démodex du I'ore, grossi 230 fois, d'aprés Csohor. cules pileux de la région du nez, chez un Chat affecté de gale sarcoptique. Mégnin l'a retrouvé plus tard (1876) dans le conduit auditif externe. Parait inoffensif.

DÉMODEX DU PORC (D. follicul orumvar. suis. - Syn. : D. phylloides Csokor, 1879). - Le màle est long de 220 ., large de 30 a $57 \%$... La femelle est longue de $2: 40$ à $260 \mu$, large de 60 à $66 \mu$. Le rostre est très développé, plus long que large; la longueur du rostre et du céphalothorax réunis est à peu près égale à celle de l'abdomen. Les wuls sont ovoïdes, un peu rétrécis et allongés aux extrémités; ils mesurent 100 à $110 \mu$ de long sur 30 à $3 \dot{t} \mu$ de large.

Cette forme, dont les firgures cicontre exagèrent la largeur, a été découverte en 1878 par Csolior. Depuis, elle a été observée par G. Neumann, Wright et Lindqrist. Elle détermine chez le Porc une affection caractérisée par des pustules variant de la grosseur d'un grain de sable à celle d'une noisette. Le siège en est surtuut au groin, au cou, à la partie inférieure de la poitrine, aux hypochondres, aux flancs, au ventre et à la face interne des cuisses. Ces pustules, qui ont leur point de dé- 
part dans la dilatation des follicules sébacés, augmentent peu à peu de volume, se réunissent quelquefois et finalement se transforment en gros abcès. Dans ceux-ci, comme dans les tumeurs, on trouve d'énormes quantitésde Démodex. - Cette maladie ne paraît pas altérer sérieusement la santé générale.

Démodex du Bøéf $(D$. folliculorum var. bovis). - Les sexes n'ont pas encore été distingués. Longueur, environ $210 \mu$; largeur, $55 \mu$. La longueur du rostre et du céphalothorax réunis est à peu près égale à celle de l'abdomen. Les wufs sont oroïdes.

Le $D^{r}$ Gros avait déjà signalé, dès $184 \%$, la présence de Démodex dans le mufle de la Vache. En 1878, Faxon retrouva ces parasites en Amérique, dans des peaux préparées pour le tannage, observation qui a été répétée depuis par Stiles. Grimm et OEhl les ont rencontrés, en Allemagne, dans des nodules de la grosseur d'un pois, disséminés sur toute la surface du corps. OEhl a obtenu la guérison par l'expression destumeurs, le nettoyage de la peau et des frictions de pommade crésylée (1).

Les peaux préparées montrent de nombreuses pustules, connues des tanneurs américains sous le nom de "pimples" (boutons), se traduisant par des nodosités de la grosseur d'un pois, et correspondant à des follicules pileux dilatés, remplis de Démodex. Un grand nombre de peaux, surtout parmi celles qui proviennent des districts du sud, montrent ces altérations, qui entrainent des pertes considérables. On estime en moyenne la moins-ralue des peaux à 20 p. 100, soit approximativement $0 \mathrm{fr}$. 90 par pièce.

Démodex De LA Chèvre (D. folliculorum var. capræ). - Le màle est lonğ de 220 à $230 \mu$, large de 50 à 330 . La femelle est longue de 230 a $230 \mu$, large de 60 à $6 \breve{3} \mu$. Le rostre et le céphalothorax réunis égalent presque la moitié de la longueur totale. Les œufs sont ellipsoïdes, longs de 68 à $\$ 0 \mu$, larges de 32 à $4 . . ; \mu$.

Observé pour la première fois (1881) sur une Chèvre, à l'École rétérinaire de Berne, par Niederhœusern, qui n'avait trouré que des larves. Retrouvé en 188 ë, par Nocard et Railliet, sur un jeune Bouc de deux ans, né el élevé à l'École d'Alfort : les Démodex existaient en abondance, à tous les états, et comme noyés dans un amas de sébum, dans des sortes de pustules de grosseur variable, occupant surtout la région des côtes et les flancs.

Désodex DU Mouton ( $D$. folliculor'um var. ovis). - Cette variété diffère surtout de celle de l'Homme par sa très grande largeur.

(1) STILEs, On Demodex folliculorum var, bovis in American Callle. The Canadian Entomologist, p. 286, 1892. - OEHL, Aearus beim Rinde. Berl. thierärztl. Wochenschr., p. 602, 1892. 
Elle a été trouvée par Oschatz dans les glandes de Meibom du Mouton.

Désodex du Cheval (D. folliculorum var. equi). - Ėrasme Wilson le dit simplement identique à celui de l'llomme.

Cet auteur l'a trouvé, en 1844, dans le produit de séerétion des glandes de Neibom. En 1843̈, Gros indiquait aussi la présence de Démodex dans le " mufle " du Cheval.

Ajoutons qu'on a signalé encore des Démodex chez le Renard (Gros), le Cerf l'Aristote (Prietsch), la Chauve-Souris de Surinam (Leydig), le Rat (Hahn), le Campagnol (Zschokke).

Famille des SARGOPTIDÉS. - Ce sont des Acariens de très petites dimensions, presque toujour's mous, blanchìtres ou roussâtres. Leur rostre ne constitue d'ordinaire qu'un suçoir imparfait : les maxilles, à peu près constamment soudées à la lèrre inférieure, forment ainsi un hypostome en cuiller, dans lequel glissent les deux mandibules didactyles; les palpes maxillaires, adherrents par leur base à la lèrre, sont inermes, à truis articles cylindriques ou coniques. Les pattes, insérées sur le tégument au moyen d'épimères et formées de cinq articles, sont disposées en deux groupes; leurs tarses se terminent par un ou plusieurs crochets sourent accompagnés d'une ventouse campanulée ou d'une caroncule vésiculeuse. Pas d'yeux ni de trachées. Ovipares ou vivipares. Larves hexapodes souvent très différentes des adultes. Métamorphoses binymphales (Canestrini), fréquemment compliquées par la présence d'une nymphe hypopiale (Mégnin). Dimorphisme sexuel souvent très accusé. - Vivent en parasites ou en commensaux, ou bien se nourrissent de matières organiques en décomposition.

6 sous-familles: Surcoptini, Cytoditinie, Analgesine, Chirodiscina, Listrophorine, Canestrinine, Tyroglyphinie.

Sous-famille des SaRcoptinés. - Ventouses copulatrices présentes ou absentes chez le måle suivant les espèces. Pas de ventouses autour de l'orifice sexuel. Pattes terminées d'ordinaire par un ambulacre à ventouse et sourent aussi par un ongle; celles des $3^{\mathrm{e}}$ et $4^{\mathrm{c}}$ paires à ambulacre fréquemment atrophié ou remplacé par des soies. Tocostome transversal.

Le groupe des Sarcoptinés ou Sarcoptidés psoriques (1) comprend

(1) Gerlach, Krätze und Rüude. Berlin, 1857. - Ch. Robrx, Mémoire zoologique et. anatomique sur diverses espèces d'Acariens de la famille des Sarcoptides. Bullet. de la Soc. impér. des naturalistes de Moscou, XXXIII, p. 184, 1860. - Fünstexberg, Die Krätzmilben der Menschen und Thiere. Leipzig. 1861. - Delarosd et Bocrauigiox, Traité de la psore. Paris, 1862. - MÉGan, op. cit,, p. 156. 
les espèces qui, vivant dans le tégument des Mammifères ou des Oiseaux, déterminent les affections cutanées connues sous le nom de gale ou de psore. Les lésions que provoquent ces parasites paraissent être dues à l'inoculation d'un produit venimeux.

3 genres:

Pattes postérieures entièrement ou presque entièrement cachées sous l'abdomen; rostre court et large ; ventouses ambulacrair'es à pédi-

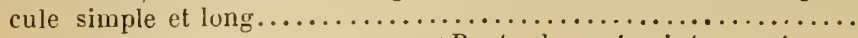

Pattes postérieures (au moins celles $\left\{\begin{array}{r}\text { Rostre long et pointu } ; \text { ventouses } \\ \text { à pédicule long, triarticulé... }\end{array}\right.$

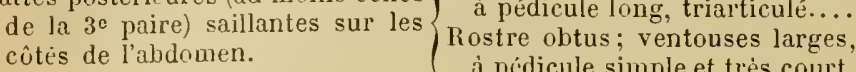

Sarcoples.

Psoroptes.

Chorisptes.

Genre Sarcopte (Sarcoptes Latreille, 1806). - Les Sarcoptes (oŕpg,

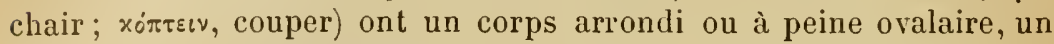
rostre court, ordinairement muni de joues membraneuses qui bordent les palpes, et des pattes courtes, épaisses, coniques, dont le tarse porte souvent une ventouse à pédicule simple et assez long. Les màles, généralement dépourvus de ventouses copulatrices, n’ont pas de prolongements ou lobes abdominaux.

3 sections ou sous-genres : Eusarcoptes, Noloedres et Knemidokoptes.

A. Sous-genre Eusarcoptes, Raill., 1888. - Face dorsale garnie d'épines et d'écailles aiguës. Épimères de la première paire de pattes sans prolongement dorsal. Anus rétrodorsal.

Espèces parasites des Mammifères.

Sareopte de Ia gale (S. scabiei Latr., 1806. - Syn.: S. exulcerans Nitzsch, 1818; S. communis Delaf. et Bourg., 1862). - Corps légèrement ovalaire et gris perle ou rouillé chez la femelle, plus arrondi et souvent rous. sàtre chez le màle, marqué de plis parallèles interrompus sur la face dorsale par un plastron grenu, puis par des saillies triangulaires aiguës (écailles dorsales) qui s'étendent jusque sur les côtés; face dorsale offrant de chaque còté, au niveau du céphalothorax (notothorax), trois épines courtes, épaisses, fusiformes, et, au niveau de l'abdomen (notogastre), sept épines plus longues et plus minces, droites ou un peu courbées, bifurquées au sommet et disposées en deux rangées longitudinales. Anus au bord postérieur de la face dorsale. Ovipare ou vivipare.

Le Sarcoptes scabiei vit dans la peau des Mammifères, où la femelle trace des galeries intra-épidermiques dans lesquelles elle dépose ses ceufs. La pullulation de ce parasite donne lieu, chez la plupart des animaux, à une forme de gale relativement grave.

Robin (1860) parait ètre le premier qui ait assigné à cette espèce ses véritables caractères et ses limites précises. Après lui, cependant, Fürstenberg en faisait encore cinq espèces différentes (S. scabiei, scubiei crustosæ, vulpis, capræ, squamiferus). Mégnin admit la plupart de ces formes à titre de variétés, et en ajouta plusieurs autres qu'il classait ainsi, par ordre de dimensions 
croissantes: S. scubici var. hominis, wis, hydrochari, capre, oulpis, lupi, cumeli, equi, suis. Les caractères sur lesquels se sont basés ces auteurs reposent notamment sur la taille des individus, sur la disposition des écailles dorsales, leurs dimensions, leur degré de chitinisation, sur la puissance des spinules du notothorax et du notogastre, sur la forme et le mode d'union de l'armure génitale du màle avec les épimères des pattes postérieures, ete.

Mais les distinctions établies sur de telles bases sont eu réalité fort arhitraires, car tous ces earactères sont loin d'offric la constance qui leur a été attribuée. La taille, en particulier, varie dans des limites assez étendues, mème quand on exanine les parasites recueillis dans une mème colonie; elle n'offre guère un peu de fixité que chez les måles. Quant aux autres caraclères, on ne peut leur attribuer qu'un sens général de variation sur les bases suivantes: chez les individus de grande taille, le corps est un peu plus allongé, les segments céphalothoraciques sont plus distincts, les téguments plus colorés, les plastrons chitineux plus apparents, les écailles dorsales plus aiguës et à revêtement chitineıx plıs épais, les spinules plus fortes; le sternite de l'appareil màle est souvent plus étroitement articulé aux épimères des pattes postérieures; en somme, tous les détails tégumentaires sont plus accusés. Et à mesure qu'on passe aux formes de plus petites dimensions (1), on les roit s'atténuer d'une façon progressire.

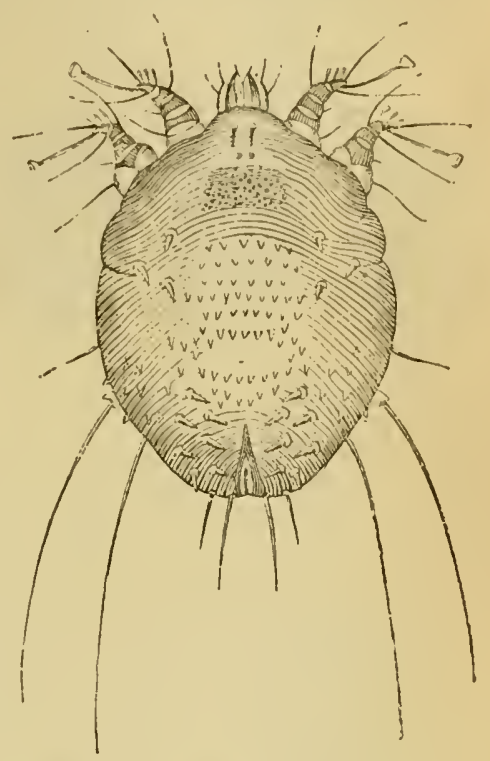

Fig. 43.̌. - Sarcoptes scabiei var. equi: femelle ovigère, grossie 100 fois, rue par la face dorsale.

D’après ces considérations, nous admettrons simplement des variétés nominales établies d'après l'habitat, tout en signalant au passage les formes de dimensions variées qui auront pu ètre observées chez un seul et mème hòte.

Il faut noter cependant que les écailles dorsales, chez la femelle origère, tendent en général à s'atrophier sur deux points, en laissan vers la ligne médiane une clairière plus ou moins nette:au niveau des épines postérieures du notothorax (clairière antéricure), ot au niveau des épines antérieures du notogastre (clairiere postérieure).

Évolutios. - Pour donner des notions aussi exactes que possible sur l'évolution et l'organisation des Sarcoptidés psoriques, sans être obligé ì de nombreuses répélitions, nous allons faire une élude spéciale clu Sarcoptes scabiei pris comme type, et nous nous bornerons à

(1) Les Acariens se mesurent en longueur' de l'extrémité du rostre (mandibules) au bord postérieur de l'abdomen ou des lobes abdominaux quand ceux-ci existent (mais non des tubercules copulateurs); la largeur se prend au point maximum, c'est-à-dire, chez les Sarcoptidés, à la partie postérieure du céphalothorax.

Railliet. - Zoologie. 
présenter ensuite de simples remarques en ce qui concerne les autres espèces et les autres genres.

Embryogénie. - Les œufs sont pondus par la femelle dans des galeries sous-épidermiques qu'elle creuse elle-même au moyen de ses mandibules. Ce sont des œufs ovö̈des, à contenu granuleux, munis d'une coque transparente. On n'a pu jusqu'à présent constáter le fractionnement du vilellus, mais on voit, à un moment donné, appa-
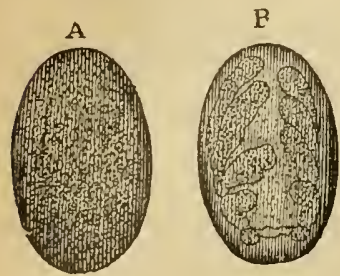

Fig. 436. - C Eufs de Sarcoytes scabiei à diver's stades de développement, grossis 150 fois. raître à sa périphérie une couche simple de cellules entourant une masse vitelline centrale et constiluant le blastoderme (Claparède). Celui-ci s'épaissit pour former une plaque ventrale, laquelle ne tarde pas à présenter, vers l'un de ses pôles, un certain nombre de bourgeons d'où dérivent le rostre et les pattes antérieures; puis, un peu plus tard, un double bourgeon donne naissance à l'unique paire de pattes postérieures de la larve. On distingue alors l'embryon avec ses trois paires de pattes bien développées et repliées sous le ventre, toutes convergeant vers le centre.

La durée de l'incubation, encore mal déterminée, paraît être seulement de quelques jours. Aussitôt après l'éclosion, les larves percent le plafond de la galerie et gagnent la surface de la peau, où elles virent quelque temps en liberté. Pour arriver à l'état adulte, ces larves ont à subir des métamorphoses assez complexes.

$L^{\text {er }}$ age: Larve. - Le petit Acarien qui sort de l'œuf ne se distingue essentiellement des Sarcoptes adultes que par l'absence des orga-

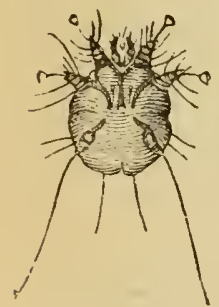

Fig. $437 .-$ Sarcoptes scabiei var. equi : larre hexapode, grossie 100 fois, rue par la face ventralc. nes génitaux et de la quatrième paire de pattes. Les deux paires antérieures portent des ambulacres à ventouse; les deux pattes postérieures sont terminées chacune par une longue soie, et, à l'arrière de l'abdomen, il existe une paire de soies analogues. Avant de passer à l'état de nymphe, cette larve doit subir deux ou trois mues, qui lui permettent de prendre un certain accroissement : au moment de chacune de ces crises, elle devient inerte, et tous ses organes se réduisent en une masse cellulaire molle aux dépens de laquelle se produisent des organes nouveaux; selon l'expression de Claparède, l'animal retourne à l'état d'œuf; et les formations nouvelles sont tout à fait comparables à celles que nous arons signalées à propos de l'embryogénie. 
Qo dige: Nymphe. $-\Lambda$ la suite d'une dernière mue, la larve donne naissance it une nouvelle forme encore dépourvue d'organes sexuels mais possédant une quatrième paire de pattes, pattes plus petites et terminées chacune par une soie plus courte et plus grèle que celles de la troisième paire. Cette forme reçoit le nom de nymphe; elle ne parait subir que peu ou point de mues; mais Mégnin prétend qu'il existe des nymphes de deux tailles différentes, les plus petites donnant des mâles, les plus grandes des femelles. Comme les larves, les nymphes rivent d'abord ì la surface de la peau, et se cachent ensuite dans l'épiderme ou dans les croùtes.

$3^{\mathrm{e}}$ àge : Mâle. Fomelle ou nymphe pubère. -

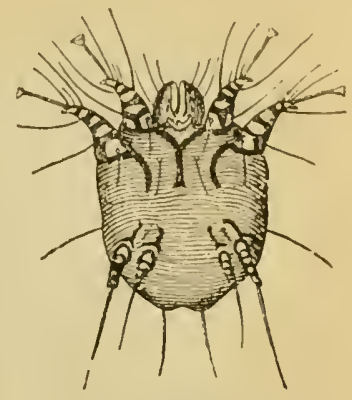

Fig. 438. - Sarcoptes scabiei vitr. equi : nymplie octopode, grossie 100 fois, vue par la face ventrale.

Cet âge est celui de l'accouplement; c'est le dernier pour les màles. Ceux-ci ont une taille à peine plus grande que celle de la première nymphe; la quatrième paire de pattes, au lieu d'être terminée par une soie comme la troisième, est pourvue d'un ambulacre à ventouse; enfin, il existe une armure génitale complexe, formée d'une pièce impaire, médiane, appelée stemite, qui à sa partie antérieure se divise en deux branches plus ou moins développées et par suite plus ou moins intimement articulées arec les épimères des pattes postérieures. A son extrémité postérieure, le sternite se divise également en deux branches, beaucoup plus grandes, qui se portent en arrière et en dehors (épisternites) : dans l'espace ainsi limité se trouve logé le pénis, qui est formé de deux pièces courbes se regardant par leur convexité, et se troure parfois recouvert par une sorte de valrule (hyposternite) capable de basculer sur un axe transversal. Au

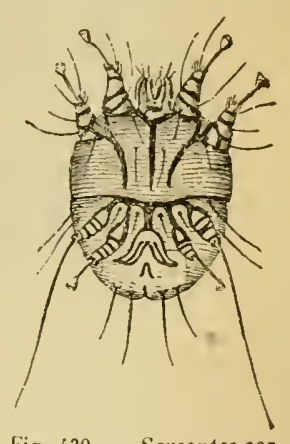

Fig. 439. - Sarcoptes scabiei var. equi: mâle, grossi 100 fois, vu par la face ventrale. moment de la copulation, l'hyposternite se renverse en arrière et décourre ainsi le pénis.

Les fernelles, qui proviendraient, arons-nous dit, des grrandes nymphes, sont d'une taille un peu supérieure à celle des mâles; elles ont le corps plus ovalaire, et leurs pattes postérieures sont toutes terminées par de longues soies. Dautre part, l'orifice anal offre d'assez grandes dimensions, et se troure surmonté d'ine boutonnière ronde (rulve) ressemblant asse\% à l'ouverture laissée par un poil arraché, et par laquelle s'effectue la fécondation (Gudden).

Les mâles et les femelles s'accouplent sans doute à la surface de la peau; mais cet accouplement n'a jamais été constaté dans l'espèce 
qui nous occupe; il doit être très fugace, car les mâles sont en nombre beaucoup moins considérable que les femelles. Ces mâles sont d'ailleurs essentiellement nomades: leur existence se passe à rechercher les jeunes femelles pubères pour les féconder. Ils se nourrissent, pense-t-on, de la sérosité quïls font sourdre en déchirant et soulevant des pellicules épidermiques, sous lesquelles ils se blottissent.

Quant aux femelles, elles ne sont pas encore arrivées au terme de leur existence. Il leur reste à assurer le sort de leur progéniture: aussi subissent-elles une dernière mue, qui les fait passer à l'état de femelles ocigères ou mieux de femelles pondeuses.

$4^{\circ}$ àge: Femelle ovigère. - A la suite de cette dernière mue, elles acquièrent, en effet, outre une plus grande taille et des soies plus

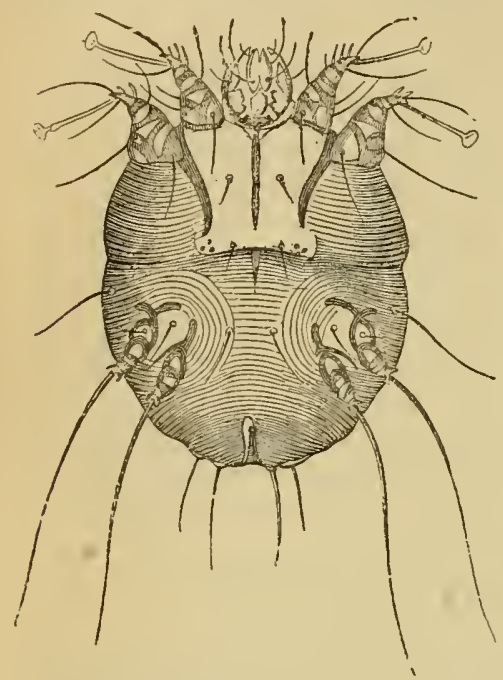

Fig. 440. - Sarcoptes scabiei var. equi: femelle ovigère, grossie 100 fois, vue par la face ventrale. longues, un organe spécial pour la ponte. La fécondation et la ponte ne s'effectuent donc pas par le même organe : c'est un fait qu'ont démontré, il y a longtemps, Bourguignon et Delafond. Le tocostome consiste en une fente transversale à lèvres plissées, située à la face inférieure du céphalothorax, en arrière des épimères des pattes antérieures : c'est l'orifice externe de l'oviducte.

Dans l'abdomen des femelles fécondées, on voit apparaître, parfois même avant la dernière mue, un ou plusieurs ceufs qui sont destinés à sortir par cet orifice. Mais la femelle ne dépose pas ses cufs à la surface de la peau: elle creuse, dans l'épaisseur de l'épiderme, une petite galerie (cuniculus) à laquelle les dermatologistes donnent le nom impropre de sillon. Pour accomplir ce travail, comme l'a vu Bourguignon, elle s’arc-boute sur les soies de ses pattes postérieures et, par des mouvements latéraux, déchire l'épiderme à l'aide de ses mandibules, de manière à soulever une lamelle, sous laquelle elle s'engage. Une fois entrée dans la galerie, ses écailles et épines dorsales s'opposent à ce qu'elle puisse rétrograder. Dans l'intérieur de ce canal, on trouve de petits points noirs qui ne sontautres que des excréments, des amas d'œufs ou de coques vides, et parfois une dépouille tégumentaire indiquant que la dernière mue s'est effectuée tardivement; de distance en distance, la paroi supérieure est percée de petits trous: 
ce sont les ouvertures par lesquelles se sont éehappées les larves. A l'une des extrémités du sillon, on distingue un petit point blane jaunâtre assez net : c'est la femclle ovigère, qu'il est possible d'enlever à la pointe d'une aigruille.

Organisatiox. - Il nolls reste à faire un examen rapide de l'organisition des Silrcoptes adultes. Pous savons que ces Acaricns ont le corps testudiuiforme, c'est-ádire convexe en dessus, plat en lessous; muni de ruatre paires de pattes, dont deux rapprochées du rostre et les deux autres situées en arrière; enfin, creusé à sa partie antérieure d'une carité (camérostome) incisée en dessous et destince à logrer la base du rostre; la paroi supérieure de cette clıambre s’appelle épistorne.

Le tígument est formé par une cuticule transparente, marquée de plis parallèles plus ou moins nomhreux, interrompus, dans le nilieu le la régrion dorsale du céphalotlırax, par un plastron clitineux yrenu et, plus en arrière, pir de petites saillies coniques assez nombreuses. Il existe en outre le nombreux appendices téğumentaires, sous forme de soies, de piquants aigus et rigides et d'épines à pointe mousse; nous ne pourons entrer ici dans le détail de toutes ces parties, et nous nous bornons à rappeler la présence de deux groupes de trois épines sur le notothorax et de deux groupes de sept épines sur le notogastre.

Le squelette dermique a pour base des épimères, en nombre éral

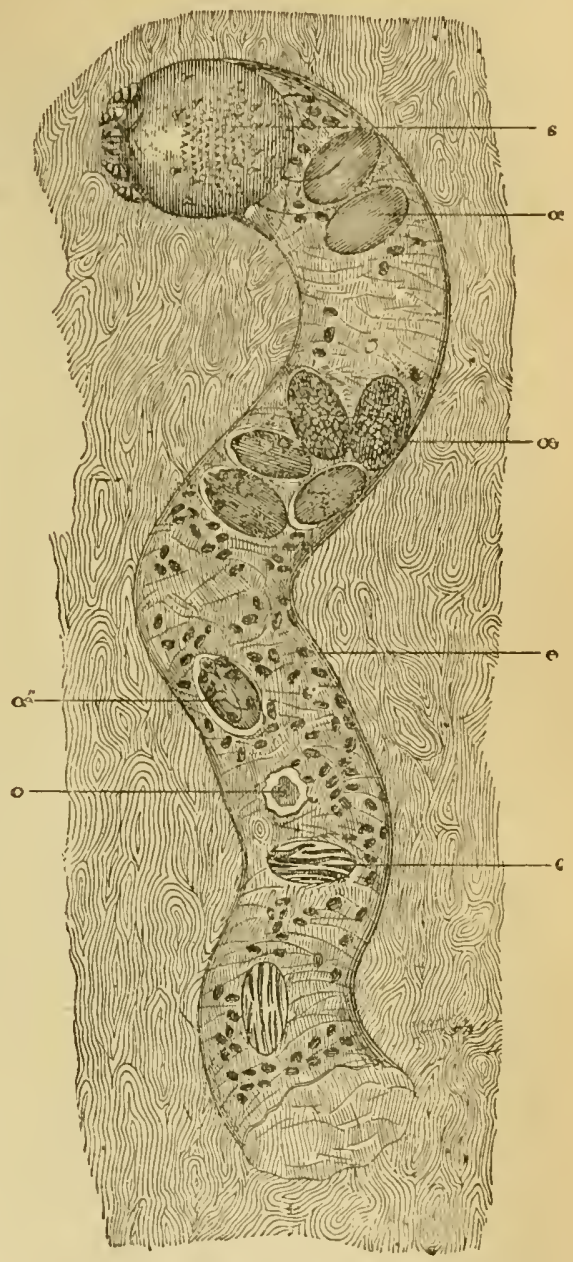

Fig. 411. - Sareopte de lllomme : femelle fécondée $(s)$ creusant sa galerie (sillon). Figure demi-schémalique, en partie daprès Gerlach. - On roil, d'arant en arrière, les orufs de plus en jlus anciens $x, e^{\prime}, x^{\prime \prime}$, puis des coques vides $c$. $o$, chemine on orifice d'échappement des laries. $c$, excríments. à celui des pattes, et chacun des cinq articles de celles-ci comprend une pièce solide; si l'on ajoute à cela les pièces du rostre et celles de larmure śénitale du mile, on aura une idée complète des formations squelettiques du Sarcopte de la gale. La pièce solide de la hanche est articulée a l'épimère correspondant; celles du trochanter, de la cuisse, de la jambe et du tarse s'articulent de mème entre elles; mais ces articulations sont plus ou moins obliques et disposées en sens divers, de manière ì permettre des mouve- 
meuls variés à l'aide de simples muscles fléchisseurs et extenseurs. Le tarse se termine par une longue soie ou par un ambulacre composé d'un pédicule transparent et d'une expansion campanulée ou ventouse, grảce aux contractions de laquelle l'adhérence est obtenue, mème sur les corps les plus lisses.

Le rostre, logé par sa base dans le camérostome et à peine caché parl'épistome,'est légèrement conique, avec l'extrémité libre obtuse, arrondie. ll se compose des pièces suivantes : deux chélicères ou mandibules, deux maxillipèdes (maxilles arec leurs palpes), une lèvre inférieure et deux joues. Les mandibules occupent le plan supérieur et sont rapprochées vers la ligne médiane

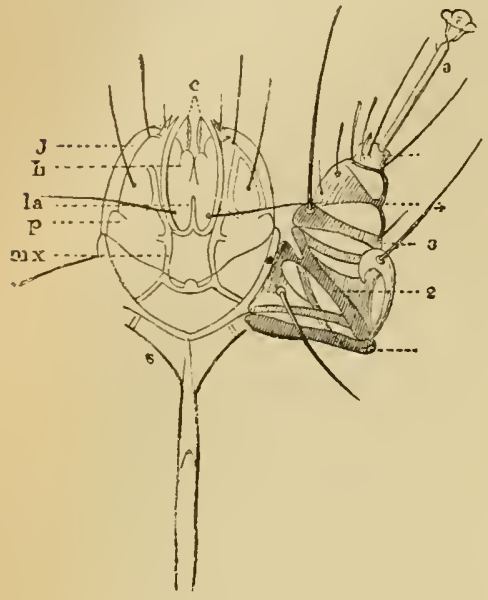

Fig. 442. - Rostre et patte de la premiere paire du Sarcoptes scabiei var. equi, au grossissement de 300 diamètres. - $c$, clıélicères ou mandibules. $m x$, maxilles. $p$, palpes maxillaires. $j$, joues. $l a$, languette. li, levre inferieure. $s$, sternum formé par la réunion en $\mathrm{Y}$ desépimères de la première paire. $1,2,3,4,3$, articles de la patte. $a$, ambulacre à ventouse (Orig.). par leur bord supérieur; chacune d'elles est constituée à la façon d'une pince d'écrevisse; l'un des mor's, le supérieur, continue la tige qui le porte; l'autre est articulé sur cette tige; tous deux sont dentés. Les mâchoires ou maxilles, situées en dessous et en arrière des mandibules, consistent en deux pièces courbées en $\mathrm{S}$ et réunies en arrière à une pièce médiane ou menton, de telle sorte que l'ensemble offre assez l'aspect d'un fer à cheval. Les palpesmaxillaives, relevés à peu près sur le mème plan que les mandibules, qu'ils contournent, sont coniques et un peu courbés, à convexité extérieure; ils se composent de trois articles, dont le basilaire, très large, s'articule avec la màchoire. La levre est représentée par une simple membrane cuticulaire qui joint en arrière les deux màchoires, se prolonge assez loin en avant et adhère par côté au bord interne des palpes; elle porte une petite languette à sa face supérieure. Enfin, en dehors des palpes, on apercoit deux expansions culiculaires transparentes, carénées, auxquelles Robin donnait le nom de joues; elles partent des bords du camérostome et suivent la courbure des palpes, sur lesquels elles s'appliquent.

La bouche est une cavité prismatique à trois faces; l'une, inférieure, limitée par la lèvre et les maxilles (hypostome), les deux autres, supérolatérales, formées par les mandibules et les palpes. A cette bouche fait suite un œsophage, qui débouche bientòt dans un large estomac offrant deux diverticules latéraux peu marqués. L'intestin est court, et se termine par un rectum assez large, rétréci en avant et en arrière. Les Sarcoptes paraissent se nourrir de sérosité; leur morsure doit s'accompagner du dépôt d'un liquide irritant.

La circulution est sans doute purement lacunaire; quant à la respiration, elle s'effectue par la surface du corps.

Bien qu'on ne distingue aucune trace de systeme nerveux, il est constant 
que les Sarcoptes ont certains sens assez développès. L.e tact s'opère surtout a l'aide des soies qui garnissent le corps, peut-ètre aussi à l'aide des palpes. On a attribué en outre à ces derniers la perception des sensations gustatircs, dont la réalité nous est démontrée, ainsi que celle des sensations olfuctives, par la prélérence des Sarcoptes pour telles espèces déterminées de Mammifères. Enfin, malgré l'absence d'yeux, ces Acariens perçoivent la lumiẻre, car on les voit toujours se diriger du còté de l'obscurité.

Quant aux organess sexuels, nous avous signalé plus lıaut leur constitution (voir p. 629 et 643 ) ; pour le surplus, nons renverrons au Mémoire de Gudden.

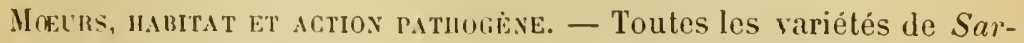
coptes scabiei n'habitent pas la même région du corps des animaux sur lesquels ils vivent, mais c'est un lait général que ces Acariens sont peu sociables et que, par suite, ils se disséminent rapidement. Leur lécondité est d'ailleurs considérable: Gerlach a calculé qu'un seul couple, dans l'espace de trois mois, peut fournir six générations. donnant un million de femelles et 500,000 mâles. On ne doit done pas ètre étonné de voir avec quelle rapidité se propargent quelquefois les aflections psoriques.

Tous ces Acariens creusent des sillons dans l'épiderme, mais ceux-ci ne peurent ètre distingués que chez les hötes à peau très fine, notamment chez l'Homme. Chez les autres, ils sont masqués, soit par les poils, soit par l'épaisseur ou les caractères particuliers de la peau, soit enfin par leur pénétration à une plus grande profondeur.

I'resque tous peurent passer d'une espèce animale à une autre, el prospèrer quelque temps sur ce terrain élranger; mais, en thèse générale, la gale qu'ils provoquent ne devient réellement grave que quand le Sarcopte envahisseur est très roisin, par ses caractères, de la variété propre à l'hôte envahi.

La prophylaxie de la gale doit se régler évidemment d’après la connaissance du mode habituel de contagion et des sources diverses qui pewrent fournir l'élément étiologique essentiel, l'Acarien.

Quant au traitement, il consiste dans l'emploi des médicaments connus sous le nom d'acaricides ou d'antipsoriques, qui sont extrêmement nombreux et variés.

Sarcopte de l'Howme (S. sc. var. hominis. - Syn. : S. hominis Raspail, 1834). - Ecailles dorsales laissant une clairière postérieure. Sternite de l'armure génitale mâle ì branches antérieures souvent très réduites, et par suite làchement articulé arec les épimères des pattes postérieures. Wäle long de 200 à $233 \mu$, large de 143 à $190 \mu$. Femelle ovigère longue de 330 a $430 \mu$, large de $2: 30$ a $330 \%$. Ovipare, quelquefois vivipare, d'après Bourguignon.

L'histoire du Sarcopte de la gale humaine, qui a été principalement étudiée par Raspail, Bourguignon et Fürstenberg, est cerlainement des plus instructires, mais nous ne pourons songer à l'exposer ici. Nous en rappellerons seulement quelques points importants. Ce sont les médecins arabes qui, les 
premiers, ont clairement indiqué l'existence de la gale, et c'est à l'un d'eux, Ibn-Zohr ou Avenzoar (xur siècle), qu'on doit la première mention d'un animalcule comme canse de cette maladie. A partir de celte époque, il semble que l'existence de cet animalcule soit généralement admise, et du xivo au xvı siècle, on voit une foule d'auteurs, comme Guy de Chanliac, Ambroise Paré, Rabelais, Fallope, Rondelet, Moufet, faire mention des cirons de Ia gale. Au xvı ${ }^{e}$ siècle, Hauptmann et Eltmüller en donnent la figure, puis Bonomo les décrit d'une façon précise, et Linné les classe sous le nom d'Acarus humanus subcutaneus (1761).

Cependant, la plupart des médecins, inhabiles à déceler l'existence du parasite, étaient arrivés à en nier l'existence. En 1812, un pharmacien de l'hòpital Saint-Louis, Galès, eut la prétention de renverser celte opinion et de montrer l'Acarien; on le regarda comme un imposteur. A la suile de cet incident malheureux, le "ciron " de la gale devint pour les médecins français un sujet de plaisanterie, et fut cousidéré comme un produit de l'imarrination des naturalistes, jusqu'au jour où un étudiant corse, Renucci, montra que le parasite se trouvail à l'extrémité des sillons, et l'enleva à la pointe d'une aiguille, à la façon des matrones de son pays (1834). La mème année, Albin Gras établissait la valeur diagnostique du sillon. Dès lors, toute hésitation disparut et l'étude de la gale entra dans une phase véritablement scientifique. Le mâle dı Sarcopte fut découvert en 1843 par lírämer, puis revu en 1851 par Lanquetin.

La gale de l'Homme débute généralement par de légères démangeaisons, qui augmentent peu à peu d'intensité, et qui subissent des exacerbations sous l'influence de la chaleur, de l'exercice et surtout du séjour au lit.

Au bout de quelques jours, si l'on examine de près les points malades, on arrive souvent à découvir des "sillons " ou galeries caractéristiques, sous forme de traìnées généralement blanchâtres ou blane grisâtre, longues de 3 millimètres à plusieurs centimètres, droites ou plus ou moins contournées. Ces sillons, qui sont creusés dans la couche cornée de l'épiderme, se montrent de préférence aux mains, dans les intervalles des doigts ou sur leurs faces latérales, aux poignets, aux coudes, aux genoux, sur le pénis et sur les seins.

En même temps que les sillons, qui sont parfois peu nombreux et difficiles à découvrir, apparaissent des éruptions secondaires. La plus importante se présente sous la forme de papulo-vésicules, dont les lieux d'élection sont à peu près les mêmes que ceux des sillons: elles se montrent le plus souvent près de l'entrée de ceux-ci. On observe aussi des papules (prurigo), souvent en très grand nombre, disséminées en des points très variés de la surface du corps, ainsi que des pustules (ecthyma), siégeant surtout aux mains, aux pieds et aux fesses. Parfois, du reste, sous l'influence des grattages, les papulo-vésicules s'enflamment et se transforment en pustules. Enfin, d'autres lésions encore, comme l'eczéma, l'impétigo et le lichen, peuvent survenir quand la maladie est de date ancienne, sans compter d'autres acci- 
dents de moindre fréquence, et des complications d'origine externe ou interne. - La gale ordinaire, fail important a noter, respecte la face et le cuir chevelu.

Les papulo-résicules sont dues ì l'action d'un venin sécrété par les Sarcoples, ainsi que l'ont élabli Gerlach et Irardy par l'inoculation du produit résultant de lécrasement d'un certain nombre de ces Acariens; celles qui sont éloignées des sillons sont peut-être dues à des màles, à des nymphes ou à des larves, dont l'existence est plus ou moins vagabonde. Quant aux excoriations, aux pustules, etc., elles sont le résultat du grattage.

La grale se transmet facilement de l'Homme à l'Homme; il est assez. rare cependant que cette transmission s'effectue par roie médiate (lits, vètements); presque toujours elle a lieu par contact intime, prolongé ou répété, et surtout par cohabitation nocturne.

Delafond et Bourguignon ont essayé, mais sans succès, d'acclimater le Sarcopte humain chez diver's animaux. Chez le Cheval, le Chien et un Singe, ils ont ru se produire une éruption éphémère ; clıez le Chat, ils n'ont obtenu aucun résultat.

Le traitement adopté gẻnéralement aujourd'hui, dans les cas simples, a été instilué par Hardy en 1852. Voici en quoi il consiste: $1^{\circ}$ Friction sur tout le corps, el en particulier dans les points d'éleclion, avec du saron mou de polasse; durée, ringt minutes; $2^{\circ}$ bain tiède dans lequel la friction est continuée; durée, une heure; $3^{\circ}$ au sortir du bain, et le corps essuyé, friction générale arec la pommade d'llelmerich, modiliée par Hardy : Axonge 300 grammes; soufre 50; carbonate de potasse $2:$; durée, vingt minutes. La pommade ne doit être enlevée qu'au bout de quatre ou cinq heures, dans un second bain.

Les vêtements sont en même temps soumis dans l'étuve à une température de $80^{\circ}$; à défaut d'étuve, on les passe au four, ou bien on les lave arec soin, puis on les traite par l'acide sulfureux.

Sarcopte de la gale crouteuse (S. sc. crustosx Fürst., 1861). - Forme de taille plus petite que le Sarcopte de la gale commune. Écailles dorsales de la femelle ovigère peu aiguës, mais assez fortement chitinisées et ne laissant pas de clairière. Épines du notogastre un peu courbées et très pointues. Sternite de l'armure màle assez étroitement uni aux épimères des pattes postérieures. Mule long de $172 \mu$, large de $133 \mu$. Femelle ovigère longue de $\$ 13 \% \mu$, large de $341 \mu$ (Fürstenhergr).

Fürstenberg a trouvé cette variété dans des croûtes recueillies par le professeur Boeck, de Christiania, chez des individus affectés d'une lorme de gale particulière, dite gale norvigienne.

Cette dermalose, signalée pour la prenière fois en 1848, par Bocck et Danielssen, est caractérisée par le développement de croûtes géantes dans lesquelles pullulent les Sarcoptes. 11 arrive parfois que 
ces croûtes apparaissent d'emblée; mais le plus souvent elles ne se produisent qu'au bout de plusieurs années ( 3 ans, Rigler, 9 ans, Vogel).

Sur divers points du corps, mais de préférence à la paume des mains, à la plante des pieds, aux poignets, aux coudes, aux genoux, on voil se former des callosités épidermiques ayant d'ordinaire 1 à 6 millimètres d'épaisseur, mais pouvant atteindre jusqu'à 30 millimètres. A l'intérieur de ces crontes, on trouve d'énormes quantités de Sarcoptes, occupant des galeries très irrégulières, et morts pour la plupart. Les individus vivants, également en très grand nombre, se rencontrent à l'intérieur de la couche muqueuse, où ils trouvent les éléments de leur nutrition. Comme résultat de cette pullulation des parasites, on a souvent noté aussi un épaississement considérable des ongles, qui sont comme rongés, minés par des Acariens, et la chute des poils ou des cheveux, - car la gale norvégienne peut s'étendre à la face et au cuir chevelu.

Deux théories sont en présence pour expliquer le développement de cette forme psorique. Selon Hebra, elle tient an terrain particulièrement favorable qu'offrent certains sujets à la multiplication des Acariens. D'après Fürstenberg, au contraire, elle est le fait d'un Sar copte particulier. Mégnin a même prétendu que ce Sarcopte n'était autre que celui du Loup; mais les différences entre les deux formes sont telles que cette opinion est insoutenable.

La gale croûteuse a été observée non seulement en Norvège, mais aussi en Allemagne, en Autriche, en France, en Danemark, en Russie et en Turquie.

Elle se transmet facilement du malade à des personnes saines, et présente une grande ténacité, ne cédant qu'à un traitement énergique et prolongé.

Sarcopte des Équidés (S. sc. var. equi. - Syn. : S. equi Gerlach, 18577, nec Hering, 1838). - Écailles dorsales assez aiguës, bien chitinisées; une clairière antérieure et une clairière postérieure. Sternite del'armure màle intimement uni aux épimères des pattes postérieures. Wâle long de 220 à $233 \mu$, large

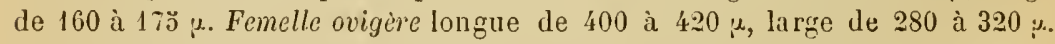

Le Sarcopte du Cheval a été découvert en 1816 par Eichstedt, et retrouvé dix ans plus tard par Delafond et par Gerlach. Mais la gale qu'il détermine était certainement connue depuis fort longtemps, et l'on peut y rattacher, en particulier, la forme que les ancicns auteurs signalaient sous le nom de "gale épizootique".

Cette gale se manifeste tout d'abord par un prurit intense; s'accusant surtout la nuit et sous l'influence de la chaleur. On voit bientôt survenir des papulo-vésicules disséminées, entraînant de petites dépilations circulaires qui se multiplient rapidement, s'étendent et finis. sent par devenir confluentes. Plus tard apparaissent des croûtes et diverses altérations secondaires du tégument. 
La maladie débute le plus souvent par le garrot, pour gagner ensuite les parties supérieures el latérales du corps; elle envahit difficilement les régions inféricures des membres, et respecte les parties garnies de crins. Sa marche est sourent asse\% rapide, et il n'est pas rare d'oloserver une généralisation complète dans l'espace d'un mois. Si les animaux ne sont pas soignés à temps, ils tombent dans un élat de marasme qui les conduit lentement ì la mort.

La gale sarcoptique se transmet très facilement du Cheval au Cheral, a l'Ane ou au Mulel, par voie immédiale ou médiate. Delafond el Bourguignou ont cherché à déterminer la durée de la vie du Sarcopte. Dans un verre de montre, à une tempéralure de 10 à $10^{\circ} \mathrm{C}$, les larves ont péri du $4^{\mathrm{e}}$ au $6^{\mathrm{e}}$ jour, les màles du ${ }^{\mathrm{e}}$ au $8^{\mathrm{e}}$, les femelles du $6^{\circ}$ au $9^{\mathrm{e}}$. A 130 ou $2^{\circ}$, les larves sont mortes du $5^{\mathrm{e}}$ au $6^{\mathrm{e}}$ jour, les

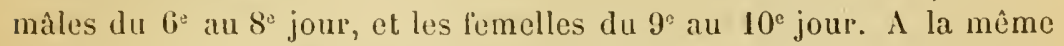
température, mais en plaçant les Acariens avec des croûtes fraîches et des fragments de litière humectés, les larves ont vécu 10 jours, les mâles 13 ì 1.4 et les femnelles 1 ' à 16 . Gerlach a obtenu des résultats analogues: dans un lambeau de peau conservant son humidité, il a vu les mourements des Acariens persister jusqu'au $28^{\mathrm{e}}$ jour. De plus, fait important, il a constaté qu'aucune variété de Sarcopte, exposée à une chaleur sèche de $60^{\circ}$, ne prolonge son existence au delà d'une heure.

La gale sarcoptique est de toute évidence celle dont les anciens auteurs avaient reconnu la transmissibilité à l’Homme, bien avan que la distinction fùt établie entre les trois formes de psore dont le Cheval peut être affecté. Les premiers cas de cette contagion paraissent aroir été signalés par Énaux et Cluaussier en $178 \%$; mais, depuis lors, on en a rapporté un nombre considérable. Les exemples les plus caractéristiques ont été relevés dans les Écoles vétérinaires et dans les régiments de caralerie. Gerlach a fait du reste, sur luimème el sur des élèves de l'École vétérin aire de Berlin, des essais de transmission du Sarcopte du Cheval : il a vu la gale se développer à des degrés divers. Chez quelques-uns de ces élèves, elle a élé limitée à une période de trois semaines au plus, et s'est alors éteinte spontanément; sur d'autres, elle a persisté de 19 ì 30 jours, et a nécessité, pour èlre guérie, des lotions alcalines suivies d'ablutions faites avec l'eau phagédénique. En somme, les faits d'observation, ainsi que ceux d’ordre expérimental, démontrent que la gale sarcoptique du Cheval se transmel à l'Homme, mais que dans heaucoup de cas elle est assez. fugace et tend ì disparaitre spontanément. Aussi bien, cette transmission est-elle relativement rare, si l'on considère la fréquence de la maladie chez le Cheval.

Il n'est pas encore bien démontré que la gale sarcoptique du Cheral soit transmissible aux divers animaux domestiques. Robert Fauvet et Grognier disent bien aroir vu la gale se communiquer du Cheral à 
l'Homme et à la Vache, mais ces faits sont peu précis. Gerlach n'a obtenu sur le Porc que des résultats négatifs.

Le Sarcopte du Cheval est généralement difficile à décourrir : pour le chercher avec chances de succès, il faut placer le Cheval au soleil ou le revêtir d'une épaisse couverture, puis gratter la peau jusqu'au sang dans les points récemment envahis, et faire l'examen microscopique de préférence dans une pièce chauffée, car la chaleur active les mouvements des Sarcoptes et les fait découvrir avec plus de facilité. On peut aussi placer le produit des grattages sur du papier noir, et rechercher les Acariens à la loupe près d'un foyer. Enfin, on a plus de chances encore de réussir en laissant les produits à examiner pendant une ou deux heures dans une solution de potasse à $20 \mathrm{p} .100$, avant de les étudier au microscope. Bien entendu, on ne doit opérer que sur des Chevaux n'ayant pas encore été traités.

Les mêmes recommandations sont d'ailleurs applicables à la gale de divers autres animaux, notamment du Chien.

Sarcopte des Bovinés. - Bien que Robin ait signalé, en 1860, la découverte du S. scatiei sur le Bœuf (Lanquelin, Reynal, Robin), il ne parail pas que cet animal héberge une variété particulière de Sarcopte. On peut supposer que ces auteurs ont eu simplement affaire à un cas de transmission d'une gale équine ou autre, car il semble que le Bœuf puisse prendre, au moins d'une façon passagère, la gale du Cheral (Grognier, Robert Fauvet) et celle de la Chèrre (Walraff).

Bieler, de Lausanne, a contracté une gale très intense pour avoir conservé dans sa poche, enfermé dans du papier, un échantillon de poils provenant d'un Bison galeux (1).

Sarcopte du Mouton (S. sc. var. ovis). - Écailles dorsales peu nombreuses, raréfièes surtout en arrière. Une faible clairière antérieure, une postérieure plus étendue. Sternite de l'armure màle làchement uni aux épimères des pattes postérieures. Mâle long de $2: 0 \mu$, large de $160 \mu$. Femelle ovigère longue de 320 à $440 \mu$, large de 240 à $330 \% \mu$.

Delafond a le premier trouvé cet Acarien, en 1858, sur des Moutons napolitains amenés à Paris. La gale qu’il détermine ne se développe guère que sur les régions dépourvues de laine, et en particulier sur la tête, d'ou le nom de noir-museau sous lequel on la désigne habiluellement en France. Ce n'est que lorsqu'elle est ancienne qu'elle se montre sous le ventre et sur les membres, en produisant des croûtes épaisses, ğris jaunâtre, dures et adhérentes. Enfin, chez certaines races de Houtons, elle peut s'étendre à tout le corps : Houton de Zackel, Mouton à queue grasse, Mouton napolitain (Roloff), Mouton southdown (Railliel). Dans ce dernier cas seulement, nous avons vu périr l'animal. Quelques anciennes observations, fort peu précises d'ailleurs, ten-

(1) Recueil de méd. vèt., 1892, p. 511. 
daient ì faire supposer que la gale du Mouton pouvait ètre transmise à l'Ilomme. En 18:8, Delafond ayant confié aux soins d'un elève de l'École d'Alfort un Mouton alteint de gale sarcopticue, vit apparatitre sur cet élève une éruption psorique très étendue, qu'on dut traiter apris une duréc de quarante-neuf jours, et qui ne disparut complètement que quinze jours plus tard. En 18ī, Gerlach tenta lui-même, à diverses reprises et aree sucè̀s, la transmission de eette gale ì un élive, et chaque fois il se vit ohligé de traiter cette maladie expérimentale pour en arrèter l'extension. Toutefois, la contagion du noirmuseau à l'Homme doit être pratiquement un fait des plus rares, calr pendant des années j'ai entretenu des animaux affectés de cette maliadie, et aueune des personnes chargées le les soigner n’a présenté la moindre éruption.

La gale sareoptique du Mouton se transmet facilement à la Chèvre (Roloff, Railliet), ce (fui tend ì faire admettre l'identité d'origine de l'affection dans les deux espèces. Nous l'avons aussi transmise à un Chien, qui en est mort après avoir communiqué à un autre Chien une éruption éphémère. Nous n’avons pas réussi sur le Lapin.

Chez le Cheval, le Bouf, le Chien, Gerlach n’a obtenu cqu'une éruption locale par le dépòt de croùtes prises sur le Mouton.

Sarcopte de la Cuère (S. sc. var. capra. - Syli. : S. caprex Fürst., 1861, nec Del. et Bonrg., 183̈ $)$. - Écailles dorsales peu aiguës en ğénéral, laissant à peine une trace de clairière postérienre. Sternite de l'armure màle paraissant làchement uni aux épimères des pattes postérieures. Mâle long de $243 \mu$, large de $188 \mu$. Femelle ovigere longue de $343 \%$, large de $342 \mu$ (Fürstenberg).

C'est Franz Müller, de Vienne, qui a découvert ce parasite, en 18:33, sur des Chèrres naines d'Afrique. Hebra le considéra comme identique à celui de l'Hoinme. Fürstenberg en fit une étude assez complète, mais arec des matériaux évidemment en mauvais état, et le regarda comme représentant une espèce distinete.

Il est eertain cependant que la gale sarcoptique de la Chèvre avait été observée cliniquement arant la déeourerte de l'Aearien qui la détermine.

Celte affection provoque toujours un violent prurit. Elle commence par la tète et les oreilles, puis gagne le trone et enfin les membres. Elle donne lieu à des croûtes sèches, furfuracées ou en plaques épaisses. Elle amène un dépérissement rapide, qui peut entraîner la mort. Les Sarcoptes sont trouvés en abondance sous les croûtes.

La gale caprine sévit quelquefois ì l'étal épizootique. Walratl, qui l'a observée sous cette lorme, de 18.11 à $18 \% 34$, dans la vallée de Präittigau, eanton des Grisons (Suisse), a constaté qu'elle se transmettait au Cheval, au Bœuf, au Mouton, au Pore et surtout à l'Homme; elle se propageail ensuite d'Homme à Homme, et affectait d'ailleur's un caractère particulièrement grave. - A Londres, Henderson a vu, en 18̈̈1, 
la gale de la Chèvre se communiquer au Cheval, et de celui-ci à l'Homme; ici encore, le prurit était extrèmement violent. Nüller et Krait ont noté également le passage de la gale de la Chèvre à l'Homme.

Walraff a ru en outre la galecaprine se communiquer au Mouton, au Boeuf, au Cheval et au Porc.

Sarcopte du Dromadare (S. sc. var. cameli). - Syn.: S. diomedarii Ger lach, 185̃i). - Nous n'avons pas encore pu étudier personnellement cet Acarien, qui a été décrit d’une façon peu précise par les auteurs.

D'après Bictt, le Sarcopte du Dromadaire aurait été découvert en 1827 par un aide d'anatomie au Jardin du roi. P. Gervais l'a retrouvé en 1841 sur un Dromadaire nouvellement envoyé d'Afrique au Muséum de Paris.

Le Dromadaire et le Chameau sont du reste très fréquemment atteints de gale. Cette affection se traduit d'abord par un prurit très violent. Elle débute par les endroits où la peau est mince, comme les aines, les ars, la face inférieure de l'abdomen, puis gagne rapidement les autres parties du corps. Des croûtes se forment, le poil tombe, la peau s'épaissit et s'excorie, et l'animal devient cachectique.

La transmission à l'Homme de la gale du Dromadaire a été notée, dès 1819, par Louis Franck, et plus tard par d'autres observateurs. Le cas le plus connu est celui de Biett. En 1827, six Dromadaires envoyés d'Égypte au Muséum d'histoire naturelle de Paris furent atteints de la gale. Les gardiens chargés de les soigner contractèrent la maladie, ainsi qu'un palefrenier d'Alfort. "L'éruption avait pris une si grande intensité chez plusieurs d'entre eux, qu'il survint des symptômes d'inflammation gastro-intestinale, et chez deux de ces hommes, vigoureusement constitués, une infiltration générale. "En Arabie, d'après Palgrave, on observe souvent aussi le passage de la gale du Chameau à l'Homme. En Égypte, Piot a observé de nombreux faits du même genre: presque tous les chameliers, dit-il, sont contaminés par leurs animaux (1).

Sarcopte du Lasia (S. sc. var. auchenix). - Écailles dorsales ne laissant pas de véritables clairières. Mâle long de 2430 u, large de 182 u. Femelle ovigère longue de $340 \mu$, large de $26 x \mu$.

Trouvé en 1858 et 1859 , par Delafond et Bourguignon, sur des Lamas du Muséum de Paris. Donne lieu à une gale qui se généralise très rapidement et amène la formation de grosses croûtes grisâtres, dures et très adhérentes. - Nous possédons une forme semblable recueillie sur la Vigogne.

Les auteurs précités ont constaté, en 18038, la transmission de cette affection à deux élèves de l'École d'Alfort chargés de donner leurs

(1) Recueil de méd. vét., 1892, p. 512. 
soins à un Lama galeux. Il survint des troubles tels qu'on dut traiter la maladie au bout din mois.

Sarcopte du Porc (S. sc. var. suis. - Syn.: S. suis et S. canis Gerlach, 18:77; S. squamiferus liürst., 1861). - Inclividus de grande taille. Écailles dorsales forles el bien chilinisées, laissant une faible clairière postérieure un peu en avant des premières épines du notogastre. Sternite de l'armure màle intimement uni aux épimères des paltes postérieures. Male long de $20 \ddot{0}$ ì $330 \mu$, large de 190 à $300 \mu$. Femelle ovigère longue de 400 à $500 \mu$, large de 320 à $390 \mu$.

Gurlt el Spinola avaient trouré, en 1847, un Sarcopte dans la grale lu Sanglier; mais c'est Delafond qui a découvert, dix ans plus tard, celui de la gale du Porc domestique.

Cette affection, qui détermine dès le début un violent prurit, paraît avoir son siège primitif à la tête (notamment aux oreilles et au pourtour des yeux), au garrot, à la croupe, à la face interne des cuisses. Elle peut ensuite envahir toute la surface du corps. L'épaisseur de la peau ne permet pas d'observer de sillons. Les poils tombent et il se forme des croûles atteignant jusquà $\ddot{j}$ et 10 millimètres d'épaisseur. Parfois les papilles cutanées s'hypertrophient el constituent des sortes de verrues. La gale généralisée conduit lanimal au marasme.

Cette affection est transmissible à l'Homme. Bateman en Angleterre, Bontekoe et Heckmeyer en Hollande, von Gemmern en Allemagne ont relaté des observations cliniques témoignant de cette transmissibilité : tantôt la maladie s’éteignait spontanément au bout d'une dizaine de jours, tantôt elle ne cédait qu'à un traitement approprié. Delafond fut contaminé en disséquant la peau dun Porc galeux : laffection évolua lentement; mais, le trentième jour, comme elle menaçait de se généraliser, on dut aroir recours à des frictions médicamenteuses. D’autre part, Siedamgrotzky rapporte qu'à l'École vétérinaire de Dresde, deux élèves s'élant appliqué sur le bras, au moyen d'un bandage, un fragment de peau provenant d'une truie galeuse, il en résulta une gale très prurigineuse qui, chez l'un, céda d'elle-même au bout de quarante-huit heures, et qu'on fut obligé de traiter cliez l'autre.

On est encore mal fixé sur la transmissibilité de la gale du Porc anx autres animaux domestiques : dans quelques essais tentés sur le Chien, le Chat et le Mouton, l'éruption a été nulle ou très fugace.

En 1877, Guzzoni a rencontré, dans la profondeur du conduit auditif externe d'un Porc atteint de convulsions épileptiformes, un Sarcopte mesurant : mâle, $168 \mu$ de long sur $128 \mu$ de large; femelle ovigère, $288 \mu$ de long sur $216 \mu$ de large. C'est une forme notablement plus petite que le Sarcopte ordinaire du Porc, lequel est remarquable au contraire par ses grandes dimensions.

Ce dernier a été vu aussi par Gurlt el Sjinola, puis par Gerlach, 
sur le Sanglier. Nous l'avons observé, avec Ménard, sur le Phacochère de Nubie. Or, une expérience de Spinola prouve que le Sarcopte du Sanglier, transporté sur le Porc domestique, détermine la gale chez cet animal. D'autre part, Gerlach a déposé le même parasite sur la peau de l'Homme : il se produisit une éruption peu étendue et faiblement prurigineuse, qui disparut sans intervention au bout de huit à dix jours.

Sarcopte du Lapix (S. sc. var. cuniculi). - Écailles dorsates de la femelle ovigère peu aiguës, mais assez fortement chitinisées, du moins en avant et sur les côtés. Une clairiere postérieure. Sternite de l'armure mảle assez làchement uni anx épimères des pattes postérieures. Mále long de 210 à $228 \mu$, large le 130 à $178 \mu$. Femelle ovigère longue de 340 à $400 \mu$, large de 260 à 300 ovipare ou vivipare.

Ce Sarcopte a été trouvé, en 1892, par Neumann, sur des Lapins provenant de l'Hérault. Nous l'avons revu quelque temps après sur des Lapins de provenance indéterminée. Il est remarquable en ce que la femelle ovigère renferme souvent un embryon bien développé. Nous avons aussi noté une grande abondance d'individus mâles.

La gale développée par cet Acarien débute au bout du nez, aux lèvres, au menton, à la base des griffes. Elle gagne ensuite la face plantaire des pattes et peut même s'étendre aux diverses parties du corps, en provoquant la formation de croûtes grisâtres, très adhérentes.

Elle est très contagieuse entre Lapins, et tue ces animaux en quelques semaines. Mais Neumann a essayé vainement de la communiquer au Chien, au Mouton, à la Vache, au Porc et au Cheral. Je l'ai transmise au Cobaye et au Furet (1).

S.rncopte du Funet (S. sc. var. furonis). - Écailles dorsales assez minces et serrées. Une faible clairière antérieure. Sternite de l'armure màle assez intimement uni aux épimères postérieurs. Nile long de 215 à $223 \mu$, large de 160 à $178 \mu$. Femelle ovigère longue de 330 à $420 \mu$, large de 270 à $300 \mu$.

La gale sarcoptique du Furel a été décrite pour la première fois en 1869, par F. Peuch. Elle est du reste extrêmement commune, el nous arons eu maintes fois l'occasion de l'étudier. Elle a son siège principal à la tête et aux pattes, mais envahit parfois le tronc tout entier, en provoquant la formation de croûtes brunes ou jaunâtres, plus ou moins épaisses. Aux pattes, les croûtes se développent surtout à la face plantaire et à la base des griffes, qui souvent acquièrent une longueur démesurée et se recourbent en haut (Peuch); d'autres fois, il ne se forme pas de véritables croutes, mais les plalanges offrent un

(1) A. Railliet, De la gale du Lapin causée par le Sarcoptes scabiei; sn transmissibilité au Cobaye et au Furet. Comptes rendus de la Soc. de biologie (9), V, p. $735,1893$. 
épaississement de la peau tel qu'elles arrivent í tripler de volume, les griffes restant normales (Railliet).

Probablement le Furel contracte-t-il cette gale en pénétrant dans des terriers de Lapins fréquentés par des Putois galeux.

Peuch n’a pas réussi, dans quelques essais, à transmettre la gale du furet au Chien, non plus qu'it l'llomme.

Sarcopte du Cumen (S. sr. var. canis). - Écailles dorsales de la femelle ovigère peu chitinisées, mais ne laissant pas entre elles de véritable clairière. Sternite de l'armure mìle lìchement uni aux épimères des pattes postérieures. Male long de 190 à $230 \mu$, large de 110 a $170 \mu$. Femelle ovigère longue de 290 à $380 \mu$, large de $23 \%$ ì 283 i..

Entrevu par quelques anciens observateurs, tels que Bose, Gohier, Bonnes, Ilertwig, puis décril assez inexactement par Gerlach, le Sarcopte du Chien a été bien étudié tout d'abord par Delafond et Bourguignon. Nous avons eu fort souvent l'occasion de l'olsserver sur les Chiens soignés dans les hôpitaux d'Alfor't.

La maladie débute le plus souvent par la tête, mais elle s'étend avec rapidité, au point d'envahir tout le corps dans l'espace d'un mois. Elle se manifeste par des points rouges, bientôt remplacés par des papules derenant résiculeuses à leur sommet, parfois mème pustuleuses. Ces boutons se crèvent et laissent une surface humide qui se dessèche ensuite en formant des croutes. Ou bien la gale se montre sèche d'emblée. La peau dépilée s’épaissit, se plisse, s'excorie et répand une odeur infecte. Le prurit est intense. L'animal tombe dans le marasme et succombe au bout de deux ou trois mois.

Vais Delafond et Bourguignon ont démontré que la propreté, le grand air, l'exercice, et avant tout un régime abondant et riche en matière animale peuvent suffire seuls à guérir l'affection, lors même qu'elle est arrivée à son dernier degré de gravité.

Cette gale se transmet facilement du Chien au Chien, par cohabitation.

La contagion à l'Homme a été établie depuis longtemps par les obserrations de Chabert, Grognier, Saurage, Viborg, Mouronval, ete., etc. Dans une épizootie de gale qui a sévi en 1890 sur les Chiens, en Allemagne, des centaines de personnes ont été contaminées; dans l'espace d'un mois, Fröhner a constaté, à Berlin, 21 cas de cette contagion. Delafond a vu la maladie envahir un élève chargé de soigner un Chien galeux; il a pu extraire, des sillons formés sur la main, des Sarcoptes qu'il a reconnus comme identiques à ecux du Chien; au bout d'un mois, on fut obligé de traiter cette gale. Cet observateur a, de plus, déposé sur lui-mème et sur trois élèves des Sarcoptes recueillis sur un Chien galeux. Sur deux de ceux-ci, l'éruption a élé très fugace. Sur l'autre élève et sur Delalond, la gale s'est bien déreloppée, a persisté six semaines et n’a cédé qu’à un traitement antipsorique. RaILLIET. - Zoologie. 
Gerlach a tenté avec succès une expérience du même genre.

Les essais de transmission de la gale du Chien aux autres animaux domestiques n'ont donné à Delafond et Bourguignon, comme à Gerlach, que des résultats nuls ou insignifiants. Chez le Cheval, toutefois, les premiers de ces expérimentateurs ont vu surrenir une éruption qui s'est guérie spontanément au bout de vingt à vingt-quatre jours.

Au mois de janvier 1880, nous avons eu l'occasion d'étudier, avec Cadiot, un Sarcopte quelque peu différent de celui qui cause la gale commune: les écailles dorsales étaient plus chitinisées, plus saillantes, sans clairière; le sternite de l’organe màle était pourtant encore làchement uni aux épimères postérieurs; le màle était long de 230 à $250 \mu$, large de 170 à $190 \mu$; la femelle ovigère était longue de 430 à $470 \mu$, large de 320 à $330 \mu$.

Il s'agit, comme on le voit, d'individus de grande taille. Nous les avons recueillis sur un Chien de montagne, atteint d'une gale généralisée qui arait débuté six mois auparavant. Ils existaient en grande abondance dans les croûtes noirâtres, fendillées, sèches et dures qui recouvraient la partie supérieure de la tête, le nez, les lèvres et surtout les oreilles.

Peut-être est-ce le même parasite que Gurlt et Fürstenberg avaient rencontré sur des Chiens galeux, et que ce dernier auteur rapportait à son Sarcoptes squamiferus. En tous cas, la gale que nous avons observée était remarquable par sa forme croûteuse et par l'abondance exceptionnelle des Sarcoptes.

Sarcopte du Loup (S. sc. var. lupi). - Écailles dorsales de la femelle ovigère aiguës, bien chitinisées, ne laissant pas de clairière; épines du nototlırax longues et arrondies. Sternite de l'armure màle étroitement uni aux épimères des pattes postérieures. Male long de 270 ,, large de 160 u. Femalle ovigère longue de 370 à $400 \mu$, large de 280 à $300 \mu$.

Trouvé en 187\%, par Mégnin, sur quatre jeunes Loups de la ménagerie du Muséum de Paris, dont toute la peau était courerte de croûtes épaisses, jaunâtres, humides, poisseuses, atteignant par places près d'un centimètre d'épaisseur. Les parasites pullulaient dans ces croûtes.

Quelques-uns de ces Sarcoptes, déposés sur le dos d'un Cheval, s'y sont multipliés en développant une gale ayant tous les caractères de celle du Loup, jusqu'à son odeur caractéristique.

Mégnin a juģé ce fait suffisant pour affirmer que la gale croûteuse ou norrégienne de l'Homme est causée par le Sarcopte du Loup, sans remarquer que ni les caractères de l'Acarien, ni ceux de la gale, n'offrent la moindre analogie dans les deux cas.

Sarcopte du Revard (S. sc. var. vulpis. - Syn. : S. vulpis Fürst., 1861). Écailles dorsales de la femelle ovigère bien chitinisées, étroites, nombreuses, sans clairière; épines du notothorax assez longues. Sternite de l'armure màle 
intimement uni aux épimères des pattes postérieures. Mule long de 2430 , large de $183 \ddot{\mu} \mu$. Femelle ovigíre longue de $442 \mu$, large de $315 \mu$.

Signalé par Walz, en 1809, cet Acarien a été étudié en 1837, par Fürstenberg, sur des spécimens provenant d'un Renard galeux tué dans l’ile de Rügen. L'affection qu’il détermine paraît siéger de préférence sur les parties supéricures du corps, depuis le bout du museau jusqu'a la pointe de la queue. Elle se traduit par le développement de croùtes sòches, pouvant atteindre jusqu'à 2 centimètres d'épaisseur.

Rayer a cité le cas d'un chasseur qui avait été atteint de gale après aroir dépouillé un Renard présentant une affection cutanée croûteuse.

Sarcorte du Lion (S. sc. var. leonis). - Écailles dorsales de la femelte ovigère peu saillantes, peu aiguës, laissant à peine une faible clairière pośtérieure. Sternite de l'armure màle très làchément uni aux épimères des pattes postérieures. Mâle long de $220 \mu$, large de 163 ¡. Femelle ovigère longue de 390 à $400 \mu$, large de 288 à $290 \mu$.

Le Sarcopte du Lion a été découvert en $183 \%$, par Delafond, sur des animaux destinés aux représentations d'un ciroque de Paris. Il a été plus récenment étudié par Johne. La gale qu'il développe débute par la tète et gagne rapidement toute la surface du corps, qui se courre de croultes. Elle est transmissible aux carnassiers, aux Cheraux et à l'Homme.

Alibert rapporte qu'un préparateur d'anatomie, en dépouillant une Lionne galeuse, contracta la gale, ainsi rque l'artiste chargé de l'empailler, le capitaine du bâtiment qui l'avait transportée, le domeslique de celrii-ci et plusieurs autres personnes qui se trouvaient à bord. Rayer cite un fait analogue. Enfin, Delafond et Bourguignon ont ru une éruption psorique survenir chez plusieurs personnes qui avaient un contact journalier avec les Lions dont il est question plus haut. Ils trouvèrent le mème parasite sur les animaux et sur l'Homme. De plus, ils déposèrent sur les bras de quatre personnes des femelles fécondées de Sarcoptes pris sur ces Lions, ainsi que sur une Hyène qui arait gagné leur gale; une éruption psoriçue se manifesta, mais s'éteignit sans cause appréciable du trentième au quarantième jour, et les quatre sujets guérirent sans traitement.

S.arcopte du Wonbat (S. se. var. wombati). - Ce parasite n'a pas été décrit: Fournier le dil simplement identique à celui de l'Homme.

Il a été découvert par Duméril dans la peau d'un Phascolome Wombat ramené d'Australie au Muséum de Paris, et présentant une large éruption crouteuse.

Le gardien de cet animal, ainsi que les aides-naturalistes qui le dépouillèrent et en préparèrent la peau, contractèrent une gale in- 
tense, à vésicules plus grosses que celles de la gale commune de l'Homme. L'emploi du soufre amena une guérison rapide.

B. Sous-genre Notoedres Raill., 1893. - Face dorsale garnie d'épines et parfois d'écailles mousses. Épimères de la première paire de pattes sans prolongement dorsal. Anus sur le notogastre.

Espèces parasites des Mammifères.

Sarcopte nain (S. minor Fürst., 1861. - Syn. : S. cati llering, 1838; Psoroptes cuti P. Gerrais, 1841 ; S. catorum Küuchenmeister, 185̃ ; S. cati et cuniculi Gerlach, 183̈7; Sarcopte notoèdre Del. et Bourg., 1862; S. notoedres Mégn., 1876; S. felis Gerl., 1877). - Corps arrondi dans les deux sexes, sans dépressions latérales, un peu plus roussâtre chez le màle que chez la femelle. Plis du tégument se confondant sur la face dorsale avec des écailles larges et mousses; quatre épines grêles de claque còté du notolhorax, et seulement six épines plus fortes, en deux rangées, de chaque còté de l'anus, lequel est situé sur le milieu du notogastre chez la femelle, un peu plus en arrière chez

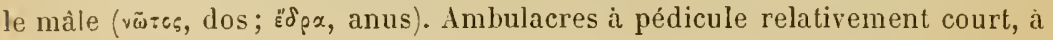
rentouse large, répartis comme dans l'espèce précédente. Ovipare.

Le Sarcopte nain vit sur les Carnivores et les Rongeurs, et creuse dans l'épiderme des galeries très courtes, dans chacune desquelles on trouve une femelle ovigère, parfois accompagnée de sa ponte.

Sarcopte nain du Ghat (S. minor var. cati. - Syn.: S. cati Hering, 1838). -

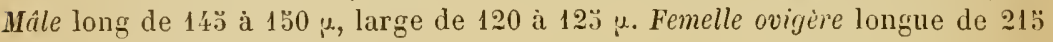

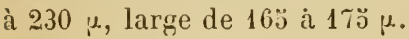

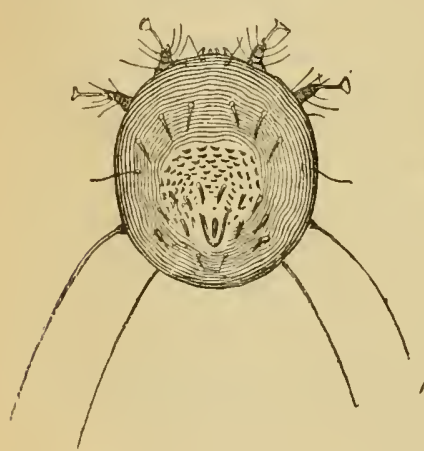

Fig. 443. - Sarcoptes minor var. cati: F femelle ovigère, vue en dessus, grossie 100 fois.

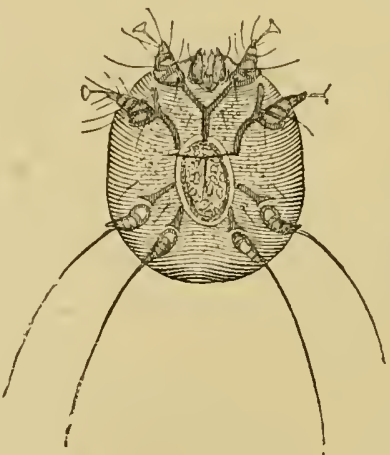

Fig. 414. - Sarcoptes minor var. cati : femelle ovigère, vue en dessous, grossie 100 fois.

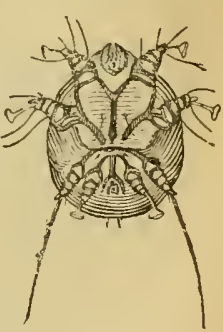

Fig. 44\%. - Sarcoptes minor var. cati : mâle, vu en dessous, grossi 100 fois.

Entrevu par Gohier (1813), le Sarcopte nain du Chat a été décrit pour la première fois par Hering (1838). Gerlach le regardait comme distinct de celui du Lapin, et c'est Fürstenberg qui a rattaché les deux formes à la même espèce.

Mais la gale qu'jl détermine avait été décrite dès 1672 par Wedelius, 
qui l'avait vue sévir en Westphalie sous forme épizootique. Cette gale débute d'ordinaire par la nuque, et gagne ensuite les oreilles, le lront, toute la tête et la partie antéricure du cou. Elle s’étend assez rarement au trone et aux paltes. Le prurit est variable. La lésion initiale est unc papule ou une vésicule qui no tarde pas à se déchirer et à se transformer en cronte. La mort survient en général au bout de quatre ì six mois, parfois mème beaucoup plus tôt. Cette gale n'est facile it guérir que lor'squ'elle est prise au début.

Le Sarcopte nain se trausmet facilement du Chat au Chat. Nous n'arons pu le communiquer au Lapin que très difficilement, et après une colıabitation de einq mois. Mais la gale, une fois transmise au Lapin, peut passer à d'autres sujets de cette espèce. Nous n'avons pas réussi à obtenir une contamination en retour du Chat par les Lapins infestés de la sorte (1).

La gale du Clıat peut aussi se communiquer an Cheval, comme l'ont observé Hertwig d'abord, puis Weber et Mégnin. Ce dernicr dit avoir en outre développé sur un Cheval une gale étendue en fixant sur le garrot de cet animal un lambeau de peau pris à un Chat galeux; mais cette gale fut arrêtéc au bout de trois semaines par une seule friction de pommade d'llelmerich.

On ignore si elle peut passer au Bœuf : le cas de Rademacher, cité par divers auteurs, parait apocryphe.

Delafond et Bourguignon l'ont transmise au Chien, et les jeunes animaux de cette espèce en sont morts. Sur un Singe, ils n'ont provoqué qu une éruption éphémère. Gerlach n'a obtenu sur le Porc que des résultats négatifs.

Mais l'affection se communique facilement à l'Homme. Hertwig rapporte qu'une servante, couchant arec un Chat galeux et presque entièrement chaure, ressentit de vives démangeaisons accompagnées d'une éruption sur tout le corps. Berthold cite le cas d'une petite fille qui, ayant laissé un Chat galeux reposer sur sa poitrine, éprouva des démangeaisons, puis une éruption. Marrel, Hering, Perroncito, Leonhard, Bieler ont relaté également des cas de contagion de la gale du Chat à l'Homme. Enfin, Gerlach a expérimenté sur des élèves de l'École vétérinaire de Berlin et sur lui-même, en déposant, sur la peau du bras, des croûtes provenant de Chats galeux : il se développa une gale locale, qui cessa d'elle-mème au bout de dix à vingt jours. Il semblerait donc résulter de ces expériences que le Sarcopte du Chat ne peut s'établir à demeure chez l'Homme et quil ne peut produire qu'une gale éphémère. L'observation de Bieler est toutefois en contradiction arec cette manière de voir.

Sarcopte xain du Lapin (S. minor var. cuniculi. - Syn. : S. cuniculi Gerl.,

(1) A. R.ALliet, Recherches sur la transmissibilité de la gale du Chat et du Lapin due au Sarcoptes minor Fürst. Comptes rendus de la Soc. de biol. (9), IV, [. 315,1892 . 
185i). - Mâle long de 142 à $133 \ddot{\mu} \mu$, large de 116 à $123 \mu$. Femelle ovigère longue de 213 à $230 ̈ \mu$, large de 163 à $175 \mu$.

Comme celui du Chat, le Sarcopte nain du Lapin avait été entrevu en 1813 par Gohier; mais c'est Gerlach qui l'a le premier décrit et figuré, en 18507.

La gale qu'il produit ressemble beaucoup à celle déterminée, sur le même animal, par le Sarcoptes scabiei; elle affecte d'abord le nez, et de là gagne les lèvres, le chanfrein, le fronl, parfois mème les oreilles, le dessous de la mâchoire inférieure et l'extrémité des pattes, jusqu'au carpe et au tarse, en donnant lieu à quelque prurit. Il se forme des croûtes épaisses, grisâtres et adhérentes. La mort survient souvent par suite de l'impossibilité de prendre les aliments.

Cette gale nous a paru très peu contagieuse : nous n’arons pu la transmettre à des Lapins par le dépôt de nombreux Sarcoptes sur la peau rasée, ni même par une cohabitation de onze jours. Nous ne l'avons pas communiquée davantage au Chat, au Rat et au Chien (1).

Gerlach a déposé sur la peau de l'Homme des Sarcoptes du Lapin, et il a constaté que, si celte peau est très fine, les Acariens s'y creusent de courtes galeries, accompagnées d'une petite élevure rouge et

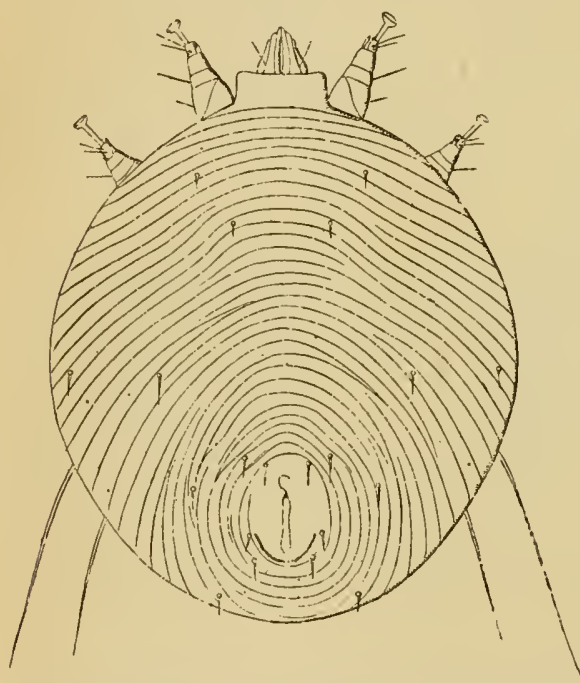

Fig. 446. - Sarcoptes alepis: femelle ovigère, vue par la face dorsale, grossie 150 fois (Orig.). parfois d'une vésicule à peine apparente ; le prurit est très faible, et tout disparaît en général dans l'espace de deux oul trois jours.

Sarcopte sans écailles (S. alepis Raill. et Lucel, 1893). - Corps arrondi dans les deux sexes, sans dépressions latérales. Plis du tégument concentriques, assez réguliers; aucune trace d'écailles sur la face dorsale ( $x$ privatif; quatre épines très grèles de chaque còté du notothorax, et six épines également très réduites, de chaque còté de l'anus, qui est reporté un peu plus en arrière que dims l'espèce précédente. Épimères postérieurs un peu plus intimement unis au sternite de l'armure génitale màle. Crochets tarsiens plus aigus. Ovipare ou vivipare. Wâle long de 170 à $180 \mu$, Iarge de 130 à $140 \mu . F e$ melle ovigère longue de 300 à $450 \mu$, large de 230 à $400 \mu$.

Découvert par Legros (1865) sur des Rats capturés au Jardin des Plantes,

(1) Loc. cit. 
cet Acarien a été retrouvé par Railliet et Lucet sur le Surmulot albinos, sur le Rat noir de grenier et sur le Campagnol amphibie ou Rat d'eau (1).

La gale qu'il létermine est localisée aux oreilles et aux orgaues génitaux; elle parait ètre constamment bénigne.

G. Colin a observé sur le Coati une forme psorique paraissant attribuable au mème Acarien.

C. Sous-grenre K'nemidolioptes Fürstenberg, 1870 (Dermatorylites Ehlers, 1873). - Face dorsale dépourvue l'épines. Épimères de la première paire de pattes émettant chacun un prolongement dorsal qui se réunit transversalement à l'autre en arrière, de façon à encadrer un plastron grenu.

Espèces parasites des Oiseaux.

Sarcopte changeant (S. mutuns Robin et Lanquetin, 18:i9 - Syn.: Sarcopte anaciuthe Del. et Bourg., 186\%; Knemidokoptes viviparus Fürst., 1870; Dermatoryctes mutans Ehlers, 1873). - Rostre large, à demi caché par l'épistome. Anus au bord postérieur de l'abdomen. Mile long de 190 à 200 p large de 120 à $130 \mu$; corps ovalaire; rostre sans joues; patles coniques,

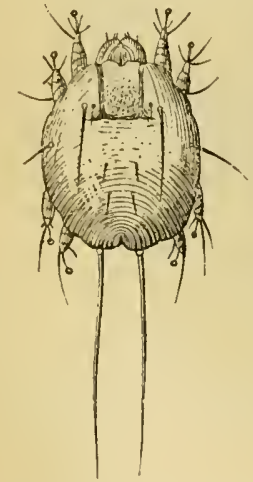

Fig. 447. - Sarcoptes mutans, de la Puule: mile, vu par la face dorsale, grossi 100 fois (G. Neumann).

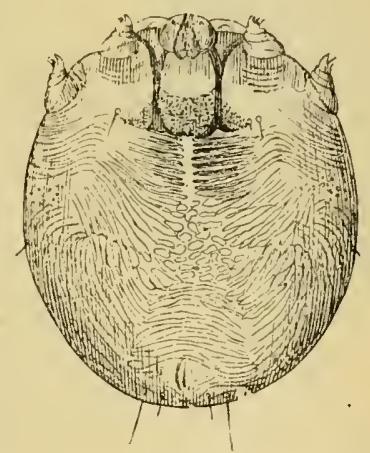

Fig. 448. - Sarcoptes mutans, de la Poule : femelle ovigère, vue par la face dorsale, grossic 100 fois (Orig.).

toutes pourvues d'ambulacre à ventouse; armure génitale située entre les deux dernières paires de pattes. Femelle ovigère longue de 408 à $\mathbf{4} 40 \mu$, large de 330 à $380 \mu$; corps en ovale très court; abdomeu d'abord aussi large que le céphalothorax; rostre á joues carénées et très larges, remplissant l'intervalle des premières pattes à la tète; face dorsale couverte en son milieu de saillies tégumentaires mamelonnées; tocostome en forme de fente transversale un peu au-dessous de l'extrémité des épimères de la deuxième paire; pattes réduites à de courts moignons coniques, sans ambulacre à ventouse. Femelle pubère semblable à la précédente, mais plus petite et à abdomen plus étroit. Nymphe ressemblant au màle, mais avec des mamelons cuticulaires. Larve hexapode ressemblant à la nymphe. Espèce vivipare.

(1) Railuet et Lucet, Note sur le Sarcopte des Muridès (Sarcoptes alepis $s p . n$. .). Comptes rendus de la Soc. de biologie (9), V, p. 40't, 1893. 
Le Sarcopte changeant ou anacanthe ( $\alpha$, privatif ; $\alpha \dot{\alpha} \alpha \vee \forall \alpha$, épine), qui a été découvert en 18.59 par Robin et Lanquetin, vit sous les écailles

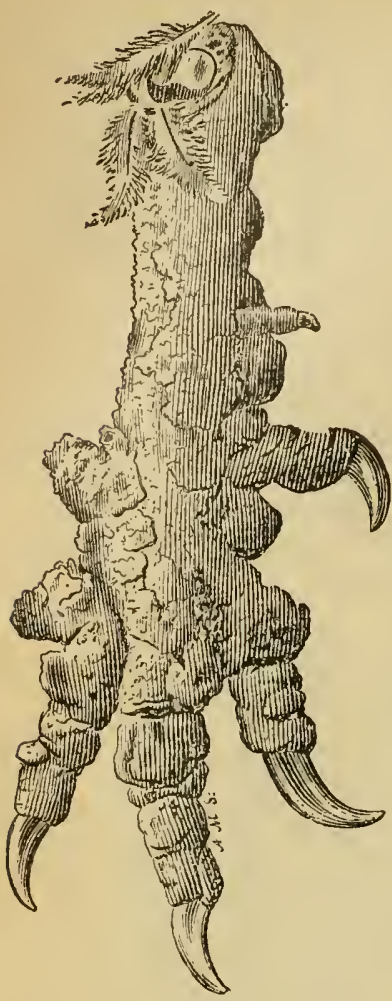

Fig. 449. - Patte de Poule atteinte de gale à Sarcoptes mutans (G. Neumann). épidermiques des pattes, très rarement sur la tête des Poules et des autres Gallinacés de basse-cour ou de parquet, tels que Faisans et Perdrix. Nous l'avons observé notamment sur le Dindon et la Pintade.

Sa présence détermine une irritation qui s'accuse par le soulèvement des écailles tarsiennes ou digitales, el par la formation de croûtes épaisses, rugueuses et mamelonnées. Le prurit paraît peu intense. La maladie a une marche très lente, et persiste souvent des mois entiers sans compromettre sérieusement la vie des Oiseaux.

La contagion entre volailles ne se manifeste que d'une façon assez restreinte; les Poules de race étrangère y sont cependant plus exposées que les autres. L'affection se transmet peut-être également aux Oiseaux de volière, tels que Passereaux et Perrocquets.

Reynal et Lanquetin ont prétendu qu'elle pouvait se communiquer aux Équidés, aux Ruminants et mème à l'Homme ; mais les données qu'ils fournissent à l'appui de leur opinion sont loin d'être concluantes.

Sarcopte lisse (S. lævis Raill., 1883). - Rostre large, à demi caché par l'épistome. Anus au bord postérieur de l'abdomen. Mâle à corps ovalaire; rostre sans joues; pattes coniques, toutes pourvues d'ambulacre ì ventouse; armure génitale située entre les deux dernières paires de patles; deux ventouses copulatrices sur les còtés de la fente anale. Femelle ovigère à corps arrondi; abdomen un peu plus large que le céphalothorax; rostre à joues carénées et très larges, remplissant l'intervalle des premières paires de pattes à la tète; face dorsale régulièrement striée, sans saillies mamelonnées ; tocostome peu distinct; pattes réduites à de courts moignons coniques, sans ambulacres à ventouse. Femelle pubère semblable à la précédente, mais plus pelite et à abdomen plus étroit. Nymphe et larve hexapode ressemblant au màle. Espèce vivipare.

Cette espèce comprend plusieurs variétés, qui vivent dans les bulbes plumeux des Gallinacés. 
Sarcopte lisse du Plgeon (S. lavis var. columbx). - Épinéres de la première paire de pattes réunis en Y cliez le mảle et reliés par une pièce transversale en accent circonllexe chez la femelle. While long de 1411 it $170 \mu$, large de 110 a $120 \mu$. Femelle ovigère longue de 270 a $310 \mu$, large de 230 a $270 \mu$.

Forme recueillie en 1883 , par Raillict et Cadiol, à la base des plumes d'un Pigeon messager. Les plumes se cassaient au ras de la peau, et, à la naissance du tuyau, on observait un petit amas de furfures épidermiques, renfermant de nombreux Sarcoptes. - Friedberger a fail, cul 1887, une observation semblable.

Sincopte lisse de la Poule (S. lavis var. gallina). - Épimères des deux premières paires libres chez la femelle. Mrile long de 170 à $180 \mu$, large de 120 à $130 \mu$. Femelle ovigère longue de 310 à $3: 30 \mu$, large de $2 \tau 0$ à $300 \mu$.

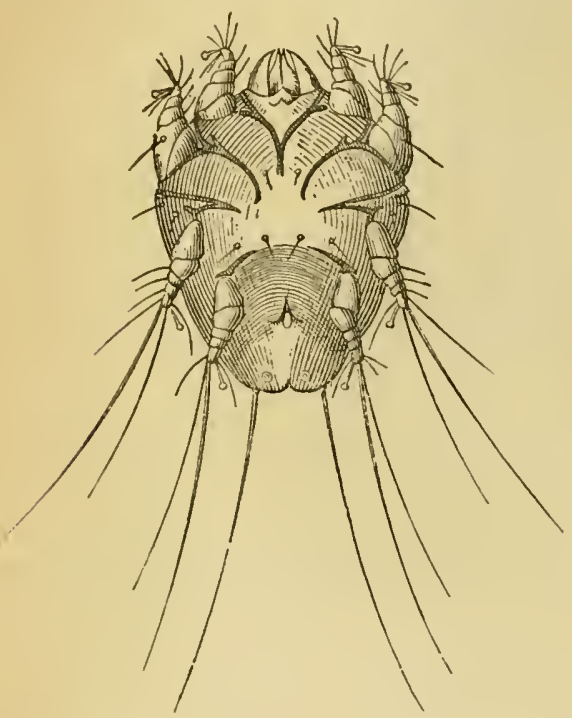

Fig. 450. - Sarcoptes læuis var. gallinap: male, vu par la face ventrale, grossi 200 fois (Orig.).

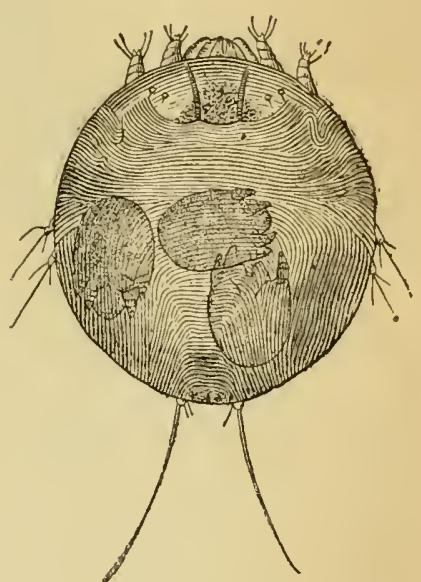

Fig. 431, - Sarcoptes lævis var. gallinx: femelle ovigère, vue par la face dorsale, grossie 1 (to fois (Orig.).

Nous avons observé pour la première fois cette variété en 1886, dans un poulailler du pays de Bray. Yous l'avons retrouvée plus tard aux environs de Paris, et Neumann l'a rencontrée sur des Poules de l'Aude.

L'affection qu'elle détermine paraît être très commune. Nous l'arons appelée gale du corps ou gale déplumante.

Elle déloute ordinairement par le croupion, et gagne peu à peu les autres parties du corps. Les plumes se détachent et la peau est ainsi mise à nu sur une étendue plus ou moins vaste; cependant, les grandes pennes de la queue et des ailes, ainsi que leurs couvertures, sont généralement conservées. La santé est rarement troublée; pour- 
tant Neunann a vu survenir, chez les Coqs en particulier, un état cachectique entrainant la mort.

La maladie sévit de préférence au printemps et en été; elle se transmet avec une rapidité remarquable, surtout par l'accouplement.

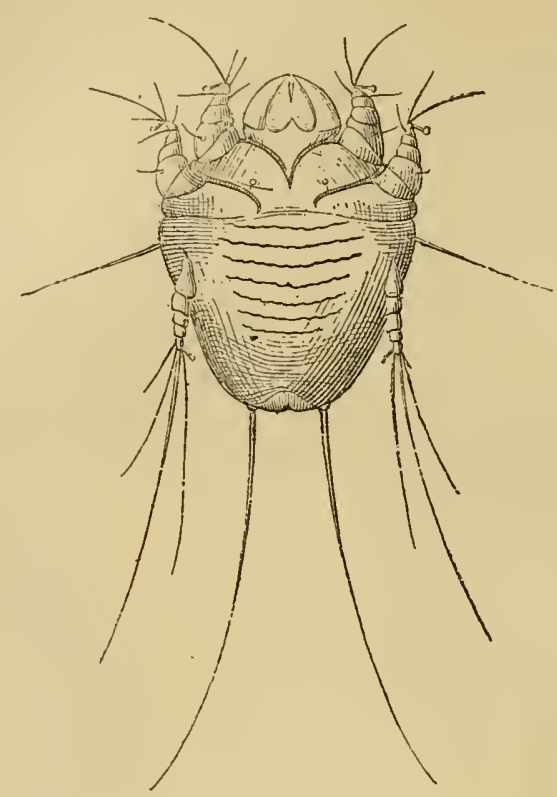

Fig. 432. - Sarcoptes lævis var. gallinæ: larve, vue par la face ventrale, grossie 200 fois (0rig.).

Mégnin parait avoir vu aussi une variété de $S$. lævis chez le Faisan. Cette forme (var. phasiani) aurait les épimères de la deuxième paire réunis par ure pièce transversale chez la femelle.

Enfin, Trouessart a trouvé des exemplaires de la mème espèce chez une Perdrix rouge, probablement élevée en captivité.

Une espèce voisine, Sarcoptes fossor (Ehlers, 1872) a été trouvée sur le corps d'un Passereau, le Munia maja.

Genre Psoropte (Psoroptes P. Gervais, 1811. - Syn. : Dermatodectes Gerlach, 1857; Dermatokoptes Fürst., 1861). - Les Psoroptes (Ч'ipx, gale; $\pi \tau$ ŕ́søstv, se cacher) ont le corps ovalaire, le rostre conique, allongé, sans joues, et les pattes longues, épaisses, à rentouses portées par un long pédicule triarticulé. Les mâles ont à la partie postérieure du corps deux prolongements ou lobes abdominaux, et sur la face ventrale, en avant de ces lobes, deux ventouses copulatrices.

Une seule espèce connue jusqu'à présent.

Psoropte commun (Ps. communis [Fürst.]. - Syn.: Sarcoptes equi Hering, 1838; Ps. equi et Ps. ovis P. Gervais, 1841; Dermatokoptes communis Fürst., 1861; Dermatodectes communis Verheyen, 1862; Ps. communis Raill., 
1883̈. - Priorité absolue: Ps. equi). - Aux caractères du gente nous ajoulerons les suivants : - Rostre peu caché par l'épistome. Céphalothorax offrant en dessus et en arant un court plastron grenu. Hale plus petit que la femelle ovigère; lobes abdoninaux terminés par de grandes soies; armure génitale complexe en avant des ventouses, entre les épinières des pattes postérieures; pattes des trois paires autérieures complètes, celles de la dernière paire sans ambulacre. Femelle ovigère montrant à la face inférieure du céphalothorax un tocostome à lèvres plissćes, dont les commissures s'appuient sur deux pièces arquées, dirigées en arrière; un ambulacre à ventouse à toutes les

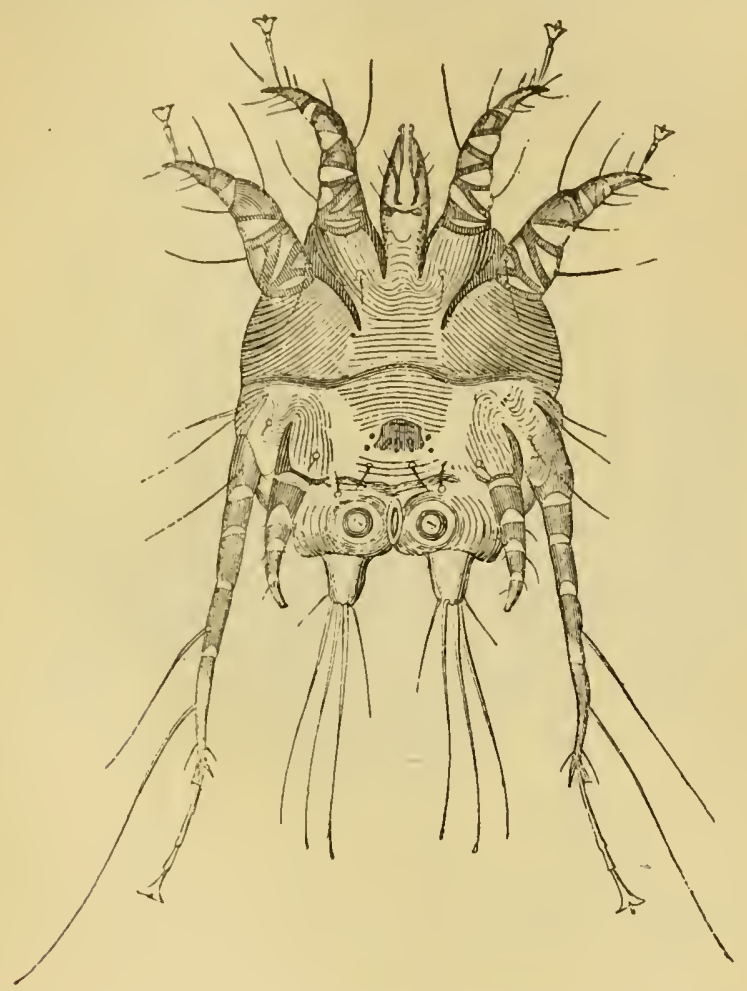

Fig. 4̇ั3. - Psoroptes communis var. equi: màle, vu par la face ventrale, gronsi 100 fois.

pattes, sauf a celles de la troisième paire, qui se terminent par des soies. Femelle puberre plus petite, sans locostome, mais avec une longue fente anale; pattes de la quatrième paire incomplètes et parfois dépourvues d'ambulacre; sur la partie postérieure de la face dorsale, deux saillies hémisphériques (tubercules copulateurs) qui s'emboìtent daus les ventouses co pulatrices du màle. Nymphe dépourvue de ces tubercules. Larve hexapode ayant les pattes de la troisième el dernière paire terminées par deux soies. Ovipare.

Le Psoropte commun ne creuse pas de galeries intra-épidermiques; il habite au milieu des croûtes dont il provorque la formation en excisant l'épiderme. Il vit toujours en société, de sorte que la gale qu’il 
détermine ne s'étend que peu à peu. Son venin parait cependant très irritant. Sa grande taille permet de le distinguer facilement à l'œil nu (1).

On admet dans cette espèce les variétés suivantes :

Psoropte des Équidés (Ps. c. var. equi. - Syn. : Surcoptes equi Hering, 1838;

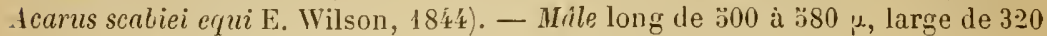
à $350 \mu$. Femelle ovigere longue de 600 à $700 \mu$, large de 400 a $440 \mu$.

Ce Psoropte parait avoir été entrevu au siècle dernier par Lonting; Gohier l'a vu nettement en 1812; Saint-Didier en a le premier donné

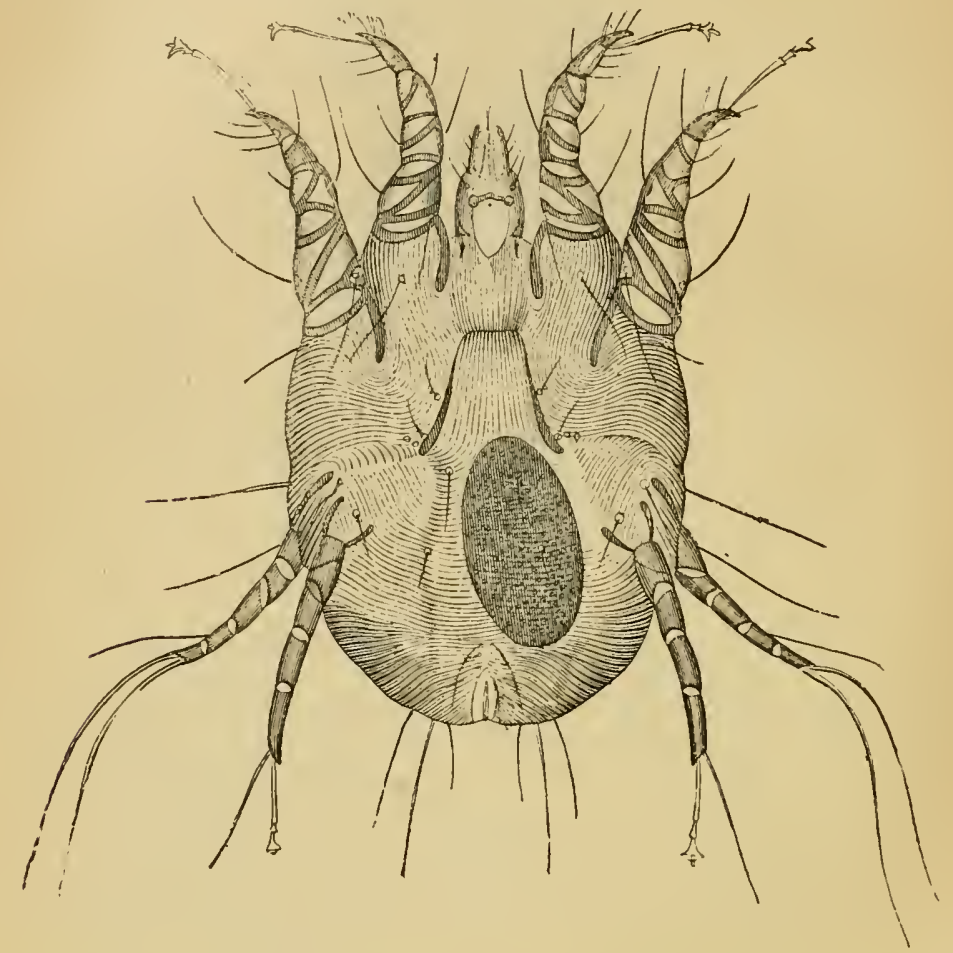

Fig. 43̆. - Psoroptes communis var. equi : femelle ovigère, vue par la face ventrale, grossie 100 fois.

la figure. Il attaque le Cheval, l'Ane et le Mulet, et se fixe de préférence sur les régions couvertes de crins.

La gale psoroptique débute presque toujours, en effet, par le bord supérieur de l'encolure et la base de la queue, déterminant un prurit assez intense. La lésion initiale est une papulo-vésicule assez large,

(1) Miyake et Scriba ont trouvé récemment dans l'urine sanguinolente d'un Homme de 37 ans, très anémique, des exemplaires d'un tout petit Acarien qu'ils nomment Nephrophagus sanguinarizes, et qu'ils comparent au Psoropte commun. Ils le soupconnent de vivre dans le rein. - Mais il nous parait impossible de voir dans cet Acarien autre chose qu'un pseudo-parasite, introduit actuellement dans l'urine (Berl. klin. Wochenschrift, p. 374, 1893). 
qui se déchire et donne lien à des crontes épaisses et quelque peu humides. La maladie progresse très lentement et, selon la comparaison classig̨ue, "s'étend ì la façon d'une tache d'lunile sur un vêtement de drap ". Arec le temps, elle envahit la plus grande partic et parfois mème la totalité de la surface cutanée. Mais la gruérison est relativement facile à obtenir.

La contagion a lieu rapidement du Gheval au Cheval par roie directe oll médiate. Du reste, la risistance vitale du Psoropte est considérable : éloigné de son hoile, il peut virre 10 à 14 jours dans une atmosphère sìche, et 20 à 30 joul's dans une écurie.

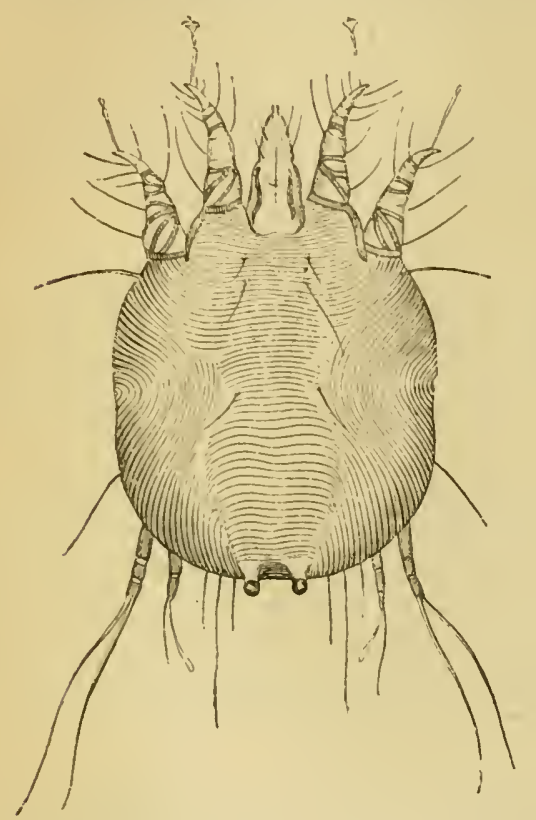

Fig. 450. - Psoroptes communis var. equi : femelle pubère, rue par la lace dorsale, grossie 100 fois.
Quelques observations anciennes de Gohier et Carrère semblaient indiquer la transmissibilité de la gale psoro-

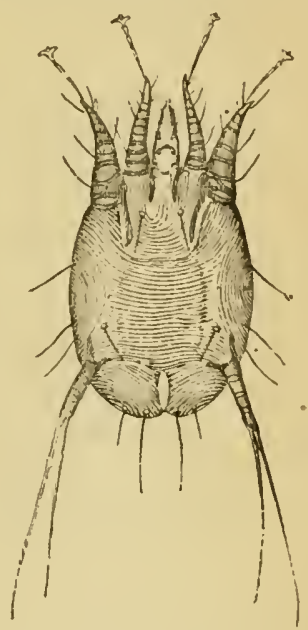

Fig. 456. - Psoroptes communis var. equi: larve hexapode, vue par la face ventrale, grossie 100 fois.

plique du Cheral au Boeuf; mais les expériences de Gerlach et de Delafond tentées dans ce sens n'ont donné que des résultats négatifs.

Le mème insuccès a du reste été constaté dans les essais de transmission du Psoropte au Mouton, au Porc, au Chien, au Chat et à l'Homme.

Psoropte des Borixés (PS. c. var. Lovis. - Syn.: Dermatodectes bovis Gerlach, 183̈i). - Mâle long de 430 à $440 \mu$, large de 300 à $320 \mu$. Femelle ovigère longue de 330 à $600 \mu$, large de 360 à $410 \mu$.

La première mention sérieuse de ce parasite est due à Dorfeuille (1813). Gohier, Delafond et d'autres observateurs l'ont ensuile retrouvé et étudié. Nous l'avons rencontré arec Lucet dans le Loiret. 
Comme chez le Cheval, la gale qu'il provoque débute à la base de la queue ou à l'encolure' et au garrot; elle s'étend de là aux régions roisines, mais se généralise rarement. Elle a une marche assez lente et se montre rémittente, s'atténuant pendant la belle saison jusqu'à donner l'apparence d'une guérison, puis s'accusant de nouveau à la fin de l'automne, à la reprise de la stabulation (Gerlach, Müller).

Les Psoroptes du Bœuf ne paraissent pas pouvoir s'acclimater sur d'autres animaux. Delafond et Bourguignon n'ont obtenu sur l'Homme aucun succès. Gohier et Müller n'ont pas réussi darantage sur le Cheval; Gohier a échoué enfin sur l'Ane et sur le Chien.

Röll et Mégnin ont observé aussi des Psoroptes sur diverses espèces de Buffles.

Psoropte du Mouton (Ps. c. var. ovis. - Syn.: Acarus scaliei de Gasparin, 1821; Sare ovis Hering, 1838; Ps. ovis P. Gervais, 18'1). - Mâle long de כ00 à $600 \mu$, large de $34_{0}$ à $370 \mu$. Femelle ovigère longue de 670 à $740 \mu$, large de 450 à $460 \mu$.

La gale commune du Mouton, c'est-à-dire la gale psoroptique, a été mentionnée ou décrite par divers auteurs latins, en tête desquels se place Caton le Censeur (vers 160 avant J.-C.). Mais c'est Walz qui a le premier, en 1809, nettement établi l'existence de l'Acarien qui la détermine.

Celui-ci, à l'inverse du Sarcopte qui vit sur le même animal, recherche les parties du corps garnies de laine; aussi la gale psoroptique débute-t-elle d'ordinaire par le dos et le garrot, s'étendant ensuite à la croupe, aux flancs, au cou. Le prurit est riolent, et la laine est bientôt arrachée çà et là. Il apparaît d'abord des papulo-résicules, qui deviennent souvent pustuleuses et donnent lieu à la formation de croûtes de plus en plus épaisses et compactes.

L'affection subit un temps d'arrêt en été, au pâturage; parfois même elle s'amende, mais reprend une grande intensité l'hiver, pendant le séjour à la bergerie. Une alimentation riche et abondante permet aux animaux d'y résister plus longtemps et même de guérir (Delafond).

Cette gale constitue néanmoins une maladie grave, qui fait périr, suivant les circonstances, de 10 à 50 p. 100 des animaux atteints et cause par conséquent des dommages considérables à l'agriculture.

Une des principales raisons de cette gravité, c'est la facilité avec laquelle s'effectue la contagion parmi les troupeaux, soit dans les bergeries, soit dans les foires et marchés, soit aux abreuvoirs.

Delafond et Bourguignon ne sont pas parrenus à communiquer la gale psoroptique du Mouton à l'Homme, non plus qu'au Cheval, au Bœuf et à la Chèrre.

Psuropte de la Chèvre (Ps. $c$. var. capra). - Mâle long de 470 à $640 \mu$, large de 270 à $400 \mu$. Femelle ovigère longue de 680 à $850 \mu$, large de 390 à $550 \mu$. 
Trouvé à Toulouse, par Pesas (1889), et à Troyes, par Nallet et Morot (1890), puis encore par Morot (septembre 1890), dans le conduit auditif externe de la Chèrre. Ne parait provoquer aucun trouble sérieux.

Une observation analogue a été faite par Ugo Caparini sur une Gazelle, et Zül'n dit avoir observé aussi dans les oreilles du Mouton des Acariens (non spécifiés).

P'soroptr: du L.APIN (Ps. c. var. cuniculi. - Syn.: Dermalodectes cuniculi Delafond, 1839). - Wâle long de 320 à 620 «. large de 310 à 400 \%. Femelle ovigère longue de $6 \tau 0$ ì $780 \mu$, large de 400 ì $480 \mu$.

Delafond a décourert ce Psoropte en 183̈i. Depuis cette époque, il a été observé très fréquemment. 11 vil dans la conque auriculaire et dans le conduit auditif externe du Lapin domestique, provoquant une irritation plus ou moins violente de ces parties, avec formation de croûtes épaisses. On l'a vu pénétrer parfois dans l'oreille moyenne et même dans l'oreille interne, occasionnant alors des troubles nerveux très graves. Nous arons obserré, par exemple, chez deux Lapins, une torsion de la tête sur le cou tellement accusée, que la màchoire inférieure était devenue supérieure : ces animaux ont pu vivre ainsi pendant de longs mois.

La contagion entre Lapins est très facile, ainsi que l'ont montré les expériences de Delafond, Möller, Zürn, Guzzoni et les nôtres. D’après Lucet, certains indiridus ou certaines familles offriraient pourtant une véritable immunité à cet endroit.

Hosœus a essayé sans succès de transmettre le parasite au Chien, au Chat, au Mouton et au Cheval. Cependant, Mathieu aurait réussi sur le Cheral, et des faits recueillis par Cagny el par Cadéac semblent parler également en faveur de la transmission à cet animal.

Genre Choriopte (Chorioptes P. Gervais et Van Beneden, 1859. Sinn.: Symbioles Gerlach, 1857, nec Redtenbacher, 1849; Dermatopha-

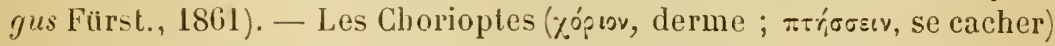
ont le corps ovalaire, le rostre légèrement conique, aussi large que long, sans joues, et les pattes longues, épaisses, à larges ventouses portées par un pédicule simple et très court. Les mâles possèdent deux lobes abdominaux, parfois très réduits, et deux ventouses copulatrices.

Choriopte symbiote (Ch. symbiotes [Verheyen]. - Syn. : Sarcoptes bovis Hering, 18千z; Symbiotes equi et $\mathrm{S}$. bovis Gerlach, 1837; Ch. caprx Gerv. et Ben., 1839; Dermatophagus symbiotes Verheyen, 1862; Syml. spathiferus IIégn., 1872; Ch. symbiotes Raill., 1883..- Priorité: Ch. Lovis). - Rostre à moitié caché par l'épistome. Face supérieure du céphalothorax offrant un plastron grenu s'étendant de l'épistome au niveau de l'insertion de la seconde paire de pattes et deux fois plus large en arrière qu'en avant. Iâle à corps prolongé en arrière par deux lobes abdominaux rectangulaires portant à leur 
extrémité chacun quatre longues soies: une externe libre et trois réunies en faisceau, dont une normale, les deux autres, accolées et superposées, étant élargies en une mince membrane foliacée. Les quatre paires de pattes pourvues d'ambulacre à ventouse; la quatrième paire courte, grêle. Femelle ovigère offrant à la face inférieure du céphalothorax un tocostome à lèvres plissées, dont les commissures s'appuient sur deux pièces arquées, dirigées en arrière; pattes de la troisième paire sans ambulacre, terminées par deux soies. $\mathrm{Fe}$ melle pubere plus petite, sans locostome, mais avec une longue fente anale et deux tubercules copulateurs; pattes de la quatrième paire terminées

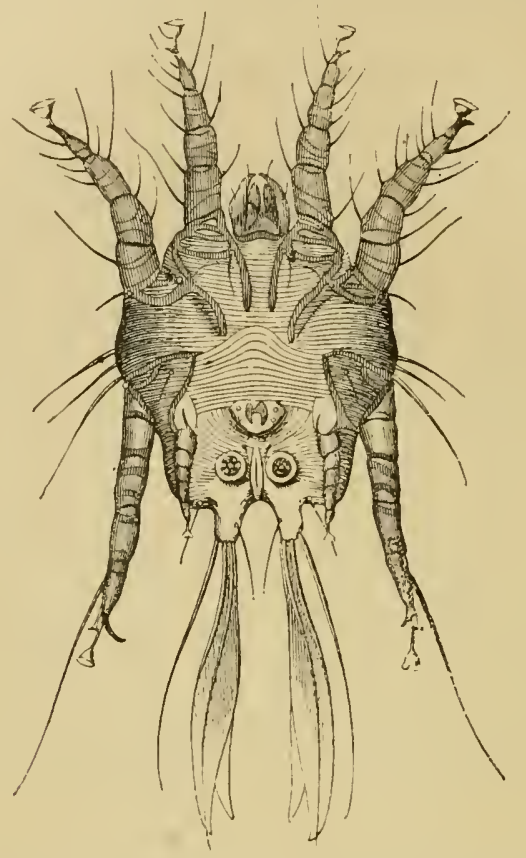

Fig. 457. - Chorioptes symbiotes var. equi : mile, vu par la face ventrale, grossi 100 fois.

par une soie. Nymphe sans tubercules copulateurs. Larve hexapode ayant les pattes de la troisième paire terminées par deux soies. Ovipare.

Le Choriopte symbiote vit, comme le Psoropte commun, en colonies qui s'étendent lentement; il ne creuse pas non plus de sillons, et son habitat est tout superficiel.

On peut en distinguer plusieurs variétés :

Choriopte des ÉQuidés (Ch. s. var. equi. - Syn. : Symbiotes equi Gerlach, 1857). - Mâle long de 280 à $330 \mu$, large de 190 à $230 \mu$. Femelle ovigère longue de 360 à $390 \mu$, large de 225 à $250 \mu$.

Cet Acarien, découvert en 18507 par Gerlach, produit chez le Cheval une gale assez bénigne, connue sous le nom de gale du pied ou du patu- 
ron. Elle débute en effet par les paturons et les boulets, notamment par ceux des membres postérieurs, et gagne ensuite les jarrets et les genoux, qu'elle dépasse rarement pour se répandre sur le ventre et jusque sur la croupe. Il se forme des croûtes et les poils tombent; dans certains cas, la peau est comme pelée (Noiset, Lucet). Le prurit est peu intense.

La gale chorioptique a une marche très lente; elle s'amende du

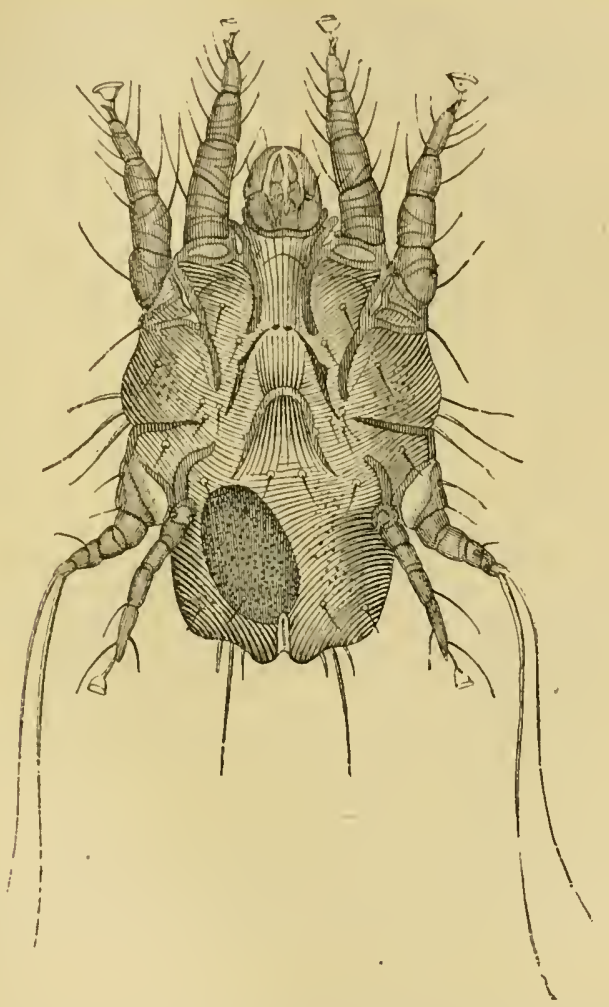

Fig. 158. - Chorioptes symbiotes var. equi : femelle ovigère, vue par la face ventrale, grossie 100 fois.

reste d'une façon remarquable pendant l'été, ainsi que l'a observé Delafond.

Elle est relativement peu contagieuse, et reste parfois localisée à un seul membre ou à un seul bipède transversal. On ne l'observe du reste que sur des Chevaux communs, mais elle est également fréquente à tous les âges.

Pas plus que Gérard, nous n'avons pu la développer par le dépôt des parasites dans le pli des paturons. Il est rrai que les animaux étaient àgés, et nous sommes porté à croire que l'infestation doit s'effectuer pendant ie jeune àge.

Sur l'Homme, Delafond et Bourguignon n'ont obtenu que des résul-

Ralluiet. - Zoologie. 
tats négatifs. Comme les Psoroptes, les Chorioptes altaquent réellement la peau, mais ils ne provoquent jamais une gale véritable et succombent dans les quarante-huit heures.

Nous avons échoué de même en déposant des Psoroptes du Cheval sur le dos de la Chèvre et dans les oreilles du Lapin.

Sur le Bœuf, Delafond et Bourguignon ont provoqué une éruption locale qui a disparu au bout de quinze à vingt jours.

Choriopte du Beuf (Ch. s. var. bovis. - Syn. : Sarcoptes bovis Hering, 1840 ; Symbiotes bovis Gerlach, 1857). - Mále long de 270 à $300 \mu$, large de 210 à $220 \mu$. Femelle ovigère longue de 380 à $390 \mu$, large de 230 à $200 \mu$.

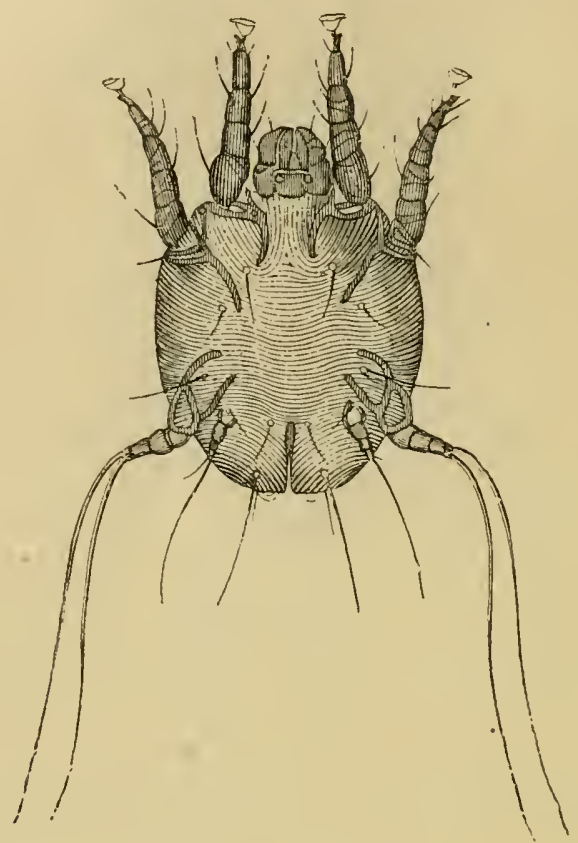

Fig. 459, - Chorioptes symbiotes rar. equi : femelle pubère, sue par la face ventrale, grossie 100 fois.

D'après Gerlach, la première mention de cet Acarien serait due à Kegelaar (1833) ; mais c'est Hering qui le premier l'a nettement décrit et figuré, en 1845.

La gale chorioptique des bêtes bovines est peu grave; les parasites restent parfois cantonnés dans le chignon ou dans le pli des paturons postérieurs, mais le plus souvent l'affection se montre localisée à la base de la queue et à la fossette de l'anus. C'est seulement à la longue qu'elle s'étend sur le cou et le dos, ou bien sur le périnée, les mamelles et les fesses.

Le Choriopte du Bœuf n'a pu provoquer la gale chez le Cheval ni chez l'Homme. Cependant, Shérémétevsky dit avoir vu plus de vingt 
fois, sur la peau d'individus galeux, le Choriopte du Boeuf, que Bogdanor déerit sous le nom de Dermatophagoides Scheremeteuskyi; Zürn l'a aussi trouvé sur la tête de l'Homme dans le cas d'alopécie; mais il s'agit là, sans doute, de simples coïncidences, dues à la pro. miscuité des malades arec les animaux, et nous ne pensons pas qu'on puisse voir dans ces Acariens la cause des affections dont les sujets étaieni atteints.

Chorlopte de la Cinerre (Ch. s. var. capræ. - Syn. : Sarcoptes capræ Delaf. et Bourg., 18̈̈7, nec Müller, 18̈̈8; Ch. capræ Gerv. et Ben., 183̈9). - Mâle long de 290 à $300 \mu$, large de 180 à $210 \mu$. Femelle ovigire longue de 310 à $360 \mu$, large de 210 it $230 \mu$.

Découvert en 183̈ , par Delafond, sur des Chèvres d'Angora, et retrouvé en 1889, par Mollereau, sur une Chèrre commune. Dans les eas de Delafond, la gale arait débuté par les parties supérieures du corps pour se généraliser lentement, en produisant des dépilations et des croûtes épaisses, dures, adhérentes. Dans l'observation de Mollereau, les lésions étaient localisées au paturon d'un membre postérieur.

Delafond n'a pu acclimater le parasite sur l'Homme.

Choriopte de Mouton (Ch. s. [?] var. ovis). - Mrile long de $310 \mu$, large de 2äıl $\mu$. Femelle longue de 370 à $400 \mu$, large de $260 \mu$ (Zürn!.

Observé par Zürn en 1874, et par Schleg en 1877. Détermine une gale analogue à celle du pied du Cheval, gale qui sévit sur les Moutons de race fine, comme les Negretti, quand ces animaux sont négligés. L'éruption s'étend rarement jusqu'à la région inguinale.

Choriopte de Lapin (Ch. s. [?]. var. cumiculi. -- Syn. : Dermatophagus cuniculi Zürn, 1874). - Signalé par Zürn dans la conque auriculaire du Lapin. Déterminerait des accidents moins graves que ceux produits par le Psoropte. Zürn le dit simplement plus grand que le Choriopte du Chien et plus petit que celui du Bœuf.

Choriopte auriculaire (Ch. auriculerum [Lucas et Nicolet]. - Syn.: Surcoptes cynotis Hering, 1838; Sarc. auricularum Lucas et Nic., 1849; Symbiotes canis Bendz, 18ã9; Symb. felis Huber, 1860; Ch. ecaudatus Mégn., 1876. - Priorité absolue: Ch. cynotis). - Rostre à moitié caché par l'épistome. A la face supérieure du céphalothorax, un plastron grenu, allongé, renforcé dans son milieu par une sorte de crête épaisse. Mâle à lobes abdominaux à peu près nuls, représentẻs à peine par deux légères saillies arrondies portant des soies : toutes les pattes munies d'ambulacres à ventouse, la $3^{\mathrm{e}}$ étant la plus grande, la $4^{\mathrm{e}}$ la plus petite; armure génitale en avant des ventouses copulatrices, entre les épimères des pattes postérieures. Femelle ovigère à tocostome sous-thoracique, en forme de fente transversalc à lèvres fortement plissées et renforcées par de petites pièces chitineuses; les deux paires de pattes postérieures privées d'ambulacre à ventouse, la dernière paire rudimentaire. Femelle pubère se distinguant de la précédente par l'absence de 
tocostome et la présence de tubercules copulateurs; pattes de la $4^{\text {e }}$ paire réduites à de simples mamelons portant chacun un seul poil. Nymphe différant de la femelle pubère par l'absence de tubercules copulateurs. Larve hexapode, à troisième paire de pattes sans ambulacre à ventouse. UKufs oblongs.

Plusieurs variètés, habitant le conduit auditif externe des Carnivores $(1)$.

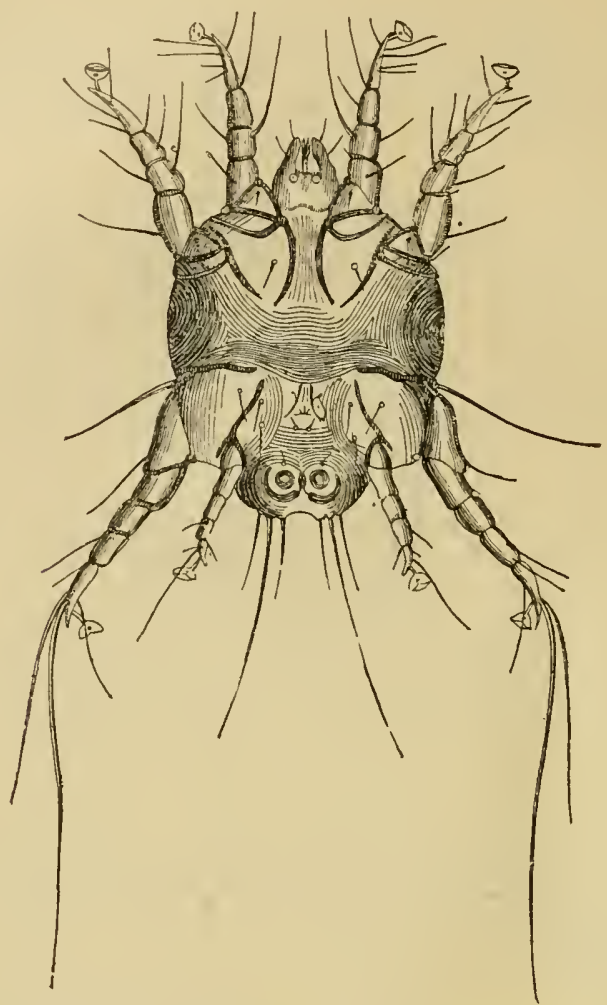

Fig. 460. - Chorioptes auricularum du Chien : màle, vu par la face ventrale, grossi 100 fois (Orig.).

- Choriopte du Chien (Ch. auricularum var. canis. - Syn. : Sarcoptes cynotis Hering, 1838; Sarc. auricularum Luc. et Nic., 1849; Symb. canis Bendz, 18ว99). - Mále long de $3 \ddot{0} 0$ à $380 \mu$, large de 230 à $280 \mu$. Femelle ovigére longue de 460 à $530 \mu$, large de 280 à $350 \mu$.

Découvert en 1834 par Hering, et revu depuis par de nombreux observateurs, cet Acarien vit dans le conduit auditif externe du Chien. On le rencontre sur des animaux de races très diverses.

L'acariase chorioptique auriculaire, ou otacariase chorioptique, donne lieu à un prurit assez violent, qui se manifeste périodiquement

(1) Raillet et Ciniot, Observations et expériences sur. l'otacariase symbiotique des Camivores. Comptes rendus de la Soc. de biologie (9), IV, p. 104, 1892. 


$$
\text { ARACHNIDES. - ACARIENS. }
$$

et amène souvent des accès de frénésie, voire de véritables attaques épileptiformes, accompagnées de eris (Guzzoni). Chez les Chiens de meute, ces' accès sont beaucoup plus violents, et ne se manifestent dordinaire que dans la périocle la plus active de la chasse (Nocard). La mort peut survenir au cours de ces attaques, lorsque le mal est ancien. D'autres fois, les animaux deviennent complètement sourds.

On trouve dans le conduit auditif, et plus ou moins profondément,

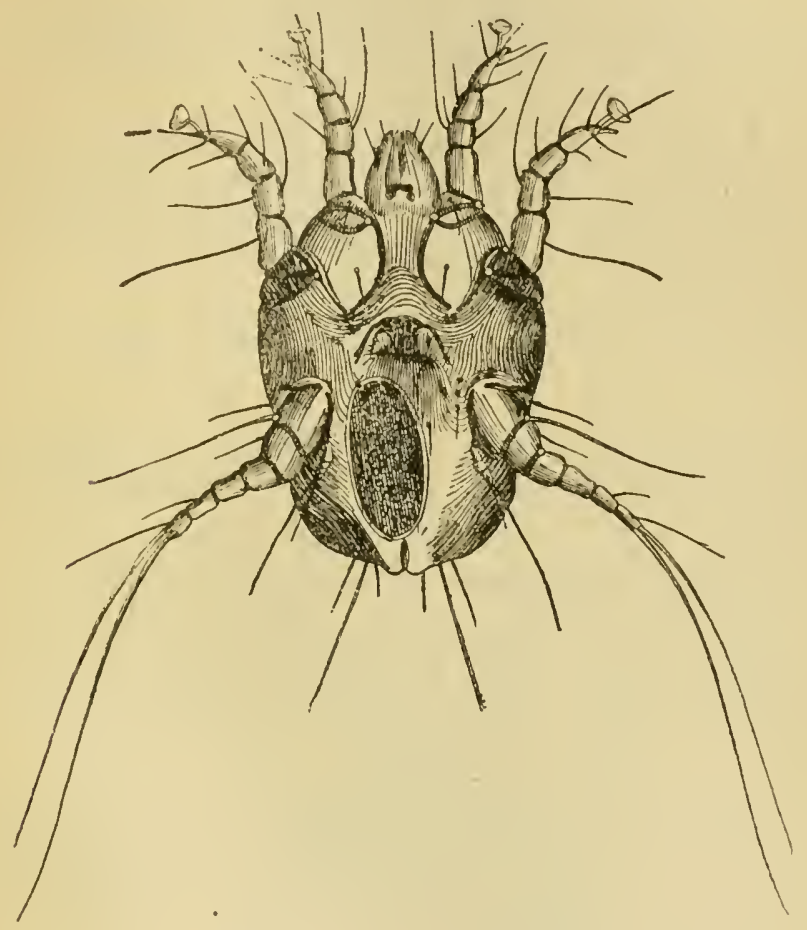

Fig. 461. - Chorioptes aurisularum du Chien: femelle ovigère, vue par la face ventrale, grossie 100 fois (Orig.).

un amas de cérumen chocolat, renfermant des Chorioptes en grand nombre et à tous les états.

La contagion a lieu facilement du Chien au Chien, comme l'ont montré Guzzoni et Nocard. Dans un essai tenté sur le Chat, Railliet et Cadiot n’ont obtenu qu'un résultat négatif.

La guérison de cette affection, comme des otacariases en général, s'obtient facilement par des injections de substances parasiticides (créosote, naphtol, etc.).

Choriopte du Chat (Ch. auricularum var. cati. - Syn.: Symbiotes felis

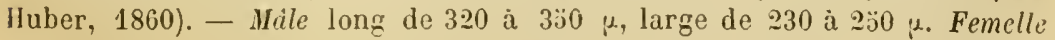
origère longue de 430 à 480 p., large de 260 à $290 \mu$. 
Observé pour la première fois en 1860, par Ch. Huber, ce parasite parait moins commun que celui du Chien.

Il a le même habitat, provoque des troubles de même ordre, y compris les attaques épileptiformes, ainsi que l'ont établi Railliet et Cadiot, et jusqu'à des accès rabiformes, comme l'a vu Neumann.

Railliet et Cadiot l'ont transmis du Chat au Chat, et du Chat au Chien : de celui-ci, la contagion s'est faite à un autre Chien.

Choriopte du Furet ( $C h$. auricularum var. furonis). - Malle long de 270 à $340 \mu$, large de 210 à $250 \mu$. Femelle ovigère longue de 380 à $450 \mu$, large de 240 à $280 \mu$.

Trouvé d'abord par Mégnin dans les oreilles du Furet. - Les sujets atteints ne paraissent pas ressentir un prurit très vif; ils restent le plus souvent assoupis et meurent en quelques semaines dans une sorte d'abrutissement. En général, les Chorioptes ne pénètrent pas dans la profondeur du conduit auditif.

Railliet et Cadiot n'ont pu transmettre ces parasites du Furet au Chien.

D'autres espèces de Chorioptes onl élé trouvées sur des animaux sauvages, par exemple Ch. setifer Mégn., sur le Renard et l'Hyène, Ch. tripilis (Michael), sur le Hérisson.

Sous-famille des GYToditinés. - Ventouses copulatrices et ventouses génitales absentes. Tous les tarses, ou au moins ceux des $3^{\text {e }}$ et $4^{\mathrm{e}}$ paires, inermes et munis d'une ventouse à long pédicule. Tocostome longitudinal.

Les Cytoditinés sont de véritables parasites internes: ils vivent en effet dans le tissu conjonctif ou dans les voies aériennes des Oiseaux.

Genre Cytodite ('yytodites Mégn., 1877. - Syn. : Cytoleichus Mégn., 1879). - Gorps arrondi. Rostre conique sans joues, recouvert à sa base seulement par l'épistome et formant un suçoir tubuleux. Pattes coniques, allongées, toutes terminées par une ventouse à pédicule simple. Mâles sans lobes abdominaux ni ventouses copulatrices.

Cytodite nu (C. nudus [Vizioli]. - Syn.: Sarcoptes nudus Vizioli, 1868; C. glaber Mégn., 1877; Cytoleichus sareoptoides Mégn., 1879; Sarc. Gerlachi Riv., 1880). - Corps blanchâtre, presque entièrement glabre. Pattes de la $2^{\mathrm{c}}$ paire offrant au tarse un cirre mousse dirigé en dehors. Mâle long de 450 à $470 \mu$, large de 280 à $300 \mu$, pourvu d'un pénis conique préanal. Femelle ovigère longue de 500 à $600 \mu$, large de 350 à $400 \mu$; tocostome longitudinal, situé entre les deux paires de pattes postérieures. Vivipare ou ovipare.

Les Cytodites (xútos, cavité) vivent en colonies dans les voies respiratoires et en particulier dans les réservoirs aériens des Gallinacés, ou l'on peut souvent les apercevoir à l'œil nu, so us l'apparence de grains de sable mobiles. On les rencontre parfois aussi dans la trachée et les bronches, et jusque dans les moindres diverticules des réservoirs, y compris les cavités des os. 


$$
\text { ARACHNIDES. - ACARIENS. }
$$

Ils paraissent sucer simplement la sérosité qui lubrifie les parois de leur habitat, et, lorsqu'ils n'existent qu'en petit nombre, leur pré-

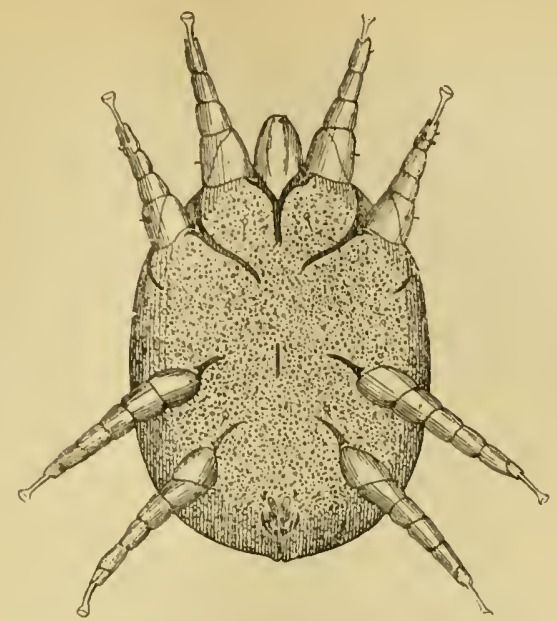

rig. 462. - Cylocites nudus, de la Poule : male, vu par la face ventrale, grossi 100 fois (Orig.).

sence ne se traduit par aucun trouble appréciable. Mais ils se multiplient quelquefois d'une façon extraordinaire, et l'on conçoit qu'ils

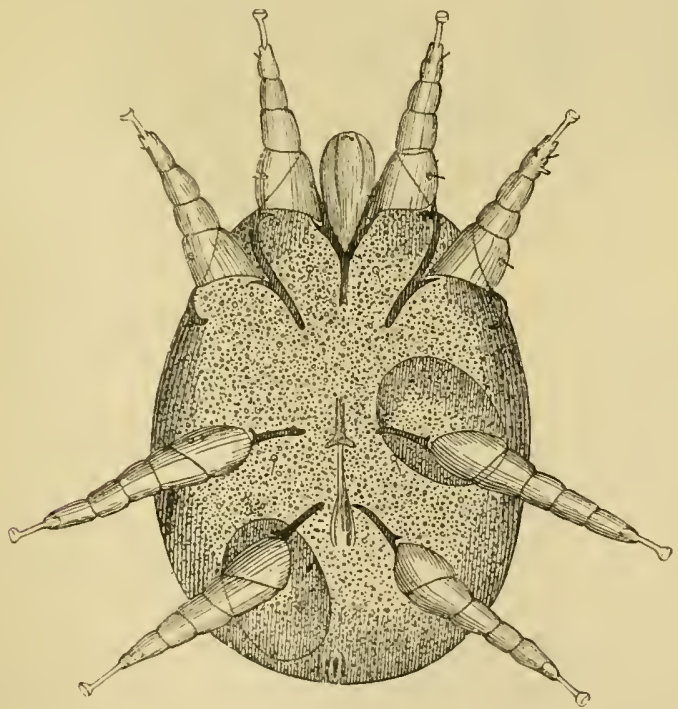

Fig. 463. - Cytodites nudus, de la Poule : femelle ovigère, vue par la face ventrale, grossie 100 fois (Orig.).

puissent être ainsi la cause d'une irritation plus ou moins vive ou de phénomènes asphyxiques.

Ajoutons que Holzendorff a trouvé dans les poumons, le foie, les 
reins, etc., de plusieurs Poules malades provenant d'une même bassecour, de nombreux nodules du volume d'un pois, dans lesquels se montraient des Cytodites.

Genre Laminosiopte (Laminosioptes Mégn., 1880. - Syn. : Symplectoptes Raill., 1883:). - Corps oblong, offrant un sillon transversal entre les deux groupes de paires de pattes; celles-ci courtes, presque glabres, munies d'ambulacres à ventouse caducs aux deux paires antérieures, persistants aux deux paires postérieures; le pédicule est simple, et la ventouse est souvent atrophiée. Anus sous-abdominal. Rostre court et large, en grande partie caché par l'épistome. Mâles sans lobes abdominaux ni ventouses copulatrices.

Laminosiopte cysticole (L. cysticola [Vizioli]. - Syn. : Sarcoptes cysticola Vizioli, 1868 ; L. gallinarum Méęn., 1880 ; Epidermoptes cysticola Ri-

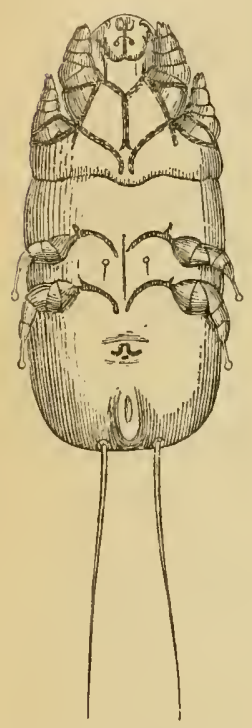

Fig. 464. - Laminosiop. tes cysticola, de la Poule: mâle, vu pari la face ventrale, grossi 200 fois (Orig.).

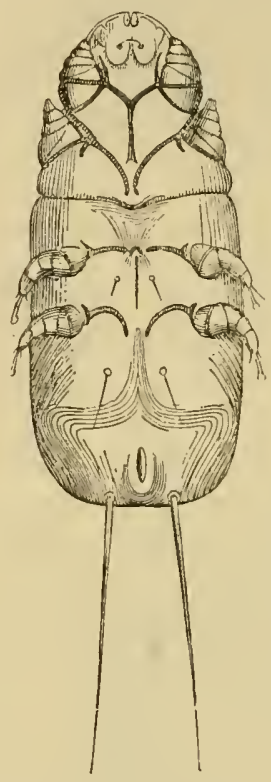

Fig. 465. - Laminosioptes cysticola, de la Poule. femelle ovigère, vue par la face ventrale, grossie 200 fois (0rig.). volta, $1880 ;$ Symplectoptes cysticola Raill., 1885.) - Corps grisâtre, offrant plusieurs paires de soies à la face supérieure du corps, et une longue paire à l'extrémité postérieure. Wâle long du 200 à $230 \mu$, large de 90 à 100 ; armure 'génitale entre les dernières pattes et l'anus. Femelle ovigère longue de 290 à $260 \mu$, large de 100 à $110 \mu$; tocostome situé entre les pattes postérieures.

Ce sont des parasites propres aux Gallinacés. D'après Rivolta, ils vivraient normalement à la surface et dans l'épaisseur de la peau, en donnant lieu à la formation de furfures. Mais on les rencontre d'ordinaire dans le tissu conjonctif sous-cutané, notamment dans les points où il est le plus lâclıe: au cou, à la poitrine, au ventre, aux flancs, aux cuisses, etc. Plus rarement ils pénètrent dans le tissu conjonctif profond. Lorsque l'un d'entre eux meurt, son cadavre agit comme corps étranger et provoque la formation d'un nodule miliaire qui ne tarde pas à subir l'infiltration calcaire : telle est l'origine de ces petites concrétions signalées dès 1850 par Voigtländer, étudiées ensuite par Vizioli, et qu'on rencontre souvent en grand nombre sous la peau des Poules, Faisans, Dindons, etc. Dans l'immense majorité des cas, leur présence ne paraît porter aucun préjudice à la santé de l'hôte; toutefois, leur multiplication excessive doit entraîner un trou- 
ble dans la nutrition, et Rivolta dit en efret avoir constaté un état de marasme extrème chez une Poule qui étail fareie de granulations acariennes, non seulement sous la peau, mais aussi entre les museles et jusque dans la cavité abdominale.

Sous-famille des anAlgésinés. - Ventouseś copulatrices existant d'ordinaire clıcz le màle. Piıs de ventouses génitales. Vulve transversale. Face dorsale le plus souvent cuirassée. Dimorphisme sexuel plus ou moins apparent, quelquefois très accusé.

Les Analgésinés sont des Acariens plumicoles, c'est-ìt-dire vivant dans le plumage les Oiseaux; ils ne représentent pas de véritables parasites, mais bien des mutualistes, comme les Ricins, à côté desquels ils virent.

Ils se renconlrent à peu près chè toutes les espèces d'Oiseaux, chacune de celles-ci en liébergeant une ou plusieurs formes qui parfois lui sont propres et d'autres fois s'observent également chez un grand nombre d'Oiseaux du même groupe. Ces Acariens se trourent entre les barbules des plumes, principalement des grandes pennes alaires et caudales et de leurs tectrices. D'après Trouessart, dont les intéressantes études ont particulièrement éclairé l'histoire de cette importante tribu, le des. sèchement de la plume, en arrêtant l'aftlux des liquides gras dont cesanimaux se nourrissent, les amène à émigrer vers la racine. Ce dessèchement peut ètre produit par la morl de l'Oiseau, par l’influẹnce du froid ou par la mue. Ainsi, en hiver, on trouve très peu d'Acariens entre les barbules des pennes de l'aile, mais on rencontre de nombreuses nỵmplı̀es et même des adultes aggglomérés au niveau de l'ombilic supérieur. Parfois même, au moment de la mue, ils cherchent à

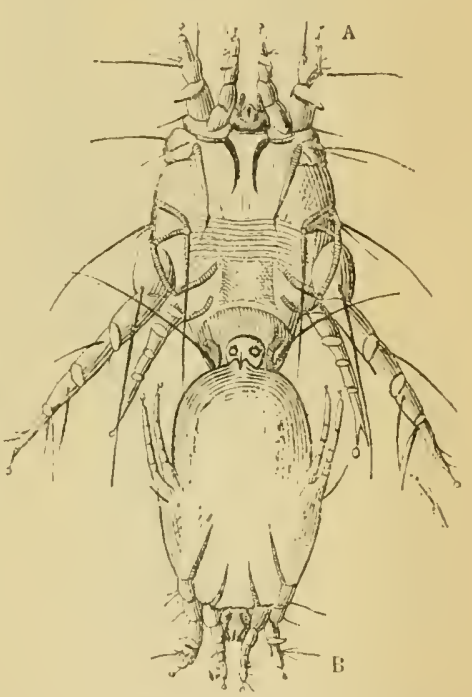

lig. 466. - Megninia columbx, du r'igeon. - A, mâle, el li, femelle pubère, accouplés, vus par la face venlrale, grossis 100 fois (G. Neumann).

gagner le tissu conjonctif sous-culané en pénétrant, par l'ombilic supérieur, dans l'intérieur du tuyau, d'où ils sortent par l'ombilic inférieur. Plus rarement, ils hivernent dans le tuyau même.

Les recherches poursuivies depuis quelques années sur ce groupe ont entrainé une multiplication progressive des coupes génériques. Le tableau de la page suirante indique les principales divisions adoptées par Trouessart (1).

(1) Les noms marqués d'un astérisque * sont ceux des genres exotiques. 


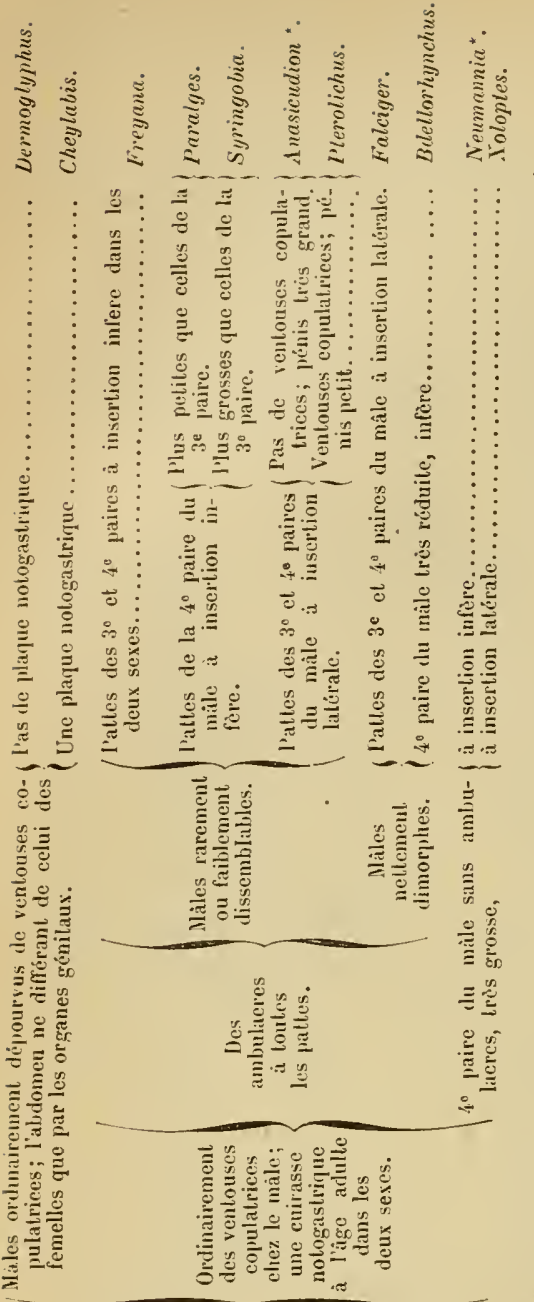

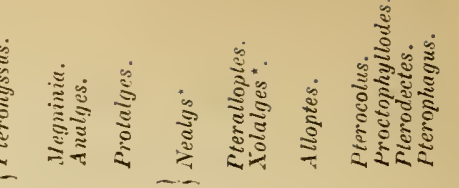

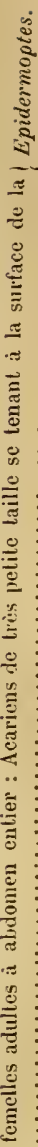

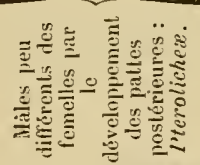

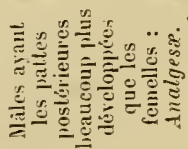

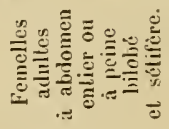

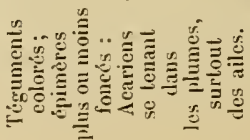

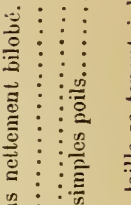

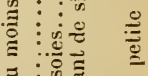

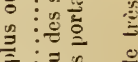


Il convient de remarquer que bon nombre de ces caractires n'ont rien d'absolu, en raison du grand nombre d'espèces que renferme chaque genre, de sorte qu'on a dútablir assez souvent des sous-genres pour classer les formes intermédiaires. Cette observation s'applique plus spécialement aux Analgesex; il est presque impossible, parexemple, de trouver la démareation en. Lre Pteronyssus et IEgninia, d'où la formation d'un sousgenre Mesalges Trt.

Nous ajouterons que, d'après Trouessart, le groupe des Proctophyyllés présente une assez grande uniformité pour qu'on puisse réunir toutes les espèces qu'il renferme dans le seul genre Proctophyllodes Rob., de telle sorte que les subdivisions indiquées dans le tabieau ne correspondraient plus qu'ì des sous-genres. Il est utile néanmoins de les conserver pour la facilité des recherches.

Nous ne pouvons guère que citer ici les espèces qui vivent sur les Oiseaux domestiques :

Dermoglyphus clongatus Mégn., de la Poule, parfois dans le tuyau des plumes. D. minor (Nörner), dans le tuyau des plumes de la poule. D. minor var. similis et D. varians Trt., dans le tuyau des plumes de la Pintade, a vec des Syringophiles.

Freyana anatina (Koch), des Canards. Fr. (Microspalax) Chanayi Trt. et Mégn., du Dindon.

Pterolichus obtusus Rob.,

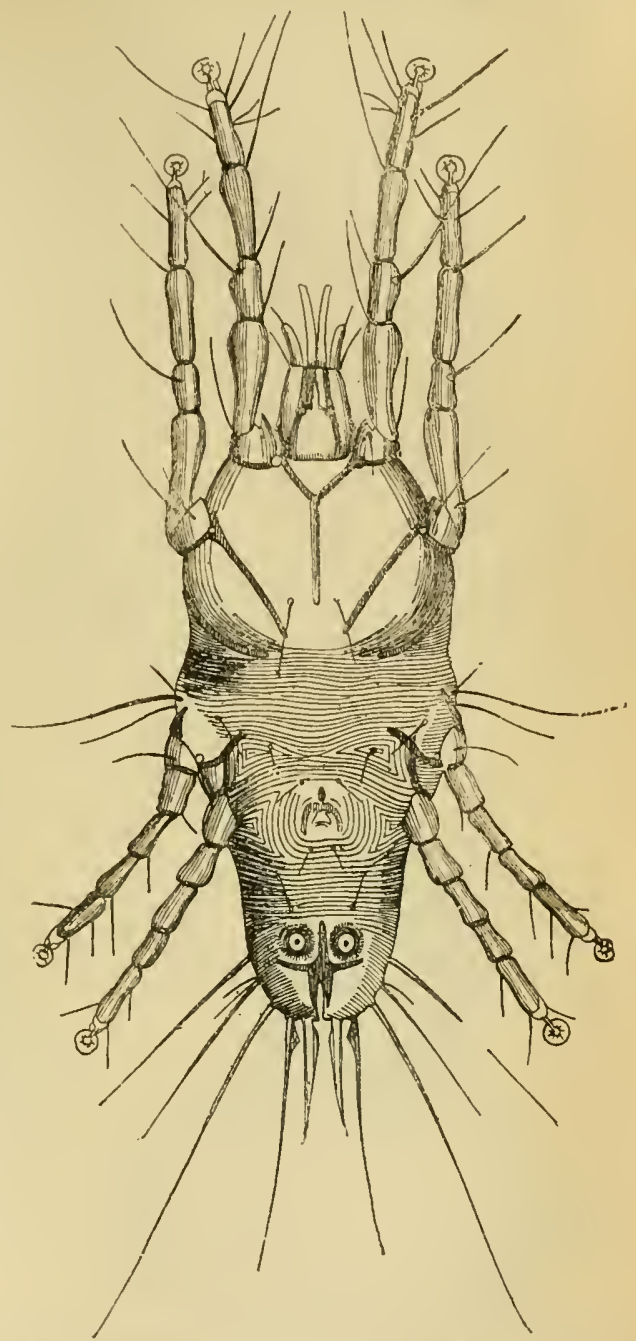

Fig. i67. - Falciger rostratus, du Pigeon : mâle à mandibules allongées, vu par la face ventrale, grossi 100 fois (Orig.).

des Poules, Faisans et Perdrix. Pt. uncinatus Mégn., des Faisan . Falciger rostratus (Buchholz), des Pigeons.

Megninia phasiani (ginglymura) (E. Wilson), des Faisans et du Paon. M. c)luınŁæ (asternalis) (Buchholz), des Gallinacés et des Pigeons. M. cubitalis (Mégn.), des Poules. M. velata (Mégn.), des Canards.

Pterophagus strictus Mégn., des Pigeons. 
Epidermoptes bilobatus Rivolta, et Ep. bifurcatus Riv., des Poules.

Quelques-unes de ces espèces méritent une mention particulière.

Le Falciger rostratus (Buchholz, 1869), qui vit dans les plumes des Pigeons, présente de singulières métamorphoses, qui lui sont d'ailleurs communes avec d'autres Acariens plumicoles. Dans des conditions encore mal déterminées, un certain nombre de nymphes pénètrent dans le tissu conjonctif sous-cutané ou périlrachéen, parfois mème dans les cavités viscérales, s'allongent, perdent à la suite d'une mue leurs organes masticateurs, et se nourrissent sur place, probablement par endosmose. Dès 1866, Robertson avait observé ces Acariens vermiformes et les avait rapprochés du genre provisoire Cellularia Montagu (1808), qui correspond au genre Hypudectes De Filippi (1861) ou au genre Hypoderas von Frauenfeld (1864); Slosarski en fit l'espèce Hypodectes columbæ (1877), et Murray l'espèce Hypoderas columbx (1877). Mais Mégnin, ayant découvert la mélamorphose indiquée ci-dessus, a pu les rattacher au Falciger rostratus, dont ils ne représentent que des nymphes hypopiales. D'après cet auteur, la transformation dont il s'agit se produirait au moment d'une mue brusque, lorsque l'Oiseau perd la presque totalité de ses plumes; les Acariens changeraient.ainsi de forme et d'habitat en rue d'échapper à la destruction : et une fois les conditions normales rétablies, les nymphes hypopiales reviendraient à l'extérieur el reprendraient leur forme première, pour suivre ensuite leur évolution régulière. Malheureusement, ces vues théoriques ne paraissent pas répondre aux données de l'observation (1).

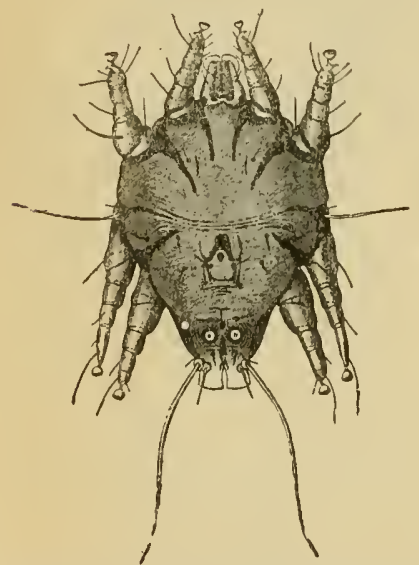

Fig. 468. - Epidermoptes bilobatus; de la Poule : màle, vu par la face ventrale, grossi 150 fois (G. Neumann).

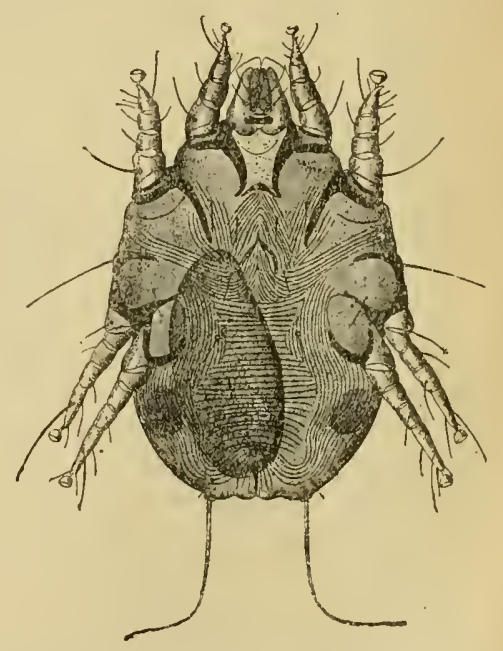

Fig. 469. - Epidermoptes bilobatus, de la Poule: femelle, vue par la face ventrale, grossie 150 fois (G. Neumann).

Le genre Epidermoptes Rivolta, 1876, renferme plusieurs espèces qui vivent d'ordinaire à la surface de la peau, au fond du plumage et au milieu du duvet.

(1) Le tissu conjonctif du Pigeon héberge aussi une forme hypopiale plus petite (Hypodectes minor), dont les relations avec le Falciger ne sont pas encore établies, et que Mégnin soujconne de représenter la nymphe mâle. 
Tel est le cas des Epidermoptes bilobatus et bifurcatus Riv., qui se rencontrent assez souvent sur la Poule. Dans certaines circonstances, ils se multiplient à l'excès, et leur présence coïncide avec des altérations cutanées qui semblent devoir leur ètre rapportées. Rivolta, Caparini, Friedberger, Neumann, Lucet et Railliet ont fait connaitre diverses observations tendant à établir le ròle pathogène de ces Acariens, qu'on peut cependant rencontrer à l'occasion sur des individus sains.

Sous-famille des LISTROPHORINÉs. - Ventuuses copulatrices toujours présentes chez le mile. Pas de ventouses autour de l'orifice sexuel. Tocostome transversal à la face inférieure du céphalothorax. Pattes munies d'anbulacres à ventouse, au moins celles des deux paires antérieures. Lèvre ou pattes postérieures formant une pince propre à saisir les poils.

Ces Acariens, autrefois désignés sous le nom de Sarcoptidés gliricoles, parce qu'on les croyait propres aux Rongeurs, vivent au fond du pelage des Mammifères, sans développer toutefois aucune lésion cutanée.

Quatre genres : Listrophorus, Iyocoptes, Criniscansor, Campylochirus.

Les Listrophores (Listrophorus Pagenstecher, 1860), ont le corps ovoïde, comprimé d'un còté à l'autre, muni d'un large plastron céphalothoracique, et la lèvre transformée en une sorte de pince à mors allongés, destinée à

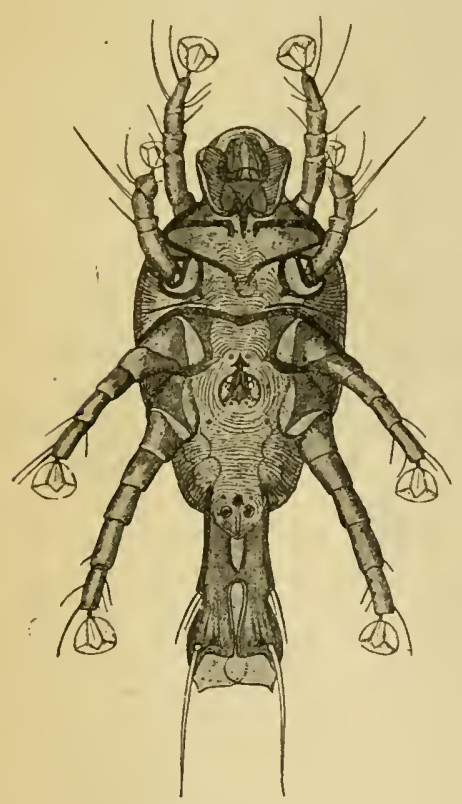

Fig. 470. - Lislrophorus gibbus, du Lapin : mâle. vu par la face veutrale, grossi 100 fois (G. Neumann). saisir les poils. Le mâle porte deux rentouses copulatrices ; son extrémité postérieure est plus ou moins échancrée; la femelle a la vulve située entre les deux groupes de pattes; son extrémité caudale est entière.

Le Listrophore bossu (L. gibbus Pag., 1860) a le plastron céphalúthoracique simplement échancré en dessus; l'extrémité postérieure du màle

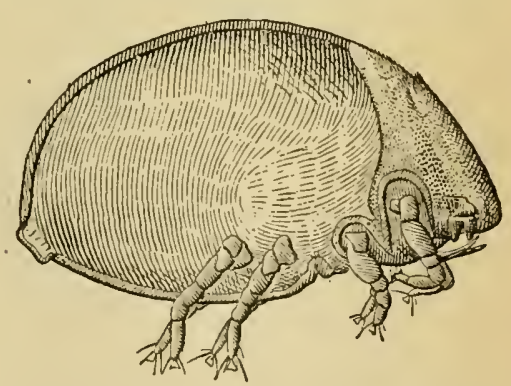

Fig. 471. - Listrophorus gibbus, du Lapin femelle, we de profil, grossie 100 fois (G. Neumann):

est pourvue d'un prolongement aplati et bifide. Longueur du màle, y compris ce prolongement : $4 \bar{\imath} 0$ à $490 \mu$; de la femelle : 450 à $500 \mu$.

Cet Acarien, qui a été découvert par Bourguignon, se trouve souvent en 
abondance dans la fourrure des Lièvres et des Lapins sauvages ou domestiques; vingt-quatre ou quarante-huit heures après la mort de l'hôte, on le voit gagner l'extrémité des poils.

Le Listrophore mustélin (L. mustelæ Mégn., 1883̈) a le plastron céphalothoracique divisé, par une scissure transversale, en deux articles mobiles l'un sur l'autre; l'extrémité postérieure du mâle est simplement échancrée. Longueur du màle : 400 à $440 \mu$; de la femelle : 450 à $540 \mu$.

Vit dans les poils du museau et de la partie antérieure du tronc chez le Furet, où il a été rencontré d'abord par Ch. Robin. Nous l'avons observé anssi sur le Putois.

Sous-famille des TYROGLYPHINÉs. - Ventouses copulatrices existant d'ordinaire chez le mâle et situées de chaque côté de l'anus (paranales); souvent, en outre, dans les deux sexes, deux paires de ventouses autour de

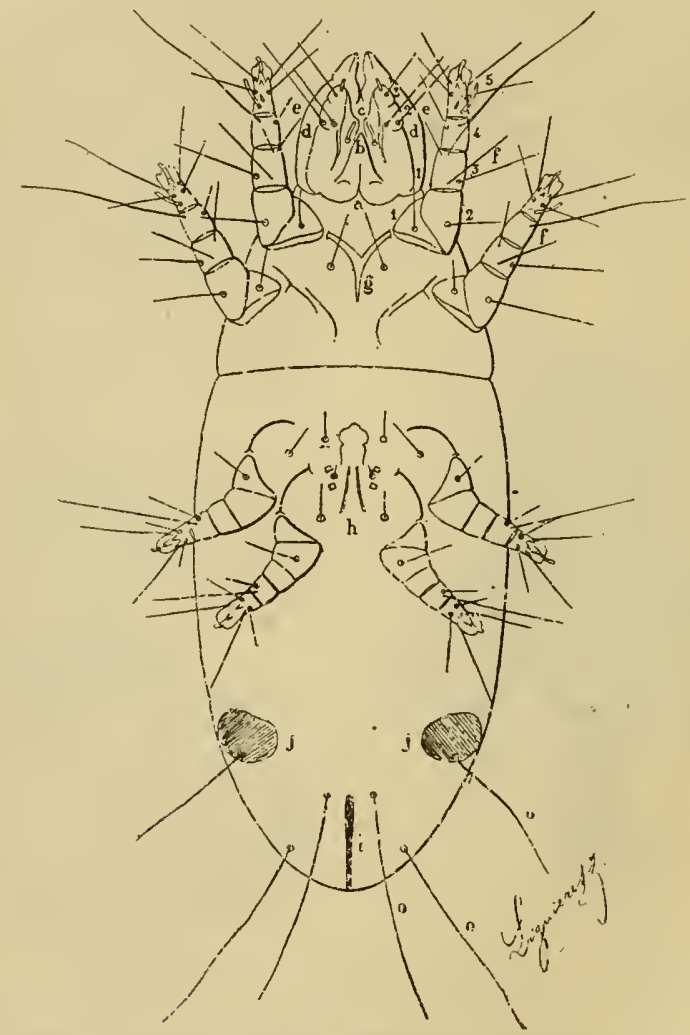

Fig. 472. - Tyroglyphus malus, fenelle ovigère, vue par la face ventrale. $-b$, anguelte. $c$, lèvre. $d$, palpes maxillaires. $e$, mandibules. $f$, pattes. $h$, organe sexuel avec les deux paires de petites ventouses génitales. $i$, anus. $j$, vésicules ovoïdes brun jaunâtre (Lignières).

l'orifice sexuel (ventouses génitales), ou plus rarement en des points variés (ventouses aberrantes). Pattes terminées par un ongle et une caroncule vésiculeuse sessile, on seulement par l'tn ou l'autre de ces organes. 
Les Tyroglyphinés ou Sarcoptidés détriticoles vivent en liberté i läge adulte, se nourrissant de matières organiques en roie de décomposition.

Comme les autres Sarcoptidés, ils présentent dans leur évolution deux stades de nymphe; mais, dans quelques genres, ces nymphes subissent de curieuses transformations, analogues à celles que nous avons indiquées a propos des Falciger. - Un certain nombre d'entre elles, a la suite d'une mue (Cliparède), deviennent cuirassées, se montrent pourvues d'organes d’adhésion, et ne laissent plus voir d'onverture buccale, anale ou génitale. Par le fail d'une nouvelle mue (Mégnin), elles reprennent leur forme première et ne tardent pas a devenir sexuées. I'après une théorie émise par ce dernier auteur, cette nymphe cuirassée ne serait qu'une forme adventive, apparaissant lorsque le milieu uutritif se dessèche ou s'épuise, et chargée alors de la conservation et de la dissémination de l'espèce. On peut la voir en effel, lorsyue les aliments font défaut, se fixer sur un animal quelconque, pourvu qu'il soit agile, et s'attacher it lui jusqu'au moment où il parvient dans un milieu favorable. Elle le quitle alors, reprend le cours de son évolution, et concourt ainsi à fonder une nouvelle colonie. - Malheureusement, cette théorie ne répond pas à la réalité des faits. Michael a pu constater que lapparition de la nymphe cuirassée n'est nullement déterminée par les mauvaises conditions du milieu nutritif. Lt Moniez a mème reconnu qu'elle se montre d'autant moins abondante que ces conditions du milieu sont plus défavorables. Il faut donc admettre qu'elle correspond à un slade normal, bien qu'elle ne semble avoir d'autre raison d'être que d'assurer la conservation de l'espèce lorsque les aliments viennent à manquer: seuls, en effet, les individus qui se trouvent alors à ce stade sont aptes á résister, tandis que tous les autres péris-

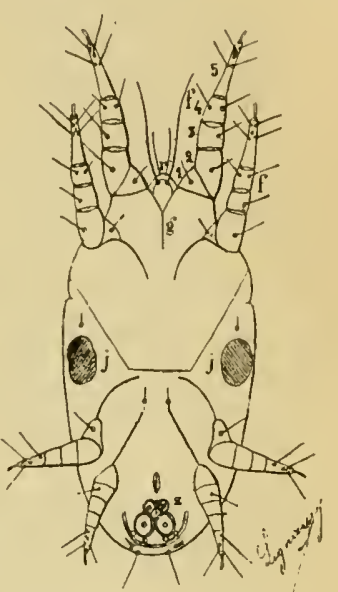

Fig. 473. - Tyroglyphus malus. nymphe liypopiale, vue par la faer. ventrale. - $\approx$, groupe sous-aldominal de petites renlouse: (Lignières). sent.

Ces nymphes migratrices ou formes de voyage avaient été décrites autrefois comme représentant des, genres particuliers, sous les noms d'Hypopus Koch, 1842, Homopus Koch, Trichodactylus Dugès. On peut du reste, avec Canestrini, en distinguer actuellement trois formes se rattachant à ces genres : - $1^{0}$ nymphes homopiales, possédant à la partie postérieure de la face ventrale deux plaques adhésives mues par des muscles puissants; $2^{\circ}$ nymphes hypopiales, les plus communes, pourvues d'un groupe sous-abdominal de petites venlouses disposées en plusieurs séries; tarses terminés par un ongle faible et une forte soie; - $3^{\circ}$ nymphes trichodactyloïdes, montrant sous l'abdomen les mèmes ventouses que les précédentes, mais ayant les tarses terminés, les uns par un ongle robuste, les autres par une longue soie.

f. Canestrini distingue les divers genres suivants parmi es Tyraglyphinés : 
1. Ventouses copulatrices chez le mâle............... 7 .

Pas de ventouses copulatrices.................... 2 .

2. Ventouses aberrantes daus les deux sexes; palpes à expan-

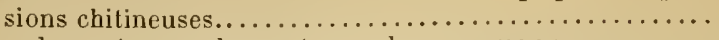

Pas de ventouses aberrantes; palpes normaux...........

3. Nymphes migratrices homopiales, vivant sur les Mammiferes. Nymphes migratrices non homopiales, ou manquant......

4. Ongle tarsien rudimentaire........................

5. Ventouses génitales absentes dans les deux sexes; tocostome derrière les épimères de la deuxième paire....... Ventouses génitales au moins dans l'un des deux sexes...

6. Ventouses génitales dans les deux sexes................ $-\quad-\quad$ chez la femelle seule..................

7. Mâleả appendices foliacés à l'extrémité postérieure du corps. Mâle sans appendices foliacés......................

8. Pas de sillon entre le céphalothorax et l'abdomen.........

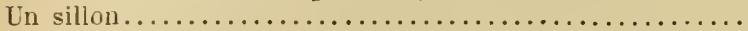

9. Pattes de la première paire, chez le mâle, épaissies et

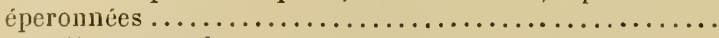

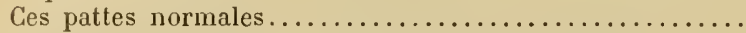

10. Tarses longs, avec caroncule; pas de dimorphisme mâle. Tarses courts, sans caroncule; dimorphisme mâle.......

Histiostoma.

3.

Homopus.

4.

Glycyphagus.

5 .

\section{Hericia.}

6. Carpoglyphus. Trichotarsus.

Histiogaster. 8. Chorloglyphus. 9.

Aleurobius.

10.

Tyroglyphus.

Rhizogtyphus.

Quelques-uns de ces gemres méritent une mention spéciale (1).

Les Histiostomes (Histiostoma Kramer, 1876; Hypopus Koch, 1841 ; Serrator Mégnin, 1880) ont un sillon entre le céphalothorax et l'abdomen; leurs tarses présentent un ongle distinct, sans ventouse. - H. feroniarum (Dufour), dans les champignons putrescents, les résidus de choucroute, etc. $H$. necrophagum (Mégn.), sur les cadavres momifiés.

Les Glyciphages (Glycyphagus Hering, 1838), qui portent des poils barbelés ou plumeux, ne montrent pas de sillons entre le céphalothorax et l'abdomen. - G. prunorum Her., 1838, ou spinipes Koch, 1841, dans la poussière des maisons ou du vieux foin, dans les tabacs, sur les substances organiques en voie de décomposition, cadavres, squelettes, produits de charcuterie altérés. - G.domesticus (De Geer, 1778), ou cur'sor Gerv., 1841, dans les mèmes milieux que le précédent ; un peu moins commun, attaquant volontiers les fruits et les matières sucrées. Ce sont probablement des individus de cette espèce que Hering avait observés sur le pied d'un Cheval affecté de crapaud : il les regardait comme propres à cette maladie et en avait fait une nouvelle espèee de Sarcopte, sous le non de Sarcoptes hippopodos. En 1867, Moriggia publiait une curieuse observation relative à la présence d'une énorme excroissance cornée sur la face dorsale de la main droite d'une vieille femme; l'intérieur de cette corne était rempli d'Acariens qu'il décrivit et figura sous le nom d'Acarus domesticus. Peut-ètre s'agissait-il de ce Glyciphage.

Il convient de rappeler encore que Busk a trouvé, en 1841, un Acarien mort dans un ulcère de la plante du pied, chez un Nègre soigné au Seaman's Hospital Ship de la Tamise : la saillie conique (2) qui existe à l'extrémité

(1) Il y aurait à ajouter encore deux genres insecticoles : Pullea Canestrini, 1884, et Hemisarcoptes Lignières, 1893.

(2) Nous devons cependant faire remarquer rue les tubercules impairs qui terminent l'abdomen des femelles uvigères ne sont pas propres aux seuls Glyciphages; 
postérieure de ce corps tend à montrer qu’il s'agissait d'une femelle ovigère de Glyciphage, et Murray en a fait un G. Buski.

En Angleterre, on observe souvent, sur les personnes qui manient le suere, une irritation passagère, mais parfois assez violente, comnue sous le nom de gale des épiciers (grocer's itch) : Murray attribue ces accidents aux flyciphases.

Dans la poussière des fourrages, on trouve encore, outre les espèces précédentes, G. intermelius, plumiger, Canestrinii, palmifer.

Les Carpoglyphes (Carpoglyphus Robin, 1869; Phycobius Can., 1888) manquent également de sillon thoraco-abdominal. - C. passularum (Her.) ou Ph. anonymus (Haller), sur les vicilles ligues sèches, les pruneaux, les conserves, rarement sur le fromage. lieinhardt, de Bautzen, l'a trouvé daus des matières vomies : il avait été sans doute introduit dans l'estomac par l'intermédiaire de fruits confits.

Dans les Chortoglyphes (Chortoglyphus Berlese, 188'), nous n'avons à signaler que $C h$. nudıs Berl., du foin et de la litiẻre.

Les Aleurobies (Aletrobius Canestrini, 1888) ont des ven touses génitales darıs les deux sexes. Le màle possède en outre des ventouses copulatrices, et il a les pattes de la première paire épaissies et armées de crochets; celles de la $\dot{4}^{\mathrm{e}}$ paire portent le long du tarse deux petits disques à ventouse. Les tarses sont terminés par une caroncule et par un crochet bien développé. Le tocostome, comme l'armure mảle, se trouve entre les épimères de la $\dot{t}^{\mathrm{e}}$ paire. Il existe un sillon thoraco-abdominal. Les nymples migratrices sont hypopiales.

L'Aleurobie de la farine (A. forinx [De Geer]; Tyr. farinx Gerv.) est de teinte pâle, avec les pattes roussàtres, celles de la première paire, chez le màle, étant très grosses, surtout au niveau du $2^{\mathrm{e}}$ article, qui porte à sa base et en dedans un éperon très fort. En arrière de chacune de ces grosses pattes, une courte soie plumeuse. Mâle long de $330 \mu$, large de $160 \mu$. Femelle ovigire longue de $600 \mu$, large de $300 \mu$; six courles soies en arrière. Nymphe hypopiale longue de $200 \mu$; cinq paires de ventouses, l'avantdernière la plus grande, la dernière la plus petite.

Vit sur des substances organiques très diverses, où il se multiplie à l'excès lorsqu'elles présentent un commencement d'altération : farines, grains, foin, paille, tabac, houblons, fromages, produits de charcuterie, cadavres, etc. Berlese l'a trouvé quelquefois rempli de spores d'Aspergillus glaucus.

Moniez (1) a observé un cas de parasitisme accidentel de cet Acarien sur l'Homme. Il existait en abondance dans des blés importés de Russie à Lille, et, lors de la manipulation de ces blés, produisit une éruption cutanée sur les ourriers.

on les rencontre aussi chez les Tyroglyphes et même chez divers Analgésinés. D'après Trouessart, ils représentent ce qui reste du canal spermatique (vagin) oblitéré et desséché, lorsque la femelle adulte sort de son tégument de femelle pubère.

(1) R. Moxiez, Parasilisme accidentel sur l'Homme du Tyroglyphus farinæ. Comptes rend. Ac. sc., CVIII, p. 1026, 1889. 
Robin, qui décrivait cette espèce sous le nom de Tyroglyphus siro, l'a trouvée en abondance dans la vieille farine de lin; il ajoute que des médecins lui en ont remis trois fois un ou deux exemplaires recueillis sur des plaies après application de cataplasmes de farine de lin. - Laboulbène en a étudié un trouvé dans l'urine d'un malade, et provenant, bien entendu, de l'extérieur.

Burke a signalé d'autre part, sous le nom de stomatilis pustulosa acarosa, une affection qu'il a rencontrée plusieurs fois chez le Cheval, et consistant en des tumeurs épithéliales de la muqueuse buccale. Dans ces tumeurs, qui ont une tendance à l'ulcération, il a trouvé souvent des Acariens qu'il rapporte à l'Acarus farinæ. Le son avarié qu'on distribuait aux Chevaux renfermait d'ailleurs les mêmes animalcules; mais il est peu probable qu'il y ait eu entre ceux-ci et les tumeurs une relation de cause à effet.

Enfin, Hering dit avoir trouvé la Mite de la farine sur le Chat d'un boulanger, atteint d'un exanthème d'apparence psorique.

Les Tyroglyphes (Tyroglyphus Latr., 1797) ont aussi des ventouses génitales dans les deux sexes. Le màle possède en plus deux ventouses copulatrices: ses pattes antérieures sont normales; celles de la $4^{\mathrm{e}}$ paire portent souvent, mais non toujours, de petits disques à ventouse sur les tarses. Les pattes sont terminées par une caroncule et par un ongle bien distinct. Le tocostome est situé entre les épimères des deux dernières paires, l'armure mâle entre ceux de la dernière. Le tégument est lisse; il existe un sillon entre le céphalothorax et l'abdomen. Les nymphes migratrices sont hypopiales.

Le Tyroglyphe ciron (T. siro [L.]) est de teinte blanchàtre ou un peu rosée. Tarses de la première paire à peine plus longs que les deux articles précédents $\left(3^{e}\right.$ et $\left.4^{\mathrm{e}}\right)$ réunis; ceux de la $4^{\mathrm{e}}$ paire plus courts. Tarses des deux premières paires munis à leur base d'une courte soie tactile claviforme. Soies du corps assez longues. Mâle long de $500 \mu$, large de $200 \mu$; pénis droit; deux disques à ventouse sur les tarses de la $4^{\mathrm{e}}$ paire. Femelle longue de $530 \mu$. , large de $280 \mu$.

Vit sur les substances organiques en voie de décomposition : fromages, farines, etc., mais est relativement rare. Nous l'avons observé, avec Moulé, sur la vanille, où Arnozan paraît l'avoir également rencontré. On l'a même accusé de produire des phénomènes éruptifs dans l'affection qu'on a décrite sous le nom de vanillisme, et qui parait être comparable à la gale des épiciers. Les personnes qui manient les vanilles " mitées " éprouvent souvent, en effet, une éruption papuleuse avec prurit intense (1).

Pour les auteurs italiens, c'est le véritable Acare du fromage, et cependant, comme Moniez, nous l'avons trouvé dans ce produit beaucoup moins fréquemment que l'Aleurobius farinæ. - Zürn rapporte que, dans certaines régions de l'Allemagne, on se livre à une sorte d'élevage de ces Acariens, en vue de la production du "fromage aux Mites, " dont on apprécie la sa-

(1) A. Layet, Élude sur le vanillisme ou accidents causés par la vanille. Revue d'hygiène et de police sanitaire, V, p. 711, 1883 (Note d'Arnozan, p. 724). 
veur acidule. Cet auteur ajoute d’ailleurs qu'il a observé à diverses reprises du catarrhe stomacal et intestinal chez des individus ayant l'habitude de consomner ce fromage.

Latreille a rapporlé au $T$. siro les Acariens rencontrés par Rolander, élève de Linné, dans ses selles, el décrits par ce dernier sous le nom d'Acarus dysenterit'. Ils provenaient d'un vase en bois dans lequel Rolander buvait chaque nuit. Lambl a vu également, à Prague, des Acariens dans les selles dysentériques des enfants.

Le Tyroglyphe allongé ( $\boldsymbol{T}$. longior frervais, 1844) a le corps blane ou jaunitre, brillant, avec deux taches noiràtres a l'abdomen. Tarses relativement longs, ceux de la $1^{\text {re }}$ et de la $4^{c}$ paires notablement plus longs que les $3^{\mathrm{e}}$ et $4^{\mathrm{e}}$ articles réunis de la patte correspondante. Pas de soie tactile claviforme aux tarses des deux premières paires. Soies du corps plus longues que dans l'espẻce précédente. Hâle long de ãö0 $\mu$, large de $280 \mu$; pénis incurvé ; deux disques à ventouse sur les tarses de la $4^{\text {e }}$ paire. Femelle longue de $610 \mu$, large de $280 \mu$.

Vit en compagnie du $T$. siro et de l'Al. farinx, mais est moins commun. I] a eu son heure de célébrité, à l'époque où Cross prétendait produire des ètres vivants sous l'influence de l'électricité : l'Acarien qu'il affirmait avoir ainsi développé n’était autre, semble-t-il, qu'une femelle de $T$. longior (Acarus horridus Turpin, 1837 ; . Crossi (les auteurs anglais).

Le Tyrowlyphe entomophage ( $T$. entomophagus [Laboulbène, 1832]) est grisâtre, brillant. Pattes très courles, moins longues que le corps n'est large; tarses plus courts que les $3^{e}$ et $4^{\mathrm{e}}$ articles réunis. Nlâle long de 120 à $400 u$, large de 60 à $200 \mu$. Femelle longue de 1300 à $300 \mu$, large de 75 à $200 \mu$.

Dans le corps des Insectes morts, surtout des Coléoptères, comme les Cantharides. Honiez l'a trouvé à Lille dans le safran. Il existe aussi sur la vanille.

On peut encore citer les Tyroglyphus ovatus Troupeau, de la farine et du frornage; T. siculus Fum. et Rob., de la Cantharide de Sicile, etc.

Les Rhizoglyphes (Rhizoglyphus Claparède, 1869; Cæpophagus Mégn., 1880) sont reconniaissables ì leurs pattes courtes et épineuses, à tarse terminé par un ongle robuste, sans caroncule. - Rh. spinitarsus (Hermann, 1804) ou Tyroglyphus echinopus Robin, dans les bulbes de Liliacées en voie d'altération, sur les racines ou les tubercules de diverses plantes. Rencontré par Baratoux et Mégnin dans le conduit auditif d'une femme atteinte d'otorrhée et se faisant des injections de décoction de racine de guimauve.

Ajoutons que Hessling a trouvé, dans la plique polonaise, deux espèces d'Acariens qu'il a décrits et figurés d'une façon imparfaite, sous les noms d'Eutarsus cancriformis et de,Colognathus morsitans; or, il ne s'agit nullement de parasites; ce sont, semble-t-il, des nymphes trichodactylö̈de et hypopiale de Tyroglyphinés.

Famille des BDELLIDÉS. - Acariens à téguments mous, couverts de poils diversement conformés, quelquefois vivement colorés. Rostre bien distinct. Palpes grèles, tactiles, libres, à dernier article 
renflé ou émoussé portant simplement des poils. Mandibules en pinces ou crochues. Le plus souvent une paire d'yeux sur le céphalothorax. Pattes toutes semblables, insérées sur le tégument au moyen d'épimères. Deux stigmates à la base du rostre. Larves hexapodes semblables aux adultes. - Acariens terrestres pour la plupart.

Deux sous-familles: Eupodinie et Bdelline.

Sous-famille des EUPoDinĖs. - Palpes médiocres ou courts, ordinairement formés de quatre articles, dont les derniers se replient généralement en dessous sur les premiers comme la lame d'un couteau sur le manche. Mandibules en pince à mors dentés. Pattes, au moins celles des cinq dernières paires, propres à la marche ou au saut, et terminées par deux ongles et un cirre cilié, rarement par un seul ongle. Orifice génital ventral, entouré de poils plus ou moins modifiés. Poils souvent ciliés, foliacés et disposés en rosette.

Ces Acariens délicats vivent librement, et se nourrissent de proies ou de substances végétales.

Genre Tydée (Tydeus Koch, 1842). - Palpes de longueur médiocre, à dernier article long, terminé par quelques soies assez courtes. Mandibules faibles. Pattes assez courtes, à tarses coniques, les postérieurs plus longs que les antérieurs. Ouverture sexuelle non entourée de ventouses. Épimères courts, non réunis. Très petits animaux, à mouvements lents.

Le Tydée importun ( $T$. molestus Moniez, 1889) est une espèce aveugle, de teinte rose; le mâle est rare; la jeune femelle est longue de $250 \mu$; la femelle bourrée d'embryons atteint $360 \mu$.

Moniez a trouvé cet Acarien en Belgique, localisé dans les jardins d'une grande ferme isolée, où il est apparu vers 1864, à la suite d'une importation de guano du Pérou. Depuis cette époque, il se montre chaque année, de juillet aux premiers froids. On le trouve en quantité fabuleuse dans le gazon, ainsi que sur tous les arbres et arbustes. Il se jette sur l'Homme, et devient surtout insupportable pendant les grandes chaleurs: il suffit d'ébranler faiblement les branches ou de marcher sur l'herbe pour être attaqué. Dès le premier jour il y a formation d'ampoules, et la trace de la piqûre persiste de trois à cinq jours. Le Tydée n'épargne pas non plus les animaux qui passent à sa portée: Chiens, Chats, Poules, Pintades, Canards; on peut le rencontrer sur tous les points du corps, mais il se fixe de préférence aux articulations, autour de l'œil, à l'anus, où il détermine la formation d'une sorte de couronne de crouttes; les jeunes Canards principalement souffrent de ses attaques et en meurent, forcés qu'ils sont de conserver les ailes et les pattes étendues, par suite de l'agglomération des Acariens aux plis des articulations.

Famille des TROMBIDIDÉS. - Acariens à téguments presque toujours mous, plus ou moins velus el souvent colorés de teintes vives. 
Rostre en suçoir conique formé par l'hypostome incurvé et contenant deux mandibules dépourvues de mors mobile, à branche principale terminée en pointe (mandibules styliformes) ou par un crochet; palpes libres, volumineux, dont l'arant-dernier ou plus rarement le dernicr article porte un ongle plus ou moins développé (palpes ravisseur's). Pattes insérées sur le tégument au moyen d'épimères, propres à lat marche, ordinairement conıposées de $\ddot{3}$ ou 6 articles et terminies par un ongle double souvent accompagné d'un cirre pectiné ou d'une petite caroncule, elc.; celles de la première paire sourent tactiles et modifiées ì cet effet. Assez fréquemment des yeux. Trachées s'ourrant, au moyen d'une paire de stigmates, à la base du rostre ou sur les côtés du céphalothorax.

Cette famille comprend un grand nombre d'espèces terrestres, les unes libres, les autres parasiles.

10 sons-familles: T'arsonemine', Cheyletina, Eryllureina, Tetranycine', Raphignathine', Rhyncholophina", Trombidinie, Scirine', C'sculinae, Limnocharinie.

Sous-fanilte des tarsonémrnés. - Palpes simples, petits, peu distincts. Mandibules styliformes, faibles. Pattes de la $1^{\text {re }}$ paire terminées par un seul crochet; jamais de cirre ni de poils caronculés. Corps diversement conformé, avec séparation assez accusée des segments. Stigmates s'ouvrant sur les cótés ou a la face dorsale du céphalothorax. Un gros cirre claviforme de chaque còté sur la face ventrale de la femelle, entre les deux premières paires de pattes. Dimorphisme sexuel très prononcé. Métamorphoses anymphales (pas de nymphe octopode).

Acariens parasites ou libres.

Genres Tarsonemus, Pedicutoides, Pygmephorus, Disparipes, Poclapolipus.

Genre Pédiculoïde (Pediculoides Targioni-Tozzetti, 1878. - Syn. : Heteropus Newport, préoccupé; Physogaster Lichtenstein, 1868, préoccupé; Spharogyna Lab. et Mégn., 1883̈). - Rostre normal et libre. Pattes de la $4^{\mathrm{e}}$ paire, chez la femelle, terminées par deux ongles et une caroncule; celles du màle modérément développées, terminées par un ongle seul. Dans les deux sexes, pattes de la première paire terminées par un seul ongle, celles des $3^{\text {e }}$ et $4^{\mathrm{e}}$ paires par deux ongles et une caroncule. Écusson dorsal segmenté. Abdomen de la femelle gravide se développant en une sphère énorme.

Animaux parasites des Insectes.

Le Pédiculoüde ventru (P. ventricosus [Newport]. - Syn. : Heteropus ventricosus Newport, 18300 ; P. tritici Targ., 1878; Sph. ventricosa Lab. et Hégn., 1885: P. ventricosus Canestr., 1888). - Corps ovale ou cylindroïde, jaunàtre, à téguments mous, à peine striés longitudinalement. Pattes à cinq articles. Mâle long de $120 \mu$, large de $80 \mu$; corps ovalaire, anguleux, ollrant à sa face supérieure six paires de soies et en arrière un plastron grenu. Femelle non gravide longue de $200 \mu$, large de $70 \mu$; corps cylindroïde, à face dorsale montrant sur le céphalothorax, en arrière des stigmates, une paire de soies, et sur l'abdomen deux paires; en outre, deux courtes soies postérieures. 
Femelle gravide différant de la précédente en ce que l'extrémité postérieure de l'abdomen s'est gonflée en formant une sphère énorme pourant acquérir un diamètre 20 fois supérieur à celui du corps : ce renflement globuleux est rempli d'œufs à tous les degrés de l'évolution, jusques et y compris la formation d'individus octopodes ayant tous les caractères de l'adulte. On peut mème distinguer dans l'utérus les individus màles des femelles : ceux-ci sont toujours accolés deux à deux et tête-bêche dans un œuf allongé qui se sépare facilement en deux parties ayant chacune une enveloppe propre.

L'espèce est donc vivipare; la femelle donne naissance à des individus mâles et femelles paraissant aptes à se féconder immédiatement, de sorte qu'on ne trouve en liberté ni larve hexapode ni nymphe (Laboulbène et Mégnin).

Le Pédiculoïde ventru vit en parasite sur les larves et les nymphes d'Insectes variés, et en particulier sur celles de la Teigne du blé. De là, il peut passer sur le corps de l'Homme.

Le premier cas de ce parasitisme accidentel a été recueilli par Lagrèze-Fossot et Montané. Du blé récolté dans la vallée de la Garonne avait été préparé en septembre 1849 et vendu quelque temps après, mais l'acheteur n'en prit livraison qu'en juin 1850. Dans cet intervalle, le blé ne fut ni pelleté, ni ventilé. Lol'squ'on l'enleva, les hommes employés au transport des sacs, ainsi que le mesureur et l'acheteur, éprouvèrent de vives démangeaisons. Cependant, une partie du chargement fut expédiée à Bordeaux, et le reste à Moissac, mais dans ces deux villes les ouvriers employés au débarquement refusèrent bientôt de continuer le travail: tous se plaignaient de démangeaisons insupportables à la poitrine, aux bras, à la face, autour du cou et sur les épaules, et chez la plupart cette irritation cutanée fut suivie d'une éruption de boutons plus ou moins enflammés, dont quelques-uns renfermaient un peu de sérosité. Lagrèze-Fossot reconnut que ces phénomènes résultaient de la présence d'un Acarien particulier, qu'il décrivit et figura sous le nom d'Acarus tritici, mais qu'il est facile de reconnaître pour une jeune femelle ou nymphe octopode de Pediculoides.

Des accidents analogues ont élé signalés depuis lors à diverses reprises, sans que toutefois la détermination spécifique du parasite ait pu être faite dans tous les cas. Citons simplement les observations de Rouyer et Robin, dans l'Indre (1868); celle de Perrens et Lafargue dans la Gironde (1872); celle de Geber à Klausenbourg, où l'Aca . rien, qui provenait de tas d'orge, est appelé Chrithoptes monunguiculosus (1879); celle de lioller à Budapest, où le parasite est pris pour une larve d'Oribate (1882); enfin, celles de Bertherand en Algérie (1888), où Moniez reconnaît des individus jeunes de $P$. ventricosus.

Au point de vue de l'agriculture, le $P$. ventricosus est un animal utile, car il détruit les larves d'Insectes. En Amérique, Webster a constaté que 32 p. 100 des larves de l'Alucite du blé (Sitotroga cercalella) étaient tuées par 
cet Acarien, et Laboulbène l'a vu, dans le midi de la France, attaquer les larves du liupreste lu chène (Corxbus bifasciatus).

Genre Tarsonème (Tarsonemus Canestrini et Fanzago, 1876. - Syn.: Chironemus Cn.et r., 187ï, préoceupé; Dendroptus Kramer, 1876; Cheylurus Trt., 1883). - Rostre normal et libre. Pattes de la quatrième paire, chez la femelle, peu déreloppées, sans ongle ni caroncule, inais terminées par deux soies; celles dı mảle très développées, terminées par un ongle robuste, et formant ensemble une pince puissante. Dans les deux sexes, pattes de la première paire possédant un seul ongle, celles des $3^{\mathrm{e}}$ et $4^{0}$ paires pourvues de deux ongles et d'une caroncule. Écusson dorsal segmenté.

Animaux vivant sur les plantes.

L.c Tarsonème nu ( $T$. intectus Karpelles, 1883̈) a été observé en Hongrio dans l'été de 1883̈. Des orges ayant été amenées de Bulgarie it Steinbruch, les ouvriers occupés à les transporter furent alleints, sur les parties nues du corps, et en particulier sur le con, d'un exanthème analogue à l'urticaire, caractérisé par des vésicules rougeitres de la grosseur d'un grain de mil et accompagné d'un prurit inteuse. Le Dr G. IIorvith reconnut que l'irritation était occasionnée par des Acariens blanchàtres, qui furent soumis a Karpelles, de Vienne, et reconnus par lui pour une espèce particulière de Tarsonemus. Il existait à la fois des nymphes et des individus adultes, ceux-ci mesurant environ 350 u. de long.

Genre Pygméphore (Pygmephorus Kramer, 1877). — Rostre faible, à pièces peu développées, et caché dans une sorte de papille céphalique. Pattes de la ł $^{c}$ paire, chez la femelle, terminées par des crochets parfois accompagnés d'une caroncule. Corps de la femelle gravide non déformé, très épineux. Abdomen indistinctement segmenté; pas de véritable écusson au céphalothorax.

Le Pygméphore ì crochets ( $P$. uncinatus [Flemming, 1884]) a été rencontré par J. Flenming sur des ouvriers de Klausenbourg qui, dẻchargeant du blé venu de Russie, furent atteints tout à coup d'un exanthème insolite. Flemming décrivit l'Acarien comme un Tarsonemus, mais Kramer montra qu'il devait ètre rattaché à son genre Pygmephorus.

Sous-famille des GHeylétinés. - Palpes ravisseurs composés de trois à cinq articles dont l'avant-dernier ou le dernier est muni d'un ongle ou de crochets plus ou moins robustes. Mandibules slyliformes ou à crochet. $\mathrm{Ou}-$ verture sexuelle du màle généralement placée sur le dos. Presque jamais d'yeux. Téguments mous et le plus souvent nus sur la facc ventrale. Stigmates s'ouvrant à la base du rostre. Dimorphisme sexuel peu prononcé. Larve hexapode ressemblant beaucoup à la forme adulte.

Ces Acariens sont libres ou parasites, les uns se nourrissant de proies vivantes, les autres de liquides d'origine animale.

Genre Cheylète (Cheyletus Latr., 1797). - Rostre volumineux. Palpes coniques, énormément épaissis à la base; avant-dernier article terminé par un fort crochet rarement accompagné d'un crochet accessoire; dernier article rudimentaire, placé au bord interne du précédent et muni de deux cirres 
pectinés. Mandibules styliformes. Pattes à 5 articles, à peu près toutes semblables, les deux premières parfois un peu plus grandes; tarses généralement terminés par deux crochets et des cirres rangés en peigne.

Acariens libres, se nourrissant d'autres petils Acariens.

Le Cheylète érudit (Ch. eruditus [Schrank, 1781]) est de teinte pàle, rarement rouge; les pattes antérieures atteignent à peine la longueur du corps; l'ongle des palpes est bifide; les soies du corps sont simples. Il mesure jusqu'à $800 \mu$ de long. D’après Beck, il se reproduit par parthénogenèse.

Son nom spécifique vient de ce qu'on le trouve parfois dans les vieux livres. Il vil en effet dans les maisons, parmi les objets poussiéreux ou les chiffons, mais il est plus commun encore dans les étables, poulaillers, pigeouniers, dans les fourrages altérés, dans les magasins de tabacs (Moniez), dans la farine envahie par les Tyroglyphes et partout en général où abondent les Acariens. Il se nourrit en effet de ces petits animaux, qu'il saisit à l'aide de ses palpes, et auxquels il parait inoculer un liquide venimeux, car on les voit tomber immédiatement dans une immobilité absolue.

Leroy de Méricourt a recueilli à Terre-Neuve, sur un officier de marine revenant de la Havane et affecté d'exanthème, trois Acariens qui se trouvaient au milieu du pus s'écoulant de l'oreille. Laboulbène les décrivit d'abord comme des Tyroglyphes (Tyroglyphus Mericourti Lab., 1851; Acaropsis Mericourti Moquin-Tandon, 1860), mais reconnut plus tard qu'il s'agissait simplement du Cheylète érudit, introduit sans doute dans l'oreille par l'intermédiaire de la charpie.

Lors de la restauration de l'église Saint-Pierre, à Londres, les tombes ayant été ouvertes et nettoyées, des myriades d'animalcules se répandirent sur les ouvriers et sur les fidèles. Des exemplaires en furent envoyés à Leuckart, qui les reconnut pour des Cheylètes érudits (R. Blanchard). - Robin, de son côté, a reçu plusieurs fois des spécimens de cette espèce rencontrés sur le corps humain ou dans les selles, et riayant occasionné d'ailleurs aucun accident. Brady a figuré le même Acarien, trouré dans ses fèces, sous le nom de $C h$. Robertsoni.

De même, on peut rencontrer, sur le corps des animaux, des Cheylètes tombés des fourrages, et Picaglia leur a attribué, dạns de pareilles conditions, le développement d'une dermatose observée sur un Cheval; mais la relation de cause à effet n'a pas été bien établie.

Le Cheyletus venustissimus Koch se rencontre dans les mêmes endroits que le précédent, mais il est infiniment moins commun.

Genre Cheylétielle (Cheyletiella Canestr., 1886). - Se distingue du genre précédent par les palpes, dont le dernier article est dépourvu de cirres pectinés, et par les pattes, qui sont terminées par un cirre foliacé ou bifide, accompagné ou non d'une paire de crochets.

Les Cheylétielles vivent en mutualistes sur les Mammifères et sur les Diseaux. 
La Cheylétielle parasitivore (Ch. parasitivorax [Mégn., 18i87) est sublıxagonale, gris jaunàtre; elle possède des palpes volumineux dont le dernier article, appendiculaire, porte seulement un poil bifide et trois poils simples. Les pattes antérieures sont plus courtes que les postérieures; les tarses sont terminés par un cirre foliacé à bords pectinés, non accompagné de crochets. Whle long de 260 à 270 u. Femelle ovigère lonsue de 390 à $430 \mu$.

Cette espèce rit dans la fourrure des Lapins : d'après Mégnin, elle ferait la chasse aux Listrophores. Canestrini dit qu'elle s'insinue volontiers entre et sous les squames épidermiques.

\section{La Cheylétielle hétéropalpe} (Ch. heteropalpa [Mégn., 1878]) est sublosangicue, de teinte jaunitre. Son rostre est plus étroit, et à palpes moins rolumincux que dans l'espèce précédente : chez la fe-

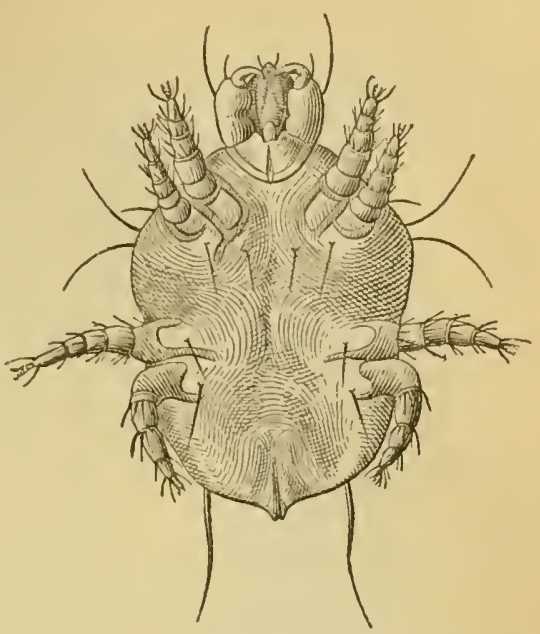

Fig. 474. - Cheyletiella parasitivorax, femelle ovigire, vue par la face ventrale, grossie 100 fois (G. Neumann). inelle, ces palpes ne dépassent pas le rostre, et le crochet du pénultième article se montre assez faible, mais très coudé; chez le màle, il dépasse notablement le rostre, et le crochet n'est que faiblement arqué. Les pattes antérieures et postérieures sont à peu près égales; leurs tarses se terminent par deux crochets fortement coudés et par un cirre bifide barbelé.

Vit à la base les plumes de divers Colombins et Passereaux; lisse à la surface de la peau de petites toiles formant des plaques blanchâtres et destinées à abriter la ponte (Pontaillié).

Genre Sarcoptérin (Sareopterinus Raill., 1893. - Syn. : Sarcopterus Nitzsch, 18t8; Harpinhynchus Mégn., 1878; Harpicephalus Can., 1886, tous noms préoccupés). - Rostre saillant, conique, obtus. Palpes épais, à 3 articles, le pénultième dépassant le dernier et muni de trois crochets, soies ou poils souvent recourbés. Mandibules styliformes. Pattes à ă articles, terminées par denx ongles et un cirre; celles des deux paires postérieures souvent atrophiées. Ouverture génitale du màle dorsale.

Parasites sur les Oiseaux.

Le Sarcoptérin nidulant (S. nidulans [Nitzsch, 1818]) porte à l'extrémité du deuxième article des palpes trois robustes crochets fortement recourbés en haut et en arrière. Les pattes des deux premières paires sont terminées par dleux ongles et un cirre bifurqué; celles des deux paires postérieures sont réduites à l'état de moignons à 3 articles et terminées chacune par un faisceau de quatre longues soies. Longueur, jusqu'à $400 \mu$.

11 vit en colonies nombreuses dans les follicules plumeux dilatés et formant des sortes de tumeurs cutanées, surtout chez les Passereaux. Mégnin dit 
toutefois avoir rencontré la nymphe pubère vagabonde dans les plumes des Pigeons et de quelques autres Oiseaux.

Berlese et Tronessart en ont fait connaître plusieurs autres espèces : presque tous les Oiseaux nourrissent des représentants de ce genre.

Genre Syringophile (Syringophilus A. Heller, 1880. - Syn.: [?] Picobia G. Haller, 1877). - Corps allongé. Rostre fort, à palpes triarticulés, simples, le

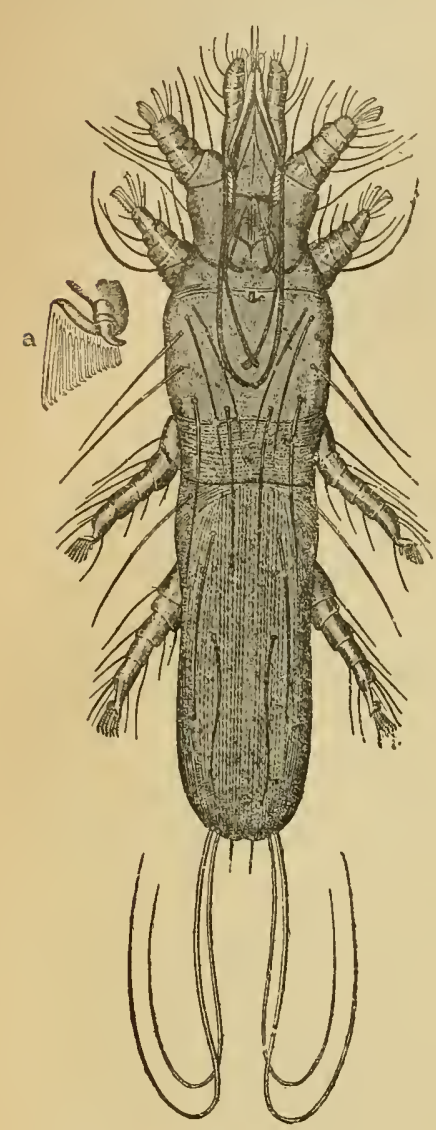

Fig. 475. - Syringophylus bipectinatus, de la Poule : femelle, vue par la face ventrale, grossie 100 fois (G. Neumann).

ment des crochels des palpes, et des peignes plus petits.

Chez le Paon.

Sous-famille des TÉTranycinés. - Palpes ravisseurs, l'avant-dernier article terminé par un ongle et portant le dernier comme un appendice tactile plus ou moins développé. Handibules styliformes. Ouverture sexuelle dans les deux sexes située en avant de l'anus. Une ou deux paires d'yeux de manière à former un tube. Pattes assez courtes terminées par deux ongles robustes et plusieurs cirres pectinés.

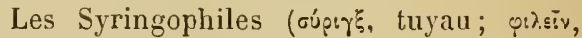
aimer) sont parasites des Oiseaux. On les trouve, dit Trouessart, dans le tuyau des plumes de l'aile et de la queue, et souvent dans celui des tectrices alaires. Ils se nourrissent aux dépens des cônes qui forment l'àme de la plume. Accidentellement, on rencontre des individus isolés en dehors du tuyau, et Trouessart pense que tous en sortent avant la mue d'automne, pour chercher un nouveau logement dans les plumes récemment poussées. Ils y pénètreraient par l'ombilic supérieur, et en sortiraient par l'ombilic inférieur, devenu libre au moment de la mue.

Syringophile bipectiné (S. bipectinatus Heller, 1880). - Corps très allongé, presque vermiforme, un peu plus large en avant qu'en arrière. Rostre losangique. Extrémité postérieure arrondie. Longueur du màle: 700 à $800 \mu$; de la femelle $900 \mu$.

Chez les Poules, Pintades (Trouessart), Pigeons, ainsi que chez un grand nombre d'Oiseaux sauvages, Canards, Mouettes, Passereaux (Poppe).

Syringrophile unciné (S. uncinatus Heller, 1880 ; Cheyletus uncinatus Poppe, 1888). - Diffère du précédent par ses formes plus trapues, le plus grand développedernier article portant trois épines. Mandi-
bules styliformes. Lèvre unie à l'épistome 
sessiles. Téguments mous, striés. Larve peu différente de la forme adulte.

Les Tétranyciués sont libres i tous les àrges; ils vivent sur les végétaux, aux dépens desquels ils se nourrissent, ou bien ì terre, dans la mousse. IIs comprennent de nombreux genres.

Genre Tètranyque (Tetranychus I. Dufour, 1832). - Corps ovalaire, un peu cordiforne chez le màle, souvent couvert de poils. Rostre en pointe conique assez grosse : mandibules formécs de deux parties; l'une basilaire, unie à sa congénère pour former unc pièce unique, l'autre styliforme très longue, aiguë, repliée à sa hase; palpes à 4 articles, le troisième onguiculé, plus petit que le quatrieme. Pattes it 6 articles, aussi longues ou plus longues que le corps, souvent poilues, et toutes terminées par un ambulacre formé de quatre ongles et de quatre poils caronculés.

Ces Acariens, généralement de grande taille, vivent en nombreuses sociétés sur toute espèce de régétaux. Ils se montrent souvent colorés en vert par les grains de chlorophylle qu'ils ont ingérés. Ils possèdent des glandes séricigènes très développées et se tissent une toile qui leur sert d'abri; la soie, rejetéc par la bouche, est dirigée par les palpes.

Les piqùres effectuces sur les feuilles par les Tétranyques et par les représentants de plusieurs genres voisins sont l'origine des altérations connues sous le nom de grise. Le Tétranyque tisserand (T. telarius [L.]) produit la "maladie rouge " de la vigue. Mais certains de ces Acariens peuvent aussi attaquer l'llomme ct les animaux.

Tel est le Tétranyque insupportable ( $T$. molestissimus Weyenbergh, 1886), connu dans l'Uruguay et la République Argentine sous le nom de Bicho colorado. Cet Acarien, de couleur rouge, vit à la face inl'érieure des feuilles du Tanthium macrocarpum; mais, depuis le mois de décembre jus¡u'au mois de février, il se jette sur les animaux à sang chaud et á l'occasion sur l'Homme. Le Bicho colorado enfonce dins la peau son rostre armé de longues mandibules recourbées, et provoque des démangeaisons insupportables.

Sous-famille des TRombidinés. - Palpes ravisseurs bien développés, à cinq articles dont le second est beaucoup plus volumineux que les antres; le $4^{\mathrm{e}}$ est armé d'un ongle puissant et porte le $5^{\mathrm{e}}$ à son bord interne, à la base de l'ongle, sous forme d'appendice tactile. Mandibules à crochet. Pattes propres à la marche, terminées chacune par deux griffes et quelquefois en outre par un cirre; celles de la première paire fonctionnant dans certains cas comme organes tactiles et offrant alors une forme spéciale. Ouverture sexuelle munie de ventouses. Des yeux pédonculés ou sessiles. Céphalothorax bien distinct de l'abdomen. Téguments mous, à couleurs vives, revètus de poils diversement conformés. Les deux stigmates à la base des mandibules ou des pattes de la première paire. Larves hexapodes assez différentes des adultes (leptiformes).

Acariens parasites à l'état de larves, libres sous la forme adulte.

3 genres: Trombidium Latr., Ottonia Kramer, Trombella berlese.

Genre Trombidion (Trombidium Latr., 179ä). - Céphalothorax protractile et rétractile, bien séparé de l'abdomen. Palpes à $\ddot{5}$ articles, le quatrième pourvu d'un ongle unique. Yeux portés chacun par un pédoncule qui parfois est très court. Tarses munis ou non d'un cirre. 
Trombidion soyeux $(T r$. holosericeum [L.]. - Syn. : Acarus holosericeus L., 1746; T. holosericeum Fabr., 1781). - Corps d'un beau rouge satiné, montrant cà et là des taches noiràtres; trapézoïde, à grande base antérieure; bord postérieur incisé au milieu, subbilobé. Toute la surface revètue de poils

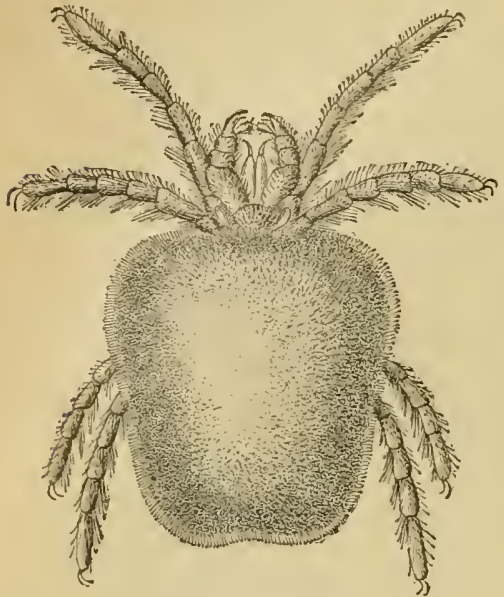

Fig. 476. - Trombidium holosericeum : femelle, vue par la face dorsale, grossie 20 fois (Orig.). rouge foncé, barbelés, ceux du notogastre et des còtés renflés en massue hérissée au sommet, ceux du céphalothorax et de la face ventrale plus longs, atténués. Céphalothorax petit, presque séparé de l'abdomen, au bord antérieur duquel il forme une sorte de crète. Palpes courts et épais, à article appendiculaire claviforme, dépassant à peine l'ongle du pénultième. Yeux longuement pédiculés. Pattes courtes, à 6 articles, revètues de poils barbelés; tarses cylindriques, les antérieurs subspatulés, tous dépourvus de cirre. Femelle plus grande et plus pàle que le màle, à poils plus courts; longue de 3 à 4 millimètres.

C'est une espèce assez commune, qu'on rencontre, au printemps et au commencement de l'été, dans le gazon des prairies, sur les talus sablonneux, plus rarement dans les jardins (1). Elle parait se nourrir de sucs végétaux. On la considère assez généralement comme la forme adulte du Lepte automnal ou Rouget.

Le Lepte automal (Leptus autumnalis [Shaw]. - Syn. : Acarus autumnalis Shaw, 1790; L. autumnalis Latr., 1793; Trombidium autumnule Gerv., 184́x; Tetranychus autumnalis Murray, 1877) est en effet une larve hexapode; il a le corps orbiculaire à jeun, oblong lor'squ'il est repu; dans ce dernier cas, il atteint facilement $500 \mu$ de long sur $33 \mu$ de large; il est de teinte rouge orangé. Le céphalothorax présente à sa face supérieure un écusson revètu de plusieurs poils, dont deux à base complexe; un peu en arrière et sur les còtés de cet écusson existent deux yeux sessiles. A la base et en dehors Ie chacun des épimères de la première paire se voit un stigmate assez large. L'abdomen, strié en travers, est garni sur ses deux faces de soies rares, régulièrement disposées et plumeuses; il montre l'anus un peu en arrière du milieu de la face ventrale. Le rostre porte des palpes dont l'avant-dernier article se termine par un ongle bifide. Les pattes, à six articles, sont terminées chacune par trois crochets grèles, dont un médian plus long.

D’après ces caractères, il est facile de reconnaître que le Lepte automnal n'est autre qu une larve de Trombididé. Raspail et Friedberger supposaient que la forme adulte derait correspondre au Trombidium

(1) L'espèce la plus commune dans les jardins est le Tromb. fuliginosum Hermann, dont la larve (Acarus aphidis De Geer) vit en parasite sur les Pucerons. 
holosericeum; Mégnin affirme lo fait, sans l'appuyer cependant de preuves eonvaincantes (1). Par contre, Claparède pensait ru ill devait s'agir d'un Tétranyciné. Au surplus, il est probable que les larves de divers Trombidides sont susceptibles de vivre en parasites sur les Vertébrés supérieurs, et que par conséquent les Rougets ou Leptus décrits par les auteurs ne se rapportent pas tous ì la mème espèce, ni peut-ètre all mème genre.

Le Lepte automnal est hien connu sous les noms vulgaires de Rouget, Acare des regains, Bête rouge, Bête d'août, Aoûti, Aoûtat, Vendangeur, etc., qui rappellent son aspect, son habitat et l'époque à laquelle il se montre. C'est en effet à la fin de l'été et en automne qu'on le voit pulluler, non seulement dans le gazon, mais aussi sur une foule de plantes, telles que groseilliers, haricots, sureaux, ctc. De là il passe sur les animaux ì sang chaud, et en particulier sur les petits Iammifères: les Taupes et les Lièrres, par exemple, en sont sourent couverts, et il est facile d'en recueillir sur ces animaux de nombreux exemplaires, car ils abandonnent le cadarre à mesure qu ïl se Fig. 477. - Rouget ou Lepte automnal, vu par la face ventrale, refroidit. Les Rougets se

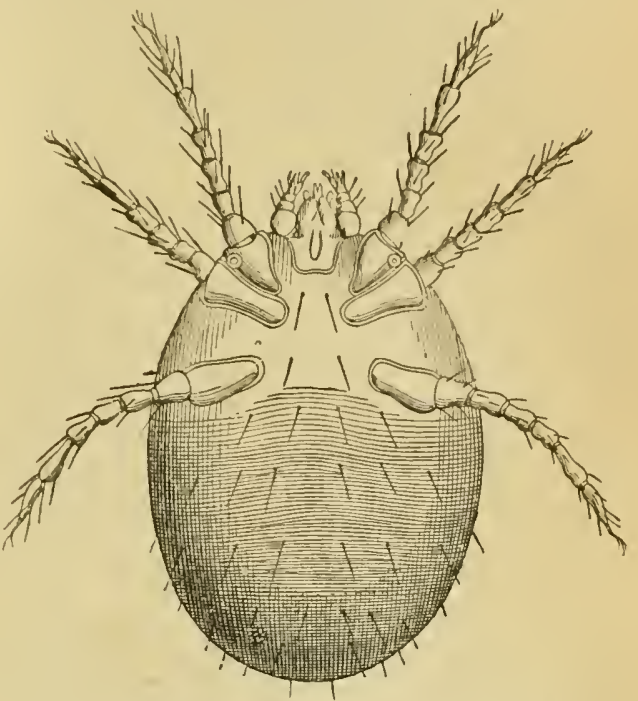
grossi 100 fois (Orig.).

montrent surtout abondants dans le centre et l'ouest de la France, en Grande-Bretagne et sur certains points de l'Allemagne.

L'Homme est fréquemment envahi par ces Acariens, lorsqu'il fréquente, à l'automne, les taillis ou les gazons infestés. Ils grimpent le long des jambes ou s'introduisent dans le cou, et gagnent rapidement les diverses parties du corps, y compris le cuir chevelu; si la ceinture ou les jarretières leur barrent le passage, ils s'accumulent et se fixent au niveau de l'obstacle. Les personnes à peau délicate, comme les femmes et les enfants, sont plus exposées à lcurs atteintes. Du reste, comme il arrive pour les Puces el les Punaises, certains individus semblent plus particulièrement recherchés par les Rougets, tandis que d'autres sont épargnés (White). - Oken avait reconnu,

(1) D'ailleurs, te Trombidion figuré par Mégnin diffiere du $T r$. holosericeum par ses yeux sessiles (placés á côté du cếphalothorax), par ses pattes à soies non plumeuses et par la présence d'un cirre entre les crochets tarsiens. 
dès 1832 , que le parasite s'implante dans la peau à la racine des poils; Jahn a montré qu'il insinue en effet son rostre dans le canal excréteur des glandes cutanées : aussi est-il fixé fortement sur place, le corps restant à la surface sous l'aspect d'un point rouge orangé à peine perceptible. Souvent plusieurs Rougets sont réunis sur un même point.

Les phénomènes que provoque la présence de ces Acariens sont très variables suivant les sujets. Tous éprouvent d'abord un prurit intense, avec une sensation de cuisson qui souvent enlève tout sommeil; il en résulte des grattages incessants, qui sont le point de départ de la plus grande partie des altérations secondaires : papules excoriées, plaques eczématoïdes, etc. Lorsque les Rougets sont très nombreux, ou que Jes sujets sont prédisposés, on peut voir apparaître des érythèmes plus ou moins étendus (érythème automnal Gruby): la peau se gonfle, devient rouge, parfois même violacée autour du point piqué, et il se forme ainsi des taches irrégulières, isolées ou confluentes, qui peurent atteindre un centimètre de diamètre : un examen attentif permet de découvrir le parasite à leur centre. D'autres fois, il survient des éruptions généralisées d'urticaire papuleuse, ou même des éruptions vésiculeuses, le tout s'accompagnant dans certains cas d'une fièvre passagère, mais intense.

Parmi nos animaux domestiques, ce sont les Chiens, et en particulier les Chiens de chasse, qui sont le plus exposés aux attaques des Leptes, ainsi que l'ont vu Defrance, Delafond et bien d'autres observateurs. Les parasites se fixent le plus souvent à la tête, aux pattes et au ventre, donnant lieu parfois à une éruption miliaire disséminée, vésico-purulente. Souvent on les trouve isolés, mais il nous est arrivé aussi d'en rencontrer une douzaine agglomérés sur un même point.

La même acariase automnale peut s'observer sur les Chats, comme l'ont vu Bose, Defrance, Delafond, etc. Elle a ordinairement pour siège, sur ces animaux, les intervalles phalangiens et l'extrémité de la queue, où apparaissent alors de petites plaies.

Chez les bêtes bovines, Johnston a observé, il y a longtemps, des Rougets dans le Berwickshire. En 1886, Moreau a vu, dans la Nièvre, deux vaches qui présentaient autour des lèvres, sur le chanfrein, les joues, les faces de l'encolure et l'extrémité des quatre membres, une éruption offrant tous les caractères de la maladie anciennement décrite sous les noms de rafle et de feu d'herbe: or, il existait entre les poils des colonies de parasites que nous avons reconnus pour des Rougets.

Johnston cite encore ces Acariens comme tourmentant les Moutons et les Chevaux, en provoquant des démangeaisons insupportables. Sur un Cheval, en particulier, l'irritation était telle que la peal semblait avoir subi l'action d'un liquide vésicant. Cavalin a également observé des Rougets sur le Cheval, en Algérie.

D'après White, les Lapins qui vivent dans les dunes du Hampshire 
en sont infestés ì un tel legré que les bourses destinées à les prendre se montrent souvent toutes rouges, et que les garenniers chargés de relerer ces filets sont attaqués de manière à présenter généralement des troubles fébriles. Les parasites peuvent même passer directement de l'animal à !'llomme : éest ainsi que Colbbold a contracté une éruption sur le hras, en caressant un Lapin de garenne qui en était couvert.

Enfin, Csokor et líloire ont signalé également l'existence de l'acariase du Rouget chez les Poules. Railliet et Lucet ont reconnu que cette affection est assez commune chez les Poussins éclos à la fin de leété ou en automne, et détermine parfois une mortalité considérable. Les parasites se fixent à la base des plumules, oì ils enfoncent leur rostre. L'irritation qu'ils déterminent est tellement vive qu'elle se traduit par une sorte d'affection épileptiforme aboutissant bientôt à la mort.

Les Rougets ne paraissent virre que quelques jours sur la peau de l.Homme ou des animaux; aussi les troubles quils provoquent nacquièrent-ils pas une gravité réelle.

Les indications prophylactiques sont des plus simples à établir, d'après la connaissance des mours de ces Acariens. Quant au traitement, il comporte l'emploi d'acaricides variés; on recommande de préférence l'huile d'olive additionnée de baume du Pérou, la teinture de pyrèthre et l'eau phéniquée (à 1 p. 100). Des bains ou des lotions d'eau vinaigrée, suivis d'application de poudre d'amidon, complètent la cure.

Leptes divers. - En Amérique, on a signalé souvent des larves hexapodes de Trombididés, d'espèces indéterminées, qui attaquent l'Homme ou les animaux: tels la Béte rouge de la Martinique, le Pou d'Agouti de la Guyane, le Tlalsahuate du Mexique, le Ciron rutilant des Savanes, le Niaibi de la NouvelleGrenade, le Colorado de Cuba, le Mouqui du Para, etc.

On connaît de même, au Japoı, sous le nom d'Akamushi, un parasite analogue, qu'on a considéré à tort comme provoquant. une maladie spéciale, appelée shima-mushi.

En Angleterre, Tilbury Fox a observé chez un enfant une grave irritation cutanée occasionnée par une larve d'Acarien, que Cobbold suppose appartenir au Rhyncholophus cinereus Dugès.

Toutes ces formes mériteraient d'ètre étudiées d'une façon plus précise.

Famille des IXODIDÉS. - Les Ixodidés sont des Acariens assez volumineux, aplatis à jeun, plus ou moins bombés lorsqu'ils sont repus, et à téguments coriaces, sur lesquels šinsèrent directement les pattes. Le rostre présente un hypostome en forme de dard muni à sa face inférieure de dents dirigées en arrière. Les mandibules sont formées d’une tige aplatie, à l'extrémité de laquelle s'articule une seconde pièce didactyle, dirigée obliquement en dehors, dont les deux 
branches, armées de crochets, ne forment pas une pince, mais un double harpon (pseudo-pince); ces mandibules sont revêtues à leur base d'une longue gaine membraneuse. Yeux sessiles ou nuls. Stigmates

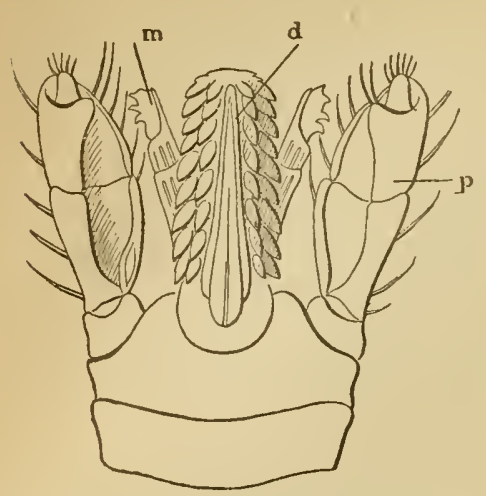

Fig. 478. - Rostre de l'lxode luexagone femelle, vu en dessous, grossi envron 50 fois. - $m$, chélicères. $p$, palpes maxillaires. $d$, dard maxillo-labial (Delafond). s'ouvrant chacun dans un péritrème (aire stigmatique) en forme d'écumoire, et situés près des pattes de la quatrième paire ou entre celle-ci

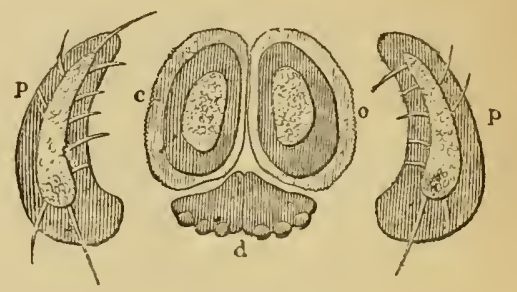

Fig. 479. - Coupe transversale du rostre de l'Hyalomma ægyptium, grossie 50 fois. - $c$, chélicères enveloppées de leur gaine. $p$, palpes maxillaires. $d$, dard maxillo-labial (G. Neumann).

et la troisième. Larves hexapodes. Nymphes octopodes. - Parasites temporaires des Vertébrés allantoïdiens.

2 sous-familles: Ixodinx et Argasinx.

Sous-famille des IXodinÉs. - Rostre terminal. Palpes libres, engainants, à quatre articles, dont les deux movens sont creusés en gouttièreà leur face interne, tandis que le quátrième, très court, est enchâssé en forme d'appendice tactile dans une fossette inféro-terminale du troisième. Pattes à six (sept) articles, hanches comprises, terminées par un ambulacre formé d'une tige biarticulée portant deux ongles et une caroncule plissée en éventail. Téguments coriaces, mais assez extensibles, renforcés toujours au moins par un écusson dorsal, lequel est échancré pour recevoir la base du rostre. Stigmates derrière les hanches de la quatrième paire de pattes.

Dimorphisme sexuel très accusé : le mâle est plus petit que la femelle, plus déprimé et souvent à contour moins régulièrement ovalaire. L'écusson dorsal est limité chez la femelle, et surtout chez la femelle adulte, à la partie antérieure du céphalothorax; chez le mâle, il couvre la plus grande partie ou la totalité du corps. En outre, le mâle présente parfois des plaques ou écussons ventraux dont le nombre et la forme sont assez variables. La base du rostre (écusson céphalique de Canestrini) offre généralement, en dessus et en arrière, chez la femelle, deux fossettes (arex porosa Berlese), qui manquent toujours chez le mâle. L'orifice sexuel mâle est situé sur la ligne médiane ventrale, souvent à une faible distance de la base du rostre; l'orifice femelle a une situation correspondante. 
Les Ixodinés sont vulgairement appelés Tiques, Tiquets, Poux des bois ou Ricins; mais ce dernier nom doit être rejeté, car il a l'inconvénient d'établir une confusion avec les Mallophages. Les espèces qui s'attaquent au Chien étaient déjà connues d'Aristote, qui leur avait donné le nom de liuvopiotrs pour exprimer qu'ils tourmentent ces animaux.

Ces $\Lambda$ cariens sont des parasites stationnaires périodiques. Encore les femelles fécondées seules paraissent-elles soumises à un parasitisme réel et nécessaire. Les licux boisés, les broussailles, les terrains couverts de hautes herbes sont le séjour habituel des Tiques, et c'est ce qui explique pourquoi les Chiens de chasse en sont souvent porteurs.

Tous les Vertébrés allantoüdiens peuvent leur servir d'lootes, et ils les choisissent assez indifféremment, surtout en ce qui concerne les larves, les nymplies et les mâles. On les trouve souvent sur des Reptiles, tels que Lézards et Tortues, sur des Oiseaux et sur des Mammifères d'ordres variés. Ces larves, nymphes et màles paraissent d'ailleurs se servir le plus sonvent des animaux en question comme de simples réhicules; cependant, on peut trouver les nymphes et les mâles implantés à demęure dans les téguments. - Quant aux femelles, dont le parasitisme est, comme nous l'avons dit, beaucoup plus accusé, elles paraissent d'ordinaire se fixer de préférence sur une espèce déterminée, en particulier sur les Nammifères et même sur l'Homme. Elles enfoncent alors leur rostre dans la peau, les mandibules pénétrant d'abord, puis le dard: les dents de celui-ci s'opposent au retrait de l'appareil, et, dès qu'il a pénétré assez profondément, les crochets des pseudo-pinces s'ancrent de chaque côté, pendant que les palpes s'appliquent à la surface de la peau. L'Acarien est dans d'excellentes conditions pour sucer le sang de son hôte, et bientôt son abdomen se dilate jusqu'à acquérir des dimensions énormes : à cet état, on a pu sourentcomparer la Tique femelle à une graine de ricin. Le rostre est tellement bien fixé dans le derme, qu'il s'arrache d'ordinaire et reste dans la plaie si l'on cherche à détacher le parasite par une traction violente. Avec plus de précautions, on évite cet accident; mais, presque toujours, le rostre enlève un petit lambeau du tégument.

L'absorption d'une grande quantité de sang est nécessaire à la femelle fécondée pour le développement de la somme extraordinaire d'ouufs qui s'accumulent bientôt dans son utérus. Une fois repue, cette femelle se laisse tomber sur le sol et pond ses œufs en tas; après quoi elle meurt. De ces œufs sortent, au bout de quelques jours, de petites larves hexapodes qui peurent vivre plusieurs mois sans manger, mais ne tardent pas en général à se jeter sur les animaux. Elles y restent le plus souvent sans s'accroître d'une manière sensible et en conservant leur teinte, puis se transforment en nymphes octopodes : celles-ci sont un peu plus grandes que les larves; elles en 
diffèrent en outre par la présence de trachées et de deux stigmates; mais elles sont dépourvues d'organes sexuels. Ces nymphes s'accroissent peu à peu, puis se transforment en mâles ou en femelles.

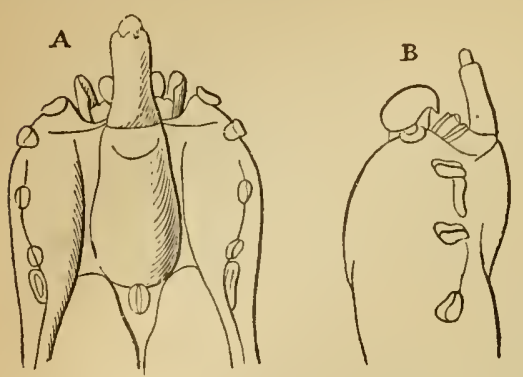

Fig. 480. - Oviscapte de l'Ixodes reduvius, d'après Genć. - A, vu de dessous. B, vu de profil. A l'extrérnité de l'oviscapte complètement étendu, on voit sortir un ouf. La vésicule située immédiatement sous la lettre B est ce que Gené appelle vessie bilobíe ou bourse séminale.

Les premiers, relativement petits, se mettent à la recherche de celles-ci; ils se fixent sur leur face ventrale, et en sens opposé, comme l'avait vu De Geer, de manière à introduire leur rostre dans l'orifice génital femelle. Ġené (1848), qui a étudié avec soin l'accouplement et la ponte de ces animaux, a vu sortir alors de ce rostre deux petits corps blanchâtres, fusiformes, qui ne tardaient pas à disparaitre : il s'agissait vraisemblablement de spermatophores. La ponte s'effectue par le même orifice qui a servi à l'accouplement : chaque fois qu'un œuf pénètre dans l'oviducte, celui-ci s'évagine et forme ainsi un oviscapte qui va déposer l'œuf entre les deux lobes d'une vésicule particulière(vessiebilobée) développée à ce moment au-dessus du rostre.

La classification des Ixodinés a été esquissée d'abord par C.-L. Kooch, puis perfectionnée par G. Canestrini, Berlese, etc. On admet aujourd'hui dans ce groupe les genres Ixodes, Hyalomma, Rhipicephalus, Dermacentor, Hæmaphysulis, Herpetobia, Hæmalastor...

Genre Ixodes (Ixodes Latr., 1793. - Syn. : Cynorhæstes Hermann, 1804, ex parte). - Pas d'yeux. Base du rostre subtriangulaire (vue en dessus). Palpes allongés, simples, non dentelés. Hanches de la première paire prolongées par une forte dent. Mále à face ventrale entièrement couverte d'écussons : $1^{\circ}$ et $2^{\circ}$ deux écussons épiméraux, occupant les còtés du corps et contenant les points d'insertion des pattes, ainsi que les stigmates; $3^{\circ}$ un écusson ventral impair, entre l'ouverture génitale et l'anus; $4^{\circ}$ et $3^{\circ}$, deux écussons périanaux quadrangulaires, sur les còtés de l'anus, se rejoignant en avant de celui-ci par leur angle antérieur interne; $6^{\circ}$ un écusson anal, trigone, entre les précédents et le bord postérieur du corps, portant l'anus vers son angle antérieur. Écusson dorsal couvrant à peu près toute la face supérieure. Pattes à tarses non dentés, à ambulacres terminaux. Péritrème ovalaire, à ouverture stigmatique également ovalaire. Femelle offrant sur la face dorsale de l'abdomen trois sillons longitudinaux, dont un médian assez court et deux latéraux s'étendant jusqu'au bord postérieur; sur la face ventrale, deux longs sillons campanuliformes, l'un entourant en avant l'anus, l'autre la vulve et gagnant le bord postérieur de l'abdomen. Péritrème et stigmate circulaires. Aires poreuses distinctes à la base du rostre.

Ixode Réduve (1. reduvius [L.]. - Syn. : Acarus reduvius et A. ricinus 
L., 1738 ; I. ricinus Latr., 1806; I. reduvius Ilahn, 1831). - La femelle a jeun a le corps ovale, aplati de dessus en dessous, arrondi au bord postérieur et de teinte roux jaunàtre; elle est longue de 4 millimètres, large de 3 ; son écusson est subpentagonal. Feconclée et repuc, elle a l'aspect d'une graine de ricin un peu déprimée, et -atteint 10 à 11 millimètres de longsur 6 a 7 milliniotres de large; elle est de teinte cendrée, passant quelquefoisan brun ou au jaunatre ; l'écusson, le rostre et les pattes sont d'un noir luisant. La face dorsale offre en avant deux sillons, et trois en arrière; a la face ventrale, on constate une lisposition un peu analogue. Les pattes sont assez grèles; des hanches de la $1^{\text {re }}$ paire se terminent charune en une dent qui va buter contre la hanche de la $2^{\mathrm{e}}$ paire ; le $2^{\text {e }}$ article qui suitla hanche est divisé en deux; les tarses sont longs et grèles,

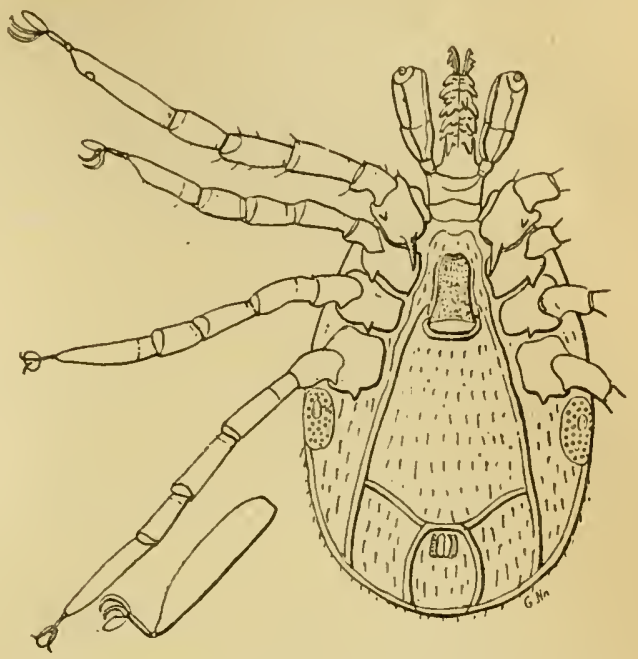

Fig. 481. - Ixodes reduvius, mâle, vu par la face ventrale, grossi 30 fois. A gauelıe, tarse de la $4^{\circ}$ paire, grossi 60 fois. (G. Neumanu, inéd.). formant à peu près le tiers de la longueur tolale de la patte; ils s'atténuent graduellement, sans gibbosilé; les ongles dépassent de très peu la caroncule. Le rostre offre des palpes à $f^{\text {er }}$ article court et cylindrique, a $2^{\text {e }}$ et $3^{\mathrm{e}}$ articles longs et creusés en gouttière; le $4^{\mathrm{e}}$, court et conique, se termine par une quinzaine de courtes

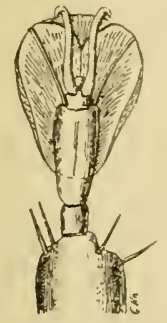

Fig. 482. - Ambulacre de l'Ixodes reduvius, grossi 300 fois (G. Neumann, inćd.).

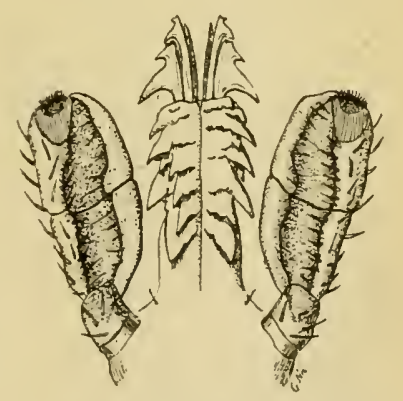

Fig. 4\$3. - Rostre de l'Ixodes reduvius mile, yu par la face ventrale, grossi 100 fois (G. Neumann, inćd.).

soies. Le dard est beaucoup plus long que large, lancéolé, et porte de cliaque còté, outre les trois petites dents du sommet, trois séries longitudinales, plus ou moins régulières, de dents bien développées, savoir une latérale à dents fortes et aiguës, atteignant leur maximum vers le milieu, une inter- 
médiaire à dents plus faibles, et une interne ne dépassant guère la moitié antérieure. Les mandibules ont le doigt interne bidenlé au sommet, et l'externe armé de cinq dents qui augmentent de puissance d'avant en arrière. Le mâle a le corps ovalaire ; à bord postérieur arrondi et entier, il est long de $2^{\mathrm{mm}}, 5$, large de $1^{\mathrm{mm}}, 5$; son écusson dorsal couvre toute la surface du corps, sauf une bordure très étroite, légèrement relevée; les pattes sont relativement longues et fortes, de teinte brune, ainsi que le reste du corps. Le dard rostral offre de chaque côté une série latérale de six à huit dents augmentant rapiłement en puissance d'avant en arrière; à la face iıférieure, les dents sont remplacées par de simples crénelures. Les nymphes et larves ont un rostre rappelant celui de la femelle. Les oufs sont ovoïdes, de teinte rousse.

L'Ixode réduve ou Ixode ricin est une espèce assez commune en France et même dans toute l'Europe. Charleton paraît l'avoir distinguée le premier : il n'avait vu que le mâle, auquel il donnait le nom de Reduvius. Ray décrivit ensuite le mâle sous le nom de Pediculus ovinus, et la femelle sous celui de Ricinus caninus. Le premier devint Acarus reduvius pour Linné et de Geer, Cynorhæstes ricinus pour Hermann; la seconde Acarus ricinus pour Linné; Acarus ricinoides pour De Geer, Cyn. reduvius pour Hermann, Ixodes ricinus pour Latreille, etc.

L'Ixode réduve attaque de préférence les Moutons, les Chèvres et les Boufs, plus rarement les Chevaux, les Chiens ou l'Homme, elc. Chez les Moutons, il se fixe sur les parties où la peau est fine et dépourvue de laine, comme l'aine ou l'aisselle; on en voit souvent aussi, d'après Mauvezin, à la partie supérieure du cou, et parfois chacune des petites plaies qu'ils provoquent devient le point de départ d'une inflammation gangreneuse qui n'est pas sans gravité. Mais d'ordinaire, les animaux ne paraissent guère s'apercevoir de la présence du parasite.

Cette espèce, ainsi que diverses autres dont la détermination n'a pas toujours été faite d'une façon bien rigoureuse, se fixe en outre fréquemment sur la peau de l'Homme, au point qu'il devient sans. intẻrêt d'en rapporter des exemples. Ce sont surtout les chasseurs et les personnes habituées à vivre dans les bois au milieu des animaux, qui se trouvent envahis. Au moment de la piqûre, on éprouve une démangeaison, suivie d'une sensation de cuisson d'intensité variable; puis une petite aréole rouge se produit à la périphérie de la piqûre. Souvenl la Tique tombe.de bonne heure et tout trouble cesse. D'autres fois, il survient des accidents plus ou moins graves: eschare, phlyctènes, ulcères, engorgement ganglionnaire, etc., qui peuvent retentir sur la santé générale (Raymondaud) et même entraîner la mort (Chillida). Ces complications tiennent peut-être à l'inoculation d'agents infectieux.

D'autres fois, les Ixodes s'introduisent sous la peau du ventre (Hussen, Desprès, Blanchard) ou de divers points du corps (Beauregard, 
Chouppe, Desnos et Laboulbène), en donnant lieu à de petites tumeurs. Dans le cas de ces deux derniers auteurs, l'espèce a été nettement lélerminée comme $I$. reduvius.

Les larves et les nymphes de l'Ixode réduve se reneontrent souvent en abondance sur le corps des Lézards, des Oiseaux et des petits Mammifères, tels que Lièvres, Lapins, Putois, Furets, IIérissons, Chauves-Souris, ete. Mégnin dit avoir vu sur un Cheval l'extrémilé des quatre membres comme farcie de pustules, sous la croûte de chacune desquelles on découvrait une nymphe; il a plus tard retiouré de semblables pustules aux oreilles des Chiens et des Lièvres. Trillibert avait déjà fait une obscrvation semblable sur un Chien, qui présentait un lxode à l'extrémité de l'oreille, dans un kyste sércux datant de six mois.

On a conseillé depuis longtemps de provoquer la chule des lxodes en les touchant avec une goutte de benzine, de pétrole ou d'essence de térébenthine. Mais ce procédé ne réussit pas toujours; on enlève alors les parasites à la main ou on les coupe a l'aide de ciseaux : si le rostre est resté dans la peau, il s'élimine en quelques jours par un travail de suppuration.

Il importe de détruire immédiatement les Ticjues afin d'empècher la ponte et, par suite, l'envahissement des locaux. Si cet envahissement a eu licu, on doit procéder à une désinfection génćrale, par exemple ì l'aide d'eau bouillante, qu'on projette dans tous les coins, en particulier vers le plafond.

Ixode hexagone. (Ionus hegxa Leach, 181\%. - Syn. : 1. sexpunctatus

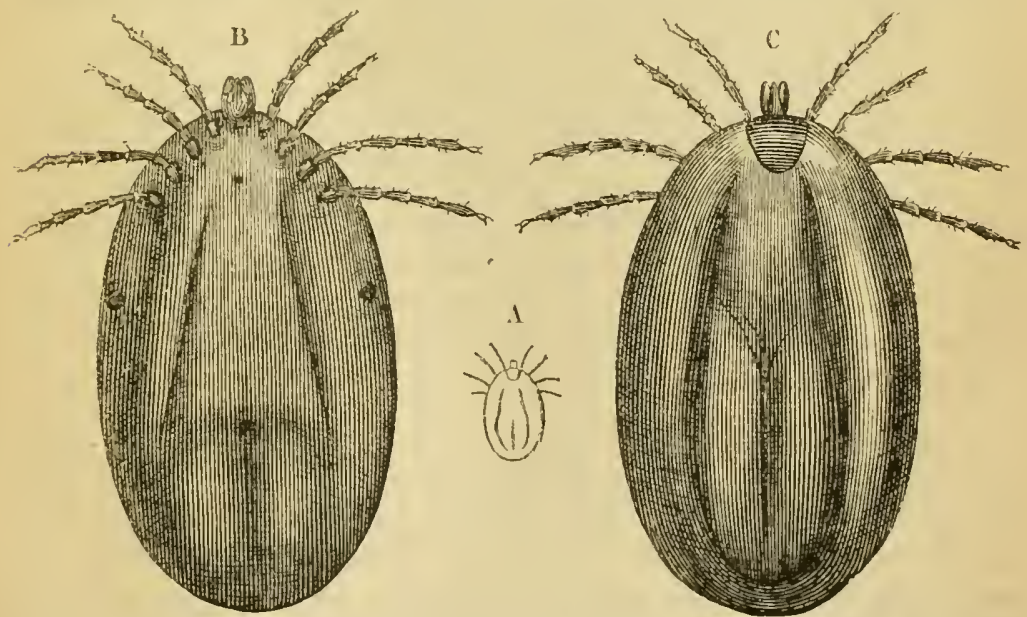

Fig. 48f, - Ixode hexagone du Chien, femelle fécondée el repue. $-\lambda$, grandeur nalurelle. B, grossie, vue par la face ventrale. $\mathrm{C}$, par la face dorsale (Orig.).

Koch, 184i ; I. vulpis Pagenstecher, 1861 : I. rieinus Mégn., 1880, nec Latr., 1806). - Cette espèce ressemble beaucoup à la précédente, tant par les 
dimensions que par la coloration; elle s'en distingue cependant par divers caractères. La femelle a des tar'ses plus courts et gibleux vers l'extrémité, où: il se rétrécissent brusquement; la caroncule n’atteint que la moilié de la longueur des ongles. Le dard rostral a les dents

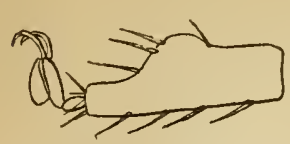

Fig. 485. - Tarse de la $4^{\circ}$ paire de l'lxodes hexagonus, grossi 60 fois (G. Neuinann, inéd.). latérales moins saillantes, et la rangée interne plus courle; il est lui-même un peu plus court. Les. mandibules ne possèdent pas de dent supplémentaire à la partie inférieure du doigt externe. Lemâle a Je corps rétréci en avant, large et anguleux en arrière, à face supérieure recouverte en entier par un écusson brun mat; le dard rostral ne présente. de chaque còlé qu'une seule rangée de cinq dents. Les nymphes et les larves ont un rostre assez différent de celui des adultes. Les œufs sont ovoïdes, de teinte fauve.

L'Ixode hexagone peut se rencontrer sur des animaux très divers : Moutons, Bœufs, Hérissons, Putois, etc. ; mais il est particulièrement commun sur les Chiens de chasse. Il se fixe même quelquefois sır la. peau de l'Homme. Comme le précédent, avec lequel on l'a maintes fois confondu, il se montre surtout de mai à octobre; cependant, nous en avons observé, même à l'état de larve, jusqu'en novembre.

On trouve souvent les larves et les nymphes en grande abondance sur le corps des petits Mammifères.

Genre Hyalomme (Hyalomma Koch, 1847. - Syn. : Amblyomma Koch, 1847). - Des yeux distincts. Base du rostre rectangulaire (vue en dessus). Palpes allongés, à premier et troisième articles dentés inférieurement. Hanches de la première paire fortement bidentées. Mále à face ventrale pourvue seulement de deux paires d'écussons : écussons périanaux, triangulaires, assez grands, et écussons externes, plus petits; parfois en outre deux écussons accessoires au bord postérieur du corps. Écusson dorsal couvrant à peu près toute la face supérieure. Bord postérieur crénelé ou festonné. Péritrème en forme de virgule à longue queue; stigmate longuement ovalaire, trigone. Pattes à tarses dentés au sommet, à ambulacre sublatéral; les postérieures plus épaisses que les autres. Femelle offrant sur la face dorsale, en arrière, trois sillons longitudinaux, et sur la face ventrale deux sillons qui convergent vers Ja fente génitale, plus un troisième allant de l'anus au bord postéricur. Péritrème en virgule à courte queue; stigmate simulant une fente. Aires poreuses distinctes à la base du rostre.

IIyaloume égyptien (H. xgyptium [L.]. - Syn.: Acarus xgyptius L., 1758; Ixodes xgyptius Audouin, 1827; H. marginatum Koch, 1847; H. xgyptium Canestr., 1890). - Le rostre est semblable dans les deux sexes: les palpes sont à peu près de la longueur du dard et portent de longues soies à leur bord inférieur, surtout au premier article; le dard est spatulé et montre à son extrémité antérieure un grand nombre de très petites dents; puis viennent de chaque côté trois séries subégales de dents plus grandes, à pointe obtuse, qui bientòt diminuent graduellement et se réduisent en arrière à de petites écailles arrondies; les mandibules ont le doigt interne 
bidenté au sommet, et le doigl externe pourvu de trois dents, l'antéricure très petite, la seconde plus forte, la Iroisième très puissante. Pattes assez longues, surtout celles de la $\dot{4}^{0}$ paire, à hanches ovalaires, celles de la $1^{\text {re }}$ paire bidentées. Tarse à crochets dépassant de moitié la caroncule. La jeune femelle est lougue de $8^{\mathrm{mm}}, 5$ à 9 millimètres, large de 3 à 7 millimètres; elle a le corps rougeàtre, aplati, subcarré, á bord postérieur parcouru par de petits sillons; son écusson est brun luisant, chagriné, subrlıomboüdal, et porte deux yeux latéraux. La femelle adulte, fécondée et repuc, atteint 11 millimèlres de long sur 7 de large (exceptionnellement 24 sur 13̈); elle est de teinte jaunàtre, et offre un écusson relativement faible; son corps est parcouru par deux sillons en avant, trois en arrière. Le malc est long de 6 à 8 millimètres, large de $3^{\mathrm{mm}}, 5$ à $4^{\mathrm{mm}}, 5$; il a le corps ovale, arrondi et festonné en arrière ; son écusson dorsal, brun roussàtre on noir, convre toute la surface à l'exception de deux étroites bordures latérales un peu relevées et jaunàtres; la face ventrale est blanchàtre, avec les écussons chatains, et porte en arrière deux saillies coniques. Les pattes de la $1^{\text {re }}$ paire ont les tarses terminés par une dent; celles des autres paires sont bidentées.

L'Ixode égyptien s'atlaque surtout aux Boufs; il a été recueilli également sur le Chien, le Chat, le Sanglier, etc. Il se trouve non seulement en Egypte, mais aussi en Algérie et dans diverses autres parties de l'Afrique, en Italie et peut-ètre dans le midi de la France. G. Neumann le signale en oulre à la Guadeloupe, où il est connu sous le nom de Tique sénégalaise, qui indique son origine.

Les animaux qui sont porteur's de ces parasites ne paraissent généralement pas en souffirir ; cependant, Lucas dit avoir vu en 18.45, dans le cercle de la Calle, des Boufs mourir d'épuisement alors qu'ils étaient envahis par des myriades de Tiques, qui se renouvelaient incessamment à la surface de leur corps. Couzin assure de même que la Tique importée à la Guadeloupe par les Bœufs sénégalais épuise avec une rapidité surprenante les Bœufs, Chevaux et Mulets. Il ajoute que, dans cette colonie, on lui fait jouer un rôle important dans l'éliologie d'une maladie spéciale, connue sous le nom de farcin: elle agit sans doute comme agent d'inoculation du micro-organisme qui détermine cette affection.

En Italie, l'Hyalomme égyptien a été plusieurs fois rencontré sur l'Homme. Ronsisvalle lui attribue la production de troubles locaux graves, accompagnés de fièrre intense et parfois de délire; il tend même à rapporter ces accidents à l'inoculation d'un próduit renimeux; mais il est plus probable que le parasite n'est là encore qu'un agent de transport d'éléments infectieux.

IIyalomme africain (H. africanum [Mégn.]. - Syn. : Ixodes africanus Mégn., 1876; I. algeriensis Mlégn., 1880). - Cette espèce est très voisine de la précédente, dont elle ne se distingue guère que par les caractères suivants : palpes à $2^{\text {e et }} 3^{\mathrm{e}}$ articles gibbeux et anguleux en dehors; dard rostral large et tronqué ; crochets de l'ambulacre tarsien dépassant la caroncule d'un tiers 
de leur longueur. Femelle fécondée et repue longue de 18 millimètres, large de 12 millimètres. Hâle long de $\tilde{b}^{\mathrm{mm}}, 8$, large de 4 millimètres; écusson dorsal couvrant toute la surface du corps sans laisser de bordure blanche; pas d'écussons extérieurs à la face ventrale, pas de saillies coniques postérieures.

Attaque les Boeufs en Algérie, de concert avec l'Hyalomme égyptien.

Genre RhipicéphaIe (Rhipicephalus Koch, 1847). - Des yeux distincts. Base du rostre (vue en dessus) hexagonale, formant de chaque côté un angle saillant. Palpes courts et larges à premier et troisième articles dentés inférieurement. Hanches de la première paire fortement bidentées. Mále et femelle semblables d'ailleurs à ceux du Hyalomma; stigmate du màle ovalaire.

Rhipicéphale sanguin (Rh. sanguineus [Latr.]. - Syn. : Ixodes sanguineus Latr., 1806 ; Ixode plombé Dugès, 1834; I. Dugesi Gerv., 1844;

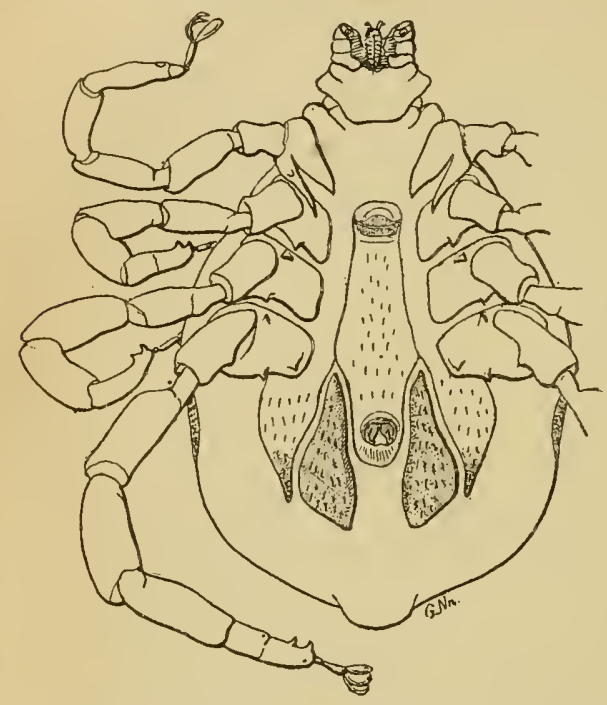

Fig. 486. - Rhipicephalus sanguineus, male, vu par la face ventrale, grossi 15 fois (G. Neumann, inçd.).

$R h$. sanguineus et $R h$. siculus Koch, 1847). - Le rostre est semblable dansles deux sexes; les palpes sont courts et forts, et leurs trois premiers articles portent à leur bord inférieur interne des soies rigides un peu dentelées; le dard est spatulé et montre de chaque còté trois rangées de dents à peu près également fortes, chaque file longitudinale comprenant environ douze dents, qui diminuent lentement d'avant en arrière; les mandibules ont le doigt interne pourvu de trois dents subégales, et le doigt externe de deux dents, l'antérieure plus faible. La femelle a le corps elliptique, pouvant atteindre 11 millimètres de long sur i millimètres de large ; l'é-

cusson dorsal est très petit, garni de pores rares, mais profonds; le tégument est glabre; le contour postérieur de la face ventrale porte quelques stries qui tendent à le faire paraître festonné. La caroncule tarsienne s'étend jusqu'aux deux tiers de la longueur des ongles. Le mâle a le corps régulièrement élargi d'avant en arrière, et quelquefois pourvu à l'extrémité postérieure d'un appendice conique; il est long de $3^{\mathrm{mm}}, 34$, large de $1^{\mathrm{mm}}, 55$; l'écusson dorsal couvre tout le corps, sauf une légère bordure sur les còtés et en arrière; cet écusson, qui porte trois fossettes en arrière, est divisé à son bord postérieur en neuf (onze) festons; la face ventrale porte, de chaque côté de l'anus, un écusson triangulaire allongé, à base postérieure, et en dehors de celui-ci une faible épine droite. Les tarses des trois dernières paires sont bidentés; 
les hanches de la première paire se terminent par deux dents, et les autres offrent à leur bord postérieur un tubcrcule obtus; la caroncule atteint environ la moitié de la longueur des ongles. Les nymphes (Phaulixodes rufus Berlese ex lioclı) ont seulement deux rangées de dents de cliaque còté du dard rostral.

Cette espèce vit dans toute l'Italie et dans le midi de la France sur les Bouf's, les Moutons, les Cliiens, les Chats, etc., et à l'occasion sur l'Homme lui-même.

Nous en possédons des exemplaires recueillis au marché de la Villette sur (les Moutons algériens (Godbille), en Égypte sur le Bœuf et le Chien (Piol), au Sénégal sur le Bưuf(Monod). L'exiguïté de son rostre la rend peu dangereuse.

Neumann en signale une petile varieté provenant de. la Guadeloupe.

D'autre part, les auteurs américains ont décrit, sous le nom d'Ixodes bovis Riley, 1869, ou de Boophilus bovis Curtice, 1890, une forme qui nous semble ètre au moins très voisine de celle-ci, et qui joue un róle importint dans la Iransmission de la fièvre du Texas (voir p. 127).

Enfin, on trouve en Ilalie une espèce voisine, Rh. bursa Can. et Fanz., 1887, assez commune sur le Mouton et le Sanglier.

Genre Dermacentor (Dermacentor Koch, 184i). - Des yeux. Palpes coniques, courts et épais. Base du rostre subquadrangulaire. Péritrème cn virgule. Face ventrale du màle dépourvue d'écussons. Hanches de la première paire bidentées. Corps revètu de dessins variés.

Dermacentor réticulé (D. reticulatus [Fabr.]. - Syn. : dcrines reticulatus Fabr., 1794; Ixodes reticulatus Latr., 1806 ; I. marmoratus Risso, 1826 ; D. reticulatus de Garlini, 1889). - Le rostre est semblable dans les deux sexes: les palpes ont le premier article court, le $2^{\text {e }}$ et le $3^{\text {e }}$ assez développés et mini de quelques soies à leur double bord interne; le dard, un peu élargi en avant, où il offre de très petites dents, porte de chaque còté quatre, puis trois séries longiludinales de dents assez fortes, qui peu à peu diminuent de grandeur et deviennent plus obtuses en arrière; les mandibules, courtes et épaisses, ont le doigt externe terminé par deux dents recourbées en dehors, et le doigt externe pourvu de trois dents qui augmentent de volume d'avant en arrière. La femelle jeune, longue de 6 millimèlres, large de $3^{\mathrm{mm}}, 8$, a le corps brun rougeitre, avec l'écusson bordé d'une patine blanc argenté qui forme un dessin élégant; cet écusson est très étendu, ponctué; le reste de la face dorsale est également ponctué, mais plus grossièrement, et parcouru par plusieurs sillons; le bord postérieur est divisé en six festons; les pattes ont des tubercules aux tarses. La femclle aclulte est très déprimée à jeun, épaisse quand elle est repue, à contour ovalaire, atteignant alors $13^{\mathrm{mm}}$, ,ै de long sur 9 millimètres de large; son écusson est médiocre, blanc argenté, avec deux taches brunes latérales, et profondément incisé en avant pour recevoir la base du rostre; l'abdomen est gris olivàtre, passant au rouge dans l'alcool; les pattes sont d'un brun rougeàtre sombre. Le male est long de 5 à 6 millimètres, large de 3 millimètres à $3^{\mathrm{mm}}, 5$; il a le corps ovalaire, élargi en arrière, l'écusson dorsal couvrant tout le corps 
et divisé en arrière en onze festons ; les hanches sont contiguës et s'élargissent de la $1^{\text {re }}$ à la $4^{\mathrm{e}}$ paire, où elles sont très développées; celles de la $1^{\text {re }}$ paire se terminent par deux fortes dents; les autres ont à chacun de leurs bords antérieur et postérieur une courte épine dirigée en arrière; les tarses de la $1^{\text {re }}$ paire sont dentés, les autres bidentés; les trois derniers arlicles de la $4^{\mathrm{e}}$ paire possèdent en dessous chacun trois saillies dentiformes.

Gette espèce existe en France et en Italie ; nous en possédons des exemplaires recueillis en février, par G. Colin, sur le Bœuf; G. Canestrini en a trouvé sur le Mouton, la Chèvre et le Bœuf; le comte Ninni en a enlevé sur le cou et sur les cuisses de ses enfants.

Nous pouvons citer encore D. americanus. (L. nec Koch) (Acarus Nigua De Geer), du nord-est des États-Unis, observé sur les bètes bovines et. plus particulièrement sur le Chien; et $D$. occilentalis Marx, du bétail de la Californie.

Genre Hémaphysalis (Hæmaphysalis Koch, 1847). - Pas d'yeux. Palpes coniques, à second article offrant une forte saillie latérale. Base du rostre quadrangulaire, avec deux fossettes. Péritrème en virgule. Face ventrale du màle dépourvue d'écussons. Hanches de la première paire à dent unique et courte; celles de la $4^{\mathrm{e}}$ paire, chez le màle, armées d'un robuste éperon.

IIémaphysalis ponctuée ( $H$. punctata Canestrini et Fanzago, 1877. Syn. : Ixodes chelifer Mégn., 1880 ; ? Pseudoixodes holsatus Haller, 1882). - Le rostre est semhlable dans les deux sexes; il est très court : les palpes ont l'angle saillant du second article plus ou moins marqué; leur bord inférieur interue est garni de soies épaisses, dentelées; le dard a de chaque cóté cinq files longitudinales de dents, sans compter les nombreuses petites dents de l'extrémité antérieure; les files internes disparaissent en arrière, en même temps que les dents externes deviennent plus petites; les mandibules ont au doigt interne deux forts crochets, au doigt externe en avant un crochet médiocre, flanqué de quatre autres très petits, et en arrière un crochet. assez fort. La femelle a le corps ovalaire, long de 12 millimètres et large de $\tau^{\mathrm{mm}}, \vec{b}$ à l'état de réplétion, de teinte plombée, parfois avec des lignes et taches jaunàtres; les pattes brun rougeàtre. L'écusson dorsal est assez petit, ovale allongé, à ponctuations serrées ; la face supérieure du corps porte en avant quatre sillons parallèles. Chacune des hanches porte une très petite épine dirigée en arrière. Le mâle a le corps allongé, brun rougeàtre ou jaunâtre, long de 4 millimètres, large de 2 millimètres; l'écusson dorsal couvre tout le corps, sauf sur une légère bordure latérale el postérieure ; en arrière il existe dix (onze) festons. Les pattes sont garnies de soies; loutes possèdent, à la base de la caroncule, une petite épine crochue, qui est peu marquée à la première paire; la caroncule atteint les deux tiers de la longueur des ongles.

Cette espèce, assez commune en Italie, vit sur les Moutons (de préférence derrière les oreilles), les Chèvres et les Daims. Nous en possédons quelques exemplaires recueillis à Alfort, en mars 1869, sur la queue d'un Taureau, par G. Colin. 
Sous-famille des argasinés. - Rostre infère (du moins ì l'état adulte), c'est-à-dire situé à la face inférieure du céphalothorax, qui forme ainsi une sorte de cliaperon (capuchon Dujardin). Palpes libres, courts, filiformes, à quatre articles peu différents les uns des autres. Pattes à six(luit)articles, hanches comprises, terminées par un ambulacre à deux ongles, mais sans caroncule. Téguments coriaces, sans plaques dorsales ni ventrales. Stigmates entre les deux dernières paires de pattes, cachés sous les hanches de la $3^{e}$ paire. Pas de dimorphisme sexuel. - Parasites des Vertébrés à sang chaud.

2 genres : Argas, Omithodoros, ce dernier à peine connu et basé seulement, d'après Koch, sur la présence d'yeux.

Les Argas (Argas Latr., 1793.- - Syn. : Rhynchoprion Hermann, 1804) sont dépourvus d'yeux. Ce sont des animaux fort plats lorsqu'ils ont eté longtemps privés de nourriture, mais leurs téguments sont asse\% extensibles, quoique coriaces, irréguliers et souvent granuleux. Par leur aspect général, ils ont une certaine ressemhlance avec les Punaises. La caroncule des tarses est avortée, surtout chez les adultes.

Ces Acariens paraissent être en général noctambules; ils se nourrissen t de sang.

Argás réféchi (A. reflexus [Fabr.]. Syn.? Acarus reflexus ou marginatus Fabr., 1794 ; Argas reflexus Latr., 1795 ; Rhynchoprion columba Hermann, 1804; Argas marginalus Contarini, 18'3). - Corps ovalaire, atteignant sa plus grande largeur en arrière

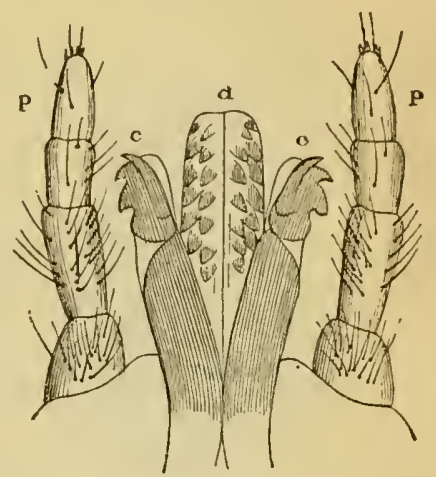

Fig. 4ST. - Rostre d'une larve d'Argas reflexus, $\mathrm{vu}$ en dessus, grossi 50 fois. - $c$, chélicères. $p$, palpes maxillaires. $d$, dard maxillo-labial. On distingue, par transparence, une parlie des dents de la face inféricure du dard (Orig.). du milieu. Tégument rugueux, marqué de fossettes et de sillons, et présentant des séries de granulations. Rostre semblable dans les deux sexes; dard arrondi à l'extrémité et muni à li face inférieure de dents nombreuses: de chaque còté de la ligne 'médiane, on en voit d'abord, en avant, quelques petites; plus en arrière, deux séries de très fortes; puis trois, quatre et jusqu'à six séries de plus en plus faibles. Mandibules à doigt interne bidenté au sommet, à doigt externe pourvu de trois dents. Palpes terminés par de petits cirres mousses. Femelle fécondée longue de 3 mitlimètres, large de 3 à jeun; longue de 6 à 8 millimètres, et large de 4 lorsqu'elle est repue; la partie centrale du corps est d'une teinte noiràtre : cette région correspond en effet à l'appareil digestif, qui envoie ses digitations ver's la périphérie, tandis que le bord reste transparent, jaunatre (un peu relevé à jeun, d'oủ le nom de l'espèce) ; vulve située à la base du rostre, entre les deux premières pattes. Wâle long de 4 millimètres, large de 3 , de teinte brune; orifice sexuel au niveau de la troisième paire de pattes. Nymphe 
octopode de la taille du màle, dont elle se distingue par l'absence de pore génital. Larve hexapode orbiculaire, à rostre terminal muni seulement de deux rangées de dents de chaque côté du dard; pas de trachées ou de stigmates; quelques soies périphériques; pattes relativement longues. OEuf ovoïde, de teinte roussaitre.

L'Argas réfléchi est assez commun en France eten Italie; par contre, il paraît rare en Allemagne et en Angleterre. Il vit dans les colombiers et se répand en plus ou moins grand nombre sur les Pigeons, dont il suce le sang. Les larves sont souvent fixées à demeure sur le corps des Pigeons; les adultes ne paraissent les attaquer qu'à de certains moments, la nuit en particulier, et on les découvre d'ordinaire, pendant le jour, cachés dans les fissures des boiseries, les crevasses des murs, etc. Les éleveurs donnent généralement aux adultes le nom de Punaises et aux larves celui de Poux de Pigeons. Ces Acariens s'atta-
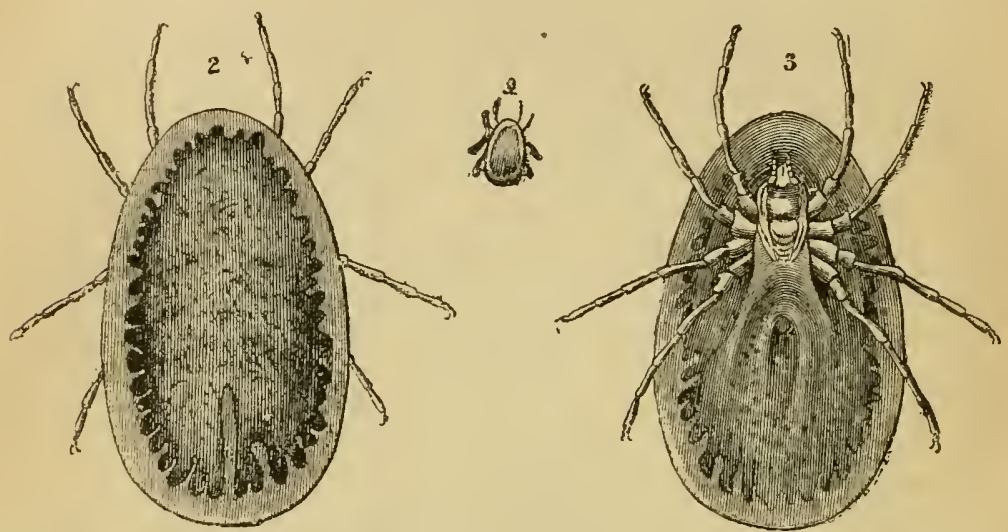

Fig. 488. - Argas reflexus, femelle fécondée et repue. - 1, grandeur naturelle. 2, grossic, vue par la face dorsale. 3 , par la face ventrale (Orig.).

quent surtout aux Pigeonneaux, mais les Pigeons adultes ne sont pas à l'abri de leurs atteintes. On les trouve fixés dans la peau du cou, de la poitrine, des ailes et en somme de presque toutes les régions du corps. S'ils n'existent qu'en petit nombre, la santé n'est pas troublée; mais, lorsqu'ils sont très abondants, ils tourmentent les Pigeons, les empêchent de dormir ou de couver, les épuisent en suçant leur sang et arrivent à les faire périr. Il ne faut cependant pas exagérer leur influence nocive, car nous avons vu des Pigeonneaux résister parfaitement aux attaques de nombreuses larves de cette espèce.

Les Argas se propagent facilement d'un local à l'autre, ì la faveur des moindres solutions de continuité. C'est aỉnsi qu'ils pénètrent souvent dans les poulaillers et même dans les maisons situées à proximité des pigeonniers. Cependant, ils ne paraissent pas tourmenter les Poules.

Sur l'Homme, ils sont susceptibles de provoquer quelques accidents. 
- Raspail a vu, en 1838, un enfant dont le cou et le visage étaient courerts de vésicules; cet enfant sortant d'un colombier, on a cru pouvoir attribuer l'éruption à des Argas, mais il s'agissait à coup sûr de tout autre chose. - En 18ä8-5ั9, Boschulte a observé un vieillard qui avait été piqué ì la jambe par un Acarien dans lequel Gerstäcker reconnut l'Argas réfléchi; cette piqûre avait donné lieu à une petite plaie suppurante entourée d'une aréole intlammatoire et accompagnée d'un œè̀me du pied; la guérison fut obtenue en quelques jours. La maison où vivait ce malade était envahie par des Argas, notamment une chambre à coucher habitée par des enfants et communiquant aree un pigeonnier; dès le soir, les murs étaient couverts de ces Acariens, qui, ì chaque instant, piquaient les enfants pendant leur sommeil. La piqûre offrait l'aspect d'un point rouge à peine marqué, et dépourvu d'aréole, mais elle ciusait, spécialement sur le trajet des nerfs et à une assez grande distance, une démangeaison intense qui persistait quelquefois huit jours. Chez une jeune fille de quinze ans, il survint une éruption vésiculeuse sur les mains, les poignets et les avant-bras. Boschultese fit piquer lui-même et vit se produire dix jours plus tard une papule très prurigineuse, qui demeura perceptible pendant des années. - En 1882, le $\mathrm{D}^{\mathrm{r}}$ Chatelin, de Charleville, a observé sur un enfant des piqûres douloureuses et un œdème assez persistant dus à des Argas qui provenaient d'un colombier évacué depuis plusieurs années. Les Acariens avaient envahi le premier étage et le rez-dechaussée de l'habitation dans laquelle était situé le colombier. Direrses personnes araient été atteintes en même temps que cet enfant. Aucune ne présenta de symptômes généraux. - Enfin, K. Alt a ru se produire récemment, dans des conditions analogues, une sorte d'urticaire accompagnée, dans un cas, d'un érythème général qui disparut au bout de quelques heures (1).

Une fois repu, l'Argas réfléchi peut vivre fort longtemps sans prendre de nourriture. Hermann en a ru survivre à huit mois, nousmême à quatorze mois, et Ghiliani à vingt-deux mois de jeûne. D'après Boschulte, il se reproduirait même en l'absence des hôtes propres it le nourrir.

Lorsqu'on trouve des Argas fixés sur les Pigeons, on peut les enlever à la façon des Ixodes. Mais il importe surtout d'en débarrasser le colombier, ce qui requiert une désinfection profonde et générale: blanchissage à la chaux, aspersions d'eau bouillante, etc.

L'Argas à chaperon pointu (A. coniceps Canestr., 1890) est une autre espèce européenne qui s'attaque également aux Pigeons. Elle a élé trouvée à Venise, dans les interstices des mosaïques de Saint-Marc, en compagnie de la précédente.

D’autres espèces ont été observées en Asie, en Afrique et en Amérique.

(1) K. ALt, Die Taubenzecke als Parasit des Menschen. Münch. med. Wochenschrift, no $30,1892$. 
Parmi les Arg.ts D'Asie, on distingue: l'Argas de Perse (A. persicus Fischer), Garib-Guez des Persans, Punaise de Miana ou Miané des voyageurs, qui s'altaque à l'Homme el dont les morsures sont souvent suivies d'accidents locaux et généraux fort graves; et l'Argas de Tholozan (A. Tholozani Lab. et Mégn.), Kéné des Persans, ou encore Punaise de Mouton, qui paraît se comporter à peu près comme le précédent.

Les Argas D'Afrique comprennent: l'Argas de Savigny (A. [Ormithodoros] Savignyi Audouin), qui habite l'Ésypte et l'Asie-Mineure; l'Argas de Fischer (A. Fischeri Aud.) et l'Argas d'Hermann (A. Hermanni Aud.), également égyptiens; l'Argas Moubata (A. Moubata Murray), d'Angola ; l'Argas de Maurice (A. mauritiumus Guér.), qui se rencontre en abondance dans cerlaines parties de l'ile Manrice, où il inquiète les Poules et mème les fait quelquefois périr, etc.

Enfin, hous citerons, comme Argas D'AMÉrique : l'Argas Talaje (A. Talaje Guér.), l’Argas Turicata (A. Turicata Alf. Dugès); l'Argas de Mégnin (A. Megnini Alf. Dugès) et l'Argas coriace (A. [Ornithodoros] coriaceus Koch), du Mexique; l'Argas Chinche (A. Chinche J. Goudot), de la Colombie tempérée; l'Argas radié (A. radiatus $=A$. americanus Riley, nec Hope), du Texas, etc. - Les Turicatas s'altaquent à l'Homme et au Porc, et leur infligent des piqùres très sérieuses. Les Argas Talaje et Chinche sucent également le sang de l'Homme; les autres infestent surtout les animaux. Une espèce indéterminée se rencontre, d'après Curtice, dans les oreilles des Chevaux, en Californie. Enfin, J. Goudot a trouvé, dans la région chaude de la Colombie, une autre espèce innomée qui attaque les Poules et force parfois les propriétaires à changer celles-ci d'habitation.

Famille des GAMASIDÉS. - Les Gamasidés ont des téguments plus ou moins coriaces, renforcés, sur la face ventrale, par des plaques chitineuses épaisses; la face dorsale elle-même est souvent cuirassée. Rostre à palpes libres, tactiles, filiformes, formés de cinq articles semblables; mandibules presque toujours en pinces ou didactyles. Pattes directement insérées sur le tégument, le plus souvent à six articles, terminées par deux crochets plus ou moins cachés dans une caroncule. Pas d'yeux. Trachées aboutissant à des stigmates situés sur les côtés du corps, entre les paltes de la $2^{\circ}$ et de la $4^{\mathrm{e}}$ paire, et ordinairement protégés par un péritrème tubulaire souscutané dirigé en avant. Larves généralement hexapodes, semblables aux adultes; deux stades de nymphe octopode. Ovipares ou vivipares.

Acariens libres ou vivant sur les animaux, se nourrissant de proies ou d'humeurs animales.

8 sous-familles : Gamasina, Lalaptine, Dermanyssina, Pleroptinæ, Celienopsinx, Zerconinx, Antennophorinx, Uropodinie.

Sous-famille des oermanyssinés. - Corps faiblement cuirassé. Écusson dorsal entier ou double. Mandibules en pinces dont liun des deux mors avorte parfois. Ouverture sexuelle mâle située au bord antérieur du sternum. Pattes toutes semblables dans les deux sexes, presque toujours inermes, terminées par une caroncule et des cro- 
chets. Stigmates situés sur la face dorsale, presque toujours munis de péritrème. Espèces vivipares ou ovipares. Larves hexapodes ou octopodes; nymphes ibontomorphes.

Acariens parasites des Vertébrés.

4 genres: Demumyssus, Leiognalhus, Lophoptes, Ophionyssus.

Genre Dermanysse (Dermanyssus Dugès, 1831). - Tégruments mous, finement striés, sauf au niveau des faibles écussons de la face supérieure et de la face inférieure. Mandibules dillactyles chez le mâle, l'un des doigts ou mors peu développé, l’autre allonı́é en une lame aiguë et ondulée; celles de la femelle transformées en un long stylet. Vulve transversale. Larves hexapodes.

Les Dermanysses (óśpux, peau ; vúcestv, piquer) sont parasites des Oiseaux (parasites temporaires).

\section{Dermanysse des volailles} (I). yallina [De Geer.]. - Syn. : Pulcx yallinx Redi, 167'; Acarus yallinx De Geer, 1778; D. avium Dugès, 1834 , pro parte; $D$. gallinx et $D$. columbinus Koch ; D. gallopavonis P. Gerv., 1844). - Corps ovale pyriforme, à grosse extrémité postérieure, un peu aplati de dessus en dessous; abdomen entouré de soies courtes et écartées. Pattes robustes, assez

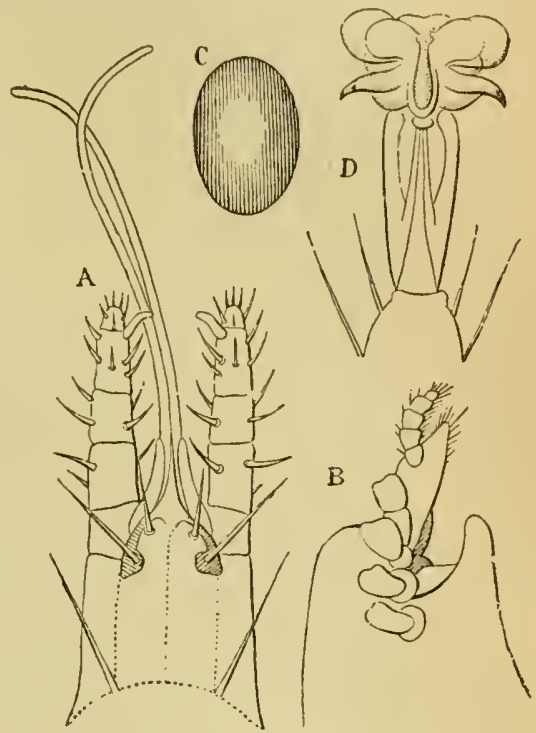

Fig. 489. - Dernanysse. - A, rostre de la femelle vu de dessous. B, vu de profil. C, aeuf. D, tarse (Delafond). courtes, les antérieures égalant à peine la largeur du corps. Péritrème se prolongeant jusqu'aux hanches de la seconde paire. Couleur variant du blanc au rouge de sang et au rouge noiràtre selon que l'animal est à jeun ou plus ou moins repu : dans ce dernier cas, on distingue par transparence le tube digestif avec ses cæcums. Mâle long de $600 \mu$, large de $320 \mu$. Femelle longue de 700 à $730 \mu$, large de $400 \mu$.

Ces Acariens, dont les allures sont très rapides, sont noctambules: ils se tiennent pendant le jour dans les fissures des poulaillers et des colombiers, dans le creux des perchoirs, dans la paille des nids, ou mème au milieu du guano, et, la nuit venue, se jettent sur les Oiseaux, dont ils sucent le sang.

Ce sont donc des parasites temporaires. Dans des cas exceptionnels, cependant, leur parasitisme devient stationnaire; on peut alors les voir, en quantité extraordinaire, sur les Pigeons, Poules, Dindons, Faisans, ete., et surtout sur les poussins. 
Leurs piquires tourmentent beaucoup les Oiseaux, les font maigrir et empêchent les femelles de couver avec assiduité. Les jeunes sujets sont quelquefois tellement envahis qu'ils succombent épuisés; on trouve alors leur cadavre criblé de Dermanysses. On les a vus pénétrer parfois, soit dans le conduit auditif externe (Lax), soit dans les cavités nasales des Pigeonneaux et des Poulets, où ils déterminent une inflammation catarrhale (Weber, Zürn).

Pour débarrasser les volailles de ces Acariens, il est nécessaire de pratiquer une désinfection profonde de leurs habitations (sulfure de carbone, eau bouillante, poussière de chaux, etc.).

Transmission à l'Homme et aux Mammifères domestiques. - Lorsque les Dermanysses sont très abondants, ils ne bornent pas leurs attaques aux Oiseaux, mais se jettent volontiers sur les Mammifères qui se trouvent à leur portée.

A. L'Homme lui-même est exposé à leurs atteintes. Alt (1824) en a trouvé sur le cou et les bras d'une vieille femme cachectique, où ils s'étaient logés dans de petites excavations. Bory de Saint-Vincent (1828) a rencontré de nombreux Dermanysses sur le corps d'une femme qui éprouvait un violent prurit (D. Boryi P. Gervais, 1844). Erdl a trouvé quatre fois, de 1840 à 1842, des Dermanysses dans des tumeurs cutanées. Raspail dit aroir vu au Petit-Montrouge, en juin 1839, beaucoup d'enfants et d'adultes couverts de boutons aux jambes et aux bras, pour avoir fréquenté des jardins fumés avec de la colombine dans laquelle pullulaient les Dermanysses. Simon a rapporté, en 18 1 , le cas d'une femme de Berlin qui, en dépit de tous les soins, était continuellement envahie par des Dermanysses; on reconnut que cette femme passait chaque jour sous un poulailler pour se rendre à sa cave. Enfin, Henderson, Itzigsohn, Judée, liramer, Goldsmith, Geber, etc., ont encore signalé des faits analogues. Besnier et Doyon affirment d'ailleurs qu'on observe assez souvent, chez les garçons ou les filles de basse-cour, ainsi que chez les personnes employées à manier ou à plumer les volailles, une éruption prurigineuse ressemblant à certaines formes de l'eczéma papuleux de la gale ordinaire, et qui acquiert parfois assez d'intensité pour engager les malades à se rendre à l'hopital. On l'observe surtout sur le dos des mains et les avant-bras dans la partie découverte pendant le travail ; mais elle peut exister aussi sur toutes les parties exposées, et même sur la généralité du tronc. Cette affection est nécessairement passagère, car les Dermanysses ne s'acclimatent pas sur la peau de l'Homme. On calme le prurit au moyen de lotions ou de bains d'eau pure, vinaigrée ou amidonnée. Lorsque, en maniant des volailles, on se trouve envahi par des Dermanysses, le meilleur moyen de s'en débarrasser, d'après Fuchs, est de s'enfoncer pendant quelque temps dans une meule de foin. 
B. Parmi les Mammifères domestiques, c'est sans doute le Cheval que les Dermanysses attaquent le plus fréquemment. La première mention de ce fait est due également à Gurlt, et remonte à 1843 ; mais l'affection cutanée du Cheval déterminée par ces Acariens n'a été nettement signaléc qu'en 18.17 par Demilly ainé, de Reims; depuis lors, elle a été l'objet de très nombreux travaux. En France, en Belgique, en Angleterre, où l'on ignorait les observations de Gurlt, on avait simplement noté l'apparition de la maladie chez les Chevaux logés il proximité des pigeonniers et des poulaillers, et on l'attribuait aux Poux ou Ricins dont se montrent sonvent couverts les Oiseaux de basse-cour, d'où le nom de phtiriase aviaire sous lequel on la désigna longtemps. Delwart et Moon avaient bien ru de petits animaux courant la nuit sur le corps des Chevaux enrahis, mais ils les araient pris également pour des Ricins. La nature du parasite ne fut décidément reconnue qu'en 1873: le 15 juin de cette année, un Cheval offrant lons les symptômes de la phtiriase aviaire fut conduit ì la consultation de l'École d'Allort sans avoir été pansé, et encore revêtu de la courerture qu'il portait la nuit. En soulevant cette couverture, on apercerait, grâce à la couleur gris clair de la robe, une foule de Dermanỵsses qui s'enfonçaient rapidement entre les poils, et dont nous avons pu faire une abondante récolte.

Lacuriase dermanyssique du Cheval débute brusquement par un prurit riolent, qui s'exagère la nuit. En mème temps survient une éruption résiculeuse; puis, par suite des frottements, l'épiderme se détache au niveau des résicules, emportant les poils ei laissant à nu de petites surfaces vives, de $\breve{s}$ à 10 millimètres de diamètre. Chacune de ces surfaces se recourre d'une croûte légère qui ne tarde pas i s'exfolier, puis elle reproduit une nouvelle couche d'épiderme glabre. Dans l'espace de deux ou trois jours, la robe d'un Cheval peut étre ainsi entièrement mouchetée, et en huit jours il est possible de voir la dépilation s'étendre à de larges surfaces continues. Parfois il survient alors une éruption secondaire de papulo-résicules, et d'autres lésions dues aux frottements. - La maladie persiste tant qu'on n'en supprime pas la cause; elle récidive dès que celle-ci reparait, et dure parfois des années, conduisant peu à peu l'animal au marasme.

Pour la voir. disparaitre, il suffit donc d'éloigner les volailles de l'écurie, et de désinfecter au besoin le poulailler ou le pigeonnier. On peut d'ailleurs hàter la guérison au moyen de quelques lotions sulfureuses, émollientes ou ca mphrées.

C. Chez le Beuf, on ne parait avoir vu jusqu'à présent le Dermanýsse des volailles que dans l'oreille. Gassner, Stadler, Schuemacher, Ostertag, Krattheim ont rapporté des cas dans lesquels les Acariens avaient pénétré dans le conduit externe, traversant parfois la membrane du tympan, et gagnant ainsi l'oreille moyenne, voire l'oreille interne. Les symptômes consistaient en une violente agitation de la tête.

R.alliet. - Zoologie. 
D. On a vu encore les Dermanysses passer sur d'autres animaux. Farez en a trouvé sur la Chèvre, Gurlt sur le Lapin, et Zürn affirme que le Chien et le Chat peuvent contracter de leur fait une affection vésiculeuse.

Delmanysse des Hirondelles (D. lirundinis [Herm.]. - Syn. : Acarus hirundinis Hermann, 1801; D. hirundinis Dugès, 1834). - Cette espèce diffère de la précédente par ses dimensions, qui sont notablement plus grandes

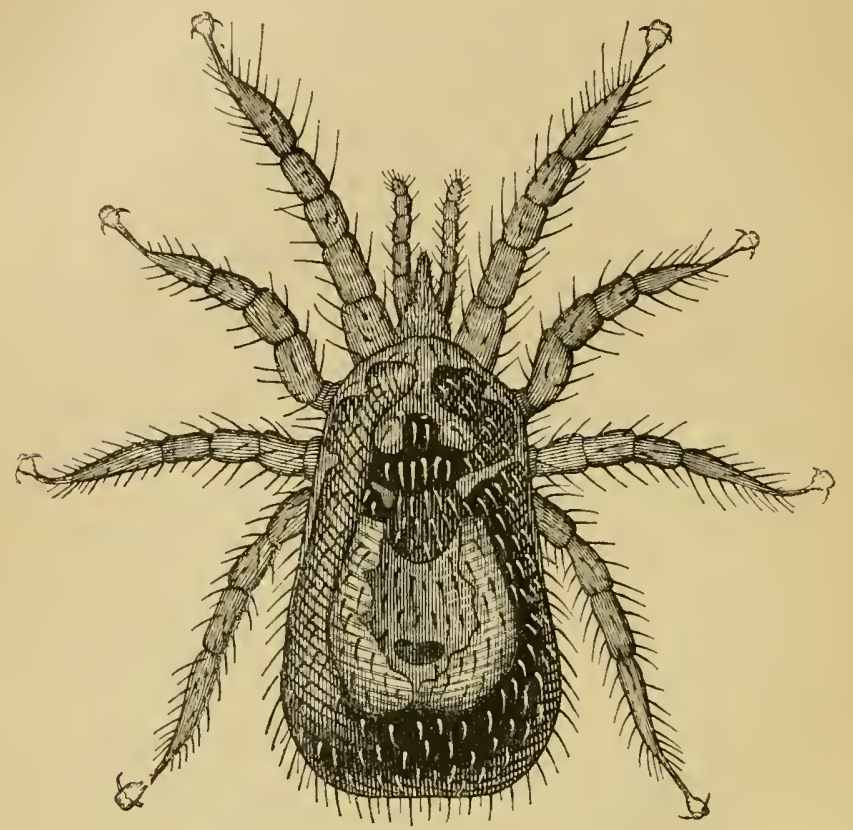

Fig. 490. - Dermanysse, femelle ovigère, vue par la face dorsale, grossie environ 30 fois (Delafond).

(1 millimètre), et par son péritrème, qui s'étend à peine jusqu'aux hanches de la $3^{e}$ paire de pattes. L'écusson dorsal forme un angle aigu en arrière.

Ce Dermanysse vit dans les nids d'Hirondelles; il est également noctambule.

Il s'atlaque parfois à l'Homme : on l'a vu passer d'un nid d'Hirondelles jusque dans une chambre habitée, ì la faveur d'un simple trou de cordon de sonnette, et causer d'insupportables démangeaisons à une personne couchée dans cette chambre.

Möbius a vu, sur huit vaches, une affection caractérisée par des dépilations arrondies, et traitée en vain depuis deux ans, qui disparut après la destruction de plusieurs nids d'Hirondelles existant dans l'étable et cachant de nombreux Dermanysses.

Les Moineaux domestiques hébergent aussi deux espèces de Dermanysses 
(D. longipes [D. avium ?] et $D$. passerinus Berlese et Trouessart) qui sans doute pourraient occasionner dans certains cas de semblables accidents.

Gayasidé de l'oreille. - Sous le nom de Gamasus auris, Leidy a donné, en 1872, la description d'un Acarien trouvé par le $D^{r}$ Ch. Turnbull dans J'oreille d'un Buuf. - Corps ovoïle, blanc, diaphane, lisse et glabre; pattes et rostre bruus, garnis de soies; tar'ses terminés par une paire de griffes et une caroncule à cinq lobes; palpes à 6 articles; mandibules en pinces didactyles; le doigt mobile muni de deux dents à son extrémité, l'autre petit et crochu. Dimensions : environ 1 millimètre de long sur $0^{\mathrm{mm}}, 8$ de large.

Turubull en avait trouvé de nombreux exemplaires se pressant daus le conduit auditif externe et en particulier sur la membrane du tympan. En poursuivant ses recherches, il le revit fréquemment dans les mêmes conditions, et fut amené à le legarder comme un véritable parasite.

b'après les caractères ci-dessus, il est facile de reconnaître qu'il s'agit bien d'un Gamasidé; mais la détermination du genre auquel il apparlieurt est à peu près impossible. Tout au plus peut-on soupçonner ru'il se rattaclıe aux Dermanyssinés ou aux Pléroptinés. Iturray en faisait, sans raison plausible, un Sejus. En tout cas, ce n'est pas un Gumusus, car tous les Gamases vivent dans la mousse ou dans les substances en putréfaction.

Genre Leiognathe (Leiognathus Canestrini, 188\%. - Syn. : ? Cryptostoma Robineau Desvoidy, 1830; Hamomyson Mégr., 1892). — Corps faiblement cuirassé; à la face ventrale, une plaque sternale et une plaque anale. Mandibules didactyles et inermes dans les deux sexes. Vulve transversale. Larves oclopodes (?).

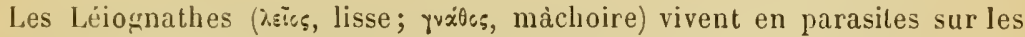
Mammifères et les Oiseaux.

Le Lẻiognathe brunatre (L. suffuscus. - Syn. : Gamasus pteroptoides Yégn., 1880, pro parte, nec 18i6) vit en colonies au fond du pelage du Lapin, et se nourrit probablement du sang qu'il obtient en piquant la peau à l'aide de ses mandibules.

Le LCiognathe bourse (L. Lursa Berlese, 1888) a le corps blanchàtre, ovalaire, environ trois fois aussi long que large, arrondi en arrière et bordé de poils assez longs. Les pattes antérieures sont plus longuẹs et plus grèles que les autres; les deux doigls des mandibules sont grèles, très aigus et transparents. Le péritrème se prolonge jusqu’à la première paire de pattes. Longueur, jusqu’à $600 \mu$; largeur, jusqu’ả $30 ّ 0 \mu$.

Cette espèce a été trouvée à liuenos-Ayres, sur des Poules (1), par Aloïs Balzan.

Le Lëiognathe des Fauvettes (L. sylviarum Canestr. et Fanzago, 1877) vit dans le nid de plusieur's espèces de Fauvettes. Moniez (2) l'a r'encoutré aux environs d'Arras et a constalé que les personues qui maniaient les nids

(1) A. Benlese, Acari austro-americani. Bollett. della Soc. Entom.1tal., XX, 1888.

(2) R. Moxiez, Leiognathus sylviarum. Revue biol. du Nord de la France, V, p. $408,1893$. 
infestés étaient aussitòt incommodées par cette vermine, qui se jetait par tout le corps, causant pendant un certain temps un vif prurit, sans d'ailleurs attaquer aucunement la peau.

Genre Lophopte (Lophoptes Mégn., 189t. - Se distingue du précédent en ce que les mandibules ont le mors fixe pourvu de deux petites dents au sommet et le mors mobile élargi, non crochu.

Le Lophopte padouan (L. patavinus Mégn., 1891) est un peu plus petit que le Dermanysse des Poules; le màle est beaucoup plus petit que la femelle et a l'extrémilé postérieure rétrécie.

Vit à demeure dans la huppe des Poules de Padoue (1).

Diverses espèces de Gamasidés se rencontrent dans les fourrages ou dans les habitations, et il importe de ne pas les prendre pour des parasites lorsqu'ils passent accidentellement sur le corps de l'Homme ou des animaux, En voici une liste, dressée par Berlese:

Fourrages: Lxlaps stabularis, funalis, cuticularis, marginatus, domesticus, casalis, miles.

Litière : Lælaps stabularis, fonalis, cuticularis, miles. Uropoda Krameri, patavina.

Maisons : Lælaps marginatus, domesticus, casalis, fænalis, cubicularis. Parfois en outre Holostuspis badius, transporté par la Mouche domestique.

Ajoutons que, d'après I'égnin, deux espèces qu'il nomme Uropoda nummularia et Trachynotus cadaverinus contribueraient à la nomification des cadavres exposés à l'air, en s'introduisant sous la peau pour sucer les tissus mous.

G. Neumann (2) a observé des troubles psychiques, avec retentissement sur la nutrition, chez une femme dont la maison était envahie par une quantité excessive de Lælıps stabularis (Koch). Les Acariens ne causaient cependant que de simples chatouillements au visage, sans aucune lésion cutanée.

5e ordre : PhaIangides. - Chélicères en forme de pinces didactyles; maxillipédes développés en palpes filiformes; pattes longues et grêles; abdomen articule, largement uni au céphulothorax; respiration trachéenne.

Les Phalaugides ou Opilions sont ces Arachnides à longues pattes que tout le monde connait sous le nom de Faucheurs. - Genres Phalangizm, Trogulus, etc.

$6^{\mathrm{e}}$ ordre: Chernètes. - Chéliceres en pinces didactyles; palpes maxillaires très grands, également diductyles; abulomen articulé, non pédiculé, suns aiguillon venimeux; respiration tracheenne.

On a longtemps rattaché aux Scorpions ces petits animaux, qui ont en effet la mème conformation des chélicères et des palpes (Pseudoscorpions). Ils sen distinguent cependant à première vue par leurs dimensions et par

(1) MÉgnis, Une acariase spéciale aux Poules Padoue. Comptes rendus Soc. de biologie (9), III, p. 759, 1891.

(2) G. Necuans, Pseudo-parasitisme du Lelaps stabularis sur une femme. Comptes. rendus Soc. de biologie, (9), V, p. 161, 1893. 
l'absence d'un postabilomen à aiguillon. Quant à leur organisation inlerne, elle est beaucoup plus simple et les rapproche des Acariens et des Phalangides. Ils possèdent des filières comme les Araignées. - Genres Chelifer, Quisium. La l'ince ou Faux-Scorpion des livres (Ch. cancroides) abonde dans les vieux livres, les lertiers, les pigeonniers, les niches des poulaillers, où elle fait li classe aux deariens et aux Insectes nuisibles.

7o ordre : Pèdipalpes. - Chilicives en griffes; palpes en griffes ou en pinces diductyles: puttes antérieures antenniformes; ublomen articulé, uni au céphalothorax par un pedicule; deux puires de poumons.

Ce sroupe est représenté par les Phrynes (Plurymus ou Tarentula) et par les Thélyphones (Thelyphonus). Ces derniers ressemblent beaucoup aux Scorpions, car ils possèdent un court postabdomen suivi d'une queue; on a supposé qu'ils avaient les chélicères munies de glandes ả venin, et leur morsure est très redoutée; pourtant il ne semble pas que cette crainte soit sérieusement justifiée : leur appareil glandulaire est postérieur, et fournit un liquide riche en acide formique, que l'animal projette vivement au dehors lorsqu'il est inquiété, d'où le nom de "Vinaigrier " qu'on lui domne au Mexique. Les Pédipalpes habitent les régions tropicales des deux mondes.

\section{HUITIE.ME ORDRE}

\section{SCORPIONIDES}

Arachicles à chelicères en petites pinces.dilaclyles; palpes maxillaires très grands, egalement en pinces; abdomen long, articulé, non pédiculé, terminé par un aiguillon venimeux; quatre paires de poumons.

Les Scorpions sont remarquables par leur's téguments coriacés, leurs longs palpes maxillaires terminés par de puissantes pinces didactyles, et leur abdomen allongé, divisé en deux parties : un préabdomen cylindrique, de sept anneaux, et un postabdomen en forme de queue noueuse, composé de six anneaux lont le dernier est prolongé par un aignillon recourbé.

Le céphalothorax porte, à sa face supérieure, trois à six paires d'yeux. La paire principale, facile à distinguer, est voisine de la ligne médiane et représente ce qu'on appelle les yeux du vertex. D'autres yeux, plus petits, situés à droite et à gauche sur le bord frontal, sont appelés yeux latéraux principaux, par opposition aux yeux accessoires, qui occupent une position wariable. Les hanches des deux dernières paires de pattes laissent entre elles un espace occupé par une pièce chitineuse de forme variable, le sternum. A la face ventrale du premier segment de l'abdomen se trouvent, en avant et au milieu, les orifices génitaux, recouverts d'un opercule; en arrière et latéralement, deux organes particuliers, comus sous le nom de peirnnes. Ce sont deux plaques étroites, articulées, portant sur leur bord postérieur une série de dents uniformes, dont chacune recoit un filet nerveux spécial. Ils permettent aux Scorpions de se maintenir pendant l'acconplement, mais paraissent en outre servir d'organes exeitaleurs, et peut-ètre mène d'organes tactiles (Clı. Brongnniart et Gaubert). En arrière des peignes, on voit sur chacun des quatre anneaux suivants deux ouvertures latérales ou stigmates, qui donnent entrée dans autant de poches pulmonaires. 
Les Scorpions sont vivipares. Ils se tiennent volontiers sous les pierres, dans les crevasses des murs, dans les celliers et jusque dans les maisons. Ils sont noctambules. On ne les trouve que dans les pays chauds. Plusieurs vivent daus les régions circumméditerranéennes. Ils se nourrissent d'Insectes, de Cloportes, d'Araignées. Lorsqu'ils aperçoivent une proie ou un ennemi, ils s'avancent liardiment, Ia quene recourbée en arc sur le dos, saisissent la victime à l'aide de leurs palpes-pinces, la frappent de leur aiguillon, puis la sucent ou la dévorent.

L'appareil venimeux est contenu dans le sixième et dernier segment du postabdomen. Il se compose de deux glandes ovalaires,

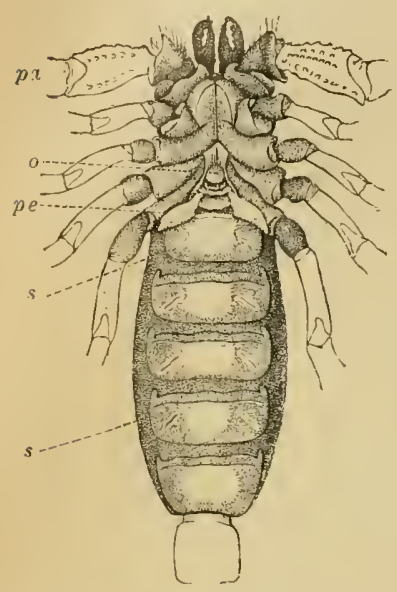

Fig. 491. - Céphalohorax el préabdomen de Scorpion, vus en dessous. - $c$, chélicères, $p a$, palpes maxillaires. n, orifice de l'oviducte. pe, peignes, $s, s$, stigmates. symétriques, appliquées l'une contre l'autre, atténuées en col vers l'extrémité postérieure et terminées chacune par un canal excréteur. Les deux canaux marchent parallèlement et aboutissent à deux orifices ovalaires situés sur les côtés et un peu audessous de la pointe de l'aiguillon.

Chaque glande offre une cavité centrale servant de réservoir au venin, et une paroi formée de trois couches, savoir, de dehors en dedans : $1^{\circ}$ une couche musculaire limitée à la face inférieure et dont les fibres sont insérées sur le tégument, de manière a comprimer la glande en se contractant, et à faire ainsi jaillir le venin; $2^{\circ}$ une couche conjonctive qui envoie des lames rayonnantes dans la carité de la glande; $3^{\circ}$ un revêtement épithélial formé de longues cellules cylindriques remplies de fines granulations.

Le venin que sécrètent ces glandes est un liquide acide, visqueux, transparent, dans lequel on retrouve, à un fort grossissement, les granulations de l'épithélium; facile à dessécher, il est soluble dans l'eau, insoluble dans l'éther et l'alcool absolu.

Son action physiologique a été bien étudiée surtout par Paul Bert et par Joyeux-Laffuie. C'est un poison du système nerveux. Entraîné dans tout l'organisme par la circulation, il va d'une part irriter les centres nerveux et provoquer des convulsions, et d'autre part, à la façon du curare, il paralyse l'action des nerfs moteurs sur les muscles striés; et cette double action se traduit toujours par une période d'excitation suivie d'une période de paralysie.

La lgravité des accidents varie d'ailleurs suivant la quantité de venin introduite et suivant la résistance des individus piqués. "Une goutte de venin, dit Joyeux-Laffuie, soit pure, soit mélangée à une petite quantité d'eau distillée et injectée dans le tissu cellulaire d'un 
Lapin, amène rapidement la mort. Les Oiseaux sont aussi facilement tués que les Mammifères. Arec une seule goutte de venin, on peut faire périr sept ou huit Grenouilles. Les Poissons et les Mollusques sont beaucoup plus réfractaires; mais, en revanche, les $\Lambda$ rticulés sont d'une susceptibilité surprenante : la centième partie d'une goutte de venin suffit pour tuer immédiatement un Crabe de forte taille. Les Mouches, les Araignées et les Insectes dint le Scorpion fait sa nourriture sont, pour ainsi dire, foudroyés par la piqüre de cet animal. "

La piqutre des Scorpions est très douloureuse. Elle est suivie d'une inflammation locale sourent accompagnée de fièvre et de vomissements. Les grandes espèces seules produisent des accidents plus grares et sont capables de donner la mort it l'llomme. Encore le fait est-il moins commun ru'on ne le pense généralement. Aucune espèce européenne ne paraît causer de piqûres mortelles. En Algérie, les cas de mort sont très rares et se rapportent toujours à des enfants. Et même dans les régions tropicales, ou la mortalité résultant de ce chef est parfois très élevée chez les enfants, il est tout à fait exceptionnel de voir succomber des adultes sains.

Comme on ne connait aucun antidote rationnel, on se borne ì com battre les accidents locaux à l'aide de lotions d'eau ammoniacale ou phéniquée, de cataplasmes ou d'embrocations liuileuses opiacées. S'il survient des nausées, on peut administrer une dose faible d'ipécacuanha. Du reste, comme dans la plupart des blessures venimeuses, il est possible d'enrayer l'absorption du renin par la succion du point piqué ou l'application d'une rentouse.

On pent répartir les Scorpions dans quatre familles: Buthidx, Telegonidx, Vejovidx, Scorpionidx.

Les BUTHIDÉs ont le sternum atténué en avant, presque triangulaire.

Les Buthus (Buthus Leach) ont les deux branches des chélicères garnies chacune de deux couples de dents.

Le scorpion européen (Buthus europæus L., Sc. occitunus Amoreux, Sc. tumetanus Herbst) est fauve rougeàtre, avec les paltes jaune pàle; la longueur tolale est de 83 millimètres, dont $4 \ddot{3}$ pour la queue; les peignes ont 20 à 30 dents, ordinaire- Fig. 492. - Scorpioneuropéen . ment $2 \pi$.

Cette espèce est commune dans le Midi de la France, sur le littoral méditerranéen, de Camnes à Banyuls; elle est aussi répandue en Espagne, en Grèce, en Égypte et en Algérie. La piqùre est caractérisée par une petite tache rouge qui s'agrandit, devient plus foncée au centre et persiste pend ant sept à huit jours, rarement jusqu'à quinze (Laboulbène). 
Le Scorpion Énée (Buthus Encas Ch. Koch) de teinle noiràtre, se trouve en Algérie, dans les chotts, près de la région saharienne.

Les Androctones (Androctonus Ehr.) diffèrent surtout des Buthus par le $5^{\text {e }}$ segment caudal, qui est caréné. A ce genre appartient le Scorpion funeste (A. australis L., A. funestus Auct.), jaune avec l'extrémité de la queue brunâtre, du sud de l'Algérie. Guyon dit avoir vu mourir des enfants qui avaient été piqués à la tête par ce Scorpion.

Les SCORPIONIDÉs sont caractérisés par un sternum tétragonal ou pentagonal.

Le genre Scorpion (Scorpio L.), renferme les plus grandes espèces connues : Sc. africanus L., de l'Afrique centrale; Sc. imperator Ch. lioch, du Gabon, etc.

Les Euscorpions (Euscorpius) ont seulement deux yeux latéraux, le front droit, la queue faible. Ce geure comprend quatre espèces françaises très voisines.

Le Scorpion commun (Eusc. flacicaudis [De Geer]) est long de 30 à 36 millimètres; il est brun foncé en dessus, avec un reflet rougeàtre; les pattes, ainsi que la vésicule située sous l'aiguillon, sont fauve rougeàtre; le dessous de la pince ou main présente une rangée oblique de quatre points pilifères. La queue est pourvue de forles carènes, les latérales irrégulièrement granulées. Les peignes ont 8 à 10 dents.

Le Scorpion flavicaude se trouve dans tout le Nidi de la France, jusqu'à Valence et Bordeaux; il est aussi répandu en Corse et en Algérie. Sa piqûre n'est guère plus dangereuse que celle d'une Abeille.

Le Scorpion italien (E. italicus [Herbst]) mesure 42 millimètres de long; il est brun noiràtre en dessus, avec des pattes brun rouge clair et une vésicule caudale brune plus foncée que les pattes; il diffère surtout du précédent par sa queue dépourvue de carènes latérales granulifères et par le dessous de la main garni d'une série de huit points pilifères.

On le rencontre à Nice, à Nonaco, dans le Nord de l'Italie et jusqu'en Turquie.

Le Scorpion des Carpathes (E. carpathicus [L.]) est long de 27 millimètres, brunàtre ou fauve en dessous, avec les pattes jaune rougeàtre et la vésicule plus claire; il se distingue d'ailleurs des deux formes précédentes par le quatrième segment caudal, qui est lisse en dessous, sans carène médiane, et par le dessous de la main à trois poiuts pilifères.

Ce Scorpion ne se trouve, en France, qu'à l'ouest du Rhône; au lieu de rechercher les plaines comme le Scorpion flavicaude, il remonte assez haut dans les montagnes.

Quant au Scorpion de Fanzago (E. Fanzagoi E. Sim.), c'est une espèce dont on ne connait jusqu'à présent que la femelle. Celle-ci, qui mesure $27^{\mathrm{m}} \mathrm{m}, 5$, est d'un brun rougeàtre foncé en dessus, avec les pattes et surtout les tarses plus clairs. Elle se rapproche beaucoup de l'espèce précélente, 
dont on la distingue cependant par le fémur du maxillipède dépourru de granulations en dessous dans la seconde moitié, et par le quatrième segment caudal muni inférieurement d'une còte faible et lisse.

Cette espèce se trouve en Espagne; elle a été rencontrée dans les Pyrénées-Orientales.

Les Ilétéromètres (Ileterometrus Ilemp. et Elır.) ont trois yeux latéraux éloignés du hord. C'est à ce genre qu'appartient le Scorpion palmé (II. maurus L., Scorpio palmatus Ehır.) brun chocolat, si commun en Algérie, oǹ il s'arance jusqu'a la còte.

Le genre Bèlisaire (Bclisarius E. Sim.) a été établi par Simon pour une espèce nouvelle, le Bélisare de Xambeu (B. Xambeui E. S.), qui est aveugle et possède un peigne à 4 dents sculement.

Cetce forme, qui ressemble à première vue au Scorpion des Carpathes et mesure $26^{\mathrm{mm}}, \breve{3}$, a été trouvée par Xambeu sous les pierres, dans les Pyrénées-Orientales. Le màle seul est connu.

Quant aux sous-familles des Télégoninés et des Véjovinés, elles ne comprennent que des espèces américaines et australiennes.

\section{NEUVIËME ORDRE}

\section{ARANÉIDES}

Arachnides a chiliceres en griffes, munies de ylandes venimeuscs; abdomen inarticule, uni au céphulothorax par un pédicule, et terminé par des fulières; respiration pulmonaire ou trachéo-pulmonaire.

Les Aranéides, plus connues sous le nom vulgaire d'Araignées, sont surtout reconnaissables à leur abdomen mou et globuleux, uni au céphalothorax par un simple pédicule. - Les yeux sont d'ordinaire au nombre de 8 ou de 6 , et sont répartis diversement à la face supérieure du céphalothorax. Les chélicères (fig. 419) sont terminées chacune par un onglet mobile, percé d'un orifice par lequel s'écoule le venin dont se sert l'animal pour tuer ou engourdir sa proie. Le venin est sécrété par deux glandes situées d'ordinaire dans le céphalothorax. Les palpes maxillaires, composés de six articles, sont en général terminés, chez les måles, par un renflement creusé en cupule, destiné à porter le sperme au contact des organes femelles. Au-lessous des màchoires se trouve une lamelle impaire formant une sorte de lèvre inférieure. - L'appareil respiratoire se compose de deux ou quatre sacs pulmonaires, et quelquefois en mème temps de poumons et de trachées. - A la partie postérjeure de l'abdomen, au-dessous de l'anus, se trouvent quatre ou six mamelons articulés et percés de petits orifices : ce sont les filières, par lesquelles sort le produit de sécrétion des glandes séricigènes. Ce produit, d'abord visqueux, se concrèle rapidement à l'air et constitue les fils à l'aide desquels les Araignées tissent leurs toiles. - Les måles sont souvent plus petits que les femelles; dans beaucoup de cas, ils vivent à l'écart, et doivent mème prendre les plus grandes précautions, avant et après l'accouplement, pour ne pas se laisser dévorer par elles. 
On a beaucoup 'exagéré l'action du venin des Araignées sur l'Homme. Walckenaer et Dugès se sont fait mordre par les plus grosses Araignées du Nord et du Midi de la France : le résultat a toujours été moindre que s'il se fût agi d'une piqùre d'Abeille. De mème H. Lucas n'a ressenti aucun trouble sérieux à la suite des morsures de Malmignattes, réputées si venimeuses. Cependant, il est certain que le venin de certaines espèces peut occasion ner de graves accidents.

2 sous-ordres :

$1^{\text {er }}$ sous-ordre : Tétrapneumones. - Les Araignées quadripulmonées sont représentées par les Mygales, qui habitent les contrées chaudes de l'ancien et du nouveau monde. - La morsure de quelques grandes espèces occasion. nerait des accidents locaux assez sérieux et mème de la fièvre chez l'Homme et les grands animaux. Ceux-ci succomberaient parfois.

2 sous-ordre : Dipneumones. - Ces Araignées, outre leurs deux sacs pulmonaires, possèdent quelquefois deux trachées.

Les unes sont vagabondes, c'est-à-dire qu'elles ne tendent pas de fils et poursuivent leur proie, soit en bondissant, comme les Saltiques (Salticus), soit en courant, comme les Lycoses (Lycosa). C'est à ce dernier genre qu'ap partient la fameuse Tarentule (Lycosa tarentula), au sujet de laquelle on a discuté beaucoup plus peut-être qu'il ne convenait. Cette espèce se rencontre dans toute l'Italie centrale et méridionale, mais surtout dans la Pouille ou ancienne Apulie, aux environs de Tarente. On raconte que les individus tarentulés (tarentulati), c'est-à-dire mordus par la Tarentule, éprouvent des phénomènes nerveux singuliers, constituant ce qu'on appelle le tarentisme. Ces individus, qui sont presque toujours des gens du peuple, font mille extravagances qui témoignent d'une grande excitation mentale : Ies uns chantent, rient, soupirent, gémissent; d'autres ont des insomnies, des tremblements, des palpitations; d'autres encore ne peuvent supporter les couleurs noire ou bleue, tandis que le rouge et le vert leur causent des sensations agréables. Pour guérir ces malheureux, on leur joue, sur un instrumen $t$ quelconque, certains airs, dont les plus actifs sont la Pustorale et la Tarentelle. Le malade se met alors à danser, et, quand il tombe de fatigue, on le porte sur un lit, où il s'endort. A son réveil, il est guéri. Des rechutes peuvent se produire, se répéter pendant des années et mème pendant toute la vie du sujet. Il est à peine besoin de faire remarquer aujourd'hui le ròle essentiel que jouent l'imagination et les préjugés dans le développement de cette névrose, dont les relations avec l'hystérie ne paraissent guère douteuses. Léon Dufour a d'ailleurs constaté sur lui-mème l'innocuité de la morsure des Tarentules.

En Bolivie, on connaît, sous le nom indien de mico, de petites Araignées sauteuses (Dendryphantes noxiosus et $D$. Sacci) dont la morsure entraînerait souvent la mort de l'Homme.

D'autres Dipneumones sont sédentaires. Telles sont les Thomises (Thomisus), qui marchent de còté et à reculons ; l'Araignée domestique (Tegeneria domestica); I'Argyronète aquatique (Argyroneta aquatica), qui vit sous l'eau dans une cloche pleine d'air ; la Ségestrie des caves (Segestria cellaria); l'Araignée porte-croix (Epeir $($ diadema), etc. A ce groupe appartient aussi la Malmignatte (Latrodectus malmignatus seu tredecimguttatus), espèce qui vit sur tout 
le littoral méditerranéen et remonte mème, en France, jusque dans le Morbihan. les assertions les plus contradictoires ont été émises au sujet de cette Araignée, que les uns accusent d'occasionner les accidents les plus graves, alors que d'autres la considèrent comme absolument inoffensive.

Les Araigrnées et leurs toiles ont joui d'une certaine réputalion en médecine; on les recommandait notamment contre les fièvres intermittentes. De nos jours, on emploie quelquefois encore les toiles d'Araignées à titre d'hémostatique, dans le cas d'lémorragies capillaires; c'est un usage qu’il importe de combattre, car il est bien établi que ce produit peut servir de réceptacle à des éléments infectieıx, notamment aı Bacille du tétanos.

\section{DIXIEME ORDRE}

\section{GALÉODES}

Arachnides à tête, thorax ct abdomen distincts; chélicères en pinces didactyles; respiration trachène.

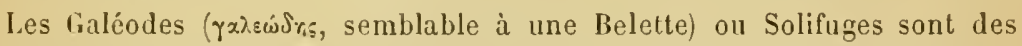
animaux de forte taille, qui tiennent le milieu entre les Arachnides et les Insectes. l.e eéphalothorax est divisé en deux segrments, dont l'antérieur, comparé à une tète, porte des chélicères didactyles, des palpes maxillaires transformés en pattes ambulatoires, et la première paire de pattes proprement dites. Le second tronçon ou thorax est formé de trois anneaux munis chacun d'une paire de pattes armées de griffes. L'abdomen est globuleux, articulé. - Les Galéodes habitent les régions chaudes du globe. Tous sont nocturnes ou crépusculaires. Bien qu'on ne leur ait pas encore reconnu avec certitude de glandes à venin, on les regarde communément comme venimeux, et leur morsure est redoutée.

Ils forment la seule famille des solpugioés, dont le type est fourni par le genre Galéode (Galeudes Oliv., Solpuga Herbst). — Le Galéode araignée (G. araneoides Pallas) est très répandu dans la Russie méridionale, en Perse, en Égypte; Pallas a rapporté des faits tendant à prouver que son renin peut ètre mortel pour l'Homme et les grands animaux. Les Chameaux et les Moutons qui se couchent en plein air seraient souvent mordus par cet Arachnide, que les Kalmonks appellent "Ver ensorcelé ». Le Galéode intrépide (Gluvi dorsalis Latr.) habite l'Espagne. Le Galeodes barbarus Lucas est commun en Algérie : le Dr Dours a observé un cas assez grave de blessure venimeuse produite par cette espèce.

\section{CLASSE V}

\section{MYRIAPODES}

Arthopodes à respiration aérienne, s'effectuant par des trachics; téte distincte du trone, qui ne montre pas de démarcation cntre le thorax et l'abdomen; une paire dantennes; nombreuses paires de paltes.

Les Myriapodes ou mieux Myriopodes (u.upio!, dix mille; reũs, pied) sont les 
animaux connus sous le nom vulgaire de Mille-pieds. Leur corps, souvent allongé et vermiforme, offre une tète distincte, mais ne comporte pas de division en thorax et abdomen. La tête porte deux antennes filiformes, des yeux simples ou plus rarement composés, et des pièces buccales plus ou moins complexes. Celles-ci comprennent un labre ou lèvre supérieure, une paire de mandibules crochues, et deux paires de màchoires parfois soudées (Chilognathes) en une seule valve quadrilobée connue sous le nom de lèvre inférieure. En outre, chez les Chilopodes, les deux premières paires de pattes fo nt l'office de pattes-màchoires. Quelquefois l'appareil buccal se transforme en sucoir.

Sous le rapport des organes internes, les Myriapodes se rapprochent beallcoup des Insectes. Le systeme nerveux offre la disposition typique que nous avons signalée chez les Annélides.

Le tube digestif, presque toujours rectiligne, présente un intestin buccal ou œsophage muni de glandes salivaires et parfois dilaté en jabot; un estomac cylindrique pourvu de nombreux cecums glandulaires; enfin, un court intestin dans lequel débouchent deux à six canaux urinaires ou tubes de Malpighi, et qui s'élargit dans sa portion terminale ou rectum, pour aboutir à l'anus, situé sur le dernier anneau de l'abdomen.

L'appareil circulatoire est tout à fait analogue à celui des Insectes, et comprend un long vaisseau dorsal divisé en autant de chambres qu'il y a d'anneaux.

Les organes respiratoires sont représentés par des trachées formant deux longs tubes latéraux et recevant l'air par des stigmates dont la situation est variable.

Quelques Myriapodes offrent des phénomènes de phosphorescence. Les Chilognathes possèdent des glandes cutanées sécrétant une substance corrosive, et les Chilopodes ont des glandes à venin annexées aux forcipules ou pattes-màchoires.

Chez tous, les sexes sont séparés. Les organes reproclucteurs se composent généralement d'un long tube impair, suivi d'un conduit excréteur simple ou plus souvent double, accompagné de glandes accessoires et parfois, chez les femelles, d'un réservoir séminal.

Les petits naissent le plus souvent pourvus de six à huit paires de pattes. Ils subissent des mues successives dans lesquelles se développent progressivement les anneaux, les pattes et mème les yeux. On peut, en somme, comparer cette évolution aux demi-métamorphoses des Insectes.

Les Myriapodes sont tous des animaux terrestres; ils vivent sous les pierres, sous la mousse et dans tous les endroits sombres et humides.

2 ordres principaux :

Deux paires de pattes sur la plupart des anneaux.... Chilognatues.

Une paire de pattes a chaque anneau.............. Chilopodes.

$1^{\text {er }}$ ordre : Chilognathes. - Myriapodes a corps plus ou moins cylindrique, pourvus de deux paires de pattes sur chacun des anneaux moyens et postérieurs.

La présence de deux paires de pattes sur chaque segment, à partir du $\ddot{a}^{e}$ ou du 6 e, est attribuée à une soudure, encore hypothétique, des somites primitifs deux à deux : aussi P. Gervais avait-il proposé pour ce groupe le nom de Diplopodes. - Les antennes sont courtes, à 7 ou 8 articles. - L'appareil 
buccal comprend un labre, des mandibules fortes et dentées, et une valve

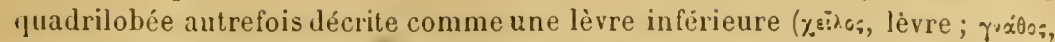
màchoire). Les Polyzonidés possèdent un suçoir. - Les stigmates s'ouvrent i la face ventrale, au-dessous de la base des hanches. De chaque côté de la région dorsale, se trouvent des pores par lesquels suinte une sécrétion acide, d'odeur infecte, servant probablement de moyen de défense. - Il existe deux orifices génitaux, situés sur la hanclıe ou derrière la hanche de la deuxième paire de pattes. - Beaucoup de Chilognathes peurent se rouler en spirale.

Genres Iulus, Blaniulus, Polydesmus, Glomeris, etc. Ces animaux se nourrissent surtout de substances végétales; il en est qui nuisent beaucoup à l'agriculture, en rongeant les seniences au moment de la germination. Tels

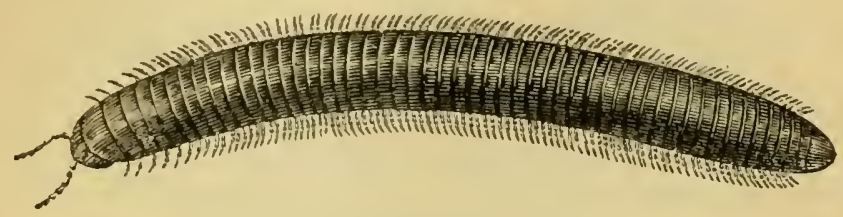

Fig. 493. - Jule.

sont : l'lulus tcrestris, le Blaniulus guttulutus, le Polydesmus complunatus, etc. La première de ces espèces ravage parfois les champs de betteraves. La. seconde attaque les racines de divers légumes et mème celles de la vigne; elle s'introduit dans les fruits tonıbés à terre (voir p. 394).

2 ordre : Chilopodes. - Myriupodes à corps déprimé, poureus d'une seule paire de pattes à chuque annean.

Les antenues sont longues, à 12 articles au moins. - L'appareil buccal se compose d'un labre, de deux mandibules médiocres et d'une valve quadrilobée représentant deux paires de màchoires. En outre, la première paire de paltes a les hanches soudées de manière à simuler une lérre inférieure à palpes pédiformes ( $\%$ ìıs, lèvre; $\pi \approx \tilde{s} s$, pied), et la seconde paire, à hanches très larges et également soudées, constilue une pince puissante dont les mols en forme de crochets (forcipules) offrent à leur extrémité un étroit orifice: c'est là que débonche le canal. excréteur d'une glande à venin qui occupe leur base. - Les stigmates souvrent sur les deux còtés des anneaux. - Il n'existe qu'un seul orifice génital situé à l'extrémité postérieure du corps, au-dessous de l'anus. - Les jeunes naissent avec 6 ou 8 paires de pattes et mème, chez les Scolopendres, avec toutes les pattes.

Gentes Scolopendra, Lithobius, Geophilus, Scutigera, etc. Ces animaux se nourrissent surtout d'Araignées et de petits Insectes.

La morsure des Scolopendres est douloureuse. Les forcipules pressent horizontalement la peau et produisent deux piqûres latérales dans chacune desquelles est déversée une goutte de renin. La Scolopendre cingulée (Ścolopendia cingulata Latr.), qui est l'espèce commune du Midi de la France, peut provoquer, par sa morsure, un gonflement local, parfois accompagué d'un mourement fébrile passa- 
ger. Aux Antilles, ì la Guyane, au Sénégal, d'autres espèces font des blessures beaucoup plus sérieuses encore. On peut adopter le mème traitement que nous avons indiqué à propos des piqûres de Scorpions.

Divers auteurs ont signalé, d'autre part, l'introduction, dans les fosses nasales et dans les sinus frontaux de l'Homme, de petites espèces du même groupe, notamment de Géophiles. La présence de ces hôtes incommodes se traduit par de violentes douleurs, persistant quelquefois pendant des années.

\section{CLASSE VI}

\section{INSEGTES}

Arthropodes à respiration aérienne, s'effectuant par des trachées; tête, thorax et abdomen distincts; une paire d'antennes; thorax portant trois paires de pattes et souvent des ailes.

Pour les anciens auteurs, y compris Linné et Fabricius, le nom d'Insectes s'appliquait à la généralité des Arthropodes. Au point de vue étymologique, en effet, il exprime l'état articulé du corps, puisqu'il est la traduction littérale du mot latin insectum (dérivé par syncope d'intersectum, entrecoupé). Mais les progrès de la science en ont restreint l'application aux seuls Articulés hexapodes.

Le corps est toujours divisé en trois régions: la tête, le thorax et l'abdomen, et le nombre d'anneaux appartenant à chacune de ces régions est à peu près constant, aussi bien que celui de leurs appendices.

La títe est en apparence formée d'un seul tronçon, mais on la regarde comme composée de quatre somites, en raison des quatre paires d'appendices mobiles dont elle est pourve : une paire d'antennes et trois paires de gnathites $(\mathbf{1})$.

Les antennes sont situées sur le sommet ou sur les còtés de la lète; elles sont formées d'articles peu mobiles et offrent une remarquable variation de forme. Quant aux pièces buccales, qui sont insérées à la partie inférieure de la tête, nous en donnerons la description en traitant des organes digestifs.

Le thorax, réuni à la tête par une partie étroite, comprend trois somites : le prothorax, le mésolhorax et le métathorax. Le premier est tantôt libre, mobile et bien développé, tantôt plus ou moins réduit et soudé au mésothorax. Le nom de corselet désigne le seul prothorax lorsque celui-ci est libre, et le thorax entier lorsque les anneaux sont soudés. Sur la face ventrale de chacun des trois somites s'articule

(1) Les yeux des Insectes ne paraissent pas avoir de rapports morphologiques avec les appendices. 
une paire de pattes. Chaque patte est composée de einq parties : la hanche, article basilaire enclavé dans une cavité de l'épimère correspondant; le trochanter, tronçon très court qui parfois se divise en deux pièces et d'autres fois se soude à l'article suivant; la cuisse, allongée et souvent fort épaisse; la jambe, égalennentlongue, mais grêle; enfin, le tarse, offrant de un à cing articles, dont le dernier porte d'ordinaire un ou deux crochels ou d'autres appendices.

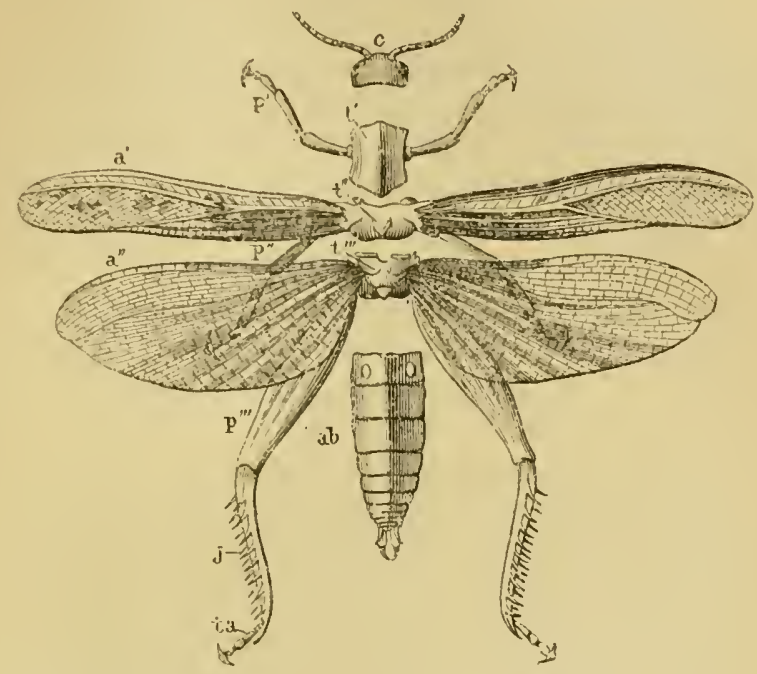

Fig. 49k. - Parties eonstilutives du eorps dinn Insecle. $-c$, la lẻte portant les yeux et les antennes. $t^{\prime}$, prollorax, portant la $l^{\text {ro }}$ paire de paltes $p^{\prime}$. $t^{\prime \prime}$, mésolhorax, portant la $2^{\circ}$ paire de paltes $p^{\prime \prime}$ et la Ire paire dailes $a^{\prime} . t^{\prime \prime \prime}$, métalliorax, portant la $3^{\circ}$ paire de paltes $p^{\prime \prime \prime}$ et la seeonde paire dailes $a^{\prime \prime}$. $j$, jambe. $t a$, tarse. $a b$, abdomen.

Les ailes, qui n'existent que chez les Insectes à l'état parfait, représentent un type spécial d'organes appendiculaires, et ne peurent ètre comparées aux membres proprement dits. Elles s’insèrent sur la partie dorsale du mésothorax et du métathorax, entre le tergum et l'épimère, au moyen de pièces courtes, de forme variable, auxquelles on donne le nom d'apodèmes articulaires ou d'osselets. Chacune des ailes consiste en une lame minee, formée de deux membranes étroitement appliquées l'une contre l'autre el soutenues par une charpente de tubes chitineux appelés nervures. Ces tubes sont destinés à livrer passage aux nerfs, aux trachées et au sang; ce sont eux qui déterminent la forme et le contour de l'aile. On distingue des nervures proprement dites : ee sont les principales, surtout celles qui partent de la base ou poinl d'insertion de l'aile; et des nervules, lignes intermédiaires, de moindres dimensions, longitudinales ou transversales. Toutes ees lignes laissent entre elles des espaces appelés cellules, qui fournissent de bons caractères de classification. - La consistance des ailes est variable. Le plus souvent elles sont membraneuses ct nues, 
ainsi qu'on le voit chez les Hyménoptères, par exemple. Celles des Lépidoptères sont membraneuses et couvertes d'écailles. Les ailes antérieures des Coléoptères sont, au contraire, cornées et forment des boucliers solides, servant peu au vol et remplissant surtout un rôle protecteur : on les nomme élytres (Êlutpov, enveloppe). Chez beaucoup d'Orthoptères, ces ailes antérieures sont simplement parcheminées (tegmina). Enfin, chez les Hémiptères hétéroptères, elles sont cornées à la base et membraneuses vers l'extrémité libre : ce sont des hémélytres. - Le nombre des ailes n'est pas constant. La plupart des Insectes en possèdent deux paires, l'antérieure appartenant au méso-

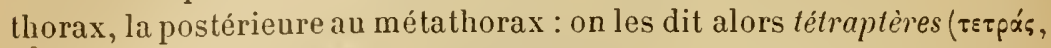
quatre; $\pi \tau s p o ́ v$, aile). Mais la paire postérieure manque quelquefois. Ainsi, chez les Diptères ( $\delta i$, deux), qui constituent un ordre naturel, elle est représentée par deux organes appelés balancier's, formés d'une petite tige ou style terminée par un bouton ou capitule. Enfin, il existe des groupes importants d'Insectes tout à fait dépourvus d'ailes ou aptères, comme les Poux et les Ricins, et tuus les ordres comprennent des espèces dont les deux sexes, ou les femelles seules, sont dans le même cas.

L'abdomen s'articule largement avec le thorax. On n'est pas toujours fixé sur le nombre de segments qui le composent, en raison de l'atrophie fréquente, de la fusion ou de l'invagination des deux derniers. Cette région est dépourvue de pattes chez l'adulte, mais elle porte quelquefois, chez les larres, des appendices transitoires connus sous le nom de fausses pattes. Sur les derniers anneaux, il existe sourent des appendices qui jouent un certain rôle dans les fonctions de reproduction et constituent ce qu'on appelle l'armure génitale.

Le système nerveux des Insectes offre un degré de coalescence assez variable, mais s'accusant toujours à mesure que l'individu évolue vers l'état parfait. Le cerveau, souvent bilobé, envoie des nerfs aux yeux, aux antennes et à la lèvre supérieure. Le ganglion sous-œsophagien distribue ses filets aux trois paires d'appendices buccaux. Viennent ensuite trois ganglions thoraciques peu distincts, innervant les organes de la région, ainsi que les appendices. Quant aux ganglions abdominaux, ils sont d'ordinaire étroitement groupés, parfois même réunis en une seule masse, et la coalescence peut aller jusqu'à la fusion totale des groupes ganglionnaires de l'abdomen et du thorax.

Les sens sont fort délicats. Le tact s'exerce surtout au moyen des antennes et des pièces buccales. L'odorat a son siège dans les antennes. Les organes auditifs peuvent s'observer sur divers points. Les sensations gustatives paraissent être perçues par certaines régions de la bouche. Enfin, les organes de la vision sont, soit des ocelles, qui se rencontrent chez les larves, ainsi que sur le vertex ou sommet de la tête de beaucoup d'adultes; soit des yeux à facettes, propres aux Insectes parfaits et situés sur les côtés de la tête. 
La conformation des organes digrstifs varie avec le régime des Insectes. En première ligne, l'armature buecale offre un aspect tout différent chez les Insectes broyeur's, liecheurs et suceurs. Dans tous les cas, cependaut, on observe les mêmes parties fondamentales, mais diversement modifiées suivant le genre de ric, ainsi que Savigny l'a depuis longtemps établi. Nous exposerons ici la disposition typique que présentent les broyeurs, et nous renverrons ì l'étude des différents ordres d'Insectes pour la connaissance des modifications que subissent les pièces buceales, ainsi que pour la démonstration de leurs homologies.

Les Insectes broyeurs, Coléoptères, Orthoptères, Pseudo-Névroptères et Névroptères, ont les pièces buccales insérées à peu près séparément sur le cadre qui limite la bouche. Elles comprennent deux organes impairs, la lère

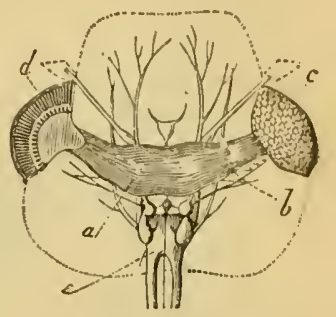

Fig. 495. - Yeux ù facetles du Ilameton. - $a$, cerreau. $b$, nerfs optiques. $c$, œil eutier. $d$, aeil coupé longitudinalenent. supérieure ou labre et la lèvre inférieure; deux organes pairs, les mandibules et les mâchoires. Le labre, qui n'est pas de nature appendiculaire, est inséré au bord supérieur du cadre buccal, sur l'épistome ou chaperon (clypeus). Au-dessous, se trouve la première paire d'appendices masticateurs, les mandibules, articulées à droite el à gauclıe de la bouche, et sourent pourvues de dents à leur bord interne : ces pièces, toujours solides, se meurent avec force d'un côté à l'autre, et sont bien propres à diviser les aliments; elles ne portent jamais d'appendice latéral. - Les mâchoires ou maxilles, situcees au-dessous des mandibules et insérées un peu en arrière, représentent la seconde paire de gnathites et offrent une organisation complexe. Chacune d'elles présente un article basilaire ou gond, suivi d'une tige qui porte d'une part, à son côté externe, par l'intermédiaire d'un petit article, écailleux, un appendice pluriarticulé ou palpe maxillaire; d'autre part, à sa partie interne et terminale, deux branches ou lobes, l'un externe, l'autre interne. Celui-ci, souvent garni en dedans d'épines, de denticules, de cils, etc., représente surtout la partie préhensile de la
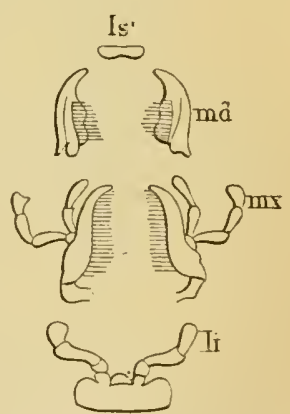

Fig. 496. - Appareil masticateur du Carabe doré. $l s$, levre supérieure. md, mandibules. $m x$, mâehoires, li, levre inférieure. màchoire. Quant au lobe externe, il est parfois composé de plusieurs articles et palpiforme : on l'appelle alors palpe maxillaire interne; d'autres fois, il surmonte le lobe interne et le recourre a la façon d'un casque, ce qui lui vaut le nom de galea (Orthoptères). Les mâchoires, et en particulier leur lobe interne, forment en se rappro. chant une sorte de pince qui maintient les aliments entre les mandi-

Railliet. - Zoologie. 
bules, puis achève la trituration grossièrement commencée par ces appendices. Une troisième et dernière paire de gnathites sert à former la lèvre inférieure. Celle-ci est en effet constituée par deux appendices analogues aux mâchoires, mais rapprochés et soudés sur la ligne médiane. Elle présente d'abord une pièce

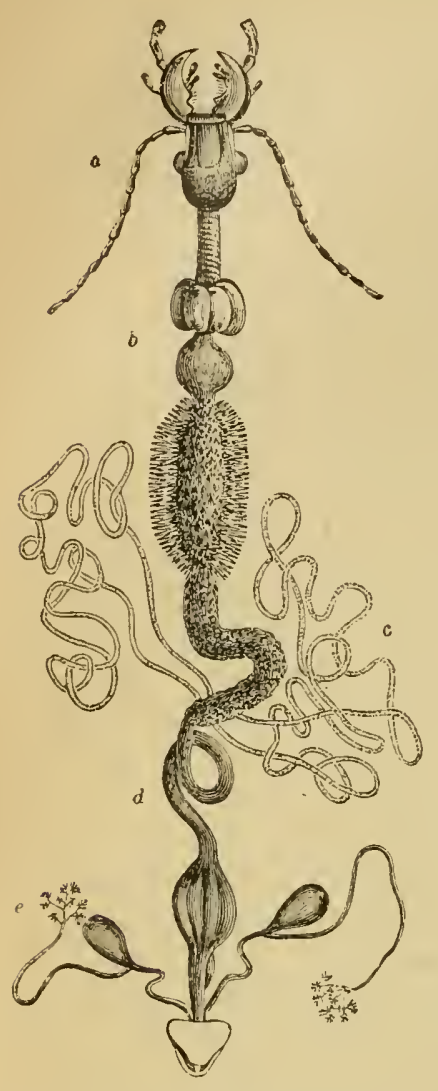

Fig. 497. - Appareil digestif diun Insecte (Carabus auratus) d'après E. Blanchard. - $a$, tète portant les antennes, les mandibules, etc. $b$, jabot et gésier, suivis du ventricule chylifique. $c$, lubes de Malpighi. $d$, intestin. $e$, glandes anales avec leur réservoir. basilaire toujours bilobée, le menton. Sur les parties latérales du menton se trouvent deux palpes maxillaires, et sur sa face supérieure, une pièce terminale, la languette, simple ou bifurquée, qui offre en général deux appendices appelés paraglosses. Il est facile de voir que le menton répond aux gonds et aux tiges des mâchoires, les palpes labiaux aux palpes maxillaires, la languette aux lobes internes et les paraglosses aux lobes externes. Le rôle de la lèvre inférieure est de retenir contre la cavité buccale les aliments que divisent les mâchoires; elle concourt en outre, surtout par ses palpes, à la préhension de ces aliments.

La bouche est suivie d'un pharynx chitineux; d'un osophage, souvent dilaté en jabot; d'un gésier ou proventricule, appareil triturant, parfois fort réduit; d'un ventricule chylifique ou estomac proprement dit, dilaté en avant et atténué en arrière; d'un intestin, séparé de l'estomac par un étranglement valvulaire et terminé par un rectum assez large qui aboutit à l'anus, situé dans le dernier anneau. - Des glandes en nombre variable peuvent être annexées au tube digestif : telles sont les glandes salivaires, qui débouchent dans le pharynx; les glandes gastriques, qui affectent d'ordinaire la forme de villosités garnissant la surface extérieure du ventricule chylifique; les canaux de Malpighi, qui sünsèrent au point de jonction de l'estomac et de l'intestin; enfin, les glandes rectales et les glandes anales.

L'appareil circulatoire se réduit à un simple vaisseau dorsal contractile ou cœur, fixé à la paroi supérieure de l'abdomen par des muscles aliformes et divisé en un certain nombre de chambres ou ventricu- 
lites. Ces chambres sont séparées par des replis membraneux offrant chacun deux orifices latéraux, par lesquels le sang pénètre du sinus péricardique dans le caur. La systole s'effectue progressirement du ventriculite postérieur vers l'antérieur, et les replis fonetionnent comme valvules pour empècher la sortie du sang et son retour en arrière. La chambre
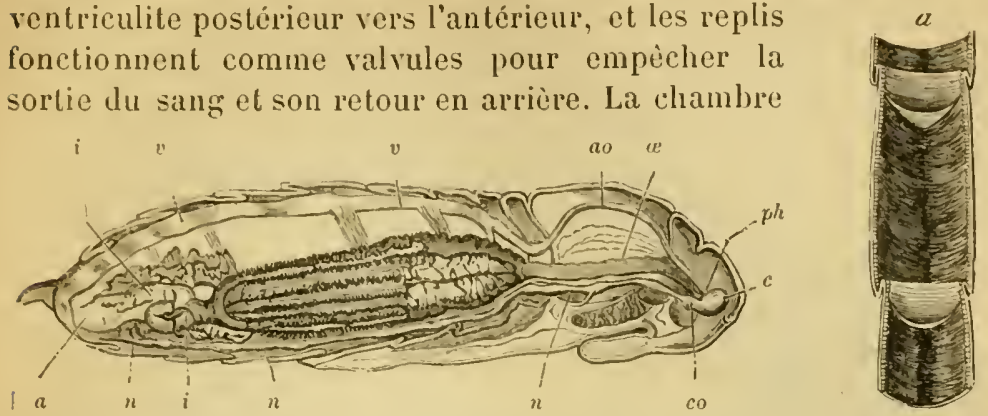

Fig. 498, - Section longitudinale d'une clurysalide de Papillon, montrant jes organes intérieur's. $-v, v$, raisseat dorsal. $a 0$, aolte. $c$, cerveau. $c 0$, collier osophagien. $n, n, n$, chaise ganglionuaire ventrale. $p h$, pharynx. $\propto$, œsophage, se continuant avec un estomac très large. $i, i$, inteslin. $a$, anus.

liig. 499. -- Porlion du vaisseau dorsal du llanneton, ouvert pour montres" les valvules et les oritices lalíraux.

antérieure se prolonge en un vaisseau aortique qui conduit le sang dans les lacunes interorganiques, et des courants réguliers le distribuent dans les différentes régions du corps.

Liappareil respiratoire est toujours trachéen. Les stigmates s'ouvrent sur les parties latérales du corps; mais on n'en trouve jamais plus d'une paire sur le même anneau, et les Insectes adultes n'en possèdent pas à la tête ni sur le dernier anneau de l'abdomen. Chez les larves de la plupart des Diptères, ils ne se rencontrent que sur le deuxième et le dernier segment. Certains Insectes aquatiques (Nèpes, larves de Cousins) ont mème l'abdomen prolongé par une sorte de tube respiratoire, qu'ils amènent par moments à la surface de l'ear.

On observe chez les Insectes des organes sécréteurs assez variés : nous signalerons, en particulier, les glandes séricigènes, qui paraissent ètre des glandes salivaires modifiées et qui fournissent la soie avec laquelle beaucoup de larres se tissent un cocon; les glandes cirieres, diversement réparties suivant les espèces; les glandes odorifères; les glandes venimeuses des Hyménoptères porte-aiguillon; etc.

Les sexes sont toujour's séparés; souvent les mâles diffèrent des femelles par une taille plus petite, des couleurs plus vives, etc. Divers Insectes offrent des cas de parthénogenèse et mème de pédogenèse.

L'appareil génital mále se compose de deux testicules, simples ou multilobés, auxquels font suite deux canaux déférents sinueux généralement dilatés en vésicules séminales ì leur partie inférieure; les glandes accessoires peurent être annexées à ces conduits pour fournir l'enveloppe des spermatophores. Les deux eanaux déférents se réunissent en un canal éjaculateur conmun, dont l'extrémité terminale 
est susceptible de se projeter au dehors sous forme de pénis tubuleux. Des pièces cornées entourent ce pénis et constituent ce qu'on appelle l'armure copulatrice.

L'appareil femelle comprend deux ovaires symétriques, formés d'un nombre variable de tubes ou vésicules ovigènes, qui débouchent de chaque côté dans un canal vecteur ou trompe. Les deux trompes

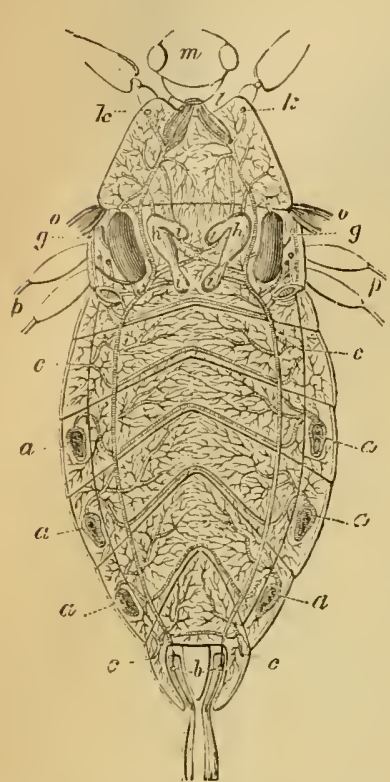

Fig. 500. - Appareil respiraloire de la Nèpe ceudrée, amplifié, d'après L. Dufour. $-a, a, a$, les faux stigmales, vus par leur face interne. $b$, stigmales du siphon respiratoire. auxquels aboutissent les deux trones irachcens principaux. $c$, insertion borgne de certaius trones trachéens. $g, h, i$, vésicules Irachéennes. $k$, trachée destincé aux membres antérieurs. $l$, faisceau de trachées destinées à la têle. $m$, portion de la tète. o, portion d'hémélı tre. $p$, portion des pattes moyenues el postérieures. se réunissent pour former un oviducte impair, dont la portion terminale représente le vagin. Des glandes sébifiques sont annexées à l'oviducte ou au vagin; en outre ces parties sont presque toujours pourvues d'une poche copulatrice, qui reçoit le sperme lors de l'accouplement, et d'un réservoir secondaire ou réceptacle séminal, qui emmagasine ultérieurement la semence. On observe aussi une armure génitale, qui sert à la ponte (oviscapte, tarière) ou se transforme en organe de défense (aiguillon).

La plupart des Insectes sont ovipares. Les œufs sont fécondés, au moment de leur passage devant le réceptacle séminal, par la pénétration des spermatozoïdes à travers une petite ouverture ou micropyle située à un de leurs pôles. Le développement de l'embryon est assez rapide; le jeune brise bientôt la coque de l'œuf et se présente sous la forme d'une larve en général bien différente de ses parents, larve qui doit, par suite, subir certaines transformations ou métamorphoses pour acquérir les caractères de l'état adulte. On peut, à ce point de vue, distinguer trois groupes parmi les Insectes : $1^{\circ}$ Quelques-uns naissent avec la forme des adultes; ils ne subissent pas de métamorphoses proprement dites et sont, pour cette raison, appelés amétaboliens (Poux, Podures); $2^{\circ}$ d'autres présentent des demimétamorphoses ou métamorphoses incomplètes ; il ne leur manque, pour arriver à l'état parfait, que des ailes et parfois quelques articles aux antennes ou aux membres: ce sont les hémimétaboliens (Sauterelles, Pentatomes); $3^{\circ}$ enfin, un grand nombre sont appelés à subir une métamorphose complète; ils apparaissent sous l'état de larves vermiformes et doivent passer par une période de repos (nymphe) avant de revêtir la forme d'Insecte parfait ou imago: 
on les qualifie alors de métaboliens (Coléoptères, Ilyménoptères, Lépidoptères, Diptères, cte.). Nous rerrons même que, chez certains Insectes (Méloüdés), la métamorphose se complique et mérite le nom d'hypermétamorphose, qui lui a été appliqué par Fabre, d'Arignon, dès 1837.

La classe des Insectes renferme un nombre immense d'espèces, présentant une inlinic rariété de formes, de mceurs, et souvent remarquables par le déreloppement de leurs facultés. Ces animaux sont répandus dans toutes les régions du globe. $A$ l'état fossile, on les

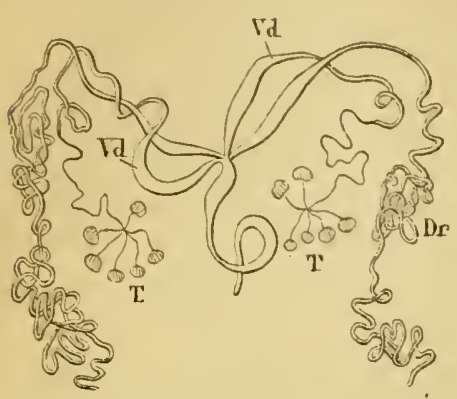

Fig. 501. - Organes génitaux mảles du Hannelon, d'après Gegenbaur. - T', lesticules. $\checkmark d$, portion renflése des canaux déférents. Dr, glandes annexes. rencontre pour la première fois dans le terrain dévonien.

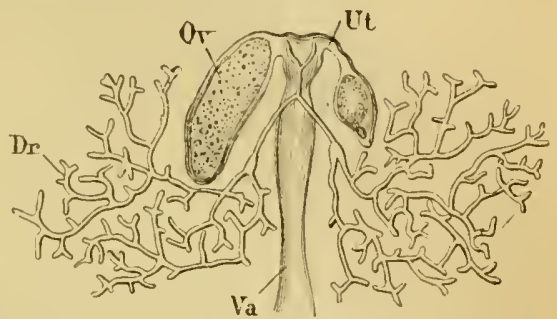

Fig. 502. - Organes génitaux femelles du Melophagus ovinus, daprès Leuckirt. - Ov, lube ovarien renfermant un ouf. $U t$, ulérus. $D r$, glandes anuexes. li, vagin.

On a proposé, pour ce groupe, des classifications assez variées. Swammerdam se basait sur les métamorphoses, Linné sur la constitution des ailes et Fabricius sur celle des organes buccaux. On fait aujourd'hui entrer en ligne de compte ces trois éléments. Toutefois il a fallu reconnaître que l'absence des ailes n'offrait aucune importance au point de rue taxinomique, et les Insectes aptères, dont les anciens auteurs formaient des ordres spéciaux, ont été rattachés comme groupes secondaires aux autres ordres.

D’après ces principes, nous adopterons la classification suivante :

Appareil buccal.

Ailes.

$\left.\begin{array}{c}\text { Ailes. } \\ \left(\begin{array}{c}\text { Deux (les postérieures étant trans- } \\ \text { formées en balanciers)............ }\end{array}\right.\end{array}\right\}$ Complètes... Drptères.

Ordres.

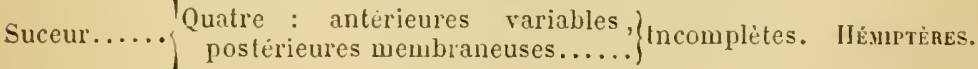

Quatre : toutes membrancuses, Complètes... Lépıoptères.
recouvertes d'écailles...........

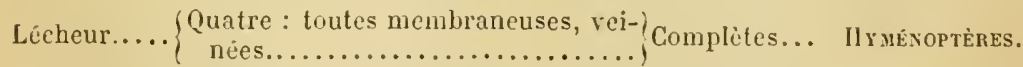

Quatre: toutes membraneuses, fine-\{Complites ... NÉVRoptéres.

ment réticulées.............. Incomplètes Pseudo-NÉvroptères.

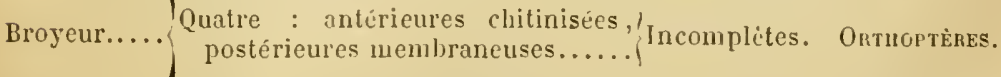

Quatre : antérieures en élytres, pos-t Complites... Colếptères.
térjeures membrancuses.......... Com 


\section{PREMIER ORDRE}

\section{DIPTERES}

Insectes suceurs, pourvus de deux ailes seulement; métamorphoses complètes.

Comme leur nom l'indique (ốs, deux; $\pi \tau$ póv, aile), les Diptères (1) ne possèdent que deux ailes, les antérieures, nues et membraneuses; mais, en arrière de chacune d'elles, on observe souvent une petite écaille (cuilleron) recouvrant elle-même une sorte de bouton pédiculé connu sous le nom de balancier. On est d'accord aujourd'hui pour roir, dans les balanciers, les ailes de la seconde paire transformées : ce sont, en tout cas, des organes très importants, car leur disparition entraîne la perte de l'équilibre et aboutit, par suite, à l'abolition du vol.

L'appareil buccal est propre à sucer et souvent à piquer : c'est une trompe ou un sucoir assez complexe et variable. La partie essenlielle est représentée par la lèvre inférieure, qui replic ses bords en dessus, de manière à constituer un canal. Dans l'iniérieur de cette gaine, existent des stylets sétiformes, qui jouent le rôle d'appareil perforant; le nombre maximum de ces soies est de six, savoir: une pièce impaire, dite épipharynx, correspondant au labre, mais prolongeant la face dorsale du pharynx; une autre pièce opposée à celle-ci, l'hypopharynx, qui continue la face ventrale du même organe; enfin, les deux mandibules et les deux mâchoires, celles-ci pourvues de palpes qui semblent annexés à la base de la trompe. Mais souvent une partie de ces soies s'atrophient, et dans certains cas (Muscidés), il ne reste que l'épipharynx et l'hypopharynx, propres ou non à perforer.

Les pieds se terminent par un tarse à cinq articles, dont le dernier est muni de deux griffes, accompagnées en général de deux ou trois coussinets en forme de semelles, dits pelotes ou pulvilles; la face inférieure de ces pelotes est garnie de poils à extrémité cupuliforme produisant une adhérence à la façon de petites ventouses. Les Diptères ont des métamorphoses complètes. Leurs larves se présentent sous deux formes distinctes : les unes sont munies d'une tête où les pièces buccales sont assez nettes, ainsi que les antennes et les yeux; les autres, beaucoup plus communes, sont acéphales, et leur extrémité antérieure est tout à fait charnue ou présente seulement deux crochets cornés. - Les larves céphalées donnent, en subissant leur dernière mue, des nymphes mobiles(Cousins) ou immo-

(1) Macquart, Hist. nat. des Insectes Diptères. Paris, 1834-1835. - R. Schiner, Fauna austriaca (Diptera). Wien, 1862-1864. - Künckel, Les Insectes (Brehm). Paris, 188'. 
biles (Taons); mais les larves acéphales ne changent pas de peau au moment de la nymphose : cette peau se durcit et donne lieu à une pupe cn tomnelet, dans laquelle se troure cacliée la véritable nymplie (Muscidés, Olistridés).

Le gente de vie des Diptères, tant i l'état de larres que sous la forme d'Insectes parfaits, offre à notre point de vue un grand intérêt. ll ne sera pas inutile, sans doute, de lournir ì eet égard quelques indications générales.

Les Mouches - c'est le nom qu'on applique rulgailement, sensu latiori, aux Insectes parfaits - se nourrissent de substances très diverses. Il en est beaucoup qui fréquentent l'Homme et les animaux, pour se nourrir de leur sang ou de leurs humeurs. Celles qui possèdent une trompe molle (Musca, Hydrotira, ete.), incapables de perforer la peau, se bornent ì sucer les produits liquides exhalés naturellement (sueur, larmes, mucus nasal, etc.) ou développés à la surface des plaies. Elles peuvent cependant à l'oecasion jouer le rôle de portevirus, e’est-à-dire servir au transport des éléments infecticux. En fréquentant les animaux malades ou les cadarres, on concoit qu'elles puissent, en effet, souiller leurs pattes et leur trompe de produits virulents ou septiques, et aller déposer ensuite ces produits sur le corps des sujets sains. Mais, en dehors des maladies dites ì "virus volatil ", comme la fièrre aphteuse, la péripneumonie, la peste bovine, une telle transmission n'est possible quà la faveur de plaies récentes, ce qui est évidemment exceptionnel.

Dautres Diptères sont pourvus d'une trompe plus puissante, qui leur permet de percer aisément la peau des Mammifères ou des Oiseaux (Ornithomyia, Stomoxys, Tabamus). lls doivent donc tourmenter davantage les animaux; de plus, ils paraissent aptes à jouer un rôle beaucoup plus actif dans la propagation des maladies virulentes, car leur trompe pénétrante, une fois souillée de produits infectieux puisés sur des cadarres ou des sujets malades, doit pouroir facilement inoculer ces produits à des individus sains.

Mais les Mouches peurent concourir encore dune façon plus indirecte à la transmission des maladies parasitaires el infectieuses. En se repaissant de matières fécales, par exemple, elles sont exposées à y recueillir une foule de microbes pathogènes ou d'œufs de parasites, qu'elles iront ensuite déposer sur les aliments de l'Homme ou des animaux, soit par simple contact, soit arec leurs excréments. Les recherches de Grassi ont établi, en effet, que les oufs de Trichocéphales, de Ténias, d'Oxyures, traversent le tube intestinal de la Mouche commune sans être aucunement altérés par les sucs digestifs; Savtshenko et Simnonds ont fait la mème démonstration pour le Bacille du choléra, etc.

Un autre point intéressant à étudier dans l'histoire des Diptères est relatif au parasitisme et au pseudo-parasitisme de leurs larves. - Kirby 
et Spence ont donné le nom de scoleciasis à la présence de larves d'Insectes dans le corps de l'Homme ou des animaux, ainsi qu'aux accidents qui en résultent; dans un sens plus restreint, ce fait pathologique est qualifié de myiasis ou de myiase, lorsqu'il s'agit de larves de Diptères.

Que celles-ci vivent normalement en parasites ou qu'elles se développent d'une façon accidentelle, leur siège est très varié. On peut les rencontrer dans le tissu conjonctif sous-cutané, les fosses nasales, les sinus, le pharynx, l'estomac, l'intestin, etc. Elles appartiennent pour la plupart à la famille des OEstridés et à celle des Muscidés.

La myiase cutanée est surtout produite par des OEstridés dont les larves, soumises à un parasilisme nécessaire, vivent isolément dans des tumeurs dont elles proroquent la formation. Les larves des Muscidés se présentent plus rarement avec ce même caractère (Ochromyia anthropophaga); dans la plupart des cas, au contraire, elles ne subissent qu'un parasitisme occasionnel, les Mouches ayant effectué leur ponte dans des plaies mal tenues ou à l'entrée des cavités naturelles telles que les oreilles, le vagin, le fourreau de certains animaux, plus rarement sur la peau et dans les oreilles de l'Homme; elles sont alors réunies en plus ou moins grand nombre sur un même point et occasionnent souvent des désordres considérables, dévorant la peau et les tissus sous-jacents comme elles feraient d'une proie morte. En ce qui concerne l'espèce humaine, les observations de ce genre, publiées jusqu'à présent, ont été presque toutes recueillies sur des gens malpropres, et en particulier sur des ivrognes endormis; elles ont été rapportées, avec plus ou moins de certitude, aux espèces suivantes: Lucilia macellaria, Lucilia Cresar, Calliphora vomitoria, Sarcophaga camaria, Sarcophila magnifica, Anthomyia pluvialis; et l'on remarquera que la plupart de ces espèces se développent normalement dans les chairs en voie de corruption.

Nous étudierons la myiase des eavités nasales chez les animaux à l'occasion des OEstrinés cavicoles; chez l'Homme, en traitant de Lucilia macellaria et de Sarcophila magnifica.

Quant à la myiase du tube digestif, très connue chez les animaux (Gastrophilus), elle a été fort discutée en ce qui concerne l'Homme, et Davaine allail même jusqu'à déclarer que tous les faits signalés comme s'y rapportant tenaient à des erreurs d'observation ou à la supercherie des malades. Cependant, il est bien établi aujourd'hui que diverses larves de Diptères, introduites accidentellement dans le tube digestif de l'Homme, peuvent y vivre un certain temps et même y poursuivre une partie de leur érolution sans être digérées. G. Joseph en a dressé la liste suivante: Piophila casci, Diosophilamelanogaster, Homalomyia incisurata, canicularis et scalaris, Hydrotza meteorica, Cyrtoneura stabulans, Pollenia rudis, Calliphora erythrocephala et vomitoria, Lucilia Casar et regina, Sarcophaga himorrhoidalis et hrmatodes, 
Eristalis arbustorum. Nous verrons d’ailleurs que cette liste doit ètre dès à présent étendue.

Aux nombreux inconvénients que nous venons d'indiquer, les Diptères ajoutent celui d'importuner, de tourmenter l'llomme et les animaux par leurs chatouillements désagréables ou leurs piqùres.

Pour éviter leurs attaques, on a recours ả divers moyens, dont la connaissance est devenue vulgaire. On peut tuer les Mouches qui fréquentent les habitations, par exemple, au moyen de substances toxiques, ou les prendre à l'aide de pièges divers. D’autre part, on les empêche d'y pénétrer en suspendant un filet à la fenètre, les mailles fussent-elles mème fort larges. I'our garantir les animaux, et en particulier les Chevaux, on emploie des filets spéciaux, des oreillères, des émouchoirs de crins, ete. Enfin, certaines substances éloignent d'emblée les Nouches; telles sont: le sue de feuilles de noyer, obtenu par décoetion ou par le simple froissement des feuilles sur le corps des animaux; l'huile de laurier; l'huile de cade ou l'huile empyreumatique, dont le principal ineonvénient est de salir la robe du Cheval et les harnais; enfin, l'huile dite de Poisson (huile de Baleine).

3 sous-ordres: Brachycères, Némocères et Aphaniptères.

PREMIER SOUS-ORDRE

\section{BRACIYCERES}

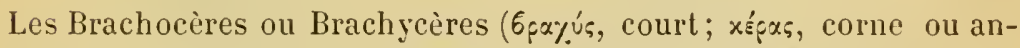
tenne) sont caractérisés par leurs antennes courtes, à trois articles, dont le dernier, plus fort et d'aspect parfois annelé, est d'ordinaire muni d'un style simple ou articulé. Le corps est ramassé; le port est celui des Mouches, sauf ruand les ailes manquent.

Famille des HIPPOBOSGIDÉs. - Encore nommés Coriacés, ces Insectes sont reconnaissables à leur corps aplati, large, élastique, à leur tête petite, et à leurs tarses munis de deux griffes puissantes, à deux ou trois dents chacune. Contrairement à la généralité des Diptères, ils ne possèdent pas de trompe labiale, mais un appareil perforateur formé par l'épipharynx et l'hypopharynx, et engainé par la moitié des mâchoires. La lèrre inférieure est très courte, et les palpes font défaut.

Les Hippoboseidés, avec le groupe voisin des Nyctéribiidés, sont connus depuis longtemps sous le nom de Pupipares ou Nymphipares. On croyait autrefois, en etfet, que la femelle domnait naissance à ses petits sous la forme de pupes; mais Leuckart a montré que la larve, bien qu'effectuant sou entière évolution dans l'utérus de la mère, se transforme en nymphe seulement après la ponte : ces Insectes sont done en réalité larizares. Ils sont parasites des Mammifères et des Oiseaux.

Genre Hippobosque (Hippotosca L.). - Ailes larges et obtuses; des jeus 
à facettes; point d'ocelles; antennes à style apical nu; ongles des tarses bidentés.

L'Ilippobosque du Cheval (H. equina L.) est long d'environ 8 millimèlres, non compris les ailes; il présente une teinte brune, avec des taches jaunes et blanchàtres; les ailes sont légèrement roussâtres.

Cet Insecte est rulgairement connu sous le nom de Mouche araignée, que lui a donné Réaumur, et qu'il doit en particulier à ses pattes longues et écartées. Il attaque surtout les Chevaux, courant arec rapidité

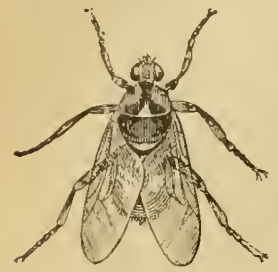

Fig. 503. - Hippobosque du Cheval, grossi deux fois. à la surface du corps, et enfonçant son suçoir dans les points où la peau est fine et peu velue: autour de l'anus, au périnée, à la face interne des cuisses. On le trouve aussi sur les autres Équidés, plus rarement sur le Bœuf, le Chien et le Porc; l'Homme lui-même n'est pas toujours à l'abri de ses atteintes. Sous l'influence de ses piqûres, certains Chevaux très irritables entrent en fureur.

Les Hippobosques reviennent avec opiniâtreté sur les animaux quand on cherche à les en éloigner; si on parvient à les prendre à la main, il est prudent de leur arracher la tête, car l'élasticité du tégument et la forme aplatie du corps leur permettent de résister à un certain degré de compression.

Rondani reconnaît dans l'ancien type $H$. equina L. les trois espèces suivantes: H. equina, qui tourmente les Ghevaux, les Bœufs, les Chiens, etc. ; H. tuurina, trouvé sur le Bœuf ; $H$. canina, qui s’attaque de préférence au Chien.

On signale en outre: H. nigra Perty, du Brésil, sur les Chevaux; H. camelina Savigny, d'Égypte, sur les Chameaux, etc.

Genre Ornithomyie (Ornithomyia Latr.). - Ailes larges et obtuses ; des yeux et des ocelles; antennes en forme de valves velues, sans style; ongles tridentés.

L'Ornithomyie aviculaire (0. avicularia [L.]) est longue de $4^{\mathrm{mm}}, \breve{a ~ a ̀ ~}$ $5^{\mathrm{mm}}, \mathrm{ă} ;$ elle est d'un jaune verdàtre; le thorax est noiràtre en-dessus; les ailes sont enfumées.

Cette espèce est parasite de divers Oiseaux vivant en liberté : Perdrix, Merles, Alouettes, etc. Nous en possédons quelques exemplaires recueillis sur le Pigeon domestique : en 1886, dans la Marne (Thary), et en 1893, dans le Nord (Éloire).

C'est elle sans doute (et non pas Ornithobia pallida ou Lipoptena cervi, dont les ongles sont bidentés) que veut désigner P. J. Van Beneden quand il parle d'une Mouche rencontrée en abondance sur la peau d'un malade de l'hòpital de Louvain.

Genre Mèlophage (Melophagus Latr.). - Les ailes ont disparu. Des yeux très petits; point d'ocelles; antennes nues, en forme de tubercules, sans style; ongles bidentés. 
Le Mélophage du Mouton (M. ovinus [L.]) mesure 3 à ä millimètres de long; il est de teinte ferrugineuse, avec l'abdomen brun grisàtre, irrégulièrement tacheté.

Cet Insecte aptère, connu des bergers sous le nom inexact de "Pou ", vit sur la peau du Mouton. Nous l'avons cependant recueilli aussi sur la Chèrre et sur le Chabin. La femelle, plus grosse que le malle, pond chacque année quatre ou cincr larves oroïdes, blanchitres. lisses el un peu aplaties, qui se fixent aux brins de laine par une de leurs extrémités, et ne tardent pas à se transformer en pupes, en passant au rouge cuivré, puis au noir.

Lorsque la toison est longue,

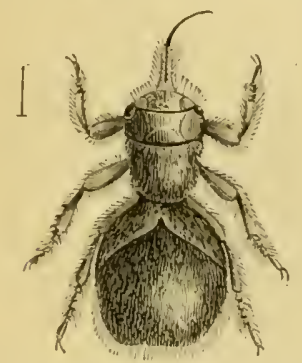

Fig. 504. - Méloplrage du Mouton, grossi. Le lrait placés a gauche indique la grandeur nalurelle.

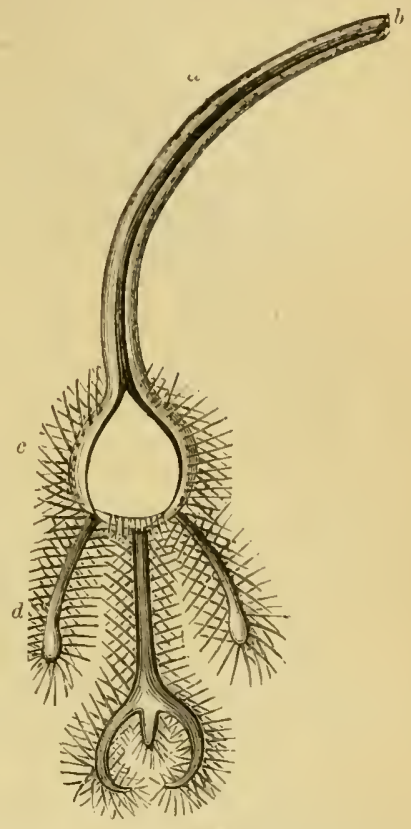

Fig. 505. - Trompe du Nelophage, fortement grossie, daprìs L. Dufour. - $a$, trompe. $b$, son extrémilé libre. $c$, renflement basilaire, arec les muscles qui s'y insèrent. $d$, tiges cornées également garnies de muscles.

les Mélophages se répandent sur toutes les parties du corps; si elle est courte, ils se réfugient dans les régions antérieures, de façon à éviter la dent des animaux. Leurs piqûres se traduisent par des points foncés, entourés d'une petite aréole plus claire; clles paraissent peu douloureuses ; cependant, quand elles sont très multipliées, elles font maigrir les agneaux.

De simples.lotions parasiticides suffisent à détruire ces parasites. D'ailleurs, la tonte en débarrasse les Moutons : en

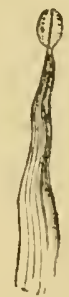

Fig. 506. - Pupe du llé- Fig. ว̃07. - Pupe, grossie, lophage du Moulon, du Mchophage du Mouton, fixéc à l'extrémilé vue par la face dorsale el d'une mèche de laine. montrant deux séries de sepl points ombiliqués. exposant quelques instants ces animaux au soleil, on roit tomber tous les Mélophages qui n’ont pas été enlevés avec la toison ou n’ont 
pas été coupés par les ciseaux. On sait enfin comment les Êtourneaux font la chasse à ces Insectes.

Famille des CESTRIDES. - Les OEstridés ont une tête hémisphérique assez volumineuse, pourvue d'une paire d'yeux à facettes séparés par un front plus ou moins large qui porte trois ocelles. Les antennes sont courtes, à $3^{\mathrm{e}}$ article muni d'un style nu ou plumeux. Il existe parfois une trompe bien développée, quoique souvent cachée dans une fente ou fossette buccale (Cutérébrinés); mais en général cette trompe demeure très petite ou mème tout à fait rudimentaire (OEstrinés). Les ailes ont des nervures disposées à peu près comme celles des Muscidés; il existe presque toujours des cuillerons plus ou moins développés. L'abdomen est mousse en arrière chez les mâles; chez les femelles, il se prolonge souvent par un oriscapte (1).

A l'état d'Insectes parfaits, les OEstres paraissent virre peu de temps, de quelques jours à quelques semaines seulement, et ce, sans prendre de nourriture; du reste, ils ne sont guère actifs que par les temps chauds et secs.

Les femelles, qui sont tantôt ovipares, tantôt vivipares, vont effectuer leur ponte sur le corps des Mammifères. Les larves, en effet, vivent toujours en parasites chez ces animaux, soil dans le tube digestif (gastricoles), soit dans les cavités de la face (cavicoles), soit encore sous la peau (cuticoles). Leur développement est assez lent, du moins dans le début; il exige en moyenne une dizaine de mois et paraît comporter en général trois mues, qui le partagent en quatre stades.

Leur corps se compose de douze anneaux, mais les deux premiers ne sont pas loujours très distincts, de sorte qu'on les compte habituellement pour un seul (anneau céphalique), ce qui ramène le total à onze. Dans quelques cas (Cutérébrinés), le dernier anneau de l'abdomen peut mème s'engager daus le précédent, ce qui fait paraître encore un segment de moins. A l'extrémité antérieure existent de petites antennes. Au moment de la naissance, toutes les larves sont munies de crochets buccaux; lorsqu'elles ont acquis leur complet développement, on constate à cel égard des variations considérables: les unes, en effet, possèdent deux paires de pièces buccales, les autres une seule; d'autres, enfin, sont tout à fait dépourvues de ces appendices. L'appareil respiratoire comprend deux ordres d'ouvertures, quon désigne sous les noms de stigmates anlérieurs et de stigmates postérieurs. I.es antérieurs sont situés entre l'anneau céphalique et le deuxième segment du corps; ils se présentent sous la forme de boutons ou de fentes

(1) Bracy Cuak, An Essay on the Bots of Horses and other Animals. London, (1797), 1815. - ID., Supplement, 1841. - A. Nuxas, Waarnemingen omstrent de Horzel maskiers welke in de maag van het paard huisresten. Tab. 6. N. Verhandling. d.1.kl. Nederl. Institut. D.4, p. 139, I \$33. Traductionallemande de C II. Ilentwig, avec additions. Magazin für die gesammte Thierheilkunde, IV, p. 1, 1838. Traduction frangrise du Mémoire et des additions, par Verueyex. Bibliothèque vétérinaire, I, p. 327, 1849. - K. Scriwab, Die OEstraciden. München, 1840; $2^{\circ}$ éd., 1858. - N. Jolr, Recherches... sur les OEstrides en général, etc. Lyon, 1846. - Fr. Brauer, Monographie der OEstriden. Wien, 1863. - A. Rallliet, Article OEstres du Nouveau Dictionnaire prat. de méd., chir. et hyg. vétér., t. XIV, p. 548, 1887. 
étroites, et parfois mème demenrent cachés dans une dépression du tégument. Quant aux sligmates postérieurs, ils ont souvent, dans le jeune àge, l'aspect de petits tubes rétractiles; chez les larves bien développées, ils consistent en des sortes de plaques chitineuses de forme variable, libres ou recouvertes par des lèrres membraneuses, et situées à l'extrémité postérieure du corps. C'est sous ces plaques stigmatiques que s'ouvre l'anus.

Au dernier stade, les larves s’accroissent rapidement : quand elles ont atteint le terme de leur développement, elles abandonnent leur hote el gagnent un abri oi elles se transforment en mymphes. La période nymplaale ne se prolonge guère au delà de quelques semaines.

A l'exemple de Brauer, nous diviserons les Obstridés en deux groupes principanx, que nous regarderons comme des sous-familles, sous les noms d'OEstrina et de Cuterebrine (1).

A. Sous-famille des cestrinés. - Pièces buccales rudimentaires ou très petites; trompe reliée à la fossette buccale par le tégument, de sorte que la face inférieure de la tète montre au plus trois nodules : le rudiment. (le trompe et les deux palpes. Style des antennes nu.

Larres à dernier amneau libre, ne pouvan $t$ janais s'engager entierement dans le préccident, et formant seul la cavité stigmatique.

Les OEstrinés sont répandus dans les deux mondes. - Ils comprennent trois sections : Gastricolx, Cavicolx et Cuticolx.

Section I : Gastricoles. - Face arec un sillon médian. Ailes sans nervure transversale terminale. Cuillerons petits, couvrant à peine les balanciers. Femelle ovipare, avec un oviscapte repliẻ en dessous et en avant.

Larves avec une ou deux paires de pièces buccales; corps conique, tronqué en arrière, atténué en avant; stigmates postérieurs cachés dans une cavité du dernier anneau fermée par deux lèvres, chacun d'eux à trois arcades courbées, sinueuses ou presque droites. Pas de bourrelets à la face dorsale, entre les anneaux. - Dans l'estomac et l'intestin des Jumentés et des Proboscidiens.

Genres Gastrophilus Leach, Gyrostigma Brauer et Cobboldia Brauer.

Genre Gastrophile (Gastrophilus Leach, 1817. - Syn.: Gastrus Meigen $1824 ;$ OEstrus Latr., 1829). Ce genre est le seul, parmi les Gastricoles, qui soit connu à l'état parfait. Les espẻees qui le composent sont d'assez petites dimensions et revètues de poils soyeux.

Les diverses phases de l'évolution ne sont pas encore

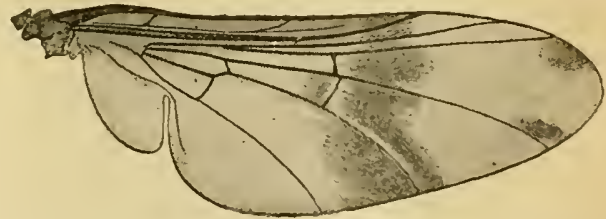

Fig. 503. - Aile de Gastrophilus equi, grossie 5 fois (0rig.). très bien connues. D'après Boas, il y a en réalité quatre stades, les deux premiers peu distincts. Les larves au dernier stade possèdent deux paires d'ap-

(1) Fr. Brauer, Nachträge zur Monographie der OEstriden. II. Zur Charakteristik und Verwandschaft der. Oestriden-Gruppen im Larven-und vollkommenen Zustande. Wiener Entomologische Zeitung, VI, p. 4, 1887. 
pendices buccaux: des mandibules courbées, dites crochets buccaux et des màchoires drites situées entre les deux crochets (fig. 511, B). Le corps ne montre pas de bourrelets latéraux ; les lèvres de la cavité stigmatique postérieure ne sont pas tuberculeuses; les arcades stigmatiques sont simplement courbées et concentriques. - Parasites des Équidés.

Gastrophile du Cheval (G. equi [Clark]. - Syn. : OEstrus bovis L., 1761 [imago]; OEstrus intestinalis De Geer, 1776; OEstrus equi Clark, 1797; G. equi Leach, 1817). - L'Insecte parfait se présente sous l'aspect d'une Mouche velue, couleur de rouille et tachetée de brun. La face supérieure du thorax est d'un brun jaunàtre en avant de la suture et offre en arrière des bandes interrompues de poils noirs. L'abdomen est brun jaunàtre,
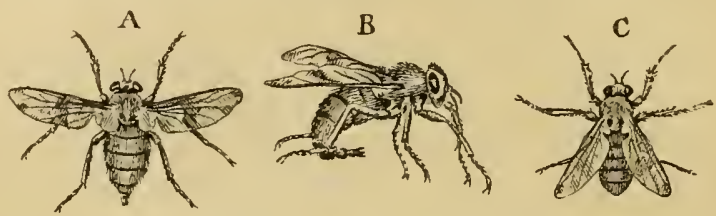

Fig. 509. - Gastrophilus equi, grandeur naturelle. - A, femelle vue en dessus. B, la mème rue de profil. $\mathrm{C}$, matle vu en dessus.

marqué de taches plus foncées, et terminé, chez la femelle, par un oviscapte noir, brillant, cylindrique. Les ailes sont transparentes, marquées dans leur milieu d'une bande transversale brune et de deux points de mème teinte vers leur extrémité libre. Les trochanters des pattes postérieures sont munis d'un crochet chez le màle, d'un tubercule chez la femelle. La longueur dı corps (non compris l'oviscapte chez la femelle) est de 12 à 14 millimètres.

Observé dans toute l'Europe, en Afrique, en Asie et dans l'Amérique du Nord.

Cette espèce est une de celles dont la vie se prolonge le plus longtemps.

Dans le courant de l'été et notamment vers le mois d'août, la femelle voltige en bourdonnant autour des Chevaux, Anes ou Mulets : elle se tient dans une position presque verticale, l'oviscapte dirigé par suite en avant et en haut, versle corps de l'animal. Dès qu'elle a choisi l'endroit convenable et amené un œuf à l'extrémité de l'oviscapte, elle se jette rapidement sur l'animal et, sans se poser, colle cet ceuf à la surface d'un poil, puis se retire pour recommencer aussitôt après. Elle peut répéter le même acte quatre à cinq cents fois de suite, en déposant chaque fois un ouf. Le contact de l'oviscapte arec les poils provoque une légère titillation d'où résulte souvent un trémoussement de la peau.

Les œufs du $G$. equi sont blanchâtres, et par conséquent faciles à distinguer sur des Chevaux à robe foncée. Ils sont de forme conique, el adhèrent aux poils par la moitié de leur longueur, du côté du sommet, au moyen d'un enduit visqueux qui ne tarde pas à se dessécher. 
Leur base (ou pòle antérieur', qui est dirigée en bas, reste libre: elle est coupée obliquement et munie d'un opereule oralaire. Leur surface est finement strice en travers. Ils sont longs de 1 mm. 2.5.

Clark prétendait que, guidée par son instinet, la femelle de l'OEstre du Cheval ne déposait jamais ses wufs que dans les régions accessibles à la langue, c'est-ì-dire ì la partie interne des genoux, en arrière des épaules et parfois ì l'extrémité libre de la crinière. Nais Numan et Joly ont fait remarguer, au contraire, qu'on en troure souvent sur le toupet, sur l'encolure, sur la croupe, derrière les jarrets, en un mot sur des parties que le Cheral ne peut lécher. Et les larres issues de ces aufs ne sont point pour cela deslinées nécessairement ì périr : sans admettre mème arec Numan qu’elles puissent rampersur la peau jusqu’a la bouche ou jusqu'à portée de la langue, n'est-il pas évident, en effel, quiun grand nombre
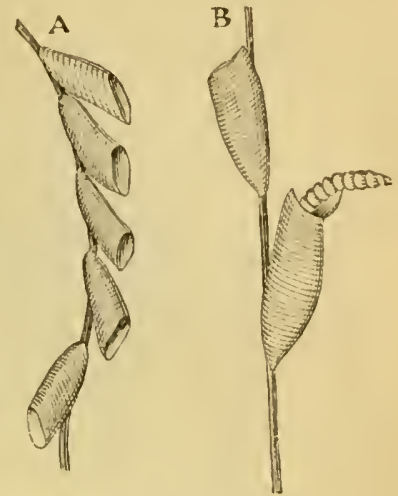

Fig. 310. - CRufs de Gastrophilus equi, fix ('s aux poils. - On voit en B l'éclosion d'une larrule. d'entre elles sont susceptibles d'être ingérées par d'autres Cheraux? Tout le monde a ru, dans les pàturages, ces animaux se lécher mutuellement.

D'après Clark, quatre ou cinq jour's suffiraient pour l'incubation des œufs du Gastrophile équin. Cette assertion est contredite par les observations de Joly, qui a vu l'éclosion survenir au bout de vingt-trois jours seulement dans un flacon liumecté el deux ou trois jours plus tard à sec. La larve s'échappe de la coque en soulevant l'opercule. Très mince et très vive, elle glisse sans doute entre les poils et détermine ainsi un léger prurit qui porte le Cheval à se lécher. Gràce aux épines dont elle est revêtue, elle adhère facilement à la langue; une fois parrenue dans la bouclıe, elle est tòt ou tard emportée dans l'estomac. Les coques rides restent fixées aux poils, et les Cheraux n'en sont débarrassés que par un pansage minutieux ou par la mue.

Les Gastrophiles ne paraissent jamais entrer dans les écuries. Ce sont donc les Cheraux qui ront aux champs ou fréquentent les pâturages, et surtout les moins bien pansés, qui sont exposés à être envahis par les larves d'OEstres. Toutefois, l'adhérence des œuf́s est telle, que les animaux les mieux tenus ne sont pas garantis d'une manière absolue.

C'est lorsque la jeune larve a pénétré dans le tube digestif du Cheral que commence réellement la vie parasilaire de l'Insecte. Nous arons donc ì nous occuper surtout de cet état larvaire. Nous jetterons d'abord un coup d'ceil rapide sur le premier stade, puis nous étudierons le dernier avec quelque détail, en raison de son importance. 
Premier stude. - D'après Joly, la larvule qui vient d'éclore est blanche, transparente, presque fusiforme, très allongée et formée de treize segments, qui sont bien visibles pendant que l'animal se déplace, mais dont les deux ou trois premiers sont invaginés l'un dans l'autre pendant le repos, ce qui rend alors la supputalion des anneaux fort difficile.

Le premier segment porte : $1^{\circ}$ deux petites antennes rétractiles, marquées à leur extrémité d'un point ocelliforme; $2^{\circ}$ deux mandibules en forme de crochets, servant surtout comme organe de fixation. Tout à fait en avant du $2^{\circ}$ anneau, existent une couronne et un faisceau d'épines mobiles, recourbées et presque aussi grandes que les mandibules, servant également à la fixation, ainsi qu'ả la progression. Des épines semblables garuissent le bord postérieur(1) de ce $2^{\mathrm{e}}$ anneau el des suivants, jusques et y compris le $10^{\mathrm{e}}$. Les trois derniers $\left(11^{\mathrm{e}}, 12^{\mathrm{e}}\right.$ et $\left.13^{\mathrm{e}}\right)$ sont tout à fait nus. Le dernier offre à son extrémité libre deux lèvres entre lesquelles on voit faire saillie, de temps en temps, deux tubes trachéens rétractiles.

Dernier stade. - La larve parvenue à la dernière période de son développement est connue de tous les vétérinaires. Elle est ovoïde, un peu aplatie sur la face ventrale, atténuée à l'extrémité antérieure, obtusément tronquée à la postérieure. Le tégument est lisse et résistant. Le cỏrps parait formé de 11 anneaux. Le premier ou anneau céphalique se compose de deux parties séparées par un léger sillon dans lequel sont implantées de petites épines. La prentière partie porte : $1^{\circ}$ les antennes, dont J'extrémité libre montre deux petits points simulant des ocelles; 20 les grands crochets mandibulaires qui servent à la fixation; $3^{\circ}$ les màchoires cornées, droites, entre lesquelles s'ouvre la bouche (fig. 511, B). Ces deux ordres de pièces buccales s'articulent avec le squelette du pharynx. En arrière de ces organes, se voient, comme au $1^{\text {er }}$ stade, plusieurs séries de spinules disposées en couronne. La deuxième partie du premier anneau est conique, à base postérieure, et pourvue latéralement d'un bourrelet surmonté d'un sillon qui aboutit aux stigmates antérieurs, lesquels sont cachés dans la partie dorsale du sillon qui sépare le premier anneau du second.

Les anneaux suivants augmentent de largeur jusqu'au $3^{\mathrm{e}}$ ou au $6^{\mathrm{e}}$, puis diminuent peu à peu; du $2^{\mathrm{e}}$ au $8^{\mathrm{e}}$ inclusivement, ils sont garnis, au bord antérieur de leur face supérieure, d'une double rangée d'épines (ou mieux de tubercules épineux) coniques, jaunàtres à la base, noiràtres au sommet et dirigées en arrière. Les épines des deux rangées sont alternes, etles antérieures sont beaucoup plus épaisses que les postérieures. Le $9^{\circ}$ anneau en est dépourvu sur le milieu de la face supérieure; le $10^{\circ} \mathrm{n}$ en porte plus sur celte face ou seulement quelques-unes par côté. A la face inférieure il existe de même une double rangée d'épines du $2^{\circ}$ au $10^{\text {e }}$ anneau inclusivement. Le $11^{\mathrm{c}}$ anneau est tout à fait nu sur ses deux faces; mais il présente en arrière une fente transversale très large, bordée par deux lèvres, une supérieure et une inférieure, mobiles, épaisses et comme vésiculeuses. Cette fente donne entrée dans une cavité, sur la paroi profonde de laquelle sont disposés les deux stigmates postérieurs, réunis par un encadrement chitineux. Ce sont deux plaques réniformes d'un brun jaunàtre, se regardant par leur bord concave, et formées chacune de trois arcs concentriques creux, marqués de petites lignes

(1) Brauer pense que c'est plutôt le bord antérieur des segments suivants, comme chez la larve completement développée. 
transrersales qui ne sont autres que de petits chevrons chitineux (tig. äll, C). Quand ces arcs sont remplis d'air, ils dessinent des bourrelets blancs sur lesquels apparaissent, entre les cherrons, des bosselures vésiculeuses. Lorsqu'ils sont vides, au contraire, leurs deux parois se rapproclient, et ils semblent canaliculés sur leur milieu. Leur cavité est mise en rapport avec l'exléricur (Meinert) par de petites fentes très fines, paires et latérales. Audessous des arcs est une couche molle, poreuse, comme sponcrieuse, qui établit la conmunication avec les trachées.

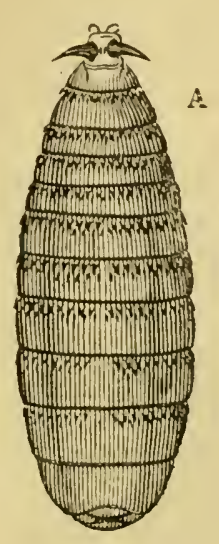

C

$\therefore$

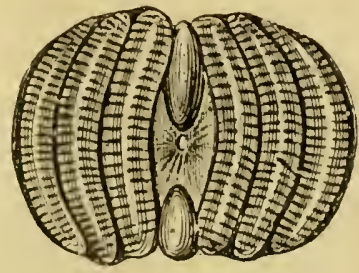

D

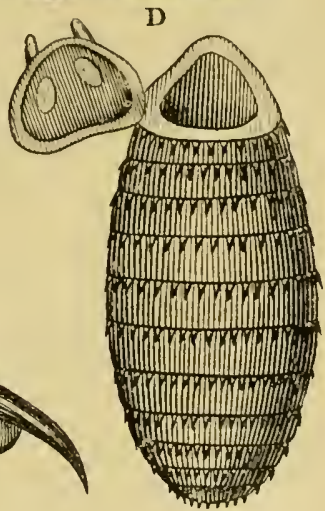

Fig. 511. - Gastrophilus equi.- A, larve au dernier stade, grossie deux fois et demie. 13, son alpareil buccal. C, ses stigmates postérieurs. D, pupe avec son opercule, grossie trois fois (Delafond).

Le siège normal des larves du Gastrophile équin est le sac gauche de l'estomac. Elles se fixent à la muqueuse blanche, de préférence au voisinage du rebord frangé de la muqueuse veloutée, où elles se montrent d'ordinaire agglomérées en plus ou moins grand nombre, et quelquefois aux abords du cardia, tantôt isolées, tantòt groupées. Elles ont la tête enfoncée dans de petites dépressions (alréoles) au fond desquelles elles se fixent à demeure à l'aide de leurs crochets mandibulaires. Il est exceptionnel de les roir installées de cette manière sur la muqueuse veloutée du sac droit. Cependant, comme l'a fait voir Numan, elles sont exposées, comme toutes les espèces d'OEstres, à des erreurs de lieu, et l'on peut même en rencontrer parfois un ou deux exemplaires dans l'œsophage ou dans le duodénum. Mais il ne faut pas confondre avec ces larves erratiques celles qui se déplacent après la mort de l'hôte et qu'on rencontre çà et là dans des autopsies prati- 
quées tardivement : celles-ci ne sont pas fixées dans des alvéoles.

Le nombre des larves de Gastrophiles qui peuvent se rencontrer dans l'estomac d'un Cheval est assez variable : il faut remarquer, du reste, que ces larves n'appartiennent pas exclusivement à l'espèce qui nous occupe. Sous le climat de Paris, nous en observons souvent de 10 à 100 et même jusqu'à 200, rarement davantage. Cependant Daubenton dit en avoir recueilli 660 . En Italie, Vallisneri en a compté 700. Mais dans les pays du nord, en Hollande, par exemple, ce sont là des cas très communs : il arrive fort souvent, dit Numan, que les larves tapissent la muqueuse stomacale au point d'en masquer presque entièrement la surface. Chez un Cheval où cet auteur en avait compté

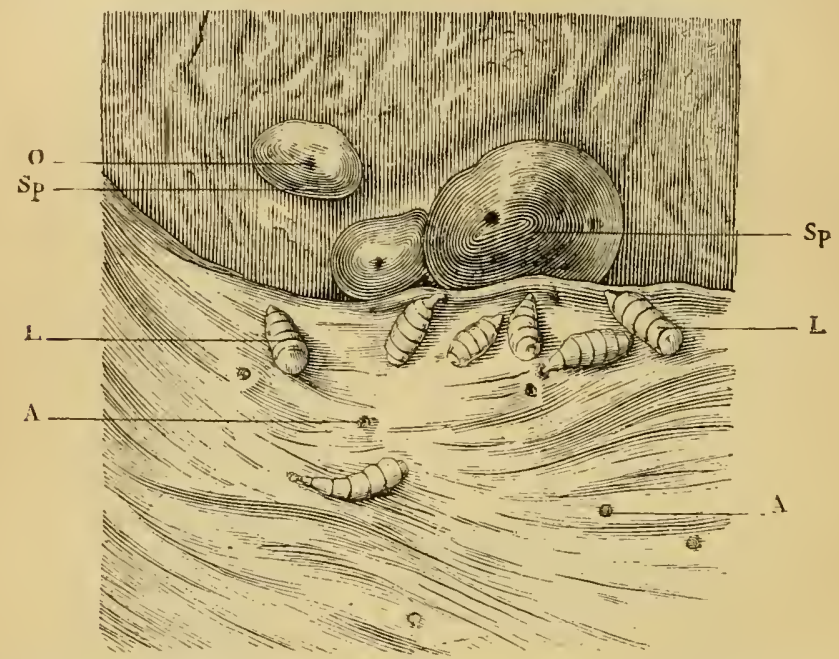

l'ig. 5t2. -- Spiroptères et larres d'(Estres dans l'estomac du Cheval. - Sp, tumeurs à Spiroptera megastoma développées dans le sac droit. 0 , orifices de ces tumeurs. L, larves de Gastrophilus equi fixées sur la muqueuse du sac gauche. A, alvéoles d'insertion des larves du Gastrophilus hæmorrhoidalis, qui ont abandonné l'estomac. $1 / 2$ de graud. nat. (Orig.).

546 de différentes espèces, 300 appartenaient au $G$. equi, 66 au $G$. hæmorrhoidalis et 180 au $G$. veterimus. Chez un autre, il s'en trourait 106ت, dont 1013 dans l'estomac, 20 dans l'intestin grêle, le cæcum et le côlon, et 27 dans le rectum.

Vers la fin de l'hiver, les larves présentent une teinte rouge assez foncée, un peu plus pâle à l'extrémité postérieure. Lorsqu'elles arrivent à la dernière période de leur développement, cette teinte s'affaiblit et passe au rouge de chair.

Il faut environ une dizaine de mois pour que l'évolution soit complète. Alors, - de mai à septembre, mais surtout en juin et juillet, - elles se détachent d'elles-mêmes et sont entrainées avec les matières alimentaires et stercorales, sans s'arrêter dans l'intestin. Au moment où elles sortent du rectum, elles mesurent 18 à 21 millimètres 
de long sur une largeur de 8 millimètres au niveau du septième anneau; clles ont une teinte de chair pîle, lavée, et les épines qui garnissentles anneaux se montrentbrunàtres à la base et noires à la pointe.

Selon la remarque de Numan, e'est surtout la nuit ou vers le matin que sont évacuées ces larves; tous les jours, pendant plusieurs semaines, on peut en trouver quelques-unes dans les matières fécales. Elles se cachent alors dans ces matières, ou s'enfoncent dans la terre meuble ; leurs mouvements se ralentissent peu ì peu, et elles ne tardent pas à devenir raides el immobiles. Après 2.4 à 48 heures en moyenne, leur teinte passe au brun clair, puis au brun foncé et au noir, et la peau se durcit pour constituer une coque luisante et solide (pupe en barillet), dans laquelle est enfermée la véritable nymphe; dans l'espace de quatre à six jours, cette transformation de la larve en pupe est complète. Celle-ci est longue de $1 \ddot{3}$ à 17 millimètres, large de 6 à 7 millimètres; elle est ovoïde, à face supérieure convexe d'avant en arrière et d'un côté à l'autre, à face inférieure convexe d'un côté à l'autre et très légèrement concave, presque plane, d'avant en arrière. Les épines qui la revêtent sont disposées exactement comme chez la larve.

La durée de l'état de nymphe est en moyenne de 30 à 10 jours. Au bout de ce temps, l'Insecte complètement développé doit briser les parois de sa prison. Pour cela, il contracte ses muscles thoraciques et abdominaux et refoule ainsi le sang dans la tète; le tégument de la région frontale se dilate en une vésicule blanchâtre, demi-transparente, qui exerce unc pression sur les premiers anneaux; un bruit sec se fait entendre : la moitié supérieure de ces anneaux cède jusqu'au niveau du quatrième, et l'ensemble se détache sous la forme d'une demi-calotte. L'Insecte fait quelques efforts pour sortir et conserve un certain temps encore sa vésicule frontale ; puis celle-ci se resserre, et la tète a acquis dès lors son aspect définitif; enfin, les ailes se déplissent et l'animal prend son rol. La plupart du temps, c'est vers six à huit heures du matin que les OEstres sortent de leur coque.

On a trouvé quelquefois des larves de Gastrophilus equi dans l'estomac des Carnivores, tels que le Chien (G. Colin, Schliepe), l'Hyène rayée et le Blaireau. Peut-ètre ces animaux les araient-ils ingérées arec les débris de Cheval dont ils étaient nourris. Bracy Clark dit pourtant que les larves, introduites dans l'estomac d'animaux autres que le Cheval, provoquent des vomissenients. C'est ce que nous avons nous-mème constalé expérimentalement ; néanmoins, il nous est arrivé de retrouver une larve bien vivante dans l'estomac d'un Chieı, 20 heures apres l'ingestion. Moniez dit en avoir recueilli deux dans l'estomac d'un Chien enfermé depuis des mois et nourri strictement de matières végétales ou de viande bien cuite.

Gastrophile hémorroïdal (G. hæmorrhoidalis [L.]. - Syn. : OEstrus hxmorrhoidulis L., 1761; G. hæmorrhoilalis Leach, 1817). - Espèce très velue, brun noiràtre. Face supérieure du thorax revètue de poils gris olivàtre 
en avant de la suture, et offrant une bande transversale noire en arrière. Abdomen blanchàtre en avant, noir au milieu, fauve doré en arrière. Ailes

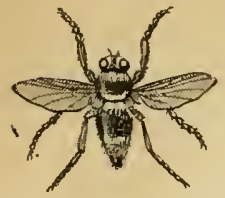

Fig. 513. - Gastroplile hémorroïdal, femelle, grandeur naturelle. transparentes, comme enfumées, sans taches. Longueur du corps, 9 à 11 millimètres.

Habite l'Europe et l'Amérique du Nord.

Le Gastrophile hémorroïdal ou OEstre du rectum a probablement une vie plus courte que l'espèce précédente : il ne faut donc pas s'étonner, dit Brauer, de le voir, quelques heures seulement après avoir quitté ses enveloppes de nymphe, chercher un individu de l'autre sexe et s'accoupler avec lui. On le prend d'ailleurs rarement en liberté.

La ponte de cet Insecte paraît n'avoir été observée jusqu’à présent que par Bracy Clark. D'après le savant vétérinaire anglais, la femelle du Gastrophile hémorroïdal dépose ses œufs sur les lèvres du Cheval. Le chatouillement qu'elle détermine sur ces parties si sensibles est très désagréable à l'animal, qui frotte alors son nez contre le sol, contre ses membres antérieurs ou contre un tronc d'arbre. Si l'OEstre persiste, le Cheval finit par s'enfuir au galop, ou méme, en dernière ressource, va se plonger dans l'eau. Quelquefois, l'Insecte paraît se cacher dans l'herbe, et de là épier le moment où le Cheval viendra brouter à sa portée. Il sort alors de la touffe, se balance quelques secondes dans l'air, puis se jette sur la lèvre et y dépose son œuf avec une merveilleuse célérité. Clark ne dit cependant pas d'une facon expresse qu'il ait trouvé les ceufs sur les lèvres du Cheval, et il avoue que celui dont il donne la figure avait été extrail de l'abdomen d'une femelle. Mais l'auteur anglais fait remarquer que, quand plusieurs de ces OEstres sont réunis dans un espace clos, ils répandent une forte odeur de moisi, odeur qui semble être percue par les chevaux au pâturage: ces animaux, dit-il, flairent l'herbe et la regardent avec anxiété, puis tout à coup s'enfuient au loin. Brauer est disposé à rapporter plutôt ces indications au lihinostrus purpureus.

L'ouf du $G$. hiemorrhoidalis est long de $1^{\mathrm{mm}}, 5 ; \mathrm{il}$ est noir, conique, comprimé, finement rayé en travers, obliquement tronqué à son extrémité antérieure et prolong̨é en arrière par une sorte de pédicelle.

On ignore quel est le temps exigé pour. son incuba-

tion. Quoi qüil en soit, on admet généralement que les

Fig. 514. - OEuf du Gastrophile bémorroïdal, grossi 10 fois. jeunes larves gagnent en rampant la cavité buccale du Cheral, et sont de là emportées vers l'estomac.

Les premières phases de l'évolution ne sont pas encore bien connues.

Larve au dernier stade. - Nous noterons seulement ici les principaux ca- 
raetères qui permettent de distinguer cette larve de la précédente. $\Lambda$ simple vue, on la reconnait à son corps moins volumineux et de forme plus allongée, ainsi qu'à sa teinte rouge foncé. Sur la face supérieure, elle présente, au bort antérieur des anneaux, dı $2^{\circ}$ au $8^{\mathrm{c}}$ inclusivement, une double rangíed'épines, celles te la première étant à peine plus développées que celles de la seconde. Sur le milieu du $9^{r}$ anneau (parfois mème des $8^{c}$ et $\tau^{e}$ ), ees épines font défaut; elles manquent en outre sur toute la moitié supéricure du $10^{\circ}$. A la face inférieure, elles se rencontrent đu $2^{\text {e }}$ au $10^{\mathrm{e}}$ anneau inclusivement, mais sont très peu déve-

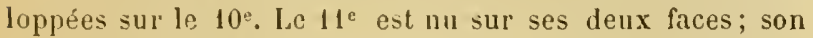
pourtour, dit Joly, est froncé comme une bourse.

Les larres du Gastrophile hémorroïdal, d'un rouge plus ou moins intense suivant l'âge (larves rouges de l'estomac Numan), mais plus prononcé à l'extrémité postérieure, se rencontrent surtout, comme celles

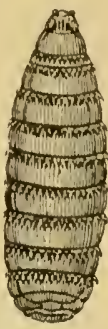

Fig. 51ว. - Larve du Gastrophile hémorroidal au dernier stade, grossie 2 fois. du Gastrophile équin, dins le sac gauche de l'estomac des Équidés; elles sont isolées ou groupées, et le plus sourent entremêlées arec celles-ci, dont elles se dislinguent à première vue par leur taille plus petite. Mais ce n'est pas là leur unique babitat, et d'ailieurs Numan les regarde comme plus sujettes que les autres à des erreurs de lieu. C'est ainsi qu'on les rencontre dans l'œsophage, où elles se fixent de préférence au roisinage du cardia. Elles peuvent encore séjourner sur la muqueuse du sac droit de l'estomac, aux abords du pylore, et jusque dans le duodénum. Enfin, elles s'arrêtent encore quelque temps dans le rectum, et semblent n'abandonner qu'à regret le tube digestif, car on les voit souvent se cramponner à la marge de l'anus, avant de se laisser tomber à terre. Aussi, ne les trouve-t-on guère dans les excréments. Dans la dernière période de leur déreloppement, elles pâlissent, puis prennent enfin une teinte verdàtre caractéristique. Elles mesurent alors 13 à 16 millimètres de long sur 6 millimètres de large au niveau du septième anneau.

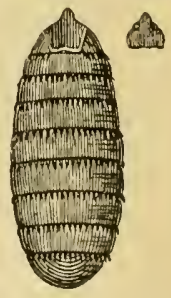

Fig. 516. - Pupe du Gastrophile hémorroïdal, avec son opercule, grossie 2 fois.

Quant à la nymphose et à l'éclosion de l'Insecte parfait, elles n'offrent rien de particulier. Lia coque de la nymphe est longue de 14 millimètres, large de 5 ì 6 .

Gastrophile duodénal (G. veterinus [Clark]. - Syn, : OEstrus nasalis L., 173̊s, pro parte; OEstrus veterinus Clark, 1797; OE. salutiferus Clark, 181ว̃; OE. duodenalis Schwab, 18'10). - Espèce très velue, d'une teinte générale noire. Face supérieure du thorax d'un brun chàtain ou doré. Abdomen variable, le plus souvent d'un brun cendré à la base, noir au milieu, et d'un noir mélangé de jaune ả l'extrémité. Ailes assez petites, transparentes. Longueur du corps, 12 à 13 millimètres. 
Dans toute l'Europe; commune en France (Railliet).

Les cufs sont blancs, elliptiques, un peu recourbés et tronqués obliquement en arant, longs de $1^{\mathrm{mm}}, 25$.

Les larves se fixent à peu près exclusirement dans le duodénum du Cheval, au voisinage du pylore.

Au dernier stude, elles présentent, au bord antérieur de la moitié supérieure des anneaux, du $2^{e}$ an $9^{\mathrm{e}}$, une simple rangée d'épines, interrompue sur

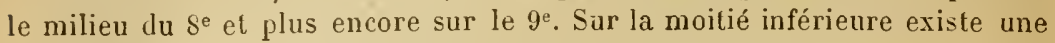

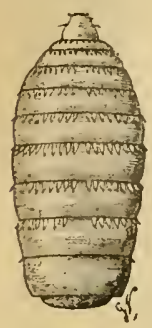

Fig. 517. - Larve de Gastrophile duodénal au dernier stade, grossie 2 fois (Orig.). semblable armature, du $2^{\mathrm{c}}$ au $10^{\mathrm{e}}$ anneau.

Elles sont d'abord blanches, avec l'extrémité postérieure rouge; quand elles ont acheré leur croissance, le corps tout entier est le plus souvent blanc jaunàtre (larres blanches Numan), et les épines sont blanches à la base, brun foncé à la pointe; ces larves mùres mesurent de 13 à 15 millimètres de long sur 6 millimètres de large au niveau du septième anneau.

Elles sont rejetées avec les excréments et ne se fixent jamais à la marge de l'anus. La coque de la nymphe, très facile à reconnaître par les rangées simples d'épines, est longue de 15 à 16 millimètres. L'Insecte parfait en sort, comme dans les autres espèces, au bout de trente à quarante jours environ.

Gastrophile des bestiaux (G. pecorum [Fabr.]. - Syn. : OEstrus pecorum et OE. rituli Fabricius, 1:94; Gastrus pccorum Meigen, 1824; Gastrophilus pecorum Schiner, 1861). - Mâle couvert de poils d'un jaune ferrugineux, sauf à la face supérieure du thorax, où il existe en arrière de la suture une bande souvent interrompue de poils noirs. Femelle d'une teinte générale brune; face supérieure du thorax et premier anneau de l'abdomen d'un jaune ferrugineux; le reste de l'abdomen noir. Oviscapte très conrt, rudimentaire. Ailes petites, ternes, enfumées. Longueur du corps, 12 à 15 millimètres.

De l'Europe centrale et orientale.

Les cufs sont noirs, allongés, elliptiques, brièvement pédiculés à leur pôle postérieur et munis à l'antérieur d'un opercule à peine aplati; ils ont une longueur de $1^{\mathrm{mm}}, \underline{Q}$.

Les larves vivent peut-être dans l'estomac, mais à coup sûr dans l'intestin du Cheval.

A l'élat de complet développenent, elles offrent sur leur moitié supérieure une double rangée de très petites épines au bord antérieur des anneaux du $2^{\mathrm{e}}$ au $8^{\mathrm{e}}$, avec interruption de plus en plus étendue sur le milieu des $6^{\mathrm{e}}, 7^{\mathrm{e}}$ et $8^{\mathrm{e}}$; les anneaux suivants sont presque toujours nus. A la face inférieure, les rangées d'épines s'étendent du $2^{\mathrm{e}}$ anneau au $10^{\mathrm{e}}$. Ces larves mesurent de 13 à 20 millimètres de long sur 7 à 8 millimètres de large.

Comme celles du Gastrophile hémorroïdal, elles séjournent quelque temps dans le rectum et s'attachent ensuite à la marge de 
I'anus ; mais elles s'en distinguent facilement en ce qu'elles ont alors une teinte d'un rouge sanguin foncé.

Elles quittent leur hóte le plus souvent en juillet et en aout, pour se transformer en nymphes. La coque de celles-ci est longue de 13 a 17 millimètres, large de 6 ì 9 millimètres, et n'est revêtue que d'épines très courtes, ce qui la fait paraitre presque nue.

Le G. pecorum est une espèce de l'Europe centrale et orientale; il est rare en Suède; en France, on a seulement rencontré sa larve (Mégnin) sur des Cheraux russes importés aux environs de Paris.

Pour terminer, nous devons encore signaler, parmi les espèces die Gastrophilus décrites par lirauer, le G. flavipes (Olivier), du sud de l'Europe (Dalmatie, Espagne; trouvé dans les Pyrénées par Brongniart), du nord de l'Afrique et de l'Asie Mineure. Bratrer pense que la larve de l'estomac de l'Ane, décrite par Malpighi, appartenait à cette espèce. D’autre part, Billıarz a trouvé au Caire, dans l'estomac du mème animal, une larve appartenant à une variété du Gastrophile du Cheval (G. equi var. asinina).

Brauer décrit en outre :

G. inermis Brauer. Larve inconnue. Pupe trouvée dans des crottins de Cheval.

G. lativentris Löw, de la Courlande. Ilòte inconnu.

G. nigricomis Löw, de la Bessarabie. Hòte inconnu.

Pathologie. - Nous arons vu que les causes qui farorisent la pullulation des larves d'OEstres sont les étés chauds et secs, le séjour aux champs et au pâturage, le défaut de pansage, etc.

Lorsque les larves sont encore jeunes ou qu'elles sont peu nombreuses, leur présence ne se manifeste par aucun symptóme particulier. Au contraire, lorsqu'elles existent en grand nombre et qu'elles ont acquis un certain développement, elles peuvent donner lieu à des phénomènes pathologiques d'une intensité variable. A cet égard, il faut cependant se tenir en garde contre les assertions des anciens auteurs, - Chabert en particulier, - qui ont établi une symptomatologie tout à fait fabulcuse. D'autre part, il serait exagéré d'admettre, arec Bracy Clark, que l'irritation provoquée par les larres d'OEstres sur la muqueuse stomacale exerce sur l'économie une influence salutaire.

Nous savons que ces larves se fixent, par leur extrémité céphalique, dans des alvéoles qu'elles creusent elles-mêmes dans la muqueuse du tube ligestif, notamment dans celle du sac gauche de l'estomac. A la vérité, le travail inllammatoire qui résulte du creusement de ces alvéoles est en général très limité et ne clonne guère lieu qu'à un épaississement progressif du fond de la cavité, qui rend difficile la perforation complète de la muqueuse. Cependant, cette perforation se produit quelquefois, et l'on concoit qu'clle puisse entrainer des accidents d'une haute gravité. Mais ce sont là des faits 
exceptionnels; dans la règle, la présence des larves des Gastrophiles n'entraîne pas de désordres sensibles, et, lorsque les larves se sont détachées, les alvéoles ne tardent pas à être comblés par un tissu cicatriciel dont la trace ne persiste que peu de temps.

Quant aux larves qui, dans les dernières semaines de leur développement, vont se fixer sur la muqueuse du rectum, et finalement à l'anus, elles peurent irriter les chevaux au point de les rendre difficiles à conduire; Hertwig a observé en 1826, dans les hôpitaux de l'École vétérinaire de Berlin, un Cheval qui, par suite de la présence d'une trentaine de larves dans le rectum et à la marge de l'anus, se livra à de tels efforts de défécation, qu'il en résulta un grave renversement du rectum, lequel ne put être guéri que par des moyens chirurgicaux.

Enfin, il y a lieu de citer le cas singulier, signalé par Rey, d'un Cheval entier dont la mort fut attribuée à la présence de larves d'OEstres dans la vessie.

Les pansages fréquents, les soins de propreté, constituent le meilleur élément de la prophylaxie.

Lorsque les larves ont pénétré dans le tube digestif et s'y sont fixées, il est à peu près impossible de les éliminer. Les vétérinaires, depuis longtemps, ont reconnu que les purgatifs et les anthelminthiques'les plus énergiques demeuraient à peu près sans action sur ces larves. L'épaisseur et l'imperméabilité de leur tégument, ainsi que leur mode d'implantation, rendent bien compte, d'ailleurs, de cette résistance. Au surplus, des expériences directes, consistant à plonger les larves dans des liquides toxiques ou dans des gaz irrespirables, ont été entreprises par divers auteurs, et en particulier par Numan. Elles ont démontré que, après un séjour de trois ou quatre heures dans l'essence de térébenthine, dans l'alcool, dans des solutions d'acide arsénieux, d'asa foetida, de noix vomique, de narcotine, de strychnine, de sulfate de cuivre, de sublimé corrosif, etc., etc., ces larves continuaient à vivre pendant plusieurs jours. Elles ne succombent que dans des liquides ou des gaz que l'organisme du Cheval serait incapable de supporter.

On ne peut donc pas songer à tuer les larves dans le tube digestif. Zürn assure même que des médicaments très actifs, comme l'arsenic, au lieu de les chasser, les poussent à s'enfoncer plus profondément, de sorte qu'il sont plus nuisibles qu'utiles.

Dans le cas oủ il existe des larves dans le rectum, il est facile de les retirer directement à la main; à plus forte raison si elles sont fixées à la marge de l'anus.

Section II : Cavicoles. - Face arec une étroite bandelette ou sillon médian. Ailes pourvues d'une nervure transversale terminale. Cuillerons grands. Femelle ovipare ou larvipare, sans long oviscapte.

Larves avec une seule paire de pièces buccales; plaques stigmatiques. 
postérieures libres ou cachées dans une eavité du dernier anneau; en dessous d'elles, un appendice qui sert, pendant la vie parasitaire, at nettoyage des plaques, et, lors de l'émigration, à la propulsion du corps. Des bourrelets dorsanx fusilormes entre les anneanx de la région moyenne (bourrelets intermédiaives). - Dans les carités nasales, les simus frontaux el le pliarynx des Ruminants, Équidés et Proboscidiens.

Genres OEstrus L., Rhinostrus Brauer, Pharyngolobus Brauer, Cephalomyia Iatr., Phuryngomyia Schiner, Cephenomyia Latr. -

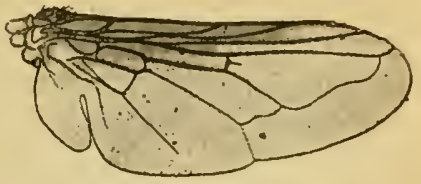

Fig. 518. - Aile d'Estrus ovis, grossic 5 fois (0rig.).

Il Caudra probablement y rapporter aussi les genres Therobia Brauer, Aulaeocephula Iacquart et Mierocephalus Schnabl, dont les larves sont jusqu’à présent inconnues.

Genre Estre (OEstrus L., 1761, pro parte. - Syn.: Cephalomyia Latr., 1823, pro parte). - Corps à poils très courts, paraissant nu. Pattes courtes, délicates. Ailes à première cellule postéricure fermée et pédiculée, à nervures transversales terminale et postérieure obliques. Front bombé, saillant. Rudiment de la trompe conique, ne dépassant pas les palpes en dessous ni en arrière. Face ventrale et extrémité de l'abdomen avec de nombreux poils longs et fins. $6^{\text {e }}$ anneau de l'abdomen en croissant transversal.

Larves à antennes largement séparées. Corps à contour ovalaire, à face dorsale trés convexe et à face ventrale plane. Au niveau de celle-ci, mais appartenant en réalité à la face dorsale, deux séries de bourrelets superposés, séparés par des sillons profonds (bourvelets latéraux supérieurs et inférieurs). Pas de rangées d'épines à la face dorsale. Cavité stigmatique postérieure large et peu profonde; plaques stigmatiques pentagonalesarrondies. - Parasites des Cavicornes.

OEstre du Mouton (OE. ovis L., 1761. - Syn. : Cephalomyia ovis Latr., 1820). - Petite espèce d'un gris jaunàtre, presque nue. Face supérieure du thorax d'un gris brun hérissée de petits tubercules noirs, sur chacun desquels s'insère un poil fin. Abdomen d'un blane jaunàtre, tacheté de noir, à rellets soyeux. Ailes transpa-

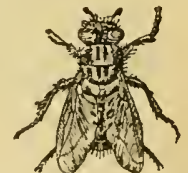

Fig. รั19. - OEstre du Mouton, grandeur nalurelle. rentes, marquées vers leur base de trois points noiràtres. Longueur du corps, 10 à 12 millimètres.

Habite l'Europe, l'Asie, l'Afrique et Ies deux Amériques : cette aire de dispersion si considérable est d'ailleurs en rappori avec celle de son hûte.

L'Insecte parfait se montre de juin à septembre; il se rencontre dans le voisinage des endroits fréquentés par les Moutons, par exemple dans les pâturages et les bergeries; on le trouve souvent sur les poteaux des clótures, ou dans les trous et fentes des murs de bergeries. Comme celui des espèces que nous avons précédemment étudiées, il voltige surtout par les temps secs et chauds, dans le milieu de la journée, et va volontiers se reposer sur les rochers élevés. Son vol est très rapide. 
La femelle fécondée se jette sur les troupeaux de Moutons. On n'a jamais vu s'effectuer la ponte; toutefois, il est presque certain, au dire de Bracy Clark, qu'elle se fait au pourtour des naseaux. Cet auteur assure, en effel, que les Moutons attaqués par des OEstres secouent la tête, frappent violemment le sol avec les pieds de devant et s'enfuient au loin, tenant le nez au ras du sol, regardant de tous côtés s'ils sont poursuivis, flairant et explorant le gazon avec inquiétude.

Des études de Léon Dufour et de Cockrill, il semble résulter que l'OEstre du Mouton est vivipare. Cockrill aurait extrait plus de trois cents larves vivantes du corps d'une seule femelle. Les œufs non fécondés, pris dans

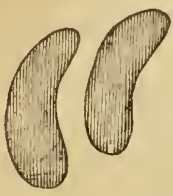

Fig. 520. - OEufs de I'CEstre du Mouton, extraits de l'ovaire, fortement grossis. l'ovaire, sont réniformes et à section transversale circulaire. Les larves qui en proviennent, déposées sur les narines de l'hôte, doivent évidemment grimper de là dans les cavités nasales et dans les sinus.

Les premiers stades larvaires paraissent être fort longs ; j'en ai fait connaitre deux, dont la description ne saurait trouver place ici.

La larve complètement développée est ovoïde, le pòle antérieur élant le plus étroit, et le maximum de largeur correspondant à peu près au $8^{\mathrm{e}}$ anneau. L'anneau céphalique montre en dessous les deux crochets mandibulaires brun noirâtre et en dessus les courtes antennes membraneuses surmontées chacune de deux anneaux chitineux ocelliformes. Sur la face dorsale convexe, du $2^{\mathrm{e}}$ au $10^{\mathrm{e}}$ anneau, on remarque entre deux anneaux successifs un bourrelet intermédiaire fusiforme très net. A la face inférieure plane, il existe sur chaque anneau, à partir du 3 e, deux petits tubercules rapprochés de la ligne médiane et un plus gros de chaque còté. Le dernier anneau est étroit et court, tronqué verticalement, et forme une cavité postérieure large et peu profonde, semilunaire; au-dessous du rebord inférieur de cette cavité se trouve l'appendice postérieur, qui en est séparé par un sillon transversal et porte deux tubercules coniques entre lesquels règnent de petites épines. Les plaques stigmatiques situées dans la cavité ontl'aspect de pentagones à angles mousses, et montrent leurs "faux orifices stigmatiques " presque au centre. - L'armature cutanée est nulle à la face supérieure et sur les bourrelets latéraux. L'anneau céphalique est mème entièrement nu. A la face inférieure, on troure au bord antérieur des anneaux, à partir du $2^{\mathrm{e}}$, des rangées alternes de tubercules charnus surmontés d'épines à pointe rouge, dirigées en arrière. Le $2^{e}$ anneau a une seule rangée sur la ligne médiane, et par côté un commencement de deuxième rangée. Les anneaux 3 et 4 ont chacun trois rangées. 5 et 6 en ont une quatrième sur les còlés. 7 à 10 en ont quatre, plus une cinquième sur les còtés. Le $11^{\text {e }}$ et dernier anneau n'en a plus que trois.

Durant ce dernier stade, les larves sont à peu près localisées dans les sinus frontaux et leurs dépendances, où elles vivent du mucus dont leur présence augmente la sécrétion. D’abord d'un blanc jaunâtre, elles présentent sur les anneaux, au moment de la maturité, des stries transversales d'un brun foncé. Elles arrivent à mesurer 20 à 30 millimètres de long sur 7 à 10 de large. 
La plupart sont complètement développées en juin et juillet, de sorte que les deux derniers stades sont très courts. Elles abandonnent alor's leur séjour à la faveur de l'ouverture située au fond du méat moyen, laquelle est cylindrique et assez lirge chez le Mouton, ainsi que l'a rappelé G. Colin, après Ilighmore; puis elles sont rejetées par les ébrouements. Elles ne tardent pas à s'enfoncer dans le sol, dans le fumier ou sous l'herbe, et, dans l'espace de vingt-quatre heures, elles se transforment en nymphes.

L'enveloppe de celles-ci, d'ahord molle et rouge arec des stries transversales noires, se durcit alors en peu de temps, en passant au brun, puis au noir.

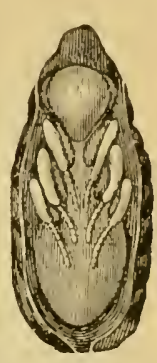

Fig. วะ1. - Pupe ouverle de lirEstrc du Mouton. grossie 3 fois (N. Jol!).

Au bout de trente à cinquante jours, l'Insecte parfait sort de sa coque.

P.tnologie. - Chez les Moutons qui hébergent seulement quelques larres isolées, la présence de celles-ci provoque à peine un léger catarrhe de la muqueuse des sinus se traduisant par un jetage muqueux accompagné d'ébrouements.

Mais, s'il existe à la fois un grand nombre de larves sur le mème sujet, il survient, au contraire, une vive irritation de la muqueuse, qui donne lieu aux phénomènes pathologiques connus sous les noms de faux tournis et de vertige d'OEstres. Ces troubles se manifestent spécialement au printemps et en été, c'est-à-dire à l'époque où les larves acquièrent leurs plus grandes dimensions; ils sont d'ailleurs plus fréquents chez les agneaux et les antenais que chez les adultes. Hertwig les a décrits avec beaucoup de précision.

L'affection débute par des symptimes de catarrhe : on observe d'abord un jetage elair, souvent unilatéral, accompagné d'ébrouements fréquents. Puis les animaux se frottent la tête et surtout le nez contre des corps résistants, ou projettent leurs membres antérieurs sur le chanfrein, comme s'ils roulaient se débarrasser d'un corps étranger.

A mesure que le mal fail des progrès, l'animal se montre plus abattu; il tient la tête basse et souvent inclinée. Parfois même, il y a une tendance au tournoiement, mais d'une façon moins régulière et moins accusée que dans le tournis véritable. En même temps, le jetage augmente et devient plus épais, mucoso-purulent; on constate souvent de la dyspnée, lue sans doute à la tuméfaction de la pituitaire; les yeux sont injectés et larmoyants, l'appétit diminue, le Mouton maigrit.

Dans les cas les plus graves, des phénomènes vertigineux se manifestent : grincements de dents, salivation, mouvements des yeux, etc. Ce sont les indices d'une terminaison fatale. La mort survient ordinaire- 
ment du cinquième au huitième jour après l'apparition des premiers symptômes; quelquefois même les animaux sont emportés dans l'espace de trois ou quatre jours.

Le diagnostic du vertige d'OEstres n'est pas sans offrir parfois une assez grande difficulté, à cause de la ressemblance qui existe entre cette affeclion et le tournis. La différence doit être établie surtoutd'après la considération des ébrouements et du jetage, qui manquent dans le tournis vrai, et d'après l'âge des animaux affectés, car on sait que le tournis

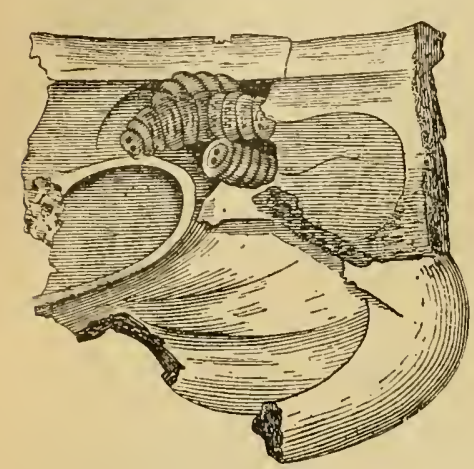

Fig. 520. - Larves d'(OEstres dans les sinus frontaux du Mouton (N. Joly). ne se montre guère que sur les jeunes.

A l'autopsie des Moutons qui sont porteurs de larves d'Olstres, on ne rencontre en général que des lésions peu importantes. Ces larves sont en nombre variable; on en compte le plus souvent de une à dix, mais Hertwig dit en avoir vu jusqu'à 40 , et Zürn jusqu'à 60 et 80 . Elles siègent à peu près exclusivement dans les sinus frontaux et leurs dépendances, c'estì-dire dans les cellules crensées à la base de l'axe osseux des cornes. La muqueuse est tuméfiée, enflammée

et recouverte d'un exsudat mucoso-purulent.

La prophylaxie ne fournit guère d'indications sérieuses.

Une fois que les larves sont fixées dans les sinus frontaux, on ne peut plus guère espérer les atteindre par la voie des cavités nasales, même ì l'aide dinjections de substances liquides. On recommande alors généralement d'effectuer la trépanation des sinus, voire l'amputation des cornes. On pénètre dans le sinus frontal du côté atteint en pratiquant l'ouverture un peu au-dessus de la ligne transversale qui réunit le milieu des deux yeux, et à quelque distance de la ligne médiane. Souvent alors, aussitôt que la lame osseuse a été enlevée par le trépan, on voitdes larves s'échapper par le fait des mouvementsqu'elles effectuent au contact de l'air. A l'aide de pinces, il est possible aussi d'en détacher un certain nombre. Enfin, on peut tenter de déloger par des injections celles qu'on ne peut atteindre directement. A la vérité, il ne faut pas espérer tuer les larves d'OEstres au moyen de ces injections, car, ainsi que l'ont établi les recherches de Fischer, elles ne le cèdent pas d'une façon bien marquée, sous le rapport de la résistance vitale, aux larves de Gastrophiles. Cependant, le contact de certains agents chimiques ou pharmaceutiques est capable de les déranger, et il y a alors quelque chance que leurs déplacements les entraînent à l'extérieur. On recommande surtout l'emploi de la benzine étendue, de l'eau phéniquée, de l'eau de chaux, de l'alcool.

Malheureusement, ce mode de traitement, appliqué à de grands 
troupeaux, occasionnerait des frais considérables : aussi n'y a-t-on recours que pour des animaux de haute valeur. Dans la plupart des cas, les proprietaires se décident à faire abattre leurs Moutons dès qu ils présentent des symptônes graves.

Nous arons, ì deux reprises, recueilli dans les sinus frontaux de la Chèvre domestique des láves d'OEstrus ovis au dernier stade; R. Blanchard a fait la même observation sur des Chèvres de Madère rederenues sauvages.

D’autre part, Kirschmann a signalé la présence de ces larves chez l'Homme; mais Löw a montré qu'il s'agissait en réalité de larves de Muscidés.

Parmi les OEstres vrais, lirauer signale encore OE. variolosus Löw, du sud de l'Afrique. Larve inconnue.

Genre Rinœstre (Rhinœstrus Brauer, 1886). - Corps à poils très courts, paraissant nu, avec de nombreux tubercules. Pattes courtes, délicates. Ailes à première cellule postérieure fermée et pédiculée, à nervures transversales terminale et postérieure obliques. Front bombé, saillant. Rudiment de la trompe long, rubanaire, s'étendant en dessous et en arrière entre les palpes splıériques, et offrant trois saillies à son extrénité. Abdomen tronqué; $6^{\text {e }}$ ou avant-dernier annean triangulaire.

Larres à antennes largement séparées. Corps à contour elliptique, à face dorsale très convexe, à face ventrale plane. Heux séries de bourrelets latéraux. Qnelques rangées d'épines à la face dorsale des premiers auneaux. Carité stigmalique postérieure étroite et profonde; plaques stigmatiques semi-lunaires. - Parasites des Équidés.

Rhinoestre pourpre (Rh. purpureus Brauer. - Syn. OEstrus nasalis De Geer, 1776, nec L., 1761; Cephalomyia purpurea Br., 1858; OEstrus purpureus Schiner, 1861). - Petite espèce presque nue, d'un brun pourpre foncé, à corps couvert de nombreux et grossiers tubercules. Face supérieure du thorax parcourue par des bandes noires, glabres, luisantes. Abdomen versicolore, d'un pourpre argentin ou grisàtre, à peine velu à l'extrémité, qui est mousse et tuberculeuse. Longueur du corps, 8 à 11 millimètres.

L'Insecte parfail, qui a été recueilli en Europe (Autriche-Hongrie, Russie, Andalousie) et en Afrique (Oran), se montre jusquà la fin de septembre. On a longtemps ignoré l'hòte chez lequel devait se développer sa larve; c'est en 1886 seulement qu'il a été déterminé par Anna Zugmayer et son frère Wolf : il s'agit du Cheral (1).

La larve au dernier stade est ellipsoïde, atteignant sa plus grande largeur vers le $g^{\text {e }}$ anneau; elle est incurvée, dans le sens de la longueur, vers la face ventrale. L'anneau céphalique porte deux crochets buccaux et deux antennes surmontées chacune de deux anneaux ocelliformes. Sur la face dorsale ou con-

(1) Fr. Bracer, Nachträge zur Monographie der Oestriden: I. Leber die von Frau A. Zugmayer und IIrn. F. Wolf enldeếle Lebensweise des OEstrus pu'pureus. Wiener Entowotogische Zeitung, V, p. 289, T'af. IV, 1856. 
vexe, du $2^{\mathrm{e}}$ au $10^{\mathrm{e}}$ anneau, on remarque entre deux anneaux successifs un bourrelet intermédiaire fusiforme. A la face inférıure, qui est plane d'un côté à l'autre et concave d'avant en arrière, il existe sur chaque anneau, à partir du $4^{\mathrm{c}}$, une paire de tubercules médians et un tubercule latéral situé en dessous du bourrelet latéral inférieur. Le dernier anneau est étroit et court, a cavité postérieure étroite et profonde, semi-elliptique; au-dessous du rebord inférieur droit de cette cavité se trouve l'appendice postérieur, qui en est séparé par un sillon transversal et porte de chaque còté un grand tubercule conique. Les plaques stigmatiques cachées dans la cavité sont semilunaires, noires; leurs "faux orifices " sont situés à leur bord concave interne.- L'urmature cutunée comprend pour la fuce supérieure : au bord antérieur de la deuxième partie de l'anneau céphalique, une double rangée de tubercules épineux. Au bord anlérieur des anneaux 2 et 3 , une triple rangée. Sur les anneaux 4 et 5 , cette triple rangée est plus ou moins interrompue vers la ligne médiane. 6 et 7 n'ont plus que quelques épines unisériées sur les parties latérales. $8,9,10$ et 11 sont tout à fait nus en dessus. Les bourrelets dorsaux intermédiaires sont tous nus. Au contraire, les bourrelets latéraux supérieurs et inférieurs sont armés, à l'exception du bourrelet supérieur de l'avant-dernier anneau. A la face inférieure, l'anneau céplalique porte quelques rangées de petites épines et de tubercules épineux. L'anneau 2 montre au bord antérieur trois rangées de semblables tubercules et le commencement d'une quatrième vers la ligne médiane. Mème garniture pour les anneaux 3 et 4 . Entre 4 et $\tilde{3}$, un bourrelet intermédiaire non distinct, mais portant une rangée d'épines; en outre, sur toute la longueur du $\check{\partial}^{\mathrm{e}}$ anneau, quatre autres rangées d'épines augmentant en grosseur de la première à la dernière. Les anneaux 6 a 10 armés comme le "̌e, mais avec des épines plus petites à partir du 8 8 . Dans les anneaux 9, 10 et 11, ces épines sont de mème grosseur dans toutes les rangées. - Longueur du corps, $17 \mathrm{~mm}, \breve{\text {; }}$; largeur au milieu, 7 millimètres.

Pathologie. - Arec Brauer, il convient sans doute de rattacher à l'OEstre pourpré la plupart des larves dOEstridés qui se développent dans les cavités nasales, les sinus frontaux, le pharynx et même le larynx du Cheval, et qui ont été signalées par un certain nombre d'observateurs, depuis Bourgelat (1760) et De Geer (1776). La présence de ces larves dans de telles régions peut entraîner des troubles sérieux et parfois même constituer un véritable danger. Quand elles sont lixées, par exemple, sur le voile du palais, au fond du pharynx et surtout à l'entrée du larynx, elles provoquent de la toux, du cornage, de la dyspnée et dans les cas graves occasionnent la mort par asphyxie. De nombreux faits de ce genre ont été recueillis dans diverses régrions. de l'Europe, et même en France (Vitry, Grépin, Pigeaire). Dans certaines. localités, les empiriques enlèveraient une partie de ces larves en introduisant dans le pharynx une sorte de brosse fixée à un manche.

Il ne nous est pas permis de nous étendre plus Ionguement ici sur les OEstrinés cavicoles. Bornons-nous par conséquent à sjgnaler le Cephalomyia maculutu Wied., dont la larve habite les sinus frontaux, les cavités nasales 
et le pharynx du Dromadaire et du Buffle, et le Cephenomyia Trompe L., dont la larre se développe dans le pharynx du Renne.

Section III : Cuticoles. - Face avec un champ médian à convexité largrement surbaissée, dit écusson facial. Ailes ordinairement troubles, pourvues d'unc nervure transversale terminale. Cuillerons grands. Femelle ovipare, avec un long oviscaple en lunctte d'approclie, se portant directement en arrière.

Larves sans crochets buccaux ou arec une seule paire; corps ovale, à facc dorsale concave, à face rentrale convexe et a trois

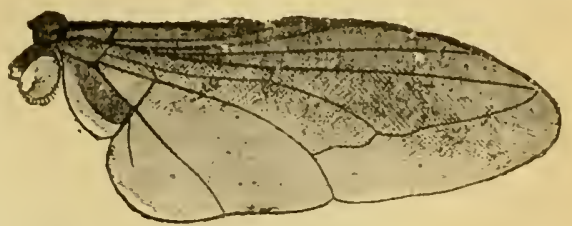
paires de bourrelets latéraux; plaques stigmatiques postérieures semi-lunaires ou arrondies. Larves vivant sous la peau des liuminants, Equidés et Rongeurs.

Cienres Hypoderma Latr., OEdemayena Latr., OEstromyia Brauer.

Genre Hypoderme (Hypoderma latr., 1823, nec Geoffroy, 1829). Espèces de taille très variable, revêtues de poils ordinairement fins et serrés; à paltes longues et fines. Cloison de séparation des fossettes antennales étroite, anguleuse. Antennes très courtes; $1^{\text {er }}$ et $2^{c}$ anneaux patelliformes. Trompe tout à fait rudimentaire. Corps oroüde. Palpes nuls.

Les larves au dernier stade sont entièrement privées de pièces buccales. Leurs antennes sont rudimentaires, non saillantes. Leur armature cutanée, constituée par de petits tubercules épineux très courts, est plus faible sur la face dorsale que sur la face inférieure. - Parasites des Ongulés.

IIypoderme du Boeuf (II. boxis [De Geer]. - Syn. : OEstrus bovis De Geer, 1776; OE. subculaneus Greve, 1818; H. bovis Latr., 1823̈). - Espèce noire, très velue. Face supérieure du thorax parcourue par trois ou quatre bandes longitudinales noires, nues, et rerêtue de poils blanchàtres ou jaunàtres en avant de la suture, noirs en arrière. Abdomen velu, d'un blanc grisàtre à la base, noir au milieu, jaune orangé en arrière. Tarière courte, cylindrique et noire. Ailes brunes, comme enfumées, sans taches. Longueur du corps (sans la tarière), 13 à 13 millimètres.

L'Hypoderme du Bouf est répandu dans toute l'Europe, y compris la péninsule scandinave; on

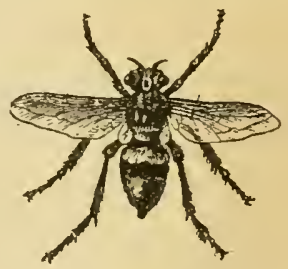

Fig. 524. - Hypoderma bovis, femelle, grandeur naturelle. l'a observé également en Asie et en Afrique, mais il ne semble pas qu'on l'ait vu dans l'Amérique du Nord.

C'esl un Insecte agile, courant très vite, mais moins aérien cependant que les Gastrophiles. Il voltige pendant une grande partie de l'été, ordinairement de la mi-juin au commencement de septembre. Il habite de préférence les pâturages fréquentés par les bêtes bovines, mais on le rencontre aussi dans les bois.

On ne connaît encore que fort peu le mode de vie de cette espèce en 
liberté, et cependant, dès l'antiquité, l'attention a été attirée sur la femelle au moment où elle va effectuer sa ponte. On sait que Virgile a chanté dans ses Géorgiques la terreur dont sont alors frappés les Bœufs. Tous les auteurs répètent d'ailleurs qu'à l'approche de la Mouche, les animaux relèrent la tête, étendent la quene et s'enfuient à la débandade en poussant de violents beuglements. Ces accès de frayeur ont reçu des paysans allemands le nom de furie des Beeufs (Biesen des Rindes). Plus d'un naturaliste, cependant, a mis en doute la relation existant entre cette frayeur et la provenance de l'Hypoderme, jusqu'au jour ou Schleicher en a démontré la réalité. "Il m’est arrivé dans une occasion, dit cet auteur en parlant du Biesen, de prendre l'OEstre sur un Bouf furieux; mais je dus le lâcher aussitôt pour ne pas être vic-

A

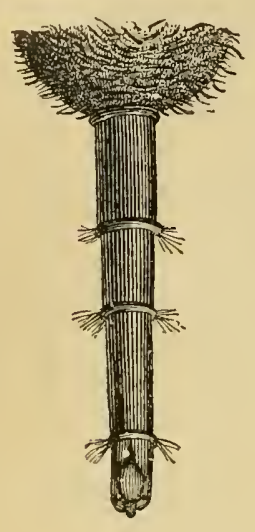

$\mathrm{B}$

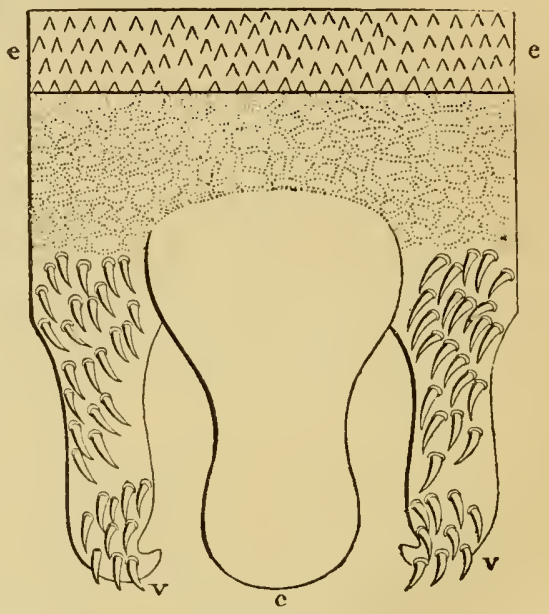

Fig. 525. - Hypoderme du Bouf. - A, tarière développée, grossie (Réaumur). B, extrémité de celte tarière, fortement grossie: $e$, épines qui revètent la surface externe de l'avaut-dernier tube de la tarière. $v$, tentacules valvaires. $c$, pièce médiane ou euiller (Joly).

time de la colère du Ruminant; heureusement, je pus le reprendre sur le sol un instant après. Il était d'ailleurs impossible de douter du but de ses attaques, car l'oviscapte effectuait encore de vifs mouvements de sortie et de rentrée. " On s'explique difficilement la cause de cette frayeur, qui sans doute est loin d'être constante. L'Hypoderme du Bœuf, comme ses congénères, est ovipare, et le simple examen de ses œufs montre qu'ils doivent être fixés sur les poils. D'après Greve, la femelle plane un certain temps au-dessus de l'animal, puis s'abat avec rapidité, plane de nouveau, se pose encore et répète ainsi ce manège une douzaine de fois dans l'espace d'une demi-heure. Au dire de cet observateur, la Vache se calme dès que l'Hypoderme s'est posé une première fois.

L'œuf est blanc, elliptique, comprimé et prolongé en arrière par un 
appendice fixateur de teinte brunattre; sa longueur est de $1^{\mathrm{mm}}, 23$. Il renferme, comme l'a ru Ilandlirsch, une larve revêtue de petites épines.

Si l'on est encore mal fixé sur le siège précis de la ponte, on ne l'est pas mieux en ce qui concerne le sort des jeunes larves. Jusqu'à ces derniers temps, on admettait sans conteste qu'elles devaient percer la peau du Bœư aussitût après leur éclosion et pénétrer directement dans le tissu conjonctif sous-cutané; mais des observations récentes ont ébranlé cette opinion. Sur l'llomme, comme l'a vu Schöyen, les larves eflectuent des trajets plus ou moins lon'ss sous la peau avant de former une tumeur et de se faire jour au dehors. Chez le Bœuf, Hinrichsen a trouvé, du mois de décembre au mois de juin (et surtout de décembre à mars), des larres jeunes dans la graisse interposée entre le périoste et la dure-mère spinale. D'autre part, la ponte ayant lieu en été, l'apparition des tumeur's qui décèlent la présence des larves sous la peau n'a lieu que dans le courant de l'hiver. Et si l'on rapproche de ces données les observations faites sur une

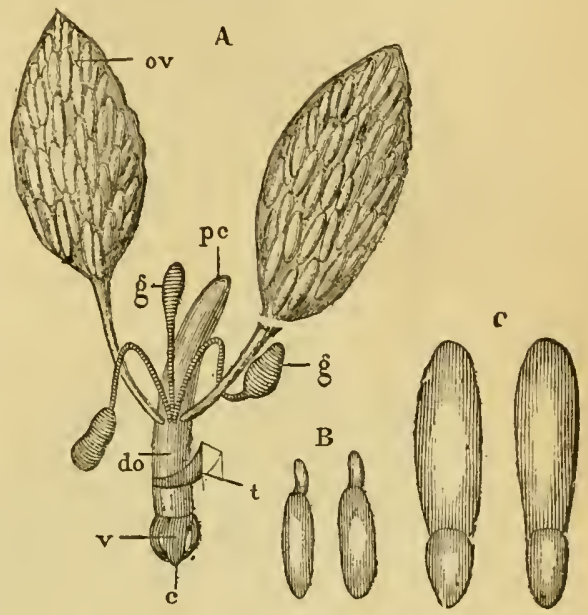

Fig. วั26. - Hypoderme du Bœuf. - A, apprareil génital femelle: $o v$, ovaires, $p c$, poche copulalrice. do, oviducte. $g$, glandes annexes. $t$, portion de l'avant-dernier Inbe de l'oviscapte. $v$, tentacules valvaires. $c$, pièce médiane ou cuiller. - B, cufs pris dans l'ovaire. C, cufs recueillis hors de lovaire (N. Joly).

espèce roisine (H. lineata) par C. Curtice, il ne semble pas irrationnel d'admettre que les larves écloses sur la peau sont ingérées à la façon des larves de Gastrophiles, et qu'elles accomplissent une phase parasitaire interne avant de revenir à la peau. En tout cas, on voit apparaitre, en automne ou en hiver, des tumeurs cutanées dont les principaux points d'élection sont le dos, les reins, la croupe, les épaules et les côtes, plus rarement la poitrine, le ventre et les cuisses. Chacune de ces tumeurs s'accroit en même temps que la larve qu'elle renferme, et finalement atteinl la grosseur d'une noix.

Il est à supposer que, comme dans les autres espèces du même genre, le développement de cette larve comprend quatre stades; mais, comme on vient de le voir, les premières phases sont encore inconnues; on n'a observé dans les tumeurs que deux formes, correspondant aux deux derniers stades.

$3^{\circ}$ stade. - Brauer a eu l'occasion d'étudier des larves extraites de tumeurs Railliet. - Zoologie. 
relativement petites, au nois de mai. Ces jarves sont allongées, claviformes et pourvues de bourrelets latéraux bien marqués. La face dorsale est presque nue, sauf sur les deuxième et troisième anneaux, qui portent de petits groupes d'épines. Sur la face ventrale, on observe des rangées transversales de semblables épines sur les bords antérieur et postérieur du deuxième et du neuvième anneau, et de petits groupes sur les parties latérales des delix premiers. Le dernier segment est garni de spinules microscopiques très serrées. Les plaques stigmatiques postërieures sont en forme de croissant et percées de petits orifices arrondis. -- A cet état, la larve mesure 15 millimètres de longueur sur une largeur de 4 millimètres au niveau du quatrième anneau.

$4^{\mathrm{e}}$ stude. - La larve est ovoïde, un peu plus épaisse en arrière qu'en avant; quand elle se contracte, elle devient presque sphérique, et lorsqu'elle s'étend, au contraire, elle offre l'aspect d'une petite nacelle, fortement bombée en dessous, plane en dessus. L'anneau céphalique montre une fossette buccale infundibuliforme, à marge m॰mbraneuse, qui ne possède aucun appendice et se trouve surmontée de deux antennes rudimentaires. Les anneaux suivants, du deuxième au neuvième, présentent de chaque côté trois bourrelets latéraux; ils portent en outre, sur leur face dorsale, deux petites verrues brillantes. Les $2^{\mathrm{e}}, 3^{\mathrm{e}}, 4^{\mathrm{e}}$ et $5^{\mathrm{e}}$ anneaux offrent, au bord antérieur de la face dorsale et des bourrelets supérieurs et moyens, de très courtes épines. Il en existe également plusieurs rangées au bord postérieur des anneaux deuxième à septième ou huitième. A la face ventrale ou concave, du deuxième jusqu'au neuvième segment, on trouve de même plusieurs rangées d'épines aux bords antérieur et postérieur. Les bourrelets inférieurs, du deuxième au huitième anneau, en sont munis à leur bord antérieur. Les deux derniers anneaux sont nus. Les plaques stigmatiques postérieures sunt en forme de croissant, ponctuées et creusées vers leur bord externe, qui est épais et mamelonné, de sillous rayonnants. - Le tégument est chagriné; sa teinte est d'abord blanche, avec les plaques stigmatiques et les spinules brun noiràtre. A l'approche de la maturité, la couleur devient d'un jaune gris sale; puis des laches brunes apparaissent sur les bourrelets latéraux et aı niveau des spinules, el ces taches s'étendent de plus en plus, tout en laissant des lignes longiludinales plus claires, jusqu'à ce que la larve devienne enfin d'une teinte brun noirâtre. - La plupart des larves arrivent à maturité aux mois de mai et de juin; on en trouve cependant quelques-unes encore vers le mois d'août. Elles mesurent alors 22 à 28 millimètres de long sur 11 à 1 ว̆ de large au niveau du huitième anneau.

Nous avons dit plus haut qu'elles sont logées dans le tissu conjonctif sous-cutané. Or, dès leur deuxième stade, elles proroquent, à la façon d'un corps étranger, une irritation qui se traduit par une inflammation circonscrite aboutissant à la suppuration. C'est ainsi que se développent les tumeurs d'OEstres, auxquelles Joly domnail, avec quelque raison, le nom de galles animales, et qui s'accroissent progressivement, de manière à acquérir leurs plus grandes dimensions vers le commencement de l'été. Chaque larve est logée dans une cavité à parois assez résistantes, qui se moule en quelque sorte sur elle. 
On ne tarde pas ì constater que celte eavité est en communication avee l'extérieur par une ouverture un peu excentrique, rapprochée tantôt du sommet, lantiot de la base.

En appuyant sur la tumeur, qui est légèrement fluctuante, on apercoit les stigmates de la larve qui viennent faire saillie au niveau de celte ouverture: la larve se tient, en effet, dans une position oblique, mais la tète toujours situće vers le fond, tandis que l'extrémité poslérienre est dirigée vers l'extérieur de manière à permettre la respiration et l'expulsion des exeréments. La perforation de la peau paraît être le résullat de la compression exercée d'une façon continue par cette extrémité postérieure ; l’orifice s'aceroit peu à peu et finit par aequérir le diancitre d'une lentille. Les bords sont le plus souvent l'evêlus, de pus conciélé.

Lorsque la larve est sur le point de quitter son hôte, èlle engage de temps en temps les derniers anneaux de son corps dans cet orifice, jusqu'à ee que celui-ci soit suffisamment dilaté. 1) après les oloservations de Réaumur. cest en gínéral le matin, entre six et huil heures, qu'elle sort de la tumeur: mais on en a vu sortir plus tard et même dans l'après-midi.

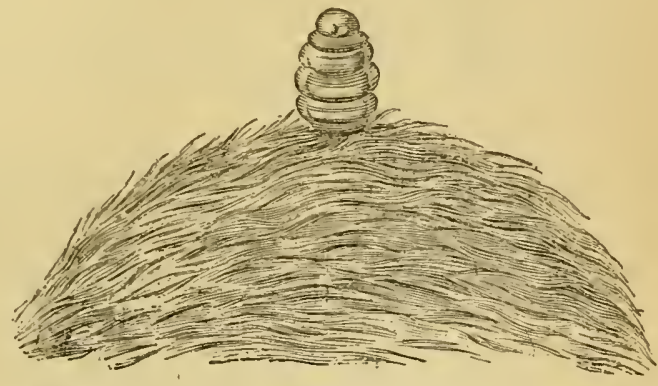

Fig. 517. - Larre d'Ilypoderma bovis soriant d'une lumeur (Réaumur). Si elle tombe dans un endroit convenable, comme une terre meuble, du fumier, des feuilles, elle ne tarde pas à s'enfoncer à plusieurs centimètres de profondeur et à se métamorphoser en nymphe.

Celle-ci offre un aspect assez variable, les bourrelets latéraux étant parfois très saillants, et d'autres fois effacés; elle est allongée, pyriforme, élargie en arrière, aplatie en dessus à son extrémité antérieure. Sa teinte, d'abord d'un bleu d'ardoise, passe ensuite au brun foncé et au noir. Sa longueur est de 20 millimètres.

Létat de nymphe dure en moyenne de vingt-six à trente jours, plus ou moins, suirant l'élévation de la température.

Pathologie. - Les tumeurs d'OEstres existent généralement en plus grand nombre sur les bêtes adultes et de bonne constitution que sur les Veaux el les animaux arancés en àge.

Le nombre des tumeurs dont peut être porteur un même animal est des plus variables. Souvent il n'en existe que quelques-unes, cinq ì dix par exemple, et en pareil cas, elles ne Iui causent aucun préjudice sérieux. Mais on en observe, dans certains cas, jusqu'ì cinquante, 
cent et même davantage, et l'on conçoit que l'économie ne soit pas alors sans en ressentir quelque doinmage. L'irritation constante qu'entretiennent les larves, la douleur qui en résulte, et d'autre part l'action spoliatrice qu'elles exercent, se traduisent en effet par un amaigrissement plus ou moins sensible ou tout au moins par un retard dans l'engraissement, et par une diminution de la sécrétion lactée. Il faut tenir compte aussi de la perforation de la peau, qui fait perdre à celle-ci une grande partie de sa valeur. On assure que les peaux tirées du sud de la Russie et de l'Orient sont souvent obtenues à des conditions exceptionnelles de bon marché, parce qu'elles sont criblées, dans certaines régions, de trous ayant cette origine.

La stabulation permanente seule est propre à soustraire, d'une façon absolue, les bêtes bovines aux attaques de ces Insectes.

Lorsque les tumeurs sunt développées, le traitement le plus simple consiste à extraire les larves par une compression méthodique, précédée au besoin d'un léger débridement. Cette simple extraction est toutefois assez douloureuse. Il convient de laver ensuite la plaie avec soin.

Hypodermes chez les Équidés. - Vallisneri, Chevalier, Clark.., Loiset, Joly, et après eux beaucoup de vétérinaires, ont constaté, chez le Cheval, la présence de tumeurs cutanées semblables à celles que nous venons d'étudier, et contenant de mème des larves d'Hypoderme. Joly rapportait ces larves à une espèce particulière, qu'il proposait de dénommer H. Loiseti: mais cette opinion n’a pas été généralement acceptée : on les a au contraire identifiées à celles de l'H. bovis. Nous en avons examiné divers échantillons provenant de France et d'Algérie, et il nous a paru, comme à Mégnin, qu'il s'agissait constamment de larves d'H. Lovis au pénultième stade. Le fait qu'elles n'arrivent jamais à leur complet développement montre que ce sont des larves égarées dans un milieu non favorable à leur évolution.

Zürn signale la présence des mèmes larves sous la peau de l'Ane, nonobstant l'opinion de Brauer, qui parait vouloir les rattacher à son H. Silenus.

On a rapporté aussi plusieurs observations démontrant que des larves d'OEstridés peuvent pénétrer jusque dans l'encéphale des Équidés. Quelques auteurs ont pensé qu'il s'agissait de Gastrophilus; mais Boas est d'avis que ce sont presque taujours, au contraire, des larves d'H. bovis, et les observations d'Hinrichsen et de Curtice semblent appuyer cette manière de voir. On conçoit que les animaux ainsi atteints succombent très rapidement.

Le prétendu Monostoma Setteni, trouvé dans l'ceil d'un Cheval (roy. p. 339), était vraisemblablement aussi une larve d'H. lovis.

Hypodermes chez le Mouton. - Zürn rapporte encore à l'H. bovis les larves rencontrées quelquefois dans le tissu cellulaire sous-cutané du dos des Moutons. Brauer suppose qu'il s'agit plutòt de l'H. lineata.

Hypodermes chez l'Homme. - A diverses reprises, on a signalé aussi la présence de larves d'OEstridés dans la peau de l'Homme, en les rapportant la plupart du temps à l'espèce nominale OEstrus hominis. Il est certain aujour- 
d'hui que la plupart des cas signalés se rapportent à l'H. bovis. Schöyen, notamment, a relevé diverses observations recueillies en Suède, en faisant remarquer que le plus souvent ces larves ont accompli des trajets assez longs sous la peau, en se dirigeant vers les épraules, le cou et la tête, avant de développer des tumeurs et de souvir un passage a travers le tégument pour s'échapper. Tous ces cas ont été observés dans les mois d'hiver; mais les larves, comme celles du Cheval, n’arrivent jamais à maturité. Les sujets envahis sont généralement des individus chargés de soigner le bétail, et Schöyen pense que c'est l'odeur de bouverie qui attire les Insectes. On peut admettre aussi que les larves écloses sur la peau du biouf sont ingérées avec les aliments, et en particulier avec le lait.

Hypoderme raye (H. lineatu [de Villers]. - Syn. : Olistrus lincatus de Villers, 1789; OEstrus supplens Walker, 1853; H. bonassi Brauer, 1875; H. lineata Br., 1838). - Espèce noire, très velue. Face supérieure du tlırax parcourue par des baudes longiludinales noires, nues, et revêtue, en avant comme en arrière de la suture, de poils gris jaunàtre mélangrés de poils noirs. Abdomen velu, blanc ou jaunàtre à la base, noir au milieu, rouge orangé en arrière. Ailes hyalines, à peine brunàtres, non enfumées comme dans $H$. bovis. Longueur du corps (sans la tarière), 12 à 13 millimètres.

Cette espèce, quoique non signalée en France jusqu'à présent, y existe fort probablement, car on l'a observée dans presque toutes les autres contrées de l'Europe. Mais elle est surtout répandue - ¿t l'exclusion de la précẻdente - dans l'Amérique du Nord. Elle a donné lieu à de très intéressantes recherches de C. Curtice (1).

La femelle effectue sa ponte sur le corps du Bœuf; mais elle parait craindre de poursuivre cet animal dès qu'il a pénétré dans l'eau. Les œufs sont fixés par groupes sur les poils des llancs, du ventre, de la queue et surtout des membres. Ces œufs sont blanc jaunàtre et longs de 1 millimètre, y compris l'appendice fixateur. Au moment de la ponte, ils contiennent déjà une larve, qui ne tarde pas sans doute à s'échapper de la coque. Curtice admet que cette larve est léchée par le Bœuf et qu'elle passe ainsi dans l'arrièrebouche et l'œsophage, où elle subit une première mue. Plus tard, vers la Noël, et jusque vers le commencement de février, elle émigre á travers les tissus, gagnc le tissu conjonctif sous-cutané du dos et perce la peau gràce aux minuscules épines de son extrémité postérieure, de manière à amener les plaques stigmatiques au contact de l'air. Après deux autres mues, elle atteint son développement délinitif.

Cette larve présente donc quatre stades, dont nous ne pouvons que signaler rapidement les caractères : $-1^{\text {er }}$ stalle. Au sortir de l'œuf, clle est blanchàtre, longue de $0^{\mathrm{mm}}, 8$, large de $0^{\mathrm{mm}}, 2 ; \mathrm{du} 2^{\mathrm{e}}$ an $12^{\mathrm{e}}$ anneau, elle est à peu près entièrement revètue de très petites épines; sur le 12 e anneau, ces épines sont plus fortes. Les pièces buccales consistent en deux mandibules en croissant, supportées chacune par une tige bifurquée. - ¿e stade. Les larves trouvées dans l'œesophage et sous la peau sont longues de 11 à 14 mil-

(1) C. Curtice, The Oxuarble of the United States. The Journal of compar. Med. and vet. Archives, XII, p. 265, 1821. - C. V. RiLEY, The Ox Bot in the United States. Insect Life, IV, p. 302, 1892. 
limètres; leur surface est lisse, à part quelques petiles épines autour de la bouche et des stigmates postéricurs; les mandibules sont plus saillantes. - $3^{\text {e }}$ stade. La larve, longue d'environ 16 millimètres, est plus alténuée en arrière qu'en avant; ses caractères sont assez semblables á ceux de la larve mûre; son revêtement épineux, assez variable, offre notamment la même disposition à la face ventrale, quoique moins abondant et moins saillant; mais l'armature dorsale est beaucoup plus pauvre, se limitant aux deux preniers anneaux ou même faisant tout à fait défaut. - $4^{\mathrm{e}}$ stade. A cet état, la larve diffère principalement de celle de l'II. bovis en ce que son armature cutanée est plus complexe. Disons seulement qu'au lieu d'avoir, comme celle-ci, les deux derniers anneaux privés d'épines, elle n'a que le dernier, c'est-à-dire l'anneau stigmatifère, entièrement nu. Au moment de quitter les tumeurs cutanées, elle est de teinte blanc grisàtre et mesure 22 à 20 millimètres de long.

Les troubles que peuvent occasionner ces larves sont identiques à ceux produits par les larves de l'Ir. buvis.

Hypoderme Diane (II. Diana Brauer, 1858). - Hypoderme gris noiràtre, avec quelques poils jaunes. Face supérieure du thorax parcourue par des bandes longitudinales noires, nues. Abdomen noir, marqueté de cendré ou d'argenté chez le màle, presque tout noir et un peu brillant chez la femelle, revêtu de poils noirs et jaunes. Ailes hyalines noiràtres, assez petites. Longueur du corps (sans la tarière), 11 à 12 millimètres.

Cette espèce n'a été rencontrée jusqu'à présent qu'en Autriche et en Allemagne. Ses larves vivent sur le Cerf et le Chevreuil.

A l'avant-dernier stade, ces larves sont lonģues de 10 à 17 millimètres, et larges au $6^{\theta}$ anneau de $4^{\mathrm{mm}}, 5$ à $5^{\mathrm{mm}}, 5$; elles sont fortement atténuées en arrière; à la face dorsale, sur la ligne médiane des $2^{\circ}$ et $3^{\mathrm{e}}$ auneaux, elle porte un très petit groupe d'épines souvent caduques; à la face veulrale, il existe une large bande d'épines aux bords antérieur et postérieur des anneaux 2 à 6 inclusivement. - Au dernier stade, la longueur peut atteindre 15 à $2 \%$ millimètres, pour une largeur de 6 à 10 millimètres an niveau du septième anneau. La forme est plus allongée et plus grèle que chez la larve d'H. bovis. La face dorsale porte, du $2^{\mathrm{e}}$ au $4^{\mathrm{e}}$ et mème au $\mathrm{S}^{\circ}$ anneau, un petit gronpe de petites épines fines et allongées, dirigées en arrière; le $10^{\circ}$ et le $11^{\mathrm{e}}$ anneau sont nus. La face ventrale porte, du $2^{\mathrm{e}}$ au $8^{\mathrm{e}}$ anneau, au bord antérieur, trois ou quatre groupes d'épines semblables, et au bord postérieur plusieurs rangées de très fines épines dirigées en avant; sur les deux bords du $9^{\mathrm{e}}$ anneau et sur le bord antérieur du $10^{\mathrm{e}}$, une rangée interrompue d'épines; le $11^{\mathrm{e}}$ est $11 \mathrm{u}$.

Parmi les observations d'OEstres cutanés recueillies sur l'llomme, il en est certainement plusieurs qui se rapportent à l'H. Diana; G. Joseph a même pu obtenir dans un cas le déreloppement de l'Insecte parfait, ce qui prouve que les larves étaient arrivées à maturité.

Outre les espèces qui viennent de nous occuper, on signale encore, parmi les Hypodermes, trois types bien établis :

Hypoderma Silenus Br., de l'Europe méridionale et de l'Asie mineure; trouvé aussi en Afrique. La larre est inconnue; il y a cependant quelque raison de 
supposer que c'est celle qui se développe parfois sous la peau de l'Ane.

II. Actxon Br., de l'Eurupe centrale. Larve sous la peau du Cerf d'Europe.

II. Clurlii (Shuckard), du Cap de Bonne-Espérance. Insecte parfait trouvé an milieu du gros bétail.

Plus deux espèees douteuses: II. heteroptera Macq., d'Algérie, et $I$. Bellieri Bigot, de lit Corse. Variétés probables de l'll. Lovis.

Geure Edèmagėne (OEdemagena Latr., 1818). - Se distingne surtoul du genre Hypoderme par la présence de deux petits palpes globuleux.

Les larves sont à peu prís également épineuses sur les deux faces.

GEdémagène dı renne (Obal. tarandi [L.]. - Syn.: OEstrus tarandi L., 1701 ; OLd. tarandi Latr., 1818 ; IIypoderma larandi Brauer, 18̈̈8). - Grande espèce très velue. Face supérieure dn therax à poils jaunes en avant de la suture, noirs en arrière. Abdomen noir, couvert de poils jaune pàle à sa base, fauves dans le reste de son étendue. Niles délicales, lıyalines. Cuisses noires ; jambes et tarses jaune grisitre. Longueur dn corps, 13 à 16 millimètres.

De la Laponie et de I'Amérique du Nord. La femelle voltige en juillet et aoùt; elle dépose ses œufs sur la peau des Rennes, qui éprouvent à son approche une frayeur exıraordinaire. Les larves se comportent comme celles de l'llypoderme du Bœuf; elles acquièrent 22 à 30 millimètres de long sur 13 millimètres de large au niveau du $7^{e}$ anueau. Les tumeur's qu'elles produisent, aussi bien que l'Insecte lui-mème, reçoivent des Lapons le nom de Kurbma. Les animaux qui en sont affectés maigrissent d'une facon très accusée, et on assure que beaucoup d'entre eux liuissent par succomber.

B. Sous-famille des CUTÉRÉbrinÉs. - Trompe coudée, rétractile dans une fossette longitudinale profonde; palpes nuls. La face inférieure de la lète montre donc une simple fente longitudinale. Style des antennes souvent plumeux en dessus. Ailes à nervure transversale terminale. Femelle sans oviscapte apparent; orifice génital dirigé en dessous et en avant.

Larves à deruier anneau pouvant s'engager dans le précédent, beaucoup plus petit et constituant parfois comme un appendice cupuliforme de celuici, qui forme la cavité stigrmatique. Une seule paire de crochets buccaux bien développés, ou très petits, pouvant mème manquer.

Toutes les espèces connues jusqu'à présent sont américaines. Les larves vivent sous la peau, quelquefois dans le scrotum. - Genres Rogenhofera Brauer, Cuterebra Clark, Dermatobia Brauer.

Genre Cutérèbre (Cutercbrc Clark, 1815). - Espèces très grandes, lourdes, à abdomen ovoüde offrant en général des reflets métalliques, et revètues de poils souvent serrés, mais relativement courts. Pattes courtes et épaisses; tarses larges, plats. Cuillerons très grands. Troisième article des antenues ovoüde ou elliptique, court, it slyle plumeux en dessus.

Les larves ressemblent de prime abord à celles des llypodermes; elles sant ovoïdes, très épaisses, revêtues d'épines et de bìtonnets pointus diversement conformés. Les stigmates postéricurs sont disposés sous forme de plaques chitineuses. - Chez les Rongeurs et les Marsupiaux, exceptionnellement chez les Cálınivores.

Cutérèbre chàtreur (C. emasculator Fitch, 1859). - Assez grande espèce, 
à thorax noir entièrement revètu de poils jaunes; écusson noir et à poils noirs. Abdomen noir, marbré et ponctué de teintes argentées sur les côtés. Ailes hyalines, enfumées. Patles noires. Longueur, 17 millimètres.

De l'Amérique dn Nord.

La larve esı ovoïde, déprimée, surtout à la face ventrale, arrondie à une extrémité et un peu acuninée à l'autre, de leinte noire brillante, revètue sur toute la surface de petites granulations saillantes, dures, anguleuses, qui lui donnent un aspect chagriné, mais dépourvue d'épines el de bàtonnets; elle montre de chaque còté trois séries de bourrelets latéraux. Pas de crochets buccaux. La longueur peut atteindre un pouce (2\% millimètres) sur une largeur moitié moindre.

Celle larve se développe dans le scrotum de l'Écureuil strié d'Amérique (Tamias Lysteri), et entraine, soit par irritation directe, soit par les morsures que se font les animaux atteints, la destruction des testicules, de sorte que, selon les chasseurs des États-Unis, la moitié des Écureuils auraient à subir les effets de cette castration parasitaire.

Cecil French (1) a récemment rapporté à la mème espèce une larve trouvée, au Collège vétérinaire de Montréal, dans le scrotum d'un Chien.

Genre Dermatobie (Dermutobia Brauer, 1860). - Créé aux dépens du genre précédent, ce groupe peut ètre caraclérisé de la façon suivante : Espèces de taille moyenne, revètues de poils courts et peu apparents, avec l'abdomen aplati offrant d'ordinaire des reflets d'un beau bleu métallique. Pattes grêles, de longueur médiocre. Troisième article des antennes rubanaire, beaucoup plus long que les deux premiers réunis, à style plumeux en dessus.

Les larves sont claviformes, fortement rétrécies en arrière, revêtues de grands tubercules et de rares ceintures d'épines. Les stigmates postérieurs se présentent sous l'aspect de trois fentes longitudinales convergentes situées de chaque còté du dernier anneau, qui est petit, cupuliforme et souvent entièrement caché dans le dixième. Il existe une seule paire de pièces buccales. - Chez les Ruminants, les Carnivores, etc., voire chez l'Homme.

Dermatobie nuisible (D. noxialis [J. Goudot]. - Syn, : Cuterebra noxialis J. Goudol, 1845; D. noxialis Brauer, 1860). - Espèce grise et bleu d'acier, presque nue. Face jaune; joues offrant une large callosité brun jannàtre et brillante. Face supérieure du thorax cendrée, avec des reflets bleus et blancs. Abdomen brillant, d'un beau bleu d'acier, à base blanc sale. Ailes d'un brun pàle. Longueur du corps, 14 á 17 millimètres.

Cette espèce appartient à l'Amérique dı Sud et à l'Amérique centrale. J. Goudot l'a observée dans la Nouvelle-Grenade (Colombie), et Brauer la signale de Bahia (Brésil). D'après te premier de ces auteurs, elle abonde, dans les régions chaudes et lempérées, sur la lisière des grands bois et dans les rastrajos, c'est-à-dire dans les parties qui offrent à la fois des taillis et des prairies. Elle constitue un véritable fléau pour le Bœuf, mais s'attaque en outre au Chien et à l'Homme.

On ignore comment l'Insecte parfait dépose ses œufs ; mais la larve pro-

(1) Cecil Frexcr, Cuterebra emasculator in Dog. Journ. of compar. Jedicine and veter. Archives, XlY, p. 379, 1893. 
INSECTES. - DIPTẺRES.

voque la formation de tumeurs cutanées semblables à celles de l'Hypoderma boris. Cette larve a élé recueillic au Venezuela, en Colombie, dans le IIonduras el au Brésil. Dauss la première de ces contrées, on l'appelle Ouche; en Colombie, elle est connue sous les noms de Nuche el de Gusuno, qui d'ailleurs paraissent sappliquer indistinctement à toutes les larves sous-cutanées.

D'après Goudot, elle est d'un blanc sale, couleur de pus, et peut atteindre 3 centimètres de long sur $8^{\mathrm{mm}}, 5$ de large au niveau du $4^{\mathbf{e}}$ anneau. Elle est pyriforme, beancoup plus épaisse en avant qu'en arrière. La bouche est munie de deux crochets.
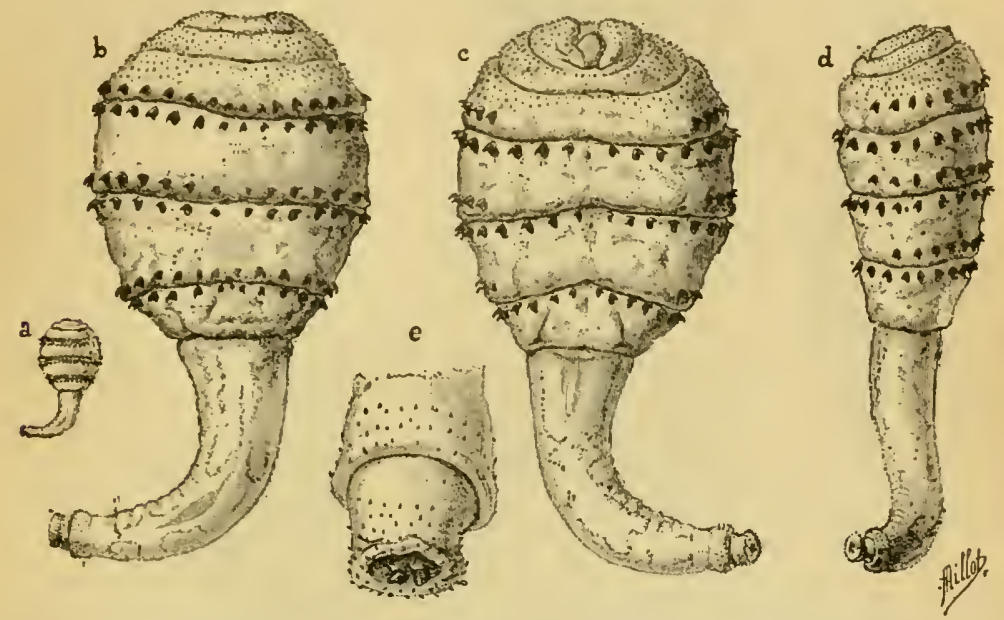

Fig. 523. - Larve de Dermatobia noxialis, du Brésil. - $a$, graudeur uaturelle. $b$, grossie, face dorsale. $c$, face veutrale. $d$, de profil et par le côté gauche. e, extrémité caudale très grossie (R. Blanchard).

Selon R. Blanchard (1), les anneaux 2, 3 et 4 sont parsemés de petiles épines noires, qui disparaissent peu à peu dans les deux suivants; les anneaux 5, 6 et $\bar{a}$ portent à leur bord antérieur une ceinture complète de forts crochets noirs à pointe recourbée en arrière ; les anneaux 4 , 5 et 6 ont à leur bord postérieur une demi-ceinture dorsale et latérale decrochets semblables. Les quatre derniers segments, qui forment la partie rétrécie du corps, sont lisses, sauf dans Ia moitié postérieure du $10^{\circ}$ et sur le $11^{\text {e }}$ tout entier, dont la surface esı revètue de très petiles épines.

Celte description est basée sur un exemplaire recueilli par Gounelle au Brésil (fig. 528), sur l'épaule d'un Européen (I889). Malgré quelques différences apparentes, elle semble bien conforme à celle de Goudot (1843), établie d'après des larves provenant de Bueufs colombiens. On peut encore rapporter à la mème forme des larves extraites de la peau de l'Homme au Venezuela (Brick, 1822), dans le IIonduras (Matas, 1887), etc., et de la peau du Mulet à Cayenne (Chapuis, 1862). Blanchard donne spécialement le nom

(1) R. Blanchard, Sur les OEstrides américains dont la larve vit dans la peau de l'Homme. Annales de la Soc. entomol. de France, LXI, p. 109, 1892. - Voir aussi sur le même sujet d'autres notes el mémoires da même auteur, dans le Bulletin et les Annales de cette Société, 189:-1894. 


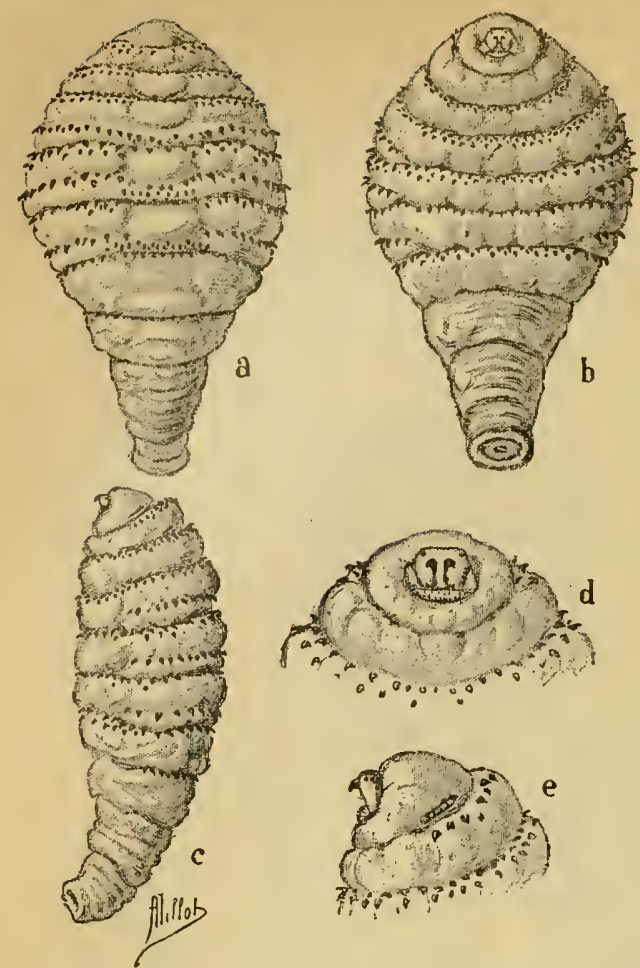

Fig. 529. - Toreel, de la Colombie, - $a$, face dorsale. $b$, face veutrale. $c$, de profil el du côté gauche. $d$, extrémité antérieure vue par la face ventrale. $e$, extrémilé antérieure vue de profil (R. Blanchard).

guar. On l'a observée en outre au Mexique, de Ver macaque à la larva du Dermatolia noxialis ; mais ce nom s'applique, dans la Guyane française, à toutes les larves sous-cutanées.

A còté de cette espèce, dont on connaît à la fois l'Insecte et la forme larvaire, la faune américaine en comprend un grand nombre d'autres dont les relations sont loin d'ètre déterminées. Nous dirons seulement quelques mots des larves les plus connues qui ont été recueillies sur le corps de I'Homme ou des animaux domestiques, et nous renverrons pour le surplus au Mémoire de Blanchard.

A Costa-Rica, on donne le nom de Torcel à une larve très commune sur le Bœuf et sur l'Homme. En Colombie, la mème larve, sous d'autres noms, se rencontre sur les mêmes hòtes, ainsi que sur le Chien et le Jaan Brésil et à Cayenue.

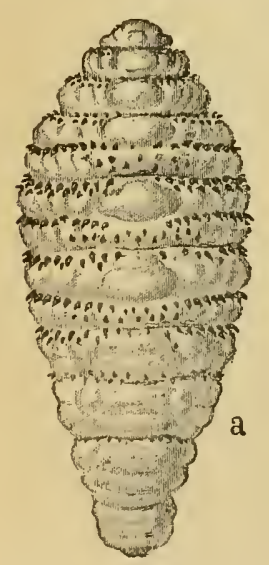

Fìg 530. - Bíchıo berne, du Brésil. - $a$, face dorsale. $b$, face veulrale. $c$, de profil el du eôlé gauelıe (R. Blanchard).

R. Blanchard considérait d'abord comme différente du Torcel la larve qui 
se rencontre fréquemment chę l'llomme au Brésil, et que l'on y désigne sous le nom de Berne ou Bicho beme. Mais il a reconnu par la suite, graice à l'examen d'un plus grand nombre d'exemplaires, que ces deux formes, hien que réellement assez dissemblables, appartiennent à une seule et mème espèce. Il inonce une série de faits tendant à démontrer que celte larve est l'état jeune de Dermatobia cyaniventris Macquart, ainsi que Brauer l'avail dójà supposé.

Blanchard résume daus le tableau suivant les principaux caractères différentiels de ces deux sortes de larres:

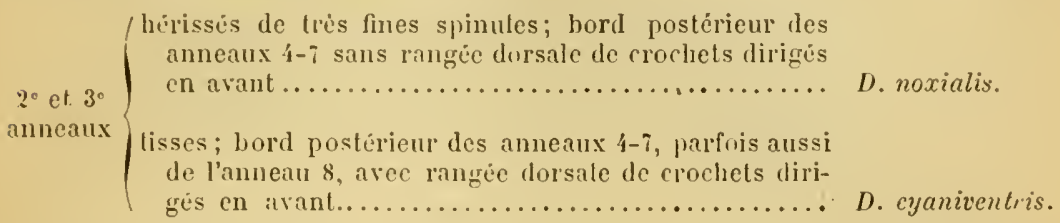

Quant au Ver moyocuil, observé au Mexique, chez l'Homme et chez le Chien, par Boucarl (1839 et 1862 ), il est identique tantòt à l'une et tantò à l'autré des deux formes précédentes; ses caractères sont trop indécis pour qu'on puisse les considérer cornme distinctifs d'une espèce particuliere.

En Afrique, lllomme et les animaux sont sans doute fréquemment envahis par des larres d'OEstridés, mais celles-ci n’ont pas encore été bien sérieusement étndiées. - Coquerel et Mondière (1) ont obserré à Portudal, près Gorée, des larves cuticoles de l'llomme et du Ghien que les indigènes rapportent à une Vouclıe (Idia Bigoti); il est bien plus probable qu'il s'agit d'un OEstriılé. - Dutrieux dit que dans l'Ouniamouési, les indigènes appellent founza ia ngûmbé, c'est-à-dire "Ver dı Bœuf ", une larve d'Insecte qui produit sous la peau du Bueuf et de l'Homme une sorle d'éruption furonculeuse; il est permis de faire à l'eulroit de cette larve la mème supposition que pour la forme précédente.

L'extraction de ces parasites s'efrectue sclon le procédé que nous avons indiqué à propos de l'Hypoderma bovis. En Afrique, les pàtres sont aidés dans ces soins par un Oiseau, le Pique-Bœuf (Buphaga aficanu), qui se nourrit des larves en question.

Les PHORIDÉS se distinguent de tous les autres Brachycères en ce que les nervures longitudinales des ailes sont indivises et non réunies par des nervures transwersales (IIypoceres).

Leurs larves vivent dans les matières organiques en décomposition. Trineura aterrima (Latr.): larres et nymphes sur les cadavres d'enfauts à demi desséchés.

Kahl a vu à Varsovie des nilliers de larres de Phor mufipes Meig. dans les matières vomies par un jeune Ilomme qui avait éprouvé de sérieux troubles digestifs.

Famille des MUSaIDiss. - Cette famille comprend toutes les Muuches

(1) Coquerit et Moxntér, . Nole sur des lares de Diptires léceloppées duns des tumeurs d'apparence furonculeuse au Sinégul. Annales de la Soc. cutomol. de France (4), 11, P. 95, 186\%. - Voir aussi Graz. hebdom. de méd. et de chir., IV, p. 100, 1862. 
proprement dites, dont Linné avait fait son genre Musca., Les ailes ont une nervation assez caractéristique, sur laquelle nous ne pouvons insister ici. Les antennes ont le troisième article lenticulaire et muni à sa base d'une soie dorsale, articulée ou non, velue ou nue. La trompe, infléchie, est constituée essentiellement par la lèvre inférieure: le plus souvent, elle est courte et terminée par des paraglosses qui forment un renflement mou (II sca); d'autres fois, elle est assez longue, cornée et piquante (Stomoxys); mais elle ne contient ni mandibules ni màchoires, bien que celles-ci soient représentées par deux palpes; il reste seulement deux pièces, parfois acérées, qui répondent à l'hypopharynx el à l'épipharynx.

Beaucoup de Muscidés - du noins les femelles - fréquentent les animaux et s'abreuvent, soil de leur sang, soit des humeurs excrétées.

On divise, dune façon un peu arbitraire, cette famille en deux groupes: Calyptérés et Acalyptérés.

$1^{\text {re }}$ section : Acalyptérés. - Cuillerons nuls.

Un certain nombre d'Insectes de ce groupe sont nuisibles aux végétaux. Tels sont les Chlorops (Chlorops) et les Oscines (Oscinis), qui altaquent les

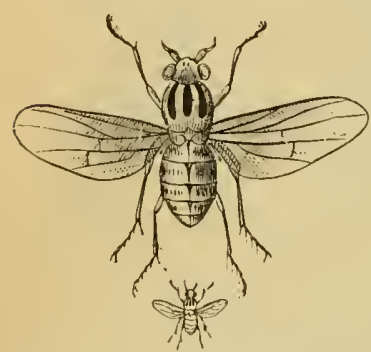

Fig. 531 . - Chlorops pumilionis des tiges du seigle, grandeur naturelle ct grossi. tiges et les épis des céréales; la Mouche des olives ou Keiroun (Dacus olex), la Mouche des oranges (Ceratitis hispanica) et la Mouche des cerises (Ortalis cerasi), qui pondent dans les fruits; la Mouche des luzernes (Agromyza nigripes), dont la larve mine les feuilles de luzerne et les couvre de taches blanches, etc. Récolter de bonne heure et brûler.

D'autres pondent dans les substances organiques, dont elles hàtent la décomposition. C'est le cas de la Mouche du fromage (Piophila casei), dont tout le monde connait la larve, qui saute en se détendant comme un ressort. Cette larve peut vivre dans le tube digestif pendant plus de vingt-quatre heures sans être digérée, et y poursuivre son évolution presque jusqu'à la nymphose. Quand il s'en troure un grand nombre à la fois, le patient éprouve des coliques assez sérieuses.

La mouche des urinoirs (Teichomyza fusca Macquart, Scatclla urinaria Robineau-Desvoidy) est très commune dans les urinoirs des grandes villes, dans les cabinets d'aisance mal tenus, etc. La larve vit dans l'urine, dans les matières des fosses d'aisance, dans les eaux corrompues; or, il arrive souvent que des malades en trouvent des exemplaires dans les cuveltes des latrines et croient les avoir rendues, soit par le vomissement (Mydæa vomiturationis Rob.-Desr.), soit avec les selles. Cependant, il n'est pas impossible qu'elles passent accidentellement dans le tube digestif: d'après les recherches de Pruvot, elles peuvent vivre jusqu'à trois jours dans l'estomac du Rat, où elles se fixent à l'aide des épines dont leur corps est revètu.

La Mouche à ventre noir (Drosophila melanogastra) vit, comme ses congénères, aux dépens des matières fermentées; elle recherche surtout les produits d'origine végétale, et cependant, d'après G. Joseph, c'est par l'intermédiaire de la crème aigrie que ses larves pénètrent dans le tube digestif de l'Homme, où elles se comportent à peu près comme celles de la Mouche du fromage. 
Les larves de Thyreophora anthropophaga Rob.-Desv. réduisent les tissus des cadavres et des pièces anatomiques en poussière impalpable. Les larves et les nymphes de Lonchæu nigrimana Meig. se rencontrent sur les cadavres desséchés.

Les Indiens mangent les larves de l'Ephydra californica Packard, qui vivent en quantité extraordinaire dans les lacs salés de l’État de Neváda.

2e section : Calyptérés. - Cuillerons plus ou moins développés, cachant le plus souvent les halanciers.

La plupart des Mouches qui composent cette section vivent du suc des fleurs; quelques-unes se nourrissent des humeurs ou du sang des animaux. Beaucoup sont créophiles, c'est-à-dire pondent sur les cadavres ou les subslances animales en décomposition, de manière que les larves, qui sont blanchâtres, coniques, obtuses en arrière, se nourrissent aux dépens de ces corps, dont elles semblent hàter la putréfuction. Ces larves donnent des pupes en barillets.

A. Sous-famille des anthomyinés. - Cuillerons médiocres ou petits, laissant en général les balancier's à découvert.

Les représentants de celte sous-famille se rapprochent beaucoup des Mouches proprement dites: ils ont, comme elles, une trompe molle et incapable de perforer la peau. Les femelies de beaucoup d'espèces, appartenant aux genres Aricia Macq., Hydrophoria Macq., Hydrotæa R.-D., etc., se jettent souvent sur les bestiaux pour sucer leurs humeurs. On signale surtont l'Ilydrotée ou Anthomyie météorique (I. meteorica), qui importune particulièrement les Chevaux par les temps orageux.

Les larves sont recouvertes de soies parfois longues et barbelées. Il en est qui vivent dans les substances végétales en décomposition. D'autres détruisent les plantes cultivées, par exemple, celles de la Mouche du chou (Anthomyia brassicx), qui perforent les racines du chou ; celles de la Mouche des betteraves (A. conformis), qui criblent les feuilles des jeunes betteraves, etc.

Introduites accidentellement dans le tube digestif de l'Homme, ces larves peuvent y séjourner jusqu'à la nymphose. Ce sont celles des Homalomyia qui ont été le plus souvent rencontrées dans les cas de myiase intestinale, tant en France qu'en Angleterre, en Bohême, en Amérique, etc. Joseph cite à cet égard $H$. scularis, canicularis et incisuruta. On les découvre en général dans les vomissements et dans les selles. Leur

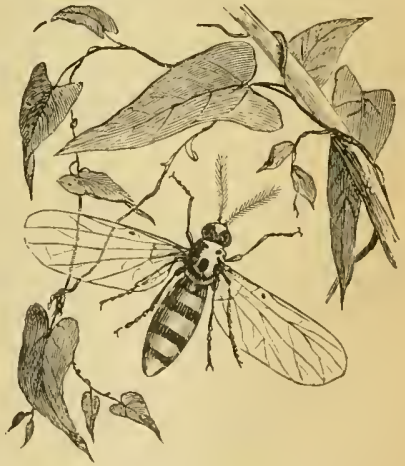

Fig. 532. - Anthomyia brassicx, grossic. présence dans l'organisme se tracluit par du malaise et des nausées lorsqu'elles siègent dans l'estomac, par une sorte de dysenterie lorsqu'clles ont passé dans l'intestin.

Nous avons eu l'occasion d'en examiner de nombreux exemplaires qu'une jeune fille prétendait expulser par la miction. 
Les larves de l'Hydrotæa meteorica peuventètre également rencontrées dans les cas de myiase intestinale.

Celles de l'Anthomyia pluvialis auraient été vues dans des plaies cutanées; Danthon a trouvé les larves et les pupes d'une espèce voisine dans le conduit auditif externe.

Ajoulons que Mégnin a recueilli dans des tombeaux les nymphes de deux espèces d'Anthomyies.

B. Sous-famille des musaines. - Style des antenıes plumeux jusqu'à l'extrémité; abdomen court, dépourvu de grandes soies (macrochètes) au bord des segments.

Le genre Mouche (Musca L.) est actuellement réduit aux seules formes qui ont pour principaux caractères : épistome peu saillant; antennes atteignant presque l'épistome, à $3^{\mathrm{e}}$ article triple du $2^{\circ}$; trompe molle, disposée pour la succion.

Ln Mowehe commune ( $M$. domestica L.), qui constitue le type de ce genre, est connue de tout le monde. A còté d'elle se rangent beaucoup d'autres espèces qui ne s'en distinguent que par des caractères de minime importance: M. bovine ( $M$. bovina), M. corvine ( $M$. corvina), M. vitripenne ( $\boldsymbol{H}$. vitripennis), etc.

Ces Mouches, d'aspect cendré ou grisâtre, vivent dans nos habitations, dans celles des animaux, dans les prairies, etc. Elles paraissent rechercher de préférence les substances sucrées, mais elles se jettent aussi sur l'Homme et sur les animaux pour sucer les produits qui humectent leurs téguments.

Les larves, qui se développent habituellement dans le fumier, peuvent passer dans le tube digestif, probablement par l'intermédiaire des matières alimentaires. C'est ainsi que Rudolphi a reconnu la larve de la Mouche domestique dans de prétendus parasites évacués par un jeune Homme et décrits par Jördens sous le nom d'Ascaris conosoma.

Les Curtonèvres (Curtonevra Macq.), Mésembrines (Mesembrina Meigen) et Pollénies (Pollenia Rob.-Desv.) ont à peu près le mème aspect et les mèmes mœurs que les Mouches proprement dites. Leurs larves se développent dans le fumier, le terreau, les bouses, etc. - Joseph cite le cas d'une personne anémique qui rejeta plusieurs centaines de larves vivantes de Pollenia rutis Rob.-Desv. - La larve et la nymphe du Curtonevra stabulans (Meigen) peuvent se rencontrer sur les cadavres exposés dans la campagne.

Genre Galliphore (Calliphora Rob.-Dess.).- Les Calliphores ont une trompe molle comme les Mouches vraies; elles s'en distinguent par leur épistome un peu saillant et le troisième article des antennes quadruple du deuxième. Elles ont en général une teinte azurée, mais peu brillante.

Calliphore de la viande (C. vomitoria [L.]). - Face noire au milieu, testacée sur les còtés, bordée de soies; joues testacées; style des antennes très plumeux; thorax marqué de quatre raies noires un peu confuses; cui- 
lerons noirs, bordés de blanc; abdomen bleu à reflets blanchatres. Longueur, 7 à 13 millimètres.

Cette espèce est la plus commune du grenre, du moins en France, où on la désigne sous le nom de Mouche blene de la viande. La femelle dépose de préférence ses oufs sur la viande. Elle en pond envi-

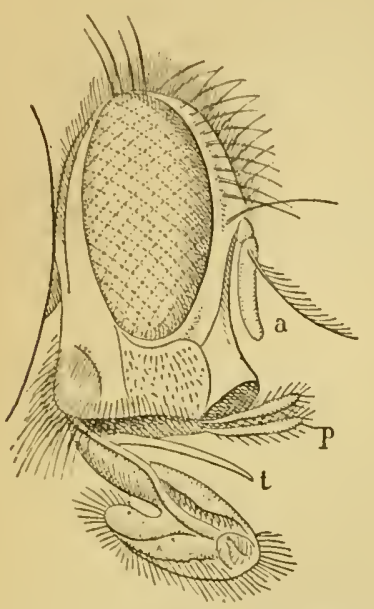

Fig. 533. - Téte de la Mouche bleue de la viande, forlement grossie. - $\boldsymbol{\alpha}_{\text {, antenne. }}$ $p$, palpes maxillaires. $t$, lrompe (Delafonl). ron 200, disposés en plusieurs tas. Les larres éclusent au bout de vingtquatre heures; elles grandissent très vite el dévorent la chair arec aridité, en même temps qu'elles en hâtent la corruption. Il suffit d'une douzaine de jours pour que ces larres passent à l'état de nymphes, et d'une même période encore pour que celles-ci donnent naissance à l'adulte.

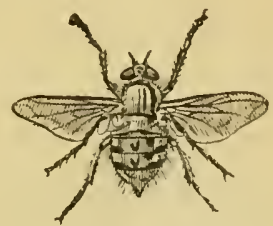

Fig. 534. - Mouche bleue de la viande, grandeur naturelle.

La Mouche bleue peut se rencontrer à tous les états sur les cadavres humains. Quelques auteurs ont signalé sa larve comme pouvant vivre dans le tube digestif el dans les cavités nasales de l'Homme.

Joseph a obserré un cas de myiase gastrique produite par une espèce voisine (C. erythrocephala). Aguirre signale aussi une grave myiase nasale occasionnée au Chili par $C$. limensis.

Genre Lucilie (Lucilia Rob.-Desr.). - Mouches à trompe molle ; épistome non saillant; antennes à troisième article quadruple du deuxième et à style très plumeux; abdomen court el arrondi, d'un beau vert à reflets métalliques.

Lucilie César (L. Cæsar [L.]). - D'un vert doré; palpes ferrugineux; face bordée de soies, blanche à reflets noiràtres; épistome d'un rougeàtre pâle; hande frontale noiràtre; antennes brunes; suture du thorax léçère; abdomen court ; pieds noirs. Longueur, 7 à 9 millimètres.

La Mouche verte ou Mouche César, qui est le type du genre, dépose ses œufs sur les matières organiques en voie de décomposition, en particulier sur les cadarres; les larves, qui éclosent rapidement, se nourrissent de chair corrompue. On sait qu il existe des "verminières " arliticielles pour la production industrielle des asticots ou guil- 
lots, dont les Oiseaux, comme les Poissons, se montrent très friands : les Lucilies, avec les Calliphores, jouent le principal rôle dans cette production.

Comme les Calliphores aussi, elles passent pour faire quelquefois des plaies superficielles de l'Homme ou des animaux le berceau de leurs larves.

D'après Joseph, on obser re fréquemment dans le tube digestif les jeunes larves de $L$. Cresar et de $L$. regina. D'après Mégnin, on trouve sur les cadavres humains les larres et les pupes de $L$. Cærar et de L. (Pyrellia) cadaverina.

Lucilic soyeuse ( $L$. sericata Meigen). - Semblable à L. Cæsar, mais verte à reflets hleus; épistome blanc comme la face; vertex vert chez la femelle; premier segment de l'abdomen noiràtre. Longueur, 8 à 9 millimètres.

Les larves de cette espèce déterminent souvent chez les Moutons, en Hollande, une myiase cutanée assez grave, connue des éleveurs sous le nom de Worm-ziekte (maladie vermiculaire). Les Insectes parfaits vont déposer leurs œufs dans les points où la peau est fine, surtout au voisinage de l'anus. Les larves percent la peau comme une écumoire et s'étendent jusque sur la croupe. La prédisposition spéciale des Moutons hollandais tient sans doute à ce que leur longue toison est souvent salie par la diarrhée.

Lucilie bouchère (L. [Compsomyia] macellaria [Fabricius]). - Cette espèce se reconnait surtout à son thorax parcouru par trois bandes noires longitudinales qui règnent sur la face supérieure des deux premiers anneaux; elle offre, dit-on, un grand nombre de variétés, dont la coloration varie du bleu au vert à reflets métalliques cuivreux ou pourprés. Longueur, 9 à 10 nillimètres.

On rencontre cette Mouche dans une grande partie de l'Amérique, depuis le nord des États-Unis jusqu'à la République Argentine. D'après quelques auteurs, on devrait rattacher à la même espèce Lucilia hominivorax Coquerel et Calliphora anthropophaga Aug. Conil; toutefois, cette manière de voir n'a pas été, jusqu'à ce jour, suffisamment justifiée.

En tout cas, la Lucilie bouchère est une Mouche redoutable. Elle dépose ses œufs dans les plaies des animaux domestiques et de l'Homme, ou bien les introduit dans les oreilles, dans les cavités nasales et jusque dans les sinus frontaux. Les larves qui naissent de ces cufs ont reçu des Américains le nom de Screw-Worms ou Vers-Vis, à cause des replis de leurs anneaux, qui simulent le filet d'une ris. A l'aide de leurs crochets buccaux, elles déchirent les tissus et déterminent en peu de temps des ravages intenses. Souvent le palais est perforé, et les larves sont rejetées par la bouche. En pareil cas, la mort 
met presque toujours fin à d'intolérables souffrances. Pour faire périr ou tout au moins déloger ees larres, on conseille surtout des injections de chlorolorme, de benzine ou d’acide phénique élendu d'eau. Dans les Républiques Argentine et de Venezuela, on a recours a l’infusion de basilic, qui donne, parail-il, d'excellents résullats.

Genre 0chromyie (Ochromyiu Macq.) - I)iffère surtout du précédent par la face verticale et la coloration jaunitre.

Ochromyic anthropophage (0. anthropophaqa Btanch.). - Mouche de teinte gris jamnatre, connue sous le nom de Mnuche du Cayor. Elle mesure 8 à 10 millimètres le long; li tète est testacée, revètue de petits poils noirs; le style des antennes est plumenx. Le horax offre en avant deux handes noires longitudinales; les ailes sont un peu enfumées. Liahdomen est courert de taches noires asse\% étrndues, surtout en arrivie.

Cette espèce est propre au Sénégal et ne se rencontre mème que dans la région situćc au sud de Saint-Louis, principalement dans le Cayor, d'où lui est venu son nom (1). la femelle dépose, dit-on, ses reufs dans le sable; en lout cas la larve. ditr Ver du Cayor, pénètre sous la peau des Hommes oll des animaux (Chien. Chat, Chère, Chacal), el sy déreloppe dans l'espace d'un septénaire. La nymphose a lieu à lextérieur. Les caractèrés qui décèlent la présence des larves dans le lissu conjonctif sous-cutané

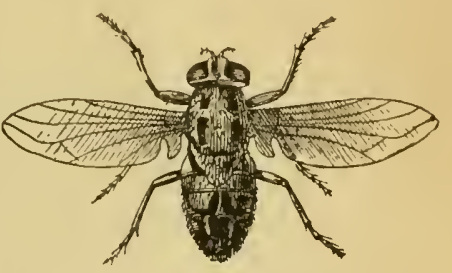

Fig. 333. - Mouche du C:ịor, grosxie deux fois (0)rig.). sont analogues à ceux que nous arons indiqués à propos de l' $/ y^{-}$ poderma bovis. Les Chiens, el en particulier les jeunes, sont parfois tellement envahis qu ils succombent.

I Natal, la larre d'un l)iptère assez semblable, sinon identique, s'observe fréquemment sous la peau de l'Homme (2).

Genre Stomoxe Stomoxys Geolr.). - Trompe solide, allongée, piquante, coudée près de la base et dirigée horizontalement; palpes ne dépassant pas l'épistome; troisième arlicle des antennes triple du deuxième ; style plumeux en-dessus.

Ce genre commence une série dont Rondani a fait une famille à part, et qui est caraclérisée surtout par la constitution de la trompe: Stomoxydx. Les Stomoxes, au premier abord, ont tout à fait l'aspect des Mouches domestiques, mais la trompe suffit pour les différencier. Cette trompe, qui dépasse la tète en arant, est conslituée par la lèvre inférieure formant gaine et ren-

(1) Bérexger-Féhaun. Trailé clinique des muladies des Européens au Sénégal, I. p. 225. 187.5. - A. Ratulete, La Mouche du Cayor. Bull. de la Soc. centr. de méd. véter., p. ii, 1884. - V. Lexolk, Moushe et Ver du Cayor. Archives vitér., P. 207, 1884.

(2) R. Blaxcharn, Contribution à l'étule des Dipitères parasites. Bullet. de la Soc. entomol. de France, p. CXX, 189:3.

Ratlitet, - Zoologic. 
fermant deux stylets acérés : hypopharynx et épipharynx. Comme celles de ces Mouches, les larves des Stomoxes vivent dans les excréments frais du Cheval, dans les fumiers; mais leur développement est plus lent.

Le Stomoxe piquant (St.calcitrans Geoff.) ou Stomoxe mulin est très commun dans nos contrées vers la fin de l'été : il se rencontre mème dans nos habitations, surtout s'il existe des écuries dans le voisinage. Au repos, on le distingue de la Mouche domestique en ce qu'il s'installe la tète en haut, tandis que celle-ci prend la position opposée.

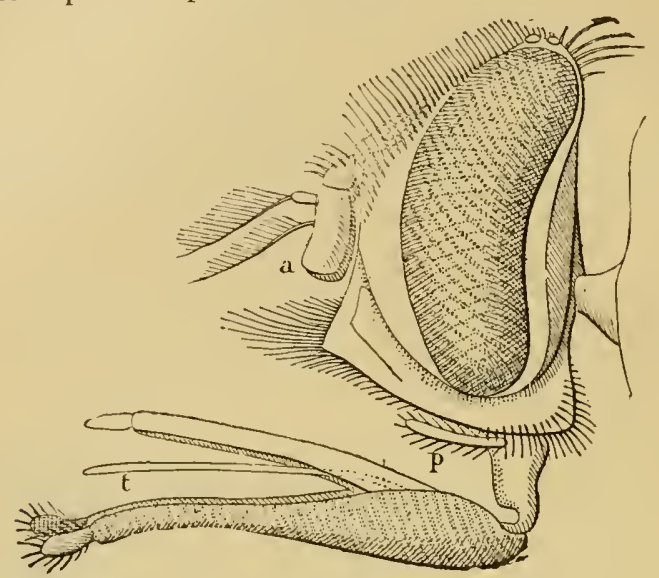

Fig. 336. - Téte du Stomose mutin, fortement grossie et vue de profil, $-a$, antemes. $p$, palpe maxillaire. $t$, Irompe (Delafond).

On donne souvent à ces Insectes le nom de Mouches piquuntes d'au. tomme. Ils se posent volontiers sur les animaux et sur l'Homme. Leur piqûre, quoique peu douloureuse, incommode beaucoup les Chevaux:

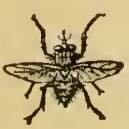

Fig. 537. - Stomoxe mulin, grandeur nalurelle. sur les sujets ì peau fine et sensible, elle détermine mème une légère inflammation locale, avec soulèvement des poils. En outre, les Stomoxes peuvent êtrc considérés comme de dangereux agents de la propagation des maladies virulentes. On concoit, en effel, que leur lrompe pénétrante puisse être souillée par des substances sepliques ou virulentes (puisées sur des cadarres ou sur des animaux malades), de façn à inoculer ensuite ces produits à des sujets sains. Toutefois, aucune preure directe n'a été donnée, jusqu'a présent, en faveur de cette manière de voir : l'inoculation artificielle de trompes souillées à dessein ne peut évidemment donner des indications de sérieuse valeur.

Genre Hématobie (Hæmatobia H.-D.).--Diflère du précédent par les palpes, qui sont aussi longs que la trompe; le troisième article des antennes est double du deuxième; le style est plumeux en dessus et très peu en dessous.

Les Hématobies sont de très petites Mouches qui vivent dans les prairies et ne pénètrent guère dans les étables. Comme leur nom l'indique, elles sont au moins aussi avides de sang que les Stomoxes. 
Elles attaquent les animatux au pàturage, surtout les bètes bovines, et on les voit sourent en grand nombre sur un méme sujet, les ailes écartées, s'introduisant entre les poils pour aller percer la peat. Leurs larves se développent dans les bouses. L'llématobie stimulante (II. slimulans [Meig.]), l'llématobie féroce (II. ferox R.-D.) et l'Hématobie à scie (1I. serrata R.-D). sont les principales espèces liancaises. - Aux Etats-Unis, cette dernière est regardée comme un róribable lléau pour le bétail.

Cienre Glossine (Glossin" IV iedemann, 1830, - Syn. Nemorhim R, bincall. llesvoidy, 1830). - Trompe trés longue; palpes de même longueur, lui servant de gaine; antemes à troisiene article quadruple du deuxième; stỵle peclimí en dessus.

Les especes de ce genre habitent l'Afrique tropicale, et peut-être l'Australie (Bigot). Elles sont un objet de terreur pour les habitants de la zone torride afrieaine, quj les désignent (ainsi d'ailleurs que d'autres

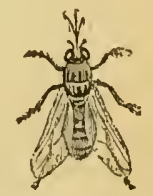

Viis. 538. - Tríl-í. grambeur nalurelle. Diptères) sous le nom vulgaire de Tsélsr. La plus célè̉re de ces espèces est la suivante :

Glossine mordante (Gl. morsilans Westwood, 1850). - - Un peu plus grande que la Mouche domestique $\left(9^{\mathrm{m} m}, \ddot{3}\right)$; teinte générale jaunitre. Trompe srèle, plus longue que la tète. Thorax d'un gris roussitre, avec quatres bandes brun noiratre longitudinales; écusson avec deux laches noircitres. Ailes légèrement enfumées. Pattes jaunitres; cuisses quelque peu teintées de brunàtre en dehors; derniers articles des tarses bruns. Abdomen jaune chitain clair en dessus, jaune pàle uniforme en dessous ; premier segment avec une macule brune diffuse, assez petite, de chaque còté; tous les segments suivanls montrant à leur hord antérieur deux demi-bandes brun noiritre, interrompues sur la ligne médiane,élargies en dehors.

La Tsétsé se rencontre à peu près dans toule l'Afriyue tentrale. Elle parait se tenir de prélérence au bord des marais, sur les buissons et les roseaux. Elle fait entendre un bourdonnement particulier, très élevé. De nombreux royageurs, entre autres Livingstone et Oswald, nous ont fait connaitre cette Mouche comme un des fléaux les plus redoutés de la zone torride africaine. Toutelois, les récits publiès à son endroit ont un caractère qui nous semble tenir beaucoup de la légende. Comme les Stomoxes, la Tsétsé atlaque l’Homme et les animaux. Elle s'élance sur ceux-ei, disent les voyageurs, avec la rapidité d'une flèche, et les mord de préférence sur le plat des cuisses et sous le ventre. Les animaux sauvages : \%èlores, Buflles, Antilopes, non plus que la Chèvre domestique (1) ne souffriraient de ces piqûres: l'Homme lui-mème en serait rarement affecté d'une façon sérieuse, Mais le Cheval, l'Ane, le Bouf, le Moulon, le Chameau et le Chien.

(1) A Mandéra (Zanguebar), la Chèvre ne résiste pas plus que les autres animaux. Il en est de méme des Anes le l'Ouniamourizi, cités également comme réfractaires R. P. Leroy, Note communiquee). 
au contraire, seraient condamnés à une mort fatale, parfois soudaine. mais surrenant plutôt au bout de quelques semaines ou de quelques mois. Des Européens ont ainsi, en peu de temps, perdu soixante, quatre-vingts et cent Bœufs, et l'on concoit que cet Insecte soit regardé comme un des obstacles les plus sérieux à la civilisation de l'Afrique centrale. En ce qui concerne les lésions trouvées à l'autopsie des animaux piqués, nous aurions à relever les plus grandes contradictions. Nous passons sur ces points, et nous laissons également de côté nombre de particularités bizarres ou invraisemblables signalées par les voyageurs. De plus amples infornations sont sans doute nécessaires pour formuler une opinion décisive sur le ròle de la Tsétsé; toutefois, il parait certain que cette Mouche, pas plus que les Stomoxes, n'a aucune action renimeuse, et que les effets de sa piqûre, s'ils sont réels, se rapportent à l'inoculation de produits virulents dont peut ètre souillée sa trompe. La nature de la maladie inoculée reste à déterminer : contrairément à ce qui a été dit, le charbon ne peut pas être incriminé, du moins dans la généralité des cas. Avec Nocard, nous avons inoculé à un Mouton la tète tout entière, avec la trompe, d'une Tsétsé rapportée du Zanguebar; le résultat a été négatif.

Les autres espèces de Glossines actuellement connues (1) sont : Gl. longipalpis Wied., 1830 (Nemorhina palpalis Rob.-Desv., 1830), de J'Afrique centrale; Gl. fusca Walker, 1849, dont nous possédons des exemplaires provenant du Zanguebar; Gl. tabaniformis Westw., 1830, de l'Afrique centrale; Gl. tachinoides Westw., 1830, de l'Afrique occidentale; Gl. ventricosa Bigot, 188̈̈, dans un lot d'Insectes provenant d'Australie.

Au siècle dernier, le royageur anglais James Bruce signalait la présence, en Nubie et en Abyssinie, d'une Mouche redoutable nommée Zimb parles Arabes et Tsaltsalya parles Ethiopiens : cetteMouche, disait-il, a:taque toutes les bêtes de somme et leur inflige de cruelles piqùres, qui entraînent la production de tumeurs assez volumineuses; elle apparaît au commencement de la saison des pluies, et cause une telle terreur aux animaux que ceux-ci désertent les pâturages et que les habitants sont obligés, durant cette saison, de se retirer dans les sables pour éviter la destruction de leur bétail. Kirby et Spence ont regardé cet Insecte comme une Pangonie; mais Westwood a montré que Bruce avait dú associer des faits d'origine diverse : les tumeurs cutanées étaient probablement occasionnées par. des OEstridés cuticoles; d'autre part, la Mouche qui détruit le bétail et dont il donnc la figure paraît être réellement une Glossine.

C. Sous-famille des sarcophaginés. - Style des antennes velu à la base, nu à l'extrémité ; abdomen pourru de grosses soies ou macrochètes au moins sur les derniers segments.

(1) J. M. F. Blgot, Diptères nouveaux ou peu connus: 26e partic. Annales de la Soc. entomol. de France, (6), V, p. 121, 1885. 
Genre Sarcophage (Saicophuga Meigen). - Espèces modérément velues, à llorax allongé, parcouru d'ordinaire par trois bandes noires longitudinales, a abdomen tacheté. Le troisiène artiele des antennes est en géníral triple du deuxième; le style est à poils également longs en dessus el en dessous.

La Sarcophage carnivore (S. carmuria L.J) se reconnait à sa tète jaunàtre, à ses palpes noirs, peu ou point saillants, a son thorax rayé de gris jaunatre, à son abdomen marqueté régulierement de cendré et à son anus noir. Longueur de la fenelle : 13 a 13 millimètres; màle beaucoup plus petif.

Cette grosse Nouche vit en plein air et recherche les substanees organiques en décomposition. Comme toutes les espèces du genren, elle est vivipare; on a calculé que son oviducte enroulé contient environ vingt mille larves. Celles-ci se comportent ì peu près comme les larves des Calliphores et des Lueilies. Elles peuvent aussi évoluer dans les plaies el dans les cavités naturelles (vagin, oreilles, fosses nasales) de l'Homme cu des animaux : J. Cloquet, notamment, a cité le cas d'un ivrogne qui arait pour ainsi dire été dévoré vivant par des milliers de ces larres.

On a rapporté í celte espèce quelques cas de myiase du tube digestif recueillis par Jördens et par Hope; le premier de ces auteurs avait décril les larves sous le nom d'tscaris stephanosoma. Cependant, G. Joseph a reconnu que les jeunes larves de $S$. carnaria et de S. striata Ileig., introduites dans l'estomac du Chien, ne pouvaient y virre et se trouvaient digérées au bout de quelques heures.

Par contre, Joseph a observé deux cas de myiase gastrique dus aux larves de $S$. hiemorrhoidalis et de $S$. hamatodes Meig., qui avaient pénétré dans l'estomac avec de la viande crue, el avaient déterminé des accidents assez sérieux. L'auteur conseille de recourir au lavage de l'estomac, après administration de naphtaline.

Sur les cadarres, on peut Irouver, outre les larves de S. camaria, celles de $S$. arvensis (Rob.-D.) el de S. laticrus (R.-D.).

Aux Indes orientales, les médecins anglais ont signalé une myiase cutanée très grave due aux larves de S. ruficornis.

La Sarcophage magnitique (S. magnifica Schiner, 1862. - Syn. : S. Wohlfuhrti Portshinsky, 187:3) a été quelquefois rangée dans un genre à part (Sarcophila Rondani, 1856). Les Sarcophiles ne diffèrent toutefois des Sarcophages vraies que par des caractères de médiocre valeur, notamment par la longueur du troisième article des antennes, qui est double au plus de celle du deuxième. Le style est très courtement velı, le front large, aussi concave chez le màle que chez la femelle, l'abdomen souvent ponctué, avec de longues soies au bord postérieur on en dehors du deruier anneau.

La Sarcophile magnifique est d'un cendré grisatre. La tète est un peu plus large que le thorax, avec le front et l'épistome peu proéminents; le vertex el le front sont noiràtres, la face et les còtés d'un blane d'argent satiné, les antennes et les palpes noirs. Le thorax est gris cendré avec trois lignes longitudinales noiràtres; l'abdomen est gris blanchàtre, à trois taches noires 
sur chaque segment. Les pattes sont noires. Longueur, 10 à $1: 3$ millimètres (Laboulbène).

Cette Muscide est bien connue depuis les travaux de Portshinsky. D'après cet auteur, elle est très commune en Russie; elle ne pénètre point dans les maisons, mais vit en plein air. Elle dépose ses larves dans les plaies de l'Homme ou des animaux, ou même

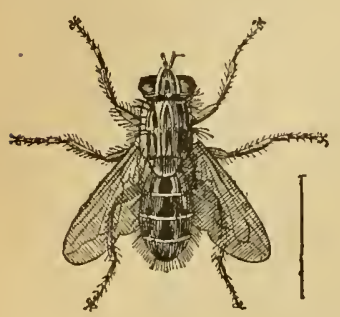

Fis. 339. - Saicophaga magnifica, mile (Lahoulbène). dans des cavités naturelles, et ces larves peuvent produire en peu de temps de très graves désordres. On voit éclore cette Mouche, à l'exclusion de toute autre, des larves recueillies sur les bêtes bovines, les Chevaux, les Porcs, les Moutons, les Chiens el même les Oiseaux domestiques, les Oies en particulier. Chez les Vaches, ces larves se rencontrenl surtout dans les organes génitaux; chez les Chiens, on les trouve souvent dans les oreilles; chez l'Homme, enfin, elles vivent dans les oreilles, le nez, le palais, les yeux, en produisant des douleurs intolérables et de sérieuses hémorragies. Dans le gouvernement de Nohiler, cette myiasis est très commune.

Mais on l'a obserrée dans d'autres régions de l'Europe, par exemple en Allemagne (Thomas) et en Roumanie (R. Blanchard).

En France, Mégnin n'a trouvé également que les larves de cette espèce dans les plaies des animaux domestiques, et Laboulbène a obtenu la même Sarcophile par l'éclosion de larves provenant des cavités nasales d'un cultivateur de l'Hérault affecté d'ozène. En Algérie, les Dromadaires sont attaqués par une espèce tout au moins très voisine.

En résumé, la Sarcophile magnifique est la Mouche des plaies par excellence, et il est probable que, dans les nombreux cas de larves des plaies signalés jusqu'à présent, bien des erreurs de détermination ont été commises à son détriment.

Genre Cynomyie (Cynomyia R.-D.). - Le troisième article des antennes est quadruple du deuxième; le style est ì poils plus longs en dessus qu'en dessous. Couleurs métalliques.

La Cynomyie des morts (C.mortuorum [Meig.]) a la tèle d un jaune doré, le thorax d'un noir bleuatre et l'abdomen d'un beau bleu violet.

On la rencontre dès le premier printemps sur les cadavres des Chiens, plus rarement des autres animaux et de l'Ilomme.

D. La sous-famille des TACHininÉS est caractérisée par le style des antennesnu ou seulement pubescent, et un abdomen ovale el conique, pourvu de soies.

Les larves de ces Diptères vivent en parasites, comme celles des Ichneumons, aux dépens d'autres larves d'Insecles, en particulier des Chenilles. - 
Genres Degeeria Meigg., Metopiu .leig., Masicera Macq., Erhinomyia Dumér., Tuchina Meig., etc.

La famille des SYRPHIDEs, qui n'offre, a notre point de vue, qu'un intérèt médiocre, comprend des liptères de grante taille, aux couleurs vives, métaliqques, rehaussées par des laches ou des bandes jaunes ou blanches. Les larres sont carmassières, ou se nourrissent de matières organiques en décomposition. - fienres Syrphus, Volucella, Eristalis, Helophilus, etc.

Les liristales (bristalis latr.) ont les antenues courtes, insérées sur une saillie du front; le troisième article est orbiculitire, muni d'une soie nue on velue. L'espèce la plus commune est l'Éristale gluante (E. tenax labr.). Au premier abord, ou prendrait rolontiers pour une Abeille l'Insecte parfait, qqui vit sur les fleurs. La femelle dépose ses wufs, tout en voltigeant, dans les eaux croupissantes. I.es larres qui sortent de ces eufs portent, à leut extrémité postériemre, un tube respiratoire rétractile, qu’elles amènent à la surface pour respirer. Ces larves, bien connues sous le nom de Vers ou Asticots i queue de rat, se rencontrent dans tous les endroits malpropres : latrines mal livées, écuries et étables oì séjourne le purin, etc. Elle sortent des eaux pour subir la nynuphose. Joseph cite un cas de myiase intestinale dù à l'Eristalis arbustorum (Fabr.).

I.es Hélophiles (Hélophilus Meig.), peu différents des Éristales, ont à peu firès le mème mode de vie el fournissent également des Vers à queue de rat. L'Ilélophile suspendu (H. pentulus Meig.) est de beaucoup l'espèce la plus répandue. Divers auteurs ont attribué à ses larves des cas de myiase du Inhe digestif. - Le prétendu IIelminthe décrit par Brera sous le nom de cercosoma n'était autre qu'une larve d'II. pendulus trourée lans le vase de nuit d'une femme.

Les ASILIDÉs méritent ì peine une simple nrention: ce sont des Insectes à corps allongé, à paltes puissantes, à trompe courte et pointue, qui font la chasse aux autres Insectes: on les qualifie queliuefois de "Mouches de proie ".

On peut recomnailre les Asiles (Asilus L.) à leurs antennes, dont le troisième article, effilé, est surmonté d'un style nu à deux articles. L'Asile frelon (A. crabroniformis L.) est réputé, à tort ou à raison, s'attaquer parfois à l'llomme et aux grands animaux, pour se repaitre de leur sang.

Famille des TABANIDÉs. - Ce sont de gros Diptìres à corps assez large et un peu déprimé. La tète est elle-mème déprimée d'avant en arrière; les yeux sont contigus chez les miles; les antennes ont le troisième article annelé, mais dépourvu de style. La nervure marginale fait le tour de l'aile; les cuillerons sont très développés. La trompe, ordinairement saillante, constitue chez les fentelles un appareil puissant et complexe : la lèvre inférieure, membraneuse, forme une gaine qui cache dans son intérieur six pièces acérées (soies des anciens auteurs), représentant les mandibules, les michoires, l'épipharynx et l'hypopharynx. Chez les miles, on ne trome plus que quatre pièces, par snite de l'atrophie des mandibules. Les tarses sout munis de trois pelotes.

Les Tabanidés fréquentent surtout les hois el les pàturages; les màles vivent du suc des lleurs; quelques femelles sonl dans le mème cas, 
mais, en général, celles-ci manifestent une extrème avidité pour le sang des animaux : leur puissant suçoir leur permet, en effet, de percer le cuir le plus épais. C'est l'été, pendant les heures les plus chaudes de la journée, quelles sont le plus redoutables. Peut-être deviennentelles, à l'occasion, des agents propagateurs des maladies virulentes.

2 sous-familles: Tabaninx et Pangoninx.

A. Sous-famille des tabaninés. - Jambes poslérieures sans éperon terminal. Point d'ocelles

(ienre Taon (Tabunus L.). - La trompe est courte, épaișse, inclinée chez le màle, verticale chez la femelle; les antemnes ont leur troisième article échancrè en croissant el divisé en cinq anneaux.

Talon automnal [T. autumnalis L.). - Cette espèce mesure 18 à 20 millimètres de long. Sa teinte générale est noiràtre. Le thorax est revètu de
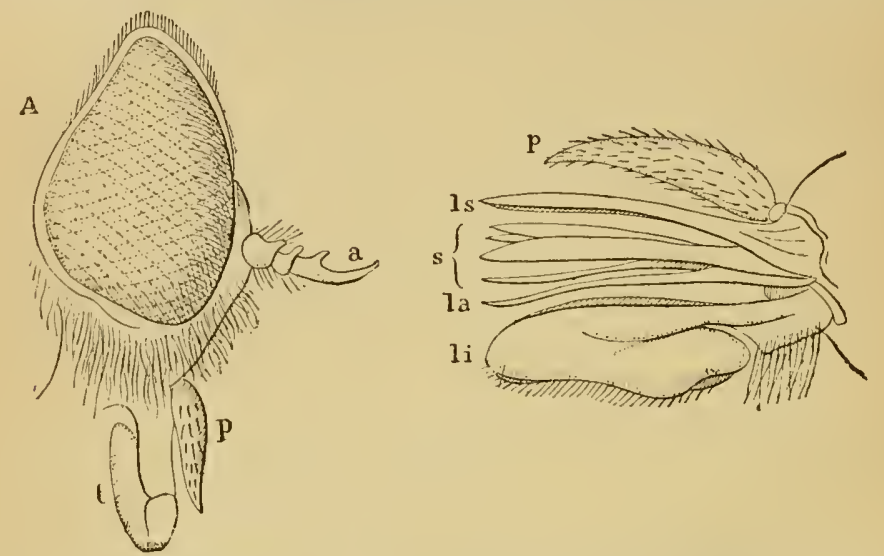

Fig. 540. - Taon autommal, femelle. $-\Lambda$, tète grossie, vue de profil : a, antennes, $p$, palpe maxillaire. $t$, trompe. 1 , délail de la trompe: $p$, palpe. $l s$, épipharyux. $s$, mandibules el maxilles. la, hypopharyn. li, lère inféricure, lormant la gaine de la trompe (Delafond).

poils yris et parcouru par quatre bandes longitudinales. L'abdomen offre trois rangées de taches blanches. Le bord extérieur des ailes est brunàtre.

Le Taon automnal est commun dans nos régions, et abonde en par-

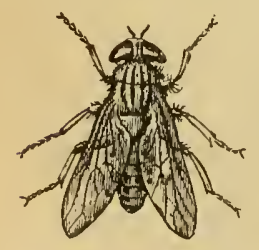

Fig. 3̈łl. - Taon automnal, grandeur natturelle. ticulier, comme la généralité des Taons, au roisinage des lieux boisés. Il se jette de préférerce sur nos grands animaux, Chevaux et Bœufs. Sa morsure, assez douloureuse, est suivie d'un écoulement de sang et donne lieu d'ordinaire à la formation d'une petite tumeur qui persiste plus ou moins longtemps.

La plupart des larves de Taons se développent dans la terre : par exception, celle du Taon automnal vit dans l'eau.

Beaucoup d'autres espèces du mème genre se rencontrent en France 
Telles sont: le Taon noir (T. morio latr.), d'un noir luisant, et dont la dent situce a la base du troisième aulicle des intennes esl prolongée en avant; le Taon des Bunfs (T. bocinus L.), le tris grande taille, avec une sente baute médiane de taclıes le long de l'abdomen; le Taon bruyant (T. bromius l..) et le Taon rustique (T. rusticus Viahr.), ces deux derniers marqués, comme le Taon automnal, de deux ou trois rantrs de taches blanches le long de l'ablomen, etc., ete.

Dans le nord de l'Alrique, notamment en Ëgyte et en Mrgérie, certaines espèces de Tarons, désignées par les Arabes sous le nom d'Fil Deluab ou Debane (la .llouche), sont accusées de produire une maladie redoutable (El Debch), qui fail péril un grand nombre de Chameaux, Chevaux el Anes. liespice incriminée en Egypte parait itre le T. albifucics löw; en Algérie, e’est le T. Womins L. En réalité, cette maladie, conme l'a montré J.-li. Piot, est tout à fait indéfiendante des piquires de Tans.

Genre Hématopote (Hamatopota Meigen). - La trompe est disposée à peu press comme celle des T'itons; mais le troisième article des antennes n'est pas échancré et présente quitre amneaux peu marqués. Les ailes sont couchées en toit et montrent presque toujours, sur un fond grisatre ou jaunatre, do nombreuses macules ou des ligues vermiculies. Pas d'o

petit Tan des pluies (H. pluxialis L.]). - Mus petit et surtout plus élancé que les Taons proprement dits, il est bien reconnaissable à ses ailes l'un gris brunatre, tachetées de blanchàtre, et ì ses yenx verditres offrant des reflets pourpres. Le thorax porte quatre bandes páles. l'abdomen a une bande dorsale pảle et des macules grisàtres latérales. Les fénurs sont d'un gris foncé; les tibias postérieurs ont dans leur milieu un anneau plus foncé. Le troisième anneau des antennes est larıement teinté de roussàtre à sa base.

Très commun à la fin de l'été; est extrèmement importun par les temps orageux; n'épargne pas l'Homme à loccasion. Il se rencontre, assure-

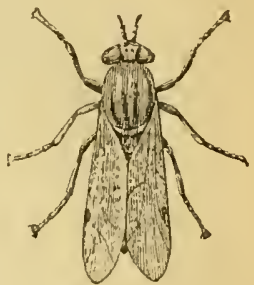

Fig. 342. - Pelil Taon des pluics, grossi drus fois (Orig.). t-on, jusqu'en Laponie, où il fait beaucoup souffril les Rennes.

On comnait trois autres especes emropéennes offrant, comme celle-ci, de nombreuses variétés: H. nigricornis Gobert, H. equonum (Fabr.), H. lunala (Fabr.).

B. Sous-famille des PANGoninés. - Jambes postérieures pourvues d'éperons terminaux. Le plus souvent des ocelles.

Genre Chrysops (Chrysops Meig.). - Les Chrysops ont trois yeux accessoires ou ocelles bien visibles; les antennes sont allongées, avec le deuxième article aussi long ou presque aussi long que le premier, et le troisième article à cinq ammeaux; les yeux sont d'un vert doré, à taches et lignes pourpres; les ailes sont fort écartées, avec des bandes ou des taches noires.

Petit Taon aveuglant (Ch. cxcutiens l.. ?). - C'est un Insecte de 8 milli- 
mètres de long seulement, un peu aplati, avec l’abdomen arrondi. On reconnaitla femelle à ses ailes noires, offrant une tache hyaline vers le milieu et une autre près de l'extrémité ; à son thorax, marqué de deux bandes grises en avant; à son abdomen, dont les premiers segments sont de teintejaune.

Commun en été. Son nom spécifique vient de ce quil attaque de

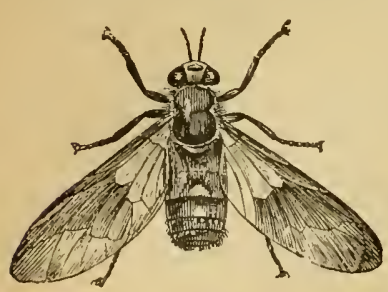

Fig. 543. - l'elit Taon aveuglant, grousi denx fois (Orig.). préférence les grands animaux autour des yeux. Il les harcèle surtout pendant les temps orageux, et, comme les précédents, sadresse parfois à l'Homme. On l'a vu provoquer chez des Chevaux de troupe une conjonclivite intense. Son rol est silencieux, au lieu d'ètre accompagné dun bourdonnement comme celui des Taons. - On trouve encore, en France: Ch. relictus Meig., Ch. quadratus Meig., Ch. marmoratus Meig.

Cienre Pangonie (Pangonia Lâtr.). - La trompe est sourent longue, grêle, horizontale; le deuxième article des antennes est plus court que le premier; le troisième article est divisé en huit anneaux. Il existe des ocelles che\% la plupart des espèces.

Les Pangonies sont de grands Diptères du midi de l'Europe et surtout des régions équatoriales. Leurs femelles sont réputées se nourrir, comme les mâles, du suc des fleurs; cependant, Macquart pensait déjà que celles dont la trompe est courte vivent à la façon des autres Tahanidés.

Nous avons dit plus haut (voy. p. 788) que le Zimb ou Tsaltsalya d'Abyssinie est plutit une Glossine qu'une Pangonie; cependant, nous arons cru pouroir rattacher à ce dernier genre un Tabanidé du Zanguebar qui pique violemment les animaux et que les "Wazigna " désignent sous le nom de "Tsétsé de la grarde espèce ".

D’antre part, Germain aurait vu, en Nouvelle-Calédonie, les Bœufs attaqués par les femelles d'une Pangonie (P.neo-caledonica Vlégn.) qu'il supposait mème aroir concouru à la propagation d'une épizootie charhonneuse.

DEUXIEME SOUS-ORORE

\section{NÉHOCÉRLS}

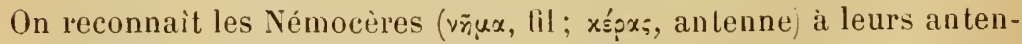
nes filiformes ou sétacées, formées de six articles au moins, de sorte que leur longueur est d'ordinaire égale ou supérieure à celle de la tête et du thorax réunis. Le corps est généralement allongé; les pattes sont longues et grêles, les ailes grandes et étroites.

Ces Insectes sont connus sous le nom de .Houcherons; on les voit sourent. en troupes immenses, surtout au voisinage des lieux maré- 
cageux, se livrer dans les airs à d'interminables évolutions amoureuses. Les premières phases du développement ont presyue toujours lieu dans l'eau.

Famille des SIMULIDÉS. - Thoüx sius sulure, cest-it-dire sans ligne de séparation entre les deax premiers segments. Jas d'ocelles. Antemes plus courtes que le thorax. Ailes très larges, coucliées, à nervure marginale ne dópassant pas le sonmet. Pattes souvent laclietées; jambes et tarses langes, comprimés. La trompe est courte, fpaisse, et ne contient que deux jièces, l'épiplıarynx et l'lypopharynx. Les mailes sont en quénéral tout autremenl colorés yue les femelles.

fienre Simulie (Simulium Latr., t80\%. - Syu. : Khayio Fabr.). -- Les Simulies sont de tout pelits biptères recounaissables à leur thorax bossu, à leurs antennes cylindriques composées de onze anticles, à leurs palpes de qualre articles, dont le dernier est allongé, a leurs ailes larges et courtes, parfois irisées. Les deux pièces contenues daus la trompe sout styliformes; par suite, cette trompe est propre ì picquer (1).

l.es Simulies se tiennent dordinaire parmi les buissons ombreux et so nourrissent de sues régétaux; mais parfois aussi les femelles se jettent sur l'llomme et sur les animaux, lont elles sucent le sang avec avidité. Bon nombre des Insectes counus et redoulés dans les pays chauds sous le nom le Moustiques appartiennent à ce genre, qui a d'ailleurs des représentants jusqu'en Laponie. Il est plus que probable que les Sinulies versent, lans la hlessure produite par leur trompe, une salive irritunte. Elles sont aptes, au surplus, à jourer le rỏle de porte-rirus.

l.es espèces en sont difficiles à distinguer, de sorte qu'il convient d'ètre réservé sur les déterminations faites en dehors du concours des diptérologistes.

Simulie de Colmmbatz (S. columbutczense Schiner, nec Fabr.) - Le rorps de la femelle est noiràtre, entièrement recouvert d'une poussière hlanchatre et de nombreux poils d'un jaune de laiton, de sorte que le dessus du thorax, surtout en avant, parait ardoisé; l'abdomen est blanc jaunâtre, mais brunàtre it la surface; les antemnes sont jaunes, les pattes en graude partie blanchìtres, les ailes lỹalines, à nervures 1 rès pàles. Longueur $3^{\mathrm{mm}}, 2$ à $3^{\mathrm{mm}}, 8$.

Cette espèce se montre en grand nomble pendant toute l'année, dit Schiner, dans le sud de la Iongrie (Banat et districts limitrophes); elle abonde également en Serbje et en Bulgarie, et on la rencontre cà et là en Autriche, voire en Allemagne. Elle tire son nom du vieux châleau en ruines de Goloubatz, situé dans le nord-est de la Serbie, sur la rive droite dı Danube.

Dès les premiers jours du printemps, les Simulies apparaissent en nombre tellement considérable, que leurs essaims simulent des nuages, qu'on peut à peine respirer sans en avaler une grande quantité, et

(1) A. Labourbèx, frticle simules du Dictionn. encyclop. des sc. méd., $(3), \mathbf{X}$. Paris, 1881 . 
qu'elles revêtent immédiatement comme d'un manteau noir les animaux sur lesquels elles se posent. Elles attaquent surtout les bestiaux dans les points où la peau est fine, au voisinage des yeux, des naseaux, de la bouche, de l'anus et des organes génitaux. Chaque piqûre donne lieu à une petite tumeur, dure et douloureuse, qui ne disparait qu'au bout de huit à dix jours. La mort survient dans certains cas aussitit après l'invasion des Moucherons, d'autres fois après quelques heures; enfin certains sujets guérissent : ces différences tiennent au nombre variable des morsures, à l'épaisseur du tégument et surtout à la sensibilité propre des sujets atteints. Les femmes, les enfants, les jeunes animaux sont à cet égard des plus susceptibles, et c'est ainsi qu'on a vu succomber des nourrissons déposés sur l'herbe des champs. Les animaux périraient souvent par suite de l'inflammation et de l'oblitération des bronches. Toutefois, d'après Tömösvary, la mort serait due seulement à la multiplicité des piqûres, ì la douleur, aux hémorragies et à l'empoisonnement du sang. En 1783, d'après Schönbauer, il n'y eut pas moins de 20 Cheraux, 32 Poulains, 60 Vaches, 71 Veaux, 310 Moutons et 130 Pores, qui succombèrent aux piqûres des Simulies dans le seul district serbe de Pojarevatz, auquel appartient Goloubatz. En 1892, d'après Boyadjier, le département de Vidin (Bulgarie) perdit de ce chef ä34 bètes bovines $(1,45 \%$ de la population totale), 220 Buffles $(13 \%)$, 22 Chevaux $(0,50 \% \%)$, 243 Moutons $(0,11 \%)$, 4.46 Chèvres $(0,90 ั \%)$ et 217 Pores $(0,86 \%)$.

Les espèces françaises de Simulies sont: S. reptans (L.) (Rhagio columbaschensis Fabr.); S. maculatum Meigen; $S$. cinereum Macquart; S. tibiale Macq.; S. ornatum Meig.; S. vernum

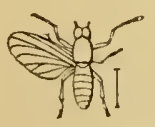

Fig. 3̈44. - Simulium reprans, d’après Westwood. Macq. - Elles se multiplient parfois aussi d'une facon extraordinaire. Les vallées humides des Cévennes et des Basses-Alpes, dit Maurice Girard, offrent parfois de véritables nuées de Moustiques noirâtres qui obscurcissent littéralement l'éclat du jour. Des ouvriers occupés au reboisement d'une partie de la montagne de l'Espérou en ont observé un jour une colonne immense, dont la longueur était de plus de 1,300 mètres, sur une largeur de 30 et une hauteur de 5̃0.

En mars et arril 1863, il y eut dans le canton de Condrieu (Rhône), sur le plateau qui sépare la vallée du Rhône de celle du Gier, une multiplication extraordinaire de Moucherons que Perret rapporta au $S$. maculatum. Tisserant constata qu'ils s'attaquaient à l'Homme aussi bien qu'aux Bœufs, Chevaux, Anes et Mulets. Les Chèvres et les Moutons étaient moins tourmentés. Huit ou dix animaux de l'espèce bovine étaient morts après quatre à douze heures de souffrances. On a voulu, à un certain moment, ne voir dans ces faits qu'une 
epizootic charhonneuse, dans laquolle les Insectes auraient joué le simple role de porte-virus. C'est lì une supposition toute gratuite.

Dautre part, il n'est pas rare de voir les Simulies pénétrer dans ies oreilles des Chevaux, Jorsque ceux-ci snnt au piturage el surtout dans les hois; en pareil cas, les piquires qu'elles eflectuent à l'intérieur de la conque donnent souvent lieu à la production de taches blanches ou monchetures lenticulaires d'un assez curieux aspect, que spinola signalail déji en 18306 . Mrgnin rapporte ces lésions ì $S$. cinereum, mais il est probahle qu'elles peuvent être provoquées par diffèrentes especes.

Il ue faut pas confondre avec les Simulies d'autres Ioucherons un peu plus gros, les Chironomes, qui appartiennent a une petite famille se distinguant le la précédente par les antenues, d'une longueur au moins égale ả celle du thorax. Ces Moucherons inoffensifs voltigent le soir en troupes immenses au bord des eaux. l.eurs larves sont commes des pichemrs sous le nom de Vers de ruse. L'espèce la plus commune est le Chironomus plumosus (1..). J'ai recueilli deux exemplaires de ses larves, rejetés dans une épistaxis par un phtisique, qui arail coutume d'aspirer chaque matin de l'eau de rivière.

Famille des CÉCIDOMY I DÉS. - Petits Nénocères différant des Simulidés par leurs ailes ciliees, dout la nervure marginale fait tout le tour, et par leurs antennes moniliformes, à poils verticillés, au moins aussi longues que le lhorax.

Ces Insectes déposent leurs aufs sur les plautes, et les larves qui en sortent. déterminent, pour la plupart, la formation de yulles, dans lesquelles elles se développent.

L'espèce indigène la plus nuisible pour l'agriculture est la cécidomyie du froment (Diplosis tritici), petit Moucheron jaune ayant un peu l'appa-
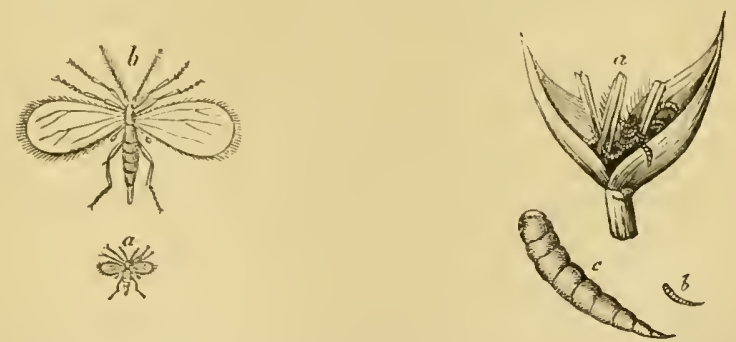

Fig. 3̈łj. - Cécidomyie lu froment, grandeur naturelle et grossie.

Fig. äi6. - Larses de la Cécidony ie du fromenl. - $a$, au milieu de la fleur. $b$, larve isolée. $c$, a mime, grosisie.

rence srelte des Consius, (pui apparait au moment de l'épiage des blés. La femelle, à l'aide de son long oviscapte, dépose ses cufs entre les glumes des épillets. I.es larres éclosent au bout de quelques jours ei sucent l'ovaire, de sorte que le grain avorte; arrivées ì leur complet développement, elles sautent a terre et ront hiverner dans le sol, pour subir une courte nymphose an commencement de l'été suirant. Bazin a conseillé, pour les détruire, d'arracher et de brùler les chaumes. 
Une autre espèce, plus funeste encore, est la Cécidomyie destructrice. (Cecidomyia destructor), très répandue en Allemagne, et redoutée surtout aux Etats-Unis, oì on la connaît sous le nom de Mouchc de Hesse. Dès le mois de mai, la femelle, rouge et poilue avec des taches et des lignes noires, pond sur les feuilles du blé; les larves glissent entre la gaine et la tige, et s’installent au niveau des nœuds : le chaume, rongé peu à peu, devient incapable de porter l'épi qui se forme, et s'affaisse au premier coup de vent. - Un certain nombre de ces larves achèvent leur évolụtion rers le mois de seplembre, et les Insectes parfaits qui en proviennent pondent sur les jeunes céréales des semailles d'automne, que les larves de cette seconde ponte dévorent. - Lichtenstein a ohservé dans le Languedoc les ravages de cette espèce.

On peut encore citer la Cécidomyic noire ( $C$. nigra), dont les larves déforment et font tomber les poires.

liamille des GULIGIDÉS. - Les Culicidés onl ume trompe longue et grèle, renfermant six soies ou pièces buccales disposées en lancettes et propres à piquer, du moins chez les femelles. Les palpes maxillaires sont à cinq articles. Les antennes, à quatorze articles, sont garnies chez les màles de poils en panache. Les ailes sont posées ì plat pendant le repos, et leurs nervures sont revètues d'écailles serrées.

Genre Cousin (Culex L.). - Les palpes sont plus longs que la trompe cliez les màles; ils sont très courts chez les femelles.

Le Cousin commun (C'. pipiens L.) peut itre pris pour type du gente. Il mesure š à 6 millimètres et se reconnait à son thorax brum jaunitre, mar'jué de deux lignes brunes, ì son abdomen gris pàle annelé de brun et à ses pieds allongés et brunatres.

Il est très commun au roisinage des eaux slagnantes, où il subit les premières phases de son déreloppement. La femelle, en effet, dépose ses oufs, au nombre de 200 a $3 \% 0$, a la surface de l'eau. Les larves qui en sortent au bout de deux jours ont l'abdomen allongé et terminé par un tube respiratoire; elles se suspendent à la surface, la lite en bas, en laissant aflleurer ce tube. Après quatre mues, elles se transforment en nymphes mobiles: cellesci sont pourvues de deux tubes trachéens qui émergent de derrière la tète; elles se tieunent, par suite, dans une position opposée à celle des larves. En trois ou quatre semaines, toutes les métamorphoses sont accomplies, et les Insectes parfaits prement leur vol.

Les femelles s’altaquent a l'Homme, surtout le soir. Elles s'annoncent par une sorte de piaulement aigu et continu. On connait en principe leur appareil buccal; remarquons toutefois que la lèrre inférieure forme un tube cylindrique ourert en dessus, sauf'à l'extrémité libre; que les mâchoires sont denticulées en clehors, et que l'épipharynx et l'hypopharynx sont sétacés. Le mécanisme de la piqûrc est assez curieux : pendant que les aiguillons s'enfoncent dans la peau, en glissant dans le tube terminal de la trompe labiale, la partie moyenne de ce tube, fendue en dessus, se courlse et forme un pli latéral. La piquîre détermine une inflammation locale, accompagnée d'unc 
douleur prurigineuse assez vive. Il y a sans doute dípôt, daus la plaic, d'une salive irritante.

Les Cousins ne paraissent pas, en général, altayuer nos animaux domestiques.

Ine autre espèce commune dans nos jays, en automne, est le Cousin annele $(C$. ammulalus.

Au genre Culrex paraissent se rallacher, en outre, les Insectes des pays chauds désignés par les voyageurs sous le non de Muringouins. el une partie peut-etre de ceux auxquels on applique la dénomination rague de Moustipues.

Au surplus, nous possédons, en Europe, lles espèces de quelques genres voisins, par exemple Anophrles monlipennis, dont les altaques sont aussi insupporlahles que celles des Cousins proprement dits.

THOKลİHE SULSーOHHIR

\section{APHAMTERES}

La plupart des auteurs modernes saccordent à rapprocher des l)iptères les Puees et genres voisins (1), dont on avait longtemps fait un ordre à part sous le nom d'. J phaniptères liirby el Spence, Siphonaptrres Latreille ou Suceurs De Geer. Ce sont, comme le dit kïnckel, des Diptères sauteurs et parasites.

Le corps est comprimé latéralement. La lìte, petile, arrondie ou anguleuse, est largement unie au thorax; elle porte deux ocelles, toujours placés en ivant des antennes, parfois rudimentaires ou absents. Les antennes, triarticulées, sont couchées au repos dans une petite fossette qui parfois se montre limitée en dehors par une lamelle chitineuse. Les pièces buccales, chez l'adulte, sont disposées pour la succion : elles comprennent : $1^{0}$ une paire de momdibules spadiformes, à bords Iranchants et denticulés, it face interne concave; 20 m stylet rigide (langue, épipharynx) compris entre ces mandibules, creusé en gouttière inférieurement et présentant en dessus une arête dentée : cest le principal agent perforateur; $3^{\circ}$ une paire de michoires libres, en forme de larges plaques foliacées, portant chacune un palpe maxillaire a quatre articles; $\mathfrak{t}^{\circ}$ une lerre infriviene courte, terminée par deux palpes labiaux et formant une gaine qui loge la base des mandibules et du piquant impair. La lèrre supé-

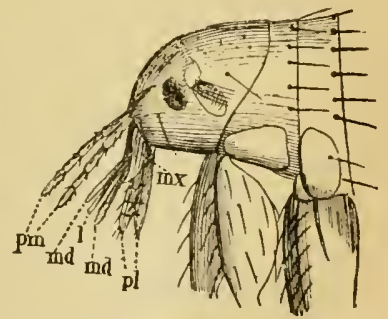

Fig. 347. - Télede la l'uee de l'llomme, grosic 30 fois. - md, matiluales. m.r, michoires. pm, palpes maxil laires. $l$, lylet impail. $p l$, palpes laliaus (Orig. .).

rieure fait défaut. Les trois segments thoraciques sont toujours dis tincts, contrairement à ce qui sobserve chez les autres Diptères; ils se composent chacun d'une partie dorsale (notum) et de deux parties latérales

1) O. Taschenberg, Die Flöhe. IIalle, 1880. 
(plcurx): sur le métathorax, celles-ci sont munies d'une grande écaille aliforme; mais les ailes proprement diles n'existent pas, mème à l'état de rudiments. Les pattes, disposées pour le saut, augmentent de longueur de la première à la dernière paire; le tarse, à 5 articles, est terminé par deux griffes. L'abdomen comprend a segments, qui se chevauchent, de sorte que chez quelques espèces, au moment de la gestation, il esl susceptible de subir une énorne distension. Le ge ou dernier segment présente en dessus un es. pace ovalaire, limité par un anneau chitineux et garni de soies et de poils; ce segment doit porter le nom de pygidium, car il couvre le cloaque. Celuici, chez le màle, est flanqué de deux plaques alirormes, constituant un appareil de fixation. A la partie inférienre de la tète, ainsi qu'au bord postérieur du prothorax, du nétalhorax et de plusieurs segments abdominaux, on peut rencontrer des épines rapprochées en peignes.

Les métamorphoses sont complètes. De l'œuf sort une larve rermiforme, apode, possédant une tête distincte suivie de douze anneaux. La tête est dépourvue d'yeux, mais porte deux antennes et une corne

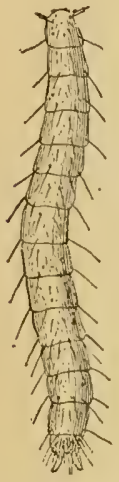

Fig. šis. - Larve de la Puee des Poules, grossie 20 fois (Orig.).

frontale caduque, qui a servi à percer la coque de l'cuf: les pièces buccales sont conformées pour la mastication. Les anneaux lu corps sont revèlus de poils, principalement vers leur bord postérieur; le dernier, très grand et double en apparence, est terminé par deux appendices incurvés servant à la marche. Arrivée au terme de sa croissance, cette larve se file généralement un petit cocon soyeux, puis mue et se transforme en une nymphe qui montre déjà ses trois paires de pattes et laisse reconnaitre son sexe; chez. le mâle, en effet, le dos est concave et l'abdomen se termine par deux pointes; chez la femelle, dont la taille est plus grande, le dos est convexe, et l'abdomen n'offre qu'une seule pointe terminale. D'abord blanche, celte nymphe se fonce de plus en plus; enfin, au bout d'un temps rariable, l'Insecle parfait sort dı cocon et se met en quête d'un hôte aux dépens duquel il puisse se nourrir.

Les Aphaniptères vivent en parasites temporaires sur les Vertébrés à sang chaud, dont ils sucent le sang; seules, les femelles de quelques espèces sont des parasites stationnaires.

Ces Insectes constituent une seule famille, celle des PULICIDÉS, qui se laisse partager assez nettement en deux sous-familles.

A. Les pulicinés ont une tète petite et des palpes labiaux à quatre articles. La l'emelle n'est parasite stationnaire à aucune époque de son existence; son abdomen ne se dilate jamais jusqu'à devenir informe.

Ce groupe comprend trois genres.

Les Puces proprement dites (Pulex L..) se distinguent des genres roisins par leurs yeux (ocelles) bien développés. 
Les femelles ne fixent pas leurs ceufs aux poils ou à la peau, mais les pondent au hasard et, le plus souvent, les laissent tomber à terre. On a dit et répété qu'elles avaient un instinct maternel très développé, et qu'après avoir sucé le sang d'un animal, elles allaient retrouver leurs larves pour leur dégorger une partie de ce sang dans la bouche ou le déposer à leur portée. Cette légende doit disparaitre. Les grains noirś desséchés qui tombent ẹa et là avec les œufs sont les excréments des Puces, et les larves les dévorent comme elles se repaissent des autres matières animales, notamment des cadavres d'Insectes.

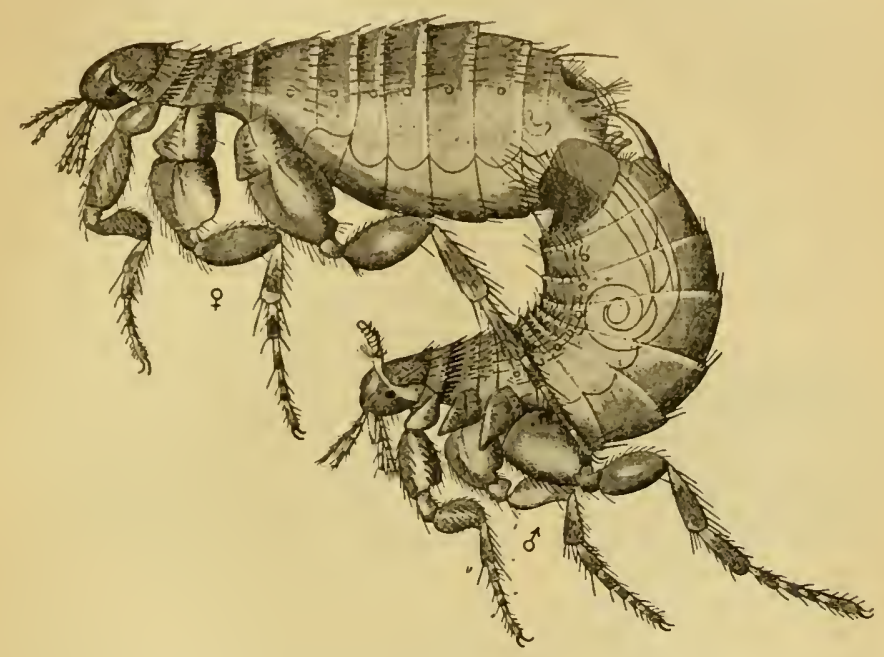

Fig. 549. - Puces de la I'oule : mále et femelle accouplés, un peu séparés par la compression de la préparation (Orig.).

Dans l'accouplement, la femelle se trouve placée sur le dos du mâle.

On connait actuellement une quinzaine d'espèces de Puces, s'attaquant, soit à l'Homme, soit aux Carnivores, aux Rongeurs, à quelques Ruminants, Édentés et Monotrèmes, soit enfin aux Oiseaux.

Taschenberg a donné une classification assez complète des formes jusqu'à présent étudiées; nous en extrayons le tableau synoptique suivant, qui ne comprend que les espèces observées sur nos animaux indigènes:

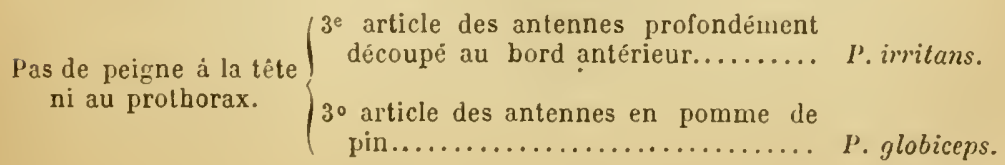

Raillitet. - Zoologie. 


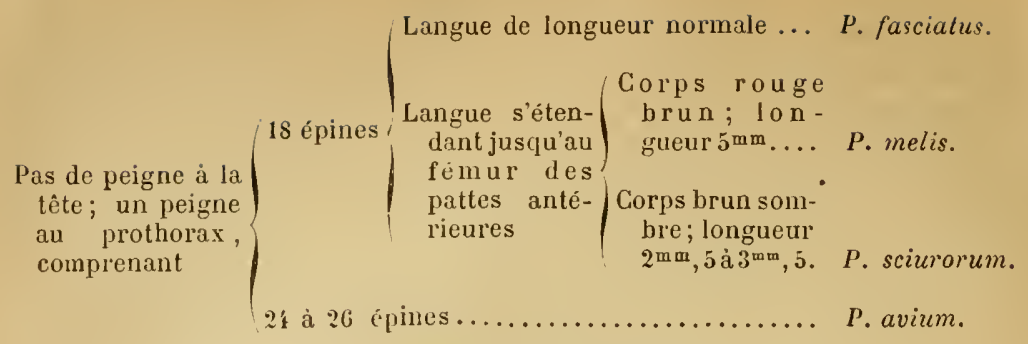

\begin{tabular}{|c|c|c|c|}
\hline & Tête arrondie & $\begin{array}{l}\text { Peignes de Ia tête et du pro- } \\
\text { thorax chacun à } 7-9 \text { épines de } \\
\text { chaque côté................ }\end{array}$ & P. serratice $\rho$ s. \\
\hline $\begin{array}{l}\text { Un peigne a la } \\
\text { tête; un pei- } \\
\text { gne au pro- } \\
\text { thorax. }\end{array}$ & $\begin{array}{l}\text { Tête anguleus } \\
\text { prothorax }\end{array}$ & $\begin{array}{l}2 \text { épines à la tête et } 3 \text { au pro- } \\
\text { thorax, de chaque côté...... } \\
\text { à } 5-6 \text { épines de chaque côté } \\
\text { épines de chaque côté......... }\end{array}$ & P. erinacei. \\
\hline
\end{tabular}

La Puce irritante ( $P$. irritans L.) a le corps ovale, de couleur assez variable, ordinairement d'un brun marron luisant; la tête est arrondie en dessus et dépourvue d'épines à son bord inférieur : le prothorax est également

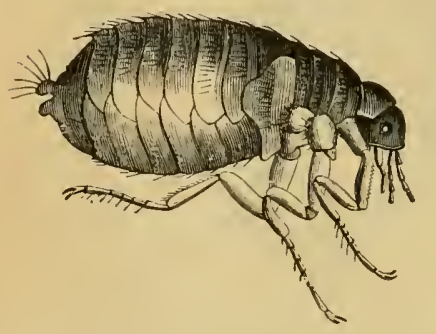

Fig. 55̈0. - Puce de l'Homme, måle. dépourvu de peigne; le $3^{\mathrm{e}}$ article des antennes est profondément incisé à son bord antérieur. Le mâle est long en moyenne de 2 millimètres à $2^{\mathrm{mm}}, 5$, la femelle de 3 à 4 millimètres; mais ces dimensions sont quelquefois de beaucoup dépassées.

La Puce irritante est un parasite de l'Homme. La femelle pond, dans les fentes des parquets, dans le linge sale, dans les coins poussiéreux, etc., huit à douze œufs blanchàtres et ovoïdes, longs de $0^{\mathrm{mm}}, 7$, larges de $0^{\mathrm{mm}}, 4$. En été, les larves éclosent au bout de 4 à 6 jours; 11 jours après, elles se transforment en nymphes, auxquelles il faut encore 12 jours environ pour devenir Insectes parfaits. L'évolution totale dure donc 4 semaines; en hiver et dans une chambre chauffée, elle exige près de 6 semaines.

La Puce est cosmopolite. Elle est surtout importune dans les pays chauds et dans les saisons chaudes. Sa piqûre, fort désagréable, s'accompagne du dépôt d'une salive irritante, et donne lieu à une hémorragie punctiforme autour de laquelle se développe un cercle d'injection rouge de 2 à 5 millimètres de diamètre, qui persiste sous la pression du doigt. Ce cercle pâlit rapidement, tandis que le point hémorragique ne disparaît complètement qu'au bout de quelques jours.

Chez les femmes, les enfants, et en général chez les sujets à peau 
délicate, il constitue une aréole tuméfiée. On peut constater en outre, chez les enfants, l'apparition de plaques d'urticaire, provoquées par le contact direct de la Puce, ou développées par voie réflexe. Enfin, quand la peau est trop couverte de piquires, son aspect simule parfois un véritable purpura (purpura pulicosa).

Chez des individus très malpropres, on a vu les Puces pondre sur la peau, et Bergh cite même les cas d'une femme atteinte de psoriasis et vivant dans la plus grande saleté, chez laquelle les larves abondaient dans les squames et à la surface des érosions produites par le grattage.

Contrairement à ce qui a lieu pour les Poux, les personnes les plus propres peuvent être attaquées par les Puces adultes, qui d'ailleurs, recherehent de préférence certains tempéraments. Il esì assez difficile d'atteindre ces Insectes, à moins qu ïls ne soient très abondants; mais certaines substances jouissent de la propriété de les éloigner. Il est de connaissance vulgaire, par exemple, qu'elles ne s'accommodent pas de l'odeur du Cheval, et que les palefreniers, les hommes qui couchent dans les écuries, etc., sont à l'abri de leurs alteintes.

La Puce à tète pectinèe $(P$. servaliceps P. Gervais, 184t. - Syn. : $P$. canis Curtis, 1826 ; $P$. felis Bouché, 1833̈) est d'un rouge brun clair; elle possède une tète arrondie en dessus et munie à son bord inférieur, de chaque còté, d'uu peigne à 7-9 épines; le bord postérieur du prothorax, dans son arceau dorsal (pronotum) est armé de la même manière. Le màle est long de 2 millimètres, la femelle de 3 millimètres.

Cette Puce vit sur de nombreux Carnivores domestiques ou sauvages, en particulier sur les Canidés et les Félidés. La variété qu'on rencontre sur

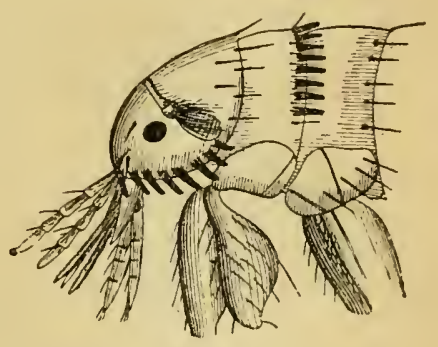

Fig. :3̈̈. - Téte de la Puce du Cllien, grossie 30 fois (0) rig.). le Chat domestique est généralement un peu plus petite que celle qui attaque le Chien : elle a la tète surbaissée en avant et les épines plus effilées; aussi l'a-t-on regardée quelquefois comme une espèce distincte.

La Puce à tête dentée est surtout abondante sur les animaux sédentaires, sur les jeunes; sur les mères pendant la période de l'allaitement, parce que ces conditions favorisent la ponte sur place et le développement des Insectes. L'érolution co plète du parasite peut même s'accomplir sur le corps de l'hôte. Sur un Chien qui souffrait depuis six mois d'une irritation cutanée avec prurit intense, mais sans éruption, Austin a recueilli, en effet, au milieu de la crasse et des pellicules épidermiques, des œufs, des coques vides, des larres à différents stades de croissance, des dépouilles de larves, des nym- 
phes et des Insectes parfaits. De même, Leuckart a trouvé, dans les croûtes de la peau eczémateuse d'un Chien, de nombreuses larves de Puces, auxquelles vraisemblablement l'éruption ne devait pas être attribuée, mais qui avaient profité sans doute de cette source abondante de nourriture. Neumann a fait une observation analogue sur un Chat.

La Puce à tête anguleuse (P.goniocephalus 0 . Taschb.,1880. - Syn. : Pulex leporis I leach, 1829) a le corps brun jaunâtre; sa tête forme, dans la partie

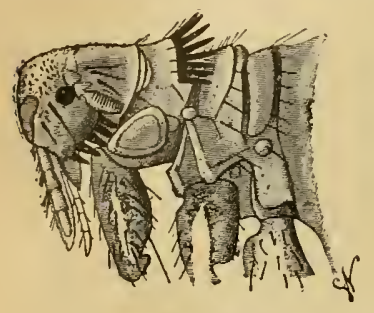

Fig. 552. - Tète de la Puce du Lapin, grossie 30 fois (Orig.). antéro-supérieure, un angle obtus faisant une légère saillie; elle porte en dessous et de chaque côté un peigne à 5-6 épines; le bord postérieur du pronotum porte aussi de chaque côté 6 épines longues et étroites. Longueur du màle $1^{\mathrm{mm}}, 6$, de la femelle 2 millimètres.

Elle vit sur les Lièvres, les Lapins de garenne et les Lapins domestiques. Il est curieux de voir avec quelle rapidité elle abandonne le corps du Lapin qu'on vient de tuer à la chasse.

La Puce des Oiseaux (P. avium 0. Tasclıb., 1880) a le corps allongé, d'un brun varié; sa tìte, arrondie, ne porte pas d'épines, mais on en trouve 12 ou 13 de

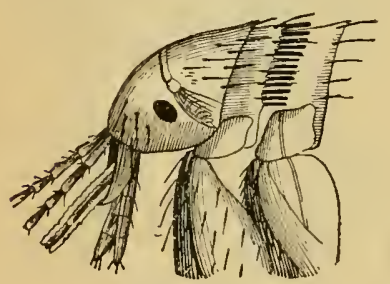

Fig. 553. - Tèle de la I'uce des Poules, grossie 30 fois (Orig.). chaque còté au bord postérieur du prothorax. Longueur du mâle 2 à 3 millimètres, de la femelle 3 millimètres à $3^{\mathrm{mm}}$,̆.

Cette espèce attaque un grand nombre d'Oiseaux; elle est commune dans les colombiers, un peu moins dans les poulaillers. Daprès Ercolani, elle fait parfois dépérir et mourir de consomption les Pigeons. C'est à tort qu'on a voulu en distinguer plusieurs espèces sous les noms de $P$. gallinæe Bouché, columbæ Stephens, hirundinis Köhler, etc.

Quant aux Puces de nos Mammifères sauvages, disons seulement que Pulex globiceps 0 . Taschb. vit sur le Renard et le Blaireau; P. fasciatus Bosc, sur le Lérot, le Surmulot, la Taupe, etc.; P. melis (Leach), sur le Renard et le Blaireau; $P$. sciurorum (Olfers), sur l'Écureuil ; $P$. erinacei (Leach), sur le Hérisson. On a signalé en outre un Pulex penicilliger Grube, de la Fouine et du Putois, un $\boldsymbol{P}$. microctenus (Kolenati), de la Fouine, un $\boldsymbol{P}$. muslelæ Schilling, de la Belette, etc.

Un certain nombre de ces espèces ont été rencontrées aussi sur d'autres animaux appartenant à des groupes assez variés; mais il ne faut pas oublier que les Puces ne sont que des parasites temporaires, 
et qu'elles peurent vivre assez longtemps loin de leur hâte, dans des lieux inhabités : il n'est done pas étonnant de les voir passer accidentellement sur une autre espèce animale. Nous avons longtemps professé cetle opinion que les Puces ainsi égarées ne piquaient pas l'hòte étranger pour en sucer le sang, mais nous avons dú reconnaitre plus tard que c'est au contraire un fait bien établi. Ainsi, la Puce irritante de l'Homme passe assez souvent sur les animaux domestiques: il n'est pas rare de la trouver sur le Chien et sur le Chat; on l'a rencontrée aussi sur le Lapin, et nous en avons mème vu recueillir dans le pli du paturon, sur un Cheval. La Puce du Chien ou du Chat peut également attaquer l'Homme; je l'ai trouvée sur le Lapin, et pourtant il m'a été impossible de l'acclimater dans un clapier où je l'avais introduite en abondance. Enfin, Lucet a montré que la Puce des Oiseaux peut infliger à l'llomme de cruelles morsures.

Les Hystrichopsylles (Hystrichopsylla 0. Taschb.) sont dépourvues d'yeux; leur tète est tronquée en avant; il existe des peignes au bord inférieur de la tête, au prothorax et sur plusieurs segments de l'abdomen; le corps est garni de soies et de poils nombreux.

Une seule espèce (H. obtusiceps Ritsema), de la Taupe et du Campagnol des champs.

Les Typhlopsylles (Typhlopsylla 0 . Taschb.) ont le corps grèle et allongé, la tète souvent très longue, arrondie en avant, les yeux très rudimentaires ou absents. Il existe des peignes à la tète ('́ épines au plus de chaque côté), au prothorax et parfois au métathorax et sur plusieurs segments de l'abdomen.

Voici le tableau synoptique des espèces qui s'altaquent aux animaux de notre région:

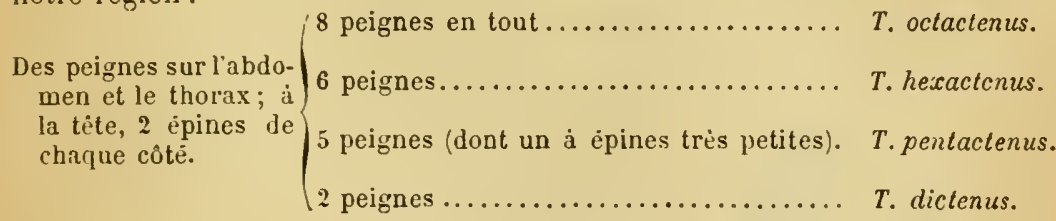

Un peigne sur le pro- au bord antér. de la fossette antennale. T. gracilis.

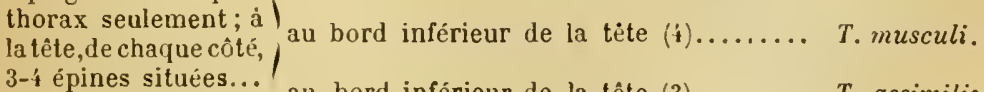

$3-4$ épines situées... au bord inférieur de la tête $(3) \ldots \ldots . .$. . assimilis.

Les Typhlopsylla octatenus (Kolenati), hexactenus (Kol.), pentactenus (Kol.), dictenus (Kol.) vivent exclusivement sur les Chiroptères; $T$. gracilis 0 . Taschb., sur la Taupe et la Musaraigne ; T. musculi Dugès, sur les Souris, les Rats et les Campagnols; T. assimilis 0. Taschb., sur la Taupe, la Musaraigne, le Mulot et le Campagnol.

A part les cas particuliers que nous avons signalés, les Puces ne constituent pour les animaux, comme pour l'Homme, qu'une simple incommodité, et ne leur nuisent guère qu'en troublant leur repos. 
Il faut ajouter cependant qu'en raison de eur mode d'attaque, on a pu les considérer comme susceptibles de jouer le rôle de porte-virus, c'est-à-dire d'inoculer à des individus sains le virus puisé sur un individu malade. Toutefois, cette accusation ne repose jusqu'à présent que sur de simples suppositions. Ce qui est bien établi, par contre, c'est que les Puces sont les hôtes intermédiaires de certains parasites à transmigrations (Voy. p. 286 et 514).

Il y a donc lieu d'éloigner ou de détruire les Puces des animaux, surtout lorsqu'elles se multiplient à l'excès. Un moyen simple de les éloigner consiste à placer dans les niches une couverture de Cheval. La litière de copeaux de sapin, vantée par quelques auteurs, ne nous a pas réussi. Les feuilles de noyer fraîches sont de beaucoup préférables. Enfin, on détruit assez facilement les Puces sur le corps même des animaux, au moyen de lotions d'eau crésylée à 5 ou 10 p. 100.

B. La sous-famille des SARcopsyllinés se compose de petites Puces á tête assez grosse suivie d'un thorax très grèle et d'un abdomen variable. La lèvre inférieure porte deux palpes labiaux non distinctenent articulés. Le troisième article des antennes n'est pas annelé.

Toutes les espèces sont extra-européennes. On les répartit entre trois genres.

Les Sarcopsylles (Sarcopsylla Westwood, 1840. - Syn. : Dermatophilus Guér.Mén., 1843; Rhynchoprion Oken, 1815, nec Hermann, 1804) ont un front anguleux et crénelé, des yeux (ocelles) petits, des máchoires très petites, à peine saillantes, une lingue (épipharynx) allongée, des mandibules fortement dentées en scie sur les côtés. L'abdomen des femelles fécondées se dilate en une masse arrondie, sans trace d'articles dans sa partie moyenne.

La Sarcopsylle pénétrante (Sarcopsylla penetrans [L.]), vulgairement Puce pénélrante, Puce des sables ou Chique, est un fort petit Insecte, car le

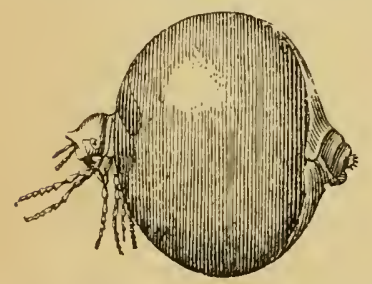

Fig. 534. - Chique gorgée, grossie (Karsten). màle, ainsi que la femelle à jeun et non fécondée, mesure à peine 1 millimètre de longueur. l.e corps est orale, comprimé d'un côté à l'autre, de teinte brun roussàtre, avec la tête un peu plus foncée.

L'accouplement a lieu anus contre anus, les deux individus restant accolés environ huit à dix minutes.

La Chique se rencontre à peu près dans toute l'Amérique intertropicale, depuis le nord du Mexique jusqu'au sud du Brésil. Elle a été introduite en Afrique vers 1872, et s'y est propagée avec une étonnante rapidité.

Elle se tient sur les herbes sèches, dans les bois, dans les plantations; elle est surtout très abondante dans le sable; enfin, on la rencontre aussi dans les habitations mal tenues, dans les cases des nègres, dans les écuries, les basses-cours, etc. De là, elle se jette sur 
l'Homme. ainsi que sur la généralité des animaux à sang chaud, domestiques ou sauvages : les Pores souffrent beaucoup de ses atlaques, de mème que les Chiens, Chats, Moutons, Chèvres, Bœufs, Chevaux, Anes et Mulets; les Oiseaux mêmes n'en sont pas exempts.

Le mále et la femelle non fécondée sont des parasites temporaires, comme les Puces vraies; ils sont à peine plus importuns que cellesci; mais la femelle fécondée, qui a besoin d'absorber une grande quantité de sang pour te développement de sa progéniture, se fixe à demeure sur l'hôte qu'elle choisit. Chez l'Homme, elle s'implante d'ordinaire sous les ongles des orteils ou dans d'autres régions du pied; chez les Mammifères domestiques, c'est également à la partie inférieure des membres qu'elle s'adresse de préférence. La douleur de la piquire est insignifiante et toule passagère, de sorte que les royageurs atteints pour la première fois n'y prennent pas garde. La Chique s'introduit entre le derme et l'épiderme, suce le sang des papilles dermiques et ne tarde pas ì augmenter de volume : la tête et le thorax ne subissent pas d'accroissement sensible, mais l'abdomen, par suite du développement des œufs, se gonfle jusqu’à acquérir le rolume d'un pois. La dilatation ne porte que sur les deuxième et troisième anneaux de l'abdomen, les autres conservant leur's dimensions primitives. Elle amène un dẹcollement progressif de l'épiderme et provoque ainsi la formation d'une petite cavité dont les parois se moulent sur le corps de l'animal. La tête occupe le fond; l'anus est tourné vers l'extérieur.

La présence du parasite est indiquée par une tumeur arrondie, de la grosseur d'un pois, circonscrite par l'épiderme et percée à son sommet d'un petit orifice laissant à peine apercevoir les derniers anneaux de l'abdomen. Le corps de la Chique, Iorsqu'elle est parvenue au terme de sa gestation, a été comparé, par suite de sa taille et de sa couleur blanchâtre, à un fruit de gui : il peut contenir une centaine d'cufs. Sa présence est le point de départ d'une irritation assez vive : la peau s'enflamme, et la pression qui résulte de ce travail inflammatoire tend à expulser la Chique à la façon d'un corps étranger. Souvent alors l'abdomen se rompt, et les œufs sont rejetés à l'extérieur, tandis que le corps demeure encore quelque temps dans la plaie et ne se détache qu'avec l'épiderme environnant.

Mais il arrive que les choses ne se passent pas d'une façon aussi régulière. La plaie se convertit souvent en ulcère; elle a de la tendance à s'étendre et à se gangrener. D'ailleurs, la présence de l'Insecte détermine une démangeaison de plus en plus vive, qui porte souvent le patient à se gratter sans mesure, et une inflammation violente peut en résulter. Si plusieurs femelles s'implantent sur un même point, les troubles sont encore plus à craindre. Chez l'Homme, il survient parfois des nécroses des os ou des tendons, donnant lieu à des fistules plus ou moins profondes, s'accompagnant d'arthrites 
et entrainant même dans certains cas la chute des phalanges. Des lésions du même genre s'observent chez les animaux : on en voit qui ont le corps couvert de cicatrices, les oreilles déformées, qui ont perdu des doigts ou une extrémité entière. R. Blanchard a examiné un pied de Porc rapporté de Monrovia (République de Libéria) par J. Jullien, et qui présentait des Chiques tellement serrées les unes contre les autres que Ia peau offrait, après leur extirpation, l'aspect alvéolaire d'un gâteau de miel.

L'œuf de la Chique est ellipsoïde, à surface finement granuleuse; il en sort une larve vermiforme, dont l'évolution est tout à fait analogue à celle des Puces proprement dites.

La Sarcopsylle galline ( $S$. gallinacea Westw.) se distingue de l'espèce précédente par son corps court et trapu, presque aussi large que long, d'une teinte rouge brun; par sa tête formant plusieurs angles peu saillants, par ses soies plus longues, plus nombreuses et plus foncées, etc. Longueur $1 \mathrm{~mm} .5$.

Cette espèce se fixe autour des yeux et sur la nuque de la Poule domestique; elle n'a encore été recueillie qu'à Ceylan, d'abord par Moseley lors de l'expédition du Challenger, puis par Green à Colombo.

Pour se garantir contre l'invasion des Chiques, on recommande de laver souvent et à grande eau les habitations, car on a reconnu que l'humidité est funeste à ces Insectes. Il est indiqué aussi de se laver les pieds ou mieux de prendre un bain chaque jour, et de faire usage de bonnes chaussures. Les onctions de teinture de rocou, d'infusion de tabac, d'huile de carapa, usitées parmi les nègres, pourraient être d'une certaine utilité en ce qui concerne les animaux domestiques.

Dès que la présence des Chiques est constatée sur un point du corps, on peut les tuer sur place au moyen de diverses substances, telles que teinture d'opium, pommade mercurielle, essence de térébenthine, acide phénique, benzine, etc. S'il en existe un grand nombre sur un espace restreint, on a recours à des applications générales de ces mêmes substances. Aux Antilles, on plonge la partie atteinte dans une décoction d'herbe à Chique (Tournefortia hirsutissima); à la Martinique, on se sert pareillement d'une décoction de tabac; en Colombie, on se contente d'applications de beurre salé.

Mais le meilleur traitement consiste sans aucun doute à extraire directement le parasite. Cette opération, qui s'appelle échiquage, est en général effectuée avec dextérité par les nègres, qui introduisent simplement, dans l'orifice de la tumeur, une épingle à l'aide de laquelle ils détachent et enlèvent l'Insecte. On doit éviter de lacérer l'abdomen de celui-ci, car les œufs répandus dans la plaie pourraient être une source de graves complications.

Les Rynchopsylles (Rhynchopsylla Haller, 1880; Hectopsylla? v. Frauenfeld, 1860) ont le front arrondi et les màchoires recourbées en crochet, fai- 
sant saillie en arrị̀re. L’abdomen des femelles fécondées est verniforme, distinctement articulé.

Une seule espèce (Rh. pulcx Ilaller; ? Hectopsylla psiltaci v. Fr.) trouvée sur un Perroquet et sur un Chiroplère.

Les Vermipsylles (Vermipsylla Shimkiévitsh, 188ä ; Helminthopsylla Raill., 1883) ont le front arrondi, les yeux assez grands et les màchoires triangulaires, en forme de lancettes pointues, mais à pointe non recuurbée en arrière. Les femelles fécondées ont l'abdomen vermiforme et articulé, comme dans le genre précédent.

La Vermipsylle Mlakurt (V. Alakurt Shimk.), dont la femelle seule est connue, a le thorax brun foncé, ainsi que les anneaux de l'abdomen; mais, lors le la gestation, ceux-ci sont très écartés les uns des autres et reliés par une membrane d'un blanc laiteux. A l'état de complet développement, elle mesure 6 millimètres.

Cette espèce, qui parait ètre, jusquà présent, limitée au Turkestan, est connue des hirghiz sous le nom d'Alakurt, qui signifie Ver ou Insecte versicolore: en effet, de noire qu'elle était au dẻbut, elle devient plus tard, par suite des modifications ci-dessus indiquées, d'un blanc de lait avec des raies de diverses couleurs. Elle vit en parasite sur les Bœufs, les Chevaux, les Moutons et les Chameaux. D'après Maïev, elle provoquerait un affaiblissement considérable de l'organisme, et pourrait même faire périr les Poulains. Elle apparait en automne, alors que la neige se montre déjà sur les montagnes, et abonde surtout au moment des grands froids.

\section{DEUXIËME ORDRE}

\section{IÉ.HIPTÈRES}

Insectes suceurs; ailes antérieures de consistance variable; ailes postérieures toujours membraneuses; métamorphoses incomplètes.

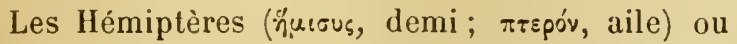
Rynchotes (\$úry. ${ }^{\circ}$, bec) ont la bouche disposée en un rostre propre à piquer et à sucer. Ce rostre a pour base une gaine constituée par la lèvre inférieure articulée, et fermée à la base et en dessus par la lèvre supérieure triangulaire; dans cette gaine sont renfermés quatre longs stylets qui

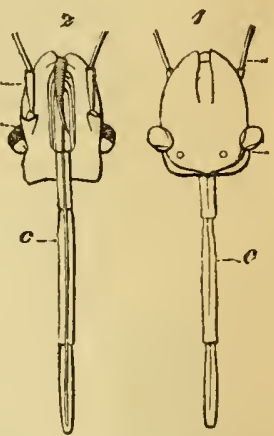

Fig. 553. - Tète grossie d'un Hémiptère, le Pentalome gris (Rhaphigastergriseus). -1, vue par la face supérieure. 2, vue par la face inférieure. $a$, yeux. $b$, antennes. c, rostre à 4 articles, rcplié en dessous. représentent les mandibules et les mâchoires. Au repos, le rostre est presque toujours replié sous le thorax, entre les pattes.

11 existe d'ordinaire quatre ailes, tantot toutes membraneuses, tantôt les antérieures coriaces à la base et membraneuses vers l'extrémité (hémélytres).

Les métamorphoses sont incomplètes : les larves ne diffèrent guère 
de l'Insecte parfait que par l'absence d'ailes; dans certains cas mème, les femelles ou les deux sexes sont aptères, et par suite les métamorphoses sont nulles.

Deux sous-ordres: Homoptères et Hétéroptères, auxquels on adjoint les Aptères ou Anoploures.

\section{PREMIER SOUS-ORDRE}

\section{HOMOPTÉRES}

Les ailes antérieures ont la même consistance dans toute leur étendue et sont presque toujours membraneuses comme les postérieures (óuós, semblable); le rostre est inséré à la partie inférieure de la tète. Ces Insectes se nourrissent du suc des plantes; les femelles sont munies d'une tarière ou oviscapte.

Deux sections: Phytophtires et Cicadaires.

$1^{\text {re }}$ section: Phytophtires. - Ces petits Insectes, que leur nom assimile à des Poux, sont parasites des végétalx. Ils comprennent trois familles principales: Coccidx, Aphidx, Psyllidx.

Les COCGIDÉS ou Cochenilles offrent un dimorphisme sexuel très accusé. Les femelles demeurent toujours aptères; elles se fixent sur les végétaux en y implantant leur rostre, deviennent informes, s'entourent en génẻral d'une matière cireuse et déposent leurs œufs sous elles. Les màles, au contraire, sont privés de rostre, mais possèdent presque toujours une paire d'ailes, et, par une exception remarquable, ils subissent une métamorphose complète.

Un certain nombre de Coccidés fournissent des produits usités daus l'industrie et même en médecine (1). - La Cochenille du Nopal

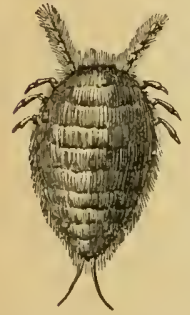

Fig. 5ั56. - Cocheuille du nopal, femelle. (Coccus cacti) est originaire du Mexique, où elle vit sur les raquettes du Cactus nopal (Opuntia coccinellifera). Elle a été importée aux Antilles, en Espagne, en Algérie, etc. La Cochenille du commerce est constituée par les corps des femelles, desséchés et débarrassés de leur fentrage cireux. C'est d'elle qu'on extrait, par des procédés spéciaux, la belle couleur rouge vif connue sous le nom de carmin, qui joue aujourd'lui un si grand ròle dans la technique histologique (Gerlach, 1838). On a longtemps employé la Cochenille en médecine ; aujourd'hui encore, Laboulbène et 0 . Larcher la recommandent dans le traitement de l'asthme et de la coqueluche.

Le Kermès des teinturiers (Kermes vermilio) vit sur le chêne garrouille (Quercus coccifera), de la région méditerıanéenne. Les corps desséchés des femelles constituent ce qu'on nomme le lermès animal ou la graine d'écarlate, produit usité, dès les temps les plus reculés, pour teindre la laine el la soie

(1) R. Branchard, Les Coccidés utiles. Bull. de la Soc. zool. de France, VIII, p. $217,1883$. 
en pourpre et en écarlate, mais supplanté en grande partie, depuis la découverte de l'Amérique, par la Cochenille du nopal. Au moyen àge et jusque ver's la fin du xvire sićcle, ce kermès jonit en médecine d'une réputation extraordinaire, surtout lorsque Mesué l'eut fait entrer dans la composition de son fameux électuairc, la confectio allermes, sorte de panacée aujourd hui tombée dans l'oubli. Le sirop de kermès, vanté plus tard comme stomachique et astringent, n'est mème plus usité.

Le Pe-la (Ericerus cerifer) est un Insecle chinois qui vit sur différents arbres et dont les femelles restent libres, tandis que les males se fixent et sécrètent une cire blanche. Cette cire de Chine est employée à la fabrication des bougies de luxe; en outre, elle jone en plıarmacic à peu près le mème rôle que notre cire d'A heille.

La Cochenille de la laque (Tuchardiu lnera) est une espèce des Indes orientales, qui vit sur des arbres variés, Ficus, Mimosa, etc. Elle produit par an deux générations, remarquables par le dimorphisme des màles. Les larves se fixent et s'entourent d'une couche épaisse de substance résineuse. La matière lirrée au commerce sous le nom de laque comprend deux substances très distinctes: la laque ol gomme-laque, produit de sécrétion exsudé par toute la surface du corps, et la teinture de laque, matière colorante rouge plus spécialement localisée dans l'ovaire. La gomme-laque était autrefois employée comme tonique et astringente.

A còté de ces quelques Coccidés utiles, il en est un grand nombre qui nuisent aux végétaux; nous citerons seulement les plus importants. Lecanium persicx, olex, hesperidum, fatiguent et épuisent les pèchers, les oliviers, les orangers. Ceroplastes caricæ nuit aux figuiers. Pulvinaria vitis attaque les vignes, surtout en treilles. Dactylopius adonidum, des plantes de serre; D. ritis, des vignes de pleine terre, dans le midi. Mytilaspis pomorum, sur les écorces des pommiers et des poiriers.

Les APHIDÉS ou Pucerons sont de tout petits Insectes pourvus d'antennes à 3-7 articles et d'un rostre triarticulé souvent très long; la plupart des individus sexués ont quatre ailes transparentes fort minces. Pattes longues, tarses presque toujours biarticulés, armés de deux grifles.

Les Pucerons proprement dits ou Aphis (Aplis L.) ont de trẻs longues antennes à sept articles; le sixième segment de l'abdomen porte, sur sa face dorsale, deux appendices ou comicules cylindriques, qui émettent une liqueur spéciale. Cette sécrétion ne doit pas être confondue avec l'éjaculation par l'anus d'un miellat sucré et incolore, dont les Fourmis sont très friandes. Ce qu'il y a de plus remarquable dans l'histoire de ces Insectes, c'est leur polymorphisme et leur reproduction parthénogenésique. Jurant tout l'été et l'automne, on observe une succession de générations composées exclusirement de femelles qui se reproduisent sans le secours de måles; puis, à l'approche de la mauvaise saison, ces femelles parthénogenésiques et vivipares donnent naissance à des mâles et à des femelles qui s'accouplent; ces dernières, une fois fécondées, pondent des œufs, qui se conservent tout l'hiver et reproduisent l'espèce au printemps suivant.

beaucoup de Pucerons nuisent aux végétaux dont ils sucent les bourgeons ou les feuilles. Citons, par exemple: Aphis mali, sur le poirier, le pommier, l'épine noire; A. sorti, Puceron rouge du pommier et du sorbier; A. per- 
sicæ, sur le pêcher; A. fabæ, sur la fève; A. granaria, sur le blé; A. trassi-

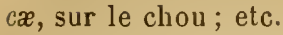

Les piqûres des Pucerons provoquent parfois sur les végétaux la formation de galles. Ainsi, la galle de Chine, qu'on emploie dans l'extrème Orient comme astringent et comme substance tinctoriale, est produite par la piqûre de l'Aphis chinensis sur les feuilles de divers arbres. La galle du pistachier ou caroube de Judée est déterminée par la piqûre de l'Aphis pistaciæ sur plusieurs espèces de pistachiers.

Parmi les genres voisins, nous nous bornerons à signaler: le Puceron lanigère (Schizoneura lanigera Harlig), qu'on regarde comme l'ennemi le plus dangereux des pommiers, et qui passe pour avoir été importé d'Amérique au commencement de ce siècle; le Puceron des galles du peuplier (Pemphigus bursarius); etc.

Un des groupes les plus intéressants des Aphidés est représenté par la sous-famille des PHyLloxérinés. Les Pucerons qui la composent se distinguent au premier coup d'œil par leurs ailes qui, au lieu d'ètre en toit comme chez les autres Aphidés, sont à plat sur le dos comme chez les màles des Coccidés.

Les Phylloxeras (Phylloxera Boyer de Fonscolombe, 1834), types du groupe, sont caractérisés par leurs antennes à trois articles. Chez les jeunes et les nymphes, le troisième article offre, près de son extrémité, un organe spécial formé d'un cadre chitineux supportant une membrane bombée: cet organe, connu sous le nom de chaton, paraît servir à l'odorat. Chez lesindividus ailés, on observe en outre un second chaton à la base du mème article.

Le Phylloxéra de Ia vigne (Ph. vastatrix [Planchon, 1868]. - Syn.: Pemphigus vitifolii Asa Fitch, 1854) apparaît sous quatre formes qui peuvent offrir un certain nombre de générations, mais se succèdent toujours dans le mème ordre: $1^{\circ}$ le gallicole (forne multiplicatrice), agame, aptère et rostré ; $2^{\circ}$ le radicicole (forme dévastatrice), agame, aptère et rostré; $3^{\circ}$ l'ailé (forme colonisatrice), agame, ailé et rostré; $4^{\circ}$ les sexués (forme régénératrice), aptères, sans rostre (1).

Biologie. - Nous allons suivre ce cycle évolutif, en partant de l'œuf d'hiver, c'est-à-dire de l'œuf pondu par la femelle sexuée. Cet œuf, découvert par Balbiani, est situé sous les écorces de la tige; son éclosion a lieu, suivant les régions, de la fin de mars à la fin d'avril.

A. Gallicole. - D’après les remarquables observations de P. Boiteau, vétérinaire à Villegouge (Gironde), l'œuf d'hiver donne toujours naissance à un Phylloxéra gallicole. A peine sorti de l'œuf, en effel, l'Insecte monte vers les jeunes feuilles, et enfonce son roslre à la face supérieure du limbe. Bientôt une dépression apparait au-dessous de lui, et il se forme une galle qui fait saillie à la face inférieure, en lui fournissant un abri plus ou moins vaste. Ce Phylloxéra, toujours agame, demeure aptère; il a le corps arrondi,

(1) Maxime Conxu, Étude sur le Phylloxera vaslatrix. Paris, 1878. - Balbiani, Le Phylloxera du chène et le Phylloxera de la vigne. Paris, 1884. - V. Mayet, Les Insectes de la vigne. Montpellier, 1890. 
un peu atténué en arrière, et ne montre jamais de tubercules sur le dos; sa teinte est d'un jaune tirant sur le veruatre. Pour arriver à son complet développement, il subit trois mues, et arrive alors à mesurer $1^{\text {ma }}, 2: 3$ de long sur 1 millimètre de large. A ussitòt après li $3^{e}$ mue, et sans accouplement préalable, il commence sá ponte, laquelle dure environ trois semaines et donne cinq à six cents aufs ellipsoïdes, longs de $300 \mu$, d'un jaune vif d'abord et passant ensuite au brun. Au bout de huit jours, l'éclosion de ces aufs commence, et les larves qui en sortent gagnent les feuilles les plus jeunes de l'extrémité des pampres, où elles vont développer de nouvelles galles et pondre à leur tour. Jusqu'en octobre, on peut voir se succéder ainsi jusqu'a i générations, le nombre d'œufs diminuant toutefois peu à peu et arrivant à tomber à 200 ou mème à 100 . Dès les premiers froids, les gallicoles adultes ou ovigères succombent, et les jeunes

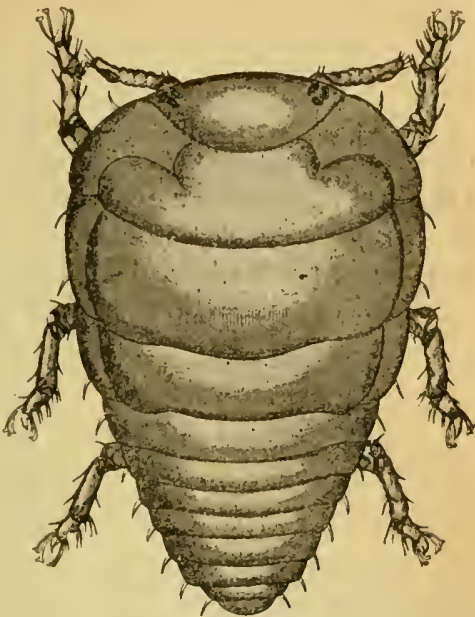

Fig. 55̃7. - Phylloxéra de la vigne: gallicole, face dorsale, grossi 50 fois (H. Cornu el Delamolte).

descendent aux racines, où ils hivernent sans manger; c'est seulement au printemps suivant qüils enfoncent leur rostre dans les radicelles et deviennent de véritables radicicoles. Cependant, il n'est pas rare de voir, dès la $3^{e}$ génération, un assez grand nombre de jeunes gragner les racines et devenir ainsi radicicoles dès la première année.

Il est à remarquer que les galles, très communes sur les plants américains, sont relativement rares sur nos cépages : cette observation a amené quelques auteurs à supposer que la forme gallicole pouvait être sautée, et que l'Insecte issu de l'wuf d'hiver descendait alors direclement aux racines. Nous devons dire quecette liypothèse ne parait pas fondée.

B. Rudicicole. - La forme qui vit sur les racines dérive toujours de la précédente, et se trouve représentée comme elle par des aptères parthémogenésiques. Les radicicoles, en effet, proviennent, soit des jeunes gallicoles descendus des feuilles, soit de générations radicicoles antérieures ayant la mème origine. Ils

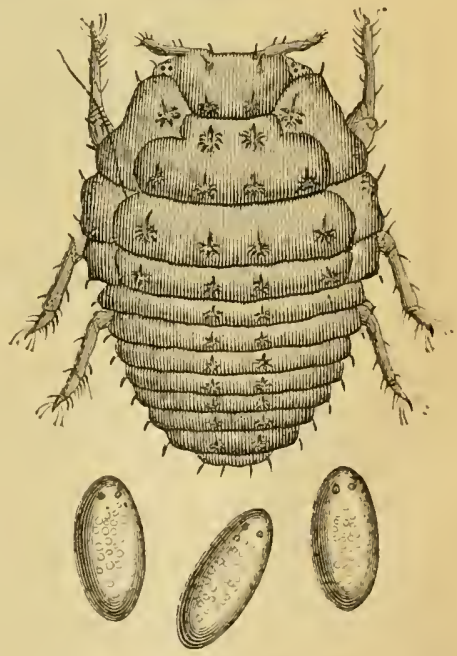

Fig. 558. - Plıylloxéra de la vigne: radieicole, face dorsale, grossi 50 fois. Au-dessous, ses rufs (M. Cornu el Delamolte). ont d'ailleurs de très grandes ressemblances arec les gallicoles des dernières générations. A l'état adulte, ils atteignent seulement 1 millimètre de long; ils possèdent sur le dos des tu- 
bercules bruns saillants, et leurs antennes sont extérieurement entaillées en bec de sifflet. Ils fixent leur rostre dans les radicelles, et développent ainsi des nodosités ou renflements caractéristiques, attribuables saus doute à l'action mécanique de l'organe. Les radicicoles sucent donc la sève et épuisent la vigne, que seuls ils font périr. Chacun d'eux pond trois à dix œufs parjour, en tout une centaine d'œufs d'un jaune de soufre au débit, et prenant peu à peu une teinte brune. De ces œufs sortent, au bout d'une huitaine de jours en moyenne, des jeunes d'abord jaunes, puis verdàtres et enfin bruns, agiles et errants. Trois ou quatre jours après l'éclosion, ces larves ont choisi sur les radicelles une place convenable; elles y enfoncent leur rostre et, dès lors, demeurent stationnaires. Elles s’accroissent rapidement, subissent trois mues, et, douze à dix-huit jours après leur naissance,

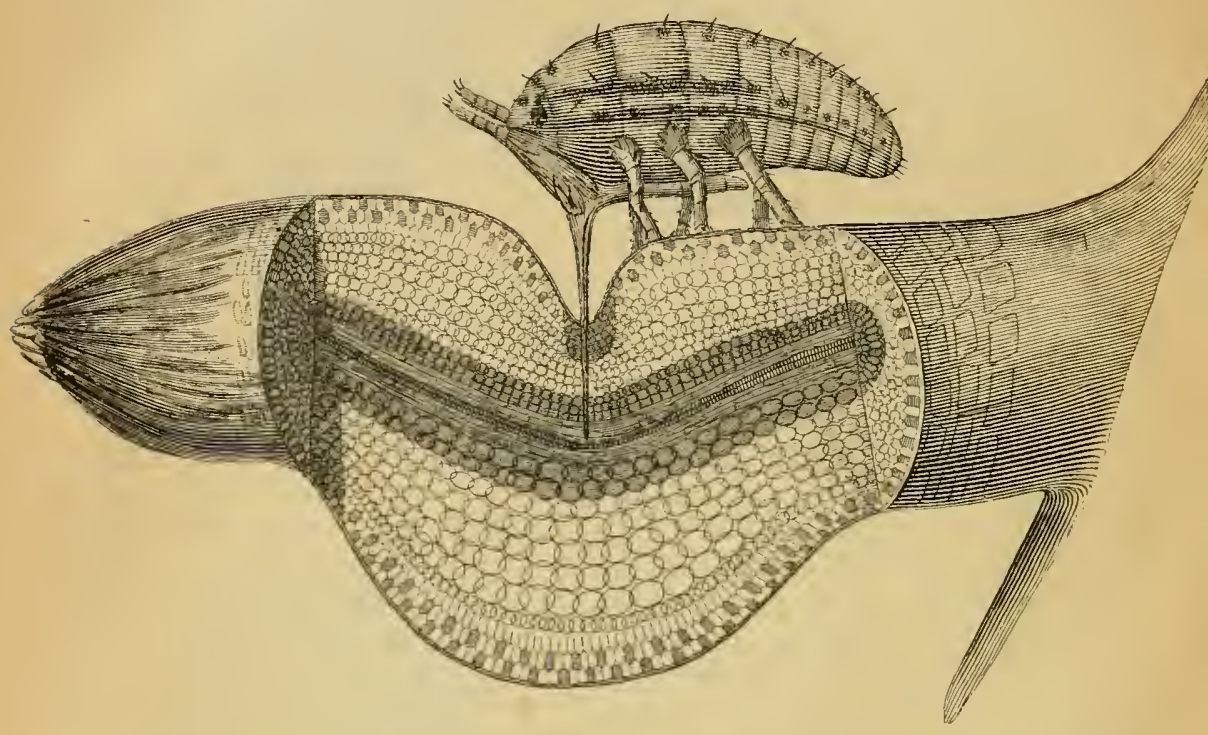

Fig. 559. - P'hylloxéra de la vigne: radicicole suçant la sève d'une radicelle de vigne européenne. Grossissement : 50 diamètres (II. Cornu et Delamolte!.

sont capables de pondre comme leurs mères. Quatre à six générations senıblables se succèdent ainsi jusqu'au retour de la saison rigoureuse.

Un certain nombre de ces radicicoles résistent mème à l'action du froid: ils passent l'hiver sur les grosses racines, cachés dans les fentes de l'écorce ou sous les plaques subéreuses, en compagnie des jeunes gallicoles descendus des feuilles à la fin de l'automne. Ces parasites, que n'ont pu détruire les froids excessifs de l'hiver 1879-80, sont connus sous le nom d'hibernants: ils reprennent leur évolution au printemps.

Ajoutons que Riley et d'autres ont réussi à transformer des radicicoles en gallicoles dans des éducations sous cloche ou en tube; mais, en dépit de ces expériences de laboratoire, il ne semble pas que, dans les conditions naturelles, les radicicoles montent aux feuilles: même lorsqu'ils sortent de terre pour émigrer, ils vont toujours aux racines. 
C. Aile. - A compter de juin ou de juillet, on voit apparaitre, parmi les radicicoles, des individus qui prennent, en grossissant, une forme plus allongée, et subissent une quatrième mue, laquelle les amène à l'état de nymphes. Ces nymphes sont surtout reconnaissables à leur thorax muni de rudiments d'ailes.

Elles ne tardent pas a quitter les radicelles, pour se rapprocher peu it peu de la surface du sol, et, après une cinquième et dernière mue, elles donnent une forme pourvue de quatre ailes. Le Phylloxéra ailé a été comparé à une minuscule Cigale; il est dépourru de tubercules et présente une teinte jaune

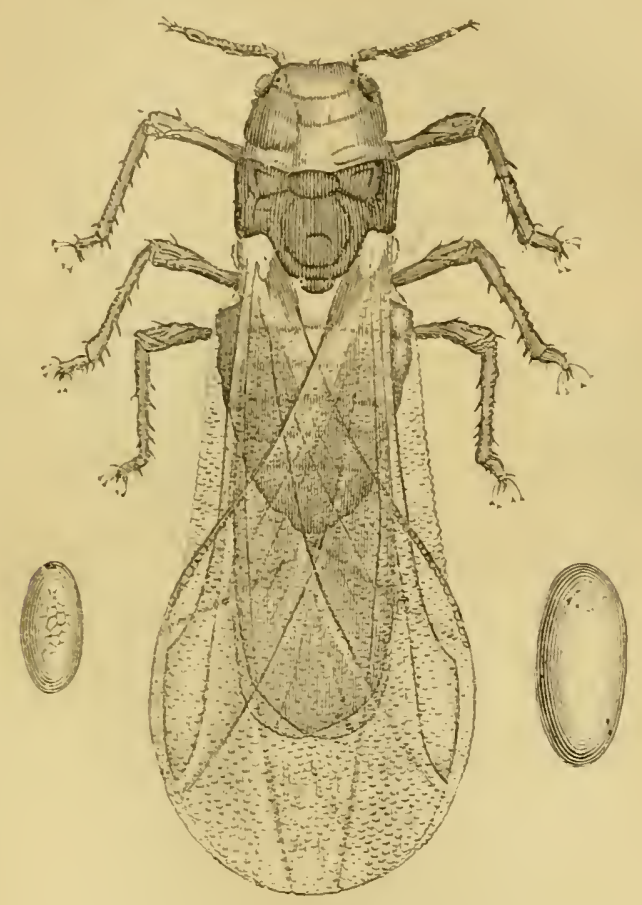

Fig. 560. - Phylloxéra de la vigue : ailé, face dorsale, grossi 50 fois. A gauehe, un euf màle. A droile, un ceuf femelle (II. Cornu et Delamotte).

rougeåtre, sauf sur le mésothorax, qui est noir. Sa taille, ailes non comprises, est tantòt de 1 millimètre, tantòt de $1^{\mathrm{mm}}, \mathbf{2 5}$. C'est d'ordinaire en juillet que se montrent les premiers ailés, et leur production se continue jusque vers le commencement d'octobre. Quoique volant assez mal, ils sont facilement emportés par le vent, et ront ainsi former au loin de nouvelles colonies. (On a cependant reconnu que les progrès de la maladie ne dépassent pas 20 à $20 ̈$ kilomètres par an.) Parvenus sur une vigne jeune et vigoureuse, ils plantent leur rostre à la face inférieure des feuilles tendres de l'extrémité des sarments, et en sucent les sucs nourriciers pendant vingt-quatre heures, après quoi ils sont aptes à pondre, car ce sont encore des femelles parthénogenésiques. Les œufs sont pondus, comme l’a montré Boiteau, à la face inférieure des feuilles ou sous l'écorce exfoliée des ceps; ils sont au nombre de 3 à 6 et de deux tailles différentes: les plus petits mesurent $260 \mu$ de long 
sur $130 \mu$ de large; les plus gros atteignent $400 \mu$ sur 200. Les premiers, qui sont plutôt pondus par les ailés de petite taille, sont relativement rares: 2 ou 3 sur 10. Tous sont de teinte blanc jaunâtre; ils éclosent au bout de liuit à dix jours.

D. Sexuès. - De ces $œ u f s$ sortent des individus sexués : les petits donnent naissance à des màles, les gros à des femelles. Les Phylloxéras sexués s'observent en général du 15 juillet au 15 novembre; ils sont très petits, dépourvus d'ailes, de rostre et d'appareil digestif: les organes de la génération seuls sont bien développés. Ils ne subissent pas de mues. Les màles, peu nombreux, sont longs de 260 à $280 \mu$; les femelles mesurent 450 à $500 \mu$. Aussitôt après l'éclosion, ces Insectes s'accouplent. L'abdomen de la femelle contient un seul œuf, qui le remplit en entier: c'est l'œuf d'hiver, qu'elle va déposer péniblement sous les écorces les plus adhérentes, principalement sous celles du

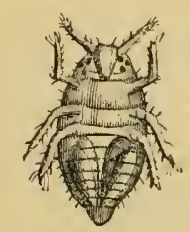

Fig. 561. - Plıylloxéra de la vigne, mâle, face ventrale, grossi 50 fois (M. Girard).

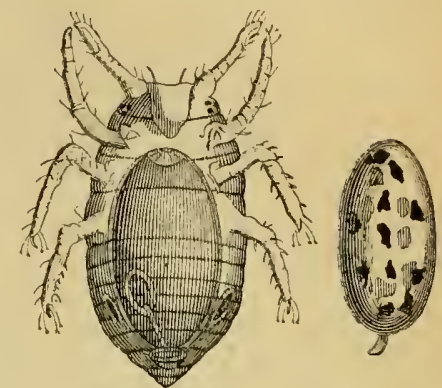

Fig. 562. - Plıjlloxéra de la vigne, femelle, face ventrale, el son œuf (œuf d'hiver), grossis 50 fois (M. Girard).

bois de deux ans, et de préférence, comme l'a montré Boiteau, à l'endroit où cette écorce est un peu déhiscente par suite de la section de la dernière taille. Elle meurt aussitôt après. L'œuf d'hiver tient le milieu, par son volume, entre les deux sortes d'œufs de l'ailé: il est long de 270 à $300 \mu$ et large de 100 à $120 \mu$; il est allongé, à còtés parallèles; on peut le reconnaître parfoìs à la présence d'un pédicelle peu distinct, qui sert à le fixer à l'écorce; mais il est surtout caractérisé par la présence d'un petit point rouge brun qui occupe le pôle opposé au pédicelle, et qui n'est autre que le micropyle. La teinte qu'il garde tout l'hiver est d'un vert olive foncé, avec des taches brunes.

Balbiani pense que l'intervention de la forme sexuée, ou, plus exactement, de la fécondation, est nécessaire pour régénérer l'espèce: à défaut de cette intervention, les colonies agames seraient destinées à s'éteindre. Disons cependant que Boileau a vu la reproduction parthénogenésique se poursuivre pendant six ans, soit jusqu’a la vingt-cinquième génération, sans paraitre encore menacée.

L'œuf d'hiver résiste très bien à un froid de $-10^{\circ} \mathrm{C}$. Le développement embryonnaire est suspendu jusqu'au printemps. Au retour de la belle saison, l'éclosion a lieu et chaque œů donne naissance, comme on l'a vu, à un gallicole. Ainsi se trouve fermé le cycle évolutif du Phylloxera vastatrix.

Dégats. - Les dégàts causés par Ie Phylloxéra se reconnaissent tout d'abord à ce qu'on appelle la tache phylloxérique. G'est un ensemble de ceps ra- 
bougris dont la végétation forme tache, en effel, sur le reste; et comme les ceps les plus malades occupent le centre, tandis que les zones périphériques sont de plus en plus vigoureuses, il se dessine une sorte de concavité, qu'on distingue à distance et qui fait donner parfois à la taclıe le nom de cuvelte phylloxerique. Au centre, on trouve des souches mortes dès la $3^{\text {e }}$ ou la ¿ année, parfois mème lès la deuxième. A la périphérie, bien des ceps sains en apparence sont d'ordinaire attaqués à une assez grande distance des hords de la cuvette. La propagation du mal s'effectue d'ailleurs, non seulement par continuité, à la façon d'une tache d'luile, mais aussi à distance, par suite de l'émigration de l'lusecte ailé ou mème par l'internédiaire de l'llonme.

Comme les troubles de la végétation sont le fait du radicicole, on s'assure de la présence de l'Insecte en arrachant les racines: si l'invasion date de loin, le chevelu a disparu; mais si elle est au contraire de date récente, on remarque, à l'extrémité ou sur la longueur des radicelles, les nodosités caractéristiques dont nous arons parlé plus hant. A leur surface, les Phylloxéras se montrent sous l'aspect de nombreuses petites taches jaunes ou brunes.

Marche du fléau. - Originaire de la partie des États-Unis située à l'est des Montagnes Rocheuses, le Pliylloxéra a été introduit en France, dans le Gard, vers 1863, par l'importation de plants de vignes américaines. Dès 1866 , des tiches phylloxériques se montraient dans Vaucluse et dans les Bouchesdu-Rhòne, mais c'est en 1868 seulement que mention fut faite de la "nouvelle maladie de la vigne " dans une publication française, par Delorme, vétérinaire à Arles. Peu à peu, les départements du Midi furent envahis, el le mal s'avança vers le nord, les régious couvertes dessinant un triangle dont la base était formée par la Méditerranée. En 1894, on compte 67 départements atteints! Et le fléau continue de progresser.

Les diverses contrées de l'Europe n'ont pas élé davantage épargnées. En Algérie, plusieurs foyers ont été découverts depuis 1883 ; mais, gràce à des mesures énergiques, l'invasion a pu ètre localisée. Enfin, les vignes sont compromises ou détruites à Madère, au Cap, en Australie, en Californie.

Destruction. - On voit que le Phylloxéra est un ennemi terrible : et le danger de ses attaques est d'autant plus redoutable que sa petitesse mème le rend difficilement accessible à nos moyens d'action. Les principaux procédés de défense actuellement adoptés sont les suivants : $1^{\circ}$ Emploi de substances insecticides, injectées dans le sol à l'aide d'appareils particuliers. On a essayé le sulfure de carbone et le sulfo-carbonate de potassium; mais la pratique a consacré la supériorité du premier de ces produits. Si les points d'atlaque sont peu nombreux dans la région envahie, il est indiqué d'employer sur ces points les traitements dits "d'extinction ", qui consistent à tuer, non seulement l'Insecte, mais la vigne elle-même, au moyen de fortes doses de sulfure de carbone, de manière à éteindre l'emblée tous les foyers d'invasion. Une fois, au contraire, que la région est notoirement atteinte, et si les vignes sont encore productives, on a recours à un traitement plus modéré, propre à détruire seulement le parasite. $2^{\circ} \mathrm{Aux}$ injections de sulfure de carbone, on peut alors ajouter le badigeonnage des ceps au moyen de mélanges insecticides (huile lourde dẹ hoville 20 kil., naphtaline brute 60 ;

$$
\text { RAILLIET. - Zoolggie. }
$$


chaux vive 120; eau 400), préconisé par Balbiani pour la destruction de l'œuf d'hiver. $3^{\circ}$ Enfin, si les vignes envahies ne donnent plus une récolte suffisante pour couvrir les frais des traitements, il y a lieu de les arracher et de les remplacer aussitôt par des plants américains appropriés au terrain: ces vignes possèdent, en effet, une résistance toute particulière, et s'il en est un grand nombre qui ne fournissent pas un vin susceptible d'ètre utilisé, on peut tout au moins s'en servir comme porte-greffes. En suivant ces indications, certains viticulteurs ont déjà pu ramener leur production au quantum qu'elle atteignait avant l'invasion. Du reste, les chiffres officiels sont très significatifs: en 1881, le total des vignes américaines plantées en France était de 8,904 heclares pour 17 départements; en 1889, il atteignait 299,801 hectares pour 4 départements.

Nous aurions pu signaler encore la submersion et la plantation dans les sables; mais ces moyens, pour excellents qu'ils soient, ne sont applicables que dans des conditions toutes particulières.

Une dernière famille de Phytophtires est celle des PSYLLIDÉS, représentée par des Insectes ailés, sauteurs, pourvus d’antennes à 8-10 articles terminées par deux soies. - La Psylle rouge (Psylla piri ou rubra) vit sur le poirier, dont elle déforme les feuilles.

$2^{\mathrm{c}}$ section : Cicadaires. - Au groupe des Cicadaires ou Homoptères proprement dits appartiennent les Cigales (Cicada L.), célèbres par leur chant, qui n'a cependant rien de remarquable. On trouve, dans le Midi de la France, la Cigale du Frène $(C$. plebeju), la Cigale de l'Orne (C. orni). Cette dernière vit sur le Fraxinus ornus et le Fr. excelsior: en piquant l'écorce pour y puiser sa nourriture, elle provoque l'écoulement d'une substance sucrée et laxative qui se concrète pour constituer la manne. On sait, toutefois, que ce produit se récolte surtout à l'aide d'incisions transversales pratiquées sur l'écorce. C'est de Sicile qu'il nous vient aujourd'hui.

Les anciens Grecs mangeaient des Cigales. Cette coutume est encore répandue chez les Australiens et les Indiens du Texas.

DEUXIĖUE SOUS-OIDHE

\section{HE்TÉHOPTÈRES}

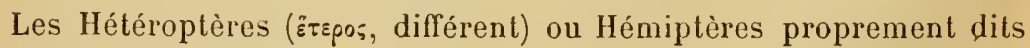
ont les ailes antérieures en hémélytres et les postérieures membraneuses; le rostre est inséré sur le front. Beaucoup d'entre eux répandent une odeur forte, due à la sécrétion d'une glande qui s'ouvre, du moins chez les adultes, à la face inférieure du métathorax, au niveau de la dernière paire de pattes. Chez les jeunes individus, d'après Kuncliel, l'appareil occupe la région dorsale de l'abdomen.

Deux sections: Hydrocorises et Geucorises.

$1^{\mathrm{re}}$ section: Hydrocorises. - Les Punaises d'eau ont des antennes courtes, à trois ou quatre articles, dissimulées au-dessous des yeux; elles vivent d'ordinaire dans la vase et se nourrissent de proies vivantes. - A ce groupe appartiennent des Insectes dont la piqûre est assez douloureuse. Tels sont les Nèpes (Nepa), à corps aplati, à abdomen prolongé par un siphon respira- 
toire, et dont l'especec la plus répandue est le Scorpion aquatique (N. cinerea); les Notonecles (Notonecta), à grosse tète, à palles postérieures longues, aplaties en rame et ciliées: le type de ces Insectes, qui ont le corps très convexe et nagent sur le dos, est la Punaise à avirons (N. glunca), commune dans leseaux dormantes. - L Les Corises (Corisu) sont des formes voisines dont le rostre est caché el qui nagent sur le ventre. Au Mexique, on recherche les œufs de deux especes de liorises, $C$. mercenaria et $C$. femoruta, qui abondent dans les lacs de Chalco et de Texcoco. Pour les obtenir, on place dans l'eau des faisceaux de jones sur lesquels les Inseetes en question vont déposer leurs aufs : ceux-ci sont recueillis et utilisés, sous le nom d'hautle (haoutle), pour la confection de galettes qui se vendent sur les marchés de Mexico, et dont les Indiens sont très friands. Ce produit a un goùt un peu acidulé, rappelant le fromage et le poisson.

2 ic section : Géocorises. - Ce sont des Punaises terrestres pour la plupart; elles ont des antennes plus longues que la tète et non cachées sous les yeux.

Elles comprennent un assez grand nombre de familles, dont quelques-unes seulement nous arrêteront.

Les RÉDUVIIDÉS ont la tète rétrécie en forme de cou derrière les yeux, et le prolhorax divisé en deux par un étranglement. - Ce sont des Punaises de proie, qui vivent du sang des Insectes, parfois mème des animaux supérieurs et de l'llomme.

Nous nous bornerons à signaler le Réduve masqué (Reduvius personalus), vulgairement Punaise-Mouche, qui se tient dans les bois ou dans les maisons, oủ il fait la chasse aux autres Insectes, les suçant à l'aide de son rostre pointu. La larve se cache dans les coins poudreux, au milieu des balayures, et s'entoure même d'une couche de poussière qui masque son aspect naturel et dissimule sa présence. Celte larve vit aussi de rapine: Linné assure qu'elle poursuit les Punaises de lit, sans doule pour sucer le sang que celles-ci ont absorbé. Mais le Réduve peut aussi piquer l'Homme, et la blessure est très douloureuse. Lalreille, atteint à l'épaule, eut le bras entier engourdi pendant plusieurs heures. Mégnin a rapporté le cas d'un peintre assailli dans un bois par un Réduve qui lui était tombé dans le cou: en quelques minutes, cet Homme eut le corps couvert de piqûres extrêmement douloureuses.

D'autres espèces se comportent de la mème manière à l'égard de l'Homme: Hirpactor cruentus, commun dans le Midi de la France; Eulyes amxna, de Bornéo et de Jura; Arilus serralus, du Brésil, qui provoque par sa piqùre une sorte de commotion électrique; le Bichuque ou Benchuea (Conorhinus nigrovarius), des pampas de l'Amérique du Sud, dont la piđgùre n'est pas moins redoutée et fait cnfler rạpidement le membre attaqué : en moins de dix minutes, cet Insecte, d'abord très plal, se gorge de sang et devient globuleux.

Les ACANTHIADÉS ou Punaises membranenses ont le corps aplati, 
des antennes à quatre articles, un rostre à gaine triarticulée appliqué dans une goutlière longitudinale sous-thoracique, des tarses biarticulés se terminant par des griffes sans peloles, el des hémélytres rudimentaires, au moins chez les femelles.

Genre Punaise (Acanthia Fabr. - Syn. : Cimex l., ex parte). - Ce genre représente la tribu des Acanthianès, qui comprend les formes dont la tète est peu rétrécie en arrière, el dont les antennes ont le premier article court et les deux derniers grêles. Le corps est aplati, ovalaire; les hémélytres sont rudimentaires; les ailes manquent.

la Punaise des lits (A. lectularia [L.]. - Syn.: Cimex lectularius L. ; A. lectularia Fabr.) est un Insecte de 4 à 5 millimètres de long sur 3 de large, ochracé ferrugineux; le corps est finement ponctué el pubescent; la tète est munie de deux yeux noirs, sphéroïdes, très saillanls, et de deux antennes à quatre articles, le premier très court, noduleux, le second cylindroïde, légèrement velu, plus grand qu’aucun des autres, les deux derniers filiformes, velus, le troisième plus longr que le quatrième; le prothorax est profondément échancré en arant et dilaté sur les côtés, qui sont réfléchis; le mésothorax porte deux moignons d'hémélytres en forme d'écailles ovalaires s'étendant sur le premier segment abdominal; les pattes se terminent par un tarse à deux articles, le premier court, le second très long, à deux crochets non accompagnés de pelotes; l'abdomen est déprimé, subarrondi, à sommet aigu, à sept segments, sans compter la pièce anale qui le termine; il atteint sa plus grande largeur en arrière du milieu.

La femelle pond en mars, mai, juillet et septembre, dans les fissures des boiseries ou sous les papiers de tenture des appartements; elle dépose chaque fois une cinquantaine d'œufs gris perle, cylindriques, un peu aryués, longs de $1^{\mathrm{mm}}, 12$. Le développement des Punaises exige environ onze mois et comporte quatre mues; les jeunes issus de la dernière ponte sont souvent détruits par les froids de l'hiver.

Les Punaises des lits sont des animaux nocturnes : elles fuient la lumière et se cachent pendant le jour dans les moindres fissures. L'odeur de l'Homme les attire, mais certaines personnes sont particulièrement atteintes: nous avons vu, dans des dortoirs, les mêmes enfants poursuivis sans relâche par ces Insectes, malgré tous les changements de lit effectués, tandis que d'autres, venant habiter le lit infesté, étaient toujours épargnés. La piqûre est assez douloureuse, ce qui tient sans doute au dépôt d'une salive irritante : elle donne lieu à une tache rougeàtre, offrant au centre un point plus foncé qui représente le point d'implantation du rostre; parfois même il survient une petite ampoule. Quand les piqùres sont confluentes, ces piqûres peuvent simuler une véritable éruption. Enfin, on peut constater une urticaire intense et un violent prurit, se manifestant non seulement sur les parties directement atteintes, mais aussi d'une manière réflexe sur tout le corps.

Avec Lucet, nous avons trouvé cette espèce en très grande abon- 
dance dans la maison d'un fermier du Loiret et dans un poulailler contigu ì cette habitation. Puton l'a rencontrée également dans un poulailler des environs de Marseille.

En absorbant le sang, les Punaises se gonflent. Elles peuvent ensuite, du moins lorsqu'elles sont adultes, demeurer longtemps sans prendre de nourriture: Audouin en a gardé une pendant deux ans dans une boite. Les larves elles-mèmes, au sortir de l'muf, peurent vivre pendant des semaines et des mois sans manger.

D'après Dewèrre (1), la Punaise des lits peut servir comme agent de transport du Bacille de la tuberculose; elle doit s'infecter surtout par le contact avec les crachats et les linges.

Il serait difficile d'établir la patrie d'origine de cet Insecte: mais il est certain que les anciens le connaissaient. Aristophane le signale sous le nom de Kópıs; Aristote en parle également; Pline l'appelle Cimex, etc. Il s'est montré à Strasbourg au $\mathrm{xI}^{\mathrm{\theta}}$ siècle. Moufet indique sa présence à Londres en 1503 , et rapporte que deux dames de cette ville avaient pris ses piquires pour les premières alteintes de ia pestc. On le trouve aujourd'hui dans toute l'Europe (sauf dans l'extrême Nord) et dans la plupart des autres parties du monde, oi les Européens l'ont transporté. Scopoli assure que dans la Carniole il acquiert des ailes : cette assertion ne parait pas sérieuse.

Pour se débarrasser des Punaises, on a recommandé l'essence de térébenthine, la pommade mercurielle, les fumigations de mercure ou d'acide sulfureux, etc. Gassend préconise d'une façon toute particulière le sulfure de carbone, qui a l'avantage d'être d'un prix peu élevé et de ne pas agir sur les couleurs; il ne faut pas oublier toutefois que ses vapeurs forment avec l'air un gaz détonant. On peut aussi insufller, dans les fissures qui servent de retraite aux Punaises, de la poudre très fraiche de pyrèthre du Caucase, ou mieux encore y lancer, à l'aide d'un pulvérisateur, une solution de sublimé au millième. On assure encore que la Passerage des décombres (Lepidium ruderale) attire les Punaises et les enivre de telle sorte qu'elles sont alors des plus faciles à détruire. Enfin, il suffirait même, dit-on, de disséminer sur le lit des feuilles fraîches de haricots: on trouverait le lendemain les Punaises fixées à la face inférieure, qui est duveteuse.

A côté de la Punaise des lits, se placent deux autres formes qui en ont été spécifiquement distinguées, et qui peut-ètre n'en sont que des variétés.

La Punaise eiliée (A. ciliata Eversmann, 1841) est beaucoup plus petile que la Punaise ordinaire; elle est d'un gris roux et revêtue de poils gris ou jaunàtres, plus longss sur les bords, d'où l'aspecl cilié.

Cette espèce a été observée dans les maisons de Kasan; elle vit isolée et se promène lentement sur les murs et sur les couvertures. Sa piqûre, fort

(1) Dewève, Note sur la transmissibilité de la tuberculose par la punaise des lits. Revue de médecine, XII, avril 1892. 
donloureuse, donne lieu à une tuméfaction assez accusée et persistante, ce qui parait tenir à la grande longueur du rostre.

La Punaise arrondie ( $A$ rotundala Signoret, 1832) est un peu moins grande que la Punaise des lits, moins orbiculaire, à prothorax présentant des bords arrondis et non marginés, d'où une forme plus convexe, plus ronde; la couleur est beaucoup plus foncée, d'un brun rongeàtre, avec les élytres plus clairs, ainsi que le bord antérieur du prothorax; les pattes sont jaunes.

Elle vit à la Réunion.

La Punaise des colombiers (A. columbaria [Jenyns, 1839]) est aussi un peu plus petite que celle des lits, mais elle est plus orbiculaire; ses an-

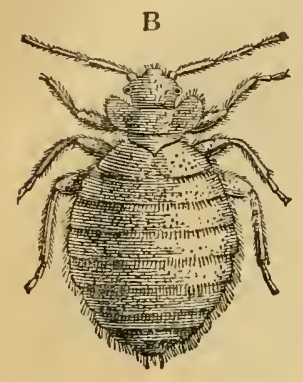

A

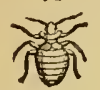

Fig. 563. - Punaise des poulaillers. - A, graudeur naturelle. B, grossie (Orig.). tennes sont plus courtes, leurs articles sont un peu moins grêles et le quatrième presque aussi long que le troisième; le thorax est un peu moins profondément échancré en avant, les angles antérieurs sont moins prolongés et les côtés moins réfléchis. L'abdomen est plus orbiculaire, à bords latéraux plus incurvés; il atteint sa plus grande largeur exactement dans le milieu. Couleur, ponctuations et pubescence comme dans la Punaise des lits; longueur : à peine $4^{\mathrm{mm}}, 7$.

Cette forme a d'abord été rencontrée dans les colombiers, où elle se montre parfois très abondanle. Elle se nourrit évidemment aux dépens des Pigeons.

Nous l'avons aussi trouvée dans les poulaillers, et souvent en quantité extraordinaire, bien qu'il n'y eût aucune communication avec les colombiers. Ces Punaises se tiennent dans les interstices des cloisons, derrière les amas de guano et même au milieu de la paille des niches, d'où elles se jettent sur les Poules, qu'elles tourmentent souvent au point d'arrêter leur développement. Les Poules couveuses, en raison de leur élat d'immobilité, sont particulièrement exposées aux attaques de ces Insectes : elles se montrent alors agitées, quittent à chaque instant leur nid, où elles ne rentrent qu'avec hésitation, et souvent finissent par abandonner leurs œufs d'une façon complète : "elles se dédisent ", suivant l'expression des éleveurs. En général, on peut reconnaître à première vue que cet abandon résulte des attaques des Punaises, en constatant à la surface des œufs la présence de petites taches noirâtres formées par les excréments de ces Insectes.

Les Punaises des poulaillers sont douées d'une résistance vitale comparable à celle des Punaises des lits : nous en avons conservé plusieurs mois dans un flacon de verre, sans leur donner aucune nourriture.

On peut leur opposer les mêmes moyens qu'on met en usage contre les Punaises des lits. 
Jenyns (1) a encore décrit une Punaise des llirondelles (A. hirundinis [Lamk.]) et une Punaise de la Pipistrelle (A. pipistrilli).

D'autre part, Towusend en aurait découvert récemment une nouvelle espèce (A. inodora [Dugès]) dans les poulaillers du Nouvean-Mexique.

l.es TINGIDÉS ont le corps assez épais, mais à bords minces et réticulés. C'est à cette famille qu'appartient le curieux Tigre du poirier (Tingis pyri), qui se nontre en septembre a la face inférieure des feuilles; d'après Carlet, il dépose ses aufs dans le parenchyme des feuilles et les recouvre de ses excréments; il est plutòt nuisible par ses déjections, qui obstruent les stomates, que par ses piquires. Enlever et briller les feuilles.

Les PENTATOMIDÉS, plus commus sous le nom de Punaises des bois ou de Punaises a bouclier, sont remarquables par leur écusson, ‘ui dépasse le milieu de l'abdomen et parfois le recouvre en entier. - Diverses espèces nuisent ¿ıx régétaux, surtout aux Crucifères. Telles sont: le Pentatome des potagers (Strachia ole-

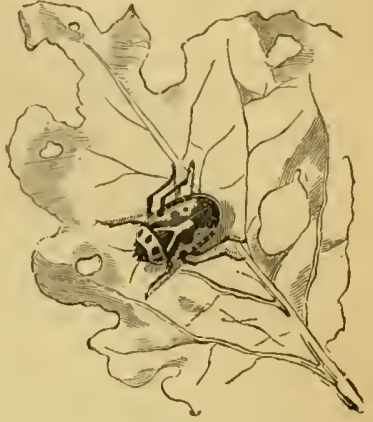

Fig. 5064. - Pentalome orné (Strachia ornata). racea) ou Punaise verte à taches rouges ou blanches; le Pentatome orné (Shrornata) ou Punaise rouge du chou (fig. 56t); etc.

TROISIĖME SOUS-ORDRE

\section{AP'TÈRES}

A l'exemple de divers auteurs, nous réunissons dans un même groupe les Poux et les Ricins, encore que les premiers seuls se rattachent nettement aux Hémiptères, et que les Ricins, par la constitution de leur appareil buccal, se relient plutôt aux Orthoptères, ou, selon Packard, aux Pseudo-Névroptères. Les uns et les autres offrent de nombreux traits communs, résultat sans doute d'une adaptation convergente, et les applications médicales qu'offre leur étude sont à peu près identiques. On les confond vulgairement sous le nom de Poux, et les entomologistes leur ont appliqué les appellations diverses d'Aplères, Parasites, Anoploures, Épizoüques, Zoophtires, I'́́diculines (2).

(1) L. Jexrys, On three undescribed species of the Genus Cimex closely allied to the Common Bed-Bug. Annals of nat. history, III, p. 241, 1839 (avec 1 pl.).

(2) Fr. Redr, Opusculorum pars I, sive Experimenta circa generationem Insectorum. Amstelodami, 1686 (1 $1^{\text {re }}$ éd. en italien, Florence, 1668). - W.-E. LeAcı, Zoological Miscellany. London, 1816-1817. - Chr.-L. Nitzsch, Die Fumilien und Gattungen der. Thierinsecten. Germar's Magazin, 1818. - II. Deswr, Monographia Anoplurorum Britanniz. London, 1842. - G.-G. Griber, Insecta Epizoa. Leipzig, 1874. - E. Piaget, Les Pédiculines. Leide, 1880 (supplément, 1885). - O. Tascnexbeng, Die Mallophagen. Halle, 1882. - A. Rallerer, diclicle Purmase, Poux, du Nouveau Diclionn. de méd. chir. et hyg. vétér., .1111, p. 60,1889 . - II. Osisus, The Pediculi and Mallophaga 
Tous sont dépourvus d'ailes, et leur développement ne comporte aucune métamorphose. Ils vivent en parasites sur les animaux à sang chaud.

Deux familles: Pediculidx et Ricinida.

Appareil buccal en suçoir; tête ordinairement allongée; prothorax

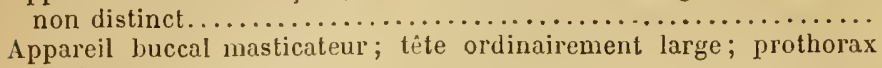

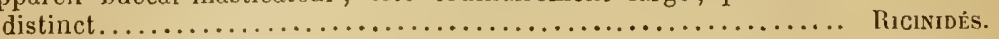

Famille des PÉDICULIDES. - Les Poux ou Pédiculidés sont caractérisés essentiellement par leur appareil buccal disposé en sucoir.

Ce suçoir est rétractile et n'est visible que quand il fonctionne. L'homologie des pièces qui le composent n'a pas encore été déterminée d'une façon bien précise; il comprend une gaine tubuleuse molle paraissant formée par la lèvre supérieure et la lèvre inférieure réunies, et pourvue à son extrémité d'un ou de deux verticilles de crochets recourbés en dehors; cette gaine contient un aiguillon creux (suçoir proprement dit) qui se termine en deux pointes très aiguës: l'Insecte fait saillir cet aiguillon hors de la gaine pour l'enfoncer dans la peau et faire jaillir le sang. Les crochets de la gaine servent à fixer l'appareil aspirateur, de manière à empêcher l'accès de l'air.

Les antennes sont à cinq, plus rarement à trois ou quatre articles, le premier plus développé. Deux yeux simples ou ocelles, distincts seulement dans quelques genres. Les bords de la tête sont renforcés par des bandes cornées.

Le thorax présente à peine les traces des trois segments qui le constituent, de sorte qu'il parait être formé d'une seule pièce; il porte au moins un stigmate de chaque côté. Les pattes se composent d'une hanche arrondie, d'un trochanter très court et incolore, d'une exisse longue et forte, d'une jambe plus longue encore, offrant souvent, à l'angle interne de son extrémité inférieure, une saillie (pouce) nue ou armée d'un ou de deux ardillons; enfin, d'un tarse à deux articles dont le second porte un ongle roluste (rarement deux) qui se replie et forme pince avec l'extrémité inférieure de la jambe, ce qui permet à l'Insecte de grimper.

L'abdomen présente six à neuf segments, le dernier arrondi chez les mâles
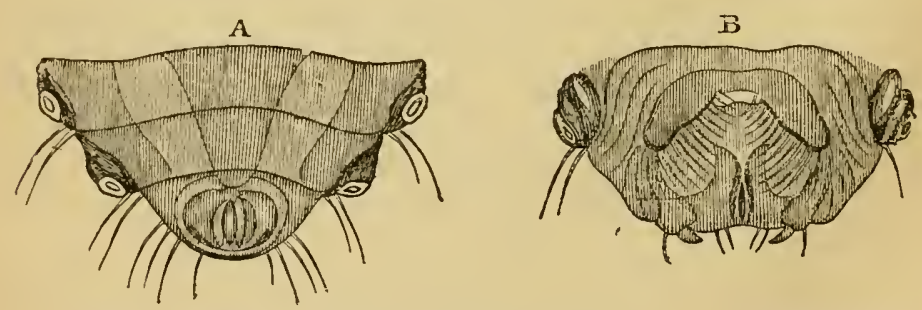

Fig. 565. - Extrémité postérieure grossie de l'Hématopinus du Porc. - A, mâle, face dorsale. B, femelle, face ventrale (Delafond).

et percé en dessus d'un large orifice cloacal par lequel émerge le pénis; échancré ou bilobé, avec deux petits appendices terminaux, chez les femelles, dont la vulve s'ouvre à la face ventrale entre les deux derniers segments:

affecting Man and the lower Animals. U. S. Depart. of Agriculture. Division of Entomology, Bulletin No 7. Washington, 1891. 
cette disposition exige que, dans l'accouplemenl, la femelle se place sur le dos du male. Le premier et le dernier segment n'ont jamais de stigmates. Les bords les segments sont souvent renforcés par des bandes cornées dites bandes lutirales.

D'autre part, il peut exister, sur ces segments, des taches transverses de forme variable, et parfois aussi des taches génitales, situées au voisinage des organes génitaux externes.

Les oufs des Poux, connus sous le nom de lentes, sont pyriformes et fixés ì la base des poils par leur petit pôle, au moyen d'une substance agglutinative. Les jeunes sortent en soulevant un opercule situe aı pôle opposé; en peu de temps, ils deviennent aptes à la procréation.

Tous les Pédiculidés vivent sur les Mammifères, dont ils sucent le sang. On en distingue actuellement sept genres:

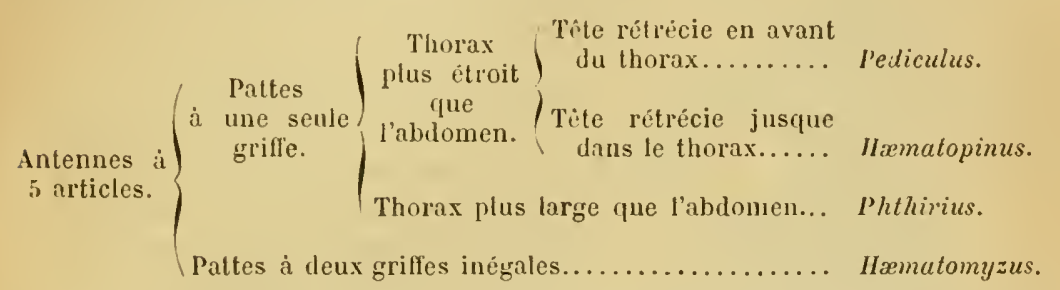

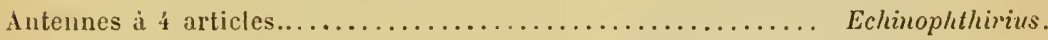

Antennes à Abdomen sans plaques latérales................ Pedicinus.

3 articles. (Abdomen à plaques semi-circulaires latérales...... IIæmatopinoides

Genre Pou (Pediculus L.). - Caractérisé par la tête rétrécie en cou avant son insertion dans le thorax, qui a le double de sa largeur; par l'abdomen à sept ou huit segrments; par l'extrémité inférieure de la jambe munie d'une saillie interne bien distincte (pouce), armée d'un fort ardillon et de quelques spinules. Le tarse porte un seul ongle; les antennes sont à cinq articles.

Le Pou de tète (P. ccrvicalis Latr., 1803. -- Syn.: P. humanus L., 1758 , pro parte; $P$. [humanus eapitis] De Geer, $1778 ; P$. capitis Nitzsch et Lamk., 1818) es! d'un cendré grisàtre, avec l'abdomen à sept segments (cinq stigmates?), un peu plus foncé sur les còtés. Le màle est long en moyenne de $1 \mathrm{~mm}$. 8, large de $0 \mathrm{~mm}$. 7; la femelle est longue de $2 \mathrm{~mm}$. 7, large de $1 \mathrm{~mm}$.

Il vit principalement sur la tête des individus malpropres, surtout des enfants et des vicillards; mais on peut le rencontrer aussi sur les diverses parties du corps, el, comme il passe très facilement d'un sujet à l'autle, les enfants les mieux soignés peuvent en ètre atteints: presque tous les bébés, dit Fournier, ont cu des Poux de tête. En Sicile, où la vermine abonde, Calandruccio dit avoir vu cette espèce transportéc par les Nouches, aussi bien que la suivante.

I a femelle pond, dans l'espace de six jours, une cinquantaine 
d'œufs qu'elle fixe à la base des chereux. Les petits éclosent au bout de cinq à six jours, et dix-huit jours après ils sont aptes à se reproduire. D'après ces données, la deuxième génération d'un Pou, survenantau hout de huit semaines environ, représenterait 2,300 individus, et la troisième, après douze semaines, 120,000 ; mais ces calculs sont heureusement trompeurs, car ils ne tiennent pas compte des nombreuses chances de destruclion que court la postérité de cette vermine.

Les Poux qui vivent sur les différentes races humaines offrent souvent quelques caractères spéciaux de minime importance, et en particulier prennent une coloration correspondante à celle de leur hote. Ainsi, d'après Murray, ceux des nègres de l'Afrique occidentale et des

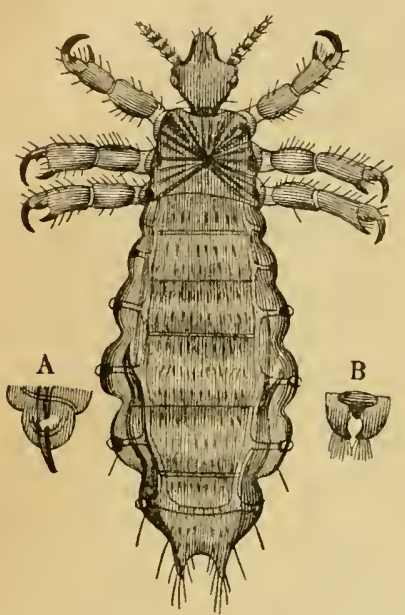

Fig. 566. - Pou de tète, femelle, de l'Honime. Grossissement : 20 diamètres. - A, extrémité postérieurc du mâlc, face ventrale. $B$, région correspondante de la femelle (Piaget).
Australiens sont presque noirs; ceux des Hindous, de teinte sombre et enfumée ; ceux des Hottentots, orangés; ceux des Chinois et des Japonais, brun jaunâtre; ceux des Indiens des Andes, brun foncé; ceux des Indiens de Californie, olive sombre; ceux des Indiens du nord de l'Amérique voisins des Esquimaux, plus pâles, à peu près comme ceux des Européens. Le même auteur a vu d'ailleurs un Pou de nègre, transporté sur la tête d'un Européen, prendre la teinte livide du parasite de la race blanche, ce qui démontre bien l'influence de l'alimentation. Peut-être, cependant, les diverses races de Poux ne sont-elles pas aptes à vivre sur une race humaine quelconque. S'il faut en croire le récitdu chirurgien d'un baleinier, reproduit par Darwin, les Poux de quelques habitants des îles Sand wich, qui se trouvaient à bord, périssaient au bout de trois ou quatre jours quand ils venaient à passer sur les inatelots anglais.

La pénétration du rostre des Poux dans le cuir chevelu détermine une irritation qui aboutit à la production de papules ou même de vésico-pustules. Celles-ci présentent l'aspect de pustules d'impétigo; elles sont souvent mélangées à des excoriations de grattage, et leur exsudation donne lieu à des croûtes qui agglutinent les cheveux. Si cet état persiste, comme il arrive parfois chez les misérables, les cheveux et les croûtes finissent par former une carapace sous laquelle fourmillent les parasites; dans ces cas, d'ailleurs rares, auxquels on donne le nom de trichoma ou de plique, la tète exhale une odeur fétide et repoussante; souvent, en outre, les ganglions lymphatiques sont engorgés.

Les Poux de tête peurent gagner les sourcils, roire la barbe chez des individus qui la laissent pousser très longue. 
Le plus souvent la pédiculose du cuir chevelu n’exige pour être guérie que de simples soins de propreté. Dans les eas un peu avancés, on recommande la poudre de staphisaigre ou de pyrèthre, lit lleur de soulie, longhuent gris, ou mieux encore le pétrole (100 grr.) additionné d'huile (:̈0 grr.) et de baume du Pérou ( $20 \mathrm{gr}$.).

On sait comment les Singes et les Chiens font la chasse ì leurs Poux. Les Singes recherchent volonticrs anssi ceux de l'Homme. $\Lambda$ Lisbonne, au siècle dernier, certaimes ggens faisaient métier de louel des Babouins pour débarrasser les pouilleux de leur vermine. On cite même quelques races humaines inférieures qui sont phtirophages, c'est-à-dire mangent elles-mêmes leurs Poux. Les Aléoutiens, les Hottentots, diverses peuplades australiennes sont dans ce cas. Les nègres de la cóte occidentale d'Afrique se lont délivrer de ces hôtes par leurs femmes, qui les croquent.

Le Pou des vetements il’. vestimenti Nitzsch, 1818. - Syn. : P. humamus L., 1738 , pro parte; $L^{\prime}$. [humanus corporis] De (ieer, 1778; P. enrporis Lamk., 1818; P. tabescentium Alt, 1824) est un pen plus grand que le précédent el présente d'ordinaire une leinte uniforme d'un blanc sale; la tète, moins arrondie en avant, porte des antennes plus longues; le thorax est moins concave sur l'abdomen, qui est à huit segrments (six stigmates). Maile longr en moyenne de 3 millimètres, large de 1 millimètre; femelle longue de $3 \mathrm{~mm}$. 3, large de $1 \mathrm{~mm}$. I'

Comme son nom l'indique, ce Pou vit dans les vêtements de l'Homme, notamment dans ceux qui sont en contact direct a vec la peau; il se dissimule dans leurs plis, oủ il est parfois difficile à découvrir. Il ne passe sur le corps que pour aller sucer le sang, et on ne le rencontre guère sur la peau qu'au moment où les malades viennent de se déshabiller. Il est très exceptionnel de le voir sur la tête.

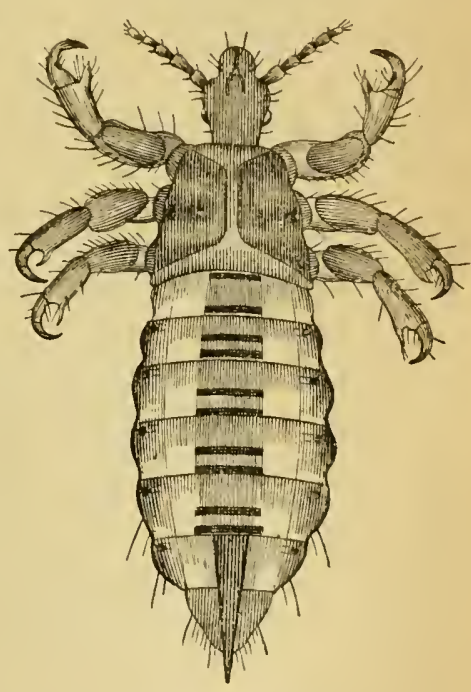

Fig. 3̈67. - Pou de corps, måle, de l'Homme, grossi 20 fois (Piaget).

La femelle pond 70 à 80 œufs; les petits qui en sortent au bout de trois à huit jours sont aptes à se reproduire quinze à dix-huit jours après leur naissance. Les lentes sont fixées dans les coutures des vêtements et aux lils de leur's tissus, en rangées régulières. Aussi les personnes très malpropres, telles que les mendiants, qui changent très rarement de cliemise, sont-elles surtout infestées de ces parasites.

On en trouve une variété noiràtre sur le corps des Ethiopiens, et une autre, d'un brun rouge, sur celui des Groenlandais.

Les lésions que déterminent les piqùres du parasite siègent surtout 
au niveau des régions où les vêtements sont serrés au corps : nuque, épaules, reins, taille, poignets, fesses, face externe des cuisses; elles consistent en saillies rosées analogues à celles de l'urticaire et en papules bientôt excoriées à leur sommet, qui se recouvre d'une croûte brunâtre (prurigo pédiculaire); elles s'accompagnent d'un prurit plus ou moins intense provoquant des grattages. A la suite de ceux-ci apparaissent des traînées recouvertes d'une faible croûte brunâtre, traînées qui sont remplacées plus tard par des cicatrices blanchâtres entourées d'une zone de pigmentation brune.

Lorsque la pédiculose du corps se prolonge, la peau des régions envahies s'épaissit et prend une teinte bronzée atteignant parfois la nuance de la peau des nègres; cette mélanodermie est un des principaux attributs de la "maladie des vagabonds ". Il peut même survenir, dans les cas de pédiculose invétérée, des pustules, furoncles, abcès, etc., entraînant des accès de fièvre, et pouvant amener, selon quelques auteurs, de la cachexie chez les vieillards.

Jusqu'à une époque assez rapprochée de nous, de nombreux dermatologistes admettaient l'existence d'une diathèse pédiculaire dans laquelle les tissus et les humeurs auraient engendré des Poux. Cette manière de voir permettait d'accepter et d'expliquer les faits extraordinaires rapportés par les auteurs anciens; à en croire ceux-ci, en effet, le poète Alcmène, le tragédien Phérécyde, Platon, Hérode, Antiochus, Agrippa, Valère-Maxime, le cardinal Duprat, Philippe II d'Espagne et bien d'autres auraient succombé à l'envahissement de la vermine pédiculaire. Dans cette redoutable maladie on trouverait souvent, en effet, les Poux rassemblés dans des tumeurs sous-cutanées : Rust, Forestus, Schenck, Wilmot, etc., et plus récemment J. Cloquet, ont cité nombre de faits de ce genre; Hebra en conteste la réalité, mais probablement à tort: pour mon compte, j'ai vu, sur une vieille jument non pansée, des Hématopinus former de véritables nids sous-épidermiques. Alt attribuait la phtiriase ou pédiculose en question à une espèce particulière $(P$. tabescentium); mais il est bien établi aujourd'hui qu'il s'agit en réalité du $P$. vestimenti, auquel les conditions de milieu permettent de se multiplier à l'excès.

Pour le traitement de la pédiculose du corps, on peut recommander des bains sulfureux ou alcalins; mais il convient avant tout de faire enlever tous les vêtements et de les soumettre à une haute température, soit à l'étuve, soit au four.

Les Phtirius (Phthirius Leach, 1813̈) ont le thorax larğe, non séparé de l'abdomen; celui-ci, un peu moins large, offre sur les còtés des saillies coniques munies de soies. Les pattes antérieures, plus grêles que les autres, ont le pouce de la jambe moins développé et la griffe plus fine.

Lunique espèce du genre est le Phtirius du pubis (Phth. pubis [L.]. Syn.: Pediculus pubis L., 1758; Ped.inguinalis Reichard, 1759; Phth. inguinalis Leach, 1815; Phth. pubis hï̈chenmeister, 1850̈). - C'est un Insecte de teinte 
blanchàtre, très pàle, parfois un peu jaunàtre; sa tète est relativement courte, un peu rétrécie en avant; son abdomen, plus large en arrière, parait formé de six anneaux, mais le deuxième porte trois stigmates et doit ètre considéré par conséquent comme résultant de l'union des $2^{\mathrm{e}}, 3^{\mathrm{e}}$ et $4^{\mathrm{c}}$. 11 est de Irès petite taille : le mile mesure en moyenne $2 \mathrm{~mm}$. 3 sur $0 \mathrm{~mm} .8$; la femelle, $1 \mathrm{~mm}$. ̋̈ sur 1 millimètre.

Le Pou du pubis ou Morpion vit sur l'Homme, et plus particulièrement sur les individus de race blanche: mais, contrairement aux Poux proprement dits, et surtout au Pou du corps, il est plus commun dans les classes aisćes de la société que dans les classes paurres. Comme son nom l'indique, il se tient d'ordinaire dans les régions génitales garnies de poils, où il demeure souvent immobile, de sorte qu'il est difficile à découvrir. Cependant, il peut se rencontrer sur toules les régions pileuses: ventre ou poitrine, aisselles, barbe, moustache, sourcils et cils; il est très rare sur les membres, plus rare encore sur le cuir chevelu.

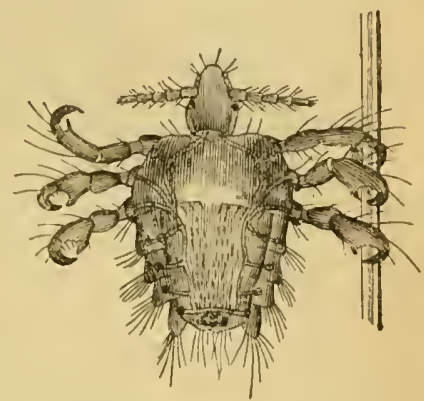

Fig. J68. - Phthirius pubis, mâle, de l'Homme, grossi yo fois (Orig.).

On l'observe plutot chez l'adulte, car il se transmet surtout par les rapports vénériens; cependant on peut le gagner aussi par l'intermédiaire des lits d'hotel, des canapés, des wagons, des haignoires, des sièges de water-closet, etc.

La femelle pond 10 à 13 œufs pyriformes, qu'elle fixe tout à la base des poils, et qui éclosent au bout de six a sept jours; les petits sont aptes à la reproduction quinze jours après leur naissance.

La phtiriase pubienne se manifeste par trois symptômes principaux : $1^{\circ}$ un pruril énervant, surtout acceusé la nuit; $2^{\circ}$ un prurigo spécial, sec, représenté par un semis de petites papules roses ou rougeâtres; $3^{\circ}$ des taches d'un gris bleuâtre, visibles surtout à contrejour, occupant la région sous-ornbilicale, les flancs, la face interne des cuisses, etc. Ces taches bleues ou taches ombrées étaient regardées depuis longtemps comme des manifestations de la fièvre typhoïde, de la fièvre synoque ou de la fièvre intermittente, lorsque Moursou fit connaittre, en 1878, qu'elles coïncidaient toujours avec la présence de Morpions. Duguet démontra, peu de temps après, qu'elles sont dues à l'inoculation d'une salive venimeuse; il les reproduisit en introduisant sous la peau le corps broyé de l'Insecte. Toutefois, certains individus porteurs de Morpions sont réfractaires ì ce venin et n'offrent jamais de taches bleues.

Le traitement classique de la phtiriase pubienne à l'aide d'onguent gris est fort sale et souvent dangereux. Il est préférable de recourir à un bain contenant 10 grammes de sublimé, dans lequel on reste 
une demi-heure, ou bien à des lotions à la liqueur de Van Swieten doublée (eau $400 \mathrm{gr}$., alcool $100 \mathrm{gr}$., sublimé $1 \mathrm{gr}$.). Les lentes sont enlevées ensuite comme celles de la lête, c'est-à-dire au peigne métallique, après lotions au vinaigre chaud étendu d'un peu d'eau.

La phtiriase des paupières, quoique connue dès les temps les plus anciens, est assez rare; on l'observe d'ailleurs plutôt chez les enfants, et même chez les nourrissons, que chez les adultes. Les parasites siègent tout à fait à la base des cils et s'apercoivent difficilement lorsqu'ils ne sont pas nombreux; les lentes et les excréments frappent davantage. Le tout s'enlève, avec quelque patience, à l'aide de pinces. Denny dit avoir vu aussi des Morpions dans les oreilles.

Enfin, il est très rare d'en rencontrer dans les cheveux, où ils émigrent sous l'influence de conditions encore mal connues (Bertarelli et Carabelli, White, Schwenk, Trouessart, Moniez). Grassi paraîl être, jusqu'à présent, le seul qui en ait rencontré de fixés à demeure, c'est-à-dire avec dépôt de lentes sur les cheveux.

Genre Hẻmatopinus (Hæmatopinus Leach, 1813̈). --Il n'existe aucun caractère sérieux qui permette de faire des Hématopinus un groupe générique distincl du genre Pediculus; cependant, l'usage a consacré cette distinction. Constatons donc que les Hématopinus sont caractérisés par leur tête, qui n'offre pas

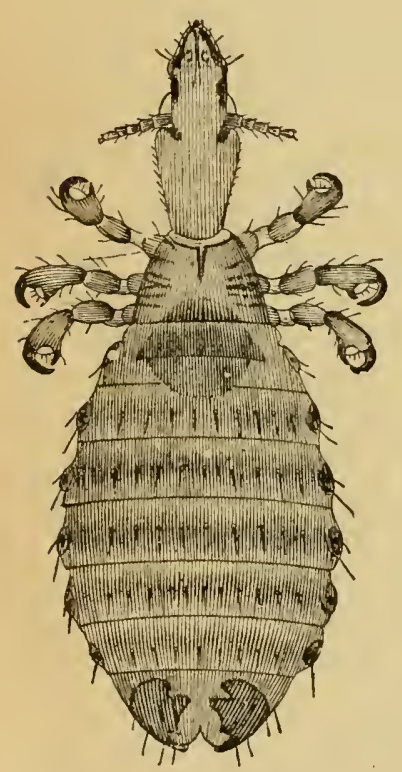

Fig. 569. - Hromatopimus mncrocephalus, femelle, du Cheval. (irossissement : 20 diamètres (Orig.). de rétrécissement postérieur brusque, en forme de cou; par leurs antennes à 5 articles; par leur abdomen à 8 ou 9 segments; par leurs tarses à une seule griffe; enfin par leurs jambes, dont l'angle terminal interne n'offre pas de pouce véritable, mais est simplement relevé, avec un ardillon coloré.

IIénatopinus macrocéphale (H. macrocephalus [Burmeister]). - Tête très allongée et très étroite ; antennes longues et poilues, insérées sur une protubérance latérale en arrière de laquelle se voit une étroite échancrure qui limite la tempe recourbée en avant. Thorax beaucoup moins long que la tête. Abdomen ovale, plus large chez la femelle, à bords continus, à peine sinueux; stigmates au milieu d'une protubérance latérale; sutures peu distincles, surtout chez la femelle; une série de poils courts sur chaque segment. Tète et abdomen gris jaunâtre; thorax brun marron; taches noiràtres; tégument ridé. - Longueur du màle: $2 \mathrm{~mm}$. 4 ; de la femelle: $3 \mathrm{~mm}$. 5 .

Sur le Chıval, de préférence à la base de la queue, dans la crinière et le toupet, ou au voisinage de ces régions. 
D'après Piaget, l'Hématopinus de l'Ane (H. asini [I.]) conslitue tout an moins une variété (colorata), earactérisce par sá teinte plus foncée, sa têle moins poilue, une tache quadrangulaire sur le sternum, et les sutures de l'abdomen bien visibles. Pourtant, ces particularités ne nous paraissent pas constantes.

IĹmantopinus du Pore (II. suis [L.].-Sy'n. : Pediculus suis L. ; P. urius Nitzsch). - Le plus grand des Pédiculidés connus. T'ète étroite et très allongée, conique et arrondie en avant; tempes à corne très aiguë, faisant saillie sur le premier article des antennes, qui sont longues et poilues. Thorax plus large et beaucoup moins long que la tète; au sternum, deux taches médianes peu distinctes; cuisses un peu étranglées vers le milieu. Abdomen ovale allongé, à bords continus; stigmates sur une protubérance latérale saillante; segments avec une série de courts poils espacés. Tète el ahdomen gris jaunatre; taches stigmatiques et tho-

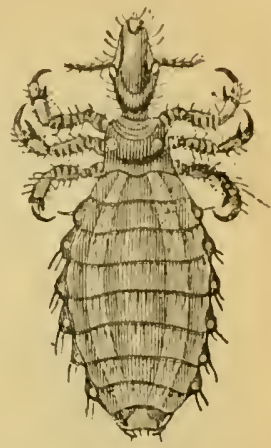

Fig. 570. - Hæmatopinus suis, femelle. Grossissement : environ 9 diamètres (Deiafond). rax brun marron : pattes fauves; tégument ridé. - Longueur du mảle : 4 millimètres; de la femelle : ö millimètres.

Sur le Porc ; occasionne sourent un prurit intense.

Redi a observé sur le Chameau un Ilématopinus (H. cameli) qui semble se rapprocher du suis.

Irématopinus eurysterne (H. eurystermus [Nitzsch]).--Tète arrondie en avant, plus allongée el parabolique chez le màle, élargie en avant de l'antenne en forme de trabécule immobile; tempe élargie en corne. Thorax beaucoup plus large que la tète. Abdomen ovale, très large chez la femelle, à 9 segments; bords ondulés; une série de courts poils sur chaque segment, et, sur la face dorsale, une série de faibles saillies du $2^{\mathrm{c}}$ au $\mathrm{S}^{\mathrm{e}}$ segment; stigmates saillants dans une protubérance latérale. Tète et thorax fauves ; abdomen jaunàtre ou grisàtre; tache génitale noiràtre. - Longueur du mảle: 2 millimètres; de la fenelle : 3 millimètres.

Sur le Bøuf, principalement dans les régions où les poils sont longs e! fourrés, et où la langlie de I'animal ne peut atteindre.

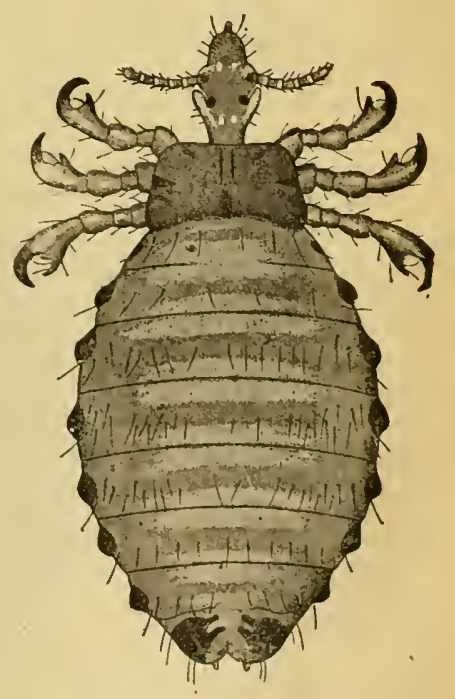

Fig. 571. - Hrmatopmus eurysternus. femelle, du Bueuf, grossi 20 fois $\left\langle\mathrm{Fi}^{\circ}\right.$. Neumaun.

Ilématopinus du Veau (H. rituli $[$ L. $])$. - Syı. : Pediculus vituli L. ; P. oxyrhynchus Nitzsch; P.tenuirostris Burm.). - Tète allongée, atteignant le maximum de sa largeur vers l'veil, un peu étranglée en arrière du sinus. Thorax à peu 
près aussi long que large, concave sur l'abdomen. Celui-ci étroit, légèrement claviforme; bande latérale non interrompue, transparente;

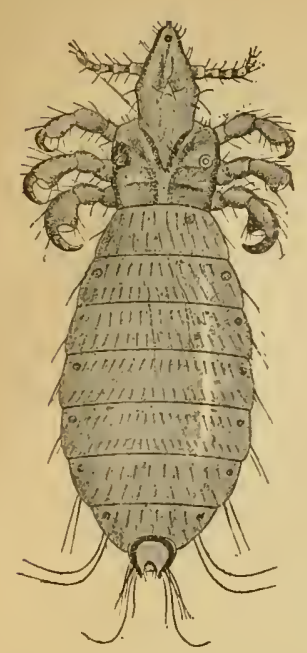

Fig. 572. - Hæmatopinus vituli, femelle, du Bouf, grossi 20 fois (i. Neumann). stigmales visibles à la face rentrale; sutures indistinctes; les segments avec une série de courtes soies caduques. Teinte générale chàtain assez foncé, plus claire à l'avant-tête, aux pattes et aux bandes latérales de l'abdomen. Longueur du màle : $2 \mathrm{~mm}$. 5 ; de la femelle : 3 millimètres.

Celte espèce avait d'abord été signalée par Linné sur les Veaux de lait, et Denny faisait remarquer combien il est curieux de voir un jeune animal offrir un parasite différent de celui que porte ordinairement l'adulte; mais elle est tout aussi commune chez celui-ci.

Signalons encore l'H. tuberculatus Giebel, du Buffle commun, et sa var. penicillata, rencontrée par Piaget sur un Zébu; celleci est caractérisée par un petit pinceau de fines soies à l'angle des segments abdominaux.

Hématopinus sténops (H. stenopsis $\mid$ Burm.]). - Tête étroite, conique, arrondie en avant, s'élargissant jusqu'au thorax, sans échancrure latérale.

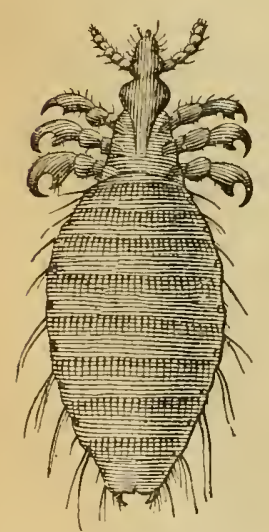

Fig.573. - Hæmatopinus stenopsis, femelle, de la Chèvre, grossi ใ̂̂ fois (G. Neumann).

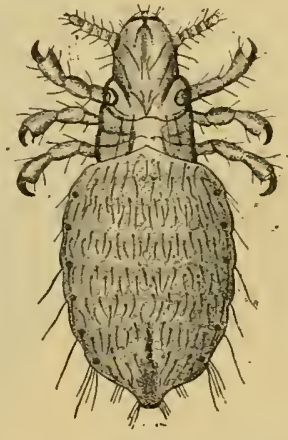

Fig. 574. - Hæmatopinus pilifer, mâle, du Clìen, grossi 20 fois (G. Veumann). Thorax très court, à peine concave sur l'abdomen. Abdomen ovale allongé, ondulé sur les bords, avec deux séries de soies sur les segments; stigmatesindistincts; deux appendices terminaux. Couleur jaune paille, grisàtre pour l'abdomen. - Longueur du màle : $1 \mathrm{~mm} .5$; de la femelle: $2 \mathrm{mil}$ limètres.

Sur la Chèvre domestique.

IIématopinus pilifère $(H$. pilifer [Burm.]). - Tète courte, à peine plus longue que large ; antennes fortes, à $3^{\mathrm{e}}$ et $4^{\mathrm{e}}$ articles égaux. Abdomen orale, plus large chez la femelle, i 9 segments, le premier moins long que le thorax; angles saillants et arrondis; stigmates marginaux; sutures indistinctes; les sept premiers segments avec deux rangées de courtes soies, l'antérieure moins serrée et moins régu- 
lière que l'autre. Teinte générale jaune sale, très pảle; tète et thorax un peu plus foncés. - Longueur dı màle: $1 \mathrm{~mm}$. 5 ; de la femelle: 2 millimètres.

Sur le Chien et le Furet. Tourmente surtout les Chiens à long poil.

Lucas a signalé aussi un $H$. licolor provenant d'un Chien de la Louisiane. 11 diflèrerait du pilifer surtout par la forme de la tête.

Ićmatopinus ventıu (H. ventricosus Denny). - Tète sublyriforme, plus large que longue, étranglée en arrière de l'antenne, et élargie à la tempe, qui est arrondie. Thorax un peu plus large que la tête, concave sur l'abdomen. Abdomen arrondi, presque aussi large que long, à 8 segments chagrinés, offrant une rangée de soies espacées. Tête, thorax et pattes chàtain clair ; abdomen blanc sale, avec deux légères taches au dernier segment. - Longueur du màle: $1 \mathrm{~mm}$. 2 ; de la femelle: $1 \mathrm{~mm} .3$ à $1 \mathrm{~mm} . \ddot{\jmath}$.

Sur le Lapin. Rare.

Famille des RICINIDÉS. - Les Ricinidés, Ricins ou

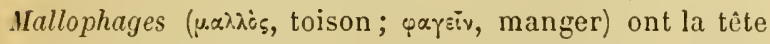
déprimée, plus large que le prothorax, ce qui permet

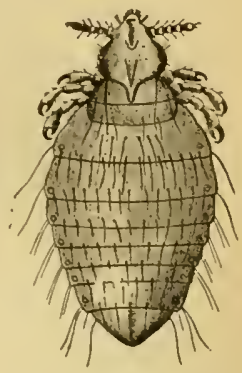

Fig. 57.0.- Hxmatopinus ventricosus, mìle, du Lapin, grossi go fois (G. Neumann). souvent de les distinguer à première vue des Poux. La forme de la tète est déterminće par un système de bandes cornées, auxquelles on applique des noms particuliers, que nous indiquerons plus loin.

La bouche est pourvue de mandibules en forme de crochets courts et presque toujours dentés à la pointe: à l'aide de ces organes, l'Insecte peut saisir énergiquement un poil ou une plumule, qu'il maintient au-devant de l'ouverture buccale; en arrière des mandibules sont les màchoires, avec des palpes distincts, puis la lèvre inférieure avec ses palpes labiaux biarticulés; la lèvre supérieure est souvent peu apparente.

Les antennes sont à 5,4 oı 3 articles. Les deux yeux ou ocelles ne sont pas toujours bien visibles.

Le prothorax est généralement assez distinct; les deux autres segments thoraciques sont d'ordinaire réunis en un seul, qu'on décrit sous le nom de métathorax. Les pattes ont à peu près la même disposition que chez les Pédiculidés.

L'abdomen est à 9 segments; cependant, les deux derniers sont parfois réunis sans suture, et il semble alors n'en exister que huit. Les sept premiers ont leurs bords renfoncés par une bande laterale, et portent le plus souvent des taches transverses. L'abdomen est tantòt nu, tantòt pourvu d'une à trois séries transversales de soies sur chaque segment. Dans la plupart des cas, la face ventrale offre la mème disposition des taches et des soies que la face dorsale. Il n'existe des stigmates que sur les bords des segments $2^{\mathrm{e}}$ à $7^{\mathrm{e}}$. Chez la femelle, on remarque souvent, en avant de la vulve, des taches génitales de forme variable.

Accouplement, ponte et érolution comme chez les Poux.

Railliet. - Zoologie. 
Les Ricinidés vivent dans le pelage des Mammifères ou le plumage des Oiseaux. Ils se déplacent beaucoup plus vite que les Poux, et cette remarque s'applique surtout aux Liothéinés. On a prétendu qu'ils peuvent sucer le sang à la façon des Pédiculidés, mais il est certain que ce n'est pas là leur nourriture habituelle. Ce ne sont pas des parasites véritables, mais des mutualistes, qui se nourrissent de produits épidermiques et enlèvent, soit aux poils (pilivores), soit aux plumes (pennivores), les débris de cette nature qui les encombrent. Trouessart a même montré qu'ils sont capables de perforer les plumes pour s'introduire dans le tuyau.

\section{2 sous-familles : Philopterinx et Liotheinx.}

Antennes à 3 ou 5 articles; palpes maxillaires invisibles ........ PhiLoptérinés. 'Antennes á 4 articles; palpes maxillaires visibles.............. LioTHÉINÉs.

A. Sous-famille des PHILoptérinÉs. - Chez les représentants de ce groupe, la partie antérieure de la tête (clypeus) est quelquefois nettement séparée de la partie postérieure par une suture. Sur les parties latérales et vers le milieu de la longueur de la tète, on remarque une échancrure plus ou moins profonde, le sinus antennal, au fond de laquelle l'antenne s'insère sur une protubérance (qu'il faut éviter de prendre pour son article basilaire). Souvent l'angle antérieur du sinus forme une saillie qui manifeste parfois des mourements propres, de manière à constituer un organe spécial, la trabécule (Docophores). Les antennes sont à 3 ou 5 articles. L'œil est situé immédiatement en arrière du sinus.

Les bandes cornées de la lête, qui ne sont pas toujours distinctes dans toute leur étendue, doivent être mentionnées ici, en raison de leur importance pour la diagnose des espèces. On nomme occipitales celles qui s'étendent de l'occiput (ou région postérieure de la tête) à la racine postérieure des mandibules; temporales, celles qui vont de l'œil à l'occiput en longeant le bord de la tempe (région latérale poslérieure); oculaires, celles qui vont de l'œil à l'extrémité des occipitales; antennales, celles qui partent de l'angle antérieur du sinus antennal et longent, en totalité ou en partie, le bord antérieur de l'avant-tête (région située en avant des antennes).

Les organes buccaux, situés à la face inférieure de la tête, comprennent, outre les mandibules, des màchoires sans palpes distincts, dentelées et très mobiles, et une lèvre inférieure portant deux palpes biarticulés.

La sous-famille des Philoptérinés correspond aux deux anciens genres Trichodectes et Philopterus; mais ce dernier a été subdivisé, de telle sorte que le groupe comprend aujourd'hui onze genres. Le tableau ci-après expose les caractères différentiels de ceux de ces genres qui renferment des espèces parasites des animaux domestiques. 
Antennes a 3 articles; tarses i une seule griffe: Pilivores.

Trichodectes.

\begin{tabular}{|c|c|c|c|}
\hline & , Corps étroit. & $\left\{\begin{array}{c}\text { Antennes du màle à } 3^{\mathrm{e}} \text { article } \\
\text { sans appendice........... }\end{array}\right.$ & Ornithobius. \\
\hline Antennes a & $\begin{array}{c}\text { Antennes } \\
\text { ditférentes } \\
\text { dans }\end{array}$ & $\begin{array}{c}\text { Antennes du mâle a } 3^{\mathrm{e}} \text { artiele } \\
\text { appendiculé............. }\end{array}$ & Lipeurus. \\
\hline $\begin{array}{l}5 \text { articles; } \\
\text { tarses } \\
\text { a deux }\end{array}$ & \begin{tabular}{c|c} 
les deux & Corps large. \\
sexes. & appendicul
\end{tabular} & $\begin{array}{l}\text { Antennes du màle à } 3^{\circ} \text { article } \\
\check{c} \ldots \ldots \ldots \ldots \ldots \ldots \ldots \ldots \ldots \ldots\end{array}$ & Goniodes. \\
\hline $\begin{array}{l}\text { griffes: } \\
\text { Pennivores. }\end{array}$ & $\begin{array}{l}\text { Antennes semblables } \\
\text { dans les deux sexes; } \\
\text { corps large. }\end{array}$ & $\left\{\begin{array}{l}\text { Pas de trabécules } \ldots \ldots \ldots \ldots \\
\text { Trabécules mobiles......... }\end{array}\right.$ & $\begin{array}{l}\text { Goniocotes. } \\
\text { Docophorus. }\end{array}$ \\
\hline
\end{tabular}

Genre Trichodecte (Trichodectes Nitzscl, 1813). - Corps large et plat; angle antérieur du simus antennal formant une sorte de trabécule; antenues à 3 articles, tantòt semblables dans les deux sexes, tantôt avec le $1^{\text {er }}$ article fort grossi chez le màle; tarses à une seule griffe; huitième ou avant-dernier anneau de l'abdomen porlant, chez les femelles, deux appendices latéraux arqués.

Les Trichodectes sont parasites des Mammifères.

Trichodecte vètu (Tr. vestitus. - Tr. pilosus Piaget, nec Giebel). - Tète plus large que longue, atteignant son maximum de largeur à la tempe, arrondie en avant et couverte de poils en dessus comme en dessous; bande antennale faisant le tour de l'avant-tête; antennes à peı près semblables dans les deux sexes. Prothorax aussi large ou plus large que le métathorax, au moins chez le mảle; tous deux couverts de poils sur les deux faces. Abdomen conique en arrière chez le màle, plus large chez la femelle; des taches médianes quadrangulaires sur les sept premiers segments; tous les segments recouverts de poils, outre une série de courtes soies implan-

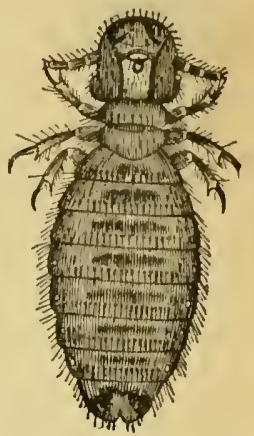

Fig. 576. - Trichodectes pilosus, femelle, du Cheval. Grossissement: 20 diamètres (0rig.). tées entre la tache et la suture; le dernier segment, chez le mâle, très saillant el arrondi, avec cinq poils de chaque cóté. Jaunàtre; taches et tête ferrugineuses; bandes brun marron. - Longueur du màle: $1 \mathrm{~mm}$. 6 ; de la femelle: $1 \mathrm{~mm}$. 8 à 2 millimètres.

\section{Sur le Cheval et sur l'Ane.}

Tricholecte pubescent ( $T r$. parumpilosus Piaget. - Syn.: Tr. equi Stephens; Tr. pilosus Giebel, nec Piaget). - Tète à peine plus large que longue, un peu aplatie en avant, plus large à la tempe et n'offrant guère 'de poils quele long des bords; antennes semblables dans les deux sexes: bandes antennales ne se rejoignant pas en avant. Thorax poilu au bord seulement; prothorax plus étroit que le inétathorax. Abdomen à bandes latérales noiràtres, visibles sur les sept premiers segments; taches transverses trapéziformes; une série de courts poils très serrés entre la tache et la suture; quelques poils sur les còtés. Tète ferrugineuse, à bandes brun marron; abdomen blanchàtre, à bandes noiràtres et taches brun marron. Longueur du màle: $1 \mathrm{~mm}$, 4 ; de la femelle: $1 \mathrm{~mm} .6$. 
Sur le Cheval; me paraitt beaucoup plus rare que le précédent, malgré l'assertion contraire de Taschenberg.

Piaget en décrit une variété (ocellata) rencontrée sur le Daw et caractérisée surtout par sa tête tronquée et par les taches transverses de l'abdomen, qui présentent à l'extrémité un œil ou espace incolore. Taschenberg a recueilli cette même variété sur l'Ane.

Une seconde variété (tarsata) a été observée sur les petits Chevaux de Java.

Les Trichodectes des Équidés sont moins importuns et moins communs que les Hématopinus; ils siègent surtout sur le garrot, les faces de l'encolure, les côtes, plus rarement sur les membres.

Trichodecte scalaire ( $\boldsymbol{r} r$. scalaris Nitzsch). - Tête à peine plus large que longue, presque parabolique et très poilue, surtout sur la face dorsale; bande antennale faisant le tour de l'avant-tête et élargie en avant; antennes relativement courtes. Prothorax plus étroit que le métathorax. Abdomen à bandes latérales bien marquées; des taches médianes; outre la série de courtes soies insérées entre la tache et la suture, quelques poils seulement sur les còtés.

Fig. 577. - Trichodectes scalaris, femelle, du Bœuf. Grossissement : 20 diamèt.(Orig.). Fond blanchàtre; bandes plus foncées; taches ferrugineuses. - Longueur du màle : $1^{\mathrm{mm}}, 2$; de la femelle: $1^{\mathrm{mm}}, 5$.

Sur le Bœuf. Se répand volontiers sur les diverses régions du corps. Gurlt et Denny disent en avoir aussi renconiré sur des Anes, mais c'étaient probablement des déserteurs.

Trichodecte sphérocéphale $(T r$. sphærocephalus Nitzsch. - Priorité :

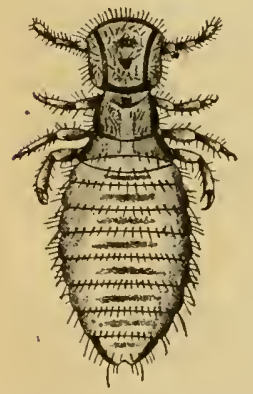

Fig. 578. - Trichodectes sphrrocephalus, femelle, du Mlouton, grossi 20 fois (G. Neumann).

Tr. ovis [L.]). - Tète plus large que longue, atteignant son maximum de largeur à la tempe, un peu aplatie en avant; bande antennale faisant le tour de l'avanttète, qui porte de longs poils à son bord; antennes poilues, plus longues chez le màle que chez la femelle. A bdomen légèrement conique en ârrière chez le màle, ovale chez la femelle; bandes lalérales un peu recourbées à la suture; sur chaque segment, une tache médiane subquadrangulaire et une simple rangée de poils courts entre cette tache et la suture. Blanchâtre; taches et tète ferrugineuses. - Longueur du màle : $1^{\mathrm{m} m}, 4$; de la femelle : $1^{\mathrm{mm}}, 6$.

Sur le Mouton. Il est surtout commun sur les animaux en mauvais état de nutrition; dans certains cas, il détériore la toison (E. Thierry). Je l'ai rencontré aussi sur un Chabin.

Trichodecte échelle ( $T r$. climax Nitzsch). - Tête plus large que 
longue, présentant en avant une échancrure large, mais peu profonde, au niveau de laquelle s'arrètent les bandes antennales, qui se recourbent en arrière; antennes un peu plus longues chez le mảle que chez la femelle: le $1^{\text {er }}$ arlicle sans épine, le $2^{c}$ plus long que le $3^{\mathrm{c}}$. Abdomen conique, surtout chez le màle, où il offre en arrière deux pelotes poilues et saillantes; bandes latéralos noiràtres, recourbées à la suture; sur chaque segment, une tache médiane, et une raugée de poils courts entre la tache et la suture. Tète et thorax rouge brun; abdomen jaune pàle ; taclıes brun marron ; bandes noiritres. - Longueur du màle : $1^{\mathrm{mm}}, 3$; de la femelle : $1^{\mathrm{mm}}, 6$.

Sur la Chève; se fixe de préférence au milieu des poils de la région dorsale.

D'après Taschenberg, le Tr. capræ Gurlt est identique au $T r$ climax; il en est de mème du $T r$. solidus Rudow, de la Chèrre de Guinée, et probablement du Tr. mambricus Rudow, de la Chère du Levant.

Piaget deccrit un $T r$. climax var. major, de la Chèvre

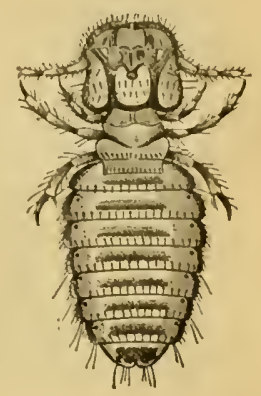

Fig. 579. - Trichodectes climax, femelle, de la Chève, grossi 20 fois (G. Neumann). d'Angora, dont la femelle seule diffère du type. Il pense que la forme recueillie par Gervais sur le même animal, et décrite par lui sous le nom de $T r$ limbatus, est la mème que celle-ci.

Quant au Tr. crassipes Rudow, de la Chèvre d'Angora, il est identique, comme l'a reconnu Taschenberg, au $T r$. penicillutus Piaget, recueilli par Piaget sur un Kangourou (Macropus penicillatus). S'agirait-il de déserteurs ? ou bien n'y aurait-il pas eu erreur dans l'indication de l'hòte?

Trichodecte Iarege (Tr. latus Nitzsch. - Priorité : Tr. canis [Retzius]). - Tète beaucoup plus large que longue, atteignant son maximum de largeur à la tempe, et tronquée en avant; antennes poilues, différentes dans les deux sexes, celles du màle ayant le $1^{\text {er }}$ article égal aux deux autres réunis; bande antennale s'arrêtant à la partie tronquée de l'avant-tète pour revenir vers les bandes occipitales, qui sont bifurquées. Abdomen très large, arrondi surtout chez la femelle, à bandes latérales peu distinctes; pas de taches médianes, mais des taches latérales mal limitées. Jaune clair; taches plus foncées : bandes de la tête brun noir. - Longueur du màle : $1^{\mathrm{mm}}, 4$; de la femelle : $1^{\mathrm{mm}}$, эั.

Sur le Chien ; fréquente particulièrement les sujets jeunes ou très vieux; les tourmente peu.

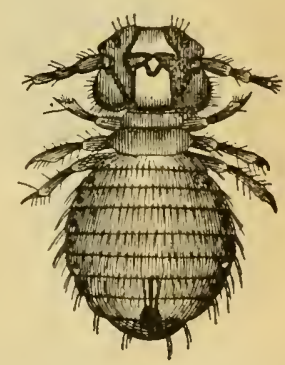

Fig. 580. - Trichodectes latus, måle, du Chien, grossi 20 fois $($ Orig.).

Trichodeete subrostré (Tr. subrostratus Nitzsch). - Tèle plus longue que large, acuminée en avant, avec une petite échancrure au niveau de laquelle s'arrètent les bandes antennales, qui se recourbent en arrière ; antennes semblables dans les deux sexes. Abdomen un peu conique en arrière chez le måle, plus large chez la femelle; des taches transversales médianes, 
étroites, sur les huit premiers segments ; le dernier segment du màle très saillant, conique et velu. Abdomen blanchàtre; têle el thorax jaune clair;

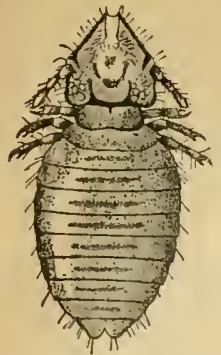

Fig.581. - Trichodectes subrostratus, femelle du Chat, grossi 25 fois (G. Neumann). bandes et laches plus foncées. - Longueur du màle et de la femelle : $1^{\mathrm{mm}}, 2$.

\section{Sur le Chat.}

Genre Ornithobie (Ornithotius Denny, 1842).-Corps alJongé et étroit, à còtés presque parallèles ; antennes à cinq articles, différentes dans les deux sexes, celles du màle ayant les deux premiers articles notablement plus longs que les autres, et le $3^{e}$ un peu renflé à l'extrémité, mais sans appendice. Bande temporale formant un pli en arrière de l'œil. Abdomen pourvu d'une seconde bande latérale parallèle à la bande marginale ; dernier segment acuminé chez le màle.

Ornithobie bucéphale (O. bucephalus Giebel.-Syn.: Pediculus cygni L., pro parle). - Téte trapézoïdale, presque aussi large que longue, un peu échan-

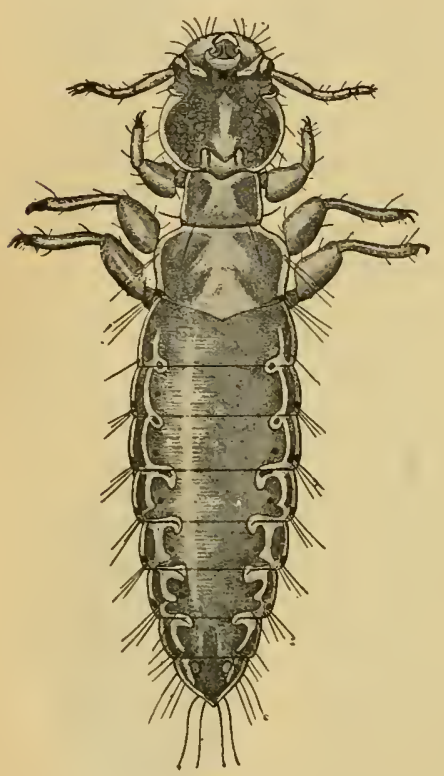

Fig. 582. - Ormithobiu sbucephalus, mâle, du Cygne, grossi 15 fois (G. Neumaun). crée en avant; sinus antennal à peine indiqué ; antennes reportées en avant. Bandes de la tète, du thorax et de l'abdomen nacrées et transparentes. Métathorax convexe en arrière, avec une pointe médiane obtuse. Abdomen ovale, nu, sauf aux angles. Teinte générale blanche. - Longueur du mâle : $3^{\mathrm{mm}}, \breve{s}$; de la femelle : $3^{\mathrm{mm}}, 5$ à $3^{\mathrm{mm}}, 6$.

Sur le Cygnus olor.

Genre Lipeure (Lipeurus Nitzsch, 1818). - Corps allongé et étroit, à cótés presque parallèles; antennes à cinq articles, différentes dans les deux sexes, celles du màle ayant le $1^{\mathrm{er}}$ article très fort, et le $3^{\text {e }}$ muni d'un appendice; dernier segment de l'abdomen du màle plus ou moins échancré.

Lipeure baguette ( $L$. baculus [Nilzsch]. - Syn. : Pediculus columbx L.; Nirmus filiformis Olfers; N. claviformis Denny. -- Priorité : I. rolumbx). - Tête très allongée et très étroite; clypeus (partie antérieure) arrondi en avant, séparé du reste par un léger étranglement et par une suture réduite à un sillon incolore, non bordé par la bande antennale qui s'arrête au niveau de cette suture. Six poils fins de chaque còté de l'avant-tête; en outre, deux appendices claviformes qui dépassent le clypeus en avant et à la base desquels s'en trouvent deux autres divergents (que n'a pas vus Piaget). Angle antérieur du sinus antennal aigu, en forme de trabécule. Métathorax d'un tiers plus long que le prothorax. Abdomen 
étroit et allongé, plus large chez la femelle ; taches latérales peu colorées, quadrangulaires. Blanc sale, taches jaune clair ; bandes presque noirâtres. - Longueur dı male : $1^{\mathrm{mm}}, 8$ a $2^{\mathrm{mm}}, 3$; de la fenielle : $2^{\mathrm{mm}}, \mathrm{t}$ à $2^{\mathrm{mm}}, 7$.

Sur les Pigeons.

Lipenre sale (L. squulidus [Nitzsch]. - Syn. : Pediculus amatis Fabr. Priorité : L. anatis). - Tète étroite, allongée en avant des antennes; clypeus séparé par une suture, au niveau de laquelle se manifeste un rétrécissement subit, marquant le point d'arrêt de la bande antennale; six poils de chaque cỏté à l'avant-tète, dont deux au clypeus, le second largement apliıti. En avant des mandibules, une fossette arcondie et très limitée ; sur le clypeus, une tache inférieure ou signaturc parallèle au bord en avant et convexe en arrière. Angle antérieur dı sinus antennal allongé en forme de trabécule. Tempe arrondie, avec une soie et une épine. Métathorax un peu rentrant. Abdomen étroit et allongé, à bandes étroites, noiràtres ; taches transverses fauves.

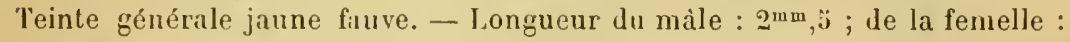
$2^{\mathrm{mm}}, 8 \ddot{\text {. }}$.

Très commun sur le Canard domestique. Taschenberg l'a trouvé aussi sur le Canard de Barbarie.

Lipeure aframé (L. jejumus [Nitzsch]. - Syn. : Nirmus crassicomis 01fers. - Priorité : L. crassicomis). - Se distingue surtout du précédent en ce qu'il ne montre pas de fossette en avant des mandibules, et que la signature du clypeus n'est guère apparente. Clypeus incolore, non bordé par la bande antenuale. Angle antérieur du sinus antennal allongé en forme de trabécule. Métathorax du double plus long que le prothorax, et offrant à chaque angle postérieur un large tubercule sur lequel sont implantées quatre courtes soies. Abdomen avec des taches latérales échancrées à leur bord antérieur. Blanc sale; taches fauve foncé; bandes noiràtres. - Longueur du màle : $2^{\mathrm{mm}}, 5$ à 3 millimètres ; de la femelle : $3^{\mathrm{mm}}, 1$ à $3^{\mathrm{mm}}, 57$.

Sur les Oies.

Lipenre de lOie (L. anseris [Gurlt]). - Tète allongée, conique, arrondie en avant; angle antérieur du sinus antennal formant une sorte de petite trabécule. Hétathorax double du prothorax, étranglé sur les côtés. Abdomen très allongé, un peu ovale, poilu, les premiers segments avec une bande latérale noiràtre, qui forme un crochet en avant. - Longueur du màle : 3 millimètres; de la femelle : $3^{\mathrm{mm}}, \mathbf{7}$.

Trouvé sur une Oie domestique par Gurlt, qui le désignait sous le nom d'Ornithobius anscris. Il nous semble difficile de ne pas identifier cette forme avec la précédente.

Lipenre hétéroğraphe ( $\boldsymbol{L}$. heterographus [Nitzschj]). - Tète parabolique en avant, où elle est limitée par la bande antennale, et très élargie en arrière de l'œil; angle antérieur du sinus antennal formant une saillie qui simule quelque peu une trabécule. Deux soies à la tempe. Métathorax anssi long que le prothorax. Abdomen ovale, allongé, un peu plus large chez la femelle, à taches médianes entières. Jaune pàle; taches fauves; bandes noiràtres. -.. Longueur du màle : $1^{\mathrm{mm}}, 7$ à $2^{\mathrm{mm}}, 4$; de la femelle : $1^{\mathrm{mm}}, 8.3$.

Sur la Poule. 
Lipeure variable (L. variabilis [Nitzsch]. - Syn. : Pediculus caponis L. Priorilé : L. caponis). - Tête arrondie en avanl, où elle est bordée par la bande

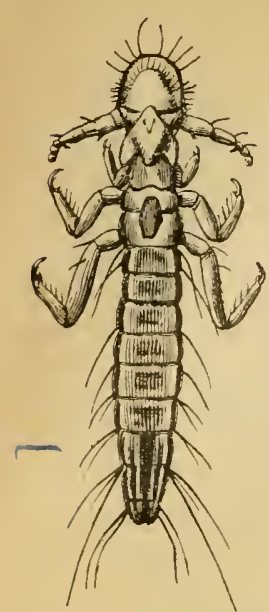

Fig. 583. - Lipeurus variabilis, mâle, de la Poule, grossi 20 fois (G. Neumann). antennale; angle antérieur du sinus antennal saillant chez la femelle, prolongé en une longue trabécule elfilée chez le mâle; tempe nue. Métathorax plus long et plus large que le prothorax. Une tache médiane sur la face sternale. Abdomen ovale très allongé, plus large chez la femelle, nu, sauf aux angles des segments, avec des taches inédianes comme évidées de chaque côté; chez la femelle, une tache génitale en forme de fer de lance, et le dernier segment bilobé. Blanc sale; taches fauve foncé, plus foncėes chez la femelle; bandes noirâtres. - Longueur du mâle; $1^{\mathrm{mm}}, 9$ à $2^{\mathrm{mm}}, 2$; de la femelle : $2^{\mathrm{mm}}, 15$ à $2^{\mathrm{mm}}, 43$.

Sur la Poule. Taschenberg et moi l'avons trouvé sur le Faisan commun. Je l'ai recueilli en outre sur la Pintade.

Lipeure polytrapèze (L. polytrapezius [Nitzsch].Syn.: Pediculus meleagridis L. - Priorité : L. meleagridis). - Grande espèce à tèle relativement courte, plus forte chez la femelle, à peine plus large à la tempe qu'en avant, où elle est très arrondie et bordée par la bande antennale; $1^{\mathrm{er}}$ article de l'antenne du mâle avec une forte excroissance à la base. Une soie à la tempe. Métathorax beaucoup plus long que le prothorax. A la face sternale, une longue tache médiane avec deux soies et deux virgules chitineuses de chaque còté; en arrière, une seconde en forme de cloche, s'étendant jusque sur l'abdomen, avec quatre soies. Abdomen ovale très allongé, plus large chez la femelle, avec deux soies médianes; deux séries de taches trapézoïdales séparées sur la ligne médiane par un large sillon; dernier segment échancré; chez la femelle, une tache génitale acuminée en arrière. Jaunàtre; taches fauves; bandes noirâtres. Longueur du mâle : $2^{\mathrm{mm}}, 8$ à $3^{\mathrm{mm}}, 6$; de la femelle : 3 millimètres à $3^{\mathrm{mm}}, 7$.

Sur le Dindon.

Lipeure de la Pintade (L. numidx [Denny]). - Tète grande, subpanduriforme, arrondie en avant, où elle est bordée par la bande antennale, et élargie en arrière de l'œil ; antennes de la femelle à second article très long. Métathorax à peu près de la même largeur que le prothorax. Abdomenovale, les sept premiers segments offrant une double série de taches qui forment deux bandes dorsales interrompues. Jaune livide; bandes et taches noirâtres. - Longueur : $2^{\mathrm{mm}}, 1$.

Trouvé sur la Pintade par Denny, qui le considérait comme un Nirme Nirmus numidx) et qui n'avait probablement vu que la femelle.

Genre Goniode (Goniodes Nitzsch, 1818). — Corps plat et large ; angle antérieurdu sinus antennal formant parfois une saillie qui simule une trabécule: antennes à cinq articles, différentes dans les deux sexes, celles du mâle ayant le premier arlicle très fort et parfois appendiculé, et le troisième toujours muni d'un appendice; tempes formant d'ordinaire un angle latéral aigu ou obtus (angle temporal). 
Les Goniodes ne se rencontrent guère que chez les Gallinacés et les Colombins.

Goniode main (Gll. minor Piaget. - Syn. : Coloceras minus 0. Taschb.). Petite espèce ayant, comme les suivantes, du reste, l’abdomen ovale, élargi, et caractérisée surtout par ce fait que les deux derniers articles de l'antenne du màle sont très réduits et difficilement visibles; métathorax arrondi sur l'abdomen. Blanc sale ou jaune pàle. - Longueur du màle : $1^{\mathrm{mm}}, 45$; de la femelle : $1^{\text {ma }}$ r, 7 .

Sur les l'igeons.

Gomiode damicome (G. damicomis Nitzsch. - Syn.: Coloceras damicorne 0. Tasclıb.). - Très voisin du précédent, dont il se distingue par sa taille plus grande et par le bord postérieur du métathorax, qui forme un angle dans son milieu. - Longrueur du mâle : $2^{\mathrm{mm}}, 1$; de la femelle: $2^{\mathrm{mm}}, 3$.

Sur les Pigeons.

Goniode stylifère (Gul. stylifer [Nitzsch]. - Syn. : Pediculus meleagridis Schrank, nec L.; Rhopaloceras styliferum O. Taschenb. - Priorité : Gd.meleagridis). - Grande espèce, très facile à reconnaìtre par ses angles temporaux, qui forment clıacun une longue corne acuminée en arrière et terminée par une soiesimple. Le métatlıorax porte cinq soies au bord postérieur. Les sept premiers segments de l'abdomen offrent sur les cỏtés des taches transversales recourbées autour des stigmates. Blanc sale; taches fauves; bandes faure foncé. - Longueur du mảle : $3^{\mathrm{m} m}, 2$ à $3^{\mathrm{mm}}, 9$; de la femelle : 3 millimètres à $3^{\mathrm{mm}}, 58$.

Sur les Dindons. Neumann l'a recueilli en outre sur la Pintade.

Goniode dissemblable ( $G d$. dissimilis [Nitzsch]). - Tète plus large que longue, plus petite chez le màle; angles temporaux saillants, mais ne formant pas de cornes; bande antennale très élargie en avant: antennes du màle avec un premier article très développé offrant un fort poil au côté interne. Cinq soies au bord postérieur du métathorax. Sur chaque segment de l'abdomen, des soies médianes et d'autres laté-

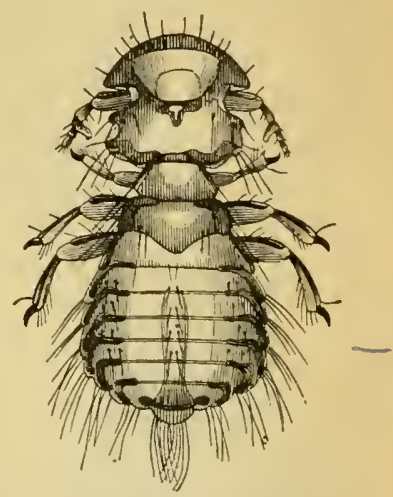

Fig. 58'. - Goniodes dissimilis, male, de la l'oule, grossi 20 fois (Piaget). rales, sans compter celles des angles; bandes latérales recourbées, avec un appendice à la courbure. Blanc sale; taches peu marquées; bandes fauves. - Longueur du mâle : $1^{\mathrm{mm}}, 93$; de la femelle: $2^{\mathrm{mm}}, 6$.

Très commun sur les Poules.

Goniode du Faisan (Gd. colchici Denny). - Diffère du précédent surtout par la présence d'une petite dent au còté interne du premier article de l'antenne du màle. - Longueur du màle : 2 millimètres; de la femelle : $2^{\mathrm{mm}}, 1$.

Sur les Faisans.

Goniode tronqué (Gd. truncatus Giebel). - Tète large, arrondie en avant; antennes du mile sans appendice an premier article. Abdomen offrant des bandes latérales arquées qui poussent un court appendice dans 
le segment précédent et s'arrètent, du moins chez la femelle, au milieu d'une tache entourant un espace incolore; entre ces taches, des soies médianes; abdomen du màle tronqué en arrière. Blanchàtre; bandes très foncées. Longueur du màle : $2^{\mathrm{mm}}, 3$; de la femelle: 3 millimètres.

Taschenberg l'a trouvé sur le Faisan commun.

Goniode de la Pintade ( $G d$. numidianus Denny). - Tête plus longue que large; antennes du màle assez longues, à troisième article recourbé et aigu, portant les deux suivants en dehors de l'axe. Métathorax plus large que la tête, acuminé sur l'abdomen, avec une bande noiràtre au bord postérieur. Abdomen ovale, avec des taches interrompues deux fois. Janne paille pàle; taches brun goudronné. - Longueur: $1^{\mathrm{mm}}, 7$.

Trouvé sur la Pintade par Denny. Peut-ètre s'agissait-il, dit Piaget, d'individus incomplètement développés.

Goniode falcicorme (Gd. falcicornis [Nitzsch]. - Syn. : Pediculus pavonis L. - Priorité : Gd. pavonis). — Grande espèce. Tète presque carrée, très aplatie en avant, surtout chez le mâle; bande anlennale étroite en avant, à bords parallèles; premier article de l'antenne màle énorme, avec un fort appendice au còté interne. Métathorax beaucoup plus large que le prothorax, mais à peine aussi large que la tète. Abdomen très large, offrant sur les còtés des taches linguiformes très foncées, entre lesquelles se voient plısieur's soies. Teinte générale blanc sale ou jaunàtre; laches fauve foncé. Longueur du màle: $3^{\mathrm{mm}}, 0 z ̃$; de la femelle : $3^{\mathrm{mm}}, 3$.

Commun sur le Paon.

Goniode à petite tète (Gll. parviceps Piaget). - Espèce voisine de la précédente, mais plus petite, à tète moins aplatie en avant, à mélathorax beaucoup plus large que la têle chez le màle, à deux soies seulement entre

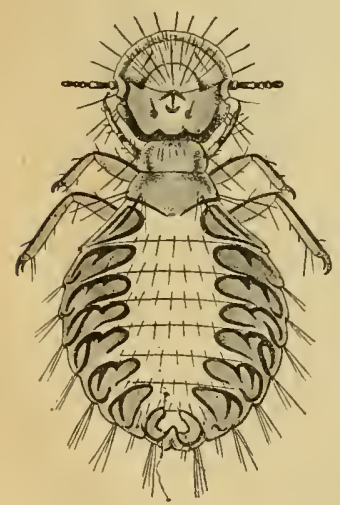

Fig. 585. - Foniocotes yigas, femelle, de la Poule, grossi 10 fois (G. Neumann).

les taches latérales de l'abdomen. - Longueur du màle : $1^{\mathrm{mm}}, 950$; de la femelle : $1^{\mathrm{mm}}, 90$.

Sur le Paon, avec le précédent.

Genre Goniocote (Goniocotes Burmeister, 1839). - Corps plat et large; sinus antenual peu profond, de sorte que l'angle antérieur ne présente pas la forme d'une trabécule; antennes à cinq articles, semblables dans les deux sexes; tempe lormant deux angles : un antérieur ou temporal, portant deux soies, et un postérieur ou occipital, avec une courte épine; dernier segment de l'abdo. men arrondi ou un peu tronqué chez le màle, bilobé ou échancré chez la femelle.

Presque tous les Goniocotes sont remarquables par leurs petites dimensions. Comme les Goniodes, ils ne vivent guère que sur les Gallinacés et les Colombins.

Goniocote géant (Gc. gigas Taschenberg, 1869. - Syn.: Gc. abdominalis Piaget, 1880). - Espèce de taille exceptionnelle, à tète presque aussi longue que large, formant un demi-hexagone; angle temporal reporté près de l'œil. Abdomen très large, ovale arrondi, muni sur chaque segment et 
par còté de longues taches transversales en forıne de langue, colorées seulement sur leur pourtour. Teinte générale jaunatre; partie postérieure dı thorax et abdomen blanc, sale; bandes et bord des taches noiràtres. Longueur du màle : $3^{\mathrm{mm}}, 3$; de la femelle : 4 millimètres.

Sur les Poules.

Goniocote compacunon (Gc. compar [Nitzsch]). - Cette espèce est de petite taille, aussi bien que les suivantes. Tète assez longue, arrondie en arant, un peu élargrie en arrière. Abdomen ovale arrondi chez la femelle, arrondi et tronqué en arrière clıez le màle, offrant de chaque còté deux bandes latérales étroites et recourbées, et des taches transversales qui ne sont guère colorées qu'à la pointe et sur les bords. Couleur blanc sale ou jaunitre. - Longueur du mile : 1 millimètre; de la femelle : $1^{\mathrm{mm}}, 4$.

Sur les Pigeons.

Goniocote reetangrulé (Gc. rectangulatus [Nilzsch]). - Tète plus développée et plus aplatie en avant chez la femelle que chez le màle. Abdomen ovale arrondi chez la femelle, arrondi et tronqué en arrière chez le màle, sans soies médianes; les sutures des segments ne sont distinctes qu'entre les trois premiers; bandes latérales simples, linéaires et élargies à la suture sur la face dorsale, très larges à la face ventrale; taches transversales latérales, pàles, unicolores. Teinte générale jaune pàle; bandes un peu plus foncées. - Longueur du màle : $0^{\mathrm{mm}}, 8$; de la femelle : $\mathrm{l}^{\mathrm{mm}}, \mathbf{5}$.

Sur le Paon. Taschenberg l'a aussi trouvé sur une Piutade à l'École vétérinaire de Berlin, et jai fait la mène observation à Alfort.

Goniocote chrysocéphale (Gc. chrysocephalus Giebel). - Se rapproche beaucoup du fic. rectangulé, dont il diffère principalement en ce que les sutures sont visibles entre les huit premiers segments. Couleur jaunàtre. - Longueur du màle : $0^{\mathrm{mm}}, 8$; de la femelle : $1^{\mathrm{mm}}, 2.2$.

Sur les Faisans.

Goniocote hologastre (Gc. hologaster [Nitzsch]. - Priorité : Gc. gallinx [Retzius]. Également très voisin du Gc. rectangulé, dont il se distingue surtout en ce que les bandes latérales ne sont pas plus larges à la face ventrale qu'à la face dorsale. Teinte générale jaune sale, plus foncée au thorax; bandes brunàtres. - Longueur dı màle : $0^{\mathrm{mm}}, 8$ à $0^{\mathrm{mm}}, 9$; de la femelle : $1^{\mathrm{mm}}, 3$.

Sur les Poules. Taschenberg en signale une variété qüil qualifie de maculata.

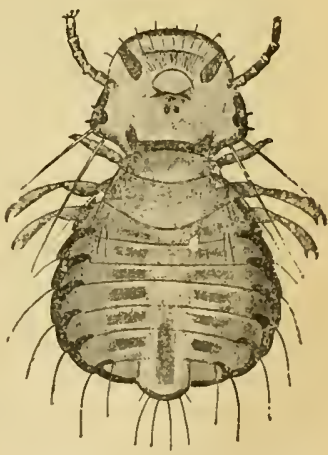

Fig. 586. - Goniocotes hologas. ter, mâle, de la Poule, grossi 40 fois (G. Neumann).

Goniocote de Burnett (Gc. Burnclli Packard, 1870). - Diffère surtout du Gc. hologastre par les antennes plus fortes, et par la tète beaucoup plus acuminée, mais moins évidée à l'insertion des antennes. Teinte générale jaunàtre, avec des stries et bandes noiratres.

Sur la Poule, aux Etats-Lnis. - Giebel et Piaget l'ont signalé par erreur sous le nom de Goniodes Burnetli.

Genre Docophore (Docophorus Nitzsch, 1818). - Corps large et plat; clypeus 
(partie antérieure de la tête) séparé du reste de la tête par un sillon incolore, la suture; angle antérieur du sinus antennal offrant un prolongement mobile on trabécule; antennes à cinq articles, semblables dans les deux sexes.

Les Docophores ne paraissent pas infester les Gallinacés ni les Colombins.

Docophore bilieux (D. icterodes [Nitzsch]). - Tète plus longue que large, triangulaire; clypeus semi-circulaire, élargi dès la suture, avec un triangle de chaque còté, formé par la bande antennale, et une tache inférieure (signature) étranglée et allongée. Prothorax moins large que le métathorax. Abdomen large, à bandes latérales d'épaisseur uniforme; sur le premier segment, une bande chitineuse interrompue sur la ligne médiane par un sillon incolore; taches latérales transverses, laissant libre le tiers médian. Couleur générale rouge brunâtre. - Longueur du màle: $1^{\mathrm{mm}}, 0$ ว ; de la femelle : $1^{\mathrm{mm}}, 3$.

Sur les Canards. On en trouve sur les Oies une variété dont Burmeister faisait une espèce à part, sous le nom de Docophore brûlé ( $D$. adustus).

Fig. 587. - Docophorus icterodes, mäle, du Canard, grossi $2 \%$ fois (G. Neumann).

Docophore du Cygne (D. cygni Denny). - Tête plus large que longue; clypeus elliptique, signature très courte. Abdomen obové; bande du premier segment large. Couleur jaunâtre. - Longueur du màle: $1^{\mathrm{mm}}, 1$ à $1^{\mathrm{mm}}, 2$; de la femelle: $1 \mathrm{~mm}, 4$.

Osborn le dit commun chez les Cygnes domestiques comme chez les Cygnes sauvages.

B. Sous-famille des LIothÉrnés. -- La tète, très élargie aux tempes, paraît triangulaire ou trilobée. En avant de la tempe, il y a parfois une échancrure (sinus orbital), dans laquelle se trouve situé l'œil, ordinairement peu distinct. Les antennes sont à quatre articles; chez les Colpocéphales et les Ménopons, elles sont assez longues pour dépasser le bord de la tête; néanmoins, elles sont d'ordinaire repliées et cachées dans une fossette de la face inférieure.

Les principales bandes de la tête, quand elles sont visibles, recoivent les noms suivants : occipitales, de l'occiput au sinus orbital ; antennales, du sinus aux mandibules; orbitales, contournant le sinus et s'avançant dans la tempe.

La bouche, reportée en avant, présente une lèvre supérieure échancrée, des mandibules, des màchoires presque cachées, portant des palpes quadriarticulés qui dépassent le bord de la tête, enfin une lèvre inférieure émarginée, avec des palpes labiaux biarticulés, difficilement visibles.

Le thorax montre en général deux segments distincts; quelquefois cependant (Trinoton), on en reconnaît trois, le mésothorax étant séparé du métathorax par une suture.

Le dernier segment de l'abdomen, chez la femelle, est ordinairement frangé de poils fins et serrés.

Ce groupe est coustitué par les ancieus genres Gyropus et Liotheum; par suite de la subdivision de ce dernier, il compte actuellement dix genres. Voici le tableau de ceux qui ont des représentants parmi les parasites de nos animaux domestiques : 
Tarses à une seule griffe : Pilivores........................... Gropus.

Tarses
a deux grifres :
Pennivores. $\left\{\begin{array}{c}\text { Thorax à trois segments distincts.............. Trinoton. } \\ \text { Thorax a } \\ \text { deux segments. }\end{array}\left\{\begin{array}{l}\text { Sinus orbital profond .......... Colpocephalum } \\ \text { Sinus orbital faible ou nul....... Menopon. }\end{array}\right.\right.$

Genre Gyrope (Gyropus Nitzsch, 1813). - Tète présentant en arrière deux échancrures qui limitent des tempes très saillantes; organes buccaux sitıés au hord de l'avant-tête; pattes courtes, à tarses indistincts, avec une seule griffe.

Les Gyropes, qui se rapprochent des I'édiculidés, vivent sur les Mammilères, principalement sur les Rongeurs.

Gyrope ovale (G. oralis Nitzsch). - Tète assez large, à tempes prẻsenlant la forme de cornes dirigées en avant; anteunes relativement longues. Abdomen ovale, large, surtout chez la femelle, crénelé sur les bords, avec deux séries de petits poils sur chaque segment. Fond blanchatre; taches de l'abdomen fauve très clair ; bandes, tarses et angrles plus foncés. - Longueur du måle : 1 millimètre; de la femelle : $1 \mathrm{~mm}, 2$.

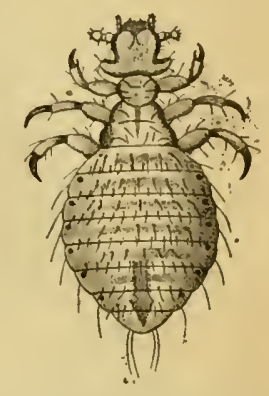

Fig.588.-Gyropusovalis, male, du Cobaye, grossi 25 fois (G. Neumann).

Commun sur le Cobaye.

Gyope grêle (G. gracilis Nitzsch. - Syn. : Pediculus porcelli Schrank. Priorité: G. porcelli). - Tète plus étroite et plus allongée que dans l'espèce précédente; palpes moins saillants; antennes plus courtes; tempes moins proéminentes. Abdomen étroit et allongé, surtout chez le màle, et presque entièrement nu. Teinte générale variant du blanc sale au jaune d'ocre; taches un peu plus foncées. - Longueur du màle : $1^{\mathrm{mm}, 05}$; de la femelle : $1^{\mathrm{mm}}, 2$.

Sur le Cobaye ; plus commun encore que le précédent.

Genre Trinoton(Trinoton Nitzsch, 1818). - Tête très arrondie en avant, comme arquée en arrière, où les tempes sont très saillantes et arrondies; un sinus orbital largement ouvert contenant un œil hémisphérique volumineux, divisé en deux par une tache; antennes courtes et cachées. Thorax remarquable par la présence d'un mésothorax séparé par une suture visible jusque sur la face sternale. Tarses à 2 griffes.

Les Trinotons infestent les Palmipèdes.

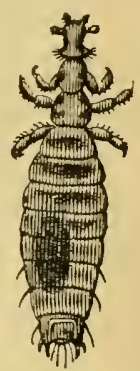

Fig. 589. - Gyropus gracilis, femelle du Cobaje, grossi 25 fois (G. Ncumann).

Trinoton sali (T. conspurcatum [Nitzsch.] - Syn. : Pediculus anseris Sulzer. - Priorité : T. anseris). - Très grande espèce. Tète triangulaire, à angles arrondis; tempe portant cinq longues soies. Thorax beaucoup plus long que la tète, arrondi sur l'abdomen. Abdomen ovale allongé, moins large à la base que le métathorax, à angles saillants; les huit premier's segments avec une tache transversale entière et une série de soies implantées sur des tubercules incolores. Blanchàtre; taches brun marron, bandes noiràtres, thorax foucé, tète fauve clair. - Longueur du màle : $5^{\mathrm{mm}}, 8$; de la femelle : $6^{\mathrm{mm}}, 3$.

Sur le Cygnus olor. Denny l'aurait trouvé aussi sur l'Oie domestique. 
Trinoton continu $(T r$. continuum Piaget). - Diffère du précédent par ses dimensions plus faibles, quatre soies seulement aux tempes, l'abdomen à angles peu saillants, avec des soies plus nombreuses sur les deux faces, et des taches transverses régulièrement échancrées au bord antérieur. - Longueur : $5^{\mathrm{mm}}, 6$ à 6 millimètres.

Sur l'Oie domestique. Ce n'est probablement qu'une variété du Tr. conspurcatum.

Trinoton pâle ( $T r$. luridum [Nitzsch]). - Diffère aussi du $T r$. conspurcatum par ses dimensions encore plus faibles, sa couleur moins foncée et quatre soies aux tempes. Métathorax un peu concave sur l'abdomen. Celui-ci à segments arrondis sur les côtés; taches transverses presque linéaires et interrompues au milieu sur les deux premiers segments, entourant un cercle incolore sur le côté ; séries de soies interrompues au milieu sur les segments deuxième à cinquième. Blanc, avec taches marron et bandes noires. - Longueur du màle : $4^{\mathrm{mm}}, 7$; de la femelle : $\breve{3}^{\mathrm{mm}}, 4$.

Sur le Canard domestique.

Trinoton raturé ( $T r$. lituratum [Nitzsch]). - Petite espèce. Tête conique, très arrondie en avant; tempe avec trois soies, dont la première est la plus courte. Thorax plus long que l'abdomen, sur lequel il est un peu convexe. Abdomen extrémement réduit par rapport aux autres parties; les segments avec une bande transverse et une série de soies; le $8^{\mathrm{e}}$ très allongé, surplombant le $9^{\mathrm{e}}$ et portant les deux longues soies caractéristiques du genre; le $9^{e}$ très court, arrondi et bordé de poils. Fond jaune clair ; tête, prothorax, mésothorax et taches de l'abdomen jaune ocre. - Longueur de la femelle : $2^{\mathrm{mm}}, 1$.

On rapporte à celte espèce le Trinoton trouvé par Denny sur une Oie domestique, et que cet auteur dénommait $T r$. squalidum.

Genre Colpocéphale (Colpocephalum Nitzsch, 1818). - Tête plus large que longue, atteignant son maximum de largeur aux tempes, arrondie en avant et offrant de chaque còlé, en arrière des antennes, une profonde échancrure (sinus ortital) au fond de laquelle se trouve l'œil ; antennes dépassant le bord de la tête; tarses à deux griffes.

Colpocéplrale turbiné(C, turbinatum Denny, 1842. -Syn. : C. longicaudum Nitzsch, 1866). - Bandes occipitales peu distinctes. Abdomen du màle ovale allongé, avec des taclıes transverses entières; abdomen de la femelle conique, avec des taches transverses qui tendent à s'effacer vers la partie médiane des quatre derniers segments; dans les deux sexes, le dernier segment arrondi et garni de nombreux poils. Blanchâtre, avec taches fauves. - Longueur du mâle : $1^{\mathrm{mm}}, 3$ à $1^{\mathrm{mm}}, 4$; de la femelle : $1^{\mathrm{mm}}, 6$.

Sur le Pigeon.

Genre Ménopon(Menopon Nitzsch, 1818). - Tête en forme de croissant, les tempes formant la partie la plus large; tantòt sans échancrure latérale, tantôt avec un sinus orbital assez distinet, en tout ou en partie occupé par l'œil; antennes courtes et repliées dans la cavité orbitale. Souvent trois taches médianes au sternum. 
Les Ménopons se rencontrent sur des Oiseaux de presque tous les ordres, et même sur des Mammifères.

Ménopon Iarare (M. Latum Piaget). - Tète un peu parabolique, presque angulaire en avant; sinus orbital en partie occupé par l'œil; un appendice au deuxième article des antennes dans les deux sexes. Thorax plus long que la tète chez la femelle, plus court chez le mảle; métathorax arrondi sur l'abdomen; les taches médianes manquant au sternum. Abdomen large, arrondi, surtout chez la femelle, ‘̀ angles saillants, avec des taches transverses et des taches latérales. Jaunàtre; taches fauve clair. - Longueur du màle : $1^{\mathrm{mm}}, \dot{4} ;$ de la femelle : $2^{\mathrm{mm}}, 2$.

Sur le Pigeon domestique. - Cette espèce est probablement identique au M. giganleum Denny, dn Colombin (Columba onas L.).

Ménopon pâle (M. pallidum [Nitzsch]. - Syn. : Nirmus trigonocephalus Olfers. - Priorité : $\boldsymbol{M}$. trigonocephatum). - Tète légèrement angulaire en avant, et un peu en croissant, les tempes étant déjetées ; sinus orbital en partie occupé par l'œil ; tempe courte et arrondie avec quatre soies et quelques poils; antennes à $2^{\circ}$ article sans appendice. Thorax égal à la tête chez le måle, plus long chez la femelle; métathorax arrondi sur l'abdomen; les taches médianes manquant au sternum. Abdomen ovale allongé, plus long et plus étroit chez le mâle, avec une seule série de soies sur chaque segment; le huitième segment de mème longueur que les précédents. Jaune sale; taches de l'abdomen fauve clair. - Longueur du màle: $1^{\mathrm{m}}, 8$ à $1^{\mathrm{mm}}, 9$; de la femelle : $1^{\mathrm{mm}}, 75^{\mathrm{m}}$.

Sur la Poule.

\section{Ménopon bisérié ( $M$. biseriatum Piaget). -}

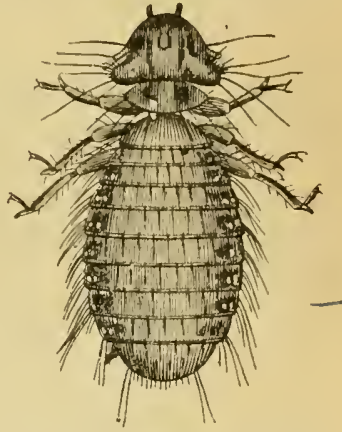

Fig. 590. - Menopon pallidum, femelle, de la Poule, grossi 20 fois (Orig.).

Diffère de l'espèce précédente par ses dimensions plus considérables, sa tête parabolique en avant, sa tempe à cinq soies, le thorax plus long que la tête dans les deux sexes, la présence de deux séries de soies sur chaque segment de l'abdomen, et le huitième segment abdominal plus long que les autres, à còtés presque parallèles. - Longueur du màle : $2^{\mathrm{mm}}, 95$ à $3^{\mathrm{mm}}, 3$; de la femelle: $2^{\mathrm{mm}}, 7 \mathrm{z}$ à $3^{\mathrm{mm}}, 22$.

Sur la Poule, le Faisan et le Dindon. Neumann l'a trouvé aussi sur le Pigeon. - C'est probablement le même que $\boldsymbol{M}$. stramineum Nitzsch et surtouı Pediculus meleamridis Panzer, du Dindon.

Ménopon allongé (M. productum Piagel). - Très voisin aussi du MI. pallidum, mais offrant, des tempes moins excavées, avec deux soies longues et deux plus courtes. Sternum avec deux laches médianes linéaires. L'abdomen, un peu plus développé chez la femelle que chez le mâle, est à còtés presque parallèles; le neuvième segment, chez la femelle, est très allongé et rétréci; chez le mảle, il est court, en ogive renversée. - Longueur du màle : $1^{\mathrm{mm}}, 5$; de la femelle: $1^{\mathrm{mm}}, 8$.

Sur le Faisan. - Il n'est pas absolument certain que cette espèce soit la mème que M. fulvomaculatum Denny, rencontré aussi surle Phasianus colchicus. 
Ménopon ì bouche noirâtre (M. phæostomum Nitzsch). - Tète allongée, rétrécie et arrondie en avant, à sinus orbital distinct; tempe étroite et déjetée, avec quatre soies et quelques poils : pas d'appendice au deuxième article des antennes. Thorax plus long que la tète. Abdomen elliptique chez le mâle, ovale allongé et plus développé chez la femelle, à angles saillants, mais arrondis, avec une seule série de soies sur chaque anneau; neuvième segment allongé et arrondi chez le màle, parabolique chez la femelle. Teinte générale jaunâtre, plus claire chez le mâle ; laches fauves. - Longueur du mâle : $1^{\mathrm{mm}}, 6$; de la femelle : $1^{\mathrm{mm}}, 5$ à $^{\mathrm{mm}}, 700$.

Sur le Paon.

Ménopon de la pintade ( $\boldsymbol{M}$. numidæ Giebel). - Espéce encore peu connue, voisine de $\boldsymbol{M}$. phæostomum. Sinus distincts. Prothorax avec trois piquants à l'angle; métathorax large, trapéziforme. Abdomen large, avec des taches latérales. - Longueur : $1^{\mathrm{mm}}, 08$.

Sur la Pintade.

Ménopon obscur ( $\boldsymbol{M}$. obscurum Piaget). - Tête en croissant, sans sinus orbital; tempe large, déjetée, avec deux soies longues et deux courtes. Thorax à peine plus long que la tête chez le màle, beaucoup plus long chez la femelle; au sternum, la première tache seule est distincle. Abdomen à angles saillants, avec une série de soies sur chaque segment; bandes latérales foncées, sans appendice. Fauve foncé. - Longueur du màle : $1^{\mathrm{mm}}, 5$; de la femelle : $1^{\mathrm{mm}}, 55$.

Sur le Canard domestique (Neumann).

Ménopon étranger ( $\boldsymbol{H}$. extraneum Piaget). - Tète en croissant, plus longue et plus étroite chez le màle, sans sinus orbital ; tempe arrondie, avec trois longues et trois courtes soies. Thorax plus long que la tèle, surtout chez le mâle; les trois taches existent à la face sternale. Abdomen ovale, à angles peu saillants; sur chaque segment, une série de soies espacées et caduques; bandes latérales noiràtres, sans appendice. Tète et taches de l'abdomen fauves; thorax plus pàle ; bandes noiràtres.-Longueur du màle : $1^{\mathrm{mm}}, 7$; de la femelle : 2 millimètres.

Piaget a trouvé deux fois ce Ricin sur le Cobaye, et chaque fois en grand nombre.

Pathologie. - Les troubles provoqués par la présence des Pédiculines à la surface de la peau recoivent le nom de pédiculose ou phtiriase

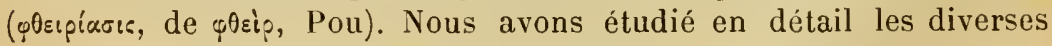
formes de pédiculose sévissant sur l'Homme; il nous reste à jeter un coup d'oil d'ensemble sur la phtiriase des animaux domestiques.

Le premier symptôme par lequel se manifeste généralement cette affection est un prurit d'intensité variable, en rapport avec l'espèce et le nombre des parasites. On conçoit que les Hématopinus, dont le rostre est conformé pour piquer, tiennent à cet égard le premier rang: on les trouve d'ailleurs au contact de la peau, dans laquelle ils enfoncent leur sucoir, en se tenant fixés à la base des poils au moyen des griffes qui terminent leurs pattes. Les Ricins, au contraire, ne se 
servent ordinairement de leurs pièces buccales que pour diviser l'épiderme et sucer le produit des sécrétions cutanées; on les trouve attachés aux poils, soit par les griffes de leurs tarses, soit par leurs mandibules en forme de tenailles dentẻes.

Sous l'influence des grattages, le poil ou le plumage devient lerne, piqué, hérissé, puis souvent tombe par places. Si l'on examine attentivement les points où se manifeste le prurit, on arrive sans difficulté à reconnaître la présence des parasites, de leurs dépouilles ou de leurs lentes. Ils se tiennent de préférence dans les régions supérieures du corps et dans les points oì la peau est mince, souple ou protégée par de longs poils. - Souvent aussi on peut constater, au bout d'un temps variable, l'existence de petites plaies ou excoriations, de croutes et en somme de lésions secondaires diverses. Quant aux lésions primitives, elles consistent tout au plus en des traces de piqûres, mais elles ne paraissent jamais comporter les papules qu'ont indiquées certains auteur's.

Si la cause persiste, les animaux, sans cesse tourmentés, finissent par maigrir et par tomber dans le marasme; mais il est rare aujourd'hui qu'on laisse le mal empirer à ce point.

La cause déterminante unique de la phtiriase, il est à peine besoin de le dire, est la contagion, qui peut s'opérer suivant divers modes : soit par un contact direct, soit par l'intermédiaire des harnais ou des instruments de pansage, soit même par la simple cohabitation des animaux affectés avec des animaux sains.

Dans la plupart des cas, il est nécessaire que ces animaux appartiennent à la même espèce : cependant, on sait que cette règle souffre quelques exceptions, puisque certains Poux sont communs à plusieurs hôtes. Kemmerer(1) aurait même constaté sur l'Homme la présence de Trichodectes (?) s'accompagnant de douleurs violentes.

En dehors de ces cas exceptionnels, il peut arriver que, par suite de la promiscuité qui règne souvent parmi les animaux domestiques, et en particulier parmi les Oiseauxde basse-cour, une espèce parasite passe sur un hote étranger; mais on reconnaît aisément ces déserteur's à leur petit nombre (ils sont ordinaircment du même sexe, des femelles), à l'absence de leurs lentes, qui sontle témoignage de la reproduction, et surtout à l'absence d'individus a différents degrés de développement.

Il est un certain nombre de conditions qui favorisent, soit la contagion, soit le développement des parasites. Telles sont la malpropreté et l'étal d’affaiblissement de l'organisme, cet état tenant, soit à la mauvaise alimentation, soit au jeune âge ou c̀ l'âge trop avancé ćes animaux, soit encore à l'excès de travail, à l'allaitement, aux maladies chroniques, etc. Enfin, sous l'influence de la stabulation permanente, la phtiriase tend à prendre une plus grande extension. Chez

(1) Journal des connaissances médico-chirurgicales, $18 j 3$.

Rialliet. - Zoologie. 
les bêtes bovines, aussi bien que chez les Moutons, elle s'aggrave toujours en hiver, tandis qu'elle diminue et semble même disparaitre lorsque les animaux sont mis au pâturage.

La prophylaxie de la phtiriase est des plus simples. Elle comporte ces indications essentielles : soustraire les animaux à la contagion et combattre les conditions favorables à l'extension du mal.

Quant au traitement proprement dit, il doit consister à tuer les Poux, et tous les Poux, puisqu'on sait avec quelle rapidité ces Insectes se reproduisent. - On isolera dabord les sujets affectés; on les pansera soigneusement hors de leur habitation; on renouvellera leur litière à de courts intervalles; on les tondra s'ils ont le poil trop long; enfin, pour les petits animaux tels que les Chiens, on aura recours aux bains, aux lavages, à la brosse et au peigne. - Ces soins préliminaires seront suivis de l'application locale de substances insecticides. Il ne faudra pas oublier d'ailleurs de renouveler cette application au bout d'une huitaine de jours, de manière à détruire les Poux éclos des lentes, lesquelles résistent souvent au traitement (elles résistent peu, dit-on, à l'action du vinaigre).

Enfin, lorsque tout un groupe d'animaux est envahi, il importe de procéder à la désinfection des habitations. On a recours le plus souvent à l'eau bouillante et à l'eau de chaux. En ce qui a trait aux poulaillers et pigeonniers, on recommande les fumigations de sulfure de carbone, ou mieux la projection de poussière de chaux vise ou de plâtre contre les murs et le plafond. Les Oiseaux sont également bien protégés contre la vermine par l'addition, au sable dans lequel ils se poudrent, de fleur de soufre ou d'autres substances insecticides.

TROISIĖME ORDRE

\section{LEPIDOPTERES}

Insectes suceurs; quatre ailes membraneuses revêtues de petites écailles; métamorphoses complètes.

La bouche des Lépidoptères ou Papillons est destinée à la succion : aussi les pièces buccales sont-elles profondément modifiées. L'organe le plus apparent est une trompe qui, au repos, est presque toujours roulée en spirale, ce qui l'a fait appeler spiritrompe. Elle est constituée par deux mâchoires très allongées et accolées, comme le démontrent les deux tubercules ou palpes rudimentaires situés à la base. Une très petite pièce membraneuse qui repose sur l'origine de la trompe représente le labre; une autre pièce triangulaire, placée audessous, figure la lèvre inférieure et porte deux longs palpes latéraux.

Les quatre ailes, membraneuses, sont recouvertes d'une poussière farineuse formée de poils raccourcis et élargis en écailles colorées et 
brillantes $(\lambda \varepsilon \pi i \varsigma$, écailles; $\pi \tau \varepsilon \hat{o}$ v, aile). Souvent, chez les Papillons crépusculaires et nocturnes, l'aile postérieure est reliẻe ì l'antérieure par' un appareil désigné sous le nom de frein, ce qui assure leur solidarité pendant le vol.

Les métamorphoses sont complètes. Les larves, connues sous le nom de chenilles, ont les organes buccaux des lnsectes broyeurs; la lèvre inféricure présente en outre un mamelon percé d'un minuscule orifice ou filière, par où s'échappe la soie que toutes ces chenilles sont aptes à filer. Indépendamment de la tête, le corps comprend douze anneaux, dont les trois premicrs portent chacun une paire de palles articulées ou ícailleuses, destinées à devenir les patles de l'adulte; les autres anneaux ne peurent offrir que des paltes membraneuses ou lausses pattes. - Les nymphes présentent d'ordinaire des colorations mélalliques brillantes, qui leur ont fait donner le nom de chrysalides; elles se renferment parfois dans un cocon soyeux. - Les

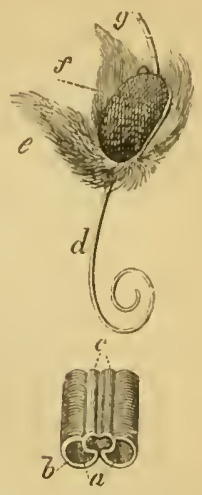

Firo. j91. - Trumpe de l'itpillon. - $e$, parlie de la tête. f, wil. $g$, base d'un antenne. $d$, trompe. $a$, $b, c$, coupe de la trompe.

Insectes parfaits, peu après leur naissance, rendent par l'anus un liquide rougeàtre: c'est lì l'origine des prétendues pluies de sang qui ont causé autrefois $\tan t$ de terreur.

Les chenilles font souvent d'énormes dégâts parmi nos récoltes ou nos plantations; aussi leur destruction est-elle l'objet de dispositions légales. En France, nous possédons une loi sur l'échenillage qui date du 26 ventóse an $\mathrm{IV}$, mais qui, malheureusement, ne peut alteindre qu'un petit nombre de chenilles.

On connait quelques cas de scoleciasis (voy. p. T44) se rapportant à des larves ou à des nymphes de Lépidoptères; mais le plus souvent la détermination spécifique est restée douteuse ou n’a pas élé faite.

La division des Papillons en Diumes, Crépusculaires et Nocturnes, adoptée en France depuis Latreille, a dù ètre abandonnée, aussi bien que la distinction

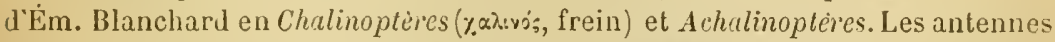
sont aujourd'hui prises pour base de la classification, et on reconnait deux souș-ordres: les Rhopulocères et les Hetérocères.

I'REMIER SOESTORDEF

\section{IIÉTÉROCÈRES}

Boisduval réunit sous ce nom tous les Papillons dont les antennes, quoique conformées très diversement, noffrent jamais de massue arrondic à l'extrémité. Ce groupe répond assez bien aux Chalinoptèrcs d'E. Blanchard, aux Crépusculaires et aux Nocturnes des anciens auteurs. 
On a subdivisé les Hétérocères en un cerlain nombre de familles plus ou moins naturelles, dont nous ne citerons que les principales: les Alucitidx, Pterophoridx, Tincidx, Pyralill , Tortricidx, qu'on réunit souvent sous la dénomination commune de Mıcrolépidoptères; puis les Phalenidæ, Noctuidæ, Bomıbycidx, Sphingidx, etc.

Les TINÉIDÉS comprennent un assez grand nombre d'espèces nuisibles.

En premier lieu, il faut citer la Teigne des grains (Tinea granella), petit Papillon nocturne dont la femelle pénètre, dès le mois de juin, dans les greniers à grains, pour pondre sur le blé, le seigle ou l'orge. Au bout d'une quinzaine de jours éclosent les larves, connues sous le nom de "Vers blancs du blé "); chacune d'elles réunit, à l'aide de fils soyeux, un certain nombre de grains, de manière à former un abri dans lequel elle se loge, pour ronger les grains extérieurement. Ces larves subissent la nymphose dans les grains évidés ou dans les fentes des planchers. On s'en débarrasse par des pelletages répétés, qui les écrasent.

Au même genre appartiennent: la Teigne des pelleteries $\{\boldsymbol{T}$. pellionella), dont les larves, souvent appelées Mites, passent l'hiver dans de petits fourreaux qu'elles se construisent aux dépens des étoffes ou des fourrures; la Teigne des tapisseries ( $\boldsymbol{T}$. tapezella), etc. La chenille blanche de $T$. cadaverina ronge les tissus des cadavres.

On range dans une tribu voisine la Sitotrogue des céréales (Sitotroga cerealella), plus connue sous le nom impropre d'Alucite. Ce Papillon fréquente les greniers à grains, comme la Teigne dont nous venons de parler; on le trouve nème parfois dans les champs de céréales. La femelle fécondée dépose ses œufs rouges sur les grains ou sur les glumes et glunelles des épis de blé, seiøle,

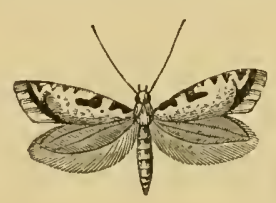

Fig. 592. - Alucile des céréales (Sitotrogı cereulellaj.

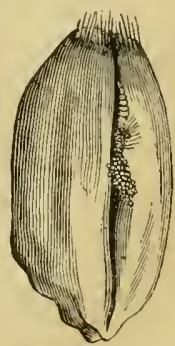

Fig. 593. - Chenille de JAJucite se disposant à pénétrer dans le grain.

orge, avoine ou maïs. Après quatre à huit jours, les larves gagnent le milieu du sillon qui existe souvent sur l'une des faces du grain, puis pénètrent dans l'intérieur et dévorent l'albumen, sans attaquer l'écorce. Elles se filent un cocon sur place pour subir la nymphose. - L'Alucite fut introduite en France, dans la Saintonge, vers 1750 ; elle s'est étendue dans tout le centre et le sud-ouest de la France. Pour détruire ces Insectes, dont les ravages sont considérables, llerpin a proposé, soit l'emploi de gaz délétères ou la privation d'air, de facon à les asphyxier, soit l'action de la chaleur, soit l'usage d'instruments, tels que le tue-teigne de Doyère, dans lesquels le grain est soumis à des chocs mécaniques.

L'Hyponomeute du prunier (IIyponomeuta padella) produit des ravages considérables dans l'Agrenais; celui du pommier $(H$. malinella) est redouté en Normandie; tous deux rongent le feuillage. 
Parmi les PYRALIDÉS, nous devons une mention aux Fausses-Teignes de la cire, qui pénètrent dans les ruches, dont les chenilles rongent les rayons. On en reconnait deux espèces: la plus commune et la plus redoutable est la grande Teigne (Galleria mellonella, tig. 607), l'autre est assez rare (Achroa grisella, fig. 606). - La larve de la Teigne des graisses (1 1 glossa pinguinalis) vit de graisse, de beurre, de lard. Elle pénètre quelquefois dans le tube digestif de l'Homme, ainsi qu'on l'a constaté plusieurs fois depuis linné. - La Pyrale dite de la farine (Pyralis on Asopia farinalis) vit dans les maisons; elle sert d'hòte intermédiaire à l'Hymenolcpis diminutu (voy. p. 296).

Les TORTRICIDES compremnent anssi quelques espèces intéressantes. Telle est la Tordeuse de la vigne (Tortrix Pilleriana), plus connue sous le nom de Pyrule. Le Papillon vole au mois de juillet dans les vignes; la femelle dépose ses œufs, réunis par plaques verlatres, ì la face supérienre des feuilles ; les chenilles, qui éclosent au bout de huit à dix jours, cherchent aussitòt un gite où elles se filent un cocon pour s'abriter et passer l'hiver. Au mois de mai suivant, elles grimpent sur les bourgeons, qu'elles rongent, ainsi que les feuilles et les fleurs qui en naissent. La Pyrale est donc pour les vignes un ravageur assez dangereux. Le moyen de destruction réputé le meilleur jusqu'à ce jour est l'échauduge, qui consiste à asperger les ceps avec de l'eau bouillante ou tout autre ingrédient capable de tuer les chenilles. - La Cochylis ou Teigne de la grappe (Cochylis ambiguella), dont la chenille, dite "Ver rouge " où "Ver de la rendangen, s'attaque aux fleurs et aux grains, cause parfois aussi des pertes assez sérieuses. - Le "Ver des fruits ", qu'on trouve assez communément dans les pommes, n'est autre que la chenille tordeuse des pommes (Carpocapsa pomonella) : on conçoit qu'il puisse passer parfois dans le tube digestif de l'Homme. Dounon l'a vu, dans un cas, occasionner une diarrhée rebelle. - La chenille du Grapholita funebrana vit de même dans les prunes, etc.

Les PHALÉNIDÉS sont remarquables par le singulier mode de progression de leurs chenilles, qui a valu à celles-ci le nom de Gémétres ou Chenilles arpentertses. - Celles de la Phalène hyémale (Cheimatobiu. brumata) rongent les feuilles et les fleurs du poirier.

Les NOCTUIDÉS comprennent beaucoup d'espèces nuisibles aux végétaux; les larves d'un grand nombre d'entre elles sont redoutées des cultivateurs et des jardiniers sous le nom de Versyris, - Citons: la Noctuelle du chou (Hamestra brassicx), dont la chenille s'introduit quel quefois dans

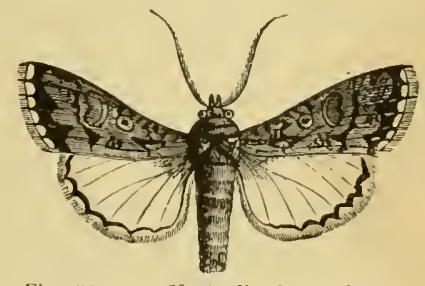

Fig. 594. - Noctuelle des moissons (Agrotis segetum). l'estomac; la Noctuelle des lourrages (Neuronia popularis), qui a ravagé, en 189.', les pàturages du Nord et de l'Aisne; la Noctuelle du gramen (Charæas graminis); la Noctuelle des moissons (Agrotis segetum), très commune et très dangereuse, son Ver gris attaquant les betteraves, choux, semailles d'automne, etc. En Australie, les indigènes mangent l'Agrotis infusa, connu sous le nom de Bugong, après avoir arraché les ailes. 
Les BOMBYGIDÉS ont un corps épais et velu; la spiritrompe est presque toujours rudimentaire ou nulle; les antennes sont pectinces chez les måles; les ailes sont en toit au repos. Toutes les chenilles filent un cocon pour subir la nymphose.

Parmi les nombreuses sous-familles de ce grand groupe, il convient de mentionner tout d'abord celle des LITHosinEs, avec son genre principal Lithosia, dont une espèce, $L$. caniola, habite les maisons et les édifices publics, même dans Paris; sa chenille vil en mai sur les lichens des toits et des nurailles. A Venise et à Padoue, on signale dans les mêmes conditions L. griseola.

A la sous-famille des LIPARINÉs se rattachent les genres Liparis, Cnethocampa, Orgya, Dasychira, dont les chenilles rongent les feuilles de nos arbres fruitiers et forestiers.

Dans le genre Liparis, nous citerons en particulier la Nonne (L. [Psilura] monacha), la Spongieuse (L. dispar), le Cul-brun (L. [Porthesia] chrysorhxa), le Cul-jaune (L. [Porthesia] similis ou auriflua). La chenille du Cul-brun est le principal ravageur de nos arbres fruitiers, et c'est elle surtout que vise la loi sur l'échenillage; mais c'est en plein hiver qu'il importe d'en détruire les nids.

Les Processionnaires (Cnethocampa) sont ainsi nommées en raison de la manière dont leurs chenilles, qui vivent en société dans des nids, sortent le soir de ces nids pour se répandre sur l'arbre qui les porte et en ronger les feuilles, ou pour s'établir ailleurs au moment des mues : une première dirige la marche et se trouve suivie d'une file d'abord simple, puis double, puis de rangées de plus en plus nombreuses, comptant jusqu'à huit chenilles, rapprochées des précédentes jusqu'à les toucher. On en connaît trois espèces européennes: la Processionnaire du chêne ( $\mathrm{Cn}$. processionea), commune aux environs de Paris, la Processionnaire des pins $(C n$. pityocampa), répandue dans le midi de la France ( $\pi$ เ $v e x x \mu \pi n$ des auteurs anciens), et la Processionnaire des sapins ( $C n$. pinivora), d'Allemagne, de Suède et de Russie.

La sous-famille des BomByarnés nous offre principalement les genres Bombyx et Gastropacha, dont le premier a souvent été démembré. On y rapporte la Livrée (B. [Clisiocampa] neustria), dont la femelle colle ses œufs en bague, par quatre ou cinq cents, autour des branches des arbres fruitiers; de ces œufs sortent, après l'hiver, des chenilles qui rongent les jeunes feuilles. Le Bombyx du trèfle (B. trifolii) donne une chenille qui vit en mai et juin sur les trèfles et les luzernes. Celle du Bombyx de la ronce (B. rubi) est connue sous le nom d'anneau du diable, car elle se roule en cercle dès qu'on la touche; elle attaque les ronces, les trèfles, les laiches, etc.

Les chenilles de divers Bombycidés sont revêtues de poils très fins qui se détachent facilement et déterminent une violente urtication lorsqu'ils parviennent sur la peau de l'Homme ou des animaux, ou qu'ils pénètrent dans son épaisseur. Les auteurs anciens, médecins (Galien, Dioscoride, Paul d'Égine, etc.) et vélérinaires (Hiéroclès) connaissaient l'action venimeuse de ces chenilles ( $x \dot{\alpha} \mu \pi \alpha$ เ ou erucx), el 
les empoisonneurs de l'ancienne Rome (pityocampa propinatores) étaient répulés faire usage des Processionnaires du Pin, puisqu’on en vint à promulguer une loi contre eux. Dioscoride leur donnait le nom

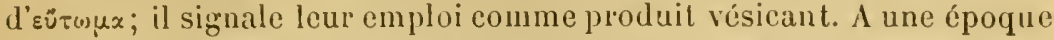
plus rapprochée de nous, Réammur, Bonnel, Geoffroy, Dorthes, puis Nicolai, Gurlt et Liilhens, Ch. Morren, Pourquier, Goossens, etc., ont rapporté à leur sujet une foule d'observations et d'expériences intéressantes.

Le tégument de certaines de ces chenilles renferme, au niveau do: l'hypoderme, des glandes unicellulaires qui s'atténuent en col et vont déboucher à la surface de la cuticule, par un orifice surmonté d'un poil creux et rigide : ces glandes contiennent de l'acide formique très concentré, que les poils inoculent en se brisant dans la peau.

Chez la chenille du Cul-brun (Liparis chysorrhxa). Goossens a reconnu que cette inoculation n'est pas nécessaire. 11 existe à la face dorsale des neuvième et dixième anneaux deux taches rouges arrondies, dont le centre est occupé par un grand nombre de petits tubercules percés chacun d'un étroil orifice. Si l'animal est inquiété, ces taches s'élèvent en forme de cône et les tubercules laissent perler des gouttelettes de liquide: celui-ci s'attache aux poils qui entourent chaque tubercule, puis se dessèche et devient pulvérulent. Si on dépose un peu de cette poussière sur la peau de la main préalablement humectée, on ne tarde pas à ressentir de vives démangeaisons. - Les mêmes faits s'observent avec Liparis dispar' et $L$. auriflua.

Chez les chenilles des Processionnaires, chaque anneau est muni, dans sa région dorsale, de boursoullures glanduleuses dont le produit de sécrétion se résout en une poussière brune impalpable qui s'attache aux poils voisins. Un peu de cette poussière, prise sur Cnethocampa processionea, détermine sur la main mouillée un prurit intense. En opérant avec la poussière de $C n$. pityocampa, Goossens éprouva de violentes démangeaisons non seulement aux mains, mais aux bras et aux jambes, en même temps que survenait un gonflement douloureux de la face. Les nids sont encore plus urticants que les chenilles, car ils renferment de nombreuses peaux de mues, desquelles se détachent aisément les poils chargés de poussière irritante.

D'autres chenilles jouissent des mêmes propriétés, par exemple celles de Bombyx rubi et de $B$. quercus, de Lithosia caniola et de L. griseola, cette dernière élant redoutée en Italie à l'égal des Scorpions.

Ces Insectes sont beaucoup plus répandus encore dans l'Amérique tropicale (Schomburgk). En Afrique, dans le pays des Bavenda, au nord du Transvaal, il existe également une chenille que les indigènes nomment Khohe et qui, mélangée aux fourrages, peut occasionner la mort des animaux domestiques.

En dehors des conditions expérimentales, les accidents occasionnés par les chenilles urticantes s'observent surtout chez les ouvriers qui 
travaillent dans les forêts de chênes ou de pins, chez les individus qui s'endorment sous ces arbres, chez les enfants qui jouent à leur ombre, etc. En 1866, on dut interdire la circulation dans certaines allées du bois de Boulogne, par suite de la grande abondance des Processionnaires du chêne. Les accidents dont il s'agit se présentent, d'une manière générale, avec les caractères que nous avons indiqués ci-dessus; on peut observer des éruptions vésiculeuses étendues, des taches rouges disséminées, le tout accompagné parfois d'accès de fièvre. On a vu survenir en outre des ophtalmies plus ou moins violentes, pourant se manifester à la fois sur un grand nombre de sujets (Wagenmann).

Des troubles beaucoup plus sérieux encure s'observent chez les animaux qui fréquentent des pâturages infestés par les chenilles, ou qui recoivent des fourrages recueillis dans de tels endroits. On a signalé, chez les Chevaux, Bœufs, Moutons, Chèvres et Porcs, des éruptions très douloureuses, rendant parfois les animaux furieux, des ophtalmies, des angines, des gastro-entérites pouvant entraîner la mort. Le plus souvent, cependant, la consommation de fourrages renfermant des chenilles ou des poils urticants détermine une simple stomatite ou une pharyngite qui disparaît en quelques jours si l'on en fait cesser la cause. - Chez les Poules et les Canards, qui avalent gloutonnement les chenilles, on observe aussi, d'après Zürn, des entérites assez graves. Les Coucous seuls font impunément la chasse à ces Insectes.

Dans la sous-famille des ENDRomanes, les antennes sont pectinées chez les mâles et chez les femelles, mais les dentelures sont beaucoup moins accusées dans ces dernières. Les ailes sont étendues, marquées d'une tache discoïdale.

Au genre Séricaire (Sericaria E. Blanch., nec Latr.) appartient le Ver à soie du mûrier (S. mori [L.]), dont tout le monde connait le papillon d'un blanc jaunàtre, à ailes faibles, peu propres au vol. La chenille, ou Ver à soie proprement dit, est glabre et blanclıâtre à maturité ; elle porte sur l'avantdernier anneau une corne étroite, recourbée en arrière.

Elle possède une paire de glandes séricigènes, en forme de tubes pelotonnés, occupant une grande partie de la longueur du corps, sur les còtés du tube digestif. Chacune de ces glandes se continue en avant par un tube plus grêle (filière) qui se réunit bientôt à son congénère. Le canal unique ainsi formé aboutit à un orifice très étroit percé dans la lèvre inférieure: c'est par cet orifice que sort le fil de soie avec lequel la chenille construit son cocon.

Nous ne connaissons le Ver à soie du mûrier qu'à l'état domestique. Cependant, l'abbé David assure qu'il existe encore à l'état sauvage dans certaines forêts de l'intérieur de la Chine, où croît spontanément le mùrier blanc.

L'ensemble des opérations qui ont pour but la production de la soie constitue l'industrie séricicole ou sériciculture (sericum, soie). L'étude spéciale des questions qui s'y rattachent est souvent appelée bacologie, du nom italien 
du Ver à soic (baco da seta). Dans le midi de la France, cet Insecte recoit le nom de magnan, et l'on appelle magnancries les établissemenls où on l'élève, magnuniers les industriels qui en dirigent I'exploitation. - On sait d'ailleur's que l'éducation du Ver à soie est liée à la culture du muirier, et en particulier du mirier blane (Morus alba).

Les æufs, qui portent daus le commerce le nom de graine le Ver à soie, ont été pondus sur le petits carrés de lainc, de toile ou de fort papier, anxquels ils demeurent adlérents. On les conserve à une tempéralure assez basse, de manière à retarder l'éclosion jusqu'à ce que les feuilles de mùrier soient bien développécs. Au moment convenable, on les soumet ì une incubation artificielle. La petite chenille qui sort de l'ouf est noiratre; elle mesure environ 2 millimètres de longueur. Elle doit subir, en général, quatre mues : les périodes de l'existence séparées par des mues recoivent le nom d'ages. A la température de $19^{\circ}$, le développenent de la larve exigeant trente-deux jours, le premier àge comprend cinq jours, le deuxième quatre, le troisième six, le quatrième sept, le cinquième dix. Chaque mue

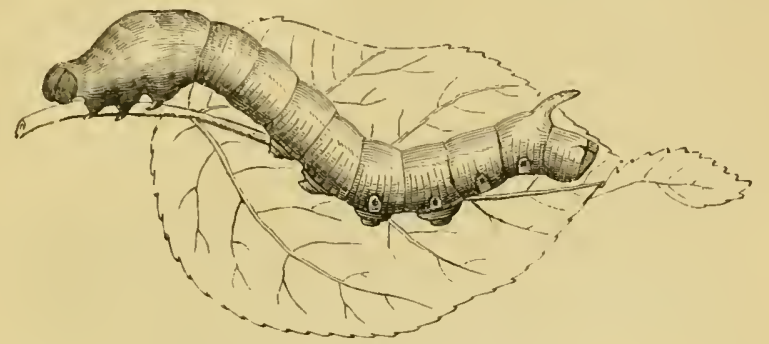

Fìn. 59 วั. - Ver à soie du mürier.

dure environ vingt-quatre heures : pendant qu'elle s'effectue, la larve perd l'appétit et le mouvement. Au contraire, daus la période qui précède, la faim paraît insatiable : c'est ce qu'on appelle la frèze ou fringale. Au septième jour du cinquième àge, cette voracité devient extraordinaire (grande frèze ou briffe) : c'est à cette époque surtout que s'élabore dans les glandes séricigènes la substance destinée à fournir la soie. A la fin de cet àge, le Ver à soie est blanc jaunàtre, translucide; il cesse de manger, dresse la tête et cherche à grimper sur les corps placés à sa portée (montée). Il commence alors à déposer en quelques points des fils grossiers, destinés à former la charpente de son cocon. La construction de celui-ci exige trois ou quatre jours, au bout desquels le Ver à soie subit sa première métamorphose ( $5^{\circ}$ mue) et passe au sixième âge, représenté par l'état de chrysalide.

La phase chrysalidaire dure quinze à vingt jours; puis, survient la seconde métamorphose, qui s'accomplit lors de la cinquième mue et fait passer l'Insecte au septième àge, c'est-à-dire à l'état de papillon. Celui-ci ramollit la soie à une extrémité du cocon, au moyen d’une sécrétion particulière, puis il en écarte les brins et se fraye un passage. L'accouplement et la ponte s'effecluent peu de temps après. Il peut arriver que les œufs des femelles vierges soient féconds.

Les cocons dont l'Insecte s'est échappé ne sont plus guère utilisables, à cause de la faiblesse du fil dans les points mouillés. Aussi cherche-t-on à 
faire périr au préalable les chrysalides : on les étouffe d'ordinaire au moyen d'un courant d'air chaud. Dès lors, le cocon appartient à l'industrie, qui en tire la soie pour la fabricalion des tissus.

Les Vers à soie sont exposés dans nos pays à diverses maladies, qui sévissent souvent à l'état épizootique. Sans parler de la touffe, accident de nature asphyxique qui se manifeste pendant les grandes chaleurs, on a décrit un grand nombre de ces maladies, que Pasteur ramène à quatre principales : la grasserie, la muscardine, la pébrine et la flacherie.

La grasserie ou jaunisse consiste dans une sorte d'infiltration huileuse du corps, survenant en général pendant le troisième âge et attribuée aux émanations putrides. Il faut éviter de laisser manger les cadavres des Vers par les Poules, car celles-ci seraient empoisomnées. - On rapproche de cetle affection la luizettc ou clairène, dans laquelle les Vers filent sans coconner et sont appelés pour cela " tapissiers ". On les utilise alors en les faisant macérer dans du vinaigre, pour étirer ensuite le liquide des glandes séricigènes, ce qui donne les " crins marins " ou "fils de Florence ".

La muscardine est une affection plus grave, de nature parasitaire. Les Vers atteints filent leurs cocons, mais périssent dans l'intérieur, sans se putréfier toutefois. Le parasite est un champignon (Botrytis bassiana), qui, après la mort de l'Insecte, se fait jour à travers les stigmates et forme une efflorescence blanchàtre à la surface du corps. On se débarrasse de cette maladie par une désinfection sérieuse de la magnanerie.

Deux autres maladies beaucoup plus graves ont commencé à se manifester avec un caractère épidémique vers l'année 1840. On les confondait d'abord sous le nom de maladie des Vers à soie, et c'est en 1867 seulement que Pasteur a démontré qu'il s'agissait de deux affections distinctes, la pébrine et la flacherie (1). - La pébrine ou gattine se traduit à l'extérieur par des taches couleur de bitume, qui s'étendent peu à peu sur le dos, le ventre et les flancs. Les Vers perdent leur activité et leur appétit, puis s'atrophient et souvent finissent par mourir, même avant de s'ètre transformés en chrysalides. Les cadavres se momifient, mais ne présentent pas d'efflorescence. Lorsque des Vers malades produisent des papillons, ceux-ci sont eux-mèmes tachés et se montrent tonjours faibles. Cette maladie est due à la présence, dans le sang et dans tous les lissus, de corpuscules ovoïdes, brillants, d'une extrême petitesse $\{4 \mu$ de long sur 2 de large), découverts en 1859 par Guérin-Menneville et connus sous le nom de corpuscules de Cornalia. Balbiani a démontré que ces corpuscules ne sont autres que des Psorospermies (Nosema bombycis) (voy. p. 160). Lorsqu'on en fait ingérer à des Vers sains, on ne tarde pas à constater, dans les cellules épithéliales et dans les tuniques musculaires de l'intestin, de petites masses protoplasmiques qui s'accroissent assez rapidement. Puis on voit apparaitre dans ces masses des globules pàles qui grossissent et prennent une forme ovalaire ou pyriforme : ce sont de jeunes spores. Au bout d'un temps assez long, ces spores ont pris plus de consistance, présentent l'aspect de corpuscules ovoïles brillants, et, après avoir absorbé toute la gangue protoplasmique, se disséminent dans l'organisme; elles sont alors mûres et reproduisent bientòt de nouvelles masses de protoplasma. Celles-ci ne sont formées en effet que par le contenu des

(1) L. Pasteur, Études sur la maladie des Vers à soie. Paris, 1870. - H. Bouley, Le progrès en médecine par l'expérimentation. Paris, 1882, p. 539. 
spores, qui s'échappe ì la faveur d'une ouverture percée à l'un des pòles. Ces dangereux parasites se transmettent des Vers malades aux Vers sains, par le simple contact ou même à distance; de plus, ils passent du corps de la mère dans les œufs, de sorte que l'embryon est infecté dès sa formation. - Pour combattre cette redoutable maladie, Pasteur a imaginé une méthode dite grainuge ccllulaire, qui a donné d'excellents résultals. On fait accoupler les papillons sur des carrés de toile, puis on laisse la ponte s'effectuer sur place, et on enferme ensuite la femelle dans un coin du carré replié et maintenu à l'aicle d'une épingle. L'hiver, alors que la suspension des travaux le permet, on exanine au microscope, i un grossissement de 300 diamètres environ, le corps de ces papillons, broyé avec un peu d'eau. Cet examen est des plus simples et souvent confié à des femmes ou à des enfants. On rejette on l'on met à part les pontes des individus corpusculenx.

La fachorie est beancoup plus difficile à vaincre. Elle se manifeste d'une façon brusque, au moment de la montée. Les Vers perdent l'appétit, demeurent immobiles et ne tardent pas à mourir : peu après, leur corps devient mou, flasque et se pourrit en prenant une teinte noiràtre. Lorsque la maladie est peu accusée, elle permet cependant la métamorphose. Cette maladie consiste dans un trouble digestif dù à la fermentation de la feuille du mûrier : on retrouve, en effet, dans le canal intestinal, les mèmes organismes que dans un liquide où l'on a fail macérer cette feuille. Ce sont des bactéries de diverses sortes, et en particulier un " ferment en chapelet " auquel on a donné le nom de Microccocus bombycis Cohn. Ce Microcoque apparait de bonne heure et semble jouer un ròle essentiel dans le développement de la maladie. - Pour éviter cette affection, Pasteur conseille d'examiner les Vers au moment de la montée et d'exclure de la reproduction la graine de ceux qui manquent de vigueur à ce moment. On a constalé, en effet, que l'affaiblissement causé par la flacherie se transmet par hérédité et constitue par suite une cause prédisposante : le Ver flat engendre des Vers prédestinés à la flacherie.

La sous-famille des SATURNINÉs comprend les plus grandes et les plus belles espèces de Papillons; leurs larges ailes sont étendues à plat dans le repos, et chacune d'elles offre vers le milieu une tache vitrée, entourée de diverses colorations.

Les Saturnies (Suturnia Schrank, Attucus L.) présentent un intérèt particulier au point de vue de l'industrie, en ce sens qu'un certain nombre de leurs espèces, provenant de l'extrème Orient, ont été importées en Francrs, sans succès il est vrai, dans le but de foumir de la soie et de compenser en partie les pertes résultanl des maladies du Ver à soie commun. Telle est d'abord la Saturnie du chène du Japon (S. Yamu-mai), espèce rustique et univoltine (une seule génération par an), dont le cocon se rapproche beaucoup de celui du Bombyx mori; on a pu l'élever en plein air, dans des taillis de chène, aux environs de Paris. - La Saturnic du chène de la Chine (S. Pernyi) ressemble beaucoup à la précédente, mais elle donne deux générations par an, ce qui est un grave inconvénient pour notre pays, car il est très difficile de mener à bien la génération d'automne.

La Salurnie du chêne de l'Inde (S. Mylittu) est encore une espèce du 
mème sous-genre; elle appartient malheureusement à une région trop chande pour que son acclimatation puisse offrir quelques chances de succès. - On a voulu encore introduire en France deux espèces d'un autre type : l'une, la Saturnie de l'ailante (S. Cynthia), propre à la Chine: l'autre, la Saturnie du ricin (S. Arrindia), originaire de l'Hindoustan; pour divers motifs, leur éducation a dù être abandonnée, et elles n'ont plus pour nous qu'un intérèt historique.

Au même genre appartiennent les beaux Papillons européens connus sous le nom de Paons de nuil: le grand Paon (S. Pavonia major L. ou S. pyri Borkh.) et Je petit Paon (S. P. minor L. ou S. carpini Borkh.).

Les SPHINGIDES ont été longtemps nommés Papillons crépusculaires, quoique certains d'entre eux voltigent aussi pendant le jour. Ils sont remarquables par leur trompe énormément développée.

Signalons, dans ce groupe, les Macroglosses (Macroglossa), les Sphinx (Sphinx), les Achéronties (Acherontia). Le fanteux Sphinx Tète-de-mort (Acherontia Atropos), dont le corps est si volumineux, possède une trompe fort courte, et offre sur le thorax un dessin qui représente assez bien un cràne humain. Sa chenille est la plus forte que nous ayons en Europe; elle s'attaque surtout aux feuilles des Solanées, et en particulier à celles de la pomme de terre. Le papillon nuit aux ruches, dans lesquelles il pénètre pour se gorger de miel.

SECOND SOUS-ORDRE

RIIOPALOCÉRES

Duméril a établi ce groupe pour toutes les espèces dont les antennes sont plus ou moins renflées à leur extrémité (ṕóràov, massue). Ces Insectes ne volent que le jour, et leurs ailes affectent, au repos, une
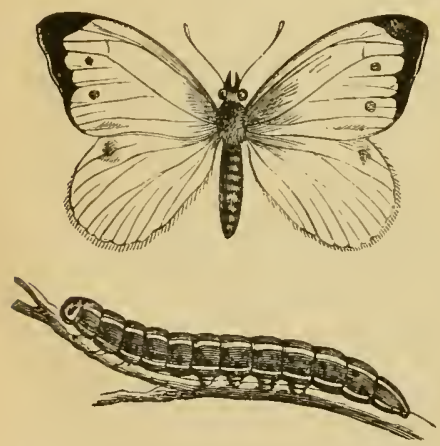

Fig. 596. - Piéride du chou et sa chenille. position verticale. Ce sont les Achalinoptères d'Émile Blanchard, les Diurnes des anciens auteurs.

Les principales familles de ce sousordre sont les Hesperidx, les Nymphalidx, les Lycenidx et les Papilionillx.

Nous signalerons seulement, parmi les PAPILIONIDÉS, les Piẻrides (Pieris), dont plusieurs ont des chenilles redoutées des agriculteurs : Piéride du chou (P. brassicæ) ou grand Papillon blanc du chou; Piéride de la rave (P. rapx $x$ ) ou petit Papillon blanc du chou; Piéride du navet (P.napi), ou petit Papillon blanc veiné de vert; les chenilles de ces diverses espèces dévorent les feuilles des Crucifères. - Les Papillons proprement dits (Papilio) offrent plusieurs espèces remarquables: grand Porte-queue (P. Machaon), et grand Flambé (P. Podalirius), de nos pays; P. Memnon (P. Mem- 
non), de la région indo-malaise : ce dernier est remarquable en ce qu'il présente trois formes distinctes de femelles, qu'on prenait autrefois pour autant d'espèces.

\section{QUITRIEME ORDRE}

\section{IIYMÉNOPERES}

Insectes lécheurs; quatre ailes membraneuses; mélamorphoses complètes.

L'appareil huccal de ces Insectes offre une constitution intermédiaire entre celle des broyeurs et celle des suceurs: il est propre à lécher. La lèvre supéricure et les mandibules sont conformées comme celles des broyeurs; au-dessous, se trouve un organe mobile, pouvant se replier sous la tête : c'est la trompe, formée par les mâchoires aplaties qui engainent la lère inférieure. Celle-ci offre une languette souvent très longue, divisée en trois lobes, dont les deux latéraux ou paraglosses sont d'ordinaire beaucoup plus courts que le médian ou languette proprement dile. Les palpes maxillaires ont un aspect variable; les palpes labiau. sont longs et aplatis. Par suite de cette organisation de la bouche, on concoit que les Hyménoptères puissent, au moyen de leurs mandibules, entamer des corps durs (Guêpes), et, à l'aide de leur languette, lécher les liquides sucrés au fond des lleurs (Abeilles) ou sur des surfaces planes (Fourmis).

Les ailes sont au nombre de quatre, membraneuses (ưứr, membrane; $\pi \tau$ osiv, aile), à nervures peu nombreuses; pendant le vol, les postérieures, plus petites, sont réunies aux antérieures par de fins crochets situés à leur bord externe.

Les métamorphoses sont complètes. Rarement les larves vivent en liberté : elles possèdent, en pareil cas, outre les patles thoraciques écail-

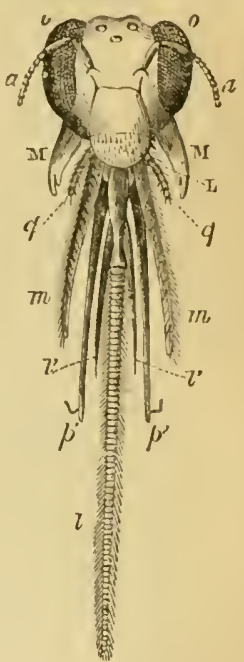

Fig. 597. - Tète d'un Hyménoplère (Anthoplıore). $-a$. antemes.o, yeuxả ficelles, entre lesquels on voit trois ocelles. L, labre. M, mandibules. $m$, machoires avec leurs palpes $q \cdot l$, languetle, avec ses lolses latéraux ou paraglosses $l^{\prime} \cdot p^{\prime}$, jalpes labiaux. leuses, six ou huit paires de pattes abdominales, ce qui leur a valu le nom de fausses-chenilles. La plupart, au contraire, sunt apodes et vivent enfermées dans des galles, dans le corps d'autres Insectes ou dans des sortes de nids. Les nymphes sont inactives, presque toujours cachées dans des eocons soyeux ou papyracés.

Les Hyménoptères occupent sans contredit le premier rang parmi les Insectes, quant à l'élération des facultés intellectuelles. Nous 
aurons du reste à citer quelques faits à cet égard, et à montrer, en particulier, l'admirable prérnyance dont témoignent les femelles dans l'éducation des larves.

\section{2 sous-ordres:}

Femelles pourvues d'une tarière........... Térébrants.

- $\quad$ à aiguillon venimeux............. Porte-Aigulloon.

PREMIER SOUS-ORDRE

\section{TÉRÉIRANTS}

Chez les femelles de ce groupe, l'oviducte est prolongé par un oviscapte saillant ou rétractile, qui sert à déposer les œufs en lieu convenable. On a partagé les Térébrants en trois grandes sections.

10 Les Phytophages ou Porte-Scie sont les seuls Ilyménoptères qui aient I'abdomen sessile, c'est-à-dire non rétréci en avant. Leurs larves ou fausseschenilles vivent en liberté sur les feuilles ou dans les tiges. Plincipaux genres: Tenthredo, Hylotoma, Sirex, Cephus. Certains Sivex perforent le plomb et d'autres métaux. La femelle du Céphus du chaume (C. pygmæus) perce la tige des céréales à l'aide de sa tarière et y dépose un ouf, duquel sort une larve qui dévore la paroi interne. L'épi se flétril alors et souvent reste stérile.

$2^{\circ}$ Les Galdicoles ne comprennent que la seule famille des Cynipides. Les femelles de ces Insectes perforent les végétaux pour y déposer leurs œufs; après l'éclosion de la larve, il se manifeste au point piqué une irritation qui détermine un afflux de sucs végétaux et aboutit à la formation d'une excroissance à laquelle on donne le nom de galle.

On connaît de nombreuses sortes de galles, car celles-ci peuvent varier suivant l'espèce d'Insecte qui les produit, le végétal qui les nourrit et mème l'organe sur lequel elles se développent.

Les plus importantes sont les Gulles de chéne ou Noix de galle, qui résultent de la piqùre du Cynips gallæ tinctorix sur les bourgeons d'un cliène de l'Asie Mineure, le Quercus lusitanica var. infectoria. La larve se nourrit surtout de l'amidon contenu au sein de la galle; au bout de cinq à six mois, l'Insecte parfait se creuse un chemin cylindrique jusqu'à la surface et s'envole. Ces galles se trouvent dans le commerce sous la forme de corps globuleux ou pyriformes, recouverts d'aspérités vers la partie supérieure. Elles sont lourdes et d'un vert foncé (galles vertes ou noires) quand la larve, incomplètement développée, est encore contenue dans leur intérieur; elles sont, au contraire, beaucoup plus légères et de teinte pàle (galles blanches) quand l'Insecte s'en est ėchappé : dans ce dernier cas, elles ont perdu de leur astringence et sont moins estimées. - On en distingue deux sortes commerciales : $1^{0}$ les Galles d'Alep, de la grosseur d'une noisette, lourdes, vert foncé, avec très peu de galles blanches; $2^{\circ}$ les Galles de Smyrne, plus grosses, pàles, légères, comprenant beaucoup de galles blanches, et, par suite, de qualité inférieure. Les Noix de galle doivent leur emploi si répandu, en mé- 
decine et dans l'industrie, à la proportion considérable de tannin (acide gallotannique) qu'elles renferment : 60 à 70 pour 100 suivant les sortes.

Nous pouvons citer encore : la petite Galle couronnée d'Alep, souvent mèlćc aux Galles d'Alep et provenant de la piquure des jeunes bourgeons par te Cynips polycera; la Galle de Hongrie, résultant de la piqùre du Cynips calicis sur la cupule du gland du chène commun; etc.

Quant aux Bédegurs, ce sont ces galles moussues et chevelues, vertes et rouges, qui se développent sur les rosiers, et en particulier sur l'églantier (Rosa canina), à la suile de la piqùre du Rhodites rosx. On a longtemps attribué à ces productions d'importantes propriétés médicinales; elles sont simplement un peu astringentes.

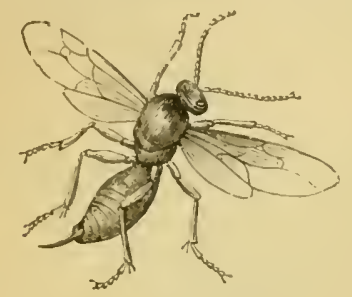

Fig. 598. - Cynips des Bédegars (Rhodites ros $x^{2}$.

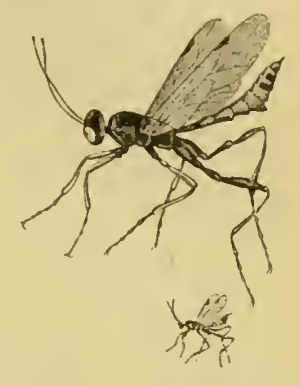

Fig. 599. - Pristomerus calcitralor.

$3^{\circ}$ Les Extomophages sont remarquables en ce que les femelles déposent leurs œufs dans le corps d'autres Insectes, et, en général, des chenilles ou des fausses-chenilles. Les larves qui sortent de ces œufs dévorent leur hòte lambeau par lambeau, en ménageant sa vie le plus longtemps possible. Ce sont donc des animaux essentiellement utiles à l'agriculture. Parmi les principaux genres, on peut citer les Ichneumon, Ophion, Pimpla, Vicrogaster, Bracon, Chalcis, etc. D’après Mariage, l'Ichneumon Panzeri délruit un cinquième environ des chenilles de la Noctuelle des moissons (Agrotis segetum). E. Blanchard a vu le Nicrogaster glomeralus détruire 197 chenilles de Piérides du chou sur 200 qu’il avait recueillies. Le Pristomerus culcitrutor. (fig. 599) est parasite du Céphus du chaume.

\section{SECOND SOUS-ORDRE}

\section{PORTE - A I G UILLON}

Au lieu d'un oviscapte, les femelles de ce sous-ordre possèdent un aiguillon, qui est toujour's caché au repos et accompagné de glandes vénénifiques; c’est une arme souvent offensive, (juelquefois seulemen t défensive. L’abdomen est pédiculé, c'est-à-dire rétréci au niveau du deuxième anneau. Les larves sont vermiformes, sans anus.

Les FORMICIDEs sont des IIyménoptères sociaux dont les colonies, connues sous le nom de fourmilieres, se composent de mâles et de femelles ailés, puis d'ouvrières aptères ou femelles avortées. Dans certaines espèces, pour la plupart exotiques, ces dernières se divisent mème en deux formes distinctes, les ouvrieres proprement dites, et les soldats, reconnaissables à 
leur tête volumineuse : ces noms indiquent suffisamment leur rỏle. Les femelles et les ouvrières sont quelquefois (Myrmicinés) munies d'un aiguillon à l'aide duquel elles se défendent. D'autres fois, l'aiguillon fait défaut (For'micinés), mais l'animal mord avec ses mandibules et recourbe en avant son extrémité abdominale pour déverser le liquide venimeux dans la blessure. Dans tous les cas, ce liquide n'est autre que de l'acide formique.

Les larves, toujours apodes, éclosent au printemps et sont nourries par les ouvrières. Au moment de la nymphose, elles se tissent souvent un cocon dans lequel elles passent à l'état de nymphes : c'est ce qu'on appelle vulgairement des oufs de Fourmis, produit très recherché pour la nourriture des Faisans. La plupart des nymphes donnent des ouvrières; les autres deviennent des femelles et des màles ailés, qui s'élèvent dans lesairs pour s'accoupler. Revenus ả terre, les màles périssent, tandis que les femelles perdent leurs ailes et tantôt sont ramenées par les ouvrières dans la fourmilière, oủ elles déposent leurs œufs, tantòt vont avec une partie de ces ouvrières fonder de nouvelles colonies.

Les maurs de ces Insectes, qui lémoignent de facultés intellecluelles très développées, ont été étudiées avec soin par d'illustres naturalistes; mais il nous est impossible d'en tracer mème une simple esquisse.

On a divisé les Formicidés en plusieurs tribus, qui comprennent de nombreux genres : Formica, Polyergus, Tetramorium, Myrmica, etc.

Les SPHÉGIDÉS ou Fouisseurs sont des sortes de Guèpes solitaires dont les femelles creusent dans le sol des nids destinés ả abriter leur progéniture. Ces femelles ont soin, en outre, de déposer près des larves

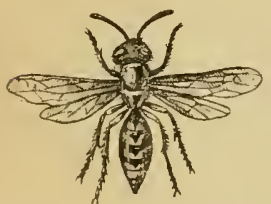

Fig. 600. - Philanthus apivorus. qui éclosent la nourriture qui leur convient, et qui consiste en Insectes d'espèces déterminées. Mais il importe que la provende se conserve sans s'altérer : pour cela, la Guèpe paralyse les seuls organes de la vie de relation, en perçant de son aiguillon lisse les ganglions antérieurs de la chaîne ventrale. On produit le mème effet lorsqu'on amène une gouttelette de quelque liquide corrosif sur les centres médıllaires thoraciqques. Fabre (d'Avignon) a publié sur ce sujet d'admirables études. - Genres Sphex, Ammophila, Bembex, Philanthus, Cerceris, Crabro, etc.

Les VESPIDÉS ou Guèpes sont surtout caractérisées par la disposition de leurs ailes antérieures qui, au repos, se plient suivant leur longueur et se placent sur les côtés de l'abdomen, sans en recouvrir la face supérieure. Les femelles sont armées d'un aiguillon défensif. Ces Insectes vivent de matières sucrées, mais nourrissent leurs larves d'autres Insectes.

Trois tribus : Masarinés, Euméninés, Vespinés.

Les deux premiers groupes se composent de Guèpes solitaires qui se comportent, les unes elı parasites (Masarıs), les autres à la facon des Fouisseurs (Eumenes, Odynerus, etc.).

Quant aux vespinés, ce sont des Guêpes sociales, comprenant des mâles, des femelles et des ouvrières ou femelles infécondes, tous ailés. Leurs nids ou guêpiers sont formés de substances végétales mâchées et imprégnées 
d'une salive riche en chitine ; ils se composent de rayons disposés horizontalement et offrant chacun un seul rang d'alvéoles, ourerts en bas. Les sociètés de (iuipes ne durent qu'une année. Les femelles fécoulées seules passent l'hiver en s'abritant dans les trous; au printemps suivant, elles fondent une nouvelle colonie.

Les Guèpes proprement dites (Vespn L.) sont souvent redoutées, tant à cause de l’ur piquiure que de l'avidité qu'elles manifestent pour les fruits. Leur aiguillon n'est pas barbelé comme celıi des Aheilles; il fléchit en s'enfonçaul daus la peau el détermine une douleur cuisante.

Le frelon ou Guèpe firelon ( $V$. Crabro L.) esi la plus grosse espèce du genre; il mesure 27 millimétres de long et se distingue assez facilement à la teinte rouggeàtre ıu'offre la moitié antérieure lu corps. Ilétablit son nid dans

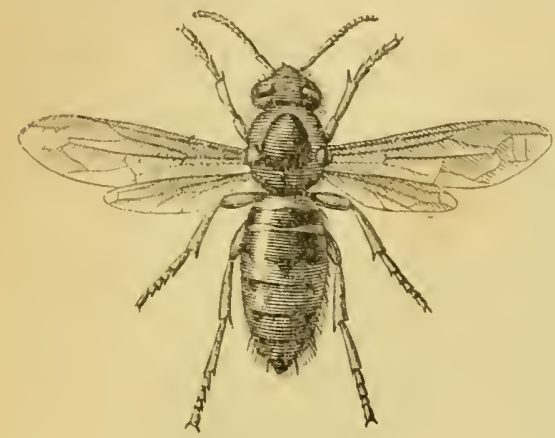

Fig. 601. - Frelon. les arbres creux, dans les ¿rreniers non fréquentés. Sa piquire est parfois sérieuse, mème chez les grands aniแกลแx.

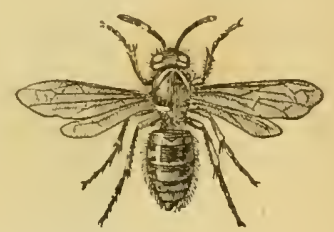

Fig. 602. - Gučpe.

La Guèpe commune (V.vulgaris L.) n'a que 18 nuillimètres de long; elle nidifie sous terre. Malgré sa petite taille, elle est aussi fort redoutable. Sa piquire est suivic parfois d'une enflure considérable, et les accidents sont naturellement beaucoup plus graves lorsqu'il s'agit de piqùres multiples. Cloquet cite des mulets qui, altachés près d'un guèpier, furent assaillis par l'essaim tout entier et succombèrent. On a observé aussi des cas mortels sur l'espèce humaine, mais la plupart résultent de piqưres faites dans l'arrièrebouche : la tuméfaction des tissus peut alors amener rapidement l'asphyxie.

On confond en général arec la Guèpe commune les autres espèces du genre Vespa: V. germanica, V. rufa, V. sylvestris, V. media; ces deux dernières établissent leur nid sur les arbres. Souvent mème on prend pour des Guèpes les Polistes (Polistes Latr.), dont une espèce bien commune est $P$. gallica. Une Poliste du Brésil, Nectarinia Lecheguana, fournit un miel parfois très vénéneux. Auguste de Saint-Hilaire en a éprouvé les fàcheux effets, ainsi que deux hommes qui l'accompagnaient.

Lorsqu'on a été piqué par l'une quelconque de ces Guèpes, il convient d'enlever d'abord l'aiguillon avec soin et d'appliquer ensuite sur la partie blessée des substances émollientes et calmantes.

Les APIDÉS ou Abeilles sont faciles à distinguer des Guèpes : leur corps est presque toujours velu; leurs ailes antérieures sont étendues et non pliées pendant le repos; les pattes postérieures des femelles ont en général la jambe et le tarse élargis et conformés pour la récolte du pollen. Presque

Ralluiet. - Zoologie. 
tous construisent des nids, et nourrissent leurs larves non seulement avec ce pollen, mais aussi avec du miel, ce qui les fait appeler quelquefois Melliféres. Comme chez les Vespidés, il en est qui vivent solitaires, d'autres qui forment des sociétés.

Les Apıós solitaires vivent par groupes qui ne comprennent que deux sortes d'individus, des mâles et des femelles. Ils ne produisent pas de cire.

Les uns (Apidés parasites ou Nomadinés), dépourvus de poils collecteurs du pollen, déposent leurs œufs dans les cellules d'espèces voisines, auxquelles elles ressemblent le plus souvent (mimétisme), et leurs larves se nourrissent aux dépens de la provision qui s'y trouve amassée : Nomadı, Melectu, etc.

Les autres ont les poils collecteurs diversement répartis, et sont divisés d'après cela en trois groupes. - Chez les Gastroléginés, c'est l'abdomen qui porte des poils courts, propres à brosser et à retenir le pollen : Chalicodoma,

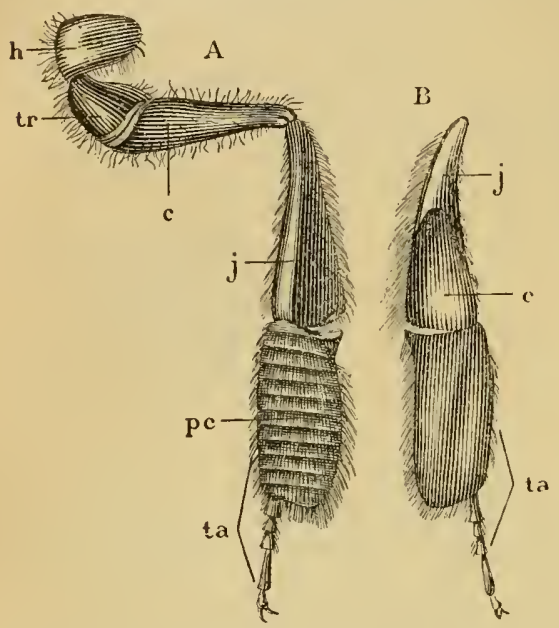

Fig. 603. - Patte postérieure droite diune ouvière. - A, face interne. B, face externe. $h$, lianclie. $t r$, trnclianter. $c$, cuisse. $j$. jambe avec sa corbeille $c$. $t a$, tarse, dont le premier article ou picee carrée $p c$ montre les rangées de poils constituant la brosse. Osmiu, Megachile. - Les Mériléginés ont lappareil collecteur reporté sur la cuisse, la hanche el les còtés de l'abdomen : Andrena, Halyctus, Colletes. - Enfin, les Podilégines ont la jambe et le tarse élargis, surtout aux patles postérieures, et disposés à peu près comme chez les Abeilles sociales, sauf l'absence de la pince tibiotarsienne : Anthophora, Eucera, Xylocopa.

Les APIdÉs socla ux comprennent trois sortes d'individus, tous ailés : màles, femelles et ouvrières ou femelles avortées. Ces dernières ont le tibia des pattes postérieures (fig. 603) élargi en triangle allongé (palette), et creusé, sur sa face externe, d'une faible cavité nommée corbeille, destinée à loger une bouletle de pollen que retiennent de longs poils implan-

tés sur les bords et constituant le râteatt. Le premier article du tarse, très développé (pièce carrée), est muni à sa face interne de rangées transversales de poils courts formant une sorte de brosse qui sert à rassembler le pollen. De plus, ce premier article du tarse est articulé avec l'angle interne du bord inférieur de la jambe, de manière à former avec celle-ci une pince destinée à saisir les lamelles de cire qui exsudent sous l'abdomen.

Les sociétés formées par ces IIyménoptères sont parfois limitées à une anıée, et d'autres fois ont une durée indéfinie. Les sociétaires annuels constituent la tribu des Bombinés; les sociétaires pérennes sont représentés par les Méliponinés el les Apinés.

Les Bombinés ou Bourdons (Bombus Latr.) ont le corps lourd et velu; leurs jambes postérieures sont armées de deux épines terminales.

Ils établissent leurs nids dans la terre. Leur miel est doux, très fin, mais 
peu abondant. Les femelles et les ouvrières sont pourvues d'un fort aiguillon, dont la piqùre est très douloureuse. B. muscorum, B. hortorum, B. terrestits.

Les MÉLIPoninÉs sont de petites Abeilles d'Amérique et d'Océanie, dont les femelles ne possèdent (qu'un aiguillou tout à fait rudimentaire : elles se défendent à l'aide de leurs puissantes mandibules.

Leur miel est souvent agréable, mais il peut ètre vénéneux. - Genres Melipona, Trigona.

Enfin, les apinés ou Abeilles proprement dites (Apis L.), qui, comme les Mélipones, ont les tibias postérieurs dépourvus des deux épines terminales signalées chez les bourdons, sont propres à l'ancien continent et représentent des Insectes mellifères par excellence. La femelle et les ouvrières sont munies d'un aiguillon.

L'Abeille commune (A. mellific L.), que tout le monde connait, constitue pour nous un Insecte des plus précieux, puisque, en raison de l'état de semi-domesticité dans lequel elle s'entretient, nous pouvons exploiter la cire dont clle fait son nid et le miel qu'elle amasse pour sa progéniture. Aussi devons-nous consacrer quelques pages à l'étude de ses mœurs et de son éducation.

A l'état sauvage, les Abeilles s'établissent dans les creux des arbres ou des rocher's; quand elles sont domestiquées, on les loge dans des ruches dont la disposition est rariable. Une bonne colonie peut comprendre 20000 à 50000 individus; la plupart sont des ouvrières ; il n'existe guère que 2000 à 3000 màles dits Faux-Bourdons et une seule femelle sexuée, connue sous le nom de rine ou de mère.

Les màles sout plus gros que les ouvrières, moins longs que la reine. Ils se reconnaissent tout d'abord a leur grosse tête circulaire, portant des yeux contigus supérieurement. Leur languette est courte; ils n'ont ni aiguillon, ni corbeilles, ni brosses. Leur seul ròle est de féconder la femelle.

La reine, uı peu plus grosse et beaucoup plus longue que les ouvrières, est de teinte plus fauve; elle n'a pas de corbeilles et ses brosses sont peu marquées; ses ailes sont plus courtes que l'abdomen; sa languette est tine et peu allongée; enfin, elle possède un aiguillon très fort et courbé, dont elle ne se sert que contre ses rivales. Elle est uniquement chargée de la ponte.

Quant aux ouvrières, qui sont d'un brun noiràtre, avec des poils cendré roussàtre clairsemés, clles ont l'appareil collecteur des pattes complet et des ailes antérieures dépassant l'abdomen. L'aiguilion est droit et moins fort que chez la reine. Ces ouvrières se partagent les travaux de la ruche : les unes remplissent les fonctions de récolteuses; les autres, celles d'arehitectes et de nourices.

Lorsqu'on examine une ruche, on y voit des rayons qui descendent verticalement du sommet et sont d'ordinaire parallèles entre eux, séparés par des espaces libres, d'un centimètre environ. Ce sont des ouvrières qui construisent ces rayons, avec la cire qu'clles sécrètent. Les rayons sont formés de deux couches de cellules hexagonales (alvéoles), adossées par le fond, de manière ì économiser le plus possible et l'espace et les matériaux de construction. On distingue trois sortes d'alvéoles. Les plus petits contiemnent, les uns du miel et du pullen, les autres des cufs ou des larves 
(couvain) d'ouvrières : ces cellules, de beaucoup les plus nombreuses, occupent le centre de la ruche. D’autres alvéoles plus grands sont destinés à l'élevage des màles. Eufin, les cellules qui doivent donner des femelles, ou

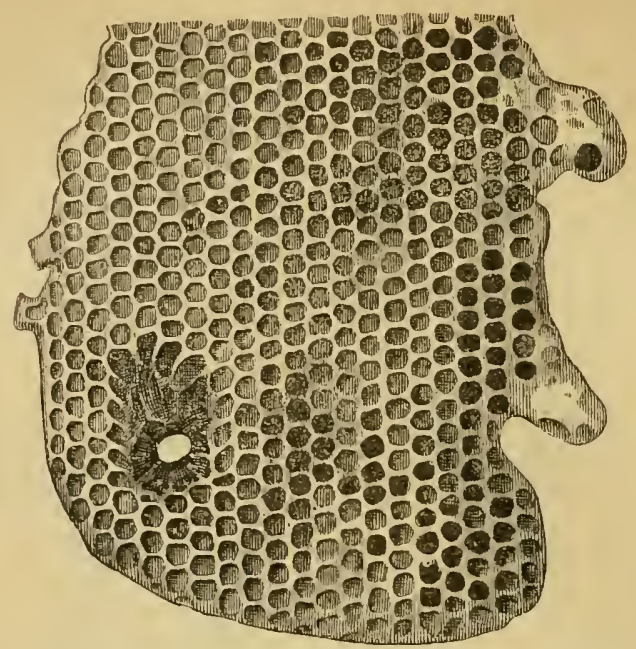

Fig. 604. - Fragment de rayon, montrant à ilroite deux cellules royales, à gauche des points d'attache a base de propolis, et un orifice de communication entre les deux faces du rayon.

cellules royales, en très petil nombre, très grandes et cupuliformes, sont généralement établies au bord des rayous.

La reine et les ouvrières passent seules l'hiver, en se nourrissant du miel enmagasiné dans la ruche. Au retoưr du printemps, la reine se met à pondre. Or, elle peut à volonté déverser ou non du sperme sur les œufs, au moment de leur passaıre devant le réceptacle séminal. Les œufs non fécondés donnent naissance, par parthénogenèse (arrhénotocie), à des Faux-

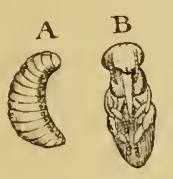

Fig. 605. - Apis mellifica. - A, larve. $B$, nymphe. Bourdons; ceux, au contraire, qui ont subi le contact du sperme, produisent des femelles. De plus, celles-ci restent incomplètes (ouvrières) ou deviennent sexuées (reines)suivant la grandeur de la cellule et la nature des aliments. Les larves éclosent au bout de quelques jours : les ouvrières leur apportent d'abord une bouillie composée de miel, de pollen et d'eau, et préalablement élaborée dans leur tube digestif; puis les larves d'ouvrières et de màles ne recoivent bientòt plus que du miel et du pollen en nature, tandis que celles contenues dans les cellules royales sont toijours pourvues d'une bouillie très nutritive et très abondante (pâtée royale). Dès que les larves sont parvenues à maturité, les ouvrières ferment leurs cellules au moyen d'un opercule de cire plus ou moins bombé, ce qui les distingue des cellules à miel, dont le couvercle est plat. Chaque larve se file alors une coque soyeuse et se transforme en nymphe. Enfin, vingt jours après l'éclosion, l'Insecte parfait (ouvrière) sort de la coque, ronge le couvercle avec ses mandibules et s'échappe. Pour les mâles, l'évolution totale est de vingtquatre jours; pour les mères, de seize seulement. 
Avant que l'une quelconỵue de ees dernieres ait achevé sa mélamorphose, la reine de la ruche quitte l'habitation avec une partie des ouvrières et des Faux-Bourdons : e'est ee gronpe énigrant qui constitue l'essaim primaire. Il s'élève en tourbillonnant dans l'air et va d'ordinaire se suspendre en grappe à une branche d'arbre. On le recueille dans une ruche renversée et enduite łe miel, en secouant la branche; dès que la mère est tombée dans cette ruche, les ourrières s'y amassent. (La loi française autorise le propriétaire d'un essaim à le rechercher partout où il s'est posé.)

Peu après le départ de l'essaim, la première jeune mère qui a atteint son entier développement sort de sa cellule. Si la populatiou de la ruche est peu nombreuse, ou si le temps est froid et pluvieux, elle met à mort, sans opposition et en les perçant de son aiguillon, les rivales qui sortent des autres cellules royales ou qui sont sur le point d'en sortir.

Si, par contre, les circonstances sont favorables à un nouvel essaimage, les ouvrières s'opposent à ces meurtres, mais retiennent captives les jeunes reines arrivées à l'état parfait et les nourrissent par un petit trou qu'elles percent de temps à aulre dans l'opercule. Au premier beau jour, la reine libre part avec un groupe d'ourrières : c'est l'essaim secondaire. Il est rare qüil se produise un essaim tertiaire. D’ailleurs, on eherche d'ordinaire à prérenir ces essaimages multiples, qui nuisent à la ruche en l'affaiblissant.

Il peut arriver, au contraire, qu'une ruche perde accidentellement sa reine; en pareil cas, les ouvrières se hàtent d'agrandir une cellule contenant un ouf ou une larve d'ouvrière, et d'apporter à cette larve la pàtée royale : elles en font ainsi une reine ou mère de sauvete.

La jeune mère établie daus une ruche doit être fécondée; elle s'élève dans les airs suivie d'un certain nombre de mâles, et fait choix de l'un d'eux. L'accouplement dure à peine quelques minutes; il se termine par la mort de l'élu, suite d'un arrachenent brusque du pénis, que la femelle garde dans son vagin pour le rapporter à la ruche : c'est le signe auquel les ouvrières constatent que la fécondation est opérée. Le sperme est emmagasiné pour le reste de la vie, soit quatre á cinq ans, dans le réservoir séminal.

Lorsqu'il n'y a plus ancune tendance à l'essaimage, et que la reine est fécondée, les ouvrières entrent dans une sorte de fureur contre les màles, qui ne sont plus désormais que des bouches inutiles; elles les pourchassent, les condamnent à mourir le faim, ou mème les massacrent en les transpercant de leur aiguillon. La vie de ces Faux-Bourdons n'est guère que de deux ou trois mois. Quant aux ouvrières, elles vivent environ six semaines en été, de telle sorte que la propulation de la ruche se renouvelle deux ou trois fois dans le cours de la lielle saison.

Quarante-six heures après son retour, la reine commence à pondre, en parcourant une à une les cellules vides des rayons : les cellules des rangées supérieures renferment du miel et sont fermées. Dzierzon admel qu'une reine vigoureuse, dans des conditions favorables, est capable de pondre 3000 œufs par jour, soit près de 300000 par an. En outre, il peut se trouver accidentellement, dans les ruches, de véritables ouvrières qui pondent des œufs màles dans les cellules vides qu'elles rencontrent.

Apicultune. - Nous ne pouvons qu'esquisser à grands traits les prineipes généraux sur lesquels repose la culture des Abeilles. L'enseignement des 
plus simples notions pratiques exigerait des développements dans lesquels il ne nous est pas permis d'entrer.

Les ruches qui nous servent à entretenir les Abeilles en semi-domesticité sont d'ordinaire construites en paille, en osier ou en bois. On en distingue deux types : les ruches à rayons fixes et les ruches à rayons mobiles (1). Les premières sont plus en rapport avec les conditions naturelles dans lesquelles vivent les Abeilles; elles permettent en effet à celles-ci de construire leurs rayons verticaux comme il leur convient, en les suspendant à une partie supérieure immobile. Les plus simples consistent en un panier en forme de cloche : clles ont de nombreux inconvénients, entre autres celui de rendre difficile la récolte du miel. On les a perfectionnées en y ajoutant une calotte ou des hausses, qui communiquent avec le corps principal de la ruche par un simple trou : les Abeilles, qui tendent toujours à construire dans les régions supérieures, établissent de nouveaux gâteaux dans la partie surajoutée, et l'on peut mettre à profit celte circonstance avantageuse, que ces gàteaux élevés sont précisément des réservoirs de miel. - Quant aux ruches mobiles, elles se composent de traverses ou cadres distincts, sur lesquels on oblige les Abeilles à construire leurs rayons, de façon à pouvoir enlever séparément chacun d'eux. On peut, de la sorte, récolter le miel en ne supprimant qu'une partie restreinte des gàteaux, ce qui économise aux Insectes tout le travail de la reconstruction. On arrive mème à laisser ces gàteaux intacts par l'emploi d'un mello-extracteur à force centrifuge, d'invention assez rćcente. En somme, le système mobiliste sacrifie la production de la cire pour obtenir un miel plus abondant et plus choisi; il offre sur le système fixiste d'incontestables avantages, au premier rang desquels se place la faculté d'observer les travaux des Abeilles et de diriger la ruche en connaissance de cause.

L'emplacement qui reçoit les ruches porte le nom de rucher. Souvent il comporte un bàtiment léger, destiné à les garantir des intempéries. On recherche, autant que possible, un endroit calme, à l'abri des grands vents et de l'humidité; la meilleure exposition est celle du sud-est.

Quant aux soins à donner aux Abeilles, ils varient suivant l'époque de l'année et suivant une foule de circonstances; nous n'avons pas à entrer dans ces détails, que la pratique seule peut enseigner dune façon sérieuse. Nous dirons seulement quelques mots des malalies qui sévissent parfois dans les ruches et des ennemis qui peuvent s'y introduire.

Une des affections les plus communes est la dysenterie, qui est toujours le résultat de l'hivernage; tantỏt elle tient au renouvellement insuftisant de l'air de la ruche et à la viciation de cet air par l'humidité et l'acide carbonique ; tantôt elle est due à la mauvaise qualité du miel récolté ; elle est, en tout cas, plus fréquente parmi les colonies faibles. On y remédie en évitant de calfeutrer les ruches en hiver, et en nourrissant les Abeilles, à la fin de cette saison, avec du sirop de sucre.

La loque, on pourriture du couvain, est une maladie beaucoup plus grave et très contagieuse ; elle est déterminée par une Bactérie mince, qui s'allonge souvent en filaments. "Les larves et nymphes atteintes de loque, dit M. Girard, deviennent molles et de couleur café au lait, leur peau se déchirant au

(1) M. Girand, Les Abeilles, organes et fonctions, éducation et produits, miel et cire. Paris, 1878. 
moindre effort; bientòt leurs corps sanieux et décomposés ne forment plus a vec la cire qu'une masse brunatre ressemblant à de la pulpe d'abricot pourri." C'est l'apiculteur lui-mème qui, par des manipulations faites saus suiss, transmet la maladie d'une ruclie ì l'autre. La prophylaxie a donc une base fort simple. Une fois le mal communiqué, on ne pourrait guère s'en rendre maitre, d'après Saunier, que par le fer et le feu, appliqués dès le début à tous les points attaqués. Lortet recommande de distribuer aux Abeilles, dès le printemps, du sirop de sucre contenant par litre 0 gr. 33 de naphtol $\beta$.

Parmi les ennemis des dbeilles, les plus redoutables sont deux Microlepidoptères de la famille des Pyralidés, vulgairement appelés fuusses Teignes de la cire. L'un, Ic plus nuisible, est dit grande Teigne (Galleriu mellonellu), à cause de sa taille; l'autre est la petite Teigne (Achroea grisella). Ces papillons vont déposer leurs œufs sur les rayons, en évitant avec soin la piquire des Abeilles; leurs chenilles ne touchent pas au miel, mais dévorent la cire. Dans les colonies puissantes, les ouvrières tuent ces chenilles à mesure qu'elles éclosent; aussi les ravages ne sont-ils jamais sérieux que daus les ruches faibles. Pour s'opposer à ces rava-

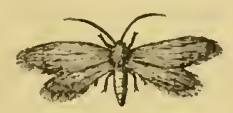

Fig. 606. - Petite Tcigne de la cire (Achrae grisella).

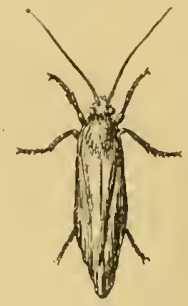

Fig. 607.-Grande Teigne de la cire (Galleria mellonella). ges, il est donc inıliqué, après avoir enlevé les parties atteintes, de fortifier la colonie d'après les procédés qu'enseigne la pratique (mariage).

Le Sphinx Tête-de-mort (Acherontia Atropos) entre aussi dans les ruches, mais c'est pour se gorger de miel; son épaisse fourrure le protège contre les piqùres. Toutefois, il ne parait pas ordinairement bien danģereux. La Cétoine du chardon (Cetonia cardui) recherche également le miel; on a vu quelquefois ces Insectes, en grand nombre, piller les ruches et en faire mourir de fain les habitants.

Le Clairon des Abeilles (Clerus apiarius) est un Coléoptère qu'on regarde à tort comme un ennemi sérieux. Sa larve, connue sous le nom de Ver rouge, ne vit, d'après Hamet, que de miel altéré, de débris d'Abeilles et de larves; elle ne touche pas aux produits des ruches saines et n'établit guère son cocon que dans les rayons attaqués par l'humidilé.

Les Asiles, les (iuèpes, les Frelons, le Philanthe apivore (fig 600) attaquent directement les Abeilles; les Couleuvres, les Lézards, les Crapauds mème, assure-t-on, les happent à l'entrée de la ruche, quand celle-ci est trop près de terre ; enfin, divers Oiseaux leur font aussi la chasse, notamment le Guèpier commun (Merops apiaster) dans l'Europe méridionale, el les Mlésanges (Parus) dans nos régions.

Produrs des Abellles. - Eı butinant sur les végétaux, les Abeilles recueillent trois substances distinctes: le nectar, le pollen et la propolis. Cette dernière est employée directement; les autres subissent une élaboration dont le résultat est la production du miel et de la cire.

$1^{\circ}$ La propolis est une sorte de résine que les Abeilles vont récolter sur les bourgeons de divers arbres, tels que peupliers, saules, sapins, etc. Elles s'en servent pour obturer les fentes de la ruche, pour fixer les gàteaux aux parois 
et même pour enduireles cadavres des aninıaux (Limaces, Mulots, etc.) qui se sont introduits dans la ruche et qu'il serait trop difficile d'expulser. G'est une substance brune ou gris jaunàtre, d'odeur un peu aromatique, dure à froid, mais se ramollissant par la chaleur. On l'a quelquefois prescrile comme résolutive.

$2^{\circ}$ Le miel provient du nectar sécrété dans les fleurs par les organes spéciaux connus sous le nom de nectaires; il peut aussi tirer son origine des exsudations sucrées qui se produisent à la surface de divers végétaux. Ces matières subissent une élaboration dans le jabot des Abeilles, qui les dégorgent ensuite dans leurs alvéoles, sous forme de miel, pour servir à leur nourriture ou à celle des larres.

Dans la plupart des localités, on a coutume de récolter le miel vers la fin de l'été; quant au mode suivant lequel on procède à cette récolte, il varie suivant la constitution de la ruche. Lorsqu'il s'agit de ruches à rayons fixes, de beaucoup les plus communes en France, on détache les gâteaux et on les place sur des claies, disposées elles-mêmes au-dessus de vases convenables. Suivant les manipulations auxquelles on a recours, on obtient alors du miel de différentes qualités. - $1^{\circ}$ Après avoir choisi les gàteaux récents, ne contenant que du miel sans pollen, on les expose simplement au soleil ou on les soumet à une chaleur très modérée, et on enlève les opercules à l'aide d'un couteau : le produit très pur qui s'écoule de la sorte est le miel vierge ou de première qualité, encore appelé miel blanc surfin. $-2^{\circ}$ On brise ensuite ces gàteaux, ainsi que ceux qui contiennent du miet mélangé de pollen, et on les soumet à une tempéralure un peu plus élevée : ainsi est obtenu le miel blanr. fin. $-3^{\circ}$ Les marcs qui résultent de cette opération renferment encore du miel qu'on retire au moyen d'une presse: c'est le miel jaune ou ordinaire, qui contient toujours de la cire. - $4^{\circ}$ Enfin, une dernière pression fournit le miel brun, plus ou moins chargé d'impuretés. - Lorsqu'on a recours aux extracteurs à force centrifuge, qui ne s'appliquent guère qu'aux rayons mobiles, on évite tout à fait le mélange de cire, et on a l'avantage de ne recueillir que des miels surfin et fin.

Le miel varie aussi de qualité suivant sa provenance. En thèse générale, celui qu'on récolte dans les régions chaudes et sèches ou sur les coteaux est supérieur à celui recueilli dans les conditions opposées. Mais l'élément dont l'influence se fait le plus directement sentir est représenté par les fleurs sur lesquelles vont butiner les Abeilles, et dont l'arome se transmet au miel sans modifications sensibles. C'est ainsi que le miel du mont Ilymetle doit sa haute et antique renommée aux Labiées qui abondent sur cette montagne, ceux de Cuba et de Valence à la fleur d'oranger. En France, on distingue, quant à la provenance, quatre sortes principales de miel (M. Girard): $1^{\circ}$ le miel de Narbonne, assez compact, blanc, grenu, odorant, à saveur aromatique très prononcée; il se récolte dans tout le Roussillon; son arome est dû principalement au romarin. On place à peu près sur la mème ligne le miel de Provence, dont l'odeur et la saveur, variables suivant la saison, sont encorc plus marquées; $2^{\circ}$ le miel du Gâtinais, moins grenu, souvent moins blanc, moins aromatique que celui de Narbonne; il provient du sud de Seine-etMarne et d'une parlie de l'Orleanais; c'est sur le sainfoin el le trèfle qu'il est en grande partie recueilli; $3^{\circ}$ le miel de Normandie ou d'Argences, analogue 
aux précédents, presque exclusivement réservé pour la table el vendu en petits pots de grès dits " canottes"; $4^{\circ}$ le micl de Bretagne, rouge brunatre, à odeur de pain d'épice, à saveur un peu àcre; il doit sa médiocre qualité anx lleurs du sarrasin. Les miels de la Champagne et de diverses autres régions, recueillis sur la mème plante, sont fréquemnent vendus sous le même nom. Cetle sorte esl employéo à la fabrication du pain d'épice; on en fail aussiusage daus la médecine des animaux.

L'inlluence des lleurs sur le micl ne porte pas seulement sur l'arome; les anciens avaient déjà reconnu que cerlaines plantes communiquent à ce produil des propriétés vénéneuses. Xénophon rapporte que les soldats de l'armée des Dix Mille, cantonnés dans la Colchide, y trouvèrent de nombreuses ruches, et que tous ceux qui mangèrent du miel vomirent, furent purgés violemment et éprouvèrent une sorte de délire; aucun d'eux, cependant, ne succomba. Tournefort et d'autres auteurs modermes ont attribué ces accidents aux fleurs l'Azalea pontica et même à celles du Rhododendron ponticum. De nos jours, Barton a reconnu que le miel récolté en Pensylvanie sur des plantes de la même famille, telles que des halmia et des Andromeda, occasionne des maux d'estomac, des romissements, des convulsions, et que ces accidents peuvent être mortels. Haller et Seringe rapportent aussi des cas graves d'empoisonnement observés dans les Alpes et dus à l'ingestion du miel recueilli sur les Aconitum Napellus el Lycoctonum. Notons d'ailleurs que le miel produit par les Bourdons et les autres Mellifères peut être à l'occasion aussi dangereux que celui des Abeilles.

Le miel est un mélange, en proportions variables, de plusieurs composés organiques définis, étendus d'eau. On y tronve d'abord des matières sucrées: du glucose déviant à droite le plan de polarisation et cristallisant en petits grains blancs agglomérés qui forment les granulations du miel; de la mellose, lévogyre, liquide et incristallisable; une petite quantité de succharose, qui disparait mème à mesure que le miel vieillit; enfin, une certaine proportion de mannite. De plus, le miel contient un acide libre, une substance colorante jaune, des principes aromatiques el des matières azotées, lesquelles proviennent sans doute du pollen.

Avec quelque soin, on peut conserver le miel pendant plusieurs années; il suffit pour cela de l'enfermer dans des barils ou de le tenir dans des vases de terre, qu'on place dans un endroil frais, mais à l'abri de l'humidité; sans ces précantions, il seraut exposé à fermenter et à aigrir. On doitéviter surtout le transvasement, car les altérations sont beancoup plus rapides lorsqu'on a détruit l'arrangrement pris par les molécules.

Uu bon miel doit posséder une odeur suave et aromalique, une saveur douce et sucrée, et être soluble en totalité dans l'ean. En France, on recherche plus particulièrement les miels solides, grenus et blancs. Mais il ne faut pas oublier que direrses fraudes ont pour but d'obtenir une apparence de bonne qualité. C'est ainsi qu'on y ajoute de l'amidon, de la farine, de la craie, etc. L’insolubilité de ces substances décèle leur présence. L'addilion de glucose solidifié est plus commune encore; le slncose est soluble dans 
l'eau; mais l'alcool trouble la solution, et l'iodure ioduré de potassium le colore en violet. Une fraude moins grave consiste à verser du miel commun sur des branches de romarin, pour lui donner l'arome du miel de Narbonne; on la reconnait d'ordinaire à la présence de feuilles ou de fragments qui se sont détachés.

Le miel est souvent employé en médecine. A dose faible, on s'en sert comme émollient ou comme édulcorant; à haute dose, il devient laxatif, surtout s'il s'agit de miel commun : on l'administre de préférence en lavements. Il sert de base aux mellites et aux oxymellites; de plus, il entre à titre d’excipient dans des préparations très diverses. Délayé dans cinq fois son poids d'eau et mis en fermentation, il donne l'hydromel vineux, boisson autrefois très recherchée et employée encore de nos jours par quelques peuples du Nord.

$3^{\circ}$ La cire est la substance grasse complexe qui forme les rayons. Elle s'accumule sur les parties latérales de la moitié antérieure (aire cirière) des quatre derniers arceaux ventraux de l'abdomen. Elle est sécrétée, non par des glandes intra-abdominales, comme on l'a prétendu, mais par des cellules glandulaires (cellules cirières) étalées en une membrane spéciale (membrane cirière) de nature épithéliale, souscuticulaire. Elle traverse la cuticule et se dépose à sa surface en lamelles incolores, recouvertes par la nıoitié postérieure de l'arceau précédent. Prise en ces points, la cire est toujours fragile; l'ouvrière l'enlève à l'aide de la pince tibio-tarsienne des pattes postérieures, puis, arec les crochets des tarses antérieurs, la porte entre ses mandibules, la pétrit, l’imprègne de salive et la rend malléable.

La cire provient du miel absorbé par les Aheilles et transformé en matière grasse dans leur organisme. Huber, le premier, démontra que des Abeilles nourries exclusivement de miel ou de sucre continuaient à construire leurs rayons, tandis que chez celles qui receraient seulement du pollen, la sécrétion ne lardait pas a cesser. Toutefois, on pouvait supposer que la cire était formée aux dépens de la graisse contenue dans le miel alimentaire ou emmagasinée dans le corps; Dumas et Milne Edwards reprirent l'expérience en dosant au préalable les matières grasses contenues en moyenne dans le corps des ouvrières d'un essaim séquestré, qui fut nourri de miel dont la matière grasse était également dosée. Ils reconnurent alors que le poids de la cire produite et des matières grasses restant dans le corps à la fin de l'expérience était notablement supérieur au poids obtenu dans le dosage primitif. La cire était donc produite aux dépens du miel absorbé.

Pour préparer la cire, on fait fondre dans l'eau le marc qui résulte de la dernière pression du miel; la plupart des impuretés tombent au fond, tandis que la cire surnage. Après une seconde fusion, on l'exprime à travers un sac en toile forte et on la verse dans des moules: c'est ainsi qu'on obtient des pains de cire jaune.

Pour la décolorer, on l'aplatit en rubans ou on la fait fondre pour la verser sur un cylindre de bois qui se meut horizontalement dans l'eau et la ré- 
duit en grumeaux. On dispose les rubans et les grumeaux en couche mince sur des toiles étendues dans les prés; sous l'influence de l'ozone, la matière colorante se détruit peu à peu. Commece procedé est trop long, on lui substitue souvent le blanchiment au chlore. La cire décolorée est dite circ blanche ou vierge. On y ajoute d'ordinaire un peu de suif pour lui rendre le liant quelle a perdu, et on la coule en petites plaques rondes. Elle est solide, opaque, cassaute, et fond vers $63^{\circ}$.

La cire est insoluble dans l'eau, soluble dans les luules grasses, la benzine, l'essence de térébenthine, le sulfure de carbone. En la traitant par l'alcool bouillant, on y reconnait la présence de trois principes immédiats. L'un est la myricine on palmitate de myricile, éther composé qui reste à peu près insoluble. Un autre cristallise en petites aiguilles par le refroidissement : c'est lit cérine ou acide cérutique. Le troisième est la cérolèine, qui resle dissoute. Quant à la matière colorante de la cire jaune, elle est peu connue.

La cire subit de nombreuses falsifications. On l'additionne surtout de suif, d'acide stéarique, de paraffine, de résines, et de matières inertes telles que sciure de bois, platre, kaolin, larine, fécule. Ces dernières substances se reconnaissent à leur insolubilité dans la benzine, qui dissout la cire. Les substances résineuses, telles que la colophane ou la poix de Bourgogne, se dissolvent dans l'alcool froid et peuvent se séparer ensuite par évaporation. La paraffine se découvre à l'aide de l'acide sulfurịue fumant et chaud : celuici carbonise la cire sans attaquer la paraftine, qui surnage. Pour déceler l'acide stéarique, on réduit la cire en grumeaux et on traite par l'eau de chaux, qui donne un trouble granuleux de stéarate de claux. Le suif, lorsqu'il est en proportion un peu considérable, dénonce sa présence par son odeur, sa saveur et la facilité avec laquelle la cire se réduit en grumeaux adhérents aux doigts, quand on la malaxe. Quant aux cires végétales ou minérales, elles se distinguent par leur densité et leur point de fusion différents ; tontefois, on fabrique depuis quelque temps des mélanges de cire l'Abeilles, de cire miıérale et de stéarine dans lesquels celte différence est effacẻe, de lelle sorte que la fraude est assez difficile à déceler.

La cire forme la base des cérats: elle entre aussi dans la composition d'une foule d'onguents ou d'emplâtres, de la toile de mai ou sparadrap de cire, des bougies employées pour la dilatation de l'urètre, eic.

Piqúre des Abeilles. - Comme la plupart des Iyménoptères supérieurs, les Abeilles sont pourvues d'un appareil venimeux et vulnérant, qui leur sert presque toujours à se défendre, rarement à attaquer. Cet appareil se compose de plusieurs parties : les organes vénénifiques et leur réservoir, l'aiguillon chargé d’inoculer le venin, et les muscles qui mettent cet aiguillon en mourement.

Les organes sécréteurs consistent en deux glandes distinctes : l'une dite glande acide, l'autre appelée glande alcaline. La glande acide, connue depuis longtemps, est représentée par un tube bifurqué situé au voisinage du rectum el aboulissant à un réservoir pyriforme (vésicule); l'extrémité postérieure de ce réservoir s’atténue en un court 
canal aboutissant à l'aiguillon. Le produit de sécrétion n'est autre que de l'acide formique concentré. La glande alcaline consiste en un simple cul-de-sac qui va également déboucher à la base de l'aiguillon. Carlet a établi que le venin résultant du mélange des liquides sécrétés par ces deux glandes est toujours acide, et que chacun de ces liquides pris isolément est incapable de produire les accidents ordinaires, et en particulier d'amener la mort des Insectes auxquels on l'inocule (1).

L'aiguillon est formé par des appendices du neuvième anneau de l'abdomen. De la région sternale de cet anneau émanent deux valves en gouttière, soudées à leur bord inférieur,

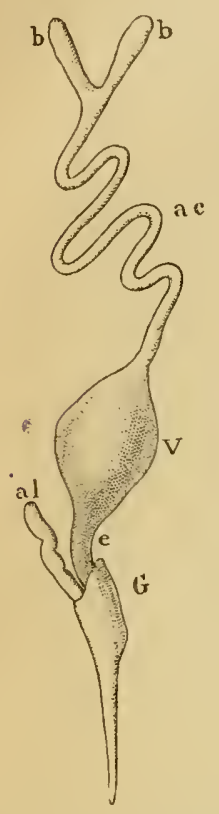

Fig. 608. - Appareil venimeux de l'Abeille, d'après Carlet. - ac, glande acide. $b, b$, ses deux branches. $V$, sa vésicule. $e$, son canal excréteur. $a l$. glande alcaline. $\mathrm{G}$, gorgeret. juxtaposées à leur bord supérieur et constituant un étui aigu et résistant : c'est le gorgeret. Quant à la partie dorsale, elle fournit deux stylets grêles, très aigus, munis ver's leur extrémité libre et en dehors de dix fines pointes rabattues en avant, et creusés en canal à leur face interne; ces stylets forment par leur accolement un dard acéré et canaliculé qui glisse dans le gorgeret et dans lequel coule le venin. Contrairement à ce qui s'observe chez les Vespidés, la vésicule du venin n'est pas contractile; Carlet a fait voir qu'elle se vide grâce à une disposition spéciale de l'aiguillon. Les stylets, en effet, présentent à leur base une pièce appendiculaire qui fonctionne à la façon d'un piston, chassant le liquide à mesure que le stylet descend dans le corps de pompe représenté par le gorgeret. L'appareil vulnérant fonctionne donc à la fois comme un trocart et comme une seringue aspirante et foulante. Le gorgeret se montre toujour's plus ou moins saillant à la pointe de l'abdomen, mais le dard est rétracté à l'intérieur et ne sort qu'au gré de l'Insecte; le plus souvent, d'ailleurs, les deux stylets se meurent alternativement.

Lorsqu une Abeille veut piquer, elle fait saillir à la fois les stylets et le gorgeret: les premiers s'enfoncent dans la peau comme le poinçon d'un trocart, et frayent la voie au gorgeret. Si c'est un Insecte qu'a attaqué l'Abeille, la plaie produite dans le tégument chitineux reste béante, et l'aiguillon en sort sans difficulté. S'agit-il, au contraire, d'un animal supérieur ou de l'Homme, la peau élastique se resserre au contact de l'aiguillon, que ses pointes barbelées retiennent souvent dans la plaie, et qui est arraché du corps de l'Abeille quand celle-ci

(1) D'après Bordas, ces deux glandes existent chez tous les Porte-aiguillon; souvent même on en observe une troisième, très réduite. 
veut fuir : une parcille mutilation entraine la mort de l'Insecte.

Les aecidents que détermine la piqqûre sont naturellement le résultat du dépôt dins la plaie d'une certaine quantité de venin; néanmoins, l'irritition est plus aceusée quand l'aiguillon est resté dans la plaie. Mais, d'une manière générale, la piqûre des $A$ beilles est moins douloureuse et moins dlangereuse que celle des Guêpes et surtout des Frelons. Inutile d'ajouter que les troubles sont d'autant plus sérieux que les piquires sont plus nombreuses.

Delpech (1) distingue trois degrés dans les accidents consécutifs aux piquires d'Abeilles. $1^{\circ}$ Dans les cas bénins, on constate simplement une douleur aiguë, une tuméfaction locale, surtout accusée si la piqùre a eu lieu sur la face, et parfois mène, chez les enfants, des nausées, un légrer noouvement fébrile, une éruption d'urticaire, ıuelques ecchymoses cutanées. $2^{\circ}$ Dans les cas intenses, les symptòmes, d'abord analogues à ceux des accidents légers, ne tardent pas ì devenir menaçants et preunent d'ordinaire la forme syncopale : on observe une faiblesse profonde, des vertiges, des nausées, de l'anxiété épigastrique ou précordiale, le refroidissement des extrémités, des sueurs visqueuses et froides, une céphala grie insupportable, souvent de l'urticaire, des picotements intenses à la surface cutanée, etc. Toutefois, ces symptòmes peuvent s'amender en peu de temps, parfois mème au bout de quelques heures seulement. $3^{\circ}$. Iais, dans d'autres circonstances, ils s'exagèrent avec plus de rapidité encore, et aboutissent à une terminaison fatale. La mort peut ètre le résultat d'un œdème des premières voies respiratoires, consécutif à une piquure de l'arrière-gorge; ou bien elle parait due à l'action toxique du venin introduit dans la circulation : presque toujours, dans ce dernier cas, la mort survient au bout d'une demi-heure. Les grands animaux, tels que le Clıeval, ne résistent guère plus longtemps à des piqưres multiples; on trouve à l'autopsie des lésions analogues à celles d'un empoisonnement septique (Clichy).

Heureusement, des accidents aussi graves sont très rares, et le traitement des piqûres d'Abeilles est en général fort simple; il est même beaucoup de personnes qui le négligent tout à fait. Lorsque l'aiguillon est resté engagé dans la plaie, il convient tout d'abord de l'extraire avec précaution, et même d'exciser au préalable le réscrvoir à venin, s'il y est resté adhérent. On a recours ensuite ì des lotions d'eau fraiche, d'ammoniaque étendue ou d'eau blanche, avec addition de quelques goultes de laudanum si la douleur est intense.

On a quelquefois utilisé la piquure des Abeilles ou des Guêpes dans un but thérapeutique (révulsion).

En deliors de l'Abeille commune du nord (Apis mellifica L.), qui a été transportée dans l'Europe méridionale, l'Asie Mineure, l'Algúrie et l'Amérique tempérée, on connait une dizaine d'autres espèces du mème genre. Parmi les principales, nous pourons signaler : l'Abeille italienne ou ligurienne ( $A$.

(1) Delpech, Les dépóts de ruches d'Abeilles. Annales d'hygiène publique, (3), III, p. 299,1880 . 
ligustica Spin.), de l'Europe méridionale; l'Abeille fasciée (A. fasciata Latr.), de l'Égypte; l'Abeille unicolore (A. unicolor Latr.), de Madagascar, transportée à l'ìle Maurice, à la Réunion et aux Canaries; etc.

\section{CINQUIÈUE ORDRE}

\section{NÉVROPTERRS}

Insectes broyeurs, à pièces buccales parfois rudimentaires; quatre ailes membraneuses; métamorphoses complètes ou incomplètes.

Les Névroptères ont les pièces buccales disposées pour broyer, mais ils deviennent parfois suceurs par suite de l'atrophie partielle de ces organes. La lèvre inférieure n'est pas fendue.

Le prothorax est distinct. Les ailes antérieures et postérieures sont semblables, membraneuses et réliculées, c'est-à-dire parcourues par de nom-

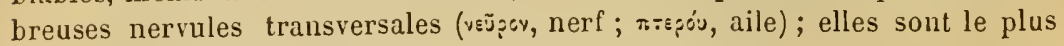
souvent velues ou écailleuses. Les tarses sont à 5 articles.
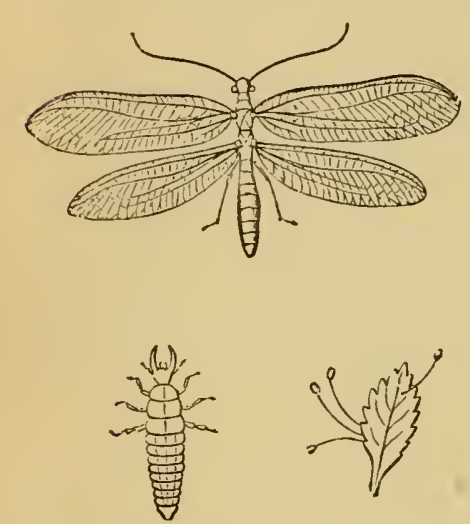

Fig. 609. - C!nysopa rulgaire : Insecte parfait, larve (Lion des Pucerons) et oufs.

Larves vermiformes ; nymphes inmobiles.

Latreille a divisé cet ordre en deux sections :

A. Phanipennes. - Ailes non écailleuses, parfois poilues sur les nervures, ne se repliant jamais. - Genres Sialis, $\mathrm{He}$ merobius, Chrysopa, Myrmeleo,Panorpa, etc. Le Fourmilion (Myrmeleo formicarius) est bien counu par la façon curieuse dont la larve fait tomber les Fourmis et autres proies dans son entonnoir de sable. Les larves des Hémérobiinés, ou Demoiselles terrestres, dévorent les Pucerons. Celle du Chrysopa vulgaris ou perla, en particulier, mérite le nom de Lion des Pucerons que lui a donné Réaumur.

B. Plicipenves. - Ailes couvertes d'écailles ou de poils, les postérieures se plissant dans le sens de leur longueur. - Les larves sont aquatiques. Celles des Phryganes s'entourent, à la façon des Teignes, d'un petit fourreau composé de grains de sable, de coquilles, de fragments de bois ou d'herbes, qu'elles trainent partout avec elles.

SIXIEUE ORDRE

\section{PSEUDO-NÉVROPTÉRES}

Insectes ordinairement broyenrs; quatre ailes membraneuses; métamorphoses incomplètes. 
Ces Insectes se rattachent aux Névroptères par leurs ailes, et aux Orthoplères par leur's métamorphoses. Leurs organes buccaux sout disposés pour broyer, plus rarement pour sucer; la lèvre inférieure offre deux moitiés distinctes.

Le prothorax est libre. Les ailes des deux paires sont membraneuses et nues, réticulées.

Les larves et nymphes sont aggiles, ne différunt que très peu de l'Insecte parfait; des rudiments d'ailes apparaissent avant la pénultième mue, et grandissent aux deux mues suivantes.

\& sections ou sous-orilres.

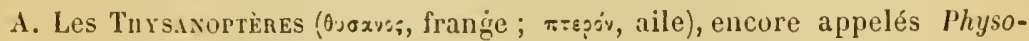
podes ou Cystipèles, ont le corps allongé, les pièces buccales disposées pour la succion, les ailes en forme de lanières ciliées, et les tarses biarticulés terminés par des pelotes en forme de ventouses. - Le Thrips des céréales (Thrips cerealium Kirby) suce les feuilles ou les épis du seigle et du froment, et fait souvent avorter un grand nombre de grains.

B. Les Conrodants ont de fortes mandibules dentelées et de grandes ailes nues; leurs larves sont terrestres. - A ce groupe appartiennent les Termites ou Fournis blanclıes, qui vivent en colonies nombreuses, formées de plusieurs sortes l'individus : sexués, ouvriers et soldats. Le Termite lucifuge (Terme's lucifugus) abonde dans le sucl-ouest de la France, où il cause quelquefois de grands dégàts, en creusant des galeries dans les bois de charpente: lextérieur est toujours respecté, de sorte qu'une maison peut s'effondrer sans qu'on en soit prévenu. Les arbres eux-mêmes sont parfois minés jusqu'a'ux branclies.

La famille des Psocides se composed'Insectes dont les ailes sont tantòt nulles, tantùt rudimentaires, tantòt bien développées. Les formes aptères reçoivent l'appellation vulgaire de Poux; elles vivent souvent dans les maisons, où elles multiplient parfois á l'excès, dans les livres, les vieux papiers, les collections d'Insectes. Le Pou des livres ou des poussières (Troctes divinaturizs) manque complètement d’ailes. Le Pou frappeur (Atropos pulsatoria) a les ailes antérieures représentées par des écailles; malgré son nom, il ne produit aucun choc. Le Locataire (Clothillu inquilina) possède deux ailes rudimentaires coriaces; Virchow l'a vu envahir une maison au point d'y rendre le séjour intolérable et d'altérer gravement la santé des habitants. - C'est sans doute quelqu'une de ces espèces que Gay décrivait en 1878 comme un parasile du Chera!, sous le nom de Trichodectes quadricornis.

C. Les Amphibiotiques ne possèdent que des pièces buccales faibles ou mème presque avortées. Ailes nues. Larves aquatiques, carnassières. - Ils comprennent les Perles (Perla) et les Éphémères (Ephemera). Celles-ci, comme leur nom l'indique, ne vivent qu'un temps très court à l'élat adulte. Elles sont toujours aussi abondantes, dans le voisinage d'Alfort, qu'à l'époque de Réaumur.

D. Enfin, les Odoxates ont des mandibules et des màchoires très fortes, des ailes nues, et leurs larves sont également aquatiques. - Les Demoiselles, comme on les désigne vulgairement, vivent dans le voisinage des eaux ; elles 
sont carnassières, et, à ce titre, rendent de grands services à l'agriculture. Leurs larves elles-mèmes donnent la chasse aux Insectes; à cet effet, elles sont pourvues d'un masque, appareil formé par la lèvre inférieure modifiée, qu'elles lancent avec rápidité sur leur proie, et qui agit à la façon d'une pince.

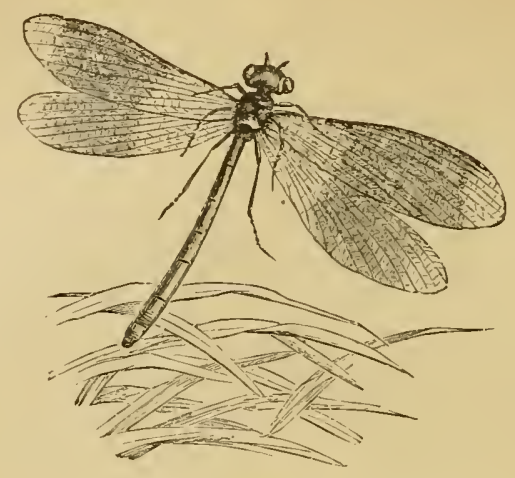

Fig. 610. - Calopteryx virgo.

- Citons les Caloptéryx (Calopteryx', les Agrions (Agrio), les Eschnes (Eschna), les Libellules (Libellula).

\section{SEPTIĖIE ORDRE}

\section{ORTHOPTÈRES}

Insectes broyeurs; ailes antérieures chitinisées, mais souples (tegmina ou pseudélytres); ailes postérieures membraneuses, plissées en éventail; métamorphoses incomplèles.

Le nom de l'ordre est tiré de la disposition des ailes postérieures, qui, re-

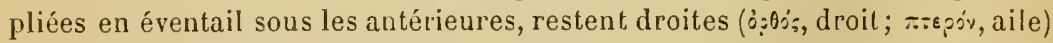
sauf chez les Forficules. Les ailes antérieures sont un peu plus courtes et parcheminées. Certaines formes sont aptères. Le prothorax est libre. Les tarses ont de 3 à 5 articles. L'abdomen est terminé par des appendices de forme diverse.

Les pièces buccales sont propres à broyer. Les mandibules sont puissantes; le lobe externe de chaque màchoire est très déveluppé et recouvre le lobe interne à la façon d'un casque, ce qui lui a fait donner le nom de galea. La languette est formée de deux lobes internes étroits et de deux lobes externes plus épais, correspondant aux galea des màchoires.

Les larves sont agiles et ne se distinguent extérieurement des adultes que par l'absence d'ailes et un nombre moindre d'articles antennaires; il n'apparait des rudiments d'ailes que dans l'intervalle des deux dernières mues.

2 sections :

A. Les Coureurs ont les pattes, tout au moins les postérieures, simplement ambulatoires, c'est-à-dire propres à la marche ou à la course. 
Ils comprennent d'abord les Forfucules ou Perec-oreilles, reconnaissables à leurs forcipules, appendices en forme de pince qui terminent l'abdomen. Ces Insectes possèdent deux élytres courts, simplement juxtaposés sur la ligne médiane, et deux ailes postérieures membraneuses deux fois repliées en travers pour se loger sous ces élytres. Contrairement à la croyance populaire, les Forficules sont inoflensifs et incapables de perforer la membrane du tympan. Ils peuvent cependant s'introduire dans les cavilés naturelles du corps de l'llomme. D’après De Geer, la femelle veille sur ses petits avec une sollicitude égale à celle que montrent les Poules pour leurs Poussins. Une espèce de ce groupe (Anisolubis anmulipes Lucas) sert d'hòte intermédiaire à l'Hymenolepis tliminuta (voy. p. 296).

Les Blattes ou Cancreluts, Cafurds, Mange-pain, etc., sont des Insectes nocturnes fort lésagréables, qui abondent dans les cuisines, dans les boulangeries et sur les navires. Ils attaquent la plupart de nos denrées alimen-

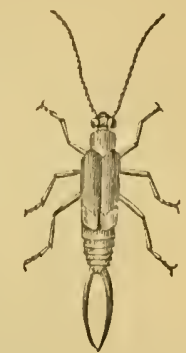

Fis.611. - Perce-oreille commun (Forficula auricularia). taires, a uxquelles ils communiquent, en outre, une odeur r'epoussante. L'espèce la plus commune chez nous est la Blatte orientale (Periplaneta orientalis), qui sert d'hơte intermédiaire au Spiroptère ensanglanté (voy. p. 538). La Blatte américaine (Per. americana, vulgairement Kakerlac), est plus grande et plus rare; d'après Vinson, elle produit sur les lèvres, en passant à leur surface pendant le sommeil, une éruption vésiculeuse particulière (herpes blattx). La Blatte germanique (Phyllodromia germanica) est plus petite que les précédentes; nous l'avons vue envahir une maison des environs de Paris à un tel degré que le mouvement des penclules en était arrèté.

B. Les Sauteurs ont les pattes postérieures fortes et conformées pour le saut. -3 familles.

Les ACRIDIDÉS ou Criquets, que l'on confond à première vue avec les Sauterelles, se distinguent de celles-ci par leurs antennes, qui atteignent au plus la moitié de la longueur du corps; par leurs tarses à 3 articles; par la tarière des femelles, qui ne dépasse jamais l'extrémité de l'abdomen et se montre formée de deux doubles valves. Les mâles produisent un son en frottant leurs cuisses contre les nervures des éJytres. Ces Insectes sont herbivores. Les femelles déposent, à la fin de l'été, leurs œufs agglutinés en amas par du mucus et des grains de sable (oothèque ou coque ovigère), soit sur les chaumes des Graminées, soil plus ordinairement dans la terre; après quoi, elles meurent. De nombreux Criquets sont sédentaires, et quelques-uns se multiplient beaucoup dans certaines années. D'autres ont des instincts migrateurs, et comme leur multiplication est souvent extraordinaire, ils changent de séjour à mesure que les réırions primitirement occupées sont dévastées. Ceux-ci sont de beaucoup les plus dangereux. On les voit en général se diriger vers le nord. A l'état de larves, c'est-à-dire tant qu'ils sont aptères, ils marchent une grande partie du jour en longues colonnes, avec une rapidité remarquable, ravageant tout sur leur route. Quand ils sont adultes, ils s'élancent en rols immenses et serrés, qu'on a pu comparer à des nuages obscurcissant le soleil, et qui descendent à terre chaque soir. Ces nuées s'abattent sur les prairies comme sur les cultures, et souvent, après leur

Railliet. - Zoologie. 
passage, toute trace de végétation a disparu. De plus, la ponte peut avoir lieu sur place, et les contrées envahies sont menacées pour la saison suivante. Enfin, l'accumulation des cadavres de ces Insectes développe des émanations pestilentielles, capables d'altérer la santé des habitants. Les invasions de Criquets constituent donc de véritables fléaux. On en constate de temps à autre dans l'Europe méridionale : la dernière qui ait été signalée en Provence date de 18'9. Mais c'est surtout en Algérie que ces Insectes se montrent redoutables. On estime que l'invasion de 1866, dans cette colonie, a occasionné une perte de 50 millions, et qu'il faut, en outre, lui imputer la famine de l'année suivante, pendant laquelle 200,000 indigènes sont morts de faim et de misère.

Les populations des régions envahies par les Criquets font souvent usage de ces Insectes comme aliment, d'où la qualification d'acridophages qui leur est appliquée. Celte coutume est des plus anciennes, car déjà Moïse la recommandait aux Hébreux. Elle est encore répandue chez les Hottentots, les Boschimans, les Indiens de l'Amérique du Sud, et même dans le Sahara algérien. Les Arabes les font cuire dans l'eau salée, puis les laissent sécher au soleil; ils en rassemblent d'énormes provisions, non seulement pour leur consommation personnelle, mais aussi pour les vendre sur les marchés de Tougourt, de Temacin et des villages voisins. Künckel dit avoir pu se convaincre qu'ils constituent un mets très acceptable; le goût de Crevette que lui attribuenl les voyageurs est assez prononcé.

D'autre part, Roulin a vu, en Amérique, les Vaches, les Moutons, les Chèvres, les Porcs et les Poules se repaître de ces Insectes, de sorte que le lait, la viande de Porc et les œufs avaient un affreux fumet de musc, ou, selon l'expression des habitants du pays, puaient la Sauterelle (hedian a langosta).

L'espèce la plus répandue en Europe est Ie Criquet rubané (OEdipoda fasciatia), qui offre plusieurs variétés caractérisées par la couleur des ailes postérieures. Ainsi, on trouve dans les environs de Paris le Criquet à ailes bleues et noires (var. cærulescens) et le Criquet à ailes rouges (var. miniata).

Le Criquet voyageur (Pachytylus migratorius) est une des plus grandes espèces émigrantes; il a environ 6 centimètres de long et 11 centimètres d'envergure; sa co-

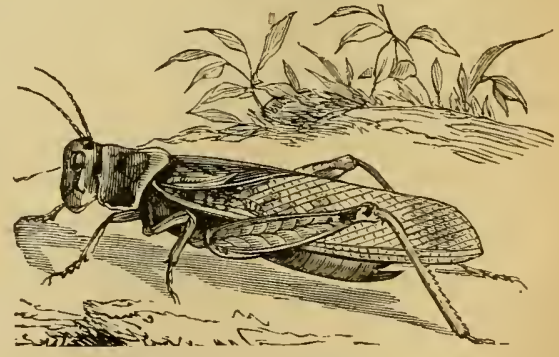

Fig. 612. - Criquet voyageur. loration est variable, mais en général le vert grisâtre domine à la face supérieure et le rouge clair à la face inférieure. L'accouplement a lieu vers la fin de l'été; il dure de douze à vingt-quatre heures, et sept jours après, la femelle dépose dans la terre un ou deux oothèques contenant chacun 60 à 100 œufs. L'éclosion a lieu au printemps suivant, et les larves subissent une série de 
mues qui les amènent en deux mois environ à l'état de nymphes (à moignons d'ailes) et d'Insectes parfaits. Cette espèce habite principalement les ìles lasses el les rives de l'embouchure du Danube; c'est de là qu'émigrent ces essaims redoutables qui ont si souvent porté la ruine dans les provinces danubiennes, la Hongrie el la Russie méridionale.

En Mggérie, deux espèces surtout occasionnent des ravages : le Griquet pèlerin et le Criquet marocain.

Le Griquet pèlerin (Schistocerca peregrina) est long le $6 \ddot{3}$ à 70 millimètres ; sa teinte varie, à l'état adulte, à mesure qu'il avance en àge: d'abord rose, il passe successivement au rouge, au gris, à la teinte terre de Sienne et enfin au jaune. La pariade et l'accouplement commencent seulement quand la coloration est devenue terre de Sienne, et se renouvellent quand elle est arrivée au jaune; la ponte n'a lieu que deux mois après la mue définitive, soit trois mois et demi apres l'éclosion des larves (Künckel). - Le Criquet pèlerin n'est autre que la Sauterelle de la Bible. La région qu'il habite à titre permanent est le centre africain, probablement la région des grands lacs, certainement celle du Tchad; il séjourne d'une façon subpermanente dans l'immense contrée qui s'élend en arrière du Sahara jusqu'au Sénégal; enfin on ne le voit s'établir que temporairement dans le nord de l'Afrique, où il ne peut guère se maintenir plus de deux années. En Algérie, il apparaît en vols immenses au nois d'arril ou de mai, et s'accouple peu après. Les coques ovigères que forment alors les femelles comprennent 80 à 90 œufs. Six semaines plus tard (parfois mème trois ou deux semaines seulement), les jeunes éclosent, el continuent les ravages qu'avaient commencés leurs parents; ils acquièrent leurs ailes dans l'espace de 4 jo jours environ, et prennent alors leur essor pour aller porter au loin la dévastation. Les principales invasions de Pèlerins observées depuis la conquête de l'Algérie sont celles de $18 \% \ddot{*}, 1866,1874$ et 1891 .

Le Griquet marocain (Sturonotus maroccanus) est beaucoup plus petit que le précédent: le mảle alteint seulement une longueur de 17 à 23 millimètres, la femelle de 20 à 33 ; sa teinte générale est roussàtre clair, relevée de taches fuuves; ses élytres sont lestacés avec des taches et des marbrures éparses brunes; ses ailes sont transparentes. La pariade et l'accouplement ont lieu en juin, et peu après les femelles se mettent à forer la terre pour y déposer leurs oothèques, qui contiennent 30 à $3 \ddot{3}$ œufs. Neuf mois plus tard, a lieu l’éclosion. Les jeunes subissent cinq mues dans l'espace de six semaines; ils sont alors à l'état de nymphes. Après cinquante à cinquante-cinq jours, ils suspendent leur émigration et les nymphes se transforment en Insectes ailés, qui prennent leur essor. - Le Griquet marocain, le plus redoutable sans doute pour notre colonie, ne vient pas, comme le précédent, du centre africain; il vit d'une facou permanente sur la bordure du Sahara, jusque sur les Hauls-Plateaux, et apparait temporairement (lors des périodes de grande sécheresse) dans le Tell, qu'il semble aujourd'hui envahir de plus en plus, ainsi qu'en témoi «nent les persévérantes observations de hünckel. Son aire de distribution embrasse d'ailleurs toutes les régions montagneuses arides du bassin de la Méditerranée.

Pour détruire les Criquets, il ne faut pas songer à s'attaquer aux individus ailés. On peut détruire les œufs en les enfouissant profondément par un labour effectué en teinps convenable. Mais le plus souvent on poursuit et on 
écrase les jeunes(larves et nymphes), ou mieux encore on les force à se diriger vers des fosses creusées à l'avance. Dans ce but, le vétérinaire militaire Durand a imaginé, en 1874, des barrages mobiles qu'il a perfectionnés peu à peu, et qui sont actuellement formés de bandes de cretonne de 80 à 83 centimètres de hauteur, surmontées d'une bande de toile cirée de 10 centimètres. On surveille la direction des Criquets, et quelques jours avant leur arrivée, on installe ces barrages en avant des terrains à préserver, en laissant libre seulement un passage qui conduit à des fosses d'enfonissement. Ces barrages sont souvent désignés sous le nom d'appareils cypriotes, parce que, dès 1871, Hehemed Saïd Pacha, gouverneur de l'ile de Chypre, avait mis en usage un procédé analogue; mais l'idée du système algérien n'en est pas moins per. sonnelle à Durand.

Les LOCUSTIDÉs sont les véritables Sauterelles ou "Sauterelles à sabre ". Ce dernier nom leur vient de ce que, chez la femelle, l'abdomen est prolongé par une tarière ensiforme plus ou moins longue. Leurs antennes sont d'ordinaire plus longues que le corps; leurs tarses sont à quatre articles. Les élytres du màle et parfois mème de la femelle portent à leur base un appareil stridulant distinct : le son est produit par une nervure dentée de l'élytre gauche qui frotte contre une région membraneuse, encadrée de nervures (miroir), de l'élytre droit. - Genres Locusta, Decticus, Ephippigera, etc. L'espèce typique est la grande Sauterelle verte (Locusta viridissima), qui se nourrit à la fois de plantes et d'Insectes. La Sauterelle verrucivore (Decticus verrucivorus) laisse couler, quand elle mord, un suc brun qu'on dit àcre et corrosif, et qui passe, en Suède, pour avoir la propriété de détruire les verrues. Le Porte-selle de Béziers (Ephippigera bitteriensis), ou Cousi-cousi, ravage les vignes dans le Bas-Languedoc; mais il est aussi très carnivore, et on se sert souvent de débris de boucherie pour l'attirer et le détruire. On l'aurait mème vu ronger la joue d'un enfant au maillot déposé dans une vigne.

Les GRYLLIDES ou Grillons ont le corps massif, les élytres courts, disposés à plat sur le dos et dépassés par les ailes postérieures; les femelles possèdent un long oviscapte. - Le Grillon des champs (Gryllus campestris L.) habite les prairies et se creuse des galeries dans la terre. Le Grillon domestique ou Cri-Cri (G. domesticus L.) vit dans les maisons; il s'abrite dans les crevasses des murailles, et de préférence au voisinage des endroits chauds.

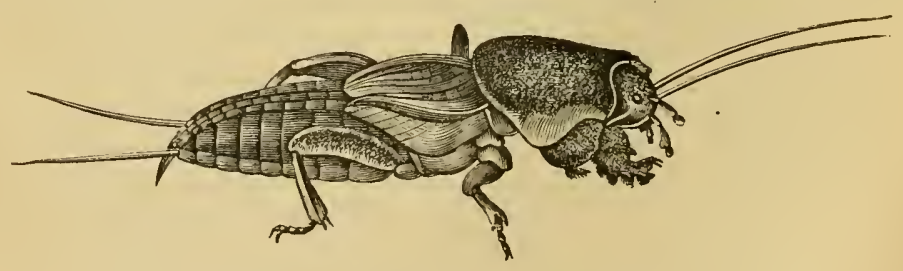

Fig. 613. - Courtilière des jardins.

- La Courtilière ou Taupe-Grillon (Gryllotalpa vulgaris Latr.) (fig. 613) est un des plus dangereux destructeurs de nos jardins. Avec ses pattes antérieures fouisseuses, elle creuse dans le sol des galeries peu profondes, ayant 
quelque analogie arec celles de la Taupe. Ciest une bête vorace, qui attaque les Vers blancs et d'autres larves nuisibles, voire celles de sa propre espèce; elle cause néanmoins beaucoup de dégàts, car non seulement elle ronge les racines, mais elle déchausse aussi les plantes en creusant ses chemins de chasse. On la détruit en enlevant les nids, ou bien en introduisant un peu d'huile grasse dans sa gralerie; on y verse ensuite de l'eau en grande quantité : l'Insecte cherche à fuir et vient périr sur le sol, asphyxié par l'huile qui obstrue ses stigmates (Vogt).

\section{ANEEXE}

\section{THYSANOUNES}

On peut, arec Burmeister, rapprocher des Orthoptères ces Insectes aptères et broyeurs, sans métamorphoses, qui ont l'abdomen terminé par des appen-

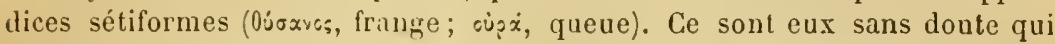
représentent le type le plus primitif des Insectes. Leurs représentants les plus connus sont les Lépismes et les Podures.

Les Lépismes ont le corps allongé, couvert d'écailles, et l'abdomen terminé par trois soies. Le Lépisme du sucre (Lepisma saccharima) ou petit Poisson d'argent, habite dans nos armoires et atlaque les substances sucrées, les papiers, les tissus.

Les Podures ont le corps ramassé, terminé par un appendice bifurqué qui se replie sous l'abdomen et leur permet de sauter avec agilité. Mégnin a signalé, sous le nom de

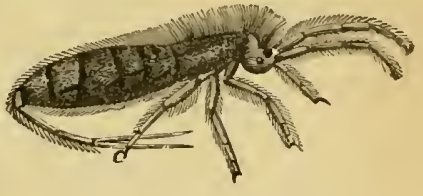

Fig. 614. - Podura villosa.

Podurhippus pityriasicus, une forme insuffisamment caractérisée, qu'il a trouvée en abondance dans des croùtes recueillies sur la peau d'un Cheval, mais qui se trourait là sans doute d'une facon tout accidentelle.

AXNEXE 11

\section{STREPSIPTERES}

Aussi bien que le précédent, ce petit groupe ponrrait constituer un ordre spécial, voisin des Coléoptères.

Les Strepsiptères (orp̧úçs, enroule-

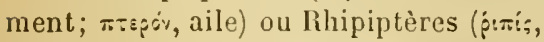
éventail), qui possèdent des pièces buccales très réduites, offrent un dinıorphisme sexuel très accusé. Les màles ont de petits élytres atrophiés, souvent mème recroquevillés après la mort, et des ailes postérieures membraneuses, très grandes, se repliant en éventail. Les femelles sont aptères, apodes et aveugles. Les larves ont trois paires de pattes bien conformées. - Les

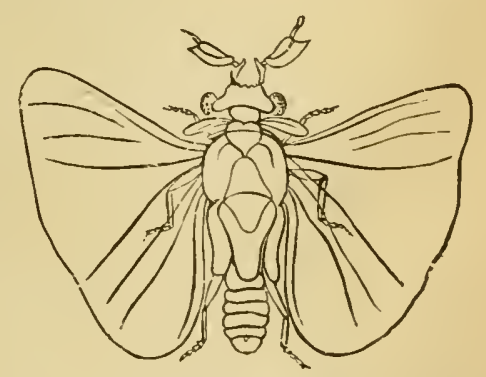

Fig. 615. - Stylops Spencei, forlement grossi, d'après Westwood.

Rhipiptères sont parasites des Iyménoptères porte-aiguillons. Les larves se fixent dans le corps des larves de Guêpes, par exemple, et suivent à peu 
près la même évolıtion que leur hôte. Les femelles restent parasites sur place, passant leur tête au dehors, entre deux segments de l'abdomen. Les màles sont libres, mais vivent peu de temps. - Genres Tenos, Styloris.

\section{HUITIEME ORDRE}

\section{COLËOPTE்RES}

Insectes broyeurs; ailes antérieures comées (élytres), non croisées; ailes postérieures membraneuses, se repliant transversalement; métamorphoses complètes.

Les Coléoptères sont caractérisés en premier lieu par leurs ailes, dont les antérieures ou élytres jouent le simple rôle d'un étui protec-

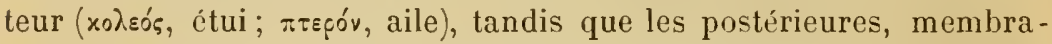
neuses, servent au vol. Les élytres ne se croisent
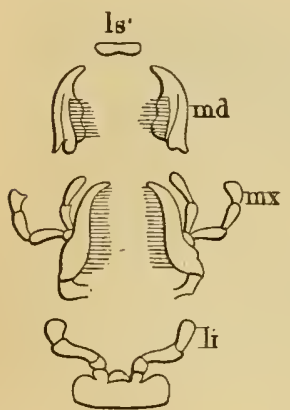

Fig. 616. - Appareil huccal d'un Coléoptère, le Carabe doré. - $l s$, lèvre supérieure. $m d$, mandibules. $m x$, mâehoires. $l i$, lèvre inférieure. de momies, sont immobiles et montrent leurs membres repliés et emmaillottés dans un mince tégument.

On a vu précédemment (p. 744) que le nom de scoleciasis est employé pour désigner les accidents qui peurent résulter de la présence des Insectes dans le corps de l'Homme et des animaux. W. Hope a proposé spécialement celui de canthariasis pour les cas où il s'agit de Coléoptères. Ces accidents sont en général de peu d'importance; ils se rapportent à des larves où mème à des Insectes parfaits de Carabes, Dytiques, Staphylins, Dermestes, Géotrupes, Hannetons, Blaps, Ténébrions, Mordelles, Méloés, Charançons, etc. Ce sont pour la plupart des Insectes qui vivent au voisinage de l'Homme ou sur les substances dont il fait sa nourriture. D'ailleurs, la plupart des cas relevés par Hope sont anciens et douteux. 
La classification dles Coléoptères a beaucoup varié suivant les auteurs. Au siècle deruier, Geoffroy avait établi un système fort commode, basé sur le nombre des articles des larses. Malheureusement, ce système, dit tarsal ou tarsien, a dù ctre abandonné, parce qu'il éloigne souvent des formes voisines et qu'il ne tient pas compte, en somme, des affinités naturelles. Toutefois, le caractère de cet ouviage nous permetlra de le conserver lans ses traits généraux, et de metlre à profil sa grande simplicité. D’après cela, nous diviserons l’ordre des Coléoptères en quatre grands groupes : Trimères, T $t$ tramères, Héteromères et Pentaméres.

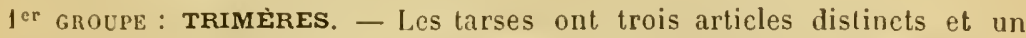
(uatrième rudimentaire (Cryptotétramères). - 2 familles : Coccinellidx et Endomychidx.

Les COCGINELLIDÉs, vulgairement Bètes à bon Dieu, comptent au nombre des Insectes les plus utiles, car ils se nourrissent de Pucerons. Leurs larves sont encore plus voraces et en détruisent une quantité énorme. La Coccinelle à sept points (Coccinella septempunctata) est une des espèces les plus communes.

$2^{\circ}$ GROUPE : TÉTRAMĖRES. - Les tarses ont quatre articles distincts et un rudimentaire (Cryptopentameres).

I.es GHRYSOMÉLIDÉS sont souvent, comme leur nom l'indique, revètus de teintes brillantes. Leurs très nombreuses espèces ont été réparties entre plusieurs tribus.

Nous citerons d’abord le Cassida nebulosa, qui détruit les jeunes plants de betteraves en dévorant les feuilles.

Les Altises comprennent un grand nombre d'espèces dont les adultes, comme les larves, attaquent des plantes diverses, mais en particulier les Crucifères. Ce sont ces petits Insectes sauteurs connus sous les noms de Puces de terre, Tiquets, etc. On les réunissait autrefois dans le genre Haltica, qui a été subdivisé par les auteurs. - La destruction des Altises offre beaucoup de difficultés. Dans la culture potagère, on saupoudre les jeunes plants de cendres ou de poussières, ou bien on les arrose avec des infusions de plantes amères; dans la grande culture, Pelonze a obtenu de bons résultats par l'emploi de sable fin imprégné de naphtaline; enfin,
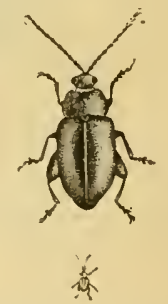

Fig. 617. - Haltica neForm, grand. nat. et grossi. on doit à Bella une muceronnière assez simple, à l'aide de laquelle on englue à la fois un grand nombre d'Insectes sur une toile enduite de goudron.

Le Colaspidème noir (Colaspidema ater), vulgairement Tégril ou Cuc, ravage les luzernes dans nos départements méridionaux. - Le Leptinotarse du Colorado (Leptinotarsa decemlineata Say) s'est acquis dans ces derniers temps une fàcheuse célébrité dans l'Amérique du Nord et s'est mème fait craindre jusqu'en Europe. C'est l'Insecte que les Américains appellent le Scarabée du Colorado (Colorodo Beetle), et que les documents officiels ont fait connaitre en France sous le nom inexact de Doryphora. Sa patrie est l'Ouest des États-Unis, oủ une Solanée sauvage lui servait de nourriture; 
mais la pomme de terre l'a bientòt attiré el multiplié dans les régions de l'Est et du Nord-Est, qui l'ont ensuite expédié en Europe. En 1877, on l'observait en Allemagne, sur plusieurs points. Il se montra ensuite en Hollande, en Suède, en Angleterre. Heureusement, on n'hésita pas à recourir d'emblée à les moyens radicaux, et la destruction de l'Insecte fut complète. En mème tomps, les gouvernements prenaient de sérieuses mesures préventives, qui réussirent à préserver l'kurope. Le Leptinotarse de la pomme de terre est d'une teinte jaunàtre, et tire son nom spécifique de la présence, à la surface de chacun de ses élytres, de cinq lignes noires longitudinales bordées chacune de deux raugées irrégulières de ponctuations. L'Insecte parfait liverne sous terre; il apparaît dès le printemps sous les feuilles, qu'il dévore; la femelle pond, ì la face inférieure de ces feuilles,

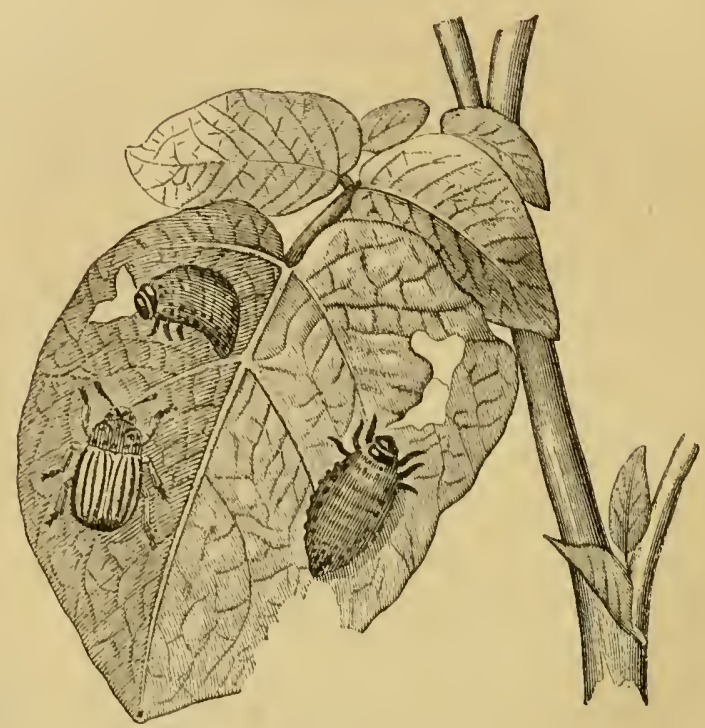

Fig. 618. - Leplinotarse (vulgairement Doryphora) du Colorado - larves entièrement développées et Insecte parfait.

des œufs jaunes réunis par plaques de 35 à 40. Les larves, d'abord rougeatres, puis jaunes, avec des taches noires, mangent les fenilles comme leurs parents. Au bout de quinze à vingt jours, elles s'enfoncent dans la terre pour subir la nymphose. Une dizaine de jours après, a lieu l'éclosion des adultes, qui fournissent eux-mèmes une seconde génération, suivie d'une troisième. Ce sont les Insectes appartenant ì cette dernière qui sont appelés à hiverner. On voit, en somme, que la Chrysomèle anéricaine attaque seulement les parties aériennes de la plante; mais celle-ci ne produit plus alors que peu ou point de tubercules. Pour détruire cet Insecte, on a préconisé l'emploi du vert de Paris ou de Scheele (arsénite de cuivre) ou bien du pourpre de Londres (arséniate de chaux coloré), soil en suspension dans l'eau, soit mélangé avec de la farine, ou encore des aspersions d'eau phéniquée au centième. Au surplus, les documents officiels indiquent la voie à suivre dans le cas d'une invasion sur le territoire français. 
L'Eumolpe de la vigne (Bromius vitis) est connu sous le nom d'Écricain ì cause des sortes de caractères qu'il dessine sur les feuilles en les rongeant. Il nuit beancoup a la vigne, et ses larves sont encore plus dangereuses, car elles perforent les racines.

Dans la famille đes GERAMBYCIDES, appelés aussi Longicomes en raison des dimensions de leurs antemnes, nous devons mentionner le Calamobie liméaire (Hippopsis gracilis), dont la larve ronge la lige du blé au-dessous de l'épi, de sorte que celui-ci tombe au moindre vent : les liges ressemblent alors à des aiguillons, d'où le non d'Aiguillonnier que les habilauts le l'onest et du midi de la France donnent à cet Insecte.

L.es Romains consommaient avec délices, sous le nom de Cossus, une grosse larve d'Insecte n'ayant certainement rien de commun avec le Lépidoptère qui porte aujourd'hui ee nom; il s'agissait probablement de la larve du Grand Capricorne (Cerambyx heros), qui vil dans le bois du chine, on peutêtre de celle dı Prionus coriarius.

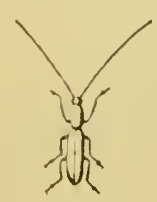

Fig. 619. - Aiguillonnier, grandeur naturelle.

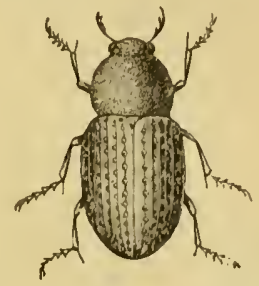

然

Fig. 620. - Hylaste du trènle, grandeur naturelle et grossi.

Les SGOLYTIDÉS sont, pour la plupart, de petite taille; ils rongent le bois (xyloplages) et causent par suite beaucoup de dommages aux arbres. - Genres Scolytus, Tomicus (Bostrichus), Hylesinus, Hylustes, etc. La larve de l'Ilylastes trifolii ronge les racines du trèfle.

Les GURCULIONIDÉS ou Charancons se reconnaissent d'emblée à leur tète prolongée en une sorte de bec portant l'appareil buccal à son extrémité.

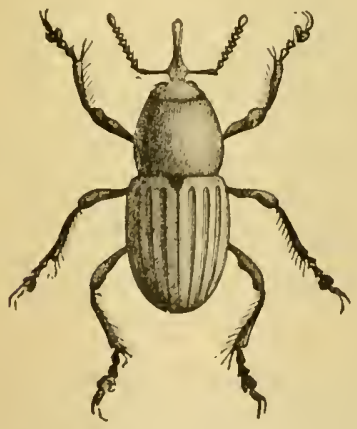

Fig. 621. - Charancon du blé, fortenient grossi.

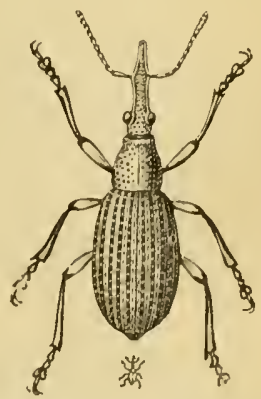

Jig. 622. - Charancon du ehou, grandeus. naturelle et grossi.

Ils percent les végétaux à l'aide de leurs mandibules, qui leur servent ensuite à porter les oufs dans les tissus où la larve doit se développer. Cetle 
famille est immense et ses espèces causent beaucoup de dégâts. - Les Calandres (Calandra) comprennent deux espèces minuscules partout répandues. L'une est le Charancon du Blé (C. granaria) (fig. 621), dont la larve dévore les grains conservés dans les greniers et subit la nymphose à l'intérieur même de ces grains. L'autre est le $C$. oryzæ. On combat ces dangereux Insectes par la propreté et la ventilation. Germain a signalé des troubles graves du côté de l'appareil respiratoire chez des Chevaux qui consommaient de l'orge devenue très poussiéreuse par le fait des Charancons. - En Amérique et dans les Indes, on mange les larves de certaines Calandres. - Les Baridius (Baridius) et les Ceutorynques (Ceutorhynchus) nuisent surtout aux Crucifères : tel est le Charançon du chou (Ceut. sulcicollis) (fig. 622). - Les larves de l'Anthonome des pommiers (Anthonomus pomorum) rongent les fleurs de ces arbres. - Divers Apions (Apion) attaquent le trèfle : A. apricans, etc. - Les Larins (Larinus) vivent sur les Composées. Les larves d'une espèce orientale (L. nidificans Guib.) produisent sur les tiges d'un Onopordon des coques dans lesquelles elles se transforment en nymphes. Ces coques sont détachées avant la sortie de l'Insecte; on les exploite surtout en Syrie. A Constantinople, elles sont connues sous le nom de Tréhala ou Tricala.

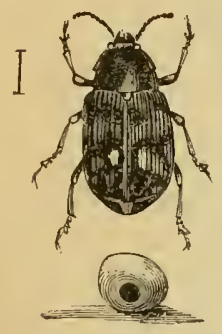

Fig. 623. -- Bruche du pois, grossi, et pois percé par le Bruche. $\mathrm{Du}$ volume d'une olive, elles sont blanc grisàtre et rugueuses. Elles contiennent de la fécule, un peu de gomme, des sels et un sucre spécial que Berthelot a appelé tréhalose. En Turquie, on emploie le Tréhala en décoction, conire les catarrhes bronchiques et mème comme aliment, en guise de tapioca.

Les BRUGHIDÉS se rapprochent beaucoup des Charançons, mais leur rostre est court et large, el leurs antennes ne sont jamais coudées. Leurs larves se dévcloppent dans les graines, surtout dans celles des Légumineuses. Les espèces qui causent le plus de dégâts sont: le Bruche du pois (Bruchus pisi) ; le Bruche commun (B. granarius), qui attaque les fèves; le Bruche à antennes pàles 'B. pallidicornis), des vesces et des lentilles; le Bruche rufimane (B. rufmanus), des fèves et des lentilles; etc.

3e GROUPE : HÉTÉRomėREs. - Les tarses des deux paires de paltes antérieures sont à cinq articles, ceux de la troisième paire à quatre articles.

Les MÉLOIDÉS, Cantharidés ou Vésicants, offrent un intérêt tout particulier, tant à cause de leur évolution complexe, qualifiée à juste titre d'hypermétamorphose, que par suite des propriélés vésicantes (dues à la cantharidine) qu'ils possèdent tous, à l'exclusion des autres Insectes.

Les Sitaris (Sitaris) sont devenus célèbres par les Juelles observations de Fabre, auxquelles il faut joindre celles, plus récentes, de Valéry Mayet.

Les recherches de Fabre ont porté sur le Sitaris mural (S. muralis Forst.; S. humeralis Fabr.). Les Insectes adultes ne vivent que peu de temps et sans prendre de nourriture. Vers la fin de l'été, la femelle dépose ses œufs à l'entrée des nids souterrains d'une Abeille solitaire, l'Anthophora 
pilipes. De ces oufs sortent, au bout d'un mois, de petites larves agiles, munies de pattes robustes, qui passent l'hiver sur place, entassées sans ordre. Au printemps suivant, ces larves affamées se mettent en mouvement et se jettent sur les Anthophores màles, qui apparaissent les premiers; cependant, c'est sur les femelles qu'elles doivent finalement s'établir: le passage de l'un à l'autre a lieu lor's de l'accouplement. A cet état, les jeunes Sitaris avaient été longtemps pris pour des sortes de Poux et décrits sous le nom de Triongulins: Fabre les désigne sous celui de laves primitives. Lor'sque la femelle de l'Anthophore va effectuer sa ponte daus les cellules qu'elle a préalablement remplies de miel, la larve parasite, toujours á jeun, se laisse tomber sur l'œuf, l'ouvre avec ses mandibules acérées, en avale le contenu, et se sert de la coque comme d'un radeau pour flotter sur le miel. Au bout de huit jours, elle subit une mue et apparait sous une nouvelle forme : cette seconde larve est molle, blanche, aveugle, ne possède que des pattes atrophiées et des pièces buccales rudimentaires. Elle emploie quatre à cinq semaines à consommer le miel de la cellule, puis se transforme en un corps inerte et segmenté, nommé psculo-chrysalicle. Le plus souvent, celte phase est de longue durée, et les dernières métamorphoses ne s’achèvent qu'au commencement de l'été de la seconde année. A la pseudo-chrysalide fait alors suite une troisième larve, assez semblable à la seconde, mais demeurant immobile et sans prendre de nourriture. Elle vit à peu près aussi longtemps que celle-ci, puis passe à l'état de nymphe véritable. Un mois après, a lieu l'éclosion de l'adulte.

Les Sitaris ne sont pas usités en thérapeutique, à cause de leur petite taille et de leur rareté relative.

Les autres Méloïdés ont une évolution analogue, leurs larves vivant également en commensales, ainsi que l'ont établi les recherches de Newport, Lichtenstein, Riley et Beauregard. Nous ne nous occuperons que des plus importants d'entre eux.

Les Cantharides (Cantharis Geoffroy) sont caractérisées par leurs antennes à onze articles, assez longues et à peine épaissies vers l'extrémité; par leurs tarses allongés, à crochets bifides, mais non pectinés; par leur corselet plus large que loug; enfin, par leurs élytres à couleurs métalliques, recouvrant tout l'abdomen et un peu déhiscents à l'estrémité.

La Cantharide ofticinale (C. vesicatoria L.), vulgairement Mouche d'Espagne, est l'Insecte vésicant par excellence. Elle mesure en moyenne 18 à 20 millimètres de long sur 4 à 6 de large. Le màle est plus petit que la femelle. La tète est cordiforme, le corselet presque carré. Les élytres sont vert doré, avec reflets métalliques, granuleux, et parcourus vers leur bord interne par deux fines nervures longitudinales. Les antennes et les tarses sont noil's.

Les Cantharides abondent surtout dans l'Europe méridionale, mais on les rencontre jusqu'en Suède. Aux environs de Paris, on ne les observe guère que tous les quatre ou cinq ans, au commencement de juin. Elles se jettent sur les frênes, dont elles dévorent les feuilles, puis sur les lilas, les troènes et autres Oléacées; rarement elles attaquent d'autres plantes. Une odeur forte et désagréable décèle leur 
présence, et on peut les voir voler autour des arbres pendant les heures chaudes de la journée.

L'évolution des Cantharides est analogue à celle des Sitaris : Lichtenstein (de Montpellier) avait déjà réussi à en suivre expérimentalement toutes les

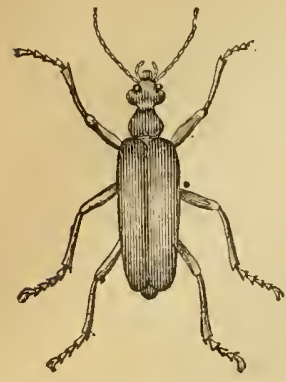

Fig. 624. - Cantharide officinale. phases, mais il restail à en déterminer les conditions naturelles. Après trois ans de recherches, Beauregard est parvenu à ce résultat. Il a reconnu la présence des pseudo-chrysalides de la Cantharide au milieu des cellules de divers Hyménoptères du genre Colletes. Les pseudo-chrysalides n'étaient pas cependant renfermées dans les cellules, mais gisaient au voisinage, dans le sable. On s'explique cette particularité en examinant l'armature buccale des larves, qui est assez puissante pour lear permettre, après avoir épuisé la provision de miel, de perforer la paroi très mince des cellules de Colletes pour s'enfouir dans le sol à quelque distance.

Actuellement le commerce de la droguerie tire en grande partie les Cantharides de la Russie méridionale.

Pour les recueillir, on choisit le matin, parce que la fraîcheur de la nuit les a engourdies. On étend des draps sous les frênes envahis, et on secoue les branches de ces arbres. Puis on tue les Insectes en les plaçant sur des tamis de crin, au-dessous desquels on fait arriver des vapeurs de vinaigre chaud, ou bien en les soumettant à une température élevée. On les dessèche ensuite au soleil, ou mieux au four ou à l'étuve. Leur poids diminue alors à ce point qu'il en faut 13 pour 1 gramme. Lorsquion veut les réduire en poudre, il y a quelques précautions à prendre pour éviter une irritation assez vive de la conjonctive et de la pituitaire. La poudre est d'un gris verdâtre et toujours parsemée de points brillants; elle a une odeur nauséeuse et une saveur àcre.

Il importe de conserver les Cantharides dans des endroits secs et dans des flacons bien bouchés. L'humidité, en effet, détruit leur principe actif. D'autre part, elles sont susceptibles d'être attaquées par des Insectes : Anthrènes, Ptines, Dermestes, Attagènes, etc., et par des Acariens: Tyroglyphes, Glycyphages, etc.; mais l'altération qui en résulte n'est pas très importante, car on a reconnu que les Cantharides rongées et vermoulues sont encore vésicantes, la proportion de la cantharidine ayant diminué tout au plus des deux cinquièmes.

On trouve quelquefois, mélangés aux Cantharides, des Cétoines dorées et quelques autres Coléoptères, mais il s'agit lả d'un accident de récolte plutôt que d'une véritable fraude. Une falsification de premier ordre, qui se pratique quelquefois en Allemagne, consiste à enlever tout ou partie du principe actif par l'immersion dans l'alcool ou l'essence de térébenthine et à 
livrer de nouveau les Canthariles au commerce; en pareil cas, on ne peut déceler la fraude que par le dosage. Parfois aussi, pour augmenter leur poids, on plonge les Insectes dans l'huile, ce qui se reconnait au toucher. Enfin, les sophistications les plus répandues portent sur la poudre, à laquelle oı mélange de l'euphorbe ou d'autres substances: un simple examen au microscope on à la loupe permet souvent de reconnaitre la présence des poudres étrangères.

Le principe actif de la Cantharide, qui est du reste le même que celui de tous les Méloïdés, a été isolé en 1810 par Bretonneau et Robiquet père; il est connu sous le nom de carthridine et a pour formule $\mathrm{C}^{10} \mathrm{I}^{12} \mathrm{O}^{4}$. C'est une substance qui cristallise en prismes incolores, rhombiques, fusibles à $218^{\circ}$, insolubles dans l'eau et dans le sulfure de carbone, peu solubles dans l'alcool froid, trẹs solubles dans l'éther, le chloroforme, les huiles grasses et les essences.

Son abondance dans le corps de l'Insecte varie suivant une foule de conditions : Fumouze en a trouvé dans certaines récoltes $\mathbf{1}^{\mathrm{gr}}, 70$ seulement par kilogramme, alors que dans d'autres récoltes la proportion s'élevait à $4^{\mathrm{gr}}, 80$. Beauregard a reconnu qu'elle est localisée d'une part dans les organes génitaux, et d'autre part dans le sang. Chez le male c'est seulement dans la troisième paire de vésicules séminales qu'on la rencontre; chez la femelle, c'est à la fois dans la poche copulatrice el dans les ovaires. Les œufs, mềme après la ponte, en renferment une proportion importante. Enfin, sa présence dans le sang explique pourquoi, depuis longtemps, on avait reconnu que les parties molles sont incomparablement plus actives que les parties dures.

On employait autrefois la Cantharide à l'intéricur, à titre d'aphrodisiaque. C'est un médicament très clangereux, qui produit, à dose un peu élevée, une vive irritation des roies génito-urinaires. A l'extérieur, on l'utilise pour ses propriétés vésicantes, sous forme de pommade, d'huile, de teinture, etc. On peut ajouter que, d'une manière générale, elle constitue la base des principaux vésicatoires usités dans la médecine de l'Homme et des animaux.

D'autres espèces du mème genre, qui se rencontrent en Algérie, en Grèce, en Italie, peuvent ètre employées comme succédanés.

Il en est de mème des espèces du genre voisin Lyttu Fabr. ou Epicautı Dejean, la plupart américaines.

Les Mylabres (IIylabris Fabr.) ont ordinairement le corps velu; leurs élytres, élargis et arrondis en arrière, sont souvent de teinte noire, avec des bandes ou des taches jaunes ou rouges; les antemes, dans les espèces d'Europe, sont à onze articles et un peu renflées en massue à l'extrémité, avec le dernier article plus grand que les autres.

Ces Insectes vivent en petites troupes sur les Graminées et les plantes basses; ils sont très timides, et lorsqu'on veut les saisir, ils se laissent tomber et "font les morts. " Künckel a déterminé leur évolution en 1890; 
ils se développent à la façon des Épicautes: leurs larves vivent dans les coques ovigères des Acridiens et se nourrissent des wufs de ces Orthoptères. L'espèce

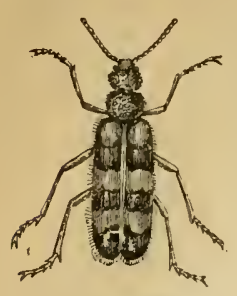

Fig. 625. - Mylabre variable. la plus importante est le Mylabre variable ( $\boldsymbol{M}$. variabilis Pallas), de l'Europe méridionale, trouvé exceptionnellement aux environs de Paris, et dont Robiquet avait déjà retiré de la cantharidine. Le Mylabre bleuàtre (M. cyanescens Illiger), qui habite aussi le Midi de la France, a été recommande par Farines, de Perpignan, comme plus vésicant encore que le précédent. Le Mylabre de la chicorée ( $M$. cichorii L.) et le Mylabre du sida (M. sidæ Fabr.) sont originaires de la Chine. Le Mylabre indien (M. indica Füssl.) s'emploie à Pondichéry, etc. Ces différentes espèces et beaucoup d'autres sans doute sont des succédanés des Cantharides. On ne les utilise guère en France; mais les vétérinaires anglais en ont souvent fait usage.

Meynier (1) a constaté en 1869 des accidents très graves chez un grand nombre d'Hommes qui avaient été envoyés en colonne dans la province d'Oran, et qui s'étaient nourris de Grenouilles ayant mangé des Mylabres. Ces Hommes présentaient les symptômes suivants: sécheresse de la bouche, soif, douleurs gastriques, mictions fréquentes et douloureuses, urines parfois sanguinolentes; quelques-uns montraient du priapisme ou du moins des érections douloureuses et prolongées; plusieurs éprouvaient des vertiges intenses. Le repos, la diète et l'usage de la tisane de lin suffirent à obtenir une guérison rapide; du reste, l'interdiction de pêcher les Grenouilles empêcha le retour de ces empoisonnements.

Déjà Vezien avail fait connaître des accidents analogues, dus également à la consommation de Grenouilles qui avaient ingéré des Insectes vésicants (Mylabris vicina et Leptoplanus Chevrolati).

Une simple mention est due aux Cérocomes (Cerocoma Geoffr.), qui ont des antennes courtes, difformes chez les mâles, et dont les espèces, méditerranéennes ou asiatiques, vivent principalement sur les fleurs des Composées. Leurs larves se nourrissent d'Orthoptères. On rencontre quelquefois, aux environs de Paris, 'le $C$. Schrfferi, Insecte d'un vert doré et pubescent, et le C. Schreberi.

Les Mèloès (Meloe L.) sont fuciles à reconnaître à leurs élytres imbriqués à la base et plus courts que l'abdomen, surtout chez les femelles, qui ont l'abdomen très gonllé; les ailes membraneuses font défaut; enfin, les antennes sont moniliformes, à onze articles.

Ce sont des Insectes de forte taille, de teinte noire ou bleuàtre, qui apparaissent au printemps dans les gazons; ils se nourrissent d'herbes et en général de plantes basses. Quand on les saisit, ils deviennent immobiles et

(1) MeYvier, Empoisonnement par la chair de grenouilles infectées par des insectes du genre Mylabris. Archives de médecine militaire, 1893, p. 53. - Vezies, Cystite cantharidienne causée par l'ingestion de grenouilles. Recueil des mém. de méd. milit., IV, p. 457, 1861 . 
laissent suinter un liquide jaunitre ou blanchàtre, répandant une odeur à la fois fade et pénétrante. Newport et Fabre ont fait connaitre leur évolution: les larres sont mellivores. - L'espèce la plus commune dans notre région est le Méloé proscarabée (M. moscarabeus L., que les véterinaires espaguols ont longtemps employé comme vésicant. On trouve encore, aux environs de l'aris, le Méloé de mai ( $\boldsymbol{H}$. majalis L.), le Méloé antomnal ( $M$. autumnalis Oliv.), etc. D’après Flening, on ulilise dans l'Hindoustan les propriélés résicantes du $M$. trianthemx, qui vit sur les lleurs de certaines Cucurbilacées.

La plupart des anciens auteurs, médecins et vétérinaires, Dioscoride, Galien, Végèce, Hiéroclès, etc., out signalé sous le nom de Buprestes

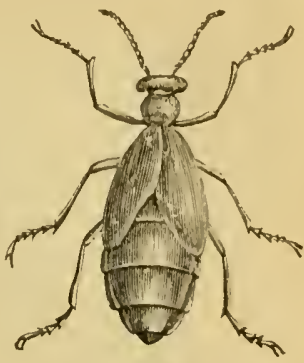

Fig. 6?6. - Méloé de nai.

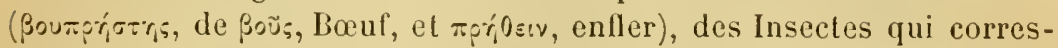
pondent, non pas aux Buprestes actuels, mais fort probablement aux Méloés. Des auteurs plus récents en ont parlé sous la dénomination populaire d'Enfle-Baufs. Ces Insectes étaient réputés produire, chez les Boufs qui les avaient ingérés, des accès de fureur, et un gonflement capable d'entrainer la mort. On les considérait d'ailleurs comme susceptibles de provoquer des accidents aussi graves sur lHomme, car la loi Cornelia punissait de mort, à Rome, ceux qui mêlaient du Bupreste aux aliments et aux boissons.

Dans la famille des TÉNÉBRIONIDÉS ou Melasomes, ainsi nommés à cause de leur couleur noire, nous avons à ciler le Ténébrion de la farine (Tenebrio molitor), qui vit souvent, à l'état adulte, dans les fourrages, et dont la larve, connue sous le nom de Ver de la farine, se rencontre surtout dans la farine et daus le son. Lorsque ces larves sont très multipliées, elles remplissent ces substances de leurs exeréments et de leurs dépouilles, à tel point qu'il n'est plus possible de les faire consommer aux animaux. Hope a relevé un certain nombre de cas dans lesquels le Tenebrio molitor aurait été rencontré, soit à l'état adulte, soit à l'état larvaire, dans le tube digestif, les cavités nasales ou mème les voies urinaires de l'Homme; mais l'authenticité de ces faits n'est nullement établie. - A la même famille appartiennent Scaurus striatus Fabr. et Akis spinosa L., qui

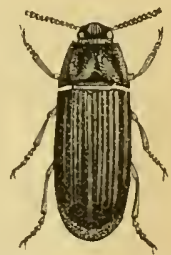

Fig. 627. - Tenebrio molitor. peuvent servir d'hótes intermédiaires à l'Hymenolepis diminuta (voy. p. 296).

Il convient de citer enfin les Blaps (Blaps Fabr.), gros Insectes d'un noir généralement mat, à élytres souvent sillonnés, et à antennes de 11 articles, les derniers globuleux et bien distincts.

Le IBlaps présagre-mort (Bl. mortisaga L.), vulgairement Scarubée puant, Porte-malheur, Sorcière de lu mort, est à peu près de la taille d'un Hanneton; il est noir', sans ailes membraneuses, mais avec des élytres prolongés en arrière par une saillie formant comme une pointe post-abdominale. 
Il se traîne lourdement dans tous les lieux humides et obscurs, dans les caves, les celliers, les coins sombres des maisons et des éeuries,'sous les tonneaux, les solives, les planchers; il se tient eaché le jour et ne sort guère que la nuit, pour chercher çà et là les matières organiques décomposées dont il se nourrit. Il laisse aux doigts une odeur fétide, qui tient à l'émission par l'anus d'un liquide spécial séerété par les glandes anales.

Cette humeur jouit de propriétés irritantes, qui se transmettent à la litière, à la paille et aux diver's aliments des animaux. Aussi les sujets qui consomment les aliments ainsi souillés, comme ceux dont les mangeoires sont visitées par des Blaps, préșentent-ils souvent des lésions sur les lèvres, le bout du nez, le bord des narines, la pituitaire et même au pourtour des yeux (1). Ces lésions paraissent se rapporter à l'affection décrite par divers auteurs sous le nom

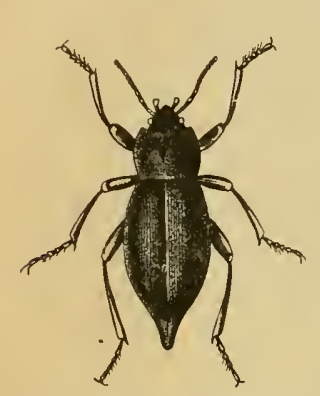

Fig. 628. - Blaps mortisaga. d'herpes labialis, Ititzausschlag, herpès phlycténoïde, rhinite pemphigoïde. Elles consistent d'abord en une injeetion de la peau et de la muqueuse nasale; peu après se produit une éruption de petites vésicules assez confluentes, accompagnée souvent d'inflammation de la pituitaire, avec érosions et jetage muqueux; enfin survient une exfoliation épidermique plus ou moins étendue. Il n'est pas rare de voir le pigment disparaître sur eertains points, laissant quelque temps des macules blanchâtres. La maladie ne dure guère que cinq à sept jours Iorsqu'on en a fait disparaître la eause. Les expériences de Bassi ont établi que les Inseetes morts n'ont plus d'aetion irritante.

Divers auteurs ont rapporté des cas de eanthariasis du tube digestif oceasionnés par le Blaps mortisaga ou sa larve.

Le Blaps mucronatu Latr. est, comme nous l'avons dit, l'hôte intermédiaire du Gigantorhynchus moniliformis (voy. p. "569;.

$4^{e}$ Groupe : PENTAMĖRES. - Il existe d'ordinaire cinq articles à tous les larses.

Les PTINIDÉS sont reconnaissables ả leur tête, qui est rétractile à l'intérieur du prothorax; ce sont des Insectes ennemis de la lumière, et dont les larves dévorent le bois (xylophages) ou d'autres substances organiques. - Citons les Ptines, et en particulier le Ptine voleur (Ptinus fur), qui vit dans les maisons et dans les fenils, et dont la larve attaque les fourrages, les herbiers, les collections d'Insectes. Les Vrillettes (Anobium) sont bien conuues sous le nom d'Ilorloges de la mort.

(1) H. Tisserant, Accidents provoqués chez le Cheval par le Blaps mortisaga, Blaps porte-malheur. Journal de méd. vétér. et de zoctechnie, p. 25, 1886. - K. Bassi, Eczema vescicoloso labiale e nasale del cavallo causato in maniera indiretla dal Blapo nero (Blaps mortisaga $L$.). Il Moderno Zooiatro, IV, p. 63, 1893. 
Aux GLERIDÉS appartient le Clairon des Abeilles (Clerus [Trichocies] apiarius), dont la larve vit dans les ruches. Celle du Cl. alcearius (fig. 630) habite le nid des Mellifères saurages.

Parmi les MALACODERMES, nous derons signaler les Lampyres (Lampyris Geoffr.), remarquables par leurs organes phosphorescents, situés à la

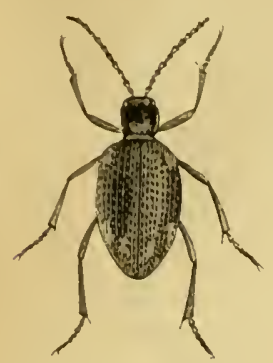

Fig. 629. - Pline voleur. face ventrale des derniers segnents de l'abdomen (fig. 631). La femelle, aptère, est bien connue sous le nom de Ver luisant. Le màle est ailé et faiblement lumineux. On trouve en France

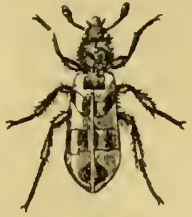

Fig. 630. - Clerus alvearius.

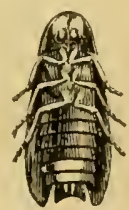

Fig. 631. - Lampyris splendidula, małle, vu par la face ventrale.

L. splendidula et L. noctiluca. Chez les Lucioles (Luciola), les deux sexes sont ailés et phosphorescents. Une espèce, Luciola lusitanica, se rencontre en France, dans le Var et les Alpes-Maritimes. Citons en outre quelques genres non phospliorescents : Telephorus, Malachius, etc., qui sont, comme les précédents, clıasseurs à l'état adulte aussi bien qu'à l'élat de larves.

Les ÉLAÉRIDÉS sont remarquables par la facon dont ils reprennent Jeur position nolmale lorsqu'ils ont été renversés sur le dos. Le prothorax, fort mobile, offre en dessous un prolongement qui peut se loger dans une fossette du bord antérieur du mésothorax. L'Insecte, auquel ses courtes pattes ne permettraient pas de se retourner, se cambre en s'appuyant par la tête et l'extrémité de l'abdomen; la pointe sternale se dégage alors de sa cavité; puis, par un brusque effort musculaire, le corps se redresse et la pointe rentre dans sa loge en faisant ressort, de telle sorte que le dos heurte violemment le plan d'appui : l'animal est lancé en l'air, et il recommence cette manœurre jusqu'à ce qu'il retombe sur ses pattes. On donne à ces Insectes les noms vulgaires de Taupins, Maréchaux, etc., à cause du bruit sec que produit, selon les uns, la rentrée du prolongement sternal dans sa fossette, selon les autres, le choc du corselet sur le sol.

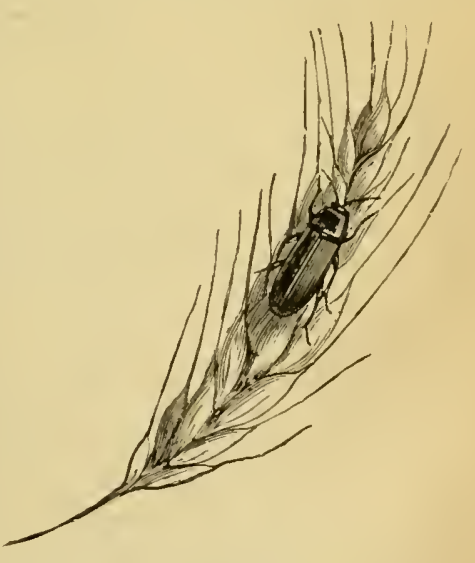

Fig. 639. - Taupin des moissons. Les larves virent sourent plusieurs années dans la terre, rongent les racines (betteraves, narets, etc.) et sont très préjudiciables à l'agriculture. Le principal genre est celui des Agriotes (Agriotes); il comprend, comme espèces 
très répandues: le Taupin des moissons (A. lineatus), le Taupin cracheur (A. sputator), le Taupin obscur (A. obscurus), etc.

Sandberg a rapportẻ une observation relative à la présence de deux larves de Lacon murinus dans l'intestin de son propre fils, àgé de dix ans.

Les SGARABÉIDÉS ou Lamellicornes sont nettement caractérisés par leurs antennes, dont les 3 à 7 articles terminaux constituent des sortes de lamelles ou de feuillets mobiles, susceptibles de s'écarter en éventail. Les diverses tribus de cette famille peuvent se répartir, suivant leur régime, entre les deux groupes des Coprophages et des Phytophages.

Parmi les Coprophages, nous citerons les Scarabées (Scarabeus L., Ateuchus Web.) qui fabriquent des sortes de boules ou de pilules avec les excréments des animaux, les Copris (Copris), les Aphodies (Aphodius), les Géotrupes (Geotrupes).

Dans le groupe des Phytophages, se rangent les Hannetons (Melolontha Fabr.), les Rhizotrogues (Rhizotrogus), les Anisoplies (Anisoplia), les Oryctes (Oryctes), les Cétoines (Cetonia), etc.

Nous devons signaler rapidement l'évolution du Hanneton commun (Melo-

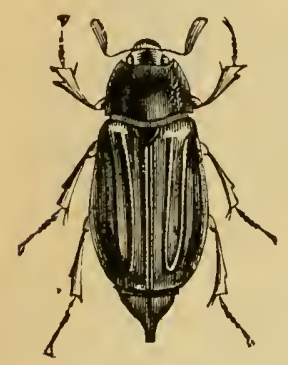

Fig. 633. - Hanneton commun.

lontha vulgaris Fabr.). Les Insectes parfaits volent surtout dans le mois de mai. Ils se jettent sur les arbres et mème sur les plantes basses, dont ils dévorent les feuilles. La femelle

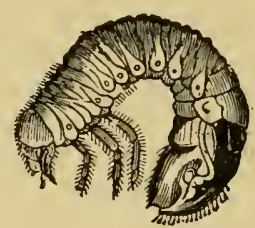

Fig. 634. - Larve du Hanneton vers la fin de la deuxième année. fécondée pond dans le sol, à une profondeur de š à 7 centi. mètres, une trentaine d'œufs de la grosseur d'un grain de chènevis; un peu plus tard, elle effectue une seconde ponte moins importante (1), puis elle meurt, ainsi que le mâle. Les larves éclosent au bout d'un mois à six semaines et se mettent bientòt à ronger les plantes voisines : ce sont ces larves qu'on connait sous le nom de Vers blancs; mais leurs dégàts ne sont guère sensibles dans le courant de la première année. Vers la fin d'octobre, elles s'enfoncent à 40 ou 50 centimètres, et se forment une petite cellule ronde dans laquelle elles hiveruent. Au printemps de la deuxième année, elles remontent vers la surface et se dispersent de tous còtés pour aller ronger les racines des végétaux. Une nouvelle hibernation a lieu à la mème époque que l'année précédente, puis les ravages recommencent, beaucoup plus sérieux encore, au printemps de la troisième année. Bientòt les larves complètement développées prennent une teinte jaune terne; elles s'enfoncent en terre, à une grande profondeur ( 1 mètre et plus), se construisent une coque en terre gàchée mélangée de salive et passent à l'état de nymphes au mois d'août ou de septembre. Au bout de quatre à six semaines, c'est-àdire avant l'hiver, l'Insecte parfait se débarrasse de la pellicule nymphale. Il remonte plus ou moins tòt vers la surface du sol, mais n'en sort qu'en avril

(1) X. Raspail, in Bullet. Soc. Zool. de France, 1891, p. 271, et Mémoires, 1893, p. 202 . 
ou en mai. La durée de cette évolution explique pourquoi l'apparition des Hannetons en grandes masses se reproduit généralement dans nos pays tous les trois ans. Dans la plupart des provinces de l'Allemagne, l'évolution exige quatre années. D’aprẻs liaspail, celte différence tient à l'influence de l'humidité. En France, on peut observer des générations de 4 ans dans les périodes sèches, tandis que les générations triennales correspondent á des périodes humides. Les ravages causés par les larves de Hannetons sont quelquefois énormes; aussi a-t-on cherché les moyens pratiques de leur faire la chasse. La Taupe et certains Oiseaux insectivores en détruisent un grand nombre; mais ce concours est insuffisant. On ramasse parfois les Vers blanes derrière la charrue; on a aussi proposé de les faire consommer sur place par les Oiseaux de basse cour; malleureusement, cette alimentation communique aux́ œufs une saveur repoussante. Le meilleur moyen préventif consiste, jusqu’à présent, dans le hannetonnage, e'est-ì-dire dans la destruction méthodique el pratiquée en grand des Insectes parfaits. D'autre part, on a récemment proposé de détruire les larves par la dissémination d'un champignon parasite (Isaria lensu) qui les allaque spontanément.

Le petit Hanneton de la Saint-Jean (Rhizotrogus solstitialis), ainsi que ses congénères, fournit aussi des larves qui causent des dégàts dans les cultures. On peut en dire autant des Anisoplies.

Les DERMESTIDÉS ont les antennes renllées en massue à leur extrémité, et à ce titre appartiennent à l'ancien groupe des Clavicornes Latr. Les larves sont poilues; comme les adultes, elles se nourrissent de matières animales desséchées. - Les Dermestes (Dermestes) et en particulier le Dermeste ¿lu lard (D. lardarius) se rencontrent dans les maisons, dans les colombiers, dans les musées, sur les cadavres; ils sont redoutés des collectionneurs. Les jeunes Pigreons sont souvent attaqués par leurs larves, qui se sont développées dans le guano. On détruit ces larves, d'après Zürn, à l'aide d'un mélange d'alcool et d'eau phéniquée. Prousi (1) a montré que des peaux de Chèvres, importées de Chine et dont le maniement avait provoqué une pustule maligne chez un ouvrier, renfermaient de nombreux exemplaires de Dermestes vulpinus à divers degrés de développement; or, le corps et les excréments de ces Insectes étaient remplis de Bacilles charbonneux encore très actifs. - Les Attagènes et les Anthrènes ont à peu près le inème mode de vie que les Dermestes : les espèces les plus connues sont Attagenus pellio et Anthrenus museorum. Heim a fait à leur endroit des observations analogues à celles de Proust.

Les SILPHIDES, qui sont aussi des Clavicornes, ont pour la plupart des mours analogues. Ils se repaissent, à tous les états, de matières animales corrompues. - Le Necrodes littoralis se rencontre souvent dans les carcasses de Chevaux et de Bœufs. - Le Silph obscura envahit les cadavres humains exposés à l'air libre. - Les Nécrophores (Necrophorus) ou fossoyeurs ont l'habitude d'enfouir dans la terre les cadavres des petits animaux, pour alimenter leurs larves. Celles-ei, comme d'ailleurs celles de divers Silphes,

(1) Proust, Pustule maligne transmise par des peaux de chevres venunt de Chine. Bullet. de l'Acad. de méd. (3), XXXI, p. 57, 1894. - F. Hem, Du rôle de quelques Coléoptères dans la dissémination de certains cas de charbon. Comptes rendus de la Soc. biol. (9), Vi, p. ¿8, 189 4. 
attaquent volontiers les Pigeonneaux au nid. - Quelques formes deviennent phytophagres lorsque leur multiplication est exubérante. Tel est le cas
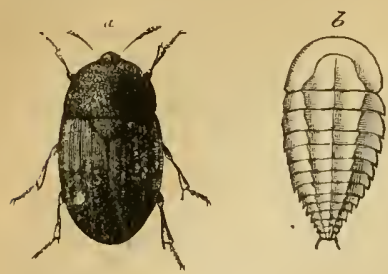

Fig. 635. - Silpha opaca. - a, l'Insecte parfait. $b$, la larve. du Silphe opaque (Silpha opaca), dont la larve dévore les feuilles des betteraves. Dans ces dernières années, cet Insecte a causé de graves dégâts dans les cultures du nord de la France. P. Hallez a montré qu'un mélange de 20 parties d'eau et d'une partie de sulfure de carbone détruit les larves sans nuire aux betteraves. Le ramassage des Insectes parfaits mérite d'ailleurs d'être recommandé.

A quelques familles voisines se rattachent des Coléoptères qui s'observent sur les cadavres humains, par exemple Hister cadacerinus, Saprinus rotundatus et Rhizophagus parallelocollis.

On rapporte aux CRYPTOPHAGIDES l'Atomaria linéaire (Atomaria linearis), qui détruit les feuilles de betteraves à la facon du Silphe opaque.

C'est à une petite famille voisine des précédentes, celle des PELTIDÉS, qu'appartient l'Insecte connu dans le midi de la France sous le nom de Cadelle

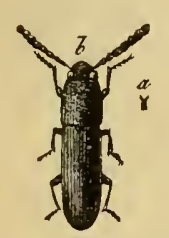

Fig. 636. - Atomaria linearis. - $a$, grandeur naturelle. $b$, grossi.

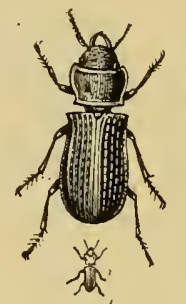

Fig. 637. - Trogosita mauritanica, grandeur naturelle et grossi.

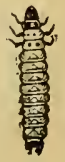

Fig. 638. - Larve du Trogosita mauritanica.

(Trogosita mauritanica), el qu'on rencontre parmi les tas de blé; contrairement à l'opinion vulgaire, on doit le regarder comme très utile, car il mange les larves des Teignes, des Charancons et des autres Insectes granivores.

Les Hydrophiles (Hydrophilus), qui sont phytophages à l'état adulte et carnassiers à l'état larvaire, les Dytiques (Dytiscus) et les Gyrins (Gyrinus), qui vivent de proies vivantes à tous les àges, sont des Insectes aquatiques appartenant à autant de familles spéciales.

Enfin, les CARABIDÉs sont aussi des Insectes carnassiers, mais ils sont tous terrestres. Ils nous rendent de grands services en détruisant les Insectes nuisibles. - Les Carabes (Curabus) sont dépourvus d'ailes membraneuses. Le plus connu est le Carabe doré ( $C$. auratus), aux élytres d'un vert bronzé, vulgairement appelé Jardinier. Les Calosomes (Calosoma) sont ailés; le C. sycophanta délruit beaucoup de Chenilles. Par une singulière exception, les Amares (Amara) et les Zabres (Zabrus) out un régime à la fois animal et vé- 
gétal. Ainsi, la larve du Zabre bossu (Z. yiblus) a plus d'une fois dévasté les champs de céréales. - Quant aux Cicindèles (Cicindela), elles sont essentiel-

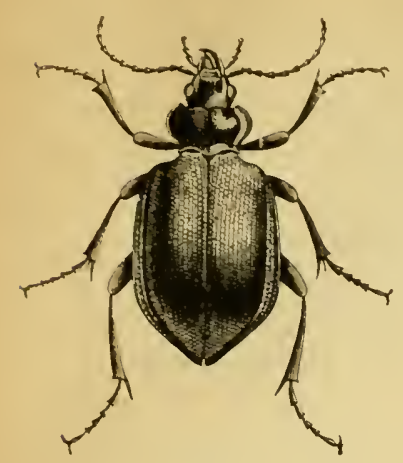

Fig. 63?. - Calosome sycophante.

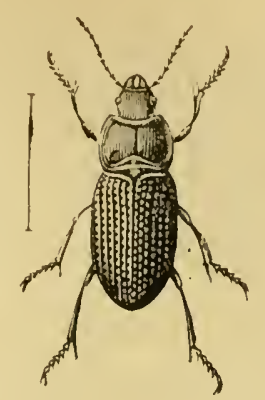

Fig. 640. - Zabre bossu.

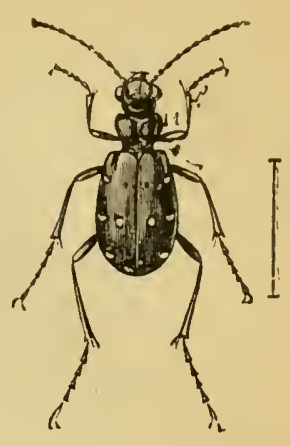

Fig. 6il. - Cicindèle champètre.

lement carnassières. La Cicindèle champètre (C. campestris) est l'espèce la plus commune aux cnvirons de Paris.

\section{SEPTIEME EMBRANCHEMENT}

\section{MOLLUSQUES}

Animaux à symétrie bilatérale, à corps mou, inarticulé, dépourvu de squelette locomoleur et de membres articulés; système nerveux central composé de trois groupes ganglionnaires.

L'embranchement des Mollusques (mollusca, noix à coque tendre)

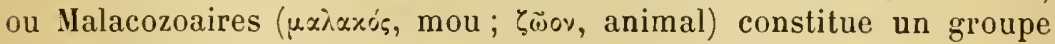
homogène, comprenant un grand nombre de formes dont le corps mou ne se montre jamais divisé en segments et ne possède ni squelette locomoteur ni appendices articulés.

La symétrie est toujours bilatérale à l'origine; mais, dans certains groupes, le corps devient asymétrique par le développement inégal des organes et l'accroissement plus considérable d'un côté du corps. - De même que chez les Arthropodes, on peut distinguer une face dorsale ou hémale, caractérisée par la présence du cour, et une face ventrale ou neurale, correspondant au système nerveux.

La partie du corps qui porte la bouche et les principaux organes des sens, bien que n'étant jamais nettement délimitée, forme parfois une tête assez distincte, ainsi qu'on le voit chez les Céphalopodes et les Gastéropodes (Céphalophores); d'autres fois, comme chez les Lamellibranches (Acéphales), elle ne se montre pas différenciée. Quant au tronc, tantôt il prẻsente une forme aplatic ou cylindroïde, tantôt 
il prend dans sa partie postérieure, qui renferme les viscères, une disposition spiralée en raison de laquelle la symétrie extérieure disparaît tout à fait.

Le tégument est mou, visqueux; au niveau de la face dorsale, il fournit un repli destiné à recouvrir le corps en partie ou en totalité, repli auquel on donne pour ce motif le nom de manteau (pallium). La surface et les bords du manteau sécrètent une enveloppe composée de matière organique (conchyoline) et surtout de calcaire riche en pigment : c'est la coquille, qui sert à protéger le corps de l'animal, et dont la forme et l'aspect sont fort variables. - Entre le corps et la surface interne du manteau, existe un espace libre constituant la chambre palléale: c'est aux dépens des parois de cette chambre que se développent les organes respiratoires.

Les muscles sont d'ordinaire étroitement unis à la face profonde du tégument, de manière à constituer une enveloppe musculo-cutanée. Au niveau de la face ventrale, ils forment une expansion plus ou moins saillante, entière ou divisée, qui sert à la locomotion : c'est ce qu'on nomme le pied.

Le systeme nerveux comprend trois groupes principaux de ganglions à chacun desquels est dévolu un rôle spécial. On distingue: $1^{\circ}$ une paire de ganglions sus-œsophagiens ou cérébroïdes (cerveau) situés sur les côtés de la bouche et réunis entre eux par une commissure qui surmonte celle-ci : les nerfs qui en émanent se rendent aux organes des sens; 20 une paire de ganglions pédieux, moteurs, émettant surtout des rameaux destinés aux muscles du pied; ils sont également réunis entre eux par une commissure transversale et se joignent aux précédents par un double connectif qui embrasse l'œsophage (collier æesophagien antérieur); $3^{\circ}$ enfin, un groupe variable de ganglions parieto-splanchniques, fournissant des filets destinés à innerver le manteau, les branchies et les organes génitaux; ils offrent, du reste, les mêmes connexions que les ganglions pédieux, et les cordons qui les unissent au cerveau forment un collier asophagien postérieur ou grand collier. Outre ces trois groupes ganglionnaires, il existe souvent aussi un système nerveux viscéral ou stomato-gastrique, analogue au sympathique des Vertébrés.

Quant aux organes des sens, ils peuvent être représentés: $1^{\circ}$ par des yeux de structure plus ou moins complexe, qui existent dans tous les groupes jouissant de la locomotion libre; $2^{\circ}$ par des otocystes, ou vésicules auditives closes, ciliées, contenant des concrétions solides ou otolithes; souvent ces résicules, au nombre de deux, sont appliquées sur les ganglions pédieux, mais, ainsi que l'a montré de LacazeDuthiers, ils n'en recoivent pas moins leurs nerfs du cerveau; $3^{\circ}$ par des fossettes olfactives ciliées, comme on en observe chez les Céphalopodes; $4^{\circ}$ enfin, par des organes tactiles divers.

Il existe toujours un canal digestif à parois propres, qui s'étend de 
la bouche, située ì la partie antérieure, jusqu'à l'anus, dont la position est variable. On y distingue un intestin antérieur (œsophage et estomac), un intestin moyen et un intestin terminal ou rectum. La carité buccale est souvent armée de mâchoires et d'une sorte de langue revêtue de dents (radula). D'autre part, à l'origine de l'intestin moyen se trouve généralement déversé le produit d'une volumineuse glande digeslive, désignée sous le nom de foie, mais répondant plutôt au pancréas des Vertébrés (hépatopancréas). Le liquide sécrété par cette glande dissout les matières albuminoïdes et contient un ferment qui transforme la fécule en glucose (Frédéricq).

L'appareil circulatoire comprend toujours un organe central ou cœur, situé sur le trajet du sang artériel, ct divisé au moins en deux cavités, une oreillette et un ventricule. Le sang est lancé dans des artères, mais revient rarement par des capillaires et des veines; dans tous les cas, il traverse un système de lacunes. En général, il existe des ouvertures qui mettent en communication le système circulatoire avec l'extérieur. - Comme chez les Arthropodes, le plasma sanguin est chargé d'hémocyanine et sert de véhicule à la fois pour les matières nutritives et pour l'oxygène.

La vie aquatique de la plupart des Mollusques indique que leur appareil respiratoire est constitué le plus souvent par des branchies, expansions du tégument qui sont revêtues de cils vibratiles, sauf chez les Céphalopodes. Dans quelques cas il se modifie cependant pour servir à la respiratien aérienne: le poumon des Mollusques est une cavité remplie d'air et tapissée par une membrane qui soutient un réseau de vaisseaux sanguins; la communication avec l'extérieur est établie au moyen d'un orifice étroit dit pneumostome.

Les organes excréteurs sont représentés, chez les Lamellibranches et même chez les Gastéropodes, par une sorte de poche glandulaire parfois double dite organe de Bojanus. Chez les Céphalopodes, les reins sont remplacés par des glandes spongieuses qui garnissent les troncs veineux.

La reproduction est toujours sexuelle. La plupart des Gastéropodes sont monoïques, ainsi que les Ptéropodes; mais les sexes sont séparés chez le plus grand nombre des Lamellibranches, ainsi que chez tous les Céphalopodes et Scaphopodes.

Le développement de l'embryon débute par une segmentation totale ou partielle, donnant lieu d'ordinaire à la formation d'une larve assez semblable à la trochosphère des Annélides. Souvent la ceinture ciliée de cette larve s'étale en un disque membraneux ou voile qui sert à la natation, et l'animal doit subir alors une métamorphose plus ou moins complexe pour arriver à l'état adulte.

D'une manière générale, les Mollusques sont organisés pour vivre dans l'eau; le petit nombre de ceux qui sont terrestres recherche même les endroits humides. Beaucoup d'espèces sont comesti- 
bles(1). Enfin, on sait le rôle important que jouent les coquilles des Mollusques dans les formations géologiques.

5 classes:

Une coquille bivalve: pas de dents ni de tête distincte (Acéphales). Lamellibraxches.

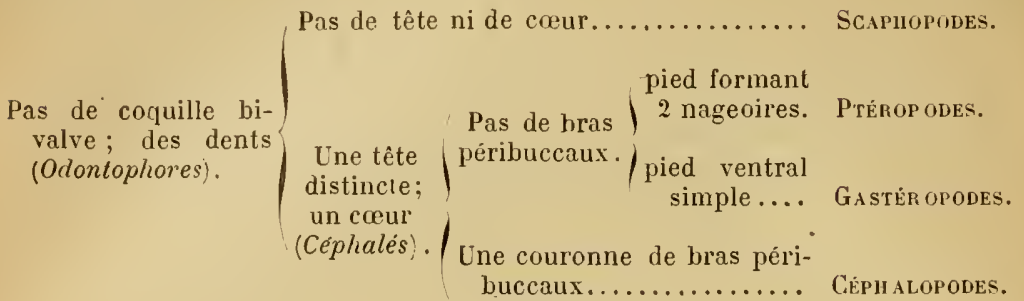

\section{CLASSE I}

\section{LAMELLIBRANCHES}

Mollusques sans tête distincte et sans dents; coquille bivalve, à valves alérales; branchies lamellaires.

Les Lamellibranches (lamella, lamelle; branchiæ, branchies), encore appelés

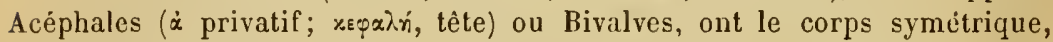
comprimé d'un còté à l'autre. Le manteau, qui naît à la face dorsale, se divise en deux lobes, l'un droit, l'autre gauche. Ces deux lobes palléaux enveloppent le corps tout entier et sécrètent chacun une des valves de la coquille. Celles-ci sont réunies entre elles par une charnière, comprenaut des dents qui s'enclavent réciproquement et un ligament élastique dont l'action tend à ouvrir la coquille quand les muscles adducteurs ne se contractent pas : au contraire de ce qui s'observe chez les Brachiopodes, l'ouverture de la coquille est donc passive. Les deux valves peuvent être sensiblement égales entre elles, et la coquille est dite alors équivalve (Moule), ou bien elles diffèrent d'une façon bien accusée, et on la dit inéquivalve (Huître); ce dernier cas tient en général à ce que l'animal est fixé : comme il se repose d'ordinaire sur le còté, la valve qui se trouve être inférieure devient plus bombée. La coquille est encore qualifiée d'équilatérale quand les bords antérieur ou buccal et postérieur ou anal sont égaux, et d'inéquilatérale dans le cas contraire. La surface externe de cette coquille peut offrir des reliefs variés; la surface interne, lisse et nacrée, ne montre que des impressions musculaires peu marquées servant à l'insertion des muscles adducteurs, et une ligne répondant au bord du manteau (impression palléale); quand il existe un siphon puissant, cette ligne décrit souvent un angle rentrant (sinus palléal). Les muscles adducteurs sont au nombre de deux; mais, chez les inéquivalves, l'adducteur antérieur s'atrophie de bonne heure et disparait, tandis que le postérieur s'avance vers le milieu de la coquille.

La locomotion s'effectue quelquefois (Pecten, Lima) par le simple jeu des

(1) A. Locard, Les Huitres et les Mollusques comestibles. Paris, 1890. 
valves, qui battent l'eau. Le plus souvent, elle est déterminée par le pied, qui peut ètre organisé pour ramper (Anodonta) et qui s'atrophie chez les animaux sédentaires (Ostreu). Assez sourent (Pecten, Mytilus), le pied contient une glande spéciale, qui sécrète une matière analoğue à la soie, se solidifiant au contact de l'eau : il se forme ainsi un paquet de filaments adhésifs, appelé byssus, au nınyen dụuel l'animal se fixe et mème se déplace. Enfin, le jeu des siphons aide quelquefois à l'action du pied (Solen).

Les trois groupes de ganglions nerveux sont pairs.

On peut rencontrer divers organes sensoriels : $1^{\circ}$ des vésicules auditives (olocystes) paires, situées au-dessous de l'osophage; $2^{\circ}$ des yeux distribués sur les bords du manteau et quelquefois a l'extrémité des Inbes du siphon; $3^{\circ}$ des organes olfuctifs ciliés situés entre l'anus et l'extrémité postérieure du pied; $\dot{4}^{\circ}$ des organes du tact, représentés par les palpes labiaux, par des papilles ou tubercules silués sur les bords du manteau, elc.

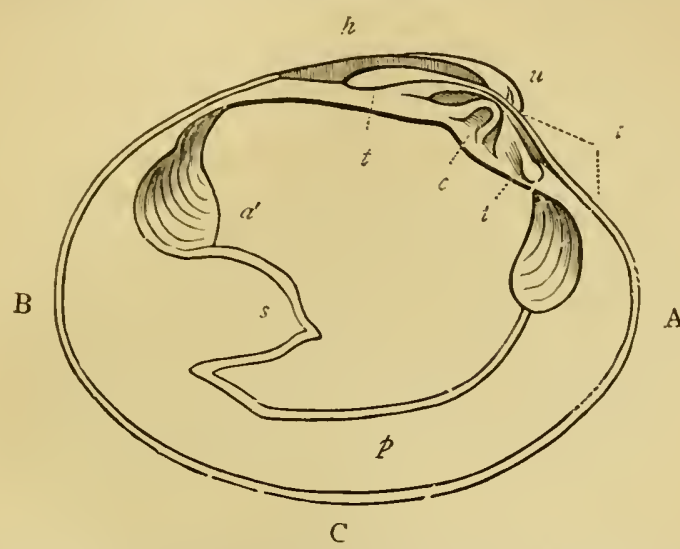

Fig. 642. - Valve gauche de la coquille du Cytherea chione, d'après Woodward. - A, bord antéricur. $\mathrm{B}$, bord postérieur. $\mathrm{C}$, bord ventral ou base. $u$, umbo. $h$, ligament. $l$, lunulc. $c$, dent cardinale. $t, t$, dents lat'śrales. $a$, adducteur antérieur. $a^{\prime}$, adducteur postérieur. $p$, ligne palléale. $s$, sinus palléal, déterminé par les muscles rétracteurs des siphous.

La bouche s'ouvre en arrière du muscle adducteur antérieur; elle est entourée par deux paires de palpes labiaux, membraneux et couverts de cils vibratiles qui servent a attirer les particules alimentaires. Un court œesophage conduit dans un estomac renflé, souvent pourvu d'un long cæcum contenant une sorte de baguette transparente, le style cristallin. L'intestin décrit de nombreuses circonvolutions entre les lobes de la glande digestive et traverse ordinairement le cœur avant de se terminer à l'anus, qui est situé en arrière du muscle adducteur postérieur et sur le trajet du courant d'eau expiratoire.

En général, le caur, inclus dans un péricarde, se compose de déux oreillettes et d'un ventricule; il occupe la région dorsale et entoure le rectum, comme on vient de le voir. Deux troncs aortiques, l'un antérieur, l'autre postérieur, partent du ventricule et vont distribuer le sang au corps; ils se divisent en rameaux multiples, qui se résolvent finalement en un réseau de lacunes ou sinus veineux dépourvus de parois propres. Chez la Moule commune, ces lacunes sont précédées de vaisseaux capillaires véritables (Sabatier). Des sinus veineux, le sang se rend - presque toujours après avoir 
traversé les parois des organes de Bojanus - dans les branchies, où il s'artérialise, et enfin rentre dans les deux oreillettes latérales. Le péricarde communique d'une part avec le système veineux, et d'autre part avec les organes de Bojanus, de telle facon que ces derniers organes permettent l'introduction de l'eau dans le sang et le rejet du sang à l'extérieur.

La respiration s'effectue par la face interne du manteau et par des branchies. Celles-ci sont au nombre de quatre : il en existe deux à gauche et deux à droite du plan médian, insérées au fond de l'angle dièdre formé par les parois du corps et les lobes du manteau. Chacune d'elles se compose de deux feuillets, l'un direct, l'autre réfléchi, affectant entre eux et avec les parties voisines des adhérences variables; ces deux feuillets sont constitués par des filaments recouverts de cils vibratiles. Le courant respiratoire est déterminé par l'action de ces cils : le plus souvent, l'eau peut entrer largement dans la cavilé palléale, mais dans certains cas (Moule) les bords du manteau se soudent en ne laissant que deux fentes, l'une pour l'entrée, l'autre pour la sortie de l'eau et des substances qu'elle contient. Parfois mêrne les lobes du manteau se prolongent au niveau de ces deux orifices en deux tubes désignés sous le nom de siphons.

L'appareil excréteur est représenté par les organes de Bojanus, sacs glanduleux situés de chaque còté du péricarde el parfois réunis sur la ligne médiane; ces glandes spongieuses éliminent l'urée et divers phosphates, et nous avons vu qu'une partie du sang y passe pour subir une dépuration avant de pénétrer dans les branclies. Les sacs de Bojanus communiquent avec le péricarde et s'ouvrent à l'exlérieur sur les parties latérales de la base du pied. Un autre organe, la glande de Keber, qui se trouve au-dessus du cœur ou tapisse les oreillettes, excrète de l'acide hippurique.

$\mathrm{Au}$ point de vue de la reproduction, les Lamellibranches se divisent nettement en deux groupes (Lacaze-Duthiers) : - $1^{\circ} \mathrm{La}$ plupart sont dicïques. Les ovaires et les testicules sont des glandes en grappe occupant les côtés du prétendu foie; dans certains cas, une grande partie de la glande pénètre dans le manteau (Moule). La structure est semblable dans les deux sexes, mais on peut cependant en distinguer la nature, même à l'œil nu, car le sperme est d'ordinaire lactescent ou jaunâtre, tandis que les cufs sont rougeàtres. Les produits génitaux sont tantòt déversés dans les sacs de Bojanus (Peigne varié), tantôt évacués par deux orifices communs avec ceux de cet organe (Moule) ou situés à còté de ceux-ci (Anodonte). - 20 Dans les formes monöques, les glandes des deux sexes sont parfois distinctes, et débouchent à l'extérieur par des conduits séparés (Pandore) ou par un orifice commun (Peigne); d'autres fois elles sont entièrement confondues de manière à former une glande dite hermaphrodite (Huître).

Les embryons des Lamellibranches sont remarquables par la présence, à leur extrémité céphalique, d'un voile ou disque circulaire, dont les bords sont garnis de cils vibratiles : c'est un organe de natation, d'où dériveront plus tard les palpes labiaux. Le tégument se soulève sur la face dorsale pour constituer le manteau. Quant au pied, il apparait sous la forme d'une saillie médiane de la face ventrale, en arrière de la bouche.

Les Mollusques de cette classe vivent pour la plupart dans la mer. Leur chair est souvent tendre et délicate. Ils ont laissé une quantité énorme de coquilles dans les couches géologiques. 
Sous-classe I : Asiphonidés. - Lamellibranches sans siphons : bords du manteau libres ou soudés sur un point.

I. Les uns possèdent un seul muscle adducteur: Moxomyares.

Famille des OSTRÉIDÉS. - Coquille inéquivalve, écailleuse ; un gros muscle adducteur au nilicu du corps; cour ne recouvrant pas le rectum; pied nul ou rudimentaire; pas de byssus.

Genre Huitre (Ostrea L.). - Les Huitres proprement dites se fixent aux fonds marins par leur valve gauche, qui est la plus excavée; l'autre est aplatie et forme une sorte de couverile.

Les Huitres comestibles constituent sans aucun doute plusieurs espèces distinctes, comprenant elles-mêmes de nombreuses variétés, mais on n'est encore que Irès incomplètement fixé à l'égard de ces déterminations. Il est incontestable d'ailleurs que l'habitat, aussi bien que le mode de culture, peut imprimer à une même forme des caractères et surtout des qualités variables; et les gourmets arrivent à reconnaître l'origine des Iluîtres avec la même précision que le cru des vins. Quoi qu'il en soit, les principales espèces d'Huîtres qu'on mange en France sont, d'après Locard : - l'Huître comestible (0. cdulis), dont la coquille, d'un galbe ovalaire un peu allongé dans le sens de la hauteur, montre de nombreuses lamelles calcaires superposées et striées; répandue à peu près exclusivement sur nos côles de la Manche et de l'Océan; - l'Huitre Pied-de-Cheval (0. hippopus), caractérisée par sa grande taille, qui atteint facilement 110 à 115 millimètres, et par l'épaisseur considérable de son test; vit sur toutes nos côtes; - l'Huître portugaise (0. angulata), à coquille allongée et tourmentée, la valve inférieure étant très profonde; acclimatée depuis peu en France, notamment à l'embouchure de la Gironde; chair fade; - l'Huître de Corse (O. Cyrnusi), espèce pouvant atteindre les dimensions du Pied-de-Cheval, mais à galbe plus allongé; vit surtout dans les étangs saumâtres du littoral ouest de la Corse et pourrait probablement s'acclimater dans ceux de la Provence; enfin, l'Huitre stentine $(0$. stentina $)$, de petite taille, souvent irrégulière, à valve inférieure dentelée; assez commune sur les côtes de Provence. - En Italie, on consomme particulièrement 0 . tarentina et 0 . adriatica, que nos éducateurs méditerranéens pourraient essayer de propager.

Sur nos marchés, on rencontre surtout des variétés de l'Huître commune ou comestible, provenant des còtes de la Manche et de l'Océan. Les plus importantes sont: Ies Gracettes ou auciennes Huîtres d'Arcachon, les Huîtres de Marennes, blanches et vertes, les Huitres de Cancale, les Armoricaines, les Sainte-Anne, etc., enfin, les Huîtres d'Ostende ou anglaises.

Organisation. - Nous nous bornerons à donner ici un aperçu élémentaire de l'organisation de l'Huitre comestible.

Quand on ouvre une Ifuitre, on doit rompre le gros muscle qui relie les deux valves, après avoir forcé la charnière pour détruire le ligament situé à la petite extrémité. Si l'on pose alors devant soi, et de préférence dans l'eau, la valve concave (gauche) qui contient l'animal, de façon que cette petite extrémité soit dirigée en avant, on voil d'abord que le corps est enveloppé dune membrane transparente, correspondant aux valves de la coquille : c'est le manteau, dont les bords garnis de franges sont libres, sauf à l'extré- 
mité antérieure, où les deux lobes se réunissent en formant une sorte de capuchon au-dessus de la bouche. Inutile de faire remarquer que l'un de ces lobes adhérait à la. valve droite et a dù en être détaché. - Le muscle adducteur, offrant deux moitiés inégalement transparentes, peut servir de point de repère. Le manteau est attaché à sa base. Immédiatement en avant, on remarque une cavité dans laquelle, sur l'animal vivant, on voit battre le cour; celui-ci se distingue du reste sans difficulté à l'aspect membraneux et noiràtre de sa région auriculaire. Les branchies sont représentées par quatre lamelles striées, superposées, qui partent de la partie postérieure du muscle et le contournent à droite pour se diriger vers l'extrémité antérieure. Au point où elles se terminent, se montrent deux autres paires de lamelles également striées, mais plus petites : ce sont les palpes labiaux, qui partent d'un orifice transversal situé à l'extrémité antérieure. Cet orifice n'est autre que la bouche, qui conduit, par un très court resophage, dans une poche

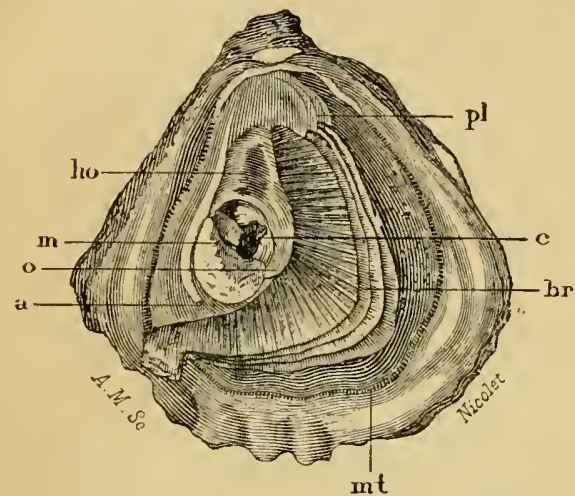

Fig. 643. - Huitre comestible, vue dans sa valve gauche. - $m$, muscle adducleur. $p l$, palpes labiaux. $b r$, branchies, $m t$, manteau. $a$, anus. $c$, ceur. $h o$, glande digestive recouverte par la glande hermaphrodite. $o$, orifice hexuel. stomacale ovoïde, entourée dune masse jaune brunàtre, la glande digestive (foie des auteurs), avec laquelle elle communique directement. L'intestin descend dans l'épaisseur de cette glande, décrit une anse el vient passer à gauche du muscle adducteur, pour se terminer vers sa partie postérieure. Autour de la glande digrestive se trouvent les glandes sexuelles, qui sont partie mâles et partie femelles, l'un des sexes prédominant souvent sur l'autre. On ne trouve qu'un seul orifice de chaque còté du corps; il est situé entre deux cordons nerveux qui partent du ganglion branchial pour se rendre, l'un au cerveau, l'autre à la branchie. "Jamais on ne manque d'arriver dans le canal si l'on fait glisser d'arrière en avant, entre les deux nerfs, une épingle fine en présentant la tête la première " (Lacaze-Duthiers). Le frai commence vers la mi-juin et se termine dans le courant d'août. Les milliers d'embryons qui sortent des œufs restent d'abord logés dans le manteau de la mère; ils nagent à l'aide de leur voile cilié et sortent bientòt au voisinage de la coquille, mais pour rentrer au plus vite en cas de danger : ils sont alors blancs et rendent l'eau laiteuse. Puis ces jeunes Huitres s'entourent d'une coquille et vont se fixer; mais un grand nombre deviennent la proie des animaux marins et en particulier des Polypes, ou mème périssent naturellement si elles n'ont pu se fixer à temps.

On trouve des Huitres dans toutes les mers, et partont elles sont recherchées pour la nourriture de l'homme. Elles vivent à une faible profondeur, quoique toujours au-dessous du niveau des plus basses marées, el forment des amas considérables, désignés sous le nom de bancs, soit sur les rochers, soit plus rarement sur les fonds vaseux; souvent mème elles s'attachent les 
unes aux autres. Leur nourriture se compose de ces myriades d'organismes microscopiques qui peuplent l'eau de la mer (Algues, Foraminifères, Infusoires, Crustacés, elc.).

De dancereux ennemis des Huitres sont les Iluitriers (Hxmatopus), les Étoiles de mer, les Ilomards, des Poissons, des Vers et même de petites Éponges (Cliona celata) qui perforent les coquilles. Les Moules leur sont également nuisibles, car le déreloppement rapide de ces petits Mollusques s'oppose bientòt à l'accroissement et mème à la nutrition des Huitres. Enfin, ces animaux hébergent un certain nombre de commensaux et de parasites.

Ostríiculture. - De nomíbreuses chances de destruction menacent donc les Huitres, tant dans leur jeune àge qu'à l'état adulte. Il faut y ajouter encore le danger qui pourrait résulter d'une pèclıe inconsidérée. Aussi le gouvernement a-t-il dì réglementer cette pèche : la vente des Huîtres est interdite en France du 15 juin au $1^{\text {er }}$ septembre (1). Mais, pour assurer le repeuplement de nos còtes, il faut surtout compter sur une culture rationnelle, basée sur des données scientifiques.

Les Romains, qui estimaient beaucoup les Huitres, s'étaient déjà occupés d'établir des purcs ou bancs artificiels. Divers essais du même genre paraissent avoir été tentés dans les deux derniers siècles; mais on peut dire que l'ostréiculture est en réalité d'origine récente. Coste en a été un des plus ardents et des plus sérieux promoteurs. - Les jeunes Huitres qui frétillent autour des individus mères et rendent l'eau laiteuse constituent le naissain. On les recueille sur des fascines formées de branchages entre-croisés, sur des tuiles creuses ou mème sur de simples pávés: puis, lorsqu'elles ont acquis un certain volume, on les transporte dans les parcs, sortes de grands bassins creusés par la mer et dans lesquels pénètrent les eaux des grandes marées, en y apportant une quantité considérable de nourriture. C'est aussi dans ces parcs qu'on dépose les Huìtres recueillies à la pèche, afin de leur faire perdre le goùt de rase qu'elles off rent le plus souvent. Ajoutons que les bancs artificiels, comme les bancs naturels, sont divisés en plusieurs zones qu'on exploite à tour de ròle, de manière à permettre le repeuplement pendant les périodes de repos. Tel est le principe des procédés d'ostréiculture employés sur nos còtes de l'Océan. - Au bout de trois à cinq ans, les Huitres ont acquis le déreloppement que nous leur voyons liabituellement. Si on les laisse plus longtemps fixées au rocher, elles prennent des dimensions plus considérables et deviennent coriaces : ainsi serait conștitıée, au dire de quelques auteurs, la forme que les zoologistes ont désignée sous le non d'Huitre Pied-de-Cheval.

Les principaux établissements ostréicoles des còtes françaises sont ceux de Courseulles, Cancale, Concarneau, Belon, Lorient, Carnac, les Sablesd'Olonne, Marennes et la Tremblade, Arcachon, Saint-Jean-de-Luz, Toulon.

Dans quelques-uns de ces établissements, notamment à Marennes, à la Tremblade, à Saint-Jean-de-Luz, à Courseulles, etc., on obtient, outre les Iluitres incolores ou blanches, des Huitres vertes particulièrement estimées, et parfois mème des Huitres brunàtres. Cette coloration est surtout accusée dans les branchies et dans les palpes labiaux. J. Chatin a montré qu'elle est

(1) Voyez Joumal Officiel, 17 janvier 1882. - Toutefois, un décret du 9 aoùt 1888 tolère la consommation locale et la vente des Huitres sur les marchés du littoral. 
due à un pigment fixé sur de fins granules protoplasmiques renfermés euxmèmes dans de grandes cellules spéciales des papilles branchiales (1). D'autre part, les recherches de Berthelot ont établi que la matière colorante n'est nullement due, comme on l'avait longtemps admis, à la chlorophylle, et Chatin père a constaté que l'intensité de la coloration est en rapport avec la richesse en fer des tissus. C'est d'ailleurs un fait bien connu qu'à Marennes, on obtient le verdissement des IIuitres en les transportant de bonne heure dans les réservoirs particuliers, appelés claires, où l'eau n'est renouvelée qu'à l'époque des grandes marées; or, la vase noire de ces claires doit sa teinte à du sulfure et à du protoxyde de fer, qui se transforment en sesquioxyde gràce à des manœuvres particulières (parage). 11 est donc supposable que la production du pigment tient à l'assimilation par les Huitres d'une certaine proportion de ces produits ferrugineux.

Emplor. - On mange les Huitres vivantes et entières. L'eau salée qu'elles contiennent et l'abondance du suc sécrélé par la glande digestive en font un aliment facile à digérer. Elles conviennent par suite aux estomacs délicats, et on les a souvent recommandées dans beaucoup d'affections chroniques, ainsi que dans la convalescence des maladies aiguës. La digestibilité est encore augmentée sous l'influence des acides faibles, ce qui justifie l'addition de jus de citron ou l'usage de vins blancs légèrement acidulés. Les Huîtres cuites sont au contraire réputées indigestes. On en préparait autrefois un bouillon qui passait pour analeptique et aphrodisiaque. Les coquilles pulvérisées étaient employées comme absorbantes, antiacides, lithontriptiques, etc. Enfin, l'eau salée contenue dans les valves était préconisée, à la dose de deux ou trois cuillerées par jour, dans le traitement des affections chroniques de l'estomac. - Depuis quelque temps, on prépare sur nos còtes de la Manche des Huitres marinées. - Ajoutons que la France consomme annuellement pour 25 à 30 millions de francs d'Huîtres; à Paris seulement, on en vend une centaine de millions d'individus.

L ingestion des Huîtres est rarement suivie d'accidents semblables à ceux que déterminent parfois les Moules. Quelquefois, cependant, elle donne lieu à des coliques et à une purgation plus ou moins sérieuse, voire à des troubles cholériformes. Nous reviendrons plus loin sur ce sujet en parlant des Moules; disons seulement ici que lintoxication paraît tenir au développement de produits spéciaux, dans le foie du Mollusque, lorsque celui-ci séjourne dans des eaux corrompues, ainsi que l'avaient déjà soupçonné $P$. Gervais et Van Beneden. On concoit d'ailleurs que cette altération de l'eau soit plus rapide en été, et c'est ce qui a donné lieu sans doute à ce préjugé d'après lequel on devrait s'abstenir de manger des Huîtres pendant les mois dont le nom ne contient pas la lettre $r$, préjugé utile, si l'on remarque qu'il concourt à favoriser la propagation de ces animaux.

(1) J. Chatıv, Du siège de la coloration chez les IIuilres vertes. Comptes rendus de l'Acad. des sc., CXVI, p. 264, 1893. - Chatix père, Nalure et cause du verdissement des Hutitres. Bullet. des séances de Ia Soc. nat. d'agriculture de France, LIII, p. 735, 1893. 
L'estime dans laquelle les amateurs tienuent les Huitres vertes a engagé certains industriels à leur communiquer une viridité artificielle par l'addition d'un sel de cuivre : cette fraude, susceptible de déterminer certains troubles dans la santé, était déjà pratiquée au commencement du xvıne siècle ; elle peut se déceler facilemeut au noyen de divers réactifs. Par exemple quelques gouttes d'ammoniaque rersées sur le corps de l'Huitre ou dans le liquide quile baigne donneraient une belle coloration bleue; avec une solution de cyanure jaune ou ferrocyanure de potassium, on aurait une coloration brun marron plus caractéristique encore.

On reconnait que les lluitres sont vivantes, soit aux mouvements du cœur, soit à la contractiou des franges dı manteau.

Les Anomies (Anomiu), pourrues d'un byssus, sont mangées à Cette, où elles sont connues sous le nom d'Estufettes, et à La Rochelle, où on les appelle Éclairs, à cause de leur phosphorescence; leur saveur est très amère.

Famille des PECTINIDÉS. - Fornıes à coquille ornée de còtes rayonnantes. Genres principaux : Pecten, Spondylus, Lima.

Les Peignes (Peeten), vulgairement P'elerines, Manteaux ou Coquilles-de-SaintJacques, sont tous conestibles; leur chair, qu'on mange crue ou cuite, est de bonne qualité. Leurs valves creuses (ricardeuux) sont utilisées pour servir des préparations culinaires variẻes, qualifiées de " coquilles ". - Citons en particulier la Grande Palourde ou Vanne (P. maximus), de la Manche et de l'Océan; la Pèlerine (P. Jacobxus), surtout méditerranéenne; la petite Palourde ou Olivette $(\boldsymbol{P}$. operculuris), de la Manche et de l'Océan; la Palourde normande (P. varius), de toutes nos còtes.

Les Spondyles (Spondylus) sont plus rarement consommés en France sous le nom d'Huitres épineuses ou Huitres rouges. Spondyle Pied-d'Ane (Sp. grderopus), de la Méditerranée.

Quant aus Limes (Lima), on n’en mange qu'une espèce méditerranéenne (L. influta), de taille passable.

II. Dimrares : coquille munie de deux muscles adducteurs.

Famille des AVIGULIDÉS.-Comprend notamment les Avicules (Avicula) et les Pintadines ou Huitres perlières (Meleagrina margaritifera). - Nos cỏtes ne présentent qu'une seule espèce d'Avicule (A. tarentina), qu'on rencontre assez souvent sur les marchés de Cette.

Famille des MYTILIDÉs. - Coquille équivalve; bords du manteau ordinairement soudés en arrière; muscle adducteur postérieur plus fort que l'antérieur; pied mobile en forme de languette, produisant un byssus. Genres principaux : Pinna, Mytilus, Modiola, Lithodomus.

Les Moules (.Iytilus) ont une coquille cunéiforme; elles vivent en colonies nombreuses sur les rochers, où elles se fixent à l'aide de leur byssus. Contrairement aux Huitres, elles se déplacent à volonté : pour cela, elles lancent de nouveaux filaments en avant des anciens et coupent progressivement ceux-ci, se hissant alors comme à l'aide d'un càble.

La Moule comestible ( $M$. edulis) est l'espèce type du genre; mais il existe en outre, sur nos cótes, un grand nombre de formes diverses : גI. herculeus, galloprovincialis, abbreviatus, rctusus, etc. 
Mrtilicclture. - En Normandie et en Brelagne, on se contente ordinairement d’aller recueillir les Moules qui sont émergées à marée basse ; mais, aux environs de La Rochelle, où le fond est vaseux, on les soumet à un système suivi d'élevage. On enfonce dans la vase de longs pieux disposés en allées régulières ou bouchots. Les plus éloignés du rivage sont formés de pieux séparés, sur lesquels se fixent les jeunes Moules; dans les autres, les pieux sont réunis par des branchagces, de manière à former une sorte de claie. C'est sur ces derniers qu'on amène définitivement les Moules, qui ont acquis au bout de deux ans la taille voulue pour ètre livrées à la consommation. Les pêcheurs vont les cueillir à marée basse sur ces bouchots clayonnés, en glissant sur la surface unie de la vase au moyen d'une sorte de petite pirogue á fond plat connue sous le nom d'acon. Quand le vent est favorable, on hisse une voile; dans le cas contraire, le pêcheur se tient sur un genou au bord de la nacelle et rame avec sa jambe libre.

Les Moules sont susceptibles de provoquer des accidents parfois fort graves chez les personnes qui les consomment, cuites ou crues. Ces accidents se présentent sous trois formes principales, qui peurent d'ailleurs s'associer ou se combiner à des degrés divers. Dans la forme la plus simple, on observe une éruption cutanée, érythème ou urticaire, accusée surtout au niveau de la face. Le second type, beaucoup plus sérieux, présente les caractères d'une gastro-entérite accompagnée de phénomènes généraux et prenant parfois une apparence cholériforme; dans ce cas, la convalescence est souvent longue, et lissue peut même être fatale. Enfin, la troisième forme, qu'on peut qualifier de nerveuse, et qui est beaucoup plus grave encore que la précédente, consiste surtout en une paralysie à marche rapide, aboutissant presque toujours à la mort.

Bien des hypothèses ont été émises au sujet de ces empoisonnements alimentaires. On a incriminé successivement, et sans raison, le séjour des Moules contre la coque doublée de cuivre de certains navires, la présence entre leurs valves de petits Crabes (Pinnothères) qui s'y logent en commensaux, le frai des Étoiles de mer qu'elles auraient mangé, etc. La cause réelle des intoxications n'a été déterminée qu'en 1886, à la suite des recherches de Max Wolff et de Brieger. En 188כ, des ouvriers de l’arsenal de Wilhelmshaven, après avoir mangé des Moules pêchées dans le port de cette ville, furent pris des symptômes les plus violents d'un empoisonnentent à forme paralytique: quatre succombèrent après une demi-heure à cinq heures de souffrances. Des Poules et des Chats, ayant ingéré les mêmes Moules jetées sur un fumier, périrent également. Or, ces Mollusques provenaient d'un bassin dans lequel l'eau est stagnante et qui recoit les égouts de la ville. Schmidtmann montra que leur toxicité était liée à la corruption de l'eau: des Moules saines prises dans l'avant-port, introduites dans ce bassin, $y$ devenaient très toxiques en quinze jours, et recourraient leur innocuité après un 
séjour dans l'eau courante. D'ailleurs, les Astéries recueillies dans le mème bassin présentaient aussi une grande toxicité (voir p. ㅇö), tandis que les Poissons et les Crevettes, animaux nomades, en śtaient dépourvus. - Enfin Brieger a pu isoler le principe toxique, qui n'est autre qu'une leucomaïne, la mylilotoxine, dont la formule est $\mathrm{C}^{6} \mathrm{H}^{15} \mathrm{AzO} \mathrm{O}^{2}$; elle a une odeur très désagréable et possède des propriétés toxiques tout à fait analogues à celles des Moules étudiées : son action est paralysante. Ces propriétés disparaissent d'ailleurs en présence d'une petite quantité de carbonate de soude, ce qui est une indication assez précieuse au point de vue de l'hygiène alimentaire. - Max Wolff a démontré que le foie seul renferme ce principe; et comme celui-ci ne se rencontre pas dans les eaux ou vivent les Moules, on peut admettre qu'il est produit directement par les cellules hépatiques dans l'état de sous-activité phỵsiologique où elles se trouvent placées par suite des mauraises conditions de milieu (voir p. 79). Ajoutons cependant que Lusting dit aroir découvert, dans les Moules provenant des eaux stagnantes des ports et des canaux, un microbe éminemment pathogène.

Ces résultats, quoique très instructifs, n’ont pas toutefois donné la solution complète du problème de l'empoisonnement par les Moules. L'action de la mytilotoxine ne rend pas compte, en effet, des accidents d'urticaire et de gasto-entérite signalés plus haut. Il y a donc lieu de supposer qu'il peut exister chez les Moules plusieurs principes vénéneux, dont un seul est actuellement connu.

Au surplus, on ne doit pas oublier de faire intervenir, dans la question de ces empoisonnements alimentaires, la notion de l'état de santé préalable du sujet. Certaines personnes, en effet, sont beaucoup plus exposées que d'autres à de telles intoxications. Cazin et Delthil ont mème observé des nourrices qui mangeaient des Moules sans en ètre nullement incommodées, alors que leurs nourrissons étaient chaque fois atteints d'urticaire. C'est que, dans l'organisme sain, bien des principes toxiques sont transformés ou très rapidement éliminés par diverses voies; tandis que, si lefonctionnement des organes d'arrêt ou d'excrétion (foie, reins, glandes sudoripares, etc.) est gèné ou enrayé par des conditions morbides, ces mèmes principes s'accumulent sur place et sont susceptibles alors de déterminer des accidents plus ou moins graves.

Les Modioles (Modiola), Muscles moussus ou Mouflons des Provençaux, se mangent crues ou parfois cuites et préparées comme les Houles. Trois espèces (H. barbata, mytiloides et Lamarckiana) sont plus particulièrement comestibles; on les trouve sur les divers points de notre littoral, mais elles ne sont guère vendues que sur les marchés du Midi.

Les Lithodomes (Lithodomus) ou Dattes de mer se creusent des galeries dans les rochers; on les mange à la façon des Huitres. Une seule espèce comestible ( $L$. lithophagus), des côtes de Provence.

Railliet, - Zoologie. 
Quant aux Jambonneaux (Pinna), ce sont de grands Mollusques peu estimés; on les mange pourtant quelquefois aux environs de Cette, et surtout en Algérie.

Parmi les ARCADÉS, nous signalerons seulement les Pétoncles (Pectunculus) ou Amandes de mer, dont deux espèces sont comestibles : P. glycimeris, Manche et Océan; $P$. violacescens, Méditerranée.

Enfin, les UNIONIDÉS comprennent les Anodontes (Anodonta), les $\mathrm{Mu}$ Jettes (Unio) et les Huitres perlières d'eau douco (Margaritana), dont diverses espèces, répandues dans nos rivières et nos étangs, sont parfois consommées dans les campagnes. A Paris mème, Anodonta cygnea est mangée sous le nom de Moule des étangs.

Sous-classe II : Siphonidés. - Lamellibranches à siphons plus ou moins développés : bords du manteau soudés en grande partie.

Nous signalerons rapidement les espèces comestibles.

Les Bucardes (Cardium), encore appelées Coques, Sourdons, Mourgues, ont une chair généralement médiocre; néanmoins, on en mange plusieurs espèces sur toutes nos côtes, notamment $C$. edule.

Il en est de même des Cardites (Cardita) ou Praires rouges : C. sulcata est consommée entre Marseille et Nice.

Mais la famille des VÉNÉRIDÉS est particulièrement riche à ce point de vue; elle comprend les genres Venus, Tapes, Dosinia, Cytherea, etc.

Les Vénus (Venus) renferment deux espèces qui se montrent sur toutes les côtes de France, et jouent un rôle important dans l'alimentation : la Praire ( $V$. verrucosa) et la fausse Praire ( $V$. gallina), celle-ci moins estimée.

Les Artémis (Dosiniu) sont peu recherchées, sauf à Cette et en Italie.

Les Clovisses (Tapes) comprennent un grand nombre d'espèces qui se vendent uon seulement sur les marchés du littoral, mais souvent aussi sur. ceux de l'intérieur. Telles sont: T. decussatus, pullaster, texturatus, Bourguignati, edulis, geographicus, etc. Dàns le Nord et l'Est, on les mange crues à la façon des Huitres; dans le Midi, on les fait souvent cuire pour les manger en ragoùt avec des épinards.

Parmi les Cythérées (Cytherea), notre seule espèce comestible est le grand C. chione (fig. 642).

A des familles voisines se rattachent encore quelques formes alimentaires.

Les Mactres (Mactra) se vendent fréquemment à Bordeaux (M. helvacea) et sur le littoral méditerranéen (M. lactea, M. stultorum).

Les Lutraires (Lutraria) sont plutôt consommées en Bretagne et dans le Boulonnais, mais elles viennent jusque sur les marchés de Paris et de Lyon.

Une seule espèce de Psammobie (Ps. vespertina) se mange sur les côtes de Provence. Chair médiocre.

Les Donaces (Donax), petites Clovisses ou Haricots de mer, reconnaissables à leur coquille triangulaire et lisse, se vendent sur tous les marchés.

Les Myes (Mya) ou Clanques ne vivent que dans la Manche et l'Océan. Chair blanche et médiocre (fig. 644).

Les Couteaux (Solen) offrent aussi plusieurs espèces comestibles, par exemple $S$. vagina, surtout commun dans l'Océan, et $S$. ensis, plus répandu dans la Méditerranée. Chair assez bonne. 
Enfin les Pholades (Pholas), Gites ou Dails, qui se creusent des abris dans les rochers, comprennent deux espèces comestibles qui vivent dans toutes nos mers (Ph. ductylus et $P h$. candidus).

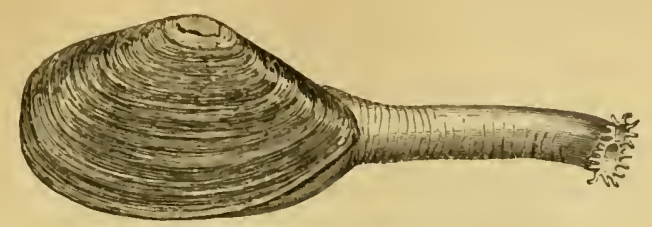

Fig. 64i. - Mye des sables (.Ma arenaria L.).

Avant de clore I'étude de ce groupe, il convient d'ailleurs de citer le Taret commun (Teredo navatis) ou Ver de vaisseur. Ce curieux Mollusque se creuse, dans le bois immergé, des galeries qu'il revèt d'une couche calcaire; il détruit ainsi les pilotis, la coque des navires, etc.

\section{CLASSE II}

\section{S CAPHOP ODES}

Mollusques dépourvus de tête, d'ycux, de caur el de branchies; pied trilobé; coquille tubuleuse ouverte aux deux extrémités; diö̈ques.

Cette classe est représentée par l'ordre unique des Solénoconques (sw)riv, tuyau ; *ơ $\%$, coquille), établi par de Lacaze-Duthiers pour le seul genre Dentale (Dentalium L.). C'est un intéressant groupe de passage entre les Acé.. phales et les Gastéropodes. Les Dentales vivent dans le sable des mers, la tète tournée vers le fond.

\section{CLASSE III}

\section{PTÉROPODES}

Mollusques à tête peu distincte; pied formant deux nayeoires aliformes latérales: corps nu ou revêtu d'une coquille univalve; monoïques.

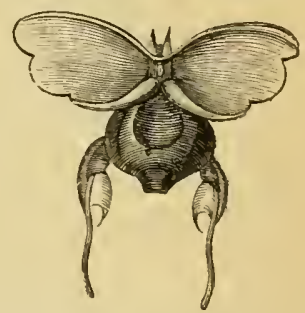

Fig. 6łว. - Ptéropodes (Hyalea cornea L.).

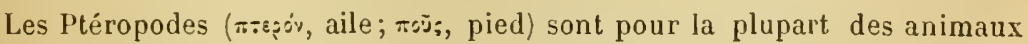
de haute mer, se déplaçant très vite à l'aide de leurs nageoires, qu'ils agitent comme des ailes. C'est surtout la nuit ou au crépuscule qu'ils apparaissent à la surface.

\section{CLASSE IV}

\section{GASTÉROPODES}

Mollusques à títe bien développée; pied ventral simple; presque toujour's une coquille univalve, en spirale ou en bouclier. 
Le nom de Gastéropodes ( $\gamma \alpha \sigma$ rnp, ventre; $\pi \check{u} \varsigma$, pied), donné à cette classe, se rapporte à la présence d'un pied large, en forme de disque, placé sous l'abdomen et servant en général à la rep̣tation ; chez les Hétéropodes, cependant, ce pied est étroit, vertical, et conslitue une sorte de nageoire.

La tête de ces Mollusques porte deux ou quatre tentacules; le corps est revêtu d'un manteau qui sécrète une coquille parfois interne ou rudimentaire (Limace), le plus souvent bien développée, univalve, enroulée en hélice, mais non cloisonnée. Dans ces coquilles spirales, on distingue : le sommet ou la pointe; louverture, par laquelle sort l'aninal; le pourtour de cette ouverture ou péristome, correspondant au bord du manteau. L'axe autour duquel se font les tours de spire constitue la columclle: il est quelquefois creux et son orifice extérieur est alors appelé ombilic. Enfin, on nomme suture le sillon formé entre les tours de spire successifs quand ils sont réunis les uns aux autres. Au lieu d'être spiralée, la coquille est parfois simplement excavée, conique (Patelle); rarement elle est multivalve (Oscabrion).

Le système nerveux n'offre plus la disposition symétrique qu'il affecle chez les Acéphales. Il existe bien deux ganglions cérébroïdes, situés au-dessus du tube digestif, et deux ganglions pédieux, qui se ramifient dans le pied; mais les ganglions pariéto-splanchniques sont au nombre de cinq et forment une chaine plus ou moins étendue (groupe asymétrique Lac.-Duth.). En outre, on observe quelquefois, vers l'origine de l'œsophage, deux petites masses ganglionnaires communiquant avec le cerveau; on les a regardées comme un système nerveux viscéral ou stomato-gastrique.

Comme organes des sens, il faut signaler : des yeux, situés habituellement au sommet ou à la base des tentacules; des otocystes, presque toujours placés sur des ganglions pédieux, mais innervés par le cerveau; des organes olfactifs ciliés situés à la base des branchies ou à côté de l'orifice pulmonaire; enfin, des tentacules servant dorganes de tact.

La bouche, souvent pourvue d'une trompe protractile, s'ouvre à l'exlrémité antérieure de la face ventrale, et donne accès dans une cavité à parois musculeuses, le bulbe buccal ou pharyngien. Sur le plafond de cette cavité, en arrière de la lèvre supérieure, se trouve une màchoire cornée; par contre, la paroi inférieure porte une saillie cartilagineuse, la langue, revêtue d'une lame cornée et transparente, appelée radula (racloir). Cette dernière est recouverte de rangées transversales de petites dents, dont le nombre et la forme sont très variables et fournissent des caractères importants pour la classification. Cet appareil masticateur jouit souvent d'une grande puissance. - Dans la cavité buccale débouchent les canaux excréteurs de deux glandes dites salivaires, mais dont le produit n'offre nullement les caractères de la salive des Vertébrés (L. Frédéricq). L'intestin antérieur comprend, outre la masse buccale, un long æsophage, qui se dilate en un estomac simple ou multiple. L'intestin moyen est très long et décrit de nombreuses circonvolutions; il est entouré par une énorme glande digestive, dont le contenu est déversé à son origine et parfois mème dans l'estomac. L'intestin terminal ou rectum est étroit et aboutit à un anus situé d'ordinaire sur le dos ou sur le côté droit de la région cervicale.

L'appareil circulatoire est assez variable. En général, le cœur', entouré d'un péricarde, se compose d'un ventricule et d'une oreillette, celle-ci tournée vers l'organe de la respiration. Dans certains cas cependant, les branchies 
étant doubles, il existe deux oreillettes, et le ventricule est, comme chez les Lamellibranches, traversé par le rectum (Haliotides). Du ventricule part une aorte, qui se divise d'habitude en deux troncs artériels, l'un se dirigeant vers la tète et le pied, l'autre se rendant en arrière pour se ramificr dans la masse viscérale. Les veines sont peu nombreuses; le sang revient plutòt par des sinus ou lacunes interorganiques.

Chez un petit nombre de Gastéropodes, la respiration est cutanée, et s'effectue alors par des appendices dorsaux qui renfernent des prolongements crecaux du tube digestif (Eolis). Le plus souvent elle a lieu par des bran. chies, qui peurent ètre parfois aussi nues et dorsales, mais qui, dans la règle, se trouvent contenues dans une cavité palléale, entre le manteau et le pied. Cette cavité respiratoire communique alors avec l'extérieur au ınoyen d'une simple fente située vers la partie antérieure du corps; ou bien les bords de

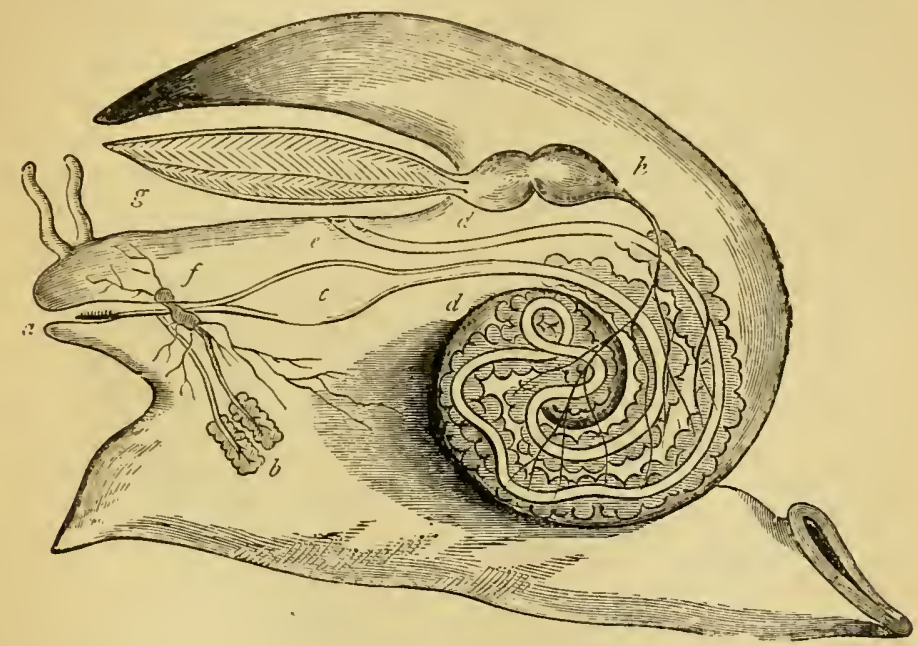

Fig. 646. - Coupe schémalique d'un Buccin. $-a$, bouche, montrant la radula. $b$, glandes salivaires $c$, estomac. $d, d$, inteslin eutouré par la glande digestive, et se terminant en $e$, à l'anus. $g$, branchie. $h$, cœur. $f$, ganglion nerveux (Huxley).

cet orifice se prolongent en un siphon protractile (Turbo). Leur forme et leur disposition sont des plus variables; elles sont rarement symétriques, et peuvent se trouver réduites à une seule. Le renouvellement de l'eau autour des branchies est déterminé par l'action des cils vibratiles qui les garnissent. Enfin, divers Gastéropodes terrestres et même aquatiques ont une respiration aérienne : le poumon résulte en pareil cas d'une simple transformation de la cavitébranchiale dont il vient d'ètre question : le plafond de cette cavité est formé par une membrane mince ou par des cloisons entre-croisées, parcourues par de nombreux vaisseaux sanguins qui dessinent un réseau à mailles serrées. La communication est établie avec le dehors par l'intermédiaire d'un conduit sinueux, qui débouche au voisinage de l'anus, presque toujours sur le còté droit de la partie antérieure du corps. Le renouvellement de l'air parait être déterminé par les mouvements alternatifs d'abaissement et d'élévation du plancher de la cavité. - Il est rare que la respiration soit a la fois branchiale et pulmonaire (Ampullaria, Oncillium). 
Le rein des Gastéropodes correspond bien aux organes de Bojanus des Lamellibranches, mais c'est ici un sac souvent impair, de teinte fauve ou brun jaunâtre, à paroi spongieuse, situé dans le voisinage du cœur et communiquant avec le péricarde. Le canal excréteur débouche à côté de l'anus. A l'occasion des organes d'excrétion, nous devons signaler aussi la présence de diverses glandes dont le rôle n'est pas bien connu : telle est la glande muqueuse qui occupe la voûte de la cavité respiratoire; la glande pédieuse des Limacidés et des Hélicidés; la glande de la pourpre des Murex, Purpura, etc. Celle-ci se trouve aussi dans la chambre branchiale: son produit, d'abord incolore, passe par diverses teintes et donne enfin une belle couleur violette quand on l'expose aux rayons solaires.

Les Gastéropodes sont les uns dioïques, les autres monoïques. - $1^{\circ}$ Aux Gastéropodes dioüques appartiennent presque tous les Prosobranches et les Hétéropodes. Les mâles possèdent un testicule ordinairement caché entre les lobes de la glande digestive, un canal déférent, une vésicule séminale et un conduit éjaculateur. Souvent à ce canal fait suite un pénis tubuleux ou simplement creusé d'un sillon; d'autres fois (Haliotides), il n'existe pas d'organe copulateur. Chez les femelles, l'ovaire occupe la situation que nous avons indiquée pour le testicule; viennent ensuite un oviducte accompagné d'une glande albuminipare et dilaté dans certains cas en une sorte d'utérus, puis un vagin et une poche copulatrice.- $2^{\circ}$ Les Gastéropodes monö̈ques comprennent les Opisthobranches et presque tous les Pulmonés. Le testicule et l'ovaire sont étroitement unis, et parfois confondus à ce point que deux acini de sexe différent peuvent ètre situés côte à còte et déboucher dans le mème conduit vecteur, ou même qu'un seul cul-de-sac est en partie mâle, en partie femelle (glande hermaphrodite, ovotestis), ainsi qu'on le voit chez les Limacidés et les Hélicidés. Cependant, malgré cette fusion, les produits sexuels peuvent se séparer. Chez le Colinacon (Helix pomatia), qu'on étudie d'habitude comme type des Gastéropodes, on observe la disposition suivante : les produits de la glande hermaphrodite passent d'abord dans un canal commun, le canal efférent, qui aboutit à un conduit plus large, à l'origine duquel se trouve une glande albuminipare. Cette partie élargie se compose en quelque sorte de deux canaux accolés et communiquant entre eux, l'un assez ample, l'oviducte, l'autre plus petit, la gouttière efferente. Cette gouttière continue directement le canal efférent; elle transporte les spermatozoïdes, puis se transforme en un tube complet et distinct ou canal déférent, dont la portion terminale est susceptible de s'évaginer de manière à jouer le rỏle de pénis : celte portion est munie en outre d'un long flagellum et d'un muscle rétracteur du pénis. Les œufs, au sortir du canal efférent, écartent les lèvres de la gouttière et passent dans l'oviducte; celui-ci ne tarde pas aussi à former un canal distinct ou vagin, auquel sont annexées : $1^{\circ}$ une poche copulatrice, destinée à emmagasiner le sperme; $2^{\circ}$ une paire de glandes divisées en nombreux culs-de-sac tubuleux, les vésicules multifides, dont le róle n'est pas connu; $3^{\circ}$ une poche $d u$ dard, à parois musculeuses, contenant un stylet calcaire ou dard qui paraît être un organe excitateur. Les conduits mâle et femelle se confondent enfin en un vestibule génital qui débouche à l'extérieur par un orifice situé sur le còté droit du cou. - Les Gastéropodes monoïques ne se comportent jamais comme de véritables hermaphrodites; le plus souvent, l'accouplement est réciproque, chaque individu fonctionnant à la fois 
comme màle et comme femelle (Escargots); d'autres fois, l'un des deux individus accouplés joue le rôle de màle et l'autre celui de femelle (Aplysies); ou mieux encore, il arrive que les animaux se réunissent en chaines et que chacun d'eux fasse l'office de mâle relativement à l'individu qui précède et de femelle à l'égard du suivant (Limnées).

La plupart des Gastéropodes sont oripares; chez quelques-uns seulement, le déreloppenent embryonnaire a lieu dans l'utérus (Paludina vivipara). Les Pulmonés uaissent avec leur forme définitive; cependant les Limnées ont un voile cilié incomplet. Quant aux Gastéropodes branchiés, ils subissent des métamorphoses; leur larve est munie, à la partie antérieure, d'un voile divisé en deux grands lobes membraneux couverts de cils vibratiles, à l'aide desquels elle se déplace dans l'eau.

La plupart des Gastéropodes sont marins; on en trouve aussi dans l'eau saumàtre ou dans l'eau dlouce; enfin, quelques-uns sont terrestres. Leur régine est variable: il en est qui se nourrissent de matières animales; d'autres sont herbirores. Ces animaux nous intéressent en particulier par suite de l'habitat qu'ils fournissent aux larves de Trématodes. On trouve surtout celles-ci chez les Gastéropodes d'eau douce, mais Ercolani a montré que les Pulmonés terrestres sont eux-mèmes susceptibles d'en liéberger un certain nombre.

4 ordres : Hétéropodes, Opisthobranches, Prosobranches, Pulmonés.

\section{$1^{\mathrm{er}}$ ordre : Hétéropodes. - Gastéropodes nus ou testacés, à respiration}

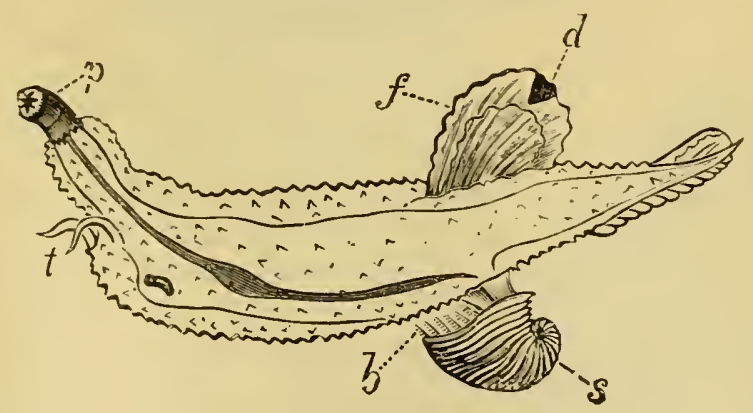

Fig. 647. - Hétéropodes : Carinaria cymbium, d'après Woodward. - $p$, trompe. $t$, tentacules. $b$, branchies. $s$, coquille. $f$, pied. $d$, disque.

branchiale, à pied vertical disposé en nageoires : diö̈ques. - Les Hétéropodes nagent en haute mer, la face ventrale tournée en haut. Ce sont des animaux à corps très transparent.

2 e ordre : Opisthobranches. - Gastéropodes a coquille nulle ou mulimentaire, à respiration branchiale; branchies et oreillettes situees en arriere du ventricule; pied horizontal; monö̈ques.

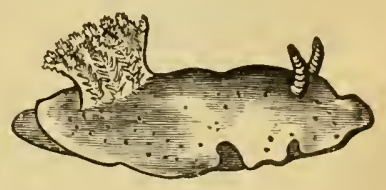

Fig. 648. - Opisthobranehes : Doris Johnstoni, d'après Huxley. - Genre principal : Aplysie (Aplysia). L’Aplysie dépilante (A. depilans L.), vulgairement appelée Lievre de mer ou Bouf de mer, est une fort grande espèce qui vit sur les bords de la Méditerranée; elle répand une odeur nau- 
séabonde qui l'a de tout temps fait regarder comme vénéneuse; cependant, on assure que certaines personnes mangent des Aplysies cuites sans s'en trouver incommodées.

$3^{\mathrm{e}}$ ordre : Prosobranches. - Gastéropodes à coquille bien développèe, $\dot{a}$ respiration branchiale; branchies et oreillettes situées en avant du ventricule; pied horizontal; dioïques.

Bon nombre de Prosobranches sont comestibles, bien qu'en général leur chair suit moins délicate que celle des Acéphales.

Ainsi, les Patelles (Patella), dont la coquille en cône surbaissé est largement ouverte à sa base, sont consommées sous le nom de Flies en Normandie, de Bernicles sur les còtes de l'Océan, et d'Arapéiles en Provence. P.vulgata, Manche et Océan. $P$. cærulea, Méditerranée.

On mange plusieurs espèces de Fissurelles (Fissurell $a$ ) à Toulon.

Les Haliotides (Haliotis), Oreilles de mer, Ormiers, Sixyeux, sont assez com-

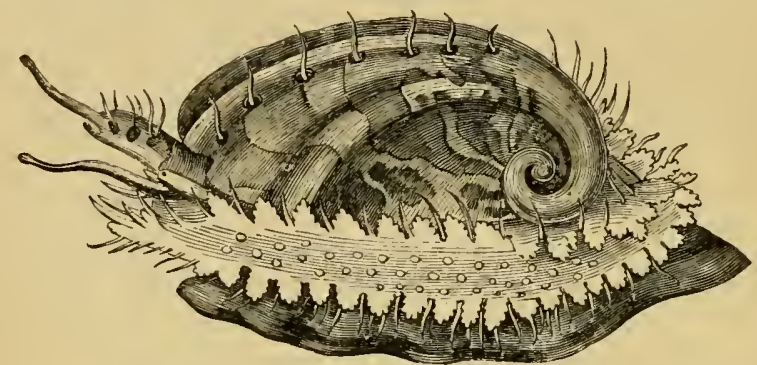

Fig. 649. - Haliotide (Haliotis tuberculata L.).

munes dals nos mers; leur chair, quoique un peu coriace, se mange ordinairement crue.

Dans quelques villes du littoral méditerranéen, on vend le Sabot (Turbo rugosus), dont la chair est également coriace.

Les Toupies (Trochus), Éplisses, Brelins, Bious rouds, comprennent aussi quelques grosses espèces comestibles.

Les Rochers (Murex), Chicorès, Bious arpus, se vendent couramment à Marseille. - Les pêcheurs mangent aussi parfois les Pourpres (Purpura).

Sur les côtes de l'Océan et de la Manche, on recueille, tant comme aliment que comme amorce, le Buccin ondé (Buccinum undatum), Calicoquot ou Escargot de mer.

Les Littorines (Littorina) sont toutes comestibles et se vendent jusque sur les marchés de l'intérieur, du moins les grosses espèces qui appartiennent au groupe de L. littorea, sous les noms de Vigneaux et de Bigorneaux.

Enfin, on mange sur les còtes de la Méditerranée plusieurs espèces de Cérithes (Cerithium), notamment le Cérithe Goumier (C. vulgatum), ainsi que des Cassidaires ou Piades (Cassidaria), dont la chair laisse beaucoup à désirer. Dans cette région, du reste, les habitants consomment sans répugnance à peu près presque tous les Mollusques de la côte.

Ces animaux peuvent pourtant occasionner des empoisonnements analogues à ceux que produisent les Moules. Polin et Labit, par exemple, citent le cas d'un homme de 28 ans qui mourut en 30 heures, à la suite de.l'ingestion d'une poignée de Bigorneaux. 
Aux Prosobranches appartiennent encore les Paludines (Paludina), Mollusques d'eau douce qui hébergent très fréquemment des larves de Trématodes.

$4^{\mathrm{e}}$ ordre : Pulmonès. - Gastéropodes nus ou testacés, à respiration pulmonaire; cœur situé en cirrière du poumon; pied horizontal; monoüques.

Nous devons une mention particulière à quelques familles de ce groupe.

Famille des LIMN EIDÉs. - Les Limnxidés ne possèdent que deux tentacules, qui portent les yeux au cỏté interne de leur base. Leur coquille est toujours mince, à pẻristome tranchant. - Ces animaux vivent dans les eaux douces; ils servent à la nourriture des Oiseaux aquatiques et des Poissons. Ce sont eux surtout qui hébergent les larves des Distomiens.

Les Limnées(Limnæa) se distinguent à leur coquille diaphane à spire pointue, le dernier tour étant plus grand que tous les autres; les deux tentacules sont triangulaires et aplatis, très contractiles. - Elles se nourrissent de substances végétales, et principalement de feuilles. La reproduction a lieu vers la fin du printemps; les individus s'accouplent en chaines. Les oufs sont agglomérés en petites masses glaireuses et transparentes. Pendant la période de l'hiver, les Limnées s'enfoncent dans la vase.

L'espèce la plus commune est la Limnée stagnale (L. stagnaiis), qu'on rencontre dans la plupart des étangs; mais celle qui nous intéresse le plus est la suivante.

La Limnée tronquée (L. truncalula Müller. - Syn. : L. mimuta Draparnaud) est caractérisée par une coquille ovoïde-oblongue, un peu ventrue, mince, d'une teinte cendrée grisảtre ou un peu violacée; la spire est composée de cinq à six tours, le dernier grand, un peu renflé, formant à lui seul les deux tiers de la coquille; celle-ci atteint une hauteur de 6 à 10 millimètres, sur un dianètre de 3 à s̆.

Cette espèce, qui offre plusieurs variétés, échappe facilement aux recherches en raison de son exiguïté et de l'habitude qu'elle a d'émigrer hors de l'eau. On la trouve souvent, en effet, à une assez grande distance des fossés, ruisseaux, étangs ou flaques d'eau, soit après les inondations, soit simplement lorsque l'herbe est humide. Elle est rapidement engourdie par la dessiccation, mais reprend son activité aux premières pluies si la période de sécheresse n'a pas été trop longue. Elle passe

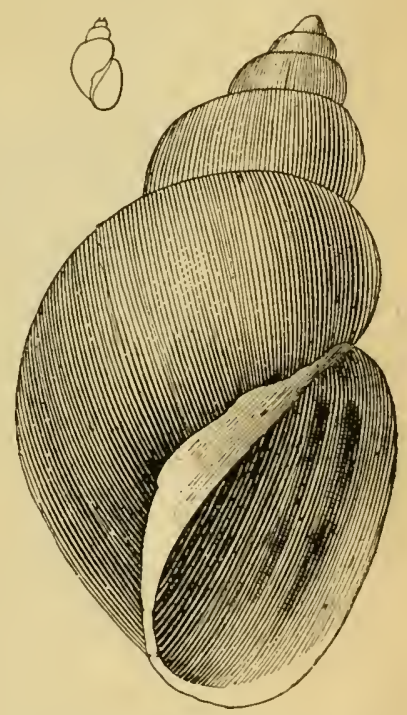

Fig. 6วั0. - Limnxa truncatula grandeur naturelle et grossie. pour frayer dans la vase, sur le bord des fossés. - Ces mours expliquent comment elle est apte à jouer le ròle d'hòte intermédiaire à l'égard du Distoma hepalicum (voy. p. 3 í).

La Limnée tronquée est répandue dans toute l'Europe, la Barbarie, la Sibérie, l'Afghanistan, le Thibet, l'Asie Mineure, le territoire de l'Amour. 
La Limnée étrangère ( $L$. peregra), qui passe également pour héberger dans certains cas les larves du Distome hépatique, habite toute l'Europe, la Sibérie, le Thibet, l'Asie Mineure, le territoire de l'Amour et certaines îles de l’océanie.

Les Planorbes (Planorbis) ont Ieur coquille enroulée presque sur un seul plan, de manière à prendre un aspect discoïde; leurs deux tentacules sont très longs. Les principales espèces sont: Planorbe corné (Pl. corneus), Planorbe caréné $(P l$. carinatus), Planorbe bordé ( $P l$. murginatus), elc.

On peut citer encore, dans la même famille, les Physes (Physa) et les Ancyles (Ancylus).

Famille des LIMAGIDés. - Ce sont des Mollusques nus : le manteau forme sur le dos un bouclier assez épais, coriace, contenant un rudiment de coquille.

Les Arions (Avion) ont l'orifice respiratoire situé en avant du milieu du bouclier dorsal. 'La coquille n'est représentée que par quelques granulations calcaires. Tout le monde connait la Limace rouge (Arion empiricorum), qui est répandue dans toute l'Europe et qui servait autrefois à préparer un " sirop de limace » employé contre la phtisie. Cette espèce et quelques autres du mème genre attaquent les plantes de nos jardins, mais ne se multiplient pas assez pour produire des dommages sensibles.

Les Limaces (Limax), dont l'orifice respiratoire est en arrière du milieu du bouclier, comprennent diverses espèces nuisibles, dont la plus dange-

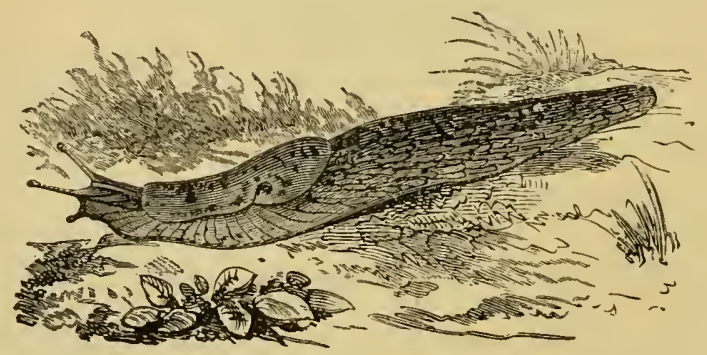

Fig. 651. - Limax agrestis L.

reuse est la petite Limace grise ou Lochette ( $L$. agrestis), qui dévore avec avidité les céréales, les prairies artificielles et les plantes potagères, surtout dans les années humides (fig. 651).

Cette forme, ainsi que $L$. cinereus et $L$. variegalus, sert d'hòte intermédiaire au Davainea proglottina (voy. p. 305).

Dans la petite famille des TESTACELLIDÉ, nous n'avons à signaler que les Testacelles (Testacella), qui possèdent une petite coquille à spire aplatie, située sur l'extrénité postérieure du corps. Il y a quelque intérêt à ne pas les confondre avec les Limaces, car elles sont caruassières et se repaissent surtout de Vers de terre.

Famille des Hériaidés. - Comme les Limacidés, ce sont des Mollusques terrestres, mais ils possèdent une coquille bien développée, spiralée, contenant la masse viscérale, qui forme un tortillon. 
Les Ilélices (Helix), conmues sous le nom d'Escargots ou de Colimaçons, ont une coquille capable de renfermer completement l'animal; ils ne possèdent pas d'opercule, mais, à l'approche de l'hiver ou pendant les grandes sécheresses, ils se retirent ả l'intérieur de la coquille et sécrètent une pellicule calcaire, l'épiphragme, qui en ferme l'ouverture et les préserve des excès de température.

On mange, en France, diverses espèces d'Escargots. D'après Moquin-Tandon, on recherche surlout dans le Nord : l'Hélice vigneronne (H. pomatia L.), l'II. némorale (H.ncmoralıs I.) et l'H. sylvatique (H. sylvatica Drap.); dans le Midi, où la consommation en est beaucoup plus considérable : l'H. chagrinée (H. asper'sa Müll.), l'H. vermiculée (H. vermiculata Vüll.), l'H. rhodostome (H. Pisana Müll.), l’II. naticoïde (H. apertı Born.), etc. Cette dernière passe pour la plus délicate; vient ensuite, au dire des gourmets, l'H. vermiculée; quant à l'H. vigneronne, si renommée sous le nom d'Escargot de Bourgogne, ce serait la plus dure. La saveur de ces animaux varie du reste avec la nourriture qu'ils ont prise, et on a mème observé des empoisonnements produits par des Escargots recueillis sur la Belladone, le Redoul, le Laurier-rose, etc. (1). Mais, en général, on ne mange ces animaux qu'après les avoir soumis à un jeùne prolongé, ou mieux encore on les recueille au sortir de l'hiver, alors qu'ils n'ont pas encore pris de nourriture. En somme, les Escargots ont une chair coriace, difficile à digérer et peu sapide : c'est pourquoi on les prépare arec des assaisonnements très relevés.

Il y a lieu de se méfier des Escargots qu'on achète tout préparés: Bougon a signalé une fraude qui consiste à remplir les coquilles ayant déjá servi, d'un mélange de poumon ou mou de bœuf ou de mouton, de sel, de farine de moutarde et de graisse de rebut.

On a cherché quelquefois à multiplier ces Mollusques. Les Romains pratiquaient l'hèliciculture, et Pline nous a transmis le nom de l'inventeur des escargotières : il s'appelait Fulvius Hirpinus. Ces cochlearia ou cochlearum vivaria étaient des parcs humides, ombragés et entourés par un fossé ou par un mur. - Actuellement, le marché de Paris est surtout approvisionné par les escargotières du département de l'Aube.

Les Escargots ont été autrefois employés en médecine. Le bouillon fait avec leur chair jouit encore d'une certaine réputation, bien que sa valeur nutritive soit insignifiante. De mème, on continue à recommander, sans motif sérieux, le sirop, la páte, les pastilles d'Escargots dans le traitement des bronchites chroniques.

Quelques Helix hébergent des larves d'helminthes (roy. p. 306 et 358 ).

CI.ASSE $V$

\section{C ÉPHA L O PODES}

Mollusques à tête distincte; pied découpé en lanières qui forment une couronne de bras autour de la bouche; corps nu ou revêtu d'une coquille univalve.

(1) A. Duras, Empoisonnements par les Escargots. Montpellier médical, mai 1873. Ann. d'hyg. publ., 18i4. - On peut d'ailleurs observer des accidents divers, en dehors de ces conditions, consécutivement à l'ingestion d'Escargots (urticaire $a b$ ingestis, etc.). 


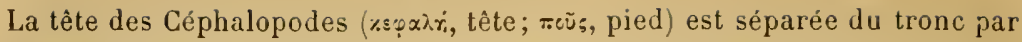
un étranglement, el porte huit ou dix tentacules ou bras de forme variable, qui servent à la locomotion et à la préhension des aliments. Ces bras offrent d'ordinaire, à leur face interne, de nombreuses ventouses disposées en séries longitudinales.

Le manteau est soudé en dessus au tégument, mais laisse à la face inférieure une cavité palléale, généralement comparable à une poche de tablier, ouverte en avant. Au niveau de cette fente palléale existe un appareil par-

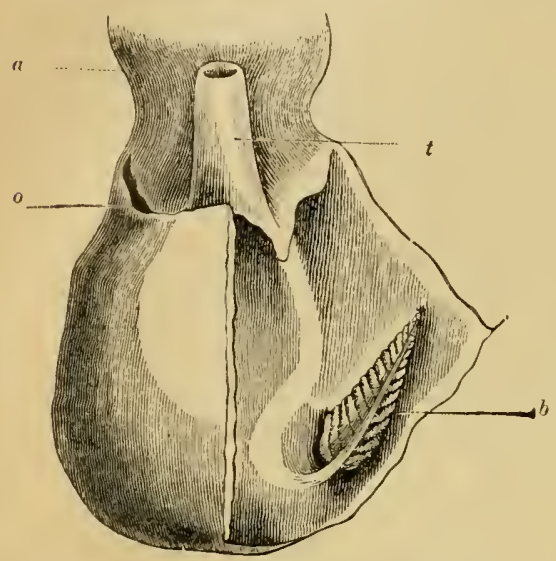

Fig. 652. - Corps d'un Poulpe, vu par la face inférieure (le manteau est fendu sur la ligne médiane, et, d'um côté, rejeté en dehors pour montrer l'intérieur de la cavité respiratoire). - $a$, base de la tète. $o$, l'une des deux ouvertures latérales par lesquelles l'eau pénètre dans la cavité respiratoire. $t$, le tube (entonnoir) pas lequel l'eau sort de cette cavité. $b$, l'une des branchies (Milne-Edwards). ticulier, l'entonnoir : c'est un tube rétréci en avant et fort évasé à sa base, par laquelle il communique largement avec la cavité palléale. C'est par cel entonnoir que se trouve expulsée l'eau qui a été introduite par la fente palléale pour les besoins de la respiration; et le jet ainsi prorluit peut servir en mème temps à la locomotion, en projetant l'animal en arrière. - Souvent il existe, sur les parois latérales du corps, des expansions du manteau en forme de nageoires (Seiche, Calmar). Il faut ajouter, enfin, que le derme offre un grand nombre de cellules chargées de pigment ou chromatophores, placées sous la dépen. dance du système nerveux et permettant à l'animal d'harmoniser sa teinte avec celle du milieu.

Quelques Céphalopodes sont pourvus d'une coquille externe bien développée (Nautile, Argonaute); d'autres ont une coquille interne rudimentaire (Seiche); enfin, beaucoup en sont complètement privés (Poulpe). - Outre cette coquille palléale, il faut noter l'existence d'un squelette cartilagineux interne, formé de différentes pièces qui servent à la protection des centres nerveux et des organes des sens, à l'insertion des muscles, etc.

Le système nerveux est disposé sur le mème type que dans les groupes précédents; mais il offre un haut degré de concentration. Les trois groupes ganglionnaires sont groupés en une sorte d'anneau œsophagien qui est conteuu dans un cartilage céphalique; on y distingue pourtant une portion lorsale représentant le cerveau et deux masses ventrales, dont l'antérieure correspond aux ganglions pédieux, la postérieure aux canglions pariétosplanchniques. On rencontre aussi un système nerveux viscéral (sympathique ou stomato-gastrique), et divers ganglions placés sur le trajet des nerfs qui se rendent à des organes importants.

Les bras et les tentacules servent comme organes du tact. - De chaque côté de la tête existe un æil très complexe, dont la constitution rappelle de fort près celle de l'œil des Vertébrés. - Les organes auditifs consistent en 
une paire d'otocystes placés dans le cartilage céphalique. Delage a montré qu'ils sont le siège de la coordination des mouvements. - Enfin, l'olfaction parail s'effectuer par deux fossettes ciliées situées derrière les yeux.

Le tutie digestif décrit une anse profonde. La bouche possède deux màchoires corıées, l'une supérieure, l'autre inférieure, celle-ci étant plus développée, de telle façon que l'ensemble représente assez bien un bec de Perroquet renversé. La cavité buccale contient une radula semblable à celle des Gastéropodes. L'wsophage est grèle, parfois dilaté en jabot (Poulpe) avant d'aboutir à l'estonac. Celui-ci possède une paroi épaisse, musculaire, et un revètement cuticulaire interne; près de la naissance de l'intestin, il présente un diverticule en cul-de-sac, dit appendice pylorique, qui reçoit les canaux excréteurs d'une volumineuse glande digestive. l'intestin est court et forme peu de circonvolutions; l'anus s'ouvre dans la cavité palléale, á la base de l'entomnoir.

L'uppareil circulatoire arrive dans cette classe à un haut degrè de développement. Le cœur est situé entre les branchies, vers la partie postérieure du corps; il est constitué par un ventricule arrondi auquel aboutissent autant de veines branchiales qu'il y a de branchies : chacune de ces veines offre avant son insertion une dilatation bien accusée qu'on regarde comme une oreillette. De ce cœur partent deux troncs artériels : une aorte céphalique et une aorte abdominale. Le sang passe ensuite dans un riche réseau capillaire, et de là se rend en partie dans les sinus veineux, en partie dans les veines, pour gagner finalement un gros tronc médian, la veine cave. Celle-ci se divise en deux ou quatre rameaux qui portent le sang aux branchies, et qui constituent des artères branchiales. Chez les Dibranches, chacun de ces vaisseaux offre, a vant son entrée dans les branchies, une dilatation contractile, désignée sous le nom de cœur branchial. - Le sang est tantòt incolore, tantòt coloré en bleu, en violet ou en vert.

Les branchies, logées dans la cavité palléale, sont au nombre de deux ou de quatre; elles ont la forme de pyramides dont le sommet est dirigé en dehors et en liaut, et se montrent composées de lamelles ou de plis serrés, disposés de part et d'autre d'un axe médian. L'eau pénètre dans la cavité palléale par la fente antérieure; après avoir baigné les branchies, elle est expulsée par la contraclion du manteau; mais la fente palléale se ferme à ce moment, et la sortie ne peut s'effectuer que par l'entonnoir.

On regarde comme appareil d'excrétion des "corps spongieux " qui occupent les rameaux de ia veine cave ou des artères branchiales et paraissent ètre des appendices glanduliformes de ces vaisseaux. - Un autre organe d'excrétion, très répandu chez les Dibranches, est la poche à encre, sac allongé dont le canal excréteur suit l'intestin terminal pour s'ouvrir, soit dans le rectum un peu avant sa terminaison, soit au dehors, en arrière de l'anus. Le produit de sa sécrétion est un liquide noir, qui se trouve expulsé par l'entonnoir et dérobe l'animal à la poursuite de ses ennemis; ce liquide, appelé encre, est employé par les aquarellistes sous le nom de sépia.

Tous les Céphalopodes sont dioïques. Les organes des deux sexes sont constitués sur le mème type et sont remarquables en re que les glandes génitales ne se continuent pas directement avec les canaux vecteurs. - L'ovaire est impair, lobé et renfermé dans un sac spécial qui reçoit les œufs. Ce sac communique avec un oviducte simple, plus rarement double (Octopodes', 
dont l'orifice se trouve d'ordinaire à la base de l'entonnoir. Sur le trajet de l'oviducte s'observe un revètement glandulaire; de plus, les Décapodes et les Nautiles possèdent une paire de glandes spéciales qui s'ouvrent, par un court conduit, près de l'orifice génital, el qui sont nommées glandes nidamentuires : leur sécrétion sert à agglutiner les œufs. - Les organes màles consistent en un testicule impair, formé de cacums ramifiés et logé, comme l'ovaire., daus un sac où tombent les spermatozoïdes. Le canal déférent est un tube. sinueux, souvent dilaté dans sa partie terminale, qui joue le rỏle de vésicule. séminale, et muni de glandes dont le produit se mélange aux spermatozoïdes. et les agglutine sous forme de petits tuhes appelés spermatophores. Ce canal déférent présente en oulre une expansion latérale ou poche de Needham, dans. laquelle s'accumulent les spermatophores, puis il se continue régulièrement par un canal éjaculateur qui débouche au sommet ou à la base d'une papille située à gauclie dans la cavilé du manteau .

La fécondation s'effectue selon un mode caractéristique et fort curieux : c'estl'un des bras du màlequi se transforme en organe copulateur (hectocotyle). Les modifications qu'il subit à cet effet sont du reste très variables quant à leur forme et à leur degré. Dans quelques cas (Argonaute, Tremoctopus), il se détache même complètement pour porter les spermatophores dans la cavité palléale des femelles: il y conserve longtemps encore sa vitalité, el Cuvier l'avait pris pour un parasite voisin des Trématodes. C'est Steenstrup qui le premier a reconnu que l'hectocotylisation est un phénomène général chě les Céphalopodes.

Les Céphalopodes sont ovipares; les wufs sont télolécithes. Le développement de l'embryon débute par une segmentation partielle. Les jeunes naissent avec leur forme définitive.

Tous les animaux de cette classe sont marins; les uns vivent sur le littoral, les autres en haute mer. lis sont très voraces, et se nourrissent en particulier de Poissons et de Crustacés. Les grandes espèces peuvent même être dangereuses pour l'Homme, en s'attachant par leurs ventouses aux membres des nageurs. Dans ces derniers temps, on a acquis la certitude que quelquesuns de ces Mollusques arrivent à une taille colossale. Les anciens Grecs et Romaius étaient très f'riands de Céphalopoles; aujourd'hui, ces animaux sont un peu délaissés; cependant, plusieurs espèces sont encore mangées par les habitants du littoral. - Les Céphalopodes sont apparus sur le globe dès la période paléozoïque; mais c'est surtout dans les terraius secondaires qu'ils se sont montrés abondants, sous la forme d'Ammonites et de Bélemnites.

2 ordres : Dibranches et Tétrabranches.

$1^{\mathrm{er}}$ ordre : Tètrabranches. - Céphalopodes à quatre branchies, it tentacules multiples rétractiles et dépourvus de ventouses, a entonnoir fondu en dessous et à coquille spiralée multiloculaire.

Les Tétrabranches ou Inacétabulés ne sont plus représentés actuellement que par le genre Nautile (Nuutilus, fig. 6.33). Il s'agit d'animaux pourvus d'une coquille contournée en spirale et divisée par des cloisons transversales en un certain nombre de chambres dont la dernière, plus vaste, est seule occupée par l'animal. Les autres chambres, successivement abandonnées à mesure de la croissance, sont remplies d'air, mais communiquent avec la dernière au moyen d'un tube central ou siphon qui contient un prolongement du corps 
du Mollusque. L'espèce la plus connue est le Nautile flambé (N. pompilius), qui habile l'archipel Indien. - Les Orthoceras, Lituiles, etc., sont des grenres fossiles de la mème familic.

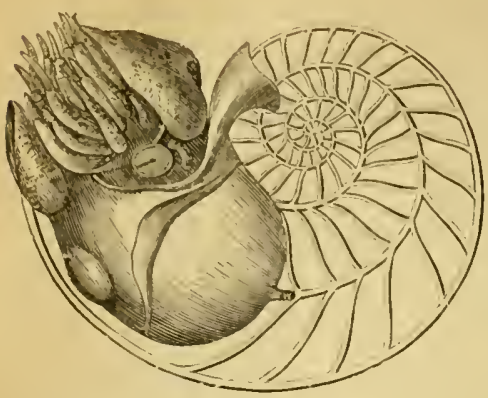

Fig. 653. - Naulile llambe (.Veutilus I'ompilius L.).

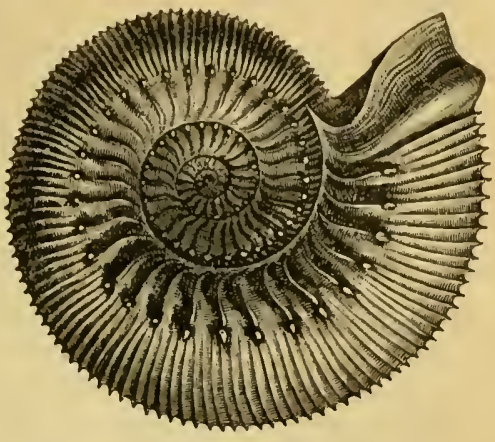

Fig. 63\%. - Ammonites Humphriesianus, de l'oolithe inférieure.

Les Ammonites se distingnent par la position du siphon, qui, au lieu d'ètre central, est situé du còté externe ou dorsal de la coquille, et par les cloisons, qui sont très irrégulières. - Genres Goniatites, Ceratites, Baculites, Ammonites (fig. 6\%̈ ), tous fossiles.

2 ordre : Dibranches. - Céphalopodes pourvus de leux branchies, de huit ou dix bras garnis de ventouses, d'un entonnoir entier et d'une poche a encre.

La présence de ventouses sur les bras a fait aussi donner quelquefois aux Mollusques de ce groupe le nom d'Acétabulifères. — 2 sous-ordres : Octopodes et Décapodes.

$1^{\text {er }}$ sous-ordre: DÉcapodes - Les Décapodes sont caractérisés par la présence de dix bras, dont huit d’égale longueur et deux autres plus longs, souvent préhensiles, en forme de tentacules, ne portant de ventouses qu'à leur extrémité. Les ventouses sont pédiculées; le corps est muni de nageoires latérales et d'une coquille interne.

Nous devons mentionner ici :

$1^{\circ}$ Les Seiches (Sepia), petiles formes à corps ovale, muni de deux nageoires latérales qui le bordent sur toute sa longneur, et d'une épaisse coquille interne, ovale et bombée, friable, principalement formée de matière calcaire. On mange ces animaux dans beau coup de ports de mer. - La Seiche commune (S. officinalis) est très répandue sur nos còtes. La coquille, connue sous le nom d'os de Seiche on sépiostaire, a été longtemps employée en médecine, à titre d'absorbant; elle entre encore aujourd'hui

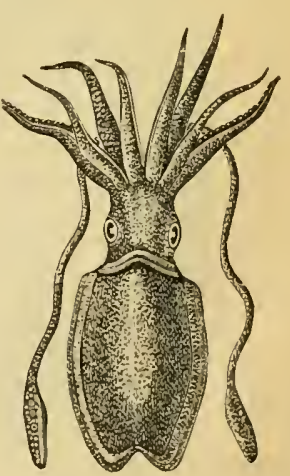

Fig. 65:. - Seiche offieinale. dans la composition de quelques poudres dentifrices. C'est aussi cette coquille qu'on donne aux Oiseaux captifs pour aiguiser leur bec. Les Seiches fixent d'ordinaire leurs cufs aux plantes marines; ces œufs sont connus des pêcheurs sous le nom de raisins de mer; 
$2^{\circ}$ Les Calmars (Loligo), qui ont le corps plus allongé et pourvu en arrière de deux nageoires triangulaires. Leur coquille est cornée, très longue, et

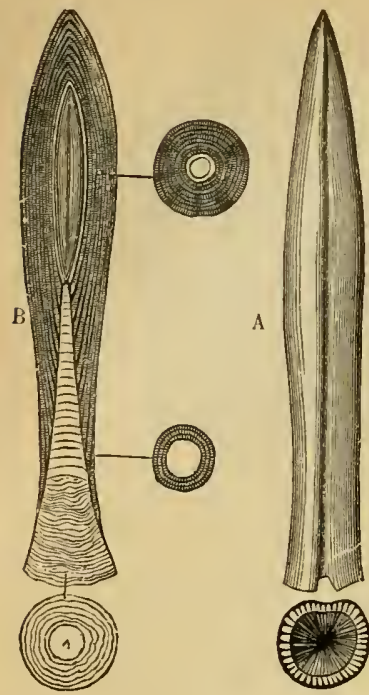

Fig. 656. - Bélemnites. - A, Belemnites acutus, du lias. - B, Belemnites hastatus, de l'oolithe moyenne. affecte la forme d'une plume à écrire. - Le Calmar commun (L. vulgaris), des mers d'Europe, est comestible : sa chair " est estimée à l'égal du Poisson le plus délicat ";

$3^{\circ}$ Les Sépioles (Sepiola), "Céphalopodes en miniature ", qui vivent en bandes et qu'on mange sur nos côtes;

$4^{\circ}$ Les Bélemnites, animaux fossiles qui ressemblaient aux Calmars, mais dont la coquille interne, disposée en cornet, se prolongeait postérieurement en un cylindre calcaire terminé en pointe et connu sous le nom de rostre; d'ordinaire, celte pièce est la seule partie qui soit conservée (fig. 656). - Genre Belemnites, Belemnitella, elc.

$2^{\mathrm{e}}$ sous-ordre : Octopodes. - Les bras sont au nombre de huit seulement, par suite de l'absence des bras tentaculaires; ils portent des ventouses sessiles. Le corps est court, dépourvu de nageoires et de coquille interne.

Les Poulpes (Octopus), aujourd'hui connus de tout le monde sous le nom de Pieuvres, Chatrouilles, Minards, etc., se distinguent à leurs bras longs, portant deux rangées de ventouses et unis à leur base par un repli de la peau; ils ont le corps arrondi, en forme de bourse. - Le Poulpe

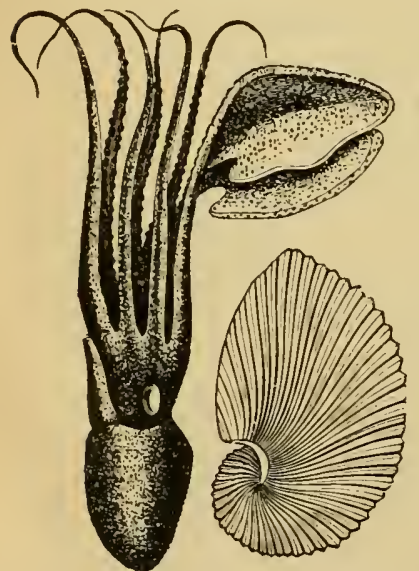

Fig. 65\%.- Argonaute papyracé, femelle. commun (0. vulgaris) abonde surtout dans la Méditerranée, et détruit beaucoup de Poissons et de Crustacés. On le consomme sur toules nos côtes.

Les Ėlédones (Eledone) n'ont qu'une seule rangée de ventouses sur les bras. Une espèce qui babite la Méditerranée, l'Élédone musquée ( $\boldsymbol{E}$. moschata), possède une forte odeur de musc; comme elle sert de nourriture aux Cachalots, on lui a attribué la production de l'ambre gris. Les marins et les pêcheurs la mangent sur les cótes de Provence.

Les Argonautes sont remarquables en ce que les mâles sont petits, dépourvus de coquille, tandis que les femelles, de plus grandes dimensions, possèdent une coquille en forme de nacelle enveloppée et comme maintenue par les deux bras supérieurs fort élargis. Ces animaux sont pélagiques. L'Argonaute papyracé (A. argo) habite la Méditerranée (fig. 657). 


\section{HUITIEME EMBRANGHEMENT}

\section{CHORDÉS}

Animaux à symétrie bilatérale, pourvus, tout au moins à l'état larvaire, d'une tige dor'sale destinè à sautenir les centres nerveux (notochorde ou corde dorsale).

Les animaux qui composent ce groupe sont loin de présenter le même degré de complication organique; néanmoins, les études embryologiques ont montré qu'il convenait de les rapprocher, en raison surtout de la possession commune d'un orgáne de haute importance, qui les distingue de tous les autres Colomates. Il s'agit

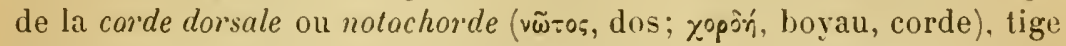
solide qui se forme aux dépens de l'entoderme sur la ligne médiane dorsale, au-dessus du tube digestif, et qui a pour fonction de supporter le système nerveux central. Celui-ci, en effet, occupe la région dorsale du corps, contrairement à ce qui s'est montré dans les groupes précédents. La notochorde apparaît constamment chez l'embryon, bien qu'avec un développement très variable; elle disparaît souvent à l'état adulte.

Ajoutons qu'un second caractère commun à tous les Ghordés est fourni par les organes de la respiration, qui proviennent toujours de la régrion antérieure du tube digestif.

4 sous-embranchements :

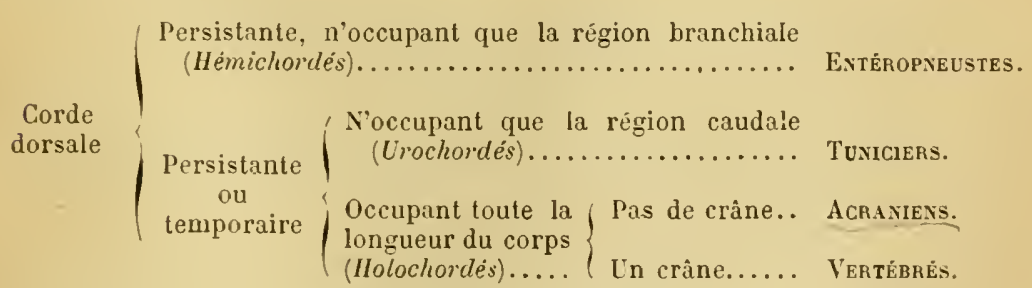

SOUS-EMBRANCIEMENT I

\section{ENTEROPNEUSTES}

Chardés à corde dorsale persistante, toujours limitée à la région branchiale.

Les Entéropneustes sont des animaux marins dont on ne connait jusqu'à présent que quelques espèces, composant un seul genre (Balanoglossus). A l'état adulte, ils ont un aspect vermiforme et pour ce motif ont été longtemps classés parmi les Vers; mais la larve, du moins dans l'espèce de la Méditerranée (B. clavigerus), ressemble d'une façon frappante à une larve 
d'Échinoderme, et J. Müller, qui la décrivit en 1868, la considéra comme telle.

Le corps des Balanoglosses est allongé, déprimé et divisible en trois régions: une partie antérieure très contraclile, la trompe; une partie moyenne ou collier entourant la base de celle-ci; enfin le tronc, qui est de beaucoup la partie la plus longue. - L'appareil digestif est cilié; la houche s'ouvre à la base de la trompe; l'anus est situé à l'extrémité postérieure du corps. - La région antérieure de l'œsophage (région branchiale) est modifiée en vne de la fonction respiratoire: sa paroi dorsale est percée, de chaque côté, d'une série d'orifices communiquant avec de courts canaux (chambres branchiales) qui vont déboucher d'autre part à sa face dorsale; ces canaux sont soutenus par des pièces cartilagineuses. L'eau pénètre par la bouche et sort par les pores dorsaux. - Le système circulatoire est développé aux dépens des lacunes de la cavité générale; il existe cependant deux vaisseaux, l'un dorsal, l'autre ventral, le premier avec un renflement (cœur). - Les sexes sont séparés. Les organes génitaux se forment aux dépens de la cavité générale.

Le squelette est représenté par une corde dorsale cellulaire, développée seulement au-dessus de la région branchiale, mais persistant pendant toute la vie. A sa périphérie, elle donne naissance à un tissu semi-cartilagineux, lequel émet des prolongements latéraux destinés à soutenir les chambres branchiales, et un prolongement médian qui s'avance dans la base de la trompe. - Le système nerveux central est représenté par un amas de fibres et de cellules nerveuses situé au-dessus de l'axe cartilagineux; de là part un nerf dorsal, qui parcourt le corps entier; il existe en outre un nerf ventral, réuni au précédent par des commissures.

D'après ces données, on voit que si les Entéropueusles sont voisins des Échinodermes, ils sont beaucoup plus étroitement liés encore aux Tuniciers et aux Acraniens. - Ces animaux vivent dans le sable de presque toutes les mers.

\section{SOUS-EMBRANCHEMENT II}

\section{TUNICIERS}

Chordés à corde dorsale persistante ou temporaire, toujours limitée à la région caudale.

Le corps des Tuniciers a tantòt la forme d'un sac, comme chez les Ascidies, tantôt celle d'un tonneau, comme chez les Salpes; il est constamment muni de deux orifices ou siphons. L'orifice afférent ou buccal sert à l'introduction des substances alimentaires et de l'eau destinée à sa respiration; l'autre fait fonction d'ouverture cloacale et porte, à ce titre, le nom d'orifice atrial (fig. 658).

L'enveloppe extérieure du corps, à laquelle on donne souvent le nom de manteau externe ou de tunique - d'où est dérivée l'expression de Tuniciers - est une cuticule sécrétée par les cellules de l'ectoderme; elle est formée d'une substance isomère de la cellulose, la tunicine. En dessous de ce tégument se trouve une couche de tissu conjonctivo-musculaire correspondant au mésoderme pariétal. L'ensemble des tissus représentés par cette couche, par l'ectoderme et par la tunique, a souvent été désigné sous le nom de manteau. 
L'orifice buccal conduit dans la cliambre respiratoire, au fond de laquelle s'ouvre un a'sophage cilié; mais, entre ces deux ouvertures, se trouve, du cơté de la face ventrale, un sillon également cilié, destiné à faciliter la marche des matières alimentaires. L'œsophage, en forme d'entonnoir, débouche dans l'estomac, auquel fait suite un intestin qui aboutit, soit à l'extérieur' (Appendiculariés), soit dans un cloaque on atrium ouvert en général non loin de l'orifice afférent. Chez beaucoup d'Ascidies composées, cette cavité cloacale est commune à plusieurs individus.

La criculation est lacunaire, mais il existe presque toujours, du còté opposé alı système nerveux - face ventrale ou liématique un organe central ou cœur simple, qui présente un phénomène remarquable : à de courts intervalles, ses contractions, qui sont rapides et régulières, changent de sens, et le sang se trouve ainsi chassé dans deux directions opposées.

Lappareil respiratoire, chez les Ascidies, est représenté par un sac branchial treillissé et cilié, suspendu dans une cuvité dite péribranchiale et parcouru par des courants

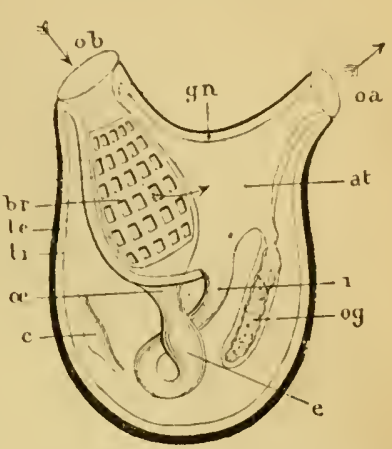

Fig. 638. - Schéma de l'organisation d'une Ascidie, en partic d'après Allmanu. - te, turique externe. $t i$, tunique in. terne. $a b$, orifice buccal. $b r$, chambre branchiale. $\propto$, ๓sophage. $e$, estomac. $i$, intestiu, $a t$, atrium. oa, orifice atrial. gn, ganglion nerveux. $c$, cœur. og, organes génitaux. sanguins. L'eau pénètre par la bouche, passe dans les mailles du treillis branchial et sort par l'orifice atrial. - Chez les Salpes, la branchie a le plus souvent la forme d'un ruban creux sans fentes. - Enfin, chez les Appendiculaires, c'est un sac rudimentaire, n'offrant que deux fentes branchiales.

Les Tuniciers sont hermaphrodites, et souvent les éléments femelles arrivent à maturité avant les éléments màles (dichogamie protogynique). Les organes sexuels occupent la partie postérieure du corps: les ovaires sont des sortes de glandes en grappe qui, chez les Ascidies, sont enveloppées par les tubes testiculaires. Les conduits vecteurs débouchent dans le cloaque, où s'effectuent mème d'ordinaire la fécondation et le développement embryonnaire. - On peut en outre observer, dans certains cas, une reproduction asexuelle par gemmiparité. Les individus résultant de ce bourgeonnement forment des colonies variées. - Chez les Salpes et mème chez quelques Ascidies, on constate une alternance régulière entre ces deux modes de reproduction (génération alternante). Ainsi, la reproduction sexuelle donne naissance à des Sulpes solituires, individus isolés d'assez grande taille, mais ne possédant pas d'organes sexuels : ces individus produisent à leur intérieur, par gemmiparité, des Salpes qui demeurent unies en chaine, ou Salpes agrégees; mais celles-ci, au lieu de se reproduire par bourgeonnement, développent chacune un œuf, qui sera fécondé par des spermatozoïdes pour donner des Salpes solitaires agames.

Le squelette est représenté par un cordon cellulaire axial qui occupe le milieu de la queue, chez les larves, et qui représente la corde dorsale. Ce cordon persiste pendant toute la vie chez les Appendiculariés (Pérennichordés); 
il disparait avec la queue, lors du passage à l'étal adulte, chez les autres Tuniciers (Caducichordés).

Le système nerveux central se montre constitué par un fort ganglion situé au-dessus du tube digestif, sur la ligne médiane dorsale. Chez les Ascidiacés, il y est toujours annexé une glande dont le conduit excréteur débouche dans la cavité branchiale, et que Julin regarde comme analogue à l'hypophyse des Vertébrés. - Il n'existe, en fait d'organes sensoriels, que de petits ocelles, des otocystes et des fossettes olfactives, qui disparaissent le plus souvent a l'état adulte.

Le developpement offre de grandes analogies avec celui des Leptocardes. Les larves, au moment de leur naissance, sont généralement pourvues d'une queue et offrent assez l'aspect de têtards. Cette queue renferme une corde dorsale et un cordon nerveux; elle persiste, avec ces organes, chez les Appendiculariés, mais elle disparait, ainsi que la corde dorsale, chez tous les autres Tuniciers; quant au cordon nerveux, il persiste seulement dans sa région antérieure, où il s'épaissit en un ganglion.

Tous les Tuniciers sont des animaux marins; les uns sont fixés à l'état adulte, les autres nagent librement; ils peuvent d'ailleurs être isolés ou réunis en colonies.

3 classes :

Une queue, une notochorde à l'état adulte (Pérennichordés)..... Appexdiculariés.

Pas de queue, pas de notochorde f Corps en forme de sac...... Ascidiacés.

à l'état adulte (Caducichordés). Corps en forme de tonnelet. Thaliacés.

I. Appendiculariés. - Ce sont des Tuniciers libres, nageurs, munis d'un appendice caudal pendant toute la vie; ils représentent en quelque sorte des Ascidies demeurées à l'étal larvaire. - Genres Fritillaria, Kovalevshya, etc.

II. Ascidiacés. - Les Ascidiacés sont ordinairement fixés; ils ont un corps sacciforme, muni de deux orifices plus ou moins rapprochés l'un de l'autre. On peut en distinguer trois groupes:

$1^{\circ}$ Les Ascidies simples ou AGrÉgÉEs, représentées les unes par des individus solitaires, les autres par des colonies ramifiées, mais dans lesquelles chaque individu possède un manteau particulier. - Ascidia L. (Phallusia Sav.), Cynthia, Ascidies solitaires. - Clavellina, Perophora, Ascidies sociales.

$2^{\circ}$ Les Ascidies conposées ou Synascidies, formant des colonies le plus souvent étoilées, enveloppées d'une tunique commune. - Botryllus.

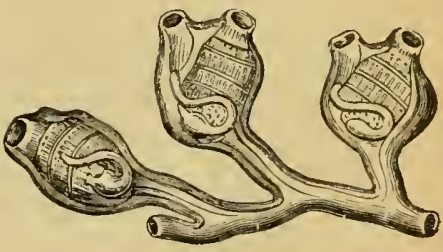

Fíg. 659. - Ascidies sociales.

$3^{\circ}$ Les Ascidies salpiformes, constituant des colonies flottantes, enveloppées d'un manteau commun; les orifices buccal et.atrial sont ouverts aux deux extrémités du corps. Animaux phosphorescents. - Pyrosoma.

III. Thaliacés. - Les Thaliacés ou Salpes sont des animaux nageurs, isolés ou agrégés, en forme de petits cylindres ou de tonnelets transparents, 
dont les deux orifices d'entrée et de sortie sont opposés et terminaux. Salpa (Salpes ou Biphores), Doliolum (Barillets).

\section{SOUS-EMBRANGHEMENT III}

\section{ACRANIENS}

Chordés à corde dorsale persistante, sétendant sur toute la longueur. du corps; pas de crane ni de vertèbres.

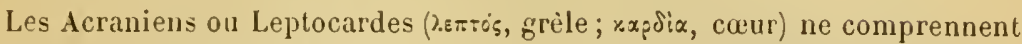
jusqu'à présent que deux espèces: l'une, le Lancelet (Amphioxus lanceolatus), qu'on trouve dans le sable de nos còtes, l'autre (Epigionichthys pulchellus) qui n'a encore été vue qu'en Australie.

Le corps de l'A mplioxus, long de 3 à 5 centimètres, est comprimé d'un cỏté à l'autre et atténué à ses leux extrémités; il est muni seulement d'une nageoire caudale, qui se prolonge sur les faces dorsale et ventrale par un léger repli du tẻgument.

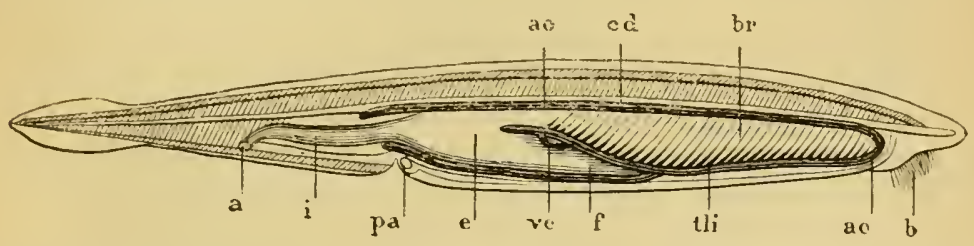

Fig. 660. - Amphioxus lanceolatus. $-b$, buuche. $b r$, chambre branchiale. $e$, portion renflée du tube digestif. $i$, portion grèlc. $f$, ciecum lıépatique. $a$, anus. $p a$, pore abdominal. $c d$, corde dorsale. $t l i$, tronc longitudinal inférieur (contractile). $a c$, arc aortique contractile. $a o$, aorte. $v c$, veine cave 'de (quatrefages).

Le squelette axial est représenté par une corde dorsale persistante, s'étendant d'une extrémité à l'autre du corps sous l'aspect d'un cordon plein et uniforme, composé de disques gélatineux empilés et réunis par des ponts. Cette notochorde est entourée d'une gaine conjonctive très résistante, émetlant des replis dorsaux qui forment un tube (canal neural), et en arrière des replis ventraux servant à abriter les vaisseaux de la queue. Le canal neural ne se dilate pas en avant pour former une cavité cranienne. - Les masses musculaires sont divisées, par des lignes obliques, en une série de segments ou myomères.

Une moelle épinière représente le système nerveux central; elle est logée dans le canal neural; mais, comme celui-ci ne présente pas de dilatation cranienne à sa partie antérieure, elle-mème ne se différencie pas en cerveau. Elle émet de chaque côté des paires nerveuses presque symétriques. - Les organes des sens sont représentés par une fossette olfactive et une tache oculaire situées à l'extrémité céphalique.

La bouche a la forme d'une fente longitudinale maintenue béante par un cadre semi-cartilagineux qui porte des cirres mobiles. Elle donne accès dans une cavité pharyngienne tout à fait analogue au sac branchial des Ascidies. Ses parois en effet, soutenues par des arcs cartilagineux obliques, perforées de nombreuses fentes latérales parallèles et couvertes de cils vibratiles, constituent de véritables branchies. Les fentes débouchent dans une cavité 
péribranchiale distincte de la cavité générale. L'eau venant de la bouche, après avoir baigné les branchies, passe donc dans cette cavité et s'échappe par un pore abdominal.

$\mathrm{Au}$ fond du sac branchio-pharyngien s'ouvre le tube gastro-intestinal, qui présente à sa partie antéro-inférieure un cæcum hépatique et aboutit à un anus situé vers le tiers postérieur de la face ventrale.

L'appareil circulatoire ne présente pas de cœur proprement dit; le sang circule cependant dans des vaisseaux clos, pulsatiles sur certains points. Ce sang est incolore, quoiqu'il charrie des globules renfermant un peu d'hémoglobine. - Les organes excréteurs ne sont pas connus.

Les sexes sont séparés, les testicules ou les ovaires sont situés sur le plafond de la cavité péribranchiale; leurs produits sont expulsés par la bouche ou par le pore abdominal.

En ce qui concerne le developpement, nous dirons seulement que les œufs, qui sont alécithes, subissent une segmentation totale et presque égale. L'embryon est mis en liberté sous forme de larve ciliée.

\section{SOUS-EMBHANCHEMENT IV}

\section{VERTÉBRÉS}

Chordés à corde dorsale persistante ou temporaire, s'étendant sur toute la longueur du corps; squelette axial composé de vertèbres et formant un crâne à son extrémité antérieure.

Pendant la période embryonnaire, tous les animaux de ce groupe présentent une symétrie bilatérale bien nette; à l'âge adulte, cette symétrie tend à disparaître à mesure que l'organisation se complique, mais il faut simplement attribuer ce fait à un accroissement inégal des parties.

Les Vertébrés sont pourvus d'un squelette interne cartilagineux ou osseux, divisible en deux parties : l'une axiale, à laquelle se rattachent la tête et le tronc; l'autre appendiculaire, constituant la base des membres.

La partie centrale du squelette axial établit beaucoup plus nettement encore que dans les autres Chordés une séparation entre les deux principales cavités du corps: la cavité neurale, qui loge le système nerveux central, et la cavité viscérale, qui renferme les organes de nutrition et de reproduction. A l'état embryonnaire, cette région centrale de l'axe est représentée par la corde dorsale; celle-ci est entourée d'une " couche squelettogène " de nature conjonctive, émettant deux replis dorsaux qui forment un canal à la moelle épinière, et deux replis ventraux qui protègent la cavité viscérale. Chez quelques Vertébrés inférieurs (Myxines), cette organisation est permanente, et l'on ne voit aucune trace de segmentation; mais, dans les formes plus élevées, on voit se former, dans la couche squelettogène, des séries de pièces cartilagineuses (Lamproies) qui finissent par constituer de 
véritables articles (Sélaciens) passant même le plus souvent à l'état osseux. Chacun de ces articles, avee ses dépendances, constitue ce qu'on appelle, en anatomie comparée, une vertèbre. Ils forment, dans leur ensemble, une ligne segmentée à laquelle on donne le nom de colonne vertébrale ou de rachis.

Une vertébre-type comprend (fig. 661): $1^{\circ}$ une pièce centrale, le corps de la vertèbre, encore nommé cycléal ou centrum; $2^{\circ}$ un are dorsal, dont l'existence est constante, et qui reçoit le nom de neural (vย̧̃̃ov, nerf), parce qu'il entoure la moelle épinière; $3^{\circ}$ un arc ventral, moins constant, destiné à abriter les viscères, et appelé hémal ( $\alpha \tilde{i} \mu \alpha$, sang), en raison de la protection qu'il fournit au système vasculaire. - Le centrum est parfois concave à ses deux extrémités: les vertèbres sont alors appelées biconcaves ou amphicaliques (àựi, des deux côtés; xoĩ lorsqu'il existe une cavité en avant et une convexité en arrière, elles sont procœliques ( $\pi \rho o ́$, en avant); enfin, on les dit opisthocœli-

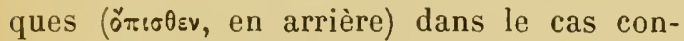
traire. Les corps sont sourent unis entre eux par des pièces élastiques appelées fibro-cartilages intervertébraux. - L'arc neural a pour bases deux lames auxquelles, d'après la nomenclature d'Owen, on donne le nom de neurapophyses; l'espace qu'elles laissent

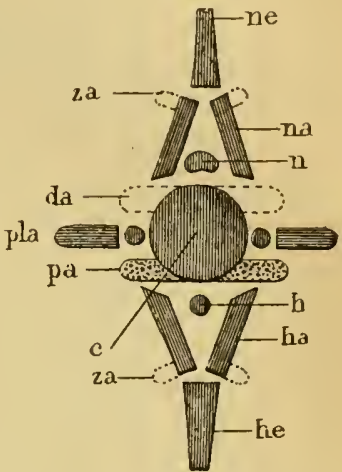

Fig. 661. - Schéma de la composition d'une verlebre, d'après $R$. Owen. - $c$, centrum. na, neura pophyses. ne, neurépine. $n$ coupe de la moelle épinière. $h a$, hémapophyses. he, hémépine. $h$ coupe du vaisseau sanguin, pla, pleurapophyses. $d a$, diapophyses. pa, parapophyses, $z a$, zygapo physes.

entre elles pour loger la moelle s'appelle le canal neural, et le long conduit formé par ces canaux élémentaires porte le nom de canal rachidien. L'are neural est d'ailleurs complété en dessus par une pièce impaire dite apophyse épineuse ou neurépine. Souvent même il se complique par le développement d'autres prolongements ou apophyses, telles que les apo. physses articulaires ou zy gapophyses, qui servent à l'articulation des vertèbres entre elles, et les apophyses transverses antérieures et postérieures (parapophyses et diapophyses). — L'arc hémal, moins constant que le neural, est comme lui constitué par deux lames, les hémapophyses, destinées en général à abriter les viscères et, dans tous les cas, protégeant les parties essentielles du système vasculaire. On distingue trois formes parmi ces hémapophyses $: \mathbf{1}^{\circ}$ les côtes de la région caudale des Poissons Ganoïdes et Sélaciens, qui se fixent au centrum et se réunissent à leur partie inférieure pour former un canal caudal prolongeant la cavité du corps; $2^{\circ}$ les os en $\mathrm{V}$ qui, chez les animaux à queue bien développée, donnent lieu aussi à une sorte de canal caudal; $3^{\circ}$ les côtes de la plupart des Poissons et des autres Vertébrés, qui sont tantôt fixées au corps de la vertèbre, tantôt articulées arec 
des apophyses transverses. Le nombre et la situation de ces côtes sont très variables. Ajoutons que divers auteurs regardent la partie vertébrale des côtes thoraciques comme une pleurapophyse, l'hémapophyse étant représentée par leur pièce sternale. La pièce impaire qui complète parfois l'arc hémal reçoit le nom d'hémépine; le sternum, qui se montre déjà chez les Amphibiens, a pour base un ensemble d'hémépines.

La colonne vertébrale comprend un nombre variable de vertèbres; on y distingue cing régions chez les Vertébrés supérieurs qui sont pourvus de membres postérieurs bien développés :-régions cervicale, dorsale, lombaire, sacrée ou pelvienne et coccygienne ou caudale.

A son extrémité antérieure, le canal rachidien offre une dilatation destinée à loger le cerveau, et le squelette axial forme, par suite, un renflement qui n'est autre que la tête. Depuis Gœthe, on regarde la tête comme composée d'un certain nombre de vertèbres; mais, si les naturalistes sont d'accord en principe sur la constitution vertébrale du squelette céphalique, ils sontloin de s'entendre sur le nombre des segments vertébraux qu'il comporte (1). Les arcs neuraux de ces vertèbres servent à la protection du cerveau et forment le crine, qui s'articule en arrière avec la première vertèbre cervicale, tantôt par un seul, tantôt par deux condyles occipitaux; quant aux ares inférieurs, les uns entourent l'entrée du tube digestif et protègent les organos de la vision, de l'odorat et du goût: ils constituent la face, et en particulier l'appareil maxillo-palatin; les autres, sitnés en arrière, servent de support à l'appareil respiratoire : Gegenbaur leur donne le nom de squelette viscéral. Ces derniers sont en nombre variable : l'antérieur (hyoïde) est seul constant; les autres (arcs branchiaux) ne se montrent que chez les animaux aquatiques, dont ils supportent les branchies; on en compte le plus souvent cinq paires; chez les Vertébrés à respiration aérienne, ils n'apparaissent que transitoirement, dans les premières périodes du développement, et ont disparu à l'état adulte.

Les membres des Vertébrés peuvent se distinguer en pairs et impairs. Ces derniers, qui n'existent que chez les Vertébrés inférieurs ou anallantoïdiens, sont représentés par des nageoires médianes; les autres, ou membres proprement dits, composent au maximum deux paires, qui offrent entre elles un parallélisme de structure très net. Chacune de ces paires est reliée au squelette axial par un certain nombre de pièces constituant ce qu'on appelle une ceinture : ceinture scapulaire pour les membres antérieurs, ceinture pelvienne pour les membres postérieurs.

La ceinture scapulaire comprend, de chaque côté, l'omoplate, le coracoïde et le procoracoïde; celui-ci, toutefois, manque chez les Cro-

(1) Voy. Lavocat, Nouvelles éludes sur le système cérébral, 1860. - Gegenbacr, Manuel d'anat. comparée, 187 ; etc. 
codiles, les Oiseaux et les Mammifères, et le coracoïde lui-même se rédıit chez ces derniers à une simple apophyse de l'omoplate. Quant ì la clavicule, qui complète souvent la ceinture scapulaire, ce n'est qu'une pièce surajoutée, d’origine dermique.

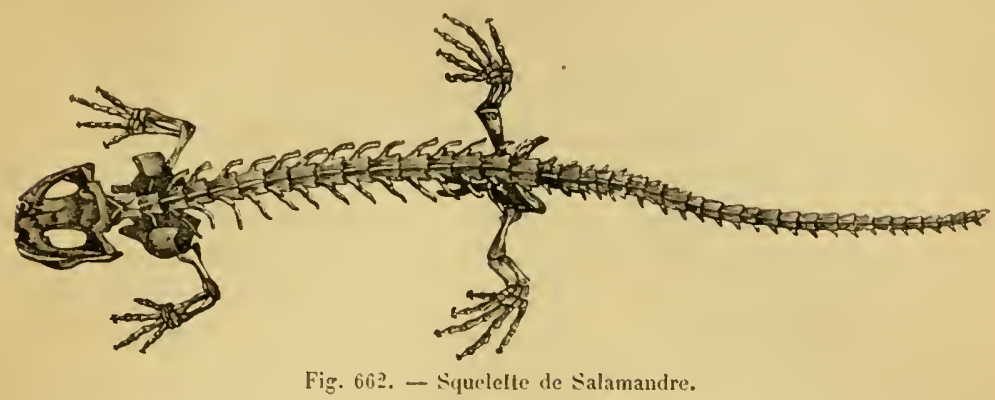

La partie mobile des membres subit diverses modifications de forme suivant le róle qu'elle est appelée à remplir (marche, vol, natation, etc.). Dans le membre antérieur, elle offre toujours trois segments principaux: le bras, l'avant-bras et la main. Le bras a pour base un seul os, l'humérus. L'avant-bras en comprend deux: le radius et le cubitus. La main complète se divise en trois régions secondaires : le carpe, composé de deux rangées principales de petits os courts, peu mobiles; le métacarpe, formé d'os longs; enfin les doigls, divisés chacun en plusieurs segments ou phalanges.

Dans les membres postérieurs, la portion basilaire (ceinture pelvienne ou bassin) est plus étroitement unie à l'axe que dans les membres thoraciques. Elle est constituée aussi, de chaque côté, par trois pièces: l'ilium, l'ischion et le pubis.

La portion mobile comprend trois segments qui correspondent à ceux des membres antérieurs: la cuisse, la jambe et le pied, ayant pour base, respectivement, le fémur, puis le tibia et le péroné, enfin le tarse, le mélatarse et les orteils. .

En outre, chez quelques Vertébrés, l'articulation du coude est protégée par un osselet déreloppé dans les tendons des muscles extenseurs, et d'ordinaire l'articulation de la cuisse et de la jambe est complétée et protégée également par une pièce de même nature, la rolule.

Il est à remarquer que, chez les Poissons, les membres se terminent par un grand nombre de rayons (membres radiés), tandis que, chez les autres Vertébrés vivants, il n'existe pas plus de cinq doigts (membres digités). "Les Poissons sont polydactyles, les Amphibiens, Reptiles, Oiseaux et Mammifères sont pentadactyles. Le nombre des doigts peut ètre réduit par régression ultérieure, mais primilivement un membre des classes ci-dessus nommées aura toujours cinq doigts. C'esl là un fait de première importance; il en résulte la conclusion que les Vertébrés ayant un nombre moindre de doigts, doivent descendre d'ancêtres pentadactyles, et que ceux qui présentent cinq 
doigts à chaque membre n'ont subi, quant à ces organes, aucune métamorphose imporlante, et ont conservé le type primitif » (Vogt).

Les différentes parties du squelette sont mises en mourement par des muscles nombreux; mais, en outre, il existe souvent d'autres muscles unis à l'enveloppe tégumentaire, et particulièrement développés chez les Vertébrés supérieurs.

La peau des Vertébrés se compose de deux couches principales: une profonde, le derme, et une superficielle, l'épiderme. Le derme est formé de fibres conjonctives auxquelles se joignent des éléments musculaires épars, des nerfs, des vaisseaux et des glandes; il contient parfois des cellules pigmentaires contractiles ou chromoblastes; enfin, on trouve à sa surface des éminences ou papilles qui renferment des corpuscules du tact. L'épiderme, de nature cellulaire, se subdivise en deux zones: les strates inférieures, formées de cellules jeunes, sphéroïdales ou polyédriques, souvent pigmentées, constituent la couche muqueuse ou de Malpighi; les assises supérieures, comprenant les cellules anciennes, devenues lamelleuses, qui tombent par desquamation, méritent le nom de couche cornée. - Les divers appendices cutanés ou phanères tirent leur origine tantôt de l'épiderme (plumes, poils, ongles, etc.), tantôt du derme, notamment par ossification des papilles (écailles des Poissons, carapace des Tortues ou des Tatous).

La partie centrale du système nerveux est représentée chez tous les Vertébrés par l'axe cérébro-spinal (encéphale et moelle épinière). Les parois de l'étui cranio-rachidien qui loge cet axe nerveux sont tapis-

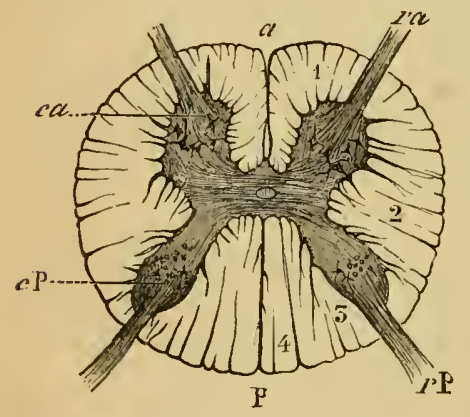

Fig. 663. :- Coupe de la moelle cervicale de l'Homme. $-a$, sillon médian antérieur. $p$, sillon médian postérieur. $c a$, corne antérieure de la substance grise. $c p$, corne postérieure. $r a$, racine antérieure d'un nerf rachidien. $r p$, racine postérieure. 1 , faisceau ou cordon antérieur de la moelle. 2, cordon latéral. 3, cordon postérieur (portion externe). 4, cordon postérieur (portion iuterne ou cordon de Goll). sées par une membrane fibreuse (duremère); l'encéphale et la moelle épinière sont eux-mêmes revêtus d'une membrane très vasculaire qui pénètre jusque dans leurs cavités (pie-mère); enfin, chez les Vertébrés supérieurs, il existe une membrane séreuse (arachnoïde) dont un feuillet tapisse la dure-mère, tandis que l'autre recouvre la pie-mère, mais sans la suivre dans les anfractuosités de la masse centrale : un liquide plus ou moins abondant s'amasse dans ces espaces sous-arachnoïdiens et porte le nom de liquide céphalo-rachidien. Quant aux faces libres de l'arachnoïde, elles sont humectées, comme celles de toutes les séreuses, par une sécré-

tion propre (liquide arachnoïdien).

Le tissu de l’axe cérébro-spinal se montre composé de deux sub- 
stances d'aspect différent : une substance blanche, formée surtout de fibres nerveuses, et une substance grise, constituée essentiellement pal' les cellules dont émanent les fibres. Ajoutons que la moelle épinière possède un canal central qui la parcourt dans toute sa longueur et se transforme dans l'encéphalc en larges eavités connues sous le nom de ventricules et communiquant les unes avec les autres.

L'encéphale, malgré ses variations extérieures, offre chez tous les Vertébrés les mèmes parties fondamentales. Chez l'embryon, ces parties se montrent sous forme de renflements vésiculaires, au nombre de trois : ce sont les vésicules cérébrales primitives, qu'on distingue en antérieure, moyenne et postérieure. Mais cet état ne persiste pas:

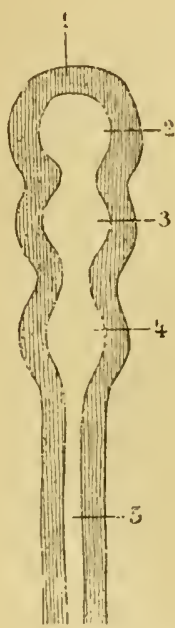

Fig. 664. - Coupe schématique des trois vésicules cérébrales primitives. - 1, 2, vésicule cérébralc antéricure. 3, vésicule cérébrale moỵcnuc. 4, vésicule cérébrale postéricure. 5 , moelle épinière.

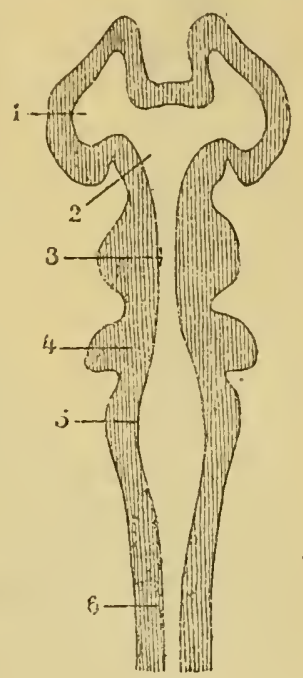

Fig. 665. - Coupe schématique des cinq vésicules cérébrales secondaires. - Cerveau antérieur: 1, vésiculc d'hémisphère cérébral. 2, vésicule des couches optiques. - Cerveau moyen: 3, vésicule des lubercules quadrijumcaux. - Cerveau postérieur : 4, vésicule du cervelet. 5 , vésicule du bulbe. 6 , moclle épinière.

les vésicules antérieure et postérieure se subdivisent chacune par un étranglement, et il apparait ainsi cinq vésicules cérébrales secondaires. $1^{\circ} \mathrm{La}$ vésicule antérieure produit deux saillies ou lobes qui donneront naissance aux hémisphères cérébraux et aux corps striés; chaque hémisphère est creusé d'un large ventricule latéral et émet en avant un lobe olfactif volumineux. $2^{\circ} \mathrm{La}$ vésicule intermédiaire constitue le troisième ventricule, qui communique, par le trou de Monro, avec les deux premiers ; ses parois latérales forment les couches optiques; son plancher donne naissance à deux invaginations latérales, les vésicules oculaires primitives, et à une invagination médiane qui produit l'hypophyse ou glande pituitaire ; enfin, son plafond fournit un diverticule constituant l'épiphyse ou glande pinéale, point de départ 
de l'œil pinéal ou pariétal. $3^{\circ}$ La vésicule moyenne produira, sur ses parois ventrale et latérales, les pédoncules cérébraux, et sur sa paroi dorsale, les lobes optiques (tubercules bijumeaux, quadrijumeaux); sa cavité n'est représentée que par l'aqueduc de Sylvius, qui met en communication le troisième el le quatrième ventricule. $4^{\circ} \mathrm{La}$ vésicule cérébrale postérieure formera sur sa paroi supérieure le cervelet; sa

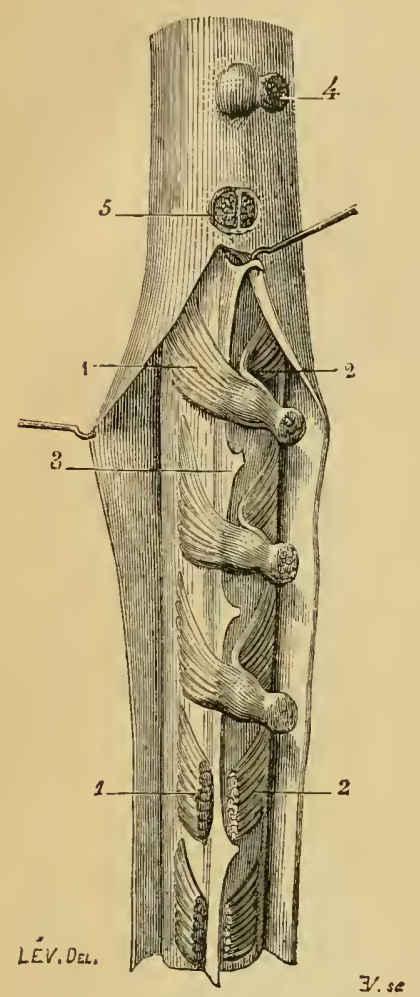

Fig. 666. - Fragment de la moelle épinière de l'Homme, avec les racines spinales, d'après L. Hirschfeld. - 1, 1, racines postérieures. 2, 2, racines antérieures. 3 , ligament dentelé. 4, gaine que la dure-mère fournit aux nerfs rachidiens. 5 , section de cette gaine. paroi inférieure donnera, chez les Mammifères, la protubérance annulaire. $\breve{\jmath}^{\circ}$ Enfin, la vésicule du bulbe correspond au bulbe rachidien ou moelle allongée; sa cavité constitue le quatrième ventricule, qui se continue avec le canal central de la moelle. - Il est à remarquer que, chez les Vertébrés inférieurs, les hémisphères sont relativement petits et laissent à découvert les autres divisions du cerveau; mais ils se développent progressivement, et, chez les Mammifères les plus élevés, ils arrivent à couvrir les lobes olfactifs en avant, les lobes optiques et le cervelet en arrière.

Le système nerveux périphérique comprend de nombreux cordons qui naissent par paires de l'axe cérébrospinal et se distinguent, d'après leur origine, en nerfs craniens et nerfs rachidiens. La plupart de ces nerfs sont mixtes, c'est-à-dire composés de fibres motrices et de fibres sensitives; tous les nerfs rachidiens, en particulier, sont dans ce cas; ils naissent distinctement par deux racines, une ventrale motrice et une dorsale sensitive.

Quant au système nerveux de la vie végétative (grand sympathique), il ne fait défaut que dans quelques formes inférieures. Il a pour base de nombreux ganglions réunis entre eux et communiquant avec le système cérébrospinal; les filets qui en partent pour se rendre aux viscères constituent en général des plexus pourvus de ganglions secondaires.

Les organes des sens présentent tous des parties différenciées du tégument, qui sont en rapport avec des nerfs. - L'appareil olfactif se compose d'ordinaire de deux cavités formées par les os de la face et tapissées par une muqueuse dans laquelle vient se distribuer le nerf olfactif. A cet appareil se rattache l'organe de Jacobson, formé 
de deux sacs émanés des fosses nasales, débouclıant dans la cavité buccale et innervés par des rameaux des nerfs trijumeau et olfactif (Gymnophiones, Saurophidiens, beaucoup de Mammifères). Le rôle de cet organe parait être de soumettre les aliments au contrôle des nerfs olfactifs. - Les yeux sont iu nombre de deux et montrent une complication variable. Le nerf optique leur fournit une expansion membraneuse, la rétine, au-devant de laquelle se placent divers milieux réfringents (cornée, humeur aqueuse, cristallin, humeur vitrée), le tout accompagné de certains appareils protecteurs ou moteurs, etc. - II

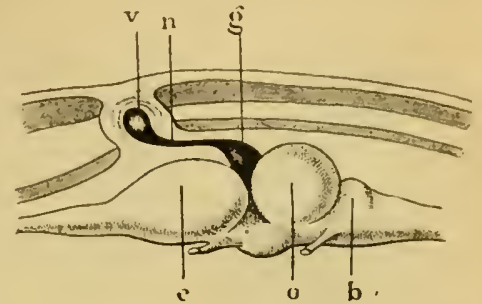

Fig. 667. - Encéphale de Lézard vu de profil dans la boile cranienne. $-b$, bulbe. $o$, lobes opliques. $c$, hémisphlìres cŕrébraux. $v$, a il pineal. $n$, filament nerveux. $g$, sa base renflée.

existait en outre, che» les Labyrinthodontes, un troisième oil ou ail pinéal, qui se montre encore bien développé chez les Lézards, notamment chez quelques espèces des pays chauds. Cet ail impair, qui oceupe le sommet de la tête, a l'aspect d'une résicule dont la paroi superficielle est renflée en une sorte de cristallin, tandis que la paroi profonde constitue une rétine impressionnable à la lumière et se continuant avec un filament nerveux renflé à sa base, laquelle est située entre les lobes optiques et les hémisphères cérébraux. L'organe dont il s'agit s'est atrophié chez les autres Vertébrés, ne

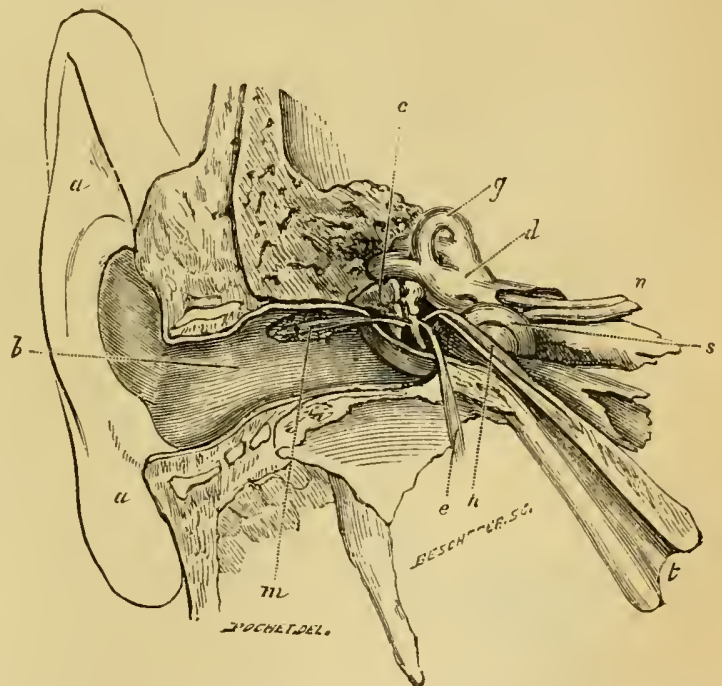

Fig. 668. - Oreille de l'Ilomme. - $a a$, pavillon. $b$, conduil auditif externe. $c$, la chaine des osselels. $d$, vestibule, $e$, muscle antérieur du marleau. $g$, canaux semi-circulaires. $h$, muscle interne du marteau. $s$, limaçon. $m$, muscle externe du marleau. $n$, nerf acouslique. $t$, trompe d'Euslache.

laissant guère subsister que son point d'origine, qui est devenu la glande pinéale. - L'organe de loüe se compose essentiellement d'une vésicule développée de chaque côté de la tête et recevant les divisions du nerf acoustique. Cette résicule (vestibule) se complique en général par la formation, dans sa partie postérieure (utricule), de trois canaux semi-circulaires, et dans sa partic antérieure (saccule), d'un diver- 
ticule spiroïde ou limaçon : l'ensemble de ces éléments constitue le labyrinthe ou oreille interne. On peut en outre observer des organes secondaires formant ce qu'on appelle l'oreille externe. - Le gout a son siège principal dans la muqueuse de la langue, qui offre à cet

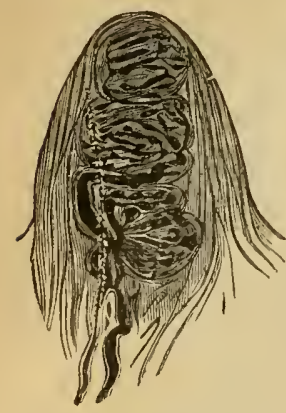

Fig. 669. - Papille cutanée pourvue de nerfs, avec corpuscule du tact ou de Meissucr, d’après Ranvier. effet des papilles spéciales, dans lesquelles vien. nent aboutir des filets nerveux émanés du glossopharyngien et du lingual. - Le tact s'effectue par la surface cutanée, au moyen de certaines papilles dans lesquelles les fibres nerveuses abou= tissent à des corpuscules particuliers (corpuscules du tact, corpuscules de Pacini). - Enfin, certains naturalistes ont admis l'existence d'un sixième sens, auquel seraient affectés, chez les Poissons et les Batraciens, des organes spéciaux (ligne latérale); mais il ne paraît y avoir là qu'une simple modification du tact.

La bouche est située sur la face ventrale et presque toujours armée de dents; il y est annexé le plus souvent des glandes salivaires. - On distingue dans le tube digestif trois régions principales: intestin antérieur, moyen et terminal. - L'intestin antérieur comprend : le pharynx ou arrière-bouche, l'œsophage, parfois dilaté en jabot, et l'estomac. - L'intestin moyen, encore appelé, en raison de son diamètre, intestin grêle, esł parfois divisible en plusieurs portions (duodénum, jéjunum et iléon); il reçoit en général le produit de deux glandes

A.

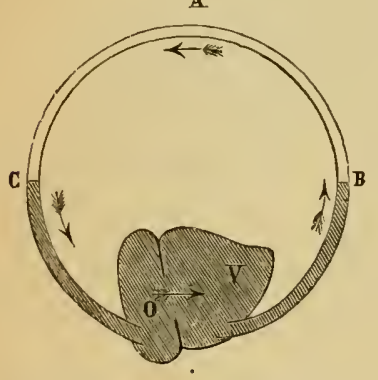

Fig. 670. - Schéma de la circulation des Poissons. - $\mathrm{O}$, oreillctte. $\mathrm{V}$, ventricule. $B$, branchies. $C$, capillaires du corps. A, aorte descendante ou dorsale. importantes, le foie et le pancréas, sans parler de celles qui sont logées dans l'épaisseur de sa paroi. - Quant à l'intestin ter. minal ou gros intestin, dans lequel on peut souvent encore distinguer plusieurs parties (cæcum, cûlon, rectum), il se termine par un orifice ventral ou anus tantot isolé, tantôt commun avec la terminaison des organes génito-urinaires (cloaque).

Chez tous les Vertébrés, l'appareil circulatoire forme un système clos, avec un cœur médian occupant la région antérieure de la cavité viscérale et entouré d'une double enveloppe ou péricarde. On peut recon. naître à ce cœur trois dispositions princir pales, entre lesquelles il existe d'ailleurs des degrés intermédiaires: $1^{\circ}$ Chez la plupart des Poissons, le cœur, situé sur le trajet du sang veineux, présente seulement une oreillette et un ventricule; il n'est traversé qu'une seule fois par le sang, el la circulation est dite-alors simple. $2^{\circ}$ Chez les Batraciens et les Reptiles, il y a deux oreillettes. 
et généralement un seul ventricule : la circulation est double (générale et pulmonaire), mais incomplète, car le sang veineux se mélange plus ou moins au sang artériel. $3^{\circ}$ Enfin, les Oiseaux et les Mammifères ont

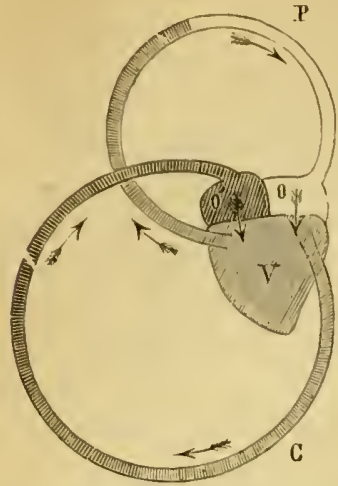

Fig. 6:1. - Seliéma de la circulation des Batraciens et des liepliles. -0 , oreilletle gauche. $0^{\prime}$, oreillelte droile. I, ventricule unique. P, poumon. C, capillaires du corps.

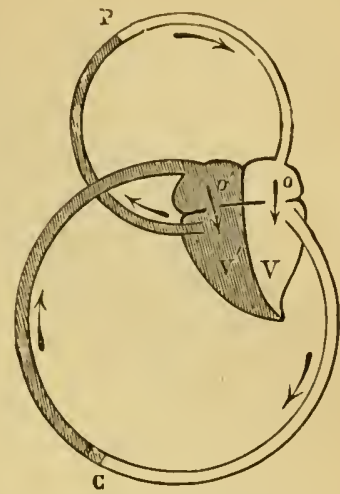

Fig. 672. - Schéma de la circulation des Oiseaux et des Mammiferes. - 0 , oreillelte gauche. $V$, ventricule gauche. $O^{\prime}$, oreillelte droite. $V^{\prime \prime}$, ventricule droil. P, poumou. C, capiliaires du corps.

un cœur à quatre cavités (deux oreillettes et deux ventricules), celles de droite ne recevant que du sang veineux, celles de gauche que du sang artériel : leur circulation est double et complète.

Toutefois, les dispositions variées que présente l'appareil circulatoire ne sont que les dérivés d'un type primitif unique. Dans les premières phases du développement embryonnaire, le cœur est toujours simple, et de sa région ventriculaire nait un tronc vasculaire (aorte ascendante), qui se divise bientôt en deux séries d'arcs aortiques latéraux; puis ceux-ci se réunissent dans un vaisseau descendant (aorte dorsale) qui fournit sur son trajet de nombreuses divisions latérales. Mais il survient ultérieurement diverses modifications en rapport avec la nature des organes respiratoires. Chez les Vertébrés à respiration aquatique, les arcs aortiques forment les vaisseaux branchiaux afférents et efférents. Lorsque les poumons se développent, ce qui entraine une division du ccur, les artères pulmonaires tirent leur origine de la paire postérieure d'arcs aortiques; les autres ares disparaissent pour la plupart, et souvent il n'en reste plus qu'un seul (aortej se continuant avec l'aorte dorsale.

Le sang charrié par les artères se distribue dans les tissus à la faveur d'un important réseau capillaire : il est ramené au cœur par des troncs veineux qui sont primitivement au nombre de quatre : deux antérieurs ou veines jugulaires, et deux postérieurs ou veines cardinales. De chaque cóté, la veine jugulaire s'unit à la cardinale pour former un canal commun (canal de Cuvier), lequel débouche, arec son congénère, dans un sinus qui précède l'oreillette. Mais cette disposi- 
tion ne persiste pas, à l'état adulte, chez les Vertébrés supérieurs. Les veines jugulaires s'unissent aux troncs veineux des membres thoraciques, et ainsi sont constituées les veines caves antérieures; les veines cardinales se réduisent (veines azygos), et le sang de la région postérieure du corps est en majeure partie ramené au cœur par un tronc particulier, la veine cave postérieure. - Ajoutons que les veines $\mathrm{du}$ tube intestinal, avant d'aborder au cœur, se réunissent en un tronc commun (veine porte) qui se ramifie dans le foie. Parfois même il existe un système porte rénal (Verlébrés ovipares).

Presque tous les Vertébrés ont le sang rouge, coloration qu'ils doivent à des globules rouges ou hématies, tenus en suspension dans le plasma, en même temps qu'un petit nombre de globules blancs ou leucocytes. Les globules rouges sont elliptiques et nucléés, sauf chez les Mammifères, où ils sont privés de noyau et presque toujours discoïdes. Le plasma est chargé du transport des substances nutritives; les hématies sont les véhicules de l'oxygène.

En dehors du système sanguin, les Vertébrés sont munis de cavités et de vaisseaux spéciaux débouchant en définitive dans les gros troncs veineux : c'est ce qui constitue le système lymphatique. Les vaisseaux lymphatiques ramènent dans le torrent circulatoire le plasma exsudé à travers les capillaires et chargé de produits de désassimilation; le liquide qu'ils renferment (lymphe) charrie des leucocytes. En outre, une partie des matériaux élaborés dans l'intestin sont emportés par des lymphatiques particuliers ou chylifères. Les ganglions lymphatiques, placés sur le trajet de ces divers ordres de vaisseaux, paraissent avoir pour rôle la formation des globules blancs ; on en rapproche d'ordinaire la rate et les autres glandes vasculaires sanguines, dont le rôle est encore peu connu.

La respiration peut, dans une certaine mesure, s'effectuer par la peau, lorsque celle-ci demeure molle et nue; mais il existe toujours des organes respiratoires, branchies ou poumons. Les branchies consistent en des lamelles membraneuses portées par le bord externe des arcs branchiaux : parfois, comme chez les jeunes têtards, elles sont extérieures. Quant aux poumons, ce sont, en principe, deux sacs membraneux, renfermant dans leurs parois de nombreux vaisseaux capillaires. Souvent ils n'occupent que la région thoracique de la cavité viscérale, et se trouvent séparés de la région abdominale par un diaphragme plus ou moins développé. Le tube qui conduit l'air dans les poumons est la trachée, dont les ramifications constituent les bronches. La trachée aboutit dans l'arrière-bouche ; à cette extrémité, elle se modifie d'ordinaire pour former l'organe de la voix ou larynx.

Chez les Mammifères et les Oiseaux, les échanges respiratoires sont toujours très actifs, et le sang possède une température propre, relativement élevée $\left(36\right.$ à $\left.43^{\circ}\right)$, qui se maintient à peu près constante, malgré de sérieuses modifications du milieu ambiant. Aussi leur corps 
donne-t-il, au toucher, une sensation de chaleur qui leur a valu le nom vulgaire d'animanx à sang chaud, auquel il serait préférable de substituer celui d'animaux à température constante. Tous les autres Vertébrés, ainsi que les Invertébrés, développent une chaleur animale beaucoup plus faible, et leur température propre oscille dans des limites assez étendues, suivant celle du milieu ambiant : de là, la sensation de froid que nous éprourons à leur contact, et le nom d'animaux à sang froid ou à température variable qui leur a été appliqué.

Les organes d'excrétion urinaire passent par deux états successifs che\% les Vertébrés inférieurs, par trois états chez les Allantoïdiens. $-1^{\circ}$ Le rein précurscur, rein céphalique ou pronéphros est un appareil très simple, qui rappelle celui des Vers; il persiste toute la vie chez quelques Poissons (Fierasfer), mais n'apparait d'ordinaire que comme organe transitoire. Il est représenté par deux canaux dits segmentaires, qui communiquent à leur extrémité et sur les côtés, par l'intermédiaire de tubes à pavillons ciliés, avec la cavité générale, et qui s'ouvrent en arrière dans le cloaque; chacun de ces tubes reçoit une artériole qui s'y pelotonne en un glomérule de Malpighi. $-2^{\circ} \mathrm{Ce}$ pronéphros est remplacé de bonne heure par le rein urimitif, corps de Wolff ou mésonéphros, qui persiste toute la vie chez les Poissons et le Batraciens, mais doit être lui-même remplacé par un rein définitil chez les Vertébrés supérieurs. Les canaux segmentaires du rein précurseur ont seuls été conservés; ils reçoivent de nouveaux tubes segmentaires à pavillons vibratiles encore ouverts dans le cœlome, tubes pourvus chacun d'un cul-de-sac qui recouvre (capsule de Bowman) un glomérule de Malpighi. Ces canaux segmentaires font ainsi toujours communiquer la cavité générale avec l'extérieur; mais, chez. les Sélaciens et les Batraciens, ils se divisent en deux canaux parallèles: le canal de Wolff, uretère primitif, qui conduit aussi le sperme, et le canal de Müller, rudimentaire chez le mâle, mais servant d'oviducte chez la femelle. $-3^{\circ}$ Chez les Vertébrés allantoïdiens, le mésonéphros a perdu sa fonction urinaire et ne sert plus quà l'évacuation des produits sexuels. Les canaux de Wolff deviennent les conduits sexuels du mâle, tandis que les canaux de Müller conserventleur qualité de conduits vecteurs femelles ou oviductes, en s'ouvrant dans la cavité générale par un pavillon. Mais il se développe un appareil uri naire nouveau, le rein définitif ou métanéphros, sans rapports avec l'appareil génital. On le voit apparaître comme un diverticule latéral (uretère) du canal de Wolff, se divisant en tubes (canalicules urinifères) pourvus de glomérules de Malpighi. Les uretères peuvent déboucher séparément ì l'extérieur; mais, le plus souvent, ils se réunissent au préalable ou même s'ourrent dans un réservoir spécial (vessie urinaire).

La reproduction est toujours sexuelle, et, sauf chez quelques Poissons et Batraciens, à hermaphrodisme constant ou inconstant, les sexes sont séparés. Les testicules et les ovaires sont presque tou- 
jours pairs et logés dans la cavité viscérale. Chez beaucoup de Poissons, les produits sexuels tombent dans la carité viscérale pour être évacués par un pore abdominal. Mais, en général, ces produits sont expulsés par des conduits particuliers (canal déférent, oviducte). Ces conduits peuvent d'ailleurs s'ouvrir isolément ou en commun dans un cloaque, ou se réunir entre eux pour déboucher, arec les organes urinaires, au roisinage de l'anus.

La plupart des Vertébrés sont ovipares. Parfois, cependant, l'éclosion de l'œuf a lieu dans l'oviducte même, et il y a ovoviviparité (Vipères). Enfin, chez presque tous les Mammifères et chez quelques Poissons, l’œuf fécondé séjourne dans une partie différenciée de l'oviducte (matrice ou utérus), à laquelle il adhère au moyen d'une zone vasculaire ou placenta, permettant des échanges actifs entre le sang de la mère et celui du jeune : ces animaux sont donc franchement vivipares.

Les œufs sont toujours télolécithes. Le développement commence par une segmentation totale ou partielle. Aussitót après sa formation, le blastoderme (roy. p. 51) montre sur un point de sa surface un épaississement cellulaire (tache embryonnaire ou aire germinative). Au milieu de cette zone, apparaît une ligne sombre (ligne primitive) qui marque le fond d'un sillon (gouttière primitive)

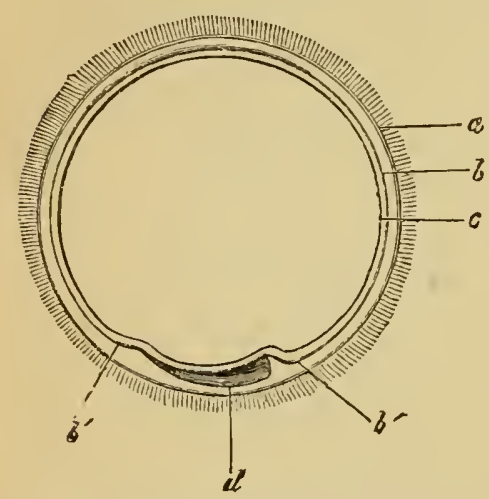

Fig. 673. - OEuf de Mammifère, au début de son développement. - $a$, membrane vitelline avec ses villosités naissantes. $b$, feuil el externe du blasloderme. $b^{\prime}, b^{\prime}$, premier soulc̀vement éphalique et caudal de ce feuillę. $c$, feuillel interne. $d$, corps de l'embryon. formé aux dépens de l'ectoderme et limité par deux bourrelets ou lames dorsales. Celles-ci se réunissent bientôt et convertissent la gouttière en un tube : c'est le point de départ des centres nerveux. D'autre part, il se développe de bonne heure, entre les deux feuillets primitifs et aux dépens de l'entoderme, une nouvelle couche cellulaire qui constitue le mésoderme. Puis, au-dessous de la gouttière, on voit se former un cylindre cellulaire : c'est la corde dorsale, qui s'atrophiera ultérieurement chez la plupart des formes, ct sera remplacée par les corps vertébraux. (Il faut remarquer que celte notochorde ne s'étend jamais jusqu'à l'extrémité antérieure du crâne : elle s'arrête au-dessous de la vésicule cérébrale moyenne). En même temps, les parties latérales et les extrémités de l'aire germinative se recourbent en dessous, c'est-à-dire vers le centre de l'œuf, de manière que le corps de l'embryon ressemble à une petite nacelle. L'intérieur de cette nacelle est tapissé par l'entoderme, et ses flancs, auxquels on 
donne le nom de lames ventrales, se rapprochent peu à peu de façon a circonserire finalement une étroite ouverture, qui n'est autre que l'ombilic.

On observe, dans le cours du développement, certains organes transitoires que nous devons signaler en raison de leur importance physiologique : nous roulons parler de la vésicule ombilicale, de l'amnios et de l'allantoide. La première se montre, d'une facon plus ou moins distincte, chez la généralité des Vertébrés; mais l’amnios et l'allantoïde sont propres aux Vertébrés supérieurs: les Batraciens et les Poissons en sont dépourrus.

La vésicule ombilicale est forméc par l'entoderme. Par suite de la convergence des lames ventrales, ce feuillet subit un étranglement, et la cavité se trouve par suite divisée en deux parties, l'une intraembryonnaire, l'autre extra-embryonnaire : la première représente la carité intestinale de l'embryon; la seeonde constitue la vésicule ombilicale ou sac vitellin, dont le contenu fournit à l'embryon les premiers éléments de sa nutrition. Quant à la partie étranglée, elle recoit le nom de conduit omphalo-mésentérique ou vitello-intestinal. La résicule dont il s'agit disparait en général de bonne heure; cependant, on la voit souvent encore suspendue à la face ventrale des jeunes Poissons.

A mesure que l'embryon šncurve en nacelle, l'ectoderme se soulève autour de lui, surtout du côté de la tête et de la queue. De là résulte la formation de replis qui se portent sur la partic convexe de l'embryon et marchent à la rencontre l'un de l'autre. Bientôt ces replis se rejoignent et se confondent, la cloison qui les sépare ne tardant pas à disparaître. Leur feuillet externe s'accole dès lors

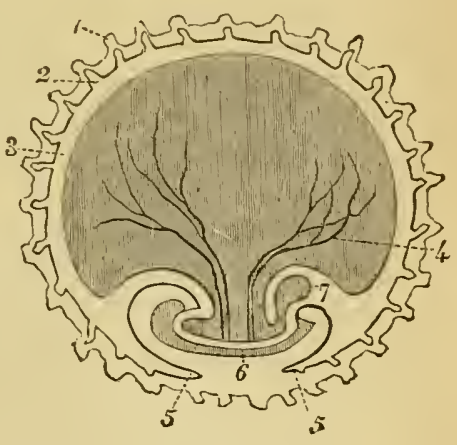

Fig. 674. - (Euf de Mammifèrc. - 1, villosités de la membrane vitelliuc. \&, feuillet externe du blasloderme, constituant le second chorion, avec ses villosités. 3 , vésicule ombilicale. 4, raisseaux de cette résicule. 5 , capuchons céphalique et caudal formés par les replis du feuillet externe du blasloderme. 6 , embron. 7 , vésicule allautoöde. à la membrane ritelline; quant au feuillet interne, il forme l'ammios. Appliqué d'abord sur le dos de l'embryon, il s'en sépare peu à peu : un liquide spécial (eaux de l'amnios) samasse dans cet intervalle, et la cavité de l'amnios se trouve constituée. Cette poche s'étend à mesure que les lames ventrales se rapprochent : en définitive, l'amnios arrive à entourer complètement l'embryon, sauf au niveau de l'ombilic.

L'allantoïde se développe aux dépens de l'entoderme. Elle naît sur la portion de ce feuillet emprisonné par le fœtus, sous l'apparence d'un petit mamelon qui ne tarde pas à se creuser d'une cavité. Cette vésicule se développe rapidement; mais l'étranglement ombilical la 
divise bientôt en deux parties: l'une, comprise dans l'abdomen du fœtus, doit former plus tard la vessie urinaire des Mammifères, tandis qu'elle se détruit chez les Oiseaux et les Reptiles; la seconde, exté-

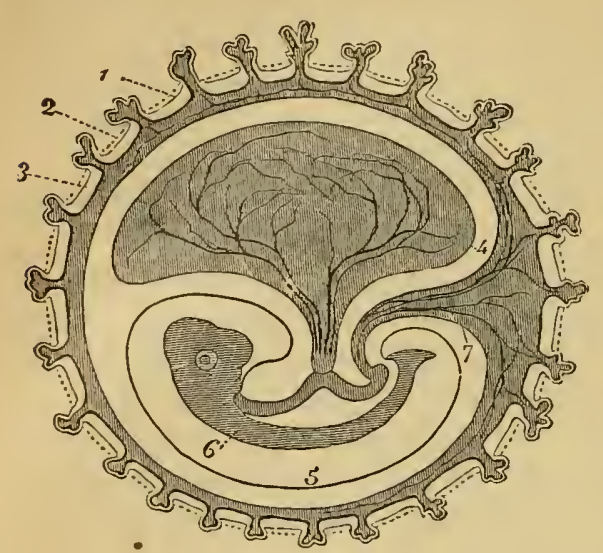

Fig. 675. - OEuf de Mammifère. - 1, membrane vitelline ou premier chorion presque disparu. 2, feuillet externe du blastoderme, second chorion. 3, allantoïde, qui a pénétré dans les villosités. 4, vésicule ombilicale. 5, les capuclıons céphalique et caudal se sont fusionnés : Ia cavité de l'amnios est formée. 6, embryon. 7, allantoïde. rieure au fœtus, très riche en vaisseaux, constitue l'allantoïde proprement dite. Celleci représente une sorte de séreuse tapissant l'ectoderme qui double la membrane vitelline, et se repliant au niveau de l'ombilic pour s'étendre sur toute la face extérieure de l'amnios.

Les vaisseaux de l'allantoïde, chez les Reptiles et les Oiseaux, demeurent étalés dans cette membrane, où ils forment un réseau capillaire. ll en est de même chez les Monotrèmes et les Marsupiaux; mais, dans le reste des Mammifères, la membrane vitelline et son revêtement ectodermique concourent à la formation d un chorion garni de villosités dans lesquelles s'introduisent des houppes vasculaires d'origine allantoïdienne : tel est le point de départ du placen la, qui permet au jeune de puiser dans l'organisme maternel les éléments de sa nuţition. Nous étudierons cet organe d'une façon plus complète en traitant des Mammifères. Quant au placenta des Sélaciens, il est formé par la vésicule ombilicale.

D'après les faits qui viennent d'être exposés, on voit que les Vertébrés se laissent aisément classer en deux grandes sections : $1^{\circ}$ les Vertébrés supérieur's, dont les embryons sont entourés d'un amnios et d'une allantoïde, et qu'on appelle encore, pour cette raison, Amniens ou Allantö̈diens; $2^{\circ}$ les Vertébrés inférieurs, Poissons et Batraciens, dont le développement ne comporte pas ces formations, ce qui les fait dénommer Anamniens ou Anallantoïdiens. Les Poissons et les Batraciens sont encore rapprochés par d'autres caractères, notamment par la possession de branchies permanentes ou transitoires, et par la persistance des reins primitifs : on les réunit parfois sous le nom d'Ichtyopsidés. De même, les Reptiles et les Oiseaux, qui sont privés de mamelles et n'ont qu'un condyle occipital, peuvent être rassemblés dans un même groupe, celui des Sauropsidés. Enfin, les Poissons seuls sont radiés, c'est-à-dire pourvus de nageoires à rayons; tous les autres Vertébrés sont digités. Le tableau suivant résume ces caractères: 
Pas d'allantoïde : ( Des nageoires ì rayons................. Porssoss.

Anallantoüdiens. '́ Des membres digités................... Batraciexs.

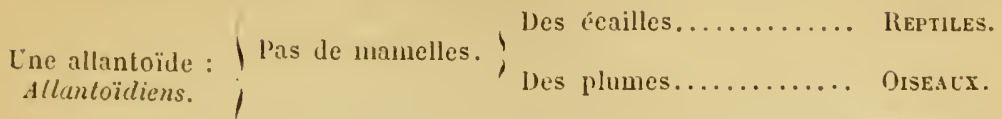

Des mamelles; des poils................. Mammfères.

\section{CLASSE I}

\section{POISSONS}

Vertébrés à sang froid, à peau généralement écailleuse, à nugeoires pourvues de rayons; cour presque toujours simple et veineux; respirution branchiale persistante, rarement branchiale et pulmonaire. Ovipares ou ovovivipares; embryons dépourvus d'ammios et d'allantoïde.

Les animaux de cette classe sont remarquablement adaptés à la yie aquatique. Le corps, de forme variable, est le plus souvent comprimé d'un còté à l'autre de manière á fendre l'eau avec facilité ; la tète se continue directement arec le tronc, et la queue elle-même n'est pas bien limitée.

La peau, loujours revètue d'un épiderme visqueux, renferme en général de nombreuses écailles, produites par les papilles dermiques. Parfois, ces écailles sout très petites et cachées sous la peau (Anguilles); dans certains cas elles font tout à fait défaut (Lamproies). Lorsqu'elles sont bien développées, on leur applique des noms variables suivant leur constitution. Ainsi, on ap-

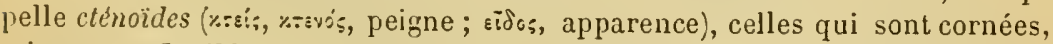
minces et flexibles, à bord libre garni de petites pointes (Perche); cycloïdes (xíxic;, cercle), celles qui, également souples, ont le bord lisse (Carpe) : ces deux sortes sont imbriquées; ganoïdes (rávos, éclat), celles qui représentent des plaques osseuses recouvertes d'émail (Esturgeon); enfin placoïdes ( $\pi \lambda \dot{\alpha} \xi$, plaque), celles qui forment des nodules osseux rendant la peau chagrinée (Squales) ou des plaques surmontées d'épines (Riaies).

Le squelette est cartilagineux ou osseux. Chez les Cyclostomes, la corde dorsale persiste en entier et sa couche squelettogène forme à peine quelques pièces cartilagineuses dorsales ; mais en général le rachis est divisé en vertèbres biconcaves, dont le centre et les interstices sont remplis par les restes de la corde. Le nombre de ces vertèbres est des plus variables. Les côtes manquent ou restent rudimentaires chez les Cyclostomes et les Sélaciens ; elles sont souvent bien développées, au contraire, chez les Poissons osseux, mais demeurent écartées à leur partie inférieure: dans le cas où elles sont réunies, c'est par l'intermédiaire des pièces osseuses dermiques, car le sternum fait toujours défaut. Quant aux organes costiformes, souvent bifurqués, qu'on rencontre entre les muscles (arétes), ils résultent de l'ossification partielle des aponévroses.

A son extrémité antérieure, le canal rachidien se dilate en une boîte cranienne. Chez les Cyclostomes et les Sélaciens, celle-ci est constituée par une simple capsule le plus souvent cartilagineuse, non divisible en pièces distincles. Elle se complique, chez les Ganoides, par l'apparition de pièces osseuses 
et finalement se montre composée, chez les Téléostéens, d'un très graud nombre d'os dans le détail desquels nous ne pouvons entrer ici. Le cràne s'unit au rachis tantòt par une sorte de condyle (Raies), tantòt par une soudure directe avec les premières vertèbres (Thons, Périophtalmes). - La màchoire inférieure est réunie au crâne par un appareil suspenseur, lequel est assez compliqué chez les Poissons osseux : c'est une sorte de cloison verticale formée d'une série de pièces dont linférieure, portant la cavité articulaire, est appelée os carré. En arrière de ce suspenseur, des plaques osseuses, au nombre de quatre, constituent une sorte de couvercle mobile quiprotège les branchies et recoit le nom d'appareil operculaire.

Le squelette viscéral a pour base une série d'arcs parallèles. Le premier est l'hyoüde, composé de deux cornes ou branches latérales très développées, qui s'articulent d'ordinaire avec l'os carré et sont réunies inférieurement par

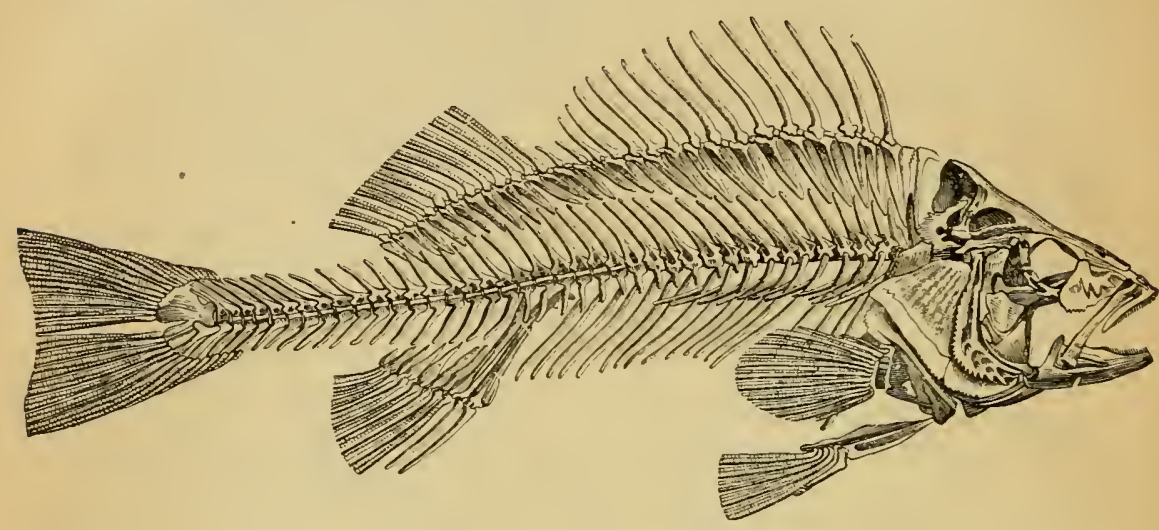

Fig. 676. - Squelette de Perche fluviatile.

un corps ou copule; ces branches portent à leur bord inférieur une série de tiges grêles et recourbées (rayons branchiostèges) supportant une membrane qui sert à compléter le rỏle des opercules. La copule se continue en avant avec l'os de la langue, et en arrière avec les copules des arcs suivants. Ceuxci, désignés sous le nom d'arcs branchiaux, sont en général au nombre de cinq paires, dont les quatre (ou trois) premières seulement portent des branchies; ils se fixent au cràne par l'inlermédiaire de petits os appelés pharyngiens supérieurs. La dernière paire demeure incomplète et représente les os pharyngiens inférieurs.

Les Poissons sont pourvus de nageoires paires et impaires. Celles-ci ont pour base des stylets osseux ou rayons qui s'articulent avec de petits os plats, dits interépineux, reliés d'autre part à l'extrémité des apophyses épineuses supérieures ou inférieures des vertèbres. Les rayons sont constitués, tantòt par de simples stylets durs et pointus: on leur donne alors le nom de rayons épineux (fig. 677); tanlôt par une série d'osselets articulés entre eux et ramifiés à l'extrémité : ce sont les rayons mous (fig. 678). On distingue les nageoires impaires en dorsale, anale el caudale. Les deux premières se divisent quelquefois de manière à former chacune plusieurs nageoires : en outre, il peut exister une petile nageoire dorsale postérieure dépourvue de rayons: on l'appelle nageoire adipeuse. La nageoire caudale est dite homocerque lorsque ses 
deux lobes sunt égaux et symétriques, et hétérocerque dans le cas contraire.

Les nageoires paires, pectorules et ventrales, correspondent aux membres des autres Vertébrés. Les premières sont suspendues à la tète et au tronc par

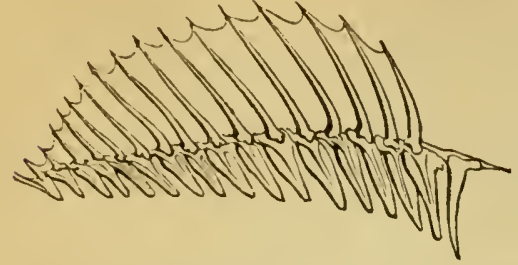

Fig. 677. - Nageoire dorsale d'un Acanthoptérygien (rajons épineus, articulés inférieurement avec les os inlerípineux).

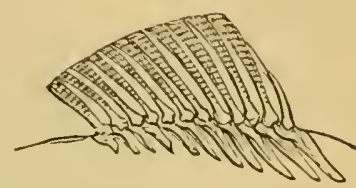

Fig. 67s. - Nageoire dorsale d'un Malacoptérygien (rayons mous, articulés inféricurement avec les os interépiueux.

une ceinture scapulaire incomplète ; elles-mèmes ont pour base un squelette d'une grande complication, terminé par des rayons. Quant aux nagreoires ventrales, qui sont supportées par une sorte de bassin rudimentaire, leur situation est très variable. Tantòt elles sont reportées en arrière sous labdomen, ce qui fait qualifier les Poissons d'abdominaux (fig. 691), tantôt elles s’avancent au-dessous des pectorales (thoraciques), ou mème en avant, sous la gorge (jugulaires ou subbrachiens, fig. 692) ; enfin, elles peuvent disparaitre (upodes, fig. 689), ainsi que les pectorales ellesnî̀mes (fig. 683).

Le système nerveux est fort simple. L'encéphale ne remplit pas la cavité cranienne; il représente en général une double série de tubercules placés à la suite les uns des autres : lobes olfactifs, hémisphères cérébraux, lobes optiques, cervelet et moelle allongée.

Les organes des sens sont également peu développés. Le tact s'exerce au moyen des lères, des barbillons ou même des nageoires. La plupart des Poissons sont d'ailleurs pourvus, de chaque còté du corps, d'un canal qui s'ouvre à l'extérieur par une série de pores constituant.ce qu'on appelle la ligne laterale. Les parois de ces canaux recoivent des terminaisons nerveuses libres on épanouies en boutons tactiles et provenant d'ın nerf latéral assez important. D’après les recherches de P. de Sède, la ligne latérale n'est autre qu'un organe da tact, permettant au Poisson d'apprécier les courants, les remous, les mouvements faibles de l'eau, et de se diriger par suite en connaissance de cause. Elle ne mérite donc pas, à propre-

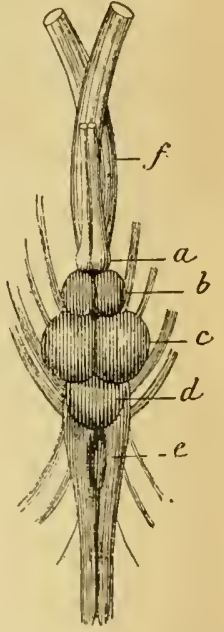

Fig. 679. - Cerveau du Biochet. $-a$, lobes olfactifs. $b$, liémis. phères cérébraux. $c$, lobes optiques. $d$, cervelet. $e$, moelle allongie. ment parler, la qualification que lui ont donnée quelques auteurs, d'organe du sixieme sens. - L'appareil olfactif comprend une ou plus souvent deux fossettes céphaliques terminées d'ordinaire en cul-de-sac. Les yeux sont grands, peu mobiles, presque toujours dépourvus de paupières. La cornée est aplatie, la pupille large, le cristallin volumineux et sphérique. Il existe en outre un repli particulier de la choroïde, analogue au peigne des Oiseaux et des Reptiles, et connu sous le nom de ligument falci- 
forme. - Le sens du goùt paraît peu développé. - L'organe auditif ne présente ni oreille externe, ni oreille moyenne, ni limaçon; il est formé simplement par le vestibule et les trois canaux semi-circulaires, parfois réduits a deux (Lamproie) ou mème à un seul (Myxine).

Nous devons signaler ici les organes électriqucs dont sont munis certains Poissons (Torpilles, Gymnotes, Malaptérures, etc.), qui s'en servent pour paralyser leur proie ou se défendre contre leurs ennemis. Ces organes, dont le siège et l'aspect sont assez variables, se composent, en thèse générale, de nombreux prismes verticaux limités par une membrane conjonctive et serrés les uns contre les autres. Ces prismes sont divisés, par des cloisons horizontales, en alvéoles superposés. Chaque alvéole renferme une couche de substance gélatinense, et la cloison horizontale supporte un riche réseau nerveux ou plaque électrique. On a comparé, en effet, cet appareil à une pile de Volta, dans laquelle la rondelle de drapserait remplacée par la substance gélatineuse, et les rondelles de zinc et de cuivre par la lame électrique. Les décharges de cet appareil ont les plus grandes analogies avec l'acte musculaire.

Contrairement à l'opinion vulgaire, divers Poissons (Harengs, Grondins, etc.) jouissent de la faculté d'émettre des sons : l'apparcil phonateur paraît ètre représenté par la vessie aérienne.

L'appareil digcstif est assezcomplexe. Chez les Cyclostomes, qui sont suceurs, la bouche est circulaire, dépourvue de mâchoires et munie de papilles cornées. Chez les Sélaciens, qui, comme tous les autres Poissons, possèdent des màchoires, elle a l'aspect d'une fente transversale située à la face inférieure de la tète. Partout ailleurs, elle est terminale. Elle est souvent garnie dedents nombreuses, portées par des pièces osseuses très diverses ou par la muqueuse (Sélaciens). Ces dents, coniques ou en crochets, ne servent guère qu'à retenir ou à briser la proie; elles sont presque toujours formées exclusivement de dentine, privées de racines et soudées à l'os qui les porte. Elles se renouvellent pendant toute la vie. La langue est rudimentaire. L'œsopliage est court et se continue avec un estomac peu distinct, séparé de l'inlestin par une valvule pylorique. A l'origine de l'intestin se trourent, chez beaucoup de Poissons, des organes tubuleux (appendices pyloriqucs) sécrétant un suc alcalin. L'intestin grêle décrit souvent des circonvolutions; sa muqueuse forme, sauf chez les Téléostéens, un repli contourné en hélice et appelé valvule spirale. Le rectum est court; il s'ouvre dans un cloaque chez les Sélaciens et les Dipnoïques, mais débouche isolément chez tous les autres Poissons. - Les glandes salivaires font à peu près constamment défaut. Le foie est volumineux, indivis ou lobé, et presque toujours pourvu d'une résicule biliaire. Le pancréas n'est jamais bien développé; il est souvent diffus et peut mème pénétrer dans le foie (Laguesse).

Chez la très grande majorité des Poissons, la circulatzon est simple. Le cœur, situé au-dessous des branchies, se compose d'une oreillette et d'un ventricule placés sur le trajet du sang veineux. Les veines qui ramènent ce sang débouchent dans un sinus communiquant avec l'oreillette. Chez les seuls Dipnoïques, celle-ci est divisée en deux loges par une cloison incomplète, et la circulation s'elfectue alors comme chez les Batraciens. Le ventricule est suivi d'un renflement élastique (bulbe artériel), muni de valvules propres à empècher le retour du sang. De ce bulbe part un tronc médian, nommé 
aorte ascendunte, qui fournit des rameaux latéraux destinés aux branchies

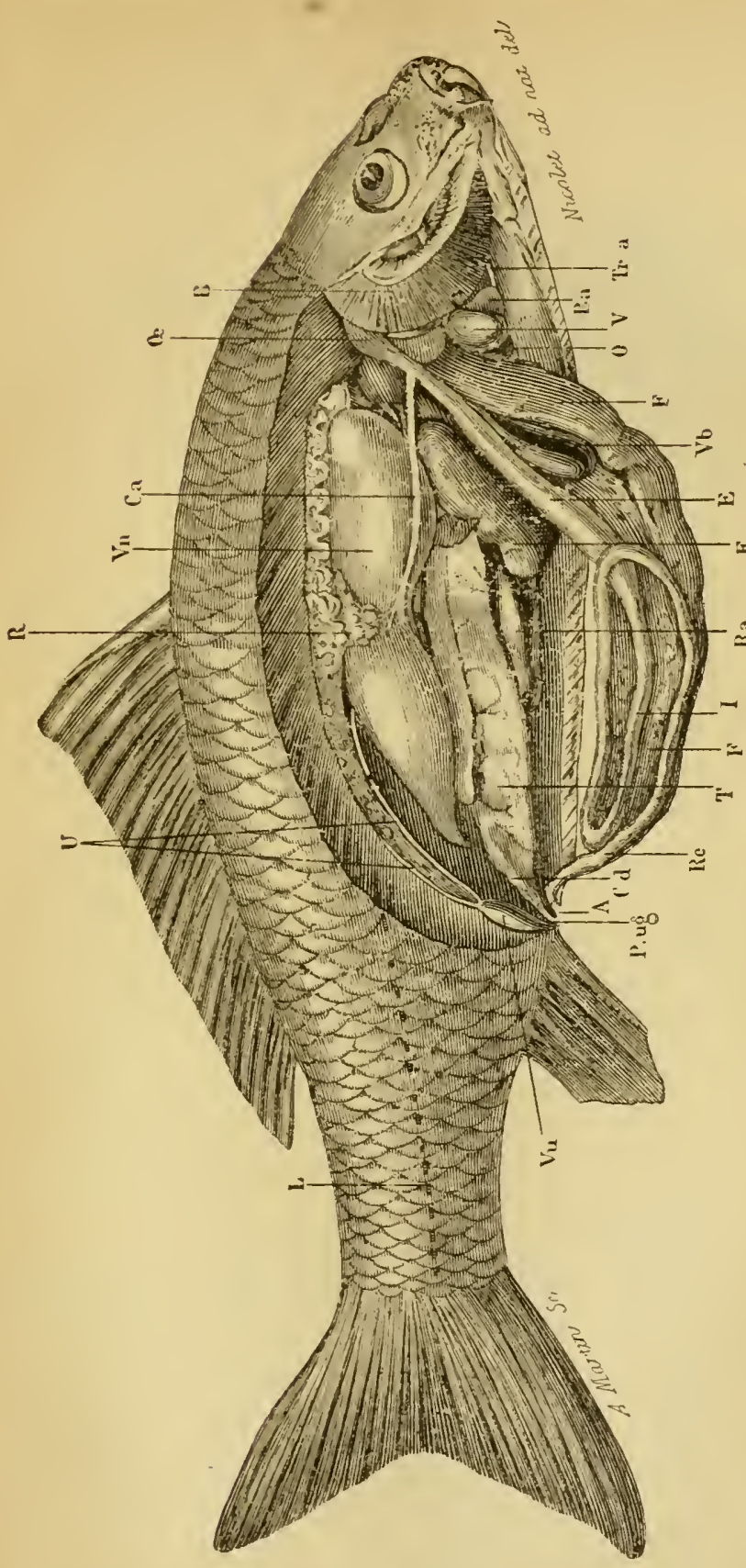

$\approx \Sigma$

官官的

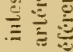

年

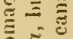

$\frac{3}{y} \equiv$

들

䒠

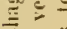

諟二品

Eอ

Si

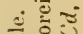

ind

$\exists$

$\cong$

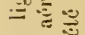

골

$1: \vec{E}$

我䓀

芒

$\because 气$

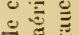

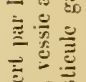

$=3$

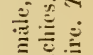

三

三

政

$\because \stackrel{0}{0}$

용

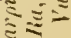

跣

空

$\stackrel{\oplus}{=}=$

苍记

$\leq=$

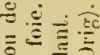

을

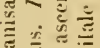

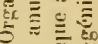

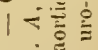

它施记

(artères branchiales). Le sang hématosé dans les branchies est repris par des reines dites artères cpibranchialıs, qui se réunissent pour former l'aorte descen- 
dante ou dorsale, laquelle distribue le sang à la plupart des organes. Les veines offrent la disposition que nous avons signalée pour les embryons des

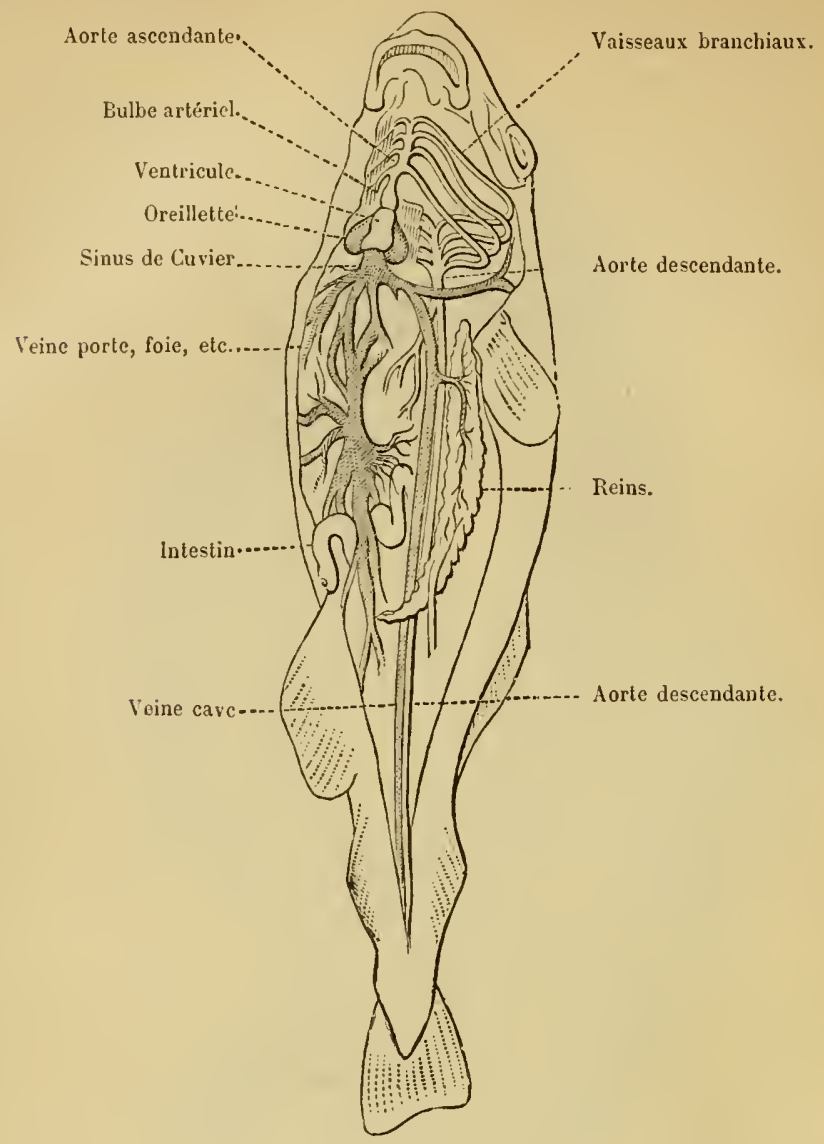

Fig. 681. - Appareil circulatoire d'un Poisson, d'après H. Milne Edwards.

Vertébrés supérieurs (Voy. p. 9ł3). Outre la veine porte hẻpatique, il existe un système porte rénal.

La plupart des Poissons respirent exclusivement à l'aide de branchies, dont la disposition est assez variable. Chez les Téléostéens et les Ganoïdes, les lamelles branchiales sont insérées sur les lèvres d'une gouttière dont est creusé le bord convexe des arcs branchiaux; elles sont presque toujours libres jusqu'à la base. L'eau nécessaire à la respiration pénètre dans la bouche, puis est poussée entre les arcs branchiaux, baigne les branchies et s'échappe par l'orifice sous-operculaire ou des oües. Dans certains cas, les branchies sont très réduites; d'autres fois, elles sont complétees par une branchie accessoire placée à la face interne de l'opercule. - Chez les Sélaciens et les Cyclostomes, le bord extérieur des branchies n'est plus libre, mais adhère à la paroi latérale de la chambre respiratoire (branchies fixes): en pareil cas, l'ouverture des ouïes, au lieu d'ètre simple, devient néces- 
sairement multiple; c'est ainsi qu'on en compte cinq paires chez les Sélaciens et jusqu'à sept paires chez les Lamproies. Dans ces derniers animaux, d'ailleurs, l'eau est amenée de la bouche dans la cavité respiratoire par une sorte de canal trachéen situé au-dessous de l'œsophagre.

Quelques Poissons sont pourvus d'organes accessoires de la respiration. Les uns, nommés Pharyngiens labyrinthiformes par Cuvier, montrent des réservoirs formés allx dépens des os pharyngiens supérieurs, et offrant des saillies spongieuses qui retiennent une certaine quantité d'eau destinée à humecter les branchies. l.es Anabas, qui sont munis d'un semblable appareil, peurent demeurer assez longtemps hors de l'eau. - D'autres Poissons, tels que le Saccobranche et I'Amphipnoüs, possèdent des sacs remplis d'air, qui recoirent du sang des artères branchiales; ces sacs servent évidemment à la respiration.

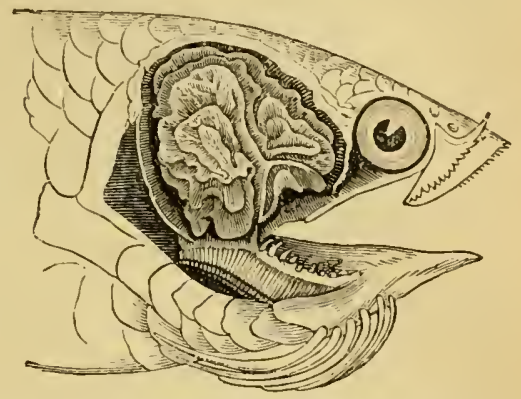

Fig. 682. - Appareil respiratoire de l'Anabas, d'après H. Milne Edwards.

Il existe souvent, dans la cavité viscérale et au-dessous de la colonne vertébrale, une poche remplie d'air, à laquelle on donne le nom de vessie aérienne ou de vessie natatoire. Elle est tantót close (Physoclistes), tantòt pourvue d'un canal aérien qui s'ouvre dans la partie antérieure du tube digestif (Physostomes). On a longtemps regardé cette poche comme un appareil hydrostatique dont les Poissons se serviraient pour faire varier le poids spécifique de leur corps et déplacer leur centre de gravité, de manière à favoriser les mouvements d'ascension on de descente. En réalité, les changements de volume que subit la ressie aérienne sont passifs et tiennent à la pression que supporte lanimal. Cet organe semble plutôt défavorable à la natation. Beaucoup de Poissons bons nageurs en sont d'ailleurs dépourvus. - La vessie aérienne est, dans une certaine mesure, un organe de respiration, et on doit la regarder comme l'homologue du poumon, malgré ses connexions nerveuses et vasculaires.

Chez les Dipnoïques, on trouve, à la place de cet organe, un ou deux sacs pulmonaires véritables.

Les reins sont formés par les corps de Wolff (mésonéphros); ils sont simples ou lobés et occupent d'ordinaire toute la longueur de la cavité viscérale, au-dessus de la ressie aérienne. Les uretères se réunissent en un tronc commun souvent dilaté à son origine en une sorte de vessie urinaire et débouchant en arrière de l’anus, par un orifice très rapproché du pore sexuel. Chez les Sélaciens et les Dipnoïques, les organes génito-urinaires, souvent confondus à leur terminaison, s'ourrent dans un cloaque.

Presque toujour's les sexes sont séparés. Quelques formes seulement sont monoïques, soit normalement (Serrans), soit d'une façon accidentelle (Carpe, Brochet, Hareng, etc.). Les glundes yénitules sont habituellement paires. Elles sont quelquefois (Cyclostomes, Anguilles, femelles de Salmonidés) dépourvues de conduits vecteurs, et les produits sexuels, tombant dans la cavité abulominale, sont évacués par un pore génital situé derrière l'anus. 
Mais d'ordinaire ces conduits existent, et s'ouvrent un peu en avant du canal urinaire ou se confondent avec lui.

Les Poissons sont surtout ovipares; il en est cependant un certain nombre chez lesquels l'éclosion a lieu dans le corps de la mère. Le développement embryonnaire s'accomplit alors dans une dilatation de l'oviducte (uterrus), et parfois même il se forme un placenta rappelant quelque peu celui des Mammifères. La fécondation est presque toujours extérieure : le màle verse son sperme (laitance) sur les œufs qui viennent d'ètre pondus. La reproduction n'a lieu en général qu'une fois par an, principalement au printemps. Dans certains cas, à l'époque du frai, les màles prennent une " parure de noce ", et des changements surviennent dans le genre de vie: réunion en bandes nombreuses, migrations, etc. Les jeunes sont presque toujours abandonnés à eux-mêmes.

Les œufs subissent en général une segmentation partielle. L'embryon ne possède ni amnios, ni vésicule allantoïde. Au moment de la naissance, le jeune porte encore une partie de la vésicule vitelline suspendue à sa face ventrale. Ce n'est que par exception qu'on observe des métamorphoses.

Le plus grand nombre des Poissons sont carnassiers, et certains d'entre eux possèdent de redoutables armes de chasse. Il en est cependant qui sont omnivores ou mème phytophages. Les uns vivent dans les eaux douces; d'autres liabitent la mer; on en connait enfin, qui passent périodiquement d'un milieu dans l'autre.

On trouve des Poissons fossiles depuis le dévonien jusque dans les couches récentes.

Poissons comestibles et Poissons vénéneux. - La chair des Poissons joue un rôle important dans l'alimentation : en France, la consommation individuelle s'élève à $10^{\mathrm{k}}, 200$ par an, dont un quatorzième seulement pour le Poisson d'eau douce. Cependant, cette chair est beaucoup moins nutritive que celle des Mammifères et des Oiseaux, quoique celle du Hareng, par exemple, contienne près de 19 p. 100 de matières azotées; elle ne saurait constituer, sans préjudice pour la santé, un aliment exclusif. Les pêcheurs de nos côtes, qui n’ont guère d'autre nourriture, ne possèdent pas, du moins à l'âğe adulte, les attributs d'une santé solide : ils sont envahis de bonne heure par l'athérome artériel et ne fournissent pas une longue carrière (Kiener). Si leurs femmes sont très fécondes, cela ne tient nullement, comme on l'a prétendu, à cette alimentation et en particulier au phosphore que contient le Poisson, car la proportion de cette substance est au moins d'un quart inférieure à celle que renferme la chair des Mamnifères.

Cuntrairement à ce qui a lieu pour les animaux à sang chaud, ce sont les Poissons carnassiers qui sont les plus délicats, sans doute parce qu'ils se tiennent de préférence dans les eaux vives. D'ailleurs, on estime beaucoup plus les Poissons ì écailles apparentes que ceux dont le tégument est lisse.

Le Poisson se putréfie fort vite, et il n'est réellement salubre que 
lorsqu'il est très frais, ce qu'on reconnait à l'éclat des yeux el à l'état humide et rouge vif des ouies; un simple lavage décèle d'ailleurs la fraude vulgaire qui consiste à teindre de sang frais les ouïes des Poissons arancés. Les empoisonnements proroqués par la chair de Poisson plus ou moins altérée sont attriluables sans doute à certaines ptomaïnes développées sous l'influence de la putréfaction; ils rentrent donc dans le cadre des accidents connus sous le nom de botulisme (voy. p. 79). Ainsi, Brieger a trouvé dans la chair de Morue corrompue la neuridine, l'éthylène dịamine, la muscarine, la triéthylamine et la gadinine.

Mais il est aussi beaucoup de Poissons dont l'usage alimentaire occasionne, quel que soit leur état de fraîcheur, des accidents parfois fort graves, notamment des troubles inteslinaux qui prennent souvent une apparence cholériforme et peuvent même entrainer l'algidité, lataxie nerveuse et la morl. Il y a évidemment alors intervention de produits toxiques développés par lactivité physiologique des tissus, et l'on peut, arec Fonssagrives, réserver à ces intoxications par leucomaïnes le nom espagnol de siguatcra. Elles sont le plus souvent consécutives à lingestion de certaines parties du Poisson, et l'on a incriminé surtout le foie, les œufs ou la laitance, les intestins, etc. Sur les Tétrodons du Japon, Ch. Rémy a démontré expérimentalement que le poison est localisé dans les organes génitaux. Du reste, on sait qu'en Europe même, les œufs du Barbeau et du Brochet déterminent sourent une purgation violente, d'ou l'indication de ne pas consommer ces Poissons pendant la période du frai. Mais on assure, d'autre parl, que certaines espèces, d'ordinaire inoffensives, peuvent devenir dangereuses sous des influences encore mal déterminées: ainsi le Thon, très estimé dans nos régions, a causé des accidents aux Antilles; le Crapaud de mer (Scorpena grandicornis) est fort apprécié à Cuba et redouté au contraire à Haïti. D'une manière générale, les Poissons toxicophores habitent surtout les mers chaudes du globe, et de grandes précautions sont à recommander lorsque, dans les régions tropicales, on se trouve en présence de Poissons mal connus des équipages. Il y a lieu en particulier d'en expérimenter les effets sur de petits animaux, et surtout de se renseigner auprès des indigènes. - On peut craindre d'ailleurs de voir la siguatère se manifester jusque dans nos pays, par suite de l'importation de Poissons exotiques facilitée aujourd'hui par les procédès frigorifiques : en pareil cas, la meilleure sauvegarde de la santé publique consisterait sans doute dans l'institution de commissions scientifiques attachées aux ports d'arrivée. - Contre la siguatère, on recommande surtout l'infusion de café, employée après les romitifs.

Poissons vulnérants et Poissons venimeux. - Beaucoup de Poissons armés d'épines ou d'aiguillons sont susceptibles de produire des bles- 
sures d'une certaine gravité; il en est même qui sont redoutables à cet égard, comme les Pastenagues, dont la queue est munie d'aiguillons barbelés. On pourrait également en citer un grand nombre qui se font craindre par leurs morsures.

Mais les plus intéressants à étudier sont ceux qui joignent à cette action vulnérante l'inoculation d'un renin (1). Chez quelques-uns, l'appareil venimeux est en rapport arec les dents (Murènes); le plus souvent il a pour annexes des aiguillons ou des épines et siège alors dans la région dorsale, ou parfois dans la région opereulaire, rarement dans la région scapulaire. Dans certains eas il est clos (Synancée, Plotose); d'autres fois il est en communication avec l'extérieur (Vires, Scorpènes), et ces deux types extrêmes sont réunis par diverses formes intermédiaires. Les glandes venimeuses peuvent être assimilées, d'une manière générale, à des follicules cutanés; aussi les rencontre-t-on plus souvent ehez les espèces à peau nue (Synancée, Plotose, Murène) que chez celles dont la peau est nettement écailleuse (Vive, Perche). Les Poissons venimeux ne se montrent que dans les régions tempérées et surtout dans les mers chaudes; ils appartiennent toujours à des formes de petite taille, à chair fine et délicate : l'appareil à venin paraît servir spécialement à leur défense.

L'introduction du venin dans les tissus détermine une douleur locale très vive, qui s'étend rapidement aux régions voisines. Souvent même cette douleur est atroce; on a vu des sujets atteints pris d'un véritable délire et s'amputer la partie lésée. Cet état s'accompagne d'une anxiété considérable, de lipothymies, parfois de syncopes qui peuvent entraîner la mort. Le point d'inoculation est bientôt le siège d'un sphacèle d'étendue variable; on peut voir survenir aussi des phlegmons graves, avec lymphangite et engorgement ganglionnaire, le tout se compliquant parfois d'une septicémie généralement mortelle. Au point de vue de son action physiologique, ce venin agit done d'abord loealement, en frappant de mort les tissus qu'il atteint; après son absorption, il provoque la paralysie motrice, puis sensitive; enfin, il semble ralentir les mouvements du cœur, qui s'arrête en diastole.

Chez les Murènes, qui possèdent un appareil venimeux palatin, le sang jouit de propriétés toxiques très accusées; il serait intéressant de savoir s'il en est de même pour les autres Poissons venimeux.

Pisciculture. - Le peu de soin que les Poissons prennent de leur progéniture, la pèche, la multiplication des établissements industriels qui déversent dans les rivières leurs produits insalubres, une foule de circonstances fảcheuses enfin ont amené le dépeuplement de nos cours d'eau. La pisciculture a précisément pour but de parer à ces inconvénients, et pour objet principal d'assurer le repeuplement des eaux au moyen de l'alevin provenant d'éclosions

(1) A. Bottarn, Les Poissons venimeux. Contribution à l'hygiène navale. Thèse de Paris, 1889 . 
artificielles. A cet effet, on conserve, dans des bassins convenables, quelques femelles et quelques màles de l’espèce qu'il s'agit de multiplier. Au monent du frai, on s'empare des femelles el, au moyen d'une pression exercée sur le ventre, on fait tomber les aufs dans des vases remplis d'eau. On arrose ensuite ces oufs arec la laitance des màles, en procédant de la mème manière; puis, une fois la fécondation opérée, on les place dans des appareils incubateurs, dont le plus connu est celui de Coste. Il consiste en une série d'auges superposées en gradins; un robinet laisse couler constamment sur l’auge la plus élevée de l'eau qui se déverse dans les autres et s'échappe ensuite. Après l'éclosion, les jeunes Poissous, qui constituent ce qu'on appelle l'alevin, sont placés dans des bassins particuliers; ils ne prennent à ce moment aucune nourriture et se bornent à consommer le reste des éléments nutritifs contenus dans le sac vitellin (vésicule ombilicale), qui fait saillie sous l'abdomen. Quand cette vésicule a disparu, on les nourrit de Vers, d'Insectes, de pain, etc., et dès qu'ils sont assez forts, on les dissémine dans les eaux qui leur conviement.

Classification. - La classification des Poissons a beaucoup varié depuis Artedi, Limé et Cuvier. Celle qui est généralement adoptée aujourd'hui est due à Jean Müller (184t) : tout au moins les ichtyologistes modernes ne lui ont-ils fait subir que des modifications secondaires.

5 ordres:

Bouche circulaire; un seul orifice nasal................... Crclosto.ies.

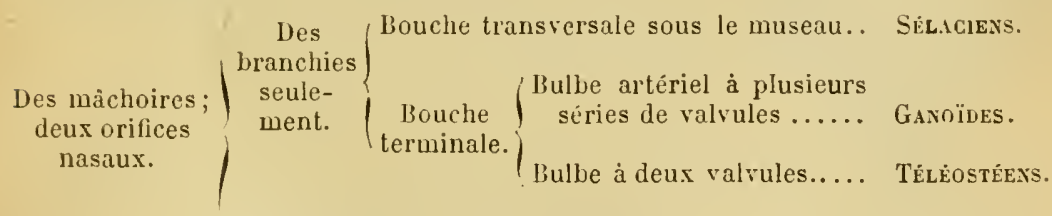

Des branchies et des poumons............ Dipnoïques.

\section{PLEIIIER ORDRE}

\section{CYCLOSTONES}

Poissons vermiformes, à squelette cartilagineux el à corde persistante; dépourvus de nageoires pectorales et ventrales; $\dot{a}$ sac nasal simple et $\dot{a}$ bouche circulaire sans michoires.

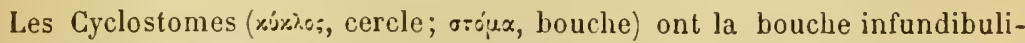
forme et armée, à l'état adulte, de dents cornées. Ils sont donc suceurs. Les

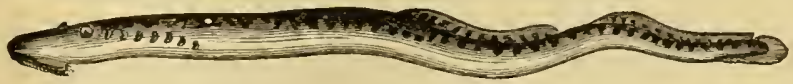

Fig. 683. - Grande Lamproic (Pelromyzon marinus L.).

branchies sont fixées sur les còtés de l'œsophage, dans 6 ou 7 paires de sacs qui débouchent en général au dehors par autant d'orifices. Il n'existe pas de vessie aérienne. Le bulbe artériel ne présente que deux valvules. 
Les principaux représentants de ce groupe sont les Myxines (Myxine), qui vivent en parasites sur d'autres Poissons, el les Lamproies (Petromyzon), animaux à métamorphoses, les larves ayant une bouche inerme et des yeux sous-culanés. La Lamproie marine ( $P$. marinus) remonte dans les fleuves au moment du frai; sa chair est assez estimée. La Lamproie fluviatile ( $P$. fluviatilis) et la Lamproie Sucet (P. Planeri) sont d'eau douce; la larve de cette dernière a été longtemps décrite comme une espèce particulière (A mmocotes branchialis).

\section{DEUXIĖ.IE ORDRE}

\section{SÉLACIENS}

Poissons cartilagineux, à bouche ordinairement transversale, située à la face inférieure du museau; branchies ficées dans des sacs distincls.

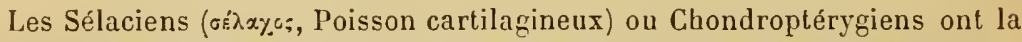
peau généralement pourvue d'écailles placoïdes. La queue est hétérocerque. Le cràne n'offre pas de divisions. Les nerfs optiques forment un chiasma. L'intestin', garni d'une valvule spirale, débouche dans un cloaque. Deux ouvertures ou évents mettent d'ordinaire l'arı ière-bouche en communication avec l'extérieur. Le bulbe artériel est muni de plusieurs rangs de valvules. Les màles possèdent des organes copulateurs; par suite, il y a toujours accouplement et fécondation interne. Un fait remarquable, déjà connu d'Aristote, c'est qu'il existe parfois une sorte de placenta fourni par la vésicule ombilicale. Ce sont surtout des Poissons marins.

2 sous-ordres :

$1^{\text {er }}$ sous-ordre : Chimériens. - Encore appelés Holocéphales ("07.0\%, en-

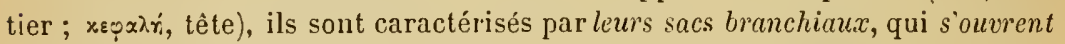
de chaque cóté par une fente.commune, recouverte par un repli cutané operculaire. Peau nue. Pas d'évents.

L'espèce la plus intéressante est la Chimère arctique (Chimæra monstrosa), vulgairement Chat de mer. Les Norvégiens retirent de son foie une huile qui est utilisée pour le pansement des plaies; sa chair est peu estimée.

$2^{\mathrm{e}}$ sous-ordre : Plagiostomes. - Ce sont les Sélaciens proprement dits. Leurs sacs branchiaux adhèrent extèrieurement à la peau et s'ouvrent au dehors, chacun par un orifice distinct. La peau est quelquefois nue. Les évents existent presque toujours. - Deux sections principales.

I. Seuales. - Ils ont le corps fusiforme et les orifices branchiaux situés sur les còtés.

Parmi les nombreux représentants de ce groupe, nous citerons : les Perlons (Heptanchus), les Grisets (Hexanchus), les Requins vrais (Carcharias) les Marteaux (Zygæna), les Émissoles (Mustelus), les Milandres (Galeus), les Pèlerins (Selache), les Roussettes (Scyllium), toutes formes pourvues d'une nageoire anale; les Anges (Squatina), les Aiguillats (Acanthias), les Sagres (Spinax) qui en sont dépourvus.

La chair de ces Poissons est en général coriace, parfois musquée ; cependant on la consomme souvent, fraiche ou conservée. Celle des Perlons et des 
Grisets a des propriétés purgatives. On a signalé des accidents : coliques, torpeur, desquamation de l'épiderme, après ingestion le foie de Roussette et de Milandre. En Chine, on apprécie beaucoup un potage aux ailerons de liequins, c'est-à-dire préparé avec les nageoires desséchées de diverses espèces de Squales.

Eufin, on retire du foie de plusieurs de ces Sélaciens: Roussettes, Aiguillat, Ĺmissole, Ange de mer, etc., une huile employée quelquefois en médecine. Cetle huile de foie de Squale s'obtient par l'ébullition dans l'eau; elle a une teinte am-

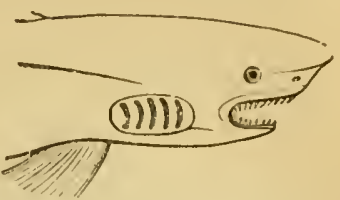

Fig. 684. - Extrémité antérieure d'un hequin (Carcharius lamin Risso). brée et laisse précipiler, par le repos, d'abondants grumeaux de stéarine. C'est un succédané de l'huile de foie de Morue; elle est mème plus riche en iode et en phosphore, mais contient un peu moins de brome et le soufre.

II. Raıides. - Corps déprimé, discoïde, terminé en général par une queue lougue et mince; fentes branchiales situées sur la face ventrale. Pas d'évents. Ovipares (Raies) ou vivipares.

Aux Rajides se rattachent : les Pastenagues (Tryyon), à queue longue, sans nageoires, armée de chaque còté d'un lonǵ dard barbelé; les Aigles de mer (Myliobates) et les Diables de mer ou Raies cornues (Cephaloptera), à queue longue et flexible, portant à sa base une nageoire dorsale et derrière celle-ci un aiguillon triangulaire barbelé ; les Raies (Raja), qui possèdent dans la quene un appireil électrique rudimentaire; les Torpilles (Torpedo), pourvues d'un appareil analogue, mais très développé, de chaque còté de la tète, etc.

La chair des Raies est assez estimée; elle est cependant peu digeste. - La peau fournit une sorte de gélatine employée pour la clarification de la bière. - En outre, on retire du foie de ces Poissons une huile qui peut, jusqu'à un certain point, remplacer l'huile de foie de Morue. Les principales

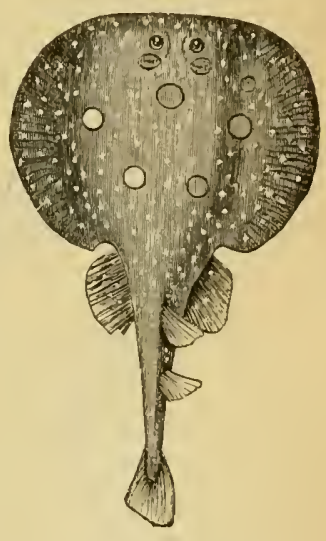

Fig. 685. - Torpille vulgaire (Torpedo narke seu oculata). espèces qui la fournissent sout la Raie bouclée, la Raie cendrée, la Pastenague commune et l'Aigle de mer. On l'extrait sur les còtes de Normandie, surtout par le procédé de l'ébullition. L'huile de foie de Raie est d'une teinte jaune clair, parfois orangée ou un peu rougeàtre, à odeur de Poisson, à sareur assez douce. Elle contient moins d'iode et de soufre que l'huile de foie de Iorue, mais plus de phosphore.

Les Pastenagues (Trygon pastinaca, $T r$. violacea) se rencontrent sur nos côtes, et la piquùre de leurs dards dentés est réputée des plus dangereuses. Aristote signalait déjà ces Poissons comme redoutables, et Pline considérail que rien n'est terrible comme leur aiguillon, car " ì la force du fer, il joint l'action du poison. "Bien que ces vues se soienı perpétuées chez les pècheurs, on n’a pas encore établi, jusqu’à 
présent, la présence d'un appareil à venin chez les Pastenagues. Ces observations s'appliquent d'ailleurs à l'Aigle de mer (Myliobates aquila) et au Diable de mer (Cephaloptera giorna).

\section{TROISIÈME ORDRE}

\section{GANOÏDE:S}

Poissons cartilagineux ou osseux, à branchies libres recouvertes par un opercule; bulbe artériel à plusieurs rangs de valvules.

La peau de ces Poissons, rarement nue, présente quelquefois des écussons osseux; mais, le plus souvent, elle est recouverte d'écailles osseuses émaillées ou ganoïdes ( $\gamma^{x}$ vos, éclat). Le squelette est cartilagineux (Esturgeons) ou osseux (Lépidostées). La queue est d'ordinaire hétérocerque. Le cràne montre des divisions distinctes. Les nerfs optiques forment un chiasma. L'intestin est pourvu d'une valvule spirale. Il existe en général des évents. On observe toujours une vessie natatoire munie d'un canal aérien. - Beaucoup de formes fossiles.

Principal genre : Esturgeon (Acipenser). Les Esturgeons vivent dans la mer, mais au printemps remontent les fleuves et leurs affluents. On les pèche

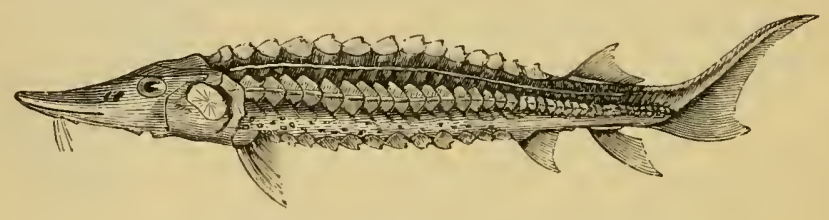

Fig. 686. - Esturgeon commun (Acipenser sturio L.).

surtout dans le Danube, le Dniester, le Volga et l'Oural. L'Esturgeon commun (A. sturio) se rencontre aussi dans le Rhòne, la Garonne, la Loire et le Rhin, rarement dans la Seine. La chair des Esturgeons est très délicate, mais peu digeste. On mange leur corde dorsale en Russie et en Vénétie. Leurs œufs constituent la base du caviar, aliment très usité en Russie, où il est consommé par toutes les classes. - Leur vessie aérienne préparée fournit une substance gélatineuse appelée ichtyocolle ou colle de poisson. La préparation consiste à la nettoyer, à la façonner et à la faire sécher à l'ombre. On trouve dans le commerce quatre sortes principales d'ichtyocolle brute : $1^{\circ} \mathrm{en} \mathrm{lyre,}$ c'est-à-dire en cylindres courbés, l'extrémité étant infléchie en dehors; $2^{\circ} \mathrm{en}$ cceur, extrémité infléchie en dedans; $3^{\circ}$ en livre, lames minces pliées en carré et réunies par un bàton qui les traverse; $4^{\circ}$ en feuilles, lames séparées. L'ichtyocolle offre la consistance du parchemin; elle est blanchàtre, demitransparente, inodore et insipide. L'eau bouillante la dissout : pour l'employer, on la découpe en petits fragments, souvent après l'avoir martelée, et on la fait bouillir quelques instants. Elle sert ainsi à clarifier le vin, la bière et beaucoup d'autres liquides. C'est également avec cette substance qu'on prépare le taffetas d'Angleterre, etc. 


\section{QUATRIEME ORDRE}

\section{TELÉOSTÉEYS}

Poissons osseux, a branchies libres recouvertes par un opercule; bulbe artériel muni d'une seule paire de valvules.

La peau est l'ordinaire recouverte d'écailles cycloïdes ou cténoïdes inbriquées. La queue est en général homocerque. Le squelette est toujours

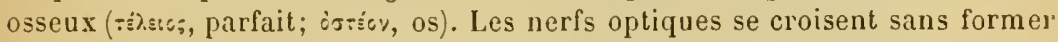
de chiasma. L'intestin est dépourvu de valvule spirale. Il n'existe pas d'évents. Presque toujours on observe une vessie aérienne.

C'est le groupe qui renferme le plus grand nombre de Poissons.

4 sous-ordres :

Corps cuirassé
Osteodermes. $\quad\left\{\begin{array}{l}\text { Branchies en houppes............ Lophobranches. } \\ \text { Branchies pectinées.......... Plectogaties. }\end{array}\right.$

Peau icailleuse, ¡Rayons mous................ Malacoptérigiens.

branchies pectinées:
Squamodermes. Rajons épineux............... Acanthoptérigiens.

PREMIER SOCS-ORDRE

\section{O P I O B R A N C II E S}

Les petits Poissons qui torment ce groupe sonl caractérisés par leurs bran-

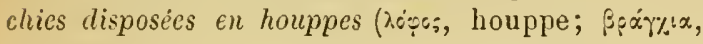
branchies), au lieu d'ètre pectinées comme chez les autres Téléostéens. La peau est ossifiée et forme une sorte de carapace. La ressie natatoire, quand elle existe, est dépourvue de canal aérien. Enfin, les màles portent les œufs depuis la ponte jusqu'a l'éclosion.

Espèces principales : Pégase volant (Peyasus volans), Aiguille de mer (Syngnathus acus), Hippocampe des anciens ou Cheval marin (Hippocampus antiquorum Leach, H. Grevirostris Cuv.).

\section{DEUXIËHE SOLS-ORDRE}

\section{PLECTOGNATIES}

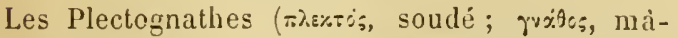
choire) tirent leur caractère principal de la disposition de la mâchoire supérieure, qui est soucléc au crâne et par conséquent immobile. Ils ont le corps globuleux ou fortement comprimé d'un còté à l'autre, et revètu d'une cuirasse dermique épaisse, sourent épineuse.

Nous devons citer en particulier les Cotlires

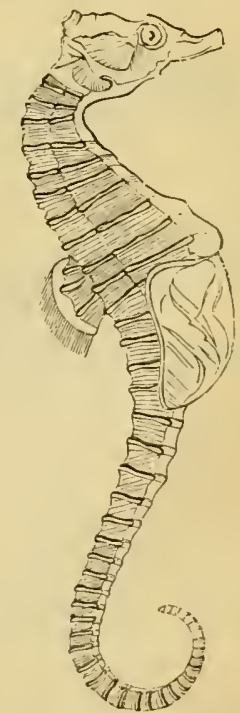

Fig. 687. - llippocampe (Hippocampus brevirostris Cur.) màle avec sa poche ovifère. (Ostracion), les Vieilles (Balistes, Monacanthus), les Mòles ou Poissons-Lunes 
(Orthagoriscus) et les Poissons globuleux (Diodon, Triodon et Tetrodon), dont la plupart des espèces, sinon toutes, sont vénéneuses et habitent les mers chaudes.

De nombreux cas de siguatère dus à la consommation de ces Poissons ont été relevés au Japon (Kaempfer, Godet, Rémy), au Brésil

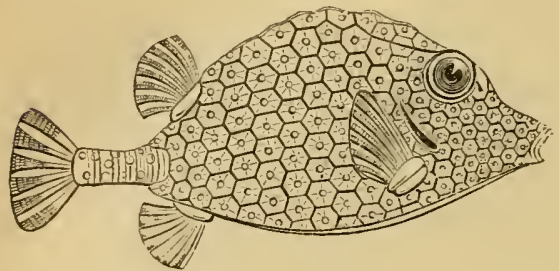

Fig. 688. - Coffre triangulaire (Ostracion triqueter).

(Pison), en Nouvelle-Calédonie (V. de Rochas), aux Antilles, au cap de Bonne-Espérance, etc. Sur les côtes japonaises, en particulier, les Poissons toxiques sont bien connus, et on leur donne le nom de fougous; leur vente est interdite par les lois. Les intoxications se produisent surtout au printemps, c'est-à-dire au moment du frai. Heckel a même constaté que le contact prolongé de la chair des Tétrodons peut entraîner l'apparition d'accidenis généraux.

TROISIÈME SOUS-ORURE

\section{A L A C OPTÉRYGIENS}

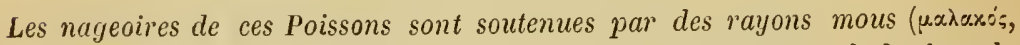
mou; $\pi \tau \varepsilon p u ́ v i c v$, nageoire); parfois cependant les premiers rayons de la dorsale

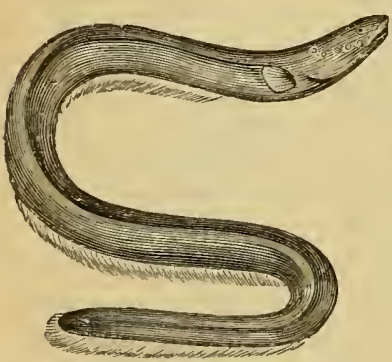

Fig. 689. - Gymnote électrique (Gymnotus electricus L.). et de l'anale sont épineux. La peau est nue ou plus souvent revêtue d'écailles cycloïdes ou cténoïdes. Les branchies sont pectinées.

2 sections.

I. Physostomes. - Vessie natatoire pourrue d'un canal aérien. Ce groupe correspond à peu près aux Malacoptérygiens apodes et abdominaux de Cuvier.

A. Physostomes apodes. - Pas de nageoires ventrales.

Comprennent les Anguilles (Anguilla), Poissons huileux, à chair indigeste, dont l'histoire est encore peu connue (fraient dans la mer); les Congres ou Anguilles de mer (Conger); les Murènes (Muræna); les Gymnotes (Gymnotus), des rivières de l'Amérique équatoriale, qui possèdent un puissant appareil électrique situé le long du dos et de la queue, età l'aide duquel ils peuvent oudroyer mène de gros animaux.

Divers auteurs ont signalé des cas d'empoisonnement par la chair de l'Anguille, du Congre et de la Murène.

D'un autre côté, les recherches de Bottard ont démontré que les Nurènes sont pourvues d'un appareii venimeux en rapport avec les 
dents. Chez la Murène Hélène (1\% helena), de la Méditerranée, le réservoir ì venin siège au palais et renferme environ 1 demi-centimètre cube de liquide chez les sujets d'un mètre de long. A celte poche sont amnexées trois ou quatre fortes dents coniques, légèrement incurvées, ì convexité antérieure, susceptibles de basculer en arrière, mais ne pouvant ètre ramenées en avant au delì de la verticale. Ces dents ne sont pas creusées d'un canal central : le venin s'écoule entre elles et la muqueuse qui leur forme une sorte de gaine.

Nicandre et Aetius affirmaient déjà que la morsure des Murènes est renimeuse: les auteurs de la Renaissance ont appuyé cette manière de voir, et les pèclieurs sont unanimes ì reconnaitre que la capture de ces Poissons réclame les plus grandes précautions. $\Lambda$ Marseille mème, on a ru de graves accidents résulter d'une morsure de Mfurène.

Un fait important, ì rapprocher des données précédentes, a été mis en lumière par Mosso : c'est que le sérum sanguin des Anguilles, des Congres et des Murènes jouit lui-mème de propriétés irritantes et toxiques. Ces propriétés sont dues à une substance particulière a laquelle on a donné le nom d'ichtyotoxine, substance qui, injectée dans les vaisseaux ou dans les tissus des Vertébrés à sang chaud, amène la mort à très faible dose. Introduite dans l'estomac, elle est inoffensive; mais ses effets se produisent si on l'injecte directement dans l'intestin grèle. Ce poison agit sur la moelle. Au total, il offre de nombreuses analogies avec le renin des Serpents.

B. Physostomes abulominaux. - Nageoires ventrales situées sous l'abdomen, en arrière des pectorales.

La famille des GLUPÉIDÉS a pour type les Itarengs (Clupea). Le Ilareng commun ( $\mathrm{Cl}$. harengus) vit en bancs immenses dans les mers du nord et du nord-ouest de l'Europe; il n'effectue pas de lointaines migrations comme on l'a cru, mais passe seulement de la profondeur à la surface de la mer, de sorte qu'il apparait sur les còtes au moment du frai. Comme il se conserve difficilement, on le sale, et souvent même on le fume en l'exposant à la fumée de hètre, ce qui donne le Hareng saur. J. Belin a fait connaitre en 1886 un cas d'intoxication par les œufs de cette espèce, et longtemps auparavant Chevallier et Duchesne avaient publié des faits d'empoisonnement par le Hareng corrompu : dans ce dernier cas, les accidents étaient dus sans doute à des ptomaïnes (éthylène-diamine et cadavérine). - Quelques espèces voisines ont été signalées comme provoquant la sigualère : la Sardine des tropiques ( $\mathrm{Cl}$. tropica), la Vélette vénéneuse (Meletta venenosa), de l'océan Indien ; le Cailleu tassart (Mel. thrissa), des mers de la Chine et des Antilles, etc. L'Esprot (Mel. sprattus), qui vit sur nos còtes, aurait occasionné du botulisne.

L'Anchois commun (Engraulis encrasicholus) se pêche sur toutes nos côtes; sa chair est peu délicate à l'état frais; on la fait mariner dans l'huile. Les Romains s'en servaient pour préparer un condiment liquide appelé garum. - On a relevé divers cas de siguatère dus à cette espèce; mais de tels faits 
sont produits couramment au Japon par Engr. juponica et dans la mer des Indes par Engr . bollama.

Les Aloses (Alosa) sont représentées chez nous par plusieurs espèces. L'Alose commune (A. vulgaris) remonte, au printemps, de la mer dans les cours d'eau, où elle va frayer. Chair estimée. La Finte (A. finta) a le même mode de vie. La Sardine (A. sardina) se pèche sur toutes les còtes de France, d'Angleterre, d'Espa@ne, d'Italie, etc. Elle vit à peu près comme le Hareng, et apparait en bancs vers la fin de l'été. Les. Sardines sont salées, ou marinées dans l'huile ou la saumure, mais on ne les fume pas.

On observe très fréquenıment, chez les pêcheurs, des cas de panaris, au point que Fonssagrives appelle cette affection " le fléau des grandes pêches. " Du Bois Saint-Sévrin en a releré, chez des soudeurs de boîtes de Sardines, une petite épidémie qu'il a cru pouroir attribuer à l'inoculation de deux microbes, l'un colorant les Sardines en rouge, l'autre paraissant représenter une race décolorée du précédent. Il est possible que le panaris des pêcheurs soit provoqué par les nombreux microbes de la putréfaction des Poissons.

D'un autre côté, Loir a vu, à Tunis, deux cas d'intoxication par des Sardines rouges; il attribue ces accidents au microbe chromogène, bien qu'il n'ait obtenu, par l'inoculation des cultures, que des résultats négatifs (1).

A la famille des ÉSOCIDÉs appartient le Brochet (Esox lucius), Poisson vorace à chair excellente. C'est l'un des hòtes intermédiaires du Bothriocé-

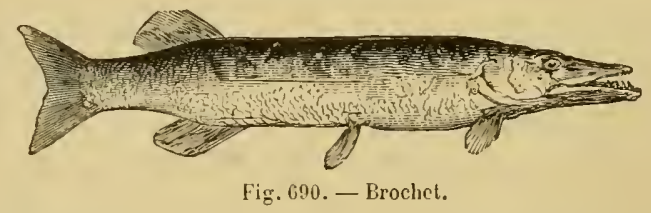

phale large (voy. p. 320). Sa laitance et ses œufs déterminent assez sourent des intoxications.

Les SALMONIDÉS sont reconnaissables à leurs écailles peu développées et à une petite nageoire adipeuse située en arrière de la dorsale. De nombreuses espèces hébergent aussi les larves du Bothriocéphale. - Saumons (Salmo) : Saumon commun (S. salar), remonte les fleuves pour aller frayer sur les fonds de gravier; chair colorée en rouge par la zoonérythrine, estimée, quoique un peu indigeste. Ombre-Chevalier (S. salvelinus), remonte rarement les fleuves. - Truites (Trutta) : Truite de rivière (Tr. fario) et Truite des lacs (Tr. lacustris), à chair tantòt pàle, tantôt saumonée. Truite de mer $(T r \cdot$ marina $)$ ou Truite saumonée, n'est pas un hybride; remonte les fleuves.

(1) Du Bols Sarvt-Sévrin, Panaris des pécheur's et microbe rouge de ta Sardine. AnnaIes de l'Institut Pasteur, VIII, p. 152, J894. - A. Lolr, Note sur plusieurs cas d'empoisonnement produits par des Sardines rouges. Comptes rendus de la Soc. de biol., (10), I, p. 141, 1894 . 
- Éperlan (Osmerus eperlamus), chair parfumée, digeste. - Ombre des rivières (Thymullus vulgaris). - Corégones (Coreyonus) : Féra (C. fera), du lac de Genère. Lavaret (C. luxaretus), du lac du Bourget, etc.

Les CYPRINIDÉs sont des Poissons d'eau douce très répandus dans nos rivières. - Carpe (Cyprinus carpio), chair un peu fade, laitance savoureuse; ses écailles servent à fabriquer la colle de poisson vitreuse; sur les rives du llon, les juifs font usage d'un caviar préparé avec ses cufs. - Carassin (Curassius rulgaris). libèle (C. gibelio). Poisson rouge ou Cyprin doré de la Chine (C. auratus). - Tanche (Tince vulgaris), peu digeste. Barbeau (Barlus fluriatilis), Barbillon des Parisiens (roir p. 138); dangereux au moment du frai, car ses œufs sont vénéneux.

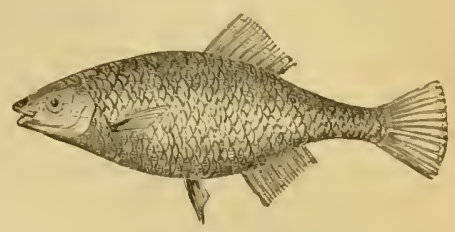

Fig. 691. - bouvière amère (Thodeus amarus L..).

- Goujon (Gobio fluviatilis), de digestion facile. - Bouvière (lihodeus amarus), chair amère. - Brème (Abrumis bruma), chair blanche, assez bonne, arec beaucoup d’arêtes. - Ablette (Alturnus lucidus), clítir molle et fade. - Gardon (Leuciscus rutilus), nageoires rouges, chair assez bonne, remplie d'arètes, comme celle de la Cheraine (L. cephalus) et de la Vandoise (L. vulgaris). - Vairon (Phoxinus lavis), chair amère. - Hotu (Chondrostomum nasus), chair très médiocre, remplie d'arêtes.

Dans les ACANTHOPSIDÉS se placent les Loches: Loche franche (Cobitis barbatula), dont la chair est très estimée, et Locle d'étang ( $C$. fossilis), molle, avec goùt de vase.

Enfin, nous signalerons dans les SILURIDÉs le Malaptérure électrique, du Nil (Malapterurus electricus); puis les Plotoses (Plotosus), de l'océan Indien, qui sont venimeux, ainsi que les Pimelodus et les Doras, de l'Amérique du Sud.

II Axacanthiexs. - Vessie natatoire sans canal aérien, parfois absente. Les nagreoires rentrales sont ordinairement jugulaires, et ce groupe répond presque aux Malucoptérygiens subbrachiens de Cuvier.

Les GADIDÉS comprennent en première ligne les Morues (Gadus). Morue commune (G. morrhua L.); les jeunes individus ont été longtemps décrits comme une espèce particuliẻre, sous le nom de Dorsch (G. callarias). Églefin (G. æglefinus). Capelan (G. minutus). - Merlan (Merlangus vulgaris), s'altère Irès vite. Colin (H. carbonarius), chair ferme, peu estimée. - Merluche (Merluecius vulgaris), chair blanche, assez bonne. - Lingue (Molva vulgaris). de digestion facile. - Lotte (Lota vulgaris), Poisson d'eau douce, un des hòtes intermédiaires du Bothriocéphale large; foie estimé; œufs souvent toxiques.

La Morue franche (G. morrhua) est l'espèce la plus importante de la classe des Poissons au point de vue de l'alimentation et des usages médicinaux. Elle peut atteindre jusqu'à $1^{\mathrm{m}}, \ddot{0} 0$ de long, et présente une teinte olivàtre en dessus, avec des taches brunes ou jaunes; le dessous est de couleur claire; comme les autres espèces du genre, elle possède trois nageoires dorsales et deux anales. 
Elle aboude dans l'Océan glacial arctique, mais se montre aussi en petit nombre sur le littoral breton, plus rarement dans Ie golfe de Gascogne et sur les cótes du Portugal. Pas plus que le Hareng et la Sardine, elle n'effectue de lointaines migrations : elle passe seulement, lors du frai, des profondeurs de la mer à la surface. C'est ainsi qu'on la voit, vers la fin du printemps, apparaître en bancs immenses le Iong des côtes du Labrador, du Groenland, de la Norvège, de l'Islande, ainsi que sur quelques plateaux sous-marins, tels que le Doggerbank de la mer du Nord et surtout le grand banc de Terre-Neuve.

La pêche de la Morue, extrèmement pénible et dangereuse, est d'une importance considérable. Cinq à six mille navires s'y livrent annuellement, et fournissent en moyenne à la consommation 36 millions d'individus. En 1882, les seuls pêcheurs français ont pris en Islande plus de 12 millions et à TerreNeuve près de 18 millions de kilogrammes de Morue. Dans ce chiffre ne sont

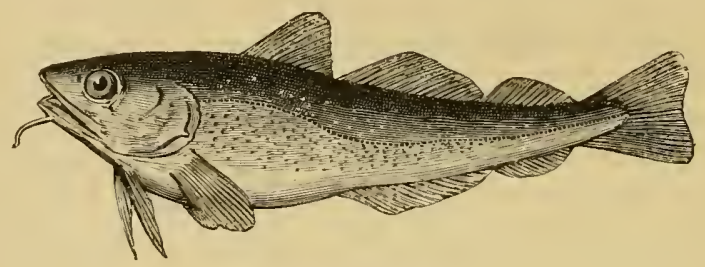

Fig. 692. - Morue franche.

pas compris, d'ailleurs, les produits de la petite pèche littorale, qui nous fournissent la "Morue fraîche ", vulgairement Cabillaud ou Cabeliau.

On conserve la Morue d'après des procédés divers, mais toujours fort simples. La tète est enlevée, le corps ouvert, les entrailles sont rejetées, le foie et les œufs mis à part. Le Poisson est alors parfois simplement conservé dans le sel : c'est ce qui constitue la Morue verte du commerce. D'autres fois, on le fait sécher à l'air, par des vents très secs et une température basse, et on obtient ainsi le stochfish. Enfin, la salaison suivie d'une dessiccation après lavage donne le klipfish. Les cufs servent à préparer un appàt (rogue) pour la pêche de la Sardine.

On sait, en outre, que le foie volumineux de la Morue fournit une huile qui est devenue l'une des plus précieuses ressources de la thérapeutique (1).

Les procédés d'extraction de l'huile de foie de Mor'ue varient quelque peu suivant les localités. A Terre-Neuve, à Bergen et en Islande, les foies sont immédiatement lavés à l'eau de mer et entassés dans des tonneaux ou des caisses le plus souvent à double paroi; puis ils sont chauffés à $60^{\circ}$ environ, soit au bain-marie, soit par injection de vapeur entre les deux parois, soit simplement par affusion d'eau très chaude. On voit alors surnager une huile teintée de jaune ou de jaune verdâtre, qu'on enlève et qu'on filtre sur flanelle : c'est ce qui

(1) A. Gautier et L. Mourgues, Sur les alcaloüdes de l'huile de foie de morue. Bullet. de l'Acad. de méd., (3), XXıII, p. 172, 1890. 
constitue l'huile pale, blanche, ou vert doré. Mais si l'on attend un peu avant de traiter les foies, ceux-ci subissent un commencement d'auto-digestion (et non de putréfaction) qui les acidifie très légèrement et liquéfie en partie l'enveloppe des cellules hépatiques : ces cellules laissent ainsi écouler au dehors l'huile et les autres matériaux biliaires qui s'y dissolvent, de sorte que le produit prend successivement une coloration blonde, madère et fauve. C'est seulement au bout de plusieurs jours ou même de plusieurs semaines que les foies se putréfient. $\Lambda$ ce moment, on a déjà enlevé, par un chauflage modéré, l'huile blonde dontil vient d'être question; mais on peut encore, par décoction avec de l'eau, extraire de ces foies altérés une dernière quantité d'une huile brune ou noire, épaisse, d'odeur félide, qui depuis longtemps ne sert plus guère qu'à des usages industriels. — En résumé, l'huile blanche extraile des foies frais ne contient pas ou presque pas de principes actifs; les huiles blondes et les noires seules en renferment, mais ces dernières ont des propriétés organoleptiques trop désagréables pour être employées à l’intérieur : ce sont donc les huiles blondes ou faures qu'il convient d'utiliser en thérapeutique.

L'huile de foie de Morue blonde a une densité qui varie de 0,928 à 0,932 ; elle ne se congèle pas à $-1 \mathrm{I}^{\circ}(1)$; enfin, si on en étend quelques gouttes sur une lame de verre et qu'on y dépose ensuite une goutte d'acide sulfurique, on voit se produire une auréole violette qui passe ensuite au cramoisi. Ces caractères permettent de la distinguer des huiles végétales ou autres qu'on a parfois tenté de lui substituer.

Sa composition, assez complexe, a surtout été bien déterminée par les recherches de Gautier et Mourgues. Elle comprend, en dehors des corps gras, six alcaloïdes ou leucomaïnes : butylamine, amylamine, hexylamine, dihydrolutidine, aselline, morrhuine. Ces bases sont combinées en partie sous forme de lécithines, en partie à les acides : l'acide morhuique (qui se comporte aussi comme un alcali faible en présence des acides minéraux), des acides gras volatils (formique et butyrique), et de l'acide sulfurique. Il existe en outre du phosphore, sous forme de phosphates, de phosphoglycérates (provenant des lécithines) et de phosphore non unissable aux alcalis; plus un peu de brome et d’iode. Enfin, on trouve des traces de matières colorantes. La matière qui donne lieu à la coloration violette, par le mélange avec l'acide sulfurique concentré, semble être un acide biliaire.

L'action thérapeutique de l'huile de foie de Morue paraît devoir être attribuée à trois groupes d’agents : $1^{0}$ aux corps gras, qui sont très assimilables en raison de leur acidité légère, de leur saponification partielle et de la présence de matières biliaires propres à en faciliter

(1) L'huile de foie de Colin se trouble et dépose des corps gras cristallisés à $0^{\circ}$. 
l'émulsionnement; $2^{\circ}$ au phosphore, qui se présente sous les formes les plus propres à l'assimilation, en partie aussi au brome et à l'iode; $3^{\circ}$ aux alcaloïdes, dont un grand nombre, la butylamine, l'amylamine et surtout la morrhuine et l'acide morrhuique, excitent à faible dose le système nerveux, activent l'excrétion urinaire et la sudoration, et corrélativement auggmentent l'appétit. L'union de ces divers éléments rend bien compte du ròle bienfaisant de l'huile de foie de Morue dans les maladies où la dénutrition est rapide, et lente la réparation, comme la scrofulose, la phtisie, la goutte, le rachitisme et la plupart des cachexies.

Dans la médecine des animaux, on utilise quelquefois les huiles noires à l'extérieur, pour leurs propriétés rubéfiantes et résolutives.

La Morue mal conservée donne lieu assez fréquemment à des cas de botulisme, surtout chez les marins et les soldats. Devoilier et Brieger y ont découvert des ptomaïnes (voy. p. 95ั7).

D'autre part, il est assez commun de voir, pendant l'été, la Morue verte ou sèche, saine ou avariée, présenter une coloration rouge, Farlow et Heckel ont reconnu que cette coloration est due à l'invasion d'un organisme se rattachant à la famille des Nostocacées, le Clathrocystis roseo-persicina. Mais il ne me semble pas que la Morue rouge présente nécessairement des propriétés toxiques. On peut d'ailleurs empêcher le développement de l'organisme chromogène en mélangeant au sel, qui parait en être le véhicule ordinaire, un vingtième de sulfibenzoate de soude cristallisé (Heckel).

Les PLEURonegtides sont des Poissons plats qui, par suite d'un mouvement de torsion s'effectuant dans

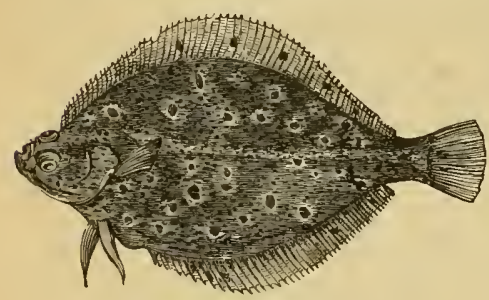

Fig. 693. - Plcuronectidé. le jeune àge, ont le cràne asymétrique et les deux yeux situés du mème côté. - Flétan ou Halibul (Hippoglossus vulgaris. - Turbot (Rhombus maximus), à peau tuberculeuse; chair crémeuse exquise. Barbue (Rh. lrvis), à pean lisse, aussi très estimée; ses œufs peuvent être toxiques. - Plie franche on Carrelet (Pleuroncetes platessa), assez. recherchée à la fin du printemps. Limande $(P l$. limanda), un peu supérieure. Linandelle ( $P l$. megastoma $)$. Flet (Pl. flesus), remonte dans les fleuves. - Sole (Solea vulyuris), chair très savoureuse.

Enfin, les SCOMBERESOGIDÉS renferment les Orphies (Belone vulgaris, B. acus), à chair sèche; les Exocets ou Poissons volants, etc. L'Orphie tropicale $(B$. caribxa) est vénéneuse, ainsi que quelques autres espèces. 
QUATIILAE SOUS-ORDLE

\section{ACANTIOPTÉHYGIENS}

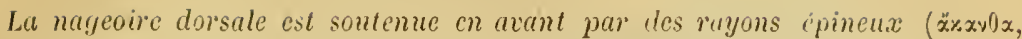
épine). La pean est ordinairement revêlue d'écailles clénoïdes. La vessie aérienne est close ou fait défaut. Les branchies sont pectinées.

2 sections.

I. P'hinyxognatues. - Os pharyngiens inférieurs soudés.

A ce groupe se rattachent les Scares ou P'erroquets de mer (Scurus), dont beaucoup d'espèces sont rénéneuses. Le Scare de Grite (Sc. cretensis), trìs recherché des anciens Romains comme des Grecs modernes, provoque parfois des accidents cholériformes mortels. Ces accidents sont plus communs a ux Antilles avec le Scare Perroquet (Sc. psittacus), el à Maurice avec la Vieille (Sc. vetula).

II. Acanthoptères. - Os pharyngiens nou soudés.

On peut les grouper, un peu arbitrairement, d'après la situation des nagreoires.

A. Acunthoptères abdominaux. - Nageoires ventrales en arrière des pectorales.

Nous signalerons parmi eux les Anabas (Anabas), Poissons grimpeurs; les Muges (Mugil), sortes de Gardons marins, à chair délicate; les Épinoches \{Gas-

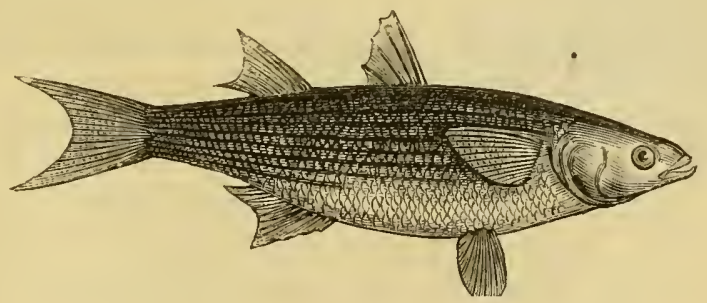

Fig. 60.4. - Muge.

terosteus), très petits Poissons de nos rivières, qui se construisent un nid; les Sphyrènes (Sphyrana). Parmi celles-ci, les Bécunes (Sph. becuna, barracuda, etc.), très voraces, ì morsure dangereuse, occasionnent souvent de graves accidents de siguatère aux Antilles et sur les cỏtes d'Amérique.

B. Acanthopteres thoraciques. - Nageoires ventrales situées sous les pectorales.

Les SGOMBÉRIDES comprennent un assez grand nombre de formes qui vivent sur nos còtes. - Maquereau (Scomber scombrus), à chair huileuse, lourde. - Thons (Thynmus). Thon commun (Th. vulgaris). Germon (Th. alalonga). Bonite à ventre rayé (Th. pelamys). - Sarde ou Bonite à dos rayé (Pelamys sarda). - Tassards (Cybium), des mers cliaudes. - Carangues 
(Caranx). Fausse Carangue (C. fallax), des Antilles et du Brésil; chair souvent très toxique, ainsi que celle de plusieurs espèces voisines. - Coryphène Daurade (Coryplixna hippurus). - Rémoras (Echeneis), se font transporter par d'autres Poissons, leur nageoire dorsale étant transformée en ventouse. - Espadons (Tiphias), màchoire supérieure allongée en forme d'épée.

La chair des Scombéridés se putréfie avec unc extrême facilité; aussi, en dehors des accidents siguatériques attribuables aux Carangues, donne-t-elle lieu souvent à des intoxications graves qu'il convient de rattacher au botulisme. On en a cité des exemples pour le Maquereau, le Thon, le Gerınon, la Bonite à ventre rayé, les Tassards, etc.

Les SPAR̃IDÉS reçoivent souvent le nom de Brêmes de Mer. - Bogule commun (Box vulgaris). - Sargues (Sargus). - Pagre commun (Pagrus vulgaris), parfois toxique. - Pagels (Payellus). Le Pagel commun (P. erythrinus) ou Capitaine peut aussi provoquer la siguatère, ainsi que l'a vu Forster aux Nouvelles-Hébrides. - Daurades (Chrysophrys). Chr. aurata et Chr. saln'a sont également regardées comme vénéneuses. - Lethrinus mambo, de l'archipel Polynésien, est vénéneux à l'àge adulte.

Les PERGIDÉS ont l'opercule dentelé ou épineux. - Perche fluviatile (Perca fluviatilis) ou Perdrix de rivière, à chair ferme et agréable; possède,

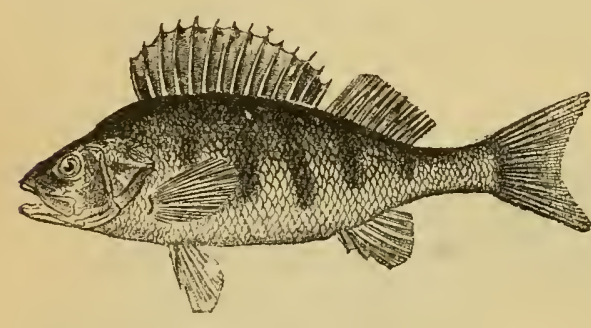

Fig. 695. - Perche fluviatile. d'après Bottard, un appareil à venin rudimentaire, situé entre la cannelure postérieure des rayous épineux dorsaux et la membrane interradiaire, et un autre, également rudimentaire, correspondant à l'épine operculaire; piqùres comparables ḋ celles des Guèpes. - Bar ou Loup de mer (Labrax lupus), assez délicat. - Gremille commune (Acerina cermua), Perche froujonnière ou Mal-appris; chair légère et de bon goùt. - Sandre d'Europe (Lucioperca sandra); chair blanche, grasse, agréable. - Serrans (Serranus). Mérou vrai (S. gigas). - Cerniers (Polyprion), à chair blanche et tendre.

Aux Antilles, on signale comme vénéneux divers Serrans comnus sous le nom de Mérous (S. arara, nigriculus, etc.), ainsi que le Sarde à dents de chien (IIesoprion jocu).

Les TRIGLIDÉS ou Joues euirassées ont une grosse tète souvent garnie de piquants. Depuis longtemps on redoute leur piqùre, et Bottard a déjà montré chez plusieurs d'entre eux l'existence d'un appareil venimeux.

Les Scorpènes ou Rascasses (Scorpana) ont une tête fortement épincuse et une peau molle, spongieuse, qui leur donnent un aspect hideux, et ce fait, joint à la crainte qu'inspire leur piqûre, les a sou- 
rent fait appeler par les marins Scorpions, Crapauds, Diables de mer. La Scorpène truie ( $\$ c$. scrofa) el la Rascasse ( $\$ c$ c. porcus), de la Méditerranée el du golfe de Gascogne, ont un appareil à venin qui siège aux rayons épineux de la nageoire dorsale et de la nageoire anale, lesquels sont annelés et entourés d'une gaine formée par la membrane interradiaire. Bien d'autres espèces sont dans le même cas. L'une des plus renommées est celle qu'on nomme aux

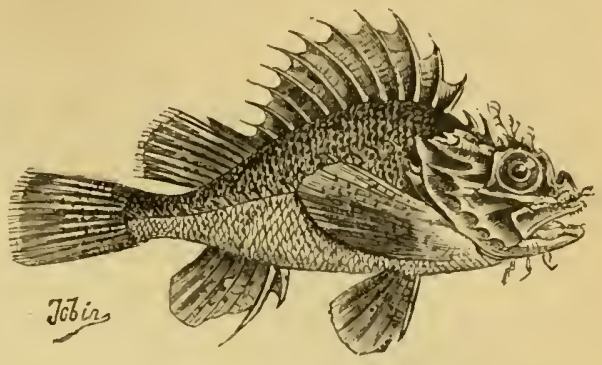

Fig. 696. - Scorpene truic.

Antilles Rascasse vingl-quatre heures (S. grandicornis), à cause de la rapidité arec laquelle ses blessures entrainent la mort. Cette espèce et quelques antres sont en outre réputées vénéneuses.

Les Ptérois (Pterois) et les Pélors (Pelor) ont un appareil renimeux du même tỵpe, siégeant également à la nageoire dorsale.

Les Synancées (Synanceia) habitent les parties chaudes de l'océan Indien et de l'océan Pacifique. L'espèce la plus connue est $S$. brachio: c'est le plus dangereux de tous les Poissons venimeux. Bottard a recueilli, à la Réunion seulement, sept cas de mort résultant de sa piqûre. L'appareil à renin a été étudié par Nadeaud, puis par Bottard : il est localisé à la nageoire dorsale, mais représente un type clos. Les treize raỵons épineux de la nageoire dorsale sont creusés, de chaque côté, d'une cannelure dont l'extrémité inférieure se trouve au niveau d'un réservoir à renin elos et isolé. Il existe done vingt-six réservoirs, dont chacun porte dans sa paroi des glandes en tube. Si l'on appuie sur les épines, ces réservoirs se crèvent et le venin jaillit arec force, en suivant les cannelures. Aussi est-ce généralement en posant le pied sur les Synancées enfoncés dans le sable que les pècheurs ou les baigneurs sont blessés.

Les Cotles ou Chabots (Cottus) ont la peau nue et la tète aplatie. Le Chabot de rivière (C.gotio) fait saillir, quand on l'irrite, son préopercule armé d'une épine, mais il ne parait pas venimeux.

Le Chaboisseau ou Scorpion de mer (Cottus scorpius) remonte sourent fort loin dans nos lleuves et nos rivières, mais va frayer dans la mer. Les pêcheurs redoutent ses piqûres. L'appareil à renin siège dans des culs-de-sac formés par le légument céphalique à la base des trois épines operculaires; mais la surface de ces culs-de-sac n'est revêtue de cellules sécrétantes qu'au moment du frai, de novembre à janvier. Le Chaboisseau à Iongues épines ( $C$. bubalis) offre un appareil semblable, mais moins déreloppé. 
Les Trigles ou Grondins (Trigla) se pèchent en grand nombre sur nos còtes; beaucoup font entendre des bruits au moment où on les sort del'eau. Grondin rouge ou Rouget commun (Tr. cuculus), souvent confondu avec le Rouget barbel, mais beaucoup moins délicat. Rouget hirondelle ou Perlon $(T r$. hirundo).

Les MULLIDĖS sont surtout reconnaissables aux deux longs barbillons qui sont implantés sous le menton. - Rouget barbet (Mullus barbatus) et Surmulet (II. surmuletus), très estimés, le premier surtout.

Les GOBIIDES sont des Poissons carnassiers vivant surtout dans le voisinage des cótes. - Goujons de mer (Gobius); aux Indes, quelques espèces sont toxiques. - Callionymes (Callionymus). Callionyme lyre (C. lyra), vulgairement Savary, Capouri, produit chez les pêcheurs des piquares douloureuses, souvent suivies de panaris; appareil à venin semblable à celui du Chaboisseau et fonctionnant de mème au moment du frai.

Les TEUTHIDÉS sont herbivores; ils portent des piquants caudaux ou dorsaux, parfois accompagnés de glandes à venin. - Le Barbier (Acanthurus chiruryus) a la queue armée de chaque còté d'une lancette ou épine tranchante; on le redoute aux Antilles à l'égal des Serpents venimeux. - Les Amphacanthes (Amphacanthus), de l'océan Indien, ont aux nageoires dorsale et anale un appareil à venin disposé sur le mème type que celui des Scorpènes.

C. Acanthoptères jugulaires. - Nageoires ventrales situées sous la gorge, en avant des pectorales.

Les BATRACHIDÉS sont des Poissons de mer ressemblant aux Chabots. - La Thalassophryne réticulée (Thalassophryne reticulata) se trouve sur la côte de Panama; la Th. tachetée (Th. maculosa) se pèche surtout à Bahia. Elles possèdent, deux appareils venimeux, demi-clos : l'un operculaire, analogue à celui du Chaboisseau, et l'autre dorsal. - Dans le genre Batrachus, on voit ces appareils subir une dégradation progressive.

Les PÉDIGULÉS sont remarquables par leur corps très élargi en avant et leur bouche énorme, armée de fortes dents. - La Baudroie épineuse (Lophius setiger), qui appartient à cette famille, est signalée comme toxique.

Les TRAGHINIDÉS ont le corps allongé, la nageoire anale étendue très loin en avant et la nageoire dorsale souvent dédoublée, la partie antérieure épineuse étant beaucoup plus courte que la partie molle.

Les Vives (Trachinus) sont représentées sur nos còtes par quatre espèces: la Vive commune ( $T r$. draco), grande Vive, Chaquedit ou Aragna, qui semble surtout nager entre deux eaux; la petite Vive (Tr. vipera), connue sous le nom le Toquet à Boulogne, de Bodercau à Dieppe, d'Arselin au Havre, qu'on trouve au milieu des Crevettes dont elle se nourrit, et qui peut s'enfouir dans le sable; la Vive Araignée (Tr. araneus), Truigme des Marseillais; enfin, la Vive à tète rayonnée, ( $T r$ radiatus), qui porte les mêmes noms que la Vive commune. Les deux dernières espèces sont très grandes et propres à la Méditerrannée. 
De tout temps les pècheurs ont redouté la piqùre des Vires. Élien, Oppien, Pline en signalaient déjà le danger. Belon, Rondelet, Ambroise Paré et bien d'autres obserrateurs ont insisté sur ce point. C'est la petite Vive qui a l’appareil venimeux le plus développé; la Vive Araignée occupe au contraire le dernier rang à cet égard. On distingue d'ailleurs un appareil operculaire et un dorsal, le premier plus développé et plus dangereux que le second. - Sur l'opercule, il existe une épine mobile à double cannelure, entourée d'une membrane làche, mais pouvint faire saillie hors de cette gaine au gré du Poisson. Cette épine est en connexion arec une cavité conique de l'opercule; de plus, les culs-de-sac formés par la gaine et la base de chaque cannelure sont tapissés de grosses cellules glandulaires, dont la fonte aboutit ì la formation d'un renin qui s'écoule par les sillons

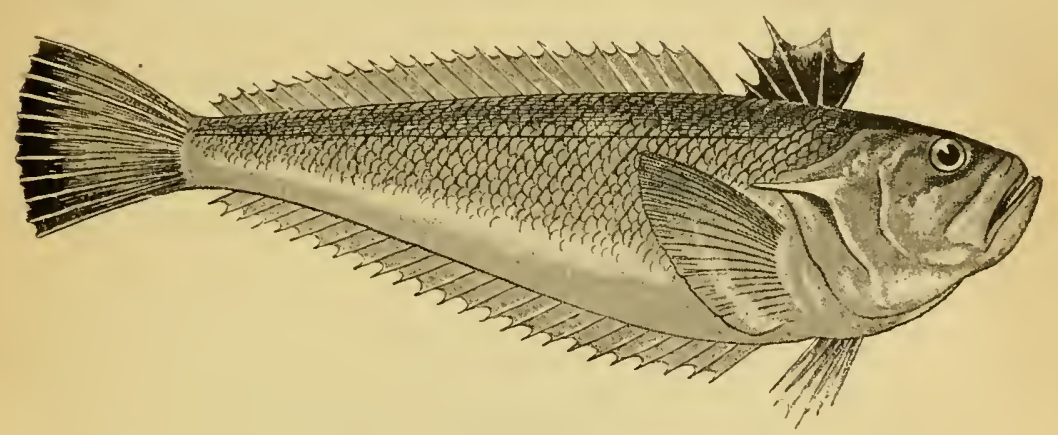

Fig. 697. - I'elite Vive (Trachinus vipera).

de l'épine lorsque celle-ci est comprimée. - L'appareil dorsal se compose de cinq à sept rayons épineux auxquels la membrane interradiaire forme une gaine. Chacune de ces épines est pourvue, en arant et en arrière, d'une cannelure tapissée de grandes cellules glandulaires pigmentées, dont le produit s'écoule le long du sillon, entre l'épine et sa gaine.

La piqûre des Vives donne lieu à des accidents locaux accompagnés de douleurs violentes et parfois de troubles généraux. Il survient d'ordinaire, peu après sa production, un pressant besoin d'uriner. Les victimes sont le plus souvent des pêcheurs, mais parfois aussi des cuisiniers, car le venin garde son activité après la mort du Poisson. Des règlements de police obligeaient autrefois les pècheurs à couper les épines des Vives avant de les livrer au commerce; mais cet usage ne s'est guère maintenu que dans quelques villes du Midi.

Les Uranoscopes (Urunoscopus) n'ont chez nous qu'un seul représentant, l'Uranoscope rat (U. scaber), la Rascasse blanche des Provençaux. L'os coracoïdien de ce Poisson est armée d'une forte épine cannelée en dessus et en dessous, et entourée d'une gaine cutanée. Le venin est sécrété par des cellules 
qui tapissent un double cul-de-sac situé à la base des cannelures. Il est sans doute peu actif, car les pècheurs ne redoutent pas les piqùres de l'Uranoscope.

\section{CINQUIEALE ORDRE}

\section{DIPNOÏQUES}

Poissons ostéo-cartilagineux, à peau écailleuse, à respiration branchiale et pulmonaine.

Les Pneumobranches ou DipnoÏques (Sis, deux; זver, respiration) offrent beaucoup d'affinités avec les Batraciens, mais se rapprochent encore plus des Ganoïdes. La corde dorsale esı persistante. Les nerfs optiques forment un chiasma. L'intestin présente une valvule spirale. La circulation est double et incomplète : le cœur a deux oreillettes incomplètement séparées; cependant il n'y a qu'un seul orifice auriculo-ventriculaire, dépourvu de valvules. La respiration s'effectue par des branchies externes ou internes et par un ou deux sacs pulmonaires.

2 sous-ordres :

Les Monopneumones ne renferment que le genre australien Ceratodus.

Les Dipneumones comprennent le genre Protopterus, de l'Afrique tropicale, et le genre Lepidosiren, de l'Amazone.

\section{CLASSE II}

\section{BATRACIENS}

Vertébrés digités à sang froid; peau nue ou rarement écailleuse; deux condyles occipitaux; circulation double incomplète; respiration branchiale transitoire ou persistante, et respiration pulmonaire à l'état adulte. Ovipares ou ovovivipares; embryons dépourvus d'amnios el d'allantoïde. Métamorphoses.

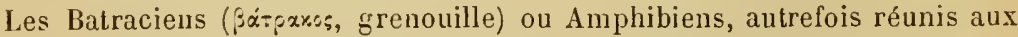
Reptiles sous le nom de Reptiles nus, en furent séparés par de Blainville. Leur conformation générale est très variable : la plupart ont le corps trapu et sans queue; quelques-uns ont une forne allongée et un long appendice caudal. Les nembres, souvent bien développés, peuvent se montrer rudimentaires ou même disparaître, soil en totalité, soit en partie.

La peau est le plus souvent nue, lisse ou visqueuse; quelquefois cependant elle est revêtue d'écailles rudimentaires analogues à celles des Poissons (Cœcilia), ou elle présente quelques plaques osseuses dermiques (Ceratophrys). Les couches superficielles du derme contiennent de nombreux chromoblastes, dont le jeu peut produire de curieux changements de coloration (Hylu).

Elle renferme de nombreuses glandes (1) formées aux dépens de

(1) Wedensuen, Die Kopfdrüsen der geschwanzten Amphitien und die glandula intermaxillaris der Anuren. Zeitschrift für wiss. Zoologie, XNII, 18i6. - G. Cal u els, 
l'épiderme, et logées dans l'épaisseur du derme, qu'elles ont refoulé. Les glandes ont en général la forme d'un utricule plus ou moinvolumincux, tapissé de cellules glandulaires dont la base repose sur une couche musculaire, et s'ouvrant à l'extérieur par un canal très étroil. D’après P. Schultze et Phisalix, il en existe deux formes que Calmels regardait comme des stades différents de l'évolution d'un seul el mème tỵpe. Les unes, très nombreuses, sont répandue: sur toute la surface de la peau et possèdent un revêtement épithélial uniforme, aplati ou cubique : ce sont des glandes muqueuses. Les autres, a répartition fixe, dont le fond montre de gigantesques cellules granuleuses, sont des glandes spécifiques; on les rencontre spécialement à la face dorsale du corps et des membres: elles forment notamment deux groupes importants, désignés sous le nom impropre de parotides, sur la nuque de quelques Urodèles ol d'un grand nombre d'Anoures.

Le produil de sécrétion de ces dernières glandes est un liquide laiteux el visqueux, constituant un véritable venin qui vient exsuder ì la surface de la peau par suite de la contraction volontaire ou réflexe des muscles cutanés. A l'état frais, ce liquide a une réaction acide. attribuable à la présence d'une certaine quantité d'acide formique. Au microscope, il montre, d'après Zalesky et Calmels, une foule de granules ou mieux de globules entourés, comme ceux dı lait, d'une enveloppe albumineuse, mais différant de ceux-ci en ce que l'eau pure les lait immédiatement éclater. Leur constitution chimique a été surtout étudiée par Calmels; mais le résultat des recherches de cet auteur ne peut être accepté qu'arec de sérieuses réserves. Ils contiendraient essentiellement des acides (isocyanacétique et homologues) en combinaison dans des corps gras complexes que Calmels nomme pseudo-lécithines. Ces corps, se dédoublant sous l'influence de la chaleur et de l'humidité, mettraient en liberté l'acide correspondant, lequel pourrait se dédoubler ì son tour en donnant une carbylamine. Or, on sait que les carbylamines ont un powroir toxique considérable. Il est à noter en outre que le venin des Batraciens abonde en cristaux de Charcot (phosphate de spermine), lesquels dériveraient aussi de la décomposition des pseudo-lécithines. Le produit des glandes muqueuses a encore été peu étudié; il paraît renfermer luimème des principes toxiques particuliers, comme on le verra plus loin. - Le renin des Batraciens résulte donc, en somme, dı mélange, en proportions variables, de deux produits bien distincts.

Ajoutons que, dans une mème espèce, ses propriétés sont plus marquées pendant la période de reproduction et chez les individus qui proviennent d'un climat plus chaud. Elles ne se perdent pas par

Étude hislologique des glandes à venin ctu Crapaud, etc. Archives de physiologie nol'm. et pathol., (3), I, p. 321, pl. VIII, 1833. - Paul Scuulze, Ueber die Giftdrïsen der Kröten und Satamander. Eine histologische Studie. Archiv für mikrosk. Anatomie, XXXIV, p. 11, 1889.

RaIlliet. - Zoologie. 
la dessiccation. Le renin agit tantòt comme poison de la moelle.(Salamandre), tantôt comme poison du cœur (Triton, Crapaud).

Comme les Batraciens ne possèdent pas d'appareil d'inoculation, ce venin ne peut aroir qu'un róle purement défensif. En outre, sa richesse en matières grasses empêche la dessiccation de la peau et assure ainsi, concurremment avec le mucus, le maintien de ses fonctions.

Le squelette offre quelques variations. La colonne vertébrale, bien développée chez les Céciliens et les Urodèles, est atrophiée chez les Anoures dans la région coccygienne, qui ne comprend qu'une seule pièce osseuse styliforme (urostyle). Les corps vertébraux conservent souvent ả leur centre des restes de la corde dorsale; leurs extrémités sont très diversement conformées. Ils sont séparés par des cartilages intervertébraux.

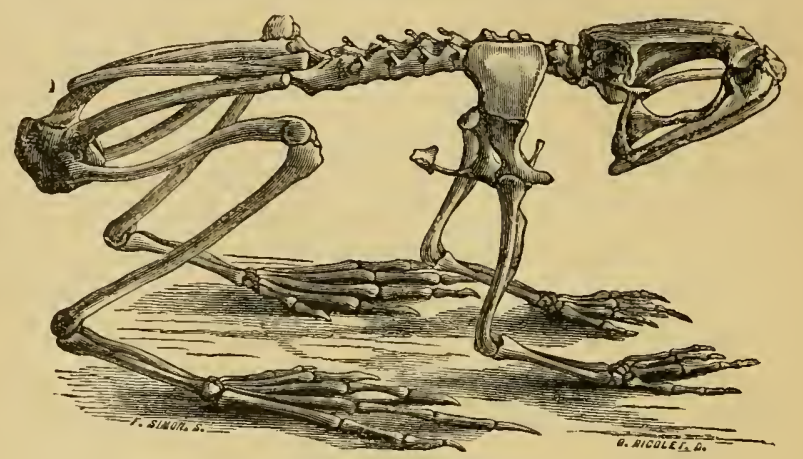

Fig. 698. - squelette de Grenouille.

Le crine demeure en partie cartilagineux; il s'articule avec le rachis par deux condyles occipitaux. La màchoire inférieure est suspendue au cràne par l'intermédiaire d'un os carré. - Le squelette viscéral subit une réduction très accusée lorsque les branchies disparaissent et sont remplacées par des poumons; il ne reste alors que l'arc hyoildien.

Les côtes, rudimentaires chez les Gymıophiones et les Urodèles, manquent généralement chez les Anoures, dont les apophyses transverses des vertèbres dorsales sont, par contre, très développées. - Les ceintures scapulaire et pelvienne, ainsi que les membres correspondants, sont absents chez les Gymnophiones. Les Urodèles ont une ceinture scapulaire interrompue en Jessous, et un bassin fort réduit. Enfin, chez les Anoures, la ceinture scapulaire est soutenue par un sternum, et le bassin est remarquable par l'allongement styliforme des os iliaques. - Le radius et le cubitus, ainsi que le tibia et le péroné, sont souvent confondus en un seul os.

Le système nerveux est à peine supérieur à celui des Poissons. Les hémisphères cérébraux sont cependant plus développés; mais le cervelet est tout à fait rudimentaire : il n'est représenté que par une étroite bandelette étendue au-dessus du quatrième ventricule.

Le toucher est assez délicat et s'exerce par la surface cutanée, notamment 
par les extrénités des pattes. - Les organes dits du sixième sons (ligne latérale) se rencontrent cliez les formes aquatiques, et en particulier chez les larves, mais ils ne sont pas contenus dans des canaux. - Les yeux sont ytuelquefois rudimentaires et cachés sous la peau (Protée, Gymnophiones). - L'organe auditif a pour base une oreille interne ne comprenant que le vestibule et les trois canaux demi-circulaires : le limacon est rudimentaire. Dans certains cas, il existe en outre une oreille moyenne (caisse du tympan), communiquant par une trompe d'Eustache avec le pharynx. - On a observé des papilles gustatives sur la langue des Anoures. - Enfin l'odorat a pour siège les fosses nasales.

La bouche est pourvue de dents prélıensiles, insérées sur les os des màchoires et du palais; ces dents manquent pourtant dans quelques espèces de Crapauds. La langue, bien développée et protractile chez la plupart des Anoures, est parfois réduite et peut mème disparaitre (I'ipa). L'œsophage, sourent revètu d'un épithélium vibratile, s'ouvre dans un estomac simple. L'intestin est court; il débouche dans un cloaque. - On n'observe pas de glandes salivaires proprement dites, mais il y a toujours un foie et un pancréas.

L'appareil respiratoire subit d'importantes modifications dans le cours des métamorphoses par lesquelles passent les Batraciens. A l'état de larves, ces animaux respirent d'abord par des branchies externes. Ces branchies sont persistantes chez les Pérennibranches; elles s'atrophient lors du passage à l'état adulte, chez les Dérotrèmes, qui conservent une fente branchiale de chaque cóté, et chez les Salamandres, qui ne possèdent plus ni branchies ni fentes branchiales. Chez les Anoures, un repli cutané se développe à la façon d'un opercule, se rabat au-dessus des branchies externes et s'unit au tégument par son bord postérieur, en ne laissant qu'un étroit orifice ou spiraculum; les branchies externes s'atrophient alors et sont remplacées par quatre paires le branchies internes. On peut observer un spiraculum de chaque còté (.Imphigyrinides), ou un seul spiraculum médian formé par la fusion des deux orifices latéraux (Médiogyrinidess), ou enfin un seul spiraculum latéral, à gauche (Lérogyrinidés). Plus tard, les branchies internes ellesmèmes disparaîtront. - Dans tous les cas, les Batraciens adultes possèdent des poumons, sous forme de sacs membraneux tantòt lisses, tantòt divisés en cellules. La respiration pulmonaire s'effectue par une sorte de léglutition; pour l'expiration, ce sont les muscles abdominaux qui entrent en jeu. - On a longtemps, en outre, attribué à la peau un ròle important dans la respiration, des frenouilles privées de leurs poumons ayant pu vivre plusieurs mois dans une eau courante; mais les recherches de Marcacci ont montré que la fonction respiratoire s'effectue alors par les cavités buccale et pharyngienne.

L'appareil respiratoire est aussi affecté à la phonation. Le coassement, qui ne s'observe guère que chez les màles des Anoures, est produit par l'entrée de l'air brusquement expiré dans des sacs vocaux annexés au pharynx.

Le changement du mode de respiration entraine une modification profonde de l'appareil circulatoire. Lorsque la respiration branchiale existe seule, le cour se compose, comme celui des Poissons, d'une oreillette et d'un ventricule suivi d'un bulbe artériel. Le tronc qui continue ce bulbe fournit une série d'ares latéraux - quatre paires en général, dont les trois premières seules forment des artères branchiales; - le sang qui sort des branchies 
est emmené par des reines branchiales qui se réunissent au-dessus de l'œsophage pour former l'aorte dorsale. Les vaisseaux branchiaux afférents et efférents communiquent d'ailleurs à leur base par une fine anastomose. - Dès que les poumons apparaissent, l'appareil circulatoire tend a prendre les caractères de celui des Reptiles: les arcs de la quatrième paire, qui gagnent directement l'aorte dorsale, donnent naissance chacun à un rameau qui se rend au poumon (artères pulmonaires). En mème temps, l'oreillette se divise en deux par le développement d'une cloison rerticale, et l'oreillette gauche reçoit le sang des veines pulmonaires. Le ventricule reste simple, mais aréolaire, et il ne permet pas, en somme, le mélange complet du sang rouge et du sang noir. - Enfin, chez les Batraciens qui ne conservent à l'état parfait que la respiration pulmonaire, les capillaires des branchies disparaissent, et le sang passe dans les branches anastomotiques basilaires, qui s'élargissent peu à peu. Des modifications secondaires peuvent survenir, notamment la disparition de certains arcs. Il faut ajouter que le sang veineux traverse un système porte hépatique el un système porte rénal.

Le systime lymplutique comprend un réseau lacunaile sous-cutané et des canaux qui accompagnent les raisseaux sanguins. Dans certains points, on rencontre des réservoirs animés de contractions rythmiques et connus sous le nom de cours lymphatiques.

L'appareil uro-génital comprend un mésonéphros double, dont la partie antérieure effilée est en rapport avec la glande sexuelle correspondante, ovaire ou testicule. Le canal segmentaire s'est divisé en un canal de Wolff dorsal et un canal de Müller ventral. Chez le màle, ce dernier reste rudimentaire; mais les canaux efférents du testieule pénètrent dans la région antérieure du mésonéphros, de sorte que les canalicules urinifères émanés de la portion antérieure de cet organe servent de voies spermatiques, alors que ceux de la portion postérieure conduisent seuls l'urine; tous se jettent dans le canal de Wolff, qui fonctionne à la fois comme canal déférent et comme

Fig. 699.

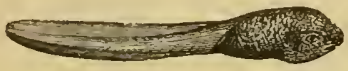

Fig. 7ul.

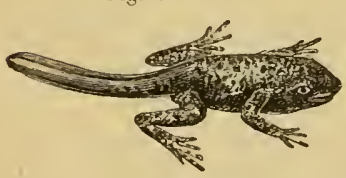

Fig. Tne.

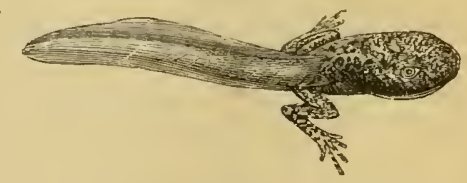

Fig. $\bar{t}(i)$.

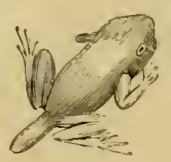

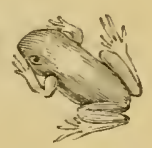

Fig. 699 à 703. - Métamorphoses des Grenouilles. - Fig. 699. Tèlard ayant perdu ses branclies externes. - Fig. 700. Apparition des deux membres postérieurs. - Fig. 701. Apparition des membre: antérieurs; disparition des branchies. - Fig. 702. Disparition progressive de la queue; respiration pulmonaire.

uretère, et va s'ouvrir dans le cloaque. Chez la femelle, le canal de Wolff sert seulement au transport de l'urine. Il n'a d'ailleurs aucune connexion avec la vessie urinaire, qui est formée par un enfoncement de la paroi antérieure du cloaque. Le canal de Müller est bien développé et joue le ròle 
d'oriducte : il s'ouvre en arant dans la cavité viscérale et recueille les œul's qui y sont tombés par déliscence de l'oxaire correspondant, et les conduit dans le cloaque, oì il va s'ourrir à còté du canal de Wolff.

Les sexes sont séparés, mais on trouve cependant, chez les mìles des Crapauds, le rudiment d'un ovaire à còté de chaque testicule. Il existe souvent des différences sexuelles passagères ou permanentes.

Quoique beaucoup de Batraciens s'accouplent, la fécondition est le plus souvent extérieure. Les œufs sont nombreux et en général aıgglutinés par une matière albumineuse : c'est ce ıुu'on appelle le frai. Quelques espèces seulement s'occupent de leur progéniture (Crapaud accoucheur, Pipa, elc.).

Le déxcloppement embryonnaire débute par une segmentation totale et inégale. L'embryon est toujours dépourvu d'amnios et d'allantoïde. Au moment de l'éclosion, le jeune animal dilfère beaucoup de ses parents; il doil presque toujours subir une métamorphose complexe pour arriver ì l'étal aduite. - La larre (tètard), qui vit toujours dans l'eau, possède comme les Poissons une queue comprimée latéralement; tlle est dépourvue de membres et respire par (les brancliies. Elle se transforme peu à per : chez les Inoures, par exemple, les membres se développent successivement et la queue se réduit jusqu'à disparaître, tandis que la respiration pulmonaire remplace la respiration branchiale. Dans les autres groupes, la queue est conservée; mais les branchies ue persistent à l'état adulte que chez les Pérennibranches.

Les Batraciens le plus complètement adaptés à la vie terrestre vivent cependant au roisinage de l'eau, dans les endroits ombragés et humides. Ils se nourrissent surtout d'Insectes et de Vers, sauf à l'état larvaire, où ils recherchent de préférence les substances végétales. - Quelques-uns sont remarquables

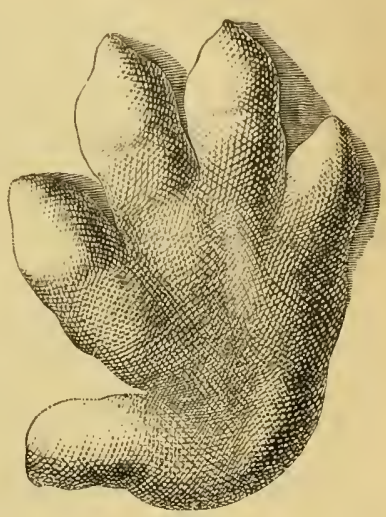

Fig. 703. - Empreinte fossile diun Labyrinthoulonte, le Cheiratherium Itriast. par leur faculté de rédintégration.

Ces animaux se montrent à l'état fossile a partir surtout de l'époque tertiaire; les gigantesques Labyrinthodontes ou Stégocéphales seuls remontent aux formations triasique, permienne et carbonifère.

3 ordres :

Pas de membres ni de queue.............. Gruxophuxes.

Des membres. $\left\{\begin{array}{l}\text { Lne queue à l'ètat adulte...... Unodètes. } \\ \text { Pas de queue à l'état adulte..... Axorres. }\end{array}\right.$

PREMIER ORDRE

\section{GYMNOPIIONES}

Batraciens vermiformes, dépourvus de membres et de queue; peau nue ou renfermant de petites écailles discoïdes. 


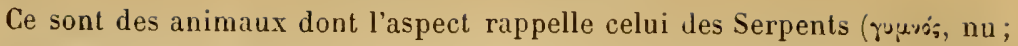
ópis, serpent); leur corps est marqué de sillons annulaires; leurs yeux sont très petits, souvent recouverts par la peau ou mème par les os du crâne. Leurs métamorphoses sont incomplètes, parfois nulles. Ils vivent dans les lieux sombres et humides des régions tropicales. - Genres Cœcilia, Siphonops, etc.

\section{DEUXIÈYE ORDRE}

\section{URODĖLES}

Batraciens à corps allongé, pourvus d'une queue et d'une ou de deux paires de membres; peau nue.

On peut diviser les Urodèles (củó, queue; $\delta \tilde{r}_{1} \lambda=\varsigma$, visible) en trois sousordres :

$1^{\text {er }}$ sous-ordre : Pérennibranches. - Trois paires de branchies externes persistantes; vertèbres amphicœliques; pas de paupières. - Le Protée (Proteus anguinus), qui habite les eaux souterraines de la Carniole et de la Dalmatie, a les yeux atrophiés et cachés sous la peau; les grandes dimensions de ses éléments anatomiques le font rechercher des histologistes. - La Sirène (Siren lacertina), de la Caroline du Sud, ne possède que les deux pattes antérieures.

2 sous-ordre : Dérotrèmes. - N'ont plus de branchies à l'état adulte, mais ont conservé d'ordinaire un orifice branchial de chaque côté du cou ( $\delta \dot{s} p$ n, cou ; трr̃ux, trou); vertèbres amphicœliques; pas de paupières. - Genres Amphiuma, Menopoma, Cryptobranchus.

$3^{\text {e }}$ sous-ordre: Salamandrides. - Pas de branchies ni d'orifices branchiaux à l'état adulte; vertẻbres le plus sonvent opisthocueliques; en général des paupières horizontales.

Une mention est due à l'Axolotl, animal du Mexique et des États-Unis, qu'on a longtemps décrit comme une espèce particulière de Pérennibranche, sous le nom de Siredon pisciformis. Or, bien qu'il jouisse de la faculté de se reproduire, ce n'est qu'une larve de Salamandride (Amblystoma mexicanum); mais il ne prend que rarement la lorme adulte et dans des conditions encore mal connues. La chair de l'Axolotl a quelque analogie avec celle de l'Anguille.

Les Salamandres (Salamandra) ont le corps épais et la queue eylindroconique; elles sont terrestres et ne vont guère à l'eau que pour y déposer leurs oufs. - On trouve en France $S$. maculosa et $S$. atra, celle-ci localisée dans les Alpes.

La Salamandre terrestre ( $S$. maculosa) a le corps noir, arec des taches jaune d'or irrégulièrement disposées. De charue côté de la ligne médiane dorsale, à partir de la nuque, elle porte une série de cryptes glandulaires; sur les parties latérales du cou, on remarque également une forte plaque ou " parotide " percée de larges pores. 
Cette espèce est répandue dans toute l'Europe à partir du sud de la Suède, dans le nord de l'Afrique et en Asie Mineure; Parâtre a montré qu'elle n'est pas rare aux environs de Paris.

Dès 18ว1, Gratiolet et Clö̈z ont appelé l'attention sur les sécrétions renimeuses de cet animal. Vulpian, Albini, Roth, Phisalix, etc., ont depuis lors étudié arec soin la production et l'action physiologique du venin (1).

Selon Phisalix, les glandes cutanées comprennent, ainsi qu'on l'a vu plus haut: $1^{\circ}$ des "glandes spécifiques ", à répartition fixe, à sécrétion blanche, crémeuse et très acide; 20 des " glandes à mucus », extrêmement nombreuses, répandues sur toute la surface de la peau et donnant un liquide filant, savonneux, très abondant, à réaction alcaline.

La sécrétion des glandes spécifiques n'est pas activée par les excitations extérieures les plus variées, mais on peut la provoquer par l'excitation de divers points du système nerveux. Le centre général qui préside à cette sécrétion a pour siège les lobes optiques.

Le principe actif du produit obtenu dans ces conditions avait déjà été entrevu par Gratiolet et Cloëz, qui l'avaient reconnu pour un alcaloïde. Zalesky l'a étudié plus complètement et l'a nommé samandarine ou salamandrine; il lui attribue la formule complexe $\mathrm{C}^{35} \mathrm{I}^{60} \mathrm{~A} z^{2} \mathrm{O}^{5}$. Soluble dans l'eau et dans l'alcool, il cristallise en longues aiguilles et donne des sels neutres avec les acides. C'est un poison du système nerveux; injecté dans les veines à l'état de chlorhydrate, il amène en peu de temps la mort, en provoquant un état convulsif très remarquable; mais il parait sans action sur le coeur.

Les glandes muqueuses sécrètent abondamment sous l'influence des excitations mécaniques, chimiques ou thermiques. Le liquide qu'elles fournissent renferme aussi un principe actif, mais celui-ci, soluble dans l'eau, est insoluble dans l'alcool ; il cristallise en aiguilles qui se groupent en cônes réunis deux à deux par le sommet. L'injection de cette substance à de petits Oiseaux ou Hammifères amène un état de stupeur avec prostration et affaiblissement musculaire ; l'animal meurt avec le cour en diastole.

Le venin représente en somme le produit des deux ordres de glandes. Son activité est considérable; il pe ut la conserver, même d̀ sec, pendant plus d'un an. Les Grenouilles et les petits Poissons succombent dans l'eau oil l'on place une Salamandre. Les Oiseaux auxquels on injecte le liquide en nature sous la peau meurent plus

(1) C. Pulsalix, Nouvelles experiences sur le venin de la Salamandre terrestre. Comptes rendus de l'Acad. des sc., CXIX, p. 405, 1889. - Puisalix et Laxalois, Action physiologique du venin de la Salanandre terrestre. Ibid., p. 482. - C. PurSalix, Sur quelques points de la physiologie des glandes cutanées de la Salamandre terrestre. Comptes rendus de la Soc. de biol., (9), II, p. 22., 1890. - Pinsalix el Coxtejeax, Nouvelles recherches physiologiques sur les glandes à renin de la Sala. mandre terrestre. Jémoires de la Soc. de biol., (9), III, p. 33, 1991. 
ou moins rapidement, après aroir éprouré des convulsions épileptiformes. Certains Mammifères, comme le Cobaỹe et la Souris, résistent mieux et reviennent à la santé après quelques convulsions. Si l'on introduit le renin par le tube digestif, il ne produit que peu on point d'effets; cependant, Phisalix a tué un tout jeune Chien par un simple dépôt de ce produit à là surface de la langue. Les Grenouilles, Tritons et Crapands succombent rapidement ì l'injection d'une seule goutte. Quant à la Salamandre elle-même, elle jouit d’une immunité relative à l'égard de son propre venin : les effets ne se manifestent cularec de fortes doses et toujours tardirement.

Cette résistance semble deroir être interprétée comme le résultat d'une accoutumance due ì l'absorption continuelle de produits fournis par les glandes cutanées (sécrétion interne). Il résulte en effet des recherches de Plisalix (1) que le $\operatorname{san} g$ de la Salamandre contient, comme le renin lui-mème, des principes actifs entièrement solubles dans l'alcool et appartenant, au moins en partie, au groupe des leucomaïnes;' ces principes ont les mêmes propriétés phỵsiologiques que le renin, mais se montrent seulement en faible proportion.

Phisalix a obtenu chez le Chien l'accoutumance graduelle ì des doses croissantes par des injections quotidiennes de chlorhydrate de salamandrine.

Les Tritons (Triton) ont le corps allongé, la queue comprimée latéralement tant que l'animal est à l'eau, la langue charnue et papilleuse. Ils sont ovipares et vivent habituellement daus les eaux dormantes: quelques espèces deviennent terrestres après avoir pondu. - On connait en France les espèces suivantes: $T r$. cristatus, $T r$. palmatus, $T r$. vulgaris, $T r$. alpestris, des environs de Paris, et Tr. marmoratus, de la France méridionale, de la Bretagne et de Fontainebleau.

Le Triton crèté ( $T$. cristatus) ou Salamandre aquatique parait représenter la plus renimeuse de ces espèces ; il porte sur toute la surlace

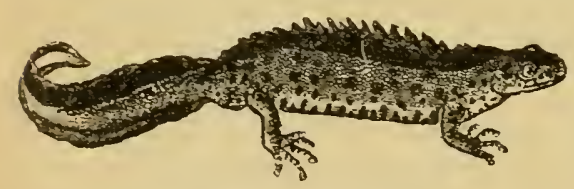

Fig. :04. - Triton ì crèle. dorsale des glandes à renin surtout développées à la queue et à la nuque. Ces glandes émettent un liquide épais, crémeux, àcre, d'odeur vireuse, à réaction acide.

Le renin du Triton est plus actif que celui de la Salamandre; il a d'ailleurs une action très différente : son effet le plus saillant, d'après Vulpian, est l'arrêt des mouvements du cœur. On a observé aussi une conjonctivite douloureuse sur des personnes qui avaient manié des Tritons ou avaient fait jaillir sur leurs yeux l'eau dans laquelle se trouvaient ces Batraciens.

1) Association française pour l'arancement des sciences. Session de Besançon, aoùt 1883 . 
D’après Calmels, ce liquide est très concentré; il ne renferme que ¿ p. 100 d'eau, de sorte qu’il se solidifie immédiatement à l'air libre. En raison de cette faible hydratation, les globules venimeux sont bien conservés, et le renin ne contient pas de carbylamine libre. Le principe actif se montrerait sous la forme d'acide éthylcarbylaminecarbonique ou acide $\alpha$-isocyanopropionique, en combinaison dans une pseudo-lécithine. En chauffant celle-ci, on obliendrait un vif dégagement d'éthỵlcarbylanine.

\section{TROISIEVE ORURE}

\section{ANOURES}

Batraciens i corps iamussi, pourvus de deux praires de membies; pros de quene: peau nue.

Les Anoures ( $\dot{x}$, privatif; cióx, queue) sont des animaux i membres bien déreloppés, les antérieurs ì quatre doigts, les postérieurs, plus puissants, à cinq doigts. A l'état adulte, ils sont surtout lerrestres et se nourrissent de Vers, Insectes, Mollusques, etc. -3 sous-ordres :

fer sous-ordre: Aglosses. - Anumes privés de lungme.

Tous les Aglosses sont des Amphigyrinidés, à rertèbres opisthocœliques. A ce groupe appartient le Pipa ou Crapaud de Surinam (Pipn amrricmur). Aussitòt après la ponte, le màle de cette espèce place les ưfs sur le dos de la femelle, oì il se forme de petites cellules dans lesquelles les larves éclosent et subissent toutes leurs métamorphuses.

2 sous-ordre : 0xydactyles. - Anoures pourzus diune langue et de doigls pointus.

A. Médiogyrinidés. - Tètards à spiraculum impair et médian; vertèbres opisthocoliques. - On peut citer dans cette section le Discoglosse (Discoylossus pictus), du sud de l'Europe et du nord de l'Afrique, dont la chair passe, probablement à tort, pour être vénéneuse; puis les Sonneurs (Bombinator) et les Alytes (Alytes), connus vulgairement sous le nom de Crapauds, mais se distinguant des Crapauds rrais par la présence de dents à la màchoire supérieure. Les Sonneurs produiraient un venin volatil, répandant une odeur alliacée et provoquant l'éternuement. Le mảle du Crapaud accoucheur (Alytes obstetricans) enroule autour de ses pattes postérieures les aufs que poud la femelle, puis se retire dans un trou, dont il sort cependant chaque soir pour manger et humecter ses œufs; au moment de l'éclosion, il gaøne une flaque d'eau, et les tètards se dégagent immédiatement de leur enveloppe. D’après E. Saurage, le renin de l'Alyte a la même action que celui du Cra. paud commun.

B. Lèvogyrinidès. - Tètards à spiraculum unique, situé du còté gauche; vertèbres procœliques.

Les Cirenouilles (Rana) ont des dents à la màchoire supérieure et au vomer; leurs pattes postérieures sont très longues. Elles sont représentées en France par Irois espèces : la Grenouille verte (R. esculcnta L.., R. virillis Rosel), la 
Grenouille rousse ( $R$. fusca Rœsel, $\boldsymbol{R}$. temporaria Duméril et Bibron) et la Grenouille agile $(R$. agilis Thomas). - On ne mange guère que les cuisses, dont la chair est blanche, savoureuse, mais peu nutritive. Il n'est pas très

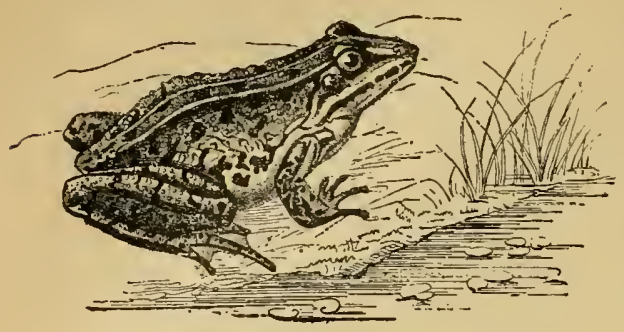

Fig. 705. - Grenouille verte. rare d'y voir substituer des cuisses de Crapauds; cellesci sont plus courtes, de sorte qu'il n'est guère possible de les réunir en nœud; elles sont en outre d'une teinte grisàtre, et laissent voir souvent le tissu conjonctif intermusculaire chargé de pigment noir.

Les glandes cutanées des Grenouilles sécrètent un venin peu actif, mais capable cependant de produire une irritation lorsqu'il est porté sur 'la conjonctive et la pituitaire, comme l'ont montré Brown-Séquard et Vulpian. Celui de la Grenouille verte, d'après P. Bert, paraît ètre à la fois un poison du coeur comme celui du Crapaud et un poison de la moelle comme celui de la Salamandre.

Les Pélobates (Pelobates) et les Pélodytes (Pelodytes) ont encore des dents à la mâchoire supérieure; leur peau verruqueuse les rapproche des Crapauds, mais leurs pattes, de longueur moyenne, rappellent un peu celles des Grenouilles. On trouve en France les Pélobates brun (P. fuscus) et cultripède ( $P$. cultripes), et le petit Pélodyte ponctué ( $P$. punctatus). Le venin de ces animaux est un liquide blanchâtre, visqueux, d'une odeur forte et pénétrante. E. Sauvage a constaté, pour le Pélobate brun, que son action participe à la fois de celle du venin de Crapaud et de celle du venin de Salamandre.

Les Crapauds (Bufo) sont dépourvus de dents aux deux mâchoires; leur peau est très verruqueuse, notamment au niveau des parotides; leurs pupilles sont horizontales, ils ont des pattes postérieures courtes. Les espèces françaises sont: le Crapaud commun (B. vulgaris) et le Crapaud des joncs ( $B$. calamita), ce dernier reconnaissable à la raie jaune qu'il porte sur la ligne médiane dorsale. Le Crapaud vert (B. viridis), dı nord de l'Afrique et de diverses régrions asiatiques, a été trouvé aussi dans le sud-est de la France.

Le venin du Crapaud commun est un produit lactescent, un peu jaunâtre, amer, nauséeux, caustique, d'une odeur vireuse. Il a une réaction acide et se concrète par l'exposition à l'air; son activité n'est pas atteinte par la dessiccation. - En injection sous-cutanée, il tue rapidement les Insectes, les Mollusques et les Vertébrés : les petits Oiseaux succombent en quelques minutes, les Chiens et les Cobayes en une heure et demie au plus, les Grenouilles en une heure. Le Crapaud commun résiste davantage; Claude Bernard a d'ailleurs établi ce fait intéressant que le renin du Crapaud calamite a une action plus énergique sur le Crapaud commun que n’en 
a sur ce dernier son propre venin, et réciproquement. Phisalix et Bertrand (1) ont rattaché cette résistance relative à la toxicité du sang, due à la " sécrétion interne " des glandes cutanées. Par les voies digestives, il ne produit pas d'accidents sensibles chez le Chien, non plus que chez divers animaux à sang froid, tels que les Couleurres; par contre, il amène rapidement la mort des Grenouilles. J.es symptômes de l'intoxication se succèdent dans l'ordre suivant: excitation, affaissement, eflorts de romissement, ivresse ou convulsions, mort. L'effet le plus saillant est, comme pour le venin du Triton, l'arrêt des battements du çeur.

Casali a extrait du venin de Crapaud ( $B$. viridis) un alcaloïde extrèmement actif, auquel il a donné le nom de bufidine. Selon Calmels, le prineipe toxique du venin de Crapaud commun serait tout à fait analogue à celui du renin de Triton. Cet auteur y aurait trouvé de lacide méthylcarbylamine-carbonique ou isocyanacétique, en combinaison dans une pseudo-lécithine. Mais, comme ce venin est plus dilué que celui du Triton, le corps gras en question serait presque entièrement dédoublé; les globules venimeux ne se trouveraient plus représentés que par leurs enveloppes vides et fragmentées, en voie de destruction : aussi le liquide contiendrait-il de l'acide isocyanacétique, lequel se serait lui-mème dédoublé en partie en fournissant de la méthylcarbylamine.

Sous le nom de phrynine, Fornara recommande un extrait de venin de Crapaud qui servirait à raviver les tissus atoniques el pourrait mème ètre utilisé à l'intérieur comme un excitant de la nutrition et du muscle cardiaque.

$3^{\mathrm{e}}$ sous-ordre : Discodactyles. - Anoures pourvus d'une langue et de doigts terminés par des pelotes discoïdes adhésives. - Tous sont des lévogyrinidés, à rertèbres procœliques. Nous citerons parmi eux les Rainettes (Hyla), qui grimpent dans les buissons ou sur les arbres, et, gràce au jeu de leurs chromoblastes, prennent rapidement la teinte du feuillage qui les entoure; les Nototrèmes (Nototrema), de l'Amérique tropicale, dont la femelle offre sur le dos une poche incubatrice; les Phyllobates (Phyllobates), et en particulier la Grenouille du Choco (Ph. chocoensis), dont les Indiens de la Nouvelle-Grenade recueillent le venin pour empoisonner leurs flèches.

Les auteurs anciens ont rapporté une foule d'observations relatives à des Batraciens qui auraient vécu plus ou moins longtemps dans l'estomac de l'Homme, en provoquant des troubles de durée et de gravité variables. La plupart de ces cas se rapporten $\mathbf{t}$ à des femmes, et il est évident qu'il s'agit surtout de supercheries hystériques. Berthold a d'ailleurs montré que les Batraciens périssent dans l'eau portée à la température du corps humain.

(1) Puisalix et Bertrixu, Recherches sur la toxicité du sang du Crapaud commun. Archives de physiologie normale et pathologique, (5), V, p. 511, 1893. 


\section{CLASSE III}

\section{REPTILES}

Vertébrés à sang froid, à peau éccilleuse ou couverle de plaques osseuses; un seul condyle occipital: circulation double incomplète; respiration exclusivement pulmonaire. Ovipares ou ovovivipares; embryons pourvus d'un amnios et d'une allantoïde.

La classe des Reptiles (reptare, ramper) commence la série des Vertébrés supérieurs ou allantoïdiens; d'après ce que nous avons dit à propos des Batraciens, on sait qu'elle ne comprend que les Reptiles écailleux des anciens auteurs. Le corps de ces animaıx est allongé, sauf chez les Tortues;

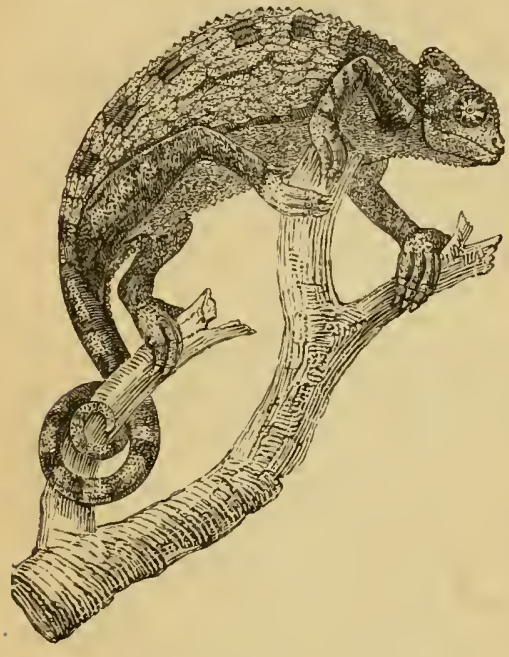

Fig. 706. - Caméléon (Chamæleon vulgaris Cuv.).

les membres sont peu développés, parfois mème rudimentaires ou absents (Serpents): ils ne servent pas d'ordinaire à supporter le corps, mais seulement à le pousser (reptation).

La peau, toujours résistante, est souvent revítue d'écailles ou de scutelles, formées par des prolongements đu derme rarement ossifiés, mais recouverts par un épiderme corné ; chez les Tortues et les Crocodiles, il existe de grandes plaques osseuses dermiques, constituant une cuirasse plus ou moins continue. - Outre une riche pignentation des couches épidermiques profondes, il faut noter la présence, dans l'épaisseur du derme, de nombreux chromoblastes dont le jeu produit ces curieux changements de couleur qui sont si marqués, par exemple, chez le Caméléon. - Les glandes cutanées sont rares chez les Reptiles.

Le squelelte présente de nombreuses variations. La colonne veriébrale ne conserve presque jamais de traces de la corde dorsale. Les vertèbres, dont le nombre est parfois considérable, sont le plus souvent procœliques. Les côles peurent se rencontrer sur toute la longueur du tronc. Chez les Ophidiens, elles sont très mobiles et non réunies inférieurement par un sternum; celui-ci s'observe, au contraire, chez la plupart des Sauriens et des Crocodiliens. Les Tortues ne possèdent pas de còtes cervicales, ni de sternum, mais les còtes qui existent dans les régions dorsale et lombaire se soudent aux plaques osseuses dermiques pour former la carapace.

Le crane, toujours petit, s'articule avec le rachis par un seul condyle occipital. La fare est allongée : les os qui constituent l'appareil maxillopalatin sont très mobiles les uns sur les autres chez les Ophidiens, ce qui permet une grande dilatation de la bouche. La màchoire inférieure s’unit 
au crìne par l'intermédiaire d'un os carrée - Le squelette viscéral est réduit à l'hyoüde, qui porte la langue el offre une ou plusieurs paires de cornes.

Les ceintures seapulaire et pelvienne font défaut chez la plupart des Opliidiens; elles sont rudimentaires chez quelques Sauriens. La partic libre des membres, antérieurs ou postérieurs, peut ètre également très réduite ou nulle; quand elle est bien développée, ello est adaptée soit à la marche (Lézarils), soit à liı natation (Tortues marines), etc.

Le systeme nerveux est encore assez restreint. Cependant, les hémisphères cérébraux commencent à recouvrir les corps optiques. Le cervelet atteint son maximum de déreloppement rhez les Crocodiliens et tend alors it prendre l'aspect de celui des Oiseaux.

L'appareil de l'olfaction n'est. biell développé que chez les Crocodiles et les Tortues; mais. chez les $0_{\mathrm{i}}$ hidiens et les Sauriens, chaque fosse nasale

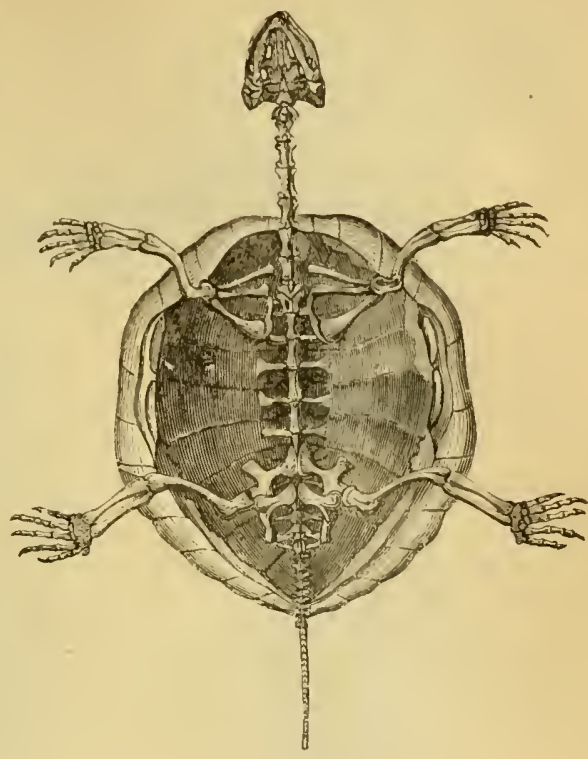

Fig. 707. -- struelette de Tortue. communique avec une cavité dile oryane de Jucobson, qui s'ouvre dans la bouche et reçoit des rameaux des nerfs trijumeau et acoustique. - Les yeux sont dépourvus de paupières chez les Serpents et quelques Sauriens, mais recouverts par la peau qui devient transparente, ce qui donne au regard une étonnante fixité. Les autres Reptiles ont deux paupières; de plus, chez les Chéloniens et les Crocodiliens, il existe à l'angle interne de l'œil une membrane nictitante ou troisième paupière, accompagnée d'une glande dite de Hurler. La sclérotique est souvent munie d'un anneau osseux. Enfin il y a parfois un peigne analogue à celui des Oiseaux. - L'œil pinéal ou pariétal (roir p. 9'l) atteint son plus grand développement chez les Sauriens : il s'engage dans un trou creusé dans le pariétal (os impair), et se trouve recouvert par une écaille plus ou moins transparente. D'après Mathias Duval et lialt, il est parfois accompagné de deux ou trois yeux supplémentaires. L'oreille externe manque toujours; chez. les Serpents, il en est de mème de l'oreille moyenne. Dans les autres groupes, la membrane du tympan est à fleur de tète, et une columelle s'applique i sa lace interne; la caisse du tympan communique largement avec l'arrière-bouclie. Quant à l'oreille interne, on y voit apparaitre un limacon non spiralé, souvent rudimentaire. - Le sens du goût est très imparfait. - Enfin, la sensibilité tactile est peu développée, à cause de la nature des téguments.

L'appareil digestif ofre d'assez importantes rariations à ses deux extrémités. La bouche est toujours très fendue. Chez les Tortues, il n'existe pas de dents, mais une sorte de bec corné. Dans les autres groupes, on ne trouve 
d'ailleurs que des dents préhensiles, coniques ou crochues, servant à retenir la proie et non à la diviser. Elles sont insérées sur les maxillaires, parfois sur les intermaxillaires. D'ordinaire, elles sont simplement soudées aux os; chez les Crocodiles, elles sont implantées dans des alvéoles. Nous verrons plus loin que certaines dents de la màchoire supérieure peuvent ètre en communication avec des glandes à venin. La langue est parfois épaisse et charnue, plus souvent mince, bifide et protractile (Serpents et Lézards); celle

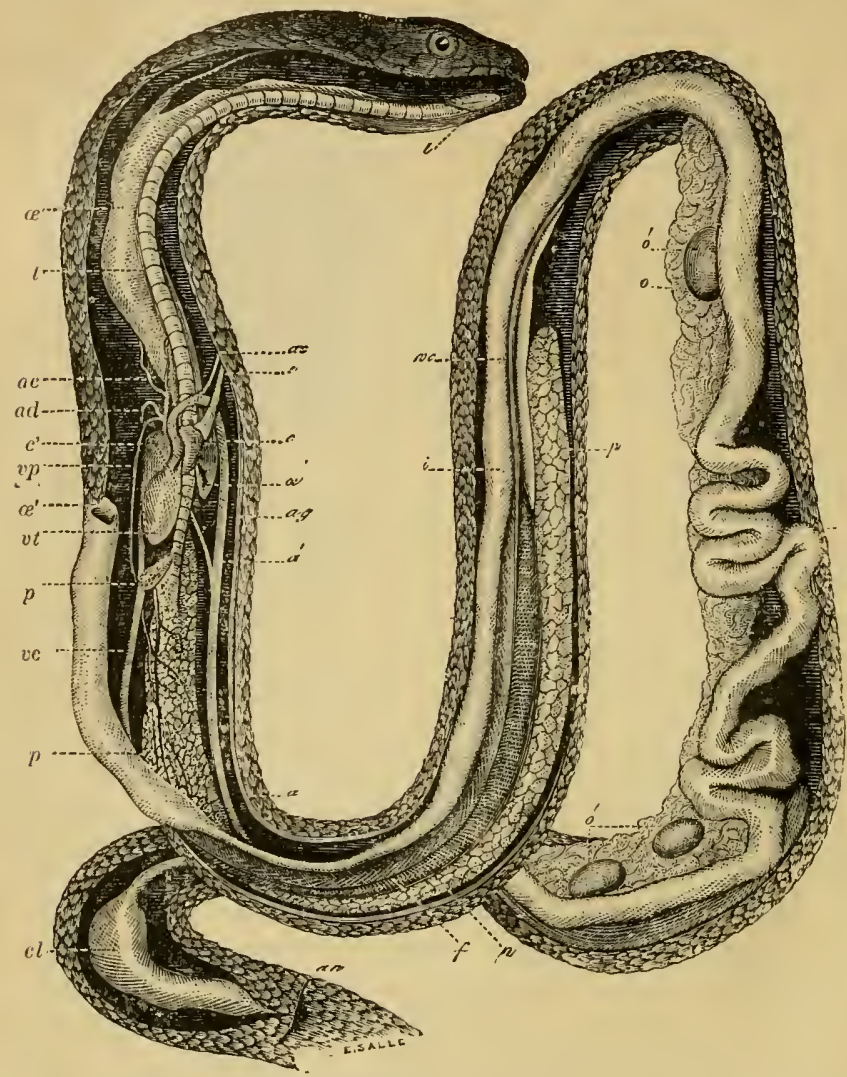

Fig. 708. - Analomie de la Couleuvre, d'après H. Milne-Edwards. - l, langue el glolle. $œ$, œso-

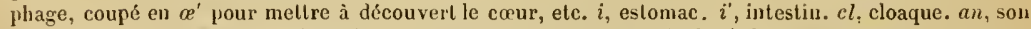
orifice. $f$. foie. $n$, ovaire. $o^{\prime} o^{\prime}$, ceufs. $t$, trachée. $p$, poumon priscipal. $p^{\prime}$, le pelit poumon. $v t$, ventricule du ceur. $c$, oreillette gauche. $c^{\prime}$, oreilletle droite. $a$, aorle gauche. $a d$, aorte droite. $a^{\prime}$, aorte ventrale. $a c$, artères carotides. $v$, veine cave supérieure. $v c$, veine cave inférieure. $v p$, veine pulmonaire.

du Caméléon est un organe de préhension et peut être dardée sur les Insectes à une distance qui dépasse la longueur du corps de l'animal. Les glandes salivaires se réduisent d'ordinaire à des glandules sous-muqueuses; toutefois, les glandes à venin doivent être regardées comme des glandes salivaires modifiées. Le voile du palais n'existe presque jamais, et par suite, le plaarynx n'est pas séparé de la bouche. L'œsophage est en général peu distinct de l'estomac. L'intestin est séparé de celui-ci par une valvule pylorique : un 
foie ct un pancréas y sont annexés. Le gros intestin, souvent dépourvis de caecum, aboutit à un cloague.

L'appareil cireulatoire se perfectionne graduellement, mais il $\mathrm{y}$ a toujours un mélange du sang veineax et du sang artériel. - Chez les Ophidiens, les Sauriens et les Chíloniens, Je cour se compose de deux orcillettes et d'un seul rentricule, mais celui-ci est divisé en denx loges par une cloison incomplète. Ces loges sont séparées chacune de l'oreillettc correspondante par une valvule. La loge gauche noffre d'ordinaire aucun orifice artéliel, mais la loge droite, qui recoit le sang veineux, en présente trois, dont un pulmonaire et deux aortiques. Le sang artériel versé dans la loge gauche doit donc passer dans l'autre compartiment pour ètre lancé dans les vaisseaux aortiques; mais, grice à une séparation bien accusée des deux ordres d'orifices, le sang arlériel ne se trouve que fort peu mélangé de sang veincux. - Chez les Crocodiles, les

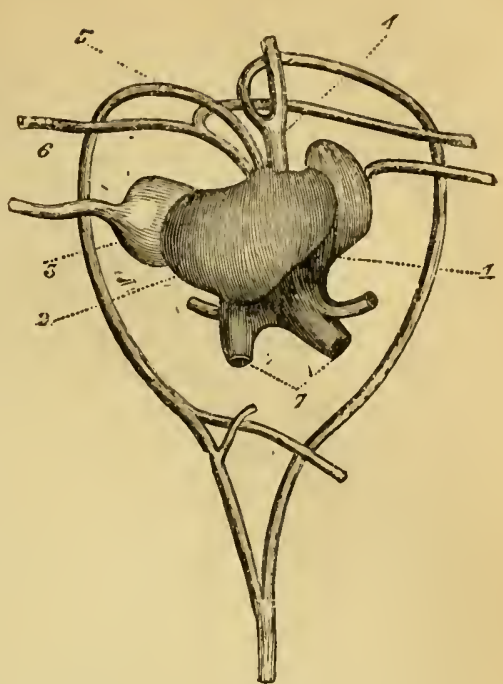

Fig. 709. - Cour et gros trones rasculaires d'une Tortuc. - 1, oreillette droite. 2, ventricule unique. 3 , oreillette gauche. 4 , aorte gauche. 5, aorte droite. 6, artère pulmonaire, divisée en deux branches se rendant chacune a un des poumons. 7 , reines cares.

deux ventricules sont séparés par une cloison complète, mais le ventricule droit émet, comme l'autre, une crosse aortique : ces deux crosses se croisent à leur origine, et communiquent entre elles, a ce niveau, par un pertuis appelé for $a-$ men de Paniza; elles vont ensuite se rénnir pour former l'aorte dorsale, mais la crosse émanée du ventricule gauche a fourni auparavant les trones artériels de la tète et des membres antérieurs. Le sang qui est distribué à ces régions n'est donc mélangé que d'une faible proportion de sang reineux, introduit par le pertuis de Panizza, tandis que celui qui se rend dans les autres parties du corps a reçu tout le sang veineux lancé par la crosse du ventricule droit. - Le nombre complet des ares aortiques provenant des trones primitifs ne peut s'observer que pendant la vie embryonnaire; il subit une réduction considérable au cours du développement. - Les veines cares débouchent dans un sinus qui communique arec l'oreillette.

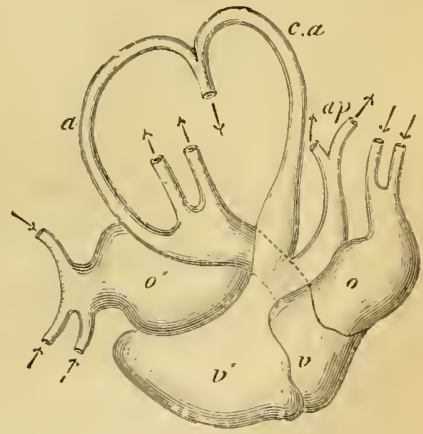

Fig. 710. - Cour et gros trones vasculaires du Crocodilc. $-v$, ventricule gauche, et $v^{\prime}$, veutricule droit, confondus en une scule masse. 0 , oreillette gauchc. $0^{\prime}$, orcillette droite recevant le sang veineux par les veines caves dilatées en un sinus terminal. $a p$, artère pulmonaire. $c u, c a-$ nal artéricl, ou crosse aortique naissant du ventricule droit et passant à gauche. $u$, crosse aortique naissant du ventricule gauche ct croisant la précédente, qu'elle va rejoindre pour former l'aorte descendante.

Le système porte rénal tend à se réduire de plus en plus. Quant au système 
lymphatique, il est assez analogue ì celui des Batraciens. Les Crocodiles possèdent des ganglions lym phatiques.

La respiration est toujours pulmonaire. Les poumons consistent en deux sacs à parois alvéolaires, tantôt simples et tantòt partagés, par des cloisons transversales, en plusieurs compartiments. Chez les Ophidiens et les Sauriens serpentiformes, l'un des poumons est plus ou moins atrophié; l'autre est allongé (fig. $708, p, p^{\prime}$ ). Le larynx s'ouvre par une glotte en forme de fente; la trachée est longue et généralement divisée en deux branches qui jamais ne se ramifient par dichotomie comme chez les Nammifères. Le mécanisme de la respiration est le mème que chez les autres Vertébrés : les mouvements d'inspiration et d'expiration se produisent mème chez les Tortues, malgré l'immobilité du thorax (P. Bert). - Le siffement des Serpents est produit parl'expulsion brusque de l'air contenu dans le poumon par la fente glottique resserrée.

Les reins se sont développés sur les canaux excréteurs des corps de Wolff (métanéphros). Ils sont souvent lobés. Les uretères débouchent directement dans le cloaque, sur la paroi antérieure duquel on remarque, chez les Lézards et les Tortues, un enfoncement isolé qui sert de vessie urinaire. L'urine n'est pas toujours fluide : chez les Serpents, elle est solide et blanchàtre.

Les organes génitaux se rapprochent de ceux des Oiseaux. Liappareil mâte se compose de deux testicules. Les canaux déférents s'mnissent souvent à l'uretère, dans leur portion terminale, de manière à constituer un court sinus urogénital. ll existe des organes copulateurs, représentés, chez les Serpents et les Sauriens, par deux tubes crecaux, invaginés au repos et situés dans les angles de la fente cloacale transversale; chez les Crocodiles et les Tortues, l'organe copulateur est simple, médian, plein, hyspopadié, fixé sur la paroi antérieure du cloaque. - Les organes femelles consistent en deux ovaires, suivis chacun d'un oviducte contenant dans sa paroi des glandes propres à sécréter les enveloppes de l'œuf, et débouchant isolément dans le cloaque. On observe des organes copulateurs rudimentaires ou clitoris, disposés d'après le même type que les organes màles correspondants.

Les Reptiles sont ovipares; pourtant, chez quelques-uns, les œufs séjournent jusqu'à éclosion dans la portion terminale de l'oviducle, qui fonctionne comme utérus (Vip̀̀res, Orvet, etc.). Ces aufs sont presque toujours abandonnés après la ponte; cependant, les Boas les couvent en s'enroulant autour d'eux. - Ils subissent une segmentation partielle. L'embryon est pourvu d'un amnios et d'une allantoïde.

La plupart des Reptiles sont terrestres; il en est aussi qui fréquentent les eaux. Un petit nombre se nourrissent de substances végétales; presque tous sont carnassiers et certains d'entre eux sont dangereux pour l'Homme, en raison de leur force ou de la possession d'un appareil venimeux. Les aniınaux de cette classe apparaissent dans les terrains primaires; mais ils sont surtout répandus dans les couches secondaires.

D'après ce qui vient d'ètre exposé, les Reptiles se rapprochent beaucoup des Oiseaux : ce sont des Vertébrés ornithoïdes, selon l'expression de de Blainville, et nous avons vu qu'on réunit souvent ces deux classes sous le nom de Sauropsidés.

4 ordres : 

lente cloacale transversale:
Saurophidiens.
Pas de paupières, ni de tympan, ni

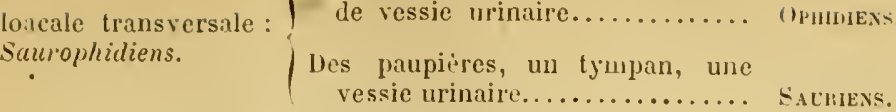
(1PHIIIENS.

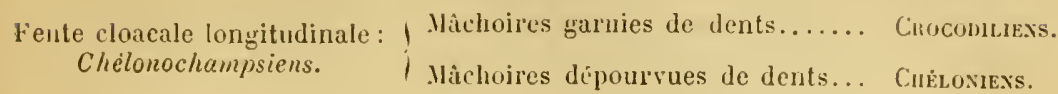

\section{PREMHER ORDRL:}

\section{OPIIDIENS}

\section{Lieptiles apodes, it orifice cloacal transversal et it bonche extensible.}

Les Ophidiens (ọ̈ıı, serpent) ont le corps cylindrique et ne possèdent que par exception des rudiments de pattes postérieures (Boas, Pythons). Le tégument est pourvu d'écailles dont la forme et la disposition varient suirant les espèces. Les parties supérieures et latérales du corps portent des séries obliques de petites écailles lancéolées, lisses (Coronella, Zamenis) ou carénées (Tropidonotus, Vipera). Les còtés et souvent le dessus de la tête portent aussi des plaques de diverses formes. La face ventrale offre de larges squames transversales, formant une rangée simple sous le tronc (gastrostèges), double sous la queue (urostiges). Les mues sont assez fréquentes : I'animal sort de sa vieille enveloppe comme d'un fourreau. - Il n'existe pas de paupières, d'oreille mojenne ni de vessie urinaire. Le pénis est double. La langue est bifide, protractile, absolument inoffensive.

Les rertèbres sont procœliques. Les còtes sont très nombreuses, mais il n'existe pas de sternum. On sait déjà que l'appareil maxillo-palatin est composé d'os très mobiles les uns sur les autres. La machoire inférieure s'articule avec un os carré nobile et long, en forme de baguette; ses deux branches ne sont pas soudées, mais unies par des faisceaux ligamenteux très làches. De là, la possibilité d'une dilatation extraordinaire de la bouche, ce qui permet aux Serpents d'engloutir des proies énormes. Le maxillaire supérieur, le ptérygoïde et le pilatin sont le plus souvent armés de dents; le premier de ces os est allongé et en porte un grand nombre, sauf chez les Protéroglyphes et les Solénoglyphes, où il reste court et ne porte que les crochets venimeux.

Les dents, qui sont le principal élément de la classitication, sont limitées parfois à l'une seulement des deux màchoires. Tous les Ophidiens possèdent des dents lisses et pleines, en forme de crochets insérés dans des alvéoles et incurvés en arrière.

Mais il en est un certain nombre qui présentent en outre des dents spéciales, creusées d'un sillon ou parcourues par un canal central, et en rapport avec une glande à venin dont elles doivent inoculer le produit de sécrétion. Ces crochets venimeux ne se développent que sur le maxillaire supérieur; ils ne sont jamais fixés dans des alvéoles, mais sont reliés simplement ì cet os par un ligament. On en observe toujours plusieurs de chaque côté, diminuant de longueur

Rall.iet. - Zoologie. 
d'arant en arrière; le premier seul reçoit le conduit excréteur de la glande à venin et se trouve solidement fixé au maxillaire; les autres sont des dents de réserve, destinées à le remplacer quand il vient à être arraché ou brisé : ce renouvellement parait même s'effectuer d'une façon normale à de certaines périodes; quelques jours suffisent pour que la substitution soit complète.

On trouve dans la bouche plusieurs paires de glandes dites salivaires, parmi lesquelles nous avons à signaler spécialement la glande labiale supérieure on glande saliraire sus-maxillaire. Elle est disposée en fer à cheval autour de la lèvre supérieure, ses deux moitiés se réunissant sur la ligne médiane. Sa partie antérieure est mème détachér des parties latérales, de manière à former une zone impaire, dite glande du rnuseau. Elle est constituée par de nombreuses glandules en grappe dont les canaux excréteurs débouchent le long du bord interne de la lèvre.

Chez les Aglyphodontes, la région post-oculaire de cette glande a subi des modifications assez considérables qui permettent de la regarder comme une glande spéciale. Celle-ci, assez volumineuse, revêt une teinte blanc jaunàıre; les cellules qui tapissent ses acini sont remplies de granulations; enfin, elle possède un canal excréteur unique, qui va déboucher au niveau des grandes dents postérieures. En somme, elle a déjà les caractères d'une glande venimeuse, bien qu'elle soit privée d'un véritable appareil d'inoculation. Ghez les Opisthoglyphes, oì elle présente à peu près les mêmes caractères, cet appareil est différencié.

La glande à venin des Protéroglyphes et des Solénoglyphes a la mème origine, mais ses rapports sont quelque peu changés en raison de ce que les dents venimeuses sont reportées en avant. Elle occupe la zone temporale et se trouve enfermée dans une capsule fibreuse sur laquelle s'insère le muscle temporal antérieur; de plus, les muscles temporaux moyen et postérieur passent au-dessus d'elle et la compriment au moment même ou ils déterminent la fermeture des mâchoires, de sorte que le venin est alors expulsé mécaniquement : il s'écoule par le canal excréteur, qui va s'ouvrir à la base du crochet venimeux. Le volume de la glande, et par suite la quantité de venin qu'elle fournit, sont en rapport plus ou moins direct avec la taille du Serpent; du reste, il convient de remarquer que la provision n'est jamais épuisée en une seule fois.

Le venin est un liquide visqueux, limpide, incolore, ambré ou verdâtre, inodore, insipide ou plus rarement amer et caustique (Cobra); il a une densité de 1,030 à 1,045\%. Au moment de l'émission, il a toujours une réaction acide. L'examen microscopique ne montre, dans le produit frais, que de rares cellules épithéliales provenant des culs-de-sac sécréteurs et des conduits excréteurs, en même temps qu'un petit nombre de granulations albumineuses. Exposé à l'air, il se dessèche en prenant l'aspect d'un vernis écailleux; il peut alors conserver très longtemps son activité, et l'on conçoit ainsi combien 
il est dangereux de manier les crochets des animaux de collections; d'ailleurs, beaucoup de peuplades sauvages empoisonnent leurs thèches avec du venin de Serpents. Il importe pourtant de remarquer que cette activité diminue dans une certaine mesure : ainsi, d'après Calmette, le renin frais de Cobra tue le lapin à la dose de $0^{\mathrm{mgr}}, 203 \mathrm{par}$ kilogramme; conservé ì l'état sec depuis un an, il neétait plus toxique qu'ì la dose de $0^{\mathrm{mgr}}, 80$; après plusieurs années, cette dose devait être portée à $1^{\mathrm{mgr}}, 30$. Au contraire, en diluant le renin dans cinq fois son poids de glycérine pure à $30^{\circ}$, le pouroir toxique sétait conservé entier pendant un an. Sous l'intluence de l'humidité, le produit subirait la décomposition putride et perdrait peu ì peu ses propriétés.

La composition chimique du venin des Serpents est encore bien peu connue. En 1843, Lucien Bonaparte, analysant le venin de la Vipère, y trouva les sulistances suivantes, à l'état de dissolution dans l'eau : de l'albumine, du mucus, une substance soluble dans l'alcool, une matière colorante jaune, une matière grasse, les sels (phosphates et chlorures), enfin une substance albuminoïde spéciale, non coagulable à $100^{\circ}$ C., qu'il considéra comme le principe actif, et à laquelle il donna le nom de viperine ou échidnine. Weir-Mitchell trouva au venin de Crotale une composition analogue, et put en extraire aussi une substance albuminoïde qu'il appela crotaline. De mène, on a trouvé dans le venin de Cobra de la najine, etc. Tous ces albuminoïdes paraissent ètre très voisins les uns des autres, et Viand-GrandMarais proposait de les réunir sous le nom générique d'échidnines ou échidnases.

En 1886, Weir-llitchell et Reichert, étudiant les venins du Crotale et du Cobra, purent en extraire trois substances différentes, qu'ils dénommèrent peptone-venin, globuline-venin, albumine-venin. La globuline-venin semble agir comme le venin complet; la peptone-venin est moins active; l'albumine-renin est inoffensive. A peu près en même temps, Wolfenden attribuait la toxicité du venin égalenent à des substances protéiques : il signalait une globuline, une sérine, une acidalbunine et une peptone.

D’autre part, Winter Blyth arait trouvé en 1877, dans le venin dı Cobra, une substance acidulée et cristallisable (acide cobrique). Enfin, en 1881-1882, A. Gautier y découvrail deux alcalö̈les n'existant qu'en très minime proportion, et du reste peu actifs : l'un provoque la défécation et produit de l'essoufflement et de la stupeur; l'autre plonge l'animal inoculé dans un long sommeil dont il s'éreille bien portant. - Ajoutons que Wolfenden n'a pu retrouver ces substances dans le venin très frais; les alcaloïdes d'A. Gautier seraient donc des ptomaïnes, développées par un commencenent de putréfaction.

En résumé, les principes actifs du venin de Serpent seraient essentiellement représentés par des matières albuminoïdes (toxalbumines) de la nature des globulines et des peptones.

Mais l'étude physiologique du venin de Vipère a permis de reconnaître que ce produit dévcloppe deux ordres distincts de phénomènes: troubles locaux et troubles généraux, qui peurent être disso- 
ciés, soit au moyen de substances chimiques (Kaufmann), soit par l'intervention de la chaleur (Phisalix et Bertrand). Le permanganate de potasse et l'acide chromique, par exemple, suppriment complètement les effets locaux; une ébullition de 20 à 20 secondes donne exactement le même résultat. Le venin semble donc renfermer deux principes actifs différents : $1^{\circ}$ une substance à action phlogogène, comparable à certaines diastases, et à laquelle Plisalix et Bertrand proposent de réserver le nom d'échidnase; $2^{\circ}$ une substance à action générale, qu'ils appellent échidnotorine.

Les troubles qui caractérisent l'action du venin sur l'organisme reçoivent le nom d'envenimation ophidienne ou d'échidnisme. Ils varient suivant une foule de conditions dépendant à la fois de l'animal inoculateur et du sujet inoculé.

En premier lieu, les différentes espèces de Serpents venimeux fournissent, ainsi qu'il a été dit plus haut, une quantité très variable de venin. Ainsi, les glandes d'une Vipère commune peuvent contenir, lorsque celle-ci na pas mordu depuis un certain temps, $0^{g r}, 07$ de renin chacune, soit $0^{\mathrm{gr}}, 14$ en tout; mais la totalité n'est pas rersée dans une blessure. Ln Péliade bérus en donne $0^{\mathrm{gr}}, 10$ seulement, tandis qu'un Cobra en offre $1^{\mathrm{gr}}, 20$ et un Crotale plus de $1^{\mathrm{gr}}, \check{0} 0$. Or, le venin agit à la façon d'un poison chimique, et par conséquent le danger des morsures est en raison de la quantité inoculée. Il faut noter en outre que le liquide ne se reproduit pas instantanément, de sorte qu'un Serpent est d'autant moins dangereux qu'il a effectué des morsures plus récentes et plus nombreuses.

Le venin des Ophidiens parait n'avoir aucune action sur les organismes unicellulaires. La plupart des Invertébrés y sont à peine sensibles, et d'une façon générale les Vertébrés y résistent d'autant mieux que leur température propre est moins élevée. Les Vertébrés à sang froid n'en subissent d'ordinaire les effets que d'une façon assez lente (à moins qu'on n'élère artificiellement leur température) et parfois même ne succombent pas; les Mammifères sont au contraire très sensibles à son endroit, et les Oiseaux le sont encore davantage. Chez les animaux d'une même classe, d'ailleurs, le degré de résistance varie suivant l'espèce, la race, le sexe, l'àge et la conslitution.

Le venin ne produit pas d'accidents lorsqu'il est introduit dans le tube digestif : Redi a pu avaler une dose sérieuse de venin de Vipère sans en être incommodé; Viaud-Grand-Narais en a goûté de même sans inconvénient, alors qu'il était atteint de gingivite scorbutique. Sans doute le poison est absorbé par la inuqueuse intestinale, mais d'une façon très lente, de sorte qu'il est éliminé sans produire d'effets sensibles. Sur la conjonctive, l'action est également nulle, comme aussi sur la peau intacte. Si la peau est excoriée, il peut se dévelop- 
per quelques effets locaux, mais on n'a jamais vu survenir d'aceidents mortels (Fontana).

Injecté dans la profondeur des lissus vivants, le venin agit arec une rapidité et une énergie variables suivant la nature de ces lissus. s'ils sont peu vasculaires, l'absorption est lente, et les accidents sont souvent peu marqués; par contre, si la régiou est riche en vaisseaux, les troubles apparaissent rapidement et prennent un caractère grave; ¿ plus forte raison si le veniu est injecté directement dans les veines. D’après liaufmann, le venin déposé sur une plaic largement ouverte ne produit qu'une escharification locale des tissus, et la mort ne survient que dans des cas exceptionnels.

Un fait remarquable, c'est que le venin d'un Serpent reste sans action sur les animaux de son espèce et même, l’une faron générale, sur les autres Serpents renimeux, que ceux-ci possèdent ou non un appareil d’inoculation différencié (1). Ciest un l'ait dı nềne ordre que celui que nous avons signalé pour les Batraciens venimeux (Voy. p. 98' et p. 987). Phisalix et Bertrand ont démontré, pour la Vipère commune et deux Couleuvres (T'ropidonolus), que l'explication peut en ètre fournie par la présence dans le sang de principes toxiques semblables à ceux du venin.

Nous ne pouvons nous arrèter à décrire en détail les symptômes de l'échidnisme. Rappelons toutefois que ces symptômes doirent être distingués en locaux et généraux. Les premiers sont essentiellement d'ordre inflammatoire; ils peuvent être assez intenses pour entraîner la gangrène des tissus et le développement de lymphangites arec engorgements ganglionnaires. Quant aux troubles généraux, ils témoignent surtout d'une action profonde sur le systìme nerveux, action qui retentit à des degrés divers sur les fonclions digestives. sur la circulation, la respiration, etc. Il n'est pas très rare même de roir se manifester des accidents lointains : cachexic, affaiblissement persistant de l'ouie, de la vue el de l'odorat, douleurs périodiques au niveau de la région blessée. La mort, dans le cas d'intoxication ophidienne, résulte, d'après Kaufmann, de l'action paralysantc qu'exerce le venin sur les pelits vaisseaux et les capillaires, d'une modification des globules sanguins qui les rend aptes à sortir des vaisseaux, enfin dune action stupéfiante et paralysante portant sur les centres nerveux, el en particulier sur le centre respiratoire. Dans quelques cas aussi, elle peut être l'aboutissant d'une infection

(1) G. Pursalix el G. Bertraxd, Toxicité du sang de la Vipère (Vipera aspis L.). Comptes rendus de l'Acad. des sc., CXV11, p. 1099, 1893. - A. Calsmette, Sur la toxicite du sang de Cobra capel. Comptes rendus de la Soc. de biol., (9, Vl, p. 11, 1894. - Id., Sur la présence de glandes venimeuses chez les Couleuvres et la toxicité du sang de ces animaux. lbid., GXVIII, p. i6, 189'. Voir aussi Archives de physiol., (5), Vl, p. 423, 189'. - S. Jolrdaix, Quelques observations à propos du venin des Serpents. Comptes rendus de l'Acad. des sc., CXVIII, p. 207, 1891. - C. Puisalix et G. Bertraxd, Sur les effets de lablation des glandes a venin chez la Vipere. Ibid., CXIX, p. 919, 1894 . 
microbienne secondaire ayant pour foyer les altérations locales.

Le venin inoculé se retrouve toujours en assez forte proportion dans les tissus altérés qui avoisinent le siège de la blessure: il s’accumule d'ailleurs dans le sang et s'élimine par les reins, par les glandes salivaires, par la muqueuse gastrique et probablement aussi par la muqueuse intestinale, enfin par la mamelle. D'après ces données, il convient de proscrire la manipulation et la consommation des viandes provenant d'animaux empoisonnés par le venin des Serpents.

En raison de la haute gravité des accidents d'échidnisme, il serait bien désirable de pouvoir communiquer à l'Homme et aux animaux utiles une immunité à leur endroit. Or, depuis quelque temps, des résultats intéressants ont déjà été obtenus dans ce sens (1). Il est de croyance vulgaire, dans certains pays, que les jongleurs et les charmeurs de Serpents se mettent à l'abri des effets du venin, soit en avalant, soit en sinoculant celui-ci à petites doses. Kaufmann a montré que de telles inoculations, fréquemment répétées, donnent lieu à une accoutumance lente et progressive, à une résistance plus grande, non à une immunité réelle. Calmette dit être parvenu, en échelonnant les inoculations à des intervalles de huit à dix jours, à donner une immunité contre des doses au moins huit fois moltelles. En 1892, le même auteur avait obtenu un léger degré d'accoutumance au moyen de venins chauffés à $98^{\circ}$; en 1894, Phisalix et Bertrand ont établi que le venin de Vipère, chauffé au bain-marie pendant cinq minutes à $73^{\circ}, 80^{\circ}$ et $90^{\circ}$, acquiert des propriétés vaccinales suffisantes pour que le sujet inoculé puisse résister à l'inoculation d'une dose égale (et mortelle) de venin actif. Enfin, Calmette a encore obtenu l’immunisation, chez les petits animaux : $1^{\circ}$ par l'injection, plusieurs fois répétée, de mélanges de venin à dose mortelle avec des quantités décroissantes de chlorure d'or ou mieux d'hypochlorite de chaux ou de soude; $2^{\circ}$ par l'injection d'une dose mortelle de venin pur, suivie de guérison conséculive à des injections de chlorure de chaux; $3^{\circ}$ par l'injection sous-cutanée, pendant plusieurs jours, de certaines substances chimiques, telles que les hypochlorites de soude ou de chaux, sans mélange de venin. L'immunité conférée par ces divers moyens paraît assez durable, bien que la limite de cette durée n'ait pas encore été fixée d'une façon précise.

Un fait important, qu'ont mis en évidence les recherches de Phisalix et Bertrand, puis celles de Calmette, c'est que le sérum des animaux immunisés de la sorte contre les venins possède lui-même des propriétés vaccinantes, et ce, non seulement contre le venin du

(1) M. Kaurmans, Le traitement des morsures de Serpent. Revue scientif., XLV, p. 180, 1590. - C. Pinsalix et G. Bertrand, Atténuation du venin de Vipère par la chaleur et vaccination du Cobaye contre ce venin. Comptes rendus Acad. sc., CXVIII, p. 288, 1894. - A. Calmetre, Étude expérimentale du venin de Naja tripudians ou Cobra capet, etc. Annales de l'Inst. Pasteur, VI, p. 160, 1892. - ID., Contribution à l'étude du venin des Serpents. lbid., VIIl, p. 275, 1 \$9i. 
mème Serpent, mais aussi contre celui des autres Ophidiens (1). D’après les premiers de ces auteurs, ces propriétés immunisantes dont jouit le sérum ne résultent pas de la circulation dans le sang de la matière vaccinante (échidno-vaccin) introduite dans l'organisme : elles n'apparaissent en elfet qu'au bout d'un certain temps ( 48 hreures), et résultent par conséquent d'une réaction de l'organisme, qui donne naissance à une substance antitoxique neutralisant physiologiquement les effets du venin. Ces résultats sont tout a fait comparables à ceux qui ont été obtenus à l'endroit de certaines maladies infectieuses, telles que le tétanos et la diphtérie. Roux a mème signalé tout récemment ce fait remarquable, que le sérum des Lapins raccinés contre la rage est antivenimeux ì un haut degré.

Le traitement de l'envenimation ophidienne comporte des indications assez précises. Lorsqu'un sujet vient d'ètre mordu par un Serpent renimeux, il faut répondre immédiatement aux trois conditions suivantes : $1^{\circ}$ opposer un obstacle à la pénétration du venin dans le torrent circulatoire; $2^{\circ}$ enrayer le développement des accidents locaux; $3^{\circ}$ chercher, s’il y a lieu, à restreindre la manifestation des phẻnomènes généraux.

$I^{\circ}$ Pour empêcher la pénétration dans le sang d'une dose toxique de venin, on recommande tout d'abord de placer, si la chose est possible, un lien modérément serré entre le cœur et la piqûre. La circulation du sang et de la lymphe se trourant de la sorte arrêtée ou du moins fort ralentic, l'absorption du venin n'a lieu que dans de faibles proportions, et son élimination survient sans qüil se déreloppe d'accidents graves. On a même conseillé d'enlever le lien de temps en temps et de le replacer un peu plus loin, de manière à éviter l'étranglement des tissus et la gangrène, tout en permettant au venin d'envahir la circulation par petites doses. Mais, d'une façon générale, la ligature ne peut être employée que comme moyen provisoire, en attendant la mise en ourre de moyens actifs.

L'un de ces moyens, qu'il est presque toujours possible d'employer, consiste à débrider, à inciser (à l'aise d'un canif, par exemple) les tissus au niveau des piqûres d'inoculation, et à faire saigner abondamment la plaie ainsi produite par des pressions exercées sur les parties roisines. La succion de cette plaie est sans danger, comme on le sait, surtout si lon a soin de cracher immédiatement le produit aspiré; mais elle n'êst peut-être pas aussi utile qu'on l'a supposé.

20 Il est de beaucoup préférable, si les circonstances le permettent,

(1) C. Phisalix et G. Bertand, Sur la propriété antiloxique du sang des animazx vaccinés contre le venin de Vipère. Comptes rendus Soc. de biol., (9), V1, P. 111, 189\%. - A. Calmetre, L'immunisation artificielle des mimaux contre le venin des Serpents, etc. Ibid., p. 120. Voil aussi p. 12' et 204. - Pusalix et Bertrand, Recherches experimentales sur le venin de Vipere. Archives de physiol. norm. et pathol., (5), V1, p. 567, 1894. - Io., Propriétés antitoxiques du sang des animaux vaccines contre le venin de Vipère. Itid., p. 611. 
de chercher à détruire le venin sur place par l'injection de substances antitoxiques, pratiquée aussitót que possible après l'application de la ligature.

Depuis longtemps on a préconisé dans ce but une foule de subs-tances dont la plupart n'ont en réalité aucune action. Tel est le cas, notamment, de l'ammoniaque, de l'alcool, de l'acide phénique, ete., etc. L'emploi des caustiques chimiques, et même de la cautérisation au fer rouge, qui agissent en détruisant les tissus et retardant l'absorption, est trop violent, trop douloureux pour être recommandé. Mais on connaît aujourd'hui plusieurs substances capables d'atténuer ou de faire disparaitre l'action toxique du venin; telles sont : le permanganate de potasse (de Lacerda), lacide chromique (Kaufmann), le chlorure d'or, les hypochlorites de soude et surtout de chaux (Calmette), l'iodure et surtout le chlorure de fer (Mitchell).

Le mode d'emploi de ces substances est assez simple : on en injecte la solution aqueuse, ì l'aide d'une seringue de Pravaz, dans les plaies d'inoculation et dans les tissus roisins jusquà une assez. grande distance; puis on enlève le lien et on lave largement la région arec une solution plus concentrée. A défaut de seringue, on verse quelques gouttes du produit dans les plaies préalablement débridées, puis on exprime bien le sang des tissus, et l'on applique enfin un pansement imbibé de la solution.

Le permanganate de potasse et l'acide chromique s'emploient en solution aqueuse it 1 p. 100; pour les injections d'bypochlorite de soude ou de chaux, il convient d'avoir en réserve une solution correspondant à 4 litres ou 4 litres 5 de chlore par litre; au moment de l'usage, on dilue $\breve{5}$ centimètres cubes de cette solution dans timètres cubes d'eau bouillie, car les dilutions étendues préparées d'arance n'ont plus d'action efficace; on doit injecter dans les tissus 20 à 30 centimètres cubes de la dilution récente.

Calmette rapporte que, dans les expériences faites sur le lapin, l'intervention simple à l'aide du chlorure de chaux, sans ligature, était toujours efficace ringt minutes après l'inoculation d'une dose de venin derant amener la mort en deux heures; de 20 à $2 \ddot{3}$ minutes, elle était encore très souvent utile. Or, chez l'Homme, il est extrêmement rare que les morsures de Serpents soient mortelles à si bref délai.

$3^{\circ} \mathrm{Si}$, en dépit du traitement local, une certainẹ quantité de venin a pénétré dans le torrent circulatoire, on voit bientôt apparaittre des accidents généraux. Bien des substances ont été préconisées encore pour combattre ces troubles, et presque toutes, il faut bien le dire, sans aucun fondement. Le but qu'il faut se proposer en pareil cas, c'est de soutenir l'énergie cardiaque du blessé, et de favoriser l'élimination du venin. La première indication peut être remplie à l'aide d'une faible dose de morphine ou de caféine administrée par la voie 
sous-cutanée. Quant à la seconde, elle comporte habituellement l'usage de l'ammoniaque el des boissons alcooliques, celles-ci données à petites doses, l'réquemment renouvelées, de manière à maintenir le malade dans un état de légère excitation, tout en évitant de l'enivrer, a cause des eflets dépressifs de l'alcool à haute dose.

Mais les récentes expériences de Calmetle laissent entrevoir un traitement général beaucoup plus simple et plus efficace: il s'agit des injections de sérum immunisant. Nous avons ru plus haut que le sérum des animaux immunisés contre les venins possède lui-même des propriétés vaccinantes, permettant de l'utiliser sous forme d'injections préventives. Calmette affirme en ontre quil possède un pouvoir thérapeutique manifeste, en ce sens qu'il est capable d'arrêter et de guérir les accidents de l'envenimation lorsqu'on l'injecte un certain temps après l'inoculation renimeuse. Ainsi, des Lapins inoculés a vec 1 milligramme de venin de Cobra meurent en 3 à 4 heures; ceux auxquels on injecte sous la peau ou dans le péritoine 5 centimètres cubes de sérum immunisant, après une demi-heure ou une heure, résistent fous; ceux qui en reçoivent la même quantité après une heure ou une heure et demie résistent encore dans la proportion de deux sur trois; passé ce délai, la guérison n'est plus obtenue, mais le traitement amène toujours une survie de 30 à 48 heures.

Les premiers résultats de la sérothérapie appliquée au traitement de l'envenimation sont donc assez encourageants pour pcrmettre d'espérer que la méthode sera bientôt applicable a l'Homme et rendra les plus grands services, surtout dans les colonies, ou chaque année des milliers de personnes doivent la mort aux morsures des Serpents venimeux.

Mais il est évident que le mieux est encore de poursuivre. autant qu'il est possible, la destruction de ces dangereux animaux. En France, nous en possédons encore un trop grand nombre (Vipères), et à direrses reprises l'attention des pouvoirs publics a dû être appelée sur les mesures à prendre à leur endroit. On a proposé, notamment, de favoriser la multiplication des animaux destructeur's de Serpents, le défrichement et l'incendie des terrains infestés, enfin, la distribution de primes aux chasseurs de Vipères.

Les animaux aptes à détruire nos Serpents indigènes sont : parmi les Oiseaux, les grands Rapaces, tels que Buses, Milans, GrandsDucs; les Corbeaux et les Pies; entin, la plupart des Oiseanx de basse-cour, notamment les Paons, Dindons, Pintades, très habiles à tuer les Vipères à coups de bec, tout en évitant leurs atteintes; parmi les Mammifères, la Fouine, le Putois, le Sanglier, le Porc et le Hérisson. Les Porcs peurent, en parliculier, rendre de grands services à ce point de vue, protégés qu ills sont par l'épaisseur de leur peau et de leur couche adipeuse sous-cutanée; mais l'animal le plus utile est encore le Hérisson. Celui-ci s'avance sur la Vipère en 
retirant son museau sous le corps, et en rabattant son casque épineux, sur lequel le Reptile frappe vainement et perd son venin. Il est cependant établi, par une expérience de Kaufmann, que le Hérisson n'est pas réfractaire au venin de la Vipère; il n'échappe au danger que par la faculté qu'il possède d'éviter les morsures.

Les défrichements et le feu contribuent aussi à faire disparaître les Serpents; mais la mesure la plus efficace pour assurer la destruction des Vipères consiste dans l'attribution de primes aux individus qui se chargent de faire la chasse à ces animaux, à la condilion toutefois que cette attribution soit faite d'une facon rationnelle : la prime à accorder par tête de Serpent présentée ì l'autorité doit être assez élevée, et d’ailleurs plus considérable pendant la période vernale, de mars à juin; en outre, la mesure doit être générale.

Les Ophidiens se laissent diviser en quatre sous-ordres : Opoterodontes, Colubriformes, Protéroglyphes et Solénoglyphes.

\section{PREMIER SOUS-ORDRE}

\section{OPOTÉRODONTES}

Ce sont de petits Serpents verniformes, à bouche étroite, non exteusible, pourvue de dents lisses, et seulement ì l'une ou à l'autre des deux máchoires (orórepos, l'un ou l'autre; óoú;, dent). Ils vivent solls les pierres ou dans des trous, et se nourrissent de Vers el d'Insectes.

Le Typhlops vermicularis, de Grèce, est la seule espèce européenne du groupe.

DEUXIÈME SOUS-ORDRE

\section{COLUBRIFORMES}

Ces Ophidieus possèdent des dents aux deux máchoires; souvent ces dents sont toutes lisses; parfois la màchoire supérieure porte en arrière des dents cannelées ou non, en rapport avec une glande à venin; en tout cas, il n'y a jamais de dents venimenses en avant, et, par suite, la morsure des Colubriformes est peu dangereuse.

On peut établir dans ce groupe trois sections principales : Tortricines, Aglyphodontes et Opisthoglyphes.

A. Les Tortricines sont de petits Serpents non venimeux, à dents lisses, à bouche non extensible; ils vivent dans les régions chaudes de l'Asie, de l'Amérique et de l'Océanie.

B. Les Aglyphodontes ne possèdent également que des dents lisses ( $\dot{\alpha}$ pri-

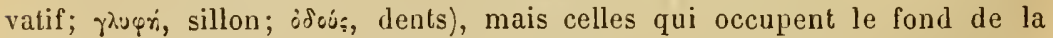
màchoire supérieure sont souvent en rapport avec une glande à venin, et partant représentent un appareil d'inoculation incomplet, ou non différencié. La gueule est extensible.

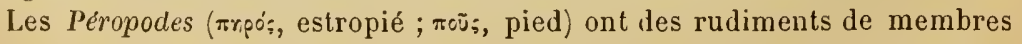


postérieurs, sous forme d'éperons cornés. Quelques-uns, comme les Pythons el les Boas, acquièrent une taille et une force qui les rendent redoulables.

Les Colubridés comprennent ỉa plupart de nos Couleuvres indigènes. Ce sont des Serpents tout á fait apodes, à corps svelte, à queue assez allongée, à tète peu large, revètue de plaques plus grandes que celles du dos, enfin à pupilles arrondies. - Dans cette importante famille se placent d'abord les Tropidonotes (Tropiclonotus), qu'on peut qualifier de Couleurres aquatiques, car clles recherchent les lieux humides et chassent volontier's dans l'eau, se nourrissant de Vers, de Batraciens et de Poissons. La Couleure à collier (Tr. natrix), dont le nom est tiré dı collier blanc jaunàtre qu'elle montre sur la muque, et la Couleuvre vipérine ( $T r$. ciperinus), qui offre à première vue de grandes ressemblances avec la Vipère commune, sont deux espèces assez répandues en France. Comme il a été dit plus haut, elles possèdent des glandes venimeuses (R. Blanchard, Phisalix et Bertrand), mais l'appareil d'inoculation, très incomplet, n'est représenté que par les dents postérieures, non cannelées, qu'enloure un manchon muqueux. Néanmoins, il n'est pas inutile de rappeler que, dans nos campagnes, les morsures des Couleuvres ont la réputation d'ètre parfois suivies d'accidents. - Aux Couleurres

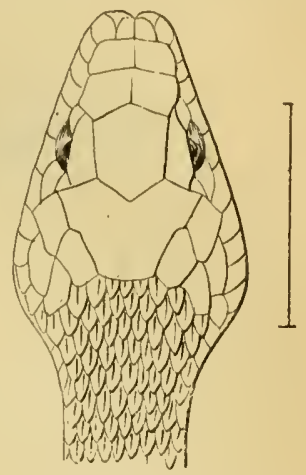

Fig. 711. - Tète de la Couleuvre à collier (Tropidonotus natrix). rraies (Coluber) se rattache la Couleuvre d'Esculape (C. Esculupii), qui se rencontre dans la France méridionale et jusquà Fontainebleau; c'est elle que les Romains conservaient dans des temples élevés au voisinage des thermes, ou le dieu de la médecine était représenté la tenant enroulée autour de son bâton, comme un symbole de prudence. - Les Rhinéchis (Rhinechis) ont le museau pointu, retroussé en boutoir. Couleuvre à échelons ( $R h$. scalaris), France méridionale; très agrressive; détruit beaucoup de Rongeurs et d'Oiseaux. - Couleuvre à quatre raies (Elaphis quaterradiatus), France mérillionale. - Couleurre verte el jaune (Zumenis viridiflavus), agressive; France méridionale. - Les Coronelles (Coronella) ont les dents postérieures plus longues que les autres, sans toutefois en ìtre séparées. Couleuvre lisse $(C$. austriac $t)$ et C. bordelaise (C. girundica), France méridionale. - En général, les Ciouleuvres se nourrissent de Vers, d'Insectes, de petits Oiseaux, etc. Quelques personnes les mangent (Anguilles de haies). D'après Jourdain, la Couleuvre d'Esculitpe, la C. lisse et la C. à échelons présentent, à l'endroit du venin de Vipère, une immunité semblable à celle que Phisalix et Bertrand ont constatée pour les Tropidonoles; il est donc probable que ces Ophidiens possèdent aussi des glandes venimeuses et un sang venimeux.

C. Les Opistuoglypues sont caractérisés par la présence, a la partie postérieure de la màchoire supérieure, de deux ou trois dents plus longues que

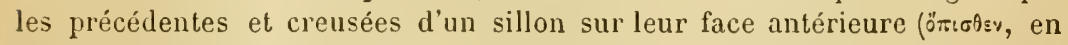
arrière; $\gamma \lambda u \varphi ̣ \dot{r}^{\prime}$, sillon). A ces crochets sont presque toujours ammexées des - Jandes venimeuses; mais, en raison de leur position, il est nécessaire que l'animal ouvre largement la bouche pour que sa morsure soit venimeuse.

Les Célopeltis (Cœlopeltis) seuls comprennent une espèce française : la 
Couleuvre maillée ou Couleurre de Montpellier (C. insignitus), qui, jusqu'à présent, n'a jamais occasionné d'accidents. Cependant, S. Jourdain et d'autres expérimentateurs ont fait périr rapidement de petits animaux (Mammifères, Oiseaux, lézards, Grenouilles) en leur implantant les crochęts de ce Serpent dans les tissus. Mais il faut, pour que la blessure soit mortelle, que la morsure dure au moins trois à quatre minutes (Peracca et Deregibus). Du reste, le Célopeltis a les habitudes des Couleurres : il lutte corps à corps arec sa victime, qu'il étreint dans ses anneaux.

TROISIENE SOUS-ORDRE:

\section{PROTÉRUGLYPIIES}

Ces Serpents sont toujours venimeux. Leurs maxillaires supérieurs por-

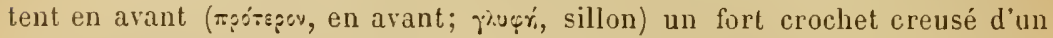
sillon antérieur et communiquant avec une glande à venin. En arrière de ce crochet, les maxillaires montrent souvent des dents pleines; celles-ci existent de même sur les palatins, les ptérygoïdiens et les mäxillaires inférieurs.

Toutes les espèces sont étrangères à l'Europe; elles sont répandues dans les régions chaudes des deux hémisphères.

On pent en distinguer deux groupes:

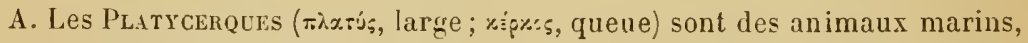
dont la queue est comprimée en rame. Ils sont répandus daus l'océan Indien et l'océan Pacifique; parfois ils remontent les grands fleuves, mais à une faible distance de l'embouchure. Les pêcheurs les ramènent fréquemment dans leurs filets; ils les redoutent au plus haut point, car leur morsure est souvent mortelle pour l'Homme. - Tels sont les Platures et les Hydrophis.

B. Les Conocerques (xüvos, còne) sont au contraire des Serpents terrestres, à queue arrondie. - C'est à ce groupe qu'appartiennent notamment les Najas $(N(\imath j a)$ ou Serpents à. coiffe, remarquables par la faculté qu'ils ont de dilater la région cervicale en écartant les còtes correspondantes, lorsqu'ils sont irrités. Le Serpent à lunettes (N. tripudians) ou Cobra capel, "Cobra de capello " des Portugais, qui porte habituellement sur le cou une tache en forme de' binocle, hibite l'Inde, et c'est même le Serpent venimeux le plus redoutable et le plus répandu dans cette région si riche sous ce rapport (en 1886 le total des décès par morsures de Serpents s'est élevé, dans tou t l'llindoustan, à 22,134, sur une population de 240 millions). L'Haje ( $\boldsymbol{N}$. haje), Aspic ou Serpent de Cléopàtre, habile l'Égypte, la Tunisie et mème l'Algérie (au sud-est de Biskra); il s'étend en Asie jusque dans l’Afghanistan; sa piqùre est très rapidement mortelle.

(UUATRIĖUE SOUS-ORDRE

\section{SOLÉNOGLYPIES}

La mâchoire supérieure est armée, à la partie antérieure et de chaque côté, d un fort crochet en communication avec une glande venimeuse, crochet parcouru par un canal central ouvert à la base et près

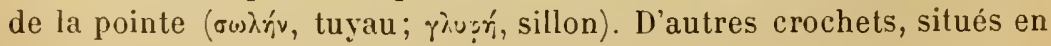


arrière de celui-ci, sont prêts à le remplacer lorsquil vient ì tomber. Le palais et la màchoire inférieure portent en outre de petiles dents pleines.

A l'état de repos, le crochet venimenx est couché en arrière, le long du palais, et protégé par un repli de la muqueuse gingivale. D'après les auteurs

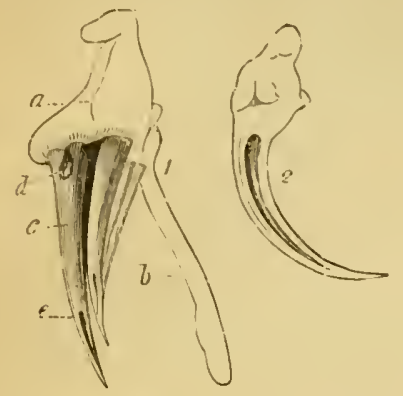

Fig. 712. - Lirochets à venin du Bothrops lanceolatus. - 1. a, maxillaire supérieur. $b$, os ptérygö̈dien externe. $c$, crochet. $d$. son orifice supérieur. $e$, l'inférieur. - 9, l'un des crocliets, fendu dans loule sa longuen. pour montres le canal central.

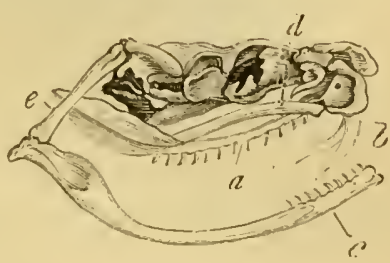

Figg. 713. - Siguelelte de la tite d'un crotale (Crotalus horrilus). - a, plérvooide, s'unissant en arris̀re à l'os carré el se contimuant en avant avec le palalin. $b$, croclıels à venin naissant sur le mavillaire supérieur mobile. $c$, maxillaire iuférieur. $l$, os iransverse. $e$, os carró, arliculé supéricurement arec le squamosil.

classiques, il se redresserait d'une façon mécanique par' le fait mène de l'ouverture des màchoires, de manière à prendre une position favorable à l'attaque. Quand la houche est fermée (fig. 713), disent-ils, l'os carré est incliné en

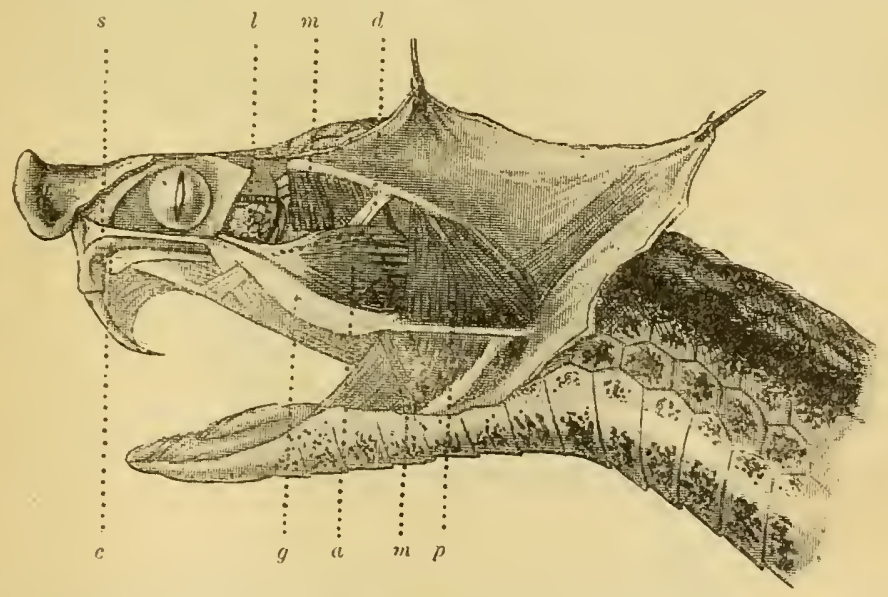

Fig. i14. - Appareil renineux de la Vipère aspic, double de grandeur nalurelle. - g, bord inféricur de la glande à venin recouverle de sa capsule fibreuse; les limites supéricure el postérieure de cette glande sont indiquées par une ligne pointilléc. $c$, eanal excréteur de la glante à venin, au niveau de son renflement. $a$, muscle lemporal antéricuı. $m, m$, lemporal moyen. $p$, lemporal postéricur. $l$, glande lacrymale. $s$, ligament de Soubeiran. $d$, lịgament supérieur de la glaude à venin.

bas et en arrière, le ptérygoïde et le palatin sont à peu près en ligne, et le transverse, articulé en arrière avec le ptẻrygoïde et en avant avec le maxillaire, maintient celui-ci de telle manière que les crochets se trouvent 
dirigés en arrière. Dès que l'animal ouvre la bouche, l'os carré se redresse, pousse en avant le ptérygoïde qui lui est uni, et par suite l'os transverse : celui-ci fait basculerle maxillaire, et les crochets prennent une position verticale. - Mais il résulte d'études encore inédites, faites par Phisalix et Bertrand sur des Vipères vivantes, que ces indications ne sont pas fondées; le crochet ne change mème pas de position quand on ouvre la bouche en évitant de tirer en avant la màchoire inférieure. En réalité, les crochets se redressent sous l'action de muscles spéciaux, et chacun d'eux peut se mouvoir indépendamment de l'autre.

Nous savons déjà que chaque glande ì venin est enveloppée d'une capsule fibreuse sur laquelle s'insère le muscle temporal antérieur, et qu'en outre, le temporal moyen et le temporal postérieur passent audessus d'elle, de manière à la comprimer fortement quand ils se contractent pour rapprocher les mâchoires. Chez la Vipère commune, celte glande se compose de quelques lobes tubuleux eux-nêmes divi-

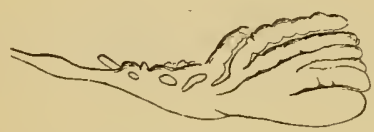

Fig. 715. - Glaude venimeuse gauclıe de la Vipère aspic, arec sa capsule fibreuse, vue par la face externe (Plisalix, inéd.).

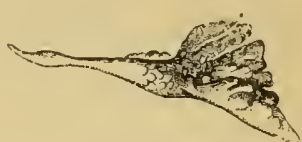

Fig. 716. - Glande venimeuse droile de la Vipère aspic, débarrassée de son enveloppe, et vue par la face interne (Plisalix, inéd.).

sés en nombreux cacums secondaires (fig. 715 à 717), dont chacun est revêtu d'une couche épithéliale à grosses cellules granuleuses (fig. 718). Le canal excréteur, assez court, aboutit à la base de la dent venimeuse; il offre à peine un léger renflement avant sa terminaison,

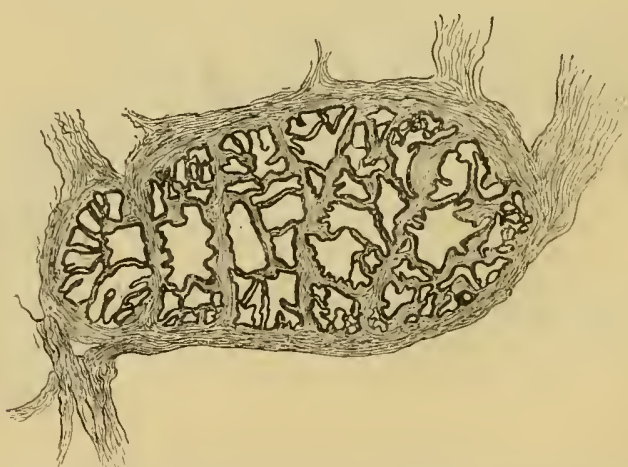

Fig. 717. - Coupe transversale d'une glaude venimeuse de Vipère aspic, grossie environ 16 fois. - Les lisérés noir's figurent les culs-de-sae épillı́liaux (Plisalix, inéd.).

mais il ne s'agit en aucune façon d'un réservoir à renin; comme on peut le voir à la simple inspection de la figure 717 , e'est la glande elle-même qui fait office de réservoir.

Les Solénoglyphes ont le corps trapu, la tête triangulaire élargie 
en arrière, la queue courte, les pupilles verticales. Ce sont en général des animaux nocturnes; ils ne s'attaquent qu’à des animaux vivants, mais se bornent à les frapper de leurs erochets, attendant ensuite

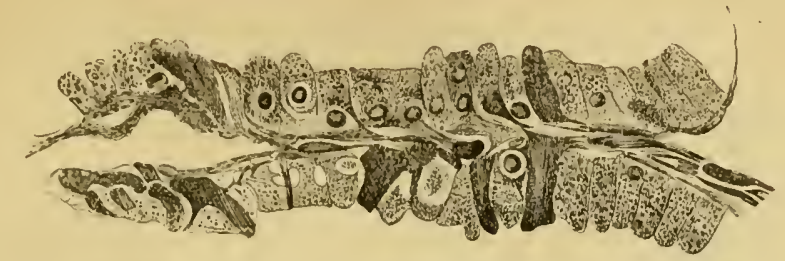

Fig. 718. - Lne des trabécules de la coupe précédente, fortement grossie (fixation à l'acide osmique picro-carminé) (Plisalix, inćl.).

que le venin ait accompli son rúle. Tous paraissent être ovovivipares : dès que les aufs sont déposés à terre, les petits en déchirent la coque molle et se dégagent en rampant.

Les deux familles les plus importantes de ce sous-ordre sont celles des Vipéridés et des Crotalidés.

Les VIPÉRIDES ont une tète large, bien distincte du cou, et dépourvue de fossette entre l'œil et la narine.

Ils compremnent sept genres (Vipera, Daboia, Cerastes, Echis, elc.), tous terrestres, propres à l'ancien continent, et répandus surtout en Afrique.

Les Vipères (Vipera Laurenti) sont caractérisées par leur tète couverte de petites écailles ou de plaques plus ou moins développées. Le museau est garni de petites plaques dans deux desquelles sont percées les narines, situées latéralement. Les plaques sous-caudales (urostèges) sont disposées sur deux rangs.

On a quelquefois classé dans un genre spécial, celui des Péliades (Pelias Herrem) certaines formes qui possèdent, sur le milieu de la tête, trois plaques contiguës assez fortes, rappelant un peu celles des Couleuvres (une frontale et deux pariétales); mais ce caractère n'est ni assez important, ni assez constant pour justifier cette séparation.

On ne trouve en France (1) que trois espèces de Vipères, dont les caractères différentiels sont indiqués dans le tableau ci-dessous, dressé par Boulenger. La première est une Vipère proprement dite; les deux autres sont des Péliades.

A. Plaque sus-oculaire ne s'étendant pas en arrière au deli de la ver-

ticale du bord postérieur de l'cil; écailles en 21 ou 23 rangées.... V. aspis.

B. Plaque sus-oculaire dépassant l'œil en arrière :

a. Écailles en 21 rangées (rarement 19 ou 23); plaque frontale á peine

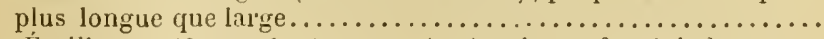

b. Écailles en 19 rangées (rarement :1); plaque frontale beaucoup

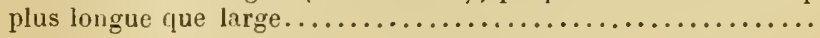

V. berus.

V. Orsinii.

Vipère aspic ( $\mathrm{I}$. aspis L..). - Elle peut atteindre $0^{\mathrm{m}}, 7 ;$ de longueur,

(1) 11. Kavfuaxi, Les Vipères de France. Paris, 1893. 
mais ne dépasse pas ordinairement $0^{\mathrm{m}}, \ddot{3} 0$ à $0^{\mathrm{m}}, 60$. La tète est aplatie, fortement élargie en arrière, recouverte d'écailles lisses en avant des orbites, où elles sont un peu plus grandes que celles du dos, puis entuilées et carénées en arrière, où elles sont plus petites. On remarque en outre, de chaque còté, ıne forte plaque sus-oculaire, qui ne dépasse pas le bord postérieur de l'œil,

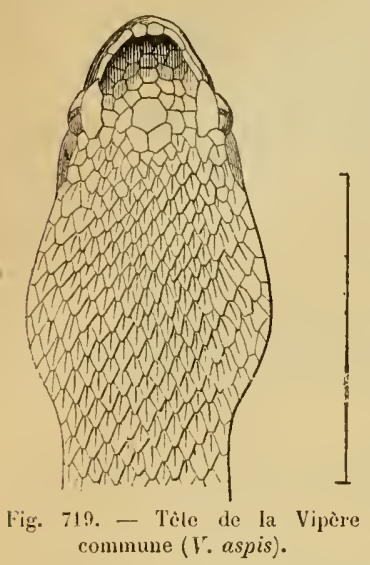

et le plus souvent, entre ces deux plaques et sur la ligne médiane, une ou plusieurs écailles irrégulières, un peu plus grandes que les autres. Le museau est tronqué et un peu retroussé. Le tronc est recouvert d'écailles imbriquées et carénées, formant 21 ou 23 rangées longitudinales. La queue est courte, conique, renflée à la base chez les màles, s'effilant graduellement chez les femelles. La couleur générale est extrêmement variable, tantòt grise, tantòt ferrugineuse, tantòt brune ou mème noire. A la face supérieure de la tète il existe des taches plus ou moins constantes: souvent, en particulier, on observe en arrière deux bandes brunes formant un $\Lambda$ ouvert ou fermé à sa pointe; entin, le los est marqué de deux séries longitudinales de taches noires réunies par des bandes transversales ou obliques, formant une raie en zigzag. Mais il y a tant de diversité dans la coloration et dans la disposition des taches qu'on ne peut guère les faire intervenir comme éléments de diagnose.

D'ailleurs, en dépit des caraclères que nous venons de donner, on rencontre des individus à peine déterminables. Peut-ètre sont-ce des hybrides de $V$. aspis et de $V$. berus.

La Vipère aspic ou Vipère commune ne se rencontre qu'en Europe et dans le nord de l'Algérie. En France, elle est très inégalement répandue : on la trouve en abondance dans certains départements, tels que la Vendée, la Loire-Inférieure, les Deux-Sèvres, Indre-etLoire, Seine-et-Marne, Seine-et-Oise, la Haute-Marne, la Haute-Saône, la Côte-d'Or, le Doubs, l'Areyron, la Haute-Garonne et les Basses-Pyrénées; elle est très rare et manque même dans d'autres, comme le Nord, l'Aisne, les Ardennes, la Marne, Meurthe-et-Moselle, l'Indre, le Cher, la Nièvre, Vaucluse, la Gironde, la Corse, etc. En ce qui a trait aux environs de Paris, on sait qu'elle abonde dans la forêt de Fontainebleau; elle se trouverait aussi dans les forêts de Sénart et de Montmorency.

L'Aspic habite surtout les lieux secs et élevés : les coteaux arides et rocailleux, les pentes sablonneuses couvertes de bruyères et de genèts; il se tient de préférence sur la lisière des bois ou des fourrés de ronces, mais on le rencontre quelquefois jusqu'au milieu des champs. Il se retire l'hiver dans des excavations souterraines, sous les souches, dans la mousse, et il n'est pas rare d'en trouver alors de nombreux individus enroulés en paquets; à ce moment, il est engourdi 
et peu dangereux. Dès le printemps, il quitte sa retraite et se montre dans les endroits découverts, exposés au soleil. Liaccouplement a lieu vers le mois d'avril, puis les Vipères se disseminent. La femelle, qui n'est apte à la reproduction que vers l'âge de cinq ans, donne d'abord deux à cinq Vipereaux; ì un àge plus avancé, elle peut en produire jusqu'à quinze. C'est au mois de septembre qu'a lieu la ponte; les petits se débarrassent aussitót de la coque de l'œuf; ils mesurent alors 13 à 20 centimètres; ils sout aptes à vivre seuls, et se mettent à la chasse des Insectes; leurs morsures sont déjà dangereuses.

Pendant la belle saison, la Vipère sort chaque jour de sa retraite dès le matin et se montre ì découvert tant que la chaleur du soleil n'est pas trop intense; mais elle reste généralement immobile, de sorte qu'on peut supposer qu'etle ne chasse que le soir ou la nuit. Elle se nourrit de Souris, Mulots, Taupes, Musaraignes, petits Oiseaux, peut-être aussi de Lézards et de Batraciens. Elle fuit en général devant l'Homme, et sa démarche est lourde, irrégulière. Mais lorsqu'elle est surprise, ou lorsqu'on l'attaque, elle se roule aussitôt en spirale, puis se détend brusquement, comme un ressort, ouvre largement la gueule, enfonce ses crochets dans la chair par un choc violent et les retire aussitôt. La blessure est facile à distinguer de celle des Couleurres, car elle ne présente que deux piqûres profondes correspondant aux deux crochets venimeux, tandis que les Couleurres font une véritable morsure, caractérisée par l'impression de toutes les dents.

Nous avons dit plus haut que la quantité de venin contenue dans chacun des appareils venimeux de l'Áspic est évaluée à $0^{\mathrm{gr}}, 07$; mais Moquin-Tandon estime que dans chaque piqûre l'animal en dépose seulement $0^{\mathrm{gr}}, 02$, soit $0^{\mathrm{gr}}, 04$ en tout. Cette faible dose est suffisante pour provoquer des troubles fort graves (intoxication vipérique), capables mème d'entrainer la mort chèz l'Homme et les animaux. En ce qui concerne l'Homme, la mortalité par piquures de Vipère présente un taux assez élevé : d'après Viaud-Cirand-Marais, sur 370 morsures relevées en vingt ans dans la Vendée et la Loire-Inférieure, il y a eu 53 cas de mort, soit 1 p. 7 ou 14,00 p. 100; sur ce nombre, 51 décès sont imputables à $V$. aspis, et 2 seulement ì $V$. berus. Mais il est certain que le chiffre de 370 reste bien en dessous de la réalité, car un grand nombre de cas sans gravité n'ont pas été connus; et c'est probablement pour cette raison que le mème auteur, dans ses dernières publications, évaluait la mortalité des blessures d'Aspic en Vendée à 1 p. 2̈, enfants compris.

Parmi les animaux domestiques, les Chiens sont ceux qui sont le plus exposés aux morsures de Vipères, notamment les Chiens de chasse; d'ordinaire les sujets atteints succombent en peu de temps, et ceux qui guérissent montrent souvent un affaiblissement marqué de 
l'odorat Les herbivores sont d'ordinaire mordus aux lèvres ou au nez, en pàturant dans les bois ou le long des buissons; assez sourent on a signalé des cas de mort à la suite de telles blessures, non seulement chez les Moutons et les Chèvres, mais aussi chez le Cheval. Roche-Lubin évaluait à une centaine le nombre des Moutons qui avaient péri de la sorte, dans le Larzac et les Causses, en 1830 . On assure, mais le fait n'est peut-être pas bien établi, que les Chats résistent aux morsures de Vipères.

Pour le traitement de ces blessures renimeuses, nous renverrons à ce qui a été dit plus haut relativement à l"intoxication ophidienne en général.

Il ne faut pas confondre l'Aspic avec la Vipère ammodyte ( $V$. ammodytes),

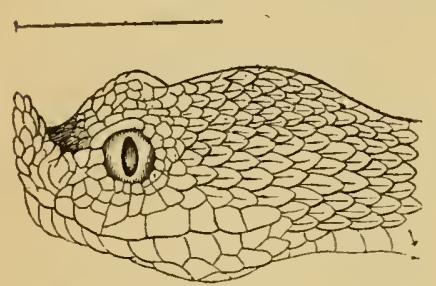

Fig. : 20. - Téte de la Vipère ammodyte (Vipera ammodytes). qui se reconnaît à son museau relevé en une pointe molle couverte d'écailles. Cette espèce habite surtout le sud-est de l'Europe; on la connait aussi du sud de l'Autriche, de l'Italie et de l'Algérie, mais c'est à tort qu'on l'a signalée en France.

Vipère bérus (Vipera berus $\left[\mathrm{L}_{j}\right.$; Pelius berus Duméril et Bibron). - Cette espèce est à peu près aussi longue que la précédente, mais son corps est plus grèle. L.e mâle atteint au maximum $0^{\mathrm{m}}, 6 \ddot{\mathrm{z}}$, la femelle $0^{\mathrm{m}}, 7 \ddot{\mathrm{z}}$. La tète est relativement plus allongée, moins élargie en arrière, et partant moins nettement séparée

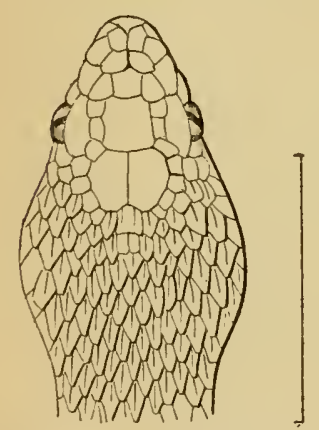

Firg. 721. - Tète de la pelite Vipère (Vipera berus). du tronc; elle porte de chaque côté une plaque sus-oculaire qui dépasse l'œil en arrière; sur le milieu existent en outre trois plaques assez développées, rappelant un peu celles des Couleuvres: une frontale à peine plus longue que large, et deux pariétales, situées immédiatement en arrière. Le museau est régulièrement arrondi. Les écailles du corps forment 21 rangées, exceptionnellement 19 ou 23. La coloration est encore variable, passant du gris au rougeàtre ou au noir; le dos porte presque toujours une ligne brune ou noire, sinueuse, souvent interrompue.

Le Péliade bérus est répandu dans une grande partie de l'Europe et de l'Asie, depuis le Portugal et l'Angleterre jusqu'en Mongolie et en Sibérie. Sa répartition en France n'est pas en rapport arec celle de l'Aspic : dans certains départements, les deux espèces sont réunies, dans d'autres on ne trouve que l'une ou l'autre. On le signale surtout dans l'ouest (Vienne, Vendée), dans l'est (Haute-Saône, Doubs, Vosges), mais il s'étend jusque dans la Somme et le Pas-de-Calais. Aux environs de Paris, il manque à Fontainebleau, mais a été vu dans la forêt de Sénart. 
Il a sensiblement le mème habitat et les mèmes mœurs que l'Aspic; on assure cependant qu'il fréquente plus volontiers les endroits humides. D'ailleurs, il est moins irascible, et ne mord que quand il est menacé directement; enfin, si l'on se rappelle qu'il est un peu moins riche en venin, on comprendra que les accidents qu'il cause soient en général moins dangereux.

Vipère d'Orsini (V. Orsinii [Bonaparte]; P'clias Ursinii (1) Bonap.). Ciette Vipère, voisine de la liérus, reste toujours de plus petites dimensions; le màle ne dépasse pas $0^{\mathrm{m}}, 43$, la femelle $0^{\mathrm{m}}, 50$. Le corps est assez lourd, plus atténué en avant qu'en arrière. La tète est relativement plus petite 'Iue chez $V$. berus; elle porte de chaque cỏté une plaque sus-oculaire qui

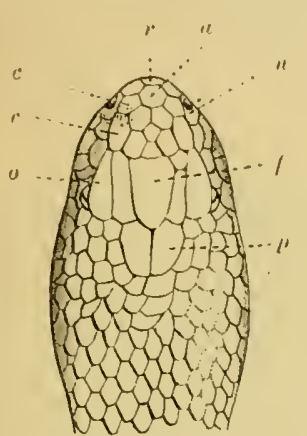

Fig. 7.ב. - - Tète de la lipère d'Orsini (Vipera Orsinii), vue en dessus, d'après Boulenger. $a$, playue apicale; $c$, canthale; $f$, fronlale: $n$, nasale; $o$. sus-oculaire: $p$, pratélale; $r$, rosirale. dépasse l'œil en arrière, et au milieu les trois plaques des Péliades: la frontale beaucoup plus longue que large. Le museau est plus élroit et un peu

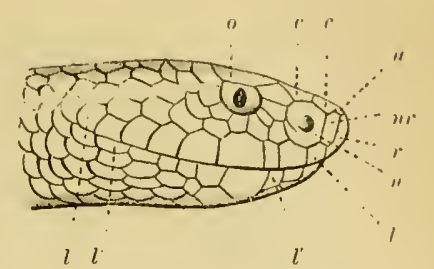

Fig. 733. - Tèle de la Vipère dOOrsini, vue de probil, d'après Boulenger. - $l$, plaque labiale supérieure. $l$ ', labiale inférieure. $m$, naso-roslrale. Les autres lellres comme i la figure 722 .

plus pointu. Les écailles du tronc sont presque toujours réparties en 19 rangées; il est exceptionnel d'en trouver 21. La coloralion est gris verdàtre ou brune, toujours plus claire sur le dos que sur les flancs; le dos porte une ligne en zigzag à angles mousses, interrompue çà et là, et d'un vert brunàtre ou d'un brun clair.

Distinguée en 1838̈, par C.-L. Bonaparte, cette espèce alvait été confondue depuis avec $V$. berus, dont Boulenger l'a décidément séparée. Elle a été trouvée dans les Abruzzes (Orsini), puis en Hongrie, en Autriche, en Bosnie et enfin en France, dans les Basses-Alpes (E. Honnorat); sa véritable patrie parait ètre la plaine de Hongrie, car en Bosnie, en Italie et en France, elle ne s'est montrée que d'une façon isolée.

On ne sait encore que peu de choses des mœurs de ce Péliade. Boulenger dil qu'il se nourrit surtout de Souris et de Lézards. Il est moins irascible encore que le Bérus, et on n'a relevé jusqu'à présent aucun cas de morsure qui lui fùt attribuable.

(1) Bonaparte a écrit U'sinii, évidemment par erreur, puisqu'il dédiait cette espèce à Orsini. 
Les Cérastes (Cerastes) ou Vipères cornues sont ainsi appelées à cause de leurs plaques sourcilières relevées en pelites cornes. - Le Céraste d'Égypte (C. cornutus) habite les régions sablonneuses du nord de l'Afrique; il est commun dans le Sahara algérien et s'étend jusqu'au Niger. Sa piqûre est des plus dangereuses.

A des genres voisins appartiennent encore : la Vipère élégante (Dabria elegans), redoutée dans l'Inde, et la Vipère heurtante (Bitis arietans), encore appelée Serpent cracheur ou Serpent minute, répandue dans toute l'Afrique.

Les CROTALIDÉS diffèrent des Vipéridés par la présence d'une fossette entre l'œil et la narine. On en connait une douzaine de genres, limités au sud de l'Asie et à l'Amérique, sauf un qui est représenté dans l'Europe orientale. Nous en citerons seulement quelques-uns.

Les Lachésis (Lachesis) ont la queue terminée par dix ou douze rangées d'écailles épineuses. - Le Surucucu ( $L$. mutus), du Brésil et des Guyanes, dépasse souvent 2 mètres de long; son venin tue rapidenent l'Homme et les gros animaux.

Aux Bothrops (Bothrops) se rapporte une espèce qui s'est acquis une triste réputation : il s'agit du B. lanceolatus, de la Martinique, de Sainte-Lucie et de la petite ille de Bequia. Ce Serpent, souvent nornmé Fer-de-lance, Vipère jaune de la Martinique, Trigonocephale des Antilles, tue en moyenne chaque année, d'après Rufz, 1 habitant sur 3000. La mortalité de ses blessures serait de 1/4 à 1/10. Il fait périr aussi les grands animaux : Rufz et Paulet ont vu des Chevaux, mordus à la tète, succomber en vingt-deux heures. D'antres espèces de Bothrops sont répandues au Brésil, dans les Guyanes, dans l'Inde et en Malaisie.

Aux Trigonocéphales (Trigonocephalus) appartient l'unique Crotalidé européen, $T r$. halys, qui habite les steppes du bassin inférieur de la Volga el de l'Oural.

Les Crotales (Crotalus) sont souvent appelés Serpents à sonnette, parce qüils on la quete terminée par une série d'étuis cornés emboités les uns dans les autres; ces étuis ou grelots sont mis en mouvement au gré de l'animal et font entendre un bruit strident. - 11 faut signaler principalement, dans ce groupe, le Durisse (Cr. llurissus), de l'Amérique du Nord, et le Cascavella ( $\mathrm{Cr}$. horridus), de l'Amérique intertropicale. Les Crotales peuvent alteindre une longueur de 2 mètres. Ils tuent en quelques minutes ou en quelques heures l'Homme, les Bœufs et les Chevaux; les Chiens résistent quelquefois. On se sert de Cochons pour les détruire.

\section{DEUXIËME ORDRE}

\section{SAURIENS}

Reptiles à fente cloacale transversale et à pénis double, généralement pourvus de deux paires de membres, de paupières, d'une caisse du tympan et d'une vessie urinaire; gueule non extensible.

Les Sauriens ou Lézards (oxúpa, lézard) ont le corps allongé, parfois semblable à celui des Serpents; les membres peuvent mème manquer en totalité 
On connait deux Fissilingues ou Lézards américains qui représentent les seuls Sauriens venimeux actuellement connus. Ce sont des Hélodermes (Heloderma), grands animaux dont le corps est couvert de gros tubercules en forme de clous ( $\tilde{\xi} \lambda$ os, clou), et dont la tête aplatie est revêtue de plaques pentagonales. $H$. horridum mesure plus d'un mètre de long; il habile le Mexique, où il est très redouté. Il possède à la mâchoire inférieure une glande en grappe dont les conduits excréteurs se divisent et vont déboucher à la base des dents, qui sont cannelées en avant. Pour que le venin sécrété par cette glande pénètre plus sûrement dans la plaie, l'animal se renverserait sur le dos au moment de l'attaque. La morsure amène rapidemen I la mort des petits animaux; elle peut aboutir au même résultat chez l'Homme. $H$. suspectum n'est pas moins redouté dans la même région.

Les Lézards vrais, dont certaines espèces passent aussi, dans nos campagnes, pour être venimeuses, ont joué autrefois un grand rôle en médecine; on leur attribuait une foule de vertus préventives ou curatives.

On a publié enfin des observations relatives à des Lézards qui auraient vécu dans le tube digestif de l'Homme; nous avons dit, à propos des Batraciens, ce qu'il faut penser de ces assertions.

On peut rattacher directement aux Sauriens de nombreuses formes fossiles, parmi lesquelles nous citerons principalement les gigantesques Iguanodons et les Ptérodactyles de l'époque secondaire.

TROISIFME ORDRE

\section{CROCODILIENS}

Reptiles à fente cloacale longitudinale et à pénis simple, à scutelles dermiques osseuses, à mâchoires garnies de dents implanties dans des alvéoles; à cloison interventriculaire complète.

Les Crocodiliens sont pourvus de quatre membres, dont les doigts sont réunis par une membrane. La màchoire inférieure est unie au cràne par

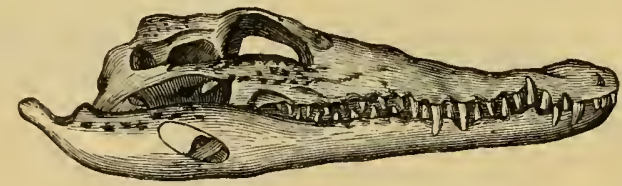

Fig. 7ํ6. - Téle osseuse de Crocodile.

l'intermédiaire d'un os carré immobile. Il existe des paupières, une oreille moyenne et même un rudiment d'oreille externe.

Ce sont des animaux aquatiques, carnassiers, souvent de grande taille et parfois dangereux pour l'Homme. - Crocodiles (Crocodilus), Afrique et sud 
de l'Asie. Cratials (Rumphostomum), Inde et Australie. Caïmans Alligator, Amérique.

On réunit quelquefois aux Crocodiliens, sous le nom d'Hydrosauriens, les

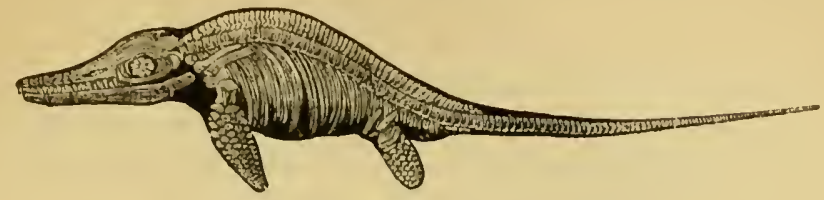

Fig. 72:. - Ichthyosaums communis, du lias.

groupes fossiles des Nothosauriens, des Plésiosauriens pt des Ichthyosauriens, qui ont vécu pendant la période secondaire.

\section{QUATRIEME ORDRE:}

\section{CIIELONIENS}

Repliles à fente cloacale longitudinale et à pénis simple, pourvus d'un plastron osseux sur le dos et sur le ventre; bec corné, dépourvu de dents; cloison interventriculaire incomplète.

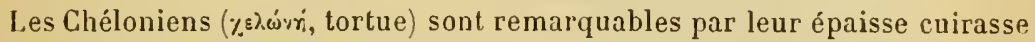
formée par des ossifications du derme unies à certaines parties du squelette interne. La partie dorsale de cette cuirasse reçoit le nom de carapace; l'autre est le plastron. La première a pour base les côtes et les apophyses épineuses des vertèbres dorsales, auxquelles s'adjoignent des plaques dermiques nombreuses; la seconde parait être d'origine exclusivement dermique. Le tout est recouvert d'épaisses plaques épidermiques constituant la substance connue sous le nom d'écaille.

L’os carré est soudé au crâne. La bouche n'est pas armée de dents, mais les màchoires sont d'ordinaire recouvertes par des gaines cornées formant un bec analogue à celui des Oiseaux. Les membres sont au nombre de quatre, parfois disposés en nageoires. Les ceintures thoracique et pelvienne offrent cetle curieuse particularité d'ètre situées à l'intérieur de la carapace.

Cerlaines Tortues sont phytophages, d'autres carnivores. On les distingue surtout d’après leur habitat. Les unes sont marines (Chelonia, Sphargis), les autres fluviales (Trionyx) ou palustres (Emys, Cistudo, Chelys), ou encore terrestres (Testudo).

Les Chélonées imbriquées ou Carets (Chelonin imbricata), de l'océan Indien et de l'océan Atlantique, fournissent l'écaille la plus recherchée. On mange la chair de beaucoup d'especes, principalement des Tortues franches ou vertes (Chelonia esculenta); cette chair est, dit-on, analogue à celle du veau. Les œufs des Tortues sont aussi très estimés des marins.

Ajoutons que ces animaux, en général inoffensifs, sont capables de faire de sérieuses morsures quand on les tourmente. 


\section{I S E A U X}

Vertébrés à sang chaud, à peau revêtue de plumes et à membres antévieurs transformés en ailes; un seul condyle occipital; circulation double, complète; respiration exclusivement pulmonaire. Ovipares; embryons pourvus d'un amnios et d'une allantoïde.

La classe des Oiseaux forme actuellement un ensemble très naturel et bien défini : son alliance intime avec la classe des Reptiles ne se trouve établie que par quelques types fossiles.

Adaptés à la vie aérienne, et partant organisés pour le vol, les

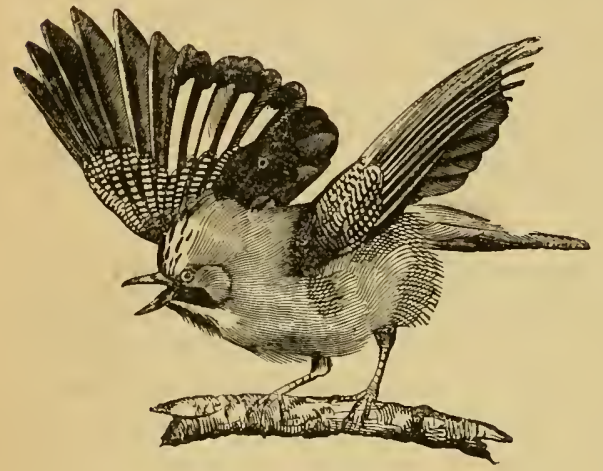

Fig. 728. - Geai commun.

Oiseaux varient peu, en effet, dans leur configuration extérieure, mais ils ne comprennent pas moins un assez grand nombre de formes aptes à grimper, à nager, à marcher ou à sauter. Le tronc est ramassé; la tête, toujours légère, est portée par un cou souvent long et mobile; les membres postérieurs sont propres à la locomotion terrestre; les ailes sont diversement conformées suivant

les facultés locomotrices de l'Oiseau, et la queue joue le role de gouvernail.

Le squelette est rendu aussi léger que possible: les os sont constitués par un tissu compact, mais creusé de vastes cavités communiquant avec des réservoirs spéciaux que nous étudierons plus loin. Cette pneumaticité, d'ailleurs, est d'autant plus accusée que les animaux sont meilleurs voiliers et plus àgés; elle n'existe point dès la naissance.

Les os du cráne, très spongieux, se soudent de bonne heure; cetle région, qui s’articule avec l'atlas par un condyle unique, est surtout remarquable par le grand développement des frontaux. La cloison interorbitaire est toujours très étendue (1). - Les os de la face sont

(1) Nous devons signaler ici une cavité spéciale, nommée cellule sous-oculaire (cella infra-ocularis Nitzsch) ou sinus sous-orbitaire, qui est très vaste chez certains Oiseaux, notamment chez les Palmipèdes; elle est située entre l'oil, le front et le bord latéral de la mandibule supérieure, et limitée en dehors par des parties molles seulement; elle communique avec les cavités nasales, tout au moins chez 
en général assez mobiles. La mandibule supérieure est constituéc presque en entier par les intermaxillaires; l'inférieure est articulée au temporal par I'intermédiaire d'un os carré ou tympanique. - Le squelette viscéral n'est représenté que par un lyyöde dont le corps s'unit en avant à un entoglosse ordinairement pair, rarement simple (Anas); les colnes lyyö̈diennes sont souvent longues et ne se réunissent pas au crìne; clicz les Pies, elles sont très allongées, ce qui explique la grande profractilité de la langue de ces Oiseaux.

La colome vertíbrale montre une région cervicale toujours longue, comprenant de 8 à 24 vertèbres mobiles les unes sur les autres et munies de cótes rudimentaires. - La l’égion dorsale présente, au contrair'c, des vertèbres immobiles, au nombre de 7 à 11 ; ces vertèbres portent des côtes, dont les deux premières restent souvent libres, tandis que les autres s'articulent avec des côtes sternales ossifiées ou os sterno-coslaux. Clıque côte vertébrale est en outre pourvue, dans sa portion moyenne, d'une apophyse aplatie, dite apophyse uncinée, qui s'appuie sur la face externe de la cóte suivante, de sorte que la cage thoracique offre une grande solidité. Le sternum est un os plat, très développé, qui couvre mème une grande partic

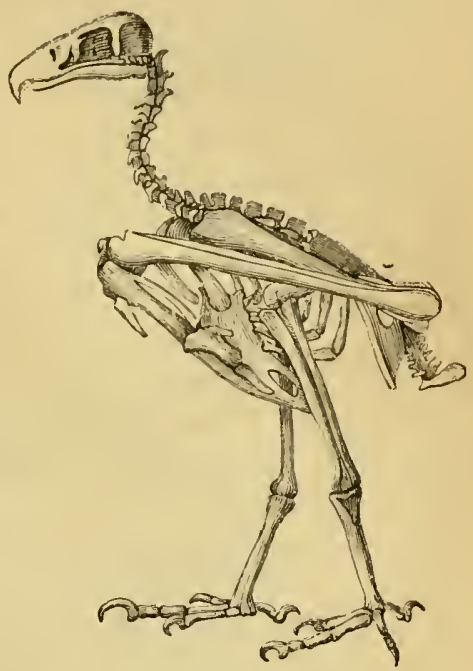

Fig. 729. - Squelelte de Vaulour (Vultur fulvus). de l'abdomen, et qui présente une sorte de carène saillante et longitudinale (bréchet), destinéc à l'insertion des puissants muscles abaisseurs de laile. Ce bréchet est peu accusé chez les faibles voiliers; il disparaît même chez les Coureurs. - Les régions lombaire et sacrée sont confondues en un seul os très allongé, le sacrum, composé de ! il 20 vertèbres. - Enfin, la région caudale, toujours courte, est formée de 7 ou 8 vertèbres petites et mobiles dont la dernière (p!ygostyle). plus développée que les autres et pourvue d'une crête saillante, reprísente $\mathbf{1}$ à $\mathbf{6}$ vertèbres soudées el sert à l'insertion des muscles moleurs des rectrices.

Les membres antérieurs sont solidement fixés au tronc. La ceinture scapulaire comprend de chaque côté une omoplate, un coracoïde et une clavicule, celle-ci restant rudimentaire chez les Ratites. L'omoplate est un os allongé et très étroit, fixé au sternum par l'intermédiaire du coracoïdien et souvent même de la clavicule. D'ordinaire,

les Oiseaux aquatiques, oi elle donne assez souvent asile il des helminthes Voy. Monostomum mulabile, p. :338). 
en effet, celle-ci se soude à celle du côté opposé pour former une pièce en $\mathrm{V}$ connue sous le nom de fourchette, qui s'unit directement ou indirectement à l'extrémité antérieure dı bréchet. L'humérus

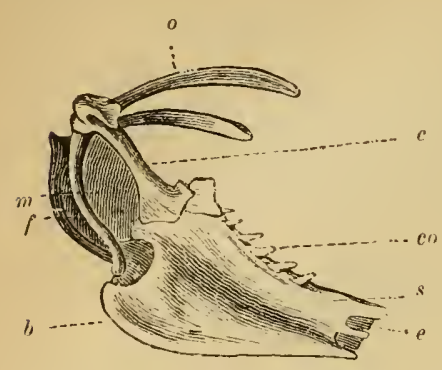

Fig. 730. - Are seapulaire el sternum d'un Oiscau. - $s$, sternum avec son bréchet $b . c$, os coracoïdien. o, omoplate. $f$, les deux clavicules formant la fourchette. $m$, membrane sterno-cléido-coracoïdienue. $c o$, côtes sternales. $e$, échancrures du sternum. a de la sorte un point d'appui très ferme. Le radius et le cubitus ne sont pas mobiles l'un sur l'autre. Le carpe est réduit à deux petits os (un seul chez les Ratites) placés sur le mème rang et articulés avec le métacarpe. Celui-ci, dans le principe, est composé de trois os, mais deux d'entre eux seulement se développent et se soudent par leurs extrémités, en laissant au milieu un espace vide. Enfin, les doigts sont presque toujours au nombre de trois: l'un, articulé à la base et sur le côté radial ou interne du métacarpe, représente un pouce formé d'une seule phalange; le second ou doigt médian, articulé à l'extrémité distale de la région métacarpienne, comprend deux phalanges; le troisième ou doigt externe, inséré à celte mème extrémité, consiste en un simple stylet osseux.

Les membres postérieur's ont pour base une ceinture pelvienne constituée par trois pièces paires: ilion, ischion el pubis. Les deux os iliaques, fort prolongés en arant et en arrière, sont unis dans toute leur longueur aux bords du sacrum. Les pubis demeurent écartés et ne forment pas de symphyse, sauf chez l'Autruche d'Afrique. Le fémur est court, dirigé en avant et d'ordinaire caché sous les plumes; souvent il existe une rotule, tantôt simple, tantôt double. La jambe est constituée presque exclusirement par le tibia; le péroné est réduit à un faible stylet situé sur la face externe de cet os et soudé avec lui; mais le tibia paraît être un os complexe (tibio-tarsien), dont la partie inférieure correspond à la division supérieure du tarse. De même, une épiphyse supérieure du métatarse (tarso-métatarsien) représente la division inférieure du tarse. Ce métatarse, souvent désigné sous le nom d'os canon (1), est formé par la soudure de trois métatarsiens : ceux des deuxième, troisième et quatrième doigts; le cinquième ne se développe pas; quant au pouce, son métatarsien est d'ordinaire incomplet et s'unit par un ligament à la partie interne ou postérieure du tarso-métatarsien. Parfois un ergot (calcar) ou éminence osseuse recouverte de corne se développe au côté interne du cannon el se soude au métatarsien du deuxième

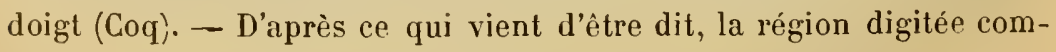

(1) Ce qu'on appelle le tarse en zoologie descriptive répond à la région métatarsienne. 
prend presque toujours trois doigts principaux, plus un pouce articulé en arrière sur son petit métatarsien styliforme. Le doigh externe lui-mème peut être porté plus ou moins en dehors, voire tout ì fail en arrière (Grimpeurs, Préhenseurs). Règle générale, le nombre des phalanges ra en augmentanl du pouce au doigt externe : $2,3,4$, s: celte formule ne souffre qu'un petit nombre d'exceptions.

Relativement aux muscles, nous avons ì signaler tout d'abord le développement considérable des pectoraux, qui sont les moteurs de l'aile, et qui trourent sur le bréchet une large surface d'im-

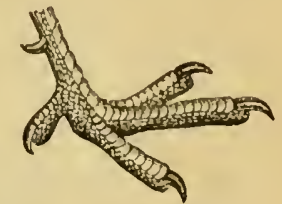

lig. 731. - I'alle de Gallinace. montrant uи ergol. plantation. Dans le membre postérieur, une disposition spéciale des muscles permet ì l'Oiseau de serrer arec les doigts la branche qui le soutient, sans aucun effort musculaire. Le droit antérieur de la cuisse prend naissance au pubis, suit la face interne du fémur, et se continue par un tendon grêle qui passe en avant de l'articulation fémoro-tibiale, pour aller se confondre avec le muscle fléchisseur des orteils. Il en résulte que, si larticulation dı genou tend à se fermer sous le poids du corps, les doigts se fléchissent et maintiennent l'animal fixé à la branche.

La peau est toujours revètue de plumes, productions épidermiques qui se développent dans des follicules au fond desquels se trouve le loulbe formateur. Une plume complète se compose d'un axe primaire ou hampe et d'une lame (vexillum) formée par des barbes. La hampe comprend un tube corné basilaire, le tuyau (calamus), continué par une tige pleine ou rachis. Le tube corné renferme les restes desséchés et spongieux de la papille, constituant ce qu'on appelle l'âme de la plume; il oflre, à chacune de ses extrímités, un petit orifice appelé ombilic. La tige porte, sur ses parties latérales, des lamelles aplaties nommées barbes, munies de barbules souvent frangées qui s'accrochent mutuellernent; sa face inférieure est parcourue par un sillon dans lequel nait sourent, près de l'ombilic supérieur, un appendice ou hyporachis pourvu lui-même de barbes.

La forme des plumes est assez variable. Lorsque la tige est réduite, les barbes souples et les barbules sans crochets, on leur donne le nom de plumules (duvet). Celles à tige grèle et à barbes atrophiées sont dites plumes filiformes. Enfin, on nomme pennes les grandes plumes qui sont insérées sur le bord de l'aile et à la queue. Les pennes de l'aile sont appelées rémiges (remigare, ramer), celles de la queue, rectrices (regere, diriger). Les rémiges fixées sur la 'main sont qualifiées de primaires, à l'exception d'un petit faisceau implanté sur le pouce (rémiges bätardes); celles de l'avant-bras sont dites secondaires, et celles de l'humérus, scapulaires. Les rectrices, souvent au nombre de 12, sont susceptibles de se mouroir ensemble ou isolément. De mème que les rémiges, elles sont recourertes à la 
base par des plumes plus petites, nommées couvertures ou tectrices.

Le renouvellement des plumes (mue) s'effectue d'une facon assez. régulière chez les Oiseaux. Il s'accomplit principalement vers la fin de l'été. La mue dite de printemps est peu importante, mais souvent alors il se produit une modification du coloris, par suite de laquelle le plumage d'hiver se transforme en parure de noces.

Il n'existe pas de glandes sébacées et sudoripares disséminées dans le tégument, mais on remarque, dans la région du croupion, une glande bilobée, appelée glande uropygienne, qui sécrète une matière huileuse propre à lustrer les plumes et à les garantir contre l'action de l'eau. Cette glande est très développée dans les espèces aquatiques. On sait que l'Oiseau se sert de son bec pour prendre la matière sécrétée et en enduire ses plumes.

Le vol des Oiseaux comprend des mouvements assez complexes. Il est nécessaire tout d'abord qu'il y ait au-dessous du corps une couche d'air suffisante pour fournir à l'aile un point d'appui; aussi les Oiseaux posés à terre commencent-ils en général par sauter. L'aile s'élève rapidement, sa face supérieure tournée en arrière; puis elle s'abaisse, cette face regardant alors en avant, et le résultat de ces changements de position est de soutenir le corps et de le faire progresser. La queue fait l'office de gouvernail.

Le système nerveux se rapproche de celui des Nammifères. Les hémisphères cérébraux sont déjà développés, mais manquent de circonvolutions; ils ne montrent pas non plus la commissure connue

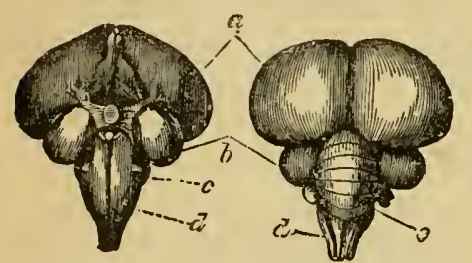

Fig. 732. - Cerveau de Dindon. - $a$, himisphères cérébraux. $b$, lohes opliques. $c$, cervelet. $d$, moelte allongée. sous le nom de corps calleux. Les lobes optiques ou tubercules bijumeaux sont encore à découvert sur les côtés et en arrière des hémisphères. Le cervelet offre un lobe médian marqué de sillons transversaux et deux lobes latéraux rudimentaires; on voit sur sa coupe un arbre de vie. Il n'existe pas de pont de Varole. Enfin, la moelle épinière est très longue; elle est remarquable par la présence, dans la région lombaire,- d'une excavation (sinus rhomboïdal) remplie par une substance gélatineuse et sans communication avec le canal central de la moelle (Mathias Duval).

L'odorat paraît peu développé. Les fosses nasales sont assez spacieuses et contiennent chacune trois cornets; elles sont séparées par une cloison incomplète; une glande nasale, située dans la région frontale, y verse le produit de sa sécrétion. - L'ouie est très délicate. On remarque quelquefois (Hibou) un rudiment d'oreille externe. L'oreille moyenne communique avec le pharynx par une large trompe d'Eustache; elle comprend un osselet unique, la columelle, qui relie la 
membrane du tympan à la fenètre ovale et correspond a l'étrier des Mammifères. L'oreille interne est analogue ì celle de ees animaux; toutefois le limaçon est a peine contourné et oflre un renflement a inpullaire appelé lagena. - Les yeux sont doués d'une grande faculté d'accommodation. Ils sont protégés par trois paupières: la troisième, connue sous le nom de membrane nictitante, est rétractile vers l'angle interne de l'ceil; à sa base débouche le canal excréteur d'un organe glandulaire, la glande de Harder. D'après P. Bert, le róle de la membrane nictitante est de ramener les larmes dans le canal lacrymal. La sclérotique présente, autour de la cornée, un anneau de plaques osseuses. La cornée est généralement très convexe : le cristallin l'est aussi chez les Oiscaux nocturnes. La pupille est toujours circulaire. Enfin, on observe presıue constamment un organe spécial, le peigne, formé par un prolongement plissé de la choroïde et dont les usages sont mal connus. - Le goût est peu développé; les aliments ne séjournent pas dans la bouche. - Quant au tact, il doit ètre également fort peu délicat; cependant, on a trouvé des corpuscules tactiles dans le bec, la langue et la peau des doigts d'un certain nombre d'Oiseaux.

L'appareil digestif est disposé d'après un plan assez. uniforme, malgré les variations que présente le régime des Oiseaux. Les mûchoires ne sont jamais pourvues de dents, mais elles offrent un revètement corné plus ou moins résistant et de forme très variable. 11 existe chez certains Oiseaux, ì la base du bec, une membrane nue et diversement colorée, qu'on appelle cire. La langue est, chez les granirores, dure, cornée et hérissée de pointes vers sa base; elle est charnue chez les Palmipèdes et surtout chez les Perroquets. Ses connexions avec l'hyoïde donnent raison de sa protractilité, accusée au plus haut degré chez les Pics. - Des glandes sont en général répandues en divers points sous la muqueuse buccale; mais on peut à peine les considérer comme des glandes salivaires, car elles ne sécrètent qu'une sorte de mucus propre seulement à humecter les aliments.

La bouche n’est pas séparée du pharynx par un voile du palais. L'œsophage suit la face postérieure de la trachée; souvent il présente, avant de pénétrer dans la cavité thoracique, un diverticule ou jabot (1), dans lequel les aliments séjournent un certain temps et commencent à se ramollir. Cet organe, rudimentaire chez les Casoars, offre son plus haut degré de perfectionnement chez les Gallinacés et les Pigeons; il manque chez les Lamellirostres, dont l'œesophage est simplement renflé, dans sa région cervicale, de manière à représenter une cavité fusiforme quand ses parois sont distendues. L'œsophage reprend ensuite son calibre primitif, pour aboutir bientôt à l'estomac. Celui-ci se divise en deux parties plus ou moins séparées : la première,

(1) En latin ingluvies: en itallen gozso, ingluvie; en allemand kropf: 
riche en glandes, recoit le nom de ventricule succenturié (1); l'autre est l'estomac musculeux ou gésier (2), appareil de trituration des ali-

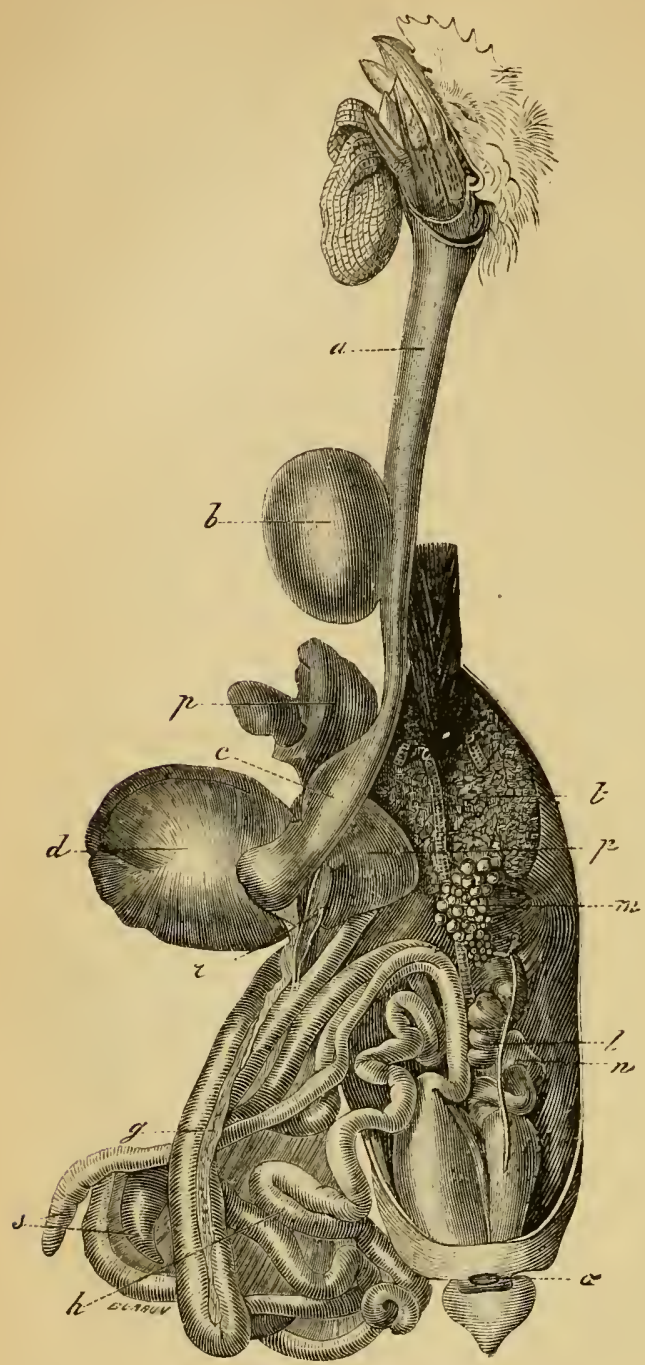

Fig. 733. - Tube digestif d'une Dindo, - $a$, resophage, $b$, jabot. $c$, ventricule succenturié. $d$, gésier. $y$, pancréas enlouté par le duodénum. $h$, intestin grêle. $l$, gros intestin. $m$, ovaire. $n$, ovillucte. $o$, cloaque. $p$, foie. $r$, vésicule biliaire. $s$, ciecums. quets); il s'ouvre dans un cloaque par un orifice muni d'un sphinc-

(1) Lat. proventriculus, echinus; ital. cchino, ventricolo ou stomaco succenturiato; all. Vormagen.

(2) Lat. ventriculus; ital. stomaco, ventricolo, ventriglio: all. Magen. carnivores, les parois du gésier sont minces et membraneuses; elles sont au contraire très épaisses chez les granivores, où on les voit composées de deux muscles puissants renforcés par des aponévroses; la muqueuse est d'ailleurs revêtue d'un e couche cornée amorphe, sécrétée par l'épithélium, et l'action triturante est encore augmentée par la présence de petits cailloux ou autres corps durs que les animaux ingèrent avec leurs aliments. On considère en général que le ventricule succenturié sécrète le suc gastrique ; cependant, d'après Jobert, ce suc serait produit par le gésier.

L'intestin n'est jamais très long, même chez les granivores; il forme d'abord une anse duodénale qui circonscrit le pancréas, puis se contourne de diverses manières. Le gros intestin présente à son origine deux appendices en cul-de-sac, dits cxcums, parfois très courts (Colombins), ou réduits à un seul (Hérons), ou tout

ments. Chez les Oiseaux 
ter qui empèche la chute des excréments. La paroi dorsale du cloaque présente une poche appelée bourse de Fubricius (fig. 736 et 737); cet organe est formé, d'après Retterer, de follicules clos, et peut ètre rapproché des amygdales; il s'atrophie plus ou moins vite à mesure que les Oiseaux deviennent adultes. - Le foie est très volumineux et divisé le plus souvent en deux lobes ì peu près égaux; la vésicule biliaire manque rarement (Pigeons); il existe deux canaux biliaires : cholédoque et eystique, celui-ci déversant la bile de la vésicule. Le pancréas, long et étroit, débouche dans l'intestin par deux ou trois canaux excréteurs.

Lappareil circulatoire ne diffère pas essentiellement de celui des Mammifères. Les deux caurs sont tout à fait séparés, quoique se présentant en une seule masse. Dans le cour droit, la valvule auriculo-rentriculaire est formée par une seule lame charnue, qui s'applique contre la cloison interventriculaire pendant la systole. Il n'y a qu'une seule crosse aortique, qui se recourbe $a$ droite après avoir fourni deux troncs brachio-céphaliques. Le système porte rénal est rudimentaire. Le système lymphatique comprend de nombreux vaisseaux munis de valvules et dans certains cas des cours lymphatiques. - La rate est petite, rouge, discoïde.

Liappareil de la respiration offre une complexité remarquable. Les narines sont situées à la base du bec et parfois recouvertes d'écailles. La partie supérieure de la trachée, qui constitue un larynx sans cordes rocales ni ventricules (larynx supéricur), s'ouvre par une fente longitudinale sans épiglotte. La trachée est longue, quelquefois sinueuse (Cygne), formée d'anneaux complets. Elle se bifurque à l'entrée de la cavité thoracique, et l'on troure à ce niveau un organe plionateur connu sous le nom de larynx inférieur ou de syrinx. Les bronches ne sont soutenues que par des demicercles cartilagineux disposés du côté externe; elles deviennent mème tout à fait membraneuses en pénétrant dans le poumon. Au lieu de se diviser par dichotomie, comme chez les Mammifères, chaque bronche traverse directement le poumon, pour aller s'ourrir à la partie postérieure, dans un sac aćrien, et on la voit émettre sur son trajet une douzaine de bronches secondaires qui rampent à la surface de l'organe, se ramifient el rentrent ensuite dans le parenchyme pulmonaire. Outre l'orifice que nous venons de signaler, on en

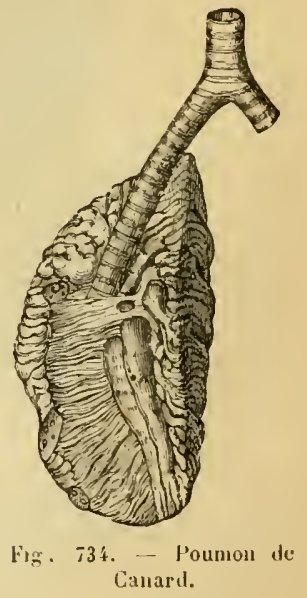
observe encore, à la face inférieure de chaque poumon, trois ou quatre autres, qui font communiquer les bronches arec des réservoirs aériens.

Les poumons, peu volumineux, ont leur face supérieure convexe 
fixée sur les côtés du rachis et sur les côtes; ils adhèrent du reste à tous les organes voisins par du tissu cellulaire : la plèvre fait défaut. - La cavité thoracique est en partie occupée par les viscères abdominaux, mais il existe cependant deux diaphragmes rudimentaires, pourvus de quelques fibres musculaires: l'un (diaphragme pulmonaire) nait du sternum et des côtes, adhère au poumon par sa face supérieure et recouvre les réservoirs thoracique et diaphragmatiques;

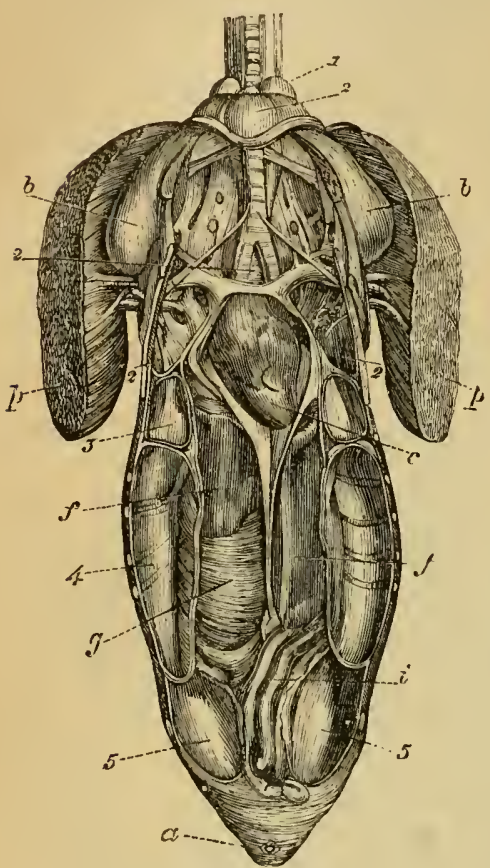

Fig. 735. - Sacs aćriens du Canard, d'apris Sappey. - 1, extrémité antérieure des réservoirs cervicaux. 2, saillie interelaviculaire du réservoir tlıoraci jue. 3, réservoirs diaphragmattiques antérieurs. 4, réservoirs diaplaragmatiques postérieurs. $\ddot{b}$, réservoirs abdominaux. $p p$, muscles jectoraux coupés et écartés. $b$, prolongement. sous-pectoral du réservoir thoracique. $c$, crur. $f, f$, foie. $g$, gín.er. $i$, intestin. $a$, anus.

l'autre (diaphragme thoraco-abdominal) est formé de deux moitiés naissant du rachis, tapissant en dedans les réservoirs diaphragmatiques et séparant les viscères thoraciques de ceux de l'abdomen.

Les réservoirs aériens sont des sacs membraneux, au nombre de neuf: $\mathbf{1}^{\circ}$ un réservoir thoracique ou interclaviculaire, impair, situé sur la ligne médiane, en avant des poumons, faisant saillie entre les deux clavicules; $2^{\circ}$ et $3^{\circ}$ deux réservoirs cervicaux, placés à la base du cou, $4^{0}$ et ${ }^{\circ}$ deux réservoirs diaphragmatiques antérieurs, placés entre les deux diaphragmes au-dessous des poumons; $6^{\circ}$ et $7^{\circ}$ deux réservoirs diaphragmatiques postérieurs, occupant une position analogue aux précédents, qu'ils suivent immédiatement; $8^{\circ}$ et $9^{\circ}$ enfin, deux réservoirs abdominaux adossés à la paroi supérieure de l'abdomen, au-dessus des viscères de cette cavité. - A l'exception des réservoirs diaphragmatiques, qui ne communiquent qu'arec les bronches, tous ces sacs aériens offrent des prolongements qui pénètrent dans les cavités dont sont creusés les os, et parfois aussi dans le tissu cellulaire souscutané. En outre, il existe un système pneumatique cervico-céphalique, en communication seulement avec les fosses nasales (Fanny Bignon).

La respiration s'effectue à peu près exclusivement par le jeu des cótes sternales sur les côtes vertébrales. Les poumons ne subissent qu'un faible changement de volume, mais les réservoirs diaphragmatiques se dilatent à chaque inspiration, el l'air s'y précipite après 
avoir traversé le poumon; au moment de l'expiration, ce thuide suit le mème chemin en sens inverse et concourt de nouveau à l'hématose. Les autres réservoirs, antérieur's et postérieurs, paraissent agir en antagonistes des premiers : ils se dilatent dans l'expiration et se contractent dans l'inspiration, cédant alors aux autres une partie de leur contenu.

La chaleur développée par les Oiseaux est toujours considérable, ce qui tient à l'activité de la respiration et à la fréquence des battements du cour, ainsi qu'ì la présence des plumes, qui ne permettent qu'une faible déperdition. La température s'élève ainsi ì $\mathbf{4 0 , 4 2}$ et jusqu'ì 4 't degrés centigrades.

Lappareil phonateur ou syrinx est, comme nous l'avons vu, une dépendance des organes respiratoires. Il peut se développer dans trois positions : $1^{\circ}$ à l'extrémité inférieure de la trachée; $2^{\circ}$ dans les bronches; $3^{\circ}$ à la jonction de la trachée et des bronches. Cette dernière disposition est de beaucoup la plus commune: la trachée se dilate en une sorte de tambour, les bronches offrent des replis rariés, et tout cet appareil est complété par des muscles, qui sont surtout puissants chez les Oiseaux chanteurs. Le syrinx manqrue chez les Autruches et quelques Vautours américains.

Les reins (métanéphros) sont logés dans des cavités anfractueuses, au-dessous du sacrum; ils sont d'ordinaire divisés en trois lobes. Les uretères débouchent dans le cloaque; il n'existe pas de ressie: l'urine, sous forme de pâte blanchâtre, s'accuınule dans le cloaque el se trouve expulsée quand celui-ci se renverse au mo-

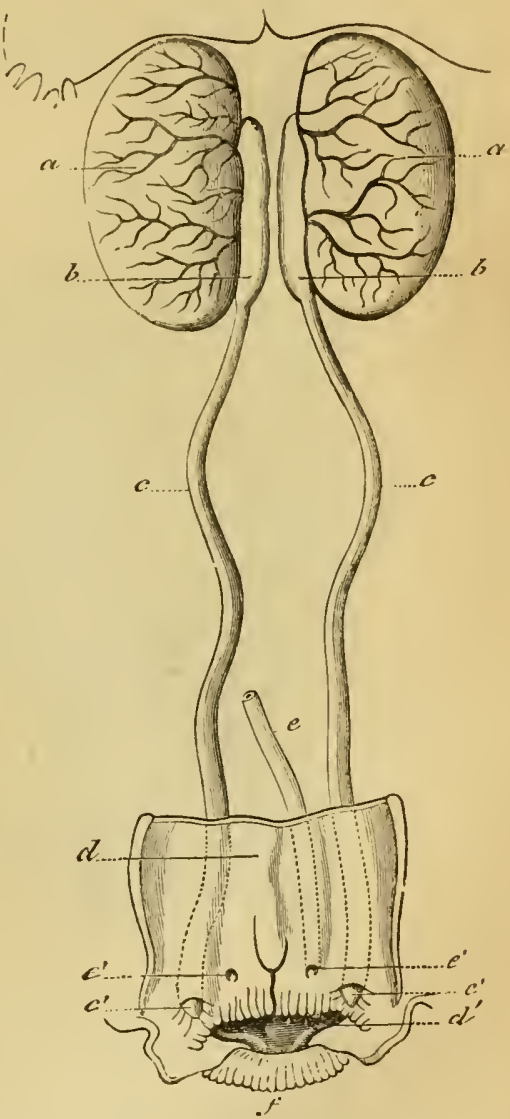

Fig. 736. - Appareil génilal du Coq. - $a, a$, lesticules. $b, b$, epididymes. $c, c$, canaux defírents, se terminant dans le cloaque $d$, chacun sur un pelil tubereule $c^{\prime} . d^{\prime}$, bourse de Fabricius. e, uretere gauchic. $e^{\prime}, e^{\prime}$, ouverlure des uretcres dans le cloajue. $f$, marge de lanus. ment de la défécation.

Chez tous les Oiseaux, les sexes sont séparés. L'appareil mále se compose de deux testicules situés dans la cavité abdominale, audessous de la partie antérieure des reins; le gauche est en général 
un peu plus développé que l'autre, et tous deux, du reste, acquièrent un volume considérable à l'époque des amours. L'épididyme se détache à peine du testicule, et se continue par un canal déférent qui se renfle souvent en une vésicule séminale et va s'ouvrir sur la paroi postérieure du cloaque, au sommet d'un petit tubercule conique placé en dehors de I'orifice urinaire correspondant. Dans certains

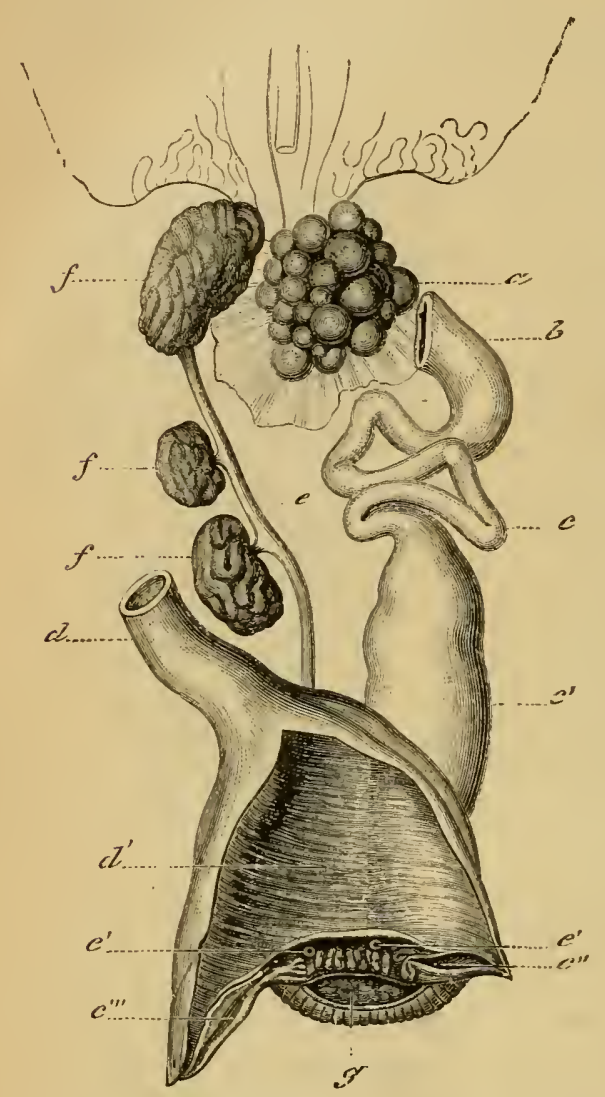

Fig. 737. - Appareil géuital de la Poule. - $a$, oraire. $b$, trompe. $c$, couduit albuminipare. $c^{\prime}$, partie de l'oviducte fonctionnant comme utérus. $d$, intestin. $d$, cloaque, dans lequel s'ouvrent, en $e^{\prime} e^{\prime}$, les deux uretères et en $c^{\prime \prime}$ l'oviducte. $c^{m}$, enfoneement qui occupe la place de l'orifice de l'oviducte atrophié. $g$, bourse de Fabricius. $f, f, f$, rein divisć en trois lobes. e, uretère droit. cas, on rencontre, entre les deux tubercules dont il s'agit, une troisième saillie qui représente un pénis (Canard).

L'appareil femelle ne comprend qu'un seul ovaire et un seul oviducte : les organes du côté droit s'atrophient de très bonne heure. L'ovaire gauche est, par suite, très développé; il est situé à la face inférieure du rein gauche, mais tend à se porter vers la ligne médiane. Il se montre sous l'aspect d'une grappe composée d'ovules à divers degrés de déreloppement : les uns petits et blanchâtres, les autres plus voluminenx et de teinte jaune, tous enveloppés d'une membrane conjonctive très vasculaire (calice), formant à la base un court pédoncule. Au moment de la maturité, les vaisseaux de cette membrane s'atrophient suivant une ligne équatoriale (stig$m a)$, et il en résulte bientôt une déchirure circulaire, à la faveur de laquelle s'échappe l'ovule. Celui-ci est constitué par un vitellus ou jaune assez volumineux, entouré d'une membrane vitelline très mince. Sur un point de sa surface, le vitellus montre un épaississement blanchâtre, discoïde, à contours un peu vagues : c'est la cicatricule, encore appelée germe ou disque proligère. La cicatricule contient à son centre la vésicule germinative (noyau de l'œuf); au moment où l'œuf est pondu, 
cette vésicule ne montre déjà plus la lache germinative (nucléole) qui était apparente alors que l'ovule se trouvail encore dans l'ovaire. Quant au vitellus, il se compose en réalité de deux parties : $1^{\circ}$ un vilellus junne, présentant une série de zones concentriques; פo un vitellus blunc, étalé en conche mince à la surface du précédent, et passant au-dessous de la cicatricule, au niveau de laquelle il émet vers le centre un prolongement renflé en battant de cloche (latchra ou noyau de Pander). Le vitellus jaune est formé de grosses sphères uniformément granuleuses; le vitellus blanc se compose de sphères plus petites, parfois groupées à lintérieur de vésicules plus grandes; la cicatricule, enfin, montre un amas de granulations extrèmement petites; mais il n'y a pas de démarcalion netle entre ces diverses parties. - Lovidıcte n'est pas seulement un conduit vecleur : il fournit encore à l'ouf divers produits complémentaires. Il se divise en trois

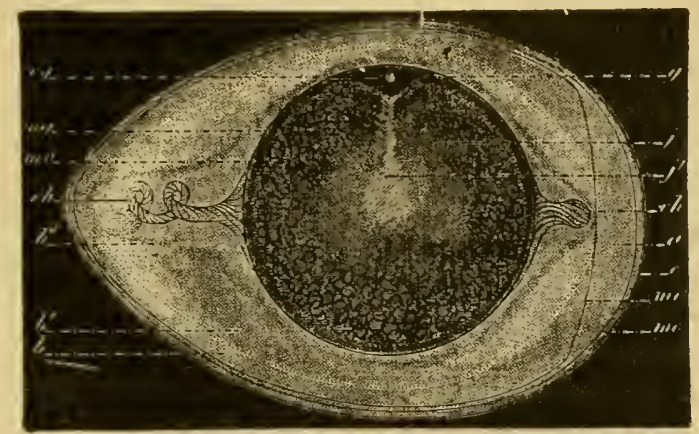

Fig. 738. - Coupe théorique de l'œul de la Poule, d'après Gerbe. - I'arlies qui erisłaient déjü duns l'ovaire : $v g$, vésicule germinative. $g$, ciealrieule. $m v$, membraue vitelline. $m g$, couche périphériłuc de vilellus blanc. $j$, jaune. $j$ ', labebra. - Parties adventives dont s'entoure l'ouf en descendant dens l'oviducle: $c h$, chalazes. $b, b^{\prime}, b^{\prime \prime}$, couches exlerne, moyeune et interne du blane d'ceuf. $m c^{\prime}$, feuillel interne de la membrane cơjuillic̀re. $m c$, leuillet externe. $a$, cliambre à air. $c$, corjuille.

régions principales : la trompe, le tube albuminipare et la chumbre coquillière (utérus). La trompe n'est pas en continuité directe avec l'ovaire, nais elle se dilate à son extrémité libre en un pavillon non frangé, qui recueille l'ovule au moment de la déhiscence du calice. Le tube albuminipare, comme son nom l'indique, sécrète l'albumine (blanc de l'cuf ou albumen) qui se dépose par couches successives autour du vitellus. On en distingue trois couches principales, de densilé différente : la première, ou couche profonde, est très compacte et, par suite du mouvement de rotation que subit l'œuf dans son trajet, elle forme à chacun des deux pòles une sorte de ligament spiralé désigné sous le nom de chaluze; les deux autres couches sont de plus en plus fluides. Enfin, dans la portion terminale de l'oviducte, l'albumen s'enveloppe d'une memírane dite coquillière ou testacée, qui se compose de deux lames el s'entoure elle-mème d'un produit de 
sécrétion calcaire, formant la coquille. Celle-ci est perméable à l'air, aussi bien que la membrane, dont les deux lames s'écartent, au pûle obtus de l'œuf, pour constituer une chambre à air.

L'accouplement, dont la durée est toujours très courte, s'effectue par la juxtaposition des cloaques renversés. La fécondation s'opère dans la partie supérieure de l'oviducte, avant le dépôt des couches d'albumine. Tous les Oiseaux sont ovipares. La segmentation est partielle; elle offre son maximum d'intensité dans la cicatricule, mais s'étend aussi à quelque distance dans le vitellus blanc et même dans le vitellus jaune, de sorte qu'il n'y a pas de distinction nette à établir entre le vitellus de segmentation et le vitellus de nutrition. Elle donne lieu, même avant la ponte, à la formation d'un blastoderme composé de deux feuillets. Pour que l'évolution se continue, l'œuf doit être soumis à une tempéralure d'environ $40^{\circ}$; aussi les parents, et en particulier la femelle, les couvent-ils d'ordinaire dans des nids construits avec plus ou moins d'art. On sait, d'ailleur's, qu'il est possible d'obtenir, au moyen d'une chaleur artificielle convenablernent réglée, les mêmes résultats que procure l'incubation normale, et que l'emploi des couveuses artificielles est entré dans la pratique industrielle (1). La durée de l'incubation varie suivant les espèces; elle est de quatorze jours, par exemple, pour le Moineau franc, de vingt et un jours pour la Poule. domestique, de trente-cinq pour le Cygne. - L'embryon possèdeune vésicule allantoïde el un amnios, comme celui de tous les Vertébrés supérieurs. Nathias Duval a reconnu d'ailleurs, chez les petites espèces tout au moins, l'existence d'un sac placentö̈de enveloppant l'albumine, qu'il absorbe peu ì peu. Les jeunes Oiseaux brisent euxmêmes leur coquille. lls présentent, au sortir de l'œuf, les traits essentiels de l'organisation de leurs parents; toutefois, tandis que ceux des espèces terrestres (Oiseaux précoces: Gallinacés, beaucoup de Palmipèdes) sont capables de suivre immédiatement leur mère et de chercher leur nourriture, les jeunes des bons voiliers, au contraire (Oiseaux nourricier's : Pigeons, Passereaux), sont nus, faibles et doivent êtrelongtemps nourris dans le nid.

Les mœurs des Oiseaux sont des plus curieuses et.des plus variées, mais il nous est impossible de nous étendre ici sur ce sujet. La plupart sont monogames, et la formation des sociétés conjugales donnelieu à de remarquables manifestations des facultés instinctives. Il convient de mentionner aussi les migrations périodiques qu'accomplissent un grand nombre d'entre eux, et dont les Hirondelles, les Cailles, les Canards saurages fournissent des exemples bien

(1) Tout le monde sait que la Poule qui couve remue fréquemment ses cufs, et que cette pratique est imitée dans l'incubation artificielle. Dareste (Comples rendus, 16 mars 1885 ) l'a justifiée en constatant que l'immobilité permet à l'allantoide de contracter avec le jaune des adhérences qui occasionnent la mort de l'embryon. 
connus. Le plus souvent, ces Oiseaux migrateurs se réunissent en bandes nombreuses et ne se séparent qu'à l'arrivée. Les uns viennent passer cliez nous la belle saison et s'y reproduire, puis se dirigent vers le sud avant les premiers frimas; les autres, au contraire, nous visitent seulement pendant l'hiver et vont nicher au printemps dans les régions septentrionales. Un fait des plus intéressants ì noter dans ces migrations, c'est l'instinct qui pousse les individus à reveni. chaque année dans le mème endroit et à reprendre possession de leur ancien nid. Les Oiseaux possèdent à un lıaut degré la faculté de s'orienter, et c'est principalement cette faculté que l'Homme a mise à profit dans l'usage des Pigeons messagers.

Les Oiseaux apparaissent ì l'état fossile dans les terrains jurassiques : tel est le cas de l'Archápteryx, qu'on a longtemps décrit comme un Lézard emplumé. Cet animal était pourvu de dents, ainsi d'ailleurs que les Hesperornis et Ichthyornis, du crétacé de l'Amérique du Nord. Mais la plupart des Oiseaux appartiennent à l'époque. tertiaire.

En dehors des espèces qui ont été réduites en domesticité et nous sont par suite d'une utilité directe, la classe des Oiseaux en comprend un grand nombre d'autres dont nous mangeons la cliair gibier ¿̀ plumes). Il s'agit alors surtout des espèces granivores, qui peuvent être plus ou moins nuisibles à l'agriculture. Par contre, les insectivores et les carnassiers nous délivrent d'une foule d'êtres incommodes ou dangereux qui nous entourent. Ajoutons que cette classe nous fournit encore des aufs, des plumes et divers autres produits dont il sera question plus loin.

La classification des Oiseaux, très difficile à établir et par lì même très variable suivant les auteurs, repose d'une manière générale sur les caractères tirés des pattes et du bec. Si l'on tient compte aussi du développement des ailes et des modifications corrélatives du squelette, on aboutit au groupement indiqué par le tableau suivant :

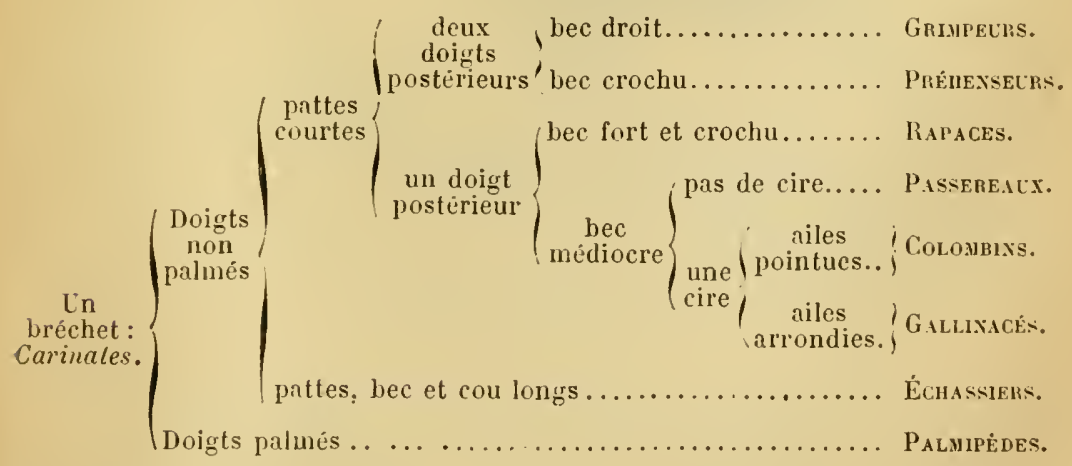

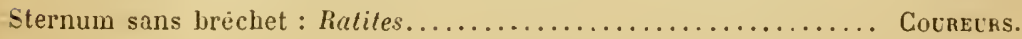




\section{PREIHER ORDRE}

\section{COUREURS}

Oiseaux à ailes rudimentaires, impropres au vol; pieds à trois ou deuxdoigts.

Les Coureurs, Brévipennes ou Struthions sont des Oiseaux de grande taille, adaptés à la locomotion terrestre, et par suite privés de la faculté de voler. Il en résulte que les muscles des pattes sont très développés, tandis que ceux des ailes sont fort réduits, modification qui entraine la disparition de la carène sternale. Les os sont pleins. Les clavicules sont rudimentaires ou nulles. Il n'existe pas de rémiges ni de rectrices.

Ces Oiseaux vivent dans les steppes des régions tropicales; ils se nourrissent de grains, d'herbes, rarement de petits animaux. Quelques-uns sont polygames.

Les Autruches d'Afrique n'ont que deux doigts à chaque pied ; leurs pubi: forment une symphyse. - Autruche Chameau (Struthio camclus), fournit aux indigènes de l'Afrique sa chair, sa graisse, ses œufs et surtout ses plumes. A différentes reprises on a tenté de la domestiquer; les essais des colons anglais au Cap de Bonne-Espérance ont fini par réussir complètement. En 1863, il y avait au Cap 80 Autrucles domestiques; en 187:, ce nombre était

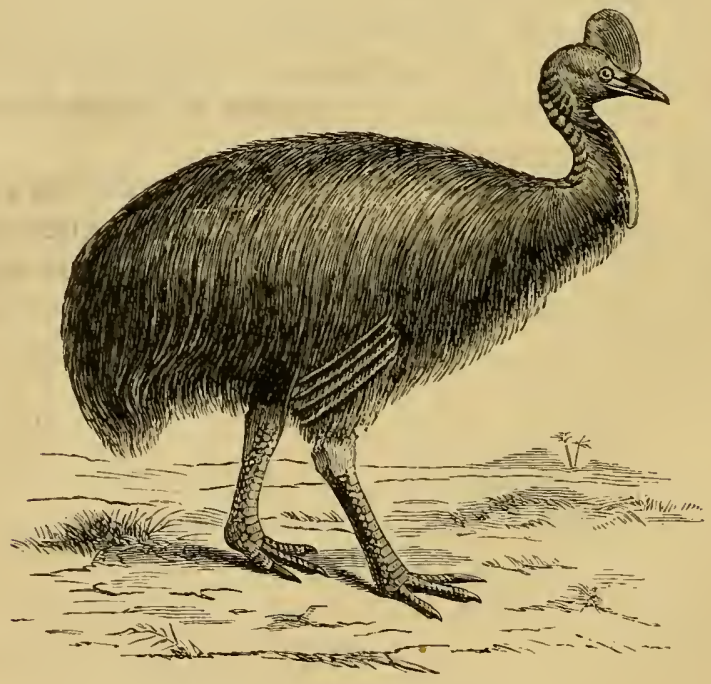

Fig. 73?. - Casoar à casque.

monté à 32,847; en 1889 il atteignait 149,684. Une Autruche pond annuellement 20 à 30 œufs, souvent même jusqu'à 43 et 50 . Màle et femelle couvent à tour de rôle, pendant 43 jours, mais dans la pratique on a recours à l'incubation artificielle. Il est à désirer que l'élevage de l'Autruche soit sérieusement poursuivi en Algérie, où avaient été faits les premiers essais. 
OISEAUY. - PALMLPEUES.

- Une autre espèce, l'Autruche des Somalis ( $\$$ tr. molybdophanes), vit dans l'est de l'Afrique.

Les Autruches d'Amérique ont trois doigts; leurs pubis sont libres. Yandon (Rhea americona), etc.

Les Casuaridés, qui sont aussi tridactyles, comprennent les Émous (Dromieus) et les Casoars (Cusuarius), australiens et océaniens.

On rapproche des Coureurs quelques autres formes d'Oiseaux terrestres qui ont également les ailes rudimentaires et le sternum dépourvu de bréchet, et à ce titre font partie du groupe des Ratites :

Les APTÉRYGidís se distinguent des Autruches par leur petite taille, leur bec long et mince, et leurs pattes munies d'un pouce. Ce sont des Oiseaux noctırnes, sans aucune défense et qui tendent à disparaitre. - Kiwi (Aptery.x australis), Nouvelle-Zélande; Aptéryx d'Owen (A. Oveni), Tasmanie.

Les Dixorntrues, aujourd'hui complètement éteints, étaient des Oiseaux gigantesques, qui ont dù périr sous la main de l'Homme. - Moas (Dinornis), Nouvelle-Zélande. - Apyornis (Epyornis), Madagascar.

\section{DEUXIEME OR DRE}

\section{PALMIPÈDES}

Oiseaux aquatiques, à doigts palmés; bec variable.

Le corps des Palmipèdes est recouvert de plumes très serrées et lustrées par une abondante matière huileuse provenant de la glande uropygienne. Les pattes sont en général courtes; les doigts sont tout à fait palmés et par suite propres à la natation. Les ailes sont parfois réduites i l'état de moignons fonctionnant comme des rames (fig. 740), et d'autres fois bien développées. Le cou est long. Le bec est tantôt long et pointu, tantôt large, obtus et revêtu d'une peau molle.

Quoique monogames à l'état sauvage, ils vivent en troupes. Leur nourriture se compose surtout de Poissons, de graines et de diverses substances régétales.

De nombreux Palmipèdes viraient déjà au bord des lacs tertiaires, en commun arec des Échassiers. A. MilneEdwards a trouvé un petit Ansériné dans les faluns de la Touraine, et des débris abondants de Canards dans les

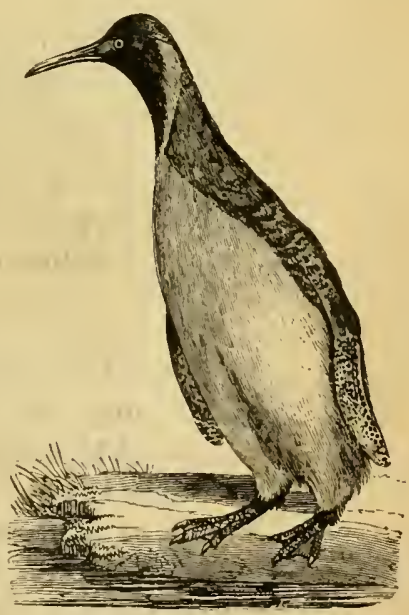

Fig. 740. - Grand IIanchot (Aptenodytes patagonica). lacs miocènes du Bourbonnais. On a signalé également la présence de Canards à la station paléolithique de Thayingen, en Suisse.

4 sous-ordres: Brachylteres, Lamellirostres, Totipalmes et Longipennes. 
$1^{\text {er }}$ Sous-ordre : Brachyptères. - Le nom de Brachyptères (Bpx\%ús, court; $\pi$ ז pòv, aile) indique que ces Oiseaux sont peu ou point aptes au vol; celui de Plongeurs, qu'on leur donne aussi quelquefois, témoigne de leurs habitudes. Ils ont les pattes reportées tout à fait à l'arrière du corps. Le bec est souvent comprimé, à bords tranchants.

Manchots (Aptenodytes), Pingouins (Alca), Guillemots (Uriu), Grèbes (Podiceps), Plongeons (Colymbus).

DEUXIÈMESOUS-ORDRE

\section{LA MELLIROSTIES}

Ces Palmipèdes sont caractérisés par un bec large, légèrement bombé en dessus et revêtu d'une peau molle, très riche en nerfs. Les bords mandibulaires sont garnis de petites lamelles cornées transversales s'engrenant entre elles, et destinées à tamiser l'eau en retenant les Vers ou autres aliments recueillis dans la vase. La langue est grande, charnue, cornée à son bord antérieur, qui est frangé de papilles représentant des plumes avortées. Le gésier est très musculeux, les cæcums sont assez longs. Les trois doigts antérieurs sont réunis par une palmature; le doigt postérieur est rudimentaire, nu ou à bords garnis d'une expansion membraneuse.

La plupart des Lamellirostres sont omnivores: ils vivent d'herbes, de graines, de Vers, de Mollusques ou d'autres animaux aquatiques. Les petits sont précoces.

On les divise en deux familles: les Phonicoptéridés ou Flamants, que leurs longues pattes font souvent classer parmi les Échassiers, et les Anatidés ou Canards.

Les ANATIDÉS se distinguent des Flamants par leurs pattes modérément développées et leur bec relativement droit. Ils se subdivisent en 4 sous-familles ou tribus: C'ygninæ, Anserince, Anatina et Merginx.

Les crgninés ont un corps volumineux et une tête petite, portée sur un cou très long; le bec est presque aussi large vers l'extrémité que vers la base et terminé par une lame cornée arrondie (onglet); le lorum (région qui s'étend entre l'œil et la racine du bec) est nu; les pattes, de hauteur médiocre, sont fortement rejetées en arrì̀re; le plumage est serré et le duvet abondant. Ces Oiseaux sont plutôt nageurs que marcheurs. Ils sont moins herbivores que les Oies, moins carnivores que les Canards.

Les Cygnes (Cygnus L.) sont les seuls représentants de cetle tribu; on en connait environ huit espèces, dont trois européennes: le Cygne sauvagre ou chanteur (C. musicus Bechstein), à bec noir à la pointe, le Cygne de Bewick (C. Bewicki Yarrell) et le Cygne muet. 
Le Cygne muet (C. olor [Gmelin]) a le plumage d'un blanc éclatan, une caroncule frontale noire surmontant un bec rouge, à bords et à onglets noirs, des pattes brunes nuancées de rougeàtre. Les jeunes sont gris et hlanc, quelquefois tout blancs.

Cetle espèce habite les còtes de la Suède et de la Norvège, et ne vient que l'hiver daus nos régious. Au printemps, la femelle pond ä à 7 œufs d’un gris noiràtre.

Le Crgae domestique ( $C$. olor domestirus Auct.), qu'on voit habituellement sur les pièces d'eau, dérive à coup sùr, et en droite ligne, du cy!gnus olor', contrairement a l'opinion de Buflon, qui le faisait descendre du Cygmus

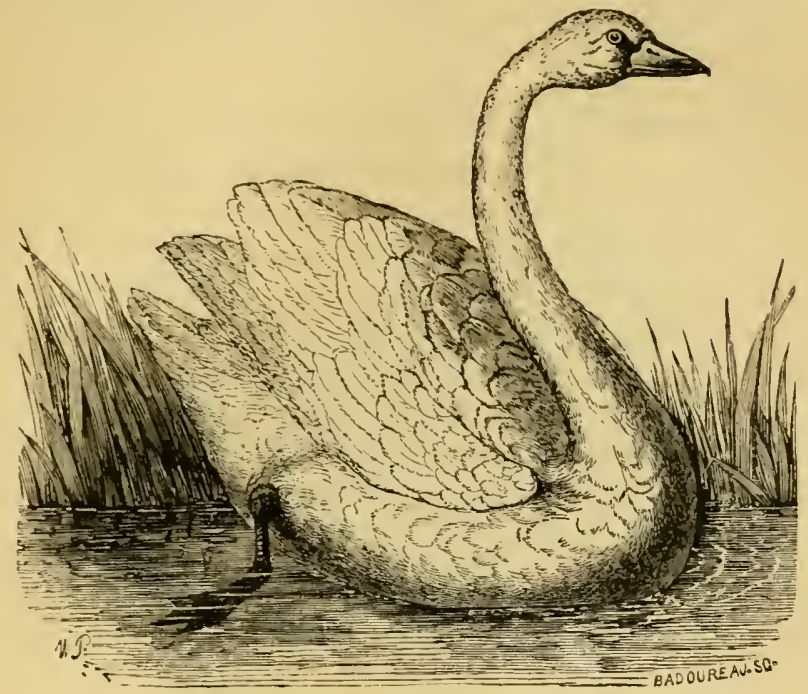

Fig. 711. - Cigne domeslique.

musicus. Mais ả quelle époque cet Oiseau a-t-jl été domestiqué? C'est ce qu'il est difficile d’indiquer d'une façon précise. Les auteurs grecs et romains parlent souvent du Cygne sauvage, sans faire aucune mention du Cygne domestique. Au contraire, on roit brusquement les auteurs de la Renaissance, et en particulier Pierre Belon, signaler celui-ci comme habituellement " nourri ès douves des chasteaux situez en l'eau ". On est ainsi porté à penser que la domestication du Cygne remonte au moyen àge.

La domestication ne l'a pas très sensiblement modifié; il est resté monogame et a même conservé en grande partie ses allures farouches et indépendantes. On ne peut l'élever que sur un bassin; placé sur une rivière, il en suivrait le cours et s'enfuirait.

La ponte, qui a lieu tous les deux jours, est de j̈ à 8 cufs et commence en février. L'incubation dure $33 ̈$ jours. Le mâle quitte peu sa femelle pendant cette période, et on doil éviter de l'approcher, car son ardeur à la défendre et sa puissance le rendent dangereux. Les petits 
vont immédiatement à l'eau. Ceux qui naissent avec une livrée grise ne la quittent que vers l'âge de deux ans. On assure qu'il faut leur mutiler les ailes avant qu'ils soient capables de voler, sans quoi ils chercheraient à fuir au moment du passage des Palmipèdes sauvages.

Ces animaux fournissent deux fois par an leurs plumes etleur duret, qui sont très recherchés. D'autre part, ils sont bons à manger vers l'âge de deux ans; mais il est bien rare qu'on les sacrifie dans ce but. La chair des vieux sujets est noire, coriace, peu agréable. Les Cygnes ne sont guère élevés, en somme, que pour orner les pièces d'eau.

En Russie, c'est surtout le Cygne chanteur qu'on entretient en domeslicité. Dans notre pays, on voit aussi quelquefois dans les parcs des châteaux différentes autres espèces exotiques.

Les ANSÉRINÉS ont la tête assez grosse, le cou de longueur moyenne, le bec convexe en dessus, aplati en dessous, un peu plus étroit et moins haut en avant qu'en arrière, et terminé par un large onglet; les pattes, de longueurmédiocre, sont moins reportées en arrière que chez les Canards et les Cygnes; elles sont emplumées presque jusqu'aux tarses; les ailes sont grandes; le plumage. est mou, le duvet très développé.

Les Ansérinés sont moins aquatiques que les autres Anatidés; ils nagent bien, mais, par suite de la situation de leurs pattes, plongent difficilement; ils se tiennent volontiers sur les rivages; enfin, leur régime est plus végétal.

Parmi les genres qui composent cette tribu, nous citerons les Oies (Anser), les Bernaches (Bernicla), les Céréopses (Cereopsis), les Chénalopex (Chenalopex), les Chens (Chen), etc.

Le genre Oie (Anser L.) est caractérisé par un bec à lamelles espacées, dirigées en arrière et saillantes en forme de dents sur tout le bord de la mandibule supérieure; les tarses sont épais, assez longs; le plumage est en général sans éclat. Les jeunes ne revêtent la livrée des adultes qu'après plusieurs mues. Ces animaux vivent en petites troupes à l'état sauvage, se nourrissant de graines et de plantes herbacées.

Les principales espèces européennes sont: l'Oie cendrée (A. cinereus), l'Oie sauvage ou des moissons (A. syliestris), l'Oie rieuse (A. albifrons), etc. Toutes nichent dans le nord de l'Europe, et ne viennent chez nous que comme Oiseaux de passage.

L'oie cendrée ( $A$. cinereus Neyer) est d'un cendré clair passant au blanchàtre sur le front et au gris brunàtre sur le dos et les épaules, les plumes étant bordées de blanchàtre. La poitrine est cendrée, avec des ondes blanchàtres sur les côtés; l'abdomen et le dessus de la queue sont d'un blanc pur. Le bord extérieur des ailes et la base des rémiges sont d'un cendré blanchâtre; les rectrices externes sont blanches, les médianes brun cendré à lisérés blancs. Le bec est jaune orangé, l'iris brun foncé; les patles sont de 
couleur chair tirant sur le jame. La frmelle est plus petite que le mile, et d'un cendré plus clair en dessus.

Prises jeunes, les Oies cendrées s'apprivoisent facilement ; cependant, les petits auxquels elles donnent naissance tendent toujours à fuir à l'époque de l'émigration. En liberté, elles pondent cinq ou six åufs quand elles sont jeunes, et plus tard sept à quatorze. Leur chair est moins grasse, mais plus savoureuse et plus parfumée que celle des Oies domestiques. L'accouplement, mème spontané, des Oies cendrẻes et des Oies domestiques, n'est pas très rare, et les produits qui en résultent sont indéfiniment fécouls.

L'Ole dosestigle (A. cinereus domesticus Auct.) offre une assez. grande variété dans le plumage; elle a les allures plus lourdes, le port moins fier

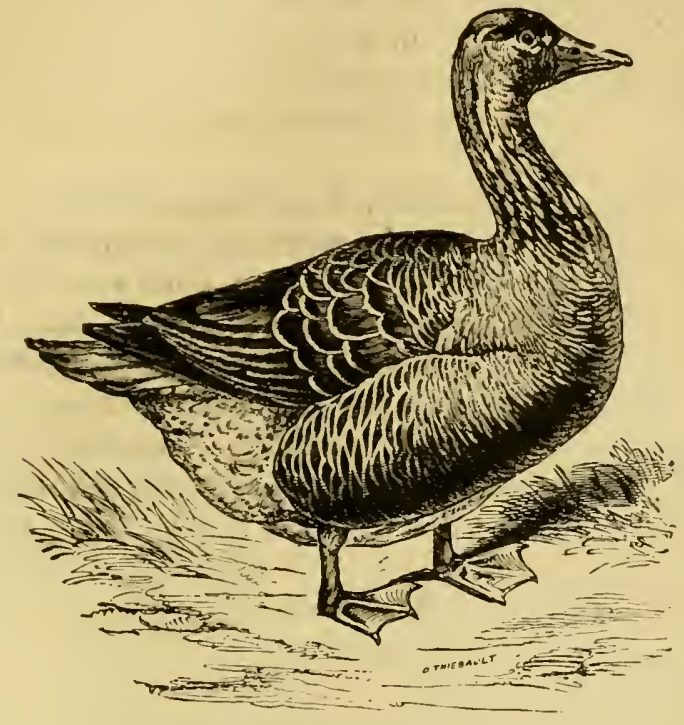

Fig. 7iz. - Oic commute.

Iue l'Oie cendrée. On en distingue en France deux races principales: l'Oie commune el l'Oie de Toulouse, cette dernière reconnaissable à son abdomen trainant.

La plupart des observateurs compétents pensent que les Oies de nos basses-cours descendent de l'Oie cendrée (A. cinereus). Darwin fait cependant remarquer que la partie inférieure de la trachée de l'Oie domestique est, d'après Yarrell, quelquefois aplatie, et que la base du bec est parfois entourée d'un anneau de plumes blanches. "A première vıe, ces caractères sembleraient indiquer un croisement antérieur avec l'Oie à front blanc A. albifrons); mais, chez cette espèce, l'anneau blanc est variable, et il ne faut pas méconnaitre la loi des variations analogues, en vertu de laquelle les individus d'une espèce peuvent revètir certains caractères d'une espèce voisine."

Il est à remarquer que nos Oies ont bien peu varié, malgré une domestication déjà ancienne. En se basant sur des textes précis, I. Geoffroy Saint- 
Hilaire a montré que, au temps d'Aristote, l'Oie devait êlre " non seulement domestique, mais commune à l'état domestique, et par conséquent domestiquée depuis longtemps; et c'est ce que confirment deux vers de l'Odyssée, où l'Oie nous est représentée comme un des Oiseaux qu'on nourrissail dans les maisons. La domestication de l'Oie date donc, en Grèce, au moins du temps d'Homère s.

Ces Oiseaux sont toujours très répandus dans nos basses-cours; on les entretient souvent en grandes troupes, qui peuvent se conduire au pâturage comme des Moutons. Ils se nourrissent d'herbes fines, de graines, d'Insectes, et ingèrent en même temps une grande quantité de sable fin.

Un mâle ou jars suffit à cinq ou six Oies. Chacune de celles-ci ne fait guère qu'une ponte par an, vers le mois de février. Elle pond de deux jours l'un, quelquefois tous les jours, et donne en moyenne 13 à 18 œufs, rarement jusqu’à 30 et $3 \%$; on lui en laisse généralement 15 à couver.

L'Oie est très bonne couveuse. L'incubation dure environ 30 jours. Pendant ce temps, elle ne quitte guère son nid qu'une fois par jour, pour manger, en ayant soin de couvrir ses ceufs avec de la paille.

Les Oisons exigent quelques soins particuliers dans les premiers jours. A l'âge de six à huit mois, ils peuvent être déjà livrés à la consommation. Dans quelques pays, principalement en Alsace et dans le bassin de la Garonne, on les soumet à l'engraissement par ingurgitation forcée. L'opération porte en général sur des animaux de six mois (Oies de Toulouse); elle dure de 18 à 24 jours. La substance à l’aide de laquelle on les gave de préférence est le maïs. La chair, qui a acquis ainsi beaucoup de délicatesse et de fumet, est alors livrée à la consommation ou disposée en conserves, el le foie est mis à part pour la fabrication des terrines et des pâtés si chers aux gourmets. Les Romains tenaient déjà le foie gras en haule estime, et nous savons qu'ils recherchaient de préférence celui de l'Oie blanche. C'est à Strasbourg qu'a été inventé le fameux pâté de foie gras, vers 1788, par un nummé Close, cuisinier normand au service du maréchal de Contades.

Outre la chair et le foie, les Oies fournissent encore, deux ou trois fois par an, leurs plumes et leur duvet, qui se vendent fort cher, et leurs grandes pennes, qui sont usitées comme plumes à écrire après avoir été hollandées, c'est-à-dire dégraissées, nettoyées, arıondies et polies. Enfin, dans quelques pays, et en particulier dans la Vienne, on soumet au mégissage la peau emplumée, qui est employée ensuite par les fourreurs sous le nom de peau de Cygne : l'Oie écorchée dans ce but est vendue en morceaux à un prix relativement peu élevé. Quant aux ceufs, ils sont d'un rapport insignifiant.

Une race de l'Anser altifrons, l'Oie à pieds pàles (A. pallipes de Sélys), vit 
en domesticité dans certaines fermes de la Belgique et de la IIollande. Son cri ressemble à un long éclat de rire.

Iu Canada, les Oies domestiques dériveut de l'Anser canadensis; en Chine, elles proviennent de l'Anser cy!moides. Ces deux espéces, et quelques autres encore, se voient assez souvent sur nos bassins. - Les anciens Égyptiens vénéraient l'oie Renard (Chenaloper xqyptiaca), qu'ils entretenaient comme animal sacré et qui est souvent figurée sur les monuments.

Les anatinés ont la tête très grosse, le bec aussi large ou plus large vers l'exlrémité que vers la base, la mandibule supérieure large, emboitant l'inféricure, le cou court ou de longueur moyenne, les jambes el les tarses courts, reportés plus en arrière que cliez les Cygnes.

Essentiellement aquicoles, ils ont un régime à la fois animal et régétal, se nourrissant aussi bien de. Vers, de Mollusques, d'Insectes et de Poissons que de graines, de racines, d'herbes, de plantes aquatiques.

Cette tribu ne comprend en réalité que le seul genre Canard (Anas L.), qu'on a subdivisé sans nécessité, et dont les nombreuses espèces se répartissent entre deux sections principales:

$1^{\circ}$ Les Anatinés proprement diss ont un cou moyen, le doigt externe plus. court que le médian, le pouce dépourvu d'expansion membraneuse. - Les principales espèces sont: le Canard sauvage (A. boschas), le Souchet commun ou Rouget de rivière (A. clypeata), le Chipeau bruyant on Rousseau (A. strepera), la Marèque Pénélope ou Canard siffleur (A. Penelope), le Pilet ou Canard-Faisan (A. acuta), la Sarcelle d'hiver ou Sarcelline (A. crecca), la Sarcelle d'été (A. querquedula), le Tadorne de Belon (1. tadorna), le Tadorne Casarca (A. casarca), le Canard carulin (A.sponsa), le Canard mandarin (A.galericulata), le Canard musqué (A. mosthata).

$2^{\circ}$ Les Fuliyulinés ont le cou gros et court, les pattes très courtes, le doigt externe aussi long que le médian, le pouce ou doigt postérieur largenent bordé.-Espèces principales : Morillon (A. fuligula), Milouinan (A. marila), Milouin (A. ferina),

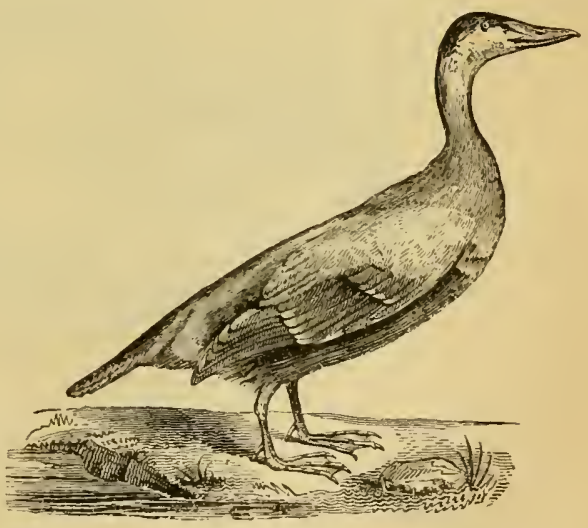

Fig. 743. - Eider (Anas mollissima). Garrot (A. clungulu), Eider (A. mollissima), Macreuse ordinaire (A. niyru), Macreuse brune (A. fusca), etc.

Ces différentes espèces émigrent chaque année; on leur fait une chasse active dans les marais ou sur les còtes, a cause de leur chair délicate et nutritive. Les Fuligulinés sont surtout des animaux marins et plongeurs. L.'Eider, qui habite les régions boréales, fournit un abondant duvet (eider ckun, d'où édredonj dont l'Homme tire utilement parti. 
Le Canard sauvage ( $A$. boschas $L$.) varie beaucoup dans son plumage suivant le sexe et l'àge. Le mile a la tète et le haut du cou verts, puis un collier blanc, le dos d'un brun cendré rayé de grisàtre, la poitrine d'un beau marron foncé, le ventre et les flancs gris blanc moiré de noiràtre ; l'aile pliée offre une belle plaque bleue (miroir) bordée en avant et en arrière par une double bande noire et blanche; les quatre rectrices médianes sont noires, à reflets pourpres, recourbées supérieurement en demi-cercle; le bec est d'un jaune verdâtre, noir à la pointe; les pattes sont d'un rouge orangé. La femelle est d'un cendré roussàtre semé de taches plus ou moins foncées; elle n'a pas les teintes brillantes ni les rectrices frisées du måle. Les jeunes, avant la première mue, ressemblent assez à la mère et sont connus sous le nom de halbrans.

Le Canard sanvage est une espèce sociable, très répandue dans tout l'hémisphère boréal. Les individus qui habitent le Nord émigrent régulièrement; ceux qui vivent dans nos régions les quiltent à peine quand les eaux sont glacées. La femelle pond huit à seize œufs d'un blanc verdàtre.

Ces animaux s'apprivoisent assez facilement; ils s'accouplent volontiers avec les Canards domestirjues et donnent avec eux des produits indéfiniment féconds.

I.e Canard domestique (A. boschas domestica Auct.) comprend comme races principales le Canard commun, le Canard de Bouen, le Cunard d'Aylestury, le

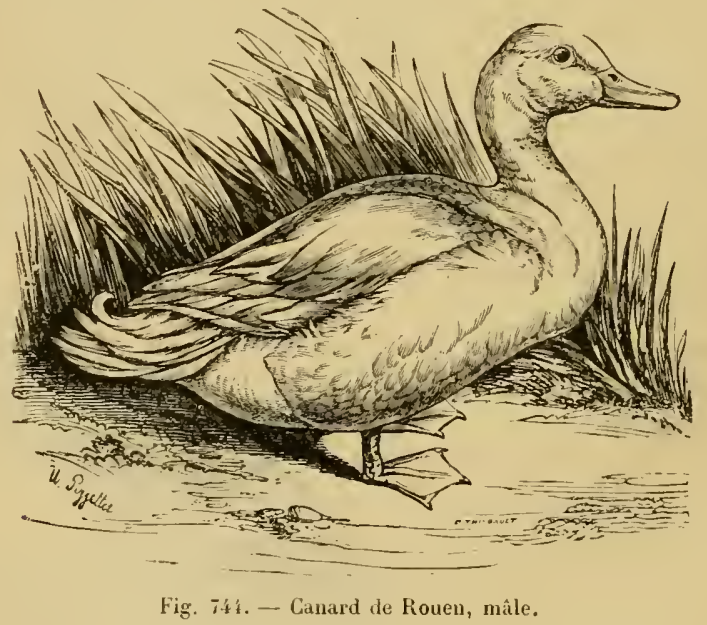

Canctrd de Pékin, habituellement élevés dans les basses-cours pour ètre mangés, puis le Canard du Labrador (ou de Buenos-Ayres), le Canard pinyouin, le Canard ì bee crochu, etc., entretenus plutòt comme Oiseaux d'ornement.

Ces diverses races dérivent-elles d'une souche unique? Darwin a rassemblé un grand nombre de documents qui tendent à donner à cette question une réponse affirnative. Pour. lui, l'ensemble de nos races a pour espèce souche le Canard sauvage. Parmi les arguments qu'il invoque, nous relèverons simplement cette. remarque que, dans la grande famille des Canards, 
celte seule espéce a, chez le màle, les quatre rectrices médianes frisées et relevées en boucles; or, on retrouve cette particularité chez toutes nos races domestipues.

La date de la domestication lu Canard a pu itre déterminée d'une facon approximative. I'après Darwin, le Canard domestique était inconnu aux anciens Eyptiens, aux Juifs de l'Aneien Testanent el aux Grees de la période homérique. Is. Geoffroy Saint-Hilaire ajoute que "chez les Romains, à l'époque de Varron, il fallait encore couvrir de filets les enclos destinés aux Oiseaux d'eau, ne possil Anas cvolure. La domestication était donc eneore très incomplète, et par conséquent récente it la fin de la république romaine ".

Un màle suflit a six femelles; mais le mâle ne soccupe jamais des couvées. La Cane pond, au printemps, cinquante à soixante ceul's. Lorsqu'elle ne couve pas ou qu'elle perd ses pelits, illui arrive parfois de donner encore quelques cul's en aout. On lui laisse d'habitude douze ou quinze oufs à couver; mais elle est médiocre couveuse, et il faut la surveiller au moment de l'éclosion, car elle sumpatiente aisément et quitte le nid avec les premiers nés. L'incubation dure 28 jours. On lait souvent couver les oufs de Cane par des Poules et mème par des Dindes.

Les petits sont voraces, faciles à élever. Au bout de trois ou quatre mois, ils ont acquis tout leur développement. On reconnaît qưn Canard peut ètre mangé quand il a les "ailes croisées ». La chair est de bonne qualité, quoique plus grasse, moins fine et moins parfumée que celle du Canard sauvage. Dans certaines régions, on engraisse les Canards à la façon des Oies, dans le but surtout d'obtenil des foies gras, qui servent à la confection de terrines el de pàtés très estimés. Ces foies se vendent plus cher que ceux des Oies.

Les oufs sont inférieurs à ceux des Poules, mais valent mieux que ceux des Oies; on les emploie souvent dans la pâtisserie, quoique les blancs ne puissent être battus en neige. Les Chinois sont friands d'œufs de Canard fermentés. Les plumes el le duvet sont un peu moins recherchés que ceux de l'Oie.

Le Canard musqué (A. moschatu L.), dont on a fait le type d'un genre Cairina, est un Oiseau de forte taille, et l'on peut dire quec'est le plus gros de tous les Canards. Il est remarquable par la présence, à la base du bee et sur les joues, de caroncules d'un l'ouge foncé, tachées de noir. Son plumage est d'un brun noiràtre; les ailes sont en partie blanches. Le bec est rouge, avec une bande transversale noirâtre; les pattes sont également rouges, avec des ongles longs et recourbés. La femelle est d'une taille beaucoup plus faible que le màle, dont elle a d'ailleurs la livrée; toutefois, le peu de rouge qu'elle présente au sommet du bec el autom des yeux ne forme pas de proéminences.

Cet Oiseau vit à l'état sauvage dans l'Amérique centrale et méridionale, depuis le Mexique jusqu'au Paraguay et au Pérou. C'est done bien à lort quon l'appelle vulgairement Canard de Barbarie ou Canard dinde. En 
raison de sa voix grave et basse, qu'on entend à peine, sauf dans les moments de colère, on lui donne quelquefois le nom de Canard muet.

A l'état domestique (A. mosehata domestica), on en élève trois variétés: une entièrement noire, une blanche, et une noire et blanche, dite bronzée.

On admettait généralement que ce Canard avait étẻ domestiqué au Brésil ; ınais les recherches de Nehring (1) tendent à montrer que sil a été soumis primitivement dans une seula contrée, c'est en réalité au Pérou, pays habité par une race très experte dans l'élevage des animaux. Il est possible, au surplus, que la domestication ait été effectuée sur divers points à la fois. File remonte en tout cas à une époque assez éloignẻe, car Colomb avait déjà trouvé le Canard musqué à l'état domestique chez les indigènes d'Haïti. Son introduction en Europe date du $\mathbf{x v i}^{\mathrm{e}}$ siècle. Vers 1350 , il commencait à se répandreen France, puisque, d'après Pierre Belon, on le vendait " par les marchez pour s'en servir es festins el noces".

Le Canard musqué, du moins à l'âge adulte, ne recherche pas autant l'eau que les autres Canards; de plus, il vole avec facilité et se perche volontiers. Sa ponte est assez abondante; ses petits s'élèvent facilement, quoique sensibles au froid. Malheureusement, c'est un Oiseau gourmand et méchant, et on ne peut giuère en recommander l'élevage. Sa chair a d'ailleurs une odeur musquée fort désagréable, ce qui lui a valu son nom. On assure, il est vrai, que cette odeur provient des plumes de la nuque et des caroncules céphaliques, et quil suffit d'enlever la tête aussitôt après avoir tué l'animal, pour éviter cet inconvénient.

Dans le midi de la France, on emploie le Canard de Barbarie, en raison de son volume, pour faire des croisements avec la Cane commune ou la Cane de Rouen. Plus rarement on utilise le Canard commun et la Cane musquée. Les produits obtenus sont connus sous le nom de mulards; ils sont le plus souvent inféconds, mais ils ne possèdent pas d'odeur musquée. Sur cent œufs de Cane ainsi fécondés, il est rare, dit-on, qu'on oblienne plus de vingt Canetons. Ceux-ci sont excellents et deviennent très gros; ils ne possèdent pas d'odeur musquée. Ce sont eux qui fournissent les foies gras employés à la confection des fameuses terrines de Nérac.

On entretient en outre, sur les pièces d'eau de nos parcs, diverses autres espèces d'Anatinés, qui ne représentent en réalité que des Uiseaux de luxe.

Les MERGINÉs sont aisément reconnaissables à leur bec étroit, crochu, unguiculé à son extrémité, et pourvu de lamelles saillantes, formant sur les bords des mandibules de petites dents de scie dirigées en arrière.

Ce groupe u'est représenté que par les Haries (Mergus). Le Harle bièvre (11. merganser) se nourrit surtout de Poissons, de sorte qu'il est redouté des pisciculteurs.

(1) A. Nenriva, Ueber die Heimat der gezähmten Moschus-Ente (Anas moschata L.). sitzungsberichte der Gesellschaft naturforschender Freunde zu Berlin, 1889, $\mathrm{n}^{\circ}$ : p. 33. - Revue des sc. nat. appliquées, (i), VI, p. 74́5, 1889. 
$3^{\text {e }}$ sous-ordre: Totipalmes. - Les Totipalmes ou Stéganopodes ont, comme leur nom l'indique, les qualre loigts, y compris le pouce, réunis par une membrane. Leurs ailes sont très granles.

Ex. : les Pélicans (Pelecanus), qui portent au-dessous de la mâchoire inférieure une grande poche nembraneuse dans laquelle ils accumulent les l'oissons qu'ils vienuent le prendre (fig. T4ï); les Cormorans (Phalacrocor $u x$ ), les Frégates (Tachypetes), les Fous (Sulu), les Phaétons ou! IPaille-en-queue (I'hueton), etc.

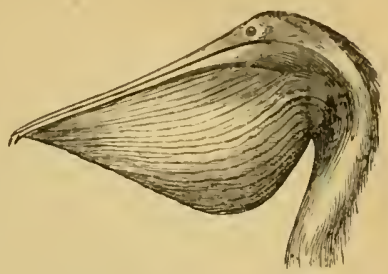

Fig. 7.5. - Tile du Pélican commun (I'elecanus onociotalus L.).

$\dot{4}^{\mathrm{e}}$ sous-ordre : Longipennes. - Ce sont des 0iseaux à ailes très longues, à vol rapide el soutenu. La palmature ne s'élend pas au pouce, qui est sourent rudimentaire.

Goélands ou Mlouettes pècheuses (Larus), Hirondelles de mer-(Sterna), Labbes ou Monettes pillardes (Lestris), Becs-en-ciseaux (Rhynchops), Pétrels (Procellaria), Albatros (Diomedea), Oiseaux de Saint-Pierre (Thalassidroma), elc.

\section{TROISIEIE ORDRE}

\section{Échassiers}

Oiseaux it pattes, bec et cou allongés.

Les Échassiers (Grallatores) doivent leur nom à la longueur de leurs pattes et surtout de leurs tarses, qui les fait paraitre comme montés sur des échasses. Le bas de la jambe est nu, comme le tarse. Les doigts, souvent grêles et allongés, sont quelquefois libres (fig. $7 \mathbf{1} 6$ ), mais plus fréquemment réunis

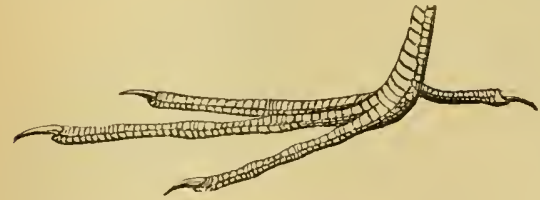

Fig. 746. - Patle de Poule d'eau (Gullinuta chloropus L.).

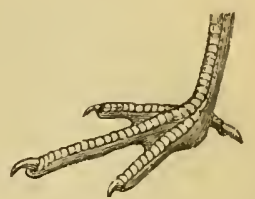

Fig. 747. - Palle de Vanneau (Vanellus cayennensis L.).

a leur base par une membrane (fig. 747). Le cou et le bec sont longs, de manière à permettre à l'animal de chercher sa nourriture dans l'eau. Les ailes ont un développement variable.

Ces Oiseaux, la plupart migrateurs, sont monogames ; ils vivent par couples, surtout au bord des eaux, ce qui leur vaut le nom d'Oiscuux de rivage. Tous sont prédateurs, bien que quelques-uns puissent rechercher en mème temps les substances végétales.

Les affinités multiples des Échassiers ne permettent guère de les diviser autrement qu'en une série de familles.

Les Churadridès ou Coureurs ont une tète assez forte, un cou court, un bec Ralliet. - Zoologie. 
médiocre, à bords très durs, un pouce rudimentaire ou nul. Courvites ( $C$ crsorius), Pluviers (Charadirus), Vanneaux (Vanellus), Huîtriers (Hæmatopus).

Les Scolopacides ou Limicoles ont une tète moyenne, très bombée, un bec

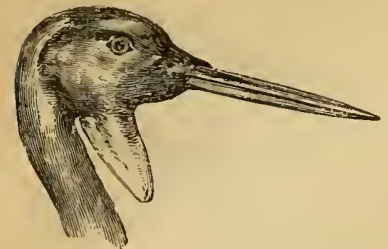

Fig. 748. - Tète de Grue caronculéc (lirus cerunculata L.). long et mince revètu d'une peau molle, des jambes grêles, un pouce rudimentaire ou nul. - Chevaliers (Totanus), Barges (Limosa), Récurvirostres (Recurvirostra), Combattants (Machetes), Bécasses (Scolopax), Bécassines (Gallinago), Bécasseaux (Limicola), Courlis (Numenius).

Les Hérodiens ou Cultrirostres sont de grands Oiseaux à petile tête en parlie nue, à coulong, à bec fort, épais, allongé, très dur, tranchant sur les bords; leurs pattes sont très longues, nues, pourvues d'un pouce qui touche le sol. - Ibis (Ibis), Spatules (Platalea), Hérons (Ardea), Cigognes (Ciconia), Grues (Grus).

Les Rullides ou Macrodactyles se rapprochent des Gallinacés; ils ont un bec fort, de longueur moyenne, comprimé d'un côté à l'autre, des pattes assez courtes, emplumées, à doigls longs et grêles, le pouce touchant le sol, des ailes courtes et arrondies. - Râles d'eau (Rallus), Ràles des prés (Crex), Poules d'eau (Gallinula), Poules sultanes (Porphyrio), Foulques (Fulica).

Enfin, les Alectoridés ou Pressirostres établissent le passage entre les Échassiers et les Palmipèdes. Ils ont un bec fort, court et bombé, souvent comprimé latéralement, des pattes lonğnes à pouce rudimenlaire, des ailes courtes, mais fortes, souvent armées d'éperons. - Outardes (Otis),

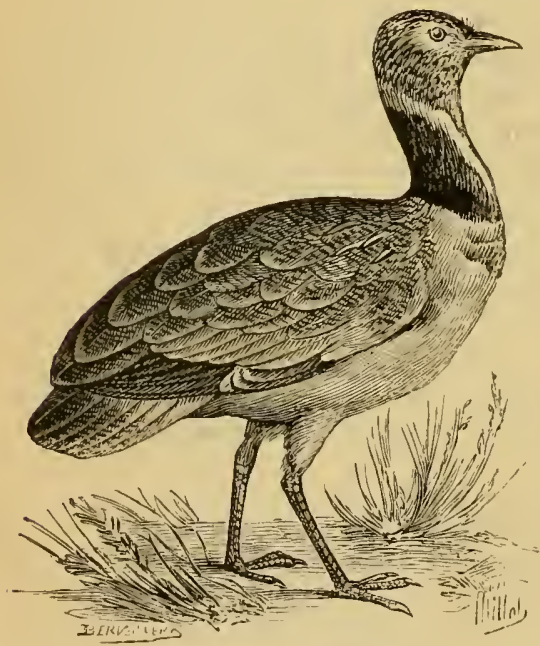

Fig. 749. - Ontarde Cancpetiòre.

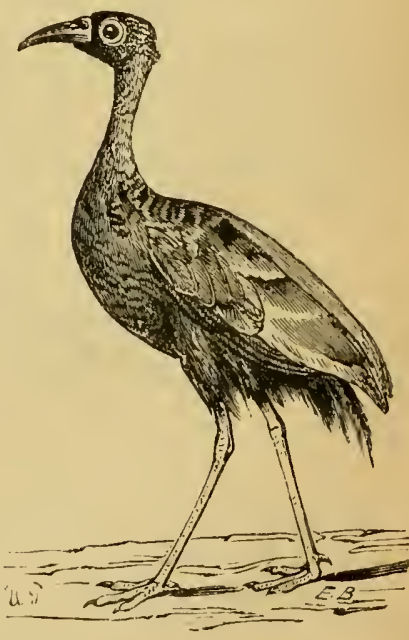

Fig. 7ว̈0. - Agami.

Agamis (Psophia), Kamichis (Palamedea), Chaunas (Chama). Les Agamis, Kamichis et Chaunas sont de grands Oiseaux doux et sociables de l'Amérique du Sud, qui s'apprivoisent facilement et peuvent ètre laissés dans les bassescours avec la volaille. Dans les Cuyanes, on trouve aussi l'Agami bruyant (Psophia crepitans) aulour des fermes et jusque dans les rues des villes; sou- 
vent mème on met a profit son naturel courageux et ses instincts autoritaires pour en faire un gardien de la basse-cour ou mème des troupeaux de Moutons.

\section{QUATRIËUE ORDRE}

\section{GALLINAGÉS}

Oiseaux terrestres, i ailes courles etariondies; bec assez fort, convexe, membraneux à la base (cire); les trois doigts antérieurs, ou les deux externes seulement, réunis à la base par une courte membrane.

Les Gallinacés ont le corps trapu, revêtu d'un plumage abondant, mais sans souplesse, la tète relativement petite, le bec convexe, plus ou moins recourlé vers la pointe, et offrant une base molle, membraneuse et garnie de plumes, entre lesquelles se trouvent les narines, recouvertes chacune par une écaille. Les pattes sont fortes, parfois emplumées jusque sur le pied; le pouce, presque toujours inséré au-dessus du niveau des autres doigts, peut se montrer tout à fait réduit. Les mâles diflìrent souvent des femelles par un plumage brillant, par la présence d'appendices cutanés érectiles, d'ergots aux tarses, ete.

Les Gallinacés sont des Oiseaux terrestres, à vol lourd et bruyant. Ils se nourrissent de baies, de graines, d'Insectes, de Vers, qu'ils découvrent d'ordinaire en grattant le sol, d'où le nom de Gratteurs ou de Pulvérateurs qu'on leur donne quelquefois. Ils sont pour la plupart polygames, el la mère s'occupe seule de sa progéniture. Les petits sont précoces: ils vont immédiatement à la recherche de leur nourriture.

Cet ordre, qui renferme les plus importantes espèces domestiques el que Claus compare très heureusement aux Mammifères ongulés, est représenté daus nos climats par deux familles principales, celles des Phasianidie et des Tetraonidie.

Les PHASIANIDÉs réalisent le type le plus parfait des Gallinacés. Ils ont la tête sourent garnie d'appendices charnus, ou surmontée d'une aigrelte. La queue est longue. Les pattes sont fortes, avec les trois doigts antérieurs réunis à la base el le doigt postérieur faible, situé au-dessus du niveau des autres; en outre, les mâles portent presque toujours un ergot. Les deux sexes sont assez différents: le mále est plus fort et plus richement orné. Ils appartiennent pour la plupart à l'ancien continent.

Cette famille se divise en plusieurs sous-familles, dont les principales seules nous occuperont : Meleagrina, Numidinx, Pavoninx, Phasianinx, Gallina.

Les MÉLÉagrinÉs ont la tête et la parlie supérieure du cou dénudées et couvertes de saillies verruqueuses colorées en bleu et en rouge; 
à la base de la mandibule supérieure existe une caroncule érectile; des sortes de fanons également érectiles pendent au-dessous de la mandibule inférieure. Les mâles ont de faibles éperons, qui disparaissent souvent sous l'influence de la domesticité. Dans les moments de passion, ils font la roue, c'est-à-dire qu'ils se pavanent en traînant les ailes, redressant en éventail les plumes de la queue, enflant leurs appendices céphaliques et faisant entendre un bruit particulier.

Ce groupe, dont on fait quelquefois une petite famille à part, ne renferme qu'un seul genre.

Les Dindons (Meleagris L.) comprennent deux espèces distinctes : le Dindon ocellé ( 1 . ocellata), du Honduras et du Yucatan, et le Dindon vulgaire.

Le Dindon vulgaire (H. galloparo L.) porte à l'état sauvage une livrée brunàtre plus ou moins métallique, et se distingue à première vue de l'autre espèce par la présence d'une louffe de crins sur le devant de la poitrine. Cette touffe est moins apparente chez la femelle, qui a en outre un plumage plus terne.

On trouve cette espèce dans une grande partie du Canada, des États-Unis el du Mexique. Les Dindons sauvages se nourrissent d'herbes, de graines, de baies, de Vers ou d'autres petits animaux. La femelle pond dix à quinze el jusqu'à vingt œufs d'un jaune crémeux pointillé de roux.

Le Dindon domestique ( $\boldsymbol{M}$. gallopavo domestica) revèt une livrée très variable

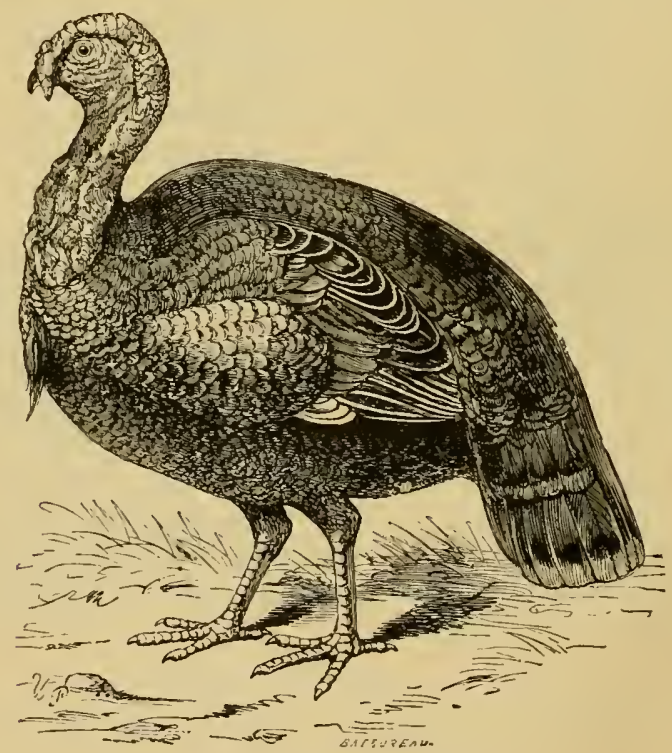

Fig. 73̈1. - Dindon domestique.

en raison de laquelle on distingue en France plusieurs variétés: le Dindon noir robuste, de forte taille, à plumage et pattes noirs; le Dindon blanc, à 
pattes roses; le Dindon des Ardemes, ronx, avec les ailes blanches à l'extrémité; le Dindon gris; le Dindon prmarhe, ete.

Les Dindons de nos basses-cours descendent sans aucun doute du Diudon vulgaire, dont ils ont la touffe pectorale de crins, et dont quelques-uns ont conservé, quoique avec moins d'éclat, la livrée métallique. Mais on distingue

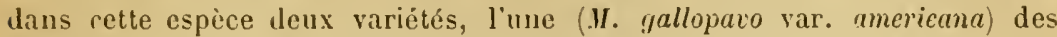
Etats-Unis, l'autre (M. gallopavo var. mexicana) du Texas et du Mexique. Or, certaines particularités du plumage montrent que les Dindons domestiques dérivent très probablement de la lernière, et cette manière de voir concorde fort bien, d'ailleurs, avec les documents historiques.

Les noms de Dindon et de Coq d'Inde viennent évidemment de ce que le Mexique et les Antilles étaient autrefois appelés les Indes occidentales. 11 y a lieu de penser que cet Oiseau avait été domestiqué par les anciens Mexicains, el que ce sont les Espagnols qui l'ont introduit en Europe. C'est en effet Oviedo qui en parla le prenier et le décrivit, en 13220 , dans son Histoire des Indes occidentules. D'ajrès I. Geoffroy Saint-Ililaire, il est bien établi que le "Coq d'Inde " a été importé en Angleterre sous IIenri VIII, et en France sous Louis XII, et qu'il était déjà " commun es mestairies " vers 1530 , comme le dit expressément Belon. C'est donc à tort qu'Anderson déclare que le premier Dindon qui fut mangé dans notre pays parut au festin des noces de Charles $\mathbf{I X}$, en 15:0. Remarquons enfin que le nom de Meleagris est le résultat d'une confusion, et provient de ce que divers naturalistes ont appliqué aux Dindons des indications fournies par les auteurs anciens relalivement aux Pintades. De même, le nom de Gallo-Pavo tient à ce qu'on avait d'abord regardé le Dindon comme résultant d'un croisement entre le Coq et le Paon.

L.e màle est querelleur et méchant; il attaque les autres Oiseaux de la hasse-cour. y compris même les Dindes et les Dindonneaux; il se jette aussi sur les Chiens et sur les enfants. S'il est jeune et vigoureux, il suffit à sept ou huit Dindes. Celles-ci sont en général plus douces. Elles pondent au printemps, vers l'àge de dix à douzc mois; elles donnent un œuf chaque jour ou tous les deux jours suivant la température, soit quinze à vingt en tout. Lorsqu'elles ont couvé de bonne heure, elles font une seconde ponte en juillet ou en aout. Malheureusement, elles ont presque toujours la manie de cacher leurs œufs au dehors. Ces cufs sont d'un jaune crémeux, pointillés de roux.

Les Dindes sont excellentes couveuses, et on estime surtout à ce point de vue la Dinde d'Italie. Elles couvent du reste les ceufs de Poule ou de Cane arec les mêmes soins que les leurs propres. On peut leur donner à couver jusqu'à vingt-deux de ces derniers. L'incubation dure 28 à 30 jour's. L'éclosion s'effectuc en général plus facilement que celle des œufs de Poules.

La Dinde est bonne mère, et surveille ses petits avec la plus grande sollicitude. Ceux-ci sont délicats et très impressionnables au froid et à l'humidité; il faut donc les entourer des plus grands soins. A l'àge de deux mois ils " prennent le rouge ", c'est ainsi que leurs caroncules et leurs pendeloques s'injectent et acquièrent leur teinte rouge défi- 
nitive. C'est pour eux une époque de crise souvent funeste (crise du rouge), surtout lorsqu'ils sont faibles à l'arance. Lorsqu'ils l'ont surmontée, ils deviennent très robustes. Vers l'âge de six à sept mois, on les considère comme adultes. On peut alors les engraisser avec avantage, mais en les laissant en liberté. On ne châtre jamais les mâles.

Les oufs de Dinde sont bons à manger, quoique moins délicats que ceux de Poule. La chair de ces animaux est très fine et tenue partout en haute estime : " un beau Dinde ", comme on dit par abus dans le langage culinaire, est le morceau de choix des gourmets, surtout lorsqu'il est abondamment garni de truffes. Les Dindons blancs, qu'on élève de préférence en Brie, sont en outre recherchés par les plumassiers, qui passent deux ou trois fois par an dans les fermes pour enlever, sur les côtés des cuisses, quelques poignées de plumes qui sont utilisées pour la parure; ils paient pour cela jusqu'à cinq francs par tête etpar an.

On a pu faire féconder la Dinde par le Coq, mais le produit est demeuré infécond.

Les Numidinés ont le corps bombé, la queue courte et abaissée, la tête plus ou moins nue et ornée de huppes ou caroncules variables, les pattes généralement dépourvues d’ergot. Ce sont des Oiseaux africains.

Le genre Pintade (Numida L.) est caractérisé par la présence d'un tubercule calleux sur le sommet de la tète et de deux barbillons sous la mandibule inférieure; le cou est nu en haut; le plumage est identique dans les deux sexes.

On distingue dans ce genre : la Pintade comnune, la Pintade mitrée ( $N$. mitrata Pall.), la Pintade pitilorynque (N. ptilorhyncha Licht.), etc.

La Pintade commune (N. meleagris L.) a le fond du plumage noir, mais finement strié de cendré et parsemé de petites taches blanches arrondies, entourées d'un cercle foncé; la poitrine et la partie emplumée du cou d'une teinte lilas; la partie dénudée d'un rouge nuancé de bleuâtre; les barbillons larges, d'un rouge vif ; le tubercule calleux d'un bleu rougeátre; le bec jaune rougeàtre; les pattes gris ardoisé. La femelle se distingue du màle par ses barbillons moins développés et moins arrondis, et son tubercule céphalique un peu moins fort.

Cette espèce se rencontre à l'état sauvage dans l'ouest de l'Afrique, et en particulier dans les iles du Cap-Vert, se tenant dans les vallées buissonneuses et les forêts; sa nourriture consiste en fruits, herbes, bourgeons, etc. Elle paraît vivre en monogamie. La femelle pond une douzaine d'œufs au milieu d'une touffe d'herbes.

La Pintade dosestipue ( $\boldsymbol{N}$. meleagris domestica), aujourd'hui répandue dans nos basses-cours, n'est autre que la Pintade commune ou à barbillons rouges: elle a du reste conservé le type de l'espèce, à part les modifications du plumage, en raison desquelles on distingue des variétés grise, blanehe, lilas, panuchée, etc. 
La domestication des l'intades doit s'ètre effectuée d'abord en Afrirple. Les Grecs on ensuite possédé la l'intarle commune, qu'ils avaient vraisemblabement recue de Cyrène ou de Cartlage; mais ce sont les liomains surtout. qui se sont occupés de la nultiplication de ces Oiseaux. Columelle indique mème d'une filcon très claire qu'on avait à Rome, outre la Pintade commune (N. meleagris), la Pintade i barbillons bleus ( $N$. ptilorhyncha), que l'Europe n’a pas conservée. P'ierre lielon croit que nos sujets actuels ne dérivent pas directement de ces l'intades romaines, mais qu'ils proviennent d'individus réintroduits il y a quelques siècles. Ajoutons que la Pintade commune rst redevenue tout à fait sauvage à la Jamäque, à Saint-Domingue, et peut-r̀tre aussi dans les iles de la Sonde.

Il faut un màle pour dix à douze frmelles. Chacune de celles-cipond erente à quarante aufs et quelquelois beaucoup plus, quand on les

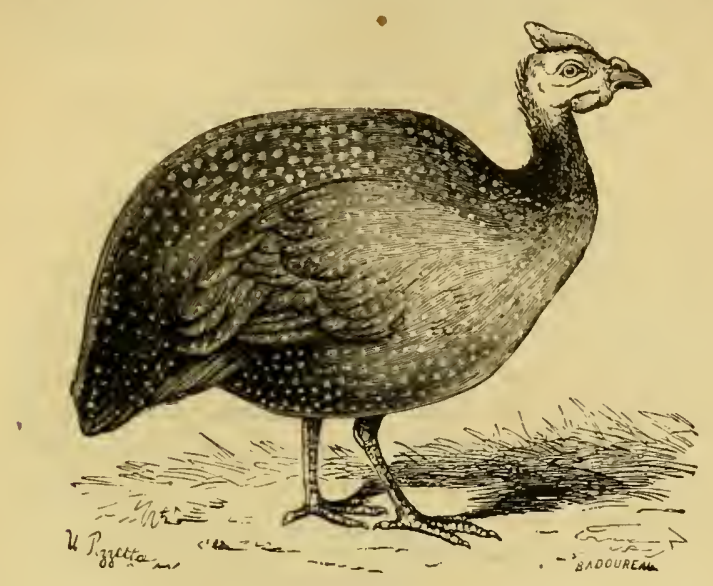

Fïg. 73̈. - - Pintade domestique.

enlève un à un; mais elle n'aime pas pondre dans le poulailler. Dı reste, elle délaisse le plus souvent ses cufs, et on est obligé de les donner à couver à des Poules ou à des Dindes. Ils sont de teinte rougeâtre ou orangée et parfois d'apparence tiquetée. La durée de l'incubation est de $\supseteq 7$ jours.

Les Pintadeaux s'élèvent à peu près comme les poussins, quoique un peu plus délicats dans le jeune àge. Dès qu'ils sont bien emplumés et que leurs barbillons sont devenus tout à faitrouges, ils se montrent très rustiques et n'exigent plus de soins particuliers. Ils se développent du reste rapidement.

Les Pintades adultes vont pitturer aux champs, mais y causent des dégâts. Il est inutile de les engraisser par des procédés artificiels et de les chaponner. Les principales causes qui s'opposent à l'extension de l'élevage de ces animaux sont leur caractère querelleur, leur manie de pondre en dehors des liabitations et leur cri désagréable.

Les oufs des Pintades sont fort bons, 'juoique beaucoup moins gros 
que ceux de la Poule commune. Quant à la chair, elle est excellente et remplace avantageusement celle du Faisan après la fermeture de la chasse. La Pintade est un véritable gibier domestique.

Par l'accouplement du Coq et de la Pintade, on a obtenu un produit paraissant stérile.

Les PavoninEs, qui sont les plus grands des Gallinacés, ont un corps épais, un cou assez long et une tête petite, surmontée d'une aigrette dressée, et dépourvue de lobes cutanés. Les yeux sont entourés d'un espace dénudé; les pattes sont armées d'un ergot chez le mâle. Celui-ci jouit, comme le Dindon, de la faculté d'étaler sa queue en éventail ; or, cette queue, qui se compose de dix-huit rectrices, se trouve cachée sous des tectrices très développées, à barbes lâches et soyeuses sur la longueur de la tige, serrées aụ contraire à l'extrémité, où elles forment une palette ou un croissant : cette extrémité élargie est décnrée de taches en formes d'yeux.

Ces Oiseaux vivent à l'état sauvage dans le sud de l'Asie.

Le genre Paon (Pavo L.), qui à lui seul représente cette tribu, comprend deux espèces bien distinctes : le Paon vulgaire $(P$. cristatus $L$.) et le Paon spicifère ( $P$. muticus $L$.), celui-ci habitant les îles de la Sonde.

Le Paon vulgaire ou à crête a la tête, le cou et la poitrine d'un beau bleu à reflets pourpres, verts et dorés, le dos vert, le ventre noir, les ailes blanches rayées transversalement de noir. Sa tète est ornée d'une huppe composée de 20 à 24 plumes à tige grêle, terminées par une petite palette verte; son bec et ses paltes sont brunàtres. Le plumage de la femelle, beaucoup moins riche, est d'une teinte générale brun clair, avec la gorge, la poitrine et le ventre blanchâtres, les ailes et la queue brunes.

Le Paon se rencontre dans l'Inde et à Ceylan, où il vil par paires. Il habite les forèts et les jungles, surtout dans les montagnes. Sa nourriture se compose de graines, de fruits, d'herbes, d'Insectes; il tue mème parfois des Serpents d'assez grande taille.

Le Paox donestique (P. cristatus domesticus), quoique le plus beau de nos Oiseaux domestiques, n'a pas le plumage aussi brillant ni aussi touffu que les individus qui vivent à l'état sauvage. On en trouve, du reste, qui sont pies ou mème blancs. On a même vu apparaitre dans certains troupeaux, en Angleterre, des sujets " $a$ épaules noires ", et Sclater les a regardés, sans raisons suffisantes, comme des représentants d'une espèce distincte ( $\boldsymbol{P}$. nigripennis) qu'il supposait exister dans quelque pays encore inconnu.

Les Paons domestiques, aujourd'hui répandus sur la plus grande partie du globe, ressemblent tellement au Paon vulgaire, qu'il est impossible de ne pas considérer celui-ci comme la souche de ceux-là. C'est l'expédition d'Alexandre qui a rapporté ce Gallinacé en Grèce, et c'est à partir de cette époquẹ seulement qu'il a été domestiqué. $A u x v^{0}$ et au xv $v^{0}$ siècle, il était encore rare en Angleterre et en Allemagne.

Dans nos basses-cours, il faut un Paon mâle pour quatre ou cinq femelles. La Paonne fait souvent dans l'année deux pontes de cinq ou 
six oufs chacune : ces orufs sont à coquille lisse, d'un blane jaunâtre. Elle les cache avec soin dans les broussailles pour les soustraire aux regards du màle, ear celui-ci, plus encore que le Dindon ou le mâle de la Pintade, chercherait i les détruire. La Paonne couve quand elle a fait librement choix de son nid et qu'elle n'est pas dérangrée par le

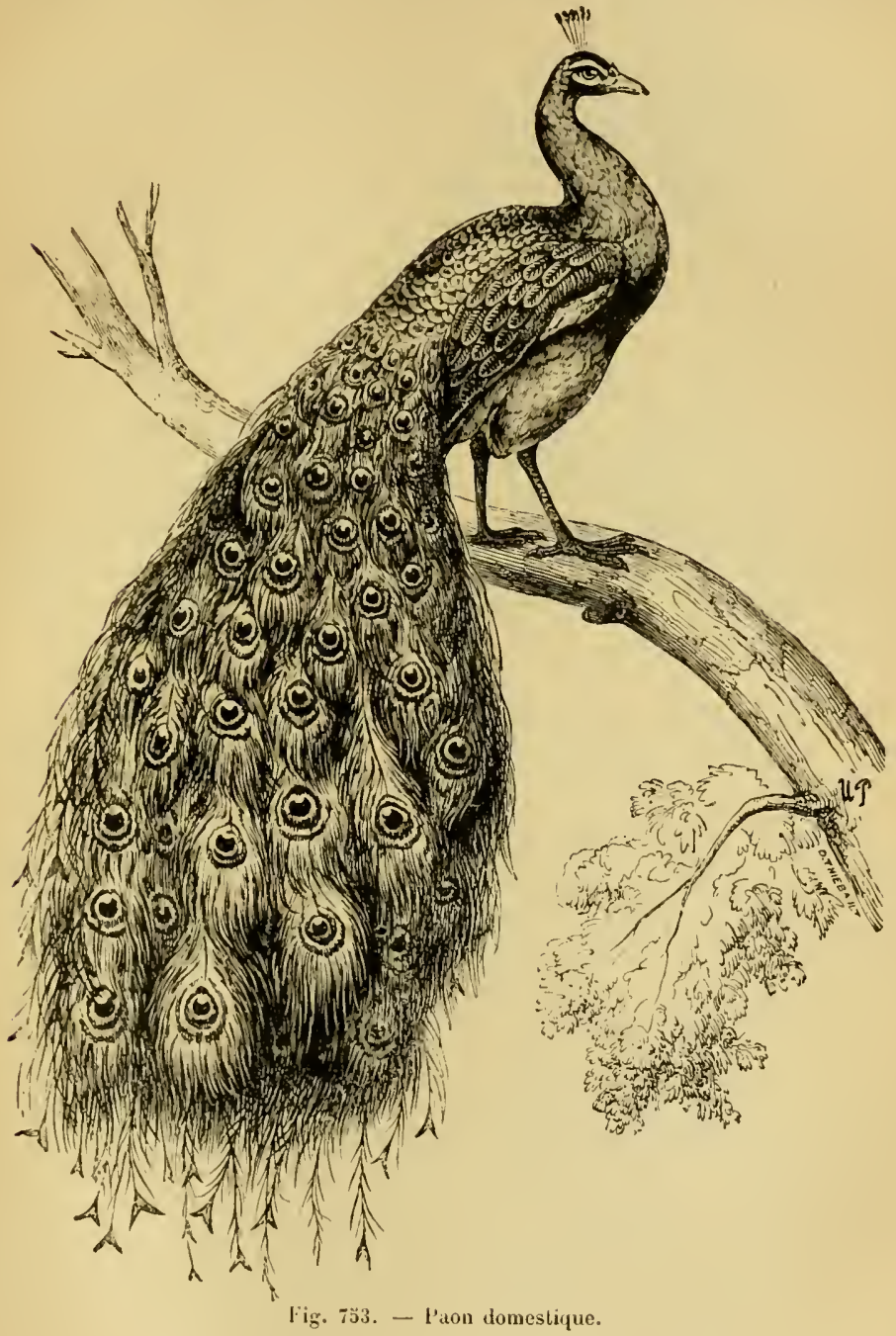

mâle; autrement, elle abandonne ses œufs, qu'il vaut mieux donner à une grosse Poule ou à une Dinde. L'incubation dure 30 jours.

Les Paonneaux se montrent surtoul délicats vers l'ìge de six semaines à deux mois, au moment où pousse leur aigrette : c'estl'équivalent de la crise du rouge chez les Dindonneaux. Ils portent d'abord une livrée faure, avec des raies brunes sur la tête, le cou et les ailes. 
Le màle ne forme sa queue que la troisième année; la femelle est adulte à deux ans.

La chair des jeunes Paons est de bonne qualité, mais il est rare aujourd'hui qu'on mange ces animaux. Les Romains, au contraire, suivant l'exemple de l'orateur Hortensius, les recherchaient beaucoup à ce point de vue; et mème, ce luxe ne suflisant plus aux empereurs, on vit figurer sur les tables de Vitellius et d'Héliogabale des plats énormes de têtes ou de cervelles de Paons, mets insipides, dit Buffon, " qui n'avaient d'autre mérite que de supposer une dépense prodigieuse et un luxe excessivement destructeur". Chez nous, les Paons sont en général des Oiseaux d'ornement; toutefois, on les élève encore dans les fermes pour leur plumage, qui est d'un bon rapport. Mais ils sont batailleurs; les mâles tuent même leurs petits, et ils ne vivent en bonne intelligence quavec les Dindons. De plus, ce sont des pillards de récoltes, aussi redoutables que les Lapins de garenne. Enfin, on sait combien sont discordants les cris qu'ils poussent surtout lorsque le temps est à la pluie.

Les Phasianinés ont la tête garnie de plumes comme le reste du corps, sauf sur les joues, qui sont nues et verruqueuses; la queue est longue, composée de seize à dix-huil rectrices disposées en toit, les médianes étant souvent très allongées.

Le genre Faisan (Phasianus L.) a été divisé par les ornithologistes; mais on est loin de s'entendre sur la valeur et la délimitation des groupes ainsi formés, et nous ne nous y arrèterons pas.

Le Faisan commun (Ph. colchicus L.) possède un fort beau plumage. Le màle a la tète et le cou vert foncé à reflets bleus, avec deux petites touffes de plumes d'un vert doré sur les còtés de l'occiput; le dessous du corps est d'un brun chàtain à reflets pourpres. La femelle est d'un gris roussàtre tacheté et rayé de noir.

Le Faisan commun est, comme son nom l'indique, originaire de la Colchide (région située entre le Caucase et la mer Noire). C'est à l'expédition des Argonautes que l'Europe est redevable de l'introduction de ce bel Oiseau, rencontré sur les bords du Phase. Aujourd'hui encore, le Faisan habite l'Asie Mineure et les côtes de la mer Caspienne. Les Romains l'ont répandu dans toute l'Europe méridionale: en plusieurs points, il y vit à l'état complètement sauvage; mais, dans nos régions tempérées, il a besoin de la protection de l'Homme, qui surveille la reproduction et élève les jeunes dans des faisanderies, avant de les mettre en liberté dans les bois. Dans ces conditions, le Faisan est presque un animal domestique.

Un mâle suffit à plusieurs femelles. Chacune de celles-ci peut pondre jusqu'à vingt-cinq et trente œufs, d'un vert jaunâtre. Toutefois, la Faisane ne se soucie guère de couver en captivité : on emploie comme couveuses de petites Poules. L'éclosion a lieu au bout de 20 ou 26 jours. Les Faisandeaux sont fort difficiles à élever. L'époque critique corres- 
pond pour eux au développement de la queue, qui s'effectue vers l'ìge de deux mois. - Le Faisan est chez nous le gibier le plus estimé.

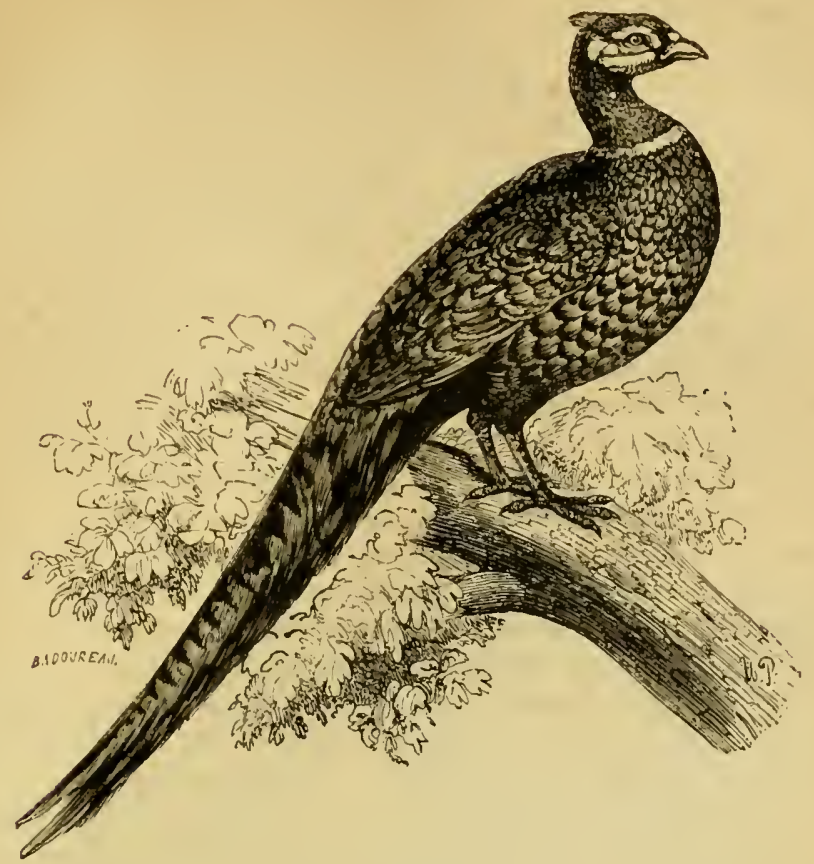

Fig. Tö. - Faisan commun.

L'Asie centrale et la Chine nous ont aussi fourni quelques belles espèces du même groupe : le Faisan doré (Ph. pictus) et le Faisan de lady Amherst (Ph. Amherstix), qui sont des Thaumalea, le Faisan argenté (Ph. nycthemerus) qui est un Gallophasis, etc. Plusieurs s'hybrident entre elles.

Les Crossoptiles (Crossoptilon), les Argus (Argus), les Polyplectrons (Polyplectron) sont quelquefois aussi rangés dans la mème tribu.

Les GALLINÉS ont pour caractères des joues nues et lisses, une crête dentelée sur la tête et un ou deux lobes charnus (barbillons) pendant au-dessous de la mandibule inférieure; la queue à 14 pennes est en forme de toit et recouverte, chez le mâle, de longues tectrices recourbées en faucille, qui retombent en arrière du corps. Ce màle possède, en outre, un éperon ou ergot puissant, arqué et aigu.

Les Coqs (Gullus Brisson) sont originaires des Indes et de la Malaisie; ccpendant, les reclierches paléontologiques et archéologiques ont démontré que des animaux de ce genre existaient déjà, sur divers points de l'Europe centrale et occidentale, à l'époque quaternaire.

Les seules espèces bien connues qui vivent actuellement à l'état sauvage sont: le Coq Bankiva (G. Bankiva ou ferrugineus), répandu non seulement dans l'Inde et dans l'Indo-Chine, mais dans toute la Malaisie et jusqu'en 
Nouvelle-Calédonie (où il a probablement été introduit par les Malais); le Coq de Lafayette (G. Lafayettei ou Stanleyi), de Ceylan; le Coq de Sonnerat (G. Sonnerati), des montagnes de Ghattes et de l'Inde orientale; le Coq Ayamalas (G. varius ou furcatus), de Java.

Ces animaux, qui sont monogames, vivent en général dans les forêts et les fourrés de bambous des montagnes, mais ils s'étendent aussi parfois jusque dans les plaines. Ils se nourrissent de graines, de bourgeons et d'Insectes.

On assure que des hybrides de ces différentes espèces se rencontrent assez fréquemment.

Le Coe domestique (G. gallinaceus Pallas, G. domesticus Auct.) est représenté par une foule de races et sous-races dont les caractères sont en quelque sorte variés à l'infini. Nous noterons seulement quelques-uns de ces caractères, utilisés pour la classification des races. Les trois couleurs fondamentales du plumage sont, comme chez la plupart des animaux domestiques, le noir, le blanc et le roux. Les pattes peuvent ètre emplumées jusqu'à la naissance des doigts. Il existe parfois une huppe sur la tète; sur les còtés ou en arrière de cette région, les plumes peuvent former des favoris ou une cravate. La crête est divisée ou frisée, etc., dans certaines races; ou bien elle s'atrophie jusqu'à disparaître entièrement. Les barbillons eux-mèmes sont plus ou moins développés. Enfin, la classification tire encore de bons caractères des oreillons, petits disques nus et colorés qui pendent au-dessous de la joue, en arrière du conduit auditif; du camail, formé par les plumes de la partie inférieure et postérieure du cou; des lancettes, plumes qui descendent des reins pour couvrir les cuisses, etc. (1).

Nous ne pouvons songer à signaler ici toutes les races que décrivent les auteurs spéciaux, d'autant qu'on ne possède encore aucune classification passable; quelques-unes seulement peuvent être citées comme types. En première ligne, il faut placer le Coq de ferme ou Coq gaulois, représentant notre race commune, primitive, qui tend à disparaître sous l'intluence des croisements; à còté de lui nous avons, en France, la race des Ardennes, puis les races de la Bresse, de Barbezieux, de la Flèche, de Houdun (à cinq doigts), de Crèreccur, etc. Parmi les races étrangères, nous signalerons les races de Padoue, dont l'origine est mal connue, de Hambourg, de Brida, italienne ou Leghorn, espargnole, de Dorking (à cinq doigts), cochinchinoise ou de Shanghaï, de Yokohama, de Bantam, de combat, négresse, etc., etc.

La plupart des naturalistes admeltaient naguère encore que les différentes races el sous-races de Poules domestiques dérivent d'une espèce unique, le Gallus Bantiva. Ils se basaient à la fois sur la ressemblance étroite que présente cette espèce arec certaines de nos races, et sur ce fait que les trois autres formes sauvages ne donnent, par le croisement avec les races domestiques, que des hybrides stériles. Mais cette manière de voir s'est trouvée sérieusement ébranlée par la découverte d'ossements de Coq dans les dépôts quaternaires de diverses régions de l'Europe, notamment dans ceux d'Olmütz (Moravie) et dans les grottes de Gourdan, de Lherm et de Bruniquel (France méridionale). Il est possible que ce Coq européen (représentant lui-mème, peut-ètre, une variété de Bankiva) ait donné naissance à quel-

(1) Voir Ch. Jaceve, Le Poulailler, 5 e édit. Paris, 188 2. 
ques-unes de nos races, et que le Bankiva de l'Inde en ait produit d'autres, importées plus tard dans nos régions et croisées, à des degrés divers, avec les premières.

Nous ne possédons aneun document capable de nous renseigner d'une façon précise sur l'épołue à laquelle remonte la domestication du Coq. Toutefois, les plus anciens manuserits démontrent qu'elle était effectuée dans l'Asie centrale dès les temps les plus reculés. Nous apprenons, en elfet, par le Zend-Aresta, que le Cơ était un des Oiseaux dont Ormuzd avait fait présent à l'humanité, el que la religion mazdéenne prescrivait aux fidèles d'élever dins leurs demeures trois animaux : un Chien, un Bœuf et un Coq, "représentant du salut matinal".

Ce Gallinacé fut importé de l'Asie méridionale en Grèce un peu après

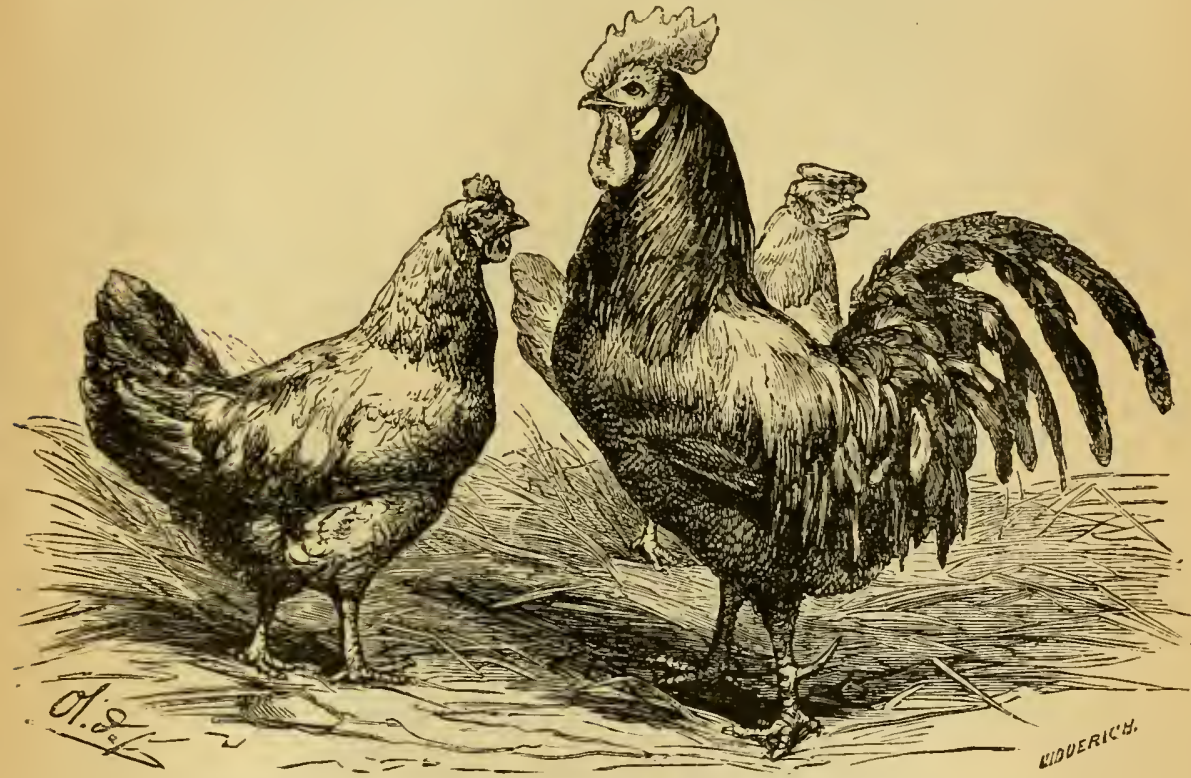

Fig. 75ว̈. - Cou et Poules, race commune.

l'époque d'llomère; de lả, il passa en Italie. Il existait en Grande-Bretagne lorsque Jules-César aborda dans cette ile; il était également élevé depuis longtemps en Gaule.

Pour que la fécondation s'opère bien, il faut en moyenne un Coq pour douze à quinze Poules : en augmentant le nombre de celles-ci, on s'exposerait à recueillir beaucoup d'oufs non fécondés (aufs clairs). La somme totale des oufs pondus chaque année par une Poule est très variable, mais peut atteindre un chiffre considérable : cent cinquante à cent quatre-vingts, quelquefois plus. La couvée habituelle se compose d'une douzaine d'veufs; la durée de l'incubation est le plus souvent de vingt et un jours. Les Poussins s'élèvent assez faci- 
lement. Vers l'àge de six semaines, ils quittent leur mère et prennent le nom de Poulets. Au bout de quelques mois, ceux-ci peuvent être livrés à la consommation. Souvent, d'ailleurs, on les engraisse par divers procédés. L'engraissement est facilité par la castration, qu'on fait subir aux Coqs vers l'âge de quatre mois : on obtient ainsi des Chapons. Quant aux Poulardes, ce sont de jeunes Poules vierges, n'ayant pas encore pondu, qu'on engraisse sans aucune opération préalable. -- Il est inutile d'insister sur l'importance alimentaire et la qualité de la chair de ces animaux, qui tiennent le premier rang. parmi nos Oiseaux domestiques. Mais, à côté de ce produil, nous. devons encore citer les arufs et les plumes, celles-ci diversement utilisées par l'industrie.

Les ceufs de Poule sont consommés dans une proportion infiniment plus considérable que ceux des autres Oiseaux, tout au moins en Europe. A Paris, il en est introduit chaque année plusieurs centaines. de millions. Or, l'œuf a tous les caraclères d'un aliment complet et, à ce titre, il remplit un rôle de premier ordre dans la bromatologieet la thérapeutique. Le jaune renferme une substance albuminoïde appelée vitelline, des corps gras, des matières extractives, des. sels, etc. Le blanc ou albumen contient de l'albumine, des graisses, du glucose, des matières extractives, des sels, etc. Enfin, l'enveloppe elle-même est formée de matières organiques, de carbonate et de. phosphate de chaux. Ces trois parties ont leur emploi médical : la coquille peut servir comme anti-acide; on l'utilise contre la diarrhée des jeunes animaux; le blanc d'œuf peut être administré avec avanlage dans les empoisonnements causés par de nombreux sels métalliques; le jaune enfin sert à émulsionner les corps gras, les résines, etc.

En croisant le Faisan commun et la Poule, ou le Coq et la Faisane, on obtient le Coquart, dont le mâle est stérile et la femelle féconde.

A côté des Coộs, dans le mème groupe ou dans des groupes voisins, on peut placer les Tragopans (Ceriornis), les Lophophores (Lophophorus), etc.

Les TÉTRAONIDÉS ont la tète toujours garnie de plumes, n'offrant au plus qu'une Dande nue au-dessus de l'œil. Les màles sont en général dépourvus d'ergots. $\Lambda$ signaler dans cette famille :

Les Lagopèdes (Layopus), à tarses et doigts emplumés. Lagopède muet (L. mutus) ou Perdrix blanche, des Alpes et des Pyrénées; plumage devenant blanc en hiver'; Lagopède d'Ecosse (L. scoticus) ou Grouse, de la GrandeBretagne.

Les Tettras (Tetrao), qui comprennent: le Coq de bruyère (T. urogallus), le Lyrure des bouleaux ou petit Coq de bruyère (T. tetrix); la Gélinotte (T. bonasia), monogame. Ces Oiseaux habitent les montagnes boisées de l'Europe et de l'Asie. 
Les Perdrix (I'crdix), dont on rencontre plusieurs espèces en france; la Perdrix grise (P. cinerea), partout répandue; la Perdrix rouge ( 1 . rubra), du midi et du centre; la Bartavelle (P. graca), de passage dans Ies monta-

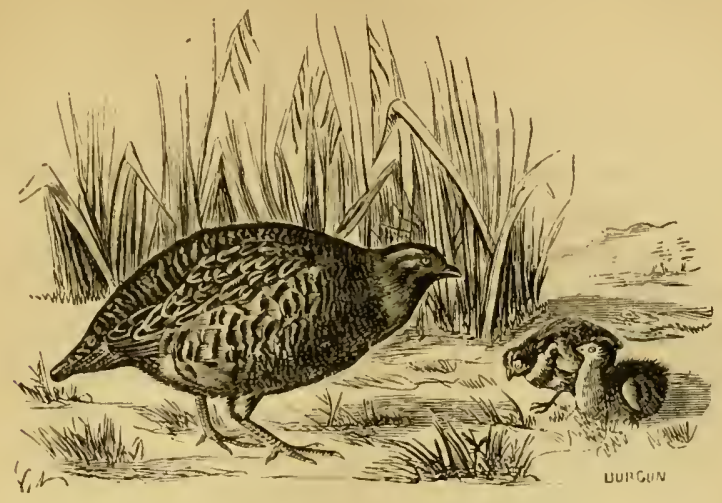

liig. 756. - Perdrix grise.

ones; la Perdrix de roche ( $\boldsymbol{P}$. petrosa), de Provence el de Corse. - Les Francolins (Francolinus) s'en rapprochent beaucoup.

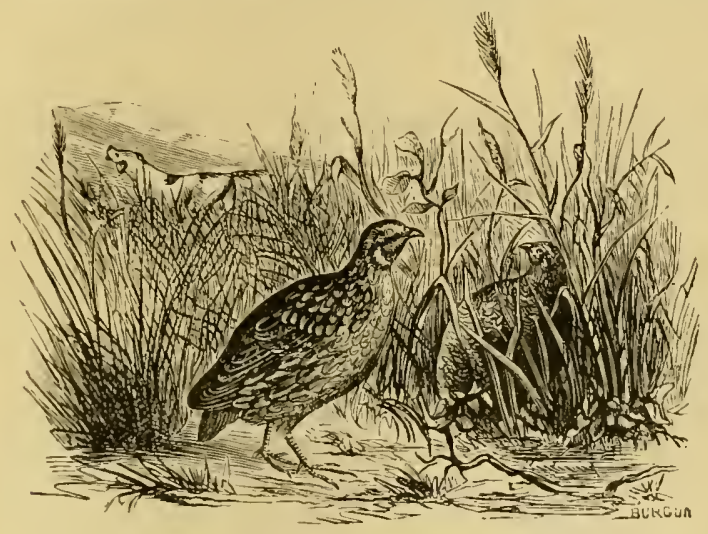

Fïg. 737. - Caille comnune.

Les Cailles (Columix), représentées chez nous par la Caille commune $(C$. vulgaris), petit gibier de passage. - Les Colins (Ortyx), Amérique du Nord.

\section{CINQUIEME ORURE}

\section{COLOMBINS}

Ailes pointues; bec faible, renflé et membraneux autour des narines (cire); le doigt postérieur articulé au même niveau que les trois antérieurs, tous ordinairement libres.

Les Colombins ou Pigeons, encore appelés Gyrateurs, ont été long- 
temps réunis aux Gallinacés, dont ils se distinguent pourtant par d'importants caractères. Ils ont le bec plus faible et sont meilleurs voiliers; leur bréchet offre des échancrures moins profondes. Les pattes sont courtes, les doigts libres ou les deux externes seulement réunis à la base. Le plumage est lisse et diffère à peine dans les deux sexes.

Tous les Pigeons sont monogames et le mâle, comme la femelle, prend part à l'incubation. Tous sont nourriciers : leurs petits, au lieu d'être précoces comme ceux des Gallinacés, naissent presque nus, les pallpières closes, et doivent attendre la nourriture que leur apportent leurs parents. Or, à l'époque de la reproduction, le jabot de ceux-ci est le siège d'une sécrétion particulière : il se produit, dans les deux culs-de-sac latéraux, un liquide crémeux que l'animal dégorge pour alimenter ses petits. Ce liquide est fourni, non par des glandes, mais par des formations transitoires au niveau desquelles se produit une multiplication active de cellules épithéliales modifiées, remplies de graisse. Cette sécrétion se continue jusque vers le vingtième jour après l'éclosion (Charbonnel-Salle et Phisalix).

A l'état adulte, les Colombins vivent presque exclusivement de substances végétales, et en particulier de. grains. Aussi sont-ils nuisibles à l'agriculture.

Les GOLUMBIDÉS sont caractérisés par leurs mandibules à bord lisse et non dentelé. Cette vaste famille a été divisée en plusieurs tribus, dans le détail desquelles nous n’entrerons pas.

Genre Pigeon (Columba L.). - Les Pigeons proprement dits ou Colombes se distinguent surtout à leur queue courte, presque tronquée à angle droit, a leur bec court et faible et à leurs doigts externes réunis à la base.

Ces Oiseaux sont répandus dans les deux mondes, mais ils sont surtout abondants sur l'ancien continent. Il en est qui perchent sur les arbres, comme le Colombin (C. wnas), d'autres qui perchent et nichent sur les rochers, comme le Pigeon de montagne (C. leuconota), de l'Himalaya, le C. rupestris de l'Asie centrale, et le $C$. livia.

Le Pigeon biset (C. livid L.), auquel on donne encore le nom de Pigeon de rocke, a presque la mème coloration dans les deux sexes. Les parties supérieures du corps sont d'un gris ardoisé plus ou moins clair; les còtés et le bas du cou sont d'un vert cliatoyant, à reflets bleus et violets; les ailes sont traversées par une bande d'un gris blanc encadrée de deux bandes noires; le croupion est d'un blanc pur; la queue est d'un gris noiràtre, avec une large bande noire terminale : le dessous du corps est ardoisé. Bec noiràtre à la pointe, iris el pieds rouges.

A côté de ce type, on a voulu distinguer, à titre d'espèces, des formes qui offrent avec lui certaines différences de plumage. Tel est le cas du Columba affinis des falaises de l'Angleterre, plus petit que le Biset, et dont les tectrices alaires sont tachetées de noir ; tel est celui du $C$. intermedia ou Biset sauvage de l'Inde, dont le croupion est souvent bleu au lieu d'ètre blanc, etc. 
Lucien Bonaparte tendait mème à regarder comme espèces distinctes le C. turricolu de l'Italie, le $C$. rupestris de la Daourie et le C. Schimperi de l'Abyssinie, qui ne diffèrent du liset que par des caractères insignifiants. Il s’agit, en réalité, de simples variétés se rattachant toutes au C. livia.

Ainsi compris, le biset, dit Darwin, " occupe une aire géographique immense s'étendant depuis la còte méridionale de la Norvège et des ìles l'arüer jusqqu'aux bords de la Méditerranée, Madère el les iles Canaries, l'Abyssinie, l'Inde et le Japon. Le plumage du Biset varie beaucoup; il est souvent taclieté; il a le croupion blanc ou bleu; les dimensions du corps et du bec présentent aussi quelq̨ues légères variatious. ")

Le Biset niche dans les crevasses des rochers ou des vieux murs; deux fois par an, dit-on, la femelle pond deux œufs blanes, que le màle lui aide à couver dans une faible mesure.

Le Pigeon domestique (C. domestica L.) comprend aujourd'lui une foule de races

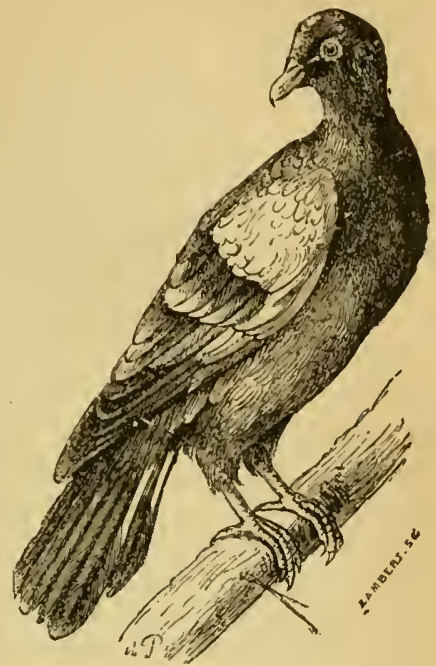

Fig. 7ös. - Pigeon fuyard ou Biset domestique. à caractères extrêmement variés, tant sous le rapport de la coloration que sous celui de la taille, des formes, des habitudes, etc. Tels sont les Pitgeons fuyards, qui ont en grande partie les caractères du Biset sauvage, les Moniluins, Hironulelles, Coquilles, Tambours, Non-

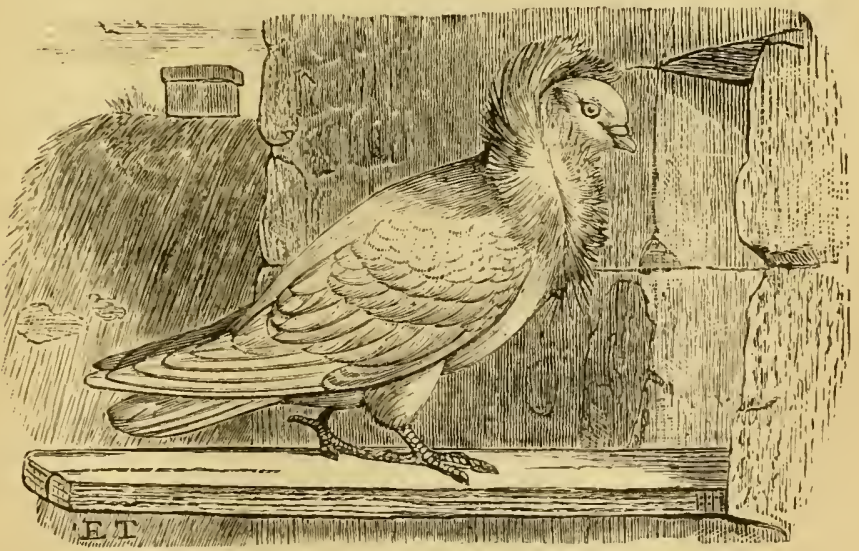

Fig. 759. - Pigeou nonnain ou capucin.

nains, Culbutants, Cravates, Paons, Polonais, Romains, Bagadais, Volants, Boulants ou Grossc-gorge, etc.

Personne, je pense, ne met en doule que le Pigeon commun de nos fermes, ou Fuyard, descende directement du Biset. Toutefois, l'origine de la première 
domestication du Pigeon est encore Irès incertaine. En Asie et en Afrique, dit I. Geoffroy Saint-Hitaire, le Piggeon parait avoir été entretenu á l'état domestique dès les temps les plus reculés; mais il n'en est pas de mème en ce qui concerne l'Europe. Les Grees ne l'ont possédé qu'un peu après l'époque d'Homère, " et ils n'avaient pas vu d'individus à plumage blanc jusqu'au $v^{\mathrm{e}}$ siècle avant notre ère: ces individus blancs venaient vraisemblablement de la Perse ".

- Mais toutes les variétés de colombier ou de volière ont-elles la mème origine? 1. Geoffroy Saint-Hilaire penchait vers l'affirmative, en faisant observer qu'on peut retrouver, dans les races les plus modifiées, une partie des caractères du Biset sauvage, et jamais ceux d'une autre espèce. Darwin a d'ailleurs accumulé un grand nombre de documents et d'observations qui viennent ì l'appui de cette opinion. Il fait remarquer, en particulier, "que l'apparition occasiomnelle chez toutes les races, surtout lorsqu'on les croise, de produits bleus, quelquefois tachetés, avec deux barres sur les ailes, le croupion blanc ou bleu, une barre à l'extrémité de la queue, et les rectrices externes bordées de blanc, fournit un argument diu grand poids en fareur de l'opinion qu'elles descendent toutes du C. liviu, en comprenant sous cette dénomination les trois ou quatre variétés ou sous-espèces sauvages que nous avons énumérées plus haut $"$. Cet auteur reproduit en outre de nombreux détails historiques desquels il résulte la preuve que presque toutes les principales races domestiques existaient avant l'an 1600 .

Les Pigeons fuyards pondent deux ou trois fois par an ; les Pigeons. de volière font jusqu'à dix pontes. Clıacune est de deux œufs blancs et se fait en deux jours. Il convient de se déloarrasser des couples qui ne donnent habituellement qu'un wuf. Ces animaux commencent à pondre dès l'âge de six mois; mais leurs facultés prolifiques diminuent beaucoup après quatre ans. Aussi doit-on supprimer les individus qui ont dépassé cet âge : la chose est facile, quand on a soin de couper chaque année l'extrémité d'un ongle à tous les Pigeons; on met de côté ceux qui ont quatre ongles coupés, et on s'en débarrasse à loccasion. Ils sont remplacés par la première couvée de l'année.

Les Pigeons domestiques ont conservé leurs habitudes monogames; il importe donc que le nombre des màles soit toujours égal à celui des femelles. Les deux sexes, à tour de róle, prennent part à l'incubation, qui dure environ 17 jours.

Au bout de trois semaines à un mois, les Pigeonneaux sonl couverts de plumes, mais encore incapables de prendre leur essor ; c'est à ce moment qu'on les recueille pour les livrer à la consommation. Il est rare qu'on songe à les engraisser.

Les Pigeonneaux sont d'un assez bon rapport quand il est possible de se procurer des grains à bas prix. Leur chair délicate est partout estimée. En outre, les Pigeons fournissent un engrais très riche. en azote, la colombine. On connait aussi leur emploi comme messagers : transportés à des centaines de lilomètres de leur nid, ils 
y reviennent à tire-d'aile et peuvent ètre, par suite, utilisés comnc porteurs de dépêches. On fait spécialement usage, dans ce but, d'une variété de Pigreon volant, le Volant messuger, qu'on appelle quelquefois Pigeon voyageur, mais quil ne faut pas confondre avec le véritable Pigeon royageur, dont il est question ci-dessous.

Les Palombes Pulumluss) ont pour représentant dans nos foréts la Patlombe à collier ou Pigecn ramier ( $P$. tor fuutus.

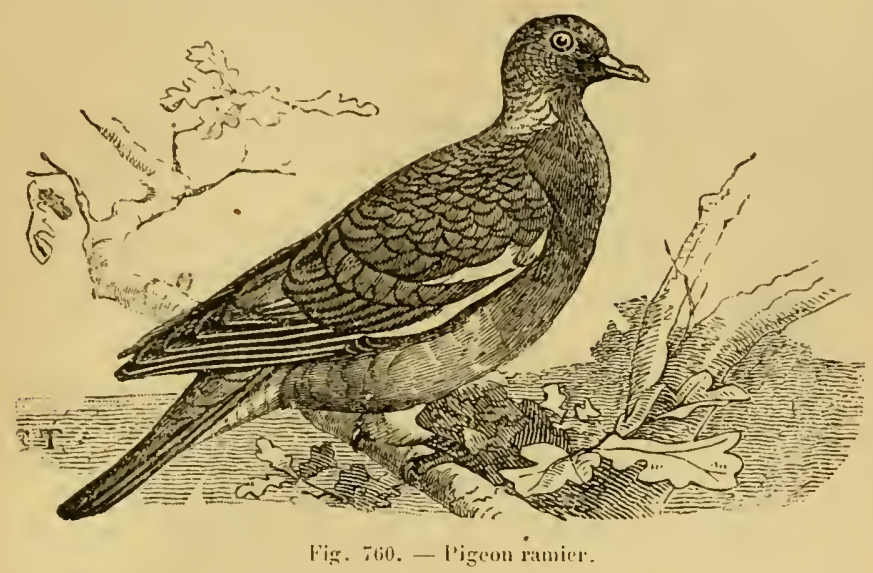

Nos Tourterelles (Turtur) comprennent une espèce indigene, la Tourterelle commune ( $\boldsymbol{T}$. auritus), et une espèce d'origine asiatique et africaine, Ia Tourterelle à collier ou Tourterelle rieuse ( $\boldsymbol{T}$. risorius), entretenue à l'état de captivité, en Europe, depuis plus de trois siècles.

A la même famille appartiennent encore les Ectopistes ou l'igeons royageurs (Ectopistes migrulorius), de l'Amérique du Nord, les Nicobars (Calonas), les Gouras (Goura), etc.

Les DIDUNCULIDÉs, qui ont la mandibule inférieure dentée, ne comprennent que les Didunculus, des iles Samoa. - On en rapproche les Drontes (Didus ineptus), qui vivaient encore aux Mascareignes il y a deux siècles. mais qui ont, depuis, complètement disparu.

\section{SIXIEME ORDRE}

\section{GRIMPEURS}

Oiseanx à bec fort et droit sans cire; deux doigts antérieurs el deu. doigls posterieurs.

Les Grimpeurs sont surtout caractérisés par la disposition de leurs doigts, presque toujours au nombre de quatre et rassemblés en deux faisceaux, ce qui leur donne une grande facilité pour grimper aux arbres. Le faisceau postérieur est le plus souvent formé par le pouce et le doigt externe. Ces 
Oiseaux ont les ailes courtes, et par conséquent le vol peu élendu; par contre, la queue est longue et serl souvent d'appui à l'animal pour grimper

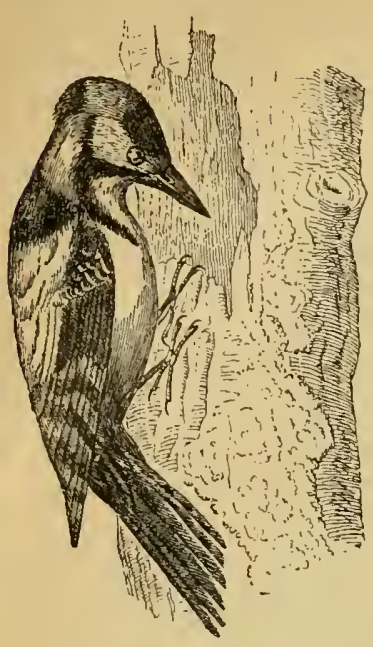

Fig. 761. - Pic épeiche. aux arbres. Tantòl le bec est long et droit, propre à frapper les arbres et à en percer l'écorce pour y chercher les Insectes (Pics); tantôt il est court et un peu recourbé (Coucous); tantôt enfin il est énorme, recourbé el à bords dentelés (Toucans). La langue est souvent allongée, mince el très protractile. Les Grimpeurs se nourrissent d'Insectes, rarement de petits Oiseaux et plus rarement encore de fruits.

Toucans (Ramphastus), Jacamars (Galbula), Couroucous (Trogon), Barbus (Bucco), Coucous (Cuculus), Pics (Picus), Torcols (Yunx), etc. Le Coucou d'Europe (Cuculus canorus) est connu de tout le monde par l'habitude qu'il a de porter (avec le bec) ses œufs dans les nids des petits Passereaux, auxquels il abandonne le soin de les couver et d'élever les petits. - Les principales espèces des Pics de nos pays sont: le Pic épeiche ( $P$. major), le Pic mar (P. medius), le Pic épeichette ou petit Pic $(P$. minor $)$, le Pic vert (P. ou Gecinus viridis).

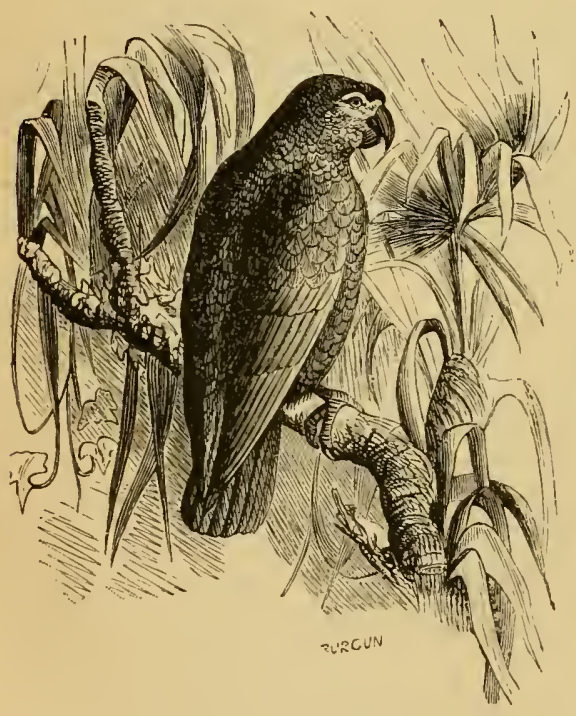

Fig. 762. - Perroquet Jaco.

\section{SEPTIEME ORDRE \\ PRÉHenseurs}

Bec fort, à mandibule supérieure crochue, à narines percées dans une cire; deux doigts antérieurs et deux doigts postérieurs.

Comme les Grimpeur's, les Perroquets ont les doigts disposés par couples, et possèdent ainsi la faculté de saisir les aliments pour les porter à leur bec, ce qui leur a valu le nom de Préhenseurs. Ils grimpent en s'aidant du bec ; mais leur vol est en général peu soutenu, les ailes étant relativement courtes. Leur queue est tantòt courte, lantôt longue. Leur langue est épaisse, charnue, peu ou point protractile. Ils se nourrissent surtout de fruits et de graines. Ce sont des animaux intelligents, doués de beaucoup de mémoire, et dont plusieurs sont capables d'imiter la 
parole humaine. On les trouve dans les régions chaudes de toutes les parties du monde, l'Europe exceptéc.

Nous citerons, parmi les nombreuses formes de ce groupe: les Cacatois (Plictolophus), de l'Australie et de l'Ocíanie; les Aras (Sittace) et les Perruches (Conurus), d'dméripue; les Perruclies ondulées (Helopsittacus), austra liennes; les Perroquets vrais (Psittacus), dont l'espèce la plus connue est le Perroquet gris à quene rouge ou Jaco (Ps. erythraceus), de la còte occidentale de l'Afrique; les Perroquets verts (Chrysotis), américains; les Loris (Lorius), océaniens; les Strigops ou Perrorfuets nocturnes (Strigops); elc.

\section{HUITIEAE ORDRE}

\section{PASSEREAUX}

Oiseaux a bec variable, dépourvu de cire; en général un doigt postérieur et trois antérieurs, les deux externes réunis ensemble à la base et quelquefois jusqu'd l'avant-dernière phalange.

Les Passereaux composent un ordre fort difticile à caractériser, en raison de la variété de formes qu'ils présentent. Ce sont des Oiseaux de petite faille ou de taille moyenne. Le bec est extrèmement variable et sert de base principale à la classification. Les tarses sont recouverts de petites écailles; le pouce est quelquefois dirigé en avant, comme les trois autres doigts (Martinets).

Un grand nombre de Passereaux sont des Oiseaux chanteurs; les autres sont appelés criards. Presque tous sont monogames. Ils se nourrissent d'Insectes, de fruits, de grains, mais on peut affirmer, en thèse générale, que ce sont des animaux

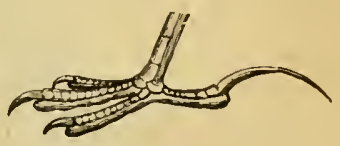

Fig. 763. - Palle d Alouetle calandre.

utiles, et qu'ils rendent à l'agriculture les plus grands services. Les espèces sont d'ailleurs d'autant plus insectivores que leur bec est plus grèle, d'autant plus granivores qu'il est plus gros.

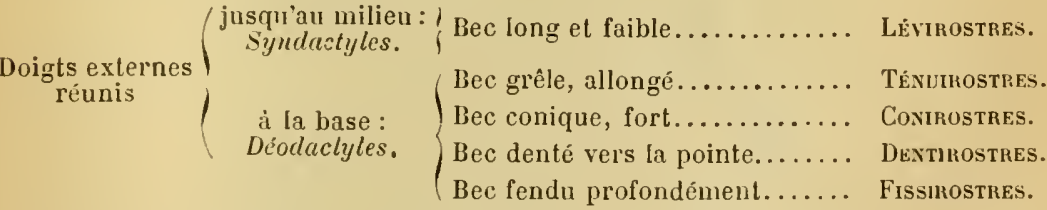

$1^{\text {er }}$ sous-ordre : Lévirostres. - Les Lévirostres (levis, taible ; rostrum, bec)

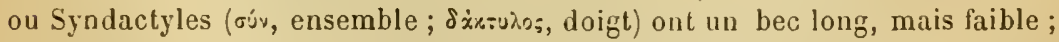
leur doigt externe, presque aussi long que le médian, lui est soudé jusqu'à l'avant-dernière phalange.

Ex. : les Nartins-Pècheurs (Alcedo), les Guèpiers (Merops), dont une espèce (H. apiaster) se rencontre dans le midi de l'Europe, où elle nuil aux ruches ; les Rolliers (Coracias), les Calaos (Buceros).

$2^{2}$ sous-ordre : Ténuirostres. - Le bec est grèle, allongé, droit ou arqué, 
sans échancrure. Ces Oiseaux, qui se rapprochent des Grimpeurs, commencent la série des Déodactyles ( $\delta \delta^{\prime} \omega$, lier), c'est-à-dire des Passereaux dont les

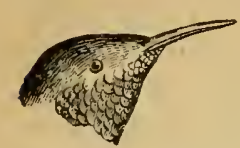

Fig. 76\%. - Tète d'Oiseau-Mlouche. deux doigts externes ne sont soudés qu’à la base. Ils sont insectivores.

Huppes (Upupa), Colibris (Trochilus), Grimpereaux (Certhia), etc.

$3^{\text {e }}$ sous-ordre : Conirostres. - Ces Oiseaux représentent le type le plus parfait des Passereaux. Ils ont le bec fort et conique, sans échancrures. Ils vivent en société et se nourrissent de grains el de fruits, mais en général ne dédaignent pas non plus les Insectes,

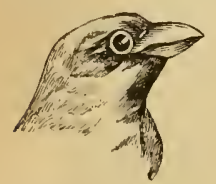

Fig. 763. - Tète de Hoineau franc. de telle sorte que souvent, au point de vue de l'agriculture, les services qu'ils rendent font plus que compenser les dégàts qu'ils causent.

Les Fringillidés sont très nombreux en espèces. Citons les Pinsons ou Fringilles (Fringilla), comprenant: le Pinson ordinaire $(F$. celebs), le Pinson d'Ardennes ( $F$. montifrinyilla), la Linotte commune ( $F$. linota), le Chardonneret (F. carduelis), etc. - Les Moineaux (Passer) : Moineau franc (P. domesticus) ; Moineau friquet (P. montanus); Verdier (P. cliloris). -

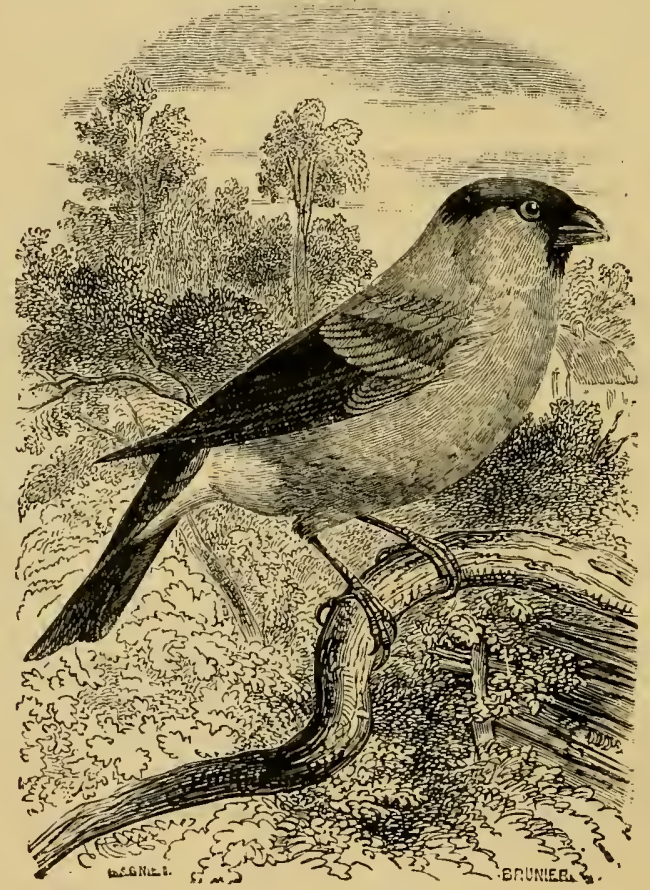

Fig. 766. - Bouvreuil commun.

Les Gros-Becs (Coccothraustes): Gros-Bec commun (C. vulgaris). - Les Bouvreuils (Pyrrhula) : Bouvreuil commun (P. vulgaris); Canari ou Serin des 
Ganaries (1'. canaria). - Les Rees-Croisés (Lo.ria) : liec-Croisé conmun (L. curvirastra).

Non loin des fringrllidés se rangent les Bruants (Emberiza): Bruant des roseaux $\{\boldsymbol{E}$. schœnichs); Bruant jaune (E. citrinella); Ortolan $(\boldsymbol{E}$. hortulunu); Proyer (E. miliaris); etc.; puis les .llonettes (Ilaudu) : Alouette des champs (.1. (1rvensis); Lulu des bois (A. arbrea); Alouette huppée ou Cochevis (.1. cristat $(t)$; Calandre vulgaire (A. culandru); etc.

$A$ quelques familles voisines appartiennent en outre un grand nombre de Passereaux répandus aujouril'hui dans nos volières, tels que les Cardinaux (Cardinalis), les Sénégalis (Lagonosticta), les Benrralis (Mariposa), les Veuves (Viduu), etc. Les Républicains (Ploceus socius), de l'Afrique méridionale, batissent en général leurs nids sous un toit commun.

On peut ranger encore dans les Conirostres les Oiseaux suivants, principalement insectivores ou même carnassiers, que divers auteurs tendent an contraire ả faire passer dans les Dentirostres: Mésanges (I'urus) : Mésange Charbonnière ( $\boldsymbol{P}$. major); petite Charbonnière $\left(\boldsymbol{I}^{\prime}\right.$. ater); Vésange à tète bleue (P. cæruleus). - Etourneaux (Stumus): Étourneau commun ou Sansonnet (St. vulyaris, débarrasse nos Moutons de leur vermine; Martins (Patstor); Pique-Baufs (Bıphaga) : Pique-Bøuf d’Afrique (B. africana), eulève les larves d'llypodermes qui se développent sous la peau des Bœufs; etc. - Corbeaux (Corvus) : Corbeau commun (Corvus corax), de la grosseur d'un Coq ; Corneille ou petit Corbeau (C. coronc); Corneille mantelée (C. cornix) ; Freux (C. frugilegus): Choucas des tours (C. monerlula). - Pies (Pica); Pie vulgaire (P. caudutu). - Geais (Garrulus) : Geai commun (G. glandarius). - Loriots (Oriolus) : Loriot vulgaire (O. gulbula); etc.

$\dot{4}^{\mathrm{c}}$ sous-ordre: Dentirostres. - Les Dentirostres on le bec tantôt subulé, tantòt faiblement recourbé; la mandibule supérieure offre une échancrure vers son extrémité. La plupart de ces Oiseaux sont insectivores.

Les Pies-grièches (Lanius) s'attaquent souvent aux petits Oiseaux. Pie-grièche grise (L. cxcubi$\left(0 r^{\circ}\right)$, Pie-grièche d'Italie (L. minor), etc.

Les Motacilliclés sont encore appelés Becs-Fins, .car ils ont tous le bec droit, long, mince et pointu; Fig. 76 . - - Téle de Pie-grièche. leur queue est longue et échancrée. - Hochequeues

(Motacilla): Hochequeue lavandière ou Bergeronnette (M. albu); Bergeronnette jaune (. flava). - Pipis (A»thus): Pipi des prés (.1. pratensis): Pipi aquatique (A. aquaticus); Pipi des arbres (A. arboreus).

Les Sylviudes se rapprochent beaucoup des précédents: Fauvettes (Sylvia): Fauvette des jardins (S. hortensis); Fauvette babillarde (S. curruca); Fauvette à tète noire (S. alricapilla), etc. - Pouillots (Phyllopueuste) : Pouillot fitis (Ph. (rochilus); Rossignol batard ou Chanteur des jardins (Ph. lypolais). - Troglodytes (Troylodylcs): Troglodyte mignon (T. parvulus), souvent appelé, mais à tort, Roitelel. - Roitelets (Rcgulus): Roitelet huppé (R. cris tatus).

Les Turdides ont le bec comprimé et garni à la base de soies courtes. Grives (Turdus), comprenant les firives proprement dites, à plumage moucheté de taches noires ou grivelures: Grive chanteuse ou des vignes (T. $m u$ sicus), Mauvis (T. iliacus), Litorne ( $\boldsymbol{T}$. pilaris), Draine (T. viscirorus); et les 
Merles, à plumage presque unicolore: Merle noir (T. merula), Merle à plastron ou de montagne (T. torquatus), elc. - Tariers (Pratincola): Tarier

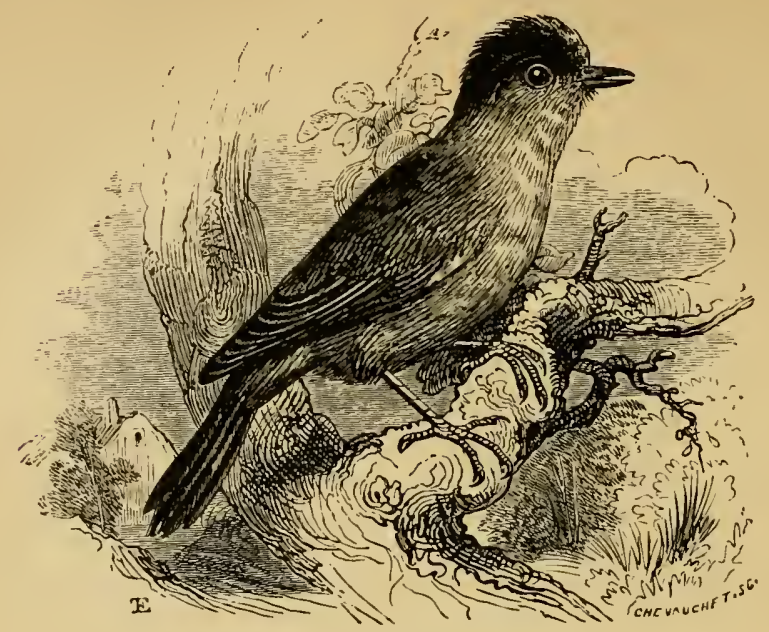

Fig. 768 . - rauvette à tète noire.

commun (P. rubetra); Tarier rubicole (P. rubicola). - Traquets (Saxicola) : Traquet motteux (S. cenanthe). - Rossignols (Luscinia) : Rossignol philomèle (L. philomela); Rouge-Gorge (L. rubicula); etc.

$5^{\text {e }}$ sous-ordre : Fissirostres. - Le bec est court, plat, non échancré à la pointe et fendu très profondément. Le pouce est quelquefois dirigé en avant, comme les autres doigts. Ces Oiseaux, qui se rapprochent des Rapaces, sont insectivores.

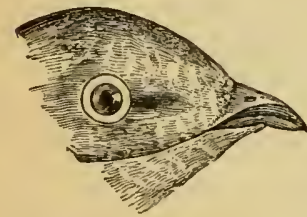

Principaux représentants : Engoulevent (Caprimulgus). - Hirondelles (Hirundo): Hirondelle de cheminée (H. rustica), à gorge rousse; Hirondelle de fenêtre ou à cul blanc (II. urbica); Hirondelle de rivage $(H$. ripari $\ell)$ à dos gris brun; etc. - Martinets Fig. 769. - Tète d'Hirondelle. (Cypselus) : Martinet noir (C. apus). - Salanganes (Cullocalia) : Salangane comestible (C. esculenta), Salangane Kusappi (C. fuciphaga), etc.

Les Salanganes vivent sur les côtes de l'Asie méridionale et des îles de la Sonde. Elles sont devenues célèbres par leurs nids, qui constituent un aliment très recherché des Chinois et qu'on importe même en Europe. Ces nids sont établis dans des cavernes obscures, dont le fond est généralement couvert par les eaux de la mer. Celiui de la Salangane comestible est formé d'une matière translucide blanchâtre ou brunâtre, et marqué de stries transversales ondulées; dans celui du Kusappi, il entre en même temps des tiges d'herbes ou d'autres corps étrangers. On a beaucoup discuté sur l'origine de la substance qui compose essentiellement ces nids : beaucoup ont pré- 
tendu qu'il s'agissait de fucus, de frai de poissons, de chair d'animaux marins, etc.; Everard Ilome a annoncé qu'elle étail due à une sécrétion du jabol; mais les observations de Bernstein paraissent démontrer qu'elle est produite par les glandes salivaires, lesquelles deviennent turgescentes pendant la saison des amours. Il s'agirait d'une matière albuminoïde, analogue à la mucine, et à laquelle Payen a donné le nom de cubilose. On récolte la plus grande partie de ces nids à Java, el on les importe en Chine, ou ils sont payés parfois un prix fabuleux.

\section{XEUVIĖ.IE ORDHE}

\section{IRAPACES}

Oiseaux a bec trés fort et crochu, offrant une cire à la base; doigts armés de griffes puissantes et recourbées (serres), les trois antérieurs réunis à la base par une courte membrane.

Les Oiseaux de proie ou Rapaces, comme les prédateurs en général, sont remarquables par leur conformation robuste, la puissance de leurs armes (bec et serres), la délicatesse de leurs sens. Leurs ailes sont longues, leur vol rapide et soutenu.

Ce sont des Óiseaux carnassiers: ils se nourrissent fréquemment de la chair des Mammifères et des Oiseaux moins puissants qu'eux; quelques-uns se contentent de cadavres. Dans tous les cas, ils maintiennent la proie à l'aide de leurs serres et la déchirent avec leur bec. Les aliments séjournent un certain temps dans le jabot, où s'effectue une sorte de triage, et les parties résistantes que l'animal ne pourrait digérer, comme les os, les poils et les

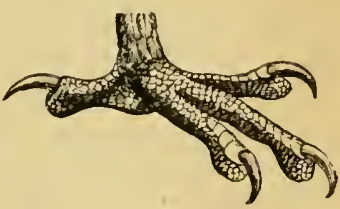

Fig. 770. — Serre de Gypaète. plumes, sont rejetées à l'extérieur. Le gésier est mince et membraneux.

Les Rapaces sont monogames. Les petits qui viennent de naître sont faibles et nus.

2 sous-ordres: Nocturnes et Diumes.

ter sous-ordre: Nocturnes. - Ils ont le bec presque toujours recourbé dès la racine et la cire cachée par des plumes sétiformes. Leurs yeux sont grands, dirigés en avant et entourés d'un cercle de plumes. Leurs ailes sont arrondies, dentées, et leurs plumes souples, ce qui permel un vol silencieux.

Ces Oiseaux restent d'ordinaire cachés pendant le jour dans les trous des murailles ou des arbres. Ils se nourrissent d'Insectes et surtout de petits Mammifères; ils s'attaquent peu aux Oiseaux. Aussi se placent-ils au premier rang parmi les animaux utiles à l'Homme. Il importe donc de s'élever avec force contre les préjugés ridicules qui les font poursuivre dans les campagnes, et en particulier contre la coutume barbare et stupide qui consiste à les fixer en croix aux portes des granges ou des habitations. Dans l'estomac d'une Hulotte, Martin a trouvé 75 grandes Chenilles qu'elle avait mangées en un seul repas, et Lenz a calculé qu'une Chevèche commune consomme par an plus de 1300 Souris ou autres petits Rongeurs. 
Tous ces Oiseaux se ressemblent beaucoup. Les genres les plus impor-

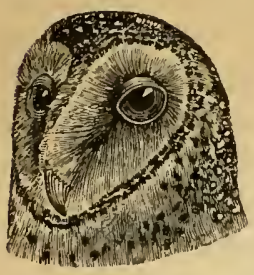

Fjg. 771. - Tële de IEEfraie commune. tants sont : les Effraies (Strix), à bec droit à la base, ì disques périophtalmiques complets, cordiformes : Effraie commune (St. flammea). - Les Hulottes (Syrnium), à disques larges, à orifice auditif petit: Hulotte ChatHuant (S. aluco). - Les Hiboux (Otus), caractérisés par la présence de deux faisceaux de plumes formant comme deux oreilles saillantes : Hibou vulgaire $(0 . v u l-$ garis). - Les Ducs $(B u b o)$, à disques incomplets, irréguliers: Grand-Duc (B. maximus). - Les Surnies (Surnia), à bec presque entièrement couvert de plumes: Chouette ou grande Chevêche (S. ululu); Chevèche commune (S. noctua); Chevèchette (S. pusserina); etc.

$2^{\mathrm{e}}$ sous-ordre : Diurnes. - Ces Oiseaux, les plus forts de toute la classe, ont la base du bec enveloppée par une cire ordinairement bien visible, les yeux latéraux, les ailes a!longées et pointues. Ils planent souvent dans l'atmosphère à une très grande hauteur, en cherchant une proie. Un certain nombre de ces Rapaces peuvent ètre classés, sans hésitation, parmi les animaux nuisibles : par exemple les Faucons, les Éperviers, les Hobereaux, les Milans, qui détruisent une grande quantité de Passereaux. Mais les espèces lourdes, comme les Buses, Busards, Harpayes, Bondrées, auxquelles leurs ailes relativement courtes ne permettent pas de poursuivre les petits Oiseaux, et qui s'attaquent par suite aux petits Mammifères ou aux Insectes, ces espèces rendent en général plus de services qu'elles ne causent de préjudice à l'agriculteur.

Tels sont les Vautours (Vultur), les Condors (Sarcoramphus), etc., qui ont la tète et le cou plus ou moins nus. - Les formes suivantes ont au contraire ces parties emplnmées : Gypaètes (Gypaetus): Gypaètes des agneaux (G. barbalus). - Aigles (Aquila) : Aigle fauve (A. fulva); Aigle impérial (A. imperiulis), etc. - Milans (Milvus) : Milan royal (M. regalis). - Buses (Buteo) : Buse commune (B. vulgaris). - Bondrées (Pernis) : Bondrée apivore ( $P$. apivorus), déterre les nids de Guèpes. - Autours (Astur) : Autour commun (A. palumbarius), chasse surtout les Pigeons. - Éperviers (Nisus): Épervier commun ( $\boldsymbol{H}$. communis). - Faucons (Falco), étaient autrefois dressés à la chasse: Crécerelle vuIgaire ou Émouchet (F. tinnunculıs); Crécerine (F. cenchris); Ilobereau (F. subbuteo); Émérillon (F. æsalon); Faucon commun (F. peregininus); Gerfaut blanc (F. candicans). - Busards (Circus): Busard commun (C. cyaneus); Harpaye (C. rufus); etc. - Serpentaires(Gypogeranus): Serpentaire reptilivore ou Secrétaire (G. serpentarius), d'Afrique ; se nourrit principalement de Serpents.

\section{CLASSE V}

\section{A M M I É RE S}

Vertébrès à sang chaud, revétus de poils et pourvus de glandes lactaires; deux condyles occipitaux; circulation double, complète; respiration exclusivement pulmonaire. Vivipares; embryons pourvus d'un. amnios et d'une allantoïde. 
Les Mammifères marquent le degré le plus élevé de l'organisation animale (1).

Chez la plupart d'entre eux, la tête, le cou, le trone et la queue constituent des régions bien séparées et, dans le cas mème oủ leurs. limites tendent a s'eflacer sur l'animal vivant, on les reconnait facilement sur le squelette.

La peau comprend, comme chez tous les Vertébrés, deux couches distinctes : le derme et l'épiderme. Celui-ci, composé de cellules juxtaposées qui forment d'ordinaire un revêtement mince el souple,

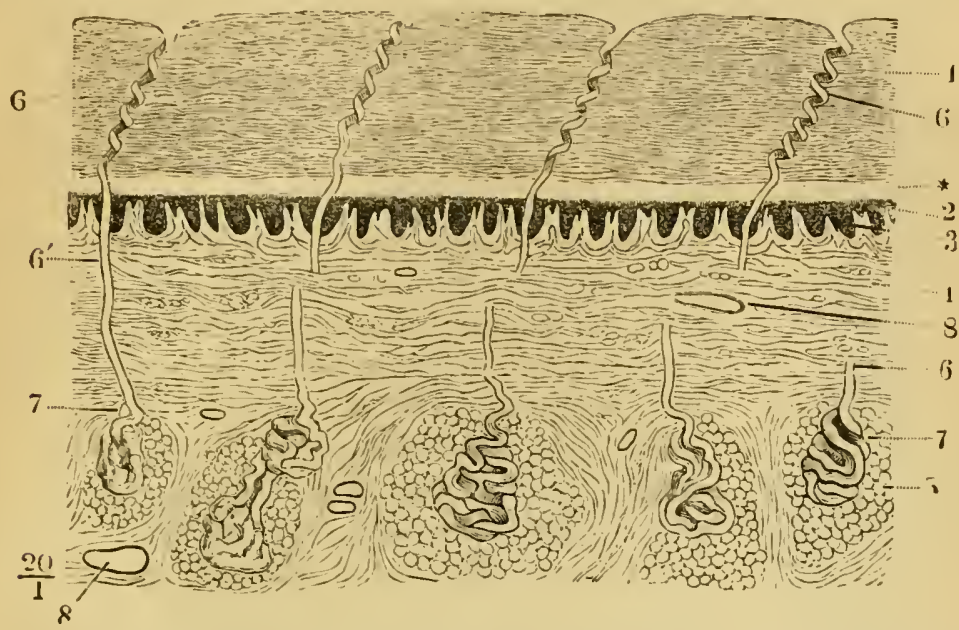

Fig. 7.2. - Seclion de la peau de l'Homme, pratiquée au niveau de la pulpe d'un doigl, parallelement aux crètes. - 1, couche comée de l'épiderme. ", portion profonde de lil mème couche, formíe de cellules moins aplaties. 2 , couche muquense. 3, papilles. 4, derme. 5, lissu adipenx sous-culan: 6, canaux excréleurs des glantes sudoripares dans l'épiderme. 6', les mémes dans le derme. 7 , glomírules des glandes suloripares. 8 , seclion diun vaisseau sanguin (Crurcillier).

se modifie sur certains points et donne alors naissance ì des productions variées : callosités, ongles, sabots, cornes, écailles, poils, glandes. Il est à remarquer que les caractères exclusifs les plus importants de la classe sont fournis précisément par certaines de ees productions : nous voulons parler du système pileux el des glandes manmaires.

Les poils existent, en effet, che\% tous les Mammifères. Ceux mêmes qui paraissent en manquer tout à fait en possèdent des vestiges, soit pendant le jeune àge, soit dans des régions où ils sont cachés par des plis. Un poil n'est autre chose qu'un appendice tégumentaire dérivé de la couche épidermique et implanté dans une étroite cavité qui pénètre jusque dans la profondeur du derme et porte le nom de follicule pileux. Celui-ci offre à son fond une saillie

(1) C. Vogt, Les Mammifères. Paris, 1884. - O. Scnumb, Les Mammifères dans leurs rapports avec leurs ancétres géotogiques. Paris, 1887. - K. A. Zitres, Traité ¿le paléntologie: Mammalia. Paris, Munich et Leipzig, 1894. 
conique, vasculaire et nerveuse, la papille, qui est l'organe producteur et nourricier du poil. Au follicule sont annexés, en outre, des glandes sébacées et un faisceau musculaire lisse qui est situé du côté de l'inclinaison du poil et s'étend de la facesuper-

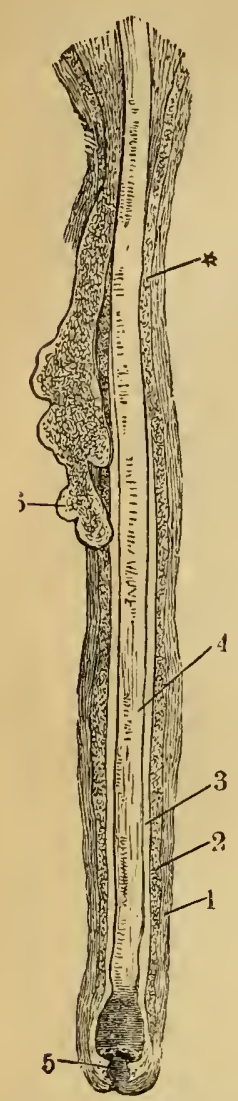

Fig. 773. - Follicule pileux du cuir chevelu de l'Homme, avec son poil, isolé par la coction et la macération. - 1, follicule pileux. \&, couche muqueuse. 3 , couche cornée de son épiderme. 4, poil. 5, papille du poil. 6 , glande sébacée annexée au follicule. *, col du follicule (Crureillicer). ficielle du derme au fond du follicule. Quand ces faisceaux, qu'on a qualifiés à juste titre de muscles horripilateurs, entrent en contraction sur une surface étendue, on voit les poils se redresser en soulevant la peau : c'est à ce phénomène qu'on donne le nom de " chair de poule ". Dans le poil luimême, on distingue une partie libre, la tige, et une partie cachée dans le follicule, la racine; celle-ci offre à sa base un renflement, le bulbe du poil, qui coiffe la papille. Sur une coupe, le poil se montre formé de trois couches superposées : une cuticule, mince lamelle constituée par des cellules cornées, une couche corticale munie de granulations pigmentaires qui font défaut dans les poils blancs, et une substance médullaire, qui peut manquer entièrement (Porc).

Le pelage des Mammifères comprend le plus souvent deux sortes de poils: les uns, plus ou moins longs et raides, sont appelés jarres; les autres, courts, fins et doux, constituent le duvet ou la bourre. Le développement relatif de ces deux éléments pileux est très variable suivant la température: le duvet se montre surtout abondant en hiver et dans les pays froids. - On donne spécialement le nom de crins aux jarres épaisses, longues et flottantes (Cheval); on appelle soies celles qui sont droites, fortes et raides (Porc); piquants, celles qui sont épaisses, rigides et pointues (Porc-épic). Quant à la laine, c'est un duvet à poils longs, fins et onduleux. - Les follicules pileux sont toujours pourvus de nombreuses terminaisons nerveuses, qui transmettent les impressions tactiles; mais cette disposition est surtout bien accusée dans les vibrisses, véritables organes du tact, qui sont implantés dans la lèvre supérieure de beaucoup de Mammifères.

La disposition et la coloration du système pileux fournissent des éléments importants à la zoologie descriptive, mais il faut tenir compte de certaines variations qui peuvent se produire sous des influences diverses. Ainsi, dans les régions tempérées, la teinte du pelage devient souvent blanche en hiver (Hermine). On sait aussi quelle a été, à cet 
égard, l'influence de la domestication : nous noterons seulement la prédominance, chez nos animaux domestiques, des trois couleurs blanche, noire et rousse. - D'autre part, il ne faut pas oublier que les poils tombent, chez beaucoup de Mammifères, d'une façon périodique, et qüils sont remplacés par d'autres se formant dans les mêmes follicules. A cette mue correspond souvent un changement de couleur.

Les ongles sont encore des formations épidermiques; ils sont tantôt plats, comme chez les Singes, tantòt crochus, comme chez les Carnivores; et, dans ce dernier cas, on leur donne le nom de griffes; mais ils ne recuuvrent jamais que la surface dorsale des dernières phalanges. Ils se distinguent ainsi des sabots, qui enreloppent completement l'extrémité du doigt. On s'est autrefois basé sur ces différences pour établir deux grands groupes parmi les Mammifères : les Onguiculés, à doigts mobiles garnis d'ongles ou de griffes, et les Ongulés, à doigts enveloppés par des sabots.

Les petites écailles cornées de la queue des Rongeurs, les grosses écailles imbriquées qui forment la cuirasse des Pangolins, l'étui des cornes des Bovidés, les cornes des Rhinocéros, etc., sont encore des formations épidermiques. Mais la cuirasse des Tatous et les bois des Cerfs, au contraire, sont produits par ossification du derme.

Les glandes cutanées sont très répandues. Les unes, appelées glandes sudoripares, sont, comme leur nom lindique, chargées de sécréter la sueur. Les autres, glandes sébacées, s'ourrent généralement dans les follicules pileux et sécrètent une substance grasse destinée à lubrifier la

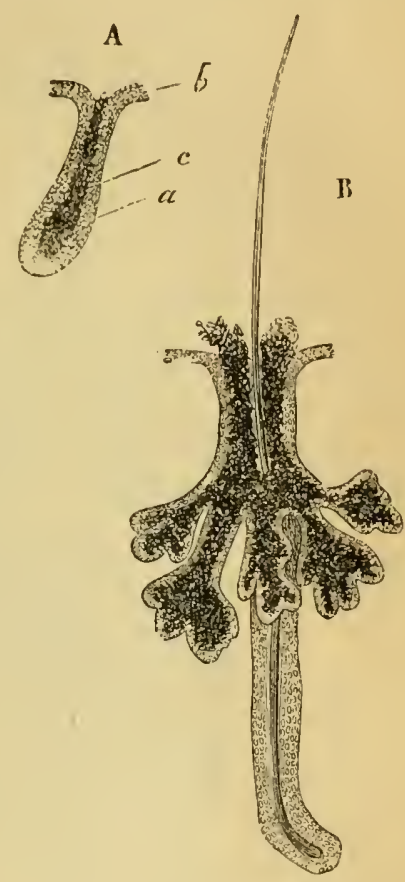
Fig. 774. - Glandes sébacées du neu, vues à un grossissement d'environ 50 diamètres. $-A$, glande utriculaire simple, sans poul. B, glande composée, souvrant à l'extérieur par un oritice commun avec un follicule pileux (Cruveillier). surface tégumentaire. Ces glandes sébacées peuvent prendre un grand développement sur certains points : ainsi sont formées les glandes interdigitales de beaucoup de Ruminants, les larmier's des Cerfs, les glandes temporales des Éléphants, les glandes anales de divers Carnivores, ete. Le plus souvent, ces glandes sont en rapport avec les fonctions de reproduction. - Quant aux glandes lactaires ou mamelles, nous nous en occuperons plus loin.

Le squelette n’est point creusé de cavités aériennes comme celui des Oiseaux; il est, par suite, beaucoup plus lourd.

Le crane est notablement plus développé que chez les autres 
Vertébrés. Les os qui le constituent, et dont quelques-uns sont d'origrine dermique, demeurent en général, durant la vie entière, réunis par des sutures. En arrière, le crâne est formé parl'occipital, lequel offre une ouverture (trou occipital) pour le passage de la moelle épinière, et, sur les côtés de cette ouverture, deux éminences (condylpss occipitaux), au moyen desquelles le crâne s'articule avec la colonne vertébrale. En avant de l'occipital se trouvent les pariétanx; au-dessous

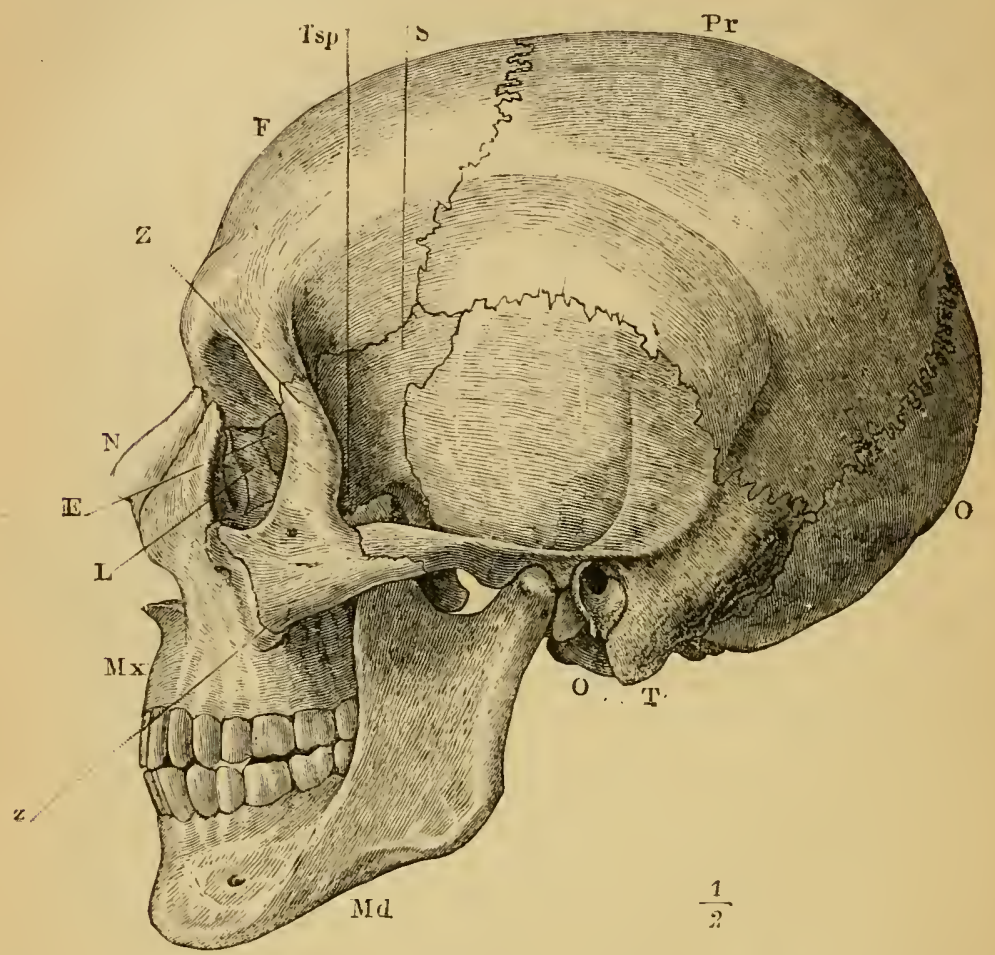

lig. 735 . - Téle osseuse de l'Homme, vue de profil. - O, occipital, [' ${ }^{\prime}$, pariélal. s', sphénoïdr. $F$. fronlal. $Z$, os malaire. $N$, os du nez. $E$, ellımoïde. $L$, os lacrsmal. $1 / x$, maxillaire supérieur. $M d$, maxillaire inférieur. $T$, lemporal. $T s \rho$, tubercule épineux. $T z$, lubercule malaire (Gruveilhier).

de ceux-ci, les temporaux, et, à la partie inférieure, le sphénoïde. Les frontaux sont situés au-devant despariétaux. Enfin, entre les frontaux et le sphénoïde existe une dernière pièce,l'ethmoïde, qui complète la boîte cranienne. - La face se compose d'un nombre d'os assez variable, plusieurs d'entre eux pouvant se réunir ou quelques-uns faisant défaut dans certains cas. En général on y distingue : les maxillaires supérieurs, les intermaxillaires, les palatins, les ptérygoïdiens, les zygomatiques ou jugaux, les lacrymaux, les sus-nasaux, les cornets, le vomer et le maxillaire inférieur. Les deux mâchoires sont les seules parties qui servent àl'implantation des dents : la mâchoire supérieure est 
formée par l'union des intermaxillaires el des maxillaires supérieurs; la mâchoire inférieure ne comprend que le seul os maxillaire inférieur. Conlrairement à ce (qui s'ohserve cliez tous les autres Vertébrés, cet os s`arlicule avec le crìne sans l'intermédiaire d'un os carré. La face présenle, dans sa région supérieure, deux fosses orbitaires, dont le cadre n est complet que chez. les Primaies. Au-dessous, sont les fosses nasales, séparées par une cloison médiane ayant pour base le romer et la lame perpendiculaire de l'ethmoïde. Enfin, ì la partie inférieure se trouve la cavilé buccale, séparće des fosses nasales par la voùte palatine, laquelle est formée surtout par les maxillaires supérieurs.

On a remarifué depuis longtemps que le développement du cràne, relativement à celui de la face, est d'autant plus considérable que l'animal est mieux doué sous le rapport des facultés intellectuelles. Les Nammifères inférieurs, tels que les Marsupiaux, ont un cràne très petit, tandis que leurs màchoires sont énormes; les Primates ont, au contraire, un cràne

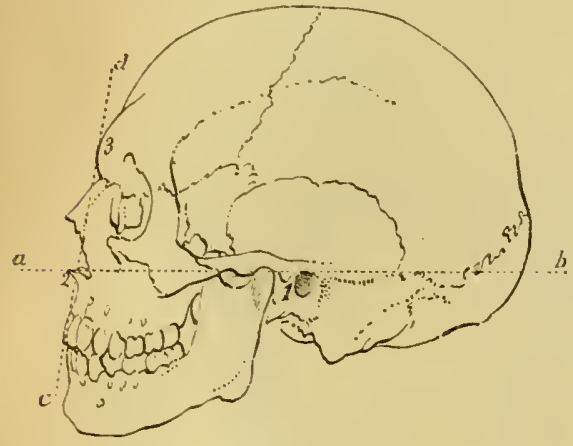

Fig. Fic. - Augle facial d'un Europien (d'aptès Camper). très raste. Il serait donc utile de posséder une mesure simple qui permit d'apprécier le rapport du cràne et de la face. Camper a proposé de prendse

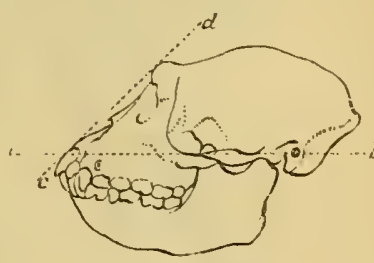

Fig. 7\%: - Angle facial d'un Singe (d'après Camper).

pour base ce qu’il a appelé l'angle facial. Cet angle est délerminé par une ligne horizontale qui passe au niveau de louverture du conduit auditif et de la base des narines ou épine nasale inférieure, et par une ligne oblique, dite faciale, qui s'étend depuis la partie la plus saillunte du front jusqu’aux incisives antérieures. Geoffroy Saint-Hilaire et Cuvier, Jacquart, Jules Cloquet, ont proposé diverses modifications à l'établissement de l'angle facial. Aujourd'hui on emploie souvent le procédé de Cloquet un peu modifié : l'angle facial a pour sommet conslant le bord alvéolaire supérieur; la ligne horizontale passe par le trou auditif, la ligne faciale par le point sus-orbitaire de Broca ou ophryon, qui répond à la limite antérieure de la base cranienne vers le bas du front.

Voici, pour quelques cas, la valeur de cet angle : Homme blanc, $72^{\circ}$;

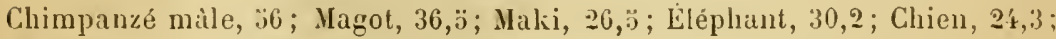
Cheral, 2: (Topinard).

Le squeletle viscéral, représenté par l'hyoïde, comprend une partie médiane, le corps, et deux paires de branches ou cornes, les anté- 
rieures fixées au temporal et les postérieures au cartilage thyroïde du larynx. Ces dernières font quelquefois défaut (Rongeurs).

La colonne vertébrale se divise en cinq régions: cervicale, dorsale, lombaire, sacrée et caudale ou coccygienne. Chez les Cétacés et les

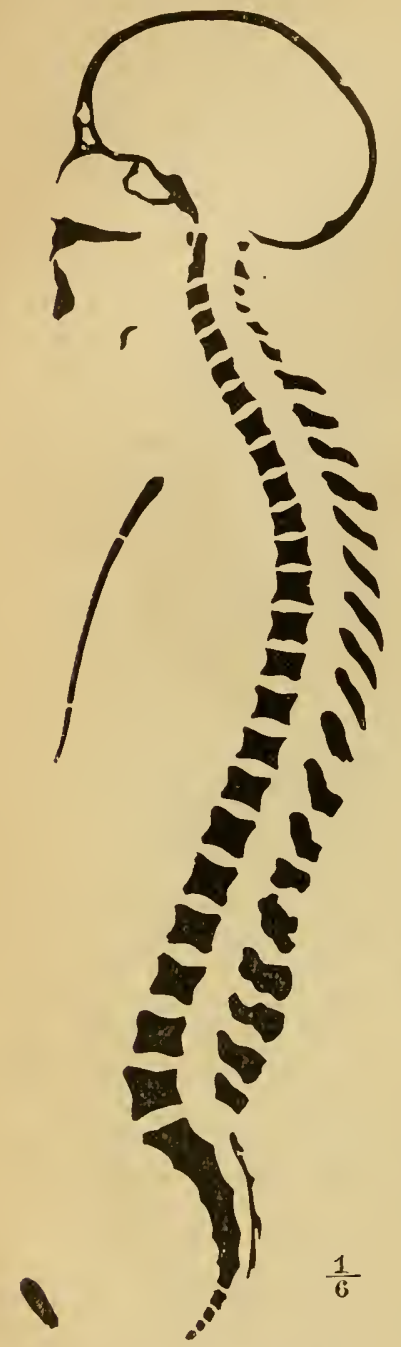

Fig. 778. - Section médiane des os du tronc de l'Homme (Cruveilhier). Sirénidés, qui n'ont pas de membres postérieurs, on n'en compte que quatre : la région sacrée est absente. - La région cervicale, d'une longueur assez variable, compte presque toujours 7 vertèbres. Cependant, le Lamantin des Amazones (Manalus australis) n'en possède que 6 ; il en est de même d'un Paresseux voisin de l'Unau (Choloepus Hofmanni) ; par contre, le Bradype à

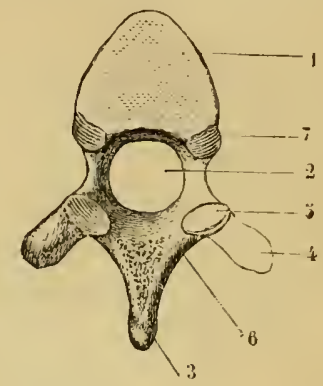

Fig. 779. - Quatrième vertèbre dorsale de l'Homme, vue par la face inférieure. - 1, eorps vertébral. 2, trou vertébral. 3, apophyse épineuse. 4, apophyse transverse. 5, apophyse articulaire inféricure. 6 , lame vertúbrale. $\bar{i}$, surface articulaire destinée à recevoir la tèle de la côte.

collier (Bradypus torquatus), en a 8, et le Bradype $\Lambda \ddot{i}$ (Br. tridactylus), 9. La première vertèbre cervicale ou atlas offre toujours deux surfaces articulaires pour recevoir les condyles occipitaux. La deuxième ou axis est presque toujour's munie en avant d'un long pivot (apophyse odontoïde) sur lequel tourne l'atlas pour effectuer le mouvement de rotation de la tête. - La région dorsale est assez variable quant au nombre des vertèbres qui la composent; on en compte le plus souvent 12 à 1 ว̆. Ces vertèbres ont des apophyses épineuses assez longues et s'articulent avec les côtes. Celles de la région lombaire, remarquables par leurs longues apophyses transverses, sont généralement au nombre de 50 à 7 . - La région sacrée comprend d'ordinaire 3 à 20 vertèbres 
soudées entre elles de manière à former un os impair, le sacrum, compris entre les deux os iliaques. - Enfin, la région caudale offre des variations très étendues: fort réduite chez l'llomme et les Singes anthropoïdes, elle est très allongée, au contraire, che\% une foule de Mamınifères, et se compose alors d'un grand nombre de vertèbres.

Les crites sont en nombre égal à celui des vertèbres dorsales. Toutes s'articulent avec ces os par leur extrémité supérieure; mais les premières seules (vraies côtes) se fixent inférieurement au sternuın; les suivantes (fausses cites) restent libres ou s'unissent ì l'extrémité sternale des vraies côtes.

Le sternum se compose d'une série de pièces ou sternèbres dont le

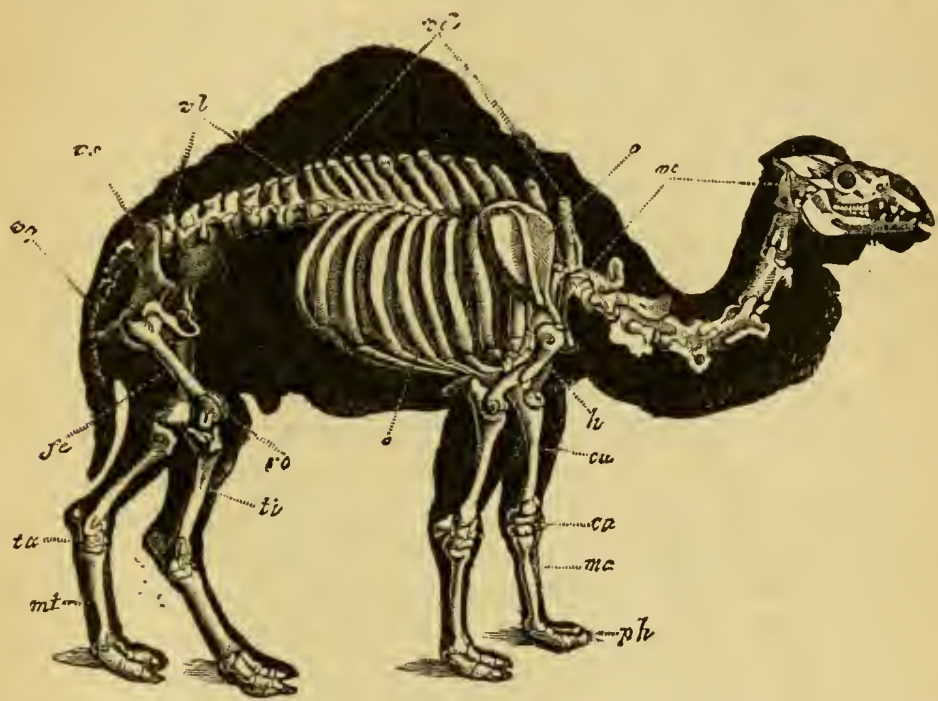

Fig. 780. - Squelelte de Dromadaire. - vs, verlèbres cervicales. $v d$, vertèbres dorsales. vl, verlebres lombaires. vs, sacrum. $v q$, verlèbres coccygiennes. $c$, côtes. o, omoplale. $h$, humérus. $c u$, eubilus. $c a$, carpe. $m c$, métacarpe. $p h$, phalanges. fe, fémur. ro, rolule. $t i$, libia. $t a$, tarse. $m t$, métalarse (Milne-Edwards).

nombre est rariable. Lorsqu'il existe des clavicules, sa partie antérieure, qui s'articule avee celles-ci, se montre toujours large (manubrium); elle reste étroite, au contraire, quand les clavicules font défaut. La partie postérieure se prolonge par une pièce cartilagineuse, l'appendice xiphoïde.

Tous les Mamınifères possèdent les membres de la paire antérieure, mais la paire postérieure manque chez les Cétacés et les Sirénidés. La ceinture scapulaire se compose, chez les Monotrèmes, de trois os: l'omoplate, la elavicule et le coracoïde; mais, chez tous les autres Mammifères, le coracoüde se soude de fort bonne heure à l'omoplate, dont il ne représente plus qu'une simple apophyse. La clavicule existe chez les formes dont le membre a des fonctions compliquées; 
elle devient rudimentaire ou nulle Jorsque ce membre sert unıquement à la locomotion et au soutien du corps.

La ceinture pelvienne, rudimentaire chez les Cétacés et les Sirénidés, où elle est représentée par quelques osselets perdus dans les muscles, comprend partout ailleurs trois os: l'ilion, l'ischion et le pubis, qui se soudent entre eux et s'unissent aux parties latérales du sacrum, de manière à former une ceinture complétée par la symphyse pubienne. Ainsi se trouve constitué le bassin. Chez les Monotrèmes et les Marsupiaux, le pubis porte deux os dirigés en avant, les os marsupiaux.

La portion mobile des membres offre une conformation très variable suivant le rôle qu'elle est appelée à remplir. Il suffit, pour s'en rendre compte, de jeter un coup d'œil sur la nageoire de la Baleine, l'aile de la Chauve-Souris, la main du Singe, la patte du Chien el le pied du Cheval. - Au membre antérieur, nous trouvons d'abord un humérus de longueur variable et souvent recourbé. Le radius et le. cubitus sont d'ordinaire plus longs que l'humérus; le cubitus présente, en arrière de l'articulation du coude, une puissante apophyse appelée olécràne. Le radius est souvent mobile autour du cubitus, ce qui permet à la main de se placer en pronation, c'est-à-dire la face palmaire tournée en arrière, et en supination, la face palmaire en avant: ces mouvements atteignent leur maximum chez l'Homme. D'autres fois, le cubitus est rudimentaire et soudé au radius (Équinés). La constitution de la main est très variable. Le nombre primitif des doigts est de cinq, mais ce nombre peut subir une réduction plus ou moins grande. C'est alors le premier doigt (doigt interne ou pouce) qui disparaît d'abord; après quoi, la marche de la régression se poursuil de deux facons différentes. Chez les Kangourous sauteurs, elle porte sur le deuxième et le troisième doigt. Chez les Ongulés, l'ordre de disparition est le suivant: $1^{\mathrm{er}}, 5^{\mathrm{e}}, 2^{\mathrm{e}}, 4^{\mathrm{e}}$. Ainsi, chez le Porc, le pouce seul $\left(\mathbf{1}^{\mathrm{er}}\right)$ a disparu; l'Hipparion a perdu en plus le doigt externe $\left(\breve{5}^{\mathrm{e}}\right)$; le Chameau, le second interne $\left(2^{\mathrm{e}}\right)$, et le Cheval, le second externe $\left(4^{c}\right)(1)$. Les métacarpiens subissent une réduction correspondante, et arrivent à n'être plus représentés que par une seule pièce, l'os du canon. Chez la plupart des Mammifères pentadactyles,

(1) Dans quelques circonstances, il peut être utile de faire usage de formules digitales pour exprimer la constitution de la main et du pied (R. Blanchard). Les doigts de la main sont indiqués au-dessus, et ceux du pied au-dessous d'un trait horizontal, par des chiffres qui représentent leurs numéros d'ordre, la numération se faisant toujours de dedans en dehors. Si certains doigts ont subi une réduction et ne servent plus, par exemple, à l'appui, on les signale par des chiffres de plus faibles dimensions. Ainsi, la formule digitale de l'Ilomme est $\frac{1.2 .3 .4 .5}{1.2 .3 .4 .5}$, car les cinq doigts ont conservé, aux mains et aux pieds, toute leur importance fonctionnelle. Celle du Porc est $\frac{2.3 .4 .5}{2.3 .4 .5}$, le doigt interne ayant disparu, et les doigts 2 et 5 ne servant plus à l'appui. Les Tapirs répondent à la formule $\frac{2.3 .4 .5}{2.3 .4}$, le membre antérieur ayant perdu le doigt 1 , et le postérieur les doigts 1 et 5 . 
le pouce, qui ne possède jamais que deux phalanges, au lieu de correspondre a l'axe du membre, eomme les autres doigts, prend une direction divergente. On passe facilement de celle disposition ì la laculté d'opposer le pouce aux atutres doigts, el l'on sail que le pouce opposable est la caractéristique de la main parlaite ou préhensile. Iu membre postérieur, l'articulation du genou est, contrairement it celle du coude, saillinte en avant; elle présente d'ordinaire une rotule. Il est rare que le tibia soit mobile autour du péroné (Marsupiaux): en général, ces deux os sont soudés, et lo dernier est rudimentaire. Le tarse est remarquable par le développement de l'astragale et du calcanéum. Le $1^{\text {rr }}$ orteil se montre quelquefois opposable (Singes); mais la disposition fondanentale du pied ne change pas pour cela, et ce pied préhensile ne mérite nullement le nom de main.

Les membres ne portent pas le poids du corps de la mime manière. Tantòt les doigts posent seuls à terre (Chat): Ies animaux sonl alor's digitigrades: tantôt toute la plante du pied, carpe ou tar'se compris, porte sur le sol (Homme) et ils sont plantigrades: il y a, du reste, des

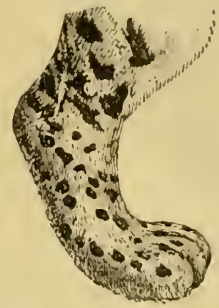

Fig. 781. - Palte poslérieure du Jaguar, anima! digiligrade.

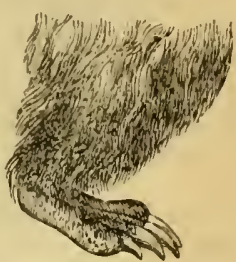

Fig. 782. - Patte postérieure de lours lirun, animal planligrade. dispositions intermédiaires, qui font appliquer aux animaux la dénomination de semi-plantigrades ou de semi-digitigrades. Les Ongulés, ne marchant que sur l'extrémité de la dernière phalange, sont dits ongulogrades.

Le système nerveux se fait remarquer par le développenent du cerveau. Les hémisphères cérébraux recourrent le cervelet en arrière; ils sont unis entre eux par une commissure désignée sous le nom de corps calleux ou mésolobe, commissure qui demeure rudimentaire chez les Monotrèmes et les Marsupiaux. Ces animaux, en outre, ne possèdent pas de circonvolutions; mais celles-ci apparaissent chez les Édentés, les liongeur's et les lnsectirores, et sont en rapport, quoique d'une faron non absolue, a vec le développement des facultés intellectuelles. Les lobes optiques ou tubercules quadrijumeaux sont beaucoup moins déreloppés que chez les Oiseaux, el souvent même sont cachés sous la partie postérieure des liémisphères; ils ne présentent aucune cavilé intérieure. Le lobe médian du cervelet, ou vermis, diminue d'importance à mesure yu'on s'élève dans la série des Mammifères, et les deux lobes latéraux, par contre, deviennent de plus en plus volumineux. Ces deux lobes sont réunis par une protubérance annulaire ou pont de Varole, qui suit leur propre développement. La moelle épinière se termine par un faisceau de nerfs appelé queue de cheval; elle ne présente jamais de sinus rhomboïdal 
Les Mammifères ont, en général, les sens très développés. L'apparę olfactif est remarquable par l'étendue de la pituitaire. Les fosses nasales communiquent arec des cavités creusées dans les os roisins

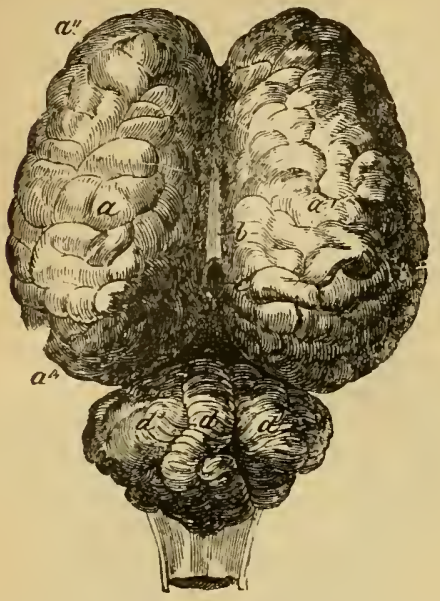

Fig. 783. - Face supérieure du cerveau et du cervelel du Cheval. - $a$, liémisphìre gauche du cerveau. $a^{\prime}$, hémisphière droit. $a^{n}$, lobe inférieur. $b$, corps calleux. $c$, point où la grande veine cérébrale sort de l'organe. $d$, lobe médian (vermis) du cervelel. $d^{\prime}$, lobe gauche. $d^{\prime \prime}$, lobe droit.

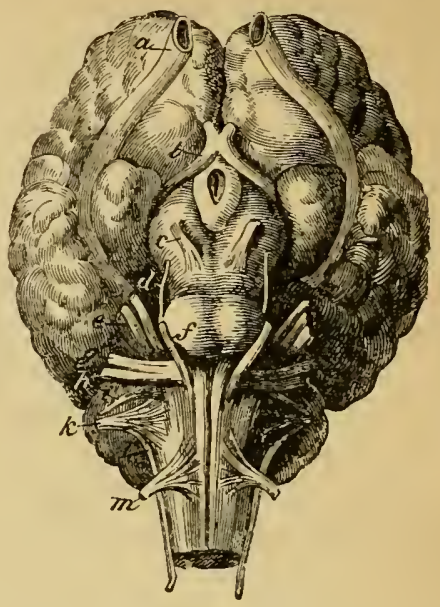

Fig. 784. - Base de l'encépliale du Cheval avec l'origine des douze paires de nerfs qui en émanenl. $-a, 1^{\text {ro }}$ paire : nerf olfactif. $b, 2^{\circ}$ paire: nerf uptique. $c, 3^{\circ}$ paire: nerf oculo-moteur commun. $d, 4^{\circ}$ paire: nerf palhétique. $e, 5^{\circ}$ paire : nerf trijumeau. $f, 6^{\circ}$ paire : nerf oculo-moteur exlerne. $g, 7^{\circ}$ paire: nerf facial. $h$, $8^{e}$ paire : nerf acous. lique. $i, 9^{e}$ paire : werf glosso-pharyngien. $k$, $10^{\circ}$ paire : nerf pneumogastrique. $l, 110$ paire. uerf spinal. $m, 12^{\mathrm{e}}$ paire : nerf liypoglosse.

(sinus frontaux, maxillaires, sphénoïdaux). Le nez, formé par la portion antérieure des fosses nasales et par des pièces cartilagineuses surajoutées, s'allonge quelquefois en trompe, comme chez l'Éléphant;

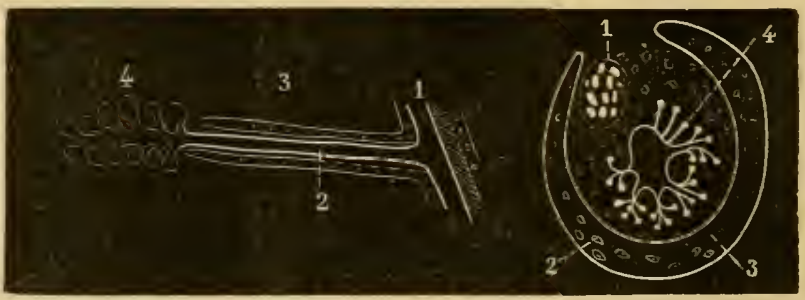

Fig. 78ว et 786. - Organe de Jacobson.

Fig. 78ว̆. - Développement chez un embryon du Chat. - Fig. 786. - Coupe chez le Ilouton. 1, eanal de Sténon. 2, cavitẻ de l'organe. 3 , enveloppe car- 1, nerf olfactif. 2, coque de cartilage. lilagineuse. 4, culs-de-sae glandulaires.

3 , eavité de l'organe. 4, glandes (schéma, d’après Ch. Kéuy).

il peut aussi se transformer en un organe fouisseur, tel que le groin du Porc. - On rattache d'ordinaire à l'appareil olfactif un organe spécial découvert par Jacobson et qui, développé surtout chez les herbivores, arrive à son maximum chez les Rongeurs. L'organe de Ja- 
cobson consiste en un canal étroit, couché sur le plancher de chaque fosse nasale, terminé en cul-de-sac đans sa partie postérieure et aboutissant en avant dans le conduit de Sténon, qui traverse l'ouverture incisive et fait communiquer la fosse nasale arec la bouche. La muqqueuse qui tapisse le canal est enreloppée d'une gaine cartilagineuse; elle contient de nombreuses glandes en grappe et reçoit une branche des nerfs olfactil's. Cette dernière particularité a fait regarder l'organe de Jacobson comme propre à recueillir les impressions odorantes des substances contenues dans la bouche, opinion qui parait peu fondée si l'on remarque que, chez les Équidés, le conduit de Sténon n'existe pas, l'ourerture incisive étant obturée par la substance cartilagineuse.

Les yeux sont rudimentaires chez les espèces qui vivent sous terre, comme la Taupe; parfois mème la peau recourre le globe de l'œil sans présenter d'ouverture (Spalax Jemni). Outre les deux paupières principales, supérieure et inférieure, il en existe une troisième, paupière interne ou membrane nictitante, qui toutefois ne peut jamais recourrir en entier le devant de l'oil, comme elle le fait chez les Oiseaux; souvent même elle se réduit à un repli de la conjonctive (pli semi-lunaire). L'angle interne de l'œil présente en outre un petit corps glanduleux, la caroncule lacrymale.

L'appareil anditif comprend d'ordinaire une oreille externe, qui manque cependant chez la plupart des animaux aquatiques et fouisseurs. L'oreille moyenne communique avec le pharynx,

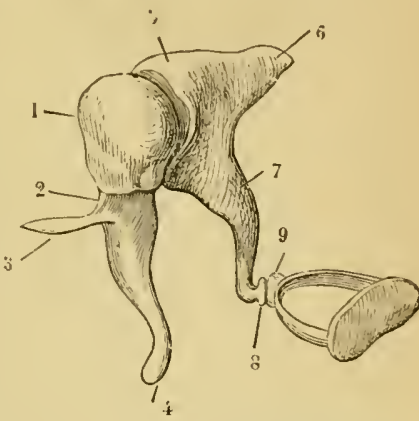

Fig. 787. - Osselets de l'ouïc dans leurs rapports réciproryues (cótédroit). - I, lèle du marteau. 2, son col. 3, apoplysse grèle. 4, exlrémité inféricure du manche. 5 , corps del'enclume. 6 , sa courlebranche. 7 , sa longue branclie. 8 , son crochet (os lenticulaire). 9, sommet de l'ëtrier.

exceptionnellement arec le canal nasal (Cétacés), par la trompe d'Eustache; elle est traversée par une chaine d'osselets appelés, d'après leur forme, marteau, enclume, os lenticulaire, étrier.

Nous n'arons rien de particulier à dire du sens du goût, qui est, en général, très développé chez les Mammifères.

Le lacl peut s'exercer par toute la surface du corps, mais certaines parties sont spécialement disposées it cet eflet: par exemple, la face palmaire de l'extrémité des doigts chez les Primates; la lèvre supérieure chez les Equidés; l'appendice digitiforme de la trompe chez les Éléphants, ete. Parfois on observe des poils taetiles, en rapport avec des terminaisons nerveuses; telles sont les vibrisses ou moustaches des Carnassiers.

L'appareil digestif ollire d'abord à considérer l'armature buccale, représentée en général par des dents. L'étude du système dentaire, 
dil Vogt, constitue la base de toute connaissance des IIammifères: il n'est aucun élément du squelette - la seule partie accessible au paléontologiste - "qui retienne avec autant de ténacité les caractères essentiels d'un type, et qui fasse mieux voir les relations d'affinité et de parenté qui peuvent exister entre les différentes formes".

Quelques genres seulement sont tout ì fait dépourvus de dents: citons à cet égard les Fourmiliers, les Pangolins, les Échidnés, les Baleines adultes. Chez les Baleines, ces organes sont remplacés par des fanons. L'Ornithorynque adulte a des sortes de dents cornées formées par le durcissement des papilles de la muqueuse buccale.

Les dents prennent naissance dans des cavités closes des mâchoires, et ne percent les gencives que lorsque leur évolution est assez a vancée. On y distingue alors trois parties: une extérieure, la couronne, une intra-alvéolaire, la racine, enfin une intermédiaire, quelquefois marquée par un rétrécissement, et appelée collet. La substance fondamentale de la dent est constituée par de l'ivoire nu dentine; c'est une substance

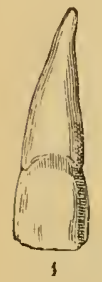

Fig. 788. - Incisive moveune supérieure de l'llomme. - 1, face antérieure. 2, face latérale. 3 , coupe médiane antéro-postérieure.

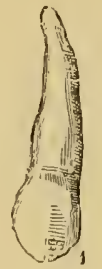

Fig. 789 . l'Homme. - 1, face antirieure. 2. face lateralc.

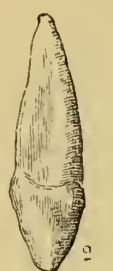

Cauiur de Fir 790 .

Grosse molaire de

l'Homme. - 1, face antérieure. 2, face latirale.

très dure, traversée par une foule de canalicules parallèles qui se dirigent de la carité interne vers la surface. Liivoire est ordinairement revêtu, au niveau de la couronne, d'une autre substance encore plus dure, l'émail, qui se compose de petits prismes juxtaposés. Une sorte de tissu osseux, le cément, recourre souvent la racine et peut même s'étendre sur la couronne, surtout dans les dents composées, dont elle comble les plis et les enfoncements. Lintérieur de la dent offre toujours une cavité, qui se montre simple ou multiple suivant qu'il existe une ou plusieurs racines. Dans certains cas, celte cavité s'ouvre largement à l"extrémité de la partie enchàssée, et la pulpe nourricière de la dent la remplit en entier; la dent continue alors à croître pendant toute la vie, à mesure que la couronne subit son usure. Comme exemples de ces dents à croissance continue (dents sans racines), nous pouvons citer les incisives des Rongeurs, les défenses des Éléphants et des Sangliers, etc. Le plus souvent, au contraire, la cavité interne se rétrécit de bonne heure vers l'extrémité, oủ elle ne s'ouvre plus que par un petit orifice : la pulpe vasculaire se trouve alors étranglée, et la croissance de la dent s'arrête d'une façon définitive. 
Lorsque les dents présentent une surface unie, on les appelle dents simples; mais parfois cette surface oflire des plissements et contournements qui les font nommer dents compliquées. On reconnait même des dents composées, résultant de la coalescence de plusieurs dents simples primitivement isolées. La distinction des dents compliquées et com. posées est, à la vérité, souvent impossible dans la pratique; nais on est convenu dappeler denticules (ou collines) les parties d'une dent qui paraissent correspondre ì des dents primitives soudées ensemble.

Les dents sont parfois toutes semblables entre elles, comme chez la plupart des Édentés; mais en général elles sont de plusieurs sortes, et on les distingue, suivant leur siège, en incisires, canines et molaires. Les incisives sont implantées sur les os incisifs ou intermaxillaires, à la màchoire supérieure; les canines naissent de l'extrémité antérieure du maxillaire supéricur, et les molaires sont situées en arrière de celles-ci, sul le mème os. Les dents correspondantes de la mâchoire inférieure portent les mèmes noms. Lorsque ces trois sortes de dents existent, la dentition est dite complètc. Assez souvent les canines font défaut (Rongeurs): on donne alors le nom de diastème ou de barres à l'espace qui reste libre entre les incisives et les molaires; le même nom est du reste employé aussi pour désigner l'intervalle qui sépare quelquefois les canines des molaires (Équidés) ou des incisives (Singes). - Les clents une fois formées peurent persister pendant toute la vic : c'est ce qui a lieu presque constamment chez les Édentés, les Cétacés et les sirénidés, qualifiés pour cette raison de Monophyodontes. Les autres Mammifères sont en général Diphyodontes, c'est-à-dire que leurs mâchoires sont le siège d'une double poussée dentaire. Les premières dents formées (dents de lail) tombent, en effet, à un moment donné, et sont remplacées par des dents nouvelles (dents permanentes). Le nombre de celles-ci est en général plus considérable que celui des pièces de la première dentition, car des molaires nouvelles apparaissent en arrière des autres : ce sont les molaires rraies; celles qui remplacent les dents de lait sont distinguées sous le nom de prémolaires. Selon la remarque de Rülimeyer, les dents de lait de beaucoup de Nammifères actuels ont une ressemblance intime avec les dents d'adulte de leurs ancêtres géologiquues.

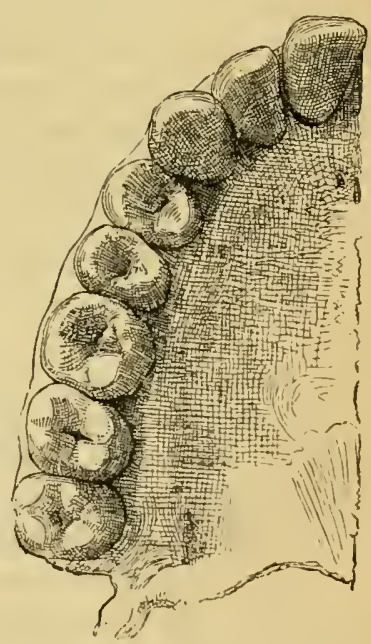

Fig. 79t. - Arcade dentaire superieure de l'Homme, une par la surface triturantc.

Pour exprimer les variations que présente la dentition des Mammifïres, on a recours à des formules dans lesquelles se trouve indiqué, pour chaque mìchoire, le nombre des différentes sortes de dents 
dont il vient d'être question. Les dents étant toujours symétriques, on se borne à inscrire celles d'un cóté. Par contre, le nombre des dents implantées dans chaque mâchoire n'étant pas toujours le même, on signale les supérieures au-dessus et les supérieures au-dessous d'un trait horizontal. On désigne même parfois les dents par leur initiale. Ainsi, la formule dentaire de l'Homme adulte est :

$$
1 \frac{2}{2} \mathrm{C} \frac{1}{1} \mathrm{P} \frac{2}{2} \mathrm{M} \frac{3}{3} \text { ou } \frac{2 \cdot 1 \cdot 2,3}{2 \cdot 1 \cdot 2,3}=32
$$

Celle du Chien domestique adulte :

$$
\mathrm{I} \frac{3}{3} \mathrm{C} \frac{1}{1} \mathrm{P} \frac{3}{4} \mathrm{M} \frac{3}{3} \text { ou } \frac{3 \cdot 1 \cdot 3,3}{3 \cdot 1 \cdot 4,5}=42 .
$$

Lorsque les prémolaires et les molaires ne peuvent être distinguées par leur forme, on les comprend sous un seul chiffre. La dentition de lait se distingue par le signe (') ajouté aux initiales. Dentition de lait de l'Homme :

$$
\mathrm{I}^{\prime} \frac{2}{2} \mathrm{C}^{\prime} \frac{1}{1} \mathrm{P}^{\prime} \frac{2}{2} \text { ou } \frac{2.1 .2}{2.1 .2}=20
$$

Beaucoup d'autres manières de formuler ont été proposées: nous adoptons la plus simple.

La bouche est limitée en avant, sauf chez les Monotrèmes, par des lèvres mobiles qui servent à la préhension des aliments, et sur les côtés par des joues qui se dilatent quelquefois en véritables poches appelées abajoues (Hamster). La langue, fixée par sa base à l'appareil hyọidien, est en général protractile et peut constituer un organe de tact ou de préhension; plus rarement, elle est immobile (Baleine). Les glandes salivaires (parotide, sous-maxillaire, sublinguale), très développées chez les herbivores, sont rudimentaires chez les Pinnipèdes, nulles chez les Cétacés.

La voûte palatine se prolonge en arrière par une cloison mobile musculo-membraneuse, le voile du palais, qui se soulève pour permettre le passage des aliments dans le pharynx. Celui-ci donne entrée dans un œsophage assez long, qui ne présente presque jamais de dilatation en jabot, et débouche dans l'estomac par un orifice appelé cardia. L'estomac est le plus souvent simple; cependant il est divisé en deux compartiments chez quelques Rongeurs, en trois chez certains Primates, et en quatre chez la plupart des Ruminants. Il est séparé de l'intestin par un bourrelet circulaire, la valvule pylorique.

L'intestin grêle est également limité en arrière par un repli valvulaire (valvule iléo-cxcale). Le gros intestin débute à ce niveau par un cæcum, qui toutefois fait défaut chez l'Ours, les Chauves-Souris et la plupart des insectivores. Au delà du cecum, l'intestin prend le nom de 
cólon, et se continue par un rectun à peu près droit, qui aboutit à l'anus. Celui-ci n'est distinct de l'orifice génito-urinaire que chez les Monodelphes, bien que les Monotrèmes seuls aient un véritable cloaque. Le régime exerce une influence considérable sur le développement de l'intestin: les herbivores sont remarquables par la longueur de l'intestin grêle et la capacité des réservoirs crecal et colique. Le contraire s'observe chez les Carnivores.

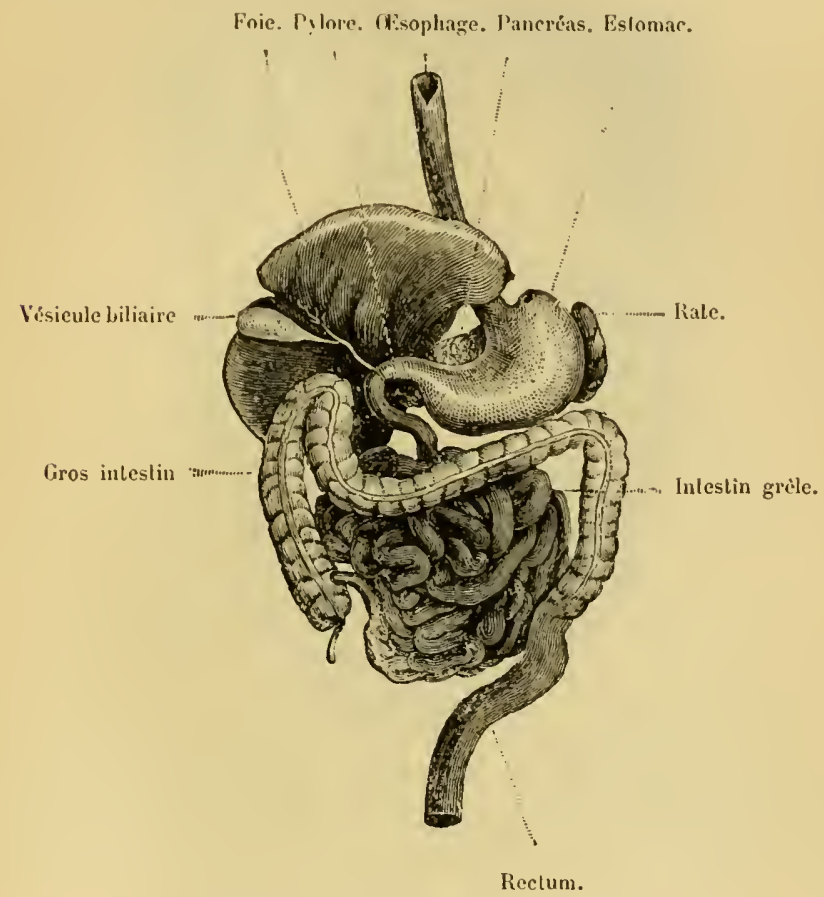

Fıg. 792. - Appareil digestif de l'Homme.

L'intestin reçoit le produit de nombreuses glandes, dont les unes sont contenues dans son épaisseur, tandis que les autres, foie et pancréas, occupent son voisinage et débouchent dans la partie antérieure de l'intestin grêle, ou duodénum. Le foie présente un réservoir (vésicule biliaire) qui manque chez quelques Ongulés (Équidés, Cerfs) et chez les Cétacés.

La circulation est double et complète. Le cœur est divisé, comme chez les Oiseaux, en deux parties ne communiquant pas entre elles et composées chacune d'un ventricule el d'une oreillette. Ces deux moitiés sont presque distinctes chez les Sirénidés, surtout chez le Dugong. Les orifices qui mettent en relation les oreillettes et les ventricules sont munis de valvules : celle du cœur gauche, divisée en deux lèvres, est appelée valvule bicuspide ou mitrale; celle du cœur 
droit, divisée en trois lèvres, recoit le nom de valvule tricuspide ou triglochine. Chaque ventricule offre un orifice artériel pourvu de trois valvules sigmoïdes, à concavité tournée vers le vaisseau. Du ventricule gauche part un tronc aortique simple qui se recourbe à gauche, pour se continuer en une aorte descendante: celle-ci se dirige rers la queue

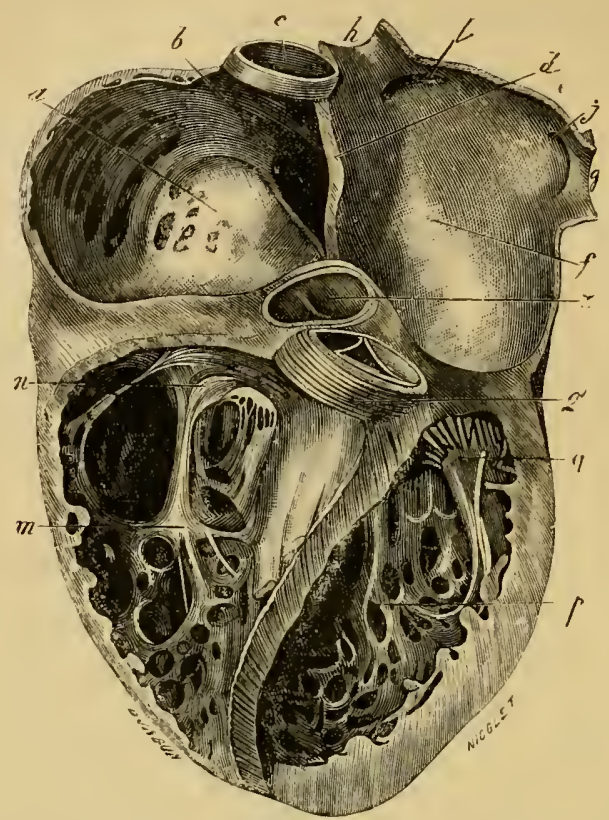

Fig. 79:, - Section longitudinale du cour de l'Homme. $-a$, oreillette droile. $b$, oriliee de la veine cave inférieure. $c$, orifice de la veine care supérieure. $d$, cloison intrr-auriculaire. $f$ : oreillelte gauche. $g, h$, lambeaux des veines pulmonaires (groupe antérienr) $j, l$, orifices des veines pulmonaires (groupe postéricur). $m$, ventricule droit. $n$, valvule tricuspide avee ses trois piliers. $o$, origine de l'artère pulmonaire. $p$, ventricule gauelıe. $q$, valsule mitrale avec ses deux piliers. $r$, origine de l'aorte (J. Béclard).

en distribuant des branches aux différents organes. De la crosse de l'aorte partent en général deux troncs artériels, — quelquefois trois ou un seul, - destinés à la tête et aux membres antérieurs. - Les hémalies ont la forme de disques biconcaves, sauf chez les Camélidés, oit elles sont elliptiques et plates. - Le système lymphatique est bien déreloppé, mais il n'existe pas de cours lymphatiques.

Lappareil respiratoire comprend deux poumons un peu inégaux, suspendus dans la cavité thoracique et recevant l'air par une trachée à peu près droite, presque toujours constituée par des anneaux cartilagineux incomplets. A sa partie antérieure, elle offre une dilatation, le larynx, dont les parois sont formées par des cartilages complexes et donnent attache à des replis musculeux ou cordes vocales, ce qui en fait un appareil phonateur remarquable. L'orifice laryngien ou glotte est surmonté d'une épiglotte mobile. A son extrémité inférieure, la 
trachée est dépourve de l'organe que nous arons signalé sous le nom de syrinx chez les Oiseaux. Elle se divise le plus sourent en deux bronches, qui se subdivisent elles-mèmes par dichotomie en bronches de plus en plus fines, de manière à devenir enfin uniquement musculo-membraneuses. Les dernières divisions se terminent dans des ampoules, les lobules pulmonaires, dont les parois forment un certain nombre de petits culs-de-sac, les vésicules ou alvéoles pulmonaires. Les poumons sont entourés d'une membrane séreuse, liı plivere, el

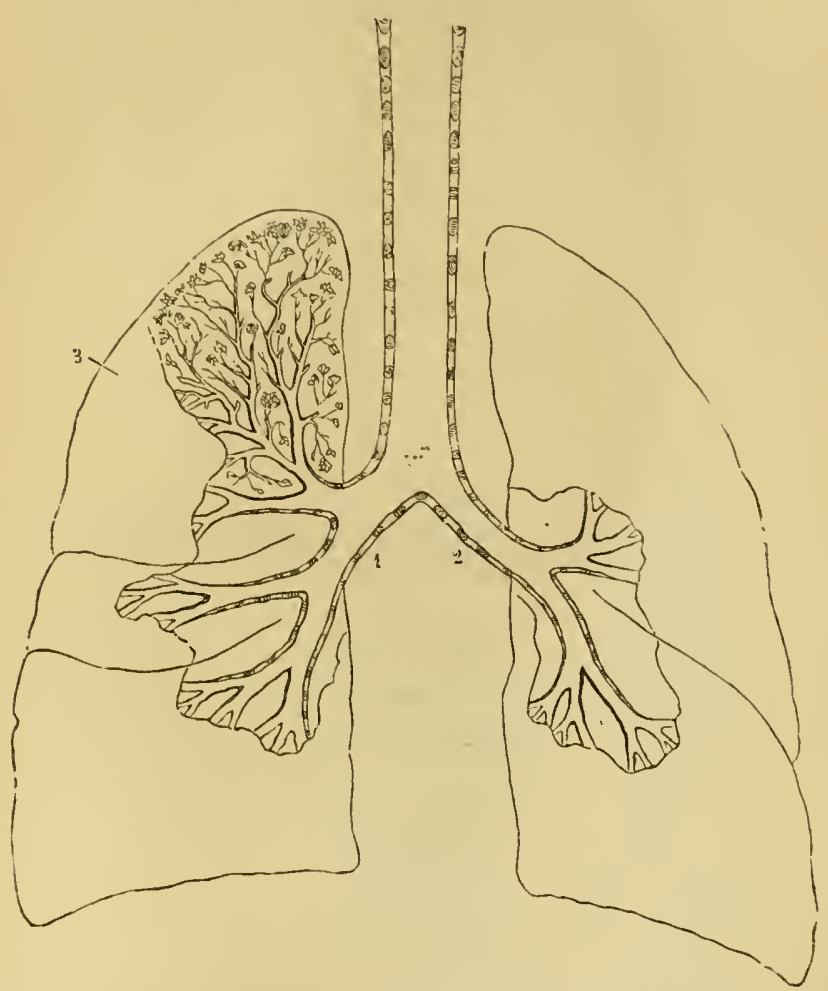

lig. :n4. - Sehíma du pounon de l'llomme et des divisions trachéo-bronchiques. - 1, bronehe droile. 2 , bronche gauclie. 3 , lohe supérieur du poumon droit (Morel et Duval).

séparés des viscères abdominaux par une cloison musculo-aponévrolique, le diapleragme.

La respiration a lieu par les mouvements de ce diaphragme, et par l'élévation ou l'abaissement des côtes, résultant de l'action de divers muscles.

Les reins (métanéphros), disposés de chaque côté de la colonne vertébrale, dans la région lombaire, constituent d'ordinaire des glandes compactes; quelquefois, cependant (Phoques, Dauphins), ils sont formés de lobules séparés. Il existe toujours une vessie urinaire, dont le conduit excréteur, canal de l'urètre, sunit aux roies génitales. 
L'orifice des organes génito-urinaires est, dans tous les cas, situé en avant de l'anus.

Tous les Mammifères mâles possèdent deux testicules, développés

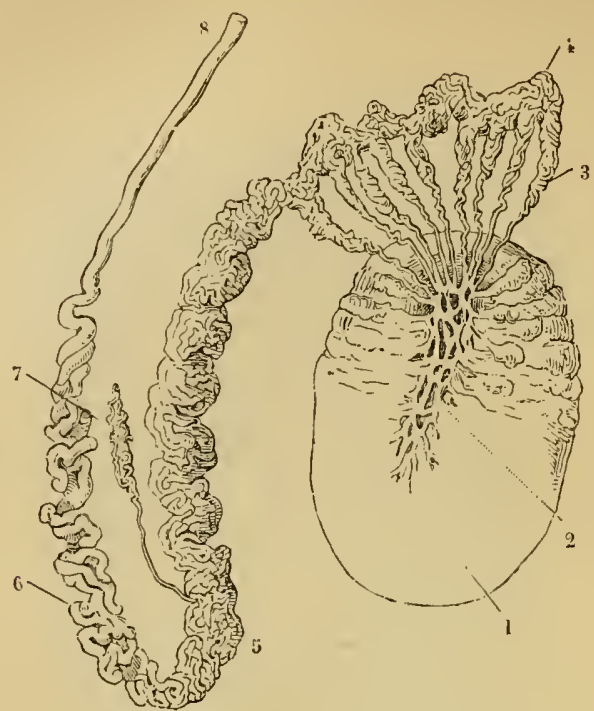

Fig. 793̈. - Schẻma des voles séminales de l'Homme. - 1, testicule. 2, rete testis. 3, cỏne séminifère 4 , tète de l'epididyme. $\tilde{5}$, queue de l'épididyme. 6 , origine du eanal déférent. 7 , vas aberrans. 8 , canal déférent.

au voisinage des reins. Chez les Monotrèmes, les Cétacés et les Sirénidés, ils demeurent en ce point; dans tous les autres groupes, ils se déplacent au moment de la naissance: ils poussent devant eux le pé-

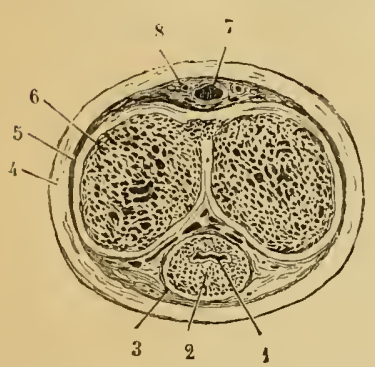

Fig. 796. - Section transversale du pénis (injecté, c'est-ì-dire en érection). - 1. canal de l'urètre. 2, son corps spongieux. 3 , enveloppe de celui-ci. 4, pean dn pénis. 5 , enveloppe fibrense des corps cavernenx. 6 , tissu érectile du corps eaverneux. 7,8 , veine et artères dorsales.

diverses glandes (prostate, glandes de Cowper).

Le pénis se compose de corps érectiles ou corps caverneux, qui sont nal, où ils restent quelquefois (Chameau, divers Rongeurs); mais, le plus souvent, ils traversent ce canal el vont se loger dans un repli cutané appelé scrotum. Dans ce dernier cas, ils rentrent assez fréquemment dans la cavité abdominable (Insectivores, Chaures-Souris) après l'époque du rut. Les canaux déférents, après avoir formé chacun un diverticule glandulaire (vésicule séminale) qui fait souvent défaut (Rongeurs, Cétacés, etc.), prennent le nom de conduits éjaculateurs et débouchent dans le canal de l'urètre. Celui-ci conduit le sperme et l'urine à travers l'organe copulateur ou pénis; il reçoit le produit de ritoine et descendent dans le canal ingui- 
d'ordinaire au nombre de trois: l'un d'eux entoure le canal urétral (portion spongieuse de l'urètre); les deux autres surmontent ce canal et se réunissent sur la ligne médiane. 11 existe quelquefois un axe cartilagineux ou osseux (os pénien). Le corps caverneux de l'urètre offre, à sa partie antérieure, un renflement appelè gland, parfois bifide (Monotrèmes, Marsupiaux), et entouré d'un repli cutané, le prépucé.

Il existe tonjours deux ovaires, sauf chez les Nonotrèmes, dont celui du cóté droit est atrophić. L'appareil vecteur se divise en trois régions distinctes: $1^{\circ}$ la trompe de Fallope, toujours paire, s'ourrant

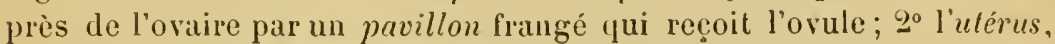
quelquefois double, à deux museaux de tanche (Lapine), d'autres. fois bipartit, à museau de tanche simple (Cobaye); ou bicorne, c'est-à-dire divisé seulement à sa partie supérieure (Ongulés, Carnivores), ou mème simple (Primates); $3^{\circ}$ le vagin, pair chez les Marsupiaux, impair chez tous les autres. Le vagin débouche en arrière de l'orifice urétral, dans un court vestibule génito-urinaire dont l'entrée

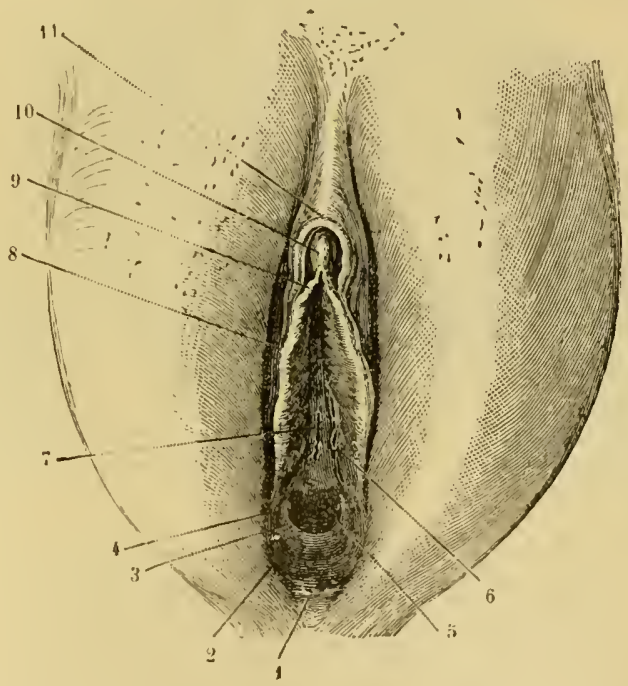

Fig. 797 . - Vulve de la Femme (les grandes lèrres son lalérale. 3, lıymen. 4, orifice de la glande vulso-vaginale. 5, orifice du vagin. 6, orifices glandulaires. (glaudes múpeuses). 7, méat urinaire. 8, petite lère droite. 9, frein du clitoris. 10, ciitoris. 11, prèfuce du cliloris.

forme la vulve. Chez les Ifonotrèmes, il ny a pas de vagin à proprement parler, mais un court canal génito-urinaire aboutissant au cloaque.

La rulve est limitée sur les còtés par deux replis cutanés, les grandes lèvres, en dedans desquelles s'en voient sourent deux autres, les nymphes ou petites levres. 11 existe aussi un organe érectile, le cli- 
toris, qui est l'homologue du pénis du màle, et peut renfermer comme lui une pièce osseuse, dite os clitoridien (Loutre). Ce clitoris est quelquefois traversé par l'urètre (Rongeurs, Taupes, Lémuriens): dans ce cas, il n'existe pas de vestibule génito-urinaire.

La présence de glandes lactaires ou mamelles est constante chez les Hammifères et particulière à ces animaux, puisqu'elle fournit le principal élément de leur caractéristique. En général, ces glandes - qui appartiennent au groupe des glandes cutanées - n'acquièrent leur complet développement que chez les femelles et ne sécrètent du lait qu'après la naissance du petit. Le lait contient toutes les substances nécessaires à la nutrition, et sert en effet de nourriture exclusive au nouveau-né jusqu'à ce qu'il ait acquis l'aptitude à prendre d'autres

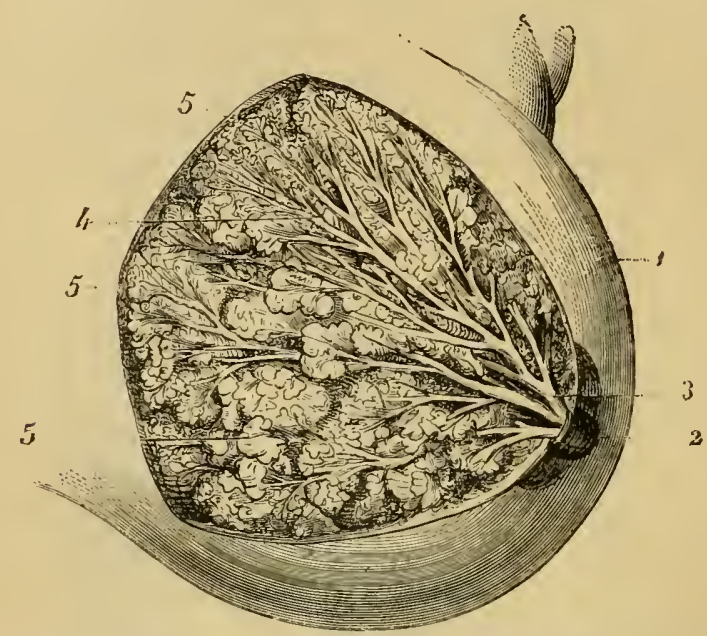

Fig. 793. - Mamelle de la Femme. - 1, peau de la mimelle. 2, mamelon. 3, cauaus galactophores. $i$, caualicules procédant des lobules et se termiuant dans les canau galactophores. 5 , lobules de la glande.

aliments. Chaque mamelle se termine par un mamelon ou tetin, excepté chez les Ionotrèmes. La situation des mamelles est variable : elles sont toujours paires et symétriques, et tantot pectorales (Primates), lantôt abdominales (Carnivores), tantôt inguinales (Jumentés, Ruminants); parfois mème elles occupent à la fois ces diverses positions. Le nombre des tetins est d'ordinaire en rapport avec celui des petits de chaque portée.

L'activité reproductrice (rut) se manifeste d'une façon périodique assez régulière clıez les animaux sauvages. Le plus souvent, le rut a lieu au printemps; dans quelques cas, c'est à la fin de l'été (Ruminants), ou même en hiver (Carnivores, Sanglier). Il se renouvelle deux fois par an chez le Chat sauvage et la Belette, et tous les mois chez la Girafe, les Singes catarhiniens et la Femme. La domesticité le rend plus fréquent. La chute des ovules s'accompagne d'une congestion de 
l'appareil génital, dout les symptòmes les plus saillants sont: la turgescence des organes extérieurs, une abondante sécrétion de mucosités, parfois mème un écoulement plus ou moins abondant de sérosité sanguinolente ou de sang pur. L'excitation vénérienne se moutre ver's la lin de la lluxion, ou même lorsqua elle a cessé.

A ces phénomènes extérieurs correspond une congestion plus ou moins intense de la muqueuse utérine, qui s'hypertrophie el montre une dilatation considérable de ses vaisseaux: souvent mème les parois vaseulaires cèdent et litissent le sang s'épancher, soit dans le derme de la muqueuse, soil dans la cavité utérine. - Mais la marche ultérieure de ce processus, qui est corrélatif à l'ovulation, varie suivant le sort r'éservé à l'ovule détaché. Si celui-ci n’est pas fécondé, l'érolution de la muqueuse s'arrète et on constate bientìt le retour à l'état de repos primitif. Si, au contraire, la fécondation a eu lieu, ce qui entraine l'arrêt de l'ovule dans l'utérus, la dilatation des vaisseaux et l'hypertrophie de la muqueuse se continuent et saecusent, et il so forme bientôt des sinus sanguins destinés it porter à l'embryon ses principes nutritifs.

L'ovule des Mammifères, toujours très petit, a sa membrane vitelline souvent doublée ì l'extérieur d'une enveloppe plus épaisse, la zone pellucide, véritable chorion produit par les cellules du follicule

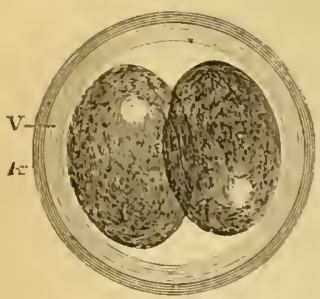

Fig. 799 .

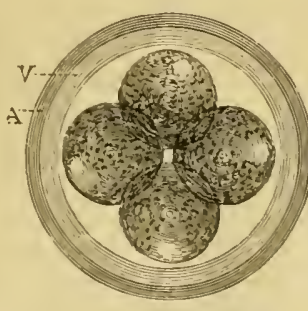

Fig. 800.

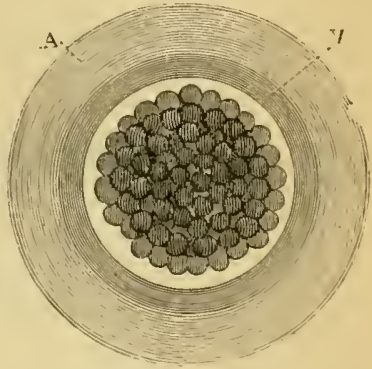

Fig. s01.

rig. 799 i su1. - Segmentation de l'ceuf diun Mammifère (un peu trop régulière). $-\Lambda$, eneloppe mupuse ou zone pellucide. $V$, membrane vilelline.

de de Graal. Il subit, sauf che\% les Monotrèmes, une segmentation totale et inégale, après quoi son enveloppe extérieure ou chorion se revêt d'une foule de villosités qui servent à le fixer en même temps cqu'ì lui fournir les élémen ls de sa nutrition. Le chorion est formé d'abord par la membrane vilelline et sa zone pellucide (charion primaire); mais sur. cette membrane, appelée à disparaitre, s'applique bientôt la portion extra-embryonnaire du feuillel blastodermique externe (feuillet épiblastique) non intéressée dans la formation de l'amnios. Plus tard, ce chorion secondaire est renforcé encore par la portion périphériqur de l'allantoïde, qui pénètre avec ses vaisseaux dans les villosités.

Celles-ci plongent, soit dans des culs-de-sac glandulaires, soit dans 
des cryptes de la muqueuse hypertrophiée; et ainsi se constitue le placenta, appareil d'échange entre la mère et le foetus, mais d'origine

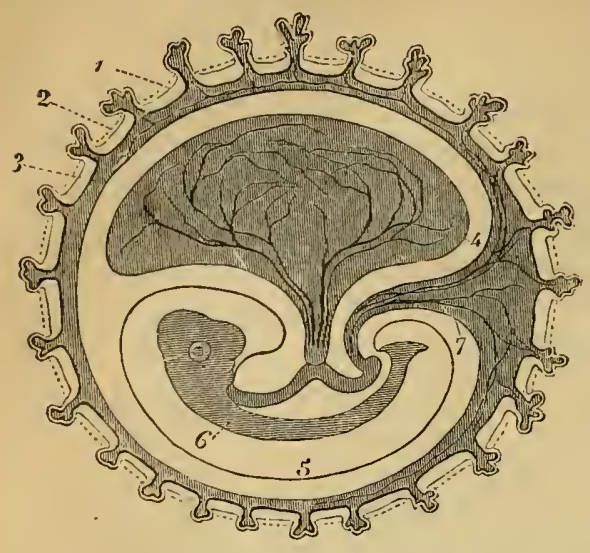

Vig. su2. - OEuf de Mammifire. - 1, membrane vitelline ou premicr chorion presque disparu. 2, feuillet externe du blastoderme, second clıorion. 3, allantoüle, ¡jui a pénètré dans les villosités. 4, vésicule ombilicale. $\because$, les capuclions céphaliq̣ue et caudal se sont fusionnés : la cavité de l'amnios est formée. 6 , embryon. 7 , allantoïde.

vasculaires sont disséminées sur toute

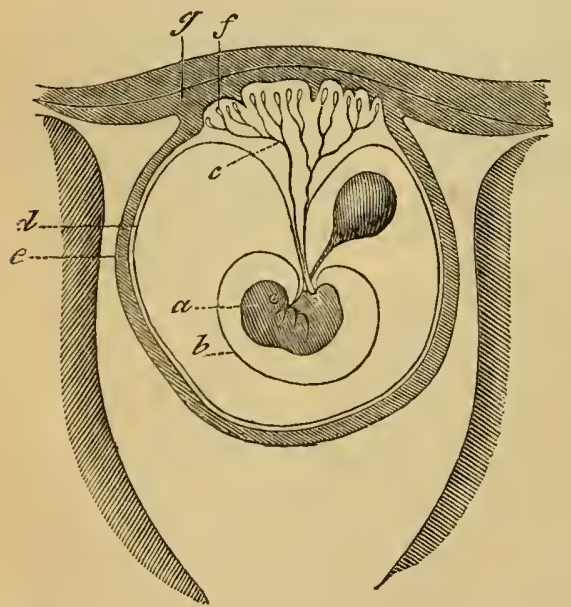

Fig. 803. - Formalion du jlacenta, d'après Cadiat. - $a$, embryon, $b$, amnios. $c$, vaisseaux du placenla. $d$, allantoïde. $e$, membrane caduque. $f$, villosités placentaires. $g$, caduque sérotiue, se coulinuant a vec la caduque vraie ou directe. centa est cotylédonaire (la plupart des Ruminants). De même, le placenta unique offre deux formes : tantôt il représente une zone essentiellement fotale. En même temps, les vaisseaux de l'allantoüde s'entourent d'une gaine formée par l'amnios, et constiluent ainsi ce qu'on appelle le cordon ombilical.

Le placenta fait défautchez les Monotrèmes et les Marsupiaux, qu'on qualifie pour cela d'implacentaires, par opposition aux autres Mammifères, qui sont tous placentaires. Chez ceux-ci, d'ailleurs, le placenta offre, dans sa forme et dans sa disposilion, des variations importantes. Et d'abord, on peut remarquer que, dans certains cas, les villosités ou touffes l'étendue du chorion: le placenta est dil alors multiple; d'autres fois, au contraire, elles sont localisées sur un espace plus ou moins restreint, et constituent en somme un placenta unique. Or, dans les placentas multiples, ces villosités peuvent être disposées de deux manières différentes : ou bien elles sont réparties à peu près uniformément à la surface du chorion, et le placenta est diffus (Jumentés, Porcins, Camélidés, Tragulidés, Cétacés, etc.); ou bien elles se groupent pour former des corps vasculaires qui se mettent en rapport avec des productions anamatrice (cotylédons), et le plalogues de la face interne de la 
annulaire occupant la partie moyenne du chorion, et on le dit zonaire

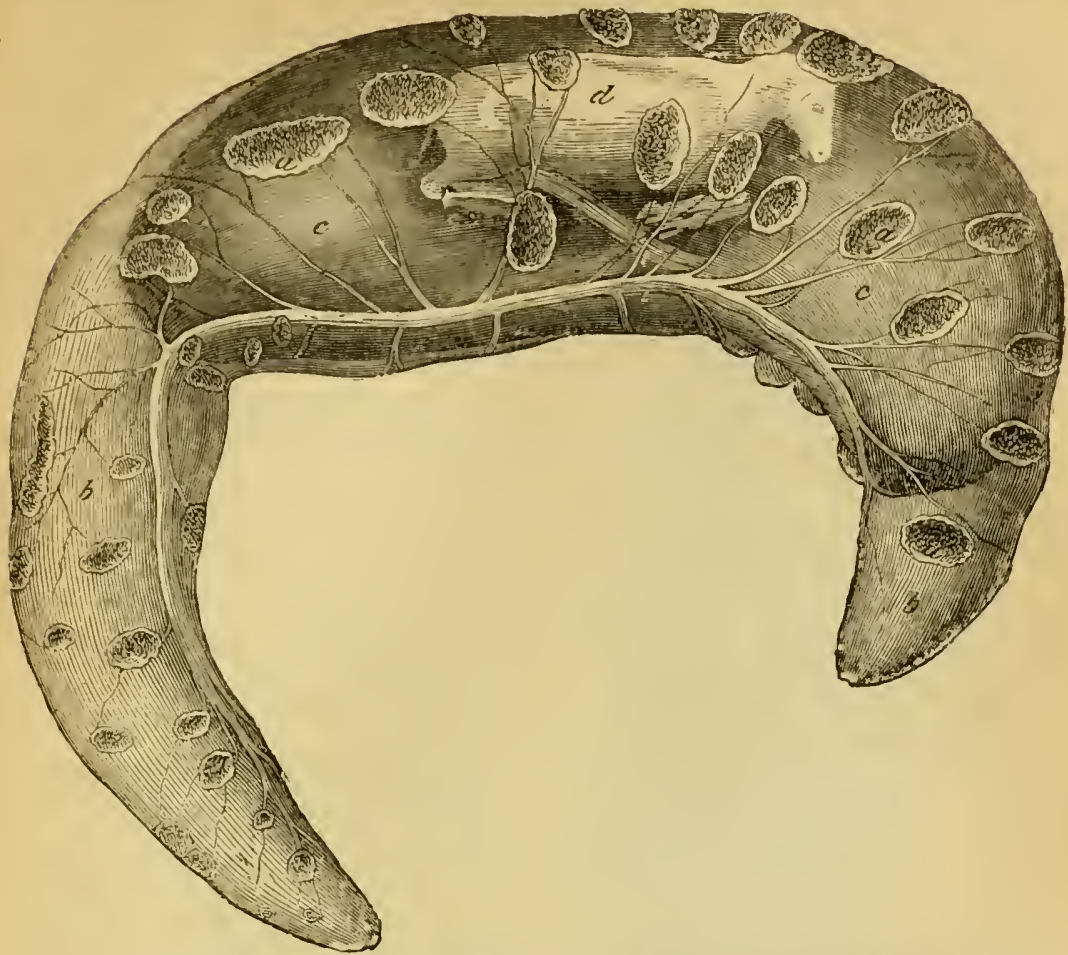

Fig. 804. - Foulus de Vache dans ses enseloppes. - $a, a$, placenta cotylédonaire. $b, b$, chorisn, auquel adhère inlérieurement l'allantoïde, $c, c$, ammios vu par transparence. $d$, foutus vu par lransparence.

(Carnivores, Pinnipèdes); tantôt il est concentré sur un espace circu

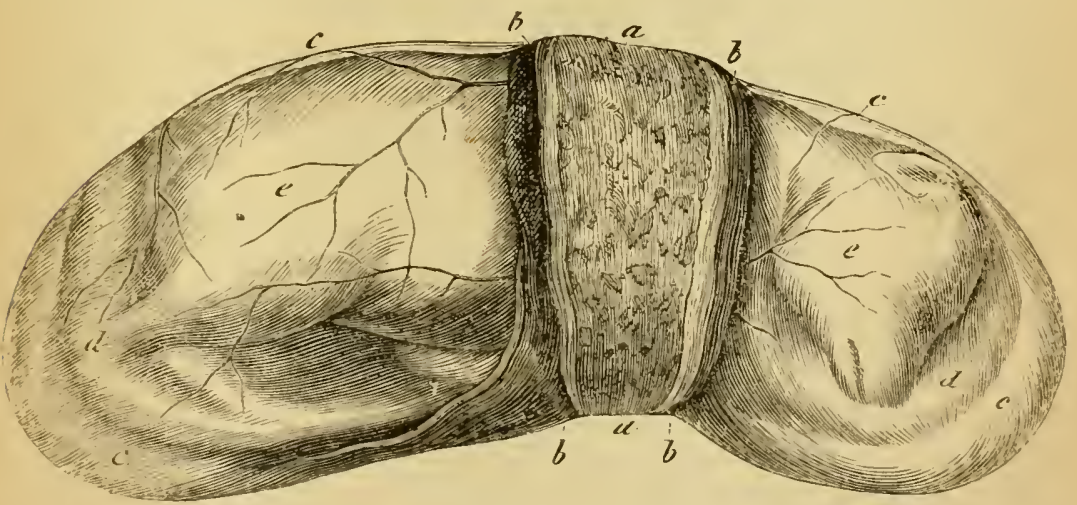

rig. soj. - Forlus de Chienne avec ses euveloppes, - $a, b$, placenta zonaire. $c$, chorion. $d$, annios vu par transparence. $e$, foetus vu à trasers les enveloppes.

laire, et on le qualifie de discoïde (Primates, Rongeur's, Insectivores). RaIlliet. - Zoologie. 
Un grand nombre de zoologistes, ì l'exemple de Huxley, ont pris le placenta pour base principale de la classification des Mammifères, en groupant les animaux à placenta multiple sous le nom d'Adécidués et les animaux à placenta unique sous celui de Décidués. Ils considèrent que, chez les premiers, les villosités choriales ne sont que faiblement unies à l'utérus, et s'en détachent au moment du part sans en entrainer aucune partie; tandis que, chez les autres, elles sont si intimement unies à la muqueuse utérine, qu'une partie de celle-ci (decidua, membrane caduque) est

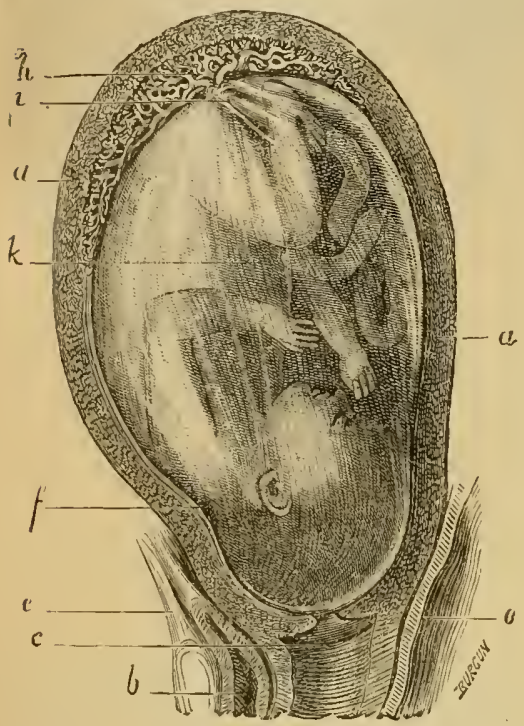

Fig. 806. - Fóntus daus l'ulérus de la Femme. $a$, paroi de l'utérus. $b$, vessie; on voit en avant la symphyse pubienne. $c$, partie supérieure du vagin; au-dessus, le col de l'ulérus. $d$, un fragment su rectum. $e$, coupe de la paroi antérieure de l'abdomen. $f$, membrane cadique et chorion, la première appliqucéc contre la paroi utérine, le second sur l'amnios. $h$, placenta discoüde. $i$, point où le cordon onbitical s'insère sur le placenta. $k$, le fœlus enveloppé dans l'amuios el baigné daus le liquide amuiotique (J. Béclard). toujours éliminée avec le produit.

On sait depuis longtemps, en effet, que chez la Femme, ainsi que chez les femelles des Rongeurs, des Carnivores, etc., le fœtus est entouré d'une membrane adventive ou caduque, qui lui est fournie par la muqueuse utérine. Le développement de cette production est dû simplement à l'hypertrophie de cette muqueuse, qui s'est accentuée, comme on l'a vir, après l'arrêt dans l'utérus de l'ovule fécondé : la portion de la membrane qui s'est repliée autour de l'œuf pour l'envelopper est la caduque réfléchie ; la zonę sur laquelle repose l'œuf constitue la caduque sérotine; enfin, le reste de la muqueuse formé la caduque vraie. - Mais s'il est vrai que les rapports entre l'embryon et la muqueuse utérine sont en général plus intimes chez les Mammifères à placenta unique que chez les autres, il n'y a pas à cet égard de différences bien tranchées (Ercolani), et en dépit de variations étendues et multiples, le placenta des Mammifères peut, au fond, se ramener à un type anatomique unique. - La nutrition du foetus s'entretient par les échanges osmotiques qui s'établissent entre ses vaisseaux et les lacunes sangui-maternelles. - En somme, on voit qu'il n'y a pas lieu de conserver la division des Mammifères en Décidués et Adécidués, et Huxley lui-même n’a pas hésité à l'abandonner.

$\Lambda$ l'exception des Monotrèmes, tous les Mammifères sont vivipares. La durée de la gestation, c'est-à-dire de la période qui s'étend depuis 
la fécondation de l'ceuf jusqu'ì l'expulsion du produit formé, est généralement en rapport avec la taille de lanimal; mais elle dépend aussi du degrré de développement que doivent atteindre les jeunes avant la naissance. Ainsi, chez les Marsupiaux, les petits sont mis au monde de bonne heure, mais dans un tel état d'imperfection, qu'ils ne tarderaient pas à périr, šils n’étaient placés aussitôt dans une poche spéciale (pocke marsupiale), dans la(quelle, suspendus aux tetins des manelles, ils poursuivent leur développement.

Les mœurs des Mammifères sont très variées. Les uns vivent isolés, sauf à l'époque du rut; les autres se réunissent en troupes. Il en est un petit nombre qui entreprennent des migrations, toujours moins lointaines, eependant, que celles des Oiseaux : tels sont les Rennes, les Bisons d'Améri(pue, les Phoques, et surtoul les Lemming's. Enfin, quelques-uns sont hibernants, c'est-it-dire passent l'hiver dans une sorte d'engrourdissement (sommeil hibernal) continu (Loirs, Hérissons) ou interrompu (Ours, Chauves-Souris). Ils ne prennent alors aucune nourriture, et vivent aus dépens de la graisse qu'ils ont accumulée pendant la bonne saison. Aussi leur température propre s'abaissel-elle d'une façon considérable.

Les premiers débris fossiles des Mammifères apparaissent dans le trias; mais on rencontre surtout ces animaux en abondance dans les terrains tertiaires et quaternaires.

Les formes actuelles se laissent grouper en 16 ordres:

()ipares Ornithodelphes

MOXOTHĖMES

Pas de placenta (Implacentaires). Double vagin (Didelphes... M.rasupiaux.

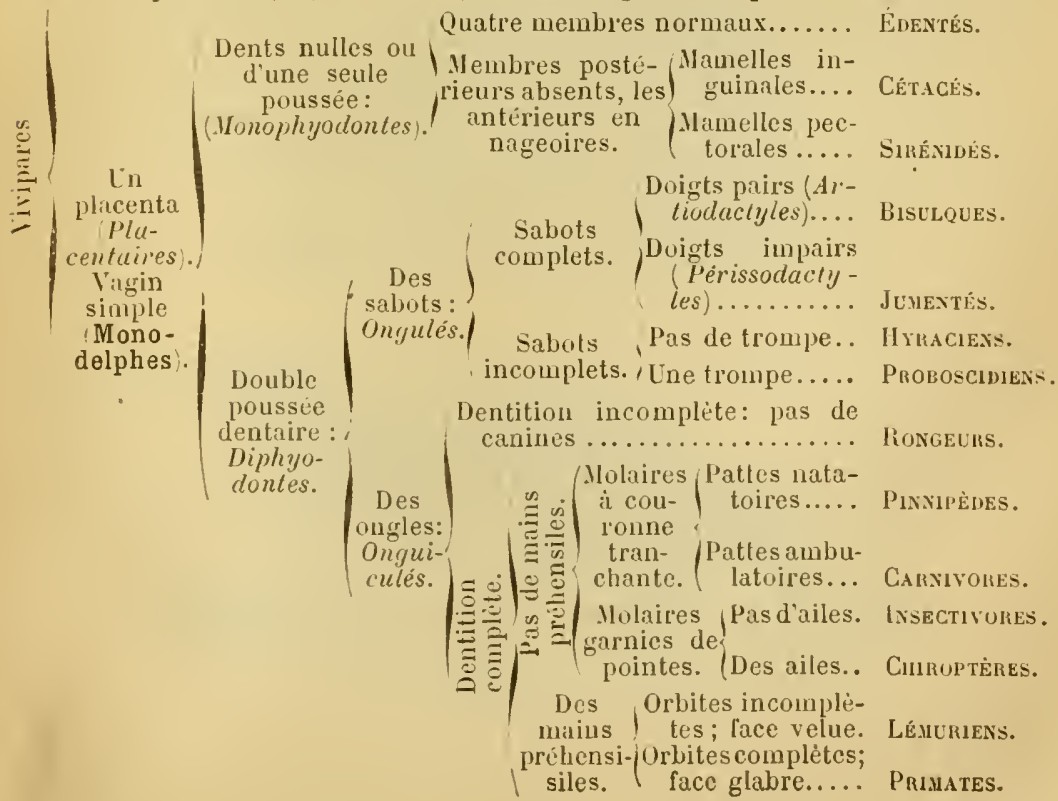




\section{PREMIER ORDRE}

\section{MONOTREMES}

Mammières ovipares, pourvus d'un bec corné et d'un cloaque; deux os sus-pubiens; deu.c os coracoïdes distincts.

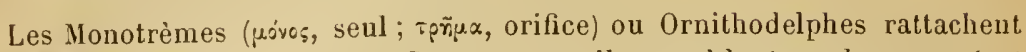
les Mammifères aux Oiseaux. Comme eux, ils possèdent un bec corné et un cloaque dans lequel s'ouvrent l'intestin et l'appareil gémito-urinaire.

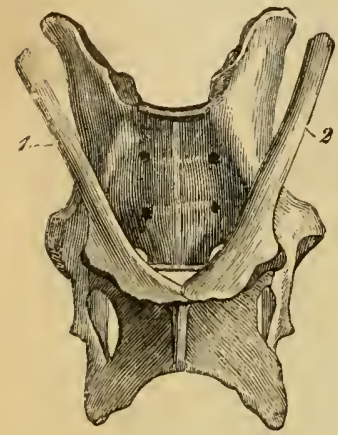

Fig. S07. - Bassin d'Ėchidné, 1,2 , les os sus-pubieus ou marsupiaus.

La ceinture scapulaire est pourvue d'os coracoïdes. Le bassin porte deux os sus-pubiens ou os marsupiaux. Le cerveau est lisse, à corps calleux rudimentaire.

Les màles ont les testicules renfermés dans l'abdomen; ils portent, au niveau de chaque tarse, un puissant ergot creusé d'un canal qui débouche près de la pointe, et qui recoit à sa base le canal excréteur d'une glande. - L'ovaire droit est presque toujours atrophié; celui du còté gauche est racémeux. Les mamelles sont abdominales; elles sont formées par des culs-de-sac glandulaires qui débouchent cóte à côte, au lieu de se réunir pour constituer des tetins saillants. Elles déversent leur lait sur un repli cutané (Ornithorynque) ou dans le fond d'une poche abdominale transitoire (Échidné d'Australie). Les œufs sont pourvus, comme ceux des Oiseaux et des Reptiles, d'une masse vitelline considérable, entourée d'une coque blanche et flexible. L'Ornithoryncue pond deux œufs dans le sable, où il paraîtles couver;l'Échidné australien en pond un seul, qu'il introduit aussitòt dans sa poche abdominale, où s'effectue l'éclosion. La segmentation est méroblastique. Au moment de la naissance, le jeune Monotrème n'a encore atteint qu'un développement très imparfait.

2 genres, représentant deux familles distinctes.

On ne connaît qu'une seule espèce d'Ornithorynque (Ornithorhynchus),

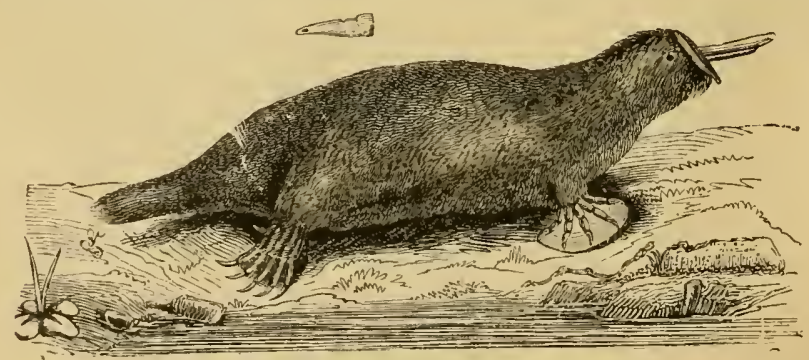

Fig. 808. - Ornithorı̨que paradoxal.

c'est l'ornithorynque paradoxal (0. paradoxus), singulier animal à corps velu, à queue aplatie, à pieds palmés et armés de griffes, à tète prolongée 
par un bec de Canard dont les mandibules portent de chaque cóté, dans Ie jeune àge, deux ou trois molaires déprimées qui sont bientòt remplacées par les mamelons cornés aplatis. - Ce Monotrème vit dans l'Australic orientale et la Tasmanie; il se creuse un terrier au bord des ruisseaux.

Le mâle possècle une forte slande situće ì la face externe du fémur, sous le peaucier; de cette grlande part un long canal excréteur qui se renfle en ampoule it la base de l'ergot tarsien, el s'atténue ensuite pour pénétrer dans la cavité centrale de celui-ci. De Blainville regardait cette glande et ses annexes comme un appareil renimeux; il appuyait cette manière de roir sur l'observation d'un individu qui avait reçu dans le bras un coup d'éperon : le membre avait enflé rapidement, et le blessé avait présenté un ensemble de symptômes analogues ì ceux qu'offrent les personnes mordues par des Serpents venimeux; il n'avait recouvré l'usage de son bras qu'après plus d'un mois. Les auteurs modernes ont contesté la nature venimeuse de eet appareil, el Verreaux a supposé qu'il était destiné à jouer un röle excitateur dans la copulation. Cependant, Martin el Fidswell ont constaté que la glande, qui est en période active de sécrétion au mois d'avril, fournit un produit légèrement venimeux : comparé au venin de certains Serpents australiens, il s’est montré วั000 fois plus faible.

Les Ėchidnés (Tuchygtossus Illiger, 1811; Echidna Cuvier, 1797, nec Forst., 17i8), ont un bec mince, dépourvu de dents, mais renfermant une langue vermiforme qui leur sert à prendre des Fourmis. L'éperon des màles

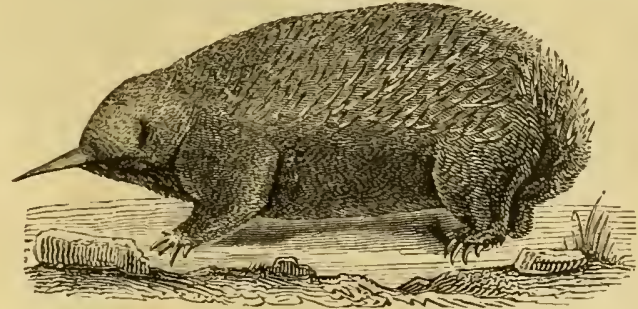

Fig. 809. - Lichidné sojeu (T. setosus).

est relativement faible. - L'Échidné Porc-épic (T. aculeatus Shaw, E. hystrix Cuv.) a le corps couvert de piquants et peut se rouler en boule comme le Hérisson; il habite les montagnes du sud de l'Australie. L'Échidné à soies (T. setosus), qui vit dans la Tasmanie, n'est qu'une variété locale du précédent. La Nouvelle-fuinée renferme trois autres espèces.

DEUXIÈME ORDRE

\section{MARSUPIAUX}

Mammifères pourvus d'une poche marsupiale, de deux utérus et de deux vagins; pas d'os coracoïdes distincts; système dentaire très variable. 
Le caractère le plus saillant des Marsupiaux est fourni par la présence d'une poche ventrale cutanée (marsupium, poche) qui enveloppe les mamelles. Cette poche, soutenue par deux os sus-pubiens ou os marsupiaux, est propre aux femelles, bien que les os existent dans les deux sexes: elle est destinée à recevoir les petits après leur naissance. Ces petits naissent prématurément, comme ceux des Monotrèmes : ils sont aveugles, nus, et, chez un animal de la taille de l'Homme, comme le Kangourou géant, ils mesurent à peine 2 centimètres. La mère les reçoil avec sa bouche et les place dans la poche en les fixant sur les longs tetins que renferme celle-ci. Ils y achèvent leur développement; et, lors mème qu'ils sont devenus assez forts pour vivre elt liberté, ils conservent encore un certain temps l'habitude de s'y réfugier.

Le cerveau est très petit, à hémisphères réduits, presque sans circonvolutions, à corps calleux rudimentaire. L'angle postérieur et inférieur de la

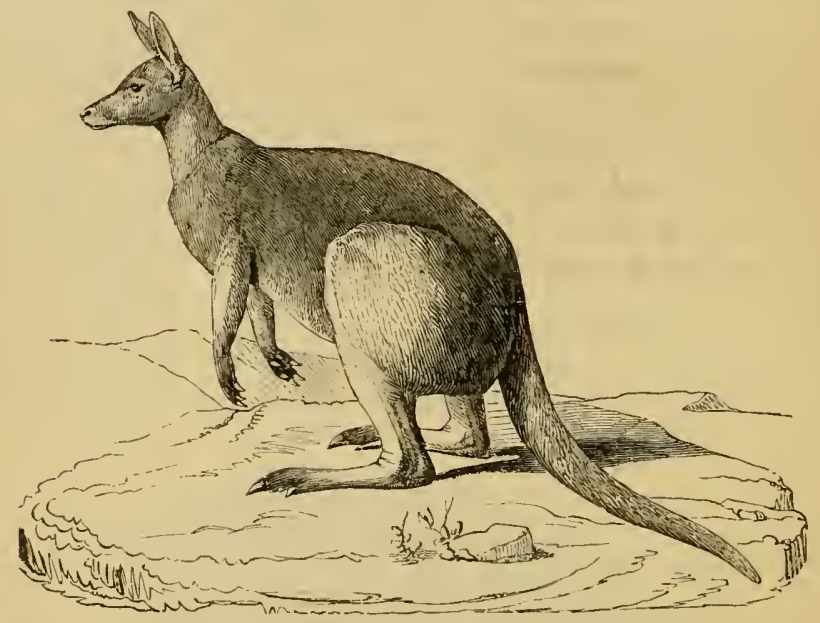

Fig. 810. - Kanguroo laineux (Maeropus lanatus).

mâchoire inférieure est toujours recourbé en dedans. La dentition, dont les caractères varient beaucoup, est souvent complète; mais elle se montre permanente, exception faite d'une seule molaire.

Les femelles possèdent deux utérus et deux vagins séparés; toutefois, ces derniers se confondent dans leur partie antérieure pour former une cavité niédiane dans laquelle débouchent les deux utérus. En arrière, les vagins aboutissent à un canal unique, canal urétro-sexuel. Pour répondre à cette disposition, la verge du mâle est, en général, terminée par un gland bifide.

Il existe, au moins dans quelques cas, un placenta vitellin, mais celui-ci reste toujours rudimentaire.

Les Marsupiaux sont, pour la plupart, des animaux terrestres, nocturnes, dont le régime est très variable. Ils habitent l'Australie, les îles océaniennes, et quelques-uns même se trouvent en Amérique.

Les animaux réunis dans cet ordre présentent, dans leur régime, leur système dentaire, leur appareil digestif, des différences considérables qui en font tantòt des Carnassiers, tantôt des Rongeurs, etc. Aussi pourraient- 
ils former, selon la remarıue de Cuvier, un groupe parallèle a celui représenté par tons les autres Mammifères réunis.

2 sous-ordres.

$1^{\text {or }}$ sous-ordre: Polyprotodontes. - Animaux carnivores ou insectivores, le taille petite ou médiocre; grimpeurs, sauteurs ou coureurs. -- Myrmécobies (Myrmecobius), Péramèles (Perumetes), Dasyures (Dusyurus). - Ici se placent les genres américaius ou Sarigues, qui onl le pouce des pieds postérieurs opposable, ce qui leur a valu le nom de Pédimanes. L'Opossun (Didelphys virginiana) est redouté daus l'Amérique du Nord, oil il dévaste souvent les poulaillers. - A. Dugès, mordu au pouce par un male de Sarigue (D. ralifornica), eut un phlegmon douloureux, avec lymphangite légère et engorŁement d'un ganglion axillaire; il se demanda si les accidents neétaient pas dus à une propriété toxique de la salive. Mais il est plus vraisemblable d'admettre que les dents du petit carnivore étaient imprégnées de produits septiques.

$2^{\circ}$ sous-ordre : Diprotodontes. - Animaux herbivores, à canines faibles ou nulles. - Kangourous-Rats (Hypsiprymmus), sauteurs de petite taille. Phalangers (Phalangista) el Pétauristes (Petaurus), grimpeurs, les derniers à parachute. Kangourous (Macropus), sauteurs, rappelant les Ruminants. Phascolomes (Phuscolomys), fouisseurs, semblables à des Rongeurs.

\section{TROISIEIIE ORDRE}

\section{ÉDENTÉS}

Mammifères à dentition incomplète (parfois nulle), composée de dents sans racines ni émail. Doigts libres, munis de sabots qui prennent la forme de griffes; placenta diffus ou discoïde.

Le nom d'Édentés, créé par Cuvier, est littéralement applicable à certains animaux de cel ordre, tels que les Fourmiliers; mais la plupart possèdent des dents. Les incisives manquent toujours, sauf chez le Tatou à six bandes;

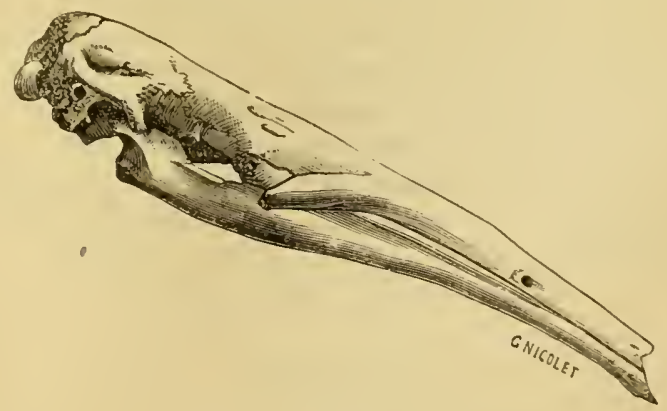

Fig. 811. - Têle de Fourmilier.

les canines elles-mêmes n'existent que rarement (Unau). Les molaires sont quelquefois en nombre considérable. Toutes ces dents sont dépourvues de 
racines; elles sont constituées par de la dentine revètue d'une couche de cément, et ne montrent aucune trace d'émail.

Les griffes, souvent très développées, falciformes, propres à fouir, sont en réalité des sabots, entourant la dernière phalange, ce qui éloigne les Édentés

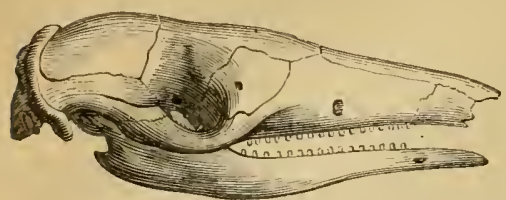

Fig. 812. - Tête du Tatou géant (Dasypus gigas Cur.). des 0 nguiculés. Le cerveau est petit, lisse; les facultés intellecluelles sont très bornées. Les mouvements sont toujours lents. Le placenta est diffus chez les uns, discoïde ou zonaire chez les autres.

Les Ėdentés sont surtout répandus dans l'Amérique du Sud. Cependant, les Oryctéropes sont africains, et les

Pangolins vivent en Afrique et en Asie. On en a retrouvé des formes gigantesques dans le diluvium sud-américain (Megatherium, Mylodon, etc.).

3 sections ou familles:

Les Vermilingues sont des animaux à langue vermiforme, enduite de salive gluante et servant d'organe de préhension. Cette langue, introduite dans les nids des Fourmis et des Termites, se charge d'Insectes, qui sont aussitòt ingérés. - Fourmiliers proprement dits, comprenant les Tamanoirs

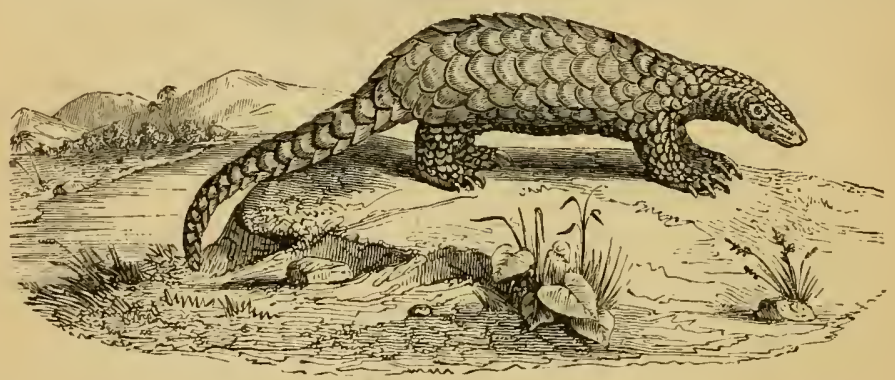

Fig. 813. - Pangolin.

(Myrmecophaga) et les Pangolins (Manis). Ces derniers ont le corps recouvert de larges écailles cornées. Oryctéropes (Orycteropus).

Les Dasrpodes ou Tatous ont le corps revètu de lames osseuses recouvertes d'un épiderme corné et formant une cuirasse sur le dos et la queue. Insectivores. - Genres Dasypus, Prionodon, etc.

Les Tardigrades sont plus connus sous le nom de Paresseux. Aspect général des Singes. Arboricoles: se nourrissent de feuilles. Estomac composé de trois parties, comme celui des Pécaris. - Aï (Bradypus tridactylus). Unau (Cholæpus didactylus).

\section{QUATRIĖME ORDRE}

\section{CÉTACÉS}

Mammifères pisciformes, à membres antérieurs transformés en nageoires; pas de mernbres postérieurs; nageoire caudale horizontale; tête se confondant avec le tronc; mamelles post-abdominales; placenta diffus. 
Par leur conformation extérieure et leur genre de vie, les Cétacés $\left\langle x_{i}=0\right.$, baleine) rappellent les Poissons. La tête, souvent énorme, n'est pas séparie du corps, lequel se termine en arrière par une nageoire horizontale formér de fibres cornées. On sait que, chez les Poissons, la nageoire caudale est toujours verticale. Les membres antérieurs, dont les doigts comprennent

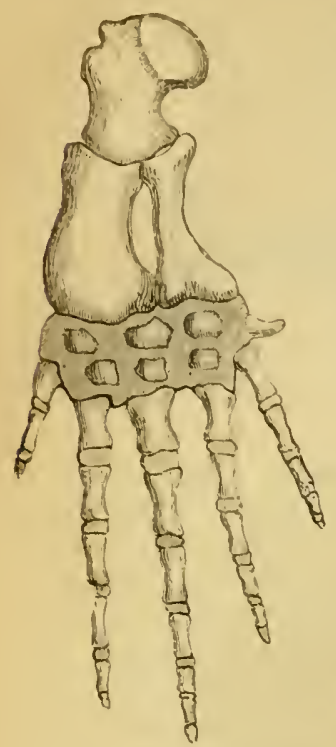

Fig. 81i. - Meubre antíricur de la Baleine franche. parfois jusqu’a 1't phalanges, sont disposés en nilgeoires; les postérieurs manquent, bien quon puisse découvir chez quelques Baleines, perdus dans les muscles, des rudiments du bassiu, du fénur et dı tibia. Ia pean est nue; cependant, on trouve quelquefois des restiges de poils à la lère supérienre, surtout chez le fotus.

Le cerreau, quoique petit, offre des circonvolutions nombreuses. Les yeux sont petits, latéraux el situés fort en arrière. L'oreille externe fait défaut. Les fosses nasales ne servent pas à l'odorat, mais seulement à la respiration; les narines, connues sous le nom d'erents, s'ourrent sur le front et se l'éunissent parfois en une seule ouverture. Le larynx

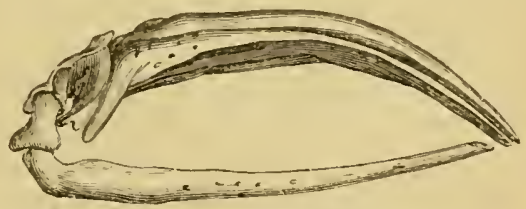

Fig. 815. - Tète de la Baleine franche (Baliena mysticetus Cur.).

fait saillie dans l'orifice inférieur des fosses nasales, qu'il obture en entier, de telle sorte que la respiration peut s'effectuer pendant que l'animal déglutit. Pour respirer, celui-ci amène le sommet de la tète à fleur d'eau, et pendant quelques instants l'inspiration et l'expiration se font à grand bruit, d'où le nom de Souffeurs donné aux représentants du groupe qui nous occupe. Chez les grandes espèces, l'expiration produit un jet de vapeur d'eau qui se condense par l'effet dı refroilissement, ce qui a donné lieu à cette opinion, encore très répandue, que les Baleines rejettent par les narines l'eau qu'elles ont avalée. - Les dents sont souvent absentes à l'àrre adulte; quand elles existent, elles sont toujours simples, à une seule racine.

Les mamelles sont situées sur les còtés de la vulve, dans des plis profonds de la peau. Le placenta est diffus.

Les Cétacés sont carnivores: ils se nourrissent de Poissons, de Mollusques, de Crustacés ou de Méduses, qu'ils avalent en quantité extraordinaire. La plupart sont marins, quelques-uns fluviatiles.

2 sous-ordres.

$1^{\text {cr }}$ sous-ordre : Denticètes. - Animaux pourvus de dents à làge adulte. Pas de fanons.

Genres Dauphin (Delphinus), Marsouin (Phocxnu), Narval (Monodon), Cachalot (Physeter), etc. Le Narval (Monodon monoceros) ne possède pour toutes dents que deux canines supérieures, qui restent enfermées dans les alvéoles 
pendant toute la vie chez les femelles, mais dont une se développe chez les mâles en une puissante défense. Cette dent était prise autrefois pour la corne d'un animal fantastique, la Licorne; elle était vantée comme alexipharmaque.

Le Cachalot macrocéphale (Physeter macrocephalus) mesure en moyenne 20 à 25 mètres de longueur : c'est le plus grand de tous les animaux actuels; on évalue son poids à 2000 quintaux. Le museau est tronqué

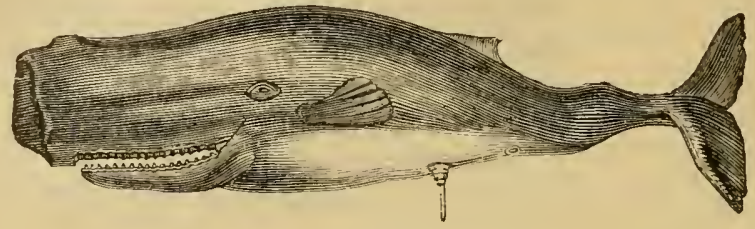

Fig. 816. - Cachalot macrocéphale.

verticalement, et l'évent simple, en forme d'S, se trouve sur le bord de cette troncature, un peu sur le côté. La màchoire supérieure est inerme chez l'adulte; l'inférieure est armée de grosses dents.

Cette espèce vit dans le nord de locéan Atlantique; d'aıtres sans doute existent dans les mers dn Sucl.

Bien que la tête soit énorme, puisqu'elle occupe le tiers environ de la longueur totale, le cràne est fort petit; mais les maxillaires sont très développés, surtout en arrière, et l'occipital offre une crête verticale fort saillante qui se contourne pour aller s'unir de chaque còté à ces os. Il résulte de cette disposition un vaste bassin ovalaire, fermé en haut par une expansion fibrocartilagineuse sous-cutanée et divisée, par une cloison horizontale, en deux chambres remplies d'une huile grasse très abondante: c'est ce réservoir complexe que les pêcheurs désignent sous le nom anglais de case. D'après les observations de Pouchet et Beauregard, l'appareil dont il s'agit, appareil du blanc (boîte à spermaceti), n'est autre que la narine droite transformée. Cette narine reste cependant ouverte à ses deux extrémités: en arrière, elle se prolonge par un conduit né du point de jonction des deux chambres, " conduit qui s'enfonce dans la fosse nasale osseuse plus étroite de ce còté, et va s'ouvrir avec l'autre narine au-dessus du voile du palais». En avant, " elle communique avec un sac nasal, qui s'ouvre lui-même dans l'évent, par un orifice où l'on peut, chez l'adulte, passer la main".

Le liquide gras contenu dans ces réservoirs ne provient pas de glandes. spéciales; il semble se former dans le tissu conjonctif, à la façon des graisses. On le puise, non dans la lumière mème de la fosse nasale, mais " au milieu d'un tissu adipeux presque transparent, prodigieusement friable ». Il tient en dissolution une substance connue sous les noms impropres de blanc de Baleine et de spermaceti. Abandonné à l'air pendant quelques jours, il laisse déposer cette substance à l'état de masse cristalline qu'on isole d'abord par la filtration à travers de grands sacs de laine, puis par une forte pression. Le produit est traité alors par une solution faible de potasse caustique qui décompose les principes colorants el les matières animales étrangères. On lave ensuite le liquide à l'eau bouillante et on le coule danıs 
des cristallisoirs: c'est ainsi qu'on obtient, par le refroidissement, le blanc de Baleine en pains carrés du poids de 1 :̈ à 20 kilogrammes.

l)'ordinaire, le produit est livré au commerce dans cet état. Il se présente sous l'aspect d'une substance grasse, solide, onctueuse au toucher, d'une structure lamelleuse, d'une odeur à peine saisissable. Il fond à 'tan. Ce n'est pas un produit pur : a la citine de Chevreul, qui le constitue essentiellement, sont encore unies des substances huileuses.

Puur obtenir la cétine à l'état de pureté, on la sépare de ces matières huileuses par l'alcool, et on la recueille alors sous forme de paillettes nacrées, onctueuses, solubles daus l'alcool et l'éther, insolubles dans l'eau, fusibles a $49^{\circ}$. En ce qui concerne sa composition, il est généralement admis que la cétine n'est autre que de l'éther palmitique ou palmitale de cétyle. Cependant, d'après Ileint principes moins importants, et la cétine serait formée, en somme, par plusieurs alcools (léthal, méthal, éthal ou alcool cétylique, stélhal) et plusieurs acides (stéarique, palmitique, cétique, myristique et coccinique) s’éthérifiant entre eux.

Le blanc de Baleine est employé pour la confection des bougies diaphanes. En médecine, on l'a recommandé, à l'intérieur, à la dose de 2 à 8 grammes, comme adoucissant, contre la diarrhée, et même comme béchique. On ne l'utilise plus aujourd'hui qu'à l'extérieur, sous forme de cérats, pommades (pommade à la sultane) et cosméliques (coldcream).

Les Cachalots fournissent encore une substance odorante très appréciée dans l'Orient, l'ambre gris (1). C'est un corps solide, qui se présente dans le commerce en masses ovoïdes ou sphériques, parfois irrégulières, dont le poids peut atteindre et dépasser 1 kilogramme, et dont la couleur, la consistance et l'odeur varient suivant la fraìcheur des échantillons. L'ambre frais est ordinairement noir à la surface, chamois à l'intérieur ; sa consistance est telle que le couteau y pénètre difficilement à froid; son odeur est désagréable, dominée par un relent stercoral prononcé. Les échantillons anciens sont secs et peuvent se casser; ils ont d'ordinaire une teinte grise ou jaunâtre; entin, le relent stercoral a disparu pour faire place à une odeur d'ambre, laquelle ne prend pourtant sa finesse que par la dissociation du produit. Il existe aussi de l'ambre complètement blanc. A la cassure, les masses d'ambre gris offrent l'aspect de calculs à couches concentriques. L'analyse chimique y décèle la présence d'une matière balsamique spéciale (2 p. 100) et d'une substance cristallisable dite ambréine, analogue à la clıolestérine (jusqu'à 85 p. 100). Au microscope, on reconnaît en effet que ces calculs sont constitués presque exclusivement par de longues aiguilles cristallines d'ambréine, disposées de diverses manières et associées à un pigment mélanique qui donne à l'ensemble sa couleur grise ou noire plus ou moins foncée. De plus, il n'est pas rare de tronver dans la masse des becs de Céphalopodes, des écailles et des arètes de Poissons, animaux dont se nourissent ies Cachalots.

(1) Pocchet et Beauregard, Nole sur l'ambre gris. Comptes rendus de la Soc. de biologie, $(9), \mathrm{W}$, p. $588,1892$. 
On peut déduire de cette constitution que les nodules dambre gris sont de simples calculs intestinaux (Servat, Marel). Jusqu'à présent, personne ne les a vus et décrits en place, mais on peut affirmer qu'ils occupent la première portion du rectum, dont la muqueuse est fortement pigmentée. Ces calculs ambréiques se forment vraisemblablement par précipitation de contenu toujours liquide de l'intestin. L'odeur d'ambre ne parait pas appartenir en propre à l'ambréine; elle est en effet répandue dans tous les organes des Cachalots et tient peut-être à leur nourriture; mais la substance odorante se trouve sans doute, au contact des cristaux d'ambréine, dans des conditions favorables d'isolement et d'expansion.

On trouve l'ambre gris flottant en pleine mer ou déposé sur les còtes de diverses régions: à Madagascar, au Japon, au Brésil, aux Antilles, etc.

L'ambre gris est surtout employé dans la parfumerie; mais on y a quelquefois recours en médecine, à titre de stimulant du système nerveux. On l'a autrefois regardé comme un aphrodisiaque puissant: il entre du reste dans la préparation des pastilles indiennes nommées cachundé, des pastilles du sérail, etc.

$2^{e}$ sous-ordre : Mysticètes. - Cétacés dépourvus de dents à l'àge adulte. Pendant la période embryonnaire, on Irouve bien, cachées dans une rainure des gencives, des ébauches de dents; mais elles ne percent jamais et ne tardent pas à ètre résorbées, pour faire place aux fanons. On nomme ainsi des lamelles cornées triangulaires, d’origine épithéliale, qui naissent de la voùte palatine et descendent verticalement, de manière à former une sorte de crible propre à retenir les petits animaux contenus dans l'eau.

Genres Rorqual (Balanoptera), Baleine (Balæna). On pèche ces animaux, notamment la Baleine franche (Balæna mysticetus), pour leurs fanons et pour l'huile abondante qui existe dans leur pannicule graisseux (huile de Baleine, dite huile de Poisson).

CINQUIĖHE ORDRE

\section{SIRENES}

Mammifères pisciformes, à membres antérieurs transformés en nageoires; pas de membres postérieurs; nageoire caudale horizontale; têle distincte du tronc; mamelles pectorales; placenta diffus.

Ces animaux ont un certain nombre de caractères communs avec les Cétacés, auxquels on les réunit quelquefois; ils en diffèrent pourtant d'une façon notable. Ainsi, les Sirènes ont la tête petite, séparée du tronc par un cou assez court, les narines situées au bout du museau, le larynx disposé comme chez les autres Mammifères. Des poils courts et raides sont épars sur Ie corps. Les dents sont différenciées. Il n'existe pas de canines, mais on trouve des incisives qui subissent un renouvellement. Les molaires sont conformées d'après le type qu'offrent les Ongulés.

Ce sont des animaux herbivores et paisibles, coliers ou fluviatiles. 
Cienres Dugong (Halicore), Lamantin (Manatus). Un troisiène genre, celui

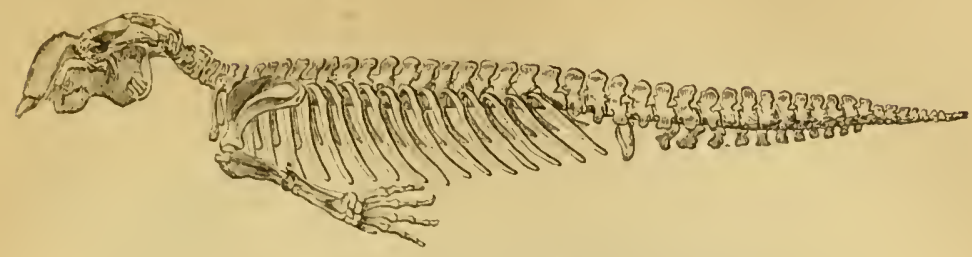

Fig. s17. - squelelle de Jugong (IIalicore dugong).

des Stellères (lihytina), qui vivaient au Kamtshatka, a été anćanti pas l'Homme vers la fin du siècle deruier.

\section{SIXIEUE ORDRE}

\section{BISULQUES}

Mammifères ongulés, ì doigts presque toujours pairs, les deux médians plus developpés; dentitioi primitivernent complète, mais tendant à se varéfier; placenta diffus ou colylédonaive.

Souvent désignés aussi sous le nom d'Artiodactyles (äpros, pair; óx́xนùos, doigt), les Bisulques (bisulca, animaux à pied fourchu) composent un ordre très riche en espèces el si étroitement uni à celui des Jumentés, que beaucoup d'auteurs les réunissent sous le nom l'Ongulès (1), en considération surtout des formes fossiles internédiaires.

On trouve, dans ce groupe, des animaux lourds et trapus et d'autres aux formes sveltes et élancées. Mais, chez tous, les doigts sont terminés par des sabots, gaines cornées obtuses dans lesquelles est en l'ermée la troisième phalange. Chez tous également, le pied est fendu, c'est-à-clire que, au lieu d'un seul doigt prédominant, comme chez les Jumentés, il y en a deux, le troisième et le quatrième. La caractéristique des Bisulques repose effectivement sur ce fait que l'axe des membles passe entre les doigts 3 et 4; ces doigts ont donc à supporter la charge principale du corps, laquelle est à peu près également répartie entre eux; par suite, ils prennent un déreloppement considérable, tandis que les autres, ayant une fonction moins active, se réduisent peu à peu, jusqu'à disparaître. Chez l'Hippopolame, qui paraît représenter une forme prinitive, les deux doigts latéraux, le ge et le $\ddot{8}^{e}$, sont presque aussi développés que les médians, et concourent á l'appui. Mais le plus souvent ces doigts latéraux demeurent très courts, sont reportés en arrière et ne tou-

(1) Les Ongulés des auteurs modernes comprennent huit groupes: Condylarthrés (éteints), Périssodactyles, Artiodactyles, Amblypodes (éteints), Proboscidiens, Toxoudontes (éteints, Typothériens (éteints; Hyraciens. 
chent pas le sol. - Chez les Porcins, les métacarpiens et métatarsiens des deux doigts médians sont encore séparables, et les os de l'avantbras et de la jambe demeurent bien développés et distincts. Les Pécaris et les Tragulidés établissent, à cet égard, la liaison entre les Porcins et les Ruminants. Ceux-ci ont leurs métacarpiens et métatarsiens principaux soudés de manière à former un seul canon; en outre, leurs doigts latéraux se réduisent de plus en plus. Les Pécaris n'ont d'ordinaire que trois doigts aux membres pos-

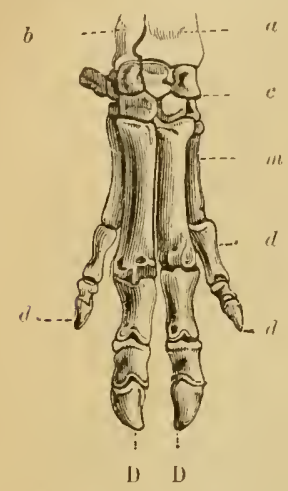

Fig. 815. - Pied antérieur du Porc. Fig. 819. - Pied postérieur de - $a b$, avant-bras. $c$, carpe, $m$, métacarpe. $d, d$, doigts latéraux. $b, \mathrm{~b}$, doigts médians, touchaut seuls le sol.

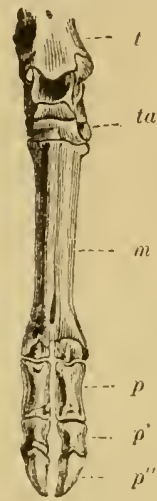

Cerf. - $t$, tibia. $t a$, tarse. $m$, métatarse ou canon. $p, p^{\prime}$, $l^{\prime \prime}, I^{\mathrm{re}}, 2^{\mathrm{e}}$ et $3^{\mathrm{e}}$ phalanges.

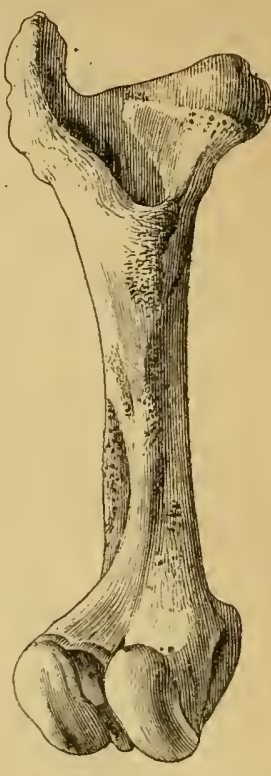

Fig. 820. - Fémul du Bouf.

térieurs; les chameaux el la Girafe n’en ont plus que deux aux quatre membres.

Le fémur ne montre jamais la saillie que nous aurons à signaler,

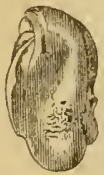
chez les Jumentés, sous le nom de troisième trochanter. L'astragale est en osselet, c'est-à-dire pourvu d'une trochlée proximale et d'une double trochlée distale. Les clavicules manquent.

La dentition, primitivement coinplète, tend à se raréFig. 8:1. - Astra- fier dans certains groupes. Ainsi, chez la plupart des gale en osselet du Eeur.

Ruminants, les incisives et les canines supérieures font défaut, bien qu'on en retrouve les germes chez les embryons. Par contre, les incisives inférieures sont augmentées d'une paire, ce qui en porte le nombre total à huit: on considère, en général, ces incisives additionnelles comme des canines déplacées et adaptées à un rôle nouveau. Les canines sont très développées chez les Porcins et les Chevrotains, en particulier dans le sexe mâle ; elles diminuent chez les Chameaux et chez beaucoup de Cerfs. Les molaires sont toujours compliquées, mais leurs principales mo- 
difications peurent se ramener à deux types: $t^{\circ}$ leurs éléments constitutifs ou denticules offrent l'aspect de cônes ou mamelous plus ou moins plissés, comme clıez les Cochons : c'est le type bunodonte (Bourós,

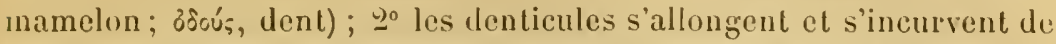
manière à former des croissants longitudinaux, bien délimilés par les rubans d'email, ainsi qu'on le voil chez les Ruminants : c'est le type sélénodonte (osinivn, lune). Entre ces deux formes extrêmes, on distingue parfois un type lophodonte (7.ótos, houppe), dans lequel les tubercules de la dent primitirement bunodonte se sont étendus et reliés par des crêtes. Les culs-de-sac de la surface de frottement sont comblés par du cément, substance qui se dépose aussi sur la surfice extérieure : après usure, la couche d'émail dessine des rubans qui séparent l'iroire des dépôts cémenteux et marquent très nettement les denticules.

Les mamelles sont ventrales (Porc) ou inguinales. L'utérus est bicorne. Le placenta est diffus, comme che\% les P'orcins, les Camélidés et les Tragulidés, ou cotylédonaire, comme chez la plupart des Rumi-

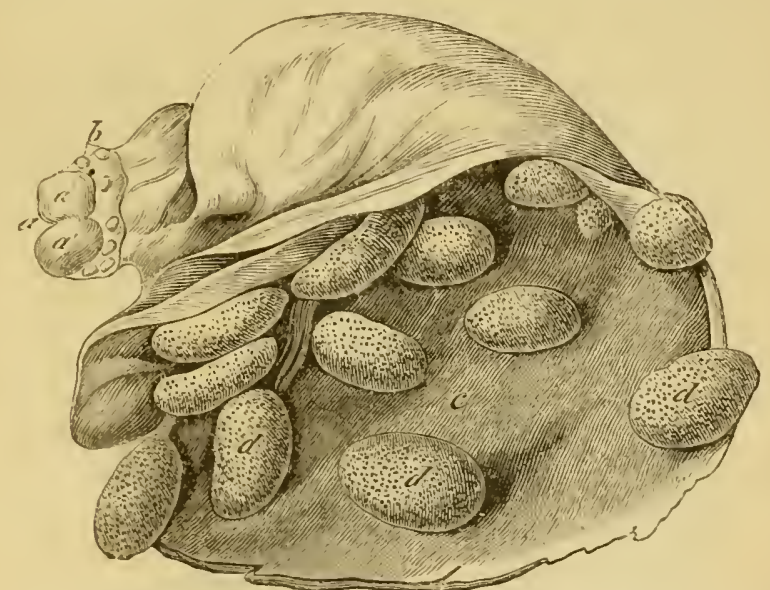

Fig. 822. - l'lérus d'une Vache pendant la gestation. - $a$, ovaire sectionni par lo milien, a'a', corps jaune. $b$, vísicules de de Graaf. $c$, surface interne de l'utérus. $d$, coḷl lédons.

nants. Les cotylédons utérins sont tantôt convexes (Vaclie), tantit discoïdes (Chèrre), tantóten cupule (Brebis). - L’estomac tend ì se subdiviser en plusieurs compartiments, et cette division, déjà indiquée chez l'Hippopotame et le Pécari, un peu plus complexe chez lés Tragulidés, est portée ì son maximum chez les autres Ruminants. Le cerveau est relativement petil; les hémisphères, qui ne couvrent jamais le feervelet, oftrent un système particulicr de circonvolutions assez compliqué dans les grandes espèces. Néaumoins, l’intelligence est toujours obtuse. - La plupart des Bisulques vivent en troupes, mais celles-ci ne possèdent pas, en général, l'organisation intelligente 
que nous observerons chez les Chevaux. Lorsqu'ils sont attaqués, ces animaux cherchent leur salut dans la fuite; rarement ils comptent sur leur propre force.

De tous les ordres de Mammifères, l'ordre des Bisulques est le plus utile à l'Homme; c'est aussi le plus nombreux en espèces après celui des Rongeurs. On le divise en deux sous-ordres: Porcins et Ruminants, paraissant avoir pour souche commune, d'après Cope, la famille éteinte des Pantolestidie, de l'éocène inl'érieur et moyen de l'Amérique du Nord.

PREMIER SOUS-ORDRE

Poncixs

Bisulques à dentition complète, à estomac souvent simple, et dans tous les cas impropre à la rumination; métacarpiens et métatarsiens des doigts médians généralement non soudés entre eux.

Les auteurs ont donné à ce groupe des noms assez variés : Artiodactyles pachydermes, Polydactyles non ruminants, etc. Nous préfé- rons celui de Porcins, et parce qu'il est simple, et parce qu'il convient bieu aux espèces actuellement vivantes. Toutes celles-c en effet, y compris l'Hippopotame, ressemblent plus ou moins à nos Porcs par l'ensemble de leur organisation. La plupart des espèces fussiles ellesmêmes ne sont pas sans offrir avec eux de nombreux rapports.

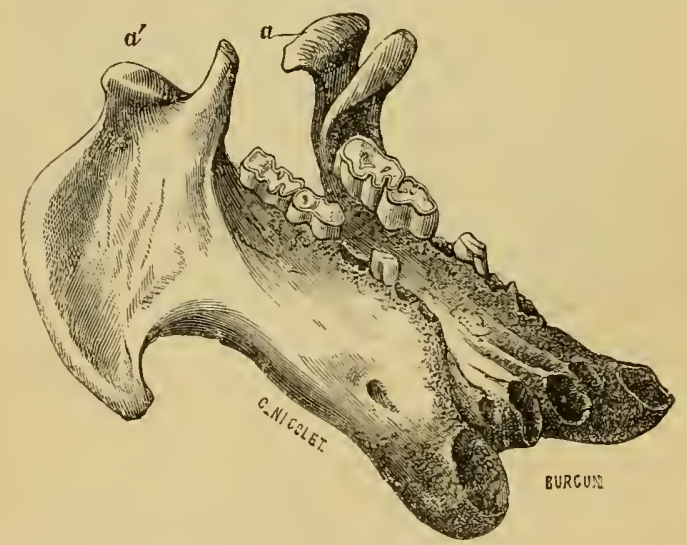

Fig. 823. - Maxillaire inférieur de l'Hippopolame. - $a, a^{\prime}$, condyles.

Les Porcins ont, en général, plusieur's paires d'incisives, des canines plus ou moins saillantes et des molaires mamelonnées. L'estomac est simple, sauf chez l'Hippopotame et les Pécaris, oủ la partie cardiaque est divisée en deux compartiments. Les métacarpiens et métatarsiens des deux doigts principaux demeurent toujours distincts, sauf chez les Pécaris, où ils commencent à se souder dans leur partie supérieure. 
Stupides et brutaux, les Porcins ont cependant certains sens, l'ouïc et l'odorat, d'une linesse remarquable. A l'élat sauvage, ils vivent dans les forèts marécageuses.

On en distingne deux fanilles : Ilippopotamida et Suider.

Les HIPPOPOTAMIDES ou Obeses sont des animanx lourds, massifs, hideux. Formule dentaire: $\frac{2.1 .4,3 .}{2.1 .4,3 .}$ Formule digitale $\frac{2.3 .4 . \% .}{2.3 .4 . \ddot{3} .}$

Ils vivent par troupes dans les grands lleuves et les lacs do l'intérieur de l'Afrique. Ils se nourrissent de plantes aquatiques. - L'Hippopotame commun (Hippopolamus amphibius) peut acquérir une longueur de $4^{\mathrm{m}}, 50$ et un poids de 2300 kilogrammes. Une autre espèce, de petite taille (II. liberiensis), a été trouvée dans lil République de Libéria. La gra isse des Hippopotames sert à fabriquer le delku, sorte de pommade dont les Nìgres s'enduisent les cheveux et le corps. La chair est délicate.

Les SUIDÉS ou Séligères ont le corps revêtu de poils raides ou soies, et supporté par des pieds dont les deux doigts médians touchent seuls le sol, les deux autres étant peu développés el reportés en arrière $\left(\frac{2.3 .4 .5}{2.3 .4 .5}\right)$. La tète est allongéc et terminée par un groin ou boutoir, élargi à son extrémité en un disque dans lequel sont percées les narines. Ce groin, soutenu à l'intérieur par une pièce osseuse, est tout à fait propre à fouir le sol. On troure, dans chaque branche des mâchoires, une a trois incisives, une forte canine ou défense et un nombre variable de molaires. Sauf de très rares exceptions (Pécaris), les canines supérieures sont recourbées en haut et suivent à peu près la mème direction que les inférieures, de sorte que, pour se défendre, les animaux frappent toujours de bas en haut et par cité. Les femelles possèdent six ou sept paires de mamelles abdominales et mettent bas un nombre correspondant de petits. Ceux-ci ont souvent une robe tachetée ou rayée.

Tous les Suidés sont des animaux nocturnes, qui vivent en troupes dans les forèts, recherchent les régions marécageuses et aiment ì se vautrer (faire souille) dans la boue. Ils passent la journée dans une retraite sombre et humide (bauge). Ils sont omnivores : bien qu'ils se nourrissent le plus souvent de racines et de tubercules, ils ne dédaignent pas les proies vivantes ou mortes qui tombent à leur portée.

Les Cochons proprement dits (Sus L.) ont pour formule dentaire $\frac{3.1 \cdot 4,3}{3.1 \cdot 4,3}=4^{4}$. Leurs incisives inférieures sont dirigées trìs obliquement en avant.

On déconvre des restes fossiles du genre Sus dans le diluvium et dans le tertiaire jusı̨u'au miocène: ces formes éteintes se continuent d'ailleurs avec les genres Hyotherium et Palxochwrus du miocène, et Charopotamus de

Rulluet. - Zoologie. 
l'éocène, mais ne paraissent pas dériver des Anoplothéridés, contrairement à ce qu'avait supposé A. Gaudry. Citons, d'après cet auteur, la série qui aboutit à notre Sanglier d'Europe: Sus chœroides et Lockarli du miocène moyen, S, antiquus, palxochœurus, erymanthius et major du miocène supérieur,
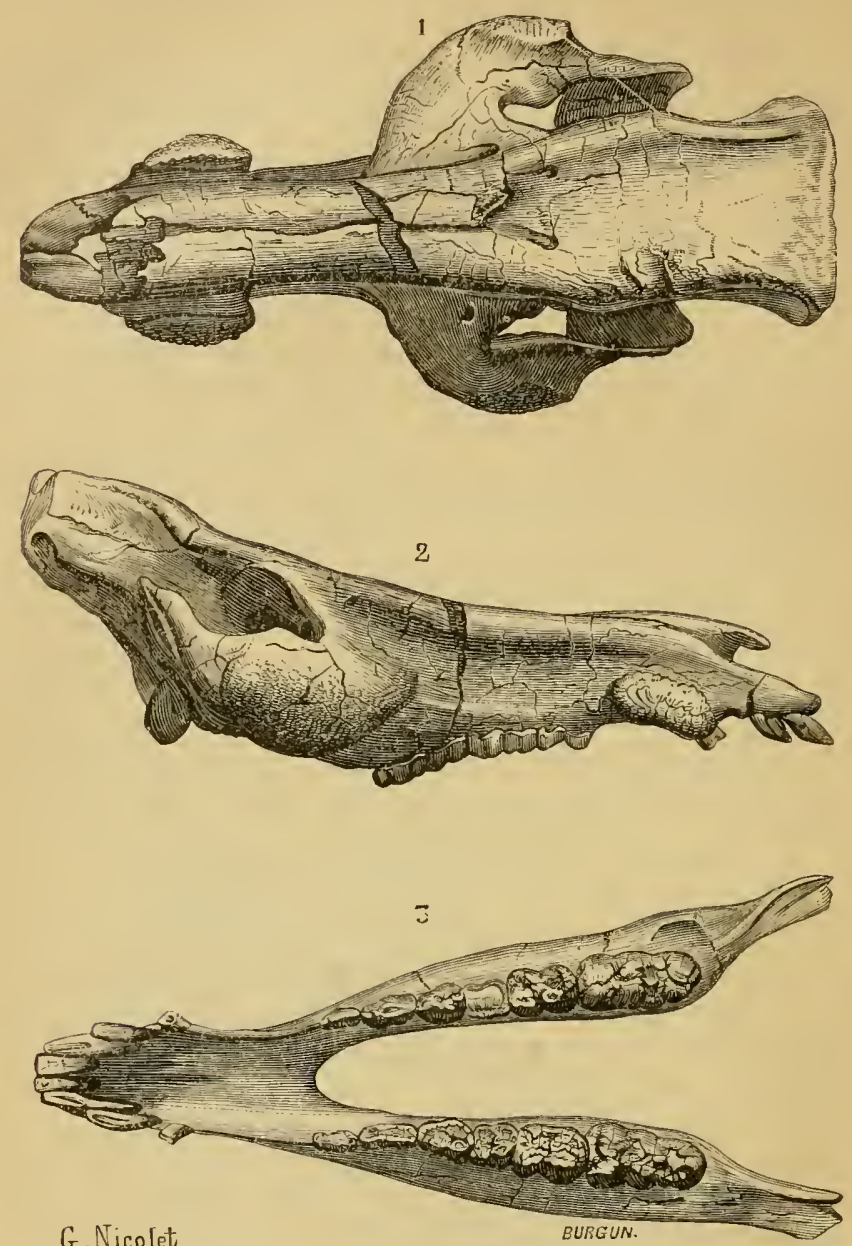

Fig. 824. - Sus erymanthius, du miocìne. - 1, tête vue en dessus. 9, lèle vue de profil. 3 , mâçhoire inférieure.

S. provincialis du pliocène inférieur, S. arvernensis du pliocène supérieur; enfin, cette série se poursuil dans le diluvium par un Sus scrofa fossilis qui ne paraît pas se distinguer du Sanglier actuel. - Ajoutons que les cités lacustres ont montré une forme toute différente, dont il sera question plus loin.

Les Cochons sauvages ont reçi le nom de Sangliers. Les mâles sont appelés Verrats; quand ils sont vieux, ils vivent à l'écart du trou- 
peau (Solitaires), sauf ̀̀ l'époque du rut; les femelles se nomment Laies, et les petits, Marcassins.

Les zoologristes ont llécrit un très grand nombre de formes de Sangliers, auxquelles ils ont attribné la valeur d'espèces. Forsyth Major, après avoir étudié une très riclıe collection de crànes, est arrivé ì réduire ces espèces à quatre principales : Sus vittutus, S. verrucosus, S. barbatus et S. scrofu.

l.e saugrlier à bandes (\$. vittutus Mïller et Schlegel) comprend, en particulier, 16 ou 17 formes, par exemple S. vittatus type, de Java, Sumatra, Bornéo, Anboine et Célèbes; S. andumunensis, s. capensis, S. indicus, S. leucomystrat (du Japon), S. timoriensis, S. moupinensis, S. semauriensis, etc. On y rattache mėne : $S$. papuensis Lesson (le Sanglier des Papous, bien connu parce que les indigénes de la Nouvelle-Guinée en élèvent sourent les marcassins dans leurs cases), qu'on a quelquefois rangé dans un genre dislinct (Porculu); S. cristatus Wagner (Sanglier à crinière), de l'Inde et de Malacca; S. scrofa meridionalis (Sanglier de Sardingne), qu'on aurait à tort rattaché au Sanglier commun d'lurope. Dans ces conditions, l'aire de dispersion de S. vittatus s'étendrait du Japon au sud-ouest de l'Afrique, et de la Sardaigne à la Nonrelle-Guinée.

Le Sanglier à verrues (S. verrucosus Müller et Schlegel), de Java, Bornéo, Céram, constitue aujourd'lui une espèce bien distincte, mais se relie étroitement aus. vittutus par une forme pliocène du val d'Arno et des monts Siralik (S. giganteus Falc.).

Le Sanglier barbu (S. barbatus Müller et Schlegel), de Bornéo, se rapproche du s. cerrucosus par ses crochets inférieurs; mais il en diffère sur tous les autres points.

Le Sanglier a'Europe (S. scrofu L.) a le corps ramassé, la tète allongrée, a front plat, les oreilles droites, les membres forts, la queue tordue. Le corps est revètu de soies raides, qui se hérissent en crinière sur la nuque et sur le dos. La teinte générale du pelage est gris foncé; les marcassins conservent jusqu’à l’àge de six mois une livrée à bandes longilndinales alternativement fauves et noires; à six mois, l'animal devient béte rousse pour les chasseurs; a 1 an, bite noire ou de compagnic; à 2 ans, ragot; à 3 ans, tier's-an; à 4 ans, quart-an ou quartenier; c'est à partir de 6 ans environ que les màles deviennent solituires.

Le Sanglier commun habite les régions tempérées de l'ancien continent; mais il disparait peu à peu devant l'Homme, et on ne le rencontre plus guère aujọurd'hui que dans les graudes forèts. Le rut n'a lieu généralement qu'une fois par an, vers décembre: à ce moment, les solitaires rejoignent les troupeaux et en chassent les màles les plus faibles; dix-huit semaines environ après l'accouplement, la laie met bas ì 6 marcassins quand elle est jeune, et jusqu'à 12 quand clle est vieille. La chair des Sangliers, et surtout des individus jeunes, est très estimée.

D'après David I.ow, les indiridus entretenus en captivité tendraient à prendre les caracteres des Porcs domestiques: les membres, dit cet auteur, deviennent plus longs, le groin s'allonge, le duvet disparait. Ces observations, d'ailleurs assez superficielles, sont loin d'avoir la portée qu'on a voulu leur attribuer. 
A l'état sauvage mêne, les Sangliers présentent des variations morphologiques très étendues. Ceux des marais, dit Brehm, sont beaucoup plus grands que ceux des forèts sèches, et les formes qui peuplent les îles de la Méditerranée sont à peine comparables ả notre type continental. De mème, le Sanglier de Barbarie constitue comme une race géographique distincte, etc.

Cochons domestiques (Sus scrofa domesticus Auct.). - La plupart des zoologistes rapportent les Cochons domestiques à une seule et même espèce, dont les divisions naturelles constituent des races. Mais, pour quelques-uns, au contraire, les différences qui existent entre les races dont il s'agit sont, en partie du moins, originelles, c'est-à-dire que les Cochons domestiques se rattachent à un certain nombre de types spécifiques primitifs.

Cette question de l'unité ou de la pluralité de sonche n'est pas d'ailleurs limitée au groupe des Cochons; elle se pose également pour la plupart des animaux domestiques. Nous devons donc exprimer ici, une fois pour toutes, notre sentiment à cet égard.

D'après Cuvier, les Cochons domestiques proviendraient du Sanglier d'Europe (Sus scrofa L.). Pritchard el Roulin ont appuyé cette manière de voir en affirmant que, dans certaines régions de l'Anérique où les Cochons sont redevenus sauvages, leur poil et leurs allures sont à peu près semblables à ceux de nos Sangliers. I. Geoffroy Saint-Hilaire pensait, au contraire, que les Cochons d'Europe descendent des Sangliers d'Asie. Les uns et les autres, d'ailleurs, paraissent bien d'accord sur ce point, que tous les Cochons entretenus en domesticité appartiennent à une seule et mème espèce.

Pourtant, cette manière de voir est sujette à discussion. D'après les indications données plus haut, les Sangliers répandus dans les diverses régions du globe représentent un très grand nombre de formes, que certains auteurs regardent comme autant d'espèces, et dont les autres font de simples races géographiques pouvant être rapportées à quelques espèces types ou " bonnes espèces ". Or, si l'on examine de même les Cochons domestiques, on est amené à reconnaître qu'ils offrent des modifications correspondantes. II suffit de comparer, par exemple, les Cochons du Tonkin avec nos lorcs normands ou gascons, pour reconnaitre que ces formes diffèrent, entre elles au moins autant que les races géographiques ou sous-espèces sauvages. Peutêtre même les premiers paraitront-ils assez différents des seconds pour que les uns et les autres soient considérés comme représentant de "bonnes espèces ", d'une valeur égale à Sus vittatus et à Sus serofa.

Mais les différences observées entre les formes domestiques ne seraientelles pas précisément le résultat de la domestication, de la culture, de la sélection effectuée par l'Ilomme ? Il est certain que le problème de la détermination des types spécifiques, déjà fort difficile à résoudre, comme on l'a $\mathrm{vu}$, pour les formes sauvages, offre des difficultés beaucoup plus grandes encore par l'introduction de ces éléments. Ce n'est pas tout: les représentants d'une même forme primitive ne se sont pas exclusivement reproduits entre eux; bien au contraire, on constate presque partout des traces de mélange, se traduisant par un défaut d'harmonie dans les caractèles et par 
des phénomènes de réversion. Dans ces conditions, il ılevient évidemment fort difficile de reconnaitre, dans les populations porcines actuelles, les types primitifs auxquels ont doit les rapporter.

A. Sanson a pensé cependant que la chose n'était pas impossible, el, se basant sur les caractères ostéologį̣ues, notamment sur ceux tirés du cràue, il a cru pouvoir affirmer que ]es diverses races de Porcs reconnues par les auteurs se raltachent à trois groupes principaux, qu'il qualifie de ruces, mais auxquels il donne la valcur d'espèces. Chacune de ces espèces ayant son origine el, partant, sa patrie distinctes, se compose d'un certain nombre de variètés produites sous l'influence du milieu, mais transmettant leurs caractères par hérédité, et correspondant par suite aux races des naturalistes.

A tilre d'exemple, nous reproduisons ici la classification des races de Porcs, telle quelle est donnée par Sanson. On remarquera que la nomenclature de l'auteur comporte toujours un qualiticatif visant la palrie d'origine de l'espèce à laquelle il s'applique.

ESPECES BRICIYCEPHILES. - Race ASIATIOHE (Sus asialicus). Variétés : Chinoise. - Siamoise. - Japonaise.

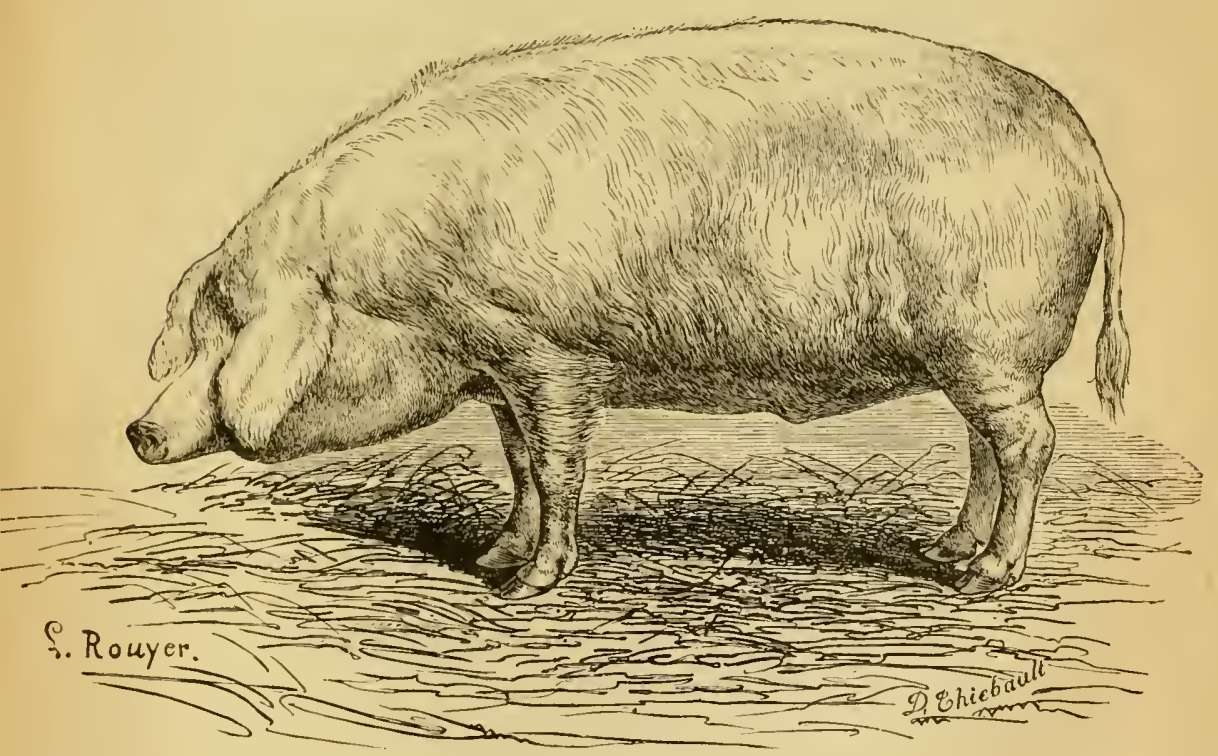

Fig. 823. - Forc normand.

R.ice celtique (S. celticus). Variétés : Angevine ou Craonnaise. - Mancelle. - Bretonne. - Normande ou Augeronne. - Romagnole.

ESPÈCE DOLICHOCÉPIIALE. - RACE IBÉRIQUe (S. ibericus). Variélés : Napolitaine. - De la Campagne romaine. - Toscane. - Grecque. - Ilongroise (dite Mangalikza). - Suisse. - Bressane. - Dauphinoise. - Quercinoise. Périgourdine. - Limousine. - Gasconne. - Languedocienne. - Provençale. - Roussillonnaise. - Béarnaise. - Espagnoles et Portugaises. 
En résumé, d’après Sanson, nous nous trouvons en présence de trois espèces naturelles, ayant chacune leur origine distincte. - Cette manière de voir procède d'une doctrine taxinomique trop radicalement différente de celle que nous avons adoptée pour que nous puissions l'accepter sans réserves; et d'ailleurs, l'auteur fait intervenir, d'une façon un peu trop exclusive, les caraclères tirés de l'examen du cràne. Cependant, on ne peut le méconnaître, l'étude de ces caractères marque un pas en avant dans la voie du progrès scientifique; et quelle que soit la valeur absolue qu'on veuille accorder aux catégories établies sur une telle base, il est certain qu'elles constituent des points de repère extrèmement utiles au point de vue des recherches ullérieures. Aussi bien, les recherches paléontologiques viennentelles chaque jour en démontrer l'importance. - Nous ne pouvons nous empèclier toutefois de regretter que l'auteur ait établi volontairement une quasi-confusion entre les notions d'espèce et de race, et qu'il ait cru devoir adopter une nomenclature à part, en dehors des règles acceptées par la généralité des naturalistes.

Au surplus, l'adoption des vues de Sanson ne viderait pas la question soulevée, et l'origine des espèces — ou races primitives — de Porcs domestiques n'en restcrait pas moins à déterminer. Aussi les auteurs se livrent-ils toujours, à cet égard, aux suppositions les plus variées. Les uns tendent à considérer que les formes primitives n'existent plus à l'état sauvage, leur confiance native les ayant fait disparailre au contact de l'Homme. Les autres, au contraire, font intervenir des formes sauvages multiples, notamment les Sangliers de l'Asie et de l'Afrique, voire les Potamochères de cette dernière région (1).

Sans doute, il n'est pas irrationnel d'admettre qu'il existe encore, de nos jours, des représentants sauvages et des représentants domestiques d'une mème espèce, et le fait est notoire dans quelques cas; cependant, il faut reconnaitre que le plus souvent les documents positifs fournis à l'appui de celte thèse résistent mal à une critique sérieuse.

Reste donc à admettre, pour les races de Porcs comme pour celles de nos principaux Mammifères domestiques, une origine propre, antérieure aux temps actuels. La question tombe alors dans le domaine de la prélistoire et de la paléontologie, et c'est à ces sciences que nous devons demander des lumières. Malheureusement, l'une et l'autre sont encore trop peu documentées, par suite des difficultés que présente l'exploration de la croite terrestre. Il est certain pourtant qu'elles nous ont fourni déjà, sur le point qui nous occupe, des renseignements précieux, nous permettant d'affirmer dès maintenant que les Porcs domestiques actuels descendent de formes déjà distinctes dans les époques préliistoriques, el nous portant mème à admettre, d'une manière très générale, que les aïeux de nos animaux domestiques sont géologiquement plus anciens que l'Ilomme qui les a domestiqués.

Donc, s'il nous est permis de conclure par une note personnelle, nous dirons que pour les Porcs, comme pour la plupart des animaux domestiques, la pluralité de souche nous paraît difficilement contestable. Et.nous enten-

(1) L'opinion la plus répandue est que les Cochons européens dérivent du Sus scrofa, et les Cochons asiatiques du Sus vittatus (notamment de la forme leuco. mystax). 
tons par lí que les principaux types auxquels se rattachent nos races actuelles étaient déjà différenciés au moment où a été effectuée leur domestieation, sans nous attarder à la question te savoir s'il convient d'accorder ì ces types la valeur de races ou d'espèees.

Domestirution. - La domesticalion du Porc dans l'Lurope occidentale date certainement, conme eelle de nos principaux Mammifìres, de l'époque robenhausiemne. Elle a été la conséquence le l'arrivée en Occident des populations qui ont introduit dans cette région l'usage des armes en pierre polie, populations qu’on suppose itre d'antiques migrateurs aryens, précurseurs des Aryas aux armes de bronze. Dans les habitations lacustres les plus ancienues, on rencontre : $1^{\circ}$ le Sanglier d'Europe (S. scrofu); un type de grande taille, souvent appelé Porc de Concise, et qui parait très voisin des Cochons actuels de nos pays; 20 une forme plus petite, le Cochon des tourbières (rius pulustris), au sujet duquel on a émis des opinions variées : lïtimeyer et Il. von Nalhusius le rapportent au type du Cochon hongrois à soies frisées, ainsi que du Sanglier de l'Inde (Sus vittatus); R. Hartmann et 1.-W. Schïtz le regaralent comme dérivant du Sus seuna ariensis (simple variété africaine du précédent, d'après Forsylì Major); enfin, Nehring le considère comme un rejeton du Sanglier d'Europe, atrophié par uıe domestication précoce. Ce dernier auteur a rattaché d'ailleurs au Pore des tourbières une forme porcine trés réduite trouvée dans une tourbière d'Allemagne, et qu'il avait d'abor'l dénommée s.. scrofa nanus.

En Chine, d'après le Chou-ling, la domesticité lu Cochon daterait au moins de quarante-neuf siècles.

" Réputé immonde par les Égyptiens, le Cochon ne figure point dans leurs peintures sépulcrales. Personne n'ignore que les Juifs l'avaient exclu aussi de leur alimentation. Les Grecs et nos ancètres, les Gaulois, le faisaient entrer, au contraire, dans la leur pour une très large part. Enfin, les Aryas primitifs connaissaient le Porc domestique et en mangeaient la chair (1). "

Carartères physiologiques. - Les mâles et les femelles de nos Cochons domestiques sont aptes à s'accoupler vers l'âge de huit mois. Le Verrat peut saillir d'abord trois Truies par jour, et plus tard quatre ou cinq. Léjaculation est toujours lente; le sperme est très épais.

La durée de la gestation est d'environ cent dix-neuf jours; on dit, comme procédé mnémonique, trois mois, trois semaines et trois jours. Le nombre des petits varie selon les races; il est souvent de dix à douze. Chaque Cochon de lait ou Goret fait choix d'un mamelon auquel il revient toujours. On sèvre d'habitude ces animaux au bout de six semaines. - Pour faciliter l'engraissement, on châtre les individus des deux sexes, avant ou après le sevrage : la femelle châtrée prend le nom de Coche; le mâle garde celui de Cochın.

Services. - Les Cochons sont essentiellement des animaux alimentaires. On peut même dire qu’à ce titre, aucun animal

(1) N. Jouy, L'Ilomme avant les métaux. Paris, 1879, p. 248. 
domestique n'est d'un usage aussi général: sur toute la surface du globe, ils fournissent aux populations la plus grande partie et souvent même la totalité de la nourriture animale. On consomme à la fois leur chair, leur lard, leur graisse interne (saindoux, axonge), leurs intestins, leur sang, etc., sous mille formes différentes. Ils ne laissent pour ainsi dire aucun déchet. La chair est grasse, peu digeste; elle s'altère rapidement et par suite occasionne souvent des accidents de botulisme; on sait en outre qu'elle peut transmettre à l'Homme le Ténia armé et la Trichine. Ajoutons qu'on racle la face interne de l'estomac des Porcs (bien plutót que de la caillette des Moutons), en vue de préparer la pepsine médicinale, agent souvent employé dans le traitement de certaines dyspepsies (1).

Quant aux services qu'ils peuvent rendre de leur vivant, ils sont assez restreints. Grognier en cite cependant quelques-uns. Dans le Périgord, on les emploie à la recherche des truffes. En Normandie, on les attachait autrefois au pied des pommiers, quils cultivaient en fouillant la terre tout autour. On raconte même que, dans les Apennins, on les utilise à la façon des Chiens de berger. "Dans certaines parties de l'Écosse, dit P. Gervais, principalement dans le Murrayshire, le Porc travaille comme bête de trait, et il n'est pas rare d'y voir un petit Cheval, un Ane et un Cochon attelés à la mème charrue. M. Grognier a vu en France de pareils attelages, et il rappelle qu'une loi les avait défendus au peuple juif. En Amérique, on lâche les Cochons contre les Serpents venimeux, dont ils font leur proie. Un arrache aux Cochons vivants des soies pour faire des brosses, des vergettes et des pinceaux. Enfin, le fumier de Cochon, quoique peu estimé, a aussi son utilité; dans le nord, on l'emploie principalement dans les champs de houblon (2). "

Hybrides. - Il n'est pas rare d'observer la fécondation de la Truie par le Sanglier. En 1872, Sanson a fait accoupler à Grignon une Truie de race celtique avec un Sanglier d'Algérie. Les petits ont montré tous les caractères extérieurs de l'espèce maternelle, sauf quelques taches noires; ils avaient également six vertèbres lombaires. Ces produits ne se sont point montrés féconds entre eux, bien que le màle possédàt des spermatozoïdes; mais les femelles ont pu ètre fécondées par un màle de l'espèce maternelle (3). E. Thierry a vu le produit màle d'un Sanglier et d'une Truie féconder une autre Truie.

Les Potamochères (Potamochœrus), autrefois appelés Chẻropotames, méritent à peine d'ètre séparés du genre Sus. Ils s'en distinguent par des formes plus fines, par la présence d'une saillie osseuse qui supporte un renflement

(1) Pour l'utilisation des produits accessoires de la charcuterie et de la boucherie, consulter L. Villain. La viande malade. Paris, 1894, p. 153.

(2) P. Gervais, Hist. nat. des Mammifères, t. Il, p. 240 . Paris, 1855.

(3) A. Saxson, Trailè de Zootechnie, 3e éd., t. 11, p. 24 et 229. Paris, 1888. 
verruqueux et se trouve située eutre l'œil et le groin, enfin par la dentition, i laquelle manque une prémolaire.

On distingue dans ee groupe le Sanglier de fuinée ( $\boldsymbol{P}$. porcus), à oreilles en pinceaux, et le Singlier a masque ( $P$. africanus sen larvatus), du sud et le l'ouest de l'Ifrique.

Les Babiroussas (Babirussa F. Cuv.) ont le corps élancé, haut sur pattes, et sont remarquables par leurs camines très développées, simulaut presque les cornes. Les supérieures remontent le long des gencives, percent la peau et se recourbent in croissant vers le front. La machoire supéricure ne porte de chaque coité que deux incisives, et les deux màchoires offrent deux prémolaires et trois molaires.

On n'cn connait qu'une espece, B. alfurus, des îles de la Sonde et des Moluques.

Les Phacochères (Phreochomus) sont faciles à reconnaître à leur tète hideuse, à large groin, por-

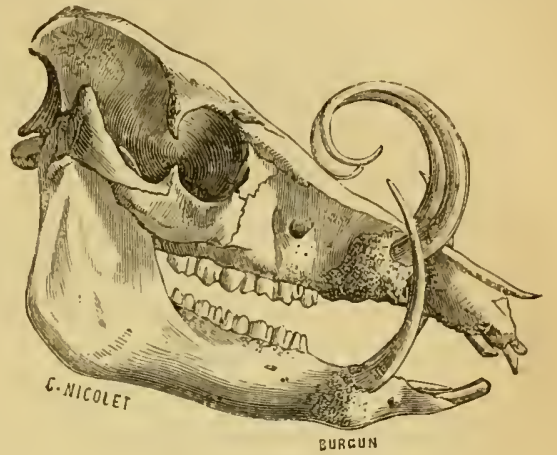

Fig. 826. - Téte de Babiroussa. taut de cliaque còté, au-dessous et en avant de l'œil, une forte éminence verruqueuse aussi grande que l'oreille et simulant une courte corne. La màchoire supérieure ne présente de chaque còté qu'une seule incisive, qui même se perd souvent chez les adultes; linférieure en montre 2 ou 3. Les canines sont tıès développées.

Deux espèces: Ie Phacochère d'Éthiopie (Ph. xthiopicus), ou Emgalo du Cap, et le Placochère d'Ėlien (Ph. africanus), du centre de l'Afrique. Ce sont les animanx farouches et très dangereux.

Enfin, les Pécaris (Dicolyles), représentanls américains de la famille des Suidés, marquent le passage des Porcins vers les Ruminarts par leur estomac ì trois compartiments, ainsi que par le commencement de soudure de leurs métacarpiens et de leurs métatarsiens. Leurs pieds postérieurs sont généralement tridactyles, par suite de l'atrophie du doiğ externe. Formule dentaire: $\frac{2.1 \cdot 3,3}{3 \cdot 1 \cdot 3,3}$. Les canines sont peu saillantes; les supérieures sont lirigées en bas. Tous ces animaux possèdent une glande cutanée lorsale qui fournit une sécrétion laiteuse d'une odeur forte et désagréable.

Le Pécari à collier (D. torquulus) habite le nord de l'Amérique. Le P'écari à lèvres blanches (D. latiutus), de plus grande taille, est de l'Amérique du Sud.

SECOND SOUS-ORDRE

RUMINANTS

Bisulques souvent dépourvus d'incisives et de canines supérieures; estomac divisé en quatre (ou trois) compartiments et propre à la rumina- 
tion; métacarpiens et métatarsiens des doigls médians presque toujours soudés on un seul os.

Tous les Ruminants foulent le sol par leurs deıx doigts médians, ce qui les a fait appeler quelquefois Didactyles. Les deux autres doigts, assez courts et terminés par des ergots, sont rejetés en arrière : dans certaines espèces, ils deviennent même rudimentaires, et arrivent enfin à disparaître (Girafe, Chameaux). Les métacarpiens et métatarsiens des deux doigts principaux sont soudés entre eux, sauf dans un genre de Tragulidés (Hyarmoschus), où la soudure fait défaut aux membres antérieurs et n'est que partielle aux membres postérieurs.

Chez un grand nombre d'espèces, on trouve, au-dessus de la fente interdigitale, une poche cutanée, velue, au fond de laquelle débouchent de nombreux follicules, qui sécrètent un liquide onctueux et souvent odorant : on donne quelquefois ì cet organe glandulaire le nom de sinus biflexe. D'autre part, on appelle larmier un sac inembraneux à parois également glanduleuses, situé dans une fosse sousorbitaire du maxillaire supérieur, et dont la sécrétion onctueuse et noirâtre prend, à l'époque des amours, une odeur particulière (Cerfs).

A l'exception des Tragulidés, des Moschidés et des Camélidés, tous les Ruminants possèdent des cornes, armes diversement constituées qui souvent sont propres aux mâles, et, dans tous les cas, sont plus développées chez eux que chez les femelles. On en distingue trois sortes : $1^{\circ}$ chez la Girafe, ce sont des saillies osseuses recouvertes par la peau non modifiée; $2^{\circ}$ chez les Bovidés ou Cavi-

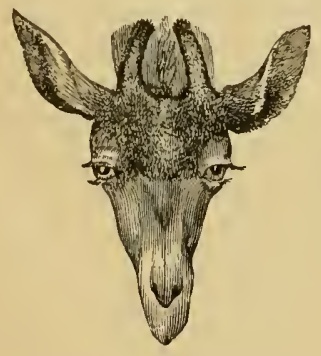

Fig. 827. - Tête de Girafe.

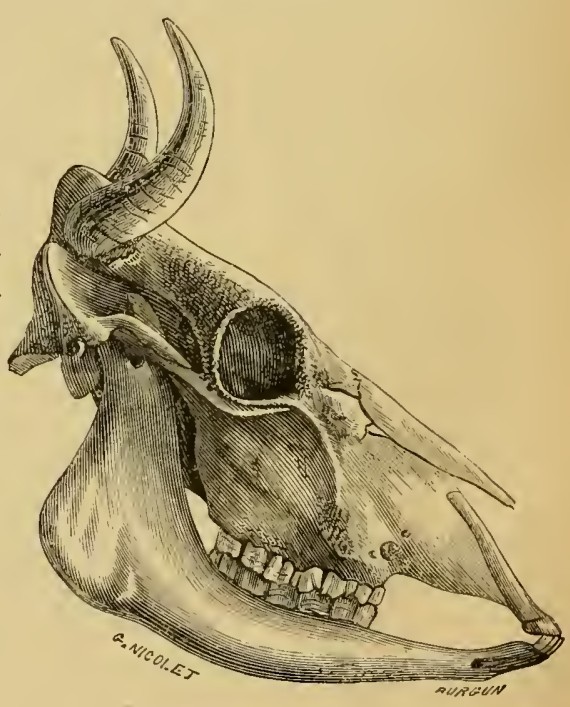

Fig. 828. - Tète de Bœuf.

cornes, il existe une cheville osseuse, pleine ou creuse, fixée solidement au crâne et revêtue d'un étui corné : ces cornes sont permanentes, comme celle du premier type; $3^{\circ}$ chez les Cervidés, on voit apparaitre d'abord des apophyses analogues à celles de la Girafe, mais terminées 
par un plateau ì perles osseuses, appelé meule ou cercle de pierrures: it des époques déterminées, ce plateau est le siège d'une sorte de poussée inflammatoire, et donne ainsi naissance, avec une rapidité étonnante, a une production osseuse ou bois qui se recourre d'une peau fine el

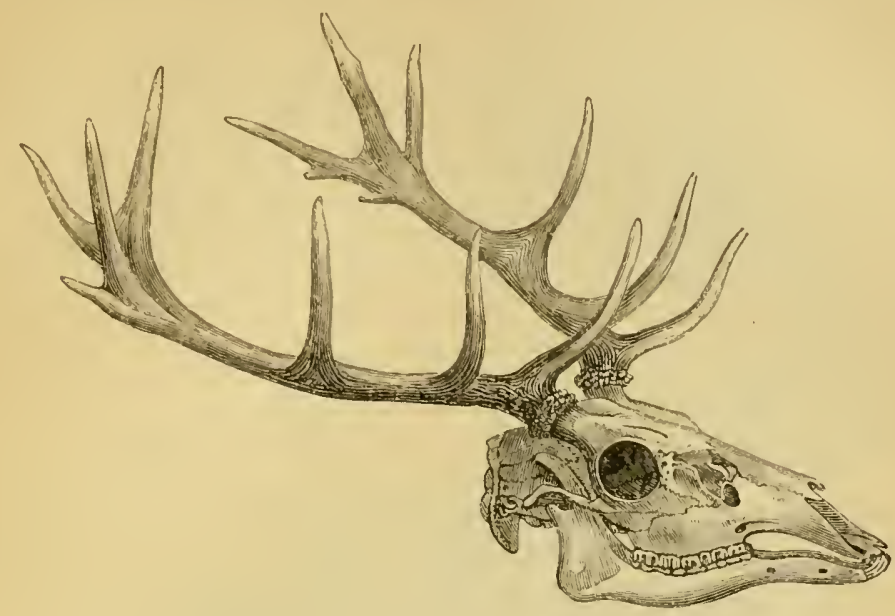

Fig. 820. - Téle el bois du Cerf d'Europe.

velue bientòt desséchée et exfoliće; puis, l'accroissement terminé, la circulation s'arrête et le bois finit par tomber. Il est à remarquer que le développement des hois est lié à la fonction des organes reproducteurs: un Cerf châtré n’en pousse plus de nouveaux, unais il conserve ceux qu'il possède au moment de l'upération.

La dentition marque une tendance à l'élimination des incisives supérieures; les Camélidés seuls en possèdent encore une sur chacun des os intermaxillaires.

Les canines supérieures se rencontrent plus souvent : elles n'ont. tout ì fait disparu que chez les Cavicornes et les Girafes. Toutes ces dents sont remplacées par un coussinet calleux du bord de la inàchoire, contre lequel viennent s'appliquer les dents inféricures. Sauf chez les Camélidés, celles-ci sont au nombre de quatre de chaque côté, réunies en demi-cercle et très obliques. L’externe, quoique représentant sans doute une canine, présente comme les autres l'aspect d'une incisive. Les molaires appartiennent au tỹpe sélénodonte; il y en a cinq à sept de chaque cìté.

L'estomac (1) offre une conformation remarquable, liée ì l'acte de la rumination. Il se compose en général de quatre compartiments. Le premier, le plus vaste chez l'adulte, est la panse (rumen); sa cavité, d'ordinaire divisée en plusieurs sacs, est tapissée par une muqueuse

(1) J.-A. Cunnen, Recherches sur l'anatomie comparée de l'estomac des Ruminants. Annales des sc. nat. (Zoologie), (8), XVI, p. 1, 1894. 
dẹpourvue de glandes, mais hérissée de papilles, lesquelles ont probablement pour fonction de régulariser la température dans les fermentations stomacales. Le deuxième, appelé bonnet ou réseau (reticulum), offre à sa surface interne un ensemble d'alvéoles de dimensions variables, limités par des cloisons de même nature que les papilles du rumen. Le troisième ou feuillet (omasus) se montre garni de lames intérieures qu'on a comparées aux feuillets d'un livre, et qui forment parfois des systèmes ou cycles complexes, mais sont toujours constituées exclusivement par la muqueuse. Enfin, le quatrième, la caillette (abomasus) offre aussi des plis longitudinaux de sa muqueuse, et au point de rue morphologique offre des rapports très étroits arec le feuillet, qui en est comme le restibule; au point de

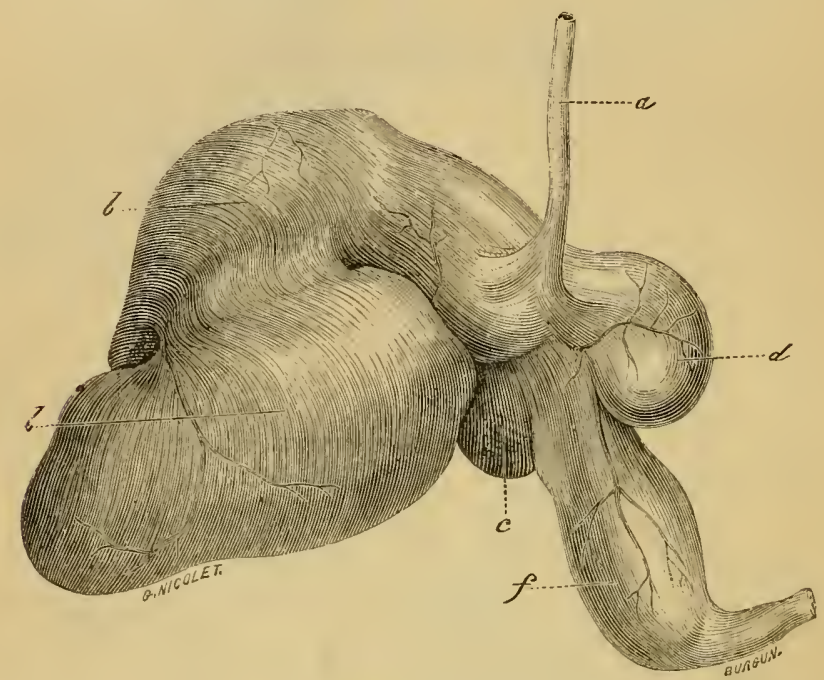

Fig. 830. - Estomac du Hlouton. - $a$, asophage. $b, b$, panse ou rumen. $c$, bonnet ou réseau. $d$, feuillel ou psautier. $f$, caillette.

vue physiologique, la caillette est l'estomac véritable, sécrétant le suc gastrique. Entre la panse et le feuillet, se trouve un demi-canal 'pu'on regardait autrefois comme la continuation de l'œsophage, et qu'on désigne pour cette raison sous le nom de gouttière csophagienne: en réalité, c'est un simple retroussement de la couche musculaire interne de l'estomac le long d'une bande médiane (fond de la gouttière) qui se trouve réduite ì la couche musculaire externe. - Chez les jeunes animaux qui tètent encore, exception faite des Camélidés, la caillette représente le compartiment le plus vaste. D'ailleurs, l'estomac de tous les Ruminants n'offre pas la constitution typique que nous venons d'indiquer. Ainsi, chez les Tragulidés, le feuitlet manque complètement et la gouttière osophagienne, toujours rudimentaire, fait parfois totalement défaut dans la partie antérieure, près du cardia. 
Chez les Camélidés, le rumen, dépourvu de papilles, présente à cliacune de ses extrémités une poche à eau formée d'alvéoles profonds qui gaufrent la surface du viscère et dont le fond et les parois sont tapissés de glandes; le réseau montre des cellules lout à litit analogues; la grouttière esoplatgienne a sa lèvre postérieure ì peinc marquée; enfin, au réseau fait suite un dernier compartiment intestiniforme, à plis longitudinaux faibles et espacés : d'aucuns l'ont regardé comme la caillette; les autres roient dans ses régions antérieures un feuillet rudimentaire. Cordier se refuse à toute assimilation avec les réservoirs gastriques des autres Rmminants, et considère que l'estomae des Camélidés ne peut être comparé qu'à celui des Pécaris.

La rumination est l'acte par. lequel les matières alimentaires, parvenues dans l'estomac après aroir subi une mastication incomplète, sont ramenées ì la bouche, où elles sont broyées à noureau, pour être ensuite définitivement dégluties et digérées. La plupart des Ruminants sont des animaux faibles et timides qui vivent dans la crainte continuelle de leurs ennemis. Aussi se hàtentils d'ingérer les herbes et les feuilles qui constituent leur nourriture, en leur faisant subir à peine une trituration grossière. Ces matières ront s'accumuler dans la panse et

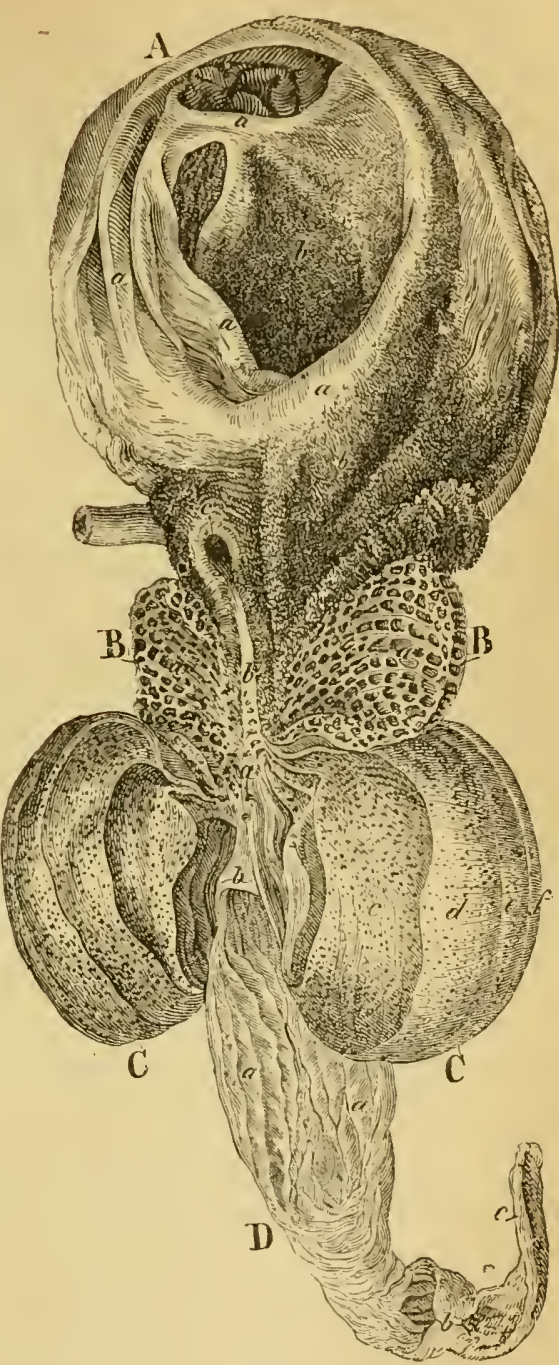

Fig. 831. - Eslomac de Ruminant, dont les quatre compartiments sont ourerts pour moulrer la surfaee intéricure. - $\mathrm{A}$, panse. $a$, piliers. $b$, papilles. $c$, ori= fice resophagien. B, tonnel. $a$, alvéoles. $b$, gouttière esophagicune. C, feuillet. $a$, poinles cornces de l'orifice du bonnet. $b$, valvule is l'orifice de la cailletle. $c$, une grande lame. $d$, une lame moyeme. $P$, une jetite lame. $f$, une lame linciairc. D, caillelle. $a$, plis longitudinaux. $b$, orifice jivloriøue. $c$, duodénum. quelque peu dans le réseau, oì elles subissent déjà certaines fermentations. Puis, les animaux cherchent un lieu tranquille et abrité, et font alors revenir les aliments 
dans la bouche, pour les soumettre à une seconde mastication (mastication mérycique).

G. Colin attribuait la réjection à la contraction du rumen, aidée par celle du diaphragme et des muscles abdominaux; mais cette contraction brusque du rumen ne peut avoir lieu, car la paroi stomacale des Ruminants ne renferme que des fibres lisses (Noack, Cordier). D'après Chauveau et Toussaint, la réjection est le résultat d'une aspiration thoracique: la glotte se ferme d'abord; puis survient une énergique contraction du diaphragme ayant pour résultat une raréfaction considérable de l'air contenu dans te thorax; cette diminution de pression se traduit par un appel des matières diffluentes situées au roisinage de la goultière wosophagienne, matières qui se précipitent dans l'œsophage; enfin, une contraction antipéristaltique de ce canal les amène daus la bouche.

Réduits en fine bouillie par la mastication mérycique, ces aliments passent dans la gouttière œsophagienne transformée en canal par le rapprochement de ses bords, et gagnent alors en grande partie le feuillet et la caillette. Le feuillet retient entre ses lames les substances qui n'ont pas été suffisamment atténuées pour passer dans la caillette : c'est donc un organe de trituration, mais il ne peut remplir ce rôle qu'après aroir proroqué l'exsiccation de son contenu. C'est dans la caillette, enfin, que s'opère la véritable digestion gastrique.

L'intestin est toujours très développé. Les mamelles, au nombre de deux ou de quatre, sont situées dans la région inguinale. Le plus souvent, chaque femelle ne donne naissance qu'à un seul petit, qui est déjà dans un état fort avancé, capable de suivre sa mère au bout de quelques heures.

Les Ruminants sont presque tous polygames; ils vivent en troupes, les mâles les plus forts marchant en tête.

Nous en distinguerons six familles : Camelide, Tragulidx, Moschida, Cervide, Camelopardalidæ Bovidie.

Les GAMÉLIDÉS ou Tylopodes, par la constitution de leur squelette et de leur estomac, par leur dentition et leur placenta diffus, mériteraient presque d'être classés dans un groupe spécial, entre les Porcins et les Ruminants typiques. Ils sont caractérisés d'abord par la disposition de leurs pieds, qui sont peu fendus et n'ont, chez les förmes vivantes, que les deux doigts médians $\left(\frac{3.4}{3.4}\right)$ terminés par de petits sabots et offrant une surface plantaire large, bombée, calleuse

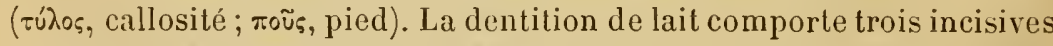
à chaque mâchoire; mais, à l'âge adulte, il n'en reste généralement qu'une seule paire à la mâchoire supérieure. Il existe, en haut comme en bas, une canine forte et pointue, et sourent, en arrière de celle-ci, une prémolaire caniniforme, séparée des autres molaires par une barre. Les Camélidés n'ont point de cornes. Ils ont un grand cou et une 
lève supérieure fendue. La vésicule biliaire fail défaut. Les mamelles sont au nombre de quatre. Les hématies sont elliptiques.

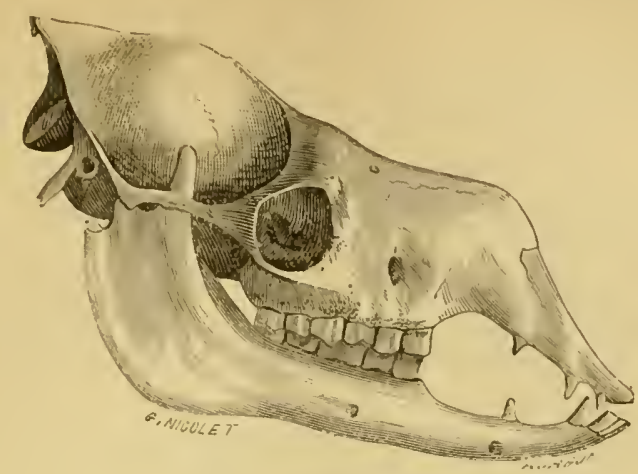

Fig. 832. - Téte de Chameau.

Ces animaux sont sociables à l'état saurage; ils vivent en troupes plus ou moins nombreuses. Tous ront l'amble.

Ils composent actuellement deux genres: Camelus et Auchenia, le premier de l'ancien, le second du noureau continent. Aux époques éocẻne et miocène, la lamille était limitée à l'Amérique du Yord.

Les Lamas (Auchenia Illiger') sont de taille moyenne, à cou long et presque rertical, à ligne dorsale droite, sans aucune apparence de bosse, it queue courte ou rudimentaire, à loison longue et épaisse. Il y a souvent des callosités, c'est-à-dire des surfaces nues et indurées, à la poitrine et aux genoux. Les deux doigts sont séparés, offrant chacun une plante calleuse. Formule dentaire $: \frac{1.1 .2,3}{3.1 .1,3}$.

Ces animaux vivent dans l'Amérique du Sud. Ils sont très doux, et ne se défendent guère qu'en lançant au visage de leur agresseur leur salive mélangée d'aliments. - On en connait quatre espèces, dont deux, le Lama et l'Alpaca, étaient déjá entièrement domestiquées lors de la découverte de l'Amérique. "Le premier animal de ce genre qu'on ait montré en France, dit P. Gerrais, y arriva par la voie l'Angleterre; on le voyait ì l'École d'Alfort en 1773. '

Le Guanaco (A. huanacu), de la taille d'un Cerf, et la Vigogne (A. vicugna), grande comme un Mouton, vivant en troupes dans les Cordillères, où on les chasse pour leur chair et pour leur toison. Ces animaux, surtout le dernier, s’apprivoisent sans trop de dilficultés lorsqu'ils sont pris jeunes.

Le Lama proprement dit (A. ylama) est un peu plus grand que le Guanaco, dont il se distingue en outre par la présence de callosités à la poitrine et aux genoux. Le pelagre est très variable quant à la couleur : il peut ètre blane, roux, brun, noir ou même tacheté.

Le Lama est entretenu à l'état domestique sur le haut plateau du Pérou. On l'a quelquefois regardé comme dérivant du Guanaco. 
Il est employé comme bête de somme pour le trafic qui s'effectue à travers les hauts cols, entre les mines et la côte. Il ne porte guère que 80 à 100 lilogrammes, et va à très petites journées, de 20 kilomètres au plus: quand il est fatigué, il se couche et refuse d'avancer. Aussi commence-t-on à le remplacer avantageusement par des Equidés, et en particulier par le Mulet. On ne se sert d'ailleurs que des mâles; les femelles sont réservées pour la reproduction. La chair du Lama est bonne; sa laine n’est guère utilisée.

L'AIpaca (A. paco) est plus petit que le Guanaco; sa toison est longue et douce, blanche, noire ou mouchetée, ce qui dénote encore un état très ancien de domesticité ; elle tombe en longues mèches de chaque còté du corps.

On entretient le Paco en troupeaux immenses, qui ne sont amenés près des habitations qu'au moment de la tonte. Sa laine est en effet très estimée, et sert à fabriquer des étoffes spéciales. Sa chair est excellente. Quelques auteurs le regardent aussi comme une simple race du Guanaco.

A diverses reprises, on a tenté d'acclimater cet animal en France, ainsi que le précédent; mais ces essais n'ont pas abouti.

Les Chameaux (Cumelus L.) sont des animaux de grande taille, à cou long et recourhé, à dos surmonté d'une ou de deux masses graisseuses en forme de bosses, el à queue courte, munie d'un pinceau terminal. Ils présentent des callosités à la poitrine, aux genoux et aux grassets. Leurs deux doigts sont unis en arrière par une plante commune. Formule dentaire $: \frac{1.1 .3,3}{3.1 .2,3}$.

On a signalé deux Chameaux dans le pliocène des monts Sivalik: l'un, $C$. sivalensis, se rapproche du Dromadaire; l'autre, $C$. antiquus, paraît avoir été de plus petite taille. On en a recueilli également dans le diluvium de la Sibérie et du sud de la Russie (C. sibiricus, $C$. Knoblochi). En Algérie, Thomas a signalé un Dromadaire des alluvions quaternaires de l'Oued Seguen, et Pomel a trouré dans une station paléolithique un crâne provenant d'une espèce distincte. - Pour ce qui est des représentants actuels du genre, on n'en connaît pas de véritablement sauvages : ceux de l'Asie centrale, qu'on a décrits comme tels, paraissent dériver d'individus domestiques qui ont repris leur liberté. On en distingue d'ordinaire deux espèces, l'une asiatique, à deux bosses, le Chameau de la Bactriane; l'autre africaine, à une bosse, le Dromadaire; mais il y a lieu de se demander si les différences que présentent ces deux types ont réellement une valeur spécifique. Ils donnent ensemble des produits indéfiniment féconds, tantôt à une seule, tantôt à deux bosses, quel que soit le sens dans lequel s'effectuent les unions. Ces produits sont utilisés comme animaux agricoles dans le sud et le sud-est de la Russie. 
Le Chameau bactrien (C.'bactrianus L.), encore appelé Chameau à deux bosses ou simplement Chameau, doit représenter la forme primitive. Il se distingue à première vue par la présence de deux hosses situées, l'une au niveau du garrot, l'autre au niveau du sacrum. Il est assez trapu et a les membres relatirement courts; son pelage est épais et rude, surtout aux épaules, autour les bosses et sur la tète; sa couleur est brun roussàtre, plus claire en été.

Le Chameau est originaire, dit-on, de l'ancienne Bactriane, aujourd'hui le khanat de Khoulm, dans le Turkestan afghan; mais il s'est répandu dans toute l'Asic centrale et orientale. Prjevalski dit l'avoir observé à l'état sauvage près du Lob-nol. Depuis un temps immémorial, il est utilisé par les Tartares, les Mongols et les Chinois; ses allures lourdes font toutefois qu'on ne l'emploie guère que comme bête de somme. C'est par lui que se fait tout le trafic entre la Chine et les pays de l'Occident. Il est indispensable à beaucoup de peuplades asiatiques nomades, quil transporte à travers les steppes, et auxquelles il fournit son lait, sa laine, sa viande et sa peau. En Perse, on l'emploie mème comme animal de guerre.

Le Dromadaire $(C$. dromedarius L.) est plus élancé que son congénère, et ses membres sont plus déliés; il ne possède qu'une seule bosse, qui occupe le milieu du dos (fig. 780); son pelage est laineux, plus long sur le cou, les épaules et la bosse, mais cependant moins fourni que celui du Chameau; sa couleur est gris roussàtre, devenant quelquefois fort claire.

Le Chameau à une bosse (1) ne se rencontre, comme nous l'avons dil, qu ¿ l'état domestique, et il comprend un assez grand nombre de variétés. "L’Arabe, dit Brehm, reconnaît bien vingt races de Chameaux; c'est une science comme la science des Chevaux; on parle de Chameaux nobles et ignobles. " En Algérie, on en distingue deux : l'une propre au bât, le Djemel; l'autre à la selle, le Mehari. Ce qu'il y a de curieux, c'est que le nom de Dromadaire est inconnu aux peuples africains qui élèvent cet animal, el que les Européens mêmes qui habitent l'Afrique ne le désignent que sous celui de Chameau. Le mot Dromedarius, employé par les Romains de la décadence, et dérivé de Káunìos opoux́s, Camelus droma, ne s'appliquait qu'aux variétés de course, telles que le Mehari du Sahara, le Bischarin du Soudan oriental, l'Iledjihn de l'Egyple.

Le Djemel ou Dromadaire de charge, qui est de beaucoup le plus fréquemment utilisé dans nos possessions africaines, y présente deux variétés : celle du Tell et celle du Sahara, la dernière plus grande et plus forte.

Domestication. - Le Dromadaire parait originaire des déserts du sud-

(1) Voy. Vintox, Mémoire sur lhistoire naturelle du Iromadaire, extrait du t. VIt du Recueil de mémoires et observations sur l'hygiène et la médecine vétérinaires militaires. Paris, 1856 . 
ouest de l'Asie, et en particulier le l'Arabie, d'où le nom de Chameau des Arabes que lui donnait Aristote.

Il a été domestiqué par les Sémites, qui l'ont amené avec eux dans le Sahara. La Bible en parle dès le commencement, et son nom hébraïque est le même que le nom égyptien.

Aujourd'hui, d'après Brehm, " son aire de dispersion se confond avec celle des Arabes : de l'Arabie ou du nord-ouest de l'Afrique, elle s'étend à travers la Syrie, l'Asie Mineure et la Perse jusqu'en Boukharie, où se trouve le Chameau à deux bosses; d'un autre côté, elle s'ćtend à travers le Sahara jusqu'à l'océan Atlantique et jusqu'au $12^{\circ}$ degré de latitude nord ».

Caractères physiologiques. - Les premières chaleurs apparaissent à trois ans et demi chez le mâle, à quatre ans chez la femelle ou Naga. La saison du rut dure environ huit à douze semaines, de janvier à mars ou avril. Le mâle, doux et calme d'ordinaire, devient alors inquiet, taquin, rétif, pousse des cris ou des hurlements, cherche à mordre ses compagnons ou son chamelier et parfois même devient dangereux. Chez beaucoup d'individus, on voit sortir de la bouche une masse rouge volumineuse, qui n'est autre que le voile du palais tuméfié; la nuque est le siège d'une sécrétion noirâtre d'une odeur forte et repoussante. C'est de six à douze ans que les Dromadaires sont le plus aptes à la reproduction. Un étalon peut faire, sans être fatigué, deux ou trois saillies chaque jour; mais on ne lui laisse guère féconder qu'une quarantaine de Chamelles par saison. L'émission du sperme est très lente, et l'accouplement se prolonge quelquefois fort longtemps.

La durée moyenne de la gestation est de douze mois. La portée est d'un seul petit. Les chaleurs reparaissent peu de jours après le part; mais les Arabes d'Algérie ont l'habitude de laisser aux Nagas une année de repos, et de ne les livrer à l'étalon que tous les deux ans. Le jeune Dromadaire naît avec les yelx ouverts : il se sèvre de lui-même au bout de 11 à 12 mois dans le Tell, de 12 à 13 mois dans le Sahara algérien. Dans le courant de la troisième année, beaucoup d'Arabes châtrent les mâles qui ne leur paraissent pas propres à devenir de bons étalons. La castration de la femelle, signalée par Pline, est inconnue en Afrique. Les Dromadaires peuvent faire un bon service pendant 20 à 22 ans.

Services. - Suivant la race à laquelle il appartient, le Dromadaire est, comme nous l'avons vu, un animal de selle ou un animal de bât. Le premier nous intéresse relativement peu, car il ne se trouve guère que vers le désert. Quant au Djemel, c'est une excellente bête de somme, qui peut porter en moyenne une charge de 300 kilogrammes, et faire ainsi 40 à 45 lilomètres par jour.

C'est surtout pour les populations qui habitent le Sahara et l'intérieur de l'Afrique, que cet animal est précieux. Sans ce navire du désert, comme 
disent les Orientaux, elles ne pourraient traverser ces espaces immenses et désolés que liufon appelait les "lacunes de la nature ".

"Tout le commerce que les Arabes font entre le nord et l'intérieur de l'Afrique, depuis nos villes du littoral jusqu'à Tombonctou, le Soudan, et au delà, n’a lieu qu’ì dos de Dromadaire et ne pourrait ìtre fait autrement. Les Arabes s'organisent en caravanes fortes quelquefois de $\& 000$ Clıameaux; et ces caravanes s'approvisionment à Tunis, ̀̀ Fez, ou dans quelqu'un de nos postes, de produits du Tell ou d'Europe, qu'elles vont vendre ou échanger contre des productions naturelles ou industriclles de l'intéricur de l'Afrique. Elles parcourent le désert en suivant ces grands chemins tracés il y a 2200 ans par llérodote, immuables étapes que suivirent autrefois les marchands de Memphis, après cux ccux de Carthage, et que suivent encore les Arabes pour aller trafiquer au delà du désert, ne vivant en chemin que de farine délayée et de daltes.

"Ces voyages sont fort longs. Quelques-uns ne durent pas moins de deux ans. Chaque Chameau reçoit en partant 200 ou 230 kilogrammes de marchandises, fait tous les jours dix ou onze lieues, quelquefois même quatorze et quinze, et se nourrit des herbes qu'il trouve sur sa route et de quelques kilogrammes de dattes, de fèves, d'orge ou de farine d'orge délayée dans l'eau, qu'on lui donne le soir..... " (Vallon).

Le Dromadaire est en effet d'une grande sobriété. Il s'accommode d'une foule de végétaux grossiers que les autres herbivores ne pourraient pas ligérer. Il peut mème se passer d'aliments pendant plusieurs jours. Par contre, lorsqu'on lui donne à volonté des fourrages verts, il en mange en quelques heures une quantité étonnante. Contrairement à l'Ane, il est peu difficile sur la qualité de l’eau. Au printemps, il ne boit presque jamais, l'eau de végétation des plantes qu’il consomme suffisant à ses besoins; en hiver, il boit tous les cinq ou six jours; en automne, tous les quatre ou cinq jours; en été, tous les deux ou trois jours, à cause de l'absence de plantes vertes. Mais, chaque fois qu'il boit, il absorbe une énorme quantité d'eau : après dix jours de régime sec, Vallon a vu un Dromadaire en ingurgiter 70 litres dans l'espace de six minutes.

Asse\% souvent, les Dromadaires ont été utilisés comme animaux de guerre. Bonaparte s’en était servi pour monter un régiment lors de la campagne d'Égypte. En Algérie, nos généraux avaient tenté de les employer dans les mèmes conditions; mais les cris qu'ils poussent au lever du soleil ayant fait quelquefois manquer les opérations, on avait cru devoir renoncer à leur usage.

Cependant, une loi promulguée le 9 décembre 1894 a crééen Algérie des corps de troupe indigènes de cavalerie montée à M ehara(1), spécialement chargés de l'occupation et de la surveillance des régions sahariennes de la colonic. - En outre, on emploie souvent aux transports, mais sans l'annexer aux colonnes, le Djemel ou Chameau de bàt.

La Chamelle fournit d'excellent lait, qui est consommé presque partout en nature. Les poils du Dromadaire servent ì la confection

(1) Pluriel de Mehari. 
de cordes, de filets et de tissus grossiers. Les excréments desséchés constituent un combustible très avantageux. La chair est de bonne qualité, quoique moins savoureuse et plus filandreuse que celle du Bœuf. Enfin, la peau fournit un cuir épais, propre à des usages divers.

Famille des TRAgulidés. - Les Tragulidés se rapprochent des Porcins par la constitution du métacarpe et du métatarse, ainsi que par le placenta, qui est diffus. Ce sont les Ruminants les plus petits; ils sont dépourvus de cornes, mais le mâle possède des canines supérieures très saillantes. Ils ne sont pas moschifères.

Les Tragulus habitent l'Inde et les îles de la Sonde. Les Hyæmoschus vivent sur la côte occidentale de l'Afrique. On les trouve par couples ou isolés dans les régions montagneuses.

Les MOSGHidÉS établissent le passage des Tragulidés aux Cierfs. Comme les premiers, ils sont privés de cornes, ont le corps relevé en arrière et des canines supérieures très saillantes chez le mâle. Mais, d'autre part, ils ont, comme les Cerfs, des métacarpiens et métatarsiens soudés, un feuillet, un

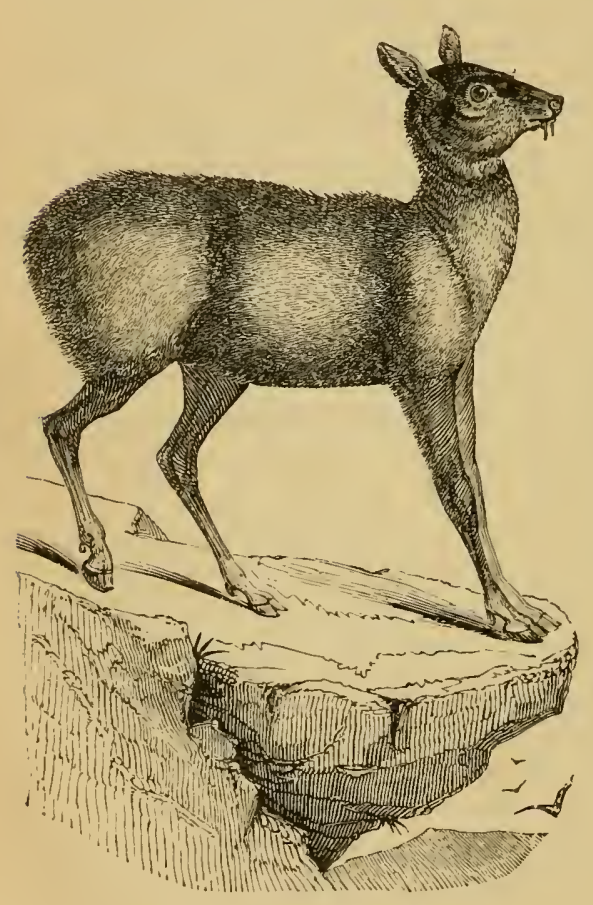

Fig. 833. - Cherrolain porte-musc. placenta cotylédonaire, etc. Aussi A. Milne-Edwards les a-t-il séparés à juste titre des Chevrotains précédents.

Le Chevrotain porte-musc (Moschus moschiferus L.) est à peine de la taille d'un Chevreuil ; les membres sont déliés, et le train de derrière est un peu plus élevé que celui de devant. La queue est courte. Le pelage est formé de poils assez longs, rudes et cassants; il est le plus souvent de teinte gris rougeâtre. On connaît d'ailleurs plusieurs variétés de Porte-musc.

Cet animal habite les sommets les plus élevés des montagnes de l'Asie centrale, où il saute et grimpe avec autant d'agilité qu'un Chamois. Il se tient caché le jour et ne va paitre que la nuit. Pour s'en emparer, les chasseurs mettent à profit l'habitude quiil a de revenir à son point de départ. On ne s'attache qu'à prendre les mâles, qui seuls fournissent du musc.

Musc. - Les Chevrotains ont en effet sous le ventre, entre l'ombilic et la verge, une poche arrondie, plus longue que large, un peu aplatie dans sa partie supérieure, qui répond aux muscles abdominaux, 
et offrant en dessous un sillon qui correspond au passage de la verge. L'orifice de cette poche, entouré de poils convergents, est très rapproché de l'orifice préputial. L'intérieur est tapissé par une muqueuse qui offre de nombreux plis, et dans l'épaisseur de laquelle existent une foule de follicules brunâtres, organes sécréteurs du musc. Che\%

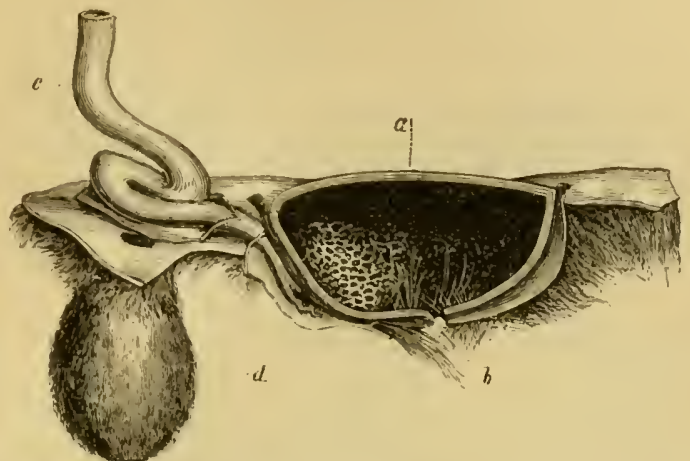

Fig. 83i. - P'oche du musc. - $a$, face supérieure adhérente aux muscles abdominaux. $b$, orifice de poche. $d$, testicule. $e$, verge.

les jeunes animaux, la poche du musc est vide et contractée; chez les adultes, elle renferme $1 \ddot{\text { à }} 20$ grammes de musc, et chez les vieux 8 à 9 grammes.

Le muse à l'état frais a la consistance du miel et une couleur rouge brunâtre. Lorsqu'il est desséché, il est solide, noirâtre et granuleux, quoique onctucux au toucher. Son odeur est forte et persistante; elle disparait quand on le mélange avec du camphre, de l'eau d'amandes amères, du soufre doré d'antimoine, etc. ; sa saveur est amère.

D'après Getger et Reimann, il renferme une petite quantité de graisse, de cholestérine, de résine amère et de principes solubles dans l'alcool, une grande quantité de sels solubles dans l'eau et de lactate d'ammoniaque.

Dans le commerce, on trouve le musc sous deux formes: en vessie, c'est-ì-dire enfermè dans la poche mème où il s'est amassé, ou hor's vessie, débarrassé de cette poche. Le premier est le plus estimé. Les poches qui le contiennent sont en général plan-convexes : la face plane est glabre, sans solution de continuité ; la face convexe, qui correspond ì la paroi externe, offre un trou médian et est revêtue de poils qui convergent vers cet orifice. Le musc étant soumis, en raison de son prix élevé, à un grand nombre de falsifications, il importe de s'assurer que la poche n'a pas été ouverte, puis recousue, ou si ce n'est pas un sac artificicl fabriqué avec la peau du Chevrotain ou de tout autre animal. On distingue, dans le commerce européen, deux sortes principales de musc en ressie : le musc Tonkin et le musc Kabardin. Le musc Tonkin présente deux variétés, l'une qui 
vient du Thibet, l'autre du Yunnan; toutes deux sont amenées à Tiensin, qui est le principal port d'exportation; Shanghaï et Canton n'en expédient que fort peu. Le musc Kabardin ou de Russie est recueilli en Sibérie et dans l'Altaï; il est peu odorant et beaucoup moins estimé que celui du Thibet; on le vend surtout en Allemagne. - Quant au musc hors ressie, on ne peut guère le recommander, tant il est sujet à être falsifié : les meilleures sortes ne renferment pas plus de 60 p. 100 de musc pur.

Le musc, qui joue un si grand rôle en parfumerie, a eu dans l'ancienne médecine une rogue inouïe; de nos jours, la plupart des médecins le considèrent comme un médicament superflu. Quelquesuns pourtant le prescrivent encore comme stimulant et comme antispasmodique.

Les GERVIDÉS sont surtout caractérisés par leurs bois, qui sont bien développés chez les màles, rarement chez les femelles (Renne). Les mâles possèdent sourent des canines supérieures. Il existe toujours des larmiers.

Les Cerfs virent, pour la plupart, en troupes dans les foretts. On les chasse pour leur chair, leur peau et leur bois. - Genres : Cerrule (Cerrulus), Cerf (Cerrus), Daim (Dama), Élan (Alces), Renne (Tarandus). Parmi les espèces les plus connues, citons : le Cerf commun (Cerrus elaphus), le Cherreuil (C. capreolus), le Daim (Dama vulgaris), le Renne. Autrefois, les Suédois apprivoisaient et attelaient les Élans.

La corne de Cerf et bien d'autres produits du mème animal ont joui d'une grande réputation, non justifiée d'ailleurs, dans l'ancienne médecine.

Le Remne (Tarandus rangifer) est à peu près de la taille de notre Cerf; il a le corps assez allongé, porté sur des membres forts, à sabots larges et écartés, à ergots très longs. Les bois ont un pédoncule court, et les andouillers, bien développés, sont de forme aplatie: en outre, l'un des deux basilaires se recourbe en avant comme une sorte de soc, dont l'animal se sert pour écarter la neige et chercher sa nourriture. C'est la seule espèce dont la biche porte aussi des bois, qui sont toutefois un peu plus faibles que ceux du mâle. Son pelage est grossięr, brun grisàtre, et pend sous la gorge; il devient fort long en hiver.

Très répandu dans notre pays à l'époque quaternaire, le Renne est aujourd'hui relégué dans les régions des deux mondes qui aroisinent le pòle arctique. Il vit à l'état saurage dans les plaines et les hauts plateaux; mais on le trouve aussi à demi domestiqué chez beaucoup de peuplades du Nord, dont il forme la base de l'existence. "Le Lapon utilise tout, dit Vogt, jusqu'au contenu de l'estomac qu'il fait bouillir comme légume, jusqu'à la moelle des os encore chaude, qu'il dérore crue. On emploie les Rennes comme bêtes de trait. On les mène en grands troupeaux, comme des moutons, sous la garde de chiens très appréciés de leurs propriétaires. 'Mais ils restent toujours demi-saurages, et retournent très facilement à la vie libre. Ils sont toujours si peu apprivoisés qu'on ne peut traire les femelles sans 
avoir altachées au moyen d'un lasso jeté autour descornes. Quant au plaisir de voyager en traîneau attelé de Rennes, on le laisse volon-

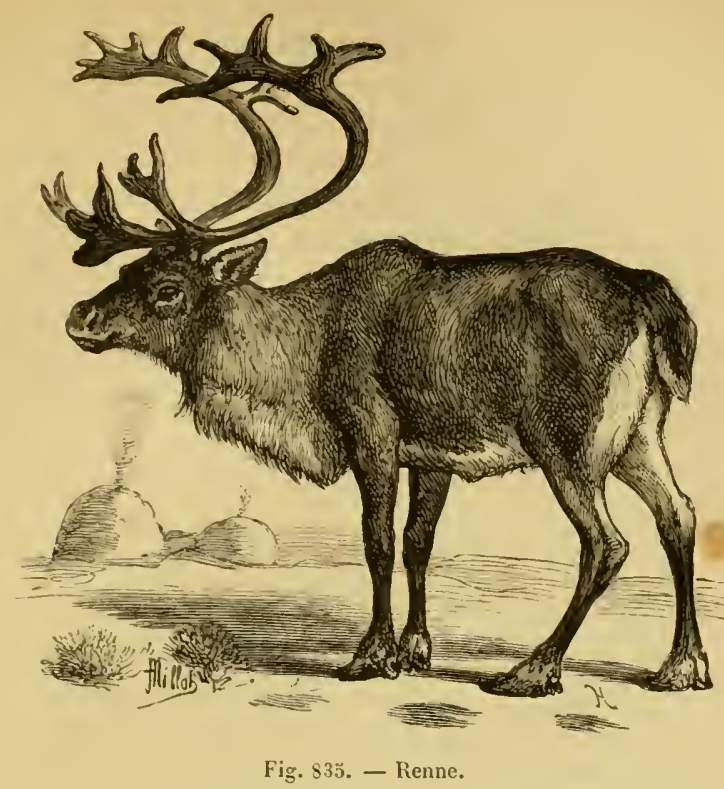

tiers aux Lapons, luabitués aux culbutes et à tous les désagréments que pourrait procurer une mule sauvage, têtue et inintellig’ente. "

Les CAMÉLOPARDALIDÉS ou Déclives (Devexa) sont acluellement représentés par des Ruminants à cou très allongé et à membres hauts, dont l'arant-train est fbeaucoup plus élevé que la région postérieure, de sorte que le dos se montre fort incliné en arrière. La tète, petite et allongée, porte deux cornes osseuses revêtues d'une peau velue, auxquelles s'ajoute, chez Ie màle, une bosse frontale impaire. Formule digitale : $\frac{3.4}{3.4}$.

Une seule espèce virante : la Girafe (Camelopardalis giraffa), le plus haut des Mammifères terrestres, qui parcourt en petites trourees les plaines de l'Afrique tropicale.

Famille des BOVIDÉS. - Les Bovidés, encore appelés Cavicornes, sont caractérisés, comme l'indique ce dernier nom, par des cornes creuses formant un étui qui enveloppe une apophyse du frontal. Cet axe osseux est tantôt plein, comme chez les Antilopes, tantôt creusé d'une cavité qui communique arec le sinus frontal, comme chez les Ioufs. - Quant à l'étui, sa croissance se continue pendant toute la vie, avec des périodes d'arrêt qui se traduisent par la formation d'anneaux plus ou moins complets. La grandeur et la forme des cornes sont très rariables. - La dentition est des plus uniformes. Les inci- 
sives et les canines supérieures manquent toujours. Les incisives inférieures, comprenant les canines modifiées, sont au nombre total de huit. Il y a de chaque côté trois prémolaires (rarement quatre) et trois molaires. La formule dentaire est donc $\frac{0 \cdot 0 \cdot 3,3}{3 \cdot 1 \cdot 3,3}=32$. Formule digitale des formes actuelles $\frac{2.3 .4 .5}{2.3 .4 .5}$.

Ces animaux sont tantòt lourds, tantòt sveltes et gracieux. Quelques-uns vivent par couples; la plupart forment des troupeaux nombreux. Il en est qui sont sédentaires; d'autres effectuent de grandes migrations. D'aucuns fréquentent les endroits marécageux; le plus grand nombre préfèrent les steppes ou même les montagnes escarpées. Plusieurs espèces ont été domestiquées dès la période de la pierre polie, et on doit les considérer comme les plus utiles parmi les auxiliaires de l'humanité.

On peut grouper les Cavicornes en trois sections ou sous-familles: Antilopinx, Ovinæ et Bovinæ.

$1{ }^{\circ}$ Les ANTILOPINÉS ne peuvent guère ètre caractérisés zoologiquement. Pallas disait avec raison que les naturalistes ont appelé Antilopes les Cavicornes qui ne se laissent classer ni avec les Bœufs, ni avec les Chèvres, ni avec les Moutons. Leurs cornes sont rondes, droites ou courbes, lisses ou non, et parfois n'existent que chez le màle; elles sont supportées par un axe osseux plein ou offrant une excavation à sa base et naissant immédiatement au-dessus des orbites. Les incisives médianes (pinces) sont en général plus dẻveloppées que les latérales.

Les Antilopes peuplent tout l'ancien monde; deux espèces seulement habitent l'Amérique. - Parmi les plus connues, nons citerons : le Gnou (Catoblepas Gnu), du Cap; le Nilgau (Portax piclus), des Indes; le Saïga (Saiga tatarica), des steppes de la Russie; la Gazelle (Gazella dorcas), de l'Afrique septentrionale; le Chamois ou Izard (Rupicapra europæa), des Alpes et des Pyrénées, dont les cornes, assez longues, effilées, recourbées en un crochel très court et pointu, étaient autrefois employées en chirurgie vétérinaire pour pratiquer la saignée au palais du Cheval; la Chèvre des nontagnes Rocheuses (Haplocerus americanus), qui établit le passage vers les Ovinés; le Takin ou Ye-Mou (Budorcus taxicola), du Thibet oriental, intermédiaire entre les Antilopinés, les Ovinés et les Bovinés; etc.

$2^{\circ}$ Les ovinÉs se reconnaissent à leurs cornes plus ou moins comprimées et annelées, supportées par une cheville creuse, grande, comprimée latéralement, naissant au-dessus des orbites. Le frontal est assez étendu, creusé de sinus médiocres. L'axe facial forme avec l'axe du crâne un angle relativement fermé. Les incisives sont toutes semblables. Les femelles ne possèdent d'ordinaire que deux mamelles.

On n’admet généralement dans cette sous-famille que deux genres, Ovis et Capra, lesquels sont mème assez peu distincts pour que divers auteurs aient cru devoir les reunir en un seul. Nous y ajouterons le genre Ovibos, souvent classé parmi les Bovinés. 
Les Moutons (Ovis L.) ont des formes plus arrondies que les Chèvres et ne portent pas de barbe; leur chanfrein est busqué, leur front plat; leurs cornes, souvent contournées en hélice, sont marquées d'anneaux tuberculeux presque complels; les chevilles osseuses sont trigones, à face antérieure plane ou convexe, à surface de section plus large que longue. Leur cràne est large; leurs os nasau. sont courts et larges. Ils possedent des larmiers et des glandes interdigitales. Leurs jambes sont grèles; leur queue est courte, mais entièrement velıe; leur pelage est formé d’un mélange de laine et de poils courts et fins.

Tels sont, dı moins, les caractères typiques du genre; mais il existe des formes qui établissent la liaison arec les Chèvres, et qui ont un chanfrein presifue droit avec absence de larmiers. - Ajoutons que, chez les Moutons saurages, les deux sexes sout pourvus de cornes; cependant, celles de la femelle, toujours plus petites et sourent moins tordues, arrivent quelquefois à dispiraitre.

Les IIoutons fréquentent les régions montagneuses de l'ancien et du nouveau monde; ils courent, sautent et grimpent sur les rochers avec une agilité remarquable. Ils forment assez volontiers des troupeaux nombreux, qui se laissent guider par de vieux chefs vigilants. Ils sattachent sans trop de diflicultés à l'Homme, qui a pu domestiquer certains d'entre eux.

A l'état fossile, on n'a guère eité jusqu'à présent qu'un petit nombre d'espèces appartenant au genre Ocis; la plus commune est le Mouflon d'Europe (O. musimon), trouvé dans les gisements quaternaires du littoral méditerranéen. 0 . primxva Gervais est une forme douleuse. 0 . Sacini Newton provient dı quaternaire le plus ancien de l'Angleterre; 0 . argaloides Nehring, d'une caverne a ossements de la Moravie. O. antiqua Pommerol, du diluvium de l'Auvergne, paraît ètre voisin de l'O. Polii actuel. Thomas a signalé 0 . tragelaphus et 0 . aries dans le quaternaire récent de l’Algérie. Nehring ne cite que deux observalions certaines d'o. aries quaternaire: une à Pottenstein, près Bayreuth (Haute Franconie), l’autre dans la "Caverne des brigands", entre Nuremberg et Ratisbonne. Rütimeyer relève cette rareté des Ovinés fossiles comme une des lacunes les plus remarquables de la paléontologie des Mammifëres.

Les Moutons sauvages actuels se laissent classer un peu arbitrairement en trois sections: les formes sans larmiers, les Argalis et les Mouflons.

$1^{\circ}$ Les Moutons sans larmiers, formes de passage vers le groupe des Chèvres, comprennent : le Mouflon a manchettes (0. trayclaphus seu Amnotragus tragelaphus), l'Arouides Arabes, qui habite le nord de l'Afrique; - le Nàhoŏr (O. Burrhel seu Pseudois Nâhoŏr), du Thibet et du Népaul; - le Mouflon à cornes cylindriques (O. cylindricornis seu Egoceros Pullusi), du Caucase.

$2^{\circ}$ On rattache aux Aryalis, dont les caractères sont beaucoup plus nettement ovins : - l'Argali proprement dit (O. ammon seu O. argali), Archar des Kirghiz, de la laille d'un Cerf, des steppes de la Sibérie méridionale; l'Argali de Kareliu (O. Karelini), du Turkestan oriental; - le Mouflon de Poli (0. Polii), Kashkar des Kirghiz, du plateau de Pamir; - le Mouflon des steppes ;0. Arkal), liotsh des Turcomans, de l'Afghanistan occidental; - 
l'Argali d'Amérique (0. montana), Biğ-horn des Américains, des montagnes Rocheuses et de la Californie; - l'Argali des neiges (0. nivicola), du Kamtshatka, etc.

$3^{\circ}$ Enfin, on range parmi les Mouflons, animaux qui se rapprochent tout à fait des Moutons domestiques : - le Mouflon d'Europe (0. musimon), à

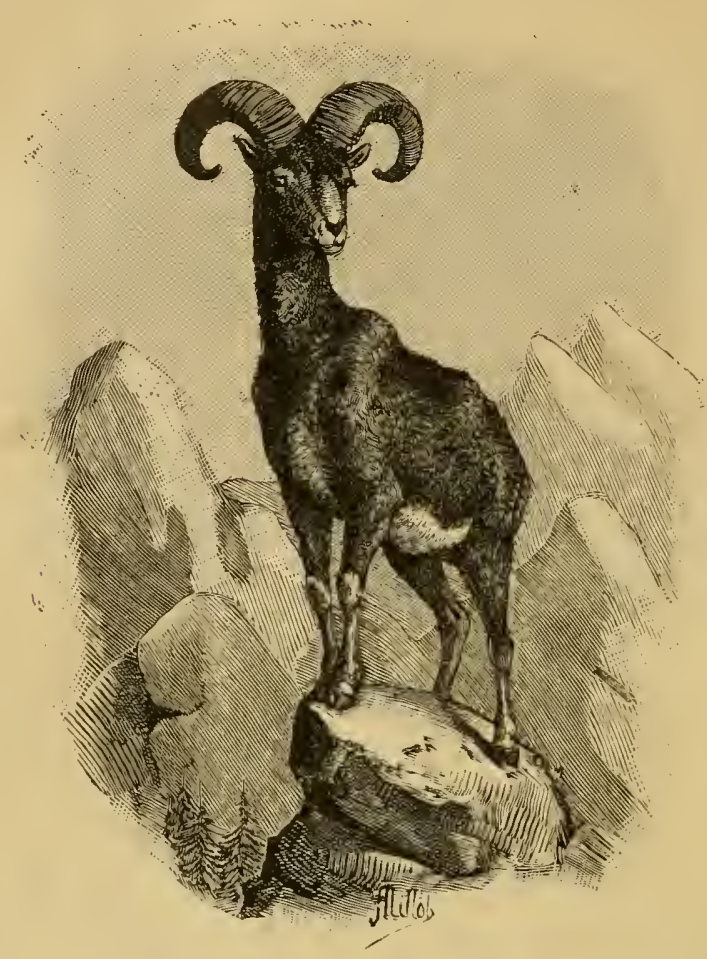

Fig. 836 . - Houflon d'Europe.

peine plus grand qu'un Mouton ordinaire et à pelage brun rougeàtre, des montagnes de la Corse, de la Sardaigne et peut-être de l'Archipel grec; le Mouflon persan (0. orientalis), de l'Asie Mineure et de la l'erse, le Mouflon de Chypre (0. cypria) ou Ophion, et le Houflon de Vigne (O. Vignei), Sha ou Shapou, du Thibet occidental, formes très voisines de la précédente; l'Urial (0. cycloceros), du Pandjab et de l'Afghanistan; etc.

Moutons domestiques $(O$. aries $L$.$) . - Les anciens naturalistes rattachaient$ toutes les races de Moutons à une seule et même espèce, qu'ils regardaient comme descendant du Mouflon d'Europe.

Cette opinion est encore soutenue par liuhn, qui la base sur les résultats obtenus à Halle en croisant ce Mouflon avec des Brebis domestiques. Nehring ne fait intervenir l'O. musimon que comme point de départ de certaines races européennes primitives à queue courte et à cornes foncées, comme le Mouton des landes du nord-ouest de l'Allemagne; il tend à admettre, arec Pallas et Brandt, qu'une grande partie de nos races à longue queue et à cornes pâles 
descend de l'Argali des steppes (0. Arkal), qui parait d'ailleurs avoir fréquenté les déserts de l'Europe centrale dans la période post-glaciaire; enfin, il suppose que le Sha (O. Viynci) a formé des races ovines asiatiques, et mème que différentes espèces d'Argalis ont concouru à la production des formes domestiques. Malheureusement, ces vues demeurent bien théoriques, de sorte que toute latitude est laissée aux auteurs qui veulent faire dériver les Moutons domestiques de formes diluviennes complètement éteintes. Scientifiquement, la question n'est point résolue. En l'espèce, d'ailleurs, il ne faut point oublier qu'on a affaire à des animaux très pétrissables, sur lesquels la domestication a pu aroir une influence modificatrice considérable. On sait, en particulier, que dans une mème race il est possible de voir des individus à cornes simples et d'autres à cornes divisées.

Sanson admet, parmi les Moutons domestiques actuels, qu'il nomme Ovilés ariétins, onze espèces rẻpondant à autant de types primitifs. Quatre sont brachycéphales, savoir: le Mouton germanique ( 0 . Aries ycrmanica), le Mouton des Pays-Bas (O. A. batavica), le Mouton des dunes anglaises $(0$. A. hibernica) et le Ilouton du plateau central (O. A. arternensis). Les sept autres sont dolichocéphales: Mouton du Danemark (O. A. ingeronensis), Mouton britannique (0. A. britannica), Mouton du bassin de la Loire (O. A. ligeriensis), Mouton

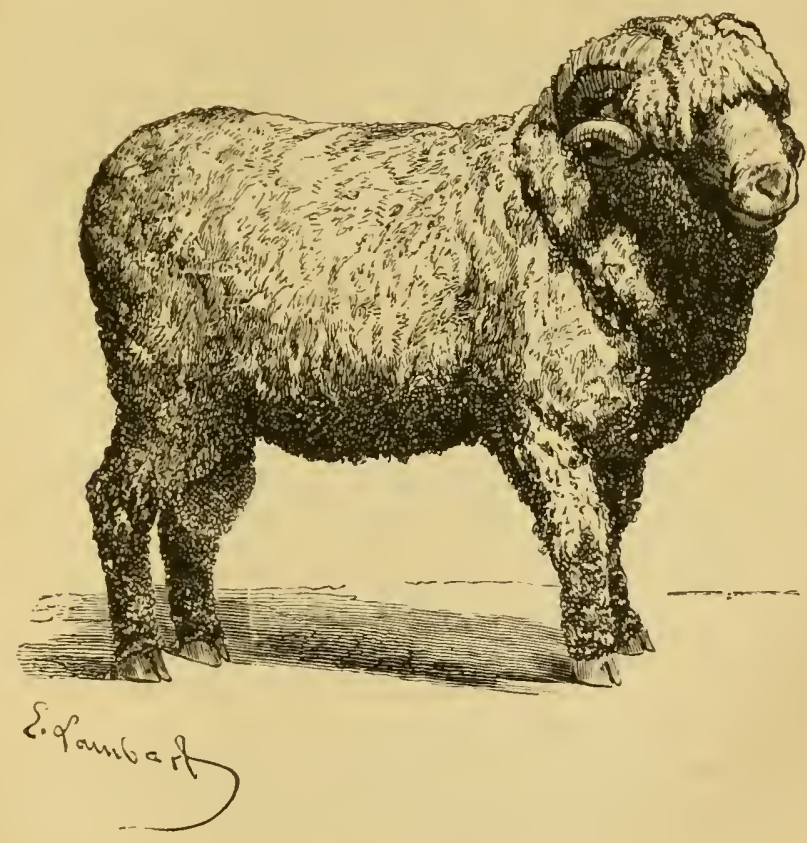

Fìg. 837. - Bếlier mérinos.

des Pyrénées (0. A. ibcrica), Mouton mérinos (O. A. africana), Mouton de Syrie ou à large queue (O. A. asiatica), Mouton du Soudan (0. A. sodunica).

Domestication. - Nous arons dit plus haut combien sont rares dans le quaternaire les débris des Moutons. Ils deviennent au contraire assez abondants. 
en Suisse, dans les palafittes qui latent de la période néolithique. C'est ainsi qu'à Font, sur le lac de Neuchàtel, on a trouvé un cràne complet du Mouton des tourbières à cornes de Chèvre ( 0 . aries palustris Rütimeyer), forme voisine du petit Mouton actuel des Grisons. Deux autres types ont été observés dans la station de Lüscherz, sur le lac de Bienne. Enfin, une forme tout à fait différente, sans cornes, a été fournie par la station de Mörigen, de l’àge du bronze (Glur). Mais il est de règle à peu près constante que les ossements de Moutons sont beaucoup plus rares que ceux de Chèvres, ce qui tend à indiquer une utilisation plus générale de celles-ci et peul-ètre une antériorité de domestication. En tout cas, il semble bien résulter de ces faits que le Mouton a été domestiqué dans notre région à la période de la pierre polie, et il y a lieu de supposer que cette domestication était déjà un fait accompli chez les peuples envahisseurs. On sait que le Mouton était domestique chez les anciens Aryas, sous le nom d'ovi (d'où ovis, ớs). En Égyple, il figure rarement sur les bas-reliefs, où la Chèvre est au contraire très commune. Mais les Hébreux entretenaient de nombreux troupeaux de Moutons, et la culture de ces animaux fut également en honneur chez les Grecs, les Romains et les Gaulois. Ils ont toujours joué, du reste, un ròle essentiel dans la vie des peuples pasteurs.

Caractères physiologiques. - Les Brebis entrent en chaleur à des époques périodiques, à partir de l'âge de huit à dix mois; lorsqu'elles ont agnelé, elles ne se montrent de nouveau en rut qu'après le sevrage de leur Agneau ou lorsqu'on cesse de les traire. Le rut du Bélier est un peu plus tardif, mais permanent: les individus précoces peuvent déjà faire la lutte, c'est-à-dire s'accoupler, vers l'âge de quinze mois. Dans l'espace de six semaines, un sujet vigoureux peut féconder 30 à 100 Brebis. On cite un Bélier du troupeau de Rambouillet qui en. a fécondé 60 en une seule nuit.

La durée de la gestalion est en moyenne de cent cinquante jours ou cinq mois. Chaque Brebis donne assez souvent naissance à deux Agneaux, parfois à trois. ll y a inconvénient à laisser durer l'allaitement moins de trois mois. En général, quinze jours ou trois semaines après la naissance, on coupe la queue des Agneaux, qui serait susceptible de salir la toison. C'est également de bonne heure qu'on pratique la castration des mâles non destinés à la reproduction. La durée naturelle de la vie du Mouton est, dit-on, de douze à quinze ans.

Services. - Les Moutons, en thèse générale, sont essentiellement des producteurs de laine et de viande.

Chez les Mouflons, comme chez la plupart des Mammifères sauvages, il existe, entre les poils rudes qui forment la base du pelage, un duvet très fin, mais peu abondant. Chez les Moutons, la proportion de ce dernier est devenue beaucoup plus considérable, mais on dislingue toujours deux sortes de poils: $1^{\circ}$ les uns, droits, raides et longs, désignés sous le nom de jarre; $2^{\circ}$ les autres fins, souples, plus longs encore et ondulés, frisés, en zigzag ou même vrillés, qui consti- 
tuent la laine. La jarre revêt la face et les membres; la laine, mélangée ou non de jarre, est disposée en mèches ondulées qui courrent le corps et dont l'ensemble forme la ioison. Les éleveurs cherchent a écarter la jarre par sélection et au coniraire à multiplier la laine. Celle-ci est imprégnée d'une matière grasse sécrétée par des glandes cutances, le suint, qu'on doit enlever en grande partie.

la viande de Mouton est en général très estimée, bien qu’elle varie de goùt et de qualité suivant l'àge, la race, le sexe, ete. On peut, avec Sanson, en distinguer trois sortes principales: $1^{\circ}$ la viande d'Agneau de lait, qui est une viande blanche; $2^{\circ}$ la riande d'Agneau serré et engraissé (de huit à onze mois), atetuellement très recherchée; $3^{\circ}$ la viande de Mouton ou viande faite. C'est un aliment très sain, ne contenant pas de parasites transmissibles à l'Ilomme (voy. p. 231).

Dans certaines localités du Midi, notamment dans les montagnes, le lait des Brebis est consommé par les ménages paurres, soit en nature, soit sous forme de beurre et de fromage. En outre, le lait est l'objet d'une exploitation industrielle très importante dans l'Aveyron, aux environs de Roquefort, oì il sert à la fabrication d'un fromage renommé (veiné de bleu par le Penicillium glaucum), fromage qu'on exporte aujourd'lui dans l'univers entier. Il entre aussi pour une faible part dans la fabrication des fromages de Saint-Marcellin et de Sassenage (Isère', du Mont-d'Or, du Mont-Cenis, etc. En Grèce, parait-il, on fabrique une grande quantité de beurre de Brebis. •

La graisse des Moutons est employée sous le nom de suif. La peau, les cornes, les onglons, les os, les issues, sont diversement utilisés parl'industrie.

Le fumier est riche; on se contente parfois, pour fumer la terre, d'enfermer les animaux dans des parcs mobiles, oủ ils passent la nuit: cette pratique est connue sous le nom de parcage.

Hrbrides. - On connait des produits résultant de l'union du Mouflon de Corse avec le Mouton dornestique. En outre, les Moutons et les Chèrres fournissent entre eux divers hybrides sur lesquels nous reviendrons après aroir fait l'étude du genre Cupra.

Les Chèvres (Capra L.) ou Caprins ont des cornes souvent très grandes, arquées en arrière et divergentes, dont la coupe est elliptique ou prismatique, et dont la face antérieure est marquée de tubérosités transversales; les cherilles osseuses sont comprimées latéralement, de manière à former une arête antérieure; leur surface de section est plus longue que large. Le crâne est étroit; les os nasaux sont longs et étroits. Le chanfrein est droit. Le menton porte une barbiche. Il n'existe ni larmiers ni sinus biflexes. La queue est courte, relevée, nue en dessous. Le pelage est rude ou soyeux, mais jamais il ne contient de véritable laine.

Là encore, il y a des formes de passagre, représentées par des Chèrres sans barbe, pourves de glandes interdigitales et de petits larmiers. - Les femelles ont toujours les cornes plus petites que les måles. 
Les Chèvres habitent les montagnes déboisées et escarpées de l'ancien continent. Ce sont des animaux actifs, remuants, inquiets, très hardis grimpeurs et sauteurs. Les vieilles femelles se chargent de la garde du troupeau pendant qu'il broute ou se repose. Les mâles répandent en général une odeur forte et désagréable, l'odeur de Bouc, qui se communique même à leur chair.

Les notions paléontologiques relatives aux Chèvres sont aussi bornées que celles concernant les Moutons. C'est qu'il est difficile, d'une part, de distinguer ces animaux Ies uns des autres, ainsi que des Antilopes, à moins de posséder des fragments importants du cràne et des cornes; et que, d'autre part, les Ovinés ont un habitat limité aux régions montagneuses. Disons cependant que les plus anciens représentants du genre (C. sivalensis, $C$. perimensis) ont été trouvés dans le pliocène de l'Inde et sont voisins des Chèvres asiatiques actuelles. Le Bouquetin des Alpes (C. ibex) est assez commun dans les cavernes à ossements el les tourbières de l'Europe centrale et occidentale, ainsi que diverses formes affines; C. primigenia, également quaternaire, serail voisine de l'Égagre. Quant à $C$. Rozeti Pomel, du diluvium d'Auvergne, c'est une forme très douteuse, de même que la plupart de celles qu'on a déterminées comme C. hircus, d'après des dents et des os isolés.

On distingue, parmi les Caprins, trois groupes secondaires dont quelques auteurs font des genres spéciaux: les Chèvres proprement dites, les Bouquetins et les Hémitragues.

Sous-genre mémitrace (Hemitragus). - Cornes de médiocre longueur, comprimées latéralement d'une façon régulière, à trois ou quatre angles et marquées de bourrelets annulaires chez le màle, arrondies chez la femelle. Mamelle à quatre mamelons.

Jusqu'à présent, on ne connait qu'nne seule espèce de ces demi-Chèvres, qui établissent le passage vers les Bovinés : c'est l'Yhàr ou Yhàral (C. jemlaica), du Népaul, remarquable par son poil long et peu fourni.

Sous-genre Bovouetrx (Ihex). - Ces animaux se reconnaissent à leurs cornes très développées, peu divergentes, triangulaires sur la coupe, et présentant, sur leur large face antérieure, de fortes tubérosités toujours très espacées. L'axe osseux des cornes serait creusé de nombreuses cellules.

Signalons: le Bouquetin des Alpes (Capra ibex), dont il ne reste plus guère que 300 individus rassemblés dans les Alpes occidentales, au val de Corne et dans les gorges qui y aboutissent; le Bouquetin des Pyrénées (C. pyrenaica), qui devient aussi très rare; le Bouquetin espagnol (C. hispanica), de la Sierra Nevada; le Bouquetin du Caucase (C. cancasica); le Bouquetin de Sibérie (C. sibirica); le Beden (C. nubiana); etc.

Sous-genre cuìrne (Hircus). - Les Chèvres proprement dites ont des cornes prismatiques à bord tranchant, divergentes et à nodosités peu marquées. L'axe osseux est en grande partie plein; sa base seule est creusée par une grande cellule. -3 espèces principales.

La Chèvre à cornes ell vrilles (C. Falconeri A. Wagner) est d'une taille un pou supérieure à celle de la Clièvre domestique. Le Bouc est muni 
de puissantes cornes fortement carúnées et contournées en hélice; celles de la femelte sont plus petites et simplement arquées. La teinte générale du pelage est brun grisitre. Outre une très longue barbe, le màle porte une sorte de crinière qui enveloppe toute la partie antérieure du corps.

On trouve la Chèvi'e à grandes cornes sur les hauts sommets de l'llimalaya thibétain; les indigènes la désignent sous le nom de Markhor.

La Chèvre Éăagre ('. Lyagrus L..) est aussi un peu plus grande que la Chère domestifue. Le lioue a des cornes longues et faibles, simplement arquées, olfrant sur la carène ou angle antérieur une douzaine de hourrelets transversaux, qui manquent clez la femelle. Le pelage est brun rougeàtre, plus clair sous le ventre et ì la face interne des membres; le chanfrein, la ligne médiane du dos et la queue sont noirs.

L'Égagre, encore appelée Chèrre à bėzourd, et connue des Persans sous le nom de Paseng, se rencontre depuis lą Grèce et les iles de l'Archipel jusqu'en Perse. Elle recherche les sommets les plus élevés des montagues. On lui faisait antrefois une chasse active, dans le but de se procurer les bézoards, e'est-à-dire les concrétions calculeuses qui, clıez elle comme chez beaucoup d'autres Ruminants, se rencontrent parfois dans la caillette, et auxquelles on attribuait nne loule de vertus médicinales. Cette Chèvre, ainsi que la précédente, s’accouple volontiers avec nos races domestiques, en domnant des produits féconds.

La Chève grazelle ( $C$. dorcas Reichenow, nec L.) possède des cornes triquètres, contournées en dehors et à carènes convergentes; son pelage (jarre), assez court, est gris rougeàtre.

Cette forme, récemment découverte dans la petite ile de Ghioura, l'une des Sporades du nord, répond peut-ètre à des Chèvres domestiques redevenues sauvages, ou à des produits de croisement de Chèvres domestiques et d'Égagres.

Chèvres domestiques (C. Hircus L.). - Sansoll recomnaît trois espèces de Chèvres domestiques (Ovilès caprins) : une brachycéphale, la Chèvre d'Europe (Ovis Capra europza), et deux dolichocéphales, la Chèvre d'Asie (O. C. asiatica) et la Chèvre d'Afrique (0. C. africana).

Mais la plupart des auteurs rattaclent les races domestiques, pourtant si variées, à une seule espèce, dont l'origine mème est fort discutée. Les uns pensent que la Chèvre domestique dérive du Bouquetin des Alpes ( $C$. ibex), qui, dit-on, s'accouple spontanément avec elle en donnant des produits féconds; d'autres font intervenir des formes voisines de même groupe; d'autres encore, parmi lesquels se place I. Geollroy Saint-Hilaire, admettent que nos races eaprines doivent itre attachées a l'Égagre et peut-ètre, secondairement, à la Chèvre de lalconer.

A notre avis, les Bouquetins ne doivent pas entrer en ligne de compte; mais il n'est guère doutcux que I'Egagre et le Markhor aient contribué à la formation des races cultivées, lont quelques-unes leur ressemblent d'une facon frappante.

En tout cas, il est à remarquer que les Chèvres domestiques retournent à l'état sauvage avec autant de facilité que les espèces sauvages se laissent apprivoiser. 
Domestication. - Il est présumable que la Chèvre, comme le Mouton, a élé domestiquée d'abord en Orient. Dans l'Europe occidentale, elle se montre assez commune parmi les débris des habitations lacustres de l'époque néolithique, et ses caractères sont identiques à ceux de nos Chèrres actuelles. D'autre part, elle est représentée dans les peintures de la quatrième dynastie égyptienne avec les oreilles pendantes, ce qui est toujours le signe d'un état de domesticité très ancien. Il est à noter, d'ailleurs, que les anciens

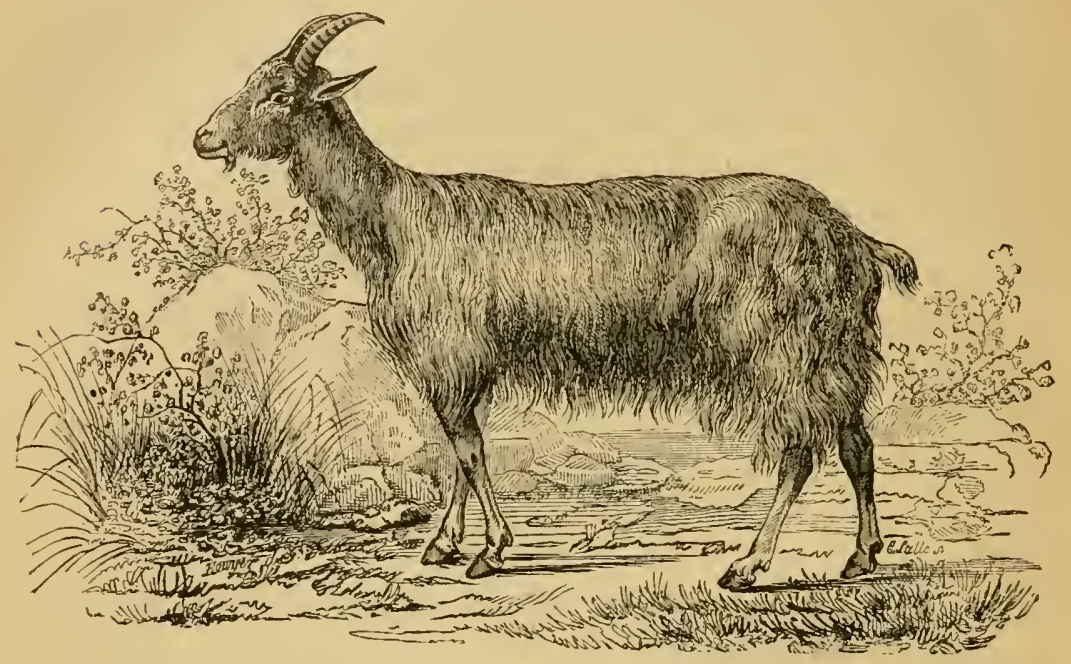

Fig. 838. - Chèrre d'Europe.

Égypliens en ont figuré au moins deux races ou variétés bien distinctes. Les Aryas primilifs connaissaient aussi la Chèvre. La Genèse, qui mentionne le Monton dès ses premières pages, en parle peu après. Il en est aussi question dans Homère et dans la mylhologie des Grecs.

Caractères physiologiques. - Au point de rue de la reproduction, les Chèvres sont un peu plus précoces que les Moutons. La femelle entre aussi en chaleur à toutes les époques de l'année, mais de préférence en novembre et en décembre, et le rut reparait une quinzaine de jours après l'accouchement. Le Bouc est encore plus prolifique que le Bélier: un sujet vigoureux peut faire aisément huit saillies en moyenne par jour et féconder 200 femelles dans la saison, qui ne dure guère plus d'un mois. On sait que le Bouc, du moins dans nos races communes, exhale une odeur forte et désagréable, qui s'exagère encore pendant le rut.

La durée de la gestation est de cinq mois, comme chez. la Brebis. Les portées doubles sont la règle. Les Cherreaux ou Cabris sont gais et faciles à élever, quoique assez frileux. On les sèvre d'ordinaire vers l'âge de cinq à six semaines. Il est rare qu'on garde les mâles pour la boucherie; dans ce cas, il importe de les châtrer de bonne heure, 
car leur chair contracterait l'odeur du Bouc. La durée naturelle de la vie est de treize à quinze et jusqu'ì dix-huit ans.

Services. - Le produit principal de la Chèvre, c'est le lait. La Chèvre est la Vache du paurre, dit Grognier. Son lait, en eflet, forme la base de la nourriture d'une foule de populations paures qui vivent dans les montagnes ou sur des terres impropres ì la culture. Elle met ces terres en valeur, parce qu'elle utilise tous les végétaux qui y eroissent, les herbes les plus dures et jusqu'aux plantes ligneuses. Aussi la voiton surtout entretenue dans les régions où l'agriculture est peu avancée. Dans le Mont-d'Or lyonnais, le lait de Chèvre (en mélange avec du lait de Vache et de Brebis) est employé à la fabrication de fromages estimés. C'est aussi en grande partie avec ce lait que se font les fromages de Saint-Mareellin et de Sassenage, dans l'Isère, et bien d'autres. Enfin, la Chèvre peut être employée comme nourrice, pour alimenter les jeunes animaux qui ont perdu leur mère: Agncaux, Veaux, Poulains, ete.

La chair des animaux adultes est peu recherchée, paree qu'on ne prend pas, en général, la peine de les engraisser; mais celle des Chevreaux est ássez appréciée des gourmets.

Les Chèvres d'Angora, de Cachemire el du Thibet ont un pelage

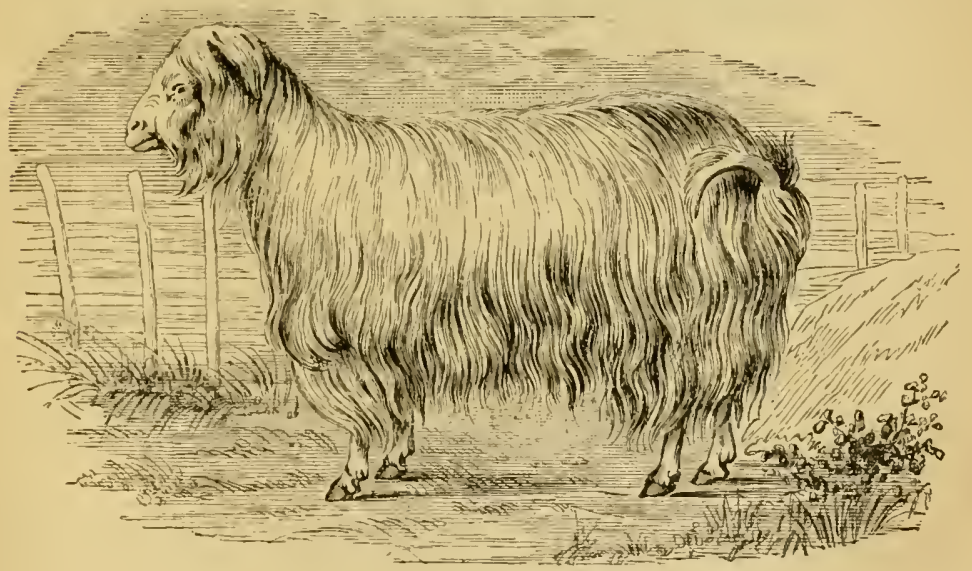

Fig. 839. - Chève de Cachemire.

mélangé, en proportions variables, d'un fin duvet qui est exploité pour la fabrication de tissus de qualité supéricure. On a tenté à diverses reprises d'acclimater ces Chèvres en Europe, dans l'intention de faire concurrence ì la fabrication hindoue; mais ces essais sont demeurés stériles, car, malgré tous les soins, ces animaux ne tardent pas à perdre leur duvet sous notre climat.

La peau de Chèrre sert surtout à faire des chaussures et des gants; 
le poil, les cornes, les issues, etc., ont aussi leur emploi dans l'industrie.

Ajoutons que la Chèvre, plus encore que le Mouton, est un animal nuisible à la culture foreslière, car elle détruit partout le plant et les jeunes pousses.

Les Ovibos (Ovibos de Blainville), très étroitement alliés aux Bovinés, ont. des cornes très larges et très rapprochécs à la base, se portant d'abord en bas et en dehors pour se relever seulement à la pointe; les chevilles osseuses sont très spongieuses, mais ne possèdent qu'une seule cavité à la base. Il existe des larmiers profonds. Le pelage est composé de poils longs et laineux; les ergots portent de petits sabots. Deux mamelles.

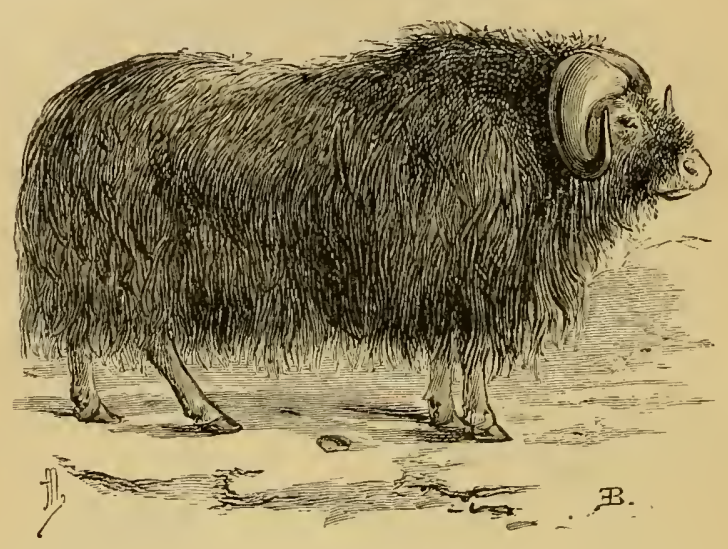

Fig. 840. - Ovibos musqué.

Une seule espèce, l'Ovibos musqué (0. moschatus), vulgairement Bœuf musqué, du Groenland et de l'Alaska. Elle était répandue dans l'Europe moyenne à l'époque quaternaire. Une forme voisine (0. priscus) l'accompagnait en Amérique.

Hхвндdes. - Nous avons déjả dit que le Bouquetin des Alpes, l'Égagre et le Markhor s'accouplent avec la Chèvre domestique, et que les produits de ces unions jouissent d'une fécondité indéfinie.

Au Jardin zoologique de Londres, on a obtenu deux produits de la fécondation de la Chèvre par le Mouflon à manchettes; mais tous deux sont morts en naissant. Flourens aurait, d'autre part, fait accoupler avec succès le Mouflon de Corse avec la Chèvre.

Mais les produits les plus intéressants résultent de l'union des Moutons et des Chèvres domestiques. D'après I. Geoffroy Saint-Iilaire, ces produits devaient être assez répandus chez les Romains. On a pu en obtenir aussi, à diverses reprises, en France et dans quelques autres pays. Les plus communs proviennent du Bouc et de la Brebis. Au Chili, ces derniers sont l'objet d'une exploitation industrielle ayant pour base l'utilisation spéciale de leur peau. Ces produits, désignés dans le pays sous le nom de Carneron linudos, sont connus en France sous celui de Chabins. Leur fécondité est illi- 
mitée, mais les proluits paraissent faire rapidement retour à l'un ou à lautre de Jeurs ascendants. Ceux qui ont été introuluits en France dans ces lernières anuées avaient à peu prés tous le type du Mouton.

$3^{\circ}$ Sous-famille des Bovines. - Les Burfs et genles voisins sont caractérisés par leurs formes lourdes et trapues, ainsi que par leurs cornes arrondies, arquées, presque toujours lisses, dont la cheville osseuse, forte el creuse, cylindrique ou triquêtre, naît assez loin en arrière de l'orbile et parfois même se trouve reportée à l’angle postérieur externe du crâne. Le fronlal a pris un très grand développement, de même que ses sinus. Le mutle est large, nu et humide; le cou est court, et la peau de sa région inféricure est souvent pendante sous forme de fanon. Sa queue est longue et terminée par.une touffe de poils. Il n'existe ni larmiers ni glandes interdigitales. Les femelles ont quatre mamelles, bien qu'elles ne produisent d'ordinaire qu'un seil petil à la fois.

Les Bovinés vivent en troupes, sous la conduite d'un vieux 't'aureau. Lorsqu’ils sont attaqués par des animaux féroces, ils se mettent souvent en cercle, de manière à présenter les cornes à l'ennemi. On les trouve dans la plupart des contrées du monde, pxeepté en Australie et dans l'Amérique du sud.

Leurs représentants se laissent ranger, selon Rütimeyer, dans :̈ sections, comprenant 8 genres:

Bubaliss : Amphibos, Probubalus, Buffelus, Bubulus. - Leprobovins : Leptobos. - Biborins: Bibus. - Bisontriss: Bison. - Taurins : Bos.

Les genres Amphibos et Leptobos ne comprennent que des espèces fossiles.

Les Probubales (Probubalıs Rütimeyer) servent de (rait d'union entre les Bceufs et les dntilopes. Ils ont un cràne allongé, un front très bombé et des cornes triquètres, courtes, presque droites, à peine annelées à la base et divergentes, naissant non loin des orbites. Le poil est clairsemé.

L'Anoa des Malais $(\mathbf{P})$. depressicornis), qui représente actuellement ce genre, est de la taille d'une jeune génisse. On lui donne souvent le nom d'Antilope de Célèbes. - Deux autres formes existaient à l'époque tertiaire.

Les Bubales (Bubalus Schmidt) ou Buffles d'Afrique se distinguent à leur front bas et bombé, a leurs cornes peu comprimées, fortement épaissies à la hase et pouvant se joindre sur la ligne médiane de manière à couvrir le front entier.

Ces Buffles à cornes rondes sont représentés à l'état fossile par B. antiquus, du diluvium de l'Algérie, que d'aucuns ont rapproché des Buffles indiens; les deux principales espèces actuelles sont: le Buftle du Cap ou de la Cafrerie (B. cuffer) et le Buffle à courtes cornes (B. brachyceros), celui-ci de l'Afrique centrale. Ce sont des animaux très dangereux, très redoutis.

Les Buffles vrais (Buffelus Rütimeyer) ou liufiles d'Asie se distinguent surtout les précédents par leurs cornes fortement comprimées, annelées, sauf 
à la pointe, insérées sur les còtés du front de manière à ne pas se toucher à la base, et recourbées en dehors, puis en arrière. Le poil est rude et très clairsemé. Le corps est Irapu.

Deux espèces tertiaires d'Asie : $B$. sivalensis et $B$. palæindicus, et une du diluvium de Dantzig: B. Pallasi. - Les représentants actuels du genre ne se rencontrent à l'état sauvage que dans les parties chaudes de l'Asie et de l'Océanie. Ils fréquentent surtout les régions marécageuses et aiment à se vautrer dans la vase.

Le Buffle commun (B. indicus) a le corps un peu allongé, le garrot assez élevé, le cou court et épais, sans fanon, la tête courte et large, les yeux petits, à expression farouche, les oreilles longues et larges, les cornes longues, assez épaisses à la base, portées obliquenent en dehor's et en arrière, puis relevées en avant et en ledans vers la pointe. La peau, presque nue sur beaucoup de points, est noire; les poils varient du gris au roux. Il esई rare de voir des individus blancs ou tachetés.

Le Buffle commun vit à l'état sauvage dans l'Inde et à Ceylan. Il paraît avoir élé domestiqué à une date relativement récente, car les plus auciens livres chinois, qui parlent du Bœuf, sont muets á son endroit, et les anciens poèmes indiens ne le mentionnent que comnie un animal redoutable et malfaisant. Sa domestication ne remonterait donc pas au delà des temps historiques; elle a dù naturellement se faire dans l'Inde. De lá le Buffle s'est répandu, sous l'influence de l'Homme, dans toute l'Asie occidentale, puis en Turquie, en Grèce, dans le bas Danube, en Italie et en Égypte. Son introduction en Italie date, suivant Paul Diacre, de 596. Au xu siècle, les moines de Clairvaux ont tenté de l'importer en France pour l'employer au labour, mais cette tentative a échoué, aussi bien que celle de 180\%, entreprise par Napoléon.

Le Buffle est un animal très utile à l'agriculture dans les régions marécageuses, mais les régions sèches ne lui conviennent en aucune façon. Sa prédilection pour l'eau est si marquée que si un convoi de Buffles rencontre une rivière ou un étang, il s'y précipite en dépit de tous les efforts. Toujours, du reste, le Buffle garde une certaine indocilité. Mais il est presque le seul des animaux domestiques qui puisse résister à l'action des effluves paludéens, et il rend par suite de réels services, notamment pour la culture du riz. G'est un très puissan i moteur, qui offre l'avantage d'un entretien facile : il se contente des fourrages les plus sees et les plus durs, récoltés dans les prairies basses et humides. Il fournit d'ailleurs un lait très crémeux et aromatique, qui sert à la fabrication d'un beurre estimé et de fromages spéciaux, tels que les provoli, les scamorze et les borelli en Italie. Par contre, sa chair, du moins à l'àge adulte, est dure et possède une odeur musquée fort désagréable. La Bufflesse porte 10 à 11 mois (moyenne 308 jours).

L'Arni est une variété géante el à grandes cornes du Bufle commun (B. indicus var. Arni); il vit dans l'Inde, tant à l'état de liberté qu'à l'état domeslique. 
On connait encore d'autres espèces du mème genre, comme le Buffle liérabau (B. sonduieus), des îles de la Sonde, souvent domestiqué, le $B$. mindorensis et le B. Mullendorffi, des Philippines.

Les Bisons (Bison II. Smith, Bonasus A. Wagner) ont le front court, très large et plit, les cornes courtes, cylindriques, épaisses, recourbées en haut et en dehors, naissant à pen de distance des orbites, qui sont très saillantes (fig. 8ł1). La toison, très épaisse, forme en avant une crinière qui enveloppe lá tète, le cou, le poilrail, les épaules etle garrot. Cettedernière région est en outre relevée par une sorte de bosse, tandis que l'arrière-train est relativement faible.

Parmi les représeutants fossiles de ce genre, que Rütimeyer place tout à cỏté des bœufs, en raison du développement des frontaux, on doil signaler un B. sivulensis du miocène de l'Inde, suivi des B. ferox et Alleni du pliocène de I'Amérique du Nord, puis du gigantesque B. latifrons du diluvium de la mème région. A cette dernière forme ont succédé deux autres lypes diluviens peu distincts, le $B$. antiquus du nouveau monde, le $B$. priscus de l'ancien, ayant lonné naissance aux deux espèces actuelles.

L'une de celles-ci est le lison d'Europe (Bison curopaus), le Wiscut des Allemands, le subr des Polonais, le Bonasus de Pline, que les naturalistes du seizième siècle ont confondu avec un autre Boviné mal déterminé, en Iui donnant les noms impropres d'Ur, A $u r$ ou furochs, noms qu'il importe d'abandonuer. Ce Bison, qui était répandu dans toute l'Europe à l'époque quaternaire, n'existe plus aujourd'hui que dans la grande forêt de Bialovicsa, en Lithuanie, et dans le centre dn Caucase. L'autre espèce est le Bison d'Amérique (B. americanus), encore appelé Buffalo, qui na-

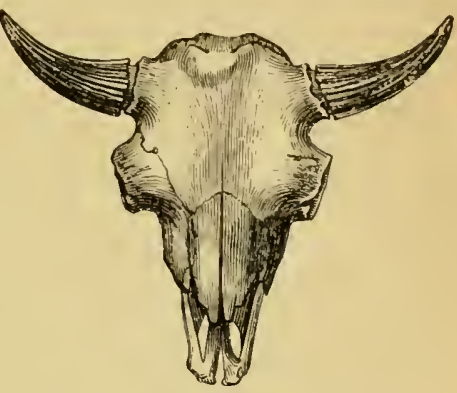

Fig. 841. - Téte du Bison d'Europe. guère parcourait en troupeaux immenses tous les États-Unis, et qui aujourd'hui se trouve relégué au nord et à l'ouest du Missouri. Après des essais de domestication poursuivis pendant cinquante ans, Tompson a affirmé que le Buffalo pouvait ètre dressé en vue du travail et de la production du lait. - Quelques auteurs ne veulent voir dans ces deux formes que denx variétés d'une mème espèce.

Les Leptobos (Leptobos Rütimeyer) ont le crâne bas et très allongé, les cornes subcylindriques, insérées à peu de distance des orbites, mais fort en dehors et dirigées en arrière (parfois nulles). - Groupe d'union entre les Antilopes et les Bibos. Représenté dans le pliocène (L. Falconeri) et le diluvium (L. Frazeri) de l'Inde. D’après Forsyth Mayor, le Bos etruscus Falconer ou Bos elatus Croizet, du pliocène (Val d'Arno en Étrurie, Val d'Issoire en Auvergne, Espagne; appartient à ce genre et non au genre Bibos, comme l'ildmet Rütimeyer.

Les Bibos (Bibos llodgson) ou Baufs-Bisons ont le cràne des Bisons, les cornes généralement courtes, épaisses à la base et l'ecourbées en haul, naissant assez loin des orbites. Les frontaux sont fort étendus en arrière; les pariétaux se réduisent à l'àge adulte. Le grarrot présente encore une surélé- 
vation qui s'atténue dans quelques formes (Banteng, Zébu). Le poil est généralement assez court.

Les Bibos sont représentés dans le quaternaire de l'Inde par le B. palæogaurus; on en connaît aussi des restes du pliocène de la Chine.

Les espèces virantes, qui sont toutes indiennes, auraient pour type primitif le Bauteng. Nous nous bornerons à les mentionner sommairement.

Le Gaur (B. gaurus) vit dans les jungles et les forêts épaisses du sud du Bengale; il paraît fort difficile à apprivoiser. - Le Gayal (B. frontalis set: gaxæus) ou Bœuf des jungles habite les montagnes de l'est el du nord-est du Bengale; on parvient sans trop de difficultés à l'apprivoiser, mais nulle part on ne le fait travailler, et on ne boit même pas son lait. - Le Banteng (B. sondaicus) ou Bœuf à fesses blanches vit dans les forèts marécageuses des iles de la Sonde; les jeunes individus s'apprivoisent facilement.

L'Yak (B. grunniens) se rapproche encore des Bisons par son front assez. large et un peu bombé, par son garrot élevé et par sa longue et épaisse toison. C'est un puissant animal, qui a quelque chose du Cheval dans la démarche. Son pelage est noir, à l'exceplion d'une bande dorsale gris argenté et de la queue, qui est blanche. Celle-ci est, en outre, garnie de longs poils qui la font ressembler à une queue de Cheval.

L'Yak est qualifié de grognnant à cause de sa voix, qui ressemble un peu au grognement du Cochon. Les anciens le connaissaient sous le nom de Poephagus. Il vit à l'état sauvage dans l'Asie centrale, notamment dans les montagnes du Thibet, à une altitude de 4000 à 7000 mètres. On lui fait la chasse pour sa chair, qui est estimée, pour sa toison et pour sa queue, usitée à titre d'ornement. D'autre part, on l'a domestiqué : les Thibétains s'en servent comme bête de somme et de selle, et se nourrissent de son lait, qui est excellent.

Le Zébu ( $B$. indicus) n'a plus de surélévation squelettique du garrot, mais celui-ci est surmonté d'une bosse de nature adipeuse; les oreilles sont pendantes, les membres fins et assez hauts. La robe, en général d'un brun roux ou châtain, varie beaucoup suivant les races.

Le Zébu ou Bœuf à bosse se trouve encore à l'état sauvage sur quelques points des Indes; mais on se demande s'il ne s'agit pas là d'individus marrons. Dans tous les cas, on considère le Bengale comme étant sa patrie : c'est là qu'il aurait été domestiqué, pour se répandre ensuite dans une grande partie de l'Asie et de l'Afrique, en donnant naissance à une foule de races diverses.

“ On en a de toute taille, dit Vogt; les Zébus de l'Afrique méridionale, ordinairement grands et bruns, ont souvent des cornes très grandes; mais dans tous les pays on trouve des races moyennes et même fort petites, égalant à peine la taille d'un gros Cochon, des races à cornes moyennes, petites, ou même sans cornes. Les Zébus marchent, trottent et galopent comme des Chevaux; ils sont très estimés comme montures, comme bêtes de somme et de trait, el chez beaucoup de peuples, surtout du sud et du centre de l'Afrique, ils forment pour ainsi dire la seule richesse. , 
En 1880, de Rochebrune signalait un Zébu à trois cornes (Bos triceros), souvent observé par lui en Sénégambie. Ce curieux animal était caractérisé par la présence, sur la région nasale, d'une protubérance osseuse surmontée d'une véritable corne. Mais Monod (1) a démontré qu'il s'agit là d'une production pathologique : c'est le résultat d'une ilritation du périoste et de la peau, consécutive aux inoculations préventives de la péripneumonie contagieuse des Bovinés, effectuées par les Maures et les Peulıls sur le chanfrein de leurs Zébus.

Endiu les Bœufs proprement dits on Taurins (Bos L.) sont caraclérisés par un front étroit et aplati, des cornes épaisses á la base et un dos droit, sans élévation au garrot. Les frontaux sont extrèmement développés et forment lonte la voùte cranienne; les pariétaux sont très réduits; les chevilles osseuses les cornes sont reportées aux angles postérieurs externes du cràne. Le poil est colurt.

On a trouvé dans le tertiaire supérieur et dans le quaternaire des restes fossiles du genre Bos très roisins des Taurins actuels. C'est ainsi que le pliocène d'Asie a fourni les B. planifrons, acutifions et plutyrhinus, auxquels ont succédé, dans les dépôts quaternaires, le B. namadicus indien et le R. primigenius Bojanus, si répandu dans le diluvium de l'Europe. Celui-ci est de heaucoup la forme la plus intéressante pour nous. D'une façon générale, il est signalé comme un animal de très laute taille, à cornes formidables. I'après direr's auteurs, ce Bouf primilif se serait maintenu, à travers les àges de la pierre polie et des métaux, jusqu'à l'époque romaine et mème jusqu'au moyen àge, lans les forèts de l'Europe centrale; mais il I’est pas établi que l'Urus de César soit autre cliose qu'un Bison, et que ceux de Sénèque et de lline ne se rapportent pas à des Bœuls marrons; quant au fameux $U$, ou Thur chassé en Lithuanie lors łu voyage diplomatique d'Herbenstain (1 1326$)$, il résulte des recherches minutieuses de Wilckens que l'auteur l'a mentionné simplement comme un animal " ayant la forme l'un Butf noir et des cornes plus grandes que celles des Bisons "; et rien dans ce portrait ne permet de reconnaitre le $B$. primitgenius.

Pl. Thomas a décourert dans le quaternaire de l'Algérie une forme un peu différente du B. primigenius Bojanus, mais paraissant se rapporter aux B. primigenius et $B$. trochoceros liütimeyer (lesquels sont néolithiques); il l’a désignée sous le nom de B. primífenius mauritanicus (cornes recourbées en avant, à pointes ramenées en dedans et en bas). Pomel a également trouvé en Algérie une espèce de grande taille, qu'il a nommée B. opisthonomus.

Enfiu, on connait encore une forme quaternaire que certains auteurs regardent comme spécifiquement distincte du B. primigenius, tandis que d'autres en font une simple variété : c'est le Bos longifrons Owen, que Wilckens identifie au $B$. brachyceros Rütimejer (néolithique). Il est de petite taille, à menıres grèles, ì cơrnes courtes et épaisses.

Actuellement, on ne connait plus de Taurins sauvages; du moins ne peut-on accepter qu'arec les plus expresses réserves les récits des royageurs qui en signalentlexistence. Il se trouve bien des troupeaux de Bœufs à demi libres ou même vivant en pleine liberté; mais tous

(1) Moson, De la peripneumonie contagieuse des Bovidés en Sénégambie (Rapport de II. Laquerrière). Bullet. de la Soc. centrale de méd. rét., XLVII, p. 460. ... Voir p. 466 et 168 . 
paraissent dériver d'animaux domestiques. Tel est le cas de ceux qu'on rencontre au milieu des pampas de l'Amérique, dans tous les pays de domination espagnole, et qu'on chasse souvent pour leur peau.

Boeufs domestiques (B. Taurus L.). - Les Bœufs domestiques appartiendraient, d'après Sanson, à douze espèces distinctes, dont six brachycéphales : Bœuf asiatique (Bos Taurus asiaticus), Bœuf ibérique (B.T. ibericus), Bœuf vendéen (B. T. ligeriensis), Bœuf auvergnat (B. T. arvernensis), Bœuf jurassien (B. T. ju^assicus), Bœuf écossais (B. T. caledonicus), - et six dolichocéphales : Bœuf des Pays-Bas (B. T. bataicus), Bœuf germanique (B. T. germanicus), Bœuf irlandais (B. T. hibernicus), Bœuf des Scythes, dit sans cornes (B. T. scythicus), Bœuf brun ou des Alpes (B. T. alpinus) et Bœuf d'Aquitaine (B. T. aquitanicus).

Cette multiplication des types spécifiques peut paraitre exagérée, surtout si l'on considère leur accumulation sur un point limité de l'Europe; mais les difficultés disparaissent quand on se borne à voir dans ces groupes, en dehors de toute idée dogmatique, des formes locales depuis longlemps différenciées, ayant fait l'objet d'études spéciales. Dans ces conditions, il faut convenir que les études anatomiques comme les découvertes archéologiques ou paléontologiques tendent à montrer que ces formes répondent, d'une manière générale, à des types bien définis, déjà distincts aux époques préhistoriques.

En étudiant les débris retirés des cités lacustres de la Suisse, Rütimeyer a reconnu qu'il existait dans cette région, dans les temps préhistoriques, trois formes distinctes de Taurins vivant sans doute à l'ćtat domestique : Bos primigenius et $B$. brachyceros, de l'époque néolithique; $B$. fiontosus, apparaissant pour la première fois à l'âge du bronze (1).

D’après lui, le B. primigenius serait apparu dans le sud-est de l'Europe, et il représenterait la souche d'une grande partie de notre bétail domestique, du moins de celui des Pays-Bas, du nord de l'Allemagne, des steppes de l'Europe orientale, etc. (B. Taurus primigenius). Sa descendance la plus directe serait la race blanche, à oreilles rouges ou noires, qui vit encore dans divers parcs de l'Écosse. Sanson combat cette opinion et considère que le " descendant légitime et direct " du B.primigenius est son B. T. ligeriensis.

Le $B$. frontosus serait originaire de la Scandinavie et sa descendance (B. $T$. frontosus Rút.) serait représentée principalement par la race à pelage tacheté, de Berne (B. T. jurassicus Sanson). On y a rattaché aussi les races à cornes courtes ou nulles (shorthorns des Anglais) et quelques autres.

Quant au B. brachyceros, il représenterait la souche de la race brune de Schwyz, ainsi que des races à robe unie de la haute Écosse, de la Bretagne, de l'Auvergne, etc. Sanson l'identifie à son B. T. ulpinus; mais il en distingue le $B$. longifrons, qui ne serait autre que le représentant ancien de son B. T. batavicus.

(1) Le B. primigenius de Rütimeyer n'est pas identique a celui de Bojanus, mais c'est la race préhistorique qui s'en rapproche le plus : aussi serait-il préférable de dire Bos Taurus primigenius, de même que B. T. brachyceros, B. T. frontosus, B. T. brachycephalus. D'autre part, Rütimeyer avait trouvé à Concise et à Neuchàtel un $B$. trochoceros qu'il a revu plus tard à Sutz et qu'il n'a plus considéré dès lors que " comme une simple variation individuelle du B. primegenius ". Pour le B. brachyceros, nous avons dit que Wilckens l'identifie au $B$. longifrons Owen, du quaternaire de l'Angleterre. 
A cóté de ces trois types, on a proposé d'en reconnaitre un quatrième, le B. Urachycephalus Wilckens, Irouvé dans les tourbières de Laybach, et qui serait actuellement représenté par un groupe de bélail à tète courte habitant le Tyrol; mais Rütimeyer est d'avis qu'il s'agit lả d'une modification accidentelle du crìne, représentant le premier degré de celle qu'on observe chez les Baufs ñatos des pampas de l'Amérique du Sud el chez divers animaux domestiques (animaux à tète de bouledogue).

On a trouvé aussi, dans les stations néolithiques de l'Espagne et de l'Italie, des restes de Bœufs paraissant avoir vécu à l'état domestique. En Algérie, Pomel a rencontré un Taurin néolithique qui lui a paru ètre presque identique au B.T. ibericus Sanson.

Nous derons mentionner encore quelques autres opinions qui ont été émises au sujet de l'origine de nos Bœufs domestiques. D'après A. Nehring, toutes les races bovines européennes dériveraient du B. primigenius; Wilckens doute, au contraire, qu'on ait pu songer à domestiquer un animal d'une tiille aussi considérable. A. Pagenstecher et A. von Frantzius regardent l'Afrique comme la patrie d'origine des Bœufs européens, mais sans mentionner l'espèce primitive qui leur aurait donné naissance. P. Kouleshov, ayant trouvé une étroite ressemblance entre le crìne du Bœuf kalmouk et ceux de la femelle du Banteng et du Zèbu, tend à faire dériver les Boufs européens des Bibos de l'Inde, et Wilckens arrive même à admettre qu'il faut chercher dans le Leptobos ctruscus, bien plutòt que dans le Bos primigenius, la forme d'origine de nos races, tout an moins des races brachycéphales.

De tout ceci on peut conclure que les recherches sont loin d'ètre assez avancées pour qu'on puisse se prononcer définilivement sur l'origine des races actuelles.

Domestication. - D'après les données qui précèdent, la domestication des races bovines européennes remonterait à la période de la pierre polie. Mais il est probable que les races asiatiques on été domestiquées sur place à une époque antérieure. A la vérité, nous voyons bien un Bœuf mentiomé par les Aryas primitifs; mais on est en droit de se demander s'il s'agit du Bœuf proprement dit ou du Zébu. Les monuments figurés de l'Assyrie el de l'Égypte nous fournissent toutefois des renseignements plus précis : on y roit représentés à la fois le Bœuf et le Zébu dans des conditions qui ne laissent aucun doute sur leur état de domesticité. D'après Joly, les peintures des salles funéraires de l'ancienne Égypte - peintures qui remonteraient jusqu'à la période néolithique - nous montrent déjà diverses races de Bœufs portant le joug et attelés à la charrue. "On y voit mème des vaches saus cornes el dont on a lié les jambes, afin de pouvoir les traire malgré la présence de leur veau, laissé à còté d'elles. " En somme, il paraît certain que les Bœufs ont été domestiqués d'abord en Orient, et que nos races occidentales n'ont été soumises à l'Homme qu'après l'arrivée en Europe des populations qui avaient accompli cette domestication primitive.

Caractères plyysiologiques. - Le Taureau se montre apte à l'accouplement vers l'àge d'un an; la Vache est un peu plus précoce. Toutelois, lorsque le mâle est encore aussi jeune, il importe de ne lui faire saillir qu'un petit nombre de femelles. 
La gestation dure en moyenne 280 jours, soit en chiffres ronds neut mois. Il n'est pas très rare de voir la Vache donner naissance à deux petits. Chose remarquable, lorsque l'un de ces jumeaux est un Veau et l'autre une Génisse, celle-ci est presque toujours inféconde. Le sevrage ne doit avoir lieu qu'après l'apparition de la première molaire permanente (quatrième de chaque rangée), soit d'ordinaire entre le cinquième et le huitième mois.

Dès que les testicules sont accessibles, on les supprime chez les individus mâles qui ne sont pas destinés à la reproduction : ces individus recoivent alors le nom de Bceufs. Assez souvent aussi on pratique la castration des Vaches : cette opération, surtout préconisée par Pierre Charlier, a généralement pour but de prolonger la période de lactation.

La durée naturelle de la vie est de quinze à dix-huit ans; mais il y a toujours intérêt à sacrifier les animaux beaucoup plus tôt.

Services. - La fonction économique la plus générale de nos Bœufs domestiques est la production de la viande. Nous consommons tantót celle du Veau, qui est une viande blanche, tantôt celle du Bœuf ou de la Vache engraissée. La chair du Taureau est dure, à peine mangeable.

Le lait de Vache est, en outre, un aliment très recherché, dont l'usage, soit en nature, soit sous forme de beurre ou de fromage, est assez répandu pour que nous n'ayons pas à y insister.

D'autre part, les Bœufs sont des producteurs de force motrice; mais, contrairement à ce que nous aurons à constater pour les Cheraux, cette force n'a presque pas d'application en dehors des travaux de l'agriculture.

Enfin, il nous suffit de citer le suif, la peau, les poils, les cornes et onglons, les os, etc., dont l'emploi est du domaine de l'industrie.

II ybrides. - On connait de nombreux exemples d'hybridation entre les différentes espèces de Bovinés.

L'accouplement entre Zébus et bètes bovines, quel que soit le scns, donne des produits (à bosse graisseuse) indéfiniment féconds.

J. Kühn a vu, au Jardin zoologique de Ilalle, l'Yak màle donner avec des Vaches de diverses races des produits remarquables en ce que les mâles étaient stériles el les femelles fécondes.

Au Thibet, l'accouplement du Zébu màle et de l'Yak femelle est entré dans la pratique industrielle, et le produit de cet accouplement (dzo si c'est un mâle, dzomo si c'est une femelle) tient le premier rang parmi les bètes de somme. L'hybridation de l'Yak màle avec la femelle du Zébu est plus rare (padzo, produit màle; tedzo produit femelle). A Halle, on a également obtenu des résultats en accouplant l'Yak et le Zébu abyssin ou Sanga. Dans tous ces cas, les produits mâles restent stériles, non les produits femelles.

Küihn a accouplé avec succès le Gayal mâle et la Vache. Gray signale un produit du Gayal (?) et du Zébu. Du reste, le Bœuf des Stiengs ou du Cam- 
boulje, qui possède une petile bosse de Zébu et sert de courrier en Cochinchine, est regardé comme un produit du Gayal et du Zébu. Bartlett a fait accoupler un Zébu ơ avec un Gayal \&. Le produit \& ainsi obtenu, accouplés avec un Bison d'Amérique $\sigma$, i donué un second produit $\&$; celui-ci, accouplé encore avec un Bison o゙, a fourni un troisième produit $\varsigma$, qui a été fécondé également par un Bison ơ.

Signalons enfin l'accouplement du Bison d'Europe et du Bisou d'Amérique avec la Vache domestique, donnant des produits qui paraissent ètre inféconds.

Quant it l'union des Buffles et des bètes bovines, clle est fort difficile à réaliser et reste toujours infruclueuse.

\section{SEPTIEME ORDRE}

\section{JUMENTÉS}

Mammifères ongulès, à doigts généralement impairs, le médian plus. développé; dentition complete, sauf parfois l'absence de canines; placenta diffus.

Les Jumentés représentent une partie des Pachydermes de Cuvier, lesquels comprenaient en outre nos Proboscidiens et nos Porcins. On leur donne quel-

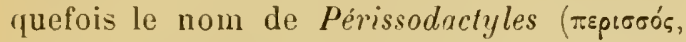
impair; $\delta \alpha ́ x \tau u \lambda \circ s$, doigt), qui ne leur est pas toujours rigoureusement applicable.

Ce sont des animaux terrestres, d'assez šrande taille, revêtus d'un tégument tantôt

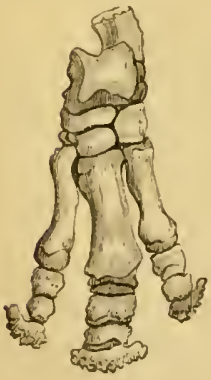

Fig. 842. - P'ied de Rlinocć- Fig. 843. - L'ied postírıeur du Cheval. ros (Kh. indicus Cuv.).

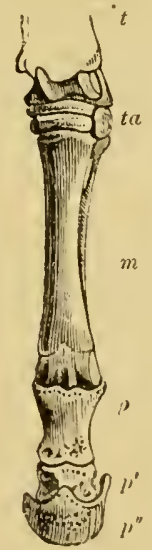

- $t$, libiit. $t a$, tarse. $m$, métatarse. $p, p^{\prime}, p^{\prime \prime}, 1^{\text {reo }}, 2^{\circ}$ et $3^{\mathrm{c}}$ phalanges.

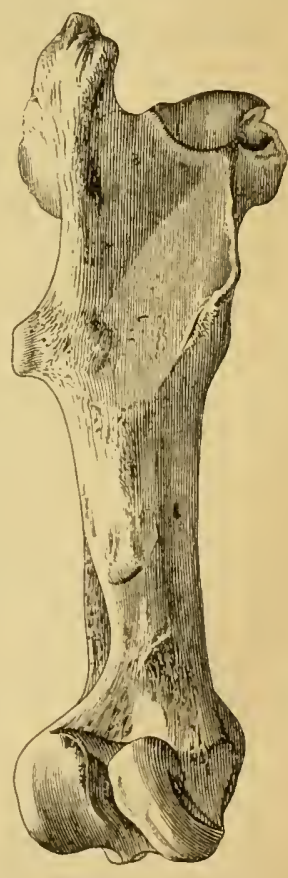

Fig. 844. - Fémur du Cheral.

épais el presque nu, tantot souple et garni de poils abondants. Jues membres sont pourvus de sabots (Ongules). Les doigts sont d'ordi- 
naire en nombre impair, et, dans tous les cas, le doigt médian prédomine sur les autres. L'axe des membres passe en effet par le milieu de ce doigt, lequel supporte ainsi la charge principale du corps et se développe pour remplir cette fonction de soutien; les autres doigts, moins actifs, se réduisent peu à peu jusqu'à disparaître. Souvent ils disparaissent d'abord aux membres postérieurs.

Le fémur est pourvu d'un troisième trochanter : c'est

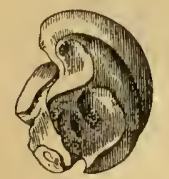

Fig. 845. - Astragale du Cheval. l'éminence à laquelle les anatomistes vétérinaires donnent le nom de tubérosité externe du corps du fémur, ou de crête sous-trochantérienne. L'astragale présente, à son articulation tibiale, une trochlée à gorge profonde; mais son extrémité distale, c'est-à-dire sa face inférieure, est tronquée et n'offre jamais de trochlée. Les clavicules manquent.

La dentition est généralement complète; cependant, les canines, toujours assez faibles, font parfois tout à fait défaut. Il existe dans tous les cas une barre plus ou moins considérable entre les molaires et les dents antérieures. - L'estomac est simple; l'intestin, fort long, présente un cæcum d'une grande capacité.

Les mamelles sont ventrales ou inguinales. L'utérus est bicorne. Le placenta est diffus. - Le cerveau est peu développé, et les hémisphères, pourvus de nombreuses circonvolutions, laissent le cervelet à découvert. L’intelligence est assez bornée. Les Jumentés sont herbivores; ils vivent en troupes dans les prairies et se montrent en général très sauvages, parfois même farouches et brutaux.

Le groupe des Périssodactyles, qu'on fait aujourd'hui dériver, comme celui des Artiodactyles, des Condylarthra éocènes, comprend plus de 80 genres (dont 3 seulement existent encore) pouvant se répartir dans sept familles : Equidx, Proterotherilx, Macrauchenillx, Tapiridx, Rhinocerotidx, Titanotheridx, Chalicotheridx. Nous nous arrèterons seulement à celles de ces familles qui renferment des espèces vivantes.

Famille des ÉQUIDÉS. - Ces animaux possèdent une tête sans cornes, offrant des os nasaux libres et pointus en avant. La dentition est complète, sauf chez les femelles, qui manquent parfois (Equus) de canines; formule dentaire $: \frac{3.1 \cdot 4-3,3}{3.1 .1-3,3}$. Les prémolaires, plus simples que les molaires dans les formes anciennes, se montrent de plus en plus semblables à celles-ci à mesure que les formes deviennent plus récentes. Les membres antérieurs se terminent rarement par quatre doigts; le plus souvent ils en possèdent trois ou un seul, comme les membres postérieurs.

Les Équidés, très riches en espèces étroitement apparentées, commencent dans l'éncène inférieur et se poursuivent jusqu'à l'époque actuelle, en nous offrant l'exemple le plus remarquable de la transformation graduelle 
el de la spécialisation d'un type particulier d'organisation. - On en distingue trois sous-familles : Hyracotherinx, Palxotherinx et Equinx, qui marquent les étapes principales et successives de l'évolution.

Les HYRAcothérinés ont encore une dentition bunodonte; leurs prémolaires, au nombre de \&, sont en général plus simples que les molaires. L.es orbites sont ouvertes en arrière. Le radius et le cubitus sont séparés, presque aussi développés l'un que l'autre; de mème du libia et du péroné. Les membres antéricurs sont à 4 doigts, les postérieurs à 3 .

Les représentants de cette tribu ne se retrouvent que dans l'éocène de I'Enrope el de l'Amérique du Nord. - Genres Hyracotherium, Eohippus, ? Helohippus, Pachynolophus, Bropalaotherium, Epihippus, elc.

Les Hyracothériums (Hyrucotherium 0wen; Pliolophus Owen) ont pour formule dentaire, comme tous les genres de la sous-famille $: \frac{3.1 .4,3}{3.1 .4,3}$. Les canines sont coniques; les molaires sont entourées d'un bourrelet à leur base. Le cràne est allongé, étroit en avant; les os nasaux sont très développés, mais non isolés a la partie antérieure. Les membres sont longs et grèles; le pied est plus long que la main. Le doigt 3 est plus fort et plus long que 2 et ' $\mathbf{x}$; ceux-ci plus forts et plus lougs que 5. Animaux de la taille d'un. Renard jusqu'à celle d'un Pointer, dont on trouve les restes dans l'éocène inférieur de J'Europe et de l'Amérique du Nord. - H. leporinum Owen : Angleterre, Allemagne. H. venticolum Cope : Amérique du Nord.

Dans le genre Éhippe (Eohippus Marsh), la dernière prémolaire supérieureest différente des molaires; les deux dernières prémolaires inférieures sont un peu plus simples et plus allongées que les nolaires. Aux membres antérieurs, existe la trace d'un cinquième doigt (1 ${ }^{\mathrm{er}}$ ) fournie par un métacarpien rudimentaire. Taille du Renard. Eocène inférieur des États-Unis. - E. pernix Marsh, E. validus Marsh, etc.

A côté de ce genre paraissent se placer les Hèlohippes (Helohippus Marsh), dont la dernière molaire supérieure a la mème structure que les molaires. Un espace libre entre les deux premières prémolaires. Éocène du Wyomingr (Bridger Beds).

Les Pachynolophes (Pachynolophus Pomel; Orohippus Marsh, pro parte) ont des molaires basses, avec un fort bourrelet basilaire; la dernière prémolaire supérieure est semblable à la première molaire, mais un peu plus courte. Le squelette est à peine connu, mais il s'agissait certainement d'animaux de petile taille. Le métacarpien 1 a disparu. Éocène inférieur, moyen et supérieur de l'Europe et de l'Amérique septentrionale. $-P$. Vismxi Pomel : éocène inférieur de Sézanne. P. (Orohizppus) agilis Marsh : éocène supérieur des États-Unis.

Les Propaléothériums (Propalæotherium P. Gerrais) ont à la màchoire supérieure les molaires semblables à celles des Pachynolophes, mais notablement plus grandes, el les deux dernières prémolaires bien distinctes; les deux dernières prémolaires inférieures sont semblables aux molaires. Squelette inconnu. Éocène moyen de l'Europe occidentale. - Pr. Isselanum Gervais. Pr. minutum Rütimeyer. 
Les Épihippes (Epihippus Marsh) ont les molaires supérieures des Pachynolophes; les deux dernières prémolaires sont semblables a un peu plus étroites à la màchoire inférieure. Le métacarpien du doigt médian (3) est beaucoup plus fort que celui des doigts 2 et 4 ; celui du doigt ä est mince et court. Éocène supérieur de l'Amérique du Nord. E. Uintensis Marsh, du Wyoming.

Les PAL ÆOTHÉRINĖs ont des molaires sélénodontes, surtout à la màchoire inférieure, où elles montrent un double croissant parfait; leurs prémolaires se sont compliquées, et les deux ou trois dernières sont généralement semblables aux molaires. Les orbites sont plus ou moins ouvertes en arrière. La coulisse bicipitale de l'humérus est simple; le jadius et le cubitus, le péroné et le tibia sont plus ou moins complètement séparés. Les membres antérieurs et postérieurs sont à trois doigts (2.3.4). Les représentants de ce groupe se trouvent dans l'éocène et le miocène de l'Europe et de l'Amérique du Nord. - Genres Pulxotherium, Paloplotherium, Anchilophus, Mesohippus, Anchitherium.

Les Paléothériums (Palæotherium Curier), dont la restauration a tant contribué à la gloire de Cuvier, ont des os nasaux très saillants, de sorte qu'on les a supposés pourvus d'une petite trompe; les deux doigts latéraux ( 2 et 4 ) étaient relativement développés et devaient toucher facilement le sol. Formule dentaire $: \frac{3.1 .4,3}{3.1 .4,3}$. Tous se rencontrent dans l'éocène supérieur de l'Europe occidentale. - P. magnum Cuv., de la taille d'un Cheval: gypses de Montmartre. P. medium Cuv., plus petit qu'un Cochon : marne de la Débrugre (Vaucluse).

Le genre Paloplothérium (Paloploticerium Owen), établi aux dépens du précédent, s'en distingue surtout par une réduction des deux doigts latéraux ( 2 et 4 ), qui devaient à peine atteindre le niveau du sol. Formule dentaire $: \frac{3.1 .4-3,3}{3.1 .3,3}$. Genre européen. - La plus ancienne espèce ( $\boldsymbol{P}$. codiciense (iaudry) vient de l'éocène de Jumencourt (Aisne). Toutes les autres sont de l'éocène moyen: $P$. annectens 0 wen, de Bembridge et de la Débruge; P. minus Cuvier, du gypse parisien, du Quercy, etc.

Ici se placent les Anchilophes (Anchilophus P. Gervais), connus seulement par des fragments de màchoires et quelques portions de crànes. Canines très fortes. Prémolaires (sauf la première, assez petite) semblables aux molaires. Éocène supérieur de l'Europe. - Anch. Desmaresti Gerv. : France, Suisse.

Dans le genre Mésohippe (Mesohippus Marsh), les prémolaires, sauf la première, sont semblables aux molaires; le rrâne est plus développé que dans ies formes précédentes; les doigts sont à peu près semblables à ceux des Paloplothériums, mais il y a aux menıbres antérieurs un métacarpien rudimentaire du doigt ö. Formule dentaire $: \frac{3.1 .4,3}{3.1 .4,3}$. Genre américain. M. Bairdi (Leidy), de la Laille d'un Mouton. Miocène inférieur du Dakota. 
il en existe encore des représentants vivants, ayant pour patrie l'Europe, l'Asie et l'Afrique. - Genres principaux: Merychippus, Hipparion, ? Hippodartylus, Protohippus, Pliohippus, Hippidion, Equus.

Le genre Mérychippe (Herychippus Leidy) n'est connu que par des fragments de màchoires. Molaires basses, mais prismatiques, à plusieurs racines; cément médiocrement abondant; molaires inférieures composées de deux croissants. Pliocène inférieur de l'Amérique du Nord. - M. insignis, M. mirabilis, du Nebraska.

Les Hipparions (Hipparion Christol, 1832; Hippotherium Kaup, 1833) ont pour formule dentaire $\frac{3.1 .4-3,3}{3.1 .3,3}$. Les canines existent sur tous les individus;
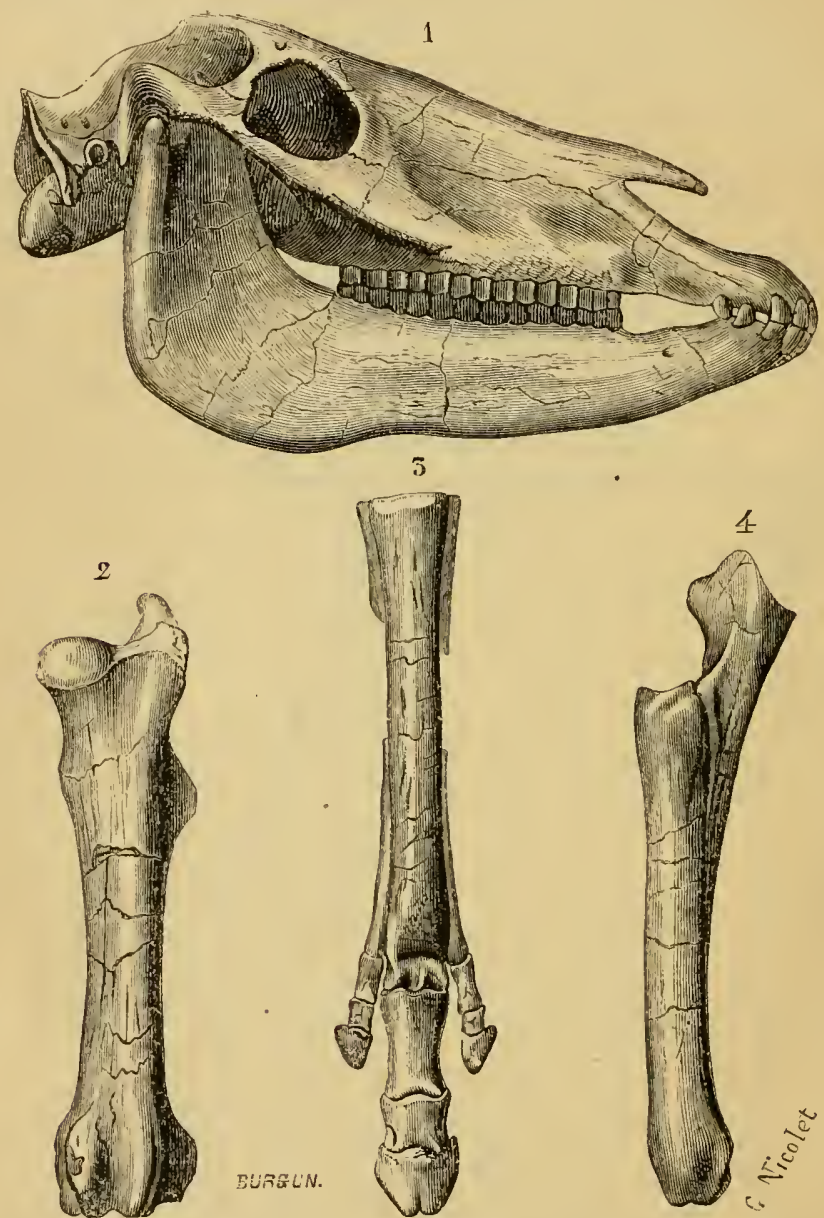

Fig. 817. - Hipparion gracile, du miocène. - 1, tête. 2, fémur. 3, pied, 4, radius et cubitus.

parfois, cependant, elles sont assez petites, et nous supposons qu'il s'agit alors de femelles. Les molaires sont beaucoup plus courtes que dans le 
MAMMIFĖRES. - JUMENTÉS.

1153

ğenre Equus; les supérieures ont le denticule antérieur interne arrondi et, à moins d'usure excessive, completement séparé du denticule antérieur médian, de manière à former une sorte d'ilot (fig. 8'r's); les inférieures sont presque équines. Le crùne est semblable à celụi du Cheval, seulement un peu plus petit el plus bis, el présentant un larmiè. Les deux doigts latéraux sont très réduits, u'atteignant plus que l'exlrémité proximale du doigt médian; on trouve encore un rudiment du métacarpien 5. La taille est intermédiaire entre celle des Anes et ıles Zèbres.

- Les Hipparions apparaissent dans le miocène supérieur des deux continents; mais on en trouve encore quelques-uns dans le pliocène. Leurs restes forment souvent des amas considérables: ils viraient sans doute par troupes nombreuses, au bord res grands lacs tertiaires. - H. mracile [Kaup] : miocène supérieur de l'Europe, de l'Algérie el de la Perse. H. crussum P. Gervais, à doigts latéraux très restreints : pliocène inférieur de Perpignan et de Montpellier. On en connait également de l'Inde, de da Chine et surtoul de l'Amérique du Nord.

Les Protohippes (Protohippus Leidy), très voisins des llipparions, ont des canines puissantes, des molaires supérieures à denticule antérieur interne uni au denticule antérieur médian et à peine plus développé que le postérieur, des molaires inférieures semblables à celles des Chevaux, mais plus basses. Cràne de Cheval, mais à orbites très grandes. Doigts d'Hipparion. Ces animaux sont limités au pliocène de l'Amérique du Nord. $P_{7}$. perditus Leidy, $P_{r}$. sejunetus Cope.

Le genre Pliohippe (Pliohippus Marsh), a peine distinct du suivant, commence la série des formes à un seul doigt $\left(\frac{3}{3}\right)$, série qui correspond à l'ancien ordre des Solipédes (solidipedes, animaux it pieds indivis) ou Monodactyles (ujvos, un seul; $\delta \dot{x} \kappa: \cup \lambda_{0}$, doigt). Molaires courtes, prismatiques sem: blables à celles des IIippidions. Crâne inconnu. Métacarpiens et mélatarsiens des doigts 2 et 4 rudimentaires. Pliocène de l'Amérique du Nord Pl.pernix Marsh, Pl. spectans Cope.

L.es Hippodactyles (Hippolactylus Cope) ont encore les caractères généraux des llipparions, mais

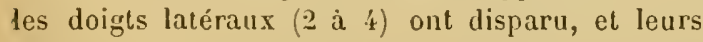

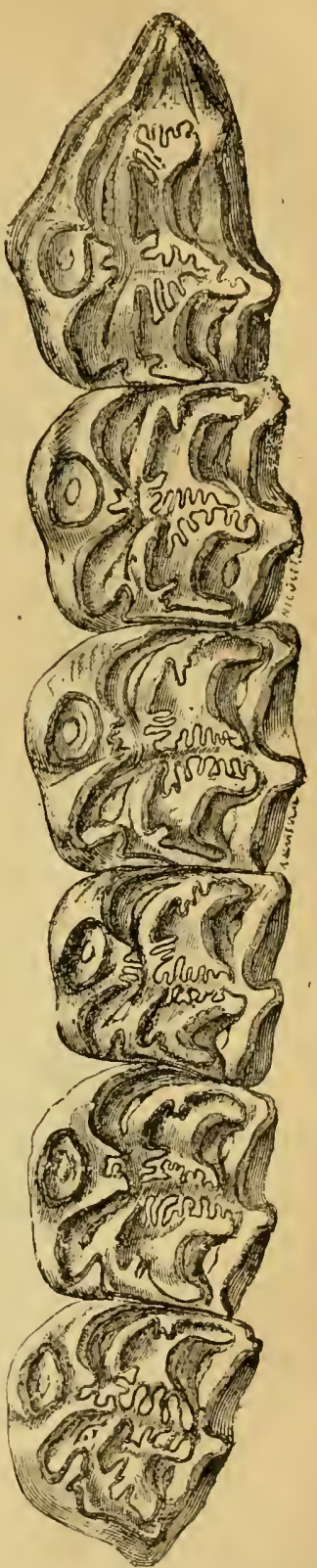

Fiz. 848. - Arcade molaire su pirieure sanche dillipparion (lioubaux el barries). métacarpiens et métatarsiens sont réduits à l'état de courts stỵlets. Pliocène inférieur. - II. antelopinus (Falconer et Caulley), de l'Inde. 
Les Hippidions (Hippilion 0wen) ont la même formule dentaire que les Chevaux. Les molaires supérieures sont fortement courbées et à racines séparées, avec le denticule antérieurinterne uni au denticule antérieur médian et à peu près égal au postérieur interne; les molaires inférieures sont semblables à celles des Chevaux. La tète est grosse, parfois pourvue d'un larmier; les os nasaux, très développés, rappellent ceux des Tapirs. Les métacarpiens et métatarsiens sont plus réduits que chez les Cheraux; il existe encore un rudiment du métacarpien ŏ. D'une manière généralc, le squelette est plus petit et plus lourd que dans le genre Equus. Les restes de ces animaux ont été découverts dans les dépòts pampéens (quaternaires, l'après Steinmann) de l'Amérique du Sud. - H. neogæum (Lund), H. nanum Burm., etc.

Genre Cheval (Equus L.). - Les principaux caractères distinctifs de ce zenre - le seul représentant actuel des Équidés - sont fournis par les mo-

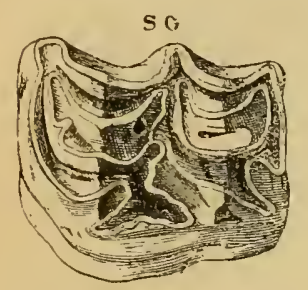

Fig. 849. - Table de frottemenl d'une molaire supírieure de Cheval (Goubaus et Barrier). laires : ces dents sont très hautes, prismatiques, sans racines séparées, et possèdent un cément très abondant; de plus, dans les molaires supérieures, le denticule antérieur interne est allongé, aplati, beaucoup plus grand que le postérieur, quoique réuni au denticule antérieur médian, contrairement à ce qui s'observe chez les Hipparions. L'illot séparé qu'il formait chez ces derniers n'est plus qu'une presqu'île.

Les espèces vivantes de ce genre sont, en général, d'assez grande taille, et remarquables par la régularité de leurs proportions. Le pelage est ordinairement lisse. La tète, maigre et allongée, avec de grands yeux vifs, des oreilles en cornets pointus et mobiles, est portée par une longue encolure.

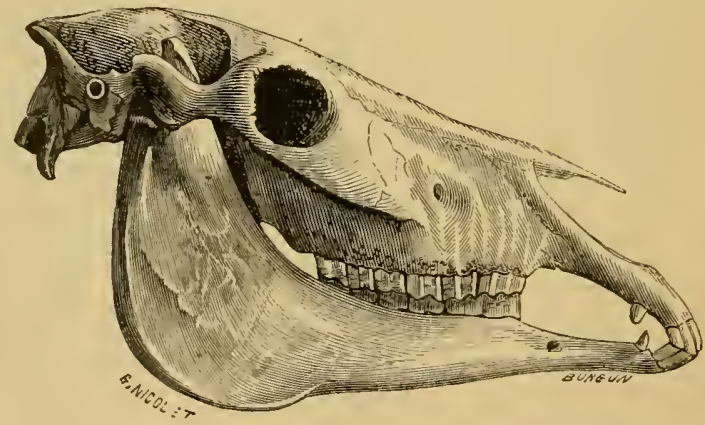

Fig. 850. - Tête de Cheval.

comprimée d'un còté à l'autre et garnie d'une crinière à son bord supérieur. Le tronc, dans son ensemble, est court et arrondi, la poitrine vaste, le ventre modérément développé. La queue est garnie de crins sur toute sa longueur ou n'en porte qu'un bququet terminal. Les membres sont hauts et bien déliés, quoique vigoureux, et se terminent chacun par un seul doigt apparent dont l'extrémité est enveloppée par un sabot arrondi. 
Il serait déplacé d'insister ici sur les caractères anatomiques du genre Equus : nous nous bornerons aux plus saillants. On sait que le seul doigt complet qui termine le membre est le $3^{\mathrm{c}}$; le $4^{\mathrm{e}}$ (exterme) et le $2^{\mathrm{e}}$ (iuterne) sont réduits chacun à son métapode (nétacarpien ou métatarsien), devenu rudimentaire et constituant un simple stylel; quant au :je et au $1^{\text {er }}$ (pouce), ils manquent tout à fait on sont représentés par des osselets inconstants qui doivent ètre regardés également comme des rudiments de métapodes.

En raison des mouvements bornés des membres, le cubitus et le péroné sont atrophiés; leur corps est mème réduit à un cordon fibreux dans une parlie de son étendue, et leur extrémité inférieure est soudée d'une facon si intime à l'os correspondant (radius ou tibia), qu'elle semble en faire parlie intégrante. Ce n'est que dans des cas exceptionnels que le cubitus et le péroné se moutrent aussi complets que clez les llipparions.

La formule dentaire est, pour la dentition de lait : $\frac{3.0 .4}{3.0 .3}=26$, et, pour la dentition définitive : $\frac{3.1 \cdot(4) 3,3}{3.1 .3,3}=40$. Les incisives, disposées en arc, présentent sur leur surface de frottement une fossette ovale (cavité dentaire extérieure) qui diminue à mesure que la dent suse; on les désigne, de dedans en dehors, sous les noms de pinces, mitoyennes, coins. Les canines ou crochets sont au nombre de deux à chaque mâchoire chez les màles adultes; elles manquent ou sont peu développées chez la généralité des femelles. Dans la dentition de lait, elles sont d'ordinaire représentées soit par un stylet grèle, couché sur la gencive, soil par un follicule atrophié. A l'àge adulte, on compte douze molaires à chaque mảchoire, soit six de chaque còlé. Toutefois, comme Daubenton l'a le premier observé, il existe dans certains cas, surtout à la màchoire supérieure, une petite dent située en avant de la première prémolaire : d'après Lesbre, c'est la prenière molaire de lait, loujours rudimentaire, qui a persisté. Le nombre des molaires se trouve alors être le mème que dans les genres fossiles d'Équidés. Cette dent tombele plus souvent avec les autres molaires de première dentition, mais elle n'est jamais remplacée. Les trois molaires de remplacement ou prémolaires res. semblent beaucoup aux trois arrière-molaires ou molaires proprement dites. Comme dans tous les types franchement herbivores, du reste, le fùt de ces dents est très allongé, el on n'observe pas une séparation bien nette de la couromne et de la racine. Elles appartiennent au type sélénodonte, c'est-àdire que leurs denticules affectent la forme de croissants : or, ces denticules sont disposés en deux rangées ou lobes, l'un antérieur, l'autre postérieur. Les molaires inférieures ne possèdent que deux denticules à chaque lobe, un externe et un interne; mais les molaires supérieures, qui sont les plus intéressantes au point de vue de l'anatomie comparée, en ont trois : externe, médian et interne.

Ceci posé, on remarquera que, dans le genre Equus, les denticules exlernes et médians des molaires supérieures dessinent une sorte de $\mathfrak{B}$ gothique, landis que le denticule interne antérieur, fortement comprimé d'un còté à l'autre, forme comme une boucle accessoire réunie à la boucle antérieure lư 'B, c'est-à-dire au denticule médian antérieur (fìg. 8'49).

1.e tube digestif offre encore quelques particularités qui méritent d'ètre sigualées. Notons d'abord l'existence des cravates suisses, qui consistent en 
deux faisceaux musculaires croisés formant, au niveau du cardia, une sorte de sphincter très puissant, qui constitue un obstacle presque absolu au vomissement. L'estomac, quoique uniloculaire, marque une tendance à se diviser en deux compartiments : l'un (sac gauche), tapissé par une muqueuse blanchàtre et résistanle, n'est en réalité qu'une dilatation de l'œsophage; l'autre (sac droil), dont la muqueuse est veloutée, de teinte rouge brunàtre, sécrète seul le suc gastrique et représente le véritable estomac. Il n'existe pas de vésicule biliaire.

Les femelles ont toujours deux mamelles inguinales; après une gestation de longue durée, elles donnent naissance, en général, à un seul petil, assez fort pour suivre immédiatement sa mère.

Les Équidés sont herbivores; mais on sait qu'ils deviennent aisément granivores en captivité, et qu'à la rigueur on peut les accoutumer à un régime animal. Ce sont des animaux sociables, qui vivent en bandes conduites par les plus vieux mâles. “Tous les Equidés, dit Brehm, sont des animaux vifs, éveillés, agiles et prudents. Il y a quelque chose d'élégant et de noble dans tous leurs mouvements. En liberté, ils vont d'ordinaire d'un trot assez rapide. Leur allure de course est le galop. Ils sont doux et paisibles vis-à-vis des animaux inolfensifs; ils fuient devant l'Homme et les grands animaux carnassiers; mais, en cas de danger, ils se défendent courageusement de leurs pieds et de leurs dents. " On a souvent répété que, pour soutenir l'attaque de leurs ennemis, ils se disposaient en cercle, la tête au centre, et répondaient à l'assaillant par des ruades. C'est là une l'able, dont l'origine doit être sans doute cherchée dans ce fait, qu'à l'approche d'un carnassier, les étalons forment un cercle protecteur autour des juments et des poulains.

En ne tenant pas compte des espèces domestiques et des individus marrons qui en proviennent, les Équidés actuellement vivants paraissent être limités à l'ancien continent. Ils habitent les steppes de l'Asie et de l'Afrique, et, comme tous les animaux qui vivent en troupes, parcourent de grands espaces pour découvrir, de nouveaux pâturages, après avoir ravagé une contrée.

État fossilp. - Les débris fossiles les plus anciens du genre Equus ont été recueillis dans le miocène supérieur; on en a trouvé davantage dans le pliocène; mais le quaternaire en a fourni le plus grand nombre. Nous nous bornerons à jeter un coup d'œil rapide sur les principales formes qui ont été observées dans les diverses parties lu monde.

Dans l'Amérique du Nord, on rencontre à la fín du pliocène l' $E$. parvulus, qui fait suite au Pliohippe, et qui se trouve lui-mème bientôt suivi d'une série d'autres formes quaternaires, telles que $\boldsymbol{E}$. pacificus Leidy et $\boldsymbol{E}$. major Dekay, de taille un peu supérieure au Cheval actnel, et $E$. occidentalis Leidy, ì peu près aussi grand que celui-ci. Mais, après s'ètre ainsi multiplié pendant la période quaternaire, le genre Equus a disparu complètement du continent américain, et cette extinction a précédé de beaucoup la découverte du nouveau monde par les Européens. 
A la suite des Hippidion, dont il a été question plus lıaut, l'Amérique du Sud a fourni des formes fossiles qu'on rapporte au genre Equus, mais qui se relient étroitement au type précédent el se rapproclıent comıne lui, par la taille et par divers autres caractères, des Asiniens et des Zébrius. Tels E. curvidens et $\boldsymbol{E}$. argentinus, des dépôts pampéens (probablemeut quaternaires) de la liépublique Argentine, et E. rectidens, du pampéen et du platien (quaternaire supérieur); $\boldsymbol{E}$. Lundi, du quaternaire de Colombie, etc.

$\mathrm{C}^{*}$ est en Asie que se rencontrent les plus anciens représentants du genre. E. siralensis Falconer et Cautley est du miocène supérieur; on l'a regardé comme un Hémionien; une autre forme, $\boldsymbol{E}$. namadicus Falc. et Caul!., plus rapprochéc des Caballins que des Asiniens, serait de la même époque. Nous savons d'ailleurs, par les observations de Nordeuskiöld, qu'on trouve en Sibérie, et mème dans l’ìle de la Nouvelle-Sibérie, une quantité extraordinaire de restes de Chevaux, associés aux ossements de Mammouths, de Rhinocéros, de Bos primigenius, de Moutons, etc.

L'Afrique n'a encore été explorée que dans les régions du nord, et les formes qu'elle a fournies sont tout à fait analogues, sinon identiques à celles rencontrées en Europe. - Quant à l'Australic, on sait qu'elle ne montre aucun débris d'Ongulé.

Enfin l'Europe a fourni une grande abondance de Chevaux, tant dans le pliocène que dans le quaternaire. - Parniles formes quaternaires notamment, il eı est qui se rapportent plutỏt aux Asiniens et aux Zébrins qu'aux Caballins; on les trouve surtout dans le sud de l'Europe. Tel est le cas de l'E. quuggoides Forsyth Major, trouvé en Italie, et de l'E. hemionus fossilis Nehring, recueilli en Allemagne. Souvent, du reste, les débris d'Équidés offrant une taille au-dessous de la moyenne ont été rapportés à l'Ane, sous le nom d'E. Asinus fossilis, peut-être sans preuves suffisantes (Weithofer). D'autres formes présentent des caractères plutòt caballins, et se rapproclient de plus en plus des vérilables Chevaux actuels. Citons d'abord, parmi les formes pliocènes, E. Stenonis Cocchi, E. fossilis Rütimeyer (nec Cuvier) et E. Larteti Cocchi, trois types qui se sont succédé directement et qui, d’après Rütimeyer, dériveraient l'un de l’autre par variation naturelle. L'E. Stenonis, du Val d'Arno (Italie), de Perrier (Puy-de-Dòme), de Chagny (Saòne-et-Loire), est remarquable en ce que ses molaires supérieures ont le denticule antérieur interne arrondi comme chez les Hipparions, bien qu'il soit encore disposé en presqu'île; ses métacarpiens et métatarsiens latéraux sont relativement plus forts et plus longs que chez les Chevaux actuels; son tarse surtout est plus complexe. Forsyth Major le tient pour identique à $E$. sicalensis. L'E. fossilis terliaire a été rencontré au Coupet (Haute-Loire) et à l'île de Lessina (Dalmatie). L'E. Larteti a été découvert au Val d'Arno et retrouvé par Forsyth Major dans une brèche plus récente d'Olivola; c'est la forme qui se rapproche le plus des Chevaux actuels. - Les Caballins quaternaires étaient primitivement confondus sous le nom d'E. fossilis Cuvier; on les a souvent appelés aussi $E$. Caballus fossilis ou mème simplement $\boldsymbol{E}$. Caballus, car il est en général fort difficile de les distinguer spécifiquement de nos Chevaux domestiques. C'est à tort que divers auteurs, se hasant sur des caractères accidentels ou d'importance secondaire, ont voulu établir les espèces $E$. aclamiticus, priscus, brevirostris, etc. Il est même difficile d’accorder une valeur spécifique à l'E. plicidens 0 wen, des cavernes 
d'Oreston, caractérisé par une lame d'émail presque aussi festonnée que chez les Hipparions. Par contre, on accepte généralement l'espèce E. robustus Pomel, du diluvium de l'Auvergne. En tout cas, les formes des Chevaux diluviens sont tellement variées, qu'on est forcé, selon Nehring, d'admettre l'existence de nombreuses races locales (ou géographiques) quaternaires.

Mais, ce qu'il est intéressant de constater, ce sont les relations étroites qui existent entre le genre Equzs et les genres éteints de la mème famille. On avait, depuis longtemps déjà, reconuu des enchaînements remarquables dans cetle succession de formes; mais les découvertes qui se sont multipliées dans ces derniers temps en Amérique ont fait connaître de nombreux éléments de transilion manquant dans la série européenne, et sont venues ainsi apporter un appui ferme à la théorie de la descendance, ce qu'on a exprimé en disant que l'évolution du Cheval est devenue le Cheval de parade des évolutionnistes. Cerles, les auteurs ne sout pas entièrement d'accord sur les détails, et bien des tableaux divers ont été dressés pour exprimer la filiation supposée des aticètres du Cheval; mais les grandes étapes n'en sont pas moins nettes, et chaque jour de nouvelles découvertes viennent aider à combler les lacunes qui existent encore, ou à redresser les interprélations et les hypothèses primitives.

Dès 1857, Richard Owen admettait que le Cheval actuel descend d'ancêtres géologiques à trois doigts, les Hipparions et les Paléolhériums. Depuis lors, nombre d'auteurs ont insisté sur cette manière de voir, en cherchant à montrer comment chez ces animaux le pied s'est simplifié peu à peu, en mème temps que se transformait la dentition et que s'élevait la taille. Ainsi, la suite des genres de l'ancien monde, Palæotherium, Paloplotherium, Anchitherium, Hipparion, Equus, montre d'une laçon saisissante la réduction graduelle des doigts latéraux ( 2 et 4 ) et le développement corrélatif du doigt médian (3). D'autre part, dans le genre Equus mème, on peut trouver toute une série de formes tertiaires et quaternaires qu'on a souvent confondues sous le nom d'E. Stenonis, et qui condnisent peu à peu, selon Forsyth Major, à l'E. Caballus actuel.

Mais les observations faites en Amérique, daus les fameux gisements situés à l'est et à l'ouest des montagnes locheuses, ont fourni, comme il a été dit plus haut, une série beaucoup plus complète. D'après le travail, demeuré célèbre, de Jarsh (1874), cette série commençait au genre Orohippus (de l'éocène supérieur), pour se continuer par les genres Mesohippus (miocène inférieur), Miohippus (miocène supérieur), Protohippus (couches inférieures du pliocène), Pliohippıs (pliocène supérieur), et aboutir au genre Equus, très répandu pendant la période quaternaire, plus tard éteint. Depuis 1874, le paléontologisle américain a d'ailleurs ajouté divers chainons à cette série : il a placé à la base un genre Eohippus (éocène inférieur), puis un autre genre encore douteux Helohippus, et intercalé entre les Orohippes et les Mésohippes le genre Epihippus (éocène moyen et supérieur).

Cope, qui a fait une étude d'ensemble des Périssodactyles de l'ancien el du nouveau monde, va beaucoup plus loin que son compatriote. Il prend Epitippus comme point de départ probable des Chevaux des deux continents, mais le fait dériver lui-même d'Ilyracotherium, et remonte par celui-ci au genre Systemodon (Tapiridés), à un genre encore inconnu d'Amblypodes, puis au genre Phenacodus et enfin à la famille des Periptychidx (Condylarthrés). 
Tu genre Epihippus, il fail dériver deux rameaux généalogiques, aboutissant l'un aux Eques américains par Palxotherium, Mesohippus, Inchitherium, P'otohippus et Hippialion, l'autre aux Equus européens par I'aloplutherium, Anchippus (Inchitherium) et Hippurion.

Cetle hypollrèse plıylogénique a été combattue par divers auteurs. Il est bien difficile, en elfel, d'admettre que des genres primitivement dislincts arrivent, dans les régions dillérentes, à converger vers un seul et mème fenre. Schlosser admet l'origine exclusivement américaine des Chevaux (1).

En Europe, los genres Propulxotherium, Pulxotherium et Puloplotherium l'une part, puis Puchynolophus et Anehilophus formeraient, d'après lui, des rameaux latéraux indépendants, éteints de bonne heure. Marie Pavlor considère, d'autre parl, Hipparion comme devant ètre exclu, du moins en Europe, de la série généalogique qui aboutit au Cheval.

En dépil de ces lifficultés, il n'est pas impossible d'expliquer la présence du genre Equus dans les deux continents à l'époque quaternaire. Il est certain que les Équidés ont eu leur plus grand épanouissement dans l'Amérique du Nord, vers le milieu de la période tertiaire; mais on a vu yue pourtant le genre Equus est apparu d'abord en Asie, à la fin de l'épaque miocène. Ne peut-on pas admettre, avec Studer, que du centre de l'ancien nonde, ce genre se soit répandu en Europe et en Afrique, d'une part, et de l’autre en Amérique? Les communications qui existaient, dans le pliocène, entre les leux continents, rendent cette manière de voir fort admissible. En tout cas, il est probable que les habitants primitifs de l'Asie ont commencé a coloniser l'Amérique avant d'aroir domestiqué le Cheval; en arrivant d'ailleurs dans cette nouvelle région, ils n'y rencontrèrent plus cet animal (:2): oll a de honnes raisons de croire que lors des grandes modilications climalériques diluviennes (époque glaciaire), il avait été chassé des hauts plateaux el avait dù gagner de nouvelles régions, où il avait succombé dans la lutte pour la vie. Rütimeyer tend même à admettre qu'alors l'habitat du Cheval s'était restreint aux parties occidentales e! méridionales de l'ancien monde.

Especes actuelles. - En $18 \mathbf{1}$, le lieutenant-colonel Ilamilton Smith divisait la lamille des Équidés en trois groupes anxquels il donnait la valeur de genres: Efums, Asinus et Hippotigris. Quelques années après, le Dr Gray, du British Museum, n'en distinguait plus que deux: Equus et Asinus. En 1869, lans son cours de mammalogie professé au Muséum, H. Milne-Edwards alopta la division de Hamilton Smith; mais, ne reconnaissant à ses groupes que la valeur de sous-genres, il leur donna les noms d'Équidés proprement ‘lits, d'Équilés asiniens et d'Équidès zèbrés. Enfin, Sanson a voulu séparer complètement les Hémiones des Anes, et, dans la $2^{\circ}$ édition de son Traité de Zootechnie, il reconnait quatre sous-genres : Équidés caballins, $\dot{E}$. asiniens, $\dot{E}$. hémioniens et $\dot{E}$. zébrés. Mais les caractères extérieurs qui distinguent les Hémiones des Ines sont assez peu saisissables pour que nous croyions devoir

(1) A l'heure actuelle, la série la plus complète des Équidés de l'Amérique du Nord comprend : Eohippus, Hyracotherium,? Helohippus, Pachynolophus (Orohippus), Epihippus, Mesohippus, Anchilherium (.Mohippus), Merichippus, Hipparion, Protohippus, Pliohippus, Equus.

(2) Il faut dire cependant qu'on a trouvé dans l'étage platien (quaternaire supérieur) de la République Argentine des restes de l'Equus recticlens associes à des débris de lindustrie humaine. 
revenir à la classification de Milne-Edwards. Nous admetlrons donc trois sous-genres : celui des Caballins ou Chevaux, celui des Asiniens, comprenant les Anes et les Hémiones, et celui des Zébrés.

Sous-genre CuEvac (Caballus). - Les Chevaux proprement dits on Équidés caballins se distinguent des Anes et des Zèbres par leur robe presque toujours dépourvue de bandes ou de raies, ainsi que par leur queue garnie de crins dans toute son ètendue. Leur crinière est longue et flottante, leurs. oreilles sont assez courtes el très mobiles, et ils possèdent en général des chàtaignes aux quatre membres (1). 5 ou 6 vertèbres lombaires.

Chevanx domestiques (E. Caballus L.). - Le Cheval domestique des auteurs comprend, d'après $\mathrm{A}$. Sanson, huit espèces distinctes, la plupart originaires de l'Europe occidentale. Quatre sont brachycéphales : le Cheval asiatique ou oriental (E. Caballus asiaticus), le Cheval africain (E. C. africanus), le Cheval irlandais (E. C. hibernicus), et le gros Cheval britannique (E. C. Uritannicus). Les quatre autres sont dolichocéphales: Cheval germanique (E. C. gcrmanicus), Cheval frison (E. C. frisius), Cheval belge (E. C. belgicus), et Cheval séquanais ou percheron ( $\boldsymbol{E}$. $C$. sequanius).

Par contre, la plupart des auteurs rapportent à une seule espèce toutes les races de Chevaux domestiques, et Nehring, daccord avec Franck (de Munich), se borne à reconnaître deux races fondamentales: le Cheval oricntul, à cràne ample, à front large, el le Cheval occidental, plus lourd, ayant un cràne allongré, un front étroit, des marges orbitaires peu saillantes.

Quelle que soit l'opinion à laquelle on se range, on peut se demander si les Chevaux domestiques ont actuellement encore des représentanls sauvages. Il est difficile de répondre d'une façon précise à cette question; cependant, il faut bien le reconnaitre, aucun des documents que nous possédons sur l'histoire du Cheval ne démontre que depuis les temps historiques, l'Homme ait jamais connu des Équidés caballins réellement sauvages.

11 existe bien, sur divers points dı globe, des Chevaux qui vivent en liberté et parcourent les plaines en troupes plus ou moins nombreuses. Mais tout porte à croire que ce sont là des animaux marrons, c'est-à-dire redevenus sauvages; et, pour certains d'entre eux, la chose n'est point douteuse. Du reste, leur robe est en général très variable, comme celle des animaux domestiques, bien qu'elle ne présente guère de teintes tranchantes. - On distingue sous le nom de Tarpans les Chevaux errants répandus dans les steppes de l'Asie centrale et jusque dans les montagnes du nord de l'Inde. Or, il résulte des renseignements fournis par Forster à Buffon, que ces. animaux ne sont autres que des Chevaux marrons. Les Tartares et les Kirghiz, il est vrai, admettent l'existence de véritables Chevaux sauvages qu'ils appellent Tarpans, et reconnaissent à côté de ceux-là des Chevaux marrons auxquels ils donnent les noms de Muzins et de Takjas; mais, jusqu'à présent, rien ne semble justifier leur manière de voir. - Dans l'A mérique du Nord, Catlin a observé des Chevaux errants offrant une foule de

(1) Maury, Sanson et quelques autres ont constaté l'absence des châtaignes aux mcmbres postérieurs d'un certain nombre de Chevaux. Sanson pense que les Chevaux sans châtaignes postérieures appartiennent toujours à la race qu'il nomme africaine, race qui se rapproche d'ailleurs des Anes en ce qu'elle ne possède que cinq vertèbres lombaires. 
nuances différentes. Il peuse avec raison que ces animaux sont issus des Chevaux introduits par les Espagnols au moment de la conquète. D'ailleurs, l'absence du Cheval sur' le continent américain avant l'arrivée des Européeus est un fait parfaitement établi (Piétrement), nonobstant l'existence, dans ce pays, de fossiles quaternaires appartenant au genre Erqus. - Les pampas de l'Amórique du Sud donnent également asile à d'immenses troupeaux de

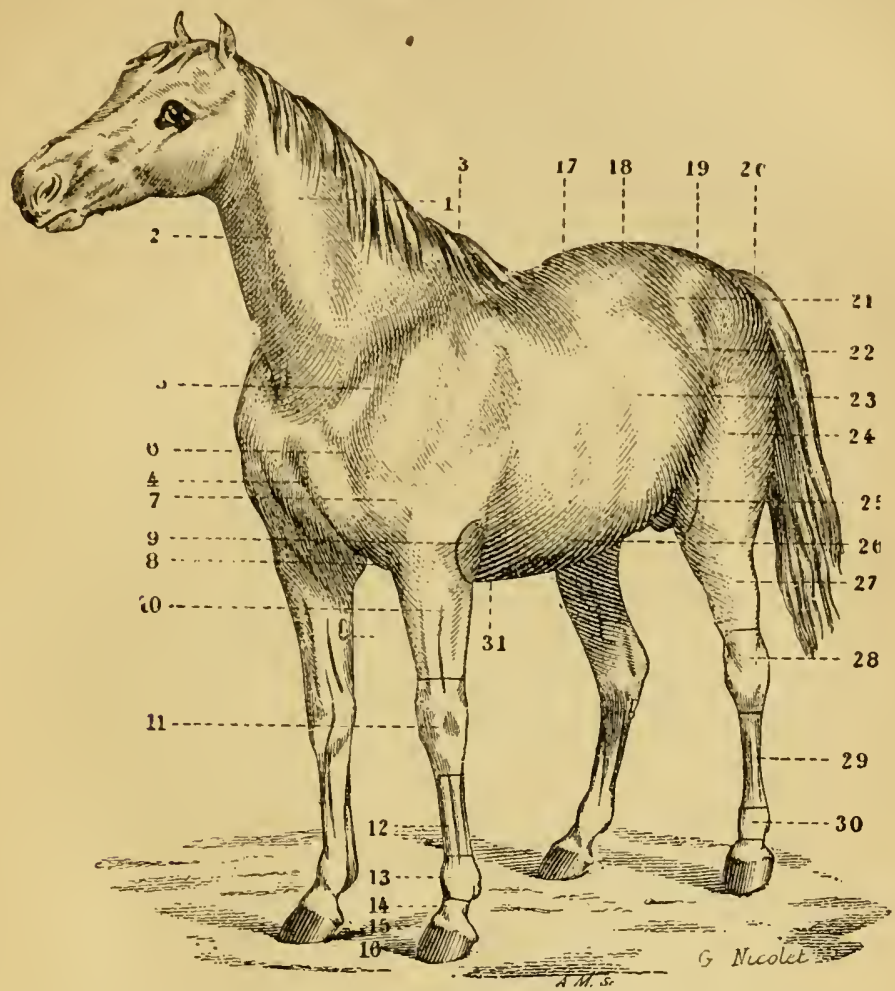

Fig. S5̃1. - Les rigions du corps du Cihesal, d'après Goubaux et Barrier. - 1, encolure. 2, goultière de la jugulaire. 3, garrol. 4, poitrail. 5, épaule. 6 , angle de l'épaule. 7 , bras. 8 , ars. 9, coude. 10 , avantLras. 11, genou. 12, canon, 13, boulet. 14, paluron. 15, couronue. 16, pied. 17, dos. 18, reins. 19, croupe. 20 , queue. 21 , hanche. 22 , flanc. 23 , còtes. 24, cuisse. 95 , grasset. 26 , ventre. 27 , jambe. ix, jarret. 2?, canon. 30, lioulet. 31, pissage des sangles.

Chevaux marrons (cimarrones), lesquels proviennent, selon d'Azara, de Chevaux andalous abandonnés par les Espagnols vers le milieu du xive siècle. Quant aux Mustangs du Paraguay, ce sont des Chevaux élevés en demi-liberté et presque sans soins. - Ajoutons qu'il existe aussi des Chevaux marrons en Océanie et probablement en Afrique, sur les bords du Niger.

Domestication. - Les principaux documents relatifs à la domestication du Cheval ont été rassemblés et analysés par Piétrement dans deux ouvrages considérables auxquels nous devons reuvoyer le lecteur, faute de pouvoir en donner ici un résumé suffisant (1). Nous nous bornerons à esquisser les traits généraux de la question.

(1) C.-A. Piétnemext, Les origines du Cheval domestique. Paris, 1870. - In., Les Chevaux dans les temps préhistoriques et historiques. Paris, 188:3. 
A l'époque quaternaire, le Cheval ètait des plus communs dans l'Europe occidentale. Il a laissé presque partout de nombreux ossements. De plus, les artistes chasseurs des cavernes du Languedoc et du Périgord l'ont sonvent gravé sur les bois de Renne, à côté du Mammouth, du Renne lui-même, du Rœuf, etc. Mais, contrairement à l'opinion de Toussaint, il n'était pas alors domestiqué : l'Homme lui faisait seulement une chasse active pour se nourrir de sa chair. On a pu en distinguer jusqu'à présent deux ou trois types : $1^{\circ}$ l'un, représenté par un cràne trouvé en 1868 dans les sablières de Grenelle, est identique, d'après Sanson, à la race percheronne actuelle (E. C. sequaniuts); $2^{\circ}$ un autre, dont les ossements les plus nombreux (crảne compris) ont été découverts dans le diluvium de Westeregeln près Magdebourg et des environs de Thiede dans le Brunswick, ainsi que dans le lœss de Romagen, non loin du Rhin, se rapproche d'une facon remarquable, d'après Nelıring, du Cheval allemand acluel (E. C. germanicus Sanson). Dans la station quaternaire de Solutré (Saône-et-Loire), on a trouvé des amas énormes d'ossements de Chevaux qu'on ne peut, en l'absence de cràne, déterminer d'une façon précise, mais qui, par l'ensemble du squelette, paraissent se raltacher à la variété ardennaise du Cheval belge (E. C. belgicus). Un autre type encore, décrit par Fraas, a été rencontré dans le diluvium des environs de Scliussenried, dans le sud-ouest du Wurtemberg. - On peut ajouter enfin, avec Schmidt, que beaucoup de stations de l'àge du bronze ont fourni les restes d'un Cheval domestiqué à squelette moins lourd que celui des précédents, et qu'on regarde en général comme d'origine asiatique.

Tout le monde est à peu près d'accord aujourd'hui sur ce point, que la domestication des races chevalines occidentales remonte seulement à la période néolithique (1). Piétrement l'attribue à l'arrivée en Occident des populations aryennes qui in troduisirent dans cette région l'usage des dolmens et des armes en pierre polie, et dont les descendants les plus purs sont les Galichas, les Savoyards et les Auvergnats. - Antérieurement à cette migration, les Aryens avaient domestiqué le Cheval asiatique à front plat et à profil rectiligne $(E$. C. asiaticus), que Piétrement appelle pour cette raison E. C. aryanus. Cette domestication avait eu lieu dans leur patrie primitive, l'Airyana vaedja, située à l'ouest des monts Alatau, aux environs du lac Balkach, sur le $49^{e}$ degré de latitude (gouvernement actuel de Sémiretchié ou des Sept-Rivières). De l'Asie centrale, celte race passa plus tard en Syrie et en Égypte, puis en Arabie : les Hébreux faisaient déjả usage du Cheval sous David, tandis que l'introduction de cet animal dans la péninsule arabique ne remonte qu'aux premiers siècles de notre ère. Le nom de Cheval arabe donné d'babitude au type principal de la race asiatique lient seulement à la culture remarquable que lui ont fait subir les guerriers arabes. Enfin, ce sont les croisades, l'expansion musulmane et les transactions commerciales qui ont amené les Chevaux orientaux dans l'Europe occidentale. - Quant à la race africaine (E. C. (fricanus), à front bombé et à cinđ vertèbres lomhaires, dont Sanson place le berceau en Nubie, elle aurait été domestiquée, d’après Piétrement, sur les hauts plateaux silués à l'occident de la Chine,

(1) Voy. cependant H. Toussant, Le Cheval dans 'la station préhistorique de Solutré, Recueil vét., 1874, p. 384-467, et Ch. Consevin, Sur quelques points de l'histoire de la domestication du Cheval, Jourual de méd. vét. et de zootechnie, 1882, p. 393. 
par les Proto-Mongols, et introduite en Egypte par les IIylisos ou Pasteurs ; c'est pourquoi cet auteur lui donne le non d'E. C. mongolicus. Elle s'est d'ailleurs méiangée de très bonne heure ì la précédente, et il est assez rare de la trouver aujourd'hui a l'état de pureté.

Caractires physiologiques. - Lapparition des chaleurs, chez la Jument, a lieu à un àge assez variable, le plus souvent vers la fin de la deuxième année ou le commencement de la troisième. L'étalon est employé d'ordinaire à la reproduction vers l'àge de trois ans : il débute par trois ou quatre saillies par semaine, et, jusqu'it l'îge de quatre ans, il convient de ne pas le laisser saillir plus d'une fois par jour, en moyenne. le rut se manifeste au printemps.

La durée moyenne de la gestation est de 336 jours, soit environ 11 mois. La portée est presque toujours d'un seul petit Poulain, Pouliche), qui nait avec les yeux ouverts et le corps revêtu de poils. Le sevrage ne doit avoir lieu que lorsque la dentition de lait est complète, c'est-à-dire entre 6 et 10 mois. Le déreloppement de l'animal est terminé vers l'ìge de cinq ans. La durée totale de la vie est très variable; d'après Bourgelat, elle serait en moyenne de 18 à 20 ans; mais on a cité des Chevaux ayant vécu 49, 43 et 49 ans (Goubaux et Barrier). On assure, depuis Aristote, que les Juments vivent plus longtemps que les Chevaux. Pour divers motifs, on fait subir la eastration à un grand nombre de sujets : le meilleur est d'opérer sur les Poulains it la mamelle. Le Cheval privé de ses testicules est qualifié de hongre. Quant à la Jument, on ne la châtre que dans de rares circonstances pathologiques.

Services. - Le Cheval est essentiellement un moteur animé, et, ì ce titre, il a rendu et rend encore de tels services à l'Homme, que son histoire est partout liée à celle de la civilisation. Sa puissance est mise à profit pour les besoins de l'agriculture, du commerce et de l'industrie, pour la chasse et la guerre, pour le luxe et les commodités de l'existence. Ses aptitudes peurent se ramener à deux principales: porter et trainer un fardeau. Cependant, on lui reconnait souvent quatre fonctions distinctes: " la selle, qui consiste à porter le cavalier à toutes les allures; l'altelage de service ou de luxe, qui consiste à trainer, aux allures vives, un véhicule léger portant un petit nombre de personnes; le trait léger, avec lourd véhicule et forte charge trainés aux allures vives; enfin le gros trait, avec véhicule et charge encore plus lourds, mais lentement trainés (Sanson)."

Le Cheral fournit encore de son vivant un fumier chaud et très estimé. En outre, diverses peuplades orientales, les Kirghiz en particulier, préparent avec le lait fermenté de jument une liqueur à laquelle on donne le nom de lioumys : c'est un liquide blanchàtre. mousseux, à odeur de petit-lait, ì saveur acide et piquante. Il renferme de l'alcool, des matières grasses, du sucre de lait, de l'acide 
lactique, des substances albuminoïdes, divers sels et de l'acide carbonique. En Europe, on fabrique souvent du koumys avec du lait de vache, tout en employant comme ferment le koumys ancien desséché ou kora; ce produit est parfois appelé galazyme. Le koumys est un excellent analeptique: on l'utilise avantageusement dans le traitement de la phtisie pulmonaire et de la plupart des cachexies.

Nos ancêtres quaternaires, ainsi qu'on l'a vu, se nourrissaient volontiers de la chair di Cheval. Les peuples orientaux, notamment ceux de race mongolique, sont dans le même cas depuis un temps immémorial. Cependant, l'hippophagie n'a pris chez nous qu'un développement fort restreint jusqu'à ces derniers temps. Quelques personnes témoignent encore d'une certaine répugnance à son endroit. C'est là le reste d'un préjugé qui tend à disparaître: en réalité, la viande de Cheval est un aliment sain, agréable et nutritif. Elle a même l'avantage de ne pas renfermer, comme celle du Porc et du Bœuf, des parasites trans missibles à l'Homme.

Les débris du Gheval sont d'ailleurs utilisés de diverses manières par l'industrie : peau, sang, graisse, os, tendons, intestins, sabots, crins, etc.

Sous-genre ANE (Asinus Hamilton Smith). - Les Équidés asiniens ou asiniformes ont une queue courte, terminée par un bouquet de crins; leur robe est plus ou moins unie, mais il existe presque toujours une raie longitudinale sur le dos (bande rachidienne), croisée parfois par une raie verticale tombant sur les épaules (bande cruciale scapulaire). Les oreilles sont assez. longues. La crinière est courte et droite. Les châtaignes manquent le plus souvent aux membres postérieurs. 5 vertèbres lombaires.

Ces animaux vivent à l'état sauvage dans les plaines de l'Asie et du nordest de l'Afrique; ils sont vulgairement confondus sous le nom d'Anes sauvages ou d'Onagres.

Leur classification (1) est très confuse, surtout en ce qui concerne les formes asiatiques. Toutefois, il est manifeste que, dans leur ensemble, ces. formes sont bien distinctes de celles qu'on observe en Afrique, de sorte qu'il est possible d'établir dans le sous-genre Asinus deux grandes sections : $1^{\circ}$ Asiniens asiatiques ou Hémioniens; $2^{\circ}$ Asiniens africains ou Asiniens vrais.

A. Les HÉMIONIENS se rapprochent un peu des Caballins par l'ensemble de leurs caractères; du reste, la plupart des auteurs qui les ont observés. les ont considérés comme intermédiaires entre les Anes et les Chevaux.

Jusqu’ả présent, deux espèces seulement sont admises sans conteste : le Kertag et le Dshigtai.

Le Kertag (E. Prjevalskyi Poliakov) est de la taille d'un fort poney; il a une tête forte, des oreilles médiocres, une encolure épaisse, des membres robustes, garnis de longs poils à la partie inférieure et terminés par des sabots arrondis; les chàtaignes existent aux quatre membres; la queue est

(1) Geran, Études zoologiques sur les Hémiones et quelques autres espèces chevalines. Ann. des sc. nat. (Zool.), XII, p. 1, 1869. 
assez longue, garnie dans sa moitié terminale d'un bouquet de erins relativement bien fourni. Le pelage est d'un gris très pàle, tirant sur l'isabelle à l'encolure et à la tite, et se fondant insensiblement sur les flancs avec le blanc pur du ventre et des membres; la criuière, le pinceau de la queue et la partie inférieure des membres sont noirs; il n'existe pas de bande rachivienne.

Cet animal vit dans les déserts de la Dzoungarie, c'est-à-dire dans l'Asie centrale, à l'ouest de la Mongolie, oì le voyageur russe Prjevalsky l'a lécouvert en 1881. On en reneontre des troupes de cinq à quinze individus, conduites par un vieil étalon. Les Kirghiz l'appellent Kertag et les Mongols Takke. On a beaucoup discuté sur ses affinités : les uns l'ont considéré, avec Poliakor, comme un Caballin ou vrai Cheval sauvage; les autres l'ont assimilé aux llémiones; la vérité est qu'il s'agit d'un llémionien assez rapproché du type Cheval.

L'Irémione (E. hemionus Pallas) est d'une taille un peu iuférieure à la moyenne de nos Chevaux; sa robe est d'un isablle clair devenant presque blanchatre sous le ventre et à la face interne des membres; la crinière et la queue sont brun foncé. La bande rachidienne n'envoie pas de prolongements sur les épaules, sauf dans quelques-unes des variétés ci-après. La tête est assez lourde; les oreilles sont un peu plus longues que celles du Cheval, mais plus courtes que celles de l'Ane. La ligne du dos est droite, un peu relevée au niveau de la croupe. La crinière est droite et bien fournie.

La forme que Pallas a décrite sous le nom d'llémione vit en troupes nombreuses lans les steppes de l'Asie centrale, depuis les frontières de la Chine jusqu'à la rive orientale de la mer Caspienne; les Mongols la désignent sous le nom de Dshigguclai ou Dshigtai. Elle est quelquefois utilisée, dit-on, pour les travaux agricoles.

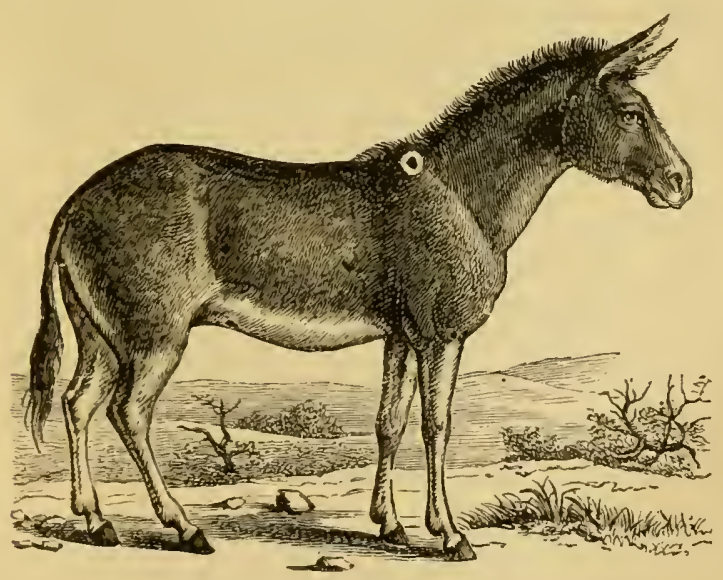

Fig. 832. - Koulan ou Faux Ontgre.

D'autres formes se rencontrent sur divers points de l'Asie, et ont été considérées par les zoologistes, tantỏt comme des variétés locales de l'Ilémione, tantòt comme des espèces distinctes.

Ainsi, on trouve, dans les régrions incultes situées entre la mer Caspienne 
et la mer d'Aral, un Asinien qui est désigné sous le nom de lioulan par les Kirghiz et autres hordes nomades de la Tartarie. Pallas le prit, bien à tort, pour le véritable Ane sauvage, l'Onagre des anciens, et lui donna pour ce motif le nom d'Equus onager. Aujourd'hui, on tend à le regarder en général comme identique au Dshigguetai.

Les vallées élevées du Thibet nourrissent aussi un animal du mème groupe, auquel on donne le nom de Kiang. Hodgson, le regardant comme une espèce distincte, l'avail dénommé d'abord Asinus equioides, puis $A$. polyodon. La plupart des naturalistes s'accordent aujourd'hui à l'identifier également au Dshigguetai de la Mongolie.

D'autre part, il existe dans le désert de la Syrie un Équidé auquel Isidore Geoffroy Saint-Hilaire a donné le nom d'Húmppe (E. hemippus), et qui se distingue de l'Hémione type par une tète plus petite et plus fine, des oreilles plus courtes, etc. Il est probable que l'Hémippe n'est autre que le Mulet fécond dont parle Aristote, et pour lequel cet auteur avait créé le nom d'Hémione; mais il ne semble pas qu'on doive le séparer spécifiquement des formes précédentes.

Par contre, on leud à faire une espèce nouvelle du Gourkour ou GHorKhur, qui vil dans le Katsh, île voisine des bouches de l'Indus. Frédéric Guvier et I. Geoffroy Saint-Hilaire l'identifiaient au Dshigtai; Gray crut y voir le Koulan de Pallas; enfin, Sclater, sans juger la question, proposa de l'appeler Asinus indicus. Au Muséum d'histoire naturelle de Paris, les sujets obtenus par l'accouplement du Gourkour et de l'Anesse se sont toujours montrés stériles.

On rapporte avec quelque doute au Gourliour l'Équidé connu sous le nom de Gour, qui se rencontre surtout dans les déserts du nord de la Perse, el dont les membres sont zébrés de brun. D’autres Gours, signalés par lier. Porter dans le sud de la même contrée, n'onı pas de raie dorsale.

Enfin on est encore plus mal fixé sur l'animal que Hamilton Smith vit à Londres vers le commencement de ce siècle, et qu'il croyait originaire de la Tartarie chinoise. Cet anteur supposa que cet Asinien n'était autre que le Yo-To-Tz: des Chinois, et en fit une espèce nouvelle, sous le nom d'Asinus equuleus.

B. Les ASINIENS vrais sont plus éloignés des Caballins que ne le sont les Hémiones; ils se rapprochent au contraire des Zébrins.

On les rencontre à l'étal sauvage dans le nord-est de l'Afrique, et c'est à ces formes africaines que conviendrait spécialement le nom d'Onagre (öves äypus ou övajpos, Ane sauvage), employe d'une façon un peu vague par Aristote, et que Pallas a eu le tort d'appliquer au Koulan. Jusqu'à présent. on en distingue deux espèces (ou races géographiques).

L'Ane des Somalis (E. somaliensis Matsclie, 1894. - Syn :? E. teniopus Heuglin, 1861; Asinus txniopus var. somaliensis Noack, 1884; E. Asinus somalicus Sclater, 1884) a une robe gris souris; la tête est gris foncé; le bout du nez, les parties inférieures du tronc et la face interne des membres sont lblancs; la raie dorsale n'est apparente qu'à la racine de la queue; la bande cruciale scapulaire manque ou se distingue a peine; les membres offrent des zébrures foncées jusque sur les avant-bras et les jambes.

Cette forme liabile le nord-est du pays des Somalis el le sud-est de 
l'Abyssinie, s'étendant au nord jusqu'i Massaua (1). - Lin Abyssinie, selon les rapporls de divers royageurs, les Anes vivent en troupes nombreuses et sont connus sous le nom de Hamur-seet, c’est-à-dire Anes qu'on chasse.

L'Ane de Nubie (L. africunus Matschie, 189'. - Syn. : E. Asimes ufricamus Fitzinger, 1866) a une robe gris rougecitre; la région buccale, les parties inféricures du tronc, la face interne des menbres et la face externe des pieds sont blanches; il existe une bande rachidienne noire, et une bande cruciale scapulaire de mème couleur; sur les membres, zébrures à peine marquées ou nulles.

Cet Ane labite surtout les grands steppes qui s'étendent entre Massaua, l'A thara et le $18^{\mathrm{e}}$ degré de latitude nord (vers la $5^{\mathrm{e}}$ cataracte du Nil).

A l'éporque romaine, il existail aussi de nombreux Anes sauvages dans le nord-ouest de l'Afrique (Élien, Irrien) et leur chair était fort appréciée; contrairement aux assertions des auteurs modernes, ces régions en possèdent eneore, - à moins qu’il ne s'agisse d’Anes marrons, - et le sous-lieutenant Brosselard a eu l'occasion d'en tuer un dans l'Oued Tidjoudjelt (Salıara) au cours de la première mission Flatters.

Anew domestiques (E. Asinus L.). - Sanson reconnait deux espèces d'Anes domestiques, l'uue brachycéplıale, l'Ane d'Europe (E. A sinus europaus), l'autre dolichocéphale, l'Ane d'Afrique (E. A. africanus).

L'auteur place le centre d'apparition de l'Ane d'Europe dans le voisinage des îles Baléares; il ajoute que les ossements de petits Équidés découverts en abondance dans le quaternaire du Midi de la France devaient appartenir à des individus de cette race.

Quant ì l'Ane domestique d'Égryte, il aurait pris naissance daus la vallée du Nil. On peut mème supposer quil dérive directement de l'Ane de Nubie. Mais, ce qui est au moins extraordinaire, c'est la découverte faite par Boucher de Perthes, dans une tourbière de la Somme, à 5 ou 6 mètres audessous du niveau de la rivière, d'un cràne d'Équidé que Sanson a reconnu ètre celui d'un Ane africain. Piétrement admet cqu'il s'agit d'un Ane domeslique amené dans la rallée de la Somme, à une époque très ancienne, par des migrateurs aryens ou des navigateurs phéniciens. On avouera que cetle conclusion est un peu lasardée. Rütimeyer n'a trouvé que quelques débris d'Anes dans les palatittes de l'àge du bronze.

Domestication. - C'est en Égypte qu'on constate les traces les plus anciennes de l'utilisation des Anes. Un bas-relief d'un hypogée de Giseh, datant de la $I^{\circ}$ dýnastie, représente deux troupeaux d'Anes. Lenormant fait remarquer d'ailleurs qu'on voit figurer cet animal sur les monuments égyptiens, aussi haut qu'on puisse remonter. "La donestication de l'Ane africain ou nilotique, dit Piétrement, est très probablement encore plus ancienne que celle des races chevalines. Elle est due aux Nubiens, ancètres des anciens Egyptiens, qui ont transmis cet animal aux Sémites du sud-ouest de l'Asie, d'où il s'est anciennement répandu depuis la mer de la Chine jusqu'à I'océan Atlantique. "L'utilisation de l'Ane clıez les Hindous remonte à une époque très reculée, ainsi qu'en témoigne la loi de Manou. Ajoutons que le

(1) Les auteurs récents ont abandonné le nom donné par Ileuglin, parce qu'ils pensent que cet auteur avait eu affaire á un Ane domestique. 
même animal était utilisé chez les Hébreux dès l'éporque d'Abrabam, et en Grèce du temps d'Hésiode.

Quant ả l'Ane européen, sa domestication "doit avoir suivi de près l'importation, dans le centre hispanique, de l'usage des dolmens et de celui des armes en pierre polie ".

En ce qui concerne les temps historiques, on assure que les Anes n'ont été employés en Angleterre que sous les rois saxons. Quant à leur introduction aux États-Unis, elle serail de date toute récente, car on l'attribue à Washington.

Caractères physiologiques. - Les facultés génératrices apparaissent, chez les Anes, un peu plus tòt que chez les Chevaux. L'ardeur génésique est aussi plus considérable : Aristote disait déjà que l'Ane est, après l'Homme, le plus lascif des animaux; et l'on sait que le Baudet, c'est-à-dire l'Ane étalon, peut faire jusqu'à huit et dix saillies par jour pendant toute la durée de la monte.

La gestation dure en moyenne 364 jours, soit un an. La portée est presque toujours simple. L'Anesse entre de nouveau en rut quelques jours après le part. L'Anon est gai et assez facile à dresser, quoiquil se montre souvent entêté. On le traite à peu près comme le Poulain; on le sèvre d'ordinaire entre six et huit mois.

Services. - L'Ane, comme le Cheval, est un moteur animé ; mais sa conformation le destine plutôt à porter qu'à traîner des fardeaux. On l'utilise dans les pays de montagne comme animal de bât. Son emploi comme animal de trait est en général peu avantageux. Il remplace le Cheval chez les petits cultivateurs : c'est lui qui porte au marché les produits de l'étable, de la basse-cour et du verger. Sa sobriété est telle qu'on le nourrit à très peu de frais; et il est encore moins exigeant sous le rapport des soins hygiéniques que sous celui de la nourriture. Aussi est-il entretenu le plus souvent avec la plus grande négligence, sinon avec brutalité, ce qui lui fait perdre ses facultés natives et lui donne un caractère rétif. Bien dressé et bien soigné, il ne le cède guère au Cheval sous le rapport de l'intelligence, et on sait qu il lui est supérieur par son tempérament, son énergie, sa résistance à la fatigue.

Le fumier d'Ane était plus estimé des anciens que celui du Cheval. Enfin l'Anesse fournit un lait qui se rapproche beaucoup, par ses qualités, de celui de la Femme, et qu'on a souvent recommandé dans le traitement des affections cachectiques. On a même établi à Paris, à l'hôpital des Enfants-Assistés, une nourricerie dans laquelle les enfants prennent directement le lait au pis des Anesses.

La chair de l'Ane est de bonne qualité. En France et en Italie, elle est surtout employée à fáre des saucissons.

Quant aux débris cadavériques, ils sont utilisés à peu près comme ceux du Cheral. Sa peau, dure et en même temps élastique, est très recherchée des mégissiers. 
Nous devons faire remarquer en terminant que l'Ane est assez seusible au froid; aussi ne le rencontre-t-on pis dans les contrées les plus septentrionales de notre continent. Cependant le père Hue affirme quaujourd'hui les Anes s'accommodent très bien du climat du Thibet et des provinces dı nord le la Chine. Mais ces animax supportent beaucoup uieux que les Chevaux la température des régions torrides.

Sous-trenre zisme (Ilippoligris Ilamilton Smith). - On applique la qualification de Kébrés aux liquidés africains lont lit robe est ornée de raies transversales foncées sur fond clair. Il existe tonjours une bande rachidienne. Leur quene n'est pourve, comme celle des Anes, que d'un bonquet terminal de crins. Ils ont la tète fine, les oreilles de moyenne grandeur, la crinière droite et courte, les sabots petits, mais fort élargis en arrière. Les chàtais̆ues manquent aux membres postérieurs. 3 vertèbres lombaires.

On en connail aujourd'hui jusqu'ì 7 espèces, ayant chacune son aire géographịue propre dont les limites sont représentées en général par la ligne de partage des eaux de lenx grands fleuves (1).

Zèbre de montagnne (E. Zebra L..). - Le plus petit des Zébrins. Taille d'un Ane, avec de longues oreilles, une coute crinière et une queue de rache. Robe ì fond blanc, rayée de noir depuis l'extrémité de la tète jusqu'aux sabots; entre l'épaule et la lıanche, les bandes latérales, non prolongées sous le ventre, sont au nombre de 12 à 1 ; ; racine de la queue rajée; sur la partie inféricure du chanfrein (bout du ne\%), une tache brun rougeâtre; ventre et face interne des membres d'un blanc pur; souvent une lignelongitudinale foncée depuis le milieu de la poitrine jusque sur le ventre.

C'est le Zèbre proprement dit, le Daw (Matschie) ou wilde Paurd, wilden Esel des colons. Il vit au Cap, jusqu'ì la chaîne de montagnes qui borde au nord le désert de Kiarrou. Il se voil très rarement dans nos ménageries. On a pu, à diverses reprises, en dompter quelques individus et les dresser pour le trait; mais, en général, ils restent assez indociles.

Couagrai (E. quag!ga Gmelin). - De petite taille, robe brun clair en avant, plus pâle en arrière; tète, encolıre et partie antérieure du tronc marquées de zébrures brun foncé; queue, face interne des membres et ventre blancs.

Entre la chaine de bordure dı Cap et la limite nord du bassin du Vaal ou Kä̈-Garip. Le Couagga a le port du Cheval. Son nom est tiré de sa voix : koua, koua. Il se laisse facilement apprivoiser, et l'on assure qu'on en royait quelquefois au Cap parmi les Chevaux de trait. On a prétendu aussi que le Couagga pourait ètre dressé à la garde des troupeaux, qu'il défendrait contre les attaques des carnassiers, notamment des Hyènes. En tout cas, cet intéressant animal est en voie de disparition, par suite le la chasse inconsidérée dont il est l'objet.

Zèbre de Burchell (E. Burchelli Gray). - De taille supérieure à celle du Zère et du Couagga, avec une tète plus caballine, des oreilles plus petites, une crinière plus longue et une queue un peu plus fournie. Robe brun jau-

(1) P. Marsche, Die afrikanischen Wildpferde als Verterter zoogcographischer subregionen. Zool. Garten, XXXY, p. 33, 1893.

Ralluet. - Zoologie. 
nàtre, avec zébrures assez larges, manquant entièrement sur la partie libre des membres el sur la queue; pas de tache brun rougeâtre sur le chanfrein; partie inférieture du corps blanche, à l'exception d'une ligne médiane foncée sur le ventre.

Le Zèlıre de Burchell est connu des colons sous le nom de Bontequagga; les Betshouanas et les Natébélés lui donnent celui de Pitshé ; c'est le Daw de la plupart des auteurs. Burchell l'a découvert au nord du Vaal ou Kaï-Garip; il existe aussi dans le pays des Zoulous; à l'ouest, on ne sait au juste quelle est la limite de son aire de dispersion dans le désert de Kalahari; la limite nord parait ètre représentée par le Limpopo. Isidure Geoffroy Saint-Hilaire a, depuis longtemps, tenté d'acclimater cette espèce dans notre pays. Des Zèbres de Burchell élevés à la ménagerie du Jardin des plantes de Paris s'y sont reproduits sans difficulté, et, dès la seconde génération, dit l'auteur, l'acclimatation était complète. Restait à établir la possibilité d'utiliser ces animaux, que la plupart des auteurs s'accordent à regarder comme farouches, irascibles et capricieux. C'est à quoi est arrivé Ménard, à la suite d'une série d'essais poursuivis au Jardin d'acclimatation (1). Il y a eu dans cet établissement jusqu’à sept Daws des deux sexes dressés et employés comme animaux de trait; à ce titre, leurs qualités maîtresses sont la force, la vigueur et la franchise, car ils ne sont pas aussi vites que les Chevaux : à cet égard, on pourrait plutòt les comparer aux Mulets. Leur docilité est telle qu'on a pu en conduire deux en figuration sur des scènes de théàtre. Les femelles ont été consacrées à la reproduction, et il est à remarquer que les sujets nés en captivité sont beancoup plus faciles à dresser que les individus pris à l’état sauvage.

Zèbre de Chapmann (E. Chapmanni Layard). - Ressemble beaucoup au Zèbre de Burchell, mais est pourtant plıs élancé, avec des oreilles plus courtes. Les zébrures d'un còté du corps vont rejoindre celles de l'autre còté sur la bande médiane ventrale; la racine de la queue est zébrée, ainsi que les membres jusqu'aux sabols; sur le bout du nez, une tache brun de café. Entre les bandes foncées du tronc, s'en trouvent de plus petites et plus ternes, depuis les hanches jusqu'au milieu du corps.

Chapmann a rencontré cette forme au nord du Limpopo; elle est surtout répandue dans la région du Zambèze.

Zèbre des anciens ( $E$. antiquorum Hamilton Smith). - Très voisin du Zèbre de Burchell, dont il se distingue par une tache brun rougeàtre sur le bout du nez, ainsi que par l'extension des zébrures sur la racine de la queue et sur les membres jusqu'aux genoux. Du Zèbre de Chapmann il est plus facile encore à distinguer par ses membres, dont la partie inférieure est blanche avec des zébrures à peine visibles, et par les bandes latérales du corps, qui ne s'étendent pas assez loin sous le ventre pour atteindre la bande médiane. Robe jaune clair, un peu lavée d'ocre; entre les larģes zébrures, des bandes brunes plus étroites.

Cet animal, que le colonel Smith nommait Daw du Congo on Zèbre de Pigafetta, vit, d'après Mlatschie, dans le Sud-onest africain (Damara), entre le

(1) Saint-Yves Méxard, Utilisation des Zèbres de Burchelt comme animaux de trail, Bullet. de la Soc. d'acclimatation, 18i4, p. 257. - Iv., Communicat. inéd. 
lleuve Orange et les bassins du Gunene et dı Cuanza; mais son habitat est probablement plus étendu vers le nord.

Zèhre de Bähm (E. Böhmi Maischie). - Très roisin des Zèbres de Chapmanu el du Damara. Robe blanche, tirant un peu sur le jaune avec l'àge; des zébrures sur le corps (environ sepl), sur la racine de la queue et sur les membres presque jusqu'aux sabots; les bandes intermédiaires signalées chez les denx formes affines font presıue entièrement défaut: elles ne se montrent un peu que sur les hanches; les zébrures du corps rejoignent la bande médiane ventrale. Aucune tache sur le chanfrein.

Entre la limite septentrionale du bassin du Zambèze et $1^{\circ} 30^{\prime}$ de latitude nord.

Zèbre de Gréry (E. Grevyi A. Mine-Edwards). - De la taille du Zèbre vrai. liobe blanche a peine lavée de gris; nombreuses zébrures brun pourpré s'étendant sur li queue el sur les membres jusqu'aux sabots; les bandes du corps, au nombre de 16 à 18 entre les épaules et les hanches, ne s'étendent que sur les còtés et laissent le ventre libre; sur les hanches, de nombreuses bandes étroites. Sur le bout du nez une tache noire.

Ce Zèbre a été connu d'abord en France par un don de Ménélik, roi du Choa, au président de la République Grévy. Il habite le pays des Somalis et le Choa, entre $1^{\circ} 30^{\prime}$ et 8 à $10^{\circ}$ de latitude nord.

H`irides. - Les Équidés constituent l'un des groupes qui ont fourni les plus nombreux exemples d'hybridation.

Ainsi, comme on le sait, le Cheval féconde l'Inesse, et le produit de cette union est connu sous le nom de Burdot. - On a obtenu aussi des produits en accouplant le Cheval avec les femelles suivantes : - Mule, produit du Cheval et le la Ilule, Iémione, Zèbre, Zèbre de Burchell, produit de l'Ane et du Zèbre o, produit du Zèbre et de I'Anesse (?), produit du Couagga et de la Jument.

L'Ine, fécondant la Jument, procrée le Mulet. D'autre part, divers auteurs ont cité des accouplements féconds entre l'Ane et les femelles ci-après :Mule, Bardote, Hémione, Zèbre, Zèbre de Burchell.

On signale également des produits obtenus par les unions suivantes : Hémione $\sigma^{*}$ et Jument, Anesse, Zèbre, Couagga, Zèbre de Burchell ; Zèbre ơ et Anesse ; - Couagga ơ et Jument, Hémione; - Zèbre de Burchell ot et Anesse.

Enlin les anciens auteurs ont décrit sous le nom de Jumart un produit qui résulterait de l'union du Cheval et de la Vache, ou du Taureau et de la Jument, ou encore du Taureau et de l'Anesse. Adanson, Bourgelat, Grognier, croyaient á l'existence du Jumart.; mais il est bien évident qu'il s'agit là d'un animal fabuleux, et que les descriptions qu'on en a données n'ont eu pour base que des animaux difformes ou monstrueux.

Mulet (E. Asino-Caballus). - Comme on vient de le voir, le nom de Mulet s'applique au produit de la fécondation de la Jument par l'Ane. C'est le Mulus des Latins, l'rüusoves des Grecs. Les caractères participent, dans une mesure très variable, de ceux des deux espèces ascendantes. La tète ressemble assez a celle de l'Ane; les oreilles, très mobiles, sont plus longues que celles 
du Cheval, plus petites que celles de l'Ane. Le cou est court, faible, le garrot peu élevé. La ligue dorso-lombaire est le plus souvent un peu voussée. La crinière et la queue sont moins garnies que chez le Cheval, mais plus que chez l'Ane. Les membres sont fins, terminés par des sabots relativement volumineux, mais se rapprochant néanmoins de ceux de l'Ane. Les chàtaignes existent quelquefois aux quatre membres; mais en général les postérieures sont rudimentaires ou font défaut. Le nombre des vertèbres lombaires est tantôt de six, tantòt de cinq. La robe est variable, le plus souvent grise.

La production des Mulets remonte à une époque assez reculée. Toutefois, les anciens monuments de l'Égypte, qui montrent si souvent des représentations de l'Ane, n'en offrent aucune du Mulet. Par contre, chez les Assyriens, qui ne nous ont laissé aucune figure de l'Ane, on trouve sur les basreliefs des représentations non douteuses du Mulet. Il existe même une légende qui fait remonter l'existence de cet animal en Assyrie jusqu'aux lemps fabuleux. Aussi Piétrement admet-il que c'est " dans les régions asiatiques situćes entre le Gange et le littoral méditerranéen de Syrie que doivent ètre nés les premiers Mulets orientaux". llomère signale l'existence des Mulets dans l'Asie Mineure et en Grèce. D’autre part, les autenrs latins nous montrent quelle était l'importance de l'industrie mulassière chez les Romains. Est-ce par ceux-ci que cette industrie fut introduite en Espagne? Il serait difficile de répondre d'une façon formelle à cette question.

Actuellement, la production industrielle des Mulets, en France, est à peu près limitée à la Gascogne et au Poitou.

Caractères physiologiques. - L'accouplement de l'Áne étalon et de la Jument ne s'effectue jamais que sous la direction de l'Homme. Ces animaux ne se recherchent en aucune façon, et souvent même on ne parvient à les unir que par des excitations ou des artifices divers. La durée de la gestation est la même que lorsque la Jument est pleine du Cheval. Les Muletons s'élèvent et se comportent à peu près comme les Anons.

En thèse générale, les Mulets sont inféconds. Pour les mâles, on ne connaît même pas, jusqu'à présent, une seule exception sérieuse - à cetle règle. Leur liquide séminal est d'ailleurs presque toujours dépourvu de spermatozoïdes normaux. Par contre, en ce qui concerne les Mules, on a recueilli des observations multiples témoignant d'un certain degré de fécondité. Saillie par un Cheral ou par un Ane, la Mule peut en effet concevoir: le plus souvent, elle avorte, ou, en cas d'accouchement normal, le jeune survit à peine quelques mois. Mais, dans quelques circonstances, on a vu les produits des Mules arriver à l'àge adulte; de Nanzio a proposé le nom de Mionhippe (Mionippo) pour celui du Cheval et de la Mule, et Panceri a appelé Onomione celui de l'Ane et de la Mule. Une Mule arabe du Jardin d'acclimatation (Catherine) a donné lieu, sur ce point, à de remarquables expériences : de 1873 à 1881, elle a fourni six produits : $1^{\circ}$ avec l'Ane d'Égypte, deux mâles qui ontété incapables de féconder 
des juments; $\underline{Q}^{\circ}$ aree un Cheval barbe, un avorton, deux femelles et un mâle; ces deux femelles, accouplées arec un Cheval japonais, ont donné des produits ressemblant au Cheval, mais chétifs et ineapables le vivre; quant au mâle, il a donné en 1888, avec une jument, un produit femelle (1). Sanson pense que les Mules fécondes sont des filles de Juments appartenant à son espèce africaine.

Services. - Les aptitudes du Nulet liennent en partie de celles du Cheval, en partie de celles de l'Ane. Au point de vue physiologique, nous dirons seulement que le Mulet possède à peu près le tempérainent de son père; il en a aussi la patience, la résistance el la sobriété.

Comme moteur, il peut être utilisé à la façon du Cheval, pour le service du trait et même de la selle. En Espagne, les Mules fournissent souvent des aftelages de luxe. Au moyen àge, les gens de robe n'employaient que des Mlules pour monture; cependant, les allures de ces animaux sont très fatigantes, cl on ne s'en sert guère que pour aller au pas. De plus, dans des localités montueuses, le llulet est, comme l'Ane, une bète de somme, avec cet avantage qu'il est plus fort : la conformation du dos et des reins est très favorable au service du bât. Sur les champs de bataille, il porte les ḅlessés en litière et en cacolet. - Presque partout on donne aux Mules la préférence sur les Mulets.

Comme animal alimentaire, le Mulet tient à peu près le même rang que l'Ane.

Bardot (E. Caballo-Asinus.) - Le Bardot résulte de l'accouplement de l'Anesse avec le Cheval étalon. Les anciens l'appelaient Hiınus. Il est de petile taille, à peu près comme l'Ane, et de formes peu élégantes. Sa lête est un peu plus légère, ses oreilles sont un peu plus courtes que celles du Mulet. Son encolure est mince, son dos fort tranchant, sa croupe avalée. Ses membres sont assez forts, ses sabots petits, serrés en talons. Il hennit comme le Cheval, tandis que le Mulet a une sorte de braiement faible, analogue à celui de l'Ane.

Le Bardot est assez rare en France et dans la plupart des contrées de l'Europe. Il n'est guère utilisé que dans quelques localités de la Sicile, où il transporte les produits des mines de soufre à travers les montagnes. Cornerin le signale en outre dans l'arrondissement de Calvi (Corse). Sa prodıction offre d'ailleurs peu d'intérêt : il rend à peine les services de l'Ane et se montre très inférieur au Cheval. Il y a donc lieu de lui préférer le Nulet. En 1859, Mucci a décril un produit de l'Ane et de la Bardote.

Famille des TAPIRIDÉS. - Animaux de taille moyenne, dont le nez se

(1) Saint-Yres Ménard, Note sur les produits obtenus d'une Mule au Jardin d'acciimatation. Revue des sciences nat. appliquées, $36^{\mathrm{e}}$ année, p. 617, 1889. 
prolonge en une sorte de petite trompe mobile; peau à poils clairsemés; formule digitale $\frac{2.3 \cdot 4.5}{2.3 .4}$.

Les Tapirs (Tapirus L.) ont pour formule dentaire $\frac{3.1 .4,3}{3.1 .4,3}$. Ils sont nocturnes, assez doux, bons nageurs, vivent dans les forèts et se nourrissent de substances végétales.

Le Tapir américain (T. americunus) est le plus gros quadrupède de l'Amérique du Sud; dans quelques districts du Brésil, on l'entretient en domesticité à la façon des Porcs, et mème comme bète de somme; néanmoins, son acclimatation ne peut avoir pour nous aucun intérêt. Le Tapir Pinchaque (T. villosus) habite le versant oriental des Cordillères, surtout dans le Pérou. Le Tapir à dos blanc (T. indicus) est de Malacca, Bornéo, Sumatra.-Formes fossiles dans le pliocène.

A cette famille se rattachent aussi les Protapirus et même les Lophiodontes éocènes.

Famille des RHINOGÉROTIDÉS. - Grands animaux à peau épaisse et plissée, nue dans les espèces vivantes; tète allongée, tronc lourd et massif, membres courts terminés généralement par trois doigts à larges sabots $\left(\frac{2.3 .4}{2.3 .4}\right)$

Les Rhinocéros (Rhinoccros L.) ont sur le nez une ou deux cornes, de

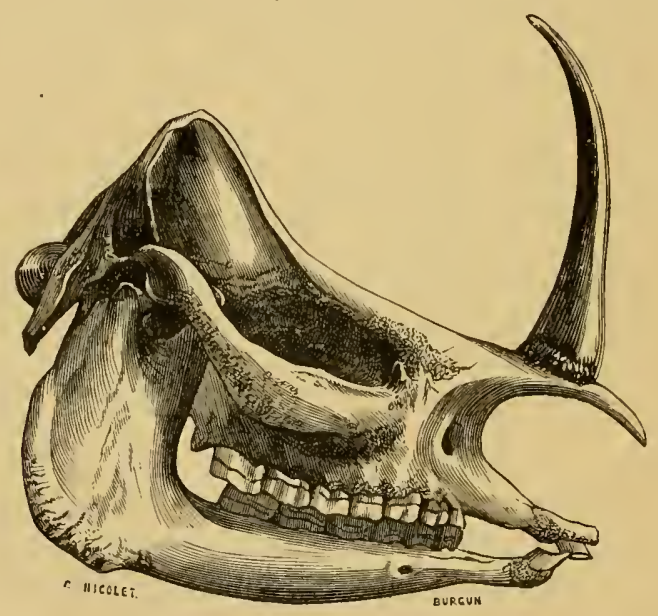

Fig. 853. - Têle de Rhinocéros.

nature épidermique, ne laissant sur les os nasaux qui les supportent que des traces rugueuses. Leur formule dentaire est $\frac{1.0 .4,3}{1.1 .3,3}$. Ce sont des herbivores généralement brutaux, plutòt nocturnes, qui vivent dans les régions chaudes de l'aucien continent et de l'Océanie, où ils fréquentent les endroits marécageux.

Nous citerons, parmiles espèces vivantes : $R h$. indicus et $R h$. javanicus, tous deux unicornes; Rh. sumatrcnsis el Rh. africanus, etc., bicornes. Parmi les 
formes fossiles, une mention particulière est due au Rhinocéros a narines cloisonnées ( $/$ h . tichorinus), espèce unicorne du diluvium, dont on a relrouvé des débris parfaitement conservés dans la glace, en Sibérie ; cet animal avait la cloison uasale ossifiée et la peau recouverte de poils laineux.

Les Accrutherium étaient déponrvus de cornes. A. incisivum, dı miocène, avait un cinquième doigt, peu développé il est rrai, aux pieds antérieurs. Iux Rhinocérotidés se raltachent aussi de nombreuses autres fornes fossiles, telles qque les Elasmotherinm, I mynodon, Hyracodon, otc.

IIUI'TIE.IIE ORDRE

\section{IIIRACIENS}

Mammifères à doigts subongulés, dépourvus de trompe; des incisives et des molaires; pas de canines; placenta zonaire.

Cet ordre des llyraciens (üpx̧, Souris) ou Lamnonges, rattaché par Cope aux Taxéopodes, n'est plus guère représenté aujourd'hui que par le genre Daman (Hyrax) que certains auteurs classent parmi les Proboscidiens et d'autres parni les Jumentés. Les Damans sont de petits Ongulés plantigrades de la taille d'un Lapin. Leur corps est couvert de poils épais. Leur dentition se rapproche un peu de celle des Rongreurs. Ils ont quatre doigts en avant, trois en arrière, réunis par la peau et couverts de petits sabots, à l'exception du doigt interne de derrière, qui porte une griffe. La plante des pieds offre des coussinets qui fonctionnent comme ventouses.

Les Damans vivent en général dans les rocailles. Ils ont l'habitude de déposer dans les fentes des rachers leurs excréments et leur urine. Au Cap, les indigènes recueillent ce mélange, qui entre dans le commerce sous le nom d'lyyracéum, et qui a été recommandé comme antispasmodique et comme astringent. On assure que certains médecins préconisent encore l'eniploi de cette substance.

Outre le Daman du Cap (H. capcnsis), on signale le Daman d'Abyssinie (H. abessinicus), le Daman de Syrie (H. syriacus), etc.

\section{NEUVIĖIE ORDRE}

\section{PROBOSCIDIENS}

Mammifères à doigts subongulés; nez développé cn trompe préhensile; deux incisives supérieures, à croissance indéfinie, en forme de défenses; pas decanines; molaires composces; placenta zonaire.

Cet ordre n'est plus représenté aujourd'hui que par les Éléphants, qui sont les plus grands des Mammifères terreslres. Ces animanx sont surtout remar-

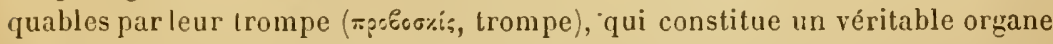
de préliension. Cette trompe est percée de deux canaux parallèles qui font suite aux fosses nasales et sont séparés par une cloison médiane; de nombreux faisceaux musculaires entre-croisés lui donnent une molilité remarquable. Elle est terminée par un appendice digitiforme doué d'une grande 
sensibilité. C'est avec cette trompe que l'animal prend ses aliments et ses boissons pour les introduire dans sa bouche; il s'en sert aussi pour se défendre.

La dentition comprend deux incisives, qui se rencontrent à la màchoire supérieure seulement, sont dépourvues de racines et d'émail, et ont une croissance indéfinie (dent de remplacement) : ce sont ces défenses qui nous fournissent l'ivoire. Les molaires sont composées de petites dents aplaties d'avant en arrière et réunies par du cément; il n'en existe souvent qu'une seule en activité à chaque branche des màchoires; mais une antre se développe en arrière et la fait tomber lorsqu'elle est usée; parfois il s'en trouve trois en même temps : une usée, une active et une jeune.

Le corps est revêtu d'une peau épaisse, à poils clairsemés. La tète est énorme, portée par un cou très court. Les yeux sont pelits; le pavillon de l'oreille est très grand et pendant. Les nembres sont épais, disgracieux, en forme de piliers; ils se terminent par cinq doigts soudés jusqu'au niveau des sabots, lesquels n'entourent que les extrémités des phalanges.

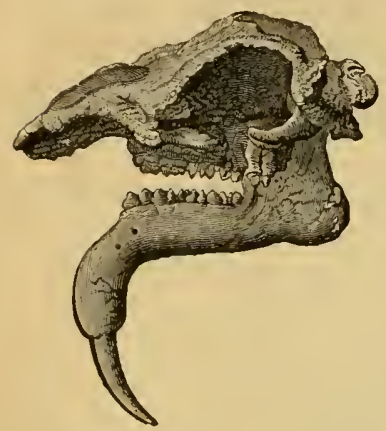

Fig. 8su. - Téle de Dinotherium (terrain miocène).

Le cerveau présente des circonvolutions très développées, mais les hémisphères ne couvrent pas le cervelet. L'utérus est bicorne; les mamelles sont pectorales, au nombre de deux.

Jeux espèces : l'Éléphant d'Afrique (Elephas: (fricanus), à front bombé, à oreilles très grandes, et l'Éléphant des Indes (E. indicus), plus petit, à front un peu concave au milieu, à oreilles plus petites, à défenses moins fortes. - Plusieurs espèces ont vécu à des époques géologiques antérieures : tel est le Mammouth (E. primigenius), du diluvium, l'E. meridionalis), du pliocène, etc.

A cet ordre se rapportent aussi d'autres genres éteints, nolamment les Mastodontes (Mastodon), qui offraient souvent deux défenses à chaque màchoire, et les Dinothériums (Dinotherium), dont la seule màchoire inférieure portait des défenses recourbées en has. Les molaires de ces animaux n'ont plus la structure lamellaire de celles des Éléphants. Ces deux genres sont apparus dès l'époque miocène.

\section{DIXIEIE ORDRE}

\section{RONGEURS}

Mammifères à doigts ordinairement onguiculés; incisives sans racines, à croissance indéfinie; pas de canines; molaires à replis d'émail transversaux; placenta discoïde.

Les Rongeurs (Glires) constituent l'ordre des Mammifères, le plus homogène et pourtant le plus nombreux en genres et en espèces. La plupart sont de petite taille, d'allures vives, et offrent un pelage souple et épais. Tous sont plantigrades, à doigts libres et mobiles, en 
gnénéral munis de griffes véritables. Leurs membres antérieurs présentent une clavicule complètc ou incomplète, earactère utilisé pour la classification. Ln autre caractère de grande valeur taxinomique est fourni par le canal infraorbitaire ou trou sous-orbitaire. Ce canal, qui prarait correspondre en principe au conduit dentaire supérieur de la généralité des Mammifères, prend chez certitines formes (Hystricomorphes) un tel développement qu'il reste seulement limité en dehors par l'apophyse zygomatique du maxillaire supérieur, larquelle va rejoindre l'os zygomatique.

Tous se nourrissent de substances régétales; quelques-uns seulement sont omnivores. Leur système dentaire est organisé pour ronger les aliments. Chaque matchoire porte deux grandes incisives courbées en arc de cercle, dont la face antérieure seule est revètue d'une couche d'èmail sourent colorée en jaune ou en rouge. Ces incisives, enchâssées dans de profonds alréoles, sont it pulpe persistante, et par conséquent continuent i croitre pendant toute la vie. A la vérité, cette croissance est contre-balancée par l'usure due au frottement, el il est à remarquer

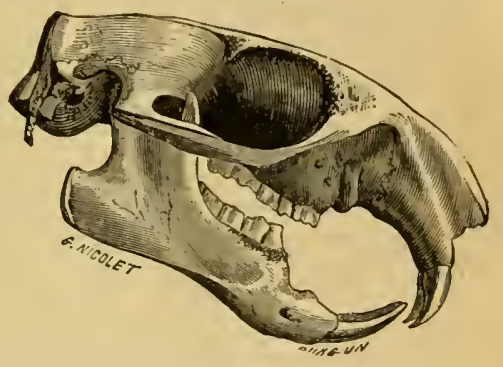

Fig. 85̃. - Téle de Narmotte. que cette usure, portant de préférence sur la face postérieure, donne aux dents un tranchant très accusé. Chez les Léporidés, il existe une seconde paire de très petites incisives à la màchoire supérieure. - Les canines font défaut, même dans la dentition de lait. - Par suite, les molaires sont séparées des incisives par une grande barre. Leur nombre varie de deux à six dans chaque branche des mâchoires. Elles diffèrent peu les unes des autres, et présentent une couronne large et aplatic. Les inasséters sont très développés, ce qui restreint beaucoup l'ouverture buccale: aussi la lèvre supérieure est-elle fendue dans son milieu pour l'agrandir. Plusieurs espèces possèdent des abajoues.

L'intelligence des Rongeurs est assez faible. Leur cerveau, toujours petit, n'offre que des circonvolutions peu accusées. Leur fécondité est souvent considérable, et il en résulte, pour certaines espèces, une pullulation extraordinaire lorsque les circonstances sont favorables. Les femelles possèdent ordinairement de nombreuses mamelles pectorales et abdominales. L'utérus est presque toujours double. Les testicules deviennent très volumineux à l'époque du rut.

Mais un fait très intéressant de la physiologie de ces animaux consiste dans la formation du bouchon vaginal, production solide qui obstrue le ragin de la femelle après la copulation. Ce bouchon, découvert par Leuckart chez le Cobaye, a été surtout étudié par Lataste, 
qui en a montré la haute fréquence (1). Il se compose de deux parties: une masse éjaculée par le mâle et une enveloppe surajoutée par la femelle; la masse principale n'est autre que le produit de sécrétion des "vésicules séminales ", si développées chez nombre de Rongeurs (Cobaye) : c'est une substance particulière, coagulable, que Lataste

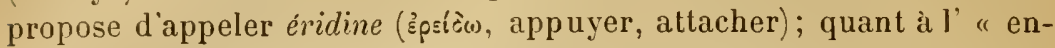
veloppe vaginale " qui revêt cette masse, elle est composée de cellules épidermiques stratifiées, détachées du vagin. Le bouchon vaginal est nécessaire à la fécondation; quand la masse est répandue hors du vagin, le coït reste stérile.

Les Rongeurs sont répartis dans le monde entier, mais on n'en trouve qu'un petit nombre d'espèces en Australie et à Madagascar. Les preiniers débris fossiles remontent à l'époque tertiaire.

Un certain nombre de ces animaux sont chassés pour leur chair ou pour leur fourrure; d'autres ravagent nos récoltes ou s'attaquent à nos provisions, et méritent d'être poursuivis à outrance.

Brandt, se basant principalement sur la structure du crànẹ, a divisé cet ordre en quatre grands groupes : Sciuromorpha, Byomorpha, Hystricomorpha et Lagomorpha, auxquels Zittel a ajouté celui des Protrogomorpha.

$1^{\text {er }}$ sous-ordre : Protrogomorphes. - Molaires $\frac{4-5}{4}$. Canal infraorbitaire assez large. Maxillaire inférieur arec une grande apophyse coronoïde. Tibia et péroné distincts ou soudés.

Ce groupe comprend la plupart des Rongeurs de l'éocène, un certain nombre de ceux du miocène, et quelques formes actuelles (4 molaires à chaque mâchoire; tibia et péroné soudés), telles que les Myoxidés ou Loirs et les Dipodidés ou Gerboises.

Les Loirs sont des animaux à crâne allongé et à queue touffue, grimpeurs, nocturnes et hibernants. Leur nourriture se compose surtout de fruits, mais ils mangent aussi des cufs et des Insectes. Le Loir vulgaire (Myoxus glis Schreber) habite de préférence les forèts de chênes et de hêtres, et fait son nid dans le creux des arbres ou des rochers. Le Lérot (Myoxus nitela Schreb.) rit au voisinage des habitations, dans les parcs, les vergers, les jardins, dont il est un des principaux ravageurs. Le Muscardin (IIuscardinus avellanarius [L.]), de la taille d'une Souris, à pelage fauve clair, vit dans les taillis et dérore les bourgeons.

Les Gerboises (Dipus) se distinguent de tous les autres Rongeurs par la longueur de leurs membres postérieurs.

$2^{\text {e }}$ sous-ordre : Sciuromorphes. - Molaires $\frac{4-\ddot{3}}{4}$. Canal infraorbitaire étroit. Naxillaire inférieur avec une haute apophyse coronoïde. Une clavicule. Tibia et péroné distincts.

Les Sciuridés ont une queue longue et touffue, des pattes antérieures à

(1) Benganiv und Leuchart, Vergl. Anatomie und Physiologie, 1852, p. 567. F. Lataste, Recherches de zooéthique sur les Mammiféres de l'ordle des Rongeurs. Bordeaux, 1887-1859. 
4 doigts, les postérieures ä..-L'Écureuil conmun (sciurus rulgaris) peut ètre pris pour type de cette famille, i laquelle appitrtiennent aussi les I'olatouches (Pteromys), remarquables par leur parachute cutanć étendu entre les membres; lęs Tanias (Tumias) ou ḱcureuils terrestres du nord; les Spermoplites (Spermophilus), plus terrestres encore; les Marmottes (Arctomys), qui vivent en société dans des terriers, et tombent dans un long et profonil sommeil hibernal, ete.

Les CASTORIDÉS ne comprenuent plus actuellement que le seul genre Castor (Castor L.). Ce sont des liongeurs aquatiques d'assez grande taille, à corps trapu, à têle épaisse, tronquée en avant, ì oreilles courtes. Les pieds sont à cinq doights munis d'ongles courts; les memlores antérieurs sont claviculés, propres à creuser et à saisir; les postérieurs sont palmés. La queue est aplatie et couverte d'écailles. 4 paires de molaires à chiıque màchoire.

Le Castor fiber (C. fiber L.) est long d'environ un mètre, $y$ compris la queue, qui atteint 30 centimètres. Son pelage est composé

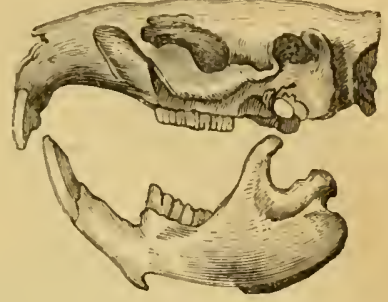

Fig. 856 . - Tète de Castor. d'un duvet très fin, de couleur marron assez foncée en dessus, plus claire en dessous.

On rencontre le Castor en Europe, en Asie et dans l'Amérique septentrionale. Toutefois, il est devenu très rare dans la première de ces régions, en raison de la chasse active qui lui est faite; on n'en trouve plus que quel-

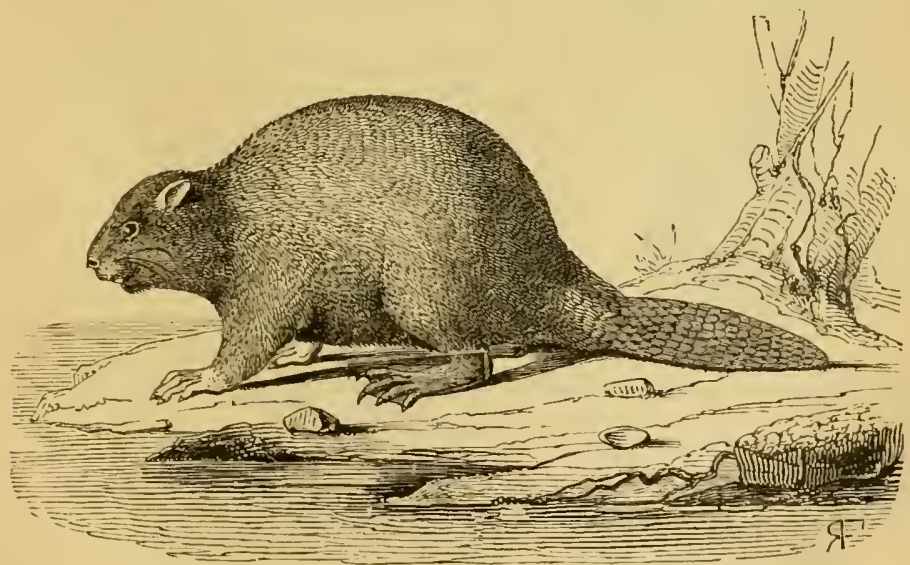

Fig. 857. - Castor.

ques-uns sur les ilots du Rhơne, en Bohême et en Silésie. Autrefois, ces animaux étaient assez nombreux en France, oủ on les connaissait sous le nom de Bièves. Dans les contríes où ils rivent en liberté complète et sans être tourmentés, ils se construisent, dans les étangs ou les cours d'eau, des huttes très complexes, qui sont une merveille dindustrie. Au contraire, 
dans les pays où ils sont traqués, ils habitent de simples galeries; qu'ils se creusent sur le bord des rivières.

On chasse le Castor pour sa chair, pour sa fourrure et pour le castoréum, substance sécrétée par des glandes spéciales qui existent chez les individus des deux sexes.

Castoréum. - Les orifices génito-urinaires et l'anus s'ouvrent dans une cavité commune ou cloaque, dont l'orifice est situé sous la queue. De chaque

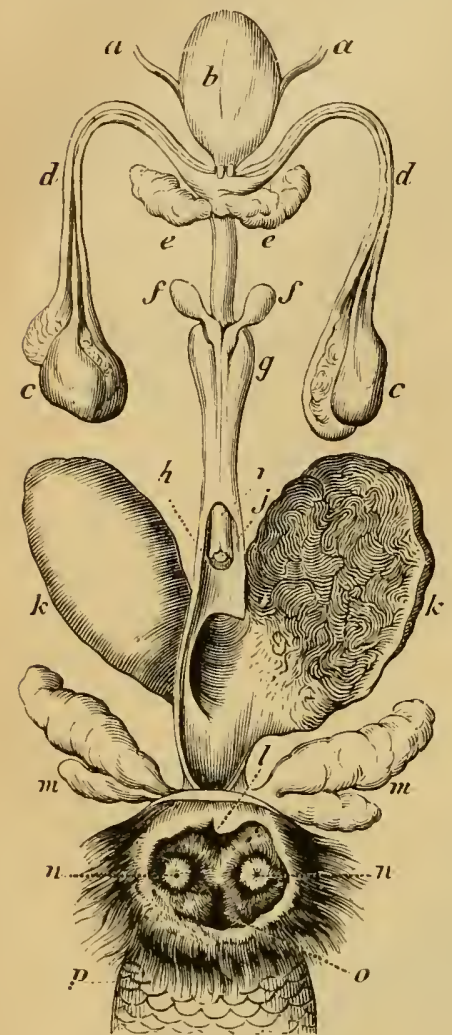

Fig. 858. - Appareil du cıstoréum, d'après Bocquillon. - $a, a$, uretères. $b$, ressie. $c, c$, testicules. $d, d$, canaux déférents. $e, e$, résicules sćminales. $f, f$, glande de Cowper. $y$, niveau de la prostate. $h$, extrémilé de la verge. $i$, prépuce. $j$, ouverture faite au fourreau qui entoure la verge, pour montrer lorifice des glandes $k, k$, qui fournissent le castoréum et dont une est ouverle. $l$, ouverture du caual préputial. $m, m$, glandes anales. $n, n$, leurs orifices. 0 , anus. $p$, yucue. cóté de ce cloaque se trouvent delıx paires de poches glanduleuses : les inférieures, simples ou plurilobées, débouchent dans le cloaque mème, en avant de l'anus : ce sont des glandes anales, qui sécrètent une huile d'une odeur infecte, sans aucun rapport avec le castoréum; celles de la paire supérieure sont plus volumineuses, pyriformes, longues de 8 à 13 centimètres chez le màle adulte, un peu moins développées chez la femelle; elles s'ouvrent dans le canal préputial ou dans le vagin; ce sont elles qui sécrètent l'humeur sébacée, onctueuse et odorante qui constitue le castoréum. Ce produit est sirupeux chez l'animal vivant; on le conserve dans les poches mèmes, qu'on enlève aussitòt après la mort, et il se concrète alors en prenant une teinte jaunàtre.

On trouve dans le commerce deux sortes de castoréum : le castoréum d'Amérique et le castoréum de Sibérie. Le premier seul est employé en France. Il se présente sous l'aspect de masses pyriformes un peu comprimées latéralement, ridées, unies deux à deux par leur sommet. Leur couleur extérieure est brun sale. Leur contenu est compact, jaune ou brunàtre, d'une odeur forte rappelant à la fois celle du Bouc et celle du musc, d'une saveur amère. L'analyse chimique a démontré que le castoréum contient un principe cristallisable, la castorine, de l'acide benzoïque, une huile volatile, des matières grasses et résineuses, et divers sels alcalins.

Le castoréum de Sibérie est en poches courtes, arrondies, plus volumineuses; son odeur rappelle celle du cuir de Russie, ce qui tient sans doute à l'écorce de bouleau dont se nourrissent les Castors sibériens.

Le castoréum passe pour stimulant et antispasmodique. Dans les pays du nord, il joue un grand rôle dans la pratique des sages-femmes et des matrones. 
$3^{\text {e }}$ sous-ordre : Myomorphes. - Molaires $\frac{3-2}{3-2}$. Trou sous-orbitaire asse\% large et placé liaut. Maxillaire inférieur avec une apopliyse coronoüde grêle et haute. Clavicule ordinairement complète. Tibia el péroné soudés.

3 familles : Cricelida, Ariculida, Muridx.

Les CRIGÉTIDÉs ont des nolaires à plusieurs racines, dont la couronne porte deux séries de tubercules groupés par paile, et montre après usure des plis d'émail sinueux. Ils possèdent des abajoues énormes, s'étendant parfois sous la peau jusqu'en arrière de l'épaule. Leur queue est courte el velue.

Le Cricet Hanster (Cricetus frumenturius Pall.) habite l'Europe tempéréc, depuis la Belgique et les Vosges jusqu'ả l'Oural. En Belgique, il se rencontre surtout dans la province de Liège. C'est un animal un peu plus gros que le Rat noir; son pelage est gris ronssitre en dessus, noir en dessous, avec

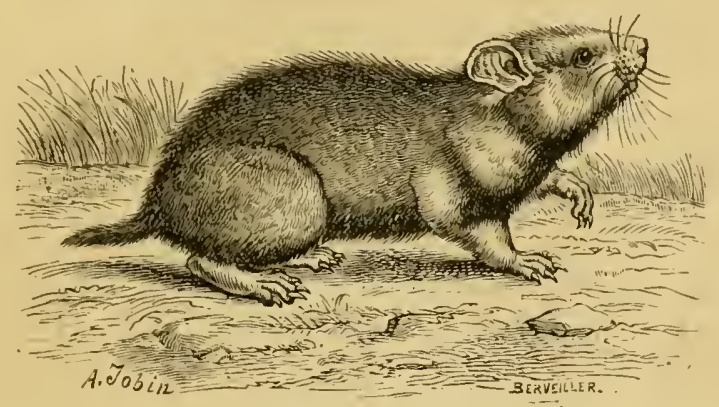

Fig. 859. - Hamster.

des taches jaunàtres latérales. Il fréquente de préférence les champs de céréales, où il creuse des terriers qu'il remplit de grains. On assure qu'un seul individu peut amasser jusqu'à un quintal de blé dans une année. Pendant l'hiver, le Hamster s'enferme dans sa demeure souterraine et vit aux dépens des provisions qu il y a accumulées. Lorsque le froid est rigoureux, il s'endort à la facon des Lọirs. On voit que c'est là un animal des plus nuisibles. Aussi lui fait-on une chasse très active, autant pour le détruire que pour s'emparer de ses provisions, qui sont conservées comme dans de véritables silos. On recounaît les terriers à la terre amassée devant le couloir de sortie.

Les ARVICOLIDÉs ou Campagnols ont des molaires sans racines séparées ou à racines imparfaites, composées de deux séries longitudinales de prismes triangulaires alternes, ce qui leur donne un aspect découpé très curienx; l’émail dessine ainsi à la surface des lignes formant une série d'angles aigus saillants et rentrants. Ces petits animaux ont d'autre part une lète forte, à museau large et tronqué, des oreilles courles, une queue courte ou médiocre revètue de poils courts.

Les Campagnols vivent dans les champs, non dans les habitations; ils se creusent des galeries souterraines. 
Les Campagnols vrais (Arvicola Lacépède) sont souvent désignés sous le nom de "lials à courte queue ". Ils ont en effet une queue de Iongueur médiocre, mais toutefois égale au moins au quart de la longueur du corps; ils ne possèdent que quatre doigts aux pattes de devant, le pouce étant rudimentaire.

Parmi les espèces indigènes, nous devons siognaler en particulier le Rat d'eaı (Arvicola amphibius [L.]), excellent nageur qui creuse ses'galeries au voisinage des rivières, parfois dans

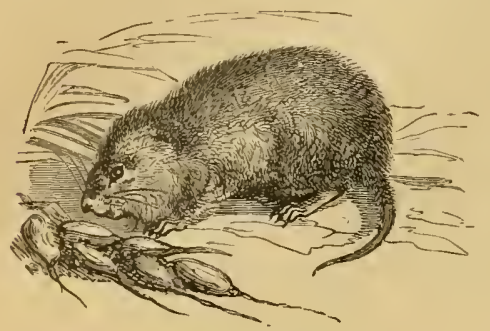

Fig. 860. - Campagnol vulgaire (Arvicola arvalis). les digues, et se nourrit de racines, de Crustacés, le Grenouilles, voire de Poissons; le Campagnol agreste (A. agrestis [L.]), brin foncé en dessus, à oreilles cachées par les poils; le Campagnol des champs (A. arvalis Pallas).

Ce dernier est de la taille d'une Souris; ses oreilles sont plus longues que le poil; sa queue est un peu plus longue que le quart du corps; le dos est d'un gris fauve foncé, le ventre d'un blanc roux sale, les pattes blanchàtres.

Le Campagnol des champs est répandu dans presque toute l'Europe. II se creuse, dans les champs cultivés, un terrier peu profond, qui consiste en une cavité de 8 à 10 centimètres de diamètre, de laquelle partent plusieurs conduits de sortie, irrégulièrement coudés. Il amasse dans cette habitation des aliments divers, et en particulier des grains. Quand les céréales commencent à mùrir, il en coupe les tiges à la base et en détache ensuite les épis.

Sa fécondité est extraordinaire : les femelles font jusqu’à six portées par an, de six à douze petits chacune, et ces petits sont déjả aptes à se reproduire dès l'àge de deux mois. On conçoit donc que, sous linfluence de certaines circonstances, ces animaux arrivent à pulluler dans une région donnée, de manière à constituer un véritable fléau pour l'agriculture.

Dans le courant de l'été 1801 jusqu'à la fin de l'automne 1802, un grand nombre de départements français furent envahis par cette vermiue et enrent leurs récoltes perdnes. Une commission de I'Institul, envoyée à ce sujet dans la Vendée, dénonça pour ce seul département une perte de $2,723,730$ francs. En 1822 , ce fut l'Alsace qui se trouva ravagée : on tua 1,0ั70,000 Campagnols en quinze jours dans le canton de Saverne. En 1850, le mème lléau sévit sur l'Allemagne: pendant l'automne, dit Lenz, il y eut tant de Campagnols entre Erfurth et Fotha, que 12,000 arpents de terre durent ètre labourés de nouveau (Brehm). Dans ces dernières années, enfin, des invasions analogues se sont produites dans le nord-est de la France, et en particulier dans le département de l'Aisne, où, sur beaucoup de points, les récoltes ont été entièrement ravagées. En thèse générale, les Campagnols ne demeurent pas dans le même canton deux années successives; mais on estime que leurs visites se renouvellent, en moyenne, deux fois tous les huit ou dix ans. Ce qu'il y a de remárquable, c'est la rapidité avec laquelle ils apparaissent et disparaissent. Il est certain qu'ils effectuent des migrations, à la facon des Lemmings, et on en a vu quelquefois des bandes 
immenses trarerser à la nage des rivières un même des bras de mer; mais, dans certains cas, leur disparition tient sans doute il ce qu'ils s'entre-dévorent ou à ce qu'ils périssent par maladie.

On s'explique aisément l'importance des ravages exercés par ces petits liongeurs, lorsqu'on sait que la consommation journalière d'un Campagnol est en moyenne de 20 grammes, soit 7 kilog. 300 pour l'année entière, sans compter ce qui est gaspillé et ce qui se pourrit daus les galeries.

Il est done indiqué de létruire, par tous les moyens possibles, des animaux aussi nuisibles. Certaines circonstances viennent d'ailleurs en aide à l'llomme dans cette lutte. Les pluies abondantes, par exemple, inondent les terriers et en font périr un grand nombre. Quant à l'action des froids intenses, elle est fort contestable. Mais les Campagnols ont de redoutables ennemis dans les animaux carnassiers: Chiens, Chats, Renards, Belettes, Putois, louines, Buses, Crécerelles, lliboux, etc., etc. Les Buses surtoul, dit Brehm, en détruisent une quantité incroyable: lilasius en a disséqué qui araient trente de ces liongreurs dius l'eslomac.

Au surplus, on a préconisé une foule de procédés et d'agents propres à détruire les Campagnols, Mulots et autres Rongeurs des champs. Ainsi, dans certaines régions, on dispose dins le sol des rases à demi remplis d'eat, où les Campagnols tombent et se noient. Ailleurs, on laboure le champ infesté, et on fait suivre la charrue d'enfants armés de bàtons ou de Cliens ratiers, Ou bien on empaisonne des grains ou d'autres substances végétales, qưon répand à l’entrée des galeries. Les agents toxiques les plus usilés sont l'acide arsénieux et le phosphore. On recommande beaucoup aujourd'hui l'emploi direct du sulfure de carbone, dont les propriétés toxiques avaient déjà été utilisées dans le mème sens en 1866, par Cloëz. Liopération se fait à la fin de l'hiver : la veille ou l'avant-veille, on passe sur le sol la herse et le rouleau, de manière à boucher tous les trous. Au moment de sulfurer, les trous habités se montrent donc seuls débouchés; un homme muni d'un récipient spécial (mulotière) fait tomber dans tout ou partie de ces trous une quantité déterminée (16 à 18 centimètres cubes) de sulfure, et un enfant muni d'un bàton tamponne tous les oritices. Le lendemain, on sulfure à nouveau les quelques trous qui ont été débouchés, et tous les Rongeurs se trourent détruits (1). Ce procédé, qui n'est pas très coûteux, a l'avantage de ne présenter aucuı danger ni pour l'Homme, ni pour le gibier.

Dans ces dernières années, Löffler en Thessalie et Danysz en France ont étudié diverses maladies infectieuses sévissant sur les Campagnols, et sont parrenus à répandre ces maladies en déposant dans les champs infestés des aliments imprégnés des produits de culture des microbes spécifiques.

Aux Arricolidés appartiennent encore les Lemmings (Myodes Pallas, et Cuniculus Wagler) et les Rats musqués (Fiber Cuvier). - Le Lemming de Norvège (Iyjodes lemmus [L.]) est connu par les migrations qu'il entreprend en troupes immenses, et dont le but n'a pas encore été bien déterminé. L'Ondatra (Fiber zilethicus Cur.), qui a les moeurs du Castor, vit au Canada, où on le chasse pour sa fourrure; il possède, au voisinage des organes génitaux externes, une glande qui sécrète un liquide blanc, oléagineux, à forte

(1) Gassexd, Destruction des Mulots. Compte rendu des travaux des conseils d'hygiene de seine-el-.llarne en 1883, p. 27. 
odeur de civette : et sa queue, qui conserve longtemps cette odeur, est employée en parfunterie.

Les MURIDES ont des molaires tuberculeuses et pourvues de racines séparées, comme les Cricétinés; mais les supérieures montrent trois séries de tubercules. En outre, ces animaux sont privés d'abajoues; ils ont la queue longue, annelée et écailleuse.

Ce sont des animaux très féconds. Ils vivent dans les champs et dans les habitations, et sont presque toujours nuisibles.

Le genre Rat (IIus L.) est le principal représentant de ce groupe. Il est surtout caractérisé par ses molaires, au nombre de trois, décroissantes de la première à la dernière. - Vogt le subdivise en deux groupes : les fats proprement dits, d'assez forte taille, chez lesquels les plis de la voûte du palais courent d'une série dentaire à l'autre, et les Souris, plus petites, où ces plis sont interrompus au milieu.

Parmi les premiers, nous devons signaler le Rat noir (Mus rattus), qu'on croit être d'origine asiatique, et qui parait avoir pénétré en Europe à la suile des croisades. Il s'est répandu dans toutes les régions du monde. Cependant, il a dù abandonner un grand nombre de localités à l'arrivée d'un autre Rat plus fort et plus féroce, le Surmulot (Mus decumanus Pall.), dont des troupes immenses auraient envahi l'Europe en 1727, en traversant le Volga à la nage. C'est ce gros Rat gris qui peuple aujourd'hui nos habitalions et surtout les égouts des grandes villes. En décembre 1849 , on en a pris 250,000 en quelques jours dans les égouts de Paris. Les Rats sont pour l'Homme des ennemis très désagréables, qui " mangent tout, détruisent tout, creusent partout $)$.

Les Souris sont en général moins dévastatrices. La Souris commune (Ius musculus) ne vit guère que dans les maisons, les greniers, les granges; elle est remplacée dans les bois par le Mulot ordinaire (Mus sylvaticus L.), fauve en dessus, blanc en dessous; dans les champs cultivés et les prés, par la Souris naine ou Mulot nain (IIus minutus Pall., M. pumilus Ét. Geoff. et F. Cuv.), brun roux en dessus, blanc en dessous, qui se construit un nid sphérique suspendu aux tiges de blé ou aux roseaux.

$4^{\text {e }}$ sous-ordre : Hystricomorphes. - Molaires $\frac{4}{4}$. Trou sous-orbitaire très large, parfois plus large que la cavité de l'orbite, livrant passage à la branche antéricure du masséter. Maxillaire inférieur avec une courte apophyse coronoïde. Clavicule complète ou incomplète. Tibia et péroné distincts.

Ce groupe comprend un assez grand nombre de familles, dont plusieurs complètement éteintes. Nous citerons, à titre d'exemples :

Les Hystricides, à dos recouvert de piquants. - Les uns sont grimpeurs : Coendou (Cercolabes prehensilis); Urson coquau (Erethizon dorsatus), etc. Les autres sont terrestres : Porc-épic d'Europe (Hystrix cristata), etc.

Les Dasyproctidés, animaux subongulés, à molaires offrant un ruban d'émail plissé. - L'Agouti (Dasyprocta aguti), de la Guyane et du Brésil, a un peu les mœurs de notre Lièvre; chair peu estimée. Le Paca (Cœlogenys paca) vit par couples dans les forêts marécageuses du Brésil et des Antilles méridionales : c'est un gibier très recherché. 
Les Lagostomidcs, sortes de Lièvres sud-américains à fourrure fine, à queue toullue. - Chinchillas (Eriomys Chinchilla, etc.). Viscache ou Lièvre des pampas (Lugostomus trichodactylus).

Famille des CAVIDÉs. - Celte famille se compose d'animaux subongulés, c'est-ì-dire pourvus de doigts qui portent, au licu de zrriftes, des ongles larges et épais, constituant des sortes de sabots. Les membres antérieurs sont ì 4 doigts, les postérieurs à 3. La plante des pieds est nue. La queue est rudimenlaire. Les clavicules sont incomplètes.

Tous les représentants actuels de cette famille appartiennent ả l'Amérique lu Sud : ce sont des animaux terrestres ou nageurs. On a découvert en outre, dans les dépòts tertiaires et quaternaires du Brésil et de la République Argentine, de nombreux genres qui se rattachent étroitement aux formes actuelles.

Les quatre genres vivants sont: Cavia, Ceradon, Dolichotis et Hydrocharus. - Le Cabiai (Hydrochærus capybara Erxleben) est le plus grand des liongeurs actuels; il a la taille d'un Cochon d'un an. Il vit par familles sur les rives marécagenses les fleuves de l'Amérique méridionale. C'est un bon nageur, qui se nourrit surtout de plantes aquatiques. Sa cliair est assez bonne. Le Nara (Dolichotis patarhonica [Shaw]) vit en troupes dans les steppes de la Patagonie et jusque dans le Brésil méridional; on le chasse pour sa fourrure: sa chair est blanche et peu savoureuse. En captivité, il se comporte comme un Lapin.

Les Cobayes (Caria Erxleben) sont de pelits animaux à grosse tète, à oreilles et pattes courtes, à queue presque nulle, à poils durs et serrés. Les membres antérieurs sunt à 4 , les postérieurs à 3 doigts. Les molaires sont constituées par deux prismes inégaux séparés, dans les supérieures par un sinus interne, dans les inférieures par un sinus externe.

Ce sont de petits animaux crépusculaires ou nocturnes, sans intelligence, 'qui vivent par petites sociétés à la lisière des bois ou dans les buissons, et se creusent des abris dans le sol. On les trouve dans toute l'Amérique du Sud. En outre, on a rencontré d'assez nombreuses espèces fossiles dans les dépòts pampéens (probablement quaternaire) de la République Argentine et dans les cavernes à ossements (quaternaire) du Brésil.

Le Cobaye A péréa (C. uperea Erxleben) est l'espèce la plus anciennement connue. Il est long de 26 à 30 centimètres, et haut de 8 ; le jelage est brun finenent mélangé de jaune sur le dos, gris jaunàtre sur le ventre, blanchàtre sur les pattes; les moustaches sont noires, les ongles bruns. En été, ces teintes deviennent plus claires, passant au gris brun sur le dos.

L'Apéréa fréquente, au Brésil, à la Guyane et dans le Paraguay, les hautes plaines, où il se cache parmi les buissons.

Le Cobaye de Cutler (C. Culleri King) est, selon Tschudi, long de 31 à 33 centimètres; la partie supérieure du corps est d'un brun noir pointillé de jaune terreux, cliaque poil étant brun noir de la base au milieu, jaune blanchìtre plus haut, enfin noiràtre à la poinle. Le muscau et lá région oculaire

Ratliset. - Zoologie. 
antérieure sont un peu plus clairs, de même que les còtés du tronc. La gorge, la poitrine, le ventre et la face interne des cuisses sont d'un jaune terreux vif, coloration très intense surtout chez les individus jeunes. La face supérieure des pieds est un peu plus foncée, leur plante est gris noiràtre; les moustaches sont jaunàtres, les ongles tout noirs.

Gette espèce, que le capitaine King avait recue d'abord du navigateur américain Cutler, n'a été vue par Tschudi que sur la côte occidentale du Pérou. Aux environs d'Yca, le naturaliste suisse en rencontrait de nombreux individus dans toutes les haies, sur tous les murs; ils ne craignaient pas l'Homme, les indigènes ne leur faisant pas la chasse. Les Péruviens, qui donnent à ce petic animal le nom de Cuy del monte, sont unanimes à le regarder conme la souche du Cobaye domestique.

Le Cobaye domestique (C. porcellus [L.]. - Syn. : Mus porcellus L., 1738 ; f. cobaya Gmelin, 1789) ou Cochon d'Inde, Guinea-pig des Anglais, Hausmeerschweinchen des Allemands, a d'ordinaire un pelage assez dur, uniforme, dont la coloration présente des plaques irrégulières jaunes, noires et blanches. Cependant on connait une race angora, une autre à poils rayonnant en rosaces; une troisième à pelagre laineux; une quatrième à pelage soyeux; d'autre part, il existe diverses variétés de coloration : albine, mélanienne, brun jaune uniforme. A. Milne-Edwards a produit cinq des formes précédentes aux dépens d'un seul couple de Cobayes ayant survécu au siège de Paris en 1870. - La voix comporte, outre le cri aigu bien connu (coui-coui), une sorte de grognement : c'est sans doute ce qui a valu à cet animal le nom de Cochon d'Inde.

Origine et domestication. - La plupart des auteurs indiquent le Brésil comme la patrie d'origine et le Cavia apcrea comme la souche sauvage du Cochon d'Inde. Voici cependant ce que disait Is. Geoffroy Saint-Hilaire au sujet de son origine : "L'introduction du Cobaye domestique ou Cochon d'Inde en Europe a eu lieu à la même époque que celle du Dindon et du Canard musqué, américains comme lui (Voy. p. 1045 et 1040). Mais ici la date de l'introduction ne se confond pas avec celle de la domestication, et peutètre l'une est-elle très éloignée de l'autre. Garcilasso de la Vega nous apprend que le Cochon d'Inde, qu'il appelle Coy, existait déjà chez les Péruviens, avant la conquète, à l'état " domestique " aussi bien qu’à l'état " champètre "; et n'eussions-nous pas ce témoignage, ce que nous savons de l'état du Cochon d'Inde au $\mathrm{xvi}^{\mathrm{e}}$ siècle atteste que sa domestication date d'une époque bien antérieure. On le voyait dès lors tel qu'il est aujourd'hui, c'està-dire à pelage bigarré de blanc, de noir ou de roux, et variable d'un individu à l'autre; preuves non équivoques d'une domesticité déjà ancienne, dont la date reste d'ailleurs entièrement indéterminée et le restera sans doute toujours. Quant à la souche primitive, les zoologistes ont cru la trouver dans l'Apéréa; mais cette espèce, qui est surtout brésilienne, a des congénères péruviens parmi lesquels on doit bien plutòt chercher le Cochon d'Inde sauvage. Jalheureusement ces espèces ne sont pas encore bien connues, et la solution de ce petit problème de zoologie historique doit être ajou rnée (1). "

(1) Isidore Geoffroy Saint-IILAire, Acclimalution et domestication des animaux utiles, 4e éd. Paris, 1861, p. 173. 
Les recherches de Nehring ont entièrement confirmé les vues de Genfroy Saint-llilaire (1). Dans des tombeaux de la nécropole d'Ancon, près l.ima, tombeaux qui datent d'une époque antéricure à la conquête espagnole, Reiss et Stübel ont recueilli des momies de Cobayes qui tiennent le milieu entre notre Cochon d'Inde d'Lurope, plus profondément domestiqué, et les espèces sauvages du genre: les unes sont concolores (brunes on hlanches), les autres bicolores (brun rougeitre et blanc joune), d'autres encore finement tachetées. D'ailleurs, avant l'arrivée des Espagnols, les habitants du royaume inca étaient arrivés à un dẹrré de civilisation relativement élevé; ils avaient des habitudes sédentaires el un goùt marqué pour l'élevage des animaux : c'est donc à eux qu'il y a lieu d'attribuer la domestication du Cochon d'Inde. En présence de toutes ces données, qu'il a réunies et étudiées avec soin, Nehring arrive en effet à cette conviclion que " le Pérou est la vraie patrie d'origine du Cochon d'Inde, et que l'espèce du genre Cavia répandue dans ce pays (Caviu Culleri King, l’après Tschudi), laquelle suivant Waterhouse est proche parente du Cariu aperea, doit itre vraisemblablement regardée comme sa souche sauvare. "

Caractìres physiologiques. - Dès l'àge de deux mois et même plus tit, le màle est en état de s'accoupler, mais il n'est apte à la fécondation qu'ì l'àge de deux mois et demiou trois mois. La femelle peut ètre fécondée dans certains cas à leux mois et mème plus tôt, mais en général elle ne se montre réellement nubile qu’à trois mois igalement. Un mâle adulte suffit à une vingtaine de femelles. La durée du rut dépasse rarement vingt-quatre heures. D’après Legallois, l'orifice du vagin serait fermé si solidement qu'il faudrait au màle "souvent quinze jours et quelquefois plus " pour en opérer le décollement. L'adhésion, ajoute cet auteur, se rétablit après la copulation, de mème quaprès l'accouchement, de sorte que le mâle du Cochon d'Inde (comme celui de la Souris) jouit de l'heureux privilège de trouver toujours à sa femelle les apparences de la virginité. Mais Lataste a reconnu que ces indications sont fort exagérées: les parois du vagin sont, ¿̀ la vérité, réunies d'une façon très intime, mais le décollement se produit d'une façon spontanée aux époques de rut, de sorte que les efforts du mâle, dans les conditions normales, aboutissent en quelques minutes. A la suite du coït, on peut constater l'existence d'un bouchon vaginal. - La durée de la gestation est de 63 jours, d'après Nehring. Comme ehez la plupart des Rongeurs, sinon chez tous, une époque de parturition est aussi une épợue de rut; aussitót après aroir mis bas, la femelle est apte ¿ recevoir le mille. Le nombre des petits de clraque portée est en général de quatre à huit; parfois il s'élève à dix ou douze; pourtant il nexiste que deux mamelles. Mais ces petits naissent ì un étal de développement très avancé : ils peurent mème manger immédiate-

(1) A. Neunivi, Ueber die Ilerkunft des Meerschweinchens (Cavia cobaya Marcgr.). Sitzungsberichte der Gesellschaft naturforschender Freunde zu Berlin. Jahr'g, 1889, p. 1 . 
ment. Laissés arec leur mère, on les voit en général téter de temps. à autre pendant une quinzaine de jours.

Services. - On élevait autrefois les Cobayes pour les manger; cependant leur chair n'a jamais été bien estimée. Aujourd'hui on les entretient surtout pour les faire servir aux expériences de physiologie et de pathologie.

Croisenents. - On a souvent affirmé, en vue d'appuyer la doctrine de l'évolution, que le Cobaye domestique ne s'accouplait pas avec l'Apéréa, regardé comme sa souche sauvage. Bien qu'une telle assertion eùt perdu toute sa valeur en présence des documents historiques recueillis par Nehring, cetauteur n'en a pas moins tenu à la soumettre à un contròle expérimental. Or, il est résulté de ses essais que les croisements entre les deux formes sont féconds, quel que soit le sens dans lequel ils sont effectués, el que les produits ainsi obtenus sont cux-mèmes féconds entre eux. Si ces rẹ́sultats ne règlent pas définitivement la question de l'identité spécifique des deux formes, du moins montrent-ils avec quelles réserves il faut accueillir certaines assertions enregistrées par les meilleurs auteurs.

$\check{\jmath}^{\mathrm{e}}$ sous-ordre : Lagomorphes. - Comprend les Rongeurs auxquels: Illiger donnait le nom de Duplicidentés : ces animaux sont remarquables en effet par la présence, à la mâchoire supérieure, d'une seconde paire de très petites incisives qui sont adossées à la face. postérieure des deux principales et forment une sorte de talon sur lequel viennent butter les incisives inférieures. Molaires $\frac{4-6}{4-0 ̈}$, sins racines séparées. Clavicule complète ou incomplète. Tibia el péroné distincts. Membres antérieurs courts, à ’ doigts, les postérieurs plus longs, ì 4 doigts. Plante des pieds couverte de poils.

Famille des LÉPoRIDÉS. - Molaires $\frac{6}{5}$. Crûne comprimé latéralement. Clavicules rudimentaires. Patles postérieures longues, disposées pour le saut. Oreilles plus ou moins longues, en forme de cornet; queue courte, relevée, velue. Six à dix mamelles. Un bouquet de poils à la face interne des joues.

Le genre Lièvre (Lepus L.) est le seul genre actuel de cette famille; il. comprend une vingtaine d'espèces virant en Europe, en Asie et dans les. deux Amériques.

Une intéressante particularité du mode de vie de ces animaux con-siste dans l'habitude qu'ils ont d'avaler leurs crottes (Morot). C'est peut-être en raison de cette circonstance qu'ils avaient été regardés. comme des animaux ruminants. C'est surtout rers le matin qu'ils se livrent à cet acte. Malgré une apparence de mastication, les crottes, recueillies à l'anus, sont dégluties sans être broyées, et s'accumulent. 
dans le eul-de-sac gauche de l'estomac. $\Lambda$ mesure qu'il en pénètre de nouvelles, les plus anciennes descendent vers le rétrécissement. Arrivées à ce niveat, elles commencent à se déformer, puis passent peu ì peu dans'le sac droit, oì elles sont bientît transformées en pulpe. C'est pourquoi on ne les rencontre guère que dans l'estomac des animaux tués le matin.

On peut dire que c'est lì un acte normal. Morot a mème cherché a le rapprocher de la rumination. Nous avons, par contre, tenté de démontrer que c’est pour les Léporidés un moyen d'éviter l'infection de leurs retraites el d'échapper à la poursuite des carnassiers.

On assure aussi que les Léporidés boivent quelquefois leur urine.

Le genre Lepus est représenté par des espèces fossiles dans le miocène de l'Asie et de l'Amérique du Nord. En France, il apparait dans le pliocène de Perpignan et de l'Auvergne (L. Lacostei Pomel). Ses représentants se montrent abondants à l'époque quaternaire, et paraissent à peu près identiques aux formes actuelles. C'est ainsi qu'on signale le Lapin de garenne $(L$. cuniculus) dans le diluvium stratifié et surtout dans les cavernes a ossements de la France méridionale, de la Ilaute-Italie, de la Belgique, de l'Allemagne et de l'Angleterre. A ses restes sont associés d'ailleurs cenx du Lièvre commun (L. timidus). Quant à ceux du Lièvre alpin (L. variubilis), on ne les rencontre que dans les dépòts quaternaires qui correspondent ì son habitat actuel.

On reconnail dans ce genre deux sections principales, celle des Lièvres et celle des Lapins.

Les LIÈ IrEs ont les oreilles très grandes, les pattes postérieures beaucoup plus longrues que les antérieures, la queue toujours bien évidente. - Ils ne se creusent pas de graleries, vivent toujours à la surface du sol et se couchent dans une dépression superficielle appelée gite. Les petits naissent les yeux ouverts; ils sont couverts de poils et assez développés.

Les Lièrres comprennent de nombreuses espèces, dont les plus connues sont: le Lièvre commun (L. timidus L.) de l'Europe moyenne; le Lièvre changeant ( $L$. variubilis Pallas), de l'Europe septentrionale; etc. Aucune de ces espèces n'est domestiquée; ellę ne paraissent mème guère domesticables. Le Lièrre commın est un gibier estimé, qui fait dans nos pays l'objet principal de la petite cliasse. La chair est noire, savoureuse et excitante.

Les L.IPIXs ont les oreilles moins longues que les Lièvres; la disproportion entre le bipède antérieur et le bipède postérieur est moins accusée que chez ces derniers animaux; ils diffèrent aussi beaucoup par leurs caractères squelettiques (Sanson, Lesbre), quoique R. Saint-Loup ait pu relier les types craniens par une série de formes asiatiques ou américaines. - Ils vivent en société et se crensent des galeries ou terriers. Leurs petits naissent nus el les yeux fermés.

On décrit plusieur's espèces de Lapins vivant à l'état sauvage. La plus connue est la suivante.

Le Lapin de garenne (L. cuniculus L.) est de petite taille; son pelage est en général d'un gris tiqueté avec un peu de roux en arrière de la tête; 
le dessous du corps est blanchàtre; la queue est courte, noire en dessus; les oreilles sont également petites, noires à la pointe; les pieds sont très velus.

Les Lapins de garenne recherchent les terrains sablonneux, les ravins, les buissons. Ils creusent leurs terriers de préférence dans les endroits exposés au soleil. Chaque couple a le sien propre. lls y restent cachés tout le jour, à moins que le terrain environnant ne leur fournisse un abri suffisant.

Ces animaux sont presque monogames. Le rut commence en février ou en mars. La Lapine, comme la Hase ou femelle du Lièvre, porte de 30 à 31 jours et met bas quatre à six ou huit petits, qu'elle dépose dans un terrier spécial, appelé rabouillère. Comme elle s'accouple aussitòt après, il en résulte qu'elle peut faire six ou sept portées par an.

On regarde en général le Lapin de garenne comme originaire, soit du nord de l'Afrique, soil de l'Europe méridionale, et en particulier de l'Espagne. Quelques auteurs lui attribuent mème pour patrie l'Afrique du Nord. Quoi qu'il en soit, il s'est répandu dans toute l'Europe centrale et méridionale. Il a mème été introduit en Angleterre par les amateurs de chasse. Daus beaucoup de points, il s'est multiplié d'une façon extraordinaire, malgré les efforts faits pour le détruire. C'est en effet, en mème temps qu'un gibier estimé, un animal susceptible de causer des pertes sérieuses à l'agriculture. Ses dégâts sont beaucoup plus importants et surtout beaucoup plus apparents que ceux du Lièvre.

Lapins domestiques ( $L$. domesticus). - Leur pelage est assez variable. Il est le plus souvent gris, mais on trouve aussi des individus roux, noirs ou blancs, et d'autres qui présentent un mélange de ces diverses couleurs. Les principales races reconnues par les auteurs sont: le Lapin commun, le Lapin bélier ou rouennais, le Lapin riche ou argenté, le Lapin blanc de Chine el le Lapin d'Anyor'a.

La plupart des naturalistes admettent que ces diverses races ou variétés dérivent toutes du Lapin de garenne; mais P. Gervais regarde cette filiation comme très douteuse, et Sanson la nie d'une façon absolue, en se basantsur les caractères craniens de ces animaux.

Domestication. - On ne possède aucun document précis relatif à la domestication du Lapin. Les ossements de Lepus font défaut dans les Kjökkenmödinger du Danemark; ceux, assez rares, qu'on truuve dans les palafittes, sont rapportés au Lièvre par Rütimeyer. Le Lapin ne devait donc pas être domestiqué à l'époque robenhausienne. Quelques auteurs pensent, d'après un passage de Confucius, que sa domestication a eu lieu en Orient. En tout cas, il n'a dù être introduit dans nos régions que fort tard. Les auteurs grecs et latins n'en parlent pas. Varron rapporte, il est vrai, que les Romains élevaient des Lièvres (commun et variable) et des Lapins (originaires d'Espagne) dans les pares ou leporaria, et quils les enfermaient parfois dans des cages pour les engraisser: les auteurs de la Maison rustique du $\mathrm{xvl}^{\mathrm{e}}$ siècle signalent aussi l'anmexion de clapiers aux garennes et motent les modifications que subissaient les Lapins par suite du séjour dans ces clapiers; mais il n'y a rien là qui dépasse ce que nous constatons tous les jours, et les documents de cette nature n'éclairent aucunement l'histoire de la domestication. 
On sait que les Hébreux rejęaient comme impure la chair du Lièvre et łu Lapin, et que, de nos jours encore, les Lapons et quelques autres peuples de l'Europe coutinuent de l'avoir en horreur.

Caractères physiologiques. - Les Lapins domestiques sont en état de se reproduire à cinf ou six mois. La durée de la gestation est de 31 jours. Chaque portée est en général de huit ì douze Lapereaux, et une lapine donne environ huit portées par an. On recommande de ne remettre la mère au màle que trois semaines apris la mise bas. La fícondation est opérée dans l'espace d'une nuit, el la Lapine peut continuer à nourrir encore ses pelits pendant une huilaine de jours. Un mâle suffit pour dix à quinze lemelles.

Services. - On entretient ces animaux dans des clapicrs . "La production des Léporidés domestiques, dit Sanson, est pratiquée partout par les cultivateurs, qui trouvent par la le moyen d'utiliser et de mettre en valeur les débris des légumes et les herbes de leur jardin, ainsi que les plantes non cultivées qu'ils vont recueillir dans les champs roisins de leur habitation. lls les nourrissent ainsi avee des aliments qui, sans eux, resteraient sans emploi. Ce sont les Lapins ainsi reproduits à peu près sans frais, qui forment la grande masse de l'approvisionnement des marchés et délerminent conséquemment le cours de la marchandise, qui ne dépasse guère 0 fr. 7̈̈le kilogramme de poids vif. " Par contre, l'élevage en grand de ces animaux n'a jamais donné de résultats avantageux, tant à cause des frais d'alimentation que par suite des conditions défavorables qu'entraine l'agglomération des animaux. - G'est surtout pour leur chair que les Lapins sont élevés; mais on utilise aussi leur fourrure. Enfin, il ne faut pas oublier que ces animaux sont de précieux auxiliaires de la physiologie moderne.

Léporidle (L. timido-domesticus). - Le Lièvre et le Lapin manifestent l'un pour l'autre une antipathie prononcée, au point qu'on a longtemps regardé comme chose impossible le rapprochement sexuel entre ces deux espèces. Cependant, au siècle dernier, Amoretti avait déjà signalé l'accouplement fécond d'un Lapin avec une Hase. Mais ce fait était oublié quand, en 18'T, Roux (d'Angoulême) parvint à obtenir un certain nombre de produits par l'accouplement du Liérre màle avec des Lapines. C'est à ces produits que Broca donna plus tard le nom de Léporides. Depuis cette époque, Gayot et quelques autres expérimentateurs ont obtenu de semblables résultats.

Les Léporides, accouplés entre eux, se montrent féconds, et se reproduisent d'une façon indéfinie. C'est pourquoi on les a considérés comme réalisant une espèce nouvelle, que IIæckel proposait de dénommer $L$. Darvini. Mais il résulte des recherches de Sanson qu'il n'y a pas la un type spécifique noureau, et que les Léporides ne tardent pas à faire relour à l'un ou à l'autre de leurs types ascendants, à la façon des réritables métis. Ceux qu'on observe actuellement sont mème si bieu revenus au type Lapin, que bien des auteurs sont portés à mettre en doute l'existence de véritables líporides. 
Aux Lagomorphes appartient aussi la petite famille des Lagomidés, représentée actuellement par les Lagomys, petits animaux ressemblant à des Cobayes, et répandus dans une grande partie de l'hémisphère nord.

\section{ONZIÈME ORDRE}

\section{PINNIPÈDES}

Mammifères onguicules, à pieds transformés en nageoires, les postérieurs dirigés en arrière; pas de nageoire caudale; dentition complète: canines fortes, molaires tranchantes; placenta zonaire.

Les Pinnipèdes (pinna, nageoire; pes, pied) sont de véritables Carnivores, que leur adaptation à la vie aquatique rapproche des Célacés. On leur a donné quelquefois le nom d'Amphilies, qu'ils ne méritent pas en réalité, puisque leur respiration est aérienne comme celle de tous les Mammifères.

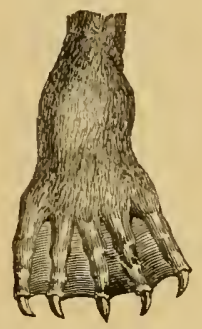

Fig. 861 . - Patte de Phoque (Phoca vitulina L.).

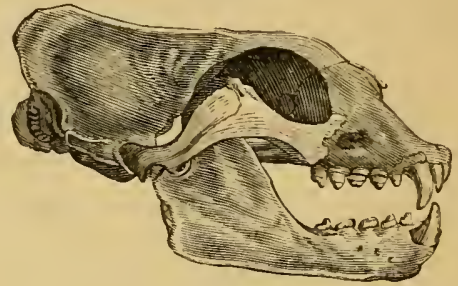

Fig. 862. - Téte de Phoque.

Ils ont le corps allongé et fusiforme, revètu de poils courts ; la tète petite et arrondie; la queue courte, non aplatie en nageoire; les membres également courts, mais terminés par une rame que forme leur main palmée, à cinq doigts armés de griffes.

La constitution du système dentaire est moins fixe que chez les Carnirores. Les incisives sont souvent en petit nombre et peuvent mème manquer; les canines sont puissantes, surtout chez les Morses, où les supérieures se transforment en longues défenses; les molaires sont uniformes.

Les femelles ont un utérus bicorne et deux ou quatre mamelles ventrales. Elles donnent naissance à un ou deux petits. Le placenta est zonaire comme chez les carnassiers terrestres.

Le cerveau est bien développé et présente de nombreuses circonvolutions. Les Pinnipèdes sont des animaux sociables, qui sont répandus dans toutes les mers, et en particulier dans les régions polaires. Ils sont assez maladroits sur la terre ferme, mais ils nagent avec aisance et peuvent plonger fort longtemps, gràce à des valvules spéciales qui produisent l'occlusion des narines, et à un large sinus de la veine cave inférieure. Ils se nourrissent de Poissons, de Mollusques, de Crustacés et d'autres animaux marins; les Morses mangent aussi des varechs. On leur fait une chasse active, en vue de leur graisse et de leur fourrure, qui sont la base de l'existence des Esquimaux. Leur chair a une sareur assez désagréable. 
Les Morses sont remaryuables par l'extrème allongement de leur's canines supérieures, qui constituent deux ẻnormes défenses dirigées en bas. - On ne connail qu'une seule espèce de Morses, la Vache marine (Trichechus rosmarus), de l'océan Cilacial arctique.

Les Phoques ont des canines courtes et sout dépourvus de conque auriculaire. - Veau marin (Phoca vilulina), de nos còtes. Phoque moine (Leptony.x monachus), de la léditerranée. Éléphant marin (Cystophora proboscidea), des mers antarctiques.

Les Otaries diffèrent des Phoques en ce quils pos-

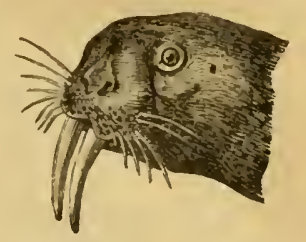

Fig. 863. - Tite de Ilorse (Trichechus rosmarus 1. .). sèdent une petite conque auriculaire et que lenrs membres, plus dégagés du corps, sont plus aptes à la marche. - Lion marin (Oturia leonina), de l'Amérique méridionale. Ours marin (0. ursina), du Girand Océan.

\section{DOUZIEAE ORDRE}

\section{CARNIVORES}

Mammifères onguiculés, ì doigts libres; dentition complète : canines fortes, molaires tranchantes; placenta zonaire.

Les Carnivores terrestres ou a doigts libres sont quelquefois réunis dans un seul et même ordre arec les Ploques et les Morses, dont on les distingue sous le nom de Fissipèdes, et même arec le groupe éteint des Créodontes.

Ces animaux, souvent forls et agiles, sont organisés surtout pour courir et pour sauter, parfois mème pour grimper ou pour fouir. Les uns soni digitigrades, les autres plantigrades; on peut même reconnaitre des semi-plantigrades, qui relèvent le tarse (Martres), et des semi-digitigrades, qui relèvent aussi le métatarse (Paradoxures). Les doigts, au nombre de cinq ou de quatre, presque toujours libres, sont armés de griffes recourluéesen crochet. Ces griffes, que l'usure maintient assez, courtes chez les coureurs (Chiens), sont longues et tranchantes chez les fouisseurs et les grimpeurs; elles se montrent surtout puissantes chez les Chats, où elles se relèrent pendant la marche sous l'action d'un ligament élas. tique qui s'étend de la deuxième à la troisième phalange.

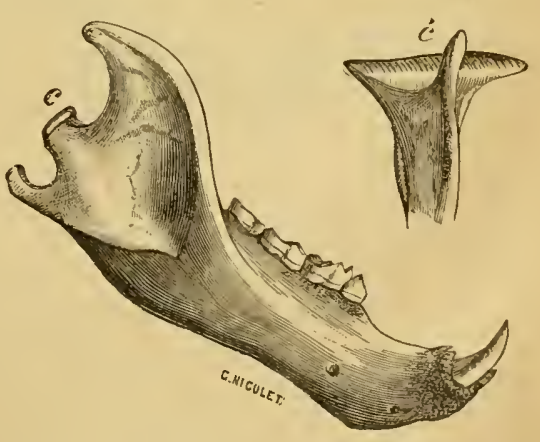

Fig. 864. - Maxillaire inférieur de l'Ours blanc. $-c$, coudyle (du côté droit). c', le mème vu de face.

Parmi les particularités que présente le squelelte, il faut noter surtout la forme très allongée, dans le sens transversal, des condyles 
de la màchoire inférieure, qui s'emboìtent exactement dans les cavités glénoïdes du temporal. Cette disposition s'oppose aux mouvements de latéralité et au glissement horizontal, de sorte que la trituration des aliments reste très incomplète; mais elle donne une grande précision aux mouvements d'abaissement et d'élévation, et rend par suite très puissante l'action des mâchoires. Les deux branches du

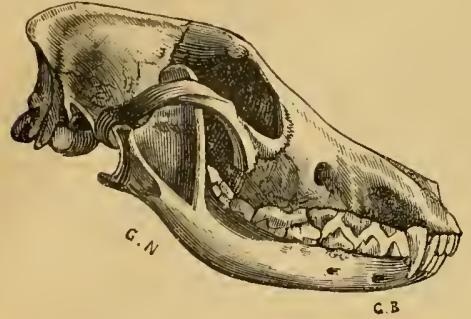

Fig. 86̈̈, - Tüte de Chien. maxillaire inférieur ne se soudent jamais entre elles. Les clavicules sont rudimentaires ou nulles.

La dentition esl fort caractéristique. Si l'on fait exception pour la Loutre marine, tous les Carnivores possèdent, de chaque côté de l'une et de l'autre mâchoires, trois incisives ef une puissante canine. Le nombre des molaires est seul variable. D'après leur forme, on distingue celles-ci en prémolaires, carnassière et tuberculeuses. Les prémolaires, dont on compte de 1 à 4 , sont en général pointues, avec une aspérité médiane; elles appartiennent, comme les incisives et les canines, à la dentition de lait. La carnassiere, qui leur fait suite, est la plus puissante de toutes les dents: sa couronne tranchante est divisée en deux ou trois lobes soutenus par un talon plus ou moins accusé. C'est à l'aide de ces dents que les os sont broyés. La carnassière supérieure représente toujours la dernière prémolaire; l'infé-

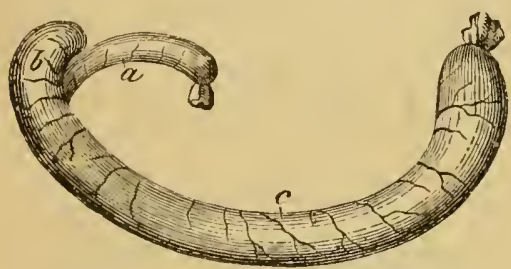

Fig. 866. - Circum el côlon du Cliat. $a$, ilêon. $b$, crecum. $c$, côlon. rieure correspond à la première molaire. Sauf dans quelques genres fossiles, il n'y a qu'une seule carnassière à chaque branche des mûchoires. En arrière de cette dent, se trouvent les luberculeuses, dont le nombre varie de 0 à 3 , et qui doivent leur nom à leur couronne aplatie, garnie de tubercules émoussés : il s'agit évidemment de dents broyeuses. - L'estomac des Carnivores est simple, l'intestin court, le cécum peu développé ou nul.

Les mâles possèdent souvent un os pénien. La verge esl logée dans un fourreau; les testicules sont contenus dans un scrotum. Les femelles ont un utérus bicorne et des mamelles ventrales. Le placenta est zonaire. Ces animaux sont monogames. Ils sont souvent pourvus de glandes anales, qui sécrètent un produit très odorant (odeur de fauve).

Les Carnivores sont assez bien doués sous le rapport intellectuel. Leur cerveau est développé et offre quelques circonvolutions; leurs 
sens sont fort délicats. Leur ggenre de vie est des plus variés; tous cependant vivent aux dépens d'animaux plus faibles; quelques-uns seulement sont omnivores. Ils sont répandus partout, sauf aux Antilles. Les premier's fossiles qui apparaissent appartiennent ì l'éocène.

7 familles : Canidx, Ursidx, Procyonidx, Mnstelidx, Virerridx, Hyanidx, Felidx.

Famille des GANIDÉS. - Les Canidés sont des coureurs digitigrades et à grifles non rétractiles, ayant le plus souvent $\ddot{j}$ doigts

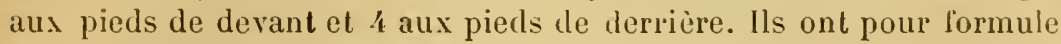
dentaire typique $: \frac{3.1 .1,3-2}{3.1 .1,3}$. Les incisives sont trilobées; les canines sont assez longues, incurvées et comprimées; les prémolaires sont moins pointues que chez les Chats; la carnassière est bien aceusée; les tuberculeuses diminuent de volume d'avant en arric̀re. Le cràne et le museau sont allongés, la queue est. longue; il existe un os pénien très développé.

Les Canidés vivent rarement par couples; la plupart se rassemblent en meutes considérables. Quelques-uns sont diurnes; beaucoup sont nocturnes ou crépusculaires. Tous chassent des proies vivantes, en mettant surtout à profit la délicatesse de leur odorat; mais ils aiment beaucoup la venaison faisandée, et certains la préfèrent mèıne ì la chair fraiche. Enfin, quelques rares espèces ont un penchant marqué pour le régime végétal. A l'état sauvage, ces animaux n'aboient jamais; leurs manifestations vocales consistent en des hurlements ou en des glapissements. Tous répandent une odenr de fauve plus uu moins accusée. Aucun d'eux ne sait grimper; ils atteignent leur proie à la course. Les femelles sont très fécondes; leurs petits viennent au monde les yeux fermés et doivent être allaités assez longtemps. Leur intelligence est assez développée, bien que beaucoup d'auteur's en aient exagéré la portée: il ne faut pas oublier que les facultés de nos Chiens domestiques résultent, en grande partie, de l'influence de l'Homme.

État fossile. - Les Canidés se présentent comme la branche la plus ancienne et la plus conservatrice des Carnivores; ils apparaissent dans l'éocène supérieur et se montrent en assez grand nombre dans le miocène, le pliocène tt le diluvium de l'Europe, de l'Asie et de l'Amérique du Nord, dans le pliocène et le quaternaire de l'Amérique du Sud et de l'Australie. On les considère en général comme dérivant des Créodontes.

Mais le genre Canis ne se montre d'une façon indiscutable que dans le pliocène des Sivalik ( $C$. Cautleyi Rose), puis dans le pliocène supérieur de la Toscane (C. etruscus, C. Falconeri Forsyth Major) et de l'Auvergne (C. meyastomoides Pomel, etc.). (Ces diverses formes se rapportent aux Thooüdes.) Probablement existe-t-il aussi dans le pliocène de l'A mérique du Nord.

Dans le quaternaire de l'Europe, on rencontre de nombreuses formes se 
rapportant, soit aux Thooïdes, soit aux Alopécoïdes. Ainsi, pour ne parler que des premières, le Loup (C. lupus L.) se montre aussi bien dans le diluvium stratifié que dans les cavernes à ossements. Le tuf volcanique de l'Auvergne renferme les restes d'un $C$. Neschersensis Croizel qui est intermédiaire par sa taille entre le Loup et le Chacal. Dans les cavernes à ossements du sud de la France, Bourguignat a signalé deux Cyons (C. europæus et Eduarsianus Bourg.), et une autre forme (Lycorus nemesianus) que lyddeker et Nehring regardent comme un simple Loup.

Les dépòts quaternaires des deux Amériques fournissent un grand nombre d'espèces du genre Canis, la plupart identiques à celles qui vivent encore actuellement dans ces régions.

En ce qui concerne les Chiens proprement dits (sous-genre Canis), la forme la plus ancienne serait représentée, d'après Boule, par une mandibule recueillie dans le pliocène du plateau central. Il faut citer ensuite le C. Miki Woldrich, découvert dans une couche qui se rapporte à la fin de la faune glaciaire et au commencement de la faune des steppes; mais ce n'est peutètre pas un Chien vrai, car on le donne comme intermédiaire entre le Chacal et le Renard. Plus tard se montre un type de taille plus élevée, que Bourguignat nomme $C$. ferus. Plus lard encore, apparaissent d'autres formes canines, qui ont été découvertes par Schmerling dans des cavernes belges de l'époque moustérienne, et dont l'une, plus forte que l'autre du double, devait ètre de la taille de nos Chiens d'arrêt. C'est à cette époque que remonteraient aussi les ossements trouvés par Bourguignat dans la grotle de Fonlamie, près St-Césaire (Alpes-Maritimes), et qui sont donnés comme se rapportant, les unsau Chien de herger, les autres au grand Dogue ou Molosse. Bourguignat les regarde comme ayant appartenu à des variétés domestiques, en se basant sur ce simple fait qu'ils étaient accompagnés de débris d'industrie humaine. On avouera qu'une telle conclusion n'est rien moins que justifiée.

Nous bornerons là nos citations de Canidés fossiles, et nous reviendrons plus loin, à propos du Chien domestique, sur les espèces ou variélés qui appartiennent à la période néolithique.

La classification des Canidés est assez difficile. Cependant, les formes actuelles se laissent ranger dans les quatre genres Canis, Lycaon, Icticyon et Otocyon, ratlachés à une même sous-fanille (Cunininæ).

Les Oreillards (Otocyon Lichtenstein) sont remarquables par le nombre de leurs dents, qui s'élève à 46, parfois mème à 48 . Molaires $\frac{3-4}{4} \cdot$ - Chien Oreillard (O. megalotis [Cuvier]), un peu plus petit qu'un Renard; deux oreilles énormes. Afrique australe.

Les Icticyons (Icticyon Lund) n'ont en général que 28 dents, et au maximum 40. I $\frac{1}{2}$, rarement $\frac{2}{2}$ ou $\frac{1}{1} \cdot$ - Chien des buissons (I. venaticus Lund), du Brésil et de la Guyane anglaise.

Les Cynhyènes (Lycaon Brookes) se distinguent des autres Canidés actuels par la présence de quatre doigts seulement aux membres antérieurs. 42 dents. - Loup peint (L. pictus) des sleppes de l'Afrique, depuis le Sahara jusqu'au Cap.

Les Chiens (Canis L.) ont presque toujours 42 dents, soil $\frac{3.1 .4,2}{3.1 .4,3}$; cepen- 


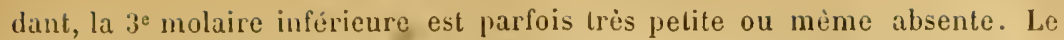
cràne est allongé che\% loutes les formes saurages ou fossiles.

On peut, avee Iluxley, diviser le genre Camis en deux groupes: Thooida et Alopecoila.

A. Les Thoordes présentent une séparation assez brusque entre le front et le dessus du museau, de sorte que ces deux régions forment entre elles un angle plus ou moins ouvert. Leur queue est de longueur moyenue et relativement peu touffue. Leurs pupilles sont circulaires. Ce sont des animaux diurnes.

A ce groupe appartienuent les sections ou sous-genres ci-après :

Les Cyons (Cyon Hodgron) ou Dholes, de l'Asie orientale, qui n'ont d'ordinaire que 40 dents. - Dhole méridional ou Buansuah (Canis juvanicus Desmarest), répandu dans le sud-est de l'Asie, depuis l'llimalaya jusqu'à Bornéo. Line rariété foncée à poil ras, l'Adjack (C. $j$. var. rutilans), habite la presqu’ile de Malacca, Sumatra, Java et probablenent Borıéo. Une autre, le Colsun du Dekkan (C. $j$. var. clukhunensis), se rencontre dans les vallées du haut Indus, ainsi que dans les forèts de lllimalaya, du Kashmir à l'Assam. Dhole septentrional (Canis alpinus Pallas), du nord de l'Asie, depuis la Sibérie jusqu'aux monts Altaï et au delà.

Les Loups (Lupus Gray), espèces à formes hautes el robustes, répandues dans les deux mondes. Le type en est fourni par le Loup vulgaire (Canis

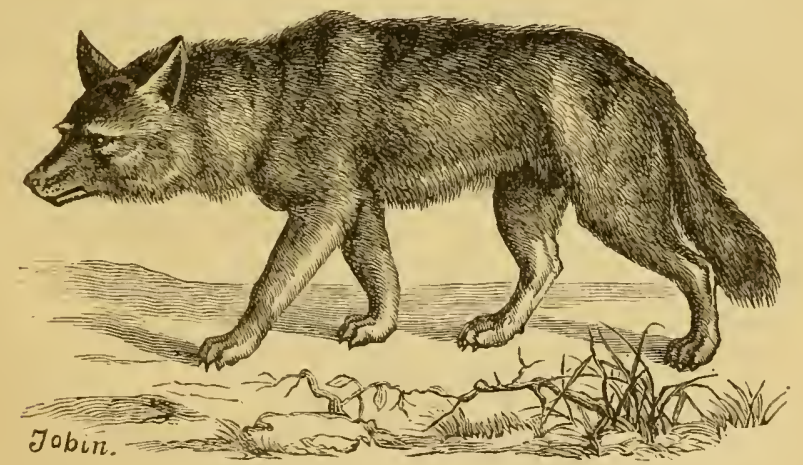

ïig. 867. - Loup d'Europe.

lupus L.). Autrefois très répandu, cet animal devient de plus en plus rare dans notre pays, gràce aux primes accordées en vue de sa destruction. En 1892 , ces primes ont été ainsi réparties : 6 Louves pleines à 1000 franes l'une, 16ł Loups ou Louves non pleines à 100 francs, et $13 \%$ Louveteatix il 40 francs, soit un total de 23380 francs pour $32 \%$ animaux. Le Loup a disparu depuis longtemps de l'Angleterre, mais on en trouve encore des bandes immenses en Russie et en Sibérie. Mirart rattache à cetle espèce, comme simples variétés, le Loup indien ou Landgak (C.l. var. pallipes $=C$. pullipes Sykes) et le Loup de I'Amérique du Nord (C. I. var. occidentalis $=C$. occidentulis De Kay). Les autres espèces de Loups sont: le Cabéru on Loup d’Abyssinie (C. simensis liüppel); le Loup à criniẻre (C.jubutus Desmarest), du Brésil 
et du Paraguay; le Loup antarctique (C. antarcticus Shaw), des iles Falkland; enfin le Loup des prairies ou Coyote (C. latrans Say), de l'Amérique, depuis Costa-Ricajusqu'au Canada.

Les Chiens vrais (Canis s. str.), cosmopolites, comprenant les nombreux types domestiques ou marrons (C. fumiliaris L.) sur lesquels nous reviendrons plus loin. On y rapporte généralement le Dingo ( $C$ familiaris dingo Blumenbach, C. dingo (iould), d'Australie. Le Dingo est quelquefois entretenu par les Australiens dans un élat de semi-domesticité ; mais c'est à peine šil s'attache à son maitre. On l'a souvent regardé comme un Chien marron, d'importation étrangère, car il fait tache dans la faune australienne; cependant, quelques observateurs assurent en avoir trouvé des débris dans le pliocène (?) de cette région.

Les Chacals (Lupulus de Blainville), Ghiens de petite taille répandus dans les régions chaudes de l'ancien monde. - Chacal indien (C. aureus L.), habite l'Inde, Ceylan, la Birmanie jusqu'au sud du Pégou, le sud-ouest de l'Asie jusqu'au Caucase, l'Asie Minenre, la Turquie; il a même survécu en Norée et dans une des îles de la Dalmatie. Chacal svelte (C. anthus F. Cuvier), Dhib des Arabes, vit en Afrique au nord du Sahara, en Égypte (C. lupaster Ehrenberg) et en Abyssinie. Chacal à dos noir (C. mesomelas. Schreber), de l'Afrique méridionale et de l'Abyssinie. Chacal à bandes ( $C$. adustus Sundewall), du centre et du sud de l'Afrique.

Les Thous (Thous Gray) ou Chacals sud-américains. - Carasissi ou Chien crabier (C. cancrivorus Desmarest), de la Guyane à la Plata. Chiè d'Azara (C. Azuræ Prinz Max. zu Wied), du Brésil au Chili et à la Terre de Feu; etc.

B. Les Alopécoldes ont un front qui se continue insensiblement avec le dessus du museau. Leur queue est longue et touffue. Leurs pupilles sont souvent ovales ou en fente verticale. Ce sont des animaux nocturnes.

Ce groupe est moins riche en espèces que le précédent. On peut y distinguer les principales sections suivantes:

Les Nyctéreutes (Nyctercutes Temminck) ou Chacals du nord et de l'est de l'Asie, ressemblant à des Civettes. - Chien Raton (C. procyonoides Gray), du Japon, du nord de la Chine et du pays d'Amour.

Les Lrocyons (Urocyon Baird), à cuurt museau, de l'Amérique du Nord. Renard tricolore (C. virginianus Schreber) ou Colishé des Apaches.

Les Renards (Vulpes Brisson), de l'Europe, de l'Asie et de l'Amérique du Nord. - Renard commun (C. vulpes L.), habite toute l'Europe, l'Asie jusqu'au sud de l'llimalaya, et le nord de l'Amérique $(C . v$. var. fulva $=C$. fulvus Desmaresi) jusqu'au Mexique. Renard blanc, Renard bleu ou Isatis (C. lagopus L.), de la région arctique. Corsac (C. corsac L.), de la Tartarie et de la Sibérie; etc.

Les Fennecs (Meyalotis Illiger, Fennecus Gray), animaux africains cracienx malgré leurs grandes oreilles. - Asse (C. chama Smith), du sud de l'Afrique. Renard pàle ( $C$. pallidus Rüppel), est et ouest de l'Afrique. Sabora (C. famelicus Rüppel), est de l'Afrique et sud-ouest de l'Asie. Fennec vrai (C. zerda Zimmermann), ou Renard du Sahara. 
Chiens domestipues (C. fumiliaris L.). - Il y a, parmi nos Chiens domestiques, une diversité telle, qu'il serait presque impossible de leur trouver un caractère spécifique commun. On a fait remarquer cependant que, contrairement aux Chiens saurages, qui ont toujours la queue pendante, les individus domestiques la portent relevée et souvent mìme recourbée en dessus; ılans ce cas, elle est en quénéral dirigée à gauche, mais cette règle est loin d'ètre absolue, contrairement à l'indication de Linué (cmula sinistro)sum recurvulu).

Les races et sous-races de Chiens, en y comprenant toutes les formes passagères produites par les croisements, sont pour ainsi dire innombrables, et il est extremement difficile de les classer. Aussi nuus bornerons-nous at citel les principaux types, sans chercher ì les grouper d'après leurs aftinités. - Lêriè's : tantòt ả long poil (Lévrier russe), lantùt à poil ras (Lévrier arabe ou Sloughi), Lérrier d'!talie ou Levron [Levrette]). - Mátins : a poil court (Màtin proprement dit, Danois, Chien de Dalmatic on l'etit-Danois); a poil long (Chien de Terre-Neuve, de montagne, de bouvier, de berger). Chicus courants : à poil ras (normands, vendéens, saintongeois, Saint-liubert, Bloodhound, Foxhound, Beagle); à poil long (Deerhound, Griffons). Chiens couchants ou d'arrét: à poil ras (Braque français, Braque anglais ou Pointer); à poil long (Épagueuls, Griffons). - Iogues : Dogue ou Mastiff anglais, Dogue de Borleaux, Dogue du Thibet, Molosse ou Grand-Dogue, Rouledogue, Mops ou Carlin. - Chiens dirers : Barbet, Caniche, King-Charles, etc.

La plupart de ces races ou sous-races sont susceptibles de s'unir entre elles. et nous ne connaissons mème d'autre obstacle à ces croisements que l'inpossibilité matérielle apportée à l'accouplement par une différence de taille trop considérable. Or, dans certains cas, lHomme provoque de tels croisements, dans le but de prodnire des types intermédiaires, doués de qualités spéciales, types qüil perpélue par une sélection attentive. C'est ainsi que prennent naissance ces innombrables formes connues sous le nom de races metisses, qui souvent ne font qu'apparaitre et disparaître, par suite des caprices de la mode, ou qui, plus rarement, sont conservées par une élite d'amateurs, à cause de l'excellence de leurs aptitudes. Telle serait, d'après les auteurs, l'origine des petits Barbets, des Doguins ou Dogues de Bologne, des Bull-Terriers, des Roquets, des Briquets, des Retrievers, etc.

D'autre part, il s'effectue tous les jours, sous nos yeux, des croisements fortuits entre des Chiens de toutes races et mème entre des Chiens déji métissés à divers degrés. Depuis Buffon, on donne à la population hétérogène, de unances variées à l'infini, qui résulte d'une telle promiscuité, le nom de Chiens de rue.

Domestication. - La confusion qui règne dans la classification des Chiens domestiques montre que nous sommes encore loin de connaitre les types primitifs desquels sont dérivées nos diverses races.

Aussi bien, l'idée reçue jusqu'à ces derniers temps, de l'unité de souche de ces races, ne pourait-elle que retarder les recherches nécessaires à la solution diun tel problème. Buffon, on le sait, regardait le Chien comme une espèce à part, n'existant plus à l'état sauvage, et dont le Chien de berger représentait la forme la plus rapprochée de l'état de nature. Güldenstiult et Pallas, qui avaient étudié le Clıacal en Orient, sont les preniers naturalistes qui aient considéré cet animal comme l'ancètre du Chien. Geof- 
Iroy Saint-Hilaire professait aussi cette opinion, sauf pour les lévriers, qu’il faisait dériver du C. simensis. Hodgson regardait au contraire le Buansuah comme la forme souche de nos Chieus. D'autres, parmi lesquels il faut citer P. Gervais, ont fait intervenir au même titre le Loup de nos pays et diverses autres espèces. Or, ce sont là des propositions qui ne s'excluent en aucune manière : l'idée de la pluralité de souche est plus admissible encore pour les Chiens que pour tous les autres Mammifères domestiques.

Seulement, la détermination des types primitifs offre ici de grandes difficultés. Sans doute, elle sera facilitée par les recherches que poursuivent avec ardeur les savants adonnés aux études prélistoriques; mais il faut reconnaîlre qu'à cet égard nous sommes encore bien peu avancés.

Quelques auteurs, avec Steenstrup, font remonter la domestication du Chien à l'époque du Mammouth; mais la plupart sont d'accord pour la reporter au début de la période néolithique. Or, il est constant que, dans le cours de cette période ainsi que des suivantes, les Chiens domestiques ont présenté plusieurs races distinctes. Il faudrait donc pouvoir déterminer quelles sont les races actuelles qui leur correspondent; et il ne serait pas inutile de savoir, en outre, si elles étaient déjả représentées ả l'époque quaternaire.

La race préhistorique la plus anciennement décrite et peut-être aussi la plus anciennement domestiquée est le Chien des tourbières (Canis familiaris palustris), qui a été découvert dans les stations lacustres de l'époque néolithique et décrit par Rütimeyer (1\$62). Cet auteur le comparait d'abord au Chien de chasse actuel, et en particulier au Chien d'arrèt; mais il reconnaît aujourd'hui, avec Studer, que le cràne de cet animal "concorde jusque dans les plus petits détails" avec celui du Chien des Papous (C. Hibcrnix Quoy et Gaimard). Jeitteles et Naumann le regardent, au contraire, comme un rejeton domestiqué du Chacal commun (C. anteus). Anoutshine déclare qu'il ressemble d'une facon frappante au petit Chien domestique des Lapons, des Samoyèdes et des Toungouz. - 11 faut noter ici que tous les crânes recueillis dans les palaffites proviennent d'individus très jeunes ou très âgés, el qu'ils ont le frontal ou le pariétal brisé à l'aide d'un instrument mousse.

Les autres races sont de l'àge du bronze. - L'une d'elles a été découverte dans les tourbières d'Olmütz et de Troppau, et Jeitteles, qui l'a déterminée en 1872, lui a appliqué la dénomination un peu complexe de Canis familiaris matris optima. Elle est beaucoup plus grande que la précédente el atteint à peu près la taille du Chien de berger. Jeitteles la faisait descendre d'un Loup indien, le Canis pallipes; Studer croit, au contraire, qu'elle dérive du Canis familiaris palustris, lequel montre une grande variabilité avant la fin de l'àge de la pierre. On donne comme ses parents les plus proches le Chien de berger, les grands Chiens de chasse et le Caniche.

En 1877, Woldrich a déterminé une troisième race, dont les débris ont été recueillis dans diverses stations de la Basse-Autriche, et qui est intermédiaire entre les deux précédèntes, d'où son nom de Canis familiaris intermedius. Woldrich lui trouve beaucoup de ressemblance avec le Loup d'Égypte (Comis luptester). Elle a dù apparaitre, dans l'Europe centrale, entre l'àge de la pierre et l'âre du bromze.

Enfin, en 1880, Strobel a fait connaître un quatrième type, le Canis f. Spa- 
lettii, encore plus petit que le $C$. $f$. palustris. Il a d'ailleurs précédé celni-ci dans l'Europe centrale. Ce $C$. $f$. Spalettii serait l'ancètre du Loulou, et le C. f. intermedius aurait donné naissance au Chien de berger. Il est à remarquer que l'ordre d'apparition de ces diverses races n'est pas le mème en Italie que dans l'Europe centrale.

Ces races sont-elles attribuables à l'influence de la domestication ? La chose est peu probable, d'autant que certains indices teudent à montrer que quelques-unes d'entre elles au moins existaient déjà à l'époque paléolithique. Il s'agirait lonc de races primitives et autochlones.

En résumé, les traces les plus anciennes de la domestication du Chien dans l'Europe occidentale et centrale se rencontrent au début de l'àge de la pierre polie, et, dès cette période, nous constatons l'existence de plusieurs races distinctes. En Orient, le Chien a été domestiqué à une époque plus reculée encore. "Si loin que nous remontions dans le passé, dit Is. GeofroySaint-Ililaire, nous le trouvons gardien des troupeaux et des habitations des peuples de l'Asie centrale et de l'Égypte. Pour les premiers, nous avons le témoignage des Nackas, et particulièrement du Zend-Avesta : la religion mazdéenne preserivait anx fidèles d'élever dans leurs demeures trois animaux : le Chien, la Vache et le Coq. Pour l'Égypte, nous avons mieux encore que des témoignages écrits : des Chiens, de plusieurs races différentes, sont représentés sur les monuments. "Lenormant en recomnaît sept (1): $1^{0}$ un Chien-Renard, identique au Chien actuel des bazars du Caire, et descendant peut-ètre du Loup d'Égypte (C. lupaster); $2^{\circ}$ le Chien du Dongolah, qui se montre à partir de la XII ${ }^{\mathrm{e}}$ dynastie, et qui est tout à fait semblable à celui qu'on rencontre encore le plus souvent dans les villages de Nubie : il dérive sans doute du Chacal du Dongolah (C. sabbar); $3^{\circ}$ le Lévrier ou Chien de chasse de l'ancien empire, qui parait ètre à peu près identique au Sloughi actuel et qui tire peut-ètre son origine du Cabéru (C. simensis); $4^{\circ}$ un grand Chien courant associé au précédent à partir de la XII ${ }^{\mathrm{e}}$ dynastie, et dont la tête est semblable à celle du Foxhound anglais; $\tilde{\partial}^{\circ}$ une sorte de Basset, animal d'agrément qui se montre seulement sous la XII ${ }^{\mathrm{e}}$ dynastie, et qui diffère de toutes les variétés actuelles de Bassets; $6^{\circ}$ un autre Chien-Renard ressemblant à ceux des bazars du Caire, mais à robe fauve tachée de brun rougge; $7^{\circ}$ un Màtin de grande taille.

Dans certains monuments égyptiens, on voit aussi le Chacal apprivoisé et prenant part à la chasse. Mais, ce qui peut paraitre tont à fait extraordinaire, c'est la domestication véritable du Chien hyénoïde ou Loup peint (Lycaon pictus), qui s'est prolongée au moins depuis la Ve jusqu'à la XII dynastie, et qui n'a cessé qu’après l'apparition du grand Chien courant ( $\left.n^{\circ} 4\right)$.

Nous n'insisterons pas plus longtemps sur l'histoire du Chien dans l'antiquité, et nous nousbornerons à faire remarquer que les Hébreux ne paraissent pas avoir possédé cet animal avant l'époque des rois.

Mais il nous reste un mot à dire au sujet des Chiens de l'Amérique. Piétrement a rassemblé un grand nombre de documents historiques desquels il résulte d'une façon incontestable qu'il existail des Chiens domestiques dans les deux Amériques, ainsi qu'aux Antilles, avant l'arrivée des Européens.

(1) ZaBorow:ki, Les Chiens domestiques de l'ancienne Égypte. Matér. pour l'hist. de l'Homme, 188', p. 529. - Voir aussi Max Siber ue Sihlwald, Des Chiens d'Afrique. Revue sc. nat. appl., 1893.

Rallliet. - Zoologie. 
" Ces Chiens étaient du reste de diverses couleurs, et ils se divisaient en plusieurs races de différentes tailles, les unes à longs poils, les autres à poils ras ou mème sans poil. Enfin, ces Chiens étaient tantôt de simples objets de luxe, tantòt des animaux alimentaires, tantôt des auxiliaires, employés soit comme bêtes de trait, soit comme bêtes de somme, et finissant généralement aussi par être mangés."

Au Pérou, en particulier, les recherches de Reiss et Stübel ont mis au jour les momies de quatre races de Chiens : un Chien de berger, un Basset, un Molosse et un Chien à poil d'Épagneul, que Nehring rapporte à une même espèce, le Chien des Incas (C. Ingæ Tschudi). D’après lui, ce Chien inca semble avoir eu pour ancêtre le Loup occidental (C. $l$. var. occidentalis), de l'A mérique du Nord; il a urait été amené par les émigrations humaines dans l'Amérique centrale d'abord, puis de là au Pérou.

Caractères physiologiques. - Les Chiens sont aptes à la reproduction vers l'àge de dix à douze mois. Ce sont des animaux très lascifs. Le mâle peut s'accoupler en tout temps; mais la femelle n'entre d'ordinaire en rut que deux fois par an, une fois en hiver et une fois en été. Ses chalcurs durent dix à quinze jours. Elle peut s'accoupler plusieurs fois pendant cette période, et, chaque fois, les deux sexes restent unis pendant un temps assez long, la séparation étant retardée par le gonflement énorme des deux renflements érectiles du pénis, qui retient celui-ci en avant des lèvres de la vulve. L'éjaculation est d'ailleurs fort lente. La partie du pénis comprise dans le fourreau a pour base, comme chez tous les Canidés, un os pénien, creusé d'une gouttière inférieure.

La gestation est de 63 jours dans les grandes races, et de 59 à 63 dans les pelites. Chaque portée est de quatre ou cinq petits; plus rarement, le nombre de ceux-ci s'élève à neuf, dix et douze. Ils naissent les yeux fermés et ne les ouvrent souvent qu'après dix ou douze jours. L'allaitement naturel se prolonge environ pendant trois mois. Dans le jeune âge, les mâles comme les femelles s'accroupissent un peu pour uriner; mais, vers l'âge de neuf à dix mois, les premiers tiennent une patte de derrière levée pendant la miction. La durée ordinaire de la vie est de quatorze à quinze ans.

Services. - Par suite du développement remarquable de ses facultés, le Chien est l'auxiliaire le plus utile que l'Homme ait jamais possédé. Il s'adapte aussi bien que son maître aux diverses circonstances dans lesquelles il est placé. Son régime se modifie sans aucune difficulté : de carnivore, il devient ichtyophage chez certaines peuplades, et le plus souvent omnivore dans les pays civilisés. Sa voix, comme nous l'avons déjà vu, se transforme également: l'aboiement, qui est en quelque sorte son langage parlé, est aussi le résultat de la civilisation, et les Chiens des peuplades sauvages, comme ceux de nos pays qui ont été abandonnés dans des régions désertes, ne savent que hurler. Ses aptitudes se multiplient : certaines races se 
prètent à des exigences trìs diverses, el tout le monde a vu les exercices compliqués que peuvent accomplir les "Chiens savants".

Un des instincts faroris des Chiens est la chasse. Or, on sait que certains de ces animaux chassent leur gibier à vue et le tuent: tels sont les Lérriers. C'est à l'aide de l'odorat, au contraire, que la plupart d'entre eux découvrent leur proie: les uns la poursuivent encore et la tuent, comme les précédents, ou l'amènent à portée du chasseur : ce sont les Chiens courants; les autres se contentent de l'indiquer au chasseur : on les nomme Chiens d'arrêt. Il en est même, comme les lietrievers el certains Epagneuls, qui n'ont d'autre office, ì la chasse, que de retrouver le gibier abattu.

Ajoutons que, dans certains cas, lc Chien est employé à la pêche, et qu'on a pu même le dresser quelquefois à la poursuite de l'Homme.

Parmi les services les plus communs du Chien, il faut citer encore la garde des habitations et la conduite des troupeaux. Plus rarement on en fait un animal de trait: en Belgique el en Hollande, il traîne de petites voitures; en Sibérie et chez les Esquimaux, on l'attelle aux traineaux. Nous ne pourons enfin que mentionner le Chien de Terre-Neuve, le Chien du mont Saint-Bernard, les Chiens d'aveugles, dont les services sont connus de tous.

La chair du Chien est assez dure el difficile à digérer; elle répugne d'ordinaire aux Européens; mais, en Chine et dans quelques autres pays, elle est très estimée. Chez les Romains, on engraissait déjà les jeunes Chiens pour l'usage alimentaire, après les avoir châtrés.

La peau et les intestins sont utilisés par l'industrie.

Hyrrides. - Il n'y a aucune preuve, dit Huxley, qu'un croisement entre deux Canidés d'espèces différentes soit resté infécond. D’autre part, les expériences entreprises par Buffon et par Flourens tendent à démontrer, quoi qu'en dise ce dernier auteur, que les produits des unions entre Chien et Loup, Chien et Chacal, etc., sont indéfiniment féconds.

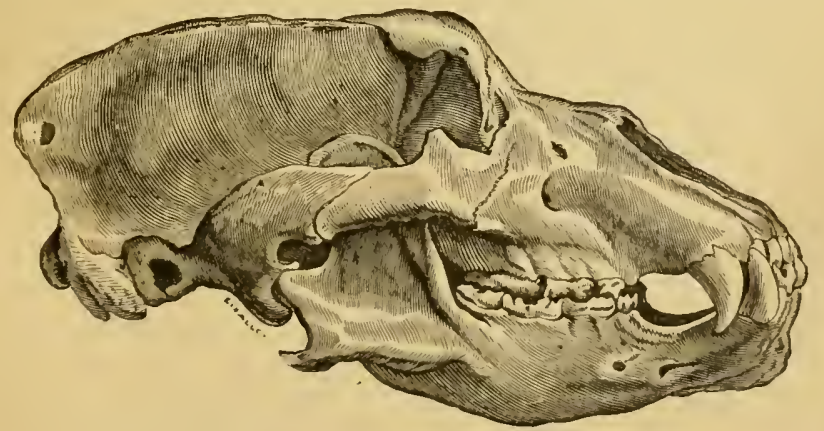

Fig. S68. - Tête d'Ursus spelæus (époque quaternaire).

Les URSIDES ont pour formule dentaire typique $\frac{3.1 .4,2}{3.1 .4,3}=42$; ils ne possèdent:pas:de véritables carnassières. Ge sont des animaux plantigrades à 
cinq doigts, à crâne allongé, à queue courte, à os pénien fort. Omnivores, se nourrissant de chair, de fruits, de racines, de miel, etc. - Espèces principales : Ours brun (Ursus arctos), des pays froids et tempérés de l'ancien continent. Ours blanc ( $U$. maritimus), des régions glacées qui entourent le pòle nord. Ours gris (U.ferox), Grizzly des Américains : habite les montagnes Rocheuses; etc. L'Ours des cavernes (U. spelæus) vivait à l'époque quaternaire.

Les PROGYONIDÉS ont $\frac{31.4,2}{3.1 .4,2-3}=40$ ou 42 dents, sans carnassières bien marquées. Comme les Ours, ils sont plantigrades et pourvus de cinq doigts en avant et en arrière; mais ils ont un cràne court et une queue longue. Animaux omnivores, inoffensifs. - Coatis (Nasua). Ratons (Procyon) ; etc.

Famille des MUSTÉLIDÉS. - Formule dentaire typique $\frac{3.1 \cdot 4,1-2}{3.1 \cdot 4,2-1}$. Carnassière très développée, terminée en arrière par un talon aplati ou comprimé. Animaux à corps souvent allongé, "vermiforme ", plantigrades, semi-plantigrades ou semi-digitigrades, presque toujours à cinq doigts. Détruisent beaucoup de petils Mammifères et d'Oiseaux. -3 sous-familles :

$1^{0}$ Les MÉlinés sont des animaux plantigrades, trapus, pour la plupart omnivores, à tuberculeuse supérieure énorme, à glandes anales très développées. - Blaireau commun (Meles taxus), des régions tempérées de l'ancien continent. Moufeltes (Mephitis). Ratels (Mellivora); etc.

$2^{\circ}$ Les MUSTÉLINÉS sont des plantigrades ou des digitigrades à griffes longues et non rétractiles; leur corps est souvent allongé ; leur dentition est adaptée à un régime presque entièrement carnivore.-Glouton (Gulo borealis), régions glaciales des deux hémisphères. Martre commune (Mustela martes), des forêts de l'Europe septentrionale et centrale. Fouine (M. foina), ennemie de nos basses-cours. Zibeline (M. zibellina), des régions froides et montagneuses de la Sibérie. Putois (Putorius fœtidus), à peu près aussi dangereux que la Fouine. Belette ( $P$. vulgaris), détruit beaucoup de petits Mammifères et d'Oiseaux, voire de Poissons el d'Érevisses. Dans les pays du nord, sa fourrure blanchit quelque pen en hiver. Hermine $(P$. erminea), mœurs semblables. Même dans nos pays, sa fourrure devient blanche en hiver, à l'exception du bout de la queue, qui demeure toujours noir. Vison d'Europe $(P$. lutreola), du nord-est de l'Europe; chassé pour sa fourrure.

Le Furet (Putorius furo [L.]) est un añmal atteint en partie d'albinisme, ainsi qu'en témoignent ses yeux rouges et son pelage blanchàtre ou jaunàtre. Quelquefois, cependant, on rencontre des individus à pelage foncé et à yeux noirs (Furets putoisés). Les caractères ostéologiques du Furet, dit P. Gervais, paraissent en tout conformes à ceux du Putois.

Si cette assertion se trouvail vérifiée, il y aurait lieu de penser que le Furet ne constitue pas une espèce distincte, mais représente une simple variété du Putois. On ne le connait d'ailleurs qu'à l'étal domestique - ou mieux apprivoisé - depuis les lemps les plus reculés. D'après Strabon, il nous viendrait de la Libye, c'est-à-dire du nord de l'A frique; mais on sait que le Putois ne se rencontre pas dans cette région, et il est probable que Strabon, 
comme plus tard Buffon, a confondu le Furet avec quelque petit Carnivore africain. Vogt pense, arec plus de raison, que celte race albine a pris naissance soit en firèce, soit en Italie, où le Putois, dans l'antiquité, remplaçait le Chat pour la chasse aux Souris. - Ajoutons qu'on a relevé des exemples d'accouplement fécond entre le Furet et le Putois.

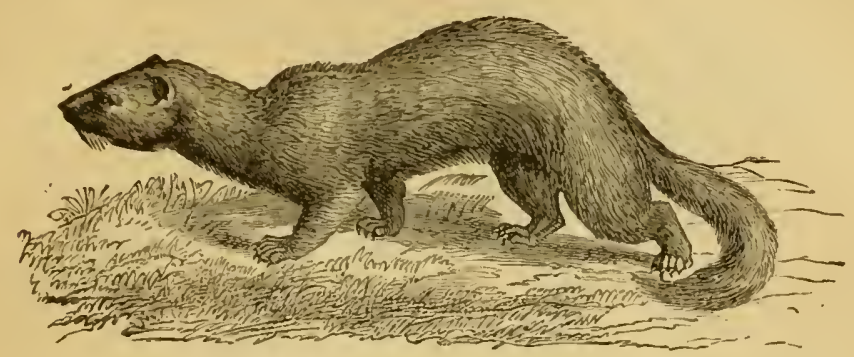

Fig. 869. - Furet.

Comme tous les albinos, le Furet se montre délicat, sensible et peu résistant aur influences extérieures. Abandonné à lui-mème, il ne tarde pas à succomber.

La femelle donne chaque année deux portées, de cinq à huit petits, qui naissent les yeux fermés et ne les ouvrent qu'au bout de deux ou trois semaines. Elle les allaite pendant environ deux mois. La gestation est de six semaines.

On vient de voir que l'Homme a dès longtemps mis à profit les inslincts sanguinaires de ce petit carnassier. En Angleterre, on s'en sert encore pour combattre les Rats; mais, en thèse générale, il est réservé pour la chasse aux Lapins.

$3^{\circ}$ Les LUTRINÉs sont des Carnivores aquatiques à corps allongé, mur nis de pattes très courtes, palmées, à cinq doigts, et d'une queue souvent déprimée. - Loutre commune (Lutra vulgaris), se nourrit surtout de Poissons et d'Écrevisses; fourrure assez recherchée. Loutre de mer (Enhydris marina), des régions polaires de l'océan Pacifique ; forme le passage vers les Phoques; très belle fourrure veloutée, d'un beau brun foncé.

Famille des VIVERRIDEs. - Formule dentaire typique $\frac{3.1 .4,2}{3.1 .4,2}$. Animaux de taille moyenne on petite, ả membres courts et grêles portant sur le sol par une partie variable de la surface plantaire, et terminés par cinq, rarement par quatre doigts, à ongles souvent rétractiles. Gràne allongé et bas ; museau étiré et pointu. Os pénien faible. Queue longue. Un grand nombre de ces animaux répandent une forte odeur musquée, due à la sécrétion de glandes spéciales. Tous sont agriles et avides de sang. Ils habitent surtout les régions chaudes de l'ancien continent.

Les Civettes (Viverra L.) sont des digitigrades à ongles rétractiles. Elles possẻdent un appareil odorifère silué entre l'anus et les organes sexuels. 
La Civette d'Afrique ( $\boldsymbol{V}$. civetta Schreb.) atteint la taille d'un Renard; son pelage est grossier, et, depuis le cou jusqu’à la queue, forme une sorte de crinière que l'animal peut hérisser à volonté; sa teinte générale, gris fauve, est relevée de bandes et de taches irrégulières brun foncé ; la queue est marquée de six ou sept anneaux noirs.

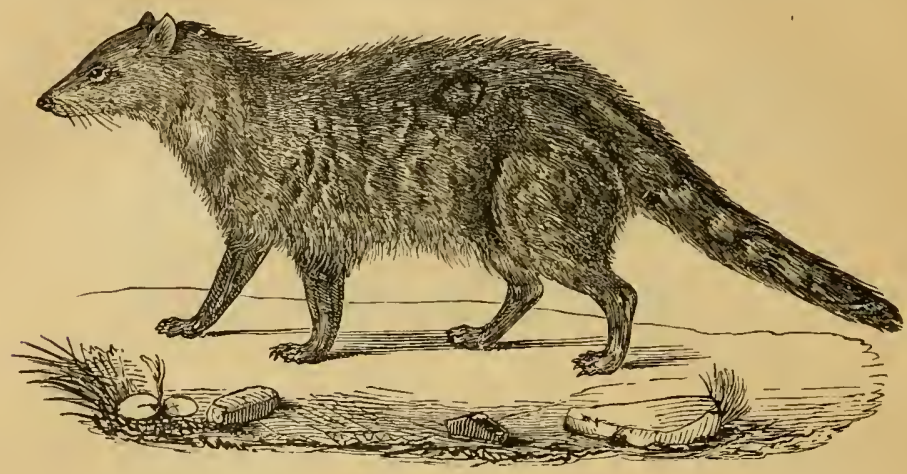

Fig. 870. - Civelte.

Cette espèce se rencontre dans toute l'Afrique centrale, depuis le Zanguebar jusqu'à la Guinée. Elle dort le jour et, la nuit venue, fait la chasse aux

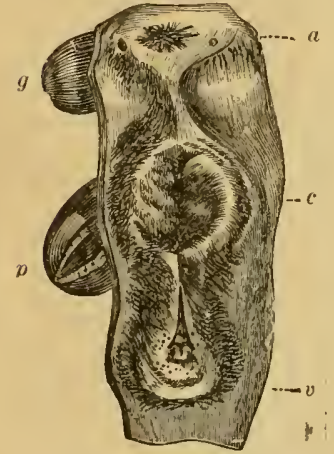

Fig. 871. - Appareil de la Civetle. - $a$, anus, de chaque côté duquel se voit l'orifice d'une glande anale. $g$, glande anale gauche. $c$, cavité dans laquelle débouchent les deux poches à civette. $p$, poche gauche, $v$, partie inférieure de la vulve. Oiseaux et aux petits Mammifères. On l'élève en captivité, dans beaucoup de contrées, pour recueillir le parfum qu'elle fournit : tous les huit jours, on vide ses poches avec une petite cuiller, et on enferme le produit dans des vases que l'on bouche avec soin.

Vicerréum. -- L’appareil odorifère existe dans les deux sexes; son ouverture est située sur le périnée, entre l'anus et la vulve chez les femelles, entre l'anus et l'orifice préputial chez les màles: c'est une fente longitudinale à lèvres velues, qui communique de chaque còté avec une poche de la grosseur d'une amande. La paroi de ces deux poches est revètue de poils courts et fins et renferme une multitude de follicules composés, qui déversent leur produit dans la cavité : c'est ce produit qui est connu sous le nom de civette parfum, et que P. Gervais a proposé d'appeler viverréum. Il ne faut pas confondre les poches à civette avec les glandes anales, qui sont situées au-dessus, et dont les orıfices excréleurs se voient sur les còtés de l'anus; la sécrétion de ces glandes, peu abondante, répand une odeur infecte.

Le viverréum ou la civette est une substance demi-fluide, onctueuse et jaunâtre, qui s'épaissit et brunit avec le temps. Son odeur pénétrante rappelle à la fois celle du musc et celle des matières fécales. 
On l'employait autrefois en médecine, au même titre que le muse; il n'est plus guère usité aujourd'hui qu'en parfunerie.

La Civette d'Asie ( $V$. ziletha L.), plus connue sous le nom de Zileth, est plus petite que la précédente et n'a pas de crinière; son pelage est brun jaunàtre, aver, des taches plus ou moins conlluentes. - Le Zibeth habite les Indes orientales, et s'étend jusqu'en Arabie. En outre, les Malais l'ont introduit dans un grand nombre d'iles de l'océan Pacifique. On l'élève aussi en captivité, et il produit du viverréum au moyen d'un appareil glandulaire analogue à celui de la Civette d'Afrique.

La Genette ( $V$. genctla L. ; Genetta vulgaris Cuvier) se trouve dans le nord de l'Afrique, en Espagne et dans le sud-ouest de la France.

Les HY AENIDES ont pour formule dentaire $\frac{3 \cdot 1 \cdot 4-3,1}{3 \cdot 1 \cdot 4-3,1-2}$. Les canines sont courtes, peu tranchantes; la carnassière supérieure est extraordinairemen puissante. Animaux digitigrades, remarquables par la disproportion qui existe entre le train antérieur, relativement élevé, et l'arrièretrain, bas et peu assuré dans la marche. Membres antérieurs ordinairement (sauf Proteles), postérieurs toujours à quatre doigts; ongles non rétractiles. Crảne court et épais; arcades

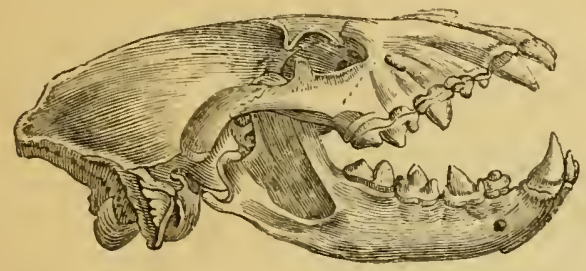

Fig. 879. - Tête de l'Hyc̀ne tachetée.

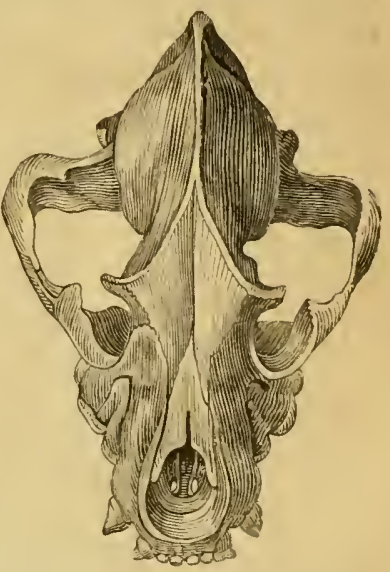

Fig. 873. - Tèle de l'Hyène tachetée vue en dessus, moutrant l'exlrème écartement des os zygomaliques.

zygomatiques écartées comme clıez les Chats; màchoires courtes et puissantes. Os pénien faible.

Les Hyènes sont des animaux nocturnes, qui recherchent surtout la charogne. Les formes actuelles, comme les espèces fossiles, ne se reneontrent que dans l'ancien monde. - Hyène rayée (Hyæna striata), nord de l'Afrique et Inde. Hyène tachetée (H. crocutu), est et sud de l'Afrique.

Famille des FÉLIDÉS. - Formule dentaire typique : $\frac{3.1 \cdot 3-2,1}{3.1 .3-2,1(-2)}$.

Les incisives sont petites, serrées, tranchantes. Les canines, souvent énormes, sont incurvées et pointues, souvent tranchantes en avant et en arrière. Les molaires sont tranchantes ; la carnassière supérieure est très allongée; la petite tuberculeuse de la mâchoire inférieure fait défaut dans presque toutes les formes actuelles. Membres longs 
et grêles, digitigrades; cinq doigts en avant, généralement quatre en arrière; griffes presque toujours rétractiles. Corps élancé, propre au saut. Tête arrondie; arcades zygomatiques écartées; museau court. Os pénien petit.

On divise cette grande famille en trois sous-familles : Ies Prorlurinæ, avec un seul représentant actuel (Cryptoprocta), de Madagascar; les IIachairodinx, Félidés éteints; enfin les Felinæ, qui seuls nous occuperont.

Ces animaux représentent le type le plus parfait des Carnassiers. La plupart sont nocturnes, bien que leurs pupilles soient tantôt rondes, tantôt en fente verticale. Ils se nourrissent de proies vivantes, dont ils s'emparent arec une adresse remarquable, grâce à la finesse de leurs sens et à la ruse qu ïls déploient. La capture se fait en général d'un seul bond; mais souvent les Félins jouent avec leur victime. Ils chassent seuls ou par couples, jamais en meutes. A l'exception de quelques espèces telles que le Lion, les Chats à griffes rétractiles sont d'excellents grimpeurs. Les Chattes sont moins fécondes que les Chiennes, surtout à l'état sauvage, où elles ne donnent guère, en général, que deux ou trois petits, qu'elles défendent avec un courage extraordinaire.

On peut distinguer, parmi les Félins, trois genres principaux: les Guépards, les Chats proprement dits et les Lynx.

Les Chats (Felis L.) ont la tête arrondie, les membres vigoureux, mais bas, et des ongles tout à fait rétractiles. Leur formule dentaire est généralement $\frac{3.1 \cdot 3,1}{3.1 .2,1}=30$.

On trouve déjả des Chats fossiles dans les terrains tertiaires; mais le diluvium fournit des formes très voisines des espèces actuelles ou même identiques à ces espèces. Le Felis spelæa était supérieur comme taille à tous les Félidés actuels. On doit sans doute assimiler le $F$. prisca au Lion actuel, le $F$. antiqua à la Panthère commune. Le $F$. catus n'est autre que notre Chat sauvage. Bourguignat le distingue sous le nom de $F$. ferus et décrit sous celui de $\boldsymbol{F}$. cutus un prétendu Chat domestique. Le $\boldsymbol{F}$. minuta est. une très petite espèce (1).

Les espèces actuelles de ce genre offrent une telle conformité dans toute leur organisation, qu'il est très difficile de les grouper en sections. Brehm a cependant essayé de le faire, en se basant principalement sur les particularités du pelage.

Les Lions ont un pelage fauve uniforme, une verrue cornée à la pointe de la queue et un train antérieur beaucoup plus puissant que le postérieur. On n'en reconnaîl en général qu'une seule espèce $(\boldsymbol{F}$. leo $)$, comprenant différentes races répandues en Afrique, ainsi que dans l'Asie centrale et occidentale.

Les Couguars n'ont de commun avec les Lions que l'uniformité du pelage,

(1) J.-R. Bourguignat, Ilistoire des Felidæx fossiles constatés en France dans les dépóts de la période quaternaire. Paris, 1879 (Matér. 1880). 
qui tire un peu sur le gris olivitre; le corps est bien proportionné, et on n’observe jamais la crinière que possèdent en général les Lions mâles. Le Couguar vrai ou Puma ( $F$. concolor) se rencoulre depuis la Patagonie jusqu'au Canarla. L'Eyra $(F$. eyru $)$ et le Jaguar ondi $\{F$. yaguarundi $\rangle$ sont de l'Amérique du Sud.

Les Tigres sont de grands Chats à favoris blanchâtres et à pelagre souple marqué de bandes transversales ondulées. - Le Tigre royal (F. tigris) étend son domaine des illes de la Sonde aux rives de l'A mour et de la Chine au Caucase. Le Tigre longibande ( $\boldsymbol{F}$. macrocelis), de Siam, de Bornéo et de Sumalra, sert de trait d'union entre les Tigres et les Panthères.

Les L'opards ou Panthères se reconnaissent à leur robe parsemée de taches arrondies, pleines ou annulaires. - Citons : la Panthère d'Afrique ( $\boldsymbol{r}$. leopar(lus), dont la Panthère d'Asie (F. panthera) n'est peut-ètre qu'une simple variété; l'Once $(F$. uncia $\rangle$, de l'Asie centrale; le Chat marbré, $F$. marmorata), de Java; le Jaguar ( $F$. onça) et l'Ocelot ( $F$. pardalis) de l'A mérique du Sud; ete.

Les Chats proprement dits sont les pelites espèces à queue longue qui se rapprochent plus ou moins de nos Chats domestiques. - Tels sont : le Chat saurage, le Chat manoul et le Chat ganté, auxquels nous devons une mention spéciale.

Le Chat sauvage ( $\boldsymbol{F}$. calus L.) est un peu plus gros que le Chat domestique ordinaire. Son pelage est plus fourni, gris chez le màle, un peu jaunàtre chez la femelle, plus clair sous le ventre; le long du dos règne une

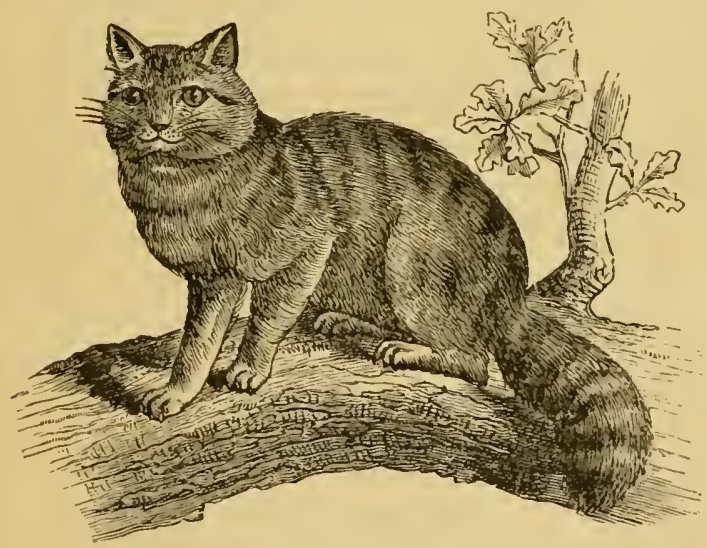

Fig. 874. - Chal siuvage.

ligne foncée, de laquelle partent des bandes transversales. La plante des pieds est noire. La ģorge offre une tache blanc jaunàtre; la queue est régulièrement annelée de noir.

C'est un animal européen, qui vit dans les grandes forêts, où il détruit une grande quantité de gibier. La femelle porte 68 jours.

Le Chat manoul (F. manul Pallas) est plus petit que le Chat sauvage; son poil est très long, doux, bien fourni, blanchàtre; sa tête est tachetée de noir, et ses joues offrent dellx bandes de la mème couleur. Sa queue, longue et touffue, est annelée jusqu'à la pointe, qui est noire. 
Cette espèce, qu'on a quelquefois rapportée au genre Lynx, remplace le Chat sauvage dans les steppes mongols et tartares.

Le Chat ganté ( $F$.maniculata, Rüppel et Temminck), d'un tiers plus petit que notre Chat sauvage, est assez élancé; son pelage est fauve, légèrement rougeàtre sur la nuque et le dos, blanchàtre sur le ventre. La plante des pieds est noire. On distingue à peine sur le tronc d'étroites bandes transversales un peu plus foncées que le fond; mais ces bandes sont bien marquées aux joues et aux pattes. Il existe, en outre, sur le haut du corps, huit raies longitudinales peu accusées, et sur les flancs des marbrures irrégulières. La queue offre trois anneaux noirs, et sa pointe est également noire.

Ce Chat vit à l'état sauvage dans le Soudan oriental, la Nubie, l'Abyssinie, et s’étend mème jusqu’en Palestine.

Nous pouvons encore citer, parmi les petites espèces plus ou moins analogues au Chat sauvage de notre pays : le Chat sauvage d'Algérie ( $F$. libyca), un peu plus faible, el le Chat cafre $(F$. cafra), un peu plus fort, mais ayant. tous deux la mème apparence extérieure; le Chat des steppes ( $F$. candata), du Bokhara; le Chat sauvage de l'Inde ( $F$. torquata); le Chat de Java ( $F$. javanensis); le petit Chat (F. minuta), de l'archipel Indien; le Chat chinois (F. chinensis), de Canton et de Formose; le Chat rubigineux ( $F$. rubiginosa), de Madras et de Ceylan, etc.

Chats domestiques ( $\boldsymbol{F}$. domeslica L.). - Les différentes races connues jusqu'à présent sont peu nombreuses relativement à celles que nous ont présentées les autres Mammifères domestiques. Les plus répandues dans notre pays sont : $1^{\circ}$ le Chat tigré, qui a, comme le Chat sauvage, les lèvres et la plante des pieds noires; $2^{\circ}$ le Chat d'Espagne, à pelage bigarré de blanc, de roux et de noir (les sujets à trois couleurs sont toujours des femelles), à lèvres et à plante des pieds couleur de chair; $3^{\circ}$ le Chat d'Angora, à poils longs et soyeux, souvent d'un beau blanc, à lèvres et pieds comme le précédent. - Citons en outre : le Chat des Chartreux, à poil fin un peu long, d'un gris ardoisé uniforme, à lèvres et plante des pieds noires; le Clıat du Khorassan (Perse), à poil long, doux et fin comme celui du Chat Angora, et d'un gris ardoisé comme celui du précédent; le Chat royal de Siam; le Chat malais, du Pégou, du Siam et de la Birmanie, à queue courte, souvent contournée en une sorte de nœud et non déroulable; le Chat de Man, répandu dans l'ile de ce nom, remarquable par sa queue très courte ou nulle, ainsi que par la longueur de ses pattes postérieures; le Chat sans queue de Crimée; le Chat roux de Tobolsk (Sibérie), etc.

Pendant longtemps, on a regardé le Chat domestique comme issu du Chat sauvage de nos forêts : c'était, en particulier, l'opinion de Cuvier. Mais, à la suite des travaux de Temminck, on est revenu sur cette manière de voir, et on regarde aujourd'hui le Chat ganté comme la souche principale des Chats que nous élevons dans nos demeures.

Le Chat domestique des Danakil (près d'Obock), observé par Maindron, offre en tout cas de grandes analogies avec le Chat ganté sauvage de la même région (Oustalet). Mais il est fort possible que les Chats élevés dans les diverses régions du monde proviennent d'espèces primitivement distinctes. Ainsi, Pallas admettait, sans preuve certaine il est vrai, que l'Angora dérive 
du Chat manoul. En outre, les caraclères des races entretenues daus une région donnée peuvent avoir été affectés, à quelque degré, par des croisements avec des espèces ou races sauvages locales. Dans l'Inde, dit-on, les Chats domestiques s'accouplent fréquenment avec le $F$. Lorquata, et beaucoup d'individus ne peurent ètre distingués de cette dernière espèce. De mème, la livrée de notre Chat tigré semble indiguer l'intervention du Chat sauvage ; etc.

Domestication. - Quelles que soient, au surplus, les formes primitives des races dont il s'agit, il est certain qu'aucune d'elles n'a été réduile de bonne heure en domesticité. Et d'abord, le Chat domestique n'était pas counu des anciens Aryens. En outre, il n'est pas prouvé que cet animal, comme le voulait Dureau de la Malle, ait été domestiqué en Cline dès une lıaute antiquité. Mais on a retrouvé de nombreuses nımies de Clıats enfouis dans les catacombes de l'Ésypte. Encore n'avons-nous pas la certitude que ces momies proviennent d'animaux domestiques. La plupart ont les caractères ostéologiques du Chat ganté; or, on sait que cette espèce vit encore en liberté en Nubie, dans la vallée du Nil; d'ailleurs, quelques-unes d'entre elles se rapportent au Lynx botté, et de Blaiuville croit avoir reconnu, dans une tète momifiée, un Lynx des marais.

Pourtant, en présence de ces observations, I. Geoffroy Saint-Hilaire est convaincu que le Clıat élait domestiqué en Égypte dès la plus haute antiquité. Et St. George Nivart déclare qu'il l'était certainement 1300 ans av. J.-C.

Les Grecs et les Romains ne paraissent avoir conmu le Chat domestique que par des observations faites en Égypte. Cependant, au dire de Vogt, cet animal " a été répandu vers le Nord par les Romains et par les peuples qui leur ont succédé, tandis que les Arabes et les Sémites en général l'ont transporté vers l'Occident $\%$. D'après Lubbock, il ne s'est montré commun en Europe que ver's le ${ }^{\mathrm{e}}$ siècle de notre ère. "Aujourd'hui, cet utile chasseur de petits rongeurs a été introduit par l'Hlomme daus le monde entier; mais, dans le $x^{e}$ siècle de notre ère, il était encore si rare, qu'il était considéré, en Angleterre, comme un animal de haut prix, pour lequel les lois fixaient des vices rédhibitoires semblables à ceux qu'on établit aujourd'hui pour les chevaux (1).

Caractères physiologiques. - Les Chats, dit frognier, "peuvent s'accoupler dès la première année de leur vie, mais ce n'est qu'à la deuxième ru'ils sont féconds. La femelle entre en chaleur deux ou trois fois par an, pour l'ordinaire à la fin de l'automne et au commencement du printemps. Elle a plus d’ardeurs que le mâle; elle l'appelle, le poursuit, avec des miaulements plaintifs, qui annoncent des besoins pressants et ụn état douloureux. Cependant la copulation lui cause des souffrances, tant parce que le inale se cramponne sur elle avec ses griffes et ses dents, que parce que sa verge est hérissée de papilles cornées. Elle crie avec fureur, elle se défend, et l'accouplement ressemble à un combat.

“ La gestation est de 50 à 56 jours. Les portées ordinaires sont de

(1) Loc. cit., p. 167. 
cinq à six petits, naissant les yeux fermés, et ne les ouvrant que vers le neuvième jour. La mère cache ses petits, de peur qu'on ne les lui enlève; elle craint que les mâles ne les dévorent, ce qui arrive quelquefois. Elle les aime beaucoup, les caresse, les lèche, joue avec eux, et ne les abandonne pas après les avoir sevrés; ce qui a lieu au bout de trois semaines ou un mois. Elle leur apporte des Souris, des Oiseaux, leur apprend à se jouer de ces petits animaux, avant de les tuer; plus tard elle les mène à la chasse. On sait combien les petits Chats sont gais, gentils et mignons. La vie moyenne est, dans cette espèce, de huit à dix ans (1). "

Services. - Les Chats sont d'utiles auxiliaires, qui débarrassent nos habitations des Souris et des Rats qui les infestent; dans le voisinage des fermes, ils contribuent également à purger les champs des Mulots et des Campagnols. Lenz estime que, dans une année où il y a beaucoup de ces petits Rongeurs, tout Chat demi-adulte mange, en moyenne, 20 Souris par jour, soit 7,300 par an, ou l'équivalent en Rats; pour les années ordinaires, il réduit ce chiffre de moitié. Les meilleurs chasseurs sont le Chat tigré et le Chat d'Espagne.

Il faut remarquer, toutefois, que les Chats détruisent aussi beaucoup de petits Oiseaux. Il en est même qui, dans les fermes, s'attaquent à la volaille, et surtout aux Pigeons: en pareil cas, on ne doit pas hésiter à les sacrifier.

La peau du Chat est employée comme fourrure. On sait, enfin, que certains commerçants peu scrupuleux substituent parfois sa chair à celle du Lapin (2). En Chine, on engraisse les Chats pour les manger.

Hyвrides. - On connait des exemples d'accouplement fécond entre diverses espèces du genre Felis, telles que Lion et Tigre, Jaguar et Panthère, Chats domestiques et autres Chats.

Les Lynx (Lynx) se distinguent des Chats par leurs jambes hautes, leur queue courte et leurs oreilles presque toujours terminées par des pinceaux de poils; en outre, ils n'ont que 28 dents.

Le Lynx ou Chat botté ( $L$. caligatus) est peu distinct des Chats; il habite l'Afrique orientale el les Indes. Le Caracal ( $L$. caracul) est à peu près aussi répandu. Le Lynx des marais ou Bubastes ( $\boldsymbol{L}$. chaus) s'étend depuis la Perse jusqu'en Abyssinie. Le Lynx du nord ou Loup-Cervier $(L$. $\operatorname{lyn} x)$ vit dans l'Europe septentrionale et pénètre quelquefois jusque dans nos régions; il est presque de la taille d'une Panthère.

Les Guépards (Cynælurus) sont des Chats par leur tête arrondie, leur longue queue et leur pelage tacheté; mais ils se rattachent aux Chiens par leurs pattes hautes et leurs ongles à peine rétractiles, qui s'émoussent par l'usage.

Ils chassent en rampant, mais poursuivent souvent leur proie. Deux

(1) L.-F. Grognter, Précis d'un cours de Zoologie vétérinaire. Paris et Lyon, 1833, p. 59 .

(2) Arm. Goubeaux, Le Lapin et le Chat, etc. Archives vét. 1883, p. 646. 
espèces : le Guépard mouclıeté ou Fuhdad des Arabes (C. guttatus), d'A frique, et le Guépard à crinière, Tshitı des Bédouins (C. jubatus), de l'Arabie et de

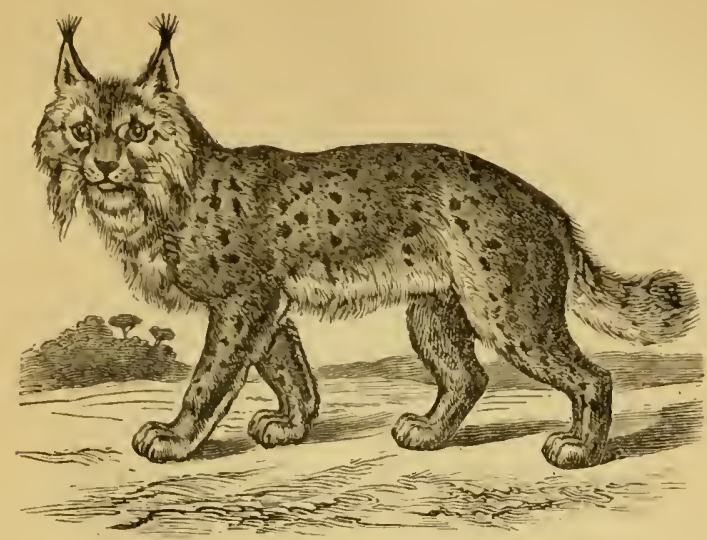

Fig. S7.s. - Lyux d'Europe ou Loup-Cerrier.

l'Asie Mineure. Ces animaux sont faciles à apprivoiser, et on les a souvent dressés à la chasse.

TREIZIËME ORDRE

\section{INSECTIVORES}

Mammifères plantigrades à doigts armés de griffes; dentition complète; molaives hérissées de tubercules pointus; placenta discoïde.

Les Insectivores sont des plantigrades de petite taille, dout l'organisation rappelle à la fois celle des Rongeurs et celle des Ch iroptères. Ils ont le corps revêtu, tantòt d'une fourrure donce et soyeuse, tantòt de poils rudes ou mème de piquants. La tète est terminée par un museau allongé, qui se prolonge parfois en une sorte de petite trompe mobile. Les yeux sont toujours très petits, en particulier chez les espèces souterraines, dont quelques-unes sont tout à fait aveugles, le globe oculaire étant recouvert par la peau. Les membres sont courts et forts, du moins chez les types fouisseurs; ils se terminent généralement par cinq doigts; les clavicules sont bien développées.

La dentition est assez variable quant au nombre et à la forme des dents ; mais les canines sont presque toujours faibles, à peine distinctes des autres dents, et les molaires sont remarquables par les tubercules coniques acérés dont est garnie leur couronne.

Les mamelles sont ventrales; le placenta est discoïde. Les Insectivores sont des animaux très féconds. Leur cerveau est peu développé et présente des caractères d'infériorité très marqués. Ces animaux ont, en général, des habitudes nocturnes ou souterraines. Ils sont voraces : leur nourriture se compose surtout d'Insectes et de Vers; mais plusieurs d'entre eux s'attaquent aussi aux animaux vertébrés, et mème à leurs semblables. On doit les 
regarder pour la plupart comme très utiles. En général, ils subissent le sommeil hibernal.

3 familles principales : Erinaceidx, Soricidæ, Talpidæ.

Les ÉRINACÉIDÉS sont bien reconnaissables à leur dos revêtu de piquants; ils ont le corps ramassé, les doigts pentadactyles, la queue courte.

Les Hérissons (Erinaceus) ont la faculté de se rouler en boule, de manière à présenter de toutes parts à leur's ennemis une surface hérissée d'épines. Notre Hérisson commun (E. europæus) se nourril surtout d'Insectes, mais il détruit aussi beaucoup de Souris, de petits Oiseaux et de Reptiles, même

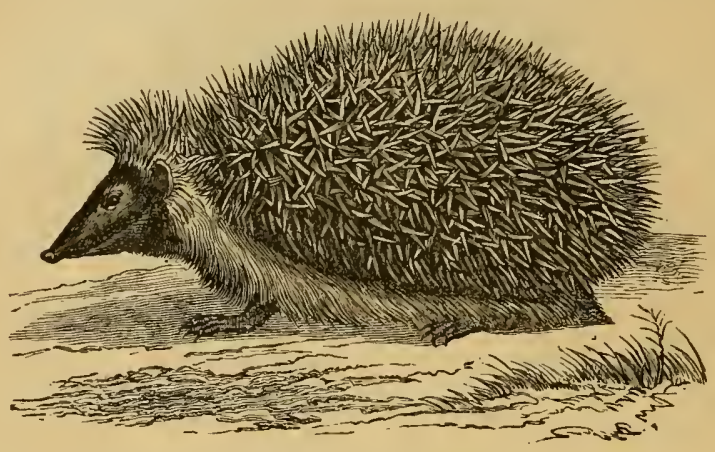

Fig. 876. - Hérisson commun.

venimeux, bien qu'il ne soit pas réfractaire au venin (Voy. p. 1002). Somme toute, c'est un animal fort utile. Ses habitudes sont nocturnes. Il se prépare sous les buissons une sorte de nid dans lequel il subit l'hibernation. On mange sa chair dans quelques localités. - A une famille voisine appartiennent les Tanrecs (Centetes), de Madagascar, qui ont des piquants plus faibles et ne se roulent pas en boule.

Les SORICIDÉS sont de très petits animaux qui ont l'aspect et les allures des Souris, mais s'en distinguent facilement à leur museau pointu, en forme de trompe. La plupart ont des mœurs sanguinaires; ils chassent la nuit, et s'attaquent parfois à des animaux plus forts qu'eux. Ils n'hibernent pas.

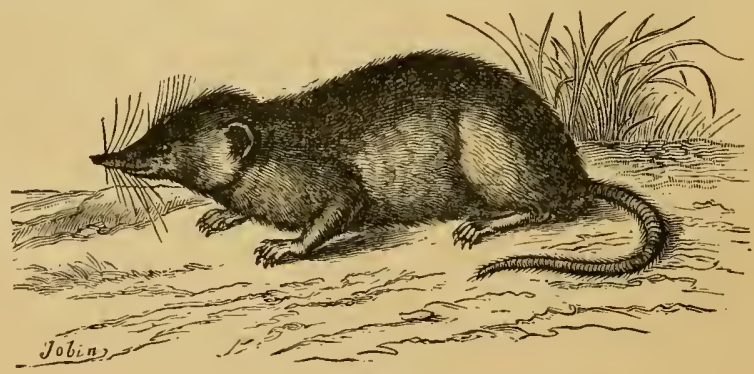

Fig. 877. - Musaraigne commune.

Les Musaraignes (Sorex) répandent une odeur musquée fort désagréable, provenant de deux glandes situées au voisinage des flancs. La Musaraigne 
commune ou Husette (S. [Crocidura] araneus) se rapproche souvent de nos habitations, surtout en liver ; on a longtemps, mais à tort, regardé sa morsure comme venimeuse (1). La Musaraigne de Toscane (S. [Crocidura] etruscus), qui se rencontre parfois dans le midi de la France, est le plus petit des Mammifères connus. La Musaraigne d'eau (S. [Crossopus] fodicns) nage fort bien à la poursuite de sa proie.

A côté des Musaraig̨nes se placent les Desmans (Myogale), qui ont une trompe assez allongée, une queue aplatie, et des pieds natatoires. Leurs deux glandes musquées sont situées sous la base de la queue. Ils virent à la façon des Lontres. Le I)esman moscovite (M. moschatu), Vuychouchol des Russes, Labite la Volga et les autres fleuves du sud-est de la Russie; il a la taille d'un llamster. Sa queue écailleuse est employée en parfumerie. Une espèce plus petite ( I. pyrenaica) se rencontre dans les ruisseaux des Pyrénées.

Les TALPIDÉS ont le corps cylindrique, la tête conique, prolongée en trompe, les pattes antérieures larges et courles, tournées en dehors et armées de griffes aplaties. Les oreilles sont dépourvues de pavillon; les yeux sont très petits, cachés dans le pelage et parfois sous la peau. Tous sont des animaux souterrains, essentiellement carnivores et d'une voracité extraordinaire.

Les Taupes (Talpa), qu'on a subdivisées en une foule de genres, sont caractérisées par leurs pattes antérieures fouisseuses, à cinq doigts. La taupe conmune ( $T$. europæa) se creuse sous terre des galeries compliquées, qu'elle étend et renouvelle sans cesse pour cherchersa nourriture, et dont le trajet est indiqué par de nombreux amas de terre ou taupinières. Sa demeure proprement dite recoit le nom de donjon: elle est d'ordinaire assez éloignée du terrain de chasse, et se reconnaît à la présence d'un assez fort monticule. Au centre existe une chambre arrondie, de 8 à 10 centimètres de diamètre, entourée de deux galeries circulaires, l'une située sur le mème plan que la chambre, l'autre, plus petite, occupant un plan plus élevé. De celle-ci partent plusieurs conduits, dont trois aboutissent dans la chambre, et cinq ou six dans la galerie inférieure, d'où rayonnent huit à dix couloirs horizontaux, qui débouchent en décrivant une courbe dans le couloir principal, c'est-à-dire dans la voie que suit la Taupe pour gagner son terrain de chasse. Un conduit de sûreté naît en outre de la partie inférieure de la

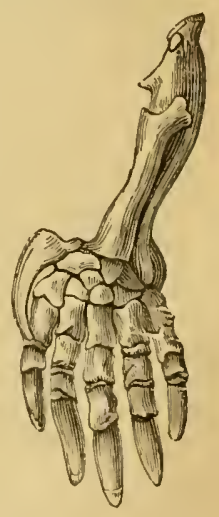

Fig. Sis. - Palle inlérieure de la Taupe. chambre. La Taupe part en chasse deux ou trois fois par jour. Elle se nourrit surtout de Vers de terre et de larves de Hannetons ou Vers blancs; mais elle se laisse périr plutòt que d'ingérer des substances végétales. C'est donc un animal bienfaisant, que les aggriculteurs ont tort de détruire aveuglément : dans la plupart des cas, les quelques dégâts qu'elle cause en déchaussant les plantes et en soulevant la terre ne sont rien en comparaison des services qu'elle nous rend, surtout si l'on prend le soin de raser les taupi-

(1) R. Saint-Loup, ayant vu mourir une Souris mordue a la patte par une Musaraigne, tend à revenil à cette opinion. Il fait observer que les Chats éprouvent une certaine crainte (ou répugnance?) à l'endroit de ces petites bêtes. 
nières. Sa destruction n'est justifiée que lorsqu'elle arrive à se multiplier d'une façon excessive, ou lorsque les plantations ont trop à souffrir de ses incursions. - On trouve, dans le midi de la France, une seconde espèce, la Taupe aveugle (Tulpa cæca), ainsi appelée parce que ses yeux sont recouverts par la peau.

\section{QUATORZIÈME ORDRE}

\section{CHIROPTÈRES}

Mammifères onguiculés, munis de deux ailes formées d'une membrane cutanée qui enveloppe les doigts très allongés des membres antérieurs, les parties latérales du tronc et les membres postérieurs; dentition complète; deux mamelles pectorales; placenta discoïde.

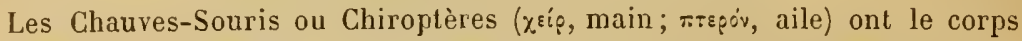
ramassé, le cou assez court, la tète petite. Les oreilles sont presque toujours grandes, parfois mème énormes, et

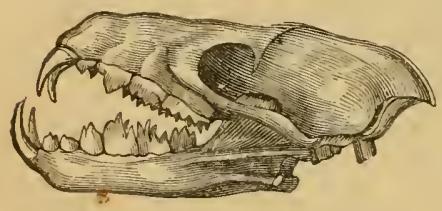

Fig. 879. - Tèle de Vampire (Phyllostomun spectrum [L.]). souvent garnies de saillies variées. Les yeux sont fort petits; le nez est nu ou orné d'appendices bizarres. La gueule est largement fendue; la dentition est complète et se ratlache au type insectivore. Les poils qui revètent le corps sont remarquables en ce que leur cuticule offre l'aspect de cornets emboités les uns dans les autres

La faculté du vol entraîne certaines modifications du squelette.

Le sternum est allongé et présente une crête longitudinale sur laquelle s'insèrent les muscles abaisseurs de l'aile. La clavicule est grande et forte. Le pouce, gros et court, est armé d'une griffe. Les autres doigts sont en général dépourvus d’ongles, et se montrent très allongés, ainsi que le bras et l'avant-bras. Aux membres postérieurs, il existe le plus souvent, au niveau du tarse, un os surnuméraire en forme d'éperon, dirigé en arrière et destiné à soutenir la peau de l'aile entre le pied et la queue. Les cinq orteils sont munis de griffes puissantes.

La membrane alaire est constituée par une duplicature de la peau, qui commence à la nuque et au cou, enveloppe les bras et les doigts, à l'exception du pouce, gagne les flancs, puis les membres postérieurs, qu'elle garnit souvent jusqu'au tarse, et enfin s'étend jusqu'à la queue. Celle-ci reste rarement libre. Avec une telle extension, cette aile constitue un puissant organe de vol, n'ayant toutefois qu'une ressemblance superficielle avec l'aile de l'Oiseau. - On sait, depuis Spallanzani, que les Chauves-Souris auxquelles on a crevé les yeux peuvent néanmoins voler avec la plus grande aisance et sans se heurter aux obstacles; cette faculté tient à la grande sensibilité de l'aile, dont la face inférieure est revêtue de nombreux poils tactiles.

Le sens de la vue est d'ailleurs très faible, aussi bien que celui de l'odorat. Par contre, l'ouïe est fort délicate. - Le cerveau ne présente pas de circonvolutions, et les facultés intellectuelles sont assez bornées. - L'utérus est bicorne, et souvent la corne et l'ovaire d'un côté sont plus ou moins réduits, comme chez les Oiseaux. Il existe deux mamelles pectorales. Les màles ont 
le pénis pendant et possẻdent souvent un os pénien. Les Chauves-Souris adultes saccouplent en automne, avant de tomber dans le sommeil hibernal. L'union se fait ventre à ventre. I.e sperme est conservé dans l'utérus pendant tout l'hiver, et c'est seulement au printemps que l'ovule se détache et se trouve fécondé. Cependant, les mảles produisent parfois une telle abondance de sperme pendant l'hihernation, que ce fluile reflue dans la vessie : de nouveanx accouplements ont donc lieu après la périoule hibernale (Rollinal et Trouessart, Mathias Duval).

Les Chauves-Souris sont des animaux nocturnes. Elles passentle jour dans des retraites obscures, suspendues par les griffes des membres postérieurs, la tète en bas, les ailes repliées. Nos espèces indigènes se nourrissent d'Insectes et d'Araignées; parmi celles des pays chauds, il en est d'ancunes qui sucent le sang des Oiseaux et des Mammifères, tandis que d'autres vivent do fruits.

De là, deux sous-ordres : les Frugivores on Mégachiroptères et les Insectivores ou Microchiroptères.

$1^{\text {er }}$ sous-ordre : Frugivores. - Ce sont des Chauves-Souris de grande taille, qui ont des molaires à couronne aplatie, un index armé d'une griffe, un museau allongé, de petites oreilles et une queue rudimentaire. - Elles habitent les forêts des régions tropicales de l'Afrique, de l'Inde et de l'Australie, où elles causent parfois d'importants dommages aux plantations, et en particulier aux vignobles.

Une seule famille : celle des Ptéropidés ou Roussettes, dont plusieurs espèces sont recherchées pour leur chair, par exemple le Kalong (Pteropus edulis), des îles de la Sonde.

$2^{e}$ sous-ordre : Insectivores. - Les molaires sont hérissées de tubercules pointus; le pouce seul est armé d'une griffe; le museau est court; les oreilles sont grandes et souvent munies d'un appendice intérieur qui fait l'office d'opercule (tragus). - Les Chauves-Souris de ce groupe, auquel appartiennent toutes nos espèces indigènes, se répartissent dans deux sections principales : Gymnorhiniens et Plhyllorhinions.

Les Gymnorhiniens ont le nez simple, lisse, c'est-à-dire lépourvu d'appen-

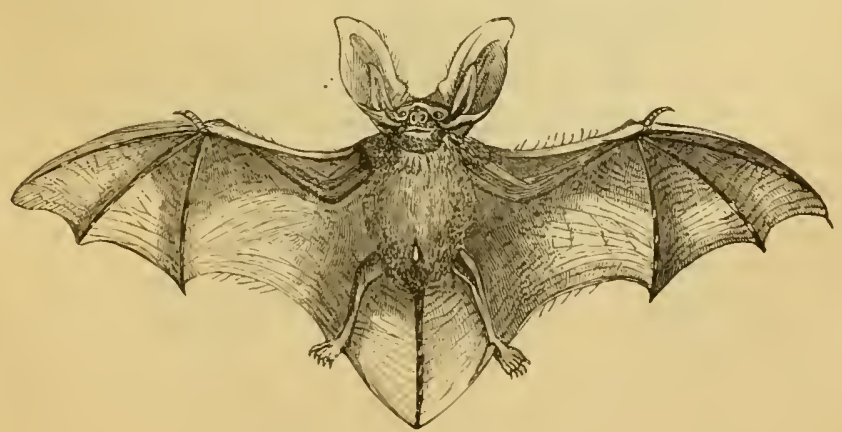

Fig. $\times 80$. - Oreillard (Plecotus auritus).

dices. Ils se nourrissent exclusivement d'Insectes. - Oreillard commun (Plecotus auritus); Barbastelle (Synotus barbastellus); Vespertilion murin Railliet. - Zoologie. 
(Vespertilio murinus); Noctule (Vesperugo noctula); Pipistrelle (Vesperugo pipistrellus); etc.

Les Phyllorhiniens sont caractérisés par leur nez, garni d'appendices cutanés plus ou moins développés. Ils se nourrissent non seulement d'Insectes, mais aussi de fruits, de sang et même de chair. - Grand Fer-àCheral (Rhinolophus ferrum-equinum), de l'Europe et de l'Asie. Vampire (Phyllostomum spectrum), du Brésil et de la Guyane, etc. A défaut d'Insectes et de fruits, les Vampires s'altaquent aux Oiseaux et aux Mammifères. C'est ainsi que les Hommes pendant leur sommeil sont souvent mordus aux orteils et les Chevaux au garrot. La plaie qui résulte de cette morsure est semblable à celle que produit une Sangsue; elle est suivie d'une hémorragie plus ou moins abondante.

\section{QUINZIEME ORIRE}

\section{LÉMURIENS}

Mammifères onguiculés, pourvus de mains et de pieds à pouce presque toujours opposable; dentition complète; face velue; orbites incomplèles; placenta en forme de cloche.

Les Lémuriens (lemures, spectres) ou Prosimiens, autrefois réunis aux Singes sous la dénomination commune de Quadrumanes, sont des animaux

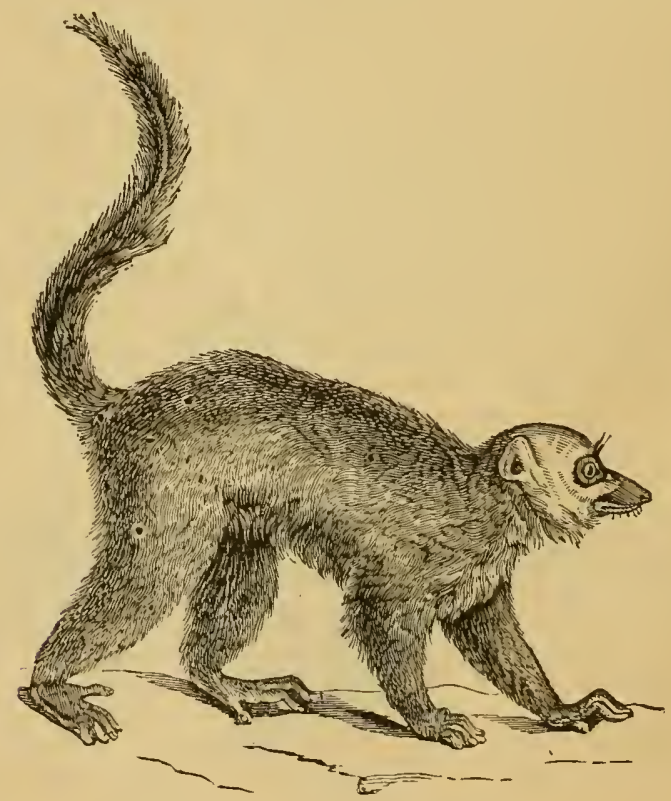

Fig. 881. - Maki it front blane.

plantigrades d'assez faible taille, revêtus d'un pelage souple et laineux. Leur face même est velue et forme un museau allongé comme celui des Carnivo- 
res; leurs yeux sont en général très grands. Les orbites sont garanties par un simple anneau osseux et communiquent largement avec les fosses temporales. La dentition offre des caractères intermédiaires entre celle des Insectivores et celle des Carnivores. Les membres antérieurs sont plus courts que les postérieurs. La disposition des doigts et des ongles est assez variable d'ordinaire : cependant, le pouce et le gros orteil sont opposables, et tous les doigts sont munis d'ongles plats, à l'exception du deuxième doigt des membres postérieurs, qui porte une forte griffe. La queue n'est jamais prenante.

Le cerveau ofre ì peine quelques circonvolutions; le cervelet reste à nu. - L'utérus est bicorne ou double. Outre les mamelles pectorales, il en existe souvent sur le ventre ou dans les plis de l'aine. Il n'est pas rare de voir le clitoris traversé par l'urètre. Le rut s'accompagne quelquefois d'un léger écoulement de sangr. Le placenta rappelle à la fois celui des Ongulés et celui des Carnivores : il se compose de villosités séparées, qui sont implantées sur toute la surface de l'œuf, sanf au niveau du pòle antél'ieur.

Tous les Lémuriens sont des animaux grimpeur's et nocturnes. Ils se nourrissent d'Insectes et de petits Vertébrés, plus rarement de fruits.

Un grand nombre habitent Madagascal : les Makis (Lemur), les Indris (Lichanolus), l'Aye-aye (Chiromys); d'autres le continent africain : les Pottos (P'lerodicticus); d'autres encore, l'Asie méridionale : les Loris (Stenops), les Tarsiers (Tarsius), les Galéopithèques (Galeopithecus). Ces derniers sont remarquables par un large repli cutané qui s'étend sur les còtés du corps et leur forme une sorte de parachute; en outre, leurs pouces ne sont pas opposables, nou plus que leurs gros orteils.

\section{SEIZIEME ORDRE}

\section{PRIMATES}

Mammifères onguiculés, ayant au moins deux membres préhensiles; dentilion complète; face glabre; orbites complètes; placenta discoïde.

Linné classait en têle des Mạmmifères, avec l'Homme et les Singes, les Lémuriens, les Chauves-Souris et jusquaux Paresseux; et il lonnait au groupe ainsi formé le nom de Primales, signifiant les promiers ou primats des animaux. On a dès longtemps éliminé de cet ordre les Paresseux et les Chaures-Souris; mais la séparation des Lémuriens est de dale relativement récente, el d'ailleur's de bons esprits la comballent.

2 sous-ordres : Simiens et Hominiens.

PREMIER SOUS-ORDRE

SIMIENS

Le corps svelte et élancé, la tète arrondie, la face aplatie, le cou bien détacłé, les membres entièrement dégagés du tronc, tous ces caractères donnent aus singes une physionomie qui rappelle de très prés celle de 
l'Homme; et cette ressemblance est rendue plus frappante encore par les allures de ces singuliers animaux.

La peau est revêtue de poils souvent longs et touffus, mais toujours plus abondants sur le dos que sur la poitrine; ces poils manquent toutefois au niveau de la face et de la région palmaire des mains et des pieds; en outre, chez la plupart des Singes de l'ancien continent, il existe sur les fesses des places dénudées auxquelles on donne le nom de callosités.

Le squelette céphalique diffère tout d'a-

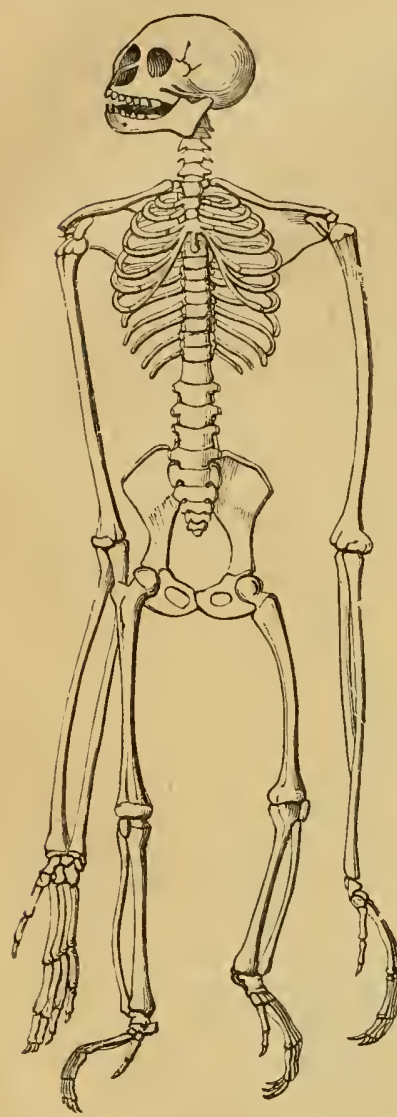

Fig. 882. - Squelette de Gibbon noir. (Hylobates lar). bord de celui de l'Homme par la prépondérance des màchoires, qui s'accuse à mesure que les animaux se rapprochent de l'àge adulte. L'angle facial de Cloquet, qui varie chez l'Homme de 56 à $72^{\circ}$, d'après les mensurations de Topinard, mesure en moyenne, chez les Singes, 30 à $35^{\circ}$. Le mème auteur a obtenu $50^{\circ}, 5$ chez un Orang jeune, et $28^{\circ}, 5$ seulement chez un mâle adulte de la mème espèce. C'est le Saïmiri (Chrysothrix sciurea) qui offre l'angle facial le plus ouvert. Mais, dans tous les cas, la boite cranienne des Singes a une capacité bien inférieure à celle de l'Homme, ce qui tient au moindre développement du cerveau. Celui-ci est d'ailleurs construit sur le mème plan que le cerveau humain, et on constate que les hémisphères recouvrent entièrement le cervelet. Le trou occipital est toujours placé en arrière; mais, chez les Singes les plus élevés, il tend cependant à se rapprocher de la face inférieure. Les yeux, placés en avant, sont séparés seulement par un pont nasal étroit et entourés par des orbites osseuses tout à fait isolées de la fosse temporale. Le nez est aplati. Le pavillon de l'oreille ressemble souvent à celui de l'Homme. Le menton n'est jamais saillant.

Les membres antérieurs sont toujours plus longs que les postérieurs. La présence d'une clavicule est constante, et Jes os des membres ont entre eux les mêmes relations que chez l'Homme. Les membres postérieurs sont faiblement musclés: les fesses sont anguleuses, les cuisses aplaties et les mollets absents. - On a l'habitude de dire que les Singes ont quatre mains, et Blumenbach et Cuvier réunissaient même ces animaux avec les Lémuriens sous le nom de Quadrumanes. Il est certain, en effet, que leurs membres postérieurs jouent le rỏle d'organes de préhension, et d'une façon beaucoup plus nette même que les membres antérieurs: le gros orteil est toujours opposable, landis que dans certains cas le pouce ne l'est pas (Ouistilis) ou même fait défaut (Golobes, Atèles). Mais ce n'est pas à dire pour cela que les extrémités postérieures constituent des mains 
véritables : au point de vue anatomique, comme l'a montré lluxley, ces extrémités sout des pieds préhensiles, d'une structure en tout comparable à celle du pied humain. Ajoutons que, dans la marche, ces pieds ne portent sur le sol que par leur bord cxterne.

La dentition est appropriée surtout à un régime frugivore, cl, quant au plan général, se rapproche tout à fiit de celle de l'Homme. Il y a toujours, de chaque còté, deux incisives un peu obliques taillées en biseau, une canine conique, très forte, et cinq ou six molaires à tubercules un peu moins mousses que dans les races humaines. La saillic considérable des canines entraine la présence d'un diastème assez élendu ì la màchoire supérieure, entre la canine et l'incisive externe, et á la màchoire inférieure, entre la canine et la première prémolaire. Les Semnopithèques et les Colobes ont l'estomac divisé en trois compartiments.

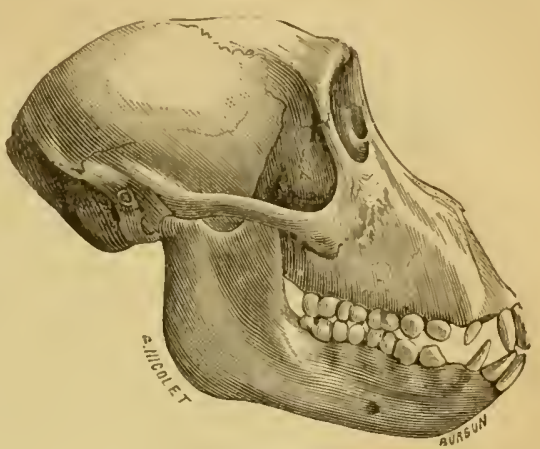

Fig. 88:3. - Tète de Singe.

Les mamelles sont pectorales et au nombre de deux seulement. L'utérus est simple, et le clitoris n'est jamais traversé par l'urètre. La période du rut s'annonce par un flux menstruel qui s'accuse d'une façon très sensible chez les Singes de l'ancien continent. La femelle met au monde un seul petit, rarement deux ou trois, qu'elle soigne avec beaucoup de tendresse. Le placenta est discoïde.

Les Singes sont des animaux grimpeurs, qui vivent sur les arbres ou dans les rochers. Beaucoup d'entre eux se servent de leur queue comme d'un organe préhensile, pour se suspendre aux branches des arbres; chez d'autres, la queue n'est pas prenante; et mème, dans certains cas, elle. est rudimentaire ou absente. Ces animaux virent pour la plupart en troupes sous la conduite d'un vieux mâle. Leur nourriture se compose surtout de fruits el de graines, et ils causent quelquefois de sérieux dégàts dans les plantations; plus rarement ils s'attaquent à des Insectes ou à de petits Vertébrés. Leurs facultés intellectuelles sont assez élevées, surtout pendant le jeune àge; ils possèdent à un haut degré la faculté d'ịmitation. En captivité, ils se montrent presque toujours gloutons, libidineux, indociles, criards et malpropres. - Ce sont des animaux des pays chauds.

3 sections : Arctopitheci, Platyrhini et Catarhini.

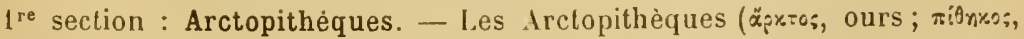
singe) ou Ouistitis sont de petits Singes de l'Amérique méridionale qui possèdent 32 dents $: \frac{2 \cdot 1 \cdot 3,2}{2.1 .3,2}=32$. Le gros orteil est opposable et porte un ongle plat; tous les autres orteils, ainsi que les doigts, sont armés de griffes. Le pouce n'est pas opposable. Le corps est revêtu de poils laineux et se termine par une queue longue et touffue, mais non prenante. Le cerveau est lisse. - Deux genres seulement : les Ouistitis proprement dits (Hapale) et les Tamarins (Midas). 
$2^{\text {e }}$ section : Platyrhiniens. - Ce sont les Cébiens ou Singes du nouveau continent. Ils ont 36 dents $: \frac{2.1 .3,3}{2.1 .3,3}=36$. Leur cloison nasale est large, de

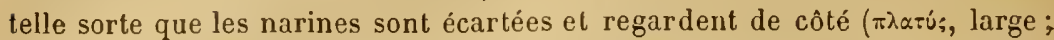
pis, nez). Les doigts et les orteils portent des ongles plats. Le pouce est parfois rudimentaire et n'est jamais opposable an mème degré que le gros orteil.

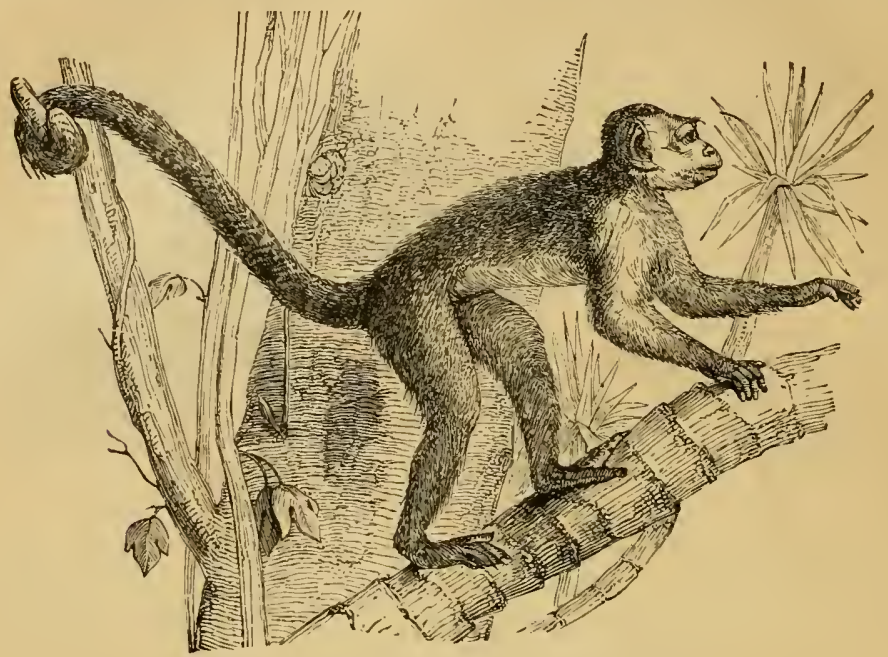

Fig. 884. - Sapajou capucin (Cebus capucinus [L.]).

La queue, qui ne manque jamais, est souvent prenante. Callosités el abajoues. font toujours défaut. - Ces animaux, exclusivement arboricoles, vivent dans les forêts vierges de l'Amérique méridionale. Ils sont inférieurs aux Singes de l'ancien monde sous le rapport des facultés intellectuelles, mais ils sont d'un caractère plus doux.

Les uns sont à queue non prenante: tels les Sakis (Pithecia), les NyctipiIhèques ou Singes de nuit (Nyetipithecus), les Saïmiris ou Singes-Écureuils (Chrysothrix), les Sagouins (Callithrix).

Les autres ont, au contraire, la queue prenante, conme les Sajous (Cebus), les Atèles ou Singes-Araignées (Ateles), les Hurleurs ou Alouates (Mycetes).

Aux Platyrhiniens se rapportent les Singes éocènes trouvés par Ameghino dans la Patagonie australe: Homunculus, Anthropops, Homocentrus, etc.

$3^{\text {e }}$ section : Gatarhiniens. - Les Catarhiniens ou Pithéciens, c'est-à-dire les Singes de l'ancien continent, possèdent 32 dents, disposées d'après le mème type que celles de l'Homme $: \frac{2 \cdot 1 \cdot 2,3}{2 \cdot 1 \cdot 2.3}=32$. Ils ont une cloison nasale étroite, et leurs narines sont dirigées en avant et en bas ( $x a: \dot{x}$, dessous; $\grave{p} i s, n e z)$. Les mains et les pieds sont préhensiles, à ongles plats; le pouce fait rarement défaut. La plupart des espèces présentent des abajoues et des callosités. La queue n'est jamais prenante; elle peut rester rudimentaire ou manquer entièrement. - Ces Singes sont remarquables par l'élévation de leurs facultés intellectuelles. Ils habitent l'Afrique, l'Asie et quelques îles océaniennes. -4 familles. 
Les Cynocéphalides sont de grands Singes terricoles, lourds et trapus, it museau de Chien, presque tous africains. - Genre Cynocéphale ou Papion (Cynocephalus).

L.es Cercopitheidés ont, au contraire, des formes légères et gracieuses. Ils habitent l'Afrique et les Indes. - Tels sont : les Macaques (Macacus), dont une espèce, le Magot (I. inuus ou Inuus ecaudatus), à queue rudimentaire, vit encore sur les rochers de fibraltar, sous la protection de la garnison anglaise; et les Guenons (Cercopithecus), qui fournissent tant de sujets à nos ménageries.

Les Semnopithècidés ne possèdent que de petites callosités et sont quelquefuis dépourvus d'abajoues. Afrique et Inde. - On distingue les Semnopithèques (Semnopithecus) et les Colobes (Colobus).

Enfin, les Anthropomorphes ou Anthropoïdes diffèrent des autres Singes par l'absence complète de queue. Ils ne possèdent pas non plus d'abajoues,

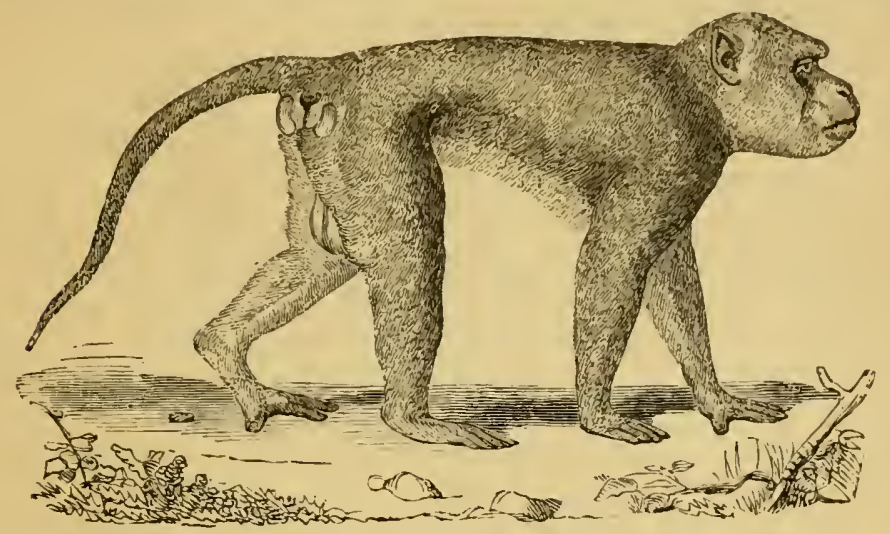

Fig. 883. - Babouin (Cynocephalus babouin Desm.).

et on n'observe de callosités que chez les (Gibbons, où elles sont d'ailleurs fort peu développées. Les membres antérieurs sont toujours très longs. Gibbons (Hylobates), asiatiques, à membres antérieurs extrèmement longs. Orang-Outang (Simia Satyrus), des forèts marécageuses de Bornéo. Gorille (Gorilla gina), du Gabon. Chimpanzé (Troglodytes niger), de la Guinée.

De nombreux Catarhiniens ont été trouvés dans les couches tertiaires et quaternaires de l'ancien continent. Les plus intéressants sont les Anthropomorphes; on en connait quatre espèces, dont deux européennes : Dryopithecus Fontani Lartet, miocène du sud de la France; Pliopithecus antiquus Gervais (probablement un Gibbon), miocène de la France et de la Suisse ; et deux asiatiques: Troglodytes sivalensis Lyddeker, pliocène de l'Inde; Simia sp. Lyd., pliocène de l'Inde.

DEUXIEHE SOUS-ORDRE

\section{HOMINIENS}

L'histoire naturelle de l'Homme (Homo sapiens L.) constitue aujour-

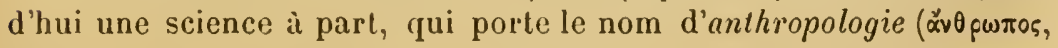


homme; $\lambda{ }_{0} \gamma_{0}{ }^{\circ}$, discours), et à laquelle sont consacrés des traitès spéciaux. C'est dire que nous ne pouvons avoir l'intention d'en faire ici une étude complète, et que nous devons nous borner à donner un simple apercu des principales questions qui s'y rapportent.

Ce qu'il nous faut constater tout d'abord, c'est que les opinions ont singulièrement varié sur le rang qu'il convient d'accorder à l'Homme dans la classification. Linné en faisait un simple genre de sá classe des Primates, sous le nom d'Homo. Cuvier, en 1800, le plaçait dans une famille spéciale, celle des Bimanes; mais, dans son l'égne animal, publié en 1829, il fit de cette famille un ordre distinct, revenant ainsi à la manière de voir de Blumenbach (1779). Pour Zenker el Carus, l'Homme constituait une classe. Enfin, - après Voltaire, - Tréviranus, Isidore Geoffroy-Saint-Hilaire, de Quatrefages et un grand nombre d'autres savants naturalistes ou anthropologistes l'ont considéré comme représentant un règne à part, le règne humain. -- Pour s'expliquer d'aussi profondes dirergences, il suffit de tenir compte et des progrès incessants de la science et surtout du point de vue différent auquel se sont placés les auteurs. Il est certain, en effet, que si l'on prend en considération le développement des facultés intellectuelles et morales, ce n'est pas trop de la création d'un règne spécial pour marquer la distance énorme qui sépare l'Homme des Singes les plus élevés. Mais si, au contraire, on ne fait entrer en ligne de compte que les caractères tirés de l'organisation, c'est-à-dire les caractères purement zoologiques, on doit reconnaitre que l'Homme mérite à peine d'être classé dans un ordre distinct. "Au point de rue anatomique, dit de Quatrefages, I'Homme diffère moins des Singes supérieurs que ceux-ci ne diffèrent des Singes inférieurs (1). ”

'L'harmonie des proportions, la pureté des lignes, la délicatessè des contours, sont des caractères qui permettent déjà d'établir à première vue une différence bien marquée entre l'Homme et les Singes. Il en est de même de la station verticale et des dispositions qui s'y rattachent: l'équilibre si parfait de la tête audessus du tronc, la double courbure en $\mathrm{S}$ de la colonne vertébrale, la. Jargeur du bassin, qui doit supporter les viscères abdominaux, la puissance de la musculature de la jambe, la largeur et la position horizontale de la plante des pieds.

En outre, le développement remarquable du cerveau entraîne des modifications considérables dans la configuration du squelette céphalique. La capsule cranienne forme une large voûte qui surplombe la face, et le trou occipital occupe à peu près le milieu de la base du crâne. La face est réduite, et le menton forme toujours une saillie plus ou moins accusée. 
Les membres antérieurs sont toujours plus courts que les postérieurs; le bras est relativement plus long, l'avant-bras el la main plus courts que che\% les Singes. La main constitue un instrument de préhension parfait; elle est de beaucoup supérieure à celle des Singes. Le pied sert simplement de support: le tarse et le métatarse, légèrement voùtés, fournissent une large base de sustentation; le sros orteil n'est pas opposable.

La dentition est analogue ì celle des singes de l'ancien monde: $\frac{2.1 .2,3}{2.1 .2,3}=32$. Les incisives sont rerticales ou parfois un peu obliques, comme dans les races prognathes. Le sommet des canines dépasse à peine celui des autres dents, et il ny a pas de diastème. Les prémolaires nont pas plus de deux racines. Les petites molaires permanentes ont deux tubercules et les grosses quatre. liestomac est toujour's simple.

Le pénis ne renferme pas d'axe osseux; il pend librement audevant du pubis. La Femme possède deux mamelles pectorales. La matrice est simple, formant une poche ovoïde. La vulve regarde en bas et en avant; le clitoris est peu développé. La clinte des ovules s'accompagne d'un écoulement de sang relativement abondant (flux menstruel). La durée de la gestation est de neuf mois (limiles extrêmes $\mathbf{2 6 0}$ et $\mathbf{9 9 4}$ jours). La Femme est, en général, unipare; cependant, elle donne parfois naissance à deux jumeaux, par exception à trois ou quatre. Le placenta est discoïde.

Au moment de la naissance, l'enfant a les testicules encore renfermés dans l'abdomen; ses pupilles sont, en général, ouvertes.

A trois ans, il posside ses 20 dents de lait $\frac{2.1 .2}{2.1 .2}$. Les dents permanentes commencent à apparaitre entre cinq et six ans, et les dents de remplacement vers la septième année. Les dernières molaires ou dents de sagesse se montrent en moyenne de dix-sept à vingt-cinq ans. Sous nos climats, la puberté se manifeste vers quatorze ans pour les garçons, à la mème époque ou un peu plus tít pour les jeunes filles. Toutefois, la jeune fille ne devient nubile, c'est-à-dire apte à la reproduction d'enfants bien constitués, que vers dix-huit à vingt-deux ans, et le jeune homme vers vingt-deux à vingt-six ans. A trente ans environ, la taille cesse de croitre; le corps s'épaissit, de manière à acquérir le maximum de son poids vers quarante ans. Puis l'activité génitale diminue chez l'llonme, la menstruation cesse chez la Femme (ménopause); et peu à peu se manifeste le ralentissement des fonctions, jusqu'à ce que survienne l'arrèt définitif.

D'après Broca, on peut ainsi distribuer les périodes de la vie humaine: " première enfance, de la naissance à la fin de la sixième annce, lorsque la première grosse molaire ou première dent permanente sort; seconde enfance, de sept à quatorze ans, à l'éruption 
des secondes grosses molaires; jeunesse, de quatorze à vingt-cinq ans, lorsque la suture basilaire est ossifiée ou la dent de sagesse sortie; age adulte, de vingt-cinq à cquarante ans, lorsque les sutures cérébrales commencent à s'ossifier; age mûr, de quarante ì soixante ans ; vieillesse, au delà de soixante ans."

Au commencement de ce siècle, la durée moyenne de la vie était, d'après Duvillard (1806), de vingt-huit ans et demi. D'après les recherches de Turquan (1860-1892), elle est aujourd'hui de 37 ans et 3 mois (36 ans 2 mois pour les hommes, 38 ans 4 mois pour les femmes). - La durée ordinaire de la vie est de soixante-dix à quatrevingts ans.

Nous avons déjà dit combien, au point de vue des facultés intellectuelles, l'Homme se trouve placé au-dessus des animaux les mieux doués. Cependant, nous savons aussi qu'il n'est aucune de ces facultés dont on ne retrouve au moins le rudiment chez quelqu'un de ces derniers. Entre les uns et les autres, on ne peut donc établir, à cet égard, une séparation absolue: il n'y a qu'une différence de degré. Différence profonde, à la vérité, et que les progrès incessants de l'humanité ne font que marquer chaque jour davantage.

Le premier élément qui ait assuré la supériorité de l'intelligence humaine, c'est, à n'en pas douter, la faculté du langage articulé ou, si l'on veut, l'usage de la parole. Il y a lieu de penser que l'Homme primitif possédait à peine la faculté d'articuler quelques sons; mais cette faculté d'articulation s'est perfectionnée peu à peu, et il a pu dès lors donner plus de précision à ses idées, les développer et les communiquer à ses semblables. Ainsi s'est établie la tradition, qui est devenue le lien commun des générations successives, et qui, en permettant aux nouveaux venus de profiter de l'expérience acquise dans le passé, a servi de base constante au progrès. D'ailleurs, à mesure que s'accroissait son fonds intellectuel, à mesure que se multipliaient ses idées, l'Homme a senti grandir le besoin de découvrir les causes, de rechercher l'origine et le but de toutes choses, et il est arrivé à s'étudier, à se connaitre lui-même.

L'Homme préHistorique (1). - L'archéologie préhistorique, encore appelée paleoethnologie ou préhistoire, a pour objet l'étude des groupes humains dont il ne nous reste aucun document écrit ou oral; elle nous renseigne sur leur industrie, leurs mœurs et leur évolution.

I. Age de la pierre. - Dès 1836, les savants scandinaves, à l'exemple de Thomsen, divisaient les temps préhistoriques en trois àyes, en se basant sur la matière de fabrication des armes et ustensiles usuels : àge de la pierre, âge du bronze, âge du fer. Cette division, parfaitement justifiée, s'est conservée jusqu'à nous; mais les progrès de la science ont nécessité un sectionne-

(1) G. de Mortillet, Le préhislorique. Paris, 1883. 
ment plus étendu, de sorte qu'on a subdivisé les àges en périodes et celles-ci en époques. C'est ainsi que l'iuge de la pierve a été partagé d'atıord, par les savants français, en trois périodes : $1^{\circ}$ période de la pierre étonnée par le feu, ou éolithique; $2^{\circ}$ période de la pierre taillée ou paléolithique $; 3^{\circ}$ période de la pierre polie ou néolithique. La première correspond aux temps tertiaires, la deuxième aux temps quaternaires, la troisième au début des temps actuels.

$1^{\circ}$ Periode iolithique. - Parmi les données les plus sérieuses relatives à l'existence de l'Homme tertiaire, il faut citer les silex taillés découverts it Thenay (Loir-et-Cher), dans le terrain miocéue, par l'abbé Bourgeois. Un? partie de ces silex ont subi l'action du feu, ce qui se reconnait a leur craquellement. Il y aurait donc eu, dès cette époque (époque thenaisienne) un ètre connaissant le feu et sachant tailler le silex. Des traces analogues out été signalées dans des assises plus récentes, miocènes et pliocènes, dans le Cantal et en Portugral. Toutefois, leur signification est encore discntée, et les auteurs mèmes qui admettent la taille intentionnelle des silex en question se refusent à l'attribuer à l'homme, mais la rapportent soit à un Singe, soit à un ètre plus élevé, précurseur de l'llomme. Dans l'Amérique du Sud, les traces sont plus nettes, mais la date des dépôts est très contestée (1).

$2^{\circ}$ Période paléolithique. - Pour G. de Mortillet, le quaternaire est caractérisé par une faune nammalogique terrestre, contenant un mélange d'espèces éteintes et d'espèces encore vivantes. Or, c'est au quaternäire, on le sait, que répond la période paléolithique ou de la pierre taillée. Edouard Lartet avait tenté de la diviser en trois époques, en se basant sur la faune: $1^{\circ}$ époque du grand Ours; $2^{\circ}$ époque du Mammouth; $3^{\circ}$ époque du Renne. Mais, ces divers animan ayant parfois vécu ensemble, la division dont il s'agit n'est guère caractéristique. C'est pourquoi de Mortillet a cru devoir en établir une nouvelle, basée sur le degré de perfectionnement de l'industrie et qui peut être acceptée à cause de son caractère schématique. Elle comprend quatre époques distinctes, qui porlent chacune le nom d'une localité typique : $1^{\circ}$ époque de Chelles (chelléenne); $2^{\circ}$ époque du Moustier (mousté-

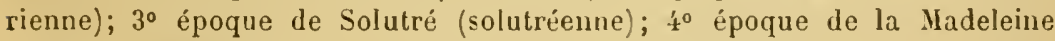
(magdalénienne).

ж. Époque chelléenne. - Assez bien représentée à Saint-Acheul, près Amiens, cette époque a été désignée d'abord sous le nom d'acheuléenne; mais cette station étant assez mélangée, on a dù en choisir une plus pure, celle de Chelles (Seine-et-Marne). Dès le début de la période quaternaire, un important phénomẻne géologique se produisit dans le bassin de Paris: le comblement du fond des vallées par des alluvions. Ce comblement fut sans doute le résultat d'un affaissement du sol et d'une grande abondance de pluies. La température était alors chaude et assez uniforme sur toute l'étendue de la France.

La faune européeune de cette époque est caractérisée par l'Elephas antiquus, auquel s'associe, vers la fin, le Mammouth (E. primigenius); elle comprend aussi l'Éléphant actuel d'Afrique (E. africanus). Signalons en outre le Rhino-

(1) Voy. E. Trouessant, Les Primates terliaires et l'Ilomme fossile sud-américain. L'Anthropologie, III, p. 257, 1892. 
ceros Mercki, forme tertiaire, I'Hippopotame (Hippopotamus amphibius), le Chevreuil (Cervus capreolus), des Bovidés, des Equidés, enfin des Carnivores, notamment le grand Óurs des cavernes (Ursus spelæus), etc.

L'Homme chelléen qui habitait nos régions ne paraît guère avoir fréquenté les cavernes, qui servaient de repaires aux animaux féroces. Il se tenait de préférence au bord des fleuves et des rivières, et c'est ce qui explique pourquoi on retrouve de nombreux débris de son industrie dans les alluvions fluviales. Cette industrie est tout à fait rudimentaire : elle ne comporte qu'un seul instrument, le coup de poing. C'est un fragment de silex, ou de quartzite, de calcaire siliceux, etc., taillé sur les deux faces et offrant la forme générale d'une amande. Cet instrument ne devait pas s'emmancher : c'était plutòt un outil. " Un outil pour tout faire. Il servait, suivant ses modifications de taille et la manière de l'employer, de hache, de couperet, de couteau, de scie, de percoir, de tranchet, de ciseau, etc. "

On a retrouvé mème des ossements de l'Homme chelléen. Les auteurs y rapportent généralement le cràne et les ossements de Néanderthal (près Dusseldorf), le cràne de Canstadt (près Stuttgard), la màchoire de la Naulette (Belgique). Mais le cràne de Néanderthal provient, selon Virchow, d'un microcéphale (probablement comme le prétendu Pithecanthropus erectus Dubois, récemment découvert à Java), et il n'est pas démontré qu'il date du diluvium; quant au cràne de Canstadt, il est certainement plus récent.

ß. Époque mousterienne. - Cette époque lire son nom de la station du Moustier, commune de Peyzac (Dordogne), station qui comprend a la fois un gisement dans l'intérieur d'une zrotte et un gisement à l'air libre, sur un plateau. Le moustérien est d'ailleurs largement représenté sur divers points de la France, de l'Europe et mème de l'dsie. Au point de vue géologique, il répond à l'époque glaciaire, caractérisée, comme on le sait, par l'extension considérable des glaciers dans nos régions. Le glacier du Rhòne, par exemple, qui n’atteint pas aujourd'hui une longueur le 8 kilomètres, en mesurait alors plus de 400 et descendait jusqu'à Lyon. Cette extension des glaciers doit s'expliquer par l'existence de froids modérés et d'une très grande humidité de l'atmosphère. En mème temps, la chute abondante des neiges et des pluies déterminait la production de violents cours d'eau qui ravinaient les vallées, démantelant ainsi les alluvions chelléennes, de concert avec des mouvements d'exhaussement du sol, fréquemment interrompus.

Parmi les nombreux représentants de la faune mammalogique, nous citerons : Ie llammouth (Elephas primigenius), le Ihhinocéros à narines cloisonnées (Rhin. tichorinus), le Cheval (Equus Caballus), l'Ane (?), le Sanglier, le Gerf élaphe, le Mégacéros (Ccrvus meguceros), ça et là le Renne (Tarandus rangifer), le Bouquetin (Capru ibex), l'Ovibos musqué (Oxibos moschatus), le Bison d'Europe (Bison europæus), le Bœuf primilif (Bos primigenius), le grand Ours des cavernes (Ursus spelæus), très abondant, l'Ours gris ou Grizzly (Ursus ferox), le Blaireau, le Loup, le Renard, l'Hyène des cavernes, le Lion, la Marmotte, etc.

L'Homme du Moustier, soumis à une température plus froide que celui de l'époque précédente, a commencé à se retirer dans les grottes, qu'il ẻtait obligé de disputer aux animaux féroces. Il a aussi éprouvé le besoin de se vêtir, et a modifié dès lors son outillage, en vue de.préparer les peaux d'animaux à lui servir de vètements. Ce qui caractérise l'industrie moustérienne, 
e’est que les pièces ne sont retouchées que sur une face : l'autre reste toujours vive et ne représente que le plan d'éclatement. On y listingue deux instruments typiques: le racloir et la pointe. Ni l'un ni l'autre ne devaient s'emmanclıer. Le racloir servait sans doute á écorcer le bois et à nettoyer les peaux, les pointes à percer le hois et les peanx.

Les ossements humains des gisements moustériens sont extrêmement rares. Citons eependant le crìne de l'Olmo (près Florence), qui est dolichocéphale, mais dont les arcades sourciliéres sont à peine marquées, et dont le front est presque vertical.

r. Époque solutrienne. - Solutré est une belle et riclıe station du Màconnais (Saòne-et-Loire), qui a louné lieu ả des études fort intéressantes. Des stations semblables ont été d’ailleurs découvertes dans diverses localités francaises et jusqu'en Algérie (Thomas); elles abondent surtout dans la Dordogue, et en particulier dans la vallée de la Vézère (Laugerie-Haute, etc.). Le climat, très humide pendant l'époque précédente, parait avoir été beaucoup plus sec à l'époque de Solutré. Par suite, les gliciers ont commencé leur mouvement de recul, les cours d'eau sont devenus moins puissants, le soleil s'est montré davantage en été, l'biver est devenu plus froid.

La faune, assez difficile à préciser, à cause des mélanges, comprenait d'abord de nombreux représentants des deux grands Bovidés de l'époque du Moustier, le Bison d'Európe et le Bœuf primitif, auxquels se joint le Bos longifions. Mais l'animal le plus répandu était le Cheval, qui se rencontre en quantité extraordinaire à Solutré mème (V. p. 1162). Après le Cheval, le Renne est l'animal le plus abondant. - On s'est demandé si ces animaux n'étaient pas déjà domestiqués. Toussaint a conelu affirmativement. Sanson est d'un avis contraire, et nous n'hésitons pas à wous rattacher à sa manière de voir. Il nous semble démontré que le Cheval vivait alors à l'état sauvage et que l'Homme le chassait pour en faire sa nourriture.

Nous ne possédons aucun document ostéologique sur l'Homme solutréen ; mais il nous reste de nombreux débris de son industrie, dont les deux plus caractéristiques sont la pointe en feuille de laurier et la poince a cran. C'est à cette époque que la taille de la pierre atteint son apogée. Ces pointes sont travaillées avec beaucoup de soin, et en général retouchées sır les deux faces. Le racloir moustérien est, en outre, remplacé par un grattoir, dont le sommet décrit un arc de cercle à bord tranchant; enfin, on trouve encore des percoirs et des scies en silex. Il apparait mème, vers la fin du solutréen, quelques pièces en os, et des essais rudimentaires de sculpture.

C'est ainsi que Piette a recueilli, dans la station de Brassempouy, des fragments de statuettes humaines (femmes) en ivoire. Elles appartiennent à deux types : l'un à nez gros, à lèvres épaisses, à menton fuyant comme celui de la màchoire de la Naulette, et remarquable surtout par le développement du système pileux, ainsi que par les masses graisseuses réparties sur les cuisses, le ventre et les bauches; l'iutre, encore peu counu, montrant une tète à coiffure égyptienne.

§.. Époque magdalénienne. - La station de la Madeleine, qui donne son non à cette époque, se trouve dans l'arrondissement de Sarlat (Dordogne), à 203 mètres de la Vézère et à 6 mètres au-dessus de son niveau. La température qui régnait alors en France, en Suisse et en Belgique, devait être de 
8 à 10 degrés plus basse que celle de nos jours. Mais l'air était très sec, et par suite les glaciers continuaient leur mouvemement de recul.

Dans la faune magdalénienne, nous avons à citer : divers Félidés, parmi lesquels le grand Chat des cavernes (Felis spelæa), le Lion (F. leo), le Chat sauvage $(F$. catus); des Canidés, tels que le Loup, le Renard, l'Isatis; des Hyænidés, notamment l'Hyène rayée et l'Hyène tachetée, une foule d'autres Carnivores, des Insectivores, des Rongeurs, entre autres le Lapin et la Marmotle; des Ruminants, parmi lesquels le Chamois, le Bouquetin, une Chèvre (Capra primigenia) très voisine de l'Égagre, l'Ovibos musqué, le Bison d'Europe, le Bœuf primitif et le Bos longifrons; des Équidés, le Cheval et peutètre l'Ane; le Sanglier' encore le Mammouth, etc.

Il y a lieu de penser que l'llomme de la Madeleine avait des mœurs nomades. Les températures extrêmes étant très accusées, le gibier devait effectuer, d'une saison à l'autre, d'importantes migrations, et l'Homme devait le suivre pour se procurer sa nourriture. Dans les points qu'il fréquentait, il s'installait parfois en pleine campagne, d'autres lois dans des grottes ou dans des cavernes, mais le plus souvent dans des abris sous roche.

Son industrie est surtout caractérisée par l'utilisation de nouvelles matières premières : os, bois de Cervidés, ivoire. La pierre (silex et jaspe) est pourtant encore employée pour la fabrication de couteaux, grattoirs et pointes vives. Il existe, en outre, des mortiers à godets en roches granitoïdes, qui servaient peut-être à triturer des couleurs minérales pour le tatouage et la peinture du.corps. Déjà, en effet, l'amour de la parure était très accusé, comme nous le montre l'usage des pendeloques. Celles-ci consistaient surtout en dents percées à la racine, et en coquilles marines, vivantes ou fossiles. Quant aux objets en os, ils étaient nombreux et variés. Citons les aiguilles à chas, qui servaient à coudre les peaux; les pointes de sagaie et de harpon, qui s'emmanchaient à l'extrémité d'une hampe de bois; les bàtons de commandement, les poignards, les boutons, etc.

L'art, qui avait pris naissance vers la fin du solutréen, s'est développé d'une façon remarquable à l'époque magdalénienne. Il se traduit d'abord par des gravures sur pierre, sur ivoire ou sur os, représentant surtout des auimaux (Poissons, Reptiles, quelques Oiseaux et beaucoup de Mammifères, y compris l Homme). On a retrouvé aussi des demi-bosses et mème des rondes-hosses ou sculptures véritables, mais jamais sur piewre : ce sont les bois de Renne qui en ont fourni la matịère.

Une màchoire trouvée dans la grotte des Fées, à Arcy-sur-Gure (Yonne), et un squelette écrasé trouvé à Laugerie-Basse (Dordogne), représentent les seuls débris autlentiques de l'Homme magdalénien. Mais les représentations artistiques dont nous venons de parler nous renseignent sur sa physionomie générale. On a trouvé, à Laugerie-Basse, un chasseur de Bisons gravé sur bois de Renne, et une femme enceinte gravée sur os. La tête du chasseur est étroite et allongée; son corps est extrêmement velu. Celui de la femme enceinte l'est de même, mais les poils sont beaucoup plus fins.

$3^{\circ}$ Période néolithique (époque robenhausienne). - La période de la pierre polie commence avec les temps actuels. Or, " sous le nom de temps actuels, dit de Mortillet, on comprend tous ceux qui se sont trouvés dans des condi- 
tions de géographie physique, d'hydrographie, de climatologie, de flore et de faune à peu près semblables à celles de nos jours. "Mais nous ignorons comment s'est effectuée la transition des temps quaternaires aux temps actuels. Les différences qui existent entre ces deux périodes sont tellemen! profondes, qu'un temps trìs long a dủ s'écouler entre elles; mais il y a à cet égard une lacuue presque absolue dans nos connaissances.

De froid et sec qu'il était à la fin du quaternaire, le climat était devenu tempéré et beaucoup plus uniforme. La première conséquence de l'élévation de la température avait été l'émigration des animaux des régious froides. Le Renne avait quitté nos contrées pour les pays du Nord, suivi sans doute de la plus grande partie de la population humaine. Le Chamois, le Bouquetiu et la Marmotte s'étaient retirés sur le sommet des montagnes. Le Mammouth, l'Hyène, les grands Félidés avaient disparu.

Nous allons voir que l'industrie avait subi des modifications non moins profondes, ou plutòt qu'une industrie nouvelle était apparue, importée de toutes pièces par une race envalissante.

La période néolithique ne comprend qu'une seule époque, dite robenhausienne, du nom (liobenhausen) d'un petit hameau suisse du canton de Zuricb.

Parmi les gisements de cette époque, nous devons citer en premier lieu les palaftes ou habitations lacustres. L'llomme avait quitté les cavernes pour descendre dans les vallées, et, s’établissant sur le bord des lacs, il avait édifié sur pilotis deslabitations en bois, ne communiquant avee le rivage que par de sim. ples passerelles, de manière à se mettre à l'abri des fauves et des populations ennemies. Les débris de ces habitations ont été découverts pour la première fois pendant l'hiver de 1833-185't, au bord du lac de Zurich. Elles sont, en effet, particulièrement abondantes en Suisse; cependant, on en rencontre dans tous les pays voisins des Alpes. En raison de leur constitution mème, les palafittes ont dủ souvent être incendiées; mais c'est gràce à ces incendies qu'on a pu quelquefois retrouver le matériel et les provisions de villages entiers, engloutis au fond de l'eau après avoir été carbonisés. - Toutes les palafittes n'appartiennent pas à l'époque de la pierre polie; il en est beaucoup aussi de l'àge du bronze et même de l'àge du fer.

A còté des cités lacustres, il existait d'ailleurs des habitutions terrestres, en nombre mème beaucoup plus considérable; mais elles ont été détruites en grande partie par le fait des travaux agricoles, et les objets qu'elles contenaient n'ont guère été conservés. D'autres gisements sont les atelier's où l'on fabriquait ces objets, les carrieres d'où l'on extrayait la matière première, les abris et grottes où l'Homme se réfugiait encore, les sépultures, etc. Une mention spéciale est due à certains gisements des bords de la mer, auxquels les Danois ont donné le nom de kjökkekmöddinger, qui signifie " dèbris de cuisine ». Ce sont des amas de coquilles provenant des Mollusques qui servaient a l'alimentation, amas au milieu desquels on découvre des foyers avec cendres et charbon, des os d'animaux brisés et une foule d'objets travaillés de main d'Homme. On a observé plusieurs de ces stations en France.

La population de l'Europe occidentale, à l'époque robenbausienne, possédait déjả une industrie fort complexe. - L'usage des silex taillés n'avait pas disparu; il était mème beaucoup plus répandu qu’à l'époque magdalénienne, en raison sans doute de la dispatition du Renne. On a, en effet, retrouvé 
des objets en pierre simplement éclatée, tels que des couteaux, et d'autres en pierre retouchée : scies, grattoirs, perçoirs, pointes de flèche, pointes de lance, poignards, etc. - Les objets en pierre polie sont moins nombreux, à la vérité; mais, comme ils n'existaient pas dans les époques antérieures, on a pu les choisir comme élément caractéristique. Ils comprennent des outils : haches, ciseaux, etc., et des armes auxquelles on donne le nom de cassetète. Les haches consistent en des fragments de pierre dure, silex, grès, granit, porphyre, jade, serpentine, etc., d'abord taillés et retouchés, puis polis avec soin sur une dalle de grès. Leur forme est variable; cependant, la plupart sont triangulaires, tranchantes à la base et parfois aussi au sommet; celles de moyennes dimensions s'emmanchaient soit dans des cornes de cerf, soit dans des manches en bois. - Les instruments en os sont devenus d'un emploi de plus en plus général : ce sont des couteaux, des poinçons, des pointes de flèche, des peignes à cheveux, etc. Les cornes de Cervidés, les dents de divers Mammifères, enfin le bois de certains arbres ont été également employés pour confectionner des instruments : vases, crochets, bateaux, etc. La poterie est aussi apparue à cette époque, ce qui prouve qu'elle a été importée : on a découvert dans les sépultures de nombreux vases en terre cuite façonnés à la main et de forme variable. Enfin, nous devons citer encore les parures en coquilles, en dents, les perles et boutons en os, ambre, jais ou autres substances.

L'art, dont nous avons constaté le développement à l'époque de la Madeleine, s'était éteint avant le début des temps actuels. Or, le peuple envahisseur n'en ayant pas le moindre sentiment, l'époque robenhausienne ne nous fournit aucune œuvre d'art qui mérite d'ètre mentionnée.

Par contre, le respect des morts apparait d'emblée avec un caractère très accentué, qui se traduit par l'érection de ces monuments qu'on a faussement attribués aux Celtes, et qu'on désigne aujourd'hui sous le nom de monuments mégalithiques. Tels sont les menhirs, ou pierres brutes fichées en terre; les alignements, ou rangées de menhirs; les cromlechs, ou enceintes formées par des menhirs; les dolmens, constitués par des dalles de champ supportant des dalles horizontales servant de plafond, et primitivement enterrés dans le sol ou sous des tumulus. Les menhirs n'étaient autres, sans doute, que des monuments commémoratifs: quant aux dolmens, c’étaient des tombeaux, contenant en général un grand nombre de squelettes. Les sépultures ne se faisaient pas exclusivement dans ces dolmens; elles se faisaient aussi dans des grottes naturelles ou mème artificielles.

Les populations néolithiques pratiquaient-elles l'anthropophagie? C'est un point sur lequel les auteurs ne se sont pas encore mis d'accord. Mais la chose parait assez peu probable si l'on remarque que non seulement elles pouvaient se procurer par la chasse un abondant gibier, dont le Bison, le Bœuf primitif, le Sanglier, formaient la base principale, mais qu'elles possédaient en outre des animaux domestiques. Le plus ancien de ceux-ci paraît être le Chien; c'est le seul qu'on rencontre dans les lijökkenmöddinger du Danemark. Viennent ensuite le Cheval, le Bœuf, la Chèvre, le Mouton et le Porc. Nais quelle est la patrie de ces divers animaux? En quel point la domestication a-t-elle pris naissance? Ce sont là deux questions auxquelles il est sans doute difficile de répondre, mais qu'on a eu trop souvent le tort de confondre. A notre avis, l'apparition presque simultanée des animaux domes- 
tiques dansl'Europe occidentale, coïncidant d'ailleurs avec l'introduction d'une civilisation nouvelle, démoutre que le principe mème de la domestication a été importé par le peuple envahisseur; il a donc dù prendre naissance en Orient. Quant à la patrie de ces animax, elle nous parait être surtout européeune. Les rapports qui existent entre les Chevaux et les Buufs des temps quaternaires, par exemple, et ceux des temps actuels, sont tellement étroits, qu'il est difficile de concevoir que les uns ne dérivent pas des autres. Que les races autoclıtones aient été modifiées, transformées dans une certaine mesure par des races importées, ce n'est point impossible; mais il n'en est pas moins vai que les premières doivent constituer la base de nos populations hovines et chevalines actuelles.

Les palafittes et autres habitations robenhausiennes nous ont aussi laissé des débris d'une foule de fruits sauvages ou cultivés : noisette, prunelle, merise, fraise, poire, pomme, mùe de ronce (servant peut-ètre à faire une liqucur fermentée), blé, orge, seigle, etc. Les céréales étaient certainement cultivées, et leurs grains, souvent mélangés, étaient conservés dans des sortes de greniers. On les broyait entre deux pierres plates, et on en formait une pàte qu'on faisait cuire sous forme de galettes : des fragments de ces pains sont parrenus jusqqu'à nous. Il y avait aussi une plante textile, le lin (Linum angustifolium), qui servait à la fabrication d'étoffes diverses et de filets.

Les sépultures robenlausiennes nous montrent tout d'abord, sur divers points, le type autochtone, franchement dolichocéphale, que nous avons signalé dans le quaternaire, mais un peu modifié. Les squelettes de CroMagnon (Dordogne), ceux de la grotte sépulcrale de l'Ilomme mort (Lozère), appartiennent tous à ce type. - Dans la grotte sépulcrale de Furfooz, près Dinant (Belgique), on a rencontré, au contraire, une race toute différente, brachycéphale ou au moins mésaticéphale : c'est évidemment une race nouvelle, la race des envahisseurs, qui venait sans doute de l'Orient. - Enfin, dans les groltes artificielles de la vallée du Pelit-Morin (Marne), on trouve des types intermédiaires, qui démontrent que les deux races se sont mêlées.

II. Age du bronze. - L'usage du bronze en Europe a pu être étudié dans les cités lacustres, dans les dolmens et les tumuli, où l'on a découvert des haches en bronze, des épingles, des rasoirs, des lingots, des moules à fondre ce métal, etc. L'industrie du bronze semble être d'origine indienue; on en attribue l'importation à une race d'llommes nomades, semblables, par leurs mœurs et leurs habitudes, aux Bohémiens de nos jours, ce qui explique le nom de période bohémienne donné à l'àge du bronze par G. de Mortillet. Les descendants de cette race ne seraient-ils pas les Tsiganes? Dans tous les cas, l'industrie dont il s'agit s'est perfectionnée sur notre sol : à l'al't de mouler le métal, seul mis en pratique dans le principe, est venu se joindre, en effet, dans une deuxième période, celui de le marteler.

III. Age du fer. - Les plus anciens monuments de l'àge du fer sont les tombes bien connues des llallstadı, près Salzbourg, on Autriche. Les Étrusques paraissent être le premier peuple qui ait importé l'usage de ce métal en Europe. En France, le fer intervient á une époque postérieure, dans les tumuli du Nord-Est, puis dans les cimetières de la Narne : son introduction parait remonter tout au plus à huit cents ans avant notre ère. Peu après, Railuet. - Zoologie. 
l'influence romaine commence à se faire sentir, et nous entrons de plainpied dans les temps historiques.

États sociaux de l'humanité. - Si nous jetons un coup d'œil en arrière nous constatons que l'Homme, peut-être frugivore à l'origine, mais bientòt devenu omnivore par suite de l'insuffisance des fruits sauvages sur notre sol, exposé d'ailleurs aux intempéries d'un climat souvent rigoureux, dut chercher dans la faune qui l'environnait les éléments de sa nourriture et de son vêtement. L'Homme quaternaire fut chasseur et pêcheur.

Cependant, à mesure que s’accroissait la population, le gibier devenait sans doute plus rare et plus difficile à atteindre. Pour s'assurer des vivres, l'Homme fut conduit à domestiquer des animaux : il devint pasteur.

Ce premier pas dans la voie du bien-être devait être suivi à bref délai d'une nouvelle marche en avant. Autant et plus peut-ètre que les peuples chasseurs, les peuples pasteurs vivent en tribus nomades, obligés qu'ils sont de chercher à chaque instant de nouveaux pàturages pour nourrir leurs troupeaux. Mais les difficultés qu'éprouvaient les premiers dans la recherche du gibier se présentent bientôt pour ceux-ci dans la découverte des pàturages. C'est alors qu'intervient l'agriculture, qui permet à l'Homme de trouver sur un point déterminé tout ce qui est nécessaire à sa subsistance.

Avec l'agriculture apparaissent en outre les grandes agglomérations d'individus; et, les abris naturels devenant par suite insuffisants, l'Homme est amené à se construire des demeures artificielles. Ainsi ont pris naissance les cités, point de départ des nations.

Or, gràce à ses animaux domestiques, l'Homme agriculteur est capable d'assurer l'avenir; et dès lors, ses facultés, s'élevant d'un degrré, peuvent s'appliquer à des objets qui n'ont pas pour but immédiat son entretien personnel.

Races humanes. - La notion de race, en anthropologie, est loin d'avoir une signification bien définie; il est évident, d'ailleurs, qu'elle doit varier suivant l'idée qu'on se fait de l'origine de l'Ilomme (1).

A cel égard, on sait que les anthropologistes se sont partagés de bonne heure en deux camps : $1^{\circ}$ Les monogenistes admettent que tous les Hommes appartiennent à une seule et mème espèce (Iomo sapiens L.), de laquelle sont dérivées des races et sous-races multiples, sous l'influence des conditions de milieu. $2^{\circ}$ Les polygénistes, au contraire, regardent comme originelles les différences qui séparent les habitants des diverses contrées du globe, et considèrent, par suite, qu'il existe plusieurs espèces humaines indépendantes les unes des autres.

Ajoutons que l'intervention des évolutionnistes n'a amené aucun rapprochement entre les deux partis. Il est mème à remarquer que ce sont souvent les plus chauds partisans de l'évolution qui soutiennent le polygénisme avec le plus d'ardeur. Aussi bien, la discussion des questions de cet ordre estelle demeurée trop rarement sur le terrain exclusif de la science.

Quelle que soit, du reste, la manière de voir à laquelle on se rattache, il est constant qu'on ne trouve plus ou presque plus, aujourd'hui, de races pures. Depuis des milliers de siècles, dit Topinard, les races ont été divisées,

(1) P. Topinard, L'anthropologie, 1ro él., 1876. - Id., Élements d'anthropologie genérale, 1885. 
dispersées, mèlées, croisées en toutes porportions; "la plupart out quitté leur langue pour celle des vainqueurs, l'ont abandonuée pour une troisième, sinon une quatrième; les masses principales ont lisparu, et l'on se Irouve en présence, non plus de races, mais de peuples lont il s'agit de retracer les origines ou que l'on classe directement..." .

"En France, où la nation est cependant si homogène et l'unité si complète, il y a des Français, mais pas de race françaisc. On y découvre, au nord, les descendauts des lielges, des Wallons et autres Kymris; à l'est, coux des Germains et des Burguules; a l’ouest, des Normands; au centre, des Celtes, qui, à l'époque mème où leur nom prit naissance, étaient formés d'étrangers d'origines diverses el d'autochtones; a midi, enfin, des anciens Aquilains et des Basques, sans parler d'ure foule de colonies, comne les Sarrasins qu'on retrouve ça et lá, les 'Teclosages qui ont laissé à Toulouse l'usagae des léformations craniennes, el les trafiquants qui passèrent par li villo phocéenne de Marseille. "

Étant donné un groupe humain, il s'agit donc de déterminer d'abord s'il représente une race pure ou s'il résulte du mélange de plusieurs éléments primitifs. Reste cnsuite à dégager le type de chacune des races composantes supposées pures, c'est-à-dire la moyenue des caractères de ces races. C'est là, sans doute, un problème très complexe et Irès difficile, et c'est à peine si, jusqu'à présent, l'anthropologie a pu déterminer quelques-uus dés lypes les plus généraux. Il ne faut pas oublicr, d'ailleurs, que le type est une conception abstraite, et qu'on aurait parfois grand'peine à retrouver, chez un représentant quelconque de la race, l'ensemble des caractères quiil comporte.

Pour déterminer et classer les raccs humaines, l'antlıropologie doit prendre d'abord pour base les caractères anatomiques et physiologiques : ce sont les seuls sur lesquels elle s'appuie directement pour établir les divisions principales du groupe humain. D'autre part, elle peut tirer d'utiles renseignements de l'ethnographie ou description des peuples, de la linguistique, de l'histoire et de l'archéologie. Cependant, il faut bien reconnaître que, dans la plupart des cas, les prétendues races secondaires établies sur ces bases ne sont autres que des peuples, c'est-à-dire des aggroméralions d'éléments anthropologiques divers.

Yous nous bornerons lone à jeter un coup d'œil sur les principaux caractères anatomiques utilisés d'ordiuaire dans la classification.

Parmi les plus importants, se placent ceux qui sont tirés de l'examen du crảne : la craniologie, on le sait, est longtemps mème demeurée l'élément primordial de l'antlıropologie.

On peut d'abord chercher à déterminer la capacité cranienne. Cetle mensuration s'effectue en remplissant avec soin la cavité du cråne de fin plomb de chasse, dont il est facile ensuite de connaitre le volume. En opérant de la sorte, on est arrivé à constater une différence très accusée entre les races inférieures et supérieures. Les Boshimans occupent le degré le plus bas de l'échelle, avec 1317 centimètres cubes; les Australiens ne sont guère mieux partagés. Mais la capacité augmente d'une façon notable dans les races jaunes, pour atteindre son maximum dans les races blanches: les Parisiens contemporains ont $15 \% 5$ centimètres cubes, et les Auvergnats 1598.

Il faut reconnaitre, d'ailleurs, que le cràne tend ì devenir plus spacieux 
à mesure que s'élève l'état intellecluel des races : celui des Parisiens du douzième siècle ne cubait que 1531. De même, il y a toujours une prédominance marquée du sexe masculin sur le féminin; mais, chose remarquable, la différence est beaucoup plus grande dans les races actuelles que dans celles des temps préhistoriques, et dans les races supérieures que dans les inférieures.

La forme générale du cràne est exprimée d'une façon assez nette par le rapport entre sa plus grande largeur et sa plus grande longueur. Or, si l'on suppose le diamètre antéro-postérieur maximum égal à 100, le diamètre transverse maximum varie, en moyenne, de 71 (Groenlandais) à 85 (Lapons). Ce rapport est désigné sous le nom d'indice céphalique. Il se formule de la manière suivante $: \frac{\text { diamètre transverse } \times 100}{\text { diamètre antéro-postérieur }}$. Le chiffre qui l'exprime sera donc d'aulant plus élevé que le cràne sera plus court. Partant de là,

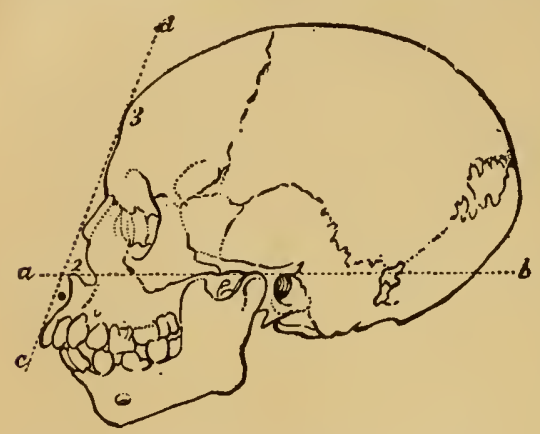

Fig. 886. - Angle facial d'un nègre, d'après Camper. on est convenu d'appeler brachycé-

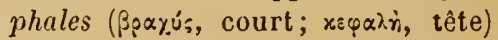
les races qui ont un indice céphalique égal ou supérieur à 80 , et dolichocéphales (Sorı\%o:, long) celles dont l'indice est inférieur à 75 . Les chiffres intermédiaires ont donné lieu, en outre, à l'établissement d'un groupe intermédiaire, celui

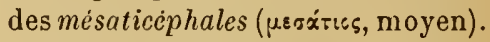

L'étude de l'angle facial fournit aussi des renseignements précieux. On sait déjà que le mode de détermination de cet angle varie beaucoup suivant les auteurs. Pour nous en tenir à l'angle de Cloquet (voy.p. 1071), voici quelques résullats obtenus par Topinard : sur 5 Auvergnats, $62^{\circ} 6$; sur

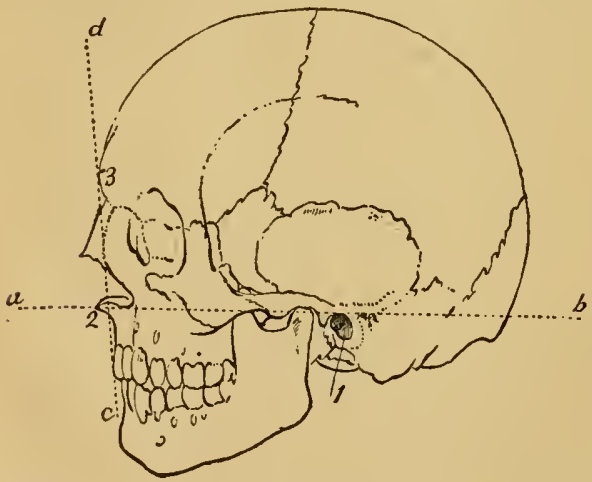

Fig. 887. - Angle facial de l'Apollon du Belvédère, d'après Camper.

5 Chinois, 59\%4; sur 5้ Nègres du Sénégal, $57^{\circ} 6$ (fig. 886). On voit que, chez les races supérieures, l'angle facial tend à se rapprocher de l'angle droit, et qu'il s'en éloigne de plus en plus, au contraire, chez les races inférieures. Un angle facial très ouvert est donc un signe évident de supériorité, et c'est là un point qu'avaient dès longtemps saisi les statuaires (fig. 887).

Le degré d'ouverture de l'angle facial marque, comme nous l'avons dit, le rapport entre le développement du cràne et celui de la face; mais l'influence de celle-ci est surtout caractérisée par la proéminence des màchoires, qui s'accuse au maximum chez les nations les plus dégradées de l'Afrique et de l'Aus- 


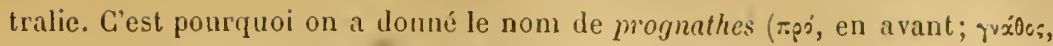
màchoire) aux races dont les michoires font nue forte saillie en avant, saillie qui entraine l'obliquité des incisives, et celui d'orthognathes (jọ)is;, droit) à celles dont le profil est à peu pı̀̀s droit. Én réalité, tous les IIommes sont prognathes, et le terme d'orlhognathisme ne peut être pris que daus un sens tout relatif.

Le nez doit ćle étudié sur le squelette et sur le vivant. - La charpente osseuse nous fournit d'abord un premier caractère, l'indice nasal du crime. C'est le rapport de lil largeur maximum de l'orifice antérieur des narines osseuses à sa longueur maximum prise le l'épine nasale à la suture nasofrontale. Depuis liroca, on nomme leptorhiniens les types chez lesquels ce rapport est inférieur à $\mathbf{4} 8$, mésorhiniens ceux qui ont un indice nasal variant

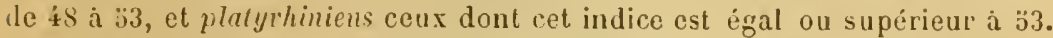
Or, tous les Nëgres d'Afrique sont platyrhiniens, tous les, Européens sont leptorhiniens, et tous les týpes jaunes sont mésorhiniens, a l'exception des Esquimaux, qui sont les plus leptorhiniens du monde. - Nais cette exception disparait lorsug'on étudie l'indice nasal du vivant, c'est-i-dire le rapport de la largeur maximum de la base du nez, en dehors de ses ailes, à sa hauteur, de la racine au point l'insertion de la sous-cloison. On constate alors que toutes les races noires forment un groupe platyrhinien (indice l08 à 89), les jaunes et rouges un groupe mésorhinien ( 81 à 69$)$ et les blanches un groupe leptorhinien (69 ì 63 ).

La couleur de lu peau varie, daus les races humaines, depuis un brun très pâle et rosé jusquu'i la nuance brun foncé qu’on pent regarder comme noire, en passant par les teintes jaune, rouge et olivàtre. Or, celte coloration a servi longtemps de base principale à la classification des races, et aujourd'hui encore, la notion qu'elle fournit est assez appréciée pour que, dans le langage courant, les grandes divisions de l'humanité soient qualifiées de races blanches, jaunes (y compris les rouges) et noires. Si d'ailleurs on associe, à la couleur de la peau, celle des yeux et des cheveux, on arrive à distinguer, parmi ces trois types fondamentaux de coloration, un certain nombre de types secondaires plus ou moins accusés. C'est ainsi qu'on distingue, dans les types blancs : $1^{\circ}$ un type blond, à peau rosée ou fleurie, à yeux bleus ou clairs, à cheveux blonds; $2^{\circ}$ un roux, à peau souvent chargée de taches de rousseur, à cheveux roux ardent ou jaune rougeàtre, à yeux gris ou verts $; 3^{\circ}$ un chatcin, à peau grisitre, à yeux verdàtres, gris ou marron, à cheveux chàtain clair ou cendrés $; 4^{\circ}$ un brun, à peau brune se bronzant à l'air, à yeux et cheveux noirs. De même, parmi les types jaunes, ou mieux, à cóté de ces lypes, qui ont une peau brun jaunàtre, des yeux noirs ou marron et des cheveux noirs, on peut admettre un sous-type rouge (Américains du Nord) et un sous-type olivâtre (Péruviens); etc.

Enfin, le système pileux, et en particulier les cheveux, fournissent aussi d'excellents caractères de races. Le plus important est celui qui résulte du degré d'enroulement des cheveux, lequel se montre d'ailleurs en rapport avec leur degré d’aplatissement. Bory de Saint-Vincent divisait déjà, d'après cette base, les races humaines en deux grands groupes : les léiolriques, à

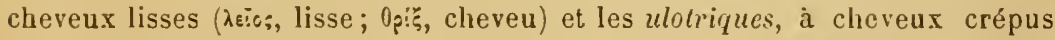

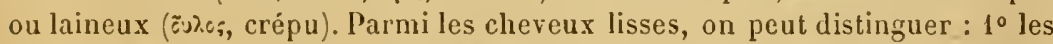
cheveux droits, raides, durs, plaqués ou tombants des races jaunes et des 
Américains; $2^{\circ}$ les cheveux ondés ou bouclés, souples et flottants, dont les races blondes offrent un bon exemple ; $3^{\circ}$ les cheveux frisés dans toute leur longueur, qu'on rencontre çà et là dans diverses races, et qui se disposent parfois en une masse globuleuse saillante ou vadrouille. Les cheveux crépus se présentent aussi snus divers aspects : $1^{0}$ ils forment quelquefois une vadrouille, comme chez les Papous, les Cafres, les Fidjiens; $2^{\circ}$ d'autres fois, ils se disposent en une nappe continue analogue à une toison de moulon (ériocomes Hackel); $3^{\circ}$ enfin, ils peuvent s'accrocher les uns aux autres de manière à constituer des vrilles ou de petites boules, laissant entre elles des intervalles qui semblent plus clairs et qu'on avait pris pour des espaces

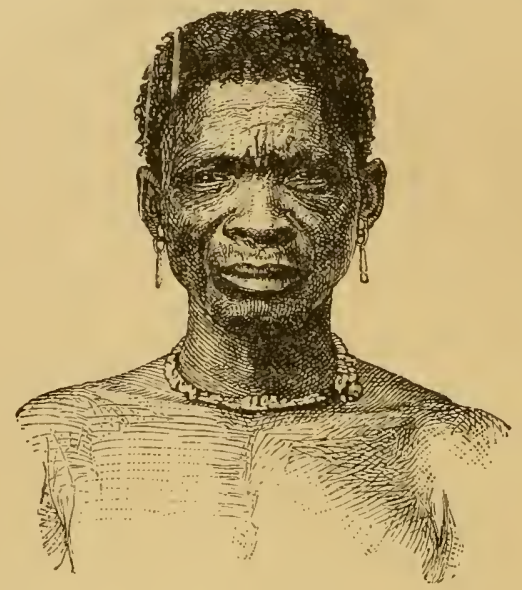

Fig. 888. - Boshiman : chere'ure en grains de poir re.

glabres: c'est la cherelure en grains de poivre, des Boshimans et Hottentots (lophocomes Hrckel).

La classification ci-après, que nous empruntons à Topinard, est établie d'après les principaux caractères que nous venons de passer en revue. Elle renferme, comme on peut le voir, quelques lacunes, mais elle offre cet avantage que chaque race y est casée à sa place naturelle, avec ses relations de parenté.

"Il n'y a de possible à l'heure actuelle, avoue l'auteur lui-même, qu'une division modeste, n'ayant d'autres prétentions que de comprendre les races les mieux dessinées, et reposant sur des caractères précis et comımodes. On la corrigera, on la changera demain, lorsque nos comnaissances auront grandi. L'essentiel, c'est qu'elle marque la phase actuelle de nos connaissances sur les points principaux." 
MAMMFERES. - PRIMATES.

1239
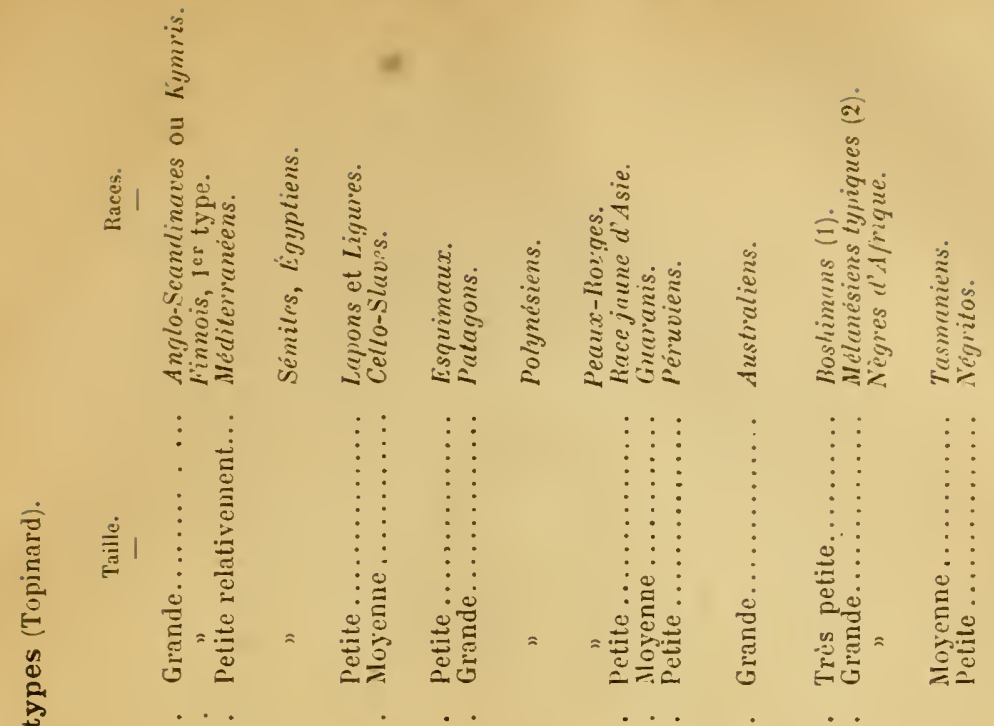

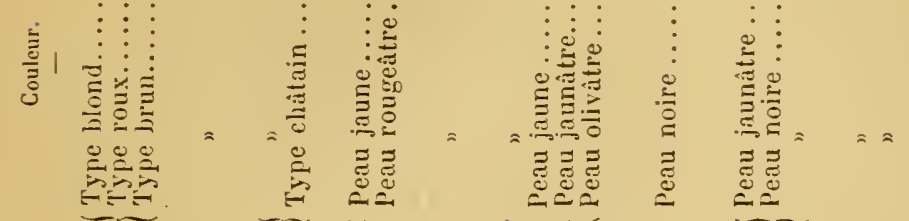

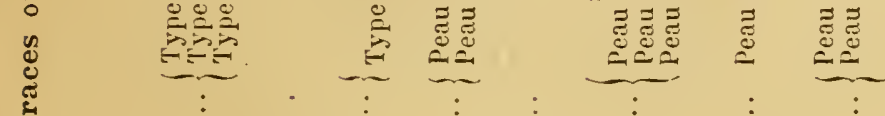

奖

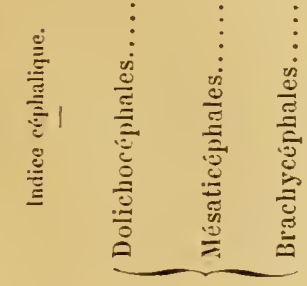

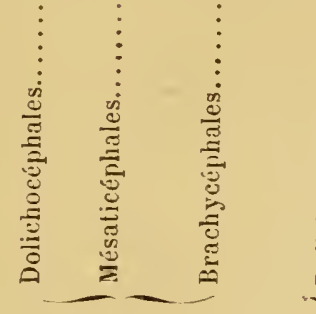

毫1

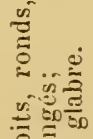

क⿺辶

के

:

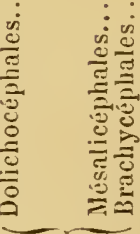

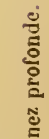

告

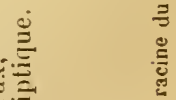

-

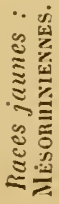

要 
RACES BLANCHES. - Le groupe des races blanches ou leptorhiniennes est encore désigné sous le nom de type europèen, parce qu'il est principalement répandı en Europe; on l'a appelé aussi race caucasique, parce qu'on suppose que c'est dans la région située au sud du Caucase qu'il a pris naissance.

Les races blanches peuvent ainsi se caraclériser : la peau reste toujouls blanche chez les enfants; elle peut devenir grisàtre chez les adultes ou se basaner par soll exposition à l'air. Les cheveux sont souples, flottants, ondés, ondulés ou mème bouclés; la barbe est abondante, ainsi que les moustaches et les favoris. Le nez est étroit et saillant, à pointe ferme. Le prognathisme est à son minimum (orthognathisme); l'ensemble des màchoires et des dents, vu de profil, forme presque une ligne droite. La bouche est petite, les lèvres minces. Les dents sont droites et serrées.

Le type anglo-seandinave, kymri ou blond, est caractérisé par des yeux bleus ou clairs, des cheveux blonds et une peau rosée ou fleurie. De même que les autres types, il ne se rencontre nulle part à l'état de pureté, mais il prédomine sur certains points, notamment en Europe. Il est surtout concentré en Islande, en Scandinavie (la Laponie exceptée) et en Écosse, "puis dans le reste des Iles Britanniques, en Danemark, Hollande, Belgique, dans les plaines de l'Allemagne, dans le nord et l'est de la France».

Les blonds sont dolichocéphales et de haute taille. Ils se sont montrés, vers l'an 300 av. J.-C.; sur les frontière's d'Égypte; vers l'an 800, ils ont envahi la còte atlantique de la Gaule, et sans doute les Iles Britanniques. "Plus tard, on les retrouve sous le nom de Gaulois, lancant des expéditions en Grèce, en Asie Mineure, en Lombardie, à Rome; puis sous celui de Belges, de Kymris, de Cambriens, de Bretons, de Germains, de Francs. "

Le type fimois le plus connu a pour principaux caractères des yeux gris ou verts, des cheveux roux ardent ou jaune rougeàtre, passant quelquefois au chàtain cendré, et une peau souvent maculée de taclies de rousseur. Il se rencontre dans le nord de la Russie.

Le type méditerranéen appartient, par les divers éléments de sa coloration, au type brun, qui est " caractérisé par des cheveux el des yeux noirs, et par ce genre de peau dite brune, qui, exposée à l'air, prend aisément une belle teinte bronzée ".

Les Méditerranéens sont les plus petits des Européens, en mettant toutefois à part les Lapons, dont la taille est encore de beaucoup inférieure à la leur. Ils sont dolichocéphales comme les précédents. On comprend dans cette race les Hispano-Portugais, les Italiens, les Siciliens, les Maltais, les Sardes, les Corses et les Berbers.

Le type sémite, auquel se rattachent les anciens Assyriens, Syriens, Phéniciens et Carthaginois, comprend aujourd'hui les Arabes et les Juifs. Le front est droit, mais peu élevé; le nez est aquilin ; les yeux sont noirs, en forme d'amande, avec de longs cils noirs; les cheveux et la barbe sont noirs et lisses; la peau se bronze facilement.

On tend à rapprocher des Sémites les Égyptiens, qui, comme eux, sont bruns el mésaticéphales.

Le type celtique a pour point de départ une population brachycéphale, sédentaire et agricole, venue dans nos régions avec la civilisation de la pierre polie. Il se rencontre aujourd'hui, plus ou moins atténué par le croisement, 
sur plusieurs points de la France, notamment en Auvergne, en Savoie et dans la Basse-Bretagne. La peau est souvent terue ou grisitre; les yeux sont en général verditres, gris ou marron ; les cheveux sont chàtain clair ou cendrés, moins beaux que ceux des lymris. La taille est moyenne.

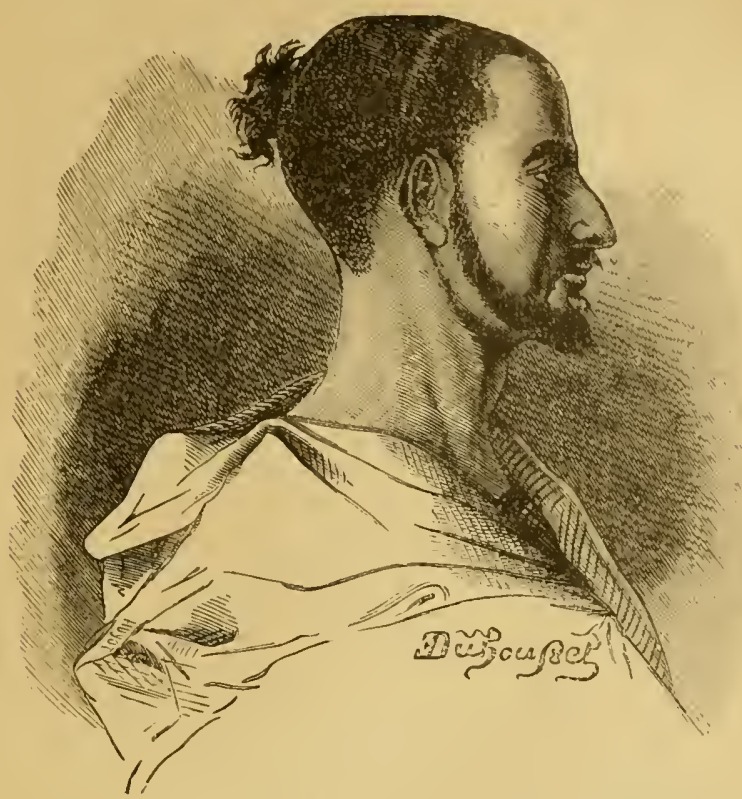

Fig. $889,-$ Type arabe d'Algírie.

Entre la France centrale et la Russie, s’étend, à travers les Vosges et la Forèt-Noire, une vaste nappe de brachycéphales, qui se poursuit mème jusque dans l'Asie centrale, chez les Galtchas. On peut donc raltacher au type celtique les Slaves, qui toutefois en diffèrent par la langie. On sait que les Slaves compremnent les Russes, Polonais, Serbes, Bulgares, Tchèques, etc.

Le type lapon est circonscrit dans les parties les plus septentrionales de la Norvège, de la Suèue et de la liussie. "Les Lapons sont de trés pelite taille et de chétive apparence. Ils ont la tète grosse, la poitrine large, la taille grèle, les jambes courtes, les extrémités fines. Leur front est large et bas, ainsi que leur face. Ils ont les yeux grands, bruns et profonds; le nez court et plat, très large à la racine; les cheveux durs, courts et noirs et peu de barbe; le teint pâle suivant les uns, jaune brun suivant les autres; les pommettes saillantes, le menton pointu. "Leurs paupières sont fendues obliquement. Ils sont brachycéphales.

Dans l'Italie septentrionale, au niveau du golfe de Gênes, on retrouve une population également braclycéphale et de petite taille, dont on a fait quelquefois une race à part, sous le nom de Ligures, et qui parait deroir se rapprocher de la précédente.

Parmi les types bruns, il nous faudrait encore signaler : le type iranien ou, si l'on veut, la branche iranienne de la famille linguistique aryenne, compre- 
nant les Aryens, qui sont demeurés en arrière au moment de l'émigration effectuée vers l'Ouest (Tadjiclis de la Perse, Arméniens, Kourdes, Géorgiens, Afghans bruns, etc.); le lype hindou, représenté dans l'Inde par les Radjpouts et surtout par les Brahmanes les plus vénérés de Mattrá, de Bénarès et de Tannesar; le type tsigane, représenté par cette population nomade à laquelle on applique les noms de Bohémiens, Gitanos, Gypsies, etc. Les Tsiganes, qui habitaieut l'Inde il y a mille ans, errent aujourd'hui par toute l'Europe.

RACES JAUNES. - Le type de coloration des races jaunes ne diffère pas d'une facon très sensible du lype brun bien accentué que nous ont fourni, par exemple, les Arabes d'Algérie et les Tsiganes. On ne peut guère le considérer que comme une étape pigmentaire plus avancée. La peau se fonce avec une plus grande facilité encore sous l'influence de l'air; elle offre en outre une addition constante de jaune ou de rouge, parfois de vert. Le corps est plus ou moins glabre. Les cheveux sont gros, droits, raides, à section transversale arrondie, et toujours d'un noir franc; les yeux sont aussi le plus souvent noirs. Ajoulons qu'il convient d'admettre un sous-type de coloration rouge pour les Américains du Nord et un sous-type olivatre pour les Péruviens.

En ce qui concerne l'indice nasal du vivant, les races jaunes sont mésorhiniennes : " nez petit, court, large à la racine, fin à la base, à lobule détaché, comme déprimé entre les deux ailes, à arète dorsale à peine indiquée ".

Le type mongol ou des races jaunes d'Asie comprend les populations

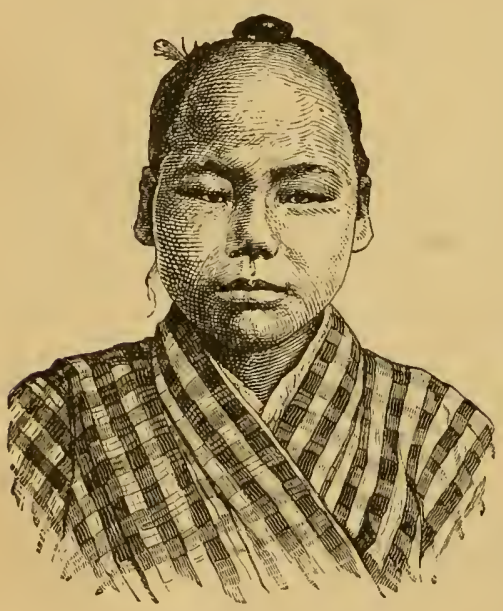

Fig. 890. - Japronais. disséminées à l'est de l'Obi, de la mer Caspienne et du golfe du Bengale; il lire soll nom d'une petite peuplade qui habite les régions sises au nord du désert de Gobi. Il est tout à fai brachycéphale. La peau est blanc jaunàtre, parfois un peu basanée. "La barbe rare, presque nulle aux favoris et au menton, se réduit a deux pinceaux grêles et quelquefois longs à la lèvre supérieure.... La tête est grosse, tantôt élevée, tantòt courte, sa capacité cranienne tenant le milieu eutre celles du nègre et de l'Européen..... La face dans son ensemble estaplatie, comme écrasée dans toutes ses par. ties, et plus large à la hauteur des pommettes, qui sont déjetées en haut et en dehors par leurs bords externe et antérieur. " Ajoutons que les paupières sont fendues obliquement, c'est-à-dire que l'angle externe est plus élevé que l'interne. La taille est nolablement inférieure à celle de la moyenne des Européens.

Le type esquimau est surtout bien caractérisé dans le Groenland, mais on le retrouve aussi dans le nord du continent américain. Il se distingue à 
première vue des raees jaunes asiatiques par son extrème dolichocéphalie. Les Esquimaux sont de petite taille, mais forts et trapus; leur face est aplatie, leurs joues sont pleines, leurs pommettes très saillantes. Leur barbe est presque nulle. Leur teint est d'un gris clair ou foncé.

Le type polynésien ou canaque s'étend des iles Tonga et de la NouvelleZélande ì l'ile de P'iques, dans l'océan Pacificue. Il est mésaticéphale. La taille est élevée; le teint, fort variable, se montre le plus souvent lasané jaunìtre, avec nuélange de bistre. La barbe est rare, les y'eux sont bien fendus, non obliques.

Le type pean-rouge est connu depuis fort longtemps, mais il ne faut pas oublier que ce nom de Peanx-Rouges vient principalement de l'habitude qu'araient les Indiens de se peindre le visage en rouge. Le lype dont il s'agit se rencontre surtout dans le nord de l'Amérique, mais on le retrouve aussi, plus ou moins mélangé, dans l'Amérique méridionale. La teinte générale de la pean est cuivée, brique ou camnelle. Les cheveux sont longs el rigides comme des crins de cheval; les sourcils sont épais, mais la barbe et les mouslaches sont rares. La fente palpébrale est variable. Les narines sont dilatées, les pommettes saillantes, les mìchoires un peu prognathes, les dents verticales. La taille est au-dessus de la moyenne.

Sigrualons, en outre : le type patagon ou tehuelche, comprenant des individus dolichocéphales à peau brun rougeàtre et de grande taille, confinés dans le sud de l'Amérique; le type guarani, égalemeut sud-américain, mais brachycéphale, moins grand, à teinte variant du rouge au jaune; le type péruxien, brachycéphale, à peau olivâtre et de petite taille; etc.

RACES NOIRES. - Les races platyrhiniennes ou noires se reconnaissent, en dehors de l'indice nasal, ì leur type général de coloration. Les cheveux

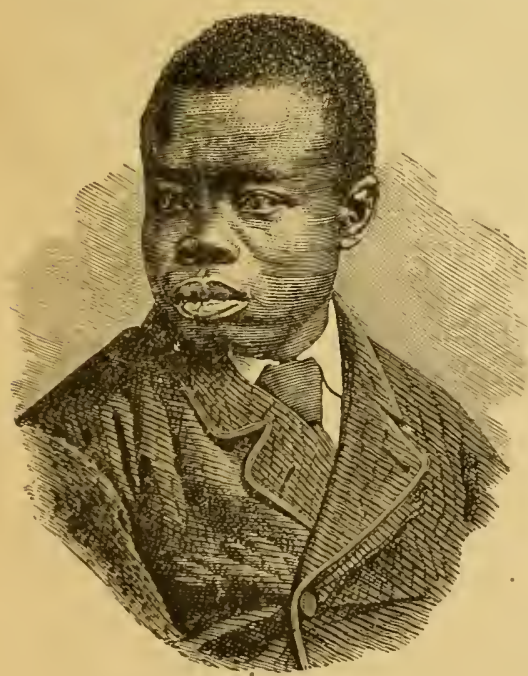

Fig. 891. - Nigre difrique. et les yeux sont noirs; la peau est noir bleuâtre et parfois même noir de jais, mais dans certains cas tend a passer au brun, au rougeâtre et au jaunâtre. D'autre part, les cheveux sont tantòt crépus, laineux, å coupe elliptique, ce qui caractérise les races nègres d'Afrique et d'Océanie, tantôt droits ou frisés, à coupe ovalaire, conme chez les Australiens.

Le nez est toujours large, plat et court, mais offre deux types assez listiucts : le mélanésien et le nègre d'Afrique. "Chez le type mélanésien, dont la plus haute expression s'observe chez l'Australien et le Tasmanien, la base est lourde, massive, boursouflée, à ailes très développées, épanouies; tandis que le type d'Afrique est relativement petit et fin, et se rapproclie un peu de quelques types des races jaunes."

Le type guincén peut fournir la caracléristique générale du nègre d'A fri. 
que. "La peau du nègre est veloutée, fraîche au toucher, luisante, et varie du noir rougeàtre, jaunàtre ou bleuàtre au noir de jais. Ses cheveux et ses yeux sont noirs, sa sclérotique lerne ou jaunâtre; des laches noires se voient sur sa langue, son voile du palais et mème sons la conjonctive. Les parties génitales sont plus foncées, le dedans des mains et la plante des pierls sont plus clairs. La barbe est rare et pousse tard. Le corps est dépourvu de poils, sauf au pubis et aux aisselles. Le cràne est dolichocéphale... Les globes oculaires sont à fleur de tète et les fentes palpébrales, néanmoins petites, sur une même ligne horizontale... Le nez est développé en longueur aux dépens de sa saillie; sa base, grosse et écrasée, par suite de la mollesse de ses cartilages, s'épanouit en deux ailes divergentes, à narines elliptiques plus ou moins découvertes. Les oreilles sont petites, arrondies, à contour mal oullé, à lobule court et peu détaché. " Le prognathisme est très accusé; le menton s'efface et les dents se projettent obliquement en avant: ces dents sont plus écartées les unes des autres que dans les races blanches. Les cheveux sont crépus, à coupe elliptique; ils forment une véritable toison (ériocomes). Les courbures du rachis sont moins prononcées, le mollet moins développé, le gros orteil plus court que dans les races blanches.

"Les négresses sont vieilles de bonne heure; leurs seins s’allongent dès la première grossesse el deviennent flasques

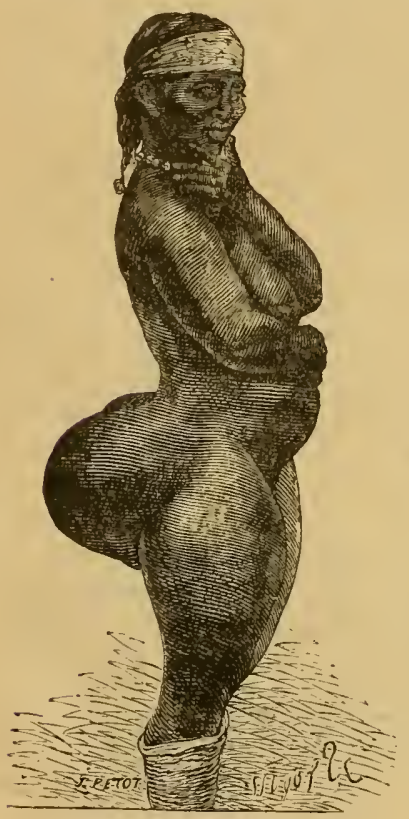

Fig. 89ะ. - Femme boshimane. et flottants. Leurs nymphes, même avant toule gestation, prennent un grand développement, ce qui a engendré la pratique très répandue de leur circoncision. "

Le type boshiman est représenté aujourd'hui par les groupes de familles nomades qui vivent dans le désert de Kalahari, situé immédiatement au nord du fleuve Orange. Traqués comme des fètes fauves par les peuplades qui les entourent, Cafres, Ilottentots, etc., les Boshimans ne tarderont sans doute pas à disparaître. Ils sont tous de petite taille. Leur peau est d'un jaune sale (cuir neuf). Leurs cheveux laineux, fortement roulés en spirale, s'accrochent les uns aux autres et forment de petites boules de la grosseur d'un grain de poivre, laissant des intervalles qui semblent plus clairs (lophocomes). Ils sont dolichocéphales et fort prognathes. Leur nez est affreusement épaté; leur bouche est munie de lèvres épaisses et retroussées; leurs oreilles sont grandes et sans lobule; leurs pommettes sont très saillantes. Le système pileux est très développé.

Mais, ce qui est surtout remarquable daus ce type, c'est la constance (1) de deux jarticularités de conformation connues sous le nom de stéatopygie

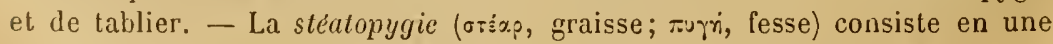

(1) Bullet. de la Soc. zoolog. de France, 1883. 
hypertrophie extraordinaire du pannicule adipeux de la régrion fessière, qui donne lieu à une masse tremblotante formant une saillie parfois énorme. La stéatopygie est particulière au sese féminin; elle apparait dès l'enfance, mais s'exagère probablement lors de la puberté. - Quant au tablier, cncore appelé voile de la pudeur, il résulte d'une simple hypertrophie des nymphes et du capuchon du clitoris, formant une sorte d'appendice vulvaire qui lombe entre les cuisses; par contre, les grandes lèvres sont plus ou moins effacées, et le mont de Vénus est tout à fait déprimé.

Ces particularités se rencontrent aussi quelquefois clıez les flottentotes; mais on sait aujourd'hui que les Hottentots ne constituent pas une race distincte, et qu’ils résultent sans doute du mélange des Boshimans avec diverses variétés de Cafres.

Le type papou ou mélanésien est répandu dans toute la Mélanésie, l'Australio exceptée. La peau est noire ou chocolat; les cheveux sont noirs, secs, crépus, et prennent le caractère ébouriffé, ou en vadrouille. La barbe et les poils du corps sont très développés. Le cràne est dolichocéplıale, le nez gros et large à la base, mais saillant et recourbé ; les lèvres sont épaisses; le menton est saillant, le prognathisme bien accusé.

Les Néo-Calédoniens se rattachent au type papou, mais ils sont mélangés de polynésien.

Le type australien se distingue à première vue des autres races noires par la présence de cheveux lisses, ondulés, bouclés ou frisés, mais non crépus. Leur coupe est ovalaire. Le système pileux est du reste fort développé sur tout le corps; les cheveux et la barbe sont longs, touffus et noirs. Le teint est noir foncé, tirant parfois un peu sur le rougeâtre. Les yeux sont noirs et profonds; le nez est gros et large à la base, mais moins écrasé que chez les nègres d'Afrique. Les Australiens sont fortement dolichocéphales et prognathes; en outre, nous savons déjả que leur capacité cranienne est très faible.

Signalous enfin le type tasmanien, mésaticéphale, à peine plus prognathe que les types européens, et à cheveux crépus, limité à la terre de VanDiémen; et le type négrito, brachycéphale, de petite taille, à cheveux laineux et à teint noir, représenté actuellement par les Mincopies des iles Andaman, les Semangs de Malacca et les Aëtas des Pliilippines. 


\section{TABLE ALPHABÉTIQQUE DES MATIEKRES}

l.es noms latins sont imprimis en italique.

A

Abajoues, 1080.

Abdomen (Arthropodes), 594.

Abdominaux (Poissons), 951, 96i.

Abeilles, 865 .

Ablette, 967 .

Abomasus, 1116.

Abramis brama, 967.

Absorbant (Système), 201.

Acalèphes, 195.

Acalyptérẻs, 780.

Acanthia, 8:0;-ciliata, 821;-columbavia, 821; - hirundinis, 823;-inodora, 823 ; - lectularia, 820 ; - rotundata, 822 ; - pipistrelli, 82:.

Acauthiadés (Acanthiadæ), 819.

Acanthianés (Acanthianx), 820 .

Acanthias, 960.

Acanlhobdellidx, 577.

Acanthocéphales, 385 .

Acanthocystis, 120.

Acanthometra, 121; - lanceolata, 121.

Acanthophorus, 544: - teunis, 545.

Acanthopsidés (Acanthopsilla), 967.

Acanthoptères, 971; - abdominaux, 971 ;

- jugulaires, 974; - thoraciques, 971.

Acanthoptérygiens, 962,971 .

Acanthums chirurgus, 974.

Acare des regains, 701 .

Acares, 625.

Acariase chorioptique auriculaire, 676 ; - dermanyssique, 720 ; - psoroptique auriculaire, 671; - du Rouget, 701.

Acaricides, 647.

Acarides, 625.

Acariens, 614, 624 .

Acarina, 631.

Acarocécidies, 632.

Acaropsis Mericourti, 696.

Acarus, 625; - ægyptius, 710; - autumnalis, 700; - Crossi, 691; - domesticus, 688; - dysenlerix, 691; - eruditus, 696;-farinæ, 690 ; - folliculorum,
631; - gallinæ, 719;-lirundinis, 722 ; - holosericeus, 700; - horridus, 691; - humanus subculaneus, ti4s; - marginatus, 715 ; - nigua, $714 ;-$ realuvius, 706, 708; - reflexus, 715; - reticulatus, 713; - ricinoides, 708; ricinus, 706, 708; - scabiei Auct., 640; - scabiei de Gasp., 670; - scabiei equi Wils., 668; - - tritici, 69t.

Accessoires (Animaıx), 67, 81.

Accidentel (Hôte), 70.

Acclimatation, 86 .

Acéphales, 901, 90'

Acéphalocyste, 264.

Aceratherium, 117.5.

Acerina cernua, 972.

Acétabulifères, 927 .

Achalinoptères, 851, 860 .

Acherlostomi (Ieterakis), 409.

Achéronties (Acheronlia), 860;-Atropos, $860,871$.

Acheuléenne (Époque), 122

Achrou grisella, 853, 871 .

Achromatine, 12.

Achtère (Achtheres), 606 ;-percarum, 604 .

Acipenser, 962 ; - slurio, 962.

Accelomates, 110.

Acon, 912.

Acoustique (Nerf), 31 .

Acraniens, 929, 933.

Acraspèdes, 193.

Acrididés (Acridid $x$ ), 881.

Acridophages, 882 .

Acrodoutes, 1013.

Actinies (Actinia), 192 ; - coriacea, equina, 192.

Actinophrys sol, 120.

Actinospharium Eichorni, 120.

Actinozoaires, 110, 189.

Adaptation, 59.

Adécidués, 1090.

Adelea, 132.

Adhérents (Palpes), 626 .

Adipeuse (Nageoire), 950. 
Alipeux (Corps), 600 ; - ('Tissu), 16.

Adjack, $119 \%$.

Adultes (Organismes), 56 .

Aiventive (Nymple), 687.

Egoceros l'allasi, 11:9.

Epyoruis (Apyornis), 1031.

Aérieme (V'essie), !5j.

Aschmes (Eschna), sso.

Agamis, 10'?.

Agamodistomum, 376.

Aganonema cysticum, $\$ 20$.

Ages (Homme), 1226 .

Aglossa pinguinalis, $8 \mathbf{3} 3$.

$\Lambda$ glusses (Batraciens), 985.

Aglyphoulontes, 1102 .

Agueau, 1132.

Agnoslus, 611 .

Agouti, 118'.

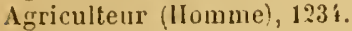

$\Lambda$ grious (Agrion), sso.

Agriotes (Agriotes), 897 ; - lineatus, obscurus, sputator, s.js.

Agromyza nigripes, iso.

Agrolis infusa, segetum, $853, \mathrm{~s} 63$.

Ai, 1096.

Aigles, 1066 ; - de mer, 961 .

Aiguillat, 260 .

Aiguille de mer, 963.

Aiguillon, 863,876 .

Aiguillonuier, 899.

Ailerons de Requins, 961 .

Aire géographique, 103; - germinative, $9: 6 ;$ - stigmatique, 704.

Aires ambulacraires, 200 ; - cirières, 87 if - interambulacraires, 200.

Akamushi, ;03.

Akis spinosa, 895 .

Alakurt, 809.

Alaurla, 1061, 1063; - arborea, arvensis, calandra, cristala, 1063.

Albatros, 10 il.

Albumen, 102i.

Albumine-venin, 995 .

Albuminipares (Glandes), 225, 322, 351 . Alburnus lucidus, 967.

Alca, 1032.

Alcedo, 1061.

Alces, 1126.

Alcyonaires, 191.

Alécithes (OEufs), 47, 51.

Alectoridés (Alectoridæ), 1042.

Aleurobies (Aleurobius), 688, 689 ; - farinæ, 689.

Alevin, 958 .

Alignements, 1232.

Alimentaires (Animaux), 67, 80 .

Allantiasis, 79 .

Allautoücle, 947 .

Allantoïdiens, 9:8, 9;9.

Allantonema, 556 .

Alligator, 1015.

Allobophora folida, 30\%.
Alloptes, 68:2.

Alopicoüles (Alopecoida), 1198.

גloses (Alosa), 966 ; - finta, sardina, vulgaris, $96 \mathrm{t}$.

Alouates, 1222.

Alouelles, 1061, 1063.

Alpaca, 1120.

Allica (Voy. Hallica), $88 \pi$.

Altises, 887.

Alucite des céréales, 852.

Alucilidx, 852.

Alvealina, 119).

Alyselminlhus pectinatus, $283 ;-$ plicatus, 279.

Alyte (Alyles), 9S5; - obstelricans, 9S5.

Amandes de mer, 914.

Amares (Amara), 900 .

Amblyomma, 711).

Amblyporles, 1101.

Amblystomum mexicanum, 932.

Ambre gris, 1099.

Ambulacraire (Sýstème), 199.

Ambulacraires (Cavilés sous-), 201.

Ambulacres (Acariens), 626 .

Ame (Plume), 10 !9.

Amélaboliens, 740.

Amibes (Amiba), 116 .

Amibocytes, 21 .

Ammocates brinchialis, 960 .

Ammodyle (Vipère), 1010.

Ammoniles, 927; - Iumphriesianus, 327.

Ammophila, S6't.

Amniens, 94\$, 949.

Amnios, 9 i⿱.

Ammotragus tragelaphus, 1129 .

Amœbes (Amœba), 116:-b!atlarum, 11i; buccalis, 118; - coli, 116;-crassa, 116 ; - croupogena, 148; - dentalis, 118 ; - Jelaginia, 117; - parasitica, 118 ; - princeps, 116, $118 ;-$ radiosa, $116 ;-$ raginalis, 118 .

Amobiens, $115,116$.

Amorphozoaires, 110.

Ausphacanthes (Ampliacanthus), 074.

Amphibiens, 9 i6.

Amphibies, 1192.

Amphibioticues, Si9.

Amphibos, 113 !.

Amphicoliques (Vertèbres), 935.

Amphigyrinidés, 979.

Amphilina, 33\%.

Amplioxus lanceolatus, 933.

Amphipnoüs, 955.

Amphipodes, 605, 606.

Amphiplyches, 332.

Amphislisena, 1013.

Amphisbéniens, 1013 .

Amphistomes (Amphistomum), 376; bolhriophoron, 37\%; - Collinsi, 37T;conicum, 376; - crumeniferum, 378;

- explanalum, 3iт; - hominis, 378; 
- lunatum, 378; - Stanleyi, 378 ; tuberculatum, 377.

Amphislomidés (Amphislomidx), 338 , 376.

Amphiuma, 982.

Amynodon, 1175.

Anabas, 955, 971.

Anacanthiens, 967.

Anales (Glandes, Insectes), 738 .

Analges, 682.

Analgesæ, 682.

Analgésinés (Analgesinæ), 639, 681 .

Anallantoïdiens, 949.

Analogies, 25.

Analogues (Théorie des), 25.

Anamniens, 948, 919.

Anas, 1037; - actela, 1037; - boschas, 1037, 1038; - b. domestica, 1038; casarca, clangula, clypeata, crecca, ferina, fuligula, fusca, galericulata, marila, mollissima, 1037; - moschata, 1037, 1039; - m. domestica, 1010;nigra, Penelope, querquedula, sponsa, strepera, tadorna, 1037.

Anasicudion, 682.

Anatidés (Anatidæ), 1032.

Anatifes, 605 .

Anatinés (Anatinæ), 1032, 1037.

Anchilophes (Anchilophus), 1150 ; - Des maresti, 1150.

Anchippus, 1151.

Anchithériums (Anchitherium), 1151; aurelianense, præstans, ullimum, 1151.

Anchois, 965.

Anereurs (Palpes), 626.

Ancyles (Ancylus), 922.

Anirena, 866.

Androclones (Androctonus), 728 ; - austratis, funestus, 728.

Andryas (Andrya), 283; - cuniculi, pectinata, wimerosa, 283.

Anémie des briquetiers, 470; - des Chats, 473; - des Chevaux, 463; - des Chiens de meute, 473, 474; - intertropicale, 470 ; - des mineurs, 470 ; des Montons, 441, 464; - pernieieuse progressive, $165,469,473$.

Anémone de mer, 192.

Anes (Asinus), 1164, 1166; - domestiques, 1167.

Anesse, 1168.

Aneuriens, 208.

Anévrysmes vermineux, 460 .

Ange, 960 .

Angiostomidès (Angiostomidx), 556 .

Angiostomum, sā6; - nigrovenosum, 55 . Angle facial, $1071,1236$.

Anglo-s sandinave (Type), 1240.

Anguilles (Anguilla), $96 \%$; - de mer, 964 . Anguilles de haies, 1003.

Anguillules (Anquillula), 549; - aceti, $519 ;$ - intestinalis, 558; - scandens,
553 ; - stercoralis, 558 ; - tritici, 553 ;

- vivipara, 549.

Anguillulidès (Anguillulidæ), $5 \mathbf{4 8}$.

Anguillulines (Anguillulina), 553; - devastator, 554; - putrefaciens, 55' ; tritici, 553.

Anguis, 1013; - fragilis, 1013.

Animalité, 8.

Anisolabis annulipes, 881.

Anisoplies (Anisoplia), 898.

Ankylostomes (Ankylostomum), 46i; duvdenale, 465.

Ankylostomose, 469.

Anneau du diable, 854 .

Aunelés, 110.

Annélides, 208, 575.

Anoa, 1139.

Anobium, 896.

Anodontes (Anodonta), 91;; - cygnea, 914.

Anomies (Anomia), 911.

Anou, 1168.

Anopheles maculipennis, 799.

Anoplocéphales (Anoplocephala), 279:cunicuti, 283;-magna, 279: - mamillana, 282; - pediculata, 280; - perfoliata, 281; - plicatu, 279;-restricta, 281 ; - strangulata, 280 ; - Vogti, 284; - wimerosa, 283.

Anoplocéphalinés (Anoplocephalinx), 268.

Anoplotæniæ, 268.

Anoploures, 823.

Anoures, 981, 985.

Anser, 1034; - albifrons, 1034, 1036; canadensis, 103i; - cinereus, 1034; cin. domesticus, 1035; - cygnoides, 1037 ; - pallipes, 1036; - sylvestris, 1034 .

Ansérinés (Anserinæ), 1032, 1034.

Intedon, 202.

Autennes, 30, 59\%.

Antenuiformes (Palpes), 6?6.

Anternophorinæ, 718 .

Antennules, 602.

Anthomyies (Anthonyia), 781;-brassicæ, conformis, 781 ; - pluvialis, 782 .

Anthomyinés (Anlhomyinæ), 781.

Anthonomes (Anthonomus), 890; - pomorum, 890 .

Authophores (Anthophora), 861, 866; pilipes, 891.

Anthozoaires, 189.

Anthrèues (Anthrenus), $899 ;$-museorum, 899.

Anthropoides, 1223.

Anthropologie, 1223.

Anthropomorphes, 12:3.

Anthropops, 1222.

Anthus, 1063 ; - aquaticus, arboreus, pratensis, 1063.

Antilopes, 1128.

Antilopinés (Antilopinæ), 1128. 
Antimeres, :7.

Antipithes, 19:.

Antipsuriques, $64 i$.

Allus, 35. 36.

Inymphale (Métanorphose), 630.

corte, 9 i3.

Soùtal, Aon̂ti, iol.

Apéréa, 1185.

Aphaniptires, $i 99$.

Aphidés (Iphidie), 811 .

Iphis, s11; - massice, chinensis, fabx, granaria, 812; - muli, persica, 811;pistuciap, \$12: - sorbi, 811 .

Aphodics (Aphoulius), 898.

Aphrodites, 593 .

Aviculture, 869 .

Apidés (Apidæ), 865.

Apinés (Apinze), 867.

Apious (Apion), 890 ; - apricuns, 890.

Apis, 86i; - fusciatu, 878; - ligustica, 878; - mellifica, 867, 877; - unicolor, 878.

Aplysies (Aplysia), 919 ; - depilans, 919.

Apoblema, 341 .

Apodèmes, 595; - articulaires, 735.

Apodes (Poissons), 951, 964 .

Apophyses des vertèbres, 935 ; - uncinées, 1017.

Appareil, 26.

Appendice, 594.

Appendicutaire (Squelette), 93i.

Appendiculariés, 932 .

Apprivoisement, 82 .

Aptenodytes, 1032 .

Aptères (Hémiptères), 823 ; - (Insectes), i36.

Aptèrygidés (Apterygiule), 1031.

Aptéryx (Apteryx), 1031; - custralis, Oweni, 1031 .

Apus, 605.

Aqueduc de Sylvius, 9:0.

Aqueuse (Humeur), 9 \&.

Aquifère (Appareil), 199.

Aquifères (Vaisseaux), 39.

Iquila, 1066; - fulva, imperialis, 1066.

Arabe (Type), 1241.

Arachnides, $(j 01,61$.

Arachuoïle, 938 .

Arachnoïdieu (Liquide), 938.

Arachuologie, 593.

llagua, 97 .

Araiguće de mer, 610 .

Araiggnóes, 729.

Aranéides, 614, 729 .

Alapèdes, 920 .

Aras, 1061.

Arc hémal, 935; - neural, 935.

Arcachou (lluîtres), 907.

Arcalés (Arcaulz), 914 .

Arcelte, 118.

A'chxopteryx, 1029.

Archar, 1 1 29.

Raillier. - Zoologie.
Arehentéron, 51 .

Archéologie préhistorique, 1226.

Archiamnélides, 577.

1rchigeles, 332 .

Archigonie, 41.

Arcs aortiques, 943; - branchiaux, 936 .

Aictiscon, Gl4.

Arctomys, 1179.

Arctopithiques, 1221

Arclea, 1042.

Arex porosie, 0 it.

Arénicoles (Arenicola), $592 ;-$ piscutorum, 592.

Irêtes, 9 «9.

Argalis, 1129.

Argas (Argus), 715: - americanus, 718; - chinche, 718 ;-coniceps, 717 ;-coriaccus, 718 ; - Fischeri, 718;-Hermanni, 718 ; - marginatus, 715; - mauritiunus, 718; - Megnini, 718; - moubute, 718 ; - persicus, 73, 718; - valiutus, 718 ; - reflexus, 73, 715; - Savignyi, 718; - taluje, 718; - Tholozani, 718; - turicata, 718.

Argasinés (Argusinx), 70t, 715.

Algonautes (Argonauta), 928 ; - argo, 928.

Argules (Argulus), (306.

Argus (Argus), 1051.

Argyronète (1rgyroneta aquatica), 730.

Ariciu, $\mathbf{7 8 1 .}$

Arilus serralus, 819.

Arions (Arion), 922; - empiricorum, 92:.

Arkal, 1129.

Armadille officinal (Armadillo officinalis), 606.

Armoricaines (Iluîtres), 907.

Armure génitale, 736,740 .

Arni, 1140.

Aroui, 1129.

Arpenteuses (Chenilles), 853.

Arrêt (Chieus d'), 1199.

Irrhénotocie, 868 .

Arsclin, 974.

Artemia, 605 .

Artèmis, 914 .

Artères, 37.

Athropodes, 110, 593.

Articulés condylopodes, 593; - (Brachiopodes), 575 .

Artiodactyles, 1091, 1101.

Artiozoaires, 110.

Irvicola, 1182; - agrestis, amphibius, urvalis, 1182.

Arvicolidés (Arvicolidx), 1 181.

Ascaltis, 186; - Gegcrïbauri, 18.

Ascarides (Ascaris), 392, 477 ; - alata, 402;- - apri, 432; - caniculæ, 402; conis, 419 ; - cati, 402; - columbre, 406; - compar, 408 ; - conosoma, 782; - crassa, 405; - clispar, 408 ; - equorum, 102 ; - felis, 402 ; - filicollis, 412: 
- funiculus, 406; - gallopavonis, 406; - inflexa, 406; - lagopodis, 408; lumbricoides L., 393; - lumbricoides lirisch, 585 ; - maculosa, 406 ; - marginala, 402, 403; - maritima, 405; martis, 419;-megalocephala, 402;-mucronata, 447 ; - mystax (canis et cati), 402, 403; - ovis, 400; - papillosa, 40i; - pellucida, 525; - perspicillum, 406; - renalis, 419 ; - stephanosoma, 789 ; -suilla, 400;-sum, 400 ; - trichiura, 478; - tricuspidata, 402; - vermicularis, 409; - vesicularis, 407: - visceralis, 419; - vituli, 430.vitulorum, 401; - Werneri, 402.

Ascaridés (Ascaridæ), 392.

Ascella, 186.

Ascidia, 932.

Ascidiacés, 932.

Aselles (Asellus), 606; - aquaticus, 596.

Asexuelle (Reproduction), 41 .

Asiles (Asilus), 791 ; -crabroniformis, 791 .

Asilidés (Asilidx), 791.

Asiniens, 1160, 1164, 1165.

Asinus, 1166 ; - africanus, 1167;equioides, equuleus, indicus, polyodon, somalicus, somaliensis, tzniopus, $t$. var. somaliensis, 1166.

Asiphonidés, 90 .

Asopia farinalis, $\$ 53$.

Aspic commun, 1007 ; - de Cléopâtre, 1004. Aspidobutlıridæ, 334 .

Aspidocotylés, 334 .

Aspirotriches, 175.

Asse, 1198.

Assimilation, $3 \dot{4}$.

Association pour la lutte, 64 .

Astacidés (Astacidæ), 608 .

Astacus, 60s; - fluviatilis, nobilis, torrentium, $60 \mathrm{~s}$.

Astérides, 203.

Astéries, 203.

Astéroïdes, 202.

Asticots, 783 ; - à queue de Rat, 791 .

Astigmata, 631 .

Astrocentres, 42.

Astroides calicularis, 189.

Astur, 1066 ; - palumbarius, 1066.

Atẻles (Ateles), 1222.

Ateuchus, 898 .

Atlas, 1072.

Atomaria linearis, 900.

Atropos pulsatoria, 879.

Altacus, 859.

Attagènes (Attagenus), \$99;-pellio, $\$ 99$. Auchenia, 1119; - glama, 1119; - huanaca, 1119; - paco, 1120; - vicugna, 1119.

Auditif (Nerf), 31.

Auditive (Vésicule), 31.

Aulacocephala, 761 .

Aulastomum, 5i8; - gulo, 585.
Aur, 1111.

Aurelia, 55; - aurita, 197.

Aurochs, 1141 .

dustralien (Type), 1245.

Autours, 1066.

Autruches, 1030.

Auxiliaires (Animaux), 67, 80 .

Avant-bras, 93 i.

Avicoles (Sarcoptes), 663.

Aviculaires, 574.

Avicules (Avicula), 911 ; - tarentina, 911.

Aviculidés (Aviculidær), 911.

Axial (Squelette), 934.

Axis, 1072.

Axolotl, 98?.

Axonge, 1112.

Aye-aye, 1219.

Azygos (Veines), 94́.

\section{B}

Babironssa (Babivussa), 1113; - alfurus, 1113.

Bábouins, 1223 .

Baco da seta, 857 .

Bacologie, 856 .

Baculites, $9: 7$.

Balænoptera, 1100.

Balancenent des organes, 25 .

Bulanciers, 736,742 .

Balanes (Balanus), 605 .

Balauoglosses (Balanoglossus), 929 ; - clavigerus, 929.

Balantidiums (Bulantidium), 177, 178; coli, 1 i6, 178.

Balbianias (Balbiania), 133 ; - gigantea. 155 ; - mucosa, Rileyi, 157.

Baleines (Balæna), 1100;- mysticetus, $1097,1100$.

Balistes, 963.

Bancs (Huiltres), 909; - (Poissons), 965. Bande bacillaire, 47\%.

Bandes céphaliques, 834 , \$44; - latérales, 895 .

Bandwurmseuche, 272.

Banteng, 1142.

Bar, 972.

Barbastelle, 121\%.

Barbe (Plume!, 1019.

Barbeau (Barbus fluvialilis), 967.

Barbeaux (Maladie des), 15 .

Barbier, 974.

Barbillou, 967.

Barbillons (Oiseaux), 1051 ; - (Poissons). 951 .

Barbue, 970.

Barbule (Plume), 1019.

Barbus, 1060.

Bardot, Bardote, 1173.

Barges, 42.

Baridius (Baridius), 890 . 
Barillets, 933.

Barres, 10:9.

Barrouxia, 132.

Bartavelle, 1055.

Bassin, 937.

Bâtardes (Rémiges), 1019

Bathybius Ilacketi, 116.

Bàton de commandement, 1230 .

Bàtomets, 31 ; - (Coque de), 217.

Batrachidés (Batrachicla), 9 if.

Batuchus, 974.

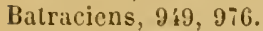

Baudet, 1165.

Baudroie èpiueuse, $97 \dot{\text { f }}$

Baugc, 110 s.

Bdellu, 584; - nilotica, 5s4́.

Bdellalomie, 580 .

Bdellidés (Bulellidæx), 631, 691.

Bdellinde, 69 .

Bileltorhynchus, 682.

Bec, 1021.

Bécasseaux, 1042.

Bécasses, 1042.

Bécassines, 1042 .

Becs-croisés, 1063.

Becs-en-ciseaux, 1041.

Becs-fins, 1063.

Bécuues, פĩl.

Bèdegars, 863 .

Beden, 113 .

Belemitella, 928.

Belemnites, 928; - aculus, hastalus, 928 .

Belette, 120:.

Bèlier, 1132.

Bélisaires (Belisarius), $729 ;-X u m b e u i$, 729.

Belone acus, caribra, vutgaris, 970.

Bembex, s6t.

Benchuca, 819 .

Bengalis, 1063.

Berceau, 103.

Bergerounctles, 1063.

Beruaches, $103 \dot{x}$.

Berne, $\because \%$.

Bernicla, 103\%.

Bervicles, 920 .

Beroés, 199.

Bête à bon Dieu, 887 ; - d'août, 701 ; noire, 1107 ; - rouge, 701 ; - rouge de la Martinique, $703 ;$ - rousse, 1107. Bézoaris, 1135.

Bibos (Bibos), 1141; - elatus, etruscus, 1141; - frontalis, gaurus, gavæus, gr unniens, indicus, patrogaurus, sondaicus, 1142.

Bibovins (Bibuvina), 1139.

Bicho berue, 779 .

Bicho colorado, 699 .

Bicho do mar, 205.

Bichuque, 819 .

Bicuspide (Valrule), 1081.

Biesen des Rindes, 768 .
Bievres, 1179.

lig-horn, 1130.

bigolneaux, 920 .

Bijumeaux (Tubercules), 1020 .

Bilharzia, 371; - bovis, 375; - crassa. $375 ;$ - hrmalobia, 371; - magna, 373.

Bilharzi-)se, 373.

Bimanes, 122f.

Binymphalt: (IJétamorphose), 630 .

Bious arpus, ronds, 920 .

Biphores, 933.

Bipolaires (Cell. nerv.), 19.

Bischarin, 1021.

lBiset, 10;0, 1057 .

Bisous (Bison), 1111;-Alleni, americanus, untiquus, europrus, ferox, latifrons, miscus, sivalensis, 1141.

Bisontins (Bisontina), 1139.

bisulques, 1091, 1101.

Bitis arietans, 1012 .

Bivalves, 90 ' .

Bivoltiues (Races), 8.59.

bladdery rabbits, 258 .

Blaireau, 1204 .

Blane de baleine, 1098.

Blanches (Races), 1210.

Blaniulus guttulatus, 733.

Blaps (Blaps), 895 ; - mortisaga, 895 ; mucroncila, 569,896 .

Blastocole, 51 .

Blastoderme, 51.

Blastomères, 50 .

Blastopore, 51 .

Blastula, 51 .

Blattes, 881 .

Blé niellé, 553 ; - rachitique, 553.

Bloud (Type), 1237, 1240.

Boas, 1003.

Bodereau, 97í.

Bollo, 164;-intestinalis, 118;-saltans, I6f; - sociulis, 118 ; - urinarius, 165.

Bouf, 1143; - à bosse, 1142; - de mer, 919 ; - des Stiengs, 1146; - musqué, 1138.

Bogue, 972 .

Bolı́mienne (Période), 1233.

Bois, 1069, 1115.

Bojanus (Corps de), 40, 903, 906.

Bombinator, 985 .

Bombinés (Bombinæ), 866 .

Bombus, 866; - hortorum, muscorum, terrestris, 867 .

Bombycidès (Bombycidæ), Sát.

Bombycinés (Bombycinæ), S54.

Bombyx (Bombyx), S54; - mori, 856; neustria, 85t; - rubi, 855; - quercus, 855 ; - trifolii, 854 .

Bonasus, 1141 .

Bondrées, 1066 .

Bonite à dos rayé, à ventre rayé, 971.

Bonnet, 1116.

Boutequagga, 1170. 
Boophilus bovis, 713.

Bos, 1143; - acutifrons, 1143: - brachycephalus. 1144; - brachyceros, 1143, 1114,1145 ; - frontosus, 1144 ; - longifrons, 1143, 1144; - namadicus, opisthonomus, planifions, platyrhinus, primigenus Boj., 1143 ; - primigenius Ruit, 1143,$1144 ;-$ promigenius mauritanicus, $1143 ;-$ taurus, $1144 ;-t$. alpinus, t. aquitanus, t. arvernensis, t. usiaticus, t. batavicus, t. biachycephalus, t. brachyceros, $t$. calelonicus, $t$. frontosus, t. germanicus, t. hibernicus, t. ibericus, t. jurassicus, $t$. ligeriensis, $t$. primigenius, t. scythicus, 1144;-triceros, 1143 ; - trochoceros, $1143,1144$.

Boshiman (Type), 1244.

Bostrichus, 889.

Bothridies, 315 .

Bothriocéphales (Bothriocephalus), 315 ; canis, 316; - cordatus, 327 ; - cristatus, 325;-decipiens, 316;-dubius, 329 ; - felis, 316 ; - fuscus, 328 ; latus, 315; - tenellus, 324; - liguloides, 327; - longicollis, 329; - Mansoni, 327; - reticulatus, 329 .

Botriocéphalidé du Pigeon, 329.

Bothriocéphalidés (Botriocephalidæe), 315. Bothriocéphalinés (Bothriocephalinx), 315.

Bothrioténias (Bothriotænia), 329;-longicollis, 329 .

Bothrops (Bothrops), 1012 ; - lanceolatus, $1005,1012$.

Botryllus, 932.

Botulisıne, 79, 957.

Bouc, 1136.

Bouche, 35 ; - primitive, 51 .

Bouchon vaginal, 1177.

Bouchots, 912.

Boule d'eau, 229.

Bouquet, 607, 608 .

Bouquetins, I134.

Bourdons, 866 .

Bourgeonuement, 15, 42.

Botirgeons médusoïdes, 194.

Bourre, 1068 .

Bourrelets (OEstridés), 761.

Bourse caudale, 390 , $\$ 18$; - de Fabricius, 1023.

Bouteille, 353.

Boutoir, 1105.

Bouton de la ligulose, 330 .

Boutons hémorragiques, $50 \%$.

Bouvière, 967.

Bouvreuils, 106?.

Bovidés (Bovidæ), 1127.

Boviués (Bovinæ), 1139.

Box vulgaris, 972 .

Brachiopodes, 203, 574 .

Brachocères, 745 .

Brachycéphales, 1236 .

Brachycères, 745 .
Brachycoelizm, $3 \mathbf{4 1 .}$

Brachylaimus, 341.

Brachyptères, 1031, 1032.

Brachyures, 607,610 .

Bracon, 863.

Lradypus torquatus, 1072 ; - tridactylus, 1096.

Branchial (Sac), 933.

Brauchiales (Artères), 953; - (Pattes), 603.

Branchiates, 601 .

Branchiaux (Arcs), 936.

Branchies, 38, 598, 903, 944, 954.

Brauchiobdellidẻs (Branchiobdellidæ), 57 .

Branchiopodes, 605.

Branchiostèges (Rayons), 950.

Branchipus, 605.

Bras (Céphalopodes), 924; - (Vertébrẻs), 936.

Brassempouy (Statuettes), 1229.

Brebis, 1132.

Bréchet 1017.

Brelins, 920 .

Brème, $96 \%$; - de mer, 972 .

Brévilingues, 1013.

Brévipenues, 1030.

Briffe, 757.

Brochet, 966.

Bromius vitis, 889.

Bronches, 944.

Bronchite vermineuse des bêtes bovines, 431; - de la Chèvre, 129 ; - du Chien, 431 ; - des Équidés, $435 ;-$ des Léporidés, 436; - du llouton, ‘29; - du Porc, 433.

Bronze (Age du), 1233.

Brosse, 866 .

Broyeurs (Insectes), $737,7+1$.

Bruants, 1063.

Bruches (Bruchus), 890; - granarius, pallidicornis, pisi, rufimanus, 890 .

Bruchidés (Bruchidæ), 890.

Brun (Corps), 57' .

Brun (Type), $1237,1241$.

Bryozoaires, 208, 573.

Buausuah, 1197.

Bubales (Bubalus), 1139; - antiquus, brachyceros, caffer, 1139,

Bubalins (Bubalina), 1139.

Bubaste, 1212.

Bubo, 1066; - maximus, 1066.

Bucardes, 914.

Buccal (Intestin), 36.

Buccins (Buccinum), 917, 920; - undatum, 920.

Bucco, 1060.

Buceros, 1061 .

Budorcas taxicola, 1128.

Buffalo, 1141.

Buftles (Buffelus), 1139; - indicus, 11'1); indicus var. Arni, 1140;-mindorensis, 1141 ; Nollendorffi, 1141 ; - palsein- 
dicus, 1140; - Pallasi, 11:0; - sondaicus, 1141; - sivalensis, 1140 .

Bufflesse, 1140.

Bufidine, 987.

Bufo, 9S6; - calamila, viridis, vulyaris, 986.

Bugong, 85?.

Bulbe artériel, 952;- le la plume, 1019; - du poil, 1068 ; - rachidien, 910 ; du rostre (Cestodes), 221.

bulla, 5 il.

Bunodonte (Type dentaire), 1103.

Buphaga, 1063 ; - africana, 1063.

Buprestes, $\$ 95$.

Bursaria. 17 i

Bursaridés (Bursaridx), 178.

Busards, 1066.

Buses (Buteo), 1066 ; - vulyaris, 1066.

Buthidés (Buthidlx), 727.

Buthus (Buthus), 727; - 2 neas, 728 ; europieus, 727.

Butschlies (Bülschlia), 174; - lanceolala, negleclu, parva, 174 .

Byssus, 905.

\section{C}

Caballins, 1160.

Caballus, 1160.

Cabeliau, 968.

Cabéru, 1197.

Cabiai, 1185.

Cabillaud, 968.

Cabris, 1136.

Cicatois, 1061 .

Cachalot, 1027, 1098.

Cachexie aqueuse de l'Homme, 470; du Mouton, 353; - seche, 354 .

Cadelle, 900.

Caducichordés, 932.

Caduque, 1090.

Cæc ulinæ, 693.

Ciecum, 1022, 1080.

Cæpophagus, 691; - echinopus, 691.

Cafalds, 881 .

Cailles, 1055.

Caillette, 1116.

Cailleu Tassart, 965.

Caïmans, 1015.

Cairina moschata, 1039.

Calamobie linéaire, 889 .

Calamus (Plume), 1019.

Calandre (Alouette), 1061, 1063.

Calaudres (Calandra), 890; - granaria, oryzze, 890.

Calaos, 1061.

Calcaires (Corpuscules), 210 .

Calcar, 1018.

Calcisponges, 186.

Calice (Câlentérés), 189; - (Oiseaux),
Calicorjuot, 920.

Caliges (Caliquus), 606.

Calleux (Corps), 1075.

Callionymes (Callionymus), 974; - lyra, 97 .

Calliphores (Calliphora), 78:; - anlhropophaga, ist; - erythrocephala, 783; - limensis, 783 ; - vomitorin, 782.

Callithryx, 1222.

Callosités, 1220 .

Calmars, 928 .

Calodium, 485; - plica, tenue, $48 j$.

Calonas, 1059 .

Caloptéryx (Calopleryx), 880; - virgo, 880 .

Cillosomes (Calosomum), 900 ; - sycophanta, 900.

Calymene, 611 .

Calyptérés, isi.

Caméléon, 988, 1013.

Camélidés (Camelidx), 1118.

Camélopardalidés (Camelopardalidæx) , $112 \%$.

Camelopardalis giraffa, 1127.

Camelus, 1120 ; - antiquus, 1120 ; - bactrianus, 1121; - dromedarins, 1121

- Knoblochi, sibiricus, sivalensis, 1120.

Camérostome, 625 .

Campagnols, 1181.

Campylochirus, 685 .

Caual infraorbitaire, 1177.

Canaque (Type), 1243.

Canards, 1037.

Canari, 106?.

Canaux en lacet, 576.

Cancale (Huitres), 907.

Cancer pagurus, 610 .

Cancrelats, $\varepsilon 8 !$.

Candona rostrala, 299.

Cane, 1039.

Canepetière, 1042.

Canestrininæ, 639 .

Canetou, 1039.

Canidés (Canidæ), 1195.

Canines, 1079.

Caninés (Caninæ), 1196.

Canis, 1196; Canis s. str., 1198; adustus, 1198; - alpinus, 1197 ; - anlarcticus, anthus, aurcus, $A$ zarz, cancrivorus, 1198; - Cuutleyi, 1195;chama, corsuc, 1198 ; - Eduardsi, 1196; - etruscus, 1195; - europrus, 1196; - ringo, 1198; - Falconeri, 1195 ; famelicus, 1198; - familiaris, 1198, 1199 ; - f. dingo, 1198 ; - f. inlemedius, f. malris optimx, f. palustris, $f$. Spalellii. [200; - ferus, 1196 ; - fulvus, 119s; - Hibernix, 1200; - Ingæ, 1202; - juvanicus, j. dukhunensis, j. vutilans, jubalus, 1197 ; - lagopns, lalians, lupasler, 1198 ; - lupus, 1196. $1197 ;-$ l. occidentalis, l. pallipes, 1197 ; 
- negastomoides, $1195 ;$ - mesomelas, 1198 ; - Miki, neschersensis, 1196 ; occudentalis, 1197; - pallidus, 1198;pallipes, 1197; - procyonoides, 1198 ; - sabbar, 1201; - simensis, 1197 ; virginianus, vulpes, v. fulva, zerla, 1198.

Canon (Oiseaux), 1018.

Canstadt (Cràne), 12:8

Canthariasis, $\$ 86$.

Cantharides (Cantharis), 891 ; - vesicatoria, 891.

Cantharidés (Cantharidæ), 890 .

Cantharidine, 893.

Capacilé crauienne, 1235.

Capelan, 967.

Capillaires, 37.

Cripillaria, 484

Capitaine, 972.

Capitule, 736 .

Capouri, 9:4.

Capra, 113:3; - iegagrus, 1135; - caucasica, 1131; - dorcas, $1135 ;-\mathrm{Fal}$ coneri, 1134; - hircus, 1135 ; - hispanicr, ibex, jemlaica, nubiana, perimensis, primigenia, pyrenaica, Rozeti, sibirica, sivalensis, 1131 .

Caprella, 606.

Capricorne, 889.

Caprimulgus, $106 \mathbf{1}$.

Caprins, 113:3.

Capsule buccale, 388 ; - centrale, 120; - spermalique, 629 .

Captifs (Animaux), 82.

Carabes (Curabus), 900 ; - auratus, 900. Carabidés (Carabidx), 900.

Caracal, 1212.

Caractères dominateurs, 91 ; - prélominants, 91 ; - sexuels secondaires, 45.

Caramote, 607.

Carangues (Caranx), 972 ; - fallax, 972.

Carapace (Tortues), 1015.

Carasissi, 1198.

Carassins (Carassius), 967; - auralus, git,elio, vulgaris, 967 .

Cấrceag, 127 .

Carcharias, 960 ; - lamia, 961 .

Carcin mémade (Carcinus mænas), 610.

Careinologie, 593.

Carlia, 1080.

Cardinaux (Cardinalis), 1063.

Cardiles (Carlita), 914; - sulcata, 914.

Cardium, 914; - edule, 914.

Carets, 1015.

Carididés (Carididæ), $\mathbf{1 . 0 7 .}$

Carinaria cymbium, 919.

Cariuates, 1029.

Carmin, 810 .

Carnassiere (Dent), 1194.

Carueros linudos, 1138.

Caruivores, 1091, 1193.
Caroncule lacrymale, 1077.

Caronculés (Pieds), 627.

Caroube de Judée, 812 .

Carpe (Poisson), 953, 967.

Carpe (Squeletlc), 937.

Carpocapsa pomonelln, 853.

Carpoglyphes (Carpoglyphus), 688, 659 ; - anonymus, passularum, 689.

Carré (Os), 950, 978, 989, 1017.

Carrelet, 970.

Cartilagineux (Poissons), 959, 960, 962, 9 i6;- (Tissu), 16.

Caryophyllæus, 332.

Cascavella, 1012.

Case, 1098.

Casoars, 1031.

Cassida nebulosa, 887.

Cassidaires (Cassidaria), 920.

Castors (Castor), 1179; - fiber, $11 \% 9$.

Castoréum, 1180.

Castoridés (Custoridar), 11 i9.

Castorine, 1180.

Casuaridés, 1031.

Casuarius, 1031.

Catarhiniens, 1222.

Caloblepas gnu, 1128.

Caucasique (Race), 1240.

Caverneux (Corps), 108 t.

Cavia, 1185; - aperea, 1185 ; - cobaya, 1186 ;-Culleri, 1185 ; - porcellus, 1186.

Caviar, 962, $96 \%$.

Cavicoles (OEstrinés), 7i8, 760.

Gavicornes, 1127.

Cavilé de von Baer, 51 .

Cébiens, 1222.

Cebus, 122:3;-capucinus, 1222.

Cécidomyidés (C'ecidomyidæx), 797.

Cécidonyie (Cecidomyia), 797 ; - destructor, 798; - du froment, 797 ; - nigra, is 8 .

Cecirlophyes, 632 .

Cécilieus, 981.

Ccinture (Hirudinées), 582 ; - pelvienne, 937 ; - scapulaire, 936.

Celienopsinæ, 718.

Cella infra-ocularis, 1016.

Cellulaire (Tissu), 16.

Cellularia, 68'́.

Cellule, 13.

Cellule sous-oculaire, 1016.

Cellules (Ailes des Insectes, 735 ; - 1nusculaires, 18, 886; - oviformes, 130; - royales, $\$ 68$.

Célopeltis, 1003.

Celtique (Type), 1240.

Cément, 1078.

Centetes, 1214 .

Ceutres de création, 103.

Centrolécithes (OEufs), 47, 51 .

Centromc̀res, 27.

Centrosome, 13.

Centrum, 93 ј. 
Cénures, 212, 251.

Cephalemyia, 701 .

Céphalés Mollusques), 904 .

Céphalin, 130.

Cephalobus, 549 .

Géphalochordés (voy. Holochordés).

Céplıalogouimes (Cephalogonimus), 341, 365; - cunealus, 369 ; - ovalus, 368 ; - pellucidus, 369.

Céphalomyies (Cephalomyia), 761 ; - maculala, 766; - ovis, 761; - purpurea, 765.

Céphalophores, 901.

Céphalopodes, 90 i, 923.

Cephaloplera, 961; - giorna, 962.

Céphalo-rachidicn (Liquide), 938.

Céphalothorax, 5\%i.

Cephenomyia, 761 ; - lrompe, $i 67$.

Céphus (Cephus), 86: ; - pygmixus, 86?. 863.

Cérambycidés (Cerambycidx), $8 \$ 9$.

Ceramby $x$ heros, 889.

Cérastes (Cerastes), 1007; - corrutus, 1012.

Ceratiles, 927.

Ceratilis hispanica, 780 .

Ceraloclus, 976.

Cercaires, 336.

Cercaria cystophora, 35i; - Dislomi hepalici, 315,347 ; - echinaloides, 366; - echinifera, 366; - ephemera, 339 ; - flava, 339; - longicaudala, 358; - spinifer $\alpha, 366$.

Lercarigère (Sac), 335.

Cerceris, 864 .

Cercocyslis, 213; - Dicranotreniz coronulx, 303; - Drepanidotxrix analine, 300 ; - Dr. fascialx, 299; Dr. gracilis, 299; - Dr. setigerx, 301 ; - Dr. sinuosæ, 301 ; - Dr. tenuirostris, 301 ; - Echinocotyles Rosseteri, 30я; - Hymenolepialis diminula, 296 ; - H. murinæ, 29?.

Cercolubes prehensilis, 1184 .

Cercomonades (Cercomonas), 163, 166, 169; - acuminata, 118 ; - unatis, 166;-biflagellata, 118; - cunis, 166; - cavia, 166 ; - gallinæ, 166 ; - globulus, $11 \mathrm{~s}$; - hepatica, 166; - hominis, 167 ; - intestinalis Lambl 1859, 169; - intestinalis Lambl 1875, 167;-ovalis, 166 ; - pisiformis, 166 ; - spharica, 166.

Cercomonadidés (Cercomonadicla), 163.

Cercopithécidés (Cercopithecida), 1223.

Cercopithiques Cercopithecus), 12:3.

Cercosomum, 791.

Cérẻbroïdes (Gauglions), 29.

Cérébro-spiual (Axe), 30.

Cérécopses (Cereopsis), 1034.

Cerfs, 1126.

Ceriornis, $105 \mathrm{t}$.

Cérithes (Cerithium),920; - vulgatum, 920. Thélicères, 61?.
| Cerniers, 972.

Cérocounes (C'erocoma), 89i; - Schxfferi, Schreberi, s94.

Ceroplastes caricx, 811.

Certhiu, 1062.

Cerveau, 939.

Cervelet, 9:0.

Cervidés (Cerviltz), 1126.

Cervules (Cervalus), 1126.

Cervus, 1126 ; - capreolus, elaphus, 1126.

Cestes, 193.

Cestodaires, 209.

Cesloden Tuberculose, 241.

Cestorles, Cestoïdes, 209, 210.

Citacés, 1091, 1096.

Cétine, 1099.

Cétoines (Ceionia), 898.

Ceutorynques (Ceulorhynchus), 890 ; sulcicollis, 890 .

Chabiıs, 1138.

Chaboisseau, 973.

Chabols, 973 .

Chacals, 1198 .

Chalazes, 1027.

Chalcis (Lépidoptères), 863 ; - (Saurieus), 1013 .

Chaleur animale, $3 \mathbf{j}, 38$.

Chalicodoma, 866 .

Chalicothéridés (Chalicotheridæ), 1148.

Chalinoptères, 851 .

Chamæleon, 1013; - vulgaris, 988.

Chambre à air, 1028; - coruillière, $102 \tau$; - incubatrice, 44 ; - palléale, 902.

Chameaux, 1120 .

Chamelle, 112?.

Chamois, 1128.

Champs latéraux, 386.

Chanteur des jardins, 1063.

Chapon, 10 is.

Chaquedit, 974 .

Charadridés (Char'adridæe), 1041.

Charadrius, 1042.

Charxas graminis, 853 .

Charancons, 889.

Charbonnières, 1063.

Chardouneret, 1062.

Charybdées, 196.

Chasse (Chiens de), 1199.

Chasseur (Ilomme), 1234

Chat, 1208 ; - bolté, 1212 ; - de mer, 960.

Chataignes, 1160; - de mer, 20 \&.

Chàtain (Type), 1237.

Chat-huant, 1066.

Chatrouilles, 928.

Chaunas (Chuına), 1012.

Chauves-souris, 1216.

Cheilostomi (Helerakis), 405.

Cheiracanllus, 546 ; - hispidus, 547 ; robustus, 5i7; - siamensis, 548.

Cheirotherium, 981. 
Chelifer, 725 ; - cancroides, 725.

Chelléenne (Époque), 1227.

Chélonées (Chelonia), 1015; - esculenta, imbricata, 1015.

Chéloniens, 993, 1015.

Chélonochampsiens, 993.

Chelys, 1015.

Chematobia brumata, 853.

Chénalopex (Chenalopex), 1034 ; - ægyptiaca, 1037.

Chenilles, 851; - (Fausses), 861; - urticantes, 854 .

Chens (Chen), 1034 .

Chernètes, $7: 4$.

Chéropotames, 1112.

Chetognathes, 571.

Chétopodes, $57 i, 590$.

Chétosomidés, 571.

Chevaine, 967.

Cheval, 1160; - de mer, 963.

Chevaliers, $10 \div 2$.

Cherêches, 1066.

Chevêchette, 1066 .

Cheveux, 123 .

Chèvre des Mcntagnes Rocheuses, 1128.

Chevreaux, 1136.

Chèvres, 1133, 1134.

Chevrettes, 607.

Chevreuil, 1126.

Chevrolle, 606.

Chevrotains, 1124 .

Cheylabis, 682 .

Cheylètes (Cheyletus), 695 ; - eruditus, 696 ; - heteropalpus, 697 ; - Mericourti, 696 ; - parasitivorax, 697; - Robertsoni, 696 ; - uncinatus, 698 : - venuslissimus, 696.

Cheylétielles (Cheyletiella), 696 ; - heteropalpa, parasitivorax, 697.

Cheylétinés (Cheyletinx), 693, 695.

Cheylurus, 695.

Chicorés, 9:0.

Chien, $1196,1198$.

Chilognathes, 732 .

Chilopodes, 732, 733 .

Chimères (Chimæra), 960 ; - monstrosa, 960.

Chimériens, 960.

Chimpanzé, 1223.

Chinchillas, 1155.

Chipeau, $103 i$.

Chique, 806.

Chirodiscinæe, 639 .

Chiromys, 1219.

Chironemus, 695.

Chironomes (Chironomus), $79 ; ; ;-p l u-$ mosus, 797.

Chiroptères, 1091.

Chirotes, 1013.

Chirurgien, 974.

Chlorocruorine, 21.

Chlorops (Chlorops), $780 ;-$ pumilionis, 780 .
Chlorose égyptieane, 470.

Choanoflagellés, 163.

Chœropotamus, 1105.

Choloepus didaclylus, 1096 ; - Hoffmanni, 1072.

Chondroplastes, 16.

Chondroptérygiens, 960 .

Chondrostomum nasus, 967.

Chordés, 110, 929.

Chorion, 46, 948, 1087.

Chorioptes (Chorioptes), 640,671 ; - auricularum, 675, 676; - aur. canis, 676 ; - aur. cati, 677; - aur. furonis, 678; - bovis, 671, 674; - canis, 675,676; - copræ, 671,674; - cati, 677; - chniculi, 675; - cynotis, 675, 676; ecaudatus, 675; - equi, 672; - felis. 675, 677 : - furonis, 678 ; - ovis, 675 ; - setifer, 678; - spalhifer, 671; symbioles, 671 ; - s. bovis, $674 ;-$ s. capræe, $675 ;-s$. cuniculi, 675;s. equi, 6i2; - s. ovis, $675 ;-$ tripilis, 678.

Chortoglyphes (Chortoglyphus), 688, 689; - nurtus, 689.

Choucas, 1063.

Chouettes, 1066.

Chromatine, 12.

Chromatophores, 924 .

Chromoblastes, 938.

Chrysalides, 851.

Chrysaora hyocella, 196.

Chrysomèle américaine, 888 .

Chrysomélidés (Chrysomeliclæ), 88 i.

Chrysopa, 878;-perla, vulgaris, 878.

Chrysophrys, $972 ;-$ curata, sabra, 972.

Chrysops (Chrysops), 793; - creculiens, 793 ; - marmoralus, quadralus, reliclus, 79'.

Chrysothrix, 1222; - sciurea, 1220.

Chrysotis, 1061.

Chyle, 21.

Chylifères (Vaisseaux), 3i.

Chylifique Intestin, etc.), 597, 735.

Chylurie, 521.

Cicada, 818 ; - orni, plebeia, 818.

Cicadaires, 818.

Cicatricule, 1026.

Cicindèles (Cicindela), 901 ; - campesiris, 901.

Ciconia, 1042.

Cigale, 81s; - de mer, 607.

Cigognes, 1042.

Ciliés (nsufoires), 162, 171 .

Cils vibratiles, $20,27,113$.

Cimænomonas, 166; - hominis, 168.

Cimarrones, 1161.

Cimex, 8:0: - cilialus, 821 ; - columbarius, 822 ; - hirundinis, 823 ; - inodorus, 823 ; - lectularius, 820 ; - pipistrelli, 823; - rotundatus, 822. 
Circulatoire Ippareili, 36.

Circus, 1066; - cyaneus, rufus, 1066.

Cire (Abeilles, 874; - (Oiseaux), 1021.

Cirières (Aires), 8i4; - (Glandes), 739.

Ciron rutilaut, $i 03$.

Cirons, 6is.

Cirre (Cestodes), 211, 22i ; - (Trémittodes), 350 .

Cirres (Annélides), 5!:2; - Infusoires, 171.

Cirripèdes, 605.

Cistudo, 1015.

Civades, 607 .

Civeltes, 1:05.

Cladocères, 605 .

Cladocotium, 342; - hepaticum, 3i2; - magnum, 356 .

Clairene, 858 .

Claires, 910.

Clairon des Aheilles, 871, 897.

Clanques, 914.

Clapiers, 1191.

Classe, 90.

Classifications, 87 .

Clathrocystis roseo-persicina, 970.

Clavellina, 932.

Clavicornes, 898 .

Clavieule, 937 .

Cléridés (Clevillä', 897.

Clerus, 897 ; - alvearius, 897 ; - apiarius, $871,897$.

Cliona celate, 909.

Clisiocampa neustria, 854 .

Clitoridien (Os), 1086.

Clitoris, 1086.

Cloaque, 942.

Cloporte, 606.

Clothilla inquilina, si9.

Clovisses, 914; - petites, 914.

Clupea, 965 ; - havengus, tropica, 96.5.

Clupéidés Clupei(læ), 965.

Clypers, i3i, 834 .

Chemidocoples, 640, 663; - columbie, 665 ; - fossor, 666; - gallinx, 66, ; - Levis, 664; - mutans, 663; - phasiani, $666 ;$; - viviparus, 663 .

Cnethocampa, 854; - pinivora, 854; pilyocampa, processionea, 85', 855.

Cnidaires, 110, 187.

Cnidoblastes, cnidocils, 188.

Coassement, 979.

Coatis, 1?04.

Cobayes, 118:.

Cobboldia, 749 .

Cobitis, 967; - barbalula, fossilis, $96 \mathrm{i}$. Cobra capel, Cobra de capello, 100 i.

Cobrique (Acide), 995.

Coecidés (Coccidla), 810 .

Coccidie (Coccidium), 13?, 134; - bigeminum, 140, 145; - cuniculi, 134; hominis, 138 ; - oviforme, 134 ; - perforans, 138, 141, 142; - Rivollai Ilarz,
142 ; - Rivoltai Grassi, 146 ; - tenellum, 142; - truncalum, 141: - Ziirni, 1 i1, 1 i2.

Coccidies, 130 .

Coceidiose hépaliłue, 137 ; - intestinale. 140 à 146 ; - nasale, 111 ; - des œul's.

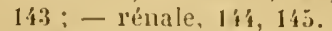

Coccidioses doutenses, 147.

Coccinelles Corcinellu), 88i; - septempunctute, 887 .

Coceinellidés (Coccinellirts), 887.

Coccothraustes, 1062 ; - velgaris, 1062.

Coccus cucti, 810 .

Coche, 1111.

Cochenilles, 810.

Cochevis, 106:3.

Cuchinchine Diarrlée de), 560 .

Cochleariu, Cochlearum vivaria, 923.

Cochon d'lnde, 1186.

Cocholls, 1105; - domestiques, 1108.

Cochylis (Cochylis ambiguclla), 853.

Cocon (Saugsuesj, 582; - (Ver a soie), 857.

Codosiga, 163.

receilia, 982.

Cœlentérés, 110, 184, 187.

roxlugenys paca, 118i.

Calognaihus morsilans, 691.

Cœlomates, 110.

Colome, 51.

Cœlomyaires, 386.

Ccelopeltis, 1003; - insignitus, 100 '.

Coendou, $118 i$.

Cœneuchyme, 190.

Conures (Conurus), 212, 215, 251 ; - cerebralis, 252; - seriulis, 257.

Cœur, 37.

Cœurs lymphatiques, 980.

Colfres, 963.

Colaspidème noir (Colaspidema ater", 887.

Coléoptères, i41, 886 .

Colibris, 1062.

Colimaçons, 923.

Colin (Oiseau), 1055; - (Poisson). 96 i.

Colishé, 1198.

Colle de Poisson, 962, 967.

Collet (Dents), 1079.

Colletes, 866, 892.

Collines dentaires, 1079.

Collocalia, 1064; - esculenta, fuciphaga, 1064.

Collosphara, 121, 122;-Huxleyi, 121

Collozoum, 121.

Colobes $\langle$ Colobus, 1223.

Colocerns damicorne, 841.

Colombin, 1056.

Colombine, 1055.

Colombius, 1029, 105.

Côlon, 1081.

Colonial (Systẻme nerveıx), 574 .

Colonies, 42.

Colonue vertébrale, 935. 
Colorado, 703.

Colorado Beetle, 887.

Colpocéphales(Colpocephalum), 845, 846; - turbinatum, 846.

Colpodes (Colpoda), 175;-cucullus, 175.

Colsuns, 1197.

Coluber, 1003; - Esculapii, 1003.

Colubridés (Colubridæ), 1003.

Colubriformes, 100?.

Columba, 1056 ; - affinis, 1056 ; - domestica, 1057; - intermedia, leuconota, livia, anas, 1056 ; - rupestris, Schimperi, turricola, 1051.

Columbidés (Columbidx), 1056.

Columelle (Cœlentérés), 190; - (Mollusques), 946; - (Oiseaux), 1020.

Colymbus, 1032.

Comatules, 202.

Combattauts, 1042.

Commensalisme, 63 .

Compsomyia macellaria, 784 .

Conchyoline, 902.

Concurrence vitale, 61 .

Conditions d'existence (Principe des), 25.

Condors, 1066.

Condylarthrés (Condylarthra), 1101.

Cônes (OEil), 31.

Confectio alkermes, 811 .

Congénitale (Infestatiou), 73.

Congres (Conger), $96 i$.

Conirostres, 1061, 1062.

Conjonctifs (Tissus), 15.

Conjonctivite vermineusc, $527,528$.

Conjugaison, 43.

Connexions (Principe des), 25.

Conorthinus nigrovarius, 819 .

Constant (Parasitisme), 69.

Contractiles (Vacuoles), 114.

Conurus, 1061.

Copépodes, 605, 606.

Copris (Copris), 898.

Coprophages, 898 .

Copulateurs (Organes', 44.

Copulatrice (Poche), 600.

Copule, 950.

Coqs, 1051; - de bruyère, 1054; d'Inde, 1045.

Coquart, $105 i$.

Coque de bảtonnets, 217.

Coque de l'œuf, 1028.

Coque (Glande de la), 225, 234 .

Coques, 914.

Coquille (Mollusques), 902 ; - (OEuf des Oiseaux), 1028.

Coquilles de Saiut-Jacques, 911.

Coquillière (Glande), 225, 334;- (Membraue), 1027.

Coracius, 1061.

Coracoïde (Os), 936.

Coræbus bifasciatus, 695 .

Corail blanc, 192; - noir, 192 ; - rouge, 191 ; - rouge (var. noire), 192.

Coralliaires, 188.

Corallium rubrum, 191.

Coral-reefs, 190.

Corbeaux, 1063.

Corbeille (Abeilles), 866 .

Corbeilles vibratiles, 185.

Corde dorsale, 929.

Cordes vocales, 1082.

Cordon ombilical, 1088.

Corégones (Coregonus), 967 ; - fer'a, lavaretus, 967.

Coriacés, 745.

Corises (Corisa), 819 ; - femorala, mercenaria, 819.

Corme (Cormus), 26.

Cormorans, 10 i.

Corne de Cerf, 1126.

Corrıće, 31 .

Corneilles, 1063.

Cornes, 1114.

Cornichons de mer, 205.

Cornicules, 811 .

Cornuspira, 119.

Coronelles (Coronella), 1003 ; - austriaca, givundica, 1003.

Corps bruns, 574 ; - en croissant, 123 ; en rosace, $124 ;$ - oviformes, 130 ; segwentés, 123 ; - sphériques, 122.

Corpuscules calcaires, 210 ; - de Cornalia, 858;-de Rainey, 150 ; - falciformes, 129 ; - marginaux, 193 ; - réniformes, 151 .

Corrélation des organes, 24.

Corrodants, 879.

Corsac, 1198.

Corselet, 734.

Corvus, I06.3;-corax, cornix, corons, frugilegus, monedula, 1063 .

Corycées (Corycæus), 606.

Coryphẻue Diulıade (Coryphæna hippurus), 972.

Cossus, 889 .

Costifer $a, 164$.

Côtes (Ccelentérés), 190; - (Nématodes), 118; - (Vertébrẻs), 935.

Cottes (Cottus), 973; - bubalis, gobio, scorpius, 973.

Coturnix, 1055.

Cotylédons, 1088, 1103.

Cotylegaster cochleariforme, 379.

Cou (Cestodes), 222.

Couagga, 1169.

Couchants (Chiens), 1199.

Couche corncé, 938 .

Coucous, 1060 .

Couguar, 1209.

Cuuleuvres, 990, 1003, $100 \mathrm{i}$.

Coup de poing, 1228 .

Courants (Chiens), 1199.

Coureurs (Échassiers), 10 il ; - (Oiseaux), 1029, 1030 ; - (Orthoptères), 880 .

Coureurs (Pieds), 627. 
Courlis, 10 ?.

Couronne (Deuts), 1078.

Couroucous, 1060 .

Courtilière, ss't.

Courvites, 10i?.

Consi-cousi, 8s'́.

Cousins, 798 .

Couteaux, 9ı́.

Couvain, 868 .

Couvertures, 1020 .

Couveuses artificielles, 1028 .

Cowper (Glaudes de), $108 i$.

Coy, 1186.

Coyote, 1198.

Crabe des Moluques, 611.

Crabes, 610.

Crabiel, 1198.

Crabro, 864 .

Cràne, 936.

Crangons (Crangon), 607 ; - vulgaris, 607 .

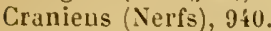

Crauiologie, 1235.

Cranque, 610.

Crapaud, 986 ; - accoucheur, 985 ; - de uler, 973 ; - de Suriuam, 985.

Crapauds, 985, 986 .

Craspèdotes, 193.

Crassilingues, 1013,

Craw-craw, 523,551 .

Créatiouisme, 92.

Crécerelle, $10 j 6$.

Crécerine, 1066.

Créodontes, 1193.

Créophiles, i81.

Crépusculaires (Lépidoptères), 851,860 . Crevette des ruisseaux, 606 ; - de table, 607 ; - grise, 607,608 ; - rose, 607 .

Crex, 1042.

Cribrella oculala, 203.

Cricets (Cricotus), 1181; - frumenlarius, 1181.

Cricétidés (Cricetille), 1181.

Cri-cri, 884.

Criniscansor, 685 .

Crivoïles, 202 .

Crins, 1068 ; - marins, 858.

Criquet marocain, $8 \mathbf{s} 3$; - pélerin, $\$ 83$; - rubané, s82; - voyageur, 882.

Criquets, ssi.

Crise du rouge, 1046 .

Cristallin, 31 .

Cristallines (Baguettes), 206.

Cristallius Cônes), 206.

Cristaux de Charcot, 677.

Critloptes monunguiculosus, $69 \mathrm{i}$.

Crochets (Ténias), 221; - à vouill, 993.

Crocidura manea, elrusca, 1215.

Crocodiles (Crocortilus), 1014 .

Crocodiliens, !93, 1014 .

Croisement, 95.

Cro-Magnon (Squelettes), 1233.

Cromlechs, 1232 .
Crossuster pappos?s, 203.

Crossoderu, 3il, 368; - linearis, 368.

Crossoptiles (Crossoplilon), 1051.

('rossopus fodiens, 1215.

Crotales Crotulus), 101:; - durissus, horridus, $1005,1012$.

Crotalislés (Crolalirlx), 1012

Crotaline, 99.;.

Crustacés, 601.

Cryptotranchus, 98:.

Cryptocystis, 213, 28i; - trichodtectis, 285,286 .

Cryptopentamères, 887 .

Cryptophagidés ('́ryptophagidx), 900.

Cryptoprocta, 1208.

Cryjtostomum, 7:3; - silfuscum, bur'su, sylvimum, 723 .

Cryptotitramères, 88 :

Ctinocyste, 19 i.

Ctéuoïdes (Éciilles), 9 ;9.

Cténophores, 188, 197.

Cténophoriques (Cauaux), 198.

Cténoténias (Clenolrnia), 278; - Gęzer, Lenckarti, pectinala, 278.

Cubilose, 1065.

Cubitus, 937 .

Cuc, $\$ 87$.

Cucu!lanus elegans, 501 .

Cuculus, I060; - canorus, 1060.

Cucurbitius, $213,223$.

Cuillerons, i4?.

Cuisse (Insectes), 73; ; - Vertébrés), 937.

Cul d'Ane, 192; - de Mulet, 192.

Cul-brun, S5t; - jatune, 85't.

Culex, 519, 798; - unnulatus, $799 ;-p i-$ piens, 793.

Culicidès (Culicidæ), 798.

Cultrirostres, 104?.

Cuma, 606.

Cumacés, 606 .

Cuniculus, $6 \dot{4} 4$.

Ciniculus, 1183.

Cuon, 1197.

Curculionidès (Curculionidie), 889 .

Cursorias, 1012.

Curtonerra, is:; - stabulans, is2.

Cutanée (Respiration), 37.

Cutérébres Cutercbra), iis; - emnsculutor, 7i5: - noxialis, i76.

Cutérébrinès (Culerebrinæ), $7 i 5$.

Cuticules (OEstrinés), ifs, $76 \%$.

Guticulaire (Membrane), 261.

Cuvette phylioxirique, 817 .

Cuvier (Canal de), $9 \mathfrak{4} 3$.

Cuy del monte, 1186.

Cyumus, 606 .

Cyauées, 19i.

Cyalhostomum tetracanlhum, $\mathbf{4} 01$.

Cybium, 9i1.

Cjoléal, $93 j$.

Cycloides (Écailles), 9:9.

Cyclopes (Cyclops), 606 ; - ag:lis, 293, 301 ; 
- brevicaudatus, 301 ; - lucidulus, 301 - quadricomis, 606 ; - viridis, 299,301. Cyelose, 11.

Cyclospora, 132.

Cyelostomes, 95?.

Cygues (Cygnus), 1032; - Bewicki, 1032; - musicus, 1032, 1034; - olor, 1033;olor domesticus, 1033.

Cygninés (Cygninæ), 1032.

Cylindraxe, 19.

Cylindrique (Épithélium), 20.

Cynxlurus, 1212; - guttatus, jubatus, 1213.

Cynhyènes, 1196.

Cynipidés (Cynipidæ), \$62.

Cynips (Cynips), 862; - calicis, 863; galtx tinctorix, $862 ;-$ polycer", 863.

Cynocéphales (Cynocephalus), 1223 ; babuin, 1223.

Cynocéphalidés (Cynocephalidæx), 1133.

Cynomyies (Cynomyia), 790 ; - mortuomum, 790.

Cynorhæstes, 706 ; - reduvius, ricinus, 708.

Cynthia, 932.

Cyons (Cyon), 1197.

Cypria ophthalmica, 299, 303 .

Cyprirtina, 605.

Cyprin doré, $96 \pi$.

Cyprinidés (Cyprinidæ), 967.

Cyprinus carpio, $953,967$.

Cypriotes (Appareils), 8st.

Cypris, 605; - cinerea, 303, 301; - compressa, 299, 303 ; - incongruens, 300 ; - ovum, 303.

Cypselus, 106:; - apus, 1064.

Cysticerciens, 212.

Cysticercoïdes, 212, 284.

Cysticerque (Cysticercus), 21?; 215 ; acanthotrias, 246 ; - Bailleti, 314; botryoides, 2i6; - hovis, 233, 240, 246; - canis, 249;-cellulosa, 241, 242,248; - elongatus, 314; - fusciolaris, 214, 250 ; - fistularis. 73, 231;- multilocularis, 246; - ovis, 230 ; - pisiformis, 215, 219, 227, 339: - de la Poule, 315; -racemosus, 246:- Tærniæ mediocanellatx. $233 ;-T$. saginatz, $233 ;-t a-$ randi, 232;-tenuicollis, 228, 230 ; visceralis, 231.

Cysticoles (Sarcoptidés), 678.

Cystipèdes, 879 .

Cystiques, 212.

Cystocephalus (voy. Globocephalus). Cystoflagellés, 163.

Cystoïlotæuiés (Cystoidotæniæx), 284.

Cystomonas, 165 ; - urinaria, 16.

Cystophora proboscidea, 1193.

Cystotrnia, 215; - conurus, 252;crassicullis, 249 ; - echinococcus, 258 ; Krabbei, 232 ; - marginata, 228 ; - saginala, 232 ; - serialis, $25 i$; - serrata, 215 ; - solium, 242.

Cystotæniés (Cystotæniæ), $21 \dot{4}$.

Cythere, 605.

Cythérées (Cytherea), 914 ; - chione, 905 , 914.

Cytode, 13.

Cytodiérèse, 14.

Cytodiques (Rhizopodes), 115.

Cytodites (Cytodites), 678; - glaber, nudus, $6 \% 8$.

Cytoditinés (Cytoditinæ), 639, 678.

Cytoleichus, 678; - sar'coptoides, 678.

Cylospermium hominis, 138 ; - villorum intestinalium canis, 145; - Zilrni, 141.

\section{D}

Daboia, 1007 ; - elegans, 1012.

l)actylius aculeatus, 592.

Dactylopius adonidum, vitis, 811.

Dactylozoïdes, 194.

Ducus oleæ, 780 .

Dails, 915.

Daims (Dama), 1126; - vulgaris, 1126.

Damans, 1175.

Daphnies (Daphnia), 605.

I)arwinisme, 99.

Dasychira, 85.5.

Dasypodes, 1096.

Jasyproita aguti, 1184.

Dasyproctidés (Dasyproctidæ), 118'.

Dasypus, 1096; - gigas, 1096.

Dasytriques (Dasytricha), 176; - muminantium, 176.

Dasyures (Dasyurus), 1095.

Dattes de mer, 913.

Dauercyste, 149.

bauphins, $109 \%$.

baurades (Chrysophrys et Coryphrna), 972.

Daw, 1170; - des colons, 1169:- dis Congo, 1170.

Debab, 793.

Debane, 793.

Debeh, 793.

Décapodes (Céphalopodes), 927 ; - (Crustacés), 605, 607.

Decidua, 1090.

Décidués, 1090.

Déclives, 1127 .

Décomposition cadavérique, 58.

Decticus verrucivorus, 884 .

Déféreni (Canal), 44 .

Définitif (IIôte), 70.

Legeeria, 791 .

Deiters (Prolongement de), 19.

Delka, 1105.

Delphinus, 1097.

Dème, 26.

Démodécidès (Demodecidæ), 631, 633. 
Démodex (Demulex), 633; - caninus, 635 ; - folliculorum, 634;-bovis, 63s; - canis, 635; - capre, 635;-cati, 637; - equi, 639; - hominis, 634; - ovis. 638 ; - suis, (i3); - phytloiles, 637 .

Demoiselles, 8i9; - terrestres, $87 \mathrm{~s}$.

Deudrocorles, $3 s^{\prime}$.

Dendroptus, 695.

Dendryphuntes nuxiosus, Sucei, 730 .

I)entaire (Formule), $10 \mathrm{so.}$

Denlale (lenlulium), 915.

Deuticètes, 1097.

Dentieules, 1079.

l)entiue, 1075 .

Dentirostres, 1061, 1063.

Dents, 107 .

1) Codactyles, 1061, 1062 .

Dermacentors Dermacentor), 713 ; - cmericanus, ilt; - occidentalis, ilt; reticulatus, 713 .

Dermanysses (Dermunyssus), 719 ; arium, 719,723 ; - Boryi, $7: 0$; - columLiuus, 719;-gallinx, 719; - galtopavonis, i19; - hirundinis, 722 ; longipes, $i 23$.

Dermanyssinés (Dermanyssinæ), 718.

Dermalobies (Dermatobia), 775, 776; cyaniventris, 779 ; - noxialis, 776, 779.

Dermalolectes, 666; - buvis, 669 ; communis, 666 ; - cuniculi, 6i1.

Dermatokoples, 666 ; - communis, 666 .

Dermatophagoides Sheremelevshyi, 675.

Dermatophayus, 671; - cuniculi, 675; - cynatis, 675;-selifer, 678; - symbiotes, 671; - tripilis, $67 \mathrm{~s}$.

Derualophiles, 6.33.

Dermatophitus, 806 ; - penetrans, 806 ; - gatlinaceus, 808 .

Dermuloryktes, 663 ; - fossor, 666 ; laxvis, 66: ; - mutans, 663.

Derme, 938.

Dermestes (Dermestes). 899 ; - lardarius, vulpinus, s99.

Dermestides (Dermestidx), 899.

Dermite granuleuse, 508.

Dermofiluriu irritans, 508 .

Dermoglyphus, 682; - elongatus, minov, m. similis, varians, 683 .

Dérotrèmes, 9s2.

Désassimilation, 3 í.

Descendance ('Théorie de la), 9?, 9s.

Deswans, 1:15.

Desmoscolécidés, 5 i1.

Destructeurs (Animaux), (;7, 80.

Détriticules (Sarcoptidés), 687.

Deutocérébron, 595 .

Deutomerite, 128.

Deuto-scolex, 5千, 2: 6 .

Développement, 15 ; - rétrograde, 23.

Levexu, 112\%.

Dhib, 1198.

Dholes, $119 \%$. lliables te mer, 961, 96:.

biapluague, 102t, 1053.

Diapophyse, 935.

Viarrhée de Cochinchine, 560.

Diasteme, 10i9.

Iribothrium, 315; - Latum, 31.5.

libothrius, 315.

bibranches, 936 , 927 .

llicercomonas, $16 \mathbf{t}$.

Diclsogamie protandrique, :2.'; - proto. gyuique, 931 .

llicotyles, 1113; - labiatus, torquatus, 1143.

Dicranoténias (Vicranotæenia), 302; sequabilis, 302,$303 ;$ - coronula, 30 : ; cuneatu, 302, 30*; - rhombuilea, 302, 303.

Dicrocnelium, 311, 356; - atbielum, 36i ; - Buski, 363; - calomalicum, 360; -- conjonclum, :365; -felineum, 365;lanceolatum, 357 ; - sinense, 362; truncalum, 36í

Dicyémides, 208.

Didactyles, 111 t.

1)idelphes, 1091.

Didelphys, 1095; - californica, virginiana, 1095.

Didesmes (Didesmis) 17'; - ovalis, quadralis, 17 .

Didunculidés (Vidunculid:e), 1059.

Vidunculus, 1059.

Didus ineplus, 1059.

Iridymozoonitie, 338.

Différencialiou, 23.

lliffugia, 115,118 .

Digenése, 5 í.

Digenèses (Trẻmatodes), 334 .

bigestif (Appareil), 35.

Digestion, $3 \mathbf{i}$.

Digitale (Formule), $107 \dot{\text { f }}$

Digiles (Vertébrès), 93i, 94\$.

Digitigrades, 1075.

1)ilıb, 1198.

Dimère (Reproductiou), 43.

bimorphisme sexuel, 101.

bimorphobiose, 392 .

Dimorphus, 169 ; - muris, 169.

Dimyaires, 911.

Dinsle, $10 \% 5$.

Dindouneau, 1045.

1)indous, $10 \mathrm{i}$ '.

bingo, 1198.

Jinollagellés, 163.

linornis, 1031.

Dinoruithes, 1031 .

Dinothériums (Dinotherium), 11 į6.

Jiodon, 96:

Dioinues (Animaux), 44.

Diomelea, 10i:

Diphyllinés (Diphyllins?), 315.

Diphyodontes, 1079, 1031.

liplacanthus nanus, 293. 
Liptasterias mubens, 203.

Diplodiuions (Diplodinium), 181, 183 ; bursa, 181: - Callaneoi, 182; - caudatum, 18:; - tentatum Fiorentini, 181; - dentatum Stein, 181; - denticulatum, 181; - eccudatum. 18:; Maggii, 181; - mannosum, 181; rostralum, 181; - uncinalum, 181; unifasciculatum, 182; - vortex, 182.

Diplodiscus, 376 ; - subclavutus, 33i.

Diplogastres (Diplogaster), 439, 5i2 ; subulatus, 552.

Diplopodes, 722.

Iriptosis tritici, 797.

Diplospora avium, 134.

Diplostominæ (?), 381.

Iliplostomum ștyptincum, 379.

Dipneumones (Araignées;, 730 ; - (Poissons), 976.

Dipnoïques, 959, 976.

Dipodidés (Dipodidx, 1178.

Diprotodontes, 1095.

Diptères, $736,7\{1,742$.

Dipus, 1178.

Dipylidiuns (Dipylidium), 28́; - caninum, 284 ; - cucumerinum, 284; - elliplicum, 290; - Pasqualei, "; - Trinchesei, 290.

Discodactyles, 987.

Discoglosse (Discoglossus pictus), 985.

Discoméduses, 196.

Discophores (Annélides), 577.

Discorbina, 119, 120.

Disparipes, 693.

Dispharages (Dispharagus), 542 ; - hamulosus, 544 ; - laticeps, 513 ; - nasutus, 544; - spiralis, 543; - uncinatus, 543.

Disporées (Coccidies), 132.

Disque proligère, 1026.

Dissépiments, 190.

Dissuciation, 41.

Distomatose (voy. Distomose).

Distomes (Distomum), 341; - albidum, 361, 364 ; - americanum, 356;-- armatum, 366 ; - bursicola, 368; - buski, 363; - campanulalum, 364; - capense, 372; - camosum, 356; - cavix, 342; cotomaticum, 360; - columbæ, 371; commutalum, 371; - complexum, "; - conjunctum, 365; - conoilleum, 366 ; - conus Creplin, 361, 364; - conus Gurlt, 361; - crassum Busk, 363; crassum Leidy, 356; - cuneatum, 369; - dilalulum, 366; - dimorphum, 37ı; - echinatum, 366 ; - echiniferum, 366 ; - endemicum, 363; - excavatum, 366 ; - felineum, 361 ; - hæmutobium, 371; - hepaticum, 342; - hepatis endemicum, 362; - hepalis innocuum, 362; helerophyes, 370 ; - japonicum, 362; lanceolalum, 355,$357 ;-\ell$. canis fa- miliaris, 361; - l. felis cati, 361; lineare, 368 ; - magnum, 356 ; - mililare, 366 ; - oculi humani, 339, 360;ophthalmobium, 360; - ovatum, 368; - ovocaudatum, 358; - oxycephalum, 368 ; - pancreaticum, 360 ; - pellucidum, $369 ;-$ perniciosum, $362 ;--$ pulmonale, $369 ;-$ putorii, $366 ;-R a-$ thouisi,363;-Ringeri, 369;-sibiricum, "; - sinense, 362; - spathulatum, 362 ; - texanicum, 356 ; - trigonocephalum, 365;-truncatum, 361, 364 ; - Westermanni, 369.

Distomidés (Distomidæ), 311 .

Distomiens, $3: 4,335$.

Distominés (Distominæ), 341.

Distomose hépatique, $353,360,361,362$; - musculaire, 376 ; - pulmonaire, 355,370 .

Distribution géographique des animaux, 103.

Dithyridies (Dithyridium), 213, 314; elongatum, 314; - martis, taxi, variabile, 315 .

Diurnes (Lépidoptères), 851,$860 ;-$ (Rapaces), $1065,1066$.

Division des plastides, $3 \dot{x}$.

Division du travail, 22.

Djemei, 1021.

Duchuies (Dochmius), 464; - ankylostomum, 465;-Balsami, 470 ; - cernuus, $474 ;$ - duodenalis, 465 ; - hypostomus, 463 ; - radialus, 475 ; - stenocephalus, 473; - trigonocephalus, 470.

Docophores (Docoptiorus), 835, 843 ; udustus, cygni, icterodes, 844.

Dogues, 1199.

Doigts, 937.

Dolichocéphales, 1236.

Dolichotis (Dolichotis), 1185; - patachonica, 1185.

Doliolum, 933 .

Dolmens, 1232.

Domestication, 81, 1232.

Domesticité, 64, 82.

Dominateurs (Caractères), 91.

Donaces (Donax), 914.

Doras, 967.

Doris Johnstoui, 919.

Dorsch, 967 .

Doryphora, 887.

Dosinia, 914.

Douve, 341 ; - du foie, 342 ; - amèricaine ou grande, $356 ;$ - lancéolée ou petite, 357 .

Dracontiase, 503.

Dracunculus Loa, 529; - oculi, 529 ; Persarum, 500.

Dragon d'Alger, 584.

Dragonneau (de Médine), 500.

Dragouneaux (Gordiacés), 562.

Draine, 1063. 
Diepanidium, 128.

Drépauidotéuias (Drepanidolania), 29s;analina, 298, 300; - collaris, 3110 ; fascialu, 298, 299; - gracilis, 29s, 299; - infundibuliformis, 298, 302; - lanceoluta, 295, 299; - setigera, 298, 301; - sinuosa, 298, 300; - tenuirostris, 298, 301 .

Dromadaire, 1073,1021 .

Dromzus, 1031 .

Diomedurius, 1021 .

Dromies (Dromia), 610.

Droutes, $105 y$.

Drosophila melanogastra, 780.

Diyopithecus Fontani, 1223.

Dshigtai, Dshigguetai, 1165.

Ducs, 1066.

Dugong, 1101 .

Duodéuum, 94?.

Duplicidentés, $118 s$.

Dure-mère, 938.

Durisse, 1012.

Duthiersinés (Dulhiersinx), 315.

Duvet (Mammifères), 1068; - (Uiseaux) 1019.

Dyseutérie des Abeilles, 870; - coccidienne, $1+1$.

Dytiques (Dytiscus), 900 .

Dzo, $11\{6$.

Dzomo, 1146.

\section{$\mathbf{E}$}

Eaux de l'amnios, 9亿.

Écaille, 1015.

Écailles (Insectes), 736, $850 ;-$ (Poissons), 949.

Écailleuses (Pattes), 851.

Ecardiues, 575.

Écarlate (Graine d'), 810.

Échassiers, $1029,1041$.

Échaudage, 853.

Echeneis, 972.

Échenillage, 851.

Échiduase, 996.

Échidnases, 995.

Échidnćs (Echidna), 1093; - hystrix, 1093.

Échidniue, 995.

Échidniues, 995.

Échidniswe, 996.

Échidnotoxine, 996.

Échidnovaccin, 999.

Echinides, 202, 203.

Echino, 10?2.

Echinorocifer echinococcus, 258.

Échinococcose, 266.

Échinocoque (Echinococcus), 212, 215, 258:

- allricipariens, 264;-endogena, 263;

- exogena, 263; - granulosus, 263; - hominis, ?66; - hydatidosus, 264; multilocularis, 26:; - polymorphus, :60, 266; - racemosus, 265; - simix, 266 ; - simplex, 263; - scolicipariens, $263 ;$ - velerinorum, 266.

Echinocotyles (Echinocolyle), 304; - Rosscleri, 3il.

Échinoderuses, 110, 198.

Echinomyiu, 791.

Echinopardium, 201.

Echinophthivius, 825.

Echimorlyyachidés (Echinorhynchidæ), 565, 569.

Échinorynques (Echinorhynchus), 569; anatis, 5li9; - analis mollissimx, 570; - angustutus, 571; - aslaci fluviatilis, 570 ; - borealis, 570 ; - boschadis, 569 ; - collaris, 569; - cumiculi, 571; - dif. fluens, 5i(); - flicollis, 570; - gigas. 565 ; - Grussii, 571; - hominis, 571; - himudinaceus, 565; - lumbricoides, 566 ; - miliurius, 570; - moniliformis, 568 ; - polymorphus, 569; - sphxrocephalus, 5:1; - spirula, 571; - torquatus, 570; - versicolor, 569; - vesiculosus, 569 .

Echinoslomum, 3\$1, 365; - echinatum, 366 ; - oxycephalum, 368 ; - trigonocephalumi, 365 .

Echinolhecæ, is7.

Echinus, $10 \% 2$

Echinus esculentus, melo, 20 '.

Échiquage, sos.

Echis, 1007.

Eclairs, 911 .

Économie de la nature, 58 .

Écrevisses, 602, 604, 603 .

Écrivaiu, 889.

Ectoderme, 51 .

Ectoparasites, 69.

Ectophytes, 69.

Eclopistes migratorius, 1059.

Ectoplasme, 13.

Ectosarquc, 13.

Ectozoaires, 69.

Écureuils, 1179.

Écusson céphalique, 70 '.

Édentés, 1021, 1095.

Édriophtalmes, 605, 606 .

Elfraies, 1066.

Egagre, 1135.

Egaré (Parasile), 70.

Églefin, 967.

Eiller, 1037.

Eiméries (Eimeria), 132; - dubia, 133 ; - fulciformis, 132, 147, 150.

Ejaculateur (Canal), 350 .

Jans, 1126.

Elaphis quaterradialus, 1003.

Elastique (Tissu), 16.

Élatéridés (Elateridæe), 897.

Électriques (Organes), 39, 952. 
Ėlédlones (Eledone), 928; - moschata, 928.

Éléments anatomiques, 12.

Éléphant (Elephas), 1176 ; - africanus, indicus, $1176 ;-$ marin, $1193 ;-$ meridionalis, 1176.

Éléphantiasis des Arabes, 520.

Élytres, 736.

Émail, 1078.

Ematozoa filaria cardiaca, 439.

Emberisa, 1063; - citrinella, hortulana, miliuris, schaniclus, 1063.

Embranchement, 90, 109.

Embryogène (Vésicule), 46.

Embryogrénie, 50.

Eubryologie, 102.

Enibryophore, 214, 218.

Émerillon, 1066.

Emgalo, 111:3.

Émissole, 960.

Émouchet, 1066.

Ėmous, 1031.

Empires, 3.

Empoisonnements alinentaires, 79.

Emys, 1015.

Encapsulement, 467.

Encéphale, 938.

Enchélydés (Enchetydæ), 173.

Enchytræus, 592; - albidus, Buchholzi, 592 .

Enclume, 1077.

Encre, 925 .

Encrines (Encrinus), 202; - liliiformis, 202.

Endoderme, 51.

Endogènes (Vésicules), 264.

Endomychidés (Endomychidær), 887.

Endoparasites, 69.

Endophytes, 69.

Endoplasme, 13.

Endoplaste, 113, 172.

Endoplastule, 172.

Endosarque, 13.

Endothéliums, 20.

Endrominés (Enctrominæ), 856.

Enfle-Boufs, 895 .

Engoulevent, 1064 .

Engraulis bollama, 966 ; - encrasicholus, 965 ; - japonica, 966.

Enhydris marina, 1205.

Entéroïde, 189.

Entéropneustes, 929.

Entocyte, $12 s$.

Entoderme, 51.

Entodiuious (Entodinium), 180; - bipalmatum, 181 ; - bursa, 180,181 ; - caudatum, 180 ; - dentatum, 181 ; - minimum, 180 ; - rostratum, 180 ; - valvatum, 181.

Entomologie, 593.

Entomophages, 862.

Entomostracés, 605 .
Entonnoir (Cœlentérés), 197 ; - (Mollusques), 924 .

Entoparasites, 69.

Entophytes, 69.

Entozoaires, 69, 209.

Entozoon folliculorum, 634.

Entroques, 202.

Envenimation, 79; - ophidienne, 996.

Éohippes (Eohippus), 1149; - pernir, validas, 1149.

Éolithique (Période), 1227.

Épaule, 936,

Epeiche, 1060.

Épeichette, 1060.

Epeira diadema, 730.

Éperlan, 967.

Eperon (Calcar), 1018.

Épervier, 1066.

Éphéuères (Ephemera), 56, 879.

Ephippigera bitteriensis, 88'.

Ephydra californica, 781.

Éphyres (Méduses), 55, 197.

Épibranchiales (Artères), 953.

Epicaula, 893.

Epicyte, 128.

Épiderme, 20.

Epidermopteæ, 682.

Epidermoptes, 682, 684; - bifurcatus, bilobatus, 684, 685; - cysticolu, 680 .

Epigionichthys pulchellus, 933.

Epihippes (Epihippus), 1150;-Uintensis, 1150.

Épilepsie otacarienne, 677, 678; - vermineuse, 227, 398.

Épimères, 594.

Épimérite, 128.

Épimérites, 594

Epinglage, 249.

Epinoche, 971.

Épipharynx, 742 .

Epiphragme, 923.

Epiphyse, 939.

Epispastiques (Insectes), 890 .

Épisternites, 594.

Épistome(Acariens), 625; - (Insectes), 737.

Epithelioma contagiosum, 148.

Epitheliomyces croupogenus, nodulogenus, 1 it8.

Épithéliums, 20.

Épizoaires, 606.

Epizoïques (Insectes), 823.

Eplisses, 920.

Eponges, 184, 187.

Equidés (Equidlæ), 1148.

quinés (Equinæx), 1151.

Equivalve (Coquille), 904.

Equus, 1154 ; - adamiticus, $115 \%$; - africanus, 1167; - antiquorum, 1170 ;argentinus, 1157 ; - asino-caballus, 1171 ; - asinus, 1167 ; - a. africanus Fitz., 1167; - a. africanus Sanson, 1167 ; - a. europxus, 1167 ; - a. jos- 
silis, 115i; - a. somalicus, 1166; bijhmi, 1171; - brevirostris, 1157; Burchelli, 1169 ; - cabullo-asinus, 1173 ; - caballus, $1160 ;-c$. africanus, $c$. asiaticus, c. belgicus, c. brilannicus, c. firisius, c. germanicus; $c$, hibernicus, c. sequnnins, $1160 ;-c$. aryunus, 1162 ; - c. mongolicus, 1163 ; - $c$. fossilis, 1157; - Chrummmi, 1170; - curvilens, 1157; - equioides, 1166 ; - equuleus, 1166; - fossilis Cnv., 1157; fossilis Rüt., 115i; - Grevyi, 11i1; hemionus, 1165;-h. fossilis, 115i;hemippus, 1166; - hinnus, 1173; indicus, 1166; - Larteti, 1157 ; - Lundi, 1157 ; - major, 1156; - mulus, 1171; - namadicus, 1157; - occidentalis, 1156 ; - onager, 1166; - pacificus, 1156 ; - parvulus, 1156 ; - polyorlon. 1166 ; - priscus, 1157; - Prjevalslyi. $1164 ;-q u a g g a, 1169 ;-$ quaggoides, 1157 ; - rectidens, 1157,1159 ; - robuslus, 1158; - sivalensis, 1157; - somaliensis, 1166; - Slenonis, 1157; - loniopus, 1166 ; - zebra, 1169.

Erelhizon dorsulus, IIS4.

Ergot, 1018, 1114.

Ericerus cerifer, $\$ 11$.

Éridine, 1178.

Érinacéidés (Erinaceid $\mathscr{C}), 1214$.

Erinaceus, 1214; - europæus, 1214.

Érinose, 632.

Ériocomes, 1238.

Eriomys chinchilla, 1185.

Éristales (Eristalis), 791 ; - arbustorum, lenax, 791.

Errants (Polychètes), 5:2.

Erratique (Parasite), 70.

Erucæ, 853,

Érythème autumnal, 70 ?.

Eiythræinæ, 693.

Escargots, 923; - de mer, \$20.

Ésocidés (Esocida), 966.

Esox lucius, 966.

Espadous, 972.

Espèce, 90, 92.

Esprot, 965.

Esquimau (Type), 1242.

Essaim, 869.

Estomac, 36.

Estufettes, 911.

Esturgeons, 962.

Ethnographie, 1235.

Etoiles de mer, 203.

Étourneaux, 1063.

Étranger (Hôtc), 70.

Etrier, 1077.

Etrilles, 610.

Eucera, 866.

Eucoleus, 485; - aerophilus, 48i; - tenuis, 185 .

Eullagellés, 163.
Euglena viridis, 161, 162.

Eulyes amana, 819.

Einmenes, $86 i$.

Euméninrs (Ėmenina'), 864.

Eiumolpe, 889.

linnices, i!):3.

Euplectella, 186.

Euplutes, $18 \%$.

Eupodiués (Eupodinip), 692.

Européen (Type), 1:i0.

Euryplevus, 611.

Eusurcoples, 6i0.

lisuscorpious (Euscorpius), 728; - carnathicus, Fanzagoi, flavicaudis, ilalicus, 728.

Euspongia, 186; - aliatica, 187; - mollissima, 186; - zimoce a, 187.

Eustrongles (Eustrongylus), 418 ; -gigas, 119 ; - tubifex, 423 ; - visceralis, 419.

Eustrongylinés (Eustrongylinx), 418.

Eutarsus cancriformis, 691 .

Éveuts (Cétacés); 1097 ; - (Poissons), 960. livolution (Doctriue de l'), 92, 98 .

Excrétion, 35, 39.

Eyra, 1209.

\section{F}

Fabricius (Bourse de), 1023.

Face, 936 .

Facettes (Yeux à), 59 i.

Facultatif (Parasitisure), 69.

Fahdad, 1213.

Faisandeaux, 1050.

Faisanderies, 1050.

Faisaue, 1050 .

Faisaus, 1050.

Faisceaux primitifs, 19.

Falcifornes (Corpuscules), 120.

Falciger, 682; - rostratus, 683, 681.

Fnlco, 1066; - æsalon, candicans, cenchris, peregrinus, subbuteo, tinnunculus, 1066.

Famille, 90.

Fanons, 1100.

Fasciola, 341, 342; - americana, 356;carnosa, 356; - elaphi, 376; - hepalica, 312; - humana, 312; - lanceolata, 357; - linearis, 368; - ovalu, 368 ; - verrucosa, 340.

Fasciolidés (Fasciolidx), 3ł1.

Faubert, 191.

Faucheurs, i:f.

Faucons, 1066.

Fausses pattes, 736, 851 .

Fauvettes, 1063, 106'.

Faux-Bourdons, 867 .

Faux-Scorpion des livres, 725 .

Faux touruis, 763.

Fecondation, 43, 47, 48.

Félidés (Felidx), 120?. 
Félinès (Felin $x), 1208$.

Felis, 1208; - cafra, 1210; - caligala, carac.sl, 1212; - culus, 1209; - cauclata, 12!0;-chats, 1212;-chinensis, $1210 ;-$ concolor, eyra, 1209; - fera, 120s; - jacanensis, 1210; - leo, 120s; - leopardus, 1209; - libyca, 1210;lynx, 1212; - macrocetis, $1209 ;-m a-$ niculala, 1210; - manul, marmoratu, 1209 ; - minuta Bourguignat, 1208 ; minnta Temminck, 1210 ; - onca, panthera, pardalis, 1209; - prisca, 120s; rubiginosa, 1210 ; - spelxa, 1:08; tigris, 1209; - torquata, 1210; uncia, yaguarundi, 1209.

Femelles, 43, 45.

Fèmur, 93\%.

Feunecs, 1198.

Fennecus, 1198.

Fer (Age du), 1:33.

Féra, 967 .

Fer-à-Cheval, 1218.

Fer-de-lance, 1012.

Festucaria caryophyllina, 339;-cervi, 376.

Feu l'herbe, 702.

Feuillet, 1116 .

Feuillets du blastoderue, 51, 5?.

Fiber, 1183.

Fibre-cellule, 18 .

Fibreux (Tissu), 16.

Fibrilles musculaires, 19.

Fibro-cartilage, 17.

Fibromes parasitaires, 5 i0.

Fierasfer, $9 \mathbf{4} 5$.

Fièvre du Texas, 127, 713.

Fil de Florence, 858

Filaires (Filaria), 499 ; - acutiuscula, 508; - sethiopica, 501; - anatis, 533; Bancrofli, 515, 526; - bovis, 527; canis cordis, 509; - capræx, 531; cardiaca, 439 ; - cervina, 526; cincinnata, 538; - clavit, 532; - conjunctivæ, 528; - cygni, 233 ; - cystica Rud., 420; - eystica (Salisbury), 515; - dermathemica, 515; - diurna, 522, 529; - equi, 524; - equina, 524, 528; - Evansi, 5:3; - lixmorhagica, 505, 525; - hepatica, 532; - hominis bronchialis, 530 ; - hominis oris, 530 ; immilis, 509; - inermis, 525, 528, 530; - imitans, 508 ; - labialis, 530;labiato-papillosa, 526; - lacrymalis, 527 ; - laticeps, 543; - lentis, 529; lienalis, 541; - $10 a, 522,529 ;-l y m-$ phatica, 530; - Mansoni, 533; - IIazzantii, 532 ; - medinensis, 500 ; - microstoma, 535; - megastoma, 533; multipapilla, 505; - multipapillosa, 505; - nasuta, 54'; - nocturna, 515, 522 ; - oculi canini, 531; - oculi humani 529 ; - Osleri, 437, 530; - palpe- bralis Pace, 528 ; - pnlpebralis Wilson, 528 ; - palpebrarum, 527 ; - prpillosa, 524 ; - papillosa hrmalica canis clomestici, 509; - perilonæi hominis, $5: 8$; perstans, 522, 551; - recondita, 513; - restiformis, 530 ; - reticulala, 538 ; - Rhodesi, 527; - sanguinis equi, 525; - sanguinis hominis, 515,$525 ;-$ noctu:na, 515 ; - s.h. var. major, 52?; - s.h.var.minor, $522 ;-$ sanguinolenta, 536 ; - scutala, 541; - strongylina, 536: - terebra, 526; - trachealis, 43i; - trispinulosa, 531; - uncinata, 543; - volvulans, 522; - IVuchereri, 515; - zebra, 78

Filaridés (Filarille), 499.

Filariose de l'llomme, 520: - hématique des Canidés, 512, 515; - hémorragique des Équidés, 507; - pulmonaire, 531 .

Filaroides mustelarum, 531.

lilets (Sangsues), 582 .

Filières, 729, 851 .

Filiformes (Palpes), 626.

Finnois (Type), 1240 .

Finte, 966.

Fissilingues, 1013.

Fissiparité, 42.

Fissipèdes, 1193.

Fissirostres, 1061,1064 .

Fissurelles (Fissurella), 920.

Flacheric, 859 .

lilagellatendiphterie, 166.

ilagellés, 162 .

Flagellum (Cellules), 20 ; - (Gastéropudes), 918: - (Infusoires), 27, 113; (Sporozoaires), 123.

l'lamauts, 1032.

Flambé (Grand), 860 .

Flet, 970 .

Flétan, 970.

Flies, 920.

Flustra truncata, 573.

Foie, 36.

Foies gras, 103b, 1039, $10 \mathrm{i} 0$.

Follicule pileux, 1067, 1068.

Fouction, 26.

Foramen caurlale, 211, 219, 350.

Foramen de Panizza, 991.

l'oraminifères, 115, 119.

Forcipules, 733 .

Forficula auricularia, 881 .

Forficules, 881 .

Formica, 86 t.

Formicidés (Formicidæ), 863 .

Formicinés (Formicinæe), s64.

Eormule dentaire, 1080 ; - digitale, 1072.

Fosse naviculaire, 1085.

Fossettes olfastives, 902 .

Fossiles, 105.

Fossoyeurs, 899.

Foll, 10 1. 
Fougrous, 96'1.

Fouine, 1204.

Fouisseurs (Hyminoptires), 864.

Foulques (Fulica), 10 2.

Foumza ia ngùmbi, 779 .

Fourchette, $101 \mathrm{~s}$.

Fourmilière (Cheval), 552.

Fourmilières, 863.

Fourmiliers, $1095,1096$.

Fourmilion, 878 .

Fouruis, 863 .

liouruis blauches, 8 i9.

Frai, 981.

Francolins (Francolinus), $105 \%$.

Frégates, $10 \mathrm{il}$.

Freilu, sil.

Frelon, 865.

Freux, 1063.

Feyana, 68:; - anatina, Chanayi, 683 .

Fivèze, $85 \%$.

Fringrale, $85 \%$.

Friugilles (Fringilla), 1062; - curduelis, calebs, linolu, monlifringilla, 1062.

Friugillidés (Fringillirlæe), 1062.

Frililluria, 932.

lirugirores (Chiropteres), 1217.

Fugu, 964.

Fulica, 10i2.

Fuligulinés, 1037.

Funicule, 5 í.

Furet, 1204 .

Furfooz (Squelettes), 1233.

Furia infermalis, is.

Furie des Boeufs, 768 .

Fusaric compar, 408; - dispar, 40s; inflexa, 405; - mystax, 402; - reflexa, 406; - strumosa, 406; - vermicularis, 409.

Fusilormes (Pälpes), 626.

Fuyard, 105\%.

Gadidés (Gadid $x$ ), 967 .

Gadıs, 967; - æylefinus, callarius, minutus, morrhua, 967.

Galazyme, $116 \dot{\text { i. }}$

Galbula, 1060 .

Gale, 640; - des épiciers, 689; — du paturon, 6i2; - folliculaire, 636 ; norvégienne, 6 \$9.

Galea, 73i, 880 .

Galéode (Galeodes), 731 ; - maneoiles, barbarus, 731 .

Galèodes, 614, 731 .

Galéopithèques (Galeopithecus), 1219.

Galère, 195.

Galerites hemisphicricus, 199.

Galeus, 960.

Galleria mellonella, 853, 871 .
Galles, 632, 997,81 ?, 862; - animales, 770 .

Gallicoles (Hyuénoptères), s62; - (Phylloxiras), si2.

Gaillinacés, $1029,10: 3$.

Gallinago, 10:2.

Gallinés (Gullina), 10:3, 10.1.

Ciallimula, 1042; - chloropus, 10 fl.

Gallo-P’avo, 10:5.

Gallophasis, 1051; - nycthemerus, 1051.

Gallus, 10:11; - bankiva, 10j1;-domesticus, 10:2; - ferrugineus, 1051 ; furcatus, gallinaceus, Lafayetlei, Sonnerati, Stunleyi, varius, $105 \%$.

Gamases (Gamasus), 723; - auris, Mleroploiles, 723.

filmasidés (Gamasidx), 631, 718.

Gaulasinés (rumusinx), 718 .

Gametes, 43.

Gammarus pulcx, 301, 5i0, 606.

(ianglionnaire (Chaine), 29, 206, 595.

Ganglions lymphatiques, 94́.

Gimoïdes (Ecailles), $949 ;-$ (Poissons), $9.59,962$.

Giapes, fivi.

Garde, 221.

Gardo11, 1167.

Garib-Guez, 718.

Garrot (Ciuard), 103i.

Farrulus, 1063; - glanderius, 1063.

liarum, 965.

Gastéropoiles, 90 t, 915.

Gasterosteus, 971.

Gastérostominés (Gasterostomince, 3ł1.

Gastricoles (OE:trinés), 74\$, 749.

Gastrodisques (Gustrodiscus), 376, 379; agypticacus, polymastos, Sonsinoi, 379. Gastroléginés (Gastroleginx), 866.

liastropacha, S5í.

Gastrophiles (Gastrophilus), 749; - equi, 750 ; - equi var. asinina, 759 ; - flavipes, 759; - hamorrhoidalis, 755; inermis, 759 ; - lativentris, 759 ; nusalis, 757 ; - nigricomis, 759 ; - pecorum, 758 ; - velerinus, 757 .

Gastrostèges, 993 .

Gastrothylax (Gastrothylnx), 378; - Cobboldi, 379; - crumeniferum, 378; élongulum, 379.

Gastro-vasculaire (Cavité), 36, 188.

Gastrozoïdes, 19i

Gastrula, 51.

Gastrus, 749; - pecorum, 758.

Gattine, 858 .

Gaur, 1142.

Gavials, 1015.

Gayal, 1142.

Gazelle (Guzellu dorcas), 1128.

Gealis, 1016, 1063 .

Gécarcius (Gecarcinus), (;10; - ruricolu, 610.

Gecinus viridis, 1060. 
Geckos, 1013.

Gélatineux (Tissu), 16.

Gélinotte, 1054 .

Gemmiparité, 42.

Gemmules, 186.

Génération, 41; - alteruaute, 53, 225.

Genetta vulgaris, 1207.

Genette, 1207.

Génisse, 1146.

Genre, 90, 94.

Géocorises, 819 .

Géomètres (Chenilles), 853.

Geophilus, 733.

Géotrupes (Geotrupes), 898.

Géphyriens, 57i.

Gerboises, 1178 .

Gerfaut, 1066.

Germe de l'œuf, 1026.

Germement, 582.

Germiducte, 212.

Germigène, 211, 333.

Germiuale (Membrane), 261.

Germinatif (Sac), 335.

liermiuative (Vésicule), 46; - (Tache), i6.

Germinatives (Cellules), 42.

Germos, 971.

Gésier (Crustacés), 603; - (Insectes), $738 ;-($ Oiseallx), 1022

Gestation, 1090.

Ghor-Kihur, 1166.

Giardia, 164; -? (Lamblia) intestinalis, 169.

Gibbons, 1223.

Gibèle, 967 .

Gigantorhynchides (Giguntorhynchidx), 565.

Gigantorynques (Gi,gantorhynchus), 565; - gigas, 565; - hirudinaceus, 565; lumbricoides, 566 ; - moniliformis, 568 .

Gigantostracés, 611 .

Girafe, 1127.

Gîtes, 915 .

Glaciaire (Époque), 1228.

Gland, 1085; - de mer, 605.

Glande, 20 ; - coquilliere, 225,$334 ;-$ ovoide, 201.

Glenocercaria flava, 339.

Glires, 1176.

Gliricoles (Sarcoptidé3), 685.

Globigerina, 119,120; - bulloides, 119.

Globocéphale (Gtabocephalus), 455; - tongemucronatus, 455.

Globules du sang, 21; - polaires, 48 .

Globuleux (Poissons), 96t.

Globuline-venin, 995 .

Globulins, 21.

Gloidium, 115.

Glomeris, 733.

Glomérules de Malpighi, 945.

Glossines(Glossina), 787; - fusca, 788 ; longipalpis, $788 ;-$ morsilans, 787; - tabaniformis, 788; - tachinoides, 788; - ventricosa, 788 .

Glossiphonies (Glossiphonia), 590; - tessellata, 590 .

Glouton, 1204.

Gluvia dorsalis, 731.

Glycyphages (Glycyphagus), 688; - Buski, 689 ;-Canestrinit, 689; - cursor, 688; - domesticus, 688; - intermedius, 689 : - palmifer, 689; - phumiger, 689; prunorum, 688 ; - spinipies, 688.

Guathites, 597.

Gnathobdellidés (Gnathobdeltidx', 577.

Guathostomes (Gnathostomum), 516;- hispidum, 547; - robustum, 547; - siamense, 548; - spinigerum, 547.

Guathostomes (Crustacés), 606.

Guathostomidés (Gnathostomidis), 546 .

Gnou, 1128.

Gobiidés (Gobiidæ),' 974.

Gobio fluviatilis, 967.

Gobius, 9i4.

Goélands, 1041 .

Gomme laque, 811.

Goniatites, 92 ;.

Gond, 737 .

Gongylouèmes (Gongylonema), 541; pulchrum, 541; - scutatum, 541; verrucosum, 54:.

Goniocutes (Goniocotes), 835, 842; - abdominalis, 842 ; - Burnetti, chrysocephalus, compar, gallinæ, gallinæ var. maculata, 843; - gigas, 842; - hologaster. rectangulatus, 843 .

Goniodes (Ganiodes), 835, 840;-Burnetti, 843 ; - colchici, damicornis, dissimilis, 841; - falcicornis, 842; - meleagridis, minor, 841 ; - numidianus, parviceps, pavonis, 842 ; - stylifer, 841 ; - truncatus, 841.

Gonuphores, 194.

Gonozoides, 194.

Gordiacés, 385, 562 .

Gordius, 562; - aquaticus, 56:, 563 ; chilensis, 563; - pulmonalis apri, 432 ; - tolosanus, varius, 563.

Goret, 1111.

Gorgeret, 876.

Gorille (Gorilla gina), 1223.

Goujon, 967 ; - de mer, 974.

Goumier, 920.

Gour, 1166.

Gouras (Goura), 1059.

Gourkour, 1166.

Goût, 30 .

Gouttière œsophagienue, 1116 ; - priultive, 9 ic.

Gozzo, 1021.

Grainage cellulaire, 859 .

Graine de Ver à Soie, \$5̃ .

Grains de ladre, 241, 248.

Grains de poivre (Cheveux en), 1238. 
Grallatores, $10 \mathrm{il.}$

Grand-Duc, 1066.

Grand'nourrice, 5i, 226.

Girand sympathique, 940.

Grapholita funebrana, 853 . .

Grasserie, 858 .

Gralteurs, $10 i 3$.

Gritloir, 1229.

Gravettes, 907.

Gièbes, 1032.

Gregarina avium intestinalis, 133; - falciformis, 132; - Lindemanni, 147;-

Viescheriuna, 150; - muris, 132.

Grégarines, 1:5.

(irenille, 9 - 2 .

Greuouilles,978, 980, 985; - du Cliuco, 987.

Griffes, 1069.

Grillous, ssu.

Grimpereaux, 1062 .

Grimpeurs, 1029, $105 \%$.

Grisel, 960.

Grives, 1063.

Grizzly, 1204.

Grocer's itch, 689 .

Groin, 110 .

Gromia, 119.

Grondins, 97千.

Gros-Becs, 1062.

Grotte des Fées (Mâchoire), 1230.

Grouse, 105 '.

Grues (Grus), 1042; - carunculata, 1012.

Gryllidés (Giyllidæ), 884.

Gryllotalpa vulgaris, 884 .

Gryllus campestris, tomesticus, 884.

Guanaco, 1119.

Guarani (Type), 1243.

Guenons, 1223.

Guépards, 1212.

Guêpes, 86i, 865 .

Guêpier (Merops), 1061.

Guérib-Guez, 718 .

Guillemots, 1032.

Guillots, 783 .

Guinea-pig, 1186.

Guinea-worm, 503.

Guinéen (Type), 12 13.

Gulo borealis, 120 .

Gusano, 77.

Gymnamœbiens, 116.

Gymnocyte, 13.

Gymnocytode, 13.

Gymnophiones, 951.

Gymnorhinieus, 1217 .

Gymnostomes, 173.

Gymnotes (Gymnotus), 96i; - eleclricus, 964.

Gymnothecæ, 485.

Gynécophore (Canal), 3i2.

Gynécophorose, 373.

Gynrecophorus. 3'1, 371;-bovis, 375; crassus, 375; - hipmatobius, 371; magnus, 373 .
Gypaètes (Gypaetus), 1066; - Unibulus, 1066.

frypogeramis, 1066 ; - serpentarius, 1066.

Gyrateurs, $105: i$.

Gyrins (Gyrinus), 900.

Gyrocotyle, 33:.

Gyropes (Gyropus), \$45; - gracilis, ovalis, poicetli, 84i5.

rijiostigma, 749.

H

IIache (pierre polic), 1232.

ILiemadipsa, 589; - zeylanica, 589.

Ilamulastor, 706.

IIrmamaba Danilevskii, 125; - immacuInta, 12'; - malarix, 122, 124; pracox, 1:4; - vinax, 121.

Iliemaphysalis, 706, i1t; - punctata, 71 t.

IIxmatobia, 786 ; - ferox, serrata, slimulans, 787.

Hæmatomonas Evansi, 165.

Ifrmutomyzus, 825 .

IIrematopinoides, 825 .

Irematopinus, 825, 830; - asini, 831 ; a. coloratus, 831 ; - bicolor, 833 ; comeli, 831 ; - eurystermus, 831;macrocephalus, 830 ; - oxyrhynchus, \$31; -- pilifer, 511, 832 ; - stenopsis, 832; - suis, 831; - tenuirostris, \$31; - luberculatus, $832 ;-t$. penicillulus, 832 ; - urius, 831; - ventricosus, 833; - vituli, 831 .

Hæmatopota, 793 ; - equorum, lumata, nigricornis, pluvialis, 793.

IIæmatopus, 909, $104 \%$.

Hæmatozoon Lewisi, 514; - subulatum, 439,552 .

IIsmenteria, 589 ; - officinalis, 590 .

IIæmomyzon, 723.

Hæmopis, 578, 584; - sanguisuya, vorax, $58 \mathrm{i}$.

Ilaje, 100t.

Ilatacaididx, 631.

llalibut, 970 .

Halicore, 1101 ; - ttugong, 1101.

IIatiomma, 121; - hexacanthum, 121.

Haliolides (Iluliotis), 920 ; - tuberculata, 920.

IIalisar'ca, 186.

Halteria, 180.

IIaltica, 887 ; - nemorum, 887 .

Halyctus, 866 .

Hamar-seet, 1167.

Hampe (Plume), 1019.

Hamster, $11 \mathrm{~S} 1$.

Ilumularia lymphatica, 530.

Hanche (Iusectes), 735.

Hannetonnage, 899 .

Hannetous, 898 .

Hapale, 1221. 
Haplocerus americanus, 1128.

Harder (Glaude de), 989, 1021.

Hareng, 965.

Haricots de mer, 915.

Harles, 1040.

Harpactor cruentus, 819 .

Harpaye, 1066.

Harpicephalus, 697.

Ilarpirhynchus, 697 .

Harpon, 704.

Hase, 1190.

Hausmeerschweinchen, 1186.

Hautle, 819.

Havers (Canaux de), 1 .

Hectocotyle, 926.

Hectopsytla, 808 ; - psittaci, 809.

Hedjihn, 1021.

Hélices (Ilelix), 923; - aperta, aspersa, nemoralis, pisana, pomatia, sylvatica, vermiculata, 923.

Hélicicullure, 923.

Hélicidés (Helicidx), 922.

Héliozoaires, 115, 120.

Helminthes, 69, 209.

Helminthiase, 74.

Helminthologie, 209.

Helminthopsylla, 809; - Alakurt, 809.

Hélodermes (Heloderma), 1014; - homidum, suspeclum, 1014.

Hélohippes (Helohippus), 589.

Hélophiles (Helophilus), 791; - vendulus, 791.

Hémadipses, 589 .

Hémal (Arc), 935 ; - (Liquide), 37.

Hémale (Face), 593, 901.

Hėmamibes, 122, 125.

Hémamobiens, 122.

Hémaphéine, 21.

Hémaphysalis, 714 .

Hémapophyses, 935 .

llématies, :1.

Hématique (Appareil), 576; - (Liquide), 37.

Hématobies, 786.

Hématoblastes, 21.

Hémato-chylurie, 521.

Hématococus, 127.

Hématopinus, 830 .

Hėmatopotes, 793.

Hématozoaires, 69 ; - de Lewis, 514 ; - du paludisme, 122.

Hématurie infertropicale, 521.

Hémélytres, 736 .

Hémentéries, 589.

Не́mépiue, 936.

Hémérobiinés (Jemerobiinæ), 8i8.

Hemerobius, 878 .

Hémérythrine, 21.

Hèmichordés, 929.

Hemicidaris intermedia, 193.

Hémimétabolieus, 740 .

Hémione, 1165.
Hémioniens, 1164.

Hémippe, 1166.

Hémiptères, 741, 809.

Hemisarcoptes, 688.

Hémisphère cérébraux, 939.

Hémistomes (Hemistomum), 381; - alatum, 382; - sp., 379.

Hémistominés (Hemistominæ), 381.

Hémitragues (Hemitragus), 1134; - jemlaicus, 1134 .

Hémocyaninc, 21, 603 .

Hémoglobine, 21.

Hémoglobinurie bactérienne, 127.

Hémolymphe, 21.

Hémosporidies, 128.

Hépatopancréas, 36 .

IIeptanchus, 960.

Hérẻdité, 41.

Hericia, 688 .

llérissons, 1214.

llermaphrodisme, 44.

IJermaphrodite (GIande), 918.

Hermine, 120 ;.

Hérodiens, 1042.

llirons, $10: 2$.

llerpes blattæ, 881; - labialis, 896.

Herpès phlycténoïde, 896.

Herpetobia, 706.

llerpetomonrs, 164 ; $\rightarrow$ Lewisi, 164.

Hespéridés (Hesperidæ), 860.

llesperomis, 1029.

Hétérakis (Heterakis), 405 ; - brasiliensis, 408 ; - columbx, 406; - compar, 40s; - compressa, 406; - differens, 409; - dispar, 408; - inflexa, 406; - lineatu, 406; - maculosa, 406;-papillosa, 406, 407,408;-perspicillicm, 406.

Hètèrocères, 851.

Hétérocerque (Nag. caud.), 951.

Hétérocotylés, 334 .

Hẻtėrocyémides, 208.

Hétérodères (Ileterodera), 554; - Schachti, 554 .

Hétérogamie, 43.

Jètérogéuie, 41 .

Hétérogone (Digenèse), 54; - (Monogeuése), 56 .

Ilètérogonje, $55,392$.

Ilétéromères, 890 ,

Hétéromètres (Helerometrus), 729 ; maurus, 729.

IIteromita, 164.

Hétéromorphes (Mảles!, 628.

Ileterophrys, 120.

Hétéropodes, 919.

Hétéroptères, 818 .

Heteropus, 693 ; - ventricosus, 693.

Hètérotriches, 177.

llétéroxèues (Parasites), 70,

Hexacanthe (Embryon), 212.

Hexactiviaires, 192.

IIrxamita, 16i; - duodenalis, 169, 170 . 
Hexanchus, 960 .

Ilexapode (Larve), 630.

llexapodes (Arliculès), 601, 73i.

Hexally yridium pinguicola, 350 ; - venurum, 33..

Jilernants (Mammiféres), 1091; - Phylloxéris), sif́.

lliboux, 1066.

Hindon (Type), 124?.

llipparions (llipparion), 1152: - gracile, c\%(lsum, 1152.

Ilippidions (Ilippidion), 115t; - nanum, neogieum, 1154.

llippoboscidés (llippoboscidie), 745.

llippobosques (llippobosca), if5; - camelina, canina, equina, nigra, luurina, 746.

llippocampes (Hippocampus', 963; - anliquorum, brevirostris, 963.

llippodartyles (Ilippodactylus', 1153; anlelopinus, 1153.

llippoglossus vulgaris, 970 .

llippophagie, 1164 .

IIippopolames (Ilippopolamus), 1105 ; amphi'ius, liberiensis, 1105.

Hippopotanides (Hippopolamida), 1105,

llippopsis gracilis, $\mathrm{s}$.

llippospongia equina, 186.

Mippolherium, 1152.

llippotigris, 1169.

lliveus, 1134.

Ilirondelles, $106 \dot{1}$; - de mer, 1041.

llirudinées, 577.

Hirudiniculture, .5s2.

llirudininés (Hirudininx), 57, 578.

llirudo, 57s; - medicinalis, 578; - officinalis, 578, - sanguisuga, 581; Irnctina, ss't.

Hirundo, I06í; - riparia, ruslica, urbica, $103 \mathrm{i}$.

IIisler cadaverinus, 900 .

IIistiogaster, $6 \times 8$.

Histiostomes (Hislinstomum). 688; - feroniarum, necrophagum, 688.

Hislologie, 15.

Histriobdellidés (Histriobdellidre), 577.

llitzausschlag, 896 .

Hojercau, 1066.

Hocherjueues, 1063.

Hog cholera, \$52.

Holoblastiques , OEufs), 50 .

Holocéphales, 960.

Hulochordés, 929 .

Holomyaires, 387.

Molostaspis badius, i24.

Holostomes (Iloloslomum), 383; - ala. tum, 382 ; - erralicum, gracile, variabile, 383 .

Holostomitlés (Holoslomidx), 338, 390.

Holoslomincs (Holos/omina), 381, 38\%.

Holothurides, 202, 205.

Hololhuries (Ilo!olhuria), 205; - edulis, Hydraires, 193. yuamensis, lremula, lubulosa, vagabunda, 20\%.

Holotriches, 173.

llomalogasIres (Ilomalogaster), 376. 379; - Ioirieri, 3i9.

Ilumalomyiu, 781; - canicularis, incisureta, scalaris, i81.

Homards (Homarus), 609; - vulgaris, (0), 609.

Iloméomorplies (Mâles), 62s.

Ilomiuiens, 1223.

llomme, 1223.

llomme mort (Squeleltes), 1233.

Ilomo, 122'; - sapiens, 1223, 1234.

Homocenlins, 1222.

llomocerque (Nag. caud.), 950.

Hourodyanuie, ?6.

llomogone (Digenese), ji; - (Monogenése), 56.

Homologite, 2. .

llomopiales (Xymphes', 687.

Homoplères, 810 .

IIomouns, $6 \mathrm{~s}$.

Ilomolypie, 25.

Homunculus, 12:2.

Hongre (Cheval), 1163.

Horloge de la inorl, 896.

Horripilateur's (Muscles), 1068.

Ilôtes des parasites, 70 .

l]otu, 9ri7.

Iluuvet, 610 .

Huile de Baleine, 1100; - de foic de Iorue, 968; - de foie de Raie, 961; - de foic de Squale, 961 ; — de Poissou, 1100 .

Iluîtles, 907 ; - épineuses, 911 ; - marinées, $910 ;-$ perlières, 911,91 ; ; rouges, 911 ; - vertes, 909.

IIuîtriers, 10 \%?

Hulottes, 1066 .

Humérus, 93i.

lluppes, 1062.

Hurleurs (Singes), 1:22.

IIyzmoschus, $11: 4$.

IIyxna, 120i; - croculu, slriata, 1207.

Hyirnidés Ilyarnidxe), 1207.

Ilyalea cornea, 915.

Il yalommes (Hyalomma), 706, 710;-ægyptium, $¥ 10$; - africanum, 711 ; - marginalum, 710 .

Hyaloplasmi, 10.

llybridation, 95 .

Hybride, 96 .

Hydatides, 253.

IIydatina senta, $5 \%$.

Hydalique (Membrane), 261.

Ilydra, 191; - fusca, grisea, viridis, vul yaris, 19 t.

IIyrhiachnidir, 631.

IIydractinia echinala, 19:3.

Hydraire (Polype), 19?. 
Hydre, 42, 194.

Hydrocèle chyleuse, 520 .

IIydrochœrus capybara, 1185.

Hydrocorises, 818 .

Hydroïdes, 193.

Hydroméduses, 188, 192.

Hydromel, 874 .

Hydrophiles (IIydrophilus), 900.

Hydrophis, 1004 .

Hydrophore (Canal), 200.

IIydrophoria, 781.

Hydrosauriens, 1015.

Hydrotées (Hydrotæa), 781; - meteorica, 781, 78?.

Hydrule, 192.

Hyènes, 1207.

Hyla, 937.

Hylastes, 889 ; - trifolii, 889.

Hylesinus, 889.

Hylobates, 1223; - lar, 1220.

Hylotoma, 862.

IIymen, 1085.

Hymėnolépis (Hymenolepis), $291 ;-d i-$ minuta, 295, 895; - flavopunctata, 295; - murina, 291, 293; - nane 291, 292.

Hyménoptères, 741, 861 .

Hyoïde, 936 .

Hyotherium, 1105.

Hypermétamorphose, 741, 890.

Hypocères, 779.

IIypodectes, 684; - columbx, 684; - minor, 684 .

IIypoder(us, 684; - columbæ, 68ł.

Hypoderme, 206.

Hypodermes (Hypoderma), i67; - Actæon, 775; - Bellieri, 775; - bonassi, 773; - bovis, 767, 772; - Clarki, 775; - Diana, 774; - heteroptera, 775; lineata, 772, 773; - Loiseli, 772; Silenus, 772, 774; - tarandi, 775.

Hypohippus, 1151.

Hypomochlion, 221.

Hyponomentes (IIyponomeuta), 852; malinella, padella, 852.

Hypopharynx, 742.

Hypophyse, 932, 939.

Hypopiales (Nymphes), 687.

IIypopus, 687, 688 .

Hyporachis, 1019.

Hypostome, 626 .

IIypostomum caryophyllinum, 339.

Hypotriches, 184.

Hypsiprymnus, 1095.

Hyracéum, 1175.

Hyraciens, 1091, 1101, 1175.

Hyracodon, 1175.

Hyracothérinés (Hyracotherinæ), 1149.

Hyracothériums (IIyracotherium), 1149; - leporinum, venticolum, 1149.

Hypax, 1175; - abessinicus, capensis, syriacus, 1175 .
Hystrichis (Hystrichis), 423 ; - anatis, 423 ; - cygni, 424; - elegjans, 423; morgorum, 423 ; - pachycephalus, 424; - tricolor, 423 ; - tubifex, 423.

Hystrichopsylles (IIystrichopsylla), 805; obtusiceps, 805.

Hystricidés (Hystricidæ), 118ł.

liystricomorphes (Hystricomorpha), 118 i. Hystrix cristata, 118ł.

\section{l}

Ibex, 1134 (voy. Capra).

Ibis (Ibis), 1042.

lchneumon(Lépidoptères), $863 ;-P$ P 863.

Ichthyornis, 1029.

lebthyosauriens, 1015

lchthyosaurus communis, 1015.

Ichtyocolle, 962.

Ichtyopsidés, 9 is.

Ieticyons (Icticyon), 1196; - venaticus, 1196.

Idia Bigoti, 779.

Iguaues, 1013.

Iguanodons, 1014.

Ihâr, Ihàral, 113 4.

llèo-cæcale (Valvule), 10 so.

Iléon, 942.

llium, 937 .

Imago, 710.

1mmntabilité des espèces, 92.

Imperforés (Foraminifères), 119.

Implacentaires, 1088, 1091.

Impression palléale, 904 .

Inacétabulés, 926 .

Inarticulés (Brachiopodes), 575.

Incisives, 1079.

Inclusions, 11.

Incubation, 1028.

Incubatrice (Chambre), $4 \dot{4}$.

Indice céphalique, 1236: -- nasal, 1237.

Indigestion ingluviale, 488 .

Individu, 26, 87 .

Indris, 1219.

Industriels (Aimaux), 67, 81 .

Inéquivalve (Coquille), 904.

Infusoires, 114, 160.

Infusoriformes (Embryons), 335.

Ingluvie, 1021.

Ingluvies, 1021.

lusecle parfait, 740 .

1nsectes, 601, 734 .

Insectivores (Chiroptères).1217; - (Mammifères), 1091, 1213.

Instinct, 32 .

Intelligence, 32.

Interdigitales (Glandes), 169

Inter-épineux $(0 \varepsilon), 950$.

lutermédiaire (Hôte), 950.

Interrayons, 198. 
Intestin, 36 ; - chylifique, 597; - pri- Kangourous-Rats, 1095. mitif, 51 .

Inuus ecaudatus, 1:23.

Invertébrẻs, 110.

Iranien (Type), 1241.

Isatis, 1:98.

Ischion, 937.

lsogamie, 4 is.

Isopodes, (i05, 606 .

liaryokinèse, 14.

fiaryophagus hominis, litt.

kashkir, 11:?.

lieber (Glaude de), 906.

lieiroun, 780 .

kiné, iss.

kentrogonides, c05.

Isospores (Isospora), 132; - avium, 13:.

Isotrichidés (Isotrichidie), 175.

Isolriques (Isotrichu), 175; - intestinulis, prostoma, 176.

Iules (Iulus), 733; - terrestris, 733 .

Ivoire, 1078.

Ixode (1xodes), 706; - xgyptiacus, il0; -- africanus, 711; - algeriensis, 711; - americanus, ilt; - bovis, 713 ; bursa, 71:3; - chelifer, 714: - Dutgesi, 712 ; - hexagonus, 709 ; - maimoratus, i13;-occidentulis, i14;-plombé, 71:; - punctutus 7I4; - reduvius, $706 ;$ - reliculalus, 713 ; _ ricinus Latr., 707; — ricinus Mégn., 709; sanguineus, $712 ;-$ sexpunctatus, 709 ; - vulpis, i09.

Ixndidés (Ixollidx), 631, 703.

Ixodinés (Ixodinæx), i0'.

Izard, 1128.

\section{$J$}

Jabot (Iusectes), 738; - (Oiseaux), 1021. Jacamars, 1060.

Jaco, 1060, 1061.

Jacobson (Organe de), 940, 1076.

Jaguar, 1075.

Jaguar ondi, 1209.

Jambe (Insectes), 735; - (Vertébrís), 937 .

Jambonneaux, 914 .

Jardinier, 909.

Jarre, 1068, 1132.

Jars, 1036.

Jaunes (Races), 1:42.

Jaunisse, 858 .

Jéjunum, 9 ł'.

Joues (Acariens), 625.

Joues-cuirassées, 9i2.

Jugulaires (Poissons), 951.

Jumart, 1171.

Jument, 1163.

Jumentés, 1091, 11\%̄.

\section{$\mathbf{K}$}

kérabau, 1141

Kermès (Kermess), 810; - vermilio, 810 .

Kermés aluimal, 810.

Kernstiele, 176 .

kertag, 116 .

lihohe, 85is.

kiang, 1166.

Kiduey-worm, 45 ?

Kiwi, 1031.

kjökkenmö̈dinger, 1 23!.

Klipfish, $96 \mathrm{~s}$.

klossia, 13:.

kinemidokoptes (Voy. Cnemidocoples).

fóllikeria, 341.

liolpodes (Kolpoda) (voy. Colpodes).

Kora, 1164.

Kotsh, 1129.

Koulan, 1163, 116'.

lioumys, 1163.

fovalevslya, 932.

Krause (Corpuscules de), 30.

ivithoptes monunguiculosus, 69'.

liropf, 1021.

Kusappi, 1064.

Kymri (type), 1240.

Kyste bruo, 555; - coceidien, 149; hydatique, 221, 259; - trichineux, 493.

\section{L}

Labbes, 1041.

Labrax lupus, 972.

Labre, $73 \%$.

Labyrinthe, 31 .

Labyriuthiformes, 955.

Labyriuthodontes, 981.

Lacerta, 1013.

Lachésis Lachesis', 1012; - mulus, 1012.

Lacon murinus, 898 .

Lactaires (Glaudes), 1086.

Lacunaire (Liquide), 37.

Lacustres (IIabitatious), 1:31.

Ladrerie du Bœuf, 2i0; - du Chien, :49; - de l'Ilomme, 219; - de la Morue, 331 ; - du Porc, 2: 8 ; - séclse, 248.

Lixlaps casalis, cuticularis, domesticus, fonalis, marginatus, miles, stabularis, i24.

Kakerlac, 881 .

Kalong, 1217.

Kamicbis, 1042.

Kangourous, 1095.

Lieluptins, its.

Lagena, 119, 120; - vulgaris, 119.

Lagena (Oreille), 1021.

Lagomorples (Lagomorpha), 1188. 
Lagomydés (Lagomydæ), I192.

Lagomys, 1192.

Lagonosticta, 1063.

Lagopèdes (Lugopus), 105́ ; - mutus, scoticus, 1054 .

Lagostomidés (Lagastomidæ), 1185.

Lagostomus triehodactylus, 1185.

Laie, 1107.

Laine, 1068, $1: 33$.

Lait, 1086.

Laitance, 956.

Lamas, 1119.

Lamantins, 1101.

Lamarckisme, 99.

Lamblidés (Lamblidx), 169.

Lamblies (Lambtia), 169; - intestinalis, 169.

Lamellibranches, 90 '.

Lamellicornes, 898 .

Lamellirostres, 1031, 1032.

Lame (Plumes), 1019.

Lames dorsales, $946 ;-$ ventrales, 947 .

Laminosioptes (Laminosioptes), 680 ; cysticota, gallinarum, 680 .

Lamnonges, 1175.

Lamproies, 959, 960.

Lampyres (Lampyris), 897; - noctiluca, splendidula, 897.

Lance d'Achille (voy. Vipera berus).

Laucelet, 933 .

Landgak, 1197.

Langoustes, 609.

Languette, 626, 738 .

Langueyage, 248.

Lanières vibratiles, 171.

Lanius, 1063; - excubitor, minor, 1063.

Lanterne d'Aristote, 201.

Lapereaux, 1191.

Lapides Cancri Astaci, 609.

Lapins, 1 !89.

Lapou (Type), 12 il.

Laque, sil.

Larins (Larinus), 890 ; - nidificans, 890. Larmier, 1114.

Larus, 10 '1.

Larve, 53, 630, 740; - de Lovén, 576.

Larvipares, 745.

Larynx, 944; - inférieur, 1023.

Latebra, 1027.

Latrodectus malmignatus seu tredecimguttatus, 730 .

Laugerie-Basse (Squelette), 1230.

Laurer (Canal de), 334.

Lavaret, 967.

Laverania malarix, 124.

Leconium hesperistum, olex, persicæ, 811.

Lècheurs (Insectes), 737, 741.

Lèioguathes (Loiognathus), 719 ; - bursa, suffuccus, sylviarum, 723.

Léiotriques, $123 \%$.

Lemming, 1183.

Lemnisques, 564 .
Lémodipodes, 606.

Lemue, 1219.

Lémuriens, 1091, 1218.

Lentes, 825.

Lentieulaire (Os), 107 .

Léopards, 1209.

Lepus, 605.

Lépidoptères, 741, 850.

Lépidostées, 962.

Lepidosiren, 976.

Lepidotrias flnvopunctata, 295.

Lépismes (Lepisma), 885; - saccharina, 885.

Lépocyte, 13.

Lépocytode, 13.

Leporaria, 1190.

Léporide, 1191.

Léporidés (Leporidæ), 1188.

Leptes (Leplus), 701, 703; - autumnalis, 700 .

Leptinotarses (Leptinotarsu), 88i; - decemlineata, 887 .

Leptobos, 1141; - etruscus, Falconeri, Frazeri, 1141.

Leptobovins (Leptobovina), 1139.

Leptocardes, 933.

Leptodères (Leptoder a), 549 ; - intestinalise, 557; - Niellyi, 523, 551; - stercoralis, 557.

Leplonyx monachus, 1193.

Leptoplana, 381.

Leptoplanus Chevrolati, 89'.

Leptorhiniens, 1237.

Lepus, 1188; - cuniculus, 1189 ; - Durwini, $1192 ;$ - domesticus, $1190 ;-L a-$ costei, 1189;-timido-domesticus, 1191 ; timidus, 1189; - variabilis, 1159.

Lernées (Lemæa), 606.

Lérot, 1178.

Les/ris, 10 i1.

Léthargie des nègres, 523 .

Lethrinus mambo, 972.

Leuciscus cephalus, mutilus, vulgaris, $96 \%$.

Leucomaïnes, 40.

Lévirostres, 1061 .

Lévogyrinidés, 979 .

Lèvriers, 1199.

Lézard (Lacerta), 1013, 1014.

Lézards, 1012.

Libellules (Libellula), 880.

Lichanotus, 1219.

Licorne, 1098.

Lièvres, 1189; - de mer, 919 ; - des pampas, 118 .

Ligament falciforme, 951.

Ligne latėrale (Vertèbrés), 94:2, 951, 979; - primitive, 9'ts.

Lignes latérales (Nématodes), 386; médianes, 386 ; - submédianes, 386 .

Ligules (Ligula), 329; - alternans, 330 ; - cingutum, 33i; - digramma, 330; Mansoni, 327; - minuta, 319; - 
monogramma, 330 ; - nolosa, 319; simplicissima, uniserialis, 330 .

Ligulinés (Ligulinæ), $315,329$.

Lima, 911; - inflala, 911.

Limaces (Limax), 922 ; - agreslis, cinereus, variegatus, $9: 2$.

Limacidés (Limacidax), 922.

Liuacon, 9:2.

Limande, 970.

Liunandelle, 970 .

limes, 911.

Limicola, 1042.

limicoles (Aunélides), 592; - (Échassiers), 1042.

Limnæidés (Limnæidx), 9?1.

Limnatis (Limmatis), 584; - granulosa, mysomelas, 589; - nilotica, 58 í.

Limuèes (Limnaa), 921 ; - minula, 921 ; - peregra, 922 ; - tiuncalula, stagna. lis, 921 .

Limnochurinx, 693.

Limosa, $104 \%$.

Limules (Limulus), 611; - moluccanus, 611.

Lineus, 385.

Linguatules (Lingualula), 616; - constricla, 624; - denliculala, 617; ferox, 617; - rhinaria, 616;- serrata, 617,618 ; - tanioides, 616.

Linguatulides, 614, 615 .

Linguatulidés (Lingrecululidx), 616.

Lingue, 967 .

Lingula anatina, 575.

Linotte, 106?.

Lion, 1:08; - des Pucerons, 878; marin, 1193.

Liothëinés (Liolheinæ), 834, 8:4.

Liotheum, S44.

Lipariués (Liparinæ), 851.

Liparis (Liparis), 854; - auriflea, 85i, 855 ; - chrysorrhxa. 854, 855; - dispar, 85t, 855; - monacha, 851; - similis, $8 \mathrm{j}$.

Lipeures (Lipeunus), 835, 838; - anatis. 839 ; - anseris, 839; - baculus, 838 : - caponis, 840; - columbx, 838;crassicornis, 839 ; - heterographus, 839 ; - jejunus, 839; - meleagridis, 840 ; - numidx, 840 ; - polytrapesius, 840 ; - squalidus, 839 ; - variabilis, 840 .

Lipoptena cervi, 746 .

Liquides nourriciers, ?0.

Listrophores (Listrophorus), 685; - gibbus, 65i): - mustels, 686 .

Listrophoriués (Listrophurina), 639, 685.

Lilhobius, 733 .

Litholomes (Lithodomus), 913; - lithophagus, 913 .

Lilhosia, 85i; - canisla, griseola, 85i, 855.

Litorne, 1063.
Littorines (Lillorina), 920 ;-littorea, 920.

Lituites, 926.

Lituola, 119.

Loa, 522, 529.

Lobés P'seudopodes), 115.

Lobounonères, 115.

Locataire, 879 .

Loches, 967.

Lochelte, 922.

Locomoteur (Appareil), $2 i$.

Locusta viridissimn, 881 .

Locustidés (Locustidix), ssi.

Loirs, 1178.

Loligo, 928 ; - vulgaris, 928.

Lombrics (Lumbicus), 591; - agricul", communis, lerrestris, 591 .

Lonchæa nigrimana, 781.

Longicornes, 889.

Longipennes, 1031, 10 il.

Lophiodontes, 1174.

Lophius seliger, 974.

Lophobrauches, 963.

Lophocomes, 1238.

Lophodonle (Type dentaire), 1103.

Lophomonas, 169.

Lophophore (Bryozoaires!, 573.

Lophophores (Lophophorus), 1054.

Lophoptes (Lophoptes), 724; - palavinus, i24.

Lophopus crystellinus, 573.

Loque, 870.

Loris (Lorius), 1061 ; - (Slenops), 1219.

Loriots, 1063.

Lorum, 1032.

Lotte (lota vulyaris), 967.

Loup, 1197; - cervier, 1212, 1213:- de mer, 972.

Loutre, 1205; - de mer, 1:05.

Lovén Larve de), 576.

Loxia, 1063 ; - cu virostra, 1063.

Lucernaires, 196.

Lucilies (Luciliu), 783 ; - Cæsar, 783 - carlaverina, 78i; - lominivorax 784; - mucellaria, 78: ; - regina, 784; - sericata, 784.

Lucioles (Luciola), 897 ; - lusitanica, 897.

Lucioperca sandra, 972.

Luizette, 858 .

Lulu, 1063.

Lumbrici luti, 234.

Lumbricus (voy. Lombrics), 591.

Lumineux (Phénomènes), 39.

Lupus, 1197.

Luscinia, 106:; - philamela, rutecula, 1064 .

Lutra v'ulgaris, 1205.

Lutraires (Lutraria), 914.

Lulrinés (Lulrinx), 1205.

Lutte, 1132; - pour l'existence, 61.

Lycaon, 1196; - piclus, 1196, 1201.

Lycénidès (Lycenidip), 860 . 
Lycorus nemesianus, 1196.

Lycoses $($ Lycosa), $730 ;-$ tarentula, 730 . Lymphatiques (Cœurs), 980; - (Glandes),

$21 ;$ - (Vaisseaux), 37.

Lymphe, 21.

Lynx (Lynx), 1212; - caligatus, caracal, chaus, vulgaris, 1212.

Lyrure des bouleaux, 1054 .

Lysiosquilla, 607; - maculata, 603.

Lytta, 893 .
Malphighi (Couche de), 93s; - (Glomérules de), 945; - (Tubes de), 40, 597, 738.

Nalthus (Théorème de), 51 .

Ilamelles, 1086.

Niamelons, 1086.

Mamestra brassiræ, 853.

Mammifères, 949, 3066.

Nammouth, 1176 .

Vanatus, 1101; - australis, 1072.

Manchots, 1032.

ITandibules, 602, 612, 737.

Nange-pain, 881.

Manis, 1096.

Mlanne, 818 .

IIanteau, 904.

Manteaux, 91s.

Manubrium, 193, 194, 1073.

.1aquereau, 971.

Mara, 1185.

Marcassius, $110 \%$.

Jiarcheurs (Pieds), 627.

Maréchaux, 897.

Mareunes (Huilres), 907.

11 arèque, $103 \%$.

Margaritana, 914.

Marginaux (Corpuscules), 193.

Mariage des Abeilles, 871.

Maringouins, 799.

Mariposa, 1063.

Markhor, 1135.

Harmottes, 1177, 1179.

Marphysa sanguinea, 593.

Marsouins, 1097.

Marsupiale (Poche), 1091, 1094.

Marsupiaux, 1091, 1093.

- (Os), 1094.

Marte, 120'

Marteau (Os), 1077.

Martins, 1063.

(Poisson), 960.

Martins-Pêcheurs, 1061 .

Martinets, 1061, 1064.

Martre, 1204.

IIasaris, 864 .

Masarinés (Masarinæ), 864.

Masicera, 791.

Masque, 880.

Masticateur (Estomac), 603.

Mastiffs, 1199.

Mastigodes, 477 ; - affuis, 481; - equir, 415 ; - leporis, 484 ; - vulpis, 483.

Mastodontes (Maslodon), 1176.

Masuri, 377.

Jảtins, 1199.

Matrice, 44.

Maturation de l'œuf, 47.

Mauthner (Gaine de), 19.

Mauvis, 1063.

Maxilles, 737 .

Haxillipèdes, 612

Maxillo-palatin (Appareil), 936. 
Medicinax (Auimaux), 67, 81 .

Médiogyrinidẻs, 979.

Méditerranéen (Type), 12 í.

Méduse oreillarde, 197.

Meduses, 193; - Ephyres, 197: Iividrolides, 194 .

Médusoïdes, 19:.

Meersehweinchen, 1186.

Megachile, sis.

Megachiroptires, $121 \%$.

Jégalithiques (Honumeuts), 12:3:.

Megatotis, 1198.

Megustomum, 169; - entericum, intestinale, 169.

Megalherium, 1096.

Megninia, 68:; - asternalis, columbie, cubilalis, ginglymura, phasiani, vetuta, 683.

Mehara, 1123.

Mehari, 1121.

Mehlis (Corps de), 225.

Heissuer (Corpuscule de), 942.

Mélanésien (Type), 1245.

Mélanorlermie, 8 ? 8.

Mẻlasomes, 895 .

Meleagrina margaritifera, 911.

Mẻléagrinés (Meleagrinæ), 1043.

Meleagris, 104'i, 1045; - gallopavo, 1044 ; - g. americana, 1045: - g. itomestica, 1044;-g. mexicana, 104.;-ocellata, 1045.

Melecta, 866.

Meles taxus, 120 '.

Mélettes (Melett $a), 965$; - sprallus, thrissa, venenosa, 965 .

Mélinés (Melinæ), 1204.

Mélipones (Mellipona), 367.

Méliponinés (Meliponina), $86 i$.

Mellifères, 866.

Mellivora, 1204 .

Mello-extracteur, $8: 0$.

Méloés (Meloc), 894; - autumnatis, mujalis, proscarabeus, trianthemæ, $\$ 95$.

Méloïdés (Meloidæ), 890.

Melolontha, 898; - vulgaris, 898.

Melons de mer, 204.

Mélophages (Melophagus), 746;-ovinus, i4t.

Melopsillacus, 1061.

Membraueuses (Pattes), 851.

Membres, 29.

Memnon, 860 .

Menhirs, 1232.

Menopoma, 98:.

Ménopons (Menopon), 84i, 846:- biseriatum, 847 ; - extraneum, 848 ; - fulvomaculatum, 817; - latum, 8:7; - numidie, 8t8; - obscurum, 8:8;-pallidum, 847;-phrostomum, 84s;-pro. ductum, 847 ; - stramineum, 847; trigonocephalum, s'î.

Menton (Insectes), 7:38.
Mephitis, 1:04.

Mire ( $A$ beilles), 867 ; - de sauveté, S69.

Meres (Sangsues), 58?.

Mergines (Merginx), 103?, $10 \mathrm{i} 0$.

Mergus mergunser, 1040.

Méride, 26.

Mirilégines (Merileqina'), 866 .

Merlin (Mertungus), 967; - carbonarius, vulgaris, 96i.

Merles, $106 \mathrm{i}$.

Merluche (Merinccius), 967; - vulgaris, $96 i$.

Méroblastiques (UEufs), 51.

Méromyaires, 387.

Herops, 1061: - apiaster, 1061.

Mérostomacés, 601,610 .

Mérous, 972.

Mérychippes (Merychippus), $1152 ;-$ insignis, mirubilis, 1152.

Méryeique (Mastication), 1148.

Mesalges, 68:3.

Mésanges, 1063.

.lésaticéphales, 1236.

Mésembrines (Mesembrina), 782.

Mésentéroïdes, 189

Mésocestoüdes (Mesocestoides', $310 ;-i m$ butiformis, $313 ;-$ lineatus, 311.

Mésocestoïdinés (Mesocestoidinx), 310.

Mésoderme, 51.

Mésogonimes (Mesogonimus), 341, 369; commulatus, 3i1; - dimorphus, 371;heterophyes, 370; - Westermanni, 369.

Mésohippes (Mesohippus), 1150; - Bairdi, 1150.

Mésolobe, 1075 .

Mésonéphros, 945.

Mesoprion joeu, 972.

Mésorhiniens, 1237.

Mésothorax, 734.

Mlésozoaires, 208.

Messagers (Pigeons), 1059.

Métaboliens (Iusectes), 74́1.

.létacarpe, $93 \mathrm{i}$.

Métamères, 27 .

Métamorphose, 53 ; - régressive, 23.

Métanéphros, 945 .

Melastigmata, 631.

Melastrongyhus longevaginatus, 433 ; paradoxus, 432.

llétatarse, 937.

llétathorax, 73 f.

Mitazoaires, 109.

Méthodes, 88 .

Métis, 96 .

Métis sage, 95 .

Vetopia, 791.

llico, i30.

Nierobes, 68.

Microcephalus, 761 .

Microchiroptères, 1217.

Vicrogaster, 863; - glomeraius, 863.

Microlépidoptères, S5:. 
Micronucléus, 172.

Microparasites, 68 .

Micropyle, 46.

Microspalax Chanayi, 683

Microsporidies, 160.

Microstomum, 384.

Midas, 1221.

Miel, 872.

Mieschéridés (Miescheridæ), 150.

Mieschéries (Miescheria), 155; - IIucti, 155 ; - muris, 155; - utriculosa, 150. Migrations (Oiseaux), 1028.

Milandres, 960.

Milans, 1066.

Miliola, 119.

Mille-pieds, 732.

Milouin, 1037.

Milouinan, 1037.

Milvus, I066; - regalis, 1066.

Mimétisme, 101 .

Minards, 928 .

Miohippus, 1151; - præstans, ultimum, 1151.

Mionhelminthes, 208.

Miouhippe, 1172.

Miracidium (Embryon infusorifor me), 335 .

Mite rouge, 701.

Mites, $6: 5 ;$ - des vêtements, $85 \%$.

Mitrale (Valvule), 1081.

Moas, 1031.

Modioles (Modiola), 913; - barbalı, Lamarchiana, mytiloides, 913.

Moelle allongẻe, 9:0; - épinière, 93S; osseuse, 17.

Moineaux, 1062 .

Molaires, 1079 .

Môles, 963.

Molluscum contagiosum, 1 \$8.

Mollusques, $110,901$.

Molva vulgais, 967.

Monacanthus, 963 .

Monas, 163; - anatis, 166; - cavire, 166 ; - crepusculum, elongata, globulus, lens, 118.

Monères, 115.

Mongol (Type), 1242.

Moniézias (Moniezia), 269; - alba, 274; alba dubia, 275; - Benedeni, 273;capræx, 275; - crucigera, 275 ; - denticulata, 274;-expansa, 269;-fimbriata, 275;-Neumanni, 274;-nullicollis, 275; - oblongicers, 275; - planissima, 273; - trigonophora, 273.

Monilor, 1013.

Monocercomonas, 163, 16t; - anatis, canis. cavix, gallinæ, hepatica, 166; - hominis, 168 ; - ovalis, pisiformis, sallans, sphærica, 166.

Munocercus, 213; - Davaineæ proglottinæ, $305 ;$ - D. tetragonx, 306; Tæniæ cunealæ, 304; - Tænix in/undibulifornis, 302 .

\author{
Monocle, 606 . \\ Monocystidées, 128. \\ Monocystis, 130. \\ Mouocyltariens, 1?1. \\ Monodactyles, 1153. \\ Munodelphes, 1091.
}

Monodan monoceres, 1097.

Monodontus cernuus, 474; - racliulus, $475 ;$ - Wedli, 47 t.

Monogenèse, 5 s.

Monogenèses (Trématodes), 331 .

Monogénistes, 1234.

Ilonoïques (Auimaux), 44.

Monomère (Reproduction), 41 .

Monomita, 16f.

Monomyaires, 907.

llonopliyodoutes, 1079, 1091.

Monopueumones, 976.

Monosporées (Coccidiẹs), 132.

Monostomes (Monostomum), 338 ; - attenuatum Molin, 338;- attenuatum Rud., 340; - caryophyllinum, 339; - flavum, 339; - Kuhni, 339; - lentis, 339 ; leporis, '216, 339; - microstomum, 338; - mutabile, 33s; - Setteni, 339; verrucosum, $3 \mathbf{4 0 .}$

Monostounidés (Monostomirlæ), 338.

Monothalames (Foraminifères), 119.

IIonotrèmes, 1091, 1092.

Monoxènes (Parasites), 70.

Montée, 857.

Monozoïques (Coccidies), 132.

Morillon, 1037.

Morphologie, 25.

Morpion, $8: 29$.

Morses, 1193.

Mortiers i godets, 1230.

Morue, 967; - Praiche, 968; - ladre, 331 ; - rouge, 970 ; - verte, 963.

.lorula, 51, 52 .

Moschidés (Moschidx), 1124 .

Moschus moschiferus, 1124.

Notacilla, 1063; - alba, flava, 1063.

Motacillidès (Motacillidæ), 1063.

Iloteurs (Nerfs), 30.

Iotrices (Raciues), 940.

Ilouche, 782; - araignée, 746 ; - bleue, 783; - César, 783; - du Cayor, 785 ; - d'Espagne, 891; - du fromage, 780: - de llesse, 798; - des urinoirs, 780; - piquante d'automne, 786 ; - verte, is3.

Moucherons, $79 \%$.

Mouches, 743, 779; - de proie, 791.

.Houettes, 1041 .

Moufettes, 120 .

Mouflons (Mammifères), 1129, 1130.

Mouflons (Mollusques), 913.

Moules, 911; - d'étang, 914.

Mouqui, 703 .

Mourgues, 914.

Moustérienne (Époque), 1228. 
Moustiques, $795, \quad 299$.

Moutons, 1129.

Mlucipares (Glindes), 579.

Ilue, 206, 593, 1020, 1069.

Iluges (1/ugil), 971.

Mlulards, 10 io.

Mule, 11 i?.

Nulet, 1171.

Muleton, 1172 .

Mulettes, 914.

Müller (Cimal de), 9i5.

Mullidés (Mullidie ), 974.

Mullus barbutus. sumulelus, 9i4.

Mulotiere, 118 s.

Mulots, 118't.

Multiloculiare (Échinocoque), 264 .

Multiplicition, 13, 41.

Multipolaires (Cellules nerveuses), 19.

Mu!us, 1171.

Muqueux (Tissu), 16.

Muraille, 189.

Murènes (.Muræna), 96:; - helena, 965.

Hurex, 920

Muridés (Muridæe), 118 i.

Ilus, 1184; - decumanus, minutus, musculus, pumilus, raltus, sylvalicus, 1134 .

Musaraigues, 1215.

Muse, 1121.

Musca, 780, 782; - bovina, corvina, domesticn, vitripennis, 782.

Muscardin, 1178.

Muscardiue, 858.

Muscardinus avellanarius, 1178 .

Muscidés (Muscidær), 7\%9.

Muscinés (.Huscinæx), 78?.

Muscles moussus, 913.

Musculaire (Tissu), 18.

Musculo-cutanée (Enveloppe), 28.

Musette, 1215.

Muslangs, 1161.

Mustela, 1204; - foina, martes, zibellina, 120 4.

Mustélidés (Musteliclx), 1204.

Mnstélinés (Iustelinx), 1204.

Mustelus, 960.

Mutualisme, 63.

Muzius, 1160 .

1ycetes, 1222 .

Mydra vomilurationis, 780 .

Hyes (Mylu), 914; - arenaria, 915.

Myéline, 19.

Myéloplaxes.

Mygales, 730 .

Myiase (Myiasis), it4.

Mylabres (Mylabris), 893 ; - cichorii, cyanescens, indica, sillæ, variabilis, vicinu, 894 .

Myliobates, 961 ; - aquila, 962.

Hylorlon, 1096.

Ilyoblastes, 18.

Iyocoptes, 685 .

Hyocyte, 128.
Myodes, I1s3; - lemnus, 1183.

Myogale, 1215; - moschula, piyenuicu 1215.

Myoleume, 19.

Myomorplies Myomorpleu), 1181.

Myoxidés (Myoxidx), 11 ss.

Jyorus, $1178:-$ glis, nitele, 1178.

Myriapodes, Myriopodes, 601, 731 .

Myriologie, 593 .

Myrmécobius (Hyrmecobius), 1095.

Myrmecophaga, 1096.

Myrmeles, sis; - formicarius, 878.

Mymica, 86t.

Myrmicines (Myrmicinx), 864 .

Mysis, 607.

Mysterious tisease, $\mathbf{4 5 2}$.

IIysticètes, 1100.

Mytilaspis pomornm, 811.

Mytiliculture, 91?.

Mytilidés (Mytiliule), 911.

Mytilotoxine, 913.

Mytilus, 911; - abbreriatus, edulis, gal-

loprovincialis, herculeus, retusus, 911.

Myxiues (Myxine), 960.

Myxobolus, 159.

Myxosporidies, 157.

Myzomimus, 541; - scutatus, 541.

$\mathbf{N}$

Naga, 1122

Nageoires, 9.70 .

Nageurs (Pieds), 627.

Nàhoŏr, 1129.

Nais, 592.

Naissain, 909.

Najas (Naju, 100i; - haje, tripudiens, 1004 .

Najine, 995.

Nanilons, 103 l.

Narval, 1037.

Nasu", 1?0t.

Natatoire (Vessie), 955.

Natos, 1115

Naturalisation, 86 .

Naulette (Ilàchoire), 1229.

Nuuplius, 604

Nautiles (Nuutilus), 926;-pompilius, 927.

Navicelles, 129.

Navire du désert, 1122.

Nealges, 682.

Nèauderthal (Ossements), 1:28.

Vebulia, 607.

Nécessaire (Parasitisme), 69.

Vecrodes lilloralis, 899.

Nécrophores (Vecrophorus), 899.

Vectarinia leckerjuana, 865 .

Needhau (Poche de), 926.

Nègres, 1243.

Négril, 887.

Négrito (Type), 1215. 
Némathclminthes, 208, 385.

Nématocystes, 188.

Nématodes, Nématoïdes, 385.

Nematoideum hominis (viscerum), 624 ; ovis (pulmonale), 427 .

Nemertes, 385.

Némertiens, 209, 384.

Némocères, 794.

Nemorhina, 787 ; - palpalis, 788.

Nẻo-Calédoniens, 1245.

Néolithique (Pèriode), 1230.

Neorhynchidæe, 565.

Népes (Nepa), 818 ; - cinerea, 819.

Vephelinx, 57 .

Nèphridies, 40.

Néphridiaux (Pores), $5 \$ 1$.

Nephrophagus sanguinarizs, 668.

Néréides, 59 ?.

Nereis, 593.

Nerveux (Système), 29; - (Tissu), 19.

Nervules (Ailes), 735 .

Nervures (Ailes), 735.

Neumannia, 682.

Neural (Arc), 935; - (Canal), 933.

Neurale (Gavitė), 934; - (Face), 593, 901.

Neurapophyses, 935.

Neurépine, 935.

Neuronia popularis, 853 .

Névroptères, 7411, 879.

Niaibi, $i 03$.

Nicobars, 1059.

Nictitante (Nembrane), 1077.

Nidamentaires (Glandes), 926.

Nids d'Hirondelle, 1064 .

Nielle du blé, 553.

Nikas (Nika), 608; - edulis, 608.

Nilgau, 1128.

Nirmus claviformis, 8:38; - crassicornis, 839 ; - fliformis, 838 ; - numidre, 840 ; - trigonocephalus, 847.

Nisus, 1066 ; - communis, 1066.

Noctiluques, 163.

Noctuelles, 853.

Noctuidés (Noctuidæi), 853 .

Noctule, 1218.

Nocturues (Lèpidoptères), 851 ; - (Rapaces), 1065.

Nodosaria, 119, 120; - hispide, 119.

Noir-museau, 652.

Noires (Races), 12 i3.

Noix de galle, $86 \%$.

Nomad", 866 .

Nomadinés (Nomadinæ), 866.

Nomenclature, 108.

Noune, 85i.

Nosema bombycis, 160, 858 ; - helminthonum, 160 .

Nothosauriens, 1015.

Notochorde, 929.

Notocotyles (Notocotyle), $339 ;$ - triseriale, $340 ;$ - verrucosum, $3 \mathbf{4 0}$.
Nolocolyfus triserialis, 340.

Notodetphys (Crustacé), 606.

Notoedres, 640, 660 .

Notogastre, 640.

Notonectes (Notonecta), 819; - glauca, 819.

Notothorax, 640.

Nototrema, 987.

Notum, 594.

Nourrice, 5i, 226.

Nourliciers (Oiseaux), 1028.

Noyau, 12, 113.

Nuche, $77 \%$.

Nucléés Rhizopodes), 115.

Nucléole, 12.

Nucleus, 12 ; - de reliquat, 129.

Nudibranches, 919.

Nuisibles (Animanx), 67.

Numenius, 1042.

Numida, 1046; - meleagris, mitrata, $1046 ;$ - ptilorhyncha, 1046, 1047.

Fumidiués (Numidinæ), 1043, 1046.

Nummuliles, 120.

Nutrition (Fonctions de), 34.

Nyctéruntes (Nyctereutes), 1198.

Nyctéribides (Nycteribidæx), 7\$5.

Nyctipithèques (Nyctipithecus), 1222.

Nymphalidés (Nymphalidæ), $\mathbf{8 6 0 .}$

Nymphe (Acariens), 630; - (Insectes), 740 .

Nymphes, 1085.

Nymphipares, 745.

Nymphon, 615.

\section{$\mathbf{0}$}

Obèses, 1105.

Obisium, 725.

Obligatoire (Parasitisme), 69.

Occasionnel (Parasitisme), 69.

Occipitaux (Condyles), 936.

ncelles, 597.

Ocelot, 1209.

Ochromyies (Ochromyia), 785 ; - anthropopkaga, 785.

Octatiniaires, 191.

Octopodes (Articulés), 601, 612; - (Mollusques), 928.

Octopus, 928 ; - vulgaris, 928.

Oculaires (Taches), 31 .

Oculi Cancri Astaci, 609.

Oculina virginea, 192.

Odouates, 879.

Odontophores, 904.

Odorat, 30 .

Odorifères (Glandes), 739.

Odynerus, 864.

Okcologie, 58 .

OEdémagènes (OEdemagena), 775; - larandi, 775.

OEdipoda fasciata, 882 ; - var. crrulcscens, miniata, 88 ?. 
OEil, 31 ; - pinéal ou parietal, 9 i0, 941 . Olsophage, 36 .

OEsophagien (Collier), 29.

Ol:sophigoslomes (OEsophagostomum), 4i:); - ucutum, 450; - columbianum, 451; - ilentalum, isl; - inflatum,449; - inflatum var. ovis, 450; - subulatum, 451; - venulosum, 450 .

Olistre (OHstrus), 749 ; - bovis De Geer, i67;-bovis L., 750 ;-duodenatis, 757; - equi, 750; - hamorrhoidalis, 755;hominis, $772 ;-$ intestinalis, 750 ; -linealus, 773 ; - nasalis De Geer, 765 ; nasalis L., i57:-ovis, 761; - pecorum, i58; - purpureus, i65; - salutiferus, i5i; - subculaneus, 767 ; - supplens, 773 ; - larandi, ^ิ5; - variolosus, 765; - veteriuus, 75i; - viluli, 758 .

OLstres, $7 \mathbf{4 8 .}$

Otstrides (OLstridie), 748 .

OEstrines (OEstrina), 749 .

OListromyia, i67.

Oliuf, 43, 46; - l'été et d'hiver (Rotateurs), 572;-ảhiver(Phylloxéra), 816 ; - de Poule, 10:śt.

Ogmogaster, 338 .

Ogygia, 611; - Guetlardi, 611.

Oic-Renard, 1037 .

Oies, 1034.

Oiscaux, 449, 1016; - de proic, 1065; de rivage, $1041 ;--.1$ louches, $1062 ;-$ de Saint-Pierre, $10 \mathrm{i} 1$.

Oison, 1936.

Olfaclifs (Lobes), 940 .

Olfactives (iossettes), 902 .

Oligochètes, 591.

Oligosporées (Coccidies), 132.

Oligotriches, 181 .

Oligozoïques Coccidies), 132.

Olivâtre (Sous-type), 1237.

Olivette, 911.

Ollulans (Ollulunus), 475 ;-tricuspis, 475 .

Olmo (Cràne), 1229.

Olynthus primordialis, 185.

Oncasus, 1116.

Ombilic (.lollusques), 946; - Plume), 1019.

Ombilicale (V'́sicule), $9 \mathbf{4} 7$.

Omble-Chevalier, 966.

Ombre des rivières, 967 .

Ombrelle, 193.

Omoplate, 9:36.

Onphalo-mésentrique (Conduit), 9:7.

Onagre (Faux), $1165,1166$.

Onagres, 1166.

Once, 1209.

Onchocerca reticulata, 538 .

Oncophora, 477.

Oncosphère, 217.

Ondatra, 1183.

Ondulantes (Membranes), 171.

Ongles, 1069 .
| Onguiculés, 1069, 1091.

Ongulés, 1069, 1091, 1101, 1147.

Ongulogriades, 1075.

Oniscus asellus, 606 .

Onomione, 1172.

Ontogénic, 103.

Onychophores, 601, 611.

Opalines, 171.

Opercule (Poissons), 950.

Ophidiens, 993.

Ophion, 1130.

Ophion, 863.

()phionyssus, 719.

Ophiostomum Pontieri, 563.

Ophiures, 203.

Ophryou, 1071 .

Ophryoscolécidés (Ophryoscolecidæ), 180.

Ophryoscolex (Ophryoscolex), 182; - Cnttaneoi, 482; - incrmis, 482.

Ophtalmic vermineuse, 526, 527, 529, $532,533$.

Opilious, 724.

Opisthobranches, 919.

(Tpisthoecliques (Vertibres!, 935.

Opisthoglyphes, 1002, 1003.

Owisthotrema, 338.

Opossum, 1095.

Opolérouloutes, 1002.

Optiques (Bâtonnets), 596;-(Lobes), 1077.

Orang-Outang, 1223.

Ordre, so.

Orei!lards (Canidés), 1196 ; - (Chiroptères), 1217.

Oreille, 30 .

Oreilles de mer, 920 ; - de Saint-Pierre. Oreillettes, 943.

Organes, 22, 26; - de Bojanus, 40;rudimentaires, $23, \quad 25, \quad 102 ;-$ segmentaires, 40.

()rganisation, 22.

Orgyia, 85t.

Oribatidx, 631

Oriolus, 1063; - galbuln, 1063.

Ormiers, 920 .

Ornithobia pallide, 746.

Ornithobies (Ornithobius), 835 ; - anseris. 839 ; - buccphalus, 838.

Ornithodelphes, 1091, 109:.

Ornithodoros, i15; - coriaceus, Savignyi, i15.

Ornithoĩdes (Vertélorís), 992.

Ormthomyies (Ormithomyiu), 746; - avicularia, i\&6.

Oruithoryuques (Omithorhynchus), 1092 ; - pavadoxus, 1092.

Orohippus, 1149; - agilis, 1149.

Orphies, 970 .

Orlalis cerasi, 780.

Orteil, 937.

Orthagoriscus, 964 .

Orthoceras, 927.

Orthognathes, 1237. 
Orthonectides, 208.

Orthoptères, 741, 880.

Orthospores (Orthospora), 132 ; - nova, 132.

Ortolan, 1063.

Ortyx, 1055.

Orvet, 1013.

Oryctéropes (Orycteropus), 1096.

Oryctes (Oryctes), 898.

Os de Seiche, 927; - lenticulaire, $107 \%$.

Oscinis, 780.

Oscules, 184.

Osmerus epertanus, 967.

Osmia, 866.

Osséine, 17.

Osselet (Astragale en), 1102.

Osselets (Ailes), 735.

Ossenx (Corpuscules), 17; - (Tissu), 17.

Ostende (Huîtres), 907.

Ostėod ermes, 963 .

Ostéuplastes, 17.

Ostracion, 963 ; - triqueter, 961.

Ostracodes, 60s.

Ostrea, 907 ; - adrictica, angulata, Cyrnusi, ellulis, hippopus, stentina, tarentina, 907.

Ostréiculture, 909.

Ostréidés (Ostreidæ), 907.

Otacariases, 676.

Otaries (Otaria), 1193 ; - leonina, ursina, 1193.

otis, 1042.

otite parasitaire, 676 .

Otocyon, 1196 ; - megulotis, 1196.

Otocystes, 31 .

Otolithes, 31 .

Ottonia, 699.

Otus, 1066; - vulgaris, $10 j 6$.

Ouche, 777.

Ouie, 31

Ouies, 954 .

Ouistitis, 1221.

Ours, 1075, 1204; - marin, 1193.

Oursins, 224.

Outardes, 1012 .

Ouvrières (Abeilles), 867; - (Fourmis), 863.

Ovaires, 43.

Ovibos (Ovibos) 1138 ; - moschatus, priscus, 1138.

Oviducte, 44 .

Ovifères (Capsules), 289.

Oviformes (Psorospermies), 130.

Ovinés (Ovinæ), 1128.

Oviparité, 52

Ovis, 1129; - cmmon, antiqua, argali, argaloides, 1129; - aries, 1129, 1130; - a. africana, arvernensis, asiatica, batavicu, britannica, germanica, hibernica, iberica, ingevonensis, ligeviensis, 1131; - palustris, 1132; -

sodanica, 1131 ; - arkal, burrhel, Palpe $\approx, 30$.
$1129 ;-c a p r a, 113 j ;-c . a f r i c a n a$, asialica, europæa, 1135 ; - cycloseros, 1130 ; - cylindricornis, 1129 ; - cypria, 1130 ;

- Karelini, 1129 ; - montana, 1130 ; - musimon, 1129, 1130; - nâhoòr. 1129 ; - nivicola, ophion, orientalis, 1130 ; - Pallasi, Polii, primæva, Savini, tragelaphus, 1129; - Vignei, 1130 .

Oviscapte, 748.

Ovacentre, 49.

Ovolestis, 918.

Oroviviparité, 53.

Ovule, 13.

Oxydactyles, 985 .

Oxyhémoglobine, 21.

Oxypteurites, 632.

Oxytriches, 184.

Oxyures (Oxyzurus), 409; - ambigua, 417; - compar, 410, 414; - curvula, 415; - equi, 415; - mastigodes, 415 ; vermicularis, 409 ; - vivipara, 549.

\section{$\mathbf{P}$}

Paca, 1184.

Pachydermes, 1104, 1147.

Pachynolophes (Pachynolophus), 1149; agilis: Vismæi, 1149.

l'achytylus migratorius, 882.

Pacini (Corpuscules de), 30, 31 .

Paco, 1120.

Padzo, 1146.

Pagels (Pageltus), 972;- erythrinus, 972.

Pagre (Pagrus vulgaris), 972.

Paille-en-queue, 1041.

Palæochærits, 1.105.

Palæothėrinés (Palæotherinæ), 150.

Palaffites, 1231.

Palcumadea, 1042.

Paléothériums (Palæotherium), 1150;magnum, medium, 1150.

Palémons (Palæmon), 607; - serratus, 598, 607; - squilla, 607 .

Paléoethnologie, 1226.

Paléolithique (Période), $122 \%$.

Paléontologie, 105.

Palettes (Abeilles), 866.

Palettes ciliées, 197.

Palinuridés (Palinuridær), 609.

Palinurus, 609; - vulgaris, 609.

Palis, 190.

Palléal (Sinus), 904.

Palléale (Chambre), 902; - (Impression). 90 '.

Patlium, 902.

Palmipèdes, 1029, 1031.

Palombes, 1059.

Paloplothériums (Paloplotherium), 1150 :

- annectens, co iiciense, minus, $\mathbf{1 1 5 0 .}$

Palourdes, 911. 
TABLE ALPIABETIQUE DES MATIẺRES.

Palpeurs (Pieds), 627.

Paludiues (Paludina), 920 .

Palumbus, 1059 ; - torquitus, 1059.

Pauaris des pêclicurs, 966.

Paucréas, 3 i.

Pander (Noyau de), 1027.

Pangolins, 1096.

Pangonies (I'engonia), 79i; - neo-caleulonica, $79 i$.

Pangouines (P'angonimis), 793.

P'unvipa, 878.

Pallse, 1115.

Pantlières, 1209.

Pantolestidés (I'antolestidx), 110i.

Pautopodes, 6lí.

Paoune, 1049.

Paonneaux, 1019.

Paous, $10: 8$; - de nuit, 860.

Papilio, 860 ; - Machaon, Memnon, P'odalivius, 860 .

Papiliouides (Pupilionid(e), 860.

Papilles segmeutaires, 578 ; - tactiles, 387.

Papillous, 850.

Papious, 1223.

Papou (Type), 1245.

Paruloxides, 611.

Paragasiriques (Canaux), 198.

Parage, 910.

Paraglosses, 738.

l'arclippus, 1151.

Pariisotriques ('araisotricha), 1ii; ampulla, colpoirlea, incisa, oblonga, ovalis, 177.

Paralges, 682.

Paramiecidés (I'aramæcidæ), 175.

Puramæcioides, 164.

Paramécies (Paramacium), 161, 175;uurelia, 175 ; - bursaria, 175.

Paraplasma, 10.

Paraplègie hydatique, 256 .

Parapodes, 576.

Parapophyses, 935.

Parasites, 67 ; - Insectes), 823.

Parasiticides, 7 .

Parasitiques (Pieds), 627 .

Parasitisue, 23, 62.

Parenchymale (Membrane), 261.

Paresseux, 1096.

Pariétal (OEil), 9'0,9ł1.

Pariéto-splanchuiques (Ganglions), 902.

Parotides (Batracieus), 977.

Parthénogenèse, 45, $5^{4}$ ).

Parure de noces, 1020.

Parus, 1063; - ater, cieruleus, major, 1063.

Paseng, 1135.

Passalurus ambiguus, 417.

Passer, 1062; - chloris, domesticus, montanus, 106\%.

Passereaux, 1029, 1061.

Pastengus, 961.
P'asteur (II)muse), 1234.

l'ustor, 1063.

Patigon ('Type), 1243.

Pàtéc royale, 868.

Patelles (I'atellu), 920; - cxru'eu, vulyalu, 9:9.

Pattes brauchiales, 603.

Pattes-maiclioires, 602,612 .

Pavillow (Ovillucte), 1027, 1085.

Pavimenteux (Epithélium), 20.

I'uvo, 10i8; - cristutus, cr. domesticus, mulicus, nigripennis, 1048.

Pavouiles (Favoninæ), 1043, 10 is.

Peau de Cygne, 1036.

Peall-rouge (Type), 124 .

Pébrine, 858 .

Pécaris, 1114.

Pêcheur (IJomme), 1234.

Peclen, 911 ; - Jacolsas, maximus, opercularis, varius, 911.

Pectinidés (Pectinidæ), 911.

Pectunculus, 914; - glycimeris, violacescens, 91'.

Pectus, 594

l'édicellaires, 199.

l'edicellina, 680 .

l'edicinus, 825.

Pédiculès (Poissons), 974.

P’édiculidés (Pediculidar), 824.

Pédiculines, 823.

Pédiculoïdes (Pediculoides), 693; - Иitici, 693; - ventricosus, 693.

Pédiculose, 826, 828, 848 .

Pediculus, 825; - anatis, 839; - anseris, 845; - bicolor, 833; - capitis, 82:; - caponis, 840 ;- cerviculis, 825 ; - columbx, 838;-corporis, 827 ; - cygni, 838; - eurystemus, 831 ; - lumanus, 825, 827;-capitis, 825;-corporis, 527 ; - inguinalis, 828 ; - macrocephalus, 830; - meleagridis L., 843 ; meleagridis Panzer, $8 \mathrm{i7}$; - meleagridis Schrank, 841;-ovinus, 708;-oxyrhynchus, 831; - pavonis, 842; - pilifer, 832 ; - porcelli, 814 ; - pubis, 828;stenopsis, 832; - suis, 831, - tabescentium, 827, 828; - tenuirosiris, 831; - tuberculatus, 832; - urius, 831 ; ventricosus, 833 ; - vestimenti, 827 ; viluli, 831 .

Pédieux (Ganglions), 902,

Pédimanes, 1095.

Pédipalpes, 614, 725 .

Pédogenése, 45.

Pégases (Pegasus), 963; - voluns, 963.

Peignes (Pecten), 911.

Peignes (Scorpious), 725; - (Yeux), 959, 1621.

Pe-la, 811.

Pélagies (Pelagia), 197.

l'elurnys sarda, 971.

Pelecanus, 10 \&. 
Pèlerines, 911 .

Pèlerins, 960.

Péliades (Pelias) 1007 ; - berıs, 1010 ; Orsinii, 1011.

Pélicans, 10 '1.

Pélobates (Pelobates), 986; - cultripes, fuscus, 986.

Pelodera, 549; - Axei, 55\%; - pellio, 550 ; - setiger $a, 550$; - teres, 550.

Pélodytes (Pelodytes), 986: - punctatus, 986.

Pélors (Pelor), 973.

Pelotes, 74 ?.

Peltidés (Pellidæx), 900.

Pelvienne (Ceinture), 936.

Pempligus, 812; - bursarius, vilifolii, 812.

Pénées (Penæus), 607 ; - caramota, 607.

Pendeloques, 1032.

Pénélope, 1037.

Péniale (Poche), 211.

Pénien (Os), 1085.

Pennes, 1019.

Pennivores, $834,835,845$.

Pentadactylie, 937.

Pentamères, 896.

Pentastomum, 624; - constrictum, 624; - denticulatum, emarginatum, 617; - fera, 617; - moniliforme, 624; rhinarium, 616 ; - serratum, 617; Selteni, 339; - trenioides, 616.

Pentatomes, 809, 823.

Pentatomidés (Pentatomidæ), 823 .

Pepsine (Glandes à), 36; - médicinale, 1112.

Peptone-venin, 995.

Péraméles ('Perameles), 1095.

Perce-oreille, 881.

Perche fluviatile (Perca fluviatilis), 950, 972 ; - goujonnière, 972.

Percidés (Percid $x$ ), 972.

Perdrix (Perdix), 1055; - blanche, 1054; - cinerea, græca, petrosa, rubra, 1055.

Pérennibranches, 982.

Pérennichordés, 932.

Perforés (F'oraminifères), 119.

Péribranchiale (Cavité), 931, 93ł.

Péricardique (Cavité), 598.

Péridiuiens, 163.

Périodique (Parasitisme), 69.

Périoste, 17.

Péripates (Peripatus), 612.

Péripatides, 611.

Periplaneta americana, orientalis, 881 .

Périsarque, 194.

Périssodactyles, 1091, 1101, 1147.

Péristome (Mollusques), 946.

Péritrème, 598.

Péritriches, 184.

Perles (Perla), 879.

Perlons, 960, 974.

Permanent (Parasitisme), 69.
Pernis, 1066 ; - apivorus, 1066.

Péroné, 937.

Perophora, 932.

Péropodes, 1002.

Perroquets, 1060, 1061; - de mer, 971.

Perruches de mer, 1061.

Personne, 26.

Péruvien (Type), 1243.

Pétauristes (Petaurus), 1095.

Petit-Morin (Squelettes), 1233.

Pétoncles, 914

Pétrels, 10 1́1.

Petromyzon, 960; - fluviatilis, 960;marinus, 959, 960 ; - Planeri, 960.

Peuples, 1235.

Phacochères (Phacochorus), 1113; xthiopicus, africanus, 1113.

Plıaéton (Phaeton), 1041.

Phagocytose, 21.

Phalacrocorax, 1041.

Phalangers (Phalangista), 1095.

Phalanges, 937.

Phalangides, 614, 724.

Phalangium, 724.

Phalenes, 853 .

Phalénidés (Phalenidæ), 853.

Phallusia, 932.

Phanères, 938.

Pharyngiens (Os), $950 ;-$ (Poissons), 955.

Pharyngobolus, 761.

Pharyngoguathes, 971.

Pharyngomyia, 761.

Pharynx (Nématodes), 388; - (Trématudes), 333; - (Vertébrés), 942.

Phascolomes (Phascolorrys), 1095.

Phasianidés (Phasianidær), 1043.

Phasianinés (Phasianinæ), 1043, 1050.

Phosicmus, 1050; - Amherstiæe, 1051; colchicus, 1050;-nycthemerus, pictus, 1051.

Phaulixodes rufus, 713.

Phenacorlus, 1158.

Philanthus, 864; - apivorus, 864.

Philoptérinés (Philopterinæ), 837.

Philoplerus, 8:37.

Phoca vitulina, 1192, 1193.

Phocæna, 1097.

Phœnicoptéridés (Phiønicopteridæ), $103 \%$.

Pholades (Pholas), 915 ; - candidus, dactylues, 915.

Phoques, 1193.

Phora rufipes, 779.

Phoridés (Phoridæx), 779.

Phoxinus lavis, 967.

Phryganes, 878.

Phrynes (Phrynus), 725.

Phrynine, 987.

Phthiviasis palpebrarum, 830 .

Phthirius, 825, 828; - inguinatis, pubis, 8:8.

Phtiriase, 826, 828, 849; - aviaire, 721 ; - pubienne, 829 . 
Phtisie vermineuse, 429, 433, 439.

Pliycobius, 688 ; - chonymus, liss.

Phyle, 107.

Phyllériose, 632.

Phyllobates (Phyllobales), 987; - chocoensis, 987 .

Phyltocoptes, 632.

Phyllodromia germanica, 881.

Phyllopneuste, 1063; - hypotais, trochitus, 1063 .

Phyllopodes, 605.

Plyyllorhiuiens, 1218.

Phyllosomes, 609.

Phyllostomum spectrum, 1216, $121 \mathrm{s.}$

Phyllotrachées, 599.

Phylloxéras (Phylloxera), 812; - vastatrix, vitisfolix, 81 ?.

Plylloxérines (Phylloxerinx), 812.

Plıylogénic, 103.

Physalies (Physalia), 195; - pelagica. 195.

Physaloptire (Physalopter $($ ), $\$ 76,-\mathrm{d} \mathbf{0}$ Chat, 47 ; - truncula, 476 .

Physaloptérinés (Physulopterina), 418, 476.

Pliyses (l'hysa), 92?.

Physeter, 1097; - macrocephalus, 1098.

Physiologie, $: 5$.

Physis intestinalis, 78 .

Physoclistes, 9.55 .

Physogasler, 693.

Physophores, 195.

Physopodes, 879.

Physostomes, 955, 96 t.

Phytoparasites, 68 .

Phytophages (IIyménoptères), 862; (Lamcllicornes), 893.

Phytophtires, 810 .

Phytoptes (Phyloplus), 632; - vilis, 632. Phytoptidés (Phytoptidæ), 631, 632.

Phytoptose, 633.

Phytozoaires, 110.

Piades, 920.

Picotice, 698.

Pics (Picus), 1060; - mujor, medius, minor, viridis, 1060.

Pied (Mollusques), $902 ;-$ (Vertébrés),937.

Pied-d'Ane, 911.

Pied-de-Cheval (Huîtrcs), 907.

Pieds ambularraires, $\because 00$.

Pie-mere, 938 .

Piérides (Pieris), 860 ; - br(tssicæ, napi, rıpæ, 860.

Pierre (Age de la) $\mathbf{1 2 2 6 .}$

Pierres d'Écrevisse, 609.

Pies (Pica), 1003; - caudata, 1063.

Pies-Grièches, 1063 .

Piestocystis, 213, 314; - Bailleti, elongatus, 314; - marlis, taxi, variabilis, 315 . Pieuvres, 928.

Pigeon, 1056; - ramier, 1059 ; - voyageur, $10 ; 9$.
Pigreonneaux, 1058.

l'igeons, 1055.

l'igmentaires (Cellules), 938; - (Taches), 206.

I'iguris reticulatu, 417 .

lilet, 1037.

Pileux (Follicule), 1067, 1068.

Pilidium, 38.5.

Pilivores, $834,835,845$.

l'imeloulus, 967.

Pimpla, 863 .

Pinces, 725.

Pinchaque, 1174.

Pinéal (OEil), 9ł1.

Pinéale (Glande), 939).

Pingouins, 10:2.

l'inna, 914 .

Pinnipèdes, 1091, 1192.

Pinnothères, 912.

Pinsons, 1062.

Pintadeaux, 1047.

Pintades, 10 i6.

Pintadines, 911 .

l'iophila casei, 780.

Pipa (I'ipa americana), 985.

Pipis, 1063.

lipistrelle, 1218.

Piquants (Échinodermes), 199; - Mammifères), 1068.

Pique-Boufs, 1063.

Pirimela denticulata, 604 .

Pisciculture, 958.

Pithecantrophus erectus, 1228.

Pithéciens, 12:2.

Pitshé, 1170.

Pituitaire (Glaude), 939.

Pityocampæ propinatores, 855.

Placenta, 53, 918, 1085.

Placentaires, 1088, 1091.

Placentoïle (Sac), 1028.

Placoïdes (Écailles), 949.

Plagiomonas, 165; - urinaria, 165.

Plagiostomes, 960.

Plagiostomum, 38í.

Plagiotoma, 177.

Plaies d'été, 508.

Planaria, 384; - alata, 382.

Plauipennes, 878 .

Planorbes ('lanorbis), 922;-carinalus, corneus, marginatus, 922.

Plantes-pièges, 556.

Plantigrades, 1075.

Planule (Planuta), 52.

Planuloïdés, 208.

Plisma, 21.

Plasmatique (Liquide), 3 i.

Plasmodes, 12.

Plastides, 12.

Plastilogène (Appareil), 201.

Plastron, 1015.

Platalea, 1042.

Plathelminthes, 208. 
Platodes, 208.

Platures, 1004.

Platycerques, 1004.

Platymyaires, 387 .

Platyrhinicns(Hommes), 1237 ; - 'Singes), 1:22.

Plecotus auritus, 1217.

Plectognathes, 963.

Plectus, 549.

Plerocercoides, 213 ; - Bollwiocephali ali, 317.

Plerocercus, 213.

Plésiosauriens, 1015.

Pleuræ 594.

Pleurapophyses, 936 .

Pleurobrachia pileus, 198.

Pleurodontes, 1013.

Pleuronectes flesus, limanda, megastoma, platessa, 970 .

Pleuronectidés (Pleuronectidæx), 970.

Plèvre, 1083.

Plexus, 30.

Plicipeunes, 878.

Plictolophus, 1061.

Plie, 9i0.

Pliohippes (Pliohippus), 1153; - pernix, spectans, 1153 .

Pliopithecus antiquus, 1223.

Plique polonaise, 826.

Ploceus socius, 1063.

Plongeous, 103?.

Plongeurs, 1032.

Plotoses (Plotosus), 96i.

Pluies de sang, 851 .

Plumes, 1019.

Plumicoles (Sareoptidés), 681.

Plumules, 1019.

Pluviers, 1042.

Pneumaticité du squelelte, 1016.

Pneumobranches, 976.

Pneumonie vermineuse, 429, 433, 436.

Poche à eau, 1117; -- à encre, 925; copulatrice, 600 ; - de Needham, 926 ; - du cirre, 211, 333, 351; -- du muse, 1125 ; - marsupiale, 1091,109 ; - péniale, 211.

Podapolipus, 693.

Podiceps, 1032.

Podiléginés (Poditeginæ), 866.

Podocotyle, 341.

Podophtalmes, 605, 606.

Podures (Podura), 885; - villosa, 885.

Podurlippus pityriasicus, 885.

Pœcilopodes, 610.

Poeplagus, 1142.

Poils, 1067.

Pointe à cran, 1229; - de harpon, 19:30; - de sagaie, 1230 ; - en feuille de laurier, 1229, ; - moustérienne. 1229.

Poisson d'argent, 885.

Poissons, 949; - comestibles et véné-

neux, 956; - plats, $970 ;$ - rouges, $/$ Porte-virus, 67 , is.

\section{- vulants, 970 .}

Poissons-Lunes, 963 .

Polaires (Globules), 48.

Polatouches, 1179.

Poli (Vésicules de), 199.

Polie (Période de la pierre), 1230.

Polistes (Polistes), 865; - galtica, 865.

Pollénies (Pollenic), 782; - rudis, 782.

Polycercus, 213.

Polyehètes, 592.

Polycystidées, 128.

Polycyttariens, 121.

Polydactyles, 1104 .

Polydesimus, 733 ; - complanatus, 733.

Polyergus, s64.

Polygastriques (Infusoires), 161.

Polygénistes, 1234.

Polymastyx, 164 .

Polymor phisme, 24.

Polymyaires, 386.

Polyuésien ('Typel, 1243.

Polyorchis, 341 .

Polypes, $115,187$.

Polyphèmes (lolyphemus), 605.

Polypides, 574.

Polypier, 189.

Polyplectrons (Polyplectron), 1051.

Polypo-méduses, 192.

Potyprion, 972.

Polyprotodontes, 1095.

Polysporées (Coccidies), 132.

Polystı midés (Polystomirlæ), 383.

Polystomieus, 33', 383.

Polystomum tænioides, 616 .

Polythalames (Foraminiféres', 119.

Polyzoaires, 573.

Polyzoïques (Coccidies), 132.

Pont de Varole, 1075.

P'ore, 1108.

Porcellions (P'orcellio), 606.

Porépic, 1184.

Poreins, 1104.

Porcula, 1107; - papuensis, 1107.

Pore excréteur, 389.

Pores amlulacraires, 200 ; - géuitiux, 223 ; - iuhalauts, $184 ;-$ segmentaires, 581.

Porifères, 184.

Porocéphales (Porocephalus), 6:4:-constrictues, moniliformis, 624.

Porospora, 130.

Porphyrio, 1042.

Portar pictus, 1128.

Porte (Veine), 994.

Porte-aiguillon, 862, 863.

Porte-malheur, 895.

Porte-muse, 1124.

Porte-queue, 860.

Porte-scie, 862.

Porte-selle, 884 
'orthesia anifua, chrysorrhan, similis, 854.

Portunes (l'orlumus), 610.

Postabdomen, 725 .

Potamochères ('’olumochorus), 1112; africauns. lurvalus, porcus, 1113.

Pottos, 1219.

Pou, 8:5; - l'Agouti, 703 ; - de corps, 827; - des livres, 879; - du pubis, \$29; - de la têle, 825 ; - des vêtemeuts, $82: ;$ - frappeur, $8 \div 9$.

Pouce (Iusecles), 8:4; - \{Vertébrés), 107 i.

Pouillots, 1063.

Poulaiu, 1163.

P'oulardes, $105 i$.

Poules, 1053; - d'eau, 1042; - sultanes, 10 i?.

Poulets, $105 \%$.

Pouliche, 1163.

Poulpes, 928.

Poumons, 38 ; - (Arachnides), 599 ; (Mollusques), $903 ;$ - (Vertébrés), 9 í. Pourart, 610.

Pourpres, 920.

Pourriture du couvain, $870 ;-$ du Mouton, $33^{3}$.

Poussins, 1053.

Poux, 823; - de Baleine, 606; - des bois, 705 ; - des livres ou poussjères, 8:9; - des Pigeons, $716 ;-$ des végétaux, 810 .

Praires, 914.

Pratincola, 10c4; - rubetra, rubicola, 1061 .

Préabdomen, 225 .

Précoces (Oiseaux), 10?8.

Prédatiou, 62.

Préfécoudation, 46.

Prẻhenseurs, 1029, 1060.

Préhistoire, Préhistorique, 1226.

Prémolaires, 1079.

Prépuce, 1085.

Présage-mort, \$95.

Pressirostres, 1042.

Primates, 1091, 1219.

Prionodon, 1096.

Prionus coriarius, 889.

Priorité (Règle de), 109.

Pristomerus calcitrator, s63.

Proælurinæ, 120 s.

Proboscidiens, 1091, 1101, 1175.

Probubales (Probubrilus), 1139;-dep'essicomis, 1139.

Procellariu, 10 \$1.

Processionuaires, 854.

Procoliques (Vertèbres), 935.

Procoracoïde, 936.

Iroctoplyllex, 682.

Proctophyllodes, 682.

Procyon, 1:04.

Procyonidés (Procyoniclæ), 1204.

Prouluctus horrilus, 575 .
Progenèse, 628 .

Progloltis, 5i, 196, 223, 226, 33i.

Prognathes, 1:37.

'Pronéphros, 9t5.

Pronucléus, 48.

Propolis, 871.

Propaléothériums (Propalæotherimm),

1149 ; - isselanum, minulum, 11 49.

Puorotrichinés (Prorotrichinæ), 173.

Pjoscolex, 54, 226, 336.

Prosimiens, 1218.

Prosobrauches (Gastéropodes), 919, 920.

Prostate, 108í.

Prostatique (Canal), 350.

Prostigmata, 631 .

Protalges, (is2.

l'rotameba, 115; - primitiva, 115.

Prolapirus, 1174.

Protée (Irroteus anguinus), 982.

Proleles, 1207.

Protéroglyphes, 100 ?, 1004.

Protérothéridés (Proterotheridse), 1148

Protborax, 734.

Protistes, 10.

Protobathybius, 116.

Protocérébron, 595.

Protogenes, 116.

Prolohippes (Protohippus), 115.; - perdilus, sejunrtus, 1153.

Protomérite, 128.

Protuplasma, 5, 10 .

Protoplastes, 116.

Protopterus, 976.

Prolo-scolex, 54, 226, 336.

Protozoaires, 109, 112.

Protrachéates, 601 .

Protrogomorphes (Protrogomorpha), 1178.

Protubérance anuulaire, 1075.

Proveutricule (Insectes), 738.

Proventriculus (Oiscaux), 1022.

Proyer, 1063.

Prurigo dermanyssique, 721 ; — pédiculaire, 828.

Psammobies (l'sammobia), 914; - vespertinu, 914.

Psautier, 1116.

I'sendalius ovis pulmonalis, 427.

Pseudo-chrysalide, 891.

Pseudo-cils, 210.

I'sendois nâ'ıoòr, 1129.

Pseudo-lécithines, 977.

Pseudo-navicelles, 129.

Pseudo-Névroptères, 741, 878.

Pseudo-parasites, 78.

Pseudo-pinces, 704 .

Pseudopodes, 27, 113.

Pseudo-poumons, 599.

Pseudo-rhabditis, 556; - stercoralis, 55i.

Pseudo-Scorpions, 614, 724.

Pseudo-tuberculose, 438.

l'seudovu, 45.

Pseudovaire, 15. 
Psilura monacha, 8jí.

Psittacus, 1061 : - eryiliraceus, 1060, 1061.

Psocidés (Psocidx), 8i!!.

Psophia, 1042; - crepilans, 1042.

Psore, 6:0.

Psoriques (Sarcoptidés), 639.

Psoroptes (Psoroptes), 640, 666;-cati, 660 ; - commumis, 666 ; - c. bovis, 669 ; - c. capræe, 670;-c. cuniculi, 671; - c. equi, 668; - c. ovi;, 670; equi, 667; - ovis, 666, 670 .

Psorosperma crouposum, 148.

Psorospermies, 127, 129;-des Articulés, 160 ; - des Poissons, 157 ; - oviformes, 130 ; - utriculiformes, 150.

Psorospermium avium, 134;-cuniculi,13'.

Psorospermose, 137, 153, 158; - folliculaire végétante, $14 \%$.

Psychodiaires, 10.

Psylles (Psylla), 818; - piri, mubra, 818. Psyllidés (Psyllidæ), S18.

P'teralloptes, 682.

Pterocolus, 68:.

Ptérodactyles, 1014.

Pterodectes, 682.

Pterodicticus, 1219.

Ptéroïs (Pterois), 973.

Pterolichcæ, 682.

Pterolichus, 68:; - obtusus, uncinatus, 683.

Pteromys, 1179.

Pteronyssus, 682.

P'terophagus, 682; - strictus, 68:3.

Ptérophoridés (I'terophoridæ), 852.

Ptéropidés (Pteropidæ), 1217.

Ptéropodes, 904, 915.

Pteroptinx, 718.

Pteropus edulis, 1217.

Pterygotus, 611.

Ptines (Ptinus), 896 ; - fur, 896.

Ptinidés (Ptinidæ), 896 .

Ptomaines, 40.

Ptychophysa, 310 ; - lineata, 311.

Puberté, 1225.

Pubis, 937.

Puce, 800; - d'eau, 605; - de mer, 606 ; - de terre, 887 ; - pénétrante, 806.

Puceronnière, $8 \times 7$.

Pucerons, 811.

I'ulex, 800 ; - avium, 801, 802, 80' ; canis, 803; - columbx, 804; - erinacei, 802, 804; - fuscialus, 802, 804 ; felis, 803; - gallinæ Bouché, 801, 804; - gallinæ Redi, 719 ; - globiceps, 801, 804 ; - goniocephalus, 802, 804; - hirundinis, 80\%; - irritans, 801; - leporis, 804 ; - metis, 802, 804; - microctenus, 804; - mustelæ, 804; penetrans, 800 ; - penicilliger, 804; sciurorum, 802, 80' ; - serratice $/ s$, $802,803$.

Pulicidés (Pulicidæ), 800 .
Pulicinés (Pulicinát), 800.

Pullea, 688 .

Pulmonés (Gastér'opodes), 919, 9?1.

Pulpe labiale (Nématodes), 396.

- Pulsatiles (Vacuoles), 39.

Pulvérateurs, 10 :2.

Pulvilles, $7+2$.

Puma, 1209.

Punaises, 818; - à avirons, 819 ; - d bouclier, 823 ; - comestibles, 819 ; de bois, 823; - d'eau, 818; - de Miama, 718; - du Houton, 718; des Pigeons, $716 ;$ - de terre, 819 ; l'ougcs. 823 ; - vertes, 823 .

Pupe, 743.

Pupipares, 745.

Purpura, 920.

Purpura puticosa, 803.

Putois, 1204.

Putorius, 1204 ; - erminea, 1204;-itatsi ; 328 ; - fotidus, furo, lutreola, vulgaris, 120 t.

Putresciue, 40.

Pycnogonides, 614, 615.

Pycrogonem, 615.

Pygidium, 800.

Pygméphores (Pygmephorus), 693, 695; - uncinatus, 695 .

Pygostyle, 1017.

Pylorique (Appendicc), 925; - (VuIvule), 1080.

Pyloriques (Appendices), 952.

Pyrales (Pyratis), 853 ; - de la Vigne, 853.

Pyralidés (Pyralidæ), 853.

Pyrellia cadaverina, 78 '.

Pyriforme (Appareil), 268.

Pyrosomum (Tuniciers), 932.

Pyrosomum bigemillam, 127.

Pyrihula, 1062; - canaria, 1063; - vulgaris, 1062.

Pythous, 1003.

\section{Q}

Quadrijumeaux (Tubercules), 1075.

Quadrille des centres, 4 ?

Quadrumanes, 1218, 1220.

Quart-au, Quartenier, 1107.

Queue de Cheval, 1075.

\section{$\mathbf{R}$}

Rabouillère, 1190.

Race, 93.

Races géographiques, 60; -.- métisses, 96.

Rachidien (Canal), 985.

Rachidiens (Nerfs), 940.

Rachis(Nématodes), $390 ;-(P l u m e), 1019$;

- (Vertébrés), 935 . 
Racines (Deuts), 10i8.

Racloir, 1:29.

Ritdicicoles (Phylloxéras), 813.

Riadiés (V'ertébrés), 937, 9is.

Radiolaires, 115, 1:0

liadius, 93i.

liculula, 903.

Ratle, 70?.

Ragot, 1107.

Raies, $96 \mathbf{l}$.

Raiueltes, 987.

llaisins de $11 \mathrm{er}, 927$.

Raju, 961.

Rajides, $9 \mathrm{Gl}$.

làle d'eau, 10 i:; - des prés, 10 i:.

liallidés (Fallidr), 10i:.

Rallus, 10 :?.

Rumphastus, 1060 .

Ramphostomum, $101 \vdots$.

Rana, 985; - agilis, 986; - esculenta, 985 ; - fusca, 986; - temporuria, 986; - viridis, 985.

Rapaces (Oiseaux), 1029, 1065.

Raphignathin.p, 693.

Rascasses, 972.

Risle, 944.

Ràteau (Abeilles), s6o.

Ratels, 120 i.

Ratites, 1029 .

Raton, 120:; - (Chien), 1198.

Rats, 118i; - il courle queue, 118?; d'eau, I182; - musqués, 1183.

Ravisseurs (Palpes), (126.

Rayounés, 110, 187, 198.

Rayons (Échinodermes), 19s; - (Pois sons), 950.

Réceptacle sẻminal, 225.

Fiécifs de polypiers, 190.

Rectales (Glandes), 738.

Rectrices, 1019.

Rectum, 1081.

Récurvirostres (Recurviroslia), 10i2.

Rédie, 336 .

Rédintégration, 57.

Réduction, 23.

Rédıves (Reduvius), s19; - personutus, S19.

Réduvidés (Reduvidx), 819.

Réduvius (Ixodes), 708.

Règne humain, 122,.

Règnes, 3.

Regulus, 1063; - cristatus, 1063.

Reine, 867; - ie sauvetė, 869.

Reins, 40; - (Vertébrés), 9 †́.

Relalion (Fonctions de), 27.

Reliquuat de diffèrenciation, 129; - de segmentation, 129.

Remak (Fibres de), 19.

Rémiges, 1019.

Rémoras, 972.

Renards, 1198.

Réniformes (Corpuscules), 151. lienne, 1126.

Reproduction (Fonctions de), 13, 11.

liepliles, 949, 988; - nus, 976.

Républicains, 1063.

liequins, 960.

Réseau (Reticulum), 1116.

Réservoirs aeriens, 1024.

Respiralion, $35,37$.

liespiratoire (Appareil), 37.

Réticulé (Tissu), 16.

Réliculés (Yeux), 597.

liéliue, 32.

liéliniens (Yeux), 597 .

Rétrogradatiou, 23.

liéversion, 96, 97.

lieviviscence, 57 .

lihabdilis (Rhablitis), 5i9; - Axei, 5:5:; - Cornwalli, 550; - genilalis, 551; Niellyi, 5\%3, 551; - pellio, 550; - setigera, 550 ; - leves, 550 ; - terricula 550 .

Rhabditis douteux, 462, 552.

Rhabditoïde (Larve), 559; - Généralion), 392 .

Thabdocoeles, 38:.

Rhabdonema, 556; - inteslinale, 55i; longum, 561; - stercorale, 557; strongyloides, 557 ; - suis, 362 ; - viriperum, si9.

Rlıbdonémidés, 556 .

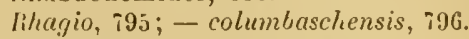

lihaphigasler griseus, 809 .

Rhea, 1031.

Rhinéchis (Rlinechis), 1003: - scalaris, 1003.

Rhinite pemphigoïde, 896 .

Rhinocéros (Rhinoceros), $1174 ;-$ africanus, indeus, javanicus, sumatrensis, $1174 ;$ - tichorhinus, 1175.

Rhinocérolidés(Rhinocerotidx),114S, 117'.

Ihinostres (Rhinostrus), 765; - purpureus, 756 , 765 .

Rhinolophus ferrum-equinum, 1218.

Rhipicéphales (Rhipicephalus), 12, i12; bursa, 713; - buvis, 127, 713; - sanguineus, siculus, 514,712 .

Rhipiptères, 883 .

Rhizocéphales, 605 .

Rhizoglyphes (Rhizoglypluus), 688, 691 ; echinopus, spinilarsus, 691.

Rhizoïdes (Pseudopodes), 115.

Rhizomouères, 116.

Rhizophagus parallelocollis, 900 .

Rhizopodes, 11f.

Rhizostomum Cuvievi, pulmo, 197.

lhizolrogues Rhizolrogus), $\$ 98$; - solstitialis, 899 .

Rhodeus amarus, 967 .

Rhodites rosæ, 863 .

Rhombozoaires, 208.

Bhombus lavis, maximus, 970.

Rhopaloceras slyliferum, $8 \mathbf{4 1 .}$ 
Rhopalocères, 860 .

Rhopalophoris, 341 .

Rhynchobdellidx, 577, 589.

Rhyuchobothridés (Rhynchobolhridx), 331.

Rhynchobothrium, 331; - erinaceus, 331.

Rhyncholouhinx, 693.

Khyncholophus cinereus, 703.

Rliynchoprion (Argas), 715; - columba, 715 ; - (Sarcopsylle), 806; - penetroms, 806.

Rleynctiops, 1041.

Rhynchopsylla, s0s; - pulex, 809.

Rhynchola, 809 .

Rhytina, 1101.

Ricardeaux, 911.

licinidés (Ricinillæ), 824, 833.

Ricins (Acariens), 705; - (Insectes), 8:13.

Ricinus caninus, 708 .

Robenhausienne (Époque), 1230.

F'och, 4+1.

Rochers, 9:0.

Rogenhofera, 775 .

Rogue, 968.

Roitelets, 1063

Rolliers, 1061.

Rongeurs, $1091,1176$.

Rorqual, 1100 .

Rossignol, 1064; - bâtêrd, 1063.

Rostellum, :21.

Rostre (Acarieus), 625; - (Bélemnites), $928 ;-$ (Cestodes), 221.

Rotateurs, 208, 572.

Rotifères, $5 \div 2$ -

Rotule, 9:37.

Rouge (Sous-type), 1237.

Rouge-gorge, 1064 .

Rouget (Acarien), 701; - (Oiseau), 1037 ; - (Poissons), 974.

Ronsseau, 1037.

Roussettes (Mammifères), 1217; - (Poissons), 960 .

Roux (Type), 1237.

Rucher, 870 .

Ruches, 870 .

Rudimentaires (Organes), 23, 25, 10 ?.

Rue (Lhiens de), 1193

Rumen, 1115.

Ruminants, 1104, 1113.

Rumination, 1117.

Rupicapra europiea, 1128.

Rut, 1086.

Rynchobdellidès, $577,589$.

Rynchopsylles, 808 .

Rynchotes, 809.

\section{$\mathbf{S}$}

Sable (Canal du), 2c0

Sabora, 1198.

Sabot (Turbo), 920.

Sabots, 1069.
Sac cercarigerc, sac germinatif, 335 .

Saccobrauche, 55\%.

Saccule (Acariens), 6:9;-- (Jammifères), 941.

Sacculina, 605 .

Sacs aériens, 1024; - vocaux, 979.

Srnolophus, 166; - Ebertli, 169.

Sagouins, 1:2?.

Sagres, 960.

Saiga (Saiga latarica), 1128 .

Saignement de nez des Chiens de meute, 473.

saïmiris, 1222.

Saindoux, 111?.

Saint-Acheul (Époque dc), 1227.

Saiut-Jacques (Coquille de), 911 .

Sainte-Anne Iluîtres), 907 .

Sajous, 1222.

Sakis, 1222.

Salamandres (Salumandra), 937, 982; alra, maculosa, 982.

Salamandres aquatiques, 934 .

Salamaudrides, 982.

Salamaudrine, $\mathbf{9 8 3}$.

Salangaues, 1064 .

Salicoque, 607.

Salivaires (Glandes), 36.

Salmo, 966; - salm, salvelinus, 966.

Salmonidés (Salmonidx), 966.

Salpa, 933.

Salpes, 932 .

Saltiques (Salticus), 730 .

Samandarine, 983.

Sandre d'Europe, 972.

Sang, 21.

Sanga, 1146.

Sang chaud (Animaux à), 39, 8 \$5.

Sang froid (Avimaux à), 38, 945 .

Sangliers, 1106.

Sangsue, 578; - de Cheval, .85; - dragou, 584; - grise, 578 ; - médiciuale, 578 ; - noire, 585 ; - officiuale, 578 ; truite, 584 ; - verte, 578 .

Sansonnet, 1063.

Saprinus rolundalus, 900.

Sarcelle, 1037 .

Salcelline, $103 \pi$.

Sarcocystes (Sarcocystis), 150; - hirsuta, 154; - hominis, 155; - Miescheri, 150; - tenelln, 153.

Sarcocyte, 128.

Sarcode, 10.

Sarcolemme, 19.

Sarcophages (Sarcophaga), 789;-arvensis, carnaria, hxmatodes, hæmomhoidalis, laticrus, magnifica, ruficornis, striata, Wohlfarti, 789.

Sarcophaginés (Sarcophaginæ), 789.

Sarcophiles (Sarcophila), 789; - magnifica, 789.

Sarcopsylles (Sarcopsylla), 806 ; - gaillinncea, 808 ; - penetrans, 806 . 
Sareopsyllinés (Surcopsyllinx), 806.

Sarcoptérins (Sarcopterinus), 697 ; - niatulans, 697 .

Sarcopterus, 697 .

Sarcoptes (Sarcoptes), 6ro;-almpis, 60\%: - auriculnum, 675,676 ; - bovis, 671 ; - canis, $655 ;-$ caprye Delitf. et Bourg , 675; - capris Fiurst., (i40, 6i.j; - culi, 6i60; - calorum, 660; - communis, (iłt); - cuniculi, 660; - cynolis, 6ii, fi7t; - cysticola, 680; - dramedurii, 65ł; - equi Gerl., 6j0; - equi Iler., 666, 668; - exulcerans, 640; - fetis, 660; - fossor, 666; - Gerlachi, 678: - hippopodos, 6s8; - hominis, 73, 64i; - lapvis, 66t; - l. columbar, 665; 1. gallinx, 665; - minor, 437, 660;m. cuti, 660; - m. cuniculi, 661;mutans, 6: 3 ; — murus, 678; - ovi. 670 ; - scabiei, 6i0; - sc. Aucheniap, (5); - sc. cameli, 65ł; - sc. canis, 65i; - sc. capræx, 653; - sc. crustosx, $6\{0,649 ;-s c$. cuniculi, 656 ; - sc. equi, 650 ; - sc. furonis, 656 ; - sc. hominis, 647; - sc. leonis, 659; - sc. lupi, 65s; - sc. ovis, 652; - sc. suis, $655 ;-s r$. vulpis, 6.58 ; - sc. wombati, 659; squamiferus, $610,655,658 ;-$ suis, 655 ; - vulpis, 640, 658 .

Sarcoptidés (Sarcoptidæe), 631, 639.

Sarcoptinés (Sarcoplinx), 6:39.

Sarcoramphus, 1066.

Sarcosome, 190.

Sarcosporidies, 150 .

Sarde à dos rayé, 971; - á dents de Chien, 972.

Sardine, 966 ; - des tropiques, 965; rouge, 966.

Sargues (Sargus), 972.

Sarigue, 1095.

Saturnies (Saturnia), 559 ; - arrindia, 860; - carpini, 860 ; - cynthia, 860 ; - mylilla, 859; - pavonia major, 860; - p. minor, 860; - Pernyi, 859; pyri, 860 ; - yama-mai, 859 .

Saturninés (Salurninæ), 859.

Saumons, 966.

Sauriens, 993.

Saurophidiens, 993.

Sauropsidés, 948, 992.

sauterelles, 88 .

Sauteurs (Orthoptères), 881.

Savary, 974.

Saxicola, 1064 ; - ananthe, 106 t.

Scaphopodes, 90t, 915.

Scapulaire (Ceinture), 936.

Scapulaires (Rémiges), 1019.

Scarabées (Scarabeus), 8:8.

Scarabeje du Coloralo, 887 ; - puant, 895 .

Scarabeidis (Scarabeilla), 899 .

Scares (Scarus), 971;-cretensis, psiltacus, velula, 971.
Scatella urinaria, iso.

Scaurus striatus, 895.

Schistocépluales, 214.

Schistocerca peregrina, 883.

Schistosomes (Schislosomum), 3i1; - bovis, 37..); - crussum, 375; - hamalolium, 371; - maquum, 373 .

Selistosomose, 373 .

S(hizoneuru lanigera, s1:.

Schizopodes, 607.

Sclivaun (Gaine de), 19.

Schwïmercyste, 149.

Sciuques (Scincus), 1013; - officinatis 1013.

Scirina, 693

Scissioll, 13, 42.

Scissiparití, $13,42$.

Sciurités Sciuridip), 11 is.

Sciuromorphes (Sciuromorpha), 11 is.

sciurus vulguris, 1179.

Sclérodermés, 189.

Selérostones (sclerostomum), 455; - armatum, 456;-caninum, 470; - denta(um, 45); - duodenale, 465; - equinum, 455,456 ; - equ. var. mujor, intestinalis, 159; - equ. var. minor, aneurismatica, 15!); - hexacanthum, 461; - hypostomum, 163;-ovinum, 463; - pinguicola, 452; - quadridentalum, 461; - robustum, 463; - syngamus, 453;-telracanthum, 461; - tracheale, 455.

Selérostomines (Sclerostominx), 418, 448. Sclerotrichum, 4ii.

Scoleciasis, 744, 851 .

Scolex, if, 2:1, 337.

Scolopacidés (Scolopacillx), 1042.

Scolopax, 1042.

Scolopendres (Scolopendra), 733; - cingulato, 733 .

Scolytidés (Scolytidx), 889.

Scolytus, 889 .

Scomber scombrus, 971.

Scombérésocidés (Scomberesocida), 970. Scombéridés (Scomberiax), 971.

Scorpènes (Scorprna), 972; - grandicornis, 95i, 97:; - poreus, scrofu, 97?.

Scorpion (Scorpio), 728; - africanus, 728; - imperator, 728; - occitanus, 727 ; palmatus, $7: 9$; - tunelanus, 727 ; de mer, 973 .

Scorpionides, 6t4, 725.

Scorpionilés (Scorpionidx), i2s.

Scorpions, i?5.

Seren-Worms, is'.

Scrotum, I0sí.

Sculigera, i:j3.

Scyllium, 960.

Scyphistome, 196.

Sébacées (Glandes), 1069.

Sébifiques (Glandes), $¥ 40$.

Secrétaire, 1066.

Sícréteur (Appareil), 39. 
Sécrétion, 39.

sedentarres (Polychètes), 59?.

Seedy-toe, 552 .

Ségestries (Segestria), $730 ;-$ cellaria, $;: 0$.

Segmentaires (Orgaues), 40.

Segmentation, 50 .

Seiches, 9:7.

Sejus auris, 7:3.

Selache, 960 .

Sélaciens, 9.9, 960 .

Sélection artificielle, 65; - naturelle, 66 - sexuelle, 67.

Sélénodonte ('Type dentaire), 1103.

Semi-circulaires (Canaux), 941.

Semi-lunaire (t'i), 1077.

Séminale (Vésicule), 44.

Sémite (Type), $12 \dot{\prime} 0$.

Semnopithécidés (Semnopithecidæ), 1223. Semnopithèques (Semnopithecus), 1223.

Sénégalis, 1063.

Sens (Organes des), 30; - sixième, 94?, 951.

Sensation Organes de), 29.

Sensitifs (Nerfs), 30.

Sensitives (Racines nerveuses), 940.

Sépia, 925.

Sepia, 927 ; - officinalis, 927.

Sépioles (Sepiola), 928.

Sépiostaire, 927.

Seps, 1013.

Sépultures robenhausiennes, 1231.

Séricaires (Sericaria), 856; - mori, 856 .

Sériciculture, 856 .

Séricigènes (Glandes), 729, 739.

Serin, 1062 .

Sérothérapie de l'échiảnisme, 998, 1001. Sérotine, 1000.

Serpents, 993.

Serpent cracheur, 1012; - ả coiffe, 100f́

- de Cléopâtre, 10104; - à luneties,

1004 ; - de mer, 1004; - minute, 1012:

- à sonnette, 1012.

Serpentaire, 1066.

Serpules(Serpula), $592 ;-$ contortuplicata, 37.

Serrans (Serranus), 972; - arara, gigas, nigriculus, 97?.

Serrator, 688.

Serres, 1065.

Sésies, 102.

Seta, 563.

Sétigères, 1105.

Sexuelle (Reproduction), 43.

Sha, Shapou, 1130.

Shima-mushi, 703.

Sialis, 878 .

Sifflement (Serpents), 992.

Sigmoïdes (Valvules), 1082.

Siguatère, Siguatera, 79, 957.

Silicosponges, 186.

Silphes (Silpha), 899; - obscura, 899 ; opaca, 900 .
(Silphidés (Silphidæ), 899.

siluridés (Siluridæ), 967.

Simia, 1.22: ; - satyrus, 1223.

Simiens, 1219 .

Simondsies (Simondsia), 545;-paradoxa, 545.

Simonea folliculorum, 634.

Simulidés (Simulidæ), 795.

Simulies (Simutium), 795; - columbntczense, 795 ; - cinereum, maculatum, omatum, reptans, tibiale, vernum, 796.

Singes, 1219.

Siuges-Araignées, 1222.

Singes-Écureuils, 122:.

Sinus antennal, $834 ;-$ biflexe, 1114 ; génital, 2:5; - orbital, 84 千́ - palléal, 90 ; - rhomboïdal, 10:0.

Siphon (Lamellibranches), 906 ; - (Nantiles), $926 ;-$ (Tuniciers), 930.

Siphonaptères, 799.

Siphouidès, 914 .

Siphonophores, 195.

Siphonops, 982.

Siphonostomes, 606.

Siredon pisciformis, 982.

Sirène (Siren lacertina), 982.

Sirènes, Sirénidés, 1091, 1100.

Sirex, 862.

Sitaris (Sitaris), 890; - humeralis, muralis, 890 .

Sitotrogues (Sitotroga), 852; - cerealella, 852.

Sittace, 1001.

Sixième sens, 942, 951.

Sixyeux, 920 .

Sloughi, 1199.

Sociétés auimales, 65 .

Soies, 1068.

Soldats (Fourmis), 863.

Sole (Solea vutgaris), 970.

Solen, 91'千; - ensis, vagina, 914.

Solénoconques, 915.

Solénoglyphes, 100?, 100t.

Solifuges, 731 .

Solipèdes, 1153.

Solitaires, 1107.

Solium, 23'.

Solpuga, 731 .

Solpugidés (Solpugidæ), 731.

Solutréenne (Époque), 1229.

Somatopleure, 51 .

Somite, 59 '.

Sommeil (Maladie du), 523 .

Sonueurs, 985.

Sorcière de la mort, 895 .

Sorex, 1214;- araneus, etruscus, fodiens, 1215.

Soricidés (Soricidæ), 1214.

Souclset, 1037.

Souffleur's, 1097.

Souille, 1105.

Sourdons, 91'. 
Souris, 11s $;$; - de mer, 593.

Sous-œsophagiens (Ganglions), 2.).

Spurganum reptans, 328 .

Sparidés (Sparidie), 9i?.

Spatules, 104?.

Spermaceti, 1098.

Spermatophores, 4 .

Spermatozoïdes, 43, 4\%.

Sperme, 47.

Spermiducte, 211.

Spermocentre, 49.

Spermophiles (Epermophilus), 1179.

sphærogyna, 693: - ventricosa, 693.

Spharularia, 5íi.

Sphargis, 1015.

Sphégidès (Ephegidx), 86t.

Sphères directrices, 13 ; - de segmentation, 50.

Sphex, 864.

Sphingides sphingidie, 860 .

Sphinx Sphinx:), 860.

Sphyrèes (Sphyrxna), 9i1; - barravuta, becunu, 9iı.

Spicules (Éponges), 185; - Nématodes), 390.

Spinax, 960.

Spiraculum, 979.

Spirale (Valvule), 952.

Spirifers, $5 i 5$.

Spiritrompe, 850 .

Spirodiuious (Spirodinium), 183:- equi, 183.

Spiroptères (Spiroptera), 53:3; - cincinnala, 53s; - gastrophila, "; - humulosa, 544 ; - laticeps, 5 13; - leporum, 4ti; - lienalis, 511; - lupi, 536; megastoma, 533; - meg. var. major, 535 ;-microstoma, 535 ; - nasuta, 544; - reticulata, 538 ; - sanguinolenta, 536 ; - scutala, 541; - strongylina, 536;uncinata, 543 ; - verrucosa, 54 ?.

Spirotriches, 17 .

Spirura, 533: - megastoma, 533.

Splanchnopleure, 51.

Spondyles Spondylus, 911 ; - gxderopus, 911.

Spongiaires, 110,184 .

Spongidés (Spongidix), 186.

Spongieuse, 854 .

Spongieux (Corps), 925.

spongilla, 18i, 186.

Sporadin, 130.

Spores, 42, 129.

Sporoblastes, 128.

Sporocyste, 336 .

Sporogonie, 42

Sporosac, 19 \%

Sporozoaires, 11', $12 i$.

Sporozoïtes, 129.

Sporulation, 4?.

Squales, 960 .

Squamodermes, 963.
Squamulina, 119.

squatina, 960.

Squelett( : ?).

Squilles (Squitla), 60i ; - mantis, 607 .

slaphylorystis, 213.

Stationnare (Parasitisme), 69.

Statoblistes, 574 .

Stauroutzes maroccanus, 893.

Stiatopygic, 1244.

Steatozoon folliculorum, 63 '.

Stéganopodes, 10 \&.

Stégocéphales, 981.

Stelières, 1101.

Stellérides, 20:3.

stelmizes, 109.

Stemmates, 597.

Stenops, 1219.

stentor polymorphus, 161, 17i; - Miilleri, 171.

Stephanurus tentatus, 452; - Nattereri, 452.

Sterna, 10 i.

Sternal (Arceau), 594.

Steruites, 594.

Sternum (Arthropodes), 59k; - (Scorpions), $725 ;-$ (Vertébrés).

Stigma, 1026.

Stigmates, 598.

Stilésias (Stilesia), 2ii;-centripunctatu, $27 \% ;-$ globipunctnta, 277.

Stockfish, 9is.

Stomaco, 102:; - succenturiato, 1022.

Stomatitis pustulosa acarosa, 690 .

Stomato-gastrique (Système nerveux), $5: 6$.

Stomatopodes, 605,606 .

Stouroxes (Stomoxys), 7 S5 ; - calcitrans, is6.

Stomoxydés (Stomoxydx), 785.

strachia oteracea, ornata, \$2:.

Strepsiptires, 885 .

Striatule, is.

Strigea, 376; - cervi, 376.

Strigops (Strigojs), 1061.

Strix, 1066 ; - flammea, 1066.

Strobile, 5i, 196, 221.

Strougle armé, $4 . j 6$; - géant, 419.

Strongles (Strongylus), 4?i; - ammonis, 139; - anatis, 423; - anseris, 447; armalus, 456; - Amfieldi, 430, 434 ; asininus, 456; - Axei, 145 ; - Blasii, 445 ; - bronchialis canis, 437, 530; cernuus, 17: ; - circumcinctus, "; colubriformis, 442; - columbianus, 451; - commutatus, 435; - contortus, 424, 439; - convolutus Ost., 4t3; - Curticei, 4.2; - dentatus, 451; - dilatalus, 449;-duodenalis, 46.5:-elegans, 423 ; - elongalus, 432 ; - equinus, 456 ; - filaria, 424; - filicollis Molin, 439; - filicollis Raill., 442; - flicollis Rud., 442, 489; - gigas, 419; - hypo- 
stomus, 463; - inflalus, 449; - inslabilis, 442; - leporum, 477; - longevuginatus, 432, 433, 530; - lupi, 536; mergorum, 423; - micrurus, 430;minutissiruss, 427; - mucronatus, 447; - nodularis, 447; - nodulosus, 417; - orispinus, 447; - Ostertagi, 443; ovinus 0 . Fabr., 463; - ovis pulmonalis, 4:7; - paradoxus, 432, 530;pulmonaris, 431; - pusillus, 436 ; quadridentatus, 465; - rudialus, 475; - renalis, 419 ; - relortæformis B:emser, 445; - retortæformis Zeder, 447 ; - rubidus, 444; - rufescens, 427 ; servatus, 448; - stenoceplaalus, 473; - strigosus, 445; - subulutus, 439, 552 ; - suis, 431; - tenuis, 448 ; tenuissimus, 415; - tetracanthus, 461; - tetragonocephalus, 470; - trachealis, 453; - trigonocephalus, 470; tubifex, 423; - variegatus, 455; - vasorum, 42i, 437; - ventricosus, 4t1;venulosus, 450; - vicarius, 444; visceralis, 419 ; - vilulorum, 430 .

Strongylidés (Strongylidx), 417.

Strongyliués (Strongylinæ), $418,424$.

Strongylocentrolus lividus, 204.

Strongyloide (Larve), 558.

Strongyloïdes (Strongyloides), 556; - intestinalis, 557 ; 一 longus, 501 ; - suis, $51 ; 2 ;-$ vivipar $a, 549$.

Strongylose bronchique, 427, 431, 43:, 435,436 ; - gastro-entérique, 441, 442; - pulmonaire, 429, 433, 436, 438; des vaisseaux, 438 .

Struggle for life, 61 .

Struthio camelus, 1030 ; - molybdophanes, 1031.

Struthions, 1030.

Sturnus, 1063 ; - vulgaris, 1063.

Style alaire, 736 ; - antennal, 75 ; cristallin, 905 .

Stylops, 886; - Spencei, 885.

Stylorhynchus, 130; - longicollis, 129.

Subbrachieus (Malacoptérygieus), 967 ; - (Poissous), 95l.

Subr, 1141.

Subulura, 409 .

Suc cellulaire, 11.

Succenturiato (Ventriglio), 1022.

Succenturié (Ventricule), 1022.

Sucet, 960.

Suceurs (Diptères), 797 ; - (Insectes), 737,741 .

Sudoripares (Glandes), 1059.

Suidés (Suidæ), $110 j$.

Suint, 1133.

Sula, $10 \dot{1} 1$.

Surmulet, 974.

Surmulot, 1184.

Surnies (Surnia), 1066; - nsctux, passerina, ulula, 1066.
Surra, 165.

Sirucucu, 1012.

Sus, 1115; - andamanensis, 1107; antiguus, 1106;- asiaticus, 1109 ; -barbatus, 1107; - capensis, 1107; celticus, 1109; - choroides, 1106 ; cristatus, 1107; - erymanihius, 1106; - giganteus, 1107 ; - ibericus, 1109 ; - indicus, 1107 ; - larvatus, 1113 ; tencomystax, 1107; - Lockarti, 1106; - major, 1106; - palæocharus, 1106 ; - palustris, 1111; - vapuensis, 1107; - provincialis, 1106 ; - scrofa, 1!07; - scr. domesticus, 1108 ; - scr. fossilis, 1106 ; - scr. meridionalis, 1107 ; - ser. nanus, 1111 ; - sennaariensis, 1107 ; timoriensis, 1107; - verrucosus, 1107 ; - vittatus, 1107 .

Suture (Mollusques), 946.

Sylvia, 1063; - atricapilla, curruca, hortensis, 1063.

Sylviadés (Sytviadx), 1063.

Symbiotes (Symbiotes), 6i1; - auriculurum, 675; - bovis, 671, 694; - canis, 675,676 ; - cynotis, $675 ;-$ ecaurlatus, $675 ;-$ equi, 671, 672; - felis, 675, 677 ; - spathiferus, 671 .

Syurétrie, 27.

Sympathique (Granr), 30.

Symplectoptes cysticola, 680.

Syuancées (Synanceia), 973 ; - brachio, 973.

Symapticules, 190 .

Synascidies, 93:.

Synchytrium Miescherianum, 150.

Syndactyles, 1061 .

Syngames (Syngamus), 453 ; - bronchialis, 455 ; - primitiuns, 453; - sclerostomum, 455; - trachealis, 453; - variegutus, 455 .

Syugamiose, 454.

Syngnathus acus, 963 .

Synhydraires, 194.

Synolus barbastellus, 1217.

Syringobia, 682.

Syringophiles (Syringophilus), 698 ; - bipectinatus, 698; - uncinatus, f998.

Syrinx, 1023, 1025.

Symium, 1066;- aluco, 1066.

Syrphidès (Syrphidær), 791.

Syrphus, 791 .

Système, 26.

Systèmes artificiels, 88 .

Syzygie, 173.

\section{$\mathbf{T}$}

Tabanidés (Tabanidx), 791.

Tabaninés (Tabaninæ), 792.

Tabanus, 792; - autumnalis, 792 ; albifaries, bovinus, bromius, morio, rusticus, 792. 
Tablicr des Hottentotes, 1: 15.

Tachardia lace $\iota, 811$.

Tache culoryounaire, 9i6; - phylloxérique, 816.

Taches bleues, 829 ; - génitales, 825 ; oubrées, 829.

Tachina, 79!.

Tachinines (Tachininx), $\mathbf{1 9}$.

Tachyglossus, 1093; - aculeatus, sctosus, 109:3.

Tachypetes, $10 \mathrm{i}$.

Tact, 30 .

Tactiles (Baguettes), 206.

Tarlornes, 1037.

Trenia, 215; - abielinu, 237 ; - ucanthotrias, 2:6; - actinioilles, 27j; - aculeuta, 276;-xgypliıc, $293 ;-x q u a$ bilis, 302, 303; - ayaina, 308 ; - albu, 274; - ammoniliformis, 251; - cunutinc, 298, 300; - anatis marilx, 309; - anserum, 299; - Benedeni, 2i3 ; bolhrioplites, 306 ; - Brandli, " ; caninu, 260, 284; - canis lagopodis, 311 ; - cantanianu, 310; - capensis, 236 ; - capræ, 275; - caprae, 617;caleniformis, 311 ; - centripunctala, $27 \%$ - cesticillus, 305; - conurus, 25:; - collaris, 300; - conica, 303; - continuu, 246; - coronula, 302; - crassicollis, 214, 249, 260; - crassula, 305, 306; - crucigera, 275; clenoides, 278; - cucumerina, 28i; cuneata, 302, 304; - cuniculi. 283; cyslicerci tenuicollis, 2:s; - Delufondi, 309; - dentala, 237; - denticulata, 274;-diminula, 295; - echinobolhrida, 305,306 ; - echinococcus, 258 ; - è cyslicerco tenuicolli, 228; - elliplica, 284, 285 ; - equina, 279, 281; - exilis, 309; - expansa, 269, 489; - fusciala, 298, $2\lrcorner 9$; - fasciolaris, 310 ; - fenestrala, 237, 246, 290; - fimbriala, 275; Ravopunctata, 295 ; - Friedbergeri, 30ذ, 308; - fusa, 246; - Giardi, 276; - globipunclala, 277; - Gœzoi, 278;gracilis, 298, 299; - hirudinacea, 565;imbutiformis, 313 ; - inermis, 232 ; infundibuliformis Gœze, 298, 302; - inf. Duj., 305; - inf. Mégn., var. phasianorum, 308; - infundibulum, 302;-Krabbei, 232; - lanceolata, 295, 299:-lalu, 315; - lalisima, 278: - leplocephala, 2J5; - Leuckarli, 278; - lineata, 311; - litteratr, 311 ; - lophosoma, 236 ; malagascariensis, 307 ; - magna, 279; - malleus, 310; - mamillana, 279, 282 ; - marginata, 228; - marmolx, 278; - mediocunellata, 232, 23\%; megalops, 309; - minima, 295; - moniliformis, 284; - murine, 291; n.ma, 293; - Veumanni, 2i4; - nigra, 236 ; - nullicollis, 275; - oblongiceps,
275 ; - ovilla, 276;-ovina, 269;-uvipunclata, 2iิ; - I’usqualei " ; - perLinata Goze, 278; - pectinala (\%eder), 28:3;-pediculala, :\$8 ; - pellucidu, :23i, 2 12 ; - perfoliula Duj., 382 ; - perfoliata Goeze, 73, 2i!, 251;-planissima, 273; - plicala, 279;-prina, 315; - prismatica, 289; - proglollina, 305 ; psculo-cucumerinu, 311 ; - pseudopllipticu, 311; - restricta, 2s1 ; rhinaria, 616; - rhomboilea, 302, 303 ; - rhopaliocephala, 283; - rhopalocephalu, 283; - Rosseteri, 301; - saginalu, T3, 23:, 234; - semileres, 251;serialis, 25i ; - servata, 21.), 260;-spr. astephana, 227 ; - serr. monostephana, $2: 7$; - setigcra, 298, 301; - sinuosu, 298, 303; - solixm L., 232, 23i, 242; solium liud., 2t2; - sol. minor, 246; sphenocephalı Uégn., 302; - sphenocephail. Rud., 307, 310; - sphenoides, 304; - strangulata, 280; - tenella, :30, 231, 246; - lenuirostris, 298, 301 ; tetragona, 305, 306; - trigonophora, 2i3; - trilineala, 303, 310; - Trinchesei, 290 ; - undulata, 310 ; - varesina, 995 ; - visceralis, 231 ; - Vonti, 281; -vulgaris L., 315; - vulgaris Werner, 237 ; - wimerosa, 283.

Tæniadæ, 213.

Tieniarhynchus mealiocanella'us, 232.

Taffetas d'Angleterl'e, 962.

Taillée (Période de la pierre), 12:27.

Takin, 1128.

Takjas, 1160.

Takké, 1165.

Talitres (Talitrus), 606.

Talpa, 1215; - cæca, 1216; - europæn, 1215.

Talpidés (Talpidæx), 121 j.

Tamanoirs, 1096 .

Tamarins, 1221 .

Tamias (Tamius), 1179.

Tanaïs (Tonais), 606.

Tauche, 967.

Tanrecs, 1214.

Taon, 792; - aveuglant, 793; - des pluies, 793 .

Tapes, 914; - Bourguignati, decussulus, edulis, geographicus, pullaster, lexturalus, 914 .

Tapiridés (Tapiridæx), 1148, 1173.

Tapirs (Tupirus), 1174; - americanus, indicus, villosus, 1174 .

Tapissiers, Sö8.

Tarandus, 1126;-rangifer, 1126 .

lardigrades (Arachnides), 614; - (Édentés), 1096.

Tarenlula, 725.

Tarentule, 730 .

Taret, 915 .

Tarière, 881,88 i 
Tariers, $106 i$.

Tarpans, 1160.

Tarse (Insectes), 735 ; - (Vertébrés), 937.

Tarsiers (Tarsius), 1219.

Tarsonèmes (Tarsonemus), 693, 695; intectus, 695 ; - uncinatus, 695 .

Tarsonéminés (Tarsoneminæ), 693.

Tasmanien (Type), 1245.

Tassards, 971 .

Tatous, 1096.

Taupe-Grillon, 884 .

Taupes, 1215.

Taupinières, 1215.

Taupins, 897.

Taureau, 1145.

Taurius (Taurina), 1139.

Taxéopoles, 1175.

Taxinomie, 87 .

Tchita, 1213.

Tectrices, 1020.

Tedzo, 1146.

Tegeneria domeslica, 730 .

Tegmina, 736.

Tegmites, 59'.

Tegonotus, 632.

Tehuelche (Type), 1243.

Teichomyza fusca. 780.

Teigues, 852; - les graisses, 85.3;de la grappe, 853; - (fausses) de la cire, 853,871 .

Télégonidés (Telegonidæ), 727, 729.

Téléostéens, 959,96:.

Telephorus, 897.

Télolécithes (OEufs), 47, 51 .

Telphuses (Telphusa), 610.

Temnoeéphalidés (Temnocephalilær), 383.

Température constanle, variable, $38,945$.

Temporaire (Parasitisme), 69.

Ténébrionidés (Ínebrionidær), 895.

Ténébrions (Tenebrio), 895; - molitor, 895.

Téuia à épine, 315 ; - algérien, 236 ; armé, 242; - feuêtré, 237, 246, 290;globuleux, 228; - inerme, 232; - lancéolé, 616: - sans épine, 234 ; - trièdre, 236, 246, 251, 255, 282, 289, etc.

Téniadés, 213.

Téniasis des Moutons, 272: - des Lapins, 283.

Teutacules, 30 .

Tentaculifères (Infusoires), $16 \%$.

Tenthredo, 862.

T'énuirostres, 1061 .

Tératologie, 25.

Térébelles, 59:.

Térébrants, 862 .

Térébratules, 575.

Teredo navalis, 915.

Tergal (Areeau), 59'.

Tergites, 594.

Tergum, 594.

Termes lucifugus, 879.
Termites, 879 .

Terricoles (Oligochètes), 591.

Test (Échinodermes), 199.

Testacée (Membrane), 1027.

Testacelles (Testacella), 922.

Testaeellidés (Teslacellidæ), 922.

Testicardines, 575 .

Testicules, 43.

Tes/udo, 1015.

Têtards, 981 .

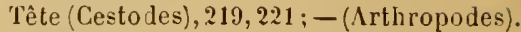
594.

Tête de mort, 860 .

Tetin, 1086 .

Tétrabranches, 926 .

Tétracotyles (Telracolyle), 337, 381; typica. 383.

Tétramères, 887.

Telrameres, 514.

Tetramorium, 864.

Tétranyeinés ('Telranyeinæ), 693.

Tétrauyques (Telranychus), 699; - cuIumnalis, 700; - molestissimus, telarius, 699.

Tetrao, 1054; - bonasia, tetrix, urogallus, 105 í.

Tétraonidés (Telrconidæ), 1043, 1054.

Tétrapneumones (Araignées), 230.

Tétraptères, 736 .

Tétrarynchidés (Tetrarchynchidæ), 331 .

Tétrarynques (Telrarhynchus), 214, 331; - erinaceus, 331 .

Tétras, 1054 .

Tétrasporées (Coccidies), 132.

Tetrastomum renale, 356.

Tetrodon, 96'.

Teuthidés (Teulhidæ), 974.

Texas fever, 127.

Thalassicola, $121 ;-$ morum, 121.

Thalassidroma, 1041.

Thalassophrynes (Thalassopleryne), 974; - maculosa, reticulata, 974.

Thaliaeés, 932 .

Thaumalea, 1051; - Amhersliæe, picta, 1051.

Thécastome, $6 ? 6$.

Thecosomum, 371; - hæmatobium, 371.

Thelasia Rodesi, 527.

Thélyphones (Thelyphonus), 725.

Thenaisienne (Époque), 1227.

Therobia, 761.

Thom inx, 485 .

Thomises (Thomisus), 730.

Thon, 971.

Thooïdes (Thooida), 1197.

Thoraciques (Poissons), 951.

Thorax (Arthropodes), 59 '.

Thrips (Thrips), 879; - cerealium, 879.

Thur, 1143.

Thymallus vulgaris, 967.

Thynnus alalonga, pelamys, vulgaris, 971.

Thyone papillosa, 205. 
Thyrevphure enthropupher!y, ist.

Thysinoptires, 8i?.

Thysanosomes (Thysunusumm, 275: -

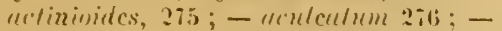
Bo(mulli, "; - fimbrialum, 275; likudi, 276; - orillum, :2ici: - murilentum. 2i?.

"Thysanumies, 885.

'Tilija, 93\%.

Tiers-au, 1107.

Tito dei gilti, $\$ 3$.

Tigre du purier, s:3.

Tigl'es, 1:09.

rince rulguris, 967.

Tineu culluverint, grunellu, pellimellu, lapezella, sis?.

Tiluéidés Tineidir, s.5.

Tingidés Tingielee, 8:?.

Tingis pyri, 823.

Tinlimuss, 1 so.

Típue senegalaise, ill.

'Tiques, 'Tiquets, 705.

Tiquets lltises, 857 .

Tisseurs (Pieds, 6:\%.

'Tissus, 15 .

Titanotherides (Titumotherilie, II is.

Tlalsahnate, 703.

Tocostome, 316, 32:3, 6?9.

Toile d'Araignée, 731 .

Tomicus, ss9.

Torpuet, 97 í.

Torcel, $7 \%$.

Torcols, 1060.

Tordeuses. 853.

Torpedu, 961; - nurke seu weulutu, 961.

Torpilles, 961 .

Tortricines, 1002.

Tortricilis (Torlrividial, 8.3.3.

Torlix Pilleriunu, 853.

Tortues, 989, 991, 1015

Tistunus, 1042.

Totipalmes, 1031, 1041.

Toucans, 1060.

'Toucher, 3C.

Toulle, 858 .

Toupies, $9: 0$.

Tourlourous, 610 .

Tournis, 255 ; - Fanx , 763.

Tourterelles, 1059.

Toxalbumines du venin de Serpent, פ乡.

Toxicozoaires, ?!).

Toxodontes, 1101 .

Trabécule, 834 .

Trachéates, 601.

Trachie Arthropodes), 38, 59s; - (Vel. tébrési, 9 it.

'Trachinidés Trachinida', 97:.

Truthinus, 974: - moneus, drum, ludiulus, cipere, $97 \mathrm{i}$.

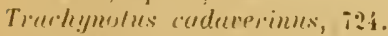

Trasopans, 105i.

Tragules Trengulus. 11:i.
Tragulides (Trenguliele", 11:i.

'lraigue, 97í.

Transformisme, 9?, 98.

'liansiloire Hôte, $i 0$.

Transmigration, io.

Trapuets, $106 i$.

Trehilit, 890.

'Tréhalose. s9t).

Trématodes, 209, :3:32.

Trépang, 205.

Triadinions Triudinium, 18:3; - renedulum, 183.

Trismopherus, 319.

Tricala, 890.

Tricherhus ı.smuns, 1193.

Trichiue Trielline, 477, ist); - rystich, ils; - reticulutu, iss; - sprimalis, 190.

Trichines intestinales, 490 ; - musculaires, 491.

Trichinose, 49\%.

Trichocépliales Trichurephulus, 477; uffinis, 481, 483: - mulis, 486; - ${ }^{\prime \prime \prime-~}$ meli. 483; - crmpunulu, 48i:- crenutus, 481; - dequessiusculus. 483;lisper. 178; - erhimopliyllus, 483; cylli, 415;- relis, 484́;-hominis, 4is: - lemmris, ii9:-leproris, 484; - uvis. 481; - pulipformis, 479 ; servalus, 483; - suis. 481; - unquirululus, 484; - vulpis, 483.

Tireherephalos. 4ĩ.

Trychocystes, 17.

'Trichodactylö̈des Nymplies), 68\%.

richuderlylus, bst.

Trichorlectes Trichuderles, $835 ;-$ ranis; 837; - гириie, 837; - rlimux, 836: - major, 83i; - mussipes, s37; equi, 835; - lulus, 836 ; - limbulus. 837. - mamliriens, 83i; - vits, 836 ; - purumpilesus, s3.; - urellulu, taisulu. 836: - penirillalus, 837; pilosws Giebel, 835 ; - nilosus liaget, 535; - quadricrinis, 879; - scalaris, 836; - sulidus, 83i : - sphsorrephalus, 836; - subroslmulus, 837: - veslilus, 835 .

Trichodes Trirhmles, $\{7 \%$, 199 ; - rassicruclu, 459 .

Trichodes (Trirhodes, 897 ; - upiurius, 897.

Trichoma, $\$: 6$.

Tricleummtyr, 160 .

Trichomonades Trichommuss, $163,16 \mathrm{i}$,

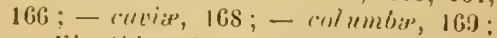
- Eberllii, 166, 169; - gullinip, 166: -- hominis, 16i, 168; - intestimalis, 165 ; - irveguluris, 165; - snis, 168; - ruginalis, 166.

Fivirhoneme "1) cuulum, 462.

Trichosomes Trichusommem, 477, 484; "renplrilum, isi; - mmulis, 486; -

Railliet. - Zoologie. 
anmulutum. 489; - brevicolte, 486:rollare, 487 ; - culumbir. 485 ; - contortum. 487; - relessiccuda, $489 ;-$ felis cati, 488 ; - lineare, 489 ; - longicolle Duj., $\$ 86$; - langicalle Pud. 486 ; - pupillosum, 489 ; - plicr, 485 ; - ietusum, 486; - tenuissimum. 48: .

Trichostomes, 173,175 .

Trichatursus, 688.

Trichotrachélidés (Trirhutrar'helidap', 4i7, Trichuris. $4 i i$.

Tricuspide Valvule, 108:.

Trigles Trigla;, 9i4; - cuculus, hirundo, 97't.

Triglidés (Triglidiop, 972 .

Triglochine (Valvule), 1082.

Trigone, 867 .

Trigonocéphale Trigonocephalus, 101'́; - hulys, 1014; - Iles Antilles, 1014.

Trilobites, 611.

Trimères, 887 .

Trineura uterrima, 779.

Trinotons Trinoton, 845; - anseris $845 ;$ - continuum, 846; - conspurcutum. $845 ;$ - liturutum, $846 ;-$ tur idum, 846; - squalidum, 846 .

Trinymphale (Métamorphose), 630 .

Triodon, 96'.

Triongulins. s91.

Trionyx, 1015.

Tripang, 205.

Tristomes Tristomum, 38:3.

Tristomidés Tristumidie. 383 .

Tritocerẻbron, 595 .

Tritons (Triton), 984; - alpestris. rristutus, murmoratus, pulmutus, vntgaris. 984 .

Trochauter (Iusectes): 735.

trachilus. 1062.

Trochosphère, 576, 903.

Trochus, 920.

Troctes divinatarius. 879.

Truglodytes Troglodytes, $1063 ;-$ - purvulus, 1063.

troglodytes Singes niger, sinalensis, 1223.

Tirogon, 1060.

Trogosite mueritunice, 900.

Trogulus, 724 .

Trumbella, 699 .

Trombididés (Trombididæe ), 631, 69*2.

Trombidinés (Tuombidinie), 693, 699.

Trombidions (Trombidium), 699; - u tumnate, holoserireum, 700.

Trompe (Acanthocéphales, ,563;- Cestodes;, 221;-(Eléphants), 1175 ;-(Entéropneustes), 930 ; - de Fallope, 1085 ; -(Némertiens), 384; - (Oiseaux), 1027.

Tropidocerce, 544 ; - fissispina, 545 ; inftulu, 545; - prrenloxt von Sieb., 545.
Tropidonotes (Tropidonotus, $1003 ;-n a-$ trix, viperinus, 1003.

Tropisures Tropisurus, 544 ; - fissispimus, 544 .

Truie, 1111.

Truites (Trutta, 966; - fario. lucustris, marinu, 966.

Trygon, 961; - pastinacr, violace t, 961.

Trypanomonas. 164; - muriem, 164.

Trypanosomes Trypanostmum), 164; Evansi, 165 ; - Nabiasi (du Lapin), 16t; - senguinis, 164; - sunguinis avium, $16 \dot{4}$.

Tsaltsalya, 788,794 .

Tsé-tsé, 787 ; - de la graude espèce, i9t.

Tshita, 1213.

Tube albuminipare, 1027.

Tuberculeuses (Dents), 1194.

Tuberculose (pseudo-) cutanée, 636 ; pulmonaire, 429, 433.

Tubes de Miescher, de Rainey, 150 ; - de Mlalpighi, 40.

Tubicoles (Annélides), 592.

Tubifex, 592.

Tue-teignes, 85?.

Tumeurs coccidiennes, 148 ; - d'OEstres, 770.

Tumulus, 1232, 1233.

Tuniciers, 929, 930 .

Tunicine, 930.

Tunique, 930.

Turbellariés, 209, 383.

Turbo rugosus, 920.

Turbol, 970 .

Turdidés (Turdids $), 1063$.

Furdus, 1063 ; - iliacus, 1063 ; - merulu. 1064: - musicus, pilaris, 1063; - turqualus, 1064: - viscioorus, 106 '.

furicatas, ils.

Turtur, 1059; - areritus, risorius, 105!?

Tuyau (Plume), 1019.

Tydées (Tydleus, 692; - molestus, 692.

Tylenchus, 553: - devastator, pulrefuciens, 554; - scandens, tritici, 553.

Tylopodes, 1118.

Types, 90; - humains, 1235.

Typhlops vermicularis, 1002.

Typhlopsylles (Typhtopsylla), 805: - ressimilis, dictenus, gracilis, hexactenus, musculi, ocfactenus, pentactenus, 805 .

Typothériens, 1101.

Tyroglyphes (Tyroglyphus), 690 ;-Crossi. 691 ; - echinopus, 691 ; - entomophagus, 691; - furinx, 689; - horridus, 691 ; - longior, 691; - matus, 686.687; - Mericourti, 696; - wvatus, 691 ; siculus, 691; - siro L., 690 ; - sim Robilı, 689.

Tyroglyphinés (Tyrnglyphina), 639, 686. 
l'kpoj, i2:2.

['otriques, 1:3:i.

l'nall, 1096.

Vacuoles pulsaliles, 39, 114

U

Vadrouille (Clieveux en, 1238, 12 í.

Vagalıouds . Ifaladie des, $8: 8$.

Vagin, 108:.

Va!finicolı ceystallino, 1 i1.

Vairon, 967.

Incinaires Imrinurit, 464; - rermu,. Vaisscau dorsal, 598.

$4 i \mathrm{i}$-duolemalis, ifi2, 465; - ruliulu, $475 ;-$ slenuceplealu, $433 ;-1$ rigumecephulu, 470;-melpis, 50 .

lncinariose, 469.

Lncinies Ipophyses, 1017.

Cuduline renurmm, 164.

L'uiuymphale (Métamorphose', 630.

Unio, 914 .

Unionidés I'niomillix', 91'.

Cnipolaires Cellules nerr., 19.

Luisexués, 4 4.

Lniti de composition, 2:.

lnivoltines Races', 85!).

Uрира, 1062.

Ur, 1141,1143 .

Vaisseaux, 37 ; - alquiferes, 39.

Vimpire, 1?18

Vialloise, 967 .

Vanillisme, 690

Vanne, 911.

Vimneanx (lunellus), tos?; - creyeunensis, 1041 .

Varaus V(unnus), 1013.

Varialbilite, 59.

Variation disordunnée, 96,97.

Varicté, 93.

Vautours, 1017, 1066.

Vaysonier, 583.

Veau, 1146; - marin, 1193.

Veines, 37 .

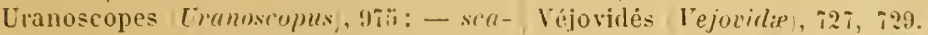

her, 975 .

Ureteres, 9 9.5.

Lrèlre, 1083.

C'rin, 1032.

Uriat, 1130.

Urinaire Vessie), 9 4́5.

Urinaires Organes', 39.

livehordés, 929.

Urocyons (Lrocyon), 11 !s.

Uirocystis, 213.

Lrodèles, 981, 982.

Urogénital (Sinus, 99?.

Urogonimus, 341 .

Uropode Krameri, nummularin, i24.

Urupodinie, ils.

Lropygieune Glande/, 1020.

Lrostèges, 993.

L'rsidies (Lrsidie, 1:203.

Urson coquain, $118 \%$.

Uists, 1201; - arrlos, 1075, 1204: ferox, 1201; - maritimus, 1204: spelarus, 1203, 1204.

Urtieaire hydatique, $26 i$.

Urticantes Chenilles), $8 \ddot{4}$.

Urtieants Organes, 171,188 .

Citus, 1143.

Usage, ?6.

Ltirus, 4 it.

Utiles Auimaux/, $6 \pi, 80$.

Utricule Oreille, 9'ו.

Utrienles psorospermiques, de Miescher, the lininey, 150.

Etriculiformes (Psorospermins, 150.

l'yo, i??

lelum (Coelentírés, 193; - Mollusques, $90: 3$.

lenu medinensis, 500.

Veudangeur, 701.

Yévéneux Animatux, 6i, i9; - (Poissons), 956 .

Vénẻridés léenerilid, ,91\%.

Venimeuses Glantes', $726,739,8 \div 5,99 \%$ $1006,1093$.

Venimeux (Animaux), 67, :9;-Lézards , 1014; - Mlammiferes . 1093; - Poissons, $95 \%$; - (Serpents, 993.

Venin, 79; - Batraciens), 9ii; Hyménoplires, S65, 875:- Sillriens, 1014; - Serpents, 994.

Vintonses Cestodes, 2:?2; - Trématodes , 33:.

Ventre (Gros', 137, 283.

Veutricolo, 1022; - succeuluriato, 1022.

Ventrieule Nématodes), $38 s$; - chylifique, 597, i3s; - succenturié, 102:?.

Ventricules du cerrean, 939; - du cour, $9 \div 3$.

Ventriculites, 738 .

Fentriculus, 1022.

Ventriglio, 1022 ; - succenturiato, 102.

Venus Venus, o11; - yollinu, verru("usil, 914 .

Ver - ì soie, 856 :- blane du blè, 852; lu Bouf, 7ig) - lle barine, 895 ; - des fruils, $553 ;-$ le llpidine, $500 ;-$ do vaisseau, 915: - dı Bauf, 759; - de la vendange, 5.53 ; - du Cayor, 785 ; - ensorecle, i31:- fourclu. 453;luisant, 897; - macaque, iss; moyocuil, iis); - ronge (Clairon), siı, 8:77; - rouge (Cochylis, 853 ; rougn (Syngatme, 153 ; - solitaire, 2:39;

Vitche, 1145; - marine, 11 !)3.

Vaehes Sallgsues', 5x?. - tricolore, 5 i7. 
Verdier, 1062.

Vermes, 205.

Vermiformia, 631 .

Vermiliugnes Edentrs), 1096 ; - Sauriens, 1013.

Verminières artificielles, $i 83$.

Vermipsylles Vermipsyllu, s09; - alulint? 80 !).

Vermis, 1075 .

Véroquin, 78.

Verrats, $1106,1111$.

Vers, 110, 205; - is queue de Rat, 791 ; - blanes, 898 ; - de terre, 591 ; - de vase, 797 ; - gris, 853 ; - intestinaux, 209 ; — plats, 208; — rouds, $385 ;$ rubanés, 210 ; - vésienlaires, 212.

Vers-Vis, 784.

Verte Glande:, 604.

Vertebres, 935 .

Vertébrés, 110, 429, 934; - inférieurs, supérieurs, 948.

Vertige d'thistres, 763.

Vésicants, 890 .

Vesicularia, 573.

Vósieule ambulacraire, 200 ; - raudale, 221 ; - embryogine, 46 ; - germinative, 46 ; - mère, 261 ; - pulsatile, 33.3; - sèminale, 44.

Vésicnles auditives, 31 ; - filles, 25i, 263 ; - multificles, 918 ; - petites-filles. 264; - de Poli, 199;-proligeres, 261 ; - pulmonaires, 1083 ; - secoudaires, 263.

I'espu, 8f5; - rrabre, germanica, mediu, rufu, sylv estris, vulgmris, 865 .

respertilions (Vespertilio, 1217; - muri$n u s, 1218$.

lesperugo noclulu, pipitrellus, 1218.

V'espidés Vespidie, s64.

Vespines (Vespinide), 864.

Vessie aérienne, 955 ; - bilobie, i06; vatatoire, 955:- urinaire, 945.

Veslibule Oreille), 941 ; génilal, 1085

V'euves, 1068.

Yexillum (Plume), 1019.

Vibraculailes, 574.

Vibratiles Cils), 20, 113 .

Vibrio trilici, 553.

Vibrisses, 1068, $107 i$.

Vidua, 106:.

Vie active, $5:$ - animale, :i; ralentie, 57 ; - vigétative, 27 .

Vieille de mer, 971.

Vieux (Orgauismes), 56.

Vigueaux, 920 .

Vigogue, 1119.

Vinaigrier, 725 .

Vipère ( Iipera), 1007 - Immoulytes,

1010 ; - uspis, 1007 ; - berus, 1007, Xiphoïde (Appendice), 1073.

1010; - cornue, 1012; - élégante,1012; Xiphosures, 610,

- fer-de-lance, 1012; - heurtante, Tololges, 68?.

1012; - janne, 1012; - Orsinii, 1007; Vuloples, bs:.
Viperides Viperidis, $100 \%$.

Viperine, 995.

Viscache, 1185.

Viscéral Systeme nerveux , 30;- Squelette, 9:36.

Viseérale Cavité, 93'.

Vison, 1204.

Vitellin Sac), 959.

Vitelliue (Nembrane), 46.

Vitellorlucte, 212, 334.

Vilellogènes, 212,334 .

Vitello-intestinal Conduit), 94

Vitellosac, 351 .

Vitellus, 46 ; - blane, $102 i$; - jaune, 1027.

Vitrée (Humeur), !\$1.

Vitulus aqualicus, 563.

Viverra, 1205; - civetta, 1206 ; - genellu, zibetha, 1207.

Viverréum, 1206.

Viverrides Viverridip, $120 \mathrm{~s}$.

Vives, $79,958,97$ '.

Viviparité, 32 .

Voile, 903 ; - du palais. 1080 ; - de la pudeur, 1245.

Volant-messager, 1059.

Fulucella, 791 .

Volrocinees, 163.

Voran, 585.

Vormagen, 1022

orlicelles, 184

Vulnérants Animaux, bi, is; - Poissons', 95 i.

Pulpes, 11 !)S.

Vullur, 10 ti6; - fulvus, 1017.

Vulve, :085.

luychouchol, 1215

W

Hedlidit, 3is8.

Wilde paaril, wilden esel, 1169.

Wisent, 1141.

Wollf Canal de, 945; - Corps de), 345.

Wombat Phascolome), 1095.

Worm-ziekte, 784 .

\section{$\mathbf{X}$}

Nenos, ssi.

Xiphias, 972 
T.MBLE MIPIIBETIUUE HES MITIBRES

Xylurvou, 866 .

Jylophages, 889, s96.

$\mathbf{Y}$

liki. 11 i2.

le-.1100, 11:8.

Yeux, 31; - d'Écrevisses, 609.

Thàr, Yhiral, 1134.

Yo-tu-t\%é, 1166 .

linnx, 1060.

Z

Zabres Zubrus, 980;-giblum, 901. Zumenis viridiflurus, 1003.

\%ères, 1169.
Zéluins, 1159.

Kebus, 114?.

Zerrominir, ils.

Zibeliue, 1206.

Zibelli, 1:07.

Zimh, iss, ig4.

\%ointhaires, 1!:?

Zoanthodeme, 190.

\%oi, 604.

\%oïle, 26 .

\%one pellucide, 10s:

\%ooides, 194.

\%oonérythrine, 96ti.

\%oonites, 2i.

Tooparasites, 68.

\%oophtires, 823.

\%oophytes, 110.

Zyg:rnu, 960.

\%ygapophyses, 935.

FIY DE LA TABLE ALPIABETIQUE DES MATILRES. 


\section{ERRATA}

Page 106, ligne 1, lire: l'érolution.

134 , ligne 17 , au lieu de : deux, lire : quatre spores.

- 160: Les Microsporidies doivent être réunies aux Myxosporidies (Thélohan).

- 166, ligne 26, au lieu de : Bacille de Löfler, lire : Bacille spécifique.

- 181: Les Diplodinium Maggii et mammosum ont été trouvés dansla panse du Bœuf.

202, ligne $i$, lire : Crinoines.

- 276, ligne 2, ajouter : Pores génitaux doubles.

- 276, ligne 7 , au lieu de: Th. vvilla, lire Th. ovillum.

- 283, ligne 16 en remontant, lire : Anoplocephala peclinala L. Blancl.

- 302, ligne 11 en remontant, après Crustacés, ajouter : ct chez les Vers.

- 322, ligne 13 en remontant, supprimer : que nous n'arons pas eu á signaler chez les Ténias.

- 331: La forme adulte du Telrarhynchus erinaceuss cst Rhynchobolhium erinuceus.

- $\quad 332$, ligne $i$, au lieu de Amphiplina, lire : Amphilina.

- $\quad 339$, ligne 2 en remontant, au lieu te: 1871 , lire : 1891.

- $\quad 3 \dot{1} 1$ et suiv. : Le nom générique Distoma (ou mieux Dislomum), ćtant préoccupé, doit ĉtre remplacé par Fascioln L., wème cu n'admettant pas la subdivision du genre.

- 341, ligne 25, au lieu de :Mesogoninus, lire : Mesogonimus.

- 341, ligne 28, et p. 372. lègende, au lieu de: Gynecophorzs, lire: Fynscophórus,

- 363, ligne 4, au lien de : 1586 , lire : 1886.

- 364: Les espèces décrites comme appartenant au sous-genre Brachylaimus doivent prendre place dans le sous-genre Dicroculium, à côtè de D. felineum.

- $\quad 365$, ligne 5 eu remontant, au lieu de : Duj.. lire : de Blainville, 1828.

- $\quad 366$, au lieu de : D. excavalum Rud., 1819 , lire : 1809.

-

375 , supprimer les lignes 11 i 22 : Sonsino a recomm que ses indications étaient le résultat d'une erreur.

- 376, fig. 248, lire : des muscles du Porc.

- 406, ligne 4, lire: $A$. inflexn Rud., 1809 et 18i9, pro parte.

-

4:30, supprimer le paragraphe: Evouunox. Nous avous recomu que les observations de Cobbold reposent sur une erreur.

439, ligue 6 en remontant, supprimer : $S t r$ ovinus (1. l'abr., 178'.

447, ligne 10 en remonlant, après Frölich, 1791, ajonter : 11ec Schrank, 1880.

โ52, supprimer le genre Slephanurus: l'espéce st. dentalus doit être

reportée dans le genre Scleroslomum, sous le nom de Scl. pinguicolu.

45j: Le nom générique Globocephulus ètant préoccupé, le remplacer par Cystocephalus, qui a le même sens (C. hongemucronalus).

it: ligne 5 , au lieu de : mouvoir, lire : nourrir.

475 , ligne $t$, an lien de: Unc. rutiula Rud., lire : (Rud.).

477, ligne 3, au lieu de : l'estomac (?), lire : le gésier.

- 487, ligne 11, au lieu de : spicules, lire : spinules. somoides (Trichosomoides crassicauda).

- 489, ligne 3 en remontant, lire: Bellingham, 19 io. 


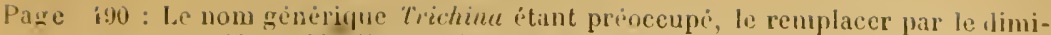
nutif Trichinelln (Trichinella spriralis).

- 511, ligue 23, apris : nombreux, ajouter : lat nuit.

- $\quad \vdots 15$, ligne a en remontant, après : Sillisbury, 1868, ajouter : nec Rud., 1819 (done cysticn perd la prioriti).

5i?, ligne 6, lire : spiroptera verrucusa Giles, 1892, nec Molin, 1859.

3i2, ligue 8 , apres : asophage, ajouter : dı Pore.

i43, ligne 3 , apris : Schneider, 1866 , ajouter : nec \%eder, 1803.

593, ligne 4, au lieu de : cixoutent, lire : sıximus.

630, ligne $\$$ en remontant, apris : métamorphoses, ajouter : anymphales.

(j5)3, ligne 21, au lien de : Vürst., 1861, lire : Müller, 1868.

66i, deruiere ligne, ajouter : et des Colombins.

fitis, ligne 2 en remontant, an licu de : actuellement, lire : accidentellement. 68:, ligne 10 en remontant, an lien de :Nealgs, lire: Nealges.

(isi, ligne 16: le genre Criniscansor doit itre rémi au geure Myocoples.

69t, ligue 7 en remontant, au lieu de : Chrithuples, lire : Crilhoptes.

i09, ligne 5 en remontant, au lieu de: Ionus hegra, lire: $l$. heragonus.

$i 24$, lignes 15 et 17 , alu lieu de : culicularis, lire : cubicularis.

7:9, ligne 16, au lieu de : sous-familles des Télégoninés et des Véjovinés,

lire : familles des Télégonidès et des Véjovidés.

749, ligne 14 en remontant, au lieu de : Latr., 1829, lire: Latr., 1818.

$76 t$, ligues 15 et 30 , au lieu de: Latr., 1825, , lire : Latr., 1818.

$i 6 \bar{i}$, lignes 17 et 27 , an lien de : Latr., $18 \% 5$, lire : Latr., 1818.

sis, ligne 7 , supprimer : ou incomplètes.

885, ligne 18, au lieu de : sacchurimu, lire : saccharina.

933, ligne 10, ajouter : Plusieur's autres formes ont été décrites récemment.

$98 i$, derniere ligne, au lieu de : 1885 , lire : 1893 .

- 106t, ligne 5, au lieu de: L. rubicula, lire: L. rubecula.

- 1196, ligne 13 en remontant, au lieu de : Cunininep, lire : Canine. 




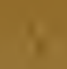

1

v.

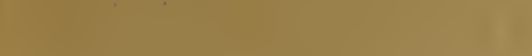

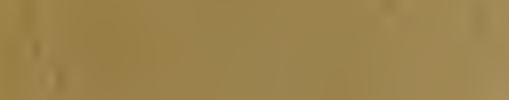

( 
